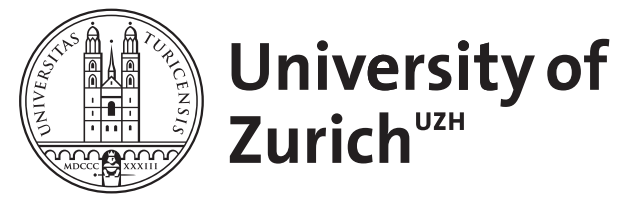

Zurich Open Repository and Archive

University of Zurich

University Library

Strickhofstrasse 39

CH-8057 Zurich

www.zora.uzh.ch

Year: 1986

Critique textuelle de l'Ancien Testament: 2. Isaïe, Jérémie, Lamentations

Barthélemy, Dominique

Posted at the Zurich Open Repository and Archive, University of Zurich

ZORA URL: https://doi.org/10.5167/uzh-150248

Monograph

Published Version

Originally published at:

Barthélemy, Dominique (1986). Critique textuelle de l'Ancien Testament: 2. Isaïe, Jérémie, Lamentations. Fribourg, Switzerland / Göttingen, Germany: Éditions Universitaires / Vandenhoeck Ruprecht. 
BARTHÉLEMY · CRITIQUE TEXTUELLE DE L'ANCIEN TESTAMENT 
Cet ouvrage est publié par l'Alliance Biblique Universelle et l'Institut Biblique de l'Université de Fribourg

Sur cet ouvrage:

Cet ouvrage traitera, en cinq volumes, des difficultés principales que le texte hébreu traditionnel de l'Ancien Testament a posées aux traductions récentes de la Bible qui ont le plus d'influence dans les cultures anglaise, française et allemande. Il présente le résultat d'un travail de dix ans (1970-1979) effectué par un comité international et interconfessionnel de spécialistes de la critique textuelle de l'Ancien Testament. Ce deuxième volume traite de 800 difficultés du Texte Massorétique des Prophètes.

Le rédacteur-éditeur, Dominique Barthélemy O.P., est professeur d'exégèse de l'Ancien Testament à l'Université de Fribourg en Suisse. 


\section{ORBIS BIBLICUS ET ORIENTALIS $50 / 2$}

\section{DOMINIQUE BARTHÉLEMY}

\section{CRITIQUE TEXTUELLE \\ DE L'ANCIEN TESTAMENT}

2. Isaïe, Jérémie, Lamentations

Rapport final

du Comité pour l'analyse textuelle de l'Ancien Testament hébreu institué par l'Alliance Biblique Universelle, établi en coopération avec

Alexander R. Hulst $†$

Norbert Lohfink

William D. McHardy

H. Peter Rüger, coéditeur

James A. Sanders, coéditeur

ÉDITIONS UNIVERSITAIRES FRIBOURG SUISSE VANDENHOECK \& RUPRECHT GÖTTINGEN 


\section{CIP-Kurztitelaufnabme der Deutschen Bibliotbek}

\section{Barthélemy, Dominique:}

Critique textuelle de l'Ancien Testament / Dominique Barthélemy. Rapport final du Comité pour l'Analyse textuelle de l'Ancien Testament hébreu institué par l'Alliance biblique Universelle, établi en coopération avec Alexander R. Hulst ... -

Fribourg Suisse: Editions Universitaires;

Göttingen: Vandenhoeck und Ruprecht.

2. Isaïe, Jérémie, Lamentations. - 1986

(Orbis biblicus et orientalis; 50/2)

ISBN 2-8271-0322-2 (Editions Universitaires)

ISBN 3-525-53692-5 (Vandenhoeck und Ruprecht)

Publié avec l'aide du Conseil de l'Université de Fribourg

(c) 1986 for the French Edition by Editions Universitaires Fribourg Suisse Imprimerie Saint-Paul Fribourg Suisse

ISBN 2-8271-0322-2 (Editions Universitaires)

ISBN 3-525-53692-5 (Vandenhoeck und Ruprecht)

Digitalisat erstellt durch Florian Lippke, Departement für Biblische

Studien, Universität Freiburg Schweiz 
$A$ Alexander R. Hulst qui nous a précédés là où la recherche fait place à l'évidence 


\section{TABLE DES MATIERES}

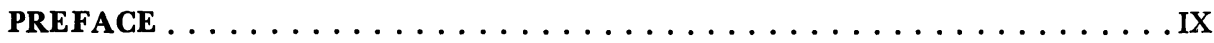

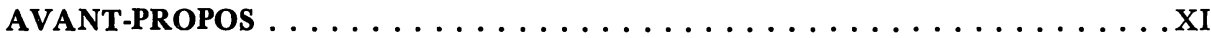

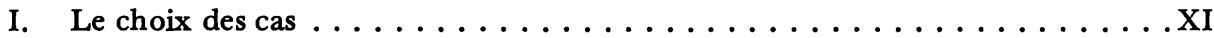

II. Structure des apparats critiques $\ldots \ldots \ldots \ldots \ldots \ldots \ldots \ldots \ldots \ldots \ldots \ldots \ldots$

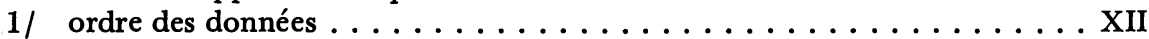

2) facteurs caractérisant les variantes. ................. XII

III. Les témoins textuels $\ldots \ldots \ldots \ldots \ldots \ldots \ldots \ldots \ldots \ldots \ldots \ldots \ldots \ldots$

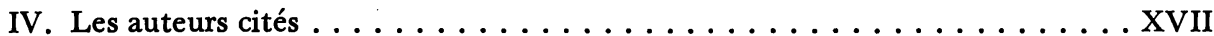

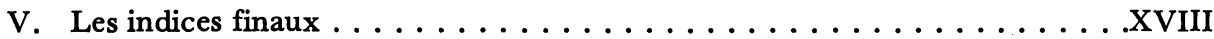

VI. La bibliographie $\ldots \ldots \ldots \ldots \ldots \ldots \ldots \ldots \ldots \ldots \ldots \ldots \ldots \ldots \ldots$

INTRODUCTION $:$ La structure de ce rapport $\ldots \ldots \ldots \ldots \ldots \ldots$

Première section $:$ Options de nos traductions . . . . . . . . . . . . . *2

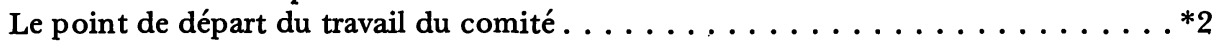

La Revised Standard Version . . . . . . . . . . . . . . . . . . . 4

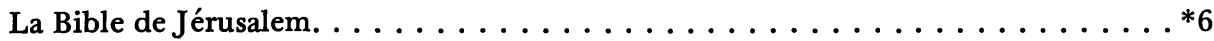

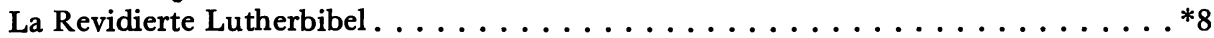

La New English Bible . . . . . . . . . . . . . . . . . . .

La Traduction Oecuménique de la Bible. . . . . . . . . . . . . . .*11

Critiquer la critique . . . . . . . . . . . . . . . . . . . . . 14

Deuxième section : Origines des corrections $\ldots \ldots \ldots \ldots \ldots \ldots$

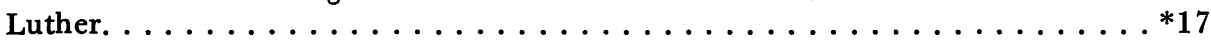

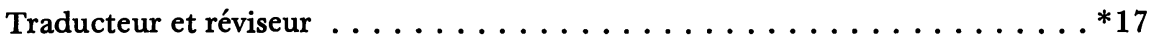

Les sources de la traduction. . . . . . . . . . . . . . . . *17

$1 /$ Isaïe . . . . . . . . . . . . . . . . . . * 17

2/ Jérémie et les Lamentations. . . . . . . . . . . . . . . . . *19

Les sources de la révision de $1540-1541 \ldots \ldots \ldots \ldots \ldots \ldots \ldots$. . . . . . . . . . . . . . . . . . . . .

Les sources d'influence extérieures ou postérieures à Luther . . . . . . . . . . . *24

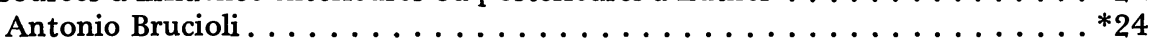

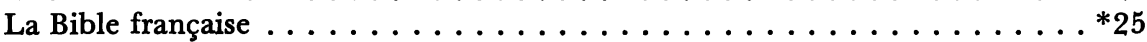

$1 /$ Olivétan et la Bible de Serrières . . . . . . . . . . . . *25

2) La Bible lyonnaise de Philibert Rollet . . . . . . . . . . . . *27

3/ La Bible française de Robert Estienne . . . . . . . . . . . *29 et *44

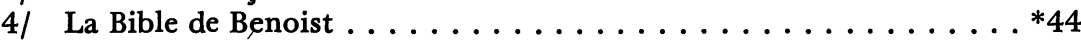

$5 /$ La Bible de Louvain. . . . . . . . . . . . . . . . . . . . *46 . . . . . . . . . . . . . . . . . . . . . . . . .

6/ La Bible de Châteillon .......................449

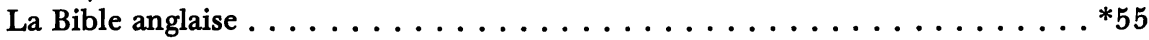

1/ La Bible de Coverdale. . . . . . . . . . . . . . . . *55

2/ La Bible de Thomas Matthew et la Grande Bible . . . . . . . . . * *56

3/ La Geneva Bible ........................ . . . . . . . . . . . . .

4 La King James Version . . . . . . . . . . . . . . . . . . . . . 61

La Bible des Pasteurs et Professeurs de l'Eglise de Genève . . . . . . . . . . . . *64

Vue d'ensemble sur la Bible en langue vulgaire au XVIe siècle . . . . . . . . . .*66

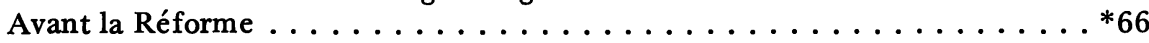

Rôle de Luther . . . . . . . . . . . . . . . . . . . *66 


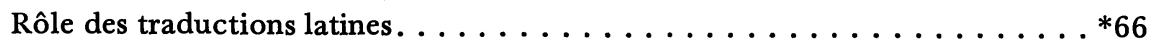

Rôle de Robert Estienne. . . . . . . . . . . . . . . . . . .68

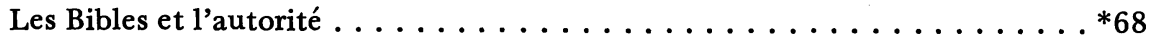

Le débat sur les aides de lecture . . . . . . . . . . . . . . . . *69

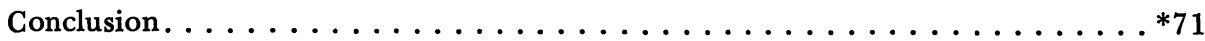

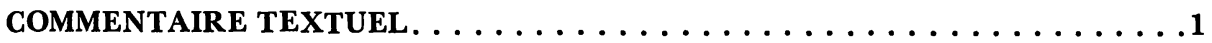

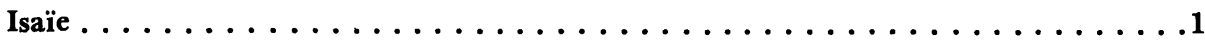

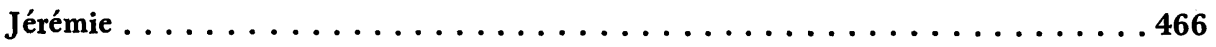

Lamentations ............................ 863

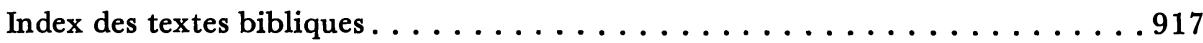

Index des auteurs cités . . . . . . . . . . . . . . . . . . 941

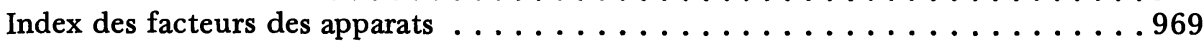

Bibliographie ......................... 975

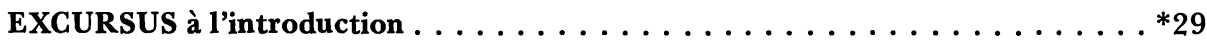

I. Robert Estienne éditeur de la Bible. . . . . . . . . . . . . . . 29

A. La première édition critique de la Vulgate . . . . . . . . . . . *29

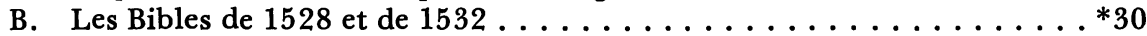

C. La Bible de 1540 : premier apparat critique . . . . . . . . . . . *31

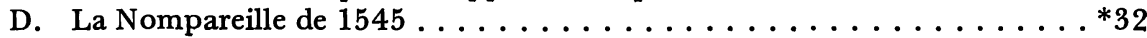

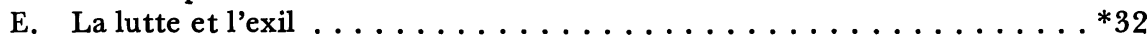

II. La Bible de Vatable aux prises avec l'Inquisition espagnole . . . . . . . . . *34

A. Les pièces officielles sur la réédition de $1586 \ldots \ldots \ldots \ldots \ldots \ldots$

B. Censures parisiennes et censures espagnoles $\ldots \ldots \ldots \ldots \ldots \ldots \ldots \ldots$

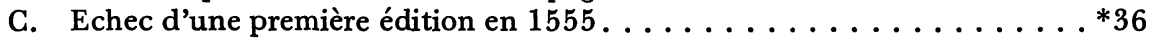

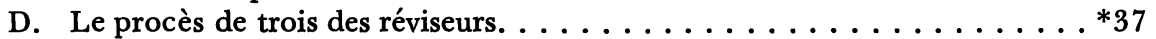

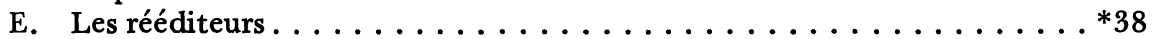

F. La correction de la Bible de Vatable par l'Inquisition . . . . . . . . . . . . . . .

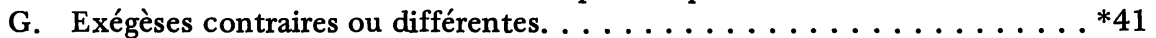

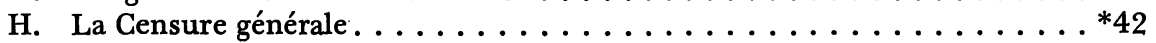

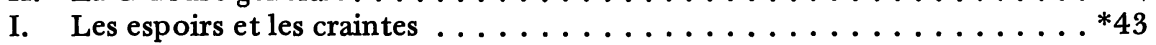

EXCURSUS au commentaire textuel : L'interprétation d'Is 52,13-15 . . . . . . 385

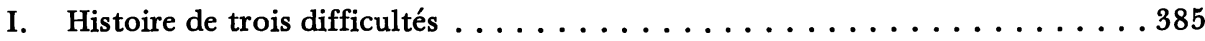

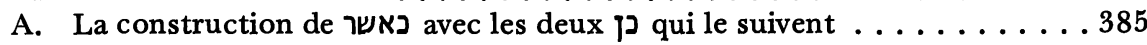

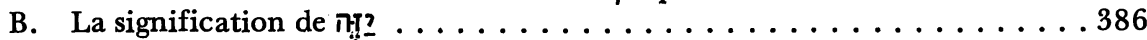

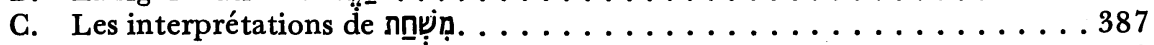

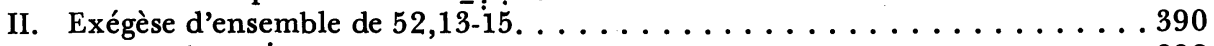

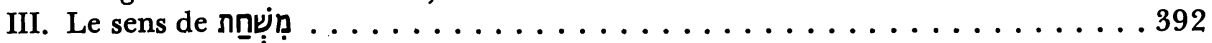

IV. Interprétations proposées . . . . . . . . . . . . . . 394 



\section{PREFACE}

Trois ans après le premier volume, consacré aux livres historiques, paraît le deuxième.

C'est à la mémoire d'Alexander R. Hulst qu'il est dédié. Ce volume contient en effet la dernière étape de notre travail à laquelle notre aîné ait participé de bout en bout. Aussi est-ce le moment d'évoquer ses interventions pleines d'expérience et de conviction, ainsi que la gaieté fraternelle dont il émaillait notre vie quotidienne.

Chacun des membres du comité a sa part dans ce travail. H. Peter Rüger pour la présentation et la mise en rapport des témoins textuels, James A. Sanders pour les données de Qumrân, Dominique Barthélemy pour l'histoire de l'exégèse jusqu'au milieu du siècle dernier, Norbert Lohfink pour les données sur l'exégèse contemporaine, Alexander R. Hulst et William D. McHardy pour de précieuses remarques critiques.

Le choix initial des problèmes traités par le comité est l'oeuvre de John A. Thompson. Eugene A. Nida a guidé le déroulement de nos travaux et Adrian Schenker, ayant enregistré nos décisions, a édité le compte rendu préliminaire.

Clemens Locher, Arie Van der Kooij et Pierre Casetti ont aidé le travail du comité.

D. Barthélemy a rédigé ce volume.

Tous les membres du comité ont eu communication du traitement des diverses difficultés et la rédaction finale a profité de leurs suggestions.

L'introduction a été soumise aux deux autres membres du comité d'édition, H.P. Rüger et J.A. Sanders.

La typographie du rapport est due à la secrétaire scientifique de l'Institut Biblique, Bernadette Schacher, dont la compétence et l'assiduité en ont permis la réalisation.

C'est à Alfred Bauer que l'on doit les têtes d'impression dont nous avons fait usage.

Les recherches bibliographiques et les corrections sont dues à Bruno Ognibeni, Marguerite Hirt, Yohanan Goldman et Oh Jine-Sook. 
La vocalisation de l'hébreu et l'accentuation du grec sont l'oeuvre de celle-ci et de Vincent Rosset.

Les indices ont été rédigés par Mariam Nabavi, Catherine Blein et Claire Aebischer.

Malgré la convergence de ces multiples efforts, nous avons conscience que bien des fautes doivent demeurer en ce travail complexe. L'éditeur du rapport serait reconnaissant qu'on les lui signale pour qu'il puisse y remédier par la suite, de même qu'il a tenu compte, en ce deuxième volume, de remarques qui lui avaient été faites à propos du premier sur le caractère incomplet et trop peu ordonné du traitement des difficultés textuelles, ainsi que sur la non-discussion des conjectures.

Des remerciements s'adressent à Frank Moore Cross Jr et à Eugene Ulrich qui ont permis que l'on fasse usage des fragments de Qumrân dont la publication leur est confiée, ainsi qu'à P. Benoit et J. Strugnell qui ont identifié les photos du lot Skehan.

Le financement de cette publication est dû essentiellement à l'Alliance Biblique Universelle et à l'Université de Fribourg.

D. Barthélemy, éditeur 


\section{AVANT-PROPOS}

Quelques caractéristiques du travail du comité ont été dégagées dans l'avantpropos du premier volume. Nous y apporterons quelques précisions dans l'introduction de celui-ci.

Nous nous contenterons ici de répéter et de compléter les indications qui faciliteront au lecteur l'usage de ce rapport.

\section{Le choix des cas}

Pour les livres d'Isaïe, de Jérémie et des Lamentations, le secrétariat de l'Alliance Biblique Universelle avait tiré de RSV, J123, RL et NEB un certain nombre de cas où une ou plusieurs de ces traductions corrigeaient le $* M$. De ces cas, le comité a retenu 685 difficultés où la correction lui semblait avoir une portée exégétique notable. Après qu'il ait traité ces cas, les décisions prises ont fait l’objet du vol. IV (Livres prophétiques I) du “Compte rendu préliminaire et provisoire sur le travail d'analyse textuelle de l'Ancien Testament hébreu" publié à New York en 1979. Ce volume du Rapport final traite de 800 cas. Cet accroissement a été principalement causé par la prise en considération de certaines corrections attestées par les notes de TOB, traduction dont le comité n'avait tenu compte qu'à propos de cas qui avaient été déjà relevés par l'une ou l'autre des quatre traductions mentionnées ci-dessus. Lorsqu'un cas n'a pas été traité par le comité, cela est précisé au début de la section "choix textuel" et aucune note n'est donnée dans l'apparat critique.

Certains recenseurs ayant critiqué la tendance du comité à ne pas attacher assez d'importance aux conjectures, ce volume - à la différence du premier - a retenu la plupart des cas consistant seulement en une conjecture proposée par une seule de nos traductions et où toute la tradition textuelle apporte un témoignage cohérent en faveur du *M.

\section{Structure des apparats critiques}

Pour la plupart des cas, un apparat critique commence par articuler de façon systématique les diverses données qui seront explicitées ensuite dans le traitement de ce cas. Il nous faut traiter ici brièvement de la structure de ces apparats critiques.

Distinguons d'abord des autres certains apparats à double entrée qui présentent deux solutions entre lesquelles le comité s'est refusé à choisir. On en rencontrera par exemple en Is 2,12; 15,9C; 33,3; 34,5A; 43,19; 44,11-12A; 66,17.19B; Jr 16, 7AB; 22,23; 23,18; 49,30C; 50,21A; 51,3C; Lm 2,13A. 


\section{1/ Ordre des données}

Les apparats normaux, c'est-à-dire à simple entrée, présentent en ordre successif :

a. La référence biblique. Lorsque le numéro du verset est suivi de "a" ou de "b", il s'agit de la partie du vs qui précède ou qui suit l'accent diviseur principal. Les lettres majuscules $A, B$ etc. distinguent diverses difficultés traitées à l'intérieur d'un même verset.

b. "cor" (correction) précède un cas où le comité a préféré une autre leçon à celle de son texte de référence (constitué par le qeré du ms de Leningrad).

c. La mention de la leçon choisie par le comité comme la plus primitive (selon les perspectives exposées en CT1*113s). Lorsque cette leçon est interrompue par un trait, cela signifie que les mots situés dans cet intervalle sont inclus. Lorsqu'elle est interrompue par des points, ces mots ne sont pas inclus.

d. La note donnée par le comité à la leçon choisie par lui : $A=$ très hautement probable; $\mathrm{B}=$ grande probabilité avec une certaine marge de doute; $\mathrm{C}=$ probable avec un coefficient de doute considérable; $D=$ quelques possibilités, mais cela demeure très incertain.

e. Les sigles des témoins qui appuient cette leçon; ou bien "bas" (base) au cas où, aucun témoin ne l'appuyant directement, elle n'est attestée qu'indirectement comme la base à partir de laquelle divergent les autres leçons.

"(crrp)" (corrompu) est mentionné lorsque l'on ne peut atteindre par la leçon choisie qu'une forme textuelle déjà corrompue.

f. Deux barres obliques séparent la leçon choisie des autres leçons qui en dépendent, leçons qui sont séparées entre elles par des barres obliques simples. Souvent une flèche indique qu'une leçon dérive d'une autre.

g. La présentation de chaque leçon ou groupe de leçons commence par la mention du 'facteur de modification" qui caractérise la relation de cette leçon ou de ce groupe de leçons avec la leçon considérée par le comité comme la plus primitive. La mention du facteur est suivie de deux points.

h. Puis viennent les sigles des témoins qui appuient la leçon en question. Ils sont séparés par des virgules lorsque leurs témoignages, tout en restant le produit d'un même facteur de modification, divergent dans leurs options.

i. Lorsqu'on l'a jugé utile pour la clarté de l'apparat, on caractérise ensuite la leçon en question. En ce cas, une forme minoritaire du texte massorétique est citée formellement. Une leçon d'une version est ou bien décrite, ou bien citée dans la langue où elle est attestée, ou bien encore on a mentionné sous "clav" (clavis) la forme hébraïque qui pourrait avoir inspiré le traducteur. On ne veut pas dire par là que le traducteur ait eu ce texte sous les yeux.

\section{2/ Facteurs caractérisant les variantes}

Tout d'abord, quelques indications limitant la portée de certains témoignages : "lacun" (lacune) indique que le passage en question et son contexte manquent dans les témoins mentionnés.

"abst" (abstention) indique que les témoins mentionnés sont inutilisables pour résoudre cette difficulté (par exemple, les mss de Qumrân pour la vocalisation d'une 
graphie défective, les versions latines pour la présence ou l'absence d'un article, les latines et les grecques pour le genre masculin ou féminin d'une forme verbale).

"incert" (incertain) indique que l'interprétation de l'apport de ces témoins demeure incertaine.

"lit" (littéraire) indique parfois qu'une leçon diverge des autres au niveau littéraire plutôt qu'au niveau textuel.

"transf" (transféré) indique qu'un passage a été transféré ailleurs par un copiste ou par un traducteur.

Nous avons donné aux pp. *71 à *74 de l'introduction à CT1 la description des divers facteurs de modification définis par le comité, dès le début de son travail, pour caractériser les leçons qu'il a identifiées.

Voici un essai pour situer par rapport à ces facteurs définis très amplement les facteurs plus spécifiques dont ce rapport fait usage.

a. Considérons d'abord les trois premiers facteurs qui entendaient apprécier les variantes du point de vue externe de leur attestation.

Le facteur 1 (étroitesse de la base d'une variante textuelle) envisageait de donner moins de poids à une variante qui ne se rencontre que dans une tradition du texte biblique, par exemple dans le Targum, la Syriaque ou la Vulgate seulement. Aucun des facteurs utilisés en ce rapport ne se rattache directement à celui-ci. Jamais en effet les décisions du comité n'ont été motivées seulement par ce fait. On a toujours fait entrer directement en ligne de compte les motifs d'altération du texte (facteurs 4 à 13). Ajoutons d'ailleurs que le comité a été amené à considérer plus souvent le Targum comme le témoin d'une exégèse traditionnelle du texte protomassorétique que comme représentant une base textuelle autonome. Quant à la Vulgate, on peut la caractériser de même, tout en ajoutant qu'elle mêle souvent à cela un témoignage sur le Grec (à travers la Vieille Latine dont elle ne s'est pas entièrement émancipée). Pour ce qui est de la Syriaque, elle est la résultante d'influences trop diverses (texte protomassorétique, Grec ancien, recension antiochienne et nombreuses déformations internes) pour que l'on puisse attacher un grand poids à son témoignage lorsqu'il est isolé.

Le facteur 2 (largeur trompeuse de la base d'une variante textuelle) envisageait le cas où plusieurs traditions textuelles ont choisi la même manière obvie d'échapper à une difficulté textuelle. La chose est encore plus frappante si l'on complète l'enquête sur les témoins textuels par un parcours de l'histoire de l'exégèse où l'on voit la même échappatoire s'imposer à des commentateurs qui n'ont pourtant certainement rien eu d'autre sous les yeux que le Texte Massorétique. Une telle option est 'dans l'air'. C'est ce que nous avons exprimé par le facteur "spont" (spontané) qui indique que cette option se présente spontanément aux traducteurs, aux exégètes, et parfois même à certains copistes.

Le facteur 3 (dépendance de plusieurs formes textuelles à l'égard d'une forme unique plus primitive) situe une forme textuelle difficile comme étant celle à partir de laquelle les autres ont divergé en cherchant diverses façons d'y échapper. Dans ce rapport, ce facteur, sans être directement exprimé, est souvent impliqué quand plusieurs variantes différentes font suite à la leçon choisie. Il se trouve exprimé indirectement par "bas" (cf. supra) ou par "elus" (cf. infra). De fait, le comité a tenu grand compte de ce facteur dans ses décisions. 
b. Abordons maintenant les facteurs 4 à 13 qui essayaient de caractériser les motifs des altérations textuelles.

Le facteur 4 (simplification du texte) caractérise une leçon comme facilitante. Il apparaît en ce rapport sous les formes :

"facil" (facilitation) suivi le plus souvent du domaine dans lequel il y a eu facilitation : "...-styl" (...stylistique), "...-synt" (...syntaxique), “...-vocal" (...vocalique). Cependant, ce caractère facilitant d'une leçon refusée par le comité n'a été mentionné que dans une minorité de cas : ceux où il a été difficile de déceler un facteur de modification plus spécifique. En une foule d'autres, il faut sous-entendre la présence de ce facteur très générique.

"schem" (schème) indique la réduction d'un ensemble d'apparence disparate à une structure littéraire plus uniforme.

"usu" (usuel) indique le remplacement d'une forme rare par une forme plus usitée.

Le facteur 5 (assimilation à des passages parallèles) entre en jeu dans ce rapport sous deux formes :

"assim" (assimilation) suivi de l'une des quatre mentions suivantes :

- Ou bien la mention précise du lieu biblique auquel ce lieu-ci a été assimilé, et parfois de la forme textuelle à laquelle on a assimilé. Ainsi, en Is 21,8: "assim 15,9G : Th $\alpha \rho ı \eta \lambda$ " indique que Th (= Théodotion), en Is 21,8 , assimile au Grec ancien ("G") de Is 15,9 lorsqu'il lit apınג (ici où le texte massorétique lit אריה, en accord avec Aquila, Symmaque, la Vulgate et le Targum). L'aspect sous lequel l'assimilation a eu lieu peut-être précisé :

-Ou bien "assim-usu" (...à une forme plus usuelle) indique une assimilation à une forme qui s'offre à la mémoire.

- Ou bien "assim-ctext" (...au contexte) suggère une assimilation globale à diverses données fournies par le contexte.

- Ou bien "assim-int" (...interne) signifie une assimilation qui a eu lieu à l'intérieur de la tradition textuelle représentée par le témoin en question.

"harm" (harmonisation) indique que, pour pallier un risque de contradiction, une influence réciproque a eu lieu entre deux passages dissonants ou entre un passage et son contexte. $L$ 'aspect sous lequel l'harmonisation a eu lieu peut être précisé (...- synt $=$ syntaxique ou ...-ctext $=$ au contexte).

Le facteur 6 (altérations textuelles requises par la traduction) s'exprime dans ce rapport sous quatre formes :

"transl" (translationnel) désignant une modification imposée ou suggérée par la structure de la langue réceptrice,

"lic" (licence) désignant une liberté prise avec le texte à l'occasion de la traduction et pour laquelle on ne peut déceler aucun motif (le domaine dans lequel cette liberté a été prise pouvant être précisé : ...-synt = syntaxique),

"paraphr" (paraphrase) lorsque cette licence s'exprime par un développement littéraire,

"transcr" (transcription) pour des modifications dues à la transcription d'un nom propre d'une langue dans une autre (cette modification pouvant être caractérisée : ...-harm = harmonisante). 
Le facteur 7 (modification du texte pour des motifs d'exégèse) revêt en ce rapport des formes variées, dont la plus usitée et la plus générique est :

"exeg" (exégèse) indiquant que la variante ainsi désignée n'est qu'une interprétation de la leçon avec laquelle elle est mise en relation (ce qui a suggéré cette interprétation peut faire l'objet d'une précision : ...-ctext = en fonction du contexte),

"expl" (explicitation) indiquant que l'interprète a explicité une expression prégnante (...-graph = explicitation d'une graphie sentie comme défective),

"abr" (abréviation) indiquant que l'interprète a abrégé son texte, que cette abréviation ait seulement consisté en une graphie défective (...-graph), ou qu'elle ait visé à resserrer l'expression (...-styl $=$ stylistique), ou qu'elle ait voulu éliminer une donnée qui faisait difficulté (...-elus = élusive),

"ampl" (amplification) indiquant que l'interprète a amplifié son texte en le délayant (...-styl= stylistique),

"emph" (emphase) indiquant que l'interprète s'est exprimé de façon emphatique pour donner plus de résonance à une donnée,

"attenu" (atténuation) indiquant au contraire que l'interprète a un peu 'gommé' certaine donnée à laquelle il voulait ôter du relief,

"modern" (modernisation) indiquant que l'interprète a mis au goût du jour certaines données qui lui paraissaient démodées, l'aspect sous lequel la modernisation a eu lieu pouvant être précisé (...-graph = graphique ou ...-lex = lexicale),

"midr" (midrash) indiquant que l'interprète s'est inspiré de traditions midrashiques, "euphem" (euphémisme) indiquant que l'interprète a voulu rendre plus décent le mode d'expression,

"theol" (théologique) indiquant que l'interprète s'est conformé à des normes théologiques.

Le facteur 8 (mauvaise compréhension de certaines données linguistiques) s'exprime en ce rapport de façon générique : "ign-ling" (ignorance linguistique)

ou spécifique : "ign-lexic" (...lexicographique), "...-gram" (grammaticale), "...-synt" (syntaxique), "...-styl" (stylistique).

Le facteur 9 (mauvaise compréhension de données historiques) a été explicité en quatre facteurs : "ign-hist" (ignorance historique), "...-geogr" (géographique), "...-cult" (culturelle), "...-real" (des realia, c'est-à-dire de certaines autres données juridiques, techniques ou autres).

Le facteur 10 (omission accidentelle de lettres, syllabes ou paroles semblables) se divise en: "hapl" (haplographie), "hom" (homéoarcton ou homéotéleuton), "homarc" (homéoarcton), "homtel" (homéotéleuton).

Le facteur 11 (répétition accidentelle d'une séquence identique) est exprimé par : "dittogr"(dittographie).

Le facteur 12 (autres erreurs de scribe) est exprimé de façon générique par : "err" (erreur) et de façon plus spécifique par :

"deform-int" (déformation interne) pour une déformation à l'intérieur d'une tradition textuelle particulière,

"err-graph" (erreur graphique),

"perm"(permutation) pour la permutation d’éléments d’une séquence,

"err-divis" (erreur de division) pour des erreurs dans la division des lettres en mots, 
"err-vocal"(... de vocalisation), "err-ponct"(... de ponctuation).

Le facteur 13 (leçons gonflées ou doublets) inclut formellement :

"dbl" (doublet), leçon incluant deux traitements d'un même texte, "confl" (conflatio), leçon gonflée, c'est-à-dire qu'elle juxtapose deux leçons attestées ou qu'elle en mélange certains éléments.

A cela s'ajoutent des: "glos"(gloses).

D'autres initatives textuelles ont été qualifiées de : "substit" (substitution) qui peut se diviser en "...-graph" (graphique), "...-lexic"(lexicale), "...-synt"(syntaxique).

Certaines des initiatives textuelles constituent une : "rest" (restauration) lorsqu'un témoin a voulu restaurer un texte qu'il estimait corrompu (c'est à cette catégorie qu'appartient la "dissim" = dissimilation, par laquelle un copiste ou un traducteur a tenté de corriger un texte où il avait cru diagnostiquer une assimilation), ou une "constr" (construction) lorsqu'un copiste ou un traducteur a essayé de donner un sens nouveau à tout un passage en le réécrivant à partir d'éléments du texte. Dans ces diverses catégories d'initiatives, la créativité littéraire se fait jour de façon de plus en plus évidente.

Mentionnons pour finir deux qualificatifs qui font suite à plusieurs de ces facteurs :

"int" (interne) pour indiquer qu'un événement s'est produit à l'intérieur d'une tradition textuelle particulière,

"elus" (élusive) pour indiquer qu'une initiative a eu pour but d'éluder une difficulté.

\section{Les témoins textuels}

Il nous reste à expliquer la manière dont les témoins textuels ont été mentionnés en ce rapport :

"M" en apparat désigne la tradition du Texte Massorétique que nous considérons comme authentique, alors que " $\mathrm{m}$ " (en apparat) désigne ses traditions secondaires. "MK" désigne un ketib massorétique et "MQ" un qeré. "Mbab" désigne une forme textuelle de tradition babylonienne et "Mtib" une forme de tradition tibérienne. "*M", sans autre précision, désigne le qeré du ms de Leningrad.

"G" en apparat et "*G" dans le texte désignent la tradition du Grec ancien que nous considérons comme authentique, alors que " $g$ " (en apparat) désigne ses traditions secondaires. Il en va de même de "V", "*V" et "V" pour la Vulgate, de "S", "*S" et " $\mathrm{s}$ " pour la Peshitto, de "T", "* $T$ " et " $\mathrm{t}$ " pour le Targum. "Tyer" désigne un Targum Yerushalmi.

Dans l'apparat, un astérisque suivant le sigle d'un témoin désigne la leçon de la première main. Une main postérieure est mentionnée par "(correct)" collé à ce sigle.

Un point d'interrogation entre parenthèses: “(?)", après le sigle d'un témoin, indique que l'on n'est pas sûr que cette leçon livre le texte authentique de ce témoin.

Un point d'interrogation sans parenthèses : "?", après le sigle d'un témoin, indique que l'on n'est pas sûr que ce témoin doive figurer en cette fonction dans l'apparat. 
Les chapitres et versets du *G de Jérémie sont numérotés conformément à l'édition de Göttingen.

Les versions dites hexaplaires sont exprimées par les abréviations "Sept", “Aq", "Th", "Sym", "Quin" en séparant les uns des autres ces sigles lorsque les leçons de ces versions sont données indépendamment les unes des autres par les témoins, et en groupant ces sigles (par ex : "AqSym") lorsqu'elles sont données par les témoins sous forme d'une leçon unique attribuée à plusieurs versions à la fois. Pour respecter nos incertitudes, les leçons données par la Syrohexaplaire en syriaque n'ont pas été rétroverties en grec.

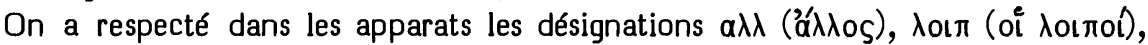

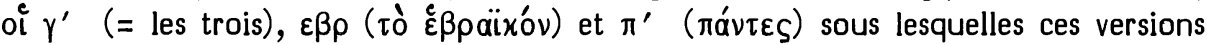
(ou d'autres) sont mentionnées en certaines scolies.

Les fragments de Qumrân sont cités par leurs sigles habituels. Dans le traitement des difficultés d'un livre, le sigle de ce livre n'est pas mentionné après Q. Ainsi, dans les pp. 1 - 465, 4Q-b = 4QIs-b; alors que, dans les pp. 466 - 862, 4Q-b = 4QJr-b.

"bTalm" et "yTalm" désignent des citations dans les Talmuds de Babylone et de Jérusalem, les références étant données dans le texte qui suit l’apparat.

"mm" désigne une massora magna et "mp" une massora parva. "La massore", sans précision, désigne celle qui est éditée par Ben Hayim in loco.

Pour des raisons de commodité, le syriaque, lorsque sa graphie propre n'a pas de rôle décisif, est transcrit en hébreu.

Il en va de même de l'arabe pour lequel nous utilisons les normes de transcription usitées dans les éditions de textes judéoarabes.

\section{Les auteurs cités}

Toutes les citations et références d'ouvrages édités sont de première main, sauf celles qui sont mentionnées comme "cité par" ou "cité selon" un autre auteur. Les citations ou références de manuscrits reposent sur une lecture à partir de microfilms ou de facsimilés, sauf pour celles des mss du *G qui sont données selon les sigles de l'édition de Göttingen, celles des mss de la *V citées selon l'édition de San Girolamo, et celles des mss syriaques bibliques autres que les Ambrosiani de la Peshitto et de la Syrohexaplaire.

Lorsqu'un auteur est lu en latin et que la citation de son nom en langue vulgaire pourrait faire difficulté (par exemple : Le Clerc pour Clericus), son nom est cité selon sa forme latine. Par contre, on cite Le Fèvre d’Etaples (et non : Faber Stapulensis), car il est lu ici en français, et Estienne (et non : Stephanus), car il est lu tantôt en français, tantôt en latin.

Les éditions des commentaires dont nous avons fait usage sont spécifiées dans la bibliographie. Lorsque nous faisons usage de plusieurs éditions, celle qui est citée est spécifiée par un chiffre collé au nom de l'auteur (par exemple, Duhm5 $=5$ e édition du commentaire de Duhm) ou au sigle de l'ouvrage (par exemple $\mathrm{J13}$ = première et troisième éditions de la Bible de Jérusalem, selon la numérotation explicitée dans la bibliographie). En dehors des références aux livres bibliques, un simple chiffre arabe 
renvoie à une ligne. Les chiffres renvoyant à des paragraphes sont toujours précédés de $\S$.

On a essayé de respecter l'orthographe des documents cités lorsqu'elle était aisément intelligible. Pour la Bible de Luther, l'orthographe est celle de l'une des éditions publiées durant sa vie.

\section{Les indices finaux}

Quant aux indices qui font suite au rapport, il importe de noter que les deux premiers sont sélectifs.

Ont été éliminées de l'index des textes bibliques toutes les références à des passages qui ne reçoivent aucun éclairage particulier du fait qu'ils sont cités en ce rapport. A propos des pages auxquelles l'index biblique renvoie, notons que sont mentionnées entre parenthèses les pages où le passage biblique en question est formellement traité par le comité à titre de cas discuté, et sans parenthèses celles où il est évoqué une ou plusieurs fois à l'occasion d'un cas distinct de lui. Lorsqu'une même page figure à la fois entre parenthèses et sans parenthèses, cela veut dire qu'en cette même page, ce passage biblique est traité à titre de cas et évoqué une ou plusieurs fois à l'occasion d'un autre cas.

Ont été éliminées de l'index des auteurs cités toutes les références à des auteurs qui se contentent de suivre l'opinion d'un autre auteur mentionné comme l'initiateur de cette opinion. C'est ce qui explique que beaucoup de noms récents y figurent plus rarement que certains noms anciens qui - dans les limites de notre information désignent les premiers initiateurs de certaines opinions, ou qui permettent de retracer l'histoire ancienne de la critique textuelle.

L'index des facteurs mentionnés se veut complet.

\section{La bibliographie}

La bibliographie entend mentionner - dans l'ordre rigoureusement alphabétique des mots ou sigles par lesquels le rapport les mentionne - tous les ouvrages, manuscrits ou édités, desquels il est fait usage dans le corps de ce rapport. Pour l'introduction, les données bibliographiques sont données au cours du texte. 


\section{INTRODUCTION}

\section{LA STRUCTURE DE CE RAPPORT}

En ce deuxième volume, nous avons établi un plan plus systématique pour le traitement de chaque cas. Certains recenseurs ont, en effet, regretté que le premier volume ne fournisse pas des données assez complètes sur les témoins textuels mentionnés par l'apparat et que seuls les témoins ayant joué un rôle déterminant dans la décision du comité soient mis en valeur dans ce commentaire. Le choix textuel fait par le comité est donc précédé par une section consacrée à la présentation des données fournies par les témoins anciens.

Certains ont reproché à notre comité d'avoir inséré son travail d'analyse textuelle dans une problématique très contingente, puisqu'il a été chargé par l'Alliance Biblique universelle de prendre position sur les options textuelles de cinq traductions récentes de la Bible en anglais, français et allemand. Pour expliciter cette problématique, le traitement de chaque cas textuel commence par une section qui présente les options de nos traductions, celle-ci étant suivie d'une autre qui retrace les origines des corrections adoptées par ces traductions.

Le travail du comité vise à fournir des conseils à des comités de traducteurs. Il nous a donc paru utile de compléter le traitement de chaque cas par une interprétation proposée, ou éventuellement plusieurs.

Les introductions à ce volume et à ceux qui le suivront voudraient apporter quelques éclaircissements sur le contenu de ces cinq sections et sur la structure de l'apparat critique offert au début du traitement de chaque cas. Nous commencerons par traiter ici des deux premières sections. 


\section{Première section}

\section{OPTIONS DE NOS TRADUCTIONS}

\section{LE POINT DE DEPART DU TRAVAIL DU COMITE}

Dans sa charge de diffusion de la Bible, l'Alliance Biblique Universelle apporte son aide à plus de 150 comités qui traduisent l'Ancien Testament en diverses langues. Ceux-ci fondent leur traduction sur le texte hébreu, mais s'inspirent souvent des options prises par les traductions de bonne qualité qui jouissent de la plus large diffusion dans les langues véhiculaires utilisées dans les régions où travaillent ces comités.

Or, depuis peu, les traductions françaises et anglaises dont ces comités font usage expliquent par des notes leurs choix textuels. C'est le cas de la Revised Standard Version, publiée en 1952, de la Bible de Jérusalem dont la première édition en fascicules parut en 1954, de la New English Bible, éditée en 1970 et de la Traduction Oecuménique de la Bible qui sortit en 1975.

Des traducteurs qui voudraient rendre avec fidélité le texte hébreu authentique se voient donc confrontés à des notes disant que le texte hébreu traditionnel est ici corrompu et que sa forme authentique peut être atteinte en se fondant sur tels manuscrits ou par l'intermédiaire de telles versions anciennes, ou encore par voie de conjecture. Ceux qui utilisent l'anglais comme langue véhiculaire trouveront des options critiques divergentes dans les notes de la RSV et de la NEB. Il en va de même avec les notes de la $\mathrm{J}$ et de la TOB pour ceux qui utiliseront le français. Placés devant des options textuelles divergentes et des appréciations différentes de l'état du Texte Massorétique, bien des traducteurs ont demandé à être guidés dans leur choix.

Nous avons exposé (en CT1 *66) la manière dont un comité a été constitué en 1969 par le secrétariat pour les projets scientifiques de l'ABU afin de fournir cette aide aux traducteurs. Les exégètes auxquels il a été fait appel ont accepté cette charge qui leur offrait l'occasion à la fois d'améliorer leur réflexion critique sur le texte et de rendre un service immédiat à des traducteurs en difficulté.

Si l'on compare la structure de l'apparat critique du premier volume de la première édition de la Biblia Hebraica de Kittel (mis en vente en 1905) et celle de l'apparat du premier fascicule (Isaïe) de la Biblia Hebraica Stuttgartensia (publié en 1968), on peut constater que leur structure est assez semblable, les différences essentielles portant sur le choix du texte de base (le ms B 19A de Leningrad a remplacé l'édition Ben Hayim à partir de BH3) et sur l'addition d'un apparat massorétique (en BHS). Ces apparats critiques informent le lecteur qu'un certain nombre de manuscrits hébreux offrent telle variante, que telles versions ont eu ici telle autre Vorlage ou que des auteurs récents proposent telle conjecture. Ailleurs, on demande au lecteur d'omettre tel mot, d'insérer tel autre ou de lire telle autre leçon, requêtes parfois affectées de "peut-être" ou de "probablement". Une problématique complexe sous-tend ces apparats dont la structure très sobre ne peut expliciter les présupposés ni les visées. 
Réfléchir sur ces visées après avoir explicité les présupposés de la critique textuelle de l'Ancien Testament, telle qu'elle se fait depuis plus d'un demi-siècle, voilà ce que désirait faire chacun des six exégètes auxquels l'ABU a fait appel. Mais cette tâche dépassait les possibilités d'un chercheur isolé. Pour avoir une réelle portée, cette "critique de la critique" devait en effet s'étendre à l'ensemble des livres constituant la Bible hébraïque. Il s'agissait donc d'une oeuvre de longue haleine. Pour que cette critique ne soit pas trop subjective, il fallait que ceux qui l'exercent soient issus de traditions confessionnelles et de formations culturelles différentes. Plutôt que de se répartir les livres bibliques à étudier, il valait mieux avoir l'occasion de confronter les points de vue et les compétences complémentaires en essayant de parvenir à des décisions communes. Les six exégètes contactés par l’ABU furent donc très intéressés à ce qu'on leur offrît la possibilité concrète de se mettre au travail et acceptèrent volontiers de participer à la session d'essai d'Arnoldshain (BRD) en 1969.

La question centrale qui se posait à tous était celle-ci : les buts d'un organisme mondial visant principalement une très large diffusion de la Bible sont-ils aisément compatibles avec ceux de la recherche scientifique de tradition universitaire? A cette question, nous avons répondu de manière affirmative pour le motif suivant. Il nous semblait que l'une des tâches les plus urgentes était de soumettre à une critique objective et rigoureuse la "critique textuelle" telle qu'elle se pratique de nos jours. Or l'ABU soumettait justement à notre discussion les 5.000 options critiques les plus caractéristiques des traductions les plus estimées diffusées dans les aires culturelles anglaise, française et allemande (car la Revidierte Lutherbibel avait été ajoutée à celles que nous avons mentionnées plus haut). Cela constituait pour nous un donné très représentatif et donc susceptible de servir de point de départ à notre entreprise de "critique de la critique".

En effet, en 1769, J.D. Michaelis a frayé la voie suivie aujourd"hui encore par la critique textuelle de l'Ancien Testament. Comme il l'explique dans sa préface à la traduction de Job datée du 15 septembre, il a voulu traduire l'Ancien Testament pour des lecteurs sans formation universitaire, en prenant la liberté de modifier la vocalisation traditionnelle et de corriger le texte là où ceux-ci lui semblaient évidemment fautifs. Mais il a indiqué en ses notes toutes les modifications qu'il a fait subir au texte reçu, en donnant pour chaque cas le sens qu'aurait dô avoir ce texte s'il l'avait laissé intact. A part le Cantique des Cantiques (qu'il ne tenait pas pour canonique), il a publié sa traduction en 13 fascicules dont le dernier (le 12e, sorti après le 13e) fut mis en vente à Göttingen, chez la veuve Vandenhoeck, il y a exactement deux cents ans, préface datée du 24 septembre 1785 . Vu qu'il s'interdisait de citer les langues anciennes dans ses notes destinées à des non-spécialistes, Michaelis a justifié ses options d'abord dans la Orientalische und Exegetische Bibliothek (à partir du tome VII publié en 1774 chez Johann Gottlieb Garbe, à Francfort sur le Main), puis dans la Neue Orientalische und Exegetische Bibliothek (jusqu'au tome VII publié en $1790 \mathrm{chez}$ Vandenhoek [sic! ] et Ruprecht à Göttingen).

En cette oeuvre, Michaelis a été le prédécesseur de nos traducteurs de la seconde moitié du XXe siècle. Ces derniers, en effet, visent eux aussi à donner au grand public des traductions littérales adaptées à l’état actuel de la langue, en signalant les points où ils s'éloignent du texte hébreu traditionnel. Présentons maintenant, par ordre chronologique, les cinq traductions dont le comité a critiqué les options. 


\section{LA REVISED STANDARD VERSION}

Lorsqu'en 1870 les deux chambres du Parlement décidèrent de soumettre la King James Version à une révision officielle, on voulut associer à cette entreprise les Américains. En cours de travail, les réviseurs anglais et américains établirent d'un commun accord que sur tous les points où leurs options ne pourraient se concilier, la décision serait laissée aux Anglais, en tant qu'initiateurs de ce projet de révision. Ainsi furent publiés en 1881 le Nouveau Testament et en 1885 l'Ancien Testament de la English Revised Version. Les Anglais avaient proposé que les préférences des réviseurs américains fussent publiées, durant quatorze ans, comme appendice en chaque exemplaire de la Bible révisée. En contrepartie, le comité américain s'était engagé à n'autoriser, durant cette même période, aucune édition de cette révision autre que celle publiée par les Presses Universitaires d'Oxford et de Cambridge. On avait envisagé l'éventualité qu’après cette période probatoire de quatorze ans, les réviseurs britanniques ou les Presses universitaires pourraient adopter dans les éditions anglaises les options américaines agréées par les spécialistes et le grand public. Mais les commissions de révision anglaises se dissocièrent en 1885, dès que leur travail eut été achevé, et les Presses ne semblaient manifester aucune intention d'intégrer tout ou partie des leçons de l'appendice au texte des éditions anglaises. C'est pourquoi les réviseurs américains décidèrent de publier une traduction intégrant les options qui avaient reçu l'approbation des deux tiers des membres de leurs commissions lors de la seconde révision effectuée à partir de 1897. Pour tenter de satisfaire les Américains, les branches américaines des Presses d'Oxford et de Cambridge publièrent à New York, en 1898, une édition de la traduction révisée où l'on avait incorporé les leçons préférées par les réviseurs américains. Mais la seconde révision entreprise par ceux-ci était trop avancée pour qu'ils pussent renoncer à l'éditer. Ce fut la American Standard Version publiée en 1901 à New York, chez Thomas Nelson \& Sons sous le titre : The Holy Bible Containing the Old and New Testaments Translated out of the Original Tongues, being the version set forth A.D. 1611 compared with the most ancient authorities and revised A.D. 1881-1885, Newly Edited by the American Revision Committee A.D. 1901, Standard Edition.

Le copyright de l'American Standard Bible fut acheté en 1928 par le Conseil International de l'Education Religieuse, dépendant des Eglises des Etats-Unis et du Canada. Sur l'avis d'un groupe de spécialistes, le Conseil mandata, en 1937, un comité de 32 membres pour réviser la traduction de manière à "incorporer les meilleurs résultats de la recherche actuelle quant au sens des Ecritures et à exprimer ce sens en une langue anglaise qui convienne à un usage cultuel public et privé et préserve ces qualités qui ont donné à la King James Version une place éminente dans la littérature anglaise". La Revised Standard Version du Nouveau Testament fut publiée en 1946 et celle de la Bible complète fut autorisée en 1951 par un vote du Conseil National des Eglises du Christ des U.S.A. Elle fut publiée en 1952 à New York sous le titre : The Holy Bible Revised Standard Version Containing the Old and New Testaments. Translated from the Original Tongues, being the version set forth A.D. 1611, revised A.D. 1881-1885 and A.D. 1901, compared with the most ancient authorities and revised A.D. 1952. L'éditeur actuel de la RSV est l'American Bible Society et son co- 
pyright appartient à la Division de l'Education Chrétienne du Conseil National des Eglises du Christ des U.S.A. Avec quelques modifications, cette révision a été officiellement adoptée par l'Eglise Catholique et autorisée par le Cardinal Heenan en 1966.

Les bases textuelles de la traduction de l'A.T. sont clairement exposées dans la préface de la RSV : “La présente révision se fonde sur le texte consonnantique, tel qu'il a été fixé au début de l'ère chrétienne et révisé par les lettrés juifs (les “Massorètes") du 6e au 9e siècle. Les signes vocaliques qui ont été ajoutés par les Massorètes sont d'ordinaire acceptés, mais là où d'autres voyelles permettent d'obtenir une leçon plus probable et plus convaincante, on les a adoptées. En ces cas, on n’a pas donné de notes, parce que les points voyelles sont moins anciens et de moindre autorité que les consonnes. - On ne s'est éloigné du texte consonnantique des meilleurs manuscrits que lorsqu'il a semblé clair que des erreurs ont été faites en copiant le texte avant que celui-ci ait été standardisé. La plupart des corrections adoptées sont fondées sur les versions anciennes (traductions en grec, araméen, syriaque et latin) qui ont été faites avant l'époque de la révision massorétique et qui, à ce titre, reflètent des états plus anciens du texte. En chacun de ces cas, une note indique la ou les version(s) d'où provient la correction. Elle donne aussi une traduction du Texte Massorétique. - Il est parfois évident que le texte a souffert au cours de sa transmission, quoiqu'aucune des versions ne fournisse une restauration satisfaisante. En ces cas nous avons pour seule ressource de suivre le meilleur jugement des spécialistes compétents en ce qui concerne la reconstruction la plus probable du texte original. Les corrections appartenant à cette catégorie sont indiquées dans les notes par l'abréviation $\mathrm{Cn}$, et une traduction du Texte Massorétique y est jointe".

Bien que la RSV ne soit qu'une petite fille de la King James Version, les caractéristiques de celle-ci y transparaissent souvent encore. Ajoutons cependant trois constatations :

$1 /$ A la suite de plusieurs autres traductions du XVIe siècle, la King James Version faisait usage d'italiques pour distinguer les mots ajoutés au texte afin de rendre la traduction plus explicite. Le procédé graphique a survécu jusque dans l'American Standard Version, mais il a disparu dans la RSV, ces gloses ayant été purement et simplement incorporées au texte. Or ces gloses en italiques avaient été souvent suggérées aux traducteurs de la KJ par des versions anciennes, principalement la Vulgate. La RSV se trouve donc avoir inséré sans le dire bon nombre de données extérieures à l’hébreu.

2/ Tout le monde admet que le placement des voyelles dans les manuscrits hébreux est un événement tardif. Lorsqu'elle souligne la faible autorité traditionnelle de la vocalisation, la RSV emboîte le pas à l'American Standard Bible et nous avons vu en CT1 *5s le peu de confiance que Luther avait dans les 'points' des juifs. Calvin aussi les mets souvent en doute dans ses commentaires. Ensuite, depuis Cappel jusqu’à l'époque moderne, les critiques estimèrent d'ordinaire que l'on devait essayer de respecter les consonnes (puisqu'elles étaient plus anciennes), mais que l'on pouvait agir beaucoup plus librement avec les voyelles. Nous avons vu (CT1*25-27) d'ailleurs que Masclef et Houbigant ont même été jusqu’à construire une grammaire hébraïque fondée exclusivement sur les consonnes; ce qui amena Kennicott à limiter à celles-ci sa grande collation de variantes des manuscrits médiévaux. La RSV a donc des prédécesseurs nombreux et anciens dans le peu d'estime qu'elle porte aux voyelles. Ce- 
pendant, notre comité a acquis au cours de son travail la conviction que la tradition vocalique massorétique est bien plus ancienne que sa fixation écrite. Ceux qui auront la patience de suivre notre étude pourront, eux aussi, le constater.

3/ Très souvent, lorsque la RSV quitte le Texte Massorétique, elle le traduit en note. Mais cette traduction n'en est parfois qu'une véritable caricature faite, semble-t-il, pour lui servir de repoussoir, ainsi qu'on pourra le voir en la comparant aux interprétations du *M que nous proposerons. Là encore, la RSV n’improvise pas. Elle dépend des commentaires récents et cela s'explique par le fait que les dictionnaires et les grammaires, depuis une centaine d'années, ne font plus grand effort pour essayer de résoudre des difficultés exégétiques que l'on s'est habitué a éluder en corrigeant le texte. Ainsi s'est établi un cercle vicieux : un texte difficile devient de plus en plus inintelligible parce que l'on a laissé tomber en désuétude les instruments qui pourraient permettre de le comprendre.

\section{LA BIBLE DE JERUSALEM}

Vers la fin de la deuxième guerre mondiale, les traductions françaises jouissant de la plus large diffusion étaient, parmi les protestants, celle du professeur de Genève Louis Segond (parue en 1880), et parmi les catholiques, celle du chanoine d'Amiens A. Crampon (publiée initialement en 7 volumes de 1894 à 1904). A côté de révisions de ces deux Bibles, l'après-guerre vit une floraison de traductions nouvelles : la Bible de Maredsous, traduite par les bénédictins de l’abbaye belge du même nom (1950), la Bible de Jérusalem (1956), la Bible de la Pléiade sous la direction de E. Dhorme (les deux volumes de l'Ancien Testament parurent en 1956 et 1959), la Bible Osty, traduite par le chanoine de ce nom (1973) et la Traduction Oecuménique de la Bible (1975). Trois causes expliquent cette soudaine prolifération des traductions en français :

$1 /$ L'âge classique de la littérature française avait été beaucoup moins marqué par la réforme protestante que celui des littératures allemande et anglaise. Cela explique qu'aucune traduction biblique n'y a joué le rôle de premier plan que la traduction de Luther ou la King James Version ont joué en celles-ci. Il restait donc pour la Bible une place à occuper dans le monde culturel français.

2/ Du fait que les chrétiens de langue française appartiennent principalement à l'Eglise catholique, l'encyclique 'Divino afflante Spiritu', publiée par Pie XII le 30 septembre 1943, avait rencontré parmi eux une large résonance. Ils y trouvaient un encouragement à se tourner vers la Bible pour essayer de s'orienter dans les bouleversements liés à l'occupation et à l'après-guerre.

3/ Depuis la fin du XIXe siècle, l’Ecole Biblique fondée par les dominicains français à Jérusalem avait formé, parmi les prêtres appartenant à cette langue, un nombre notable de bons exégètes.

Parmi les Bibles françaises publiées après la guerre, celle qui rencontra le plus large écho fut 'La Sainte Bible, traduite en français, sous la direction de l'Ecole Biblique de Jérusalem'. Sa réalisation est due à l'initiative de Th.-G. Chifflot, dominicain de Paris, directeur littéraire aux Editions du Cerf. En étroite coopération avec R. de Vaux, 
directeur de l'Ecole Biblique, il organisa la traduction de la Bible en 43 fascicules qui parurent de 1948 à 1954 avant d'être réunis en un volume en 1956 sous le titre susdit. De 1955 à 1962 tous les fascicules furent profondément remaniés et certains ont été réédités quatre fois avant que le résultat de ces remaniements ne soit publié en un volume sous le titre : 'La Bible de Jérusalem' en 1973. Cette entreprise de traduction associa 33 traducteurs exégètes à une douzaine de professeurs d'université ou d'écrivains experts dans le maniement du français. Les exégètes catholiques les plus compétents de France et de Belgique wallone participèrent à ce travail. Chaque fascicule fut confié à une équipe composée d'un traducteur et de deux réviseurs, l'un contrôlant l'exégèse et l'autre le français. Le traducteur d'un fascicule intervenait comme réviseur dans la réalisation d'un autre fascicule. Ces fascicules et leurs remaniements étaient accompagnés d'amples introductions et d'une annotation assez dense portant, entre autres, sur la critique du texte. C'est à partir d'eux que fut construite l'édition en un volume de 1956, puis celle de 1973. Le maître d'oeuvre de l'édition de 1956 fut Th.-G. Chifflot et celui de l'édition de 1973 fut D. Barrios-Auscher, les professeurs de l'Ecole Biblique de Jérusalem assurant l'essentiel de la révision d'ensemble et la rédaction des introductions. En même temps qu'une traduction française, la Bible de Jérusalem offrait au lecteur cultivé et non théologien une présentation condensée et accessible des principaux résultats de l'exégèse actuelle ainsi qu'une introduction à la lecture du texte de l'Ecriture. En vingt-cinq ans, elle a été testée sur quatre bancs d'essais successifs pour assurer sa mise au point : la première édition en fascicules, puis celle en un volume, ensuite les rééditions des fascicules et enfin la deuxième édition en volume. Le résultat parut suffisamment convaincant pour que des droits d'adaptation fussent acquis en allemand, anglais, espagnol, italien, etc.

La manière dont la Bible de Jérusalem use de la critique textuelle mérite quelques remarques :

1/ Comme c'était le cas pour RSV, J puise surtout ses options textuelles dans les apparats critiques de la 2e et de la 3e éditions de la Biblia Hebraica de Kittel. Cependant, il s'y ajoute une influence caractéristique exercée par les options et les apparats de la Bible du Centenaire, publiée par les exégètes protestants de langue française de 1928 à 1947.

2/ L'édition de 1956 déterminait ainsi les bases textuelles de la traduction : "Les traductions ont été faites sur les textes originaux, établis par un travail critique. Pour le détail de la critique textuelle, on se reportera à l'édition en volumes séparés." Dans l'édition de 1973, les perspectives sont moins ambitieuses : "Les traductions ont été faites à partir des textes originaux hébreux, araméens et grecs. Pour l'Ancien Testament, on suit le texte massorétique, c'est-à-dire le texte hébreu établi aux VIII-IXe s. ap. J.-C. par des savants juifs, qui en ont fixé la graphie et la vocalisation. C'est le texte que reproduisent la plupart des manuscrits. Lorsque celui-ci présente des difficultés insurmontables, on s'est référé à d'autres manuscrits hébreux ou des versions anciennes, grecque, syriaque et latine principalement."

3/ Si l'on analyse les options critiques de $\mathrm{J}$, à travers les deux premières éditions des fascicules (J1 et J2), jusqu’à l'édition en un volume de 1973 (J3), on peut constater que l'audace des corrections diminue progressivement et que l'effort déployé pour trouver un sens au *M progresse nettement. Lorsque John A. Thompson a sé- 
lectionné les problèmes que le comité aurait à traiter, il s'est fondé sur J2. Mais le travail du comité s'est effectué (du moins pour les livres prophétiques) en fonction de 33. Il a donc paru utile de mentionner toujours ici les options successives de J123.

\section{LA REVIDIERTE LUTHERBIBEL}

Vers le milieu du XIXe siècle, la Bible de Luther circulait en une douzaine de formes distinctes. La fidélité de cette traduction au texte original laissait à désirer sur de nombreux points, constatation que les traductions plus récentes - entre autres celle de Michaelis - rendaient de plus en plus évidente. Le développement qu'avait subi la langue vivante depuis le XVIe siècle donnait une allure vieillotte à de nombreux passages et l'Ecriture présentait alors parfois une atmosphère un peu irréelle et légendaire, ce qui ne facilitait guère son usage catéchétique pour la mission intérieure.

H.E. Bindseil effectua en 1836 pour la Cansteinsche Bibelanstalt une révision du texte de Luther, puis il rassembla dans sa grande édition critique de la traduction biblique de Luther ( 7 vol., 1840-1855) tous les matériaux requis pour une recension des diverses formes existantes. En 1852 se réunit pour la première fois à Eisenach la Conférence des Eglises Evangéliques Allemandes. Mais ce fut un écrit publié en 1855 par le prédicateur de Hambourg Mönckeberg sur “La traduction biblique de Luther et la Conférence de Eisenach" qui remua l'opinion publique et amena le Kirchentag Evangélique Allemand de Stuttgart, en 1857, à la décision de réviser la Bible de Luther. La Conférence de Eisenach confirma en 1863 cette décision et fixa pour base à cette révision l'édition de la Cansteinsche Bibelanstalt. Les autorités ecclésiastiques de Prusse, de Saxe, de Hanovre et de Wurtemberg déléguèrent des représentants pour organiser le travail de révision avec les Sociétés Bibliques qui en assumaient la responsabilité principale. On décida de prendre en considération toutes les éditions parues du vivant de Luther et de ne pas se limiter à l'édition finale de 1545. Le choix entre les leçons donnerait priorité à la forme qui s'accorderait le mieux avec le texte original. Les modifications qui s'avéreraient nécessaires devraient tenir compte du vocabulaire de la Bible de Luther. L'Ancien Testament fut révisé de 1871 à 1881 et une édition provisoire de la Bible parut en 1883. L'opinion publique critiqua vivement le caractère timoré des retouches et la couleur démodée de la langue. Une nouvelle révision essaya de tenir compte de ces critiques et le fruit en fut une 'Edition révisée par mandat de la Conférence des Eglises Evangéliques Allemandes' que la Cansteinsche Bibelanstalt publia en 1892. Cependant on avait laissé survivre en cette édition bon nombre d'archaïsmes linguistiques. La ponctuation et l'orthographe ne correspondaient pas aux normes enseignées dans les écoles. La Bible de Luther y étant un objet d'enseignement, ces archaïsmes suscitèrent de vives protestations. Aussi la Société Biblique principale de Saxe proposa-t-elle encore une révision qui aboutit en 1912 à la publication d'une 'Edition revue à nouveau selon le texte approuvé par la commission des Eglises Evangéliques Allemandes'. Pour l'Ancien Testament, cette édition demeura normative jusqu'en 1955.

La multiplication de traductions modernes largement diffusées développa le besoin d'une relation plus immédiate et plus claire avec le texte original. Aussi les So- 
ciétés Bibliques décidèrent-elles en 1921 d'entreprendre une nouvelle révision. En 1924, la commission des Eglises Evangéliques Allemandes établit une connexion avec les Sociétés Bibliques en se réservant le droit à une surrévision et à l'approbation finale. En 1928, la commission des Eglises et les Sociétés Bibliques formulèrent des principes qui obtinrent l'agrément des divers comités de révision successifs. Ces principes ouvraient le champ à des remaniements plus importants. Ils admettaient, en effet :

- le caractère normatif du texte original,

- la correction des fautes de traduction évidentes,

- l'élimination des mots, des formes et des syntaxes vieillis qui prêteraient à des contre-sens ou à des non-sens.

Les drames de la guerre et de l'après-guerre freinèrent la révision. En 1955, une édition provisoire de l'Ancien Testament fut soumise pour avis aux Eglises des Länder, aux Sociétés Bibliques et aux Facultés de Théologie. La plupart des avis donnés requirent des remaniements approfondis. Des théologiens de la DDR purent participer à la dernière phase de révision de l'Ancien Testament. Les deux testaments révisés furent approuvés en 1964 par le Conseil de l'Eglise Evangélique et l'Association des Sociétés Bibliques en Allemagne. En 1965, le synode de l'Eglise donna son approbation à Francfort et à Magdebourg. La RL fut publiée en 1967, sous le copyright de la Württembergische Bibelanstalt de Stuttgart, sous le titre : 'Die Bibel oder die Ganze Heilige Schrift des Alten und Neuen Testaments nach der Uebersetzung Martin Luthers'.

A propos de l'usage fait, par la Revidierte Lutherbibel, de la critique textuelle, il faut relever certaines données :

1/La RL n'a pas de notes textuelles. Il est donc difficile de se rendre compte si une divergence entre sa traduction et le $* M$ provient d'une initiative prise consciemment par ses réviseurs. Aussi sera-t-il toujours nécessaire de la comparer avec les diverses éditions de la Bible de Luther (jusqu'à 1545) pour déterminer s'il s'agit là d'une particularité caractérisant la traduction initiale, ou bien d'une option relevant de la révision.

2/ La Bible de Zurich, qui avait échangé en 1667 son dialecte alémanique pour le haut-allemand, a subi de 1907 à 1931 une révision très radicale aboutissant à une nouvelle traduction sur les textes originaux. Cela fut possible parce qu'elle ne dépendait que du Conseil de l'Eglise du canton de Zurich. Ses options textuelles exercèrent une influence notable sur celles de la RL. Ces dernières demeurèrent, cependant, beaucoup plus conservatrices et respectueuses des options caractéristiques de la traduction de Luther.

\section{LA NEW ENGLISH BIBLE}

En mai 1946, l’Assemblée Générale de l’Eglise d’Ecosse reçut du Presbytère de Stirling et Dublane une suggestion provenant du Rev. G.S. Hendry. Celui-ci estimait que la langue de la King James Version, déjà archaïque lorsque la traduction fut faite, était devenue, depuis, encore plus définitivement archaïque et difficile à comprendre. Aussi recommendait-il qu'une traduction de la Bible fût faite en langue contemporaine. 
L'Assemblée Générale décida d'entreprendre une démarche auprès d'autres Eglises. Cela aboutit en octobre, à Westminster, à une réunion de délégués de l'Eglise d’Angleterre, de l'Eglise d'Ecosse et des Eglises Méthodiste, Baptiste et Congrégationaliste. Ils recommandèrent d'entreprendre une nouvelle traduction plutôt qu'une révision (d'abord envisagée par les Presses d'Oxford et de Cambridge) et de laisser les traducteurs libres d'employer la langue contemporaine en s'affranchissant de la langue "biblique" traditionnelle. En janvier 1947, une seconde séance réunit les mêmes délégués avec les représentants des Presses Universitaires. Sur requête de ce groupe les Eglises constituèrent leurs délégués en un 'Comité pour la nouvelle traduction de la Bible'. Le comité, dont le premier secrétaire fut le Rev. Hendry et le premier président, le $\mathrm{Dr}$ J.W. Hunkin, évêque de Truro, tint séance à partir de juillet et, lors de sa troisième séance, en janvier 1948, on invita l'Eglise Presbytérienne d'Angleterre, la Société des Amis, les Eglises du Pays de Galles et celles d'Irlande, la Société Biblique Britannique et Etrangère, ainsi que la Société Biblique Nationale d'Ecosse à s'y faire représenter. Toutes acceptèrent. Plus tard vinrent aussi des observateurs désignés par $l^{\prime} E$ Elise Catholique Romaine d'Angleterre et d'Ecosse.

Pour réaliser la traduction, le Comité désigna trois commissions de professeurs d'exégèse ayant respectivement la charge de l'Ancien Testament, des Apocryphes et du Nouveau Testament. Pour chaque livre, on confia à un exégète la tâche d'établir un projet de traduction qui, après avoir été communiqué aux membres de la commission concernée, fut discuté par elle, verset par verset, jusqu'à ce que l'on se mît d'accord sur le sens de chaque phrase. En cas d'incertitude sur une option importante, on mentionna en note le sens qui $n$ 'avait pas été retenu. Le projet résultant de l'accord de la commission des traducteurs fut soumis ensuite à une quatrième commission de conseillers littéraires qui le retournèrent avec des propositions de retouches à la commission de traducteurs afin que celle-ci contrôlât si ces retouches n'en affectaient pas le sens. Après une navette entre les deux commissions, le projet ayant réuni leur double accord fut soumis au Comité. Coordonnant l'ensemble du travail, les membres du Comité eurent de nombreuses réunions avec les membres des diverses commissions et le Comité siégea régulièrement deux fois par an dans la Jerusalem Chamber de l'Abbaye de Westminster, là où 350 ans plus tôt, avaient siégé les traducteurs de la King James Version.

Le vice-président du Comité et directeur de la traduction fut le Dr C.H. Dodd. Depuis 1965, le directeur adjoint fut Sir G.R. Driver. C'est lui qui signa l'introduction à l'édition de l'Ancien Testament avec notes textuelles plus complètes qui fut publiée en 1970 par les Presses universitaires d'Oxford et de Cambridge. Cette introduction explique les options retenues par les traducteurs dans le domaine de la critique textuelle. Il y est dit que la standardisation du texte, réalisée après 70 , aboutit à un texte éclectique fondé sur des principes arbitraires plutôt que scientifiques; que le texte hébreu, tel qu'il nous a été transmis, est plein d'erreurs de toutes sortes dues à des archétypes défectueux, à des fautes successives de copistes et souvent à leurs tentatives maladroites pour rectifier des bévues; que les exégètes juifs du moyen âge ont essayé d'expliquer des mots rares à partir de traditions survivantes ou en les comparant avec l'arabe, ces tentatives n'ayant pas été toujours couronnées de succès. La NEB fait donc appel aux précieux acquis de la philologie comparée pour expliquer des mots 
et des phrases de l'hébreu qui, jusqu'ici, n'avaient pas été compris en leur vrai sens. La NEB se fonde sur la 3e édition de la Biblia Hebraica de Kittel. Mais, vu le mauvais état du texte transmis, les traducteurs se sont considérés comme libres de ne pas tenir compte des voyelles et de revocaliser le texte consonnantique partout où cela paraissait souhaitable. Pour corriger les erreurs qui se sont produites dans la transmission du texte consonnantique, les traducteurs ont surtout eu recours aux versions anciennes. Cependant, en dernier ressort, ils ont fait appel à des conjectures. Les corrections textuelles ont été indiquées en note, sauf celles qui ne portent que sur la vocalisation. A ces notes $s^{\prime}$ ajoute une autre source précieuse d'information sur les options textuelles de la NEB. C'est un ouvrage publié en 1973 par L.H. Brockington aux Presses universitaires d'Oxford et de Cambridge sous le titre 'The Hebrew Text of the Old Testament', avec le sous-titre : 'les leçons adoptées par les traducteurs de la New English Bible'. Sur la jaquette, il est précisé que sont mentionnées toutes les variantes par rapport à $\mathrm{BH} 3$, que ces variantes portent sur la ponctuation, sur la division des mots ou sur le texte consonnantique.

L'usage fait de la critique textuelle par la NEB mérite quelques remarques.

1/ Grâce au relevé de Brockington, la NEB est, de toutes les traductions récentes, celle dont les options textuelles nous sont rapportées de la façon la plus précise. Cependant ce relevé n'est pas aussi complet qu'il le prétend. Pour la Genèse, par exemple, les notes de NEB indiquent 83 variantes par rapport à BH3. Brockington, pour sa part, en compte 131. Mais un relevé systématique permet de dénombrer 180 variantes textuelles réelles, sans tenir compte de certaines traductions trop libres pour permettre de déterminer leur base textuelle.

2/ La forte personnalité et la grande compétence de G.R. Driver ont exercé une influence déterminante sur les options textuelles et translationnelles de l'Ancien Testament de la NEB. Il n'est pas certain que cette influence soit aussi durable que les éditeurs de cette traduction pouvaient l'espérer.

3/ A la différence de la plupart des autres traductions récentes, NEB ne craint pas d'effectuer dans les livres poétiques des remaniements de structure d'une certaine ampleur basés sur une conception de la métrique hébraïque : permutation de versets ou de groupes de versets, omission de stiques. Pour une traduction qui vise à tenir la place occupée jusqu'ici par la King James Version, il n'est pas sûr que tous ces remaniements parviendront à s'imposer. Il est frappant, par exemple, que J1 était assez audacieuse en ce domaine et que $\mathrm{J3}$ est beaucoup plus discrète.

\section{LA TRADUCTION OECUMENIQUE DE LA BIBLE}

En 1963, les Editions du Cerf, ayant achevé le remaniement des fascicules de la Bible de Jérusalem, envisageaient la nouvelle édition en un volume. Elles invitèrent un certain nombre d'exégètes protestants à participer à cette réalisation. Ceux-ci venaient d'être appelés à participer à une révision de la traduction de Segond et hésitaient à se charger simultanément de deux révisions. Aussi se demanda-t-on si le moment n'était pas venu de réaliser en commun une traduction nouvelle qui fût vraiment oecuménique. 
Comme le patrimoine littéraire français ne possédait aucune traduction qui ait réussi à s'imposer, des tentatives pour réaliser une traduction interconfessionnelle avaient déjà été amorcées, avant la révocation de l'Edit de Nantes, par Richard Simon, puis, en 1866, par la Société nationale pour une traduction nouvelle des livres saints en langue française, mais ces essais n'aboutirent pas. En 1963, la situation avait évolué en plusieurs domaines. $D^{\prime}$ abord, les sciences bibliques s'étaient largement développées et, depuis la deuxième guerre mondiale, les exégètes appartenant aux familles confessionnelles et intellectuelles les plus diverses avaient pris l'habitude de mettre en commun, dans nombre de publications et congrès, les résultats de leurs travaux. Ils avaient ainsi appris à confronter les traductions et interprétations propres à leurs divers milieux. D'ailleurs le deuxième Concile du Vatican allait envisager, dans la Constitution Dei Verbum (VI, 22), que, “l'occasion s'en présentant, avec l'accord de l'autorité ecclésiastique, des traductions soient réalisées en commun avec les frères séparés, traductions qui pourront être utilisées par tous les chrétiens". De plus, l'Alliance Biblique Universelle, groupant un certain nombre de Sociétés Bibliques protestantes, avait été invitée à participer à la réalisation de projets interconfessionnels de traduction afin d'éviter que la diffusion de la Bible soit contrariée par la diversité des versions présentées par les Eglises séparées.

Sans que l'on renonçât aux révisions en cours de la Bible de Jérusalem et de celle de Segond, les Editions du Cerf et les Sociétés Bibliques donnèrent leur accord au projet de Traduction Oecuménique de la Bible et s'engagèrent à en assurer la publication. Malgré des différences considérables dans leurs habitudes et leurs principes, les deux éditeurs parvinrent à un accord complet assurant l'équilibre administratif et financier de l'entreprise. D'une part, du côté catholique les Editions du Cerf et du côté protestant les Editions Les Bergers et les Mages assumèrent la responsabilité de publier cette traduction dans une édition dite "intégrale" en deux volumes, comportant des introductions et un appareil de notes assez développées. D'autre part, l'Alliance Biblique Universelle, avec l'agrément des Eglises protestantes intéressées, prit la responsabilité de publier cette nouvelle version accompagnée du minimum d'aides indispensables à tout lecteur de la Bible.

Un Comité d'édition, groupant les responsables des Editions du Cerf et de l'Alliance Biblique Universelle, s'assura la collaboration d'une centaine d'exégètes catholiques, protestants et orthodoxes. Chaque livre de la Bible fut confié à deux traducteurs, un protestant et un catholique, chargés de remettre leur traduction à des équipes coordinatrices restreintes qui assurèrent la liaison entre les groupes de travail, spécialement en ce qui concerne l'homogénéité du vocabulaire de base. Peu nombreux, les biblistes orthodoxes de langue française firent parvenir, sur l'ensemble des textes traduits, des remarques et des avis dont il fut tenu compte pour la mise au point finale. De plus, les traductions furent soumises à des réviseurs littéraires et à divers spécialistes qui apportèrent également leurs observations. La version définitive fut finalement mise au point par les traducteurs de chaque livre, compte tenu des remarques reçues et de l'avis des coordinateurs. Contrairement à la Bible de Jérusalem où chaque livre traduit paraissait sous les noms et la responsabilité de son traducteur et de ses réviseurs, la Traduction Oecuménique de la Bible n'a jamais nommé les traducteurs de chaque livre. Elle mentionne seulement, au début de l'édition intégrale, 
les noms des huit membres du comité d'édition, de ses quatre conseillers et de ses cent treize collaborateurs qui portent collectivement la responsabilité de l'ensemble de la traduction.

On commença par réaliser et publier en 1967, avec de copieuses annotations, la traduction de l'Epître aux Romains en estimant que ce serait un test : la traduction oecuménique de la Bible ne se heurterait pas à des obstacles infranchissables si l'épître aux Romains pouvait être présentée dans une version française agréé par tous.

En 1973 sortit le Nouveau Testament de l'édition intégrale, en 1975 son Ancien Testament, en 1977 l'édition en un volume avec annotation réduite au minimum, édition où l'on réintroduisit en 1982 les introductions et les cartes.

La préface de l'Ancien Testament de 1975 précise que l'A.T. est traduit sur le texte massorétique qui “est l'aboutissement d'une longue tradition dont la transmission, extrêmement fidèle dans l'ensemble, n'a cependant pas toujours pu conserver intactes les formes originelles. Or, tels autres manuscrits hébraïques (Qumrân) et telles versions anciennes (grecques, latines, syriaques, araméennes) présentent des variantes dignes d'attention. Néanmoins, dans l'état présent de la critique textuelle, le texte massorétique a été adopté comme base de travail, quitte à ce que l'on indique en note les variantes importantes des autres manuscrits, en particulier celles de la version grecque des "Septante". Les cas relativement rares où l'on s'éloigne du texte massorétique sont signalés en note. Cette décision de suivre le texte massorétique a été prise tant pour des raisons scientifiques que dans un esprit d'ouverture à l'égard du judaïsme, comme une pierre d'attente pour une traduction de l'Ancien Testament qui pourrait être entreprise conjointement par des savants chrétiens et des savants juifs".

La prudence des responsables de la traduction s'exprime encore plus clairement dans la section de l'introduction à l'A.T. consacrée à 'la transmission du texte' (22-25). Après avoir mentionné les manuscrits de Qumrân, le Pentateuque des Samaritains et la Septante, les traducteurs ajoutent: "Toutes ces formes du texte pré-massorétique nous offrent parfois un texte plus clair et intelligible que lui. D'où la tentation de beaucoup d'exégètes, surtout entre 1850 et 1950, de faire appel à elles pour 'corriger' le texte massorétique considéré comme souvent corrompu... Certains critiques n'hésitaient pas à 'corriger' le texte massorétique chaque fois qu'il ne leur plaisait pas, soit pour un motif littéraire, soit pour un motif théologique. Par réaction, d'autres s'en tenaient au texte massorétique, mais quand il était manifestement insoutenable, ils essayaient de trouver dans l'une ou l'autre des versions anciennes une variante qui leur parût préférable. Ces méthodes ne sont pas scientifiques et, surtout la première, elles sont dangereusement subjectives... La solution vraiment scientifique consisterait..., par une étude très minutieuse de l'ensemble des variantes, [à] établir 'l'arbre généalogique' des témoins que nous possédons...; ainsi, sans aucune conjecture subjective, rétablir l'archétype qui est à la base de tous les témoins. Généralement cet archétype remonte aux environs du IVe siècle avant J.C. ... Presque toujours cet archétype est séparé de l'original par une période plus ou moins longue et alors on est bien obligé, pour passer de l'archétype à l'original, de recourir à certaines conjectures, mais en appliquant avec prudence des principes critiques bien établis. Malheureusement ... ce travail critique exige de telles compétences et de telles recherches 
qu'il ne pourra pas être réalisé avant plusieurs décennies. Aussi, pour éviter les fantaisies de corrections fallacieuses, les responsables de la T.O.B. ont-ils décidé de suivre le plus près possible le texte massorétique, mais en l'éclairant par le travail des grands exégètes juifs du Moyen Age : Rashi, Ibn-Ezra, Qimhi, etc.".

L'usage fait de la critique textuelle par la TOB suggère les constatations suivantes :

$1 /$ Les positions énoncées par les coordinateurs dans la préface et l'introduction ont reçu l'agrément de principe de l'ensemble des traducteurs. Elles manifestent donc une double tendance qui se fait jour parmi les exégètes de langue française. D'abord une défiance de plus en plus marquée à l'égard des suggestions des apparats critiques : “omettre..., lire..., insérer..., transposer..., joindre... etc.". Ensuite un intérêt grandissant pour les commentaires juifs médiévaux édités dans les Miqraot Gedolot.

2/ L'autonomie marquée qui a été laissée aux traducteurs entraîne une assez grande diversité, de livre à livre, dans la manière dont le texte a été critiqué. On ne risque cependant pas de faire erreur en disant que, dans la critique du texte, la TOB fait preuve de beaucoup plus de réserve que la Bible du Centenaire ou que la première édition des fascicules de la Bible de Jérusalem.

\section{CRITIQUER LA CRITIQUE}

Depuis qu'ont paru ces cinq traductions, d'autres traductions visant une diffusion beaucoup plus large ont été faites, selon le principe de l'équivalence dynamique, en chacune de ces langues. En langue anglaise, 'Good News Bible', avec le sous-titre 'The Bible in Today's English Version' a été publiée en 1976 en deux éditions distinctes : l'une américaine et l'autre anglaise. En allemand, 'Die Bibel in heutigem Deutsch' avec le sous-titre 'Die Gute Nachricht des Alten und Neuen Testaments' fut éditée en 1982. En français, 'La Bible, Ancien et Nouveau Testament. Traduite de l'hébreu et du grec en français courant' sortit en 1982 également. Quoique la Good News Bible ait vu le jour avant que notre comité ait achevé son travail, nous avons renoncé à faire porter notre étude sur ses options textuelles, parce que celles-ci sont souvent difficiles à déceler, la traduction par équivalence dynamique ne laissant pas transparaître assez nettement le texte de base.

Le travail de notre comité a duré dix ans (de 1970 à 1979) et la publication de ce rapport final prendra au moins dix autres années. Pendant ce temps, chacune des traductions dont nous avons étudié les options se trouve en état de révision plus ou moins avancé, si bien que notre base de référence a déjà perdu de son actualité. Cela ne signifie pourtant pas qu'elle ait rien perdu de son intérêt. En effet, cette période de 1945 à 1975, qui a vu s'élaborer les révisions ou traductions que nous venons de présenter, se caractérise comme le moment où l'acquis des cent années précédentes dans le domaine de la critique textuelle influence enfin explicitement des traductions qui se veulent destinées au grand public, tout en demeurant littérales.

Cet acquis s'était élaboré à travers les grands commentaires allemands de la fin du siècle dernier ou du début de celui-ci : le Kurzgefasstes exegetisches Handbuch de Leipzig, le Handkommentar de Göttingen, le Kurzer Hand-Commentar de Tübingen. Il avait été condensé dans les apparats critiques de The Sacred Books of the Old 
Testament de Haupt et des trois premières éditions de la Biblia Hebraica de Kittel, puis diffusé par les diverses éditions de Die Heilige Schrift des Alten Testaments de Kautzsch et enfin par la Bible du Centenaire. Avec RSV, J, RL, NEB et TOB, c'est la grande majorité des exégètes américains, français, allemands et anglais qui met en pratique cet acquis scientifique pour établir le texte qui servira de norme à une révision ou de base à une traduction. Voilà vraiment la critique textuelle telle que l'on en faisait usage dans les milieux exégétiques de ces trois langues, dans le troisième quart du vingtième siècle.

Le secrétariat de l'Alliance Biblique Universelle soumettait à notre comité les 5.000 options textuelles les plus caractéristiques de ces traductions. Nous avons accepté de les étudier, car nous avons estimé disposer là d'un donné assez ample et assez varié, donc représentatif de la critique textuelle telle qu'elle se pratique et telle que chacun d'entre nous avait eu l'occasion de l'exercer.

Comment critiquer l'usage contemporain fait de la critique textuelle de l'A.T.? Comme nous l'avons relevé dans les déclarations de principes de plusieurs de nos traductions, les traducteurs font surtout appel à la critique correctrice lorsqu'ils éprouvent des difficultés à interpréter le Texte Massorétique. La critique de ce procédé requérait, à notre avis, quatre démarches successives : après avoir interrogé nos traductions sur leurs options respectives, il nous paraissait utile de rechercher les origines historiques de celles-ci afin de les situer en une perspective qui permette d'apprécier leur portée. Il faudrait ensuite relever l'apport des divers témoins textuels, puis peser le choix suggéré par ce bilan des témoignages. Il serait utile, enfin, de voir comment ce choix textuel permet de répondre aux difficultés qui ont motivé les interventions correctrices de nos traductions. Le présent rapport s'efforce de retracer la succession de ces démarches à propos de chacun des cas qui nous ont été soumis. Selon l'intérêt méthodologique que présente l'une ou l'autre des étapes de cet itinéraire critique en tel ou tel cas, nous avons développé plus ou moins la section qui lui est consacrée.

Il peut paraître prétentieux d'intituler ce rapport : 'Critique textuelle de l'Ancien Testament'. Il s'agit plutôt, en effet, d'une critique de cette critique. Mais, pour réaliser ce propos avec assez de sérieux, nous avons été amenés à entreprendre la recherche la plus étendue et - pour certaines des démarches mentionnées - la plus poussée qui ait été effectuée jusqu'ici. Il nous paraissait nécessaire d'étendre notre étude à l'ensemble de la Bible hébraïque. Comme notre comité a dû limiter à 5.000 le nombre des cas qu'il pourrait traiter de façon suffisamment approfondie, nous avons parfaitement conscience de n'avoir soumis le vaste territoire du Texte de l'Ancien Testament qu'à une triangulation à très larges mailles. D'autres compléteront nos relevés et exploreront en détail des domaines que nous n'avons pu que parcourir. 


\section{Deuxième section}

\section{ORIGINES DES CORRECTIONS}

Il faut d'abord déterminer ce qui, dans les options dont témoignent nos cinq traductions, est une correction critique et ce qui ne l'est pas. La question se pose explicitement pour celles d'entre elles qui sont des révisions de Bibles traditionnelles plus anciennes. Lorsque la traduction ne correspond pas au texte massorétique, s'agit-il d'une option critique du réviseur ou s'agit-il plutôt d'une initiative pré-critique ou proto-critique du traducteur initial ou de ses prédécesseurs?

C'est pour RL que cette question se pose avec le plus d'acuité, et cela pour deux motifs :

1/ Les révisions subies par la traduction de Luther ont été, nous l'avons vu, bien plus discrètes que celles qu'ont subies d'autres Bibles traditionnelles, par exemple celle de Zurich ou la King James Version. Aucune autre Bible n'a exercé en effet une influence aussi déterminante sur une langue de haute culture, car la traduction de Luther a joué un rôle essentiel dans la fixation du haut-allemand et c'est elle qui a fait de ce dialecte la forme littéraire classique de l'allemand. On ne touche donc à ce trésor littéraire qu'avec le plus grand respect. W. Gundert qui a eu un rôle de premier plan dans l'organisation de la dernière phase de la révision (TRE VI 269,48s) a d'ailleurs donné des informations très intéressantes (ibid. 270,13-21 et 271,24-28) sur ce point. Certes, les réviseurs avaient établi, comme leur premier principe, “die Massgeblichkeit des Urtextes" (RGG3 I 1221,42). Mais cette "normativité" reconnue au texte original entra parfois en conflit avec le respect éprouvé pour l'herméneutique spécifique de Luther (TRE VI 271,16-28). Cela explique pourquoi les options pré- ou proto-critiques de Luther ont été souvent laissées intactes par les réviseurs.

2/ Déjà Houbigant, puis Lowth et ensuite, beaucoup plus nettement, les critiques allemands de la fin du XVIIIe et du XIXe siècle, ont été tellement influencés par les options de la Lutherbibel qu'ils y ont souvent puisé les orientations conscientes ou inconscientes de leur critique du texte massorétique. Souvent, plutôt que de corriger le texte hébreu traditionnel là où il est difficile à interpréter, on dirait qu'ils se sont efforcés de trouver dans les versions anciennes des bases textuelles pour les options qui caractérisaient leur Bible allemande traditionnelle. Il n'est donc pas surprenant que les apparats critiques de la Biblia Hebraica de Kittel, où ont abouti les suggestions de ces critiques, se trouvent en une relation ambigüe avec RL. On serait d'abord tenté de croire que les réviseurs (qui ne donnent pas de notes textuelles) ont fondé leur révision sur les propositions de ces apparats. Cependant, une comparaison de RL avec les états originaux de la Lutherbibel suffit à montrer que les réviseurs n'ont pris, en la plupart de ces cas, aucune initiative critique, mais ont simplement laissé intacte une option de Luther. Ce sont au contraire les critiques textuels du XIXe siècle qui ont orienté leur critique dans le sens de cette option.

Ce que nous venons de dire de l'influence exercée par la Lutherbibel sur RL, vaut, dans une moindre proportion, pour la King James Version à l'égard de RSV. Cepen- 
dant, c'est l'ensemble des options prises par les exégètes de l'occident chrétien, entre 1515 et 1615 environ, qui a exercé, parfois inconsciemment, une influence déterminante sur la manière dont nos traducteurs abordent le texte massorétique, et donc sur les difficultés auxquelles ils se heurtent les uns après les autres.

Nous allons donc présenter maintenant les sources d'influence auxquelles notre étude a fait appel pour expliquer le patrimoine pré- ou proto-critique dont nos traductions sont les héritières. En effet, il existe de bonnes études (par ex. H.-J. Kraus, Geschichte der historisch-kritischen Erforschung des Alten Testaments, NeukirchenVluyn 3/1982) sur la recherche critique, à l'époque moderne et contemporaine. Nous avons traité en CT1 ${ }^{*} 2-63$ des débuts de la critique textuelle jusqu’à J.D. Michaelis. Mais il n'existe pas d'étude envisageant, en leur interdépendance, les origines des traditions bibliques allemande, française et anglaise fondées sur l'hébreu. Aussi voudrions-nous étudier les relations immédiates et médiates de ces Bibles avec le texte auquel elles prétendent se rattacher, en ce qui concerne l'Ancien Testament.

Commençons donc par présenter, à propos des livres bibliques qui font l'objet de ce volume, Luther et les sources qui l'ont influencé. Puis nous traiterons des sources d'influence postérieures à sa traduction.

\section{LUTHER}

Aux pages *4 à *9 de l'introduction à CT1, nous avons relevé ce qui, dans l'herméneutique de Luther, dans son attitude à l'égard des Juifs et dans sa conception de la critique textuelle avait pu motiver et orienter l'activité critique qu'il a déployée surtout dans la révision de sa traduction de l'A.T. en 1539-1541. Présentons maintenant son activité de traducteur et les influences qu'elle a subies.

\section{Traducteur et réviseur}

Luther avait commencé en 1517 son activité de traducteur à propos des sept psaumes pénitentiels. Après avoir pris, durant son séjour à la Wartburg, la décision de traduire toute la Bible, il traduisit en 11 semaines le Nouveau Testament. Celui-ci parut à Wittenberg le 21 septembre 1522 et dut être réédité dès le mois de décembre. La publication de l'Ancien Testament suivit immédiatement : en 1523 le Pentateuque, en 1524 les livres historiques, puis les hagiographes. Mais l'édition d'ensemble des prophètes ne sortit qu'en mars 1532 . Elle avait cependant été précédée, au printemps 1526 par l'édition de Jonas puis celle d'Habacuc, en fin décembre 1527 (avec le millésime 1528) par celle de Zacharie et, au début d'octobre 1528 par celle d'Isaïe. La première édition de la Bible complète parut en août 1534. De fin novembre 1540 jusqu'à mi-février 1541, Luther révisa sa traduction des prophètes.

\section{Les sources de la traduction}

\section{1/Isaï}

Pour ce livre, l'édition des prophètes de 1532 ne fait que reprendre (en la grevant de nombreuses fautes d'inattention) l'édition princeps de 1528. Ce sont donc les sources de cette dernière qu'il convient de préciser.

La Bibliothèque Universitaire de Heidelberg possède encore, sous la cote "Pal. Germ. 731", le manuscrit de la traduction de Luther, depuis le début jusqu’à 33,1. 
Ce manuscrit a été édité en WA.DB II 1-39. Quant à l'édition de 1528, elle est reproduite sur les pages paires de WA.DB XI/1 16-188. Mentionnons que Luther donna un cours universitaire sur Isaïe, avec des interruptions, de l'été 1527 au 22 février 1530. Avant 1914, on ne connaissait le contenu de ce cours que par "In Esaiam Prophetam Scholia ex D. Mart. Lutehri [sic!] praelectionibus collecta" publié à Wittemberg en 1532 et réédité de façon plus étoffée en 1534 (ces deux éditions étant reproduites en WA XXV 87-401). Il fallut attendre le début du $X X e$ siècle pour que l'on découvrît, dans le ms. theol. lat. Q.20 de la Bibliothèque Royale de Berlin, la reportatio d'Antonius Lauterbach (éditée en WA XXXI/2 1-585) qui nous offre un excellent témoignage sur ce cours. Commencé avant l'édition de la traduction et achevé après, le cours de Luther constitue le commentaire le plus autorisé de celle-ci.

Pour la traduction d'Isaïe, comme pour tout l’A.T., la première source utilisée par Luther fut l'édition en petit format de la Bible hébraïque publiée à Brescia par Gershom Soncino (24-31 mai 1494). H. Volz (WA. DB XI/2 XX, n.48), d'accord avec $H$. Ulbrich, estime que Luther utilisa également une édition in-folio de la Bible hébraïque. Quelques indices, que nous relèverons plus loin, suggéreraient qu'il s'agit de la Bible rabbinique de Félix de Prato éditée à Venise en 4 volumes (1516-17) par Daniel Bomberg. En plus du texte hébreu, cette édition plaçait sous ses yeux le targum (dont elle est l'édition princeps) auquel elle ajoute, pour Isaïe et Jérémie, le commentaire de David Qimhi et, pour les Lamentations, celui de Rashi.

H. Volz (WA. DB XI/2 XL, note) pense qu'il n'est pas exclu que Luther ait pu suivre occasionnellement, dans sa traduction d'Isaïe, l'interprétation d'Oecolampade. Celui-ci avait publié, en effet, à Bâle en 1525 chez Andreas Cratander, "In Iesaiam prophetam hypomnematôn, hoc est, commentariorum, libri VI". Johannes Husschin, connu depuis son adolescence sous le nom d'Oecolampadius, avait donné en effet, dans l'aula magna de l'université de Bâle, d'avril 1523 à juin 1524, devant 400 auditeurs appartenant à la bourgeoisie de la ville (sans compter les étudiants et les prêtres) un cours sur les textes hébreu et grec d’Isaïe qui eut un rôle très important dans le déclenchement de la Réforme à Bâle. Dans une lettre écrite à Nicolas Gerbel de Strasbourg, vers la fin de juin 1523 (WA XII 57,18s), Luther disait se réjouir vivement de ce qu'Oecolampade enseignât alors Isaïe à Bâle, quoique cela déplût à beaucoup. Le commentaire qu'il publia ensuite était entre les mains de Luther lorsqu'il donna son cours. Ce dernier conclut, en effet, le prologue du cours (selon l'édition de 1534 des Scholia) en disant : "Oecolampade a fait un assez bon travail, quant à la grammaire, quoique, sur certains points, il ne soit pas d'accord avec nous". Nous aurons l'occasion de noter l'influence réelle exercée par Oecolampade sur Luther et Brucioli.

Luther a eu aussi un contact continuel avec la Vulgate qui lui était très familière. Il s'est également inspiré de temps en temps de la vieille traduction allemande faite sur la Vulgate, éditée et rééditée à partir de 1466 (où Johannes Mentel la publia à Strasbourg pour la première fois). Il la lisait probablement (ainsi que le montrent certains de ses choix translationnels) dans une édition dérivant de celle que Günther Zainer donna à Augsbourg en 1475.

Luther, lorsqu'il traduisit Isaïe, disposait aussi de la traduction latine de la Bible publiée en 1527 par Sanctes Pagnini, chez Antoine du Ry, à Lyon; première traduction des textes originaux faite depuis celle de Jérôme. Elle fut également la première 
à numéroter les versets (numérotation qui fut d’ailleurs omise dans la réédition que Michel. Servet en donna également à Lyon, chez Hugues de la Porte et Gaspard Trechsel en 1542). Il avait aussi certainement à sa disposition une édition de la postille de Nicolas de Lyre qu'il cite souvent.

Dans une lettre à Johannes Lang (WA. Briefwechsel II 547) du 29 mai 1522, Luther envoie à son correspondant un lexique hébreu acheté jadis à Erfurt, parce qu'il l'a moins annoté que celui que Lang lui avait prêté et qu'il conserve. Il pouvait s'agir là du lexique qui occupe les pp.32 à 545 du 'De rudimentis hebraicis', in quarto, que Johannes Reuchlin avait édité à Pforzheim chez Thomas Anshelm, en mars 1506. Mais les données fournies par Reuchlin étaient très pauvres. Or il est évident que Luther a dô faire usage, pour sa traduction d'Isaïe, d'aides lexicographiques plus développées. Plusieurs indices montrent qu'il peut s'agir du 'Vocabularium hebraicum totius veteris testamenti cum aliis dictionibus chaldaicis ibi contentis' d'Alphonse de Zamora, in-folio de 682 colonnes qui avait été achevé d'imprimer à Alcala chez Arnaldo Guillermo de Brocar, le 17 mars 1515 en introduction à l'Ancien Testament de la polyglotte.

Quand Luther parle de grammaire hébraïque, il mentionne (WA. Briefwechsel VIII 176,20 et WA. Tischreden V 220,11.24) Santes [Pagnini] et [Sébastien] Münster. La grammaire la plus complète dont on disposât à l'époque où il traduisait Isaïe était, en effet, les 'Institutiones hebraicae', in-quarto de 428 p. que Pagnini avait publié à Lyon, chez Antoine du Ry, le 1er octobre 1526. Cette grammaire, fondée sur le Mikhlol de Radaq, avait largement supplanté les 75 pages que Reuchlin avait consacrées à la grammaire dans le $3 e$ livre de ses 'Rudimenta' et les 60 colonnes qu'Alphonse de Zamora lui avait dévouées. Ces dernières avaient été achevées d'imprimer le 31 mai 1515 en conclusion du volume d'introduction à l'Ancien Testament de la polyglotte d'Alcala.

Luther a dû faire usage aussi d'une édition de la Septante. S'agissait-il de la polyglotte d'Alcala dont le 4 e volume de l'Ancien Testament contenant les prophètes et les trois premiers livres des Maccabées avait été achevé d'imprimer le 10 juillet 1517, ou de l'édition de la Septante qu'Alde et son beau-père André avaient publiée à Venise en février 1518 ? Il est difficile de répondre à cette question. En effet, alors qu'Oecolampade, dans son commentaire, cite souvent la Septante en comparaison avec l'hébreu, Luther, qui cite fréquemment l'hébreu dans son cours sur Isaïe et entremêle volontiers son enseignement de mots grecs tirés du Nouveau Testament ou du langage des humanistes - mots qu'Antonius Lauterbach a notés avec précision dans sa reportatio -, semble n'avoir cité que très rarement la Septante. Pour s'en rendre compte, notons simplement que Lauterbach n'en rapporte qu'une seule citation formelle, à propos d'Is 60,17. Mais il n'est pas certain que Luther l'ait directement tirée de la Bible grecque, puisqu'Oecolampade cite ici explicitement ce texte en le commentant dans le sens où Luther l'utilisera.

\section{2/ Jérémie et les Lamentations}

Luther avait commencé en février 1530 à traduire Jérémie, puis, préoccupé par le péril turc, il l'interrompit pour traduire les oracles contre Gog en Ez 38 et 39 . Il la 
reprit, à la forteresse de Cobourg, au début de mai et l'acheva vers la mi-juin. Il la retoucha ensuite en de nombreux endroits, comme le montrent les multiples corrections que porte son autographe. Celui-ci a été conservé par la bibliothèque ducale de Gotha, sous la cote "Ch. B. 142". Il contient la traduction, jusqu'à 51,28. A partir de 20,16, il semble qu'il ait été recopié, par Luther lui-même (cf. WA. DB II XV, n.2). Le manuscrit a été édité en WA. DB II 40-147.

La traduction parut en 1532 avec celle des autres prophètes sous le titre 'Die Propheten alle Deudsch', édition qui est reproduite sur les pages paires de WA. DB $\mathrm{XI} / 1$ 190-390.

Pour traduire Jérémie et les Lamentations et les retoucher de 1530 à 1532, Luther disposait d'un certain nombre d'ouvrages auxquels il n'avait pas encore eu accès, en 1528, lorsqu'il avait traduit Isaïe.

Un traducteur sérieux s'inspire des traductions faites avant lui et les a sous les yeux durant tout son travail. Ne pas les utiliser serait faire preuve de légèreté. Les recopier serait du plagiat. Luther ne peut être accusé d'aucune de ces deux fautes.

L'anabaptiste Ludwig Haetzer, originaire de Bischofszell en Suisse et ancien protégé de Zwingli, aidé, à partir de 1526, par Hans Denck, avait traduit sur l'hébreu les Prophètes et sa traduction, sous le titre 'Alle Propheten, nach Hebraischer sprach verteutscht' avait été achevée d'imprimer le 13 avril 1527 par Peter Schöffer, à Worms. Dans la 2e partie de ses 'Annotationes', imprimées à Leipzig en 1536 par Melchior Lother l'ancien, Georg Witzel (qui avait été jusqu'en 1531 en relation personnelle avec Luther) avait comparé la Bible de Luther de 1534 avec la traduction de Haetzer et avait conclu à une influence évidente des Prophètes de Worms sur l'oeuvre de Luther. Depuis, les opinions ont varié, les Mennonites ayant tendance à souligner les indices de dépendance et d'autres à les estomper. Il est, de fait, possible que Luther ait fait usage de la traduction de Haetzer. En effet, le 4 mai 1527, il écrivait déjà à Spalatin (WA. Briefwechsel IV 197, 10) qu'il la possédait à Wittenberg. Vers la même date, il précisait à Wenzeslaus Link (ibid. 198, 6-8) : “Je ne méprise pas les Prophètes qui ont été traduits à Worms, si ce n'est que l'allemand en est assez obscur, ce qui tient peut-être à la nature de cette région." En septembre 1530, rédigeant à la forteresse de Cobourg le 'Sendbrief vom Dolmetschen', Luther y écrit (WA. XXX/2 640, 28-32) : “J'estime qu'aucun faux chrétien, ni aucun esprit sectaire ne peut traduire fidèlement, comme cela apparaît dans les Prophètes mis en allemand à Worms. Beaucoup de zèle y a été dépensé et ils ont imité de près mon allemand. Mais des Juifs étaient là qui n'ont montré guère de respect pour le Christ. Autrement, l'art et le zèle auraient été suffisants". H.Volz, dans l'Excursus qu'il a inséré en 1960 dans WA. DB XI/2 CXIII - CXXXIII, a été le premier à soumettre à une étude précise les relations existant entre la traduction de Haetzer et l'autographe de Luther. Il en a tiré les conclusions suivantes ( $p$. CXXXIs.) : "Le contenu de ces exemples qui dépassent la cinquantaine, mais ne prétendent pas être exhaustifs, devrait rendre évident que Luther (qui, d'ailleurs, dans son mansucrit, note à propos de Os 10,14: "Vide hetzer") a réellement fait usage de la traduction de Haetzer/Denck. A ce propos, il faut distinguer trois possibilités : premièrement, que Luther se soit dès le début attaché au texte des Prophètes de Worms et l'ait conservé inchangé lors de l'impression; deuxièmement, que Luther ait d'abord adopté la traduction de Worms, puis l'ait corrigée ensuite dans 
son manuscrit en faveur d'une autre interprétation; troisièmement, que la formulation qu'il avait choisie lui-même au début ait été remplacée ensuite dans sa copie par le texte de Worms". Volz cite des cas prouvant la réalisation de chacun de ces trois types d'intervention, en des situations où ni le contenu de l'hébreu, ni l'influence de la Vulgate ne permettent d'expliquer les similitudes caractéristiques qu'offre la traduction de Luther par rapport aux Prophètes de Worms.

En trois ans, la traduction faite par Haetzer et Denck eut 13 éditions en différents formats et en divers endroits. Elle ne devait pas laisser Zwingli indifférent. Dès le 5 mai 1527, Franz Kolb lui écrivait de Berne (Zwinglis Briefwechsel III, Leipzig 1925, 126) : “Entre autres, j'ai appris que tu allais traiter de la traduction des Prophètes qui a été récemment publiée par Heczer et Denck. On me dit qu'elle ne te plaît pas entièrement. Je t'en prie de par Dieu, mon frère, si, dans ladite traduction, tu veux corriger, ajouter ou omettre quelque chose, ne t'occupe que de ce qui fait difficulté et que l'on ne saurait accepter sans commettre une grave erreur. Ajoute et omets avec bienveillance, avec une charité non feinte, de peur qu'un tort soit causé à notre foi et à l'évangile que nous professons. Rien, en effet, n'entrave notre route et ne nuit tant à la parole de Dieu que cette controverse perpétuelle entre vous qui êtes nos maîtres." Le 15 mai, Jörg Regel (ibid. 134) informe Zwingli que l'on a interdit la vente de la traduction des Prophètes à Nuremberg (interdiction qui fut édictée sur l'avis d'Osiander).

L'émoi causé par la traduction anabaptiste des Prophètes et le grand succès qu'elle eut en librairie tient au fait que Luther avait traduit coup sur coup et édité les trois premières parties de l'Ancien Testament en 1523 et 1524, alors qu'il laissait attendre depuis trois ans la quatrième (qui n'allait sortir qu'en 1532) : les Prophètes. Or, en cette période de fermentation religieuse, on attendait avec impatience de pouvoir lire les prophètes en langue vulgaire.

Editée à Wittenberg, la Bible de Luther avait été aussitôt rééditée à Bâle. Ainsi, en 1523, l'édition princeps du Pentateuque avait eu 2 rééditions à Wittenberg et 4 à Bâle. Il fallut attendre deux ans pour qu'une adaptation des trois premières parties de la Bible de Luther en dialecte zurichois parut chez Christoph Froschauer, en 1525, à Zurich. En 1527, le marché bâlois semblait saturé, puisque l'on n'y fit qu'une réédition du Pentateuque de Luther. A Zurich, par contre, la diffusion se développait, puisqu'en cette année on réédita deux fois chacune des trois parties. Le manque d'une traduction des Prophètes en allemand s'était vivement fait sentir en 1526, à la foire d'automne de Francfort. Christoph Froschauer qui y était allé, comme d'habitude, tenir son stand de libraire, écrivait, en effet, à Zwingli, le 18 septembre (Zwinglis Briefwechsel II, Leipzig 1914, 717) : “On se plaint vivement... que vous n'ayez pas traduit en allemand les Prophètes". Or voilà qu'en mars 1527, les Anabaptistes lançaient leur traduction des Prophètes sur un marché qui l'engloutissait avidement.

Depuis 1525, Zwingli et Jud avaient organisé, avec la participation de plusieurs autres lettrés, des séances d'exégèse et de traduction de l'Ancien Testament auxquelles on donna le nom de "Prophezey", par allusion à 1 Cor 14 . A propos de Jr 38,23 (ci-après, p. 721), nous indiquerons comment ces séances de travail étaient organisées. Pour l'instant, mentionnons simplement que l'on y faisait usage de la Vulgate et du texte hébreu, Zwingli ayant pour tâche d'expliciter l'apport de la Septante 
qu'il lisait dans sa Hausbibel, constituée par un exemplaire de l'édition Aldine. Cette Hausbibel, annotée par lui, est actuellement conservée par la Bibliothèque Centrale de Zurich. La Prophezey avait traité du Pentateuque (du 19 juin 1525 au 26 décembre 1526), puis des livres historiques (de janvier au 1er septembre 1527). Mais, à l'étude de la $2 \mathrm{e}$ partie de la Bible, on ne fit pas suivre celle de la 3e (les Hagiographes). On passa directement à la 4e (les Prophètes) dont on traita depuis le 2 septembre 1527 jusqu'au 16 janvier 1529. Et le fruit de ce travail fut édité le 1er mars 1529 par le fidèle Christoph Froschauer, sous le titre 'Das vierde teyl des alten Testaments. Alle Propheten, auss Ebraischer sprach, mit guten treuwen und hohem fleyss, durch die Predicanten zu Zürich, inn Teutsch vertolmätschet'. Zwingli, à la 2e page du prologue, explique pourquoi les prédicants de Zurich ont finalement décidé d'éditer la 4e partie qui manquait alors à la Bible de Luther : "Quoiqu'une traduction des Prophètes ait été publiée récemment, elle a été accueillie avec une grande défiance par beaucoup de gens simples et loyaux, parce qu'elle provient des Anabaptistes. Pour autant que nous l'ayons consultée, en de nombreux endroits, elle a rendu en allemand avec zèle et fidélité les lettres de l'hébreu. Mais qui n'éprouverait de la défiance et de l'horreur à l'égard de la traduction qui émane de ceux qui ont été les vrais initiateurs des sectes et des cliques qui, aujourd'hui, dans l'Eglise de Dieu, nous ont suscité plus de trouble que la Papauté n'en a jamais causé". Il semble donc bien que ce soit la parution des Prophètes de Worms au printemps 1527 qui amena la Prophezey de Zurich à passer directement des livres historiques aux Prophètes, en septembre de la même année. On estimait urgent d'opposer à la traduction des sectaires une autre doctrinalement sûre et, puisque Luther était occupé à d'autres tâches, on en prit l'initiative.

Luther, nous l'avons dit, a fait usage des Prophètes de Worms. Les prédicants de Zurich en ont fait un usage encore plus marqué, usage normal dans les circonstances où l'on se trouvait alors et qui n'entrave pas la liberté de jugement des traducteurs. Mais il semble que l'on n'ait pas jusqu'ici étudié de façon précise l'influence exercée par la traduction des Prophètes de Zurich sur celle de Luther, pour les livres que celui-ci n'avait pas encore traduits en 1529. Dans le commentaire textuel qui suit, nous essaierons d'éclaircir ce point pour Jérémie et les Lamentations que Luther ne traduisit qu'en 1530.

Il y a certains cas où H.Volz (WA.DB XI/2 CXXVI) estimait que Luther, ayant d'abord adopté la traduction de Worms, $y$ avait substitué ensuite une traduction personnelle; mais une comparaison avec la traduction de Zurich aurait montré que c'était cette dernière qui, chez Luther, avait supplanté le texte de Worms. Voici de cela deux exemples :

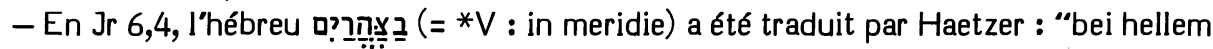
tag", De même, Luther écrit d'abord: "bey hellem tage". Puis il corrige cela en "weil es noch hoch mittag ist". Ensuite il se reprend, et raye "mit" dans l'avant-dernier mot. Or la traduction des Prédicants de Zurich porte ici : "weils noch hoch tag ist".

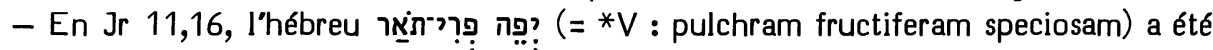
traduite par Haetzer : "der mit schönenn früchten geziert ist". Luther écrit d"abord : "der mit schonen fruchten gezieret". Puis il corrige cela en : "schonen fruchtbarn". Or la traduction des Prédicants de Zurich porte ici : "einen schönen, eyn fruchtbaren, eyn hüpschen". Elle s'inspire ici clairement de la *V et tient plus explicitement compte des trois mots de l'hébreu que la forme abrégée retenue par Luther. 
H.Volz n’a pas fait entrer la traduction des Prédicants de Zurich en ligne de compte dans la comparaison qu'il a établie entre la traduction de Luther et celle de Haetzer. En conséquence, il a conclu à une influence directe en des cas où celle-ci a pu s'exercer par l'intermédiaire de la traduction de Zurich. Par exemple (p. CXXVII),

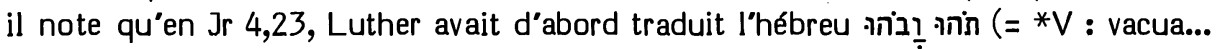
et nihili) par "wust und leer", comme il l'avait déjà fait en Gn 1,2. Puis il a corrigé le 2e mot en "öde". Or Haetzer offre ici "wüst und öd". Ajoutons que les Prédicants de Zurich ont adopté littéralement ici la traduction de Haetzer. Même situation en

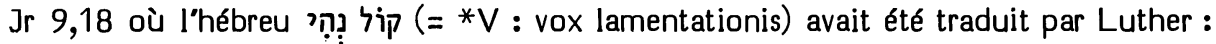
"ein geschrey". Puis il a inséré, avant le substantif, l’adjectif "kleglich". Volz fait remarquer que Haetzer offre ici : "eyn kläglich geschrey". Mais Luther a pu emprunter cette leçon aux Prédicants de Zurich qui l'avaient déjà adoptée.

Les quelques indices que nous venons de fournir montrent que l'on aura intérêt à compléter l'étude de H.Volz sur les relations entre la traduction des Prophètes par Luther et les Prophètes de Worms par une autre comparaison entre les options de Luther et celles des Prédicants de Zurich.

Il faut signaler un autre instrument de travail que Luther n'avait pas à sa disposition en 1528 quand il traduisait Isaïe, mais dont il put faire usage pour traduire Jérémie en 1530. C'est l'énorme 'Oșar leshon ha-qodesh, hoc est Thesaurus linguae sanctae' (2752 colonnes) que Sanctes Pagnini publia en 1529 chez Sébastien Gryphius, à Lyon.

\section{Les sources de la révision de 1540-1541}

La révision des Prophètes de 1540-1541 a abouti à deux produits immédiats, tous deux édités par O. Reichert en WA.DB IV 39 à 278. Il s'agit, en premier lieu, du procès-verbal des séances de révision, rédigé par Rörer et conservé dans le ms Jena Bos q. 24c; puis des annotations portées par Luther lui-même dans son exemplaire de l'édition de 1539 de l'Ancien Testament, exemplaire conservé à la Bibliothèque de Jena sous la cote 'Appendix Manuscriptorum $\mathrm{Nr} 24$ '.

Mathesius, dans son 13e sermon (cf. WA.DB III XVs), nous a gardé le souvenir de ces révisions de 1540 qui se tenaient quelques heures avant le repas du soir. Luther réunissait chez lui son 'Sanhédrin' constitué de J.Bugenhagen, J.Jonas. C.Cruciger, Ph.Mélanchthon, M.Aurogallus. Souvent des savants venus de l'extérieur se joignaient à eux, comme B.Ziegler et J.Forster, très bons hébraïsants. Luther arrivait avec sa vieille Bible latine et sa nouvelle Bible allemande. Il avait aussi toujours avec lui le texte hébreu. Mélanchthon, lui, avait le texte grec, Cruciger avait la Bible hébraïque avec le targum. Les professeurs étrangers apportaient leurs rabbins. Bugenhagen usait d'une Bible latine qui lui était très familière. Chacun avait étudié le texte à partir des sources dont il disposait. Luther mettait un texte en discussion. Chacun donnait alors son avis en essayant de dégager la propriété de la langue ancienne et de s'éclairer par l'interprétation des anciens exégètes. Rörer notait l'essentiel.

Un instrument de travail paru depuis la traduction des Prophètes était disponible pour la révision. Il s'agit de la traduction latine que Münster avait publiée à Bâle avec le texte hébreu et des annotations tirées des rabbins. Le premier tome, paru en 1534, contenait le Pentateuque et les livres historiques. Il présentait la traduction comme 
nouvelle "\& quoad fieri potuit, hebraicae veritati conformata". Il disait avoir tiré ses annotations “e Rabinorum commentariis". En 1535, Münster publia le second tome contenant les Prophètes, les Hagiographes et, pour finir, les cinq Megillot. Dans la rédaction de son titre, il tint compte de la défiance des Réformateurs de Zurich et de Wittemberg à l'égard de l'exégèse rabbinique. Il dit en effet avoir puisé ses annotations "vel ex Hebraeorum commentariis, vel ex probatioribus latinis scriptoribus". Par contre, il accentua la prétention de sa traduction à l'exactitude, disant des livres bibliques que "sic ad Hebraicam veritatem genuina versione in latinum sunt traducti, ut ne quidem ad latum unguem ab ea dissideant".

Un produit plus définitif de la révision de 1540-41 est constitué par les éditions de la Bible de Luther, à partir de la seconde des deux éditions que Hans Lufft publia en 1541.

\section{LES SOURCES D'INFLUENCE EXTERIEURES OU POSTERIEURES A LUTHER}

Nous voudrions centrer ici notre étude sur les débuts de la Bible française et ceux de la Bible anglaise. Mais d'abord disons un mot de l'Italie.

\section{Antonio Brucioli}

Vers les débuts de la Réforme, les grands carrefours culturels furent Bâle, Lyon et Venise. Dans le domaine qui nous concerne, Lyon se signale comme lieu d'édition de la traduction de Pagnini, de sa grammaire et de son Thesaurus hébreu (de 1526 à 1529); Bâle comme celui des commentaires d’Oecolampade et des éditions successives de la Bible de Münster. A partir de 1517, Venise prend une place de premier plan dans l'édition de la Bible hébraïque et de toute la littérature juive. En effet, le Juif converti Félix de Prato, devenu religieux augustin, fit la connaissance à Rome d'un marchand anversois établi à Venise : Daniel Bomberg qu'il convainquit de fonder une imprimerie hébraïque. Celle-ci fonctionna de 1516 à 1548 et ses typographes étaient surtout des convertis et des juifs. Le 1er décembre 1517, Bomberg acheva d'imprimer la première Bible Rabbinique (éditée par Félix de Prato). En même temps, sortit une autre édition in-quarto ne contenant que le texte biblique, avec des variantes et des qerés marginaux. Elle était destinée à une plus large diffusion. Mais, comme elle était l'oeuvre d'un converti, les juifs l'accueillirent avec défiance. Bomberg confia alors aux deux fils de Baruch Adelkind l'édition d'une autre Bible in-quarto publiée en 1521. En 1524-1525, Jacob ben Hayim ibn Adonya, originaire de Tunis, édita la première Bible massorétique (et deuxième Bible rabbinique). Bomberg avait aussi publié, le 26 Tishri 1523, la concordance biblique hébraïque de Isaac Nathan ben Kalonymos, sans parler de plusieurs éditions bibliques partielles, de commentaires bibliques, de grammaires et de dictionnaires hébreux. En dehors de cela, pendant les trente années de fonctionnement de son officine, Bomberg édita le talmud de Jérusalem (1522-1523), réédita trois fois les 37 traités du talmud de Babylone (travail dont il dit, dans une lettre à Reuchlin, avoir été chargé par le pape Léon X). Il édita la Mishna, la Mekhilta, le Sifra, les Sifré, la Pesiqta, le Midrash Rabba, le Midrash Tanhuma, le Mishné Tora de Maïmonide, le Semag de Moïse de Coucy, les livres liturgiques de la plupart des rites du judaïsme, etc. En permettant à Daniel Bomberg d'éditer, avec une probité 
indiscutée et non troublée par la censure, l'ensemble du patrimoine du judaïsme, Venise s'est acquis un renom qui dépasse de loin le milieu occidental et l'époque de la Renaissance. Il n'est donc pas surprenant que la première Bible italienne traduite sur l'hébreu sortit à Venise.

Zurich avait été la première ville d'occident à publier (en 1529), à partir de l'hébreu, une Bible complète en langue vulgaire. Comme nous l'avons dit, ses trois premières parties étaient constituées par des adaptations de la Bible de Luther et la quatrième par l'oeuvre que les prédicants avaient réalisée au cours de leur "Prophezey", dans le choeur du Grossmünster. Ce fut en mai 1532 que le Florentin Lucantonio Giunti publia à Venise la première Bible 'en langue toscane' qui ait été traduite 'de la vérité hébraïque' (pour l'A.T.) et du grec (pour le N.T.). Le traducteur en était Antonio Brucioli 'serviteur de Jésus-Christ, notre Seigneur et Sauveur', ainsi qu'il se désigne dans le colophon. Les deux volumes de l'Ancien et du Nouveau Testament commencent chacun par une longue dédicace à François 1er, roi de France. Brucioli était en effet, comme beaucoup de 'chrétiens évangéliques', un protégé de la belle-soeur du roi, Renée de France, duchesse de Ferrare, à laquelle il dédia d’ailleurs le premier des trois tomes du gros commentaire (2611 colonnes) de l'Ancien Testament qu'il publia également à Venise, en octobre 1540, avec une édition révisée de sa traduction, chez Bartholomeo de Zanetti, originaire de Brescia. On a souvent dit que Brucioli savait peu d'hébreu et que, pour la plus grande partie, sa traduction de l'Ancien Testament se fonde sur la traduction en latin faite par Sanctes Pagnini. Les contacts littéraux sont nombreux et indiscutables. Mais, nous le verrons, il existe des endroits où Brucioli, en 1532, semble avoir été le premier hébraïsant chrétien à découvrir le sens exact de l'hébreu et à se dégager de l'influence de la Vulgate. Il faut donc, semble-t-il, prendre au sérieux l'aveu fait par Brucioli dans l'avis au lecteur où il reconnaît avoir été très aidé “par le très grand rabbin Elias Levita qui dépasse tous les autres rabbins hébreux de notre temps dans la grammaire de cette sainte langue hébraïque". Brucioli qui habitait alors Venise put en effet avoir aisément contact avec Elias Levita qui s'y était réfugié à la fin de l'année 1528 et travaillait chez Bomberg. Il travailla même en 1544 pour Francesco Brucioli (frère d’Antonio) qui venait d'ouvrir à Venise une maison d'édition.

\section{La Bible française}

\section{1/ Olivétan et la Bible de Serrières}

Brucioli a exercé une influence notable sur le premier qui traduisit la Bible en français à partir des langues originales : Pierre Robert Olivétan. Celui-ci, originaire de Noyon en Picardie et cousin de Calvin, était, en 1531, maître d’école à Neuchâtel. Guillaume Farel et Antoine Saunier participèrent au Synode vaudois qui se tint en septembre 1532 au val d’Angrogne. On y constata "qu'il seroit grandement expédient et nécessaire de repurger la Bible selon les langues Ebraicques et Grecques en languaige Françoys". On chargea Olivétan de cette révision. Elle fut publiée avec une préface de Calvin, chez Pierre de Wingle, Picard comme eux, à Serrières, petit village au sud de Neuchâtel. Olivétan date du 12 février 1535 la dédicace que "l’humble et petit Translateur" adresse à "L'Eglise de Jésus Christ". L'impression fut achevée le 4 juin de la même année. 
Il explique qu'il a travaillé en "conférant toutes translations anciennes et modernes, tant Grecques que Ebraicques, jusque à l'Italien et Alleman, en tant que Dieu m'en a donné à congnoistre". Il explique ensuite que lorsque les Grecs ont lu dans l'hébreu autre chose que ce que nous y lisons aujourd'hui, il a souvent noté en marge leur option. Lorsqu'il a suivi les Septante ou la Vulgate pour interpréter l'hébreu d'une manière non conforme aux "poincts des Rabins et Grammairiens Ebrieux", il a mentionné en marge le sens qui correspondrait à ces points.

Olivétan offre, en effet, en marge de la Bible de Serrières, un apparat critique plus fourni et plus développé que ce qui en survivra dans les révisions postérieures. Aucune des grandes traductions antérieures, ni celle de Pagnini, ni celle de Luther, ni celle des Prédicants de Zurich, ni celle de Brucioli n'avait fait un tel effort pour informer ses lecteurs des autres interprétations possibles, des opinions des Rabbins et de ce que lisent l'Hébreu, le Grec, la Vulgate ou le Chaldéen. Donnons quelques exemples. Ils montreront la place importante qui revient à Olivétan, aux origines de la critique textuelle.

Dans les notes marginales de sa traduction des Psaumes, il conjecture 35 fois, pour le Grec, une Vorlage hébraïque distincte du texte hébreu édité qu'il a sous les yeux. Voici ses neuf premières conjectures :

- En Ps 2,9 : "Tu les desrompras". En interprétant "gouverneras", le Grec a rattaché תרעם à lieu de רער à

- En Ps 4,3 : "en diffamant ma gloire". En interprétant "serez vous de coeur pesants", le Grec et la translation commune ont lu un 'bet' au lieu du 'kaf' de לכלימה. - En Ps 16,1: "Michtam". En interprétant "inscription du tiltre", le Grec et la translation commune ont lu un 'bet' au lieu du 'mem' final de מכתם.

- En Ps 17,11 : "Ils nous environnent". En interprétant le complément comme "me", le Grec a lu 2 au lieu de ù la fin du verbe.

- En Ps 19,5: "le cours d'iceulx". En interprétant "le son d'iceulx", le Grec a lu קולם au lieu de קום

- En Ps 19,14: "de ce qu'il a commis". En interprétant "des choses estranges", le Grec a lu un 'resh' au lieu du 'dalet' de מזדים.

- En Ps 22,17: "ils ont percé", selon le Grec et la translation commune qui lisent כרו ou bien rejettent le 'alef' de כארי. Les hébreux lisent aujourd"hui : “comme le lion" et le Chaldéen : "mordants comme lions".

- En Ps 29,1 : "des princes". En interprétant "moutons", le Grec et la translation commune ont lu אילים au lieu de אלים.

- En Ps 42,5: “en flotte, et les accompaignoye". En interprétant "au tabernacle admirable", le Grec a lu un 'resh' au lieu du second 'dalet' de אדדם

Rien que dans les Psaumes, le Grec est cité 60 fois par Olivetan, “Rab. Kimi" (= Radaq qu'il pouvait lire dans la Bible rabbinique de Félix de Prato) l’est 16 fois, "Rab. Ezra" et "Rab. Salo" ( = Ibn Ezra et Rashi qu'il pouvait lire dans la Bible massorétique de Ben Hayim) le sont respectivement 11 fois et 9 fois.

Olivétan manifestait donc dans la Bible de Serrières un goût et une capacité remarquables pour l'analyse critique du texte, ainsi qu'une curiosité exceptionnelle pour l'exégèse des rabbins. Il disait aussi avoir fait appel à l'italien et à l'allemand. On trouve en effet des influences évidentes de Brucioli et de Luther. Cependant il 
n'a pas mentionné les deux sources principales de sa traduction : la traduction latine de Pagnini et surtout la traduction française de Le Fèvre d'Etaples. Peut-être estimaitil que leur emploi allait de soi.

Martin Lempereur avait en effet achevé d'imprimer, le 10 décembre 1530 à Anvers, la première édition de la Bible complète traduite en français par Jacques Le Fèvre d'Etaples. Celui-ci la présente comme "translatée selon la pure et entière traduction de sainct Hierome, conférée et entièrement revisitée, selon les plus anciens et plus corrects exemplaires". Quoi qu'en dise Le Fèvre, sa traduction n'avait pas la Vulgate comme seule base. Prenons pour exemple la manière dont il traduit le dernier mot de Ct 7,6 qui est, en hébreu, pliée) par plis". Or la Vulgate porte : "(sicut purpura regis vincta) canalibus", ce mot "canalibus" étant retenu par Pagnini dans sa traduction. La traduction de Le Fèvre se trouve, pour ce mot, correspondre exactement à celle que Luther avait éditée en 1524 : “(wie die purpur des königs) ynn fallten (gebunden)". Olivétan donnera ici : "(comme l'escarlate du Roy liée) par plis". Etant donné que Luther, Le Fèvre et Olivétan semblent assez isolés dans leur interprétation de ce mot au sens de "plis" (= falten), il est fort probable que l'édition princeps de la traduction française de Le Fèvre (dont dépend Olivétan) ait été influencée par la traduction allemande de Luther. En tout cas le "selon la pure et entière traduction de sainct Hierome" demande à être pris 'cum grano salis'. Il était, en effet, difficile, en un temps où tout le monde essayait de 'ressourcer' dans les langues originales l'interprétation de la Bible, de s'en tenir strictement à la Vulgate.

La Bible de Serrières a eu une très riche postérité. Nous ne décrirons pas ici toutes les rééditions et révisions qu'elle a subies. Nous nous attacherons seulement à quatre d'entre elles qui nous ont paru plus caractéristiques et que nous citons régulièrement dans l’étude qui suit.

\section{2/ La Bible lyonnaise de Philibert Rollet}

En 1551, Philibert Rollet publiait à Lyon une Bible sous le titre : "La Bible en Françoys, qui est toute la saincte Escriture, en laquelle sont contenus le Vieil \& Nouveau Testament, récentement revus et fidèlement corrigés selon l'Ebrieu, Grec, \& Latin". Cette formulation caractéristique suffit à signaler une descendante de la Bible de Serrières dont le titre était : "La Bible, qui est toute la Saincte escripture. En laquelle sont contenus le Vieil Testament \& le Nouveau, translatés en Françoys. Le Vieil de l'Ebrieu \& le Nouveau du Grec". On notera que l'édition de Rollet ne présente pas les deux Testaments comme 'translatés à partir de l'hébreu et du grec', mais comme 'récemment revus et fidèlement corrigés' selon l'hébreu, le grec 'et le latin'. En effet, cette petite fille d'Olivétan vise à une diffusion dans les milieux catholiques, à partir de ce carrefour culturel qu'est Lyon. De nombreux indices, en effet, nous montrent que nous avons là le point d'arrivée des mutations subies à Lyon par la Bible genevoise issue de celle de Serrières. Le premier de ces indices est la correction de "l'Eternel" en "le Seigneur" dans la citation d'Is 1,2 placée sous le titre.

Le texte de la Bible de Rollet est celui de la traduction d'Olivétan, sous la forme révisée éditée pour la première fois à Genève par Jean Girard en 1540, Bible appelée 'Bible à l'épée', à cause de la marque de l'éditeur (une épée dégaînée tenue en main 
verticalement) qui figure sur la page de titre. Cette révision eut lieu sous l'autorité de Antoine Marcourt, Jean Morand, Henri de la Mare et Jacques Bernard, pasteurs qui avaient la charge de l'Eglise pendant que Calvin était exilé de Genève (de 1538 à 1541). Elle se caractérise surtout par une large influence de la traduction latine que Münster avait éditée à Bâle en 1534-35.

Cette révision genevoise d'Olivétan passa ensuite à Lyon où elle fut éditée en des formes de plus en plus catholicisées : en 1544 chez Sulpice Sabon pour Antoine Constantin, en 1545 chez Godefroy et Marcellin Beringen frères (qui la rééditèrent en 1546), en 1547 par Jean Pidier et Nicolas Bacquenois ainsi que par Guillaume Rouillé et Thibault Payen (qui la rééditèrent en 1548), en 1550 par Balthazar Arnoullet, en 1551 par Jean de Tournes et, finalement, la même année, par Philibert Rollet.

Si on compare la Bible éditée par Rollet à son ancêtre, la Bible de Serrières, on y note les marques de 'catholicisation' suivantes.

- La page de titre est décorée par une gravure sur bois représentant Saint Jérôme avec une auréole, son chapeau de cardinal étant suspendu derrière lui à une branche d'arbre. A genoux devant un crucifix portant l'inscription 'INRI', il se frappe la poitrine avec un caillou. Une chapelle sur une falaise sert de fond au tableau.

- Les dédicaces, préfaces et avant-propos de Calvin et d’Olivétan ont été omis et remplacés par un 'Répertoire et Indice des plus notables et principales matières, contenues en la Bible', répertoire qui occupe 56 colonnes. Ce répertoire provient, pour l'essentiel, d'un 'Indice des principales matières contenues en la Bible' que la Bible de Serrières donnait sur 66 colonnes à la fin du dernier volume. Il est intéressant de noter que de nombreuses expressions ont été rendues inoffensives. On ne coordonne plus le mot 'images' avec 'idoles'. Quand on parle des cérémonies en mauvaise part, on les qualifie de 'judaïques'. On ne dit plus que les abus que les princes doivent réformer sont ceux 'de l'Eglise', etc.

- La Bible de Serrières plaçait entre les deux Testaments 'Le volume de tous les livres Apocryphes, contenus en la translation commune, lesquels n'avons point trouvés en Ebrieu ny en Chaldée', ce titre étant suivi par une 'épistre de l'authorité d'iceulx, selon Eusèbe et sainct Hierosme', épistre où l'éditeur précisait que ces livres "ne sont point reçus ni tenus comme légitimes tant des Ebrieux que de toute l'église". Rollet, lui, laisse ces livres à leur place traditionnelle parmi les autres : 3e, 4e Esdras, Tobie et Judith entre Néhémie et Esther; Sapience et Ecclésiastique entre le Cantique et Isaïe, Baruch entre les Lamentations et Ezéchiel; 1er, 2e Machabées et l'oraison de Manasses à la fin de l'Ancien Testament.

- Les curiosités critiques d'Olivétan ont disparu de la Bible de Rollet : plus d'hébreu dans les marges, plus de rabbin mentionné. Seules deux allusions (en français) à la leçon du Grec ont survécu pour tout le Psautier.

- Alors que la Bible de Serrières était seulement décorée de lettrines, l'édition de Rollet comporte 209 illustrations qui sont l'oeuvre de Georges Reverdy.

- La Bible de Rollet s'achève par 'la table des Evangiles et Epistres qu'on lit à l’Eglise aux Dimanches et Festes'. Elle y tient la place qu'occupait, dans la Bible de Serrières, l'Indice final que Rollet a transféré au début, après l'avoir expurgé.

Cette rapide présentation montre la grande diffusion dont la 'Bible à l'épée', sous des formes plus ou moins catholicisées, a joui sur le marché lyonnais. Nous avons 
retenu dans notre documentation sur les Bibles du XVIe siècle l'édition Rollet parce qu'elle représente, en 1551, le point ultime de cette pénétration et de ce succès. Ses rééditions ne comporteront plus aucune originalité spéciale. En effet la révision genevoise précalvinienne de 1540 sera supplantée ensuite par une fille cadette de la Bible de Serrières : la révision publiée par Robert Estienne en 1553.

\section{3/ La Bible française de Robert Estienne}

C'est en 1546 que parut, chez Jean Girard, à Genève, la première révision de la Bible d'Olivétan dont Calvin se soit chargé. Elle n'a pas été rééditée, mais fut remplacée, en 1551, par la deuxième révision de Calvin, publiée chez Jean Crespin. Ce fut, toutefois, la révision publiée en 1553 par Robert Estienne qui eut le plus large succès. En effet, la même année, elle fut réimprimée par Jean Girard et par Adam et Jean Riveriz et, en 1555, elle parut en une édition que se partagèrent Antoine Cercia, René Houdouyn, Pierre Pignot et Pierre Sorel, tous libraires de Genève, et en une autre de Jean Crespin. Elle domina ensuite le marché genevois, jusqu’à la parution de la révision des 'Pasteurs et Professeurs de l'Eglise de Genève', édition à laquelle nous consacrerons un paragraphe spécial.

Avant de présenter cette Bible française d’Estienne, il nous semble nécessaire de dire quelques mots de son éditeur et du destin des Bibles qu'il publia.

\section{EXCURSUS}

\section{Robert Estienne éditeur de la Bible}

Lorsqu’il édita, à Genève en 1553, sa Bible française, Robert Estienne avait déjà une longue expérience d'éditeur de la Bible. Il ne produisit jamais d'Ancien Testament grec. Mais, de 1539 à 1544, il publia une Bible hébraïque in-quarto, en fascicules et, de 1544 à 1546, une autre in-16º plus exacte que la première. Ces Bibles, remarquables surtout pour la beauté de leur typographie, ont mérité à leur éditeur d'être nommé, le 25 juin 1539, par François Ier 'Imprimeur du Roy en hébrieu et latin'. Leur qualité est inférieure à celle des Bibles de Bomberg. Elles n'auraient suffi à attirer à Robert Estienne ni ennuis, ni renommée durable. Il en alla tout autrement avec la Bible latine où ses essais de critique textuelle le forcèrent à quitter Paris pour se réfugier auprès de Calvin à Genève.

\section{A. La première édition critique de la Vulgate}

Le premier éditeur qui ait tenté d'améliorer par la critique le texte de la Vulgate semble être Bernardin Gadolo, originaire de Brescia, prieur du couvent camaldule de St Michel de Murano. Il publia chez Paganino de Paganinis, à Venise, la première édition unissant la Glose ordinaire à la Postille de Nicolas de Lyre. Dans la dédicace (datée du 27 janvier 1495) qu'il adresse au cardinal Francesco Piccolomini, il explique que tous les éditeurs qu'il a d'abord contactés ont été effrayés par les dépenses et le labeur que requerrait une édition si complexe. Il dut donc s'engager auprès de Paganino de Paganinis à assumer lui-même la révision de tout le texte de la Bible. Aussi, 
explique-t-il, “je me suis procuré, non sans peine, tous les livres de la Bible déjà imprimés, ainsi que cinq manuscrits. Et, parcourant le texte que les imprimeurs allaient prendre pour archétype, partout où apparaissait quelque chose d'erroné ou de douteux, j'ai inspecté très attentivement chacun des ouvrages, j'ai supprimé, avec grande application, ce que, par référence à eux, j'ai découvert d'inexact dans ce texte; et les inexactitudes étaient en très grand nombre. En agissant ainsi, je certifie, et Dieu m'en est témoin, que je n'ai ajouté ou changé que ce qui, à partir de quelqu'ancien ouvrage, apparaissait comme devant être évidemment ajouté, changé ou omis. J'ai préféré laisser intactes certaines choses qui me semblaient requérir des corrections, plutôt que de corriger en me fondant sur mon avis personnel, sans l'appui de quelque auteur". Si l'on compare l'édition réalisée par Gadolo à une autre édition courante alors, comme par exemple la petite Vulgate in- $16^{\circ}$ éditée à Bâle, le 26 octobre 1495, chez Jean Froben de Hamelburgk, on se rend compte qu'il parvint, par cette méthode, à éliminer un bon nombre des fautes que se transmettaient toutes les éditions précédentes.

Mais les cinq in-folios de Gadolo n'ont pas eu une grande influence sur les éditions suivantes de la Vulgate, pas plus, d'ailleurs, que le texte de la Vulgate que le cardinal Ximenès dit avoir recensé sur des manuscrits vieux de huit siècles avant de le placer dans l'Ancien Testament de sa polyglotte d'Alcala. Il fallut attendre Robert Estienne pour que le texte de la Vulgate fût soumis à une critique efficace. On ne saurait, en effet, faire entrer sous la dénomination de 'critique textuelle de la Vulgate' les Vulgates retouchées sur l'hébreu et le grec (et non sur des témoins latins) par Andreas Osiander (parue à Nuremberg en 1522), Johannes Petreius (Nuremberg, 1527), Johannes Rudelius (Cologne 1527) et Luther (éditée, pour le Pentateuque, les livres historiques et le Nouveau Testament à Wittemberg en 1529 et rééditée en WA.DB V).

\section{B. Les Bibles de 1528 et de 1532}

Dès l'âge de 19 ans, Robert Estienne, imprimant à Paris, chez son beau-père Simon de Colines, un Nouveau Testament latin in-16 ${ }^{\circ}$, avait éveillé la suspicion des théologiens de Sorbonne. Il s'était permis, en effet, de retoucher certains passages qu'il estimait altérés. A partir de 1524 il commença à recueillir des matériaux pour une édition plus correcte de la Bible latine. Il fit venir d’Espagne la polyglotte d’Alcala dont il avait entendu vanter l'exactitude. Il découvrit dans la bibliothèque de St Germain des Prés un manuscrit très ancien et rempli de corrections qui lui parurent excellentes. Dans celle de St Denis, il en trouva un autre d'une qualité presque aussi bonne. Il les collationna, sur des feuilles séparées, avec les meilleures éditions existantes. En 1528, il édita sur ces bases sa première Bible. Les innovations introduites dans le texte provoquèrent des critiques. Il reconnaît d'ailleurs n'avoir pas toujours été suffisamment exact dans ses collations. Il entreprend alors des recherches plus étendues. Cela aboutit à son édition de 1532. Celle-là aussi suscite le déplaisir des gens de Sorbonne "criant sans fin et sans mesure, à leur façon accoutumée, dit Estienne, que j'avais corrompu la Bible ... car ils appelaient corruption tout ce qui était purifié de cette bourbe commune, à laquelle ils étaient accoutumés". Pourtant l'éditeur avait collationné, cette fois, cinq manuscrits anciens de St Germain, deux de St Denis, d'autres de St Victor, la polyglotte d'Alcala, un correctoire de Sorbonne, l'édition in- $16^{\circ}$ Froben 
1495 de Bâle et l'édition Schoiffer 1462 de Mayence, ainsi que d'autres sources pour le Nouveau Testament et les Psaumes. Il gardait par devers lui un commentaire textuel où il avait noté avec exactitude les témoins qui appuyaient chacune de ses corrections. Il était prêt, disait-il, à en donner connaissance à quiconque lui demanderait d'en rendre compte. De fait, l'édition de 1532 offre un texte plus corrigé que celle de 1528. Cependant, Estienne n'arrive à obtenir des gens de Sorbonne aucune critique précise portant sur telle ou telle correction. Selon des amis bien informés, il n'aura plus d'ennuis avec les théologiens parisiens s'il se contente désormais d'imprimer le texte des éditions les plus anciennes en réservant la marge intérieure de son livre à la mention des leçons qu'il estime préférables. Chacune de celles-ci sera affectée de sigles désignant les témoins sur lesquels elle s'appuie. Or, la marge intérieure de l'édition de 1532 était entièrement occupée par des notes indiquant avec précision ce qui distinguait le texte hébreu de la Vulgate. Elle pouvait paraître ainsi une critique permanente de la Vulgate, accusant celle-ci d'infidélité à la Veritas hebraica que Jérôme avait pourtant prétendu traduire. Si donc on réservait la marge intérieure aux variantes des témoins de la Vulgate,on ferait cesser, du même coup, ce perpétuel procès intenté à la seule base biblique dont disposaient la plupart des théologiens de Sorbonne, étant donné leur faible connaissance de l’hébreu et du grec.

\section{La Bible de 1540 : premier apparat critique}

Dans la magnifique Bible qu'il édita en 1540, Robert Estienne, du fait de la susceptibilité des docteurs parisiens, se trouva donc offrir aux lettrés la première édition critique vraiment scientifique : son texte reproduisait une édition ancienne de bonne qualité, et la marge, avec des repères précis, présentait un choix des variantes les plus intéressantes avec l'exacte indication des témoins de chacune. On pourrait penser qu'il avait désarmé par là ses censeurs. Ce ne fut pas le cas. En effet, Estienne avait fait publier en même temps, en latin et en français, sous forme de placards à afficher sur les murs pour l'édification des fidèles, deux extraits de sa Bible : 'les Dix Commandements' et 'la Somme de toute la Saincte Escripture', sorte de résumé des enseignements de la Bible placé comme préambule à celle-ci et amplifié, entre l'édition de 1532 et celle de 1540 . Or, la Sorbonne, nous dit-il, reprochait à sa somme qu'elle contenait "une doctrine pire que celle de Luther". Lorsqu“Estienne put enfin obtenir l'approbation de 15 maîtres de la Sorbonne et le privilège du Roi, la Faculté ordonna à l'éditeur Jean André d'imprimer les Dix Commandements, suivis des Commandements de l'Eglise. De plus, Estienne nous raconte que ces Dix Commandements avaient été "difformés et corrompus par un certain Odoard qui, des deux premiers commandements, n'en a fait qu'un, ôtant la prohibition, qui est là expresse, de former et adorer les images, et puis a déchiré en deux membres, plutôt que divisé, le dernier Commandement, afin de parfaire la dizaine". Odoard n'avait rien inventé là. Il exprimait une tradition commune à l'Eglise latine depuis Augustin : celle de grouper en un seul les deux premiers commandements et de dédoubler le dixième. Cette tradition s'exprimait clairement dans la forme traditionnelle des Commandements de Dieu selon les catéchismes français, telle qu'elle s'est maintenue, depuis le 'Manuale seu instructorium curatorum' édité à Lyon le 13 février 1505, jusqu'au milieu du XXe siècle : les deux premiers commandements sont unis en un seul (avec 
omission de l'interdiction des images) : “Un seul Dieu tu adoreras et aimeras parfaitement"; alors que le dixième est dédoublé en : “L'oeuvre de chair ne désireras qu'en mariage seulement. Bien d'autrui ne convoiteras pour le garder injustement." On comprend le scandale que causa Robert Estienne en placardant dans la ville de Paris les Dix Commandements selon la Vulgate d'Ex 20,2-17. Il les avait d'ailleurs très légèrement retouchés, ajoutant "ut adores illud" après "sculptile", au vs 4, et omettant les vss $5 b$ et 6, ainsi que "quam Dominus Deus tuus dabit tibi" à la fin du vs 12.

\section{La Nompareille de 1545}

Cependant, Estienne préparait déjà une nouvelle Bible qui parut en 1545. Elle présentait des innovations propres à inquiéter les théologiens de Sorbonne.

- Les Bibles de 1528, 1532 et 1540 étaient des in-folios coûteux et difficiles à déplacer. Il s'agissait cette fois-ci de deux petits in-octavo imprimés en caractères très fins.

- Deux traductions latines étaient juxtaposées. L'une reproduisait le texte de la Vulgate selon l'édition de 1540, avec les variantes marginales, mais sans indication des sources de ces dernières. L'autre était une traduction nouvelle faite sur l'hébreu. Estienne n'en nommait pas l'auteur et disait seulement l'avoir choisie de préférence à celle de Sanctes Pagnini. Il confessait que celle-ci était la plus exacte. Mais il estimait son extrême littéralisme trop peu intelligible pour le public auquel il destinait cette édition. De fait, cette nouvelle traduction était l'oeuvre de Leo Jud, collaborateur intime de Zwingli. Elle avait été achevée et publiée à Zurich en 1543 par Bibliander, après la mort du traducteur.

- Cette traduction nouvelle était accompagnée de très copieuses annotations. Estienne expliquait dans son avant-propos sa double intention : comparer cette traduction à celle de Pagnini et expliquer les difficultés qui subsisteraient dans l'hébreu malgré ces traductions. Pour cela, il avait fait appel à de fidèles auditeurs de François Vatable, professeur royal d'hébreu, qui lui avaient communiqué les notes prises à ses cours. Il avait donc rédigé les annotations à partir de l'enseignement de Vatable et des notes figurant dans la marge “des Bibles que nous avons imprimées dans les années précédentes", expression qui fait vraisemblablement allusion à l'édition de 1532.

\section{E. La lutte et I'exil}

La Bible de 1545 suscita une violente tempête en Sorbonne. N'était-ce pas un véritable commentaire d’Ecriture Sainte que l'on publiait là, avec privilège du roi, en le plaçant sous le nom d'un professeur d’hébreu du Collège Royal! Pour comprendre cette indignation, il faut se souvenir que c'est sur le conseil de Guillaume Budé que François Ier avait fondé en 1530 le Collège du Roi constitué de deux lecteurs de grec et de deux lecteurs d’hébreu dont le premier était Vatable. L'Université, jalouse de ses privilèges, avait incité sa Faculté de théologie à poursuivre les lecteurs d'hébreu devant le Parlement comme incompétents pour enseigner l’Ecriture Sainte. Mais le roi avait refusé de soumettre la compétence de ses lecteurs au jugement des théologiens. Ladite Faculté n'était donc guère disposée à fermer les yeux lorsque l'on éditait, sous le nom de l'un des lecteurs qu'elle avait accusés d’incompétence, un commentaire d’Ecriture, type d'ouvrage que les professeurs de théologie s'estimaient seuls 
habilités à produire. Robert Estienne, en 1546, sachant qu'on allait l'accuser devant le roi, prit les devants et s'ouvrit de ses inquiétudes à Pierre du Chastel, évêque de Mâcon et grand-aumônier. Sur leur proposition à tous deux, le roi ordonna aux théologiens de communiquer leurs censures par écrit et de les motiver, de sorte que son imprimeur pût les publier conjointement avec sa Bible "afin que, par ce moyen, les lecteurs fussent avertis de ne tomber, par mégarde, en quelque annotation qui ne sentît Jésus Christ". Mais les docteurs de Sorbonne voulaient obtenir du Parlement ou du Roi que l'on fît défense à Robert Estienne de vendre sa Bible annotée. Ils se rendaient compte que, s'ils communiquaient censures et motifs par écrit, ceux-ci deviendraient objet d'une controverse publique. Aussi acceptèrent-ils seulement de formuler leurs censures oralement, devant le Conseil Etroit, "parce que les Théologiens n'ont pas accoutumé de montrer par écrit ce qu'ils jugent être hérétique, mais seulement de parole". Après discussion, ils se rendent compte qu'ils n'obtiendront pas ainsi la suspension du privilège royal. Ils se résignent à envoyer "quinze passages qu'ils avaient notés". Là-dessus, François Ier meurt et son fils Henri II, également favorable à Estienne, lui succède. Mais ce roi influençable finit par promettre aux Théologiens qu'il interdira définitivement à son imprimeur de vendre les Bibles annotées, à condition qu'ils communiquent le reste de leurs censures. "Par ce moyen, dit Estienne, il m'eât fallu perdre toute la peine que, jusqu'à présent, je me suis efforcé d'employer en la sainte Escripture et bonnes lettres, et qu'ai, de ferme propos, délibéré y dédier jusqu’à la fin de ma vie". Robert Estienne fit alors dire au roi, par Du Chastel, qu'il était "contraint d'abandonner le pays... Lors, le Roi répondit que, pour cela, il ne me fallait point laisser le pays, seulement que je me donnasse garde à l'avenir; ajoutant que j'eusse bon courage, et que je poursuivisse, comme de coutume, à faire mon devoir, à orner et embellir son imprimerie". La lutte avait épuisé Robert Estienne. Dès la mort du roi François, il avait mis son imprimerie sous le nom de ses enfants encore mineurs. Puis, il avait fait passer ceux-là l'un après l'autre, par Strasbourg ou par Troyes (où il avait de la famille et des relations) vers Lausanne. Il se réfugia lui-même à Genève (où il fit venir ses enfants) dans les derniers mois de 1550. Le 27 juin 1551, ses biens furent mis sous séquestre. Mais le roi Henri manifesta une dernière fois sa faveur à Robert en faisant lever le séquestre dès l'année suivante en faveur des enfants, sur intervention de Charles, frère du fugitif, leur tuteur. Tout de suite, Robert réouvrit son imprimerie à Genève. Le premier livre qu'il y publia, dès 1551, fut une traduction grecque du catéchisme de Calvin, ouvrage qu'il n'édita en français (sa langue originale) qu'en 1553 et qu'il publia aussi en hébreu (dans une traduction d'Emmanuel Tremellius, dont nous aurons à reparler plus tard), le 24 août 1554. En 1552, Robert publia, en latin (le 23 juin) puis en français (le 13 juillet), les censures prononcées par les théologiens de Sorbonne (telles qu'il était arrivé à se les procurer par certains d'entre eux) avec sa réponse à ces censures, le tout précédé d’une apologie où il explique les motifs de son exil volontaire, apologie dont nous avons tiré toutes les citations précédentes.

Ce fut donc la Bible de 1545 qui transforma les tracasseries en persécution. Ce petit bijou de finesse et d'exactitude typographique fut appelé par les bibliophiles 'la Nompareille'. Il figura bientôt dans toutes les éditions de l'Index des Livres Prohibés : Paris 1549, Louvain 1550, Venise 1554 et Rome 1559. 


\section{La Bible de Vatable aux prises avec I'Inquisition espagnole}

L'index espagnol de 1551, reproduisant celui de Louvain, censurait la Bible d’Estienne de 1545. D'ailleurs, les inquisiteurs, lors d'une perquisition qu'ils firent à Séville en 1552, en saisirent trois exemplaires. Aussi fut-elle intégrée dans la liste des "impressions de la Bible qui ont besoin de correction et de censure" que l'Inquisition espagnole publia en 1554 à Valladolid sous le titre de 'Censure générale contre les erreurs dont les hérétiques récents ont parsemé la Sainte Ecriture'. Imbonati (219-229) nous a conservé l'énumération détaillée des corrections à effectuer dans l'Ancien Testament de la Bible de 1545. Quant au Nouveau Testament, sa 'nouvelle traduction' et ses 'annotations' devaient être entièrement omises, ainsi que l'Index des choses et des énoncés contenus dans les livres de l'Ancien et du Nouveau Testament' qui occupait 60 colonnes à la fin de la Bible d'Estienne.

\section{A. Les pièces officielles sur la réédition de 1586}

L'index espagnol de 1559 avait réitéré la prohibition de la “Bible éditée à Paris par Robert Estienne avec une double traduction, vulgate et nouvelle, et avec des annotations de Vatable". C'était l'édition de 1545 que tous les lettrés avaient pris l'habitude d'appeler 'Bible de Vatable'. Or cette Bible fut rééditée à Salamanque en des circonstances que retracent 7 documents figurant au début et à la fin de l'édition dans le but de l'authentifier et d'éviter que sa diffusion ne soit entravée.

Le 26 janvier 1569, Gaspard de Portonariis, libraire à Salamanque, présenta une requête au Conseil de l'Inquisition générale d’Espagne. Il faisait remarquer que la Bible de Vatable avec double traduction figurait à l'Index des livres prohibés et qu'il désirait l'imprimer parce qu'elle pouvait être très utile pour les personnes instruites. Aussi demandait-il à leurs Seigneuries de la soumettre aux personnes qu'elles estimeraient compétentes pour l'expurger et la corriger. Les membres du Conseil agréèrent cette requête et écrivirent, le 1er février 1569, au Maître Francisco Sancho, chanoine de Salamanque, doyen de la Faculté de théologie et commissaire du SaintOffice. Ils l'informaient de la démarche du libraire en précisant qu'il désirait aussi imprimer le Nouveau Testament dont l'Inquisition avait demandé autrefois l'omission. Le Conseil chargeait donc Sancho de corriger cette Bible et le Nouveau Testament et de lui envoyer l'exemplaire corrigé avant que l'impression ne commençât. Il accomplit cette tâche en collaboration avec d'autres membres de la Faculté de théologie de Salamanque. Ils étudièrent cette Bible durant de nombreuses séances et signèrent leur censure qu'ils communiquèrent au Conseil, disant que, sur cette base, il était possible d'imprimer cette Bible, impression qui serait "chose très utile et importante".

Le 20 mars 1571, Gaspard de Portonariis demanda au Conseil de lui envoyer une attestation de son approbation des censures de Sancho pour qu'il pût commencer l'impression conformément à ces censures. Le 21 avril 1573, le Conseil du Roi Philippe II, vu l'accord du Conseil de l'Inquisition générale, l'autorisa à imprimer ou à faire imprimer ladite Bible, conformément aux censures de Maître Sancho. On précisait que tout exemplaire de cette Bible ne pourrait être vendu que revêtu de la signature du commissaire désigné par l'Inquisiteur général pour en attester la conformité aux censures susdites. Avant la mise du livre sur le marché, il devrait être soumis en outre 
au Conseil royal pour que celui-ci pût contrôler l'exécution des conditions mises à l'édition et fixât le prix de vente de l'ouvrage. Enfin, le 11 décembre 1585, Gaspar de Quiroga, cardinal de Tolède, Inquisiteur général, désigna frère Roman de Vallezillo, bénédictin, commissaire du Saint Office à Medina del Campo, pour contrôler la conformité des exemplaires aux censures formulées par l'Inquisition. Il devait en outre contrôler et retoucher chaque exemplaire et y apposer ensuite sa signature, avec le jour, le mois et l'année où il aurait achevé le contrôle dudit exemplaire. Ceux des exemplaires qui se trouvaient à la cour royale devaient être soumis au contrôle du $\mathrm{Dr}$ Pedro Lopez de Montoya. Selon ce document, Gaspard de Portonariis réalisa l'impression en 1584 et fut aidé financièrement par Guillermo Robilio et Benito Boyer (dont les noms se retrouvent à la page de titre sous les formes latinisées de Guilielmus Rouillius et Benedictus Boierius).

En date du 6 février 1586, l'éditeur reçut un privilège royal protégeant, pour une durée de 20 ans, son édition contre les faussaires. Le 22 février 1586, le Conseil royal fixa le prix de vente à 7 maravédis par feuille imprimée. Dans notre exemplaire, le certificat de conformité est signé par le frère Roman de Vallezillo, commissario de Inquisicion; sa révision avait été achevée le 20 juin 1586 au monastère de Medina del Campo.

\section{B. Censures parisiennes et censures espagnoles}

C. du Plessis d'Argentré dans la Collectio judiciorum de novis erroribus, t. II, Paris 1728, pp. 143-160, a publié les censures des docteurs de Sorbonne contre les Bibles de Robert Estienne. Il les a empruntées aux registres de la Faculté de Théologie de Paris, les 46 premières étant datées du 14 novembre 1547 et les 120 suivantes du 15 mai 1548. Si on les compare aux censures espagnoles de 1554-1559 publiées par Imbonati, et aux corrections de 1569-1571 réalisées sous le contrôle de R. de Vallezillo dans la réédition de Salamanque, un certain nombre de particularités apparaissent.

1/ La censure parisienne de 1547 concluait que les Bibles éditées par Robert Estienne en 1528, 1532, 1534, 1540, 1545 et 1546 devaient être supprimées (supprimenda sunt) “d'abord parce qu'on y a inséré audacieusement de nombreuses choses qui s'opposent aux bonnes moeurs, à la piété, aux décrets des saints Pères et aux doctrines de la foi; et aussi parce qu'elles sont parsemées de nombreuses erreurs, d’assertions scandaleuses, impies, de tendance luthérienne, orientées vers une hérésie depuis longtemps condamnée, bien plus un certain nombre d’affirmations clairement hérétiques et même de blasphèmes. En outre, dans le texte même de ces Bibles, de nombreux passages ont été témérairement modifiés, certains ont été omis, d'autres ajoutés d'une manière qui diverge d'avec la forme textuelle authentique reçue jusqu'ici par l'Eglise; ce qu'on ne saurait permettre à une personne privée ni de faire ni de publier". La censure de 1548 ajoutait que ces Bibles, ainsi que les Nouveaux Testaments et les Psaumes édités par Robert Estienne devaient être mis dans le catalogue des livres condamnés (librorum reprobatorum).

Les 166 censures réparties en 5 catalogues distincts constituent des listes assez hétéroclites. On a affaire, semble-t-il, à des dossiers successifs fournis par les théologiens au Conseil Etroit du roi dans le seul but d'obtenir la confiscation des Bibles et leur interdiction. 
2/ La censure espagnole de 1554 ne visait pas à interdire l'usage des Bibles de Robert Estienne. J.M. de Bujanda (Index de l'Inquisition espagnole 1551, 1554, 1559, Sherbrooke 1984) a publié des documents qui montrent très clairement le but visé par la Censure des Bibles de 1554. Il s'agissait de sortir de la situation critique créée en Espagne par la publication (en 1551) des interdictions de Bibles promulguées à Louvain en 1550. Le 29 janvier 1552, le Conseil de l'Inquisition générale s'adressait à Domingo de Soto et à Francisco Sancho en ces termes (Bujanda 78, n. 101) : “Vous savez bien que le catalogue des livres interdits mentionne plus de trente éditions de la Bible qui doivent être saisies et confisquées. Etant donné le petit nombre de celles qui restent dans le royaume si aucune des dites Bibles n'est rendue, nous désirons que celles en lesquelles il ne se trouve que peu d'erreurs et que l'on peut corriger facilement soient rendues à leurs propriétaires." Aussi demanda-t-on aux deux maîtres de Salamanque de noter toutes les erreurs qui se trouvaient en chacune des éditions, ce qu'ils firent avec l'aide d'autres professeurs de la Faculté de théologie pour trente trois éditions. Ils communiquèrent ensuite leurs listes au Conseil de l'Inquisition. Les théologiens d'Alcala réalisèrent un travail semblable sur seize autres éditions. D'autres encore furent analysées par diverses commissions. La censure de 1554 eut donc pour but d'énumérer les 103 éditions de la Bible que leurs possesseurs devaient, dans un délai de 60 jours, communiquer à l'Inquisition pour qu'elles soient expurgées (au prix d'un demi réal chacune). Il était désormais interdit d'importer des Bibles censurées, même si elles avaient été corrigées auparavant.

La liste de censures publiée par Imbonati n'a donc pas pour but, comme celles de Paris, de motiver une interdiction. Elles guidaient les inquisiteurs chargés de corriger la Bible Estienne de 1545 en vue de sa remise en circulation.

\section{Echec d'une première réédition en 1555}

L'interdiction d'introduire de nouveaux exemplaires des Bibles censurées pesait lourdement sur tous ceux qui considéraient la "Bible de Vatable" comme la meilleure source d'information sur la signification du texte hébreu de l'Ancien Testament. Cela explique la réédition de cette Bible en 1555 à Salamanque par André de Portonariis. Il la prétendait corrigée et révisée par Domingo de Soto. Lorsqu'en 1559, on prépara une nouvelle édition de l'Index espagnol où cette réédition allait figurer, Soto écrivit à Bartolomé Carranza (V. Beltrán de Heredia, Domingo de Soto, BTE 20, Salamanca 1960, 413, n.21) : “Ils ont retenu une bible imprimée à Salamanque. Je figure sur son titre et elle se place sous mon patronage à titre de correcteur. De ma vie, je ne l'ai vue ni ne sais en quelle langue elle a été imprimée. J'ai adressé à l'Inquisition une plainte contre l'imprimeur et ils disent qu'ils répareront mon honneur aux dépens de l'imprimeur." De fait, l'Index de 1559 la mentionna en ces termes : "Biblia Salmanticae per Andream de Portonariis anno 1555, cujus correctio, sive recognitio falso imponitur fratri Dominico de Soto Segoviensi, theologo ordinis praedicatorum". Cette édition fut donc saisie et jointe à d'autres livres séquestrés qui, à Tolède, remplissaient cinq chambres du palais du cardinal. Le 10 juillet 1561, une demande fut adressée au Conseil pour lui demander ce qu'il fallait en faire : "Il y a d'autres Bibles qui ne contiennent aucune des erreurs mentionnées dans la censure ni aucune autre. Il semble qu'elles ont seulement été interdites parce que l'imprimeur 
avait dit à tort qu'elles étaient corrigées par frère Domingo de Soto et imprimées à Salamanque par André de Portonariis". La décision du Conseil fut inscrite en marge de la demande : “Qu'elles soient brûlées parce qu'elles contiennent de nombreuses fautes". L'ordre ne fut cependant pas exécuté, puisqu'au siècle suivant on constatait dans la ville impériale l'existence d'un dépot de ces bibles "corrigées par Soto". Elles étaient déjà à moitié pourries (Beltrán de Heredia 413). De fait, André de Portonariis imprima à Salamanque 29 oeuvres diverses de Soto de 1550 à 1569. Dominique de Portonariis en imprima 4 de 1569 à 1572 et Vincent de Portonariis une en 1580.

Vu l'échec de la tentative de 1555 pour rééditer la Bible de Vatable, ce fut le quatrième des frères De Portonariis, Gaspard qui, le 26 janvier 1569, entreprit auprès du Conseil de l'Inquisition générale, la démarche que nous avons racontée. Domingo de Soto était mort le 15 novembre 1560. Aussi la tâche de corriger la Bible de 1545 en vue de cette réédition fut-elle confiée à Francisco Sancho, un des rédacteurs de la censure de 1554. Ses collègues de la Faculté de Théologie de Salamanque l'aidèrent à cette révision. Les plus actifs furent Luis de Leon, Juan Gallo, Juan de Guevara, Leon de Castro, Gaspar de Grajal et Martin Martinez de Cantalapiedra.

\section{$D$. Le procès de trois des réviseurs}

Après l'achèvement de la révision (janvier 1571), trois des réviseurs (Luis de Leon, Gaspar de Grajal et Martin Martinez) furent dénoncés à l'Inquisition par certains de leurs collègues. On reprochait, entre autres choses, à Martin Martinez d'“avoir préféré Vatable, Pagnini et les juifs et les rabbins à la traduction Vulgate et au sens des saints et des docteurs de l'Eglise catholique" et d'avoir "ôté et diminué l'autorité et la vérité de l'édition Vulgate en disant et affirmant qu'elle a beaucoup de faussetés et qu'on en peut faire une autre meilleure" (Acte d'accusation du 6 mai 1572, selon A. Coster, Luis de Leon : Revue Hispanique 54 (1922) 291). A Luis de Leon on faisait les mêmes reproches et l'on ajoutait : “il a dit que, même si le sens et l'explication des [prophètes par les] Evangélistes étaient vrais, l'interprétation des juifs et des rabbins pouvait l'être aussi, même si c'était un sens différent, affirmant que l'on pouvait produire des explications nouvelles de l'Ecriture". On lui reprochait aussi d'avoir “mal parlé des Septante, disant qu'ils ne savaient pas bien l'hébreu, et qu'ils ont mai traduit l'hébreu en grec" et d'avoir "affirmé que le Concile de Trente n'a pas défini comme étant de foi l'édition Vulgate de la Bible, mais qu'il l'a seulement approuvée" (Coster 271s). Le cas de Gaspar de Grajal était encore plus grave. On lui faisait grief d'avoir dit "qu'il avait corrigé deux ou trois cents passages de la Sainte Ecriture qui étaient erronés dans l'édition Vulgate", d'avoir "dit et affirmé que les saints ne donnent pas le sens littéral à l’Ecriture parce que le sens littéral doit se chercher chez les rabbins", d'avoir "dit et affirmé publiquement que la traduction des Septante est erronée et qu'elle ne correspond pas à l"hébreu" et "que la Vulgate n'a pas été déclarée canonique ni ne l'est, parce qu'il n'est pas établi que le traducteur eût l'esprit de Dieu et que, dans le texte Vulgate de la Bible, il n'y a de foi que les principales propositions et non les autres" (Coster 277-280). Grajal, arrêté le 1er mars 1572, mourut en prison le 8 septembre 1575 et sa mémoire fut lavée de l'accusation d'hérésie par le Conseil en un autodafé qui se tint le 28 septembre 1578. Quant à Luis de Leon et à Martin Martinez de Cantalapiedra, arrêtés le 26 mars 1572, ils furent réprimandés, 
avisés de traiter de ces matières avec plus de prudence et finalement libérés, le premier le 11 décembre 1576 et le second le 4 juin 1577. A la fin de 1572, Gaspar de Quiroga avait succédé à Diego de Espinoza comme Inquisiteur général. Ce changement joua certainement un rôle dans le dénouement des procès intentés aux trois professeurs. Luis de Leon reprit son enseignement à la Faculté. Martin Martinez, lui, mourut le 18 novembre 1579, sans avoir obtenu le recouvrement des arriérés de son traitement professoral pour les six ans qu'il avait passés en prison. Ces événements tragiques n'empêchèrent pas la réédition de la Bible révisée. Mais ils eurent sûrement une influence sur le long délai qui sépare l'autorisation donnée à Gaspard de Portonariis par le Conseil royal (1573) de l'impression (1585). L'éditeur, dans une requête au Conseil royal (mentionnée dans le privilège d'impression) affirme d'ailleurs qu'il a été empêché d'imprimer cette Bible durant douze ans après en avoir reçu l'autorisation. Il se plaint que lui et ses associés ont dépensé à cette impression la plus grande partie de leur fortune. Il semble que ce soit durant ces douze ans que le Conseil de l'Inquisition soumit aussi la Bible de Vatable à la censure des théologiens d'Alcala.

\section{E. Les rééditeurs}

Qui sont les frères De Portonariis et les deux coéditeurs mentionnés dans les titres et les documents initiaux de l'édition? Voici ce que la Bibliographie lyonnaise de $\mathrm{H}$. Baudrier (réimpression de Paris 1964 vol. $\mathrm{V}$ et IX) nous apprend à leur sujet. Originaire de Trino, dans le marquisat de Monferrato, Vincent de Portonariis vint à Lyon, à la fin du XVe siècle, travailler comme ouvrier chez Balthasar de Gabiano, libraire originaire d'Asti. Vers 1506, il s'établit à son compte et ses éditions prospèrent jusqu'en 1547 où il meurt sans enfants. Il ș'était associé son frère Dominique dont il employa les quatre fils Pierre, Gaspard, André et Vincent. Il les institua ses héritiers, ainsi que leurs deux soeurs, et laissa à Dominique la jouissance de ses biens. Ce dernier administrait les succursales de son frère à Medina del Campo et à Salamanque lorsque la mort de celui-ci l'obligea à rentrer à Lyon pour reprendre la maison d'édition qui, dès lors, périclita entre ses mains. Ses fils administraient les succursales espagnoles: André celle de Salamanque et Vincent celle de Medina del Campo. Pour ne pas concurrencer son père et ses frères, Pierre s'établit en 1552 papetier à Rochetaillé. Gaspard aida d'abord son père, puis celui-ci lui céda la direction de la maison lyonnaise vers 1556. Il édita à Lyon sous la marque de "l'ange" (qui avait été celle de son oncle et de son père) jusqu'en 1568. André, lui, avait soumissionné sans succès auprès de l'Inquisition pour éditer la Censure des Bibles de 1554; on lui préféra l'offre plus avantageuse de Francisco Fernandez de Cordoba de Valladolid. Il mourut, semblet-il, à Salamanque vers la fin de l'année 1567. Dominique et son fils Gaspard vinrent alors s'y établir et y transférèrent la marque de "l'ange".

Le patronyme du premier coéditeur est 'Rouillius' dans le titre de l'ouvrage et 'Robilio' dans le document de l'Inquisition. Il s'agit de Guillaume Rouillé (selon l'orthographe que Baudrier préfère à 'Roville'). Il naquit vers 1518 à Dolus, près de Loches en Touraine, et acquit sa formation de libraire à Venise auprès de Giovanni Giolito de Ferrari, puis en 1542, de son fils et successeur Gabriel. Sur recommandation de ce dernier, Rouillé entra au service des Portonariis à Lyon en 1543. Vincent de Portonariis avait d’ailleurs été déjà associé en 1510 pour une édition à Giovanni 
Giolito de Ferrari. Vers 1544, Rouillé épousa Marguerite, fille de Dominique de Portonariis, et commença une brillante carrière d'éditeur qui dura jusqu'à sa mort, en juin 1589. En 1568, il acheta aux Portonariis la maison "de l'ange" ( $n^{0} 54$ de la rue Mercière et $n^{0} 25$ du quai St Antoine). Il fut dès lors en relation étroite avec ses beaux-frères qui écoulaient ses livres à Salamanque, et avec Benoît Boyer ( $=$ 'Boierius" dans le titre et 'Boyer' dans le document de l'Inquisition). Ce dernier, riche libraire de Medina del Campo, avait, dès 1571, des livres en dépôt chez de nombreux libraires lyonnais et leur servait de dépositaire en Espagne. En septembre et octobre 1580, on le voit présent à Lyon où il règle ses comptes avec les libraires. Guillaume Rouillé éprouvait des difficultés à récupérer les sommes que lui devaient ses dépositaires espagnols. Ainsi, par exemple, en septembre 1579 (Baudrier IX 95), ses beaux frères de Salamanque lui étaient redevables d’environ 1.300 écus d'or. La coédition Portonariis-Rouillé-Boyer recouvrait donc probablement une opération financière visant un double but : d'une part le remboursement des dettes de G. de Portonariis à l'égard de Rouillé et d'autre part le recouvrement par Boyer des sommes dues par Rouillé comme dépositaire de ses exportations à Lyon. Tout le monde espérait, en effet, que la réédition de la Bible de Vatable serait un succès de librairie. En 1584, Rouillé (Baudrier IX 103 et $V$ 115) envoya à Séville son jeune fondé de pouvoir, Jean-Baptiste Buysson. Celui-ci y fit relier cent Bibles de Vatable à destination des Indes.

L'Inquisition générale d'Espagne ne pouvait pas ignorer qui était Guillaume Rouillé. Certes, en 1584-1586 - époque où il finance la réédition espagnole de la Bible de Vatable -, il pouvait apparaître comme un grand éditeur catholique. Il avait, en effet, édité les Canons et Décrets du Concile de Trente en 1564, 1565, 1566, puis (avec l'Index des livres prohibés) en 1572, 1577, 1580 et 1584, ainsi que le Catéchisme dit du Concile en 1567 et 1579. Il avait également édité, en 1578, 1583 et 1586 , le Missale Romanum. Il y reproduisait un bref de Grégoire XIII qui avait été accordé le 22 mai-1573 à “G. Rouillius, typographus ac bibliopola Lugdunensis, quod ipse, qui in tumultibus et seditionibus ab haereticis superioribus annis in regno Franciae excitatis, fidem catholicam semper tenuit et secutus fuit..." Dans le Missel de 1578, Rouillé faisait cependant usage d'une suite de vignettes qu'il avait déjà utilisée en 1562 dans un Nouveau Testament français protestant d'origine genevoise.

En effet, de 1545 à 1562, il avait contribué activement à la diffusion à Lyon des Bibles genevoises en français. Dès 1545, première année où il publia sous son nom, il partagea avec G. Arnoullet l'édition du Nouveau Testament de Genève, selon la révision que Calvin en avait donnée en 1543 chez J.Girard. Puis, en 1547, il fit imprimer par Jean Pidier et Nicolas Bacquenois la Bible de Genève qui avait été introduite pour la première fois dans l'édition lyonnaise en 1544 par Antoine Constantin, son associé à l'époque. En 1547, Rouillé ne possédait pas encore de bois gravés pour les illustrations. Il utilisa alors ceux de Thibault Payen qu'il prit comme coéditeur. Cette Bible fut rééditée par Rouillé et Payen en 1548, année où tous deux, associés à Constantin, publièrent le Nouveau Testament de Genève. Volant de ses propres ailes, Rouillé réédita seul ce Nouveau Testament en 1550. Quatre ans plus tard, il le publia en trois états différents dont deux en français et un en latin et français, qu'il réédita en 1557, 1558 et 1561. Le Nouveau Testament français fut édité à nouveau en 1562, augmenté de la 'table des matières' qui figurait dans les éditions 
de Genève depuis 1556. Ce ne furent pas là les seules éditions bibliques de Rouillé. Il édita également en 1558 la traduction "de l'hébreu en latin et en français" des Psaumes, Proverbes, Ecclésiaste, Cantique des Cantiques, Sapience et Ecclésiastique. Cette traduction, publiée sans mention du nom du traducteur, était l'oeuvre du calviniste Louis Budé. Elle était parue pour la première fois en 1551, à Genève chez Jean Crespin, l'éditeur attitré de Calvin. Rouillé partagea avec lui plusieurs éditions jusqu'en 1566 (Baudrier IX 308). Chose plus surprenante, en 1547, 1549 et 1550, Rouillé publia en italien le Nouveau Testament d'Antonio Brucioli; il le réédita en 1552 et en 1558, mais sans mention du nom du traducteur. Ajoutons que le premier Index des livres prohibés publié par le Saint-Siège, celui de Paul IV en 1559, mentionnait formellement : "Novum Testamentum Lugduni apud Guilielmum Rouillium 1545".

L'éclectisme de Rouillé au début de sa carrière se manifeste par les dix éditions successives des oeuvres de Marot de 1546 à 1561. Il édita également, en 1555, le Décaméron de Boccace en italien et, de 1551 à 1560, quatre fois en français dans une traduction dédiée à Marguerite de Navarre dont il publia en 1549 “le miroir de l'âme pécheresse". La même année, il fit paraître en français et en latin les Apophthegmes d'Erasme et en latin les Dialogues sacrés de Sébastian Châteillon. La prise de Lyon par les protestants en 1562 et les troubles religieux qui s'ensuivirent provoquèrent un net changement dans la politique éditoriale de Guillaume Rouillé. Ainsi, fort du bref de Grégoire XIII, il pouvait se présenter aux inquisiteurs espagnols, en 1584-1586, comme le plus célèbre éditeur catholique de Lyon.

\section{F. La correction de la réédition de la Bible de Vatable par I'Inquisition}

La page de titre datée de 1584 porte la mention “Cum Privilegio Hispaniarum Regis" et le titre : "Biblia Sacra cum duplici translatione \& Scholiis Francisci Vatabli, nunc denuò à plurimis, quibus scatebant, erroribus repurgatis, doctissimorum Theologorum, tam almae Universitatis Salmanticensis, quàm Complutensis iudicio : ac Sanctae \& generalis Inquisitionis iussu".

Les exigences de l'Inquisition pour cette réédition furent bien moindres que celles qu'elle avait présentées en 1554 pour la correction des exemplaires confisqués.

1/ En 1554 (Imbonati 227b), l'Inquisition exigeait la suppression complète pour le Nouveau Testament, de la 'nova translatio' et des 'scholia'. La réédition, au contraire, les conserva avec seulement de légères corrections.

L'Index des choses et des énoncés contenus dans les livres de l'Ancien et du Nouveau Testament fut remplacé par un 'Index biblique' dû au jésuite Jean Harlemius. Ajoutons que la réédition de 1587 est encore plus complète que la Bible de 1545. En effet, les scholies des Psaumes, beaucoup plus développées, furent empruntées au 'Liber Psalmorum Davidis' que Robert Estienne avait publié à Paris en 1546, selon la promesse qu'il en avait faite en achevant hâtivement sa Bible de 1545.

2/ En 1554, l'Inquisition ne se contentait pas de la mention “Ex officina Roberti Stephani" figurant en bas de la page de titre. Elle demandait d'ajouter (Imbonati 219a): "Monemus Lectorem, translationem novam, \& scholia horum Bibliorum à Roberto Stephano, Auctore damnato, primum edita, \& depravata fuisse". Dans la réédition, elle préfère omettre toute mention du nom de Robert Estienne. 
3/ Voici un échantillon de la censure de l'Ancien Testament : sur les 123 corrections requises en 1554 (selon Imbonati 223-229) pour Psaumes, Proverbes, Ecclésiaste, Cantique, Sagesse et Isaïe, seules 96 ont été réalisées dans la réédition de Salamanque, dont 90 par l'imprimeur et 6 à l'encre par Roman de Vallezillo. Les 27 omissions sont dues, semble-t-il, à des étourderies car elles se suivent d'ordinaire par groupes de deux ou de trois.

4/ En 1554, le Nouveau Testament n'avait pas fait l'objet de censures détaillées (on demandait alors d'en omettre entièrement les scholia). Cela explique que la commission de 1569-1571 ne disposait pas de la première liste des censures parisiennes de 1548 qui portaient justement sur les annotations des Nouveaux Testaments de Robert Estienne. Vatable, professeur d'hébreu, n'avait eu aucune part dans ce secteur des annotations de la Bible de 1545. Celles-ci n'étaient, pour la plupart, que des emprunts au Nouveau Testament d'Estienne édité en 1543, comme l'avaient d'ailleurs relevé les théologiens parisiens. Vu leur ignorance des censures parisiennes, les réviseurs de Salamanque laissèrent sans retouches plus d'une trentaine de propositions d'Estienne que la Sorbonne avait qualifiées plus ou moins sévèrement d'hérétiques, suspectes d'hérésie, favorisant l'hérésie, schismatiques, téméraires, fausses, erronées, captieuses etc.

\section{G. Exégèses contraires ou différentes}

Lors de son procès, Luis de Leon (Coster, Revue Hispanique 53 (1921) 241-243, notes) raconta une altercation survenue entre Leon de Castro et lui-même durant la révision de la Bible de Vatable : "Je me souviens qu' ... en examinant les explications nouvelles que donnait $V$ atable, et la façon dont il fallait les admettre ou les rejeter, mon avis fut le suivant : ... que, lorsque tous (les saints) sont d'accord pour expliquer un passage de la même façon, cette explication doit être tenue pour certaine et catholique, surtout en ce qui touche la foi ou les moeurs; mais que, sans rejeter cette explication, et en la respectant comme je viens de le dire, s'il existe un autre sens qui n'y soit pas contraire, bien qu'il en diffère, et qui soit catholique et de bonne doctrine, on peut l'admettre, mais en lui accordant moins d'autorité qu'au premier que donnent les saints; et je le prouvai par des raisons et des textes tirés de saint Augustin. Cela mécontenta maître Leon [de Castro]; mais je me souviens que maître Francisco Sancho m'approuva et allégua pour le confirmer un passage d'Aristote, dans lequel il déclarait que ce n’était pas la même chose d'être contraire que d'être différent; et, en conséquence, les autres maîtres l'approuvèrent. Et ce fut d'après cette règle que nous corrigeâmes ladite Bible, et lorsque nous trouvions quelque chose de contraire à l'avis des saints, ou qui ne fat pas de bonne doctrine, nous le supprimions, et ce qui n'était pas contraire, bien que ce fût différent, nous le laissions". Luis avait pris exemple de la phrase d'Isaïe "Generationem ejus quis enarrabit ?", phrase qui se trouve en Is 53,8 et se retrouve citée en Act 8,33. En ces deux endroits, la 'nova translatio' est identique à la Vulgate: "qui racontera sa génération ?"' Les 'Saints' s'accordent à voir ici une allusion au caractère ineffable de l'engendrement miraculeux du Sauveur. Or, en Act 8,33, 'Vatable' commentait: "Ici, 'génération' désigne ses contemporains. Le sens est : qui pourra dépeindre l'injustice des hommes qui vivront à son époque, puisqu'ils vont le mettre à mort quoiqu'il soit juste." En 1548, les Théologiens de Paris 
avaient fait de ce commentaire le $13 \mathrm{e}$ article de leur liste, qualifié de la censure suivante : "Cette interprétation est complètement étrangère (omnino aliena) à la compréhension absolument authentique (rectissima) de l'Eglise et des saints Docteurs". La commission de Salamanque conserva ici la scholie de 'Vatable', ajoutant seulement en marge : "exégèse nouvelle qui ne doit pas déroger à l'exégèse des saints". En Is 53,8 la même note fut imprimée en marge de cette scholie de 'Vatable" : "son époque, c'est-à-dire la perversité de son époque. Il commence à s'indigner contre les contemporains du Christ, c'est-à-dire : 'qui donc sera capable d'exprimer par des paroles la perversité des Juifs qui vivront à l'époque du Christ !" Plus tard, le commissaire Vallezillo raya à l'encre la scholie, si bien que l'on ne comprend plus sur quoi portait la note marginale des réviseurs.

Comme on peut le constater, ceux-ci ont essayé d'introduire un certain pluralisme exégétique, sur l'initiative de Luis de Leon et sous l'influence de la logique aristotélicienne qui avait trouvé un bon avocat en Francisco Sancho. Mais l'omission finale de la scholie de 'Vatable' sur Is 53,8 fut probablement une conséquence de l'exemple qu'en avait tiré Luis de Leon au cours de son procès.

Leon de Castro n'admettait pas qu'un même passage de l'Ecriture pût avoir plusieurs sens. Dans le 7e paragraphe de sa déposition contre Luis de Leon (Coster ibid. 352) il expliquait en effet que celui qui accepterait cette idée renoncerait à la possibilité de convaincre les hérétiques. Luis de Leon lui répondit: “L'expression 'convaincre' a deux significations bien différentes : convaincre les juifs et les hérétiques à leur propre jugement, chose impossible si Dieu n’éclaire pas leur intelligence, puisqu'ils interprètent l'Ecriture autrement que les catholiques et qu'il n'est point d'autorité reconnue par les deux parties qui puisse trancher le différend; et les convaincre au jugement de l'Eglise, c'est-à-dire montrer, au moyen de témoignages de l'Ecriture, entendus comme les entendent les Saints et les Conciles, que leurs opinions sont erronées" (Coster ibid.).

Le 12 février 1574, devant le tribunal réuni au complet, Luis de Leon (Coster ibid. 372) obtint de consulter l'exemplaire de la Bible de Vatable qui portait les corrections des réviseurs et qui avait été approuvé par leurs signatures. Il y trouva, non corrigée, la scholie sur Ps 8,6 où 'Vatable' dit : "Plusieurs lieux [de l'Ecriture] ont un double sens, à savoir l'un prophétique et l'autre non prophétique, c'est-à-dire nu et simple". Il fit constater que cette affirmation n'avait été l'objet d'aucune observation et qu'elle se trouvait donc couverte par la signature de Leon de Castro lui-même.

\section{H. La Censure générale}

La possibilité d'exégèses différentes, mais non contraires, justifiait l'édition de deux traductions différentes et d'annotations mettant en valeur des sens non traditionnels. Luis de Leon proposa alors de rédiger une 'censure générale' où la commission de révision formulerait ses intentions et préciserait (Coster ibid. 242, n.1) que "pour notre compte, nous ne voulions pas nuire à la Vulgate en laissant la traduction nouvelle de cette Bible, et qu'en admettant ces explications de Vatable nous ne voulions pas les préférer ni les égaler à celles des saints, mais que l'interprétation et la traduction nouvelles n'étaient reçues qu'en tant qu'elles servaient à mieux faire entendre la Vulgate, et que nous ne donnions aux gloses de Vatable pas plus d'autorité qu'à celles de n'importe quel docteur particulier". 
La rédaction de cette censure subit quelques péripéties, rapportées par Luis de Leon (Coster ibid. 242-244) et aboutit finalement au texte imprimé, au début de la Bible, sous le titre de 'Censure générale par le sénat des théologiens de Salamanque et d'Alcala sur l'exemplaire de la Sainte Bible avec double édition latine et scholies'. Le mot 'censura generalis' signifie ici 'avis d'ensemble', traduction que nous avons adoptée dans le texte suivant :

“L'avis d'ensemble a été formulé que la nouvelle édition n'est pas littéralement conforme à l'hébreu, mais que c'est plutôt une paraphrase assez pure dans son style et dans sa latinité, et que ni elle, ni les Scholies ou les Annotations marginales n'ont plus d'autorité, pour ce qu'elles ont en propre, que l'opinion de n'importe quel docteur en des matières controversées.

En outre, on peut admettre la traduction nouvelle là où elle diffère de la Vulgate sans lui être contraire ni s'opposer à la foi catholique et à la tradition de l’Eglise, à condition de sauvegarder l'honneur et la dignité que le décret du Concile de Trente reconnaît à la Vulgate, de sorte que l'édition Vulgate soit reconnue comme vraie et comme plus sûre que toutes les autres et qu'elle doive être préférée aux autres éditions en tant que plus conforme à la vérité hébraïque. Il ne faudrait pas juger ni admettre que la nouvelle édition ou l'exégèse de ses scholies nuisent en quoi que ce soit à la Vulgate ou en diminue l'autorité ni non plus celle des Saints ou des exégèses qui sont courantes parmi eux. Au contraire, là où elles ne déforment pas les interprétations consacrées et ne sont pas contraires à l'enseignement de l’Eglise ou aux interprétations de l'ensemble des Saints pères, on doit recevoir comme probables ces scholies dont la plupart sont prises des commentaires des Juifs; si bien que, lorsqu'on les compare aux exégèses des Saints, apparaîtra avec évidence la sublimité des interprétations de l’Eglise et des Saints en même temps que l’Esprit vivifiant qui les pénètre, en contraste avec la platitude des Juifs qui se collent à la lettre morte sans se représenter rien de plus élevé et qui défigurent parfois par une exégèse et un commentaire faux les oracles portant sur le Christ. Enfin ces scholies aideront ceux surtout qui ne connaissent pas la langue hébraïque à obtenir une certaine compréhension des sens variés que les mots ont chez les Hébreux, ainsi que de la syntaxe et des tournures qui caractérisent cette langue".

\section{Les espoirs et les craintes}

Dans l'Index de 1583, l'Inquisiteur général Quiroga, sur le point de donner son accord définitif à l'impression, mentionna deux fois la Bible d’Estienne de 1545. Il reprenait la condamnation figurant dans les éditions précédentes de l’Index. Deux pages auparavant, il signalait : "Biblia ibidem [= Parisiis] ab eodem [= Roberto Stephano] impressa anno 1545, cum duplici translatione et annotationibus, quae Biblia Vatabli vulgo dicuntur, nisi repurgentur seu sic repurgata denuo prodierint excussa".

Cet accord suscita cependant assez vite des remords chez les inquisiteurs d'Espagne. F.H. Reusch (Der Index der verbotenen Bücher, Bonn 1883 I 204) précise en effet qu'en 1613 d'abord, puis en 1632, on dut rendre tous les exemplaires pour de nouvelles corrections. Enfin en 1790, l'Inquisition se résigna à mettre à l'Index cette édition pourtant publiée “Sanctae \& generalis Inquisitionis iussu”. Triste fin d'une tentative qui, juste après le Concile de Trente, ne manquait pas d'audace. 


\section{3/ La Bible française de Robert Estienne (suite de la p. *29)}

Selon le colophon, son impression fut achevée le 9 juin 1553. Cette Bible in-folio reprend le cadre de titre et la marque célèbre de l'homme à l'olivier qui avaient déjà décoré les pages de titre des Bibles de 1532 et de 1540. Espérant la diffuser en France, Estienne n'a pas mentionné Genève. La seule référence figurant en dessous de la marque est : "L'Olivier de Robert Estienne M.D. LIII." Ce volume contient aussi les belles planches gravées autrefois sur les indications de François Vatable pour la Bible de 1540 : 1 pour la Genèse, 11 pour l'Exode et 8 pour le premier livre des Rois. Au début de chaque livre figurent également les magnifiques lettrines déjà utilisées par Estienne dans ses Bibles de 1532 et de 1540. Enfin, c'est la première Bible complète en français dont les versets soient numérotés ( 25 ans après que Pagnini l'ait fait pour sa Bible latine).

L'annotation est sobre et précise. Pour une part, elle reprend celle de la Bible de Serrières, et pour le reste, elle se rattache aux annotations de 'Vatable' dans la Bible de 1545.

Pour les Psaumes, Estienne, à la suite de l’édition Crespin de 1551, a adopté la traduction de Louis Budé en indiquant parfois en marge la leçon d’Olivétan.

Pour les Apocryphes, il a reproduit l'édition Crespin de 1551 et, pour le Nouveau Testament, sa propre édition publiée l’année précédente à Genève.

La véritable originalité de la Bible de 1553 réside dans les sommaires très détaillés, avec références aux versets, qui précèdent chaque chapitre. Il y a là une sorte de commentaire continu destiné à guider la lecture.

Cette Bible, nous l'avons déjà dit, connut un grand succès sur le marché de Genève. Estienne avait cependant omis la mention de la ville de Calvin dans l'espoir d'obtenir en France aussi une large diffusion. Mais l'opinion catholique était trop prévenue contre lui pour que cela fût possible. Sous un nouvel avatar, sa Bible faillit cependant réaliser dans l'édition française une large percée.

\section{4/ La Bible de Benoist}

René Benoist était curé de St Eustache, paroisse la plus peuplée de Paris, à l'époque. Il fut surnommé "le pape des halles" à cause de son zèle pastoral et de la grande influence qu'il exerçait sur le peuple de Paris. Dans les temps troublés de Charles IX et d'Henri III, il apporta toujours au roi un appui fidèle. Appelé par Henri IV pour le préparer à son abjuration, il devint son confesseur. Défenseur acharné des droits des curés parisiens, Benoist s'attira cependant l'hostilité des Frères Mendiants et des Jésuites. Partisan du Roi, il était mal vu des ligueurs et du légat du Pape. Il avait, par contre, l'appui résolu de l'évêque de Paris.

Benoist était aussi "professeur des Saintes Lettres" à la Faculté de théologie de la Sorbonne. Comme la diffusion des Bibles de Genève jouait un grand rôle dans la propagande protestante, la meilleure façon de protéger les catholiques contre leur influence était, selon lui, d'en organiser l'édition et la diffusion en un état soigneusement expurgé. Les intentions de Benoist nous sont connues grâce à une apologie publiée par Du Plessis d'Argentré (Collectio II 435-441). Benoist affirmait ne pas en être l'auteur. Néanmoins ses collègues de la Faculté y décelaient son style et luimême reconnut en avoir fourni les sources. Selon cette apologie, Benoist a voulu 
“ramener les hommes à salut, \& les remettre ou retenir au sein \& obéissance de l’Eglise Catholique, Apostolique \& Romaine, de la doctrine, moeurs \& traditions de laquelle il n'a jamais voulu décrocher, ni se détourner si peu que ce soit, tant en public qu'en privé, la faisant obéir à tout son pouvoir. C'est pourquoi il n'a fait difficulté de répéter des hérétiques tout ce qu'il a pensé être bon et pouvoir édifier, soit au Texte, soit aussi aux Annotations, Propositions, Arguments et Scholies, imitant Abraham \& David \& Job. Lesquels, ayant surpris \& vaincu les pillards, ont non seulement répété et pris d'iceux ce qui leur appartenait, mais aussi ont pillé les pilleurs, comme les enfants d'Israël les Egyptiens." Il se réfère ensuite à la sentence des anciens selon laquelle "quiconque prononce la vérité, elle vient du Saint Esprit". D’ailleurs, comme "les hérétiques ont pris de nous le Texte de l’Ecriture", ils ont aussi "pris les annotations des saints Docteurs". Il a donc pensé avoir le droit "de répéter l'un comme l'autre, repurgeant de l'un \& l'autre, le mieux qu'il lui a été possible suivant la règle et détermination des députés du Concile de Trente, ce qui y avait été mélangé par l'astuce de Satan, lequel tâche toujours à semer sa zizanie au champ de l'Eglise parmi la bonne semence de la parole de Dieu \& salutaire Religion". Il a voulu présenter cette Bible avec un armement agressif et défensif en "remarquant les lieux qui confirment notre foi" et "proposant catholiquement les lieux par lesquels les hérétiques oppugnent les Catholiques".

Benoist communiqua le fruit de son travail “à plusieurs doctes Docteurs ses confrères de la Faculté de Théologie, autrement dite la Sorbonne de Paris". Ils l'approuvèrent par 18 signatures, alors que deux auraient suffi. Puis il en confia l'impression à quatre éditeurs de Paris : Sébastien Nyvelle, Gabriel Buon, Nicolas Chesnau et Michelle Guillard qui publièrent cette Bible simultanément en 1566. Le 7 novembre, Jacques Le Fèvre, syndic de la Faculté, en acheta un exemplaire au prix de 5 livres et 15 sols. Il donna la Genèse à contrôler au doyen Jean Benoît, les Psaumes et les Prophètes à Antoine de Mouchy et se chargea du Nouveau Testament. Il confia à maître de Courselles le reste du Pentateuque et à maître Dalesden Choletaeus les livres historiques. Dans une réunion tenue fin avril 1567, les 18 signataires de l'approbation reconnurent ne pas avoir agi sur mandat de la Faculté et ne pas avoir lu tout l'ouvrage qu'ils approuvaient. Le 15 juillet, la Faculté, sur la base des 30 censures qualifiées par ses délégués, décida d'interdire cette traduction et fit savoir aux éditeurs qu'ils ne devraient plus l'imprimer ni la vendre. Le motif principal de l'interdiction était que "presque tout ce qui se trouve dans la Bible et les Scholies provient des Bibles des Ministres de Genève" (ibid. 430a).

René Benoist se déclara tout prêt à corriger sa Bible si on lui communiquait les points sur lesquels portaient ces corrections. L'évêque de Paris et le Parlement requirent également communication des "choses dignes de correction". La Sorbonne refusa. Alors René Benoist publia à nouveau sa traduction, en 1568, chez les quatre mêmes éditeurs, traduction accompagnée, cette fois, du texte de la Vulgate. Le Nouveau Testament fut édité cinq fois : à Paris en 1566, 1568 et 1569; chez Plantin à Anvers en 1567 et chez Hovius, à Liège, en 1572, avec privilège pour six ans accordé par “Monseigneur Gerard de Groisbeeck, Evêque de Liège, Duc de Bouillon".

En 1572, la Faculté n'avait toujours pas obtenu que Benoist consentît à l'interdiction pure et simple de sa traduction. Il exigeait la confirmation de cette censure 
par l'évêque de Paris qui, évidemment, s'y refusait. Aussi exclut-elle Benoist de son corps professoral. Dans son apologie (440a), Benoist affirmait que sa Bible avait déjà été diffusée à plus d'un million d'exemplaires, soit sous forme complète soit sous forme de Nouveau Testament. Il ajoutait que sa traduction, “s’il y a mal, est véritablement un rare péché \& un crime fort nouveau, ne s'étant jamais trouvé Docteur de Paris qui ait voulu, osé ou daigné - quelque besoin qu'en ait eu ce tant excellent Royaume de France - mettre la sainte Bible en Français. Or je ne sais pourquoi, car notre Langue n'est point maudite ni excommuniée plus que les autres". Et il dépeignait (438) "quelques-uns des premiers de cette grande \& tant insigne Faculté de Paris, dite vulgairement la Sorbonne, lesquels estiment leur grandeur non à écrire, mais à reprendre \& censurer ce qu'écrivent les Doctes et Industrieux". Il les comparait aux bourdons qui sont inutiles aux abeilles et les opposait aux "Catholiques savants et diligents Docteurs Théologiens de Louvain qui ont été joyeux par une charité Chrétienne \& amour du bien public \& non aucunement envieux... Et comme ils sont prudents et avisés, ne se voulant abuser ni légèrement approuver une chose de telle importance \& conséquence comme est la divulgation de la Bible en vulgaire, c'est-àdire en Français pour les Français, ils l'ont derechef visitée diligemment, tant au Texte qu'aux annotations, \& puis finalement ont baillé telle approbation que s'ensuit : ‘Cette Bible traduite en Français selon la version commune avec toutes ces annotations, comme elles sont réunies ou corrigées, se peut fort bien imprimer et à grande utilité de tous Catholiques \& confusion des hérétiques', dont ils donnent bon témoignage, l'ayant toute bien lue et examinée. Signé, Frère Jean Henten, Docteur, Régent de la Faculté de Louvain, Michaël de Bay sacrae Theologiae Regius Professor Lovanii, Jodocus Tiletanus, Augustinus Hunaeus".

\section{5/ La Bible de Louvain}

Selon B.Th. Chambers (Bibliography of French Bibles, Genève 1983, 414s), ces quatre théologiens de Louvain sont bien ceux qui ont signé, le 23 février 1567, l'approbation du Nouveau Testament publié par Plantin à Anvers. Or celui-ci, dont les “Annotations et expositions des lieux les plus difficiles" étaient bien attribuées à "M. René Benoist, docteur, etc.", n“était, en principe (Chambers 381), que la dernière partie d'une Bible complète qui, pour lors, ne parut pas. En 1573 Plantin republia ce même Nouveau Testament sous le titre : “Le Nouveau Testament de nostre Seigneur Jesus Christ, Traduict de Latin en François, Par les Theologiens de Louvain". Un privilège lui garantissait le droit exclusif d'imprimer, vendre et distribuer tant l'Ancien que le Nouveau Testaments traduits du latin en français par les "Théologiens de Louvain". Chambers (415) relève que seule l'omission du nom de Benoist et de ses notes distingue l'édition de 1573 de celle de 1567. Il note aussi que “ces théologiens n'avaient rien à voir avec la traduction. C'étaient bien plutôt les autorités qui avaient approuvé le Nouveau Testament de 1567" avec des corrections minimes.

En 1578 Plantin édita la Bible complète désignée depuis comme 'Bible de Louvain". Chambers (422) précise à son sujet que "quoiqu'il y ait quelques changements dans le texte de Benoist, la différence la plus frappante est l'omission complète de son nom et de toute note autre que les références scripturaires". 
Entre-temps, la Sorbonne conclut qu'elle n'obtiendrait ni du Roi ni du Parlement ni de Pierre de Gondi, évêque de Paris, la mise à exécution de son interdiction de la Bible de Benoist. Aussi demanda-t-elle au pape Grégoire XIII la confirmation de ses censures. Tout le dossier lui fut soumis par le cardinal de Pelevé, Archevêque de Sens et, le 3 octobre 1575, le pape interdit entièrement la traduction de René Benoist "sur peine d'anathème et excommunication". La Sorbonne pensait ainsi avoir exorcisé le fantôme de Robert Estienne. Elle ne pouvait admettre en effet que ce spectre se projetât depuis Paris sur toute la France.

Pourquoi la réaction de Louvain fut-elle différente ? L'explication se trouve dans la préface de Jean Henten de Malines (alors hiéronymite, mais dès l'année suivante dominicain) à la Bible latine de 1547. Il constate que la diffusion de la Bible et l'enseignement scripturaire sont les voies les plus utilisées pour répandre l'erreur dans le peuple. Il s'agit surtout de modifications non du texte, mais des index, des préfaces, des notes marginales et des sommaires. Là, même si l'on n'emploie que des expressions bibliques, la propagation de l'erreur "est d'autant plus pernicieuse que l'on dissimule le venin sous le miel qu'on propose". "Il n'y a personne qui ignore, pour ne citer qu'un cas parmi beaucoup, quel travail assidu et quelles dépenses a supporté Robert Estienne, imprimeur royal à Paris (que je nomme par éloge) pour mettre à notre disposition des Bibles très soignées et parfaitement correctes... Et cependant de faux chrétiens ont influencé cet homme courageux, des loups rapaces dissimulés sous des peaux de brebis l'ont inspiré surtout dans les annotations marginales, les préfaces et les index. Et puisqu'ils ont corrompu par ces ajouts même les meilleurs livres des Saintes Ecritures et des docteurs Catholiques, sa Majesté Impériale a eu parfaitement raison de décider que ces livres pernicieux, en quelque langue qu'ils soient, seraient retirés des mains du peuple. Et les Bibles, dans ce domaine, occupent la première place." Il explique ensuite que toutes les Bibles contraires - sous quelqu'aspect que ce soit - à la religion chrétienne ont été retirées de la circulation par décision impériale et que "nous ( = Henten et d'autres ?) avons obéi à l'ordre, au conseil et à l'avis de théologiens de cette académie de Louvain qui sont à la fois les plus respectables et les plus cultivés, ainsi que d'un jugement très pénétrant". Puis il expose en détail le projet réalisé par cette édition : la Vulgate, depuis longtemps utilisée par l'Eglise, doit demeurer stable. Aussi Henten et ses collaborateurs s'en sont-ils procuré les meilleures éditions (il signale ici l'édition où Robert Estienne a mentionné de nombreux codices en marge, c'est-à-dire celle de 1540) et tous les manuscrits anciens qu'ils ont pu trouver. En les comparant, ils ont essayé de ramener la Vulgate à sa pureté originelle, "sans vouloir nous mêler de déterminer si elle correspond toujours aux textes hébreux et grecs". Notons en passant que, lorsque le P. Manriquez, Maître du Sacré Palais, reproduisit à Venise en 1571 l’édition de Henten, la double mention de Robert Estienne disparut de la préface.

La première édition de la Vulgate révisée par Jean Henten parut en 1547 chez Barthélemy de Grave. Les théologiens de Louvain avaient pour but d'appliquer le décret sur la Vulgate publié le 8 avril 1546 par le Concile de Trente. En vue de cela, l'empereur Charles Quint avait accordé le 9 novembre 1546 et pour trois ans à "Barthélemy de Grave, Imprimeur juré de nostre université de Louvain... de pouvoir imprimer les Bibles en trois langues, Latine, Française et en Flamand... approuvées par 
Messieurs les Docteurs de la sainte Théologie de Louvain..." (Chambers 168s). Le 9 mai 1546, la Faculté de théologie de Louvain avait publié un index des livres prohibés qui comptait, comme Henten nous l'a dit, de très nombreuses Bibles. En conséquence, Charles Quint avait chargé les professeurs de cette même $F$ aculté de publier le plus vite possible une Vulgate, puis des traductions française et flamande. La révision rapide de la Vulgate, dont s'était chargé Henten, empruntait presque toutes ses leçons aux Bibles d’Estienne de 1532 et 1540 (Quentin 135s). En 1574, au nom des théologiens de Louvain, Luc de Bruges en réalisa une révision plus approfondie publiée chez Plantin.

Barthélemy de Grave utilisa son troisième privilège pour publier en 1548 'Den gheheelen Bybel ... Met grooter naersticheyt ende arbeyt nu corts in duytsche van nyews ouerghestelt wt den Latijnschen ouden text ... onlancs te Loeuen by sekeren gheleerde wt beuel der Keyserlijcker Maiesteyt ghecorrigeert ende aldaer Ghedruct'. Cette édition avait été préparée par Claes van Winghe, chanoine régulier à Louvain, sous le contrôle de Peter de Corte et de Govaert Stryrode, professeurs à l'Université. Fondée sur l'édition de la Vulgate de 1547, elle fut remplacée en 1553 par l'édition de J. van der Haghen parue à Louvain chez A.M.Bergaigne et souvent rééditée depuis lors.

Le deuxième privilège de Barthélemy de Grave portait sur une Bible française. En 1550 il publia en collaboration avec Antoine Marie Bergagne et Jehan de Waen “La Saincte Bible nouuellement translatée de Latin en François, selon l'edition Latine, dernierement imprimée à Louvain : reueuë, corrigée \& approuvée par gens sçavants, à ce deputez". Il s'agit d'une révision de la Bible de Le Fèvre d'Etaples sur l'édition Henten de la Vulgate par Nicolas de Leuze, sous le contrôle de Pierre de Corte. François de Larben coopéra lui aussi à cette révision. Darlow \& Moule (II 387) estime à 200 le nombre des éditions de cette traduction. Selon Chambers (169 et 422s), au contraire, celle-ci n'eut pas de postérité directe, et ce fut l'édition Plantin 1578 qui engendra, jusqu'à la fin du siècle, toutes les Bibles françaises non calquées sur le texte de Genève. Or, nous l'avons vu, l'édition Plantin 1578 est la Bible de René Benoist privée de son nom et de ses annotations puis munie de l'approbation des théologiens de Louvain. Dans les diverses Bibles qu'ils éditèrent, les Lovanistes supprimèrent toujours les armes que la Réforme trouvait dans les annotations. Ils s'opposaient en cela à René Benoist qui avait cru pouvoir retourner ces armes contre leurs auteurs.

Du Plessis d'Argentré (Collectio II 534) note en effet que la traduction française de René Benoist, après avoir été "entièrement interdite" par le bref de Grégoire XIII, fut expurgée par les Théologiens de Louvain puis souvent rééditée à partir de 1582, date où elle apparut pour la première fois revêtue des approbations de Docteurs théologiens de Paris. En 1581, en effet, deux docteurs de Sorbonne l'approuvèrent sous la forme où les théologiens de Louvain l'avaient publiée à Anvers, en 1578. Dans l'édition publiée à Lyon en 1582 chez Jean Pillehotte, ces approbations figurent après les préfaces et la liste des livres de la Bible. Le privilège royal, daté du 28 août 1581, précise que cette traduction a été "maintenant revue suivant la volonté du Roi par des Docteurs en la faculté de Théologie de Paris". Le premier censeur, fait curieux, est "Frère Jacques Maistret, Docteur Théologien en la faculté de Paris, Evesque de Damas, \& Suffragant de Lyon". Il atteste que "[en] ceste presente Bible, traduite, reveuë \& 
corrigee par les Docteurs en Theologie, de l'université de Louvain ... nous n'avons rien trouvé qui ne soit bon \& Catholique, \& veritablement traduicte pour l'utilité des Chrestiens". Or, c'était justement ce même Jacques Maistret, à l'époque encore Prieur du couvent des Carmes de Lyon, qui avait été chargé par la Faculté de Théologie (Du Plessis d'Argentré, II 433s) de faire parvenir à Rome "un gros paquet de Livres \& papiers empaquetés en toiles cirées" : le dossier de condamnation des Bibles de René Benoist. Il contenait (ibid. 432) "ces Bibles de Genève dont il a quasi tout extrait, les Bibles [ $=$ de $R$. Benoist] desquelles il est question, tant de la première édition $[=1566]$ que de la seconde $[=1568]$ avec nos censures \& actes". Or Maistret avait accompli, semble-t-il, sa tâche de censeur un peu rapidement. Sinon, il aurait remarqué que la seule des censures de la Sorbonne de 1567 qui portât sur la traduction de René Benoist (et non sur les annotations) concernait Gn 4,13: “Lors Caïn dit au Seigneur, mon iniquité est plus grande qu'elle me puisse être pardonnée". La censure de Jean Benoît était ainsi rédigée : "Cette traduction de la phrase de la Vulgate : 'major est iniquitas mea, quam ut veniam merear' est pervertie et la phrase, telle quelle, est erronée, hérétique et blasphématoire et empruntée aux Bibles de Genève". La dernière affirmation est exacte. $R$. Benoist avait en effet adopté dans son texte la traducton citée en rnarge dans la Bible d’Estienne de 1553. Mais Maistret aurait dû remarquer que la traduction censurée en 1567 comme "erronée, hérétique et blasphématoire" était demeurée intacte dans la Bible où il concluait n'avoir "rien trouvé qui ne soit bon \& Catholique".

René Benoist accepta la condamnation romaine et fut le témoin discret du succès clandestin de sa Bible française. La Faculté de théologie le réintégra et il en fut le doyen de 1598 à 1607. A ce titre et durant ce temps, il exigea des explications et obtint des rétractations de plusieurs suspects. Il fit condamner par la Faculté des gens qui soutenaient des propositions dérogeant au ministère pastoral ou à l'ordre hiérarchique (cf. Du Plessis d’Argentré, Collectio II 534).

\section{6/ La Bible de Châteillon}

Un fil continu, quoique parfois inavoué unit la Bible de Serrières à celle de Louvain en passant par celles d'Estienne et de Benoist. Disons maintenant quelques mots d'une Bible mârie dans l'isolement et qui ne fut jamais rééditée, celle de Sébastian Châteillon. Celui-ci fut "the only really innovative 16th-century translator of the Bible into French" (Chambers 221).

Notre source principale est ici l'ouvrage de F.Buisson: "Sébastien Castellion, sa vie et son oeuvre", 2 vol., Paris 1892. Les citations tirées de ses Bibles sont empruntées, pour la Bible latine, à l'édition Oporin (Bâle 1556) et, pour la Bible française, à l'édition unique publiée en 1555, chez Jean Hervage à Bâle. Comme nous l'avons déjà indiqué (CT1 *9), nous retenons l'orthographe "Châteillon". parce que lui-même et ses fils écrivent ainsi leur patronyme (alors qu'en latin il écrit 'Castalio").

Sébastian Châteillon, originaire de St Martin en Bugey, étudia d'abord le grec et le latin au collège de la Trinité à Lyon. Puis il vint habiter auprès de Calvin à Strasbourg. A cette époque (1540), Calvin, banni de Genève et réfugié auprès de Bucer, avait ouvert le premier 'séminaire protestant' de langue française. Lorsque, en 1541, il fut rappelé à Genève, il nomma Châteillon, âgé alors seulement de 24 ans, régent du 
collège de Rive. Là, aidé de deux bacheliers, il formait ses élèves aux langues classiques et au français. Selon 'L'ordre et manière d'enseigner en la ville de Genève' (1538), "l'un des régents, comme délaissant cette gravité ordinaire de maître, expose couramment de latin en français quelque propos de l'Ecriture Sainte, mais en ce faisant il construit le texte de mot à mot, à la mode commune d'enseigner grossement en toutes écoles. Puis après il propose et présente familièrement aux enfants le latin, selon la manière et ordre qu'il l'a déclaré, et iceux le tournent en français, comme chacun en a pu retenir et mettre en sa mémoire; or en cela un chacun d'eux répond en son tour jusqu'à la fin d'une clause ou d'une sentence, et pendant cela les autres franchement le reprennent d'un coeur gaillard et délibéré, à qui en aura. En ce faisant, on confère la diversité des langues et des livres, et même les enfants, sans étudier ni travailler, profitent beaucoup en la Sainte Ecriture" (Buisson I 148s).

Cet enseignement conjoint du latin et du français servait donc en même temps d'initiation à la Bible. Châteillon en condensa le fruit dans un petit manuel : les "Dialogi sacri latino-gallici, ad linguas moresque puerorum formandos". Les quatre livres de ces dialogues se divisaient de la manière suivante : le 1er, de 33 dialogues, s'achevait par 'Samson'; le 2e, de 39, allait jusqu'à 'Sedecias'; le 3e, de 18, allait de 'Tobias' à 'Veritas' (la question disputée de 3 Esd 3-4); le 4e, de 47, allait de l'Annonciation jusqu'au Jugement dernier. Conformément au titre, il s'agissait de faire dialoguer les personnages bibliques en latin classique. Châteillon suivait d'assez près le récit biblique. La première édition parut à Genève en 1542-1543. Le premier livre juxtaposait au latin une traduction en un français simple et vivant. Ce manuel eut un très grand succès et, après avoir été plus ou moins retouché et amputé de la traduction française, il fut souvent réédité à Bâle, Cologne, Lyon, Medina del Campo, Anvers, Leipzig. Après la mort de Châteillon, il parut, enrichi par des notes de lui à Augsbourg, Francfort sur le Main, Leyde, Brême, Tubingue, Llandaff, ou sans notes à Prague, Bautzen, Londres, Smalkalde, Magdebourg, Wittenberg, Lubeck, Heidelberg, Edimbourg, Paris, Dublin, Debreczen, Kaschau, Presbourg et Cobourg. Enfin des éditions critiques en furent données à la fin du $17 \mathrm{e}$ siècle et au cours du 18e siècle à Leipzig, Francfort, Giessen et Bâle.

Châteillon expliquait son propos dans une lettre au grand pédagogue et humaniste Mathurin Cordier : "J'avais extrait des livres sacrés des hébreux des dialogues vivants et agréables" (Buisson I 159, n.1). Ces dialogues n'étaient qu'un premier essai pour faire parler les personnages bibliques en vrai latin et en un français vivant. En effet, dès le 11 septembre 1542, Calvin écrivait à Viret: “Apprenez maintenant les fantaisies de notre Sébastien : il y a de quoi vous faire rire et vous mettre en colère. Il y a trois jours il vint à moi. Il me demanda s'il ne me conviendrait pas de laisser publier sa traduction du Nouveau Testament... Je répondis que je ne voulais pas en empêcher l'impression, mais que cependant j'étais disposé à tenir la parole que j'avais donnée à Jean Girard, c'est-à-dire d'examiner et de corriger ce qui demanderait correction. Il repoussa cette condition. Il s'offrit pourtant à venir me lire son manuscrit, si je voulais lui fixer une heure. Je l'avertis que jamais, quand il me donnerait cent couronnes, je ne consentirais à me lier à des rendez-vous à heures fixes, et ensuite à disputer parfois pendant deux heures sur un seul mot. C'est là-dessus qu'il est parti, visiblement peiné" (Buisson I 183). 
Fin janvier 1544, Châteillon et Calvin entrèrent en conflit. Depuis deux ans, "Maître Bastian, régent des écoles" demandait au Conseil de Genève une augmentation de son salaire. Vu la cherté de la vie, il ne pouvait plus entretenir les deux bacheliers et assurer le fonctionnement du collège. Sa requête rejetée, Châteillon démissionna de son poste de régent et posa sa candidature pour le ministère pastoral. Calvin la refusa. Châteillon donnait, en effet, au Cantique des cantiques une signification érotique et aussi, dit Calvin : "il ne pouvait partager notre sentiment... [en ce] que nous acceptons dans le catéchisme la descente du Christ aux enfers, comme signifiant ce frisson de conscience qu'il éprouva en se présentant pour nous devant le tribunal de Dieu pour expier nos péchés par sa mort, en transférant sur lui-même la peine et la malédiction... Il ne niait pas que la doctrine que nous professons ne fût pieuse et sainte; toute la question était de savoir si c'était bien là le sens du passage. Nous avons d'abord entrepris de l'amener par voie de raisonnement à notre opinion; nous avons réfuté, comme nous l'avons pu, les arguments qu'il nous opposait. N'ayant rien gagné par là, nous avons enfin cherché une autre voie : nous lui avons montré... qu'en effet nous ne blâmions pas les églises qui admettaient une autre interprétation; et que notre seul souci était d'empêcher les inconvénients graves qui naîtraient de la diversité des explications. Il répondit qu'il ne voulait pas promettre ce qu'il ne pourrait tenir que contre sa conscience" (Buisson I 198).

Cette opposition entre les deux hommes était encore latente. Le premier éclat eut lieu le 30 mai suivant. Calvin en informa Farel en ces termes: "Notre Sébastien s'est emporté contre nous dans une sortie aussi violente que possible. Il y avait hier à la congrégation, pour l'explication familière de l'Ecriture, environ soixante personnes. On étudiait ce passage : 'Nous montrant en toutes choses ministres de Dieu, par une grande patience, etc.'(2 Co 6,4ss). Il se mit à tisser une antithèse perpétuelle pour établir sur tous les points le contraste entre nous et les ministres de Christ. Voici son jeu d'esprit : 'Paul était serviteur de Dieu, nous le sommes de nous-mêmes; il était très patient, nous très impatients; il passait les nuits pour se consacrer à l'édification de l'Eglise, nous passons la nuit au jeu; il était sobre, nous ivrognes; il était menacé par les séditions, c'est nous qui les excitons; il était chaste, et nous débauchés; il fut enfermé en prison, et nous y faisons enfermer quiconque d'un mot nous a blessés. Il a usé de la puissance de Dieu, nous de celle d'autrui. Il a souffert de la part des autres, nous persécutons des innocents.' Que vous dirai-je encore ? Bref une attaque sanglante. Je me suis tu pour le moment, afin de ne pas allumer devant tant d'étrangers une vive discussion. Mais je suis allé porter plainte aux syndics" (Buisson I 210s).

Le 11 juillet, Châteillon quitta sa charge de régent et chercha en vain un emploi scolaire ailleurs en Suisse romande. En août, il se réfugia à Bâle chez l'imprimeur Oporin. En avril 1545, Calvin écrivit à Farel : "Si vous saviez ce que ce chien déblatère contre moi, - c'est Sébastien que je veux dire, - vous trouveriez les moines doux et modérés en comparaison... Maintenant, il vomit son venin à pleine bouche. Il dit que c'est par ma tyrannie qu'il a été chassé du ministère pour que je puisse régner seul" (Buisson I 239). C'est vraisemblablement à cette époque que Châteillon entra comme correcteur d'imprimerie chez Oporin. Jusque vers 1553 - date où il devint professeur de grec à l'Université de Bâle -, Châteillon vécut très pauvrement, avec une famille de huit enfants. 
Il consacrait alors tous ses efforts à une double traduction de la Bible : en latin, d'abord, puis en français. Le Pentateuque latin sortit en août 1546, le Psautier en septembre 1547 et enfin la Bible complète qui eut trois éditions du vivant de Châteillon : en 1551, 1554 et 1556. En même temps que l'édition in-folio de la Bible, Oporin publiait à part le Nouveau Testament in-16 .

L'ordre des livres de la Bible de Châteillon en constitue une première particularité. Pagnini, dans sa traduction latine de 1527-1528, avait pris l'initiative de grouper dans une classe spéciale, entre le "Vetus Instrumentum" et l" "Evangelium secundum Matthaeum", les "Libri Agyographi qui non sunt in Hebraeo inter Canonicos Libros". Les réformateurs l'ont suivi et ont nommé cette catégorie: "Livres Apocryphes". Châteillon, lui, se sépare de cette tradition et place les livres dans l'ordre classique de la Vulgate. Cependant, il place le troisième livre d'Esdras juste après Esdras-Néhémie et le quatrième avant les livres des Maccabées, à la fin des Prophètes. A partir de l'édition de 1554, il encadre les livres des Maccabées par un résumé de données historiques tirées des Antiquités Judaïques et de la Guerre Juive de Flavius Josèphe. Il reprend ainsi la vieille tradition de l'Historia Scholastica de Pierre le Mangeur et des Bibles historiales. Ces ajouts, tirés de Josèphe, sont imprimés en italique pour que "celui à qui ce supplément déplairait puisse ne pas le lire".

On note, dans l'établissement du texte, le souci d'être aussi complet que possible. Dans son "avertissement aux lecteurs", il précise que "pour les livres qui existent en hébreu, lorsque nous avons trouvé dans la vieille traduction grecque ou latine quelque chose qui n'existait pas dans l'hébreu, nous l'avons inséré en notant ces insertions par les lettres $G$ ou $L$, la lettre $H$ signalant le retour à l'hébreu. Nous avons fait de même pour les livres traduits du grec, lorșque le latin présentait quelqu'excédent." Ainsi, le ch. 5 d'Esther apparaît comme une vraie marqueterie, avec 7 emprunts au grec et 2 au latin. La traduction de Judith, de son côté, signale 117 emprunts au latin. Les copieuses annotations finales (156 colonnes) mentionnent de nombreuses corrections critiques du texte traduit.

De son latin, Châteillon a essayé d'éliminer tous les hébraïsmes : ceux qui y sont attachés, dit-il, feraient mieux de lire l'hébreu. Dans la préface de sa traduction du Pentateuque, il explique : “J'ai entrepris de faire parler Moïse en latin comme il aurait parlé s'il s'était exprimé en cette langue, c'est-à-dire avec autant de facilité et d'élégance qu'il a en hébreu." Cet effort pour latiniser la Bible a des conséquences grammaticales et lexicographiques. Le traducteur s'en explique au début de ses annotations : il a fait un usage systématique du discours indirect qui caractérise le latin par rapport à l'hébreu et n'a pas craint de décliner tous les noms propres dont il respecte les formes latinisées traditionnelles. Quant au choix des mots, il a utilisé d'abord (dans le Pentateuque de 1546 et dans la première édition de sa Bible) des substitutions audacieuses: "genius" au lieu de "angelus", "lavare, lavacrum" au lieu de "baptizare, baptismum", "collegium" au lieu de "synagoga" et "respublica" au lieu de "ecclesia". (Buisson I 318). Mais, dans les éditions postérieures, Châteillon a rétabli presque toutes les vieilles transcriptions du grec devenues traditionnelles dans le latin de l'Eglise.

Cette traduction latine se caractérise aussi par des transpositions osées fondées sur une herméneutique hardie. Ainsi, en Gn 6,2, il traduit בני־האלהים par "hominum 
potentissimi" et note à ce propos: “'Les plus puissants des hommes'. Il y a dans l'hébreu 'les fils des Dieux'. Mais les hébreux font souvent usage de substantifs au lieu des adjectifs qui sont plus rares en leur langue. Fils des Dieux s'emploie donc au sens de 'divins', c'est-à-dire 'éminents'. C'est ainsi que, dans le Ps 82 les juges et ceux qui gouvernent les autres sont appelés dieux ou divins, et en Jb 41 les puissants. De même, les français utilisent le mot 'Dieu' pour désigner ce qui excelle en une catégorie, comme un 'feu de Dieu' lorsqu'il est magnifique ou un 'homme de Dieu' quand il est pieux et religieux. Les latins, eux aussi, parlent du 'divin Platon'. Quant au mot 'fils', il équivaut souvent à 'homme'. Ainsi les 'fils d'Israël' sont les Israélites ou les mâles de ce peuple. Les 'fils d'homme' sont les hommes. De même les français disent 'enfant de Lyon' pour Lyonnais, 'enfant de ville' pour citoyen, 'enfant perdu' pour un homme déshonoré, et les grecs : 'fils des Achéens' pour Achéens, et 'enfants des médecins' pour médecins. C'est en ce sens que j'ai interprété ici l'expression 'fils de Dieu'. Si pourtant quelqu'un est ici en possession d'une interprétation qui soit plus vraie, je ne veux pas qu'il s'attache à la mienne. En effet, ces mots sont ambigus et je doute, moi aussi". Ce mélange d'audace et de réserve rend Châteillon particulièrement attachant. Lorsqu'une latinisation plus poussée risquait d'en appauvrir le sens, le traducteur a conservé la tournure hébraïque. Ainsi, sur 'la mère de tous les vivants" (Gn 3,20), il note : "Chez les hébreux, les hommes sont parfois désignés en référence à la vie, alors que les latins les appellent 'mortels'. Mais ici, à cause du nom [d'Eve], on ne peut les dire 'mortels'. De plus, le nom 'vivant' - qu'on le dise de l'homme ou de Dieu - est riche de plusieurs sens que le nom 'mortel' n'offre pas".

Châteillon acheva sa traduction latine en 1550. Il s'attaqua aussitôt à la traduction française qu'il termina au printemps 1553. Jean Hervage en acheva l'impression en mars 1555. A la différence de sa Bible latine qui visait un public de lettrés, sa Bible française s'adressait aux ignorants, les "idiots", comme on les appelait dans le langage de l'époque. Il s'en explique dans l'AAvertissement touchant cette translation" : "Quant à ce que dans les annotations je n'ai pas rendu raison de ma translation en certains lieux, comme j'ai bien fait en la latine, je l'ai fait à cause qu'il m'eût fallu mettre beaucoup de mots Ebrieux et Grecs et Latins, et j'écris ici pour les Français, qui n'ont que faire de ces langues tant étranges. Et quand j'écris que je n'entends pas un tel passage, ou un tel, je ne veux pas pourtant donner à entendre que j'entende bien tous les autres; mais je veux dire que dans les autres j'y vois quelque peu, et en ceux-là je n'y vois goutte; et je le fais aussi afin qu'en quelques tels passages on ne se fie pas trop en ma translation... Quant au langage Français, j'ai eu principalement égard aux idiots, et pourtant ai-je usé d'un langage commun et simple, et le plus entendible qu'il m'a été possible. Et pour cette cause, au lieu d'user de mots Grecs ou Latins qui ne sont pas entendus du simple peuple, j'ai quelques fois usé des mots Français, quand j’en ai pu trouver; sinon j'en ai forgé sur les Français par nécessité, et les ai forgés tels qu'on les pourra aisément entendre, quand on aura une fois ouï ce que c'est; comme serait dans les sacrifices ce mot 'brûlage', lequel mot j'ai mis au lieu de 'holocauste', sachant qu'un idiot n'entend, ni ne peut de longtemps entendre, que veut dire holocauste. Mais si on lui dit que brûlage est un sacrifice auquel on brûle ce qu'on sacrifie, il retiendra bientôt ce mot, par la vertu du mot brûler, lequel il entend déjà." Il demande ensuite qu'on l'avertisse lui-même, ou que l'on informe ses lecteurs 
des fautes possibles contenues dans sa traduction, "principalement si c'est quelque faute dangereuse", et il conclut en ces termes : “Combien qu'en cette besogne j'aye, par la grâce de Dieu, travaillé long temps, continuellement, à grand loisir, en bonne santé, et d'un grand courage, toutefois encore désormais ( $s^{\prime i l}$ plaît à Dieu) si j'y trouve quelque faute, soit par avertissement d'autrui, soit autrement, je mettrai peine, Dieu aidant, de la corriger. Que s'il vient une autre translation qui soit meilleure, j'espère que cette-ci ne sera pas marrie de lui faire place."

La traduction de Châteillon est une oeuvre nouvelle. Celle de Genève, au contraire, est le fruit de nombreuses retouches, car elle remonte, par la Bible de Serrières, à Le Fèvre d'Etaples. De ce fait, la Bible de Châteillon nous apparaît, aujourd'hui encore, beaucoup plus vivante et jeune que la Bible d'Estienne publiée en 1553. Le passage de la mort de Rachel illustre bien la différence entre ces deux traducteurs. Voici d'abord la version Estienne : "En après ils partirent de Beth-el, et y avait encore environ une demi lieue de pays pour venir en Ephratha. Lors Rachel enfanta, et eut difficulté en son enfantement. Et comme elle était au travail de son enfantement, la sage femme lui dit : Ne crains point, car ce te sera encore ici un fils. Et au département de son âme, quand elle mourait, elle appela son nom Ben-oni." Et voilà le style Châteillon : "Et quand ils furent partis de Bethel, et furent venus à une dînée près d'Ephrata, Rachel enfanta, et enfanta à grand peine. Et comme elle avait beaucoup de peine d'enfanter, la sage femme lui dit : N'aie peur, car c'est encore un fils. Mais elle, en rendant l'âme (car elle en mourut), le nomma Benoni"' (Gn 35,16-18). Par son style, cette traduction méritait de devenir un grand classique français. Elle ne connut cependant qu'une faible diffusion. Bèze et Calvin, en effet, le 10 octobre 1559, dans la préface d'une révision de leur Nouveau Testament, prémunissaient en ces termes leurs lecteurs contre les traductions de Châteillon: "Sébastien Chastillon, homme si bien connu en cette Eglise, tant par son ingratitude et impudence, que par la peine qu'on a perdue après lui pour le réduire en bon chemin, que nous ferions conscience non seulement de taire son nom (comme jusqu'ici nous avons fait), mais aussi de n'avertir tous chrétiens de se garder d'un tel personnage comme instrument choisi de Satan pour amuser tous esprits volages et indiscrets. Certainement, s'il y eut onques une épreuve d'ignorance conjointe avec une témérité effrontée, jusqu’à se jouer de l'Ecriture sainte et l'exposer en risée, tout cela se trouvera dans les translations et écrits de celui dont nous portons tel témoignage à notre grand regret" (Buisson II 251).

Les relations entre Calvin et Châteillon s'étaient dégradées encore davantage après la publication par ce dernier, sous le pseudonyme de Martin Bellie, du "Traité des Hérétiques" (1554), en réponse au supplice de Michel Servet (27 octobre 1553). Il reprochait aux Evangéliques, dont les frères étaient morts martyrs sur les bûchers, d'en dresser à leur tour pour y brûler ceux qu'ils jugeaient hérétiques. Cette protestation de Châteillon contre la condamnation de Servet amena Calvin à dire à son propos en 1555 : “il est si pervers en toute impiété que j’aimerais cent fois mieux être papiste" (Buisson II 61). D'autre part, Calvin tenait à ce que les calvinistes de langue française n'utilisent qu'une seule traduction. Ainsi ce ne sera qu'en 1644 qu'apparaîtra à Genève une nouvelle traduction, celle de Diodati, après une opposition de la Compagnie des Pasteurs qui aura duré trente ans. 
Vu de France, Châteillon était un protestant; mais Genève l'avait mis à l'index et il vivotait, réfugié à Bâle en un milieu alémanique. En ce triple isolement, on le comprend aisément, sa traduction ne trouva pas accès au public français. Cela interdit à ses néologismes (du type de 'brûlage') de s'imposer. Et ils demeurent encore aujourd'hui des bizarreries. En d'autres circonstances, ils eussent créé un vocabulaire biblique authentiquement français. Tout en dénonçant ces bizarreries, Richard Simon (349) estimait que Châteillon "était beaucoup plus savant dans les langues... que les Docteurs de Genève". Il considérait que "Théodore de Bèze et ses confrères, ne pouvant souffrir qu'il y eût d'autre traduction française de la Bible que celle qu'ils avaient publiée, ... donnèrent des marques évidentes de leur jalousie, n'ayant pas fait justice à Castalio, qui avait beaucoup plus de mérite qu'eux". Selon O.Douen, secrétaire général de la Société biblique de France au moment où $F$.Buisson rédigeait son étude sur Châteillon, la Bible française de celui-ci "l'emporte sur la révision de Calvin, soit quant au fond, soit quant à la forme, dans une multitude de passages... et elle a exercé une heureuse influence dont on trouve la trace dans les révisions postérieures; encore auraient-elles gagné à s'en inspirer davantage. Dans une lecture qui n'est pas absolument complète, nous avons relevé quatre-vingt-quinze passages qu'on peut citer avec certitude comme des améliorations introduites par Castalion et qui, en dépit de toutes les préventions que l'on avait contre lui et contre son oeuvre, ont définitivement pris place dans nos Bibles protestantes. Sa version française marque un progrès considérable sur celle de 1553, au point de vue de l'intelligence du texte, et un progrès plus considérable encore au point de vue du langage" (Buisson I 435s). En dépit de ses qualités, la Bible française de Châteillon demeure aujourd'hui encore, une belle inconnue.

Laissons maintenant en suspens l'histoire de la Bible française. Nous reviendrons, à la fin de ce panorama des Bibles du XVIe siècle, sur la révision de la Bible de Genève, en 1588, par les "Pasteurs et Professeurs" de cette ville. Cette Bible fait appel, en effet, à des sources latines que nous allons présenter au cours de l'histoire de la Bible anglaise, car elles ont exercé sur elle une influence très directe.

\section{La Bible anglaise}

Des études d'ensemble sur l'histoire de la Bible anglaise, comme par exemple S.L. Greenslade, English Versions of the Bible A.D. 1525-1611, en The Cambridge History of the Bible III 141-174, nous dispensent d'en retracer les étapes. Nous nous limiterons à étudier ici les sources utilisées par les divers traducteurs et réviseurs.

\section{1/ La Bible de Coverdale}

Nous nous référons ici au facsimilé : “The Coverdale Bible 1535", Folkestone 1975, publié avec une introduction de Greenslade. Coverdale fut le premier à éditer (en 1535) une Bible complète en anglais. Dans l'état original de sa page de titre, il parle de sa Bible comme "faithfully and truly translated out of Douche and Latyn in to Englishe". Dans sa préface à Henry VIII, il précise : "I have nether wrested nor altered so moch as one worde for the mayntenaunce of any maner of secte : but have with a cleare conscience purely and faythfully translated this out of fyve sundry interpreters, havyng onely the manyfest trueth of the scripture before myne eyes." 
Dans son Prologue adressé "unto the Christen reader", il explique : "to helpe me herin, I have had sondrye translacions, not onely in latyn, but also of the Douche interpreters: whom (because of theyr synguler gyftes \& speciall diligence in the Bible) I have ben the more glad to folowe for the most parte, accordynge as I was requyred. But to saye the trueth before God, it was nether my laboure ner desyre, to have this worke put in my hande: nevertheles it greved me the other nacyons shulde be more plenteously provyded for with the scripture in theyr mother tongue, then we."

Quelles sont les cinq traductions sur lesquelles Coverdale s'est fondé ? Pollard (Records of the English Bible, Folkestone 2/1974,12) s'accorde avec Greenslade (introduction au facsimilé, 14) pour en nommer quatre : en allemand, la traduction de Luther et celle de Zurich; en latin, la Vulgate et Pagnini. Quant à la cinquième, il s'agit, selon Pollard, du Nouveau Testament et du Pentateuque traduits et édités par Tyndale. Greenslade penche aussi vers cette conclusion, mais relève que Coverdale mentionne seulement les langues allemande et latine. Il s'agirait donc plutôt de la traduction du Nouveau Testament en latin par Erasme. Cependant Coverdale l'a, semble-t-il, peu utilisée. Peut-être alors fait-il allusion à la traduction allemande des Prophètes publiée en 1527 par Haetzer et Denck à Worms. Sans doute considérait-il comme allant de soi l'usage qu'il avait fait des parties déjà publiées de la traduction de Tyndale. Les contrôles que nous avons effectués confirment les conclusions de diverses études récentes : même lorsqu'il s'est fondé sur Tyndale, il l'a beaucoup modifié, le plus souvent selon la Bible zurichoise de 1531. Tyndale, pour sa part, quoiqu'hébraïsant, s'était appuyé principalement sur Luther et Pagnini lors de sa traduction du Pentateuque publiée le 17 janvier 1530.

Coverdale n'a donc pas fait directement usage de l’hébreu et sa traduction a été supplantée par d’autres Bibles plus étroitement liées aux langues originales. C'est pourquoi nous ne nous référons pas à elle dans notre ouvrage.

Selon Greenslade, la Bible de Coverdale fut achevée d'imprimer le 4 octobre 1535, probablement à Cologne, chez Cervicorn et Soter. Peter Quentel aurait organisé l'essentiel du travail auquel James Nicolson, Néerlandais établi à Southwark, mit la dernière main. La disgrâce, puis l'exécution (19 mai 1536) d’Anne Boleyn empêchèrent Thomas Cromwell de publier dans ses 'Injunctions' de juillet 1536 une ordonnance aux termes de laquelle, dès le 1er août, toute église paroissiale devrait mettre à la disposition de ses fidèles la Bible complète en latin et en anglais. Toutefois la Bible de Coverdale se vendit bien, puisque Nicolson la réédita deux fois en 1537.

\section{2/ La Bible de Thomas Matthew et la Grande Bible}

Tyndale, arrêté à Anvers par la police de Charles Quint, fut supplicié le 6 octobre 1536. Ce lettré compétent en grec et en hébreu avait eu cependant le temps de pousser sa traduction de l'Ancien Testament jusqu’à la fin des Chroniques. Cette traduction passa dans les mains de son ami John Rogers. Sous le pseudonyme de 'Thomas Matthew', il fit imprimer à Anvers une nouvelle Bible pour laquelle Cranmer avait obtenu l'autorisation du Roi. On y trouvait la traduction de Tyndale, du début de la Genèse à la fin des Chroniques, ainsi que son Nouveau Testament. Le reste était de 
Coverdale. L'originalité principale de la Bible de Rogers résidait dans les nombreuses aides de lecture (Sommaires, tables, index et plus de 2000 notes) empruntés pour la plupart aux Bibles françaises de Le Fèvre d'Etaples et d'Olivétan, ainsi qu'à de nombreux commentateurs. Le tout avait une tonalité nettement protestante.

Le 5 septembre 1538, Henry VIII publia une 'Injunction' à l'intention du clergé. Il lui ordonnait de placer en chaque église paroissiale "one book of the whole Bible of the largest volume in English'. La moitié des frais incombait aux paroissiens. Cette injonction requérait l'impression d'un grand nombre de Bibles. C'est pourquoi Cromwell, avec l'accord de Cranmer, chargea Coverdale de réviser une nouvelle 'Grande Bible'. On la fit imprimer à Paris chez François Regnault, sous la responsabilité éditoriale de Richard Grafton et d'Edward Whitchurch munis, à cette fin, d'une autorisation de François Ier. Cependant les notes de la 'Bible de Matthew' avaient causé un scandale parmi les évêques anglais. Aussi le roi Henry VIII publia-t-il le 16 novembre 1538 une proclamation qui interdisait la publication de Bibles annotées sans son approbation formelle. Coverdale supprima donc, par mesure de sécurité, les notes de la Bible de Matthew. Pour réviser l'Ancien Testament, il s'aida surtout de la Bible latine et hébraïque publiée en 1534-1535 par Sébastien Münster. Comme les relations s'étaient tendues entre la France et l'Angleterre, l'Inquisition confisqua chez Regnault les feuilles imprimées et les entreposa à l'Université de Paris. La confiscation dura du 17 décembre 1538 à novembre 1539 (Pollard, Records 21). La publication de la Bible eut lieu, semble-t-il, au début de 1540 et elle compta sept éditions jusqu'en décembre 1541. Les deuxième, troisième, cinquième et septième éditions portaient sur leur page de titre: "This is the Bible appoynted to the use of the churches". En effet, malgré l'exécution de Cromwell en juillet 1540, Henry VIII renouvela son injonction en mai 1541 : à la Toussaint, chaque paroisse devrait avoir placé la Bible à la disposition de ses paroissiens, sous peine d'une amende de 40 shillings par mois de retard. Pourtant, de décembre 1541 à la fin du règne de Henry VIII (1547), il n'y eut plus d'édition de Bibles anglaises. Cela tient probablement au fait que, lors de la Convocation de janvier 1542, la majorité des participants avait estimé souhaitable un rapprochement entre la Bible anglaise et la Vulgate. Une centaine de mots, selon Gardiner, nécessitaient en effet une latinisation. Ce travail de révision fut d'abord confié à des évêques et à des lettrés, puis transféré aux universités. Cela n'aboutit à rien, conformément, semble-t-il, au voeu secret de Cranmer (Greenslade, introduction au facsimilé 25).

Sous Edouard VI, il y eut de nombreuses rééditions de la Grande Bible et de celles qui l'avaient précédée.

\section{3/ La Geneva Bible}

Sous Marie Tudor, aucune Bible ne fut éditée en Angleterre. Nombre d'entre elles furent détruites, sans pourtant qu'eût été publiée une interdiction formelle des Bibles en langue vulgaire. Cependant, réunis autour de William Whittingham, un certain nombre de lettrés, réfugiés à Genève, préparèrent une révision très approfondie de la Bible anglaise. Cette Bible, imprimée par Rowland Hall, fut publiée pour la première fois à Genève en 1560 . Elle présente trois particularités qui contribuèrent à son succès. $D^{\prime}$ abord c'est un in- $4^{\circ}$, ce qui facilitait son usage familial, à la différence 
des énormes bibles d'églises éditées auparavant. Ensuite, elle est la première Bible anglaise à porter la numérotation des versets. C'est également la première à être imprimée en caractères romains et non gothiques. Pour ces deux innovations, les éditeurs se sont inspirés des Bibles genevoises de Robert Estienne. Ils leur ont également emprunté la plupart des corrections qu'ils ont fait subir à la 'Grande Bible'. Présentons tout d'abord la Bible latine éditée par Robert Estienne en 1557 car elle exerça sur eux une grande influence.

Elle porte comme titre et sous-titre : 'Biblia Utriusque Testamenti. De quorum nova interpretatione et copiosissimis in eam annotationibus lege quam in limine operis habes epistolam'. Le Nouveau Testament, traduit et annoté par Théodore de Bèze, est daté en sa page de titre de 1556 et en son colophon du 1er mars 1557. Les notes sur les Apocryphes sont de Claude Baduel qui, pour la traduction latine, a suivi de près la polyglotte d'Alcala. Robert Estienne a centré son effort sur les livres canoniques de l'Ancien Testament (datés de 1557). Dans sa lettre au “lecteur pieux et vraiment chrétien", il explique qu'il a entrepris cette édition parce qu'il estime avoir enfin en main presque tous les moyens nécessaires. Comme pour l'édition de 1545, il donne deux traductions latines et des annotations. Mais le format (ici in-folio) et le contenu en diffèrent. La Vulgate imprimée en petits caractères n'a en marge que des parallèles. Son texte intègre maintenant les leçons que les éditions de 1540 et de 1546 donnaient en marge avec leurs témoins. La traduction nouvelle - qui occupe ici la première place -, n'est plus, comme en 1545, celle de Leo Jud, mais celle de Sanctes Pagnini “dont tout le monde s'accorde à reconnaître qu’elle est préférable, étant la plus fidèle". Estienne a obtenu, dit-il, deux exemplaires de la première édition de cette traduction, corrigés et retouchés par le traducteur lui-même. Il dispose aussi des annotations de Pagnini portant sur l'Ancien Testament. Ensuite, de façon plus détaillée qu'en 1545, il précise que les notes prises aux cours de Vatable ont été revues par lui. Elles avaient été prises par Bertin qui lui succéda ensuite. L'enseignement de Vatable était basé sur la traduction de Pagnini. Il s'en éloignait parfois cependant, après l'avoir critiquée. C'est pourquoi Estienne a retouché la traduction de Pagnini d'abord à partir des corrections de celui-ci et ensuite à partir des options de Vatable. Il a cependant respecté - ainsi que Pagnini l'avait fait - les hébraïsmes. Quant aux annotations, elles ont au moins quatre sources distinctes. Les deux premières consistent dans les notes prises aux cours de Vatable et les annotations autographes de Pagnini. Ensuite, Estienne a explicité les hébraïsmes du texte, en se fondant principalement sur le Thesaurus de Pagnini. Enfin, dans les passages difficiles, il a ajouté les diverses interprétations qu'il a rencontrées chez les commentateurs juifs et chrétiens. La présentation de la traduction de Pagnini offre, de son côté, deux particularités. D’abord, Estienne y a distingué de manière plus systématique, par un caractère plus petit - et, ici, cursif - les mots sans base hébraïque immédiate, tentative amorcée par les Bibles de Zurich et de Serrières. Puis, il a permis une meilleure prononciation des noms propres, en insérant dans leurs transcriptions des lettres hébraïques destinées à pallier aux carences des lettres latines. En conclusion, soulignons l'erreur commise par les éditeurs des Critici Sacri lorsqu'ils attribuent à “Vatable" l'ensemble éclectique des annotations de cette Bible de 1557. Ils auraient été plus proches de la vérité s'ils avaient publié sous ce nom les annotations de la Bible de 1545, puisque ces dernières 
ne dépendent, semble-t-il, que de deux sources : Vatable et les notes des Bibles antérieures de Robert Estienne.

Cette Bible de 1557 et la Bible française éditée par Estienne en 1553 sont les deux sources principales dont dépend la Geneva Bible de 1560 pour les éléments caractéristiques de son texte et de ses notes. C'est ce que nous voudrions montrer à propos de quelques passages difficiles des Bénédictions de Jacob (Gn 49).

La Grande Bible de 1540 traduisait ainsi 49,3 : “Ruben myne eldest sonne, thou art my myghte and the beginnynge of my strength, the noblenesse of dignyte and the noblenesse of power." Ge corrige seulement les deux emplois de 'noblenesse' en 'excellencie' dont aucune des Bibles anglaises précédentes ne faisait usage ici. Cette correction se fonde sur la traduction de Pagnini selon l'édition de 1557 : “excellentia dignitatis, \& excellentia roboris". En effet son édition de 1527 portait : "excellentia, dignitas, \& excellentia fortis" et l'édition de 1542 : “excellens dignitate, \& excellens fortitudine".

Tyndale rendait les deux premiers mots du vs 4 par: "As unstable as water". Sous la forme "unstable as water", cette traduction a survécu dans la Grande Bible de 1540, la Bible des Evêques de 1602, la KJ et la RSV. Coverdale avait traduit le premier mot : "Thou passest forth swiftly" où - malgré la correction facilitante en 2e p. - l'on reconnaît la Bible de Zurich (1531) : “Er fart eylets schnäll dahin". Ge offre ici : "Thou wast light". Elle interprète, comme l'annotation d'Estienne le suggère, l'hébraïsme "Levitas fuit tibi" que la Bible de 1557 offrait dans la traduction de Pagnini. L'édition de 1527 portait ici la leçon erronée : “Levi (sicut aqua)" et l'édition de 1542 : “Labilis (ut aqua)" qui correspond assez exactement à la traduction de Tyndale.

Tyndale donnait ensuite : "(thou shalt therfore not) be the chefest". Coverdale, la Grande Bible de 1540 et la Bible des Evêques de 1602 gardent cela, en omettant 'therfore'. Ge corrige en : "(thou shalt not) be excellent" qui correspond à "non excelles" de Pagnini (1557) - les éditions de 1527 et de 1542, quant à elles, portaient : "non habebis excellentiam".

Puis Ge offre : "because thou wentest up to thy fathers bed" qui est la traduction de la Grande Bible de 1540 et "then didest thou defile my bed" qui équivaut à “Even then dyddest thou defyle it" de la Grande Bible.

Mais la difficulté principale de la Bénédiction de Ruben réside dans le dernier mot du vs 4 : 2 : La Vulgate ne l'a pas traduit et il a suscité les exégèses les plus variées. Ici, Tyndale offrait : "with goynge uppe" (conservé par Coverdale et par la Bible des Evêques de 1602). Cela émane de Luther et de Zurich : “mit dem auffsteygen". La Grande Bible de 1540 porte ici : “and it was no more my couche", leçon que Coverdale a empruntée à Münster (1534) : “\& stratum meum esse desiit". Ge donne : "thy dignitie is gone", tiré de la Bible de 1553 : “\& la dignité s’en est allée" et de l'annotation de la Bible de 1557 : "עלה Ad verbum, ascendit, id est abiit \& evanuit... sensus est, dilapsam esse, ac extinctam excellentiam Ruben". Ici, KJ traduira : "he went up to my couch", d’après la traduction de Tremellius : "stratum meum ascendit", et considérera cela comme une apostrophe adressée par Jacob à ses autres fils.

Le début du vs 11 était traduit par Tyndale : "He shall bynde his fole unto the vine, and his asses colt unto the vyne braunche". Les quatre derniers mots rendent 


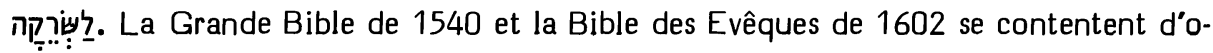
mettre le mot 'vyne", conformément au "\& ad palmitem" de Münster. Coverdale traduisait : "to the noble braunch" où l'on reconnaît : "an den edlen reben" de Luther et de Zurich. Ici, Ge donne : "unto the best vine" basé sur "ad vitem optimam" de Pagnini selon l'édition de 1557; alors que l'édition de 1527 portait "et ramum" et celle de 1542 "et ad ramum".

Tyndale traduisait le vs 12 : "his eyes are roudier than vyne, and his teeth whitter then mylke". Cette interprétation en comparatifs des deux prépositions מן se retrouve chez Coverdale et dans la Grande Bible de 1540. Mais Ge traduit: "His eyes shalbe red with wine, and hys tethe white with milke". Cette interprétation en causatifs des prépositions vient de la Bible de 1553 : “Ayant les yeux vermeils de vin, \& les dents blanches de lait" et de l'annotation de la Bible de 1557 : "Rubescent etiam oculi virorum Juda ab ipso vino, tanta abundantia vinum proferret terra illa : quin \& lactis in ea tribu tanta erit copia, ut dentes ipsius ex frequenti ejus usu sint albicaturi." Notons que cette double traduction par "with" sera retenue par la Bible des Evêques de 1602 , la KJ et la RSV.

Tyndale rendait le début du vs 21 par : “Nepthali is a swyft hynde", traduction conservée par Coverdale et par la Grande Bible de 1540. On y reconnaît : "Naphthali ist ein schneller hirs" de Luther et de Zurich. Ici, Ge préfère : "Naphtali shalbe a hynde let go". C'est la traduction de Pagnini : “cerva dimissa", interprétée selon le premier sens proposé par l'annotation de la Bible de 1557 : “id est quae venatione capta non occiditur". La Bible des Evêques de 1602 portera : “a hinde sent for a present". C'est le deuxième sens de la même annotation : “Alii vertunt 'cerva missa', subauditur : 'ad aliquem principem', quae solet esse pulcherrima". La suite de cette annotation a pu inciter Ge à corriger ici la Grande Bible : "Putant quidam laudari celeritatem in tribu Nephthali : at doctioribus alius sensus magis probatur".

La deuxième partie du vs 22 était traduite par Tyndale : "the doughters come forth to bere ruele". Cela vient de Luther : “die tochter tretten eynher ym regiment". Coverdale préfère: "the doughters go upon the wall" inspiré de la Bible de Zurich : "die töchtern gond här auff den mauren". La Grande Bible de 1540, avec : "the daughters ran upon the wall", a été retouchée selon Münster : "filiae discurrerunt super murum". Ge corrige cela en : "the smale boughes shal runne upon the wall" suggéré par une annotation de la Bible de 1557 : “Doctiores non interpretantur concursum fore virginum super muros, quas illexerit arboris conspectus : sed continuam esse metaphoram scribunt, ramusculos filias vocari existimantes".

Au vs 24, après "the myghtye God of Jacob", Tyndale ajoutait : "out of him shall come an herde man a stone in Israel", traduction qui sera conservée par la Grande Bible de 1540 et par la Bible des Evêques de 1602. Coverdale, lui, met cette expression au pluriel : "Of him are come herdmen \& stones in Israel", ce qui correspond à Luther: "Aus jnen sind komen Hirten, und Steine in Israel". Ge corrige en : "of whome was the feeder appointed by the stone of Israel", et note sur 'stone' : "That is, God". La Bible de 1557 portait : “unde pascens lapidem Israel". Estienne explique dans l'annotation: "Alii vertunt 'pastor lapidis' in genitivo : lapidem accipientes pro familia. Doctiores ad Deum referunt qui pastoris munus servo suo injunxit." $\mathrm{KJ}$ corrige ce passage en "From thence is the shepherd, the stone of Israel" sous l'in- 
fluence de Tremellius : "unde fuit pastor \& lapis Jisraëlis" expliqué par la note : "id est, a Deo ipso eodem evectus est eo usque, ut victum Aegyptiis et aliis gentibus suppeditaverit, fueritque Israelitis lapis perfugii".

Dans les trois derniers cas, nous avons vu Ge adopter l'interprétation que les annotations de la Bible de 1557 attribuaient aux "doctiores". Ces quelques exemples permettent de constater que la traduction de Tyndale, se fondant principalement sur Luther, sert de base à celles qui la suivent. Nous notons aussi le lien étroit unissant la Bible de Coverdale à celle de Zurich (et, en deuxième lieu, à celle de Luther), la Grande Bible à Münster, Ge et la Bible des Evêques aux très riches données fournies par Estienne (surtout dans sa Bible de 1557) et enfin KJ à Tremellius.

La Geneva Bible ne fut jamais l'objet d'une autorisation officielle. Elle devint cependant extrêmement populaire. Elle supplanta même les autres Bibles dans l'Eglise d'Ecosse. Ce fut la Bible de Shakespeare et de la plupart des familles ainsi que des Puritains qui s'établirent en Nouvelle Angleterre. Entre 1560 et 1644 elle ou son Nouveau Testament furent réédités au moins 140 fois. De toutes les Bibles anglaises, ce fut elle qui concurrença le plus longtemps la King James Version.

\section{4/ La King James Version}

Elisabeth, après son avènement, renouvela l'injonction de son père ordonnant qu'“un exemplaire de la Bible complète du plus grand format en anglais" soit mis à la disposition des fidèles en chaque église. Vu le nombre requis, une nouvelle édition était nécessaire. Parker reprit le projet de Cranmer qui avait échoué dans les dernières années du règne d'Henry VIII : répartir entre des évêques et quelques autres prélats les livres de la Bible pour les réviser. Le 5 octobre 1568, avec le premier exemplaire de la Bible révisée (qui allait recevoir le nom de 'Bible des Evêques'), Parker expliquait à la Reine les principes qui avaient régi la révision. On ne s'était éloigné de la Grande Bible que là où elle était en désaccord avec l'original grec ou hébreu. Pour suivre plus fidèlement celui-ci, on avait fait usage de Pagnini (vraisemblablement dans l'édition Estienne de 1557) et de Münster. On s’était abstenu de notes agressives ou polémiques - critique implicite à l'égard du Nouveau Testament de Tyndale, de la Bible de 'Thomas Matthew' et de la Geneva Bible -. On avait marqué d'un signe les sections trop peu édifiantes pour prêter à une lecture publique. Enfin on avait substitué des euphémismes aux mots qui, dans les Bibles précédentes, pouvaient choquer comme obscènes ou inconvenants (Pollard, Records 297s). Jusqu'à sa mort (17 mai 1575), l'archevêque Parker empêcha, semble-t-il (Pollard 39s), que la Geneva Bible soit imprimée en Angleterre. Il voulait faciliter ainsi la diffusion de la Bible des Evêques. Mais, après cette date, la Geneva Bible se répandit largement, si bien que les puritains comme les prélats sentirent bientôt les inconvénients d'une situation où la Bible qu'on lisait chez soi ne correspondait pas à celle qu'on entendait à l'église.

En janvier 1604, Jacques Ier convoqua une conférence à Hampton Court pour écouter les doléances des puritains et envisager les réponses possibles. La séance où l'on décida de traduire à nouveau la Bible fut relatée par William Barlow, doyen de Chester (Pollard, Records 46s). Les deux initiateurs du projet furent le $\mathrm{Dr}$ John Reynolds, porte parole des puritains et président de Corpus Christi College à Oxford, et le Roi lui-même. Reynolds exposa trois infidélités des Bibles officielles alors en 
usage par rapport à l'original grec ou hébreu :

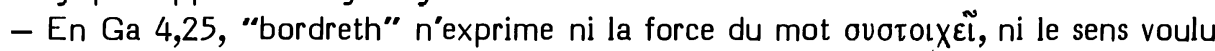
par l'Apôtre, ni le rôle de ce mot dans le contexte. $\mathrm{KJ}$, notons-le, retiendra ici la traduction de Ge : "answereth".

- En Ps 105,28, les Bibles officielles portaient : “they were not obedient", alors que l'original porte : "they were not disobedient". C'était en effet la leçon de Ge. Mais KJ préférera : "they rebelled not".

- En Ps 106,30, les Bibles officielles donnaient : "Then stood up Phinees and prayed", en contraste avec l'original : "and executed judgement". C'était encore la leçon de Ge que $\mathrm{KJ}$ allait retenir.

L'évêque de Londres remarqua alors qu'on ne pouvait tenir compte de l'avis de chacun, sous peine de devoir sans cesse reprendre la traduction. Alors le Roi exprima le voeu que l'on fasse des efforts spéciaux pour aboutir à une traduction uniforme. Il déclara n'avoir jamais vu jusqu'alors une Bible bien traduite en anglais. Mais la pire de toutes, à l'avis de Sa Majesté, était la Geneva. Le travail devrait être accompli par les plus instruits des deux Universités, révisé par les Evêques et les plus instruits de l'Eglise, puis présenté au Conseil Privé et finalement ratifié par l'autorité Royale, de sorte que l'ensemble de l'Église soit obligé d'utiliser cette Bible et nulle autre. Sur une remarque de l'évêque de Londres, le Roi interdit de placer des notes marginales. En effet, dans une Geneva Bible qu'une Dame anglaise lui avait donnée, il avait remarqué certaines notes très tendancieuses, fausses et séditieuses témoignant de trop de conceptions dangereuses et perfides. Par exemple, en Ex 1,19, la note marginale a permis la désobéissance aux rois et en $2 \mathrm{Ch}$ 15,16, la note a reproché à Asa de s'être contenté de déposer sa mère et de ne pas l'avoir tuée.

- En Ex 1,19, à propos de la désobéissance des sages-femmes aux ordres du Pharaon, Ge note en effet : "Their disobedience herein was lawful".

- En 2 Ch 15,16, Ge remarque : "herein he shewed that he lacked zeale : for she oght to have dyed bothe by the covenant and by the Lawe of God : but he gave place to foolish pitie". On comprend que cette note ait inquiété le Roi.

Donc les puritains et le Roi s'accordaient sur la nécessité d'une nouvelle traduction. Mais, alors que ceux-là voyaient dans la Geneva Bible le modèle à suivre, le Roi voulait la disparition de cette Bible dont les notes constituaient une menace pour son autorité.

Le doyen de Westminster et les professeurs royaux d'hébreu d'Oxford et de Cambridge suggérèrent des noms de traducteurs et l'on constitua 6 équipes de 7 à 10 membres chacune. Des deux équipes de Westminster, une avait la charge du début de l'A.T. jusqu'au 2e livre des Rois, l'autre des Epîtres de S. Paul et des Epîtres Canoniques. De celles de Cambridge, une se chargeait de l'A.T. depuis le premier livre des Chroniques jusqu’à l’Ecclésiaste et l'autre de l'ensemble des Apocryphes. Enfin, une équipe d'Oxford prenait les Prophètes et les Lamentations, l'autre les Evangiles, les Actes et l'Apocalypse. Quand, au bout de quatre ans (deux de travail individuel et deux de travail de groupe), les équipes eurent fini leur travail, deux délégués de chacune constituèrent à Londres un comité de douze membres chargé de la révision et de l'unification de la traduction. Ils travaillèrent durant 39 semaines. Bilson, évêque de Winchester, et Miles Smith, futur évêque de Gloucester, apportèrent les dernières retouches. Bancroft, évêque de Londres, qui avait manifesté peu d'enthousiasme pour 
le projet initial de Reynolds, obtint en dernière heure encore 14 retouches à la traduction.

L'essentiel de la révision consista à intégrer dans la Bible des Evêques les éléments les plus valables de la Geneva Bible. Cependant, les traducteurs firent appel aussi à toutes les Bibles anglaises précédentes, valorisant même souvent des trouvailles de Tyndale que celles-ci n'avaient pas retenues. On omit toute note marginale autre que des parallèles bibliques, des traductions plus littérales sur l’hébreu et quelques interprétations offertes en alternative. Parmi les sources qui n'étaient pas encore disponibles à l'époque où se préparait la Geneva Bible, celle dont les réalisateurs de la King James Version firent le plus grand usage fut la traduction latine de Tremellius et Junius.

Emanuele Tremellio, Juif né en 1510 à Ferrare, se convertit au christianisme et fut baptisé en 1540. En 1542 il s'enfuit d'Italie avec le réformateur Pierre Martyr Vermigli. En 1549, il enseignait l’hébreu à Cambridge. En 1559, il fut nommé précepteur du fils du duc de Zweibrücken et, en 1561, il obtint une chaire à l'université de Heidelberg. En 1571, il commença sa traduction latine de la Bible. François du Jon (= Junius) l'aida et traduisit les Apocryphes. Pour le Nouveau Testament, on édita côte-à-côte la traduction de Théodore de Bèze (qu’Estienne avait donnée dans sa Bible de 1557) et une traduction faite par Tremellius sur le syriaque. La traduction de l'Ancien Testament est l'oeuvre de Tremellius et elle demeura intacte jusqu'à la troisième édition à Londres en 1585 chez Henry Midleton. Ensuite, Junius la retoucha de façon peu heureuse dans les éditions parues à Genève en 1590 et à Hanau en 1596. Tremellius a traduit l'hébreu de façon assez précise. Cependant, lorsqu'une traduction littérale était inintelligible, il la plaçait en marge et donnait dans le texte une tournure plus latine. La traduction est enrichie de nombreuses notes exégétiques qui explicitent le sens et motivent les interprétations. Comme Estienne en 1557, et comme la Geneva Bible, il utilise l'italique pour les mots de son texte sans fondement immédiat dans la langue originale, procédé que la King James Version respectera elle aussi, jusqu’à ce que la RSV ait décidé d'y renoncer.

Dans certains passages difficiles, l'influence de la traduction de Tremellius sur la $\mathrm{KJ}$ est évidente. En voici quelques exemples tirés de la Genèse.

En 3,4b, selon Tyndale, le serpent dit à la femme : "tush ye shall not dye", à quoi Coverdale ajoute : “the death". La Grande Bible de 1540 et la Bible des Evêques de 1602 suivent Coverdale, mais omettent "tush". Ge traduit : "Ye shall not dye at all", ce qui correspond à une annotation de la Bible de 1557 : "Hebraismum sic quidam reddunt, Nequaquam moriemini", leçon qui est d'ailleurs celle de la Vulgate. Ici $\mathrm{KJ}$ rompt avec ses devancières et traduit : "Ye shall not surely die". Cette modification s'explique par une note de Tremellius : "Satanas... ex dubitandi particula qua usa est Cheva, infert non esse certum mortem secuturam... : non enim dicit moriendo non moriemini, id est, utique non moriemini... sed inverso vocum ordine, tantum negat mortis certitudinem".

En 4,22, Tyndale présentait Tubal-Caïn comme : “a worker in metall and a father of all that grave in brasse and yeron". Coverdale le corrige en : "a worker in all connynge points of metall \& yron". La Grande Bible de 1560 et la Bible des Evêques de 1602 préfèrent : "which wrought cunningly every craft of brasse and of yron". Ge change seulement "which" en "who". KJ s'éloigne de ces traductions avec : "an instructor of every artificer in brass and iron". Elle suit Tremellius qui donnait: 
"qui erudivit omnem fabrum aerarium \& ferrarium", et notait que le mot "qui acuit" a pour complément les artisans et non les métaux.

En 22,14, Tyndale rend le dicton final par: "in the mounte will the LORde be sene". C'est la traduction de Pagnini (1527): "in monte Dominus videbitur". Cette traduction a été conservée par la Grande Bible de 1540, la Geneva Bible et la Bible des Evêques de 1602. Coverdale, lui, avait préféré : "Upon the mountayne shal the LORDE provyde", ce qui s'inspire, peut-être, de Jérôme ou de Nicolas de Lyre. Ici encore, $\mathrm{KJ}$ se détache des traductions antérieures et donne : "In the mount of the LORD it shall be seen". L'idée de faire du tétragramme un génitif complétant le mot précédent lui est venue de Tremellius : "in monte Jehovae providebitur".

Nous avons déjà étudié ci-dessus à propos de Ge, le cas très caractéristique du dernier mot de 49,4. Ces exemples seront complétés par de nombreux autres, tout au long de ce travail.

Concluons cette rapide étude des sources de la Bible anglaise par quelques remarques. Tout d'abord, son développement est postérieur à celui des Bibles allemande et française. Dans l'Ancien Testament, elle a toujours pris des traductions allemandes et latines comme moyens d'accès au texte hébreu, mais elle a choisi ces intermédiaires avec un excellent discernement. D'autre part, les nombreuses révisions suscitées par l'histoire mouvementée des débuts de l'Eglise anglicane ont permis une amélioration continue de la Bible anglaise jusqu'à la King James Version, produit le plus achevé de la recherche biblique du XVIe siècle. La Bible allemande, par contre, est restée longtemps figée dans l'état où le génie de Luther l'avait léguée à son peuple.

\section{La Bible des Pasteurs et Professeurs de l'Eglise de Genève}

En 1588 parut une révision de la Bible de Genève qui offrait de nombreuses innovations. D'abord, elle porte le sous-titre : "Le tout revu et conféré sur les textes Hébrieux et Grecs par les Pasteurs et Professeurs de l'Eglise de Genève" sans mention d'éditeur. Un 'Avertissement aux marchands libraires et imprimeurs' précise que les gains éventuels obtenus par la diffusion de cette Bible serviront “à la communauté des pauvres réfugiés de divers pays \& nations en cette Eglise". Il est donc demandé aux libraires et imprimeurs de respecter cette intention en évitant de tirer un profit illicite de la contrefaçon de cette Bible. D'autre part, cette Bible fut publiée simultanément en trois formats : in-folio, in-quarto et (avec des notes réduites) in-octavo. De fait, elle dut avoir un très gros tirage, car elle ne fut pas réimprimée avant le début du $X V I I e$ siècle. Au cours de ce siècle elle fut rééditée sans modification, tous les cinq ans environ.

Les documents relatifs à cette révision ont été publiés par Ch.Borgeaud (Histoire de I'Université de Genève I, Genève 1900, 319-323). Deux hommes sont à l'origine de cette initiative : Théodore de Bèze, le successeur de Calvin, et Corneille Bertram, lecteur d"hébreu à l'Académie de Genève. Ce dernier, qui signait "Bertramus", était né en 1531 à Thouars en Poitou sous le nom de Bonaventure Bertrand. De 1553 à 1556, il étudia l'hébreu à Paris sous Jean Mercerus, professeur au Collège Royal. Les troubles liés aux premières guerres de religion l'obligèrent à dissimuler son identité sous un nouveau prénom, puis à se réfugier à Genève. En 1562, il fut nommé pasteur dans le village de Chancy. Il épousa la nièce de Théodore de Bèze. 
Au moment de sa création, Calvin avait offert le poste de lecteur d'hébreu à Mercerus qui refusa. Ensuite, il avait fait appel à Emmanuel Tremellius. Celui-ci, disposé à accepter, n'avait pas obtenu du duc de Zweibrücken la permission de quitter le collège d'Hornbach dont il était recteur. Aussi est-ce le gendre de Tremellius, Antoine Raoul Chevalier, originaire de Vire en Normandie et ancien élève de Vatable, qui fut nommé lecteur d'hébreu en 1559. Lorsqu'en septembre 1566, il demanda un congé pour raison de santé, ce fut vraisemblablement Bertram qui le remplaça. En tout cas, il lui succéda le 13 janvier 1567. En 1574, il publia une grammaire comparée de l'hébreu et de l'araméen, et en 1577, il réédita le Thesaurus de Pagnini, avec des additions de Mercerus et d’Antoine Chevalier. Dès 1569, il entreprit, avec Bèze, la révision de la Bible française de Genève. Ils envisagèrent d'abord de la rééditer chez Jérémie des Planches. Cependant des plaintes contre cette initiative étaient parvenues au Conseil de Genève, prétendant "qu'ils la font imprimer avec plusieurs nouvelles annotations et corrections, même, dit-on, qu'ils ont changé quelques versets et chapitres, ce qu’étant ainsi serait occasion de quelque scandale". Le Conseil convoqua Des Planches, puis Bèze qui fournit les précisions suivantes :

Après que Bertram et lui aient revu une première fois toute la Bible, la Vénérable Compagnie leur avait adjoint trois autres de ses membres : Charles Perrot, Jean Jacquemot et Jean-Baptiste Rotan. Quand les cinq achoppaient à quelque difficulté, ils la soumettaient à la Vénérable Compagnie. D'ailleurs, cette révision avait été entreprise sur la demande des Eglises de France dont le Synode avait délégué deux de ses membres à Genève pour s'informer du travail accompli. Si l'on n'avait pas demandé d'autorisation au Conseil, c'est parce qu'aucune des révisions précédentes n'avait fait l'objet d'une telle autorisation. Bèze et Perrot attestaient d'ailleurs que l'on n'avait rien changé ni aux chapitres $\mathrm{ni}$ aux versets. Ils ajoutaient que les emprunts effectués suffisaient à couvrir les frais principaux.

Ils ne précisaient pas que c'était le réviseur Jean-Baptiste Rotan (Borgeaud 322) qui avait avancé l'argent. Celui-ci était en effet le fils fortuné d'un patricien de $\mathrm{Pa}$ doue. Ses relations parmi les banquiers lombards lui permirent, en 1588, de négocier un emprunt contracté par Henri de Béarn (ibid. 240). Aussi la Compagnie, plaçant de grands espoirs en ce prétendant, avait-elle fait relier un magnifique exemplaire de la Bible aux armes de France et de Navarre que Rotan avait pour mission de remettre à Henri IV. Mais, au moment où le cadeau de Genève allait lui être offert, Henri s'engageait - avec les encouragements de Rotan - dans une politique de conciliation entre Catholiques et Protestants, si bien que le cadeau compromettant revint à la Bibliothèque de Genève où il porte la cote $\mathrm{Bb} 553$.

La préface de la Bible est l'oeuvre de Théodore de Bèze "selon certains points qui furent prescrits par la Compagnie". Il y expose la méthode employée par les réviseurs: “Nous avons conféré l'ancienne translation Française de la sainte Bible sur les principales impressions diverses des textes Hébrieux, Grecs \& Latins, puis sur les diverses interprétations Latines, tant dans les livres Canoniques qu'Apocryphes, que nous avons pu recouvrer, desquelles nous avons été très grandement aidés, ayant reconnu en icelles, outre le savoir des translateurs, une singulière piété \& fidélité, sans toutefois nous être du tout assujettis à aucune d'icelles". Bertram (Borgeaud 322, note) précise qu'une fois achevé le travail de la commission des cinq, il se chargea de rédiger les notes plus détaillées requises par certains passages. 
Comme nous le verrons dans la suite de ce travail, c'est la traduction latine de Tremellius qui a inspiré le plus fréquemment la Bible des Pasteurs de Genève. Mais il ne faudrait pas méconnaître le rôle important que joua aussi, dans la révision de 1588, la traduction de Pagnini retouchée par Arias Montano. Notons que Bèze, dans sa préface, passe sous silence les emprunts très notables faits par la Bible de 1588 à la traduction de Sébastian Châteillon.

En conclusion, relevons que les options translationnelles de 180 passages de cette Bible donnèrent lieu, en 1618 et 1619, à une vive controverse entre le jésuite Pierre Cotton et le professeur genevois Bénédict Turretin.

\section{VUE D'ENSEMBLE SUR LA BIBLE EN LANGUE VULGAIRE AU XVIe SIECLE}

\section{Avant la Réforme}

L'Allemagne, la France et l'Italie possédaient des Bibles traditionnelles, traduites à partir de la Vulgate. On les imprima sous des formes plus ou moins révisées. Ce fut, semble-t-il, en Allemagne que ces premières éditions eurent la plus large diffusion. En Angleterre, par contre, où le français était longtemps demeuré la langue dominante des gens cultivés, la traduction de la Bible en anglais à partir de la Vulgate (vers 138083) ne fut pas imprimée. Oeuvre de disciples de Wyclif, elle éveilla à ce titre la défiance de l'épiscopat. Pour réaliser une traduction en langue vulgaire fondée sur les textes originaux, la culture germanophone se trouvait donc bien préparée. Les cultures francophone et italophone, elles, avaient déjà été sensibilisées à la Bible; alors que la culture anglophone n'avait pas été atteinte par elle.

\section{Rôle de Luther}

La décision prise par Luther de traduire toute la Bible en allemand, à partir des langues originales, et la réalisation (de 1521 à 1524) de la première partie de cette traduction sont des événements essentiels. Une logique rigoureuse lie cette entreprise de traduction en langue vulgaire aux deux principes de "l’Ecriture seule" et de la "clarté de l'Ecriture". Parce que la foi (qui, seule, justifie) ne peut se fonder que sur l'Ecriture seule, il faut mettre celle-ci à la portée de tout croyant. Et parce que l’Ecriture n'est pas obscure mais claire, il s'agit de la rendre accessible à tous, en langue vulgaire. La diffusion de la Bible en langue vulgaire est donc une implication directe de la doctrine de Luther. Le rôle d'initiateur de Luther dans le domaine de la Réforme se double donc tout normalement d'un rôle d'initiateur en celui des traductions en langue vulgaire à partir des langues originales.

\section{Rôle des traductions latines}

Nous l'avons constaté tout au long de ce travail, les traductions faites en latin à partir de l'hébreu et du grec jouèrent constamment un rôle d'intermédiaires entre les textes originaux et la langue vulgaire. Lorsque Luther parle de chrétiens bon connaisseurs de l'hébreu, ce sont Pagnini et Münster qu'il évoque.

L'influence la plus durable a été exercée par la traduction de Pagnini en ses quatre éditions principales du XVIe siècle : 
- l'édition princeps chez Antoine du Ry, à Lyon. Sa page de titre porte la date '1528', mais le colophon, à la fin de l'Apocalypse, précise que cette 'Veteris ac novi instrumenti nova translatio' a été achevée d'imprimer le 29 janvier 1527.

- la rédition par Michel Villanovanus (= Servet) chez Hugues de La Porte, à Lyon, en 1542.

- la réédition par Robert Estienne, à Genève, en 1557.

- la réédition par Arias Montano, entre les lignes de l'hébreu, dans le volume VII de la polyglotte d'Anvers publié en 1571. Cette réédition se fonde sur l'édition de Lyon 1542. Lorsqu'Arias Montano corrige Pagnini, sa correction est en italique et la leçon de Pagnini figure en marge.

Un mystère plane sur les liens existant entre la réédition de Genève 1557 et celle de Lyon 1542. En effet, dans le prologue de sa Bible, Servet affirme avoir consacré à la traduction de Pagnini beaucoup d'efforts "post omnia eius annotamenta... Annotamenta, inquam, quae ille nobis quâm plurima reliquit. Nec solum annotamenta, sed \& exemplar ipsum locis innumeris propria manu castigatum". Or Estienne, nous l'avons dit, émet à peu près les mêmes prétentions dans le prologue de sa Bible de 1557 : "Nacti enim sumus duo ex prima illius editione exemplaria, in quibus non solum typographica errata non pauca, nec levia, manu propria ipse author correxerat, sed multos etiam locos diligentius \& accuratius quàm antea examinatos, recognoverat. Venerunt etiam in manus nostras eiusdem Sanctis in Vetus Testamentum annotationes." Ces annotations étaient autographes, comme Estienne le précise sur Ps 1,2 où il cite : "Sanctes in suis annotationibus manu scriptis, quas apud me asservo." Comment Estienne a-t-il obtenu les deux exemplaires de la première édition corrigés par Pagnini lui-même? Comment les annotations autographes de Pagnini sur l’Ancien Testament sont-elles parvenues entre ses mains? Si Estienne se sert en 1557 à Genève des mêmes sources dont Servet disposait en 1542 à Lyon, c'est probablement parce que ce même Servet a été supplicié à Genève en 1553.

Après la traduction de Pagnini dont l'influence s'exerce donc tout au long de ce siècle, mentionnons celle de Münster (Bâle 1534-35) dont l'influence est surtout décelable dans les premières révisions que la Bible de Serrières subit à Genève (à partir de 1540) et dans la révision qui aboutit à la Grande Bible anglaise de 1540.

La traduction latine de Leo Jud, publiée à Zurich en 1543, fut utilisée par Estienne dans sa Bible de 1545 avant qu'il la remplaçât en 1557 par celle de Pagnini. Elle n'eut pas grande influence sur les traductions en langue vulgaire. La traduction latine de Châteillon (1551) en eut encore moins au XVIe siècle. Douen (Buisson I 417) a relevé l'erreur commise à son sujet par R. Simon (650a). Celui-ci prétendait en effet que la traduction française de Châteillon "a été faite sur sa version latine". Cependant, les traductions française et latine diffèrent dans leur interprétation de l'hébreu. Châteillon, lui-même, estimait avoir gagné en exactitude de l'une à l'autre. Sa traduction latine retrouvera pourtant une certaine vogue de 1697 à 1778, rééditée une fois à Francfort, deux fois à Londres et six fois à Leipzig.

Enfin, la traduction latine de Tremellius eut un fort impact chez les Calvinistes de Genève. Tremellius avait, en effet, été lié de près à la fondation de la chaire d’hébreu de l'Académie de Genève et sa traduction avait été complétée par François du Jon (= Junius), ancien étudiant de cette Académie demeuré en contact étroit avec Genève où il fit réimprimer ladite traduction en 1590. 
Comme nous l'avons vu, la traduction de Tremellius marqua aussi de son empreinte la King James Version. Le traducteur s'était en effet réfugié à Oxford en 1548, avec Pierre Martyr Vermigli. Il avait ensuite enseigné l'hébreu à Cambridge avant de quitter l'Angleterre à l'avènement de Marie Tudor (1553). Les liens qu'il y avait conservés expliquent les trois éditions successives de sa traduction à Londres, en 1580, 1581 et 1585. Elle était sûrement à la disposition de tous les traducteurs de la Bible de 1611.

\section{Róle de Robert Estienne}

L'ancien imprimeur de François Ier réfugié auprès de Calvin a exercé une influence de premier ordre sur les traductions bibliques françaises et anglaises du XVIe siècle.

Son édition révisée de la Bible de Genève en 1553 a été en effet la Bible officielle des Calvinistes de langue française, jusqu’à la révision de 1588. Comme nous l'avons montré, René Benoist, puis les théologiens de Louvain, lui ont assuré une large diffusion chez les Catholiques aussi, malgré des retouches pour la rapprocher de la Vulgate (dont Estienne avait d'ailleurs été, en ce siècle, le meilleur éditeur).

L'influence d’Estienne sur la Geneva Bible anglaise (et, à travers elle, sur la King James Version) s'est surtout exercée par l'intermédiaire de sa Bible latine de 1557 que les réfugiés anglais ont eu sans cesse sous les yeux pour guider leur interprétation.

D'ailleurs, les deux traductions et les annotations contenues dans la Bible de 1557 ont constitué la partie centrale de la triglotte publiée à Heidelberg en 1586 “ex Officina Sanctandreana", avec d'un côté une colonne hébraïque et, de l'autre, une colonne grecque (reproduisant la Septante de la polyglotte d’Alcala). Le réalisateur de cette édition fut probablement Corneille Bertram, après son départ de Genève.

\section{Les Bibles et l'autorité}

Les traducteurs de la Bible en langue vulgaire entrèrent souvent en conflit avec les autorités religieuses et civiles. Cependant, la politique des autorités catholiques varia selon les régions : Flandres, France ou Espagne.

La politique de Charles Quint fut constante. Elle était déjà clairement exposée dans un placard publié à Malines le 17 juillet 1526 (Fr. H. Reusch, Die Indices Librorum Prohibitorum des Sechzehnten Jahrhunderts, BLVS 176, Tübingen 1886, 23) : “Seront confisqués et brûlés ... tous les évangiles, épîtres, prophéties et autres livres de la Sainte Ecriture en Allemañd, Flamand ou Français portant des apostilles ou des gloses ou ayant des préfaces ou prologues comprenant des faussetés ou des erreurs ou des doctrines de Luther et de ses adhérents réprouvées par la sainte église ou contredisant l'enseignement commun et la doctrine de celle-ci." En réponse à l'interdiction, éditée le 8 avril 1546 par le Concile de Trente, d’imprimer ou de vendre “sans l'autorisation des supérieurs ecclésiastiques, les livres de la Sainte Ecriture portant des annotations et des commentaires de n'importe qui souvent sans mention de l'éditeur ou avec une fausse mention, et - ce qui est plus grave - sans nom d'auteur", la Faculté de théologie de Louvain publia, le 9 mai, un 'Catalogue de livres interdits' comprenant de nombreuses Bibles. Cependant l’Empereur ne voulait pas laisser ses sujets sans Bibles. Il ordonna donc aux théologiens de Louvain de réviser une Bible latine, une Bible fla- 
mande et une Bible française. Nous avons vu comment ils réalisèrent cet ordre à partir de 1547 en évitant toute annotation. Nous avons aussi noté que ces Bibles de Louvain pénétrèrent en France où les docteurs de Sorbonne finirent par les approuver formellement.

En France, les Bibles latines de Robert Estienne subirent les premières les critiques de la Sorbonne, de 1547 à 1550. Le Roi (François Ier, puis Henri II) essaya de protéger son éditeur et d'obtenir des théologiens des censures qui permissent de corriger ces Bibles, au lieu de l'interdiction pure et simple que voulait la Sorbonne. Un conflit semblable eut lieu de 1567 à 1575, à propos des Bibles françaises de René Benoist. En aucun de ces deux conflits les théologiens parisiens ne manifestèrent clairement la volonté de remplacer les Bibles qu'ils interdisaient.

En Espagne, l'Inquisition interdit toute traduction de la Bible en langue vulgaire, si bien qu'il fallut attendre $1791-93$ pour que parût à Valence, traduite par Philippe Scio de San Miguel, la première traduction catholique complète de la Bible en espagnol (faite sur la Vulgate, naturellement). Cependant, le Conseil de l'Inquisition générale adopta une position plus nuancée à l'égard des Bibles en langues anciennes. Ce sont des espagnols, notons-le, qui furent les maîtres d'oeuvre des deux premières polyglottes : celle d'Alcala (grâce au cardinal Ximenès) et celle d'Anvers (que l'on doit à Arias Montano). Comme nous l'avons vu, lorsque la promulgation en Espagne (en 1551) de l'Index de Louvain entraîna la confiscation par l'Inquisition de la plupart des Bibles latines, celle-ci veilla à ce qu'elles fussent corrigées et rendues à leurs possesseurs. Lorsque, plus tard, les lettrés manifestèrent le désir d'avoir à leur disposition la 'Bible de Vatable' interdite par la Sorbonne, l'Inquisition espagnole organisa une révision de cette Bible et la publia munie de son approbation formelle. Cette attitude, nous l'avons vu en détail, tranche sur les positions souvent bien plus raides des autres autorités catholiques à l'égard des Bibles à annotations protestantes.

Les Eglises de la Réforme connurent, elles aussi, bien des difficultés du fait de traductions bibliques non-autorisées en langue vulgaire.

Nous avons évoqué les inquiétudes de Luther et de Zwingli lorsque les Anabaptistes Haetzer et Denck publièrent, en 1527, la première traduction allemande des Prophètes à partir de l'hébreu. Les Prédicants de Zurich s'efforcèrent de la remplacer par leur traduction de 1529.

La décision de Châteillon de traduire le Nouveau Testament suscita, nous l'avons vu, l'inquiétude de Calvin, et sa traduction française de la Bible l'hostilité conjointe de Bèze et de Calvin.

En Angleterre, les modifications survenues dans la politiques religieuse des souverains se traduisirent par de multiples révisions de la Bible anglaise, ainsi que nous avons pu le constater, puis par une tentative de Jacques Ier pour éliminer la Geneva Bible en imposant une nouvelle traduction.

\section{Le débat sur les aides de lecture}

L'essentiel du conflit entre les autorités catholiques et les éditeurs de la Bible au $X V I e$ siècle a porté sur les aides de lecture. En effet, les éditeurs ajoutaient d'ordinaire au texte biblique des préfaces, avertissements, sommes de toute l’Ecriture, index bibliques, résumés de chapitres, annotations et scholies variées. A travers cela se transmettait une interprétation théologique polémique favorable à la Réforme. 
L'autorité catholique a varié dans son attitude à l'égard des aides de lecture. La Sorbonne les censura et se fonda sur ces censures pour faire interdire les Bibles en question. Charles Quint fit remplacer les Bibles annotées par des éditions sans notes. L'Inquisition espagnole corrigea les annotations en omettant ce qui avait une saveur protestante. Seuls René Benoist et les éditeurs anglais du Nouveau Testament de Reims tentèrent audacieusement d'inverser le coefficient polémique en un sens favorable au catholicisme.

En Angleterre, Henry VIII, puis Jacques Ier se défièrent des annotations (surtout celles de la Bible de Matthew ou de la Geneva Bible) à cause de leur tendance antiinstitutionnelle.

Théodore de Bèze, dans l'avant-propos de la Bible de 1588, explique que les recenseurs auraient volontiers omis les annotations marginales, car "par ci devant, il s'en est trouvé en quelques impressions quelques unes assez impropres". Mais ils ont cédé à "l'instante réquisition de plusieurs gens de bien, mettant en avant que tous n'ont pas le moyen de lire les commentaires entiers, ni le jugement assez ferme pour en recueillir et bien choisir la substance".

Au XVIIIe et au XIXe siècle les positions protestante et catholique allaient s'inverser. Le 13 juin 1757, la Congrégation de l'Index donna en effet pouvoir aux Evêques d'autoriser les traductions de la Bible en langue vulgaire, à condition qu'elles soient “éditées avec des annotations empruntées aux saints Pères de l’Eglise ou à des hommes compétents et catholiques". Cette condition fut répétée dans le Code de Droit Canon du 27 mai 1917 ( $\$ 1391)$. Dans le Code du 25 janvier 1983 ( $\$ 825)$, il est seulement requis que ces traductions soient “munies des explications nécessaires et suffisantes".

En sens inverse, l'article I des statuts édictés en 1804 pour la British and Foreign Bible Society lui assignait comme but "to encourage a wider circulation of the Holy Scriptures, without note or comment", à la manière des rois Henry VIII et Jacques Ier. La quasi-totalité des Bibles protestantes renoncèrent donc désormais à toutes notes ou commentaires, puisque cette renonciation était la conditio sine qua non pour l'obtention des généreuses subventions anglaises. Cependant l'Alliance Biblique Universelle a adopté une position plus souple, puisque son Conseil mondial, réuni en 1980 à Chiang Mai (Thaïlande), a décidé (II, \$2.4) d”“aider le lecteur à comprendre le sens du texte biblique en incluant des aides et introductions dans toutes les publications bibliques". On se trouve assez près des "explications nécessaires et suffisantes" que requerra le Code de Droit Canon catholique de 1983.

Les positions inversées des Protestants et Catholiques au XIXe siècle correspondaient mieux aux options caractéristiques de la Réforme et de l’Eglise catholique que les positions sur lesquelles toutes deux s'étaient placées au cours du XVIe siècle. En effet, selon les Réformateurs, la Parole de Dieu n'a pas besoin de l'aide des hommes pour se faire entendre; alors que, selon la tradition catholique, la seule lecture authentique de l'Ecriture est celle qui s'effectue en Eglise et en une relation vivante avec le Magistère. Cependant, les Catholiques ont maintenant mieux compris qu'il faut distinguer des aides de lecture d'ordre historique, textuel ou littéraire (dont les Protestants reconnaissent aussi maintenant la grande utilité) et des “notes et commentaires" ti- 
rant des conclusions théologiques dont la place n'est pas nécessairement dans la marge d'une Bible, même si les glossateurs du moyen âge et Luther lui-même aimaient les placer là.

\section{CONCLUSION}

Dans cette introduction, nous avons relaté les conditions dans lesquelles ont été élaborées les cinq traductions dont les options ont servi d’objet à notre "critique de la critique".

Mais deux d'entre elles (RSV et RL) sont des révisions de Bibles datant de la Réforme, et les trois autres - nous le verrons - dépendent souvent, dans leurs options textuelles, des traductions qui les ont précédées. En outre, au cours de son travail, le comité a eu maintes fois l'occasion de constater que la grande autorité dont a joui la Bible de Luther a tracé souvent la voie de la critique du texte massorétique. Nous avons noté aussi que la Vulgate a exercé une influence à longue portée aussi bien sur les Bibles protestantes que catholiques.

C'est pourquoi nous avons estimé utile de préciser les conditions dans lesquelles ont mûri les Bibles en Allemand, Français et Anglais au cours du premier siècle de la Réforme protestante. Cela a été pour nous l'occasion de constater et d'analyser le rôle essentiel qu'ont joué les traductions latines faites sur l’hébreu. Au XVIe siècle, le latin était la langue véhiculaire des lettrés. Aussi les traductions latines ont-elles exercé alors une fonction analogue à celle qu'exercent aujourd'hui la RSV, la NEB, la J ou la TOB auprès des comités de traduction d'Afrique ou d'Asie ayant pour langue véhiculaire l'anglais ou le français.

Enfin, nous avons jugé utile, en ce XVIe siècle où l'appel à l'évangile a interpellé si dramatiquement les autorités institutionnelles, d'expliciter les données des conflits qui ont eu lieu entre les diffuseurs des "nouvelles Bibles" et ces autorités. Il nous semblait requis, en effet, d'apporter quelques coloris complémentaires et quelques nuances à la représentation que l'on se fait d'ordinaire de ces conflits. Peut-être fautil cependant nous excuser auprès du lecteur si la personnalité de Robert Estienne et les avatars de la Nompareille nous ont engagé - sous forme d'excursus - en quelques détours qui nous ont donné l'occasion de tester la conception que les théologiens de Salamanque se faisaient, peu de temps après le Concile de Trente, de l'authenticité de la Vulgate et la manière dont une théorie de la pluralité des sens bibliques leur permettait de la concilier avec la curiosité qu'ils éprouvaient pour les enseignements de "Vatable". 



\title{
COMMENTAIRE TEXTUEL DES PROPHETES
}

\author{
Isaïe, Jérémie et Lamentations
}





\section{ISAIE}

\section{1,7 זרים}

Options de nos traductions :

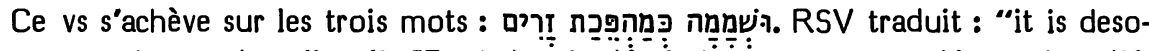
late, as overthrown by aliens". J3: "c'est la désolation comme une dévastation d'étrangers". TOB paraphrase : "elle est désolée et comme bouleversée par l'envahisseur".

$J 12$ donnaient : "c'est un désert, comme après la catastrophe de Sodome". NEB : "it is desolate as Sodom in its overthrow". RL : "alles ist verwüstet wie beim Untergang Sodoms". J2 et NEB notent "Sodome" comme une conjecture.

Origines de la correction :

Dans une partie de ses notes omise par la réédition de Francfort, Houbigant remarque qu'il vient d'être dit que la dévastation du pays est causée par le fait que "des étrangers dévorent (la production de) votre sol devant vous". Ici, il est dit que cette dévastation est "comme un bouleversement (causé par) des étrangers". Or une comparaison se prend normalement à partir d'une autre matière et non à partir de la même matière. Donc le mot "étrangers" n'est pas à sa place en cette comparaison. D'autre

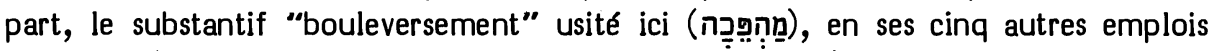
bibliques (Dt 29,22; Is 13,19; Jr 49,18; 50,40; Am 4,11) désigne toujours le cataclysme qui a détruit Sodome et Gomorrhe. Or Sodome va être bientôt mentionnée (aux vss 9 et 10). Donc il corrige ici, par conjecture, "étrangers" en "Sodome", traduisant : "talisque est, qualis Sodomae vastitas".

Cette conjecture, adoptée par Ewald2 est passée ensuite dans les apparats de HSSAT234, BH235, Cent.

Ces critiques ne connaissaient pas le commentaire de Yéfet ben Ely qui rapproche cet oracle de Am 4,11: “J'ai causé en vous un bouleversement comme le bouleversement de Dieu qui a frappé Sodome et Gomorrhe". Il estime donc qu'en Is 1,7, l'expression "comme un bouleversement d'étrangers" signifie que le Seigneur bouleverse certain lieu de leur pays comme il a bouleversé Sodome. Il les a en effet menacés en Dt 29,22 qu'au jour de sa colère "tout le pays d'Israël ne sera que soufre et sel... comme le bouleversement de Sodome et de Gomorrhe, d'Adma et de Șeboïm que le Seigneur a bouleversées dans sa colère et sa fureur".

Cette exégèse fut reprise ensuite par Radaq, expliquant que Sodome et Gomorrhe sont dites ici "étrangers" parce que leurs habitants étaient étrangers à la crainte de Dieu. Après qu'Isaïe de Trani ait adopté cette exégèse, c'est celle qu'Abravanel mentionne en premier, ajoutant que les gens de Sodome se conduisaient aussi en étrangers (et non en hôtes) à l'égard des hommes. 
En 1525, Oecolampade (s'inspirant évidemment de Radaq) commente : “Ces châtiments n'auront pas lieu d'une manière courante, mais à la manière dont je bouleverse les cités qui sont étrangères à ma crainte, c'est-à-dire à la manière dont j'ai bouleversé Sodome et Gomorrhe, ainsi qu'il est annoncé en Dt 29." Cette exégèse sera reprise par Estienne en ses notes à la Bible latine de 1557. Nous voyons donc Houbigant transformer en correction critique ce qui était une exégèse traditionnelle fondée sur une interprétation en génitif objectif de l'expression "bouleversement d"étrangers".

\section{Les témoins anciens :}

Le *M est appuyé par tous les témoins. En 1Q-a une pliure a fait disparaître le 'resh' mais les autres lettres sont clairement lisibles. Le ${ }^{*} G$ et la $* V$ ont compris le génitif comme subjectif : un bouleversement réalisé par des ennemis. La ${ }^{*} S$ est trop littérale et le ${ }^{*} T$ trop midrashique pour que leur option exégétique soit discernable.

\section{Choix textuel :}

Pour ce mot, le texte était déjà stabilisé au début du deuxième stade, c'est-à-dire au niveau du 'texte attesté le plus primitif". Le comité a attribué au *M la note "A".

Est-il probable que "Sodome" soit ici la leçon originale et que ce mot ait été ensuite assimilé à "étrangers" qui figure cinq mots avant celui-ci ?

- Procksch a fait remarquer que, lorsqu'il est fait ailleurs mention (c'est-à-dire dans les cinq endroits indiqués plus haut) du "bouleversement" que Dieu fit subir à Sodome, celle-ci n'est jamais isolée en cette formule, mais Gomorrhe lui est toujours associée. La forme textuelle conjecturée par Houbigant serait donc en dissonance avec cette formule classique qui réapparaîtra en son intégrité en ce même livre $(13,19)$. Ajoutons d'ailleurs qu'en 1,9 et 1,10 qui offrent une clé à l'allusion chiffrée de 1,7, Gomorrhe figurera deux fois associée à Sodome.

- Delitzsch estime que la conjecture dont nous traitons méconnaît le goût que présente l'ensemble du livre d'Isaïe pour la reprise emphatique d'un mot (ici celle du mot "étrangers"). Notons en effet que la dernière proposition de ce vs a pour sujet le mot

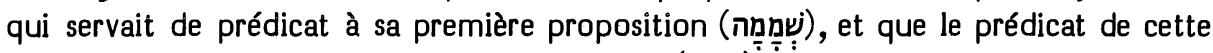

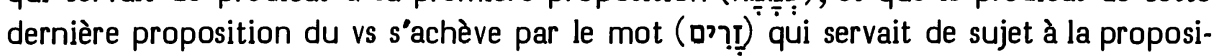
tion précédente.

\section{Interprétation proposée :}

Ainsi que nous l'avons dit, le ${ }^{*} G$ et la $* V$ interprètent le génitif "étrangers" comme un génitif subjectif : comme un bouleversement causé par des étrangers. No-

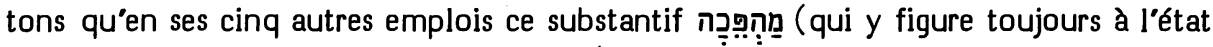
construit et précédé de la préposition "kaf") présente deux constructions distinctes : ou bien (en Is 13,19; Jr 50,40; Am 4,11) il joue le rôle d'un infinitif suivi de son sujet (Dieu) et d'un double accusatif (Sodome et Gomorrhe) introduit par la particule d'accusatif; ou bien (en Dt 29,22 et Jr 49,18) il sert de nom d'action avec Sodome, Gomorrhe et leurs voisines pour génitif (sans que l'agent divin soit mentionné). Donc, lorsqu'il sert de nom d'action, le génitif qui le suit est un génitif objectif. 
Hitzig a estimé impossible de considérer ici "étrangers" comme un génitif subjectif parce que, lorsque le verbe הפך est utilisé pour relater une catastrophe, il ne s'agit jamais d'une dévastation causée par des hommes, mais toujours d'un cataclysme qui a Dieu pour auteur (Gn 19,21.25.29; Dt 29,22; Jr 20,16; Am 4,11; Jon 3,4; Jb 9,5).

Le comité comprend donc ici : "comme un bouleversement subi par des étrangers". Il y a là une allusion au vs 2 par lequel débute cet oracle ("j'ai fait grandir des fils et je les ai élevés; eux, ils se sont rebellés contre moi") et surtout à la finale du vs 4 (נכזרוי אחור) compris comme : "ils se sont faits étrangers en reculant". Donc, non seulement le Seigneur les livre en proie aux barbares ("des étrangers dévorent la production de votre sol devant vous"), mais il va les traiter comme il avait traité ces barbares (c'est-à-dire des peuples auxquels il n'est pas lié par les liens de l'alliance).

Si l'on se permet de gloser un peu, on pourrait (en comprenant à la grecque le mot "barbare") traduire : "et cette dévastation sera comme le bouleversement que Dieu inflige aux barbares". Le simple emploi de l'expression classique évidente l'allusion à Sodome et Gomorrhe, allusion qui sera explicitée aux vss 9 et 10.

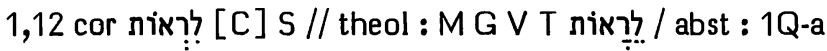

Options de nos traductions :

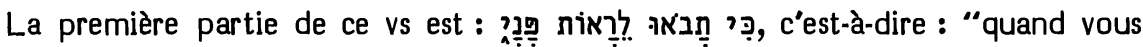
venez pour (vous) faire voir (devant) ma face".

Nos cinq traductions respectent toutes le mode nifal de l'infinitif. Cependant, NEB note : "littéralement : pour voir ma face". Et Brockington fait remarquer que cette alternative suppose une vocalisation en 'qal' de l'infinitif (תiאר? ), avec la *S.

Origines de la correction :

Michaelis (OEB), tout en notant que le ${ }^{*} G$ et le ${ }^{*} T$ ont lu ici le nifal, estime plus vraisemblable le qal que la *S a lu: "pour voir ma face". Cette correction a été demandée ensuite par les apparats de HSAT34, Cent et BHS. Notons que BH3 hésitait à la demander et que $\mathrm{BH} 2$ ne présentait la variante qu’à titre informatif. Parmi les traductions récentes, elle a été adoptée par ZB, Eü. Osty la présente en note comme probable.

Luther respecte le nifal dans sa traduction (comme le font la plupart des traducteurs du XVIe siècle). Mais, en 1527, dans son cours (WA. XXXI/2.10), il précisait qu'il s'agit ici surtout des prêtres qui entraient derrière le voile et se présentaient devant le Seigneur. Il ajoute : "qui ergo intrabant, dicebantur videre faciem Domini", remarque qui ne semble pas correspondre à sa traduction. Ici, il s'inspire du commentaire publié à Bâle en 1525 par Oecolampade. Celui-ci (p.13a) y dit en effet : "Sacerdotes intrabant, plebs in atriis stabat. Unde de sacerdotibus dicitur, quod videant faciem dei." Cela correspond à ce qu'il a traduit (p. 10b) : "Quum veneritis ad videndum faciem meam." Sous son influence, Brucioli, en 1532, traduira : “... per vedere la faccia mia" et dans son commentaire des Prophètes (publié en 1540 et dédié au Cardinal Hippolyte d'Este), il intègre littéralement l'explication du réformateur bâlois: 
"Et i sacerdoti entravono, \& la plebe stava ne gli anditi, onde si dice de sacerdoti che vegghino la faccia di Iddio." L'influence d'Oecolampade s'exerce encore sur la traduction et le commentaire publiés à Venise en 1563 par le dominicain Foreiro qui participa au concile de Trente. Il explique : "Ego Hebraismum retinui, 'ad videndum faciem meam'. Qui ad templum veniebant, dicebantur 'videre Dei faciem'."

Les témoins anciens :

Le troisième apparat de HUB attribue la vocalisation de cet infinitif en qal à "RG", c'est-à-dire "des manuscrits hébreux cités dans les collations de de Rossi et de Ginsburg'. Lorsqu'on contrôle ces données, elle se réduisent malheureusement à fort peu de choses. Ginsburg nous dit en effet qu'un ms des collations Kennicott-de Rossi porte ici la vocalisation לרֵ Etant donné que Kennicott ne mentionne pas les voyelles, voyons de Rossi. Celui-ci nous explique en effet que la première main de son ms espagnol 575 (du XIVe siècle) avait vocalisé ainsi, mais qu'une main ancienne a rétabli la vocalisation du nifal. $L$ 'attestation de la variante dans la tradition massorétique se réduit donc à une erreur de scribe corrigée peu après.

D’ailleurs une massore (Weil §2209) précise que cette forme avec sa vocalisation caractéristique en infinitif nifal apparaît trois fois dans la Bible (ici, en Ex 34,24 et en Dt 31,11).

Le seul témoin textuel ferme de la vocalisation de cet infinitif en qal est la *S dont la traduction למחז n'a pas de variantes dans la collation de Diettrich et est reprise par Ephrem en son commentaire.

1Q-a a la même graphie que le *M et on ignore si son scribe lisait là un nifal ou un qal. Le *G et le *T lisent clairement un nifal. C'est également à cette forme que se rattache la traduction libre de la $* V$.

\section{Choix textuel :}

La graphie sans "hé' de l'infinitif nifal que le *M offre dans les trois cas relevés par la massore n'est pas sans exemple. On trouve en effet aussi nijỵ en Ex 10,3. Il est cependant instructif de comparer les trois cas où l'infinitif construit nifal de ce verbe 'voir' est écrit sans "hé" aux huit cas où il est écrit avec "hé". Dans ces trois graphies exceptionnelles, et en elles seules, il s'agit de l'expression classique "se faire voir (devant) la face (du Seigneur)" au sens de : visiter le temple, s'y rendre en pèlerinage. Quant aux graphies normales, elles se répartissent entre divers emplois de : se manifester, apparaître, se présenter. Ajoutons que dans les deux autres emplois (Ex 34,24 et Dt 31,11) de la graphie exceptionnelle, cet infinitif se rattache à "la face du Seigneur ton Dieu" par la particule d'accusatif "א̣; alors que, dans ses emplois courants avec graphie normale, c'est toujours par la préposition "ֵָ que l'infinitif nifal est lié à la personne à laquelle on apparaît, devant laquelle on se présente (Lv 13,7; Jg 13,21; 1R 18,2).

On peut juger souverainement improbable que se trouvent réunies sur les trois cas groupés par la massore (et sur eux seuls) les quatre particularités suivantes :

1) une graphie d'infinitif nifal sans "hé",

2) un rattachement par la particule d'accusatif de cet infinitif à la personne devant laquelle on se présente (en Ex 34,24 et Dt 31,11 où il y a lieu d'exprimer un tel rattachement), 
3) le sens de : visiter le temple,

4) un ensemble de graphies consonnantiques qui conviendrait parfaitement à des infinitifs qal.

Cette constatation a amené le comité à conclure que nous avons affaire en ces trois cas à une correction théologique visant à remplacer l'expression "voir la face de Dieu" par l'expression "être vu par la face de Dieu".

Nous rencontrerons en Is 33,7 une correction symétrique de celle-ci, visant à remplacer dans la bouche de Dieu l'expression: "je me ferai voir d'eux" par l'expression "je les verrai".

Notons à ce propos que הִ désignait, dès avant Hillel (début du traité Hagiga de la Mishna), le devoir de "comparaître" sur l'esplanade du Temple aux trois fêtes de pèlerinage. Or ce mot ne désigne pas l'acte de "se faire voir", mais l'acte de "voir", comme cela est clairement attesté par le contexte de la Mishna à propos du "zab" (ראה ראיה ראשונה en Zabim II 2). On peut donc conclure qu'au début de notre ère, le souvenir de l'expression originale demeurait encore marqué dans la terminologie.

Il est cependant frappant que la volonté d'éliminer cette expression s'est déjà fait jour chez le ${ }^{*} G$. Mais il est vraisemblable que la ${ }^{*} S$ atteste une survie de l'expression originale (plutôt qu'une erreur du genre de celle que commettra plus tard Oecolampade).

En limitant à "C" la note qu'il attribue à la correction, le comité a voulu marquer une certaine hésitation sur la valeur à accorder au témoignage textuel de la ${ }^{*} 5$.

Interprétation proposée :

Luzzatto (30) a traité de cette correction théologique dans les termes suivants : “L'intention du prophète est de dire 'pour voir la face', et cette métaphore établit une analogie avec le comportement d'un homme qui rend visite à son supérieur. Cette analogie métaphorique se retrouve exprimée par l'expression 'En effet, puisque j'ai vu ta face comme on voit la face de Dieu' $(G n 33,10)$. Pourtant, en se fondant sur la tradition qu'ils avaient héritée des sages du Second Temple, les ponctuateurs ont, par déférence, corrigé l'expression, en vue des gens simples qui ne comprennnent pas l'analogie et la métaphore... Ils ont voulu éloigner une interprétation anthropomorphique, évitant que l'on ne s'imagine l'homme comme voyant la face de Dieu". McCarthy (197-202) considère ce groupe de corrections de "voir la face de Dieu" en "apparaître devant Dieu" comme constituant l'un des indices les plus clairs que des corrections théologiques ont réellement eu lieu dans le texte qui nous a été transmis.

La retouche théologique n'a porté ici que sur la vocalisation et on peut considérer l'expression originale comme encore attestée par la graphie consonnantique. Quoique la tradition de lecture euphémique remonte à une époque qui précède la traduction grecque, il semble que la tradition de lecture originale était encore connue du traducteur syriaque.

Le comité conseille donc aux traducteurs de placer celle-ci dans le texte et de mentionner en note la traduction de la retouche vocalique. 


\section{Options de nos traductions :}

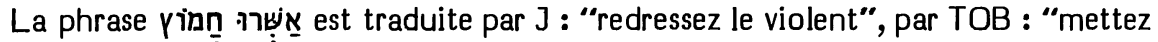
au pas l'exacteur" et par RSV : "correct oppression", c'est-à-dire que ces trois traductions donnent au complément une valeur active.

Quant à NEB, elle le traduit en passif : "and champion the oppressed" sans note. Cependant Brockington précise que cela suppose que l'on vocalise Une note de TOB estime aussi qu'il faudrait, comme l'a fait le ${ }^{*} G$, corriger la vocalisation si l'on voulait comprendre : "faites droit à l'opprimé". RL donne ici : "den Unterdrückten".

Origines de la correction :

Koppe garde la vocalisation du $* M$, l'interprétant comme un nom abstrait : "oppression". Mais il estime que le *G et la *S ont lu un shureq à la place du holem lorsqu'elles ont interprété cette forme en participe passif. Bredenkamp a opté pour cette correction vocalique, suivi (entre autres) par BH3, Cent, HALAT.

\section{Les témoins anciens :}

$1 Q$-a est identique au ${ }^{*} M$, mais ne nous apporte aucun indice sur la manière dont il prononçait ce 'waw'.

Toutes les versions (*G, Th, Aq, Sym, *V, *S, ${ }^{*} T$ ) ont traduit ce mot par un participe passif. On ne saurait conclure, pour autant, qu'elles aient lu ici un shureq. En effet, des exégètes médiévaux qui lisaient le *M l'ont interprété de la même manière.

\section{Choix textuel :}

Tous les glossaires hébreu-français (ABCDEF) traduisent ici : “tolu" (c'est-àdire : lésé) en accord avec Rashi qui donne à ce mot le sens de גזול. Déjà Judah ben Qoreish (Bargès $99=$ Katz 185) disait que ce mot a ici le sens de ממוס qu'il interprétait très probablement en participe passif, en contraste avec חומץ (Ps 71,4) qu'il disait correspondre à (l'édition Bargès ayant omis ce second cas qui est pourtant mentionné à la suite du premier dans le ms unique de la Risâlah, fol. 65a).

Les données fournies par Abulwalid (Ușul 235, 3s) sont ambigües. En effet, selon le ms de la Bodléienne, il traduit ce mot par טלום (= tyran), mais selon le ms de Rouen il le traduit par טליס (= tyrannisé), alors que ce passage manque dans le ms London BL Or 4837. La traduction yוק qu'Ibn Tibbon donne de ce mot est elle aussi ambigüe car on peut la vocaliser avec ḥolem ou avec shureq.

Radaq en son commentaire établit la même équivalence que Rashi (ce qui amènera Isaïe de Trani à dire qu'ici un shureq a été transformé en ḥolem). Mais en ses Shorashim, il dit qu'il s'agit d'un adjectif. C'était l'opinion d'Ibn Ėzra le rapprochant de la forme קִ En accord avec eux, Aaron ben Joseph dit que c'est un adjectif au sens de : celui qui est opprimé et subit la violence.

Delitzsch fait remarquer en effet que certains adjectifs de cette forme peuvent exprimer un état, en concurrence avec des participes passifs, par exemple le pluriel

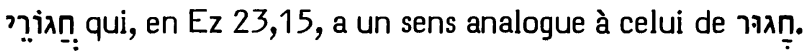


Il n'est donc pas nécessaire de supposer que les versions anciennes aient vocalisé ici d'une manière qui diffère du *M. D'ailleurs, lorsque RL traduit ici “den Unterdrückten", elle emprunte le participe passif à Luther (“den Verdruckten"). En effet, au XVIe siècle, on s'accorde pour traduire ainsi ce mot : "confractum" (Oecolampade), "oppressum" (Pagnini, Münster, Tremellius en accord avec la *V), "the oppressed" (Ge, KJ que NEB recopiera en prétendant corriger le *M), "celuy qui est foulle”" (Olivetan, Pasteurs), "l'oppresso" (Brucioli).

Il est donc apparu au comité qu'il ne s'agit très probablement ici que d'une question d'exégèse. C'est ce qu'il a voulu marquer en attribuant au *M 5 " $A$ " et 1 " $B$ ".

Interprétation proposée :

On peut envisager ici trois sens pour cette vocalisation.

1) Comme Aaron ben Joseph l'a proposé : un adjectif qui équivaudrait à un participe passif. Delitzsch a montré que ce n'était pas impossible. Luzzatto fait remarquer, en faveur de cette interprétation, que la tâche d'un juge est plutôt de réparer les torts que de rééduquer les criminels. Rignell (Chapter 1, 151) estime, lui aussi, que cet adjectif substantivé désigne ici celui qui vit sous l'oppression. Il s'agirait alors d'un adjectif intransitif du type qatôl ( $=$ qatâl $)$ dont Barth $(\$ 129 \mathrm{c})$ a bien montré qu'ils ont souvent pour correspondants en arabe ou en syriaque des qatîl.

2) Delitzsch et Barth $(\$ 27 \mathrm{~g})$ préfèrent cependant rattacher ce mot aux adjectifs transi-

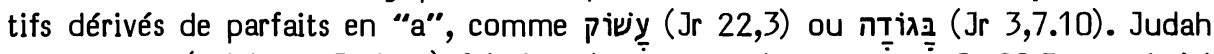
ibn Balaam (suivi par Parḥon) fait le même rapprochement avec Jr 22,3 et voit ici un adjectif ayant le sens d'un participe actif. Saadya (tel que Derenbourg, p. 2, n. 10, l'interprète) donnait déjà à ce mot un sens actif. Gesenius (commentaire et Lehrgebäude, 487 et n. s), Ewald (Lehrbuch \$152b) et König (Lehrgebäude II 124) optent aussi pour ce sens.

3) Certains exégètes juifs anciens ont vu ici un infinitif absolu avec valeur de nom d'action. C'est le cas des karaïtes David ben Abraham (I 560, 73) et Yéfet ben Ely (traduisant : אלטלם = "la violence").

Le comité estime que la deuxième interprétation (adjectif transitif équivalant à un participe actif) est la plus probable. Le mot dérive de la racine yn II (attestée en akkadien au sens de "spolier, dépouiller") qui est d'un usage fréquent en araméen. Il faut distinguer nettement cette racine de en araméen, est représentée par yn.

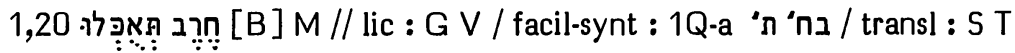

Options de nos traductions :

RSV ("you shall be devoured by the sword") et RL ("so sollt ihr vom Schwert gefressen werden") ont suivi l'option générale des traductions du XVIe siècle.

$J$ et TOB ("c'est l'épée qui vous mangera") ont pris la liberté d'inverser la construction en faisant usage de la forme active du verbe.

Brockington nous informe que la traduction de NEB ("locust-beans shall be your only food") suppose une vocalisation : 
Origines de la correction :

Cette correction vocalique s'inspire probablement de Cheyne qui, dans les Adden-

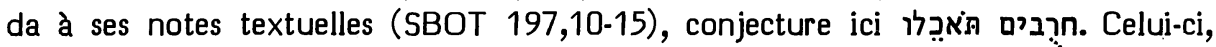
quoiqu'il ne le mentionne pas, a vraisemblablement pris cette idée chez Bacher qui, la même année (1899), venait de mentionner (Amoräer III 120) que certains midra-

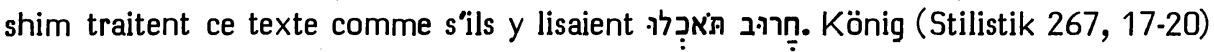
considère le résultat de cette conjecture de Cheyne cómme "plus humoristique que tragique".

\section{Les témoins anciens :}

Les midrashim mentionnés par Bacher témoignent ici d'un jeu exégétique du type des al-tiqré à intention homilétique. On ne saurait donc fonder une correction textuelle sur de telles bases.

Quant au ${ }^{*}$ G et à la $* V$, il ne faut pas croire avec Lowth qu'ils aient lu תאכלכם. Kocher (cité par Rosenmüller) a eu raison d'objecter à cela que leur traduction par une forme active constitue une simple facilitation translationnelle.

Houbigant avait restitué, comme Vorlage de la *S et du *T, בחרב ת. Or 1Q-a atteste cette leçon. Aussi Wildberger et Kaiser l'adoptent-ils.

\section{Choix textuel :}

Gesenius (Lehrgebäude 821) a bien expliqué la construction du * $\mathrm{M}$ : Iorsqu'un verbe, à la voix active, régit un double accusatif, son passif n'est accompagné que d'un seul accusatif, le second devenant sujet ou étant, à ce titre, inclus dans le verbe.

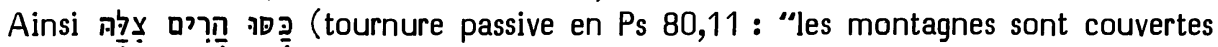
de son ombre", c'est-à-dire : de l’ombre de cette vigne) aurait pour correspondant actif : (= "elle a couvert les montagnes de son ombre"). De même,

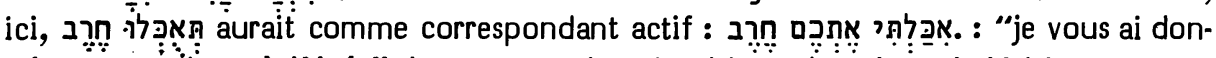
nés en nourriture à l'épée". La construction du *M est donc la seule légitime pour un pual, c'est-à-dire pour le passif d'une forme (le piél) qui régit un double accusatif. Elle ne serait pas acceptable pour un nifal, du fait que l'actif qui lui correspondrait (le qal de (אכל ne se construit pas avec un double accusatif. Ce serait donc méconnaître la syntaxe que d'admettre l'ellipse d'une préposition avant le complément.

Comme Kutscher (p. 410) le fait remarquer, 1Q-a a méconnu cette syntaxe. Il

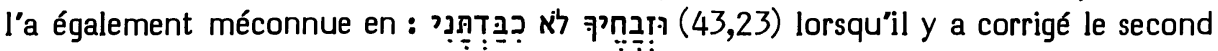
accusatif en ובזבחיכה.

Tenant compte du caractère hapax de ce pual, le comité a attribué au *M la note "B".

Interprétation proposée :

En fonction de l'analyse qui vient d'être faite, il faut respecter ici dans le pual son sens de passif du piél. C'est-à-dire qu'il ne faut pas traduire comme si l'on avait un nifal : "vous serez mangés par l'épée", mais bien : "vous serez livrés en nourriture à l'épée".

Hitzig, suivi par Duhm et Driver (Notes), a estimé qu'ici c'est l'épée qui est donnée pour nourriture. Pour appuyer cette interprétation, Driver montre que cette expression 
est usitée en arabe. Mais en hébreu biblique, il est souvent dit que l'épée mange des personnes et l'expression "la bouche de l'épée" est très courante, alors qu'il n'est jamais dit que quelqu’un mange l'épée.

\section{1,21 מלאתי [B] M 1Q-a V S T // expl : G pr Clwv}

Options de nos traductions :

J insère "Sion" avant : "pleine de droiture", en se fondant sur le *G.

Origines de la correction :

HSAT34 et Cent ajoutaient déjà ce mot pour des motifs de métrique. Pour les mêmes motifs, HSAT34 stigmatisaient comme une glose les deux derniers mots du vs, alors que c'était dans les trois mots qui précèdent ceux-ci que Cent reconnaissait une glose.

J1 suivait Cent sur ces deux points en omettant la glose ainsi diagnostiquée. $\mathrm{J} 23$ ont rétabli les mots ainsi omis et ne font plus état de l'existence d'une glose, mais elles ont conservé l'ajoute de "Sion".

En HSAT1, Guthe ne proposait pas ces corrections. C'est à Duhm qu'il les a empruntées. Notons cependant que Budde (Klagelied 33) avait conclu que ce vs 21 n'avait pas besoin de correction pour constituer deux vers d'une qina. Puis (ibid. 245ss), faisant droit à une suggestion de Stade (Geschichte I 613) qui voyait la qina se poursuivre dans les vss $26 s s$, il a estimé que ce mètre convenait à Is 1,21-31. Dans son étude sur les chants funèbres hébreux, Jahnow (p. 253s) a développé l'idée de Budde en la nuançant. Elle a caractérisé les vss $21-23$ comme la parodie d'une lamentation. Le "comment" initial et le rythme caractéristique de la qina frappent l'attention, mais le mètre est tantôt distendu, tantôt resserré. Aussi n'estime-t-elle pas utile de retoucher le texte.

Les témoins anciens :

Le *G lit "Sion" comme une apposition à "ville fidèle" qui précède. Wildberger a cependant fait remarquer avec finesse que ce mot "Sion" a plutôt pour but de fournir un complément d"objet à מלאת lu en accompli piél. On obtient ainsi : "j'ai rempli Sion de droit", ce qui fait écho à 33,5 : “il a rempli Sion de droit et de justice".

\section{Choix textuel :}

Estimant surprenant que le Seigneur prenne la parole au début d'une péricope qui se présente comme une lamentation funèbre, Wildberger a estimé qu'il faut en rester au texte du *M. Le *G aura emprunté "Sion" au vs 27 où ce mot est aussi lié à משפט.

Il semble donc qu'un copiste de l'hébreu, méconnaissant la valeur poétique du hireq compaginis et lisant מלאת comme un accompli piél, a inséré "Sion" pour servir de complément à ce verbe. Seul le ${ }^{*} G$ nous atteste cette tradition textuelle, alors que 1Q-a apporte ici à la forme plus sobre du *M un appui précieux.

Le comité a attribué la note "B" à l'absence du mot "Sion". 
Interprétation proposée :

"Sion" est une glose exacte. Mais sa non-explicitation ajoute à la tension dramatique. On devra donc se contenter de mentionner éventuellement en note l'existence de cette glose dans le *G.

\section{1,29 יבשו ... חמדתם [B] M 1Q-a // harm-synt : G V S 3e pl, m T 2e pl}

\section{Options de nos traductions :}

29b offre une interprétation aisée : "et vous serez confus à cause des jardins que vous avez choisis". Mais 29a, clairement parallèle à cela, débute (selon le *M) par un verbe à la 3e pers. pl. : "Car ils auront honte des térébinthes que vous avez désirés".

Alors que $J 3$ respecte le $* M$ en faisant usage ici d'une tournure impersonnelle : "on aura honte", nos autres traductions (RSV, J12, RL, NEB, TOB) corrigent en 2e pers. pl. (= "vous aurez honte") la 3e pers. pl. offerte par le *M.

Origines de la correction :

Alors que HSAT34 fondaient sur le *G une généralisation de la 3e pers. pl. aux 5 verbes des vss $29 \mathrm{~s}, \mathrm{BH} 23 \mathrm{~S}$ et Cent appuyaient sur 3 mss et le *T la correction du premier verbe en $2 \mathrm{e}$ pers. pl. que nos traductions ont effectuée. C'est Houbigant qui a proposé cette correction sur le témoignage du ${ }^{*} T$.

\section{Les témoins anciens :}

C'est dans l'apparat critique de Kennicott que $\mathrm{BH} 23$ ont trouvé les sigles de 3 "codices" qui auraient ici la 2e pers. pl. Il s'agit de : cod. 150 (Bible de Berlin) et cod. 182 (Prophètes de Iéna). Sur ces deux mss, Kennicott donne en sa Dissertatio Generalis, p. 83 , n. b et pp. 86 s, n. b des listes de variantes qui prouvent le caractère assez fantaisiste de leur texte. $A$ ces deux témoins il ajoute la $2 e$ édition (1536) de la Bible de Münster. Mais la 1e édition (1535) porte la leçon courante du *M.

$1 Q$-a s'accorde avec le *M pour les verbes de ce vs et du suivant.

Le *T a traduit le premier verbe par une 2e pers. pl. Saadya et Yéfet ben Ely l'ont suivi en notant que le stique parallèle prouve que la 3e pers. a ici la valeur d'une 2e pers.

Le *G, nous l'avons dit, assimile en sens inverse, généralisant la 3e pers. pl. du premier verbe aux 3 autres verbes de ce vs et à celui du vs 30 . La*S fait de même.

La $* V$ n'étend la 3e pers. pl. qu'au verbe suivant, respectant pour $29 \mathrm{~b}$ et pour 30 les 2e pers. pl. du *M.

Choix textuel :

Le fait que les assimilations des versions aient lieu en deux sens opposés appuie I'hétérogénéité du texte du ${ }^{*} M$.

Cette lectio difficilior est aussi appuyée par le témoignage ancien de 1Q-a.

Le poids des quelques témoins du *M qui appuieraient la variante est négligeable.

Après qu'il ait été parlé de Sion à la 3e pers. en 21, elle a été apostrophée en 22-26, puis la 3e pers. est revenue en 27. 
Ici (vs 29) la 3e pers. pl. ne surgit que pour un verbe, suivi de 4 verbes à la $2 \mathrm{e}$ pers. pl.

Le comité a attribué la note " $B$ " à cette leçon du *M.

Interprétations proposées :

Ce passage de l'exclamation à l'apostrophe a été noté par König (Stilistik 239, 30-36) comme fréquent dans le livre d'Isaïe.

Il faut donc respecter ici le surgissement soudain de la $2 e$ pers. après un verbe initial à la 3e pers. (qui s'harmonisait bien avec le contenu du vs précédent).

Ceux des traducteurs qui estimeraient trop abrupt ce changement de personne peuvent faire usage d'une tournure impersonnelle : "on aura honte", comme Pasteurs, puis $\mathrm{J} 3$ l'ont fait.

1,31 [B] M // assim-ctext : 1Q-a V 2e pl, G S T 3e pl

Options de nos traductions :

Le * $M$ est traduit par RSV ("the strong ... and his work"), J ("le colosse ... et son oeuvre"), RL ("der Starke ... und sein Tun") et TOB ("l'homme fort ... son travail") sans note textuelle.

NEB traduit : "the strongest tree ... and what is made of it". Brockington rattache

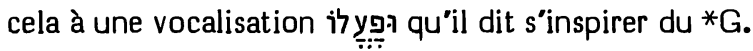

Origines de la correction :

NEB a pu prendre sa correction vocalique dans les apparats de HSAT34 ou de $\mathrm{BH} 23 \mathrm{~S}$ qui se réfèrent au *G.

Cette correction a été proposée par Michaelis. Il avait traduit ici : “die Mächtigen ... und ihre Werke", expliquant qu'une traduction littérale de l'hébreu serait : "der Mächtige ... und der inn gemacht hat". Il rend compte de sa traduction (OEB) en expliquant que, le $* M$ ayant vocalisé ce mot en participe actif (= son fabricant), une interprétation en "son oeuvre" requiert cette correction vocalique. Il ajoute que la mise des deux substantifs au pluriel tient seulement au fait qu'il juge cela plus coulant en allemand.

\section{Les témoins anciens :}

Toutes les versions (*G, *V, *S, *T) ont compris le premier mot au sens de "force" et le second au sens de "oeuvre". Elles toutes et 1Q-a ont affecté chacun de ces deux mots de suffixes pluriels. Suffixes de la $3 e$ pers. dans le $* G$ et la $* S$ qui ont un verbe à la $3 e$ pers. pl. au vs 30 . Suffixes de la $2 e$ pers. dans la $* V$ et $1 Q-a$ qui ont un verbe à la $2 \mathrm{e}$ pers pl. au vs 30 . Notons qu'en 1Q-a le maintien de l'article devant le premier mot montre le caractère secondaire du suffixe.

Le *T qui avait un verbe à la $2 \mathrm{e}$ pers. pl. au vs 30 a explicité ici "des impies" pour gloser les suffixes de la 3 e pers. pl. dont il use. 


\section{Choix textuel :}

Le comité a considéré toutes ces assimilations ou gloses comme facilitantes.

Quant à la correction vocalique proposée par Michaelis et adoptée par de nombreux exégètes dont NEB, elle mérite une étude plus approfondie.

Notons d'abord que la grande majorité des traductions du XVIe siècle ont compris ce mot au sens de "fabricant". C'est le cas d'Oecolampade, Pagnini, Arias Montano, Brucioli, Münster, Olivetan, Estienne, Calvin, Châteillon, Ge, KJ. Le sens "oeuvre" a été pourtant choisi, sous l'influence de la *V, par Luther, Tremellius, Pasteurs, et il figure en marge de $\mathrm{KJ}$.

Dans l'exégèse juive plus ancienne, le sens "fabricant" est adopté par Yéfet ben Ely, les glossaires hébreu-français, Rashi, Ibn Ezra, Eliézer de Beaugency et Radaq (qui a influencé la plupart des traducteurs du XVIe siècle). Cependant le sens "oeuvre" a été adopté, sous l'influence du *T, par Saadya, Judah ibn Balaam, Isaïe de Trani et Abravanel.

Judah ibn Balaam estime qu'au sens de "oeuvre" qu'il lui reconnaît ici, ce mot devrait être vocalisé comme il l'est en Jb 36,24 (= (=) ḥolem que nous avons ici caractérise le participe actif. ìl relève cependant la même forme irrégulière (avec ḥolem au lieu du qameș hatufuf) en Jr 22,13, alors que la forme

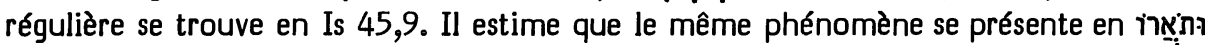
de Is 52,14, la forme régulière in se rencontrant en $1 \mathrm{~S} 28,14$.

Ces irrégularités ont été enregistrées également par les grammairiens récents : Gesenius (Lehrgebäude §47.5), Ewald (Lehrbuch §60b), Böttcher (Lehrbuch $\S 387,4$ ), Olshausen (Lehrbuch 291), König (Lehrgebäude II 493), Gesenius/Kautzsch ( $\$ 93 q)$, Bauer/Leander (582 u'), Bergsträsser (I §28e), Joüon ( $\$ 96 \mathrm{Aj}$ ), Lambert $(\$ 557)$. Il importe de préciser que, lorsque ces deux mots portent un suffixe de la 3e pers. m. sg., la forme 'normale' ( = avec qameș ḥatuf, engendrant un hatefef qames après la gutturale) se rencontre en tous les cas où ces mots ne sont pas précédés d'un 'waw', alors que la forme dite 'anormale' ( $=$ avec ḥolem, puis ḥatef patah après la gutturale) se rencontre en tous les cas où ces mots sont précédés d'un 'waw'.

Selon HUB, le ms babylonien Eb 16, vocalisant ici le 'aïn' en qibbus, confirme que cette forme se rattache à 'oeuvre' et non à 'fabricant".

Le comité a conclu que l'interprétation "son oeuvre" ne suppose ici aucune correction vocalique.

S'il a attribué au *M 4 "B" et 2 "C", c'est pour le protéger contre les suffixes au pluriel qui ont été ajoutés à ces deux mots en tous les autres témoins textuels.

\section{Interprétations proposées :}

\section{L'interprétation la plus vraisemblable est ici : "le fort ... et son oeuvre".}

Mais il peut être utile de mentionner en note l"autre interprétation : "le fort ... et son fabricant" qui est tout aussi possible grammaticalement et possède un solide enracinement dans la tradition exégétique.

Ehrentreu (Sprachliches XXX 6-8) a montré, à partir du Talmud Babli (Shabbat 20b), qu'il doit $y$ avoir ici un jeu de mots entre préparé). A l'étape suivante de sa préparation, celui-ci sera transformé en filasse et en étoupe (très aisément inflammable). 
Cette association verbale sous-jacente explique bien le premier membre de phrase : "L'homme fort (évoque : lin à demi préparé) deviendra de l'étoupe et son oeuvre une étincelle, et ils brûleront tous deux ensemble, sans personne pour éteindre." Ce "tous deux ensemble" concerne l'homme fort et son oeuvre.

\section{2,6 מקדם 2B] M 1Q-a Sym // exeg : G V S T clav}

Options de nos traductions :

Le *M est compris au sens temporel ("depuis longtemps") par 33 et au sens géographique ("par l’Orient") par TOB.

Comprenant ce mot au sens géographique, RSV le fait précéder par "of diviners (from the east)" et RL par "Wahrsagerei (wie die im Osten)". RSV précise que cette ajoute est conjecturale.

Quant à NEB, elle donne à la place de ce mot : "with traders", précisant en note : "ou bien : hawkers". Et Brockington explique que cela suppose comme lecture :

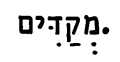

Origines des corrections :

La correction de NEB est une conjecture de Driver (TLP). Il la fonde sur l'arabe "qadâ" "il a été forcé par la paurreté à émigrer du désert" et sur le syriaque "qad(d)î̀" "il a commercé avec profit." C'est construire sur du sable.

Quant à RSV et RL, l'ajoute qu'elles proposent remonte, à travers les apparats de $\mathrm{BH} 23 \mathrm{~S}$ et HSAT2, à Lowth qui a eu l'idée d'insérer avant מקסם mot מקדם lequel Brenz et Houbigant (qu'il cite) voulaient le remplacer. Ce mot serait donc tombé en tous les témoins par une quasi-haplographie.

Les témoins anciens :

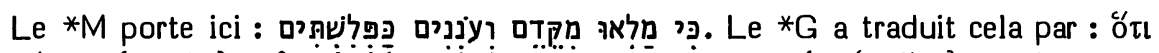

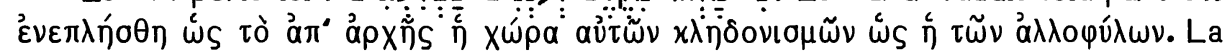
mise du verbe au singulier et l'explicitation du sujet constituent une assimilation à

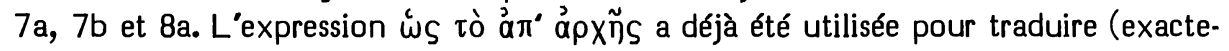
ment) en 1,26 et il en fera de nouveau usage pour traduire (très librement, comme ici) nِys en 63,19. Ici, Ziegler (p. 107) a suggéré de façon très vraisemblable que le traducteur entend se référer à $D t 18,14$ où il est dit (selon le ${ }^{*} \mathrm{G}$ ) que les peuples dont Israël va hériter le pays $x \lambda \eta \delta \delta o ́ v \omega \nu$ (ou : $x \lambda \eta \delta \delta o v i \sigma \mu \omega \tilde{\omega})$... áxov́oovtal. L'expression "comme autrefois" entendrait donc se référer à cette situation de l'entrée en Canaan décrite par le Deutéronome. Il semble donc bien que le ${ }^{*} G$ s'est contenté d'interpréter largement le *M.

Cette interprétation de מקדם n'est pas propre au *G. On la retrouve dans la *S et la $* V$ (qui peuvent dépendre du*G), ainsi que dans le *T. Isaïe de Trani paraphrasera ainsi le *M: "מקדם" signifie c'est-à-dire conformément aux actions des Amorites."

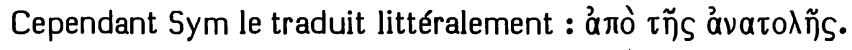

$1 \mathrm{Q}$-a appuie le $* M$, ne s'en distinguant que par des graphies pleines. 


\section{Choix textuel :}

Estimant que les versions ne se distinguent qu'au niveau translationnel du ${ }^{*} M$ que $1 Q$-a appuie fermement, le comité a attribué au *M la note " $B$ ".

Interprétation proposée :

On retrouve en Is 9,11 et 11,14 קִ désignant l'est par opposition aux Philistins désignant l'ouest.

De même que "Ophir" signifie en Jb 22,24 l'or qui vient d'Ophir, "Orient" peut évoquer ici les superstitions et la divination qui viennent de l'Orient.

Vitringa a suggéré que "être rempli" peut signifier ici une inspiration de devin, de même que Mi 3,8 dit "grâce à l'esprit du Seigneur, je suis rempli de force, d'équité et de courage".

Dans son commentaire sur Job, Schultens a rapproché de ceci Jb 15,2: “est-ce qu'un sage répondra par une science de vent (דעת רוח), et est-ce que le vent d'orient

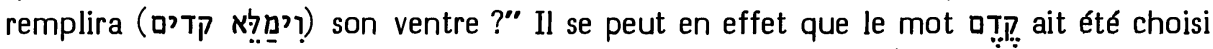
(parmi d'autres termes possibles pour exprimer la même idée) parce qu'il évoque le "vent d'orient" qui fane et dessèche.

Quant à la valeur de la préposition en מקדם, il semble qu'avec le qal de ce verbe, elle ne puisse introduire seulement ce dont on est rempli (comme ce serait le cas avec le nifal). Il faut donc lui garder une valeur d'origine: "ils sont pleins de ce qui vient de l'orient" (c'est-à-dire : des superstitions de l'orient). TOB a traduit largement : "ils sont submergés par l'Orient".

2,9 ולא תשא M Aq Sym V // attenu : 1Q-a om 9b-10, S T clav ואל תשא ולא ולא

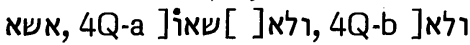

\section{Options de nos traductions :}

La valeur prohibitive de la négation du *M est clairement respectée par RSV ("forgive them not!"), J12 ("ne leur pardonne pas") et 33 ("ne les relève pas!").

TOB garde cette valeur en l'atténuant : "tu ne saurais leur pardonner".

$\mathrm{RL}$ remplace la prohibition par une énonciation: "und du wirst ihnen nicht vergeben".

NEB, donnant en note la traduction littérale du *M, conjecture : "and how can

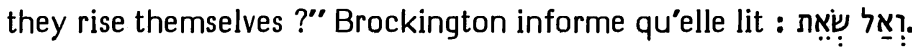

\section{Origines des corrections :}

RL retouche à peine la traduction de Luther ("das wirstu jnen nicht vergeben"). Parmi les traducteurs du XVIe siècle, ont opté comme lui pour une énonciation au futur : Pagnini, Brucioli, Münster, Estienne, Châteillon. Ont traduit en prohibition : Oecolampade, Olivetan, Jud, Ge, Tremellius, Pasteurs, KJ (que RSV a reproduite littéralement).

NEB suit ici une proposition de Driver (TLP) qui, sans le préciser, développe une conjecture de Duhm substituant שאת à תשת. 


\section{Les témoins anciens :}

Un certain nombre de témoins lisent ici la négation ולא, transformant ainsi la prohibition en une énonciation au futur. C'est le cas de 4Q-a, 4Q-b, *S et *T.

Quant au verbe qui suit la négation, 4Q-a l'a mis au pluriel en un contexte trop lacuneux pour qu'on puisse l'interpréter. En 2,6 le *G avait transformé en 3e pers. sg. la 2e pers. sg. adressée à Dieu. Ici, il la transforme en 1e pers. sg.

Le *M est formellement appuyé par Aq, Sym et la *V.

$1 Q$-a a omis $9 b$ et 10 , reprenant le texte en 11 qui répète la thématique de $9 \mathrm{a}$.

\section{Choix textuel :}

Ce cas n'a pas été soumis au comité.

Il est frappant de noter que, tout au long de l'histoire de l'exégèse, la tendance réapparaît de comprendre la négation אל suivie du jussif comme ayant en poésie le sens d'une simple prédiction, sens qui, en prose, s'exprimerait par suivi de l'indicatif. Cette exégèse cherche à arrondir les angles du texte. D'autres disent que cette phrase constitue une ajoute tardive.

Ces exégèses, comme les diverses variantes textuelles, veulent - par des initiatives variées - éviter que le prophète ait sommé le Seigneur de ne pas pardonner aux auteurs des agissements qu'il décrit. Mais est-il probable que cette sommation ait pour auteur un retoucheur tardif ou même un scribe du texte prémassorétique? Il est plus vraisemblable que les diverses variantes textuelles sont tout aussi facilitantes que les options des traducteurs ou des exégètes que nous avons mentionnées.

Il serait donc regrettable de leur emboîter le pas.

Interprétation proposée :

Le sens le plus naturel de cette expression est : "ne leur pardonne pas!" (cf. Gn 18,24.26; Nb 14,19; Os 1,6; Ps 99,8). Le sens "ne les relève pas !" choisi par J3 peut être évoqué à l'arrière-plan, du fait de 9a qui précède. Mais il ne saurait être considéré comme le sens directement visé.

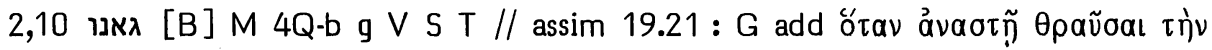
$\gamma \tilde{\eta} \nu$ / lacun : $1 Q-a$

Options de nos traductions :

A la fin de ce vs, J ajoute: "quand il se lèvera pour faire trembler la terre". Elle dit emprunter cela au $* G$.

RSV, RL, NEB et TOB n'ajoutent rien au vs du *M.

Origines de la correction :

C'est en se fondant sur le ${ }^{*} G$, confirmé par l'Arabe et un ancien ms (du *M), que Lowth a ajouté cette ligne, de manière à identifier ce refrain à la forme qu'il aura aux vss 19 et 21.

J a pu trouver cette ajoute requise par les apparats de Cent, BH23S, HSAT23. 
Les témoins anciens :

Cet "ancien ms" cité par Lowth est le ms 96 de Kennicott (Prophètes de St John de Cambridge) que celui-ci assigne à la fin du XIVe s. Lowth et Kennicott s'accordent pour dire qu'en ce ms cette ligne se distingue par une leçon la leçon הארץ a que ce même ms offre (en accord avec tous les autres témoins du ${ }^{*} M$ ) à la fin des vss 19 et 21 . HUB copie cette ajoute sans tenir compte de la variante susdite et précise qu'elle n'est pas vocalisée en ce ms. Ce témoignage isolé et tardif est négligeable.

$L$ 'ajoute du *G est l'une des initiatives qu'il a prises pour assimiler entre elles, par enrichissement mutuel, les diverses occurrences de ce refrain. Il a en outre ajouté

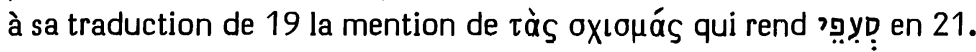

Nous avons déjà signalé que 1Q-a omet ce vs.

\section{Choix textuel :}

Le 'moins' que le *M présente par rapport au *G ne peut s'expliquer par un accident textuel, alors que le 'plus' du *G s'explique par une tendance à enrichir ce refrain par une phrase présente en ses deux reprises.

Quant à 1Q-a, il est possible qu'il dépende d'une tradition littéraire où ce refrain ne figurait pas encore ici. Il est plus probable que l'on a dans l'omission de ce vs une conséquence secondaire de l'omission volontaire de $9 \mathrm{~b}$.

En lui attribuant la note " $\mathrm{B}$ ", le comité a voulu protéger la forme intermédiaire du ${ }^{*} M$ dans sa spécificité littéraire.

\section{2,12 ונשא ושפל [C] [C] M V S T (vel : assim-ctext) // cor-a (vel :}

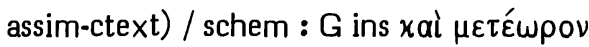

Options de nos traductions :

Le *M a été traduit par J ("sur tout ce qui est élevé, pour qu'il soit abaissé") et RL ("und über alles Erhabene, dass es erniedrigt werde").

TOB l'a un peu allégé : "et altier et qui sera abaissé", sans donner de note textuelle.

RSV traduit : "against all that is lifted up and high", disant que le dernier mot est une conjecture qui s'inspire du *G, alors que le sens de l'hébreu serait "low".

NEB traduit "for all that is high and lifted up" en prétendant suivre le *G, le sens de l'hébreu étant "low". Brockington précise que le dernier mot est corrigé en ịi실.

\section{Origines des corrections :}

Quoiqu'elle ne le précise pas, il se peut que TOB se soit inspirée du second apparat de BH7 précisant que, au lieu de ועל כל נשא, 1Q-a lit ונשא.

RSV et NEB peuvent dépendre des apparats de BH23S et de HSAT3.

\section{Les témoins anciens :}

Nous venons de mentionner la forme plus brève offerte par 1Q-a.

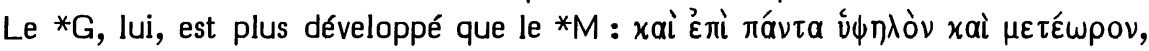

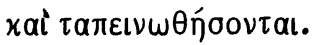


La $* V$, la $* S$ et le $* T$ ont la même ampleur que le *M.

Th et AqSym nous sont connus de façon trop fragmentaire pour que l'on puisse en tirer un témoignage sur ce point.

\section{Choix textuel :}

Michaelis (OEB) traduit sans hésiter les deux derniers mots du $* M$ par "Hohes und Niedriges". Il estime difficilement acceptable d'avoir en ce membre deux mots formant contraste, alors que leur correspondent, dans le membre précédent, deux synonymes ("orgueilleux et élevé") : "Selon la relation habituelle des deux membres dans le vs hébreu, ou bien il faudrait placer dans le premier 'haut et bas' comme dans le second, ou bien - si l'on garde dans le premier deux synonymes - placer aussi dans le second membre deux synonymes". Michaelis estime que le ${ }^{*} \mathrm{G}$, conscient de cette difficulté, a choisi la seconde de ces échappatoires en traduisant par antiphrase comme il lui arrive assez souvent - ושפל par xaì $\mu \varepsilon \tau \varepsilon$ Éwov. Quant à lui, il choisit la première solution et conjecture au lieu de "orgueilleux" un mot exprimant la bassesse.

Lagarde, considérant que le contexte n'énumère' rien que des choses élevées, estime que ונשלגב a dû précéder la place qu'il occupe.

Duhm interprète sans discussion le dernier mot du *M comme un adjectif. Cela l'amène à lui préférer le mot conjecturé par Lagarde ou bien גבה , en s'inspirant du *G

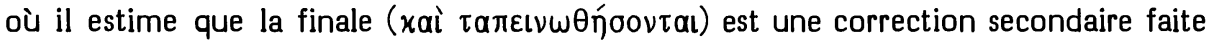
à partir du *M.

Il importe cependant de noter qu'aucun témoin du ${ }^{*} G$ n'omettant la finale en question, il est tout aussi vraisemblable que $x a i$ $\mu \varepsilon \tau \varepsilon ́$ wpov soit ici une glose du traducteur inspirée par $\tau \tilde{\omega} \nu \tilde{u} \psi \eta \lambda \tilde{\omega} \nu$ xai $\mu \varepsilon \tau \varepsilon \omega ́ p \omega \nu$ qui, au vs suivant, traduira du *M.

Les choix textuels de Michaelis, de Duhm, de RSV et de NEB reposent sur une interprétation en adjectif du dernier mot du *M. Il faut cependant noter qu'il a été interprété comme un accompli inverti par Saadya, David ben Abraham (II 698,62s), Yéfet ben Ely, Ibn Ezra, Eliézer de Beaugency, Radaq et Isaïe de Trani. C'est déjà ainsi qu'il avait été interprété par toutes les versions anciennes $\left({ }^{*} G, T h, A q S y m\right.$, $* V$, *S et ${ }^{*} T$ ), le ${ }^{*} G$, Th et le $* T$ le traduisant largement par un pluriel.

Notons cependant qu'Abravanel voyait opposés en ce vs deux types d'orgueilleux : ceux qui ont l'extérieur hautain ("orgueilleux et hautain") et ceux qui l'ont humble ("élevé et humble"). Cela supposait une interprétation en adjectif. Mais le premier commentateur qui ait mis formellement en question cette interprétation en verbe semble avoir été Oecolampade en 1525. Traduisant "et humile" (ce en quoi il sera suivi par Jud: "ac humilem", Brucioli : "\& basso" et Olivetan : "et abaissé"), il s'expliquait ainsi en son commentaire : "Pour "humiliabitur" j'ai traduit 'humile'... D'autres, en effet, veulent que qui le précède. A moi, il me semble un nom... Je sais que Jérôme, avec la $L X X$ et Jonathan, a traduit différemment. A toi de juger, lecteur, si ce sens est vraiment fondé. Je ne voudrais ni sembler ni prétendre préférer mon avis à celui des autres. Je propose ce qu'il m'en semble."

L'interprétation en accompli inverti a cependant été adoptée par Pagnini, Luther, Münster, Brucioli (éd. 1540), Vatable, Rollet, Estienne, Châteillon, Ge, Tremellius, Pasteurs et KJ. 
Dans son lexique, dont on sait la grande influence, J. Buxtorf sr avait pourtant donné comme première forme pour l'adjectif la vocalisation avec qameṣ et șéré, alors qu'elle ne peut se fonder clairement que sur Ez 17,24 (selon le texte de la Bible Rabbinique de Félix de Prato et selon un certain nombre de mss dont celui de Radaq, alors que les mss tibériens classiques s'accordent avec la plupart des éditions et une massore citée par Norzi pour vocaliser ce mot avec deux qameș). Cela suffit à expliquer le préjugé d'où sont partis presque tous ceux qui veulent corriger ici ce mot (qu'ils comprennent eux aussi comme un adjectif). Pourtant le Thesaurus de Pagnini, puis le dictionnaire de Cocceius et le Thesaurus de Gesenius avaient été très formels pour interpréter ici ce mot en accompli inverti. C'est d'ailleurs ce qui est clairement suggéré par les autres emplois de la même forme aux vss 11 et 17.

On a souvent reproché au * $M$ (au cas où on l'interprète en verbe) qu'une mention de l'abaissement final serait déplacée ici où le prophète accumule les images de hauteur et d'élévation. Mais König considère qu'en ce verset les trois premières désignations sont ironiques et que la conclusion y est une anticipation du résultat final, procédé stylistique fréquent dans la littérature hébraïque (et que nous avons noté plusieurs fois en CT1). Dans son Hermeneutik (88, n.3), König relève le même procédé stylistique dans la stèle de Mésha, l. $6 \mathrm{~s}$.

C'est cette interprétation du vs 12 comme une prolepsis des vss 13 à 17 qui a amené la moitié des membres du comité à préférer la leçon de $1 \mathrm{Q}$-a à celle du *M (où un ועל כל aurait pénétré par assimilation à celui qui précède et aux 8 autres qui suivent). En effet, "sur tout orgueilleux et hautain et élevé" serait détaillé en 13-16, alors que "et il sera abaissé" le serait en 17 où la même expression est reprise.

Cependant l'autre moitié des membres du comité (frappée du fait que le deuxième "et sur tout" est attesté par le ${ }^{*} G$ malgré la variante qui distingue celui-ci du *M) a estimé que l'assimilation au contexte avait joué en sens inverse, ועל כל נשא ayant été, en 1Q-a, victime d'une assimilation à la forme des deux mots qui l'encadrent.

En attribuant la note " $\mathrm{C}$ " à chacune de ces deux options, le comité laisse le choix aux traducteurs, en leur conseillant d'indiquer en note celle des deux options qu'ils n'auront pas retenue.

Interprétations proposées :

Seule l'interprétation du dernier mot en verbe semble faire droit au $* M$.

Si on choisit la leçon de $1 \mathrm{Q}-\mathrm{a}$, on pourra donc traduire "contre tout ce qui est orgueilleux, hautain et altier, mais qui sera abaissé". Si l'on préfère celle du *M, on traduira: "contre tout ce qui est orgueilleux et hautain, contre tout ce qui est altier, mais sera abaissé". 


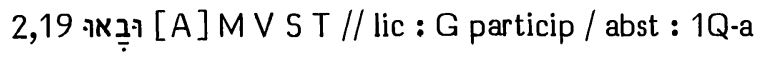

Options de nos traductions :

Alors que le *M (suivi par RSV, J et RL) vocalise ce verbe en accompli inverti 3e pers. pl., NEB et TOB traduisent "get you" et "entrez", sans notes. Brockington précise que NEB s'inspire du vs 10 pour vocaliser ici : וּבארו

Origine de la correction :

A travers $\mathrm{BH} 23$ et HSAT3, cette vocalisation conjecturale en impératif remonte à Bredenkamp qui se référait déjà au vs 10 .

Les témoins anciens :

Le ${ }^{*} G$ a pris la liberté de traduire ce verbe comme si l'on avait affaire à un hifil et

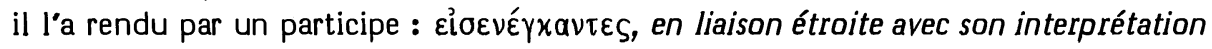
(également libre) de ce qui précède : "et ils cacheront toutes les idoles fabriquées, les introduisant dans les cavernes..."

$1 Q$-a est consonnantiquement identique au $* M$ dont toutes les autres versions $(* V, * S$ et $* T)$ appuient la vocalisation en traduisant par un verbe à sens futur à la 3e pers. pl. précédé d'une conjonction.

\section{Choix textuel :}

Bredenkamp et ceux qui ont adopté sa conjecture interprètent au vs 10 בai et וְ ְִ comme des impératifs, ainsi que Duhm le fait en prétendant que des infinitifs absolus seraient bien trop faibles pour exprimer la menace tonnante qui conclut cette strophe. König estime que ce jugement méconnaît absolument la valeur syntactique de l'infinitif absolu, renvoyant sur ce point à Gesenius/Kautzsch §113y.

De fait, l'interprétation en impératifs est ici celle de Saadya, Radaq et Abravanel. Elle est présentée en second par Ibn Ezra. Mais l'interprétation en infinitifs absolus est celle de Yéfet ben Ely, Rashi, Eliézer de Beaugency. C'est la première présentée par Ibn Ezra. C'est aussi celle des glossaires ABCF. La traduction suivante est donnée par ACF (avec des variantes très légères) : “à venir à roche et à être repont".

Parmi les versions anciennes, la $* V$ traduit par des impératifs sg., le ${ }^{*} G$ et la $*^{*}$ par des impératifs pl., alors que le *T semble avoir vu là des infinitifs qu'il glose.

Au XVIe siècle la plupart traduisent au vs 10 des impératifs sans rien noter. Pourtant Olivetan indique en marge la possibilité de traduire par des futurs. Vatable est seul à expliciter ce point en ces termes : "Chez les hébreux, l'infinitif est pour un futur, et c'est ainsi que le paraphraste chaldéen a traduit...". Cette interprétation en infinitif absolu a été adoptée ici par Hitzig, Dillmann/Kittel, Ehrlich, König et Procksch. Elle donne en effet un plus grand relief ('il s'agit d'entrer... et de se dissimuler...") que l'impératif qui, d'ailleurs, requerrait plutôt des formes plurielles.

Si une interprétation en infinitifs absolus convient mieux au vs 10 , la conjecture de Bredenkamp perd son point de référence et les accomplis invertis que le *M offe au vs 19 sont alors la reprise normale des infinitifs absolus du vs 10 .

Considérant que la variante du ${ }^{*} G$ se situe au niveau de l'interprétation, le comité a attribué au *M la note " $A$ ". 
Interprétation proposée :

En 10 : "il s'agit d'entrer... et de se dissimuler...". En 19 : "et l'on entrera...".

$3,1 \mathrm{~b}$

Options de nos traductions :

Seule de nos cinq traductions, NEB omet ce qui suit l'atnah, c'est-à-dire : "tout soutien de pain et tout soutien d'eau", en signalant en note cette omission comme conjecturale.

Origines de la correction :

BHS signale cela comme une addition. HSAT234 impriment cela comme une glose.

Ce jugement remonte à Gesenius. Il estime que l'explication authentique de משען ומשענה (expression obscure par laquelle s'achève la première partie de ce vs) est constituée par les vss 2 et 3 . Ne comprenant pas cela, un glossateur a voulu rajouter une explication plus verbale de ces mots. Cette glose explicative ne correspond pas à celle que vont donner les vss suivants et interrompt la relation immédiate qu'ils devraient avoir avec les mots à expliquer.

Le diagnostic de Gesenius a été accepté par Hitzig (signalant que Gesenius a rétracté ses doutes plus tard), Knobel, Nägelsbach, Bredenkamp, Dillmann/Kittel, etc.

Ont omis cette glose de leur texte : Duhm, SBOT, Schmidt.

Les témoins anciens :

Aucun n'omet ces mots.

Choix textuel :

Ce cas n'a pas été soumis au comité.

Si l'on devait admettre que cette explicitation est postérieure à ce qui la précède et à ce qui la suit, on est pourtant forcé de constater qu'elle fait partie de toutes les formes textuelles connues. Elle fait donc partie intégrante du livre d'Isaïe dans les états en lesquels il a été canoniquement reçu.

Bien que plusieurs commentateurs récents (Wildberger, Vermeylen, Kaiser) considèrent comme un fait acquis le caractère de glose de 1b, il peut être utile de mentionner un certain nombre d'arguments en faveur d'une appartenance de ces mots au texte primitif de cette prophétie.

1) 3,1 constitue une phrase typiquement isaïenne. Cela apparaît assez clairement si on compare (avec Delitzsch) :

3,1 : “Car voici que le Seigneur YHWH Sabaôt retire de Jérusalem et de Juda soutien et soutènement, tout soutien de pain et tout soutien d'eau"

à 25,6: "Et YHWH Sabaôt fera pour tous les peuples sur cette montagne un festin de viandes grasses, un festin de vins vieux, de viandes grasses succulentes, de vins vieux décantés". 
Il serait regrettable de détruire l'une de ces phrases majestueuses.

2) Les vss 2 à 7 expriment d'abord le retrait des catégories d’hommes qui assurent la stabilité et la prospérité de la société (2-3), puis l'anarchie qui en résulte (4-5) et enfin, lorsqu'il s'agit de motiver le refus qu'oppose un homme compétent à se charger du gouvernement, ce motif (7) est qu'il n'a pas de pain dans sa maison.

3) Stylistiquement nous avons donc par le mot-clé "pain" une inclusion unissant le vs 1 au vs 7, et en 1b ce trait typiquement isaïen que constitue le bref jaillissement d'une idée qui sera ensuite exposée au terme d'un ample développement. Eliminer ce jaillissement initial détruirait la tension poétique.

Interprétation proposée :

Si certains traducteurs étaient convaincus du caractère de glose de ces mots, ils devraient indiquer cela en note, mais conserver dans leur texte ces mots comme un élément constitutif du livre biblique d'Isaïe.

\section{אמרו אסרו 3,10 אמרו 3 [B] M 1Q-a ThAq Sym V S T // err-graph et dbl : G clav}

Options de nos traductions :

Le *M est traduit par RSV ("tell the righteous that it shall be well with them"), par J ("dites : le juste, qu'il est heureux !") et par TOB (“Dites : le juste est heureux").

Par contre, RL traduit : "Heil den Gerechten, sie haben es gut !" et NEB : "Happy the righteous man! all goes well with him". Brockington nous précise que

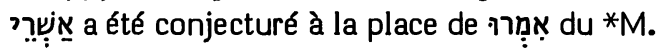

\section{Origines de la correction :}

A travers $\mathrm{BH} 235$ et HSAT 234, cette conjecture remonte à Lowth qui, constatant que le ${ }^{*} G$ avait ajouté à la leçon du *M une forme de la racine אסר, proposait de lire ou bien אמרו אשרי "bless ye" ou bien = "say ye, blessed is". A cela, Koppe ajoutait la remarque que le אוי qui suit semble bien exiger que l'on lise אשרי à la place de אמרו

Michaelis (OEB) déclarait avoir fait la même conjecture indépendamment de Lowth, estimant que cette rencontre en montrait la probabilité. Il faudra cependant attendre une centaine d'années avant que la conjecture de Lowth soit remise en circulation par Grätz (Psalmen 139, 1.33), Bredenkamp, Duhm, Cheyne, etc.

\section{Les témoins anciens :}

La graphie אמורו de 1Q-a montre qu'il a lu ici un impératif, comme le *M. Même interprétation en ThAq et Sym, ainsi que dans la *V, la *S et le *T.

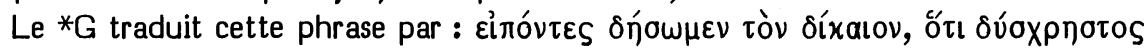

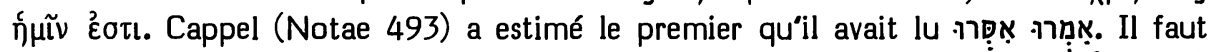

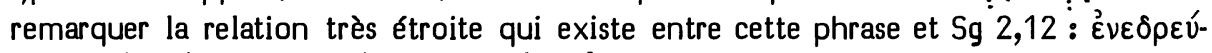

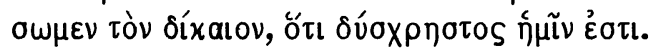




\section{Choix textuel :}

La relation caractéristique du ${ }^{*} G$ avec $S g$ 2,12 peut s'expliquer par une influence de ce vs d'Isaïe en sa traduction grecque sur l'auteur de la Sagesse. On peut, en effet, déceler en $\mathrm{Sg}$ de nombreuses autres influences du livre d'Isaïe. Cependant Larcher croit que nous avons plutôt affaire ici à une altération du ${ }^{*} G$ d'Isaïe sous l'influence de $\mathrm{Sg} 2,12$.

Comme Cappel l'a noté, le ${ }^{*} G$ a intégré en doublet une variante de אמרו où un 'samek' remplaçait le 'mem'. Cela l'a amené à traduire par antiphrase כי־טר qui suit immédiatement. Il est difficile de fonder une correction textuelle sur un usage aussi libre fait par le traducteur de sa Vorlage hébraïque; cela d'autant plus que 1Q-a apporte au *M un appui très formel (sa 2e main ayant seulement ajouté un "lamed" facilitant avant le mot צד).

A la suite de Koppe, ceux qui ont accepté la conjecture de Lowth ont généralement fait remarquer qu'elle établissait un balancement harmonieux avec אוי qui commence le vs 11 . On peut noter en effet que le livre d'Isaïe se caractérise, parmi les autres écrits prophétiques, par l'usage qu'il fait de (3 fois) et des formes intensives du verbe de même racine ( 3 fois). Cependant ces expressions ne se retrouvent pas ailleurs en balancement avec אוי. En effet, le seul cas que l'on pourrait invoquer serait au début de 32,20 : אשריכם, puis au début du vs suivant $(33,1)$ : הוי. Mais tous les mss étudiés par Oesch ( $T$ 16*) s'accordent pour isoler 33,1 comme constituant une section distincte de ce qui le précède.

A propos de la construction du אמרו צדיק כישרב les verbes signifiant "voir" ou "savoir" sont, en hébreu biblique, immédiatement suivis par l'objet de la vue ou du savoir. Ce n'est qu'ensuite qu'est mentionnée la propriété ou la caractéristique que la vue ou le savoir mettent en relief en cet objet. C'est ainsi que Gn 1,4 s'exprime : וירא אלהים את־האור כי־טוב (cf. aussi Gn 49,15; Ex 2,2) ou 1 R 5,17 : ידעת את־דוד אבי כי לא יכל :cf. aussi Ex 32,22; 2 S 3,25). Notre cas a été considéré comme analogue à ceux-là par Ewald (Lehrbuch §336b), Delitzsch, König. Holladay (Passage 485s) a fondé cette assimilation sur le sens de "remarquer" (incluant à la fois "voir" et "dire") qu"il estime être ici celui du verbe אמר.

A cause du solide appui que le ${ }^{*} M$ reçoit de $1 Q$-a et des témoins autres que le ${ }^{*} G$, le comité lui a at tribué 5 " $\mathrm{B}$ " et 1 " $\mathrm{C}$ ".

Interprétations proposées :

La plus simple est : "dites du juste qu'il est heureux". Cependant Bahbout (Interpretazione 24s) a proposé de voir ici une consigne adressée par le prophète aux juges : “Déclarez à propos du juste qu'il est bon, qu'ils se nourrissent du fruit de leurs oeuvres. Malheur à l'impie mauvais, qu'il soit traité selon ce que méritent ses actions." On aurait là une réaction contre "ceux qui déclarent le mauvais bon et le bon mauvais" $(5,20)$. Et cela préparerait la triste constatation de 3,12b. Cette interprétation ne saurait être éliminée. 


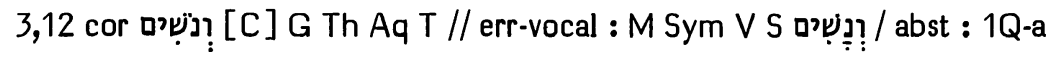

Options de nos traductions :

Alors que RSV, RL et TOB comprennent ce mot au sens de "femmes", en conformité avec la vocalisation du *M, J traduit "des exacteurs" et NEB "and usurers", $\mathrm{J}$ disant suivre des "versions", alors que Brockington attribue à NEB une vocalisation

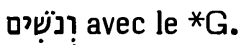

Origines de la correction :

Cette correction a été proposée par BHS, Cent et HSAT34. Déjà Cappel (Critica 775) avait attribué à la Vorlage de ${ }^{*} \mathrm{G}, \mathrm{Th}, \mathrm{Aq}$, *T cette variante vocalique, sans pourtant se décider clairement à l'adopter (Notae 493). Clericus estime cela inutile. C'est Houbigant (dans une partie de ses notes omise par.l'édition de Francfort) qui a adopté la variante, suivi par Michaelis (OEB) et Doederlein. Un siècle plus tard, cette correction sera reprise par Grätz, Marti, Condamin, mais suscitera l'indignation de Ehrlich : "Trois des versions grecques, parmi lesquelles la Septante que l'on exalte jus-

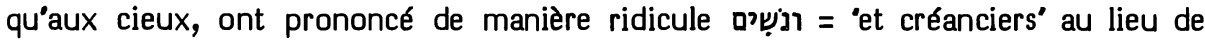
ונְִשים, et cela est enregistré dans la Biblia Hebraica de Kittel !" Cette protestation n'empêchera pas Gray, Feldmann, Procksch, Fohrer, Wildberger, Vermeylen (147), Kaiser etc. d'opter pour la variante.

Les témoins anciens :

1Q-a n'a pas à intervenir ici où il s'agit de vocalisation.

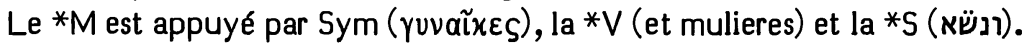

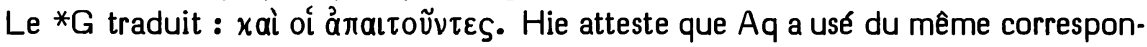
dant. Th traduit : $\delta$ avelotaí et le *T : וכמרי חובא.

Ces versions ont donc vu ici un dérivé du verbe נשהה (= prêter).

Choix textuel :

Il est frappant de noter que l'interprétation "créanciers" se retrouve attestée parmi les exégètes juifs, quoique Ehrlich ne semble pas en avoir eu conscience.

Dans le midrash Rabba (sur Est 1,9) est rapportée l'opinion de R. Huna (vers 325) sur Is 3,12a $\beta$ qu'il paraphrase : "ils tombent sur eux comme des créanciers" (ce mot étant au singulier dans l'édition de Wilna et dans le ms Oxford 164, mais au pluriel dans le ms Vatican 291). Parḥon déclare que ce mot est ici comme רנושים et qu'il s'agit de celui qui prête à son compagnon. Le glossaire $C$ traduit : "et prêteurs", ajoutant ensuite l'exégèse de Rashi : "et faibles". Les glossaires ABF traduisent : "et femmes", mentionnant comme un autre sens : "et prêteurs" qui figure comme une ajoute de seconde main dans le glossaire $E$ (dont la première main ne traitait pas de ce cas). Enfin Aaron ben Joseph dit que ce mot a ici le même sens qu'en 50,1 (= "ou qui parmi mes créanciers"). Remarquons cependant que "femmes" est ici l'interprétation de Saadya, Yéfet ben Ely, Radaq, Isaïe de Trani et Abravanel.

Pagnini (Thesaurus3 1712) estime inutile ici une correction vocalique pour expliquer l'exégèse "usuriers" du *T : celui-ci aurait cru lire ici le pluriel d'un adjectif (dans Thesaurus1 1504, Pagnini vocalisait par erreur la 2e syllabe avec qames au 
lieu de segol). S'il en est ainsi, nous n'aurions affaire ici qu'à une question d'exégèse. Le comité a jugé cependant plus vraisemblable d'admettre avec Rashi que le *T a vocalisé ici en participe actif, car le participe est attesté 9 fois dans la Bible, alors que la forme adjectivale, suggérée par Pagnini, ne l'est pas.

Le choix entre la leçon du *M ("femmes") et la variante ("créanciers") dépendra en grande partie du sens que l'on attribuera à מ̣̣ dans le stique précédent.

Toutes les versions anciennes $\left({ }^{*} \mathrm{G}\right.$, ThSym, $\left.A q,{ }^{*} \mathrm{~V},{ }^{*} \mathrm{~S},{ }^{*} \mathrm{~T}\right)$ s'accordent pour y voir un participe du verbe "grappiller". C'est aussi l'opinion des karaïtes Yéfet ben Ely et David ben Abraham (II 400, 87s) ainsi que la 2e opinion présentée par Abravanel.

$Y$ voient un participe au sens de "moquant" : les glossaires ACEF qui traduisent "gâbant". Rashi y voit un adjectif de même sens.

Ḥayyuj suggère que ce mot a le même sens que לִ̣iy (= jeune enfant). C'est l'opinion de Saadya, Abulwalid (Ușul 521, 1.25), Ibn Ezra (précisant qu'il s'agit d'un adjectif avec 'mem' préfixé), Judah ibn Balaam, Eliézer de Beaugency, Radaq, et la première opinion d'Abravanel.

Parmi les traducteurs du XVIe siècle, Oecolampade (1525) commence par traduire ici : "racemant" (= grappillent). Luther, lorsqu'il commente ce passage en son cours durant l'Avent de 1527, traduit (selon la reportatio d'Antonius Lauterbach, WA. XXXI/2, 32, II. 15-18) : "exactores sui spoliaverunt" et commente : "exactores racemant, deglubunt, schinten und schaben". Cependant, sa traduction (publiée en 1528) porte ici : "Kinder" et tout le commentaire de ce passage a disparu de la forme éditée de son cours (WA. XXV). Brucioli va évoluer dans le même sens : en 1532, sa traduction, elle aussi, donne : "lo diracimolano", sous l'influence d'Oecolampade; alors qu'en 1540, il corrige cela en : "sono fanciugli". Comme nous l'avons vu pour Is 2,12, Brucioli est en 1532 sous l'influence d'Oecolampade, alors qu'en 1540 il passe sous celle de Pagnini. Il en va de même de Luther entre le moment où il donne cette partie de son cours et celui où il publie sa traduction. En effet, Pagnini, sous l'influence de Radaq, a rendu ce mot par "parvulus" dans sa traduction qu'il publie en 1527. Comme cela avait été le cas pour Is 2,12, nous trouvons Olivetan ("font vendange") et Jud ("racemando spoliant") sous l'influence d'Oecolampade, alors que Münster, Rollet, Estienne, Châteillon, Ge, Tremellius, Pasteurs et $\mathrm{KJ}$ sont passés sous l'influence de Pagnini. Notons toutefois que Mercerus, annotant Pagnini (Thesaurus3, 1965), voit ici le sens "racemat", avec une transparence en double sens faisant allu-

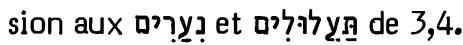

En effet, de manière analogue à ce que nous avons noté à propos de 2,6, sur une suggestion de Schultens, il se peut qu'ici le mot מִ̣ ait été choisi parce qu'il évoque עיל (= jeune enfant) et les jeunes gens de 3,4. Il n'y a cependant pas de motif valable pour voir ici autre chose qu'un participe polel de על על pris en son sens normal de "grappiller".

La plupart des exégètes ont trouvé une difficulté à ce prédicat au singulier d'un sujet pluriel. Mais, en 60,17, on retrouvera le même participe נגְלְִׁ dans la même situation de sujet pluriel d'un prédicat au singulier. Cette fois-là, ce participe pluriel est en parallèle avec un substantif abstrait au singulier : un cas comme dans l'autre, de l'administration, c'est-à-dire du corps des fonctionnaires. 
On comprendra donc, en 3,12aa : “mon peuple, son administration grappille" (c'està-dire passe et repasse pour voir s'il y a encore quelque chose à prendre, après l'avoir dépouillé comme on vendange une vigne).

Si l'on considère ce sens comme le plus probable pour מִִ̣ on peut estimer que c'est sous l'influence de נְשִים du stique suivant que le sens de "jeune enfant" a été donné à ce mot par Saadya et ceux qui l'ont suivi. Mais, une fois que l'on a restitué à "grappillant" son sens métaphorique qui semble ici très bien en place, le choix de la vocalisation jevevient très probable pour le stique suivant. C'est pourquoi le comité a attribué à cette correction vocalique la note " $\mathrm{C}$ ".

Interprétations proposées :

On pourra donc interpréter ainsi 12a : "mon peuple, son administration le grappille et des usuriers dominent sur lui". Mais il sera bon d'indiquer en note que la vocalisation du *M suppose une interprétation: "mon peuple, des enfants l'administrent et des femmes dominent sur lui."

\section{3,13 עמו [B] M 1Q-a V T // assim 14 : G S clav}

\section{Options de nos traductions :}

33 et TOB suivent le *M en traduisant "les peuples".

Mais RSV, J12, RL et NEB traduisent "son peuple", disant suivre le *G et la *S.

Origines de la correction :

A travers les apparats de Cent, BH23S et HSAT34, Cheyne (SBOT) et Grätz, cette correction remonte à Lowth qui semble avoir été le premier à emprunter au *G une correction en iny. Cappel (Notae 473) avait déjà fait remarquer que le ${ }^{*} G$ a lu ainsi.

Pour comprendre l'initiative de Lowth, il faut noter une particularité des traductions anglaises antérieures à lui, telle que la relève le Oxford Dictionary (People, §1.d). Au sens de "nations" correspondant aux pluriels de l'hébreu et du grec, la forme singulière "people" avait été laissée constamment inchangée par les traductions de Tyndale et de Coverdale, ainsi que dans les autres traductions basées sur elles (mais non dans celle de Reims). Il en a été presque toujours ainsi en celle de Genève et dans celle de $1611(=\mathrm{KJ})$, alors que les réviseurs de $1881-5$ ont uniformément substitué "peoples".

Etant donné qu'au vs 12 on lit deux fois : "mon peuple" et au vs 14 une fois "son peuple", puis au vs 15 une fois "mon peuple", on comprend qu'ici la traduction "to judge the people" (sur laquelle Ge et $\mathrm{KJ}$ s'accordent en fonction du principe susdit) ne laissait pas paraître clairement aux lecteurs anglais qu'il dôt s'agir de "peuples" au pluriel. On était donc habitué à comprendre cela au sens d'un singulier comme, par exemple, en Ex 18,13 où la même expression "to judge the people" est usitée par Ge et KJ pour traduire le complément d’objet : אתזהעם. On comprend donc que Lowth ait été habitué, comme tout familier de la $\mathrm{KJ}$, à comprendre ici en fonction du contexte : "la population" (d'Israël) et que, voulant traduire Isaïe sans s'éloigner 
inutilement de la $\mathrm{KJ}$ (Preliminary, lxxii), il ait préféré sauver le singulier (apparent !) de cette traduction en faisant usage de la leçon du ${ }^{*} G$.

\section{Les témoins anciens :}

Le pluriel du *M se trouve attesté par 1Q-a, la *V et le *T, alors que la*S (עמה)

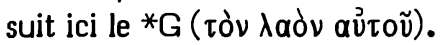

\section{Choix textuel :}

Nous venons de noter que cette forme plurielle עמים est encadrée par quatre formes au singulier : "mon peuple" ou "son peuple". La leçon $d u{ }^{*} G$ assimile à ce contexte. Aussi le comité a-t-il attribué la note "B" à la lectio difficilior du *M.

\section{Interprétations proposées :}

En Am 1,3 à 2,5, le prophète commence par proclamer les verdicts des peuples qui entourent Israël pour préparer la condamnation redoutable qui va frapper Israël lui-même.

Il semble que, de même, ici un cadre de jugement universel est ébauché, jugement qui va, dès le vs suivant, se concentrer sur le peuple du Seigneur.

Gesenius, Hitzig, Knobel et Duhm ont compris ici ce pluriel "peuples" (comme en Dt 33,3.19) comme désignant les tribus d'Israël. Ce n'est pas impossible, mais il serait difficile de trouver d'autres cas de cet usage dans la langue d'Isaïe.

3,24 כי תחת /B [ בי תחת M Aq Sym S // abr-elus : G V clav om : 1Q-a add בשת / midr et confl : T

Options de nos traductions :

J, RL, NEB et TOB traduisent le *M en comprenant כי comme un substantif (J : "la marque au fer rouge", RL : "Brandmal", NEB : "branding", TOB : "une marque infamante").

RSV traduit : "instead of beauty, shame", l'ajoute du dernier mot étant empruntée à $1 \mathrm{Q}$-a.

Origines de la correction :

Lowth considérait déjà que quelque chose manquait à la fin de ce vs.

Milik (Note 216) a considéré que 1Q-a, en ajoutant בשת à la fin du vs, permettait de garder à כa valeur normale de conjonction. A sa suite, Nötscher (Hapaxlegomena 300), Wildberger et Kaiser ont adopté l'ajoute de 1Q-a.

Driver (Scrolls 25) considère que c'est par méconnaissance de la valeur substantivale de 3 que $1 Q$-a a été amené à cette ajoute.

\section{Les témoins anciens :}

Alors que 1Q-a offre un mot de plus que le $* M$, il semble que le $* G$, ne pouvant trouver un sens à כי תחת, n'en a pas tenu compte dans sa traduction. Il a joint le mot יפי au vs suivant et donné de 25a, ainsi complété, une traduction très libre : xai ó

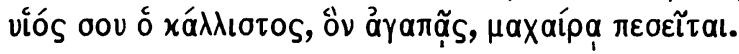


La *S a respecté les consonnes du *M, mais considéré cette cinquième occurrence de Comme Warszawski le note, cela lui a permis de garder à 2 son sens de conjonction.

$L a * V$ a suivi l'option du ${ }^{*} G$, en restant plus proche du $* M$, dans sa traduction de 25 a (pulcherrimi quoque viri tui gladio cadent).

Le *T offre une leçon gonflée dont le premier élément est constitué par un développement midrashique à partir de la leçon de la ${ }^{*} S$ et le second élément par une traduction toute proche de celle de la*V.

Une leçon gonflée analogue, quoique bien plus proche du $* M$, est donnée par

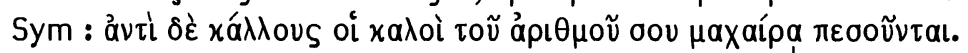

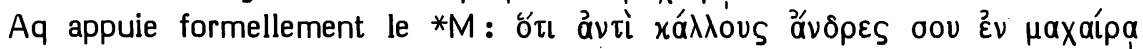

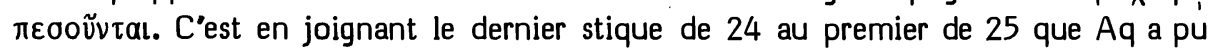
garder à כ sa valeur de conjonction. Avouons cependant que cette jonction n'aboutit pas à un sens très heureux.

Il semble que l'on puisse également retrouver le $* M$ à la base de l'ajoute de la

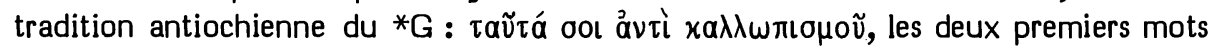
étant une paraphrase de la conjonction initiale.

\section{Choix textuel :}

Les témoignages en faveur du texte consonnantique du ${ }^{*} M$ sont assez solides et les témoignages divergents sont assez dispersés pour que l'on puisse opter pour la lectio difficilior offerte par le *M.

Quant à la vocalisation de $ת$ n en verbe par la *S et vraisemblablement par le *T, elle semble influencée par la familiarité de leurs traducteurs avec la racine araméenne תחנ. On ne peut donc en tirer une variante préférable à la vocalisation du *M.

Aussi le comité a-t-il attribué au *M 5 " $\mathrm{B}$ " et 1 "C $\mathrm{C}$ ".

Interprétations proposées :

Ceux qui conservent le *M en laissant à כ כ sa valeur habituelle de conjonction interprètent selon l'une des deux lignes suivantes :

1) Ils joignent 24b au vs suivant, avec Aq, Sym, Saadya, Judah ibn Balaam,

2) ils glosent la conjonction par "cela", avec l'antiochienne, Rashi, Ibn Ezra, Isaïe de Trani, Olivetan, ou par "tout cela" avec Yéfet ben Ely, Radaq, Abravanel, Luther.

La plus ancienne mention d'une interprétation de ce mot au sens de brûlure se trouve sur les lèvres de l'Amora babylonien Raba (mort en 352). Selon le Talmud Babli (Shabbat 62b), il fit remarquer que Is 3,24b est semblable au proverbe qui dit : "à la place de la beauté une brôlure". Le proverbe a ce sens si, à la place de כיבא (= souffrance) donné par les éditions du Talmud, on adopte la leçon כואה donnée par Radaq en ses Shorashim (sous כוה).

Hayyuj, dans son commentaire (Kokovzov 14) présente cette exégèse comme déjà traditionnelle. Elle est adoptée par Joseph Qimḥi (Zikkarôn 13,21), ainsi que par le glossaire C : "cuisson en lieu de biyâté" (= beauté).

Cette exégèse aura un grand succès dans les traductions du XVIe siècle. Oecolampade, Pagnini, Münster et Jud s'accordent pour le rendre par "adustio" et Tremellius par "ustio". Brucioli (en 1540) par "abruciamento", Estienne par "bruslure", Châteillon et Pasteurs par "hasle", Ge et KJ par "burning". 
A l'exégèse en conjonction et à l'exégèse en substantif correspondent deux accentuations, distinctes sur quatre points.

La première accentuation, qui caractérise les mss tibériens classiques et les éditions courantes, n'a pas d'accent sous 2 et lie ce mot par un maqqef au suivant dont le 'taw' initial est rafé et muni d'un tifḥa.

L'accentuation correspondant à l'exégèse de כי en substantif le munit d'un tifḥa et ne le relie pas par un maqqef au mot suivant dont le 'taw' initial est muni d'un dagesh et d'un merka.

Cette seconde accentuation, avec les quatre données qui la caractérisent se trouve attestée par un nombre notable de témoins. Parmi ceux auxquels nous avons accès, nous l'avons trouvée en une édition, l'édition princeps de la Bible (1488), et 8 mss: Erfurt 3, Copenhague 2 et 4, Hamburg 27, Vatican ebr 3, Berne, London BL Add 15,451, Paris BN hébr 6. Dans l'apparat de leurs éditions, Ginsburg dit l'avoir rencontrée en 10 autres mss, J.H. Michaelis encore en deux autres d'Erfurt. Baer (adoptant cette accentuation) ajoute à cela un ms de Francfort et Luzzatto (qui l'adopte lui aussi) un ms des Prophètes lui appartenant. Lilienthal (327) a relevé aussi l'absence de maqqef dans le 2e ms de Königsberg.

HUB "would present in toto" the known data concerning the biblical text, its variants and its development" (Sample edition, préface). Il est regrettable que cette importante variante dans l'accentuation n'y soit même pas mentionnée.

Cette variante d'accentuation a été jugée inauthentique par Freedman/Cohen. Prenant appui sur Is 1,17, ils estiment en effet que, dans un verset à cinq membres parallèles, la dichotomie majeure $(=$ atnah $)$ doit se placer après le $3 e$ membre et non après le quatrième, comme c'est le cas en cette variante. Il leur semble donc que cette variante est une retouche ébauchée qui n'a pas été poussée jusqu’à ce déplacement de l'atnah qui en eât été l'aboutissement logique. Mais ce raisonnement ne saurait se fonder sur un seul exemple. On peut en effet citer Jos 11,16 comme contenant exactement la même suite d'accents disjonctifs que Is 3,24 , alors que le membre qui y suit l'atnah est le dernier d'une suite de six membres parallèles. Précisons d'ailleurs qu'en Is 3,24 , si l'on suit la variante d'accentuation et l'interprétation qu'elle implique, les quatre premiers membres sont dans l"ordre "à la place de $x: y$ ", alors que l'ordre s"inverse dans le cinquième membre : " $y$ à la place de $x$ ", si bien que Freedman/Cohen errent en disant ( $p .41)$ que les trois derniers mots $y$ "seraient seulement la cinquième d"une série d'expressions parallèles".

Même parmi ceux qui n'acceptent pas ici l'exégèse en substantif, les grammairiens admettent très généralement כִּ comme pouvant être une dérivation nominale normale à partir de la racine כוה. C'est le cas de Hayyuj (Kokovzov 14), Joseph Qimḥi (Zikkarôn 13, 1l. 17-21), Radaq (Mikhlol 121a), Gesenius (Lehrgebäude 510), Ewald (Lehrbuch 382), Böttcher (Lehrbuch §438), König (Lehrgebäude II 64), Bergsträsser (I $\$ 17 f)$.

En 24a, on a eu quatre constructions semblables : "au lieu de ceci, cela". Il est parfaitement normal que 24b apporte comme conclusion: "cela au lieu de ceci".

Il s'agit ici vraisemblablement d'une marque au fer rouge. Stade ( $\mathrm{Zu}$ Jes. 133s) suggère qu'il s'agit de cicatrices causées par l'application thérapeutique du cautère contre des maladies variées. Il y a plus de chances que Gesenius ait raison d'y voir 
des marques au fer rouge appliquées ordinairement sur le front des esclaves. Il cite à l'appui un extrait d'un récit où le verbe arabe כוי est employé en ce sens.

4,5 בי על־כל־כבוד [B] M 4Q-a G V S // glos : g add xupíov / paraphr : T / abr-styl :

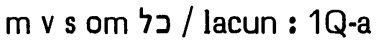

Options de nos traductions :

Le *M a été traduit par RSV : "for over all the glory there will be a canopy", J3: "car sur toute gloire il y aura un dais" et RL : "ja, es wird ein Schutz sein über allem, was herrlich ist".

NEB, sans note, traduit: "for glory shall be spread over all as a covering".

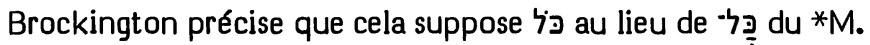

TOB - estimant (en note) que le sens littéral du *M est : "au-dessus du tout, la gloire (sera) un dais"- traduit : "et au-dessus de tout, la gloire du Seigneur sera un dais." 312 traduisaient de même (sans note) : “Car au-dessus de tout, la gloire de Yahvé sera un dais."

Origines des corrections :

La correction vocalique signalée pour NEB par Brockington était suggérée par les apparats de $\mathrm{BH} 2 \mathrm{~S}$.

A la suite de Clericus, Houbigant (en une partie de ses notes omise par l'édition de Francfort) avait jugé que כל ne doit pas être lié à ce qui suit et il traduisait : "omnibus enim gloria obumbrabit". Lowth, traduisant : "Yea, over all shall the Glory be a covering", jugeait que le maqqef a jeté une obscurité sur cette phrase et fourvoyé la plupart des traducteurs.

J12 et TOB ont ajouté le tétragramme en génitif après "gloire", ajoute proposée par les apparats de Cent, BH3, HSAT34. En effet, Rosenmüller avait objecté à Lowth que jamais Tìำ non déterminé ne signifie la gloire de Dieu. Aussi Marti a-t-il suggéré cette ajoute en s'inspirant du ms $A$ du *G.

Les témoins anciens :

1Q-a a sauté par homéotéleuton du יומם de 5 a à celui de 6 a.

4Q-a appuie le texte du *M et semble unir כבוד plutôt à ce qui le précède qu’à ce qui le suit.

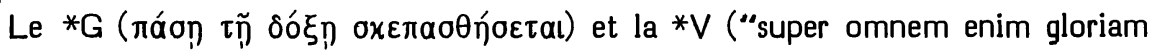
protectio") appuient le *M.

Un certain nombre de témoins ont senti le besoin de déterminer le mot "gloire". Le ms $A$ du $* G$ ajoute xupíov. Le *T paraphrase très largement. Dans cette paraphrase, il ne tient pas compte du mot כל que certains témoins du*M, de la $* V$ et de la*S omettent par abréviation stylistique.

Notons ici que la *S des polyglottes présente cet état textuel fautif omettant ce mot, alors que l'édition de Mossul, en accord avec tous les mss anciens, donne un texte qui appuie formellement le $* M$. 


\section{Choix textuel :}

Le texte consonnantique du ${ }^{*} M$ est donc fermement appuyé en face de gloses ou d'une omission qui 'sont dans l'air', comme conséquences d'une fausse construction syntaxique.

Contre la construction proposée par Houbigant et Lowth (et adoptée par $\mathrm{J12}$ et NEB), Rosenmüller, après avoir objecté que "gloire" indéterminé ne suffit pas à signifier la gloire de Dieu, a ajouté à cela qu'il est difficile de préférer Ṭִּ (nor-

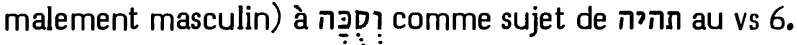

La construction du $* \mathrm{M}$ se comprend au mieux si l'on considère (avec le ${ }^{*} G$ ) กฺ̣ comme un parfait pual. Il semble que le Siracide fait allusion à ce texte ainsi interprété en 40,27b où le ms de Masada offre : ועל כל כ[בוד] חפתה que le *G tra-

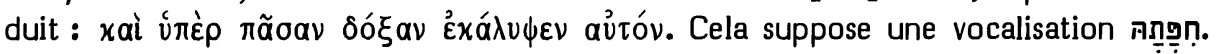

Le comité a attribué au *M la note "B".

\section{Interprétations proposées :}

Il semble préférable de donner ici à על כל, avec le Siracide et le *T, un sens de transcendance. Il vient d'être dit en 5a que le Seigneur "créera sur tout emplacement du mont Sion et sur ses assemblées une nuée le jour avec de la fumée et l'éclat d'un feu flamboyant durant la nuit". Le prophète ajoute : "oui, de manière supérieure à toute gloire, c'est couvert". Mais il n'est pas impossible de comprendre : "oui, sur toute chose glorieuse, il y aura un dais." Puis le vs 6 commence : "et une hutte servira à ombrager..."

\section{5,1 שירת דּרוֹדִי [A]}

\section{Options de nos traductions :}

Le *M est traduit par J3 ("le chant de mon ami"), RL ("ein Lied von meinem Freund") et, de manière libre, par TOB ("le chant du bien-aimé").

Sans note, RSV donne : "a love song".

J12 donnaient "de son amour" en disant qu'elles corrigeaient.

NEB traduit : "my love-song", sans note. Mais Brockington précise que cela suppose une vocalisation : ידָר.

Origines des corrections :

$\mathrm{Ni}$ BH23S, ni HSAT234 ne proposent de correction sur ce mot.

La correction (clandestine) de RSV peut remonter, à travers Cent ou SBOT, à Lowth. Celui-ci traduisait "a song of loves" en rapportant l'opinion de Secker selon qui cette terminaison n'est pas ici un suffixe 1e pers. sg. mais doit être comprise comme un état absolu masc. pl., de même qu'en Mi 6,16 et Lm 3,14. Lowth accepte cette interprétation, mais préfère admettre qu'un signe d'abréviation pour un 'mem' final a été méconnu par un scribe.

La correction de J12, estimant qu'une forme (= de son amour) était requise par le suffixe 3e pers. m. sg. du mot suivant, remonte, à travers Condamin, à Houbigant. 
Celle de NEB remonte, à travers Marti, à Cersoy qui traduisait cela : “mon chant amical".

Les témoins anciens et le choix textuel :

Tous les témoins s'accordent avec le *M. Le comité a donc attribué à celui-ci la note "A".

Hayyuj (Kokovzov 14) faisait déjà remarquer que דודידידי et désignent tous deux ici le Seigneur qui inspire au prophète de composer ce chant en son nom. Il semble en effet que, comme dans la plupart des emplois du 'lamed auctoris', il faut comprendre ce 'lamed' comme 'au nom de'. Rashi aussi glose ce 'lamed' par 'de la part de..., au lieu de...' et 'par mandat de...'

Interprétation proposée :

On pourrait traduire: “Que je chante, au nom de mon ami, le chant de mon bien-aimé sur sa vigne".

Le prophète tient à maintenir une ambiguïté sur l'identité de son ami, de son bien-aimé et de la vigne de celui-ci. Cette ambiguïté est un trait essentiel d'une parabole provoquant, grâce à son ambiguitté, l'auditeur à prononcer un jugement qui, une fois l'ambiguitté finalement résolue, se trouve le condamner lui-même. La parabole de la brebis du pauvre (2 S 12,1-4) permet ainsi à Nathan d'amener David à se condamner lui-même (5-7). De même, la parabole de la vigne va permettre à Isaïe d'amener les "habitants de Jérusalem et les gens de Juda" $(5,3)$ à se condamner eux-mêmes lorsqu'ils comprendront (vs 7) que cette vigne, c'est eux-mêmes.

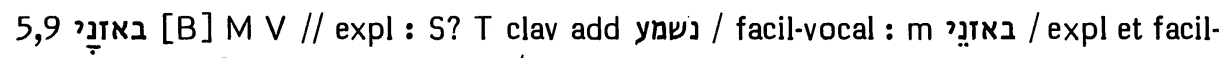

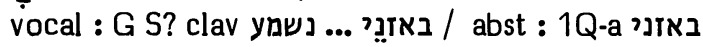

Options de nos traductions :

Il est impossible de traduire le ${ }^{*} M$ sans quelque glose.

RL explicite : "es ist ... das Wort des".

RSV, J, NEB et TOB explicitent : "a juré". Brockington se réfère au *G pour suppléer y

Origines de la correction :

RSV et TOB n'ayant ici aucune note, il se peut qu'elles aient seulement explicité "a retenti le serment" (TOB) ou "has sworn" (RSV) de même que Tremellius avait explicité "juravit" comme postulé par la formule de serment qui suit.

La suggestion d'emprunter un verbe initial à la Vorlage corrigée du ${ }^{*} G$ a été

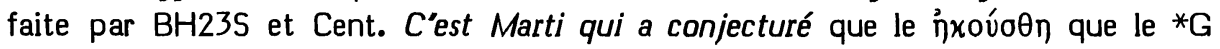
offre en début de vs est un بִ lu faussement comme adoptée par Condamin, Gray, Wildberger etc. 
Les témoins anciens :

Quelques mss mentionnés par de Rossi vocalisent le 'nun' en séré (au lieu du qameș). Münster fait de même en son édition de 1535. Ont traduit de même "aux oreilles du Seigneur" : Oecolampade, Luther, Brucioli, Münster, Jud, Rollet et

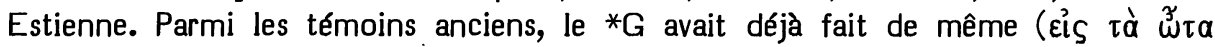
xupíou). Warszawski (16s) se demande si la *S n'a pas déjà lu ainsi, quoique l'absence de "dalat" avant le mot מריא qui suit rende la chose peu vraisemblable.

1Q-a apporte un appui précieux au texte très sobre du *M.

Les versions ont dâ le gloser. Le ${ }^{*} G$, la ${ }^{*} S$ et le ${ }^{*} T$ ont explicité le verbe "entendre". La* $\mathrm{V}$ a glosé "sunt haec", suivi du nom divin au génitif.

\section{Choix textuel :}

La massore protège la vocalisation qames du 'nun' en précisant que ce mot ainsi vocalisé et porteur de ce même accent (tifhạ) ne se retrouve qu'en 22,14. C'est dans le ms de Petrograd sur 5,9 que cette massore (bien interprétée par Ginsburg, Massorah, IV p. 43b) est la plus explicite. Ce rapprochement a d'ailleurs été suggéré par Lowth et retenu par Gesenius et Rosenmüller. Il nous fournit, de fait, un parallèle très caractéristique. En effet, en 22,14 comme en 5,9, on a en ce mot suivi du tétragramme l'introduction d'un serment divin commençant par et contenant une malédiction qui se rattache étroitement à une situation scandaleuse qui vient d'être décrite auparavant.

Il est apparu au comité qu'il fallait garder la vocalisation qameṣ qui trouve en ce parallèle un bon appui. D'autre part, l'appui que 1Q-a apporte au texte consonnantique du $* M$ confirme que toutes les ajoutes des versions sont des explicitations translationnelles. Le comité a donc attribué au *M la note "B".

\section{Interprétations proposées :}

Le suffixe de la 1e personne se réfère-t-il au prophète ou au Seigneur? Dans

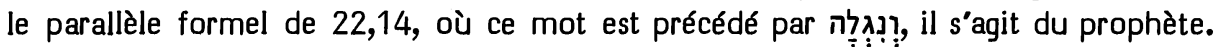
La $* V$, la *S, le *T, Tremellius, Pasteurs, KJ, RSV, J, RL, NEB, TOB ont estimé que c’était le cas ici aussi.

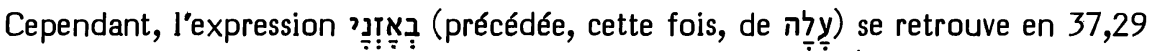
où le suffixe de la 1e personne se réfère évidemment au Seigneur (mais où ce mot n'est suivi ni du tétragramme ni d'une formule de serment). Yéfet ben Ely, Ibn Ezra, Radaq, Pagnini, Vatable, Olivetan, Ge, Luzzatto ont interprété de même ici le suffixe comme se référant au Seigneur.

Etant donné l'exactitude du parallélisme avec 22,14, il a semblé au comité plus vraisemblable de référer le suffixe au prophète et d'admettre, avec König, que le verbe "a juré" a été passé sous silence par le prophète comme allant de soi avant la formule caractéristique de serment qui suit : "à mes oreilles, le Seigneur Sabaôt (a juré) :".

Il n'est cependant pas impossible de comprendre, en s'inspirant de 37,29 : “(cela est monté) à mes oreilles, (à moi) le Seigneur Sabaôt !", le serment de malédiction étant introduit par cette affirmation que le Seigneur a eu connaissance de ces scandales. 
Options de nos traductions :

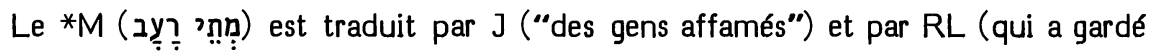
la traduction large de Luther : "Hunger leiden", en retouchant "werden" en "müssen" avant ces mots).

NEB traduit (sans note) : "are starving to death", Brockington précisant que cela suppose que le 'mem' soit vocalisé séré avec la *S. Sans notes, RSV ("are dying of hunger") et TOB ("mourra de faim") supposent la même option.

Origines de la correction :

Nos traductions ont pu trouver cette vocalisation demandée par l'apparat de $\mathrm{BH} 3 \mathrm{~S}$. Foreiro semble avoir été le premier à proposer formellement cette vocalisation.

Les témoins anciens :

De Rossi (IV 230) signale deux de ses mss comme vocalisant ici le 'mem' avec séré. Cependant, en Is 22,2 , une $\mathrm{mp}$ du ms d'Alep signale comme hapax la vocalisation 끄, confirmant indirectement pour notre cas la vocalisation du 'mem' avec shewa.

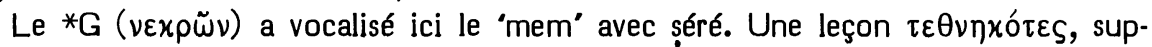
posant la même vocalisation, est attribuée par le ms 710 à Sym et à la Quinta. Etant donné que ce ms est seul à citer une Quinta d'Isaïe, on peut se demander s'il ne s'agit pas ici de Théodotion. La*V (interierunt), le *S (מיתיהון) et le *T (מיתו) supposent aussi cette vocalisation șéré.

Le fait que 1Q-a ait ici la même graphie que le *M doit être interprété comme un appui formel apporté à la vocalisation shewa. En effet, dans tous les endroits de ce livre $(8,19 ; 22,2 ; 26,14.19 ; 37,36 ; 38,1 ; 59,10)$ où le *M a le mot nמ au singulier ou au pluriel (écrit toujours défectivement avec șéré), 1Q-a écrit toujours ce șéré en graphie pleine avec 'yod'.

Il n'en va pas de même de cette graphie en une citation de ce texte faite par le pesher 4Q162 (DJD 5, 15s). En effet les graphies de ce pesher sont deux fois contre une plus défectives que celles du*M.

\section{Choix textuel:}

La leçon avec șéré est postulée ici par un jeu de mots aramaïsant où ce mot est lu comme un participe afel de אתא dans le Talmud Babli (Soța 48a) où R. Joḥanan (vers 250) glose ces mots par "faisant venir la faim dans le monde". D'ailleurs c'est également avec séré que Rashi et Abravanel paraphrasent ce mot en "mourront par la faim" et que les glossaires ACDEF le traduisent par "morts (de faim)".

Cependant Saadya, Yéfet ben Ely, Radaq et Isaïe de Trani attestent clairement la leçon avec shewa, Radaq précisant en son commentaire que la grammaire n'autorise pas l'interprétation du Targum.

Au XVIe siècle, l'interprétation "morts" se rencontre chez Brucioli (1540), Châteillon et Pasteurs; alors que la leçon avec shewa a été traduite plus ou moins littéralement par Oecolampade, Pagnini, Luther, Brucioli (1532), Münster, Olivetan, Jud, Vatable, Ge, Tremellius, KJ. 
La liaison entre "famine" et "mourir" est suffisamment fréquente dans la Bible pour que l'on puisse considérer ici la vocalisation avec sẹ́ré comme nettement facilitante.

Luzzatto a cependant montré qu'une analyse un peu attentive du contexte favorise ici la vocalisation avec shewa. En effet, ceux qui les mènent en exil les font, certes, souffrir de la faim, mais n'ont pas pour but de les exterminer par la faim.

Etant donné cela et l'appui que $1 Q$-a apporte à la leçon plus difficile du $* M$, le comité a attribué à celle-ci la note "B".

Interprétation proposée :

A propos de Gn 34,30, Ehrlich a fait remarquer que מִימים (= groupe d'hommes) a très souvent une nuance dépréciative de "pauvres hères". D'où ici "pauvres affamés" qui fait un excellent contraste avec mot en ce sens en 41,14.

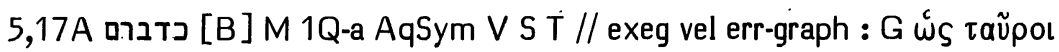
5,17B גרים [B] M 1Q-a 4Q-b AqSym V S // assim-ctext vel err : G åpves / constr : T

\section{Options de nos traductions :}

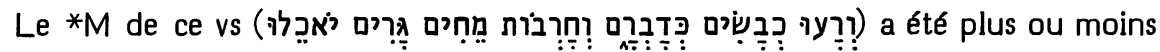
retouché par toutes nos traductions.

NEB le déclare inintelligible et le remanie largement: "Young rams shall feed where fat bullocks once pastured, and kids shall graze broad acres where cattle grew

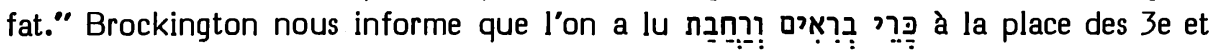
4 mots du vs et que l'on a vocalisé le "gimel" de l'avant-dernier avec un qibbus.

Luther traduisait : "Da werden denn die Lemmer sich weiden an jener Stat, und Frembdlinge werden sich neeren in der Wüsten der Fetten". RL (qui n'a pas de notes justificatives) a ainsi retouché cette traduction: "Da werden dann Lämmer weiden wie auf ihrer Trift und Ziegen sich nähren in den Trümmerstätten der Hinweggerafften."

RSV traduit: "Then shall the lambs graze as in their pasture, fatlings and kids shall feed among the ruins." A propos de "kids" elle se réfère au *G, indiquant que le *M signifie "aliens".

J traduit : "Les agneaux paîtront comme dans leurs pâtures, les pacages dévastés des bêtes grasses seront la nourriture des chevreaux." Elle précise que "chevreaux" suit le *G, alors que le *M dit "étrangers".

TOB traduit : "Des agneaux paîtront là comme en leur pâturage et des chevreaux à l'engrais brouteront sur les ruines." Elle mentionne comme autre traduction de $17 \mathrm{~b}$ : "des nomades se nourriront dans les ruines où étaient les bêtes grasses."

\section{Origines des corrections :}

La conjecture sur laquelle NEB s'appuie pour reconstruire les $3 e$ et $4 \mathrm{e}$ mots du texte vient de Ginsberg (Emendations 53s). Quant à son option de se contenter d'une correction vocalique pour donner à l'avant-dernier mot le sens de "chevreaux", elle 
a été suggérée par Driver (LTP 38s) et adoptée par BHS. Cependant, la forme de cette vocalisation est celle que Schleusner (I 443) avait proposée.

Sur les quatre autres traductions qui donnent le même sens à ce mot, deux (RSV et J) se réfèrent au ${ }^{*} G$. J2 précisait que cela implique une leçon qu'elle a pu puiser dans les apparats de Cent, BH3S, HSAT234 et qui remonte à Durell et à Secker cités par Lowth.

Les témoins anciens :

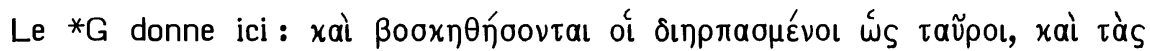

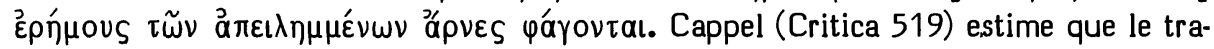

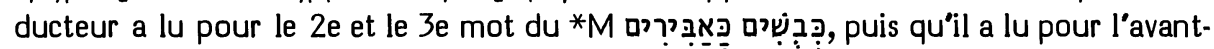

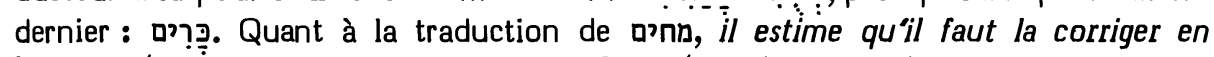

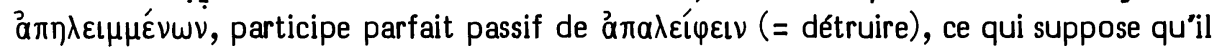
a dérivé cette forme du verbe מִ auquel ce verbe grec correspond le plus souvent dans la Bible. Cette dernière correction, avec la dérivation qu'elle suppose, est attribuée par Seeligmann (11 n.8) à Schleusner. Celui-ci, en effet, copie (I 375 et II 117) Cappel sans le nommer. La seule originalité de Schleusner est la suggestion susmentionnée : que le ${ }^{*} G$ a pu dériver l'avant-dernier mot de 'gûr' qui ne signifie pas seulement "jeune lion", mais qui se dit de tous les animaux qui têtent encore leur mère.

$1 Q$-a est consonnantiquement identique au ${ }^{*} M$ dont il ne se distingue que par deux graphies pleines dont la deuxième (מיחים) confirme la vocalisation du *M, alors que la première (כבושים) confirme la Vorlage que Cappel avait suggérée pour le *G.

4Q-b, très lacuneux, appuie גרים qui se trouve justement être le mot que RSV, $J, R L$ et TOB s'accordaient à vouloir corriger.

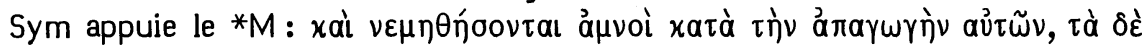

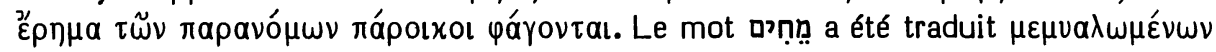
par Aq qui offre le même correspondant en Ps 66,15. Sa traduction ici par Sym est semblable à celle (רשיאיא) que le *T en donne dans une paraphrase qui oppose impies et justes.

Ce même mot a été compris comme un qualificatif de celui qui le précède par la $* V$ (et pascentur agni iuxta ordinem suum, et deserta in ubertatem versa advenae comedent) et la *S (ונרעון אמר̈א בזדקהון • וחרבתא דאתבני עמוֹא נאכלון אנין).

\section{Choix textuel :}

Les leçons critique. Ici, seul le $*$ G prend clairement d'autres options.

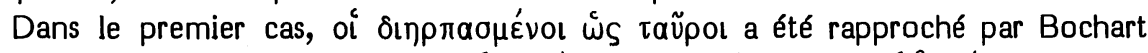

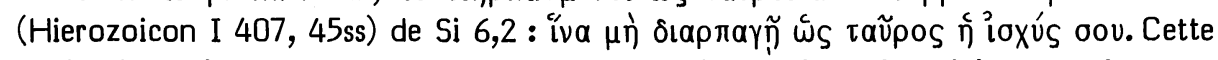
traduction n'entretient malheureusement pas de relation plus claire avec le texte hébreu qui lui correspond : ותעבה חילך עליך (second membre d’un vs introduit par un

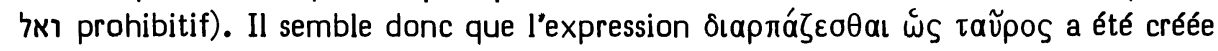
par le traducteur du Siracide à partir d'une fausse interprétation du ${ }^{*} G$ de Is 5,17 où le ẃs porte en réalité sur le verbe "paîtront" qui précède.

Dans le second cas, ápves a pu être suggéré au ${ }^{*} G$ par une réinterprétation de כבשים du stique précédent qu'il avait interprété une première fois en participe passif. 
Clericus semble avoir raison de juger que vouloir deviner ce que le ${ }^{*} G$ a compris en ce $v s$, c'est tirer au sort dans les ténèbres.

Le *M est paru au comité suffisamment appuyé par 1Q-a, Sym et Aq. Aussi lui a-t-il attribué 4 "B" et 2 "C".

Interprétations proposées :

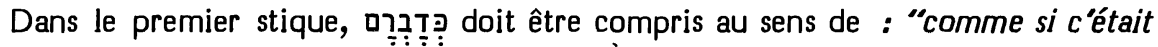
leur pâturage habituel".

Le second stique pose quelques questions :

D’abord, il est plus vraisemblable que aṇ est le génitif du mot qui le précède: "les ruines des moelleux", c'est-à-dire "ce qu'ont déserté les hommes prospères". Mais il n'est pas impossible qu'il s'agisse d'un adjectif qualifiant le mot suivant (avec le même sens que dans son seul autre emploi biblique : Ps 66,15 où cet adjectif est substantivé au sens de "bêtes grasses").

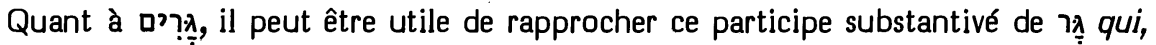
en Is 11,6 , désigne des bêtes qui pâturent en transhumant. On pourrait donc traduire : "des transhumants". Dire qu'ils "mangent les ruines" signifie qu'ils dévorent les vergers ou les vignobles dont les clôtures sont ruinées et qui ont été abandonnés par les sédentaires qui les cultivaient.

On pourra donc traduire, ou bien: "et des bêtes transhumantes dévoreront ce qu'ont déserté les hommes prospères", ou bien: "et de grasses bêtes transhumantes dévoreront ce qui a été laissé en ruines".

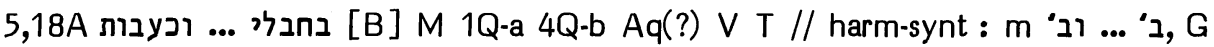
כ' כ'... וכ' Sym

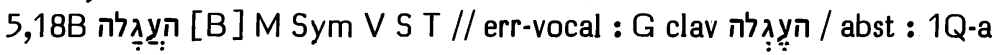

Options de nos traductions :

Comparons nos traductions au *M sur deux points.

D'abord, la différence qu’établit celui-ci entre la préposition 'bet" de בחבלי la préposition 'kaf' du parallèle apparent וכעבות. Sur ce point, le *M est respecté par RSV et J, mais RL ("mit ... mit") et TOB ("avec ... avec") harmonisent sur la base du "bet", alors que NEB ("like ... like") harmonise sur la base du "kaf'.

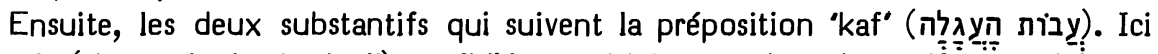
33 seule ("un trait de chariot") est fidèle au *M. Le premier substantif est traduit par un pluriel en RSV ("ropes"), J1 ("les attèles"), J2 ("les traits"), RL ("-seilen") et TOB ("des traits"), aucune de ces traductions n'ayant de note sur ce point où seule NEB ("a rope") s'accorde avec J3 pour suivre le *M. Quant au second substantif, RSV, J23, RL et TOB y ont reconnu un chariot. Mais 31 y voit "un veau" en disant

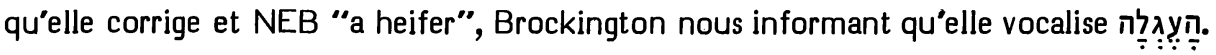

Origines des corrections :

Houbigant a proposé d'harmoniser les prépositions sur la base du 'kaf' en s'inspirant du ${ }^{*}$ G. Il a été suivi en cela par Lowth, Grätz etc. NEB a pu lire cette suggestion dans l'apparat de BHS. 
Pour harmoniser les prépositions sur la base du 'bet', RL n'a pas eu besoin de suivre les propositions de Knobel ou de HSAT4. En effet, elle s'est contentée de copier Luther que Pasteurs suivra aussi en cette harmonisation probablement inconsciente (que TOB reprendra).

Quant à la traduction de תì par un pluriel, le fait qu'aucune de nos traductions ne note cela comme une correction montre qu'il s'agit d'une inattention, comme ce fut déjà le cas pour la majorité des traducteurs du XVIe siècle (Oecolampade, Pagnini, Luther, Brucioli, Jud, Châteillon, Ge, Pasteurs). Le singulier avait cependant été respecté par Münster, Olivetan, Tremellius et KJ.

Enfin une vocalisation de l'avant-dernier mot du vs en Cappel (Notae 495) comme Vorlage du *G. Elle a été adoptée par Grätz, Ehrlich. Notons qu'Oecolampade traduisait déjà "vitulae".

Les témoins anciens :

*M présente une alternance entre une préposition 'bet' en 18a et une préposition 'kaf' en 18b. En cela, il est appuyé par 1Q-a et 4Q-b, ainsi que par la *V, le *T et l'une des traductions hexaplaires (Lütkemann $52 \mathrm{n} .217$ ayant montré que l'attribution à Aq est douteuse).

Une harmonisation sur la base du 'kaf' est attestée par le *G, la *S et Sym, alors qu'une quinzaine de mss des collations Kennicott et de Rossi harmonisent sur la base du 'bet'. L'édition Soncino 1488 fait de même.

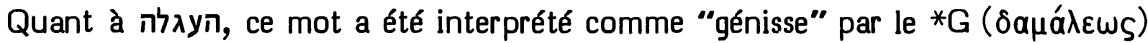

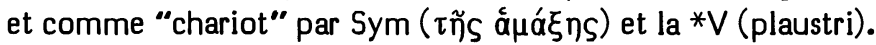

Le mot y par lequel la ${ }^{*} S$ et le ${ }^{*} T$ traduisent cela offre une graphie consonnantique qui est équivoque en ces deux langues ("chariot" ou "génisse"). Notons cependant, à propos de la *S, que le point en haut par lequel l'Ambrosianus distingue ce mot s'accorde avec l'exégèse d'Ephrem et la vocalisation de Sionita dans la polyglotte de Paris pour nous orienter vers le sens "chariot". Quant au *T, le Chaldäisches Wörterbuch de Levy montre la grande incertitude qui règne dans les vocalisations de ces deux sens selon les éditions. Cependant un ms à vocalisation soignée, comme l'Urbinates 1, offre ici en Os 10,11 etc.

\section{Choix textuel :}

Le fait que l'alternance des prépositions qu'offre le *M soit attestée aussi par 1Q-a et 4Q-b montre que les harmonisations offertes en un sens par certains témoins du ${ }^{*} M$, et dans l'autre sens par le ${ }^{*} G$, Sym et la ${ }^{*} S$ sont des facilitations. C'est pourquoi le comité a attribué la note " $B$ " aux leçons dissymétriques du * $M$.

Quant à la vocalisation de l'avant-dernier mot du vs, le ${ }^{*} G$ semble seul à l'avoir lu comme "génisse". Notons d'ailleurs qu'il est plus normal de parler de la corde d'un chariot (indispensable pour sa traction) que de la corde d'une génisse (dont elle est indépendante). Le comité a aussi attribué la note "B" au * $M$ sur ce point. 
Interprétations proposées :

Si l'on respecte la distinction des prépositions, le premier stique exprime une action réelle alors que le second se situe au niveau métaphorique. Quelle est l'action

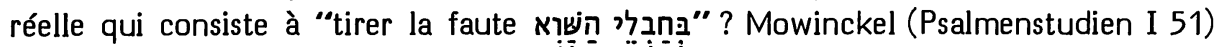
voit là une allusion aux cordons noués qui jouaient un grand rôle dans la magie babylonienne. Wildberger a adopté cette exégèse. Il s'agirait donc de ceux qui attirent la faute par des cordons magiques. Mieux vaut peut-être cependant traduire avec TOB : "avec les cordes de l'imposture". Cette traduction plus large n'interdit pas l'interprétation de Mowinckel (vers laquelle la note de TOB oriente ses lecteurs), mais évite de limiter l'interprétation à cette seule hypothèse.

Comme c'est souvent le cas (et comme l'ont fait la plupart des traducteurs), il faut sous-entendre la préposition "bet' après 'kaf" dans le second stique : "et comme avec le trait d'un chariot".

לגוים ... להם ... יבואו 5,26 לגור 5

Options de nos traductions :

Le *M dit que le Seigneur dressera un étendard pour "les peuples" (pluriel), puis qu'il "le" (singulier) siffle et que "il arrive" (singulier).

Gênées par ce passage du pluriel au singulier, nos cinq traductions ont toutes corrigé le substantif pluriel "les peuples" en un singulier. Seuls J23 ont une note disant qu'il s'agit là d'une conjecture d'après le contexte. Brockington précise que

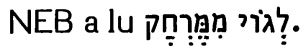

Origines de la correction :

La mise au singulier du substantif a été proposée par Koppe, suivi par de nombreux exégètes. Alors que Koppe voyait dans le 'mem' final de ce mot une dittographie de celui qui commence le suivant, c'est Roorda (cité et suivi par Duhm, puis par

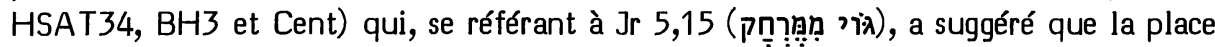
originelle de ce 'mem' final était avant le 'mem' initial du mot suivant, préférant l'hypothèse d'un déplacement à celle d'une dittographie.

Les témoins anciens :

1Q-a appuie entièrement le ${ }^{*} M$ dans cette lectio difficilior. Il en va de même de la*V et du*T.

Aucun témoin ancien n'appuie l'option de nos traductions. C'est en sens contraire (en mettant au pluriel il "les" siffle et "ils arrivent") que le *G et la *S ont harmonisé cette hétérogénéité des nombres.

ThAqSym sont fidèles au *M pour "il le siffle", mais leur leçon n'est pas connue pour le verbe final.

Choix textuel :

Certains traducteurs du XVIe siècle avaient déjà harmonisé. Sur la base du pluriel : Luther, Châteillon, Ge et KJ. Sur la base du singulier : Jud. 
Face à ces facilitations divergentes, le comité a attribué la note " $\mathrm{B}$ " à la lectio difficilior du *M dont 1Q-a montre l’ancienneté.

Interprétations proposées :

Tremellius, puis Drusius ont pensé résoudre la difficulté en comprenant iל comme "et il siffle vers soi", c'est-à-dire : pour les appeler à venir vers lui (= le Seigneur). Mais, dans les deux autres cas (Is 7,18 et $\mathrm{Za} \mathrm{10,8)}$ où la préposition 'lamed" introduit un complément de ce même verbe, il s'agit des destinataires du sifflement, c'est-à-dire de ceux qu'il appelle.

Mieux vaut admettre que le singulier désigne jusqu'au vs 30 l'unique armée constituée par ces nations lointaines. C'est ce que suggère clairement ị (c'est-à-dire : en cette armée) au vs 27.

Donc "Le Seigneur dressera un étendard pour les nations lointaines. Il la sifflera des extrémités de la terre, et la voici en hâte, agile, qui vient. En elle nul n'est fatigué, nul ne trébuche..." Il faudra évidemment noter que "la ... la ... elle" désigne l'armée ainsi mobilisée.

השמ...הכבד...השע 6,10 6 [C] M V T // theol : G Sym S indicat, 1Q השמן..הכבד...השע

Options de nos traductions :

RSV, J, RL et TOB respectent les impératifs du *M.

NEB traduit: "this people's wits are dulled, their ears are deafened and their eyes blinded" sans rien noter. Cependant, Brockington indique que ces trois verbes ont été vocalisés en parfaits hofal, en s'inspirant du ${ }^{*} G$ pour le premier.

Origine de la correction :

Alors que tous les traducteurs du XVIe siècle semblent avoir respecté les impératifs de ce vs, Cappel a été le premier (Notae 496) à suggérer que le ${ }^{*} G$ avait vocalisé le premier d'entre eux en accompli hofal.

Etant donné qu'il ne s'agissait là que de correction vocalique, Houbigant a traduit en indicatifs ("populus iste pingue reddidit cor suum; fecit sibi aures hebetiores, clausit oculos suos") sans rien noter. Doederlein, acceptant le diagnostic de Cappel sur la Vorlage du *G, estime cette leçon préférable.

Présentant ces impératifs comme ayant la valeur de futurs, Gesenius, dans la 1e édition de sa traduction (citée par Rosenmüller) donnait : "Verstockt seyn wird das Herz dieses Volks, seine Ohren tob, seine Augen verblendet." Mais, dans la 2e édition, il est revenu à "Verstocken sollst du das Herz dieses Volkes, seine Ohren betäuben, seine Augen verblenden". De fait, les exégètes postérieurs semblent avoir respecté les impératifs du *M jusqu’à ce que Grätz propose de vocaliser les deux premiers en parfaits hofal (estimant que le 3e n'avait pas besoin d'être corrigé pour cela), $s^{\prime}$ appuyant pour cela sur le ${ }^{*} G$ et la $* S$. Il ne semble pourtant pas que cette correction ait eu grand succès avant que NEB ne l'adopte. 
Les témoins anciens :

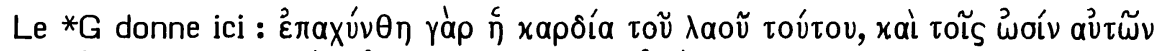

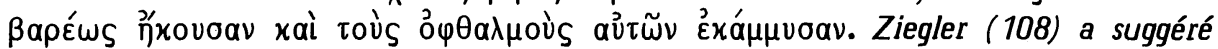

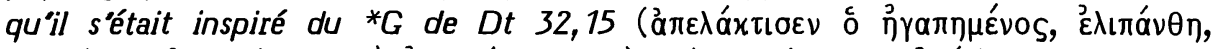

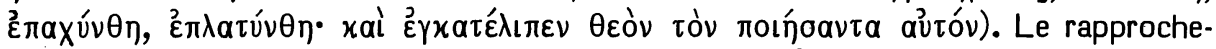

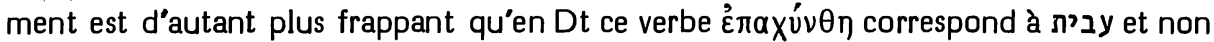

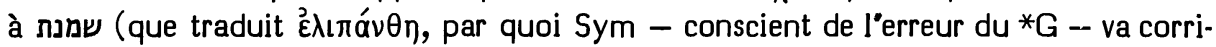
ger la traduction de celui-ci en Is 6,10).

On serait tenté d'admettre avec Kutscher (344) que le 'nun' a été omis accidentellement en השמ que 1Q-a donne à la place du premier impératif, ou bien (ibid 292) qu'il s'agit d'un simple essai pour clarifier le texte (שמם semblant plus facile à lier avec ל : cf. Ps 143,4). Mais Brownlee (Meaning 186ss) a montré que cette retouche est liée à trois autres (deux remplacements de ואל a par var 9 et le remplacement par un "bet' du 'waw' initial de ולבבו en 10b). Il s'agirait là de corrections délibérées visant à obtenir le sens suivant : "(9)... écoutez bien, parce que vous pouvez comprendre; voyez bien, parce que vous pouvez saisir! (10) Désole le coeur de ce peuple, bouchelui les oreilles et détourne ses yeux - de peur qu'il ne voie avec ses yeux et qu'avec ses oreilles il n'entende. Qu'avec son coeur il comprenne, et qu'il se convertisse et soit guéri." Dans ce contexte, le début du vs 10 est compris dans le sens de ce qui sera présenté en Is 33,15b comme le comportement du juste: "se bouchant les oreilles pour ne pas écouter les paroles homicides et fermant les yeux pour ne pas regarder ce qui est mal". En tout cas, 1QHodayot VII 2s a rapproché ces deux vss en lisant Is 6,10 selon le texte de 1Q-a : "Mes yeux se sont détournés de regarder ce qui est mal et mes oreilles d'écouter les paroles homicides. Mon coeur a été désolé par les mauvais desseins." Dans cette traduction, les correspondances verbales du français soulignent celles de l'hébreu. Avant Brownlee, Wallenstein avait déjà fait remarquer que l'auteur des Hodayot ne considérait pas la leçon השמ de 1Q-a comme une erreur, puisqu'il faisait usage de ce passage d'Isaïe sous cette forme, ayant donc lu ici l'impératif סהㅡ.

Donc, par deux voies distinctes, le ${ }^{*} G$ et $1 Q$-a ont évité que le prophète reçoive du Seigneur l'ordre d'endurcir le coeur de son peuple. La *S a ici qui, en Syh, traduit exactement le *G. Comme Ephrem l'a compris et comme Warszawski le souligne, le traducteur a, lui aussi, traduit par des parfaits de l'indicatif les impératifs du *M. Nous avons vu que Sym a, lui aussi, conservé l'option du ${ }^{*} G$, se bornant à rectifier le choix du verbe.

$L a * V$ et le ${ }^{*} T$ ont traduit fidèlement par des impératifs.

\section{Choix textuel :}

La suggestion de lire ici des accomplis hofal à la place des impératifs ne serait défendable que pour le premier d'entre eux, du fait que "coeur" est au singulier. Mais elle ne l'est pas pour les deux suivants, car "oreilles" et "yeux" sont au duel et précèdent ces verbes, de sorte que la syntaxe ne permettrait pas (en cette hypothèse) de laisser les verbes au singulier.

Hie a dit très justement qu'il est vain de faire appel ici au texte du ${ }^{*} G$ pour éviter ce qui pourrait sembler blasphématoire dans les impératifs de l'hébreu. En effet, 
il existe assez d'autres textes bibliques où Dieu nous est présenté comme endurcissant les coeurs pour qu'un problème herméneutique d'une telle ampleur rende dérisoire le remède qu'une facilitation textuelle tenterait d'apporter.

Par 3 "C" et 3 "B", le comité a estimé devoir préserver ici la lectio difficilior du *M que personne n'aurait eu l'audace d'introduire après coup par voie de retouche.

Interprétation proposée :

Gesenius, nous l'avons dit, a d'abord estimé pouvoir traduire les impératifs par des indicatifs sans avoir, pour cela, besoin de corriger le texte. Des traductions qui se veulent aisément accessibles enveloppent ici l'expression aussi ferme que limpide du *M. Ainsi BHD : "Rede zu ihnen, damit ihre Herzen verstockt werden...". Mieux vaut préserver avec HSAT, ZB et RL le "Verstocke das Hertz dieses Volcks" de Luther et ne pas décharger les exégètes de leurs responsabilités.

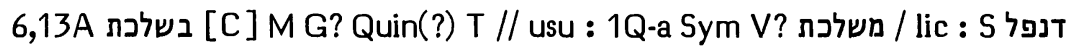
6,13B בס [C] M 1Q-a Quin(?) T // assim-ctext : m Sym? V? / lacun : G S

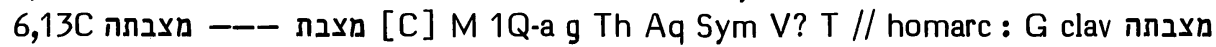
$\longrightarrow$ rest : S clav מצבתה זרע קדש מצבתה מצת

Options de nos traductions :

13b est traduit selon le *M par RSV (“ "like a terebinth or an oak, whose stump remains standing when it is felled." The holy seed is its stump."), par J ("comme le térébinthe et comme le chêne qui une fois émondés n'ont plus qu'un tronc; leur tronc est une semence sainte.") et par RL ("doch wie bei einer Eiche und Linde, von denen bei Fällen noch ein Stumpf bleibt. Ein heiliger Same wird solcher Stumpf sein".).

J12 וכאלון וכל, le considérant comme une dittographie du mot précédent.

TOB traduit: "comme le chêne et le térébinthe abattus, dont il ne reste que la souche - la souche est une semence sainte." Elle disait suivre 1Q-a pour lire "abattus" au lieu de "quand on l'abat" du *M et de beaucoup de mss grecs.

Après "like an oak or a terebinth", NEB estime l'hébreu obscur et conjecture : "a sacred pole thrown out from its place in a hill-shrine". Brockington précise que

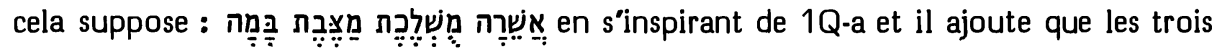
derniers mots du $* M$ ont été omis en s'inspirant du *G.

Origines des corrections :

L'omission proposée par 312 l'a d'abord été par les apparats de $\mathrm{BH} 23$ en liaison avec la demande de corriger ℶ⿱ en et, peut-être, le *G.

Les divers éléments de la correction complexe de NEB sont présentés dans les apparats de $\mathrm{BH} 7$ et de $\mathrm{BHS}$. Ces éléments se trouvent réunis dans la conjecture proposée par Iwry (Massebah), en s'inspirant essentiellement de 1Q-a.

L'omission des trois derniers mots du vs a pu se fonder sur HSAT34 disant qu'ils manquent encore dans le ${ }^{*} G$ et $n$ 'ont donc été ajoutés au texte que plus tard. 


\section{Les témoins anciens :}

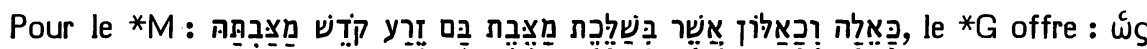

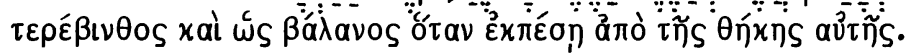

Hie a conclu de cela que rien ne correspondait dans le ${ }^{*} G$ à ce que la $* V$ traduit par : "semen sanctum erit id quod steterit in ea", c"est-à-dire aux trois derniers mots du *M. Nous avons vu que Brockington tire encore du *G la même conclusion.

Cependant Ziegler (48) a suggéré que le *G a pu sauter, par erreur, de מצבת à מצבתה. En effet, le pronom suffixe 3e pers. f. sg. de ce dernier mot est reconnaissable

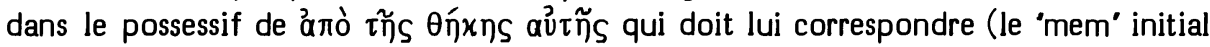
ayant été interprété en préposition). Ce seraient donc les quatre mots précédant ce dernier mot que le ${ }^{*} G$ aurait omis par homéoarcton.

Hie traduisait: "sicut terebinthus et sicut quercus quae proiecit fructus suos, sanctum semen erit quod steterit in ea". La *V corrigera la relative en "quae expandit ramos suos". Alors que la relative de Hie faisait encore allusion au gland qui tombe de sa cupule (que le ${ }^{*} G$ avait cru lire ici), la relative de la $* V$ est une construction sans rapport clair avec אשר בשלכת מצבת בם *M. Le ms 710 (sous une attribution douteuse à la Quinta, à la place de laquelle Lütkemann suggère Th) offre pour ces quatre

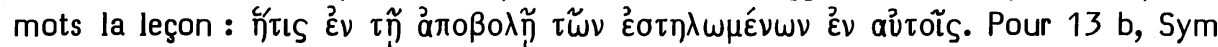

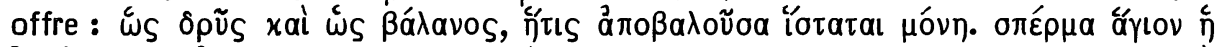

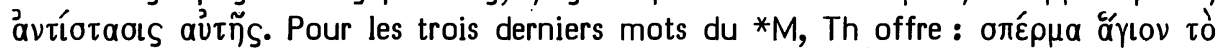

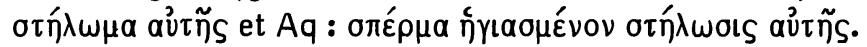

La ${ }^{*} S$, comme le ${ }^{*} G$, a compris ainsi la relative : "comme le gland qui est tombé de sa cupule". Elle y ajoute une traduction assez littérale des trois derniers mots en y gardant, pour le dernier, la racine dont l'hébreu faisait usage : נצבתה (= son plant).

Le *T traduit ce mot de même, avec un suffixe pluriel motivé par une ample paraphrase midrashique : “comme un térébinthe et comme un chêne qui, lorsque leurs feuilles tombent, semblent desséchés quoiqu'ils conservent encore leur sève pour susciter d'eux une semence, ainsi les exilés d'Israël seront rassemblés et reviendront dans leur pays, parce que leur plant est une semence sainte".

La tradition textuelle du *M offre une seule variante notable : une centaine de mss cités par de Rossi offrent ici בה au lieu de mss tibériens classiques s'accordent sur la leçon ą̧, mais le ms du Caire précise que c'est l'un des 4 cas où l'on conjec-

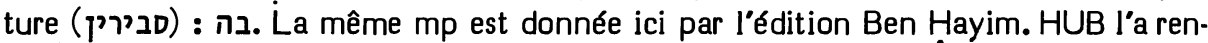
contrée sous la même forme dans le ms Leningrad II Firk 124, et sous la forme "on fait erreur (מטען)" dans le ms Leningrad II Firk 9. Ce cas est noté comme sebir en de nombreux autres mss (par ex. ms des Jésuites de Cologne, ms de Berne, ms Urbinates 1). Les 3 autres cas sont, selon Frensdorff (Massora 370) : Jg 2,22; Is 30,32; 63,19. Norzi (sur Is 63,19) estime plus exacte une liste de 3 sebirin incluant notre cas, mais excluant Is 63,19. Ginsburg (Massorah IV 174 \$23) a trouvé cette liste dans le $\mathrm{ms}$ London BL Arund Orient 16. Le ms de Leningrad, en $\mathrm{Jg} 2,22$ et en $\operatorname{Pr} 28,4$, classe ce cas dans une liste de בם à propos desquels "on fait erreur" (מטעין). Ces diverses listes protègent donc la leçon qu'elles estiment authentique contre une autre qui a envahi un grand nombre de mss.

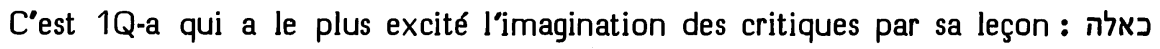
במה זרע הקודש מצבתה .וכאלון אשר משלכת מצבת. 
Choix textuel :

Il semble bien que ce soit Arias Montano, par sa traduction littérale et obscure de משלכת par "in eiectione", qui est à l'origine de l'interprétation du *M qui est devenue ensuite la plus fréquente : "lors de l'abattage". En ce cas, מצבת signifiera la

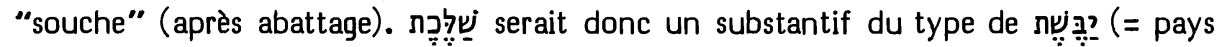
desséché : Ex 4,9; Ps 95,5), רִּ (= fièvre : Dt 28,22) etc. Ce serait cependant le seul emploi de ce substantif alors que le verbe de même racine est fréquent aux formes causatives (alors qu'il n'est pas usité aux formes intensives). On comprend donc que la leçon de 1Q-a ait intéressé les exégètes, puisqu’elle semblait offrir ici un participe hofal. Brownlee (Text 296), après avoir fait remarquer cela, a noté que במה que 1Q-a אשר משלכת מצבת במה doit signifier: "quand la stèle d'un haut-lieu est renversée". A cela, Iwry (229s) et Albright (254) ont ajouté une correction conjecturale du relatif en "Ashérah", obtenant ainsi : "et comme le chêne d"Ashérah" (Albright) ou : "et comme un chêne, ou une Ashérah" (Iwry).

Mais Skehan (State 23) a fait remarquer, peu après, qu'un espace important, en 1Q-a, sépare במה du mot qui le précède. Ces espaces indiquant, dans la graphie de ce $\mathrm{ms}$, des divisions de sens, les interprétations proposées par Brownlee, Iwry et Albright n'ont donc aucune chance de correspondre à ce que le scribe entendait écrire. Brownlee (Meaning 239) et Sawyer (Reading 111), notant eux aussi l'existence de cet espace, en ont conclu que ce mot ne pouvait avoir ici le sens de "haut-lieu". Brownlee y voit une graphie pleine de "en eux" et Sawyer un interrogatif : "en quoi ?". On comprend donc que Wildberger et Kaiser aient renoncé à faire appel à 1Q-a pour trouver ici la mention d'un haut-lieu et de ses accessoires.

Quant au participe משלכת que NEB et TOB empruntent à 1Q-a et que Sym semble appuyer, nous verrons plus loin qu'il s'agit probablement d'une facilitation venant de la méconnaissance du sens d'un toponyme.

Kittel (en BH23) s'appuyait sur le sebir בה pour omettre conjecturalement וכאלין. Mais la mention d'un sebir est une mise en garde de la part de massorètes qui veulent protéger contre cette facilitation la leçon qui leur semble authentique. D'ailleurs la leçon est protégée contre sa concurrente par les témoignages de 1Q-a, de la leçon attribuée à la Quinta et du ${ }^{*} T$. Sym et la ${ }^{*} V$ sont trop libres pour qu'on puisse en tirer un clair témoignage en faveur de בה qui semble assimiler au suffixe du dernier mot du vs.

En traitant du ${ }^{*} G$, nous avons montré que son abrégement de la fin du vs tient à un homéoarcton. Il ne témoigne donc pas d'un état littéraire plus sobre. Sur ce point, la *S dépend de lui.

Pour ces trois problèmes textuels, le comité a attribué aux leçons du *M la note “C”.

Interprétations proposées :

Avant le XVIe siècle, seuls Eliézer de Beaugency et Abravanel semblent avoir compris בשלכת comme désignant l'élagage d'un arbre. Aucun ne semble avoir compris cela comme l'abattage. Déjà à la fin du Xe siècle, Yéfet ben Ely mentionne trois inter- 
prétations entre lesquelles les exégètes antérieurs à lui se divisent à propos de ce mot : 1) pour certains, c'est le nom d'un quartier de Jérusalem qui est aussi mentionné en 1 Ch 26,16: "la porte de Shallèkèt"; 2) pour d'autres, il s'agit du fait de jeter son feuillage, en une signification qui serait normalement celle du hifil; 3) pour d'autres enfin, il s'agit de ceux qui s'en vont en exil, le 'bet' et le 'shin' étant préfixés, comme en בשלמי (Jon 1,7).

La troisième interprétation ne semble pas avoir de partisan connu, à propos d'Is 6,13.

L'interprétation en nom abstrait désignant la chute des feuilles est celle pour laquelle optent : le *T, Rashi, la 1e leçon des glossaires ABCDEF, la 1e leçon du commentaire de Radaq et la 2e de ses Shorashim, Isaïe de Trani, Oecolampade, Luther, Brucioli, Münster, Olivetan, Estienne, Châteillon, Ge, KJ.

L'interprétation en toponyme est la plus sérieusement enracinée chez les exégètes anciens : Saadya, David ben Abraham, Yéfet ben Ely, Parḥon, Ibn Ezra, Aaron ben Joseph, 2e exégèse des glossaires, 1e exégèse des Shorashim de Radaq et 2e de son commentaire, 2e exégèse d'Abravanel, Pagnini, Tremellius, 2e exégèse de Pasteurs.

Cette dernière exégèse semble celle qui sinsère le mieux dans le contexte. Shallèkèt apparaît en tout cas en 1 Ch 26,16 comme un toponyme servant à désigner une porte de la muraille ouest du temple. Il peut s'agir ici de deux arbres situés en ce lieu, arbres qui avaient subi un incendie qui les avait privés de tout leur feuillage et de leur ramure fine. Leurs troncs et les branches maîtresses semblant morts et desséchés par le feu avaient cependant donné le jour à toute une végétation nouvelle. On pourrait donc traduire : "Et $s^{\prime}$ il en subsiste encore un dixième, il sera livré au feu, comme le chêne et le térébinthe dont à Shallèkèt il ne reste qu'un tronc. Son tronc est une semence sainte." Le suffixe féminin singulier du dernier mot, comme les deux suffixes et les deux verbes féminin singulier de 13a ont pour antécédent "le pays" (sur quoi finit le vs 12) entendu comme : la population du pays (sens que nous retrouverons en 11,4).

On ne saurait cependant éliminer deux autres interprétations attestées : celles qui voient en ce mot un substantif abstrait désignant ou bien la chute des feuilles, ou bien l'élagage.

\section{7,1 יכל [A ] M T // assim 2 R 16,5 (יכלו) : 1Q-a G V S}

\section{Options de nos traductions :}

Le verbe singulier כיכ du *M a été traduit par un singulier en J. Mais il l'a été par un pluriel en RSV" ("they could"), RL ("sie konnten") et TOB ("ils... purent"). Quant à NEB, l'usage de "could" sans sujet pronominal lui permet de maintenir une certaine ambiguïté, quoique la traduction de ופק par "with Pekah" oriente l'interprétation vers le singulier (alors que sa traduction par "and Pekah" en KJ l'orientait vers le pluriel). 
Origine de la correction :

HSAT234 et $\mathrm{BH} 23$ demandent de lire ce verbe au pluriel en se référant à la leçon plurielle qu'offre le parallèle de $2 \mathrm{R}$ 16,5. Déjà Houbigant proposait cette leçon qu'il lisait ici en ${ }^{*} \mathrm{G},{ }^{*} \mathrm{~S},{ }^{*} \mathrm{~V}$.

\section{Les témoins anciens :}

1Q-a s'accorde avec le ${ }^{*} \mathrm{G}$, la ${ }^{*} \mathrm{~V}$ et la ${ }^{*} S$ pour lire ce verbe ici au pluriel; la ${ }^{*} S$ ayant poussé l'interassimilation jusqu’à identifier Is 7,1 et 2 R 16,5.

Orlinsky (Studies IV 333, n.9) prétend que le ms Kenn 193 lit ce verbe au pluriel. Il dit ensuite qu'un examen sporadique de ce ms montre qu'il n'a aucune affinité avec 1Q-a. Un certain nombre de confusions sous-tendent ces affirmations. En effet le ms Kenn 193 est le ms G. 2 sup de l’Ambrosienne de Milan que Bernheimer décrit comme Cod hebr 1 dans son catalogue (p. 1s) en précisant (en accord avec Kennicott, Dissertatio Generalis 87s) qu'il ne contient que le Pentateuque. Orlinsky a vraisemblablement confondu avec le ms 173 dont Kennicott dit qu'il lit ici יכלו. Or un examen local de ce ms (= ms Copenhague, hebr 1) montre qu'il porte par correction la leçon courante (écrite défectivement), la première main ayant vraisemblablement écrit la graphie pleine יכול attestée par 25 mss de Kennicott. HUB aurait donc pu se dispenser de reproduire la fausse indication de Kennicott.

\section{Choix textuel :}

En 2 R 16,5, ce verbe est précédé par la phrase : “et ils l'assiégèrent" dont le verbe est déjà au pluriel. Le vs suivant (6) n’a pas de connexion narrative avec celui-ci.

En Is 7,1 le verbe qui précède est y. Le récit au singulier se continue donc ici. D’ailleurs, le vs suivant (2) souligne la relative passivité d’Ephraïm (= Peqah) par rapport à Aram (= Recîn). Ici, le singulier doit donc être protégé contre la tentation de l'assimiler au pluriel du parallèle des Rois. Kittel pousse d'ailleurs le goût de la correction jusqu'à l'absurde lorsque, en $\mathrm{BH} 23$, il prend appui sur Is 7,1 pour proposer le singulier en 2 R 16,5, tout en prenant appui sur 2 R 16,5 pour demander le pluriel en Is 7,1. BHS a heureusement réduit ces propositions à de simples informations.

Considérant la variante comme une assimilation au parallèle du livre des Rois, et optant en tout cas pour le maintien dans leur spécificité littéraire de chacun des deux textes parallèles, le comité a attribué au * $M$ la note " $A$ ".

\section{Interprétation proposée :}

Parmi les traducteurs du XVIe siècle dont aucun n'entendait corriger le *M, ce verbe a été traduit par un pluriel, sous l'influence de la ${ }^{*} \mathrm{~V}$, en : Luther, Brucioli, Jud, Olivetan, Rollet, Estienne, Châteillon, Pasteurs et $\mathrm{KJ}$, alors que le singulier avait été respecté par Oecolampade, Pagnini, Münster, Ge et Tremellius. Il s'agit donc ici plus d'une question d'interprétation que de correction textuelle.

Le *M porte littéralement : "Recîn ... monta, et Péqah ... à Jérusalem pour l'attaquer, et il ne put pas lui donner l'assaut."

Si l'on traduit le premier verbe (au singulier) par un pluriel (“Recîn et Péqah montèrent") on sera obligé de mettre aussi le suivant au pluriel. Mieux vaut donc, en Is 7,1 où l'initiative du roi d'Aram est soulignée, traduire le premier "et" par 
"avec" : "Recîn ... monta, avec Péqah ... à Jérusalem pour l'attaquer, et il ne put pas lui donner l'assaut."

\section{7,11 שאָלה [B] M S T // incert : 1Q-a G Th Aq Sym V}

Options de nos traductions :

TOB traduit ce mot par : "demande-le"; alors que RSV, J, RL et NEB comprennent ce mot comme "vers le Shéol", seul Brockington postulant pour cela une vocalisation ḥolem de la lettre 'alef'.

Origines de la correction :

Luther semble avoir été le seul avec Foreiro, au XVIe siècle, à traduire ce mot comme s'il avait lu ce holem. Il garde en effet, pour le traduire, le mot "Hell" que la vieille traduction allemande (Kurrelmeyer VIII 374,10 ) utilisait pour traduire ici la *V.

Quant à Foreiro, il disait ne pas tenir compte des voyelles et interpréter ce mot au sens de "inferno", comme s'opposant à ("sursum").

Cela a fait protester Mercerus (en sa note sur Pagnini, Thesaurus3, col 2810) :

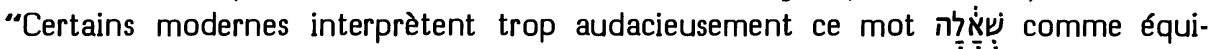

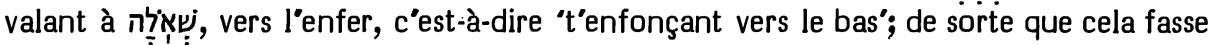
contraste avec 't'élevant vers le haut' qui suit. Je n'approuve pas cela, à moins que tu ne corriges la leçon".

Clericus penchait vers cette correction qui a été adoptée par Lowth, Michaelis et beaucoup d'autres à leur suite jusquà HSAT234, BH23S et Cent.

\section{Les témoins anciens :}

Seules les trois dernières lettres de ce mot sont conservées en 1Q-a qui ne porte pas témoignage sur sa vocalisation.

Le ${ }^{*} G$ s'est contenté de عís $\beta a ́ \theta$ os pour traduire ce mot et celui qui le précède.

La *S a interprété ce mot en impératif de שאל.

Le fait que le ${ }^{*} T$ répète cet impératif une seconde fois en sa traduction assez libre indique qu'il a fait de même.

Quant à Th, Aq, Sym et la *V, ils ont reconnu en ce mot le Shéol.

Choix textuel :

Le seul commentaire midrashique de ce passage semble être celui du Tanḥuma Buber (Wayyésé §14) où le signe évoqué par ce mot et celui qui le précède est explicité en : "que les morts revivent ou que Qorah remonte du Shéol". Cela suppose évidemment une interprétation analogue à celle des versions hexaplaires et de la ${ }^{*} V$.

Cependant, il semble que toute l'exégèse littérale juive ait rattaché cette forme au verbe "demander", hésitant entre un infinitif (possibilité évoquée par Radaq en Mikhlol 14b) et un impératif (ibid. 15a). En faveur de cette seconde analyse, on peut

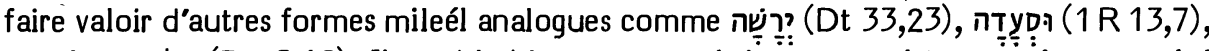

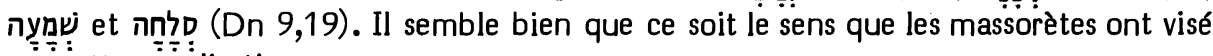
par cette vocalisation. 
Pourtant, Vitringa a suggéré que le sens "vers le Shéol" a pu être visé ici par les vocalisateurs qui n'auraient préféré le qames au holem que pour obtenir une meilleure assonance avec לְ. Cette opinion a été adoptée par Ewald, alors que Delitzsch voyait ici une modification phonétique due à la pause, rapprochant cela d'un certain nombre d'autres cas où un qameș est substitué à un ḥolem en situation pausale. König a d'abord (Lehrgebäude II 538s) critiqué l'analyse faite par Delitzsch, puis (commentaire) il l'a estimée possible comme alternative à celle d'Ewald.

Quelle que soit la justification qu'ils en donnent, la quasi-totalité des exégètes actuels acceptent (du fait du contraste avec למעלה) l'interprétation : "vers le Shéol".

Quatre membres du comité ont estimé avec König que l'on pouvait admettre les analyses d'Ewald ou de Delitzsch; aussi ont-ils attribué au * $M$ la note " $B$ ".

Deux autres membres du comité ont pensé que la vocalisation du ${ }^{*} M$ postulait une interprétation à partir de la racine "demander" et qu'il s'agissait là d'une correction théologique pour ne pas faire demander à Dieu un acte semblable à l'acte criminel de la pythonisse d’En Dor. Aussi ont-ils estimé devoir corriger le qameṣ en ḥolem pour retrouver le sens original et ils ont attribué la note " $\mathrm{C}$ " à cette correction.

Interprétation proposée :

La convergence de Th, Aq, Sym et la *V sur le sens "vers le Shéol" indique que cette interprétation mérite d'être conservée comme ayant été classique à l'époque protomassorétique et atteignant probablement le sens original de ce texte.

On peut cependant conseiller d'indiquer en note l'interprétation "demande" qui a dominé toute l'exégèse littérale juive et presque tous les traducteurs chrétiens du $\mathrm{XVIe}$ siècle.

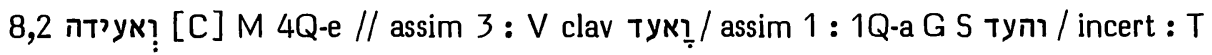

Options de nos traductions :

RSV ("and I got") et RL ("und ich nahm") traduisent ce verbe par un passé sans rien noter. TOB fait de même ("et je pris") en disant suivre le *M et en ajoutant que le vs précédent inviterait à lire l'impératif comme l'ont fait $1 Q-a$, le ${ }^{*} G$ et le ${ }^{*} T$.

$J$ traduit par "et prends" en disant suivre le *G. NEB fait de même ("and fetch")

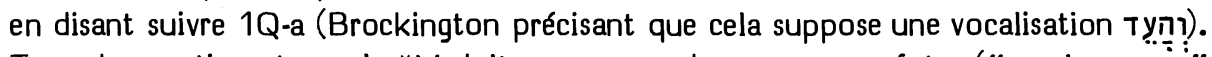
Tous deux estiment que le * $M$ doit se comprendre comme un futur ("que je prenne" selon J, ou "and I will fetch" selon NEB).

\section{Origines des corrections :}

Au XVIe siècle, la *V (et adhibui) a été reprise par Oecolampade, Jud, Calvin, Foreiro et Tremellius. Ont traduit aussi par un passé : Luther, Münster, Olivetan, Rollet, Estienne, Châteillon, Ge, Pasteurs, $\mathrm{KJ}$. L'interprétation de cette forme en passé est donc bien enracinée dans la tradition exégétique.

Cependant, Vitringa a noté que l'exégèse midrashique voit ici un futur ayant Dieu pour sujet et visant des prophètes futurs que Dieu décide de susciter pour attester plus tard la réalisation de cet oracle. Il estime pourtant que constituer des témoins 
sied mieux à des hommes (cf. Jr 32,10) qu'à Dieu et qu'il faut donc interpréter ici ce verbe comme un passé ayant le prophète pour sujet. Reconnaissant qu'ici la vocalisation massorétique exprime le futur (puisque le 'waw' n'est pas porteur d'un qames), il hésite à admettre que cette vocalisation soit erronée et il renvoie à certains autres cas groupés par Glassius (417s) comme exemples de futurs tenant lieu de passés.

Ce sera Michaelis (OEB) qui requerra ici la correction du shewa en qameș pour justifier l'interprétation traditionnelle de ce verbe en passé.

La correction de ce verbe en impératif a été demandée ici par Hitzig, se fondant sur le ${ }^{*} G$, le $* T$ et la $* 5$. Le fait qu'elle ait été adoptée par Duhm lui a valu de l’être ensuite par HSAT234, BH2 et Cent; alors que BH3 préférait la correction de Michaelis. $\mathrm{BHS}$ se contente de données informatives.

\section{Les témoins anciens :}

4Q-e est identique au $* M$.

1Q-a porte ici un impératif : והעד que le *G (תoínoov) et la *S (וסהד) semblent bien avoir lu ici. Selon certains de ses mss, Saadya a fait de même.

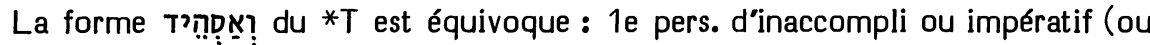
encore 3e pers. d'accompli, ce qui n'entre pas en question ici).

$\mathrm{La} * \mathrm{~V}$ a compris les consonnes du $* \mathrm{M}$ en inaccompli inverti. Notons que Saadya a fait de même, selon d'autres mss.

\section{Choix textuel :}

La massore (Weil §1230) intègre ce cas en une liste de cinq (avec Dt 31,28; Jr 6,10; Ps 50,7 et 81,9), pour les distinguer d'une vocalisation hapax du 'waw' par qames en $\mathrm{Ne}$ 13,21. Cependant Abulwalid (Luma 55,10s et Opuscules 339) classe formellement notre cas parmi les futurs employés à la place d'un passé.

Pagnini et Brucioli semblent seuls à avoir respecté, au XVIe siècle, le futur exprimé par le *M. Cette leçon suppose que Dieu continue le discours qu'il a adressé au prophète au vs précédent : "et je vais me constituer des témoins fidèles". La difficulté offerte par cette leçon tient au fait que c'est Isaïe qui va devoir les prendre à témoin (cf. Jr 32,10.25). On comprend donc qu'on ait trouvé deux échappatoires : par assimilation au vs 3 , la *V a vu ici un récit fait par Isaïe; ou bien (par assimilation au vs 1 ) $1 \mathrm{Q}-\mathrm{a}$, le ${ }^{*} \mathrm{G}$ et la ${ }^{*} \mathrm{~S}$ ont lu ici un troisième impératif adressé par Dieu au prophète.

Delitzsch a raison de noter que le Seigneur dit ici ce qu'il a l'intention de faire et que le prophète comprend, sans qu'on ait besoin de le lui dire, que c'est par son office que cela doit se réaliser.

Kaiser fait deux objections à une correction en impératif. D'abord, cet ordre devrait précéder le 2e impératif "écris". Ensuite, comme Gesenius/Kautzsch ( \$119s) l'a noté, la personne du dativus commodi doit s'accorder avec celle de la forme verbale.

Cinq membres du comité ont attribué au $* M$ la note "C", alors qu'un membre attribuait cette même note à l'impératif lu ici par 1Q-a, le *G et la *S. 
Interprétation proposée :

Rignell (Orakel 40s) voit ici l'expression d'une intention du prophète. Il paraît préférable d’y voir, avec Delitzsch, la fin du discours que le Seigneur a adressé à celuici : "Je compte prendre pour témoins...".

8,6 ומחמשׁוֹש [B] M 4Q-f G V S T // facil-vocal : 1Q-a ומשיש / incert : 4Q-e

Options de nos traductions :

TOB traduit "et se réjouit au sujet de", en disant que c'est le sens propre du terme hébreu.

Après ce mot, NEB omet par conjecture les 4 mots qui achèvent ce vs. Elle traduit ce mot par "and gently", Brockington précisant que cela suppose une correction du shewa en qames sous le 'mem'.

RSV ("and melt in fear before") et J ("et a tremblé devant", notant : litt. fondu) disent conjecturer. RL fait de même avec "und in Angst zerfliesst vor".

Origines de la correction :

La conjecture de NEB, pour ce qui est de l'omission de la fin du vs, remonte à Giesebrecht (Immanuelweissagung 228s). Elle avait été adoptée par Burkitt (Waters), HSAT234 et BHS. Cependant, tout en optant tous pour le même sens, Giesebrecht et HSAT34 proposaient de corriger en סiּn, alors que Burkitt, HSAT2 et BHS gardaient la leçon du *M (où ils considéraient les 'śin' comme tenant la place de 'samek').

RSV, J et RL supposent la même correction ou lecture pour ce mot, mais ils gardent la fin du vs. Hitzig se contentait ici d'interpréter le * $M$ en ce sens, considérant la construction avec l'accusatif (au lieu de מְִּ̣נֵ) comme une exception. C'est Bredenkamp qui a proposé de corriger en סiסמ̣, infinitif absolu à valeur adverbiale. Duhm a ajouté à cela la correction de la préposition suivante, transformant l'exégèse de Hitzig en une double correction. C'est en cet état que cette correction a été adoptée par les apparats de $\mathrm{BH} 2$ et Cent.

Les témoins anciens :

4Q-f appuie le *M.

$1 \mathrm{Q}-\mathrm{a}$ lit un 'yod' à la place du second 'waw'. C'est vraisemblablement le mot suivant, interprété en particule d'accusatif, qui a motivé ici cette lecture en participe hifil au sens de "et réjouissant Recîn". Cela a d'ailleurs entraîné en 1Q-a la répétition de cette particule avant le complément suivant. Nous aurons l'occasion de constater plusieurs fois que 1Q-a, quoique distinguant clairement le 'Waw' et le 'yod', semble avoir eu un archétype où ces deux lettres se confondaient (ce qui est le cas de 4Q-e dont la leçon se trouve, de ce fait, affectée ici d'un coefficient d'incertitude). Il est donc vraisemblable qu'ici le copiste de 1Q-a (ou l'un de ses prédécesseurs) a résolu de façon facilitante et fausse cette ambiguïté.

Il semble que tous les autres témoins ont lu le $* M$ et l'ont interprété plus ou moins librement par des formes verbales où l'on reconnaît le sens de joie ou de préférence. 
Choix textuel :

Toute correction ou interprétation voyant ici une forme de מ (= se liquéfier) se heurte à des difficultés sérieuses qui entraînent presque inévitablement d'autres corrections. D'abord, ce verbe s'emploie normalement au nifal (19 fois), un hifil et un qal faisant figure d'exceptions. Ensuite, lorsque la cause de la liquéfaction est exprimée, cette cause est introduite par une préposition complexe commençant par ᄁ̣̣. Enfin, le mot "coeur" est normalement explicité lorsque ce verbe sert de métaphore pour le découragement.

La seule variante réelle étant celle de $1 Q-a$, le comité a attribué au $* M$ la note "B".

Interprétation proposée :

C'est une identification spontanée de "ce peuple" avec Juda qui est à la base de toutes les difficultés d'interprétation. Or les plus anciennes exégèses littérales qui nous sont connues (Jérôme et Yéfet ben Ely) l'identifient avec Israël (comme ce sera le cas en 9,15).

En effet, il est dit au vs 7a: "c'est pourquoi le Seigneur fera monter contre eux les eaux puissantes et abondantes du fleuve", et seulement en 8a: "puis il passera en Juda...". La seule interprétation naturelle est de considérer "eux" de 7a comme se référant à "ce peuple", celui-ci se trouvant placé avant Juda sur le trajet de l'invasion assyrienne.

En ce cas, "ce peuple" désignera le peuple du royaume du nord, ainsi que les partisans qu'il peut avoir en Juda. Il ne sera alors pas difficile de dire qu'il "dédaigne les eaux de Siloé" (c'est-à-dire ne se fie pas dans le secours qu'il pourrait recevoir du Seigneur et de la maison de David) et qu'il "se réjouit avec" Recîn et Péqah. En effet, "ce peuple" plaçait dans la coalition syro-éphraïmite et le détrônement d'Akhaz son espoir de résister à la poussée assyrienne.

Par contre, en 7,2, le mot inge, se référant à Akhaz, désigne "ses partisans".

Précisons qu'ici ש̣ est un nom verbal à l'état construit. Gesenius (Lehrgebäude 725s) a classé ce cas parmi ceux où un nom verbal tient la place d'un verbe. Dans son commentaire, il ajoute que l'état construit est dû à la préposition qui suit (comme pour כשמחַת בַּקציר en 9,2). On retrouve en 66,10 la même racine liée à la même préposition.

On traduira donc: "Puisque ce peuple a dédaigné les eaux de Siloé qui coulent doucement et (trouve son) bonheur en Recîn et dans le fils de Remalyahu...".

\section{8,8 ארצך}

Options de nos traductions :

Le *M est respecté ici par RSV, J, RL et TOB.

NEB traduit "the land" sans possessif, mais fait précéder "God is with us" par

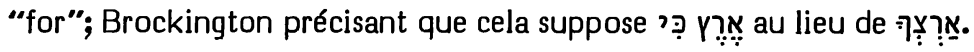


Origine de la correction :

C'est Duhm qui a eu l'idée d'omettre ce suffixe et de transformer son 'kaf' en une conjonction identique à celle qui précédera ya la fin du vs 10. La suggestion a été adoptée par Marti et Gray (à qui NEB a pu l'emprunter), alors que Duhm luimême y renonçait à partir de la $3 e$ édition de son commentaire.

\section{Les témoins anciens :}

1Q-a, 4Q-e et 4Q163 s'ajoutent à tous les témoins connus auparavant pour appuyer le ${ }^{*} M$, seuls un sous-groupe de la recension origénienne et un autre de la recension antiochienne omettent le possessif de $\tau$ ñ $X \tilde{\omega} \rho a_{\varsigma}$ oov.

Choix textuel :

La conjecture de Duhm repose sur sa conviction que "Emmanuel" désigne n'importe quel enfant qui pourrait naître à cette époque. Cela rend impossible d'en faire l'objet d'une apostrophe ("ta terre"). En effet, dans les deux premières éditions de son commentaire, Duhm considérait encore le vs 8 (jusqu”à "terre" inclus) comme authentique. A partir de la 3 e édition, il considère $8 \mathrm{~b}$ comme une glose eschatologisante, ce qui lui permet d'en conserver le texte intact.

L'identification de l'Emmanuel est un problème trop complexe pour que l'on puisse se permettre de retoucher un texte sur lequel tous les témoins s'accordent, en fonction d'une solution que l'on veut donner à ce problème. Seule la démarche inverse caractérisera une saine exégèse. Le * $M$ a donc reçu la note " $A$ ".

\section{Interprétation proposée :}

Duhm a toujours considéré les deux "Emmanuel" par lesquels s'achèvent les vss 8 et 10 comme inauthentiques. Or ces deux fins de versets sont attestées par 1Q-a et 4Q-e. 4Q-f est lacuneux pour la fin du vs 10. Tous les autres témoins les attestent.

On doit donc considérer ces deux finales en "Emmanuel" comme des termes à méditer, termes qui sont placés en situation analogue ou antithétique selon l'interprétation protectrice ou agressive qu'on donne à l'image de l'extension des ailes.

Presque tous les modernes (cf. Vermeylen 223) l'interprètent en un sens protecteur.

Cependant, en Jr 48,40 et 49,22, l'extension des ailes d'un oiseau sur un pays signifie une invasion et c'est le sens que Yéfet ben Ely (donnant aux ailes le sens d'armées), Judah ibn Balaam (interprétant de même), Rashi (citant le Tanḥuma) et Radaq ont donné ici à cette image. König et Young préfèrent cette exégèse qui maintient $8 b$ dans la continuité de 7 et $8 a$.

En ce cas les deux "Emmanuel" (qui, selon tous les témoins analysés par Oesch $T$ 6*, achèvent chacun une section) marquent, l'un, le fond du châtiment, l'autre, le gage de l'espérance.

On pourra donc traduire : “et le déploiement de ses ailes occupera toute l'étendue de ton pays, ô Dieu-avec-nous !" Ici le châtiment apparaît comme un amer démenti de la confiance qu'évoque le nom donné à l'enfant; alors qu'à la fin de 10, cette confiance est confirmée par : “... prononcez une parole : elle ne tiendra pas, car ‘Dieu est avec nous'." 
Options de nos traductions :

RSV (“be broken"), RL (“tobet") et TOB (“tremblez") traduisent le *M.

J12 ("apprenez-le"), J3 ("sachez") et NEB ("take note") disent suivre le *G, Brockington précisant que la leçon postulée est דִ̣:

Origine de la correction :

Déjà Hie (disant que le ROU de l"hébreu signifie "congregamini" ou "infirmamini" et "confringimini") notait que le "scitote" du *G s"explique par la similitude du 'dalet' et du 'resh'.

Estimant que la leçon du *M est sujette à plusieurs difficultés, c'est Lowth qui, avec l'accord de Secker, a proposé de suivre ici la leçon du *G. Cette proposition a été adoptée par Grätz (Psalmen, 131,29), Cheyne, puis les apparats de HSAT234 et Cent. NEB dépend probablement de Driver (TLP).

\section{Les témoins anciens :}

Le ${ }^{*} G(\gamma \nu \tilde{\omega} \tau \varepsilon)$ est seul à lire clairement cette variante.

4Q-e est illisible pour la première lettre de ce mot, selon la photo dont nous disposons. En 4Q-f l'identification de cette première lettre comme 'resh' ou 'dalet' est incertaine. Le fait que Morrow ne mentionne rien à propos de ce mot indique que Skehan n'a pas relevé en ces fragments une leçon qui soit distincte du *M.

1Q-a porte clairement un 'resh'.

Pour ThAqSym, Théodoret offre une longue leçon où ce mot est traduit par ouva $\theta \rho o i ́ \sigma \theta \eta \tau \varepsilon ;$ alors que, pour les mêmes trois versions, le ms 710 offre $\sigma \alpha \theta \rho \circ \tilde{o} \sigma \theta \varepsilon$. La longue leçon de Théodoret ne peut valoir entièrement pour les trois versions et Field l'a attribuée à Sym. Lütkemann en conclut que la leçon du ms 710 doit appar-

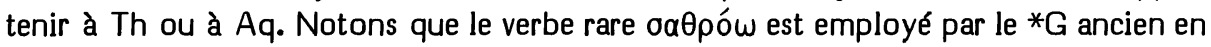
Jg 10,8 pour traduire le verbe hébreu $y$ רien ne prouve cependant que la version qui a usé ici de cette traduction y a lu la même Vorlage. On peut seulement conclure de là que la Vorlage d'une version, à l'identification incertaine, est elle-même incertaine. Mais elle a bien lu ici un 'resh'.

La *V et le *T offrent le même sens "rassemblez-vous, coalisez-vous" que la leçon de Théodoret.

Quant à la *S, sa leçon rivest certainement une exégèse du *M pour lequel le sens "trembler" a été proposé par d'autres.

\section{Choix textuel :}

Considérant que le vrai problème, ici, porte surtout sur l'interprétation du *M que le *G est seul à contredire (à cause d'une fausse lecture de 'resh' en 'dalet'), le comité a attribué au *M la note " $B$ ". En effet le ${ }^{*} G$ a voulu voir en ce verbe un parallèle de "prêtez l'oreille" qui constitue en réalité une incise; alors que le vrai parallèle de notre verbe est "ceignez-vous", deux fois présent en $9 b$. 
Interprétations proposées :

Si Lowth a quitté le *M, c'est parce qu'il y voyait diverses difficultés. Cheyne et Gray estiment aussi qu'il n'est pas explicable de façon satisfaisante. NEB va jusqua le dire "unintelligible".

De fait, les possibilités d'interprétation ne manquent pas.

Nous avons vu que l'interprétation sur laquelle Sym, la ${ }^{*} V$ et le ${ }^{*} T$ s'accordent est "alliez-vous, coalisez-vous". Cette exégèse sera adoptée ensuite par Rashi, les glossaires ABCDEF (qui traduisent "accompagnez"), Eliézer de Beaugency, Abravanel, Oecolampade (qui garde "congregamini" de la *V), Brucioli (en 1532: "congiungnetevi"), Olivetan ("assemblez-vous"), Jud ("societatem inite"), Châteillon ("bendés vous"), Ge ("gather together on heaps"), Tremellius ("consociamini"), Pasteurs ("alliez-vous"), KJ ("associate yourselves"). Il est sûr que l'influence conjuguée de la $* V$ et du ${ }^{*} T$ a été pour beaucoup dans le succès de cette exégèse. Ceux qui ont adopté cette exégèse ont vu dans la forme du *M un dérivé de רעה II. Mais la vocalisation holem ne pourrait se justifier que si le pual (non-attesté pour ce verbe) possédait un impératif. Cette difficulté explique le fait qu’aucun des grammairiens et lexicographes juifs ou chrétiens ne semble avoir retenu ce sens.

La signification qui est la plus attestée parmi ceux-ci est celle de "briser" ou bien au sens intransitif ("être brisé") ou bien au sens transitif ("briser"). Sont partisans du sens intransitif : Saadya, Abulwalid (Ușul 672,32s), Radaq (Shorashim), Pagnini. Optent pour le sens transitif : Yéfet ben Ely, Ibn Ezra, Münster, Vatable, Brucioli (en 1540). Optent pour "briser" sans se prononcer sur l'option en transitif ou intransitif : Menahem ben Saruq (5e sens de $y$ ), Hayyuj (Kitâb 123,18), Judah ibn Balaam, Parḥon (Aruk). Tous ceux de ces exégètes qui connaissent l'analyse trilittère des verbes faibles rattachent cet impératif aux verbes à deuxième radicale 'waw'. C'est Mercerus (en Thesaurus3 2668 et 2741 de Pagnini), qui, par comparaison avec l'araméen, a conclu qu'il devait s'agir d'un verbe à deuxième radicale redoublée. Cette analyse a été adoptée ensuite par les lexicographes.

Luther semble avoir été le premier à opter pour le sens "être mauvais" de la même racine verbale, en son cours sur Isaïe de 1527 . Selon la reportatio d'Antonius Lauterbach (WA. XXXI/2), Luther y a utilisé comme lemme le "congregamini" de la *V et d'Oecolampade, mais a indiqué que le sens de l'hébreu est "estote mali, ostendite quid possitis". De fait, l'année suivante, il traduisait ce verbe par "seid böse". En cette exégèse, il semble n'avoir été suivi par aucun traducteur du XVIe siècle (Foreiro se contentant d'évoquer cela comme une possibilité). Aussi est-on surpris de voir Delitzsch présenter cette exégèse comme celle de la majorité des exégètes. De fait cette exégèse semble n'avoir eu une vogue réelle que parmi les exégètes germanophones du XIXe siècle et du début du XXe : Gesenius (Thesaurus), Hitzig, Knobel, Ewald, Delitzsch, von Orelli, Dillmann/Kittel, Duhm, Marti, Schmidt, Feldmann, Fischer. La plupart d'entre eux y ont vu le sens de "se déchaîner furieusement", sans qu'il soit aisé de le justifier de façon précise.

Le sens de "trembler, avoir peur" a été reconnu ici par la *S, Kopf (275 n.4, faisant appel à l'arabe) et TOB.

Celui de "vociférer, pousser le cri de guerre" (רוע) a été admis ici par Saeb $\phi$ (143), H. Barth (136), H.-P. Müller (47, n. 3). 
Si l'on tient compte des parallèles "ceignez-vous" (9b) et "formez un projet" (10a), qui sont des impératifs ayant ce même vocatif "peuples" comme sujet, les sens les plus aptes seraient d'abord le plus ancien et le plus classique : "alliez-vous, coalisez-vous", puis "poussez le cri de guerre". Cependant "brisez" au sens transitif peut être admis à titre de résumé par anticipation de ce à quoi visent les projets guerriers des rois. Le sens intransitif ("soyez brisés") pousserait encore plus loin l'anticipation.

Ces deux derniers sens sont les seuls des quatre qui puissent être tirés d'une interprétation régulière de la vocalisation du $* M$ (qui convient à une racine à deuxième

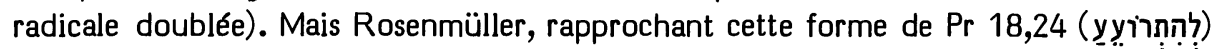
estime qu'une réalisation yע de ce bilittère peut servir ici d'équivalent à sa réalisation

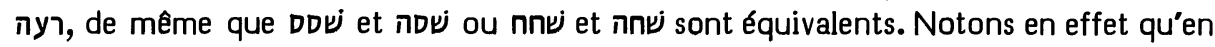
$\operatorname{Pr} 18,24$ (que le *G ancien n'a pas traduit) le sens de "s'associer, devenir amis" a été reconnu par Th, la *V, la *S et le *T. Il se peut d'ailleurs qu'ici, le souci de créer une assonance avec inin ait motivé le choix de cette réalisation plus rare de ce bilittère. Quant à "poussez le cri de guerre", on doit faire trois objections à cette interprétation. D'abord, cette signification est attachée à la forme yu du bilittère (dont l'impératif qal serait (רצר ( Mais cette objection ne serait pas plus décisive que celle que Rosenmüller a réfutée à propos de "alliez-vous". Les deux autres objections ont plus de poids : "pousser le cri de guerre" se dit seulement aux formes causative et intensive. Et surtout, ni les versions, ni l'exégèse littérale juive ni les traducteurs du XVIe siècle ne semblent avoir eu l'idée de faire appel à cette interprétation. Si l'on ne pouvait faire appel à aucune autre interprétation satisfaisante, cette dernière objection ne serait nullement rédhibitoire. Mais nous venons de voir que ce n'est pas le cas.

On proposera donc en premier le sens : "broyez, peuples, et soyez écrasés !", en deuxième : "soyez brisés, peuples, et soyez écrasés !" (ces deux sens se rattachant à un verbe bien connu par ailleurs), en troisième : "alliez-vous, peuples, et soyez écrasés !" (qui a pour lui son attestation traditionnelle très ancienne et l'argumentation de Rosenmüller).

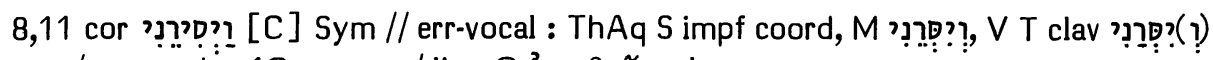

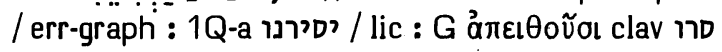

Options de nos traductions :

RSV ("and warned me"), 33 ("et qu'il m'a appris"), RL ("und er mich warnte"), NEB ("and he warned me") et TOB ("et qu'il m'a enjoint") ne mentionnent pas qu'ils s'éloignent du *M.

En note, NEB donne comme alternative : "or : and he turned me", Brockington

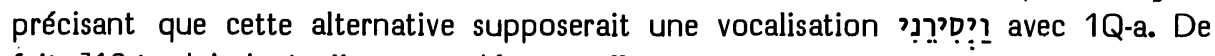
fait, J12 traduisaient : "pour me détourner", sans note. 
Origines des corrections :

Nous verrons que la traduction de RSV, J3, RL, NEB, TOB, quoique la plus classique, suppose probablement une correction vocalique.

Quant à $\mathrm{J12}$ et à l'alternative de NEB, elle correspond à l'une des suggestions faites par BH3S, cette dernière attribuant cette leçon à 1Q-a, Sym et la *S. Cette suggestion remonte à Foreiro et à Michaelis (OEB), ce dernier se fondant sur Sym et la *S.

\section{Les témoins anciens :}

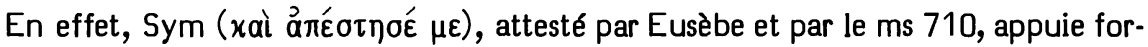
mellement cette correction. Mais la *S (רנסטיני) a lu ici cet inaccompli comme coor-

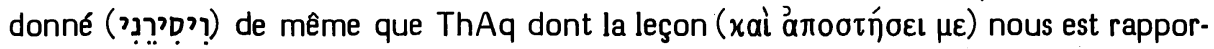
tée par le ms 710.

Quant à 1Q-a, Wildberger dit (et BHS et Brockington laissent entendre) qu'il lit ici ויסירני. C'est inexact. Sa leçon est יסירנו. Il est probable que la confusion yod/ waw qui régnait en son archétype a été résolue de façon facilitante en un suffixe de la 1e pers. du pluriel, par assimilation aux 4 verbes à la $2 \mathrm{e}$ pers. du pluriel qui se trouvent dans les 2 vss suivants. Koenig (Herméneutique 322, n. 69) a , en tout cas, tort de prétendre que le scribe de 1Q-a confond 'waw' et 'yod' quand ils sont liés à 'nun'. Voir, à ce propos, la fin de 6,8 en 1Q-a : les 'yod' y sont clairement spécifiés.

De nombreuses allusions ont été faites à ce vs dans la littérature de la communauté

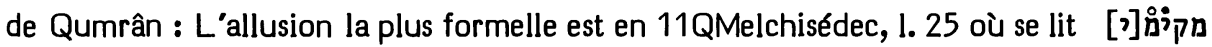

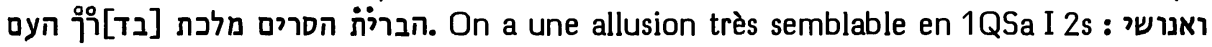

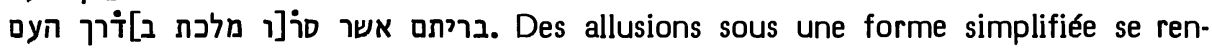
contrent dans le Document de Damas VIII 16 et XIX 29 : שבי ישראל סרו מדרך העם et en 4Q174 I 14 où se lit סרי מדוך en un passage mutilé qui contenait une citation formelle de notre texte.

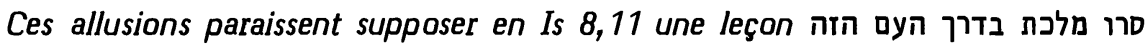

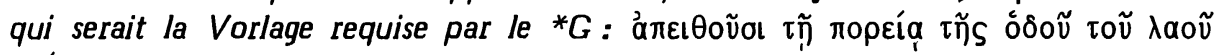
toútou.

La *V (erudivit me) et le *T (ואלפני) ont, comme le *M, vu ici une forme du verbe יסר

\section{Choix textuel :}

Même les partisans les plus fidèles du *M l'ont estimé ici insatisfaisant.

Alors que Saadya et Yéfet ben Ely le traduisaient par "il m"a appris" (comme la *V et le *T), Abulwalid (Opuscules 50s) estimait cette interprétation inexacte : "Selon moi, יח est un futur de la première radicale a été insérée dans la deuxième, comme dans צְִִרָה (Is 44,12). On en fait d'ordinaire le parfait d'une forme lourde (= piél) où le șéré remplace le patah, comme ailleurs le patạ̣ tient lieu du séré". Il répète cette analyse en ses Ușul (287,22-25).

Tenant à l'exégèse de cette forme en passé, Judah ibn Balaam conclut de l'analyse d’Abulwalid que la vocalisation du *M est insatisfaisante: "A la place du séré, il devrait y avoir un patạ puisque c'est un parfait de la forme lourde". 
Radaq, lui aussi, a accepté l'analyse d'Abulwalid et, dans son commentaire, il opte pour le parfait, comme l'avait fait Judah ibn Balaam : "le șéré sous le 'resh' est à la place d'un patah qui serait normal en cette forme, comme c'est le cas en (1 R 2,8)". Dans sa grammaire, il traite trois fois de cette forme et son opinion évolue. D'abord (Mikhlol 26b) il considère Is 8,11 comme un cas où "il arrive que la troisième radicale du parfait piél ait un séré". Puis (94b) il hésite : "le futur de יסר a parfois le 'yod' défectif comme en Is 8,11 ou en Os 10,10 ... mais il se peut aussi qu'en Is 8,11 on ait affaire à un piél et que le séré y tienne la place du patah de ?ִ ְue l'on attendrait ici". Enfin (96b) il voit en notre forme un futur, la citant (comme Abulwalid) à titre d'exemple de futur à 'yod' radical assimilé analogue à Is 44,12. Dans ses Shorashim à propos du piél de ce verbe, il traite de notre forme et hésite encore : "Ici la 3e radicale a un șéré, ce qui est contre l'analogie. Mais peut-être que c'est un qal et que le 'yod' écrit est celui de la préformante, le 'yod' radical étant assimilé dans le

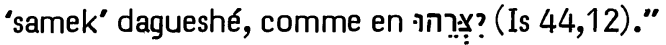

Duran $(83,23)$, Isaïe de Trani et Elias Levita (Zikronot) optent ici pour un parfait piél à șéré irrégulier.

Comme König (Syntax §413f) l'a noté, le fait que l'atnah précède le mot que nous analysons indique que ce verbe n'a pas été senti par les accentuateurs comme prolongeant l'expression infinitivale cède. Le * $M$ ne doit donc pas se comprendre comme "lorsque sa main m'a saisi et qu'il m'a enjoint" (ce qui supposerait un inaccompli inverti relatant un événement ponctuel), mais : "ainsi m'a parlé... et il m'enjoignait" (l'inaccompli coordonné ayant une valeur fréquentative convenant bien à une action éducative).

Pour résumer les données pouvant orienter un choix textuel, notons d'abord que la forme dérivée de 2 ? que le *M donne ici n’y a été lue que par la *V et le *T, alors que 1Q-a, ThAq, Sym et la ${ }^{*}$ y y ont vu un inaccompli hifil de (le ${ }^{*} G$ et certaines allusions dans les écrits de Qumrân semblant y avoir lu un accompli pluriel qal du même verbe). La construction du verbe יסר avec מ̣ן serait un hapax, alors que celle de סור avec cette préposition est fréquente.

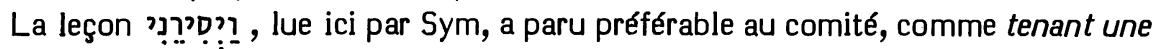
place intermédiaire entre celle du ${ }^{*} M$ et celles de $1 Q$-a et $d u{ }^{*} G$. En fonction de l'analyse qui précède, cet inaccompli inverti constitue un prolongement normal de la circonstancielle infinitivale qui précède. Le comité a attribué à cette leçon la note "C".

Interprétation proposée :

On pourra donc traduire: “lorsque sa main m'a saisi et qu'il m’a détourné de marcher sur la route de ce peuple".

8,13 תקדישו [A] M 1Q-a 4Q-h G Sym V S T

8,14 למקדש [A] M 1Q-a G Aq Sym V S // paraphr : T

Options de nos traductions :

Ces deux leçons du *M ont été respectées par RSV ("you shall regard as holy" et "a sanctuary"), J3 ("vous proclamerez saint" et "un sanctuaire") et TOB ("vous 
tiendrez pour saint" et "un sanctuaire"). $\mathrm{J} 2$ traduisait par "qu'il faut sanctifier" et "le sanctuaire".

Mais 31 donnait : “qui complote" et omettait le second mot en se référant au *T. RL donne : "verschwört euch" et "ein Fallstrick".

NEB donne : "you must count "hard" "et "your "hardship" en notant qu'il s'agit de conjectures parce que l'hébreu est inintelligible en ce contexte. Brockington précise

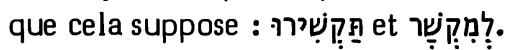

\section{Origines des corrections :}

En 8,12 se rencontrent deux emplois de la racine קשר. Considérant que le 'resh' et le 'dalet' se confondent aisément et que la distinction entre cette racine et celle à laquelle appartiennent les deux mots que nous étudions ne tient qu'à une permutation du 'shin' et du 'dalet/resh', Lowth a repris une conjecture de Secker suggérant

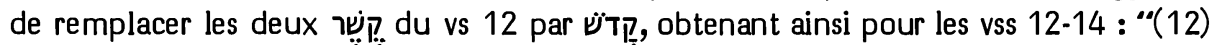
Ne dites pas saint tout ce que ce peuple dit saint, et l'objet de leur crainte, ne le craignez pas ni ne le redoutez. (13) C'est le Seigneur Sabaôt que vous tiendrez pour saint, c'est lui que vous craindrez, c'est lui que vous redouterez. (14) Il sera un sanctuaire et une pierre que l'on heurte..." Après avoir formulé cette conjecture, Secker hésitait, estimant que Jr 11,9 et Ez 22,25 rendaient acceptable l'usage fait ici par le *M de la racine קשׁ. Lowth, estimant à juste titre que ces deux passages n'illustraient pas bien le sens de cette racine en Is 8,12 , reprit à son compte avec conviction la suggestion de Secker, suivi en cela par Lagarde, Bredenkamp, Stade (Zu Jes 137), Grätz, HSAT234, Oort (Emendationes), Ehrlich (Miqra), Loisy (238s), Gray (hésitant), Ziegler (EB), Tur-Sinai (Contribution 174s).

Partant toujours du même axiome que l'une des racines est, en ce contexte, une corruption de l'autre, Duhm a inversé la problématique. Ici, il estime que ce sont les

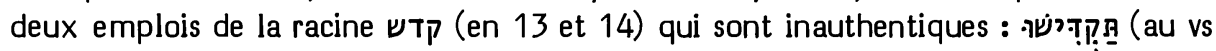
13) serait une corruption de den macht zum Verschwörer !" Quant à לִ לִ (au vs 14), reprenant une éventualité envisagée puis repoussée par Lowth, Duhmi estime (à la suite de Bredenkamp) que c'est une fausse variante pour לִ. Dans les premières éditions de son commentaire il omettait donc ce mot en 14a, le considérant comme destiné par un scribe à remplacer (ר) למוקש de 14b. Mais, dans la 5e édition, au lieu de l'omettre, il le remplaçait par למוקש qui se trouverait ainsi deux fois présent en ce vs.

Le premier état de la conjecture de Duhm a été adopté par $\mathrm{BH} 2$ et $\mathrm{J1}$; alors que le second état l'a été par BH3 (se fondant sur le *T) et RL.

Dans la ligne de la conjecture de Duhm pour le premier mot, Driver (Passages

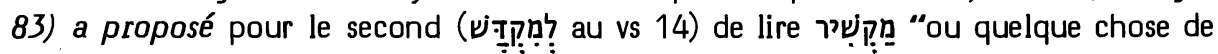
semblable". Cette proposition sera adoptée par Kaiser, alors que Wildberger préfé-

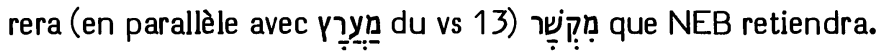

\section{Les témoins anciens :}

Le *M est appuyé par 1Q-a pour les deux emplois de chacune des deux racines en question. 4Q-h l'appuie pour les trois premières lettres de תקדישו qui, seules de ces quatre mots, $y$ sont conservées. 
Le *G concorde avec le *M pour la traduction de תקדישר (ápláoate) et de למקדש

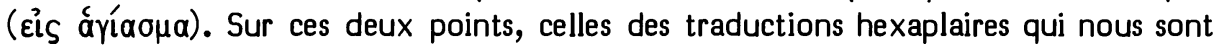
connues (Sym dans le premier cas, Aq et Sym dans le second) lui sont identiques.

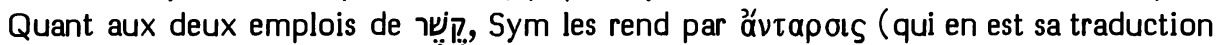
aussi en $2 \mathrm{R} 11,14 \mathrm{bis}$ ), alors que ThAq (attestés pour le premier par le ms 710) les

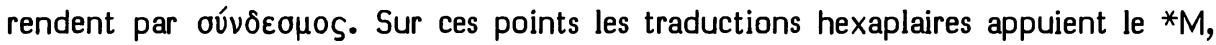

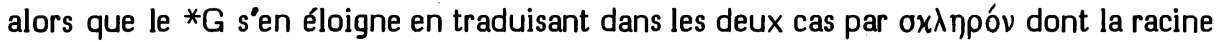
correspond très couramment à la racine hébraïque קשׁה (leçon issue de plutôt que de קדe).

La *V, en chacun de ces quatre cas ("coniuratio" bis en 12, "sanctificate" en 13 et "in sanctificationem" en 14), appuie clairement le *M.

C'est également le $* M$ que la ${ }^{*} S$ (victime d'un homéotéleuton dans les polyglottes de Paris et de Londres) traduit en 12(bis) par מרדא (comme en 2 R 11,14bis), en 13 par קדשר et en 14 par למקדשא.

Quant au *T, lui aussi traduit le *M en 12(bis) par מרוד et en 13 par תימרון קדיש.

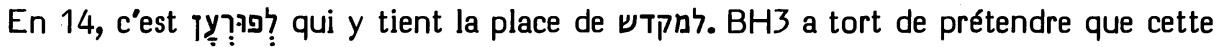
traduction suppose une Vorlage לִ לִ puisque le ${ }^{*} T$ traduit cette expression, plus

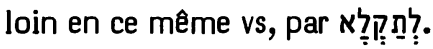

\section{Choix textuel :}

Lowth interprétait justement dans la KJ (reproduisant Ge sur ce point) : "a confederacy" et ne voyait pas ce que pouvait avoir de répréhensible l'alliance entre les deux états indépendants de Syrie et d'Israël que ce mot désigne. C'est cela, nous dit-il, qui l'incita à corriger le *M par conjecture. Mais, au XVIe siècle, Thomas More (Apology ch. 44) considérait ce mot comme "an odiouse heyghnouse name". Déjà Chaucer, traduisant littéralement "a conjuracioun" (en Boèce, de Consolatione Philosophiae II, prosa 6,62), notait sur ce mot : "which I clape a confederacye". La difficulté initiale de Lowth tient donc au fait que ce sens était vieilli à son époque.

A la présence de un sanctuaire et une pierre d'achoppement. Cela entraîne deux remarques. D'abord que l'atnah séparant ce mot du suivant souligne qu'il s'agit de deux éventualités placées en contraste. Ensuite, que l'on retrouve le même contraste encore plus abrupt à l'intérieur de l'expression צuiּ sui suit. Le Seigneur en tant que "roc" est le refuge absolument sûr. Or il se trouvera devenir le "roc sur lequel on trébuche". Lohfink (Isaias 103) a bien noté le caractère surprenant de ce rapprochement. D'autre part, l'authenticité de 13 est confirmée par 29,23 où l'on retrouve ce hifil de קדֹ lié (comme ici) au hifil de yר. Or la critique littéraire admet d'ordinaire que cet autre texte dépend de celui-ci.

Il n'existe en tout cas aucune base textuelle pour unifier les quatre cas qui nous concernent sur la base de l'une ou l'autre des deux racines que le ${ }^{*} M$ y atteste.

Interprétation proposée :

En 8,6 nous avions considéré comme préférable de comprendre sous הַ הַ le royaume du nord et les partisans qu'il pouvait avoir en Juda, c'est-à-dire ceux qui 
plaçaient dans une politique d'alliance régionale leur espérance de résister à l'expansion assyrienne. Il est évident que des oracles comme ceux de 7,18-20 ou bien le nom de Prompt-Butin-Proche-Pillage donné par Isaïe à son fils devaient être interprétés par "ce peuple" comme une collusion avec l'envahisseur assyrien. On devait donc considérer les interventions d'Isaïe comme une conspiration en faveur de l'Assyrie. Aussi Isaïe précise-t-il que le danger ne réside pas dans cette prétendue conspiration, mais dans le fait que, si l'on ne sanctifie pas le Seigneur, celui-ci, au lieu d'offrir un sûr refuge, deviendra une pierre d'achoppement pour Israël et Juda. Et il ajoute (vs 18) que, loin d'être les agents d'une conspiration, lui et les enfants que le Seigneur lui a donnés sont (par leurs noms) des signes et des présages en Israël, de la part du Seigneur Sabaôt qui réside sur le mont Sion.

\section{8,21 ำ [B] M Sym V // expl : T / assim 19 : G / incert : 1Q-a S}

Options de nos traductions :

RSV ("through the land") et TOB ("le pays") notent qu'elles explicitent le mot "pays" qui n'est pas dans le *M.

J ("dans le pays") et RL ("im Lande") explicitent de même, sans note.

NEB traduit par "over them", Brockington précisant que cela suppose une vocalisation i̇.

Origines des corrections :

Déjà Yéfet ben Ely et Radaq explicitaient le mot "pays" dans leurs commentaires. Parmi les traducteurs du XVIe siècle, ce mot a été explicité (avec ou sans indication de son caractère adventice) par Pagnini, Vatable, Münster, Calvin, Châteillon, $\mathrm{Ge}$, Tremellius, Pasteurs.

La conjecture de NEB remonte, à travers Driver (Isaianic 45), à Ginsberg (Allusion).

\section{Les témoins anciens :}

$1 \mathrm{Q}$-a, identique au *M, était-il lu comme suffixe masculin ou féminin ?

La même incertitude plane sur la graphie de la $* S$, quoique le point diacritique du ms Ambrosianus, la vocalisation de Sionita et l'apparat de Diettrich s'accordent sur son interprétation en féminin. Ephrem explicite lui aussi l'antécédent "pays", comme le fait le *T.

$L a * V$ (per eam) appuie clairement le *M.

Sym traduit $\mathfrak{k} \xi$ ảutoṽ. Comme l'indique le contexte en lequel il est cité par Procope, ce pronom a pour antécédent la Loi (en hébreu féminin, mais en grec masculin). Sym a donc lu le *M. Le fait qu'il l'ait traduit par un masculin est une exigence purement translationnelle.

Comme NEB le fera, le *G faisait déjà de נקשה ורעב le sujet du verbe. En ces conditions, sa traduction de בar ế $\varphi^{\prime}$ ú $\mu$ ăs (comme la mise à la $2 \mathrm{e}$ pers. du pl. de trois verbes de ce vs) est une assimilation au suffixe et au verbe à la $2 e$ pers. du pl. de 8,19 . 


\section{Choix textuel :}

On ne peut dire avec certitude si $1 \mathrm{Q}$-a et le traducteur de la *S ont compris le suffixe comme masculin ou féminin. Il est vraisemblable que le ${ }^{*} G$ l'a compris comme un masculin.

Cependant le *M est bien appuyé par Sym, la *V et le *T.

Aussi le comité lui a-t-il attribué la note "B".

Interprétation proposée :

Comme Knobel (à propos de 1,6) l'a noté, les suffixes se réfèrent souvent à un contenu de pensée qui n’a pas encore été désigné par le substantif qui lui convient, ce qui est le cas ici comme en 1,6; 5,14.30; 14,31; Ps 39,7; 68,11.15.

Le plus vraisemblable est qu'il s'agit ici du pays (ארץ étant féminin) ou de Jérusalem.

Si l'on a affaire ici à un fragment d'oracle, il est possible que le substantif était explicité en une partie non conservée, ainsi que Wildberger, J et TOB l'ont suggéré.

Le sujet inexprimé des verbes à la $3 e$ pers. m. sg. de ce vs et du suivant peut être "ce peuple" de 8,11.12. Ce serait déjà lui que désignait le dernier suffixe du vs 20 . S'il s'agit d'un fragment, la non-expression du sujet s'explique encore plus aisément.

9,2(3) לו [C] MQ G? S T // incert : 1Q-a לוא err : MK Sym V לא

Options de nos traductions :

RSV ("thou hast increased its joy") et J3 ("tu as fait croître sa joie") traduisent par le possessif "its" ou "sa" le qeré iל.

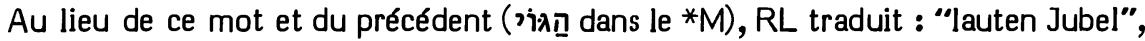
J1 : "leur jubilation", J2 et TOB : "leur allégresse" et NEB "their joy and". J2 explique qu'elle conjecture הֵַ et Brockington dit que NEB fait de même. Pourtant, la note de NEB laisserait plutôt croire qu'elle entend lire : הגיל והגדלת (faisant usage du 'waw' du qeré comme conjonction).

Origines de la correction :

RL, J12 et TOB ont pu trouver cette conjecture proposée par les apparats de Cent, BH23S et HSAT234. Elle avait été proposée par W. Selwyn (cité par Gray) en alternative avec celle que NEB semble lui avoir préférée. Son succès est dû à ce que Duhm l"a adoptée tout en notant que Is 26,15 lisait déjà rìn en Is 9,2, à ce qu'il semble.

Les témoins anciens :

Le *M offre ici un qeré iל en concurrence avec le ketib לא.

Le ketib a été lu ici par Sym (selon Eusèbe et Procope, alors que le ms 710 ajoute à son sigle ceux de $\mathrm{Th}$ et $\mathrm{Aq})$ et par la *V.

Le qeré l'a été par la *S et le *T (qui traduit librement par להון). 
A la place de ce mot et du verbe suivant, le ${ }^{*} G$ offre : ó $x a \tau n ́ \gamma a \gamma \varepsilon \varsigma$. Cappel

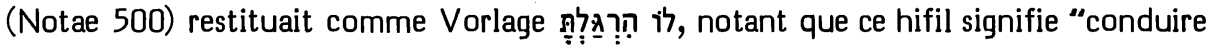
pas à pas". Etant donné qu'aucun témoin du ${ }^{*} G$ n'insère ici de négation, il est vraisemblable que le ${ }^{*} G$ a lu le qeré.

$1 Q$-a écrit ici לוא. Cette graphie est équivoque. En effet, en ce ms il peut s'agir d'une graphie pleine pour לא (ce qui est le plus souvent le cas). Mais il peut s'agir aussi d'une façon de souligner le caractère vocalique du 'waw' final (comme pour כיא). Elle vaut alors pour iל (ce qui est le cas en 3,11; 5,26; 36,22; 40,10; 44,14bis; 57,18; 59,16). Des graphies de ce genre peuvent être à l'origine de ce type de qeréketib.

\section{Choix textuel :}

A supposer que les conjectures proposées par Selwyn touchent juste, elles reconstituent un texte que plus aucun témoin n'a connu et que (très probablement) l'auteur de Is 26,15 ne connaissait déjà plus. Ces conjectures nous feraient donc sortir du cadre de notre recherche.

D'ailleurs, contre la forme הגילה de la conjecture, Ehrlich a objecté que cette forme féminine appartient à la langue postexilique. Contre la forme הגיל noter que שיל précède toujours lorsque ces deux substantifs sont associés (Is 16,10; Jr 48,33; Jl 1,16; Ps 43,4; 45,16).

Le seul choix textuel qui s'offre à nous est entre le qeré et le ketib qui sont tous deux attestés anciennement, ainsi que nous l'avons vu.

La tradition de ce qeré est déjà mentionnée dans le traité Sopherim. Tous les exégètes juifs expliquent le qeré. Certains expliquent aussi le ketib. Ainsi Rashi lui trouve deux sens : d'abord que la joie a été accrue pour ce peuple (= qeré), mais non (= ketib) pour ses ennemis; puis que la joie d'Ezéchias ne fut pas (= ketib) parfaite, parce qu'il lui fut dit $(39,6)$ : “Des jours viennent où sera emporté à Babylone tout ce qui est dans ta maison." La première explication du ketib que donne Rashi sera reprise par Radaq et la seconde par Abravanel en leurs commentaires.

Quant à Ibn Ezra, il arrive à donner au ketib le même sens qu’au qeré, puisqu'il estime que le sens de cette négation est qu'il n'y avait pas eu auparavant de joie comme celle-là.

En face de cette unanimité des exégètes juifs médiévaux en faveur du qeré, on est surpris de voir les traducteurs chrétiens du XVIe siècle d'abord unanimes en faveur du ketib. C'est en effet la leçon que choisissent Oecolampade, Pagnini, Luther, les Prédicants de Zürich, Brucioli, Münster, Olivetan, Jud, Rollet, Estienne, Ge, Tremellius, $\mathrm{KJ}$.

Ce large succès du ketib a une double cause. D'abord l'influence de la $* V$ (dont Oecolampade et Pagnini se contentent de recopier la traduction). Ensuite du fait que les premières éditions du *M (par exemple la Bible de 1488 ou celle de Brescia 1494) ne donnaient aucun qeré en marge, les traducteurs qui en faisaient usage étaient en droit de penser que לא était, de manière incontestée, la leçon de l'hébreu. Il fallut attendre la Bible rabbinique de Félix de Prato (en 1517) pour que l'on prît conscience ici de l'existence de la leçon rivale לר qu'il donnait en marge, à laquelle le *T (qu'il éditait) se rattachait clairement et que Radaq (qu'il éditait) commentait en premier. 
En 1525, la Bible massorétique de Ben Hayim révélait exactement la situation en donnant en marge la leçon ל̀ titre de qeré, en donnant en haut de cette page la mm des "15 לא que l'on écrit avec 'alef', mais que l'on lit avec "waw" et en éditant en marge les commentaires de Rashi et d'Ibn Ezra.

On comprend donc qu'un certain nombre des traducteurs du XVIe siècle semblent ignorer l'existence ici d'un qeré et que, parmi les premiers qui, dans leur commentaire, manifestent cette connaissance, Oecolampade et Calvin attribuent la lecture לu que les juifs font de ce texte à l'incapacité de ceux-ci à comprendre le sens authentique (et paradoxal) de la leçon לא.

Le premier qui ait eu l'audace de traduire selon le qeré paraît avoir été Châteillon en ses Bibles latine (parue en 1551) et française (en 1555). Il semble que la Bible des Pasteurs de Genève (comme souvent influencée par Châteillon) soit la seule (en 1588) à l'avoir suivi sur cette route. Avec Luther ("Du machest der Heiden viel, damit machestu der Freuden nicht viel") et KJ ("Thou hast multiplied the nation, and not increased the joy") les Bibles allemandes et anglaises resteront inertement fidèles pendant des siècles à la leçon du ketib. Le fait que ces deux grandes traditions bibliques de l'occident chrétien soient restées fixées sur cette leçon qui est peu en harmonie avec le contexte explique pourquoi la conjecture de Selwyn-Duhm a rencontré un tel succès.

En effet le qeré est apparu préférable à 4 membres du comité qui lui ont attribué la note "C" alors qu'un autre votait "C" pour le ketib et qu'un autre attribuait la note " $A$ " au $* M$, sans choisir entre qeré et ketib.

Interprétation proposée :

Les nombreux partisans que le ketib a eus au XVIe siècle lui ont trouvé des interprétations variées : Selon Oecolampade, “tu as multiplié le peuple, mais tu n'as pas rendu grande la joie" signifie que, alors que l'Eglise se multipliait durant les persécutions, "on allait et on pleurait répandant la semence" (Ps 126,6), comme Jésus l'avait annoncé (Jn 16,20): "le monde se réjouira, alors que vous pleurerez". Mais (Mt 5,5) "heureux ceux qui pleurent, car ils seront consolés". Il existe en effet une antithèse entre les larmes et la joie intérieure qui ne peut être causée que par la consolation de l'Esprit Saint. Mais les "hébreux" qui ne veulent pas attribuer ici à לא une valeur négative ignorent cette antithèse. Comme on le voit, on est ici assez loin d'une critique textuelle objective du type de la brève note de Châteillon : "intellige לא pro לו positum".

L'année (1525) où Oecolampade publiait son commentaire sur Isaïe, Luther, le jour de Noël, eut l'occasion de prêcher sur ce texte. Voici l'exégèse qu'il en donnait, selon la reportatio de Rörer (WA. XVII/1 502,4-10) : "Du hast das volcks vil gemacht, aber der freuden wenig. Iam numerat propheta, wie es zu ghet, quando lux illa oritur. Una pars gaudet, altera irascitur. Iudaei ubi vident hanc lux oriri et numerum augeri, indignati volebant ipsi tantum esse populus per opera sua. Ibi volebant eos perdere, qui fidebant sola misericordia. Sic hodie, quando praedicamus fidendum sola misericordia, wirt der freud wenig, quia inimici werden druber zornig : meinstu, das unser veter narrn sein gewest ?" Dans son cours sur Isaïe de 1528 (WA. XXXI/2 68, 22-30), puis dans son enarratio sur le ch. 9 d'Isaïe en 1543/44 (WA. XL/3 615-622) 
il développe la même exégèse. Mais, en ce dernier ouvrage il manifeste sa connaissance du qeré dans les termes suivants : "Rabini non curant cohaerentiam illam aut consequentiam, sed lacerant eam et depravant Prophetarum dicta, ut hoc loco pro adverbio 'non' legunt pronomen 'ei', ad hunc modum : 'Multiplicasti gentem, ei magnificasti laeticiam'. Sic violenter corrumpunt et depravant Prophetae sententiam, cum nec res nec consequentia consentiat."

Les explications que nous avons données ci-dessus montrent suffisamment pourquoi Oecolampade et Luther s'attachaient à une forme textuelle qui leur était familière depuis toujours et se défiaient de la tradition de lecture des "hébreux" ou des "rabbins".

De fait, c'est le qeré que choisissent ici celles de nos traductions (RSV et J3) qui demeurent fidèles au ${ }^{*} M$. C'est en effet la leçon qui convient au contexte, le ketib provenant probablement d'une fausse interprétation d'une graphie pleine semblable à celle de 1Q-a. L'anticipation du complément לו avant le verbe répond à une intention d'emphase.

Une traduction littérale serait donc: "tu as multiplié la nation, pour elle tu as fait croître la joie; ils se sont réjouis devant toi comme on se réjouit à la moisson, comme on exulte lorsqu'on partage le butin."

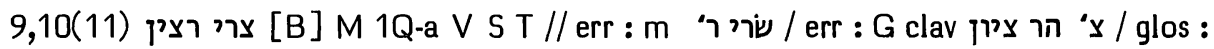
t ins דישראל

Options de nos traductions :

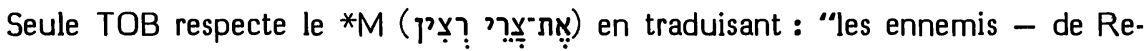
cîn -" et en indiquant qu’elle considère les mots placés entre tirets comme étant probablement une glose.

RSV traduit seulement : "adversaries" par conjecture.

J12 traduisaient : "ses ennemis" en disant lire צִ̣ leçon que Brockington attribue aussi comme Vorlage à "their foes" que NEB conjecture.

J3 traduit : "son adversaire Raçôn" notant qu'il s'agit d'une conjecture.

RL traduit : "ihre Bedränger, nämlich Rezin".

Origines des corrections :

La conjecture de J12, NEB est mentionnée par BHS comme ayant été proposée. Elle l'a été par Bredenkamp, Ehrlich, Gray, Procksch.

RL a adopté la même conjecture, sans omettre le mot qui suit.

C'est une conjecture de Duhm (transmise par Cent et $\mathrm{BH} 23$ ) que $\mathrm{J3}$ a adoptée

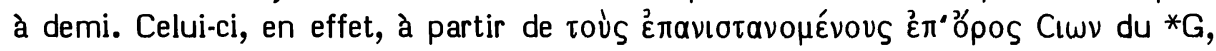

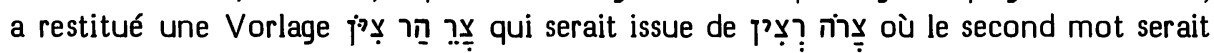
une glose interprétative.

D'où vient la conjecture de RSV ? Le caractère indéterminé du substantif y est peu compatible avec la particule d’accusatif de l’hébreu. 
Les témoins anciens :

La Vorlage restituée par Duhm pour le *G est peu vraisemblable. Mieux vaut, avec Cappel (Notae 500), admettre qu'il a lu צרי הר צ', ce qui amène Michaelis à traduire : "die Widersacher des Berges Zion".

Houbigant avait proposé de lire ici ְִำ à la place de Lowth (suivi par Doederlein et Ewald) a adopté cette leçon en notant qu'elle est confirmée par 22 mss (dont 2 anciens) du *M. Cependant, comme HUB le montre, les mss tibériens classiques sont d'accord pour appuyer la leçon צִִ

1Q-a, avec de simples variantes orthographiques, appuie le *M.

La *V (hostes Rasin) et la *S (לאלו̈צוהי דרצן) traduisent, elles aussi, le *M.

Le *T, dans sa forme la plus sobre (attestée par le ms Urbinates 1 et, avec de légères variantes, par le ms Reuchlin et les éditions de Félix de Prato et de Ben Hayim)

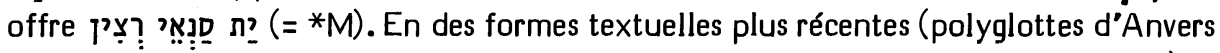
et de Londres, mss yéménites de Sperber et de Stenning et ms Paris BN hébr 1325), il insère דישראל, obtenant : “les ennemis (ou : l'ennemi) d'Israël, Recîn". Il semble bien que cette glose facilitante constitue un événement secondaire dans la tradition textuelle du *T.

\section{Choix textuel :}

Le *M a fait difficulté aux traducteurs et aux exégètes. En effet, ce qui précède et ce qui suit laisse attendre que le vs 10 exprime un châtiment d'Israël, or il nous parle d'une intervention des adversaires de Recîn contre lui. On comprend donc que nos cinq traductions essaient d’éliminer ces "adversaires de Recîn", puisque ce n'est pas le sort de celui-ci qui est en jeu.

Déjà Luther traduisait ici : “Denn der Herr wird des Rezins Kriegsvolk wider sie erhöhen." Dans son cours de 1528, il glosait en effet "hostes Rasin" de la *V par "et hostilem exercitum eius", glose qui ne nous a été conservée que dans la reportatio d'Antonius Lauterbach (WA. XXXI/2 73,10s).

La lectio difficilior du *M apparaît clairement comme la forme d'où ont divergé les autres formes textuelles. Aussi, le comité lui a-t-il attribué la note "B".

\section{Interprétations proposées :}

2 R 16,9 raconte que le roi d'Assyrie écouta l'appel à l'aide d'Akhaz, "se rendit à Damas dont il s'empara; il en déporta les habitants à Qir et mit à mort Recîn." On peut conclure de cela que l'expression "les ennemis de Recîn" est ici une périphrase pour désigner les Assyriens et ceux d'entre les Araméens qui, à cette occasion, prirent le parti de l'envahisseur. C'est vraisemblablement pour rappeler aux Ephraïmites l'échec de leur alliance avec Recîn qu'Isaïe fait usage de cette périphrase où "contre lui" ne veut pas dire "contre Recîn" mais "contre Israël", ainsi que cela est explicité dans le vs suivant. 


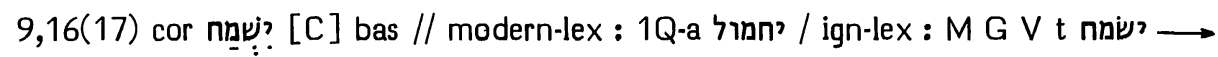
theol S T clav neِve?

Options de nos traductions :

Le *M לאי?:? a été traduit par RSV ("does not rejoice") et J3 ("ne trouvera plus sa joie").

J12 traduisaient "n'épargnera pas" en se fondant sur 1Q-a. Il est fort possible que RL ("kann ... nicht verschonen") ait fait de même, la variante יחמול de 1Q-a figurant dans l'apparat supplémentaire de $\mathrm{BH} 7$.

NEB traduit "showed no mercy" et TOB "ne sera pas favorable", Brockington précisant que cela suppose une leçon nמְِ:?•

\section{Origines des corrections :}

Estimant que le contexte ne s'accorde pas avec le sens "se réjouir", Lagarde a conjecturé ici יפשס = (יפסח), au sens que ce verbe a en EX 12,13.23.27 : "sauter pardessus" pour épargner. Cette conjecture a été adoptée par HSAT234, Dillmann/Kittel, Cheyne, Duhm, H. Schmidt.

Grätz a conjecturé ici יחמל, suivi par Ehrlich. La découverte de cette leçon en 1Q-a lui a donné un regain d'attrait (cf. James 66s).

Perles (Notes 63) a remarqué qu’en Si 36,17 le grec ẻ $\lambda \varepsilon ́ n o o v$ correspondait au

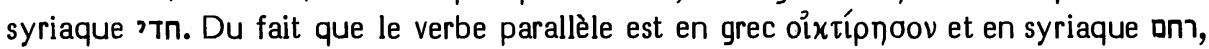
il a supposé que le traducteur grec avait interprété exactement et le traducteur syriaque inexactement un hébreu שמח qui aurait le sens de l'arabe 'samuha' : "être bon, bienveillant, généreux". Retrouvant en Is 9,16 ישמח en parallèle avec an', Perles y a vu une confirmation de son hypothèse et conjecturé un déplacement du point diacritique.

Les témoins anciens :

1Q-a porte ici בחמול (la graphie pleine ayant été ajoutée par la 2e main).

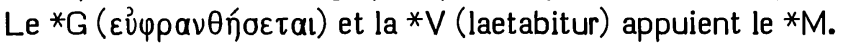

La ${ }^{*}$ p porte ici 1 dont le point en haut indique une forme intensive, ainsi que Sionita et Warszawski l’ont interprété. Donc: "le Seigneur ne donnera pas de joie à propos de leurs jeunes gens".

Le *T, selon les éditions de Félix de Prato et de Ben Hayim, ainsi que selon les polyglottes d'Anvers et de Londres est conforme au *M, lisant : על עולמוהי לא יחדי Mais les mss Reuchlin (contre les données fournies par Sperber), Urbinates 1 et Paris BN hébr 1325, ainsi que les mss yéménites utilisés par Sperber et Stenning lisent : 'ית ע' ל ל ' c'est-à-dire : "le Seigneur ne réjouira pas leurs jeunes gens". Il semble bien que la leçon des éditions classiques a été assimilée au *M, alors que les mss nous

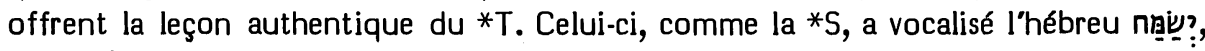
afin d'éviter un anthropomorphisme. Saadya a fait de même.

\section{Choix textuel :}

R. Meyer (Probleme 230) a interprété la leçon de 1Q-a comme une modernisation de la forme conjecturée par Perles, à une époque où le sens de celle-ci était 
encore connu du scribe qui a opéré cette retouche, mais où ce verbe n’était presque plus en usage. Comme Wildberger l'a fait remarquer, la leçon de 1Q-a offrirait donc un appui indirect à la conjecture de Perles. Driver (Scrolls 24) et Brownlee (Meaning 176s) acceptent cette interprétation qui avait été suggérée déjà par Burrows (Readings II 27). Donner (68) suggère que le substitut choisi par 1Q-a provient du vs 18.

On peut donc considérer la leçon ?ְִׁׁ comme faisant l'objet d'une attestation textuelle indirecte, en tant qu'elle nous offre la base à partir de laquelle ont divergé la leçon du *M (par une ponctuation facilitante causée par une ignorance lexicographique) et la leçon de 1Q-a (par une modernisation lexicographique).

Quatre membres du comité en ont jugé ainsi et ont attribué à cette leçon la note "C", alors que deux autres ont opté pour le * $M$ avec cette même note.

Notons qu'en $\mathrm{Si} 36,17$, l'hébreu ne nous a été conservé que par le ms $\mathrm{B}$ (découvert deux ans après que Perles ait formulé sa conjecture). Or il porte ici on que l'on retrouve identique dans le parallèle du vs suivant. Cette identité peut être l'indice d'une modernisation analogue à celle qu'a subie le texte de $1 Q$-a.

Interprétation proposée :

Le sens de la correction est : "le Seigneur ne témoignera pas de bienveillance à ses jeunes gens".

Mais il pourrait être bon d'indiquer en note la leçon “ne trouvera pas sa joie en ses jeunes gens" sur laquelle le *M, le *G et la *V s'accordent.

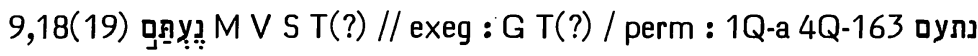

Options de nos traductions :

Le *M de 18a porte :

Le verbe a fait des difficultés aux exégètes. Sans note, il est traduit par RSV : "the land is burned", par RL: "brennt das Land" et par NEB : "the land is scorched".

J1 traduisait également sans note : "le pays est incendié". J2 garde cette traduction en disant la fonder sur le $* G$, alors que l'hébreu est corrompu. 33 traduit: "la terre a été brûlée" en se référant au grec, alors que l'hébreu serait inintelligible.

TOB traduit: "le pays est ébranlé", disant se fonder sur la*S, la*V et, pour une part, 1Q-a; alors que le ${ }^{*} G$ et le ${ }^{*} T$ ont lu "est embrasée" et que l'hébreu serait corrompu.

\section{Origines des corrections :}

L'évolution subie par $\mathrm{J}$ dans son appréciation du $* M$ avait déjà été vécue par HSAT. En effet HSAT2 traduisait : "brannte das Land" sans note, alors que HSAT34 disent le * $M$ inintelligible.

Quant à l'appui que 3123 prennent sur le *G pour traduire : "est incendié" ou "a été brûlée", il vient des apparats de $\mathrm{BH} 23$ qui conseillent de lire avec le *G et le *T נְְִּת (Vorlage suggérée par Krochmal que Dillmann/Kittel cite ici).

Enfin, c'est Duhm qui a conseillé de prendre appui sur la *V et la ${ }^{* S}$ pour lire ici "ist verwirrt". 
Les témoins anciens :

1Q-a porte ici נתעם confirmé ici par $ם \dot{y}[\Omega$ en 4Q-163, fragm. 4-7, col. 1, l. 14.

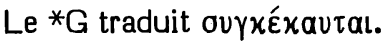

Selon les éditions courantes (polyglotte de Londres, Sperber, Stenning), le *T

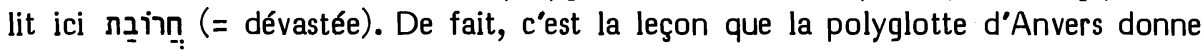
ici en accord avec les mss Reuchlin, Urbinates 1 et Paris BN hébr 1325. Pourtant, la leçon du *T pourrait aussi être חִ (= brûlée) que les éditions les plus anciennes (Félix de Prato et Ben Hayim) donnent ici et qu'Elias Levita commente à propos de l'article עr des Shorashim de Radaq. C'est également la forme sous laquelle Rashi cite le *T en son commentaire, selon l'édition princeps. L'exégèse que le ${ }^{*} T$ donne de ce mot coïnciderait alors avec celle du ${ }^{*} \mathrm{G}$.

La *V traduit ici "conturbata est", Hie donnant "contremuit" à quoi correspond exactement la traduction תyт de la *S.

\section{Choix textuel :}

Ce cas n'a pas été soumis au comité.

L'un des plus anciens essais pour rattacher cette forme à une racine connue par ailleurs est celui de David ben Abraham qui (II 404,25s) propose de la rattacher à la racine איכה יועם זהב (Lm 4,1), c'est-à-dire : “comment l'or s'est-il assombri, a-t-il perdu son éclat ?"), en admettant que le 'taw' est adventice. Selon Ibn Ezra, Moshé ibn Giqatilla optait lui aussi pour cette dérivation en disant que le 'taw' est celui du hitpaél. Ibn Ezra considère cela comme une grave erreur. Pinsker (Liqquté qadmoniot 147) note que David ben Abraham a considéré à tort le hitpaél hébreu comme pouvant transférer son 'taw' après la première radicale, à la manière de la 8 e forme du verbe arabe, alors que l'hébreu n'opère ce type de permutation qu'après une sibilante. Discutant de l'opinion de Moshé ibn Giqatilla, Vitringa conclut que cette analyse traite la forme נת comme si c'était Ajoutons que cette analyse prend comme point de référence le nitpaél mishnique plutôt que le hitpaél biblique.

Il est surprenant de trouver attestée à Qumrân (1Q-a et 4Q-163) cette forme נתעם sur laquelle semble vouloir porter l'analyse de David ben Abraham et de Moshé ibn Giqatilla. Faut-il en conclure que c'est cette leçon qu'ils ont eue sous les yeux ? Ou doit-on penser, au contraire, que les scribes de Qumrân, déjà partisans de ce rapprochement exégétique avec Lm 4,1, ont opéré cette permutation pour faciliter ce rapprochement ? Kutscher (296) considère la leçon de 1Q-a comme tout aussi énigmatique que celle du *M. Cependant (508), il la rapproche de deux autres cas (תפראת en 13,19 et מודעיו 14,31) où la consonne qui, dans le $* M$, suit une gutturale se trouve, en 1Q-a, la précéder. Il semble donc qu'il n'y ait aucune lumière à tirer de la leçon de $1 Q-a$.

Le sens de "obscurcir, couvrir" que David ben Abraham et Moshé ibn Giqatilla essayaient de justifier par une analogie grammaticale critiquable est demeuré longtemps solidement enraciné pour ce mot dans l'exégèse littérale juive, puis chrétienne.

Dans un passage du dictionnaire de David ben Abraham (II 439,35 à 440,38), qui ne nous a été conservé que par les compendia de Lévi ben Yéfet et d'Ali ben Israël, celui-ci fait deux autres suggestions. Il estime d'abord que ce mot signifie : "le pays 
a été obscurci", au même sens que la 7e forme du verbe ony de l'arabe. Il rapporte aussi que certains voient ici une substitution de gutturales pour נחת (ce qui sera la $2 \mathrm{e}$ exégèse du glossaire $\mathrm{C}$ ). La première de ces deux suggestions a été faite aussi par Abulwalid (Ușul 556, 7s) et Ibn Barûn (83s) renvoyant à Abû Iṣ̣âqq az-Zajjâj et au kitâb al-'Ayn. Peu avant Ibn Barûn, Judah ibn Balaam avait déclaré ne pas trouver ce sens de "s'obscurcir" attesté dans le kitâb al-“Ayn (qui, dit-il, donnait à סתy le sens de "tarder"), mais dans le kitâb az-Zâhir d’Ibn Anbârî. Ce sens de "s'obscurcir" est adopté ici par Yéfet ben Ely. Cette équivalence avec l'arabe est attestée aussi par Tanhum Yerushalmi, Ibn Ezra, Radaq (Shorashim), Pagnini (Thesaurus), J.D. Michaelis (OEB). Du même rapprochement avec l'arabe, Judah ben Qoreish (Katz $140=$ Bargès 79) tirait le sens proche de "est couverte".

A la suite de Reuchlin, presque tous les traducteurs du XVIe siècle ont adopté le sens de "être obscurci".

Une autre dérivation à partir de l'arabe a été proposée par J.H. Michaelis en ses notes sur la Bible de Halle, en référant ce mot à ás̆ Koppe a prétendu qu’en arabe áñर̀ signifie "a brûle". Gesenius a réfuté cette opinion. Pourtant, il a accepté l'opinion de J.H. Michaelis, tout en reconnaissant que, dans le QamOs, cette signification est assez isolée et sans relation avec les autres sens de Cette dérivation a cependant été accceptée par Rosenmüller, Luzzatto, von Orelli. Dans son Thesaurus, Gesenius faisait même état de parallèles éthiopiens et puniques pour appuyer ce sens. Mais BDB a souligné le caractère incertain du passage de "chaleur étouffante" à "être brûlé". Pour appuyer cette interprétation (attestée par le *G

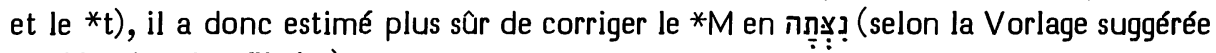
par Krochmal qu'il cite).

Le sens "être obscurci" avait été considéré comme convenant mal au contexte par ceux des exégètes qui étaient partisans de "être brûle". Delitzsch (suivi par Nägelsbach), conscient des bases lexicographiques fragiles de ce dernier sens, a cru trancher le noeud gordien en traduisant par "carbonisé", ce qui lui permet de tenir l'interprétation traditionnelle de "obscurci" en voyant en ce noircissement l'effet du feu.

Moran (Root) a proposé de voir plutôt dans le 'mem' final de ce mot un 'mem' enclitique "si familier en ugaritique", ce qui permettrait de rattacher le mot à la racine נוע et de justifier le sens de "être instable, tituber" que la *V et la *S semblent avoir décelé ici. Cette proposition a été adoptée par Hummel (Mem 94), Young, Morrow, Kaiser2 et le Supplementum (179) de KBL. Avant toute connaissance de l'ugaritique, Saadya traduisait déjà ce mot par אצטרב (= est secoué) et Dunash (Contre Saadya §151) nous précise que Saadya considérait ici נas comme équivalant à הy. Dunash, quant à lui, estimait cette analyse impossible, considérant que נyת était un nifal de aתy. Entre Saadya et la découverte de l'ugaritique, cette équivalence avec נy avait été proposée par Bredenkamp et le sens "conturbata est" avait été considéré par Duhm comme celui qui correspond le mieux au contexte.

Wildberger estime que le parallélisme avec l'hémistiche qui suit montre que le ${ }^{*} G$ a trouvé à peu près le sens exact, sans que nous soyons en mesure de reconstituer une Vorlage. Il opte donc pour : "est roussi" ("ist versengt").

Kaiser qui, en 1963 (2e édition), acceptait l'analyse de Moran, est revenu en 1981 (5e édition) au sens de "s'est obscurci" ("verdunkelte sich") en invoquant la même relation avec l'arabe que David ben Abraham suggérait déjà et que von Mutius (Sprachvergleichung 17s) a récemment remise en valeur. 
Concluons que les exégètes se sont divisés depuis très longtemps entre trois interprétations principales : "être brûlé", "être secoué" ou "s"obscurcir". Aucune de ces interprétations ne peut se fonder sur une analyse philologique vraiment convaincante. Il est probable qu'elles se fondent surtout sur ce que leurs partisans ont considéré comme suggéré par le contexte plus ou moins large de ce mot.

Il semble donc déplacé de prétendre corriger le $* M$ en fonction de la variante (tout aussi mystérieuse) de 1Q-a ou en fonction de la Vorlage que certains ont cru pouvoir assigner au ${ }^{*} \mathrm{G}$.

\section{Interprétations proposées :}

L'image du feu, de l'incendie et de la flamme domine le vs 17 et le début de 18a. Il est donc normal que le *G et le *t aient voulu lire ici le sens de "être brûle".

L'expression "conturbata est terra" de la *V et l'expression זעת אר qui lui cor-

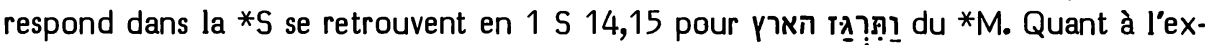
pression "contremuit terra", dont Hie fait usage ici, elle se retrouve dans la $* V$ de 2 S 22,8 = Ps 18,8; 77,19; Jl 2,10; Na 1,5 avec le même correspondant en la *S (sauf

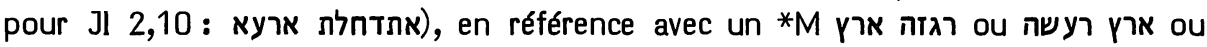
ותרעש הארץ. On rencontre aussi plusieurs fois dans la Bible les hifil des mêmes verbes avec le substantif ארץ comme complément d’objet (Ps 60,4; Jb 9,6; Is 14,16). Il semble donc que la $* V$ et la ${ }^{*} S$ ( $s$ inspirant peut-être de Sym dont nous ne connaissons pas la leçon) ont fait usage ici d'un lieu commun du style épique biblique, cette expression leur semblant appelée par le sujet "terre" et l"ambiance catastrophique du contexte.

Quant au sens "s"obscurcir", l'obscurcissement de la terre apparaît dans un contexte catastrophique en Am 8,9, mais il ne s'agit pas d'un lieu commun aussi ressassé que l'ébranlement de la terre qui titube. D'autre part la relation de l'obscurcissement avec le contexte précédent et suivant est plus subtile que celle de l'incendie (trouvé ici par le ${ }^{*} G$ et le $\left.{ }^{*} t\right)$. Certains ont même refusé ce sens d'obscurcissement comme convenant mal au contexte. Mais Kaiser a bien vu que $17 \mathrm{~b}$ nous montre l'incendie prenant dans les sous-bois et en faisant monter des volutes de fumée. $L$ 'obscurcissement de la terre par ces nuages de fumée qui coupent le jour en est donc la conséquence normale. Ajoutons enfin que, des trois sens concurrents, celui-ci est celui pour lequel on peut évoquer le parallèle lexicographique le plus plausible (avec l'arabe). On pourra donc traduire : “(17) Oui, la méchanceté brûle comme un feu qui dévore épines et ronces. Elle enflamme les taillis de la forêt. Ils s'élèvent en tourbillons de fumée. (18) Sous l'emportement du Seigneur Sabaôt le pays est obscurci et le peuple est comme une proie pour le feu."

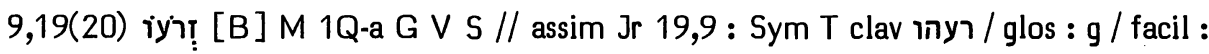
4Q-e זרעי

Options de nos traductions :

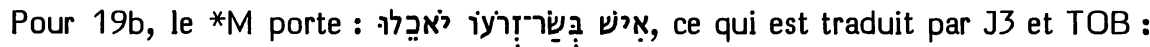
"chacun dévore la chair de son bras". 
312 traduisaient : "chacun dévore la chair de son voisin", disant lire iy? en s'appuyant sur "les versions". RSV traduit de même : "each devours his neighbor's flesh" en s'appuyant sur le ${ }^{*} T$ et se référant au ${ }^{*} G$. RL aussi traduit : "ein jeder frisst das Fleisch seines Nächsten".

Quant à NEB, elle traduit ici : "each feeds on his own children's flesh", sans note; Brockington précisant que cela suppose une vocalisation : iyา?̣.

\section{Origines des corrections :}

La correction choisie par J12, RSV et RL a été demandée par Cent et HSAT34 qui la fondent sur le ${ }^{*} \mathrm{G}$.

Secker (cité par Lowth) semble avoir été le premier à la proposer en y voyant la

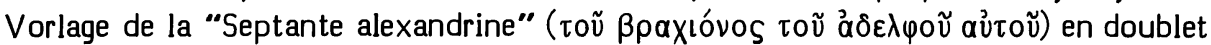
avec la leçon du *M. Il précise que Jr 6,21 offre cette graphie et que yר est traduit par åo $\delta \lambda \varphi o ́ s ~ e n ~ G n ~ 43,33$. Lowth ajoute à cela que le *T (קריביה) a lu évidemment cela au lieu de la leçon du *M et que Jr 19,9 offre exactement la même expression : ואיש בשר רעהו יאכלו. Il lui semble que cette correction offre l'avantage de faire du vs suivant l'explication de cette énonciation globale.

La correction de NEB reprend un al-tiqré proposé par le Talmud Babli (Shabbat 33a). Notons que R. Joḥanan (en Talmud Babli Taanit 5a) commente ce texte à la fois selon cette tradition homilétique et selon la leçon du $* M$ : Que mange-t-on au cours d'une famine qui dure sept ans? La première année, on mange ce qui reste dans les maisons, la deuxième ce qui est encore sur les champs, la troisième la viande des animaux purs, la quatrième celle des animaux impurs, la cinquième celle des animaux répugnants et rampants, la sixième la chair de ses fils et de ses filles, et la septième celle de ses propres bras, pour accomplir ce qui est dit en Is 9,19b. Talmon (Aspects 127) estime que ce al-tiqré se fonde sur une ancienne variante textuelle.

\section{Les témoins anciens :}

1Q-a, par une graphie pleine זרוע, appuie formellement la leçon du ${ }^{*} M$. 4Q-e lit ici זרעיו Cette leçon qui respecte la graphie défective du *M se contente de la mettre au pluriel, vraisemblablement parce que cela semble mieux convenir au fait que chacun a deux bras. Il ne peut s'agir d'un pluriel de yרֵ, car ce mot, fréquent dans la Bible au sens de "postérité", y est senti comme collectif et n'y apparât jamais au pluriel en ce sens.

Ce que Secker citait comme "Septante alexandrine" c'est l'édition du ms A par Grabe qui, pour 19b (du*M) et les deux mots qui précèdent, offre : xaì oủ $\mu$ ì

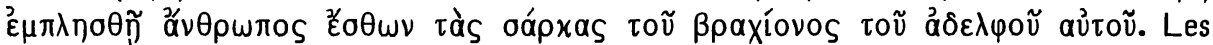
mots $\tau 0$ ơ $\alpha$ $\delta \varepsilon \lambda \varphi \circ \tilde{~ y ~ s o n t ~ u n e ~ g l o s e ~ a ̀ ~ l ' a t t e s t a t i o n ~ a s s e z ~ m a r g i n a l e . ~ L a ~ t r a d i t i o n ~ t e x t u-~}$ elle ancienne du ${ }^{*} G$ ne les porte pas. $L e{ }^{*} G$ ancien est donc un supporter explicite $d u * M$.

D'ailleurs, il est peu vraisemblable que cette glose soit issue d'une recension du *G sur la base d'une Vorlage רעו. En effet, en faveur d'une correspondance de åo $\delta \lambda \varphi o^{\prime} S$ avec y? ?n on peut citer Gn 43,33 et Jr 31,34 (selon le ms A). Mais, en ce dernier cas, il s'agit d'une transposition (du correspondant de avec celui de רחיו) qui n'est attestée que par le ms $A$ et la recension origénienne. Et la correspondance isolée de 
Gn 43,33 ne suffit pas pour la rendre vraisemblable ici. Mieux vaut admettre que

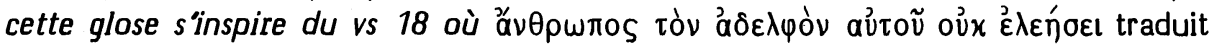
fidèlement le *M.

Le *T porte ici קריביה que Lowth, suivi par plusieurs, a considéré comme traduisant une forme du substantif yר. Cependant, tous les emplois en Isaïe de ce substantif $(3,5 ; 13,8 ; 19,2 ; 34,14 ; 41,6)$ ou de son féminin par le *T en faisant usage de la racine חבר. On doit donc considérer comme peu vraisemblable la Vorlage suggérée par Lowth. Il importe de noter que le *T a traduit ici très librement 19b par גבר נכסי קריביה ייבזון, ce qui est exactement la traduction

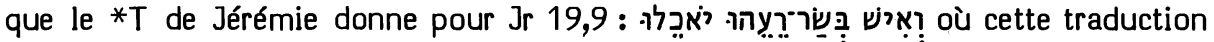
est également fort libre. Il semble donc que le $* T$ ait assimilé à ce texte ou plutôt qu'il a harmonisé la paraphrase de ces deux textes.

Sym ne nous est connu ici qu'en arménien. Ziegler restitue pour sa leçon la forme

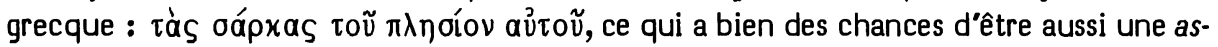
similation à Jr 19,9 .

La $* V$ et la $* S$ traduisent littéralement le $* M$.

Choix textuel :

Contre la leçon iy? proposée ici par Secker, notons qu'elle n'apparaît qu'en Jr 6, 21 alors que l'on trouve plus de 115 fois que Secker n'est pas le premier a avoir suggéré de lire ici "son prochain" au lieu de "son bras". Déjà le glossaire A traduisait ici : "chair de son prucheyn", et, plus explicitement, le glossaire B explique qu'il suit le *T pour traduire : "l'avoyr de son procheyn proaront", les glossaires $C$ (2e leçon) et $F$ donnant des leçons très proches. Quant aux glossaires C (1e leçon), D et E, ils se réfèrent à Ez 22,6 (לִ (לְ ) pour traduire "à s"aïtore" ou "à s'aïtoyre", c'est-à-dire "à son aide" (substantif dérivé de "adjutorium"). Ici encore, il s'agit seulement d'une traduction interprétative, ces glossaires précisant que le sens de Ez 22,6 est le même que celui de לy

Il semble donc qu'ici la leçon du $* M$ est bien appuyée et n'a pas de rivales notables. Aussi le comité lui a-t-il attribué la note "B".

Interprétation proposée :

Gesenius (Thesaurus 433b) appuie sur l'usage de l'arabe et du syriaque un sens de "aide, auxiliaire" qui se trouve correspondre à l'option de la moitié des glossaires.

On ferait bien de préserver ici la traduction "son bras" en explicitant le sens susdit en note.

10,4A בלתי כָּרָר [B] M 1Q-a 4Q-e // exeg : G Th Sym V S / constr : T

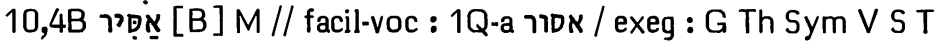

10,4C הרוגים [B] M 1Q-a g V S T // lacun : G

Options de nos traductions :

Pour 4a, le *M offre : par : "Nothing remains but to crouch among the prisoners or fall among the slain", 
J par : "pour ne pas ramper parmi les prisonniers, tomber parmi les tués", RL par : "Wer sich nicht unter die Gefangenen bückt, wird unter den Erschlagenen fallen" et TOB par: "on ne pourra que se courber parmi les prisonniers et tomber parmi les victimes".

NEB donne ici : "so that they do not cower before the gaoler or fall by the executioner's hand", sans note. Brockington précise que cela suppose des vocalisations

\section{Origines des corrections :}

La première et la troisième des corrections de NEB avaient déjà été proposées par Tur-Sinai (Contribution 182). Pour la deuxième, il proposait de lire אִ̣. NEB a préféré s"inspirer de la variante graphique de 1Q-a.

\section{Les témoins anciens :}

Pour 4a, 1Q-a ne se distingue en effet du *M que par une vocalisation אסור. La même variante existe pour le même mot אֵַ en 42,7 (alors qu'en 24,22, qui est sa seule autre attestation avec cette graphie dans le *M, 1Q-a l'a omis par haplographie). Kutscher (366s) suggère qu'il s'agit là, de la part de 1Q-a, d'une modernisation, la forme avec 'yod' du *M semblant être la plus ancienne. Notons $\mathrm{Jg} 16,21.25$ où le ketib offre des formes de ce mot avec 'yod' auxquelles le qeré fait correspondre des formes avec 'waw'. En tout cas, la leçon de 1Q-a a de fortes chances d'avoir le même sens que celle $d u{ }^{*} M$ et de devoir se lire אָסוּר (comme l'indique le participe passif parallèle (הרוגים.

Pour ce qui nous en est conservé, 4Q-a appuie le *M: ] בלתי כרע תחת[. Le 'bet' initial n'y était pas précédé d'un 'lamed' prépositionnel que certains critiques (de Houbigant à BH3) ont diagnostiqué avant ce mot. En effet, si c'était le cas, la hampe du 'lamed' apparaîtrait sur la partie de l'interligne de ce fragment qui nous a été conservée.

Le *G n’a pas traduit les trois derniers mots de 4 a. Pour les trois derniers mots

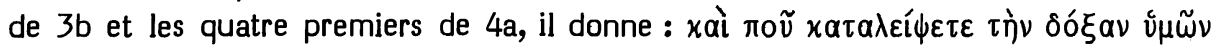

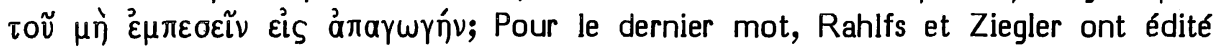

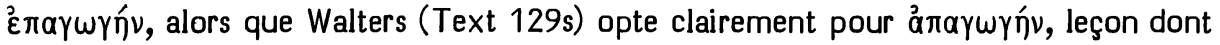
Seeligmann (21) avait déjà relevé l'intérêt.

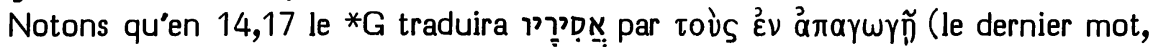
ici aussi, selon Walters, ibid.). Il y a donc de fortes chances qu'en 10,4 le * $G$ ait lu la leçon אסיר du *M.

Les formes recensées du ${ }^{*} G$ ajoutent (sous astérisque dans la recension origé-

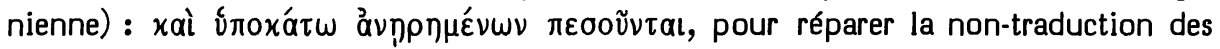
trois derniers mots de $4 a$.

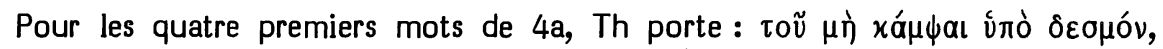

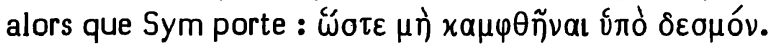

La *V traduit ainsi 4a: "ne incurvemini sub vinculo et cum interfectis cadatis". Ces trois traductions semblent donc avoir lu אֵסוּר (= lien).

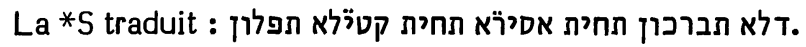

Le *T traduit: בכן בר מן ארעכון אסירין תתאסרון ובר מן קרויכון קטילין תתרמון תמון תמון 
Notons que toutes ces versions appuient une lecture de הרוגים en participe passif (et non actif).

Le début du *T essaie de construire à partir du mot araméen (= terre), faute de comprendre le mot כר כans la construction difficile du début de ce vs. Pour le reste, ces versions ont fait ce qu'elles ont pu pour comprendre le *M.

\section{Choix textuel :}

Considérant le texte difficile du *M comme fermement appuyé, pour l'essentiel,

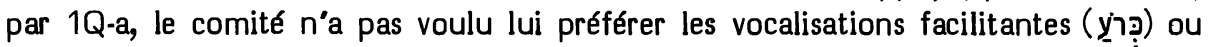
rajeunies (אָסר) que certains ont voulu lui substituer. Aussi, en un vote global, lui a-t-il attribué, pour ce demi-verset, la note " $B$ ".

Il faut mentionner ici une conjecture séduisante que Lagarde a présentée en

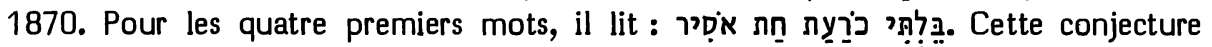
("Belti s'affaisse, abattu est Osiris") se contente de faire passer un 'taw' du début d'un mot à la fin du précédent et d'effectuer des retouches vocaliques. Elle a été adoptée par un certain nombre d'exégètes (dont Duhm) jusqu'à Fohrer. Wildberger a objecté à cette conjecture que ni Osiris ni Belti n'apparaissent ailleurs dans la Bible et que l'on ne possède aucun indice que ces divinités aient joué un rôle à Jérusalem. Budde (Jesaja 69) avait donc raison de considérer cette reconstruction comme "ganz verfehlt".

\section{Interprétations proposées :}

Il est intéressant de noter qu'Isaïe de Trani paraphrase déjà par מאסיר par הרצחו dans le sens actif que choisiront les conjectures de Tur-Sinai et de NEB. Mais, dans l'analyse qui suit, il précise cependant que ces deux mots désignent ceux qui subissent ces actions et non ceux qui les exercent.

A la suite de Radaq, Gesenius (après Vitringa, Noldius, Lowth) a compris ici le 'yod' final de בלתי en suffixe de la 1e pers. (= sans moi). Mieux vaut cependant considérer ici (comme dans la plupart des emplois de cette particule) le 'yod" comme paragogique.

Deux lignes d'interprétations principales se présentent : Saadya (suivi par la plupart des exégètes) a compris cette particule au sens de : "il ne restera plus qu’à...", plaçant les deux phrases ainsi introduites en parallèle.

De Dieu (approuvé par Rosenmüller) a noté qu'après cette particule on peut sous-entendre un relatif et comprendre : "à moins que... " ou "si... ne... pas", faisant de la première phrase une subordonnée et de la seconde la principale. Cette interprétation a l'avantage de mettre en valeur le contraste entre l'accompli (dans la 1e phrase) et l'inaccompli (dans la 2e). Cette valeur de la particule se retrouve en Gn 43,3: "vous ne verrez pas ma face à moins que votre frère ne soit avec vous", ou en Ex 22,19: "celui qui sacrifie à quelque dieu sera anathème, à moins que ce ne soit au Seigneur seul".

Reste à préciser le sens de תח en ses deux emplois. Cette préposition peut en effet signifier ou bien "sous" (cf. Is 14,19), ou bien "en tant que", "à la place de" (sens que nous reconnaîtrons en Jb 34,26). Il est fort possible que l'auteur joue ici avec ces deux sens. 
On conseillera donc de traduire : "A moins qu'on ne se soit courbé en tant que prisonnier, on tombera sous les tués."

Mais on ne saurait éliminer la possibilité de : "Il ne restera plus qu'à se courber à la place du prisonnier, à tomber à la place des tués (c'est-à-dire : à prendre la place de ceux que vous avez faits prisonniers et que vous avez tués)."

\section{יפקד 10,12 אפקד}

\section{Options de nos traductions :}

La première personne du *M est respectée par RL ("ich will heimsuchen") et TOB ("j"interviendrai").

Ont corrigé ici en troisième personne : RSV et NEB ("he will punish"), J ("il châtiera"). Ces deux dernières fondent sur le *G leur leçon ("ק̣?:

\section{Origine de la correction :}

Houbigant lisait (à travers Walton) comme "Septante" l'édition Sixtine du *G

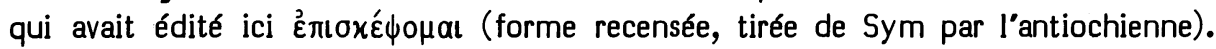
Il lui a donc fallu s'appuyer sur l'Arabe de la Polyglotte (qu'il croyait, à tort, indépendante ici du ${ }^{*} G$ ) pour corriger ici en 3e personne, “car il est clair qu'ici c’est le prophète qui parle et non Dieu".

Nos traductions ont pu trouver cette correction demandée par les apparats de Cent, HSAT34, BH2 (hésitant), BH3S (n’hésitant plus), à la suite de Duhm et de Cheyne (qui la fonde sur le ${ }^{*} G$ ).

\section{Les témoins anciens :}

La première personne du *M a ici l'appui de $1 Q-a$, de Sym, de la *V, de la *S et du*T.

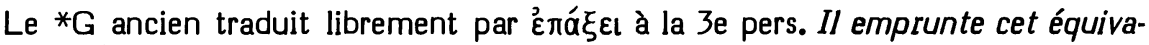
lent, comme souvent, au Pentateuque (Ex 32,34; 34,7). Le choix de cette traduction pour ce verbe l'amène à lui donner valeur transitive et à lui assigner pour complément d'objet (qui, dans le *M, est un génitif, complétant le mot לבר dדi qui le pré-

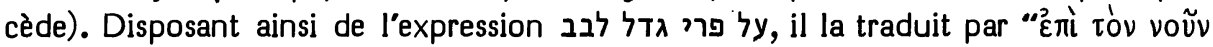

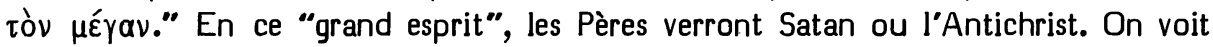
que c'est l'ensemble de l'interprétation du ${ }^{*} G$ qui nous conduit assez loin du ${ }^{*} M$.

\section{Choix textuel :}

Ce surgissement soudain d'une première personne non introduite surprend. Mais tout le monde comprend qu'ici le verbe פק ne peut avoir pour sujet que "le Seigneur" qui a été mentionné à la 3e pers. en 12a. Il n'y a donc aucune équivoque à craindre.

König a rassemblé (Stilistik 249,19-22) 17 cas où, dans le livre d'Isaïe, a lieu un passage soudain de la $3 e$ pers. à un discours direct, souvent sans la moindre formule introductive.

Ici, une correction en $3 e$ pers. serait une évidente facilitation. Aussi le comité a-t-il conservé la leçon du * $M$ en lui attribuant 3 " $B$ " et 3 " $C$ ". 
Interprétation proposée :

Pour introduire ce passage soudain au discours direct, on pourra faire usage d'une incise : “dit-il", comme TOB l’a fait.

10,25 תבליתם [C] M 1Q-a(?) V T // err-graph : m G t תבליתם incert : S

Options de nos traductions :

Ce mot est traduit par RSV : “their destruction", par J : “leur perte", par RL : "sein Verderben" et par TOB : "leur ruine".

Seule NEB, jugeant le *M obscur, conjecture "will all be spent" (c'est-à-dire

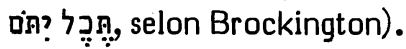

Origine de la correction :

Estimant insatisfaisantes les exégèses traditionnelles de ce mot, Luzzatto a pro-

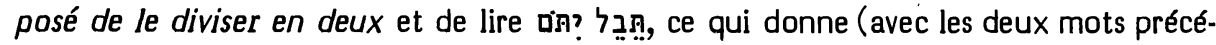
dents du *M) : "et ma colère contre le monde cessera". Cette conjecture a été adoptée par Grätz, Perles (I 37), Marti, Oort, Procksch.

Driver (LTP 39), estimant qu'il ne s’agit pas ici de la colère de Dieu contre le monde, mais contre les Assyriens, adopte la conjecture de Luzzatto en en corrigeant le premier mot en ment".

Notons cependant que ce mot n'est pas attesté en hébreu et n'oublions pas que Ehrlich a remarqué que jamais la Bible n'emploie le verbe תמם en relation avec la "co-

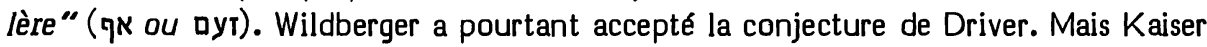
qui l'acceptait en sa 2 e édition est revenu au * $M$ dans la cinquième.

Les témoins anciens :

De Rossi cite 4 mss et quelques éditions comme ayant ici la leçon תכליתם (avec 'kaf'). HUB nous montre clairement que tous les mss tibériens classiques portent ici la leçon avec "bet'. On a ici le seul emploi du mot תבלית dans la Bible, alors que y figure 5 fois. Ce second mot, en tant que plus connu, est cité par Hayyuj (Kitâb sur בלה), Judah ibn Balaam et Ibn Ezra pour expliquer la dérivation du premier. Il est donc vraisemblable que la variante avec 'kaf' assimile involontairement au mot le plus usuel. Ici la massore signale ce mot comme hapax, mais cela ne permet pas de trancher entre les deux leçons qui, l'une ou l'autre, seraient hapax avec ce suffixe.

1Q-a semble lire un 'waw' a la place du 'yod' mais a certainement un 'bet' et non un 'kaf'.

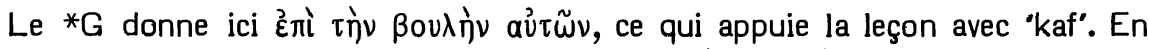

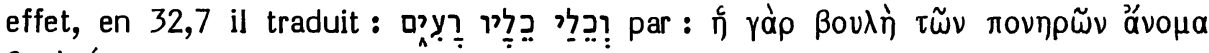

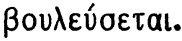

En traduisant : על עממיא עבדי תבלא, le *T montre qu'il a lu la leçon avec 'bet', un seul ms portant pour le dernier mot תכלא, selon Sperber.

Comme nous le verrons, en traduisant : "super scelus eorum", la *V se rattache à une tradition d'exégèse qui suppose la leçon avec 'bet'. 
Le mot tion" (éventuellement au sens moral) ou "annihilation".

\section{Choix textuel :}

A l'intérieur de la tradition textuelle du *M, l'attestation de la leçon avec "bet" est solide. Elle reçoit de 1Q-a un appui notable.

L'existence de ce mot ne fait aucune difficulté de principe. Sa relation avec le

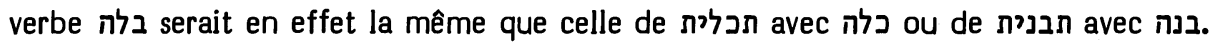

Cependant son caractère hapax, joint au fait que le ${ }^{*} G$ a très probablement lu la leçon avec 'kaf', entraîne certains doutes à l'égard de cette leçon. On notera en effet, dans la tradition textuelle du*M, des oscillations entre יבלו en Jb 21, 13 (où il s'agit d'un qeré-ketib) et 36,11 (où mss et éditions sont divisés).

Craignant cependant que la leçon avec 'kaf' soit une facilitation, le comité a préféré la leçon du *M en lui attribuant la note " $C$ ".

\section{Interprétation proposée :}

L'exégèse juive s'est divisée entre deux lignes d'interprétation.

La première se rattache au *T qui, ici, a repris la traduction

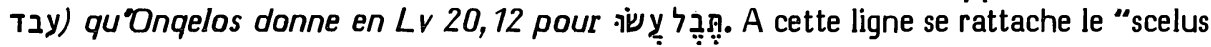
eorum" de la*V. Rashi, citant Lv 20,12, explique : "il s'agit des injures et des blasphèmes que m"ont adressés les serviteurs du roi d"Assur". Les glossaires DE (ainsi que la $2 e$ exégèse des glossaires $A C$ ) donnent "leur lédure" en se référant à $L v 20,12$ (le glossaire $F$, en $2 e$ exégèse dans le même contexte, donnant : "leur ordure"). Ibn Ezra glose : "et ma fureur et ma colère s'accompliront contre eux à cause de leurs grands méfaits".

Sous l'influence de la *V et du *T (et, peut-être, de Rashi) plusieurs traducteurs du XVIe siècle s'engagent dans cette voie : Oecolampade: "scelera eorum", Prédicants : "jre laster", Luther : "jre untugent", Brucioli : "l'abominatione (et, en 1540 : le sceleratezze) di quegli", Jud : "ignominiam eorum", Olivetan : "leurs meschancetez".

Luzzatto a objecté à cette interprétation que לֶู désigne les unions interdites, ce qui n'a rien à voir avec les crimes que l'on peut reprocher aux Assyriens. On doit

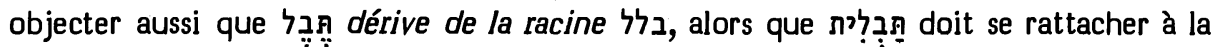
racine בלה dont le sens est "usure" et "consomption". C"est ainsi que Saadya et Yéfet ben Ely ont compris ce mot, suivis par tous ceux des grammairiens qui interprètent les racines faibles comme trilittères: Hayyuj (Kitâb sur בלה), Abulwalid (Ușul 94,6s), Judah ibn Balaam, Ibn Ezra (2e interprétation), Tanḥum Yerushalmi, Radaq, Isaïe de Trani, puis, parmi les traducteurs du XVIe siècle, Pagnini ("consumptionem eorum"), Vatable et Arias Montano ("eversionem eorum"), Münster et Calvin ("abolitione eorum"), Rollet ("leur perdition"), Estienne et Pasteurs ("leur destruction"), Ge et KJ ("their destruction"), Châteillon ("ejus excidium" et "le mettre a male fin"), Tremellius ("consumptioni istorum"). Il semble que le *T offre,

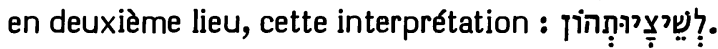

Dans l'interprétation précédente, l'expression ואפי על תבליתם devait se comprendre : "et ma colère porte sur leur crime"; alors que, dans celle-ci, elle signifie : 
"et ma colère vise à leur destruction". De fait, la préposition hy peut exprimer le propos que l'on vise (cf. BDB II $1 \mathrm{f}(\mathrm{d})$ ).

Ce dernier sens est le plus vraisemblable. En 10,25, le Seigneur annonce en effet que son $ם$ पy ( = l'indignation contre Israël qui, en 10,5,' avait été présentée comme un bâton mis par Dieu dans la main des Assyriens) a cessé. Maintenant son (= sa colère dont, en 10,5, Assur avait été désigné comme l'instrument contre Israël) va se tourner contre eux ( $=$ les Assyriens qui viennent d'être évoqués en 10,24 comme frappant le peuple du Seigneur) pour les détruire.

\section{0,27 [C] M 1Q-a V S(?) // assim-ctext : G / midr : T}

Options de nos traductions :

TOB traduit : "le joug cédera devant l'abondance", en notant qu'une traduction littérale serait : "le joug sera détruit à cause de la graisse".

J3 traduit : "et le joug sera détruit (....)". Elle note que les derniers mots (qu'elle estime incompréhensibles) signifient littéralement : "devant la graisse".

RSV, J12, RL et NEB s'accordent sur les points suivants :

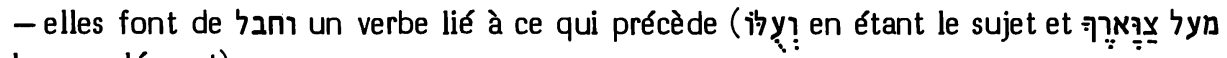
le complément),

- elles voient en by une forme du verbe עלה,

- elles donnent à מפני une valeur locale,

- elles restituent à la place de שמן un toponyme : Rimmôn ou (selon J12) éventuelle-

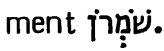

Origines de la correction :

C'est W.R. Smith (cité et discuté par Bredenkamp) qui a proposé le premier de

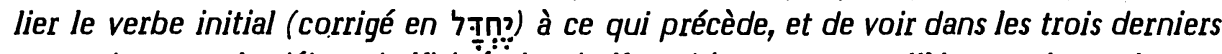
mots de ce vs le début de l'itinéraire de l'envahisseur, en parallèle avec les trois pre-

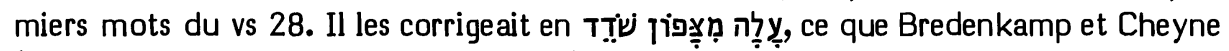
(par ailleurs favorables à sa conjecture) trouvaient trop éloigné du *M. Aussi Duhm

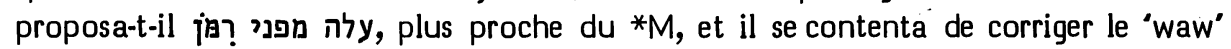
initial de וחבל en 'yod'. Sous cette forme, la conjecture a été adoptée par RSV, RL et NEB; alors que J12, avec "son joug cessera de peser sur ta nuque. Il s'avance du côté de Rimmôn", combinaient la conjecture de W.R. Smith (pour le verbe initial) avec celle de Duhm (pour les trois mots suivants).

Les témoins anciens :

A part une graphie pleine $y, 1 Q$-a est identique au ${ }^{*} M$.

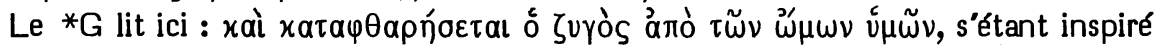

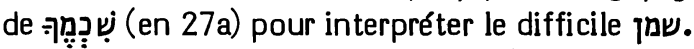

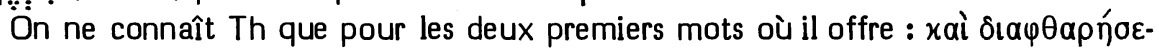

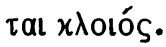

Avec "et conputrescet iugum a facie olei", la *V traduit littéralement le *M.

La *S a été éditée par Sionita sous la forme : מוש qui correspond à tous les mss (sauf l'Ambrosianus qui lit משוחא), quoique plusieurs omettent les seyamé. Sionita 
a traduit ce mot par "juvencarum" (= génisses), ce qui correspond à l'exégèse d'Ishodad de Merv. Cependant Diettrich (XXIX) considère comme originale ici la leçon d'Ephrem qui, selon l'édition romaine, lit ici au ${ }^{*} M$.

Le *T a ici un midrash : "et des peuples seront brisés de devant le Messie", ce qui atteste la syntaxe d"ensemble du $* M$ et le dernier mot qui fait particulièrement difficulté.

\section{Choix textuel :}

Ni la variante assimilante du ${ }^{*} G$, ni le midrash du ${ }^{*} T$ ne sauraient fonder une correction du *M. Au cas où l'intuition de base de W.R. Smith serait exacte, elle atteindrait un état très ancien du texte. Les témoins conservés appuient assez fermement le *M. C'est pourquoi le comité lui a attribué la note " $C$ ".

\section{Interprétation proposée :}

Kaiser, en sa 2e édition, suivait la conjecture de Duhm révisée par Procksch (avec Samarie au lieu de Rimmôn comme toponyme). Dans la cinquième, il revient au *M, en estimant que la conjecture ne permet pas de se tenir sur un sol ferme.

Mais le *M demeure très difficile : que veut signifier “et le joug s'anéantira du fait de la graisse" ?

Certes, Dt 32,15 nous présente le peuple du Seigneur comme un jeune taureau qui a "engraissé" (1), c'est-à-dire pris des forces en de riches pâturages, et qui, de ce fait, a rué, c'est-à-dire a secoué le joug. Or, en 10,26, il a été dit que le Seigneur tournera son bâton contre Assur qui lui a d'abord servi de bâton pour frapper Israël. En 27a, il est dit qu'en conséquence de ce retournement de la colère du Seigneur (25b) contre Assur, le joug de celui-ci glissera du cou d'Israël. A ce point de l'oracle, il est trop tard pour dire qu'Israël secouera le joug.

Il semble que Radaq ait mis l'accent sur l'intention de l'auteur en soulignant l'aspect paradoxal de l'expression: “D'ordinaire, c'est l'inverse qui se passe : car la graisse du cou du boeuf est anéantie par le port du joug." Selon Buber (Bemerkungen 193), 27b ne serait pas la description d'un événement qui fait suite aux précédents, mais un proverbe ("le joug finit par céder sous la pression de la graisse"). Ce proverbe serait cité ici pour évoquer le caractère durable de cette libération. Il peut signifier qu'un animal dont les forces s'accroissent est de plus en plus difficile à maîtriser, ce qui sera le cas d'Israël, ayant retrouvé les forces qui lui permettront de défendre son indépendance.

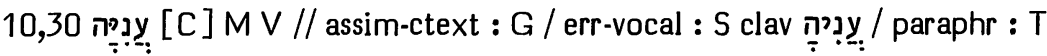

Options de nos traductions :

Seule TOB traduit le *M ("malheureuse").

RSV et NEB ("answer her"), J ("réponds-lui"), RL ("gib ihm Antwort") corrigent selon la *S en 
Origine de la correction :

C'est Lowth qui, le premier, a traduit ici "answer her" en prenant appui sur la *S, Gesenius ayant proposé la vocalisation susdite.

Nos traductions ont pu trouver cette correction requise par les apparats de Cent, $\mathrm{BH} 235$ et HSAT234.

\section{Les témoins anciens :}

$1 Q$-a est consonnantiquement identique au $* M$, mais inutilisable en cette question de vocalisation. Notons cependant qu'il marque un plus grand espace entre les mots et ce qui les précède qu'entre ces mots et les deux qui les suivent; ce qui, nous le verrons, suggère une interprétation analogue à celle du *M.

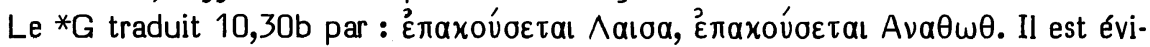
dent que, interprétant עניה à partir du verbe répondre), il a harmonisé la traduction de ce mot avec celle de הקשיבי. S'il les traduit par des futurs, c'est qu'il a traduit ainsi tous les verbes (qu'il s'agisse d'impératifs ou d'accomplis) depuis du vs 27.

La *V, avec "paupercula Anathoth" (que Hie glose par "vel obediens sive humilis") traduit clairement le *M.

La *S, en traduisant ועני ענתות, ne tient pas compte du "hé" final du premier mot et l'assimile aux deux impératifs féminins qui précèdent.

Le *T paraphrase : "ceux qui résident en la paurre Anatot", comme il avait paraphrasé auparavant : "ceux qui habitent à Laïsh".

\section{Choix textuel :}

La leçon du *M se comprend mieux si l'on considère (qui se retrouve en 54, 11 en tant que prédicat d'une ville) comme le prédicat d'une phrase nominale dont le sujet est le toponyme qui suit. Cette phrase constituerait un parallèle à 31a: נדדה מדמנה.

En Ne 11,32 se suivent trois toponymes : 'yod' consonnantique serait ainsi confirmé) a pu être choisi ici pour évoquer ce toponyme voisin.

La variante donnerait plus de mouvement à cet oracle. Mais la $* S$ ne lui apporterait qu'un appui assez incertain.

Le comité a donc préféré garder le * $\mathrm{M}$ avec la note " $\mathrm{C}$ ".

Interprétation proposée :

Ces deux mots et ceux qui les suivent sont à joindre, comme TOB l'a fait.

On pourra traduire : "Anatot est misérable, Madména est sur les routes."

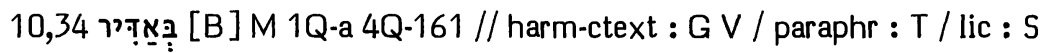

Options de nos traductions :

Le *M est traduit par RL (“durch einen Mächtigen"), J3 (qui glose "sous les coups d'un Puissant") et TOB (interprétant en "bet' essentiae: "majestueux", et mentionnant en note : "par un puissant"). 
RSV donne : "with its majestic trees" qu'elle qualifie de conjecture, en se référant au $* G$ et à la $* V$. NEB, sans note (ni rien en Brockington), donne : "with its

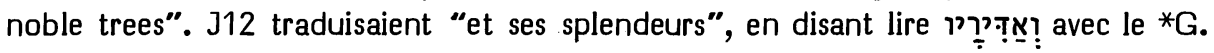

\section{Origine de la correction :}

Grätz avait proposé de corriger ce mot en בארזיו (= avec ses cèdres). Perles (I 75) a été inspiré par cette suggestion et a proposé, sans corriger le *M, d'interpréter ici

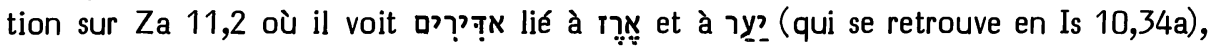

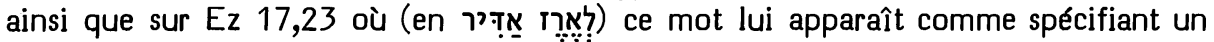
type de cèdres. Notons que Löw (III 22) refuse que אַ pִ puisse signifier le cèdre dans les divers endroits de la Bible où Perles croyait l'avoir reconnu.

Simultanément avec Perles, Cheyne (96,46), estimant que אִַ est un synonyme pour les cèdres du Liban en Za 11,2, propose de corriger (en Is 10,34) en באדיריו. Marti, Condamin et HSAT34 ont adopté la correction de Cheyne au sens de 'cèdres', alors que Gray l'a acceptée au sens de "its majestic (cedars)". C'est en cet état que nos traductions ont hérité de cette correction.

Les témoins anciens :

Le *M porte, pour 33b et 34 : ורמי הקומה גדועים והגבהים ישפלו: ונקף סבכים

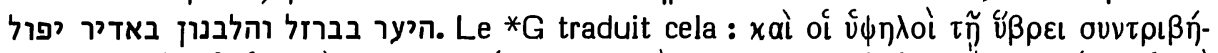

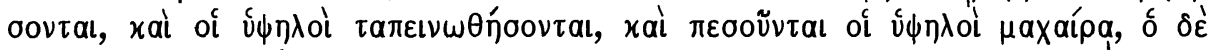

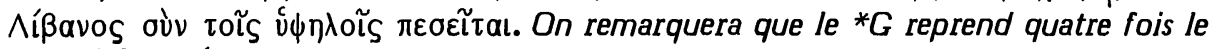

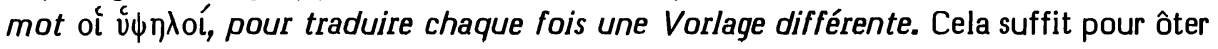
toute portée à son témoignage textuel en ce cas où $1 \mathrm{Q}-\mathrm{a}$ appuie fermement le ${ }^{*} \mathrm{M}$.

En effet, pour 33b et 34, 1Q-a est identique au $* M$. Dans le lemme du commentaire 4Q161, la leçon באדיר est attestée.

Le ms 710 attribue à $A q$ une leçon ioxupós dont l'index porte sur Níßavos. Lütkemann $\left(84, n^{2}\right.$ 412) montre bien que l'on ne peut accepter ni la localisation, ni l'attribution de cette leçon.

En traduisant ici "cum excelsis", la *V se contente de copier le *G.

La leçon בשובחה de la *S est une traduction large du*M dont le "bet" a été compris comme un 'bet' essentiae.

Le *M midrashise, ayant compris ici אדיר comme une désignation du pays d’Israël.

\section{Choix textuel :}

Les options des versions montrent seulement les difficultés qu'elles ont eues à interpréter ce mot.

La leçon du *M est bien appuyée par Qumrân. Aussi le comité lui a-t-il attribué la note "B".

Interprétations proposées :

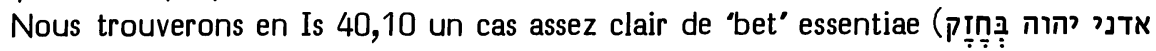

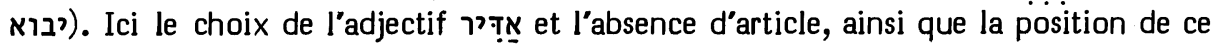


mot entre le sujet et le verbe favorisent une interprétation en 'bet' essentiae (proposée par König et choisie par TOB).

Cependant la tradition exégétique a surtout retenu ici une interprétation de ce

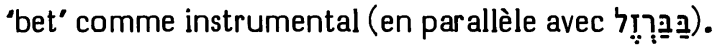

Le fait que la première exégèse : "Majestueux, le Liban tombera" ou "le Liban, avec toute sa majesté, s'écroule."

On ne saurait cependant éliminer la seconde : “Le Liban, par un puissant (c'està-dire : sous les coups d'un puissant) s'abat."

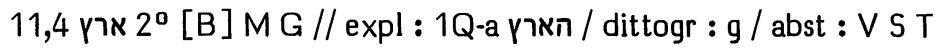

Options de nos traductions :

Le *M est traduit par RSV ("the earth"), J3 et TOB ("le pays").

Une correction conjecturale en ץ'? ỵ (selon $\mathrm{J} 2$ et Brockington) est adoptée ici par J12 ("le violent"), RL ("den Gewalttätigen"), et NEB ("the ruthless").

Origine de la correction :

C'est Gesenius qui, tout en estimant que l'on pouvait s'en passer, a conjecturé ici une correction de אֶֶֶ, Cette conjecture a été adoptée par Lagarde, Dillmann/Kittel, Cheyne, Duhm, Grätz, Marti, Oort, Condamin, Gray, Halévy, Ehrlich, Feldmann, Procksch, Fohrer, Tur-Sinai (Contribution 186), Vermeylen (272, n.2), Wildberger, Kaiser. Nos traductions ont pu trouver cette correction demandée par les apparats de Cent, $\mathrm{BH} 235$ et HSAT234.

Les témoins anciens :

1Q-a fait précéder de l'article les deux emplois de ce mot en ce vs. Dans l'ensemble du livre, il ajoute 12 fois l'article avant ce mot et l'omet 2 fois.

Le ${ }^{*} G$ ancien n'a pas d'article ici (alors qu'il en a un pour le premier emploi). Il semble bien que ce soit par dittographie (THNГHN) que l'article a pénétré, ici aussi, dans les témoins antiochiens et quelques autres.

$\mathrm{La} * \mathrm{~V}$ ne peut témoigner sur ce point, pas plus que la $* \mathrm{~S}$ et le $* \mathrm{~T}$.

Choix textuel :

La seule variante sur laquelle les témoins textuels peuvent donner prise serait donc une ajoute (facilitante) de l'article. Contre elle, le comité a attribué " $B$ " à la leçon du *M.

Interprétation proposée :

En relation avec אִ doit désigner ici (comme Luzzatto l'a noté) l'ensemble des habitants du pays (comme nous l'avons vu ci-dessus, p. 44). Ce mot va même jusqu'à désigner (l'ensemble de) l'humanité en Gn 11,1.9 où il s'agit de הארץ)-(כל). 
"Frapper du bâton" est une expression courante pour "éduquer"(cf. Pr 23,13s). Dans le cas du "bâton de la bouche", ce sens est encore plus probable. Ici, on veut dire que le rejeton de Jessé redressera, réformera par ses décrets la population du pays. Pour compléter cette action, il éliminera le méchant par le verdict de condamnation qu'il lui infligera.

La conjecture suppose, à tort, que "frapper du bâton" est parallèle à "mettre à mort", alors que ces deux actions sont, au contraire, clairement distinguées en $\mathrm{Pr}$ 23,13 .

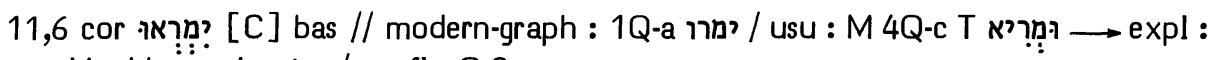
$\mathrm{V}$ add morabuntur / confl : G S

\section{Options de nos traductions :}

RSV ("and the fatling"), J3 ("et la bête grasse") et RL ("und Mastvieh") traduisent le *M.

$\mathrm{J12}$ ("paissent") lisaient ?ִ? qu'elles attribuaient aux "versions".

TOB traduit "seront nourris" qu'elle distingue de "et la bête à l'engrais" qu”elle attribue au *M.

NEB “shall grow up" suppose une correction en ?ִpְ̣ pour laquelle Brockington se réfère au ${ }^{*} \mathrm{G}$.

\section{Origines des corrections :}

6a étant constitué de deux phrases dont chacune est faite d'un verbe ayant pour sujets deux noms d'animaux, les critiques, depuis Houbigant, ont cherché dans la première phrase de $6 b$ un verbe qui puisse avoir lui aussi des noms d'animaux pour sujets. Houbigant (en une partie de ses Notes omise par la réédition de Francfort)

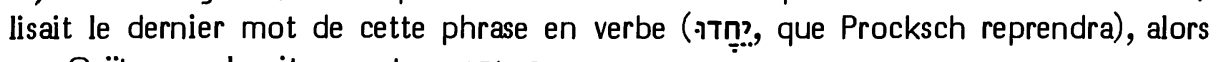
que Grätz remplaçait ce mot par

C'est Perles (Dictionary 385) qui a proposé de lire, à la place du 3e nom, le verbe ימראו quil vocalisait en hofal, le hifil seul étant usité dans la Mishna (en Shabbat XXIV 3, sous une forme d'ailleurs élidée : ממריאים qu'il restaure en מריאים).

Guthe (HSAT234), Cheyne, Marti, Cent proposent aיỵ:; Ehrlich, König et BH3 :

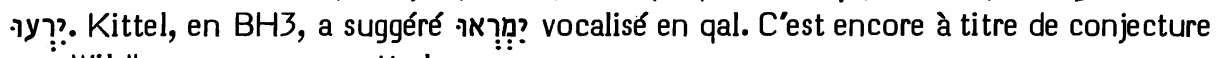
que Wildberger propose cette leçon.

Cependant Greenberg (Stabilization 164, n. 51), Brownlee (Meaning 217s) et Talmon (DSIa 123s) ont clairement mis en valeur l'appui que 1Q-a apporte à cette leçon.

Les témoins anciens :

Alors que 4Q-c est identique au *M, 1Q-a offre ici ימרו. Comme dans la Mishna, I' 'alef' est élidé. Kutscher (505) a relevé en 1Q-a une vingtaine d'autres cas d'élision de la lettre 'alef' en des radicaux de divers mots. Cinq autres fois cette lettre est réintroduite au-dessus du mot. Ces omissions s'expliquent par l'affaiblissement de cette laryngale dans la prononciation. 


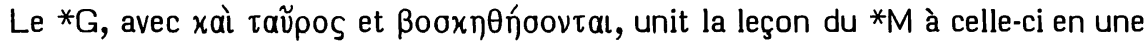
leçon gonflée. Le verbe en est l'élément ancien, le nom d'animal (dont le placement varie selon les témoins) a été ajouté ensuite, ainsi que Ziegler (Untersuchungen 64) l'avait bien diagnostiqué.

La *S, avec ותורא ot et נרון ofre une leçon gonflée identique.

Dans la *V (où ce mot est traduit par "et ovis"), l’adverbe "simul" est explicité par "morabuntur".

Le *T (ופטים) traduit fidèlement le *M.

\section{Choix textuel :}

Le fait que ce soit le seul emploi de ce verbe dans la Bible explique que le ${ }^{*} M$ ait cru, en cette énumération d'animaux, y reconnaître le מ̣ (= bête engraissée) qui réapparaît huit fois dans la Bible.

En ugaritique (Aistleitner \$1663), le verbe "mr" signifie "engraisser" au sens intransitif. C'est le sens qui semble utilisé ici où le comité a attribué la note "C" à ?ְְִּ., considérant cette forme comme indirectement attestée par les diverses leçons, à titre de base à partir de laquelle elles ont divergé.

Interprétation proposée :

On pourra donc traduire: "le veau et le lionceau s'engraisseront ensemble".

11,11 שנית [C] M 1Q-a ThAq Sym V T // facil : G (om שנית et expl סוז סal) / expl : S

Options de nos traductions :

Le *M est traduit par RSV ("a second time"), J3 et TOB ("une seconde fois") et RL ("zum zweiten Mal").

$\mathrm{J12}$ traduisaient : "lèvera (de nouveau)" sans note.

NEB traduit: "make ... (more) glorious" sans note. Cependant Brockington in-

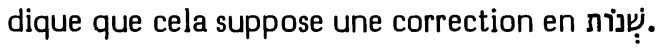

Origines des corrections :

J12 reprenaient la traduction de Cent qui précisait qu'elle supposait une correc-

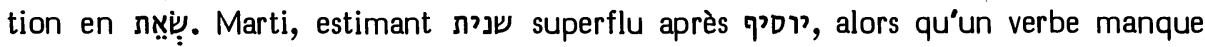
pour décrire le mouvement de la main, a proposé cette correction en s'inspirant de 49,22. Cette conjecture a été adoptée par Oort, Condamin, Gray, Ehrlich, Feldmann, Procksch, Wildberger, Kaiser. Elle a été requise par les apparats de HSAT34 et (avec hésitation) par ceux de $\mathrm{BH} 23$.

C'est Thomas (Root 175s) qui a proposé de reconnaître ici une racine שנ ayant le sens de l'arabe סִ ס (= "obtenir un rang élevé", selon Lane qu'il cite). Ici il propose de lire l'infinitif piél de cette racine, alors que Brockington (par erreur ?) en propose l'infinitif qal. Wildberger a objecté que l'on ne peut pas établir que cette racine hébraique ait eu ce sens. Cependant, en BHS, Thomas maintenait sa proposition. 
Les témoins anciens :

Pour ce vs, 1Q-a appuie fermement le *M.

Strugnell (199), tout en reconnaissant que le 'shin' et le 'taw' sont mutilés, croit reconnaître le mot שאת comme seul conservé en une ligne d'un fragment non classé qu'il considère comme appartenant à 4Q165. La lecture vraisemblable de מכוש à la ligne suivante l'amène à considérer que nous avons affaire à Is 11,11 et que le mot isolé susdit doit tenir la place de שנית du. Cette reconstitution supposerait des lignes de 50 à 55 signes (ou intervalles), alors que les fragments les mieux conservés (par ex. les fragments 4 et 5) de 4Q165 attestent des lignes de 66 à 76 signes (ou intervalles). Cette identification est donc beaucoup trop peu certaine pour que l'on puisse fonder sur elle une argumentation textuelle ainsi que Morrow (48) a cru pouvoir le faire. En effet une lecture שאר est tout aussi probable, cette suite de lettres apparaissant deux fois en 11,11 selon le *M.

Le ${ }^{*} G$ semble avoir porté sur l'hébreu (de *M et de $1 Q$-a) le même jugement que

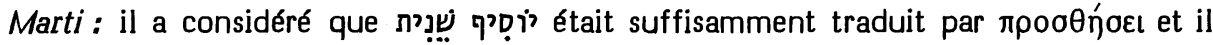

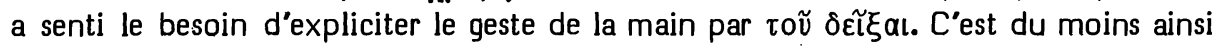
que Schleusner (II 56) et König interprètent sa manière de faire.

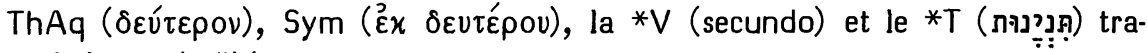
duisent la leçon du *M.

Driver (Hebrew Notes 242) a estimé que la leçon de la *S (תניא דאידה) supposait

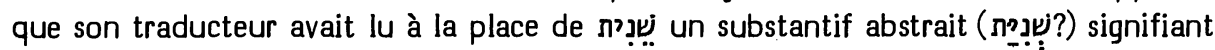
une "action répétée". Il est plus vraisemblable que le traducteur a voulu expliciter, par une traduction large, ce qu'il comprenait dans le *M.

\section{Choix textuel :}

Le hifil de יסף veut simplement dire "agir à nouveau". L'auteur veut qualifier cet acte comme une “acquisition", un "rachat" (לקנות) répétant l'acte par lequel il a acquis, racheté son peuple lorsqu'il était au pouvoir des Egyptiens. C'est ce caractère de répétition qu’il exprime par l'adverbe שנית. Le mot "sa main" évoque la mise en oeuvre de sa puissance. Aucun verbe ne spécifie cette mise en oeuvre (étendre, manifester, brandir etc.) parce que l'auteur n'a pas voulu qu'une autre représentation d'action vienne s'insérer entre שנית (qui retouche par une précision) et לוסיס sur lequel cet adverbe porte formellement.

Le comité a attribué la note " $C$ " au *M solidement appuyé par 1Q-a, considérant les variantes comme facilitantes ou explicitantes.

\section{Interprétation proposée :}

On aura intérêt à expliciter de façon aussi sobre que possible le geste de la "main" du Seigneur. Par exemple : “Il adviendra en ce jour-là que le Seigneur mettra de nouveau en oeuvre sa main pour racheter une seconde fois le reste de son peuple." On pourra noter que "sa main" signifie clairement en ce contexte "sa puissance". 
Options de nos traductions :

Fidèle à KJ (qui entendait suivre le *M), RSV traduit ici : "and ... will utterly destroy".

TOB n'indique pas sur quoi elle se fonde pour traduire "domptera".

NEB traduit par "will divide", en conformité avec l'exégèse du *M proposée par Driver (Homonyms 59).

Pour traduire "asséchera", J dit lire רְְִ avec les "versions".

RL fait de même en traduisant "und ... wird austrocknen".

Origine de la correction :

J a suivi l'option de Cent (qui se référait à $* G * V * S$ ) en interprétant (comme Cent) le *M au sens de "vouera à l'anathème".

RL a pris la traduction de HSAT234 qui attribuait au *M le sens de "wird mit dem Banne belegen" ou "wird bannen".

Cappel (Critica 782) semble avoir été le premier à proposer de corriger en והחריב en se fondant sur le $* T$. Houbigant reprend cette proposition en se fondant lui aussi sur le $* T$, alors que Doederlein se fonde sur ${ }^{*} G * T * V$ et Rosenmüller sur ${ }^{*} S * T$. Lowth (traduisant "shall smite with a drought") informe que le *T (et peut-être le *G) lit החריב. Michaelis (OEB) garde le *M qu'il estime avoir été lu par Aq, Sym et Th. Il note que *G, *T, *S et *V ont traduit comme s'ils avaient lu והחריב. Mais il estime cependant qu'il se peut qu'ayant lu comme nous, ils aient traduit librement. Gesenius note que le *G a traduit aussi en Jr 25,9 החרים par ${ }^{*} \xi \varepsilon \rho \eta \mu o ́ w$. Aussi garde-t-il le *M, suivi en cela par Hitzig.

La proposition de correction de Cappel a été reprise ensuite par Luzzatto, Bredenkamp, Duhm, Dillmann/Kittel, Grätz, Perles (I 34), Cheyne, Marti, Oort, Condamin, Ehrlich, Gray, Feldmann, Procksch, Fohrer, Wildberger, Kaiser. Elle est requise par les apparats de HSAT234 et BH23. Cependant, BHS demande de garder le *M.

\section{Les témoins anciens :}

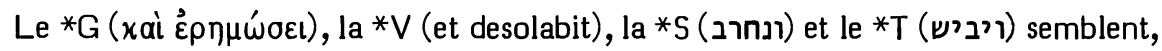
à première vue, avoir lu ici והחריב.

Cela rend d'autant plus frappant le fait que 1Q-a porte ici la même leçon והחרים que le ${ }^{*} M$. D'ailleurs de Rossi note qu'il n'a rencontré והחריב en aucun ms du *M.

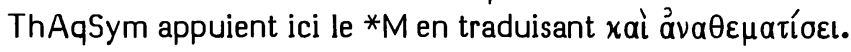

\section{Choix textuel :}

Dans sa Critica, Cappel affirmait que le *T a lu החריב. Juste après, Buxtorf jr (734) niait cette affirmation. Il avait en effet constaté que Rashi, Ibn Ezra et Abravanel faisaient appel à la notion d'assèchement pour commenter la leçon du * $M$, et que la traduction allemande des juifs donnait ici : "er wird vertrocknen". Or personne ne prétendra que ces divers témoins aient lu la variante dans leur texte. Buxtorf jr concluait donc que c'était déjà dans le but d'interpréter le *M que le *T avait fait choix de la traduction ויביש. 
Cappel semble avoir été impressionné par cette critique de sa critique, puisque, dans ses Notae (501), il renonce à appuyer sa variante sur le *T. Ajoutons d'ailleurs que le ms de Rossi 1232 sur lequel S. Buber a basé son édition du Midrash Tehillim (401), sous l'influence de cette interprétation courante, écrit והחריב lorsqu'il cite Is 11,15 .

Quant à la traduction du *G, Lohfink (ThWAT III 194) a suggéré que ẻ p a pu être choisi pour créer une assonance avec חר. Il serait en tout cas faux de croire que le ${ }^{*} G$ a ici pour seule Vorlage ce que le traducteur lisait en Is 11,15. Sur trois

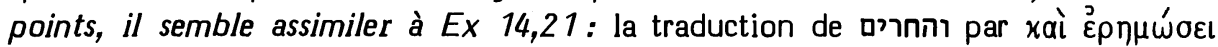
et la non-traduction de לשון s’inspirent vraisemblablement de וישם את־הים לחרבה,

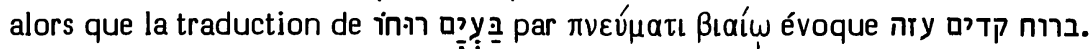

HUB cite Is 37,11.18 comme exemple d'une certaine neutralisation sémantique de la distinction existant entre les racines חרב et. En effet, en 37,11, les messa-

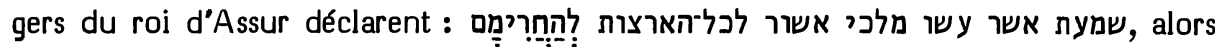
qu'en 37,18, Ezéchias reprend le même thème en sa prière dans les termes suivants :

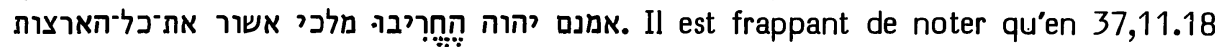
(comme en 11,15) 1Q-a concorde avec le *M en ces options, et que le *M du parallèle de $2 R$ 19,11.17 fait de même.

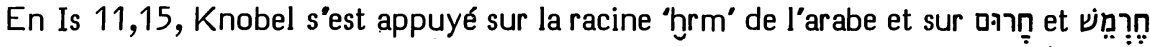
de l'hébreu pour donner à החרים le sens de "diviser, séparer". Lorsque Driver (Homonyms 59) reprend la même exégèse liée à la même dérivation, il semble ignorer Knobel et tous deux paraissent ne pas se douter que la même opinion avait déjà été formulée par Judah ben Qoreish (Bargès 89 = Katz 167), David ben Abraham (I 586,135-139), Abulwalid (Ușul 248,23 à 249,8), Ibn Barûn (53), Tanḥum Yerushalmi en liaison avec Lv 21,18 qu'Abulfaraj Harûn (13b) rattachait déjà à cette racine arabe.

En continuité avec ces lexicographes judéoarabes mais sans référence à la langue arabe, Radaq maintient ici dans son commentaire le sens de "diviser", en liaison avec לגזר ים סוף לגזרים (Ps 136,13). Notons que ce sens est réintroduit par Mercerus dans la 3e édition du Thesaurus de Pagnini (801), mais il n'est pas repris par Buxtorf (Lexicon). La dérivation arabe est rentrée sous la forme d'un ח II en KBL et HALAT.

Comme on le voit, la leçon du *M en Is 11,15 a été souvent interprétée au sens de "dessécher" sous l'influence d’Ex 14,21 ou au sens de “diviser" en s'inspirant de l'arabe.

Lohfink (ibid.) estime cependant que le sens normal de “détruire entièrement, anéantir" est bien en place ici, du fait que ce verbe est en parallèle avec והניף ידו על En effet, cette expression désigne une menace contre un ennemi (ce que nous aurons l'occasion de confirmer à propos de 13,2).

Le comité a attribué à la leçon du *M la note "B".

Interprétations proposées :

Il faut déconseiller de traduire ici par "dessécher". Il s'agit là d’une assimilation facilitante à la description du passage de la Mer Rouge.

Il est possible que les lexicographes judéoarabes et HALAT aient raison de comprendre ce verbe au sens de "diviser".

Cependant le parallèle avec "il brandira sa main contre" donne un excellent contexte pour "il vouera à l'anéantissement." 


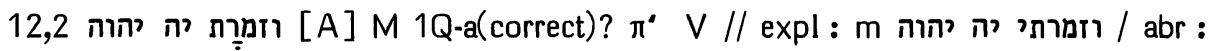
m 1Q-a* G יה יהוה / יה / transl : T (cf. 26,4)

Options de nos traductions :

RSV ("the LORD GOD is ... and my song") et RL ("Gott der HERR ist ... und mein Psalm") ont tenu compte de la répétition du nom divin.

En traduisant : "et mon chant c'est Yahvé", J note qu'elle suit le *G et 1Q-a, en se référant à Ex 15,2; alors que le *M porte ici : "et le chant et Yah (c'est) Yahvé".

NEB traduit : "the LORD is my ... and defence", Brockington précisant qu'elle

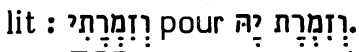

TÓB், sans note, traduit : “et mon chant, c'est le SEIGNEUR !”

Origine de la correction :

J, NEB et TOB corrigent de même. Cette correction est demandée par les apparats de Cent, BH23S et HSAT3. Comme autre option, Cent (en accord avec HSAT24) propose d'omettre plutôt יהוה et de garder יה

BH235 mentionnent 2 mss du *M comme lisant וזמרת avec les "versions". BH23 citent la tradition origénienne du ${ }^{*} G$ et plusieurs mss du *M comme omettant יה, omission que BHS attribue à 2 mss, ainsi qu'au *G et à la *V. HSAT2, par contre, estime que le ${ }^{*}$ G omet יהוה.

Clericus semble avoir été le premier à demander de corriger ici זמרתי en זמרת. C'est Houbigant qui a ajouté à cette demande celle d'omettre היA Ayant remarqué que dans le ms 42 de l'Oratoire (l'actuel ms hébr 9 de la BN de Paris où se lit וזמרתי) le mot י achève une ligne, alors que la suivante commence par le tétragramme, il en a conclu que ces deux lettres ont été faussement interprétées par un scribe tardif comme étant un nom divin autonome, alors qu'elles devaient constituer un de ces bourrages de fin de lignes pour lesquels les scribes font souvent appel aux premières lettres du mot suivant (qu'ils reprennent ensuite en entier au début de la ligne suivante).

Les témoins anciens :

Le ms Kenn 355 (= Paris BN hébr 9) est seul à porter dans son texte la leçon וזמרתי. Le second ms cité par BH23S est le ms 380 de de Rossi qui note cette leçon en marge. Etant donné que Radaq fait remarquer dans son commentaire qu'ici a le sens de וזמרתי, de Rossi a raison de penser que, dans son ms 380 (ms allemand écrit en 1296), cette leçon marginale est une suggestion exégétique, plutôt qu'une variante.

Seuls deux mss (Kenn 109 et 128) omettent 3 . Cela suffit à indiquer que la présence ici de ce mot dans le *M est beaucoup plus ancienne qu'Houbigant ne l'imaginait. Cependant Kennicott signale וזמרתיה écrit en un seul mot en son ms 30, auquel il faut ajouter le ms 2 de Königsberg selon Lilienthal (331) et le ms 419 de de Rossi, selon ses Scholia.

Un nombre nettement plus grand de mss ( 8 de Kennicott et 12 de de Rossi, 9 d'entre eux ayant été corrigés ensuite) omettent le tétragramme. Le motif pour lequel יהוה cette seconde omission est plus fréquente que la première est que יה est présent dans les parallèles de Ex 15,2 et Ps 118,14. 
La première main de 1Q-a offre ici : וזמרתי יהוה. Mais la seconde main a ajouté un 'hé' dans l'interligne, juste après le premier 'yod', visant ou bien la forme וזמרתיה attestée ici par quelques mss du *M, ou bien la leçon du *M.

En accord, semble-t-il, avec la première main de $1 \mathrm{Q}-\mathrm{a}$, le ${ }^{*} \mathrm{G}$ offre ici : xai $\eta$

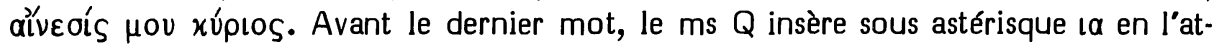
tribuant à "tous", c'est-à-dire toutes les colonnes hexaplaires autres que celle de la Septante.

Ce doublement du nom divin est également attesté par la *V ("et laus mea Dominus Deus"). Cependant le mot "Deus" a été omis par l'édition Sixtine et l'édition Clémentine, conformément au texte de l'édition d'Estienne de 1540 (alors que son apparat en signalait la présence dans 2 mss de St Denis et 3 mss de St Germain). On sait que les théologiens de la Sorbonne avaient obtenu d’Estienne que les leçons qu'il estimait critiquement préférables à la recension parisienne de la $* V$ et qu'il avait fait passer dans le texte de son édition de 1532 ne soient mentionnées que dans l'apparat de l'édition de 1540. Ici, le correctoire de St Jacques et celui de Guillaume de Mara attestent l'authenticité du mot "Deus" que l'édition de san Girolamo a retenu. Celle-ci étant parue en 1969, on comprend que BHS (parue pour Isaïe en 1968) prétende encore que la *V omet ce mot.

La*S (ושובחי מריא הו) est en accord avec le *G.

Le *T offre ici : ותושבחתי דחילא מ dont les deux derniers mots traduisent aussi en sa seule autre occurrence en ce livre $(26,4)$.

Concluons donc que toutes les versions explicitent après וזמרת un possessif de la 1e pers. sing. (comme celui qui affecte le mot précédent). Le double nom divin est attesté par les versions hexaplaires, la *V et le *T.

Choix textuel :

Il faut distinguer ici en *M deux difficultés textuelles :

1) La vocalisation qameș et l'absence de pronom suffixe du deuxième mot de la

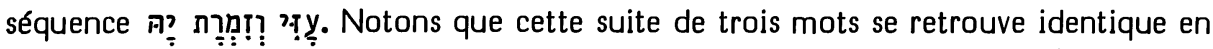

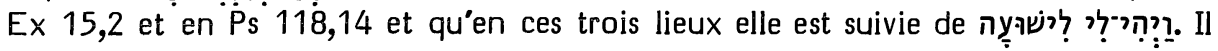
s'agit donc là d’un verset liturgique stéréotypé. Le fait que les difficultés susdites se retrouvent dans le $* M$ des trois endroits et que les mêmes échappatoires qu'ici se retrouvent attestées par les divers témoins nous engage à respecter la leçon difficile du $* M$.

La raison d'être du qameș sous le 'resh' est d'éviter une interprétation de ce mot en état construit (= patah). Radaq (Mikhlol 13b) a en effet relevé qu'en dehors des

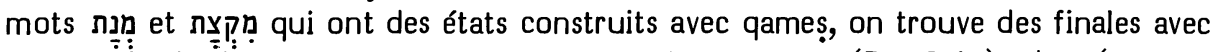

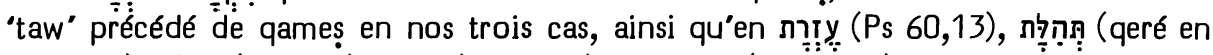

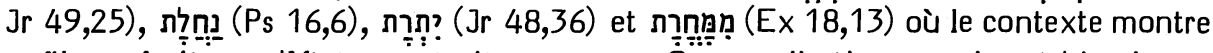
qu'il ne s'agit pas d'états construits normaux. Ćes vocalisations paraissent bien intentionnelles, quoiqu'en un plus grand nombre de cas analogues (que Radaq cite auparavant) les vocalisateurs aient fait usage de finales avec 'taw' précédé d'un patah qui laisseraient croire à des états construits normaux. Dans זמרת la tradition exégétique

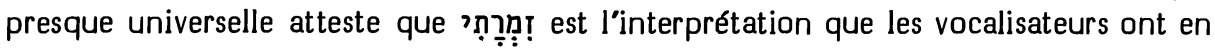
vue. 
Geiger (274-279) a signalé que, dans la tradition textuelle prémassorétique, une tendance s'est manifestée pour protéger de la profanation la forme brève ọ du tétragramme en l'absorbant dans le mot précédent comme une simple désinence anodine. Il a signalé également, dans la même tradition textuelle, une réaction en sens inverse, visant à protéger ce même ṇִ contre le risque d'une telle absorption. Dans la ligne tracée par Loewenstamm (Strength 469), on peut résumer ainsi les étapes qui, selon Geiger, auraient conduit du texte original au $* M$ en notre cas : la forme originelle זמרתיה זמרת aurait d'abord, pour le motif théologique susdit, été absorbée en (comme la $2 \mathrm{e}$ main de $1 \mathrm{Q}$-a et certains mss du $* M$ l'attestent encore) à la manière

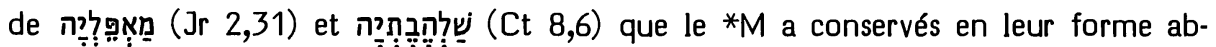
sorbée et que Geiger (276) cite. Ensuite, du fait que l'usage liturgique avait maintenu la tradition d'interprétation originelle de cette forme, on aurait voulu la restaurer, à un moment et dans un milieu où l'on n'osait pas ajouter le 'yod' qui avait été sacrifié lors de l'absorption susdite. On se serait donc contenté de séparer les deux mots en signalant la portée du second par le mappiq et en vocalisant qameṣ la finale du premier pour éviter qu'il soit interprété comme un état construit se référant directement au second.

Loewenstamm considère ce processus comme rendant le mieux compte, en notre cas, de la leçon du *M. Cependant il faut noter que nous avons affaire ici à une formule liturgique très ancienne préexistant aux compositions littéraires qui en font usage. Lorsque l'on suit Geiger dans sa fine analyse des traitements très divers que le nom ${ }_{0}$ a subis en ses diverses occurrences dans le ${ }^{*} \mathrm{M}$, on est frappé par l'identité

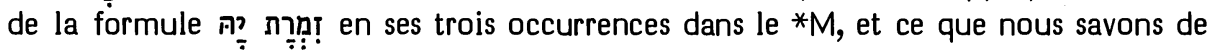
la manière dont le ${ }^{*} \ddot{*} M$ a été transmis rend peu vraisemblable qu'il s'agisse là d'une uniformisation finale d'états textuels distincts. Il semble donc que la graphie זמרת יה doive tirer son origine d'une époque bien plus ancienne que celle en laquelle se sont déroulés les processus inconstants que Geiger a évoqués.

Ainsi que nous l'avons noté en CT1 (401), Luzzatto (Propheten 77s) a noté l'habitude des scribes d'omettre la dernière lettre d'un mot en des cas où elle se retrouve comme première du mot suivant. N'aurions-nous pas ici un cas analogue ? Loewenstamm (ibid.) estime cette éventualité très improbable, parce que cette graphie exceptionnelle semble particulièrement déplacée juste après la graphie normale ע. On peut dire au contraire que, cette graphie normale assurant l'interprétation authentique de וזמרת qui lui est coordonné, on peut se permettre plus aisément de ne pas écrire le pronom suffixe de ce mot.

Le motif qui nous pousse à faire appel ici à cette habitude scribale décelée par Luzzatto, c'est qu'il s'agit d'une particularité graphique très ancienne, puisque, dans les lettres de Lakish (cf. Torczyner, Letters 54) on la trouve attestée en deux lignes

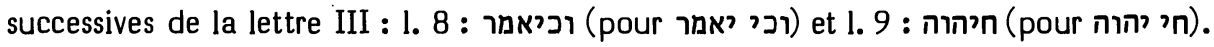

2) Une seconde difficulté textuelle est constituée par le redoublement du tétragramme: sous sa forme abrégée, puis sous sa forme pleine. Geiger (278) en a conclu qu'à l'époque où la forme abrégée (et originelle) était absorbée en זמרתיה (senti alors comme un simple substantif abstrait), on avait senti la nécessité d’ajouter le tétragramme pour rendre à la phrase son sens originel. Mais pourquoi cela n'a-t-il eu lieu que dans 
l'occurrence de ce verset liturgique qui se trouve dans le livre d'Isaïe et pas dans celles qui se trouvent dans le Cantique de l'Exode ou dans le Psaume?

C'est ici qu'il importe de remarquer que c'est en Is 26,4 que se trouve la seule autre occurrence biblique du redoublement יִּנ丶, et que c'est également dans ce livre (en 38,11) que se trouve le seul redoublement de la forme abrégée : tons que 12,2; 26,4 et 38,11 sont les trois seuls endroits du livre d'Isaïe où apparaît la forme abrégée ị?, et nous serons en mesure de conclure que nous avons en ces redoublements une caractéristique littéraire du livre d'Isaïe, caractéristique littéraire que le copiste de 1Q-a a fait disparaître chaque fois (omettant יה la première fois, transformant le tétragramme en יהיה la deuxième fois, et omettant l'un des deux יה la troisième fois).

Le comité a estimé que la leçon difficile du *M était certainement authentique et lui a attribué la note " $A$ ".

\section{Interprétations proposées :}

Que le pronom suffixe de la 1e personne doive être suppléé dans l'interprétation après וזמרת, c'est ce qui est rendu pratiquement certain par la formule : arṣ 'zk dmrk (Ug. $V 553,1.9$ ) où on voit les pronoms suffixes (ici de la 2e pers.) placer en parallèle le substantif ' ' $z$ ' et le substantif ' $\mathrm{dmr}$ '. Dans ce même hymne (RS 24.252) d'Ugarit (ainsi que Loewenstamm, p. 465, l'a fait remarquer), le sens de "jouer d'un instrument à cordes" est garanti pour le verbe 'dmr' par la qualification du dieu Had (ibid. 551,

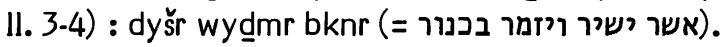

D'ailleurs, en hébreu biblique, la racine זמר est liée à ì en ce même sens dans l'expression : עזי אליך אזמרה (Ps 59,18). Il y a donc toutes les chances pour qu'ici (י) זמרת doive signifier : celui qui est l'objet des chants que j'improvise sur le kinnôr, c'est-à-dire de mes psaumes. En effet on retrouve dans les Psaumes le piél de זמר lié à l'évocation de la force ou de la puissance divine (21,14; 66,2-4).

Comme Loewenstamm (ibid. 465) l'a fait remarquer, après la publication, en 1968, de l'hymne susdit, il n'est plus exact de prétendre, avec HALAT et Barr (29), que l'on doive distinguer entre deux racines protosémitiques dont l'une : 'zmr' signifierait "jouer d'un instrument de musique" et l'autre "dmr" signifierait "protéger" ou "être puissant". En effet, 'zmr' n'a pas d'enracinement ancien dans les langues sémitiques, son emploi en arabe dérivant vraisemblablement du syriaque qui semble bien l'avoir emprunté à l'hébreu biblique. Par contre, 'ḍmr' a déjà à Ugarit le sens de "jouer d'un instrument à cordes" et celui de désignation d'une catégorie de guerriers.

Concluons que l'interprétation de beaucoup la plus vraisemblable est celle qui est en même temps la plus classique : “ma force et l'objet de mes psaumes, c’est Yâh le Seigneur...".

\section{פתח [B] פ פ 13,2 1Q-a 4Q-a Aq // facil-synt : Sym V S T / constr : G clav}

Options de nos traductions :

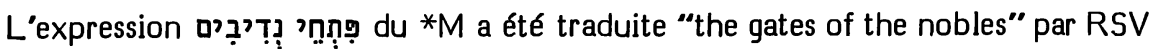
(= KJ), "aux portes des Nobles" par J, “durch die Tore der Fürsten” par RL (= Luther) et "aux portes des seigneurs" par TOB. 
A la place de cela, NEB donne : "draw your swords, you nobles", Brockington précisant que cela suppose que le premier mot soit corrigé en פִִ̣ avec le * ${ }^{*}$.

\section{Origine de la correction :}

Koppe a proposé ici de lire avec le *G l'impératif פִפּ, à la place de le comprenait (comme l'avait fait le ${ }^{*} G$ ) au sens de "ouvrez!". C'est Procksch qui a proposé de le prendre au sens de "dégainez!". Cette correction a été adoptée par Bach (58, n.1), BHS et NEB. Notons que Lohmann (62) avait proposé de placer cet impératif à la place de בבאו, avant פתחי.

\section{Les témoins anciens :}

Le ${ }^{*} G$ a assimilé sa traduction de 13,2a à celle de 40,9. En effet, après $v \psi \omega \dot{\text { - }}$

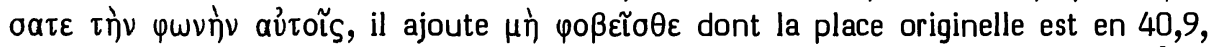

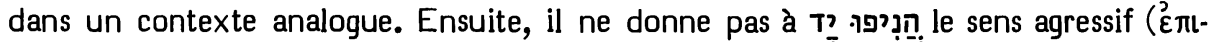

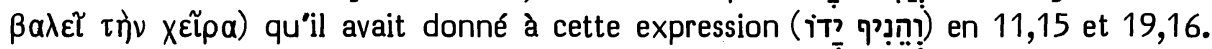

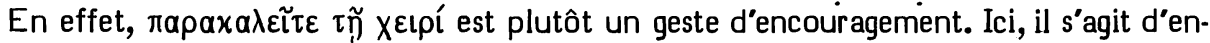

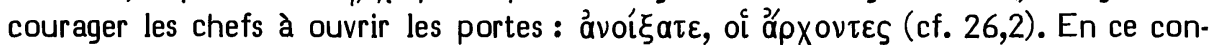
texte, assez différent de celui du ${ }^{*} M$, le ${ }^{*} G$ semble avoir interprété le pronom-suffixe להם, à la fin de 2a, comme ayant pour antécédent les נדיבים de la fin de 2b. Le Seigneur demande que l'on élève un étendard, puis que l'on crie aux chefs de ne pas craindre et qu'on les encourage d'un geste de la main à ouvrir les portes. Dans ce contexte le $* G$ est incapable de tirer parti de ces tiers mystérieux que 3a désignera par

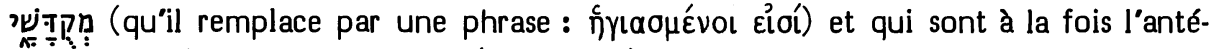

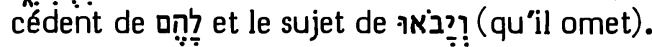

1Q-a et 4Q-a (qui est presque intact pour 13,2) appuient le *M, sauf pour ויבאו pour lequel 1Q-a offre יבוא et 4Q-a יבאו (Ia première lettre pouvant être un 'waw'). 4Q-I appuie le *M pour une suite de cinq mots dont le dernier est ויבאו. Donc aucun de ces mss de Qumrân n'appuie le *G en l'une ou l'autre des initiatives qui le caractérisent.

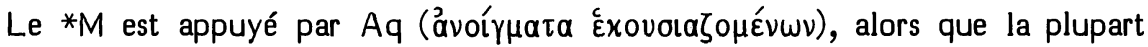

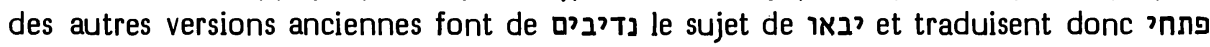
comme s'il était à l’état absolu. C'est le cas de la *V : "ingrediantur portas duces". Il est vraisemblable que c'est dans le même contexte qu'il faut placer la leçon xằ

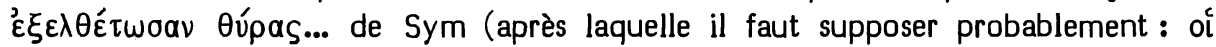

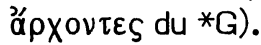

Faisant aussi des "princes" le sujet du verbe "entrer", le *T a traduit "en ses portes", en ajoutant un pronom suffixe de la 3e pers. sg., suffixe masculin selon certains témoins ou féminin selon d'autres.

La *S nous est donnée en deux états textuels : l'un identique au *M et l'autre, vraisemblablement plus ancien, qui ajoute à "portes" un suffixe de la 2 e pers. f. sg.

\section{Choix textuel:}

Le *M est assez nettement appuyé par les mss de Qumrân et par Aq, alors que le ${ }^{*} G$ est isolé dans le remaniement qu'il a fait subir à ce passage et que les autres versions divergent dans leurs facilitations syntactiques.

Le comité a donc attribué au * $M$ la note " $B$ ". 
Interprétation proposée :

On sait qu'en Mi 5,5 certains attribuent au pluriel du substantif ngֶ le sens de "épées dégainées". Ce sens a été adopté ici aussi par Menahem ben Saruq, Abulwalid (Ușul 594,10-12), Judah ibn Balaam et Doederlein. Juste après le verbe בוא, ce sens est peu probable, alors que celui de "portes" est très naturel.

Les "portes des nobles" peuvent être une désignation dérisoire pour Babel au moment où les guerriers des steppes de Médie y pénètrent pour s'en emparer. C'est ainsi que cette expression a été comprise par Saadya, Rashi et les glossaires, Yéfet ben Ely, Ibn Ezra et Radaq.

On a objecté à cette interprétation qu'elle suppose que, dans le même vs, on décrit la mobilisation des guerriers mèdes et la prise de Babylone. Cela ne fait pas difficulté. Nous avons mentionné en effet en CT1, p. 17, des présentations synthétiques introductives qui anticipent le dénouement d'un récit.

Ainsi que nous l'avons dit à propos de 11,15, l'expression הניף יד désigne une menace contre un ennemi. Elle réapparaît encore en ce sens en 19,16. La signification menaçante du geste s'adresse à la ville dans laquelle vont pénétrer ceux que les émissaires divins (à qui l'oracle s'adresse) auront mobilisés (2a). Ces mobilisés seront désignés par des termes génériques au vs 3 , puis identifiés formellement au vs 17 .

On pourrait donc traduire : "Sur un mont chauve, dressez un étendard, poussez un cri vers eux. Brandissez la main, et qu'ils entrent par les Portes des Nobles."

\section{3,13 ארגיז [B] M 1Q-a 4Q-a.b Th Aq Sym V S T // assim 12G : G 3e pers.}

Options de nos traductions :

La première personne du hifil qu'offre ici le *M a pour sujet Dieu, comme c'était déjà le cas pour trois verbes à la 1e pers. en 11 et un en 12, et comme ce sera le cas du participe précédé de הנני en 17.

Cette première personne est respectée par RSV, J23, RL et TOB.

Mais J1 traduisait par: "les cieux seront ébranlés", sans note, et NEB par : "the heavens shall shudder", en signalant qu'il s'agit d'une conjecture. Brockington précise

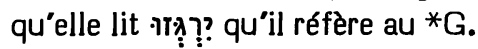

Origine de la correction :

Estimant qu'au vs 13 seuls les premiers mots sont dits par le Seigneur, Duhm a jugé préférable de lire ici, avec le *G, une 3e pers. pl. dont "les cieux" soient le sujet. Cette proposition a été adoptée par Marti, HSAT3, Gray, Procksch, Fohrer, Kaiser et Wildberger.

Les témoins anciens :

L'option du ${ }^{*} G$ se situe dans une construction d'ensemble. En 14, il va expli-

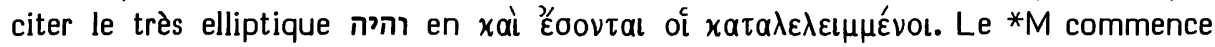
le vs 12 par le verbe אוֹ אוֹפִיר a la le pers. du hifil. L'assonance avec le mot achève ce vs est un indice qu'il s'agit là d'un élément du texte original. Cependant le *G, déjà là, traduit ce verbe (et le mot אנוש qui le suit) par xă हैoovtal of xata- 


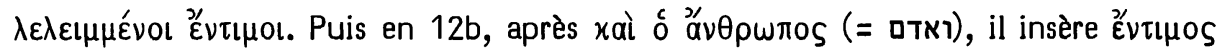
ع̌otal. Ayant donc fait des deux compléments d’objet du verbe transitif אוקיר des sujets d'un verbe intransitif, il opère de même pour le vs 13 ( $\delta$ yà oủpavòs $\theta v \mu \omega$ $\theta$ ńoદtal) où il est donc très peu vraisemblable qu'il ait lu une Vorlage qui motive ses options, et où il a plutôt assimilé à la syntaxe de ותרעש הארץ qui fait suite à notre verbe.

La leçon ארגיז du *M se retrouve dans les 3 mss de Qumrân dont le texte nous a été ici conservé : 1Q-a, 4Q-a et 4Q-b.

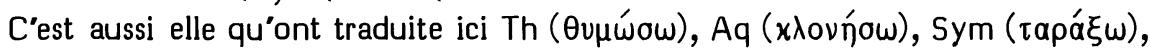
la *V (turbabo), la*S (ארגז) et le *T (אזיע).

Choix textuel :

On ne saurait emprunter ici au ${ }^{*} G$ un élément isolé de son option d'ensemble pour rendre plus coulante la syntaxe de l'hébreu. Aussi le comité a retenu la leçon $d u * M$ en lui attribuant la note "B".

Interprétation proposée :

Duhm et ceux qui ont adopté sa correction ont estimé que seuls les premiers mots de ce vs sont dits par le Seigneur, puisque "aussi vais-je ébranler les cieux" est suivi par "et la terre remuera de sa place sous la fureur du Seigneur Sabaot et au jour de son ardente colère".

Cela ne constitue pas formellement un passage de la 1e à la 3e personne. D'ailleurs la 1e pers. réapparaîtra, après des phrases descriptives, au vs 17. Il s'agit plutôt ici d'une explicitation du nom divin dans un but emphatique.

Is 13,13 n'est pas le seul verset de la Bible où le Seigneur apparaît d'abord comme sujet d'un verbe, puis où le nom divin réapparaît, pour produire un effet d'emphase, en un complément de ce même verbe. Cela se retrouve en Gn 1,27a; 19,24; Ex 16,7a; Dt 6,24a; 7,8a; 1 R 13,9a; Ez 37,1a où le sujet divin figure à la 3e pers. Mais en trois autres cas (Os 1,7a; So 1,8; Ps 50,23b), ce sujet figure à la 1e pers., comme c'est ici le cas.

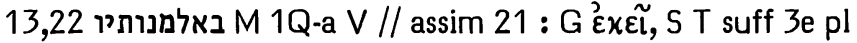

Options de nos traductions :

RSV traduit "in its towers", sans note.

Sur "dans ses tours", ] note que le *M porte "veuves".

RL traduit "in ihren Palästen" (= Luther).

En notant que le *M porte ici "her widows", NEB conjecture : "her mansions". Brockington dit que, en accord avec quelques mss, cela suppose une correction en

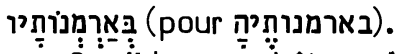

Sur "dans ses châteaux", TOB note que le *M porte "ses veuves".

Origine de la correction :

Houbigant a proposé de corriger ici en בארמנותיו, suivi en cela par Vogel (en ses notes sur Grotius), Lowth, Doederlein, Bredenkamp, Dillmann/Kittel, HSAT24. 
Duhm, Cheyne, Gray, Procksch et BHS ajoutent à cela une mise au féminin du suffixe masculin.

D'autres ne corrigent que le suffixe, considérant que le 'lamed' au lieu du 'resh' est une simple variante linguistique. C'est le cas de HSAT3 et de Wildberger.

Les témoins anciens :

Le *M présente ici deux difficultés :

1) il offre un 'lamed' où l'on attendrait un 'resh'. Ce 'resh' a été introduit par la 2e main du ms Kenn 3 et il a été corrigé en 'lamed' par la 2e main du ms de Rossi 737. Ces hésitations sont négligeables.

2) dans les vss 21 et 22 se succèdent diverses formes de pronoms suffixes dont les antécédents sont difficiles à déterminer :

- un suffixe 3e pers. m. pl. en 21a (où il est précédé par deux 㕰 et suivi par deux autres, tous les quatre compléments d'un verbe au pluriel),

- un suffixe 3e pers. m. sg. (celui de באלמנותיו) en 22a (alors que le parallèle בהיכלי $\lambda$ y ne porte pas de suffixe),

- deux suffixes 3e pers. f. sg. en 22b.

Le *M n'offre pas de variante sur ces suffixes.

1Q-a offre ici באלמנותו qui ne se distingue du *M que par l'absence de 'yod' après le 'taw'. En effet le nombre pluriel du substantif est garanti par la graphie pleine de la désinence de celui-ci. Cette leçon appuie donc entièrement celle du *M. Quant aux suffixes pronominaux, la seule variante offerte par 1Q-a est l'ajoute d'un suffixe

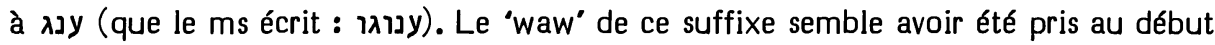
du mot suivant (où le *M lit une conjonction que 1Q-a n'a pas).

Le ${ }^{*} G$ a construit très librement, rendant באלמנותיו par un simple عُxع̃ qui assimile aux trois occurrences de cet adverbe dans le vs précédent. Le traducteur a agi tout aussi librement à l'égard des suffixes. Comme nous l'avons vu faire en 13,12.13, il a inversé la construction d'un verbe en 13,20a où תשכ, selon le $* M$ et $1 Q-a$, a pour sujet Babel, alors que cet intransitif est transformé par le ${ }^{*} G$ en un verbe transitif qui a Babylone comme complément : ع $\theta$ woıv عis aủinjv. Ayant obtenu ainsi un complément pronominal féminin, il en fait usage en 20b pour traduire les deux שִ dont le premier devient aủ

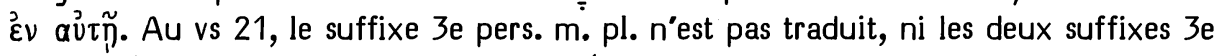
pers. f. sg. en 22b. Par contre, en 22a (que le traducteur a assimilé partiellement à

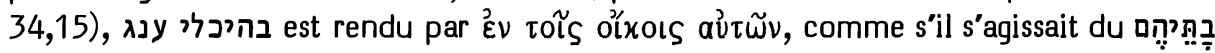
dont le suffixe avait été négligé en 21.

$\mathrm{La} * \mathrm{~V}$, la ${ }^{*} \mathrm{~S}$ et le $* T$ ont compris ici des palais ou des demeures, sans qu'on puisse savoir si ces versions ont lu un 'resh' ou un 'lamed" dans le radical de ce mot. La *V respecte les suffixes du *M, bien que sa traduction par "eius" la dispense de spécifier le genre masculin ou féminin des suffixes de la 3e pers. sg. en 22a et b. La *S et le ${ }^{*} T$ respectent les suffixes du $* M$ en $21 a$ et $22 b$. Mais elles mettent au pluriel le suffixe de 22a, en l'assimilant à celui de 21a. 


\section{Choix textuel :}

Ce cas n'a pas été soumis au comité.

Il est d'abord amusant que, BHS ayant consacré une note à l'absence de shewa sous le 'mem' dans le ms de Leningrad (absence que ni BH3 ni HUB n'avaient senti le besoin de noter), Wildberger demande de remarquer cette absence, alors qu'il ne s'agit que de l'étourderie d'un scribe isolé.

Distinguons maintenant les deux difficultés que présente le ${ }^{*} \mathrm{M}$ :

1) Sans qu'on puisse savoir si elles ont lu un 'lamed' ou un 'resh', toutes les versions anciennes ont compris ici "palais" et non "veuves".

Yéfet ben Ely témoigne ici de deux exégèses : l'une qui considère ici et en Ez

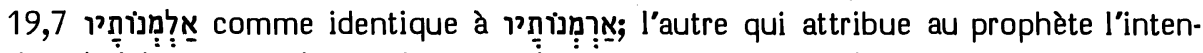
tion de laisser entendre par le choix de cette forme que ces demeures sont comme des conjointes qui sont devenues veuves par la disparition des rois qui les habitaient. La première exégèse est celle d'Abraham ha-Babli (214,9-11), Saadya, David ben Abraham (I 105,310-312), Abulwalid (Ușul 50,30s), Rashi, glossaires, Radaq (commentaire), Isaïe de Trani, Abravanel (1e exégèse), Oecolampade, Pagnini, Luther, Brucioli, Münster, Prédicants, Jud, Rollet, Estienne, Châteillon, Ge, etc. Pour des motifs d'orthodoxie grammaticale, la seconde exégèse a été adoptée par Ibn Ezra, Radaq en ses Shorashim (où il est contredit par Elias Levita disant qu'en araméen le 'resh' et le 'lamed' s'échangent), Servet (en notes sur Pagnini 1542), Estienne (en notes sur Pagnini 1557), Arias Montano, Tremellius, Pasteurs, KJ. Comme seconde exégèse, Abravanel propose une dérivation à partir de ארּּלִ qui semble n'avoir pas eu de succès.

2) Parmi ceux qui n'ont pas, comme la ${ }^{*} S$, le ${ }^{*} T$ et $K J$, transformé ce suffixe en pluriel, les traducteurs latins (avec "eius") ou français (avec "ses") ont pu profiter d'une ambiguïté qui (sans qu'on ait besoin de corriger) laissait entendre un possesseur féminin (= Babel). Luther et d'autres ont, nous l'avons dit, traduit par un possessif féminin. Parmi ceux qui ont tenu compte du fait que ce suffixe est au masculin sg., Bredenkamp lui donne pour antécédent 'le Chaldéen'. Ibn Ezra et König lui donnent 'chacun d'entre eux'. Cependant Michaelis et Knobel voient ici le roi de Babel. En effet, on peut voir à la fois dans la substitution du 'lamed' au 'resh' (que le contexte laisse attendre), et dans la soudaine apparition de ce suffixe masculin non introduit (là où on attendrait un féminin se référant à Babel) une intention sarcastique : les demeures ruinées du palais royal où résident maintenant les bêtes sauvages sont veuves du roi autour duquel gravitaient les cérémonies dont elles offraient jadis le cadre.

\section{Interprétation proposée :}

Servet traduisait : "in viduatis domibus eius". Au XVIe siècle, le français possédait encore, lui aussi, un verbe "veufver" au sens de "rendre veuf (ou : veuve)". Puisqu'il ne dispose plus d'un tel verbe, on pourra (avec la Bible des Pasteurs de Genève) traduire : "en ses palais désolés", avec une note expliquant le genre masculin du possesseur auquel ce pronom se réfère. 
רבים 14,2 עמים

Options de nos traductions :

Le *M est traduit normalement par RSV, J, RL et TOB. 1Q-a.

NEB traduit ici “many nations", Brockington précisant qu’elle ajoute רבים avec

Origine de la correction :

Elle peut provenir de l'apparat critique complémentaire de $\mathrm{BH} 7$.

Les témoins anciens :

1Q-a est seul à ajouter רבים ici après. Aucun ms du *M ni aucune version ancienne n'appuie cette ajoute, ainsi que James (68) l'a fait remarquer.

Choix textuel :

Ainsi que Kutscher (545) l'a noté, l'expression yמים רבים réapparaît plusieurs fois dans le livre d'Isaïe $(2,3.4 ; 17,12)$. Il se peut qu'en $1 Q$-a l'addition amplifiante de ce mot ait été suggérée par Za 2,15, verset analogue où figure : גוים רבים.

Le comité a attribué ici à la leçon sobre du *M 3 " $B$ " et 3 " $A$ ".

Interprétation proposée :

Il est regrettable que GNB ("many nations") et DHH ("muchas naciones") aient suivi le texte amplifié de NEB.

"Des peuples les prendront et les amèneront au lieu qui est leur" a plus de grandeur que "de nombreux peuples les prendront...".

14,4 cor מרהבה / [C] 1Q-a // err-graph : M מדהבה / harm-ctext : G S, Sym, V, T / incert : Aq fames

Options de nos traductions :

RSV donne ici : "the insolent fury". Elle dit suivre $1 Q$-a et se réfère au ${ }^{*} G$, à la $* V$ et à la $* S$.

J donne : "son arrogance" selon les "versions" et 1Q-a.

RL donne : "das Toben".

NEB donne : "his frenzy", Brockington précisant qu'elle lit מִַ avec 1Q-a.

TOB donne "son arrogance", disant qu'elle corrige une consonne de l'hébreu.

Selon RSV, le sens de la leçon du *M est incertain. Selon J, le *M est corrompu. Selon NEB le mot du $* M$ est inconnu. Selon TOB, le $* M$ est inintelligible. Donc toutes nos traductions le corrigent.

Origine de la correction :

Nos traductions ont pu trouver cette correction demandée par les apparats de Cent, $\mathrm{BH} 23 \mathrm{~S}$ et HSAT234.

Comme nous le verrons, elle remonte à Michaelis. 
Les témoins anciens :

1Q-a lit clairement ici מרהבה. Cependant, les écrits trouvés à Qumrân émanent d'un milieu qui faisait usage du mot מדהבה. Les contextes dans lesquels l'auteur des Hodayot l'emploie deux fois (1QHodayot 3,$25 ; 12,18$ ) nous montrent qu'il lui attachait un sens de "persécution, oppression". Ces parallèles récemment découverts paraissent d'autant plus prometteurs que ce sens est bien celui que l'on attend en Is 14,4. Mais il faut remarquer que ces deux emplois utilisent ce mot dans la forme exacte qu'il a en Is 14,4 : à l'état absolu féminin singulier sans article. Et il est inquiétant de rencontrer dans le Document de Damas $(13,9)$ une néoformation : לכל qui semble bien avoir été construite sur la base d'une pseudo-racine quadrilittère. Ajoutons à cela le fait que Hodayot 12,18 ("et il n'y aura plus de מדהבה") semble n'être rien d'autre qu'une transposition d'Is 14,4 (ainsi que Carmignac, Textes 265 , l'a noté). Tous ces indices convergent pour nous montrer que ce que les écrits de la communauté de Qumrân nous offrent, ce ne sont pas des manifestations de la vitalité d'une racine hébraïque דהב, mais plutôt les réutilisations érudites d'un hapax biblique interprété en fonction de son contexte. Il semble donc bien que l'auteur des Hodayot faisait déjà de ce mot un usage analogue à celui qu'en feront les païtanim des onzième et douzième siècles comme Rabbénu Gershom Meor ha-Gola (Davidson א §2651), R. Ephraïm ben R. Isaac de Regensburg (ibid. $\$ \$ 4397$ et 6652), etc. Tout ce que l'on peut conclure de certain à partir des réutilisations qui ont été faites de ce mot à Qumrân, c'est que la communauté disposait déjà, à côté de 1Q-a, d'autres textes d'Isaïe où ce mot figurait avec la graphie 'dalet' qu'il a dans le *M.

Les versions anciennes sont de peu de secours :

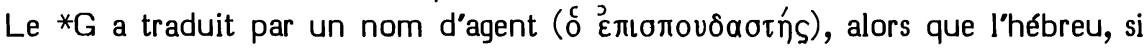
on le rapproche de substantifs analogues se rencontrant dans le livre d'Isaïe (מַכְ en

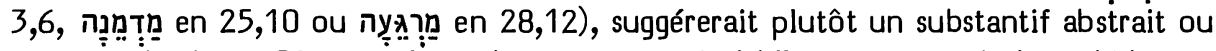
un nom de chose. C'est que le traducteur grec a choisi là un terme technique désignant au $2 e$ siècle av. J.-C. un fonctionnaire de l'administration égyptienne ayant pour charge de faire rentrer les taxes liées au transport des céréales (pap. Tebtunis 1083). Il semble

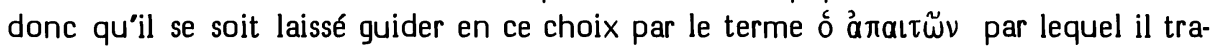
duisait (ici comme en 9,3) le participe ij que le stique précédent offrait en situation parallèle. Ce terme se situe en effet lui aussi dans la zone du vocabulaire de la perception des taxes. En agissant ainsi, le ${ }^{*} G$ méconnaissait les finales féminines du substantif hébreu et du verbe qui le précède.

La ${ }^{*} S$ présente la même option que le ${ }^{*} G$ qu'elle semble avoir traduit fidèlement par מחפטנא que la Syh réutilisera sans le modifier.

Hie attribue à Aq la leçon "fames". Cappel (Critica 827 et 832 ) suggère qu'il a

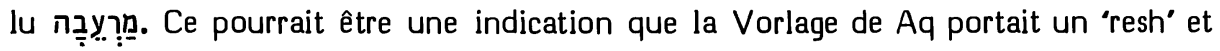
non un 'dalet'.

$\mathrm{La}$ *V traduit ce mot par "tributum", voyant dans ce substantif féminin une désignation de ce que reçoit le percepteur ("exactor") que Jérôme reconnaît (ici comme

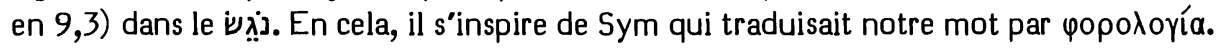

Le *T a paraphrasé "la puissance des méchants", en parallèle avec la paraphrase "le pouvoir de ceux qui nous asservissent" qu'il avait donnée pour le stique précédent. 
Concluons de cela que les versions ont traduit ce mot en fonction du sens (clair pour elles) du participe qu'elles trouvaient dans le stique qui précède et où la reprise du même verbe suggère qu'il a une valeur analogue. Elles ont donc fait comme fera Menahem ben Saruq qui dira de ce mot qu'il faut l'interpréter selon le sens offert

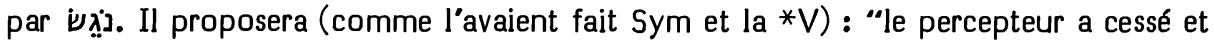
sa perception (מגשתו) a cessé".

\section{Histoire de l'exégèse :}

Le midrash Wayyiqra Rabba $(338,4 \mathrm{~s})$ nous rapporte comme une tradition anonyme qu'il s'agit ici de la tête d'or à laquelle Nabuchodonosor est comparé en Dn 2,38. Le lexicographe karaïte David ben Abraham (I 372,5ss) reprend cette exégèse, voyant prophétisée ici la cessation du pouvoir de ce roi.

Dès ses débuts, la lexicographie comparée - sachant la correspondance qui existe entre le 'dalet' et le 'zaiin' dans le mot qui désigne l'or - a décelé en ce dérivé de דהב un aramaïsme, y voyant (en fonction du contexte) la désignation d'une taxe payée en or. C'est l'opinion d'Abraham ha-Babli (213,3-9), de Judah ben Qoreish (Bargès $16=$ Katz 30) et d'Abulwalid (Ușul 153,18s). Radaq (Shorashim) voit ici un qualificatif désignant Babylone comme pleine d'or ou comme percevant un tribut d'or sur les royaumes.

Reuchlin, dès 1506 dans ses Rudimenta, avait interprété ce mot (à partir de l'araméen et de la $* V$ ) comme "aurum tributarium quo recognoscimus dominium". Cette interprétation se retrouve littéralement chez Oecolampade, Münster et Jud; ainsi que, transcrite en italien, chez Brucioli ("l'oro tributario") et, transcrite en français, chez Olivetan ("l'or tributaire"). Mercerus (sur le Thesaurus3 de Pagnini, col. 452) s'opposera à cette traduction, estimant que ce mot est un qualificatif de Babylone.

Pagnini, dans la première édition de sa traduction (dont l'impression fut achevée le 29 janvier 1527), donnait "tributum" ( $* \mathrm{~V})$, en demandant pourtant en ses errata : "pro tributum scribe plena auro". Sur cette correction, Pagnini s'explique ainsi en 1529, dans la première édition de son Thesaurus (391) : "nous avions d'abord placé dans notre traduction 'tributum' et j'avais écrit au-dessus de ce mot, pour le remplacer, 'plena auro'. Mais le correcteur n'a pas réalisé cette modification. J'ai donc dô corriger dans les errata ce mot dont certains autres ont cependant fait usage." $\mathrm{Ce}$ "nonnulli alii" semble bien désigner Luther qui, de mai à octobre 1528, avait réalisé et édité sa traduction d'Isaïe où il a, en effet, conservé "der zins(e)" de la vieille traduction allemande (Kurrelmeyer VIII 391, 20) faite sur la *V. Luther n'a vraisemblablement jamais lu les errata de Pagnini et n'a pas retouché sa traduction sur ce point. Mais Servet a réalisé la correction demandée par Pagnini dans la réédition de la traduction de celui-ci qu'il a publiée à Lyon en 1542. Cela n'empêchera pas Philibert Rollet ("le tribut") et Châteillon ("tributum" et "le tribut") de demeurer fidèles à la traduction de la $* V$.

Dans ses notes, publiées par Robert Estienne en sa Bible de 1545, Vatable glose : "quomodo desiit extorquere tributum ab Israelitis urbs avara ?" Du fait que ce mot est dans un contexte d'exaction et de tyrannie, Calvin, dans son commentaire édité en 1551, estime probable que ce mot désigne ici "l'avarice et la convoitise insatiable que les Babyloniens éprouvaient pour l'or". Dans sa révision d'Olivetan, publiée en 
1553, Estienne donne: “celle qui convoite l'or". En rééditant Pagnini en 1557, il corrige ici en "cupida auri", et, dans les notes qu'il joint à cette édition, il suggère en hésitant : "exactrix auri". En 1560, la Bible anglaise de Genève montre sa dépendance à l'égard de Calvin et d'Estienne en traduisant: "the golde thirstie Babel". La King James Version corrigea en "the golden city", notant en marge : "or exactresse of gold". La note marginale vient de celle de la Bible d'Estienne de 1557, alors que la correction du texte provient de Tremellius qui traduisait "aurea". Pour achever ce panorama, notons que la Bible des Pasteurs de Genève de 1588, impressionnée par l'allure de participe hifil de ce mot, a inversé l'exégèse de Calvin en paraphrasant: "celle qui faisait les gens tous d'or".

Comme on peut le constater, les versions, les lexicographes et les exégètes semblent avoir tâtonné en prenant leur inspiration en certaines des trois données que nous avons relevées:

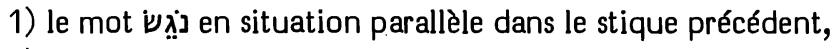

2) l'analogie avec le mot araméen désignant l'or,

3) la désinence féminine de ce mot et du verbe dont il est sujet.

Michaelis (OEB XI 153, n. e) explique que, dans son cours d'exégèse, il en était venu à conjecturer ici une leçon מרהבה au sens de "insistante, hâtant le rythme,

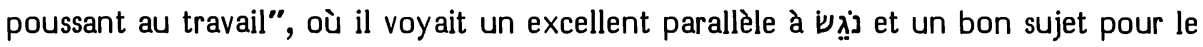
verbe annotée d'Isaïe que Doederlein publia en 1775 que celui-ci avait relevé dans une édition du $* M$ publiée à Thessalonique la forme exacte qu'il avait conjecturée. Michaelis ajoute à cette note : "ma joie serait vaine s'il ne s'agissait là que d'une faute d'impression". Cependant, dans la traduction qu'il publia en 1779, il donna ici : "die zur Arbeit dringende Gebieterin". Dans ses notes destinées aux "Ungelehrte", il expliquait : "J'ai suivi ici une autre leçon, car je ne puis traduire la leçon courante autrement que comme 'celle qui est couverte d'or' (die übergüldete)". La même année, il explique cela de façon plus détaillée (OEB XIV 148s) en disant qu'il lit avec le *G, la *S et l'édition de Thessalonique המרהבה. Il estime devoir quitter la leçon du * $M$, car il s'estime incapable d'en tirer le sens: "celle qui réquisitionne l'or" que Lowth en tire sans rien noter sur ce point. En effet, l'hébreu se distingue justement de l'araméen en ce qu'il appelle l'or דהב inב et not, à supposer que l'auteur veuille ici mettre sur les lèvres des Israélites ce mot aramaïsant, il n'existe aucun indice qu'il ait jamais eu le sens qu'on lui attribue. A quoi il faut enfin ajouter que les hébreux n'avaient pas la coutume romaine d'appeler le tribut "or", mais "argent". En 1782, Michaelis (OEB XVIII 99) note sa déception de ne trouver dans l'apparat de Kennicott aucun ms pour appuyer la leçon qu'il avait choisie. De Rossi non plus n'a trouvé cette leçon en aucun ms. D'ailleurs l'appui apporté par l'édition de Thessalonique est des plus faibles, puisqu'il s'agit, selon la préface de Doederlein, d’une édition "plurimis in locis vitiosa" publiée en 1607. Dans son oeuvre posthume (Supplementa ad lexica hebraica, publiés en 1792, p. 2339s), Michaelis estime probable qu'il s'agit là d'une faute d'impression. Il ne renonce cependant pas à sa correction qu'il fonde sur le *G et la $*$ S.

Gesenius a accepté la correction de Michaelis en notant qu'on retrouve un parallélisme entre les verbes רה שג en Is 3,5. Il traduit ici (14,4) “die Erpressung", 
précisant en commentaire qu'il s'agit de contrainte et de corvée. Après Gesenius, cette leçon a été acceptée par presque tous les exégètes et, ainsi que nous l'avons noté, par nos cinq traductions. Le fait que cette conjecture de Michaelis soit aujourd'hui clairement attestée par 1Q-a semble lui apporter un sérieux appui. En effet, lorsque Michaelis s'interrogeait sur l'éventualité d'une faute d'impression dans une édition du XVIIe siècle, il n'aurait pas osé rêver que la leçon qu'il conjecturait se trouvait formellement attestée dans un manuscrit datant du IIe siècle avant J.-C., manuscrit qui gisait dans une jarre hermétiquement close, à l'intérieur d'une grotte murée, dans le désert de Juda.

\section{Choix textuel :}

Cependant, Orlinsky (Studies IV 336) estime qu'il n’y a pas besoin de réfléchir longtemps pour préférer ici le *M à 1Q-a : “On a de la peine à admettre qu'un original מדהבה מרהבה ait été mal un traducteur après l'autre, ainsi que par les copistes incomparablement supérieurs et plus soigneux qui sont responsables de la tradition textuelle massorétique. Par contre, il n'est pas surprenant que le texte de 1Q-a ne soit sur ce point rien d'autre qu'une 'amélioration' du difficile מדהבה. C'est, une fois de plus, un cas où la lectio facilior a remplacé en $1 Q$-a la lectio difficilior du texte hébreu qui nous a été préservé." Malheureusement Orlinsky (Madhebah) n'a pas réussi à expliquer de façon plausible la leçon du *M qu'il interprète à partir du contexte.

De fait, il suffit d'admettre une confusion 'resh-dalet', type de confusion que la Okhla (Frensdorff $\$ 122,123$ et Diaz Esteban $\S 147$ ) a relevé en plusieurs endroits du *M. Cette confusion aurait eu pour origine une négligence de scribe, puis se serait développée par simple copie de l'exemplaire fautif, s'étendant ainsi à l'archétype du texte massorétique et à un manuscrit connu de l'auteur des Hodayot. Par contre, 1Q-a émanerait d'une lignée textuelle qui aurait échappé à cette corruption. Quant aux versions, le fait qu'elles se soient laissées guider par le contexte ne nous permet pas de savoir laquelle des deux leçons elles ont lue.

Il est plus difficile d'imaginer qu'à partir d'un original constitué ici par un dérivé d'une racine דהב inconnue par ailleurs en hébreu, on serait passé, par une simple négligence de scribe, à un dérivé de la racine רהב, racine dont Is 3,5 nous montre qu'en ce même livre elle constitue un parallèle de la racine iv qui, justement, - par une coïncidence qui défie la vraisemblance - se trouve ici aussi en situation de parallèle dans le stique voisin.

Le comité a attribué à la leçon de 1Q-a 3 "B" et 3 "C".

\section{Interprétation proposée :}

Le parallèle d'Is 3,5 nous oriente vers un sens de "arrogance" qui convient bien ici : "Comment l'oppresseur a-t-il disparu, l'arrogance a-t-elle disparu." 


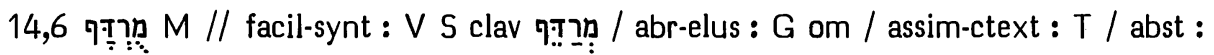
$1 \mathrm{Q}-\mathrm{a}$

Options de nos traductions :

Quatre d'entre elles ont traduit ce participe comme s'il s'agissait d'une forme active : J : "les pourchassant", RL : "und verfolgte", NEB : "and persecuted them", TOB : "les persécutant". Seule cette dernière fait remarquer que le sens du *M serait "persécuté" et qu'elle lit le sens actif en changeant les voyelles. Brockington précise que NEB lit

Origines de la correction :

Le premier qui ait formellement proposé cette correction vocalique est Foreiro qui estime que la $* V$ vocalisait ainsi. Cappel (Critica 776) pense que le ${ }^{*} T$ aussi lisait cela. En ses Notae (502) il estime que cette vocalisation en piél offre un sens préférable. Dathe (cité par Doederlein) a adopté cette vocalisation en l'attribuant aussi à la $*$ S.

Nos traductions ont pu trouver cette correction requise par l'apparat de BHS et proposée comme une alternative par celui de BH3. Notons toutefois que RL s'est contentée de copier ici Luther qui, comme déjà Oecolampade, s'est laissé influencer par la $* V$, comme le feront ensuite Brucioli, Olivetan, Rollet, Estienne et Châteillon.

Les témoins anciens :

$1 Q$-a est identique au $* M$, sans que l'on sache comment on le vocalisait.

Le ${ }^{*} G$ n'a pas traduit ce mot, faisant des deux mots qui suivent un complément de la phrase qui précède.

La *V a traduit par des participes présents ("caedentem" et "subicientem") le participe hifil par lequel commence 6a et le participe qal par lequel commence 6b. Elle fait de même (persequentem) pour ce mot.

La *S conserve la racine de ce mot mais le traduit par un participe actif peal.

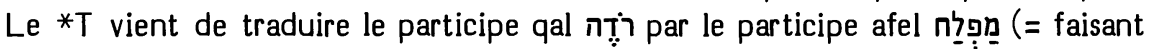
travailler) qu'il reprend pour traduire ce mot. Comparant $6 \mathrm{~b}$ à $6 \mathrm{a}$, Doederlein conclut qu'il faut lire ici un substantif jouant par rapport à n̦̣ le rôle qu'en 6a le substantif ַַּ joue par rapport à une Vorlage מִִּ qui lui semble satisfaire exactement à la condition qu'il avait formulée. Il s'est appuyé sur la dérivation de מרמה à partir de רמה pour conjecturer ici ce nom abstrait non attesté en hébreu. Malgré sa base fragile, cette conjecture a été adoptée par Vogel, Koppe, Gesenius, Hitzig, Knobel, Ewald et requise par les apparats de HSAT234, BH23, Cent. Wildberger préfère cependant en rester à une correction en actif de la forme passive du *M puisque manque tout argument pour appuyer l'existence du substantif inventé par Doederlein.

\section{Choix textuel :}

Ce cas n'a pas été soumis au comité.

Oecolampade et Luther, nous l'avons dit, avaient, sous l'influence de la $* V$, traduit ce mot en un sens actif. Cela a éveillé une protestation de Münster précisant que ce participe est passif et non actif "ut quidam ex recentioribus inepte verterunt". 


\section{Ici, toute correction vocalique est évidemment facilitante.}

Interprétations proposées :

$L$ 'exégèse la plus classique du $* M$ est celle qui considère le participe hofal comme complément d’objet du verbe suivant : "celui qui était objet de persécution, il ne l'épargnait pas". C'est l'interprétation de Radaq, Pagnini, Vatable, Calvin, Ge, Vitringa, etc.

D'autres ont fait de ce participe passif le prédicat du participe actif qui précède. Ainsi Tremellius ("Dominans iracunde gentibus agitatur persecutione quam non cohibebit") suivi par Pasteurs et KJ.

D'autres encore ont considéré ce participe comme un complément d'objet du participe actif qui précède. Ainsi Servet (en marge de sa réédition de Pagnini en 1542): "Dominantem in furore gentibus et persecutionem passo absque ulla cessatione". Münster a considéré ce participe comme qualifiant le substantif (pluriel !) qui le précède : "Dominantem in ira gentibus, persecutionem passis (ab eo) absque ulla miseratione".

A ces diverses tentatives, on est en droit de préférer une exégèse qu'Aurivillius (395s) a proposée et qui a été adoptée par Rosenmüller et Delitzsch. Le participe hofal peut avoir en certains cas valeur de nom. Ainsi, מְִּּב en Is 29,3 ou en $1 \mathrm{R} 7,37$ et ailleurs, pour citer des formes qui ont tantôt des emplois nominaux, tantôt des emplois verbaux. Ici aussi, selon Delitzsch, la signification glisse de "celui qui est objet de persécution" au "fait que l'on soit objet de persécution", une analyse

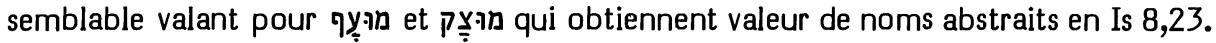
D'ailleurs, c'est un substantif qui est le mieux en place avant la négation (cf. Is 32,10; Jb 41,18). Cette interprétation fait de la seconde moitié du vs un parallèle exact de la première : "frappant les peuples avec fureur de coups incessants, subjuguant les nations avec colère d'une persécution sans ménagement". C'est l'exégèse que RSV a adoptée.

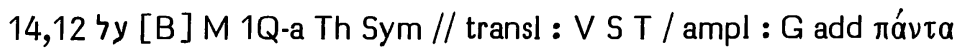

Options de nos traductions :

L'expression low", par J3: "vainqueur des nations", par NEB : "sprawling helpless across the nations" et par TOB : "toi qui réduisais les nations".

312 traduisaient: "toi qui vassalisais toutes les nations", s'appuyant sur le *G pour corriger y en כל :De même, RL traduit : "der du alle Völker niederschlugst".

Origine de la correction :

C'est Duhm 1 qui a suggéré de s'inspirer du *G pour remplacer לע מל מל מל motivant cette correction par le fait qu'en Ex 17,13 le verbe חל חל construit avec l'accusatif. Cette suggestion est devenue un ordre en Duhm2, ordre suivi par HSAT34 et Cent, alors qu'il redevient une suggestion en $\mathrm{BH} 23 \mathrm{~S}$. 
Les témoins anciens :

Gunkel (132, n.6) a estimé que גורים est la fausse résolution d'une abréviation גוי גרוית טרares", le sens étant : “gisant sur des cadavres". Cette hypothèse a été admise par Cheyne, Marti et Gray. Il est frappant de noter que 1Q-a a justement ici, sans 'mem' final. Est-ce autre chose qu'une coïncidence ? Van Leeuwen (179) estime que 1Q-a, ayant compris גרים comme le mot "gewî" (= dos) affecté d'un 'mem' enclitique, a omis ce 'mem'. Quoi qu'il en soit, 1Q-a porte ici לy, comme le *M, et non כל.

Le *G, avec ó ả ${ }^{*}$, cipe hébreu, ce qui a commandé le choix de la préposition par laquelle il traduit ensuite celle du *M. Il est inexact de dire qu'il a lu כל a la place de על. Mieux vaut dire que l'ajoute de "toutes" avant "les nations" constitue ici une amplification analogue à celle que nous avons rencontrée en 14,2 ("de nombreux peuples") dans $1 Q$-a et à celle que nous rencontrerons en 41,11 ("tous les hommes") dans le *G et en $1 \mathrm{Q}$-a.

Th et Sym, traduisant ici $\varepsilon^{2} \pi^{\circ} \varepsilon^{2} \theta \nu \eta$, montrent qu'elles ont lu לy et non.

En fonction du verbe dont elles font usage, la*V, la *S et le *T ont rendu diversement la préposition du *M, mais aucune de ces versions n'offre d'indice qu'elle ait lu כל.

\section{Choix textuel :}

Abulwalid (Ușul 232,1-3) a suggéré que חלש appartient à la catégorie des verbes transitifs qui gouvernent leur régime tantôt de façon directe, tantôt à travers une préposition. Aurivillius (408s) a noté que שלח eux aussi se construisent tantôt avec את, Gesenius a suggéré qu'ici la nuance peut être celle qui distingue en allemand "siegen über" de "besiegen". Delitzsch, suivi par von Orelli, a suggéré, en fonction du contexte, que cette construction avec לy évoque l'influence des astres : “toi qui répands l’abattement sur les nations". Cela serait un qualificatif de "astre brillant, fils de l'aurore" et cela formerait un contraste avec "te voilà abattu à terre".

Quoi qu'il en soit de ces nuances, le comité a résisté à l'ajoute de "toutes" par 4 "B" et 2 "A".

Interprétation proposée :

Judah ben Qoreish (Bargès $39=$ Katz 65) et Saadya ( 70 mots, 37,25) estiment que ce verbe signifie ici, comme dans le Talmud de Babylone (Shabbat 149b), “tirer au sort". Cette exégèse risque cependant d'impliquer un cercle vicieux puisque c'est justement sur Is 14,12 que le Talmud s'appuie pour montrer que ce verbe a ce sens.

Certains exégètes ont proposé de comprendre ici שִ̣̂n en un sens intransitif : "gisant, pantelant, affaibli". Mais cela semble plutôt être le sens de l'adjectif nַ, alors que l'usage qui est fait ici du participe actif, invite à s'inspirer du verbe d'action qui apparaît en Ex 17,13 sous la forme verbe, Bronznick lui reconnaît comme sens de base : "couper au niveau de la tête, étêter", par exemple lorsqu'on moissonne en ne coupant que les épis. Le sens ici serait donc "décapitant les nations"(en tuant ou déportant leurs rois ou leur noblesse). 
Il ne faut pourtant pas exclure l'interprétation la plus traditionnelle qui est ici "affaiblir", d'où l'on peut tirer "défaire, subjuguer, vassaliser".

14,19 כנצר [C] M 1Q-a Th Aq(?) V S // transcr-harm : G ws vexpós / exeg: Sym T / err-graph : Aq(?) clav כנצר

Options de nos traductions :

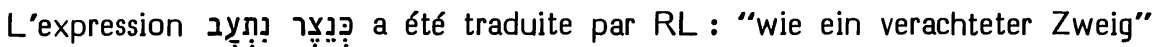
(= Luther) et par 33 : "comme un rameau dégoûtant".

RSV avait traduit : "like a loathed untimely birth" en se référant au *T et à Sym;

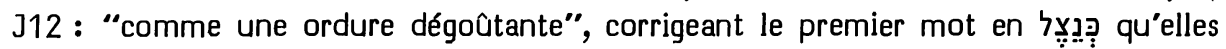
attribuent au *G avec hésitation; NEB : "mere loathsome carrion" avec même correction et même attribution; TOB : "comme un exécrable avorton", appuyant la même correction sur "les versions".

Origine de la correction :

C'est Nestle (Miscellen 127-129) qui a suggéré que cette leçon a été lue ici par $A q$, le ${ }^{*} G$ et Hie. Cette donnée a pénétré ensuite dans les addenda de $\mathrm{BH} 2$ et en $\mathrm{BH}$, à titre informatif.

Auparavant, Michaelis (Supplementa 1671), suivi par Schleusner (II 311) et Ge-

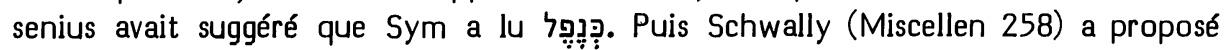
d'adopter ici cette leçon, suivi par de nombreux critiques.

Les témoins anciens :

$1 Q$-a est identique au *M.

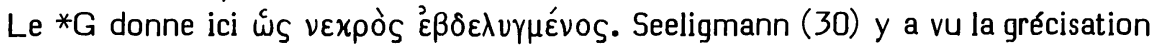
d'une transcription de la leçon du *M. Le traducteur s'est probablement inspiré pour cela de כפגר qu'il n'a pas traduit dans la fin de ce vs.

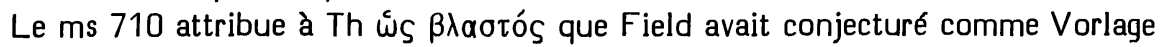
pour "germen" que Hie lui attribuait. Il a donc lu le *M.

Eusèbe, le ms 710 et Hie s'accordent pour attribuer à Sym ẃ $\varsigma^{\prime \prime}$ éx $\tau \rho \omega \mu \alpha$.

En son livre $\mathrm{V}$, Hie attribue à $\mathrm{Aq}$ : "quasi sanies polluta". En son livre VI, il lui attribue ' $x$ w $\rho$ qu'il traduit par "tabes" (= pus, liquide émanant d'un cadavre en voie de corruption) et "paedor" (= puanteur). Après avoir donné cette leçon, Hie fait remarquer qu'en 11,1 le même mot hébreu a été traduit ảxpé $\mu \omega \nu$ par Aq. Ce rapprochement est-il cause de la confusion qui a amené le ms 710 à attribuer ici à Aq:

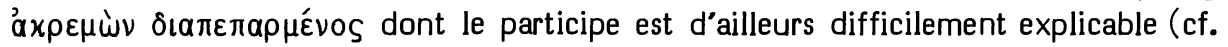
Lütkemann, note 515) ? La leçon que Hie attribue ici à Aq correspond exactement au sens du mot נגֶֶ, tel que le donne le Talmud, cité par Jastrow (929b) : un cadavre en voie de dissolution, ou la sécrétion qui s'en écoule.

La *V (quasi stirps inutilis) a lu ici le *M (ainsi que Hie nous l'atteste formellement en son livre $V)$.

La*S (איך נורבא) traduit le *M. 
La vraie leçon du *T n'est pas vחִ̣̣ que donnent ici les Miqraot Gedolot et la polyglotte de Londres, ni

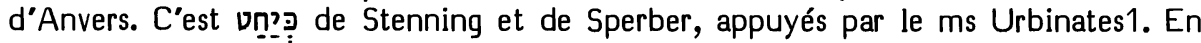
se fondant sur le syriaque (où יחט traduit le grec "̌x $\tau \rho \omega \mu \alpha$ ), on traduira ce mot par "avorton".

Faut-il conclure de là, avec Michaelis, que Sym (et le *T) ont lu ici כנפל ? Il $s$ 'agit plutôt d'une interprétation rabbinique du ${ }^{*} M$, interprétation que le Talmud Yerushalmi (Shebiit IV 8) attribue à R. Eleazar (début du 4e s.) à propos d'Is 49,6 lu selon le ketib : ונצירי ישראל. Il s'agirait là des avortons d'Israël que Dieu promet de ressusciter. Il semble donc que la leçon du $* M$ ait pu prêter à l'interprétation de Sym et du *T. Notons d'ailleurs que Saadya, qui lisait sûrement' le *M, a traduit de même.

\section{Choix textuel :}

Cependant, Yéfet ben Ely traduit ici par "rameau" ( citement ce texte de Dn 11,7 et d'Is 11,1. De même, Abulwalid (Ușul 449,33s) explique qu'il s'agit d'un jeune plant qui est inapte à être planté parce qu'il est rabougri. C'est pourquoi on le rejette.

A cela, Ehrlich ajoute que le mot נצר a été choisi par le prophète pour désigner Nabuchodonosor parce que cette finale est la seule partie de son nom (נבוכדנצר) qui évoque quelque chose en hébreu.

Le comité a attribué à la leçon du *M la note "C".

Interprétation proposée :

On pourra donc traduire : "comme un surgeon exécré", en notant que le mot hébreu pour "surgeon" correspond aux deux dernières syllabes du nom de Nabuchodonosor.

Les fondements lexicographiques de l'interprétation de Sym, du *T et de Saadya sont trop peu solides pour qu'on la conseille.

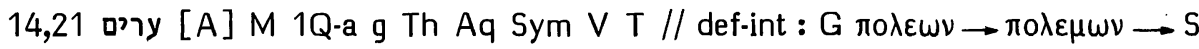

Options de nos traductions :

RSV et NEB traduisent ce mot par "cities", J3 et TOB par "villes".

$J 12$ omettaient ce mot, le considérant comme une glose.

RL le traduit par "Trümmer".

Origines des corrections :

Ce mot a été considéré comme une glose par HSAT34, BH23 et Cent. Son omission a été conseillée par BHS. Duhm y voyait une variante portant sur les deux mots précédents.

C'est l'apparat de HSAT2 qui conseillait de corriger ce mot en 0 ?y qu'il traduisait par "Trümmer" que RL a adopté. Cette conjecture remonte à Hitzig et a été adoptée par Grätz et Cheyne. 


\section{Les témoins anciens :}

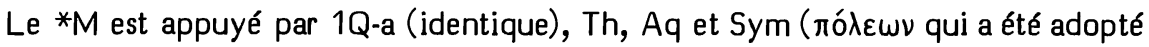
par certains témoins de la recension origénienne), la $* V$ (civitatum).

Hie précise (en son livre V): "in hebraeo scriptum est pro 'civitatibus' ARIM quod nos transferre possumus et "adversarios'." Ce deuxième sens a été retenu par le *T (בעלי דבב selon Sperber appuyé par le ms Urbinates 1).

Le ${ }^{*} G$, selon la traduction que Hie en donne (en son livre VI) lisait, lui aussi, "civitatum" (=

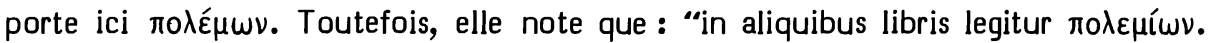

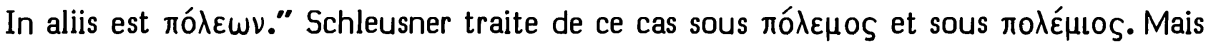
l'apparat de l'édition de Göttingen n'a pas trouvé un seul témoin pour la leçon ro-

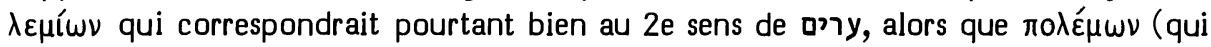
$n^{\prime} y$ correspond pas et qui est attesté par tous les témoins les plus anciens du ${ }^{*} G$ )

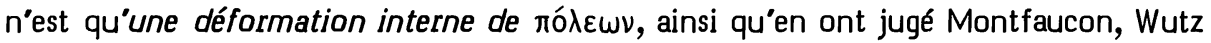
(I 33 où il rapporte d'autres cas de déformation d'un de ces mots en l'autre), Fischer (Schrift 12), Gehman (Errors 399) et Wildberger. C'est par recension sur le texte protomassorétique que Th, Aq et Sym ont rétabli cette forme originelle.

La *S (קרבא) a traduit ici le *G déformé.

\section{Choix textuel :}

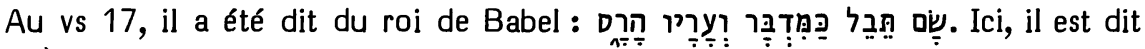
(vs 21a): "préparez pour ses fils l'égorgement pour la faute de leurs pères", puis :

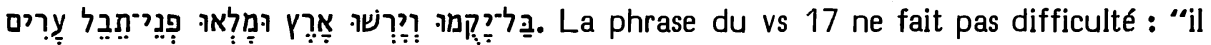
a mis le monde à l'état de désert, il en a démoli les villes". Quant au vs $21 \mathrm{~b}$, on le comprend d'ordinaire comme : "ils ne se lèveront pas et ne s'empareront pas de la terre et ne rempliront pas de villes la face du monde."

Mais Vitringa estime peu logique que l'on craigne des fils du destructeur de villes qu'ils remplissent le monde de villes. Il fait remarquer d'ailleurs que ce sens supposerait ici un piél (cf. Jb 3,15) alors que l'on a un qal.

Sentant cette difficulté, Radaq (Shorashim sur yור) estime que l'on peut voir en ומלאו un contraste avec ce qui précède : puisque le roi de Babel détruisait les villes, lorsqu'il sera mort et que ses fils, égorgés, n'auront pu s'emparer de la terre, “alors des villes rempliront la face du monde". Cependant, Gesenius estime syntactiquement nécessaire que la négation s'oppose-t-il à cette exégèse en contraste.

Puisqu'il ne peut donc s'agir, dans les 4 derniers mots du vs 21, que du dernier des dangers que la survie des fils aurait entraînés, Vitringa et Gesenius se voient dans la nécessité d'adopter l'option du *T donnant ici à वִִ̣ le sens de "ennemis".

Mais, après Gesenius, un vent de conjectures a soufflé. Estimant que "la face" du monde n'est pas un lieu normal pour des "ennemis", Hitzig, nous l'avons dit, a conjecturé ici des "ruines". Ewald, en s'inspirant de 13,11, a proposé yִyִ Knobel a suggéré a repris, en lui donnant le sens de "combats", la conjecture עִ צִ à laquelle Houbigant donnait le sens de "brigandages". H. Barth (Worte) préfère lire צרים.

Contre ces diverses conjectures, le comité a attribué à la leçon du *M la note " $A$ ", puisqu'elle est à l'origine de toute la tradition textuelle. 
Interprétation proposée :

De fait, les vocalisateurs ont vraisemblablement compris ם?ר au sens de "ennemis". En effet, le ms de Leningrad atteste ici en mp que ce cas est l'un des 8 où ce mot est pris au sens d'hostilité. Et l'édition Ben Hayim donne sur Mi 5,13 la mm correspondante qui précise que les 7 autres cas sont $1 \mathrm{~S} 28,16$ (à propos duquel, cf. CT1, 217); Mi 5,10.13; Ps 9,7; 139,20; Dn 4,16; Jr 15,8.

Cette interprétation a pour partisans plus ou moins résolus le *T, Hie, Yéfet ben Ely, Menahem ben Saruq, Levi ben Yéfet (cf. David ben Abraham, II 429, note 49), Hayyuj (Kitâb 112,13), Jacob ben Reuben, Ibn Ezra, Parḥon, Tanḥum Yerushalmi, Rashi, glossaires, Aaron ben Joseph, Radaq, Isaïe de Trani, Abravanel, Oecolampade (attribuant ici à la LXX la leçon $\pi 0 \lambda \varepsilon \mu \mu^{\prime} \omega v$ ), Luther (en 1528), Pagnini, Münster, Brucioli, Olivetan, Vatable, Ge.

Mais le sens de "villes" est donné ici par Saadya. C'est celui que préfèrent Judah ibn Balaam et Eliézer de Beaugency. C'est celui que donnent en premier Jérôme et Yéfet ben Ely. Il est donné en second par Ibn Ezra, Aaron ben Joseph et Radaq. Parmi les traducteurs du XVIe siècle, Pagnini le donne en second dans son Thesaurus. Il est adopté par la traduction des Prédicants de Zurich, puis par Luther (dans sa révision de 1540), Estienne, Châteillon, Tremellius, Pasteurs et KJ. Il avait été donné en second par Münster, Olivetan et Estienne (en ses notes sur la réédition de Pagnini en 1557). On voit donc que les traductions allemandes, françaises et anglaises sont passées de "ennemis" à "villes" en quoi elles se sont stabilisées.

Ce sens de "villes" est rendu ici plus probable pour plusieurs motifs : D'abord la liaison entre ערים et apparaissait déjà au vs 17 où le sens de "villes" était évident. Ensuite, si on lisait "ennemis", on devrait y voir les fils soucieux de venger la mort de leur père. Or on ne voit pas comment ils suffiraient à remplir la face du monde. D'ailleurs le parallèle de 27,6 suggère de construire : "et la surface du monde ne se remplira pas", ce qui appelle plutôt le complément : "de villes".

21b évoque donc ce que l'on peut craindre si on laisse survivre certains des fils : qu'ils s'emparent du pouvoir, conquièrent la terre et que la surface de l'univers se couvre de villes. On craint donc qu'ils ne créent un empire fortement structuré (après que leur père, selon le vs 17, ait détruit les structures des royaumes en dévastant l'univers et démolissant les villes). Sur cette signification des villes, cf. CT1, 512 .

\section{4,30A בכורי [B] M 1Q-a Aq Sym V S // lic : T / constr : G}

Options de nos traductions :

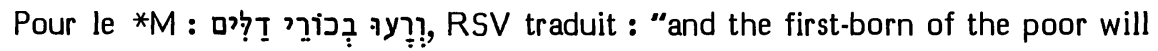
feed", J3 : "car les premiers-nés des pauvres auront leur pâture" et TOB : "les plus misérables auront un pâturage".

J12 donnaient ici : "mais les pauvres paîtront dans mes pâtures", conjecturant, pour le 2e mot : 'רְּ et et précisant que la tradụction littérale en serait "dans ma pâture". RL donne : "die Geringen werden auf meiner Aue weiden" et NEB : "But the poor shall graze their flocks in my meadows", Brockington faisant ici la même conjecture que 32 . 
Origine de la correction :

Houbigant traduisait ici : "et pascentur primogenitis meis pauperes, seu fructibus optimis", ce qui suppose que le 'yod' final soit compris comme pronom suffixe de la 1e pers. sg. et que le mot soit vocalisé 'רֵּ习习习̣. En traduisant : "the poor shall feed on my choice first-fruits", Lowth suppose la même vocalisation.

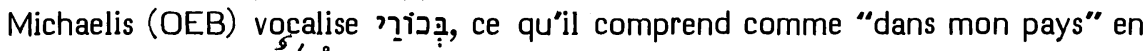
s'appuyant sur l'arabe כُ “district”. Il attendait de trouver une graphie défective en des manuscrits importants pour pouvoir vocaliser "en mes pâturages". Plus tard (OEB XVIII 110), il estima que cette deuxième conjecture avait été rendue bien plus vraisemblable par le fait qu'il avait trouvé cette graphie défective en cinq mss, pour la plupart remarquables, de Kennicott.

J12, RL et NEB lisent cette conjecture au singulier comme l'avait fait Duhm et, à sa suite, $\mathrm{BH} 23$.

HSAT34 et Cent conjecturaient ici pentir de Cheyne craignant que le sens de "pâture" pour ’כ̣ ne soit pas assez assuré pour que la conjecture de Michaelis puisse se fonder dessus.

Les témoins anciens :

Thomas, en BHS, note ici : "pc Mss בכרי exacte pour les traductions de $\mathrm{J} 12$ et de NEB sil était vrai que les mss qui écrivent ici ce mot. défectivement vocalisaient ainsi. Kennicott cite ici 5 mss auxquels ni de Rossi ni Ginsburg n'en ajoutent de nouveaux. Or, les trois d'entre eux que nous avons pu contrôler, c'est-à-dire le ms des Jésuites de Cologne et les mss 1 et 2 de la Bibliothèque Royale de Copenhague, ont la vocalisation normale du *M.

D'ailleurs 1Q-a appuie la graphie pleine du texte tibérien classique, alors que 4Q-o, lacuneux, n'atteste que les deux dernières lettres de ce mot et le mot suivant.

De fait, la seule variante attestée est dans le ${ }^{*} G$ qui n'a pas traduit ce mot, mais

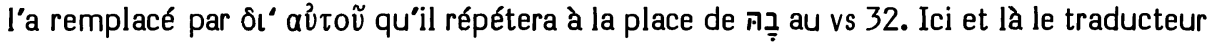
a construit son texte de manière à souligner que c'est le Seigneur qui sauve les pauvres et les humbles de son peuple.

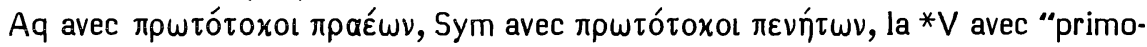
geniti pauperum" et la*S avec בוכרי מסכנא appuient formellement le *M.

Quant au *T, il a exprimé librement la valeur superlative de l'expression en traduisant : "les pauvres du peuple".

Choix textuel :

Puisque les seules variantes existantes sont des libertés de traduction, le comité a attribué à la leçon du * $M 4$ " $B$ " et 2 " $A$ ".

Interprétation proposée :

L'exégèse traditionnelle considère ici l'expression "premiers-nés" comme ayant valeur de superlatif relatif. Il s'agit des plus misérables des misérables (cf. König, Syntax $\$ 309$ a qui associe à ce cas Ps 89,28 et Jb 18,13). On peut voir sur ce point les commentaires de Hitzig, Knobel, Delitzsch, von Orelli et Kaiser. L'image est audacieuse, mais pas plus que celle de la "racine du serpent" au vs précédent. 30a est à comprendre comme une première ébauche de $32 \mathrm{~b}$. 
14,30B יהרג . [B] M t // facil-vocal : S / assim-int : 1Q-a V 1e p., G T 3e p.

Options de nos traductions :

En 30b, le *M fait difficulté en offrant le premier verbe à la 1e pers.: "je ferai mourir" et le second à la $3 \mathrm{e}$ : "il tuera". Aucune de nos traductions ne respecte exactement cela.

Toutes respectent la 1e pers. du *M pour le premier verbe ("I will kill" en RSV et NEB, "je ferai mourir" en J et TOB, "will ich ... töten" en RL).

Mais le second est traduit par une 1e pers. par RSV : "I will slay", J : "je tuerai" (toutes deux attribuant cela à 1Q-a et à la *V), NEB : "(I will) put ... to death"

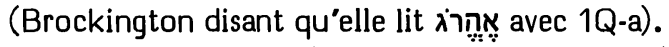

TOB traduit: "(et ce qui restera de toi) sera tué", sans note, ce qui suppose pourtant une forme passive féminine (et non active masculine) puisque le sujet de ce passif est, dans le $* M$, un substantif féminin.

\section{Origines des corrections :}

Grätz (Psalmen 135, l. 19) semble avoir été le premier à proposer formellement la correction du 2e verbe en 1e pers. adoptée ensuite par Bredenkamp, Duhm, Cheyne, Marti, Condamin, Procksch, Fohrer, HSAT34, Cent, Driver (Scrolls 25). Il importe cependant de noter que (sous l'influence de la *V?) Luther, en 1528, traduisait : "will ich ... tödten, und ... erwürgen"; alors que, à partir de 1540, il a révisé sa traduction en insérant "wird er" avant le second infinitif.

Quant à la TOB, elle ne se doutait vraisemblablement pas qu'elle avait eu un prédécesseur en Châteillon traduisant : "e ferai mourir ... e ta reste sera tuée". Elle n'a pas signalé que cette option pouvait $s$ 'appuyer sur la ${ }^{*} S$ ainsi que nous le verrons.

\section{Les témoins anciens :}

Les mss du *M sont unanimes à témoigner de la discordance entre le premier verbe de $30 \mathrm{~b}$ à la 1e pers. et le second à la 3e pers. En cela, le *M n'est appuyé que par une minorité de témoins du *T (dont le ms Reuchlin).

Tous les autres témoins textuels ont interassimilé ces deux verbes : le ${ }^{*} G$ et les autres témoins du *T ont interassimilé sur la base de la 3e pers.; alors que 1Q-a et la *V l'ont fait sur la base de la 1e pers.

La *S a traduit le second verbe par somme si elle l'avait vocalisé en nifal. Cette facilitation est 'dans l'air', comme le montre le fait que Châteillon et TOB aient opté indépendamment pour la même traduction.

Notons que 4Q-o appuie le $* M$ pour le premier verbe, mais est lacuneux pour le second.

\section{Choix textuel :}

Ces interassimilations en sens contraires confirment indirectement la discordance des personnes qu'offre le ${ }^{*} M$ dont la lectio difficilior a reçu du comité la note " $\mathrm{B}$ ".

\section{Interprétations proposées :}

Clericus, Nägelsbach et König font de la "famine" (ברִ masculin) le sujet du verbe final à la 3e pers. m. sg. 
Presque tous les autres exégètes qui suivent le *M (depuis Hie jusqu’à Delitzsch, en passant par Yéfet ben Ely et Vatable) donnent le "saraf volant" de 29b pour sujet à ce verbe. Il s'agit là d'un roi redoutable pour la Philistie.

En effet, il faut distinguer vraisemblablement d'une part la famine, fléau indépendant de l'initiative humaine, auquel on attribue, à ce titre, Dieu pour auteur, et d'autre part une expédition guerrière assyrienne venant du Nord (vs 31) qui tuera ceux que la famine aura épargnés.

Traduire avec Pasteurs par un impersonnel "on tuera" semble ici facilitant.

\section{5,2 עלה הבית ודיבן [B] M 1Q-a V // facil-synt : S T / assim 1 : G}

Options de nos traductions :

TOB traduit : "On monte au temple, à Divôn" sans note.

RSV conjecture: "The daughter of Dibon has gone up" en disant que le *M porte : "the house and Dibon".

J12 portaient : “On monte au temple de Dibôn", disant lire avec la *S : au lieu du *M: "au temple et à Dibôn".

J3 porte : "Elle est montée, la fille de Dibôn", disant conjecturer cela avec le *T et la*S.

RL porte : "Es geht hinauf die Tochter Dibon".

NEB porte : "The people of Dibon go up", se référant à Jr 48,18 pour conjec-

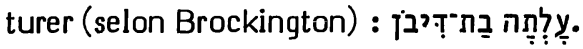

Origines des corrections :

J12 a pu trouver en Cent l'attribution de cette leçon à la *S. Houbigant semble avoir été le premier à proposer d'omettre la conjonction et de traduire : "ascendunt ad templum Dibon". Lowth, corrigeant de même (en se fondant sur le *T et la *S), traduit : "He goeth up to Beth-Dibon". Aurivillius (690) objecte à cela que ce toponyme ne réapparaît nulle part et qu'il faudrait omettre encore l'article pour pouvoir traiter ב en état construit.

La correction adoptée par RSV, J3, RL et NEB a été conjecturée par Duhm, puis requise par les apparats de HSAT34, $\mathrm{BH} 235$ et Cent.

\section{Les témoins anciens :}

$1 Q-a$ ne se distingue du *M que par une graphie pleine.

La $* V$ (ascendit domus et Dibon) appuie aussi le *M.

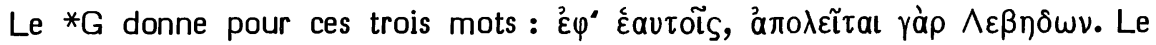
verbe initial a donc été interprété comme une préposition suivie d'un suffixe pronominal. Puis, הבית gênant le traducteur, il l'a remplacé par un verbe que le vs précédent lui offrait déjà deux fois.

La *S et le *T ont facilité dans le sens d'Houbigant et de Lowth. J3 (à la suite de $\mathrm{BHS}$ ) a tort de les invoquer à l'appui de la conjecture de Duhm. 


\section{Choix textuel :}

Etant donné l'appui que $1 Q$-a et la $* V$ apportent au $* M$, il est peu vraisemblable que la ${ }^{*} S$ et le $* T$ aient lu une Vorlage où manquaient la conjonction et l'article.

Le comité a attribué 4 " $B$ " et 2 "C $C$ " à la lectio difficilior du * $M$.

Quant à la conjecture que Duhm fonde sur le parallèle de $\mathrm{Jr} 48,18$, il faut admettre que, si elle est exacte, elle atteint un état textuel plus ancien que l'archétype d'où émane notre tradition textuelle.

Interprétations proposées :

Rashi a opté pour une construction qui fait violence aux teamim : "Moab est monté au temple et les hommes de Dibôn sont montés sur les hauts-lieux". Cette construction semble n'avoir été adoptée au XVIe siècle que par Servet (en sa réédition de Pagnini) et par Calvin.

La plupart des traducteurs et exégètes du XVIe s. suivent la construction de Radaq : "Moab est monté au temple et à Dibon où sont les hauts-lieux".

Cependant la *V, Yéfet ben Ely, Ibn Ezra, Aaron ben Joseph, Pagnini (en 1527) et Foreiro s'accordent pour construire : "Ha-baith et Dibôn sont montés aux hautslieux". Il est vraisemblable en effet que Ha-baith est ici un toponyme. En effet le vs précédent groupe deux toponymes et le stique suivant en groupera deux autres. Enfin, si nous rapprochons ces trois mots des trois premiers mots du vs 4 , nous y retrouvons, en une construction identique, un verbe au singulier en début de vs, suivi par deux toponymes coordonnés qui en sont les sujets. Cette construction semble donc préférable.

Si l'on est gêné par ce toponyme, inconnu par ailleurs, on respecte aussi bien les teamim en traduisant : "Dibôn lui aussi est monté au temple, sur les hauteurs, pour pleurer".

Notons que la stèle de Mésha, trouvée à Dibân, avait été érigée par Mésha à la "bâmâh" pour Kamosh (I. 3). Le roi y dit avoir rebâti Beit-Bâmôt (I. 27) qui avait été détruit.

15,3 שB [B] M 1Q-a V S T // assim-usu : G

Options de nos traductions :

RSV, J3, RL et TOB suivent le *M en faisant de "sur ses toits" un premier complément (coordonné au second: "et sur ses places") de : "tout le monde se lamente" (qui fait suite à ces deux compléments).

En disant s'inspirer de $\mathrm{Jr} 48,38, \mathrm{J12}$ insère "on hulule" comme verbe dont dépend le premier de ces deux compléments.

NEB traduit "they cry out on the roofs" disant conjecturer ce verbe en s'inspirant du *G; Brockington précisant que c'est קָּ qui est inséré avant le premier complément. 


\section{Origines des corrections :}

A travers les apparats de Cent, $\mathrm{BH} 23 \mathrm{~S}$ et HSAT34, la conjecture de $\mathrm{J12}$ vient

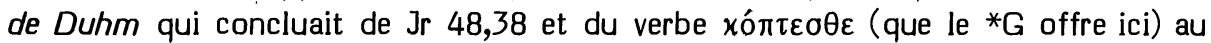
manque d'un mot (vraisemblablement מִִ̣ après "sur ses toits". Rudolph (Jesaja 134), estimant qu'un mot de cette importance n'aurait pu disparaître, préférait une forme du verbe נהה.

NEB suit une suggestion de Driver (Hebrew 163 et Mistranslations 124). Celui-ci, s'inspirant du syriaque, a postulé ici קִ קִ d'un verbe inattesté en hébreu biblique. Il lui suffit d'admettre une haplographie de chacune de ses deux consonnes pour expliquer ici sa disparition. Malheureusement, ce verbe syriaque désigne les clameurs guerrières et non les lamentations. Quant à son dérivé y ק en hébreu talmudique, il désigne d'abord l'appel à venir picorer que l'on adresse aux poules. Rien de tout cela n'est vraisemblable en ce contexte.

\section{Les témoins anciens :}

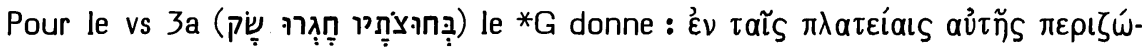

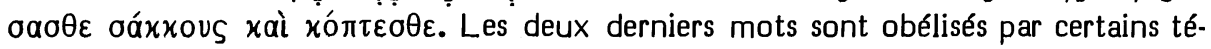
moins de la recension origénienne. Leur présence ici s'explique vraisemblablement par une assimilation à d'autres lieux bibliques où se retrouve l'expression : $\pi \varepsilon \rho \iota \zeta \omega ́$ -

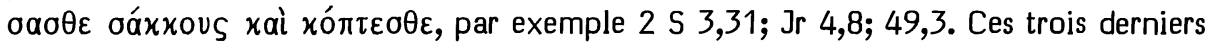
passages du * $M$ ont en commun trois éléments : d'abord le verbe tif, puis le mot piv y est au pluriel, et enfin ce mot y est directement suivi par l'impératif pluriel du verbe ספד. Ici, l'expression grecque est identique à ce qu'elle est en ces trois autres cas, quoique le verbe שק soit dans le *M au parfait et que y soit au singulier. Il semble donc que, dans le ${ }^{*} G$ de Is 15,3 , il y ait eu assimilation

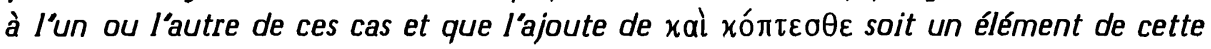
assimilation.

On trouve d'ailleurs en 1Q-a le premier élément de cette assimilation dans la vocalisation חגורו qui, en ce ms, est caractéristique de l'impératif.

Ni $1 Q$-a, ni la*V, ni la *S, ni le *T n'insèrent ici de verbe.

Choix textuel :

On a motivé cette ajoute d'un mot par les exigences métriques. En effet, le parallèle de $\mathrm{Jr}$ 48,37-38a offre un rythme plus régulier. Mais rien ne nous garantit que le livre d'Isaïe ait intégré ce poème dans un état métrique intact.

Contre les assimilations facilitantes de $1 \mathrm{Q}-\mathrm{a}$ et du ${ }^{*} \mathrm{G}$, le comité a estimé utile de préserver la spécificité du texte du *M par la note " $B$ ".

Interprétation proposée :

On joindra donc "sur ses toits et sur ses places", comme complément de "tout le monde se lamente" qui suit; la phrase précédente (3a) s'achevant par "on a ceint le sac". 
15,5 לבי [C] M V S // assim-ctext vel theol : 1Q-a 1Q-b? G לבו / constr : T

Options de nos traductions :

RSV, RL, NEB et TOB respectent la 1e pers. du possessif ("mon coeur") du *M.

$\mathrm{J12}$ traduisaient : "le coeur de Moab gémit", en disant suivre le *G de préférence au *M qui porte : "mon coeur sur Moab gémit".

33 traduit : "son coeur crie en faveur de Moab", en attribuant la leçon "son coeur" au *G et au *T.

Origines des corrections :

Si l'on en croit Michaelis (OEB V 175), c'est Struensee qui a choisi la leçon "le coeur de Moab" en disant que le *G a lu ici לב sans pronom suffixe. Michaelis (ibid. et XIVa 5) estime que le *G a plutôt lu לבו, leçon que l'on peut attribuer aussi au *T et qu'il adopte. Lowth fait de même. Cette leçon a été adoptée par de nombreux critiques jusqu'aux apparats de HSAT34 et de Cent.

\section{Les témoins anciens :}

Le possessif 1e pers. du *M est clairement appuyé par la *V et la *S.

$1 Q$-a et (vraisemblablement) $1 Q$-b ont écrit un 'waw' à la place du 'yod'. Le ${ }^{*} G$

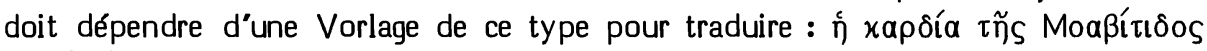

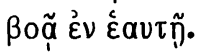

Aurivillius (698) a objecté à Michaelis et à Lowth que, en face de la cohérence d'ensemble de la tradition textuelle du $* M$ et de l'appui que la $* V$ et la $* S$ lui apportent, il est incertain que la traduction large du *T ("en leur coeur, les Moabites disent") suppose une Vorlage לבו.

\section{Choix textuel :}

Aussi Duhm ne s'appuie-t-il que sur le ${ }^{*} G$ pour proposer ici la leçon suggérée par Struensee ou celle que Michaelis a préférée. Quant à Cheyne, après avoir suivi Lowth, il revient au *M qu'il estime plus fin.

La leçon לבו est cependant préférée par Marti qui estime qu'une participation du prophète serait ici tout à fait perdue dans l'évocation des plaintes des Moabites. Mais Wildberger relève que cette participation s'exprime aussi en 16,9.11 (et en ce

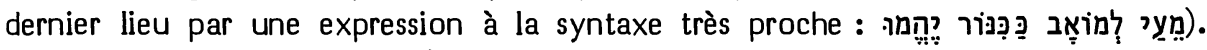
D'ailleurs, comme Aurivillius (697) l'a noté, l'auteur de Jr 48,36 lisait déjà ici le suffixe de la 1e pers. L'un des passages a-t-il influencé l'autre ? Il est plus vraisemblable qu'ici la leçon לבו soit issue d'une assimilation aux suffixes de לו לו dפשו qui précèdent. Il se peut d'ailleurs que, dans le choix de cette leçon, un certain rôle ait été joué par la volonté de ne pas laisser le prophète s'attendrir sur le sort d'un ennemi; certains scribes ne comprenant plus que cet attendrissement a des résonances de sarcasme. Ehrlich et Rudolph (Jesaja 134) ont noté que la variante donne une syntaxe maladroite.

Le comité a attribué à la leçon du *M 4 "C $C$ " et 2 " $B$ ". 
Interprétation proposée :

"Mon coeur crie pour Moab."

15,9A מי דימון / מי דיבון S / usu : M 1Q-b V T // assim-ctext : 1Q-a g clav

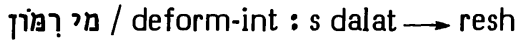

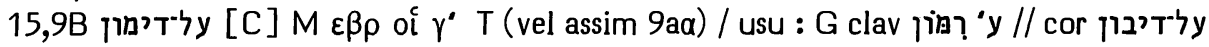

[C] 1Q-a g $\vee \mathrm{S}$ (vel assim-usu) / deform-int : $s$ dalat $\longrightarrow$ resh

Options de nos traductions :

J ("les eaux de Dimôn ... sur Dimôn"), RL ("die Wasser von Dimon ... über Dimon") et NEB ("the waters of Dimon ... for Dimon") respectent la leçon du *M pour les deux occurrences de ce toponyme en ce vs.

RSV ("the waters of Dibon ... upon Dibon") et TOB ("les eaux de Divôn ... aux (malheurs) de Divôn") disent s'appuyer sur 1Q-a et plusieurs versions (RSV mentionnant $d$ 'abord la $* V$ et y ajoutant une référence à la $* S$ ).

Origine de la correction :

On a longtemps admis, avec Delitzsch, que Dimôn était une variante dialectale de Dibôn que l'auteur a préférée ici pour faire assonance avec "dam" = sang.

Il semble que ce soit Baumgartner (Zweiter Bericht) qui a proposé le premier de corriger ici en Dibôn en se fondant sur 1Q-a.

Les témoins anciens :

En effet, 1Q-a lit en 9AB la leçon avec 'bet'. Cette même leçon apparaît aussi chez certains témoins du ${ }^{*} G$ (dont Eusèbe et Basile). Elle constitue également la leçon originelle de la *S (attestée comme telle par Ephrem), quoique, dans la plupart des témoins, le 'dalat' ait été déformé en 'resh' par un faux placement du point diacritique.

Le *G ancien témoigne pour la leçon avec 'mem', bien que le traducteur ait pris le 'dalet' pour un 'resh', sous l'influence du toponyme bien connu Rimmôn.

La leçon du *M (avec 'dalet' et 'mem') est appuyée formellement en 9AB par le *T. En 9A, elle l'est en outre par 1Q-b (qui est lacuneux pour 9B). En 9B, elle l'est par ThAqSym et "l"hébreu" selon le ms Marchalianus du *G (qui ne cite pas leur leçon pour 9A, si l'on en croit l'édition de Göttingen du *G).

Jusqu'en 1969 toutes les éditions de la *V (et encore l'édition Weber parue cette année-là) donnaient en 9AB Dibon. Cette même année, l'édition critique de San Girolamo a été la première à donner en $9 A$ Dimon et en $9 B$ Dibon, en s'appuyant sur deux témoins anciens : le ms de Fleury et la 2e main du ms de St-Gall. D'ailleurs, Hie commente 15,9 une première fois dans le livre $V$ de son commentaire et une seconde fois dans le livre VI. En ces deux lieux toutes les éditions (et encore celle du CChr en 1963) donnent pour lemme en $9 A B$ Dibon au livre $V$, mais (toujours pour 9AB) Dimon au livre VI. Cependant, au livre VI, le codex Sangallensis 115 du IXe siècle (qui n'est pas conservé pour le livre V) porte (selon le CChr) en 9A Dimon et en 9B Dibon. Nous avons contrôlé directement 2 mss du Vatican : le Palat lat 172 du 
IXe siècle et le Vat lat 321 du Xe siècle. Tous deux au livre $V$ et le Palat au livre VI ont la même alternance : en 9A Dimon et en 9B Dibon (le Vat lat ayant au livre VI en $9 A B$ Dibon). Cette alternance (qui vient confirmer le choix fait par l'édition San Girolamo de la *V) est d'ailleurs commentée par Hie au livre VI (selon les éditions) : "aquae autem Dimon...", puis "super ... Dibon ... additamenta congeminent". La ferme distinction respectée entre $9 A$ et $9 B$ par Jérôme est d'autant plus intéressante qu'elle ne lui vient pas d'une conclusion topographique, car il affirme au livre $V$ que, jusqu'en son temps, la même bourgade est nommée indifféremment Dibon ou Dimon.

\section{Choix textuel :}

Les géographes (Musil, Arabia I 157; Abel II 372; Simons §1261; Lemaire/Baldi 285) s'accordent pour identifier Dimon de $9 A$ à khirbet Dimneh à $12 \mathrm{~km}$ au N. de Kerak, position forte (900 $\mathrm{m}$ d'altitude) qui commande l'accès des eaux de Mgjeysel à $4 \mathrm{~km}$ au N.-O. de Rabba, en tête du wâdi Beni Hammad. Ce serait le même site qui est appelé Madmén dans le texte analogue de jr 48,2. Lemaire/Baldi estime que Is 15,9B (lu Dibôn avec 1Q-a) s'identifie (comme Dibôn d'Is 15,2) à Dibân, site bien connu à 5-6 km au N. de l'Arnôn.

Le 'dalet' initial en 9A et en 9B est assez attesté par les géographes et les témoins textuels (contre le ${ }^{*} G$ et une partie de la ${ }^{*}$ ) pour être jugé certain.

La quasi-totalité des témoins opte ensuite ou bien pour 'mem' en 9A et en 9B, ou bien pour 'bet' en 9A et en 9B. Il est possible qu'une alternance originelle de 'bet' et de 'mem' (ou de 'mem' et de 'bet') ait été homogénéisée après coup par certains sur la base du 'mem', par d'autres sur la base du 'bet'.

$\mathrm{La} * \mathrm{~V}$ et Hie attestent ensemble une alternance : 'mem' en 9A et 'bet' en 9B.

Considérant que cette alternance rejoignait les conclusions des géographes récents (qui ignoraient qu'elle fût attestée dans la tradition textuelle), le comité (dans sa session d'Arnoldshain en 1969, où il eut pour la première fois à traiter de ce cas) l'a considérée comme originale.

Cependant, reconsidérant plus tard sa décision, le comité a noté ensuite que " $\mathrm{Di}$ bôn", en ce contexte (cf. 15,2 et les parallèles de Jr 48,18.22), a bien des chances d'être issu d'une assimilation du toponyme rare Dimôn (qui ne réapparaît qu'en Jos 15,22 ) au toponyme plus fréquent Dibôn ( 11 fois dans la Bible). D'ailleurs le vs 6 qui, avec une structure semblable, ne contient qu'une seule localisation, nous engage, en ce vs aussi, à n'en voir qu'une seule.

Aussi le comité a-t-il maintenu sa décision de préserver en 9A, comme pratiquement certaine (note " $B$ "), la leçon du * $M$, mais, pour 9B, il s'est divisé à égalité ( 3 " $C$ " et 3 "C") entre les leçons "Dimôn" et "Dibôn".

Interprétation proposée :

En 9B, il est conseillé aux traducteurs de faire figurer en note la leçon qu'ils ne choisiront pas. 
15,9C אריה [C] M AqSym V (vel err-graph) / deform-int : S yod $\longrightarrow$ nun / assim 2 S 23,20 et Is 29,1G : G Apınd / midr : T // cor ארוה [D] 1Q-a (vel err-graph)

Options de nos traductions :

RSV, J, RL et TOB gardent ici le *M en lui reconnaissant son sens normal : "un lion".

NEB traduit : "for I have a vision", Brockington précisant qu'elle conjecture אֶרֶֶֶ.

Origine de la correction :

La leçon choisie par NEB est une conjecture (mentionnée en BHS) qui remonte à Hoffmann (Versuche 104, note). Pour son auteur, elle était liée à une seconde :

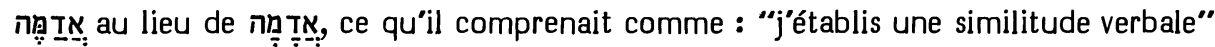
(entre "Dimôn" et "dam" = sang).

Les témoins anciens :

1Q-a porte ארוה dont la lecture est certaine, si on se réfère à אריה écrit par le scribe en 11,7 et 35,9.

Pour transcrire ici Apın $\lambda$, il est très possible que le $* G$ se soit laissé influencer par "les deux Ariel de Moab" de 2 S 23,20.

HUB mentionne à tort $A q$ et Sym à propos de cette leçon "Ariel". Dans l'édition

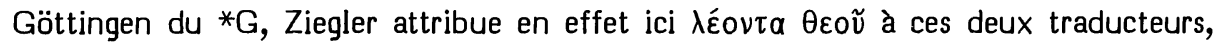
mais le second mot est une ajoute conjecturale de Klostermann (Eusèbe, Onomasticon $36,24)$ soucieux d'identifier le texte de l'Onomasticon d'Eusèbe à l'adaptation qu'en a faite Jérôme; alors que celui-ci a glosé la leçon d'Aq et de Sym à partir du commen-

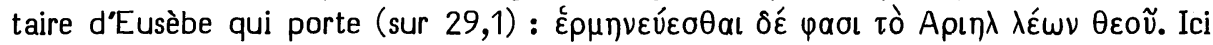
$(15,9)$ le ms 710 attribue formellement à Sym la leçon $\lambda \varepsilon ́ o v \tau \alpha(=* M)$.

La *V (leonem) lit ici le *M.

Tous les témoins de la *S portent ici וארנא (= et je penserai). Rosenmüller et Warszawski ont raison de suggérer qu'il faut lire ואריא (= * M). On sait en effet la fréquence des glissements entre le 'yod'et le 'nun' dans l'écriture syriaque.

Le *T donne ici un midrash ("un roi montera avec son armée pour piller") à la base duquel on peut reconnaître la leçon du $* M$.

\section{Choix textuel :}

Dans une partie de ses notes qui n'a pas été retenue par la réédition de Francfort, Houbigant a été gêné de voir ce "lion" voisiner avec les "ajoutes" qu'il interprète comme des apports d'eau supplémentaires. Aussi, sans proposer de correction formelle, il interprète la leçon du *M à partir du verbe רוה et traduit : "Faciam enim ut Dimon supereffluat; inundabo eos, qui de Moab fugerint." Rosenmüller nous informe que Doederlein a adopté cette suggestion et traduit : “eumque (rivum Dimonis) irriguum faciam fugitivis Moabitis".

Halévy (478), sans connaître la suggestion d'Houbigant et de Doederlein, a re-

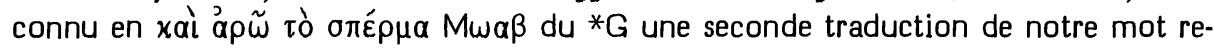
posant sur une lecture אַרְֶ, compris au sens de "je féconderai" en l'irriguant. 
Du fait que 1Q-a atteste maintenant la leçon pressentie par Houbigant, Doederlein et Halévy, la moitié du comité l'a adoptée ici avec 1 "C" et 2 "D".

L'autre moitié du comité, notant qu'en 21,8 nous nous résignerons à conserver un autre "lion" encombrant, a jugé plus prudent de garder ici (par 3 " $C$ ") la leçon du *M. On a fait remarquer que "un lion" est l'exécuteur normal des châtiments divins en $1 \mathrm{R} 13,24$ ou $2 \mathrm{R}$ 17,25.

Interprétations proposées :

Si on opte pour la leçon du *M, on pourra traduire : "Les eaux de Dimôn sont pleines de sang! Mais j’en imposerai davantage à Dimôn (ou : à Dibôn) : pour les fugitifs de Moab, le lion."

Si l'on était tenté par la leçon de 1Q-a, ce vs pourrait être : “Les eaux de Dimôn sont pleines de sang ! Car je donnerai des affluents à Dimôn (ou : à Dibôn) : j'inonderai les fugitifs de Moab."

Il serait bon d'indiquer en note l'interprétation qui n’a pas été retenue.

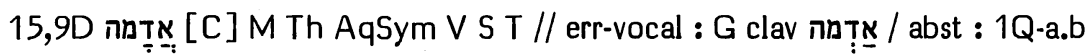

Options de nos traductions :

RSV, J, RL et TOB ont suivi le *M en lisant ici le substantif "sol, terre".

NEB traduit : "of Admah", sans note; Brockington précisant qu’elle vocalise אִַ

\section{Origine de la correction :}

Selon Vitringa, c'est Cocceius qui, le premier, a proposé de reconnaître ici dans le texte du *M la ville d’Adama. Faisant remarquer que, lorsque ce mot désigne cette ville, il est vocalisé patah, shewa, qameṣ et non ḥatef-patah, qameṣ, qames, Vitringa se borne à voir dans le * $M$ un jeu de mots évoquant le nom de cette ville. Michaelis (OEB $\vee 195$ ), sans citer ses prédécesseurs, estime cette correction vocalique opportune, car les Moabites, en tant que descendants des filles de Loth (survivantes de la destruction des quatre villes), méritent d’être appelés par dérision “les survivants d’Adama". Il note que c'est ainsi que le ${ }^{*} G$ a compris ce mot. Doederlein et Aurivillius ont adopté cette vocalisation.

Cependant, Rosenmüller a objecté que l'expression "les survivants d'Adama" manquerait de précision et d'exactitude pour désigner la postérité des émigrés de Sodome. Le livre d'Isaie ne mentionne d'ailleurs que Sodome et Gomorrhe comme villes alors détruites $(1,9 ; 13,19)$. Cela n'a pas empêché Duhm de lire ici ce nom de ville, ce en quoi il a été suivi par Fohrer et Kaiser.

\section{Les témoins anciens :}

Le témoignage de $1 \mathrm{Q}$-a et de $1 \mathrm{Q}-\mathrm{b}$ ne saurait éclairer ce cas.

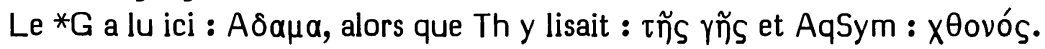

Les autres témoins (la $* V$, la ${ }^{*} S$ et le ${ }^{*} T$ ) lisent ici le substantif qu'offre le ${ }^{*} M$. 
Choix textuel :

Pour éviter la confusion faite par le ${ }^{*} G$, la mp des mss du Caire, d’Alep et de Leningrad (avec $\mathrm{mm}$ en. Weil §512) précise que nous avons ici l'un des onze emplois du substantif (et qu'il ne s'agit donc pas du toponyme).

Gesenius a fait remarquer qu'en poésie aucun article n'est nécessaire avant ce substantif.

Le comité a retenu la leçon du *M par 4 "C $\mathrm{C}$ " et 2 "B".

Interprétation proposée :

On peut comprendre "le reste du sol" comme désignant ceux qui sont restés sur le sol nourricier, par opposition aux fugitifs qui ont cherché refuge ailleurs et viennent d'être mentionnés.

Ne pourrait-on pas mentionner que ce mot évoque aussi le nom de la ville qui fut détruite en même temps que Sodome (selon Dt 29,22) ?

16,1A שִל [C] M 1Q-a.b? Th Hie S? // err-vocal : m 1Q-a.b? S? T 3e pl / midr : V imper sg / assim 15,9: G 1e sg

16,1B בר / בר משל אר / facil-synt : $\mathrm{S} /$ lic $: \mathrm{T} /$ incert $:$ Th

Options de nos traductions :

RL ("schickt dem Landesherrn die Lämmer") et $\mathrm{J12}$ ("envoyez des agneaux au souverain du pays") se distinguent par une mise au pluriel du mot "agneau". J2 présente cela comme une conjecture. RSV ("they have sent lambs to the ruler of the land") et NEB ("the rulers of the country send a present of lambs") font de même, mais ajoutent à cela la vocalisation du verbe initial en accompli 3e pers. pl. (au lieu de l'impératif pl. du *M). Brockington précise que NEB a lu en outre מִשְֵׁ

$J 3$ et TOB, fidèles au *M, traduisent : "envoyez l'agneau du maître (TOB : du souverain) du pays", comprenant "agneau" comme un état construit gouverné par le mot qui suit.

Origines des corrections :

Déjà Luther ("Lieber schickt, yhr Landsherrn, Lemmer") atteste le pluriel des deux substantifs et il explique en son cours (WA. XXV 147,28) qu'il comprend cela en un sens ironique: "envoyez maintenant des victimes au temple du Seigneur, au cas où vous pourriez éloigner de vous le malheur qui menace. D'où vous vient cette soudaine piété ?" La mise au pluriel du mot "agneau" a été proposée par Procksch qui fait précéder ce mot d'un 'lamed' de datif. Rudolph (Jesaja 135) adopte ces deux conjectures, supposant que le * $M$ a sauté d'un 'mem' au 'mem' suivant.

Quant à la mise au pluriel construit du mot "souverain", c'est Grätz (Geschichte II/A 258, note 3) qui l'a proposée en 1875.

La vocalisation du verbe initial en accompli 3e pers. pl. est une suggestion faite par Duhm. 
Les divisions anciennes du texte :

Toute l'exégèse chrétienne occidentale a été influencée par le fait que les inventeurs médiévaux de la division en chapitres en aient fait commencer un, dans la *V, au début de ce verset. Oesch ( $T 10^{*}$ ) nous montre que ni à Qumrân, ni dans la tradition $d u{ }^{*} M$, aucune division en sections n'y correspond.

Les éditions du ${ }^{*} G$, depuis la Sixtine, ont adopté la division en chapitres et commencent donc le ch. 16 par 'Aлоо $\varepsilon \lambda \tilde{\omega}$ qu'elles séparent donc des mots qui précèdent. Cependant, la Sixtine note que Basile et Cyrille lient ce verbe à ce qui précède. En effet, Basile (PG XXX 644C) et Cyrille (PG LXX 404B et 405A) font clairement de "le reste d'Adama" le complément d'objet de "j'enverrai". D'ailleurs, Théodoret $(76,18)$ fait de même. Cette syntaxe est confirmée par la ponctuation du papyrus 965 : un point en haut après $\mathrm{APIH} \wedge$ et un point avant $\mathrm{MH}$. Notons que Basile

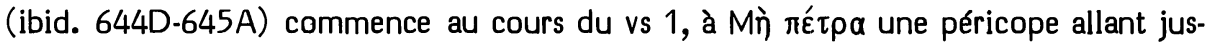
qu'à la fin du vs 5 . Cette division est confirmée par le fait que, dans un vieux recueil de Testimonia attesté par l'épître de Barnabé (XI \$\$2-3) et le dialogue de Justin (CXIV §5), une citation d'Isaïe commençant à Mì rétpa fait suite à Jr 2,13. La mise en page du codex Sinaiticus confirme exactement l'extension de la péricope commentée par Basile. L'édition Aldine, fidèle à cette tradition, plaçait une simple virgule

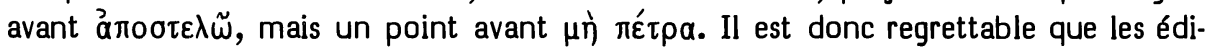
tions récentes (Swete, Rahlfs et Göttingen) aient suivi la Sixtine dans ce placage indû d'une division de tradition latine sur le texte de la Bible grecque.

La division médiévale de la $* V$ en chapitres, lorsqu'elle a fait commencer son ch. 16 à "emitte agnum", s'est inspirée de la très ancienne série $A$ des "Capitula" qui (cf. *V, ed. San Girolamo, p. 16) commence ici un Capitulum (de même extension que l'actuel ch. 16) sous le double titre : "De Domino Christo et sermo super Moab". C'est à l'origine de cette tradition que se situe Hie, lorsque, dans le livre VI, il groupe les vss 1 à 5 en commençant, lui aussi, par 'emitte agnum'.

En résumé concluons que Jérôme a emprunté à la tradition grecque l'idée que les vss $1-5$ constituent une péricope. Mais il a pris l'initiative d'anticiper de quelques mots (avec la tradition hébraïque) le début du vs 1. Cet “agneau dominateur de la terre" dont l'envoi se trouve ainsi commandé au début de cette péricope, il l'interprète tout naturellement (dans le livre $V$ de son commentaire) comme étant le Christ que Moab doit envoyer de la roche du désert (qui est Ruth, aïeule de Jésus) jusqu'au mont de la fille de Sion (qui est Jérusalem, c'est-à-dire l'Eglise). Voilà les perspectives qui se sont trouvées directement associées à l'initiative de faire commencer un chapitre au début de 16,1.

Il est cependant intéressant de noter que certains traducteurs du XVIe siècle (par exemple Luther et Tremellius) ne commencent pas de chapitre en 16,1. Ils désignent en effet comme ch. 15 les cinq derniers vss de notre ch. 14, ce qui les amène à unir en un même ch. 16 nos chapitres 15 et 16.

Or, selon le ms Ambrosianus de la *S et celui de la Syh, la tradition syriaque constitue un seul chapitre avec nos chapitres 15 et 16, après avoir constitué un chapitre avec les 5 derniers vss du ch. 14 (selon la *S) ou les 4 derniers (selon la Syh). Selon Ephrem, un lemme du commentaire commence par מן כאפא, alors que les 
premiers mots de ce vs ont été commentés avec le précédent. Selon les polyglottes, ce sont les derniers mots du ch. 15 qui sont transférés au début de 16.

Selon le ms 710 , Th s'accorde avec le ${ }^{*} G$ pour associer les deux derniers mots de 15,9 au verbe qui commence 16,1 . Mais alors que le ${ }^{*} G$ les lui associait comme complément d'objet direct, Th le fait comme un complément d'objet indirect.

Pour en revenir au ${ }^{*} M$, les huit témoins anciens étudiés par Oesch ( $\left.T 10^{*}\right)$ s'accordent pour faire commencer une péricope en 15,1 et la suivante en 16,5 (ou 16,7 selon le ms de Leningrad). Quant à la division en sedarim, un sédèr commence en 14,2 et le suivant en 16,5. Ajoutons que ni 1Q-a, ni 1Q-b ne font commencer une péricope en 16,1.

Les témoins anciens :

\section{1) Sur $16,1 \mathrm{~A}$}

Nous avons dit que Duhm a conjecturé une vocalisation du 'shin' du verbe initial avec qameș (= accompli) au lieu du hịreq du $* M$ (= impératif). Wildberger attribue cette vocalisation avec qameș à des "manuscrits orientaux". Or, ni Alba Cecilia ni Yeivin ne relèvent l'existence d'aucun témoin babylonien pour les chapitres 11 à 22 d'Isaïe. Il n'y a pas non plus de divergence mentionnée à propos de ce mot dans les listes traditionnelles de divergences entre les orientaux et les occidentaux. Enfin le ms de Petrograd des Prophètes postérieurs (que l'on pourrait qualifier éventuellement de "oriental") a ici un hireq, sans que Strack mentionne rien à son propos. Wildberger n'aurait-il pas confondu le sigle "Edd" (que BH3 donne ici) avec les sigles "Ea, Eb, $E c$ " qui désignent en effet en $\mathrm{BH} 3$ des "variae lectiones codicum orientalium" (cf. Prolegomena XXVI) ? D'ailleurs, $\mathrm{BH} 3$ a tort de parler de plusieurs éditions. Il semble que Kittel ait mal interprété l'expression plurielle "Biblia Soncinensia" par laquelle de Rossi (selon Prolegomenon CXXXIX) désigne l'édition princeps de la Bible publiée en 1488 , édition qui semble bien être le seul témoin hébreu de cette vocalisation (postulée aussi par la Vorlage du *T qui paraphrase : "qu'ils fassent monter des tributs vers le Messie d'Israël").

Pour le verbe initial de 16,1, la tradition textuelle de la $* S$ est divisée. Sous l'influence de la Syh, l'ensemble des éditions et trois mss des XVIIe et XVIIIe siècles traduisent ce verbe par un imparfait, 1e pers. sg. Les mss anciens se divisent entre les leçons שדרו et sans que l'on puisse préciser s'il s'agit là de parfaits ou d'impératifs.

On serait tenté de penser que Jérôme ne témoigne pas ici pour le *M. En effet les éditions, même "critiques", de sa traduction et de son commentaire donnent ici "emitte". Mais, pour ce qui est de la *V, les premières mains des mss de Fleury et de Saint-Gall ont ici "emittite" qui a survécu partiellement, sous la forme "emittit" dans la première main du ms de Bobbio. Quant au commentaire, voici les données que fournissent les mss Palat lat 172 et Vat lat 321 auxquels nous avons fait appel en 15,9AB. Au livre V, dans le lemme, le Palat et le Vat ont "emitte". Au livre VI, dans le lemme, tous deux ont "emittit", la 2e main du Palat ayant corrigé en "emittite". Après le lemme, tous deux lisent : "Hoc quod de hebreo interpretati sumus "emittite agnum dominatorem terrae" potest etiam legi", puis le Palat : "'emittite" et le Vat : " "emittit", et enfin tous deux : "agnum dominatori terrae" ". Ces données complexes 
montrent d'abord que nous ne disposons pas avec le CChr (qui donne en chacun de ces lieux "emitte" sans variante) d'une édition critique du commentaire de Jérôme. Elles montrent ensuite que les trois leçons "emitte", "emittit" et "emittite" ont existé en divers endroits du commentaire de Jérôme, la première étant caractéristique du lemme du livre $V$ et de la $* V$, la troisième étant qualifiée par Jérôme de traduction "selon l'hébreu" et la deuxième n'étant vraisemblablement qu'une mutilation de la troisième. On peut donc dire que, là où Jérôme prétend attester l'hébreu, c'est bien le *M qu'il atteste. Quant à la leçon "emitte", c'est une interprétation midrashique chrétienne : appel au Seigneur pour qu'il envoie l'agneau gouverneur du monde (cf. Ap 5,12). La signification en est soulignée par l'insertion d'un vocatif "Domine" que Jérôme y fait, vers 395 , dans les deux citations qu'il donne de ce vs en ses lettres LIII 8 et LIV 17, insertion qui a pénétré en plusieurs mss de la *V. Il est curieux de noter que, dans un minuscule grec, le ms 106 (Ferrare, XIVe s.), une traduction

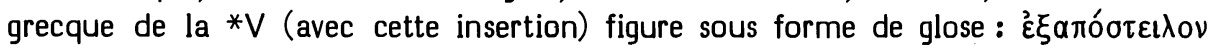

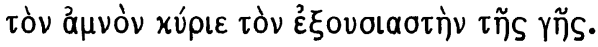

Le ${ }^{*} G$ traduit ce verbe en $1 e$ pers. sg., dans la suite de la 1e pers. દ̉má $\xi \omega$ qui rendait אשית en 15,9 et de la 1e pers. ảow̃ que le traducteur avait ajoutée, en se laissant guider par אריה (où nous avons vu qu'il n'avait pas reconnu un lion). Il a ainsi trois phrases coordonnées.

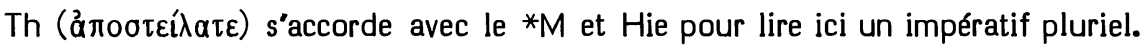

$1 Q-a$ et $1 Q-b$ sont consonnantiquement identiques au *M. Mais leur témoignage ne nous éclaire pas sur la vocalisation.

2) Sur $16,1 \mathrm{~B}$

La division des mots du *M est appuyée par la *V et, semble-t-il, par 1Q-b qui isole le mot כר de ce qui le précède et de la suite (qui n'y est pas conservée).

La *S, au lieu de כר לבר (le "lamed" y étant une cheville syntactique translationnelle). Ishodad de Merv interprète les mots בר שליטר de la *S comme un aramaïsme pour שליטנא (= chef). Quelques mss du *M ont ici.

Connu par une scolie du ms 410, Th, pour כר משל, donne seulement äpxovia. Ou bien, comme le suggère Lütkemann, une syllabe $x \alpha \rho$ (transcrivant l'hébreu כר) est tombée avant ce mot; ou bien Th a lu בר interprété à la manière d'Ishodad.

1Q-a ne sépare pas les lettres כרמשל, alors que le ${ }^{*} G$ (peut-être sous l'influence

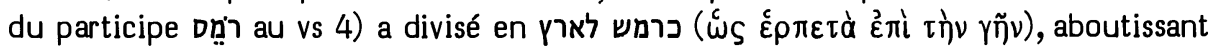
à un sens qui n’a attiré aucun exégète.

\section{Choix textuels :}

Pour $16,1 \mathrm{~A}$, les consonnes du $* M$ sont fermement attestées et la vocalisation en impératif a l'appui de Th et de Hie, alors que la vocalisation en parfait ne reposerait que sur une édition du *M et la paraphrase du *T.

Pour 16,1B, la leçon בר est un aramaïsme facilitant. Les blocages de consonnes attestés par le ${ }^{*} G$ et $1 Q$-a diffèrent entre eux, alors que le ${ }^{*} M$ est appuyé par la ${ }^{*} V$ et, semble-t-il, 1Q-b.

Le comité a donc, en ces deux cas, attribué au *M la note "C". 
Interprétation proposée :

Joseph Qimhi (Galuy 30 et 108) a proposé pour le *M un sens fort acceptable: כר y a la valeur collective de "tribut d'agneaux" du (= qui est dû au) souverain du pays. Pour ce tribut, on se référera à $2 R 3,4$.

16,4 נדַח [C] M V / נדחחי / facil-synt : G 5 t clav clav : 1Q-a

\section{Options de nos traductions :}

Les principales traductions du XVIe siècle respectaient le pronom suffixe de la 1e pers. qui sépare en *M le pluriel "expulsés" de "Moab" qui le suit : Luther : "Las meine veriagten bey dir herbergen, Liebes Moab sey du jr schirm..."; Brucioli : "Habitino in te gli scacciati miei Moab, sia nascondimento à quegli..."; Pasteurs : "Que les dechassés de mon peuple seiournent chez toi, ô Moab : sois-leur une cachette..."; $\mathrm{KJ}$ : "Let mine outcasts dwel with thee, Moab, be thou a covert to them...".

En contraste avec cela, nos cinq traductions traitent ce mot comme s'il s'agissait d'un état construit pluriel gouverné par "Moab" : RSV : "the outcasts of Moab"; J : "les dispersés de Moab"; RL : "Moabs Verjagte"; NEB : "the homeless people of Moab"; TOB : "les réfugiés de Moab". Comme il ne s'agit que d'une correction vocalique (șéré au lieu de patah)), aucune d'entre elles ne se sent tenue d'expliquer son option par une note.

Origine de la correction :

Cappel (Notae 504) a remarqué que le ${ }^{*} G$ a lu ici un état construit pluriel. Houbigant a traduit "profugi Moab", sans note sur ce point, puisqu'il méprise la tradition vocalique (cf. CT1 *27). Lowth traduit : "the outcasts of Moab", leçon qu"il dit confirmée par le ${ }^{*} G$ et la ${ }^{*}$, suivi par Michaelis (OEB), Doederlein et de nombreux critiques jusqu'aux apparats de HSAT234, BH23S et Cent dont nos traductions dépendent probablement.

Les témoins anciens :

$1 Q-a(=* M)$ ne nous dit rien de sa vocalisation.

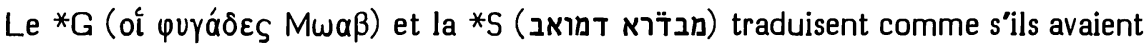
lu un état construit.

En *T, l'état construit (מטלטלי) est attesté par l'édition de Félix de Prato, celle de Ben Hayim et la polyglotte de Londres. Mais la polyglotte d'Anvers, les mss Reuchlin, Urbinat.1, Paris hébr 1325 appuient la leçon מטלטליא de Sperber et de Stenning.

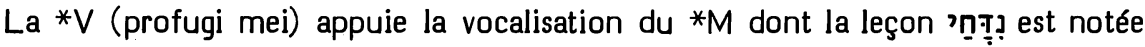
par la mp (dans la massore éditée et les mss d'Alep et de Leningrad) comme hapax,

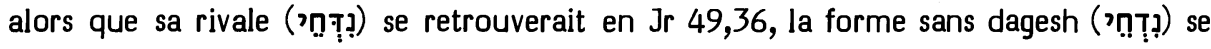
retrouvant en Is 11,$12 ; 56,8$ et Ps 147,2. Ajoutons que BHS a tort de proposer de lire cette variante "avec 2 mss". Il s'agit, selon de Rossi, de la 1e main de son ms 440 et, semble-t-il, de la 1e main de son ms 20. Ces leçons ayant été ensuite corrigées, la variante n'est attestée par aucun témoin massorétique en son état actuel. HUB a également tort d'attribuer cette variante à "G", sigle signifiant des "manuscrits hé- 
breux cités dans la collation de Ginsburg". Celui-ci, en effet, ne dit avoir trouvé cette variante en aucun des mss qu'il a collationnés, mais il l'attribue seulement "à 2 mss Kennicott-de Rossi (cf. supra), au *T, au *G et à la *S."

Comme le note Lütkemann (108, n. 581), les leçons de Th et de AqSym sont vraisemblablement incomplètes et ne peuvent donc porter témoignage sur présence ou absence d'un pronom suffixe.

\section{Choix textuel :}

Geiger (300), considérant la variante comme originale, voit dans la vocalisation du *M une correction théologique pour éviter qu'Israël ait à accueillir des évacués de Moab.

Cependant, Gesenius préfère interpréter le suffixe 1e pers. sg. comme pléonas-

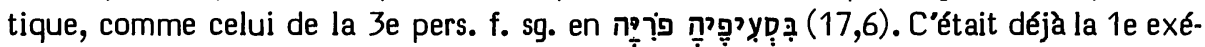
gèse proposée ici par Yéfet ben Ely. Sur cet usage pléonastique des suffixes pronominaux, cf. Gesenius (Lehrgebäude 734ss) et König (Synt \$284a). Cela suppose que l'on recule d'un mot ici le zaqef. Comme le suggèrent Dillmann/Kittel et Rudolph (Jesaja), il peut y avoir là un indice que Moab est une glose explicitant le suffixe qui précède.

Delitzsch, lui, sans déplacer le zaqef, voit en Moab un casus pendens qui, en tant que nom de peuple, sera repris par le suffixe pluriel de iht.

Considérant la variante comme une facilitation syntaxique, le comité a attribué la note " $C$ " à la lectio difficilior du *M clairement appuyée par Jérôme.

Interprétations proposées :

L'exégèse de Delitzsch est assez recherchée, mais non impossible. C'est celle qui respecte le mieux le *M : "Que mes expulsés puissent séjourner chez toi. Les Moabites, sois un abri pour eux."

Au prix d'un déplacement du zaqef, on peut cependant comprendre, avec Gesenius: "Que mes expulsés - à moi, Moab - puissent séjourner chez toi. Sois un abri pour eux."

\section{6,7 תהגו [B] M 1Q-a Aq Sym V S // assim 6G : G 2e sg / assim 7aT : T 3e pl}

\section{Options de nos traductions :}

La 2e pers. pl. du *M est respectée par $J 3$ ("vous gémissez") et traduite en impératif par RSV ("mourn").

Elle est corrigée en 3e pers. pl. par $\mathrm{J12}$ qui dit conjecturer : "ils gémissent" ( = TOB sans note), RL : "werden sie seufzen".

En traduisant "he shall mourn", NEB conjecture (selon Brockington) הִֶֶ:"

Origines des corrections :

$\mathrm{RL}$ dépend ici de Luther qui traduisait ce mot et les deux suivants par : "werden die verlemeten seufftzen". Selon la reportatio de A. Lauterbach (WA. XXXI/ 2 106,23-26), Luther, dans son cours sur Isaïe, a, de fait, expliqué ce verbe comme 
une 3e pers. pl. :“Kir Harezeth, gement claudi i.e. meditabuntur apud se verba doloris...". Pourtant, il ne saurait y avoir là une influence de la*V. D'ailleurs, la vieille traduction allemande, avant l'édition de Zainer, donnait ici "redt". Ce mot doit être interprété comme un impératif pluriel, puisqu"il traduit "loquimini" de la *V. Mais il prête aussi à une interprétation en 3e pers. sg. En ce cas, son sujet doit être "die die sich frewent uber die mauren des gebachen ziegels" qui précède. Ce serait donc un verbe à la $3 e$ pers. du pluriel (et non du singulier) que l'on attendrait ici. Cela explique pourquoi Zainer a corrigé "redt" en "redent". C'est vraisemblablement sous l'influence de cette $3 e$ pers. pl. de la vieille allemande que Luther a traduit ici une $3 e$ pers. pl., alors que ses prédécesseurs (Oecolampade, Pagnini) et ses successeurs (Münster, Brucioli, Olivetan, Jud, Rollet, Estienne, Ge, Foreiro, Tremellius, Pasteurs, $\mathrm{KJ}$ ) respectent la 2e pers. pl. du *M (et de la *V). Seul Châteillon ("se pleindront") fait exception, vraisemblablement influencé par la traduction large, par un ablatif absolu, qu'il avait donnée en latin ("plangentibus").

Duhm ("werden sie seufzen") reprend tout naturellement la traduction de Luther, considérant comme "indubitable" qu'il faut corriger en 3e pers. pl. la 2e pers. pl. du *M. Comme presque toujours, Marti lui emboîte le pas en considérant le 'taw' initial de la leçon du $* M$ comme une dittographie de celui qui le précède. Par l'intermédiaire des apparats de HSAT34, BH23S et Cent, cette correction s'est transmise à $\mathrm{J} 12$ et TOB.

Ces critiques semblent ignorer que Houbigant avait déjà proposé cette correction en se fondant sur le *T.

Quant à la correction de NEB en 3e pers. sg., elle a été suggérée par Grätz, se référant au parallèle de $\mathrm{Jr}$ 48,31. Wildberger dit qu'un manuscrit lit ici יהגה et il ajoute, entre parenthèses : "voir aussi le *广". Nous verrons que cette donnée est inexacte.

\section{Les témoins anciens :}

HUB ne signale que deux variantes dans la tradition textuelle du $* M:$ d'abord, dans le ms 96 de Kennicott, une graphie יהגו : Il s'agit là du ms 182 : ms des Prophètes de Jéna où les Prophètes sont donnés avec le *T auquel le *M a été assimilé sur ce point. De Rossi (Scholia) cite cette variante en la rapprochant du ${ }^{*}$ T. Mais ni lui, ni Kennicott, ni Ginsburg, ni HUB n'appuie les dires de Wildberger. Il semble que celui-ci a mal compris une note de l'apparat de BHS : "frt I c Ms "הֶ cf. *T", complétant la forme abrégée par une finale au singulier.

La 2 e pers. pl. du *M est appuyée par 1Q-a $(=* M)$, Aq ( $\mu \varepsilon \lambda \varepsilon \tau \tilde{́} \sigma \alpha \tau \varepsilon)$, Sym $(\varphi \theta \varepsilon ́ \gamma \xi \alpha \sigma \theta \varepsilon)$, la *V ("loquimini" avec variante: "loquemini" en des témoins de la recension alcuinienne) et la*S (תנהמון).

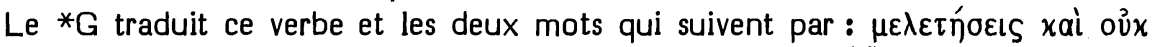

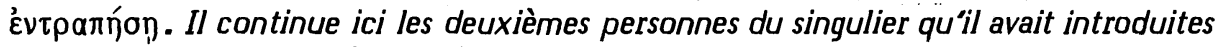

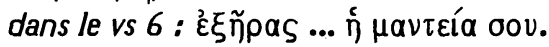

Le *T, nous l'avons dit, offre ici une 3e pers. pl. : ימרון. En cela, il assimile ce verbe a la traduction plurielle ("les Moabites se lamentent") qu'il avait donnée dans le début de ce verset pour le singulier à valeur collective du *M: "Moab se lamente". 
Choix textuel :

Les variantes divergentes du ${ }^{*} G$ et du $* T$ sont des assimilations facilitantes. La lectio difficilior du ${ }^{*} M$ est solidement attestée. Elle doit leur être préférée. C'est ce que le comité a estimé en lui attribuant la note "B".

Interprétation proposée :

Dillmann/Kittel a noté que le passage à l'interpellation ne surprend pas en Isaïe : cf. 16,9; 3,12; 17,10. König renvoie ici à 1,5 où une 2 e pers. pl. après des 3 e pers. pl., pour animer le style.

On pourra donc traduire: “C'est pourquoi Moab sur Moab se lamente, tout entier il se lamente. Au sujet des gâteaux de raisins de Qir-Harèsèt vous gémissez, tout consternés".

16,10 השבתי [C] M 1Q-a Sym V S T // theol : G pass 3e sg

Options de nos traductions :

La 1e pers. du *M n'a été respectée que par NEB ("I have silenced").

Les autres l'ont remplacée par une $3 e$ pers. à valeur passive ou intransitive : RL : "ist ein Ende gemacht", J : "a cessé", TOB : "ont cessé" et RSV : "is hushed", ces deux dernières disant qu'elles suivent le ${ }^{*} G$.

Origine de la correction :

Ayant conclu que ce n'est pas Dieu qui parle ici, Lowth estime que le ${ }^{*} G$ a lu ici un accompli hofal à la 3e pers. m. sg. et opte pour cette leçon. Il est suivi en cela par Duhm, Dillmann/Kittel, Cheyne, Marti, Condamin, Gray, Halévy, etc., puis les apparats de HSAT34, BH23S et Cent où nos traductions ont pu trouver cette suggestion.

Les témoins anciens :

Ici le *M est appuyé par 1Q-a ( $=* M)$, Sym (ع̈лavoa), la *V (abstuli), la *S (אבטל) et le *T (אבטילית).

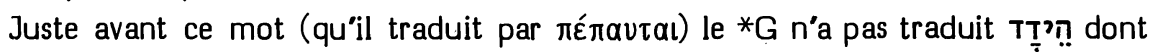
il semble ne pas connaître le sens. En effet, il l'a traduit au vs précédent par $x \alpha \tau \alpha$ ratńow, en s'inspirant du contexte dans lequel il apparaît au vs 10 .

Choix textuel :

Knobel fait remarquer que Dieu parlait déjà clairement en 15,9.

König trouve osé d'inventer en cette occasion un hofal de ce verbe quand on a en Is 13,11 et 21,2 des parallèles à la forme du *M avec Dieu pour sujet.

La forme verbale que le $* M$ offre ici se retrouve dans le parallèle de Jr 48,33 selon le *M. Notons d'ailleurs que le parallèle de Jérémie met clairement les paroles de compassion pour Moab dans la bouche de Dieu (cf. "oracle du Seigneur" en 48,30). C'est ce que le ${ }^{*} G$ ne peut tolérer. Aussi défigure-t-il les השבתי trop révélateurs d'un sujet divin en Is 16;10 et Jr 48,33 et omet-il l'incise "oracle du Seigneur" en Jr 48,30 . 
Le *G a voulu qu'en Is 16,9 et 16,11 on interprète spontanément "je pleure", "je t'arrose de mes larmes", "mes entrailles" et "mon sein" comme se référant au prophète. Il n'a en effet pas compris le caractère sarcastique de ces expressions de compassion, ou n'a pas osé attribuer à Dieu ce sentiment.

Le comité a attribué à la leçon du *M 4 "C" et 2 "B".

Interprétations proposées :

Y a-t-il ici, ainsi que nous l'avons décelé en 10,12, un surgissement soudain du "je" divin, alors que ce serait le prophète qui disait "je" au vs 9 et qui le redira au vs 11 ? Ou bien, comme le suggère le parallèle de Jr 48,30-36, n'est-ce pas toujours Dieu qui dit "je" en ce contexte ? Il faut reconnaître une certaine ambiguïté sur ce point à la forme littéraire que cet oracle présente dans le livre d'Isaïe.

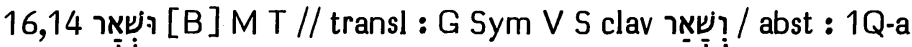

Options de nos traductions :

Le *M vocalise ce mot en substantif. Cette option est plus ou moins respectée par RSV ("and those who survive") et J3 ("un reste" en une traduction très libre).

Mais ce mot est traduit par un verbe en RL ("dass ... übrigbleibt"), en TOB ("il en restera", sans note) et en NEB ("shall be left" qui, selon Brockington, suppose

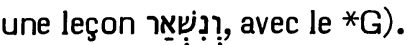

J12 conjecturaient ici : "son reste".

Origines des corrections :

$R L$ dépend ici de Luther qui traduisait : "das ... uberbleibe". Parmi les traducteurs du XVIe siècle, Châteillon (“que ... il n'en restera") semble être le seul autre à traduire ce mot par un verbe.

Il se peut que TOB dépende seulement de Cent qui traduisait : “il n'en subsistera", sans note.

Luzzatto s'est demandé pourquoi on n'a pas ici la vocalisation en parfait qal רְִִּ comme en $1 \mathrm{~S}$ 16,11. En 1901, Ehrlich (Miqra) a proposé de corriger ainsi. En 1906, Kittel (BH1) a suivi cette suggestion. En 1912, Ehrlich (Randglossen) ayant noté le caractère hapax du qal et doutant de son authenticité - estime fausse (verkehrt) la correction qu'il proposait en 1901. En 1937, Kittel (BH3) se contente d'informer que ${ }^{*} G$, ${ }^{*} S$ et $* V$ ont lu

Quant à la conjecture de J12, c'est Procksch qui l'a proposée.

Les témoins anciens :

1Q-a ( $*$ *M) ne dit pas comment on le vocalisait.

Pour le ${ }^{*} \mathrm{~T}$, la polyglotte de Londres, les éditions Sperber et Stenning et le ms Urbinates 1 s'accordent à vocaliser la lettre 'alef' avec un qames. Cela signifie que ce mot est lu en substantif.

Toutes les autres versions anciennes (*G avec $x \alpha \dot{i} x \alpha \tau \alpha \lambda \varepsilon \iota \varphi \theta \tilde{\sigma} \sigma \tau \alpha \mathrm{l}$, Sym avec

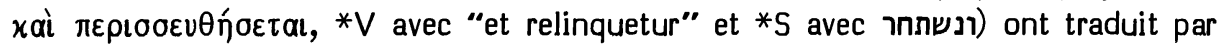
un verbe. 


\section{Choix textuel :}

Selon Rudolph (Jesaja), les versions ont seulement facilité en traduisant.

De fait, le ${ }^{*} M$ s'explique comme une phrase nominale, selon l'analogie de 10,19 où le verbe יהיו sert à expliciter l'aspect du futur, alors qu'ici cet aspect a déjà été suffisamment exprimé par ונקלה. Le parallèle de 21,17 (où on a pour prédicat le verbe intransitif מעט מעצר (liés comme en 10,25 et 29,17) comme

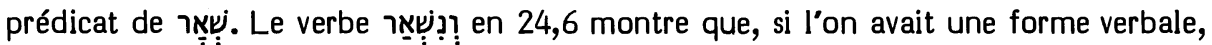
elle aurait plus de chance d'être au nifal qu'au qal.

Le comité a attribué au *M la note " $\mathrm{B}$ ".

Interprétation proposée :

"Et le résidu sera peu de chose, pas important."

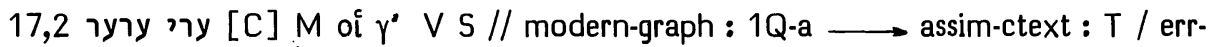
ponct : $\mathrm{s}$ resh $\longrightarrow$ dalat / harm So 2,9: G clav עדי עד ועד

\section{Options de nos traductions :}

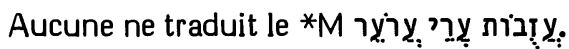

RSV conjecture : "her cities will be deserted for ever" en se référant au *G que J dit suivre en traduisant : "abandonnées pour toujours, ses villes." RL porte : "seine Städte werden verlassen sein für immer". TOB dit s'inspirer du grec pour traduire : "les villes qui en dépendent (lit : ses villes) seront abandonnées pour toujours". Parmi ces traductions, seule J2 donne une Vorlage qu'elle dit conforme au *G : y

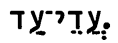

Pour NEB ("for ever desolate"), Brockington donne une Vorlage plus sobre : :

\section{Origines des corrections :}

Cappel (Notae 505) a suggéré que le *G, au lieu de "Aroer", a lu ici Ty 'Tַy. C'est Lowth qui, se fondant sur cette suggestion, a choisi la leçon du ${ }^{*} G$, suivi par Lagarde, Bredenkamp, Grätz, Cheyne, König, Kaiser et les apparats de HSAT34, $\mathrm{BH} 23$ auxquels nos traductions ont pu l'emprunter.

NEB a ici une forme simplifiée qui a été proposée par Duhm comme Vorlage du *G.

\section{Les témoins anciens :}

Houbigant (en une partie de ses Notes omise par la réédition de Francfort) a

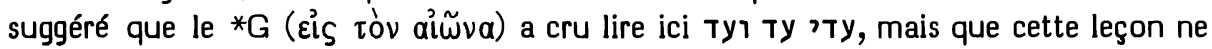
peut être authentique. De fait, cette Vorlage est plus proche de yרוy (écrit ainsi avec 'waw' en bon nombre de mss) que les autres reconstitutions qui ont été proposées. Mais cette expression surchargée n'existe pas en hébreu biblique et n'a donc aucune chance d'être authentique. Seeligmann (73), après avoir montré des cas où le ${ }^{*} G$ d’Isaïe s'inspire évidemment du ${ }^{*} G$ du Dodécaprophéton, a suggéré ici une influence du ${ }^{*} G$ de So 2,9 . Il y a plutôt eu interinfluence de ces deux lieux. 
Selon Kutscher (114), la graphie de 1Q-a עורער préserve en sa finale une désinence typiquement transjordanienne, alors que, pour sa première syllabe, on trouve un bon parallèle en $1 Q$-a en עומרה d'une simple modernisation graphique de ce toponyme.

Selon le ms Q du *G, "les trois" (= ThAqSym) ont traduit littéralement עזבות ערי

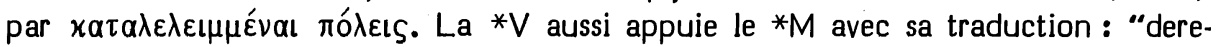
lictae civitates Aroer".

Les éditions de la *S portent ici de דעצועיר. Rosenmüller a cru qu'il s'agissait d'une faute d'impression; alors que Michaelis (OEB), remarquant que la même particularité se retrouve en $\mathrm{Nb}$ 32,34; Dt 2,36 etc., a cru qu'il s'agissait d'une faute de ponctuation de Sionita. Mais Diettrich atteste que cette ponctuation erronée figure dans tous les mss qu'il a consultés et que seul Ephrem ponctue différemment en דערועיד. Cette dernière précision est inexacte, puisque l'édition romaine d'Ephrem sur laquelle Diettrich (XII) prétend se fonder - porte דערועירור les chances de représenter la forme originale de la $* S$.

La tradition textuelle du *T est incertaine. A la place du toponyme "Aroer", l'édition princeps de Félix de Prato donne חִִִ̣ leçon reproduite par l'édition Ben

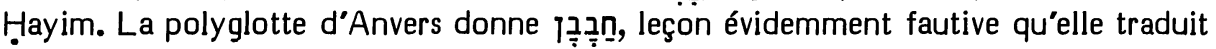
par "dilectae". La polyglotte de Londres reprend la leçon des Bibles rabbiniques avec de légères variantes vocaliques. Le ms Urbinat. 1 porte le ms Reuchlin. Les éditions de Sperber et de Stenning, basées sur des mss yéménites, offrent cette leçon précédée d'une conjonction 'waw'. Dans son apparat, Stenning mentionne un ms de Nürnberg comme appuyant la leçon de l'édition princeps, leçon qui semble présupposer une Vorlage identique à 1Q-a interprétée en pulpal à partir

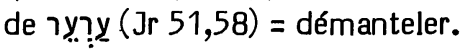

\section{Choix textuel :}

Contre le choix fait par Lowth de la leçon du *G, Michaelis (OEB) a objecté que Damas n'est pas restée longtemps désertée, puisqu'elle réapparaît comme capitale par la suite.

Selon Delitzsch, c'est parce qu'il évoque le sens de "démanteler" que ce toponyme a été choisi ici de préférence à d'autres lieux également touchés par l'invasion de Téglat-Phalasar. Hitzig justifie ici cette affirmation que "les villes d'Aroër sont désertées" en expliquant qu'en cas d'attaque ennemie, les agglomérations non fortifiées, dépendantes d'une ville à rempart, sont abandonnées parce que leurs habitants se sont réfugiés dans la ville forte.

Selon $\mathrm{Jg} 11,26.33$, il existe dans le territoire de Gad, à la frontière du territoire ammonite, une Aroër entourée de "villes" non nommées. C'est vraisemblablement d'elle qu'il s'agit ici.

Le prophète semble avoir imaginé que l'envahisseur aborderait Israël par la Transjordanie, ce qui ne fut pas le cas. En outre, la ville de Damas ne fut pas anéantie, comme 17,1 le prévoyait, mais devint la capitale d'une province assyrienne florissante. Dans ces discordances entre l'oracle et l'événement, Donner (41) voit un argument pour placer cet oracle entre 735 et 733 . En ce cas, il ne faut pas chercher ici une relation historique de l'invasion. 
Le comité a attribué à la leçon du *M la note "C".

Interprétation proposée :

“Les villes d'Aroër, abandonnées, seront pour les troupeaux."

\section{7,5 [A]}

Options de nos traductions :

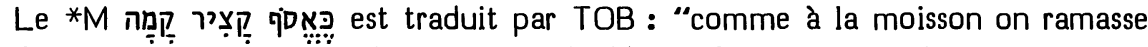
le blé", par RL : "wie wenn der Schnitter die Halme fasst", par RSV : "as when the reaper gathers standing grain" et par NEB : "as when the harvester gathers up the standing corn", aucune de ces traductions n'ayant ici de note textuelle.

31 donnait: "comme lorsque le faucheur prend à brassée les tiges", J2 corrigeant "faucheur" en "moissonneur" et précisant qu'elle conjecture une vocalisation קֵָن.J3 donne : “comme lorsque le moissonneur récolte le blé".

Origines de la correction :

La vocalisation conjecturée par J a été proposée par les apparats de HSAT34, $\mathrm{BH} 23$ et Cent. Bredenkamp semble avoir été le premier à la proposer, suivi par Marti, Duhm 5, Condamin, Ehrlich, Procksch, Kaiser.

Sans avoir l'intention de modifier la vocalisation, Yéfet ben Ely et Radaq comprenaient déjà קִạ au sens de "moissonneur", suivis en cela par Pagnini qui, en son Thesaurus (2193), rapproche ce mot de Tự où il voit un autre adjectif à valeur substantivale. Cette exégèse est adoptée ensuite par Ge, Tremellius, Pasteurs et KJ. Delitzsch appuiera lui aussi l'interprétation de ce mot en "nom intensif actif", au

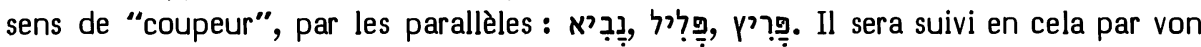
Orelli, Dillmann/Kittel, Duhm12, Gray, Halévy, König (cf. Lehrgebäude II 131, n.3).

Les témoins anciens :

$1 Q$-a est identique au $* M$. Toutes les versions anciennes ont interprété ce mot comme "moisson" ou bien au sens de "blé mâr (sur pied)" (*G, *S, *T), ou bien au sens de "acte de moissonner" (*V).

\section{Choix textuel :}

Oecolampade traduisait dans le premier sens "sicut congregans messem segetis stantis". C'était déjà l'interprétation de Saadya, Ibn Ezra, Eliézer de Beaugency. Il sera suivi en cela par Brucioli, Münster, Olivetan, Châteillon, Foreiro, Cocceius. Gesenius a vu ici une métonymie où "moisson" est pris pour "moissonneur", de même que מִ̣ (= rébellion) est pris pour "rebelle" en Ez 2,7.8; 44,6 ou pị (= sainteté) pour "saint" en Lv 21,6.

Luzzatto s'oppose à l'interprétation de Radaq (au sens de nom d'agent) en prétendant (à tort) que l'on ne trouve pas de substantifs ainsi vocalisés au sens de participes actifs. Il s'oppose aussi à l'exégèse de Gesenius, car il estime que ces métonymies supposent une identification du rebelle perpétuel à la rébellion (de même qu'en 
Ps 109,4 celui qui ne cesse de prier dit : "je suis prière"), ce qui ne saurait être le cas pour le moissonneur. Aussi Luzzatto interprète-t-il : "(lorsque quelqu'un ramasse) lors de la moisson (la récolte)". C'était déjà l'interprétation de la *V (in messe), de Rashi, Abravanel et Luther ("in der Erndte").

Le comité a attribué au *M la note " $A$ " pour souligner que les témoins textuels ne présentent aucun indice d'une autre vocalisation et que l'histoire de l'exégèse ancienne ou récente offre des possibilités variées d'interprétation.

Interprétations proposées :

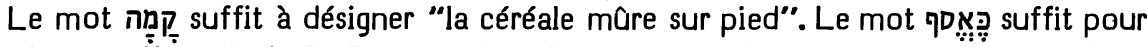

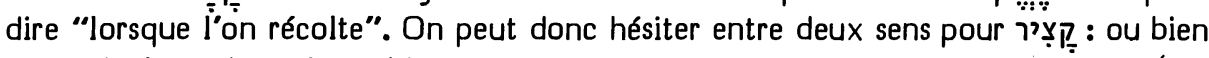
"lors de la moisson", ou bien "le moissonneur". Cette dernière interprétation (appuyée par les parallèles rassemblés par Pagnini, Delitzsch et König) semble celle qui justifie le mieux le pronom suffixe de וזר deux mots plus loin, ainsi que Rosenmüller l'a fait remarquer. Peut-être s'agit-il d'ailleurs d'une glose en l'un ou l'autre de ces deux sens.

17,9A כע [C] M G // assim-ctext : 1Q-a V pl / expl : T / midr : S

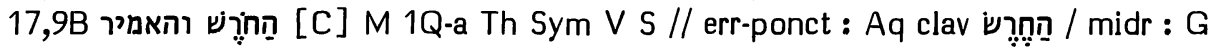

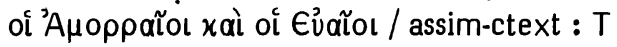

Options de nos traductions :

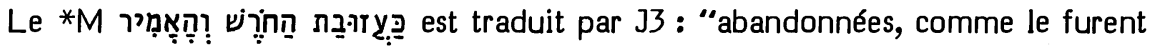
les bois et les maquis" et par TOB : "abandonnées, comme le furent les bois et les sommets".

Pour cela, RSV donne: "like the deserted places of the Hivites and the Amorites", J12 : "abandonnées comme le furent celles des Amoréens et des Hévéens (J2 : Amorites ... Hivvites)", RL : "verlassen sein wie die Städte der Hewiter und Amoriter", NEB : "deserted like the cities of the Hivites and the Amorites". 32 et NEB

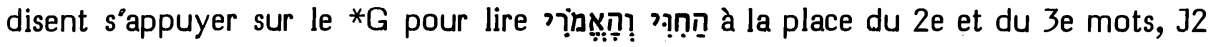
ajoutant qu'elle s'appuie sur le ${ }^{*} G$ pour mettre au pluriel le premier.

Origines des corrections :

Nos traductions ont pu trouver ces corrections proposées par les apparats de HSAT2 (qui les attribue à Lagarde), HSAT34, BH23S et Cent.

\section{Les témoins anciens :}

1Q-a lit ici : כyזובות החרש האמיר, un 'waw' ayant été suspendu ensuite au-dessus du début du 3e mot. La *V aussi mettra le premier mot au pluriel (derelictae). Ces deux témoins ont voulu accorder ce participe avec "villes" qui précède, faute de saisir le sens de l'expression dont il fait partie.

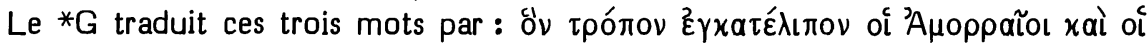
€ủãol, ce que nous expliquerons plus loin. 
Hie vocalise l'hébreu comme le fait le * $M$ : "hores" et "amir". Dans la *V, il traduit cela par "aratra et segetes", en disant que Th s'est contenté de transcrire l'hébreu en "ars" et "emir", alors que le second de ces mots a été transcrit "emir" par Aq et "amir" par Sym. Quant au premier, dit-il, il a été traduit "testa" (= tesson) par Aq et "silva" (= forêt) par Sym. Ce dernier, comme la *V, s'est contenté là d'interpréter le *M, alors que Aq a cru y lire

La *S aussi s'est contentée de transcrire ces deux mots. Elle a traduit le mot qui les précède par איך גובא (= comme la citerne). Ephrem, en citant cette expression, omet la conjonction avant le 3e mot, ce qui donne : "comme la citerne de חרש dont il est dit (qu'elle a été abandonnée...)".

Le *T, en s'inspirant du contexte, donne ici : “comme une ville qui a été ruinée et transformée en tas de pierres", la racine אמר ayant évoqué pour le targumiste : רמ.

\section{Choix textuel :}

Michaelis (OEB) a fait remarquer que, depuis 1769, dans son cours (à Göttingen), il choisissait ici la leçon du *G; que Struensee (à Halberstadt) en 1773, sans savoir cela, choisissait la même leçon dans sa traduction; et que Lowth l'a choisie aussi, indépendamment des deux Allemands, dans sa traduction parue en 1778, en faisant remarquer que son père corrigeait déjà de même. Il concluait : “C'est rarement que, chez des critiques indépendants, on rencontrera un tel accord. Si ce n'est pas le critère de la vérité, c'est du moins le critère d'une haute vraisemblance." Il ajoute ensuite que Dathe adopte lui aussi cette leçon. Michaelis omet toutefois de dire qu'Houbigant, s'inspirant du *G, corrigeait déjà האמרי en.

Doederlein refuse de suivre le ${ }^{*} G$, car il juge cette leçon trop éloignée de celle du * $M$ et il se défie de la grande négligence du traducteur grec d'Isaïe. Gesenius estime aussi "très scabreux d'adopter une telle leçon sur la foi d'un traducteur à qui on peut faire aussi peu de confiance dans le domaine critique". Knobel considère que "sur ce traducteur fantasque et, en ce cas, désemparé, il serait difficile de se fonder". Delitzsch dénote à l'inversion des deux noms de peuples (que le ${ }^{*} G$ livre dans leur ordre traditionnel) la fausseté de la "conjecture téméraire" du *G (alors que Duhm s'appuiera justement sur ce fait pour montrer que c'est le *M qui a retouché le texte en voulant, pour plus de vraisemblance, placer "la forêt" avant "le rameau").

Hitzig et Ewald estiment que le ${ }^{*} G$ a pourtant pressenti quelque chose d'exact. Selon Hitzig en effet (comme déjà selon Saadya) ce sont des noms de villes qui se cachent sous האמיר et Selon Ewald, "le fourré" évoque les Hittites, habitants du bas-pays, alors que "la cime" évoque les Amorites, habitants du haut-pays.

En 1873, c'est Grätz (Geschichte I 61, n.2) qui, considérant le *M comme incompréhensible, et cherchant des documents sur la manière dont les Israélites se sont emparés des villes de la montagne d'Ephraïm, a souligné la convergence existant entre (1) le ${ }^{*} G$ (mentionnant l'abandon des villes par les Amorites et les Hivvites), (2) certaines données de Procope (De bello Vandalico II 10) prétendant que, dans la ville numide de Tigisis, deux colonnes de marbre portent une inscription phénicienne disant : "c'est nous qui avons fui à l'approche du brigand Josué" et (3) la mention, dans la littérature talmudique, que les Girgasites ont émigré en Afrique à l'approche de 
Josué. On comprend donc que Grätz, historien en mal de documents, ait préféré ici le ${ }^{*} \mathrm{G}$ au $* M$.

A sa suite, la leçon du ${ }^{*} G$ a été adoptée par Lagarde, Bredenkamp, von Orelli, Duhm, Dillmann/Kittel, Cheyne, Marti, Gray, Ehrlich, Halévy, Procksch, Fohrer, Kaiser, Wildberger.

Wellhausen (Rec. Dillmann), s'inspirant de Hitzig et du *G, a proposé de lire " חרשת האמרים : "comme la dévastation de Haroset, la ville des Amorites, qu'ils ont abandonnée devant les fils d'Israël".

A propos des traditions juives évoquées par Grätz, notons que Rashi, après avoir exposé le peshat de ce vs, ajoute un résumé du midrash : “comme l'abandon des villes des Amorites qu'ils ont laissées ruinées à l'époque de Josué". Cela se fonde sur un midrash rapporté en Tosefta Shabbat VII 25 par Rabban Shiméon ben Gamaliel : “Il n'existe pas de peuple plus paisible que les Amorites. Nous avons trouvé rapporté en effet qu'ils ont cru en Dieu et ont émigré vers l'Afrique où Dieu leur a donné un pays aussi beau que le leur." Il s'agit là d'un récit étiologique de la fondation de Carthage par les Phéniciens. D'autres formes de cette tradition mentionnent, au lieu des Amorites, les Cananéens ou les Girgasites. Mais il est intéressant de noter que cette forme-ci, la plus ancienne (vers 70 ap. J.-C.) mentionne bien les Amorites.

Faut-il penser que ces midrashistes se sont inspirés d'Is 17,9 lu dans une forme plus proche de celle que le ${ }^{*} G$ aurait connue ici, forme dont le $* M$ serait une déformation plus tardive ? Si nous remarquons que 1Q-a a déjà ici un texte substantiellement identique au ${ }^{*} \mathrm{M}$, il est plus vraisemblable que le ${ }^{*} G$ atteste déjà ici une interprétation midrashique d'un texte de ce type, texte que Th transcrira, faute de le comprendre.

Le comité a donc retenu le texte difficile du $* M$ en lui attribuant la note "C".

Interprétation proposée :

Delitzsch comprend

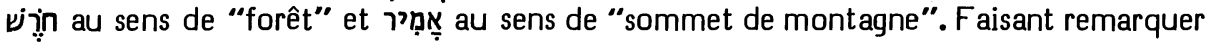
qu'après la conquête israélite, les localités situées sur les voies de communication sont demeurées vivantes, ayant seulement changé d'habitants, il note que ce furent celles qui se trouvaient moins accessibles, parce que situées dans la forêt ou dans la montagne, qui, abandonnées, tombèrent en ruines. C'est un sort semblable que cet oracle annoncerait aux villes fortes: elles seront comme les habitats abandonnés qui parsèment la forêt et la montagne, habitats que l'on a abandonnés à l'approche des fils d'Israël.

Mais ce sens de "sommet de montagne" pour le troisième mot n'a pas de parallèles, et celui de "forêt" ne s'impose pas pour le deuxième. Cet emploi de ש̛ר̧ se trouve rapproché d’Ez 31,3 par Judah ben Qoreish (Bargès 21 = Katz 39), David ben Abraham (I 590,217) et Abulwalid (Ușul 253,3s) qui lui donnent le sens de "ramure, branche". Quant à אִִ̣, Ibn Ezra y voit la "cime" (de l'arbre), s'appuyant à la fois sur 17,6 et sur l'arabe. Aaron ben Joseph, se fondant sur cette exégèse, explique : “Lorsqu'un homme va pour se procurer des fûts écorcés dans la forêt, il ne se préoccupe pas de la ramure et de la cime qu'il laisse sur place. De même, les ennemis ont abandonné une partie du pays d'Israël. Et c'est cela que signifie : 'qu'ils ont abandonné 
à l'approche des fils d'Israël'. Il veut dire que les sept nations ont abandonné leurs villes aux jours de Josué comme la ramure et la cime et se sont enfuies, et leur pays a été déserté par eux."

On peut donc considérer l'expression "comme un abandon de ramure et de cime" comme une expression toute faite, tirée de la pratique des bûcherons, et servant à désigner l'abandon de ce qui est inutile, lors d'une migration.

Une traduction possible de ce vs serait donc: "en ce jour-là ses villes fortes seront comme l'abandon de ramure et de cime que l'on a fait à l'approche des fils d'Israël, et ce sera une désolation".

ישאון 17,12 לאמים [B] hab M 1Q-a 4Q-a G V T // hom : m S om

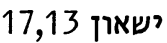
לאמים [B] hab M 1Q-a 4Q-a G V S T //.hom : m om

Options de nos traductions :

Le *M, après avoir achevé le vs 12 par ושאון לאמים כשאון מים כבירים ישאון, commence le vs 13 par לאמים כשאון מים רבים ישאון

RSV, J3, RL et TOB traduisent tout cela, J3 plaçant (comme J2) entre parenthèses la phrase initiale du vs $13 . J 1$ omettait cette phrase, estimant qu'elle cache une lacune. NEB l'omet avec "quelques mss".

Origine de la correction :

C'est HSAT3 qui considérait la phrase initiale du vs 13 comme une répétition erronée de ce qui précède, répétition ayant fait disparaître une phrase originale de trois ou quatre mots. L'apparat de Cent a demandé cette omission, alors que HSAT4 se contentait (pour des motifs de métrique) d'omettre le mot לאמים. BH23 attribuait (à titre informatif) cette omission à $8 \mathrm{mss}$ du *M et à la *S.

Les témoins anciens :

Pour cette reprise, le *M a l'appui de 1Q-a. 4Q-a est fragmentaire, mais les longueurs de lignes (entre 63 et 67 lettres) garantissent la présence de cette reprise.

Quant aux mss Kennicott et de Rossi que l'on invoque çomme n'ayant pas cette reprise, deux des mss Kennicott (plus la 1e main d'un ms de Rossi) omettent le premier élément de la reprise, alors que cinq mss Kennicott omettent le second. Ces omissions sont dues à des accidents d'homéoarcton ou d'homéotéleuton.

Ce qu'omet la $* S$, à la suite d'un accident analogue, ce sont les cinq derniers mots du vs 12 et non les cinq premiers du vs 13 .

Le $* G$ organise autrement cette matière textuelle, sans l'alléger.

$\mathrm{La} * \mathrm{~V}$ et le ${ }^{*} \mathrm{~T}$ appuient clairement le $* \mathrm{M}$.

Choix textuel :

Les considérant comme une reprise erronée de ceux qui les précèdent, Kennicott (note sur Lowth, Poesis 236) a proposé d'omettre les cinq premiers mots du vs 13 dont il constatait l'absence en quelques mss. Lowth (en son commentaire) hésitait à les omettre car il considérait comme également vraisemblables une omission 
ou une ajoute accidentelles. Doederlein préférait les garder en reconnaissant une valeur poétique à cette répétition. Gesenius proposait l'omission, car il estimait plus probable, de la part des scribes transmetteurs du texte, qu'ils aient transmis sans l'omettre une ajoute accidentelle. En cela, Gesenius a été suivi par Duhm, Cheyne, Marti etc.

Cependant, Hitzig et Knobel s’étaient opposés à cette omission, Hitzig notant la variation כבירים au lieu de considérant la présence du premier des deux éléments comme nécessaire pour appuyer ce qui suit, Knobel estimant que cette répétition crée un effet de contraste avec la fuite craintive qui est mentionnée ensuite.

König voit ici des paronomases caractéristiques du style de l'auteur.

Etant donné le caractère accidentel des quelques omissions attestées dans la tradition textuelle et le solide appui que 1Q-a et $4 Q-a$ apportent à la leçon du ${ }^{*} M$, le comité a attribué à celle-ci la note " $B$ ".

Interprétation proposée :

On peut traduire ainsi les vss 12 et $13 a$ :

"Malheur! un tumulte de peuples nombreux! Ils sont tumultueux comme les mers sont en tumulte! Un vacarme de peuplades! Elles font un vacarme comme le vacarme des eaux puissantes! Les peuplades font un vacarme comme le vacarme des grandes eaux. Mais il le réprimande, et, de loin, cela s'enfuit..."

\section{ביום 18,4 בח 1C ] M 1Q-a T // err-graph : m G V}

Options de nos traductions :

Le *M est suivi ici par RSV, J, RL et TOB.

NEB traduit : "at (harvest) time", Brockington précisant qu”elle corrige en avec le *G.

Origine de la correction :

NEB a pu trouver cette correction requise par les apparats de HSAT34 et de BHS.

Lowth voyait en la leçon du $* M$ une erreur due, vraisemblablement, à la présence de inğ, six mots avant. Aussi choisissait-il la variante qu'il rencontrait en 5 mss du *M, le $* G$, la $* S$ et la $* V$. Ce choix a été fait, à sa suite, par Doederlein, Grätz, Gray et Wildberger.

Les témoins anciens :

Il est clair que le *G (ífúpas) a lu ici ביום

$C$ 'est de son option que dépendent vraisemblablement la $* V$ et la $* 5$. Hie, au livre VII, dit en effet : "et quomodo nubes roris in die messis et in fervore aestatis gratissima est, etc.", ce qui suppose la connaissance des deux leçons.

Une douzaine de mss du *M ont ici $1 Q$-a et par la massore. Une liste de la Okhla (Diaz Esteban $\$ 58=$ Frensdorff $\S 57$ ) précise en effet que c'est en ce vs que se rencontre l'unique occurrence de ce mot. La mention de son unicité se trouve également dans la $\mathrm{mp}$ du $\mathrm{ms} \mathrm{d}^{\prime} \mathrm{Alep}$ et dans celle du ms du Caire. Cette précision semble avoir un triple but. D’abord le *M offre 


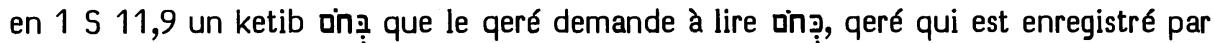
la Okhla (Diaz Esteban $\$ 137=$ Frensdorff $\$ 149$ ) dans la liste des onze mots où un ketib 'bet' doit être lu 'kaf'. La mention de l'unicité de la leçon d'Is 18,4 vise donc à éviter qu'on lise $1 \mathrm{~S} 11,9$ selon son ketib. Mais elle peut viser aussi à éviter qu'on

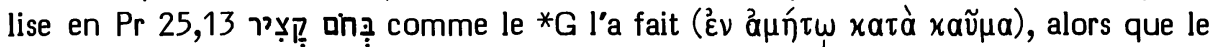

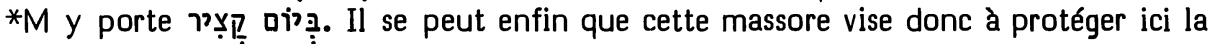
leçon du $* M$ tibérien classique (que $1 \mathrm{Q}$-a et le ${ }^{*} T$ appuient) contre une assimilation à כ qui précède de six mots, assimilation qui a eu lieu en certains mss du*Met du*T.

\section{Choix textuel:}

Quoique la leçon du ${ }^{*} M$ tibérien classique soit aisée à identifier ici et que l'appui que 1Q-a lui apporte ait plus de poids que l'écart du ${ }^{*} G$ (qui, en $\operatorname{Pr} 25,13$, s'écarte du $* M$ en sens inverse), le comité a voulu manifester la relative incertitude de la situation en attribuant 1 " $C$ " à la variante, alors que la leçon du $* M$ recevait 1 " $B$ " et 4 "C".

\section{Interprétation proposée :}

Il faut distinguer en ce vs ự qui, comme dans les trois autres emplois de cette expression, signifie "lorsque s"échauffe" et notre ơṇ̣ signifiant "sur la chaleur". Le même mot on garde dans le premier cas sa valeur verbale d'infinitif et prend dans le second valeur de nom abstrait (comme en Gn 8,22 ou Jb 24,19, par exemple).

On pourra donc traduire: "Lorsqu'un temps clair s'échauffe en pleine lumière, lorsqu'un nuage de rosée (descend) sur la chaleur de la moisson." Il serait inexact de caractériser cela comme une répétition pure et simple du même mot.

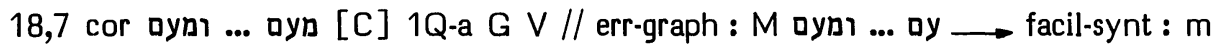

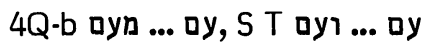

Options de nos traductions:

En 18,2 où l'on a une séquence de trois termes: "nation, peuple, nation", l'articulation de ces termes est : "allez messagers, messagers rapides vers une nation élancée et glabre, vers un peuple redouté de près et au loin, nation etc." La reprise de la préposition "vers" présente ce qu'elle introduit comme une apposition à ce qu'elle introduisait la première fois. Cette apposition est suivie d'une seconde apposition.

En 18,7 on retrouve une séquence de trois termes qui sont, cette fois, “peuple, peuple, nation", chacun de ces termes ayant, dans le même ordre, les mêmes qualificatifs que les trois termes du vs 2 . Mais ici l'articulation des deux premiers termes n'est plus la même et le *M doit se traduire : “en ce temps sera apporté en présent au Seigneur Sabaot un peuple élancé et glabre, et en provenance d'un peuple redouté de près et au loin, une nation etc." Il semble donc ne plus s'agir de deux désignations du même peuple (comme au vs 2), mais de deux peuples différents dont le premier est un présent apporté, alors que, du second, provient un deuxième présent constitué par le troisième terme ("une nation etc."). 
Aucune de nos traductions ne respecte cette articulation en 18,7. Trois d'entre elles (RSV, J, NEB) ajoutent "en provenance de" avant le premier "un peuple". Les deux autres (RL, TOB) omettent cette expression avant le second "un peuple" et traduisent le verbe "apporter" par une forme active dont 'peuple', 'peuple" et "nation' sont le sujet et les appositions de ce sujet.

\section{Origines des corrections :}

La première des deux solutions a été proposée par les apparats de HSAT234, BH23S et Cent. Mais c'est déjà la traduction de Le Fèvre d'Etaples, puis celles d'Olivetan, Châteillon, Pasteurs, ainsi que de Pagnini révisé par Estienne (1557).

Quant à la seconde solution, c'était déjà celle de Luther.

Les témoins anciens :

Le *M présente donc la double difficulté de faire correspondre à ay une forme où ce substantif est précédé à la fois d'une préposition et d'une conjonction. Il est seul à cumuler ces deux difficultés.

Certains de ses témoins (cinq mss de Kennicott et la 1e main d'un autre) ont omis le 'waw' qui causait la seconde. Déjà, 4Q-b avait fait de même.

Ceux des autres témoins textuels qui lisent (avec le *M) ay pour le premier terme lui ont assimilé le deuxième en omettant la préposition qui le précède dans le $* M$. Il s'agit d'abord de la *S qui, traduisant le verbe par une forme transitive active, a déjà pris la même option que reprendra Luther. Il peut s'agir aussi du *T qui semble avoir assimilé au vs $2:$ "vers le peuple... et vers le peuple..."

$1 Q$-a et le ${ }^{*} G$ introduisent déjà le premier terme par la préposition qui introduira le second, obtenant un texte très coulant et évitant du même coup la deuxième difficulté, puisque ומעם se coordonne très naturellement à $L a * V$ se rattache à cette ligne textuelle, l'omission de la conjonction n'y étant qu'un allègement translationnel.

\section{Choix textuel :}

La leçon très naturelle des bibles françaises anciennes dérivait donc inconsciemment du $* G$, à travers Le Fèvre d’Etaples et la $* V$. Elle a été adoptée formellement par Foreiro et Tremellius, puis fondée explicitement sur le ${ }^{*} G$ et la $* V$ par Clericus, suivi par Houbigant, Lowth, Michaelis (s'opposant en OEB à l'option de Luther et de la *S choisie par Doederlein), Aurivillius (370), Rosenmüller, Knobel, Ewald, Bredenkamp, Duhm12, Dillmann/Kittel, Cheyne, Marti, Condamin, Gray, Procksch, Fohrer, Kaiser, Wildberger.

Gesenius estime que l'on peut, à partir de la seconde occurrence de "peuple" où elle figure, sous-entendre la préposition avant la première occurrence de ce mot. Hitzig s'oppose à cela, car "la préposition ne peut déployer aucune force en arrière". Mais il revient à Luther en suggérant que le verbe ירבי peut avoir un sens actif éventuellement transitif. Delitzsch1 fait de ay le sujet et considère ומעם comme partitif, alors que Delitzsch2 y voit la mention de dons complémentaires. Duhm5 en revient clandestinement à l'option de Luther en corrigeant le hofal en hifil et en omettant (sans le dire) la préposition et la conjonction avant la reprise de "peuple". 
Au XVIe siècle, le *M avait été suivi fidèlement par Oecolampade, Münster et $\mathrm{Ge}$. Cette leçon se caractérise donc essentiellement par le fait que c'est en un peuple (et en une nation) que consiste le présent apporté au Seigneur. Cela a pu être lu ici par celui qui a rédigé Is 66,20 et, peut-être, Is 45,14 . Aussi deux membres du comité ont-ils accordé la note " $\mathrm{C}$ " à cette lectio difficilior.

Cependant trois membres ont accordé la note "C" à la variante de 1Q-a et du *G (dont dépend la $* \mathrm{~V}$ ), estimant que le ומעם qui suit est un fort argument pour le caractère original de cette leçon qui permet de rétablir en 18,7 le parallélisme rigoureux que 18,2 établissait entre les trois membres de cette séquence.

\section{Interprétations proposées :}

On pourra donc traduire : "en ce temps un présent sera apporté au Seigneur en provenance d'un peuple élancé et glabre, et en provenance d'un peuple redouté de près et au loin, d'une nation etc.". Mais il serait bon de mentionner en note la leçon du * $M$ : "en ce temps sera apporté en présent au Seigneur un peuple élancé et glabre et, en provenance d'un peuple redouté de près et au loin, une nation etc.".

\section{9,7 על־פי יאור [B] M 1Q-a.b 4Q-b S T // exeg : V / constr : G}

\section{Options de nos traductions :}

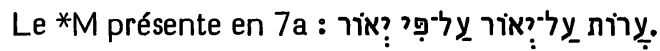

Cela a été traduit par RSV : "There will be bare places by the Nile, on the brink of the Nile", par J3 : "Les herbes du Nil sur les bords du Nil", par TOB : "La jonchaie le long du Nil et à son embouchure".

Sans note textuelle, J1 donnait : "dénudés seront les bords du Nil" et J2 : "les herbes des bords du Nil".

NEB qui, selon Brockington, omet par conjecture les trois derniers mots, traduit : "the lotus too beside the Nile". RL a une traduction très semblable: "Und das Gras an den Wassern wird vergehen."

\section{Origines des corrections :}

RL retouche à peine Luther qui portait: "und das Gras an den wassern verstieben".

Tous ceux qui ont corrigé le *M ont considéré comme surchargée l'expression redondante constituée par les cinq derniers mots de 7a. Pour alléger, Luther et NEB n'ont pas tenu compte des trois derniers de ces cinq mots, alors que $\mathrm{J} 12$ ne tenaient pas compte des deux qui les précèdent. Ce deuxième type d'allègement a été proposé par les apparats de HSAT4, BHS et Cent. Quant à l'allègement de NEB, il dérive du jugement de Gray (considérant les trois derniers mots comme une variante douteuse des deux qui les précèdent) et d’Ehrlich (décrétant que ces trois mots ne sont pas une expression hébraïque).

Les témoins anciens :

Pour cette expression redondante, le ${ }^{*} \mathrm{M}$ a l'appui précieux de 1Q-a, de 1Q-b (quoique le premier des cinq mots soit absent et le deuxième mutilé du fait d'une 
lacune) et de 4Q-b (quoique le dernier de ces mots soit absent du fait d'une lacune). Notons qu'en 1Q-b la lettre finale mutilée du mot qui précède על פי יאור a toutes les chances d'être un 'resh', mais ne peut être un 'taw'.

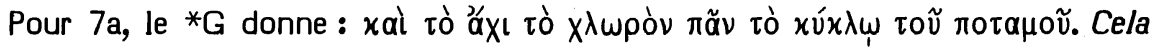
semble avoir été construit assez librement en s'inspirant de Gn 41,2.18 et d'Ex 7,24 où l'on retrouve (transcrivant ou traduisant assez fidèlement d'autres bases hébra-

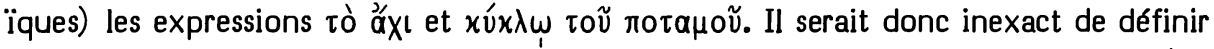
la relation du ${ }^{*} G$ avec le ${ }^{*} M$ en se contentant de dire avec BHS qu'il a omis על יאור.

La *V rend 7a par : "nudabitur alveus rivi a fonte suo", traduction dont Hie ne rend pas compte. Pour Jérôme, la "bouche" du fleuve est vraisemblablement sa source.

$\mathrm{La} * S$ et le $* T$ attestent l'expression redondante du $* M$, quoique le $* T$ la traduise de façon plus large.

\section{Choix textuel :}

Seuls les $3 \mathrm{mss}$ de Qumrân et la *S apportent ici un témoignage textuel caractéristique. Ce témoignage appuie formellement la leçon du $* M$, alors que les traductions plus libres du ${ }^{*} G$, de la $*^{*} V$ et du ${ }^{*} T$ s'éparpillent sans témoigner de façon claire d'une autre Vorlage.

Delitzsch a fait remarquer que le triplé emphatique de יאור en ce vs correspond à celui de מצרים en 19,1.

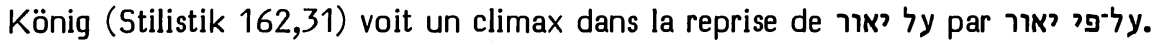

Etant donné la ferme attestation textuelle de la leçon du*M, le comité lui a attribué la note "B".

Interprétation proposée :

Avec Yéfet ben Ely, Dillmann/Kittel, Dhorme, Wildberger et Kaiser, il vaut mieux comprendre "sur la bouche du Nil" au sens de "à l'embouchure du Nil". Il s'agit vraisemblablement d'une distinction entre la vallée du Nil ("sur le Nil") et le Delta ("sur la bouche du Nil").

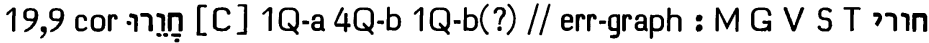

\section{Options de nos traductions :}

RSV ("white cotton") et J ("étoffes blanches") entendent traduire le *M.

Les autres traductions donnent ici un verbe : RL : "werden erbleichen", NEB : "shall grow pale" et TOB : "deviendront livides", Brockington précisant que cela suppose une vocalisation

Origine de la correction :

Sans un mot d'explication, Koppe avait proposé de lire ici חuzzatto a re-

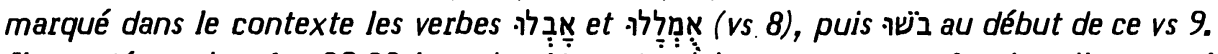

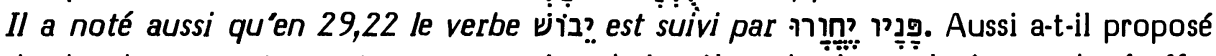
de chercher en notre mot une expression de la pâleur du visage plutôt que des étoffes blanches ou des filets (interprétation habituelle du *M). Un de ses étudiants lui ayant 
objecté que le verbe פחר n'a ce sens que lorsqu'il est associé à Luzzatto fit remarquer que le verbe analogue חפ peut être employé avec ou sans ce substantif. Pinsker (133) a donc proposé de lire ici חִִֵ̣, leçon adoptée ensuite par Grätz, Bredenkamp, Perles (I 50, n. 1), Marti, Condamin, Gray, Ehrlich, Feldmann, Procksch, Fohrer, Kaiser, Wildberger.

\section{Les témoins anciens :}

Le *G a vu ici le "byssus". Il semble donc avoir reconnu le substantif ר:ּ (cf. Est 1,6; 8,15). La *V (subtilia) et le *T (qui traduit par "filet") ont cru reconnaître ici in (= trou).

La *S donne ici le substantif חדותא (= joie). Warszawski a proposé de corriger cela en חור qui, en Gn 40,16, traduit יר̣in. Mais il semble ne pas avoir remarqué

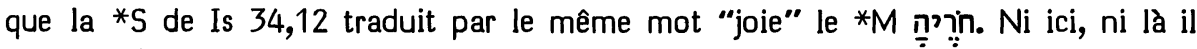
n'existe de variante dans la tradition textuelle de la $*$ S, si l'on en croit Diettrich.

En 1Q-a et 4Q-b la leçon חור est certaine. En 1Q-b elle est probable, bien qu'on ne puisse entièrement exclure une lecture 'yod' de la dernière lettre.

\section{Choix textuel :}

Les motifs mis en avant par Luzzatto ont amené le comité à préférer la variante attestée par les mss de Qumrân. Il lui a attribué la note "C".

Interprétation proposée :

On peut traduire "les tisserands blêmiront".

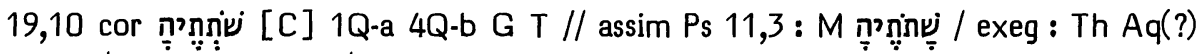
$\mathrm{V} /$ deform-int $: \mathrm{gt} /$ constr $: \mathrm{S}$

\section{Options de nos traductions :}

Aucune de nos traductions ne porte de note textuelle concernant ce mot que RSV traduit: "the pillars of the land", alors que TOB y voit : "ceux qui préparent les boissons"; alors que J ("ses tisserands"), RL ("die Weber"), et NEB ("Egypt's spinners") se tournent vers les professions du textile.

\section{Origines des corrections :}

S'inspirant de la traduction de Michaelis "die Weberstühle", Koppe a eu l'idée (à partir du ${ }^{*} G$ ) de voir plutôt en ce mot un participe de שׁת en le vocalisant Il concluait du *G et du *T que cela devait signifier "tisserands". Mais lui, ainsi que Rosenmüller qui l'a suivi, ne parvenait à justifier cette forme qu'à partir de racines à troisième radicale faible fourniẹs par l'araméen, le syriaque et peut-être l'arabe.

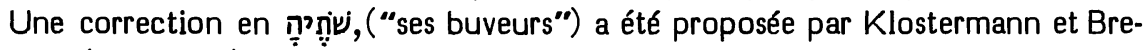
denkamp (qui le cite).

En s'inspirant du Thesaurus de Gesenius (1487b), Duhm1 a suggéré que le participe décelé par Koppe (leçon qu'il adopte) peut être l'expression copte pour "tisserand"(cf. Crum, 598, sous $\omega \nmid T=$ vqávins). Cependant, Dillmann/Kittel ayant pré- 
cisé que l'hébreu ne connaît en ce sens que la racine à troisième radicale faible, Duhm

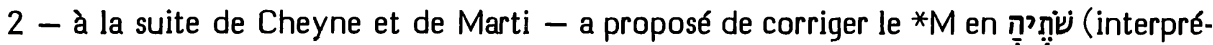
té au sens de "ses tisserands"). Cette leçon a été diffusée par Gesenius/Buhl (sous يِّn, I), HSAT34, BH23 et Cent.

Eitan (Loan Word 419), se fondant sur le copte et l'égyptien, a proposé de corriger la vocalisation en par le prophète pour donner plus de couleur locale à son oracle. Cette correction a été acceptée par BHS, alors que KBL a cru pouvoir conserver, en ce sens de "ses tisserands", la vocalisation du *M.

Les témoins anciens :

1Q-b offre ici une graphie défective identique à celle du *M. Il est donc impossible de savoir comment son scribe vocalisait cette forme. Il n'en va pas de même avec 1Q-a et 4Q-b dont la graphie pleine שותתיה atteste formellement la vocalisation conjecturée par Koppe.

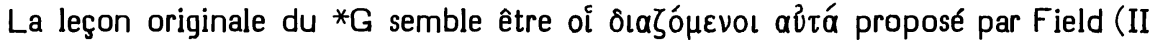
567) et retenu par Ziegler (Untersuchungen 194) sans qu'il exploite les données de

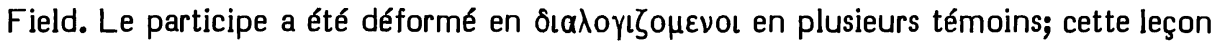

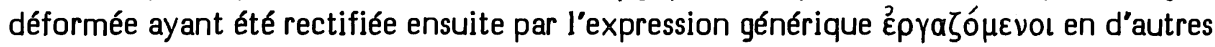
témoins (cf. vs 9).

La *S semble s’être inspirée de ce mot du *M (qu'elle dérive de שתח = boire) pour insérer למשתיא dans sa traduction du stique suivant. C'est en fonction de la même étymologie que Th voit ici les terres grasses de l’Egypte ( $\tau$ à níova aủ̃ñs), ce que la *V, plus littérale, traduit "inrigua eius".

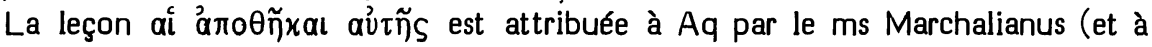
Sym par Ziegler). Cette traduction dérive ce mot de la racine שמתת dont il est fait usage en Ps 49,15; 73,9.

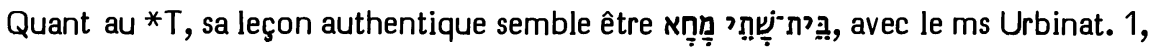
les éditions de Félix de Prato et de Ben Hayim donnant un shewa à la place du premier qames du dernier mot. Le sens en est, selon Levy (Chald. Wörterb. II 23 et 521) : "les ateliers de ceux qui tissent du tissu". Dans une partie des témoins le "ḥet" a été déformé en "hé".

\section{Choix textuel :}

Les vocalisateurs massorétiques ont eu pour intention de rapprocher ce mot mystérieux de תīnِ (Ps 11,3) ainsi que l'ont noté les exégètes judéoarabes; Yéfet ben Ely et David ben Abraham (II 712,25s) voyant ici des "canaux d'irrigation", alors qu'Abulwalid (Ușul 712,32ss) et Judah ibn Balaam voient ici des "nasses" à poisson.

La tradition de l'exégèse "tisserands", encore accessible au *G et au ${ }^{*} T$, s'est donc perdue ensuite. Th, Aq (ou Sym?), la *V, la *S et les vocalisateurs ont tâtonné, cherchant ici autre chose qu'un nom de profession que Koppe a été le premier à y retrouver. La vocalisation qu'il conjecturait s'est trouvée confirmée aujourd'hui par les mss 1Q-a et 4Q-b. D'ailleurs l'ugaritique (UT, Glossary §2504) connaît 'štt', adjectif, au sens de "tissé". Rien ne prouve donc que l'hébreu biblique n'ait pas eu cette 
racine verbale en usage. Il est, par conséquent, inutile de la vocaliser comme un mot emprunté à l'égyptien. Mieux vaut, avec les scribes de Qumrân qui connaissaient encore ce verbe en ce sens, vocaliser ici ce mot en participe.

C'est pourquoi le comité a choisi cette variante avec la note "C".

Interprétation proposée :

"Ses tisserands" (c'est-à-dire les tisserands de l'Egypte, ou les tisserands du lin cardé, mentionné au vs 9 ).

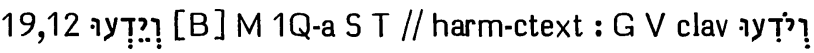

\section{Options de nos traductions :}

$J 3$ et TOB traduisent le *M par "et que l'on sache".

Les autres traductions donnent à ce verbe une valeur causative. RSV traduit : "(let them...) and make known", RL : “(dass sie...) und anzeigen", NEB : “(to...) make known", J12 : "et qu'ils te fassent connaître". J12 et Brockington fondent cette correction sur le ${ }^{*} G$, ce dernier précisant que cela suppose une vocalisation

Origine de la correction :

Sous l'influence de la *V, ce verbe a été traduit en causatif par Pagnini : "et notificent", Luther : "(Las sie...) und anzeigen", Brucioli : "notifichino", Olivetan : "et te notifient".

Secker s'est appuyé sur le ${ }^{*} G$ et la $* V$ pour lire : יודיעו. Il a été suivi en cela par Lowth (qui le cite), Duhm, Cheyne, Marti, Condamin, Gray, Ehrlich, Procksch, Kaiser, Wildberger, HSAT34 et BHS.

Michaelis (OEB) estime que le $* M$ peut éventuellement être vocalisé en hifil défectif, mais il hésite à quitter le qal.

Les témoins anciens :

1Q-a porte ici la même graphie que le *M. Il témoigne donc très probablement en faveur du qal, puisqu'il est fidèle aux graphies pleines pour l'imparfait hifil de ce verbe.

Le *G donne ici xai عiлátwoav. En 48,6 un qal de ידע se retrouve faisant suite à un hifil de נג (ce qui est déjà ici le cas). Le *G le traduira aussi par عĩras.

$\mathrm{La} * \mathrm{~V}$ donne ici "et indicent".

Le $* T$ et la $* S$ traduisent littéralement le *M.

Choix textuel :

A première vue, le *M présente la difficulté que "qu'ils sachent" devrait précéder "qu'ils annoncent" et non le suivre. Une correction facilitante est donc 'dans l'air'.

Le comité a attribué au *M la note " $B$ " pour le protéger contre l'une des facilitations tentées par le $* G$, la $* V$ et maints autres traducteurs. 
Interprétations proposées :

Münster (suivi par Michaelis et Doederlein) traduit : "s'ils savent". Gesenius a fait remarquer que ce sens était déjà celui que proposait Saadya. C'est d'ailleurs celui que retiendra Luzzatto. Quant à Gesenius, il propose ou bien de donner à ce verbe un autre sujet ("que l'on sache" = J3, TOB), ou bien de lui donner le sens de "étudier, s'enquérir". Jr 5,1 peut être invoqué en faveur de ce deuxième sens, puisque ce verbe y est suivi par le verbe בקיש.

Dillman/Kittel voit ici un retour voulu sur une présupposition du "qu'ils annoncent" : "et (d'abord) qu'ils sachent."

Cette interprétation est la plus probable. Mais on peut aussi traduire "pour que l'on sache".

בקרבְּם [C] M 1Q-a 4Q-b V S // assim-ctext : G T clav בקרבְּה 19,14

Options de nos traductions :

Seule RSV respecte le suffixe féminin singulier du *M: "within her".

Les autres traduisent comme s'ils avaient lu un suffixe masculin pluriel : $\mathrm{J12}$ ("en eux"), RL ("über sie"), NEB ("into them"), J3 ("au milieu d'eux"), TOB ("en eux"). Seule NEB note qu'elle suit le ${ }^{*} \mathrm{G}$, Brockington précisant que l'on corrige en

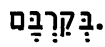

Origine de la correction :

Déjà Luther traduisait : "unter sie" et Ge : "among them".

Secker a estimé peut-être préférable de lire avec le ${ }^{*} G$ בקרבם et Lowth (qui le cite) ajoute que le *T a lu de même. Michaelis (sous l'influence de Luther ?) traduit "sie" (pluriel) sans note. Doederlein, avec "eis", fait de même. La correction de Secker a été adoptée par Cheyne, Marti, Condamin, Gray, Fohrer, Kaiser, Wildberger.

Nos versions ont pu la trouver requise par les apparats de HSAT4, BH3S et Cent.

Les témoins anciens :

Traduisent par un pronom pluriel : le *G (aủtõ̌s) et le *T (ביניהון).

$1 Q$-a et $4 Q-b$ ont un suffixe "hé", comme le *M.

Celui-ci est appuyé par la*V (in medio eius) et la*S (בגוה).

Choix textuel :

Rosenmüller et Gesenius, précisant que le suffixe féminin porte sur le pays d’Egypte, estiment que le ${ }^{*} G$ et le ${ }^{*} T$ ont seulement traduit librement (comme, d'ailleurs, Luther et $\mathrm{Ge}$ ).

$L$ 'appui que les mss de Qumrân apportent à la leçon du ${ }^{*} M$ a engagé le comité à la retenir avec 3 "C" et 2 "B".

Interprétation proposée :

En faveur de la correction, Cheyne a fait remarquer qu'en Os 5,4 il est dit qu'un

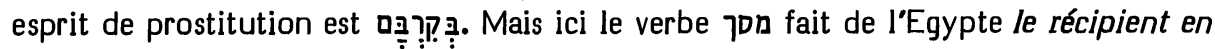


lequel le Seigneur mélange, comme une boisson capiteuse, un esprit de vertige. Il ne faut donc pas traduire ce verbe par "répandre" ou "verser", comme l'ont fait presque toutes les traductions récentes, mais par "préparer" ou, si l'on ose le terme, "mixer". Alors, le complément "en elle" ne fait plus de difficulté.

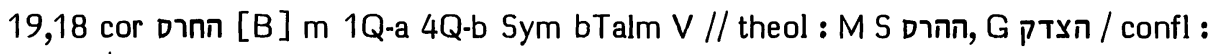
$T /$ incert : ThAq apes

Options de nos traductions :

RL se contente de transcrire ici "Ir-Heres". TOB transcrit et traduit : "Ir-Hahèrès - Ville de la Destruction". La traduction qu'elle donne montre qu'elle adopte la leçon avec 'hé' du *M. La chose est moins certaine pour RL qui s'est contentée de reproduire la transcription que Luther glosait en marge par "Irheres heisset Sonnestad, und achten viel es sey Heliopolis". Cette glose suppose la leçon avec "ḥet'. J12 transcrivaient aussi "Ir-Hahèrès", expliquant en note les problèmes posés par ce toponyme.

RSV et NEB traduisent ici "the City of the Sun", Brockington précisant que l'on adopte la leçon avec "ḥet' avec 1Q-a et quelques mss. J3 donne: "ville du soleil", sans note.

\section{Origines de la correction :}

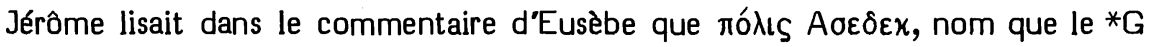
donne à cette ville, signifie "ville de justice", alors que Sym traduit le nom de cette

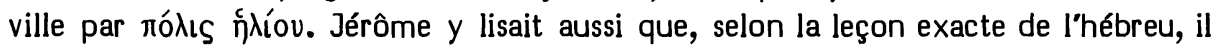
est dit H APEC ПO^IC, ce qu“Eusèbe estime pouvoir traduire "la ville de la terre". Notons à ce propos que le ms de Florence, qui nous atteste le texte le plus complet du commentaire d'Eusèbe, porte ici $H$ APEOПO $\wedge I C$, leçon que Ziegler a retenue dans son édition de ce commentaire. Mais Hie nous dit que, du fait que dans l'hébreu est écrit ici ARES, "l'un des nôtres" (il s'agit d’Eusèbe) a été induit en erreur, croyant qu'il s'agissait là de "la terre", alors que celle-ci s"écrit avec d'autres lettres. Il semble donc qu'un $C$ a été déformé en $O$ (sous l'influence du toponyme 'Арєómo৯ıs, ville de Moab bien connue des lecteurs de l'Onomasticon d'Eusèbe) dans la tradition textuelle dont est issu le ms de Florence. Le ms Marchalianus du ${ }^{*} G$ nous indique en effet que Th et $A q$ avaient transcrit ici $A P \in C$ (ce qui, selon leurs coutumes de transcription, ne permet aucune conclusion sur la nature de la gutturale initiale).

Hie corrige Eusèbe, disant que Sym a mieux fait d'interpréter ce toponyme comme "ville du soleil", ARES étant un mot équivoque qui peut signifier ou bien "soleil", ou bien "tesson", de sorte que l'on peut penser ou bien à la ville d'Héliopolis (à propos de laquelle il renvoie à Flavius Josèphe) ou bien à celle d'Ostrakiné.

Cette discussion de Jérôme montre qu'il n'a pas conscience que puisse se poser un problème sur l'identification de la première consonne du toponyme hébreu. En effet, les deux traductions qu'il évoque supposent toutes deux un 'ḥet' (et non le "hé" du *M). Pourtant Jérôme connaît bien la distinction existant entre les gutturales de l'hébreu, ainsi que Brønno (Aussprache) l'a clairement démontré. En tout cas, il adopte dans la $* V$ la traduction de Sym. 
Passons à l'étude des hésitations des exégètes du XVIe siècle.

En 1525, Oecolampade traduit exactement le *M par "civitas devastationis". Mais il ne semble pas être au clair sur la question que pose la première consonne, puisqu'il commente : "הר solem et dissipationem significat".

En 1527, Pagnini, sans note, se borne à transcrire "civitas Heres". En 1528, Luther transcrit "Irheres" avec une scolie disant que cela signifie "ville du soleil" et que beaucoup estiment qu'il s'agit d'Heliopolis. Luther traduisait à partir de l'édition Brescia 1494 qui porte ici החר avec un 'het'. Il n'a donc pas de motif de s'éloigner de Jérôme dans son exégèse. D'ailleurs, dans l'édition de 1532 de son cours sur Isaïe (WA. XXV 155,43) il reprend la même donnée: " 'civitas solis'. Dicunt Heliopolin esse". C'est vraisemblablement en se fondant sur Luther qu'en 1529 Zwingli (en son commentaire d'Isaïe) et les Prédicants de Zurich (en leur traduction allemande des Prophètes) donneront "Heliopolis". Quant à Pagnini, c'est dans son Thesaurus (482), sous הריס, qu'en 1529 il s'explique sur sa traduction en précisant qu'il y a ici dans l'hébreu une double leçon : l'une, dans le texte, avec "hé' et l'autre, en marge, avec "het'. C'est en effet le cas dans la Bible rabbinique de Félix de Prato qui laisse croire par là que l'on aurait un ketib 'hé' avec qeré 'het', car c'est sa manière habituelle de noter les qeré-ketib. Pagnini ajoute que cette leçon avec 'ḥet', lue par Jérôme, est aussi celle qui a inspiré Jonathan qui traduit en son *T : "la ville de Bethshemesh (c.-à-d. maison du soleil) qui est destinée à être détruite". Pagnini conclut en disant que, selon Radaq, ce nom signifie "ville de destruction".

Brucioli, en 1532, traduit : "Citta di sovversione", sous l'influence d'Oecolampade. Mais, en son commentaire de 1540, sous l'influence de Luther, à qui il emprunte sa scolie, il donne : "citta di Sole".

Dans sa Bible hébraïque avec traduction latine, Münster, en 1534, donne en son texte la leçon avec 'het' et en marge celle avec 'hé', en traduisant selon cette dernière : "civitas desolationis" et en disant que c'est l'exégèse commune des "hébreux", quoique "certains' lisent ici avec "ḥet" : "ville du soleil".

L'évolution de la traduction française issue d'Olivetan est instructive. Celui-ci, en 1535, traduit "cité du Soleil", notant en marge : "ou : Heliopolis". Châteillon demeurera dans cette ligne en sa traduction latine (en 1551) comme en sa traduction française (en 1555) avec "Heliopolis". Mais les premières révisions d'Olivetan (jusqu'à celle que Philibert Rollet édita à Lyon en 1551) remplacèrent la note marginale sur Heliopolis par : “ou : de désolation", scolie évidemment empruntée à Münster. Calvin avait commenté Isaïe en 1549 et publié en 1551 la première édition de ce commentaire. Se fondant vraisemblablement sur Münster, il y prenait parti contre l'interprétation "ville du soleil" qu'il attribuait à une fausse lecture de la gutturale initiale concluant que ce mot signifie en réalité exécration et malédiction. On comprend donc que, dans la réédition d'Olivetan que Robert Estienne donna à Genève en 1553, "cité désolée" remplaça "cité du Soleil". Mais là où l'influence de Münster est la plus évidente, c'est dans la réédition de la traduction de Pagnini que le même Estienne donna à Genève en 1557 : il y donne "civitas nHereds", ce qui (selon ses règles précises de transcription) signifie un 'het' initial, en correspondance exacte avec le texte hébreu de Münster. Et, alors que les notes de Vatable, dans la Bible Estienne de 1545, ne mentionnaient qu'Heliopolis (selon le $* \mathrm{~T}$ ) ou Alexandrie comme sens de ce mot, 
les notes de la Bible de 1557 ajoutent à cela que 'Heres' se lit aussi avec 'hé', c'est pourquoi 'certains' (= Münster) lisent : "civitas desolationis".

La Geneva Bible, publiée en 1560 par les calvinistes anglais, traduisait "citie of destruction". Tremellius traduit "civitas destructionis". La révision d"Olivetan publiée en 1588 par les pasteurs de Genève porte "ville de destruction". Rappelons que c'était en ces termes que Pagnini rapportait dans son Thesaurus l'interprétation de Radaq. Corneille Bertram, hébraïsant de Genève, rééditera d'ailleurs à Lyon ce Thesaurus en 1577.

Enfin la King James Bible, au début du siècle suivant, reprendra la traduction de la Geneva Bible, en se contentant de noter en marge les options de Luther et d'Olivetan : "or of Heres, or of the Sunne".

Après avoir retracé les hésitations des hébraïsants occidentaux de l'époque précritique, étudions le débat entre la leçon avec 'hé' et la leçon avec 'ḥet' à l'époque critique.

C'est Foreiro qui ouvre ce débat en 1563 en prenant nettement position pour la leçon avec 'het'. Il commence par s'étonner que Pagnini et Münster aient emboîté le pas à Radaq en considérant ce mot ou comme un nom propre, ou comme signifiant "désolation, destruction". Ce sens lui semble inacceptable ici, puisque le prophète ne saurait vouer à la destruction l'une des cinq villes qui auront accepté la vraie foi. Foreiro, comme plusieurs de ses prédécesseurs, prend la leçon marginale de la Bible de Félix de Prato pour un qeré et rappelle que Helias l'Allemand (= Elias Levita) considère les qeré marginaux comme offrant, d'ordinaire, la leçon la plus authentique, celle qui doit servir de base à l'exégèse. Il ajoute que la grande similitude entre le 'ḥet' et le "hé' explique aisément une erreur graphique et qu'en ce cas il faut préférer la forme avec 'het' qui est donnée en premier dans la leçon gonflée du ${ }^{*} T$ et qui est la seule dont traite Hie. Enfin, en citant Hérodote et Strabon, il montre qu'Héliopolis avait eu en Egypte la réputation d'être la ville des sages et des prêtres les plus instruits dans la religion et la culture traditionnelle. Par conséquent, il s'agit de la ville qui aura le plus de difficulté à abandonner cette religion et cette culture. Dire donc qu'Héliopolis (désignée ici comme "la ville du soleil") sera l'une des cinq villes d’Egypte qui se convertiront au Seigneur, cela reviendrait à dire, dans le cadre de la civilisation grecque, que cinq villes de Grèce se convertiront et qu'Athènes sera l'une d'entre elles.

Optent, comme Foreiro, pour la leçon avec "het", au sens de : "ville du soleil": Clericus, Houbigant, Grotius, Vitringa, Secker (cité par Lowth).

A partir du milieu du XVIIIe siècle, quelques nouvelles options, au succès peu durable, ont été proposées.

En 1749, Iken (cité par Rosenmüller) a proposé de s'inspirer du toponyme “Léontopolis", nom de la ville du nome héliopolitain où Onias avait choisi de construire son temple. Notant que ón désigne le lion en arabe, il a vu dans la leçon du *M une allusion à ce toponyme et a été suivi en cela par Michaelis (OEB V 171 et XIVa 34), Doederlein, Duhm et Marti. A cela, Rosenmüller a objecté à juste titre que cette désignation arabe du lion est, en réalité, un qualificatif : “vorace" et que l'on n'a aucun indice ni que la racine הר ait eu la même valeur en araméen ou en hébreu, $\mathrm{ni}$ - à plus forte raison - que l'on ait, en ces langues, transféré cette désignation au lion. 
Gesenius avait cru, à partir du dictionnaire de Castle (887), pouvoir donner à la racine הרס un sens de "rédemption, libération", tiré du syriaque. En cela, il a été suivi par Rosenmüller. Mais plus tard, dans son commentaire, il explique que le dictionnaire de Bar Bahlul (659, 6ss) - où Castle a puisé ce sens - l'a justement tiré d'un essai d'exégèse de la transcription que la *S a donnée du mot hébreu en Is 19,18. Il y aurait donc un cercle vicieux à s'inspirer de ces exégèses conjecturales pour interpréter l'hébreu sur la transcription duquel elles ont été construites.

Parmi ceux qui ont opté pour la graphie avec 'het', certains ont voulu dériver ce mot de l'arabe óńn (= garder, protéger). C'est ce qu'a fait Rosenmüller (après l'échec de la proposition précédente) en croyant pouvoir attribuer à Saadya une "tra-

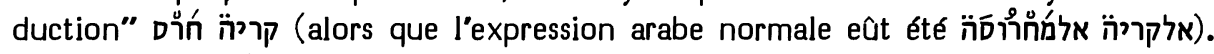
De fait, Saadya (28, n. 4) s'est borné à transcrire ici קריה אלהרס, comme nom propre de la ville. Sans contrôler la leçon de Saadya, Knobel et Ewald ont opté pour cette exégèse.

D'autres ont considéré comme la leçon primitive עיר הֵַָד Vorlage que révèle

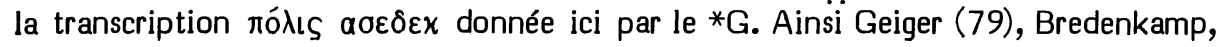
HSAT2, Cornill (Composition 88, note), Gray, Simons ( $\$ 1276$ ), Kaiser.

Ont repris, à partir de la graphie avec "ḥet", l'exégèse "ville du soleil" : Nägelsbach, Knabenbauer, Delitzsch 4, Dillmann/Kittel, Condamin, Fohrer, KBL, Wildberger, HALAT.

\section{Les témoins anciens :}

En parlant de Jérôme, nous avons déjà mentionné les leçons du *G, de ThAq et de Sym. En accord avec Sym, la *V traduit ici "civitas solis".

Nous avons déjà dit que la ${ }^{*} S$ se borne à transcrire la leçon du $* M$, alors que le *T offre une leçon gonflée qui attribue la première place à la leçon avec 'ḥet' (qu'il

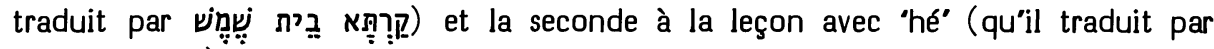

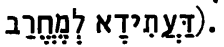

Nous sommes en mesure d’ajouter à cela quelques données moins connues.

1. Dans le Talmud de Babylone, la seule (et triple) citation formelle de ce texte se trouve en Menahot 110a. Si on le lit selon l'édition Bomberg, ou selon l'édition de Constantinople (1511) des Haggadot ha-Talmud, on se trouve devant la situation bizarre suivante : trois fois de suite Is 19,18 est cité selon la leçon avec 'hé'; la troisième fois, il est dit : "et d'où sait-on que ההרס (sic !) signifie le soleil ? à cause de לח en Jb 9,7." Il est paradoxal que l'on veuille justifier ce sens qui ne convient pas à cette leçon avec 'hé' par un texte où ce mot commence par "ḥet'.

Ce texte talmudique n'est pas repris dans les éditions du Yalqut Shiméoni, mais il l'est dans l'édition Spira du Yalqut ha-Makhiri. Is 19,18 n'y est cité que deux fois : la 1e fois avec 'hé' et la 2e avec "ḥet', avant que Jb 9,7 soit cité avec "ḥet'.

Si on se tourne vers les deux mss qui nous ont conservé cette partie du traité Menahot du Babli, on trouve dans le ms de Munich trois mentions d'Is 19,18, toutes trois avec 'ḥet', alors que Jb 9,7 y est cité avec 'hé' (!). Dans le ms Vatican ebr 120, on ne trouve que deux mentions d'Is 19,18, toutes deux avec 'het', comme aussi la citation de Job. 
Notons encore que le ms de Rossi 1172 du Yalqut Shiméoni (le seul que nous possédons pour cette partie d'Isaïe) rapporte notre passage du Talmud: Is 19,18 y est cité deux fois, toutes deux avec 'hat', comme c'est le cas aussi pour la citation de Jb 9,7 .

On peut conclure de cela que les éditions les plus anciennes du Talmud avaient déjà assimilé au ${ }^{*} M$ les citations $d{ }^{\prime} I s ~ 19,18$, alors que les trois mss auxquels nous avons pu avoir accès citent ce texte dans sa leçon Dาn, avec "het":

Une confirmation de la leçon Dาח dans la citation biblique faite par le Talmud Babli nous est fournie par Nathan ben Yehiel qui la mentionne sous 'het' dans l'ordre alphabétique de son dictionnaire, cela aussi bien dans les mss que dans les éditions de celui-ci.

2. A cela s'ajoute que deux témoins (1Q-a et 4Q-b) de ce passage d'Isaïe ont été retrouvés à Qumrân et que tous deux portent la leçon avec 'ḥet'.

On voit donc que la leçon avec 'ḥet' est la plus anciennement attestée dans la tradition juive palestinienne dont Jérôme était donc un fidèle témoin. Peu de temps avant Jérôme, on trouve d'ailleurs R. Simon ben Pazzi (début du $4 \mathrm{e}$ s.) rapportant les deux mêmes identifications qui seront reprises par Jérôme et dont nous avions signalé qu'elles ne peuvent convenir, l'une et l'autre, qu'à la leçon avec 'ḥet'. Selon la Pesiqta de-Rab Kahana (ed. Mandelbaum 126) et selon la Pesiqta Rabbati (87a), il dit en effet, si l'on en croit les éditions : “עיר ההרס, c'est Ostrakiné; שמש, c'est Héliopolis". Comme S. Buber (ed. de la Pesiqta de-Rab Kahana, 63b, n. 36) l'a fait remarquer, il s'agit là en réalité (comme c'est le cas chez Hie) de deux exégèses de la leçon ער ערe en Is 19,18.

3. Quelques mss du *M (dont le ms Urbinates 1) ont ici la leçon avec 'ḥet'. Cependant, la massore appuie clairement la leçon avec 'hé' qui domine largement la tradition textuelle du *M. Ginsburg (Massorah IV ה§32) considère comme l'une des plus anciennes parties de la massore une liste de 31 mots lus avec un 'hé' dont chacun est hapax. Le but de cette liste est de protéger ces mots hapax contre une graphie avec "het'. La forme la plus complète de cette liste est celle qui se trouve trois fois (Is 52,11; 62,9; Am 4,3) dans le ms de Petrograd des Prophètes. Des formes plus anciennes (mais omettant Is 56,10 ) se trouvent dans le ms des Jésuites de Cologne sur Is $16,4 \mathrm{~s}$ et en $\pi \S 7$ de la massore finale éditée (qui lui est identique). Une forme ancienne omettant en outre Ez 7,16 se trouve dans la seconde partie du ms de la Okhla de Halle ( $\$ 147$ ). Les formes de cette liste attestées par le ms de Petrograd sur Ez 23,24, par le ms BL Add 15451 et par la Okhla de Paris (Frensdorff $\$ 211$ ) ne sont ni anciennes ni complètes. Il est important de noter qu'en tous ces états cette liste intègre notre cas (en Is 19,18) comme un cas où il faut éviter de transformer le "hé" en "het". Cela concorde avec le texte de tous les mss tibériens classiques.

4. Il nous reste à préciser ce que l'on peut tirer des données fournies par Josèphe sur la fondation par Onias du temple de Léontopolis. Tout d'abord, Iken a eu tort de chercher en הר une désignation du lion, interprétation qui aurait amené Onias à choisir la "ville du lion" pour y construire son temple. Nous avons dit la fragilité 
de l'argumentation linguistique d'Iken. Ajoutons à cela qu'on ne trouve aucune trace d'une telle interprétation dans la tradition exégétique et qu'aucun des 'documents' cités par Josèphe n'offre cette motivation pour le choix d'Onias.

La Guerre Juive ne mentionne pas le toponyme Léontopolis, mais seulement le nome d'Héliopolis (I $\S 33$ et VII §426) dans lequel Onias bâtit un temple. Josèphe précise (VII \$432) que c'est Isaïe qui avait annoncé la fondation par un juif de ce temple en Egypte.

En Ant XII $\S 388$ et XX $\S 236$, s'exprimant de manière succincte, Josèphe dit seulement qu'Onias obtint de Ptolémée Philométor et de sa femme Cléopâtre un emplacement dans le nome d'Héliopolis où il construisit un temple semblable à celui de Jérusalem. En aucun de ces deux passages Léontopolis n'est mentionnée. C'est en Ant XIII $\$ 62-73$ que nous avons la notice la plus développée sur la construction du temple d’Onias. Après avoir répété $(\$ 64)$ les données succinctes sur la prophétie d'Isaïe qu'il avait fournies dans la Guerre Juive (VII §432), Josèphe prétend copier une pétition d’Onias à Ptolémée et à Cléopâtre, puis la réponse de ceux-ci à Onias. Dans l'un et l'autre document, il s'agit de restaurer un temple égyptien ruiné situé dans la forteresse de Boubastis la Sauvage, dans la ville de Léontopolis, dans le nome d'Héliopolis. La motivation biblique est donnée à la fin de la pétition ( $\$ 68)$ dans les termes suivants : "Le prophète Isaïe a, en effet, prédit ceci : 'il y aura un autel en Egypte au Seigneur Dieu', et il a prophétisé beaucoup de choses analogues à propos de ce lieu". La citation biblique formelle ne porte donc pas sur le vs 18, mais sur le suivant. Dans le début de sa pétition, Onias raconte qu'après avoir parcouru la CoeléSyrie et la Phénicie, il est arrivé avec les Juifs à Léontopolis dans le nome d’Héliopolis. Puis, ce qui l'amène à choisir le vieux temple de Boubastis la Sauvage pour le restaurer, c'est que le lieu foisonne de bois de toutes sortes et d'animaux sacrés, c'est-à-dire qu'il offre une ample réserve de matériaux de construction, de combustibles et de victimes sacrificielles. Il semble donc que ce n'est pas l'exégèse de notre texte biblique qui a motivé l'implantation du temple, mais les commodités offertes par le lieu. Mais pourquoi 'Onias' conclut-il de manière vague qu'Isaïe "a prophétisé beaucoup de choses analogues à propos de ce lieu" ? La chose s'éclaircira peut-être plus tard.

Retenons pour le moment que les 'documents' liés à la fondation du temple ne se réclament pas formellement d'Is 19,18 et du toponyme qui y est mentionné. Mais il faut rappeler que, en dehors de ces documents, Josèphe a l'habitude de situer succinctement le temple d'Onias "dans le nome d'Héliopolis".

Il importe ici de rappeler que, selon Gn 41,45 , le patriarche Joseph épousa Asenath, fille de Poti-Phéra qui était prêtre de Ôn; Ôn étant traduit exactement dans le *G par "Héliopolis". Glosant sur cela, l'apologète juif alexandrin Artapan (Eusèbe, Praeparatio IX 23) attribue aux "Syriens" entrés en Egypte avec la famille de Joseph la construction du temple d'Héliopolis. Quant au prêtre égyptien Manéthon (Josèphe, Contre Apion I 250 et 265), il fait de Moïse un prêtre égyptien d'Héliopolis. On voit donc qu'en Egypte, des traditions propagées en milieu juif comme en milieu égyptien rattachaient étroitement à Héliopolis le séjour des Hébreux avant l'Exode. 


\section{Choix textuel :}

Nous sommes maintenant peut-être en mesure de situer les unes par rapport aux autres les trois leçons qui rivalisent à propos du toponyme d'Is 19,18: celle du *M, de

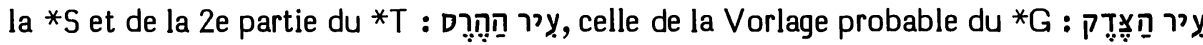
et celle de deux mss de Qumrân, de Sym, de la *V, de la première partie du *T et de la citation du Talmud de Babylone : עיר הַחֶרִֶ

S'il s'agit d'abord de situer l'une par rapport à l'autre les deux leçons qui nous ont été conservées en hébreu et qui ne diffèrent que par le choix de 'hé' ou de 'ḥet', il est presque certain qu'il faut donner la priorité à la leçon avec 'het'. En effet, elle est la plus anciennement attestée dans le judaïsme palestinien : depuis le milieu du $2 e$ s. av. J.-C. à Qumrân (où nous trouverons attestée à propos de 49,12 une autre tradition de topographie égyptienne préférable à celle du *M); alors que Sym et le Talmud la montrent en usage dans le judaïsme pharisien antérieur à Jérôme qui l'adopte en ne discutant que sur son interprétation. Le *T s'est d'ailleurs senti obligé de lui faire place avant de la 'compléter' par la leçon avec "hé'. Et il est fort probable que ceux des mss médiévaux qui l'attestent sont des survivants d'archétypes où la leçon avec "hé' n'avait pu encore la supplanter. Un autre motif de priorité pour la leçon avec 'ḥet', c'est que סר̣n, quoique d'un emploi peu fréquent, est un mot bien attesté en hébreu biblique pour désigner le soleil, alors que ס̣̣ n'est pas un mot hébreu, mais seulement une retouche dysphémique du premier, par allusion au verbe הרémolir). Sym, la Pesiqta et Hie nous montrent que le judaïsme palestinien interprétait ici ער הר comme désignant Héliopolis, le lieu - précise Jérôme - où Onias construisit son temple. On comprend donc que l'on se soit permis une correction théologique dans le sens que le ${ }^{*} T$ explicita dans la 2e partie de sa leçon gonflée : pour indiquer que ce temple, du fait qu'il dérogeait à la loi de l'unité de sanctuaire, était voué à la destruction.

Le Talmud Babli (Aboda Zara 46a), partant de Dt 7,26 (où il est dit des accessoires de l'idolâtrie : "tu les détesteras et en feras un objet d'abomination"), explique comment on doit déformer les toponymes liés à l'idolâtrie : "s'il s'appelait בית גליא, כליא,

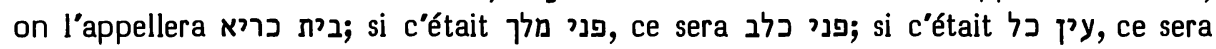
קוץ clairs : "face de roi" sera transformé en "face de chien" et "tout oeil" sera transformé en "épine dans l'oeil". C'est ainsi que "soleil" devint “destruction".

Quant à la leçon du ${ }^{*} G$, il faut d'abord admettre qu'elle est la transcription de עyִ leçon qui se réfère clairement à Is 1,26 où ce titre est promis à Sion restaurée par le Seigneur en sa fidélité première. Il semble que le traducteur grec, voyant lui aussi ici une mention de la ville et du temple bâtis par Onias, a voulu affirmer ainsi l'authenticité du culte qui se célébrait en cette “nouvelle Jérusalem". Une telle intention serait plausible à l'époque même où Onias fut obligé à s'exiler en Egypte, loin de Jérusalem, à cause des pressions persécutrices des Séleucides. Considérant le sanctuaire de Jérusalem comme profané par un grand prêtre non légitime, il voulut établir en son lieu d'exil les bases d'un culte légitime. Van der Kooij (60s) a raison de suggérer que le traducteur grec d'Isaie était vraisemblablement un partisan d'Onias qui voulait défendre son temple contre les critiques des palestiniens. Ce serait le motif pour lequel il aurait omis de traduire 36,7b qui rappelle la loi de l'unité de sanctuaire. 
C'est vraisemblablement aussi le motif pour lequel il s'est contenté de transcrire тódıৎ $a \sigma \varepsilon \delta \varepsilon x$. Il s'agissait de montrer aux juifs hébréophones qui critiquaient l'initiative d'Onias que la leçon 'authentique' du texte prophétique assimilait la citésanctuaire qu'il avait construite à la sainte Sion.

Quant aux 'documents' cités par Josèphe, il est frappant de noter dans la réponse de Ptolémée et de Cléopâtre la surprise des souverains : "nous nous demandons si ce temple bâti dans un lieu impur ... sera agréable à Dieu". Ici perce clairement l'esprit critique de juifs hostiles au projet d'Onias. Josèphe (Guerre Juive VII §431) luimême décèle d'ailleurs dans ce projet d'Onias: "l'intention de rivaliser avec les juifs de Jérusalem, car il leur en voulait de son exil et il espérait que, par la construction de ce temple, il y attirerait la multitude loin de la métropole". Josèphe semble bien épouser là les préjugés du clergé de Jérusalem (cf. Seeligmann 93). Aussi n’est-il pas étonnant que nous ne puissions faire fond sur ces 'documents' pour trouver un exposé objectif et complet des motifs qui amenèrent Onias à choisir le lieu où il allait établir le sanctuaire qu'il entendait bâtir. Dans la pétition d’Onias (qui peut avoir un noyau authentique) l'affirmation vague qu'Isaïe "a prophétisé beaucoup de choses analogues à propos de ce lieu" peut recouvrir une argumentation biblique qui a été gommée

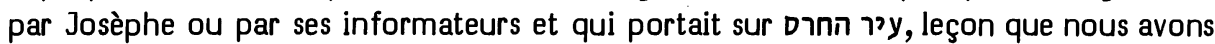
reconnue avoir plus de chances que les deux autres de représenter ici l'original. On pourrait se fonder sur Sym et Hie pour inférer qu'Onias lisait déjà cela comme "ville du soleil" et qu'il fut amené par cet oracle à s"établir dans le nome d'Héliopolis, des commodités matérielles l'amenant ensuite à fixer son choix sur Boubastis la Sauvage. Le fait qu'Onias, en entendant formellement accomplir l'oracle d'Is 19,19, ait décidé de construire son temple dans le nome d'Héliopolis peut servir d'indice que l'exégèse de Sym, de Simon ben Pazzi et de Hie a des chances de remonter au 2e s. av. J.-C. Ajoutons que l'usage fait de ce texte par Onias a vraisemblablement abouti à ce qu'il soit défiguré ensuite en deux sens opposés par ses partisans et par ses adversaires.

Le comité a attribué à la variante 4 "B" et 1 "C".

\section{Interprétation proposée :}

Il reste à répondre à une objection que l'on peut formuler contre l'interprétation

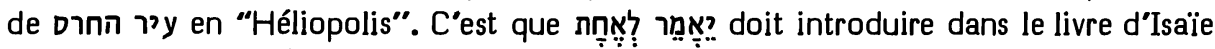
(cf. 4,$3 ; 32,5 ; 62,4$ ) un nom symbolique et non un toponyme. Il est donc vraisemblable que l'intention du prophète n'est pas de désigner purement et simplement Héliopolis par ces mots. En effet, pour désigner Héliopolis, la Bible utilise normalement la transcription אich du toponyme égyptien (Gn 41,45.50; 46,20), d'ailleurs déformé de façon dysphémique en אִִ̣ (= malheur) dans le *M de Ez 30,17. Même si Onias a interprété l'oracle comme désignant Héliopolis, cette interprétation ne fait pas entièrement droit à l'intention du prophète. Il s'agit plutôt pour lui de montrer que la conversion des cinq villes d'Egypte au Seigneur donnera à l'une d'entre elles le rayonnement d'une vraie "ville du soleil". En s'exprimant ainsi, le prophète fait une simple allusion à la ville d'Egypte qui, actuellement dans les ténèbres, se prétend indûment la cité du dieu-soleil Atûm et la dépositaire des traditions sacrées sur la grande Ennéade.

Le plus exact serait donc de traduire, avec J3, "la ville du soleil". 
Options de nos traductions :

Cette semi-préposition de l"hébreu est traduite par RSV ("by"), J1 ("par l'intermédiaire"), J23 et TOB ("par le ministère"), RL ("durch").

A sa place, NEB donne: "to", Brockington précisant qu’elle lit wֶ avec le *G.

Origine de la correction :

NEB semble avoir été impressionnée par Gray qui estimait que l'emploi de ici est extraordinaire, car la communication concerne le prophète seul et ne doit être transmise à personne d’autre. Déjà Gesenius, estimant que le Seigneur ne parle pas ici "par l'intermédiaire" du prophète mais "au" prophète, s"était inspiré d’une suggestion de Schultens (Opera minora 29s) pour donner à cette -semi-préposition le sens qu’a en arabe, c'est-à-dire "devant, en présence de".

Les témoins anciens :

La leçon du ${ }^{*} M$ se retrouve en $1 Q-a$, la ${ }^{*} S$ et le $* T$. La*V la traduit littéralement (in manu).

Le *G traduit par npós. Comme Sollamo (174) le note, cette traduction s'explique bien ici par l'influence du contexte. En 1 R 16,12 on retrouve, d'ailleurs, le même procédé de traduction.

HUB a noté que le ms Kennicott 30 porte ici אל. Cette variante avait échappé aux collations de Kennicott et de de Rossi. De même que la traduction du ${ }^{*} G$, cette variante isolée signifie seulement que cette leçon est ici 'dans l'air'.

Choix textuel :

Luzzatto a très bien vu que l'expression "en ce temps-là le Seigneur parla par le ministère d'Isaïe fils d'Amoç" vise à introduire le geste prophétique que le Seigneur lui ordonne d'accomplir (dans la suite du vs 2) et dont le Seigneur donne l'interprétation au peuple dans les vss 3-5. Par le ministère d'Isaïe qui accomplit ce geste, le Seigneur parla au peuple. Le "en disant" du vs 2 n'introduit pas cette parole que Dieu adresse au peuple, mais le préalable de cette parole, c'est-à-dire l'ordre adressé à Isaïe d'accomplir le geste prophétique en lequel s'exprime cette parole.

C'est faute d'avoir compris ce sens du texte que certains ont cru devoir corriger en fonction d'une interprétation superficielle du contexte immédiat.

Interprétation proposée :

TOB fournit une excellente interprétation de ce passage : "En ce temps-là, le Seigneur avait parlé, par le ministère d'Isaïe, fils d'Amoç : 'Va, lui avait-il dit, dénoue etc." " 
Options de nos traductions :

RSV (“we fled"), J (“nous avons fui"), RL (“wir ... geflohen sind"), TOB (“pour nous réfugier") ont traduit le * $M$.

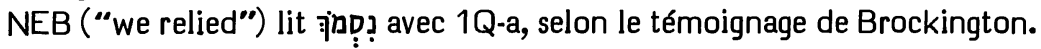

Origine de la correction :

Il semble à Kutscher (268s) que 1Q-a - estimant que les gens de Juda ne se sont pas enfuis alors en Egypte, mais ont seulement cherché à s'appuyer sur son aide a préféré ici le verbe סמך qu'Is 36,6 utilise pour la coalition avec l'Egypte.

C'est vraisemblablement pour les mêmes motifs que NEB a retenu cette leçon.

Les témoins anciens :

Toutes les versions anciennes $\left(* G, * V,{ }^{*}, * T\right)$ ont ici traduit littéralement le $* M$. du $* M$.

$1 Q$-a est seul à offrir ici נסמך, dans un contexte par ailleurs identique à celui

Choix textuel:

לעזרה complète aussi le verbe נוס 10,3 au sens de "chercher de l'aide auprès de quelqu'un".

D’autre part, שמ complète mal le verbe סמך qui se construit normalement avec לy.

Pour ce motif, et à cause de l'isolement de la leçon de 1Q-a, le comité a retenu la leçon du *M avec la note " $C$ ".

Interprétation proposée :

“Voici ce qu'est devenu le pays vers lequel nous regardions, où nous nous précipitions pour y chercher secours."

21,1 מדברים [B] M of $\gamma^{*}$ V S // harm ctext : 1Q-a דבר ים / abr-elus : G om / ים / paraphr : T

Options de nos traductions :

Le *M a été traduit par RSV ("concerning the wilderness of the sea"), J ("sur le désert de la mer") et TOB ("sur le désert maritime").

RL donne seulement : "für die Wüste".

NEB donne: "A wilderness : ... rough weather". Brockington explique qu'elle a vocalisé le second mot avec ḥolem, y voyant une graphie défective de יìn.

Origines des corrections :

Marti a suggéré de considérer מדבר seul comme appartenant au titre de l'oracle, alors que r serait le reste du premier mot de l'oracle. Cette vue a été adoptée par Procksch. Wildberger et Kaiser (comme RL) préfèrent considérer que ים est une glose dont la signification est obscure. 
NEB suit une suggestion de Driver (TLP 46s) qui lit ici "jour" (au lieu de "mer") et, se fondant sur l'akkadien, estime que cela signifie ici "temps de tempête, démon de la tempête".

Les témoins anciens :

1Q-a offre ici דבר ים. Comme Kutscher (227s) le suggère, le scribe a pu être influencé par le mot משא qui précède (le mot "parole" suivant "oracle" en Za 9,1; $12,1 ; \mathrm{Ml} 1,1)$.

Le *G atteste מדבר, mais non qu qui a pu le gêner en ce contexte.

Le *M a été traduit littéralement par ThAqSym ('̌prnjov $\theta a \lambda a ́$ oons), la *V (deserti maris) et la *S (דמדברא דימא).

Le *T paraphrase : “Oracle des armées qui viennent du désert comme les eaux de la mer."

Choix textuel :

La leçon de 1Q-a et celle du ${ }^{*}$ ne se distinguent chacune du $* M$ que par une variante, alors qu'elles diffèrent entre elles par deux variantes. Le *M a donc de sérieuses chances d'être la plus originale des formes textuelles qui nous ont été conservées. Aussi le comité lui a-t-il attribué 3 " $B$ " et 2 "C $\mathrm{C}$ ".

Interprétation proposée :

L'exégèse de cette expression en ce contexte fait difficulté, mais pas plus que celle d'autres titres "emblématiques" donnés à d'autres oracles contre les nations (cf, 22,1; 30,6). Il faut voir ici une expression énigmatique analogue à celle dont il est fait usage en 18,1. Ici, le mot מדבר a été emprunté à la suite du vs; de même que בערב, dans le titre de 21,13 l'a été à la suite du vs 13.

On traduira donc littéralement : "oracle du désert de la mer".

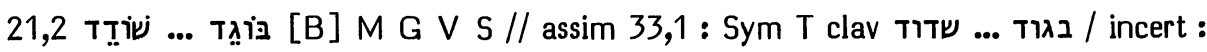

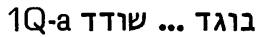

Options de nos traductions :

Le $* M$ a ici deux participes actifs du qal qui ont été traduits par des formes actives en RSV, J, RL et TOB.

Mais NEB les traduit par des passifs ("betrayed ... despoiled") et Brockington explique qu’ils sont vocalisés

Origine de la correction :

NEB a suivi en cela une option de Scott (Inside 280) qui s'inspirait de données fournies, à titre informatif, par l'apparat de BH3. C'est Haller (SAT II/3 18) qui semble être à l'origine de cette conjecture.

Les témoins anciens :

Le $* G$, la*V et la $* S$ ont traduit ici par des formes actives. 


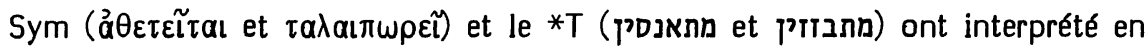
passifs.

Les graphies de 1Q-a (identiques à celles du $* M$ ) sont équivoques, car 1Q-a offre en 15,1 des graphies pleines identiques à celles de 21,2 en deux cas où le *M vocalise des graphies défectives en accompli pual.

\section{Choix textuel :}

On peut considérer ces reprises de participes actifs qu'offre le *M comme gênantes si l'on estime que le sujet est Babylone. Mais Dillmann/Kittel a précisé que les sujets de ces deux participes sont Elam et la Médie (mentionnés juste après). Babylone, elle, nous sera présentée aux vss $4 \mathrm{~s}$ comme banquetant dans l'insouciance.

Comme le note König, le participe passif (concernant Babylone) supposerait déjà accomplie l'expédition punitive qui sera ordonnée juste après.

C'est sous l'influence de 33,1 que certains témoins ont traduit ici en passif. Le comité a attribué ici au *M 3 "B" et 2 " $\mathrm{C}$ ".

\section{Interprétation proposée :}

"Le traître trahit et le dévastateur dévaste." Comme le note TOB, ce sont des expressions qui rappellent que les Elamites et les Mèdes, autrefois alliés à Babylone pour abattre l'empire assyrien, se tournent à présent contre elle. Il s'agit là d'un résumé anticipé de l'oracle qui suit.

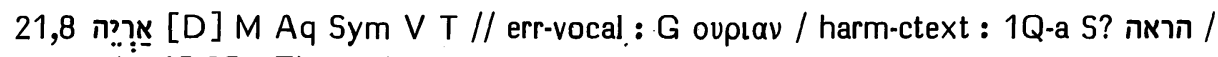
$\operatorname{assim} 15,9 G$ : Th apınd

Options de nos traductions :

Ce mot du *M paraît signifier "un lion".

Cependant, toutes nos traductions s'appuient sur 1Q-a pour lire ici "הֶֶ, RSV traduisant : "he who saw", J12: "le voyant", J3: "le guetteur", RL : "der Späher", NEB : "the look-out", TOB : "celui qui regarde".

Origines de la correction :

Lowth, estimant que la *S a lu ici הראה, a adopté cette leçon. Michaelis (OEB), s'inspirant lui aussi de la *S, dit avoir choisi cette leçon indépendamment de Lowth. Ils ont été suivis par Dathe, Doederlein (qui le cite), Lohmann (61), Haller (SAT II/3 17), Procksch, $\mathrm{BH} 3$ et Cent, avant que cette leçon n'ait été trouvée attestée par $1 \mathrm{Q}-\mathrm{a}$. A partir de là, cette leçon a été adoptée par presque tous les exégètes.

\section{Les témoins anciens :}

1Q-a offre en effet ici הראה.

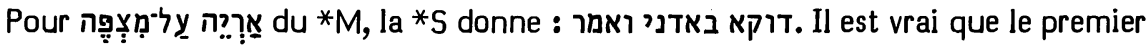
mot traduit הֶֶ en 2 Ch 16,10. Mais il est également vrai que ce mot correspond bien plus souvent à la racine צפה; alors qu'ici rien, dans la *S, ne correspond clairement aux deux mots suivants du ${ }^{*} \mathrm{M}$ où cette racine intervient. Il faut donc maintenir un certain coefficient de doute dans l'interprétation du témoignage textuel de la ${ }^{*}$. 


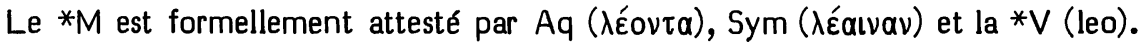

Le ${ }^{*} G$, sous l'influence vraisemblable de 8,2 , a cru reconnaître ici le nom propre Oupíav, confirmant ainsi la graphie consonnantique du $* M$.

Th a transcrit par Apın $\lambda$, influencé probablement par l'option prise par le ${ }^{*} G$ en $15,9$.

Pour les deux premiers mots du vs, le *T donne : "Le prophète a dit : le bruit des armées venant avec leurs chars est comme un lion (ou : est plus qu'un lion)", la première leçon étant attestée par les polyglottes d'Anvers et Londres, ainsi que par une citation en Radaq; alors que la seconde est celle de la Bible de Félix de Prato, de celle de Ben Hayim et des divers mss connus. En tout cas, le *T atteste qu'il connaît la leçon du*M.

\section{Choix textuel :}

Marti, Condamin, Gray, HSAT34 ont préféré conjecturer אֶֶּ, plus proche de la leçon du *M. Duhm et Feldmann ont opté pour רֵֵ

Ibn Ezra, Clericus, Koppe, Rosenmüller, Gesenius, Hitzig, Knobel, Delitzsch, Ewald, Knabenbauer ont jugé préférable de sous-entendre un "kaf' comparatif avant le mot "lion" du *M. lion !"

Luzzatto, von Orelli, Ehrlich (Miqra) ont compris le *M comme un cri: “au

Rappelons que nous avions déjà trouvé dans le * ${ }^{*} \mathrm{M}$ en $15,9 \mathrm{C}$ uncombrant et incertain. Il est possible qu'en ces deux cas le *M ait gardé la bonne leçon, mais que le sens exact de celle-ci nous échappe.

Etant donné qu'un glissement vers la variante ne se comprend que trop bien, quatre membres du comité ont préféré garder ici le $* M$ tout en reconnaissant qu'il est difficilement intelligible. Aussi ne lui ont-ils accordé que la note " $\mathrm{D}$ ", alors qu'un membre attribuait à la variante הָ la note "C".

Interprétation proposée :

En l'absence d'une interprétation du *M suffisamment probable pour qu'on puisse la conseiller aux traducteurs, on devra leur proposer de suivre (avec nos cinq traductions) la variante qui leur donnera un sens convenant bien au contexte.

Cette décision schizoïde se trouvera en parti rééquilibrée par une note mentionnant qu'on lit dans le *M: "un lion", leçon à laquelle il est difficile de donner ici un sens acceptable.

\section{2,3 נמצאיך [B] M 1Q-a V S T // exeg : G oi á áviعs}

\section{Options de nos traductions:}

Le *M a été traduit ici par RSV : "(all) of you who were found", 33 : "ceux qu'on a trouvés", RL : “die man von dir gefunden hat", TOB : "ceux qui ont été retrouvés".

$J 12$ ("les plus vaillants des tiens") et NEB ("your stoutest warriors") disent lire ק? 
Origine de la correction :

C'est Duhm qui a restitué cette Vorlage pour le ${ }^{*} G$ et l'a adoptée, suivi par les apparats de BH23S, HSAT4 et Cent. Driver en 1940 (Hebrew 163, n. 4), estimant qu'elle laissait le 'nun' inexpliqué, avait refusé de l'adopter. En 1968 (TLP 47, n. 2), il se résigne à la suivre et NEB fait de même.

\section{Les témoins anciens :}

Le *M a été lu ici par la *V (qui inventi sunt), la *S (דאשתחרו בכי, tombé par homéotéleuton dans les polyglottes) et le *T (דאשתכח בך).

HUB, à la suite de Duhm et de ceux qui l'ont suivi, a considéré comme allant de soi que, dans le ${ }^{*} G$, c'est of toxúoviعs ह̉v ool qui correspond à notre mot. Schultens (Opera Minora 267), qui était déjà de cet avis, expliquait cette correspondance par une analogie avec les sens secondaires de Schleusner III 129) le rapprochait de l'araméen מצי. Mais il est plus vraisemblable que Trommius et Hatch/Redpath ont raison d'estimer qu'ici, dans $l e{ }^{*} G$, c'est of

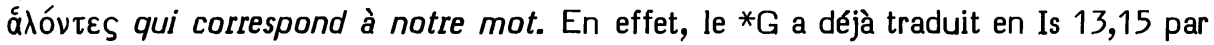

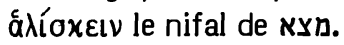

\section{Choix textuel :}

Il semble donc qu'aucune Vorlage divergente ne soit clairement attestée ici. C'est pourquoi le comité a attribué au *M la note " $B$ ".

Interprétation proposée :

Le parallèle que le $* G$ a établi avec 13,15 est intéressant pour l'interprétation de notre passage. En effet, il s'agit là aussi de fuyards rattrapés par l'ennemi et auxquels est promis le sort qui sera celui de Sédécias en $2 R$ 25,5. On traduira donc ici comme TOB l'a fait : "ceux qui ont été retrouvés".

\section{2,6 ברכב אדם [A]}

Options de nos traductions :

Le *M est traduit par J3 ("avec chars montés"), RL ("mit ... Wagen, Leuten") et TOB ("sur des chars ... montés").

Pour ces deux mots, RSV ne donne que "with chariots" en notant que l'hébreu de cette ligne est obscur.

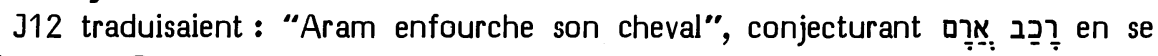
référant au *G.

NEB traduit : "to the chariots of Aram", en ne corrigeant que le deuxième mot.

\section{Origines des corrections :}

Lisant le nom de peuple "Qir" en 6b et notant qu'en Am 9,7 Aram est lié à Qir, Houbigant a conjecturé de lire ici ארם au lieu de. Ce nom de peuple ne pouvant figurer en sandwich entre des chars et des cavaliers, Houbigant a cru pouvoir tirer de xai àvaßátaı du *G une Vorlage ורכב qu"il vocalise en verbe. Il obtient ainsi : "et 
Aram est monté sur des chevaux". C'est l'état dans lequel la conjecture a été adoptée par BH3, Cent, J12.

Lowth accepte la conjecture d'Houbigant. Mais, après "Aram", il se contente d'ajouter la conjonction 'waw' qu'il lit en un certain nombre de témoins du *M, obtenant ainsi : "avec les chars d'Aram et avec des cavaliers". NEB a adopté une forme plus discrète (sans ajoute du 'waw') de cette conjecture.

Les témoins anciens :

Tous les témoins sont, ou bien identiques au *M (1Q-a), ou bien des traductions plus ou moins libres de sa leçon ( $\left.{ }^{*} \mathrm{G}, \mathrm{Th}, A \mathrm{~A},{ }^{*} \mathrm{~V},{ }^{*} \mathrm{~S},{ }^{*} \mathrm{~T}\right)$.

Kennicott lit ורכב en un ms du XIVe siècle, attestation isolée et sans poids.

Choix textuel :

Houbigant et Lowth ont estimé que la mention d'un peuple (Elam) dans le stique précédent et d'un autre (Qir) dans le suivant rendait presque nécessaire en celui-ci la mention d'un troisième peuple.

De fait, Elam et Qir figurent en deux stiques étroitement parallèles qui commencent par le nom du peuple en position de sujet précédé par 'waw' et suivi par un verbe à l'accompli que complète enfin un nom d'arme au singulier à valeur collective. Que le premier de ces stiques soit suivi par un complément d'accompagnement tel que l'offre le $* M$, cela ne détruit pas ce parallélisme; alors que celui-ci serait perturbé par I'entrée en scène d'un autre peuple dans la syntaxe proposée par Houbigant ou dans celle que propose Lowth.

A cause de la cohérence de la tradition textuelle, le comité a attribué au *M la note "A".

Interprétation proposée :

Les teamim de l'hébreu, ainsi que l'ajoute facilitante d'un 'waw' après le 2e mot en quelques mss du $* M$, montrent qu'il faut comprendre: "avec des chars de personnel, (et) des cavaliers". Le génitif אדם veut les distinguer de chariots à bagages. En 21,9, le génitif איש peut avoir la valeur de char "individuel". Mais nous manquons de parallèles pour appuyer cette suggestion. En tout cas, la reprise au vs suivant $(22,7)$ de la dualité רכרשים et doit nous éviter de comprendre ici le premier de ces deux termes en verbe, à la suite d'Houbigant, ou le deuxième en participe, à la suite de Driver (LTP 40s).

On traduira donc : "avec des chars montés, des cavaliers".

גבור 22,17 גבר

Options de nos traductions :

J ("homme !") et TOB ("beau sire") entendent traduire le *M.

RL ("wie ein Starker") reprend Luther.

RSV traduit, sans note : "O you strong man".

NEB donne: "as a garment", Brockington précisant qu’elle conjecture Tגֶֶֶֶ à la place de ce mot. 
Origines des corrections :

C'est Ginsberg (Emendations 55s) qui, s'inspirant de Jr 43,12b, a proposé cette conjecture qui a été adoptée par Driver (TLP 48s) et par NEB.

Sans le dire, RSV suit ici Gray qui proposait de traduire ainsi ce mot qu'il vocalisait ị̇ạ. Déjà Michaelis (OEB), estimant que le substantif en bonne part, alors qu'ici ce vocatif doit avoir une tonalité injurieuse, vocalisait ainsi et traduisait : "du Räuber !"

Les témoins anciens :

La conjecture de Michaelis se trouve appuyée par 1Q-b dont la graphie pleine (גבור) atteste cette vocalisation.

Par contre, 1Q-a apporte au *M un témoignage précieux, car sa graphie défective contraste avec les graphies pleines quíl a dans les neuf cas où le *M porte רią en ce livre.

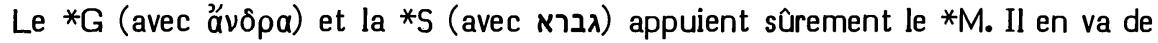
même de la *V (gallus gallinacius) selon l'attestation formelle de Hie. Celui-ci ajoute que toutes les colonnes des hexaples portent ici "virum" (c'est-à-dire la leçon du *G).

La tradition textuelle du *T est divisée. Une leçon la tradition yéménite (à laquelle se rattachent les éditions de Stenning et de Sperber). Une leçon la polyglotte d'Anvers (la même leçon à l'état emphatique étant donnée par Félix de Prato, Ben Hayim et la polyglotte de Londres).

\section{Choix textuel :}

Le mot fois רị. Cette variante est donc ici facilitante.

Michaelis estimait que ce vocatif doit avoir une tonalité injurieuse. C'est pourquoi il corrigeait. Mais le *M est encore plus sarcastique dans l'usage qu'il fait ici d'un nom honorable.

Le comité a donc retenu ici le *M avec 3 "B" et 2 "C".

Interprétation proposée :

Pagnini et Luther - influencés par le Talmud de Babylone (Sanhedrin 26a) à travers Rashi et le *T - ont compris : "à la manière dont un homme (et non une femme) jette", c'est-à-dire : avec force. Mais mieux vaut comprendre "homme" ici comme un vocatif, à la suite de Yéfet ben Ely et d'Ibn Ezra.

TOB rend assez bien la portée sarcastique de ce vocatif par "beau sire".

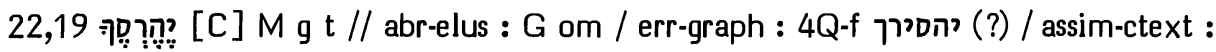
אהרסך 1Q-a ה S S T clav

Options de nos traductions :

Aucune ne donne ici un verbe actif à la 3e pers.sg. $(=* M)$.

Il se peut que RSV veuille en fournir une périphrase par : "and you will be cast down". 
Les autres donnent un verbe actif à la 1e pers. sg., en accord avec le stique précédent et les quatre vss suivants : J12 : "je t'arrache", RL : "(ich will... ) und dich aus (deinem Amt) stossen", NEB : "(I will... ) and drive you from", 33 : "je vais t'arracher de", TOB : "(je vais... ) te déloger de". Brockington précise que NEB corrige en

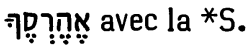

Origine de la correction :

Au XVIe siècle la 3e pers. du *M était conservée dans leur traduction par Oecolampade, Pagnini, Münster, Ge, Foreiro, KJ. La vieille traduction allemande (Kurrelmeyer VIII 409,49s), en accord avec la *V, traduisait ici : "ich ... entsetze dich". C'est vraisemblablement sous son influence que Luther traduit : "von ... will ich dich setzen". Ensuite cette 1e pers. se retrouvera en Prédicants, Jud, Brucioli, Olivetan, Rollet, Estienne.

Houbigant, se fondant sur la $* S$ et la $* V$, a proposé de corriger ce verbe en une 1e pers. et il a été suivi par de nombreux critiques jusqu'aux apparats de HSAT34, $\mathrm{BH} 3 \mathrm{~S}$ et Cent.

\section{Les témoins anciens :}

1Q-a donne seulement ici הרסך. Kutscher (352) voit là une assimilation partielle au verbe précédent que le scribe aurait compris comme un accompli coordonné (et non inverti).

Morrow (72), en 4Q-f, a lu un 'yod' initial (יהסירך) en supposant que l'on avait là un inaccompli aramaïsant, avec insertion du 'hé'. De fait, la lettre est plus verticale qu'un 'yod', quoiqu'elle soit plus courte que la plupart des 'waw'. On a peut-être là la trace de l'hésitation d'un scribe devant une leçon inexplicable due à la permutation accidentelle du 'resh' et du 'samek'.

Le *G n'a pas senti le besoin de traduire ce second verbe du verset, la recension

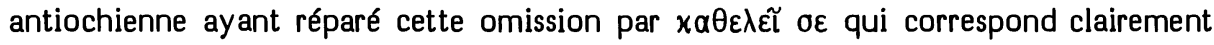
au $*$ M.

La *V (deponam te) et la *S (ואסחפך) ont traduit ce verbe par une 1e pers.

Selon l'édition de Félix de Prato, celle de Ben Hayim et la polyglotte de Londres, le *T traduit ici par la 3e pers. de l'inaccompli paél du verbe מגר. Selon la polyglotte d'Anvers, le ms Reuchlin et les mss yéménites, il s'agit du même verbe à la 1e pers. Enfin, selon le ms Urbinates 1, il s'agit du verbe (à la 1e pers. de l'inaccompli paél). Cette dernière leçon est la plus vraisemblablement originale puisque c'est bien ce verbe araméen qui traduit l'hébreu הרס en Is 14,17 et 49,17.

\section{Choix textuel :}

Dans ce bref verset dont le parallélisme chiastique est évident, le passage de la première à la troisième personne a fait difficulté pour la $* \mathrm{~V}$, la $* \mathrm{~S}$ et le $* T$ qui ont conservé la première personne, par une assimilation facilitante au contexte qui précède et qui suit.

Le comité a attribué 3 " $C$ " et 2 "B".à la lectio difficilior du *M. 
Interprétation proposée :

On interprète d'ordinaire cette $3 e$ pers. comme un retour momentané à la situation des vss 17-18a, après que le prophète, sous le coup de l'impatience, ait fait usage de la 1e pers. à sujet divin en début de verset. Voir les références à König que nous avons données ci-dessus à propos de 10,12.

Cependant, il vaut peut-être mieux, avec Luzzatto, donner pour sujet à cette 3e pers. le "maître" de Shebna qui a été mentionné à la fin du vs précédent : après que Dieu ait ébranlé Shebna, son maître (dont il est la honte) l'arrachera de son lieu (= le déposera de sa charge). La Bible des Pasteurs de 1588 traduisait : “Et je te jetterai hors de ton rang, tellement qu'on te déboutera de ton état."

\section{3,1A מבית [C] M 1Q-a.b 4Q-a S // abr-elus : G om / assim 14 : T / lic : V} 23,1B מבוא [B] M 1Q-a 4Q-a V T // lic : G S

\section{Options de nos traductions :}

La difficulté se situe ici au niveau syntactique : comment articuler entre eux et avec leur contexte trois termes que le $* M$ juxtapose en faisant précéder chacun par la même préposition :

Le *M est traduit par RSV : "without house or haven. From the land..." J3 : "plus de maison et plus d'entrée. Du pays..." TOB : "plus de maison ... en arrivant de l"île..." RL : "dass kein Haus mehr da ist ! Wenn sie heimkehren aus dem Lande...".

J12 donnaient: "votre forteresse... C'est en venant du pays..." en disant lire מִyִ à la place du premier mot.

"NEB donne : "the harbour ... the port of entry from...", Brockington précisant

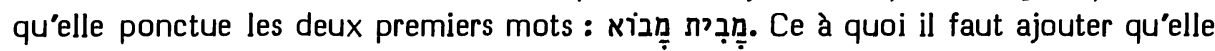
n’a pas jugé utile de traduire le mot "pays" avant le toponyme qui le suit.

\section{Origines des corrections :}

312 ont trouvé leur correction proposée par les apparats de Cent, $\mathrm{BH} 23$ et HSAT34. C'est Cheyne qui a introduit ce mot ici en le prenant au vs 14 . Il a été suivi en cela par Marti, Duhm2, Condamin et Gray. Feldmann a trouvé cette correction trop peu fondée et Duhm5 l'a abandonnée, préférant considérer le premier mot comme une variante du deuxième.

NEB, pour ses deux corrections, suit Eitan (Contribution 69) qui propose de lire מִạ au sens de "asile pour la nuit". Ben Yehuda (Thesaurus 2768, n. 1 et 2773, n. 1) cite ce mot comme employé par Ezra ben Ezekiel ha-Babli, auteur du début du XVIIIe s. qui l'aurait emprunté à l'arabe. Cela a donné à Ben Yehuda l'idée de suggérer que c'est peut-être déjà ce mot qui se trouve en Is 23,1. On voit que la base de cette inférence est fragile. A la suite de Ehrlich (qu'il ne cite pas) Eitan suggère aussi la correction vocalique du deuxième mot que NEB a adoptée.

\section{Les témoins anciens :}

Le *M est fermement appuyé par 1Q-a qui atteste les trois termes, par 4Q-a qui n'est conservé que pour les deux premiers et par 1Q-b qui ne l'est que pour le premier. 
Le *G n'a rien qui corresponde au premier terme et il a paraphrasé le deuxième

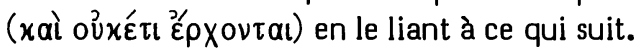

Sur les deux premiers מן, la *V (domus unde venire) et le *T (מחרזיהון מלמיתי) ont paraphrasé le premier et respecté le deuxième, alors que la *S (מן ביתא מיתינא) a fait l'inverse.

Choix textuel :

Etant donné la difficulté de la syntaxe et la fermeté des témoins hébreux anciens, il semble bien qu'il n'y ait pas de Vorlage différente à chercher derrière les traductions plus ou moins lâches des versions anciennes.

Le comité a donc attribué la note " $C$ " au *M en 23,1A (où le * $G$ pourrait ne pas avoir lu ce mot en sa Vorlage) et la note "B" au *M en 23,1B.

Interprétations proposées :

Une interprétation exacte du $* M$ doit tenir compte du fait que le zaqef qaton porte sur le deuxième terme. Elle doit également tenir compte d'une reprise des cinq premiers mots de cette deuxième partie du vs en 23,14 . Elle doit enfin noter en 24,10 l'expression

Le sujet de שִ n'est pas exprimé, mais il ressort des deux d'exclusion qui suivent : il s'agit de tout refuge portuaire sur la côte de Phénicie dévastée.

מִבִ faisant suite à ce verbe a une valeur analogue à celle de paisant suite

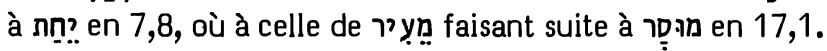

L'infinitif suivant précédé de מן exprime, ici comme en 24,10, une conséquence négative.

Le sens sera donc: "Il y a eu destruction, faisant disparaître tout habitat, de sorte qu'il n'y a plus où débarquer. Du pays de Kittim, ils en ont reçu la nouvelle."

Si l'on renonce à suivre les teamim et à s'inspirer de 23,14 , on peut joindre le deuxième terme à ce qui suit : “...habitat. Dès qu'ils sont arrivés du pays de Kittim, ils en ont reçu la nouvelle."

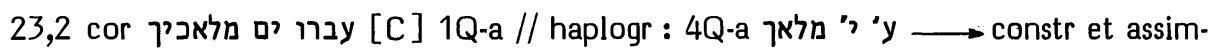

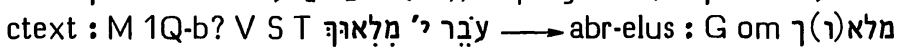
23,3A ובמים [B] M 1Q-a.b 4Q-a // facil-synt : G V S clav : T במים (it T

Options de nos traductions :

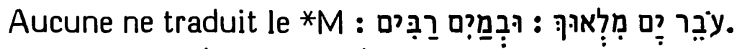
ser..."

RL donne: "(von Sidon.) Ihre Boten zogen übers Meer, und ... über grosse Was-

J12 portaient : "dont les commis parcouraient la mer aux eaux immenses", disant conjecturer 'mal'akô' au lieu du troisième mot.

RSV offre: "your messengers passed over the sea and were on many waters", en disant suivre $1 Q-a$.

NEB dit: "people whose agents cross the great waters". Brockington dit qu'elle

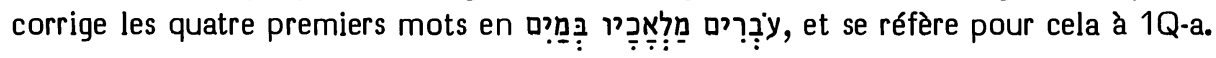


J3 énonce : "toi dont les messagers passent les mers, aux eaux immenses", en disant que cela suppose une leçon

TOB exprime : "dont les commis franchissent la mer. A travers les grandes eaux..." Elle dit suivre $1 \mathrm{Q}-\mathrm{a}$.

\section{Origine des corrections :}

J12 s'inspiraient de Cent qui traduisait: "dont les envoyés parcouraient les grandes eaux", en conjecturant une leçon identique à celle que propose Brockington. La justification offerte par J12 se singularise donc par le fait qu'elle accorde à "envoyé" une valeur collective, ce qui lui permet de ne pas corriger les deux premiers mots du *M.

En cet état, cette conjecture vient de Duhm. Celui-ci estimait difficilement explicable le suffixe $2 e$ pers. fem. du dernier mot du vs 2 , aucun vocatif féminin n'ayant été mentionné auparavant. Déjà Houbigant avait suggéré d'omettre le sof pasuq et la conjonction qui commence le vs suivant. Mais Duhm eut l'idée de rapprocher cette

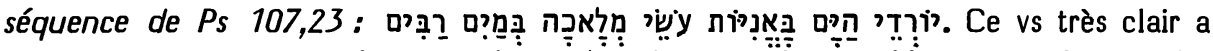
en commun avec notre séquence : les navires, la mer et le complément "sur les grandes eaux". Mais il est surtout précieux en ce qu'il nous offre dans le même ordre et dans une structure parfaitement intelligible les quatre consonnes du dernier mot du vs 2 qui offraient la difficulté principale dans le *M. Si l'on attire à la fin du vs 2 les deux premiers mots du vs 3 , en en détachant le 'waw' initial dont on fait le suffixe du mot

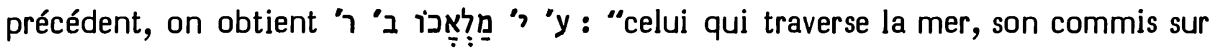
les grandes eaux".

Les autres traductions se sont inspirées de 1Q-a dont il nous faut traiter maintenant.

Les témoins anciens :

La découverte de 1Q-a apporta à la conjecture de Duhm une confirmation partielle en donnant : עברו ים מלאכיך ובמים רבים d'une ligne et les deux suivants au début de celle qui suit. Mais ce qui nous est conservé de 1Q-b (et qui inclut le mot le plus difficile) semble identique au $* M$ : ] [ים מלאוך ובמים

Quant à 4Q-a, il semble bien porter : עברו ים מלאך ובמים רבים. La lettre initiale est un 'alef' corrigé en 'caïn'. Du troisième mot les trois premières lettres sont conservées ainsi que la base d'un 'kaf' final, base qui semble trop proche du 'alef' pour qu'un 'waw' puisse s'insérer entre ces deux lettres.

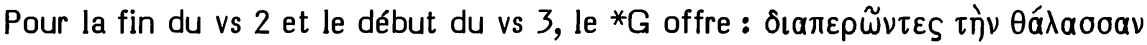

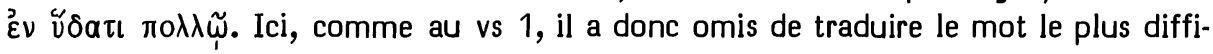
cile. Il a interprété en collectif le participe singulier et n'a pas lu la conjonction initiale du vs 3 , ou n'en a pas tenu compte.

$L a * V$ traduit : transfretantes mare repleverunt te in aquis multis. Il est frappant que ce soit par ces mots que Hie (livre $V$ ) commence son vs 3 . Il a conservé dans la ${ }^{*} V$ les deux dernières options du ${ }^{*} G$, mais complété - conformément au ${ }^{*} M$ - sa traduction en insérant le mot que le ${ }^{*} G$ n'avait pas traduit.

$L a * S$ présente les mêmes options que la $* V$. 
Traduisant, lui aussi, le premier mot par un pluriel, le *T traduit littéralement la fin du vs 2 , mais remplace le début du vs 3 par une construction très libre.

Choix textuel :

A supposer qu'Houbigant et Duhm aient eu raison de conjecturer que les deux derniers mots doivent servir de complément au troisième, on est déçu de constater qu'une conjonction leur interdit cette fonction dans les trois mss de Qumrân. Remarquons aussi que $1 \mathrm{Q}$-a et $4 \mathrm{Q}$-a donnent pour le premier mot un accompli pluriel auquel le troisième mot offre un sujet pluriel normal, dans la forme que lui donne 1Q-a, forme dont 4Q-a semble se distinguer par une haplographie. Il est possible que le *M soit issu d'un essai pour interpréter cette ruine.

Etant donné que cette réinterprétation modifie sérieusement le sens de ce mot, quatre membres du comité ont choisi la leçon de 1Q-a comme plus proche de l'original et lui ont attribué la note " $C$ ", alors qu'un membre attribuait au *M la même note. Quant au premier mot du vs 3, le comité a été unanime pour préserver la conjonction qui le précède et qu'attestent les 3 mss de Qumrân. A cette leçon a été attribuée la note "B".

Notons ici que le fait que le *M lit y yu singulier peut s'expliquer par une assimilation à רִ̣i qui précède.

Interprétation proposée :

Nous donnerons à la fin du cas prochain l'interprétation des vss $2 b$ et $3 a$.

23,3B יאור ... יותהי [B] M 1Q-a 4Q-a V S T // abr-styl : G om

Options de nos traductions :

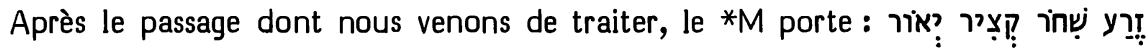
.

RSV traduit: "your revenue was the grain of Shihor, the harvest of the Nile; you were the merchant of the nations". J12: "Le grain du Nil, la moisson du fleuve était sa richesse qu'elle vendait au monde entier". J3: "Le grain du Canal, la moisson du Nil, était sa richesse. Elle était le marché des nations". RL : "und was von Früchten am Schihor und von Getreide am Nil wuchs, brachte man nach Sidon hin..., und du warst der Völker Markt geworden". TOB : "les semailles du Nil, la moisson du Fleuve étaient son revenu : elle était le marché des nations".

Bien que RSV et RL fassent entrer en scène quelques $2 \mathrm{e}$ pers. par assimilation à ce qui précède, l'ensemble de ces traductions entend être fidèle au * $M$.

Il n'en va pas de même avec NEB qui donne: "whose harvest is the grain of the Shihor and their revenue the trade of nations". Brockington dit que cela suppose une leçon קִạ à la place du 3e et du 4e mot et une vocalisation dû ajouter que cela suppose aussi une omission du 6e mot.

Origine de la correction

Les 2 corrections retenues par Brockington étaient proposées par BHS. Les 3 corrections que nous mentionnons l'étaient par HSAT34 et BH3. Si l'on en croit BHS, 
toutes ces retouches auraient, plus ou moins, l'appui du *G; alors que Duhm, qui a été le premier à proposer l'ensemble de ces corrections, ne se réfère au ${ }^{*} G$ que pour omettre le $4 \mathrm{e}$ et le $6 \mathrm{e}$ mot.

Les témoins anciens :

1Q-a appuie entièrement le ${ }^{*} M$ et $4 Q$-a ne s'en distingue que par une graphie יואר à laquelle Morrow (73) a trouvé de bons parallèles.

Le ${ }^{*} G$ fait des deux premiers mots la fin d'une interrogation dont la suite est la

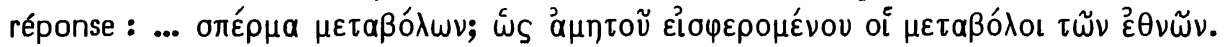
Dans cette interprétation très libre, la non-traduction du $4 \mathrm{e}$ et du $6 \mathrm{e}$ mot est probablement, de la part du ${ }^{*} G$, un allègement semblable à ceux que nous l'avons vu opérer en $23,1 A$ et 23,2 .

La $* V$ (semen Nili messis fluminis fruges ejus et facta est negotiatio gentium) traduit littéralement le $* M$.

Dans la *S (זרעא דתגרא חצדא נהרא עללתה הות תאגורתא לעממא) on reconnaît tous les éléments du $* M$, moins la conjonction qui précède le 6 e mot du $* M$ (et qui, selon Diettrich, n'est attestée, dans la tradition textuelle de la ${ }^{*} S$, que par un $\mathrm{ms} d u$ XVIIe s.).

Nous avons déjà dit que le *T remplace le début du vs 3 par une construction très libre. Dans la suite, on reconnaît clairement (והות et) (נהרא es deux mots que Duhm propose d'omettre.

\section{Choix textuel :}

Le ${ }^{*} M$ est fermement appuyé ici par $1 Q-a, 4 Q-a$ et la ${ }^{*} V$. Le ${ }^{*} G$ multiplie les allègements translationnels. Le comité a attribué la note " $\mathrm{B}$ " au maintien des deux mots que le ${ }^{*} G$ n'atteste pas.

Interprétation proposée :

23,2b-3a peut se traduire: "Marchand de Sidon, tes commis franchissaient la mer. A travers les grandes eaux, les semailles du Nil, la moisson du fleuve était son revenu."

Le possessif "son" porte sur Tyr qui n'a pas encore été mentionnée explicitement. De même, en Nahum, Ninive n'est nommée qu'en 2,9 après avoir été plusieurs fois apostrophée par des pronoms suffixes au féminin singulier.

\section{3,4 לאמר [A ] M 1Q-a 4Q-a G V T / abr-styl : S om}

Options de nos traductions :

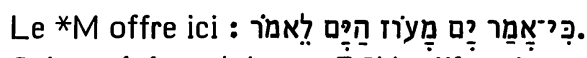

Cela a été traduit par RSV : "for the sea has spoken, the stronghold of the sea, saying" et.par RL : “denn das Meer, ja, die Feste am Meer spricht”.

J1 donnait: "car la mer déclare" et J2 : "car ainsi parle la mer", toutes deux considérant "la forteresse de la mer en disant" comme une glose et l'omettant à ce titre. 
Ajoutons enfin qu'au cas où Duhm aurait eu raison d'identifier ici une glose, cela constituerait un développement littéraire antérieur à la séparation des diverses traditions textuelles. Mais il est aussi possible que nous ayons là une reprise analogue à celle dont nous avons traité en 19,7, lieu où le *M était appuyé, rappelons-le, par les trois témoins de ce texte à Qumrân. On ne saurait exclure non plus l'hypothèse que "forteresse de la mer" soit ici un vocatif désignant Sidon.

Interprétation proposée :

Il semble préférable d'articuler ainsi la traduction: "Sois confuse, Sidon, car la mer a déclaré, la forteresse de la mer, disant :".

Mais il n'est pas impossible de comprendre l'incise en vocatif : "ô forteresse de la mer".

23,5 כאשֶׁ [A] M 1Q-a // expl : G V S T

26,9 כאשֶׁ [B] M 1Q-a S // expl : V T / constr : G

Options de nos traductions :

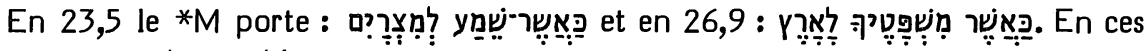
deux cas, un verbe semble manquer.

RSV traduit : "when the report comes to Egypt" et : "when thy judgments are in the earth"; J1 : "En apprenant ces nouvelles, les Egyptiens" et "Iorsque tes jugements paraissent sur terre" (J2 modifiant la traduction de 23,5 en : "L'apprenant, les Egyptiens"); RL : "Sobald es die Aegypter hören" et "wenn deine Gerichte über die Erde gehen"; J3: "Quand la nouvelle parviendra en Egypte" et "lorsque tu rends tes jugements pour la terre"; TOB : "Quand l'Egypte l'apprendra" et "Quand tes sentences s'exercent sur la terre".

Alors que toutes ces traductions ont explicité des verbes, Brockington indique que NEB a, en ces deux endroits, corrigé la vocalisation du $* M$ en "When the news is confirmed in Egypt" et : "when thy laws prevail in the land".

Origine de la correction :

C'est une conjecture que Driver (LTP 37 et 43) a d'abord formulée à propos d'Ts 1,17; 26,9. Il fait appel au sens araméen de cette racine verbale : "être fort". Ensuite, il a étendu cette conjecture (Ezekiel 300, n. 4) à six autres passages bibliques, avant que les traducteurs de NEB n'en fassent usage aussi pour 23,5.

Les témoins anciens :

En ces deux cas, $1 Q$-a appuie le $* M$.

En 23,5, 4Q-a, lacuneux pour le premier mot, appuie le *M pour les deux suivants.

En 23,5 les versions se sont contentées d'expliciter un verbe à la place du substan-

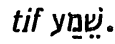

En 26,9 le*G semble avoir lu אin, ainsi que Michaelis (OEB XIVa 66) l'a noté en

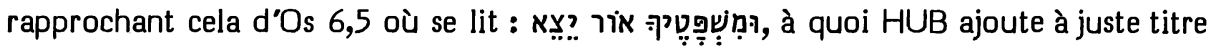




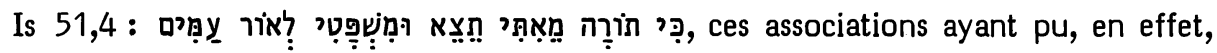
inspirer le traducteur qui a voulu offrir une prolongation à la nuit et à l'aurore qui précèdent en 9a. Le traducteur s'est laissé influencer par un thème de la théologie sapientielle: l'étude des commandements de Dieu éclaire la conduite de l'homme

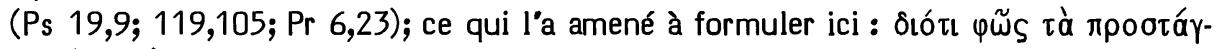

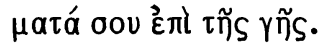

En 26,9 la *V et le *T ont explicité des verbes, alors que la *S a cru déceler une comparaison.

Choix textuel :

En 26,9 il ne s'agit pas (comme le *G l'a interprété) des commandements de Dieu, mais (cf, vs 8) de ses sentences, c'est-à-dire des verdicts de châtiment par lesquels il frappe les impies. Cela s'oppose à la grâce accordée à l'impie (vs 10).

Le comité a voulu préserver les tournures elliptiques du $* M$ en lui attribuant la note " $A$ " en 23,5 (où aucun témoin n'atteste autre chose) et la note " $B$ " en 26,9 (où il se peut que le ${ }^{*} G$ ait lu une autre Vorlage).

Interprétation proposée :

Selon Delitzsch, en ces deux cas (23,5 et 26,9), le verbe à sous-entendre après כאשר est suggéré par la préposition "lamed" qui suit : en 23,5: "dès que la nouvelle atteint l’Egypte" et en 26,9: "dès que tes sentences atteignent la terre".

23,10A עברי [C] M 4Q-c V S // err-graph : 1Q-a G עבדי / paraphr : T

23,10B כיאר [B] M 1Q-a 4Q-c V S T // abr-elus vel constr : G 23,10C מזח [B] M 1Q-a V // exeg : S T // constr : G

Options de nos traductions :

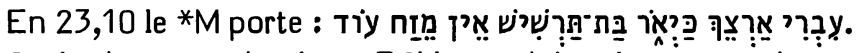

Seule de nos traductions, RSV a traduit cela sans corriger : "Overflow your land like the Nile, $O$ daughter of Tarshish; there is no restraint any more".

Toutes les autres traductions effectuent en ce vs une, deux ou trois corrections : J12: “Cultive la terre, fille de Tarsis, le port n'existe plus !"; RL : “Bebaue dein Land, du Tochter Tarsis! Denn es gibt keinen Hafen mehr"; NEB : "Take to the tillage of your fields, you people of Tarshish; for your market is lost"; TOB : "Cultive la terre comme le long du Nil, fille de Tarsis : il n'y a plus de port"; J3 : "Cultive ton pays comme le Nil, fille de Tarsis, car il n'y a plus de chantier maritime".

Toutes ces traductions lisent dans le premier mot $(=23,10 \mathrm{~A})$ un 'dalet' au lieu du 'resh'. Cette correction est appuyée sur le *G par J123 et NEB. Elle l'est sur 1Q-a par 33 et TOB; cette dernière prétendant qu'elle se fonde aussi sur "plusieurs versions".

J12, RL et NEB omettent le troisième mot $(=23,10 \mathrm{~B})$. Cette omission est appuyée sur le *G par $J 12$ et NEB.

$\mathrm{J12}$ et NEB lisent inṇ à la place du septième mot $(=23,10 \mathrm{C})$. J2 appuie cette correction sur le ${ }^{*} \mathrm{G}$, alors que $\mathrm{J1}$ et NEB la présentent comme une conjecture. La 
leçon ainsi choisie est traduite "port" par J12 et "market" par NEB; alors que TOB traduit "port" en disant tirer ce sens du *M et en précisant que "le mot traduit par 'port' signifie 'ceinture' (cf. Ps 109,19). Les deux ports de Tyr, au nord et au sud, pouvaient apparaître comme la ceinture de la ville".

\section{Origines des corrections :}

23,10A : Nos traductions ont pu trouver cette correction requise par les apparats de $\mathrm{BH} 235$ et Cent. Elle a été proposée par Michaelis. Celui-ci traduit : "Baue dein Land" en se fondant sur le *G et en expliquant (OEB) : "La riche ville marchande doit maintenant devenir une ville terrienne et se nourrir en cultivant les champs. Que l'on transpose cette scène à Hambourg où à Amsterdam et l'on sentira la transformation que cela impliquerait." Il estime que cette leçon est "remarquablement frappante" et l'adopte donc. Il a été suivie en cela par Bredenkamp et Grätz, avant que son insertion dans l'apparat de Kittel n'en assure la large diffusion.

23,10B : Cette omission a été proposée par les apparats de $\mathrm{BH} 235$ et Cent. Elle remonte à Duhm, estimant que "mit dem Nil ist erst recht nichts anzufangen". Notons pourtant que d'autres exégètes (Michaelis en OEB, Bredenkamp, Dillmann/Kittel

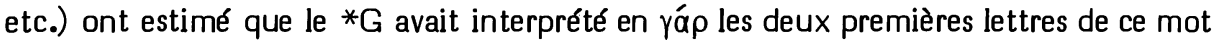
pour construire un début de phrase.

23,10C : Cette correction a été proposée par les apparats de HSAT34, BH23 et Cent. Ayant déjà fait appel (à propos de 23,2 et $3 A$ ) au Ps 107,23, c'est au vs 30 du même Psaume que Duhm a emprunté cette conjecture. KBL a proposé, en s'inspirant de l'égyptien, de comprendre la leçon du *M comme "chantier de construction de navires". Cela explique que $\mathrm{J3}$ et BHS aient renoncé à la correction à laquelle $\mathrm{J} 2$ et $\mathrm{BH} 3$ demeuraient encore attachés. HALAT hésite entre cette interprétation et la conjecture de Duhm.

Les témoins anciens :

Pour 23,10A, 1Q-a lit la leçon avec 'dalet' que l'on attribuait (depuis Michaelis) comme Vorlage au ${ }^{*} G$. Pour les deux autres leçons, $1 Q$-a appuie le $* M$ (avec une graphie pleine en 23,10B).

4Q-c nous est préservé pour les trois premiers mots du vs. Un large espace qui suit le premier mot semble rattacher celui-ci au vs 9. Ce mot est écrit עבורי, ce qui indique qu'il a bien été lu comme un impératif, avec la vocalisation pausale que le $* M$ lui donnera au vs 12 (sous un zaqef qațon). Pour 23,10B, Morrow (74) a lu en $4 Q-c$ une graphie pleine. La graphie défective $(=* M)$ est cependant presque certaine, car une seule jambe verticale est préservée entre 'alef' et la lacune. Au sommet de cette jambe commence un trait presque horizontal tout à fait semblable à celui qui constitue le sommet des 'resh' de cette écriture (alors que les nez des 'waw' sont bien plus inclinés).

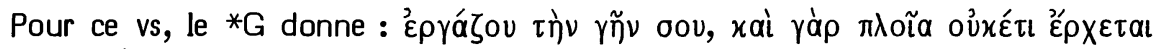

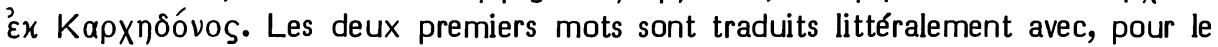
premier, une Vorlage où le 'resh' a été lu en 'dalet'. Cette lecture 'agricole' rend inutilisable le 3e mot. C'est pourquoi, à la place de la suite du vs (où le *M était fermement appuyé par $1 \mathrm{Q}-\mathrm{a})$, le ${ }^{*} \mathrm{G}$ offre une belle phrase qui n'a guère de rapport avec le 
*M. Ziegler (Untersuchungen 144) a raison de suggérer que, pour expliciter ce passage

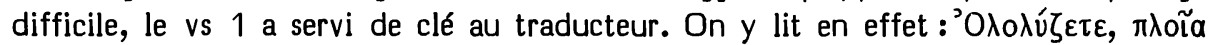

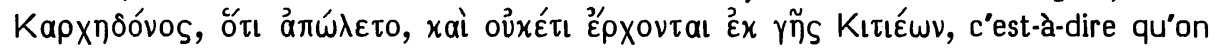
y lit tous les éléments qui se retrouvent, autrement organisés, en notre phrase du vs 10.

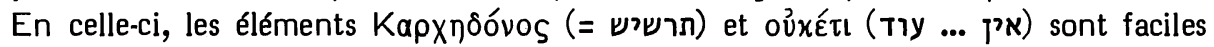
à repérer. Van der Kooij (Commentary 40) estime que l'interprétation qui est à la base de la traduction très libre constituant dans le ${ }^{*} G$ la deuxième phrase de Is 23,10 est : "car la fille de Tarsis (c.-à-d. Carthage) n'est plus un port"; ce qui supposerait, en $23,10 \mathrm{C}$, non pas une variante, mais une métathèse interprétative du 'zaïn' et du 'het'.

La $* V$ traduit assez littéralement le * $M$ : "transi terram tuam quasi flumen filia maris non est cingulum ultra tibi". Hie (livre $V$ ) confirme en effet que c'est THARSIS qui correspond à "maris" (à propos du vs 1 ) et que c'est IOR qui correspond à "flumen".

Michaelis (OEB) a suggéré que la *S a dû rattacher $23,10 \mathrm{C}$ à la racine arabe זٓ de la ${ }^{*} S$ de celle du ${ }^{*} T$, estime que l'on a seulement là une traduction large du ${ }^{*} M$ pour en expliquer le sens.

Le *T a, en effet, paraphrasé 10a: "émigre de ton pays comme les eaux du fleuve". Puis il traduit "fille de Tarsis" (en usant de la même clé que Hie pour ce toponyme): "fuis vers la province de la mer". Et il donne pour les trois derniers

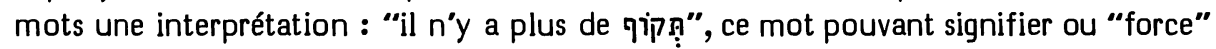
ou "forteresse".

\section{Choix textuel :}

En $23,10 \mathrm{~B}$ et $23,10 \mathrm{C}$, le comité n'est pas arrivé à la conviction que les témoins anciens ont disposé d'une Vorlage distincte du ${ }^{*} M$, aussi a-t-il attribué à celui-ci la note "B".

En $23,10 \mathrm{~A}$, l'accord de $1 \mathrm{Q}-\mathrm{a}$ avec le ${ }^{*} \mathrm{G}$ atteste l'existence de la variante avec 'dalet' au lieu du 'resh'. Ces deux leçons ne diffèrent que par une confusion faite par un copiste. S'il s'agit de décider laquelle de ces deux leçons a le plus de chances d'être

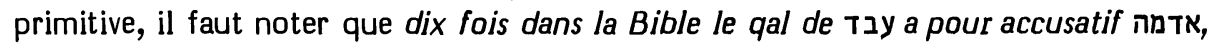
alors qu'il semble n'avoir jamais en cette fonction ארץ (עבר avec l'accusatif, ce verbe signifie normalement "traverser la mer" (cf. Is 23,2) ou "traverser un fleuve" (2 S 19,40s). Ce même verbe avec l'accusatif désignant un pays est employé en Is 33,21 à propos de la domination de ce pays (comparé à un delta aux larges bras) par un empire étranger comparé à un grand navire. Ailleurs (Is 8,8), ce verbe signifie "inonder", ce qui est recouvert par l'inondation pouvant être à l'accusatif ( $P s$ 38,5). Ajoutons qu'une interprétation des deux premiers mots comme "cultive ton pays" convient beaucoup moins bien à "comme le Nil" que "inonde ton pays" ou "traverse ton pays". C'est pourquoi le ${ }^{*} G$ n'a pas traduit ce terme de comparaison et J12, RL, NEB l'ont omis.

Le comité a donc estimé préférable de conserver en 23,10A le verbe du *M en l'un des sens susdits et il a attribué à cette leçon 4 "C" et 1 " $\mathrm{B}$ ". 
Interprétation proposée :

L'interprétation de ce verset dépendra beaucoup du sens que l'on attribuera à nIn $(23,10 \mathrm{C})$. Il semble qu'il s'agisse là d'une ceinture que l'on portait de façon permanente, à même le corps (Ps 109,19). Jb 12,21 parle du " "מִַ des forts". En effet, dans la Bible, la ceinture évoque la force, ce qui a inspiré ici la périphrase du *T (qui a d'ailleurs été suivi par Pagnini, Vatable, Münster, Olivetan, Rollet, Châteillon, Ge, $\mathrm{KJ}$ et F oreiro).

Ici l'image semble être celle de la ceinture-corset (משTّ"ה selon l'interprétation arabe que Yéfet ben Ely rapporte ici comme traditionnelle) qui retient le ventre et l'empêche de s'affaisser. De même, les eaux du fleuve, aussi longtemps qu'elles sont retenues par la digue, ne peuvent inonder le pays. Mais lorsqu'elles ne sont plus endiguées, elles s'épandent librement.

Le sens serait alors: "Répands-toi dans ton pays comme le Nil, fille Tarsis, il n'y a plus de digue."

Koppe et Gesenius semblent avoir raison de considérer ici la ceinture-digue comme désignant l'autorité tyrienne qui ne laissait pas à ses colonies une liberté commerciale à laquelle elles aspiraient. C'est ce qui ressort assez clairement du fragment des archives tyriennes concernant l'époque assyrienne que Josèphe (Ant IX \$§283-287) cite à travers Ménandre d’Ephèse.

Il n'est cependant pas impossible de comprendre, avec Luzzatto, la "ceinture" comme un pagne porté à même le corps dans le but de couvrir la nudité. Il s'agirait en ce cas du départ des captifs nus : "traverse ton pays, comme on traverse un fleuve, fille Tarsis, plus même un pagne".

Mais, de même que "fille Sion" désigne d'ordinaire Jérusalem, "fille Tarsis" doit désigner ici la ville de Tarsis et on ne voit pas comment la dévastation de la Phénicie entraînerait la déportation des habitants de ses colonies les plus lointaines (Tarsis évoquant le bout du monde en Jon 1,3). Il faut donc préférer l'interprétation de Koppe et de Gesenius.

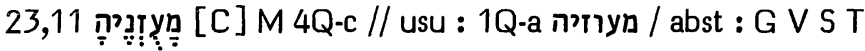

Options de nos traductions :

La plupart d'entre elles entendent traduire le *M : RSV : "its strongholds", J et TOB : "ses forteresses", RL : "seine Bollwerke".

Brockington indique que NEB, en traduisant "the marts of (Canaan)", corrige la vocalisation en

Origine de la correction :

NEB suit en cela une suggestion de Driver (TLP 49) qui entend tirer ce sens : "lieu où la marchandise est distribuée" de l'arabe "ac zana' qui signifierait "partagea, distribua".

Les témoins anciens :

1Q-a porte ici מעוזיה. 
4Q-c, lacuneux, a préservé la base du 'zaïn', puis les trois dernières lettres de la leçon du *M.

Les versions ont traduit au sens de "force" (le *G et le *T) ou de "forts" (la *V et la $*$ S), sans que l'on puisse savoir si elles ont lu une graphie avec ou sans 'nun'.

\section{Choix textuel :}

Les bases sur lesquelles construit Driver sont fragiles. Il ne s'agit là en effet que

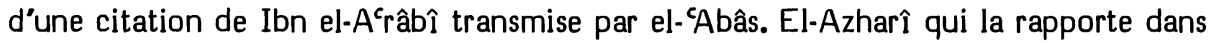
son Tahdhib (II 138) estime que, dans ce cas, le 'nun' a supplanté un 'lam'. On voit donc la grande imprudence qu'il y aurait à vouloir inférer l'existence d'une racine hébraïque à partir d'une exception phonétique arabe. Aussi faut-il regretter que GNB ait introduit dans son texte des "centers of commerce" fondés sur cette hypothèse improbable.

Saadya traduisait ici "ses villes fortes". En effet, les exégètes judéoarabes Yéfet ben Ely, Judah ibn Balaam et Abulwalid (Luma 76,14-26) s'accordent pour considérer le "nun" ici comme excédentaire, les deux derniers estimant que son ajoute tient la place d'un dagesh forte. König (Lehrgebäude II 473) admet la réalité de ce processus de dissimilation progressive des géminées qu'il estime prouvé en arabe et en grec. Mais il doute que les quelques cas que l'on en cite en hébreu suffisent à montrer son existence en cette langue. Les grammairiens plus récents (Gesenius/Kautzsch $\$ 200$, Lambert 43, n.2, Bauer/Leander 564, Bergsträsser I $\$ 20$, n. b.), considérant ces cas comme trop isolés, y voient des fautes textuelles.

Böttcher avait dérivé ce mot d’un singulier ș̣̂y semblable à ạ et traduit : "ses petites villes fortes". Eitan (Contribution 70) a voulu voir ici le reste d'un pluriel archaïque pour lequel il cite divers parallèles bibliques. Kutscher (445) suggère plus précisément que le 'nun' peut vouloir représenter ici une caractéristique de la désinence du pluriel en phénicien, le prophète voulant peut-être imiter la façon de parler des Tyriens. Talmon (Aspects 124) préfère voir ici une intercontamination entre la leçon de 1Q-a et une leçon מעוניה non attestée ici. Il souligne à juste titre les glissements textuels entre מעוך comme épithète de Dieu en des textes parallèles. HALAT (577) retient cette explication.

Considérant qu'il ne s'agit ici vraisemblablement, dans la leçon de 1Q-a, que d'une variante orthographique et que le 'nun' excédentaire du *M est aussi attesté par 4Q-c, le comité a voté par 4 " $C$ " et 1 " $B$ " en faveur du * $M$.

Interprétation proposée :

La vocalisation suggère une équivalence avec tique confirme cela.

On traduira donc : "ses forteresses".

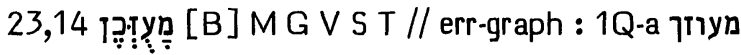

\section{Options de nos traductions :}

La plupart d'entre elles s'accordent pour donner ici à ce mot son sens ordinaire : RSV : "your stronghold", J et TOB : "votre forteresse", RL : "euer Bollwerk". 
Brockington nous précise que NEB fonde sa traduction "your haven" sur une correction vocalique en :

Origine de la correction :

NEB se fonde vraisemblablement sur Eitan (Contribution 70) qui distingue un riỵn (= refuge), dérivé de עy, de celui qui signifie "forteresse" et est dérivé de זry. Il conclut qu'en ce chapitre on peut traduire ce mot par "harbor".

Les témoins anciens :

1Q-a offre ici מעוז que Kutscher (398) considère comme inexplicable. Il se demande si un 'mem' n'a pas été gratté après le 'kaf'.

Les versions traduisent "votre force" ou "votre forteresse" montrant qu'elles ont vocalisé ce mot comme elles le font d'ordinaire et qu'elles y ont lu un suffixe de la 2 e pers. pl.

Choix textuel :

HALAT (577) estime que les deux riỵ̣ ont été confondus en hébreu biblique et sont difficiles à distinguer sémantiquement. La correction vocalique suggérée par Brockington semble donc superflue.

Quant à la leçon de 1Q-a, c'est elle qu'il faudrait adopter ici si l'on appliquait le critère de la lectio difficilior de façon absolue. Pourtant, du fait de l'isolement total de ce témoin, le comité a préféré garder la leçon du *M par 4 " $\mathrm{B}$ " et 1 "C".

Interprétation proposée :

Pour qu'il offre non seulement un refuge contre les tempêtes mais un lieu sûr en cas d'invasion, un port doit être fortifié. C'est donc au niveau de l'analyse de la signification et pas seulement au niveau de la vocalisation que l'on peut constater une étroite coalescence des valeurs "forteresse" et "port". Si l'on traduit par "refuge" (avec Koenig et BFC), on exprime ces deux valeurs.

24,4A אמללו מרום [C] M T // harm : G pl, 1Q-a 4Q-c V S sg

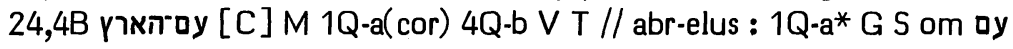

Options de nos traductions :

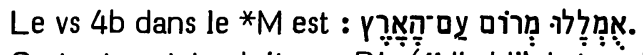

Ce texte est traduit par RL ("die Höchsten des Volks auf Erden verschmachten") et par J3 ("l'élite du peuple de la terre s"étiole") qui se contentent d'harmoniser (en deux sens opposés) le nombre du verbe initial avec celui du substantif qui le suit.

RSV ("the heavens languish together with the earth", sans note), J12 ("le ciel avec la terre dépérit") et TOB ("avec la terre dépérissent les hauteurs") vocalisent (selon J2) )

Selon Brockington, NEB lit מְ̣ avec le *G à la place de ces deux mots. Elle traduit : "the earth's high places sicken". 
Origines des corrections :

RSV, J12, TOB ont pu trouver la conjecture qu'ils adoptent proposée par les apparats de HSAT34, BH23S et Cent. C'est Michaelis (OEB) qui a estimé inacceptable le *M tel qu'il est vocalisé : "le haut (c'est-à-dire : l'élite) du peuple du pays". Il objecte que l'expression yo signifie ailleurs "la populace", en contradistinction avec "l"élite". Il estime donc qu"on ne peut parler de "l'élite de la populace". Aussi suggère-t-il que l'on peut vocaliser le premier mot avec hireq au sens de "avec".

La correction de NEB à partir du ${ }^{*} G$ a d'abord été proposée par Grätz, puis reprise par Procksch.

\section{Les témoins anciens :}

$4 Q-c$ ne se distingue du $* M$ que par la mise du verbe initial au singulier.

$1 Q$-a atteste aussi cette variante et $y$ ajoute une omission de ay par sa première main. Ce mot est omis aussi par le ms Kenn. 72 (fin du XIVe s., accompagné d'une traduction latine) dont le témoignage isolé n'aurait aucun poids.

La Vorlage de la $* S$ correspond à cette $1 \mathrm{e}$ main de $1 \mathrm{Q}$-a.

Le ${ }^{*} G$, lui aussi, omet 口y; mais, ayant le verbe initial au pluriel, il traduit le mot suivant par un pluriel : oi vi $\psi \eta \lambda$ oí.

La *V (infirmata est altitudo populi terrae) a une Vorlage analogue à 4Q-c.

Le ${ }^{*} T$ appuie le ${ }^{*} M$ en sa discordance du nombre du verbe initial avec celui du substantif qui le suit.

\section{Choix textuel :}

On voit que le ${ }^{*} M(=* T)$, avec le verbe initial au pluriel et le mot suivant au singulier, offre une lectio difficilior à partir de laquelle les autres témoins ont bifurqué vers des harmonisations en sens opposés. Le ${ }^{*} G$ a mis les deux mots au pluriel, alors qu'ils ont été mis tous deux au singulier par 1Q-a, 4Q-c, la *V et la *S.

Quant à la présence de $\square y$, elle est attestée par le *M, 4Q-b, la 2e main de 1Q-a, la $* V$ et le ${ }^{*}$ T; ce mot étant omis par la 1 e main de $1 Q-a$, le ${ }^{*} G$ et la ${ }^{*}$. Ceux de ces témoins qui, ayant ce mot, le vocalisent ou le traduisent lui reconnaissent le sens de "peuple".

Contre la vocalisation conjecturale de ce mot par hireq (= avec) proposée par

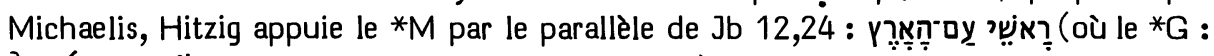

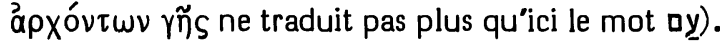

Dillmann/Kittel note en $4 a$ le parallélisme entre תרץ et en montrant que le

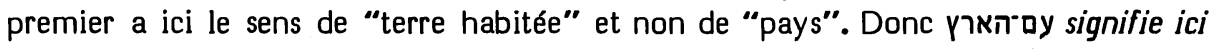
"la population du monde", sens qui s'impose aussi en Is 42,5 : לעם (où le suffixe féminin renvoie à הארץ mentionné dans le stique précédent). Delitzsch ajoute à cela que l'on retrouve הy désignant l'humanité en Is 40,7.

La valeur pejorative de "peuple non éduqué dans la Torah" pour yate date du retour de l'exil, moment où les déportés, en revenant, trouvent dans le pays une population formée de Judéens restés sur place après 586 et d'immigrés non-juifs, population qu'ils considèrent comme impure. On comprend donc qu'après que cette expression ait été spécialisée en ce sens, le copiste de 1Q-a ou le traducteur grec (dont la *S dépend en ce domaine) l'ont estimée inacceptable dans le contexte d'Is 24,4. 
Commettant le même anachronisme, Michaelis et les modernes jugeront cette leçon inadmissible parce qu'ils la liront eux aussi dans l'optique de l'état de la Judée au retour de l'exil, optique qui n'est pas celle dans laquelle les livres d'Isaïe ou de Job situent cette expression. Dans le contexte où nous sommes, ce serait plutôt qui aurait une valeur péjorative de ce type (cf. Jr 47,2; Ez 7,7) ou éventuellement

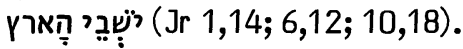

Ici, le substantif abstrait מרום tient la place de "les gens haut placés". Le fait que le verbe précédent soit au pluriel vise à préparer cette valeur de collectif concret.

Trois membres du comité ont donc opté pour la lectio difficilior du $* M$ et lui ont attribué la note " $C$ " en l'estimant parfaitement justifiable. Deux autres membres ont cependant préféré la leçon plus sobre et claire de la première main de 1Q-a (אמלל מרום הארץ) au sens de "les hauteurs de la terre s"étiolent".

Interprétation proposée :

La leçon du *M, retenue par la majorité du comité, peut se traduire : “Ceux qui constituent l'élite de la population du monde s'étiolent."

24,16A רזי־לי רזי-[B] M 1Q-a ThSym V // midr : T / abr-elus: G om / lic: S

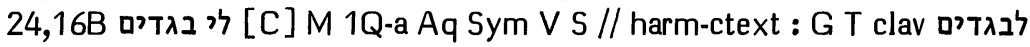

\section{Options de nos traductions :}

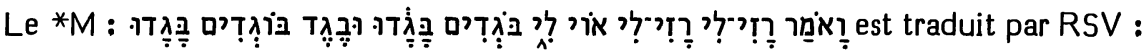
"But I say, 'I pine away, I pine away. Woe is me ! For the treacherous deal treacherously, the treacherous deal very treacherously"."; par RL : "Aber ich muss sagen : 'Wie bin ich so elend! Wie bin ich so elend! Weh mir! Denn es rauben die Räuber, ja, immerfort rauben die Räuber'."; J3: “Mais j’ai dit : ‘Quelle épreuve pour moi! quelle épreuve pour moi! malheur à moi !' Les traîtres ont trahi, les traîtres ont tramé la trahison!"”; TOB : "Mais je dis : Je suis à bout, je suis à bout! Malheur à moi ! Les traîtres ont trahi. Trahison ! Les traîtres ont trahi."

J12 traduisaient: "Mais je dis : 'Assez! assez! Malheur à ces violents qui font violence, à ces violents qui font violemment violence!" ", J2 précisant que cela sup-

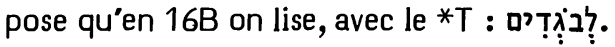

NEB traduit: "But I thought, Villainy, villainy! Woe to the traitors and their treachery! Traitors double-dyed they are indeed!" Brockington précise qu'en 16A

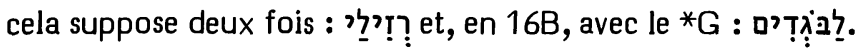

\section{Origines des corrections :}

Pour 16A, NEB suit une conjecture de Rabin (Miscellanea 387, n. 13) qui suggère de lire en un seul mot רזילי analogue à l'arabe 'radhîl, radhl' (= ignoble, méchant) et de traduire : "Oh méchanceté, oh méchanceté", en considérant le "yod' final comme un suffixe exclamatif.

Pour 16B, J12 ont adopté une variante donnée, à titre informatif, par BH3; alors que NEB suit une proposition de Grätz, Procksch, Kaiser et de BHS. 
Les témoins anciens :

1Q-a ne se distingue du *M que par le fait qu'il écrit plene le premier בגדים.

Le ${ }^{*} M$ a d'ailleurs conscience de l’originalité de sa graphie défective précédant une graphie pleine, puisqu'une $\mathrm{mp}$ (dont la $\mathrm{mm}$ figure ici dans la massore éditée) précise que ce mot (précédé ou non d'un 'waw') n'est écrit plene qu'en cinq endroits : Ha 1,13; Ps 25,3; Pr 2,22; 23,28 et le second emploi de ce mot en ce verset-ci.

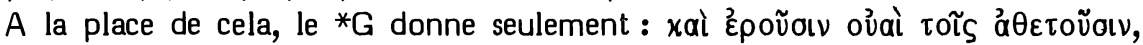

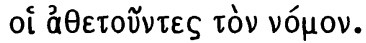

Th, Aq et Sym, là où ils nous sont connus, confirment le *M, sauf pour le premier mot où ils donnent bien un singulier mais gardent la 3e pers. du ${ }^{*} G$ (ThAq : xaì ह̉ par Eusèbe à Sym comme répété, et à Th, sans le répéter, par Hie et Syh qui unit les

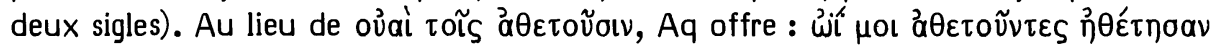

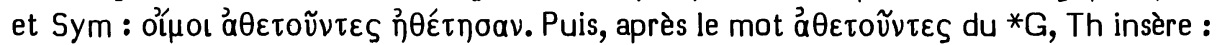
xà à $a \varepsilon \varepsilon \sigma^{\prime} \alpha \nu$ ả $\theta \varepsilon \tau o u ́ v \tau \omega \nu$.

La $* V$ traduit: "et dixi secretum meum mihi secretum meum mihi vae mihi / praevaricantes praevaricati sunt / et praevaricatione transgressorum praevaricati sunt." Bien que Jérôme n'ait pas eu le courage de répéter cinq fois de suite la même racine, c'est une traduction fidèle du *M.

$\mathrm{La}{ }^{*} \mathrm{~S}$, comme les traductions hexaplaires, traduit le premier mot par une $3 \mathrm{e}$ pers. sg. (דאמר). Pour le reste, elle est fidèle au *M dont elle allège la traduction en n'explicitant pas les deux pronoms suffixes affectant le mot "secret" qu'elle a cru lire ici.

Le *T semble avoir lu pour $16 \mathrm{~B}$ la même Vorlage que Brockington attribue au *G. A part cela, il offre une traduction midrashique de la partie qui précède l'atnaḥ (“le prophète a dit : le secret de la récompense des justes m'a été montré, le secret du châtiment des impies m'a été montré"), alors que la fin est traduite en conformité avec cette dernière phrase: "malheur à ceux qui font violence, car ils subiront la violence, et au pillage des pillards, car voici qu'ils seront pillés."

\section{Choix textuel :}

Le fait que les préoccupations des massorètes se concentrent ici sur une graphie défective à préserver confirme la stabilité du texte hébreu que 1Q-a nous atteste de façon caractéristique. Le *M est aussi fermement attesté par la $* V$ et, pour l'essentiel, par Th Aq Sym et la *S.

Il présente cependant quelques difficultés : Si l'on interprète avec Th, Sym, la *V , la *S (et le *T, sous sa paraphrase) l'expression רזי־ au sens de : "mon secret est à moi", il est difficile que le prophète puisse attribuer ces deux pronoms de la 1e pers. à un mystère révélé à lui par Dieu. Mais si la 1e pers. a pour sujet Dieu, on voit mal que Dieu puisse dire (juste après) : "malheur à moi !" Or il est difficilement admissible que les trois "à moi" qui se suivent ne désignent pas la même personne.

En face de ces difficultés, le ${ }^{*} G$ offre presque trop de solutions. On peut être tenté en effet de s'appuyer sur lui ou bien pour remplacer לִ בי בגדים par ou bien pour ajouter à cela (avec Liebmann, Condamin, Gray) l'omission des deux רזי לי לי לי לי Chacune de ces deux corrections suffirait... et le ${ }^{*} G$ nous les suggère toutes deux à 
la fois (étant appuyé par le *T pour la première). Mais il est plus inquiétant qu’à la place des quatre derniers emplois juxtaposés de la racine בבגד, il ait seulement : of

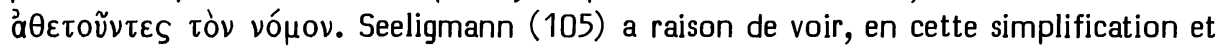
cette mention de la Loi, un indice des conceptions religieuses personnelles du traducteur.

En contraste avec la fermeté des témoins qui entourent le ${ }^{*} \mathrm{M}$, le ${ }^{*} G$ apparaît comme ayant fait oeuvre littéraire créatrice, en omettant ou retouchant ce qui lui faisait difficulté, c'est-à-dire l'entrée en scène d'une première personne qu'il avait peine à identifier, et la juxtaposition de cinq emplois d'une même racine qu'il ne savait comment articuler entre eux.

En $16 A$ où nous n'avons affaire qu'à une omission par le *G ou à une retouche conjecturale, le comité a attribué à la leçon du *M la note " $B$ ".

En 16B où le *T s'associe au *G pour ce qui semble être une retouche harmonisant avec leur exégèse de ce qui précède, un membre du comité a attribué au ${ }^{*} \mathrm{M}$ la note " $B$ ". Trois autres lui ont attribué la note " $C$ " et un autre a voté " $C$ " pour la variante du ${ }^{*} \mathrm{G}$ et du ${ }^{*} \mathrm{~T}$.

Interprétations proposées :

Gesenius/Buhl, Gray, Ehrlich ont estimé que la vocalisation ירִ entendait rattacher

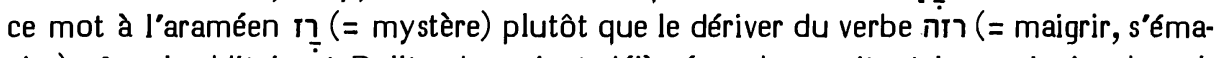
cier). A cela, Hitzig èt Delitzsch avaient déjà répondu en citant les analogies de

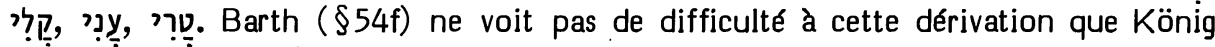
(Lèhrgebäude II 134) estime normale.

De fait, il semble que Saadya ait été le premier à proposer cette interprétation "maigreur" adoptée ensuite par Judah ibn Balaam, Ibn Ezra, Radaq (qui justifie l’accentuation mileél par le fait qu'un monosyllabe suit), Oecolampade, Luther, Prédjcants, Zwingli, Pellican, Jud, Olivetan, Brucioli (1540), Châteillon, Ge, Tremellius, Pasteurs, KJ.

Le sens "secret", attesté par toutes les versions anciennes, l'est aussi par le Talmud de Babylone (Sanhedrin 94a), Yéfet ben Ely, David ben Abraham (I 189,14-17 et II 600,8s), Abulwalid (Ușul 674,9-12), Rashi, glossaires ABCDEF, Joseph Qimḥi selon Radaq (en Shorashim), Pagnini, Brucioli (1532), Münster, Rollet.

Entre ces deux sens, Vatable hésite. Calvin estime que l'exégèse "secret" peut s'étendre à tout ce qui est intime et propose donc en son commentaire : "intestina mea". Estienne suit cette suggestion en traduisant : "mes entrailles, mes entrailles".

Le mot nר (= secret) a été emprunté au persan par l'araméen, puis par l'hébreu (attesté dans le Siracide et à Qumrân). On comprend qu'il se soit tout naturellement présenté à l'esprit du traducteur araméen d'Isaïe et, sous son influence, à Jérôme et à de nombreux exégètes juifs médiévaux. Encore récemment, Niehaus (Raz) a suggéré que l'analogie qu'offre Is 24,17s avec Dn 5,25-28 est un solide argument pour choisir ici cette interprétation.

Pourtant, un certain nombre d'arguments rendent plus vraisemblable ici un substantif dérivé de רזי D'abord, le fait que cette racine est clairement attestée en Isaïe $(10,16 ; 17,4)$. Puis, le fait que le lien contextuel cré par la place de l'atnah suggère une expression de même tonalité que "malheur à moi !" qui suit. Ensuite, le fait 
qu'il s'agit d'introduire par là la constatation désespérante exprimée en 16b. Enfin, le fait que l'on obtient ainsi une bonne antithèse (introduite par "mais je dis") à l'acclamation qui précède immédiatement : צִבְי לֵַַּדּיק.

Si l'on adopte, pour ces motifs, cette interprétation, on attribuera au prophète la $1 e$ pers. qui s'exprime en ce vs et le texte ne présentera plus de difficultés notables. L'autre interprétation a cependant un enracinement traditionnel suffisamment ferme pour qu'elle mérite d'être mentionnée en note.

\section{5,2 זרים [B] M 1Q-a 1Q-b(?) V S // exeg vel err-graph : G / paraphr : T}

\section{Options de nos traductions :}

L'expression ארֵרמוֹן זְרִים est traduite par RSV : "the palace of aliens", par RL : "die Paläste der Fremden", par J3: "la citadelle des étrangers" et par TOB : "la forteresse des barbares".

$\mathrm{J12}$ avaient traduit sans note : "la citadelle des orgueilleux", traduction empruntée à Cent qui spécifiait que cela supposait qu'on lise

NEB donne ici : "every mansion in the cities (= רמיר) is swept away", Brockington précisant que cela suppose une vocalisation conjecturale : זִ

\section{Origines des corrections :}

La correction retenue par Cent et 312 avait été proposée par Houbigant, puis requise par l'apparat de HSAT34 et signalée à titre informatif par celui de BH235.

La vocalisation conjecturale de NEB s'inspire probablement d'une suggestion de Driver (Notes 44). Celui-ci, estimant qu'un verbe est requis ici, lisait 'zôram', forme passive de 'zâram', verbe qui signifierait "emporter". De cette racine dériverait 'zèrèm' ( $=$ averse) dont le sens serait en réalité : "une pluie qui balaye tout devant elle". NEB a retenu cette suggestion en préférant vocaliser en participe passif.

\section{Les témoins anciens :}

A la suite de Lowth, Kennicott signale $2 \mathrm{mss}$ du $* M$ comme ayant ici la leçon avec 'dalet'. Cependant, pour éviter une confusion facile entre ces deux mots, la massore (Okhla de Halle, 2e partie, \$174) précise que Is 13,11; MI 3,15.19; Ps 86, 14 ainsi que dans le Ps 119.

Alors que $1 \mathrm{Q}$-a appuie le ${ }^{*} \mathrm{M}$, on peut, dans la lecture de $1 \mathrm{Q}-\mathrm{b}$, hésiter entre un 'yod' et un 'waw' (ainsi que c'est fréquemment le cas en ce ms).

Le *G donne ici : $\tau \tilde{\omega} \nu$ ảos $\beta \tilde{\omega} \nu$.

La *V (alienorum) et la *S (דנוכריא) traduisent le *M que le *T paraphrase par

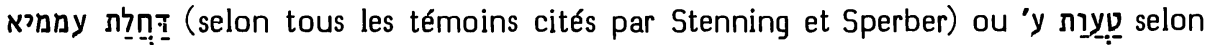
le ms Urbinates 1, c'est-à-dire "le culte idolâtre des peuples".

\section{Choix textuel :}

Emerton (Problem 68-70) a clairement montré la faiblesse des bases linguistiques sur lesquelles repose la suggestion de Driver. 
Lowth, ayant trouvé deux mss du *M pour attester ici la leçon avec 'dalet', a estimé que le ${ }^{*} G$ l'avait eue pour Vorlage ici et en 25,5. En effet, c'est bien la racine

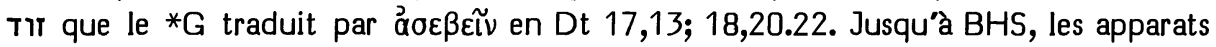
critiques ont donc continué à fonder cette leçon sur le $* G$ et de nombreux critiques, jusqu’à Wildberger, ont adopté cette correction. Notons cependant que le ${ }^{*} G$ d'Isaïe a ảoeßńs là où le *M a ר̣, non seulement en 25,2 et 5 , mais aussi en 29,5. Mais il $n$ 'est pas nécessaire d'admettre que le traducteur avait une autre Vorlage. En effet, le mot זרים (cf. Is 25,3.5; 29,5). En Ps 54,5 et 86,14, il se partage avec aי̣ le rôle de parallèle de ce mot. Cela ajoute au concept assez neutre d'étranger une connotation de violence. D'ailleurs, il est caractéristique qu'en Isaïe le traducteur grec rend aussi ז̣ par ămı otos en 17,10; l'infidélité étant pour lui une notion proche de celle d'irreligion.

Que זרים soit bien en place ici et au vs 5, cela est confirmé par l'assonance ainsi créée avec les deux emplois de 'zèrèm' au vs 4 et celui de 'zemîr' au vs 5.

Aussi le comité a-t-il attribué la note " $B$ " à la leçon du *M.

Interprétation proposée :

Comme TOB l'a fait et comme nous l'avons suggéré en 1,7, nous suggérons de traduire en faisant ressortir la valeur de violence et celle de méconnaissance des traditions religieuses et culturelles d'Israël que la notion d"étrangers" implique. En français, le mot "barbare" dit bien cela.

\section{5,4 קיר [A] M V S T // lic : G}

\section{Options de nos traductions :}

Le vs $4 a$ vient de déclarer : "Car tu as été un refuge pour le faible, un refuge pour le pauvre en sa détresse." 4b commence par ajouter à cela : “... un abri contre le

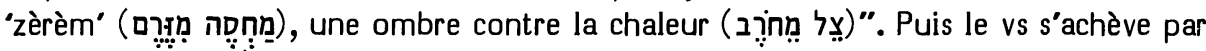
une explication (qui, selon l'opinion de Foreiro et de presque tous les exégètes ré-

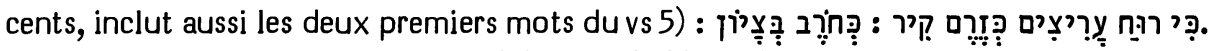

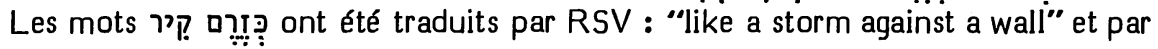
TOB : "comme l'orage contre une muraille".

J dit conjecturer ip et traduit : "comme la pluie d"hiver". Traduisent de même, mais sans note textuelle : RL ("wie ein Unwetter im Winter") et NEB ("like an icy storm").

\section{Origine de la correction :}

L'expression קִירֶ, au sens de "un 'zèrèm' frappant un mur" a paru à Cappel (Notae 510) très difficile à admettre; aussi a-t-il proposé de donner ici à ריר le sens de "froidure, hiver", en le dérivant de קרִ "très forte douleur' dérive de צר "lier'." Lowth propose ou bien de suivre Cappel en cette dérivation "de même que עריר dérive de ערור en bans sa traduction allemande, Michaelis a suivi cette suggestion, puis (Supplementa 2190), n'ayant trouvé aucun témoin en faveur de ip, il est revenu au *M, suggérant d’interpréter ce mot à partir 
de l'arabe qîr (= goudron, poix) et voyant là une allusion à la pluie de bitume brâlant qui détruisit Sodome.

Corrigent en קi : Knobel, Bredenkamp, Duhm, Dillmann/Kittel, Marti, Oort, Liebmann, Condamin, Feldmann, Procksch, Fohrer, Wildberger. Cette correction est requise par les apparats de HSAT34, BH23S et Cent. Contre cette conjecture, Halévy note que ip signifie le froid intense, mais non la saison hivernale.

Les témoins anciens :

Carmignac (Passages 42) dit lire "plutôt un 'waw" " pour ce mot en 1Q-a. Il est apparu au comité qu'en ce ms (comme en 1Q-b) on lit clairement un 'yod'.

En refusant les dérivations par lesquelles Cappel et Lowth veulent appuyer leur exégèse, Rosenmüller a fait remarquer que le témoignage des versions anciennes et des exégètes antérieurs à Cappel est unanime en faveur de l'interprétation "mur".

Rien dans le ${ }^{*} G$ ne peut être identifié comme correspondant à ce mot. Liebmann, Ziegler (Untersuchungen 82) et HUB interprètent de façon très différente les intentions du traducteur. Il semble avoir construit très librement (ainsi que Coste, 44, le suggère) et ne saurait donc servir de témoin pour critiquer le *M.

Choix textuel :

En face de la conjecture ip, le comité a constaté l'unanimité de ceux des témoins dont on peut reconstituer la Vorlage. Aussi a-t-il attribué au *M 3 " $A$ " et 2 " $B$ ".

Interprétation proposée :

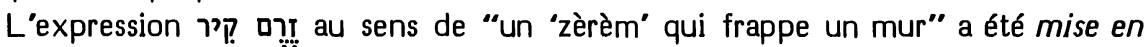
relation par Delitzsch avec Is 9,3 où "la verge de son épaule" signifie "la verge qui frappe son épaule".

Pour le mot ț que ce mot se dit des fortes pluies et des inondations qu'elles causent. On pourrait donc traduire par "pluie d"orage" ou par "déferlement des eaux" (en faisant allusion à la situation évoquée par Mt 7,25.27).

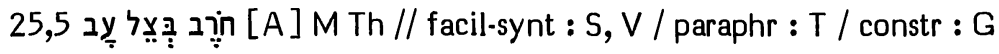

Options de nos traductions :

Ces trois mots ont été traduits par RSV : "as heat by the shade of a cloud", par J12 : "comme la chaleur à l'ombre d'un nuage", par RL : "wie du die Hitze brichst durch den Schatten der Wolken", par J3: "la chaleur tiédit à l'ombre d'un nuage" et par TOB : "comme fait à la chaleur l'ombre d'un nuage".

NEB omet ces trois mots, Brockington se référant pour cela au *G.

Origine de la correction :

Selon Duhm, la plus grande partie de ce vs est faite de gloses successives. NEB suit ici BHS qui demande d'omettre ces mots parce qu'ils ne sont pas attestés par le *G. 
Les témoins anciens :

1Q-a ne se distingue du *M que par une scriptio plena.

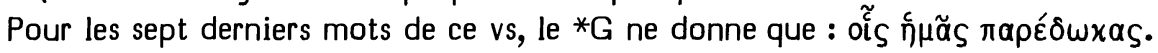
Coste (49) a raison de dire qu'en ce vs le * $G$ "est presque totalement détaché de l'hébreu". Il ne saurait donc apporter un témoignage à la critique du *M.

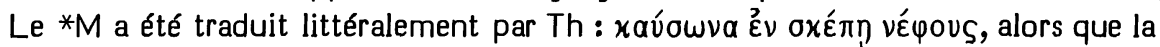
*S le fait précéder d'une conjonction et que la $* V$ et le $* T$ facilitent la syntaxe par une préposition comparative. Le ${ }^{*} T$ construit très librement sa paraphrase ("comme l'ombre d'un roc frais dans un pays aride, ainsi est le repos du souffle des justes"), mais il n'y a pas de motif de supposer qu'il ait lu autre chose que le *M.

Choix textuel :

Constatant ici encore l'unanimité des témoins dont on peut reconstituer la Vorlage, le comité a attribué au *M 3 " $A$ " et 2 "B".

\section{Interprétation proposée :}

5b peut se traduire: “Comme la chaleur sous l'ombre d'un nuage, le péan des violents s'assourdit."

26,5 ישפילה [C] M V T // abr-styl : 1Q-a 4Q-c(?) G S v om 26,7 ישר [B] M 1Q-a V S T // abr-styl : G om / incert : 4Q-c

Options de nos traductions :

Un bon nombre de reprises caractérisent le style de ce morceau :

1/au vs 3 : שלום שלום

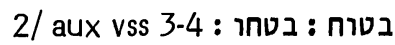

3/au vs 5 : בשפילנה ישפילה

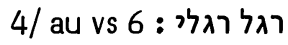

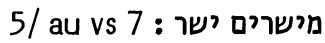

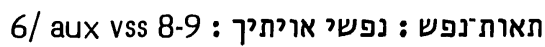

La plupart de nos traductions essaient d'alléger ces reprises, parfois en modifiant la syntaxe indiquée par les teamim. Seule 33 a pris le parti de les souligner pour mettre en valeur cette particularité stylistique. RSV estompe la 1e et omet la 5 e. 312 omettent la 1e et la 4e. RL omet la 1e et la 5e. NEB omet la 3e et la 4e. TOB omet la 1e. Parmi ces omissions, deux seulement font l'objet de notes textuelles : celle de la 3e par NEB et celle de la 5e par RSV. Nous ne traiterons donc formellement que de ces deux-là.

Origines des corrections :

La demande d'omettre ישפילה au vs 5 a été formulée par les apparats de HSAT34 et $\mathrm{BHS}$.

Celle d'omettre ישר au vs 7 l'a été par BHS. Mais il ne faudrait pas croire que RL, en se contentant de "machst du gerade" pour traduire ישר ... תפלס, ait entendu faire oeuvre critique. Elle s'est bornée à retoucher légèrement Luther qui avait traduit cela par "machstu richtig". 
Les témoins anciens :

1Q-a omet la 2e, la 3 e et la 4 e de ces reprises.

Selon un calcul de l'ampleur possible des lacunes, il semble que 4Q-c omette la 3e et la 6e. Pour la reprise du vs 7, voici l'état de 4Q-c : les quatre premières lettres du premier mot précèdent une lacune de cinq lettres ou espaces. Puis, le texte reprend par 'resh' et 'waw' comme fin du second mot. En outre, un 'waw' a été suspendu audessus de l'espace qui, dans le premier mot, sépare le 'shin' du 'resh'. A-t-on voulu corriger en "mishôr" proposé ici par Ehrlich ? Il est difficile de formuler un jugement sur des indices si fragmentaires.

Aucune de ces six reprises n'a été traduite par le *G. Il semble qu'il y ait là une option systématique du traducteur en ce contexte.

Quant à la $3 e$ et à la 5 e reprises, elles sont toutes deux attestées par la $* V$ (confirmée par Hie), certains témoins ayant omis la première par haplographie interne.

La 3 e reprise $n$ 'est pas attestée par la *S, alors que la 5 e l'est.

Pour ces deux reprises, le ${ }^{*} \mathrm{~T}$, tout en gardant à chaque mot un correspondant, a diversifié ses traductions.

\section{Choix textuel :}

Pour la $3 e$ reprise, le $* M$ n'est appuyé que par la $* V$ et le $* T$. Les massorètes ont d'ailleurs senti que la reprise de était une particularité textuelle menacée. Pour éviter tout accident, les mp des mss d'Alep et de Leningrad ont noté ces deux mots comme hapax.

Pour la 5 e reprise, 1Q-a et la ${ }^{*} S$ s'ajoutent aux appuis que le $* M$ avait dans le cas précédent.

Talmon (Double 177) a jugé que la 3e reprise constituait, dans le *M, une leçon gonflée. Le comité, considérant que ces reprises sont caractéristiques du contexte et que les divers témoins ont souvent tendance à les éviter par allègement, a estimé plus prudent de suivre le $* \mathrm{M}$ auquel la note " $\mathrm{C}$ " a été attribuée en 26,5 (3e reprise) et la note " $B$ " en 26,7 ( 5 e reprise) où il est mieux attesté.

\section{Interprétations proposées :}

Pour la 3e reprise, Irwin (Syntax 242) propose de séparer les deux formes verbales en plaçant l'atnah après la première. Il montre que cela permet de faire du premier distique un chiasme et du second un parallélisme, en même temps que la répartition des syllabes accentuées en chacun de ces membres se trouve très améliorée. Il est permis cependant de se demander si l'auteur vise ici des symétries poétiques parfaites ou si la reprise du substantif précédent par un suffixe féminin n'a pas pour but de créer une distension à laquelle l'accentuateur du $* M$ a fait droit par son placement de l'atnạ̣. Les déplacements intentionnels d'équilibre sur fond de structures symétriques constituent un des moyens d'expression favoris de la poésie biblique. On pourrait donc traduire le *M: "Car il a mis à bas les habitants de l'altitude, de la cité inaccessible, qu'il a abaissée, abaissée jusqu'à terre, il lui a fait mordre la poussière." Le déplacement d'accent, proposé par Irwin, donnerait : “Car il a mis à bas les habitants de l'altitude, il a abaissé la cité inaccessible; il l’a abaissée jusqu'à terre, il lui a fait mordre la poussière." Il est permis de préférer le jardin à l'anglaise que nous offre le *M au jardin à la française qu'Irwin nous propose. 
Pour la $5 e$ reprise, la tradition offre deux manières d'interpréter le *M. Hayyuj (Kokovzov 22) fait de avec le verbe final, il donne: "tu nivelles horizontal le chemin du juste". En effet, ce verbe montre alors que l'adjectif désigne une droiture dans le domaine de la hauteur et non dans celui de la largeur. Cette exégèse a été reprise par Hitzig, Knobel, Delitzsch, von Orelli, Dillmann/Kittel.

Saadya et Yéfet ben Ely, suivis par la plupart des exégètes postérieurs, ont vu en cet adjectif un vocatif s'adressant à Dieu: "Pour le juste, le chemin est droiture. Toi, le droit ! tu aplaniras le sentier du juste." C'est, entre autres, l'interprétation d'Oecolampade, de Pagnini et de la KJ ("thou most upright, doest weigh the path of the iust").

\section{קוינו 26,8}

Options de nos traductions :

Le *M est traduit littéralement par RSV, J, RL et TOB.

NEB suit 1Q-a en omettant le pronom suffixe et traduit 8a par : "We too look to the path prescribed in thy laws, O LORD."

Origine de la correction :

NEB a suivi là une suggestion de BHS.

Déjà Lowth avait traduit ce mot et le suivant par "We have placed our confidence in thy name" en expliquant que le *G, la ${ }^{*} S$ et le ${ }^{*} T$ ont lu ici קוינו.

Les témoins anciens :

$1 Q$-a atteste formellement cette leçon sans pronom suffixe.

En $4 Q$-c seule la première lettre de ce mot et la base de la deuxième sont conservées.

Le *G n'a lu aucun des deux suffixes 2 e pers. m. sg. de 8 a et il construit ce verbe

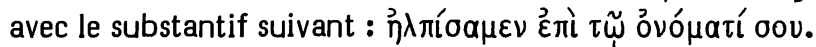

La ${ }^{*} S$ et le ${ }^{*} T$ ont lu le premier suffixe de 8a, mais non le second. Ces versions offrent la même construction que NEB.

$\mathrm{La} * \mathrm{~V}$ est seule à traduire exactement le $* \mathrm{M}$ : Et in semita iudiciorum tuorum Domine sustinuimus te.

Choix textuel :

Ce suffixe fait en effet difficulté si l'on pense que חị rivalise avec lui comme complément d'objet du verbe. Mais on n'espère pas un chemin. On espère que quelqu'un viendra sur ce chemin. $L a * V$ (suivie en cela par RSV, J, RL et TOB) a eu raison de considérer ce substantif comme un accusatif adverbial, ce qui fait disparaître la difficulté.

La construction syntactique de NEB l'amène, par contre, à gauchir le sens du verbe (à la suite de la ${ }^{*} S$ et du $* T$ ).

Le comité, considérant l'omission du suffixe comme due à une méconnaissance de la syntaxe, a at tribué au *M 3 "C $\mathrm{C}$ " et 2 "B". 
Interprétation proposée :

On pourra traduire : "Oui, sur le chemin tracé par tes sentences, Seigneur, nous espérions en toi."

26,9 : cf. p. 166.

26,16A פקדוך : פ פ $\varepsilon \mu \nu \eta \sigma \theta \eta \nu \longleftarrow \varepsilon \mu \nu \eta \sigma \theta \eta \mu \varepsilon \nu$

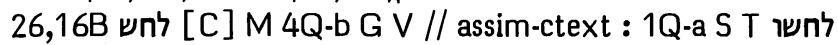

26,16C למו [B] M 1Q-a V // assim-ctextG : G clav לנו / abr-styl : S T om

Options de nos traductions :

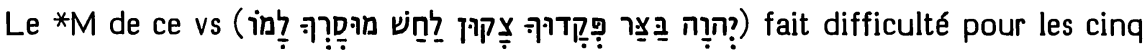
derniers mots.

RSV a traduit : “O LORD, in distress they sought thee, they poured out a prayer when thy chastening was upon them." Après le mot "prayer", elle note que l’hébreu est incertain.

J3 donne : "Yahvé, dans la détresse ils t'ont cherché, ils se répandirent en prière car ton châtiment était sur eux." Sur "prière", elle note que le sens est incertain.

TOB écrit : "SEIGNEUR, dans la détresse on a recours à toi. Quand tu sévis, on se répand en prières."

Les autres corrigent le *M :

$J 12$ ('Yahvé, dans la détresse nous te cherchons; l'angoisse de l'oppression était ton châtiment sur nous") s'appuyait sur le *G pour mettre le premier verbe à la $1 \mathrm{e}$ pers. pl. et pour lire מַצ au lieu du $4 \mathrm{e}$ et du 5 e mots.

RL (“HERR, wenn Trübsal da ist, so suchen wir dich; wenn du uns züchtigst, sind wir in Angst und Bedrängnis") semble présupposer des options analogues.

NEB ("In our distress, O LORD, we sought thee out, chastened by the mere whisper of thy rebuke") suppose, selon Brockington, la première correction de $\mathrm{J12}$, puis une vocalisation họolem de la seconde syllabe du $4 \mathrm{e}$ mot. Cette dernière correction et l'exégèse d'ensemble dépendent de Driver (Notes 45).

Origines des corrections :

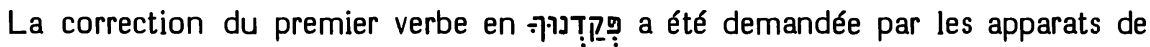
BH3S et Cent. Elle a été proposée par Lowth, se fondant sur le ${ }^{*} G$ et deux mss du *M.

La correction du 4e mot en quelque substantif plus connu dérivé de יצק = צוק, au sens de "détresse" ou "oppression", a été proposée par Koppe, puis beaucoup de critiques.

La correction du 5e mot en үחַ a été proposée par Grätz.

Celle du 7e mot en לִ a été proposée, en se fondant sur le *G, par Lowth. Elle a été requise ensuite par les apparats de HSAT34, BH3S et Cent. Elle est impliquée (quoique non spécifiée) par les traductions de J12 et RL. 
1) Pour le 3e mot (פקדון), deux mss Kennicott lisent פקדנוך. HUB précise à propos du ms 150 que seule sa $1 \mathrm{e}$ main porte cette leçon.

Selon Fischer (Schrift 42), la leçon originelle du ${ }^{*} G$ est ici $\varepsilon \mu \nu \eta \sigma \theta \eta \mu \varepsilon \nu$ oov, bien que Ziegler (éd. Göttingen du ${ }^{*} G$ ) ait choisi ici $\varepsilon \mu \nu \eta \sigma \theta \eta v$ oov. Cette seconde leçon semble bien être une forme mutilée de la première qui correspond mieux à l'option du ${ }^{*} G$ pour la 1e pers. pl. à propos du dernier mot de ce vs.

En 1Q-a, Talmon (DSIa 71) a lu un 'yod' à la place du 'waw' du *M. De fait, la hampe de cette lettre est courte, mais pas plus que celle du 'waw' du tétragramme en début de ligne. En tout cas, cette lettre n'a pas le nez développé de tous les 'yod' du contexte. Il est donc nettement plus vraisemblable que c'est un 'waw'.

Les traductions littérales de la $*^{*}$ et de la ${ }^{*}$, ainsi que la paraphrase du $* T$ se fondent ici sur le $* M$.

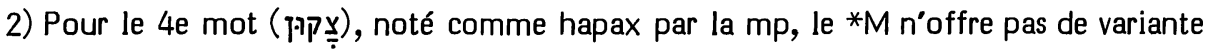
interne.

Les mss 1Q-a et 4Q-b sont identiques au *M.

Comme nous le préciserons plus loin, les options des versions anciennes à propos de ce mot se situent au niveau de l'exégèse et non de la critique textuelle.

3) Pour le 5e mot (שחל), le *M semble appuyé par 4Q-b (malgré une photo peu lisible). En 4Q504, col V, 17, une allusion atteste de ce mot le 'het' et le 'shin' après une lacune. Cette leçon appuie le *M. La*V (murmuris) se fonde, elle aussi, sur lui.

1Q-a donne ici לחשו qui semble aussi avoir été lu par la *S (לחשו) et le *T (פוו מלפין ... בחשית selon le ms Urbinates 1). Pour l'interprétation du témoignage du *T, l'opinion de Gottstein (Jesaia-Rolle 59) semble préférable à celle de Kutscher (317).

Le ${ }^{*} G(\mu \iota x \rho \tilde{a})$ est difficile à interpréter (cf. Emerton Notes 15s), mais il semble se référer à une leçon sans 'waw' final.

4) Pour le 6e mot (מוסרך), 1Q-a offre מוסריך. Mais la forme singulière de ce substantif en *M est appuyée par tous les autres témoins (y compris 4Q504, col V, 17, avec מוסרכה .

5) Pour le 7e mot (למו), le suffixe de la 3e p.pl. a été lu par le*M, 1Q-a et la*V (eis). Le *G l'a interprété en 1e p. pl. La ${ }^{*} S$, le ${ }^{*} T$ et 4Q504, col. V, 17, ont omis ce mot.

Choix textuel :

1) Notons d'abord qu'avec פקדוך entre en scène une 3e p. pl. difficile à situer. Il ne saurait s'agir en effet de ceux que le Seigneur a exterminés au vs 14 et dont il a fait disparaître le souvenir. Il est donc très naturel de lire ici une 1e p. pl. en assimilant à $12 \mathrm{~s}$ et à 17b-18a. HUB mentionne que S. Buber a trouvé, pour la citation de ce vs en Midrash Tehillim (au début du Ps 63), des mss portant פקדנוך. On peut ajouter à cela 
une citation dans le Midrash Shir ha-Shirim Rabba. L'édition de Wilna (26) y a la leçon courante du *M, alors que le ms Oxford, Bibl Bodl, Seld. A sup 102, fol 282v, donne ici פקדנוך. Cette leçon facilitante figure aussi en deux simanim de la Okhla de Halle (Diaz Esteban $\S \S 38$ et 58). Rappelons qu’elle a pénétré en deux mss Kennicott. Dans la paraphrase que 4Q504, col V, 16 donne de ce mot et de son contexte immédiat, la 1e pers. pl. est dominante, apparaissant plusieurs fois sous forme suffixée. Tout cela prouve seulement que cette facilitation est 'dans l'air'. Nous avons noté, à propos du témoignage du ${ }^{*} G$, que celui-ci semble avoir choisi ici la $1 e$ pers. pl. en harmonisant avec son option concernant le dernier mot du vs. Ces deux options assimilent au contexte plus large.

La lectio difficilior du *M étant bien appuyée par 1Q-a, la *V, la *S et le *T, le comité lui a attribué la note "B".

2) Pour le mot צִ בָק une interprétation en substantif est déjà attestée par la paraphrase חש בצקון en 4Q504, col V, 17. Cette interprétation est d'ailleurs vraisemblablement présupposée par 1Q-a, puisqu'il entoure ce mot de deux accomplis à la 3e pers. pl.

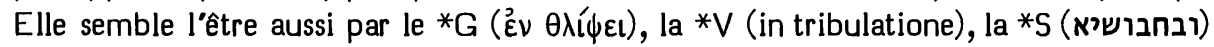
et le *T (ובעקתהון). Ben Yehuda (5611s) montre que ce hapax a eu une grande vogue

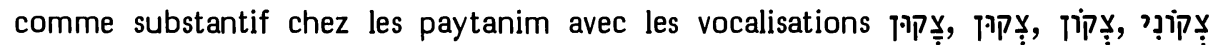
(avec suffixe 1e pers.), צִקָוֹנים (au pluriel). Fidèle à cette tradition, Saadya en fait usage de la sorte en son Siddur (311) :

Il est intéressant de noter que, dans sa traduction d'Isaïe, le même Saadya est le plus ancien exégète qui interprète ce mot comme un verbe (à la 3e pers. pl. de l'accompli). Il traduit וצבמّ (= et ils ont versé) et commente (Ratzaby 49): "J"ai dérivé

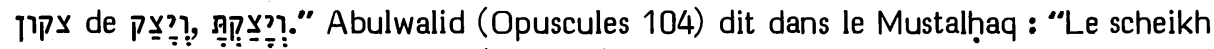
Isaac ibn Giqatilla croit que צקון (Is 26,16) est un pluriel de l'accompli de צוק le 'nun' est ajouté comme dans יִ יִדיוּן (Dt 8,16). J'approuve fort cette opinion." Elle a été approuvée ensuite par Judah îbn Balaam, Ibn Ezra et Radaq. Le sens de "verser" étant proche de celui de יצִיָּ en Jb 28,2; 29,6, ces deux derniers exégètes hésitent entre une racine 'caïn-waw' ét une racine 'pé-yod'. Gesenius voit là deux modalités différentes d'une même racine. L'analyse d'Isaac ibn Giqatilla est encore celle de Bauer/ Leander (404). Notons cependant que l'interprétation en substantif a survécu chez Rashi et dans les glossaires ABCDEF qui traduisent צקון לחש "versement de prière".

Comme on le voit, les problèmes posés par ce mot sont des problèmes d'analyse grammaticale et d'interprétation plutôt que de critique textuelle. En effet, la préposition 'bet' que la plupart des témoins explicitent avant ce mot a pour but de lui donner une intégration syntactique symétrique de celle de $\underline{\text { צַב. }}$.

3) Il semble que, pour 1Q-a, la ${ }^{*}$ S et le ${ }^{*} T$, la leçon לחשר (au lieu de לחש du ${ }^{*} M$ ) est une retouche faisant de ce mot un verbe parallèle à פקדוך (que ces trois témoins ont lu, deux mots avant, avec le ${ }^{*} M$ ); car ils manquaient d'un tel verbe en ce demiverset, du fait qu'ils ont interprété צקון en substantif.

Quant au *G et à la *V (qui s'accordent ici avec le *M), ces versions semblent interpréter ce mot comme un déterminant (génitif ou adjectif) du précédent qu'elles avaient, elles aussi, compris comme substantif. 
Les témoignages de 4Q-b et de 4Q504 s'ajoutant à ceux du *G et de la *V en faveur du *M, le comité a opté pour sa leçon. Mais il ne lui a attribué que la note " $C$ " du fait que 1Q-a atteste la variante לחשו.

4) C'est d'ailleurs la mise de ce verbe au pluriel qui a amené 1Q-a à mettre également au pluriel (מוסריך) le substantif qui le suit et qu'il a dû interpréter comme en étant le sujet.

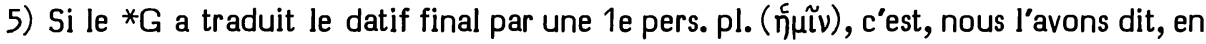
harmonisation avec la traduction analogue qu'il a donnée de פקדוך, cette double option assimilant à $12 \mathrm{~s}$ et à $17 \mathrm{~b}-18 \mathrm{a}$.

C'est par souci d'allègement stylistique que ce mot a été omis par certains autres témoins.

L'appui apporté au ${ }^{*} M$ par $1 Q$-a et la $* V$ a engagé le comité à lui attribuer la note "B".

Interprétation proposée :

Etant donné que toute correction du ${ }^{*} M$ serait ici facilitante, il ne nous reste qu’à l'interpréter.

Les teamim suggèrent de considérer צקון comme ayant, en cette seconde partie du vs, une fonction semblable à celle que פקדוך avait dans la première; alors

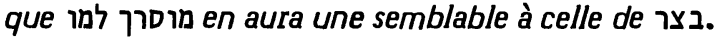

Si l'on interprète צִ comme "ils ont répandu", לח en dépend comme accusatif et signifie "un susurrement" ou "un marmonnement" de prière à voix basse.

On pourra donc traduire: "Seigneur, dans la détresse ils t'ont recherché, ils ont répandu un marmonnement quand ton châtiment les atteignait."

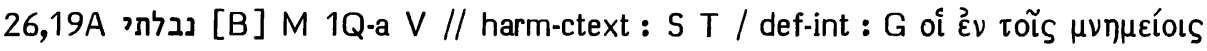

Options de nos traductions :

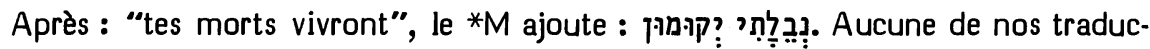
tions ne traduit le premier mot selon le *M.

RL ("deine Leichname") et 33 ("tes cadavres") assimilent le possessif à celui qui précède, sans rien noter.

RSV et NEB donnent "their bodies", Brockington renvoyant à la *S pour une

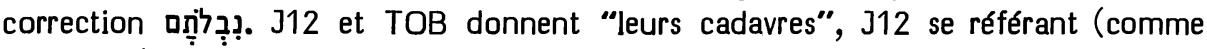
aussi RSV) à la *S et au *T.

Origines des corrections :

Houbigant a conjecturé ici le suffixe 2e pers. sg. que Procksch, puis RL et 33 ont adopté.

C'est Vogel, en ses notes sur Grotius, qui a noté ici le suffixe 3e pers. pl. de la *S et choisi cette leçon. Cette correction a été ensuite requise par l'apparat de Cent. 
Les témoins anciens :

Le *M est appuyé par $1 Q$-a et par la $* V$ (interfecti mei) qui explicite le collectif par un pluriel.

$\mathrm{La} * S$ et le $* T$ ont un suffixe de la 3e pers. pl.

Quant au ${ }^{*}$ G, Liebmann (ZAW 1902, 51-55) a signalé comme très vraisemblable que des interpolations chrétiennes ont pénétré en toute sa tradition textuelle. Or Seeligmann (25s) s'accorde avec lui pour en signaler une dans le proche contexte de notre vs. Ziegler (Untersuchungen 67) estime précisément (avec Ottley qu'il cite)

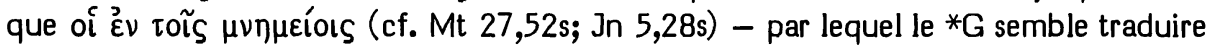
notre mot - constitue l'une de ces interpolations. S'il en est ainsi, elle a remplacé la forme authentique du ${ }^{*} G$ à laquelle nous ne pouvons plus avoir accès.

\section{Choix textuel :}

C'est parce que la *S et le *T comprenaient ce mot au sens de "les cadavres de tes morts" (qui viennent d'être mentionnés), que ces versions ont traduit comme si elles lisaient "leurs cadavres". Il s'agit donc là d'une harmonisation au contexte immédiat.

$L$ 'appui que $1 Q$-a et la $* V$ apportent à la lectio difficilior du * $M$ a paru suffisant au comité pour attribuer à cette leçon la note " $\mathrm{B}$ ".

\section{Interprétations proposées :}

Sans savoir qu'il reprenait une suggestion de Yéfet ben Ely, Rosenmüller a jugé que le 'yod' qui achève ce mot est paragogique. Il fonde ce jugement sur le fait que le mot garde ici la vocalisation de l'état absolu, alors qu'ailleurs, à l'état suffixal,

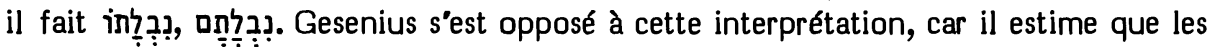
finales paragogiques affectent seulement des états construits ou des mots étroitement liés à des prépositions qui les suivent. Böttcher (Lehrbuch $\$ 370.4$ et $\$ 498.3$ ) relie cette vocalisation à d'autres cas où le maintien de la structure vocalique de l'état absolu tient à la nécessité d'ajouter un accent secondaire pour mieux mettre en valeur un mot.

Il faut comprendre ici ce mot comme un collectif, sens que BDB (615b) lui attribue aussi en Is 5,25; Jr 7,33; 9,21; 16,4; 19,7; 34,20; Ps 79,2. L'alternance entre "tes morts" et "mes cadavres" semble souligner que ce sont les mêmes qui sont les morts de Dieu (pour qui ils ont subi la mort) et les morts de la communauté (dont ils faisaient partie). Pourtant, les exégètes ont hésité à dire qui parle ici à la 1e personne : Dieu ou la communauté.

Certains voient en ce vs 19 le début d'un oracle qui se poursuit ensuite en 20 ("va, mon peuple, entre dans tes chambres"). Ce serait alors Dieu qui parlerait et qui proférerait les deux impératifs : "réveillez-vous et criez de joie, hôtes de la poussière !" Et ce serait la communauté reconnaissante qui interromprait l'oracle pour constater : "car ta rosée est une rosée de lumière..."

D'autres font de ce vs la fin de la prière communautaire qui le précède. Ce serait alors la communauté qui parlerait à la 1e pers. Après avoir demandé à Dieu de ressusciter ces morts, la communauté adresserait à ceux-ci les deux impératifs comme un témoignage de sa certitude d'être exaucée, certitude qui lui permet d'anticiper 
l'ordre que Dieu leur adressera. La constatation : "car ta rosée..." clôt enfin cette prière par l'énoncé de la certitude de la résurrection.

L'étude des divisions traditionnelles du texte biblique permet d'affirmer que c'est la seconde interprétation qui est la mieux enracinée dans la tradition. En effet Oesch ( $T$ 13*s) montre que les témoins massorétiques et $1 \mathrm{Q}$-a s'accordent pour attester une division avant le vs 20 , alors qu'aucun d'entre eux n'en atteste avant le vs 19.

\section{6,19B הָקיצו ורַננו [C] M V // assim 19a : 1Q-a G S T futur / incert : Th Aq}

Options de nos traductions :

Les deux impératifs du *M sont traduits par RSV, J, RL et TOB.

NEB donne ici (sans note) des futurs : "They ... will awake and shout for joy",

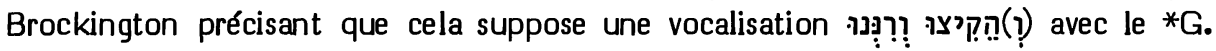

Origine de la correction :

Cette correction a été proposée par Duhm, puis requise par les apparats de

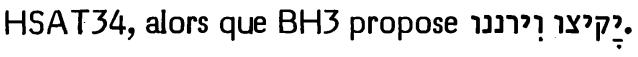

Les témoins anciens :

1Q-a offre exactement la leçon conjecturée par $\mathrm{BH}$.

Seule la *V (expergiscimini et laudate) appuie ici les impératifs du *M.

Les autres versions traduisent par des futurs.

Le contexte du commentaire d'Eusèbe a pu influencer la forme temporelle des verbes quil attribue à Th et à Aq. On ne peut donc se fonder sur leur témoignage en ce domaine.

\section{Choix textuel :}

Les futurs sont ici des facilitations syntactiques assimilant aux deux verbes initiaux du vs.

Le comité a estimé préférable la lectio difficilior du *M à laquelle il a attribué la note "C".

Interprétation proposée :

A propos du cas précédent, nous avons traité de la signification que prennent ces impératifs, dans le contexte d'ensemble à l'intérieur duquel ils se situent.

\section{7,2 cor חמד [C] m G T? // err-graph : M 1Q-a V S חמר}

\section{Options de nos traductions :}

Le texte de BHS porte ici חמד. Si on y compare nos cinq traductions, on jugera qu'elles suivent le $* M$. Pourtant deux d'entre elles ( $J$ et NEB) disent en note qu'elles quittent le $* M$ qui porte חמר. De fait, BH3 portait ici en son texte רח. Or BH3 et $\mathrm{BHS}$ entendent bien, toutes deux, éditer (sauf mention contraire) le texte du ms de Leningrad. 
Leçon du *M tibérien classique :

Que porte donc ici ce ms? Si l'on se fonde sur le facsimilé édité à Jérusalem en 1970, on lirait plutôt un 'dalet'. Cependant le mot y porte une mp le signalant comme hapax, ce qui ne peut valoir que pour חֶ. En effet, discutée en Is 32,12; Ez 23,6.12.23; Am 5,11 . D'autre part, ici, il n’y a pas de rafé visible sur la lettre finale, alors que le rafé est bien visible sur le 'dalet' final de en chacun de ses cinq emplois (où jamais n'apparaît une $\mathrm{mp}$ ). Concluons de cela que $\mathrm{BH} 3$ avait raison de lire un 'resh' comme la lettre voulue par celui qui, plaçant les rafé, prit la responsabilité de distinguer les 'resh' des 'dalet'.

Sur tous ces points, la situation est la même dans le ms du Caire où la graphie des 'resh' et des 'dalet' ne se distingue que par la présence ou l'absence de rafé ou de dagesh, ainsi que dans le ms d'Alep et dans celui de Petrograd qui distinguent en outre clairement le tracé des 'dalet' de celui des 'resh' et portent ici clairement un 'resh'. De même le 'resh' est bien distinct, avec la mp : hapax, dans l'édition Ben Hayim qui ne note pas les rafé. Dans le ms de Munich de son Sefer Zikronot, Elias Levita, sous דִ̣n, précise qu'en Is 27,2 il faut lire la leçon avec 'resh' et il donne pour simân : 'resh-resh, dalet-dalet', ce qui veut dire qu'en Isaie on trouve d'abord deux 'resh' qui se suivent en (27,2), puis deux 'dalet' qui se suivent en שרם חמר (32, 12). Il semble donc que l'on puisse conclure avec fermeté qu'ici le *M doit porter la leçon avec 'resh' et que la leçon avec 'dalet' provient d'une erreur de déchiffrement du ms de Leningrad par BHS.

Cependant, si nous remontons d'un siècle, il est frappant de voir que l'édition la plus diffusée du XIXe siècle, celle de Letteris, porte ici (par exemple en son tirage de Berlin 1866) la leçon avec 'dalet'. Cela vient du fait que Letteris reproduit avec peu de changements l'édition de Van der Hooght (Amsterdam et Utrecht 1705) qui était considérée à son époque comme le textus receptus. Or celle-ci reproduit le texte de l'édition de Joseph Athias (Amsterdam 1661) à laquelle elle ajoute en appendice des variantes tirées d'autres éditions. Pourtant, Houbigant, dans les notes à son édition (en 1753), remarquait que l'édition de Van der Hooght se distinguait de la réimpression d'Athias par Leusden (en 1667) par le fait qu'elle lisait ici un 'dalet', alors que l'autre lisait un 'resh'. Cette particularité allait avoir des conséquences importantes pour la critique textuelle.

En effet, Rosenmüller dit qu'en plusieurs 'codices', parmi lesquels plusieurs éditions, on lit la leçon avec 'dalet'. Michaelis (OEB) dit que c'est dans le commentaire de Lowth qu'il a appris que beaucoup de mss et d'éditions collationnés pour Kennicott appuient cette leçon. Michaelis écrivait cela en 1779 et Lowth avait publié son commentaire à Londres en 1778. De fait, lorsque Kennicott publia en 1780 le deuxième volume de sa Bible contenant Isaïe, on put y trouver des données détaillées sur ce point. La leçon avec 'dalet' figurait dans son texte, selon la décision qu'il avait prise de se servir de l'édition $V$ an der Hooght comme base de référence. Il citait dans son apparat, en faveur de la variante avec 'resh', 33 mss et 6 éditions, plus 6 mss incertains et 1 par correction. Or, en fin d'Isaïe, il énumérait 89 'codices' (72 mss et 17 éditions) "per totum collati", à côté d'un plus grand nombre de "codices" qui n'avaient été collationnés qu’en des lieux choisis. Or, pour la variante qui nous intéresse, parmi les 46 'codices' invoqués à l'appui de la leçon avec 'resh', seuls figuraient 
les sigles de 42 des 89 "codices per totum collati". On pouvait donc être tenté de conclure du silence enveloppant les autres membres de ce groupe que $44 \mathrm{mss}$ et 3 éditions appuyaient la leçon avec 'dalet'. C'est la conclusion que Lowth en avait tiré. Mais l'homme de confiance de Kennicott, Bruns (Mendis 229s) accusa en 1783 son ancien employeur d'avoir retenu dans son texte une faute d'impression (la leçon avec 'dalet'), alors que Van der Hooght avait pourtant, dans son appendice, demandé qu'on la corrige. Bruns précisait que la leçon avec 'dalet' se trouve dans l'édition princeps de la Bible (Soncino 1488). Il inférait en outre du silence de Schulze qui avait collationné à Berlin, sur l'exemplaire de Luther, l'édition Brescia 1494, que celle-ci devait avoir aussi cette leçon.

En 1786, dans le 3e volume de ses Variae Lectiones, de Rossi aborde cette question. Après avoir collationné plusieurs exemplaires de l'édition Brescia 1494 (portant tous la leçon avec 'resh'), il concluait que l'édition Soncino 1488 est la seule antérieure à Van der Hooght à avoir porté la leçon avec 'dalet'. Il ajoutait que, parmi ses mss, 35 avaient la leçon avec 'resh', plus 5 par correction. En 1788, dans l'appendice au $4 \mathrm{e}$ volume, il allait ajouter 6 autres mss à cette liste. En face de cela (mis à part 2 mss douteux) son ms 174 était seul à attester la leçon avec 'dalet'. Cette forte disproportion amena de Rossi à se défier de l'argument de silence que Lowth croyait pouvoir tirer des collations de Kennicott. Il fit remarquer, pour motiver cette défiance, que le $2 \mathrm{e}$ ms de Königsberg avait été collationné par Lilienthal sur l'édition de Halle (ainsi que celui-ci le précise à la p. IV de sa préface) et que quatre mss de Turin avaient été collationnés sur l'édition de Simonis (ainsi que Kennicott l'avait mentionné à la p. 125 de sa Dissertatio Generalis). Or, ces deux éditions offrant la leçon avec 'resh', il était nécessaire d'interpréter le silence des collationneurs comme une confirmation de cette leçon. Aussi estimait-il que de nombreux mss "silencieux" n'attestaient vraisemblablement pas la leçon avec 'dalet' de Van der Hooght. Pour se convaincre de cela, il suffisait en effet de remarquer que Kennicott lui-même (ibid.) avait précisé : "Il n'est pas douteux que quelques erreurs inévitables se sont introduites dans les variantes des 'codices per totum collati'. En effet, les collationneurs ne se sont pas toujours servis de l'édition de Van der Hooght, mais il leur est arrivé de faire usage d'autres éditions."

Après que de Rossi ait ramené à 39, par sa remarque, les 44 mss "silencieux" de Kennicott, nous avons contrôlé les 9 mss de ce groupe auxquels nous avions accès. Aucun d'entre eux ne porte la leçon avec 'dalet'. Le 201 a une lacune qui va de Ez 11, 19 à Is 41,17. Sur les 8 autres, un seul (le 149) porte la mp désignant ce mot comme hapax. Sur ces 8 , trois $(173,180,242)$ ne notent pas les rafé mais ont un 'resh' nettement distinct. Les cinq autres $(149,171,172,175,228)$ ont la coutume de noter le rafé et n'en ont pas ici. Ces résultats entièrement négatifs s'accordent avec le fait que Ginsburg ne cite qu'un seul ms (le ms Londres BL Add 14760) et une édition (Soncino 1488) à l'appui de la leçon avec 'dalet' (sur les 39 mss et 11 éditions qu'il mentionne comme contenant le livre d'Isaïe). HUB a donc manqué d'esprit critique en attribuant la leçon avec "dalet" à "KRG (mlt)", ce qui veut dire (HUB, Sample Edition 41) au moins dix témoins. Il est plus vraisemblable que le nombre de vrais témoins pour la leçon avec "dalet' qui se dissimulent parmi les 30 "silencieux" restants de Kennicott ne doit pas dépasser une ou deux unités. 
Cependant, de Rossi (ibid.) défendit contre Bruns la manière dont l'édition Van der Hooght avait été utilisée par Kennicott. Celui-ci avait en effet cité la leçon de l'appendice de cette édition dans son apparat, sous le sigle 659F, la considérant (conformément aux intentions exprimées par Van der Hooght) comme une variante et non comme une correction. Etant donné qu'elle est attestée au moins par deux ou trois témoins, la leçon avec 'dalet' du texte de Van der Hooght a pu être empruntée à une source manuscrite ou éditée.

Nous possédons d'autres indices que la leçon avec 'dalet' est demeurée 'dans l'air' durant de nombreux siècles. HUB relève sa présence dans le Tanhuma édité (qu'elle cite selon l'édition Mantoue 1563) en Mishpatim $\$ 5$ (où on peut ajouter qu'elle était déjà offerte aussi par l'édition Constantinople 1520-1522, ainsi que par les mss Oxford, Bibl Bodl, Opp. Add. fol. 66 et de Rossi 261, alors qu'elle est corrigée en 'resh' dans le ms Oxford, Bibl Bodl, Hunt. Don. 20). HUB cite aussi à l'appui de la leçon avec 'dalet' le Tanhuma Wayyelek $§ 2$ selon l'édition de Mantoue. En ce passage, absent de l'édition de Constantinople, cette leçon est appuyée par le ms de Rossi 261. HUB cite aussi, en faveur de cette leçon, le midrash Bamidbar Rabba $\$ 10.2$ (35a), selon l'édition Constantinople 1512 (où on peut ajouter que le ms Oxford, Bibl Bodl, Opp. Add. fol 3 lit ici un 'resh' avec les éditions courantes). HUB cite encore pour la leçon avec 'dalet' le Midrash Tehillim §8.1 (73) selon l'édition Buber. On peut ajouter qu'en Shemot Rabba 30.1, le ms Oxford, Bibl Bodl, Opp. Add. fol 3 porte deux fois la leçon avec 'dalet' (cette leçon n'ayant été corrigée que la première fois en 'resh'). Notons que, dans les cas où les contextes de ces midrashim sont assez explicites, c'est la leçon avec 'resh' qu'ils postulent. Il semble donc qu'on ne puisse tirer aucun argument textuel de ces cas de graphie avec 'dalet' en certains témoins textuels des midrashim. Cela nous montre simplement une tendance à assimiler la forme hapax avec 'resh' à la forme plus usuelle avec 'dalet'.

Si l'on veut confirmer que la leçon authentique du * $M$ est bien celle avec 'resh', on peut ajouter encore deux données: Notons d'abord que le seul ms babylonien connu comme portant ce passage est le ms Hebr $4^{\circ} 1191.1$ de la Bibliothèque Nationale et Universitaire de Jérusalem (Yeivin IV 423). Il porte la leçon avec 'resh' et sa massore atteste que ce mot est hapax en cette graphie avec 'resh'. D'autre part, tous les lexicographes et exégètes juifs médiévaux que nous avons consultés s'accordent sur la leçon avec 'resh' : Saadya, Judah ben Qoreish (Bargès $20=$ Katz 38), Menahem ben Saruq ( $3 e$ sens de חמ), David ben Abraham (I 561,87s), Yéfet ben Ely, Abulwalid (Ușul 235,12s), Judah ibn Balaam, Parhon, Rashi, glossaires ABCDEF, Joseph Qimḥi (Galuy 130), Ibn Ezra, Joseph Qara, Eliézer de Beaugency, Radaq, Aaron ben Joseph, Joseph ibn Kaspi (fol 127a), Isaïe de Trani, Abraham ben Yehuda, Abravanel. Nous n'avons rencontré que deux fois la leçon avec 'dalet' chez ces auteurs : Le glossaire C a d'abord écrit un 'dalet' avec rafé, puis a corrigé (sa traduction "vineuse" garantissant la leçon). L'édition et le ms unique (Vatican ebr 402) du Sepher ha-Galuy de Joseph Qimḥi portent la leçon avec 'dalet'. Mais l'exégèse qu'il donne postule la leçon avec 'resh'.

Contre la leçon avec 'dalet', 1Q-a appuie la leçon avec 'resh'. La forme חומר 
qu'il lui donne est interprétée par Kutscher (375) comme un glissement du type 'qatl' vers le type 'quṭl' sous l'influence de la labiale qui suit.

$\mathrm{La} * \mathrm{~V}$ et la *S appuient clairement la leçon avec 'resh'.

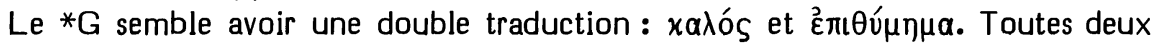
(et la seconde très explicitement) se fondent sur la leçon avec 'dalet'.

De Rossi, avec l'ensemble des exégètes, considère que le *T appuie la leçon avec 'dalet'. Notons pourtant qu'en 32,12 où le même mot réapparaît dans le *M, le *T le traduit bien plus clairement. Ici, on peut seulement dire que sa traduction "une vigne plantée dans une bonne terre" ne trahit aucune connaissance de la leçon avec 'resh' et qu'elle peut être une paraphrase de la leçon avec 'dalet', paraphrase s'inspirant de $5,1 \mathrm{~s}$.

\section{Choix textuel :}

Le comité s'est partagé entre les deux leçons.

En faveur de la leçon avec 'resh', il faut noter les attestations convergentes du *M, de $1 Q$-a, de la $* V$ et de la $*$. Il faut remarquer aussi qu'un glissement de la leçon hapax à la forme plus usuelle semble plus aisé qu'un glissement en sens inverse.

En faveur de la leçon avec 'dalet', on peut faire valoir que, le passage de l'une des leçons à l'autre étant purement accidentel, certains motifs internes amènent à considérer que c'est la leçon avec 'dalet' qui a le plus de chances d'être primitive en ce contexte : D'abord l'expression

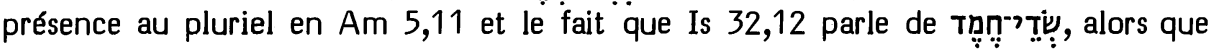
Jr 3,19; Za 7,14 et Ps 106,24 usent de l'expression est normalement spécifié par l'arbre qui y est planté (par ex. כרס Iִ en J 15,5) et

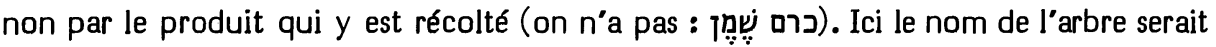

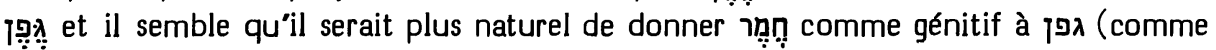

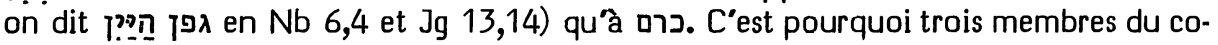
mité ont attribué la note " $\mathrm{C}$ " à la leçon avec "dalet".

Etant donné cependant que ce cantique fait contraste avec celui de la vigne en 5,1-7 et qu'il veut en être l'abrogation (comme Yéfet ben Ely l'a bien senti), il est parfaitement possible que le poète a repris le vocable ợ de 5,1 en lui donnant déjà le sens formel de "vignoble" qu'il y a, et que nח̣ est seulement à ses yeux l'équivalent poétique (cf. Dt 32,14) de 1?... Pour la préciosité de notre poète (il s'inspire du

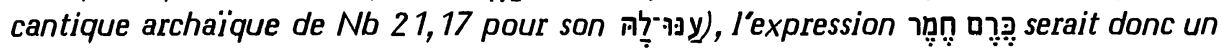
équivalent plus noble de ??:? la note " $C$ " à la leçon avec "resh".

Interprétation proposée :

Le comité suggère donc plutôt : "la vigne délicieuse". Mais il faudrait mentionner en note la leçon du *M : "la vigne à vin". 
27,4 חמִמִ [B] M 1Q-a V // assim-ctextG : G S clav ממ̣n / midr : T

Options de nos traductions :

Le *M a été lu selon diverses exégèses par RL : "(ich) zürne (nicht)", RSV : "wrath", J12 et TOB : “colère", d’une part, et NEB : “wine", d'autre part.

$\mathrm{J3}$ traduit: "muraille" en expliquant qu’elle a conjecturé la vocalisation

Origine de la correction :

C'est dans l'apparat de Cent que 33 a pu trouver requise cette vocalisation. Cent laisserait croire en effet qu'il s'agit d'une conjecture, alors qu'Houbigant la fondait explicitement sur le ${ }^{*} G$ et la ${ }^{*} \mathrm{~S}$. L'initiateur de cette correction semble être Foreiro qui la proposait à titre de conjecture.

En traduisant "wine", NEB n'entend pas quitter le *M, mais l'interpréter comme Driver (ḥ̣̂mâh 133) l'a proposé.

Les témoins anciens :

La traduction "muraille" est liée dans le *G à un parti-pris exégétique qui, dans les vss $2-3$ et le premier mot du vs 4 , voit une ville forte assiégée qui sera prise durant la nuit et dont la muraille s'écroulera durant le jour. Il s'agit donc d'une construction littéraire aussi libre que cohérente (cf. Seeligmann 26s). Il ne faudrait pas la démolir à notre tour pour faire entrer certaines de ses pierres dans une construction éclectique.

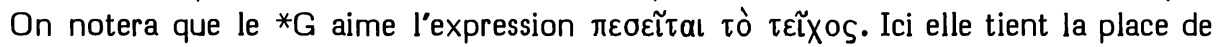

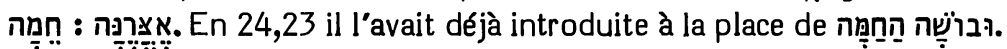

En ces deux cas, il est très improbable que la graphie défective $(=* M)$ de $1 \mathrm{Q}$-a recouvre cette leçon "muraille". En effet, en ce ms, le mot המ̣in est toujours (c'est-àdire 12 fois, car 2,15 n'est pas conservé) écrit plene; alors que, sur ces 12 fois, le *M l'écrit deux fois $(22,11$ et 60,10$)$ defective.

$L a * V$ (indignatio) traduit le *M.

Le *T s'évade en un ample midrash qui n'a de relation avec aucune Vorlage repérable pour ce mot.

La *S offre ici שורא (= muraille). Il peut y avoir là une influence du *G dont ce mot traduira la leçon dans la Syh.

La tradition textuelle du $* M$ semble entièrement cohérente. HUB cite cependant pour les deux premiers mots de ce vs une leçon חומה אוי en une citation de ce vs en Tanḩuma Mishpatim $\S 5$, selon l'édition de Constantinople. Il faudrait ajouter à cela qu'ici l'édition de Mantoue et l'ensemble des mss du Tanḩuma édité que nous avons consultés (mss de Rossi 261; Oxford, Bibl Bodl, Hunt Don 20; Opp 187; Opp Add fol 66) attestent la graphie normale : חמה אין, et que, dans le passage parallèle (Mishpațim §4) du Tanḥuma Buber, l'édition ainsi que tous les mss que nous avons consultés (mss de Rossi 1240; Oxford, Bibl Bodl, Opp 20; Mich 577) portent la graphie pleine חימה אין. Sur le fond constitué par cette double tradition textuelle, la leçon de l'édition de Constantinople apparaît comme une simple faute d'impression, ainsi que le souligne la déformation du deuxième mot. 
Choix textuel :

Ni HSAT234, ni BH23S n'ont proposé ici de corriger le *M. Sa vocalisation est appuyée par la $* V$ et, presque certainement, par $1 Q-a$. Le comité lui a attribué la note "B".

Interprétation proposée :

27,4a est la clé de cette seconde parabole de la vigne et s'oppose à 5,5a de la première. C'est parce qu'il n'est plus en colère que le Seigneur la garde nuit et jour contre ceux qui pourraient y faire irruption $(27,3 b)$ au lieu d'y faire une brèche et de la laisser piétiner (5,5b). C'est parce qu'il n'est plus en colère qu'il arrache et brûle les épines et les ronces $(27,4 \mathrm{~b})$ au lieu de les laisser pousser $(5,6 a)$. C'est parce qu'il n'est plus en colère qu'à tout moment il l'arrose $(27,3 a)$ au lieu d'interdire aux nuages de pleuvoir sur elle $(5,6 \mathrm{~b})$.

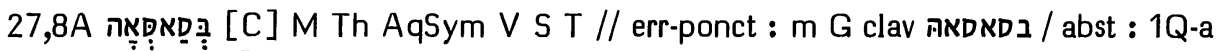

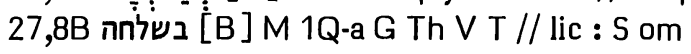

Options de nos traductions :

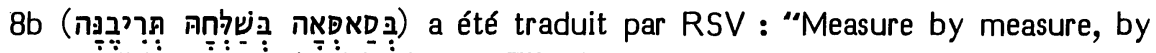
exile thou didst contend with them". Elle dit s'inspirer de la* $V$, de la *S et du *T pour traduire le premier mot, parce que le sens de ce mot hébreu est inconnu.

NEB traduit: "and his quarrel with her ends in brushing her away". Selon Brockington, cela suppose deux corrections conjecturales : d'abord la ponctuation mappiq du 'hé' final du premier mot, ensuite l'omission du deuxième mot.

Quoiqu'elles ne le notent pas, la première de ces deux corrections est présupposée par les traductions de $\mathrm{J12}$ ("tu l'as châtiée en l'expulsant, en l'exilant"), RL ("indem du es wegschicktest und wegführtest, hast du es gerichtet"), J3 ("en la chassant, en l'excluant, tu as exercé un jugement"), TOB ("il a fait leur procès en les chassant, en les expulsant").

Origines des corrections :

En ses deux corrections, NEB dépend de Driver (Verbs 371s). Koppe avait déjà suggéré d'interpréter en suffixe pronominal le "hé" final du premier mot. Hitzig a donc proposé de le munir d'un mappiq.

Les témoins anciens :

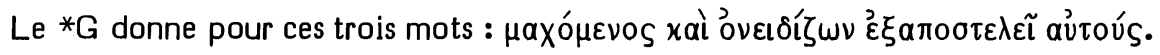
Le premier participe correspondant à la racine ריב et le verbe final correspondant à

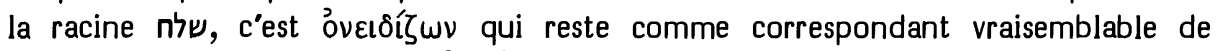
בסאסאה, étant entendu que aủtoús peut correspondre aux trois 'hé' finaux de ces mots. On peut donc en conclure que le ${ }^{*} G$ appuie la première correction de NEB, mais pas la seconde.

Notons que de Rossi a trouvé en deux mss un mappiq dans le "hé' final du premier mot. Norzi, ne trouvant ce mappiq en aucun ms, le considérait cependant comme 
impliqué par l'exégèse de Rashi (בסאה שלה), exégèse correspondant à la traduction des glossaires CDE : "en sa mesure".

$\mathrm{La}{ }^{*} \mathrm{~S}$ ne traduit pas le $2 \mathrm{e}$ mot. C'est qu'elle s'est contentée d’une périphrase portant sur le 1er et le 3e mot, en omettant d'expliciter le sens du deuxième.

1Q-a appuie le *M, sans que l'on puisse préciser comment il a compris le "hé" final du premier mot.

Pour ce mot, toutes les versions postérieures au ${ }^{*} G$ ne sont que des exégèses du *M, rien ne suggérant qu'elles en ont interprété le 'hé' final en pronom suffixe.

\section{Choix textuel :}

En 27,8A, la seule question que pose le texte porte sur la présence ou l'absence de mappiq. Etant donné que la finale du mot suivant en porte un, son omission par le ${ }^{*} M$ et les versions (postérieures au ${ }^{*} G$ ) constitue une lectio difficilior à laquelle le comité a attribué la note " $C$ ".

En 27,8B, la non-traduction du $2 \mathrm{e}$ mot du vs par la *S est une simple licence translationnelle. Aussi le comité a-t-il attribué à la leçon du *M (attestée par tous les autres témoins) la note "B".

Interprétations proposées :

L'interprétation de toutes les versions postérieures au * $G$ repose sur une base qui a été bien dégagée par Abulwalid (Ușul 471, 5-19) et par Gesenius : L'intention des

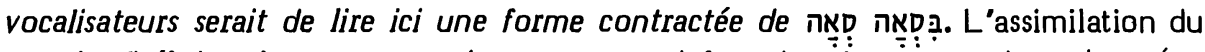
premier "hé' dans la consonne suivante a engendré un dagesh, comme dans

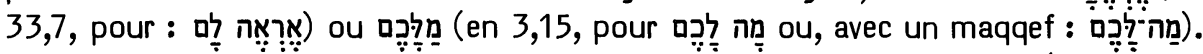

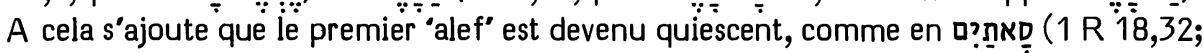
2 R 7,1.16.18). Le qameṣ, transféré au 'samek', est devenu patạ à cause du dagesh qui le suit. $L$ 'absence de mappiq dans le 'hé' final confirme cette analyse de la vocalisation.

Nathan ben Yehiel (qui admettait encore dans son 'Aruk des racines bilittères) classait sous le bilittère סאיאו : הס D deux formes verbales de la Mishna Aboda Zara

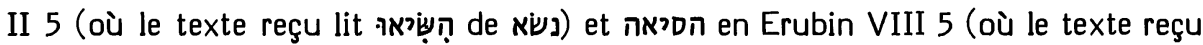
lit העתיקה (= déplacement). Castle a fait entrer cette "racine"dans son Lexicon heptaglotton sous (2444) en lui attribuant le sens de "migravit". Dans la même notice, il le rapproche de l'arabe ס́ qui provient d'une onomatopée par laquelle on appelle les ânes pour qu'ils boivent. Dans la colonne suivante, il suggère que notre סאסאה, que l'on interprète d'ordinaire comme "mensura", pourrait aussi venir de סֵַ au sens de "migrare fecit", le "hé" étant alors un pronom suffixe. Pour fonder cette suggestion, il renvoie aux données qu'il a fournies sous סאא. Et il conclut en faisant remarquer que ce sens s'accorde bien avec le mot suivant :

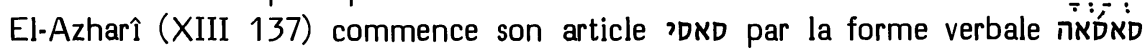
qu'il emprunte à Ibn el-Acrâbî et à laquelle il donne le sens de : "il l'a réprimandé". Plus loin, il çite le kitâb al-`Ayn, le plus ancien dictionnaire arabe, d'où il tire que "le

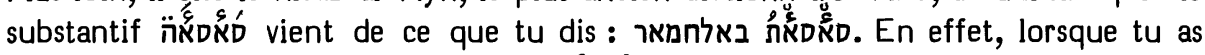
chassé l'âne pour qu'il avance, tu as dit : סאא סאר". 
Donc les bases lexicographiques empruntées par Castle à Nathan ben Yehiel sont sans valeur, mais le rapprochement qu'il suggère avec l'arabe a de bons fondements dans la lexicographie ancienne de cette langue. Aussi ce rapprochement a-t-il été bien des fois repris par les exégètes (cf. König, Lehrgebäude I 655-658). C'est l'option retenue pour notre cas par HALAT.

Gray a critiqué cette dérivation en prétendant que c'est du fait que אֶא סignifie "faire le bruit que font les conducteurs de chameaux ou d’ânes pour accélérer leurs bêtes" que l'on a inféré indûment que le mot en arrive à signifier plus généralement "expulser". A cela, Driver répondait en citant un proverbe arabe où ce verbe est employé au passif avec des personnes et non des animaux comme sujet. Il en concluait justement qu'à la voix active le verbe peut avoir un accusatif de personne comme complément.

Pourtant, le Tahdhib d’El Azharî n'étant pas encore édité à l'époque, Driver ne trouvait dans le Lisân el- ${ }^{\circ}$ Arab d'Ibn Manzêr que la construction du verbe arabe avec la préposition 'bâ' et ne savait pas que Ibn el-A'râbî la construisait avec l'accusatif du suffixe. Ajoutons que le sens de "réprimander" donné par celui-ci à cet emploi du verbe correspond bien à ỏveloí $\zeta \omega \nu$ du *G.

Il est cependant frappant de noter que Ibn Barûn (71), lorsqu'il cherche une étymologie arabe pour בסאסאה, fait appel (sous l'influence du ${ }^{*} T$ ) à סואסקיה, pluriel de סואז́ (= égal).

Concluons donc que l'intuition divinatoire de Castle a peut-être touché juste et nous aide, en faisant appel à l'arabe, à retrouver le sens perçu par le *G. Mais, à partir

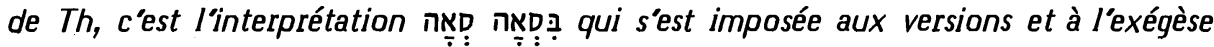
juive.

Cette exégèse traditionnelle interprète le "hé' final comme la finale du substantif, ce qui postule l'absence du mappiq. Tandis que le ${ }^{*} G$ et la dérivation inspirée par l'arabe en font un pronom suffixe, ce qui postule sa présence.

En conformité avec son choix textuel, le comité recommande donc l'interprétation : "mesure pour mesure", mais il pourrait être utile d'indiquer en note que l'on peut comprendre aussi : "en l'effarouchant".

28,1 גיא [B] M Th Aq Sym V S T // modern-graph vel assim-ctext : 1Q-a גאי / assimctext : $\mathrm{G}$

28,4 גיא [B] M V S T // modern-graph vel assim-ctext : 1Q-a גאי / assim-ctext : G

Options de nos traductions :

Le *M offre le mot 2 en un contexte identique au vs 1 et au vs 4 . RSV y traduit ce mot par "valley", J et TOB par "vallée", RL par "Tal".

NEB donne au vs $1:$ "revellers dripping (with perfumes)" et au vs $4:$ "dripping

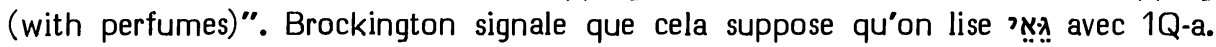

\section{Origine de la correction :}

NEB dépend ici de Driver (Drink 48-50).

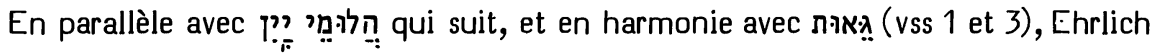


avait proposé de lire גָאִ שמנים . Cette conjecture avait été adoptée par Halévy et Rost (Zu Jesaja). Driver et NEB ont estimé que 1Q-a appuyait cette leçon.

Les témoins anciens :

De fait, 1Q-a écrit ici deux fois גאי.

Le *G écrit deux fois toũ őpous.

Th, Aq et Sym corrigent cela en yáparyos.

La *V traduit par "vallis", la *S par נחלא et le *T par חילא.

Choix textuel :

Th, Aq, Sym, la *V, la *S et le *T appuient clairement le *M.

$L e{ }^{*} G$ a été amené, par la présence de ראש juste avant, à choisir le mot "montagne" comme un génitif apte à le compléter. De la même manière, Yéfet ben Ely considère que ראש גיא désigne les collines.

1Q-a écrit deux fois ici גאי. Il se peut que ce soit le résultat de l'initiative d'un scribe qui aurait harmonisé avec le contexte, ainsi qu'Ehrlich proposera plus tard de le faire. Mais il faut noter avec Kutscher (180) que ce sont toutes les graphies ${ }^{2} \cdot \mathrm{X}$ (que le ${ }^{*} M$ offre en $\left.22,1.5 ; 28,1.4 ; 40,4\right)$ que le scribe de 10 -a semble avoir voulu éliminer (en $22,1.5$ et 40,4 , il écrit ' $\lambda$ sans 'alef').

Pour comprendre la portée de cette option, il importe de noter que, en ce rouleau, la finale 'yod-alef' signifie un ' $̂$ ' long; la présence de la lettre 'alef' ayant pour but d'éviter que l'on considère le 'yod' final comme une consonne ou comme signifiant ביא ,מיא ,כיא (passim), פרביא (40,5), פרביא (34,5) etc. La lettre 'alef' joue un rôle analogue après 'waw' : éviter qu'on le considère comme une consonne ou comme signifiant la voyelle ' 0 ', mais assurer qu'il sera lu comme 'ô'. On la rencontre par exemple en (cf. ci-dessus, p. 61 et Kutscher 171-174). En fonction de ces principes, גיא risquerait d'être lu "gî̀". C'est probablement pour éviter cette vocalisation que le scribe rem-

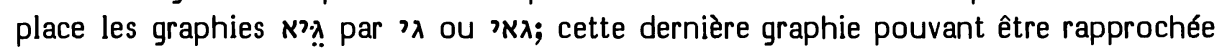

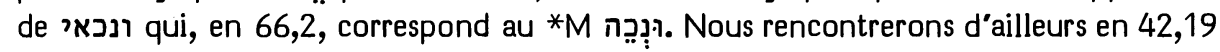
un indice que 1Q-a utilise parfois la lettre 'alef' comme mater lectionis pour le séré.

HUB mentionne ici la traduction אלמקתדרין que Saadya donne pour ce mot et considère comme probable qu'il a interprété à la manière de Ehrlich une graphie identique à celle de 1Q-a. Ce n'est pas impossible. Mais il est également possible que, comme le fera Ehrlich, il a seulement harmonisé au contexte une interprétation qui se fonde sur le ${ }^{*} M$.

Puisqu'il semble qu'il faille retirer à la conjecture d'Ehrlich l'appui que Driver avait cru trouver en $1 Q-a$, le comité a conservé ici la leçon du $* M$ en lui attribuant la note "B", à cause du ferme appui qu'elle reçoit des versions postérieures au *G.

Interprétation proposée :

Driver et NEB, en suivant la conjecture de Ehrlich, avaient proposé pour ce mot le sens de "ruisselant", en s'inspirant très librement de l'arabe. Jackson $(89, n .3)$ considère que Driver n'a pas justifié cette interprétation et il estime qu’elle oblitérerait la référence aux murailles de Samarie qui s'écrouleront aussi vite que se fane la couronne 
de fleurs d'un noceur. Irwin estime que chacun des quatre mots : "couronne, orgueil, buveurs, Ephraïm" par lesquels commence le vs 1 est développé dans la suite du vs : "couronne" par "fleur qui se fane", "orgueil" par "éclat de la parure", "buveurs" par "assommés par le vin"' et "Ephraïm" par "tête de la vallée plantureuse". Il voit en effet en cette "tête" de la vallée une allusion à Samarie qui est la "tête" d"Ephraïm $(7,9)$. Or le parallèle entre Ephraïm et Samarie revient en Is 9,8; Jr 31,5s; Os 7,1. Aussi refuse-t-il la correction susdite qui démolirait cette structure stylistique.

Wildberger suggère que le vs 1 a été, après coup, glosé à partir du vs 4 où il estime (contre Rost) que ג ג est la leçon originale et parfaitement claire : l'orgueilleuse couronne des buveurs d'Ephraïm est ici la capitale Samarie sise sur une colline que l'on peut considérer comme une "tête" dominant la vallée fertile sur laquelle elle sélève.

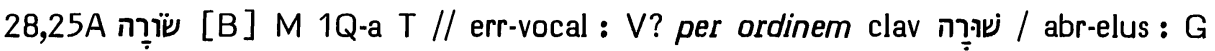
$S$ om

28,25B נסמן [B] M 1Q-a T / exeg : ThAq V / abr-elus : G S om

Options de nos traductions :

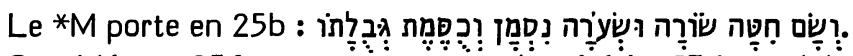

Considérant 25A comme un nom de céréale, 33 le traduit par "le millet". RSV et NEB le traduisent par "in rows", Brockington précisant qu'en NEB cela suppose une correction en שִּרָּ. Notons aussi que RSV traduit 25B par "in its proper place".

C'est à 25A et à 25B que correspond en RL : “ein jedes, wohin er's haben will".

$\mathrm{J} 12$ et TOB omettent $25 \mathrm{~A}$ et $25 \mathrm{~B}$, les considérant comme des synonymes (J1), des gloses (J2) ou des céréales non identifiées (TOB). C'est à ce dernier titre que $\mathrm{J3}$ et NEB omettent 25B; Brockington précisant que, pour cette omission, NEB se fonde sur les mss Sinaiticus, Alexandrinus et Marchalianus du *G.

Origines des corrections :

$\mathrm{RL}$ s'est contentée de rajeunir légèrement la traduction assez libre de Luther : "jglichs wo ers hin haben wil".

L'omission de 25A est requise par les apparats de HSAT24, BH23 et Cent, à titre de dittographie du mot suivant. En requièrent également l'omission : HSAT3 et $\mathrm{BHS}$; cette dernière se fondant, comme $\mathrm{BH} 23$, sur le ${ }^{*} \mathrm{G}$ et la ${ }^{*} \mathrm{~S}$.

Quant à l'omission de 25B, elle est requise par les apparats de HSAT234 à titre de céréale inconnue, par celui de Cent à titre de dittographie du mot suivant et par celui de $\mathrm{BH} 23 \mathrm{~S}$ en se fondant sur divers témoins textuels.

Sans rien noter là-dessus, Lowth avait traduit 25b: "and sow the wheat in due measure; and the barley, and the rye, hath its appointed limit". Koppe crut devoir faire remarquer que l'évêque avait omis $25 \mathrm{~B}$ avec la ${ }^{*} \mathrm{~S}$. Cette interprétation des intentions de Lowth ne semble pas exacte. Dans sa traduction, c'est "appointed" qui rend 25B, ce que l'on peut conclure en la comparant à celle de Ge et de KJ qui, pour les quatre derniers mots du $* M$, donnent : "and the appointed barley and the rye in their place", KJ précisant en marge que l'on peut aussi comprendre : "and barley in 


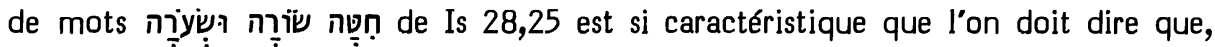
pour l'auteúr de Is 28,25 , שור doit aussi avoir le même sens que dans les lignes 6 et 9 de cette inscription, c'est-à-dire probablement le sorgho. Nous avons en tout cas là un argument très valable pour ne pas partager la crainte de Koppe que ce mot soit une variante de שערה.

Quant à נסמן, mot qui, nous l'avons dit, a été omis par le *G et la *S, la recension origénienne (suivie par la $* \mathrm{~V}$ ) y a vu le mil, alors que le $* T$ (selon la vocalisation du

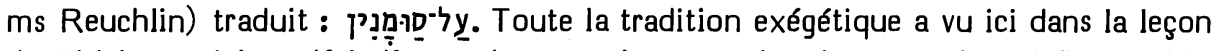
du *M le participe nifal d’un verbe auquel se rattacherait pִ qui, en hébreu mishnique, signifie "marque, repère". On a donc compris : "en un lieu déterminé". On a

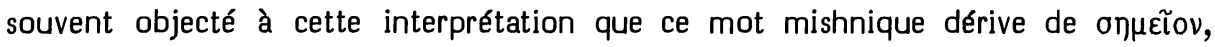
onuaívw et qu'on ne saurait donc y rattacher notre hapax biblique. Cependant König (Wörterbuch 303s) tient fermement à ce sens pour ce hapax, en l'estimant fondé de

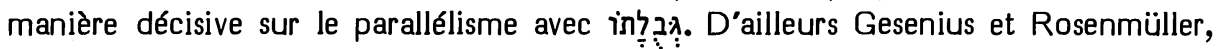
en leurs commentaires, se sont demandés s'il ne faudrait pas inverser l'ordre des dépendances étymologiques, ces mots grecs dérivant plutôt d'une racine sémitique. Chantraine dit de ces mots grecs que leur étymologie demeure obscure: "On répète l'étymologie de Brugmann qui évoque skr. lexical "dhyā-man" n. "pensée" tiré du verbe "dhyấyati" "penser", ce qui va pour la forme mais moins bien pour le sens".

Quoi qu'il en soit des origines de ces mots grecs, Delitzsch semble avoir raison d'assigner au verbe סמן une origine sémitique. Il faut peut-être le rapprocher du mot akkadien très usité (AHw II 1044b) simānu(m) qui désigne le "temps fixé".

Le comité, estimant que la tradition textuelle n'apporte rien qui puisse entrer en concurrence avec les deux leçons difficiles du *M, a attribué à celles-ci la note " $B$ ".

\section{Interprétations proposées :}

En liant גבלתו et au mot qui précède chacun d'eux, les teamim du *M reconnaissent à ces trois substantifs des fonctions analogues d'apposition : "et il met le blé en שורה et l'orge en l'épeautre en lisière de cela". En cette perspective qui correspond à une tradition de lecture ancienne, il faudra donner à שị le sens défini par Dalman : "en rangées". On pourra cependant indiquer en note que le sens originel de ce mot, en ce contexte, semble être de désigner une céréale distincte du blé et de l'orge : vraisemblablement le sorgho.

Quant à נִסְִמִ on l'interprétera, en un cas comme en l'autre, au sens de "en un lieu déterminé".

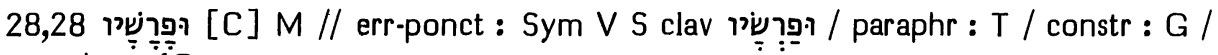
abst : $1 \mathrm{Q} Q-\mathrm{a}$

Options de nos traductions :

Ce mot du *M a été traduit par RSV : "with his horses", par RL: "und ihrem Gespann", par 33 : "et son attelage" et par TOB : "et l'attelage".

312 corrigeait ce mot en וּרְּרִ

Malgré une erreur de placement du point diacritique en Brockington, il semble bien que NEB entende corriger de même pour traduire ici : "and break it up". 
Origine de la correction :

Duhm avait objecté au *M qu'une mention des chevaux est superflue après que l'on ait mentionné le passage de la roue du chariot. Leur place éventuelle, estime-t-il, eût été en avant. Aussi a-t-il proposé cette correction de ponctuation et donné à cette leçon le sens de : "So wirft er es einander".

Les témoins anciens :

Aucun témoin n'appuie formellement le *M.

$1 Q$-a lui est consonnantiquement identique mais ne fournit pas d'indication relevant de la ponctuation.

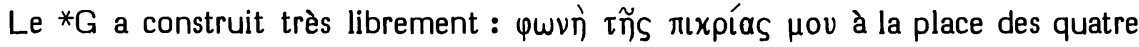
premiers mots de $28 \mathrm{~b}$.

Sym a traduit ce mot par taĩ d'un ongulé. Il a été suivi en cela par la*V et la $* S$. Cette leçon ne convient pas, car le suffixe de la 3e pers. m. sg. se réfère, en ce contexte, au paysan.

Pour les trois derniers mots du vs, le *T paraphrase : "et il sépare le froment et jette la bale au vent".

Choix textuel :

Le *T suppose une interprétation en verbe de ce mot, avec placement du point diacritique à gauche. Sym, la $* V$ et la $* S$ l'ont interprété en substantif en plaçant le point diacritique également à gauche. Quant au *M, il l'interprète en substantif et place le point diacritique à droite.

Il n'y a rien à tirer du ${ }^{*} G$. Quant à $1 Q-a$, on peut seulement en dire qu'il a vu là un substantif.

Radaq avait répondu d'avance aux objections de Duhm en faisant remarquer que $28 b$ reprend en ordre inverse les deux techniques de dépiquage des épis qui avaient été mentionnées en 27a. Les deux mentions des "roues du chariot" (avec le mot différent pour "roue") se correspondent en effet clairement. De même, les "chevaux" (de 28b) correspondent au "trâ̂neau à dépiquer" (de 27a). Cette correspondance chiastique suffit en effet à justifier la mention des chevaux ici. Columelle (2, 20, 4) précise en effet que “s'il s'agit d'écraser le blé sur l'aire, il n'est pas douteux que cela se réalise mieux par des chevaux que par des boeufs, et si l'on dispose de peu de paires de bêtes, tu peux ajouter une tribula et une trahea, deux moyens d'écraser très facilement les épis." Pline l'Ancien dit lui aussi (Hist. Nat. XVIII 298) que "en certains endroits on écrase la moisson avec des tribula sur l'aire, ailleurs sous les pas des juments". Xénophon (Economique XVIII 4) atteste déjà l'usage de chevaux pour le dépiquage.

Le sens du *M étant satisfaisant et les ponctuations divergentes correspondant moins bien aux intentions stylistiques relevées par Radaq, le comité a conservé la leçon du *M en lui attribuant la note "C".

Interprétation proposée :

"Il met en marche la roue de son chariot et ses chevaux, il ne le broie pas." 


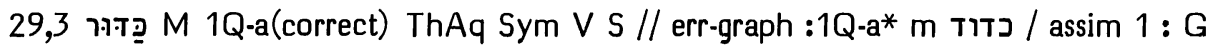

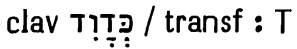

Options de nos traductions :

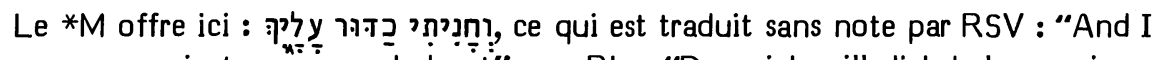
will encamp against you round about", par RL : "Dann ich will dich belagern ringsumher", par NEB : "I will throw my army round you like a wall" et par J3 : "je camperai en cercle contre toi."

J12 avaient traduit : "je camperai contre toi comme David" et TOB traduit : “Comme David, je camperai contre toi," disant s'appuyer sur le ${ }^{*} G$ pour lire

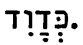

\section{Origines de la correction :}

Cappel (Critica 588s) a relevé que la leçon du *G ("comme David") supposait une lecture en 'dalet' du 'resh' final et il a estimé le sens ainsi obtenu "très commode"; ce qui entraîna une protestation de Buxtorf Jr (622) qui estimait tout aussi "commode" la leçon du *M et remarquait qu'elle a un bon parallèle en 22,18 (que la massore en rapproche).

La leçon "comme David" fut adoptée ensuite par Houbigant, puis par Lowth (notant que la graphie avec 'dalet' final se retrouve en deux mss de Kennicott et peutêtre en deux autres), Bredenkamp, Cheyne, Marti, Oort, Condamin, Ehrlich, Halévy, Schmidt, Procksch, Cent, BHS, HALAT. Kaiser s'est élevé contre le fait que HALAT ait accepté cette leçon à la place de celle du *M qui lui semble préférable à titre de lectio difficilior en face de celle du ${ }^{*} G$ qui assimile au vs 1 . Etant donné les moyens de siège redoutables (vss $3 b, 5$ ) que le Seigneur va mettre en oeuvre, Wildberger estime qu'une référence au siège que David fit subir à Jérusalem établirait une comparaison en porte-à-faux. H. Barth (Worte 185) pense, lui aussi, qu'il vaut mieux en rester à la leçon du *M.

\section{Les témoins anciens :}

La collation de Kennicott a relevé une leçon avec 'dalet' final dans les mss 150 et 245 , ainsi que, peut-être, dans les mss 93 et 158 . HUB a contrôlé le ms 150 et noté que le 'dalet' de la première main y avait été corrigé en 'resh'. Nous avons contrôlé le ms 158 ( $\mathrm{ms}$ des Jésuites de Cologne). La lecture 'resh' y est très probable quant à la forme de la lettre et elle est confirmée par l'absence du rafé en ce ms où tous les 'dalet' non dageshés portent des rafé. Il semble bien en tout cas que dans chacun de ces mss on a (comme dans le ms 158) la vocalisation du*M. Ajoutons que la massore précise que cette forme ne se rencontre que deux fois (ici et en 22,18).

La 2 e main de $1 Q-a$ est identique au $* M$, mais sa 1 e main semble avoir écrit un 'dalet' final. Il paraît s'agir là d'une simple erreur graphique. Si le scribe avait voulu écrire "comme David", il aurait fait usage de la graphie pleine avec 'yod', comme il le fait pour les 9 emplois de ce nom (que le *M écrit toujours défectif en Isaïe).

Le *G porte ici clairement ${ }^{c} \varsigma \varsigma \Delta \alpha v i \delta$.

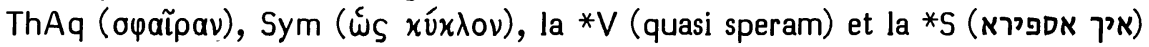
ont lu le *M. 
Dans le *T, il semble que la paraphrase de ce mot (par "en un jour de fête tout autour" donné à la fin du vs précédent) et celle du verbe qui le précède (par "et je ferai camper les armées") ont été interverties.

\section{Choix textuel :}

Ce cas n'a pas été soumis au comité.

Duhm a refusé la leçon du ${ }^{*} G$ parce qu'elle suppose que l'on interprète (ainsi que

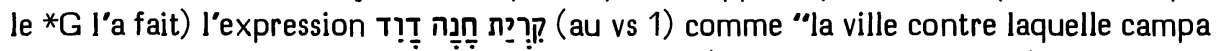
David", alors que la construction de חע (à la différence du vs 3) oriente vers une interprétation : "la ville où David établit son camp", c'est-à-dire où il fixa sa résiחנה avec l'accusatif en Ps 53,6 où nous accepterons le sens "assiéger".

La leçon du ${ }^{*} G$ semble pourtant être une assimilation facilitante au vs 1 , alors que la lectio difficilior du ${ }^{*} M$ est bien appuyée par la $2 e$ main de 1Q-a et l'ensemble des versions postérieures au ${ }^{*} G$.

Interprétation proposée :

Rosenmüller, Gesenius et beaucoup d'autres ont compris "comme le cercle", en se référant à í ú usité par les arabes en poliorcétique. Dunash

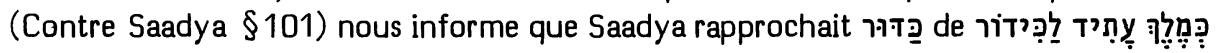
en Jb 15,24 où le contexte montre qu'il s'agit d'une entreprise belliqueuse. Böttcher (Aehrenlese) et Luzzatto ont repris ce rapprochement. Il n'est pas impossible qu'en Is 29,3 , la vocalisation massorétique ait modelé indâment ce mot sur celui qui signifie "ballon" en hébreu plus tardif (et qui est mieux à sa place en Is 22,18).

Il semble bien, en tout cas, qu'il s'agisse ici de "camper en cercle contre", au sens de Lc 19,43.

\section{9,5 זדים זדריך [C] M G? V S T // err-graph 1Q-a G?}

Options de nos traductions :

Ce mot est traduit sans note : "deiner Feinde" par RL, "of your enemies" par NEB, “de tes ennemis" par J3 et TOB.

RSV traduisait "of your foes" en disant faire une conjecture. $\mathrm{J1}$ traduisait "de tes ennemis" en disant corriger et $\mathrm{J} 2$ précisa ensuite que cela supposait la conjecture צריך.

Origine de la correction :

Zwingli traduisait déjà ici le *M par "hostium tuorum" en expliquant que c'est un sens authentique de ce mot hébreu. La traduction des Prédicants de Zurich ("deiner feynden") a fait de même, ainsi que Pellican (en son commentaire), Servet (corrigeant la traduction de Pagnini), Vatable (en ses annotations), Châteillon. HSAT2 traduisait encore "deiner Feinde" sans note. Voir, à ce propos, l'interprétation de Ehrlich (sur 25,5) et de Driver (Ezekiel 148).

C'est Grätz qui a conjecturé ici צִ̣: Cette conjecture a été adoptée par HSAT34 et (avec hésitation) par $\mathrm{BH} 23$. 
Cent se contentait de gloser : "des étrangers, tes adversaires", comme l'avaient fait, jadis, Münster et Rollet.

Les témoins anciens :

1Q-a porte ici $ך$ ' que Lowth avait conjecturé.

Sur la relation entre II et TI, voir ci-dessus notre traitement de 25,2 où nous avons montré que le ${ }^{*} G$, en traduisant ici $\tau \tilde{\omega} \nu$ à $\sigma \varepsilon \beta \tilde{\omega} \nu$, peut avoir lu la leçon du $* M$.

La *V (ventilantium te), la *S (דיושקיכי) et le *T (מבדרין) ont compris ici "tes vanneurs".

\section{Choix textuel :}

C'est d'ailleurs ainsi que le ${ }^{*} M$ est interprété ici par Yéfet ben Ely et Aaron ben Joseph. On retrouvera la même interprétation pour ẹ en Jr 51,2 de la part de AqSym, la *V et Yéfet ben Ely. En Jr 51,2, Radaq donne en premier l'exégèse "étrangers" (c'est-à-dire qu'il voit en cette forme un participe de comme seule interprétation); mais il estime également possible de voir en ce mot un adjectif dérivant de la racine "lamed-hé", comme כִ (Dt 28,32) ou (Lm 5,17) dérivent de racines de ce type.

Sans le savoir, Pagnini, en sa traduction éditée en 1527, suit les mêmes options que Yéfet ben Ely. Il traduit en Is 29,5: "dispergentium te" et en Jr 51,2 : "ventilatores". Dans sa traduction d'Isaïe (publiée en 1528), Luther donne : "die dich zurstrewen", et en celle de Jérémie (publiée en 1532) : “worfler". Qu'il y ait là une influence de Pagnini, cela est rendu évident si l'on remarque que dans la reportatio qu'Antonius Lauterbach a conservée du cours que Luther donna sur ce passage d'Isaïe vers la fin de 1528, celui-ci mentionne deux fois (WA. XXXI/2 173,22 et 24) la "multitudo dispergencium", élément caractéristique de la traduction de Pagnini (en contraste avec "ventilantium te" de la *V ou "alienorum tuorum" d'Oecolampade).

Notons qu'en Is 29,5 comme en Jr 51,2 il s'agit évidemment du vannage. Il est très vraisemblable qu'un double sens "étrangers/ vanneurs" est voulu en ces deux endroits.

$S^{\prime}$ il s'agit de porter un jugement sur la variante de $1 Q-a$, il faut mentionner que Irwin a relevé un indice qui engage à lui préférer en Is 29,5 la leçon du *M : המון apparaît trois fois dans le contexte (deux dans le vs 5 et une dans le vs 7). Ses trois

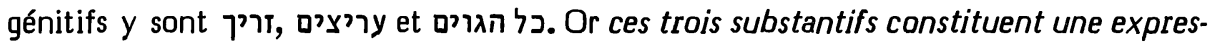
sion stéréotypée en Ez 28,7 et 31,12 : זרים עריצי גוים Leur association ne doit donc pas surprendre en Is 29,5 .

Le comité a attribué ici à la leçon du *M 4 "C $\mathrm{C}$ " et 1 " $\mathrm{B}$ ".

Interprétation proposée :

Ci-dessus (p. 3), nous avons noté que זרים a la connotation de "barbares envahisseurs". C'est son sens ici, sens que nous avions rencontré aussi en 25,2. Il serait bon d'expliquer en note le double sens "étrangers/vanneurs". 


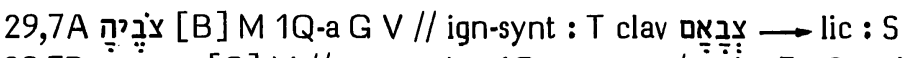

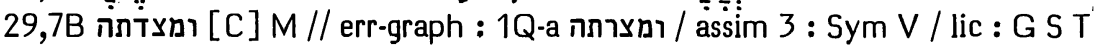

Options de nos traductions :

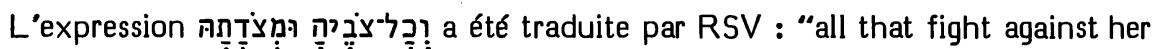

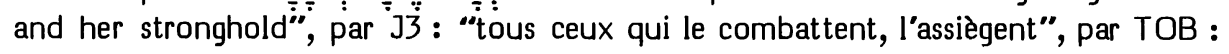
"pour tous ceux qui combattaient contre elle, l'investissaient".

RL traduit : "mit ihrem ganzen Heer und Bollwerk".

NEB traduit: "all their baggage-trains and siege-works". Brockington précise que cela suppose que le premier mot est vocalisé sִ et qu’avec $1 \mathrm{Q}$-a le second est lu •.

j12, traduisant "et de tous ceux qui la combattent, des retranchements" disait

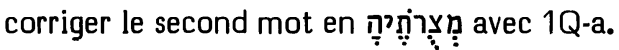

\section{Origines des corrections :}

Une première particularité commune à RL et à NEB consiste à traduire les deux pronoms suffixes féminins singuliers comme s'il s'agissait de pronoms masculins pluriels se référant à "la horde de tous les peuples en guerre contre Ariel" dont il vient d'être parlé. De la part de RL, il ne s'agit pas là d'une correction textuelle mais seulement du maintien d'une liberté de traduction de Luther qui donnait ici : "sampt alle jrem Heer und Bolwerg." Ajoutons que cette traduction suppose aussi que צִיְִ n'est pas compris comme un participe actif mais comme un synonyme du substantif צִבְָּ

Est-ce sous l'influence de la traduction de Luther que Lowth a pris appui sur le *T pour corriger en masculins pluriels les deux suffixes du *M et pour corriger 29,7A en צִבְ:

La vocalisation צִa rapportée par Brockington s'inspire vraisemblablement de l'akkadien șumbu(m) $(=$ subbu) par lequel BDB, KBL et HALAT expliquent le substantif צִ (= litière, chariot à bagages).

Quant à 29,7B, la correction de son 'dalet' en 'resh' avait déjà été proposée, avant la découverte de 1Q-a, par Bredenkamp, Duhm, HSAT34. Bredenkamp voyait en

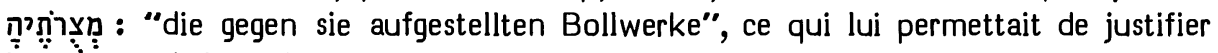
le contenu de la traduction de Luther.

Les témoins anciens :

1Q-a appuie la graphie du *M pour 7A, mais il écrit ומצר pour 7B.

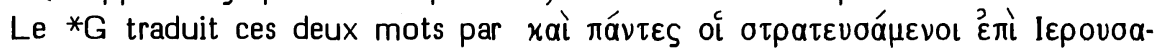

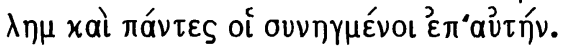

Sym n'est connu que pour 7B (cf. Ziegler, Notizen 89) où il porte roגıopxíal, par assimilation à 29,3 où il a traduit מִ par noגıopxías.

La *V traduit: "et omnes qui militaverunt et obsederunt", n'explicitant le suffixe qu'après le mot suivant : "adversus eam".

La ${ }^{*} S$ a modifié la syntaxe, omettant les deux premiers de ces suffixes ainsi que la conjonction qui suit le second et traitant les deux mots qui les portent comme des substantifs déterminés par le participe pluriel qui les suit. En traduisant 7B par ו, la ${ }^{*}$ S semble dépendre du ${ }^{*} G$ qui, lui, s'était laissé guider par le contexte. 
Le *T, nous l'avons dit, avait déjà pris les deux options qui seront celles de Luther. Il $y$ ajoute une interversion de 7A et de 7B.

\section{Choix textuel :}

Pour la séquence des suffixes féminin singulier en $7 b$, le *M a l'appui de $1 Q-a$, du ${ }^{*} G$ et de la *V (quoique celle-ci n'explicite que le dernier d'entre eux).

La non-écriture de l'"alef' radical en צִ צִ a été signalée par Hayyuj (Kokovzov 26) et ne fait pas difficulté. Nous retrouverons en effet en Za 9,8 un glissement de la forme 'lamed-alef' de cette racine à une forme 'lamed-hé' dans le cas du substantif.

Quant à la construction de ce participe avec un suffixe à l'accusatif (et non précédé par la préposition לy comme aux vss $7 \mathrm{a}$ et 8 ), on en a un bon parallèle en Ps 53,6 (alors que la construction avec cette même préposition est plus fréquente). Irwin a suggéré de façon fort vraisemblable que la forme très ramassée (sans écriture de l"alef' et sans préposition entre le participe et son suffixe) vise à préparer une amplification progressive passant de ce mot très bref à לה. Dans cette séquence qui s'amplifie en progressant, il y a une reprise emphatique de

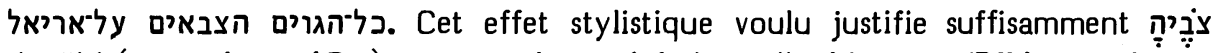
du *M (appuyé par 1Q-a) pour que le comité ait attribué la note " $B$ " à cette leçon.

Nous avons noté que, dans sa traduction, Sym a assimilé ומצדת à de 29,3. La *V a fait de même en traduisant ici "obsederunt" et "in obsidionem" en 29,3. Il n'en va pas de même avec 1Q-a. En effet, s'il écrit en 29,7B un 'resh' au lieu du 'dalet' de la leçon du *M, il avait écrit un 'dalet' au lieu du 'resh' de la leçon du *M en 29,3. On ne peut donc s'appuyer sur lui pour assimiler ces deux leçons. Kutscher (260) semble plutôt avoir raison de suggérer que le scribe savait (par un début de tradition massorétique?) que l'un de ces mots a un 'resh' et l'autre un 'dalet', mais il a pris en cela une option inverse de celle du*M. On trouve en effet entre 1Q-a et le *M une interversion analogue des racines קפז 14,23 et 34,15. Or Irwin a bien montré

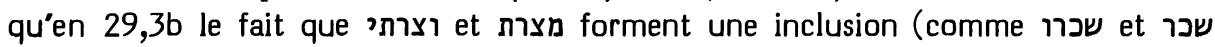
en $29,9 b$ ) indique que c'est la leçon avec 'resh' qui y est bien en place. La tradition ancienne - attestée à sa manière par 1Q-a - sur la différence 'resh/dalet' existant entre ce mot de 29,3b et celui qui nous occupe en 29,7b apporte donc un appui à la leçon du ${ }^{*} M$. Etant donné pourtant l'incertitude qui règne toujours dans la distinction "dalet/resh', le comité a attribué 3 " $C$ " à la leçon du * $M$ et 2 " $C$ " à la leçon de $1 \mathrm{Q}-\mathrm{a}$.

\section{Interprétations proposées :}

La leçon du *M doit être comprise comme le féminin de מִּ avec une vocalisation exceptionnelle en " $\partial$ " (la vocalisation plus courante de ce féminin étant en

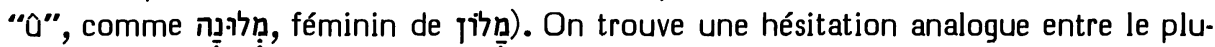

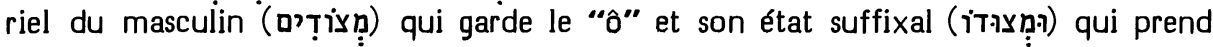
le "a".

Ici ce substantif a une valeur collective d'ouvrages de fortification. Il peut s'agir de fortifications qui défendent Sion (ainsi que l'ont compris Gesenius, Hitzig et Delitzsch). Mais le contexte rend plus vraisemblable qu'il s'agit des ouvrages fortifiés construits contre elle par les assaillants (ainsi que l'ont compris Radaq, Luzzat to et Kaiser). 


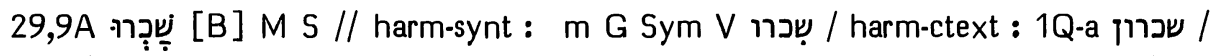
abst :

29,9B בְנד [B] M S // harm-synt : 1Q-a Sym V imp / abr-styl : G om / abst : T

Options de nos traductions :

Toutes nos traductions rendent ces deux accomplis par des impératifs : RSV : "be drunk ... stagger", J : "soyez ivres ... titubants", RL : "seid trunken ... taumelt", NEB : "be drunk ... reel", TOB : "soyez ivres ... titubez". Seul Brockington note que cela suppose des corrections vocaliques en le ${ }^{*} \mathrm{G}$ et la seconde sur la $* \mathrm{~V}$.

Origine de la correction :

Les accomplis à la 3e pers. qu'offre ici le $* M$ sont déroutants entre 9a qui est à l'impératif et 10 où réapparaîtront des suffixes de la 2e pers.

La *V avait assimilé aux impératifs de 9a en traduisant ici : "inebriamini ... movemini". La vieille traduction allemande (Kurrelmeyer VIII 425,54) avait donc ici : "werdet trunck ... wert bewegt". Luther n'a pas eu l'attention attirée sur la vocalisation en accomplis des verbes hébreux. Préoccupé surtout de corriger l'interprétation lexicale du second verbe (qu'il traduit : "daumelt"), il garde la traduction du premier ("werdet truncken"). Il se peut qu'en cela Luther ait été influencé par le fait qu'Oecolampade, lui aussi, avait gardé les impératifs de la *V. Les ont suivis en cela : Brucioli, Olivetan et Jud.

Pagnini, lui, avait traduit fidèlement ces deux verbes comme des accomplis à la 3e pers. pl. Mais il avait même étendu cette traduction aux deux verbes qui les précèdent. Cette option caractéristique a été suivie par Münster, Rollet, Calvin, Estienne, Châteillon, Ge.

Tremellius avait respecté les valeurs d'impératifs du $2 \mathrm{e}$ et du $4 \mathrm{e}$ verbes du vs, mais traduit les 4 autres en accomplis $3 e$ pers. pl.

Traduisent tous les verbes du vs par des futurs : Zwingli, Prédicants, Pellican.

Le premier exégète à avoir respecté exactement la succession de temps du *M semble avoir été Foreiro, suivi par Pasteurs, $\mathrm{KJ}$ etc.

Michaelis (OEB) semble avoir été le premier critique à proposer de fonder sur les divergences de certains témoins textuels une correction formelle du *M en impératifs. La familiarité avec la traduction de Luther explique en partie que cette traduction ait été adoptée par les apparats de HSAT34, BH23S et Cent.

Les témoins anciens :

Michaelis avait relevé des vocalisations en impératif de 9A dans l'édition de Nissel et dans celle de Buxtorf. A cela, de Rossi (IV Appendix) ajoute deux de ses mss et la 1e main d'un 3e. HUB mentionne également cette vocalisation dans le ms 93 de Kennicott.

Il est vraisemblable que 1Q-a a vocalisé en impératif 9B qu'il écrit נעור (alors que, pour l'accompli culté syntactique). Quant à 9A qu'il écrit שכרון, Yalon (Rec. Burrows 168a) y avait vu un accompli avec nunation (cf. ci-dessus en Is 26,16 ). Mais, du fait que le scribe 
semble ne pas avoir respecté l'accompli qui suit, Kutscher (324) semble avoir raison

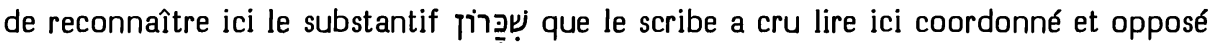
au substantif l?.- $_{.}$. Kutscher suggère une explication de l'erreur du scribe en notant que le qal du verbe est inusité en hébreu rabbinique où le nitpael tient sa place.

Le ${ }^{*} G$ a traduit $9 A$ par un impératif ( stylistique.

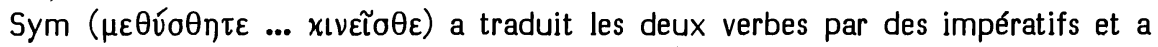
été suivi en cela par la $* \mathrm{~V}$.

Avec des participes, la $* S$ donne une traduction du $* M$.

Le témoignage du *T est équivoque, la vocalisation de la 3e pers. pl. de l'accompli et celle de l'impératif pluriel ne se distinguant pas pour les deux verbes 'lamed-yod" dont il fait usage ici.

Choix textuel et interprétation proposée :

Rosenmüller a bien noté qu'après avoir dit à ses interlocuteurs: "Soyez stupides et stupéfaits, soyez aveugles et sans vue", il offre ceux-ci en spectacle au public: "Ils se sont enivrés, mais non de vin; ils ont titubé, mais non de boisson", puis il interpelle à nouveau ceux dont il vient de parler : "car le Seigneur a versé sur vous un esprit de torpeur, il a fermé vos yeux...". Nous retrouverons une alternance analogue en 41,21s : 2e pers. pl. en 21, 3e pers. pl. en 22a et 2e pers. pl. en 22b.

Le comité a choisi avec 4 " $B$ " et 1 " $C$ " la lectio difficilior du * $M$ dont le relief stylistique mérite d'être mis en valeur.

\section{9,22 אֶּ [A ] M 1Q-a Sym V // exeg : G S T}

Options de nos traductions :

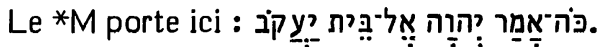

RSV traduit : "Thus says the LÓRंD ... concerning the house of Jacob".

RL traduit : "spricht der HERR ... zum Hause Jakob".

Ainsi que le précisent $\mathrm{J} 2$ et Brockington, les autres traductions conjecturent une vocalisation de (la maison de....)" (TOB), "the God (of the house of...)" (NEB).

Origine de la correction :

Nos traductions ont pu trouver cette correction requise par les apparats de HSAT34, BH23S et Cent.

C'est Lowth qui a suggéré de lire ici le nom divin au lieu de la préposition, estimant d'une part que cela convient mieux à la relative qui suit, et d'autre part que les paroles introduites par ce début de verset ne s'adressent pas directement à la maison de Jacob.

\section{Les témoins anciens :}

Cette conjecture n'a aucun appui textuel ni traditionnel.

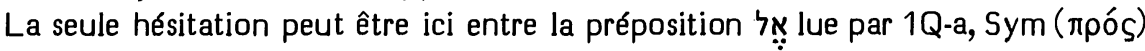




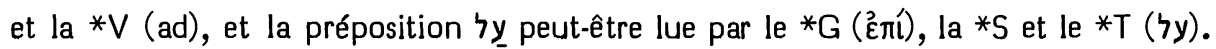
Mais cette variante éventuelle nous éloignerait de la possibilité de lire ici un nom divin. Il est cependant plus probable que ces versions ont seulement donné une exégèse exacte du sens que revêt ici la préposition du ${ }^{*} M$.

Choix textuel :

Envisageons les deux objections de Lowth contre le *M:

$1 /$ La première critique la place de la relative dans le $* M$. König justifie cette place en disant que l'on n'a pas voulu séparer la préposition אמר qu verbe qui la gouverne. En effet, si l'on avait reporté le complément אל־בית יעקב après la relative, on aurait pu comprendre à tort : 'le Dieu de la maison de Jacob'. Par contre, le contenu de la relative montre avec évidence que l'antécédent du relatif est le Seigneur. Aussi cette proposition peut-elle être éloignée sans difficulté du nom divin, celui-ci devant demeurer juste après le verbe dont il est le sujet, pour ne pas écarteler l'expression classique כה־אמר יהוה.

2/ La seconde objection méconnaît d'autres cas en Isaïe où la préposition hֵ: après un verbum dicendi, introduit celui dont on parle et non celui à qui l'on parle. Ainsi en 37,21 : "à propos de Sennachérib", en 37,33 : "à propos du roi d'Assur", ce second cas étant très semblable au nôtre. Voir aussi ci-dessous notre traitement de 38,19 .

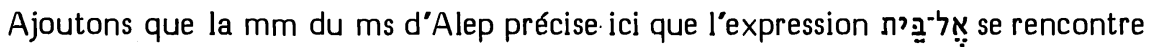
deux fois en ce livre (ici et en 2,3), cela pour éviter qu'on l'assimile aux expressions plus fréquentes על־יבית (14,17).

Face à la conjecture, le comité a attribué la note " $A$ " à la vocalisation de ce mot en préposition.

Interprétation proposée :

Il n'est pas impossible de garder ici à la préposition son sens courant, ainsi que Luther (suivi par RL) l'a fait: "Le Seigneur a parlé ainsi à la maison de Jacob".

Il semble pourtant préférable de comprendre avec KJ (et RSV): "Le Seigneur a parlé ainsi, à propos de la maison de Jacob."

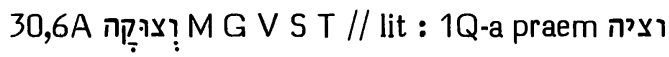

Options de nos traductions :

TOB est ici seule à corriger le *M en ajoutant "et de l'aridité" après "au pays de la détresse, de l'angoisse". Elle dit emprunter cette ajoute à 1Q-a.

Origine de la correction :

TOB semble assez isolée dans son adoption de cette ajoute qu'elle place d'ailleurs après $6 A$, alors que 1Q-a l'a avant. 


\section{Les témoins anciens :}

1Q-a est seul à ajouter וציה. Talmon (Aspects 113) estime que c'est une variante (due vraisemblablement à une erreur graphique) destinée à l'un des deux mots qui l'entourent. Un scribe l'aurait insérée indûment dans son texte. Koenig (Herméneutique 237-248) motive par la spiritualité essénienne cette leçon de 1Q-a et la suivante. N'y a-t-il pas là un anachronisme?

\section{Choix textuel :}

Ce cas n'a pas été soumis au comité.

Peut-être sous l'influence de cette ajoute, 1Q-a va donner à la place de $6 \mathrm{~B}$ une leçon facilitante s'harmonisant avec elle. Ces deux retouches s'inspirent de Dt 8,15 et de Ps 63,2.

TOB n'est pas conséquente en ne suivant 1Q-a qu'en 6A (mais pas en 6B).

$L$ 'analogie existant entre la forme de ce mot et celle des deux qui l'entourent rend possible que son absence dans les autres témoins soit due à une haplographie. Cependant l'association qui existe en 1Q-a entre ce "plus" et la leçon facilitante qui suit rend vraisemblable que la leçon plus sobre et plus difficile du ${ }^{*} M$ est ici primitive.

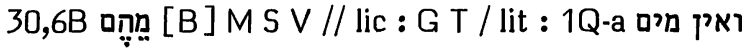

Options de nos traductions :

Le *M a été traduit assez explicitement par RSV ("from where come").

C'est également le $* M$ qui doit se trouver à la base des traductions plus libres de RL ("wo ... wo") et de TOB ("de ... du ... de ... du").

Par contre, J dit conjecturer añ lorsqu'elle traduit "rugissant"; alors que Brockington nous informe que NEB conjecture מي lorsqu'elle traduit "roaring".

\section{Origines des corrections :}

Grätz (Geschichte II/A 235, n.1) a proposé de lire ici "rugissent", en corrigeant en הִמִ̣ la leçon "inintelligible" du *M. Ensuite Klostermann (cité par Bredenkamp) a conjecturé añj que HSAT34, BH23 et Cent ont adopté ici. A la suite de S. Grünberg (cité par König), BHS a gardé les consonnes du *M en proposant ici un participe hifil

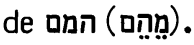

\section{Les témoins anciens :}

$1 \mathrm{Q}$-a a pris une initiative littéraire (inspirée par sa leçon de $6 \mathrm{~A}$ ?) en écrivant à la

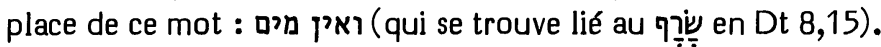

La *V (ex eis) et la *S (ומנהון) appuient formellement la leçon du *M que le *G ( $\varepsilon x \varepsilon \tilde{I} \theta \varepsilon v)$ et le *T ( = le lieu de) traduisent librement.

\section{Choix textuel :}

Un participe au sens de "rugissant" semblerait en effet, à première vue (après les deux noms d'animaux qui précèdent), créer un bon parallèle par rapport au participe "volant" (après les deux noms d'animaux qui suivent). Cependant, König a 
montré le caractère illusoire du parallélisme ainsi créé en faisant remarquer que "volant" spécifie formellement le substantif qui le précède et lui seul; alors que "rugissant" s'appliquerait aux deux substantifs qui le précèdent, et cela comme une simple épithète décorative.

Dans le cas de la plus attrayante des conjectures, celle de Grünberg, König ajoute que le verbe המה, que I"hébreu biblique n'utilise qu'au qal, $n$ 'y a pas le sens de "mugir, rugir".

Estimant la leçon du ${ }^{*} M$ solidement attestée, le comité lui a attribué 4 "B" et 1 “C”.

Interprétations proposées :

Le *M est susceptible de deux interprétations. Ou bien le pronom pluriel désigne formellement les habitants et par enallage leur pays. On traduirait alors : “... là d'où (surgissent) lion et lionne, vipère et dragon volant". Ou bien ce pronom se réfère à צרה וצוקה (König, Syntax §346q), ces bêtes fauves constituant certains de ces périls. On traduira alors: "Au pays de la détresse et du péril - la lionne et le lion en sont, la vipère et le dragon volant - ils apportent leurs richesses sur le dos des ânes...". Cette deuxième interprétation est plus vraisemblable.

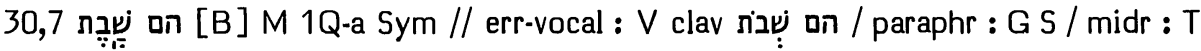

Options de nos traductions :

Le $* M$ nous offre, comme une désignation emblématique de l'Egypte, les trois mots :

Voici ce que nos traductions offrent pour cela: RSV : "Rahab who sits still";

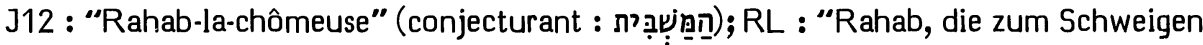
gebracht ist"; NEB : "Rahab Quelled" (Brockington disant qu'elle conjecture : ת) l'immobile".

Origines des corrections :

Rahab apparaît ailleurs (Ps 87,4) comme un surnom de l'Egypte avec laquelle ce mot est ici en parallèle. En lisant dans le *M juste après ce mot : שבת on comprend que les critiques, à partir de la fin du XVIIIe siècle, aient été tentés d'unir cela en המשבת, voyant là un épithète de Rahab. Ce participe doit être vocalisé en piél de שבת selon Doederlein (cité par Vogel) et (indépendamment de lui) Lowth, en hifil de שבה selon Vogel, en hofal de שבה soederlein2 (en 1780). Michaelis (OEB XI 155 et XIVa 98) préfère le hifil de שבת, suivi par Bredenkamp, BH23 et J12; alors que Hensler (cité par Gesenius) en préfère le hofal, suivi par Gunkel (39), Budde (sur Jb 9,13), Dillmann/Kittel, Cheyne, BH235, Cent, NEB, J3 et probablement RL.

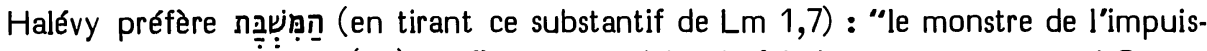
sance". Enfin Schunck (52) préfère un participe hofal de שוב, ce pour quoi Cent a opté elle aussi. 
Les témoins anciens :

On est frappé de remarquer que la coupure entre le $2 e$ et le $3 e$ de ces trois mots est déjà clairement attestée par 1Q-a (qui passe à la ligne entre ces deux mots, alors

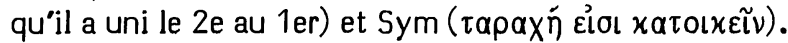

Le *G (suivi par la *S) a d'abord paraphrasé en s'inspirant d'une option prise par lui en 28,29. Il semble avoir repris ensuite שבת en $x a \theta i ́ \sigma \alpha \varsigma$ du vs 8. La *V est plus près du texte et a compris le dernier mot comme un impératif du verbe שבת. Le *T a profité de la difficulté du texte pour y broder un midrash.

\section{Choix textuel :}

Certains exégètes récents ont préféré interpréter le *M plutôt que le corriger. Ainsi Donner (159) et Kaiser.

De fait, le pluriel הם correspond à celui de 7a. Ici il reprend le mot רהב en y explicitant les Egyptiens comme désignés par ce surnom. Il y a une opposition voulue entre ce qu'évoque la racine רהב (= turbulence importune) et le substantif

Comme Delitzsch l'a bien compris, le pronom de la 3e pers. sert ici à identifier, comme en Gn 14,2.3 etc.

C'est à la fois à cause de ses appuis textuels anciens et à cause de sa difficulté que le comité a donné ici au *M 3 "B" et 2 " $\mathrm{C}$ ".

Interprétations proposées :

Les teamim relient les deux premiers de ces trois mots. On peut donc comprendre : "eux (que l'on appelle) Rahab (= turbulence), (ils sont) inaction"; ou bien : "(seraient-)ils Rahab ? (ils sont) inaction !"

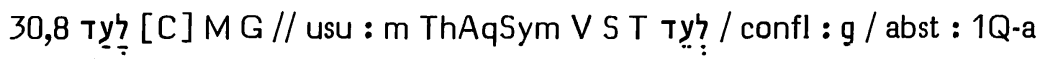

Options de nos traductions :

En 30,8b, le *M offre :

C'est traduit par RL: “dass es bleibe für immer und ewig" et par 33 : “que ce soit pour un jour à venir, pour toujours et à jamais."

Le *M est corrigé explicitement par J12 : “pour servir dans l’avenir de perpétuel témoignage" et par NEB : "that it may be there in future days, a testimony for all time." Elles vocalisent tỵ, Brockington précisant que cette correction a l'appui d'Aquila.

Cette correction se limitant aux voyelles, elle n'est pas signalée en RSV : “that it may be for the time to come as a witness for ever", ni en TOB : "et que ce soit pour l'avenir un témoin perpétuel".

Origine de la correction :

Dans sa traduction, Oecolampade (en 1525) avait traduit לִ ici par "usque in aeternum". Dans la traduction qu'il publie deux ans plus tard, Pagnini garde ici la traduction de la*V : "in testimonium". Vraisemblablement sous son influence, Luther, 
dans la traduction d'Isaïe qu'il publie en 1528, donne ici : "das es sey ein zeugnis". C'est dans son Thesaurus (en 1529) que Pagnini explique (col. 1657) que pour traduire ainsi le *M, il s'est appuyé sur le commentaire de Radaq qu'il traduit ainsi : “Nam populus rebellis est, ut testificari feci (העידותי) illis per prophetas, quibus tamen non obtemperarunt. Idcirco scripta est increpatio, scriptum est malum illis venturum, ut sint testes (כדי שתהיה לעדות)." L'option de Pagnini a été suivie par Olivetan, Rollet ("en tesmoingnage") et Foreiro (in testimonium). Quant à Luther, son cours sur Isaïe (WA. XXXI/2 186,6) donnait ici : "et sit illis in testimonium perpetuum". Mais, à partir de 1534, il corrige sa traduction de $8 \mathrm{~b}$ en : “das es bleibe fur und fur ewiglich". Sous son influence, Estienne, en 1553, donnera pour cela, en corrigeant Olivetan : "a fin qu'elle demeure a tousiours et a iamais". Tous les autres traducteurs du XVIe s. semblent avoir compris le *M au sens de "a perpétuité".

Cependant, après Foreiro, une tradition d'exégèse du ${ }^{*} M$ au sens de "en témoignage" s'est continuée (sans conscience de corriger le texte) chez Clericus (quod erit monumentum), Grotius (testimonium) et Houbigant (ad testimonium). Ont conscience de corriger pour pouvoir lire ainsi : Lowth, Michaelis (OEB), Gesenius, Rosenmüller, Knobel, Ewald, Knabenbauer, Bredenkamp, Delitzsch, Grätz, Duhm, Dillmann/Kittel, Marti, Cheyne, puis les apparats de HSAT234, BH23S et Cent.

\section{Les témoins anciens :}

De Rossi (Scholia) a rencontré le 'aïn' vocalisé șéré en l'un de ses mss et dans la $1 \mathrm{e}$ main d'un autre.

$1 Q$-a appuie la graphie du $* M$, mais on ne peut savoir comment ses lecteurs le vocalisaient.

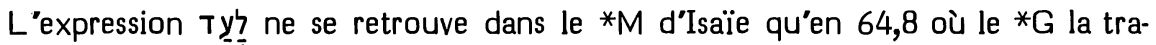
duit ẻv xaıpữ. Notons d'autre part qu'en 8,23 le *G a paraphrasé le mot אַ sans

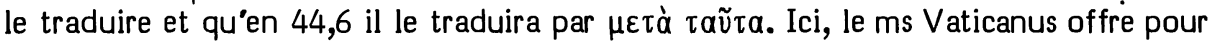
8b : OTI ECTAI EIC HMEPAC TAYTA KAIPW KAI EWC EIC TON AIWNA. II semble bien que l'on ait ici une ruine de l'état originel du ${ }^{*} G$ : (META) TAYTA $(E N)$ KAIPW qui appuierait donc le $* M$. Ici l'antiochienne a une leçon gonflée unissant celle du *G et celle de ThAqSym qui, pour les deux mots hébreux susdits,

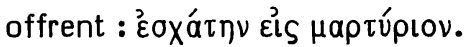

Ce sens de "en témoignage" a également été donné au mot que nous étudions par la *V, la*S et le *T.

\section{Choix textuel :}

La leçon du *M est retenue par Vitringa (après des hésitations), Hitzig (l'estimant plus probable parce que ce mot est encadré par deux déterminations temporelles), par Luzzatto et par Delitzsch1 (qui voit un climax entre ces trois déterminations temporelles: pour l'avenir, pour le plus lointain avenir, pour l'avenir sans fin) et von Orelli.

Deux membres du comité ont attribué la note "B" à Tỵ?, impressionnés par les parallèles de Dt 31,19.21.26; Jos 24,27 et faisant remarquer que lorsqu'on veut

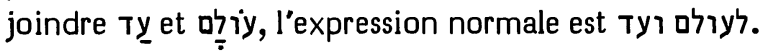


Cependant, deux membres du comité ont attribué la note " $C$ " au *M et un autre "B", estimant que Tỵ est une facilitation suggérée par le contexte; alors que Jb 19,24

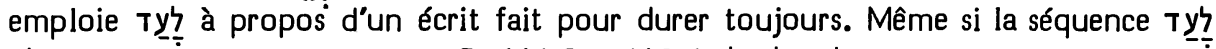

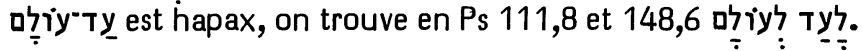

\section{Interprétation proposée :}

Nous avons mentionné ci-dessus la traduction assez fidèle de J3. Ajoutons à cela la traduction plus libre mais suggestive de Châteillon : "qui dure pour le temps à venir, à jamais au grand jamais".

\section{0,17 אחד (10) [B] M 1Q-a 4Q163 of $\gamma^{\circ} T$ // abr-transl : G V S om}

\section{Options de nos traductions :}

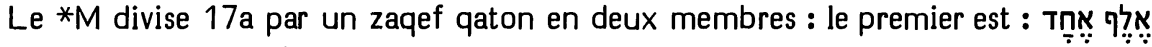

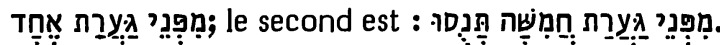

Certaines de nos traductions ont explicité dans leur traitement du premier membre le verbe qui figurera dans le second. C'est le cas de RSV : “A thousand shall flee at the threat of one"; RL: "Denn euer tausend werden fliehen vor eines einzigen Drohen"; NEB : "When a thousand flee at the challenge of one".

TOB a cru traduire fidèlement le *M en évitant cette explicitation : "Mille et un seront sous la menace d'un seul".

$\mathrm{J12}$ traduisaient : “Mille s'enfuiront à la menace d'un seul" et $\mathrm{J} 3$ traduit : "Mille trembleront devant la menace d'un seul", ces trois éditions disant lire du deuxième mot.

\section{Origine de la correction :}

Les exégètes ont été gênés par l'absence de verbe dans le premier membre et par l'apparente absence de climax entre le premier et le second membres.

Pour répondre à la seconde difficulté, Houbigant et Lowth ont voulu insérer dans le second membre un nombre supérieur à "mille".

Duhm a cru résoudre les deux difficultés à la fois en considérant le premier membre comme une glose. Il ajoutait qu’une expression comme אלף אחד "n'est supportable que dans une glose".

Ehrlich a cru répondre à toutes les difficultés en conjecturant la correction qui sera adoptée par $\mathrm{J123}$ (à travers l'apparat de $\mathrm{BH} 3$ ). Il interprète ainsi 17a : "Mille trembleront à la menace d'un seul, et à la menace de cinq vous prendrez la fuite."

\section{Les témoins anciens :}

Sur tous les points où le *M de 17a fait difficulté, il est appuyé entièrement par une citation en 4Q163 (fr. 23) et (à part une omission du second הרת) par 1Q-a.

"Les trois" ( = ThAqSym) appuient formellement le *M avec Xıاıàs $\mu$ ía.

Le ${ }^{*} \mathrm{G}$, la $* V$ et la ${ }^{*} S$ ont estimé pouvoir se dispenser d'expliciter leur traduction. En cela, ils ont l'accord de Judah ibn Balaam et de Radaq qui considèrent ici ce mot comme superflu (de même que lorsqu'il suit איש en 1 S 1,1). 
Cette impression que ce mot est superflu a été partagée par le scribe d'un fragment d'un midrash sur Qohélet, trouvé dans la Genizah du Caire (Ginzé Schechter I $169,4)$. Il omet en effet ce mot en une citation de 17a.

\section{Choix textuel :}

Il est apparu au comité que la non-traduction de אח (10) et même son omission en une citation ne sont que des allégements secondaires, la présence de ce mot en *M étant solidement appuyée par 1Q-a, 4Q163 et "les trois". Aussi a-t-il attribué la note "B" à la leçon du *M.

Interprétations proposées :

Luzzatto estime que ce mot vise ici à établir une correspondance plus explicite avec אחד ( $\left(2^{\circ}\right)$ : "un millier devant la menace d'un", plutôt que "mille devant la menace d'un".

Gesenius, Ewald, König donnent à אלף אחד le sens de “mille à la fois". Yéfet ben Ely propose d'interpréter cela comme "un millier rassemble" (et non un millier dispersé). Si la menace d’un seul est capable de faire fuir un millier rassemblé, quelle serait son effet sur des dispersés! Ajoutons à cela que pour comprendre la syntaxe du *M en ce premier membre, il faut y sous-entendre le verbe qui figure dans le second membre. C'est d'ailleurs ce que la plupart des traducteurs ont fait à la suite du *G.

D'autre part, Hitzig a bien montré que le climax entre le premier et le second membres de 17a est clair si l'on considère 17 b comme un complément du verbe par lequel s'achève 17a : “devant la menace de cinq, vous prendrez la fuite jusqu’à ce qu'il ne reste de vous que comme un mât au sommet d'un mont et comme un signal sur une colline." C'est-à-dire que cinq suffiront, par leur menace, à mettre en fuite presque tous les habitants du pays. Ce sens serait affaibli si - à la suite du *G, de Houbigant ou de Lowth - on insérait un chiffre, même très élevé, après ce verbe.

30,19 יחנך [B] M G Sym V S T // expl : 1Q-a add tetragram

Options de nos traductions :

Seule NEB a senti le besoin d'expliciter le tétragramme comme sujet de ce verbe : "the LORD will show you favour". Elle fonde cette initiative sur le témoignage de $1 \mathrm{Q}-\mathrm{a}$.

Origine de la correction :

NEB peut dépendre ici de l'apparat de BH7 qui mentionne formellement ce 'plus'.

Les témoins anciens :

A côté de cette explicitation en 1Q-a, il faut noter la non-explicitation du sujet divin en tous les autres témoins textuels.

Choix textuel :

L'explicitation du sujet est évidemment facilitante. Sa non-explicitation dans le 
*G (qui, par ailleurs, comprend l'infinitif absolu précédant le verbe 3e pers. comme un impératif) est une preuve suffisante du caractère originel de la leçon sobre du ${ }^{*} M$ à laquelle le comité a attribué la note " $B$ ".

Interprétation proposée :

La présence du tétragramme en 18b et de 20a, ainsi que l'emploi des verbes et en ce passage, suffisent à éviter toute ambiguïté sur le sujet de ce verbe.

30,22 [A [A] M G Aq V S // lic : T / abst : 1Q-a

Options de nos traductions :

Le *M a été traduit par RSV : "you will scatter them"; J : "tu les rejetteras"; RL : "und werdet sie wegwerfen" et TOB : "Tu les jetteras".

Selon Brockington, NEB a vocalisé

Origine de la correction :

C'est Perles (II 60) qui a conjecturé ici cette vocalisation (au sens de "tu les abhorreras") dérivée d'une racine זיר qu'il rapproche de l'arabe et de l'akkadien, racine à laquelle se rattacherait aussi (avec une valeur intransitive) بִ en Jb 19,17 qu'il comprend comme "est horrible".

Driver (Notes 45s), sans citer Perles, et en gardant le sens de "être étranger", propose la même vocalisation. Il y voit un hifil à valeur dénominative : "tu les trajteras comme étrangers (c'est-à-dire illicites)."

BH3S ont adopté cette vocalisation. BHS suggère que le *T peut avoir lu ainsi.

\section{Les témoins anciens :}

De fait, le *T se sert ici du afel de רחק (répété 3 fois) pour traduire aussi bien

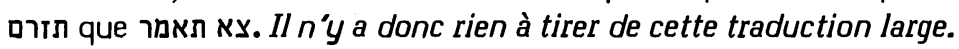

Le *G, Aq, la *V et la *S ont rattaché ce verbe à la racine rinsi que la vocalisation du *M le suggère. Le *G a cependant dédoublé en deux actes successifs le traitement que subissent ici les idoles : elles sont broyées finement et dispersées. Cela peut $s^{\prime}$ inspirer du traitement subi par le veau d'or en Ex 32,20 ou par la statue en Dn 2,34.

\section{Choix textuel :}

Le *M a reçu du comité 4 " $A$ " (de la part de membres qui estimaient que toute la tradition textuelle se rattachait au $* M$ ) et 1 " $B$ " (de la part d'un membre qui estimait que le ${ }^{*} \mathrm{~T}$ pouvait avoir eu une autre Vorlage).

Interprétation proposée :

La vocalisation du *M rattache cette forme à la racine זרה qui signifie: "disperser au vent la menue paille par le vannage". Ici, "disperser" a le sens de "jeter au loin", ce qui est aussi le sens de ce verbe en Nb 17,2 à propos de braises dont le contact est interdit. Le contexte de ce passage s'accorde bien avec ce sens. 
Options de nos traductions :

Ce mot du *M a été traduit par RSV : "the towers", J : "les forteresses", RL : "die Türme", TOB : "les tours".

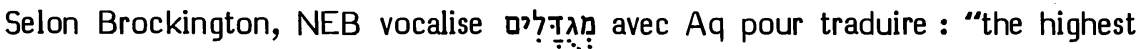
in the land".

Origine de la correction :

Cappel (Critica 812) a fait remarquer qu'en Is 33,18 Sym, en traduisant tov̀s

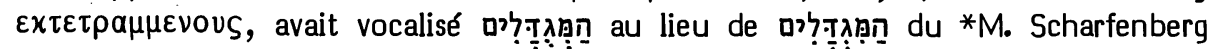
note là-dessus ( $n$. 551) que la même vocalisation est requise par la leçon de ThAq ( en Montfaucon. De fait, pour Aq, mieux vaut lire en Is 33,18, avec Eusèbe : tov̀s $\mu \varepsilon \gamma a \lambda$ uvoú́vous.

En 30,25 Lowth n'a pas donné à ce mot le sens de "tours", mais de "puissants" en notant que Sym, Aq et le *T ont compris ainsi. Michaelis (OEB), s'inspirant d'Aq, vocalise ce mot en participe piél ou hifil. Doederlein et Koppe choisissent la vocalisation en piél. Gesenius critique cette vocalisation comme ne pouvant avoir un sens intransitif. Rosenmüller estime que les versions mentionnées ont seulement voulu exprimer le sens de la métaphore hébraïque. Presque tous les exégètes suivants sont de son avis.

Aussi NEB est-elle assez isolée à vouloir corriger la vocalisation de ce mot en participe pual "avec $A q$ ", nous dit Brockington.

Les témoins anciens :

$1 Q$-a est identique au $* M$, mais on en ignore la vocalisation.

Le *M est compris comme "tours" par le *G, la *V et la *S.

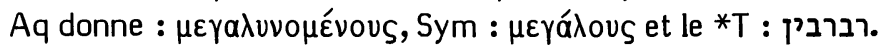

Le ms Barberini offre pour ThAq une leçon douteuse : $\mu \varepsilon \gamma a \lambda \omega v$ únous. Field

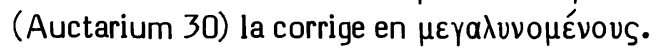

Choix textuel :

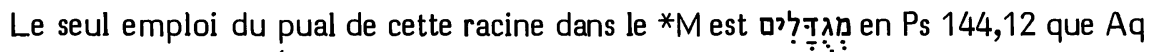
traduit par $\mu \varepsilon \mu \varepsilon \gamma \alpha \lambda \nu \mu \mu \varepsilon ́ v \alpha$.

Etant donné le littéralisme de ce traducteur, le fait qu'il n'utilise pas ici (Is 30,25)

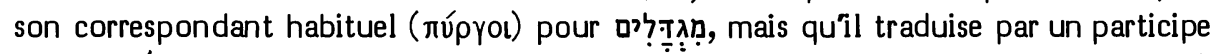
de $\mu \varepsilon \gamma a \lambda u ́ v \varepsilon ı \nu$, semble indiquer qu'il a vocalisé ce mot autrement que ne l'a fait le $* M$.

Il faut cependant préférer la vocalisation du ${ }^{*} M$ car, ainsi que Irwin l'a noté, le vocabulaire de 2,14s est repris en 30,25 qui s'en inspire évidemment. C'est pourquoi le comité a attribué à la vocalisation du *M la note " $\mathrm{B}$ ".

Interprétation proposée :

On traduira donc "tours"; mais la mention (juste avant) du "grand massacre" montre que ce mot est à prendre au sens métaphorique. 


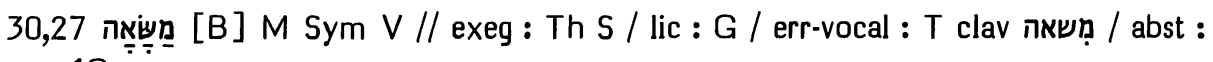
$1 \mathrm{Q}-\mathrm{a}$

Options de nos traductions :

Les mots and in thick rising smoke"; par J12: "ardente est sa colère, lourde son oppression"; par RL : "Sein Zorn brennt, und mächtig erhebt er sich"; par TOB : "sa colère est ardente, écrasante"; par 33 : "ardente est sa colère, pesante sa menace".

Ce n'est que pour NEB ("his anger blazing and his doom heavy"), qu'une correction vocalique en

\section{Origine de la correction :}

Si l'on remonte dans l'histoire des traductions anglaises, on notera que $\mathrm{KJ}$ donnait : "and the burden thereof is heavy", indiquant par l'emploi de l'italique qu'elle ne lisait pas 'thereof' dans le *M mais l'ajoutait pour rendre plus coulante sa traduction. Il est intéressant de noter que la Geneva Bible, en 1560, traduisait déjà de même, mais écrivait ce mot en caractères romains, réservant à 'is' l'italique. En effet, les traducteurs genevois pouvaient lire dans les notes qu'Estienne ajouta en 1557 à sa réédition de la traduction de Pagnini que la traduction littérale du *M est ici "et gravitas oneris ejus", le possessif (qu'Estienne a ajouté à la note de Vatable) n'étant pas écrit en italique. Ce possessif vient de "grave onus ejus" que Calvin donne en lemme en son commentaire (en 1551). D'ailleurs, Calvin n'avait pas été le premier à avoir interprété le 'hé' en pronom-suffixe (féminin ?) quoiqu'il n'ait pas de mappiq. Saadya (qui lisait certainement le *M) faisait déjà de même (ורים הולה

Les témoins anciens :

La graphie de ce mot avec "hé" final est appuyée par 1Q-a dont nous ne savons comment il interprétait cette lettre.

Le *G n'a pas tenu compte du 'hé', considérant ce mot comme un état construit dépendant du substantif suivant.

Th, la *S (et le *T) ont interprété ce 'hé' comme un pronom suffixe de la 3e pers. m.sg.

En outre, le *T a interprété le 'mem' initial de ce mot comme étant la préposition מן.

Sym et la *V ont interprété ce mot comme un nom d'action : "l'acte de porter".

\section{Choix textuel :}

La continuité existant entre Th, la *S, Saadya, Calvin, Estienne, Ge et KJ montre qu'il s'agit ici d'une exégèse qui est 'dans l'air', plutôt que d'une variante dans la ponctuation.

H. Barth (71) a noté que, dans cette théophanie du "nom du Seigneur", tous les substantifs porteurs d'un suffixe 3e pers. m. sg. ("sa narine", "ses lèvres", "sa langue", "son souffle") sont des anthropomorphismes accentués. Il n'est donc pas conseillé de placer משאה (qui n'exprime ni une partie, ni une fonction du corps) en parallèle direct avec eux. 
Le comité a considéré ici l'interprétation en suffixe de ce "hé" comme une exégèse qui assimile indûment au contexte. Aussi a-t-il attribué à la leçon du *M la note " $\mathrm{B}$ ".

Interprétation proposée :

Pagnini (et gravitas oneris) est presque le seul à avoir reconnu à Tiّ sa valeur de substantif abstrait, alors que ce mot est très généralement traduit en adjectif, comme s'il était vocalisé qameṣ et séré. Dans la plupart des cas, il s'agit là d'une simple facilitation spontanée.

Quant à añ 6,1 , comme une colonne de fumée qui s'élève. Ainsi que Sasson (Unrecognized 92) l'a noté, le pluriel de ce substantif se trouve dans la lettre IV 10 de Lakish (cf. Torczyner 79). Selon Luzzatto, le mot כבד en dit la densité, l'épaisseur, comme c'est le cas pour l'adjectif de même racine, à propos de la nuée sur le Sinaï en Ex 19,16.

La traduction littérale serait donc: "sa narine est ardente et lourdeur d'exhalaison"; le mot "narine" (= colère) ayant deux prédicats dont le premier dit l'aspect feu et l'autre l'aspect fumée.

Une traduction plus libre, avec une légère retouche syntactique, peut être : "sa narine est ardente et ce qui s'en exhale est épais".

En tout cas, l'image de l'exhalaison dense et le contexte (lèvres, langue, souffle) engagent à ne pas remplacer le signifiant (narine) par le signifié (colère).

30,32 מוסדה [C] M V // lic : G T / harm-ctext : 1Q-a / err-graph : m S

Options de nos traductions :

TOB n'a pas traduit explicitement ce mot.

RSV le traduit par "punishment" et RL par "Zucht" sans rien noter. J donne : "châtiment" et NEB : "chastisement", J2 et Brockington précisant que cela suppose une correction en מוּר avec quelques mss.

Origine de la correction :

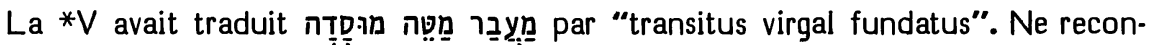
naissant aucun sens acceptable au 3 e mot ni à l'interprétation que la $* V$ en donne, Clericus propose de corriger le 'dalet' en 'resh' et donne au mot ainsi obtenu le sens de "châtiment" ou de "supplice" qui lui semble convenir fort bien au contexte. Lowth, ayant trouvé cette leçon en deux mss, l'adopte, estimant que la *S a lu ainsi. Il est suivi par Michaelis (OEB), Knobel et Cent; alors que Duhm a préféré lire le "hé" final en suffixe 3e pers. m. sg., suivi par Marti, Oort, Condamin, Feldmann, BH23S, Fohrer, Irwin et Wildberger. Ce dernier s'est laissé induire en erreur par BHS qui prétendait que les "quelques mss" qui lisent un 'resh' au lieu du 'dalet' vocalisent ce 'resh' avec un ḥolem. BHS est arrivée à cette donnée erronée en resserrant indûment l'annotation de BH23 qui était : "I c nonn MSS מוסרוּ, vel potius מוּסרוּ".

Les témoins anciens :

De Rossi (Scholia) attribue à deux mss de Kennicott, à la première main d'un de 
ses mss, ainsi qu'à trois éditions de Pesaro, une variante avec 'resh' à la place de 'dalet'. Cette variante se retrouve en un ms et une édition de Wayyiqra Rabba $(661,3)$ et comme $2 \mathrm{e}$ exégèse du glossaire $\mathrm{C}$.

Le *G et le ${ }^{*} T$ semblent avoir traduit largement le *M; alors que 1Q-a s'en distingue en écrivant un 'waw' ( = suffixe 3e pers. m. sg.) à la place du 'hé' final.

Lowth, de Rossi et Warszawski ont suggéré que la *S (דשועבדא) a lu la variante avec 'resh' en sa Vorlage. Mais, en Pr 22,15, la *S traduit מוסר (employé comme génitif de שבט) par par peut donc hésiter ici sur sa Vorlage.

\section{Choix textuel :}

Contre les variantes avec 'resh', Ehrlich a fait valoir que מוסר signifie une peine qui a pour but l'amélioration du sujet, alors que le Seigneur entend détruire Assur et non l'améliorer.

Quant à l'interprétation du 'hé' final en suffixe possessif, c'est l'option que prend le glossaire $E$ et celle que le glossaire $D$ offre en second et le glossaire $C$ en troisième. Radaq (Mikhlol 26b) cite en effet notre mot comme un cas où le 'hé' final est un suffixe 3e pers. f. sg., quoiqu'il n'ait pas de mappiq. De fait, la massore atteste cette particularité pour notre mot qu'elle intègre dans une liste de 18 ou 19 cas de mots où le 'hé' final est sans mappiq, bien que le contexte postule une exégèse en suffixe. Cette liste est donnée par Ginsburg (Massorah $\pi$ \$37) et la Okhla (Frensdorff $\$ 43$ et Diaz Esteban \$44), ainsi que le ms Paris BN héb 1 et le ms Vatican ebr 448 sur Ex 2,3, ou encore les trois listes amplifiées que le ms Londres BL Or 4445 offre sur Ex 2,3; 9,18 et Lv 1,15. Cette massore est éditée dans la massore finale ( $\$ 15$ ). Cependant elle paraît absente des mss tibériens classiques (Alep, le Caire et Leningrad) qui se contentent de noter parfois en mp si ces formes sans mappiq sont uniques, sans suggérer (en les regroupant) une exégèse.

Il est d'ailleurs frappant de noter qu'en accord avec la quasi-totalité de l'exégèse juive médiévale, le même Radaq, dans son commentaire, semble traiter ce 'hé' final comme une simple désinence féminine.

Le comité a estimé devoir protéger le *M (appuyé par la $* V$ ) contre les diverses facilitations que beaucoup lui préfèrent. Il lui a at tribué la note " $C$ ".

\section{Interprétation proposée :}

Le mot מוסדה est considéré comme un participe hofal par Saadya, Yéfet ben Ely, Ibn Ezra, Isaïe de Trani; et comme un substantif par les glossaires, Radaq, Abravanel (alors qu'Eliézer de Beaugency hésite entre ces deux analyses).

Parmi les exégètes plus récents, Vitringa voit ici un participe et, rapprochant cela de $\mathrm{Ha}$ 1,12, il considère que c'est Assur qui est "le bâton institué" par le Seigneur.

Dans la tradition tibérienne classique, מטה est vocalisé avec șéré (et non segol). Luzzatto a fait remarquer que cette vocalisation engage à le considérer comme un état construit, ce qui entraîne une interprétation du mot suivant en substantif.

A la suite de Gesenius, Rosenmüller, Hitzig et Delitzsch, König (Wörterbuch) donne à ce mot le sens métaphorique de "chose décidée", c'est-à-dire "destin". On interprétera donc: "Et chaque passage du bâton du destin, que le Seigneur appliquera sur lui (= sur Assur), sera accompagné par des tambourins et des cithares." Il s'agit donc des coups qu'Assur recevra du Seigneur. 
גם 30,33 ג

NEB omet cette phrase en la considérant (avec HSAT3 et BH23) comme une addition au texte original. Mais un tel jugement relève de la critique littéraire et non de la critique textuelle.

Le comité a donné " $B$ " au *M pour indiquer qu'il présente certaines difficultés. Celles de nos traductions qui ont conservé ce passage n'ont pas fait choix d'autres leçons de préférence au $* M$. Le comité $n$ 'a donc pas traité formellement de ces difficultés.

32,6 חושב [C] M ThSym V //exeg : 1Q-a T

Options de nos traductions :

Le *M porte ici : רִ ְִ qui est traduit par RSV : "and his mind plots iniquity", par RL: "und sein Herz geht mit Unheil um", par TOB : "et dans son coeur il médite le mal" et par $\mathrm{J3}$ : "et son coeur s'adonne au mal".

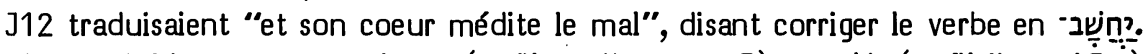
Brockington hésite entre cette leçon (qu'il attribue au ${ }^{*} G$ ) et in (qu'il lit en $1 \dot{Q}-\hat{a}$ ) pour justifier la traduction "and will hatch evil in his heart" de NEB.

Origines des corrections :

Grätz s'appuie sur le ${ }^{*} G$ et sur la ${ }^{*} S$ pour corriger le verbe comme $J 12$ le fera. Cette correction a été adoptée par Duhm12, Marti, Cheyne, Condamin (s'appuyant aussi sur le *T), HSAT34, Procksch et Cent. Duhm5 (s'inspirant du *T?) suggère plutôt une forme de תשת.

La découverte de 1Q-a a été interprétée par Burrows (Readings I 20), Ziegler (Vorlage 55), James (101-103) comme appuyant les versions contre le *M.

Les témoins anciens :

1Q-a, à la place de ce verbe, porte חושב.

Le *G traduit par vońocl, la *S par nשת שתתין.

ThSym (

Choix textuel :

Orlinsky (Studies I 154) a relevé que, lorsque le *M d'Isaïe porte le verbe le *G use toujours de $\lambda$ oүí (240) ajoute que la *S fait de même. Le fait que ThSym et la *V appuient formellement le $* \mathrm{M}$ et que les trois versions aberrantes usent ici de correspondants autres que ceux par lesquels elles traduisent ailleurs חשב laisse donc penser qu'elles n'ont pas lu une Vorlage semblable à 1Q-a, mais qu'elles ont improvisé sur la base du *M. Orlinsky (ibid. 155) a d'ailleurs relevé que Rashi et Radaq glosent ici y en faisant spontanément usage de la racine חשי

Le verbe פעל d'alleurs employé pour une action commise "avec le coeur" en Ps 58,3, ou pour un dessein que l'on conçoit sur sa couche en Mi 2,1. D'autre 
part, le יֶֶר est ce que "façonne" le coeur en Gn 8,21. En ces contextes, il n"est pas étonnant que le $* M$ fasse usage de עש pour l'action du coeur qui est de concevoir et de méditer. Et il n'est pas plus étonnant que des copistes (1Q-a) ou des traducteurs aient préféré exprimer cette action de manière plus explicite : méditer, concevoir, etc. Ajoutons que le "coeur" est à l'origine de l'action selon l'anthropologie biblique (Nb 24,13; Mt 5,28; Mc 7,21s).

Le comité a attribué 5 "C" au * $M$ et 1 "C $C$ " à $1 Q$-a.

Interprétation proposée :

Ici, la leçon du *M aboutit à une construction chiastique : "parler", "faire", "faire", "parler".

On peut traduire : "Car l'insensé dit l'insanité et son coeur commet le mal en commettant l'impiété et en disant sur le Seigneur des choses aberrantes."

32,13 [B] M 1Q-a V T // abr-styl : G S om / err : m om

Options de nos traductions :

Après avoir dit: "Sur le sol de mon peuple, épines et ronces croîtront", le *M ajoute un second complément de lieu, parallèle au premier, sous la forme :

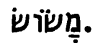

Ces mots sont traduits par RSV : "yea, for all the joyous houses", par J12 : "sur toute maison de joie", par RL : "um alle Häuser voll Freude", par NEB : "in every happy home", par J3: "comme sur toute maison joyeuse", par TOB : "sur toutes les maisons joyeuses".

Donc seule RSV traduit clairement כי, en conservant la traduction de Ge et KJ. $\mathrm{J} 3$ traduit comme si elle lisait כy. Les autres ne tiennent pas compte de la particule, seule d'entre elles NEB notant qu'elle l'omet avec le *G.

Origine de la correction :

Halévy a suggéré que ce כי est le faux départ d'un copiste qui avait commencé à écrire la ligne suivante. HSAT34 et $\mathrm{BH} 23$ proposent de l'omettre sans se fonder sur aucun témoin textuel. Cent fonde cette omission sur le ${ }^{*} \mathrm{G}$ et la ${ }^{*} \mathrm{~S}$, alors que BHS la fonde sur "un ms", HUB précisant qu'il s'agit d'un ms de la collation de Kennicott.

\section{Les témoins anciens :}

Le ms 178 que Kennicott signale comme omettant ce mot est le ms Copenhague Kong Bibl hebr 2. Ce mot y a été omis par la 1e main. Mais le vocalisateur, notant cette omission, l'a réparée en marge. Cette simple étourderie d'un scribe ne saurait servir d'argument textuel.

De fait, le ${ }^{*} G$ et la $* S$ ne rendent ce mot que par une simple conjonction. Mais cela ne prouve pas avec certitude qu'il était absent de leur Vorlage.

$1 Q$-a est d'accord avec le *M pour l'attester.

$L a * V$ (quanto magis) et le *T (ארי) ont lu le *M. 
Choix textuel :

Une omission de כי manquerait donc de témoignage textuel formel et serait facilitante. C'est ce que le comité a exprimé en attribuant la note " $B$ " au *M.

Interprétations proposées :

En Is 3,24 nous avons estimé vraisemblable que ’ִ̣ ait valeur de substantif au sens de "trace de brôlure". Ici aussi, Tremellius a traduit : "ustio (in omnibus domibus laetis)". KJ donne comme alternative en marge la traduction: "burning". Cocceius (cité par Vitringa) et Vogel préfèrent ici ce sens. Michaelis (Supplementa 1220s) propose, en fonction du stique précédent, de voir ici en (= brûlure) l'ortie dont le nom, en latin (urtica) comme en allemand (Brennessel), évoque une plante "brûlante". Ce nom serait parfaitement en place en ce contexte, mais aucune confirmation lexicographique n'en a été fournie (ce que Michaelis reconnaît d'ailleurs en OEB XXII 14s).

כe retrouve, au sens de "certes", en 1 Ch 29,11, employé pour introduire avec emphase un nouveau substantif dans la même fonction que d'autres qui le précèdent. C'est le sens qui est ici aussi le plus probable.

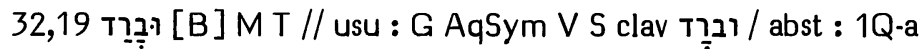

Options de nos traductions :

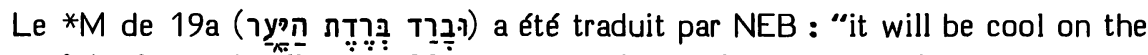
slopes of the forest then" et par TOB : "mais la forêt s'écroulera sous la grêle".

J12 traduisaient : "la forêt sera abattue" et 33 : "et si la forêt est complète-

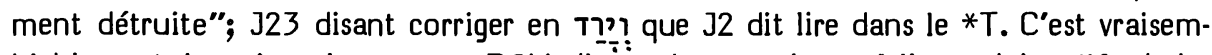
blablement la même leçon que RSV dit conjecturer lorsqu"elle traduit : "And the forest will utterly go down". RL (“aber der Wald wird niederbrechen") semble aussi la présupposer.

Origine de la correction :

La correction proposée par 323 a d'abord été conjecturée par Secker, se référant à $\mathrm{Za} \mathrm{11,2.} \mathrm{Lowth} \mathrm{a} \mathrm{signalé} \mathrm{cette} \mathrm{leçon} \mathrm{comme} \mathrm{attestée} \mathrm{par} \mathrm{un} \mathrm{ms} \mathrm{de} \mathrm{la} \mathrm{Bodléienne} \mathrm{(le}$ ms 30 de Kennicott). Elle a été adoptée par Koppe, Doederlein, Bredenkamp, Grätz, Duhm, Marti, Halévy, Feldmann, Procksch, Fischer, Ziegler (EB), Fohrer, Wildberger, ainsi que par les apparats de HSAT34, BH23S et Cent.

Les témoins anciens :

La mp imprimée et celle du ms du Caire signalent comme hapax la vocalisation patah de la $2 e$ syllabe de ce mot (alors que la même forme se rencontre trois fois avec cette syllabe vocalisée qameș).

Cependant le *G, AqSym, la *V et la *S semblent l'avoir lu en substantif, en l'assimilant aux autres occurrences avec qameṣ.

Consonnantiquement identique au ${ }^{*} \mathrm{M}, 1 \mathrm{Q}$-a ne saurait témoigner sur ce point.

Quant à la variante du ms 30 de Kennicott, HUB nous apprend qu'elle n'est attestée que par la première main de ce ms. Cette faute de scribe, éliminée par le correcteur, n’a donc aucune valeur de témoignage textuel. 


\section{Choix textuel :}

Dillmann/Kittel a fait remarquer que la leçon רִ רִ ne serait ici en place que si

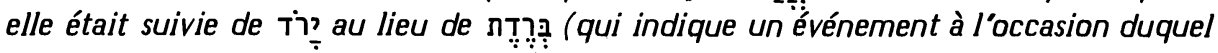
a lieu celui qu'exprimé le verbe initiali).

Quant à la lecture de la 2e syllabe avec patah ou avec qameș, le comité a attribué la note " $\mathrm{B}$ " à la leçon hapax du *M pour la protéger contre une assimilation facilitante à la vocalisation plus usuelle.

\section{Interprétation proposée :}

S'inspirant de l'arabe, Reider (Contributions 88) a compris le verbe initial comme “il fera froid". Driver (TLP 52s), puis NEB interprètent de même. Ils ne semblent pas se douter que Saadya a déjà cru déceler un contraste froid/chaleur entre les deux stiques de ce vs.

Si l'on tient compte de l'expression ירד יער en Za 11,2, le sens normal du *M est ici : “Et il y aura de la grêle tandis que la forêt s'abattra". C'est ainsi qu'il a été compris par Yéfet ben Ely. Cependant Rashi et Radaq ont compris ברדת comme un substantif dérivé de la racine ברד = grêle : "et il grêlera une grêle de la forêt", ce qui signifierait que la ville sera protégée de la grêle, celle-ci ne tombant que sur la forêt. Ont compris de même : Pagnini (en 1527) : “Grandinabit autem grando in sylva", suivi par Brucioli (en 1532). Mais en son Thesaurus (en 1529), Pagnini (col 273) traduit exactement : "et grandinabit in descensu sylvae".

L'auteur de ce texte a voulu réaliser une paronomase artificielle où fait

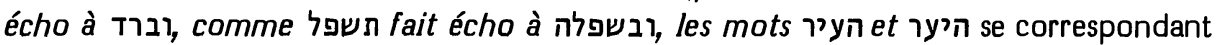
aussi. Une autre paronomase artificielle existait entre et 15 יער 15 au vs

TOB a traduit largement mais exactement : “Mais la forêt s’écroulera sous la grêle et la ville tombera très bas."

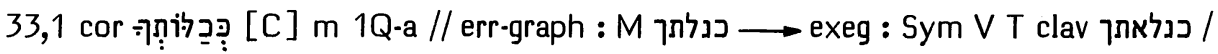
harm-ctext : G, $S$

\section{Options de nos traductions :}

Le mot traduction essentiellement identique à celle de $\mathrm{KJ}$ : “when thou shalt make an end to". RL l'a traduit : "wenn du ein Ende ... gemacht hast" (= Luther).

Les trois autres traductions donnent des interprétations identiques. Mais, alors que $\mathrm{J12}$ et TOB traduisent sans note par : "quand tu auras fini", NEB et J3 disent que

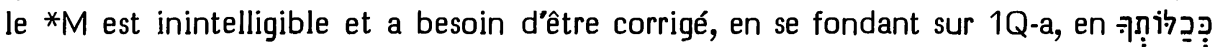
pour être traduit par: "after all your (betrayals)" (NEB) ou : "quand tu auras terminé" (J3).

Origine de la correction :

Cappel (Notae 513) semble avoir été le premier à demander de corriger ici en

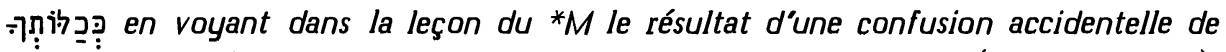
'kaf' àvec 'nun'. Cette proposition a été adoptée par Vogel, Secker (cité par Lowth), 
Doederlein. Michaelis (OEB), très attiré par cette conjecture, n'ose cependant l'adopter sans l'appui d'aucun témoin manuscrit, “car la leçon est si coulante qu'elle n'aurait pas disparu de tous les mss, au cas où elle serait de la main d'Isaïe". Gesenius (Thesaurus 888) l'adopte pourtant, suivi par Knobel, Luzzatto, Bredenkamp, Delitzsch4, von Orelli, Grätz, Duhm, Dillmann/Kittel, Marti, Cheyne, Oort, Ehrlich (Miqra), Halévy, Procksch, Fischer, Ziegler (EB), Fohrer, Irwin, Wildberger, HSAT234, BH235, Cent.

Les témoins anciens :

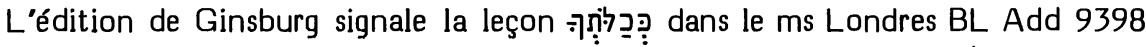
(allemand du XIIIe s.). Mais il est plus important de noter que 1Q-a (seul témoin pour ce passage à Qumrân) porte ici ככלותך.

Le ${ }^{*} G$ avait ici dans sa Vorlage un mot inintelligible pour lui (vraisemblablement la leçon du*M). Aussi s'est-il laissé entièrement guider par לבגד (qui suit immédiatement) compris comme "pour un vêtement". Cela l'a amené à traduire : ẃ ò̀s ('żi íaríov), croyant trouver ici la comparaison qui sera développée en 50,9 et 51,7s.

Sentant que, du fait du net parallélisme entre les deux stiques qui constituent $1 \mathrm{~b}$, le mot en question doit avoir un sens semblable à celui de tentée de répéter ici sa traduction de ce mot parallèle.

Sym (ó̃av xomıáọ̣), la *V (cum fatigatus desieris) et le *T (כד תלאי) ont vu ici la racine לאה avec chute du 'alef' : "lorsque tu te seras fatigué".

\section{Choix textuel :}

Comme Abulwalid (Opuscules 155s) l'a bien vu, les vocalisateurs ont rapproché

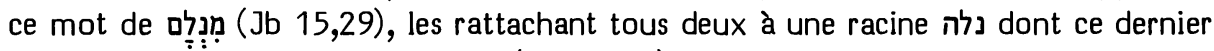

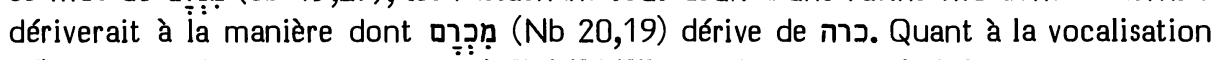

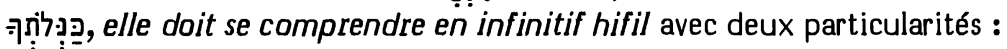

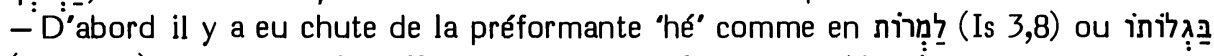
(Jr 27,20). Notons que la préformante est attestée en un ms Kennicott.

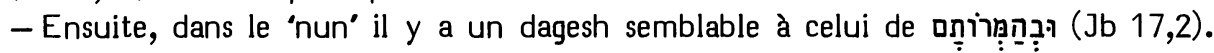
Judah ibn Balaam précise que ce dagesh vise ici à éviter une confusion dans la prononciation, parce que le 'nun' et le 'lamed' sont émis par le même organe.

David ben Abraham (II 273,6s) présente en deuxième lieu cette interprétation en suggérant un lien avec la racine arabe ניל (= obtenir). Le sens serait donc: "lors de ton obtention de la trahison". Il est cependant frappant que Judah ben Qoreish (que nous suivrons en adoptant cette analyse en Jb 15,29) n'a pas eu l'idée de la proposer ici (pas plus que Saadya et Yéfet ben Ely) et que David ben Abraham lui-même (ibid., l. 8ss) lui préfère une troisième interprétation selon laquelle il s'agirait (ainsi que Sym, la *V et le *T l'ont pensé) de la racine לאה.

Cependant, la première interprétation rapportée par David ben Abraham (ibid., 1. 4ss où il la juge "faible"), attribuée à Ibn Giqatilla par Judah ibn Balaam, et présentée comme sienne par Hayyuj en son commentaire de $1 \mathrm{R}$ 18,44 (Kokovzov 9), est que le 'nun' de ce mot est excédentaire et qu'il faut donc l'interpréter comme

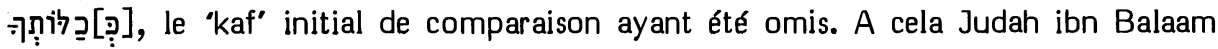


objecte qu'il n'est pas dans l'habitude des Hébreux d'ajouter un 'nun' qui n'a pas de sens, et d'omettre une particule qui détermine le sens.

Il est frappant de noter que - tout en suivant Menahem ben Saruq pour rattacher ce mot et celui de Jb 15,29 à un bilittère נל - Rashi et les glossaires (ACDEF) estiment qu'ici ce mot a le même sens que ככלותך. Radaq, en adoptant l'analyse d'Abulwalid, donne à ce mot le sens de "lorsque tu achèveras, lorsque tu finiras". Il a été suivi en cela par Reuchlin (325) et par Pagnini (Thesaurus 1421).

Gesenius a fait remarquer que le piél de כלה correspond aussi au hifil de תמם Dn 9,24, alors que les qal de ces deux racines se correspondent en Is 16,4.

Etant donné qu'ici c'est une simple faute de copiste qui sépare l'une de l'autre la leçon כנלתך a cest la leçon celle de ces deux leçons que le parallélisme poétique fait attendre ici qui a le plus de chances de représenter le texte original. Aussi le comité a-t-il attribué 5 "C $C$ " et 1 "D" à la variante de $1 Q$-a.

Interprétation proposée :

"Quand tu auras achevé de..."

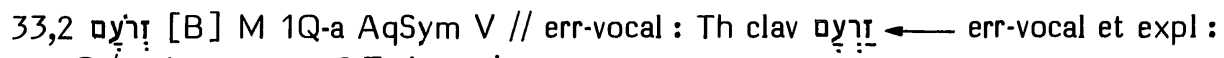

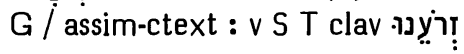

Options de nos traductions :

Dans le *M, le mot fixes de la 1e pers. pl. qui le précèdent et un suffixe de la 1e pers. pl. qui le suit. Il n'est donc pas étonnant que nos cinq traductions aient toutes assimilé ce suffixe à ceux qui l'entourent.

Brockington et $\mathrm{J12}$ attribuent cette correction en זִ à "quelques mss", J ajoutant à cela des "versions".

Origine de la correction :

Estimant que le latin ne peut se permettre de tels changements de personnes, Clericus a traduit par un possessif de la $1 \mathrm{e}$ pers. pl. Houbigant corrige le *M estimant qu'il a été victime d'une erreur de copiste. Cette correction a été adoptée ensuite par la plupart des exégètes, jusqu'aux apparats de HSAT234, BH23S et Cent.

\section{Les témoins textuels :}

BH23 attribuent à "nonnulli manuscripti" la leçon זִּ De fait, en ses Scholia, de Rossi la signale comme attestée par la première main de son ms 2. Dans ses Variae Lectiones, il disait que l'édition de Venise 1518 (= la Bible rabbinique de Félix de Prato) donnait en marge la leçon זינתינת. Lowth, Kennicott et Michaelis s'exprimaient déjà ainsi et HUB reproduira cette donnée. Or la Bible rabbinique de Félix de Prato donne en marge תינו sans que - en aucun des deux exemplaires que nous avons contrôlés (l'un de la British Library et l'autre du Vatican) - ne figure dans la ligne aucun circellus permettant de repérer le mot sur lequel porte cette variante. En cette ligne, le mot auquel elle correspondrait le mieux est ישועתנו pour lequel Kennicott 
mentionne 18 codices porteurs de cette graphie pleine du 'yod'. Les "nonnulli manuscripti" se réduisent donc à la première main d'un seul manuscrit.

Cette lectio difficilior du $* M$ se retrouve en $1 Q$-a.

Le pronom suffixe de la 3e pers. pl. est attesté aussi par Th et AqSym, ainsi que par les meilleurs témoins de la *V (où elle est confirmée par le Correctoire de Guillaume de Mara) et par Hie.

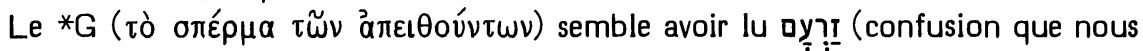
retrouverons en 48,14 et qui sera conservée ici par Th), avec le souci d'expliciter le pronom suffixe de la $3 e$ pers. pl., ce que le traducteur a fait en laissant s'exprimer sa prédilection pour le mot å $\pi \varepsilon 1 \theta \varepsilon i ̃ \nu$ (cf. Seeligmann 105).

On ne s"étonnera pas qu'une part notable de la tradition textuelle ait assimilé le suffixe de la $3 e$ pers. pl. aux trois suffixes de la 1e pers. pl. qui l'entourent. C'est le cas d'une forme glosée du *G ("semen nostrum") citée par le Speculum (399). On retrouve le possessif sous cette forme assimilée dans une grande partie des témoins de la*V et en tous ceux de la ${ }^{*} S$ et du*T.

\section{Choix textuel :}

La leçon du *M est apparue au comité assez fermement attestée et la variante si clairement facilitante que זִִ̣ a reçu 4 " $\mathrm{B}$ " et 2 “ $\mathrm{C}$ ".

Interprétations proposées :

On pourrait penser que la 3e pers. pl. désigne, de façon anticipée, les "peuples" et "nations" qui seront mentionnées au vs 3. Il s'agirait alors du "bras" qui les attaque.

Mais presque toute la tradition exégétique voit dans la $3 e$ pers. pl. les Israélites des générations futures ou des groupes avec lesquels le prophète n'est pas en contact. Il demande à Dieu d'être leur "bras", c'est-à-dire leur aide. Ce sens est le plus naturel.

33,3 מדממתך [C] [C] M ThAq V S T (vel err-graph) // cor-a (vel errgraph) / harm-ctext : G

Options de nos traductions :

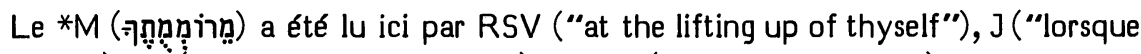
tu te lèves"), RL ("wenn du dich erhebst") et TOB ("quand tu te lèves").

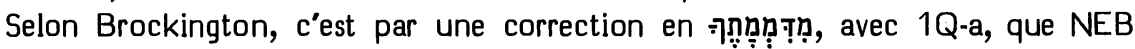
traduit : "at thy rumbling".

Origine de la correction :

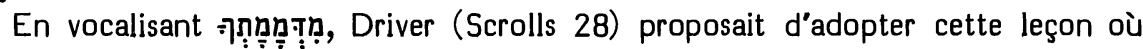
il voyait "the low rumble of thunder ... in the present passage that accompanying a theophany".

Plus tard, Driver (Notes 46) a préféré conserver le 'resh' du *M qu'il vocalise

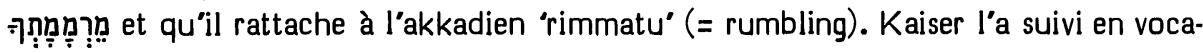

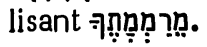


Les témoins anciens :

La seule variante qu'offre 1Q-a en ce vs porte sur ce mot où il écrit 'dalet' à la place de la séquence 'resh-waw' du *M.

On ne peut savoir ce que le ${ }^{*} G$ a lu pour ce mot où il répète toṽ yóßov oov qu'il venait de donner pour המון. Nous avions déjà noté le même procédé de la part du traducteur en 10,34 et 15,2.

Le *M est appuyé par ThAq (ảmò í $\psi \omega ́$ ócús oov), la *V (ab exaltatione tua), la *S (מסקן רמותי גבורן) et le *T).

\section{Choix textuel :}

A propos de la variante de 1Q-a, Kutscher (228) fait remarquer que דממה se trouve trois fois dans la Bible dont deux en connexion avec קול (1R 19,12; Jb 4,16), mot avec lequel celui dont il s'agit ici se trouve justement mis en parallèle. Cette leçon semblerait donc bien en place ici. On peut ajouter à cela qu'en Is 13,4 où se retrouve קול המות que cette expression est mise en parallèle. Or on peut admettre des glissements de sens entre les réalisations 'lamed/hé" et "aïn/'aïn" du bilittère $\mathrm{Q}$.

Pour ces motifs, la moitié des membres du comité a attribué " $\mathrm{C}$ " à la leçon de 1Q-a.

Cependant l'autre moitié des membres du comité a attribué " $C$ " au *M. Notons que Wildberger garde ici le * $\mathrm{M}$, après discussion.

Interprétations proposées :

Si l'on garde le *M, on pourra comprendre ou bien "quand tu te dresses", ou bien "quand tu élèves (la voix)".

Si on adopte la leçon de 1Q-a, on pourra donner à ce mot son sens classique de "accalmie" ou bien (avec Lust 94-99) celui de "mugissement".

33,4 שללכם [B] M 1Q-a // expl : V S $\longrightarrow$ glos : G, paraphr : T

Options de nos traductions :

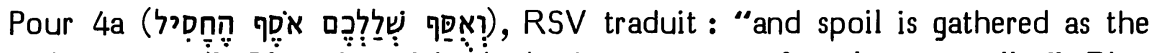
caterpillar gathers", J12 : "on fait "du butin comme en font les sauterelles", RL : "da wird man Beute wegraffen, wie die Heuschrecken wegraffen", TOB : "le butin s'amasse comme s'amassent les sauterelles" et $\mathrm{J3}$ : "on amasse chez vous le butin comme amasse le criquet". Quoique $\mathrm{J3}$ ait été seule à expliciter le suffixe possessif affectant le deuxième mot et que toutes les traductions aient explicité une particule de comparaison avant le troisième mot, aucune n'a de note textuelle.

Seule NEB (expliquée par Brockington) justifie sa traduction: "their spoil is swept up as if young locusts had swept it", en disant lire ịִ ְִ à la place du deuxième mot et en se référant au *T pour cela.

Origine de la correction :

Duhm a estimé que le suffixe de la 2e pers. m. pl. du deuxième mot est encom- 
brant, rien ne précisant à qui il renvoie. Il estime aussi qu'il manque une particule comparative avant le troisième mot. Ces deux difficultés sont réglées si on sépare les consonnes de ce suffixe en les faisant suivre d'un 'waw'. On obtient ainsi la particule comparative requise. Cette conjecture a été adoptée par Marti, Cheyne, Condamin, Perles (II 7), Feldmann, Procksch, Fischer, Ziegler, Fohrer, Kaiser, Irwin, Wildberger, $\mathrm{BH} 2, \mathrm{HSAT} 34$ et Cent. $\mathrm{BH} 3$ appuie cette variante sur le $* T$ auquel $\mathrm{BHS}$ ajoute la $* \mathrm{~V}$ et la $*$ S.

Les témoins anciens :

Pour ce mot, 1Q-a appuie le ${ }^{*} M$, quoique le 'mem' y ait la forme d'un 'mem' cursif (et non final). Mais cette particularité est trop fréquente en ce rouleau pour qu'on puisse en tirer quelque conclusion.

Toutes les versions anciennes explicitent, avant le troisième mot, une particule comparative. Mais toutes gardent le suffixe de la 2e pers. pl. du deuxième mot, la*V et la ${ }^{*} S$ le traduisant littéralement, alors que le $* T$ use d'une périphrase à la $3 e$ pers. Quant au $* G$, entre le suffixe et l'explicitation de la particule comparative, il insère

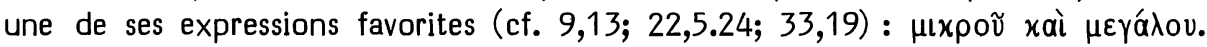

Choix textuel :

Duhm se trompe en croyant nécessaire une particule comparative. König a relevé que sa conjecture méconnaît le goût que l'hébreu a pour lier un verbe fini à un nom d'action de même racine qui est déterminé de manière à spécifier le processus évoqué par le verbe. Il relève, à propos de notre cas, que le complément d'objet interne du verbe actif se maintient lors de la mise de ce verbe au passif (Synt $\$ 329 f$ ).

Quant au possessif de la $2 \mathrm{e}$ pers. $\mathrm{m}$. pl., son surgissement soudain ne surprend pas dans le livre d'Isaïe (cf. 1,5a etc.). On rencontrera un problème textuel analogue à celui-ci au vs 11 .

En face de ce qui semble n'être que des explicitations translationnelles, le comité a attribué au *M 5 "B" et 1 "A".

Interprétations proposées :

On traduirait donc littéralement : "on amassera votre butin d'un amassement de criquet", c'est-à-dire ou bien : comme les criquets amassent, ou bien : comme on amasse les criquets.

33,5 מִּלִ [B] M V S // theol : G, T / abst : 1Q-a 4Q-c

Options de nos traductions :

Le *M a été traduit par RSV ("he will fill"), J ("il comble"), RL ("er hat ... erfüllt") et TOB ("il remplit").

Selon Brockington, NEB corrige le ḥireq initial en patạ̣ (= impératif) pour traduire : "if you fill". 
Origine de la correction :

Elle peut s'être inspirée du*T.

Les témoins anciens :

$1 Q$-a et $4 Q-c$, identiques au ${ }^{*} M$, ne nous informent pas sur leur vocalisation.

Le *M, appuyé par la *V (implevit) et la *S (ומלה) interprète ce verbe comme un accompli piél dont Dieu est le sujet.

Pour éviter de faire de Dieu la cause immédiate de cette action, le *G (ẻve$\pi \lambda \eta ́ \sigma \theta \eta$ ) lit ce verbe comme un passif dont Sion est le sujet, alors que le *T (לאמר) לממלי (ליל présente ici Dieu comme commandant d'agir et non comme agissant lui-même.

\section{Choix textuel :}

Estimant qu'il faut préférer la leçon du *M à ces corrections théologiques, le comité lui a attribué la note " $\mathrm{B}$ ".

Interprétation proposée :

Il s'agit vraisemblablement ici dans le *M d'un accompli prophétique indiquant que, du point de vue de Dieu, l'action est déjà accomplie, même si elle a encore à se réaliser. C'est pourquoi nos traductions hésitent légitimement entre les diverses virtualités (futur, présent ou passé) de cet accompli.

\section{3,6A עִ עִ [B] M 1Q-a Th Aq Sym V S // paraphr : T / midr : G} 33,6B אוצרו [B] M 1Q-a ThAqSym V S T // expl : G

Options de nos traductions :

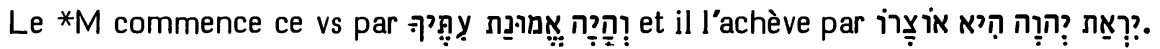

RSV traduit ces deux phrases par: "and he will be the stability of your times... the fear of the LORD is his treasure". J12 traduisaient : "ta durée est solide ... la crainte de Yahvé est son trésor". J3 traduit : "et ce sera la sécurité pour tes jours ... la crainte de Yahvé, tel est son trésor."

TOB, en traduisant la fin par "tel sera ton trésor" a assimilé le suffixe de 6B à celui de $6 \mathrm{~A}$.

NEB traduit $6 \mathrm{~A}$ par "of the age", ce qui, selon Brockington, suppose une correction de $6 A$ en Brockington, implique une mise au féminin du suffixe masculin.

Cette deuxième correction est présupposée par la traduction "Zions Schatz" que RL offre pour $6 \mathrm{~B}$.

Origines des corrections :

$\mathrm{BH} 23$ et Cent avaient proposé de corriger en suffixes de la 3e pers. f. sg. les deux suffixes de $6 \mathrm{~A}$ et de $6 \mathrm{~B}$.

Les témoins anciens :

Les deux suffixes du ${ }^{*} M$ sont appuyés par 1Q-a, Th, Aq, Sym, la *V et la ${ }^{*}$. 


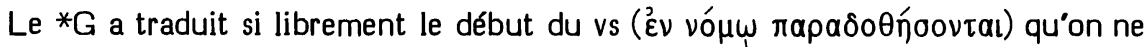
peut préciser ce qu'y fut sa Vorlage. Quant à 6B, il en explicite le suffixe par le génitif $\delta$ sxalooúvns.

Pour traduire le début du vs, le *T use d'une paraphrase où la $2 e$ pers. m. sg. du suffixe de $6 \mathrm{~A}$ intervient. Quant au suffixe de 6B, il le traduit exactement.

\section{Choix textuel :}

Le comité a attribué " $B$ " aux leçons difficiles constituées par ces deux suffixes du *M pour les protéger contre les diverses assimilations qui les menacent.

Interprétation proposée :

Les traductions de RSV et de J3 sont fidèles.

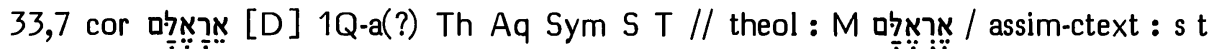

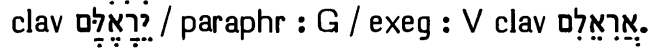

\section{Options de nos traductions :}

Pour 7a le *M offre deux phrases de deux mots, séparées par un zaqef qaton:

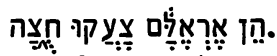

Aucune de nos traductions ne se fonde sur cette leçon.

J12 donnaient: "Voyez, Ariel se lamente dans les rues", J2 précisant que cela

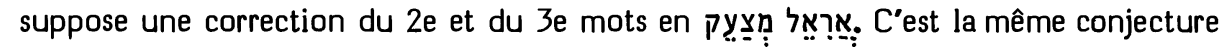
que $\mathrm{J} 3$ rend par "Voici qu"Ariel pousse des cris dans les rues".

Une autre option est commune aux quatre autres traductions :

RSV traduit : "Behold, the valiant ones cry without"; RL : "Siehe, die Leute von Ariel schreien draussen"; NEB : "Hark, how the valiant cry out for help" et TOB : "Voici : ceux d"Ariel poussent des cris dans les rues". Parmi elles, seule NEB nous est

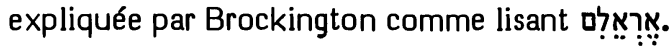

Origines des corrections :

La correction adoptée par J était requise par l'apparat de Cent.

Quant à la vocalisation adoptée par NEB, elle a été proposée par Gesenius et Grätz.

Les témoins anciens :

Pour justifier sa correction, Gesenius mentionne la variante אראלים en 8 mss dont il estime que les auteurs ont vraisemblablement compris ce mot comme une forme plurielle au sens de "les héros, les preux". De Rossi énumère en effet 3, et peutêtre 4, mss de sa collection dont la 1e main portait une graphie avec 'yod' et 4 mss que Kennicott mentionne comme portant cette graphie. Deux de ces derniers ont été contrôlés par HUB qui signale pour le ms 150 que seule la 1e main atteste la variante, et pour le ms 96 que la vocalisation y est celle du *M classique, c'est-à-dire avec qames. sous le 'lamed', en discordance avec la graphie avec 'yod'.

La mp signale d'ailleurs ce mot comme unique, ce qui attire l'attention sur lui, sans en préciser les caractéristiques. 
1Q-a (seul témoin de ce passage à Qumrân) écrit en deux mots ארא למ en finissant par un 'mem' cursif (et non final).

Le ${ }^{*} G$ a paraphrasé $7 a$. De cette paraphrase, on peut seulement dire qu'il semble avoir divisé ce mot en deux et dérivé la première partie de la racine ירא.

Le commentaire d'Eusèbe cite isolément la leçon de Th et celle de Sym qui ont

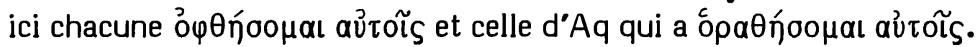

La *S a été éditée par Gabriel Sionita comme נתחזא להון dans la polyglotte de Paris, leçon que les éditions courantes ont reprise. Cependant, Diettrich mentionne que les quatre plus anciens témoins de la ${ }^{*} \mathrm{~S}$ d'Isaïe (l'Ambrosianus, le Londres $\mathrm{BL}$ Add 14,432, le Florence Laurentiana Or 558 et le commentaire d'Ephrem) lisent ici אתחזא להון. On peut considérer cette leçon comme la forme originale de la *S. Running (Investigation II 46) la rattache, à travers la Vieille Syriaque, à la leçon de $1 \mathrm{Q}-\mathrm{a}$.

Selon Sperber, le *T de Jonathan est ici תתגלי להון. Mais, en son commentaire, Radaq le cite sous la forme אתגלי להון. C'est cette dernière leçon qui se trouve paraphrasée dans le "Targum Yerushalmi" donné en marge inférieure du ms Reuchlin : איתגליתי על אברהם אבוהון. Il est très probable que l'on atteint par ces deux témoignages un état plus ancien du *T.

La *V (videntes) se rattache, selon Hie, à la tradition rabbinique qui interprète ce mot comme une désignation des anges, sa racine étant ici identifiée comme ראה.

\section{Choix textuel :}

1/ Comme nous l'avons mentionné en 27,8A (à propos de

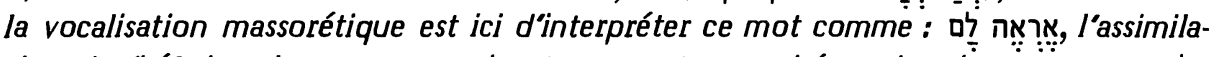
tion du 'hé" dans la consonne suivante y ayant engendré un dagesh comme en

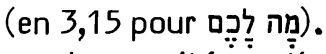

Le comité a estimé que le ${ }^{*} M$ a introduit le qal afin que Dieu voie les hommes au lieu d'être vu par eux. Ici, où Dieu est le sujet et les hommes sont complément, il s'agit d'une correction théologique inverse de celle qui a eu lieu si souvent de qal en nifal lorsque les hommes sont sujet et Dieu complément (cf. ci-dessus Is 1,12). Cette correction a donc pour point de départ une base identique à la Vorlage de $T h, d^{\prime} A q$, de Sym, de la *S ancienne et du *T ancien : לִ אִ cost-à-dire : "je me manifesterai à eux".

Remarquons que l'interprétation en deux mots a survécu au moyen âge où on la trouve adoptée par David ben Abraham (II 4,2s), Dunash ben Labrat (contre Saadya $\S 57)$, Joseph Qimhii (Galuy 72), le Manuel du Lecteur (355, fin) et Tanḥum Yerushalmi. Tous semblent interpréter le verbe en hifil : "je leur montrerai".

2/ Si l'on peut reconstituer de la sorte, de manière assez sûre, le lien qui relie la vocalisation massorétique aux interprétations des versions juives du début de notre ère, il est frappant de noter qu'une tout autre voie d'interprétation a pris une place prédominante dans l'exégèse juive traditionnelle.

Notons d'abord qu'un certain nombre de citations en des midrashim (énumérés ici par HUB) lisent אראלים, leçon que nous avons vue écrite par la 1e main d'un 
certain nombre de mss énumérés ici par de Rossi. Cette leçon semble bien liée à une poésie que Bar Qappara prononça à l'occasion de la mort de R. Judah ha-Nasi (au début du IIIe siècle). Dans cette poésie (citée en Talmud Babli Ketubot 104a), il emploie deux fois אראלים au sens de "anges". Depuis ce temps, cette désignation a eu une grande vogue en hébreu rabbinique (cf. Ben Yehuda 374s). Du fait qu'ici le mot מלאכי שלום semble être en parallèle avec, on comprend qu'on l'ait lu facilement comme אראלים. Il est même possible que cette lecture en Is 33,7 soit à l'origine de la poésie de Bar Qappara. Elle survit en tout cas chez un certain nombre d'exégètes médiévaux qui interprètent ce mot comme si le 'mem' final était une désinence du pluriel et non un pronom suffixe. C'est le cas de la $* V$, de Yéfet ben Ely, Jacob ben Reuben, Menahem ben Shelomo (Eben Boḥan en Qobeṣ I 319), Aaron ben Joseph, glossaires CDE, Radaq.

Cependant d'autres exégètes soulignent que ce mot est singulier et mettent souvent en valeur le pronom suffixe 3e pers. m. pl. C'est le cas de Menahem ben Saruq, Rashi, glossaires ABF et Joseph Qara qui donnent à ce mot le sens de "leur autel". D'autres interprètent ce mot comme "leur messager" et y voient un singulier employé au lieu d'un pluriel. C'est le cas d'Abulwalid (Ușul 657,26s). Isaïe de Trani rapproche

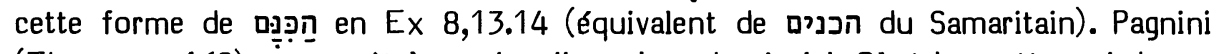
(Thesaurus 162) reconnaît à ce singulier valeur de pluriel. C'est Luzzatto qui donne de cette particularité l'explication la plus plausible. Il remarque d'abord qu'on retrouve

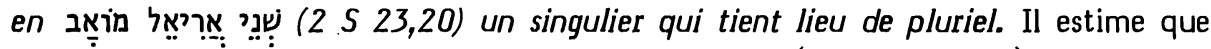
c'est parce que ce substantif est senti comme composé ("lion de Dieu"). Faire porter le pluriel sur le génitif אي créerait un contre-sens. Le faire porter sur le premier membre (אריות אל) défigurerait le substantif. On a donc gardé celui-ci au singulier avec valeur plurielle en ces deux cas où le contexte guide suffisamment l'interprétation. Quant à la chute du 'yod' central de אריאל, Nägelsbach la rapproche de la chute du 'yod' de 'Abiner' (1 S 14,50) en 'Abner' (passim).

Bochart (Hierozoicon I 716s) donne 4 exemples de "lion de Dieu" comme surnom d'un puissant guerrier dans les littératures arabe et persane, une des attestations de ce surnom se rattachant à la vie de Muhammad.

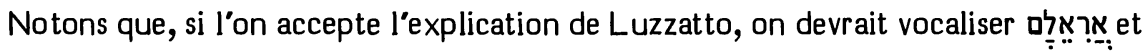
comprendre "leurs vaillants guerriers".

Reconnaissant ce cas comme très difficile, le comité a accordé 2 " $\mathrm{D}$ " à cette

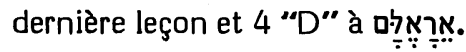

Interprétation proposée :

Si l'on tient compte du zaqef qaton, on pourra traduire : “Je me ferai voir d'eux; ils pousseront des cris dans les rues."

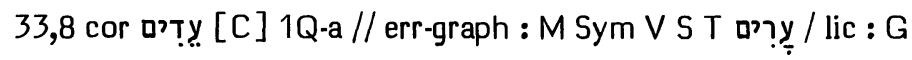

Options de nos traductions :

Le *M porte en 8b trois phrases : חִפַר

Les deux premières sont traduites par TOB : "L'alliance est rompue, les villes rejetées." 
J2 disant lire duire la deuxième phrase par "on a ... méprisé les témoins" et "witnesses are despised".

Brockington dit que NEB vocalise 1Q-a yִ עִ pour traduire cela: "treaties are flouted".

Origines des corrections :

Houbigant avait conjecturé ici يִ يִ estimant ce mot bien en place après la mention de l'alliance dont ceux-ci ont été les témoins; les derniers mots du vs ("il n'a tenu compte de personne") apportant à cela une conclusion adéquate. Cette conjecture avait été adoptée par Duhm (estimant qu'un chef de guerre peut mépriser des fortifications, selon $\mathrm{Ha}$ 1,10, mais non des villes, il note le lien entre "témoin" et "alliance" en Gn 31,44s), Marti, Gunkel (Jesaia 33), HSAT34, BH23, Procksch, Fischer. Depuis qu'elle a été confirmée par 1Q-a, cette leçon a été adoptée par la plupart des exégètes.

Cependant, Fitzmyer (Sefîre 24) a suggéré de rapprocher la leçon de 1Q-a de l'araméen ע. עִ עִ

Les témoins anciens :

1Q-a donne עים

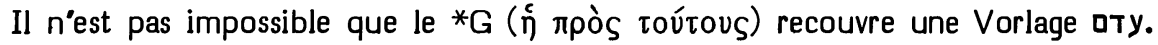
La leçon clairement appuyée par Sym, la *V, la *S et le *T.

\section{Choix textuel :}

Etant donné que les deux leçons ne sont séparées l'une de l'autre que par la confusion $T / 7$, les membres du comité ont apprécié de façons différentes le sens dans lequel le glissement a eu lieu, la leçon 2 "C".

Interprétation proposée :

On traduira donc: "il a méprisé les témoins". Mais il serait bon de mentionner en note la leçon du $* M$.

\section{3,11 רוחכם [B] M 1Q-a G Th // expl : V, S / paraphr : T}

\section{Options de nos traductions :}

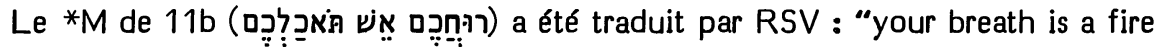
that will consume you"; par RL : "euer Zorn ist ein Feuer, das euch selbst verzehren wird" et par TOB : "votre souffle est le feu qui vous dévorera".

J donne : "mon souffle, comme un feu, vous dévorera", disant s'appuyer sur le *T pour lire "mon souffle".

NEB donne : "a wind like fire shall devour you", Brockington se référant à la *V pour une correction du premier mot en i⿱⺈ 
Origines des corrections :

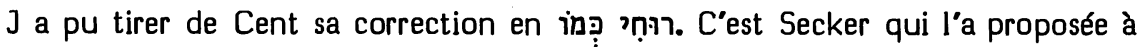
titre de conjecture. Lowth a estimé que מימרי a été adoptée par. Halévy, Gunkel (Jesaia 33), BH23, Ziegler (EB), Fohrer.

La conjecture de NEB remonte à Doederlein. Elle a été adoptée par Procksch, Kaiser, BHS et Irwin.

Les témoins anciens :

Le *M est formellement appuyé par $1 Q-a$, le ${ }^{*} G$ et Th.

$\mathrm{La} * \mathrm{~V}$ explicite une préposition après "votre souffle", et la *S en explicite une avant.

Quant à la paraphrase très libre du *T, Rosenmüller a bien montré combien il est difficile d'en reconstituer la Vorlage.

Choix textuel :

NEB a tort de faire appel à la *V qui a respecté le possessif "vester". Quant à Lowth et J, c'est en vain qu'ils essaient de fonder une correction sur la paraphrase $d u * T$.

Ce problème textuel est analogue à celui que nous avons rencontré au vs 4.

Estimant le $* M$ solidement appuyé par $1 Q-a$, le $* G$ (et Th dont la citation s'arrête après ce mot), le comité lui a attribué 5 " $B$ " et 1 " $A$ ".

Interprétations proposées :

Le *M ne fait pas de difficulté. On peut le comprendre avec Ehrlich qui voit dans "feu" le prédicat d'une phrase nominale dont le mot "votre souffle" est le sujet, alors que le verbe "vous dévorera" est une relative déterminant ce prédicat : "votre souffle est le feu qui vous dévorera" (= TOB).

Ou bien, avec König, on peut comprendre le mot "votre souffle" comme sujet du verbe "vous dévorera", le mot "feu" étant une apposition à ce sujet: "votre souffle, comme un feu, vous dévorera".

La comparaison du "souffle", sortant de la narine irritée, avec un feu est classique. L'autocombustion des impies a déjà été évoquée en 1,31.

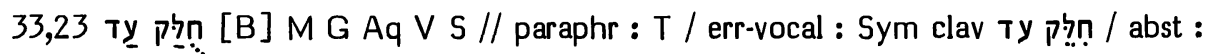
1Q-a

Options de nos traductions :

Pour la phrase du *M : אִִ RSV traduit : "then prey and spoil in abundance will be divided"; ;1 : "“olors on prendra part à un énorme butin"; J2 : "alors on se partagera un énorme butin"; RL : "Dann wird viel Beute ausgeteilt werden"; TOB : "Alors, on partagera le produit du pillage, en quantité"; J3: “Alors on s'est partagé un énorme butin".

Notons seulement que le mot ty semble s'être évanoui dans les traductions de $\mathrm{J}$ et de RL. 
NEB, quant à elle, se réfère au *T pour corriger (aux dires de Brockington) le 2e et le 3 e mot de cette phrase en have a full share of the spoil."

Origine de la correction :

Il semble que ce soit Gesenius/Buhl (564b) qui a formulé la conjecture que NEB reprendra. Driver (TLP 54) a servi d'intermédiaire en suggérant pour le verbe un qal au lieu du piél proposé par Gesenius/Buhl et BHS.

\section{Les témoins anciens :}

$1 Q$-a atteste les deux mots du $* M$ mais ne saurait témoigner sur leur vocalisation.

Une massore (Weil §2337) précise que l'on a ici l'un des deux emplois (l'autre étant Gn 49,27) de Ty au sens de "butin". C'est bien ainsi que ce mot a été compris par Aq, la *V et le *T (qui paraphrase). Par contre, le *G, la *S et Sym l'ont compris comme préposition, ce dernier ayant vocalisé le verbe précédent à une forme active, alors que le ${ }^{*} G$ et la $* S$ font porter la préposition sur le verbe qui la précède.

\section{Choix textuel :}

Estimant que cette difficulté est plus exégétique que textuelle, le comité a attribué au *M la note "B".

\section{Interprétation proposée :}

Ici comme en $\mathrm{Nb} 31,12$, Ehrlich distingue שְִׁׁ - où il voit le butin livré par les guerriers au chef de guerre qui le répartit entre tout le peuple - de (ou serait le butin que chaque guerrier s'approprie lors du pillage. Même si, en des textes poétiques, les deux mots sont souvent nivelés par le parallélisme, cette distinction semble fondée. Or, ici, le fait que les impotents peuvent eux-mêmes prendre part au pillage montre qu'il y a tant de biens à piller que tout n'aura pas été emporté avant qu'ils n'arrivent. Cette intervention efficace des פִפְִ a pour parallèle le début du vs suivant où ceux-ci ont pour symétriques ceux qui disent חִ חִ (= je suis malade),

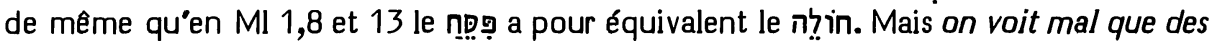
aveugles soient chargés de la répartition équitable du butin partagé; alors qu'il est utile d'avoir précisé - utilité que méconnaissent ceux qui veulent omettre le dernier mot de cette phrase - qu'il y a énormément de butin à partager, pour expliquer l'intervention des impotents qui est mentionnée juste après comme une illustration de cela.

On peut traduire : “alors la prise d’un abondant butin est répartie".

34,5A תראה [C] תרְָּה [C] 1Q-a T (vel ign-cult)

\section{Options de nos traductions :}

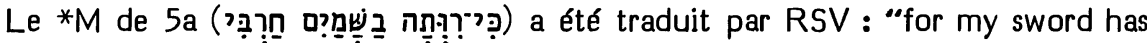
drunk its fill in the heavens"; par J12: "car mon épée est enivrée dans les cieux"; par RL : "denn mein Schwert ist trunken im Himmel" et par TOB : "mon épée, dit le Seigneur, est ivre dans les cieux". 
Pour cette phrase, NEB donne : "for the sword of the LORD appears in heaven". Réservons la correction du sujet pour le cas suivant et considérons d'abord celle qui porte sur le verbe. Selon Brockington, celui-ci est lu

Origine de la correction :

Lowth, ayant traduit: "for my sword is made bare in the heaven", s'expliquait ainsi : "Il semble y avoir ici quelque impropriété selon l'état actuel du texte : 'mon épée est rendue ivre, ou est baignée, dans les cieux', ce qui anticipe et n'exprime pas en son lieu propre ce qui appartient au vs suivant : car l'épée de Yahvé n'avait pas à être baignée ou gorgée de sang dans les cieux, mais à Boçra et dans le pays d’Edom. Dans le ciel, elle était seulement préparée pour le massacre. Pour remédier à cela, l'archevêque Secker propose de lire בדמים à la place de בשמים, en se référant à Jr 46,10. Mais même cela est prématuré et n'est pas en son lieu propre. Le *T, pour תתגלי a (= sera révélée, ou exposée). Peut-être a-t-il lu נראתה ou que soit le texte - différent, je pense, de l'actuel - qu'il a pu trouver en son exemplaire, je suis le sens qu'il en a exprimé."

Driver (TLP 55) critique RSV en estimant "difficilement croyable" que l'épée de Dieu se soit enivrée, "vraisemblablement de sang", dans les cieux. Puisque le verbe du * $M$ "ne donne aucun sens", il faut accepter sans hésitation, estime-t-il, la leçon de $1 \mathrm{Q}$-a.

Les témoins anciens :

Celui-ci, en effet, lit ici תראה, c'est-à-dire l'une des deux formes verbales conjecturées par Lowth comme Vorlage du *T.

Le *G ( $\left.{ }_{\varepsilon}^{2} \mu \varepsilon \theta \dot{v} \sigma \theta \eta\right)$, la *V (inebriatus est) et la *S (ותתרוא) ont traduit le *M en donnant à ce verbe un sens intransitif.

Il est frappant qu'ici le *T traduit ce verbe par ת ת qu'il répète en $5 b$ pour traduire ורח (!); alors qu’au vs 7 il rend $* M$ et $1 \mathrm{Q}-\mathrm{a}$ ) de façon normale par . ותרוֹי

Choix textuel :

Nous reconnaîtrons (en Jb 10,15 et $\operatorname{Pr} 11,25$ ) à certaines formes de ראה la valeur

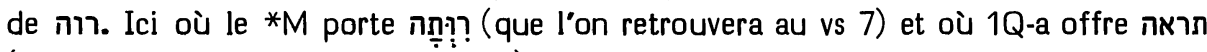
(alors qu'au vs 7 il appuiera le $* M$ ), on peut se demander si le $* M$, sous l'influence du vs $7, n$ 'aurait pas interprété faussement la leçon de $1 \mathrm{Q}-\mathrm{a}$ (en lui donnant la valeur de רוה que le *T aurait trouvée encore intacte en sa Vorlage.

Cependant, en $5 a$, le $* G$, la $* V$ et la $* S$ ont lu la même forme verbale que le $* M$, forme qu'il faut comprendre (en 5 et en 7), selon Abulwalid (Luma 140,19s) comme un piél intransitif. Gesenius/Kautzsch ( $\$ 52 k)$ est d'accord et attribue à ces piél intransitifs une valeur intensive.

Si on vocalise la leçon de 1Q-a comme מִ̣ר (= se manifestera), cela évoque l'astre semblable à une épée qui (selon Josèphe, Guerre VI \$289) apparut au-dessus de Jérusalem avant la prise de la ville. Si on suit la leçon du *M, l'épée enivrée de sang évoque Dt 32,42 et Jr 46,10 (où le même verbe se retrouve). 
En faveur de la leçon de 1Q-a, on peut faire remarquer la dissymétrie qu'elle établit entre le vs 5 et le vs 7 , et on peut penser que l'assimilation par le *M du vs 5 au vs 7 peut avoir un motif théologique, ainsi que l'a suggéré Cavalletti : détourner l'attention d'une interprétation superstitieuse des signes célestes.

En faveur de la leçon du $* M$, on peut faire valoir que le vs 7 regroupe (en un autre contexte) beaucoup de termes qui ont déjà été employés dans les vss 5 et 6 :

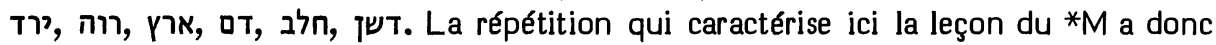
bien des chances d'être originale. Quant à l'idée que l'épée divine s'enivre dans le ciel avant de descendre frapper Edom, elle se retrouve en 24,21 où Dieu châtie en haut l'armée d'en haut, avant de châtier sur terre les rois de la terre. Comme le fait remarquer la Mekhilta (sur Ex 15,1), "tu trouves ainsi que le Saint, béni soit-il, ne va châtier les royaumes dans le monde à venir qu'après avoir châtié d'abord les 'princes' (c'est-à-dire les anges auxquels ces royaumes sont confiés)". Parmi les illustrations qu'il donne de ce principe, le midrash cite notre texte; cette interprétation s'accordant bien avec 34,4.

Driver a complètement méconnu le contexte culturel qu'offre cette tradition exégétique. Peut-être $1 Q$-a et le $* T$ ont-ils, pour le même motif, éprouvé la même difficulté que lui à l'égard du *M.

Le comité, voyant que chacune des deux leçons possède de sérieuses chances de représenter ici le texte original, a divisé ses voix à égalité, attribuant la note " $\mathrm{C}$ " à chacune.

Interprétations proposées :

Selon le choix textuel que fera le traducteur, ou bien : “mon épée s'est enivrée dans les cieux", ou bien "mon épée apparaît dans les cieux".

34,5B חרבי ... חרמי [A]

Options de nos traductions :

RSV, J, RL et TOB suivent le *M en traduisant ces possessifs de la 1e pers. sg.

NEB, nous l'avons vu, traduit le premier "the sword of the Lord". Brockington précise que cela suppose une correction en חרב יהוה. Elle enveloppe la traduction du second mot en une périphrase: "(on the people) whom he dooms to destruction", ce qui, selon Brockington, suppose une correction du suffixe en une 3e pers. m. sg.

\section{Origines des corrections :}

Dillmann/Kittel suggère de considérer le 'yod' final du premier mot comme une abréviation du tétragramme, abréviation qu'un scribe aurait mal comprise en la prenant pour un suffixe de la 1e pers. sg.

A cela Cheyne ajoute que, dans le second mot, un scribe a méconnu le 'waw' d'un suffixe de la 3e pers. m. sg. en lisant à sa place un 'yod' pour l'assimiler au suffixe erroné du premier mot.

Ces deux conjectures ont été adoptées par Marti, Duhm5, Feldmann, HSAT34, Fohrer, Kaiser, Wildberger. 
D'autres attribuent au premier de ces deux mots comme au second des suffixes de la 3e pers. m. sg. C'est le cas de Ehrlich, Procksch, Fischer.

Les témoins anciens :

Tous appuient les suffixes de la 1 e pers. sg. du $* M$.

\section{Choix textuel :}

On motive ces corrections par le fait qu'il n'y a pas eu auparavant de mention du nom du Seigneur qui permette de situer cette première personne qui surgit ainsi sans être annoncée. Mais König rapproche ceci de 10,12; 22,19 et 33,13 où un thème divin se signale de la même manière par le surgissement soudain d'une première personne non annoncée. En 34,6 le passage à la troisième personne constitue une variation sur ce thème ainsi signalé. On a rencontré une variation semblable en 1,4 après la première personne de 1,3 .

34,7 ب̣: [B] M 1Q-a G V S T // abr-elus : Sym om

Options de nos traductions :

RSV ("with them"), RL ("mit innen"), TOB ("en même temps") et J3 ("avec eux") ont traduit plus ou moins largement la préposition du *M et le pronom suffixe qui la suit.

J12 ont corrigé ce mot en ạִ et traduit: "des peuples" (puis, deux mots plus loin, ay au lieu de aỵ, en traduisant : "un peuple").

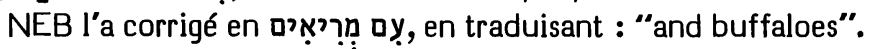

Origines des corrections :

La double conjecture de $\mathrm{J1} 2$ remonte à Procksch à travers Cent.

Quant à celle de NEB, elle remonte à Duhm qui a conjecturé de restituer ici une désignation d'animaux (מריאים) à la place du pronom suffixe de yמם Elle a été adoptée par Marti, HSAT4, BH3, Fohrer, Wildberger.

Les témoins anciens :

Pour ce mot, la leçon du *M a l'appui de 1Q-a (quoique le second 'mem' y soit

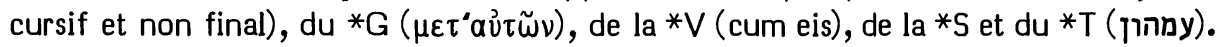

Quant à Sym, il semble ne pas avoir traduit ce mot. Ziegler (Notizen 92) estime

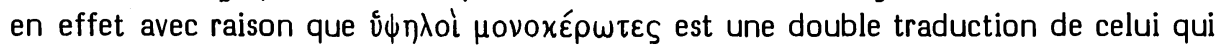
précède.

Choix textuel :

Pour tenir compte de la leçon allégée de Sym, le comité $n^{\prime a}$ attribué au *M que la note "B".

Interprétations proposées :

Il se peut que "avec eux" renvoie aux animaux mentionnés en $6 a$. 
Mais il est plus probable que Condamin a raison de référer "avec eux" au peuple (vs. 5) d'Edom (vss 5 et 6), du fait que le pronom suffixe de "leur terre" (au vs 7b) ne saurait se référer à des animaux.

\section{4,12 חריה [B] M G ThAqSym V S // paraphr : T / substit-synt : 1Q-a וחריה}

\section{Options de nos traductions :}

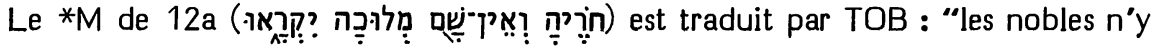
proclameront plus de roi" et par J3 : "De nobles, il n'y en a plus pour proclamer la royauté".

NEB le traduit: "and its frontiers (shall be a jumble of stones). No king shall be acclaimed there" sans rien noter.

RSV traduit: "(and the plummet of chaos) over its nobles. They shall name it No Kingdom There", en précisant que l"hébreu omet "over".

J12 offre ici : "les satyres y feront leur demeure, ses nobles ne seront plus, on n'y proclamera plus de rois", en précisant que la première phrase qui manque dans l"hébreu est traduite d'après le *G. RL suppose la même base pour traduire : "Und Feldgeister werden darin wohnen, und seine Edlen werden nicht mehr sein. Man wird dort keinen König mehr ausrufen".

\section{Origines des corrections :}

Il se peut que NEB s'inspire de Driver (LTP 46) pour lier le premier mot de 12a au vs précédent et lui donner le sens de "its frontiers" (alors que Driver propose "its circumference", faisant un appel improbable à l'akkadien).

C'est Lowth qui a estimé que la jonction de חריה avec le vs 12 embarrasse ce vs et le rend inexplicable. Aussi joint-il ce mot au vs 11 en suppléant une ou deux lettres qui semblent avoir été perdues, ce qui donne על חרריה (en s'inspirant de חבר?רים en Jr 17,6, à quoi il donne le sens de "scorched plains"). De cela, RSV a retenu l'ajoute de la préposition et la jonction avec le vs 11 , mais non la correction du mot.

L'ajoute importante de $\mathrm{J12}$ et de RL remonte à Duhm qui a emprunté au ${ }^{*} \mathrm{G}$

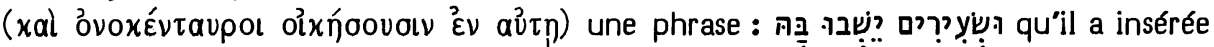

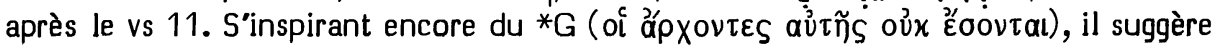

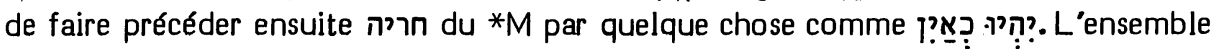
de cette restauration est adopté par Cheyne, Marti, HSAT34, BH23 et Cent.

\section{Les témoins anciens :}

Pour le premier mot de $12 a$, le $* M$ est appuyé formellement par le ${ }^{*} G$ (oi

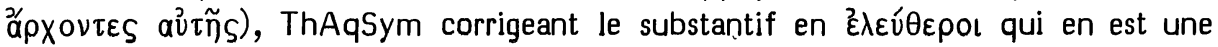
traduction plus exacte, comme l'est aussi celle de la *V : "nobiles eius".

La *S use ici de la même traduction qu'en 19,9, ainsi que nous l'avons déjà observé ci-dessus, p. 139.

Le *T paraphrase : “ceux qui prétendaient être libres de naissance et refusaient de se soumettre à un royaume".

Quant à 1Q-a, il ne se distingue ici du *M que par l'ajoute d'une conjonction avant חריה (comme déjà au vs précédent, avant תהו). 
Choix textuel :

Lowth a fait remarquer que l'édition princeps des Prophètes, celle de Soncino 1486, porte ici חור חריה, ce qu'il estime "plus près de la vérité" et ce qui l'engage à redoubler le 'resh' de ce mot. Kennicott a retenu cette variante dans son apparat. Mais ח'est, en cette édition, qu'un simple remplissage de fin de ligne, comme on en rencontre, six autres fois, en cette page.

La conjonction ajoutée par 1Q-a ne favorise pas la conjecture de Duhm dont les

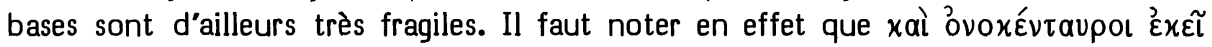
xatolxńoovalv a déjà traduit en 13,22: וענה איים באלמנותיו, juste avant la mention

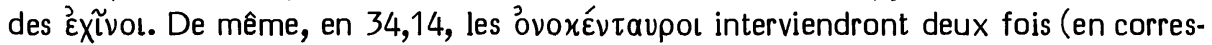
pondant, la deuxième fois, à ליליל), juste avant que l'Ex Ẽvos soit mentionné (vs 15). Ces données font de l'apparition de ces mêmes òvoxéviaupo à la fin de 34,11 (où les Ẻxũvol viennent d'être mentionnés) une interpolation harmonisante.

Quant aux autres éléments sur lesquels on pourrait fonder une Vorlage plus ample

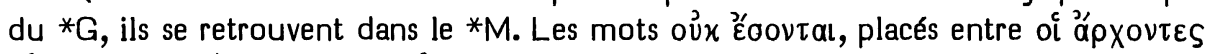

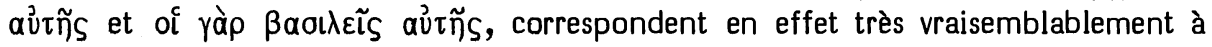

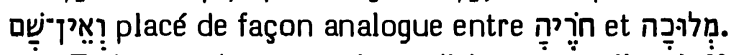

Estimant donc que la tradition textuelle n'offrait que des arguments très faibles pour une correction éventuelle du ${ }^{*} M$, le comité a attribué à celui-ci la note " $B$ ".

Interprétations proposées :

La phrase constituée par 12a est interprétée par Saadya : "il n'y aura plus en elle aucun de ses nobles; comment donc ferait-on appel à eux pour la royauté ?", ce qui correspond bien aux teamim.

Yéfet ben Ely comprend : “ses nobles - il n'y a là personne qu'ils puissent appeler à la royauté".

Ibn Ezra se contente de préciser que יקראו est un pluriel impersonnel et qu'il faut sous-entendre מלוכה ל- Cela donne : "ses nobles - il n'y en a là aucun que l'on puisse appeler à la royauté". C'est la construction retenue par Vitringa, Rosenmüller et préférée par Gesenius.

Delitzsch comprend: "ses nobles - il n'y a pas de royauté qu'ils aient à proclamer". König interprète de même.

Gn 36,31-39 indique en effet qu'Edom avait une royauté élective. Si l'on tient compte d'Is 34,12b, il faut peut-être distinguer les "nobles" (סר? (ח) qui sont les élec-

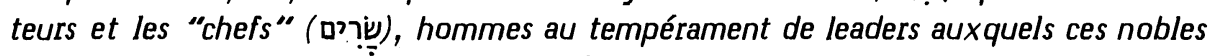
pourraient faire appel lorsqu'il s'agit d'élire un roi. Ce serait alors la traduction de Yéfet que la phrase : "tous ses chefs (שריה) ont disparu" conclurait le mieux.

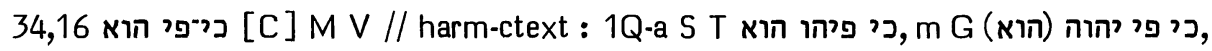
בי פיהו m ביפוא

Options de nos traductions :

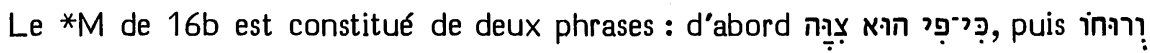

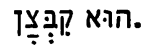


Aucune de nos traductions ne respecte le $* M$ pour la première phrase.

Sans rien noter, RSV traduit: "for the mouth of the LORD has commanded" et TOB : "car c'est la bouche du SEIGNEUR qui a donné l'ordre".

Ont pris une autre option : J12: "car c'est sa bouche qui a ordonné", RL : “denn sein Mund gebietet es", NEB : "for with his own mouth he has ordered it" et J3 : "c'est ainsi que sa bouche l'a ordonné". J précise que cette traduction se fonde sur $1 Q$-a.

Origines des corrections :

Déjà Yéfet ben Ely disait que פי פי פיהוה a est puisque l'on a ensuite et non רowth, sans connaître ce prédécesseur, a pris appui sur cinq mss pour lire le tétragramme à la place de הוא. Il a été suivi en cela par Doederlein. L'insertion du tétragramme a été ensuite requise par Knabenbauer, Duhm et les apparats de HSAT34, BH23S et Cent.

Ont interprété le *M comme s'ils y lisaient "sa bouche" au lieu de "ma bouche" : Saadya, Oecolampade, Brucioli, Münster, Olivetan (= Rollet, Estienne), Châteillon et Ge. Ensuite, cette interprétation a été reprise, comme correction textuelle en par Houbigant, Gesenius, Ewald, Knobel, Bredenkamp, Grätz, HSAT2. La découverte de cette leçon en 1Q-a l'a fait adopter par certaines de nos traductions.

\section{Les témoins anciens :}

Quelques mss du *M (parmi lesquels le ms Erfurt 3) ont פִ à la place du 2e et du 3e mots de la première phrase.

Quelques autres mss (parmi lesquels le ms Paris $\mathrm{BN}$ hébr 6 dont le vocalisateur a corrigé cela) ont le tétragramme à la place du 3e mot. 1Q-a porte à la place du 2e mot.

La forme plurielle du verbe דרש et le tétragramme que le *M (appuyé par 1Q-a) offre dans le début du vs 16 ont été transférés plus loin en ce même verset par le *G

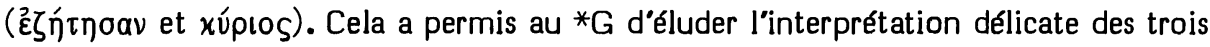
premiers mots de la première phrase du *M.

La ${ }^{*}$ S et le $* T$ ont traduit comme s'ils avaient lu la leçon de $1 Q$-a ou celle du ms Erfurt 3.

Seule la $* V$ atteste clairement le *M comme source de sa paraphrase : "quia quod ex ore meo procedit ille mandavit".

\section{Choix textuel :}

La leçon du *M est ici difficile et les témoins anciens, comme les exégètes postérieurs, ont essayé diverses facilitations qui sont 'dans l'air' et qui ont pénétré en quelques témoins de la tradition textuelle du ${ }^{*} M$.

Quatre membres du comité ont attribué la note " $C$ " à la leçon du *M pour la protéger contre ces corrections facilitantes.

Deux membres ont attribué la note " $C$ " à la leçon de 1Q-a, estimant que la leçon du *M est issue d’une haplographie de הi. 
Interprétations proposées :

Rashi (suivi par Ibn Ezra, Radaq et Pagnini) comprend le pronom suffixe du premier mot de la seconde phrase (le possessif masculin de "son souffle") comme renvoyant au substantif "bouche" de la première phrase (comme en Ps 33,6: "et par le souffle de sa bouche toutes leurs armées"). Cette traduction classique a été reprise à la fin du XVIe siècle (sous l'influence de Tremellius) par les Bibles française (Pasteurs) et anglaise $(\mathrm{KJ})$. Elle présente l'inconvénient de traiter le substantif nר comme un masculin (qui serait repris par le pronom qui le suit et serait le sujet du verbe achevant la seconde phrase).

N'ayant pas l'idée d'interpréter le pronom suffixe de רוח comme se référant à la bouche, Saadya, Yéfet, puis les traducteurs du XVIe que nous avons énumérés (à propos de l'origine de l'option de J, RL et NEB) ont référé ce pronom suffixe au Seigneur, ce qui les a amenés à traduire la première phrase comme s'ils y lisaient "la bouche du Seigneur" ou "sa bouche". La même clé interprétative est vraisemblablement à l'origine des variantes des témoins anciens.

La meilleure interprétation est ici celle de Luther qui traduit : "Denn er ists der durch meinen Mund gebeut, und sein Geist ists, der es zusamen bringet". L'interprétation de פי au sens de "par ma bouche" peut s'appuyer sur Ps 17,10 et 66,17. On pourra donc traduire 16b: "puisque, par ma bouche, c'est lui qui l'a commandé et que, par son esprit, c'est lui qui les a rassemblés".

Vers le début de 1529, Luther paraphrasait ainsi la première phrase, dans son cours sur Isaïe (WA. XXXI/2 220,13): "Ipse est, qui iubet me loqui, non est mea opinio".

ילכו 35,6 בערבה

Options de nos traductions :

Comme le fait le $* M$, quatre de nos traductions (RSV, J, RL et TOB) ont attribué au verbe du membre de phrase précédent une fonction semblable dans le membre de phrase constitué par les deux derniers mots de ce vs.

NEB préfère ajouter י. י (à ce que dit Brockington) en se fondant sur 1Q-a. Elle traduit : "and torrents flow in dry land".

Origine de la correction :

Alors que James et Wildberger en restent au $* M$, Kaiser a proposé d'adopter le "plus" de 1Q-a.

Les témoins anciens :

Seul de tous les témoins, 1Q-a offre un verbe spécifique (ילכו) pour le dernier membre de phrase.

Choix textuel :

Aucune cause d'accident ne saurait expliquer une omission de ce verbe chez tous les autres témoins, alors que son ajoute pour parfaire le parallélisme s'explique aisé- 
ment. Mieux vaut donc penser que 1Q-a a explicité ici un verbe qui convient bien au contexte, ainsi que le montre Qo 1,7bis.

Aussi le comité a-t-il retenu la leçon du *M en lui attribuant la note "B".

Interprétation proposée :

“parce qu'auront jailli des eaux dans le désert, et des torrents dans la steppe".

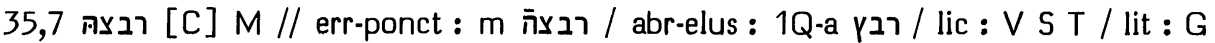

Options de nos traductions :

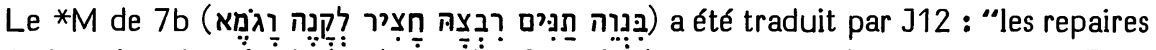
où gîtaient les chacals deviendront des fourrés de roseaux et de papyrus"; par RL : "wo zuvor die Schakale gelegen haben, soll Gras und Rohr und Schilf stehen"; par TOB : “dans le repaire où gîte le chacal, l'herbe deviendra roseau et papyrus" et par J3: "dans les repaires où gîtaient les chacals on verra des enclos de roseaux et de papyrus".

RSV offre : "the haunt of jackals shall become a swamp, the grass shall become reeds and rushes". Elle note seulement que la première phrase est le fruit d'une conjecture.

NEB, selon Brockington, à la place du 3e mot, lit "instead of reeds and rushes, grass shall grow in the rough liand where wolves now lurk".

Origines des corrections :

RSV ("shall become a swamp") semble dépendre d'une conjecture de Ruben

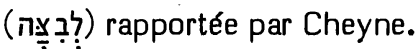

NEB adopte ici une suggestion de Driver (TLP 55).

Les témoins anciens :

Les mss tibériens classiques (d'Alep, du Caire et de Leningrad) s'accordent avec le témoignage de Norzi pour attester un mappiq dans le 'hé' final, alors que Rashi prétend le contraire. Le témoignage des manuscrits médiévaux du *M est divisé sur ce point, ainsi que celui des glossaires : $A$ et $F$, traduisant "son recorbement", en supposent un, alors que $C$ ("recorba") n'en lit pas. Yéfet ben Ely, selon le ms Londres BL Orient 2501, rapproche ce mot de שְְִׁרִ (Is 30,13). Par ce rapprochement, il atteste le mappiq.

1Q-a a omis le 'hé' final dont l'interprétation lui faisait peut-être difficulté.

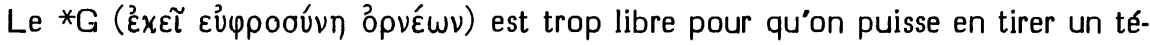
moignage.

La *S a inversé les deux membres de $7 b$ en une traduction large.

Etant donné la relative liberté de traduction de la $* V$, il se peut que ce soit la leçon du *M qu'elle ait traduite par "habitabant".

Le *T a d'ailleurs usé d'une liberté semblable. 
Choix textuel :

En lui attribuant la note "C", le comité a voulu protéger la leçon du texte tibérien classique contre des simplifications et facilitations diverses.

Interprétation proposée :

La leçon du *M est difficile. C'est pourquoi traducteurs et interprètes ont hésité sur l'antécédent du pronom suffixe féminin singulier. Il semble difficile de suivre Saadya et Yéfę qui donnent pour antécédent à ce pronom suffixe "le bétail" qui serait sous-entendu. Mieux vaut admettre que ce suffixe porte sur " En effet, un suffixe féminin singulier peut reprendre un pluriel masculin ou féminin désignant des animaux ou des choses (cf. König, Syntax $\$ 348 g h$ ).

On pourra donc traduire : "dans le repaire des chacals, leur gîte".

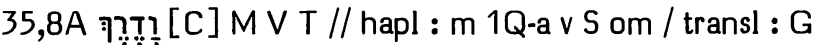

Options de nos traductions :

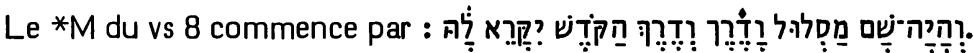

Seule J3 traduit cela : "il y aura là une chaussée et un chemin, on l'appellera la voie sacrée".

RSV, RL, TOB et NEB traduisent comme si le $4 \mathrm{e}$ mot était absent du texte, seule cette dernière précisant qu'elle l'omet avec 1Q-a.

$\mathrm{J12}$ traduisaient le 3e et le 4e mots par "une route pure", en se fondant sur le *G.

Origines des corrections :

L'omission du $4 \mathrm{e}$ mot a été proposée par Houbigant, adoptée par Lowth et requise par HSAT2 et Ehrlich. Après la découverte de cette omission en 1Q-a, Wildberger l'a adoptée.

C'est Cheyne qui, se fondant sur le *G, a proposé de remplacer le 4 e mot par l'adjectif "pur" portant sur le mot précédent. Cette correction a été adoptée par Marti, Procksch et Kaiser et requise par les apparats de HSAT34, BH3S et Cent.

Les témoins anciens :

La mp des mss du Caire et d'Alep note comme hapax le $4 \mathrm{e}$ mot, de peur qu'il ne soit identifié au suivant, puis omis par haplographie, comme ce fut le cas en un certain nombre de mss cités par Kennicott et de Rossi. En ceux que nous avons pu contrôler, l'omission a d'ailleurs été réparée par la 2e main.

1Q-a omet le $4 \mathrm{e}$ mot mais répète le $2 \mathrm{e}$.

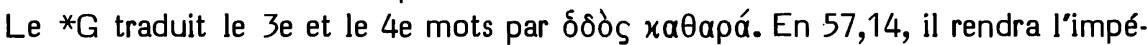

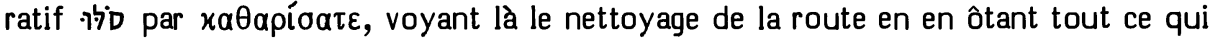
peut entraver le passage (Schleusner III 135s). Le *G semble avoir considéré ici le 3e et le $4 \mathrm{e}$ mots comme constituant un hendiadys.

La *V et le *T attestent la présence du $4 \mathrm{e}$ mot, alors que la *S l'omet vraisemblablement par haplographie, ainsi que certains témoins de la ${ }^{*} V$ l'ont fait aussi. 


\section{Choix textuel :}

La répétition du mot óóós dans le ${ }^{*} G$ semble bien correspondre à celle de ודרך dans le *M. 1Q-a et la *S sont donc les seuls témoins anciens qui attestent nettement l'absence du $4 \mathrm{e}$ mot.

A deux membres du comité, il est apparu qu'ils nous témoignent en cela de la leçon primitive qui aurait subi une dittographie dans le $* M$, la $* V$ et le $* T$. Aussi ont-ils attribué la note " $C$ " à l'absence de ce mot.

Quatre membres du comité ont attribué la note " $\mathrm{C}$ " à la leçon du ${ }^{*} \mathrm{M}$, estimant que $1 Q$-a et la ${ }^{*} S$ ont été victimes d'une haplographie analogue à celle qui a touché une partie de la tradition textuelle du ${ }^{*} M$ et de la ${ }^{*} V$.

Interprétation proposée :

Le suffixe féminin de

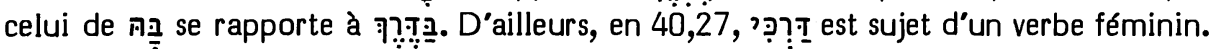

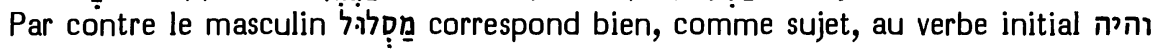
et comme antécédent au pronom suffixe de יעברנו et au pronom והוא

On pourra donc traduire : “il y aura là une chaussée - une voie que l'on appellera la voie sacrée - par cette chaussée, l'impur ne passera pas..."

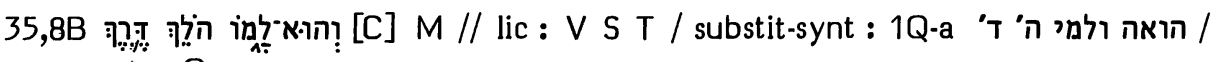
constr : $\mathrm{G}$

Options de nos traductions :

Le *M établit par l'atnah la division principale du vs après le deuxième de ces quatre mots. Les deux premiers mots entretiennent donc une certaine relation avec

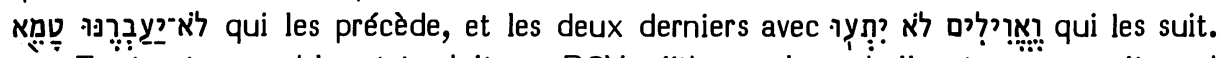

Tout cet ensemble est traduit par RSV : "the unclean shall not pass over it, and fools shall not err therein", en précisant que l'on a omis après "it" une phrase qu'offre l'hébreu : "and he is for them a wayfarer". $J 12$ traduisent : "aucun impur n'y passera, les insensés n'y erreront pas", en précisant que l'hébreu porte après "passera" : "elle sera pour eux quand il aura à faire ce chemin" (selon J1) ou "il sera pour eux, faisant chemin (?)" (selon J2) qui est une glose.

RL traduit: "Kein Unreiner darf ihn betreten; nur sie werden auf ihm gehen; auch die Toren dürfen nicht darauf umherirren."

J3 traduit : "l'impur n'y passera pas; c'est Lui qui pour eux ira par ce chemin, et les insensés ne s'y égareront pas", en précisant que certains considèrent la deuxième de ces trois phrases comme une glose.

TOB traduit : “l'impur n'y passera pas - car le Seigneur lui-même ouvrira la voie - et les insensés ne viendront pas s'y égarer". Elle précise que la deuxième phrase peut aussi se comprendre : "ce sera pour eux le chemin à suivre".

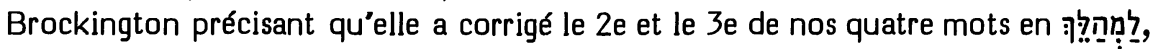
NEB traduit : "and the unclean shall not pass along it; it shall become a pilgrim's way, no fool shall trespass on it".

Notons qu'aucune de nos traductions ne manifeste une conscience de la place de l'atnah. 


\section{Origines des corrections :}

L'interprétation de 33 et TOB, faisant du Seigneur l'antécédent non explicité de והוא, remonte à Calvin qui, en 1551, écrit en son commentaire : “Clausulam versus ubi dicitur 'et ipse ambulans' varie torquent interpretes. Quidam enim vertunt : Haec via erit ipsorum, assueti viae et imperiti non errabunt. Alii : Haec via erit filiis Israel, et ambulantes non errabunt, quamvis sint imperiti. Rectius tamen meo iudicio demonstrativum pronomen ad Deum refertur, ac si dixisset, Deum praeiturum ut sit dux viae ac monstrator." Cette interprétation est entrée dans la Bible française par la révision d'Estienne, en 1553, et dans la Bible anglaise par la Geneva Bible, avant que, sous l'influence de Tremellius, la King James ne la relègue en marge puis que Lowth ne la ressuscite.

L'omission par RSV et $\mathrm{J12}$ des quatre mots dont nous traitons remonte à Duhm qui y a vu une glose à faire passer en marge.

Quant à la correction de NEB, elle a été proposée par Driver (Glosses 126, n. 8).

Les témoins anciens :

1Q-a est seul à transférer la conjonction du premier mot au deuxième et à terminer ce deuxième mot par un 'yod' (au lieu du 'waw').

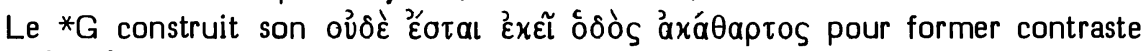

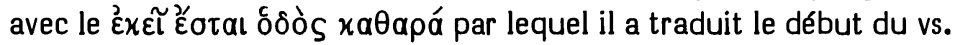

La *S s'est inspirée de la phrase négative du ${ }^{*} G$ en omettant l'adjectif, car celuici n'avait pas de terme de contraste en sa traduction du début du vs.

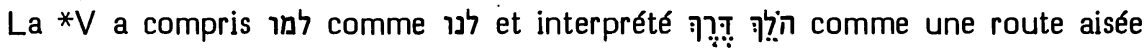
à parcourir.

Le *T semble avoir interprété ces quatre mots comme : "mais il y aura pour eux ( = la chaussée et la voie) des faisant-route", ce qu'il a rendu librement par une phrase négative : "mais les faisant-route ne cesseront pas."

Choix textuel :

Les prises de parti divergentes des témoins textuels ne permettent de reconstruire, comme point de départ de leurs divergences, rien qui soit préférable au ${ }^{*} M$. Aussi le comité a-t-il attribué à celui-ci la note "C".

Interprétation proposée :

L'exégèse qui convient le mieux au *M semble être celle de Rashi : Après que l'on ait dit qu'aucun impur ne passera par cette chaussée, il est ajouté : "Mais elle sera pour eux", c'est-à-dire que cette chaussée sera réservée aux infirmes guéris qui ont été mentionnés aux vss 5 et 6. Puis il est précisé: "Quant à ceux qui y chemineront, même s'il s'agit d'écervelés, ils ne s'égareront pas." 


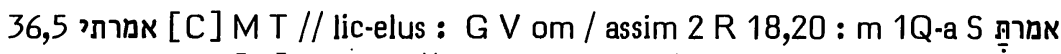
2 R 18,20 אמרנמר [B] M g S T // abr-styl : G om / lic : V

\section{Options de nos traductions :}

Ce début de Is 36,5 est assimilé à celui de $2 \mathrm{R}$ 18,20 par RSV, NEB ("Do you think", en se fondant sur 1Q-a), RL ("Meinst du"), J ("Tu t"imagines", J12 se fondant sur des mss), TOB ("Tu as dit").

Origine de la correction :

Parmi les traductions du XVIe siècle, une minorité seulement (Zwingli, Prédicants, Châteillon français) ont assimilé la leçon d'Isaïe à celle des Rois.

Cette assimilation a été demandée formellement par Houbigant et la quasi-totalité des critiques qui l'ont suivi. Elle est requise par HSAT234, BH23S et Cent.

Les témoins anciens :

Dans le parallèle de $2 \mathrm{R} 18,20$ le $* M$ a la 2 e pers. m. sg. de l'accompli alors qu'ici il a la 1e pers. de cette forme. Une massore atteste ce hiilluf (Weil $\$ 2158$ ).

La leçon d'Isaïe a été assimilée à celle des Rois en une vingtaine de mss du *M, en $1 \mathrm{Q}$-a et dans la $*$ S.

Le ${ }^{*} G$ ancien $n$ 'a traduit ce mot en aucun des deux endroits, seule la recension

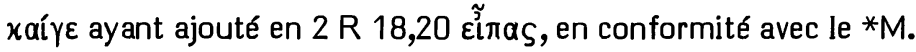

La $* V$, très libre en Is 36,5 , ne permet pas de conclure à ce qu'elle a lu sur ce point. En 2 R 18,20 il est vraisemblable que "inisti consilium" a le *M pour Vorlage.

Le *T appuie le hilluf du *M.

\section{Choix textuel :}

Le comité a tenu à protéger le hilluf du ${ }^{*} M$ contre le risque d'assimilation. En Is 36,5 il a attribué " $C$ " au *M, car, appuyé par peu de témoins, il est probable qu'il n'est pas primitif. Mais il demeure possible que tous les témoins divergents aient assimilé à la leçon plus facile des Rois.

En 2 R 18,20 le comité a attribué "B" au *M car il y est mieux appuyé.

Interprétation proposée :

Selon la forme textuelle des Rois, on interprétera ainsi ce passage : “Tu t'es dit : de simples paroles en l'air valent stratégie et vaillance pour faire la guerre".

Selon celle d'Isä̈e, ce verset est lié à celui qui précède : "Ainsi parle le grand roi, le roi d'Assur : 'Quelle est cette confiance en laquelle tu te fies ? (5) Je me suis dit : de simples paroles en l'air lui tiennent lieu de stratégie et de vaillance pour faire la guerre'."

36,9 פחת [B] M 1Q-a G Sym V s T // abr-styl : S om

Options de nos traductions :

Ce mot est traduit par RSV ("captain") et TOB ("gouverneur"). 
J, RL et NEB l'omettent ici comme elles l'ont omis dans le parallèle de $2 R$ 18,24; $\mathrm{J} 3$ précisant qu'elle y voit une glose ou une dittographie.

Origine de la correction :

A propos de $2 R 18,24$ où ce vs se retrouve identique, nous avions noté (CT1, 410) que le mot תח l'avait omis par conjecture à titre de glose érudite tardive.

En liaison avec les options prises en $2 \mathrm{R}$ 18,24, HSAT234 et BH23 considèrent ici ce mot comme une glose. Cent l'omet sans rien noter. BHS conseille de l'omettre.

Les témoins anciens :

Ici, ce mot figure dans toute la tradition textuelle ( $y$ compris 1Q-a), sauf les témoins les plus anciens de la ${ }^{*} S$ qui l'omettent.

Comme HUB le signale, un certain nombre de citations midrashiques, ignorant la signification de ce mot, l'ont déformé en פחרת (= “peu, moins" en hébreu rabbinique).

Choix textuel :

Certains critiques ont vu dans le fait que ce mot est à l'état construit une chose inacceptable qui confirme qu'il s'agit d'une glose. Cependant, cette construction syntactique trouve une analogie en בתולת בת־ציון (2 R 19,21 = Is 37,22). En ces deux cas communs à Isaïe et aux Rois, le substantif qui devrait être à l'état absolu est mis à l'état construit par assimilation à son apposition qui est elle-même à l'état construit.

Plutôt que de considérer פֵַ comme une glose érudite à ce qui suit, c'est “l'un des plus modestes serviteurs de mon maître" qu'il faut considérer comme visant à expliciter la portée de ce mot.

Le mot nח̣̣, étant employé déjà en $1 R$ 10,15; 20,24 et étant déjà usité en akkadien, n'a en tout cas rien de déplacé en ce contexte.

Le comité l'a retenu ici avec la note " $B$ ".

Interprétation proposée :

Il est conseillé de faire usage d'un terme assez vague, par exemple "officier".

\section{6,19 ספרוים [A]}

Options de nos traductions :

Selon le *M on lit : “Où sont les dieux de Hamat et d'Arpad, où sont les dieux de Sepharvaïm, ont-ils délivré aussi Samarie de ma main ?" Le *M de 2 R 18,34 ne s'en distingue que par l'insertion de "de Héna et de Iwa" après "de Sepharvaïm" et par l'omission du 'waw' avant כי.

On est évidemment surpris de voir mentionnée l'inefficacité de ces dieux étrangers à délivrer Samarie de la main du roi d'Assyrie.

RSV et TOB respectent ce texte difficile.

Les trois autres insèrent une phrase après "Sepharvaïm" : J : "où sont les dieux du pays de Samarie ?" en se fondant sur le *G et la Vetus Latina de 2 R 18,34; RL : 
"und wo sind die Götter des Landes Samarien ?" et NEB : "where are the gods of Samaria ?" en se référant à la Septante lucianique de 2 R 18,34.

Origine de la correction :

Nos traductions ont pu trouver cette insertion requise ici par les apparats de HSAT234, BH23S et Cent.

Les témoins anciens :

Dans la tradition textuelle d'Isaïe, ce 'plus' n'est attesté par aucun témoin textuel.

Choix textuel :

Le $* G$ ancien de $2 \mathrm{R} 18,34$ - représenté par l'antiochienne et la marge du ms de Léon (Vercellone II 622b) - insère avant "qu"ils aient" l'interrogation : "où sont les dieux du pays de Samarie ?"

Sans être impossible à l'époque des faits, la mention de Samarie comme nom d'une $\chi \omega$ wpa orienterait vers l'idée que ce 'plus' est une glose tardive. D'ailleurs, si ce 'plus' était un élément original du texte, on ne s'expliquerait pas qu'il manque à la fois dans le ${ }^{*} M$ des deux formes parallèles des Rois et d'Isaïe alors qu'il ne prête pas à chute accidentelle.

Luzzatto voit ici dans la leçon du *M une figure de style ayant pour but d'alléger : "Où sont les dieux de $A, B, C$ ? (ont-ils délivré $A, B, C$ de ma main ? où sont les dieux de $Z$ ?) ont-ils délivré $Z$ de ma main ?" On pourrait en effet rapprocher cette figure de style de celle que nous avons remarquée en CT1 346 à propos de 1 R 7,15.

Il semble cependant qu'une exacte reçonstitution du contexte historique puisse suffire à justifier le $* M$ en sa littéralité. En effet, comme l'indique la mention en premier de Hamat et d'Arpad, alors que Samarie vient en dernier, il s'agit vraisemblablement de la coalition menée par Ilu-bi’di (ou Ia'u-bi’di) de Hamat contre Sargon II en la $2 \mathrm{e}$ année du règne de celui-ci, soit plus d'un an après la prise de Samarie par Salmanasar V. Samarie étant mentionnée également en dernier dans les deux narrations de la coalition (Luckenbill II, $3 \S 5$ et $27 \S 55$ ), il est normal de voir en son impuissance à secouer le joug assyrien un signe de la complète impuissance des dieux des initiateurs de la coalition : les dieux des coalisés du nord n'ont pas pu résister au roi d'Assyrie ni, à plus forte raison, arracher Samarie à sa main.

Cette reconstitution du contexte historique montre que le ${ }^{*} \mathrm{M} \mathrm{s}^{\prime} \mathrm{y}$ insère bien et impose de le protéger contre une contamination par la glose facilitante $d u{ }^{*} G$ des Rois.

Du fait que cette glose n'est attestée ici par aucun témoin textuel, le comité a attribué au *M la note " $A$ ".

Interprétation proposée :

Nous l'avons donnée au début de cette étude. 
Options de nos traductions :

RSV ("and when he heard it"), RL (“als er das hörte") et TOB (“à cette nouvelle") traduisent le *M.

J (“de nouveau") et NEB ("again") corrigent en lèle de 2 R 19,9.

Origine de la correction :

$\mathrm{J}$ et NEB ont pu trouver cette assimilation au parallèle des Rois requise par les apparats de HSAT23 et de BHS.

Les témoins anciens :

Ici, la leçon du *M est appuyée par la*V, la*S et le *T.

Dans le parallèle de 2 R 19,9, le *M porte רִּ en accord avec toute la tradition textuelle.

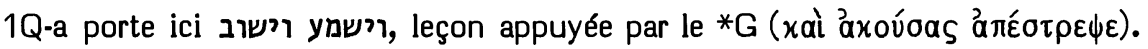

1Q-b porte en début de lacune ]ושיש. Du fait que la transcription de Sukenik (PI. 2) contient des vides dans le remplissage de la lacune qui suit, on serait tenté de croire que ce témoin aussi appuyait la leçon double. Mais la photographie montre l'inexactitude de la transcription du fragment 11 : le 'kaf' final de מל לa la 2e ligne) doit être à la verticale de l'extrémité du 'resh' final de לאמר (3e ligne), ce qui force à resserrer de trois lettres le remplissage de la lacune et en résorbe les vides. Il est donc probable que $1 Q$-b appuie ici le $* M$.

\section{Choix textuel :}

Faut-il considérer en Is 37,9 la leçon de 1Q-a et de la Vorlage du ${ }^{*} G$ comme une conflation des leçons qui caractérisent chacun des deux parallèles? Ou bien faut-il considérer que le $* M$ et ses supporters ont omis ici וישב par un homéoarcton avant Iישלח La première éventualité est apparue plus probable au comité qui a attribué au *M la note "C".

Il faut en tout cas éviter d'assimiler ce texte à son parallèle des Rois.

Interprétation proposée :

"Quand il entendit cela" ou "A cette nouvelle".

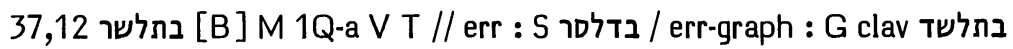

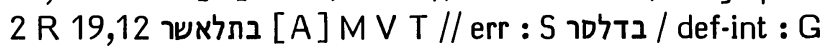

\section{Options de nos traductions :}

RSV, RL, NEB et TOB transcrivent exactement ce toponyme du *M.

Ici et dans le parallèle de 2 R 19,12 J conjecture "Tell Basar". 
Origine de la correction :

Cette conjecture a été proposée par Winckler (que Marti cite en y adhérant).

Les témoins anciens :

Ici, le *M porte écrit

Il $n^{\prime} y$ a rien à tirer des états diversement corrompus du *G en $2 R$ 19,12; alors qu'ici le $*$ G nous orienterait vers une forme à 'dalet' final.

La *V et le *T appuient le * $M$; alors que la $* S$, dans les deux endroits, a un 'dalat' à la place du 'taw' (assimilant ce toponyme à la transcription qu'elle a donnée pour le royaume d'Aryok en Gn 14,9).

\section{Choix textuel :}

Simons ( $\$ 1686)$ a cependant montré la possibilité d'autres identifications (TilBarsip ou Til-Ashûri). Etant donné cette incertitude et l'absence de leçons rivales préférables fournies par d'autres témoins textuels, le comité a estimé devoir garder dans les deux cas la leçon du * $\mathrm{M}$. Il a simplement voulu marquer la légère incertitude qui émane de la lecture d'un 'dalet' final dans la Vorlage $d u{ }^{*} G$ d'Isä̈e en accordant seulement la note " $B$ " au * $M$ en cet endroit.

Interprétation proposée :

Avec RSV, RL, NEB et TOB, on pourra transcrire "Telassar".

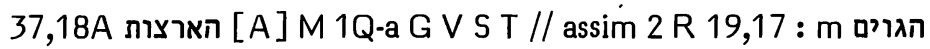

37,18B cor : in fine om ואת ארצם [B] 1Q-a // assim 2 R 19,17M: M G V S T add ואת ארצם

Options de nos traductions :

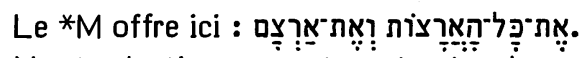

Nos traductions se partagent entre deux options :

RSV offre: "all the nations and their lands"; $\mathrm{J}$ : "toutes les nations (et leurs pays)" et TOB : "toutes les nations avec leurs pays". J2 précise que le premier sub-

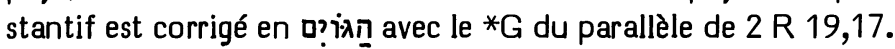

RL donne seulement : "alle Länder" et NEB : "every country"; Brockington précisant que les deux derniers mots ont été omis avec $1 \mathrm{Q}-\mathrm{a}$.

Origines des corrections :

Parmi les traductions du XVIe siècle, le *M a été traduit littéralement par Oecolampade, Pagnini et Foreiro (omnes terras et terram eorum), suivis en cela par Brucioli ("tutte le terre, \& la terra di quegli").

La plupart des traducteurs suivants ont fait usage de deux substantifs distincts : Luther ("alle Königreiche sampt jren Landen"), Zwingli (regna et regiones eorum), Prédicants ("alle reych und land"), Münster (regiones et terram earum), Olivetan et Estienne ("tous les pays \& la terre d'iceux"), Ge ("all lands, \& their countrey"), Pasteurs ("tous les païs, \& leurs contrees"). 
Jud, s'inspirant vraisemblablement du parallèle de 2 R 19,17, a traduit : “cunctas Gentes, \& regiones earum", comme s'il lisait את־כל־הגוים au lieu de את־כל־הארצות. Il a été suivi en cela par Châteillon, Tremellius et $\mathrm{KJ}$. Lowth note qu'un certain nombre de mss du *M lisent ainsi et il adopte cette leçon, suivi par la plupart des exégètes, y compris les apparats de HSAT234, BH23S et Cent.

Cependant, Houbigant, avant de se décider lui aussi à puiser dans le parallèle des Rois, avait d'abord suggéré d'omettre plutôt la finale : ואת'ארצם. Cette suggestion a été reprise par Ehrlich et Procksch. Après que 1Q-a ait attesté cette omission, elle a été adoptée par James (118s), Fohrer, Wildberger.

\section{Les témoins anciens :}

Une quinzaine de mss du *M (parmi lesquels le ms des Jésuites de Cologne et l'Urbinates 1) lisent la leçon que Lowth a adoptée. Il s'agit vraisemblablement de leur part d'une assimilation au parallèle des Rois.

$1 Q$-a omet les deux derniers mots du vs.

La leçon du *M ("tous les pays et leur pays") a été lue par toutes les versions, mais le ${ }^{*} G$, la $* V$ et le ${ }^{*}$ ont utilisé deux substantifs distincts pour éviter cette répétition du même substantif; alors que la $* S$ a interprété les deux derniers mots du vs comme le début du vs suivant.

\section{Choix textuel :}

A propos de 2 R 19,17 nous avons noté (CT1 411s) que le *G ancien n'y traduit pas et nous avons admis, avec Talmon (Case), que la Vorlage du *G (avec seulement (את הגוים) représente l'état original de la forme littéraire des Rois, alors que, dans le parallèle de Is 37,18, l'état original est représenté par 1Q-a (avec seulement (את כל הארצות Ensuite, s'inspirant de ce dernier texte, un glossateur a ajouté à ואת ארצם avant qu'un autre glossateur ne les ajoute, 2 R 19,17 les mots de façon assez peu intelligente, à Is 37,18.

Le comité a fait ici deux votes :

Il a attribué la note "A" à הארצות du *M, afin de protéger cette leçon contre une assimilation à הגוים du parallèle des Rois.

Foreiro ayant estimé que le ${ }^{*} M$ peut signifier ici : "tous les pays (étrangers) et (les pays qu"ils ont annexés, en faisant) leur pays", un membre du comité a voté " $B$ " pour le *M, estimant qu'il peut avoir ici ce sens. Quatre membres du comité ont voté "B" pour la leçon de 1Q-a, c'est-à-dire pour omettre les deux derniers mots.

\section{Interprétation proposée :}

"Les rois d"Assyrie ont ravagé tous les pays".

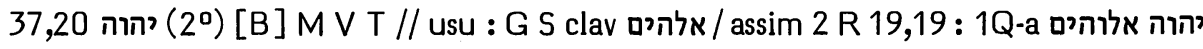

\section{Options de nos traductions :}

Cette prière d'Ezéchias - selon le texte d'Is 37,16 et celui du parallèle de $2 \mathrm{R}$ 19,15 - avait commencé par l'affirmation : “C'est toi qui, seul, es Dieu pour tous les 
royaumes de la terre". Selon Is 37,20 elle s'achève par : "et tous les royaumes de la terre sauront que toi seul es Seigneur", alors que le parallèle de 2 R 19,19 ajoute "Dieu", obtenant : “... que toi seul, Seigneur, tu es Dieu".

Ici, RSV et TOB ont respecté la finale caractéristique d'Isaïe, alors que J, RL et NEB l'ont assimilée à celle des Rois; J2 et NEB se fondant, pour ce faire, sur 1Q-a.

Origine de la correction :

C'est Lowth qui a proposé d'assimiler ce texte au parallèle plus développé des Rois. Cette proposition a été reprise par la plupart des exégètes et intégrée dans les apparats de HSAT234, BH23S et Cent.

Les témoins anciens :

1Q-a a inséré אלוהים après le tétragramme.

Le *G et la *S ont remplacé, dans leur traduction, "Seigneur" par "Dieu". La*V et le $* T$ appuient le $* M$.

Choix textuel :

Dans les confessions de foi bibliques, "toi seul" a généralement "Dieu" pour prédicat. On comprend donc que certains témoins aient remplacé ici "Seigneur" par "Dieu" et que d'autres aient ajouté "Dieu" après le tétragramme, faisant passer celui-ci du rôle de prédicat à celui d'un vocatif, ce qui est le cas dans le parallèle des Rois (malgré les teamim).

La lectio difficilior du *M d'Isaïe n'est cependant pas impossible. On retrouve en effet le tétragramme comme prédicat de "toi seul" dans la confession de Ne 9,6. Il s'agit là probablement d'une variante de la formule du Shema: "le Seigneur notre Dieu est l'unique Seigneur".

Interprétation proposée :

"et tous les royaumes de la terre sauront que toi seul, tu es le Seigneur".

37,21A אלי [C] M G V S T // ign-synt : 1Q-a אליו

37,21B אשור [B] M 1Q-a V T // ign-synt et assim 2 R 19,20 : G S add שמעתי

Options de nos traductions :

Ici, le *M d'Is 37,21 offre une lectio difficilior : Après "ainsi parle le Seigneur

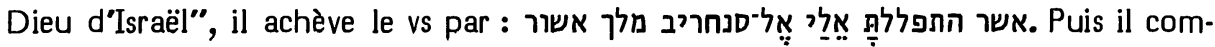
mence le vs 22 par : "Ceci est la parole que le Seigneur a prononcée à son propos".

Le *M est traduit par RSV : "Because you have prayed to me concerning Sennacherib king of Assyria, (22) this is the word that the LORD has spoken concerning him"; et par J : "à propos de la prière que tu m’as adressée au sujet de Sennachérib, roi d'Assyrie. (22) Voici l'oracle que Yahvé a prononcé contre lui."

RL donne pour cela: "Was du von mir erbeten hast wegen des Königs Sanherib von Assyrien, habe ich gehört. (22) Dies ist's, was der HERR über ihn spricht"; et NEB : "I have heard your prayer to me concerning Sennacherib king of Assyria. 
(22) This is the word which the LORD has spoken concerning him". Brockington précise que cela suppose, après אשור avec le une insertion de et le parallèle de 2 R 19,20.

TOB donne : “Ainsi parle le SEIGNEUR Dieu d'Israël, auquel tu as adressé ta prière au sujet de Sennakérib, roi d’Assyrie. (22) Voici..." sans note textuelle.

\section{Origines des corrections :}

L'ajoute faite par NEB (et RL) a été proposée par Vogel, Lowth et la plupart des exégètes récents, y compris HSAT234, $\mathrm{BH} 235$ et Cent.

TOB présuppose pour 21A une correction en par Marti et Ehrlich, puis adoptée par Wildberger après qu'elle se soit trouvée attestée par 1Q-a.

\section{Les témoins anciens :}

Pour 21A, 1Q-a atteste la leçon conjecturée par Marti.

Le *G (ク̉xovoa) et la *S (שמyת) lisent, l’un au début et l'autre à la fin de la relative, l'ajoute proposée par Vogel.

Pour 21A et 21B, le *M a l'appui de la*V et du*T.

\section{Choix textuel :}

La leçon du ${ }^{*} G$ et de la $* S$ constitue une assimilation à la leçon plus facile du parallèle de 2 R 19,20. Elle vise à créer une proposition principale de laquelle la relative puisse dépendre.

1Q-a a facilité en un autre sens, afin de lier la relative à la phrase qui la précède.

Le comité estime cependant préférable la leçon du $* M$ et considère que la relative se rattache au verset suivant.

C'est faute d'avoir compris cette syntaxe que les deux variantes susdites ont divergé $d u * M$ en des sens opposés.

En $21 \mathrm{~A}$, le comité a attribué au *M 5 " $\mathrm{C}$ " et 1 " $\mathrm{B}$ ".

En 21B, il lui a attribué la note " $B$ ".

Interprétation proposée :

"Pour ce qui est de la prière que tu m'as adressée au sujet de Sennachérib roi d’Assur, (22) ceci est la parole que le Seigneur a prononcée à son propos".

Nous avons déjà rencontré plusieurs fois des glissements entre la 1e et la $3 e$ personne lorsqu'elles désignent Dieu en ce livre.

Quant à אֶ: au sens de "à propos de", voir ce que nous en avons dit en 29,22.

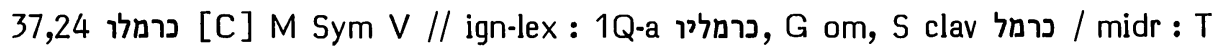

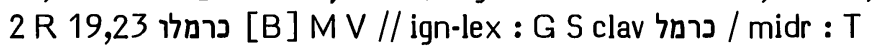

Options de nos traductions :

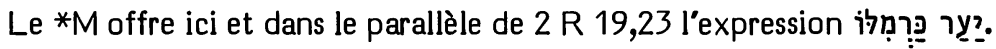

Dans les deux endroits, RSV la traduit : "its densest forest", J et TOB : "son 
parc forestier" et RL en 2 R 19,23: "im dichtesten Wald" et ici : "in seinen dichtesten Wald".

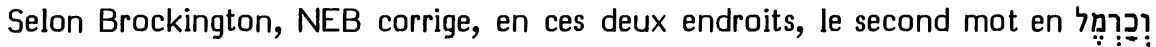
et traduit : "of forest and meadow". En 2 R 19,23, elle se réfère au *G.

\section{Les témoins anciens :}

Pour כרמליו 1Q-a offre ici. Peut-être un scribe, interprétant ce mot comme "verger", a-t-il estimé qu'un seul verger ne peut suffire à constituer une forêt.

Ici, le ${ }^{*} G$ ancien ne traduit pas ce mot. En 2 R 19,23 le ms Vaticanus donne

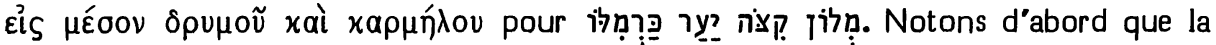
traduction des deux premiers mots est trop libre pour qu'on puisse tirer de ce témoin des conclusions significatives, et ensuite que le ${ }^{*} G$ ancien semble avoir lu ici avec

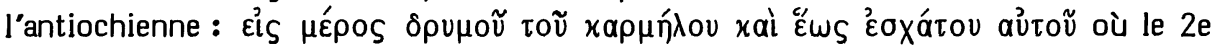
mot de l'hébreu est traduit après le $3 e$ et le $4 \mathrm{e}$.

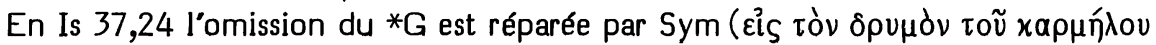
aủंoṽ) suivi par la *V (saltum carmeli eius), celle-ci ayant la même traduction en $2 \mathrm{R} 19,23$.

*S, dans les deux endroits, semble avoir compris "Carmel" en toponyme.

Dans les deux endroits, le *T midrashise selon les mêmes lignes d'interprétation qu'en Is 10,18.

Choix textuel :

A propos de la non-traduction de ce mot ici par le ${ }^{*} G$ ancien, notons qu'en 10,18, seul endroit d'Isaïe où ce mot se retrouve affecté d'un pronom suffixe, le ${ }^{*} G$ a encore évité de le traduire.

L'identité de la leçon offerte par le *M en ces deux lieux parallèles contraste avec l'éparpillement de ceux des témoins qui improvisent des facilitations.

Du fait que 1Q-a s'ajoute en Isaïe aux témoignages divergents, le comité n’y a attribué que la note " $C$ " au * $M$; alors que, dans le parallèle des Rois il lui a attribué la note "B".

Interprétation proposée :

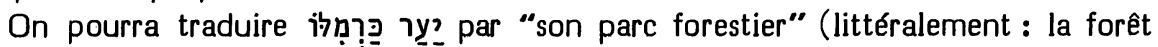
de son parc).

\section{7,25 מים / I ] M Sym V S T // assim 2 R 19,24 : 1Q-a add G}

Options de nos traductions :

La seule variante qu'offre, selon le *M, le parallèle de 2 R 19,24 est un 'plus' de זרים après מים

RSV et TOB ont respecté ici l'absence de ce qualificatif.

Il a été ajouté par RL ("fremde Wasser"), J ("des eaux étrangères") et NEB ("the waters of a foreign land"). $\mathrm{J}$ appuie cette ajoute sur le parallèle des Rois. NEB ajoute à cet appui celui de 1Q-a. 
Origine de la correction :

Houbigant avait déjà diagnostiqué dans le ${ }^{*} M$ d'Isaïe une omission de ce qualificatif par homéotéleuton et la plupart des exégètes ainsi que les apparats de HSAT234, BH23S et Cent avaient proposé d'insérer ce mot ici.

Les témoins anciens :

L'omission de ce mot par le *M est appuyée ici par Sym, la*V, la *S et le $* T$.

1Q-a offre le qualificatif qu'Houbigant estimait manquant.

Quant au *G, il n'a de commun avec le *M en ce vs que la traduction du mot מים et de celui qui le suit, bien qu'il les permute.

\section{Choix textuel :}

Par 4 "B" et 2 "C", le comité a voulu protéger le *M d'Isaïe contre une assimilation au parallèle des Rois. Nous avons en effet déjà conclu que 1Q-a assimilait à ce parallèle en 36,$5 ; 37,9.20$.

37,27A cor הנשדף [C] 1Q-a V T (crp) // err-graph : ושדמה / abr-elus : G om / incert : Sym, $S$

37,27B cor קדים [B] 1Q-a // homarc : M V S T om / abr-elus : G om

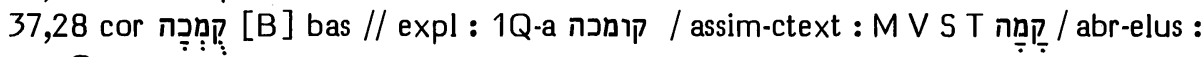

G om

\section{Options de nos traductions :}

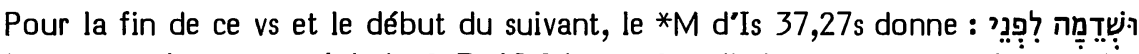

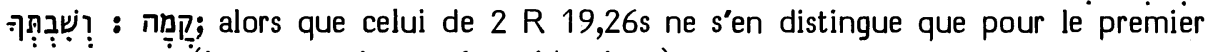
mot : ושישדפה (la ponctuation en étant identique).

En Isaïe, seule TOB entend traduire le ${ }^{*} M$ : "et dans la campagne, avant maturation. Quand tu t'assieds...".

RSV se contente d'assimiler le premier mot au parallèle des Rois et traduit : "blighted before it is grown. "(I know) your sitting down..." ".

Sִ קִדים et elle insère קוpantre celui-ci et le suivant. Pour ces trois corrections elle se réfère à 1Q-a. Elle traduit : "blasted before the east wind. (I know) your rising up and your sitting down".

J traduit : "et guérets, sous le vent d'orient. Quand tu te lèves et quand tu t'assieds...". Elle offrait, dès 31 , la $2 \mathrm{e}$ et la 3e corrections de NEB en se référant à 1Q-a.

En traduisant : "das verdorrt, ehe es reif wird. (Ich weiss) von deinem Aufstehen und Sitzen", RL présuppose la 1e et la 3e corrections de NEB.

\section{Origines des corrections :}

Comme nous l'avons noté (CT1 413), un siècle avant la découverte de 1Q-a, Thenius, en commentant les Rois, estimait difficilement évitable une correction de en קדים. Quant à Wellhausen, il proposait (Bleek4 257, n.1) plutôt de transférer les deux derniers mots du premier verset au début du verset suivant sous la forme : 


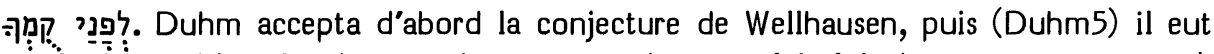

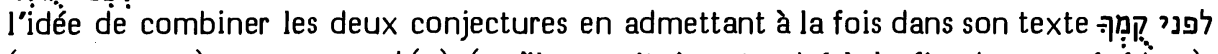
(avant (משלפני קדים et) (qu'il pensait être tombé à la fin du vs précédent). Cette intuition de Duhm fut confirmée par la découverte de 1Q-a (sauf pour ce qui est de la répétition de לפני).

\section{Les témoins anciens :}

1Q-a porte ici : הנשדף לפני קדמ קומכה ושבתכה, un 'yod' ayant été ajouté ensuite au-dessus de l'intervalle séparant le 'dalet' et le 'mem' du 3e mot.

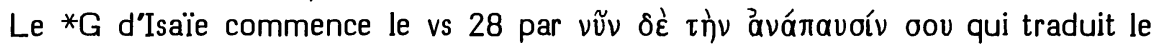
*M. Quant à la fin du vs précédent, il l'écourte tellement qu'il y est inutilisable.

Pour 27A, on ne saurait restituer une Vorlage assez certaine pour Sym (ñitıs

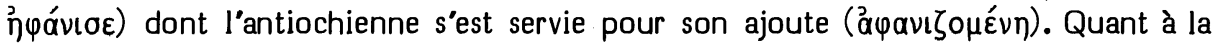
*V (quae exaruit) et au *T (Tשלוק), c'est à la leçon de 1Q-a qu'ils correspondent le mieux. La *S traduit ce mot de la même manière qu'elle a traduit le mot correspondant dans les Rois. On ne peut donc savoir avec certitude ce qu'elle y a lu.

Pour les deux derniers mots du vs 27 , le $* M$ a été traduit, de façon plus ou moins libre, par toutes les versions.

\section{Choix textuel :}

Iwry (Qumrân 29) a montré de façon convaincante que l'herbe (חצח qui précède ce passage) est normalement menacée de dessèchement (Is 40,6-8; 15,6; Jb 8,12; Ps 90,6), que l'agent caractéristique du dessèchement est le vent d'est (קדים, cf. Ez

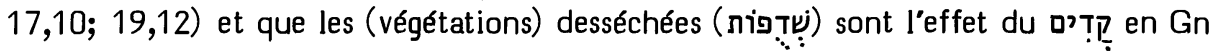
41,6.23.27.

Wildberger a donc eu raison de reconnaître comme originale la forme que $1 \mathrm{Q}-\mathrm{a}$ nous livre pour la fin du vs 27 et pour le début du vs 28 (où "ton lever" complète et équilibre parfaitement les trois infinitifs qui suivent).

Comme nous l'avons noté (CT1 412), le * $G$ ancien des Règnes nous permet de remonter à une Vorlage ושרפה לפני קמך où (à part la déformation d'un 'dalet' en 'resh')

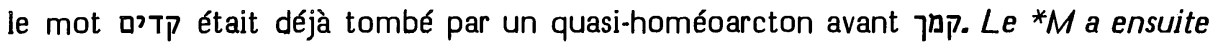
corrigé en קמך inintelligible. Si le *M est issu d'un manuscrit faisant usage de graphies pleines pour les suffixes (קמכה), cette correction a consisté seulement en l'omission d'un 'kaf'. Elle a été ensuite étendue au lieu parallèle.

En $27 \mathrm{~A}$ la leçon du $* M$ a peu de chances de représenter l'original. En effet, d'une part ce singulier est un hapax en face de 5 emplois de שדמות où Lehmann et Croatto/ Soggin voient un terme technique faussement interprété en pluriel. D'autre part, Gn 41,6.23.27 nous font plutôt attendre en 27A un mot de la racine

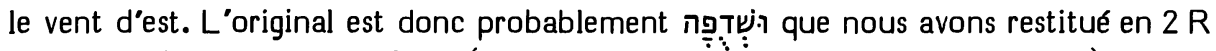

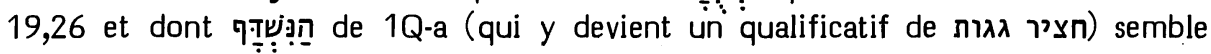
être ici une forme rajeunie. En effet, alors que le nif̣al du verbe n'est pas attesté en hébreu biblique, Levy (Talm. Wörterb. IV 512b) précise qu'en hébreu rabbinique il n'est employé qu'au nifal et au nitpael.

Pour ne pas risquer d'assimiler au parallèle des Rois et pour respecter l'homogénéité de la leçon de $1 Q-a$, le comité a estimé ici plus prudent d'adopter הנשדף qui, quoique modernisé, respecte le sens original. 
Le comité a donc attribué à 4 " 4 "C" et 1 "D", et à la leçon du *M 1 "D".

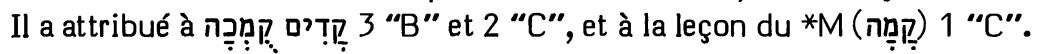

Interprétation proposée :

"ils sont devenus comme les plantes des champs et la verdure du gazon, comme l'herbe des toits desséchée sous le vent d'orient. (28) Quand tu te lèves ou t'assieds, quand tu sors ou tu entres, je le sais".

\section{7,29 יען התרגזך אלי [B] M G V S T // homtel : 1Q-a om}

\section{Options de nos traductions :}

Selon le *M, le vs précédent s'est achevé par ואת התרגזך אלי. Cette quasi-répétition est respectée dans leurs traductions par RSV, RL et TOB.

Ces trois derniers mots du vs 28 ont été mis entre parenthèses en $\mathrm{J} 3$ comme doublet vraisemblable omis par le *G. Ils ont été omis par $\mathrm{J12}$ et NEB, Brockington nous précisant que ce sont les trois premiers mots du vs 29 que NEB entend omettre avec 1Q-a.

Origine de la correction :

L'omission des trois premiers mots du vs 29 a été requise par Duhm, Cheyne et Marti.

Ce sont pourtant les trois derniers mots du vs 28 que les apparats de HSAT4 et $\mathrm{BH} 23$ ont considérés comme une addition, avant que la découverte de 1Q-a n'amène BHS à demander d'omettre les trois premiers du vs 29.

\section{Les témoins anciens :}

1Q-a omet en effet ces trois mots. Il s'agit vraisemblablement d'un homéotéleuton sur אלי

$\mathrm{BH} 3$ (dont $s^{\prime}$ inspire J3) disait que le ${ }^{*} \mathrm{G}$ omet les trois derniers mots du vs 28 .

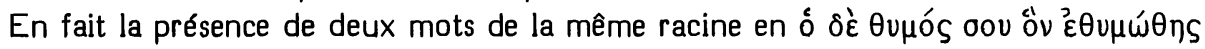
semble bien être une traduction allégée de la quasi-répétition qui a fait difficulté aux critiques. Le ${ }^{*} G$ du parallèle de $2 R 19,27$ s, beaucoup plus littéral, suit de très près

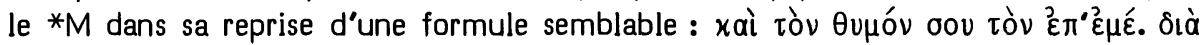

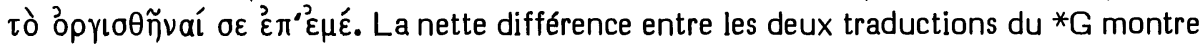
que cette reprise caractéristique n'est pas passée d'un lieu à l'autre par une assimilation intérieure au grec, mais que chacun des traducteurs l'a lue en sa Vorlage, de même qu'elle se trouve dans. le ${ }^{*} M$ de chacun des deux endroits. Il en va de même pour la $* V$, la $* S$ et le $* T$.

\section{Choix textuel :}

Quoique les témoins du *M soient ici unanimes, il n'est pas absolument impossible que ces mots aient été réintroduits dans le $* M$ et dans la Vorlage des versions à partir du parallèle des Rois (où aucun témoin ancien autre que deux mss du *M 
n'en atteste l'omission). C'est pourquoi le comité s'est contenté d'attribuer au *M ici 4 "B" et 2 "C".

Interprétation proposée :

"(Quand tu te lèves ou t'assieds, quand tu sors ou tu entres, je le sais) et aussi quand tu trembles de rage contre moi. (29) Parce que tu trembles de rage contre moi (et que ... je mettrai mon croc à ta narine)."

\section{7,36 ויצא ] ] ]}

Options de nos traductions :

Seule J fait précéder ce vs par "cette même nuit", J3 référant cette ajoute au parallèle de $2 \mathrm{R} 19,35$.

Origine de la correction :

Cette ajoute a été requise par les apparats de BH23S et de HSAT4.

Choix textuel :

Le 'plus' ריהי בלילה ההוא étant présent en toute la tradition textuelle de 2 R 19, 35 et absent de toute la tradition textuelle d'Is 37,36 , le comité a attribué la note " $A$ " à l'absence de ce 'plus' ici, afin de mettre en garde contre l'assimilation d'un parallèle à l'autre.

\section{8,5 הנני יוסף] ] ]}

\section{Options de nos traductions :}

Seule de nos traductions, J insère avant ces mots : “je vais te guérir; dans trois jours tu monteras au Temple de Yahvé", J3 se référant au parallèle de 2 R 20,5.

Origine de la correction :

$\mathrm{J}$ a pu trouver cette insertion requise par l'apparat de $\mathrm{BH}$.

\section{Choix textuel :}

La tradition textuelle des Rois est unanime pour la présence de ce 'plus' et celle d'Isaïe unanime pour son absence. Notons que le parallèle des Rois est caractérisé par d'autres 'plus' : cinq mots en 20,4, deux mots en 20,5a et quatre mots en 20,6b.

Il faut laisser à la forme textuelle d'Isaïe la plus grande sobriété qui la caractérise en ce passage.

Le comité a attribué la note " $A$ " à l'absence de ce "plus". 
Options de nos traductions :

En conformité avec le parallèle de 2 R 20,7-9, J et NEB ont pris deux initiatives : elles ont d'abord inséré Is 38,21-22 après 38,6, puis elles ont fait la transition entre cela et Is 38,7 en ajoutant : "Isaïe répondit" (J) ou "and Isaiah said" (NEB) par quoi débute 2 R 20,9.

Origine de la correction :

En jugeant qu'il s'agit en Isaïe d'une ajoute très tardive, Duhm a inséré ici les vss 21-22, estimant qu'ils ont été originellement destinés à occuper ce lieu.

L'ajoute initiale au vs 7 a été proposée par Procksch et BHS.

Les témoins anciens :

Les vss 21-22 étaient originellement absents de 1Q-a où une seconde main les a ajoutés.

Tous les autres témoins attestent leur présence.

Aucun témoin n'atteste ni leur transfert ici ni l'ajoute proposée par Procksch.

Choix textuel :

Il ne faut pas assimiler l'une des traditions textuelles à l'autre.

Les traducteurs pourraient cependant indiquer en note que les vss Is 38,21-22 sont peut-être en Isaie une ajoute secondaire, puisque la première main de $1 \mathrm{Q}-\mathrm{a}$ ne les atteste pas. La reconnaissance du caractère secondaire de ces deux versets ne doit cependant pas entraîner leur omission, car leur présence en tout le reste de la tradition textuelle d'Isaïe n'est pas due à un accident textuel, mais à une initiative rédactionnelle. Il faut d'ailleurs noter que leur contenu se distingue de celui des vss parallèles des Rois.

Par la note "A", le comité a entendu protéger le texte d'Isaïe contre ces assimilations au parallèle des Rois.

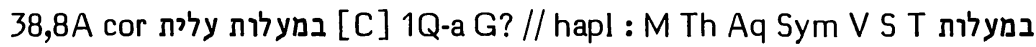

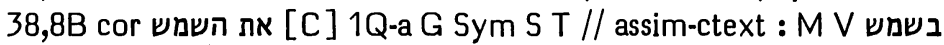

\section{Options de nos traductions :}

Voici, en Isaïe, selon le ${ }^{*} M$ de 8 a, la manière dont le Seigneur présente à Ezé-

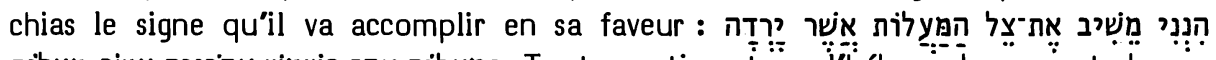

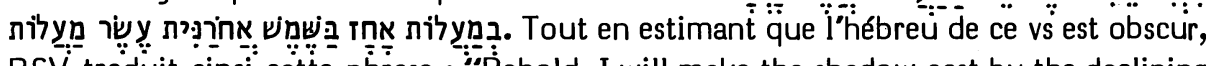
RSV traduit ainsi cette phrase : "Bंehold, I will make the shadow cast by the declining sun on the dial of Ahaz turn back ten steps." NEB traduit: "Watch the shadow cast by the sun on the stairway of Ahaz: I will bring backwards ten steps the shadow which has gone down on the stairway." Cette traduction libre ne prétend pas corriger le *M.

TOB traduit : "Voici que, sur le cadran d'Akhaz, je vais faire revenir en arrière l'ombre qui est déjà descendue : elle reculera de dix degrés." RL traduit : "Siehe, ich 
will den Schatten an der Sonnenuhr des Ahas zehn Striche zurückziehen, über die er gelaufen ist." Ces deux traductions semblent ne pas tenir compte de 8B.

J12, sans rien noter, traduisaient: "Je vais faire reculer l'ombre de dix degrés que le soleil a déjà descendus sur les degrés d'Achaz." 33 traduit : "Voici que je vais faire reculer l'ombre des degrés que le soleil a descendus sur les degrés de la chambre haute d'Achaz - dix degrés en arrière." Elle note ici deux corrections : D'une part, les mots "de la chambre haute" sont insérés avec 1Q-a. D'autre part, on lit "le soleil" avec les versions et le ${ }^{*} T$, à la place de "avec le soleil" que le $* M$ place plus loin.

\section{Origines des corrections :}

Les deux corrections de $\mathrm{J} 3$ sont requises par l'apparat de BHS.

\section{Les témoins anciens :}

En 8a, 1Q-a offre deux variantes par rapport au *M : Il insère y entre le 8e et le $9 e$ mots, et il lit את השמש à la place du 10e mot. Notons qu'en $8 b, 1 Q-a=* M$.

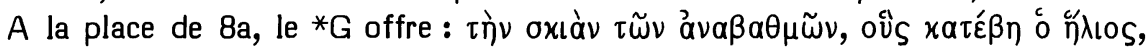

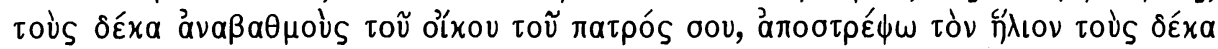
¿’ $\alpha \alpha \beta a \theta \mu o u ́ s$. Comme le note Kutscher (540), il se peut que, dans cette leçon très différente de celle du *M et de $1 Q-a$, les mots toũ oóxou correspondent au 'plus' תלי de 1Q-a. Notons que les autres témoins (Th, Aq, Sym, la *V, la *S et le *T) n'offrent rien qui corresponde à ce 'plus'.

Quant à בַּ du du *M, à la place de quoi 1Q-a offre il semble bien que

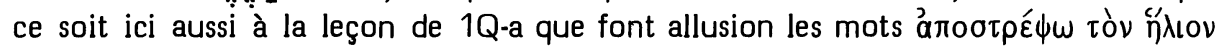
du *G. La préposition 'bet' du *M ici n'est attestée que par la ${ }^{*} V$ (ecce ego reverti faciam umbram linearum per quas descenderat in horologio Achaz in sole retrorsum decem lineis). Hie déclare s'être inspiré de Sym pour traduire par "horologium" le 2e emploi de מyלות. Selon Ziegler, c'est dans la citation qu'en fait Théodoret que la traduction de Sym pour 8a nous a été le mieux conservée. Or Sym lisait ici : ióov̀

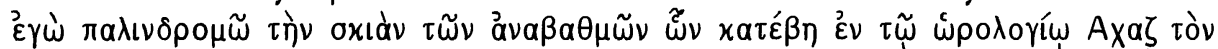

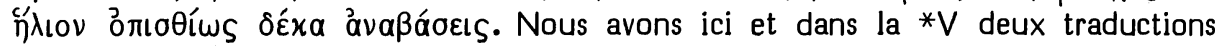
assez littérales du ${ }^{*} M$; la seule différence entre elles deux étant que Sym semble avoir

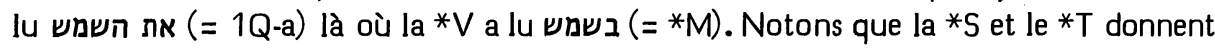
ici שמשא sans trace de la préposition "bet" du *M.

\section{Choix textuel :}

La différence existant entre la $* V$ et Sym suggère que, pour $8 B$, une modification de la leçon de $1 \mathrm{Q}$-a en celle du $* \mathrm{M}$ a pu avoir lieu à l'époque protomassorétique, peut-être sous l'influence de במעלות, deux mots auparavant.

Quant au 'plus' de 1Q-a (et peut-être du ${ }^{*} G$ ) en $8 A$, il faut noter que l'expression אלית se retrouve (cf. CT1 419) en 2 R 23,12. Or cette expression serait bien en place ici où la vraisemblance d'une haplographie subie par le *M est plus grande que celle d'une dittographie ayant produit par hasard cette bonne leçon en 1Q-a. Ajoutons que le contexte de 2 R 23,12 est suffisamment différent de celui-ci pour qu'une influence de ce passage sur le nôtre ne soit pas à craindre.

Le comité a donc attribué à ces deux leçons de 1Q-a 4 "C" et 2 "B". 
Interprétation proposée :

8a peut se traduire: "Voici donc que je vais faire reculer l'ombre des degrés qu'elle a descendus sur les degrés de la chambre haute d'Achaz - le soleil de dix degrés en arrière" (c'est-à-dire : je vais faire reculer le soleil de etc.).

Cette reprise du complément de "je vais faire reculer" sous la forme de "le soleil", peut s'expliquer par le fait que le verbe féminin ירדה ne semble pas en accord avec son sujet apparent צي qui a normalement des accords masculins (par ex. $2 \mathrm{R}$ 20,9.10).

38,9 מכת / מכת / incert :

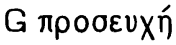

Options de nos traductions :

Seule RSV traduit clairement le *M par "a writing".

Parmi les autres, seuls $\mathrm{J}$ et TOB notent qu'elles conjecturent ( $\mathrm{J} 2$ précisant qu'il

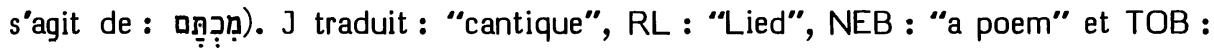
"poème".

Origine de la correction :

C'est en 1859 que Delitzsch (Psalter I 116) a estimé qu'il fallait peut-être lire ici מכתם. Il estimait en effet que le Cantique d'Ezéchias unit deux caractéristiques dont on rencontre l'une ou l'autre dans les psaumes ainsi intitulés : d'une part, l'introduc-

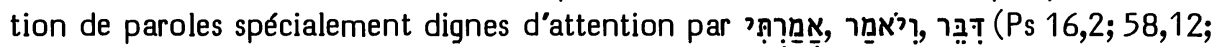
60,8; Is 38,10.11) et d'autre part la reprise de telles paroles sous forme de refrain (Ps 56,5.11s; 57,6.12; 59,10s.18; Is 38,12b.13b). Par cette conjecture, Delitzsch inversait une suggestion de Gesenius qui, dans son commentaire d'Isaïe, avait suggéré que nous avons ici en מכתב la forme authentique du mot qui, dans le Psautier, aurait été déformé en מכתם. Entre-temps, Hitzig avait protesté contre la suggestion de Gesenius en estimant impensable que la racine très usitée כתב ait pu être déformée en כתם.

Cette conjecture de Delitzsch a été adoptée par la plupart des exégètes suivants ( $y$ compris König) et les apparats de HSAT34, BH23S et Cent.

Les témoins anciens :

La leçon מכתם est attestée ici par le ms Oxford, Bibl Bodl, Opp Add fol 3 (espagnol du XVe s.) dans la citation de ce vs en Bereshit Rabba (éd. Albeck 718,6). Notons cependant que des mss plus anciens de ce même midrash (par exemple les mss London BL Add 16,406 et 27,169 ou le ms Paris BN hébr 149) ont ici la leçon du *M. On retrouve encore la leçon מכתם dans le lemme du commentaire de Yéfet ben Ely, selon le ms London BL Or 2501 (du XVIe s.). Notons cependant que cette leçon y est formellement contredite par le commentaire qui la suit et que deux mss plus anciens du même commentaire (London BL Or 2548 et Leningrad Bibl Saltykov Shchedrin Hebr I 569) ont dans le lemme la leçon du $* M$.

1Q-a, ThAqSym, la *V et la $* S$ appuient clairement le $* M$.

Le *T a paraphrasé sur la base du $* M$. 
Quant à la leçon $\pi \rho \circ \sigma \varepsilon u x \eta ́ ~ d u * G$, il semble bien qu'elle ne correspond pas au *M. Il n'est pas impossible qu'elle traduise מכתם, quoique le ${ }^{*} G$ des Psaumes (plus

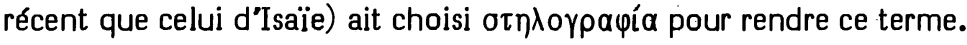

\section{Choix textuel :}

La conjecture de Delitzsch a été jugée très probable par le comité. Il semble que les deux témoins tardifs et isolés d'une tradition secondaire du $* M$ aient été assimilés au titre qui revient plusieurs fois dans le Psautier. Quant au ${ }^{*} G$, un membre du comité, estimant qu'il permettait de fonder la leçon מכתם, a attribué la note " $A$ " à celle-ci. Jugeant plus probable que le ${ }^{*} G$ a traduit largement en s'inspirant du contexte, les cinq autres membres du comité ont attribué la note " $A$ " au $* M$ auquel aucune variante réelle ne semble s'opposer.

Interprétation proposée :

Le sens "un écrit" ne faisant aucune difficulté réelle, cette traduction devrait être donnée. La conjecture de Delitzsch, avec la référence aux psaumes en question, pourrait figurer en note.

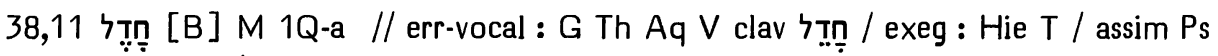
49,2: m S חלד

Options de nos traductions :

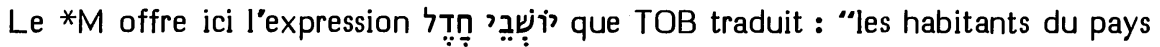
où tout s'arrête".

Brockington informe que NEB a corrigé en deuxième mot par "the world", ce que RSV faisait déjà sans rien noter. J dit conjecturer la même Vorlage pour traduire "du monde". RL traduit de même "der Welt".

Origine de la correction :

Saadya et Yéfet ben Ely comprennent déjà ici ce mot au sens de "monde". D'ailleurs Judah ben Qoreish (Bargès $57=$ Katz 91) et Abraham ha-Babli (199,5) estiment qu'il y a eu ici une permutation des deux dernières consonnes. Cette interprétation, en fonction d'une permutation diagnostiquée ici, se retrouve chez Abulwalid (Ușul 212,12 et Luma 338,2), Joseph Qara, Ibn Ezra, Radaq, Isaïe de Trani.

Ont proposé de corriger en חְִֶֶ: Michaelis (OEB), Bredenkamp, Delitzsch4, Duhm, Dillmann/Kittel, Cheyne et la plupart des critiques. Cette correction est requise par les apparats de BH23, HSAT4 et Cent.

\section{Les témoins anciens :}

Deux mss Kennicott, trois mss de Rossi (et la première main de trois autres) et le ms de Petrograd (où la leçon postérieure) lisent ici חל חל

La *S offre ici חפרץ qui, en Ps 17,14; 89,48; Jb 11,17, traduit חֶ:

Pour ce mot et son contexte immédiat, 1Q-a appuie le *M. 
Le contexte immédiat du ${ }^{*} G$ n'est pas clair, mais on peut conclure qu'il vocalise

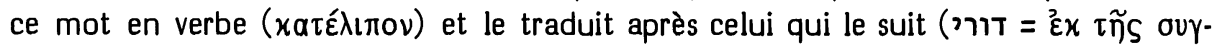

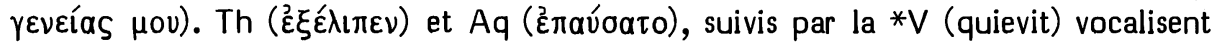
aussi en verbe (דָ̣) et transfèrent le sof pasuq avant ce mot (en traduisant le mot précédent comme s'il était à l'état absolu).

Dans son commentaire, Jérôme change d'opinion et traduit ce mot en substantif, à la fin du vs 11 (quietis). Mais il garde cependant le verbe qui y correspondait au début du vs 12 (cessavit) en s'inspirant de la traduction de Th.

Le *T, comme Jérôme, a une double traduction. Dans une ample paraphrase, il le rend d'abord par ארעא dans le vs 11, puis par פסק dans le vs 12. Le premier de ces deux mots est le correspondant du *T pour חֶֶ en Ps 17,14; 49,2 (mais pas en Ps 89, 48 ; Jb 11,17).

Choix textuel :

David ben Abraham (I 523,47-52) commente ainsi ce mot du *M: "Ce monde est appelé ainsi ici à cause de l'empêchement pour l'homme d'y subsister de façon durable. Et puisque ceux qui l'habitent n'échappent pas au néant et à l'anéantissement, il dit : 'J'avais pensé : je ne regarderai pas vers un homme ensuite et je ne résiderai pas avec les habitants de l'empêché, c'est-à-dire de ce monde qui s'anéantit'." Cette exégèse entend donc interpréter לד̣ ("l'empêché") comme incluant à la fois חִ ("ce monde") et ("qui s'anéantit"). Dans la même ligne, Rashi voit ici le séjour des morts désigné comme "la terre cessante et privée de vie". Quant à Ibn Ezra, il suggère, en une deuxième exégèse, qu'il s'agit là de ce monde qui cessera d'avoir des hommes en lui.

Parḥon et Aaron ben Joseph interprètent ici cette expression comme "les habitants du moment", c'est-à-dire de l'éphémère.

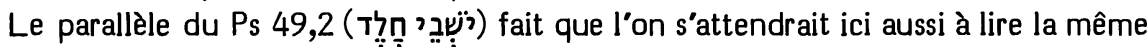
expression. Mais nous retrouvons dans le livre d'Isaïe des endroits $(13,22 ; 38,17$; $41,14.24 .29 ; 48,10 ; 51,16 ; 63,14 ; 64,6)$ où l'auteur semble avoir eu l'intention - par un lapsus voulu - de dérouter son lecteur en lui offrant un mot là où le contexte lui en faisait attendre un autre, les deux mots ayant cependant entre eux une analogie suffisante pour que l'un évoque l'autre.

Il est donc apparu au comité qu'il fallait respecter ce qui est probablement un procédé littéraire de l'école isaïenne.

Il n'est toutefois pas impossible que nous ayons ici une permutation du type שלממה/שמלה HALAT, le suggèrent.

Le comité a attribué la note " $B$ " à la leçon du *M.

Interprétation proposée :

“Les habitants de l'éphémère". 
Options de nos traductions :

Le *M a été traduit par RSV ("I have rolled up"), RL ("zu Ende gewebt hab ich"), TOB ("j'arrive au bout du rouleau de") et J3 ("j'ai enroule").

J12 conjecturaient "tu enroules".

NEB conjecture en se référant à 1Q-a : "thou hast cut short."

\section{Origines des corrections :}

Pour expliquer la traduction de NEB, Brockington dit qu’au lieu de קפדתי du *M, elle a lu ספפרפרִ avec 1Q-a. De fait, Driver (TLP 56) précisait que 1Q-a lit (comme le *M) la première personne. Aussi conjecturait-il de la corriger en deuxième personne.

La conjecture de $\mathrm{J} 12$ remonte à Clericus estimant qu’Ezéchias n'avait pas pris l'initiative de couper lui-même sa vie. Comme la plupart des exégètes antérieurs à Gesenius, il attribuait en effet au verbe du *M le sens de "couper".

Les témoins anciens :

Un certain nombre de témoins ressentaient déjà la difficulté à laquelle Clericus sera sensible. C'est pourquoi Aq traduit ce verbe par un pluriel impersonnel; alors que $T h$, Sym, la *V, la *S et le *T le traduisent par un passif. Notons à ce propos qu'il semble préférable de ne pas corriger en première personne avec Ziegler les troisièmes personnes du singulier ( $T$ h et Sym) ou du pluriel ( $\mathrm{Aq}$ ) que le ms Barberini donne pour ces leçons.

1Q-a nous apporte une attestation précieuse pour la première personne du $* M$. Il s'est contenté de rajeunir l'expression en remplaçant le verbe hapax du*M (auquel il attribuait le sens de "couper", comme le fera la *V) par le verbe qui, en hébreu plus tardif, signifie "couper les cheveux ou la barbe".

Ici comme pour le cas suivant, le ${ }^{*} G$ construit trop librement pour que l'on puisse tirer de sa traduction des conclusions sur sa Vorlage.

\section{Choix textuel :}

Il semble préférable de donner au verbe du *M, avec Gesenius, le sens de "enrouler", qui explique bien le nom du hérisson : Tịp. Comme le tisserand qui a achevé son travail l'enroule pour laisser disponible le métier à tisser, Ezéchias doit déjà achever son règne et laisser la place à un autre. Il y a ici de la part d'Ezéchias non pas l'initiative d'un suicide, mais un acte de résignation à une fin qui lui semble proche. Nous interpréterons dans le même sens la difficulté suivante.

Remarquons d'ailleurs que les exégètes judéo-arabes anciens (Saadya, Yéfet ben Ely et David ben Abraham) ne donnaient pas à ce verbe le sens de "couper", mais celui de "plier".

Comme König l'a noté, ce verbe à la première personne est en parallèle avec les deux אמרתי qui commencent les vss 10 et 11.

Le comité a attribué à la leçon du *M la note " $\mathrm{B}$ ". 
38,13 שוריתי / שפותי / assim-ctext : T / hom : 1Q-b S om vs 13

Options de nos traductions :

Aucune ne traduit le *M.

RSV ("I cry for help"), RL ("schreie ich"), J12 ("je crie") et J3 ("j'ai crié")

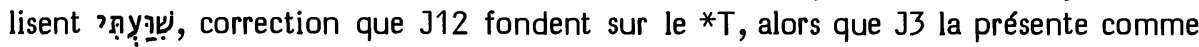
une conjecture.

TOB ("je serai réduit à rien") et NEB ("I am racked with pain") se fondent sur 1Q-a, Brockington précisant la vocalisation : שِ.

Origines des corrections :

C'est Houbigant qui a le premier conjecturé la leçon que RSV, RL et J ont retenue. C'est Velthusen (cité par Koppe) qui a suggéré que le *T a lu cela. La correction a été proposée par les apparats de HSAT234, BH23S et Cent.

Quant à NEB, c'est à Driver (TLP 56) qu'elle emprunte sa traduction de la leçon de $1 Q$-a. Celui-ci s'inspire en cela de l'arabe, alors que TOB (comme probablement déjà

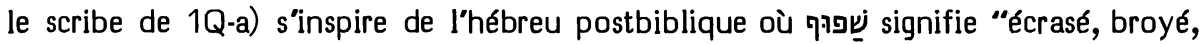
réduit à la dernière extrémité".

Les témoins anciens :

1Q-a offre ici שפותי que Kutscher (293) interprète comme TOB le fera.

Il est difficile de dire si $\pi a \rho \varepsilon \delta \delta o ́ \theta \eta \nu$ du ${ }^{*} G$ entend traduire ce verbe ou celui qui le précède.

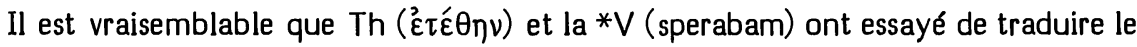
*M.

La *S (comme 1Q-b) a omis tout le vs 13 par homéotéleuton.

Quant au *T, sa traduction "j'ai rugi" lui a été probablement suggérée par "comme un lion" qui suit.

\section{Choix textuel :}

Le *M est assez peu appuyé, mais rien ne s'oppose à lui qui ait quelque chance de représenter une forme plus primitive du texte.

Le comité lui a donc attribué la note "C".

\section{Interprétation proposée :}

Gesenius semble avoir raison de faire porter "comme un lion" sur "il brisera"

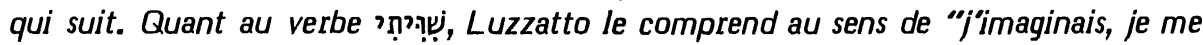
représentais", suivi en cela par Buber, ce qui correspond bien au sens de ce verbe en Ps 16,8. Le sujet de "il brisera" est très probablement le Seigneur (ainsi Buber) plutôt que la maladie (Jérôme et Luzzatto).

On traduira donc: "je m'imaginais que, jusqu'au matin, tel un lion, il aurait brisé tous mes os". 
38,14A עגור [C] M 1Q-b Th Aq V // facil-synt : 1Q-a S ערור / assim-usu : Sym / abrelus : $\mathrm{G}$ om / confl : $\mathrm{T}$

Options de nos traductions :

Tout en considérant l'hébreu comme incertain, RSV traduit ce mot par "or a crane" et TOB par "ou un passereau".

Selon une note de J2, J23 entendent traduire alors que, pour $\mathrm{J1}$, cette traduction correspondait à une omission du deuxième mot.

NEB traduit : "as if I were a swallow" en disant omettre, avec le *G, le deuxième mot.

Pour ces deux mots, RL se contente de "wie eine Schwalbe".

Origine de la correction :

Bredenkamp (citant Klostermann) et Duhm estiment que le second mot a été importé ici à partir de Jr 8,7. HSAT23 portent le même jugement; alors que HSAT4, $\mathrm{BHS}$ et Cent fondent là-dessus l'omission dudit mot.

Les témoins anciens :

1Q-a porte ici עוגר. Selon Kutscher (318), le scribe, ignorant ce mot, l'a traité en participe qal qualifiant le mot qui précède.

1Q-b doit probablement être lu כסיס עגור.

Etant donné le caractère très libre du ${ }^{*}$ G, le fait qu'il ne donne pas un correspondant spécifique ici à ce mot ne permet pas de conclure qu'il ne l'a pas lu en sa Vorlage.

La *S (דמנצרא) et la seconde traduction donnée par le *T (ומנציף) semblent reposer sur la leçon de $1 \mathrm{Q}-\mathrm{a}$.

Cappel (Critica 836) a fait remarquer que Sym ( $\left.\varepsilon_{\varepsilon}^{3} \gamma \varepsilon \varepsilon \chi \lambda \varepsilon \varepsilon \sigma \mu \varepsilon \varepsilon_{\eta}\right)$ semble avoir lu ici סִגרוּ. Là-dessus, Scharfenberg note que le *T, en sa première traduction (דאחיד), semble avoir lu de même (à moins que ce ne soit yִyy).

Th et $\mathrm{Aq}$ se sont contentés ici de transcrire le $* M$ (transcription déformée en AGOR selon Jérôme, ou aүpou selon le ms Barberini).

$\mathrm{La}$ *V traduit les deux mots par "sicut pullus hirundinis".

\section{Choix textuel :}

Il faut rapprocher ce passage de Jr 8,7 où on lit dans le *M: : qeré du second mot avec 'yod' s'y opposant à un ketib avec 'waw'. Ici le mot qui nous concerne se présente comme un nom d'oiseau coordonné aux deux qui le précèdent.

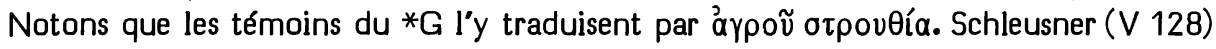
a suggéré que le premier de ces deux mots du ${ }^{*} G$ est issu d'une transcription de l'hébreu (aүovp) ayant subi une déformation analogue à celle que le ms Barberini lui a fait subir en Is 38,14 dans la leçon de Th et Aq. Une fois que le ${ }^{*} G$ de Jr 8,7 a eu déformé cette transcription en un génitif de ảץpós, le mot suivant a probablement été ajouté pour fournir à ce génitif un nominatif sur lequel il puisse se construire.

En Is 38,14 où il n'existe pas de qeré traditionnel pour distinguer la forme du substantif signifiant "cheval", il est très vraisemblable que רịּ est une glose que I'on a empruntée au parallèle de Jérémie afin d'indiquer qu'il ne s'agit pas ici en 
Isaï du cheval, mais de l'oiseau qui - en ce parallèle - est mentionné sous ce nom

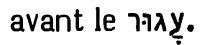

Comme nous l'avons noté, le caractère très libre du ${ }^{*} G$ nous empêche d'y trouver un témoignage valable sur une Vorlage où cette glose ne figurerait pas encore.

D'ailleurs l'ajoute de cette glose constitue une initiative rédactionnelle et non un accident. Le comité l'a donc conservée avec la note "C".

Interprétation proposée :

On a proposé pour רִּ̣ le sens de "grue" (Bochart, Hierozoicon II 68-80). Cependant la grue ne pépie pas. Mieux vaut donc comprendre ici ce mot comme une épithète de celui qui le précède, mot qui désigne l'hirondelle ou le martinet. Etant donné notre grande incertitude et le fait que ce mot a pour but de distinguer celui qui le précède du "cheval", on pourra traduire : "l'hirondelle migratrice", avec une note indiquant que cette épithète est vraisemblablement une glose.

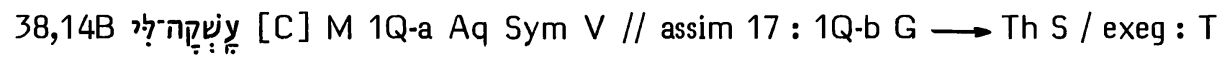

Options de nos traductions :

Le *M est traduit, sans note textuelle, par RSV ("I am oppressed"), RL ("ich leide Not"), TOB ("je suis écrasé") et 33 ("je suis accablé").

$\mathrm{J12}$ traduisaient : "occupe-toi de moi", J1 disant suivre les versions, et J2 conjecturant שִ Selon Brockington, NEB fait la même conjecture pour traduire : "pay heed ... for me".

Origine de la correction :

Ce sens d'impératif avec ce déplacement du point diacritique avait déjà été proposé par Koppe. Le rattachement à cette racine a été adopté par Cheyne, Duhm, Marti, Oort, Procksch, Cent et BHS.

Les témoins anciens :

1Q-a porte ici : חשקה

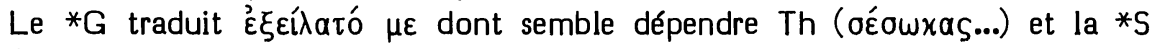
(פצני).

Nous verrons que les autres versions anciennes se situent aisément parmi les diverses interprétations rivales que nous allons présenter dans la suite de cette étude.

\section{Choix textuel :}

Notons d'abord qu'Houbigant, croyant devoir interpréter le *M comme un verbe, constatait que ce verbe se construit d'ordinaire avec l'accusatif, alors que la présence ici d'un 'lamed' prépositionnel conviendrait mieux au verbe ici la présence. 1Q-b est venu confirmer cette conjecture. Il semble bien pourtant qu'il s'agisse là d'une assimilation au vs 17 où $1 Q-b$, nous le verrons, lit ce verbe en accord avec le $* M$. Le fait que le $* G$ ait, au vs 17 , traduit ce verbe par cí $\lambda$ ov montre qu'il a vraisemblablement lui aussi interassimilé les deux verbes. 
Avant de retracer l'histoire de l'exégèse de la leçon que le *M offre pour ce mot, il importe de remarquer que le ms de Leningrad, celui d'Alep et celui du Caire s'accordent pour affecter d'un meteg le qameș initial. Norzi atteste lui aussi cette graphie comme authentique.

Les exégètes judéo-arabes anciens s'accordent pour voir là un accompli à la 3e pers. f. sg. Le commentaire de Saadya (qui se trouve inédit dans le ms Cambridge T.-S. Ar 22.116 et qui est cité par les Disciples de Menahem, 47s) interprète ce verbe en intransitif ( טלמת = a été violentée), en explicitant "mon âme" pour sujet. Les karaïtes Abulfaraj Harûn (Kitâb al-Mushtamil 73a), Yéfet ben Ely et David ben Abraham (II 431,84s) traduisent en transitif ( citant "la maladie" pour sujet.

L'interprétation de ce mot a fait l'objet d'un grand débat entre Menahem ben Saruq (8a), Dunash ben Labrat (107*), les Disciples de Menahem (47s), Jacob Tam (87) et Joseph Qimhii (Galuy 51 \$117). Menahem classe ce mot avec des substantifs féminins à sens abstrait. Dunash lui reproche cette interprétation, affirmant que, dans la première syllabe on a un qameș ḥațuf et que ce mot est un impératif. Les disciples de Menahem s'appuient sur les mss de Tibériade et sur Saadya pour dire que c'est un qames gadol et que ce mot est une 3e pers. f. sg. de l'accompli. Jacob Tam adopte cette analyse et explicite comme sujet "le sommeil" (qui s"est dérobé). Joseph Qimhi, s'appuyant sur Abulwalid (Usul 553,10s), analyse de même et explicite comme sujet "ma maladie". Cette interprétation sera reprise par les glossaires $A$ et $F$, Ibn Ezra et Radaq (comme première exégèse en son commentaire); alors que Rashi et Joseph Qara comprennent ce mot (à la suite de Dunash) comme un impératif (en ses Shorashim), malgré le meteg (citant un autre cas de meteg dans un impératif de même forme en Ps 86,2). Notons à ce propos que le *T ("reçois ma prière") semble avoir lui aussi interprété ce mot en impératif, en improvisant un sens qui soit parallèle à celui de l'impératif suivant.

C'est Gesenius (Lehrgebäude 43, n.1) qui a, le premier, précisé que, lorsque le meteg se trouve placé dans la syllabe antéprétonique (ce qui est le cas ici, du fait du maqqef), il a seulement pour but d'indiquer la place de l'accent secondaire, tout en laissant au qameș qu'il accompagne sa qualité de qameș hațuf. Il propose ici (comme

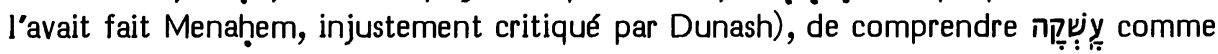

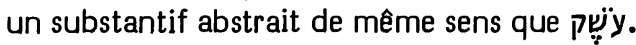

Gesenius ne semble pas avoir su que Menahem de Lonzano (80b), à la fin de son Abôdat Miqdash (qui constitue le troisième "doigt" de ses Sheté Yadôt) avait déjà affirmé que ce type de meteg ne transforme pas le qameș hațuf en qameṣ gadol. Toutefois, Norzi (au dernier folio du traité sur le Maarîk qui achève le vol. 4 de la Minhat Shay) déclare ne pas oser suivre l'opinion de Lonzano, parce qu'elle s'oppose à l'opinion qui a été reçue par nombre de grammairiens très estimés.

Ajoutons que la graphie pleine de 1Q-a et la vocalisation babylonienne du ms de Petrograd confirment qu'il ne s'agit pas ici d'un qameș gadol.

Estimant que les vraies questions qui se posent ici sont des questions d'analyse et d'interprétation, le comité a attribué la note " $C$ " à la leçon du $* M$ afin de la protéger contre la variante de $1 \mathrm{Q}-\mathrm{b}$ ou contre la tentation de retoucher sa ponctuation avec Koppe. 
Interprétation proposée :

Il s'agit vraisemblablement ici d'un appel au secours analogue à ריליל que nous avons analysé en 24, 16.

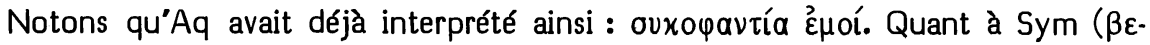
ßíaoral) et à la $* V$ (vim patior), il est difficile de dire s'ils entendent traduire largement un substantif abstrait, ou bien s'ils lisent ici un accompli à la 3e pers. f. sg.

Rosenmüller a noté un contraste semblable entre les racines ערב en Ps $119,122$.

Cette exégèse en substantif abstrait a été adoptée ici par Ewald (Lehrbuch 88), Luzzatto, Böttcher (Lehrbuch I 128), Delitzsch, König (Lehrgebäude I 99), Begrich $(39, n .1)$ et Wildberger. Michel (67) estime que la désinence "-âh" donne à cette forme la valeur d'un nom d'unité.

Ce substantif signifie donc la pression violente que le créancier exerce sur son débiteur.

On pourra donc traduire : “Seigneur, on me fait violence, sois mon garant !"

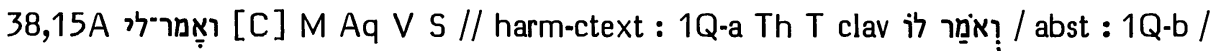
lacun : $G$ om $15 a$

Options de nos traductions :

Le *M a été traduit par RSV : "for he has spoken to me" et par TOB : "pour qu'il me réponde".

$\mathrm{J12}$ traduisaient : “de quoi lui parlerai-je" et $\mathrm{J3}$ : "et que lui dirai-je". RL traduit : "(was soll ich...) und was ihm sagen".

NEB offre : “what can I say to the LORD”, Brockington précisant qu'elle corrige en וְאמֵַר ליהוה

$\mathrm{J}$ et NEB se fondent sur le *T. J12 se référaient en outre à 1Q-a.

Origine de la correction :

Cappel (Critica 834) avait conjecturé iो וְא comme Vorlage pour Th dont on ne connaît que aủiū. Houbigant a proposé d’adopter cette leçon en notant que le * T a lu ainsi. La suggestion d’Houbigant a été suivie par Duhm, Cheyne, Oort, Ehrlich (Miqra), Begrich (41), Procksch, Fischer, Ziegler (EB), Fohrer, Kaiser, Wildberger, ainsi que par les apparats de BH23S, HSAT4 et Cent. C'est elle qui a été adoptée par J et RL.

Les témoins anciens :

En 1Q-a, Burrows avait cru lire ואומר ליא. Löfgren (62) hésitait à lire cela ou לוא. Nyberg (86) dit cette seconde lecture indubitable. En effet, quoique le pied du 'waw' soit bref, il n'y a pas de place pour le nez d'un 'yod'. Mais la comparaison avec le dernier mot de la ligne précédente rend certaine une lecture לוא qui est d'ailleurs seule compatible avec la graphie pleine de la première personne de l'inaccompli qui précède. 
En 1Q-b Sukenik avait lu : ואר. Loewinger (Variants 157) a corrigé cette lecture en : ור. Cependant l'excellente photographie publiée par Sukenik semble bien donner raison à celui-ci, le trait reliant les deux sommets de la lettre étant légèrement ascendant et non descendant (comme c'est le cas pour les 'dalet'). Des traces ténues de la jambe gauche du 'alef' sont encore perceptibles. Notons d'ailleurs qu'ici une leçon répétant le verbe דבר est fort improbable.

Cette partie du vs n'a pas été traduite par le *G.

Le *M est appuyé par Aq, la *V et la ${ }^{*} S$; alors que Th et $* T$ (ainsi que nous l'avons noté) semblent avoir lu la leçon de $1 \mathrm{Q}-\mathrm{a}$.

\section{Choix textuel :}

La variante semble assimiler aux deux mots qui précèdent. Aussi le comité a-t-il retenu la leçon du * $M$ avec la note "C".

Interprétation proposée :

15a peut s"interpréter : “Que dirai-je ? alors qu'il m'a fait une déclaration et qu'il l'a réalisée." On retrouve ces deux derniers verbes dans la même connexion en Nb 23, 19. Il s'agit ici de la déclaration du Seigneur au vs 5 , promettant de prolonger la vie d’Ezéchias. Le “que dirai-je" introduit l'action de grâces des vss 16 à 20.

38,15B אדדה כל־שנותי [C] M // exeg: Sym V Hie / lic : T / ign-synt : Th Aq / assim

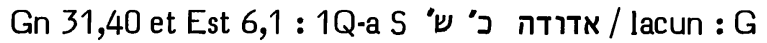

Options de nos traductions :

Le *M a été traduit par TOB : “je dois traîner toutes mes années", et par J3 : “je m'avancerai toutes mes années durant".

RSV ("all my sleep has fled") dit conjecturer en se référant à la *S. RL traduit de même : "entflohen ist all mein Schlaf."

J12, en traduisant : "je te glorifierai toutes mes années durant", conjecturaient

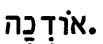

Selon Brockington, NEB corrige en הṬंד avec 1Q-a, lorsqu’elle traduit : “I wander to and fro all my life long".

Origines des corrections :

La correction adopté par RSV et RL avait été proposée par l'apparat de $\mathrm{BH} 3$ et remonte par Ehrlich à Bredenkamp.

Celle de $\mathrm{J12}$ vient de Procksch et Begrich (42). Elle remonte à Grätz. Fohrer et Wildberger l'ont choisie, eux aussi.

NEB a suivi Driver (TLP 56).

Les témoins anciens :

1Q-a offre ici אדודה. Gottstein (Bemerkungen 218, n.4) et Kutscher (263s) ont vu ici une forme à vocalisation pausale d'un inaccompli qal de TTנ. Cette leçon aurait servi de Vorlage à la traduction ואנד de la*S. Notons cependant que Nyberg 
(93s) dérive la leçon de 1Q-a de la racine דוי (= être malheureux) dont il croit lire ici un hitpael.

Cette partie du vs n'a pas été traduite par le *G.

Ce mot a présenté de grosses difficultés aux versions anciennes. Il a été interprété

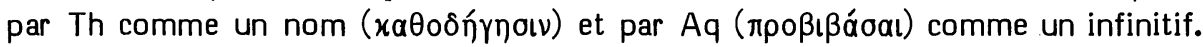
Pour ces deux traducteurs, il s'agit là d'un complément du verbe qui précède. La *V

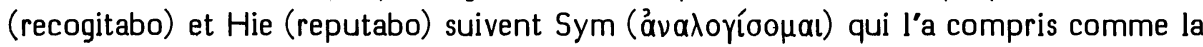
première pers. sg. de l'inaccompli d'un verbe transitif. Il semble que le *T ait exprimé plus librement une interprétation analogue.

Warszawski (61) avait déjà noté que la *S traduit comme si elle avait lu et qu'elle semble sêtre inspirée de Gn 31,40 où on lit racine נדר. On retrouve d'ailleurs le même verbe avec le même sujet en Est 6,1.

\section{Choix textuel :}

Cette perspective sur la leçon de *S (et peut-être sur celle de 1Q-a) est assez attirante. C'est pourquoi, le comité n'a attribué que la note "C" à la leçon du *M. Il a cependant estimé celle-ci bien appuyée par une tradition exégétique assez ferme.

\section{Interprétations proposées :}

En une exégèse qui semble avoir orienté les options de 1Q-a et de la ${ }^{*}$, bon nombre de commentateurs juifs médiévaux (Saadya, première exégèse de Yéfet ben Ely, Judah ibn Balaam, Rashi, Joseph Qara, Eliézer de Beaugency) ont compris ici : "j'ai fui tous mes sommeils".

Cependant Hayyuj (Kitâb 253,10s) affirme que cette forme ne se rattache pas à la racine נג, mais il ne dit pas à laquelle elle se rattache. Cela a amené Abulwalid (Opuscules 123-125) à comparer ce verbe אַָר à de Is 14,14. Il en a conclu qu'il s'agit d'un hitpael de דה , forme qui, selon Levy (Talm. Wörterb. I 378) se retrouve dans le Talmud Babli (Baba Meșia 25b), à propos de colombes dont les ailes sont liées, au sens de "avancer lentement" ou (Baba Bathra 23b), pour des oiseaux dont les ailes sont liées, au sens de "avancer par sauts". Notons que, dans la Mishna Shabbat XVIII 2, le piél de ce verbe est employé à propos d'une mère qui fait marcher son petit enfant, c'est-à-dire le mène lentement.

Ici, il s'agit probablement de "marcher à pas lents". Il n'est pas impossible qu'il s'agisse (cf. Ps 42,5) d'un défilé solennel d'action de grâces pour célébrer sa guérison. Mais la fin du vs rend plus vraisemblable qu'il s'agit de la démarche d'un infirme.

Si l'on admet, avec les vocalisateúrs massorétiques, cette interprétation en hitpael correspondant à ces parallèles de l'hébreu rabbinique, les mots complément temporel : “durant toutes mes années".

38,16 עליהם יחיו ולכל־בן חיי רוחי [C] M 1Q-b Aq // facil-synt: V S / midr : T / constr : G / err-graph : 1Q-a עליהמה וחיו ולכול בהמה חיו רוחוח

Options de nos traductions :

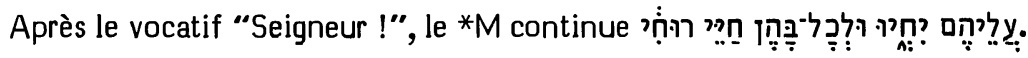



spirit."

RSV a traduit cela : "by these things men live, and in all these is the life of my

$\mathrm{RL}$ omet ce passage.

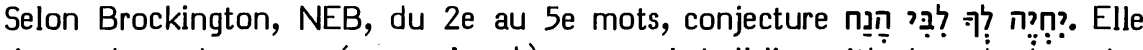
traduit ces deux phrases : "(yet, o Lord,) my soul shall live with thee; do thou give my spirit rest."

J12 donnent : "(Seigneur,) c'est pour toi que vivra mon coeur et que vivra mon

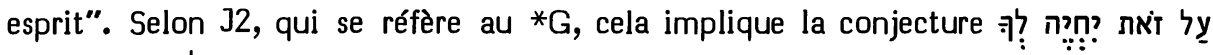

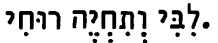

$\mathrm{J} 3$ se fonde sur 1Q-a pour corriger "en elles" du *M en "en eux" et "mon esprit" du *M en "son esprit", et elle traduit : "(le Seigneur) est sur eux, ils vivent et tout ce qui est en eux est vie de son esprit". Il semble bien que ce soit une option textuelle analogue qui fonde la traduction de TOB : "(le Seigneur) est auprès des siens : ils vivront et son esprit animera tout ce qui est en eux".

Origines des corrections :

En omettant ce passage, RL a suivi l'initiative de HSAT34.

L'essentiel des corrections conjecturées par NEB et par J12 vient de Duhm (הנח et).

Les témoins anciens :

La leçon difficile du ${ }^{*} M$ se retrouve en $1 Q-b$ pour les quatre premiers mots cités ci-dessus qui y sont seuls conservés, mais qui sont les plus difficiles de ce vs.

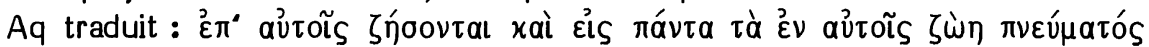
$\mu o v$. Pour être un décalque parfait du $* M$, il ne manque à cette traduction que d'avoir distingué les genres masculin et féminin des deux suffixes de la 3e pers. pl.

En dehors de graphies pleines et d'une assimilation du suffixe féminin pluriel au suffixe masculin pluriel qui le précède, $1 Q-a$ ne se distingue $d u{ }^{*} M$ que par quatre confusions entre 'yod' et 'waw'.

Le *G a paraphrasé en construisant autrement les lettres de sa Vorlage : $\pi \varepsilon \rho \grave{~}$

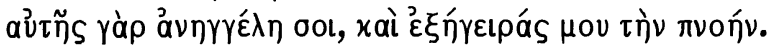

$\mathrm{La} * V$ (sic vivitur et in talibus vita spiritus mei) a allégé légèrement la syntaxe, alors que la *S (מריא עליהון נחון מטל הלין חיא דרוחי) a relié 16a à la fin du vs précédent.

Le *T midrashise : "à propos de tous les morts, tu as dit que tu les vivifierais et, avant eux tous, tu as vivifié mon esprit."

Choix textuel :

Le *M étant attesté assez fermement, face à des facilitations variées, le comité l'a retenu, avec la note " $C$ ".

Interprétation proposée :

Le problème posé par ces mots se situe essentiellement au niveau de l'interprétation. Notons quatre points : 
1/ Les pronoms suffixes masculin (ה-) et féminin (הן-) peuvent exprimer la richesse d'un ensemble (cf. en 3,1 משען ומשענה). Il s'agirait ici des interventions salvatrices du Seigneur auxquelles il a été fait allusion au vs 15 par "il m”a fait une déclaration et il l'a réalisée."

2/ Après le verbe 'vivre' la préposition לy introduit ce dont on vit (cf. Dt 8,3 et Gn 27,40), c'est-à-dire, en ce contexte, ce grâce à quoi on retrouve la vie, ce par quoi on guérit. La forme יחיו est ici un pluriel impersonnel : “Seigneur, c'est grâce à ces (interventions) que l'on revit." Le pronom pluriel de la 3e pers. à valeur neutre se retrouve en Ez 33,18.19 où il est lié aux deux mêmes prépositions - בע en complément des verbes 'vivre' et 'mourir'. Les trois derniers mots sont donc ici à comprendre comme : "c'est en ces choses qu'est la vie de mon souffle". On rencontre aussi le substantif 'vie' construit avec - ב- pour introduire ce grâce à quoi on retrouve la vie en $\operatorname{Pr} 16,15$.

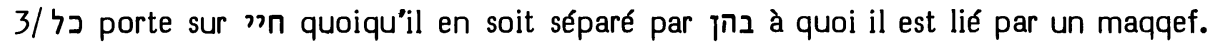
Nous analyserons une construction analogue en Os 14,3. Deux passages ( $2 \mathrm{~S} 1,9$ et Jb 27,3) s'épaulent mutuellement pour attester une autre construction de même type. 4/En ולכל la conjonction suivie de la préposition 'lamed' introduit seulement un nouveau sujet (en parallèle au sujet sous-entendu du verbe précédent). On a la même situation en ולשרים (32,1).

En tenant compte de ces diverses données, on peut proposer : "Seigneur! c'est grâce à cela que l'on revit et c'est en ces choses que réside toute la vie de mon souffle."

\section{חש חשכת [B] M 1Q-a.b G Sym S T // exeg : V clav חשקת}

Options de nos traductions :

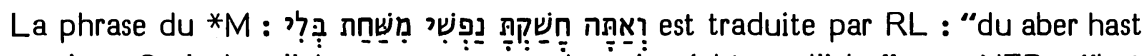
dich meiner Seele herzlich angenommen, dass sie nicht verdürbe"; par NEB : "but thou by thy love hast brought me back from the pit of destruction"; et par TOB : "tu t'es attaché à ma vie pour que j'évite la fosse".

RSV traduit: "but thou hast held back my life from the pit of destruction". Elle note que 'held back' est conjecturé en s'inspirant du ${ }^{*} \mathrm{G}$ et de la ${ }^{*} \mathrm{~V}$, alors que l'hébreu porte 'loved'. Lorsque J traduit : “c'est toi qui as préservé mon âme de la fosse du néant", elle ne note rien.

Origine de la correction :

Cent, plus explicite, précise que le *M porte ici 'aimé' et que 'préservé' est em-

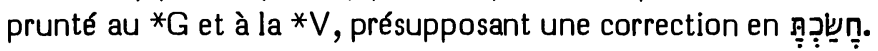

Cette correction remonte à Houbigant qui, notant que une préposition à son complément, a proposé de corriger ici en חשכת, forme en laquelle il voit la Vorlage de la *V. Cette correction a été adoptée par Lowth ( $y$ voyant aussi la Vorlage du ${ }^{*} G$ ), Bredenkamp, Duhm, Grätz, Dillmann/Kittel, HSAT234, $\mathrm{BH} 235$, Cent. 


\section{Les témoins anciens :}

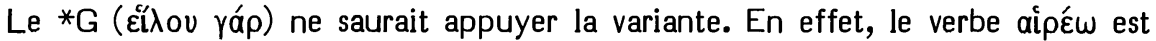
usité dans le ${ }^{*} G$ pour exprimer un amour véhément (cf. 1 S 19,1). Il convient donc fort bien ici au *M. D’ailleurs la réédition Didot du Thesaurus d’Estienne consacre un article particulier à ce sens (I 1039A) qu'elle illustre par ces deux cas du *G.

Ici 1Q-a et 1Q-b appuient fermement le *M que Sym (Eủóóxnoas), la *S (צבית) et le *T (אתרעיתא) ont suivi aussi.

Quant à la *V (eruisti), une comparaison avec la traduction par Jérôme de Jb 33,18 (eruens animam eius a corruptione) montre qu'il a cru lire ici חשنכת.

Choix textuel et interprétation proposée :

Les trois plus anciens exégètes karaïtes dont le commentaire nous ait été conservé ici sont Abulfaraj Harûn (Mushtamil 63a), David ben Abraham (I 228,41) et Yéfet ben Ely. Ils s'accordent pour interpréter ici ce verbe en son sens normal de "aimer passionnément".

Pourtant Saadya traduit ce verbe par צדתת (selon le ms Paris BN hébr 1325), c'est-à-dire "tu as retenu, tu as empêché", ce qui est son correspondant normal pour le verbe חשוֹ (cf. Ecker 203). D'ailleurs Judah ibn Balaam cite cette interprétation en remarquant que "c'est comme s'il avait dit חשכת en substituant un "kaf" au "qof"."

Des parallèles comme Jb 33,18 ou Ps 78,50 amèneraient en effet à conclure que c'est bien cette leçon que le contexte et la syntaxe postulent ici. Il est cependant fort possible que, si ivi est construit avec la syntaxe de שש en un contexte où l'on attendrait ce verbe, c'est justement pour l'évoquer en un sens prégnant: "tu t'es attaché à mon âme au point de l'arracher à la fosse" (cf. les autres cas analogues mentionnés en 38,11). Il se peut donc que la *V et Saadya, conscients de cette intention, aient seulement voulu la rendre perceptible par leur traduction.

C'est pourquoi le comité a attribué à la leçon du *M la note " $B$ ".

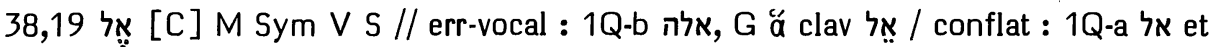

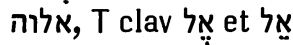

Options de nos traductions :

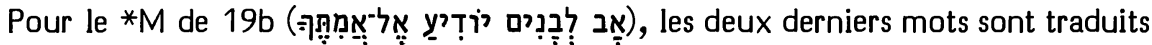
par RSV : "thy faithfulness", par J et TOB : "ta fidélité" et par RL : “deine Treue".

Brockington nous dit que NEB vocalise l'avant-dernier mot avec un șéré, ce qui l'amène à traduire : “thy truth..., o God."

Origine de la correction :

Ne tenant pas compte de la vocalisation massorétique, Houbigant traduit : "patres filiis notam faciunt, ô Deus, veritatem tuam". Ce seront Grätz et Ehrlich qui tireront de cette traduction la conséquence : corriger le segol en șéré.

Driver (Scrolls 27) a attaché de l'intérêt à la variante אלוה de 1Q-a. C'est peut-être ce qui a engagé NEB sur cette voie. 
Les témoins anciens :

La massore, en identifiant les deux derniers mots de 19 à ceux de 18, appuie la vocalisation segol.

1Q-a donne ici une leçon gonflée dont le premier membre ne se distingue du *M que par les graphies pleines, typiques de ce $\mathrm{ms}$, alors que le second membre (dont les graphies défectives indiquent que cette leçon émane d'une autre tradition textuelle) porte le vocatif אלוה à la place de la préposition אֶ:

1Q-b donne ici אלה à la place de cette préposition. Cela peut être la seconde leçon de 1Q-a en une graphie défective; quoique le fait que 1Q-b soit lacuneux en Is 44,8 (seul autre emploi de ce nom divin en ce livre) rend impossible de contrôler s'il avait'犺 aussi cette graphie.

On peut également comprendre la leçon de $1 \mathrm{Q}-\mathrm{b}$ comme le démonstratif pluriel. En effet, le *T offre ici, lui aussi, une leçon gonflée dont le premier membre (גיחון דכל אלין (גבורתך traduit largement une Vorlage identique au *M; alors que le second קשוט) suppose une lecture en démonstratif pluriel.

Il se peut, d'ailleurs, que le relatif $\alpha$ du ${ }^{*} G$ suppose, lui aussi, cette lecture.

Par $\pi \varepsilon \rho i ́$, Sym a voulu traduire le ${ }^{*} \mathrm{M}$.

La *V a assimilé cette préposition à une particule d'accusatif et ne l'a donc pas traduite.

Choix textuel :

Ces divers témoins se rattachent donc à trois lectures de אל :

$1 /$ lu avec segol et interprété en préposition,

2/ lu avec séré et interprété en nom divin au vocatif,

3/ lu avec șéré et interprété en démonstratif pluriel (comme en 1Ch 20,8).

Le fait que l'on ait déjà rencontré en ce cantique une épiphore reliant la fin du vs 13 à celle du vs 12 rend probable que la massore ait raison de signaler ici une autre épiphore reliant la fin de ce vs à celle du vs 18.

Le comité a estimé que cela appuyait suffisamment la leçon du *M pour qu’on la retienne avec la note " $\mathrm{C}$ ".

Interprétation proposée :

Comme Gesenius l'a fait remarquer (ici et en Thesaurus 104a), la préposition אֶ. signifie souvent (comme nous l'avons remarqué en 29,22 et 37,21) “à propos de, au sujet de" après les verba dicendi. Cette interprétation est acceptée ici par HALAT (375a) et Wildberger.

On pourra traduire : "le père instruira ses fils en ta fidélité" afin de faire ressortir le parallèle avec “... n'espèrent plus en ta fidélité" qui achève le vs précédent.

38,21-22 cf. p. 261. 
Options de nos traductions :

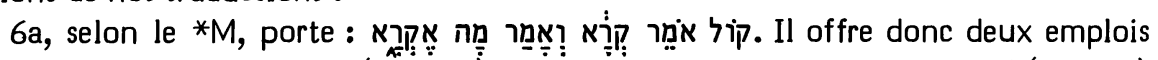
du verbe "dire", le premier (2e mot) étant un participe actif, et le second (4e mot) étant un accompli coordonné à la 3e pers. m. sg.

Pour ce second emploi, le *M est respecté par NEB ("and another asks") et TOB ("l'autre dit"), un sujet ayant seulement été explicité par elles.

Les autres versions traduisent par une première personne : J12: "et je répondis", RSV : "and I said", RL : "und ich sprach", J3 : "et je dis". J12 disent s'appuyer sur

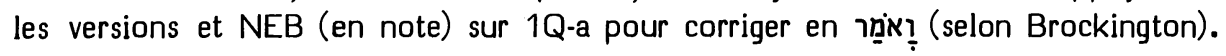

Origine de la correction :

Houbigant a traduit : "ego igitur dixi", sans rien noter, puisque les voyelles n'ont pour lui aucune autorité. Lowth a fait de même avec "and I said". Ils ont été suivis par la plupart des exégètes, y compris HSAT34, BH23S et Cent. Doederlein semble avoir été le premier à demander formellement la correction vocalique.

Les témoins anciens :

La vocalisation du *M en 3e pers. m. sg. est appuyée formellement par la *S et le *T (ואמר).

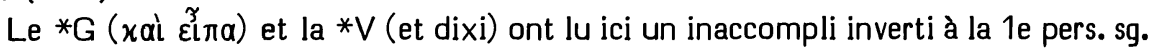

1Q-a offre ici ואומרה. Faut-il interpréter cette forme comme un inaccompli cohortatif ou comme un inaccompli inverti?

Notons d'abord que ce verbe n'apparaît dans le *M que deux fois ( $G n$ 46,31; Ps 42,10$)$ à la 1e pers. sg. de l'inaccompli cohortatif, alors qu'il y figure 18 fois à la

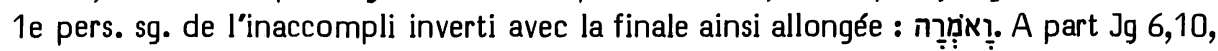
il s'agit là de livres tardifs : 4 emplois en Daniel, 2 en Esdras et 11 en Néhémie; alors

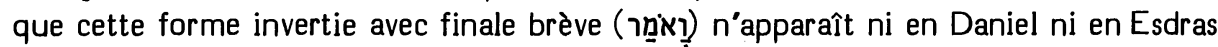
(mais se rencontre 10 fois en Néhémie).

Le *M d'Isaïe porte 5 fois cette forme invertie (toujours avec finale brève). Or

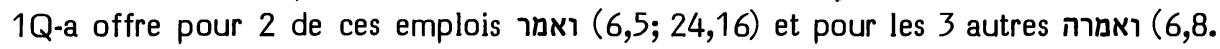
11; 41,9), un 'waw' étant suspendu après la lettre 'alef' en 41,9. On peut donc conclure qu'en Is 40,6 ואומרה est une façon normale pour le scribe de 1Q-a d'écrire la 1e pers. sg. de l'inaccompli inverti de ce verbe.

Observons en passant que dans le Pentateuque Samaritain cette forme invertie avec finale longue apparaît 2 fois $(E \times 3,17$; Dt 9,26) à la place de la forme à finale brève du *M.

\section{Choix textuel :}

Le *M a été conservé ici par König, Rignell, North, Bonnard. En effet, l'auteur d'Is 40 - 55 ne parle presque jamais de lui-même. Aussi est-il peu vraisemblable qu'il se mette en scène ici, comme le note Bonnard: "il se contente de faire parler plusieurs voix, échos de la Voix divine et ... de sa propre voix, sans se mettre lui-même en avant." En effet, au vs 1, Dieu charge de mission plusieurs messagers; au vs 3 'une voix' 
s'adresse encore à plusieurs destinataires, alors qu'au vs 6 'une voix' donne un ordre à un messager. Puis au vs 9 un ordre est donné à 'une porteuse de bonne nouvelle'. König fait remarquer encore qu'il est peu probable que le prophète interroge ici sur le message qu'il a à transmettre, après l'avoir clairement formulé aux vss 1 et 2.

La variante peut avoir été influencée par les récits de vocation prophétique où le prophète se met souvent en scène à la 1e personne (cf. Is 6,5.8.11; Jr 1,6).

Le comité a attribué au *M la note "C".

Interprétation proposée :

Yéfet ben Ely estime que la voix du vs 3 était celle d'un ange, alors qu'il s'agit ici de deux anges qui dialoguent comme cela a lieu aussi en $\mathrm{Za} 2,8$. On peut supposer aussi que l'auteur met en scène un esprit qui recevrait ses consignes au conseil divin (cf. 1 R 22,19.23; Jb 1,6-12; 2,1-6).

vs 7 [B] M ThSym Aq g 1Q-a(corr) V S T // hom : m 1Q-a* G om

Options de nos traductions :

7b porte : "certes, le peuple, c'est de l'herbe". RSV, RL et TOB traduisent cela de façon normale.

J23 placent cette phrase entre parenthèses.

$\mathrm{J1}$ et NEB conjecturent son omission à titre de glose.

Origine de la correction :

Koppe a prétendu se fonder sur le *G pour omettre אכן חציר העם qu'il estime être une glose. Il a été suivi en cela par Gesenius et Hitzig. Mais Knobel a fait remarquer que l'on ne peut fonder une omission de ces trois mots sur l'accident textuel plus ample subi par le ${ }^{*} \mathrm{G}$. Aussi Duhm a-t-il dû présenter comme une conjecture leur omission, suivi en cela par de nombreux exégètes.

\section{Les témoins anciens :}

Déjà Hie avait diagnostiqué ici dans le ${ }^{*} G$ un homéotéleuton sur צ'. Le même phénomène a été diagnostiqué en 1Q-a par un lecteur ancien qui a rajouté le passage manquant. Notons qu'on pourrait tout aussi bien interpréter cet accident comme une omission du vs 7 par homéoarcton. Selon Kennicott, le même accident s'est produit en ses mss 95, 168, 224, 384. Mais Lilienthal (338) ajoute que le ms 224 a inséré en marge le passage manquant. De Rossi signale la même omission de la part de la première main de cinq de ses mss.

\section{Choix textuel :}

Il n'est pas certain que 7b soit une glose. En effet, אֵָ est caractéristique d'Is 40 - 55 où il réapparaît trois fois $(45,15 ; 49,4 ; 53,4)$, alors qu'il est absent des autres parties du livre. Quant à "le peuple" au sens de "l'humanité, on le retrouve en 42,5 (cf. 44,7 ). 
A supposer même qu'il s'agisse d'une glose, il s'agirait là d'un jugement littéraire. La critique textuelle n'a pas les moyens de proposer une omission de ces trois seuls mots.

Le comité a donc décidé, par 5 " $\mathrm{B}$ " et 1 " $\mathrm{C}$ ", de les conserver ici.

Quant à la forme textuelle courte, Koenig (Réouverture 236) nie que celle-ci puisse être issue de la forme du *M par un accident de nature haplographique. Il fonde cette négation sur le fait que, le *M semblant avoir un "caractère compilatoire", sa "priorité originelle" ne "s"impose" pas. Mais il n'est malheureusement pas nécessaire qu'un texte soit dans son état originel pour qu'il puisse prêter à des fautes de copie. Il nous semble en effet que le ${ }^{*} M$ est doublement exposé à des accidents de copie (possibilités d'homéotéleuton et d'homéoarcton) et que les attestations distinctes du *G, de 1Q-a et de plusieurs mss du *M nous montrent que de tels accidents se sont produits à plusieurs reprises (bien que la forme mutilée ait pu se transmettre ensuite de scribe à scribe entre certains des témoins de la forme courte).

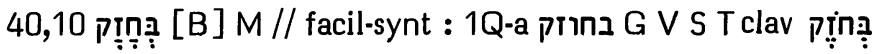

Options de nos traductions :

Seule RL ("gewaltig") traduit assez clairement ici le *M.

RSV ("with might"), NEB ("in might"), TOB ("avec vigueur") et J3 ("avec puissance") ne notent rien.

Pourtant, J12 disaient corriger avec les versions, lorsqu'elles traduisaient comme 33.

Origine de la correction :

Déjà Olivetan (suivi par Rollet et Estienne) traduisait "en force", traduction adoptée par Ge ("with power"), sans prétendre corriger le texte.

Michaelis (OEB) semble avoir été le premier à proposer formellement de corriger la vocalisation en בְ̣n, correction adoptée ensuite par Duhm, puis BH23, Cent et de nombreux exégètes et traducteurs récents.

Les témoins anciens :

Le 'bet' essentiae (que nous avons déjà trouvé en 10,34) étant assez rare en hébreu, le scribe de $1 Q-a$, ainsi que Kutscher (373) l'a noté, l'a lu en 'bet' instrumental et a interprété le mot ainsi introduit comme un substantif abstrait: "avec force". Cette leçon facilitante a été lue spontanément par toutes les versions anciennes.

Choix textuel :

A la suite de Tremellius, Pasteurs, la variante marginale de $\mathrm{KJ}$, Vitringa, Vogel et Lowth ont compris le "bet" au sens de "contre". Cependant, de Dieu et Noldius $(157$, n. f) voient ici un "bet' d'état ou de mode : "en homme fort, en tant que Puissant", comme en Ex 6,3 : "je leur suis apparu en El Shaddaï". König (Syntax $§ 332$ $\mathrm{m} 2$ ) et Gesenius/Kautzsch ( $\$ 119 \mathrm{i})$ ont opté pour cette interprétation en 'bet' essentiae. 
En effet, juste après, la mention de "son bras" montre que le Seigneur vient sous les traits du Puissant, de celui qui a tiré jadis son peuple d’Egypte à main forte et à bras étendu.

Les partisans anciens et récents de la variante "avec force" ont méconnu l'intention subtile de l'auteur. Elle n'est pas d'affirmer platement que le Seigneur dispose d'une grande puissance, mais plutôt de nous le montrer intervenant comme Dieu de I'Exode.

Jugeant cette exégèse très bien en place en ce contexte, le comité a attribué au *M la note "B" malgré son isolement.

Interprétation proposée :

Littéralement : “en tant que Puissant". Une traduction plus libre serait : “dans sa force" (Koenig) où le possessif rend l'adjectif.

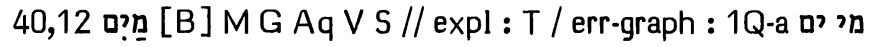

Options de nos traductions :

Le *M a été traduit par RSV et NEB ("the waters") ainsi que par RL ("die Wasser"); alors que J ("l'eau de la mer") et TOB ("les eaux de la mer") disent-corriger selon 1Q-a.

Origine de la correction :

Estimant que la leçon du *M est trop vague et inadéquate, puisque tout homme

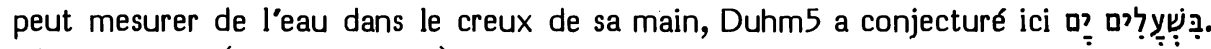
Köhler, Elliger (Verhältnis 225), Cent, Westermann ont suivi Duhm. Fohrer.

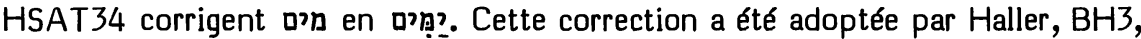

La découverte de 1Q-a a fourni ici une variante qui a été adoptée par J123, puis par Bonnard et TOB.

Les témoins anciens :

1Q-a porte en effet ici מי ים.

Quant au lemme de 4Q165, il est lacuneux jusqu'au mot qui suit celui-ci. Morrow (112) a donc tort de se fonder sur la façon dont Allegro (DJD $\vee 28$ ) a rempli cette lacune pour prétendre que ce ms appuie la leçon du *M contre celle de 1Q-a.

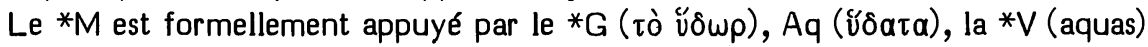
et la *S (מכא), alors que le *T a paraphrasé : "toutes les eaux de l'univers".

Choix textuel :

Lorsque l"état construit מֵ est suivi en hébreu biblique par le génitif aי, ce génitif est toujours déterminé ou par l'article (Ex 15,19; Am 5,8;9,6; Ps 33, j) ou bien par une désignation locale (סרוף en Dt 11,4; Jos 2,10). Il y a donc peu de chances que la leçon de 1Q-a soit originale.

On peut cependant argumenter en faveur d'une leçon "mer" en relevant que la tombe d'Aï (Davies 29a, lignes 18s) mentionne dans un hymne à Aton, comme 
images de quantités énormes: le sable des rivages mesuré avec un certain type de mesure, la mer mesurée avec un autre type de mesure, les montagnes pesées avec la balance, etc. Les similitudes sont frappantes. Mais en Is 40,12 ces mesures sont des actes accomplis par Dieu lors de la création. Elles sont mentionnées pour montrer qu'aucun homme n'aurait pu les effectuer avec les moyens et les unités de mesure qui sont à sa disposition. D'autre part, l'hymne d'El-Amarna ne parle pas d'une mesure des cieux, alors que Is 40 - 55 insiste sur le fait que le créateur a "tendu les cieux" $(42,5 ; 44,24 ; 45,12 ; 48,13)$. Il faut donc qu'il en ait mesuré l'extension. Or, ici, il

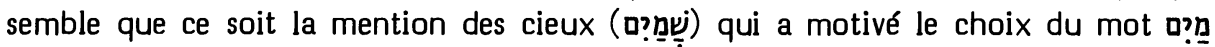
juste avant. Notons que l'assonance existant entre ces deux mots reviendra en con-

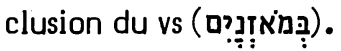

Dans ce contexte, מִ ne signifie évidemment pas "de l'eau", ainsi que Duhm l'estimait, mais "l'ensemble des eaux", ainsi que le *T l'a bien compris. Le vs 12 nous offre donc le trio "eaux, cieux, terre", c"est-à-dire le trio originel de Gn 1,1s; "eaux" étant cependant ici (comme d'ailleurs "cieux") sans article. Notons qu'en Jb 28,25 la même racine מדד (cette fois sous forme substantivale) est encore liée à ${ }^{\prime}$ qui est précédé par les cieux, la terre et le souffle (ce dernier y étant jaugé, alors qu'il est pesé en Is 40,13). Cette similitude de termes en des contextes analogues, quoique non matériellement identiques, nous montre que ces termes y sont bien en place.

Le comité a attribué au *M 4 "B" et 2 "C".

Interprétation proposée :

Le pluriel "les eaux" suggérera bien qu'il s'agit là de l'ensemble des eaux. Il est normal d'expliciter en français un article (comme pour "les cieux", juste après).

40,14 וילמדהו דעת [B] M 1Q-a(corr) ThAqSym V S T // lacun : 1Q-a* om 14b-16 / abr-styl : $G$ om

Options de nos traductions :

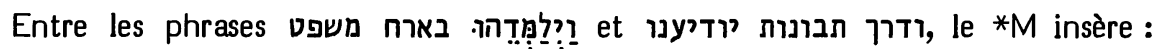

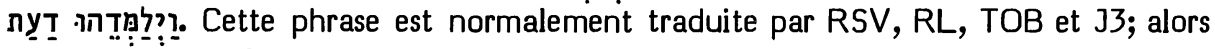
que $\mathrm{J12}$ et NEB l'omettent avec le *G.

Origine de la correction :

Duhm estime que le mot דy est absolument incolore dans le contexte et note que le verbe qui le précède est déjà apparu trois mots avant. Il juge que la petite phrase constituée par ces deux mots sépare deux membres qui se correspondent ("les chemins du jugement' et 'la voie de l'intelligence'). Il est d'avis que cette phrase manque dans le ${ }^{*} G$, ce qui lui semble un argument textuel pour l'omettre. Il a été suivi en cette proposition par Cheyne, Marti, Oort, Condamin, Köhler, Haller, Feldmann, Praetorius (Nachträge), Elliger (Verhältnis et BK), Fischer, HSAT4, BH23S. 
Les témoins anciens :

La présence de cette phrase ici est attestée par ThAqSym, la *V, la ${ }^{* S}$ et le ${ }^{*} T$ (qui paraphrase).

Le scribe de 1Q-a (à cause d'une Vorlage défectueuse ?) a omis 14b.15.16 en laissant vides deux lignes et demi en lesquelles une main plus récente a inscrit ce passage en un état qui ne se distingue du $* M$ que par des variantes orthographiques.

Le ${ }^{*} G$ n'offre rien qui corresponde à ces deux mots, ni rien qui traduise dans la phrase précédente.

Choix textuel :

Elliger (BK) estime que le ${ }^{*} G$ a été traduit à partir d'une Vorlage où manquait le mot בארח. Dans le *M, les deux mots que nous discutons constitueraient originellement une (mauvaise) conjecture marginale visant à suppléer au manque susdit en des mss du type de la Vorlage du *G. Puis un scribe les aurait insérés à tort dans le texte.

Grätz a estimé que c'est la première occurrence de וילמדהו qu'il faut omettre comme dittographie de la seconde. Pour cette omission, il s'appuie sur le *G et la *S.

Volz suit la proposition de Grätz et propose, en outre, de transférer avant le mot בארח. Il estime en effet que ce mot est tombé en des mss du type de la Vorlage du ${ }^{*} G$, puis qu'il a été réinséré à une fausse place avec le verbe qui le précédait.

Si l'on concluait en effet que le ${ }^{*} M$ constitue une forme surchargée, la glose qu'il inclut constitue plutôt la réparation d'un accident textuel qu'un accident de ce type. C'est dire qu'une omission de cette glose serait du ressort de la critique littéraire. $D$ 'ailleurs, le ${ }^{*} G$ ne nous apporterait pas une forme textuelle préférable, puisque tout le monde admet que בארח (attesté par le *M et non par le *G) a toutes les chances d'appartenir au texte original.

Remarquons d'ailleurs que le ${ }^{*} G$ a tendance à abréger dans tout le contexte en laissant des mots non traduits : 2 au vs 11 (ובחיקו ישא), 2 au vs 12 (תכדו (ערן),

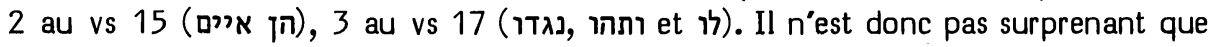
3 mots n'aient pas de correspondant précis au vs 14.

Puisque le ${ }^{*} G$ n'offre qu'un soutien très faible à cette omission qui, d'ailleurs, relèverait plutôt de la critique littéraire, le comité a voté " $B$ " pour le maintien de ces deux mots dans le texte.

40,17 מאפם 4B] M // lic : S T / abr-styl : G / assim-ctext : 1Q-a V וכאפם

\section{Options de nos traductions :}

Seules RSV ("less than nothing") et NEB ("mere nothings") mettent en valeur le "mem" prépositionnel de la leçon du *M.

J3 dit s'appuyer sur 1Q-a lorsqu'elle traduit "pour néant" au lieu de "moins que néant" du*M.

Les autres traductions ("néant" en J12, “als nichtig" en RL et “comme néant" en TOB) ne s'expriment pas sur leurs intentions. 
Origine de la correction :

Une correction du *M en כאפם avait déjà été proposée par Delitzsch (Fehler 115a), Köhler, Elliger (Verhältnis), BH3. Depuis la découverte de 1Q-a, elle a été adoptée par Fohrer, North, Bonnard, BHS, Elliger.

Les témoins anciens :

1Q-a offre ici וכאפס, Vorlage possible de la *V (et quasi nihilum).

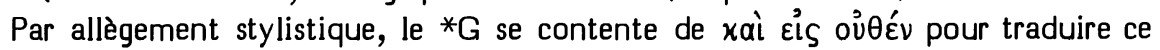
mot, celui qui le précède et celui qui le suit.

La *S ("pour la destruction et pour l'épée") et le *T ("extermination et destruction") traduisent librement ce mot et le suivant.

Il importe de noter que l'auteur des "Paroles des luminaires" de Qumrân (4Q504 1-2 III 3) fait clairement allusion à ce passage d'Isaïe. En Recueil 202, Baillet disait lire sur l'original une "minuscule trace du 'mem' " entre le mot אפס la conjonction qui le précède, alors qu'en DJD VII 141, il transcrit Díi sans préposition, quoique la photo (pl. L) semble laisser place pour une lettre dans la lacune qui sépare le 'waw' du 'alef'.

\section{Choix textuel :}

Remarquons que la seule fois de tout le *M où $ס$ est précédé de la préposition 'kaf' se- trouve en Is 41,12 où $1 Q-a=* M$. Le scribe de $1 Q$-a a tendance à généraliser cette construction qu'il a transférée à 34,12 où la préposition excédentaire a été exponctuée ensuite.

Le fait que מאפס soit ici dans le *M un hapax biblique et que cette leçon ait causé des difficultés aux exégètes nous engage à considérer la leçon de $1 \mathrm{Q}-\mathrm{a}(=* \mathrm{~V})$ comme facilitante, par harmonisation avec כאין qui précède et avec les trois prépositions "kaf" du vs 15. Aussi le comité a-t-il attribué au *M 4 "B" et 2 "C".

\section{Interprétation proposée :}

Il faut noter que les traducteurs du XVIe siècle ont commencé (sous l'influence de la *V) par traduire ce mot en lisant la préposition 'mem' comme s'il s'agissait d'un "kaf'. C'est le cas de Pagnini (pro nihilo), Luther ("wie ein nichtiges"), Brucioli ("per niente"), Olivetan ("comme chose de neant"). C"est Münster qui a mis en valeur le 'mem' (minus quam nihilum), suivi par Calvin qui (sous l'influence de Radaq ?) a rapproché cet emploi du 'mem' de celui de Ps 62,10. Ensuite, la traduction de Münster a été insérée par Estienne dans sa réédition de la traduction de Pagnini (en 1557), d'où elle a pénétré dans la Geneva Bible (en 1560) et dans la Bible des Pasteurs de Genève (en 1588). Mercerus l'a insérée dans la reédition du Thesaurus de Pagnini (en 1577) sous la forme "minus nihilo". Dans la langue allemande, elle a pénétré par la traduction de J.D. Michaelis. Dans la langue anglaise, la King James et Lowth l'ont conservée. Dans la langue française, la Bible du Centenaire et la traduction en français courant l'ont diffusée.

Cependant Gesenius (sous l'influence de la traduction de Luther ?) a proposé d'interpréter ce 'mem' comme l'équivalent d'un 'bet' essentiae, en se référant à l'arabe. Cette position a dominé l'exégèse allemande (ce p̣étant parfois expliqué comme parti- 
tif ou comme indicateur d'origine) jusqu'à ce que l'interprétation "moins que rien" soit reprise par König (Syntax $\$ 352 z$ ) et Volz. Cette dernière interprétation remonte à Ibn Ezra et à Radaq en leurs commentaires de ce vs. Elle est celle qui en ce contexte (et en celui de 41,24) rend le mieux compte de la préposition.

\section{0,21 מוסדות [A]}

Options de nos traductions :

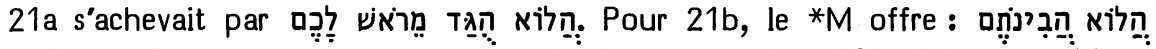

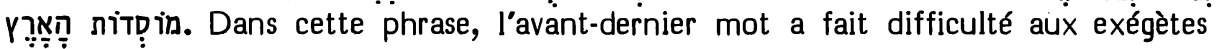
et à nos traducteurs.

Les deux derniers mots ont été traduits par J : "la fondation de la terre" et par TOB : "le fondateur de la terre" (notant : littéralement "les fondations").

RL ("von Anbeginn der Erde") et RSV ("from the foundations of the earth") semblent avoir lu une préposition sans rien noter.

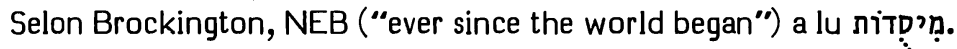

Origine de la correction :

Estimant que מוסדות (= fondements) s'insère très mal dans le contexte, Houbigant a conjecturé מהוסדת à quoi il attribue le sens de "depuis que fut fondée (la terre)." Vogel (en ses notes sur Grotius et en ses notes sur Cappel, Critica 55) estime mieux rendre compte du 'taw' final en vocalisant מְִִִּ. Ce serait la rareté de cette forme infinitivale (du type לֶֶֶ) qui aurait amené les vocalisateurs massorétiques à vocaliser en substantif pluriel, rompant par là le parallélisme avec מֵֵن

Lowth décèle plutôt dans le *M la chute d'un 'mem' prépositionnel initial qui aurait été l'élément central d'une séquence de trois 'mem'. Doederlein hésite entre la proposition de Vogel et celle de Lowth. Ensuite le *M est respecté par Gesenius, Rosenmüller, Hitzig, Knobel, Delitzsch, Knabenbauer, Bredenkamp, von Orelli. Puis une correction en מיִ est proposée par Duhm, Gunkel (138), Cheyne, Marti, Condamin, Feldmann, HSÄT34, BH2S; ce substantif étant mis au singulier par Köhler, Volz, BH3, Fischer, Ziegler (EB), Elliger (Verhältnis et BK) et Westermann. Notons que la correction de Lowth sera reprise après lui par Grätz et König.

\section{Choix textuel :}

Aucune variante n'est attestée dans la tradition textuelle.

Interprétations proposées :

Comme nous venons de le voir, la critique textuelle a fait effort pour faire de ce mot une détermination temporelle parallèle à מֵن de 21a.

Déjà Oecolampade traduisait "a fundamentis" sans justifier en son commentaire la raison d'être de cette préposition. De fait, il a pu s'inspirer de Radaq qui paraphrase le *M par ממוסדות. Luther, en son cours sur Isaïe (WA. XXXI/2 278,25) a repris en lemme la traduction d'Oecolampade à laquelle correspond sa traduction allemande ("von anbegin" que RL conserve). Ont fait de même : Brucioli ("da fondameriti"), 
Münster ("ex fundamentis"), Estienne ("des fondemens" qui dérive de Calvin = Münster), Tremellius ("inde a fundamentis"), $\mathrm{KJ}$ ("from the foundations" que RSV conserve) et Pasteurs ("dès les fondemens").

Donc les traductions allemande, anglaise et française exprimaient traditionnellement ce que les conjectures (à partir d'Houbigant) ont essayé de justifier par des corrections.

D'autres (Oort et Ehrlich) ont conjecturé ici מי יסד את que Bonnard et TOB ont ensuite proposé à titre d'exégèse, tous semblant ignorer que Rashi interprétait déjà ainsi.

Cette exégèse n'est pas impossible. Yéfet ben Ely et Vitringa, eux, ont vu ici une allusion au récit de la création. On peut aussi, avec Luzzat to, Delitzsch, Bredenkamp et von Orelli, laisser à ce mot son sens de "fondements". Il s'agirait des piliers qui, selon la représentation du monde traditionnelle, supportent la terre. Si on "considère" sur quels "fondements" le monde trouve sa stabilité, on découvre qu'il tient celle-ci de "celui qui trône sur le dôme de la terre" (vs 22).

41,2 Tִ??:- [C] M Th V // midr : T / err-vocal : 1Q-a / err-graph : G $\rightarrow$ S

Options de nos traductions :

Selon le *M, ce vs commence par: “Qui a suscité de l'orient celui que la justice appelle sur ses pas ?" Puis viennent deux phrases brèves coordonnées :

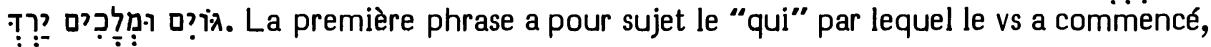
alors que le pronom suffixe du 2e mot se réfère à "celui que". Cette première phrase se traduit sans difficulté : "il livre devant lui des nations".

Voici comment la seconde phrase est traduite par nos traductions. RSV : "so that he tramples kings under foot"; J12: "et abaisse les rois"; RL : "und Könige ... dass er ihrer mächtig wird"; TOB : "abaisse les rois"; J3 : "et assujettit les rois."

Selon Brockington, NEB conjecture, à la place du dernier mot : כריר et elle traduit : "and makes kings go down before him".

Origine de la correction :

J.D. Michaelis traduit : "und trieb Könige in die Flucht". En OEB, il explique que la vocalisation du *M suppose l'interprétation classique en inaccompli apocopé de רדה. Mais il estime qu'ici on ne saurait motiver le choix d'une forme apocopée. Notant dans le Coran (XXXIII 25) un emploi du verbe "̛́ au sens de "mettre en déroute" les ennemis, il propose donc ici une vocalisation רִ en inaccompli qal de רדרד , notant que ce verbe réapparaît en 45,1 dans ce sens.

La conjecture de Michaelis a été adoptée par Ewald (avec le sens de "étendre par terre"), Duhm, Volz, Westermann, Bonnard. Notons que König, dans sa Syntax ( $\$ 364 f$ ), adoptait cette conjecture, alors que, dans son dictionnaire (433a) et dans son commentaire, il conserve le $* M$.

North (suivi par NEB) ajoute après ce verbe le mot תחת.

Hitzig (Psalmen II 440, note) a proposé de lire ici Tị’, conjecture adoptée par Wellhausen (Rec. Dillmann 1121), Dillmann/Kittel,HSAT234, BH2, Feldmann, Köhler. 
$\mathrm{BH} 3$ et Elliger (Verhältnis) hésitent entre les conjectures de Hitzig et de Michaelis. Le fait que 1Q-a ait appuyé celle de Hitzig a amené BHS et Elliger (BK) à l'adopter.

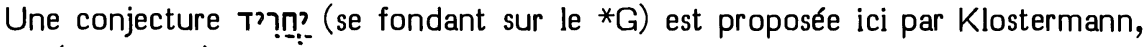
Cheyne (qui le cite) et Marti. Ehrlich a conjecturé Tᄁ̣??:

\section{Les témoins anciens :}

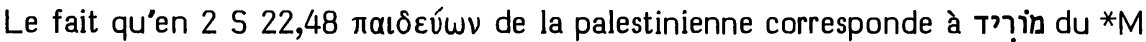
montre qu'une certaine confusion régnait dans certains mss hébreux entre les diverses réalisations du bilittère רדי

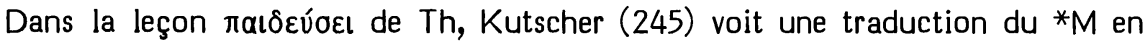
fonction du sens que le verbe רדה a en hébreu rabbinique (= éduquer sévèrement). On trouvera la même correspondance pour Th et Quin en Ps 68,28.

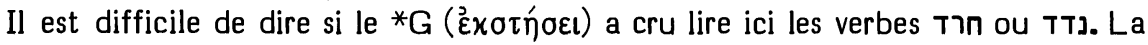
*S (נתורון) a suivi le *G.

Ziegler (Sylloge [224]) estime que "obtinebit" de la *V tire son origine du verbe

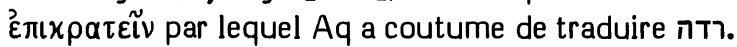

La leçon du *T tient à son exégèse abrahamique de cette péricope. Le targumiste y a vu la victoire d'Abraham sur les rois.

\section{Choix textuel :}

Michaelis a élevé une objection contre la présence d'une forme apocopée en ce contexte et cette objection a déchaîné un flot de conjectures.

S.R. Driver (Tenses Ch. V) a cependant réuni un certain nombre de cas où le mode volitif de l'inaccompli précédé d'un "waw' a la valeur de "de sorte qu'il puisse...". Il insère parmi eux le cas qui nous intéresse (p. 68). Il s'agit d'événements dont la réalisation est rendue possible par la réalisation d'un autre événement mentionné juste avant. Ce cas-ci se distingue par le fait que - par un souci d'emphase que Delitzsch a noté - le complément d'objet ("des rois") est inséré entre le 'waw' et le verbe.

Estimant donc la leçon du *M comme satisfaisante et suffisamment appuyée par Th et la ${ }^{*} V$ en face de variantes divergentes, le comité lui a attribué la note " $C$ ".

Interprétation proposée :

La forme normale de l'inaccompli hifil (?רָ? aurait prêté à une traduction : "il livre devant lui des nations et fait fouler aux pieds des rois".

L'usage qui est fait ici de cet inaccompli sous forme apocopée engage à traduire : "il livre devant lui des nations, de sorte qu'il puisse faire fouler aux pieds des rois", le second "il" renvoyant à "lui". C'est-à-dire que Cyrus pourra établir ses officiers comme gouverneurs sur des royaumes.

41,3 לבא יבוא 1Q-a לא יבינו / abr-elus : G om

Options de nos traductions :

Après que 3a ait donné le verbe רבוֹy ("il passe" ou "il parcourt"), 3b porte

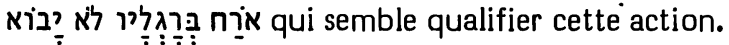


RSV traduit: "He ... passes ... by paths his feet have not trod"; RL : "Er ... zieht ... hindurch und berührt den Weg nicht mit seinen Füssen"; TOB : "il ... passe outre ... sans mettre pied à terre".

J12 donnaient sans note textuelle : “Il ... s'avance ... ses pieds n'effleurent (même) pas la route"; alors que J3, traduisant : "Il ... passe ... par un chemin que ses pieds ne font qu'effleurer" précise : "litt. "il ne foule pas de ses pieds"', ajoutant que cela suppose une correction du dernier verbe en יבוּס.

NEB traduit : "he ... passes on ... swifter than any traveller on foot", Brockington précisant que cela suppose une vocalisation șéré, au lieu de patah, de la seconde syllabe de $3 b$.

Origines des corrections :

La correction de $\mathrm{J3}$ est une conjecture proposée par Grätz (cf. infra le cas 41, 25B).

Quant à la correction vocalique signalée par Brockington, elle est certes requise par HSAT34. Cependant, NEB semble n'avoir pas eu conscience de faire autre chose qu'interpréter le *M. Ap-Thomas (47, n.10) rapporte en effet que Driver faisait remarquer que le participe actif qal de ארח, lorsqu'il est suivi d'un accent conjonctif (Jb 31,32; $\operatorname{Pr} 10,17$ ), est vocalisé patạ et non șéré.

\section{Les témoins anciens :}

1Q-a atteste pour ce verbe une leçon בינו. Elle suppose le rattachement des deux derniers mots au vs suivant dont le premier mot devient le complément d'objet de ce verbe. Les parallèles de 43,10 et 44,18 ont pu influencer cette variante.

Le *G n'a pas traduit ces deux mots.

La *V (non apparebit) est interprétée par Hie comme indiquant qu'il ne sentira pas la fatigue de la route. Il semble donc que l'on ait là une traduction large ne présupposant pas une autre Vorlage.

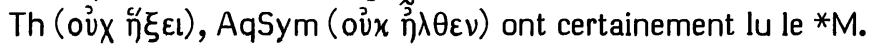

La *S (לא נל (לא עלת) et le ne sont probablement que des interprétations du $* M$.

\section{Choix textuel :}

Au milieu de variantes éparses, Th et AqSym appuient fermement le *M auquel le comité a attribué la note " $\mathrm{C}$ ".

Interprétation proposée :

Ce verbe peut se comprendre comme un inaccompli d'habitude : "un chemin où il n'avait pas coutume de s'engager". Mais cette exégèse, adoptée par Rashi, donne à cet inaccompli une autre valeur qu’à ceux qui précèdent et elle ne valorise pas le complément "avec ses pieds".

Etant donné que Cyrus est présenté en 46,11 comme un oiseau de proie et que le verbe aura en 41,25 le sens de "fouler aux pieds", il vaut mieux, avec Saadya, lui reconnaître ce sens ici aussi : "un chemin qu'il ne foule pas de ses pieds". Pour l'image, cf. Dn 8,5. 
Options de nos traductions :

Alors que RSV, J, RL et TOB traduisent ici le *M, NEB qui traduit "all who" insère לכ̣ avant ce mot en se fondant sur 1Q-a.

Les témoins anciens :

1Q-a insère ici נול, mais il a omis יהיו כאין au début de 11b.

Le *G insère ici $\pi a ́ v \tau \varepsilon \varsigma$ sans rien omettre.

1Q-b, ThAq, Sym, la *V, la *S et le *T appuient ici le *M.

Choix textuel :

Une ajoute (par assimilation à 11a) est ici plus facile à expliquer qu'une omission. D'ailleurs nous avons déjà relevé des amplifications semblables de la part de 1Q-a en 14,2 et du *G en 14,12.

Le comité a donc attribué au *M 3 " $\mathrm{B}$ " et 3 "C $\mathrm{C}$ ".

41,14 מֶת M G Sym S // midr et harm-ctext : T / err-vocal et harm-ctext : 1Q-a Th Aq

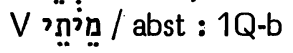

Options de nos traductions :

Le *M a été traduit par RSV ("you men of"), RL ("du armer Haufe"), NEB (“poor louse"), J3 (“pauvres gens").

$\mathrm{J12}$ traduisaient "chétif ( $\mathrm{J1}$ : petit) vermisseau", conjecturant רמת en séférant au $*$ G.

TOB donne : “à présent cadavres”, disant corriger la vocalisation selon 1Q-a, Th, Aq et la *V.

Origines des corrections :

La conjecture de $\mathrm{J12}$ a été proposée par Ewald, adoptée par Duhm et Grätz, puis requise par les apparats de $\mathrm{BH} 23$ et Cent qui se réfèrent au ${ }^{*} \mathrm{G}$.

La correction vocalique de TOB a été proposée par Calvin.

Les témoins anciens :

La leçon de 1Q-b est identique au *M mais nous en ignorons la vocalisation. De Rossi (Scholia 56a) signale que la première main de son ms 543 a vocalisé ici le 'mem' avec șéré. C'est ce qu'atteste la graphie מיתי de 1Q-a. Cependant la mp dont nous avons traité ci-dessus en 5,13 confirme indirectement ici la leçon avec shewa.

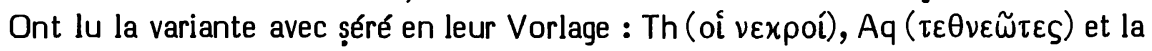
*V (qui mortui estis ex).

La *S offre ici ומנינה. Selon Ishodad de Merv qui vocalise 'mnînèh', comme le fera Gabriel Sionita, il s'agit du petit de la sauterelle quand il n'est pas capable de voler. Notons cependant que Sym traduit ici ảpı $\theta \mu o ́ s$. Etant donné le lien fréquent qui unit la *S à Sym, il semble donc qu'il faille vocaliser ici 'mènyônèh', ainsi que 
le suggère Weisz (sans avoir noté ce rapprochement). Ce sens de "nombre" s'inspire vraisemblablement de l'expression מִִּּ מספר (Gn 34,30; Dt 4,27; Jr 44,28; Ps 105,12; 1 Ch 16,19) usitée au sens de "en petit nombre". C'est aussi à cette interprétation que se rattache la traduction ỏ $\lambda$ ı

Le *T traduit par "clans", en parallèle à "tribus" par quoi il a rendu תולעת, deux mots avant.

\section{Choix textuel :}

Ce cas n'a pas été soumis au comité,

C'est ce parallele avec le 'ver' qui a guidé la vocalisation "morts" ou la conjecture "vermine".

Il faut cependant noter que les suffixes féminins qui suivent nous montrent que תולעת יעקב ח ח'est pas un parallèle rigoureux que c'en est plutôt une apposition. Or, en 5,13, nous avons adopté pour le sens de "pauvres hères" qui convient également ici.

Interprétation proposée :

Driver (LTP 399) estimait que la leçon du *M "qui est parfaitement correcte" signifie "lice" (= poux). Il se basait pour cela sur la lecture d'une tablette akkadienne par B. Landsberger. Mais Elliger mentionne que Landsberger a corrigé en 1962 sa lecture, ôtant toute base à l'hypothèse de Driver. C'est donc à tort que NEB s'est fondée sur celle-ci pour donner ici au *M le sens de "louse" (par assimilation à "worm" qui précède).

Abravanel a cependant raison d'estimer que le choix du mot מִici, à côté de "vers (de cadavre)" (que תולעה signifie formellement en Is 14,11, comme תולעת en Is 66,24), vise à suggérer (= morts). Nous avons déjà trouvé en 38,11.17 et retrouverons encore en ce livre certains de ces jeux de mots subtils entre ce que dit le texte et ce qu'appelle le contexte. Il serait bon de les mentionner en note.

On pourra donc traduire: "Ne crains pas, Jacob, toi vermine, Israël, pauvres hères, cest moi qui t'aide..." Il serait bon de noter cependant que le complément " $\mathrm{t}$ " " du dernier verbe renvoie au mot "vermine" et que "pauvres hères" est exprimé ici par un mot qui, en ce contexte, suggère le sens de "cadavres".

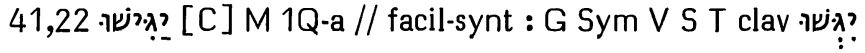

\section{Options de nos traductions :}

A propos de la séquence analogue de 29,9, nous avons déjà (ci-dessus, p. 208) analysé $41,21 \mathrm{~s}$ : $2 \mathrm{e}$ pers. pl. en 21 , 3e pers. pl. en 22a et 2e pers. pl. en $22 \mathrm{~b}$. Un passage encore plus brusque de la $2 \mathrm{e}$ à la $3 e$ pers. aura lieu en un contexte très semblable en 45,21a.

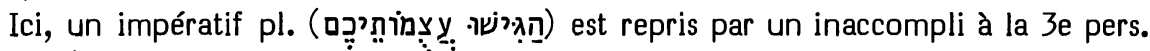

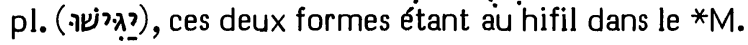

Le hifil de cette reprise est respecté par RSV ("let them bring them") et par J3 ("qu'ils produisent"). 
Les autres (J12 et TOB : "qu'ils s'avancent", NEB : "let them come forward") corrigent le hifil en qal, $\mathrm{J12}$ se fondant sur les versions et NEB (selon Brockington) sur le *G.

Origine de la correction :

C'est Grätz qui a proposé de corriger en qal ce hifil, en se fondant pour cela sur le *G et la *S. Il a été suivi en cela par Cheyne, Marti, Oort, Condamin, Ehrlich, Haller, Feldmann, Fischer, Ziegler (EB), North, Bonnard, HSAT234, BH23S et Cent.

Les témoins anciens :

Il faut noter que le *M, garanti ici par une mm (Weil \$1601; Frensdorff, Massora

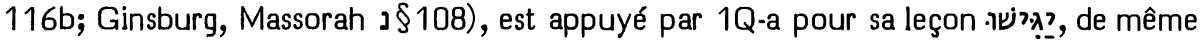

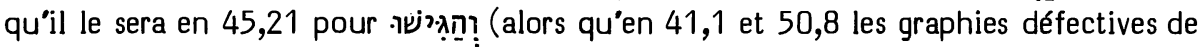
$1 \mathrm{Q}$-a s'accordent avec les vocalisations en qal du *M). Cependant, en 41,22 comme en 45,21 , toutes les versions anciennes ont traduit comme si ces verbes étaient au qal.

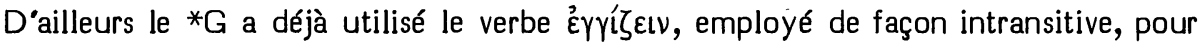
traduire הרבישו 41,21.

\section{Choix textuel :}

Pourtant, en 45,21, aucun exégète récent ne propose formellement de corriger le $* M$. Une minorité d'entre eux (par ex. TOB = Bonnard) traduit pourtant au sens intransitif ("mettez-vous en avant") à la suite de Luther ("machet euch erzu") et d'Olivetan ("et approchez"). La grande majorité, soulignant l'analogie avec 41,21s, traduit ce verbe comme il l'avait été en 41,21, en explicitant le complément qui lui avait été donné en ce lieu (ainsi RSV "and present your case" ou J3 "produisez vos preuves").

Est-ce seulement un certain esprit moutonnier qui a amené, en 41,22, la grande majorité des exégètes modernes à suivre les traces de Grätz ? Il semble que cela tienne plutôt au traitement différent que les traductions les plus influentes du début du XVIe

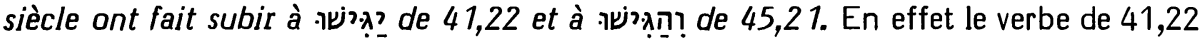
est traduit comme s'il s'agissait d'un qal par Oecolampade : "appropinquent", Pagnini (1527 = 1542 = Arias Montano): "accedant", Brucioli : "accostinsi", Châteillon latin : "adsint" et français : "qu'ils s'avancent"; alors que ces mêmes traducteurs respectent en 45,21 le hifil du *M: Oecolampade : "et approximari facite", Pagnini (1527 = 1542 = Arias Montano) : "et accedere facite", Brucioli : "et fate accostare", Châteillon latin : "et proferte" et français : "e mettés en avant".

Le comité a attribué ici au *M 5 " $C$ " et 1 " $B$ ".

Interprétation proposée :

Le plus naturel est de donner ici à ce hifil sans complément d'objet le même sens que l'on donnera à celui de 45,21 qui se trouvera dans la même situation. En ces deux cas, on pourra sous-entendre ensuite le complément qui a été mentionné après l'impératif hifil du même verbe en 41,21. Le verbe peut être : "produire", "présenter", "exposer" et le complément : "arguments", "preuves", "raisons". 


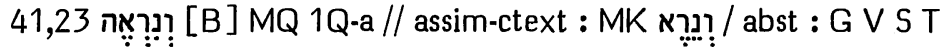

\section{Options de nos traductions :}

Seules J12 ("et que ... nous le voyions") et TOB ("et nous verrons") traduisent le *M.

RSV donne ici : "(that we may be...) and terrified", RL : "(damit wir...) und erschrecken", NEB : "(anything that may grip us with...) awe", J3: "(que nous éprouvions...) et de la crainte". Seul Brockington note que NEB a suivi le ketib en

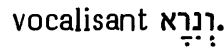

\section{Origine de la correction ;}

En effet, BH3S et Schoors (217) présentent cette vocalisation comme étant celle du ketib. C'est Lowth qui a proposé de lire plusieurs exégètes postérieurs. Cependant, ceux qui ont proposé cette conjecture ne prétendaient pas y voir un ketib. Le ketib est en effet vocalisé רְְֵ par Gesenius, Hitzig, Delitzsch, von Orelli, Duhm, Cheyne, Marti etc. qui y voient le volontatif correspondant à l'indicatif qu'offre le qeré. Gordis $(\$ 50)$ intègre ce cas dans une liste de six qeré offrant des inaccomplis à forme pleine en face de ketib apocopés.

Les témoins anciens :

1Q-a lit ici le qeré. Toutes les versions attestent le sens "et nous verrons" ou "et que nous voyions", sans qu'il soit possible de déterminer si elles ont lu le ketib ou le qeré.

\section{Choix textuel :}

Le parallèle apparent constitué par 41,10a a servi à la diffusion de la conjecture de Lowth. On y voit en effet le verbe ỵְִุ en une fonction semblable à celle du verbe תִִ (= craindre). Radaq reconnaît que ce contexte suggérerait pour ce premier verbe le sens de "craindre", mais il suit la tradition qui le rattache à Depuis cette époque, un verbe שתת (= craindre) est apparu deux fois en une inscription de Karatépé (Donner/Röllig 26AII.4) et l'ugaritique a fait connaître un verbe "ttc" (= craindre) (UT Glossary \$2763; Aistleitner \$2956) qui apparaît lui aussi en une fonction semblable à celle de "yr". Meyer $(\$ 70,3 g)$ à la suite de Alt (qu'il cite), KBL (Supplement 192), North et Wildberger ont donc vu en תשת עת un qal de (à vocaliser plutôt patah avec l'édition du *M de 1488, la première main du ms de Petrograd et 27 mss contrôlés par Ginsburg) et non plus un hitpaél de שעת (vocalisé qameș par la plupart des éditions, l'ensemble des mss tibériens classiques et 15 des mss contrôlés par Ginsburg). Il semble en effet que ce soit en 41,10 la meilleure interprétation. Faut-il étendre cette interprétation à 41,23 où cela nous engagerait à adopter la conjecture de Lowth ?

Il faut noter en Gn 24,21 l'existence du participe hitpaél שִ̣ qui s'accorde mal avec les sens habituels de la racine שאות (= vacarme). Le sens de contempler, fixer du regard) lui convenant par contre fort bien, les lexicographes (cf. KBL III y voient d'ordinaire un analogue de שעאה (שיחה Cela nous montre que le hitpaél de ce dernier verbe n'est pas entièrement résorbable en un qal de עת. 
En Is 41,23 la vocalisation הִ ְִ place sous le 'taw' un qameṣ qui convient au hitpaél que les vocalisateurs y on 'reconnu. Ewald (Lehrbuch \$228c) et Delitzsch expliquent cette forme comme un volontatif suivi de la désinence du cohortatif. A la rareté de ce fait s'ajoute la particularité que cette désinence n'est pas accentuée. Böttcher (Lehrbuch \$1075.4) voit un lien entre ces deux particularités. HUB spécifie que le seul ms babylonien qui nous soit connu (Eb 51) porte un patah (tenant ici la place du segol tibérien) dans la dernière syllabe. On aurait alors un inaccompli normal. Cependant, Alba Cecilia lit en ce ms un qameș et la photo qu'édite Yeivin (IV 326) ne permet pas de trancher la difficulté de lecture.

Une interprétation de cette forme en qal de שתת supposerait que le 'taw' soit vocalisé shewa. Mais ici le contexte n'impose pas cette interprétation. Cette deuxième partie du vs constitue en effet un parallèle à la première où analogue à celle de ונשתyה ונראה. Ce sont donc bien des-verbes exprimant une constatation que l'on attend à la fin de ce verset. D'ailleurs, il serait parfaitement acceptable qu'un prophète dise par dérision : "que nous éprouvions de la peur et de la crainte !" Mais, comme Duhm1 l'a noté, cela détonnerait ici où c'est le Seigneur qui parle.

Notre auteur, nous avons eu plusieurs fois l'occasion de le noter (sur 38,17 etc.), est assez subtil pour jouer avec des formes qui s'évoquent les unes les autres. Il est donc vraisemblable qu'ici, en liant le verbe ראה avec le hitpaél de שעה, il ait voulu évoquer le lien qu'il avait établi en 41,10 entre le verbe ירא et le qal de שתע. Ne transformons pas cette évocation en identification.

Le seul choix textuel réel est ici entre le qeré et le ketib, c'est-à-dire entre un indicatif et un volontatif de ראה. Le comité, estimant qu'un volontatif n'est pas nécessaire après un premier volontatif qu'il prolonge, a considéré le ketib comme assimilant à la forme qui précède et a donc préféré le qeré par 4 " $B$ ", 1 " $A$ " et 1 "C".

Interprétation proposée :

"que nous puissions (observer) et constater". On pourrait indiquer en note que les verbes choisis ici évoquent cependant par allusion le sens de "que nous éprouvions (de la peur) et de la crainte".

41,24 מאפע / [C] M // abr-elus : 1Q-a om / exeg : G clav מארע / assim-ctext : V S T

\section{Options de nos traductions :}

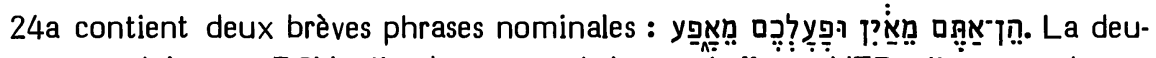
xième est traduite par RSV : "and your work is nought", par NEB : "your works are rotten", par RL : "und euer Tun ist auch nichts", par TOB : "vos réalisations, moins que néant".

Disent corriger le *M: J12 ("et vos oeuvres néant") lisant ("et votre oeuvre, c'est moins que néant") disant conjecturer cela.

Origine de la correction :

Vogel a conjecturé ici מאפס, conjecture qui a été formulée aussi de façon indépendante par Michaelis (OEB) et Lowth (se fondant sur le *T et la*V). En effet, 
Schindler (cité par Clericus) avait estimé que cette leçon constitue la Vorlage de la*V. Après que Doederlein et Dathe (qu'il cite) aient corrigé ainsi, beaucoup d'exégètes les ont suivis, y compris HSAT234, $\mathrm{BH} 23$ et Cent.

\section{Les témoins anciens :}

Il y a longtemps que ce mot a fait de grosses difficultés aux traducteurs comme aux exégètes. C'est sans doute le motif (cf. Kutscher 551) pour lequel il est absent de 1Q-a. Cependant, on connaissait à Qumrân des formes textuelles d'Is 41,24 où ce mot figurait et on l'interprétait en fonction du contexte et en le rapprochant de

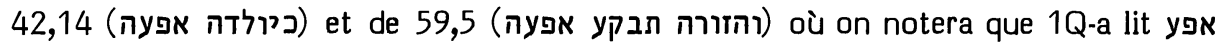

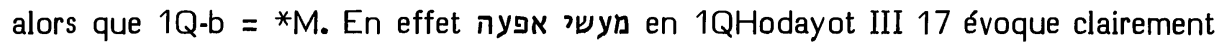
Is 41,24 (ופעלכם מאפע), tandis que 1QHodayot II 27s (למזורות יבקעו אפעה) évoque Is 59,5 et $1 Q$ Hodayot III 12 (והרית אפעה) évoque Is 42,14. Il n'est pas certain que l'auteur des Hymnes ait lu en Is 41,24 les mêmes consonnes et voyelles que dans les deux autres endroits d'Isaïe, mais nous voyons qu'il avait dégagé de ces trois endroits une notion commune que l'on peut caractériser à partir des trois indices suivants : - en II 28, le parallélisme avec שרוא,

- en III 12, l'opposition avec הרית גבר (de la ligne 9) et le parallélisme avec הרית (de la ligne 17), - en III 18, le parallélisme entre כול רוחי אפעה et en עול (ct.

Le sens de "serpent" (cf. infra) mis en avant par Dupont-Sommer (Ecrits) et Carmignac (Textes) semble moins bien correspondre à l'ensemble de ces données que celui de "néant, illusion" retenu par Driver (cité en Wernberg-Mф́ller, Note 325, n.3), Lohse et HALAT.

En Is 41,24 , le ${ }^{*} G$ semble avoir traduit מאפע par ${ }^{3} x$ ץñ (ainsi que Ziegler, Untersuchungen 152, le suggère). Fischer (Schrift 55) estime que cette traduction s'inspire de l'araméen מארע. Mais rien ne prouve que le traducteur avait ce mot en sa Vorlage.

Les autres versions se sont inspirées ou bien de l'analogie graphique avec מאפס (cf, 40,17 dont nous avons traité ci-dessus) ou bien du parallèle avec מיא. La *V (ex eo quod non est) et le *T (לא מדyם) se sont en effet laissé guider par le parallèle, alors que la *S (מן חרבא) reprend ici la traduction libre dont elle avait fait usage en 40,17 .

\section{Choix textuel :}

La plupart des exégètes juifs feront comme ces trois versions. Ce sera le cas de Saadya, des "poterim" cités par Menaḥem ben Saruq (31b), ainsi que de David ben Abraham (I 136,131s), Yéfet ben Ely, Abulwalid, Aaron ben Joseph, Judah ibn Balaam, Tanhuum Yerushalmi, Radaq, Abravanel.

Le midrash Wayyiqra Rabba (638,5s et $640,1-3)$ rapportait que R. Levi (début du IVe siècle) interprétait ce mot comme un notarikon : ou bien il peut s'agir de cent appels (מאה פעיוה, en considérant le 'mem' et le 'alef') ou bien d'un appel (פעייה אחת, en ne considérant que le 'alef'). Cela atteste clairement qu'il lisait ici ce mot. Mais cela laisse supposer que, dans son milieu, on ne lui connaissait pas de sens évident. Cette interprétation en "appel, cri" se fonde sur l'emploi verbal de אֵפְּy en Is 42,14. Elle se retrouvera chez Rashi, Joseph Qara et les glossaires ABCDEF. 
Certains essaieront d'établir un lien entre l'exégèse "néant" et l'exégèse "cri" par "halètement, haleine". C'est le cas de Ibn Ezra et Eliézer de Beaugency.

D'autres enfin, moins nombreux, interprètent ici ce mot en fonction des trois cas (Is 30,6; 59,5; Jb 20,16) où אִפְּ est un serpent : Menahem ben Saruq, Moshe Qimḥi (cité par Radaq en ses Shorashim), “certains" mentionnés par David ben Abraham, par Parhon (en son commentaire) et par Abravanel.

Durant le moyen âge, אפע fut en usage chez les poètes juifs pour exprimer un mode d'être très instable. C'est en ce sens que ce mot apparaît en un piyyut alphabétique pour le Yom Kippur (Davidson $\kappa$ §8819). On comprend donc que Tobia le traducteur (karaïte de Constantinople), lorsqu'il entreprit, au XIe siècle, de traduire en hébreu les oeuvres de théodicée de Yusuf al-Bașîr, choisit ce mot pour traduire l'arabe Yेy (= "accident" opposé à "substance").

Nous avons mentionné le refuge que certains exégètes d'Is 41,24 ont cherché, à partir du XVIIIe siècle, en une correction du texte. Il est pourtant intéressant de noter que Michaelis (OEB), lorsqu'il put constater que la forme qu'il avait conjecturée ne figurait en aucun ms hébreu, retira sa conjecture, jugeant (contre Lowth) que la prétendue variante du *T et de la *V devait se réduire à une simple tradition d'exégèse. Aussi a-t-il préféré rattacher ce mot à la racine arabe פעי (= souffler) en se fondant sur Schultens (Hamasa 420). Il estimait que le substantif signifie "souffle". Mais il ne pouvait savoir que ce même Schultens, dans le dictionnaire hébreu qu'il laissa inédit (ms New York, JThS, 2918, p. 470), émit plus tard une réserve à l'égard de ce rapprochement, du fait que ce mot d'Is 41,24 n'a pas le 'hé' final qui, en אֶפְֶ (= vipère) est radical, ainsi que le montre la racine arabe en question.

Nous pouvons conclure que $l e{ }^{*} M$ nous atteste ici un état textuel très ancien. Ce mot inconnu a été traditionnellement interprété grâce au voisinage de plọ à l'analogie avec מאפס (40,17). Faut-il penser que l'auteur a voulu, encore une fois, offrir un mot légèrement distinct de cette dernière forme pour évoquer en même temps (= vipère) que ses lecteurs connaissent grâce à Is 30,6;59,5 ? En ce cas, ce möt entrerait lui aussi dans la catégorie que nous avons ouverte en 38,11.

Une correction en מאפס serait en tout cas ici inutile, sans fondement textuel et probablement erronée.

Aussi le comité a-t-il conservé le *M par 4 " $C$ " et 2 "B".

Interprétation proposée :

On traduira donc "moins que rien" (comme en 40,17). On pourra noter que le mot employé évoque aussi par allusion le sens de "pire qu'une vipère".

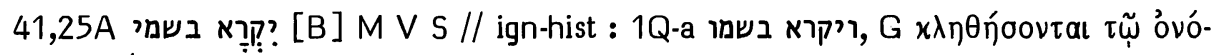
אגברניה במי

Options de nos traductions :

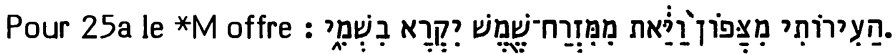

RSV traduit : "I stirred up one from the north, and he has come, from the rising of the sun, and he shall call on my name"; RL : "Von Norden habe ich einen kommen 
lassen, und er ist gekommen, vom Anfang der Sonne her den, der meinen Namen anruft."

J12 conjecturent pour les deux derniers mots: "je l'ai appelé par son nom". 33 conjecture : “il est appelé par son nom" en se référant à 45,3.

TOB donne : "il s'entend appeler par son nom", disant qu'elle met le verbe au passif et s'appuyant sur 1Q-a pour la correction du pronom suffixe.

NEB traduit 25a: "I roused one from the north, and he obeyed; I called one from the east, summoned him in my name". Brockington prétend à tort qu'elle vocalise le 3 e verbe :

\section{Origines des corrections :}

Bredenkamp semble avoir été le premier à proposer de corriger les deux derniers mots. Hésitant à admettre que le prophète ait pu dire que Cyrus invoquera le nom du

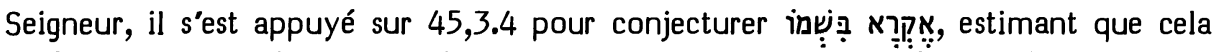
améliore le parallélisme avec le verbe initial. Cette leçon a été adoptée par $\mathrm{BH} 23$, Cent, J12, Westermann.

Dillmann/Kittel note que, s'il s'agit d'un appel de Cyrus par Dieu, il faut mettre le verbe à l'accompli : קראתי בשמו, leçon adoptée par Cheyne, Marti, Feldmann, Elliger.

$D^{\prime}$ autres se contentent de vocaliser le verbe du $* M$ en nifal et de mettre le suffixe à la 3e pers. m. sg. C'est le cas de Condamin et, après la découverte de $1 \mathrm{Q}-\mathrm{a}$, celui de BHS, Bonnard, TOB, J3. Brockington a tort de dire que NEB fait de même. Elle semble avoir corrigé le verbe en 1e pers. sg. du qal, mais gardé le suffixe du *M.

\section{Les témoins anciens :}

Pour ces deux mots, le $* M$ a l'appui de la $* V$ (vocabit nomen meum) et de la *S (ונקרא בשמי), cette dernière faisant précéder (comme 1Q-a) le verbe par une conjonction.

Le suffixe 1e pers. du 2e mot est attesté en outre par le ${ }^{*} \mathrm{G}$ et le ${ }^{*} \mathrm{~T}$, seul 1Q-a le lisant en $3 e$ pers. (ce qui présuppose probablement une lecture du verbe en nifal). Le ${ }^{*} G$ a lu aussi le verbe en nifal. S'il le met au pluriel, c'est parce qu'il a lu un peu avant ויאת du *M ou de ויאת du lau lieu de. Cela l'a amené à attribuer deux compléments d'objet au verbe initial du vs. Il doit tenir compte de cela dans la traduction du verbe suivant.

Le *T, au lieu de ce verbe, dit "je le fortifie". Elliger estime que la 1e personne de ce verbe peut remonter à la Vorlage du targumiste. C'est peu probable.

\section{Choix textuel :}

Il est vrai que ni $1 Q$-a, ni le ${ }^{*} G$, ni le ${ }^{*} T$ ne parlent de Cyrus comme invoquant le nom du Seigneur, mais ceux des modernes qui ont quitté ici le $* M$ ont tort de considérer comme improbable ici sa leçon. Il ne s'agit pas, en effet, d'espérer une conversion de Cyrus au judaïsme, mais plutôt d'affirmer, comme l'a compris Estienne (note sur ed. 1557), que "il se réclamera" du Seigneur, ce dont ces oracles du DeutéroIsaïe lui offrent justement les moyens. De fait, dans son édit (Esd 1,2), Cyrus affirme : “tous les royaumes de la terre, YHWH, le Dieu des cieux me les a donnés, et il m'a 
chargé lui-même de lui bâtir une maison à Jérusalem qui est en Juda". Quoi qu'il en soit de l'authenticité de cet édit, la prétention ainsi formulée nous aide à comprendre ce que l'auteur d'Is 41,25 pouvait avoir en vue. D'ailleurs de telles prétentions n'ont rien d'invraisemblable de la part de Cyrus qui (ANET2 315s) dit avoir été choisi par Marduk pour régner sur le monde entier. Il dit avoir rétabli les cultes de Babylone dont les rituels avaient été troublés par Nabonide. Il se professe un serviteur dévot de Marduk et invoque tous les dieux de Babylone. Dans ce contexte, la leçon du ${ }^{*} M$ est très vraisemblable.

Il se peut cependant qu'à d'autres époques où l'on ne comprenait plus la religiosité syncrétiste de Cyrus, elle ait paru évoquer une conversion au judaïsme. Certains scribes ou traducteurs l'auront corrigée afin de ne pas laisser ici un oracle que I'histoire aurait démenti.

Le comité a attribué au *M 4 "B" et 2 "C $C$ ".

Interprétation proposée :

On notera que $1 \mathrm{Q}$-a, le ${ }^{*} \mathrm{G}$ antiochien et la ${ }^{*} S$ ont fait précéder le verbe d'une conjonction. Cela nous amène à préciser que, dans le $* M$, cette petite phrase est une relative qui sert de complément au verbe initial du vs: "J"ai fait surgir à partir du nord - et il arrive - celui qui, depuis le soleil levant, se réclame de mon nom et piétine les gouverneurs comme de la boue..."

Par rapport à Jérusalem, le Nord est la direction d'où viennent les envahisseurs qui ont contourné le désert. Lorsque le prophète dit que "depuis le soleil levant" Cyrus se réclame du nom du Seigneur, il fait vraisemblablement allusion à quelque proclamation faite en Babylonie.

ויבואו 41,25B ויבא [C] M // err-vocal : V / glos : T / err-synt : 1Q-a G S

Options de nos traductions :

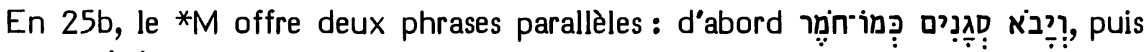

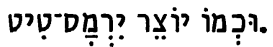

La première de ces phrases est traduite par RSV : "he shall trample on rulers as on mortar", par J12: "il a piétiné les satrapes comme de l'argile", par RL : "Er zerstampft die Gewaltigen wie Lehm", par NEB : "he marches over viceroys as if they were mud", TOB et J3 : "il piétine les gouverneurs comme de la boue". RSV, J2 et J3 mentionnent une correction conjecturale du verbe initial, J2 le corrigeant en

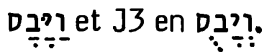

Origine de la correction :

C'est Clericus qui a fondé sur le *T une correction en רִיְ:. Lowth cite Secker qui adopte cette correction en notant que le mot suivant commence par un 'samek'.

Estimant que, dans le *T, la leçon וידוש quest qu'une glose sur וייתי quícède, et constatant qu'aucun ms n'appuie la conjecture fort probable de Clericus, Michaelis (OEB) renonce à corriger le $* M$. 
Luzzatto a cependant repris la suggestion de Clericus, estimant que la leçon du * $M$ vient d'une erreur d'audition. Cette correction a été adoptée par de nombreux exégètes jusqu'à HSAT234, BH23S, Cent. La plupart d'entre eux la considèrent comme une conjecture, BHS se référant cependant au *T.

\section{Les témoins anciens :}

Comme Michaelis l'a remarqué, le *T a glosé ici (en s'inspirant de ce qui suit). En dehors de cette glose et du fait que la $* V$ (et adducet) a vocalisé en hifil, la seule variante notable consiste en ce que $1 Q-a$, le ${ }^{*} G$ et la ${ }^{*}$ S ont fait de Dגנים le sujet du verbe qui précède, verbe que, de ce fait, ils ont mis au pluriel. Ils se trouvent alors en difficulté avec le complément כמו חמר qui suit. 1Q-a laisse cette difficulté entière.

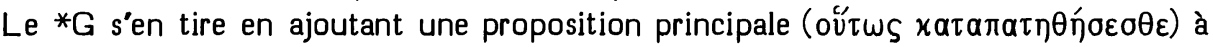
la fin du vs; alors que la *S se contente d'insérer un verbe (ונתדישון) pour y articuler ce complément.

Choix textuel et interprétation proposée :

Tous les témoins semblent bien dériver du texte plus sobre du *M où

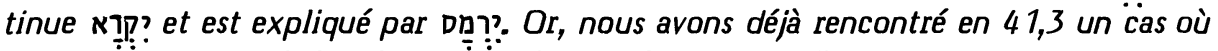
le sens qui convenait le mieux aù verbe בוא était "fouler", ce qui, notons-le, est aussi le cas en $\mathrm{Ps}$ 36,12. Mentionnons en $\mathrm{Na}$ 3,14 un autre usage parallèle caractéristique

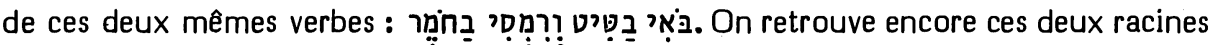
en même fonction dans Is 28,15 et 18 , la même phrase se trouvant en ces deux versets

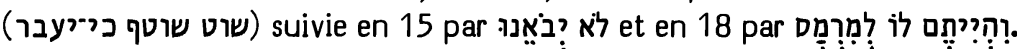

Cela encourage à interpréter ici בוא corriger ce verbe en chacun de ces cas, ainsi que Grätz le propose.

Le comité a attribué au *M 3 "B" et 3 "C".

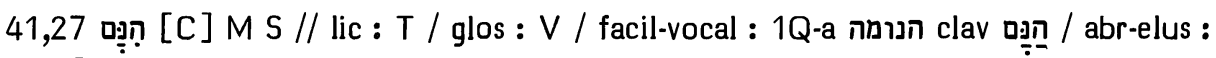
G om

Options de nos traductions :

Pour 27b, le *M offre : "et à Jérusalem je donne un messager de bonheur",

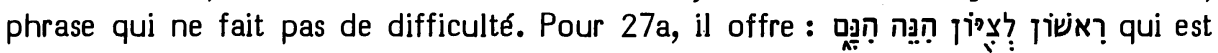
difficile à interpréter.

Cette phrase a été traduite par J3: "Prémices de Sion, voici, les voici"; par RL : "Ich bin der erste, der zu Zion sagt : Siehe, da sind sie."

RSV dit conjecturer pour cela: "I first have declared it to Zion", alors que $\mathrm{J12}$ conjecturent : “D'avance, j'avais dit à Sion : 'Les voici'."

Selon Brockington, au lieu du dernier mot, NEB lit avec 1Q-a : הַ lorsqu'elle traduit : "Here is one who will speak first as advocate for Zion." Sur la même base, TOB traduit : “C'est pour Sion que voici, tout premier, celui qui parle."

\section{Origines des corrections :}

RSV et $\mathrm{J12}$ dépendent de $\mathrm{BH} 23$ qui, à la place des 3e et $4 \mathrm{e}$ mots, proposent de

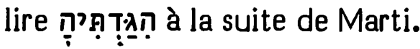


NEB semble suivre Guillaume (Readings 40s), alors que BHS suit Bonnard.

Les témoins anciens :

Le *M est traduit littéralement par la *S (הלן אנין) et plus librement par le *T ("voici qu'ils viennent"), alors qu'il est glosé par la *V ("dicet ecce adsunt"). Au lieu de traduire les $3 e$ et $4 e$ mots (qu'il ne comprenait vraisemblablement pas), le ${ }^{*} G$ a anticipé ici la traduction du verbe final de ce vs.

1Q-a, au lieu du 4e mot, porte הנומה.

\section{Choix textuel :}

Guillaume (Readings 40s) semble avoir raison de voir dans la leçon de 1Q-a un participe de נמה. Estimant que l'hébreu ne connaît cette racine que dans la composition de noms propres, il a rapproché ce participe du verbe arabe נמי dont l'un des sens est "annoncer un événement" et en a conclu qu'il faut introduire un verbe נמה dans le dictionnaire hébreu. Barr (183) considère cette conclusion comme précaire. Aussi HALAT ne retient-il pas cette racine.

Ils semblent ignorer que ce même participe actif נומה se trouve dans le Talmud Yerushalmi, Yebamot XII 1 (Ms Leiden Scaliger 3, vol II, fol 30a, ligne 4 ab imo = éd. Venise 12c, ligne 12) et dans la Tosefta Yebamot XIV 5, selon le ms d'Erfurt tel que l'a déchiffré Lieberman (p. 52, apparat sur ligne 38). D'autres preuves de l'existence d'un verbe נמה en hébreu rabbinique palestinien se trouvent en נמיתי (Tosefta Ohalot V 12 selon le ms d'Erfurt lu par Zuckermandel 603,9), נמינו (Mishna Gitțin VI 7 selon l'Arukh de Nathan ben Yehiel, oנ §1, éd. Schlesinger 357b). A côté de ces formes dérivant de נמה, un plus grand nombre de formes dérivent de ex.: נמנו ,נמתי (נות est donné en Tosefta Yebamot XIV 5 par le ms de Vienne (édité par Lieberman). Cette forme participiale réapparaît souvent dans les écrits talmudiques et midrashiques.

En Mishnajot III 89, note 47a, Petuchowski reproduit une communication de J. Barth. Celui-ci estime que, dans le même sens de "donner une information", les deux

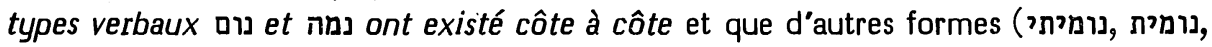
(נומנו sont des néoformations défectueuses faites par des lettrés à l'époque où la langue était encore vivante, en s'inspirant de l'hébreu biblique נאום

Il est donc fort probable que la leçon הנומה de 1Q-a ait pour origine une vocalisation 1Q-a, c'est qu'elle offrirait un substantif que peut qualifier l'adjectif initial : "Premier à Sion voici l'annonciateur, et à Jérusalem je donne un messager de bonheur."

Cependant, étant donné que nous n'avons aucun indice de l'emploi d'un verbe נמה ou en sens à l'époque biblique, il est apparu plus prudent au comité d'en rester à la vocalisation du * $\mathrm{M}$ auquel il a attribué la note " $\mathrm{C}$ ".

Interprétation proposée :

Notons d'abord que le vs 27 est à comprendre en référence aux vss 26 et 28s qui l'encadrent et qui soulignent l'incapacité où sont les idoles d'annoncer l'avenir. Il est donc très vraisemblable que l'adjectif initial "premier" porte sur le Seigneur. En effet, dans le Second Isaïe, ראשון(sans article) lui est réservé (cf. 41,4; 44,6; 48,12). 
Le Seigneur est donc évoqué ici par ce mot, puis cette évocation est reprise par la 1e personne du verbe final : "je donne". En ce cas, "je dis" est facile à sous-entendre pour porter le datif "à Sion", d"autant plus que ce datif est immédiatement suivi de l'exclamation "voici !".

L'ensemble du vs sera alors: "Je suis le premier (à dire) à Sion : 'voici, les voici !' et à Jérusalem je donne un messager de bonheur." Chaque moitié du vs a donc trois éléments: "à Sion" et "à Jérusalem" se correspondent, comme "je suis le premier (à dire)" et "je donine" se correspondent. De même "un messager de bonheur" correspond au message de celui-ci : "voici, les voici !". On voit donc que, si l'on rapporte l'adjectif "premier" à "l'annonciateur" (selon la variante), on ne dispose plus de parallèle pour "je donne".

Il est vraisemblable que le pronom suffixe désigne les exilés dont le retour a déjà fait l'objet du message de la "messagère de bonheur" en 40,11. Ce sont "les humiliés et les indigents" qui ont été évoqués en 41,17 comme faisant route à travers un désert transformé en campagne irriguée et boisée. Quand c'est à Sion que Dieu parle, un simple suffixe 3e pers. m. pl. suffit pour évoquer les absents (cf. 49,20s; 51,20; 54,1-3).

\section{1,29 אִ אִ אִיְן / C ] M Th Sym V // assim 28 : 1Q-elus : G om}

Options de nos traductions :

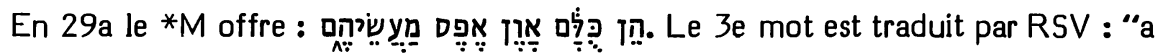
delusion", par NEB : "what empty things" et par TOB : "une malfaisance".

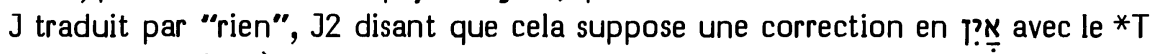
(auquel J3 ajoute 1Q-a). RL traduit : "nichts".

Origine de la correction :

Dans la même ligne d'interprétation que J et RL, HSAT2 traduit "nichtsnützig", HSAT34 "nichtig", Cent "rien" et Young "naught" sans éprouver le besoin d'une note textuelle.

Cependant une correction du 'waw' en 'yod' a été demandée par Ehrlich, Duhm5, Haller, Elliger, Fohrer, Westermann, BH23. North fait appel à 1Q-a pour appuyer cette correction.

\section{Les témoins anciens :}

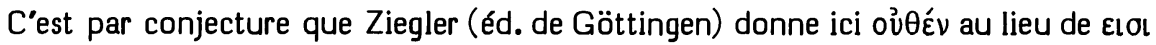
qu'offrent tous les mss grecs. En Untersuchungen (54) il reconnaît que rien ne correspond dans le ${ }^{*} G$ aux trois premiers mots du $* M$.

Cependant le *M est appuyé clairement par Th (ǻôเxol) et par Sym (dont la leçon, identique à celle de Th, a été déformée dans sa tradition textuelle en aolxol). C'est d'eux que dérivent la ${ }^{*} V$ (iniusti) et l'ajoute áósxol de l'antiochienne.

1Q-a porte ici אין. On pourrait penser que la *S (לא מדם) et le *T (למא) ont lu cela aussi. 
Choix textuel :

Cependant Saadya (qui a sûrement lu le *M où la leçon avec 'yod' n'est attestée que par un unique ms du XVe siècle) traduit comme la *S et le *T. D'ailleurs "vanité" est la traduction du glossaire C (le seul qui traduise ce mot). Ibn Ezra nous informe en effet que "certains disent que le 'waw' tient ici la place d'un 'yod"." Et Altschüler, dans la Meșudat Șiyon, précise que ce mot a le même sens que תהפ qui le suivent : quelque chose qui est sans profit ni réalité.

On ne sera donc pas étonné que ce mot ait été traduit par Pagnini, Musculus et Tremellius "vanitas", par Luther "eitel mühe", par Münster et Châteillon "vani", par Brucioli "vanita", par Rollet et Châteillon "vains" (alors qu"Olivetan, suivant la *V, avait traduit "injustes"), par Pasteurs "vanité", par Ge et par KJ "vanitie". On serait donc tenté de considérer que ce cas relève de l'exégèse plutôt que de la critique textuelle.

Il n'est cependant pas impossible que l'auteur ait fait exprès, par le choix de ce mot, d'établir une tension entre ce que dit le texte et ce qu'appelle le contexte, ainsi que nous l'avons déjà remarqué en 38,11.

Estimant que la variante de 1Q-a assimile aux deux ואין du vs précédent, le comité a attribué au *M 3 " $\mathrm{B}$ " et 3 "C". Rappelons que 1Q-a dérive d'un archétype où le 'yod' et le 'waw' se distinguaient mal.

Interprétations proposées :

Il faut noter que le $* M$ unit ce mot à celui qui le suit comme constituant deux prédicats juxtaposés pour "leurs oeuvres", de même que "vent et vide" offrent deux prédicats pour "leurs statues". On obtient donc: "Les voici tous : leurs oeuvres sont malfaisance, néant; leurs statues sont vent et vide."

Par contre, Th et la $* V$ structurent ce vs en trois membres, ce qui donne : "Voici qu'ils sont tous malfaisants, leurs oeuvres sont néant, leurs statues sont vent et vide."

\section{2,3 [A]}

Options de nos traductions :

Le *M offre en 3b : לאמְמֶת יוציא משפט. Le premier mot est traduit "faithfully" par RSV, "fidèlement" par J, "in Treue" par RL et "à coup sûr" par TOB.

NEB donne ici "on every race", Brockington précisant que cela suppose une vocalisation

Origine de la correction :

Notant que l'on a déjà trouvé dans le dernier stique du vs 1 deux des trois mots qui constituent le dernier stique du vs 3 et que le 3e mot y est לגוים, Scherschewski a conjecturé que l'intention du prophète était ici de dire לִ. Cette conjecture, diffusée par Perles (Dictionary 388), a été mentionnée par BH3.

Choix textuel :

Le *M a l'appui de la tradition textuelle unanime. 
Perles estimait que la syntaxe de la leçon du *M était difficile à justifier. König a répondu à cette objection en notant la construction analogue de לִ en 32,1.

Contre la conjecture, remarquons que le livre d'Isaïe emploie 11 fois le mot איים quạ qui sert en 34,1; 43,9 de parallèle à en 41,1; 49,1 de parallèle à alors que le mot Ajoutons que, de mềme que le premier tiers de 4 (לא יכהה ולא ירוץ) reprendra 3a (comme l'indiquent ses deux verbes précédés de négations), de même le deuxième tiers de 4 (עדי־ים בארץ משפט) reprendra 3b (comme l'indique son dernier mot). Or, dans cette deuxième phrase du vs 4, il s'agit bien d'établir le droit dans le pays, réalisation qui, selon la phrase suivante, amènera les 'îles' à attendre son enseignement. Donc, placer déjà en $3 b$ 'toutes les races" (selon la traduction de NEB) serait anticiper indûment sur le développement (ce qui n'est pas le cas dans la finale du vs 1 qui joue le rôle de sommaire par rapport à tout l'oracle).

\section{Interprétations proposées :}

On peut faire valoir des arguments ou bien pour une traduction du type de "fidèlement" (J), "avec loyauté" (Osty), "selon la vérité" (Koenig) ou bien pour une autre du type de "à coup sûr" (TOB), "réellement" (BFC).

42,4 ולתורתיו M 4Q-h $\pi^{\circ}$ V S T // modern-graph : 1Q-a ולתורתו / deform-int : G ONOMATI —NOMW

\section{Options de nos traductions :}

Le *M est traduit par un mot au singulier en RSV ("his law"), RL ("seine Weisung"), NEB ("his teaching") et J3 ("son enseignement").

TOB dit suivre 1Q-a en traduisant "ses lois". Cependant J12 traduisaient déjà "ses instructions" sans note textuelle.

Origine de la correction :

Un an avant la découverte de 1Q-a, en 1947, Humbert (en Cent) traduisait ici ce mot par "ses instructions", en notant : "Litt. : sa tôrâ. Ce mot ne désigne pas ici la loi écrite, mais les directions et enseignements que donneront les prédicateurs de la vraie religion (cf. Is 2,3)." J12 ont traduit comme Humbert, sans note textuelle.

Est-ce sous l'influence de ces traductions que Bonnard (= TOB) corrige explicitement ce mot selon 1Q-a?

Les témoins anciens :

1Q-a porte en effet ici ולתורתיו.

Mais le singulier du *M est appuyé par toutes les colonnes hexaplaires (sauf celle du $* G$ ), par la $* V$, la $* S$ et le $* T$, ainsi que par $4 Q$-h (qui écrit ici défectivement : (ולתרתו).

Il semble bien que, comme Fischer (Schrift 13) le suggère, ovouatı soit ici dans le *G une corruption interne de $\nu$ o $\mu \omega$. En effet, en 42,24, pour l'hébreu בתורתו, un

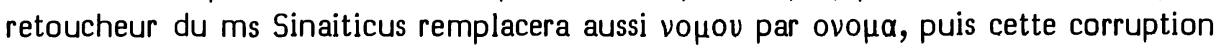
y sera éliminée. 
Choix textuel :

Ce cas n'a pas été soumis au comité.

Bonnard a hésité à suivre l'autre variante du même scribe (ינחילו, deux mots plus loin). En effet, le hifil de cette racine ne semble guère convenir au contexte.

Il ne semble pas avoir remarqué, en 42,24, que 1Q-a porte aussi la graphie בתורתיו (seul autre cas en Isaïe où ce mot devrait avoir le suffixe 'waw'). Comme Ben-Hayim (Șurat 94s) l'a noté, ces 'yod' sont excédentaires et ne manifestent pas des pluriels. $C^{\prime}$ 'est ce qu'on peut relever en de nombreux autres endroits de ce ms où le contexte rend un pluriel impossible : ידיו en 59,17 etc.

On ne saurait donc prendre appui sur 1Q-a pour corriger ici ce mot en pluriel.

Interprétation proposée :

Rien n'empêche de traduire ici ce mot par un pluriel (par ex. : "ses instructions" avec Cent, 312 et BFC) pour montrer qu'il ne s'agit pas d'une nouvelle "Torah". Mais cela ne requiert aucune correction textuelle.

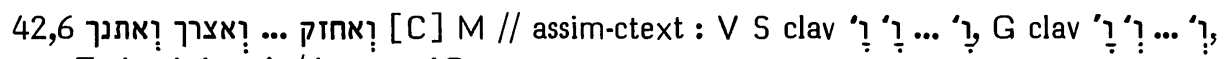

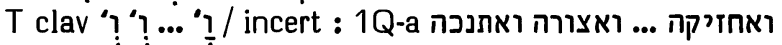

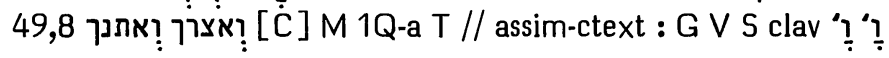

Options de nos traductions :

Au vs 6, après un accompli (קראתיך), le *M offre trois inaccomplis coordonnés. Dans le parallèle de 49,8 le 2e et le 3 e de ces inaccomplis coordonnés sont repris par le *M après deux accomplis (עניתיך עז... עזרתיך).

En 42,6 RL est seule à ne pas traduire ces inaccomplis par des passés : "Ich ... und halte dich ... und behüte dich und mache dich".

Les autres traduisent cela par des passés : RSV : "I have taken you ... and kept you; I have given you"; J12 : "je t’ai pris ... et je t’ai formé, je t’ai désigné"; TOB : "je t'ai tenu ... je t'ai mis en réserve et je t'ai destiné"; J3 : "je t’ai saisi ... et je t'ai modelé, j’ai fait de toi"; NEB : “I ... have ... and taken you ... I have formed you and appointed you". Seul Brockington note que cela suppose une vocalisation qames des 'waw' précédant les inaccomplis. Pour ce faire, il se fonde sur la *S pour les deux premiers et sur le ${ }^{*} G$ pour le troisième.

En 49,8 J1 et NEB omettent les deux inaccomplis et les deux mots qui les suivent, voyant là une interpolation issue de 42,6. 32 conserve cette phrase en la plaçant entre parenthèses. Du fait de cette omission par NEB, Brockington n'a pas l'occasion d'argumenter en faveur d'une correction en passés. Les autres traductions (sans rien noter ici non plus) portent des passés. RSV : "I have kept you and given you"; J2 : "je t'ai formé et je t’ai désigné"; RL : "Ich ... und habe dich behütet und bestellt"; TOB : “je t’ai mis en réserve et destiné"; 33 : “je t’ai façonné et j’ai fait de toi”.

Origines des corrections :

En 42,6 et en 49,8 , sous l'influence de la $* V(42,6$ : et adprehendi ... et servavi 
et dedi te; 49,8 : et servavi te et dedi te), Luther (42,6: "Ich ... und habe dich ... gefasset, und habe dich behütet, und habe dich ... gegeben"; 49,8: "Ich ... und hab dich behut, und ... gestellet") a traduit ces inaccomplis coordonnés par des passés, alors que Pagnini (42,6: "\& appraehendam ... \& custodiam te, \& dabo te"; 49,8: "\& conservabo te, \& dabo te"), Pasteurs (42,6: "\& prendrai ... \& te garderai : \& te ferai"; 49,8 : "si te garderai, \& te donnerai"), Ge (42,6: "I ... and wil holde ... and I wil kepe thee, and give thee"; 49,8: "and I wil preserve thee, and wil give thee") et KJ (42,6: "I ... and wil hold ... and will keepe thee, and give thee"; 49,8: "and I will preserve thee, and give thee") ont respecté les contrastes temporels du $* M$.

C'est vraisemblablement l'accoutumance à la traduction de Luther qui a amené Delitzsch à proposer de vocaliser en 42,6 et en 49,8 avec qames les "waw" de ces inaccomplis. En cela, il a été suivi par Duhm (pour le 1er inaccompli de 42,6), S.R. Driver (Tenses $\$ 174$ pour les inaccomplis de 42,6) et, pour les cinq inaccomplis, par Cheyne, Condamin, König, Elliger (Verhältnis et BK), Bonnard, BH23S, HSAT34 et Cent.

\section{Les témoins anciens :}

Nous avons dit que la *V traduit tous ces inaccomplis par des parfaits. La $* S$ en fait des accomplis (42,6: וגבלתך ויהבתך : ואחדת ... וחילתך ויהבתך). Le *G traduit

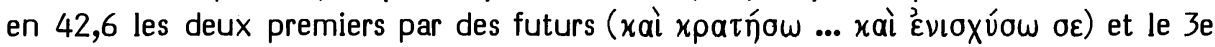

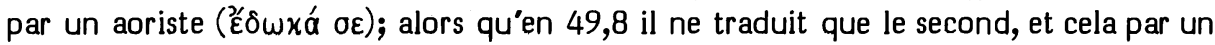

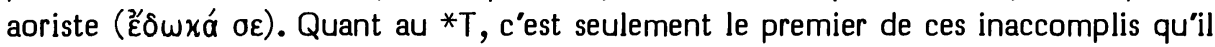
rend par un accompli (ואתקפית).

On ne peut savoir comment 1Q-a vocalisait les 'waw'. Pour le premier inaccompli, il donne ואחזיקה. Or nous avons vu à propos de 40,6 que l'inaccompli 1e personne à finale allongée précédé d'un 'waw' y est une forme ambigüe. En 49,8 1Q-a a assimilé les deux accomplis précédents aux inaccomplis dont nous traitons. 1Q-b, 4Q-b et 4Q-h, là où ils sont conservés, ont des graphies identiques à celle $d u * M$, mais ne nous renseignent pas sur leur vocalisation.

\section{Choix textuel :}

Dillmann/Kittel, Bauer/Leander (279, note) et Volz (pour 42,6, car il omet le passage en 49,8) ont préféré laisser à ces inaccomplis coordonnés de forme brève leur spécificité. Ewald (Lehrbuch \$347a où il ne traite que de 42,6) voit ici l'expression d'un dessein.

Il est possible que cette vocalisation en shewa des 'waw' de ces inaccomplis constitue, ainsi que Gesenius/Kautzsch ( $\$ 107 b, n .2$ ) le suggère pour 42,6, une relecture, théologiquement orientée, de cet oracle prophétique, pour donner une portée d'avenir à ce que le prophète aurait mentionné à titre d'événement passé.

Le comité a cependant estimé devoir respecter la portée éventuelle de la vocalisation actuelle, considérant comme une facilitation, par assimilation aux passés qui précèdent, une correction en inaccomplis invertis. Aussi a-t-il attribué au *M 4 " $C$ " et 2 "B". 
Interprétation proposée :

Dans la ligne suggérée par Ewald, on pourra traduire :

- en 42,6: "Je t'ai appelé ... de sorte que je te prenne la main, que je te protège (ou : forme) et que je fasse de toi."

- en 49,8: “Je t'ai exaucé et ... je t'ai secouru, de sorte que je te protège (ou : forme) et que je fasse de toi."

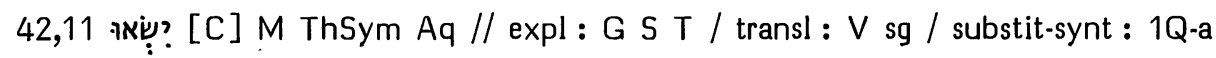
4Q-h? sg

Options de nos traductions :

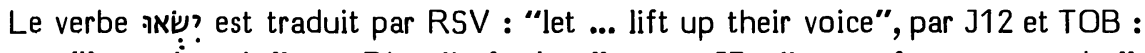
"que ... élèvent la voix", par RL : "rufet laut" et par J3 : "que se fassent entendre".

NEB traduit cela : "let ... rejoice", Brockington précisant que cela suppose une correction vocalique en שעוֹ?

Origine de la correction :

C'est Guillaume (Root) qui propose de lire ici un verbe שنאה semblable au verbe שאא de l'arabe (= se réjouir). Notons que déjà Houbigant proposait de reconnaître ici un verbe ה́א́ au sens de "faire du vacarme" (c'est-à-dire avec 'shin'); alors que le *T, la *S et le *G lui semblaient avoir lu יששו de.

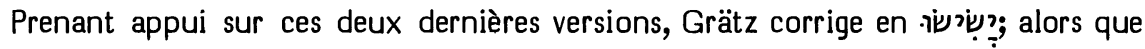

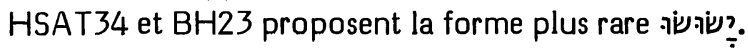

Les témoins anciens :

Le ${ }^{*} G$ (dont la ${ }^{*} S$ dépend) et le ${ }^{*} T$ ont seulement anticipé ici (pour résoudre l'ellipse du complément d'objet de ce verbe) la traduction qu'ils donneront pour le verbe רָר par lequel commencera $11 \mathrm{~b}$.

Quañt à la *V, elle a essayé à tort de donner à ce verbe un sens intransitif (sublevetur) que nous rencontrerons en $\mathrm{Na} 1,5$, mais qu'il n'a pas en ce contexte-ci.

$1 Q$-a et $4 Q$-h lisent ce verbe au singulier. Cela correspond en $1 Q$-a à une omission de la conjonction avant le $3 e$ mot du vs. Le fait que $4 Q$-h soit lacuneux après le $2 e$ mot nous empêche de motiver son option.

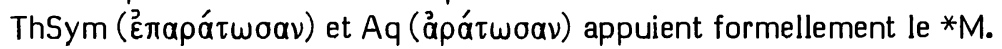

Choix textuel :

Déjà Menahem ben Saruq (sous שיא unissait Is 42,11 et Jb 21,12 comme des cas où le mot "voix" est sous-entendu. En Isaïe, d'autres cas d'une même ellipse s'offrent en 3,7 et 42,2 . Ici le verbe qui commence $11 \mathrm{~b}$ suffit à assurer cette solution de l'ellipse.

Le fait que deux mss de Qumrân portent ici le singulier a amené le comité à attribuer seulement " $C$ " au ${ }^{*} M$. Il est en effet possible que le verbe au singulier dont font usage la plupart des versions se trouvait déjà en leur Vorlage. 
Interprétation proposée :

"Que ... élèvent la voix".

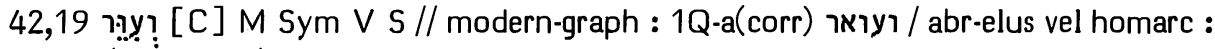
G / midr : T / assim 19a : m 1Q-a* וחרש.

Options de nos traductions :

Alors qu'en 19a c"est "sourd" qui sert de parallèle poétique à "aveugle", le *M répète "aveugle" dans les deux membres de 19b. Etant donné que le vs 18 adressait cet oracle aux sourds et aux aveugles, on comprend que plusieurs témoins textuels et exégètes aient essayé de rétablir en $19 \mathrm{~b}$ le balancement : aveugle - sourd.

Respectent ici la leçon du *M : RSV ("or blind") et RL ("und so blind").

Corrigent comme indiqué ci-dessus : J ("et sourd") et TOB ("sourd") disant se fonder sur 2 mss et sur Sym; NEB ("so deaf") qui, selon Brockington, lit ?ִ? avec 2 mss.

Origine de la correction :

C'est Houbigant qui a fondé sur Sym cette correction suivi par Lowth et la plupart des critiques jusqu'à BH23S, HSAT34 et Cent.

Les témoins anciens :

La variante mentionnée par Brockington se lit en effet dans le ms 80 de Kennicott et dans la 1e main du ms de Rossi 267, manuscrits allemands du XIIIe et du XIVe siècles sans autorité spéciale.

Le scribe de 1Q-a avait d'abord commencé, lui aussi, par écrire un 'het', puis l'a raturé. Quant au 'alef' qu'il a inséré après le 'waw' en ועואר, il revient en ce mot une autre fois en ce vs et encore une fois en 43,8. Kutscher (163) a suggéré que $c$ 'est une mater lectionis pour 'șéré', graphie dont nous avons trouvé un autre exemple en $(28,1.4)$.

La leçon authentique de Sym est celle que donne Théodoret $(168,34)$. Elle est conforme au *M que la *V (quis caecus) et la *S (ועוירא) appuient également.

Les mots כמלאכי אשלח מי עור ont été omis par le *G. Il se peut que ce soit par souci de facilitation (comme Houbigant l'a pensé). Il se peut aussi que ce soit par homéoarcton. Quant à la traduction de notre mot par un (verbe) pluriel, cela dépend d'une option précédente du *G concernant le mot "serviteur" en ce vs.

Le midrash que le *T offre ici n'apporte aucun témoignage textuel sur le point qui nous occupe.

\section{Choix textuel :}

Houbigant ne connaissait Sym qu'à travers Montfaucon qui le lisait en Procope de Gaza (édité par Curterius) reproduisant une citation d'Eusèbe. Or celui-ci, dans son commentaire $(275,28)$, déforme Sym par deux assimilations : pour les trois derniers

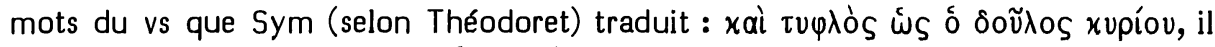

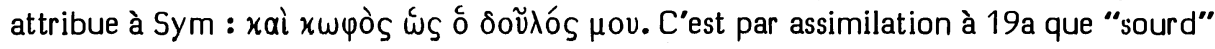


y a remplacé "aveugle" et que "mon serviteur" y a pris la place de "le serviteur du Seigneur".

Déjà Schleusner (Opuscula 351) avait corrigé par conjecture la seconde faute, et c'est dans cet état, à demi corrigée, que la leçon de Sym a été éditée par Field, reprise par Ziegler (éd. de Göttingen) en son apparat hexaplaire, puis utilisée par HUB, North, BHS, J, Bonnard, TOB et Schoors. Cependant la citation de Sym par Théodoret était connue à partir de l'édition que Möhle a donnée du commentaire de celui-ci sur Isaïe en 1932, édition dont Ziegler n'a intégré les données qu'à titre informatif.

Cette déformation de "aveugle" en "sourd" par assimilation à 19a se retrouve dans la traduction de Saadya. D'ailleurs Abulwalid (Luma 296,25) et Judah ibn Balaam estiment qu'ici ועור est pour וחרש.

Concluons que le ${ }^{*} M$, dans sa leçon déroutante, a ici l'appui direct de $1 Q-a$, de Sym, de la *V et de la *S. Il a l'appui indirect du *G qui a bien lu ici "aveugle" et non "sourd". Aussi le comité a-t-il attribué au *M 3 "C" et 3 "B".

Interprétation proposée :

Selon Hitzig, cette répétition de "aveugle" là où l'on attendrait "sourd" vise à insister sur l'idée que celui qui doit être une lumière pour les nations et ouvrir les yeux des aveugles (vss 6 et 7) est lui-même enténébré, lui-même aveugle. Nous présenterons, à propos de 42,20, une interprétation d'ensemble de 42,18 à 22.

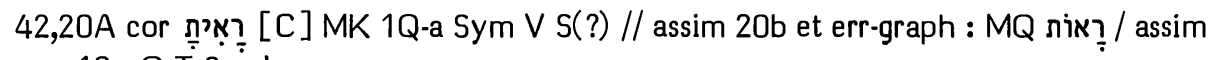
$18: \mathrm{G}$ T $2 \mathrm{e} \mathrm{pl}$ 42,20B תשמר [B] M 1Q-a Sym V // assim 18 : G S T 2e pl 42,20C ישמע [C] M 1Q-a // assim 20a : m Sym V 2e sg / assim 18: G S T 2e pl

Options de nos traductions :

20a débute par un mot (20A) dont le qeré est רְאוֹ et dont le ketib porte un 'yod' à la place du 'waw'.

20a s'achève par un verbe (20B) à la $2 e$ pers. m. sg. (ou 3e pers. f. sg.), alors que $20 \mathrm{~b}$ (dans une situation qui semble parallèle) s'achève par un verbe (20C) à la 3e pers. m.sg.

$1 /$ Seules deux de nos traductions (RSV et J1) ont lu 20A selon le qeré, ce qui les a amenées à respecter le $* M$ en $20 \mathrm{C}$, mais à le corriger en 20B, RSV y introduisant une 3e pers.: "(he) ... does ... observe" et $\mathrm{J1}$ une forme impersonnelle : "faire attention". 2/Deux autres ( $R L$ et J3) prennent un parti nettement opposé : elles lisent $20 \mathrm{~A}$ selon le ketib, ce qui les a amenées à respecter le * $\mathrm{M}$ en 20B, mais à le corriger en $20 \mathrm{C}$ où elles lisent une 2e pers. : RL : "du hast ... gehört" et J3 : "tu ... entendais".

$3 /$ Les trois autres (J2, TOB et NEB) choisissent le ketib en $20 \mathrm{~A}$ et le $* M$ en $20 B$. Elles essaient cependant d'éviter de corriger $20 \mathrm{C}$ en $2 \mathrm{e}$ pers. Ou bien elles font appel à une forme impersonnelle (J2 : "entendre" et TOB : "on entend") ou bien on corrige le qal en nifal (NEB, selon Brockington, pour traduire : "is heard"). 
Origines des corrections :

La solution (1) remonte à Luther ("Es ist wol viel sehen, aber man behelts nicht, Man hat die oren offen, und höret doch nichts").

La solution (2) remonte à Radaq, estimant que le passage à la 3e pers. en $20 \mathrm{C}$ est une pure variation stylistique qu'il illustre ici par שמער עמים כלם (Mi 1,2).

Les témoins anciens :

1Q-a (ראיתה) porte le ketib en 20A et appuie la discordance des personnes du *M en 20BC.

Une soixantaine de mss du $* M$ ont mis $20 \mathrm{C}$ à la 2 e pers. en l'assimilant à $20 \mathrm{~B}$, quoique la massore (Weil §1179) confirme la 3e pers. de 20C.

Sous l'influence du vs 18 , le ${ }^{*} G$ et le $* T$ ont mis à la 2 e pers. pl. ces trois formes verbales. La ${ }^{*} S$ a fait de même pour 20BC, alors qu'en $20 \mathrm{~A}$ sa graphie תר, qui est équivoque, a été lue en 1e pers. par Gabriel Sionita. Mais Ephrem l’a lue en 2e pers., ce qui est plus vraisemblable.

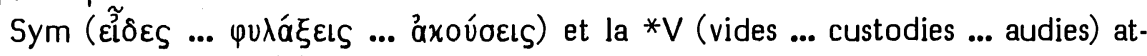
testent déjà la solution (2).

\section{Choix textuel :}

Il est aisé de justifier et de valoriser stylistiquement la discordance des personnes que le $* M$ offre en 20BC : En 19a le Seigneur parle de son serviteur. En 19b d'autres parlent du serviteur du Seigneur. En 20a le Seigneur s'adresse à son serviteur à la 2e personne. En 20b d'autres parlent du serviteur à la 3e personne.

Ces alternances s'expliquent par le développement de l'oracle' : En 18 le Seigneur a appelé les sourds à écouter et les aveugles à voir. En 19a le Seigneur dit qui est aveugle et sourd : "mon serviteur ... que j'envoie". En 19b d'autres constatent à leur tour la cécité de Meshullam, du serviteur du Seigneur. En 20a le Seigneur explique à son serviteur (à la $2 \mathrm{e}$ pers.) en quoi consiste sa cécité. En 20b d’autres expliquent (à la 3e pers.) en quoi consiste la surdité du serviteur du Seigneur. Puis, ces mêmes autres, en 21 et 22, méditeront sur le projet du Seigneur et sur le sort de son peuple. Ainsi les vss 19 et 20 assurent, par des reprises dialoguées, le passage de l'exorde du Seigneur à la méditation des spectateurs.

Dans ce contexte, le ketib "tu as vu" semble mieux en place que le qeré "on voit" qui semble provenir d'une assimilation indue à $20 b$ (avec quoi 20a doit, au contraire, faire contraste). Cette assimilation a dû être occasionnée par une graphie indistincte des 'yod' et des 'waw' telle qu'elle se rencontre en plusieurs mss d'Isaïe de Qumrân. Ajoutons à cela que les infinitifs absolus en תi- sont très rares (Is 22,13 et $\mathrm{Ha} \mathrm{3,13),}$ alors qu'il est normal qu'un infinitif absolu continue un accompli (Gesenius/Kautzsch $\S 113 z)$.

En $20 \mathrm{~A}$ quatre membres du comité ont voté " $\mathrm{C}$ " pour le ketib et deux ont voté " $\mathrm{C}$ " pour le qeré, estimant qu'une assonance voulue avec rį̣ a été méconnue par le ketib.

En $20 B$ où le $* M$ et $1 Q$-a ont l'appui de Sym et de la $* V$, le comité leur a attribué la note "B".

En $20 \mathrm{C}$ où ils n'ont pas cet appui, ils ont reçu la note "C". 
Interprétation proposée :

“Tu as beaucoup vu, mais tu ne retiens pas. Les oreilles sont béantes, mais il n'entend pas."

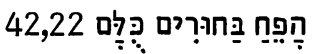

Options de nos traductions :

Sans note textuelle, RSV traduit : "they are all of them trapped in holes", RL : “sie sind alle gebunden in Gefängnissen", J3 : “on les a tous enfermés dans des bassesfosses".

J12 traduisaient : "tous sont pris au piège dans des cavernes", J2 disant corriger

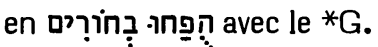

Pour traduire "all of them ensnared, trapped in holes", NEB sent le besoin (selon Brockington) de corriger le premier mot comme $\mathrm{J} 2$ l'a fait.

Quant à TOB, elle estime que le *M signifie : "on a séquestré les hommes d"élite, eux tous". Aussi dit-elle avoir besoin de modifier une voyelle pour traduire: "on les a tous séquestrés dans des fosses". S'agit-il d'un shewa à la place du patah du deuxième mot ou bien d'un ḥolem à la place de son shureq ?

Origine des corrections :

Pour obtenir le sens sur lequel toutes nos traductions s'accordent, la correction adoptée par J2 a été requise par Duhm, Dillmann/Kittel, Cheyne, Marti, Feldmann, Volz, Elliger (Verhältnis), Muilenburg, HSAT2, BH3, Cent.

Les témoins anciens :

A part une scriptio plena du 3e mot, 1Q-a est identique au *M dont 4Q-g (conservé seulement pour le $3 \mathrm{e}$ mot) appuie la scriptio defectiva.

En dehors d'une vocalisation nֵַ par le ${ }^{*} G$, la $* V$ et la $* S$, les versions se bornent vraisemblablement à interpréter ce texte, ainsi que l'histoire de l'exégèse nous le mon-

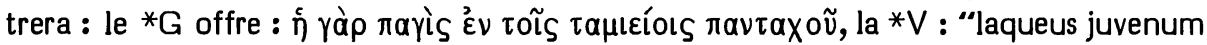
omnes", la *S : פותא אינון כלהון גדו̈, le *T : אתחפיאו בהתא עולימין כולהון.

\section{Choix textuel :}

Ce cas n'a pas été soumis au comité.

Sans prétendre corriger le *M, Luther traduisait : “Sie sind allzumal verstrickt in Hülen" et KJ : "They are all of them snared in holes".

En effet, Radaq tirait ce sens du $* M$ qu'il interprétait ainsi : "il veut dire que leurs ennemis les piègent dans les 'trous' où ils s'étaient dissimulés, c'est-à-dire qu'ils les prennent à leur propre piège. 'Trous' est une expression dépréciative pour les cavernes. Déjà les Philistins disaient (1 S 14,11) : 'Voici les hébreux qui sortent des trous où ils s'étaient dissimulés'." Piéger les réfugiés dans leurs cavernes, c'est ce que firent souvent, dans le désert de Juda ou en Galilée, les troupes chargées de réprimer les diverses révoltes. Josèphe (Ant XIV 421-430 et Guerre I 309-313) nous explique comment les soldats d'Hérode prenaient au piège les 'brigands' qui s'étaient réfugiés dans les falaises de Haute-Galilée. 
D’ailleurs פִִ̣ peut être un infinitif absolu hifil de génominatif de nפِ. Et cet infinitif absolu peut avoir, comme en 22,13 , pour but de rendre vivante la narra-

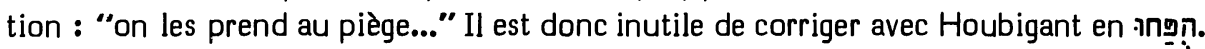

Quant à בַחוּרִ déjà David ben Abraham (II 455,3), karaïte palestinien coñtemporain des derniers massorètes, le comprenait comme "dans les trous", ce qui sera l'exégèse d’Abulwalid (Ușul 565,14-16), Judah ibn Balaam, Ibn Ezra, Tanḥum

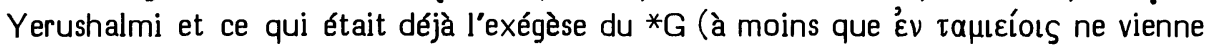
de בחדרים). En effet, de même que Is 11,8 vocalise רִ le singulier que 2 R 12,10 et Ez 8,7 vocalisent in, il est fort possible que Is 42,22 vocalise

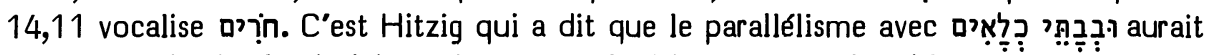
requis que le 'bet' soit ici aussi sans article. Mais on peut fort bien opposer 'des cachots' ( $=$ ceux, quels qu'ils soient, en lesquels les ennemis détiennent les gens qu'ils ont pris) et 'les trous', c'est-à-dire les cavernes bien connues où ces réfugiés ont établi leurs gîtes, comme l'avaient déjà fait ceux de l'époque de Saül et le feront ceux des époques suivantes.

Il n'y a donc pas à corriger le *M pour y trouver le sens que J12, NEB et TOB veulent exprimer et qui est, en effet, le plus probable.

Interprétation proposée :

"On les prend tous au piège dans les trous."

\section{2,24 חטאנר [B] M 1Q-a V S // harm-ctext : G T 3e pl}

\section{Options de nos traductions :}

Ce verbe à la 1e pers. pl. est suivi, dans le *M, par deux verbes à la 3e pers. pl. Cette séquence est respectée par RSV, RL, J3 et TOB (ces deux dernières tirant parti de formes impersonnelles).

$\mathrm{J12}$ unifient leur traduction sur la 1e pers. pl., sans note textuelle.

NEB unifie sur la 3e pers. pl., Brockington précisant qu’elle lit חְְְִ avec le *T.

Origines des corrections :

La correction de NEB a été proposée par Houbigant puis adoptée par Lowth qui attribue cette leçon au *G et au *T. Cette suggestion a été suivie par Grätz, Oort, Marti, Praetorius.

J12 semblent isolées dans leur option.

Les témoins anciens :

En ce changement de personnes, le $* M$ a l'appui de $1 \mathrm{Q}$-a et de la $* V$.

Les autres versions ont harmonisé : le ${ }^{*} G$ et le ${ }^{*} T$ sur la $3 e$ pers. pl., la ${ }^{*} S$ sur la 1e pers. pl.

Le *T du ms Reuchlin respecte le changement de personnes du *M. Mais il semble avoir été recensé sur son texte du *M avec lequel il alterne, verset par verset. Notons en effet que le ms Urbinates 1 appuie le ${ }^{*} T$ des autres témoins. 
Choix textuel :

Michaelis, dans sa traduction, avait unifié sur la 3e pers. pl. et s'en était expliqué ainsi : "'an dem sie sich versündiget hatten', littéralement : 'an dem wir uns versündiget hatten', de sorte que le prophète parle au nom de son peuple avec lequel il se solidarise. En hébreu, des changements de personne de cette sorte sont permis, alors qu'en allemand ils blessent. Or j'estime ne pas avoir à exprimer dans la traduction toutes les aspérités exotiques de la construction, aboutissant à un texte pénible pour le lecteur, transformant en réalité la Bible en charabia. C'est pourquoi je transpose, à la manière dont nous parlons en allemand, et j'espère qu'on ne m'imputera pas cela comme une infidélité."

En OEB, où il s'agit de justifier les options textuelles sous-jacentes à sa traduction, il s'exprime ainsi : "Lowth traduit comme moi, mais fait un pas de plus et lit חטאו en se référant au ${ }^{*} G$ et au *T. Mais ces témoins me laissent incertain. Qui me dit en effet qu'ils n'ont pas agi comme moi ? n'auraient-ils pas lu חטאנו mais, ne se sentant pas tenus à imiter toutes les aspérités de la construction, n'ont-ils pas traduit à la 3e pers. conformément au génie de leur langue ? Là où il ne s'agit que de simples anomalies et aspérités de la construction, je n'ose pas conclure à partir des versions anciennes ce que le traducteur a lu, mais je me préoccupe du témoignage des manuscrits hébreux. Or, je crois pouvoir conclure du silence de l'évêque [= Lowth] qu'ici ils sont unanimes à porter ivאנו."

Partageant ce sentiment, le comité a attribué au *M la note "B".

Interprétation proposée :

Au vs 23 le prophète s'est adressé à la 2 e pers. pl. ("qui d'entre vous") à un auditoire dont ici ("nous avons péché") il se montre solidaire. Il s'agit en effet d'une confession qui vaut pour le passé des convertis comme pour les non-convertis. Puis, juste après, il parle des pécheurs à la 3e pers. pl. (“ils n'ont pas voulu ... et ils n'ont pas entendu"). Il peut s'agir là des pères ou plutôt de la part du peuple qui a refusé de se convertir, part avec laquelle le prophète et son auditoire de convertis refusent de se solidariser.

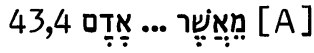

\section{Options de nos traductions :}

La vocalisation du *M a été respectée par RSV, J, RL et TOB.

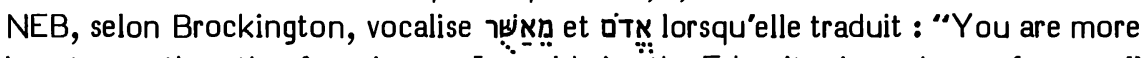
precious to me than the Assyrians ... I would give the Edomites in exchange for you."

Origine de la correction :

Cette conjecture concernant la vocalisation de ces deux mots a été proposée par Maalstad.

Celle concernant "Edom" avait déjà été suggérée par Ehrlich (qui préférait garder

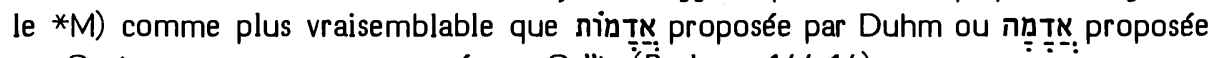
par Oort, ou encore אִיִ proposée par Grätz ('Ṕsalmen 144,14). 


\section{Les témoins anciens :}

Pour ces deux mots, la vocalisation du ${ }^{*} \mathrm{M}$ a l'appui de tous les témoins textuels, y compris $1 Q$-a et $1 Q-b$. En effet, quoique ces deux mss ne soient pas ponctués, ils donnent une indication assez claire dans le fait qu'ils s'accordent avec le $* M$ en des graphies défectives de ces deux mots. Or le nom d'Assur est toujours écrit plene en ses 44 mentions dans le $* M$ d'Isaïe et en $1 Q$-a, ainsi que dans les 4 d'entre elles (en 19,23.24.25; 20,1) pour lesquelles 1Q-b est conservé. Il en va de même pour Edom dans ses 4 mentions dans le $* M$ d'Isaïe et en $1 Q$-a, ainsi que dans celle d'entre elles $(63,1)$ pour laquelle $1 Q$-b est conservé.

\section{Choix textuel :}

La double conjecture de Maalstad est assez attirante du fait qu'en 3b des peuples étrangers (Mișraïm, Kush et Seba) ont été mentionnés comme des rançons que le Seigneur a données à la place d'Israël.

Mais Maalstad a fait lui-même remarquer qu'on peut se demander si le prophète de la seconde moitié du sixième siècle a des motifs de choisir Assur, empire depuis longtemps écroulé, comme un élément de comparaison. A cela Elliger ajoute que le choix d'Assur comme un cas typique de peuple précieux aux yeux de Dieu serait assez surprenant.

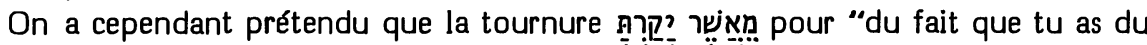
prix" serait unique en hébreu, ce qui la rendrait improbable. Ehrlich a noté (sur Lv 12,4) que beaucoup de verbes hébreux intransitifs - et יקר est du nombre - n'ont pas אשר d'infinitif construit. Cela entraîne la nécessité de faire usage d'une périphrase, avec suivi d'une forme personnelle, lorsque l'on souhaiterait faire usage d'un infinitif avec suffixe (du type de מִִ̣ en 48,4) qui serait ici la tournure naturelle. Il est également possible que la périphrase vise à mettre en valeur l'aspect de l'accompli (en connection avec les deux accomplis qui suivent et en contraste avec l'inaccompli qui fait suite au 'waw' d'apodose en 4b) qu'un infinitif n'aurait pu exprimer.

Quant à Edom, R. Eléazar (début du IVe siècle) proposait (Talmud Babli, Berakot 62b) déjà de le lire ici dans un al-tiqré homilétique... ce qui nous indique, en tout cas, que ce n'était pas la vocalisation coutumière de ce mot pour ses auditeurs. Il s'agissait là pour ce prédicateur d'une évocation de l'empire romain comme dans un autre al-tiqré (non explicite, celui-là) que Bacher (Amoräer I 372, n.2) et Theodor (Bereshit Rabba I 74, n. 1) ont diagnostiqué de la part de Resh Laqish (milieu du IIIe siècle), à propos de Is 45,12 .

Contre la conjecture Edom, on notera que ce modeste royaume ferait piètre figure à côté de Mișraïm, Kush et Seba aux richesses légendaires. D'ailleurs la mention d'un peuple précis serait déplacée en $4 \mathrm{~b}$ où - après en avoir donné le motif en $4 \mathrm{a}-$ l'auteur entend reprendre en termes plus génériques le contenu de $3 \mathrm{~b}$. Dans cette reprise les expressions indéterminées: "de l"humanité" et "des peuples" veulent évoquer par deux fois (comme l'indique la reprise "à ta place" et "à la place de ta vie") les trois peuples qui avaient été énumérés en $3 \mathrm{~b}$.

On a prétendu que אדם au sens collectif de "des hommes" ne serait pas en place ici, puisqu'Israël fait lui aussi partie de l'humanité. Mais Ehrlich a finement noté (sur Gn 3,2) que l'hébreu biblique semble opposer souvent un genre entier à une espèce 
de ce genre, sans préciser que, par la mention du genre, il entend seulement les autres espèces du genre en question, car cela va de soi pour l'auditeur.

Il faut signaler que la paire parallèle לאמים/אדם, qui n'apparaît qu'ici dans la Bible, a été signalée par Watson (Pairs 465) en ugaritique, dans l'ordre inverse.

\section{Interprétation proposée :}

"Du fait que tu as du prix à mes yeux, que tu as de la valeur, et que moi je t'aime, je donne des hommes en échange de toi et des peuples en échange de ta vie."

\section{עבדי 43,10 ועבדי [B] M G V T / assim-ctext : S pl / substit-synt 1Q}

\section{Options de nos traductions :}

Ici, le *M est ambigu puisqu'il peut s'interpréter comme :

$1 /$ "c"est vous qui êtes mes témoins ... et (qui êtes) mon serviteur", ou bien comme : 2/ "mes témoins, c'est vous... et (c'est aussi) mon serviteur".

Celles de nos traductions (RSV, RL, TOB et J3) qui ne corrigent pas le *M le comprennent selon l'interprétation (1).

Dans la perspective de cette interprétation, J12 et NEB traduisent le 2e prédicat par un pluriel : "mes serviteurs" et "my servants", J12 spécifiant que cela suppose une correction vocalique.

\section{Origine de la correction :}

Marquant par là son mépris pour la vocalisation traditionnelle, Houbigant traduisait ce mot par un pluriel, sans rien noter. Vogel a fait remarquer que "rien n'empêche de prononcer ce mot avec les voyelles du pluriel". Puis Michaelis (OEB) a noté que l'édition de Halle du $* M$ signale cette vocalisation plurielle d'Erfurt et que cela lui semble plus coulant, du fait des pluriels qui précèdent et qui suivent. De Rossi (IV 232) signale aussi cette vocalisation dans la 1e main de son ms 211 et dans la *S. Cette leçon a été adoptée par Bredenkamp, Duhm, Cheyne, Köhler, Haller, Volz, Ziegler (EB), Fohrer, Elliger, HSAT34 et BHS.

\section{Les témoins anciens :}

Le témoignage d'un ms du $* M$ et de la première main d'un autre est négligeable pour la mise au pluriel de ce mot. Il en va presque de même de la *S où la variante tient à la présence ou à l'absence des seyâmé. En effet, après qu'on les ait placés sur סהדי (en conformité avec le pronom pluriel qui précède), on est évidemment incliné à les placer aussi sur ועבדי

Le ${ }^{*} G$ lit, comme le *M, ce mot au singulier. C'est par simple allègement translationnel qu'il n'explicite pas le pronom suffixe, le possessif étant très suffisamment exprimé par la relative qui suit.

La seule variante notable est apportée par 1Q-a qui n'a pas de 'waw' avant ce mot, alors que tous les autres témoins textuels l'attestent. 


\section{Choix textuel :}

Une mise de ce mot au pluriel constitue ici une assimilation au contexte. Elle est d'ailleurs très faiblement attestée. Quant à l'absence de conjonction, 1Q-a en est le seul témoin. On peut y voir un indice que 1Q-a a opté pour l'interprétation (1), c'est-à-dire que, pour lui, il y a identité entre le (ou les) serviteur(s) et "vous mes témoins".

Le comité a attribué au *M la note "B". teur".

Nous retrouverons en 44,26 un problème portant sur le nombre du mot "servi-

\section{Interprétations proposées :}

La deuxième personne "vous" doit déjà désigner Israël, comme elle le fera clairement à partir du vs 14. La seule question difficile à trancher est de savoir si“mon serviteur que j'ai choisi" désigne ici - selon l'interprétation (1) - Israël (comme en 41,8) ou bien - selon l'interprétation (2) - Cyrus (comme en “mon serviteur ... mon choisi" en 42,1). Quoique la plupart des modernes, à partir de Delitzsch, choisissent la première interprétation de la syntaxe de 10a, la quasi-totalité des anciens (depuis Yéfet ben Ely jusquà Hitzig) ont choisi spontanément la seconde interprétation.

Cyrus a donc été choisi pour que les Israélites, peuple aveugle et sourd $(43,8)$ sachent, croient et comprennent que le Seigneur est le seul Dieu (10b), et qu'après que l'intervention de Cyrus leur ait témoigné de cela, ils en deviennent à leur tour les témoins dans le procès où les païens (8) et le Seigneur (10) affrontent leurs témoins.

\section{3,13 מBיום [B] M 1Q-a // glos : S / exeg : G V T}

Options de nos traductions :

L'expression "ehe denn ein Tag war", par NEB : "from this very day" et par TOB : "oui, désormais".

J12 donnaient : “depuis l'éternité" et J3 : “de toute éternité", J2 notant que cela suppose une correction du second mot en angyion avec les versions.

Origine de la correction :

Oort (Jez) se réfère au *G et à la *V pour corriger מיום en מעולם, correction adoptée par HSAT2, Haller et BHS. Duhm ajoute cela à la leçon du *M, suivi en cela par Marti, Condamin et Feldmann.

\section{Les témoins anciens :}

$1 Q$-a est identique au $* M$.

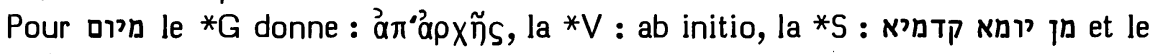
*T : מעלמא.

\section{Choix textuel :}

Elliger (Verhältnis 237) dit : “Lorsque les versions lisent 'depuis l'éternité pour 
qụ, il n'est pas exclu qu'à leurs yeux cela soit une interprétation conforme au sens de cette expression."

En BK il est encore plus formel: "Le ${ }^{*} G$ est justement ici un témoin peu sûr, car il ne traduit ni אני הוא qui précède, nui suit et qui ne sera ajouté que par la recension lucianique. La *S 'à partir du premier jour' n'est évidemment rien d'autre qu'une interprétation d'un simple מיום que sa Vorlage, comme le*M, comportait. $L a * V$ 'ab initio' correspond au ${ }^{*} G$ et la même tradition exégétique s'exprime encore une fois d'une autre manière en 'depuis l'éternité' dans le *T. L'interprétation est donc la même dans toutes les versions, y compris la ${ }^{*} S$, et la forme hébraïque sous-jacente est donc probablement aussi identique. C'est user d'une méthode extrêmement contestable que de se fonder, pour accéder à la forme hébraïque, sur le *T dont il est bien connu qu'il ne mérite pas confiance sur ce point, et de considérer donc מِ̣ comme l'original, en laissant de côté la *S avec son clair oìn. En tout cas, ce qui, dans les versions, apparaît comme une autre forme textuelle n'est en réalité qu'une interprétation $d u * M . "$

On comprend ainsi que Cheyne ait déjà déclaré : "Je regrette de ne pouvoir accepter la correction trop aisée (מעולם (pour, ou à côté de que le *T (*G?) a suggérée à Oort, Ryssel, Duhm, Gunning".

Le comité a donc attribué au *M la note " $\mathrm{B}$ ".

Interprétations proposées :

La plupart des exégètes anciens ont compris מיום comme : “à partir du moment où il y eut un jour" (Rashi, Aaron ben Joseph, Gesenius, Hitzig) ou "avant qu'il y eut un jour" (Abulwalid en Luma 252,1, Judah ibn Balaam, Radaq, Vitringa). Hitzig

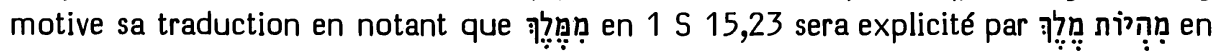
15,26 .

A partir d'Ewald, ceux des exégètes contemporains qui gardent le *M (Luzzatto, Knobel, Delitzsch, Nägelsbach, Dillmann/Kittel, Pieper, König, North, Bonnard, Elliger) comprennent מיום au sens qu'il a en Ez 48,35 : "désormais, par la suite".

Il peut être intéressant de remarquer qu’à propos de ce verset, le Yalqut haMakhiri cite un passage du Tanḥuma (inconnu par ailleurs) où R. Yoḥanan (milieu du IIle siècle) explique : "Lorsque le Saint, béni soit-il, se tint sur la montagne du Sinaï et déclara: 'c'est moi le Seigneur ton Dieu', soudain les idoles disparurent totalement." Saadya (Kitâb al-Amânât 103,11-14) suggère lui aussi qu'il peut s'agir ici du jour du Sinaï et Yéfet ben Ely se fonde vraisemblablement sur la même exégèse lorsqu'il voit ici une référence à l'époque de Moïse.

A la racine de ces exégèses rabbiniques anciennes, il y a vraisemblablement une interprétation où מיום est construit sur les deux mots qui le suivent, constituant avec eux un seul complément temporel d'une proposition principale qui est introduite par

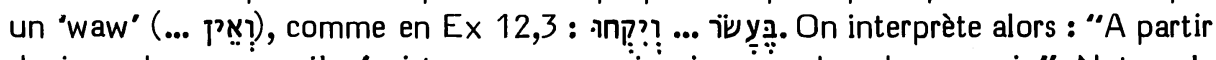

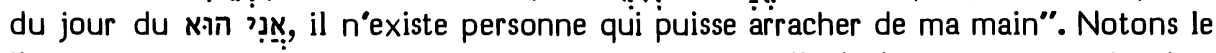
lien entre ces mêmes membres de phrase אני הוא et "il n'existe personne qui puisse arracher de ma main" en Dt 32,39. D'une façon moins midrashique, on pourrait lier ainsi le vs 13 au précédent : "Vous êtes mes témoins - oracle du Seigneur - et moi je suis Dieu ! De plus, dès lors que je suis tel, il n'y a personne qui puisse arracher hors de 
ma main. J'agis, et qui pourra l'inverser ?" Cette exégèse suppose que renvoie ici à אני־אל qui qui précède, de même qu'en 41,4, dans אני הוא renvoyait au tétragramme de אני יהוה qui précédait. Cela est fort possible.

On ne saurait prétendre que cette vieille interprétation doive être préférée aux deux autres qui, depuis Rashi, se partagent les faveurs des exégètes, mais elle mérite d'être prise en considération.

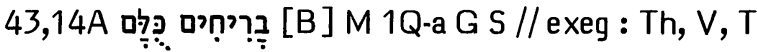

Options de nos traductions :

Traduisent le *M : RSV : "all the bars", NEB : "as they flee", TOB : "tous ... en fugitifs".

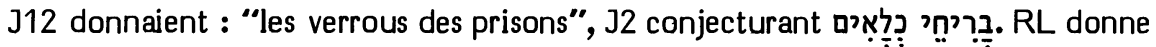
de même : "die Riegel eures Gefängnisses".

33 donne : "tous les verrous", corrigeant le premier mot en בְר?יחִים

Origines des corrections :

La conjecture de $\mathrm{J} 12$ a été proposée par $\mathrm{BH}$. Cent s'en distingue en vocalisant shewa la première syllabe. Cette suggestion qui remonte à Köhler a été adoptée par Ziegler (EB) et Fohrer.

RL a lu un suffixe 2e pers. pl. à la fin du 2e mot, selon la proposition de Volz. Elliger (Verhältnis) hésitait entre la conjecture de Köhler et celle de Volz. En BK il revient au *M.

Avant J3, Dillmann/Kittel avait déjà suggéré que l'interprétation du 1er mot en "verrous" suppose la vocalisation shewa de sa première syllabe, opinion qu”Elliger (BK) a reprise.

Les témoins anciens :

1Q-a ne se distingue du *M que par une graphie pleine du 2e mot.

Quant aux versions anciennes, nous verrons qu'elles n'attestent que des exégèses variées du *M.

Choix textuel :

C'est pourquoi le comité a attribué au *M 4 "B" et 2 "A".

Interprétations proposées :

Les versions ont compris le premier mot de trois façons qui se sont disputé les choix des exégètes jusqu’à nos jours.

Le *T (במשוטין) considère ce mot comme correspondant à באניות (= sur des navires) qui va suivre. Comprenant le 'bet' comme préposition, il donne à ריחיח (e sens de "rames, avirons". Il est suivi en cela par Rashi et par les glossaires ABCDEF. Analysant de même, David ben Abraham (I 273,133-136) traduit פי אלמראכב אלריחיה (= dans les bateaux à voile). Cette exégèse sera reprise par Sahl (cité par Aaron ben Joseph), et Yéfet ben Ely explique que ñ? est un nom qui désigne une petite embarca- 
tion. Dans la même ligne, Ehrlich a estimé que ce mot signifie quelque chose qui est poussé par le vent, d'où un bateau à voiles. North, de façon hésitante, s'est aventuré dans la même direction. Notons en passant que le midrash Ekha-Rabbati (79a) comprend en ce mot : "avec des meules". Du fait qu'il n'y avait pas de pierres à Babel, il était nécessaire d'y importer des meules. Aussi, lorsque Nabuchodonosor capturait des jeunes gens dans le pays d'Israël, il chargeait sur eux des meules pour qu'ils les portent à Babel.

$L a{ }^{*} V$ donne à ce mot le sens de "verrous", ce qui est aussi l'avis de Joseph Qara, d'Tbn Ezra, d'Aaron ben Joseph et d'Abravanel.

Une interprétation, citée comme déjà traditionnelle par David ben Abraham et par Yéfet ben Ely, donnait à ce mot le sens de "nobles", à partir de celui de "grand et imposant" que l'on attribuait à ce mot comme qualificatif de Leviathan en Is 27,1 et Jb 26,13. Cette interprétation est adoptée ici par Eliézer de Beaugency. Elle semble remonter à Th dont Hie cite ici la leçon "fortes".

Mais l'exégèse la plus largement représentée est celle qui voit ici un adjectif

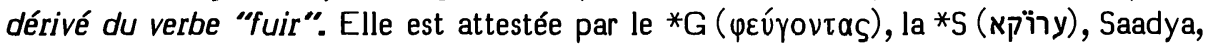
Abulwalid (Usul 112,29-32 et 113,15s), Joseph Qimhi (Galuy 20) et Radaq. Abulwalid estime que, bien que ce même mot au même sens de "fuyards" se retrouve à l'état suffixal avec un shewa à la place du qameș en Is 15,5, il n'y a pas là plus de dif-

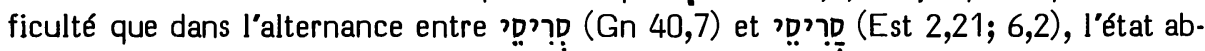
solu du pluriel de ces deux mots gardant toujours le qames.

Il est frappant de noter que l'exégèse de la *V ("verrous") est celle qui a eu le plus de succès dans les traductions récentes (HSAT34, Cent, RSV, J, RL, Koenig, Osty, $\mathrm{NAB}, \mathrm{Eü}, \mathrm{GNB}, \mathrm{DHH}, \mathrm{BFC}$ ). C'est en se rendant compte que le mot suivant s'accorde mal avec ce sens qu'un certain nombre de critiques l'ont corrigé en un dérivé nominal de la racine כל (= enfermer, détenir).

Les traductions bibliques du XVIe siècle s"étaient divisées entre le sens de "fugitifs" et celui de "verrous". Oecolampade en 1525 et Pagnini en 1527 ayant traduit "fugitivos" avaient en effet été suivis par Luther en 1528 ("flüchtigen"). Mais, dans son Thesaurus (275), en 1529, Pagnini avait déclaré que l'on peut aussi comprendre ce mot au sens de "vectes". La même année, Luther, dans son cours sur Isaïe (WA. XXXI/2 336,35 à 337,8) discutait les deuX interprétations "vectes" et "fugitivos" en donnant la priorité à la première. A partir de 1534, il corrigeait d'ailleurs sa traduction en "Rigel" (qui avait d'ailleurs figuré, à titre d'alternative, en marge des éditions précédentes). Il notait en outre qu'il s'agit là d'une métaphore pour désigner les princes. Ensuite, l'exégèse "fugitifs" fut retenue par Brucioli, Münster, Olivetan, Vatable, Estienne, Ge, Pasteurs, alors que "verrous" fut retenu par Zwingli, Prédicants, Pellican, Jud, Châteillon, Musculus, Foreiro, Tremellius et la marge de $\mathrm{KJ}$ (qui, en son texte, $s$ 'inspirant vraisemblablement de Luther, explicite la métaphore par "all their nobles"). Notons que Driver (Studies $\vee 39$ ), n'ayant pas conscience du passé très ancien de l'interprétation "nobles", a essayé d'appuyer sur la langue syriaque l'option de KJ. Il est intéressant de noter qu'Elliger (BK) prétend que la traduction "vectes" de la *V (qu'il adopte) suppose que le "bet' ait été lu avec shewa. Or Hie nous dit explicitement qu'il lisait ici Barihim. 
L'exégèse "fugitifs" (adoptée ici par Vitringa, Gesenius, Rosenmüller, Delitzsch König, Buber, Bonnard, NEB et TOB) est celle qui convient le mieux au contexte. Elle ne requiert pas la correction en בִ בִ que propose Westermann.

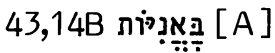

\section{Options de nos traductions :}

Seule TOB traduit ce mot par "navires".

En disant vocaliser תוִּ présupposée par RSV ("to lamentations"), RL ("zur Klage") et NEB ("to groaning").

Origine de la correction :

Cette correction est adoptée aussi par Koenig, Osty, NAB, GNB, DHH et BFC. Elle est requise par les apparats de HSAT34 et de Cent. D'ordinaire, on attribue cette conjecture à Ewald. Mais il faut noter que c'est une exégèse ancienne. Dans la réédition par Servet, en 1542, de la traduction de Pagnini, avec des variantes marginales qu'il dit emprunter aux papiers de ce traducteur, une variante porte ici : "cum luctibus clamoris eorum". Et déjà Yéfet ben Ely cite un exégète qui disait interpréter les deux derniers mots de ce vs : צִ צִגיר בכאהם (= la clameur de leur pleur).

\section{Les témoins anciens :}

Ici, la tradition textuelle unanime interprète "navires", 1Q-a attestant sa vocalisation par une mater lectionis 'waw'.

\section{Interprétation proposée :}

"Les navires de leur acclamation", c'est-à-dire "les navires qui retentissaient de leurs cris de triomphe" sont bien en place dans ce contexte : "A cause de vous (c'est-àdire en votre faveur) j'ai envoyé (quelqu'un) à Babylone. Et je les ferai tous descendre en fuyards, et (je ferai descendre) les Chaldéens dans les navires (qui ont coutume de retentir) de leurs acclamations." Notons que la racine רנן, fréquente dans le Second Isaïe, $y$ a toujours le sens d'acclamation joyeuse.

43,19 נתיבות [C] 1Q-a (Vel assim 16) Options de nos traductions :

Ce mot du *M a été traduit par RSV ("rivers"), RL ("Wasserströme") et J3 ("des fleuves").

J12 et TOB donnent : “des sentiers", NEB "paths". Toutes précisent qu'elles corrigent selon 1Q-a où J2 lit נתיבות, alors que Brockington hésite entre cela et נתיבים.

Origine de la correction :

Avant la découverte de $1 Q$-a, le texte du * $M$ n'a guère préoccupé les critiques. Ensuite, certains ont préféré la variante de 1Q-a (North, Ziegler (EB), Fohrer, Bonnard, 
Schoors 94), alors que d'autres (Muilenburg, James, Westermann, Elliger) en restaient au $*$ M.

Les témoins anciens :

Quoique les premiers éditeurs aient lu en 1Q-a נתיבים, il faut, avec HUB, y lire plutôt נתיבות. En effet, le 'waw' est très distinct et, si l'on tient compte d'une fente du cuir, la lettre finale est très comparable au dernier 'taw' de la même ligne. Inutile de retracer ici le débat animé sur ce déchiffrement qui s'est déroulé en BASOR, du $n^{0} 121$ au $n^{0}$ 126. Le meilleur témoignage demeure la photo infra-rouge publiée en BASOR 121 (1951) 14.

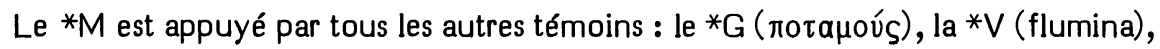
la *S (נהרות) et le *T (נהרוון).

\section{Choix textuel :}

Il est très difficile de choisir entre les deux leçons rivales. Contre "sentiers", on peut dire que ce mot est un parallèle appelé naturellement par "route" qui précède, d'autant plus que ces deux mots ont déjà été parallèles au vs 16 . Contre "fleuves", on peut dire que c'est le fait que ce mot va être lié à ạ au vs 20 qui a entraîné ici une anticipation erronée.

Le don de l'eau dans le désert a déjà été promis en 41,18, comme il a été promis en 40,3 et 42,16 que route et sentiers y seront créés.

En cet oracle (43,16-21), le rappel (exprimé en deux membres parallèles) de la création d'une route dans la Mer Rouge $(43,16)$ inaugure la promesse (exprimée en deux membres parallèles) que des fleuves fertiliseront le désert $(43,20)$. Il est très difficile de dire si $19 \mathrm{~b}$ doit constituer une promesse (route et sentiers) complémentaire de celle (eau et fleuves) de 20, ou si $19 \mathrm{~b}$ doit constituer une transition (route et fleuves) entre 16 (route et sentiers) et 20 (eau et fleuves).

Le comité s'est divisé, attribuant 3 " $C$ " à chacune des deux leçons.

Interprétation proposée :

Il serait bon que figure en note la leçon qui n'aura pas été retenue dans le texte.

\section{3,25 אזכר [B] M 1Q-b G V S T // spont : 1Q-a add עוד}

Options de nos traductions :

Le *M est traduit par RSV, J, RL et TOB; alors que NEB (selon Brockington) y ajoute Tiy avec 1Q-a, pour traduire : “I ... will remember ... (no) more".

Origine de la correction :

Ce 'plus' de 1Q-a a été adopté, metri causa, par North.

Les témoins anciens :

HUB signale ce même 'plus' en un ms de Kennicott. Il s'agit du ms du consistoire de Stuttgart. Schelling précise que ce mot n'y est pas ponctué, ce qui veut dire que le vocalisateur l'a jugé excédentaire. 
En dehors de 1Q-a, tous les autres témoins textuels ( $y$ compris $1 \mathrm{Q}-\mathrm{b}$ ) omettent ce mot.

\section{Choix textuel :}

Il ne peut y avoir aucun lien de dépendance entre le ms de Stuttgart (Haftarot du XIVe siècle) et 1Q-a. Le fait qu'ils se rencontrent dans l'ajoute de cet adverbe indique seulement qu'elle est 'dans l'air'. Kutscher (541) a noté en effet son caractère facilitant : Après "je ne me souviendrai", on attend en effet naturellement "plus" (Jr 31, 34), quoique "pas" soit parfaitement possible.

Estimant ici une omission de cet adverbe moins vraisemblable que son ajoute, le comité a attribué au "moins" du *M la note " $B$ ".

\section{3,28A ואחלל שרי קדש [C] M 1Q-a V T // theol et substit-synt : G S}

\section{Options de nos traductions :}

Le $* M$ présente ici le Seigneur comme profanant les princes du sanctuaire. C'est ce que RSV, RL, TOB et 33 ont traduit.

Mais 312 donnaient "tes princes ont profané mon sanctuaire" et NEB : "and your princes profaned my sanctuary", disant suivre le *G pour lire

Origine de la correction :

C'est Houbigant qui a mis en circulation cette conjecture à partir du ${ }^{*} G$ et de la *S. Il a été suivi en cela par Lowth, Doederlein, Grätz, Oort, Cheyne, Condamin, Volz, HSAT34, Cent et BHS.

\section{Les témoins anciens :}

Dans le *M, 1Q-a, la *V et le *T, le verbe "profaner" a pour sujet le "je" divin et pour complément d'objet les "princes du sanctuaire"; alors que dans le *G et la *S il a pour sujet les "princes" et pour complément d'objet le "sanctuaire".

\section{Choix textuel :}

Notons qu'en 47,6 se rencontre une situation analogue : selon le *M, 1Q-a, 1Q-b, la *V, la *S et le *T, le verbe "profaner" y a pour sujet le "je" divin et pour complément d"objet "mon héritage"; alors que selon le *G ce verbe y a pour sujet une $2 e$ pers. qui, selon le contexte immédiat, désigne la "fille des Chaldéens" (le complément d'objet demeurant le même).

Il semble bien que, dans un cas comme dans l'autre, le traducteur grec (suivi ici par la *S) n’a pu supporter que ce soit le Seigneur lui-même qui profane les princes du sanctuaire ou son propre héritage. Il a donc opéré les retouches syntactiques qui permettent d'éviter cela. L'idée exprimée ici par le ${ }^{*} G$ se retrouve dans le $* M$ en So 3,4. Notons qu'une correction par le $* M$ en sens inverse serait beaucoup plus difficilement explicable.

Pour cette construction syntactique, le comité a attribué au * $\mathrm{M} 5$ "C" et 1 " $\mathrm{B}$ ".

Nous préciserons l'interprétation de la phrase en traitant du cas suivant. 


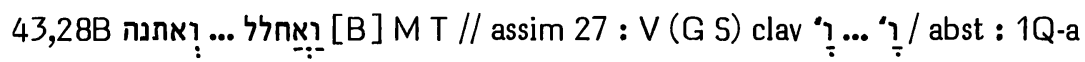

\section{Options de nos traductions :}

Le *M porte en ce verset deux inaccomplis coordonnés. Cependant, toutes nos traductions les traduisent par des passés, ce que Brockington motive par une vocalisation en qameș des deux 'waw' initiaux.

Origine de la correction :

C'est Delitzsch qui a proposé cette vocalisation, suivi en cela par Bredenkamp, Dillmann/Kittel, Marti, Duhm5, Feldmann, König, HSAT2, BH23, Volz, North, Elliger.

\section{Les témoins anciens :}

$\mathrm{La} * \mathrm{~V}$ a assimilé le temps de ces verbes à celui de ceux du vs précédent.

Quant au $* G$ et à la $* S$ leur retouche syntactique (que nous venons d'étudier en $28 \mathrm{~A}$ ) a entraîné une assimilation encore plus marquée.

$1 \mathrm{Q}$-a offre une finale allongée pour le premier verbe et non pour le second. Nous avons déjà noté à propos de 40,6 et de 42,6 le caractère ambigu des formes allongées en ce manuscrit.

\section{Choix textuel :}

Les deux inaccomplis coordonnés du $* M$ ont été traduits en futurs par Pagnini et Pasteurs. Cependant, ils ont été interprétés comme des accomplis invertis, sous l'influence de la ${ }^{*} V$, par Oecolampade, Luther, Zwingli, Olivetan, Estienne, Châteillon, $\mathrm{Ge}, \mathrm{KJ}$.

Jusqu’à Ewald (Lehrbuch §233a), des grammairiens ont prétendu que le patah du premier 'waw' était issu de l'allègement d'un qameṣ. C'est Böttcher - suivi par S.R. Driver (Tenses $70, n .2$ ) - qui a fait remarquer que la traduction par un passé narratif requerrait une vocalisation du 'waw' avec qames; alors que l'intention des ponctuateurs a été d'exprimer un futur, comme l'a fait le *T. Cela a amené Delitzsch - pour sauver l'interprétation traditionnelle en passé narratif - à corriger en qameṣ, ainsi que nous l'avons mentionné.

Notons que Yéfet ben Ely, comme le *T, traduisait ces verbes par des futurs. Le fait que Saadya les ait traduits par des passés a amené Abulwalid (Luma 178,18 et 22) à spécifier que ces deux verbes sont en réalité des futurs, et que leurs 'waw' devraient normalement avoir des qames, puisque ces futurs tiennent ici lieu de passés, particularité assez fréquente sur laquelle il s'est d'ailleurs étendu en ses Opuscules (338341). Radaq, lui, respecte explicitement le sens de futur de ces deux verbes.

Pour la vocalisation de ces deux 'waw', le comité a attribué au *M 5 " $B$ " et 1 " $A$ ".

Interprétation proposée :

Si l'on veut respecter la portée de l'aspect du verbe hébreu, il ne faut pas essayer d'opter ici entre un sens passé et un sens futur. L'inaccompli simplement coordonné veut souligner que l'événement ainsi exprimé est la conséquence de ceux qui ont été mentionnés auparavant. Il s'agit donc d'une postériorité relative et d'une consécution logique. Cela ne précise pas si l'interprétation globale doit situer l'ensemble de cette séquence dans le passé, le présent ou le futur. 
Ici, où nous avons une conséquence des événements relatés par le vs 27 , on pourra traduire : "aussi ai-je dû profaner (ou : dégrader) les chefs du sanctuaire, livrer Jacob à l'anathème et Israël aux outrages".

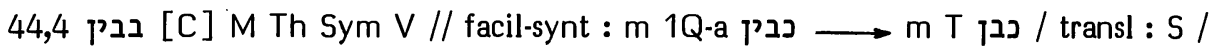
constr : $G$

Options de nos traductions :

Aucune de nos traductions ne traduit directement le *M.

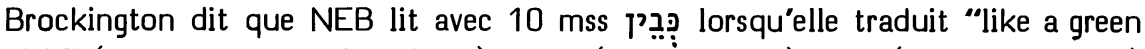
tamarisk" (pour ce mot et le suivant). TOB ("comme en") et J3 ("comme parmi") semblent lire la même leçon, quoiqu'elles n'aient pas de note textuelle.

Pour ce mot et le suivant, RSV donne : "like grass amid waters", J12 : "comme l'herbe entourée d'eau", RL : "wie Gras zwischen Wassern", J2 précisant qu'elle lit :

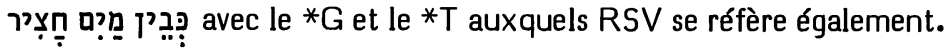

\section{Origines des corrections :}

La leçon adoptée par NEB, TOB et J3 a été proposée par Vogel, Grätz et Bredenkamp. L'exégèse que NEB en donne a été proposée par Allegro (Meaning) בין serait un arbre dont le nom apparaît en akkadien, araméen et arabe. Cette interprétation a été adoptée par North, BHS et Schoors $(79$, n.1).

La leçon adoptée par RSV, J12 et RL a été proposée par Houbigant à partir du *G et choisie par Lowth, Ewald, Duhm, Dillmann/Kittel, Cheyne, Condamin, Haller, Elliger (Verhältnis), Ziegler (EB), Fohrer, Westermann, HSAT2, BH23 et Cent.

\section{Les témoins anciens :}

Sur la leçon בבין les mss d'Alep, du Caire et de Leningrad s'accordent avec l'édition Minḥat Shay du *M. Cependant cette leçon a causé de sérieuses difficultés à ses lecteurs, ce que montrent ses nombreuses déformations dans les mss.

La plus fréquente de ces déformations est une simple omission du 'yod', variante attestée par 24 mss Kennicott, 21 mss de Rossi, la première main de 10 autres et la seconde de 2.

Ensuite vient une transformation du premier 'bet' en 'kaf', variante attestée par 2 mss Kennicott et la première main de 4 autres, 3 mss de Rossi, la première main d'un autre et la seconde d'un autre.

Ces deux variantes s'ajoutent l'une à l'autre en 3 mss Kennicott, la première main d'un autre, 3 mss de Rossi et la seconde main d'un autre. Parmi les mss attestant cette dernière forme de la variante, le 2e ms de Königsberg (selon Lilienthal 339s) vocalise le 'bet' avec segol. En effet, le *T a interprété ici : "comme une pousse d"herbe" et Eliézer de Beaugency explique : "comme un petit rejeton, comme celui d'une herbe". Ils semblent donc avoir lu cette variante et compris : "comme un fils d'herbe".

Contre l'édition Baer du *M (77) qui considère בִבְּ comme le *M authentique, il faut souligner que la leçon בבין des témoins du texte tibérien classique a été lue ici 
par Yéfet ben Ely (qui traduit פימא בין), ainsi que par Rashi et Radaq (qui y voient une expression analogue à בתוך).

1Q-a lit ici la 2e variante (כבין) en laquelle il faut voir une facilitation syntactique.

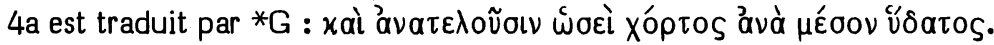

Selon Eusèbe qui les cite séparément, Th et Sym donnent $x \lambda$ óns à la place du dernier mot du ${ }^{*} G$. Sym (et, semble-t-il, Th) omet le $3 e$ et le $4 \mathrm{e}$ mot du ${ }^{*} G$ en retenant les $1 \mathrm{er}, 2 \mathrm{e}, 5 \mathrm{e}$ et $6 \mathrm{e}$ mots. Tous deux appuient donc le *M de $4 \mathrm{a}$. Il en va de même de la $* V$, quoiqu'elle explicite par un pluriel la valeur collective du dernier mot de $4 a$ : "et germinabunt inter herbas". Il est naturel qu'aucune de ces trois versions n'explicite formellement la préposition 'bet' du mot que nous étudions.

La leçon de la *S (מן בינת) semble n'être qu'une liberté translationnelle identique à celle que prendra Saadya en traduisant : מן בין

Choix textuel et interprétation proposée :

Nous avons noté que la correction du 'bet' prépositionnel en 'kaf' est presque sûrement facilitante. Quant à l'exégèse proposée par Allegro, elle suppose que soit mentionné ici, comme un objet de comparaison bien connu, un arbre dont le nom n'apparaîtrait probablement qu'ici dans la Bible. Elle suppose aussi que חציר (dont Allegro corrige le 'yod" en 'waw') joue ici le rôle d'un adjectif au sens de "vert".

Contre l'emprunt fait par Houbigant au ${ }^{*} G$, Ehrlich objecte d'abord que la préposition devrait être liée à "herbe" et non à "entre", et ensuite que, "eaux" étant un simple pluriel d'immensité, l'expression "entre les eaux" est sujette à caution. De fait, il est peu vraisemblable que le ${ }^{*} G$ traduise une Vorlage différente du $* M$. Il paraît avoir construit un membre parallèle à $4 \mathrm{~b}$ en s'inspirant des "eaux" de 3 et de 4b.

Les grammairiens anciens ont essayé de faire face à la difficulté du *M. Abulwalid (Luma 69,14-16) dit que le 'bet' est superflu. Radaq aussi estime que le 'bet' initial est une simple ajoute explicative et non nécessaire au sens. Aussi Pagnini (reprenant cette précision en ses Institutiones 389b et en son Thesaurus 218) n'en a-t-il pas tenu compte dans sa traduction (éditée en 1527) où il a suivi la *V: "inter", ce que Brucioli a adopté ("fra").

Cependant Luther (s'inspirant peut-être d'Ibn Ezra) traduisit "wie", ce qui fut adopté par Olivetan, Estienne et Châteillon. La plupart des autres traducteurs ont lu dans l'édition de Félix de Prato la leçon a d'ailleurs été reprise dans l'édition in-quarto publiée par Bomberg la même année (1517) et dans l'édition in-quarto parue chez le même éditeur en 1521. En effet, Zwingli déclare : "Hebraea sic habent ad verbum : "Et germinabunt sic inter herbam'." Quant à lui, il dédouble cette préposition complexe en "mixtim ... sicut", ce que la traduction des Prédicants de Zurich rend par "wie ... undereinander". La plupart des autres traducteurs (Oecolampade, Münster, Jud, Ge, Tremellius, Pasteurs, KJ) traduisirent cela littéralement par "comme entre". La traduction de Pagnini fut corrigée en ce sens par Servet (en 1542) et par Estienne (en 1557). Ensuite, Arias Montano réagit dans le sens d'un littéralisme inintelligible: "in inter". On comprend que Simon (317a) ait dit de sa version: "elle rend l'Hébreu mot pour mot \& selon le sens Grammatical : mais je ne croi pas qu'on doive donner pour cela a Arias Montanus la qualité de Fidissimus Interpres : au-contraire, on lui fera beaucoup plus de justice 
en le nommant Ineptissimus Interpres." Son confrère Houbigant (I prolegomena 178) partageait ce jugement, considérant la traduction d"Arias Montano "horridam, inficetam, obscuram, talem denique, qualem composuisset, si quis homines deterrere ab Sacris Codicibus legendis voluisset". Aussi n'est-il pas surprenant qu'Houbigant à qui Walton imposait ici l'interlinéaire d'Arias Montano ait été chercher refuge auprès de la Septante.

Il est cependant possible de donner du *M une interprétation acceptable. En effet, $P$ a des usages nominaux au sens de "intervalle". La leçon du *M peut donc - ainsi que Rashi et Radaq le pensaient - être une expression analogue à Đing̣, expression où le 'bet' prépositionnel n'aurait pas de portée bien spéciale. On connaît en effet un bon nombre de cas où 'bet' est employé de façon redondante (cf. Noldius 157-161). Cette opinion est celle de König (Lehrgebäude II 315) qui traduit : "ils pousseront au milieu de l'herbe, comme des saules au bord des cours d'eau". L'absence de "kaf" comparatif en 4a s'explique parce que, dès le verbe initial, on est déjà en pleine métaphore, celle-ci se développant de façon progressive au long du verset.

Le comité a attribué au *M la note "C $C$ ".

44,5A ?ִקְר?ִ [C] M G V S T // harm-ctext : Sym clav / abst : 1Q-a

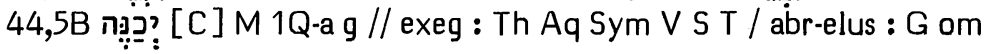

Options de nos traductions :

RSV, J, RL, NEB et TOB s'accordent pour traduire ces deux verbes par des réfléchis ou des passifs. Pour 5A, J12 et NEB disent suivre Sym, Brockington disant que cela implique une vocalisation Brockington postulant une vocalisation יִ: avec la *S.

Origines des corrections :

L'initiative de traduire ces deux verbes par des passifs remonte à Luther qui traduit chacun d"eux par "wird genennet werden". De même Calvin : "vocabitur... cognominabitur". Deux réfléchis apparaissent en Estienne ("s'appellera ... se renommera") et $\mathrm{KJ}$ ("shall call himselfe ... surname himselfe"). Ces traductions traditionnelles se sont prolongées jusqu'aux modernes, le passif de Luther survivant en RL et les réfléchis d'Estienne et de $\mathrm{KJ}$ survivant en RSV, NEB, J et TOB.

Pour justifier cela, une vocalisation du premier verbe en nifal et du second en pual est postulée par HSAT234, BH23S et Cent. La première remonte à Lowth qui la fonde sur Sym et la seconde à Oort, Grätz l'ayant ensuite fondée sur la *S et Duhm ayant diffusé ces deux corrections parmi les exégètes.

\section{Les témoins anciens :}

1Q-a a des graphies identiques au *M. Il est impossible de savoir s'il lisait en 5A un qal ou un nifal. Mais en 5B, les données fournies par Kutscher (139s) montrent qu'il ne lisait probablement pas un pual.

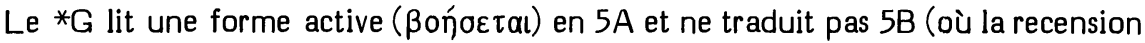
origénienne et l'antiochienne répètent le verbe de $5 A$ ). 
Th, Aq et Sym sont cités séparément par le commentaire arménien de Chrysos-

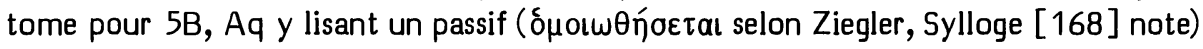
et les deux autres une forme réfléchie.

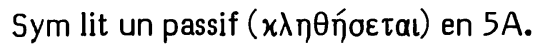

$L a * V$ traduit $5 A$ en actif (vocabit) et $5 B$ en passif (adsimilabitur).

$\mathrm{La} * \mathrm{~S}$, selon toute sa tradition directe, lit un actif en $5 \mathrm{~A}$ (Ephrem étant seul à lire נתקרא). En 5B elle lit un réfléchi (נתכנא).

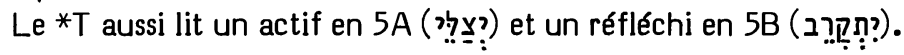

Choix textuel :

Sym a interprété le premier verbe comme une attestation d'appartenance personnelle, en assimilant à 48,1. Quant à l'interprétation réfléchie ou passive du second par presque toutes les versions, elle dépend elle aussi de leur exégèse d'ensemble du texte.

Notons à ce propos que la Bible ne connaît le verbe כנה qu'au piél.

Nous verrons d'ailleurs que les vocalisations actives du *M se justifient aisément. Le comité a estimé devoir les respecter par 4 " $\mathrm{C}$ " et 2 " $\mathrm{B}$ ", en considérant les cas de ces deux verbes comme solidaires.

Interprétations proposées :

Pour sauver l'interprétation en passifs, devenue traditionnelle dans les traductions occidentales, Vitringa avait proposé de considérer nos deux verbes comme des impersonnels à valeur passive. A cela on peut objecter que le fait que le même démonstratif I̦ précède chacun des trois premiers verbes du vs et que ce pronom est de façon évidente le sujet du premier et du troisième impose de le considérer aussi comme sujet du deuxième.

"Appeler du nom de Jacob" signifie "faire usage du nom de Jacob pour appeler", c'est-à-dire - comme Ehrlich le suggère - donner à ses enfants des noms qui trahissent leur descendance de Jacob, ou bien : faire ressortir cette filiation comme honorable dans la manière dont on interpelle les gens.

Quant au verbe employé en 5B, il semble signifier en 45,4: “donner un surnom qui caractérise une mission", alors qu'en Jb 32,21s il signifie seulement "flatter" (vraisemblablement en attribuant des titres d'honneur à celui à qui on s'adresse). On peut donc, avec Hitzig, y voir le sens de "faire usage de "israélite 'comme d'un titre flatteur".

L'interprétation d'ensemble la plus vraisemblable est qu'il s'agit là d'Israélites tièdes qui, dans l'exil, essayaient de dissimuler leur appartenance et qui, maintenant, ne craignent pas de l'afficher.

\section{4,7A ויגידה [B] M 1Q-a g V S T // substit-lexic : G}

Options de nos traductions :

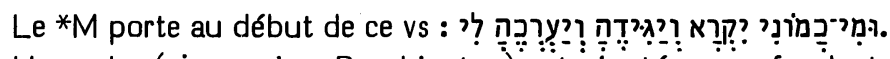

Un verbe (inys, selon Brockington) est ajouté, en se fondant sur le *G, entre le 2e et le 3e mots, par J2 ("qu"il se lève") et NEB ("let him stand up"). 
Origine de la correction :

C'est Oort (Jez) qui a proposé d'insérer ce verbe, suivi d'un 'waw' conjonctif, selon le ${ }^{*} \mathrm{G}$. Cette insertion a été requise par les apparats de HSAT2, BH23S et Cent.

\section{Les témoins anciens :}

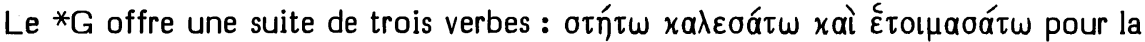
suite de trois verbes du *M. On comprend qu'il ait voulu remplacer par un autre verbe la première occurrence du verbe "annoncer" qui réapparaît en une position plus natu-

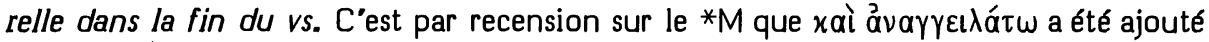
ensuite dans presque toute la tradition textuelle $d u{ }^{*} G$.

Pour la suite de trois verbes qu'il offre, le $* M$ a l'appui de $1 Q-a$, de la $* V$, de la *S (celle-ci invertissant seulement les deux derniers) et du *T.

\section{Choix textuel :}

De la substitution effectuée par le ${ }^{*} G$ ancien, on ne saurait donc tirer ici l'ajoute d'un verbe.

Sur ce point, le comité a attribué au *M la note "B".

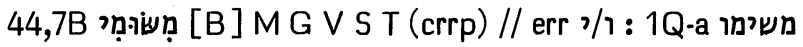

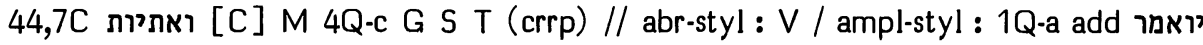
44,7D יגידו [A] [A]

44,7E למו [B] M 1Q-a V // assim 8 : G / usu : T / abr-elus : S om

\section{Options de nos traductions :}

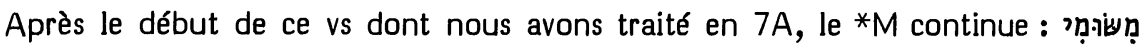

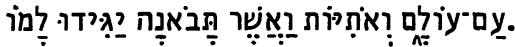

Aux quatre premiers mots correspond en RSV : "Who has announced from of old the things to come ?", en 312 : "Qui a fait entendre dès l'éternité ce qui devait arriver", en RL : "Wer hat vorzeiten kundgetan das Künftige ?", en NEB : "let him announce beforehand things to come", en TOB : “depuis que j"ai établi la multitude qui remonte à la nuit des temps; qu'il dise les choses qui arriveront." et en $\mathrm{J3}$ : "depuis que j'ai constitué un peuple éternel, ce qui se passe, qu'il le dise."

Pour les trois premiers mots, TOB et $\mathrm{J3}$ ont traduit le $* \mathrm{M}$. A la place du premier mot et de la première lettre du deuxième, $\mathrm{J} 2$ a conjecturé yِ nִụn (ce qui vaut aussi

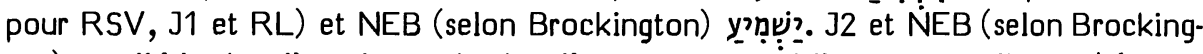
ton) ont lié la deuxième lettre du deuxième mot au troisième en vocalisant מִ̣̣̂, ce qui vaut aussi pour RSV, J1 et RL. Avant le quatrième mot, J2 et NEB ont omis le 'waw' (ce qui vaut aussi pour RSV, J1 et RL). Quant à J3 et TOB, c'est sur 1Q-a qu'elles s'appuient pour ajouter après ce mot : "qu'il dise".

Aux quatre derniers mots correspondent en RSV : "Let them tell us what is yet to be", en 312 : "et les choses à venir qu'on nous les révèle", en RL : "Sie sollen uns verkündigen, was kommen wird", en NEB : "let him declare what is yet to happen", en TOB : "et celles qui viendront, qu'on nous les annonce" et en $\mathrm{J3}$ : "et ce qui doit arriver, qu'il le leur annonce". 
Pour l'avant-dernier mot, seule NEB (selon Brockington) dit corriger en T:??, bien que 33 semble faire de même. Quant au dernier mot, RSV et 32 disent y lire avec le *T un suffixe 1e pers. pl. (ce qui vaut aussi pour J1, TOB et RL), NEB omettant ce mot sans le dire.

\section{Origines des corrections :}

C'est Oort (Jez) qui a conjecturé, pour les 4 premiers mots, les corrections adoptées par RSV, J12 et RL. NEB offre une variante de cette conjecture. Bonnard est à l'origine de l'option de TOB et de 33 qui refuse cette conjecture mais ajoute : "qu'il dise".

La mise au singulier du dernier verbe remonte à Oort (Jez). Quant à la correction du suffixe final en 1e pers. pl., elle a été suggérée par Duhm et Grätz.

\section{Les témoins anciens :}

Pour les trois premiers mots, 1Q-a ne se distingue du * $M$ qu'en ce qu'il inverse la place du 'yod' et celle du 'waw' dans le premier.

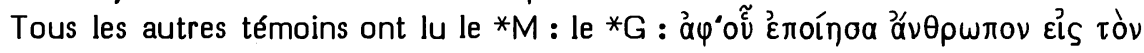
aîuva; la *V : ex quo constitui populum antiquum; la *S : מן דסמת עמא לעלם (le *T : משויתי עמא דמן עלמא.

Pour le quatrième mot, seule la $* V$ n'a pas traduit la copule (pour alléger son style); alors que celle-ci est attestée dans tout le reste de la tradition textuelle. Notons ici que, dans les trois emplois en ce livre du participe אתוּ (= les la ${ }^{*} \mathrm{~S}$ traduit signes). Ici, elle offre une leçon gonflée : "les signes à venir".

1Q-a est seul à ajouter יואמר après ce mot, tous les autres témoins (y compris 4Q-c) s'accordant avec le * $M$ sur son absence.

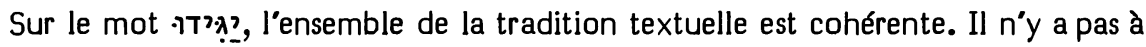
tenir compte de la mp non attestée que Weil a extrapolée ici en BHS à partir de la mm inexacte que le ms de Leningrad offre sur $1 \mathrm{~S} 27,11$.

Sur le dernier mot, les options des témoins divergent, la 3e pers. pl. du *M ayant

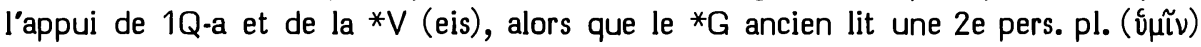
et le *T une 1e pers. pl. (לנא); la ${ }^{*} S$ omettant ce mot, comme elle a déjà omis en ce même verset.

\section{Choix textuel :}

La conjecture de Oort a suscité un grand intérêt et a été adoptée par de nombreux exégètes. Au cas où elle représenterait un état originel du texte, elle échappe aux prises de la critique textuelle, car cet état a disparu de tous les témoins qui nous ont été conservés. On ne saurait, en effet, considérer comme une survivance du מי מי מי initial la graphie מי שומי qui se trouve dans le ms Kennicott 96, daté de la fin du XIVe siècle.

A propos de 7B, il faut noter que l'infinitif construit de ce verbe présente des formes où le radical porte un 'yod'. C'est le cas de Jb 20,4, du qeré de $2 \mathrm{~S} 14,7$ et du ketib de Is 10,6 (où d'ailleurs 1Q-a lit le qeré). Quant au suffixe de la 3e pers., 1Q-a en a déjà lu un dans le mot qui précède. Ces changements de personne conviennent mal au contexte. Nous avons noté que 1Q-a émane d'un archétype où la graphie du "yod" et du 'waw' prêtait à confusions. Pour ce mot, le comité a attribué " $B$ " au *M. 
A propos de 7C, nous avons dit que l'omission du 'waw' était faiblement attestée. Quant à l'ajoute de יואמר par 1Q-a (à la place de la conjonction qui suit ce mot), il est vraisemblable que l'on a là une ajoute symétrisante. En effet, ce verbe équilibre le יגידו du dernier membre de phrase. Le déséquilibre actuel du texte dans les autres témoins peut avoir été causé par la perte d'un état textuel originel que la conjecture de Oort permet peut-être de restaurer. Au niveau de l'histoire textuelle, l'absence de יואמר serait en ce cas plus primitive que sa présence. Pour ce mot, le comité a attribué "C" au *M.

$L$ 'absence de variante en 7D impose la note " $A$ ".

Quant à $7 \mathrm{E}$, le ${ }^{*} \mathrm{G}$ a assimilé aux deux verbes qui suivent, alors que le ${ }^{* T}$ a utilisé la 1e pers. pl. qui est naturelle en ce type de défis. La dispersion des options montre ici que la lectio difficilior du $* M$, de $1 Q$-a et de la $* V$ a des chances d'être la plus primitive. C'est pourquoi le comité lui a attribué 4 " $B$ " et 2 " $C$ ".

Interprétation proposée :

La conjecture de Oort nous fait peut-être accéder à l'original de ce texte. Mais le ${ }^{*} M$ en représente la forme attestée la plus ancienne. C'est à titre d'état canonique le plus primitif qu'il intéresse le traducteur de la Bible et que nous devons en expliciter le sens.

L'expression ậiy ay se retrouve en Ez 26,20, comme la massore le relève. Elle signifie l'humanité d'autrefois qui est morte aujourd'hui. Le même mot ay désigne la population terrestre (à laquelle le Seigneur a donné la respiration) en Is 42,5 . Ici (pour ce verbe, cf. Pr 8,29) est une référence chronologique : “depuis que j'ai établi l'humanité des premiers temps". teamim à cette référence chronologique) est à comprendre à la lumière de 41,4:

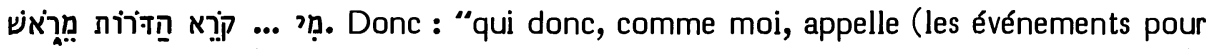
qu'ils surviennent) ?" Dans les deux verbes suivants, les suffixes de 3e pers. f. sg. (à valeur neutre) désignent ce qui a été ainsi "appelé" : "qu'il me raconte cela et me mette en ordre cela à partir du moment où j'ai établi l'humanité des premiers temps." Donc 7a parle des événements passés alors que $7 \mathrm{~b}$ parlera des événements futurs : "et les choses à venir, et celles qui arriveront, qu'ils les leur annoncent !"

Delitzsch a proposé de comprendre le למו qui achève ce vs comme un datif éthique désignant la personne dans l'intérêt de qui l'action a lieu : "qu'ils l'annoncent dans leur propre intérêt." Mais cela constituerait un vrai piège stylistique après le verbe "annoncer" qui requiert le datif pour son complément. Mieux vaut donc admettre avec Ehrlich que cette 3e pers. pl. désigne les peuples qui doivent faire valoir les prétentions de leurs idoles à la divinité : "et les choses qui arriveront, qu'ils (= ces faux dieux) les leur (= à leurs peuples) annoncent". Du fait que ces peuples sont la descendance du "peuple des premiers temps", ils sont suffisamment évoqués par le contexte.

On voit que c'est calomnier le *M que de dire, avec de nombreux exégètes récents, que, dans ce vs, il n'offre aucun sens. L'interprétation que nous venons de présenter est, pour l'essentiel, tirée de Radaq. 


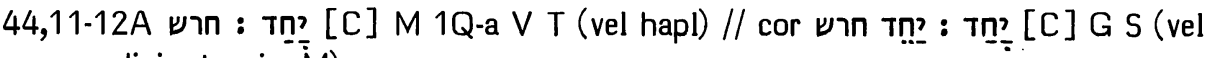 err-divis et assim $\dot{\mathrm{M}}$ ).}

\section{Options de nos traductions :}

Au début du vs 12, le *M porte comme "le forgeron". Ces deux mots sont directement suivis du substantif et le verbe qui suit est précédé d'un 'waw'. Un verbe semble donc manquer pour articuler entre eux les trois premiers mots.

NEB fait de ces mots le sujet du verbe "sharpens" et TOB du verbe "apointe", verbe qu'elles disent emprunter au ${ }^{*} G$ (auquel TOB ajoute la ${ }^{*}$ S), Brockington précisant qu'il s'agit de Tחי?

RSV conjecture une forme verbale ("fashions it") à la place du 3e mot.

\section{Origine de la correction :}

C'est Gesenius qui a suggéré que le ${ }^{*} \mathrm{G}$ a reporté le mot $T$ י (qui, dans le $* M$, clot

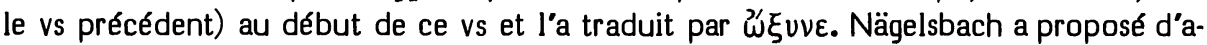
dopter cette leçon, ce que demandent aussi les apparats de HSAT2, BH2.

Quant à la conjecture de RSV, elle remonte à Lowth vocalisant מ̣: Notons qu'aucun verbe de cette racine n'est attesté dans la Bible.

\section{Les témoins anciens :}

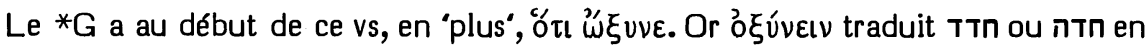
$\operatorname{Pr} 27,17$; Ez 21,14.15. Le fait que, selon l'éd. Göttingen, le ms 544 omet å $\mu \alpha$ à la fin du vs 11 peut sembler confirmer l'hypothèse de Gesenius selon qui ce 'plus' est issu du transfert au début du vs 12 du mot $T^{2}$ 'que le $* M$ offre à la fin du vs précédent. Il est cependant peu probable que ce $\mathrm{ms}$ du XIe siècle témoigne de l'état primitif du ${ }^{*} G$, alors que tous les autres témoins, y compris le papyrus 965 (début du IIle siècle) attestent la présence de á $\mu \alpha$ à la fin du vs 11 . Si l'on considère la Vorlage du ${ }^{*} G$ comme représentant le texte originel, il faudrait donc admettre que le *M a été privé d'un T!̣?, au début du vs 12, par haplographie.

1Q-a appuie très formellement le ${ }^{*} M$. Il use en effet de la graphie יחדיו qui lève toute ambiguité sur le sens de cette forme. Puis un vide sépare nettement ce mot du début du vs 12; un vide de même importance séparant ensuite le vs 12 du vs 13 .

$L$ 'articulation entre les vss 11 et 12 s'effectue dans la *V (... confundentur simul. Faber ferrarius...) et dans le *T (........ comme dans le *M. En effet, l'insertion de ויע par les mss Reuchlin et Urbinates 1 au début du vs 12 est une dittographie de ce même verbe figurant juste avant, en ces deux mss, comme conclusion du $* M$ du vs 12 .

La *S, en insérant דלטש au début du vs 12 , suit le *G.

\section{Choix textuel :}

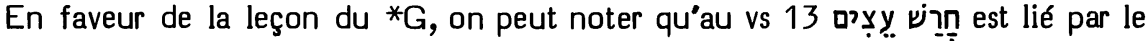
verbe נִטר au substantif qui le suit. On attend un lien semblable entre substantif qui le suit. Or le hifil de חד (חדה (ח), au sens de "rendre tranchant", désigne bien ce que fait le forgeron pour former la lame du 
ham II 422,41s définit comme un instrument avec lequel on rectifie les arêtes et les angles du bois) que les glossaires BCDE et la 2e exégèse de F traduisent par "doloire".

Contre cette leçon, on peut envisager qu'un transfert de de la fin du vs 11 au début du vs 12 a eu lieu dans la Vorlage $d u{ }^{*} G$, puis que la fin du vs 11 y a été complétée par recension sur un texte de tradition prémassorétique, aboutissant à y réinsérer le mot perdu par ce transfert. Ajoutons à cela que la leçon de la Vorlage du *G présenterait, entre le début du vs 12 et le début du vs 13 , une dissymétrie dans l'ordre sujet/verbe (dissymétrie qu'elle a d'ailleurs essayé de corriger en faisant passer le verbe final du vs 12 au début du vs 13).

En faveur de la leçon du ${ }^{*} M$, on peut d'abord noter l'appui caractéristique que

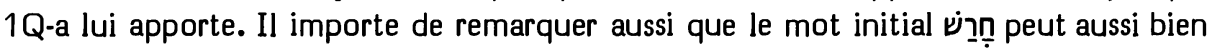
être un accompli à la 3e pers. m. sg. que l'état construit du substantif ש̉ำ possible que l'intention de l'auteur soit de lui faire jouer tour à tour ces deux rôles mais que, voulant éviter de le répéter, il l'ait sous-entendu deux mots plus loin. Il est également possible que les trois premiers mots du vs 12 soient à considérer comme un casus pendens incluant un participe "fabriquant" sous-entendu : "un fabricant en fer (fabriquant) une doloire". Après ce casus pendens, l'accompli précédé de 'waw' est en situation tout à fait normale, comme on le voit en $\mathrm{Nb}$ 19,11; $1 \mathrm{~S}$ 17,20; 25,27; 2 R 11,7; Is 9,4.

Contre la leçon du ${ }^{*} \mathrm{M}$, on peut envisager que le ${ }^{*} M$ et $1 Q$-a soient tous deux issus d'un archétype qui, au début du vs 12, aurait perdu un mot par haplographie, alors que la Vorlage du *G aurait échappé à cet accident.

Le comité s'est divisé entre ces deux leçons, attribuant 3 "C" à chacune.

Interprétations proposées :

Si on opte pour la leçon du *G: "Un artisan sur fer effile une doloire".

Si on opte pour la leçon du *M: "Un artisan sur fer (a fabriqué) une doloire" ou : "Un artisan sur fer (qui fabrique) une doloire..."

44,12B יפעל / [C] M 1Q-a(corr) // facil-synt : V T clav 12b : G $\rightarrow$ יS / incert : $1 \mathrm{Q}-\mathrm{a}^{*}$

Options de nos traductions :

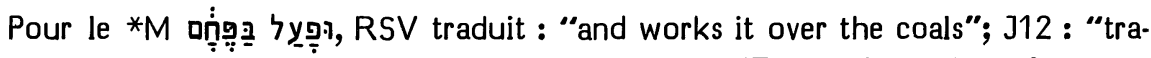
vaille sur des braises"; RL : "macht ... in der Glut"; NEB : "his work ... from the coals"; TOB : "le passe dans les braises"; 33 : "fabrique ... sur des braises".

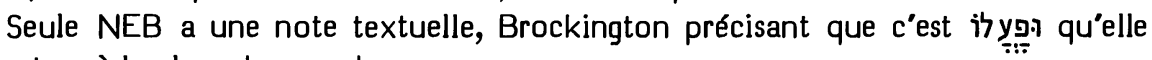
conjecture à la place de ce verbe.

Il est cependant probable que RL et 33 ont lu ici

Origines des corrections :

Cette dernière correction a été proposée par Duhm, Cheyne et North. Quant à la conjecture de NEB, elle est consonnantiquement identique à celle que Cent proposait ici. 
Les témoins anciens :

1Q-a semble avoir obtenu la même leçon que celle du *M par correction, à partir

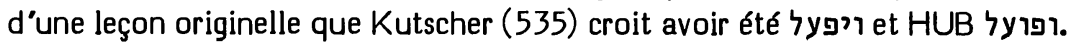

La *V (operatus est) et le *T (עביד) traduisent comme s'ils avaient lu une leçon semblable à celle que Duhm a proposée.

Le ${ }^{*} G$ a anticipé ici la traduction qu'il donnera en $12 b$ pour ce verbe suivi d'un suffixe 3 e pers. m. sg. et la ${ }^{*} S l^{\prime}$ a suivi.

Choix textuel :

Estimant la leçon du ${ }^{*} M$ plus difficile que ses concurrentes, quoique syntactiquement justifiable, le comité lui a donné la note "C".

Interprétation proposée :

La syntaxe a été expliquée à propos du cas précédent. On pourra traduire : "Il a travaillé sur des braises...", car il n’est pas nécessaire d'expliciter la conjonction.

\section{תשאני 4 ת [C] M 4Q-b G V S T // usu : 1Q תנשי}

Options de nos traductions :

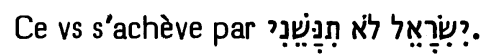

Les deux derniers mots sont traduits par RSV : "you will not be forgotten by me", par J : "je ne t'oublierai pas", par RL : "ich vergesse dich nicht", par NEB : 'you shall not forget me" (sans note textuelle). Brockington précise qu'elle vocalise

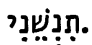

TOB traduit : "tu ne me décevras pas" en disant corriger avec 1Q-a.

Origines des corrections :

La vocalisation signalée par Brockington est celle que BHS a proposée à la suite de Oort (Jez) et de HSAT2.

TOB suit une option de Bonnard.

Les témoins anciens :

1Q-a écrit תשאני. En appuyant sur cette leçon la traduction que TOB retiendra, Bonnard dit qu'il s'agit de la racine נשא 'Plus précisément, pour obtenir ce sens, il

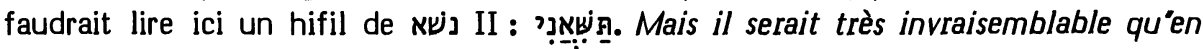
cette seconde partie de 1Q-a on écrive ainsi cette forme. On rencontre en effet dans le

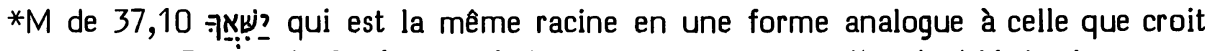
reconnaître Bonnard. Or 1Q-a y écrit ישייכה avec un 'yod' redoublé. La leçon que 1Q-a offre ici a plus de chances de se rattacher à la racine très usitée נש et de devoir

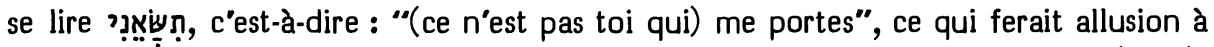
"je vous ai portés" (cf. 46,4) et au fait que les fidèles des idoles les portent $(46,7)$.

Le *M est appuyé ici par 4Q-b et il a été compris au sens de "ne m'oublie pas" par le ${ }^{*} \mathrm{G}$, la $* V$, la ${ }^{*} \mathrm{~S}$ et le ${ }^{*}$. 


\section{Choix textuel :}

Ce sens a été reconnu ici par Saadya, les glossaires $A$ et $C$, Eliézer de Beaugency, Luther, Rosenmüller et Luzzatto.

Ont compris : "Tu ne seras pas oublié de moi" : Yéfet ben Ely, Abulwalid (Ușul 462,24), Ibn Ezra, Radaq, KJ, Gesenius, Ewald, Knobel, Delitzsch, Dillmann/Kittel, König.

En faveur de la première interprétation on a fait valoir que l'etpeel (qui correspond en araméen au nifal hébreu) de נשי a en araméen palestinien le sens actif de "oublier" et se construit avec un accusatif. Mais on s'attendrait dans ce cas à avoir la négation prohibitive אֵ et non la négation énonciative לא.

En faveur de la seconde interprétation on a fait valoir que le pronom suffixe du verbe peut avoir ici, comme dans la langue tardive, valeur de datif (Ewald, Lehrbuch $\S 315$ b; Böttcher, Lehrbuch §875b; König, Syntax §21). D'autre part, cela correspond mieux au sens du nifal hébreu, ainsi qu'au type de négation employé ici. Nous retrouverons d'ailleurs en 65,5 un suffixe verbal à valeur de datif.

Le comité a attribué 5 " $C$ " au * $M$ et 1 "C" à $1 Q$-a (lu comme Bonnard le propose).

\section{Interprétation proposée :}

Ici le contexte appelle une assurance donnée par Dieu à Israël. Ce sera seulement

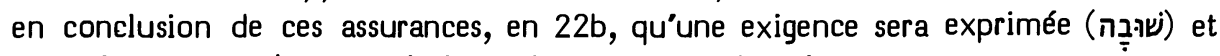
motivée par un

On pourra donc traduire littéralement : "Tu ne seras pas oublié de moi" ou, plus largement : “je ne t’oublierai pas”.

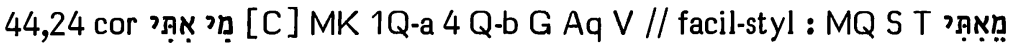

\section{Options de nos traductions :}

Le *M a ici un ketib en deux mots : מי אתי (= qui (était) avec moi ?) et un qeré en un mot ( $=$ de moi-même).

Le qeré a été traduit par NEB ("alone").

Le ketib a été traduit par RSV ("who was with me ?"), par J12 ("qui m'y aidait ?"), par TOB ("qui m"assistait ?") et, semble-t-il, par RL ("ohne Gehilfen"), ainsi que par $\mathrm{J3}$ ("sans personne avec moi").

Seule RSV présente comme une "autre leçon" le contenu du qeré.

Les témoins anciens :

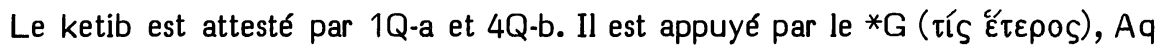
("qui avec moi ?") et la *V ("et nullus mecum").

Le qeré a l'appui de la*S (מני ולי) et du*T (בגבורתי).

Histoire de l'exégèse :

Les exégètes juifs médiévaux expliquent, comme d'habitude, le qeré; Ibn Ezra et Radaq ajoutant à cela l'exégèse du ketib. Rosenmüller fait de même. Delitzsch, Ehrlich, Volz, Rignell préfèrent le qeré. 
Le ketib est préféré par Gesenius, Knobel, Ewald, Luzzatto, Dillmann/Kittel, Duhm, König, North, HSAT234, BH23, Cent, Elliger (Verhältnis et BK), Bonnard.

Choix textuel :

Ces deux états textuels ont des sens très proches l'un de l'autre.

On a fait valoir en faveur du qeré qu'il s'insère de façon plus souple dans le développement. De plus, Jos 11,20 montre que cette expression serait aussi bien adaptée ici que le serait מִִ̣ usité en Os 8,4.

Cependant, en faveur du ketib, il faut noter que le Second Isaïe aime beaucoup les questions rhétoriques commençant par pạ.

Le comité a donc attribué au ketib 3 " $\mathrm{B}$ " et 3 " $\mathrm{C}$ " en considérant que le qeré était une facilitation stylistique.

Interprétation proposée :

On pourra traduire littéralement avec Koenig: "qui avec moi ?" ou, plus librement, avec TOB : “qui m’assistait ?"

\section{4,25}

Options de nos.traductions :

Sans note textuelle, ce mot est traduit par RSV : "of liars", RL : "der Wahrsager", NEB : "false prophets" et J3 : “des augures".

TOB s'accordait avec J2 pour dire que le *M signifie ici "bavardages". Cependant, J12 donnaient ici "magiciens" selon une conjecture םִִ̣? alors que TOB donne "augures", estimant que l'on "peut supposer la présence d'un mot emprunté à l'akkadien et signifiant 'augure'."

Origine de la correction :

J12 et TOB dépendent ici de Cent où Humbert traduit "augures" en lisant "bârîm" (de l'akkadien "bârû"). Déjà Budde (HSAT4), tout en traduisant "Schwätzer" (= bavards), notait que la traduction est peu sûre, car l'on souhaiterait, à côté des de-

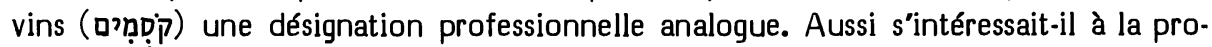
position, faite par Haupt, de corriger à partir de l'assyrien. Celui-ci (SBOT sur $\operatorname{Pr} 1,8$ ), partant d'une suggestion de Zimmern, a en effet eu l'idée de retrouver dans l'hébreu biblique (en corrigeant en en Is 44,25 et Jr 50,36) la désignation (barû) des devins babyloniens.

Les témoins anciens :

1Q-a a omis ce mot qui a été ajouté ensuite. 1Q-b est identique au *M.

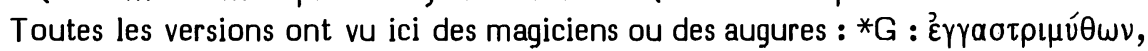
*V : divinorum, *S : דזכוכובד,

Choix textuel :

Ce cas n’a pas été soumis au comité. 
$\mathrm{J12}$ disaient conjecturer "bârîm" pour traduire ici "magiciens", alors que J3 traduit "augures" sans note textuelle. C'est que KBL (108b) proposait la conjecture susdite, alors que HALAT a créé un article Tֵㅡ V sur l'autorité de Noth (Aufsätze II 267s) qui se réfère à G.R. Driver pour lier notre mot a à un mot amorrite "baddum" attesté à Mari où il désigne un fonctionnaire que l'on croit être un devin.

Lorsque RL donne ici "Wahrsager", il ne faudrait pas croire qu'elle tire ce sens d'une correction en ex ou d'une exégèse inspirée par les découvertes de Mari. Elle recopie seulement Luther qui recopiait Zainer (cf. Kurrelmeyer VIII 472, apparat sur la ligne 46) qui traduisait ainsi "divinorum" de la *V. Les versions anciennes ont en effet, nous l'avons vu, compris ce mot comme un synonyme de קסמים qui le suit. Luther a été suivi par Münster, Olivetan, Châteillon et Ge; alors qu'au XVIe siècle, une autre école (Brucioli, Tremellius, Pasteurs, KJ) traduit ce mot par "menteurs" à la suite de Pagnini. Cette dualité d'interprétations opposait déjà Sym aux autres versions, puis Menahem ben Saruq à Judah ben Qoreish (Katz 19 = Bargès 9), de même qu'elle opposera plus tard David Qimhii (en Shorashim, sous בד בד à son père Joseph. Les premiers rapprochaient ce substantif du verbe בדא : "inventer, fabuler" (d'où : menteurs); alors que les seconds, notant le parallèle avec קסמים, remarquaient que le *T traduit aussi par אִ̣ le le mot $1 \mathrm{~S} 28,3$ (d'où : devins).

Sous l'influence dominante de Radaq, les dictionnaires ont attribué à notre mot le sens de "beaux parleurs, menteurs". Cela a amené les exégètes allemands du siècle dernier à chercher la première occasion (que leur offrit l'akkadien) pour fonder, au prix d'une correction textuelle, la traduction "Wahrsager" à laquelle ils étaient habitués depuis les origines de la Bible allemande. Les découvertes de Mari ont permis d’obtenir le même résultat sans avoir à corriger le texte.

Interprétation proposée :

On peut donc traduire ce mot du *M par : "magiciens, augures, devins".

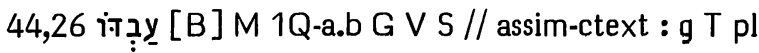

\section{Options de nos traductions :}

Ici le Seigneur se présente (selon le *M) comme "réalisant la parole de son serviteur et faisant aboutir le dessein de ses envoyés". Seule de nos traductions RSV traduit littéralement "his servant". Par une simple retouche stylistique, trois d'entre elles expriment à la 1e pers. : "mon serviteur" (J23 et TOB). Mais trois autres mettent ce mot au pluriel : RL en gardant la 3e pers. : "seiner Knechte", J1 et NEB en usant de la 1e pers.: “mes serviteurs" et "my servants". Brockington précise que NEB lit עַבְִּ avec le ms Alexandrinus du*G.

Origine de la correction :

C'est Houbigant qui a opté ici pour une traduction en pluriel et Vogel qui a proposé de corriger en la forme que lira NEB, proposition qui a été acceptée par de nombreux exégètes jusqu'à BH235 et Cent. 
Les témoins anciens :

1Q-a et $1 Q$-b apportent ici au *M un appui précieux, le singulier étant respecté

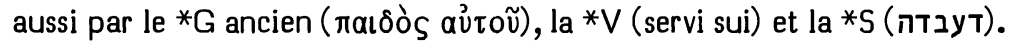

En l'assimilant à "ses envoyés" qui suit et aux innombrables "mes serviteurs les prophètes", le *T a mis ce mot au pluriel : עבדוחי צדיקיא. Le ms Alexandrinus

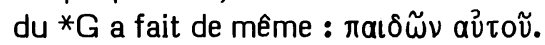

\section{Choix textuel :}

Jugeant évident le caractère facilitant de cette assimilation, le comité a attribué au *M 3 "B" et 3 "A".

Interprétation proposée :

La "parole du serviteur du Seigneur" peut être (entre autres interprétations) la parole de Jérémie (ch. 30-33; 50; 51) sur le retour et la restauration (selon Hitzig), ou le projet de Cyrus (vs 28) disant de Jérusalem : “qu'elle soit rebâtie !" (selon Bonnard).

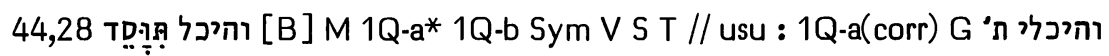

Options de nos traductions :

Le *M est traduit par RSV ("and of the temple, "Your foundation shall be laid" "), $\mathrm{J12}$ ("et du (J1 : au) temple : "sois rétabli" "), RL (“und zum Tempel : Werde gegründet), TOB (“et pour le Temple : 'Sois à nouveau fondé !" ") et J3 (“et au Temple: "Tu seras rétabli" ").

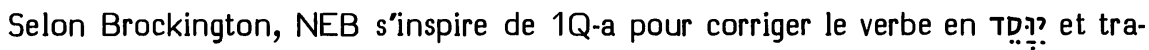
duire : "and the foundations of the temple may be laid".

Origine de la correction :

Cette correction remonte à Ryssel (HSAT2) et à Dillmann qu'il cite. Ils se fondent sur l'affirmation que היכל est masculin.

\section{Les témoins anciens :}

1Q-b appuie le *M.

Quant à 1Q-a, il offre תוסד (dont le 'waw' semble issu d'un 'yod' retouché) avec un 'yod' suspendu au-dessus de l'intervalle qui sépare le 'taw' initial de ce mot du 'lamed' final du mot précédent. NEB (selon Brockington) a interprété le 'yod' comme destiné à remplacer le 'taw' initial du verbe, alors que HUB l'interprète comme destiné à le précéder. Mais il semble plutôt qu'il faille, avec Kutscher (156), voir en ce 'yod' un suffixe 1e pers. sg. destiné au 'temple' qui précède.

En cela, 1Q-a nous offrirait donc la Vorlage du *G ( $x$ à tòv ỡxov tòv ápióv $\mu o v \theta \varepsilon \mu \varepsilon \lambda(\omega ́ \omega)$ qui prend, en outre, la liberté de traduire le verbe passif par un actif, comme il le fait en $1,20.22 ; 27,13 ; 42,19$.

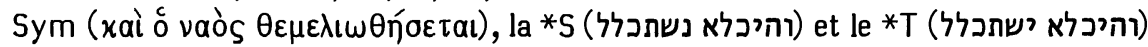
n'ont pas éprouvé de difficulté à faire du “temple" le sujet du verbe; alors que la *V (et templo fundaberis) a vu dans le verbe une $2 \mathrm{e}$ pers. m. sg. 
Choix textuel :

Il est vrai qu'en $\mathrm{Na} 2,7$, le mot היכל précédé d'un article est le sujet d'un verbe au masculin. Il en va de même lorsque ce mot a pour génitif "du Seigneur" en Ag 2,18 et Esd 3,6. Mais en Is 44,28 et 66,6 (seuls emplois de ce mot en Is 40 - 66), ce mot est sans article, en situation de quasi-nom propre. Etant donné qu'en akkadien 'ekallu' est presque toujours féminin, rien n'empêche qu'ici il ait un accord verbal au féminin. En tout cas, Yéfet ben Ely et Radaq précisent que ce mot peut avoir ces deux types d'accords.

La leçon du *M ne fait donc pas difficulté. Quant à l'ajoute du suffixe 1e pers. sg. par 1Q-a et le ${ }^{*} G$, elle est facilitante et méconnaît l'usage de ce mot en quasi-nom propre qui vient d’être signalé.

Le comité a donc attribué au *M 4 "B" et 2 "C".

\section{Interprétations proposées :}

L'exégèse la plus vraisemblable du verbe est celle qui y voit une 3e pers. f. sg.; mais il n'est pas impossible d'y voir une 2e pers. m., en supposant que le 'lamed' qui précède 'Yerushalaïm" ait une double fonction.

On pourra donc traduire ou bien : "et que le Temple soit (à nouveau) fondé", ou bien : "et au Temple : 'sois (à nouveau) fondé"."

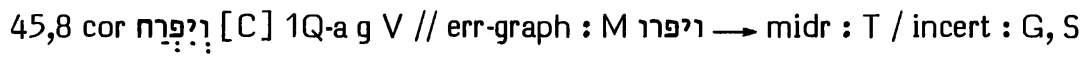

Options de nos traductions :

Après "que la terre s'ouvre", le *M offre yẹ:?"?:?:? Le fait que le verbe soit au pluriel a fait difficulté aux exégètes et aux traducteurs.

Sans note textuelle, ce verbe a été traduit par 31 : "que ... fructifie", 32 : "que mârisse", RL : "und bringe", NEB : "that it may bear the fruit", J3 : "et produise", TOB : “que s'épanouisse".

En disant suivre 1Q-a, RSV traduit : "that ... may sprout forth".

\section{Origine de la correction :}

Luther a traduit le verbe (selon la ${ }^{*} \mathrm{~V}$ ) comme un singulier dont le sujet serait "la terre". Comme c'est souvent le cas, l'influence combinée de la *V et de Luther a orienté ensuite la critique textuelle. Houbigant a mis au singulier le verbe du *M (solution adoptée par HSAT234, BH23S et Cent). Lowth (dans l'original anglais et dans la traduction de Koppe) lit ici (en disant suivre le ${ }^{*} G$, la ${ }^{*} V$ et la ${ }^{*} S$ ) : ריפרה. Pourtant Michaelis (OEB) le cite comme proposant ?ִ? leçon adoptée ensuite par Grätz et Perles (I 30) qui la reconnaissent dans le verbe $\ddot{\beta} \dot{\lambda} \alpha \sigma \tau \eta \sigma a ́ \tau \omega$ du *G (recensé). Cheyne l'attribue aussi comme probable à la *V et à la *S. Depuis que cette conjecture s'est trouvée attestée par 1Q-a, elle a été adoptée par North, James, Bonnard.

\section{Les témoins anciens :}

1Q-a lit ici ריפרי

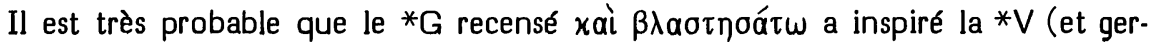


minet) et que cette leçon suppose une Vorlage identique à $1 Q$-a qui aurait été lue ici par Th ou par Sym.

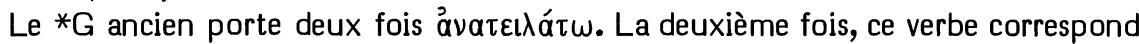
(comme 22 fois dans le ${ }^{*}$ ) au verbe La première fois, il est difficile de dire si ce verbe (qui ne peut correspondre à פת correspond à une Vorlage identique à $1 \mathrm{Q}$-a ou si un texte identique à celui de $* M$ a été traduit de façon facilitante en anticipant ce qui sera la traduction du verbe suivant, ainsi que nous avons vu le ${ }^{*} G$ agir en $38,14 \mathrm{~B}$ et en 42,11 .

Le singulier רנסגא de la*S semble ne pas avoir d'autre Vorlage que le*M.

Le *T ("que les morts revivent") semble construire sur la base du *M dont son midrash exploite le pluriel.

\section{Choix textuel :}

1Q-a va laisser non traduits les 4 derniers mots de ce vs et son scribe semble bien avoir pris deux initiatives en ce vs : d'abord ויזל au lieu de

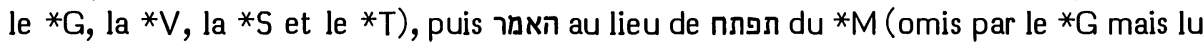
par 1Q-b partiellement mutilé, la $* V$, la $* S$ et le $* T)$. Tout cela peut s'expliquer en fonction d'un mauvais état de la Vorlage de 1Q-a. En ce cas, ויפרח peut être une restauration facilitante $d^{\prime} u n$ ויפרו illisible. Mais le $* G$ recensé et la $* V$ attestent presque certainement la même leçon sans nous livrer d'indices inquiétants sur leur Vorlage.

Etant donné que la leçon de 1Q-a et celle du ${ }^{*} M$ ne se distinguent que par une corruption graphique et que l'on n'aurait jamais l'idée de considérer ויפרו comme la forme non corrompue au cas où le *M nous livrerait ויפרח, le comité a préféré la leçon de 1Q-a par 3"C" et 1 "D".

Cependant deux membres du comité ont attribué " $\mathrm{C}$ " à la leçon du *M.

\section{Interprétation proposée :}

Les partisans du *M considèrent, à la suite de Gousset (696b) et de Luzzatto, que l'on peut considérer ici le verbe פרה comme transitif, yִِ? en étant le complément d'objet. Le sujet de ce verbe peut être les cieux, les nuages et la terre mentionnés dans le début du vs. Rignell estime qu'après "et que la terre s'ouvre", le sujet naturel de "produire des fruits" est "les sources" sous-entendu. Il ne semble pas se rendre compte qu'il retrouve ainsi la plus ancienne exégèse juive connue : celle de R. Lévi (début du IVe siècle) qui, en Bereshit Rabba (122,4ss), estime que le sujet de ce verbe est constitué par les eaux d'en haut (qui, ici, servent de métaphore au don céleste du Yצ et les eaux d'en bas (auxquelles l'ouverture de la terre laisse passage).

Si l'on passe du signifiant au signifié, le verbe au pluriel peut avoir pour sujet "la terre", comme c'est le cas en Gn 41,57 où ce mot signifie "les habitants de la terre". C'est en effet eux qui, ayant reçu des cieux le don du

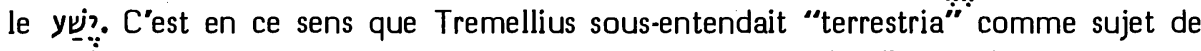
ce verbe et que, sous son influence, la Bible des Pasteurs de 1588 traduisait : "et que l'on produise le salut", puis la King James : "and let them bring forth salvation".

Le comité conseille pourtant, en suivant 1Q-a, de traduire ici : "et que le salut pousse (ou : germe)". 


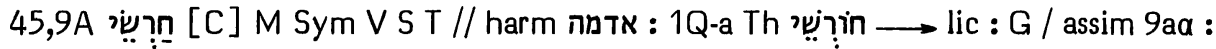 Aq clav חִ חִ}

\section{Options de nos traductions :}

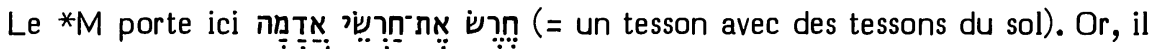
vient de donner, en un membre de phrase qui s'offre, à première vue, comme parallèle à celui-ci : "Malheur à celui qui se querelle avec son potier (יצר (2)" et il va donner juste

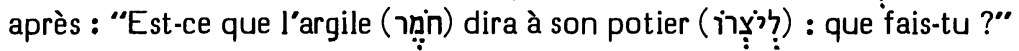

$9 A$ est traduit comme nous venons de le faire par Rُ $\mathrm{R}$, J et TOB.

RSV donne ici : "an earthen vessel with the potter" en notant qu'elle conjecture une autre leçon pour ce mot.

NEB donne: "or the earthenware with the hand that shapes it", Brockington disant qu’elle vocalise

\section{Origines des corrections :}

Sous l'influence des deux membres de phrase qui l'encadrent, Oecolampade a traduit ce passage : "testa cum figulis luti". Luther l'a suivi en cela ("nemlich, der Scherben mit den Töpffern des Thons") en utilisant déjà la terminologie dont il fera usage lorsqu'il traduira le membre de phrase suivant par : "Spricht auch der Thon zu seinem Töpffer...". Une traduction analogue de 9A se retrouve chez Brucioli, Olivetan et Châteillon.

Münster a réagi avec netteté contre cette option : "les nôtres ont transformé ici le tesson en potier, par ignorance de la grammaire hébraïque." Calvin estime que ceux qui comprennent ce mot au sens de artisans ou potiers ont lu ici un 'shin' par déplacement du point diacritique.

Foreiro semble avoir été le premier à proposer clairement de corriger les points : "Presque tout le monde comprend le pluriel חרשי qui est ici au sens de 'tessons' ou 'vases de céramique'. Mais moi, en effaçant les points, je l'ai pris pour le participe du verbe חרש qui signifie 'accomplir une oeuvre', comme le font les laboureurs ou les artisans. Nous pourrions dire "ouvriers'." Il explique ensuite le motif de sa correction : la préposition את vient d'être utilisée dans le membre de phrase précédent, au sens de "(se quereller) avec". Il s'agissait de se quereller avec son potier. Or, quelle querelle d'un tesson avec des tessons peut-on imaginer qui contribue en quoi que ce soit à ce contexte ? C'est pourquoi la *V a dû traduire ce deuxième par "de" (alors qu'elle avait rendu le premier par un datif s'articulant sur le verbe "contradicit").

\section{Les témoins anciens :}

Les critiques textuels vont trouver ensuite des témoignages pour appuyer la traduction d'Oecolampade et Luther (transformée en option explicite par Foreiro) en face de la critique de Münster.

Cappel (Critica 812), se fondant sur le commentaire de Procope de Gaza édité

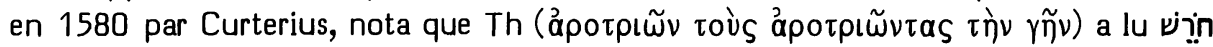
. אתת 350 ans plus tard, le commentaire d’Eusèbe a été redécouvert et ses fragments hexapläres édités par Ziegler (éd. Göttingen du ${ }^{*} G$ ) en 1939, nous faisant connaître

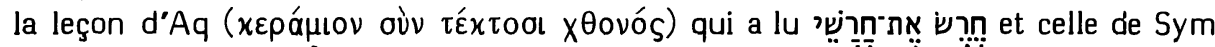

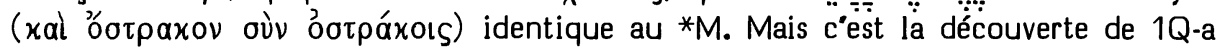


qui est venue apporter à la conjecture de Foreiro un témoignage textuel formel.

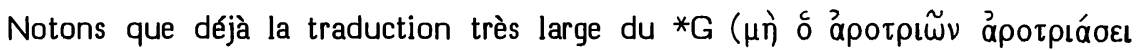

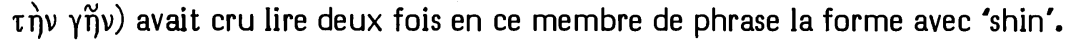

Mais la *V (testa de samiis terrae), la *S (חצפא מן חצפיה דארעא) et la paraphrase du *T ("des images d'argile qui ont été faites avec la poussière du sol") appuient le *M dans sa position des deux points diacritiques.

\section{Choix textuel :}

C'est la proximité du mot אדמה qui a conduit le ${ }^{*} G$, Th et (très probablement) $1 Q$-a à lire ici deux fois la racine "labourer". Aq, lui, place d'abord le point diacritique à gauche, puis à droite. En cela, il a voulu assimiler étroitement à la structure du membre de phrase précédent.

Comme Kutscher (238) l'a fait remarquer, le fait que ce membre de phrase soit étroitement lié à celui qui le précède sans en être une simple réplique montre que le * $M$ a raison de placer les points diacritiques à gauche. On attend en effet ici un objet qui "se querelle avec son potier". La seule difficulté réelle est celle que Foreiro a signalée : étant donné qu'une querelle entre tessons n'a rien à voir en ce contexte, est-il vraisemblable que nous ayons en deux membres de phrase successifs deux valeurs distinctes pour la préposition את? On peut répondre à cette difficulté en admettant que le prophète a justement voulu jouer sur la polysémie de cette préposition.

Le comité a attribué au *M la note " $C$ ".

Interprétation proposée :

"Malheur à qui entre en conflit avec son potier, (lui) tesson (qui a place) avec les tessons de terre."

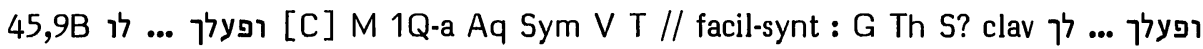

\section{Options de nos traductions :}

Selon le *M, 9b commence par "Est-ce que l'argile dira à son potier : que fais-tu?"

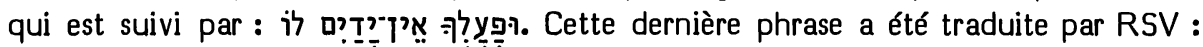
"or 'Your work has no handles" "; TOB : "et l'oeurre réalisée par toi dira-t-elle : "Il n"a pas de mains !'?"; 33 : "ton oeuvre n'a pas de mains".

Les autres traductions semblent inverser les suffixes du premier mot et du quatrième : J12: “son oeuvre lui dit-elle : 'Tu es manchot'?"; RL : “und sein Werk : Du hast keine Hände !"; NEB : "or his handiwork say to him, "You have no skill'?". Seuls NEB et Brockington ont une note textuelle, et celle-ci ne porte que sur le premier suffixe.

Origine de la correction :

Houbigant a conjecturé ici לפעלו à la place du premier mot et à la place du quatrième, ce qui donne: “à son fabricant: 'tu n'as pas de mains'." Lowth a admis cette seconde conjecture et, pour la première, s'est contenté de ופעלו, en traduisant comme Houbigant. 
La conjecture d'Houbigant a été acceptée par Koppe et Ryssel (HSAT2), alors que celle de Lowth l'a été par Duhm, Dillmann/Kittel, Cheyne et la plupart des exégètes, ainsi que HSAT34, BH235 et Cent. C'est elle qui a été suivie par J12, RL et NEB.

Les témoins anciens :

Le suffixe 2e pers. sg. de ופעלך est formellement attesté par 1Q-a, Th (xaì tò

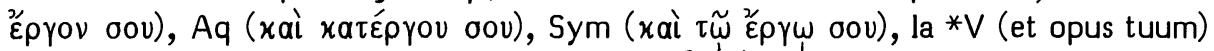

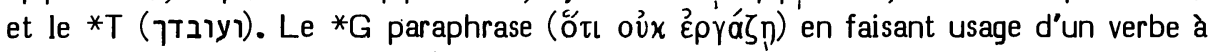
la 2e pers. sg. Quant à la *S ("et je ne suis pas l'oeuvre de tes mains"), elle est trop libre pour prêter à une reconstruction de sa Vorlage.

Le suffixe 3 e pers. sg. du $4 \mathrm{e}$ mot est attesté en 1Q-a (qui a glosé en insérant

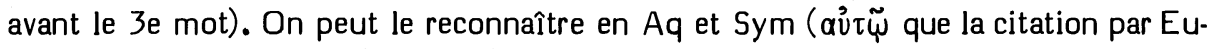

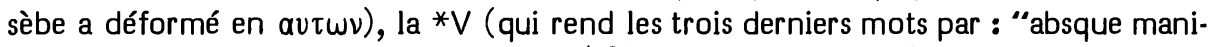

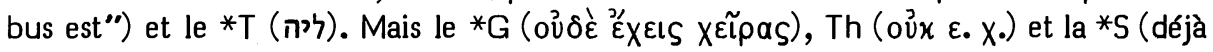
citée) traduisent comme s'ils avaient lu un suffixe 2e pers. sg.

\section{Choix textuel :}

Ces dernières versions montrent surtout la difficulté qu'elles ont eue à trouver un sens à ce passage. Il serait donc imprudent de s'éloigner ici du *M auquel le comité a attribué 4 "C" et 2 "B".

\section{Interprétations proposées :}

1/Foreiro a proposé de comprendre "mains" au sens de "anses" et a été suivi par Luzzatto, Ehrlich, Buber, RSV. Mais le pluriel de "anses", même lorsqu'il n'y en a que deux, est toujours ידות.

2/ Certains ont sous-entendu "dira" après "ton oeuvre", sous l'influence du היאמר initial de 9b: “Est-ce que l'argile dira à son potier : que fais-tu ? et (est-ce que) ton oeuvre (dira) : il n'a pas de mains."

3/ L'exégèse de Luther (qui était déjà celle de Yéfet ben Ely) a été reprise par plusieurs : voyant en ceci la suite de ce qui précède, il interprète "mains" comme "dextérité, adresse" et comprend le suffixe 3e pers. sg. du $4 \mathrm{e}$ mot comme se référant à l'oeuvre : "et ton oeuvre ne témoigne d'aucune adresse".

4/ Ibn Ezra, König et Leene interprètent ledit suffixe comme se référant à celui qui agit et ils supposent un redoublement du sujet : “... et ton oeuvre (est l'oeuvre de quelqu'un qui) n'a pas de mains."

Etant donné que la racine לפ semble ne jamais désigner dans la Bible une fabrication ni un fabriqué, mais que, dans le Second Isaïe, elle semble désigner l'oeuvre divine de salut d'Israël réalisée au moyen de Cyrus, on préférera les exégèses 3 et 4. 
45,10 הוי האומר incert : g V S T / exeg : G clav האמר

Options de nos traductions :

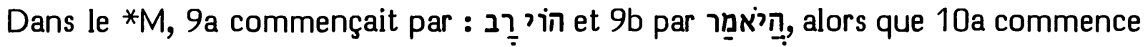
par : הiֹי אמֵר. Ces deux derniers mots ónt été traduits littéralement par RSV, J, RL et TOB; alors que NEB conjecture (selon Brockington) הִיִמֵ pour traduire : "will the babe say".

Origine de la correction :

C'est Oort qui a proposé cette conjecture transformant la malédiction en question rhétorique. Ryssel (HSAT2) a signalé cette conjecture qui a été adoptée par BHS.

Duhm1 estimait que le ${ }^{*} G$ a lu sant le 'hé' en particule interrogative. Éhrlich et Duhm5 acceptent la conjecture de Oort en la vocalisant en nifal.

Les témoins anciens :

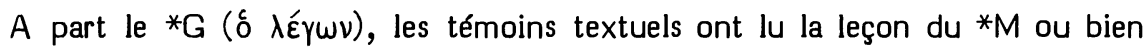
הוי האומר (avec 1Q-a), sans qu'il soit possible de les répartir avec certitude entre ces deux leçons.

Choix textuel :

A propos de la leçon de $1 Q-a$, notons que ce ms donnait déjà cette même leçon

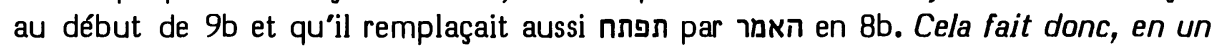
étroit contexte, trois האומר que 1Q-a a lus et que le *M ignore.

Quant au *G ancien, il a déjà méconnu le précédant du *M (en 9a) et il méconnaîtra le suivant (en 55,1 ).

Le texte est donc ici assez instable, mais aucune forme textuelle concurrente n'est clairement préférable à celle du * $M$ auquel le comité a attribué la note " $C$ ".

Interprétation proposée :

"Malheur à qui dit..."

45,11 יוצר ה' [B] M 1Q-b V // subst-synt : 1Q-a Geg : S / confl : T Options de nos traductions :

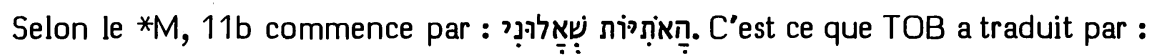
"exigez donc de moi les choses à faire".

RSV dit conjecturer lorsqu'elle traduit : "will you question me". De même, J12 donnent : "Est-ce à vous de m"interroger", et RL : "wollt ihr mich zur Rede stellen".

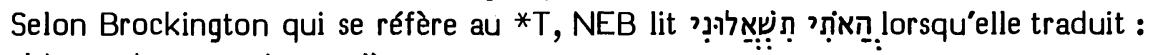
"would you dare question me".

Quant à J3, elle dit conjecturer הִּ lorsqu’elle traduit : “on me demande des signes". 
Origines des corrections :

La conjecture de RSV et celle de NEB supposent que l'on transfère le 'taw' final du substantif au début du verbe que l'on vocalise alors en 2e pers. m. pl. de l'inaccompli. Cela a été conjecturé par Secker cité par Lowth. Ehrlich avait proposé de faire précéder ce verbe de הִֵַn. Sous cette forme, la conjecture a été adoptée par BH3, Cent, RSV, J12 et RL.

La forme, plus proche du *M, retenue par NEB avait été conjecturée par Driver (Studies $\vee 39$ ) qui considère la répétition de l'accusatif 1e pers. sg. comme emphatique.

Les témoins anciens :

On pourrait être tenté d'appuyer la leçon de $\mathrm{J3}$ sur $1 \mathrm{Q}-\mathrm{a}$, la *S et le ${ }^{*} \mathrm{~T}$, mais ce seraient des appuis illusoires.

En effet, 1Q-a offre bien ici האותות. Mais Kutscher (217) voit seulement en cela une normalisation de la forme participiale (où la rétention du 'yod' ne s'impose pas nécessairement). Nous avons déjà traité de la *S (אתו̈) à propos de 44,7C. Son témoignage n'a donc ici rien de spécifique. Quant au *T, il a ici une leçon gonflée : "les signes qui vont venir", analogue à celle que la *S offrait en 44,7C.

Une autre variante porte sur le lien entre ce mot et celui qui le précède (et achève 11 a, selon le $* M)$. 1Q-a et le ${ }^{*} G$ lisent celui-ci sans pronom suffixe faisant de ces deux mots un attribut du Seigneur : celui qui modèle les choses à venir.

Notons que le *M a l'appui total de 1Q-b et de la *V (plastes eius / ventura interrogate $\mathrm{me})$.

\section{Choix textuel :}

A propos du choix entre "signes" et "choses à venir", remarquons que "choses à venir" est bien en place peu avant "je l'ai suscité" (vs 13); de même que ce mot, en 41,23 , précédait "j'ai suscité" (41,25).

Quant au possessif de "son modeleur", il faut reconnaître que le verbe "modeler" trouve en "Israël" un complément d'objet qui correspond fort bien à la théologie du Second Isaïe $(43,1.21 ; 44,2.21 .24)$.

Aussi le comité a-t-il attribué au *M 5 "B" et 1 " $C$ ".

Interprétation proposée :

L'interprétation la plus vraisemblable est celle de Gesenius et Rosenmüller : 'Vous pouvez m'interroger sur l'avenir, mais, pour ce qui est du sort de mes fils et de l'ouvrage de mes mains, laissez m'en la charge". On retrouve le piél de (ayant une communauté pour complément) introduit par hy au sens de "confier à quelqu'un la charge de cette communauté" en 1 Ch 22,12 (cf. 2 s 6,21; 7,11). Ce verbe, qui réapparaîtra en un contexte normal à la fin du vs suivant, a évidemment ici une valeur un peu ironique.

Il faut distinguer la prévision de l'avenir - question classique pour justifier des prétentions à la divinité (cf. 41,23; 44,7) - et les requêtes portant sur l'ouvrage des mains du Seigneur, requêtes qui constitueraient des interférences inadmissibles dans le déroulement de son plan de salut. 


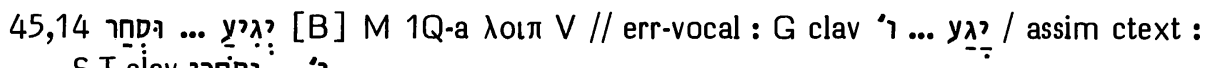
S T clav

Options de nos traductions :

Ici le *M coordonne deux substantifs abstraits "la production de l'Egypte et le commerce de l'Ethiopie" avec un nom de peuple : "et les Sabéens". Cette particularité a été respectée par RSV, RL et 33.

TOB, en traduisant le premier substantif par "la main d'oeuvre", facilite le groupement des trois termes.

312 donnent : "les fellahs" et "les commerçants" pour les deux premiers substantifs. 32 précise conjecturer deuxième.

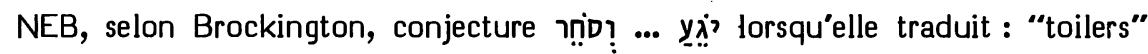
et "merchants".

Origines des corrections :

Ne se souciant que des corrections consonnantiques, Houbigant a corrigé le premier de ces mots (et interprété les deux) en participe singulier, obtenant exactement la conjecture que Brockington attribue à NEB.

Quant à J12, elles suivent une conjecture de Humbert (en Cent) pour le 1er mot et, pour le 2e, la leçon ị: quị que $\mathrm{BH} 3$ assigne pour Vorlage à la *S.

Les témoins anciens :

Pour ces deux mots, le *M est appuyé par 1Q-a, par les colonnes des hexaples

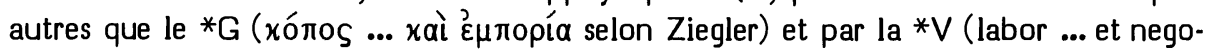
tiatio).

Le ${ }^{*} G$ a compris le premier mot comme un verbe ( $\varepsilon$ है $l^{\prime} E$ Egypte et le commerce de l'Ethiopie.

La $* S$ et le $* T$ lisent le premier mot comme le $* M$, mais (par assimilation aux Sabéens qui suivent) ils personnalisent le second en y lisant un participe pluriel.

Choix textuel :

Le *M donne un sens excellent si on comprend qu'il s'agit là des trois peuples que le Seigneur a promis en 43,3 de livrer aux Perses en échange de l'affranchissement $d^{\prime \prime I s r a ̈ ̈ l . ~ C ' e s t ~ l e ~ p r o d u i t ~ d u ~ t r a v a i l ~ d e ~ l ' E g y p t e ~ e t ~ c e l u i ~ d u ~ c o m m e r c e ~ d e ~ l ' E t h i o p i e ~}$ ainsi que les captifs Sabéens qui sont les sujets du premier יעברו יהיו Mais, à partir de là, les quatre derniers inaccomplis ne peuvent avoir que des sujets humains, c'est-à-dire les Sabéens.

Le comité a attribué au *M la note " $B$ ".

Interprétation proposée :

“Le fruit du travail de l’Egypte, le profit de l’Ethiopie et les Sabéens, gens de haute taille, passeront chez toi et t'appartiendront. Ces gens te suivront, ils passeront enchaînés..." 


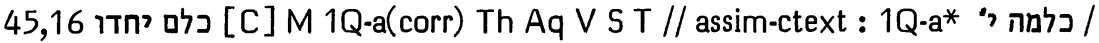 $\operatorname{assim} 41,11: G$}

\section{Options de nos traductions :}

Selon le *M, 16a ("ils sont honteux et même confus, eux tous") s'achève par 吼? a alors que 16b ("ensemble ils s'en vont dans la confusion, les fabricants d'images") commence par parallèles d'un chiasme. Cependant, selon un procédé qui lui est habituel, la mise en page de $\mathrm{BH} 235$ les regroupe et les isole par des blancs, en fonction de corrections que l'apparat suggère et dont nous aurons à traiter.

Dans la tradition de KJ et de Luther, RSV ("all of them... together") et RL ("alle ... und miteinander") séparent clairement ces deux mots en respectant les teamim.

Méconnaissant les teamim (sous l'influence des versions ou de la mise en page de $\mathrm{BH} 3 \mathrm{~S}$ ), $\mathrm{TOB}$ et $\mathrm{J3}$ croient respecter le ${ }^{*} \mathrm{M}$ en traduisant ces deux mots par "tous ensemble".

C'était, en effet, le sens que $\mathrm{J} 2$ (à la suite de Cent) leur donnait dans la note où elle indiquait que (à la suite de J1) elle les corrigeait, selon le *G, en כל־ֵּרִריר, pour traduire librement : "ceux qui s'enflammaient contre toi".

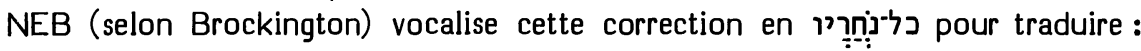
"those who defy him".

Origines des corrections :

C'est Köhler qui, se fondant sur le ${ }^{*} G$, a proposé de lire ici la leçon que $J 12$ ont trouvée dans les apparats de $\mathrm{BH} 3$ et de Cent.

La vocalisation retenue par NEB a été proposée pour cette correction par North, se fondant sur une suggestion formulée par Driver (LTP 398) à propos de 41,11 et de 45,24.

\section{Les témoins anciens :}

1Q-a offre ici, à la fin d'une ligne, כלמה avec un 'waw' suspendu au-dessus du 'kaf'. Au début de la ligne suivante se voit le début du mot suivant, la fin de ce mot ayant disparu dans une lacune.

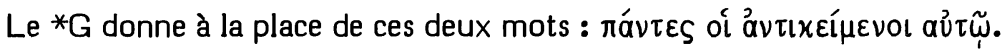

Le *M est appuyé par Th ("eux tous ensemble"), Aq ("tous ensemble"), la *V (omnes simul), la *S (כלהון אכחדא) et le *T (כלהון כחדא).

\section{Choix textuel :}

La leçon de la seconde main de 1Q-a est la graphie pleine de ạ̣ en en ce ms (cf. $44,9 ; 60,4)$. La graphie de la première main en était une déformation sous l'influence du substantif ment. En soi, cette séquence du verbe et du substantif de même racine est tout aussi

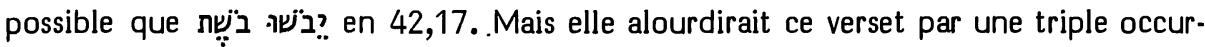
rence de la même racine, alors que le *M offre une simple assonance qui est probablement voulue par l'auteur. 


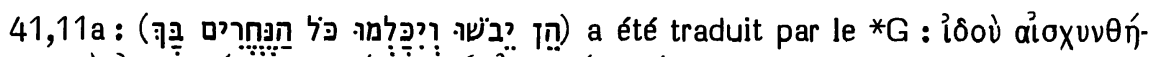

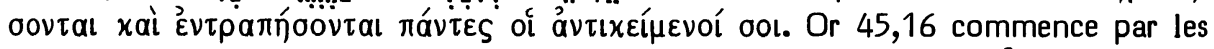

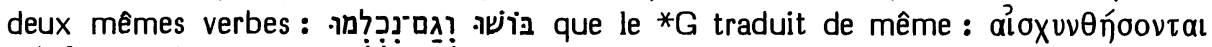
xaì é è juste après, dans la suite "kaf-lamed' et dans la suite 'het-dalet', quelque chose d'analogue à ce qui lui avait inspiré la suite de sa traduction en 41,11. Mais on ne saurait faire fond sur un tel rapprochement, car les trois emplois bibliques du nifal de חרה introduisent leur complément par la préposition "bet'. Notons d'ailleurs qu'en 45,24, le *G ne saura plus reconnaître cette racine en in חา.

Le comité a attribué ici au *M 3 "B" et 3 "C $C$ ".

Interprétation proposée :

En respectant les teamim, on séparera les deux parties du vs 16 comme Luther et $\mathrm{KJ}$ l'ont fait, en évitant de joindre (avec les versions) les deux mots dont nous venons de traiter. Nous avons donné au début de cette étude une traduction littérale.

45,24A לי אמר / לאמר / harm-synt : 1Q-a V // usu : G clav : ליא יאמר : S

Options de nos traductions :

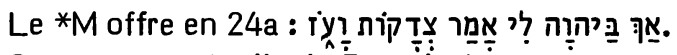

Sans note textuelle, le $\mathrm{B}$ e et le $4 \mathrm{e}$ mots sont traduits par RSV : "it shall be said of me" et par NEB : "men shall say".

TOB se fonde sur 1Q-a pour justifier le futur de "dira-t-elle de moi"(le sujet étant la "langue" mentionnée à la fin de 23).

$\mathrm{J12}$ lisent (selon J2) לאמר avec le ${ }^{*} \mathrm{G}$ et la $* \mathrm{~V}$, en transférant ce mot en début de verset: "en disant: (Par Yahvé seul)". J3 lit de même et prétend que le *M signifie : "En Yahvé seul il m'a dit".

RL traduit : "(Mir sollen ... alle Zungen schwören) und sagen : (Im Herrn)".

Origines des corrections :

J suit une proposition que Lowth fondait sur le ${ }^{*} G$ et que Koppe a complétée en demandant le transfert du mot en début du vs. Acceptée par de nombreux exégètes, cette correction est requise par les apparats de $\mathrm{BH} 3 \mathrm{~S}$ et de Cent.

TOB suit Bonnard qui propose de vocaliser en qal la leçon que 1Q-a lisait probablement en nifal. Notons que cette correction, avec vocalisation nifal, avait été conjecturée par Shalom Modena (cité par Luzzatto) et adoptée par Oort (Jez) et Ryssel (HSAT2). La vocalisation qal a été préférée par Dillmann/Kittel, BH2 et HSAT34.

Les témoins anciens :

La leçon du *M tient une position intermédiaire (avec un 'yod") entre 1Q-a qui a lu deux 'yod' : ליא יאמר et le *G $(\lambda \varepsilon ́ \gamma \omega \nu)$ qui n'en a pas lu, ayant assimilé cela à l'expression usuelle לאמר : לאמר. 
La *V (dicet meae) traduit comme si elle avait lu, elle aussi, un inaccompli. La *S, mettant le verbe au pluriel (ונאמרון) et n'exprimant pas son complément לי traduit, elle aussi, par un futur.

Le *T (y) appuie le *M.

Choix textuel :

$L e{ }^{*} M$ semble bien être à l'origine de toutes les facilitations divergentes des variantes.

C'est pourquoi le comité lui a attribué 4 "C $\mathrm{C}$ " et 2 "B".

Interprétations proposées :

$\mathrm{La} * \mathrm{~V}$ a relié ל אמר comme une incise. Cette option a été suivie par Luther $(=\mathrm{RL})$ : “... und sagen : Im Herrn habe ich" et par KJ : "Surely, shall one say, in the Lord have I".

Mais les teamim lient les deux mots que la *V avait séparés. On comprendra donc la préposition 'lamed" au sens de 'de', comme en 41,7: "disant de la colle". Quant à l'accompli à la 3e pers. sg., il faut lui donner un sens impersonnel, comme en 25,9a. Cet accompli entre des inaccomplis se situe, comme eux, dans le futur et a pour but de mettre en relief l'événement exprimé par ce verbe (cf. 47,9; 51,11b). Donc l'incise pourra être traduite : “on dira de moi". Déjà Saadya interprétait le 'lamed' en ce sens et traduisait l'accompli (à la suite de plusieurs versions) par un futur.

45,24B יבואו יבושר M Sym // harm : m G V S T / err-divis : 1Q-a יבוא ויבשו

Options de nos traductions :

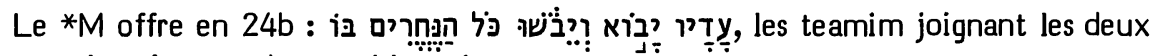
verbes en les séparant de ce qui les suit.

Le premier verbe a été traduit en pluriel par toutes nos traductions, seule TOB notant qu'elle suit en cela 21 mss hébreux, 1Q-a et des versions.

Origine de la correction :

Au XVIe siècle, le singulier du *M était respecté par Oecolampade, Pagnini, Brucioli, Rollet, Estienne, Châteillon (latin), Ge, Tremellius; alors que Luther (sous l'influence de la *V?) le traduisait par un pluriel, suivi en cela par Olivetan et $\mathrm{KJ}$.

Châteillon ("viendra-on") et Pasteurs ("quiconque viendra") optaient pour un impersonnel.

C'est Houbigant qui a proposé de corriger en יבאו en se fondant sur le ms Alexandrinus du $* G$, la $* V$ et la $*$ S. Cette correction est demandée par les apparats de HSAT2, BH23S.

Budde (en HSAT34) préfère transférer le 'waw' initial du deuxième verbe à la fin du premier.

Les témoins anciens :

Dans la tradition massorétique ancienne, deux listes distinctes présentent des cas 
de formes du verbe בוא où on lit le singulier, alors qu'on conjecturerait (= sebirin) le pluriel. Ces listes ont pour but de protéger le texte biblique contre la variante facilitante notée par Bonnard et TOB en de nombreux mss du *M. Il s'agit d'abord d'une liste de 6 cas fermement attestée deux fois par le ms du Caire (sur Is 45,24 et sur Ez 20,38) et une fois par le ms de Petrograd (sur Ez 14,1), et ensuite d'une liste de 8 cas tout aussi fermement attestée par la 2e partie de la Okhla de Halle (fol. 69a), par le ms des Jésuites de Cologne, le ms Londres BL Orient 4445 et le ms Erfurt 3 (sur $\mathrm{Nb}$ 13,22). Chaque liste a sa structure caractéristique et toutes deux intègrent

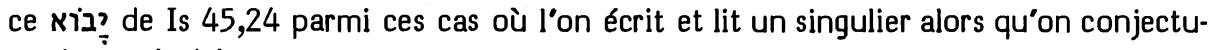
rerait un pluriel.

Confirmant la conjecture de Budde, 1Q-a porte ici : יבאו יבושו. Le *G recensé

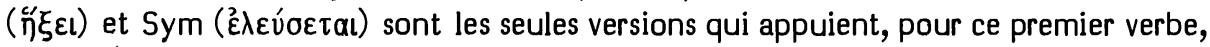

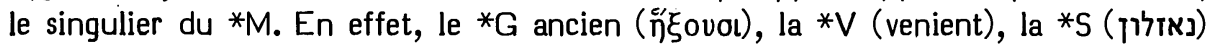
et le *T (qui paraphrase : "par sa parole ils viendront") ont tous traduit par un pluriel.

Toutes ces versions, comme les mss aberrants du $* M$, font précéder le deuxième verbe par une conjonction. Il est donc très probable qu'ils sont seulement ici des témoins anciens de la tradition du sebir; alors que $1 Q$-a se distingue du $* M$ par une vraie variante textuelle portant sur la division des deux mots.

Choix textuel et interprétation proposée :

Ce cas n'a pas été soumis au comité.

Faut-il placer le 'waw' à la fin du premier mot (avec 1Q-a) ou au début du second (avec le *M)?

Il se peut que ce soit la tradition du sebir qui - en face d'une Vorlage où la division des mots n'était pas claire - a guidé le scribe de 1Q-a vers cette division qui prive le deuxième verbe d'une conjonction souhaitable. Il est frappant, en tout cas, que les teamim qui lient étroitement les deux verbes s'accordent avec le sebir pour postuler une interprétation du deuxième verbe comme parallèle au premier. Wickes (II 136) atteste pourtant qu'une autre tradition d'accentuation sépare ces deux verbes par un zaqef qațon.

Si on considère comme facilitantes la variante de $1 Q$-a et l'exégèse postulée à la fois par le sebir et par la tradition d'accentuation courante, l'exégèse la plus naturelle est de donner un sens impersonnel à ce verbe au singulier (comme on vient de le faire pour אִ אִדִיו établit une coupure à la fin du monologue du Seigneur.

L'ensemble peut se traduire :

22 "Tournez-vous vers moi et soyez sauvés, tous les confins de la terre,

Car c'est moi qui suis Dieu, et il n'y en a pas d'autre.

23 Je l'ai juré par moi-même.

De ma bouche est sorti ce qui est juste, une parole sans retour.

Oui, devant moi fléchira tout genou,

Toute langue jurera :

24 Seulement dans le Seigneur - dira-t-on de moi - sont justice et force !'

On viendra vers lui;

Alors que seront honteux tous ceux qui s'étaient échauffés contre lui." 


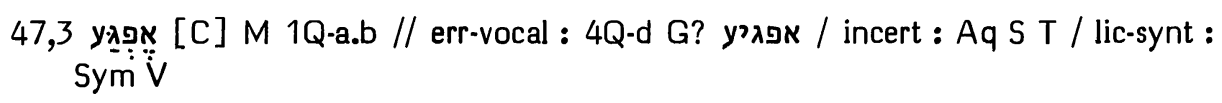
Options de nos traductions :

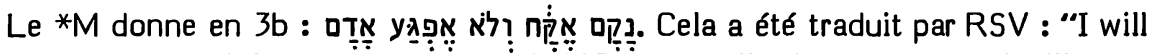
take vengeance, and I will spare no man", $\mathrm{NEB}$ : "I will take vengeance, I will treat with none of you", TOB : "La vengeance, je la prendrai, et je n'aurai pas recours à un homme".

312 donnent : "Je vais me venger et personne n'interviendra!" Pour le verbe final, $\mathrm{J} 2$ dit se fonder sur Sym et la * $\mathrm{V}$; alors que c'est par conjecture que J3 donne : “j'exécute ma vengeance et personne ne s'y opposera".

$\mathrm{RL}$ donne : "Ich will mich rächen, unerbittlich".

Origines des corrections :

Houbigant hésitait entre une mise de ce verbe au hifil (1e pers. sg.) ou à la $3 e$ pers. m. (sg. du qal). La première correction a été adoptée par Lowth et la seconde par Volz, puis BHS.

RL suit ici une suggestion de Grätz et Cheyne qui a été adoptée par HSAT34,

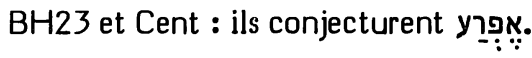

Les témoins anciens :

1Q-a appuie le *M.

4Q-d porte אפגיע, confirmant la première conjecture d'Houbigant. Il est probable

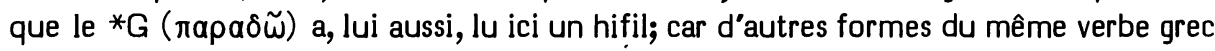
correspondent en 53,6 et 12 au hifil de ce verbe hébreu. Il est impossible de préciser si Aq (ảravińow), la *S (אפג) et la paraphrase du *T ("et je rendrai ton jugement différent de") ont lu un qal ou un hifil.

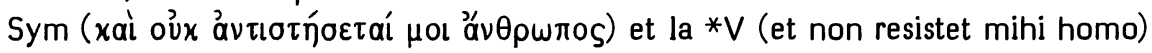
appuient la seconde proposition d'Houbigant.

Choix textuel et interprétations proposées :

Sans prétendre à corriger le *M, Luther traduisait, lui aussi, de même, en permutant le sujet et le complément d'objet : "und sol mir kein Mensch abbitten" et Olivetan faisait de même : "et nul homme ne pourra venir au devant".

Notons que le verbe פגע, lorsqu'il est employé au qal avec l'accusatif, signifie le plus souvent: "se trouver sur la route de quelqu'un". Au hifil, il peut avoir le sens d'un causatif du qal. Mais il signifie plus souvent : "se placer en obstacle sur la route de quelqu'un". Cela se comprend d'ordinaire au sens métaphorique de "s'opposer à la réalisation d'un projet", cette opposition pouvant consister en une intercession ou en une résistance. Si le hifil signifie "intercéder" ou "résister", le qal exprime souvent le comportement par lequel l'auteur du projet fait face à cette opposition. On peut donc le traduire ici ou bien comme : "je n'accepterai l'intercession de personne", avec Saadya, Yéfet ben Ely, Abulwalid (Ușul 561,25-28), Judah ibn Balaam, Isaïe de Trani; ou bien : "je ne rencontrerai la résistance de personne" (c'est-à-dire : je n'en tiendrai pas compte). C'est le 2e sens proposé par Ibn Ezra, sens préféré par Aaron ben Joseph, Eliézer de Beaugency, Rosenmüller, Luzzatto. 
En 64,4 nous aurons l'occasion de nous interroger à nouveau sur le sens du qal de ce verbe qui semble mieux convenir ici au contexte que le hifil.

Le comité a attribué au *M 4 "C" et 2 "B".

47,4 גBלנו [B] M 1Q-a.b. G Th Aq Sym V S T // glos : g praem عĩ

Options de nos traductions :

Selon le ${ }^{*} M$, le vs 4 ne contient pas de verbe et constitue une phrase nominale précédée d'un casus pendens et suivie d'une apposition (selon TOB : “Celui qui nous rachète, son nom est le Seigneur, le tout-puissant, / le Saint d'Israël") ou bien deux phrases nominales incluses l'une dans l'autre (selon RSV : “Our Redeemer - the Lord of hosts is his name - is the Holy One of Israel").

Les autres traductions voient en "celui qui nous rachète" le sujet d"un verbe "dit" ou "a dit" qu’elles ajoutent à partir du *G (selon NEB et J). La suite du vs se comprend alors comme une relative : "dont le nom est le Seigneur des armées, le saint d'Israël".

RL ("ich will mich rächen, unerbittlich, spricht unser Erlöser") et NEB ("I will treat with none of you, says ... our ransomer") considèrent que c'est le verset précédent qui constitue la chose dite; alors que J (“Notre rédempteur... dit: Assiedstoi") considèrent qu'il s'agit du verset suivant.

Origine de la correction :

C'est Duhm qui a suggéré de s'inspirer du ${ }^{*} G$ pour lire אמר à la place de qui achève le vs 3 , puis de lier le vs 4 , ainsi introduit, à la péricope qui précède. RL a adopté la correction en cet état où HSAT34, BH3 et Cent l'ont transmise.

NEB et J, avec Volz, l'ont adoptée sans omettre אדם.

Les témoins anciens :

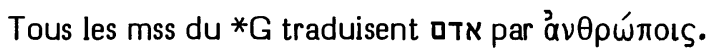

Un nombre important de témoins du ${ }^{*} G$ (parmi lesquels la 1e main du Sinaiticus, le Vaticanus et une citation en Hippolyte) n'ont ici aucun verbum dicendi. Les

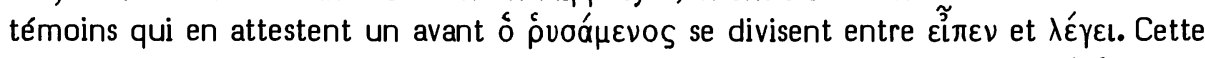
situation textuelle semble indiquer que l'ajoute de ce verbe constitue un événement secondaire dans la tradition textuelle $d u{ }^{*} G$.

Tous les autres témoins textuels, y compris $1 \mathrm{Q}-\mathrm{a}, 1 \mathrm{Q}-\mathrm{b}$ et Th, Aq, Sym, omettent ce verbum dicendi et $1 Q$-a isole par deux espaces blancs le vs 4 de ce qui le précède et de ce qui le suit.

Notons à ce propos que les mss tibériens classiques et certains autres commencent une péricope avant le vs 4 . C'est le cas des mss d'Alep, du Caire et de Leningrad, ainsi que de celui de Petrograd. Cependant, c'est après le vs 4 que certains autres mss commencent une nouvelle péricope. C'est le cas du ms Reuchlin, du ms Londres BL Add 15451 et du ms de Rossi 2. D’autres enfin ne commencent de nouvelle péricope ni avant ni après ce vs. Citons parmi eux le ms des Jésuites de Cologne, le ms des Prophètes de Berne et le ms Urbinates 1. 


\section{Choix textuel :}

C'est au "goél" d'exercer la vengeance. Le vs 4 constitue donc, après l'affirmation divine de 3b, une bonne transition préparant le nouvel oracle contre Babylone des vss 5 à 15 .

Etant donné le caractère adventice du "verbum dicendi" attesté par le *G, le comité a attribué au *M 3 " $A$ " et 3 " $B$ ".

Interprétation proposée :

Parmi les deux traductions citées au début de cette étude, l'interprétation de TOB paraît plus naturelle que celle de RSV.

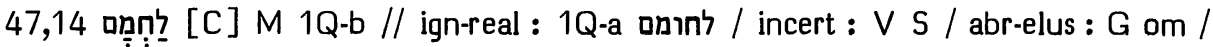
midr : $T$

Options de nos traductions :

Le *M offre en 14b : אִין

J12 ont compris le 3e mot comme "pour le pain".

RSV, RL, TOB et J3 ont compris : "pour se chauffer".

Selon Brockington, NEB vocalise לִ avec 1Q-a pour traduire : "to warm them".

Origine de la correction :

La vocalisation Avec Koppe, Michaelis (OEB) et Doederlein, il la considère comme grammaticalement préférable, pour obtenir le sens de "pour qu'ils se chauffent". HSAT34 et BH3 avaient suggéré de corriger ainsi avant que Driver (Scrolls 25) fasse remarquer que 1Q-a appuyait cette correction.

Les témoins anciens :

De Rossi (Scholia 57) a retrouvé cette vocalisation dans son ms 380 . Il est curieux de noter qu'elle est celle que donnent ici tous ceux des glossaires hébreu-français médiévaux qui sont vocalisés, c'est-à-dire $C D E$ en graphie pleine et $F$ en graphie défective.

1Q-a écrit ici לחומם, mais la graphie de 1Q-b semble identique à celle du *M.

Il est difficile de dire comment la *V (quibus calefiant) et la *S (לנורהון) ont vocalisé ce mot.

Le *G s'est évité un choix en ne le traduisant pas.

Rien ne le concerne directement dans le midrash que le *T donne à sa place ("il n'y aura ni reste ni rescapé").

Choix textuel :

Il faut noter que la vocalisation attestée par 1Q-a avait déjà été conjecturée ici

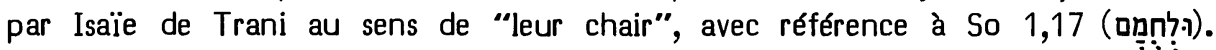
C'est vraisemblablement pour qu'on ne vocalise pas ainsi qu'une $\mathrm{mm}$ est donnée ici dans le ms Paris BN héb 6 et dans l'édition Ben H.̣aim, précisant que לְ se rencontre six 
fois dans la Bible (en Ez 4,13; 12,19; Is 47,14; Os 9,4; Jb 30,4; $\operatorname{Pr} 30,25$ ). Quatre des emplois de cette forme (Ez 4,13; 12,19; Os 9,4; $\operatorname{Pr} 30,25)$ signifient certainement "leur pain". Mais Joseph Qimhii (Galuy 40 et 78) rapproche notre cas de Jb 30,4 au sens de להתחמם (= pour se chauffer) qui est le sens que les glossaires ABCDEF reconnaissent à ce mot ici, ainsi que le seul glossaire (F) qui s'exprime sur $\mathrm{Jb}$ 30,4. Il faut noter que deux mss (le ms des Jésuites de Cologne et le ms Erfurt 3) donnent ici sur ce mot une $\mathrm{mp}$ disant que c'est l'un de deux cas semblables. Cette massore veut peut-être unir ces deux cas comme témoins d'un même sens.

Ce sens de "pour se chauffer" a été reconnu ici par Hayyuj (Kokovzov 196), Abulwalid (Luma 246,24s où il dit que la forme normale serait anל comme en $A g$ 1,6; et Luma 108,22 où il rapproche cette forme de לִ en Is 30,18), Rashi, Ibn Ezra, Judah ibn Balaam, Eliézer de Beaugency, Radaq, Jacob ben Reuben (en $2 \mathrm{e}$ exégèse), Aaron ben Joseph.

En dehors de l'exégèse "leur chair" (que nous avons déjà mentionnée à propos d'Isaïe de Trani), Yéfet ben Ely propose ici l'exégèse "leur pain", qui est celle de Saadya et de David ben Abraham (II 159,17) et sera proposée en premier lieu par Jacob ben Reuben. Il y a bien des chances que ce soit elle que la vocalisation massorétique ait visée ici; alors que l'exégèse "pour se chauffer" serait un essai pour lire dans le *M le sens de la variante de 1Q-a.

En face de cette situation, quatre membres du comité ont voté pour le $* \mathrm{M}$ avec "C" et deux ont voté pour $1 Q-a$ avec "C".

Interprétation proposée :

Les traducteurs du XVIe siècle semblent pourtant unanimes à interpréter ce mot en "pour se chauffer" et ils ont été suivis par la plupart des exégètes récents.

C'est Cocceius (sous an) qui a clairement opté pour "leur pain", suivi par Rosenmüller, von Orelli et Rignell. Notons en faveur de cette exégèse le parallèle caractéris-

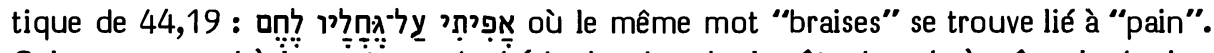
Cela correspond à lí coưtume des b́édouins de cuire la pâte du pain à même les braises (cf. Dalman IV 29-31).

Lorsqu'ensuite on ne comprit plus ce lien intime entre les braises et le pain, on chercha dans ce texte un sens de "se chauffer" qui semblait plus naturel.

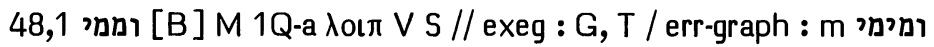

Options de nos traductions :

En parallèle à "(vous) qui (êtes) appelés du nom d'Israël", le *M de 1a continue :

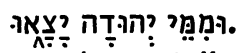

Le mot "eau" a été traduit ici littéralement par RL et J3, alors que TOB traduit plus largement par "sources" et que J12 et NEB interprètent en "semence".

RSV dit conjecturer autre chose lorsqu'elle traduit : "from the loins".

Origine de la correction :

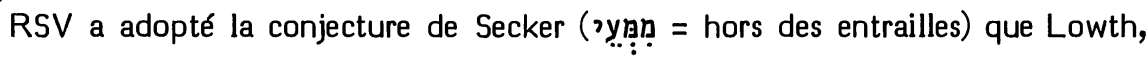


en la faisant connaître, estimait déjà inutile. Elle avait aussi été adoptée par Duhm, Grätz, Cheyne, puis par les apparats de BH23, HSAT34 et Cent.

\section{Les témoins anciens :}

La graphie du *M est appuyée par 1Q-a, alors qu’une quarantaine de mss médiévaux (qu'une seconde main a souvent corrigés), ainsi que les éditions Soncino 1488 et Brescia 1494, écrivent ici מִימ̣.

Le ${ }^{*} G$ a exprimé le sens (of $\hat{\varepsilon} \xi$ ) en supprimant l'image à laquelle les autres ver-

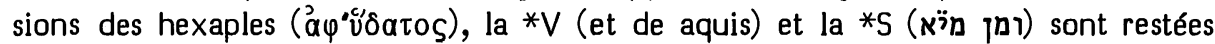
fidèles.

\section{Choix textuel :}

Le comité a attribué au *M 5 "B" et 1 " $A$ ".

Interprétation proposée :

En traduisant "de la semence", le *T s'est contenté d'interpréter cette métaphore que l'on retrouve en Nb 24,7 ("l'eau déborde de ses deux seaux") où elle est interprétée par le *G ("un homme sortira de sa semence"). Ici, Rashi fonde son exégèse sur ce parallèle. Cette exégèse traditionnelle est garantie par le parallélisme avec le stique qui précède, ce parallélisme étant lui-même garanti par celui qui existe entre les deux stiques suivants.

\section{ותחלתי 48] M G V S T // err-graph : 1Q-a}

Options de nos traductions :

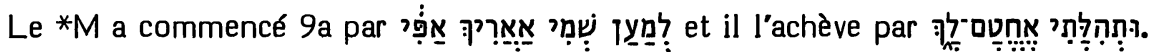

Presque toutes nos traductions ont répété avant le premier mot du $2 \mathrm{e}$ stique la préposition qui commence le vs : RSV : "for the sake of my praise", J12: "à cause de mon honneur", RL : "und um meines Ruhmes willen", TOB : "par égard pour la louange qui m'est due", $\mathrm{J3}$ : "pour mon honneur".

NEB transfère au vs 11 (cf. infra) ce premier mot du 2e stique de 9a.

Origine de la correction :

NEB dépend de BHS qui propose une conjecture de Volz.

Celui-ci, estimant que la préposition initiale ne peut avoir une double fonction et que, au vs 11 , un substantif de ce type manque, a estimé répondre aux deux difficultés par ce transfert.

\section{Les témoins anciens :}

Ce mot est lu ici par toute la tradition textuelle.

Seul 1Q-a lit un 'het' au lieu du 'hé'. On rencontre en ce ms d'autres confusions entre ces deux consonnes, confusions relevées par Kutscher (506). 
Choix textuel :

La graphie erronée de $1 Q-a$ n'a attiré personne.

Le comité a attribue " $B$ " au * $M$.

Interprétation proposée :

Gesenius/Kautzsch ( $\$ 119 \mathrm{hh}$ ) regroupe autour de celui-ci un certain nombre de cas où une préposition étend sa fonction jusqu'au substantif correspondant du second membre, à l'intérieur d'un parallélisme poétique.

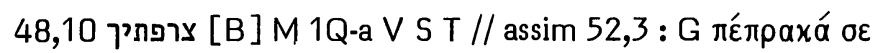

Options de nos traductions :

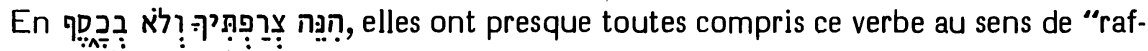
finer" ou "éprouver".

$J 3$ lit "je t'ai acheté" avec le *G, estimant que, si l'on conserve ici la leçon du *M "je t’ai épuré", il est tentant de lire, avec 1Q-a, en 10b "je t’ai éprouvé" au lieu de "je t'ai choisi". Mais elle estime qu'alors il faudrait corriger ici "non pour de l'argent" en “comme de l'argent", ce qui n'est appuyé par aucun témoin.

Origine de la correction :

C'est Koppe qui a fait remarquer que Lowth traduit ici "as silver" en lisant, avec la *V, ככס ככa.

La seule remarque que faisait Lowth portait sur le verbe du stique parallèle בחנתיך et se demandait si la *S et le *T n'ont pas lu cela. Il hésitait cependant à conclure en ce sens car le verbe בחר possède en araméen le sens de "éprouver".

C'est Oort (Jez) qui, le premier, semble avoir proposé à la fois les deux corrections בכנתיך en fondant la seconde sur la*s. Ces deux corrections ont été requises ensuite par $\mathrm{BH} 3$ et Cent, puis par $\mathrm{J12}$.

La leçon du ${ }^{*} G$ ne semble avoir intéressé personne avant $\mathrm{J} 3$.

Les témoins anciens :

Le *M est appuyé, pour pạp par tous les témoins, sauf le *G qui traduit

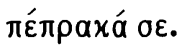

\section{Choix textuel :}

Forbes (VIII 247) signale déjà dans les tablettes cappadociennes l'expression 'kaspum sarrupum' (dérivée du verbe 'surupu' = raffiner) pour désigner l'argent raffiné, c'est-à-dire obtenu par coupellation. C'est évidemment le sens que ce verbe doit avoir en ce contexte où le comité a attribué la note "B" à la leçon du *M.

Mais le 'bet' essentiae du complément (= comme on le fait pour l'argent) a été confondu par le ${ }^{*} G$ avec le 'bet' pretii (= à prix d'argent) qui introduit ce même complément en 52,3. C'est ce qui l'a amené à traduire ici ce verbe par "vendre" qui se trouve dans l'hébreu de 52,3 (et qui revient, à propos d'Israël, en 50,1). 
Quant à la substitution du verbe בחר en 10b, elle est 'dans l'air' (cf. Za 13,9). Radaq dit en effet qu'en ce contexte c'est le sens du verbe du *M. Il est d'ailleurs vraisemblable que le prophète a voulu laisser transparaître qui caractérise dans le Second Isaïe $(41,8.9 ; 43,10 ; 44,1.2)$ la relation du Seigneur avec son Serviteur Israël. 1Q-a a réalisé cette substitution, ainsi que le feront le ms 245 de Kennicott et le ms 440 de de Rossi. Mais mieux vaut respecter le mode allusif de l'expression, mode dont nous avons groupé plusieurs exemples en 38,11.

Interprétation proposée :

“Voici que je t'ai épuré - mais pas comme on le fait pour l'argent - / Je t’ai choisi dans le creuset de l'humiliation".

Il serait bon d'indiquer en note que le verbe hébreu qui dit "choisi" évoque en même temps "affiné".

\section{8,11 cor איחל [C] 1Q-a 4Qc.d V S T // theol : M t יחל $\longrightarrow$ expl : G}

Options de nos traductions :

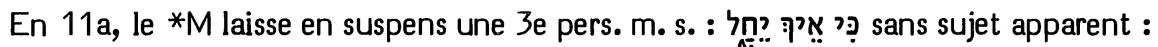
"car, comment serait profané ?"

RSV, J et TOB ont emprunté au *G un sujet : "mon nom".

RL a mis le verbe à la 1e pers. : "dass ich nicht gelästert werde".

En 48,9 nous avons indiqué que NEB déplace תהלתי pour en faire le complément de ce verbe.

\section{Origines des corrections :}

Nous avons traité en 48,9 de l'origine de la conjecture de NEB.

RL n'a pris ici aucune initiative. Elle reproduit Luther qui, lui-même, reproduisait une vieille traduction allemande de la *V (citée par Kurrelmeyer VIII 481, apparat) et a été suivi en cela par Olivetan.

Quant à RSV, J et TOB, elles suivent une proposition des apparats de HSAT2, $\mathrm{BH} 23 \mathrm{~S}$ et Cent, proposition qui remonte à Lowth se fondant sur un ms du *M et sur le *G.

Les témoins anciens :

C'est au ms 96 de Kennicott (fin du XIVe siècle) que Lowth fait allusion. Ce que nous dirons de l'histoire de l'exégèse montrera l'origine de cette glose explicitante.

Nous possédons pour ce passage trois mss d'Isaïe provenant de Qumrân : 1Q-a, 4Q-c et 4Q-d. Tous s'accordent pour écrire ici איחל.

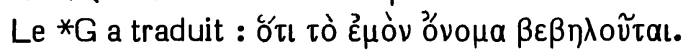

Au lieu de "à cause de moi", le *T a glosé "à cause de mon nom", ce qui permet à la plupart de ses témoins de traduire ensuite littéralement la 3e pers. sg. du verbe. Il semble cependant que sa leçon originale soit אתחל, attesté ici par le ms Reuchlin et le ms Urbinates 1.

Tous les mss de la *V (blasphemer) et de la *S (אתטוש) attestent, pour ce verbe, la 1e pers. sg. 
Choix textuel :

L'appui que les trois mss de Qumrân apportent à la variante nous force à lui accorder de sérieuses chances de représenter le texte original.

Il faut vraisemblablement rapprocher la forme איחל איחם (de qu'ils attestent de תמם) en Ps 19,14 où Radaq (Mikhlol 130,10s) voit un nifal.

Nous avons vu en $43,28 A$ (où nous avons cité 47,6 ) des cas où le ${ }^{*} G$ a voulu éviter que le Seigneur ne profane les chefs du sanctuaire ou bien son héritage. Ici c'est le ${ }^{*} M$ qui semble, par la simple omission d'un alef, avoir voulu éviter que le Seigneur soit profané. La lectio difficilior du *M semble donc issue d'une correction théologique (cf. McCarthy 207-209).

Il semble que la leçon originale ait encore été lue par la ${ }^{*} \mathrm{~V}$, la ${ }^{*} \mathrm{~S}$ et les témoins les plus anciens du *T.

Quant au ${ }^{*} \mathrm{G}$, il offre une exégèse de la correction théologique du ${ }^{*} \mathrm{M}$ en explicitant "mon nom" comme sujet du verbe à la 3e pers. m. sg.

Notons d'ailleurs que la même explicitation sera donnée par Rashi, Judah ibn Balaam, Radaq, Pagnini, Münster, Estienne, Pasteurs, Ge et KJ. Le choix critique de Lowth et de RSV ne fera donc que fournir un fondement à une glose familière aux biblistes anglophones.

Quatre membres du comité ont voté " $C$ " pour la variante des mss de Qumrân et deux ont voté " $C$ " pour le *M.

Interprétation proposée :

“Car comment serai-je profané ?" ou : “Car comment me laisserai-je profaner ?".

48,14A בלכם ... בהם [B] M 4Q-d V T(?) // harm 3e p. : 1Q-a G / harm 2e p. : m S T(?)

Options de nos traductions :

Un contraste existe dans le *M entre la 2e pers. pl. "rassemblez-vous tous et écoutez" dans le premier stique et la 3e pers. pl. "qui d'entre eux a annoncé ces choses" dans le deuxième stique.

Ce contraste a été respecté par RSV, J23, RL et TOB.

$\mathrm{J1}$ et NEB ont harmonisé sur la 2e pers. pl., Brockington fondant cette harmonisation sur de nombreux mss.

Origine de la correction :

C'est Houbigant qui a proposé cette correction en se fondant sur 2 mss et la *S. Lowth l'a suivi en dénombrant 21 mss. BH3S et Cent ont repris cette option, $\mathrm{BH} 3$ comptant 40 mss.

Les témoins anciens :

Les éditions Soncino 1488 et Brescia 1494 appuient les témoins de la forme בכם, alors que בהם est attesté par les mss du Caire, d'Alep et de Leningrad ainsi que les éditions de Felix de Prato, de Ben Hayim et celles qui les ont suivies.

Le contraste entre la $2 e$ et la $3 e$ pers. est attesté aussi par $4 Q-d$, la ${ }^{*} V$ et une partie des témoins du *T (dont le ms Reuchlin). 
Tous les témoins de la *S et une partie de ceux du *T (dont le ms Urbinates 1 ) $s$ 'accordent avec les témoins aberrants du *M pour harmoniser sur la 2e pers.

Harmonisent sur la 3e pers.: 1Q-a (donnant pour le premier stique : קבצו כלם

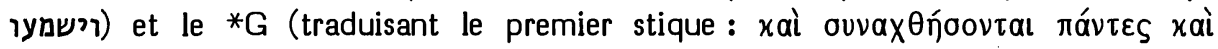
a’ov́oovtal).

\section{Choix textuel :}

Le contraste des personnes attesté par le $* M$ authentique, $4 Q-d$ et la $* V$ a reçu du comité 5 "B" et 1 " $A$ ". Il constitue la base d'où deux formes facilitantes ont divergé.

Interprétation proposée :

Ce contraste se justifie très bien : la 2e pers. s'adresse à Jacob et Israël, interpellés en 12a; alors que la 3e pers. désigne les "autres" prétendants à la divinité évoqués à la fin du vs 11 .

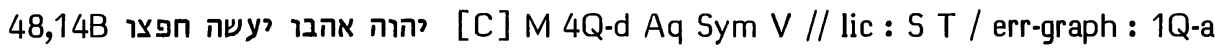
יהוה אוהבי וישה חפצי / facil-synt : G

Options de nos traductions :

Le *M a été traduit par RSV ("The LORD loves him; he shall perform his purpose"), RL ("er, den der HERR liebt, wird seinen Willen ... beweisen"), TOB ("celui que le Seigneur aime exécutera son bon plaisir") et J3 ("Yahvé l'aime, il accomplira son bon plaisir").

J12 traduisaient : "Mon ami accomplira mon bon plaisir" avec 1Q-a.

NEB traduit semblablement : "that he whom I love shall wreak my will". Mais Brockington dit que NEB a lu, en s'inspirant du *G, אà à la place des deux premiers mots du *M. Cette indication ne répond pas à la traduction de NEB.

Origines des corrections :

Les traductions de $\mathrm{J12}$ et de NEB correspondent à une conjecture de Duhm

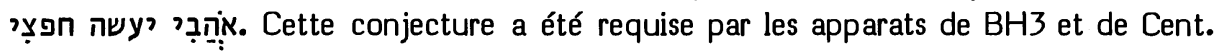

\section{Les témoins anciens :}

Le *M est entièrement appuyé par 4Q-d.

Sym (auquel Ziegler a tort de vouloir ajouter un deuxième relatif), tel que nous l'ont conservé Procope de Gaza et (partiellement) Eusèbe, traduit le * $M$ : óv ó xúplos

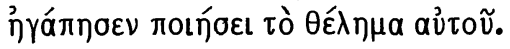

La *V le fait aussi de façon très littérale : Dominus dilexit eum faciet voluntatem suam.

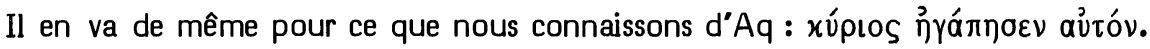

1Q-a offre ici : יהוה אוהבי וישה חפצי. Notons d'abord que le scribe a omis un 'aïn', comme il l'a fait en six autres cas relevés par Kutscher (507); cette lettre ayant été, quatre fois sur sept, ajoutée ensuite au-dessus du mot. D'autre part, comrne cela 
arrive souvent en des passages difficiles, le scribe a mal distingué les 'yod' et les 'waw' de sa Vorlage dont nous avons noté qu'elle distinguait peu ces deux lettres.

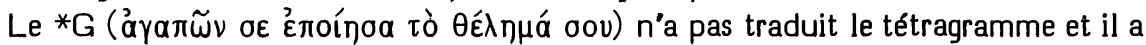
joué librement avec la personne des suffixes (qu'il assimile à l'interpellation de 12a) et celle du verbe (qu'il assimile aux trois verbes du vs 15).

La *S ("le Seigneur a aimé qu'il accomplisse sa volonté") et le *T ("le Seigneur qui a aimé Israël accomplira sa volonté") ont traduit librement le *M.

Choix textuel :

La syntaxe du *M est subtile mais se retrouve ailleurs dans le Second Isaïe. "LeSeigneur-l'-a-aimé" est un quasi-nom propre de Cyrus (reprenant celui de Salomon en 2 S 12,24), comme en 41,2: "La-justice-l'-appelle-sur-ses-pas". Ce nom-phrase a ici fonction de sujet du verbe "fera"; de même qu'en 41,2 le nom-phrase avait fonction de complément d'objet de "a suscité". On retrouve en 41,24 une brève phrase : "Il-vous-choisit" exerçant, cette fois, la fonction de sujet d'une phrase nominale.

Le texte bon mais subtil du *M est ici fermement attesté. C'est pourquoi le comité l'a retenu avec la note "C".

Interprétation proposée :

Ces noms-phrases devront être traduits par des relatives : ici "celui que le Seigneur a aimé"; en 41,2 : "celui que la justice appelle sur ses pas". On traduira de même par "celui qui vous choisit" le sujet de la phrase nominale de 41,24b.

48,14C חירֵ [C] 48,14D כשרדים [C] M 1Q-a G S // facil-synt : V T praem prep

Options de nos traductions :

Les deux derniers mots de ce vs constituent dans le * $M$ une phrase très elliptique : 政.

A la suite de KJ, RSV traduit ainsi : "and his arm shall be against the Chaldeans". $\mathrm{RL}$ traite ces deux mots comme parallèles aux deux qui les précèdent : "( $\mathrm{Er}$... wird seinen Willen an Babel beweisen) und seinen Arm an den Chaldäern".

$J$ et TOB s'appuient sur le *G pour traduire "et la race des Chaldéens" (J) ou "et son engeance, les Chaldéens".

NEB (selon Brockington) conjecture be scattered".

Origines des corrections :

$\mathrm{RL}$ reproduit Luther sans avoir pris d'initiative critique. Cependant Houbigant a proposé de corriger en ajoutant une préposition 'bet' avant 14D. Lowth, trouvant cette préposition dans l'édition princeps des Prophètes (Soncino 1486) l'a adoptée. Michaelis (OEB) ne voyant cette préposition attestée par aucun ms du ${ }^{*} M$ (ce que de Rossi confirme) y a renoncé. Cependant Delitzsch4, HSAT34 et BH2 insèrent la préposition. 
C'est Duhm qui a proposé de lire זִ: avec le *G, leçon adoptée par les apparats de $\mathrm{BH} 3 \mathrm{~S}$ et de Cent.

Quant à NEB, elle suit une conjecture de Driver (Notes 47s).

Les témoins anciens :

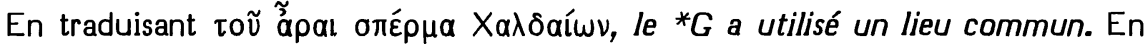

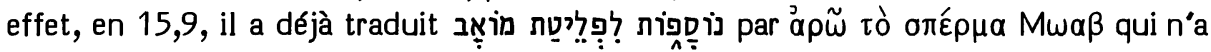
pas de relation plus directe avec l'hébreu.

1Q-a omet la conjonction (interprétant probablement : “... contre Babel dont les Chaldéens sont le bras"), alors que cette conjonction est attestée par la *V (et brachium suum in Chaldaeis) et la paraphrase du *T ("et il manifestera la force du bras de sa puissance contre les Chaldéens"). Notons que ces deux versions ont étendu à 14D l'effet de la préposition qui affecte le mot "Babel".

La ${ }^{*} S$ dépend ici du ${ }^{*} G$. En effet, Diettrich atteste que, selon l'édition de Mossul et presque tous les mss anciens, elle traduit 14C par ובזרעא (le 'zaïn' ayant été déformé en "alaf" dans certains mss, déformation qui s'est transmise à toutes les autres éditions).

\section{Choix textuel :}

Pour l'absence de préposition en $14 \mathrm{D}$, le ${ }^{*} \mathrm{M}$ a l'appui de $1 \mathrm{Q}-\mathrm{a}$, du ${ }^{*} \mathrm{G}$ et de la *S (la *V et le *T en explicitant une); alors que la leçon du *M en $14 \mathrm{C}$ a l'appui de la $* V$ et du $* T$ (1Q-a, le ${ }^{*} G$ et la ${ }^{*} S$ s'en éloignant vers des facilitations diverses). La lectio difficilior du ${ }^{*} M$ semble donc constituer la base d'où divergent les autres témoins.

Le comité a attribué à la leçon du *M 3 "C" et 3 " $\mathrm{B}$ ".

Interprétations proposées :

L'exégèse la plus probable est celle d'Isaïe de Trani : וזרעו serait parallèle à יהוה אהבו (dont nous avons traité en 14B). Il faudrait donc sous-entendre après ce mot : יעשה חפצו ב־, emprunté au stique précédent. Dans le contexte des titres qui lient Cyrus au Seigneur ("son oint" en Is 45,1), il n'y a aucun inconvénient à ce qu'il soit désigné ici comme "son bras".

On peut donc traduire : “Celui que le Seigneur a aimé exécutera sa volonté contre Babylone et son bras l'exécutera contre les Chaldéens" ( $=\mathrm{KJ})$.

Mais on ne peut éliminer l'exégèse qui voit en "son bras" une désignation pour "son oeuvre de puissance", ce qui amènerait à traduire : "Celui que le Seigneur a aimé exécutera sa volonté contre Babylone et il exécutera son oeuvre de puissance contre les Chaldéens" (= Luther).

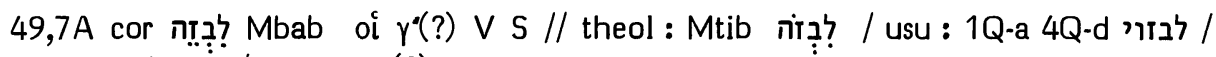
paraphr : T / lic : G Th(?)

Options de nos traductions :

Après "Ainsi a parlé le Seigneur, le rédempteur d'Israël, son Saint", le *M offre

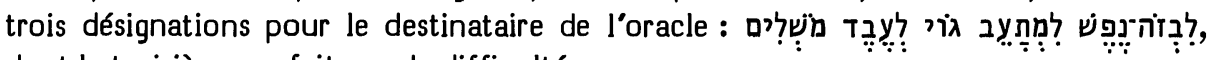
dont la troisième ne fait pas de difficulté. 
Les deux premières sont traduites par RSV : "to one deeply despised, abhorred by the nations" et par RL : "zu dem, der verachtet ist von den Menschen und verabscheut von den Heiden".

J12 traduisaient : "à celui dont la vie est méprisée et qu'abominent les nations". J2 précisait que "est méprisée" est attesté par des mss et par 1Q-a (alors que le *M signifierait "pour mépriser") et que "qu'abominent les nations", littéralement "abominé des nations", se fonde sur les versions, alors que le *M signifierait "abominant les nations".

Avec une note textuelle moins précise, 33 traduit : "à celui dont l’âme est méprisée, honnie de la nation".

TOB traduit: "à celui dont la personne est méprisée et que le monde regarde comme un être abject", précisant que la première désignation (littéralement "à un méprisé dans sa personne") est lue selon $1 \mathrm{Q}-\mathrm{a}$, la $* \mathrm{~V}, \mathrm{la} * \mathrm{~S}$ et le $* \mathrm{~T}$, alors que la deuxième l'est selon les versions. Selon TOB, le *M signifierait: “à un mépriser d'une personne, à celui qui regarde le monde comme un être abject".

NEB traduit : "to one who thinks little of himself, whom every nation abhors",

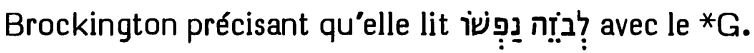

\section{Origines des corrections :}

Pour 7A, c'est Driver (LTP 401) qui a formulé cette Vorlage du *G en conseillant de l'adopter, ce que NEB a fait.

Quant à l'option de J et de la TOB, elle a été requise par les apparats de HSAT2, de $\mathrm{BH} 23$ et de Cent avant la découverte de 1Q-a. Cette correction en לִזְְ avait été proposée par Clericus.

\section{Les témoins anciens :}

BHS prétend qu'un fragment babylonien de la Geniza du Caire atteste ici la leçon לִבְּ. C'est inexact, car il s'agit du ms Oxford Bodl Heb d 64, fol. 1b qui, selon le facsimilé très clair de Yeivin, comme selon l'édition d'Alba Cecilia, porte לï̇ ( = לִבְI). De Rossi dit avoir trouvé en 2 mss et dans la 1e main d'un autre le 'zaïn' vocalisé séré et non ḥolem, alors qu'un quatrième le vocalisait segol.

1Q-a et 4Q-d offrent ici לבור.

La *V (ad contemptibilem) et la *S (לדמסתליא) ont lu ici une forme passive.

Pour ces deux désignations, le *T offre une paraphrase où il semble les permuter : à̀ ceux qui sont méprisés parmi les peuples, à ceux qui sont déplacés parmi les royaumes".

Selon Théodoret, les 'trois' ont ici un participe passif : $\varepsilon^{3} \xi \circ v \theta \varepsilon \nu \eta \mu \varepsilon ́ v o v$, alors que Hie attribue à Th un actif : "ei qui despicit". Chrysostome (cité par Ziegler) semble appuyer le témoignage de Théodoret.

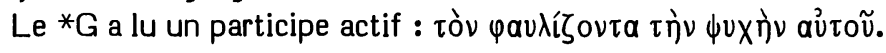

Choix textuel :

La leçon לִבְִ que le *M tibérien offre ici constituerait, pour une forme "lamedhé', une vocalisation unique. Gesenius soulignait que la vocalisation normale devrait être בִּזִה (état construit de 


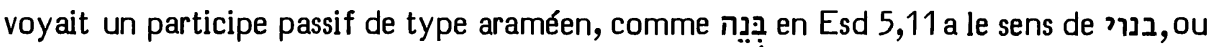

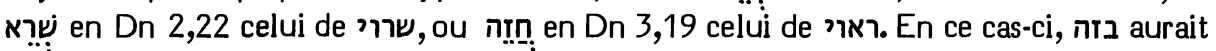
le sens de בזוי

Or nous voyons que le seul témoin préservé du ${ }^{*} M$ babylonien porte ici la vocalisation postulée par Gesenius et Luzzatto, vocalisation qui est proposée dans les quelques mss tibériens cités par de Rossi. 1Q-a et 4Q-d l'ont remplacée par la forme hébraïque courante du participe passif. Il est impossible de dire laquelle de ces deux formes la $* V$, la $* S$ et (vraisemblablement) les 'trois' ont lue.

Quant à la vocalisation du ${ }^{*} M$ tibérien, elle a peut-être voulu camoufler le sens passif de cette forme, comme celle que nous relèverons dans le prochain cas.

Le comité a attribué à la vocalisation babylonienne 5 "C $C$ " et 1 " $D$ ".

Interprétations proposées :

Le sens peut être : “à quelqu'un de méprisé quant à la personne", c’est-à-dire “à une personne méprisée"; ou bien : "à quelqu'un de méprisé par chaque personne", c'est-à-dire "à celui qui est méprisé par tous".

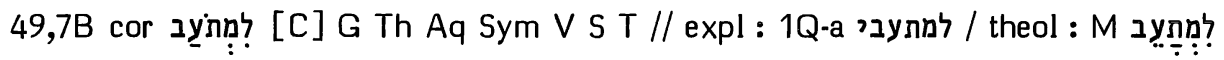

Nous avons traité des options de nos traductions à propos de $7 \mathrm{~A}$.

Origine de la correction :

Oort (Jez) a proposé de vocaliser ici בỷ. Cette vocalisation en participe pual a été adoptée ensuite par HSAT234, BH235 et Cent, ainsi que par de nombreux exégètes parmi lesquels Ehrlich et König.

Les témoins anciens :

Ce participe a été compris au sens passif par toutes les versions (le ${ }^{*} \mathrm{G}, \mathrm{Th}, \mathrm{Aq}$, Sym, la*V, la *S et le *T).

1Q-a s'est contenté de mettre au pluriel le participe :למתעבי, pour en expliciter la valeur collective.

\section{Choix textuel :}

Ont interprété ce participe au sens passif : Saadya, Abulwalid (Luma 310,3s disant qu'un participe pual serait normal ici), Rashi, Eliézer de Beaugency, Radaq, Isaïe de Trani.

Yéfet ben Ely respecte le sens actif : "car ils détestent les opinions religieuses de tous les peuples du monde et ne mangent pas leurs nourritures et ne boivent pas leurs boissons et ne contractent pas de liens de parenté avec eux; et quand vient le sabbat, une coupure se fait entre eux".

Subtilement, Ibn Ezra suggère qu'il peut s'agir ici d'un causatif : "qui suscite la détestation de la part des païens". Delitzsch répond à cela qu'un causatif devrait être ici : "qui rend les païens détestables", ce qui serait un contre-sens. 
Le comité a considéré la vocalisation en pual comme suffisamment attestée par les versions et l'a adoptée par 5 "C $C$ " et 1 " $\mathrm{B}$ ", en considérant la vocalisation du *M comme une correction théologique visant à éviter de dire qu'Israël est détesté par les païens.

Interprétation proposée :

Le sens peut être : “à celui qui est détesté par chaque nation”.

49,8 : cf. p. 303.

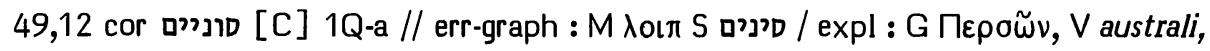
דרומא Tורי Th

Options de nos traductions :

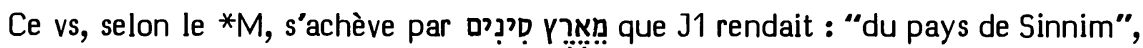
J23 : "du pays de Sînîm" et RL : "vom Lande Sinim".

RSV et NEB donnent ici : "of Syene" et TOB : "d"Assouan", Brockington disant que NEB conjecture Dִ a avec 1Q-a (auquel TOB se réfère aussi).

Origine de la correction :

Cette correction avait déjà été proposée par Cheyne et Marti, puis $\mathrm{BH} 2$ (en addenda), HSAT34, BH3 et Cent avant la découverte de 1Q-a. Après cette découverte, elle a été adoptée par BHS et la plupart des exégètes.

Les témoins anciens :

1Q-a écrit ici סוניים, alors que les colonnes hexaplaires autres que le ${ }^{*} G$ ont “sinim" et la *S דסנים.

La *V interprète en "australi" et le ${ }^{*} T$ en דרומא, alors que le *G traduit par

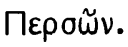

Choix textuel :

Bochart (Phaleg 275,37-55) a noté que, du fait que le nord et l'ouest sont nommés ici explicitement, le terme מִ̣n (qui précède le nord) a bien des chances de désigner l'est, et le toponyme מאריץ סינים (qui suit l'ouest) de désigner le sud, comme la *V et le *T l'ont d'ailleurs compris. Il propose de s'inspirer d'une correction conjecturale qu'il fait d'une opinion de Saadya citée par Radaq pour comprendre ici le pays des Pélusiotes. Notons en passant que Derenbourg (sur Saadya in loco) a montré que Radaq, en son commentaire d'Isaïe, ne cite pas la traduction donnée ici par Saadya (où celui-ci se contente de transcrire par "pays de Sîn"), mais celle que celui-ci donne pour הַ הַ de Gn 10,17.

Michaelis (Spicilegium II 32-42) a objecté à cela que le prophète semble vouloir évoquer ici les origines lointaines de ceux qui arrivent à Sion. Or Péluse, à l'est du delta est tout proche de la Terre Sainte. Aussi a-t-il suggéré d'identifier ce toponyme 
à Dִ qui est deux fois rapproché de jen Ez 30,15 et 16. Cette deuxième ville (= Thèbes) a été bien identifiée par le *G à Diospolis au vs 16 , où pọ a été identifiée par lui à Syène (= Assouan). Mais au vs 15 , ju ayant été confondu par le ${ }^{*} G$ avec qj (= Memphis), il a transcrit p par Saïs, profitant de ce qu'il avait l'occasion de mettre ce toponyme à l'accusatif ('żi Cáıv). S'inspirant de l'option du *G en Ez 30,16, Michaelis propose de reconnaître aussi la région d'Assouan en Is 49,12.

Doederlein avait émis une réserve lorsque cette suggestion lui était venue à l'es-

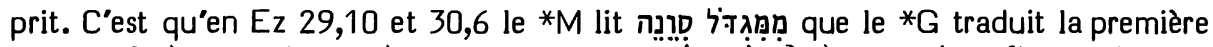

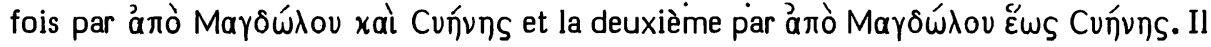
y voit une indication que Syène se disait en hébreu Ḍְִנ et non $A$ cela Michaelis (Supplementa 1725s) répond en proposant de vocaliser en ces deux endroits Dִירנ, considérant le "hé" final comme désinence de l'accusatif directionnel, ce que le $*$ *G semble d'ailleurs avoir lu en 30,6. Ainsi “de Migdol à Sewén" exprimerait toute l'Egypte, d'une extrémité à l'autre. Il doit cependant reconnaître que le toponyme ainsi obtenu continue à se distinguer de סין d'Ez 30,15.16 et de סינים d'Is 49,12 par la présence d'un 'yod' là où l'on attendrait un 'waw'. Mais Hérodote (II 29s) indique très clairement qu'Eléphantine (en face de Syène) était la ville de garnison qui gardait (sous Psammétique et sous les Perses) la frontière méridionale de l’Egypte, après quoi on entrait dans le désert. Aussi Michaelis (Spicilegium 41) estime-t-il que Syène pouvait fort bien représenter pour le prophète la limite méridionale du monde civilisé.

Alors que la plupart des exégètes cherchaient ici la Chine (quoique les transcriptions arabes et syriaques de son nom fassent usage d'une interdentale emphatique), la suggestion de Michaelis a été reprise par Grätz, Cheyne et Marti.

La découverte des papyri d'Eléphantine a fourni trois attestations (Cowley pap. $24,33 ; 33,6 ; 67,3)$ du gentilice (à dérivation persane), la première attestation le munissant d'un pluriel araméen. Notons à ce propos que lesdits papyri n'attestent aucun gentilice dérivé de Yeb (= Eléphantine).

Enfin la découverte de 1Q-a a apporté l'attestation formelle de la forme requise avec ' $w a w^{\prime}$ 'radical au lieu de 'yod'. On peut se demander si le fait que le ${ }^{*} G$ ait traduit ici "des Perses" n'indiquerait pas que la tradition s'était maintenue à l'époque du traducteur qu'Assouan avait été une colonie militaire des Perses.

Si l'on objecte que le scribe de $1 Q-a$ a pu harmoniser avec les parallèles d'Ezéchiel, on peut répondre que ces parallèles sont littérairement trop atypiques pour qu'ils aient pu exercer une telle influence. Rappelons-nous, par contre, que 1Q-a nous avait conservé en 19,18 une tradition de topographie égyptienne qui nous avait paru authentique.

Le comité a attribué ici à la leçon de 1Q-a la note "C".

Interprétation proposée :

Littéralement : "du pays des gens de Syène", c’est-à-dire "de la région d"Assouan". 
ואלוהי (A] M 1Q-a* (et 2e corr) G V S T // dissim : 1Q-a(corr) ואדנִי 49,14

\section{Options de nos traductions :}

Dans la traduction de ce mot, nos traductions semblent offrir certaines hésitations.

Les premiers tirages de RL ont écrit "HERR" tout en capitales, graphie que Luther réserve au tétragramme (alors qu'il écrit ici les deux " $r$ " en minuscules).

J donne ici "le Seigneur".

RSV traduit "my Lord" et TOB "mon Seigneur" sans notes. à $1 \mathrm{Q}-\mathrm{a}$.

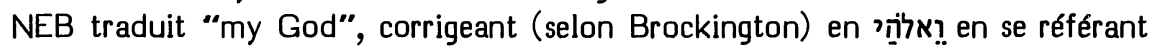

\section{Origines des corrections :}

RSV et TOB suivent Budde (HSAT4) qui a proposé de vocaliser ici lַ et de traduire "mein Herr" au sens de "mon époux".

NEB dépend peut-être de North qui dit: " "1Q-a a ואלוהי 'et mon Dieu” écrit audessus de ואדני. Ce n'est pas la leçon originale, mais cela indique que la communauté de Qumrân lisait le tétragramme comme 'adônây' et, suivant la règle générale, évitait la répétition du mot en des stiques parallèles. Nous pouvons faire de même et traduire אדני par "my God'."

\section{Les témoins anciens :}

Comme le note Kutscher (529), le mot écrit au-dessus de la ligne en 1Q-a a été ensuite annulé en plaçant un point avant et un point après lui.

De nombreux mss massorétiques portent ici ויהוה avec les éditions Soncino 1486 et 1488 . Cependant une massore (Weil $§ 2390$ ) précise que nous avons ici un des 3 cas où ce qeré 'wadonây' correspond au ketib ואדני.

Toutes les versions donnent ici l'équivalent normal de ce qeré, sans que l'on puisse préciser le ketib qu'elles ont lu en leur Vorlage.

\section{Choix textuel :}

Le comité a estimé que cette velléité de retouche du scribe de 1Q-a ne saurait suffire à fonder la traduction "mon Dieu".

Quant à la vocalisation proposée par Budde, le fait que le vs 15 développe l'image de l'attachement d'une mère pour son enfant rend cette interprétation conjugale peu probable.

D'ailleurs la difficulté à laquelle ces diverses corrections tentent de faire face ne pouvait exister pour l'auteur biblique qui ne se pliait pas encore à la convention du qeré perpétuel 'adonây' pour le tétragramme.

Le comité a donc attribué au * $M 5$ " $A$ " et 1 " $B$ ".

Interprétation proposée :

La vraie réponse à cette difficulté est de distinguer graphiquement les cas où "le Seigneur" correspond au ketib אדני de ceux où il correspond au tétragramme (le SEIGNEUR). 


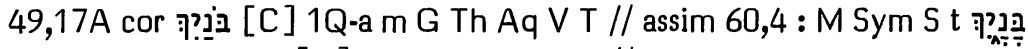

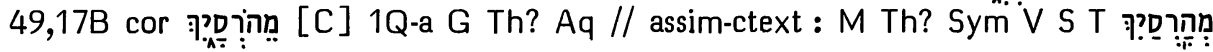

\section{Options de nos traductions :}

Le *M offre ici un premier stique très bref : מִהְרו (= tes fils se hâtent), et un

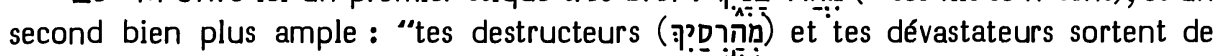
toi."

Aucune de nos traductions ne traduit en 17A "tes fils" pour donnent "tes bâtisseurs" (RSV, RL, TOB, J3) ou "tes rebâtisseurs" "(j12, NEB), la note la plus précise étant en TOB qui se fonde sur 1Q-a, la *V, le *T et un ms hébreu pour vocaliser 翟.

En 17B, le *M est traduit par J12 et TOB ("tes démolisseurs"), J3 ("ceux qui te détruisent") et RL (“die dich zerbrochen ... haben").

Mais NEB, aux dires de Brockington, vocalise מִּ pour faire de ce mot le dernier du premier stique qu'elle traduit: "those who are to rebuild you make better speed than those who pulled you down". Quoiqu'elle ne notât rien, RSV traduisait déjà de même : "your builders outstrip your destroyers".

\section{Origines des corrections :}

En 17A, nous verrons que la leçon ou l'interprétation "tes bâtisseurs" ont eu une vogue continue depuis le ${ }^{*} G$ ancien jusquà nos jours.

En 17B, il a fallu attendre 1909 pour que Budde, en HSAT3, propose de fonder sur "les versions" la vocalisation que NEB adoptera.

\section{Les témoins anciens :}

Le ${ }^{*} G$ a d'abord pris l'initiative de traduire le verbe initial par un adverbe (xaì $\tau a x u ́)$. Puis, en 17B, il a lu nמ̣ en donnant à la préposition un sens d'origine :

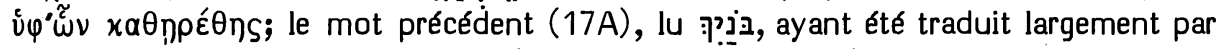

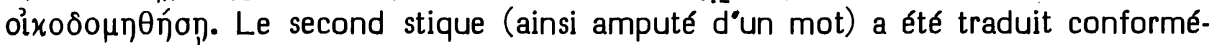
ment au *M.

Nous ne connaissons Th et $\mathrm{Aq}$ (comme d'ailleurs Sym) que par le commentaire attribué à Chrysostome et conservé en arménien. Une chose est certaine, c'est que tous deux ont lu d'origine, ainsi que le ${ }^{*} G$ l'avait fait. Sur ces deux points, Sym témoigne des leçons du $* M$.

1Q-a, avec מהרו בוניך מהורסיך nous a préservé exactement pour le premier stique (le second étant identique au ${ }^{*} M$ ) ce que l'on peut inférer comme ayant été la Vorlage $d u{ }^{*} G$ et de Aq. Ces deux versions sont pour nous des témoins d'autant plus précieux qu'elles n'ont pas compris ce texte où la préposition 'min' a un sens de comparatif : "tes constructeurs iront plus vite que tes destructeurs".

La *V traduit ce vs par "Venerunt structores tui destruentes te et dissipantes a te exibunt". Hie clarifie la syntaxe dans son lemme : "Venerunt structores tui et qui te destruxerunt et dissipaverunt exibunt a te".

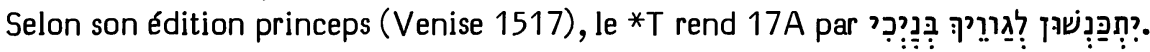
Selon l'édition Ben Hayim, il rend ce mot par Selon la polyglotte d’An- 


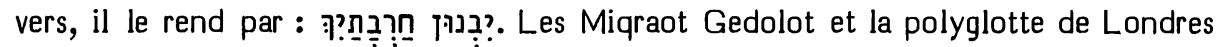
copient Ben Hayim avec des nuances dans la vocalisation. Les éditions Stenning et Sperber suivent la polyglotte d'Anvers avec tous les mss connus par Sperber, plus les mss Paris BN hébr 1325 et Urbinates 1 dont il n'a pas fait usage. On peut donc conclure que, sous réserve de nuances dans la vocalisation, c'est le texte authentique du *T, les deux premières Bibles rabbiniques (ainsi que les éditions qui les ont copiées) ayant assimilé ce texte à celui du *M. Pour le second stique, le *T suit le *M.

La $* V$ et le $* T$ (comme probablement Th) ont donc un état textuel mixte qui lit $17 \mathrm{~A}$ selon $1 \mathrm{Q}$-a contre le $* \mathrm{M}$, mais $17 \mathrm{~B}$ selon le $* M$ contre $1 \mathrm{Q}$-a.

$\mathrm{La} * S$ (comme l'avait fait le ${ }^{*} G$ ) traduit le premier verbe en adverbe et voit dans les deux participes des épithètes de "tes fils" : "Bientôt tes fils qui te détruisent et te dévastent sortent de toi."

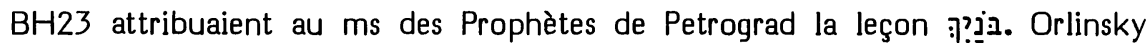
(Meḥqârîm 7 7; State 27) dit et répète que cette mention est sans fondement et que, si Kittel avait, comme lui-même l'a fait, contrôlé le facsimilé édité par Strack, il aurait pu constater que la vocalisation y est conforme à celle du $* M$ tibérien. Ces dires d'Orlinsky ont influencé Kutscher (225, n.2). Pourtant, si Orlinsky avait consulté le commentaire joint par Strack à son édition, il y aurait lu (011) que la 1e main avait écrit ذניך (= ceux qui te construisent).

Histoire de l'exégèse de 17A :

Judah ibn Balaam (selon la traduction de Derenbourg) déclare ici : "בניך. Je dois d'abord dire que je n'ai trouvé aucune copie où בניך ait un 'ḥolem' sur le 'bet', jusqu'à ce que j'aie eu en mains le commentaire de quelques Parschiot par Rab Samuel Haccohen le Gaon, où il a divisé la racine 'bet-nun' en différentes parties et a rangé cet exemple de מהרו בניך dans la signification de 'bâtir', avec בנה בניתי (1 R 8,13). Si cela est juste - et je ne le crois pas - il aurait vu le mot avec un 'holem', puisqu'il l'a considéré comme un participe dans le sens de 'bâtir'; peut-être s'est-il appuyé pour cette option sur la fin du verset qui est : les démolisseurs et les destructeurs; mais tout cela est fondé sur une erreur : בנים אתם est comme (Dt 14,1) sans aucun doute; Saadya s'est associé à l'opinion de R. Samuel en l'adoptant dans la traduction d'Isaïe."

De fait, Saadya traduit bien ici באנוך et Derenbourg indique que cela correspond à une Vorlage בוניך. Mais celui-ci ne semble pas avoir noté une remarque de Dunash ben Labrat (Contre Saadya, fin) nous informant que Saadya considérait qu'ici une

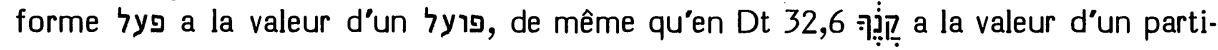
cipe actif. Donc, pour traduire en participe actif, Saadya ne faisait appel à aucune autre leçon que celle du *M tibérien. Il est d’ailleurs frappant de noter que Vitringa (qui ne connaissait pas la notice de Dunash) a noté, à son tour, que la vocalisation , in interprétée comme aramaïsante, pourrait justifier la traduction 'structores tui'

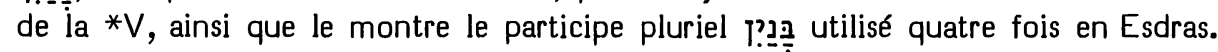
Mais il ajoute que les vocalisateurs étaient assez prudents pour épargner à leurs lecteurs une si redoutable ambiguité.

Il est sûr, en tout cas, que la vocalisation du *M est doublement protégée : d'une part par une mp notant comme unique la vocalisation 7? ב̇ en Ez 27,4, et d'autre part par une mm (Ginsburg Massorah 2§378) citant notre cas parmi les 18 cas de vocali- 
sation parmi les exégètes juifs postérieurs.

Aussi est-on surpris de constater que cette exégèse a eu de la peine à acquérir droit de cité parmi les exégètes et traducteurs chrétiens du XVIe siècle.

Sous l'influence de la *V, Oecolampade, en 1525, garde "structores tui".

C'est d'ailleurs ainsi que Pagnini, en 1526 (Institutiones 106a) traduit ce mot lorsqu'il le cite à titre d'exemple grammatical, en s'intéressant à son pronom suffixe. Mais, dans sa traduction biblique (en 1527), il le rend par "filii tui".

Cependant Luther traduit: "deine bawmeister". Il n'a jamais retouché cette traduction et, dans son cours sur Isaïe (WA. XXXI/2 406,18-24), il ne semble pas soupçonner que le sens puisse être autre que 'structores tui' de la *V sur quoi il construit son exégèse de ce stique.

Brucioli ("i figlioli tuoi") en 1532 est fidèle à la traduction de Pagnini. Mais Münster (en 1535), tout en vocalisant בִּרִ leçon par laquelle Michel Servet remplacera le "filii tui" de Pagnini dans la réédition qu'il donnera de la traduction de celui-ci en 1542. Notons que, dans la réédition de Pagnini par Robert Estienne, en 1557, la traduction authentique sera préservée. Mais il notera en bas de page: "Filii tui : בניך structores tui. aedificatores tui." Dans la réédition de Pagnini corrigée par Arias Montano (en 1571 dans la polyglotte d'Anvers), celui-ci, prenant pour base l'édition de Servet, réintroduit (comme le suggérait Estienne) la leçon de la $* V$.

Zwingli, en 1529, traduit le vs 17 : "Properabunt ad instaurandum te, qui te disiecerant, et qui te vastarunt, in te versabuntur". La même année, la Bible des Prédicants de Zurich porte : "Die dich zerstört habend / werdend eylen dich widerumb zebauwen : unnd die wüst gelegt habend / werdend in dir wonen." Pellican commentera ensuite la $* V$ en ce sens. Quand Jud voudra donner de ce mot une traduction plus littérale, ce sera encore "aedificatores tui". Le groupe de Zurich est donc unanime sur le sens de "bâtisseurs".

Sous l'influence de Münster, Olivetan, en 1536, traduit : "ceulx qui te edifieront", traduction qui sera conservée en ses rééditions par Rollet (en 1551) et par Estienne (en 1553). Châteillon garde en latin la leçon de la *V et donne en français : "tes bâtisseurs". Calvin, dans son commentaire, ne semble pas soupçonner la possibilité d'une interprétation autre que celle-là. Il ne faut donc pas s"étonner si la Geneva Bible, sans proposer de variante, traduit : "Thy buylders". Parmi les exégètes du milieu du siècle, Brenz ne retouche pas la $* V$, Musculus garde la traduction de Münster et Foreiro celle de Jud.

Cependant Vatable, en ses notes, s'attachera à la traduction authentique de Pagnini : "filii tui". Ce sera Tremellius qui, reprenant cette traduction en 1579, dans sa Bible latine, suscitera dans les domaines français et anglais un retour au ${ }^{*} \mathrm{M}$. A sa suite, la Bible des Pasteurs de Genève, en 1588, donne : "tes enfans" et la King James Version : "Thy children".

Choix textuel :

Cette longue fidélité à la $* V$, à la suite d'Oecolampade, Luther, Münster et Olivetan explique pourquoi Cappel (Critica 863) a noté la différence de vocalisation 
existant ici entre le *M et la Vorlage (en participe qal) qu'il infère pour le ${ }^{*} G$ et la $* V$.

Etant donné qu'il ne s'agit là que d'une question de vocalisation, Houbigant traduit "qui te aedificabunt" sans note.

A propos de Is 62,5, Lowth (Poesis 619s) propose ici aussi cette interprétation.

Tout en reconnaissant que "tes fils" s"insèrent bien dans le contexte, Michaelis (OEB) préfère corriger la vocalisation pour obtenir un meilleur contraste avec les participes suivants.

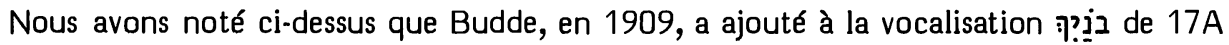

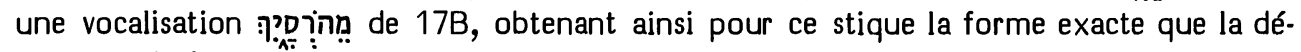
couverte de 1Q-a allait attester, quarante ans plus tard.

On peut invoquer en faveur de ces corrections vocaliques les deux motifs suivants : 1/ "Arriver rapidement" ne s'exprime pas, en hébreu biblique, par le piél de employé seul, mais ou bien en combinaison avec le verbe בוא (cf. Ex 2,18; 1 S 4,14; 25,34), ou bien avec un complément de destination repérable par une préposition directionnelle (cf. $\operatorname{Pr} 7,23$ ) ou un accusatif locatif (cf. Gn 18,6; Na 2,6). Normalement ce piél se combine comme auxiliaire avec un verbe d'action dont il dit la rapidité, ce qui est le cas dans la leçon de 1Q-a. 2/ Le piél de הר n'est attesté dans le *M - en dehors de ce cas - qu'en Ex 23,24. Au contraire, le qal (30 fois dans la Bible) en est la forme active normale.

Ajoutons que la structure syntactique de ce vs est plus cohérente dans la leçon de 1Q-a qu'elle ne l'est dans celle du*M.

Pour ces motifs, le comité a attribué la note "C", en 17A et en 17B, aux leçons de 1Q-a.

Ce sont vraisemblablement des parallèles du type de 60,4 qui ont influencé le *M dans

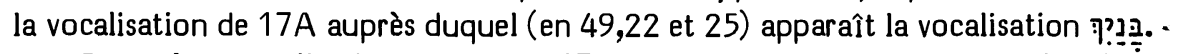

Quant à la vocalisation du ${ }^{*} \mathrm{M}$ en $17 \mathrm{~B}$, il se peut qu'elle tire son origine d'une interprétation en préformante participiale du 'mem' initial de ce mot, par assimilation à la structure du mot qui le suit.

Nous rencontrerons encore en 54,13 et 62,5B des hésitations entre "fils" et "bâtisseurs".

Interprétation proposée :

“Tes rebâtisseurs ont gagné de vitesse tes destructeurs et tes démolisseurs sortiront de chez toi."

49,19 תצר [B] M 1Q-a T // facil-synt : G V S

Options de nos traductions :

Le *M offre au milieu de ce vs une anacoluthe : "Car tes ruines et tes dévastations et ta terre en démolitions ... car te voici maintenant trop à l'étroit pour tes habitants." 19a commence donc par כי כי et comprend trois substantifs coordonnés munis de suffixes de la 2e pers. f. sg. Puis la construction est interrompue et reprise au début de 19b par introduisant, cette fois, un inaccompli à la $2 \mathrm{e}$ pers. f. sg. dont le sujet est constitué par le possesseur des trois suffixes des substantifs précédents.

L'anacoluthe a été respectée par RSV, J1 et TOB. 
RL, J23 et NEB traduisent en donnant les substantifs de 19a comme sujets au verbe initial de 19b. J3 note qu'en cela elle suit les versions.

Origine de la correction :

Alors que Duhm suppose une lacune au milieu du vs, Oort a proposé de corriger le verbe en

Notons que RL se contente ici de suivre Luther.

Les témoins anciens :

1Q-a et le *T appuient l'anacoluthe du *M.

Le ${ }^{*} G$, la $* V$ et la $* S$ ont précédé $R L, J 23$ et NEB en leur option.

Choix textuel :

Au XVIe siècle, la syntaxe du *M a été respectée par Oecolampade, Pagnini (éditions de 1527 et 1557), Brucioli, Olivetan, Vatable, Tremellius et Pasteurs. Mais la facilitation syntactique de la $* V$ a été adoptée par Luther, Zwingli, Prédicants, Münster, Servet (rééditant Pagnini, puis non retouché par Arias Montano), Châteillon, Calvin, Estienne, Ge, KJ.

Contre cette facilitation, le comité a attribué au *M la note " $\mathrm{B}$ ".

Interprétation proposée :

TOB a traduit avec souplesse: “Oui, dévastation, désolation, terre de démolition que tu es, / oui, désormais tu seras trop étroite pour l'habitant."

49,21 וגולה וסרה /C] M Th Aq Sym V S T // facil-synt : 1Q : וסלה וסורה : G om

Options de nos traductions :

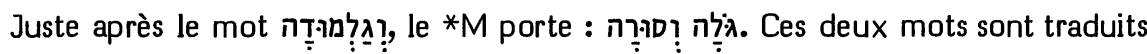
par RSV : "exiled and put away", RL : "vertrieben und verstossen", TOB : "en déportation, éliminée", 33 : "exilée et rejetée".

$J 12$ et NEB omettent ces deux mots comme manquants dans le *G.

Origine de la correction :

C'est Ruben (cité par Cheyne) qui a proposé de voir en ces deux mots une dittographie du mot précédent. HSAT34 et Cent ont proposé de les omettre.

Les témoins anciens :

1Q-a porte : וגלה וסרה, le 2e mot semblant issu d'une correction.

Le ${ }^{*} G$ ancien $n$ 'a rien qui corresponde à ces mots.

Th, Aq, Sym, la *V, la *S et le *T les traduisent.

Choix textuel :

La suggestion de Ruben n'est pas impossible.

Même s'ils sont le résultat d'un développement littéraire à partir d'une dittographie, la présence de ces deux mots en 1Q-a nous montre qu'ils faisaient partie du con- 
tenu littéraire de I'Isaïe hébreu déjà au $2 e$ siècle avant J.-C. Il ne faut donc pas les omettre.

Le comité a attribué au *M la note " $C$ ".

Interprétation proposée :

“en déportation et à l’écart".

49,24 cor עריק 1C] 1Q-a G V S Tyer // theol : M ThAq Sym T

Options de nos traductions :

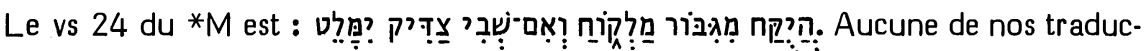
tions ne traduit l'avant-dernier mot en conformité avec ce texte. RSV le rend par "tyrant", J12 par "guerrier", RL par "einem Gewaltigen", NEB par "ruthless", $J 3$ et TOB par "tyran". Toutes ont lu y yִ en se fondant sur 1Q-a, la*V, la *S et en se référant au *G.

Origine de la correction :

Châteillon déjà proposait de lire cela avec la ${ }^{*} V$. A partir de Lowth, la plupart des exégètes ont opté pour cette correction qui est requise par les apparats de HSAT234, BH23S et Cent.

\section{Les témoins anciens :}

$1 Q$-a lit ici ץ'y.

$\mathrm{La} * \mathrm{~V}$ (a robusto) et la *S (דעשינא) lisent ici le mot dont elles feront usage pour traduire y au vs 25. Cependant Hie ("mundus enim in maligno positus est, quem nullus justorum vincere potuit") trahit la connaissance de la leçon du *M. Cela peut être par l'intermédiaire des hexaples, puisque ThAq traduisent ici ó́xaıov et Sym Sıxaíov.

Le *T de Jonathan (דשבו זכאין) traduit le *M. Mais un "targum yerushalmi" est donné en marge du ms Reuchlin. Il porte au lieu de cela : דשבו בנוי דישמעאל תקיפא (les mots מן צדיקיא ayant été ajoutés ensuite en fin de ligne, nettement hors de l'alignement). Etant donné que ce même targum traduira au vs 25 y par l'expression : תקיפיא דבית ישמעאל, on peut conclure qu'au vs 24 ce targum lisait aussi yר, puis que sa leçon a été gonflée ensuite par recension sur le *M ou sur le *T de Jonathan.

Le ${ }^{*} G$ peut faire difficulté. En effet l'avant-dernier mot du texte hébreu du vs 24 y est traduit par ảó́xws, alors qu'en 25 y y est traduit par mapà loxúovtos. Notons d'abord que l'usage d'un adverbe pour traduire ce substantif au vs 24 tient à ce que שבי y a été traduit par un verbe. Mais la racine åठ $\delta x^{*}$ a servi déjà deux fois $(25,3.4)$ au ${ }^{*} G$ pour traduire $\gamma^{2}$, alors qu'il n'a pas fait usage de la racine 'oxu* pour cela. Cependant, il en a fait usage pour traduire מערצה 10,33. On peut donc considérer comme très probable qu'en 49,24, le *G a lu la leçon de $1 Q-a$.

Choix textuel:

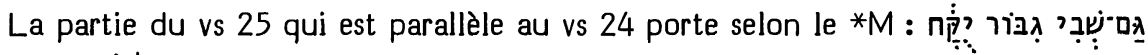
••• 
Au vs 24 , quelle leçon est primitive : צדיק du *M ou ער 1Q-a ?

On obtient avec la leçon de 1Q-a une correspondance exacte de tous les termes employés. Mais on peut se demander si 1Q-a n'a pas tendance à accentuer le parallélisme entre les deux phrases. En effet, il n'a pas la permutation de שלקוח de qui les distingue selon le $* M$. Mais on peut répliquer à cela que 1Q-a offre deux formes distinctes du verbe לקח (un qal pluriel et un nifal singulier), alors que le $* M$ offre deux fois un pual singulier.

D'autre part, le vs 24 doutait que ces événements pussent se réaliser. Et - ainsi que Châteillon l'a noté - la raison d'être de la reprise du vs 24 dans le vs 25 est de montrer que c'est exactement cela qui se réalisera. Il semble donc que la modification voulue d'un mot attendu (que nous avons déjà notée comme caractéristique du style de la seconde partie du livre d'Isaïe) ne serait pas en place ici où l'on a besoin, au contraire, d'une reprise des mêmes termes.

Il est donc plus vraisemblable que la leçon du $* M$ est une déformation de celle de $1 \mathrm{Q}-\mathrm{a}$ dont elle est graphiquement assez proche.

De fait, le vs 24 fait appel à une constatation d'expérience: "Est-ce que l'on arrache à un guerrier sa prise ? Le captif d'un homme brutal s'échappera-t-il ?"' Mais la fin du vs 23 était : "Et tu sauras que je suis le Seigneur, ceux qui espèrent en moi ne seront pas confus." Il est donc assez tentant de lire le vs 24 comme parlant du Seigneur. Et on peut comprendre que, dans cette ligne de lecture, on ait été gêné de lui voir attribuer le qualificatif ערי צדיק (= "juste" et, par extension : "vainqueur"). Le vs 25 est demeuré intact, car il ne prêtait pas à cette interprétation.

Le comité s'est divisé, attribuant 4 " $C$ " à la leçon de $1 Q$-a et 2 "C $C$ " à celle du *M.

Interprétation proposée :

“Est-ce que l'on arrache à un guerrier sa prise ? Le captif d'un homme brutal s'échappera-t-il ?"

50,4 בבקר בבקר [B] M 1Q-a V S T // def-int : G ПPOC— ПPWI / incert : Sym

Options de nos traductions :

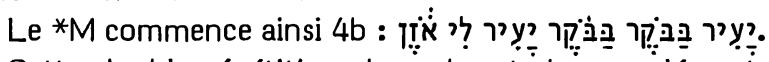

Cette double répétition du verbe et du complément temporel est exprimée par RSV : "morning by morning he wakens, he wakens my ear" et par J3 : "il éveille chaque matin, il éveille mon oreille".

La répétition du verbe n'est pas exprimée par J12 : “tous les matins il éveille mon oreille", ni par RL : "alle Morgen weckt er mir das Ohr", ni par TOB : "matin après matin, il me fait dresser l'oreille", aucune de ces trois traductions ne notant cette omission.

Seule NEB (selon Brockington) se réfère au ${ }^{*} G$ pour omettre les deux premiers mots en traduisant : "... in the morning; he sharpened my hearing". 
Origine des corrections :

Duhm a proposé de voir dans les deux premiers mots une variante des trois suivants et de les omettre à ce titre. BHS propose cette omission en disant que l'un des deux בבקר manque en un ms, dans le *G, dans la Vieille Latine et dans l'Ethiopienne.

\section{Les témoins anciens :}

Les deux dernières versions citées par $\mathrm{BHS}$ n'apportent pas un témoignage séparé puisqu’elles dérivent du *G.

Quant au ms de Kennicott qui omet ce mot, son autorité est sans poids en face de la mm (Weil §688) qui énumère les 13 endroits du *M où ce mot est redoublé. Ginsburg (Massorah $2 \$ 440$ ) dit avoir rencontré dix-sept fois cette massore sans y relever de variantes.

1Q-a appuie le *M dans son contenu et dans ses teamim en se contentant d'y ajouter deux conjonctions : ויעיר בבוקר בבוקר ויעיר לי אוזן.

Le ${ }^{*} G$ a rendu le premier par p̌

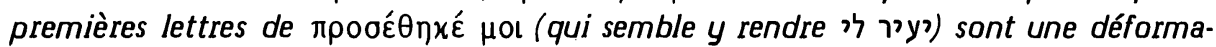
tion interne de $\pi \rho \omega$ í (ce qui nous donnerait une Vorlage identique au $* M$ ). En effet, en 28,19 le *G rendait cette répétition de בבקר par une simple répétition de $\pi \rho \omega$ í.

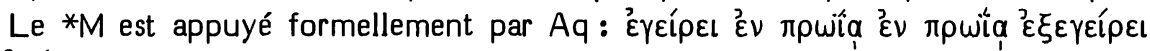
$\mu \circ \mathrm{o}$ w̌ríov, et par la *V : erigit mane mane erigit mihi aurem.

Pour Sym, Eusèbe donne une leçon inutilisable certainement corrompue.

La *S a lu le *M, mais s*est inspirée du *G pour traduire le second נעבד par.

Le midrash que le ${ }^{*} T$ donne ici atteste au moins une répétition du complément temporel.

\section{Choix textuel :}

La leçon du *M, d’Aq et de la *V (appuyée aussi par 1Q-a) n’a donc pas ici de concurrente sérieuse.

C'est pourquoi le comité lui a attribué 4 "B" et 2 "C".

Interprétation proposée :

"Il éveille matin après matin, il m’éveille l'oreille."

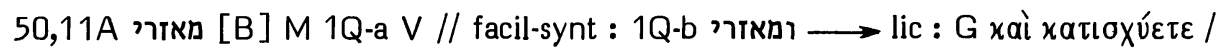
assim-ctext : CD S ומבער / midr : T

Options de nos traductions :

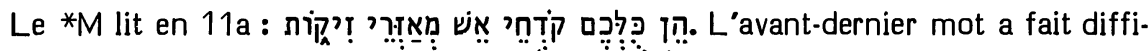
culté aux traducteurs. RL a traduit: "(die ihr...) und Brandpfeile zurüstet", J3: "qui vous armez de flèches incendiaires", TOB : "qui formez un cercle de brandons".

Les autres traductions corrigent ce mot en מִִִִ (selon J2 et Brockington) en se fondant sur la *S et se référant au *G. RSV traduit: "(you...) who set brands alight", J12: "vous attisez des braises", NEB : "(you who...) and set fire-brands alight". 
Origine de la correction :

C'est Secker (cité par Lowth) qui a suggéré cette Vorlage pour la*S. Cette leçon a été adoptée par Knobel, Bredenkamp, Duhm, Dillmann/Kittel et d'autres jusqu’à HSAT234, BH23S et Cent.

Les témoins anciens :

Le *M est appuyé par 1Q-a et par 1Q-b (ce dernier faisant précéder ce participe par une préposition).

La $* V$ (accincti) traduit le $* M$.

Weisz et BHS ont admis (à la suite de Secker) que la *S (ומגוזלי) avait lu ici ומאירי Mais Koppe a suggéré qu'elle a peut-être lu ici le verbe בער. En effet, elle a

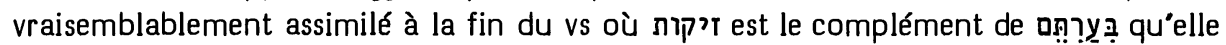
a traduit par דגוזלתכון. Une allusion à ce vs en CD 5,13 a d'ailleurs subi la même assimilation, puisqu'on y lit : קדחי אש ומבערי זיקות.

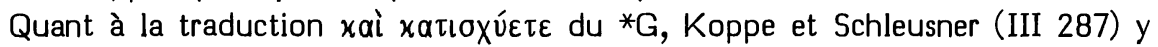
voient, à la suite de Schultens (Opera minora 105s), une interprétation arabisante du *M.

Le midrash du *T est inutilisable comme témoin textuel.

\section{Choix textuel :}

On ne peut fonder sur la *S une correction du *M. Celui-ci étant bien appuyé par 1Q-a, 1Q-b et la *V, le comité lui a attribué la note " $B$ " en considérant qu'il $s$ 'agit surtout d'une question d'exégèse.

Interprétations proposées :

Dans le même sens que l'allusion du CD et la traduction de la *S, Abulwalid (Ușul 32,12-14) rapproche בערתם dest (qui lui est parallèle en 11b) pour conclure que ce participe a le sens de מבערי, sens qui est donc analogue à celui de קִָ̣ qui le précède. Cette opinion sera suivie par Judah ib Balaam et Radaq.

Yéfet ben Ely obtient le même sens en respectant la valeur normale de la racine hébraïque. Selon le ms Londres BL Orient 2548 (écrit durant sa vie et donné par son fils Lévi à la synagogue des karaïtes), il traduit ici מאזרי זיקות, par מִגירי אלשראר, c'est-à-dire : 'faisant flamber les étincelles' (alors que les mss plus récents de son commentaire, comme le ms Londres BL Orient 2502 ou le ms Leningrad Saltykov Shchedrin Heb I 568, ont ici : מוזרי אלשראר, c'est-à-dire 'serrant ou aidant les étincelles"), et il donne l'explication suivante : "Il compare leur action à celui qui allume le feu en battant le briquet et l'apprête après qu'il n'était plus, lorsqu'il dit קדחי אש. Ensuite, comme ils craignent qu'il ne s'éteigne, ils prennent des lambeaux et en enveloppent ces étincelles qui prennent dans ces déchets allumes-feu, comme il dit זיקות sont les étincelles jaillies du briquet ou les parcelles d'amadou incandescentes. Il s'agit d'entourer ces braises avec des lambeaux de matériaux combustibles pour qu'elles les enflamment et qu'ainsi le feu prenne.

Sans connaître Yéfet, Vitringa a retrouvé à peu près la même exégèse : “Si קדח signifie 'tirer du silex une étincelle', comme on le fait avec les briquets, מאזרי זיקות signifiera 'entourer de combustibles secs', et il en sort une flamme lumineuse." 
La traduction de זיקות par 'étincelles' se retrouve chez les judéo-arabes Saadya, Abulwalid, Judah ibn Balaam, Tanḥum Yerushalmi et dans les glossaires judéo-français ABCDEF qui donnent 'estancéles'.

Selon Rashi, il s'agit de braises ardentes que l'on jette avec la fronde. En effet, en Pr 26,18 les प्̣ semblent bien être des armes de jet mortelles mentionnées avec les flèches. Et en Si 43,13 on rencontre les זיקות en parallèle avec l'éclair.

L'expression "se ceindre de" peut signifier 's'armer de, se munir de'. On pourrait donc avoir ici : "vous qui vous munissez de flèches incendiaires", ou (si l'on craint un anachronisme) "... de brandons enflammés".

Cependant, il semble bien qu'il faille préférer pour ce participe piél le sens transitif (le sens réfléchi étant réservé au hitpaél en hébreu biblique). On préférera donc : "vous qui attisez (littéralement : entourez) des étincelles", selon l'interprétation de Yéfet.

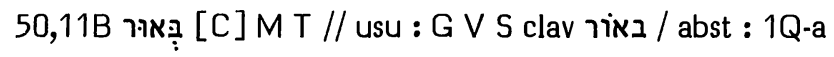

Options de nos traductions :

Elles ont toutes compris ce mot au sens de "flamme" ou "brasier". Seule RSV traduit "light", sans note.

Origine de la correction :

Il ne s'agit pas en RSV d'une initiative critique, car c'est la traduction de KJ qui copie, en cela, Ge.

Les témoins anciens :

Le *G ( $\left.{ }^{*} \tilde{w} \varphi \omega \tau i\right)$, la *V (in lumine) et la *S (בזהרא) ont vocalisé ce mot avec holem, alors que le *T offre une périphrase où n'apparaît que la notion de 'feu'.

$1 \mathrm{Q}-\mathrm{a}$ ne nous dit rien de sa vocalisation.

\section{Choix textuel :}

Emboîtant le pas à Oecolampade, toutes les traductions en langue vulgaire du XVIe siècle qu'il nous a été possible de consulter (Luther, Brucioli, Prédicants, Olivetan et ses rééditions, Châteillon, Pasteurs, Ge) ont suivi ici la *V, sans se douter que la vocalisation est shureq et non holem. Münster a fait de même. Par contre, Pagnini avait bien traduit "in foco" et Tremellius l'a suivi.

Les apparats critiques récents ne demandent pas ici de corriger le *M. Notons en effet que אוּר est parallèle à (= four) en 31,9 et qu'ici "brasier" convient bien au châtiment souhaité par le prophète pour ceux qui 'jouent avec le feu'.

En attribuant seulement " $\mathrm{C}$ " au ${ }^{*} \mathrm{M}$, le comité a voulu marquer la relative incertitude de cette vocalisation.

Interprétation proposée :

“dans le brasier (ou : l'ardeur) de votre feu". 


\section{Options de nos traductions :}

Nos traductions donnent des singuliers pour ces deux mots, sauf RL et $\mathrm{J} 12$ qui offrent des pluriels : "ihr Völker und ihr Menschen" et "peuples; nations", J2 se fondant sur des mss et la *S.

\section{Origine de la correction :}

Lowth, notant le pluriel עמים en deux mss et le pluriel לאמים en neuf mss, notant aussi que la $* S$ atteste ces deux pluriels, propose d'adopter cette variante et suggère que le *M est issu d'abréviations du type 'y mal interprétées par les scribes. En faveur de cette leçon au pluriel, il note que 51,4-6 porte sur la vocation des nations et des terres lointaines.

Cette hypothèse que des abréviations auraient été mal comprises a été reprise à propos de ces deux mots par Driver (Abbreviations 115).

La mise au pluriel de ces deux mots est requise par HSAT234, BH3S et Cent.

Les témoins anciens :

Ce sont 3 et 12 mss que les apparats récents citent en faveur de ces deux pluriels.

La leçon du *M est appuyée en ces deux cas par 1Q-a et 1Q-b. Elle l'est aussi par la *V (populus meus et tribus mea) et le *T (מי וכנשתי).

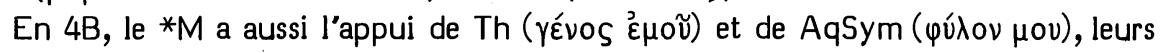
leçons n'étant pas connues en $4 \mathrm{~A}$.

Quant au ${ }^{*} G$, Seeligmann (51) a montré que c'est en conformité avec des traditions rabbiniques qu'il interprète לאמים (qu'il semble avoir lu ici au pluriel) par "rois". En tout cas, il traduit 4A par "mon peuple" au singulier.

La *S traduit par deuX pluriels sans possessifs : אמו̈תא et.

\section{Choix textuel :}

Ce cas ne figure pas parmi les trois cas de qeré y avec sebir עמים que la massore (Weil §3435) a enregistrés. Il faut noter que c'est seulement en ces trois cas traditionnels (2 S 22,44; Ps 144,2; Lm 3,14) que Abulwalid (Luma 266,1-4) estime que les scribes ont omis le 'mem' du pluriel pour alléger la graphie. Nous avons d'ailleurs montré (CT1 308) qu'en 2 S 22,44 la tradition du sebir est facilitante. Nous ne reconnaîtrons pas non plus comme authentique la forme conjecturée par le sebir en Lm 3,14 et en Ps 144,2.

C'est vraisemblablement par assimilation aux pluriels עמים en $4 b$ et 5 et en 5 qu'une partie assez marginale de la tradition textuelle a mis ici au pluriel les deux mots dont nous traitons. Si le pluriel est attesté par plus de mss hébreux et si le ${ }^{*} G$ s'ajoute aux témoins pour 4B, c'est parce que le singulier לִ est d'un usage beaucoup plus rare que le pluriel et constitue donc une lectio difficilior.

Le comité a attribué au *M la note "B".

"Accordez-moi votre attention, ô mon peuple; ô ma nation, prêtez-moi l’oreille". 
Options de nos traductions :

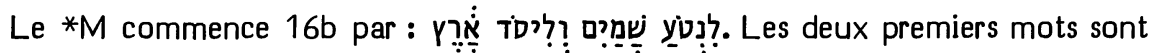
traduits par NEB : "that I might fix the heavens" et par TOB : "en plantant les cieux".

En se fondant sur la ${ }^{*} S$ et se référant au vs 13 pour corriger en șụ, J12 donnent : "lorsque j'ai tendu les cieux". RL : "auf dass ich den Himmel von neuem ausbreite", RSV : "stretching out the heavens" et J3 : "pour tendre les cieux" se rattachent à la même option.

Origine de la correction :

Houbigant, puis Lowth, ont proposé cette correction parce que l'expression "planter les cieux" ne se retrouve pas dans la Bible, alors que "étendre les cieux" revient fréquemment en ce livre.

Cette correction a été adoptée par la plupart des exégètes et requise par les apparats de HSAT234, BH23 et Cent.

Les témoins anciens :

1Q-a ne se distingue du *M que par une graphie pleine.

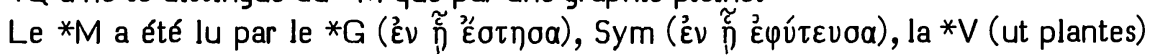
et $A q$ (que Hie dit conforme à la $* V$ ).

La *S traduit דמתחת comme si elle avait lu

Le midrash du *T est inutilisable comme témoin textuel.

Choix textuel :

Dans un contexte dérivant du $* G$, la $* S$ a assimilé à 40,22; 42,5; 44,24; 45,12; 51,13 où c'est le verbe נטה qui exprime l'action du créateur à l'égard des cieux.

Cependant, il ne s'agit pas ici, comme dans lesdits parallèles, d'un rappel de l'oeuvre du créateur, mais d'une oeuvre future que le Seigneur veut accomplir au moyen de son serviteur. "Planter" a ici le sens de "faire pousser à neuf", comme "fonder", qui est dit en parallèle à propos de la terre, veut dire "bâtir à neuf". Il s"agit de la rénovation de l'univers dont parlera la dernière partie du livre $(65,17$ et 66,22). Le verbe "planter" a le même sens métaphorique en Ps 94,9 où il a pour parallèle "modeler".

Une fois de plus (cf, 38,11), le livre d'Isaie nous offre un mot là où le contexte nous en laissait attendre un autre; la différence entre eux étant assez ténue pour que l'un d'entre eux évoque l'autre.

Le comité a attribué au *M 4 "A" et 2 "B".

Interprétation proposée :

"J'ai mis mes paroles dans ta bouche, dans l'ombre de ma main je t'ai caché, pour planter des cieux et pour fonder une terre, pour dire à Sion : 'mon peuple, c'est toi'" 


\section{Options de nos traductions :}

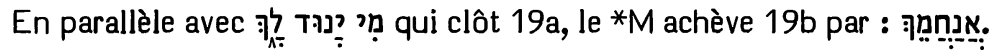

Brockington précisant qu'on lit ?ִ et RSV que l'on se fonde sur $1 \mathrm{Q}-\mathrm{a}$, le $* \mathrm{G}$, la $* V$ et la ${ }^{*} S$, toutes nos traductions offrent un verbe à la 3 e pers. sg. dont le pronom précédent est le sujet : RSV : "who will comfort you ?", J12 : "qui te consolerait ?", RL : "wer hat dich getröstet ?", NEB : "who can comfort you ?", TOB : "qui te réconfortera ?", J3 : "qui t’en consolera ?".

Origine de la correction :

Déjà Luther traduisait : "Wer solt dich trösten", Münster et Calvin : "et quis consolabitur te ?" et Châteillon : "qui êt celui qui te console". Avant eux, Saadya traduisait déjà ainsi.

Foreiro est le premier à avoir proposé formellement de corriger cet 'alef' en 'yod'. Cette correction a été adoptée par la plupart des exégètes et requise par les apparats de HSAT234, BH23S et Cent.

\section{Les témoins anciens :}

Seul le *T, par sa glose אלהין אנא, montre que sa Vorlage portait, comme le *M, un verbe à la première personne.

$1 \mathrm{Q}$-a et toutes les autres versions connues (le $* \mathrm{G}, \mathrm{Sym}$, la $* V$ et la ${ }^{*}$ ) expriment ici une 3e pers. m. sg. qui forme un parallèle exact avec la fin de 19a.

\section{Choix textuel :}

Yéfet ben Ely, Rashi, Ibn Ezra, Eliézer de Beaugency et Radaq comprennent le *M au sens de : "par qui te consolerai-je ?", c'est-à-dire : "quel peuple te mentionnerai-je (comme ayant été aussi durement traité que toi) ?".

Dans le même sens, on rencontre en Lm 2,13: “Quel témoignage te citerai-je ? que te comparerai-je ? qu'égalerai-je à toi pour que je te console ?" En Na 3,7, après

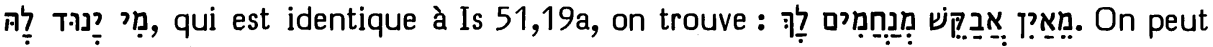

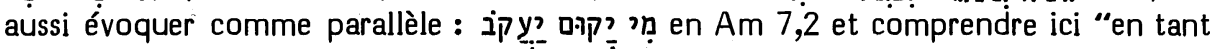
que qui (c'est-à-dire : à quel titre) pourrais-je te consoler ?".

La variante est si évidemment facilitante que le comité a retenu le ${ }^{*} M$, malgré son isolement presque total, en lui attribuant la note " $\mathrm{C}$ ".

\section{Interprétations proposées :}

"par qui te consolerai-je ?", ou éventuellement : "à quel titre pourrais-je te consoler ?"” 


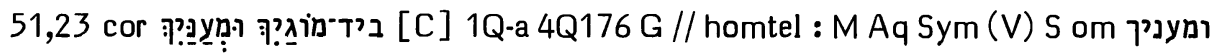
ביד מוניך err-graph : T clav

\section{Options de nos traductions :}

Le vs 23 dans le *M commence par duit normalement par toutes nos versions, au sens de "tortionnaires". Mais NEB, après "your tormentors", ajoute : "and oppressors", Brockington précisant que cela suppose une ajoute de

Origine de la correction :

Ziegler (Vorlage 42) a mis en valeur ce 'plus' comme commun à 1Q-a et au *G et il l'a adopté dans sa traduction (EB). BHS propose, avec hésitation, d'insérer

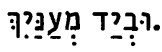

Les témoins anciens :

Après le 3e mot du *M, 1Q-a insère ומעניך.

Selon Strugnell (231), 4Q176 (= Tanḩumim) cite ce texte sous la forme מוגיך ומו ומענ]יך, le 'nun' étant douteux, et les lettres ומו (qui ont été rayées ensuite) étant considérées par Strugnell comme un faux départ de ומרניך, dont il dit que ce mot "se retrouve dans le Targum et dans quelques mss de Kennicott".

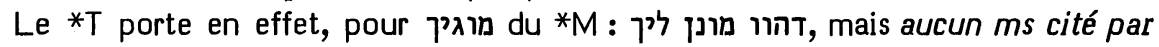
Kennicott ne porte ici מוניך. En effet, Kennicott dit avoir trouvé cette leçon en ses "codices" 264 et 300. Mais 264 désigne l"édition de la Bible de Brescia 1494 qui, en effet, porte cette leçon; alors que 300 désigne l'apparat critique de la Bible Minḩat Shay où, en son commentaire, Norzi conjecture seulement que la Vorlage du *T portait vraisemblablement cette leçon. Il ne fait là que recopier une annotation d'Elias Levita sur les Shorashim de Radaq (éd. Venise, col. 185).

Comme Ziegler l’a noté, ici le ${ }^{*} G$ semble bien traduire la leçon de 1Q-a par $\tau \tilde{\omega} \nu$

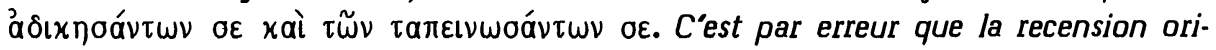
génienne obélise le premier participe comme n'ayant pas de correspondant dans le ${ }^{*} M$, alors que c'est le cas du second.

Jérôme s'est laissé influencer par le faux placement de cet obèle lorsqu'il a conservé dans sa *V "eorum qui te humiliaverunt". Mais la *V peut cependant servir de témoin indirect pour la leçon brève du *M.

Aq ( blablement lu le *M.

\section{Choix textuel :}

Un membre du comité a attribué la note " $B$ " au *M, estimant que le "plus" de $1 Q$-a et du *G est une glose que le *M ignore encore.

Les cinq autres membres ont voté " $\mathrm{C}$ " en faveur de ce 'plus' en considérant que ce mot est tombé par homeotéleuton dans le ${ }^{*} M$.

Interprétation proposée :

"Je la mettrai dans la main de tes tortionnaires et de tes oppresseurs." 
Options de nos traductions :

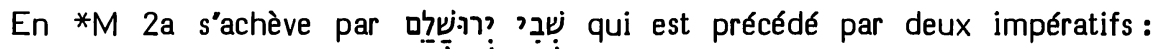

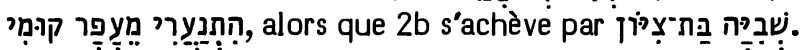

TÓB a traduit littéralement $2 \mathrm{~A}$ par "toi, la capture".

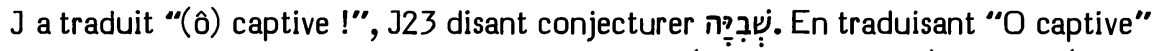
RSV dit aussi avoir conjecturé. Sans rien noter, RL (“du Gefangene") et NEB (“captive") traduisent de même.

Remarquons que $\mathrm{J12}$ et RSV attribuent au *M le sens de "assieds-toi", alors que $\mathrm{J} 3$ lui attribue le sens de "captivite".

Origine de la correction :

Luther avait déjà traduit "du gefangene". Delitzsch ayant objecté à cette exégèse (qu'il n'adoptait pas) qu’elle exigerait de lire ici (comme en 2b) proposé de corriger ainsi, suivi, entre autres, par HSAT34, BH3 et Cent.

Le fait que NEB, en lisant "captive Jerusalem", estime ne pas corriger peut venir de ce que Driver (Abbreviations 115) voit dans la leçon du *M une abréviation de l'adjectif féminin.

\section{Les témoins anciens :}

Le 'waw' dont 1Q-a fait précéder ce mot montre qu'il l'a compris en impératif.

Selon DJD V 62, 4Q176 (= Tanḥumim) lit ici שובי. Il semble donc avoir assimilé à la forme de l'impératif précédent, obtenant ainsi un sens qui convient mal au contexte.

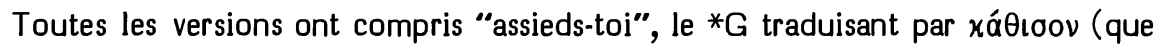
תבי l'antiochienne fait précéder d'une conjonction), la *V par "sede", la *S par et le *T par "siège sur le trône de gloire".

\section{Choix textuel :}

Alors que toutes les versions et la quasi-totalité des exégètes juifs du moyen âge ont compris ce mot au sens de "assieds-toi (sur le trône)", Radaq semble seul à comprendre ce mot au sens de "captivité (de Jérusalem)".

Sous cette influence, Oecolampade avait traduit : "captivitas", alors que Pagnini - se fondant (comme il le précise en Thesaurus 2460) sur le *T, Rashi et Ibn Ezra avait préféré : "sede".

Cependant, Luther a traduit "du gefangene". Dans son cours sur Isaïe (WA. $X X X I / 2$ 421,28-36), il explique ce choix : après que 52,1b nous ait promis que ni les tyrans païens, ni les juifs hypocrites n'auront de part à l'administration de l'Eglise, 52,2 fait correspondre à ces deux types de tyrans (corporels et spirituels) deux captivités de l'Eglise, l'une corporelle (représentée par la poussière), l'autre spirituelle (représentée par les liens).

Tout au long de son cours sur Isaie, Luther a sous les yeux Nicolas de Lyre qui avait déjà interprété des persécuteurs païens l" "incirconcis" et des persécuteurs juifs l"impur" en 52,1. Mais, avec la quasi-totalité de la tradition exégétique, Nicolas de 
Lyre lit ensuite : "assieds-toi, Jérusalem", et il explique ainsi ces mots : "installe-toi sur le siège d"honneur, oracle qui fut accompli lorsque Rome qui était la capitale de l'univers a été faite le siège du souverain pontife par Constantin". On comprend que l'interprétation d'Oecolampade ait paru préférable à Luther. Brucioli semble avoir été seul à traduire aussi en ce sens, tous les autres traducteurs du XVIe siècle ayant opté pour le "assieds-toi" de la *V et de Pagnini.

Cependant l'interprétation de שִִִׁ au sens de "captivite" a été reprise par Koppe, Gesenius (Thesaurus 1352a) et Hitzig.

Contre cette interprétation, on a pourtant objecté que le substantif שְִִׁ est masculin et ne saurait donc être visé par l'impératif féminin qui le précède, et ensuite que ce mot est séparé par les teamim de "Jérusalem" et lié à cet impératif (liaison encore accentuée par le dagesh du 'shin' selon les mss d'Alep, du Caire et de Leningrad).

Ajoutons qu'un impératif : "trône !" forme un bon contraste avec 47,1 où il était demandé à Babylone de descendre (de son trône) et de s'asseoir dans la poussière, de s'asseoir à même le sol, sans trône. Ici, il est demandé à Jérusalem (que l'on imagine assise à même le sol) de secouer sa poussière, de se lever et de s'asseoir (sur le trône). Il se peut d'ailleurs qu'il y ait une assonance voulue entre ce mot et

Le comité a attribué au *M la note "B".

Interprétation proposée :

"Hors de la poussière ébroue-toi, dresse-toi, trône, Jérusalem !"

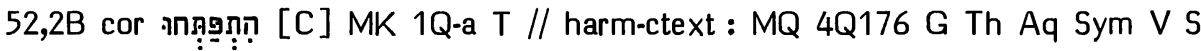

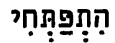

Options de nos traductions :

C'est le qeré que presque toutes ont traduit avec "loose" (RSV et NEB), "dégage" (J12), "mach dich los" (RL) et "fais sauter" (TOB).

Cependant $\mathrm{J3}$ se fonde sur 1Q-a pour préférer le ketib : "(les chaînes) sont tombées (de ton cou)."

Origine de la correction :

Le ketib avait déjà été préféré par Luzzatto, Nägelsbach, Budde (HSAT34), Praetorius (Nachträge).

Les témoins anciens :

Le ketib est attesté par 1Q-a et il a été lu par le *T (אתפסקו).

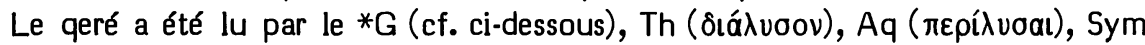

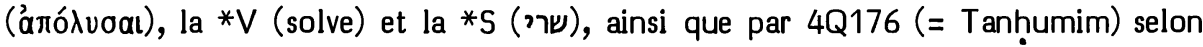
DJD V 62.

De nombreux témoins du $* G$ donnent ici हैx $x$ vooal qui semble préférable à हैx $x$ $\delta$ voal que Rahlfs et Ziegler ont retenu et qui est une corruption interne $(\Lambda / \Delta)$ par assimilation à ěvóvoal qui est apparu deux fois dans le vs précédent. Nous avons vu d'ailleurs que Th, Aq et Sym font tous usage de dérivés à préfixes de la racine $\lambda u^{*}$. 
Choix textuel et interprétation proposée :

Le qeré lit ici un impératif féminin en parallèle exact avec l'impératif hitpaél qui a ouvert ce vs. Le ketib, lui, annonce une bonne nouvelle (conséquence de la politique de Cyrus) : "ils se sont détachés, les liens de ton cou, captive fille de Sion!" Cette bonne nouvelle justifie les impératifs de 2a. Le fait que le mot suivant ne soit pas précédé de la préposition מ̣ s'accorde mieux avec une lecture selon le ketib.

C'est pourquoi quatre membres du comité ont attribué "C" au ketib, alors que les deux autres attribuaient " $\mathrm{C}$ " au qeré.

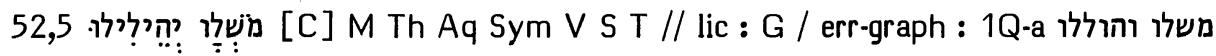

Options de nos traductions :

Le *M a été traduit par RSV ("their rulers wail"), J ("ses maîtres poussent des cris de triomphe"), RL ("seine Tyrannen prahlen") et TOB ("ses despotes hurlent").

NEB, selon Brockington, se réfère à $1 Q$-a pour lire ?ִ et traduire: "their rulers derided".

\section{Origine de la correction :}

NEB s'inspire vraisemblablement de Driver (Scrolls 26) qui estime que 1Q-a con-

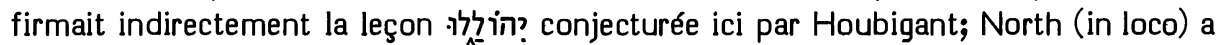
donné au poél de הלל (en se référant à 44,25) le sens de "tourner en dérision".

\section{Les témoins anciens :}

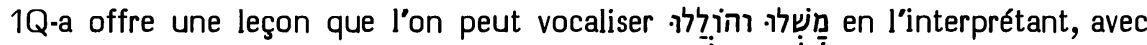
Rignell (77), "ils ont mis en proverbes et tourné en dérision", c"est-à-dire : "ils ont ridiculisé par des dictons".

Dans sa traduction très libre de ce vs, le ${ }^{*} G$ donne trois verbes à la $2 \mathrm{e}$ pers. pl.:

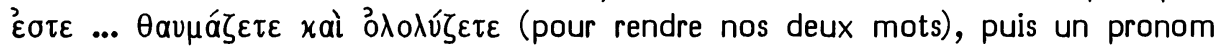
2e pers. pl. : $\{\mu \tilde{a} s$. Rien ne nous prouve cependant qu'il ait lu rien de tel en sa Vorlage. En effet, lorsque le *G ajoute à "mon nom est sans cesse blasphéme" les deux "plus" "à cause de vous" et "parmi les nations", il s'inspire plus d'Ez 36,20-23 que d'Is 52,5b. Quant au choix du verbe $\theta a v \mu a ́\} \varepsilon \tau \varepsilon$ pour rendre משלו, Ziegler (Untersuchungen 162) a noté que c'est un correspondant dont le ${ }^{*} G$ d'Isaïe fait volontiers usage pour des verbes qu'il a de la peine à comprendre (cf. 14,16; 52,15; 61,6).

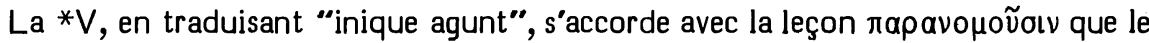
ms Barberini attribue à AqSym. Cela suppose seulement que l'on a dérivé יהילילו de de la racine הל à laquelle la racine grecque $\pi a \rho a v o \mu^{*}$ correspond dans le ${ }^{*} G$ de $P s 5,6$; 75,5. Cependant l'attribution de cette leçon grecque à AqSym doit être mise en doute. Mieux vaut en effet attribuer à Aq oaxpúovouv avec Eusèbe (confirmé par Hie : fle-

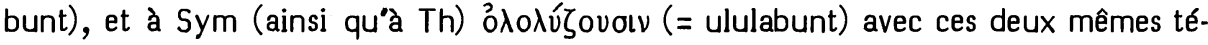
moins. On peut se demander si le ms Barberini ne nous offre pas ici (en l'attribuant à tort à AqSym) une rétroversion grecque de la *V, ainsi qu'il l'a fait dans le début du Dodécaprophéton en l'attribuant à la Quinta (cf. Barthélemy, Etudes 54-65). 
La *S traduit le *M par מיללין. Le *T l'a fait aussi par משתבחי. En effet, Rashi et les glossaires ( $A B C D E F$ qui donnent 'pourvanteront') ont tiré du *M le sens du *T.

\section{Choix textuel :}

Deux membres du comité ont préféré la leçon de 1Q-a avec la note "C".

Les quatre autres membres, estimant que toutes les autres leçons se rattachent $a u{ }^{*} M$, ont attribué la note "C" à celui-ci.

\section{Interprétation proposée :}

Si nous suivons le * $M$, une question d'exégèse se pose :

Le hifil (toujours intransitif) de יל peut-il avoir ici un sens de cris de triomphe

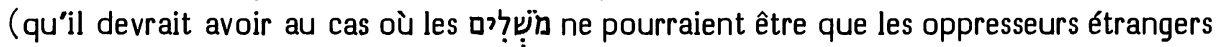
d'Israël) ? Ou bien משְִׁלִים peut-il désigner les leaders nationaux des Israélites déportés (au cas où le hifil de לל’ devrait être réservé à des hurlements de douleur) ?

Le commentaire inédit de Saadya (dans le ms Cambridge T.-S. Ar 1b 71) précise qu'il s'agit ici des maîtres d'Israël, c'est-à-dire des fils de David et d'Aaron. Ibn Ezra aussi y voit les grands d'Israël. Quant au hifil de לל', son sens normal est bien celui de "hurler de douleur". Il est donc apparu au comité que la seconde éventualité était préférable à la première.

\section{2,6 לכן (20) [C] M oi $\gamma^{\bullet} T$ // facil-synt : 1Q-a G V S om}

\section{Options de nos traductions :}

Ce 2e לכן est traduit par RSV ("therefore"), TOB ("dès lors") et J3 ("c'est pourquoi").

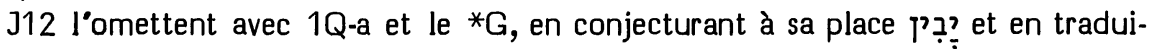
sant : "il comprendra". NEB fait de même ("they shall know"), alors que RL se contente d'omettre ce mot.

Origine de la correction :

N'ont pas tenu compte de ce 2e לכן dans leur traduction: Saadya (qui n'en tient pas plus compte dans son commentaire inédit du ms Cambridge T.-S. Ar 1b 71), Luther, Olivetan et ses rééditions par Rollet et Estienne. La plupart des autres traducteurs du XVIe siècle en tiennent compte.

Lowth a fondé sur le ${ }^{*} G$, la $* V$ et la $* S$ une omission de cette reprise. Budde (HSAT34) et Ehrlich ont proposé de lire יָרִי à sa place, proposition adoptée par Cent.

\section{Les témoins anciens :}

Cette reprise n'est attestée ni par $1 \mathrm{Q}-\mathrm{a}$, ni par le ${ }^{*} G$, ni par la $* V$, ni par la ${ }^{*} \mathrm{~S}$;

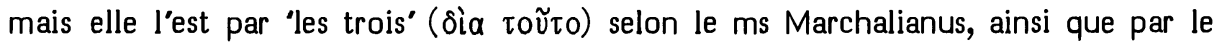
*T (בכן). 
Choix textuel :

Le comité a décidé, par 4 " $\mathrm{C}$ " et 2 "B", de protéger le *M contre une omission évidemment facilitante.

Interprétations proposées :

Parmi les commentateurs anciens auxquels nous avons accès, le premier qui essaie d'articuler syntactiquement ces deux לכן semble être Yéfet ben Ely. Il nous rapporte les opinions de deux commentateurs antérieurs à lui (qui écrit dans la seconde moitié du Xe siècle).

Le premier commentateur (dont Yéfet juge l'opinion probable), notant qu'il y a deux לכן, explique que le premier se réfère à ce qui a été dit auparavant de l'oeuvre du Seigneur à l'égard des nations, alors que le deuxième se réfère à l'oeuvre du Seigneur à l'égard d'Israël, oeuvre exprimée par כי אני הוא המדבר הנני.

Le deuxième commentateur cité par Yéfet considère le second לכנ comme une simple reprise du premier dans la continuité du discours.

Nous avons bien là en effet les deux possibilités d'articulation syntaxique de ces deux לכן. Le choix entre elles dépendra du sens que l'on attribue à ?ִ̣̣ : explicatif ou causal.

Presque toutes les traductions modernes optent pour le sens explicatif : "que". On doit alors expliciter avant cette particule une reprise de $y$ T‥ et on obtient : “'C'est pourquoi mon peuple va savoir quel est mon nom, c'est pourquoi (il va savoir) en ce jour que je suis celui-là même qui déclare : 'Me voici!'." Dans cette option, le 2e לכן n'est qu'une reprise emphatique du premier sans fonction autonome dans le discours. Un traducteur peut donc être tenté de l'omettre pour alléger la phrase.

L'option préférée par Yéfet, celle de son premier commentateur, donne au second לכן une valeur causale qui le suit. On obtient : “C'est pourquoi mon peuple va savoir quel est mon nom; c'est pourquoi ce sera en ce jour, parce que moi, celui qui parle, me voici !". Comme dans l'autre option, le premier "c'est pourquoi" tire une conséquence des événements mentionnés auparavant. Mais, selon cette option-ci, le deuxième "c'est pourquoi" anticipe le "parce que..." qui va suivre : ce sera en "ce jour" (= le jour de la rédemption) que le peuple apprendra quel est le nom de son Dieu, parce que le fidèle et le tout-puissant entre en scène pour réaliser ses promesses.

Notons que l'on trouve souvent dans le livre d'Isaïe des לְֵֵ qui sont motivés par des 'ᄁִ̣ qui les suivent : cf. 5,24; 10,24s; 16,7s; 27,9s; 28,14s; 61,7s. La préférence accordée par Yéfet à l'opinion de son premier commentateur dénote donc un sens avisé de la syntaxe de ce livre.

\section{ברחמים ציון 52,8 [B M 1Q-b G V S T // glos : 1Q-a add}

Options de nos traductions :

RSV, J, RL et TOB achèvent le vs par "Sion", comme le fait le *M. Mais NEB (selon Brockington) y ajoute avec 1Q-a :

Origine de la correction :

James a proposé d'adopter le 'plus' de 1Q-a. 


\section{Les témoins anciens :}

Après ברחמים 1Q-a est le seul à ajouter. Kutscher (543) a fait remarquer la similitude avec Za 1,16: et surtout avec la phrase בשובך לציון ברחמים qui se trouve dans les Dix-huit bénédictions.

\section{Choix textuel :}

Il est en effet vraisemblable que le 'plus' de 1Q-a (alors que 1Q-b $={ }^{*} M$ ) est dû à une influence liturgique. Une même influence s'est peut-être exercée sur le ${ }^{*} G$ pour

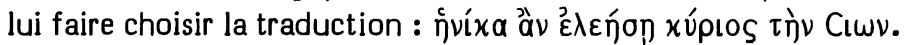

Il a semblé au comité qu'une glose (en 1Q-a) s'expliquait ici mieux qu'une mutilation (dans le *M). Il a attribué au *M la note "B".

\section{2,14 עליו 5 [B] M 1Q-a G V // assim-ctext : m Th v S}

\section{Options de nos traductions :}

Ce suffixe de la $2 e$ pers. m. sg. est traduit par une 3e pers. m. sg. en RSV ("at him"), J ("à sa vue"), RL ("über inn") et TOB ("à son sujet"). RSV et J se fondent sur la *S et le *T, auxquels TOB ajoute un ms hébreu.

NEB garde le suffixe 2e pers. m. sg. en le glosant : "at you, my people", puis elle transfère les sept derniers mots du vs 14 après 53,2 .

\section{Origines des corrections :}

Les deux corrections de NEB (glose et transfert) avaient été proposées par Driver (Servant 91). Celui-ci cite Marti comme ayant proposé le transfert.

Quant à la correction du suffixe adoptée par les autres traductions, elle a été formellement demandée par Houbigant, se fondant sur la ${ }^{*} S$ et le ${ }^{*} \mathrm{~T}$, auxquels Lowth a ajouté un ms de la $* V$ et deux mss anciens (du $* M)$. Elle a été ensuite adoptée par la plupart des exégètes et requise par les apparats de HSAT34, BH23S et Cent.

\section{Les témoins anciens :}

Dans la tradition textuelle du $* M$, le suffixe $3 e$ pers. m. sg. n'est attesté que par la 1e main du ms Kenn 576 et la 2e main (cf. Lilienthal 344) du ms Kenn 224.

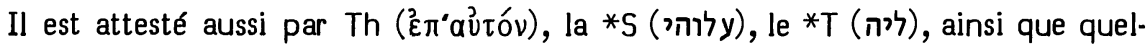
ques $\mathrm{mss}$ de la $* \mathrm{~V}$ (le ms de Léon et des mss de l'Université de Paris).

Le ${ }^{*} G$ a respecté ici la 2 e pers. sg. du suffixe ('ع̇ ố), mais il lui a assimilé les 2 suffixes 3 e pers. m. sg. que l’hébreu offre dans la suite du vs : tò عَ̃ós oov xaì 门̇ $\delta$ ó $\xi \alpha$ oov.

Le contraste entre les suffixes du *M est exactement attesté par 1Q-a (ליכה, puis מראהו ותוארו) et le *V ("super te", puis "aspectus eius et forma eius") confirmée en cela par le lemme de Hie.

1Q-b ne nous est pas conservé pour ce premier suffixe du vs 14 , mais il appuie le *M pour ceux qui suivent. 


\section{Choix textuel :}

Si l'on se fonde sur les très nombreux commentaires et traductions d'exégètes juifs rassemblés pour cette péricope par Neubauer/Driver, on remarque que certains ont unifié les suffixes sur la 3e personne. C'est le cas de Saadya, Yéfet ben Ely (commentaire), Joseph ben Nathan, Tanḩum Yerushalmi, Moshe Kohen ibn Crispin (avec parallèles justificatifs), Isaac Abravanel.

Cependant Saadya, dans son commentaire inédit (dans le ms Cambridge T.-S. Ar 1b 71), respecte la 2e pers., ainsi que Yéfet dans le lemme et la traduction qui introduisent son commentaire.

Parmi les traducteurs chrétiens du XVIe siècle, Zwingli, Prédicants, Jud, Châteillon (latin et français) et Robert Estienne (dans sa réédition de Pagnini en 1557) traduisent ce premier suffixe du vs 14 par une 3e pers. sg. sans rien noter.

Notons que d'autres unifient tous les suffixes du vs 14 sur la 2 e pers. (comme l'avait fait le ${ }^{*} G$ ). C'est le cas d'Eliézer de Beaugency et d'Isaac Lopez, ainsi que d'Olivetan et de Pasteurs.

Comme on peut le constater, I'harmonisation des suffixes sur la $3 e$ pers. présente les caractéristiques d'une leçon qui est 'dans l'air', c'est-à-dire qui réapparaît chez de nombreux traducteurs ou commentateurs qui n'ont pas eu contact entre eux, comme une facilitation qui vient spontanément à l'esprit.

Du fait que le suffixe de la $2 \mathrm{e}$ pers. est isolé par rapport à ce qui précède (le serviteur dont le Seigneur parle à la 3e pers. au vs 13) et à ce qui suit (les deux suffixes de la $3 e$ pers. dans la suite du vs 14), les tentatives d'harmonisation sur cette 2e pers. ont été plus rares.

Cet isolement de עִ dans son contexte en fait ici une lectio difficilior. Du fait qu'elle est solidement implantée dans la tradition textuelle de haute époque, le comité lui a attribué la note "B".

Interprétation proposée :

Voir l'excursus sur 52,14-15, après le prochain cas.

\section{2,15 יזה [B] M 1Q-a.b ThAq Sym V S T // assim-ctext : G}

\section{Options de nos traductions :}

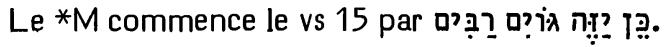

RL traduit : “so wird er viele Heiden besprengen" et RSV : “so shall he startle many nations". RL mentionne en marge l'interprétation de RSV qui reconnaît que le sens du verbe est incertain. NEB traduit, sans note: “so now many nations recoil at sight of him".

J12 donnent ici : "de même des multitudes de nations s'en étonneront", disant

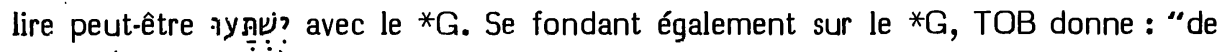
même (à son sujet) des foules de nations vont être émerveillées" et J3 : “de même des multitudes de nations seront dans la stupéfaction". 
Origine de la correction :

Déjà Zwingli et Olivetan ont dit s'inspirer du *G pour traduire ce verbe, le premier par "ipsum deprecabitur" et le second par "sesmerveilleront pour lamour de luy". Ont traduit aussi selon le *G : Clericus, Vogel (suggérant une Vorlage Chandler, Durell, Jubb, Lowth (qui cite les quatre précédents), Condamin ("il est difficile de dire quel est le verbe hébreu lu par les Septante; on peut cependant adopter ce sens comme le plus plausible dans le contexte"), Ehrlich, Haller et Praetorius (Nachträge) suggèrent יתמהו, Köhler (suggérant ישעו), Duhm2 et Westermann (ירגזו), $\mathrm{BH} 3$ et Cent (ישתע).

Les témoins anciens :

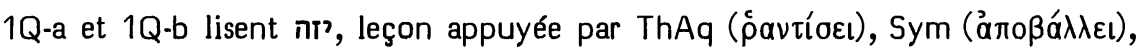
la *V (asperget), la *S (מדכא) et le *T (יבדד).

Le *G porte ici $\theta$ avpáooovtal. Mais nous avons déjà noté, à propos de 52,5, que $c$ 'est un verbe auquel le ${ }^{*} G$ d'Isaïe fait appel lorsqu'il a de la peine à traduire un verbe de sa Vorlage. Ici, la particule de comparaison qui introduit ce verbe établit correspondance avec celui ( ${ }^{3} x \sigma \tau$ ńfoovial) qui commence le vs 14 . Cette correspondance a guidé le traducteur dans le choix du verbe et de sa forme grammaticale.

Choix textuel :

Le comité a estimé peu probable que le ${ }^{*} G$ ait lu autre chose que la leçon du $* M$ et il a attribué à celle-ci 3 " $B$ " et 3 " $A$ ".

Interprétation proposée :

Voir l'excursus ci-après.

\section{EXCURSUS}

L'interprétation de 52,13-15

Le comité a eu parfaitement conscience que ces deux cas textuels des derniers vss du ch. 52 ne sont que des épiphénomènes par rapport à une difficulté syntactique concernant la manière dont le כאשר initial du vs 14 doit se construire avec les deux כן qui le suivent, et par rapport à deux difficultés exégétiques coordonnées portant l'une

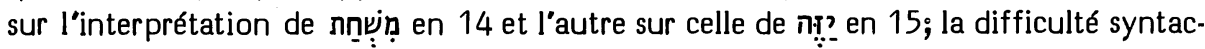
tique et les deux difficultés exégétiques étant elles-mêmes connexes. Nous ne pouvons donc pas nous dispenser d'aborder cet ensemble de difficultés en nous référant (entre autres) à l'ample documentation exégétique juive réunie par Neubauer/Driver.

\section{Histoire de trois difficultés}

A. La construction de כאשר avec les deux כן qui le suivent

La construction la plus fréquente chez les exégètes juifs consiste à faire de ce qu'introduit le premier 5 une citation de ce que les "nombreux" disent de "toi" dans leur stupéfaction qui a été introduite par כאשר. C'est l'interprétation de Rashi, 
Joseph Qara, Abraham ibn Ezra, Moshe ben Nạman, Aaron ben Joseph, Isaac Elyah Kohen, Abraham Farissol, Isaac Troki, Gershon ben Nathan, Abraham ben Yehuda Hazan, Naphtali et David Altschüler, Manasseh ben Israël.

Chez les traducteurs chrétiens du XVIe siècle, certains font de même (par ex. Tremellius : "dicentes : adeo corruptum esse..."). Mais la Geneva Bible a eu l'idée de considérer cette phrase comme une parenthèse et elle traduit: "As manie were astonied at thee (his visage was so deformed of men, and his forme of the sonnes of men) so shal he sprincle manie nations...". La King James Bible a conservé ces parenthèses. La même option survit en RSV, TOB, J3 avec la seule différence qu'elles ont remplacé les parenthèses par des tirets.

Que l'on traite cette phrase comme une citation ou comme une parenthèse, on doit conclure avec Duhm que "14 et 15a constituent une structure stylistique affreuse, dans l'éventualité où le texte serait en bon état. כאשר est suivi par deux כן dont le second seulement correspond à cette particule comparative. Admettre que le premier כi introduit une parenthèse ne facilite rien. Tout lecteur y verra naturellement le correspondant de כאשר et devra se corriger après coup. Que cette correction ne s'impose pas spontanément, les anciennes versions le prouvent, puisque l'idée d'une parenthèse ne s'est pas présentée à elles. D'ailleurs, même si cette idée s'était présentée à l'esprit d'un Jérôme, on ne serait pas autorisé pour autant à attribuer au poète cet enchevêtrement artificiel et malheureux." Cette constatation a amené Duhm à proposer des corrections importantes de la structure syntactique, propositions qui ont varié au fil des rééditions de son commentaire. Quant à Michaelis (OEB), Dillmann/ Kittel, König (Stilistik 126,37s), BH23, Volz, ils ont préféré corriger ce כי כי

Il est pourtant permis de se demander si l'on est tenu d'admettre comme un dogme que, dans le texte $d u{ }^{*} M$, seul le second כאשר est le correspondant du initial. Nous suggérerons qu'une exégèse d'ensemble, qui permettrait de considérer les deux כן כאשר comme correspondant tous deux à la particule comparative, mériterait d’être, à ce titre, prise en considération. En effet, la structure ... כאשר ... כן כש כש du ${ }^{*} M$ est clairement attestée par 1Q-a, 1Q-b et le ${ }^{*}$ G. Elle correspond ici, en poésie, à ce qu’est en prose la structure .... כאשר ... כן כן וכן (Ex 1,12; Jos 11,15).

\section{B. La signification de ה? ?}

ThAq, la *V, puis Pagnini, Luther, Châteillon, Brenz, Musculus, Ge, Foreiro, KJ traduisent "il aspergera". Mais le hifil de נזה se construit normalement avec l'accusatif du liquide que l'on fait jaillir (la personne ou l'objet aspergé étant introduit par une préposition, le plus souvent : עy). C'est pourquoi l'ensemble des exégètes juifs, à partir du haut moyen âge, a interprété ici au sens métaphorique ce "il fera jaillir" dont l'accusatif de liquide est "de nombreuses nations".

L'interprétation : "il expulsera (ou : dispersera) de nombreuses nations" a eu pour supporters : Sym, le *T, Saadya, Jacob ben Reuben le karaïte (1e exégèse), Isaïe ben Mali, Moshe ibn Crispin, Moshe ha-Kohen de Torresillas, le commentaire anonyme du ms Vatican ebr 509 (fol. 64), Shemuel Lanyado, Joshua Segre, Herz Homberg. De nombreux modernes ont compris, au sens métaphorique : "il fera sursauter...". Mais les nations sont difficilement comparables à un liquide. Aussi, s'inspirant d'Is 63,3, certains exégètes ont-ils compris : "il fera jaillir (le sang) de nombreuses na- 
tions." C'est le cas de Salmon ben Yeruham, Yéfet ben Ely, Abraham ibn Ezra, le commentaire arabe du ms Oxford Bodl Hunt 206, Tanḩum Yerushalmi, Aaron ben Joseph, Isaac Abravanel, Moshe el Sheikh, David Altschüler, la Bible des Pasteurs de 1588.

D’autres ont compris : "il fera parler (litt. : il fera jaillir les paroles) de nombreuses nations" : Joseph et David Qimhi, Shelomo Astruc, Isaac Elyah Kohen, Saadya ibn Danan, Shelomo ben Melek, Isaac Troki, Abraham Farissol, Moshe de Salerne, Manasseh ben Israel, Isaac Orobio de Castro, Jacob ibn Amram, Münster, Olivetan (en note), Vatable.

D'autres enfin ont compris les nations comme destinataires de cette aspersion de paroles : "il enseignera (litt. : il aspergera de paroles) de nombreuses nations". C'est le cas de Jacob ben Reuben le karaïte (2e exégèse), Moshe ben Nahman, Shelomo Levi, Luther (WA. XXXI/2 430,1-4), Münster (en note), la Bible des Pasteurs de 1588 (en note).

Il faut avouer que toutes ces interprétations métaphoriques sont assez tirées par

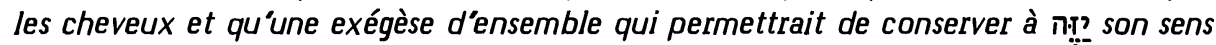
normal rituel de "asperger" mériterait d'être, à ce titre, prise en considération. Ajoutons à ce propos que Delitzsch, dans la $4 \mathrm{e}$ édition (1889) de son commentaire, a répondu à l'objection portant sur la construction de ce verbe, objection qu'il avait luimême soulevée dans la première édition (1866) de ce même commentaire. Il avait d'abord relevé, en effet, qu'on ne rencontre jamais le hifil de נזה construit avec l'accusatif de la personne aspergée (celle-ci étant introduite par une préposition, le plus souvent : y). Mais il a remarqué ensuite le cas du hifil de ירה (au sens de : lancer des flèches). Lui aussi se construit d'ordinaire avec l'accusatif du missile lancé (cf. $1 \mathrm{~S}$ 20,20.36; 2 R 19,32), alors que le but visé est introduit par une préposition (cf. 2 S 11,24; 2 Ch 35,23). Cependant, en certains cas, le hifil de ירה (sans complément de missile) peut être construit avec l'accusatif du but visé. C'est le cas en Ps 64,5 :

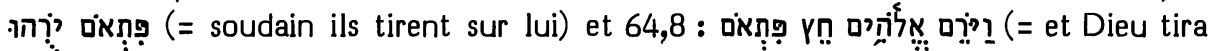
sur eux : une flèche soudaine). Le fait que l'accent diviseur principal du verset sépare ici les deux premiers mots de ceux qui les suivent montre que ceux-ci sont compris comme une ajoute explicative et non comme un complément d'objet. Le français connaît aussi ces flottements dans la construction du verbe "tirer". On dit : "tirer un coup de feu sur un oiseau", mais aussi "tirer un oiseau". Delitzsch conclut de sa remarque sur la construction du hifil de ירה que l'on ne doit pas nier la possibilité - analogue - d'une construction du hifil de נזה avec l'accusatif de la personne aspergée.

Les constructions de ce verbe avec un accusatif de liquide et l'introduction par לy de l'objet aspergé signifient précisément : faire jaillir tel liquide sur tel objet (ou telle personne); alors que les constructions sans accusatif de liquide, avec seulement un accusatif d'objet ou de personne, pourront signifier : accomplir le rite d'aspersion sur tel objet ou telle personne.

\section{Les interprétations de بִ}

Guillaume (Readings $4 \dot{1}$ ) a cru faire le point de la situation en 1957 en disant : "Jusqu”à maintenant, tous les auteurs, tant anciens que modernes, ont compris le 
mot (משחת) comme signifiant que la forme et l'apparence du serviteur étaient de quelque manière défigurées, et ils ont de la sorte amené ce vs en parallèle avec le passage de 53,2s qui le suit de près et qui dit : 'il n'avait ni forme ni apparence' en peignant un homme défiguré par la souffrance."

De fait, en leur grande majorité, les traducteurs et commentateurs ont rattaché ce mot à la racine שחת.

La plupart d'entre eux ne nous permettent pas de déceler l'analyse grammati-

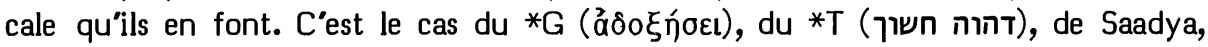
Yéfet ben Ely, etc.

Parmi ceux qui donnent une analyse, certains l'interprètent comme un substantif : Salmon ben Yeruham lui donne la valeur de "corruption, ravage", ce substantif étant d'une structure semblable à celle de teur" (= destructrice étant sa majesté).

D’autres l'interprètent en adjectif : c'est l'exégèse d'Abraham ibn Ezra, Radaq, Aaron ben Joseph, Shelomo ben Melek, Herz Homberg.

D’autres enfin y voient un participe passif, certains l'interprétant comme (en nifal) : les glossaires CDE et Tanhum Yerushalmi; d'autres comme hofal) : Abulwalid (Opuscules 32s), Judah ibn Balaam, Isaïe ben Mali.

Guillaume ajoute : “Il n’est pas exagéré de dire que, sans la conception chrétienne d'un messie souffrant, il ne viendrait à l'esprit de personne de lire dans ce verset l'idée d'une onction."

Il semble donc ignorer que cinq exégètes juifs (au moins), échelonnés entre le XIIe et le XIXe siècle, ont proposé de lire ici l'idée d'une onction. Il peut être utile d'expliciter un peu ces exégèses qui semblent méconnues.

Au XIle siècle, dans son Sepher ha-'Osher, le karaïte de Constantinople Jacob ben Reuben, après avoir donné l'exégèse classique, ajoute une autre opinion : “comme les gens ont été stupéfaits à ta vue, ainsi il sera grand et משחת et son apparence sera meilleure que celle de tout homme". Il ajoute que ce mot est à expliquer "comme זאת מִשְַׁחת אהרן (Lv 7,35)". Or, en ce contexte, il s'agit du privilège découlant de l'onction sacerdotale.

A la même époque, le rabbin français Eliézer de Beaugency commente ainsi ce passage : "Comme beaucoup ont été stupéfaits à propos de toi, jadis, parce que tu étais méprisé et déficient d'entre les hommes, homme de douleur et connu de la maladie - et ils s'étonnaient de ton allure et de ton aspect, parce que tu n'étais pas comme le reste des hommes -, ainsi que ton allure et ton aspect soient משחת chose estimée et exaltée au-dessus du reste des hommes. Et comme beaucoup ont été stupéfaits à propos de toi - et ils ne t'ont pas estimé et ils t'ont éloigné d'eux -, ainsi ת ת tu jetteras à ton tour loin de toi des nations nombreuses. משחת : estimé et grand,

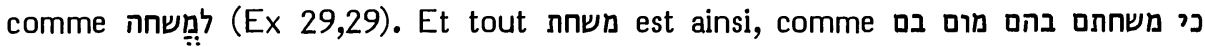

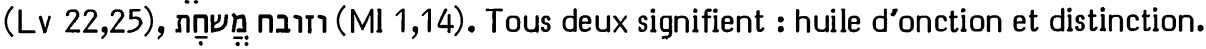
Et tous deux, je les ai expliqués en leur lieu avec une explication claire et conforme à la vérité. De plus, la séquence ne peut pas être correcte avec un autre sens, du fait de la signification de כאשר par rapport au כן qui le suit, qui est la même que celle de la séquence וכאשר יענו אותו כן ירבה וכן יפרץ (Ex 1,12). De même : comme ils ont

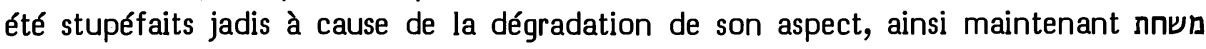
et estimé est son aspect." 
Au XIVe siècle, Shelomo Astruc de Barcelone (Neubauer/Driver I 123) commente : “Comme le Seigneur a donné pleine mesure en tes coups, ainsi il donnera pleine mesure en ton bonheur, de sorte que la dignité de cet oint en son onction dépassera celle des autres oints par le rayonnement de son visage. Et par 'son apparence', c'est-à-dire sa belle apparence, il veut dire l'apparence de ses vêtements plus splendide que celle de tous les hommes qui furent avant lui."

Au XIXe siècle, M. Ehrentreu (cité par S.D. Luzzatto) estime que la vocalisation avec hireq (alors qu'on attendrait un qameṣ hațuf) a pour but de rapprocher ce mot

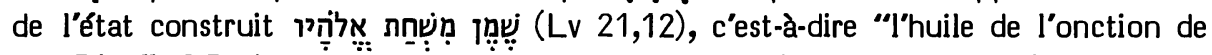
son Dieu". S.D. Luzzatto approuve ce jugement, quoique tous deux voient en cette vocalisation une correction théologique ayant pour but d'éviter au serviteur un qualificatif ("défiguré") évoquant une tare.

Récemment, Komlosh (Countenance 219), tout en voulant dériver ce mot de

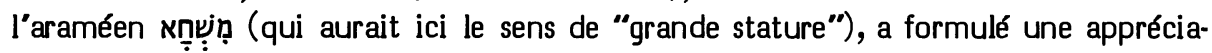
tion intéressante sur les trois exégèses de Jacob ben Reuben, Eliézer de Beaugency et Shelomo Astruc. Il estime que "ces trois interprétations nous amènent plus près d'une solution de cette difficulté que tous les autres commentateurs, parce qu'en donnant à ce mot un sens positif, le contenu du passage 52,13-15 est rendu uniforme, si bien qu'il n'y a plus aucun besoin de transposer le vs 14 ou de le transférer pour qu'il fasse suite à 53,2."

Parmi les commentateurs chrétiens, cette interprétation a été proposée au XVIe, puis au XVIIe siècle par deuX exégètes de valeur dont chacun a cru être le premier à l'esprit duquel elle se présentait.

En 1565, Foreiro s'exprimait ainsi à propos d'Is 52,14, après avoir mentionné l'exégèse traditionnelle de ce passage : "A cause de certains noeuds que je n'arrivais pas facilement à dénouer, je n'ai pas craint de présenter une autre interprétation qui ne respecte pas moins le texte que la précédente et qui semble mieux convenir à l'usage hébreu. Quand ces deux conditions sont réunies, il n'y a pas à craindre d'offrir du neuf... On traduit le mot משחת par 'détruit' ou 'ignoble' en le dérivant du verbe שחת 'ruiner entièrement'. Mais si nous disons que son 'mem' est radical et qu'il dérive du verbe משח 'oindre', il signifiera 'onction' ou 'onguent', comme en Ex 25,6 et Lv 7,35 'voici l'onction d'Aaron' et Ex 30,25 'l'huile d'onction, de sainteté'. Cela donnerait : 'De même que beaucoup furent stupéfaits (ou : sifflèrent) à son propos en voyant l'ignominie de la croix, ainsi son apparence sera une onction supérieure à un homme', c'est-à-dire supérieure à quiconque. Il s'agit de ce qui se lit en Ps 45,8 : 'ton Dieu t'a oint d'une huile d'allégresse supérieure à tes compagnons'. Quant à : 'et son aspect supérieur aux fils des hommes', ce peut être ce qui est dit au même psaume (vs 3) : 'tu es d'une beauté supérieure aux fils des hommes'. Ou bien le mot 'aspect' est régi par 'onction' : 'et l'onction de son aspect est supérieure à celle des fils des hommes...' Ajoutons que c'est dans le génie de l'hébreu de comprendre כאשר, lorsque כui correspond, comme 'plus ... plus', comme en Ex 1,12: 'plus on le maltraitait, plus il se multipliait'. Nous pouvons donc comprendre : "à la mesure de la stupéfaction ... à cette même mesure sera transcendante son onction' et 'de même que beaucoup furent stupéfaits à cause d'une si profonde déchéance ... de même il en aspergera et purifiera beaucoup'. Il y a là une allusion aux aspersions qui se faisaient 
avec l'eau et les cendres de la vache rousse, ainsi qu'aux diverses aspersions par le sang."

En 1689, les "Annotata in Esaiae cap. 53 et finem cap. 52" de Louis Cappel faisaient l'objet d'une publication posthume. En ce commentaire très détaillé, Cappel s'exprime ainsi à propos du mot qui nous occupe : "De la racine משח 'oindre' dérive מִִuִ 'onction' (Ex 31,11) où il s'agit de cette huile sainte et précieuse dont Aaron füt oint avec ses fils, de même que tout le tabernacle et tous ses instruments et son mobilier. L'état construit de ce mot מִ̣ se rencontre souvent. On pourrait interpréter à partir de là le sens des paroles du prophète : 'ainsi l'onction de son visage dépassera celle des autres hommes', c'est-à-dire : Quoique les hommes soient stupéfaits de l'apparence humble et méprisable de ce serviteur de Dieu, pourtant cet Oint ou Messie de Dieu est en réalité plus excellent que tous les autres hommes. De sorte qu'il semble y avoir là une allusion tacite au titre de Messie. C'est presque de la même manière que le psalmiste dit que le Christ a été oint par Dieu d'une huile d'allégresse transcendant ses compagnons (Ps 45,8). C'est donc en un sens qui n'a rien d'absurde et qui convient même que l'on pourrait dire du Messie 'que son visage est oint de préférence au visage des autres hommes'. Comme cependant il ne se trouve aucun des exégètes anciens ou modernes qui ait dérivé de cette racine ce mot משחת et l'ait pris au sens de "oindre", renonçons à cette interprétation" (Notae 9).

De fait, la plus ancienne des interprétations de ce mot au sens de "onction" est celle dont nous témoigne vraisemblablement la variante facilitante משחת en 1Q-a. En 1950 (Etudes 17), j'avais proposé de comprendre ce mot comme "j'ai oint". Yalon (Rec. Burrows 171, n.84) a préféré voir là un participe hofal avec un 'yod" excédentaire. Nötscher (Hapaxlegomena 301), Brownlee (Servant 10-12; Mšh̆ty 27s) et Chamberlain (Functions 369, n.1) ont admis l'interprétation que j'avais proposée pour la leçon de 1Q-a, alors que Reider (Mšhty 27), Rubinstein (Variant) et Driver (Servant 92) ont opté pour la suggestion de Yalon. Mais Bruce (Exegesis 56) estime difficile de mettre sérieusement en doute pour cette leçon l'interprétation "j"ai oint". Enfin Kutscher (262) considère que la leçon de 1Q-a "semble exprimer que le scribe conçoit le Serviteur du Seigneur comme le Messie oint". Il estime que "l"hypothèse de Reider est forcée".

En tout cas, Guillaume faisait erreur en prétendant qu'une exégèse en "onction" de משחת serait impensable hors de la conception chrétienne d'un messie souffrant.

\section{Exégèse d'ensemble de 52,13-15}

Abordons maintenant de façon connexe les problèmes que nous venons de situer séparément.

En 52,13-15, on peut distinguer cinq membres. Le premier, introduit par הנה, contient deux inaccomplis et deux accomplis invertis à la 3e pers. du sg. dont le sujet est “mon serviteur". Le deuxième, introduit par כאשר, contient un accompli à la 3e pers. du pl. dont le sujet est "beaucoup" avec un complément à la 2 e pers. du m. sg. ("sur toi"). Le troisième, introduit par כן, ne contient que deux phrases nominales où apparaissent deux possessifs de la 3e pers. du m. sg. Le quatrième, introduit par כן, contient deux inaccomplis : le premier est à la 3e pers. du m. sg.; son sujet semblant 
servir de complément ("sur lui") au deuxième inaccompli (à la 3e pers. du pl.) qui a pour sujet "des rois". Le cinquième membre, introduit par כי, contient deux propositions principales dont les verbes sont des accomplis à la 3e pers. du m. pl., chacune étant affectée d'une relative.

A partir de cette analyse descriptive, on peut formuler quelques modestes hypothèses.

A/ Il existe à la fois une distinction et une correspondance entre :

- (1) un événement passé exprimé, dans le 2e membre (כאשר) par l'accompli שממו comme concernant "toi" et

- (2a), d'une part, une qualification exprimée de façon intemporelle, dans le 3e membre (= premier כנשחת משת, par le prédicat nominal que

- (2b), d'autre part, des événements exprimés dans le 4e membre (= second כן) par deux inaccomplis יזהצו et événements qui, de ce fait, sont vraisemblablement contemporains de ceux qui ont été annoncés dans le 1er membre (= הנה).

$\mathrm{B} / \mathrm{Du}$ fait de cette contemporanéité, il est très vraisemblable que c'est “mon serviteur" (mentionné dans le 1er membre) à qui se réfèrent les possessifs de la 3e pers. m. sg. du 3e membre, le verbe à la 3e pers. m. sg. du début du 4 e membre et le complément à la $3 e$ pers. m. sg. du verbe à la 3e pers. m. pl. qui suit en ce $4 \mathrm{e}$ membre. Le 5e membre (כי exprime en deux accomplis pluriels רתבוננו et a motivation de l'inaccompli pluriel יקפצו qui les précédait (dans le 4e membre). Le sujet de cet inaccompli : "des rois" vaut très vraisemblablement pour les trois verbes pluriels du 5e membre.

C/ De cette première mise en place, nous pouvons conclure qu'il existe vraisemblablement une correspondance entre "ton" sort passé (2e membre) et le sort futur de "mon serviteur" (1er, 3e et 4e membres). Or nous sommes au clair sur le sens global du 1er membre (annonce de l'exaltation et de la glorification future de "mon serviteur") et du 2e membre (consternation passée des "nombreux" à propos de "toi"). Les modestes hypothèses que nous venons de formuler nous permettent de suggérer que les $3 \mathrm{e}$ et $4 \mathrm{e}$ membres ont des chances d'exprimer (comme le 1er) le sort glorieux de "mon serviteur". Il y aurait donc triple contraste entre : "ton sort-passé-consternant"

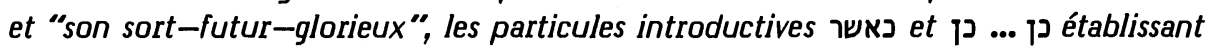
une correspondance formelle entre ces sorts contrastés.

Précisons tout de suite que le motif pour lequel la grande majorité des exégètes a interprété le 3e membre (= premier כן) dans la ligne du 2e membre (= כאשר) - c'està-dire comme exprimant une situation consternante - semble bien être le fait que les substantifs מראה et reviennent en 53,2 dans la description d'une situation consternante. Or 53,1-10 est introduit par 52,15b comme une longue méditation des rois sur la situation consternante puis glorifiée de quelqu'un dont ils parlent à la 3e pers. m. sg. en faisant usage de verbes qui sont principalement à l'accompli ou à l'inaccompli inverti. Si l'on avait donc à mettre en relation la situation décrite par 53,1-10 avec l'une de celles qui sont évoquées en 52,13-15, on pourrait cependant penser plutôt que les souvenirs évoqués par 53,3 (= "nous n'avions pas éprouvé d’estime pour lui") et par 53,4b (= “mais nous, nous l'avions estimé touché, frappé par Dieu et humilié") 
correspondent à ce qu'évoque le 2e membre (כאשר) de 52,13-15 (= "comme beaucoup avaient été consternés à ta vue") plutôt qu’à ce qu'évoquent les $3 \mathrm{e}$ et $4 \mathrm{e}$ membres ( 52,14 celui qui parle est le Seigneur qui rappelle "leur" réaction à "ton" égard, alors qu'en 53,3s ceux qui parlent sont les rois qui se rappellent "notre" réaction à "son" égard.

De cette analyse, il ressort que, si l'on donne à משחת en 52,14 valeur d'onction, il serait cependant inexact de parler ici d'un Messie souffrant. En effet, "son" onction (celle du Serviteur glorifié) et "sa" mission ("il fera le rite d'aspersion") se trouvent à la fois en contraste et en correspondance avec "ton" passé consternant de mépris et d'humiliation. Dans cette hypothèse, la charnière entre la destinée de souffrant et celle de Messie-prêtre réconciliateur de ses bourreaux se trouve exprimée en 53,10-11 où le Seigneur (vss 11-12) prolonge la méditation des rois en explicitant la mission glorieuse de son Serviteur. C'est après que le souffrant ait accepté la mort comme un sacrifice expiatoire $(53,10)$ pour le péché de ceux qui le méprisaient $(53$, 4-5) qu'il sera oint comme prêtre et réconciliateur (53,10b-11) de tous ceux-là des fautes desquels il s'était chargé $(53,12)$. Il $y$ a donc contraste et correspondance entre deux destins successifs. Alors que, dans l'interprétation évangélique de la destinée de Jésus de Nazareth, c'est celui qui a déjà été oint par la descente de l'Esprit au début de sa vie publique qui va ensuite souffrir pour réconcilier.

\section{Le sens de}

A l'intérieur de cette structure d'ensemble, il n'est pas impossible que le mot a ạt été choisi comme un mot ambigu qui dit "onction" et qui évoque "destruction". En 1939, Wordsworth (cité par Brownlee, Servant 11, n. 14) estimait que ce

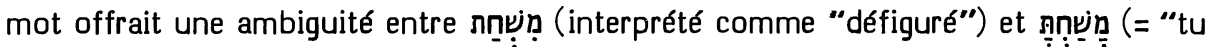
as oint"). En 1953, Brownlee (Servant 11) a estimé que la vocalisation massorétique de ce mot en état construit vise à maintenir une ambiguité entre deux dérivations possibles de cette forme : ou bien à partir d'un état absolu nִ (= onction), ou bien à partir d'un état absolu מִ (= destruction). Il ajoute que "la tradition orale qui précède l'oeuvre des massorètes peut fort bien avoir transmis la vocalisation 'mišḩat' pour cette raison précise qu'elle admet une interprétation messianique". Il estime que, fondée sur cette tradition, la leçon de 1Q-a "représente seulement une construction plus aisée dans le but de rendre claire l'implication messianique que l'on soupçonnait dans le mot "mišhat'." Koenig (Herméneutique 370s) adopte cette interprétation de Brownlee et ajoute: “Le style est hermétique et allusif, mais c'est là précisément une caractéristique oraculaire. Le mot problématique évoque à la fois une épreuve et une élévation aux honneurs, et c'est l'indication que l'épreuve exilique du Serviteur (= la Synagogue d'exil, qui représente éminemment Israël) sera suivie d'une restauration glorieuse."

L'ambiguité objective de la vocalisation nמִ̣ n'est pas à nier. La massore a d'ailleurs conscience de l'ambiguité d'une autre forme qui peut être dérivée, elle aussi, de l'une ou l'autre des racines משחח et Il s'agit d'une massore citée par Abulwalid (Opuscules 33) et que l'on rencontre dans le ms Vatican ebr 448 sur Lv 22,25, ainsi 
que dans la liste très ancienne de paires de ce type qu'offre la Okhla (Diaz Esteban $\S 60$ = Frensdorff $\S 59$ ). Elle précise que מִ se rencontre “deux fois et en deux sens" (là et en Ex 40,15). En effet, en Ex 40َ,iَ 15 la tradition exégétique voit en cette

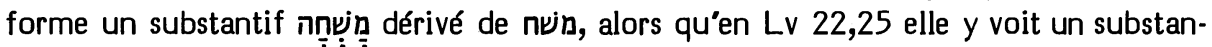
tif

İl est cependant notable que les 7 emplois bibliques de 52,14 dérivent tous clairement de מִִ̣̣ (attesté 16 fois à l'état absolu) et que, pour cette forme, il n'existe qu'une tradition massorétique très récente (en $\mathrm{mp}$ du $\mathrm{ms}$ Madrid Bibl Univ hebr 1) pour attester que ce mot a ici un sens distinct de celui qu'il a en ses autres emplois bibliques.

Etant donné cette situation, il a paru au comité plus prudent de donner ici à תִַụ comme sens de base celui de "onction". En effet $L v$ 16,32 exprime clairement le lien entre l'onction et le rite d'expiation : "Accomplira le rite d'expiation le prêtre qu'on a oint", c'est-à-dire, selon Lv 21,10, “le prêtre qui est plus grand que ses frères, celui sur la tête de qui a été répandue l'huile de la "mišhâh"'. En Ex 30,31-32 il est dit de cette huile : “Ce sera pour moi l'huile de la 'miṣ̣̌at" de sainteté pour vos générations. Sur la chair d'un homme (אדם) on n'en versera pas." Or l'essentiel du rite d'expiation consiste en l'aspersion de sang que le Grand Prêtre fait devant le propitiatoire pour purifier le sanctuaire "des impuretés des fils d'Israël et de leurs révoltes, c'est-à-dire de tous leurs péchés" (Lv 16,15-16). Lorsqu'il s'agit de la glorification du Serviteur, les notions cultuelles subissent évidemment une transfiguration métaphorique. Mais, dans cette ligne, la succession : "onction transcendant les hommes", puis "il aspergera" présente une réelle cohérence.

Il faut reconnaître que, dans le texte du *M, l'insertion syntactique de présente des difficultés, quelle que soit celle des deux dérivations pour laquelle on opte.

A/ Que l'on voie ici un état construit de struit soit suivi d'une préposition peut surprendre. Cependant on rencontre cette anomalie avec la préposition 'min' en Gn 3,22; Is 28,9(bis); Jr 23,23(bis); Ez 13,2; Os 7,5. Comme le montrent ces exemples, il semble s'agir d'une syntaxe recherchée, plutôt que relâchée.

B/Que le מַּ (= apparence, prestance) et le figure, distinction) du serviteur soient une "onction hors des hommes" ou qu'ils soient une "destruction hors des hommes", cela ne constitue pas un mode d'expression très naturel. Notons cependant que l'idée que l'onction met à part des autres hommes (Ex 30,32) ou met le Grand Prêtre au-dessus de ses frères ( Lv 21,10) ou encore met le roi au-dessus de ses compagnons (Ps 45,8) est un lieu commun. Avec "destruction", le sens le plus naturel de מן serait causatif : “destruction par les hommes". Quant à dire que l'apparence et la figure "sont onction" ou bien "sont destruction", König (Syntax §306r) cite un grand nombre de cas où des substantifs servent de prédicats en tenant lieu d’adjectifs. Ici, ces substantifs seraient à la place de "oint" ou "détruit". Quant à dire qu'une prestance et une distinction sont "ointe" ou "détruite", dans un cas comme dans l'autre il s'agit de métaphores et l'une n'est pas plus dure que l'autre.

En résumé, le comité n'a pas osé faire un choix tranché entre ces deux interprétations. Mais les motifs qui lui font préférer le sens "onction" sont : 


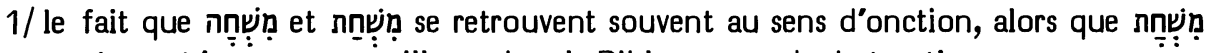

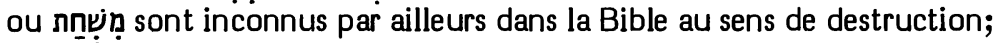

2/ le fait que "onction" s'insère de façon normale dans la structure de 52,13-15 (balancement de כאשר avec כן équilibre entre 2e et 3e personne), alors que “destruction" forcerait à admettre une construction très peu naturelle et risque d'imposer une correction du suffixe 2e pers. en suffixe $3 e$ pers. dans le 2 e membre;

3/ le fait que l"“onction" habilite à "accomplir le rite d'aspersion".

Le motif principal pour lequel le comité s’est refusé à éliminer l'interprétation "destruction" est qu'elle est profondément enracinée dans la tradition. Mais notons que "onction" est déjà indirectement attestée par la leçon de 1Q-a qui est le plus ancien témoin textuel dont nous disposons.

Pour finir, rappelons que, depuis Abulwalid (Opuscules 32s), certains exégètes

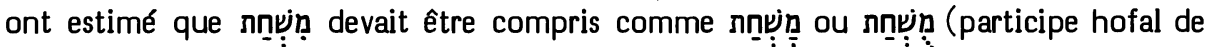
שחת). Aussi ne faut-il pas s'étonner que les critiques du texte aient essayé de trouver dans la tradition textuelle massorétique des attestations pour cette vocalisation. Thomas, en BHS, dit qu'un ms porte מושחת et que la "tradition babylonienne" vocalise מְִ̣. Ces deux affirmations débordent ce que l'on peut tirer des témoignages textuels. İl est vrai que la 1e main du ms Hamburg 6 (= Kenn 612) a écrit מושחת. Mais le 'waw' a été ensuite rayé et le 'mem' a été vocalisé hireq. Par contre, le ms Hamburg 27 vocalise ici le 'mem' avec qames, ce qui semble ne pas avoir été remarqué par les critiques. Quant à la "tradition babylonienne", nous l'ignorons pour la vocalisation de ce mot, le seul ms à vocalisation babylonienne connu ici étant celui de Petrograd en lequel Kahle (Geniza 137) a reconnu “un intéressant specimen d'un texte mixte appartenant au développement final de la ponctuation babylonienne fortement influencée par la massore tibérienne". Diez Macho lui aussi (Manuscritos 17) estime sa vocalisation supralinéaire "très influencée par la tibérienne". Or Pinsker (155) y a

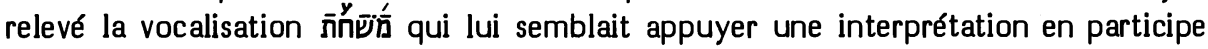
hofal (malgré la présence d'un patah dans la dernière syllabe). Le facsimilé de Strack confirme cette lecture, mais celui-ci commente (p. 011) que Pinsker n'a pas remarqué que la 1e main avait un hireq sur le 'mem'. A cela, Rubinstein (Variant 477) objecte que “il n'est pas du tout évident à partir du facsimilé que la leçon a subi la retouche en question". Mais il y a là un cercle vicieux, étant donné que c'est Strack lui-même qui est l'auteur du facsimilé où (comme nous l'avons constaté en 49,17A) il copie l'état textuel final, réservant à son commentaire les indications sur les leçons de première main. On ne saurait donc tirer du repentir d'un scribe une "tradition babylonienne".

\section{Interprétations proposées}

L'interprétation suivante est la plus probable :

•(13) Voici que mon serviteur prospérera, il montera, s'élèvera, sera très haut placé. (14) Comme beaucoup furent atterrés à ton propos, ainsi sa prestance (sera l'objet $d^{\prime}$ ) une onction surhumaine et sa distinction (sera l'objet d'une onction) dépassant les mortels, (15) ainsi il fera l'aspersion de nations nombreuses et, devant lui, des rois fermeront la bouche; car ils voient ce qui ne leur avait pas été raconté, ils méditent un événement inouï." 
Mais il faut reconnaître que l'interprétation suivante est la plus traditionnelle : “(13) ... (14) Comme beaucoup furent atterrés à ton propos - tellement sa prestance (était atteinte $d^{\prime}$ ) une défiguration inhumaine et sa distinction (était atteinte d'une défiguration) l'excluant des mortels - (15) Ainsi il fera sursauter des nations nombreuses..."

Quelle que soit celle de ces deux options qu'un traducteur retiendra, il serait souhaitable qu'il évoque en note l'ambiguité du mot "onction / destruction".

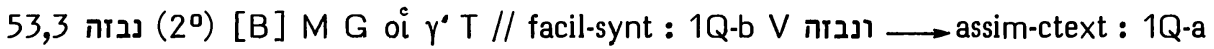
ונבוזהו

Options de nos traductions :

En fin du vs 3, le *M reprend ici le participe nifal נִבְזָ (= "méprisé") par lequel ce vs avait commencé, puis il l'explicite par : "et nous n'avons pas eu d'estime pour lui".

Le *M a été traduit par RSV : "he was despised", J12 : "il était méprisé", RL : "er war so verachtet", TOB : “oui, méprisé", J3 : "méprisé".

Selon Brockington, NEB corrige en despised him".

Origine de la correction :

Le premier critique qui ait proposé de voir dans le "nun' initial du participe nifal une préformante de la 1e pers. pl. de l'inaccompli semble être Martini en 1791 (cité par Gesenius) qui propose de lire נִבְבְּה en collant à ce mot la conjonction initiale du suivant. Gesenius accepte cette suggestion en estimant cependant que le suffixe est inutile; mais que, par contre, une conjonction est requise avant ce mot. La conjecture de Martini est reprise par Grätz et, avec une conjonction, par Ehrlich. Dillmann/Kittel ayant fait remarquer qu'un inaccompli s'insérait mal ici, Budde (HSAT34) vocalise en inaccompli inverti : wannibzéhû.

Les témoins anciens :

A partir de la racine synonyme בונבוזהו 1Q, forme très proche de cela. La *S avait, elle aussi, lu ou interprété de même : ושטניהי

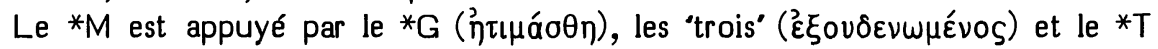
(בסירין). Il l'est indirectement par 1Q-b (ובזה) et la*V (et despectus) qui se sont contentés de faire précéder ce mot d'une conjonction.

Choix textuel :

La leçon de 1Q-a et de la *S s'explique comme une assimilation au verbe qui suit et aux deux verbes de $2 \mathrm{~b}$.

Dans la leçon du *M, il faut comprendre cette reprise de "méprisé" comme voulue par l'auteur pour causer un effet de martèlement (cf. CT1 sur 1S 19,23) par lequel les "rois" expriment l'intensité de leur remords. 
Le comité a attribué au *M la note " $B$ ".

Interprétation proposée :

Il faut reprendre ici la traduction donnée à ce mot en début de ce vs.

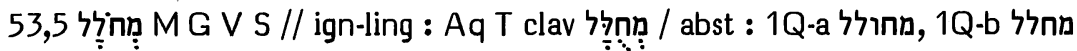

Options de nos traductions :

Elles ont traduit ce participe par "transpercé, blessé", sauf TOB qui traduit par "déshonoré" en se fondant sur Aq et le *T pour corriger la vocalisation en s'inspirant de 43,28 et de 47,6.

Origine de la correction :

Bonnard explique qu'il s'agit d'une vocalisation מִ̣. BH3 avait proposé en hésitant cette correction à la suite de Köhler.

Les témoins anciens :

Ils se divisent entre les deux sens de base de חל Le sens "transpercer" a été

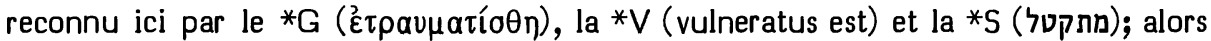

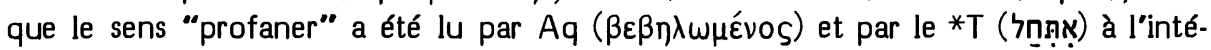
rieur d'un midrash qui considère ce participe passif comme concernant le Temple.

On ne peut savoir si la graphie pleine de 1Q-a ou la graphie défective de 1Q-b impliquent des prononciations de ce participe en pual ou en polal.

\section{Choix textuel :}

Ce cas n'a pas été soumis au comité.

La grammaire massorétique réserve au sens "transpercer" les intensifs de type polél et polal. C'est le cas du participe actif nִ en Is 51,9. Les vocalisateurs lisent donc ici le sens de "transpercé", ainsi que l'ont reconnu Abulwalid (Uṣul 209,13-15) et Luzzatto.

Aq (comme ailleurs Sym et Th) distingue mal les diverses réalisations du bilittère חל. C'est ainsi qu'en 51,9 il croit lire une forme dérivée de חול.

Le *T offre ici le midrash suivant : "Et c'est lui qui édifiera la maison du sanctuaire qui a été profanée à cause de nos révoltes, livrée à cause de nos fautes." Comme le fera TOB, le *T s'est inspiré de 43,28 et 47,6 où le piél de ןנת. Ce midrash constitue seulement une étape dans les nombreuses retouches par lesquelles, en ce début du ch. 53, le ${ }^{*} T$ essaie de transformer en gloire la peinture humiliée du Serviteur. S'il prend la liberté de rendre "broyé" par "livré", on est incliné à refuser de prendre appui sur le *T pour vocaliser notre participe.

Le parallèle "broyé" que l'hébreu offre ici s'accorde mieux avec "transpercé" qu'avec "déshonoré, profané". 
Interprétation proposée :

"Mais lui, il était transpercé à cause de nos révoltes, broyé à cause de nos perversités."

53,8A עמי [C] M 1Q-b G Th Aq Sym V S T // harm-ctext : 1Q-a(corr) ממו / incert : 4Q-d / lacun : 1Q-a*

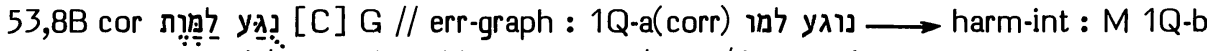

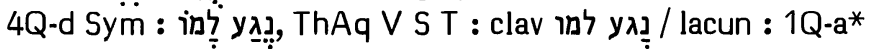

Options de nos traductions :

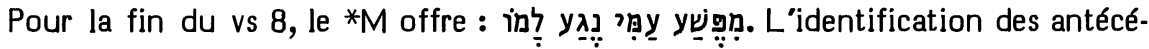
dents de ces deux pronoms suffixes a causé de graves difficultés aux exégètes. Toutes nos traductions ont corrigé ici le *M.

RSV donne : "stricken for the transgression of my people"; J12: "pour nos péchés, il a été frappé à mort"; RL : "da er für die Missetat meines Volks geplagt war"; NEB : "stricken to the death for my people's transgression"; TOB : "à cause de la révolte de son peuple, le coup est sur lui"; J3 : "qu'il ait été frappé pour le crime de son peuple".

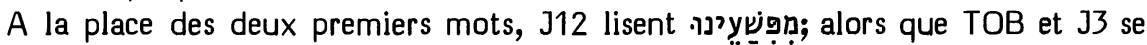
contentent de corriger le suffixe du 2 e mot en íg y avec $1 \mathrm{Q}-\mathrm{a}$.

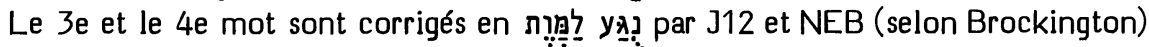
en se fondant sur le ${ }^{*} \mathrm{G}$. J3 se contente de conjecturer cette vocalisation pour le participe.

Origines des corrections :

C'est Cappel (Critica 734) qui a reconstitué ici la Vorlage du ${ }^{*} G$ et a suggéré de l'adopter, suivi en cela par Houbigant, Vogel, Lowth, Koppe, Michaelis, puis de nombreux critiques et les apparats de HSAT234, BH235 et Cent.

Pour les deux premiers mots, la conjecture de $\mathrm{J} 12$ était requise par les apparats de HSAT34, BH3 et Cent.

Quant à l'adoption de la leçon עמו 1Q-a, elle avait été proposée par Bonnard.

Les témoins anciens :

A/8A. Parmi les versions, seul un lectionnaire syropalestinien atteste ici un suffixe de la 3e pers. : דקהלה, leçon dont on ne peut rien conclure pour la critique du *M, étant donné les influences multiples subies par cette version dérivée du *G.

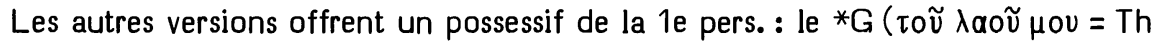
et Sym), Aq ( $\lambda \propto \circ \tilde{v} \mu \circ v)$, la *V (populi mei), la *S (מדע), le *T (עy).

Le témoignage des mss de Qumrân pose des problèmes :

1/En 1Q-a, les quatre derniers mots de ce vs ont été ajoutés après-coup dans un large blanc laissé par le scribe. Dans cette ajoute, on lit clairement עמו

2/En 1Q-b, Sukenik a lu עמי. Elliger (Nochmals 138) estime que la lettre finale pourrait aussi être un 'waw'. Pourtant la hampe inclinée et l'allure ramassée de la lettre semblent bien confirmer la lecture de Sukenik. 
3/4Q-d a été lu עמו par Morrow. Mais, en cette écriture, certains 'yod' finaux ressemblent encore plus à des 'waw' (cf. en ce même fragment הנני de פ2,6 ou פ $54,1)$. Il semble donc imprudent de conclure.

B/8B. Ici, 1Q-b et 4Q-d appuient la leçon du *M, dont l'ajoute de 1Q-a ne se distingue que par l'insertion d'un 'waw' entre les deux premières lettres du premier mot.

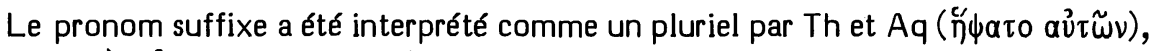

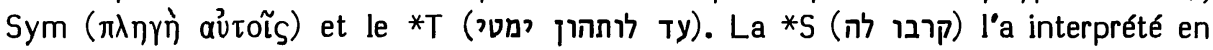
singulier.

Quant à la $* V$, son texte original semble être celui qu'a retenu l'édition de San Girolamo : "percussit eos". Elle a l'appui de Hie et des correctoires médiévaux. Elle possède une tradition manuscrite ancienne équivalente à celle de "percussit eum" que l'édition Weber a retenu.

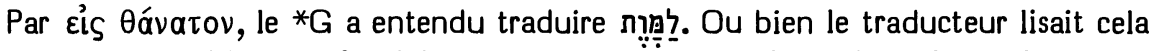
en sa Vorlage. Ou bien il a fait ici une conjecture en s'inspirant du vs 12 où il traduira

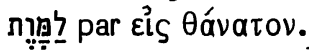

Quant au passif "̋X $\mid \eta \eta$ du *G, il apporte un témoignage indirect pour une vocalisation y. fluencé par la traduction qu'il a donnée au vs 7 pour יובל.

\section{Choix textuel :}

$A / 8 A$. Le seul témoignage solide en faveur d'un suffixe 'waw' est ici celui de 1Q-a. Mais nous avons déjà eu l'occasion de noter que le scribe de ce ms (qui distingue nettement le "yod" du "waw') devait disposer d'une Vorlage où cette distinction n'était pas claire. Cela explique très suffisamment qu'ici il ait opté pour un suffixe 'waw' qui s'harmonise plus aisément avec le contexte (דורו) qu'un suffixe 'yod".

La leçon y étant très faiblement attestée, le comité a attribué la note "C" à la leçon du *M. La difficulté est ici d'ordre exégétique plutôt que textuelle.

$B / 8 B$. Il est assez impressionnant de noter que, mis à part le *G, toutes les autres versions, ainsi que $1 Q-a, 1 Q-b$ et $4 Q-d$ appuient la leçon du $* M$. Le ${ }^{*} G$ est donc seul à témoigner (éventuellement) pour la variante

Cependant 1Q-a, avec sa vocalisation ju, sembile témoigner d'un état textuel intermédiaire où le "taw' de למות était déjà tombé, mais où la vocalisation en parfait pual du mot qui précède n'avait pas encore été corrigée en une vocalisation substantivale (נוֶּ) plus apte à précéder la préposition 'lamed' affectée d'un pronom suffixe.

Cette constatation rend plus probable que למו est issu d'une mutilation accidentelle de למות.

Ajoutons qu'en ce contexte, c'est bien un pual et non un nifal que l'on attend. En effet, le seul emploi biblique du nifal de ce verbe $($ Jos 8,15$)$ signifie "subir une défaite militaire"; alors que le piel et le pual s'emploient pour une "plaie' dont Dieu frappe un individu. Selon les contextes, il semble s'agir normalement de maladie.

Cinq membres du comité ont voté "C" pour la variante, alors qu'un membre a attribué " $C$ " à la leçon du * $M$ à cause de sa très forte attestation textuelle. 
Interprétation proposée :

Si l'on admet - ainsi que nous l'avons proposé à propos de 52,13-15 - que 53,1-10 est une méditation des rois sur le destin du mystérieux souffrant, on peut admettre que, dans ce monologue, le "nous" désigne les rois et les peuples pris ensemble, alors que "mon peuple" y peut désigner le peuple de chacun de ces rois : "C'est à cause de la révolte de mon peuple qu'il (= le Souffrant) a été touché à mort" (si on corrige en Cette interprétation considère les quatre derniers mots du vs comme une phrase indépendante, ce qui suppose que (comme l'ont fait RSV et J3) on relie l'un à l'autre (malgré l'atnah du $* M$ ) les deux membres précédents : "Parmi ses contemporains, qui s'est inquiété qu'il ait été retranché de la terre des vivants ?" Parmi ses contemporains, personne n’a cherché à approfondir la signification de la mort du Souffrant. Mais, maintenant, le roi qui parle en explique la cause.

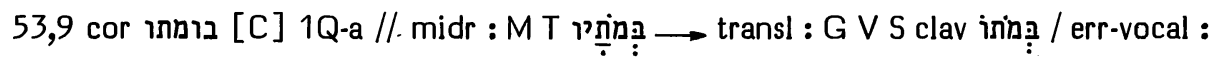
$\mathrm{m}$ ב⿱艹

Options de nos traductions :

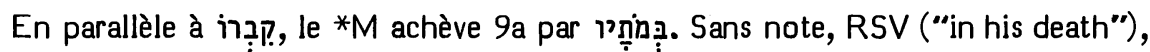
J1 ("à sa mort") et RL ("als er gestorben war") traduisent ce mot par un singulier.

Les autres traductions s'appuient sur 1Q-a pour corriger en inמ̣g (J2) ou en

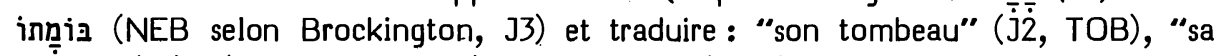
tombe" (J3), "(he was assigned...) a burial-place" (NEB).

Origine de la correction :

La vocalisation retenue par $\mathrm{J} 2$ a été proposée par Foreiro et reprise par Duhm et Bonnard. Celle que retiennent NEB et J3 se fonde sur la graphie de 1Q-a et a été proposée par Albright (High Place 245).

Les témoins anciens :

De Rossi a trouvé la vocalisation בְמָת en deux de ses mss et dans la 1e main d'un autre. Elle se rencontre aussi dans le ms Urbinates 1. Cependant le shewa sous le "bet' est garanti par une massore (présente dans le ms des Prophètes de Petrograd et dans les mss Paris BN hébr 2 et 6 , Vatican ebr 468 et 482, ainsi que dans l'édition Ben Hayim) signalant ici ce mot comme unique (pour le distinguer de cette même forme avec le 'bet' vocalisé qameṣ attestée en trois éditions diverses d'un même texte : 2 R 18,22; Is 36,7 et 2 Ch 32,12).

$1 Q$-a donne ici בומתו Notons à ce propos que, pour (Is 14,14) et pour

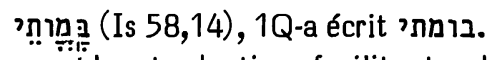

Une traduction facilitante du *M par un singulier est attestée par le *G (ávì

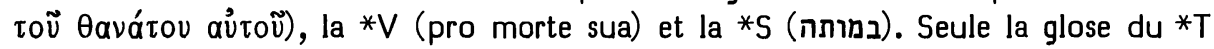
offre pour ce mot un contexte pluriel. 


\section{Choix textuel :}

Le *M est interprété par presque toute la tradition juive : “en ses morts". Il s”agirait des divers types de supplices imposés à Israël par les goyîm. Pour cet usage de חִ au pluriel, on cite Ez 28,10.

Trois commentateurs juifs s'orientent pourtant vers une autre interprétation : - Ibn Ezra : “Certains disent que le mot במתיו est de la racine (Dt 33,29), le sens étant la construction que l'on établit sur la tombe. במתיו serait donc semblable à קברו... Si quelqu'un objecte que la vocalisation de מבּ ne modifie pas dans

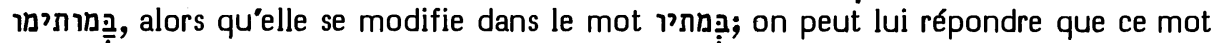

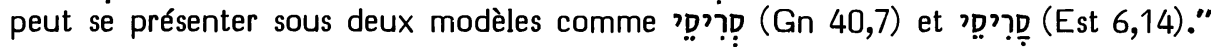
- Saadya ibn Danan interprète ici ce mot comme sanctuaires et synagogues.

- Luzzatto suit l'exégèse d'Ibn Ezra en citant comme partisans de cette exégèse Lowth, Martini, Lockemacher et la 2e édition de Gesenius.

Parmi les exégètes du XVIe siècle, cette interprétation est celle d'Oecolampade (excelsa sua), de Brucioli ("i excelsi suoi"), d'Olivetan et d'Estienne ("son monument"). Forster (cité par Mercerus en Thesaurus3 de Pagnini), en fonction de cette exégèse, demande de vocaliser 'bamothau' au lieu de 'bemothau'. Nous avons traité de Foreiro à propos de $\mathrm{J} 2$.

Dans son Thesaurus (188b), Gesenius rapproche ce mot de Nous le suivrons en y reconnaissant à ce mot le sens de "leurs monuments funéraires".

A propos des graphies de 1Q-a (בומתו ici, בומתי en 14,14 et 58,14), rappelons que le Dr Jubb (cité ici par Lowth) estimait déjà que la lexicographie hébraïque a le tort de confondre un mot במה (במות : במות (pluriel signifiant "un lieu consacré à la divinité", avec un mot במות (pluriel : במותים) désignant une "hauteur". En ce sens (attesté en Is 14,$14 ; 58,14)$, il s'agirait en Is 53,9 plus spécifiquement de tumulus funéraire. On notera qu'en Is 16,12 et 36,7 où il s'agit clairement de lieux de culte, 1Q-a n'écrit pas de 'waw' dans la première syllabe. Il faut noter que les graphies de 1Q-a confirment l'opinion de Bauer/Leander (597h') qui voyait dans a le pluriel construit d'un singulier תñ. En corrigeant l'intuition de Jubb, on peut donc dire que l'on a confondu dans la vocalisation massorétique, puis dans les dictionnaires, un

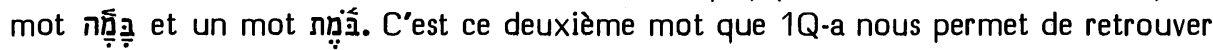
en Is 53,9 .

Le comité a attribué la note "C" à la leçon de 1Q-a.

Interprétation proposée :

“On a mis chez les méchants son tombeau et chez le riche son mausolée."

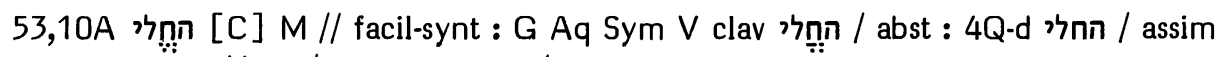
5:1Q-a ויחללהו / assim-ctext : S / midr : T

Options de nos traductions :

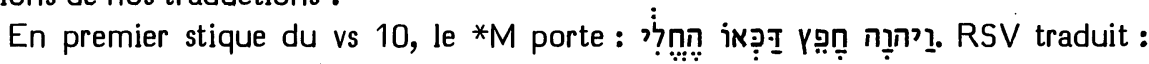
"Yet it was the will of the LORD to bruise him; he has put him to grief" en précisant que l"hébreu dit, pour le dernier mot : "made him sick". En reconnaissant que 
ce mot signifie : "il l’a fait souffrir", TOB traduit : "Mais, SEIGNEUR, que, broyé par la souffrance, il te plaise".

Disant lire יִ̣nב avec le *G, J12 traduisent : "Yahvé s'est plu à l’écraser par la maladie (J2 : souffrance)." J3, sans note, donne : "Yahvé a voulu l'écraser par la souffrance" et RL : "So wollte inn der HERR zerschlagen mit Krankheit."

Pour ce mot et les deux suivants (אִם (se), NEB lit (selon Brockington): הֶח et elle traduit : "Yet the LORD took thought for his tortured servant and healed him who had made (himself a sacrifice for sin)."

\section{Origines des corrections :}

La conjecture retenue par NEB était déjà mentionnée en BHS. Elle émane de Begrich (Studien 64) et a été diffusée par Driver (Servant 96) après avoir été signalée par North.

La leçon retenue par $\mathrm{J} 12$ a été proposée par $\mathrm{BH} 23$ et Cent. Elle avait été suggérée comme Vorlage du ${ }^{*} G$ par Clericus, puis adoptée comme correction textuelle par Houbigant, puis Lowth.

Les témoins anciens :

La plupart des versions ont lu ce mot en substantif, comme si elles avaient voca-

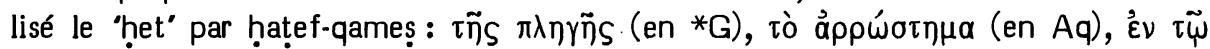

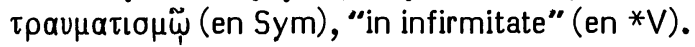

4Q-d a la graphie du *M, sans qu'on puisse préciser s'il lit ici un verbe ou un substantif.

ויחללהו de 1Q-a semble une leçon facilitante basée sur une lecture de החלי en verbe $(=* M)$, mais s'inspirant, pour rendre cette forme plus intelligible, du parallelisme que le vs 5 avait établi entre מדכא et.

La *S a interprété ce mot en infinitif (ונחשיוהי), comme le mot qui le précède.

Le midrash du *T n'apporte pas de témoignage textuel sur ce cas.

Choix textuel et interprétation proposée :

Le *M חִ̣n a été analysé de façon concordante par Ibn Ezra, Judah ibn Balaam, Radaq, Aaron ben Joseph et Tanhum Yerushalmi. Il s'agit d'une forme défective se rattachant aux verbes à 3e radicale 'alef' (cf. CT1 401 où nous avons précisé que

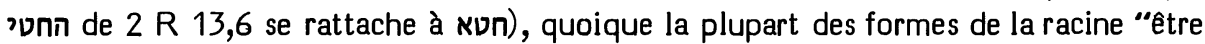

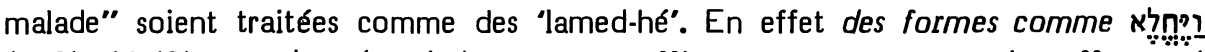

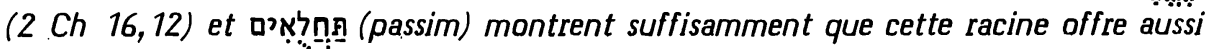
des réalisations "lamed-alef".

Il semble donc qu'il faille voir en ce mot un accompli hifil à la 3e pers. m. sg. : "il a rendu malade". Cependant Dillmann/Kittel a fait remarquer que cela se connecte mal avec les trois mots qui précèdent et que l'on a coutume d'interpréter comme : "le Seigneur a voulu le broyer".

C'est pourquoi nous avons vu la plupart des versions lire ici un substantif, suivies en cela par Yéfet ben Ely, Oecolampade, Luther, Olivetan et Châteillon (avant qu'Houbigant ne corrige en ce sens). 
Il n'est cependant pas possible de porter un jugement sur ce mot avant d'avoir analysé de façon satisfaisante celui qui le précède : 200,5), il s'agit d'un infinitif avec suffixe accusatif. Ibn Ezra ajoute qu'il s'agit d'un piél comme stantif אכָּ]. Tout en reconnaissant qu'une vocalisation du 'kaf' par qames serait plus

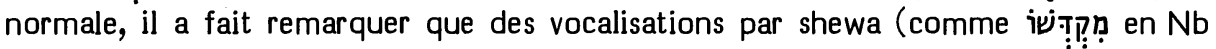
18,29) alternent en cette position avec des vocalisations par qameṣ. Ce mot signifierait alors "celui qu'il a frappé", comme nִ en Ps 69,27 signifie "ceux que tu as blessés". Luzzatto accepte cette exégèse en ajoutant, comme exemple d'une vocalisation par shewa : ị̂ en 2 S 14,13 qui signifie "son repoussé", c'est-à-dire : celui qu'il a repoussé. Gousset avait proposé de comprendre direct au sens technique de "agréer" un sacrifice que ce verbe a en Is 1,11; Os 6,6; Ps 40,7; 51,18.21. Cette exégèse permet de faire de dent est le mot qui précède, mot dont elle a pour but d'expliciter le pronom suffixe : "Le Seigneur a agréé son broyé, qu'il avait mis à mal." Cela évite la nuance sadique de la traduction courante : "Le Seigneur a pris plaisir à le broyer", phrase à laquelle le verbe qui suit s'attache - nous l'avons vu - plus difficilement.

Le comité a attribué à la leçon du *M la note " $C$ ".

53,10B תשים [C] M 1Q-a 1Q-b(?) 4Q-d? // lic : G, V, S / midr : T

Options de nos traductions :

Le *M achève le vs 10 par trois principales : "il verra une postérité, il prolongera des jours et le vouloir du Seigneur réussira par sa main". Ces trois propositions sont

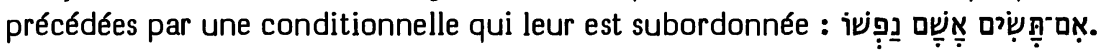

TOB a interprété le verbe en 2e pers. m. sg. et traduit : "daigne faire de sa personne un sacrifice d"expiation".

$\mathrm{J}$ traduit: "s"il offre sa vie en sacrifice expiatoire", mais J3 dit que le verbe a été corrigé selon la *V sur laquelle RSV se fonde aussi pour traduire : "when he makes himself an offering for sin". RL traduit de même : "Wenn er sein Leben zum Schuldopfer gegeben hat."

Nous avons traité de la conjecture de NEB et de son origine à l'occasion du cas précédent.

Origine de la correction :

Ici, RL n'a fait que copier Luther. Avaient traduit de même, comme s'ils lisaient un verbe à la 3e pers. m. sg. : Münster, Jud, Olivetan, Rollet, Estienne, Châteillon, Ge. Cependant Michaelis (OEB) a fait remarquer que cela supposerait une correction en ישים, correction qui a donc été demandée par Ewald2, Grätz (Psalmen 136,6s) et requise par les apparats de HSAT34, BH23 et Cent.

Les témoins anciens :

La leçon du *M a l'appui de 1Q-a. 1Q-b mutilé n'en atteste que les trois dernières lettres. $4 Q-d$ porte ici תשם. Mais il ne semble pas qu'il puisse servir de témoin pour la 
vocalisation en passif (트) proposée par plusieurs depuis Houbigant et Lowth. En effet, dans le peu de fragments de ce ms qui nous sont conservés, il lui arrive une dizaine de fois d'omettre des matres lectionis présentes dans le *M.

Il est possible que ce soit une leçon défective de ce type que la $* S$ a traduite par un passif (אתתסים). La *V (si posuerit) et le ${ }^{*} G(\varepsilon \dot{a} \nu \delta \tilde{\omega} \tau \varepsilon)$ divergent dans leur essai pour rendre la leçon difficile du ${ }^{*} M$. Quant au ${ }^{*} T$, comme souvent dans cette péricope, il se réfugie dans le midrash.

Choix textuel et interprétation proposée :

La construction la plus naturelle se fondera sur une interprétation de שים au sens de "déposer une victime sur l'autel", comme Isaac en Gn 22,9. Ici, il s'agit d'un

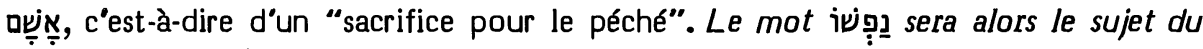
verbe: "si son âme offre un sacrifice d'expiation". Ici "son âme" est évidemment ce qui offre et ce qui est offert.

Cette exégèse s'accorde bien avec celle qui a été proposée par Gousset et Luzzatto pour le début du vs: "Le Seigneur a agréé le broyé par sa main (litt. : son broyé), celui qu'il avait mis à mal : si son âme offre un sacrifice d'expiation, il verra une descendance..."

Le comité a attribué 3 " $B$ " et 3 " $C$ " à la leçon du *M.

53,11 יראה אור 1B] 1Q-a.b 4Q-d G // theol vel err : M ThAqSym V S T om אור 53,12A cor ח [B] 1Q-a.b 4Q-d G Sym S T // assim 6 et 8 : M V sing

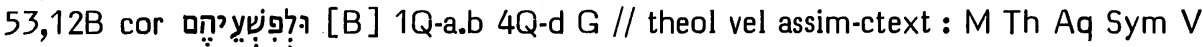

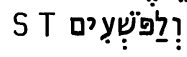

Il est nécessaire de grouper ces trois cas qui posent un même problème d'attestation textuelle.

Options de nos traductions :

A/ Le *M divise 11a en deux stiques par le zaqef qaton. Le premier comporte

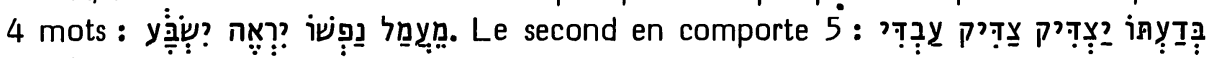

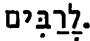

Le premier stique est traduit par RSV: "he shall see the fruit of the travail of his soul and be satisfied" et par TOB : "Ayant payé de sa personne, il verra une descendance, il sera comblé de jours." RSV explicite donc un complément: "the fruit" et TOB deux : "une descendance" et "de jours".

Après יר:? cette ajoute sur $1 \mathrm{Q}$-a à quoi $\mathrm{J3}$ ajoute le ${ }^{*} \mathrm{G}$, complété en $\mathrm{J} 2$ par $1 \mathrm{Q}-\mathrm{b}$. La division des deux stiques est respectée par RL : "Weil seine Seele sich abgemüht hat, wird er das Licht schauen und die Fülle haben" et par J : "Après les épreuves de (J3 : A la suite de l'épreuve endurée par) son âme, il verra la lumière et sera comblé." NEB repousse l'atnah pour traduire: "After all his pains he shall be bathed in light, after his disgrace he shall be fully vindicated." 


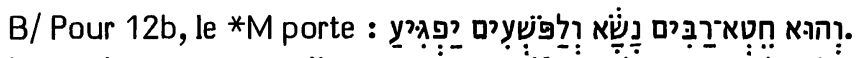

La seule note textuelle portant sur l'une de nos traductions est en Brockington, et elle est inexacte puisqu'elle renvoie à $1 Q$-a pour justifier par une vocalisation 草 la traduction de NEB : "and ... for their transgressions".

\section{Origines des corrections :}

C'est Houbigant qui a proposé de se fonder sur le ${ }^{*} G$ pour ajouter sition reprise, avec ou sans corrections complémentaires, par de nombreux critiques, puis par les apparats de $\mathrm{BH} 3$ et de Cent, avant d'être confirmée par les mss de Qumrân.

HSAT34 avaient proposé de corriger 12B en en (Vorlage 50) a considéré cette dernière leçon comme originelle.

\section{Les témoins anciens :}

4Q-d est un ms qui, comme 1Q-b, est assez proche du *M pour ce qui est du texte et des graphies. Pour 53,11 à 54,1 il est assez bien conservé. Pour la plus grande partie de ces trois vss, nous possédons donc 4 ou 5 témoins anciens : *M, 1Q-a, 1Q-b, 4Q-d et la Vorlage du ${ }^{*} G$ (là où elle peut être atteinte avec assez de sécurité à partir de la traduction).

Or, si nous comparons au *M la partie conservée de 1Q-b (témoin qui en est le plus proche), on peut relever les variantes suivantes :

$1 /$ une différence graphique consistant en une graphie pleine : יסבול (en 53,11) qui est attestée aussi par 4Q-d et 1Q-a.

$2 /$ trois variantes réelles :

- un 'plus' en 53,11 : ראה après : Ce 'plus' se retrouve en 4Q-d (où le 'alef' seul est conservé, suivi d'une lacune de l'importance requise pour 'waw' et 'resh'), en 1Q-a

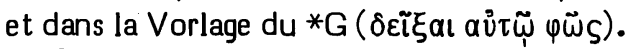

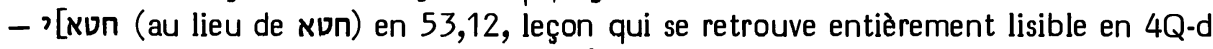

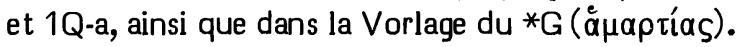

- ולפשעיהם) (au lieu de ולפשעים) en 53,12, leçon qui se retrouve (ולפשעיה]) en 4Q-d, ainsi qu'en 1Q-a (avec la graphie ולפשעיהמה) et que le ${ }^{*} G$ a lu en sa Vorlage (xai

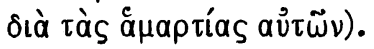

Pour ces trois versets, le *M porte 198 lettres, alors que 163 lettres sont lisibles en $4 \mathrm{Q}-\mathrm{d}$. En dehors des variantes que nous venons de mentionner, ce ms ne se distingue du $* M$ que par :

- une graphie défective : עצמם en 53,12 contre 1Q-a (1Q-b n'étant pas conservé), - l'ajoute d'une conjonction avant le premier לא de 54,1 avec 1Q-a, contre 1Q-b et la Vorlage du *G.

Pour ces trois mêmes versets, indépendamment des variantes tenant à ses graphies longues et de celles qui ont été déjà mentionnées, $1 \mathrm{Q}$-a ne se distingue du $* \mathrm{M}$ que par : 1/ une graphie défective : יפג en 53,12 contre 1Q-b (4Q-d n'étant pas conservé). Kutscher (150) a montré contre Wernberg-Mфller (qu'il cite) que 1Q-a présente bon nombre de graphies défectives portant sur des 'yod'. Il est donc fort douteux qu'il y ait ici une intention de lire un nifal. Kutscher (362s) suggère que le qal peut avoir été plus familier au scribe que le hifil (à cause de Gn 23,8 ). 
2/ trois ajoutes de conjonctions : וישבע en 53,11 avec le *G (contre 1Q-b et 4Q-d), ולוא 53,11 contre 4Q-d et le *G (1Q-b n'étant pas conservé) et en 54,1 contre 4Q-d et le *G (1Q-b n'étant pas conservé).

3/ une confusion waw/yod : עבדו 53,11. Comme nous l'avons noté, en effet, le scribe a un archétype où 'waw' et 'yod' ne sont pas nettement distincts. Cela l'a amené à méconnaître ici ce suffixe 1e pers. isolé. Le passage à la 1e pers. ne s'imposera à lui que par le verbe initial du vs suivant.

Il est très frappant que, pour ces trois versets, si l'on ne tient pas compte de quelques ajoutes de conjonctions, trois de nos témoins hébreux (les trois mss de Qumrân) sont $d$ 'accord avec le ${ }^{*} G$ contre le ${ }^{*} M$ sur les trois seules variantes réelles clairement attestées qui se font jour en eux. Nous avons donc affaire, pour ces versets, à un type textuel ancien incluant les trois mss de Qumrân et la Vorlage du ${ }^{*} G$, type dont le *M se distingue par trois variantes réelles. Cette situation est d'autant plus remarquable que Roberts (Text 582a), qui ignorait encore le témoignage de 4Q-d, jugeait que 1Q-b “est aussi semblable qu'il est humainement possible à ce qui est devenu plus tard pour le rabbinat le texte standard et orthodoxe... Les seules variantes textuelles notables existant entre le $* M$ et $1 Q$-b sont en Is 53,11-12 et elles ont aussi l'appui du *G. Par conséquent elles indiquent une erreur possible dans la transmission interne du * $\mathrm{M}^{\prime \prime}$.

Le complément אור n'est attesté au vs 11 ni par la *V, ni par la*S, ni par le *T. Si l'on en croit Field, le ms Barberini attribue ici à ThAqSym une leçon continue où ce mot est clairement absent.

En 12A, le singulier du *M est attesté par la *V (où "peccatum" a l'appui de Hie et du correctoire de Guillaume de Mara), alors que Sym, la*S et le *T ont traduit par un pluriel.

En 12B, la leçon וִ du *M a été lue par Th, Aq et Sym selon le PseudoChrysostome (399), par la $* V$ (et pro transgressoribus), la *S (ובעוע) et le *T (ולמרודיא).

\section{Choix textuel :}

La plupart des exégètes juifs médiévaux ont explicité au vs 11 , après "il verra" un complément qưils estiment sous-entendu: la prospérité, une rétribution, une postérité, la réalisation de ses désirs, etc.

Cappel (Notae 58s), se fondant sur le glissement entre les racines גוה et, a estimé qu'ici ?ִ?ִ peut avoir la valeur de ?ִ?ְ? et signifier "il sera abreuvé", en parallèle exact avec "il sera rassasie" qui suit immédiatement. Houbigant et Koenig (Herméneutique 277-280) estiment que la leçon "il sera abreuvé, il sera rassasie" représente un état textuel très ancien; mais que, dans l'état rédactionnel actuel, le rapprochement avec ?ִ?ְֶ (vs 10) impose le sens de "voir". L'ajoute de "la lumière" après "il verra" au vs 11 constituerait en ce cas une glose rédactionnelle postérieure, visant à expliciter le complément du verbe ainsi interprété.

Avant de connaître les mss de Qumrân, Seeligmann (119), traitant du 'plus' du * $G$ en 53,11 , concluait : “Dans notre traduction, il est permis au raĩs $\theta \varepsilon \circ 0 \tilde{~ d e ~ c o n-~}$ templer le $\varphi \tilde{\omega} \varsigma$ ( $\gamma \nu \omega ́ \sigma \varepsilon \omega \varsigma)(53,11)$ ! Evidemment, selon la conception du traducteur, la figure prophétique du Messie se dissout dans l'image qu'il se fait de l'extatique hellénistique." Les découvertes de Qumrân ont forcé Seeligmann à une mise au point. 
Il y affirme d'abord (Phôs 131, lignes 2.3) que le parallèle entre ישבע et בדעתו, c'est-à-dire entre connaissance et lumière, qu'établit la leçon commune à Qumrân et au *G, n'est pas vraisemblable dans la Bible mais respire une atmosphère prégnostique. D'ailleurs, avec Ehrlich, il corrige (133, lignes 1-3) le *M en ישבע ברעתו, en s'inspirant de Ps 88,4. Ensuite, il montre que la "lumière", comme parallèle à la "connaissance" joue un rôle fondamental dans la théologie de la secte de Qumrân. D'où il conclut (137, lignes 3-5) que l'ajoute de אור dans les mss de Qumrân est un élément sectaire. Puis, décelant dans la Sagesse de Salomon des traits typiquement "qumrâniens", il estime (141, lignes 9-11) avoir établi la probabilité d'une influence exercée par les doctrines de la secte de Qumrân sur la pensée du judaïsme alexandrin. Il ne serait donc pas surprenant de retrouver dans le ${ }^{*} G$ certains de ces traits.

On peut objecter à Seeligmann que l'expression ראה אור peut fort bien apparaître en des contextes qu'on ne saurait soupçonner de gnosticisme. Ainsi en Jb 3,16:

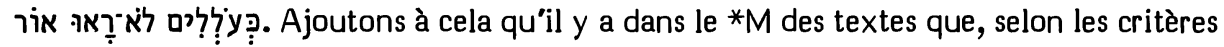
de Seeligmann, on serait amené à juger prégnostiques; ainsi Ps 36,10 : Remarquons enfin qu'il est souverainement improbable qu'un texte de type extrêmement proche du $* M$ (ce qu'est $1 Q-b$ ), un texte d'une tradition graphique et textuelle qui en est nettement distincte (ce qu'est 1Q-a), un autre texte de tradition graphique et textuelle assez proche du $* M$ (ce qu'est $4 Q-d$ ) et enfin un autre texte (la Vorlage du ${ }^{*} G$ ) que Seeligmann (87) considère comme étant, avant 140 av. J.-C., en circulation dans le judaïsme alexandrin se trouvent avoir subi, tous les quatre, trois corrections précises qu'il est impossible de situer, toutes les trois, dans la catégorie "sectaire prégnostique" que Seeligmann a élaborée en 1957 pour défendre la position qu’il avait prise en 1948 à propos du 'plus' $\varphi \tilde{\omega} \varsigma$ du *G.

Les quatre textes concordants sont de types nettement distincts et nous n'avons aucun indice à Qumrân d'une activité recensionnelle visant à créer un type textuel standard. Il est donc plus vraisemblable que, sur ces trois points, c'est le ${ }^{*} M$ qui a ou bien subi des accidents ou bien réalisé des retouches. Plutôt que de soupçonner de modification théologique prégnostique les quatre textes attestant en 11 : "la lumière" après "il verra", il serait de meilleure méthode de chercher un motif théologique à l'absence de ce mot dans le *M. Mais il peut aussi s'agir d'une omission accidentelle. Quant à la transformation de רְ ְְ en 12b, étant donné l'exégèse que ceux qui en sont les plus anciens témoins donnent du ${ }^{*} M$ en 53,12 (Th : et impios

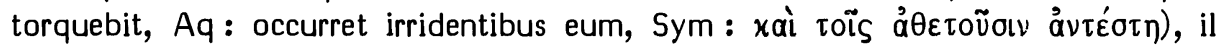
est possible qu'ici - comme nous l'avons déjà vu en Is 49,7 - nous ayons affaire à une correction théologique visant à éviter à Israël de souffrir de la part des païens. Mais cette correction peut aussi avoir été causée par une simple assimilation à ce même mot déjà apparu en 12a. Enfin le passage de חטאי à nout s'être effectué dans le *M sous l'influence de "la faute de nous tous" (en 53,6) et "la révolte de mon peuple" (en 53,8).

Si nous ne trouvions ces trois variantes qu'en des types textuels nettement distincts du ${ }^{*} M$, nous $n$ 'oserions pas proposer de corriger celui-ci, de peur d'attenter à sa spécificité. Mais le fait que 1Q-b (que l'on est en droit de considérer comme prémassorétique) les atteste lui aussi a engagé le comité à opter en ces trois cas pour ses leçons auxquelles le comité a attribué 4 " $\mathrm{B}$ " et 2 "C $\mathrm{C}$ ". 
Interprétation proposée :

Notons d'abord que le ${ }^{*} M$, lorsqu'il rattache בדעתו au stique suivant, a l'appui de 1Q-a qui insère une conjonction avant ce mot. De même, $4 Q-d$ sépare plus ce mot de ce qui le précède que de ce qui le suit. Une lacune de 1Q-b empêche de recueillir sur ce point son témoignage. Cette division des deux stiques a également l'appui des onciaux de la *V (cf. édition de San Girolamo) et du commentaire de Hie.

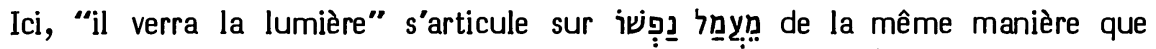
רְאו אוֹר גִגדוֹל en Is 9,1, s'articule sur ce qui précède cette phrase (à partir de la fin de $8,2 \dot{0})$. C'est-à-dire qu'il vaut mieux comprendre מעמל נפשר comme "émergeant de ce qu'il a souffert (littéralement : hors de la peine de son âme)" plutôt que comme "à cause de ce qu'il a souffert".

On peut donc traduire 53,11a : “Emergeant de ce qu'il a souffert, il verra la lumière, il s'en rassasiera".

Quant à 53,12b, on peut le traduire : "alors que lui, il a supporté les fautes des multitudes; tandis que, pour leurs révoltes, il s'interposait."

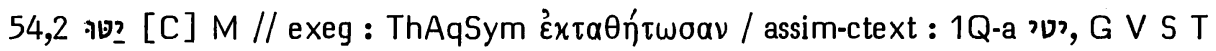
clav הַ הִַ

Options de nos traductions :

Après avoir commencé 2a par "élargis l'espace de ta tente" et avant de dire en $2 b$ : "allonge tes cordages et affermis tes piquets", le *M continue 2a par : תiy'???

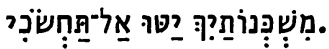

Cette phrase est traduite par RSV : “and let the curtains of your habitations be stretched out; hold not back"; par TOB : "les toiles de tes demeures, qu'on les distende ! Ne ménage rien !"

Au lieu du 3e mot, NEB (selon Brockington) lit הִ̣ avec le *G, en le traduisant par "spread wide". J dit s'appuyer sur les versions pour traduire "déploie". RL traduit de même : “und breite aus".

Origine de la correction :

RL a seulement conservé la traduction de Luther qui a pu être influencé par la *V. La familiarité avec la traduction de Luther a amené Duhm, Grätz, Oort, Cheyne, puis les apparats de HSAT34, BH23 et Cent à proposer de corriger en הַ en se fondant sur le *G, la*V, la *S et le *T.

Les témoins anciens :

Le *G ( $\pi \tilde{n} \xi \circ v)$, la *V (extende), la *S (מתוחי) et le *T (יתיבי) ont assimilé aux trois impératifs f. sg. qui entourent ce verbe.

ThAqSym, en traduisant par un passif ( $\varepsilon \varkappa \tau \alpha \theta \eta ́ n \omega \sigma \alpha \nu)$, ont simplement explicité le sens de ce pluriel interprété comme impersonnel. Olivetan et Tremellius feront de même.

1Q-a, en créant une forme impossible : 'יט, a mal résolu l'ambiguité 'yod/waw' de son archétype, sous l'influence des finales des participes voisins. 
Choix textuel :

Contre l'option facilitante des versions, le comité a attribué au *M 4 "C" et 2 "B".

Interprétation proposée :

En réalité, le verbe s'articule sur l'impératif qui le suit : "et que l’on déploie les toiles de tes demeures, ne lésine pas", c'est-à-dire : "et ne lésine pas à ce que l'on déploie..."

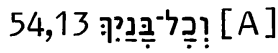

Options de nos traductions :

Elles comprennent "tous tes fils", sauf NEB, qui (selon Brockington) se réfère

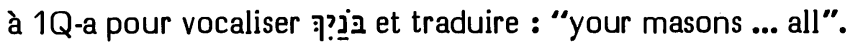

Origine de la correction :

C'est Houbigant qui (dans une partie de ses notes omise par la réédition de Francfort), notant en 13b le retour de ce mot, a estimé préférable de lire en cette première occurrence: "tes constructeurs". Cette conjecture a été proposée par les apparats de HSAT34, BH23 et Cent.

\section{Les témoins anciens :}

North et Beuken (Identity 59, n.1) ont mal interprété l'apparat critique complémentaire ajouté par Eissfeldt en BH7. De fait, 1Q-a est identique au ${ }^{*} M$ pour la première occurrence de ce mot en ce vs. C'est pour la seconde qu'une $2 \mathrm{e}$ main a suspendu un 'waw' au-dessus de l'intervalle qui sépare le 'bet' du 'nun' de בניכי

Le *M est appuyé par toute la tradition textuelle.

\section{Choix textuel :}

Selon Michaelis (OEB), Doederlein, en sa première édition, acceptait cette correction vocalique de la 1e occurrence de ce mot, en prétendant que toutes les versions lisaient ainsi. Michaelis corrige cela en : "toutes les versions lisent comme le *M". Mais il accepte cependant cette correction pour les deux occurrences du mot, en se fondant sur le fait qu'il s'agit, dans le contexte, de la construction de la ville. Doederlein, dans sa deuxième édition, vocalise ainsi la 2e occurrence du mot et ne prend plus appui sur les versions, mais sur le Talmud Babli Berakot 64a. C'est encore une erreur, car c"est à propos de la 1e occurrence que R. Eleazar [ben Pedat] rapporte en ce lieu que R. Hanina [ben Hama] (1e moitié du IIIe siècle) disait : "ne lis pas 'tes fils', mais ברוניך"; et il en concluait que les disciples des sages accroissent la paix dans le monde.

Dans son inventaire des al-tiqré, McCarthy (159) a relevé des traditions analogues à propos de 1 Ch 2,18 où (en Talmud Babli Soṭa 12a) il est dit : "ne lis pas 'ses fils" mais 'ses constructeurs' (ברניה)"; et à propos de Dt 8,9 où (en Talmud Babli Taanit 4a) il nous est dit (vers 400, par R. Ashi qui le tenait de R. Abba) : “ne lis pas 'ses 
pierres' (אבניה), mais 'ses constructeurs' (בוניה)". On voit donc que les al-tiqré aboutissant à lire le participe actif de בנה étaient un lieu commun de l'exégèse haggadique.

Le principal intérêt de ces traditions pour la critique textuelle est d'attester que, dans le milieu d'où elles émanent, la vocalisation normale de ces mots n'était pas celle que suggèrent ces al-tiqré. Cependant, comme c'est le cas pour un certain nombre de ces traditions, il est possible que cet al-tiqré proposant de lire "constructeurs" au lieu de "fils" ait été suggéré par le fait qu'en d'autres endroits de la Bible ces variantes s'opposaient l'une à l'autre, comme c'est le cas entre les leçons de la 1e et de la $2 \mathrm{e}$ main de 1Q-a en 54,13B. Rappelons qu'en 49,17A nous avons opté pour "constructeurs" avec de nombreux témoins, contre le *M qui avait "fils". Nous retrouverons d'ailleurs un débat portant sur le même point en 62,5B.

Ici, avec la tradition textuelle unanime, il faut garder "fils".

Interprétation proposée :

Il n'est cependant pas impossible que l'auteur ait voulu laisser à ses lecteurs la possibilité de jouer sur l'équivoque que ce mot appelle. Notons en effet qu'en d'autres passages du Talmud Babli les mêmes conclusions homilétiques sont tirées de notre texte, sans qu'il soit demandé de vocaliser autrement (cf. Yebamot 122b, Nazir 66b). Les traducteurs pourraient donc indiquer en note l'ambiguité qui s'attache aux deux emplois de ce mot en ce verset.

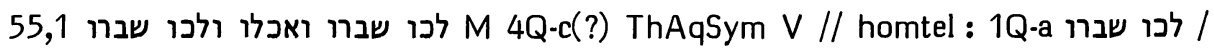
abr-styl : S / abr-styl et harm-ctext : G / schem : T

Options de nos traductions :

Cinq impératifs se suivent dans le *M au début de 55,1b.

Ils sont tous exprimés par les traductions de RSV, RL, NEB et J3; alors que $J 12$ omettent les deux derniers en disant se fonder sur le ${ }^{*} G$ et $1 Q-a$, tandis que TOB remplace le dernier ("demandez du grain") par "buvez" en se fondant sur le *G.

\section{Origine des corrections :}

Comme J12, BHS entend fonder sur $1 \mathrm{Q}-\mathrm{a}$, le ${ }^{*} \mathrm{G}$ et la $* S$ l'omission des deux derniers impératifs. Quant à TOB, elle dépend des données textuelles confuses fournies par Bonnard.

\section{Les témoins anciens :}

Notons d'abord que 4Q-c n'est pas conservé pour ces mots, mais qu'un calcul du nombre de signes par ligne permet d'inférer avec une quasi-certitude qu'il n'omettait aucun mot du *M.

Le *M est appuyé en outre par ThAqSym qui sont cités par le ms Barberini comme faisant suivre la traduction des deux premiers impératifs (attestée dans le ${ }^{*} G$ ) par celle des trois suivants.

Il est appuyé enfin par la *V (properate emite et comedite venite emite).

1Q-a omet les trois derniers impératifs. Il semble qu'il ait été victime d'un homéotéleuton, accident subi aussi par les mss 17 et 80 de Kennicott. 
Le *T midrashise en symétrisant, comme si sa Vorlage avait répété le 3e impératif après le cinquième.

$\mathrm{La}$ *S est le seul témoin qui puisse fonder la correction de J12. Elle se contente en effet d'omettre les deux derniers impératifs (qui répètent les deux premiers).

A cette omission des deux impératifs le *G ajoute un remplacement de "mangez" par "buvez" pour harmoniser au contexte de boissons.

Choix textuel :

Ce cas n'a pas été soumis au comité.

Le ${ }^{*} M$ offre ici une lectio difficilior suffisamment bien attestée pour que nous ne lui préférions pas les textes accidentés ou facilitants qui rivalisent avec lui.

Interprétation proposée :

Les teamim lient étroitement le 1er et le 2e impératif, ainsi que le $4 \mathrm{e}$ et le $5 \mathrm{e}$. On peut donc traduire : "Venez vous procurer du grain et mangez, venez vous procurer du grain..."

להמה 56,5 לB [B] M 1Q-b // assim-ctext : 1Q-a G ThSym Aq V S T

Options de nos traductions :

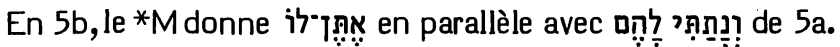

Aucune de nos traductions ne traduit littéralement ce pronom suffixé 3e pers. m. sg.

TOB le rend par l'adverbe de lieu " $y$ ".

Toutes les autres l'ont assimilé au pronom suffixe pluriel de 5a; NEB (selon Brockington) se fondant sur $1 \mathrm{Q}$-a pour lire des versions.

Origine de la correction :

Prenant appui sur les versions, Lowth a proposé de lire ici למו et a été suivi par la grande majorité des exégètes et les apparats de HSAT34, BH23 et Cent; alors que BHS proposait la forme להם plus courante, mais plus éloignée du *M.

\section{Les témoins anciens :}

Le *M est appuyé ici en sa lectio difficilior par 1Q-b. Ce seul appui est suffisamment caractéristique pour qu'on puisse considérer sa leçon comme fermement attestée.

Cependant toutes les versions (le ${ }^{*} \mathrm{G}$, ThSym, Aq, la *V, la *S et le $* T$ ) lisent ce suffixe au pluriel.

Eliézer de Beaugency dit en son commentaire : “J'atteste à propos de tous les manuscrits de notre royaume que le ketib y est אתן לו et le qeré להס "On aucun qeré n'est mentionné ici par Gordis ni, semble-t-il, par personne d'autre. D'ailleurs la tradition manuscrite du *M semble ici unanime, ni Kennicott, ni de Rossi, ni Ginsburg ne signalant de variante. Notons seulement que Saadya assimile dans sa traduction et que la Pesiqta Hedhatta éditée par Jellinek (Bet ha-Midrash VI 64) écrit להם dans la citation qu'elle donne de ce passage. 
Choix textuel :

Les traductions les plus influentes du XVIe siècle (Pagnini, Luther, Brucioli, Olivetan, Châteillon, Ge, $\mathrm{KJ}$ ) ont traduit ici en pluriel, si bien que RSV et RL n'ont eu besoin de prendre aucune initiative textuelle sur ce point.

Le comité a estimé utile de protéger le *M (appuyé par 1Q-b) contre cette assimilation qui est 'dans l'air'. Aussi lui a-t-il attribué la note "B".

Interprétation proposée :

Il semble qu'il faille donner à ce suffixe une valeur particularisante : “à chacun d'entre eux", indiquant qu'un nom éternel sera attribué en propre à chacun. C'est l'exégèse de Yéfet ben Ely et de Vitringa, Rosenmüller, König. En effet, il est peu vraisemblable qu'il s'agisse (ainsi que Scullion, Texts 106, l'a proposé) d'un nom inscrit sur la T? mentionnée en 5a; car cela obligerait à donner deux sens distincts à נתן ל־ en deux membres parallèles (et d'ailleurs נתן yל conviendrait mieux à ce sens).

56,12 אקחה [B] M 1Q-b (אקח) Aq // assim-ctext : 1Q-a (ונקח) Th V S T / lacun : G om 12

Options de nos traductions :

Le *M donne en 12a : "Venez, que je prenne du vin et que nous buvions..." Une tentation existe d'assimiler le $2 \mathrm{e}$ verbe aux formes plurielles des deux verbes qui l'entourent.

RSV est la seule de nos traductions à corriger ce verbe en pluriel ("let us get"), en se fondant sur $1 \mathrm{Q}-\mathrm{a}$, la $* \mathrm{~V}$, la ${ }^{*}$ S et le $* T$.

Origine de la correction :

Sous l'influence de la *V, Pagnini (sumamus) et Luther (“lasset uns ... holen”) avaient traduit ce verbe par un pluriel. Lowth a opté ensuite pour cette leçon en notant qu'un ms ancien du *M l'atteste et qu'un grattage sur un autre peut en être une attestation indirecte. RSV s'est probablement fondée sur les données de $\mathrm{BH} 7$ qui signalait 1Q-a comme appuyant cette variante que l'apparat informatif attribuait au *T.

Les témoins anciens :

Le *M a ici l'appui de 1Q-b (malgré l'absence de finale cohortative) et de Aq $(\lambda \hat{n} \psi \circ \mu \alpha \mathrm{l})$.

1Q-a donne le pluriel ונקח, comme Th ( $\lambda \alpha ́ \beta \omega \mu \varepsilon \nu), ~ l a * V$ (sumamus), la *S (נסב ) et le *T (ונסבי).

Le *G omet ce vs.

Choix textuel :

La leçon du *M ne fait pas de difficulté spéciale. Il faut la protéger contre cette assimilation au contexte. Le comité a attribué au *M la note " $\mathrm{B}$ ". 
Interprétation proposée :

"Venez, je vais prendre du vin et nous boirons..."

57,8 יד חזית [B] M 1Q-a Sym V S T // assim Ez 16,25; 23,19 : G

Options de nos traductions :

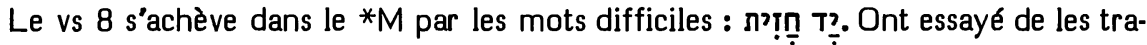
duire : RSV : "you have looked on nakedness", RL : "und buhltest mit ihnen", TOB : "le membre, tu l'as contemplé !", J3 : "tout en contemplant le monument".

J12 donne : "tu as multiplié tes prostitutions avec eux en regardant la stèle", J2 disant qu'elle se fonde sur le ${ }^{*} G$ pour insérer les sept premiers mots. NEB (selon

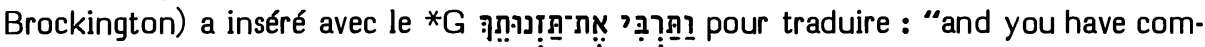
mitted countless acts of fornication in the heat of your lust".

Origine de la correction :

L'ajoute faite ici par J12 et NEB a été proposée par Duhm, Cheyne, Marti et BH3 (qui font suivre ces trois mots de אִִ̣).

Les témoins anciens :

1Q-a est identique au *M.

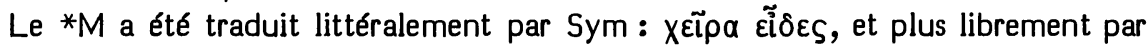
la *V : "manu aperta".

La *S et le *T ont traduit ici comme en 56,5 le mot T' par "lieu".

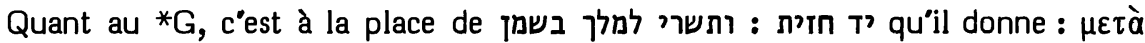

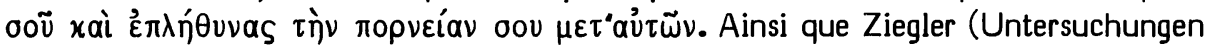
129) et Seeligmann (74) l'ont remarqué, le ${ }^{*} G$ d'Isaïe s'est servi de la traduction litté-

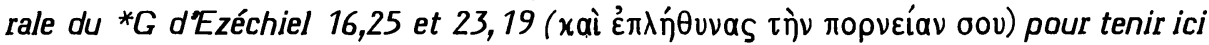
la place d'un texte qu'il ne savait pas traduire. Cet emprunt a pu être suggéré par la

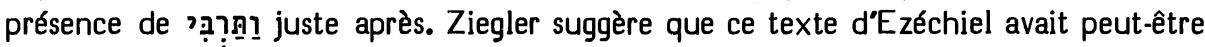
déjà pris place dans la Vorlage du ${ }^{*} G$ d’Isaïe. Ceci est peu vraisemblable, d'une part parce qu'on s'expliquerait mal en ce cas l'identité du ${ }^{*} G$ d'Isaïe avec le ${ }^{*} G$ d’Ezéchiel (ce qui suppose que le contact a eu lieu dans le grec plutôt que dans l'hébreu), et d'autre part parce que $1 \mathrm{Q}$-a (comme tous les témoins, à l'exception du ${ }^{*} G$ ) appuie fermement le *M.

Choix textuel :

Estimant très bien attestée la leçon difficile du *M, le comité lui a attribué 4 " $B$ " et 2 "A".

Interprétation proposée :

L'interprétation la plus vraisemblable de Ṭִ est en ce contexte : "pouvoir". Donc : "Iorsque tu en vois la possibilite", c'est-à-dire : lorsque l'occasion s'en offre.

Mais il n'est pas impossible qu'il s'agisse du membre viril, quoique le verbe qui suit ne rende pas ce sens très plausible. 
Options de nos traductions :

Les trois premiers mots du * $M$ du vs 9 sont traduits par RSV : “You journeyed to Molech with oil”, par RL : “Du bist mit Oel zum König gezogen”, par TOB : “Tu as dévalé vers Mélek avec de l'huile" et par 33 : "Tu t'es approchée de Mèlèk avec des présents d'huile".

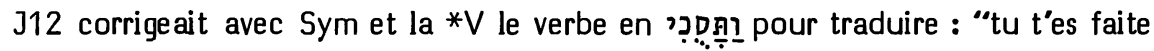
belle pour Mélek avec de l'huile".

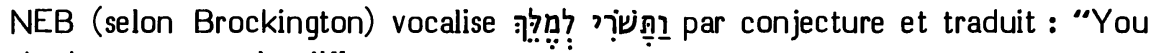
drenched your tresses in oil".

Origines des corrections :

La correction adoptée par $\mathrm{J12}$ avait été proposée (avec les mêmes appuis textuels) par Cheyne, puis Marti, HSAT34.

NEB suit Driver '(Isaianic 54)' qui conjecturait pourtant un hireq et non un segol sous le 'mem'. Avant de formuler en 1967 cette conjecture, Driver, en 1934 (Studies VII 389), traduisait : "thou wast glistening ... before the king", et en 1950 (Words 58s) il traduisait : "thou wast drenched ... for the king".

Les témoins anciens :

1Q-a est identique au *M.

Nous avons traité du $* G$ à propos du cas précédent.

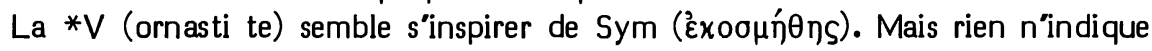
que celui-ci ait lu ici la Vorlage que Cheyne lui a prêtée. En effet, chacun des autres emplois que Sym fait de ce verbe grec (Is 61,10; Ps 144,12) correspond à un verbe hébreu différent.

Il est plus probable que Sym, la *V et la *S (ואשתבחתי) ont essayé de traduire la leçon commune au ${ }^{*} M$ et à $1 Q-a$, sans que nous puissions préciser comment elles vocalisaient ce verbe.

Le midrash du *T est inutilisable pour la critique textuelle.

Choix textuel :

Le comité a attribué au *M 4 " $B$ " et 2 " $A$ ".

Interprétation proposée :

Il est apparu au comité que l'exégèse la plus intéressante était ici celle de Rashi

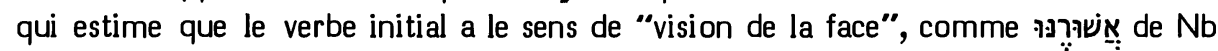

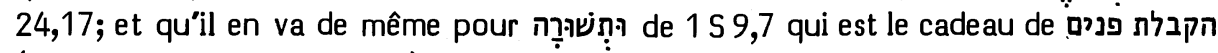
(c'est-à-dire de présentation). Les glossaires $A$ et $C$ traduisent "et présentas" ou "et regardas (ou : égardas)".

Quant à Mélek, cela a bien des chances d'être ici un nom divin. On traduira donc : "tu t'es présentée à Mélek avec de l'huile" ou : "tu as fait présent d"huile à Mélek". 
Options de nos traductions :

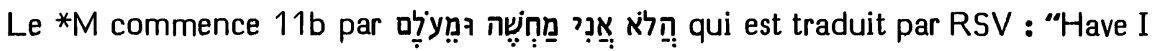
not held my peace, even for a long time", par TOB : “Moi, n'est-ce pas, je suis depuis longtemps resté inactif" et par J3: "N’étais-je pas silencieux et depuis longtemps ?"

$\mathrm{J12}$ traduisaient : "Moi, n'est-ce pas, je me suis tu et j'ai fermé les yeux", disant vocaliser וּרַy avec les versions. NEB, selon Brockington, fonde la même vocalisation sur le *G pour traduire: "Did I not hold my peace and seem not to see". RL traduit de même : "Ist es nicht so : Weil ich schwieg und mich verbarg."

Origine de la correction :

C'est Lowth qui a suggéré que le ${ }^{*} G$ et la $* V$ ont vocalisé comme $\mathrm{J} 2$ l'indique. Il a proposé cette correction qui a été adoptée ensuite par de nombreux exégètes et requise par les apparats de $\mathrm{BH} 23 \mathrm{~S}$ et Cent.

Les témoins anciens :

Il est vraisemblable que le ${ }^{*} G(\pi \alpha \rho \circ \tilde{\omega})$ et la $* V$ (quasi non videns) ont vocali-

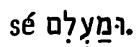

Mais il est frappant de noter que 1Q-a et 4Q-d attestent une scriptio plena ומעולם (דמלם

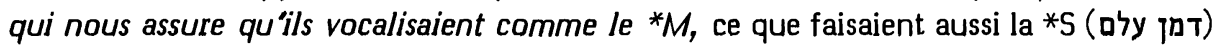
et le *T (מעלמא).

La massore (Weil §3352) note, pour préserver la vocalisation du $* M$, que la leçon ריִמִ se rencontre trois fois dans la Bible (Is 57,11; 64,3; Ps 90,2) dont deux fois pleine et une fois défective.

Choix textuel et interprétation proposée :

La correction proposée par Lowth aurait un bon parallèle en Ps 10,1 où le complément normal

Mais Is 42,14 : se distinguant de ce parallèle par un 'waw' à valeur emphatique : "et cela depuis très longtemps".

Deux membres du comité ont voté "C" pour la variante, estimant que la leçon du *M est issue d'une assimilation à 42,14.

Les quatre autres membres, frappés par l'appui que les graphies pleines de 1Q-a et de 4Q-d donnent à la vocalisation du * $M$, ont attribué à celui-ci la note " $C$ ".

\section{7,17 בערון ב [A ] M 1Q-a 4Q-d ThAqSym V S T // exeg : G}

Options de nos traductions :

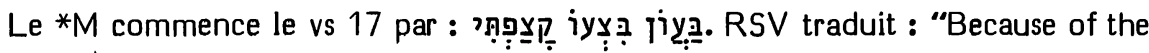
iniquity of his covetousness I was angry"; 312 : "A cause de l'iniquité de sa violence j'ai été irrité"; RL : "Ich war zornig über die Sünde ihrer Habgier"; TOB : "Par la perversité de sa rapine, j’ai été irrité" et 33 : “Contre sa criminelle cupidité j’ai été irrité". 


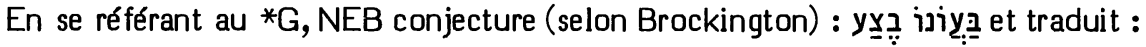
"For a time I was angry at the guilt of Israel".

Origine de la correction :

C'est Lowth qui a proposé, comme Vorlage du *G, la leçon adoptée par BHS et NEB; après que Houbigant ait proposé, dans le même sens et sur la même base : בעונו פתy.

Les témoins anciens :

Le *M est confirmé ici par 1Q-a et, pour le second mot, par 4Q-d (lacuneux pour le premier mot). Il a été lu par ThAqSym, la *V, la *S et le *T.

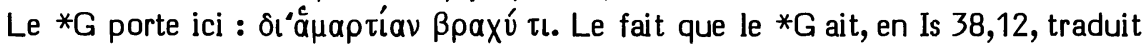

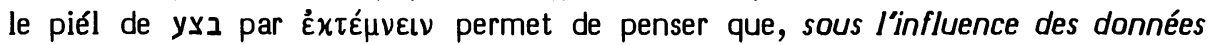
temporelles offertes par 54,7s et 57,16, il a élaboré ici cette traduction sans avoir à faire appel à une autre Vorlage que le *M. C'est l'opinion de Fischer (Schrift 63s) et de Bergmeier (Streben 95s).

\section{Choix textuel :}

Le comité a attribué à la leçon du *M.4 "A" et 2 " $B$ ".

Interprétation proposée :

En rapprochant cette expression de בעול רכלתך גלוליכן et 28,18) et de (Ez 23,49), on traduira : "à cause de son délit en matière de gain".

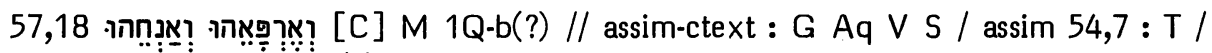
hom :m 1Q-a 4Q-d(?) om ואנחהו

Options de nos traductions :

RSV, RL, TOB et 33 traduisent toutes littéralement, à peu près : “mais je le guérirai et je le conduirai".

$J 12$ corrigent avec le ${ }^{*} G$ et la *S le 2 e verbe en je le guérirai, je le consolerai".

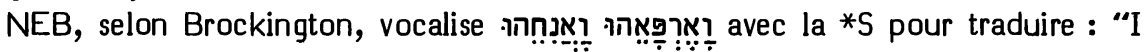
cured him and gave him relief".

Origines des corrections :

La correction de 32 a été proposée par Grätz, puis BH3, et celle de NEB par Oort (Jez).

Les témoins anciens :

1Q-a omet le deuxième verbe. Il peut être tombé ou par homéoarcton ou par homéotéleuton. Le fait que cette omission se retrouve en deux mss de Kennicott montre qu'un tel accident menace ce mot dont les deux dernières lettres sont identiques à celles du mot qui le précède et les deux premières lettres identiques à celles du mot qui le suit. 
1Q-b atteste le deuxième verbe juste après une lacune dont la taille laisse place à la leçon du *M.

4Q-d atteste la finale du premier verbe juste avant une lacune dont la taille semble mieux convenir à la leçon de $1 \mathrm{Q}-\mathrm{a}$.

Sous l'influence de l'inaccompli inverti et de l'accompli qui précèdent, les deux inaccomplis coordonnés du ${ }^{*} M$ ont été interprétés comme invertis par le ${ }^{*} G, A q$ (qui n'est connu que pour le premier), la $* V$ et la $* S$. Notons que, parmi les traducteurs du XVIe siècle, Oecolampade, Pagnini, Brucioli, Olivetan et Pasteurs ont fait de même.

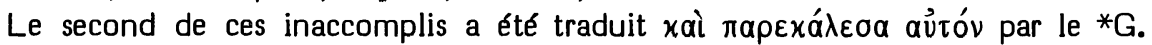

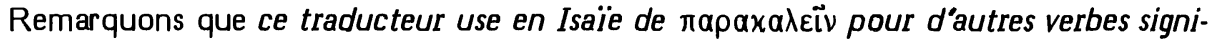
fiant "mener" (le piél de נהל 40, en 49,10). Il est peu vraisemblable qu"en chacun de ces cas le ${ }^{*} G$ ait lu lu dans sa Vorlage. Notons d'autre

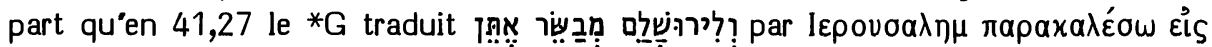

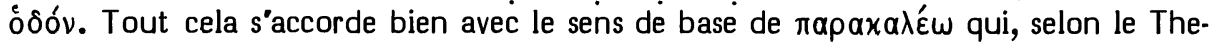
saurus d'Estienne (VII 273), est "evoco, accerso, advoco". Schleusner (IV 198), à propos d'Ex 15,13, précise : "conduire pas à pas et doucement en appelant, ainsi que les bergers font avec leurs troupeaux". C'est donc à tort que Grätz, Cheyne, BH3, Rowlands (Targum 190), Bonnard et Talmon (Aspects 122s) ont conclu que le ${ }^{*} G$ a lu

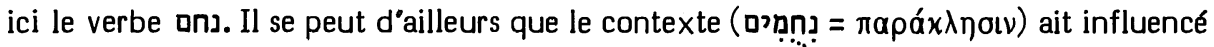
l'option du *G.

Quant à la *S, elle dépend sur ce point du ${ }^{*} G$, puisque le correspondant qu’elle offre ici sert à traduire ce même verbe du ${ }^{*} G$ dans la Syh non seulement ici, mais en Gn 37,35 et Ps 69,21.

Au verset précédent, nous avions estimé que le *G était sous l'influence de 54,7s. Ici c'est le *T qui semble assimiler à עזתיך וברחמים de ce vs 7.

Choix textuel :

Il est amusant de noter que les deux corrections que NEB dit emprunter à la *S aboutissent à une traduction identique à celle que Pagnini donnait, par erreur, du ${ }^{*} M$ en 1527 ( $\mathcal{E}$ sanavi eum et requiescere feci eum), traduction qu'il a rectifiée dès 1529 en son Thesaurus ("\& ducam eum", col. 1378), mais qui a pourtant survécu (à travers la réédition de Pagnini par Servet), sans qu'Arias Montano la retouche, jusque dans la traduction interlinéaire de la polyglotte de Walton.

Le comité a attribué à la leçon du *M la note " $\mathrm{C}$ ".

Interprétation proposée :

"Mais je le guérirai et je le conduirai."

59,18 לאיים גמול ישלם [B] M 1Q-a Th Aq Sym V S T // abr-styl : G om

Options de nos traductions :

$\mathrm{RSV}, \mathrm{RL}$ et $\mathrm{J3}$ traduisent littéralement ces trois mots que comporte $18 \mathrm{~b}$ selon le *M.

TOB les traduit en signalant que ce stique constitue vraisemblablement une glose, car il manque dans le ${ }^{*}$ G. 
J12 et NEB l'omettent pour ce motif.

\section{Origine de la correction :}

Michaelis (OEB) a dit de ces trois mots: “J'ai déjà mentionné que la Septante omet ces mots et ils me sont extrêmement suspects, quoique je ne puisse dire comment une ligne entière de ce type est arrivée dans le texte et y a été acceptée aussi universellement après l'époque de la Septante, si elle n'est pas de la main d'Isaïe. C'est justement pourquoi j'aimerais bien la conserver et pouvoir me borner à corriger le mot suspect לאיים. Mais tout ce que je tente (par ex. לאיבים, ou לראַים = terribili) me déplaît."

Ces trois mots ont été éliminés à titre de glose par Oort (Jez), Duhm, Cheyne, Marti et les apparats de HSAT34, BHS.

\section{Les témoins anciens :}

Pour les quatre derniers mots du vs 17 et tout le vs 18 , le ${ }^{*}$ G offre seulement :

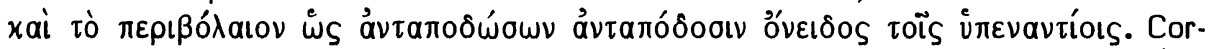

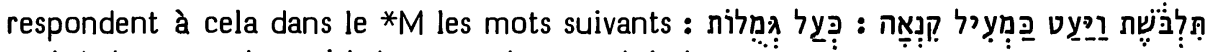

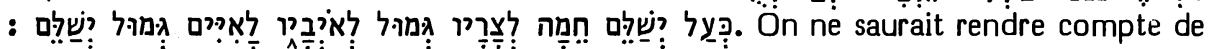
cette situation à partir de la remarque de Michaelis. Il s'agit en effet d'une réécriture abrégée et non d'une simple omission des trois derniers mots de l'hébreu.

Le *M est solidement appuyé par 1Q-a qui lui est identique pour tout ce que nous venons de citer. En tout cela, il est aussi appuyé par Th, Aq et Sym cités séparément l'un de l'autre pour tout ce passage.

La présence de $18 \mathrm{~b}$ est attestée aussi par la $* \mathrm{~V}$, la $* 5$ et le $* T$.

\section{Choix textuel :}

On ne possède pas de base textuelle pour alléger la syntaxe très redondante du *M auquel le comité a attribué 5 "B" et 1 "A".

Interprétation proposée :

Si l'on admet que les adversaires et ennemis du Seigneur (18a) sont les Israélites pécheurs sur lesquels la rétribution divine va s'exercer, ce dernier stique veut marquer l'universalité de la rétribution: elle s"étendra jusqu'aux nations les plus lointaines de l'occident (les "îles"). Cela prépare l'affirmation (vs 19) que l'on craindra depuis l'occident le nom du Seigneur et depuis le soleil levant sa gloire.

On peut traduire ce vs : "Selon les agissements il rétribuera, fureur pour ses adversaires, représailles pour ses ennemis; même aux îles il rétribuera des représailles."

\section{0,1 אורי [B] M 1Q-a.b Aq Sym V S // expl : G v T add Iepovoa $\eta \mu$}

Options de nos traductions :

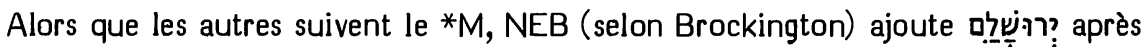
קוּמִ avec le *G et traduit le début de ce vs : "arise, Jerusalem, rise clothed in light". 
Origine de la correction :

Driver (Once 80 ) a suggéré qu'il y a eu ici dans le $* M$, après le 'yod' final de l'impératif féminin, haplographie d'un 'yod' servant d'abréviation pour le toponyme.

Les témoins anciens :

NEB et Brockington ont tort de dire que le *G insère le vocatif "Jérusalem" après "lève-toi". En effet, le ${ }^{*} G$ ne traduit pas cet impératif mais il répète "resplendis" et insère "Jérusalem" après le deuxième. Le ${ }^{*} G$ a particulièrement besoin ici de ce toponyme car, en 59,20, il a traduit le "et viendra à Sion" du *M par "et viendra pour Sion". Notons qu'en 51,9 le *G avait déjà inséré ce vocatif à contre-temps.

Le ${ }^{*} T$ aussi insère ici ce vocatif qu'il insérera aussi au vs 4 , selon sa tendance à la paraphrase.

Ce vocatif a pénétré dans les témoins vulgaires de la *V et dans ses éditions, jusquà l'édition Clémentine incluse. Cependant Hie disait que ce mot n'est pas dans l'hébreu et doit être marqué d'un obèle. D'ailleurs, Estienne, en son édition de 1540, signalait l'absence de ce mot en trois mss de St Germain des Prés qui sont aujourd"hui les mss Paris BN lat 11505, 11553 et 11937 . Aussi optait-il pour leur omission.

$L$ 'absence de ce vocatif dans le ${ }^{*} M$ est solidement appuyée par 1Q-a, 1Q-b, Aq, Sym et la*S.

Choix textuel :

Le comité a attribué au *M 5 "B" et à la variante 1 " $A$ ".

60,5 ורחב [C] M 1Q-a ThAqSym V S T // err-graph : m / incert : G

Options de nos traductions :

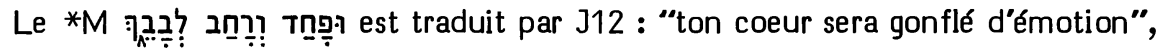
par TOB : "ton coeur frémira et se dilatera", par J3 : "ton coeur tressaillira et se dilatera", par RL : "und dein Herz wird erbeben und weit werden".

RSV donne : "your heart shall thrill and rejoice" en notant qu'à la place du deuxième verbe, l'hébreu porte "be enlarged". NEB, selon Brockington, corrige

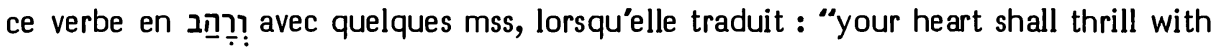
pride".

Origine des corrections :

La correction adoptée par NEB a été proposée par Grätz et Cheyne.

Les témoins anciens :

La massore précise que la racine רהב écrite avec "hé" ne se rencontre que 12 fois dans la Bible et elle énumère ces 12 cas. Cette massore se trouve dans le ms de Paris de la Okhla (Frensdorff $\$ 205$ ) et elle a été éditée quatre fois par Ben Hayim (en Is 30,7; Ps 89,11 et Jb 9,13). Comme Norzi le fait remarquer ici, c'est l'éditeur de la massore et non la liste elle-même qui, sur Is 30,7, a ajouté : "et un autre cas, me semble-t-il, en Is 60,5". Cette remarque de Norzi avait déjà été formulée par Buxtorf jr 
(836s). La garantie que cette massore apporte à la leçon du *M ici avait déjà été soulignée par Mercerus (en une note sur le Thesaurus3 de Pagnini, col. 2641s). Il mentionnait que Hayyuj (Treatises, Punctuation $142=$ VII $=123$ ) a lu cependant ce verbe ici avec un "hé". Mais ce grammairien a été contredit sur ce point par Judah ibn Balaam et par Radaq (Shorashim sur רהב). Mercerus mentionnait également que la Concordance hébraïque (Meïr Netib de R. Nathan) classe ce cas sous la racine avec "hé". Cappel (Critica 920s) notait la même option dans la concordance de Buxtorf. Et Buxtorf jr. (837), reconnaissant l'existence de cette variante, expliquait avoir fait figurer les deux leçons dans la concordance. De fait, la leçon avec "hé" a été retenue par l'édition princeps de la Bible (Soncino 1488), quoiqu'elle soit faiblement attestée dans les mss. Mais les éditions suivantes (Brescia 1494, Félix de Prato, Ben Hayim) portent la leçon avec "het".

La Vorlage du *G xà દ’xorńon est difficile à identifier, car ce verbe ne correspond ailleurs dans la Bible ni à רחב, ni à רחב. Notons d'autre part que le ${ }^{*} G$ n'offre ici que trois verbes pour les quatre du $* \mathrm{M}$. Il est donc possible qu'il ait omis notre verbe et

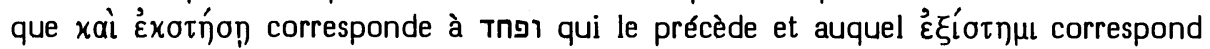
trois fois (Jr 36,24; Os 3,5; Mi 7,17).

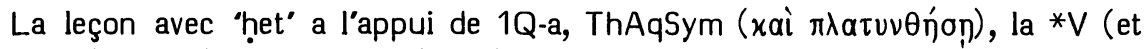
dilatabitur), la *S (ונרור) et le *T (ויפתי).

Choix textuel :

La leçon avec 'het', solidement attestée ici, a un bon parallèle en Ps 119,32 qui est suffisamment différent pour n'avoir pu influencer notre texte.

Le comité a attribué à la leçon avec "ḥet" 2 " $B$ " et 2 " $C$ " et à la leçon avec "hé" 2 "C".

Interprétation proposée :

"Ton coeur frémira et se dilatera" ou, plus librement : "Ton coeur sera gonflé d'émotion".

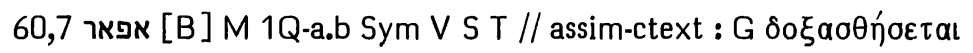

Options de nos traductions :

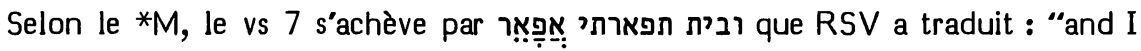
will glorify my glorious house"; RL : "denn ich will das Haus meiner Herrlichkeit zieren"; TOB : "oui, je rendrai splendide la Maison de ma splendeur"; J3 : "et je glorifierai ma maison de splendeur".

NEB, selon Brockington, corrige le verbe en glory shall be added to glory in my temple". Sans note, J12 traduisaient : "pour embellir le temple de ma Splendeur".

Origine de la correction :

Duhm et $\mathrm{BH} 2$ avaient suggéré de lire ce verbe à la 3e pers. m. sg. de l'accompli du nifal avec le ${ }^{*} G$, option adoptée par l'apparat de Cent. 
Les témoins anciens :

Le *M est appuyé par 1Q-a (après une retouche de la préformante au verbe),

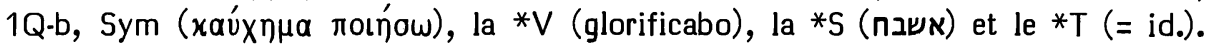

En 60,13 le *G ne traduira pas : "et je rendrai glorieux le lieu où sont mes pieds", phrase qui, comme celle-ci, exprime le bilan de riches cadeaux consacrés au sanctuaire sous la forme d'une initiative du Seigneur énoncée à la première personne. Ici,

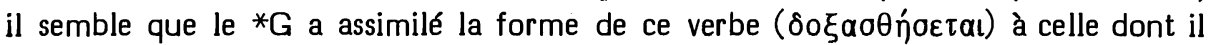
avait fait usage pour traduire

\section{Choix textuel :}

Le comité a attribué au *M 3 "B" et 3 "A".

Interprétation proposée :

"Et je rendrai splendide la maison de ma splendeur."

בלילה 60,19 [C] M 1Q-b // err-synt : V S / glos : 1Q-a G T add

\section{Options de nos traductions :}

Après avoir commencé par "Le soleil ne sera plus pour toi comme une lumière

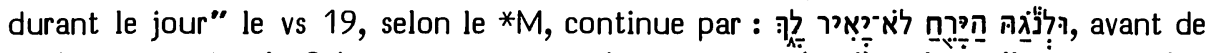
s'achever par "et le Seigneur sera pour toi comme une lumière éternelle et ton Dieu comme ta splendeur".

La phrase en question est traduite par J : "la clarté de la lune ne t'illuminera plus" et par RL : "und der Glanz des Mondes soll dir nicht mehr leuchten".

Selon Brockington, NEB s'appuie sur $1 \mathrm{Q}-\mathrm{a}$ et le ${ }^{*} \mathrm{G}$ pour ajouter premier mot et traduire: "nor the moon shine on you when evening falls". La même ajoute est faite par RSV : "nor for brightness shall the moon give light to you by night" et par TOB : "ce n'est plus la lune, avec sa clarté, qui sera pour toi la lumière de la nuit".

\section{Origine de la correction :}

C'est Lowth qui, se fondant sur le ${ }^{*} G$ et le ${ }^{*} T$, a proposé cette ajoute à la place du premier mot ou après lui. Koppe a préféré la placer après le cinquième mot pour être plus fidèle au ${ }^{*} G$ et obtenir un meilleur parallélisme, préférence que RSV et TOB semblent avoir partagée.

En l'un ou l'autre endroit, cette ajoute a été requise par les apparats de HSAT234, $\mathrm{BH} 35$.

\section{Les témoins anciens :}

Le mot הירח est inséré aprè 1Q-a et le *T. Il est placé après le 5e mot par le *G. Omettent ce mot : 1Q-b, la *V et la *S.

\section{Choix textuel :}

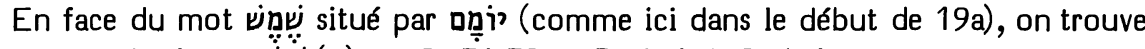
le mot רִּרִ situé par 
qu'ici une omission de "durant la nuit" s'expliquerait plus difficilement qu'une ajoute.

Cette ajoute qui est 'dans l'air' provient pourtant ici d'une méconnaissance du

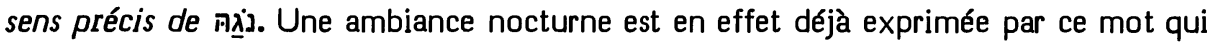
signifie une lueur dans la nuit ou bien l'irradiation d'un foyer lumineux dans les ténèbres.

Considérant ce mot comme une ajoute redondante, le comité a attribué au *M la note "C".

Interprétation proposée :

$L a{ }^{*} V$, la ${ }^{*} S, R L$ et $J$ ont tort de considérer ce mot (muni d'un zaqef gadol) comme un état construit dépendant du substantif qui le suit. Mieux vaut comprendre : "ni, comme lueur, la lune ne t'éclairera".

\section{יקוממו 61,4 ודור}

Options de nos traductions :

Seule NEB (selon Brockington) ajoute avec 1Q-a pịn? à la fin de ce vs pour traduire : "and restore".

Origine de la correction :

Ce 'plus' était mentionné dans les apparats informatifs de BH7S.

James (213) a noté que Duhm5 estimait déjà qu’un verbe manquait à la fin de ce vs et que $1 \mathrm{Q}$-a semblait donc appuyer sa conjecture.

Les témoins anciens :

Le 'plus' de 1Q-a n'est appuyé par aucun autre témoin.

Choix textuel :

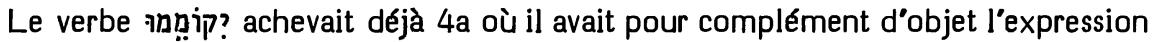

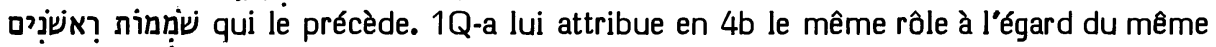
substantif repris ici, alors que le ${ }^{*} M$ (en accord avec les autres témoins) fait de ce substantif repris le second complément d’objet du verbe וחדשו qui commence la 2e partie du vs.

Rubinstein (Agreement 320) rapproche ce cas de 60,19 (que nous venons de traiter) comme exemples de la tendance de $1 Q$-a à ajouter des mots pour perfectionner le parallélisme des membres de phrases. Kutscher (545) inclut ce cas parmi les nombreux autres où le mot ajouté par ce ms se rencontre dans le même vs ou un vs proche.

Le comité a attribué la note " $\mathrm{B}$ " à la syntaxe plus brève et moins plate du *M.

Interprétation proposée :

"Ils restaureront les villes en ruines, les lieux dévastés depuis de nombreuses générations." 
Options de nos traductions :

En 6b, après "vous vous nourrirez de la richesse des nations", le *M conclut :

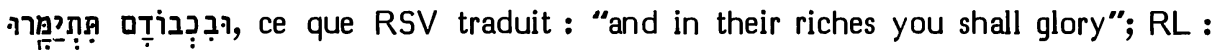
"Ihr werdet... und euch ihrer Herrlichkeit rühmen"; TOB : "et vous vous féliciterez de capter leur gloire"; 33 : "vous leur succéderez dans leur gloire".

$\mathrm{J12}$ donnaient : "et vous vous ornerez de leur opulence", en lisant "en le *G.

NEB conjecture (selon Brockington) furnished with their riches".

\section{Origines des corrections :}

J12 a adopté une proposition de Cheyne, Marti et Cent.

NEB dépend d'une conjecture de BHS, s'inspirant de l'arabe.

\section{Les témoins anciens :}

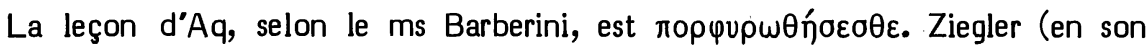
édition du ${ }^{*} G$ ) et Talmon (Aspects 117) disent que Hie a faussement cité cette leçon

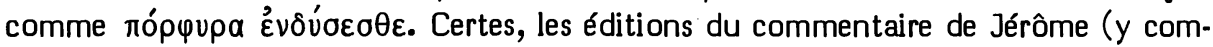
pris celle du CChr) donnent bien cela. Mais le ms Londres BL Egerton 2831, du VIIIe siècle (seul ms que le CChr ait consulté pour les livres XVII et XVIII du commentaire) porte ici ПОР $\Phi$ Y $W O H C € C O €$ où il est facile de restituer deux 'thêta' à la place des deux derniers 'omikron', ce qui nous donne exactement la leçon rapportée par le ms Barberini. Ce sont les éditeurs de Jérôme qui, pour restituer la leçon grecque à partir de transcriptions plus corrompues, se sont inspirés trop directement de la traduction latine que Hie en donne juste après : "id est : purpura vestiemini". Il ne faut donc pas rendre Jérôme responsable des fausses conjectures de ses éditeurs.

1Q-a donne ici תתיאמרו. Cette graphie explicite une dérivation de cette forme à partir de אמר II (= culminer, dépasser en hauteur) à laquelle se rattachent aussi claire-

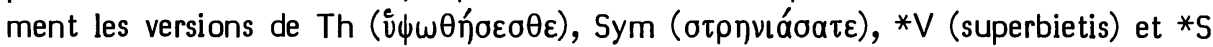
(תשתבחון). Talmon (Aspects 117) a montré que Aq s'explique aussi probablement

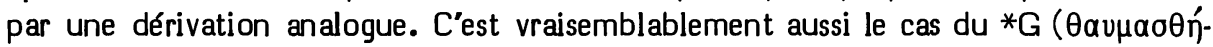
$\sigma \varepsilon \sigma \theta \varepsilon)$ et du *T (תתפנקון).

\section{Choix textuel :}

Considérant ce cas comme plutôt exégétique que textuel, le comité a attribué au *M 1 "A", 3 "B" et 2 "C".

\section{Interprétations proposées :}

La dérivation retenue par 1Q-a et les versions anciennes l'a été également par Ibn

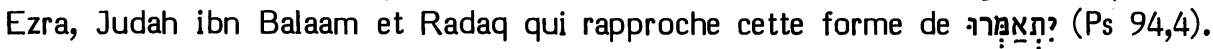
Sous l'influence de Radaq et de la *V, les principaux traducteurs du XVIe siècle ont opté pour cette exégèse : Pagnini (exaltabimini), Luther ("werdet ... euch rhümen"), Pasteurs ("et vous vanterez"), KJ ("shall you boast your selves"). C'est égale- 
ment la dérivation retenue par Vitringa, Delitzsch, König, HALAT (sous אמר II). Selon cette exégèse, on pourrait traduire : "vous tirerez orgueil de leur gloire" ou "vous vous pavanerez dans leur gloire".

Saadya et David ben Abraham (II 230,36) traduisent תתבדלון que Yéfet ben Ely accepte en commentant : "Il s'agit des vêtements de cérémonie et de rechange ainsi que des armes d'apparat. On dit 'vous vous changerez' car ils se changent comme les gens se changent en revêtant ces sortes de vêtements." Cette exégèse suppose une assimilation de מור àn. Elle est offerte aussi par les glossaires ABCDEF qui traduisent: "serez changés". Puis elle sera reprise par Hitzig, Knobel, Ewald, Gesenius (Thesaurus 601), Dillmann/Kittel, ainsi que par Bauer/Leander (403). On peut estimer que le תחת qui commence le vs suivant appuie cette exégèse. Il faudrait donc comprendre: "vous vous changerez avec leur gloire", c'est-à-dire : "vous revêtirez leur gloire".

61,7A ירנו [A] M 1Q-a Th V S T // lacun : G om 7a / facil-synt : g sing

Options de nos traductions :

A la place de ce verbe du *M, J12 conjecturent Iִ et traduisent "et les crachats", NEB (selon Brockington) conjecture

Pour RSV, J3 et TOB, voir le cas suivant.

$\mathrm{RL}$ ne traduit pas ce mot.

Origines des corrections :

La conjecture retenue par $\mathrm{J12}$ remonte à Klostermann et a été adoptée par Cheyne (qui le cite), Marti, HSAT34 et Cent. La conjecture de NEB en constitue une variante proposée par Driver/Miles (II 287, note).

\section{Les témoins anciens :}

Tous les témoins ont lu ici un verbe (sauf le ${ }^{*} G$ qui n’a pas traduit 7a). Tous l'ont lu au pluriel (sauf une partie de la tradition textuelle d'une ajoute secondaire du ${ }^{*} G$ où il a été mis au singulier par facilitation syntaxique).

\section{Choix textuel :}

Le comité a attribué à la leçon du *M la note " $A$ " pour la protéger contre des corrections conjecturales qui se sont multipliées dans les traductions récentes.

Interprétation proposée :

Nous aborderons maintenant le problème posé par l'interprétation des verbes et suffixes à la 3e pers. pl. ici et dans le contexte. 
61,7a-9a חלקם ... יירשו ... להם ... פעלתם ... להם ... זרעם וצאצאיהם G V T // dissim : $1 Q-a \mathrm{~S} 2 \mathrm{e}$ pl

\section{Options de nos traductions :}

Les préformantes ou suffixes des 7 mots que nous avons relevés dans l'apparat ont posé une difficulté à beaucoup d'interprètes, car il est difficile de leur attribuer le même support qu’au verbe ?ִ qui quécède immédiatement le premier mot relevé.

$\mathrm{J} 3$ pense échapper à cette difficulté par une traduction large des trois derniers mots de 7a : "au lieu de l"humiliation, les cris de joie seront leur part."

Comme nous l'avons vu, J12 et NEB ont corrigé en substantif le verbe précédent; alors que RL ne l'a pas traduit.

RSV a corrigé en $2 e$ pers. pl. toutes les préformantes et tous les suffixes de la $3 e$ pers. pl. que le *M offre au vs 7 .

TOB a corrigé en $2 e$ pers. pl. les 7 mots que nous avons mentionnés dans l'apparat, en se fondant sur $1 \mathrm{Q}$-a et sur la $*$ S.

Origines des corrections :

Les corrections retenues par TOB ont été proposées par Bonnard.

Les témoins anciens :

Les préformantes et suffixes des $2 e$ et $3 e$ personnes pl. que le $* M$ offre en 7 et 9 ont l'appui de la $* V$ et du $* T$, ainsi que du ${ }^{*} G$ ancien pour $7 b$ et 9 et de l'ajoute du ${ }^{*} G$ pour 7 a (que le ${ }^{*} G$ ancien n'avait pas traduit).

1Q-a offre des préformantes et suffixes de la 2e pers. pl. pour les 7 mots relevés. La *S fait de même et étend ces $2 e$ pers. pl. jusqu’à la fin du vs 9.

Choix textuel :

Cette difficulté n’a pas été soumise au comité.

Interprétation proposée :

La meilleure semble être celle qui a été mise en circulation par Tremellius et développée par Vitringa. Elle considère לכן comme l'articulation essentielle du vs 7. Ce qui précède cette particule décrit l'état humilié du peuple dans l'exil et ce qui la suit décrit le sort heureux qui en sera la compensation.

Donc: "Au lieu de la honte dont vous avez eu une double part, et des outrages dont ils clamaient : 'c'est la part de ces gens !'; à cause de cela, ces gens hériteront de leur pays une double part, une joie perpétuelle leur appartiendra." Ce qui crée la difficulté exégétique, c'est que, dans le ${ }^{*} M$, à partir de existent pour les verbes et suffixes à la 3e pers. pl. : d'une part, les païens (auxquels se réfèrent "ils clamaient" et "leur pays") et, d'autre part, ceux dont les païens clament que les outrages sont "leur part", c'est-à-dire le peuple d'Israël durant l'exil. Dans la traduction que nous avons donnée, nous avons mis en valeur l'entrée en scène de ce second suppôt par "ces gens". 


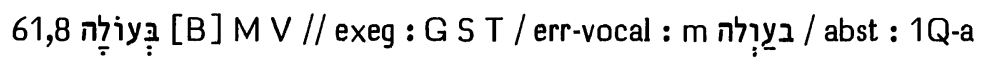

Options de nos traductions :

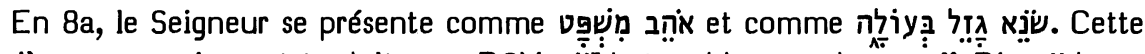
deuxième expression est traduite par RSV : "I hate robbery and wrong", $\mathrm{RL}$ : “der ... Raub und Unrecht hasst", J12 : "je hais la rapine et le crime", NEB : "I ... and hate robbery and wrong-doing", TOB : "je hais le vol enrobé de perfidie", J3: "moi ... qui hais le vol et l'injustice". J, NEB et TOB disent corriger la vocalisation du dernier mot pour lequel J2 et Brockington donnent

Origine de la correction :

Cette correction vocalique a été proposée par Grotius se fondant sur le ${ }^{*} G$ et le *T. Elle est requise par HSAT234, BH2S et Cent.

Les témoins anciens :

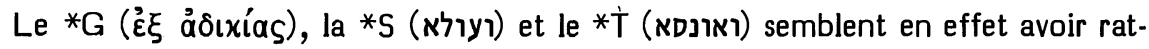
taché ce mot à la racine hy.

De Rossi (Scholia) signale un ms et la 1e main de quatre autres comme portant la variante vocalique choisie par J2 et NEB.

La *V (in holocausto) appuie la vocalisation הִ̣iỵ̣ des autres témoins du *M.

On ignore la manière dont $1 \mathrm{Q}-\mathrm{a}$ vocalisait sa graphie pleine identique à celle du *M.

Choix textuel :

Saadya (מע אלגרםם) semble avoir lu la variante contre laquelle une massore du ms du Caire met en garde en notant que cette forme ה̦̣iỵạ est unique et quà son propos certains font erreur (דמט). Dans le ms d'Alep, une autre massore appuie indirectement cette forme. Elle précise en effet que בעולה ou se rencontrent deux fois avec une graphie pleine dans ce livre : une fois ici et une fois en 40,16. Le rapprochement de ces deux formes et la caractérisation de leur graphie indique que l'auteur de cette massore situe spontanément ce mot par rapport à a ỵ yet non par rapport à

A part l'écart commis par Saadya, la tradition d'exégèse juive semble ferme pour l'interpréter au sens de "holocauste". D'ailleurs, Radaq cite en parallèle Ml 1,13 où le Seigneur dit ne pas agréer qu'on lui offre un Rộ. Donc préter : "de la rapine à titre d"holocauste".

Ajoutons que de Dieu (229), notant qu'en Ps 58,3 et 64,7 le pluriel sibiy se rattache à la racine עול a estimé que l'interprétation "crime" ne nécessite pas que l'on corrige la vocalisation.

Considérant que ce cas est surtout une affaire d'exégèse, le comité a attribué au *M la note "B".

Interprétation proposée :

Ainsi que Luzzatto l'a noté, la présence de la préposition 'bet' s'accorde mieux avec une interprétation du substantif en "holocauste". Le parallèle signalé par Radaq appuie aussi cette exégèse qui convient bien au livre d'Isaïe où ce thème n'est pas déplacé (cf. 1,13: "je ne puis supporter forfait et fête"). 
On ne saurait cependant juger impossible l'interprétation de nos traductions.

On préférera donc: "je hais la rapine offerte en holocauste". Dans l'autre ligne d'interprétation, TOB a essayé de rendre la préposition par : “je hais le vol enrobé de perfidie".

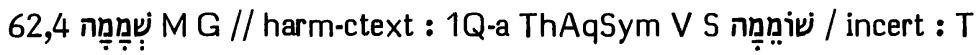

Options de nos traductions :

Après que le prophète ait annoncé à Sion : "on ne t'appellera plus "délaissée"", il poursuit: "et on n'appellera plus ta terre "Desolate" en RSV et NEB, "Einsame" en RL, “Désolation" en J3.

$\mathrm{J} 12$ traduisaient "Abandonnée" et TOB : "la Désolée". Elles précisent qu'elles lisent שenghec 1Q-a.

Origine de la correction :

Ces traductions dépendent, à travers Cent, de $\mathrm{BH} 23 \mathrm{~S}$ et de HSAT34. Ce sont Oort (Jez.), Duhm et Cheyne qui ont proposé cette correction. Malgré le silence de Brockington, NEB semble l'avoir adoptée, ainsi que RSV et RL.

Les témoins anciens :

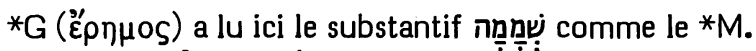

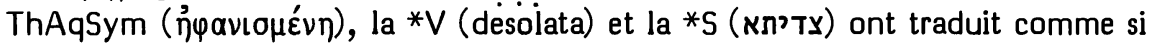
elles avaient lu le participe שִ que 1Q-a atteste ici.

La leçon du *T (צ'א) est plus ambigüe.

\section{Choix textuel :}

Ce cas n'a pas été soumis au comité.

Au XVIe siècle, le substantif est respecté par Luther ("eine wüstunge") et la Bible des Pasteurs de 1588 ("la desolation"). Les autres traducteurs (influencés par la $* V$ ?) donnent un participe.

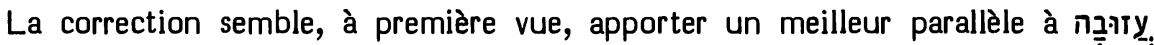
qui précède.

Il faut noter cependant que le participe שị au singulier, en ses trois emplois bibliques (2 S 13,20; Is 54,1; Lm 1,13) désigne toujours une femme. Par contre,

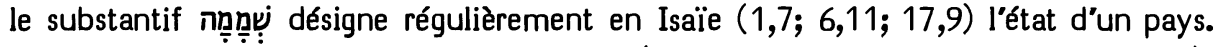
En 64,9 ce substantif désignera Jérusalem (en parallèle avec

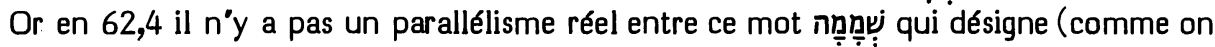

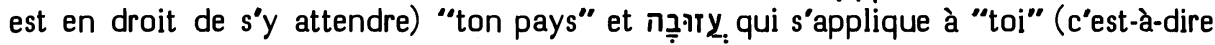
Sion-Jérusalem considérée comme une femme). En 54,1 aussi c'est bien une femme qui était désignée comme שׁ. La vocalisation du ${ }^{*} M$ tient compte de ces nuances et doit donc être respectée en face d'une variante harmonisante.

Interprétation proposée :

"et on n'appellera plus ta terre dévastation". Ou bien, avec BFC : "et on ne nommera plus ton pays "la terre dévastée'." 


\section{Options de nos traductions :}

Le *M offre en 5a : 5 :

Les quatre premiers mots sont traduits sans note textuelle par RSV: "For as a young man marries a virgin", RL : "Denn, wie ein junger Mann eine Jungfrau freit", NEB : "For, as a young man weds a maiden" et 33 : “Comme un jeune homme épouse une vierge."

$\mathrm{J12}$ donnaient déjà la traduction de $\mathrm{J3}$, mais $\mathrm{J} 2$ disait corriger pour cela avec $1 Q$-a les deux premiers mots en "parce qu'un jeune homme épouse..." TOB, elle aussi, dit ajouter "comme" avec 1Q-a quand elle traduit: "En effet, comme le jeune homme épouse sa fiancée."

\section{Origine de la correction :}

C'est Houbigant qui a proposé de corriger les deux premiers mots du $* M$ en כבעל, כי־כבעל ou en corrections qui ont dominé ensuite les apparats critiques.

Les témoins anciens :

Le *M a ici l'appui de 1Q-b et de la *V (habitabit enim), alors que la leçon de

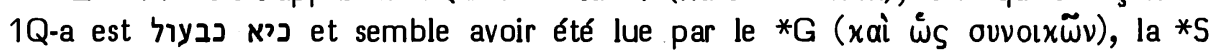
(מטל דאיך דבעל) et le *T (ארי כמא דמתיתב).

\section{Choix textuel :}

Ce cas n'a pas été soumis au comité.

Remarquons d'abord que l'interprétation donnée par nos traductions ainsi que par le *G, la *S et le *T était déjà celle des traducteurs allemands, français et anglais du XVIe siècle. C'est d'ailleurs déjà l'exégèse proposée ici par Saadya, Yéfet ben Ely, Rashi, Ibn Ezra et Radaq qui, pourtant, lisaient certainement le *M.

Il faut en effet, avec Ehrlich et König, rapprocher la construction que nous avons ici : כיזיבעל בחור ... יבעלוך בניך de celle qui se trouve en 44,3 : כי אצק־מים ... אצק רוחי . Ces deux cas dont la syntaxe est identique s'appuient mutuellement. Dans les deux cas, il s'agit en effet d'une relation établie entre un événement habituel exprimé à l'imparfait (en 44,3: "je répands de l'eau sur ce qui est assoiffé et des ruissellements sur ce qui est sec" et en 62,5: "un jeune homme prend possession d'une vierge") et un événement prophétisé exprimé lui aussi par l'imparfait du même verbe (en 44,3 : "je répandrai mon esprit sur ta postérité et mes bénédictions sur tes rejetons" et en 62,5 : "tes fils prendront possession de toi").

Il est évident que le sens de cette expression est bien celui que 1Q-a, puis l'immense majorité des traducteurs et des critiques ont proposé pour 62,5. C'est-à-dire que כִ̣ a valeur affirmative portant sur le 2e imparfait. Mais pourquoi, en ces deux cas, la particule comparative a-t-elle été omise avant le premier imparfait ? Parce que -כְ̣ peut précéder un infinitif ou un participe, mais pas un verbe à une forme personnelle. En ce cas, il faudrait כאשר qui, lorsqu'il suit כִי en début de la protase d'une comparaison (Is 55,9; 66,22; Jr 13,11), a כן comme répondant en début de l'apodose. Mais en 44,3 et 62,5 où l'on veut jouer sur la reprise de l'imparfait d'un même verbe, 
cette articulation serait sentie comme trop lourde. C'est pourquoi on omet toute particule de comparaison, se contentant d'exprimer la relation par cette reprise de l'imparfait du même verbe.

Notons qu'en 44,3 presque tous les exégètes ont méconnu la valeur d'élément de comparaison qui est celle de la première phrase à l'imparfait et lui ont donné la valeur d'annonce prophétique. Grâce à cette confusion, la critique correctrice n'a pas eu à intervenir. Ici, par contre, "un jeune homme prend possession d'une vierge" ne peut être interprété comme une annonce prophétique. C'est ce qui a motivé, depuis 1Q-a jusqu'aux apparats critiques contemporains, une correction de hyב?? en לyבִ̣. Dans le but d'offrir un fondement à une interprétation qui est, de fait, l'interprétation authentique de la leçon du ${ }^{*} \mathrm{M}$, on a méconnu la syntaxe de celui-ci et on l'a défigurée.

Interprétation proposée :

Nous proposerons à la fin du prochain cas une interprétation d'ensemble de cette phrase.

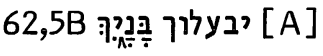

\section{Options de nos traductions :}

Le *M est traduit ici par RSV : "so shall your sons marry you" et par TOB : "tes enfants t'épouseront".

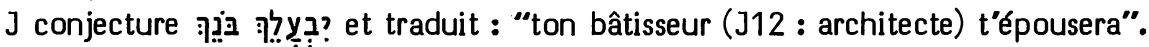
RL traduit de même : "so wird dich dein Erbauer freien".

Quant à NEB, elle donne : "so you shall wed him who rebuilds you", Brockington

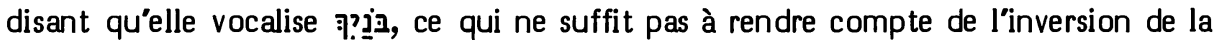
syntaxe.

\section{Origine des corrections :}

Lowth (Poesis 618s), comprenant le *M comme : "tes fils t"épouseront", choqué par cette image d'inceste, corrige en 习?]j̣ et comprend : "ton créateur t"épousera", en notant que, dans le parallèle de 54,5 ("̈oui, ton époux, ce sera ton créateur, lui dont

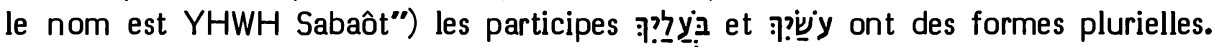
Il estime donc qu'ici un participe de forme analogue a été mal compris par le ${ }^{*} G$ et par les vocalisateurs du *M. A cette suggestion qu'il accepte, Koppe ajoute le cas de Ps 149,2 où, à propos du Seigneur d'Israël, on trouve la forme

Lowth ne voyait pas de difficulté à la forme plurielle du verbe s'accordant à celle du participe conjecturé. Certes, on rencontre des verbes au pluriel ayant pour sujet אלהים lorsqu'il a valeur de singulier. Mais ici Duhm et Cheyne, en acceptant la conjecture de Lowth, préfèrent corriger en singulier, obtenant la leçon que $\mathrm{J}$ a adoptée à la suite de HSAT34, BH235, Cent et de nombreux autres exégètes.

Les témoins anciens :

Tous appuient le *M, y compris $1 Q$-a qui, pour le 2e mot, a la même graphie que lui. 


\section{Choix textuel :}

Il importe de noter avec Luzzatto qu’en hébreu biblique le verbe בעל , même lorsqu'il a pour complément d'objet une femme, ne signifie pas formellement l'épouser, mais la faire entrer dans sa possession, dans sa "maison".

Ajoutons avec Vitringa que la Bible parle des בעלי ירחו" (Jos 24,11) ou des 9 9,46) au sens de citoyens de ces localités.

C'est par méconnaissance de ces données sociologiques que l'on a pu trouver choquante la leçon du ${ }^{*} M$ qui ne l'est pourtant pas plus que la situation mentionnée en Jn 19,27.

Interprétation proposée :

"En effet, de même qu'un jeune homme prend en sa possession une vierge, tes fils te prendront en leur possession."

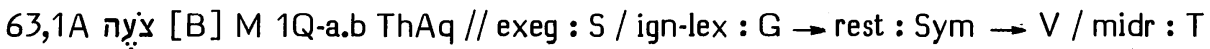

Options de nos traductions :

Ce participe du *M a été traduit sans note par RSV : “marching", RL : “der ... einherschreitet", NEB : "stooping", TOB : "arqué".

$J 12$ lisent 7 צỵ avec Sym et la *V et traduisent : "qui marche". J3 lit de même par conjecture et traduit : "s'avançant".

Origine de la correction :

Pour traduire ce participe, la plupart des traducteurs du XVIe siècle s'étaient inspirés de la *V (gradiens) : Luther : "der ... einher trit", Münster : "obambulans", Olivetan : "marchant", Châteillon : "qui marche", Ge : "he ... walketh", KJ : "travelling".

Michaelis, en ses notes sur sa traduction, estimant que le sens du *M est "der sich krümmet", considère que Luther a lu une autre leçon qu'il adopte d'ailleurs. En OEB, il dit qu'il s'agit de $T y \underline{x}$ que la $* V$ a lu. Cette correction a été adoptée par beaucoup ensuite, $y$ compris HSAT234, BH23 et Cent.

\section{Les témoins anciens :}

La leçon du *M a l'appui formel de 1Q-a alors que 1Q-b lacuneux assure la présence de la lettre qui fait difficulté : le "hé" final.

Le *T offre ici un midrash d'où on ne peut tirer un témoignage textuel.

HALAT (974a) conseille de lire ici Tỵ צ avec Sym, la *V et la *S. Remarquons d'abord, avec Weisz (59) que la *S (עין) a traduit de la même manière en 51,14. C'est un indice qu'elle a lu ici la leçon du *M.

Quant à la *V, sa traduction "gradiens" semble être un simple emprunt à Sym : ßáv vw. Le fait que la *V se sert du même correspondant en 51,14 montre que Jérôme lisait le même mot hébreu en ces deux endroits.

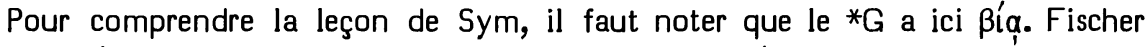
(Schrift 66) a suggéré que l'origine de cette traduction (que Hie trouvait peu intel- 
ligible) serait une leçon permutée צy interprétée en fonction de l'araméen. En effet, le *T fragmentaire traduit le verbe עשק (= agir avec violence) par y en Lv 5,21 et le Neofiti le traduit ainsi en Lv 5,21 et 23. La suggestion de Fischer est donc assez vraisemblable.

Notons que le ${ }^{*}$ G, ne sachant pas interpréter ce même mot nỵ en 51,14, avait donné pour ce vs, sans rapport avec l'hébreu : "lorsque tu seras sauvé, il ne tiendra pas et ne durera pas", à la place de quoi Sym (cité en latin par Hie) avait : "cito infernus aperietur et non morietur in corruptionem", sans que l'on puisse déceler le lien existant entre "infernus" et צy. Il est donc vraisemblable qu'ayant méconnu le sens de ce mot en 51,14, Sym s'est inspiré du ${ }^{*} G(\beta เ \alpha)$ pour le traduire en 63,1 par $\beta a i ́ v \omega \nu$ (en s'aidant peut-être aussi de la ressemblance graphique avec Tyy). La $* V$ a ensuite emprunté cette traduction à Sym avant de l'étendre à 51,14 où elle retrouvait le même mot.

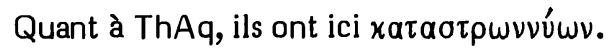

Choix textuel :

La traduction de ThAq correspond à l'exégèse de David ben Abraham (II 519, 8s), exégèse qui confond les réalisations 'lamed-hé" et "pé-yod' du bilittère yצ.

On voit donc que ce verbe a causé de sérieuses difficultés aux exégètes anciens. Le comité a cependant attribué au * $\mathrm{M}$ la note " $\mathrm{B}$ " en estimant que $c$ "est la seule leçon fermement attestée, alors que les autres ont de grandes chances de n'être que des essais d'exégèse inspirés par des rapprochements graphiques.

Interprétation proposée :

La meilleure exégèse est ici "se cambrant". Après Schroeder qu'il cite, Gesenius (Thesaurus 1177a) en explicite les bases lexicographiques par des emplois caractéristiques de la racine arabe אג̇y. Cette exégèse a été retenue par Delitzsch, König et Bonnard (= TOB).

63,1B בַב M T // err-vocal : G? Sym $\rightarrow$ V clav רִ̣/abst : 1Q-a

\section{Options de nos traductions :}

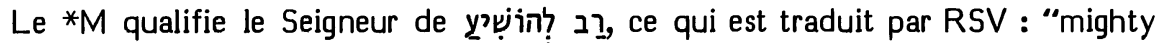
to save", J12: "et qui me montre grand pour sauver", RL : "und bin mächtig zu helfen", NEB : "who am strong to save", J3 : "qui suis puissant pour sauver."

TOB donne ici : "qui querelle pour sauver", en vocalisant le premier mot avec qameș selon des versions.

Origine de la correction :

C'est Michaelis (OEB) qui a proposé de lire רִ selon Sym et la*V. Cette proposition a été reprise par Marty (Cent), puis Bonnard et TOB.

Les témoins anciens :

$1 \mathrm{Q}-\mathrm{a}(=* M)$ ne nous informe pas sur sa vocalisation.

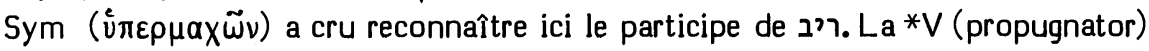
dépend de lui. 
Le *G (xaì xpíolv) semble avoir déjà rattaché ce mot à cette racine.

La *S et le *T font usage pour traduire de la racine araméenne סגא, montrant par là qu'ils ont vocalisé comme le *M.

Remarquons d'autre part que le $* G$, la $* V$ et la $* S$ traduisent ici comme s'ils avaient lu avant ce mot un 'waw' qui, de fait, figure en de nombreux mss du *M. Cependant, l'absence de ce 'waw' est fermement attestée ici à la fois par 1Q-a, par Sym et par la Okhla (Diaz Esteban $\S 31=$ Frensdorff $\S 30$ ). Pourtant nous n'avons pas tenu compte de cette variante dans l'apparat parce qu'elle n'a pas de conséquence directe pour le sens.

\section{Choix textuel :}

Ce cas n'a pas été soumis au comité.

Il est certain qu'en Isaïe $(19,20$ et 49,25$)$ le verbe ריב se retrouve en parallèle avec le hifil de $y$ re. Mais ici il ne s'agit pas de parallèle, comme le montre la préposition 'lamed".

Notons qu'en 2 Ch 14, 10, il y a contraste entre רֵي au sens postulé ici par le contexte.

Interprétation proposée :

Dillmann/Kittel explicitent le sens : "qui possède de nombreux moyens." Donc : "plein de ressources pour sauver".

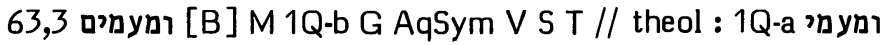

Options de nos traductions :

RSV, RL, NEB et TOB traduisent ici par le pluriel : "et parmi les peuples"; alors

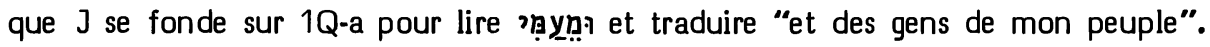

Origine de la correction :

Selon Dahood (Lexicography IV 412), le *M offre ici un 'mem' enclitique que 1Q-a s'est contenté d'omettre, n'offrant ainsi rien d'autre qu'une orthographe modernisée. Ni lui, ni J ne semblent avoir conscience qu'une tradition exégétique juive attestée par Yéfet ben Ely et Abravanel dit que ומעמים désigne ici le peuple d'Israël. Yéfet explique cela en mettant ce vs en relation avec Is 59,16 et avec Ez 25,14. En ce dernier passage, en effet, le Seigneur dit qu'il confiera "à Israël, mon peuple" l'exercice de sa vengeance contre Edom. Or, ici où le Seigneur veut exercer cette vengeance contre Edom, il constate que "il n'y a pas un homme avec moi", ce qui l'oblige à exercer seul sa vengeance. Mais ce constat a été fait, dans les mêmes termes, en 59,16 où cela signifiait que personne ne pratiquait la justice en Israël. C'est en fonction de ces perspectives que Radaq commente ainsi le "il n'y a pas un homme avec moi" de 63,3 : “il veut dire qu'Israël ne possède pas de mérites, et qu'il aurait été le coopérateur de Dieu s'ils avaient eu des mérites". Abravanel rapproche ce passage de Dt 33, 19 où il estime que yמים désigne aussi les tribus d'Israël. Ajoutons à cela Dt 33,3 où Rashi attribue ce sens à ce même pluriel. 
Comme on le voit, plusieurs tentatives exégétiques ont précédé la correction textuelle de $\mathrm{J}$.

Les témoins anciens :

Alors que 1Q-a écrit ici ומעמי, le pluriel du *M est appuyé par tous les autres

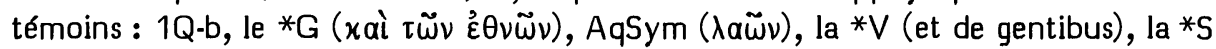
(מן עממןא), le *T (במשרית עממיא).

Choix textuel :

Il semble qu'ici la $\mathrm{mp}$ indiquant cette forme comme unique veut la protéger contre la variante de $1 \mathrm{Q}-\mathrm{a}$ (forme présente en Ex 8,4) qui est vraisemblablement liée à la tradition d'exégèse que nous avons explicitée.

Notons d'ailleurs qu'en 1Q-a la présence de cette variante est liée à l'omission des trois stiques suivants que cette correction en "mon peuple" prive de l'antécédent pluriel que la leçon du ${ }^{*} M$ offre aux trois suffixes pluriels qu'ils contiennent.

Le comité a attribué la note " $\mathrm{B}$ " au * $\mathrm{M}$, estimant que la tradition exégétique susdite et la variante de 1Q-a assimilent aux nombreuses formes à la 1e personne qui entourent.

Interprétation proposée :

C'est parce que pas un seul individu en tous les peuples n'a pris son parti, en l'aidant à fouler au pressoir, que le Seigneur les a tous foulés dans sa colère, transformant le monde en un gigantesque pressoir.

/ ואשברם [B] M 1Q-a.b ThSym V // abr-elus : G, T om / err-graph : ואשכרם 73,6 deform-int $: S$ † $\rightarrow$ T

Options de nos traductions :

Nous ne traiterons pas formellement du fait que tous les inaccomplis coordonnés que le ${ }^{*} M$ offre en ce contexte sont traduits d'ordinaire comme $s^{\prime} i l$ s'agissait d'inaccomplis invertis.

Ce deuxième verbe du vs 6 a été interprété comme "enivrer" par RSV, RL et TOB.

J12 donnent ici : "je les piétinai" et J3 "je les ai brisés", J23 disent lire avec des mss hébreux. Dans un sens analogue, NEB donne: "I pierced them", sans note.

Origines des corrections :

Driver (Scrolls 29) a fait une hypothèse lexicographique que NEB a reprise. Il ne faut donc pas croire qu'elle ait voulu corriger ici.

Quant à la correction de J, à travers les apparats de Cent, BH23S et HSAT234, elle remonte à Cappel (Critica 1020s). Celui-ci, voyant mal comment "piétiner" peut précéder "enivrer", a conjecturé ici ואשברם qu'il estime avoir été lu par le *T. En suggérant cela, Cappel (comme Houbigant qui adopte cette correction) semble ignorer 
ce que Lowth révélera : que de nombreux mss (ainsi qu'une édition ancienne) lisent ainsi. Lowth ajoute que la ${ }^{*}$ S, elle aussi, a lu de même.

\section{Les témoins anciens :}

Cette dernière affirmation de Lowth a été tout de suite critiquée par Koppe et Michaelis (OEB). Celui-ci note en effet que le verbe דוא (= affliger) que les polyglottes offrent ici ne traduit jamais שבר dans la *S. Il estime donc qu'on a là un placement erroné par Gabriel Sionita du point diacritique distinguant le 'resh' du 'dalat'. Pourtant, Weisz (59s) fera remarquer que ce cas de placement surprenant du point diacri-

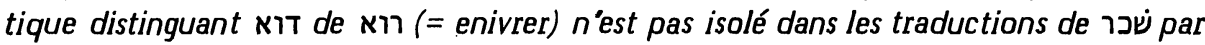
la *S. En effet, sur les 19 emplois bibliques du verbe שכر, la *S le traduit 15 fois par רוא, aussi bien selon le ms Ambrosianus que selon les polyglottes. En 3 autres emplois (Is 63,6; Jr 48,26; $\mathrm{Na} \mathrm{3,11)} \mathrm{il} \mathrm{est} \mathrm{traduit} \mathrm{par} \mathrm{aussi} \mathrm{bien} \mathrm{selon} \mathrm{le} \mathrm{ms} \mathrm{Ambrosianus}$ que selon les polyglottes. Dans le dernier cas ( $\mathrm{Lm} 4,21)$ les polyglottes donnent le verbe רוא Alors que l'Ambrosianus porte. Albrektson (3) y a trouvé tous les mss conformes à l'Ambrosianus. Il semble donc que, sur ces 19 cas, Sionita a été 18 fois fidèle aux options des mss et qu'une seule fois ( $L m$ 4,21) il y a été infidèle, mais dans un sens inverse à celui que Michaelis soupçonnait. En ces quatre cas où les mss placent le point diacritique en bas, il semble que le ponctuateur ait été infidèle à l'intention du traducteur qui était, là comme ailleurs, d'interpréter ce verbe שכר au sens de "être ivre, enivrer". Le ponctuateur (dont les fantaisies ont été si fidèlement respectées par les copistes et par Sionita) a cependant placé le point en bas parce qu'il estimait que le sens de "être affligé, affliger" correspondait bien à ces contextes-là. En tout cas, il n'y a aucun motif de penser que le traducteur ait lu là le verbe שבר qu'il traduit d'ordinaire par תבר.

Quant à la leçon du *T, elle non plus ne saurait appuyer cette variante en faveur de laquelle Cappel et Lowth l'invoquaient. En effet, il importe de noter que la traduction que le *T donne ici : ואדוששנון est le correspondant normal qu'il utilise pour le verbe hébreu בוס. Or ce verbe figure dans le *M au début de ce vs où le *T donne à sa place קטל. Il semble donc que, gêné par le verbe "enivrer" du *M pour les mêmes motifs que Cappel, le *T ne l'a pas traduit, mais qu'il a traduit à sa place le verbe qui le précède dans le *M, après avoir mis à la place de ce verbe précédent un verbe qui lui paraissait convenir au contexte.

De Rossi mentionne la variante ואשברם en 25 mss du *M et dans la 1e main de 12 autres. L'édition Soncino 1488 portait cette variante, mais l'édition Brescia 1494, ainsi que celles de Felix de Prato et de Ben Hayim, en accord avec les mss tibériens classiques lisent ואשכרם avec 'kaf', forme sur laquelle la mp attire l'attention en la signalant comme hapax.

Ce mot et le suivant $n$ 'ont pas été traduits par le ${ }^{*} G$ ancien qui apporte ainsi une autre solution à la difficulté à laquelle se heurteront le *T, puis Cappel.

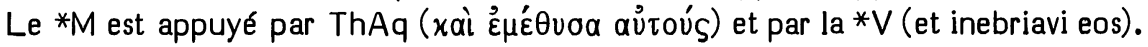
Cependant, du fait que 1Q-a donne ici ואשכירמה qu'il a l'appui de 1Q-b : ואשכירם, il est permis de se demander si l'on ne se rapprocherait pas d'un état textuel plus originel en vocalisant ici en hifil. Le comité n'a cependant pas voulu tenir compte de cette particularité qui ne modifie pas le sens. 


\section{Choix textuel :}

Le fait que Cappel ait suggéré ici une variante qui se trouve en plusieurs mss, alors qu'il ignorait cela, montre que cette variante est 'dans l'air'. Michaelis (OEB) fait d'ailleurs à ce propos une remarque amusante : “M. Struensee a le mérite d'avoir été le premier à traduire ici 'ich zerbrach sie', comme s'il avait lu ואשברם avec 'bet'. Il ne fait aucune remarque là-dessus; il ne dit pas qu'il lit autre chose que ce que porte le texte imprimé, comme il a coutume de le faire ailleurs et comme cela eût été son devoir. Je suppose donc qu'il ne s'agit pas d'une conjecture critique, mais d'une heureuse erreur des yeux". Ensuite, Michaelis dit accepter cette correction parce que Lowth l'a trouvée en 27 mss et dans l'édition de 1494 (autre erreur - de Lowth cette fois - pour 1488). Mais il ne semble pas soupçonner que ces mss peuvent dériver d'une "erreur des yeux" analogue à celle qu'il a repérée chez Struensee. D'ailleurs, à la différence de Buxtorf jr (981) que son père avait initié à la massore et qui était capable par là de peser le caractère plus ou moins traditionnel d'une leçon, Michaelis - comme tant d'exégètes de son époque et des cent cinquante ans qui suivirent avait tendance à faire plus confiance aux variantes attestées par un certain nombre de mss médiévaux du *M qu'aux leçons attestées par les éditions courantes, et cela sans disposer de moyens qui lui eussent permis de mesurer la qualité de ces divers témoins.

Considérant le *M comme bien appuyé en face d'une variante qui est 'dans l'air', le comité lui a attribué la note "B".

\section{Interprétation proposée :}

C'est vraisemblablement la difficulté exégétique soulevée par Cappel qui a amené le ${ }^{*} G$ à ne pas traduire ce verbe, qui a engagé le ${ }^{*} T$ a lui attribuer la traduction de celui qui le précède, qui a donné au ponctuateur de la *S l'idée de placer son point en bas et qui a orienté les yeux de certains scribes du ${ }^{*} M$ vers la variante avec 'bet'. Cette difficulté est pourtant aisée à résoudre si (à la suite de Bonnard) on rapproche ce passage de 49,26 où il était dit: "je ferai manger à tes oppresseurs leur propre chair et, comme d'un vin-giclant-du-pressoir, ils s'enivreront de leur propre sang". Or il faut commencer par piétiner les peuples pour qu'en jaillisse le sang dont ils s'enivreront.

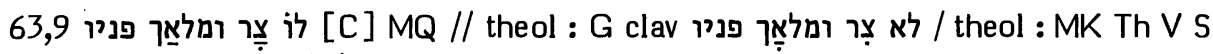

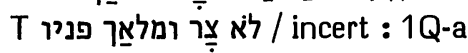

Options de nos traductions :

RSV traduit le qeré du *M en 9a: "In all their affliction he was afflicted, and the angel of his presence saved them."

Les autres se sont fondées sur le *G : J12: "... dans toutes leurs angoisses. Ce ne fut ni un messager ni un ange, mais sa face qui les sauva"; RL : "... in all ihrer Not. Nicht ein Engel und nicht ein Bote, sondern sein Gesicht half ihnen"; NEB : “... in all their troubles. It was no envoy, no angel, but he himself that delivered them"; TOB : “... dans toutes leurs détresses. Ce n'est pas un délégué ni un messager, c'est lui, en personne, qui les sauva"; $\mathrm{J3}$ : “Dans toutes leurs angoisses, ce n'est pas un messager 
ou un ange, c'est sa face qui les a sauvés." Cela suppose, selon J2, que l'on suive le ketib pour le premier mot que nous avons cité dans l'apparat; selon J2, NEB et J3, que l'on vocalise hịreq le deuxième; et selon NEB, que l'on vocalise patặ le 'alef' du troisième.

Origine de la correction :

Le premier qui ait attiré l'intérêt sur la leçon du ${ }^{*} G$ semble avoir été Olivetan. Lowth l'a adoptée, suivi par Landesberg (cité par Schorr, Tiqqune 92), Geiger (Zeitschriften 417s), Oort (Jez), Duhm, Cheyne, Marti, Condamin, Ehrlich, Pieper, Haller, Feldmann, Volz, Fohrer, Westermann, Bonnard, ainsi que les apparats de HSAT34, $\mathrm{BH} 235$ et Cent.

\section{Les témoins anciens :}

Ici, la seule différence textuelle qui existe entre 1Q-a et le *M consiste en ce que le mot sur lequel porte le qeré-ketib y est écrit לוא. Nous avons déjà noté (p. 61)

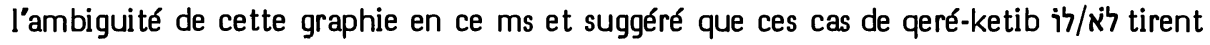
peut-être leur origine de graphies ambigües לוא provenant de mss ayant des traditions orthographiques analogue à celle de $1 \mathrm{Q}-\mathrm{a}$. A propos de $1 \mathrm{Q}$-a, il importe encore de noter qu'un espace notable y sépare ומלאך de, ce qui rend peu vraisemblable que son scribe ait lu ce vs à la manière du ${ }^{*} G$.

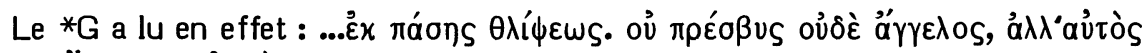

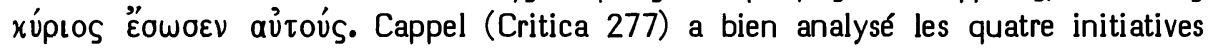
caractéristiques prises par le traducteur :

1/il a rattaché ברו à la fin du vs précédent,

$2 /$ il a lu

3/il a considéré la négation précédant ce mot comme portant aussi sur le mot ומלאך qui le suit,

4/il a compris פניו au sens de "lui-même".

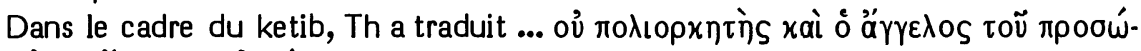

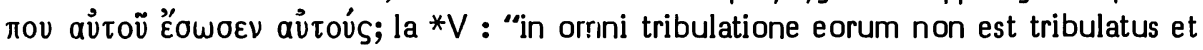
angelus faciei eius salvavit eos"; la *S : "en toutes leurs calamités il ne les a pas affligés et l'ange de sa face les a libérés"; le *T : "en toute époque où ils péchèrent devant lui de sorte qu'il amenât sur eux la détresse il ne les a pas affligés et l'ange envoyé de devant lui les a rachetés".

\section{Choix textuel :}

La plupart des traducteurs du XVIe siècle avaient opté pour le qeré massorétique (que, d'ailleurs, les éditions du *M de Soncino 1488 et de Brescia 1494 donnaient dans leur texte, sans mention du ketib). C'est la leçon que donnent seule Pagnini, Münster, Brucioli, Rollet, Ge et $\mathrm{KJ}$; alors que Oecolampade, Luther, Calvin et Pasteurs la donnent en mentionnant aussi le ketib (celui-ci étant choisi par Zwingli, Prédicants, Olivetan, Châteillon, Tremellius et Arias Montano). 


\section{A. Le ketib}

Il n'existe pas de tradition normative portant sur le ketib. Hie traduit: "non est tribulatus", mais il connaît la tradition du qeré : "pro 'non' legi potest et "ipse'." D'autre part, il sait que le ketib peut s'interpréter au sens intransitif (qu'il a choisi) : "il n'éprouva pas d'affliction", ou au sens transitif (non tribulavit eos) : "il ne les affligea pas". Aussi explique-t-il ces trois sens en son commentaire. Cependant, tous les autres témoins du ketib se situant dans la tradition protomassorétique ou massorétique semblent avoir choisi le sens transitif. C'est le cas de Th, de la ${ }^{*}$, du ${ }^{*}$ T, de Saadya, Rashi et Radaq.

Mais il semble que l'on rende mieux compte de la raison d'être de la négation en interprétant le ketib à la manière dont l'a fait le ${ }^{*} G$ dont la leçon a eu, nous l'avons dit, une très large influence sur l'exégèse moderne. Les racines de cette interprétation sont d'ailleurs très anciennes. En effet, dans la Mekhilta (I 53), à propos de l'annonce de la plaie des premiers-nés ("et je frapperai" en Ex 12,12), il est demandé : "dois-je entendre par les mains d'un ange ou par les mains d'un envoyé ? il y a un enseignement en 12,29 : 'et le Seigneur frappa tout premier-né' : pas par les mains d'un ange ni par les mains d'un envoyé." La haggada pascale (54) s'exprime de même en commentant Dt 26,8 : "'Et le Seigneur nous fit sortir d'Egypte" pas par les mains d'un ange, ni par les mains d'un Saraph, ni par les mains d'un envoyé, mais le Saint béni soit-il, en sa gloire et en sa personne."

Nous avons là un thème mis en valeur par le livre des Jubilés (15,30-32) : "Il a choisi Israël pour être son peuple et il les a sanctifiés et rassemblés du milieu des fils des hommes. Car il y a de nombreuses nations et de nombreux peuples et tous sont siens. Mais sur chacun il a placé des esprits avec le pouvoir de les faire se détourner de lui. Par contre, il n'a placé sur Israël aucun ange et aucun esprit, car c'est lui-même qui est leur chef et il les protégera et les réclamera hors du pouvoir de ses anges et de ses esprits et de toutes ses puissances, pour qu'il puisse les protéger et les bénir, pour qu'ils puissent être siens, et que lui il puisse être leur désormais et pour toujours."

A l'origine de ce thème, il faut placer Dt 32,8-9 selon la forme que le *G lui a donnée : "Lorsque le Très-Haut a réparti les peuples, lorsqu'il a dispersé les fils d'Adam, il a établi les territoires des nations selon le nombre des anges de Dieu. Et la part du Seigneur, ce fut son peuple Jacob, et son cordon d'héritage ce fut Israël." C'est cela que le Siracide $(17,17)$ reprend explicitement dans un passage pour lequel l'hébreu ne nous a pas été conservé : "Lors de la division des nations de toute la terre, à chaque nation il a assigné un chef, et la part du Seigneur, c'est Israël." Comme on peut le constater, ce thème était donc bien vivant vers le IIe siècle av. J.-C., date à laquelle le ${ }^{*} G$ traduisait: “Ce n'est pas un ambassadeur ni un ange, mais c'est le Seigneur lui-même qui les sauva."

\section{B. Le qeré}

Le qeré massorétique constitue lui aussi une tradition exégétique cohérente et ancienne. Dans la Mekhilta de R. Shimeon ben Yohäi (2,1-2 et 34,7-8), dans la Mekhilta de R. Ishmaël (I 113s) et dans le Talmud Babli (Taanit 16a), ce vs est rap-

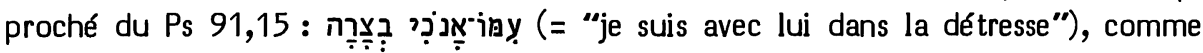
constituant les deux témoignages bibliques que le Seigneur partage les détresses collectives (Is 63,9) et individuelles (Ps 91,15). 
Les deux seules leçons qui méritent de rivaliser l'une avec l'autre, du fait de leur cohérence interne et de leur enracinement traditionnel, sont donc le ketib lu selon le ${ }^{*} G$ et le qeré du ${ }^{*} \mathrm{M}$. Or il est peu probable que la leçon du ${ }^{*} G$ soit primitive, et cela pour trois motifs :

- Alors que מלאך a un sens profane de "envoyé" et un sens spécialisé de "ange" du Seigneur, le mot צִ n'est employé dans la Bible qu'au sens profane.

- Lorsque le mot פנים suivi d'un pronom suffixe exprime, à titre de sujet d'un verbe, la personne du Seigneur ou d'un homme, ce verbe se met au pluriel (Ex 33,14.15; $2 \mathrm{~S}$ 17,11).

- La construction lue ici par le ${ }^{*} G$ postulerait une particule adversative avant פניו (par exemple יפ̣, comme en 62,4 ou 65,20 ).

On a objecté contre le * $M$ que l'expression "ange de la face" $n$ 'apparaît dans le judaïsme qu'à l'époque post-biblique. Mais il ne faut pas considérer ici "l'ange de sa face" comme un représentant de la catégorie tardive des "anges de la face". Il s'agit de l'ange en lequel se manifeste et agit sa présence. Il faut voir ici une appellation qui combine deux expressions apparaissant dans la Torah comme sujets des actes rédempteurs de Dieu : "un ange" (Nb 20,16) ou "mon ange" (Ex 23,23) et "ma face" (Ex 33,14) ou "ta face" (Ex 33,15).

On a objecté encore contre le qeré du *M que l'ordre naturel des mots devrait être conforme à צִ צַרִ $(49,20)$. Mais l'inversion est ici requise par la nécessité de mettre en valeur le destinataire divin : "en toutes leurs afflictions, c'était lui qui était affligé".

En réalité, depuis l'époque du ${ }^{*} G$ jusqu'à nos jours, c'est le caractère anthropopathique du qeré qui a surtout fait difficulté aux exégètes. Pourtant ce caractère est tout aussi marqué en d'autres passages de la Bible comme $\mathrm{Jg} 10,16$ ou Ps 91,15. Là où la crainte de l'anthropopathisme apparaît le plus nettement, c'est dans l'exégèse peu naturelle qu'Abulwalid (Ușul 605,6-10) donne du qeré : il considère le suffixe de צ comme portant sur Israël et il interprète un verbe transitif se rattachant au sens de צור = rocher. Donc: "en toutes leurs afflictions il l'affermissait". Il semble que Judah ibn Balaam ait été seul à adopter, par la suite, cette exégèse.

Mentionnons comme partisans du qeré en son sens naturel : Yéfet ben Ely, Dunash ben Labrat (contre Menaḥem, 46*,20 à 47*,3 et 85*,7 à 13), Ibn Ezra, Eliézer de Beaugency, Vitringa, Hitzig, Knobel, Luzzatto, Delitzsch, Ewald, Nägelsbach, Knabenbauer, von Orelli, Dillmann/Kittel.

Le comité a attribué au qeré 3 "C" et 1 "B", alors que le ketib a reçu 2 "C". Interprétation proposée :

"En toutes leurs afflictions c'est lui qui était affligé, et l'ange de sa face les a sauvés." 


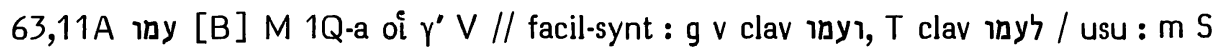
/ עבדו / abr-elus : G om

\section{Options de nos traductions :}

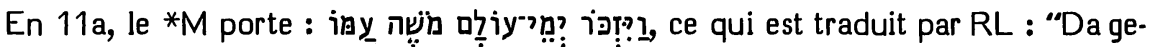
dachte sein Volk wieder an die vorigen Zeiten, an Mose"; NEB : "Then men remembered days long past and him who drew out his people"; TOB : "Son peuple alors se rappela les jours du temps de Moïse."

RSV, sans note, traduit: "Then he remembered the days of old, of Moses his

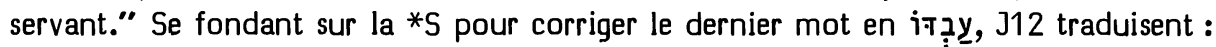
"Ils se souvinrent des jours du passé, de Moïse son serviteur." Ajoutant à cela le témoignage de mss, 33 traduit : "Mais il s'est souvenu des jours d'autrefois, de Moïse, son serviteur."

Origine de la correction :

La correction de RSV et de J a d'abord été proposée par Houbigant et Lowth, puis requise par les apparats de HSAT34, BH3 et Cent.

Les témoins anciens :

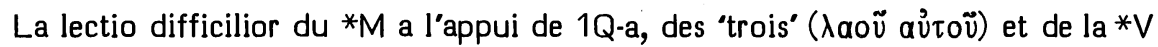
(populi sui).

Vraisemblablement parce qu'il ne savait traduire ce mot, le *G l'a omis avec les deux qui l'entourent.

Un certain nombre de témoins de la $* V$ et de l'ajoute origénienne font précéder ce mot d'une conjonction (dont Estienne, à la suite du correctoire de St Jacques, a décelé le caractère inauthentique).

Le *T a compris "pour son peuple".

La variante בִבְ est attestée par de rares mss du *M, par l'édition Soncino 1488 et par un certain nombre de citations midrashiques (Tanḩuma Buber Genèse 204; Yalqut Shiméoni, éd. Salonique V col 305d, 8inf; col 308a, 5inf; VII col 233b, 15inf), ainsi que par la *S (עבדה).

Choix textuel :

Faire précéder ce mot d'une conjonction constitue la facilitation la plus aisée. C'est l'exégèse proposée par Yéfet ben Ely et Ibn Ezra. C'est ainsi que traduisent Pagnini, Brucioli, Münster, Olivetan, Pasteurs, Ge et KJ.

Radaq a préféré suivre le *T en insérant la préposition 'lamed' avant ce mot.

Quant à la variante serviteur" (EX 14,31; Jos 9,24; 11,15; 1 R 8,56; Ps 105,26), elle constitue ici une facilitation qui est 'dans l'air'.

Situant la difficulté au niveau de l'exégèse, le comité a attribué au *M la note "B".

Interprétations proposées :

Judah ibn Balaam a fait de משֶׁ le participe du verbe attesté en Ex 2,10, exégèse qu'Tbn Ezra refuse, que la Bible des Pasteurs de 1588 présente comme option marginale et que Luzzatto, puis NEB adoptent. 
Il semble que l'exégèse qui rend le mieux compte du *M est celle de Saadya et de Rashi, reprise ensuite par Châteillon et Foreiro, puis Rosenmüller, Delitzsch, König, RL, Bonnard, TOB :

- ou bien faire de "son peuple" le sujet de "se souvint" : "alors son peuple se souvint des jours d'autrefois, de Moïse", ce dernier mot pouvant être une glose explicative plus tardive,

- ou bien faire de "Moïse" et de "son peuple" deux précisions, l'une portant sur le sujet et l'autre sur le complément du verbe initial: "alors on se souvint des jours d'autrefois, son peuple (se souvint) de Moïse". Cette deuxième option est celle qui correspond le mieux aux teamim.

Du fait que le 'souvenir' mentionné dans le verbe initial s'exprime en 11b-14 sous forme d'un rappel nostalgique des prouesses du Seigneur, il est clair que c'est le peuple (et non le Seigneur) qui se souvient, puis qui suppliera en 15.

\section{3,11B רֵา [C] M 1Q-a Aq V // harm-ctext : m G S T רִ̣}

\section{Options de nos traductions :}

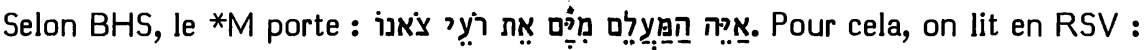
"Where is he who brought up out of the sea the shepherds of his flock ?"; J12: “Où est celui qui retira de la mer le pasteur de son troupeau ?"; RL : "Wo ist denn nun, der aus dem Wasser zog den Hirten seiner Herde ?"; NEB : "Where is he who brought them up from the Nile with the shepherd of his flock ?"; TOB : "Où est Celui qui fit remonter de la mer le pasteur de son troupeau ?"; J3 : "Où est-il, celui qui les sauva de la mer, le pasteur de son troupeau ?".

Sur l'avant-dernier mot, NEB et TOB indiquent la possibilité de le lire au pluriel.

Identification de la leçon du $* M$ :

Les éditions récentes du $* M$ hésitent en effet sur l'identification de la leçon authentique du *M tibérien. Alors que $\mathrm{BH} 2$ écrivait nỵ̂n, elle notait qu'elle suivait en cela l'édition Ben Hayim, en accord avec le ${ }^{*} \mathrm{G}$ et le ${ }^{* T}$. Mais elle signalait que de nombreux mss offrent 'minus recte' : ' 'ỵj. Cela n'a pas empêché BH3S (du fait de leur décision de reproduire le ms de Leningrad) d'adopter dans leur texte la leçon avec 'yod' (que BHS demande d'ailleurs de corriger en 'hé'). Laquelle de ces deux leçons peut prétendre à représenter le texte tibérien classique ?

Les traducteurs du XVIe siècle disposaient de Bibles hébraïques où dominait la leçon avec "hé. C'est en effet elle que donnaient (avec la graphie הyֶin) les éditions Soncino 1488 et Brescia 1494, ou (avec la graphie הỵ̂) les éditions Félix de Prato, Bomberg in-quarto 1517 et 1521, Ben Hayim et Münster (celles de Félix de Prato et de Münster donnant en variante marginale la leçon avec 'yod"). On comprend donc qu'une traduction en singulier ait été adoptée par Oecolampade, Pagnini (éditions de 1527 et de 1557), Luther, Zwingli, Prédicants, Brucioli, Calvin, Ge, Tremellius, Pasteurs, $\mathrm{KJ}$ (cette dernière donnant le pluriel en variante marginale). Cependant, Münster (optant pour sa variante marginale) traduisait en pluriel, suivi par Olivetan, Servet (rééditant Pagnini en 1542) et Châteillon. Mais, sous l'influence conjuguée de Luther, 
de la Bible des Pasteurs et de KJ, l'occident chrétien s'est habitué à lire ce mot au singulier pour lequel continuent à opter le plus grand nombre de nos traductions.

Si nous remontons plus haut dans l'histoire, le singulier était lu ici par Saadya, Rashi, Ibn Ezra, Eliézer de Beaugency, Isaïe de Trani; alors que le pluriel l'était par Yéfet ben Ely, Radaq et Abravanel.

En inspectant les mss auxquels nous avons accès, nous trouvons :

- la graphie רֶֶ๊ dans les mss Reuchlin des Prophètes, Vat ebr 482 et Nürnberg Ebner 2,

- la graphie רֵِ dans les miss Bern 92, Vat ebr 3, Londres BL Add 15,451, Hamburg 6 et 27 , Copenhague 5 ,

- la graphie 'ỵj dans les mss du Caire, d’Alep, de Leningrad, Petrograd des Prophètes, des Jésuites de Cologne, Paris BN hebr 6, 26, 82, 1325, Vat ebr 468, Urbinates ebr 1, New York JThS 232, Madrid Bibl Univ hebr 1, Erfurt 3, Copenhague 1, 2, 4, 8, et dans la 2e main du ms de Rossi 782.

Le nombre et la qualité des attestations pour cette dernière graphie s'imposent donc de façon évidente.

D'ailleurs, il est intéressant de noter que Ben Hayim (dont l'édition porte la leçon avec "hé) contredit son option en éditant deux fois (sur Gn 46,34 et sur Ps 80,2) une massore disant que הỵา vocalisé qameș (terminologie des massorètes pour șéré) s’écrit 4 fois avec 'hé' : en Gn 4,2; 46,34; 47,3 et Ps 80,2. D'où l'on peut déduire que la graphie הỵ̂n ne serait pas légitime en Is 63,11.

Dans son Séfer Zikronot (ms München fol. 449b et ms Paris fol. 458a), Elias Levita précise que deux fois nỵ̣ est mileél (Gn 4,2; 46,34) et deux fois milrâ (Gn 47,3; Ps 80,2). Pour respecter la massore, sans contredire la graphie avec 'hé' qui domine les éditions circulant à son époque, Levita est donc amené à intégrer Is 63,11 parmi les הỵ écrits avec segol! Ce qui nous montre les périls qu'il y a à ne pas compléter l'usage de la massore par celvi des mss anciens.

Ajoutons encore un argument en faveur de la graphie avec 'yod' : Le Talmud Yerushalmi (Soṭa $\vee 4$ ) - selon l’éd. 1523 et selon le ms Leiden - déclare que : “tous les Israélites, même les plus petits, disaient le cantique comme Moïse. C'est ce qui est écrit en Is 63,11. Il n’y est pas écrit את רועה הצאן mais רועה צאנו ce qui enseigne qu'il les a tous faits רועים." On ne peut tirer cette conclusion de ce texte. Ne faut-il pas admettre que, dans la forme originelle de cette tradition, le "il n'est pas écrit ... mais ..." ne portait pas sur "le troupeau" ou "son troupeau", mais sur "berger" ou "bergers"?

Concluons donc que la graphie avec 'yod' représente le texte tibérien classique.

Les témoins anciens :

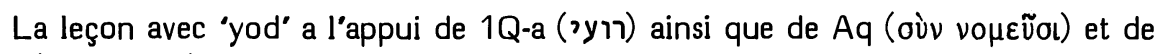
la *V (pastoribus).

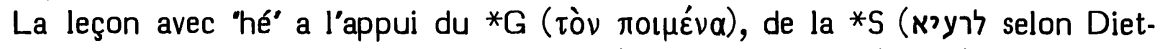
trich attestant qu'un seul ms offre ici les seyamé), ainsi que du *T (כרעיא).

Choix textuel :

L'appui que Aq et la *V apportent à la leçon avec 'yod' nous montre que celle-ci 
s'enracine dans le texte protomassorétique. L'appui que 1Q-a apporte à cette lectio difficilior a engagé le comité à la choisir avec la note " $\mathrm{C}$ ".

Interprétation proposée :

Selon la suggestion de Radaq et de la marge de $\mathrm{KJ}$, on peut rapprocher ce pluriel de Ps 77,21 en y voyant Moïse et Aaron. La leçon avec 'hé' a été influencée par la mention de Moïse peu avant, ainsi que par le pronom suffixe de קִִּ̣ peu après (pronom suffixe qui porte en réalité sur le peuple).

On pourra traduire : "Où est celui qui les fit remonter de la mer, avec les pasteurs de son troupeau ?"

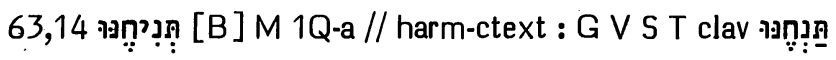

Options de nos traductions :

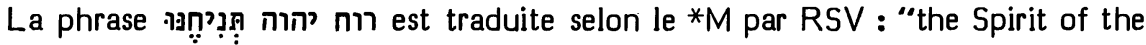
LORD gave them rest", J : "l'Esprit de Yahvé les menait au repos", RL : "so brachte der Geist des HERRN uns zur Ruhe", TOB : "l"Esprit du Seigneur les menait au repos".

Selon Brockington, NEB, avec la *V, vocalise by the spirit of the Lord".

Origine de la correction :

La vocalisation du ${ }^{*} M$ fait de ce verbe un hifil de précède ("descendait") et celui qui suit ("tu as conduit") suggéreraient plutôt ici une forme de ("mener").

Sous l'influence de la *V et de Pagnini ("ducet eos"), Luther a traduit : "welchs... treibet". Dans cette ligne, la correction que NEB retiendra a été proposée par Lowth et Michaelis (OEB) suivis par beaucoup d'exégètes jusqu'à HSAT34 et BH3S.

Les témoins anciens :

Par la présence du 'yod', 1Q-a appuie le *M, alors que le * G, la *V, la *S et le *T ont traduit au sens de "mener".

Choix textuel :

Abulwalid (Usul 416,24-29) estime qu'ici la racine נוח est employée au sens de הח qal ou hifil, le sens étant le même que dans l'emploi du qal de ce dernier verbe en Ps 77,21. Ibn Ezra adopte cette opinion, de même que les glossaires ACDEF qui traduisent "mènera lui". Pourtant, le glossaire B traduit "laisses nous" en précisant que certains disent "mènes nous".

Le sens de "faire reposer" est reconnu ici par Yéfet ben Ely selon qui le pronom suffixe se réfère à Israël. Par la nuée qui les guidait, le Seigneur leur fixait la place où ils devaient décharger leurs bagages, selon Nb 9,20.23: "sur l'ordre du Seigneur ils établissaient le camp". 
D'autres ont essayé d'intégrer les deux sens : ainsi Saadya: “les guidait en sécurité", ou Servet (rééditant Pagnini en 1542): "quiete ducit", ou Tremellius : "quiete egit eum", ou la Bible des Pasteurs : "les a menés tout bellement".

Le comité a estimé qu'on avait ici un cas de plus où le livre d'Isaïe se joue à nous offrir un mot distinct (quoique très proche) de celui que le contexte suggérerait (cf. ci-dessus, p. 265). Il a donc gardé la leçon du *M avec la note "B".

Interprétation proposée :

La traduction de la TOB (et de J) exprime assez bien cette transparence, laissant apparaître "guider" derrière "faire reposer". Une note serait utile pour indiquer cela.

\section{וגבורְתך 63,15A וגבור M T // usu : m 1Q-a G V}

\section{Options de nos traductions :}

Elles ont toutes traduit ce mot par un singulier (RSV : "and thy might", J: "et ta puissance", RL: "und deine Macht", TOB : "et ta vaillance" et NEB : "thy valour"), seule TOB faisant remarquer que le *M porte ici : "tes prouesses".

\section{Origine de la correction :}

Peut-être sous l'influence de la *V et de l'édition Soncino 1488, la plupart des traducteurs du XVIe siècle donnent ici un singulier. C'est le cas de Oecolampade, Pagnini (éd. de 1527 et de 1557), Luther, Zwingli, Prédicants, Brucioli, Münster contre son texte, Olivetan et ses rééditeurs, Jud, Ge, Tremellius, Pasteurs, KJ. La traduction par un pluriel se lit chez Servet (rééditant Pagnini en 1542), Châteillon, Arias Montano et dans la marge de Tremellius.

Le pluriel ayant donc été méconnu par les Bibles les plus diffusées, il n'est pas étonnant que les Bibles actuelles traduisent par le singulier.

\section{Les témoins anciens :}

Etant donné le goût de 1Q-a pour les graphies pleines, il serait surprenant que n'ait pas été lu en singulier par son scribe, de même que ce mot a été traduit en singulier par le *G, la *V et la *S.

De Rossi et Ginsburg signalent un certain nombre de mss du *M qui vocalisent le 'resh' en singulier (avec un qames). C'est le cas de trois (de Rossi 2, Vat ebr 3 et 468) sur les vingt-huit mss auxquels le comité a eu accès. Tous les plus anciens (mss du Caire, d’Alep, de Leningrad, de Petrograd, de New York JThS 232, Reuchlin, Ebner 2 de Nürnberg, Erfurt 3) s'accordent sur la vocalisation họolem. L'édition Soncino 1488 vocalisait ce mot en singulier. Le pluriel a été donné ensuite par les éditions Brescia 1494, Félix de Prato, Ben Hayim et Münster.

La vocalisation en pluriel est garantie par deux types de massores. L'une (en mp des mss du Caire, Reuchlin, Ebner 2, Erfurt 3) précise que ce mot se trouve deux fois dans la Bible, ici et en Ps 145,4; certains états de cette mp précisant qu'il est écrit une fois defective (ici) et une fois plene (dans le Ps), quant au 'yod'. Une autre mp (en mss d'Alep, Petrograd, Leningrad, Berne, Londres BL Add 15451, Madrid Univ.1, 
Paris BN 82, Hamburg 6, Copenhague 2) précise que le pluriel de ce mot avec un suffixe 2e pers. m. sg. (avec ou sans préposition auparavant) se rencontre trois fois, dont une fois dans la Torah (Dt 3,24), une fois dans les Nebiim (Is 63,15) et une fois dans les Ketubim (Ps 145,4). En certains de ses états, cette mp précise que, en ses deux premières occurrences, ce mot est écrit defective (quant au 'yod") et la troisième fois plene. La mm correspondante est attestée ici par les mss de Leningrad, de Berne et de Londres BL Add 15451. Cependant son état le plus ancien et le plus précis semble être celui que le ms Vat ebr 448 donne sur Dt 3,24.

\section{Choix textuel :}

Ce cas n'a pas été soumis au comité.

Du fait qu'en Dt 3,24 et en Ps 145,4 ce mot est mis en parallèle avec le mot מעשיך, sa valeur de pluriel est assez facile à reconnaître. Ici, la situation est plus complexe parce que, avec une graphie entièrement défective, il est coordonné au singulier

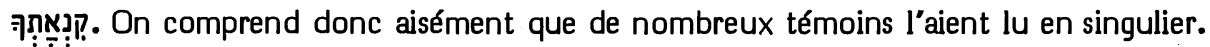

\section{Interprétation proposée :}

Le singulier de ce mot signifie la puissance, alors que le pluriel signifie les actes de puissance, c'est-à-dire les prouesses. Ce dernier sens est particulièrement bien en place ici, car ce sont bien les prouesses qui manifestent la jalousie que le Seigneur éprouve pour son peuple et ce sont elles dont l'auteur déplore l'absence à son époque dans la conduite du Seigneur à l'égard de son peuple.

אלינו ה־ 63,15B אלי התאפקו [B] M 1Q-a V // transl : ThAqSym / assim 16: G S T clav

Options de nos traductions :

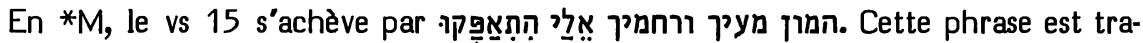
duite par RSV : "The yearning of thy heart and thy compassion are withheld from me", par RL: "Deine grosse, herzliche Barmherzigkeit hält sich hart gegen mich", par TOB : "... l'émoi de tes entrailles ? Tes tendresses pour moi ont-elles été contenues ?", par J3 : "Le frémissement de tes entrailles et ta piété pour moi se sont-ils contenus ?"

J12 corrigeaient les deux derniers mots, selon le *G, en אַ אַ et traduisaient : "... le frémissement de tes entrailles ? Ah ! ne rends pas insensible ta pitie". Selon Brockington, NEB conjecture la même leçon et insère נֵ entre les deux mots. Elle traduit : "... thy burning and tender love ? Stand not aloof".

Origine de la correction :

Ce sont Oort (Jez), Duhm et Cheyne qui ont conjecturé l'une ou l'autre des leçons que $\mathrm{J12}$ et NEB adopteront, conjectures qui ont été diffusées par HSAT34, BH3 et Cent.

Les témoins anciens :

Le *M est appuyé par 1Q-a et la *V. 
Il l'est aussi par ThAqSym qui ne mettent le verbe au singulier que parce qu'ils l'accordent à $\tau o ̀ ~ \pi \lambda \tilde{\eta} \theta$ os du * $G$ dont ils font son sujet.

La *S a confondu les racines אפק et הפק.

La seule variante notable consiste (de la part du ${ }^{*} G$, de la ${ }^{*} S$ et du ${ }^{*} T$ ) en une assimilation du suffixe $1 e$ pers. sg. aux quatre suffixes $1 e$ pers. pl. qui suivent dans le vs 16.

\section{Choix textuel :}

Contre cette assimilation facilitante, il faut protéger le singulier qui personnifie le peuple et donne un fort relief à un reproche dont la suite montrera le caractère passionné. Le comité a attribué au *M la note "B".

Interprétation proposée :

Il y a ici une affirmation exagérée constituant une sorte de réquisitoire : "l'émoi de tes entrailles et tes compassions se sont contenus envers moi !" Par cette accusation et par celle, analogue, qu'il formulera en 19a, l'auteur veut forcer le Seigneur à intervenir (19b).

\section{3,18 ירשו עם / [C] M 1Q-b(?) V T // facil-synt : 1Q-a S G}

\section{Options de nos traductions :}

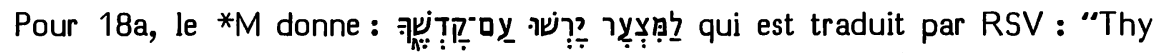
people possessed thy sanctuary a little while", par RL : "Kurze Zeit haben sie dein heiliges Volk vertrieben", par TOB : “C'est pour peu de temps que ton peuple saint est entré dans son héritage", par $\mathrm{J3}$ : "Pour bien peu de temps ton peuple saint a joui de son héritage."

$\mathrm{J12}$ avaient traduit : "Pourquoi des impies ont-ils envahi ton sanctuaire", J2 disant lire pour les trois premiers mots : NEB ne diffère, selon Brockington, que par le verbe central qu'elle lit بְ̣ en traduisant : "Why have wicked men trodden down thy sanctuary".

Origines des corrections :

L'ensemble de la conjecture de $\mathrm{J} 2$ remonte, à travers $\mathrm{BH} 2$, à Gesenius/Buhl (453b). Le premier mot en avait été proposé par Grätz (Psalmen 124,4). La forme de cette conjecture que NEB retient provient de Driver (LTP 405).

Les témoins anciens :

En mettant le verbe au singulier, 1Q-a montre qu'il considère "peuple" comme en étant le sujet : "Durant peu de temps, ton peuple saint a joui de son héritage". La *S fait de même.

La $* V$, telle que Hie l'interprète en la glosant, considère au contraire le premier mot de 18b ("nos adversaires") comme sujet de "ont possédé" dont "ton peuple saint" est le complément d'objet. Le ${ }^{*} T$, fidèle au ${ }^{*} M$, le construit en sens inverse.

1Q-b lacuneux assure la présence du 'mem' final de $\mathrm{ay}$. 


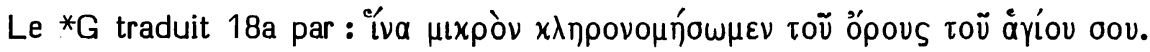
Notons qu'en 57,13 le *G a lu "ceux qui s'attachent à moi hériteront ma montagne sainte" (alors que le ${ }^{*} M$ avait le singulier). En 65,9 le *G lira "et je ferai sortir la semence de Jacob et celle de Juda, et elle héritera ma montagne sainte, et mes élus et mes serviteurs hériteront et s'y établiront." On comprend donc que le *G ait brodé sur ce thème familier et cher pour clore la supplique du vs précédent. Plutôt que reprendre déjà la plainte, le traducteur a préféré prolonger la supplique.

Choix textuel :

Le *G construit ici trop librement pour apporter un témoignage textuel utilisable.

Le comité a attribué au *M 3 " $B$ " et 3 " $C$ " en estimant qu'on ne saurait lui opposer rien d'autre que la facilitation syntaxique de $1 Q$-a et de la*S.

Interprétations proposées :

On respecte bien les teamim en attribuant à "durant peu de temps" et à "nos adversaires" une fonction portant sur les deux stiques à la fois: "durant peu de temps ils ont possédé ton peuple saint, nos adversaires ont foulé ton sanctuaire".

On peut aussi les respecter en attribuant cette double fonction à "durant peu de temps" et à "ton sanctuaire" : "durant peu de temps ton peuple saint a possédé, (puis) les adversaires ont foulé ton sanctuaire".

La première construction est cependant préférable, car l'auteur semble vouloir dire qu'une brève domination des ennemis sur le peuple et sur le sanctuaire a suffi pour que nous ressemblions à des gens sur qui tu n'aurais jamais dominé et sur qui ton nom n'aurait jamais été invoqué.

ירדו 64,2) ירדת (B] M 1Q-a V S T // lic : G / harm-ctext : ThSym clav

Options de nos traductions :

63,19b portait : "Ah ! si tu déchirais les cieux, tu descendrais, à ton approche fondraient les monts".

Selon le *M, 64,2 porte: “En accomplissant des prodiges que nous n'attendions pas, tu descendrais, à ton approche fondraient les monts."

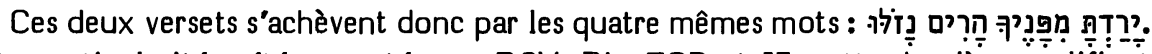
Cette particularité a été respectée par RSV, RL, TOB et J3, cette dernière qualifiant de glose la reprise que $\mathrm{J12}$ omettaient à ce titre.

NEB se contente d'omettre le premier de ces mots, Brockington disant qu'en cela elle suit le ${ }^{*}$.

Origines des corrections :

Duhm a proposé d'omettre ces quatre mots qui sont qualifiés de glose par $\mathrm{BH} 23 \mathrm{~S}$ et de répétition erronée par HSAT234 et Cent. 


\section{Les témoins anciens :}

Il n'est pas exact que le ${ }^{*} G$ omette ירדת. En effet, si l'on compare la traduction que le *G donne ici pour les quatre derniers mots de ce vs à celle qu'il a donnée pour les quatre derniers mots de 63,19, on constate qu'en 64,2 ce sont נזלו לא נקוה

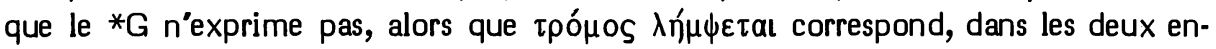
droits, à ירדת (sans qu'il soit aisé de justifier cette correspondance). Il faut donc noter que le ${ }^{*} G$ apporte ici à la présence de ce mot la même attestation que celle qu'il lui avait apportée en $63,19 b$ où tous les mots du *M avaient leurs correspondants dans le *G.

La seule variante sur ce mot est celle qu'attestent ThSym liant ce verbe au stique qui le précède (comme cela avait été le cas dans le $* M$ de 63,19 ) et le traduisant ici (en fonction de cette option) par une 3e pers. pl.

Choix textuel et interprétation proposée :

Contre cette variante, le comité a attribué la note " $B$ " au * $M$ dont nous avons proposé une interprétation au début du traitement de ce cas.

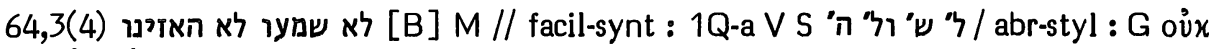

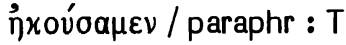

Options de nos traductions :

Ici, le *M est traduit par TOB : “(Jamais) on n'a entendu, (jamais) on n'a ouï dire" et par 33 : "(Jamais) on n'avait ouii dire, on n'avait pas entendu".

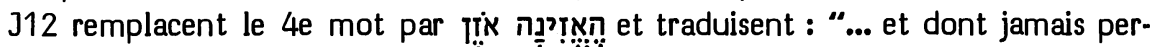
sonne n'entendit parler ! Nulle oreille n'a entendu (J1 : ouï)".

A la place des trois derniers mots, selon Brockington, NEB lit : traduit : "(Never) has ear heard".

Le mot "oreille" intervient aussi dans les traductions de RSV : "(From old) no one has heard or perceived by the ear", et de RL : “... und das man (von alters her) nicht vernommen hat. Kein Ohr hat gehört..."

Origines des corrections :

Cette mention formelle de l'oreille figurait déjà chez Luther, en Ge et KJ. On peut reconnaître là une influence de la $* V$.

Se fondant sur le parallélisme et sur la citation de Paul (1 Co 2,9), c'est Duhm qui a suggéré la leçon que $\mathrm{J12}$ ont retenue et qu'elles ont pu trouver proposée par les apparats de $\mathrm{BH} 23 \mathrm{~S}$ et de Cent.

Les témoins anciens :

Le *M est appuyé ici par 1Q-a, la *V et la *S qui ne se distinguent de lui que par l'insertion d'une conjonction avant la deuxième négation.

Pour ces quatre mots, le *T donne : “aucune oreille n'a entendu la voix de la puissance ni écouté la parole qui fait trembler". Cette paraphrase est trop libre pour qu’elle puisse suggérer une Vorlage autre que le *M. 
Pour ces deux verbes et les deux négations qui les précèdent, le ${ }^{*} G$ se contente de traduire : ỏux ỉxov́oa $\mu \varepsilon v$. Comme souvent, il a méconnu l'intention emphatique de la réitération. Il a aussi ôté à l'énonciation son caractère universel en mettant les énoncés à la 1e pers. En ces deux particularités, il est sûrement secondaire.

Choix textuel :

Lorsque la *V traduit האזינו par "auribus perceperunt", elle se contente d'expliciter "oreille" dont ce verbe est un dérivé. On peut d'ailleurs constater que le mot

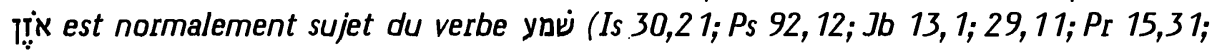
20,12; 25, 12), alors qu'il n'est pas sujet de האזין.

Aussi le comité a-t-il attribué au *M la note "B".

Interprétation proposée :

"(Jamais) on n'avait entendu, on n'avait ouï dire".

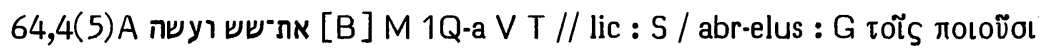

Options de nos traductions :

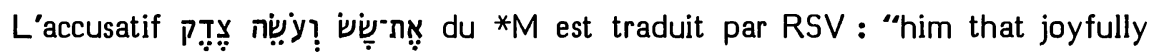
works righteousness", par TOB : "celui qui se réjouit de pratiquer la justice", par NEB : "him who rejoices to do what is right" et par $\mathrm{J3}$ : "celui qui, plein d'allégresse, pratique la justice".

J12 omettent שש et la conjonction qui le suit, traduisant seulement : "ceux qui pratiquent la justice (J1 : le droit)". De même, RL traduit : “denen, die Gerechtigkeit übten".

Origine de la correction :

C'est en s'inspirant du $* G$ que Duhm a suggéré cette correction adoptée ensuite par les apparats de BH23S et Cent.

Les témoins anciens :

En cette syntaxe un peu difficile, le *M est appuyé directement par 1Q-a, la *V et le *T.

$\mathrm{La} * \mathrm{~S}$ a traduit largement, interprétant la particule d'accusatif comme la préposition "avec" et le mot suivant comme un substantif abstrait.

Le ${ }^{*} G$ a simplifié en ne retenant que ce qui lui semblait l'essentiel et en mettant

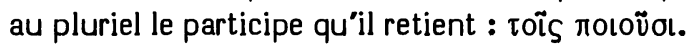

Choix textuel et interprétation proposée :

Quant à la syntaxe du *M, König (Synt $\S 361 \mathrm{k}$ ) a fait remarquer qu’après les verbes exprimant la joie, l'objet de cette joie peut s'exprimer par un verbe à la même forme coordonné au premier. Donc on peut interpréter ceci : "celui qui se réjouit de

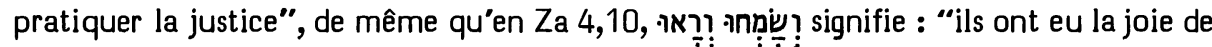
voir". D'ailleurs cette interprétation est celle dü*T, ainsi que de Rashi, d’Eliézer de Beaugency et de Châteillon. 
Le comité a attribué à la leçon du *M la note "B".

24,4(5)B בהם עולם ונושy [B] M 1Q-a Sym V // facil-synt : S / assim 63,17a : G / paraphr : $T$

Options de nos traductions :

Le *M commence 4b par "Voici que toi tu t'es courroucé et nous avons péché",

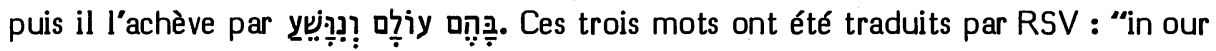
sins we have been a long time, and shall we be saved ?", par TOB : "c"est sur ces chemins d'autrefois que nous serons sauvés", par 33 : "Nous sommes à jamais dans tes voies et nous serons sauvés".

J12 corrigeaient en nous étions rebelles". De même, RL traduit : "als wir von alters her gegen dich sündigten und abtrünnig wurden".

Selon Brockington, NEB se réfère au *G pour corriger en

Origines des corrections :

C'est Lowth qui a proposé de restaurer, comme Vorlage du*G, ונפשע, conjecture à laquelle Michaelis (OEB) a préféré ורנרשy. C'est Oort qui a proposé de faire passer le 'mem' final du premier mot au début du second.

$\mathrm{J12}$ ont choisi la forme de la conjecture que suggérait $\mathrm{BH} 3$.

Les témoins anciens :

1Q-a ne se distingue du *M que par la graphie longue du suffixe du premier mot.

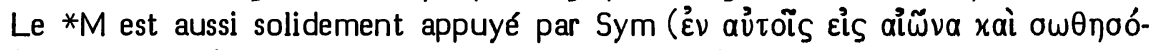
$\mu \varepsilon \theta \alpha$ ) et par la *V (in ipsis fuimus semper et salvabimur).

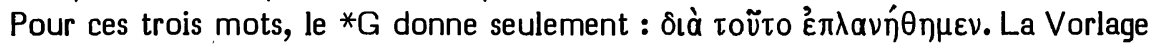
suggérée par Lowth n'est pas certaine. En effet, en 22,5 le ${ }^{*} G$ a traduit yูî́? par $\pi \lambda a \nu \tilde{\omega} \nu \tau a l$ et en 41,10 yผ̣: un bilittère ye qu'il croit reconnaître ici. Ajoutons qu'ici le *G a vu un lien avec 63, $17 \mathrm{a}$, ce qui explique vraisemblablement sa traduction simplifiée des deux premiers mots.

La *S traduit le $* M$ en faisant du premier mot un complément du verbe qui le précède et en omettant la conjonction avant le troisième.

Le *T traite de même le premier mot et paraphrase le deuxième en : "par les oeuvres de nos ancêtres justes d'autrefois" qui sert de complément au verbe final.

\section{Choix textuel :}

La leçon difficile du *M étant bien attestée, le comité lui a attribué la note "B".

Interprétation proposée :

Il importe de donner ici une interprétation qui tienne compte de l'ensemble du vs et tire profit de l'histoire de l'exégèse : 
1/ La place du zaqef dans le *M impose de séparer בהם du verbe qui le précède. Cette séparation est déjà attestée vers 225, par R. Joshua ben Levi, selon le Talmud Babli (Taanit 8a). Elle l'est aussi par la *V que Hie glose ainsi : "qui semper fuimus in peccatis, tua tantum salvabimur misericordia".

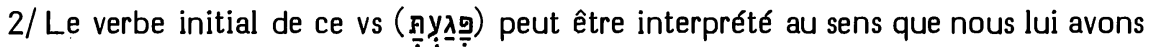
reconnu en Is 47,3: "tu as accepté l'intercession de..." C'est l'exégèse de Saadya, David ben Abraham (II 446,21-27), Yéfet ben Ely (1e exég.), Jacob ben Reuben (1e exég.), Judah ibn Balaam, Ibn Ezra (2e exég.), Radaq (2e exég.) et de presque tous les exégètes chrétiens du XVIe siècle. Mais il faut donner comme seconde possibilité : "tu as soudain mis à mort", selon Yéfet ben Ely (2e exég.), Abulwalid (Ușul 561, 29-31), Rashi, Joseph Qara, Jacob ben Reuben (2e exég.), Ibn Ezra (1e exég.), Radaq (1e exég.) et Isaïe de Trani.

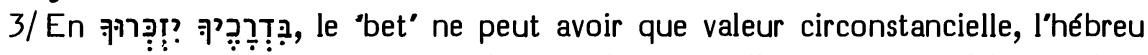
exprimant toujours à l'accusatif la réalité que l'on rappelle ou dont on fait mention. Le sens sera donc : "eux qui, sur tes chemins, faisaient mention de toi". Joseph Qara semble avoir raison de voir en ces "chemins" les conduites sévères ou miséricordieuses de Dieu à l'égard des hommes.

4/ Hormis le *G, tous les exégètes anciens comprennent le début de $4 \mathrm{~b}$ comme : "tu t'es mis en colère parce que nous avons péché". C'est l'interprétation de Hie, Saadya, Yéfet ben Ely, David ben Abraham, Rashi, Joseph Qara, Radaq, Isaïe de Trani, Pagnini, Luther, Olivetan, Jud, Tremellius, Pasteurs, KJ. C'est en effet une vue courante de l'orthodoxie juive, puis chrétienne, de faire de "tu t'es irrite" (verbe קצר) la conséquence de "nous avons péché" (verbe חט au qal) selon la relation entre ces deux verbes attestée en Nb 16,22. Mais le sens normal de l'inaccompli consécutif est d'exprimer la conséquence (et non la cause) de l'accompli qui le précède. Or le contexte de ce vs rend possible de faire du péché d'Israël une conséquence du courroux divin, en conformité avec 63,17a ("pourquoi nous fais-tu errer, Seigneur, loin de tes chemins, et endurcis-tu nos coeurs, loin de ta crainte ?") et avec $64,6 \mathrm{~b}$ ("du fait que tu nous a caché ton visage, tu nous as liquéfiés au pouvoir de notre péché"). Cela correspondrait aussi très bien à ce qui précède immédiatement, car cela créerait un contraste suggestif entre "eux qui, sur tes chemins, faisaient mention de toi" et nous qui avons péché ( $c$ 'est-à-dire avons profané ton nom en ne faisant pas mention de toi pour attester ta justice) lorsque ton courroux (c'est-à-dire la conduite sévère du Seigneur) nous a atteints. On comprendra donc plutôt : "mais toi tu t'es irrité et nous avons péché".

5/Dans l'exégèse du dernier membre, la question centrale est la détermination de l'antécédent de cédent sont :

- a) le sujet de יזכרוך, c'est-à-dire ceux dont tu accueillais l'intercession: “c'est par eux, toujours, que nous serons pourtant sauvés" (en donnant au 'waw' initial du verbe la valeur de 'pourtant'). C'est l'interprétation du *T, de Saadya, Yéfet ben Ely, Rashi, Joseph Qara, Ibn Ezra, Isaïe de Trani, Pagnini, Münster.

-b) les "chemins" qui occupent une position symétrique en 4 a et y sont introduits par la même préposition 'bet'. C'est l'opinion de Judah ibn Balaam, Calvin, Estienne, $\mathrm{Ge}$, Tremellius, Pasteurs, KJ, Grotius, de Dieu, Rosenmüller, Ehrlich, König. Comme il s'agit des voies de Dieu, on peut comprendre : “c'est pourtant toujours sur eux (= ces chemins) que nous aurions trouvé le salut". 
Faut-il aussi suggérer l'exégèse de R. Joshua ben Levi et de Gesenius ? Ils comprennent ונחטא au sens de "et nous avons expié" (Gesenius : und wir büssen) et comprennent en un sens neutre : "par ce moyen". Ce qui donnerait : "Mais toi, tu t'es irrité et nous expions. C'est par ce moyen, toujours, que nous serons sauvés." On hésite à proposer cela, car cette exégèse du verbe manque de base et celle du complément pronominal est une solution désespérée.

Mieux vaut retenir les deux interprétations les plus traditionnelles :

- la première est : "Tu as accueilli celui qui trouvait sa joie à faire la justice, ces gens qui sur tes chemins faisaient mention de toi. Mais toi, tu t'es irrité et nous avons péché. C'est pourtant toujours sur ces chemins que nous aurions trouvé (ou : que nous trouverons) le salut."

- la seconde est : "Tu as soudain attaqué celui qui trouvait sa joie à faire la justice, ces gens qui sur tes chemins faisaient mention de toi. Mais tu t'es irrité et nous avons péché. C'est pourtant toujours par ces gens que nous serons sauvés."

La première de ces deux interprétations est la plus probable.

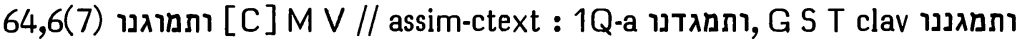

\section{Options de nos traductions :}

Le *M achève le vs 6 par רַת Cela a été traduit par RL : “(du) ... und lässt uns vergehen unter der Gewalt unsrer Schuld" et par TOB : "tu as laissé notre perversité nous prendre en main pour faire de nous des dissolus."

J2 (s'appuyant sur les versions) et NEB (s'appuyant, selon Brockington, sur le

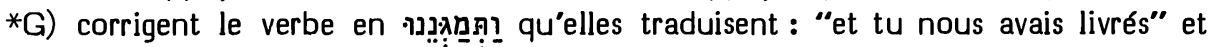
"(thou hast)... and abandoned us". Avec des notes textuelles moins précises, RSV traduit : "and hast delivered us" et 33 : "et tu nous as livrés".

\section{Origine de la correction :}

C'est Houbigant qui, à cause du contexte, a proposé, en s'appuyant sur les versions anciennes, cette correction qui a été adoptée par la plupart des critiques et que nos traductions ont pu trouver requise par les apparats de HSAT234, BH3 et Cent.

Les témoins anciens :

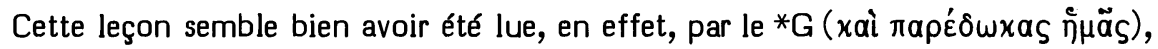
la *S (ומסרתנא) (ואשלמתן) et le *T Cappel (Critica 789) a suggéré cette Vorlage pour le $* T$, le *G et la*V.

On peut cependant hésiter sur la Vorlage de la *V (et allisisti nos).

1Q-a porte ici ותמגדנו. Selon DISO (142), le pael de ce verbe signifie en palmyrénien : “donner libéralement".

\section{Choix textuel :}

Il est frappant que des traducteurs qui lisent certainement le $* M$ traduisent : "tu nous a livrés". C'est le cas de Saadya et de Yéfet ben Ely, quoique ce dernier estime "plus authentique, sous l'aspect de la langue" de traduire : "tu nous as broyés, tu nous as brisés", ce qui coïncide avec l'interprétation de la *V. 
C'est le fait que ce verbe soit suivi ici par ביד (= au pouvoir de) qui explique que traducteurs et exégètes aient été tentés de l'interpréter à partir de מגן (= livrer).

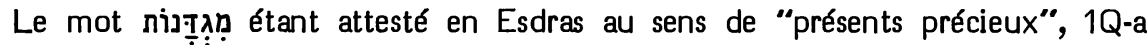
semble avoir voulu adapter ce verbe au contexte qui suggère en effet le sens de "donner".

Le comité a attribué la note "C" à la lectio difficilior du *M.

Interprétation proposée :

Le sens du verbe du *M est bien celui de "se liquéfier, fondre". C'est ainsi qu"il a été compris (en le rapprochant d’Ex 15,15) par Menahem ben Saruq, Ibn Ezra, Abulwalid (Ușul 367,7) et Radaq.

Notons que, dans le vocabulaire de la guerre sainte, la démoralisation des vaincus s'exprime en disant que leur coeur "se liquéfie", ce qui s'exprime d'ordinaire par le verbe מסD (Dt 1,28; 20,8; Jos 2,11; 5,1; 7,5; Is 13,7; Ez 21,12; Na 2,11). Mais, en poésie, on emploie aussi (au qal) en ce sens : Ez 21,20 (cantique de l'épée); Am 9,5; Ps 46,7 (en ces deux derniers textes, la terre symbolise ses habitants). Dans l'oracle de guerre sainte figure aussi נתתי בידך (= j'ai livré en ton pouvoir) en Jos 6,2; 8,1; Jg 7,7. Comme Delitzsch l'a bien vu, nous avons ici une expression prégnante unifiant les deux thèmes. "Tu nous as liquéfiés au pouvoir de" signifie : "tu nous as fait perdre courage et nous as livrés à". Delitzsch a également fait remarquer qu'il n'est pas nécessaire de corriger ce qal en intensif pour qu'il puisse avoir valeur transitive. Il cite à l'appui de cette affirmation כון en Jb 31,15; שוב en Is 52,8 et Ps 85,5; ainsi que מוש Za Za.9.

Nous avons ici un cas de plus où le livre d'Isaïe emploie un mot qui se rattache à une racine légèrement distincte de celle que le contexte suggère, voulant par là que l'un des mots évoque l'autre (ainsi que nous l'avons noté ci-dessus, p. 265). Dans le milieu d'où émane $1 \mathrm{Q}$-a, cette subtilité n'était plus comprise. Aussi a-t-il corrigé ce verbe en fonction du contexte.

\section{קורא [C]}

Options de nos traductions :

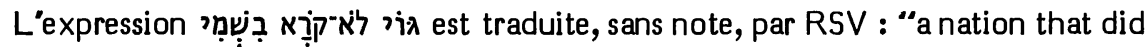
not call on my name", par RL : "... einem Volk, das meinen Namen nicht anrief", par J12 : "une nation qui n"invoquait pas mon nom", par NEB : "a nation that did not invoke me by name".

En conservant la traduction de J12, TOB et 33 précisent qu'elle suppose que l'on corrige avec les versions le *M qui signifie : "qui n'était pas appelée par mon nom". Brockington note que NEB vocalise avec le *G קị p.

Origine de la correction :

Une correction en קרָר pa euté requise ici par de nombreux critiques depuis Ewald jusqu'aux apparats de HSAT234, BH23 et Cent. 
Les témoins anciens :

Une $\mathrm{mm}$ que le $\mathrm{ms}$ du Caire donne sur Is 48,8 atteste que la forme קెרָ se rencontre six fois dans le *M (Is 48,8; 58,12;61,3; 62,2; 65,1; Ez 10,13).

En Is 48,8; 58,12; 61,3 et 62,2,1Q-a a reconnu la valeur du pual, mais l'a remplacé par une 3e pers. pl. du qal à valeur impersonnelle. Ici, 1Q-a, par une graphie identique à celle du *M, semble indiquer qu'il a lu un qal.

En 4Q-b, Morrow (163) atteste la leçon מורא. S'agit-il (comme dans le *M) d'un accompli pual ou bien d'un participe qal (que le *T מצלי semble avoir lu ici) ?

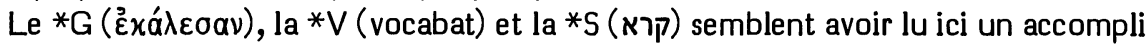
du qal.

Choix textuel et interprétation proposée :

Une valeur passive a été reconnue à cette forme par Saadya, Yéfet ben Ely, Rashi, Ibn Ezra, Radaq, Pagnini, Brucioli, Tremellius, KJ, Vitringa, Gesenius, Rosenmüller, Hitzig, Knobel.

Cependant Judah ibn Balaam estime que c'est un participe qal vocalisé en traitant la lettre 'alef' comme une gutturale.

Peut-être sous l'influence de la *V, ce verbe a été traduit en actif par Oecolampade, Luther, Zwingli, Olivetan, Münster, Châteillon et Ge.

A la suite d’Ewald, des exégètes plutôt conservateurs comme Luzzatto, Delitzsch ou König ont proposé de corriger ce pual en qal. En effet, si l'on veut dire : "un peuple qui n'est pas appelé de mon nom"; on emploie ailleurs le nifal $(43,7 ; 48,1)$ et non le pual. Celui-ci, en ses cinq autres emplois de ce livre, signifie “on appelle” et est relié par la préposition 'lamed' à la personne que l'on appelle. Il semble donc que ce soit l'accompli du qal qui est mieux en place ici au sens de "à un peuple qui n'invoquait pas mon nom", ce qui forme un excellent parallèle avec "à ceux qui ne demandaient pas" et "à ceux qui ne me cherchaient pas" du début de ce vs.

Il n'est pas impossible qu'ici la vocalisation en pual ait été suggérée par l'emploi du mot גוי (au lieu de pour Israël; ce qui a amené à y voir un oracle concernant les prosélytes provenant de peuples qui ne sont pas appelés du nom du Seigneur.

Le comité a attribué à la leçon 4 " 4 "C" et à celle du *M 1 "B" et 1 "C".

\section{בכליהמה 65,4 בליהם}

\section{Options de nos traductions :}

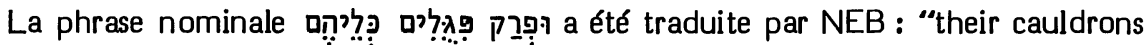
full of a tainted brew" et par TOB : "et leurs plats ne sont qu'un brouet d'ordures".

Cependant, sans notes textuelles, RSV traduit : "and broth of abominable things is in their vessels", J12 : "et mettant dans ses plats des mets immondes",RL: "und haben Greuelsuppen in ihren Töpfen" et 33 : "et met dans ses plats des morceaux impurs". 
Origine de la correction :

Il est vraisemblable que ces dernières traductions se sont inspirées des apparats de HSAT34, BH3S et Cent qui proposent de lire avant le dernier mot un 'bet' prépositionnel.

Notons cependant que, sans avoir l'intention de corriger le $* M$, presque tous les traducteurs du XVIe siècle ont soupçonné l'ellipse de cette préposition et l'ont explicitée. C'est le cas de Oecolampade, Pagnini, Luther, Zwingli, Münster, Brucioli, Olivetan, Rollet, Estienne, Châteillon, Ge, Pasteurs, KJ.

\section{Les témoins anciens :}

$1 Q-a$, la *V et le *T explicitent cette préposition.

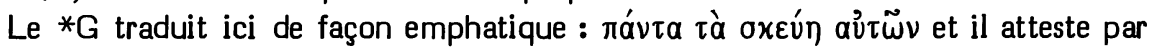
là l'absence de cette préposition.

Choix textuel et interprétation proposée :

Comme c'est le cas en plusieurs langues (dont le français), il faut considérer avec Michaelis (OEB XIVa 207) que le contenant sert ici à désigner le contenu; de la même manière que, dans la liturgie juive, on parle de "coupe" pour désigner le vin qui la remplit. TOB a traduit en ce sens.

Le comité a attribué au *M la note "B".

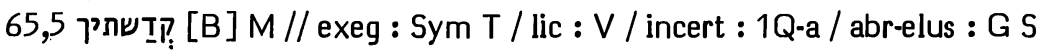

\section{Options de nos traductions :}

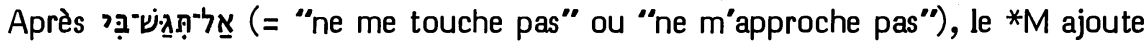

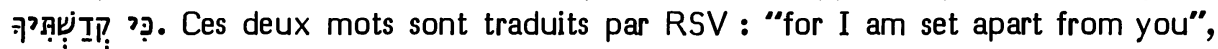
par RL : "denn ich bin für dich heilig" et par NEB : "for I am too sacred for you".

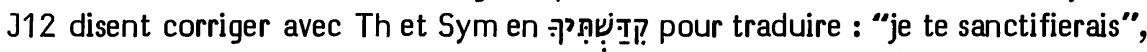
traduction que $\mathrm{J3}$ conserve en omettant la note textuelle. TOB dit fonder sur deux versions la traduction : "car je te rendrais sacro-saint".

Origine de la correction :

Ce sont HSAT34, BH3 et Cent qui ont attribué à Th et à Sym une vocalisation de ce verbe en piél. Cette correction a été demandée ici par Geiger (Urschrift 56 et 172), Bredenkamp, Dillmann/Kittel, Duhm, von Orelli, Condamin, Haller, Feldmann.

Les témoins anciens :

Ryssel ( = HSAT3) a eu tort d'affirmer que Th et Sym ont lu ici un piél. En effet,

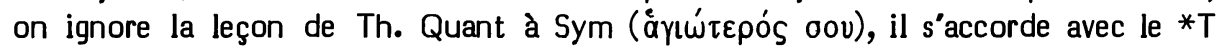
pour comprendre ici : "je suis plus saint (*T : pur) que toi", ce qui est l'interprétation du *M que donnent Saadya, Yéfet ben Ely, Abulwalid (Luma 273, 15s), Judah ibn Balaam, Rashi, Ibn Ezra, Radaq, Oecolampade (commentaire), Pagnini, Münster, Olivetan (marge), Rollet, Ge, Tremellius, KJ. 
La graphie de 1Q-a ne permet pas de déterminer s'il a ici un qal ou un piél. faire.

Le ${ }^{*} G$ a lu ici un qal et a préféré ne pas traduire le suffixe dont il ne savait que

C'est vers la *S (דמקדש אנא) que BHS se tourne pour appuyer une correction en piél. Mais Weisz semble avoir raison d’y voir une traduction du *G.

Par "immundus es", la *V semble avoir traduit largement le *M compris comme : en référence à toi, je suis saint.

Choix textuel et interprétation proposée :

Le qal du *M a été compris au sens de "rendre saint" par Eliézer de Beaugency, Oecolampade (traduction), Luther, Zwingli, Brucioli, Olivetan (traduction), Jud, Châteillon.

De Dieu a cependant fait remarquer que l'ellipse d'un 'lamed' avant un suffixe est plus normale en hébreu que celle d'un מן comparatif. Aussi comprend-il : " $j e$ suis saint par rapport à toi", c'est-à-dire : tu ne peux m'approcher sans danger; interprétation adoptée par Rosenmüller, Delitzsch et König.

Nous avons déjà traité en 44,21 d'un suffixe verbal à valeur de datif. Cette interprétation est celle qui convient le mieux ici.

Le comité a attribué au *M 3 "A" et 3 " $B$ ".

65,6 ושלמתי [B] M 1Q-a AqSym V // lic : S / midr : T/ homtel : G

Options de nos traductions :

Après

La plupart de nos traductions respectent cette reprise. Mais NEB la reporte à la fin du vs 7 (et non en son début, comme le prétend Brockington).

Origine de la correction :

C'est Duhm qui a conjecturé que ces trois derniers mots du vs 6 ont pénétré ici dans le texte à partir d'une variante marginale destinée à la fin du vs suivant.

Les témoins anciens :

1Q-a appuie clairement le *M en sa construction caractéristique.

Il est vraisemblable que la Vorlage du ${ }^{*} G$ omettait la reprise du verbe par homéotéleuton. A moins qu'il n'ait ici, comme en 64,3 , méconnu l'intention de la réitération.

$\mathrm{La} * \mathrm{~S}$ a traduit "je rendrai et je rendrai" par "je rendrai au double"; alors que le *T, pour "et je rendrai", dit "je livrerai à la seconde mort".

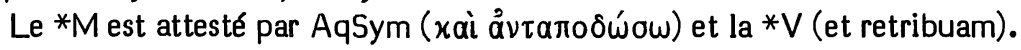

Choix textuel :

Le comité a attribué à la leçon du *M la note "B".

Interprétation proposée :

La réitération a valeur emphatique : “... que je n’aie payé de retour, oui payé de retour..." 


\section{5,7 yונתיכם ... אבותי כם [B] M 1Q-a V T // assim-ctext : G S 3e pl}

\section{Options de nos traductions :}

Le *M achève le vs 6 par : “... que je n’aie payé de retour, oui payé de retour en leur giron". Puis il commence le vs 7 par à-dire : "Vos fautes et les fautes de vos pères tout à la fois, dit le Seigneur."

Seule de nos traductions, $\mathrm{J} 3$ respecte à peu près cette difficulté en liant étroitement les deux vss: "que je n"aie réglé leur compte, réglé à pleine mesure, puni vos fautes et les fautes de vos pères, toutes ensemble, dit Yahvé."

Mais les autres traductions se sont demandées qui sont ces gens (mentionnés à la 3e pers. pl. : "en leur giron") sur lesquels le Seigneur va châtier "vos fautes et les fautes de vos pères".

A propos du cas précédent nous avons vu que NEB avait éliminé de la fin du vs 6 la 3e pers. pl. TOB a fait de même par une traduction libre : "jusqu”à ce que j'aie payé de retour, payé de retour en plein coeur vos perversités et les perversités de vos pères".

RSV, J12 et RL ont corrigé en suffixes 3e pers. pl. les deux suffixes initiaux du vs 7; RSV disant se fonder pour cela sur le ${ }^{*}$ G et la $*$ S.

Origines des corrections :

Nous avons rattaché à Duhm l'option de NEB.

Celle de RSV, J12 et RL est requise par les apparats de HSAT34, BH23S et Cent. Elle remonte à Houbigant, Lowth, Oort (Jez), etc.

Les témoins anciens :

Dans cette séquence difficile des suffixes de la $3 e$, puis de la 2 e pers. pl., le *M est appuyé par $1 \mathrm{Q}-\mathrm{a}$, la $* \mathrm{~V}$ et le $* \mathrm{~T}$.

Le ${ }^{*} G$ et la ${ }^{*}$ ont ici deux suffixes de la $3 e$ pers. pl., ayant assimilé à celui qui précède.

Choix textuel et interprétations proposées :

Spontanément, Luther a pris la même option que le *G et la *S; alors que Zwingli a pris l'option inverse, généralisant la 2e pers. pl.

Une autre solution de la difficulté syntaxique est celle que suggère la division des versets effectuée par le $* M$ : il interprète les quatre premiers mots du vs 7 comme une phrase nominale : "Vos fautes et les fautes de vos pères sont conjointes". C'est la solution adoptée par Saadya, Radaq, Münster, Calvin, Estienne, Châteillon, Ge.

Cependant, l'interprétation qui convient le mieux au texte est de considérer ces mots ("vos fautes et les fautes de vos pères tout à la fois") comme les compléments d'objet du verbe qui achève le vs 6 ("que je n'aie payé de retour, oui payé de retour en leur giron"). Le possessif "leur" se réfère au "peuple rebelle" dont les actes d'idolâtrie ont été décrits à partir du vs 2 et seront encore évoqués dans la suite du vs 7. Ce passage signifie que "vos" fautes (c"est-à-dire celles de ceux, parmi les contemporains, qui acceptent d'écouter le prophète) et celles de "vos pères" (c'est-à-dire celles des générations antérieures d'Israël) seront "payées de retour" dans le giron 
de ce "peuple" (vss 2 et 3) qui, en sa majorité, commet l'idolâtrie et méprise le prophète et ses fidèles.

Il faut donc conseiller d'établir une continuité entre la fin du vs 6 et le début du vs 7 , ainsi que l'ont fait Rashi, Olivetan, Jud, Tremellius, Pasteurs, KJ.

Le comité a attribué la note " $B$ " aux suffixes de la 2e pers. pl. du *M, sans se prononcer sur la position du sof pasuq précédent.

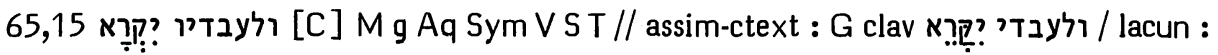
1Q-a

Options de nos traductions :

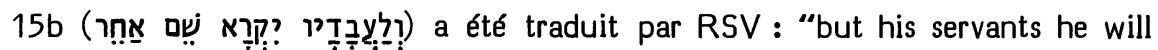
call by a different name", NEB : "but his servants he shall call by another name", J3: "mais à ses serviteurs il donnera un autre nom".

Cependant $\mathrm{J12}$ fondaient sur le ${ }^{*} \mathrm{G}$ une traduction: "mais à mes serviteurs sera donné un nom nouveau". La même Vorlage est postulée par RL: "aber meine Knechte wird man mit einem andern Namen nennen" et TOB : "mais en faveur de mes serviteurs sera évoqué un Nom tout différent".

Origine de la correction :

Cette correction a été proposée par Klostermann (cité par Dillmann/Kittel et par Cheyne) et adoptée par les apparats de HSAT34 et de Cent.

\section{Les témoins anciens :}

Les éditions de Rahlfs et de Ziegler conforment le *G ancien au *M pour ולעבדיו; alors qu'il est plus vraisemblable qu'il lisait (selon ses témoins les plus anciens) toĩs

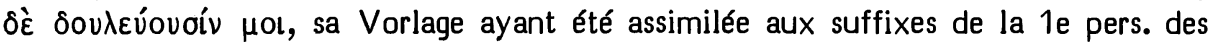
quatre לבחירי (en 15a). La lecture en nifal du verbe suivant $s^{\prime}$ expliquerait par là.

$1 \mathrm{Q}-\mathrm{a}$, ici comme en d'autres endroits, a été copié à partir d'une Vorlage où les 4 derniers mots du vs 15 et les 4 premiers du vs 16 étaient manquants ou illisibles. Le scribe a laissé pour eux une ligne vide. Puis, faute de pouvoir remplir cette lacune à partir d'une Vorlage, il a improvisé une soudure, achevant le vs 15 par תמיד, puis commençant le vs 16 par והיה הנשבע (qui s'inspire de la suite du vs).

Aq, Sym, la *V, la *S et le *T appuient clairement le *M.

Choix textuel et interprétation proposée :

Par la phrase: "mais pour ses serviteurs il proclamera un autre nom", le *M passe de façon souple de la formule de malédiction qui précède ("que le Seigneur te fasse mourir") au prédicat divin ("Dieu de l"Amen") qui sera usité comme formule de bénédiction et de serment parmi les serviteurs du Seigneur.

Le comité a attribué au *M la note "C". 
Options de nos traductions :

Ces deux impératifs ont été traduits par RSV : "be glad and rejoice", par RL : "Freuet euch und seid fröhlich", par NEB : "Rejoice and be filled with delight" et par J3 : "soyez pleins d"allégresse et exultez".

$J 12$ traduisaient : “Qu'on soit dans la jubilation et qu'on se réjouisse".

Se fondant sur 1Q-a et le *G, TOB donne : “c'est un enthousiasme et une exultation".

Origines des corrections :

En traduisant ces impératifs par des formes impersonnelles, 312 se sont inspirées

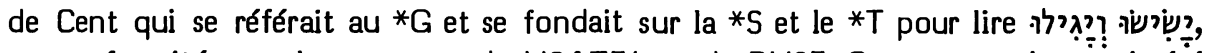
en conformité avec les apparats de HSAT34 et de BH23. Cette correction avait été proposée par Grätz, Duhm, Cheyne, etc.

Quant à TOB, elle suit ici une suggestion de Bonnard.

Les témoins anciens :

Le *M a ici l'appui de 1Q-b (qui n'esț conservé que pour le second mot).

Il est difficile de dire ce que le ${ }^{*} G$ a lu ici, car il a traduit très librement 18a :

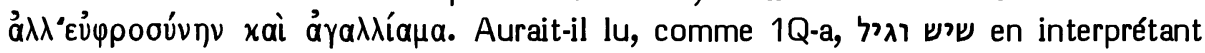
le premier mot comme un substantif modelé sur le type du second?

La *V traduit ces impératifs par des $2 e$ pers. du futur : "sed gaudebitis et exultabitis".

La *S et le ${ }^{*} T$ ont traduit par des 3e pers. du futur: "ils se réjouiront et exulteront".

\section{Choix textuel :}

Ce cas n'a pas été soumis au comité.

Les deux substantifs de 1Q-a sont vraisemblablement destinés à servir d'antécédents au relatif qui suit.

Aux vss 13 à 15 ceux que la malédiction menace sont désignés par la 2e pers. pl., alors que les serviteurs élus de Dieu sont désignés par la 3e pers. pl. Ici, le *M s'adresse brièvement, à la 2 e pers. pl. par deux impératifs, à des gens à qui il est demandé de se réjouir et d'exulter. On comprend que cette brève apostrophe (qui n'a rien de surprenant en ce livre) ait gêné certains traducteurs qui ont préféré ici une $3 e$ pers. pl., en fonction de ce qui précédait. C'est le cas de la *S et du *T, mais aussi d'Oecolampade, de Luther, d'Olivetan, de Jud et d'Houbigant (sans rien noter). Grätz a voulu offrir une base textuelle à cette lecture traditionnelle en proposant la correction que nous avons présentée ci-dessus.

Interprétation proposée :

Il faut respecter cette brève apostrophe, comme l'ont fait RSV, RL, NEB et J3. 
66,2 ויהיו [B] M 1Q-b ThAqSym V T // assim-ctext : 1Q-a והיו / assim Ps 50,10 : G S

Options de nos traductions :

$\mathrm{RL}$ a conservé la traduction "was da ist" que Luther avait donnée du *M.

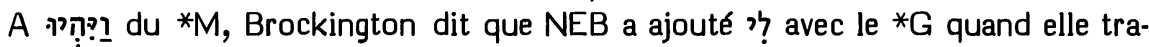
duit : "and (all these) are mine".

C'est quִ que $\mathrm{J12}$ lisent avec le *G et la *S quand elles traduisent : "et (tout cela) est à moi". Mêmes références en RSV pour traduire : "and so (all these things) are mine". TOB dit suivre deux versions pour traduire : "et ils sont à moi". Quant à J3, elle traduit : "quand (tout cela) est à moi" sans note.

Origine de la correction :

C'est Houbigant qui a fondé sur le ${ }^{*} G$ cette correction sous la forme où NEB l'adopte à la suite de Lowth et de Oort (Jez).

Sous la forme où les autres traductions l'adoptent, elle remonte à Klostermann (cité par Dillmann/Kittel). Elle a été requise par les apparats de HSAT4, BHS et Cent.

Les témoins anciens :

A la place de l'inaccompli inverti du $* M, 1 Q$-a offre un accompli coordonné. Kutscher (354) a remarqué le même phénomène (pour le verbe היה), en 22,7 et 48,18, sous l'influence vraisemblable (comme ici) d'un accompli qui précède.

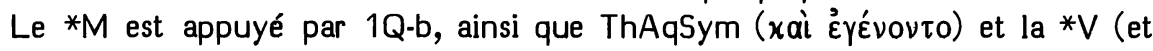
facta sunt).

L'interrogation du *T (הלא הואה) se fonde sur la leçon du *M.

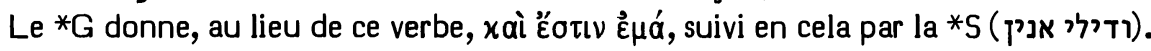

Choix textuel :

L'inaccompli inverti du *M (comme le ויהי de Ps 33,9) évoque le récit de la création (Gn 1,3): "Dieu dit : 'que la lumière soit !' et la lumière fut." Cela convient d'ailleurs bien ici où "toutes ces choses" désigne au premier chef le ciel et la terre mentionnés au début du vs précédent, c'est-à-dire l'ensemble de l'univers auquel sera opposé en $2 b$ "celui-ci", c'est-à-dire cet individu en sa situation précise d'abattement.

Quant à la leçon du ${ }^{*} G$, elle semble avoir été influencée par Ps 50,10 où le Seigneur motive son refus des victimes par le fait que ces animaux lui appartiennent déjà. C'est la fin du vs précédent ("quelle maison me construiriez-vous et quel serait le lieu de mon repos ?") qui a appelé ce rapprochement dans l'esprit du traducteur. Cependant l'affirmation solennelle que l'univers a été créé par le Seigneur suffit parfaitement à décourager quiconque d'y élever une maison pour le Créateur.

Le comité a attribué la note " $\mathrm{B}$ " à la leçon plus sobre du " $\mathrm{M}$ ".

Interprétation proposée :

“Toutes ces choses, ma main les a faites, et elles furent, toutes ces choses, oracle du Seigneur !" 
Options de nos traductions :

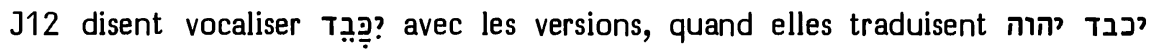
par: "que Yahvé montre sa gloire". C'est sur le *G que 33 dit fonder sa traduction : "que Yahvé manifeste sa gloire". Sans note textuelle, RSV traduit : "let the LORD be glorified", RL : "lasst doch den HERRN sich verherrlichen", TOB : "Que le SEIGNEUR montre donc sa gloire" et NEB : "let the LORD show his glory" (Brockington disant qu'elle fonde sur le ${ }^{*} G$ une vocalisation identique à celle de $\mathrm{J} 2$ ).

Origine de la correction :

Cette vocalisation en nifal a été requise par Grätz, Duhm, Dillmann/Kittel, Cheyne et les apparats de HSAT234, BH23S et Cent.

Les témoins anciens :

On ne peut savoir si 1Q-a et 1Q-b lisent ici un qal ou un nifal.

La plupart des versions anciennes ont traduit ce verbe par des passifs ou des

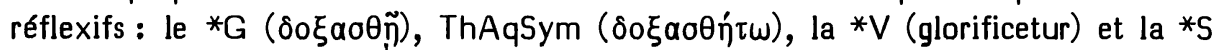
(נשתבח).

Le *T (יסגי יקרא) traduit probablement le *M.

Choix textuel et interprétation proposée :

Comme en 48,9, les teamim (suivis fidèlement par tous les exégètes juifs) font ici de למען שמי le complément de l'inaccompli qui suit (verbe dont ce complément n'est séparé, dans un cas comme dans l'autre, que par un pashta). Donc: "en vue de ma renommée le Seigneur est glorieux". Le qal de כבד a ici la même valeur qu'en Jb 14,21. Il s'agit donc là d'une catégorie de juifs qui monopolisent la gloire du culte au profit de leur propre prestige, alors qu'ils excluent ceux qui tremblent à la parole du Seigneur.

La $* V$ a respecté les teamim, si l'on en croit la division en cola et commata attestée par ses mss les plus anciens et exprimée dans l'édition de San Girolamo (alors que l'édition Weber la modifie).

Mais ensuite, sous l'influence de Mt 24,9 ("vous serez haïs par toutes les nations à cause de mon nom"), presque tous les traducteurs et exégètes chrétiens ont lié "à cause de mon nom" à ce qui précède ("qui vous haïssent et qui vous excluent"). Parmi ceux qui respectent les teamim, on ne peut guère mentionner que Tremellius, Vitringa, J.H. Michaelis, Rosenmüller, Hahn et Stier (ces deux derniers étant cités par Dillmann/Kittel).

Il est évident que, si on lie "à cause de mon nom" à ce qui précède, on est obligé de donner à יכבד יהוה la valeur d'un événement désiré et annoncé par "vos frères qui vous haïssent et qui vous excluent". Il est alors clair qu'un nifal convient mieux pour exprimer : "que le Seigneur manifeste sa gloire !" Aussi ne faut-il pas s"étonner que cette lecture en nifal ait eu un large succès.

Il semble cependant qu'il faille conserver la forme moins usitée du qal qui convient fort bien au contexte, à condition que l'on respecte les teamim, ce à quoi le parallèle de 48,9 nous engage. 
Le comité a donc attribué au * $M$ la note " $C$ ", en accordant sa préférence à l'exégèse suggérée par les teamim.

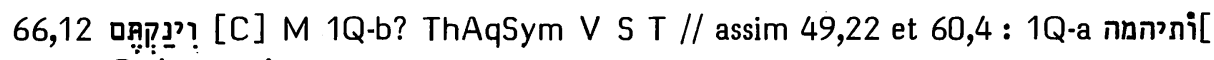

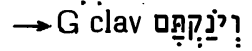

Options de nos traductions :

Le *M est traduit par RSV : "and you shall suck", NEB : "it shall suckle you", TOB et J3 : "vous serez allaités".

$J 12$ corrigent avec le *G en en duit de même : "ihre Kinder".

Origine de la correction :

Duhm a proposé de corriger, selon le ${ }^{*} G$, la vocalisation du $* M$ en tant sur l'opportunité de corriger la 3e pers. m. pl. du suffixe en une 3e pers. f. sg. qui s'accorderait mieux à ce qui précède. Il proposait aussi de corriger en 3e pers. f. pl. les deux verbes à la $2 \mathrm{e}$ pers. $\mathrm{m}$. pl. qui suivent. Cette double proposition a été adoptée par de nombreux critiques et les apparats de HSAT34, BH23S et Cent.

Les témoins anciens :

La tradition pré- et protomassorétique est ici assez cohérente. En effet, 1Q-b, quoique très mutilé, atteste וינקתם et confirme que le dernier verbe est à la 2e pers.

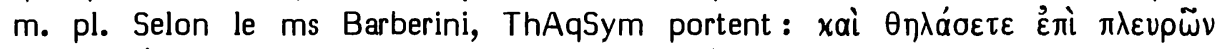

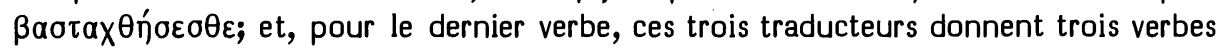
différents qui sont tous à la 2e pers. pl.

1Q-a apporte un appui remarquable à la proposition de Duhm dans la fin de ce

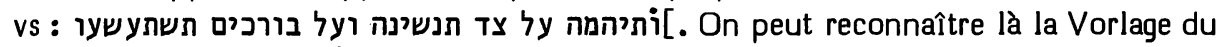

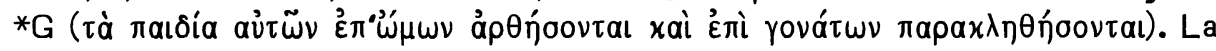
seule différence est que, pour le dernier verbe, 1Q-a lit (comme le $* M$ ) une 2e pers. pl., alors que le ${ }^{*} G$ l'assimile en $3 e$ pers. pl. au verbe qui précède.

\section{Choix textuel :}

On peut être tenté de penser que la forme textuelle la plus primitive est celle de 1Q-a, le *M ayant assimilé la forme du premier verbe à celle du second, alors que le *G (ou sa Vorlage) aurait fait l'assimilation inverse. Aussi deux membres du comité ont-ils attribué à la leçon de $1 \mathrm{Q}$-a la note "C".

Cependant les quatre autres membres ont attribué cette même note à la leçon du *M pour les motifs suivants.

D'abord, une vocalisation de וינקתם en accompli du verbe ינק est préférable à une vocalisation qui y reconnaîtrait le mot יָjo suivi d'un suffixe de la 3e pers. m. pl. En effet, les 6 emplois bibliques de cette forme féminine ségolée désignent tous des rejetons d'arbres; alors que la forme masculine יị , tout en pouvant elle aussi avoir ce sens (Is 53,2) est la désignation normale (les 10 autres fois) du nourrisson humain. D'autre part, en ce vs introduit par כי, le verbe explicite très natu- 


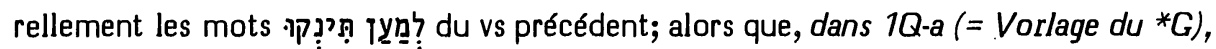
le pronom suffixe de la 3e pers. m. pl. n'a pas d'antécédent naturel (ce pourquoi la plupart des partisans de la variante ont corrigé le suffixe en 3e pers. f. sg.). Il semble

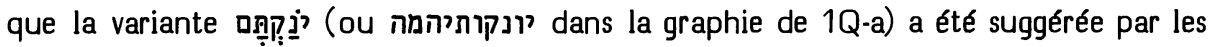
mots suivants qui ont fait penser un lecteur à ובנתיך על־כתף תנשאנה 49,22 en à en 60,4.

Par ailleurs, il ne semble pas que la leçon dissymétrique que 1Q-a offre en 12b (un verbe à la $3 e$ pers. f. pl. et l'autre à la $2 \mathrm{e}$ pers. m. pl.) soit préférable à la leçon symétrique du *M. En effet, le parallélisme entre les deux phrases de $12 b$ est si serré qu 'il est vraisemblable qu 'il s'y agisse des mêmes sujets (ou bien "vous" du * $\mathrm{M}$, ou bien "leurs nourrissons" de la variante). Les motifs que nous venons de donner nous engagent à préférer en ce cas la 2e pers. m. pl., en continuité avec ?ִ Il faut alors penser que 1Q-a a retouché le premier verbe seulement (sous l'influence de 49,22 qu'il a d'ailleurs, comme ici, écrit sans 'alef'), laissant le second verbe à la $2 \mathrm{e}$ pers. m. pl. sans le retoucher. Ensuite, le ${ }^{*} G$ ou sa Vorlage aura assimilé la forme du second verbe à celle du premier.

Interprétation proposée :

Les traductions françaises récentes usent d'ordinaire d'une forme passive : “vous serez allaités". Au XVIe siècle, ce verbe était usité au sens de têter. Aussi Olivetan, Estienne et Pasteurs traduisaient-ils : "vous allaiterez". Mieux vaut traduire ce verbe par un actif : "vous têterez", ou, comme le fait Châteillon : "en têtant (vous serez portés)".

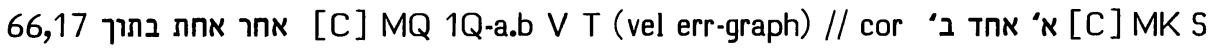
Th(?) (vel err-graph) / incert : Sym / assim Ez 8,7ssG : G

Options de nos traductions :

Ici, un ketib "un" s'oppose à un qeré "une".

Celles de nos traductions qui ont traduit le *M l'ont fait selon le ketib. C'est le cas de RSV, RL, J et. TOB, les deux dernières notant cela explicitement.

Selon Brockington, NEB se fonde sur la ${ }^{*} S$ pour corriger les deux premiers mots en

Origines des corrections :

La majorité des exégètes récents ont préféré le ketib au qeré. C'est l'option de $\mathrm{BH} 235$ et de Cent.

C'est Böttcher (Proben 33) qui a proposé la correction que NEB adoptera.

Les témoins anciens :

1Q-a et 1Q-b appuient le qeré.

$\mathrm{La} * \mathrm{~V}$, en ses éditions courantes, depuis l'édition princeps jusqu'à l'édition Clémentine incluse, portait ici : "post ianuam intrinsecus". L'édition San Girolamo a corrigé le deuxième mot en "unam". Gadolo (en 1495) avait déjà adopté cette leçon, 
suivi par la 2e édition de Robert Estienne (en 1532). En effet, Nicolas de Lyre l'avait remarquée comme celle des mss corrects. Selon cette leçon, la $* V$ témoigne pour le qeré.

La *S traduit חת חת חד. Mais Hie attribue à ThSym une leçon "alter post

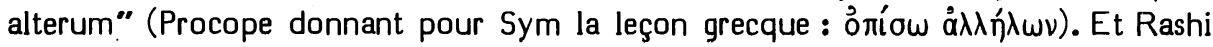
commente : “ils se sanctifient et se purifient pour célébrer le culte, une communauté après que sa compagne ait achevé son culte". Par ce commentaire, il entend seulement gloser le *T qui avait traduit : סיעא בתר סיעא. Il semble donc que tous ces traducteurs (auxquels on peut ajouter une note marginale de Servet sur sa réédition de Pagnini, ainsi que Châteillon, Tremellius et Pasteurs) ne font que gloser le *M que la *S semble lire selon le ketib, alors que le ${ }^{*} T$ le lirait selon le qeré. Quant à Sym, sa leçon grecque ne nous permet pas de préciser son choix.

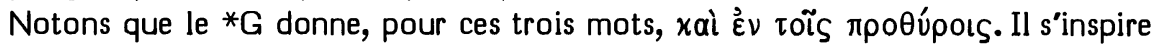

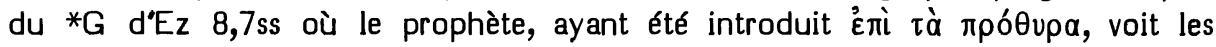
$\beta \delta \varepsilon \lambda u ́ \gamma \mu \alpha \tau \alpha$ (mot repris en Is 66,17) de la maison d'Israël.

\section{Choix textuel :}

Une tradition exégétique ancienne interprète le "une" du qeré comme désignant un arbre ou un pieu sacré : une ashérâh. Témoignent de cette exégèse : Saadya, Yéfet ben Ely, Abulwalid (Ușul 630,13s), Ibn Ezra, Joseph Qara, Ge, KJ. Quant à Radaq, estimant qu’à son époque plus personne n'adore les ashérot, il sous-entend (avec le

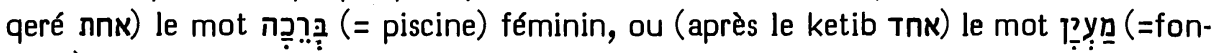
taine) masculin. Il s'agirait d'un bassin de purification situé au milieu du jardin. Cette exégèse a été adoptée par Pagnini, Rollet et Estienne.

Le comité s'est trouvé divisé à égalité entre le qeré ( 3 "C $\mathrm{C}$ ") et le ketib ( 3 "C $\mathrm{C}$ ").

\section{Interprétations proposées :}

Si l'on choisit le qeré, le sens le plus vraisemblable est : "ceux qui... (en se rendant) aux jardins pour servir une (Ashéra) qui est au milieu". Si l'on choisit le ketib, on pourra suivre Gesenius, Delitzsch et Dillmann/Kittel : “ceux qui... (en se rendant) aux jardins, imitant quelqu'un qui est au milieu". Il s'agirait d'imiter les gestes d'un mystagogue (cf. Ez 8,11 où soixante-dix anciens encensent les idoles, ayant Yaazinyahu “au milieu” d'eux).

66,18A ואנכי [B] M 1Q-a V // expl : G S T

באתי [C] M 1Q-b(?) // assim-ctext : 1Q-a באה 66,18B, G V S T clav באר

\section{Options de nos traductions :}

Le *M offre deux difficultés en ce vs :

- d'abord, aucun verbe ne relie le premier mot ("mais moi") aux deux mots qui suivent ("leurs actions et leurs desseins"),

- ensuite, on se demande à quel sujet féminin rapporter le mot

Pour résoudre la première difficulté, TOB glose : “C'est moi qui motiverai leurs actes et leurs pensées"; J permute le premier mot avec les deux suivants (dont elle 
fait les sujets du verbe final du vs 17): "leurs actions et leurs pensées finiront du même coup, oracle de Yahvé", ou, selon J3: "d'un même coup finiront, oracle de Yahvé, leurs actions et leurs pensées". Selon Brockington, NEB insère *S, et traduit : "for I know their deeds". RSV fait de même, en se fondant sur le *G et la *S: "For I know their works". RL traduit aussi: "Ich kenne ihre Werke".

Pour résoudre la seconde difficulté, NEB (selon Brockington) lit avec le ${ }^{*} G$

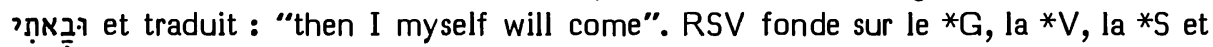
le ${ }^{*} T$ une correction semblable et traduit: "and I am coming". Par conjecture, J12 corrigent en : "je viens" que TOB donne ici sans note, alors que J3 et RL (également sans note) traduisent : "je viendrai" et "(ich...) und komme".

\section{Origines des corrections :}

- 18A. Notons que "je vois" ou "je connais" a été suppléé spontanément ici par Saadya, Pasteurs et KJ. Cappel (Notae 519) estimait absolument nécessaire de suppléer ici "je connais". Lowth, se fondant sur le *G, la *S et le *T, pensait pouvoir

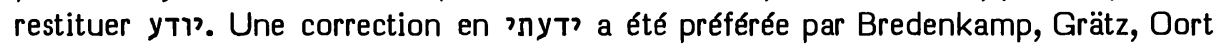
(Jez). La permutation adoptée par J a été proposée par Duhm, Marti, Condamin, Cent, etc.

- 18B. Parmi les traducteurs qui ont fait comme s'ils avaient lu ici "je viens" ou "je viendrai", citons Luther, Olivetan et Châteillon. La correction retenue par NEB a été proposée par Oort (Jez).

\section{Les témoins anciens :}

- 18A. L'ellipse est attestée par 1Q-a. Notons que la longueur des lacunes en 1Q-b montre que ce ms appuie probablement le *M sur ce point. Le verbe "connaître" est explicité ici par le ${ }^{*} G$ et la ${ }^{*}$, alors que le ${ }^{*} T$ paraphrase en "sont manifestes devant moi". La *V ("ego autem opera eorum...") respecte l'ellipse.

- 18B. Ici, 1Q-b, très mutilé, semble avoir lu le *M, alors que 1Q-a offre באו par

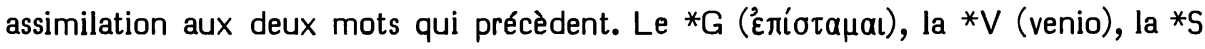
(דאתית) et le *T (עתידנא) ont déjà traduit ici une 1e pers., comme le feront nos traductions.

\section{Choix textuels :}

- 18A. Michaelis (OEB) a fait remarquer que tout traducteur se doit de restituer ici un mot pour traduire de façon intelligible cette expression elliptique, mais que cela ne prouve nullement qu'il a lu ce mot en sa Vorlage hébraïque. Il estime beaucoup plus frappant le fait que le mot conjecturé par Lowth n'apparaît en aucun des mss collationnés par Kennicott. A cette ellipse du *M, le comité a attribué 4 " $B$ " et 2 " $A$ ". - 18B. La leçon de 1Q-a correspond à l'exégèse que suggéreront David ben Abraham (I 179,18-20), Rashi et Joseph Qara. Mais Radaq fait remarquer que ce mot peut avoir pour sujet תỵ ( = moment) sous-entendu, comme c'est le cas en Ez 21,12 et 39,8. Ont traduit en ce sens : Pagnini, Brucioli, Münster, Ge, Pasteurs, KJ. Les teamim considèrent ce mot comme un participe féminin et le séparent de ce qui le précède en l'articulant avec ce qui suit. Cela confirme l'exégèse de Radaq. Pour ce mot, le comité a attribué au *M 4 "C" et 2 "B". 
Interprétation proposée :

Vitringa, Rosenmüller et Knobel estiment qu'on a ici un style très coupé exprimant la vive émotion de l'auteur. "Quant à moi" figure en nominatif absolu, comme en 59,21 ou en Ps 73,2.28. La construction est rendue ici plus obscure par une aposiopèse intervenant après "leurs actions et leurs desseins", comme c'est le cas en d'autres menaces ou serments (Ez 34,8; Ps 89,36).

On peut donc interpréter ainsi 18a :

“Quant à moi - étant donné leurs actions et leurs desseins - le moment vient de rassembler toutes les nations et toutes les langues..."

66,19A פול [C] M 1Q-a.b Hie S T // def-int $\wedge \rightarrow \Delta:$ G фOY $\Delta$ / exeg : V

Options de nos traductions :

C'est (selon Brockington) en se fondant sur le ${ }^{*} G$ que NEB lit ici (avec RSV, J, RL et TOB) : פור.

Origine de la correction :

C'est Knobel qui a proposé cette correction, suivi par de nombreux exégètes et les apparats de HSAT234, $\mathrm{BH} 235$ et Cent.

Les témoins anciens :

Le *M est appuyé ici par 1Q-a, 1Q-b, la *S et le *T, alors que le ${ }^{*} G$ lit $\Phi$ ouo.

La *V donne pour ce mot: "in Africa", mais Hie précise qu'il lit ici Phud ou Phul, confirmant ainsi la leçon du ${ }^{*} M$ et celle $d u * G$.

Choix textuel :

Ici, ce mot est lié à לוּ, alors qu'en Jr 46,9; Ez 27,10; 30,5 c'est פוּר qui est lié à ce toponyme. On comprend donc que l'on ait eu l'idée, en se fondant sur le ${ }^{*} G$, de proposer ici cette correction.

Il est cependant plus probable d'admettre avec Schleusner (Opuscula 363) que $\Phi O Y \Delta$ soit une déformation de $\Phi O Y \wedge$ ayant eu lieu à l'intérieur de la transmission du ${ }^{*} G$ (sous l'influence directe de $\wedge O Y \Delta$ qui suit, et sous l'influence indirecte de Gn 10,6) que d'admettre qu'en hébreu un 'teț' ait été déformé en 'lamed'. Aussi la majorité du comité a-t-elle estimé utile de maintenir ici la leçon $d u{ }^{*} M$ pour qu'elle puisse exercer la sagacité des géographes. Cette leçon "Poul" a donc reçu 3 " $\mathrm{C}$ " et 1 " $\mathrm{B}$ ", alors que la leçon du *G a reçu 2 "C $"$ ".

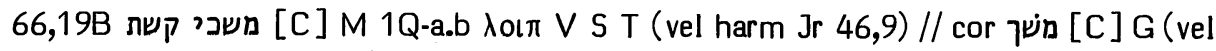
assim $E z$ 38,2.3; 39,1)

Options de nos traductions :

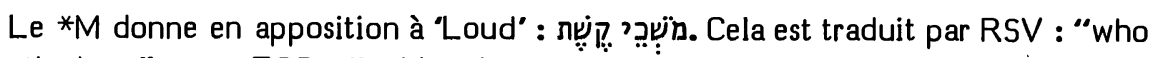
draw the bow" et par TOB : "qui bandent l'arc". 
A la place de ces deux mots, 312 donnaient "Moshek, Rosh" en se fondant sur le *G. Se fondant sur la même base, NEB donne "Meshek, Rosh", alors que RL donne : "Meshech und Rosch".

$\mathrm{J} 3$ dit suivre le *G en ne donnant que "Meshek" pour les deux mots.

Origines des corrections :

En s'inspirant de la leçon du *G, Lowth a conjecturé que la leçon originale devait être ici משך que le *M aurait glosé parce qu'il interprétait ce mot en participe. Cette suggestion a été suivie par beaucoup jusqu’à BHS. En outre, Duhm a conjecturé que (pour רשר (pom de peuple lié à Meshek et Tubal en Ez 38,2.3; 39,1) se dissimulait sous le mot קשת. Cette suggestion a été adoptée par HSAT34, BH23 et Cent.

\section{Les témoins anciens :}

Ici, la leçon du *M est appuyée par 1Q-a, les colonnes hexaplaires autres que le *G (qui portent “tendentes arcum” selon Hie), la *V (“tenentes sagittam”, à corriger, selon Hie, en "tendentes sagittam"), la*S (דנגדין בקשתא) et le*T (דנגדין ומחן בקשתא).

Pour ces deux mots, le.*G offre xaì Mooox.

\section{Choix textuel :}

Notons que la leçon que le ${ }^{*} \mathrm{M}$ offre ici trouve un appui dans le parallèle non

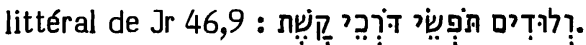

On peut donc argumenter ici en deux sens opposés : - ou bien משך lu par le ${ }^{*} G$ est primitif, nos témoins hébreux ayant midrashisé en s'inspirant de Jr 46,9;

- ou bien le midrash attesté par ces témoins est primitif (reposant sur un vieux jeu de mots entre le nom de peuple משך et le verbe homonyme) et le ${ }^{*} G$ (qui, nous l'avons constaté, connaît le * $\left.{ }^{*} d^{\prime} E z e ́ c h i e l\right)$, ne pouvant faire passer ce midrash en grec, s'est contenté de le décrypter.

Le comité a attribué 3 "C" à chacune de ces deux éventualités.

Interprétations proposées :

Ceux qui suivent le *M traduiront: "qui bandent l'arc", alors que ceux qui suivent le *G donneront, à la place de cela : "Meshek". 


\section{JEREMIE}

\section{2,16 ירעוך [B] M Aq S // paraphr : T / err-graph : m G V}

Options de nos traductions :

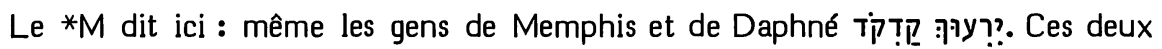
derniers mots sont traduits par RSV : “have broken the crown of your head", NEB : "will break your heads", TOB : "te défoncent le crâne".

J corrige le verbe en ?ִִִּ et traduit : "t'ont rasé le crâne". RL traduit de même : "scheren ... dir den Kopf kahl".

Origine de la correction :

La conjecture de J vient des apparats de $\mathrm{BH} 3$ et de Cent. A travers Duhm, elle remonte à Houbigant.

\section{Les témoins anciens :}

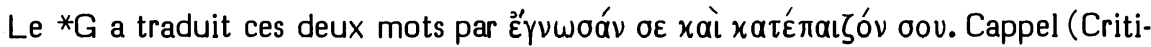
ca 219) a reconnu là une Vorlage ידעוך pour le premier verbe. Il a suggéré que la*V (constupraverunt te usque ad verticem) avait tiré de la même Vorlage un sens obscène.

$\mathrm{BH} 2$ dit que cette leçon avec 'dalet' est attestée par $6 \mathrm{mss}$ du *M. De Rossi précise qu'il s'agit d'un ms et de la $1 e$ main de cinq autres. Pour protéger la leçon du $* M$, une mp du ms d'Alep la note comme hapax.

Syh donne pour Aq: רן רע que Field traduit par "confringent", alors que Ziegler (éd. Göttingen) suggère comme alternative "pascent". Ce sens est rendu plus

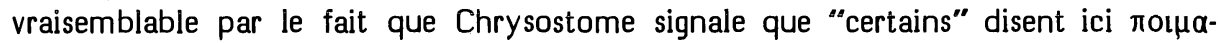
voṽolv.

La leçon avec 'resh' a été lue aussi par la *S (נרעונכי).

Le *T paraphrase "tuent tes hommes forts et pillent tes biens". Cela suppose une interprétation "fracasser" ou "brouter"de la leçon du *M.

Choix textuel et interprétation proposée :

1/ Approuvé en cela par Reuchlin (494), Nicolas de Lyre interprétait ici le *M au sens de "confregerunt". En ce sens de "briser", il avait été précédé ici par Rashi, les glossaires ABCDEF, Joseph Qara, Menahem de Posquières, Moshé ben Sheshet, Parḥon, Radaq (commentaire et Shorashim sous רער), Joseph ibn Nahmias, Isaïe de Trani. Jacob ben Reuben ("frapper") se rattache aussi à cette tradition exégétique.

$L a$ forte influence de Nicolas de Lyre explique que la vieille traduction allemande (Kurrelmeyer IX 8,42) - qui suit en principe la *V - ait écrit ici "zerbrachen dich". 
Pagnini a adopté lui aussi la traduction de Nicolas de Lyre, suivi en cela par Luther ("zuschlahen ... dir den kopff"), Brucioli ("ti spezorno la dirizatura"), Ge ("have broken thine head") et Estienne ("t'ont casse le sommet"). Ce sens sera conservé par les traductions classiques en français et en anglais (Pasteurs : "te casseront le sommet" et KJ : "have broken the crown of thy head").

Cependant, la $* V$ avait d'abord guidé les traducteurs de Zurich (Prédicants : "habend deinen halss geschent" et Zwingli : "cervicem tuam constupraverunt") et Olivetan : "te ont diffame le couppet".

2/ Une autre tradition d'exégèse remonte à Yéfet ben Ely qui comprend ici "ils te brouteront" et explique : "C'est intentionnellement que l'Ecriture emploie ici cette expression. En effet, de même que l'habitude des bestiaux est de paître dans la campagne, partie après partie, de même les Egyptiens brouteront Israël moment après moment." Comme nous l'avons vu, cette interprétation se rattache probablement à Aquila. Notons aussi que la $* S$ que Gabriel Sionita a interprétée ici au sens de "contundent" l'avait été d'abord, en sa traduction arabe par Pethion ibn Ayyub al-Sahhâr, au IXe siècle, au sens de "paîtront".

Cette exégèse du ${ }^{*} M$ est représentée aussi par Joseph ibn Kaspi, Tremellius, Buxtorf (Lexicon), Cocceius, C.B. Michaelis, Venema, Vogel (sur Grotius), Leiste, Rosenmüller, Gesenius (Thesaurus), Ewald, Henderson, Nägelsbach, Keil, Graf, Luzzatto, von Orelli, Giesebrecht, Cornill, Condamin, Nötscher.

Notons que c'est contre l'exégèse de Nicolas de Lyre "confringunt" (qu'il connaissait à travers Pagnini et Arias Montano) qu'Houbigant a proposé sa conjecture יערוך au sens de "nudant tibi", ajoutant que l'on avait coutume de découvrir la tête des prisonniers de guerre.

Michaelis (OEB), au contraire, traduisant ici (avec Luther) : "zerschlagen dir"

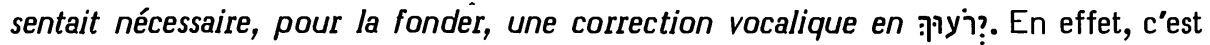
bien l'exégèse proposée par Yéfet ben Ely ("brouteront") qui correspond le plus naturellement à la forme "lamed-hé" reconnue ici par les vocalisateurs du *M.

A la suite de Leiste, c'est Graf qui a offert ici la plus fine analyse exégétique du *M. Il note d'abord que le sens "fracasser le crâne" ne serait pas en place ici où il ne saurait s'agir de l'anéantissement d'Israël. Puis il note ici dans le *M la combinaison de deux images : celle de "dévorer en broutant" que le verbe exprime directement (et à laquelle Jr 6,3;12,10; Mi 5,5 offrent de bons parallèles) et celle de "tondre le crâne" qu'évoque le complément קדקד qui réapparaît en un contexte analogue de dévastation d'un pays en Jr 48,45 (une image analogue ayant été employée en Is 7,20). En Jr 47,5, ce sera Gaza qui subira une tonsure en signe de deuil. La chevelure tondue marque aussi la dévastation et le deuil en Is 3,17 et en Jr 48,37.

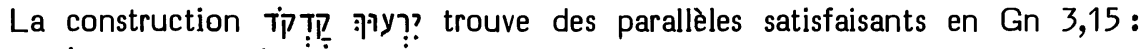

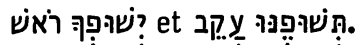

Quoique la combinaison des deux images puisse dérouter au premier abord, elle s'insère bien dans l'imaginaire de Jérémie. Aussi le comité a-t-il attribué la note "B" à la leçon du *M en proposant l'interprétation: "Même les gens de Memphis et de Daphné te brouteront le crâne". Une note explicative pourrait tenir compte des données rassemblées par Graf. 
Options de nos traductions :

Comme cause de la calamité évoquée en $16 \mathrm{~b}$, le $* M$ mentionne ici le fait que

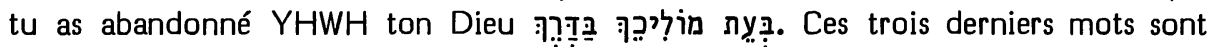
traduits par RSV : "when he led you in the way", RL : "sooft er dich den rechten Weg leiten will", TOB : "au temps où il était ton guide sur la route", J3 : "alors qu'il te guidait sur la route".

J1 considérant ces trois mots comme une mauvaise dittographie du début du vs $18, \mathrm{~J} 2$ notait leur absence dans le $* G$ et toutes deux (ainsi que NEB) les omettaient.

\section{Origine de la correction :}

Pour cette omission, nos versions dépendent des apparats de HSAT34, BH3S et Cent. C'est Movers (32) qui a suggéré que ces trois mots sont une dittographie des quatre qui les suivent : ועתה מה־לך לדרך. Cette suggestion a été adoptée par. Cornill (SBOT), Oort et Duhm.

\section{Les témoins anciens :}

Seul le ${ }^{*} G$ ancien omet ces trois mots dont la présence est attestée par les recensions origénienne et antiochienne, ainsi que par la $* \mathrm{~V}$, la $* S$ et le $* T$.

\section{Choix textuel :}

Ainsi que Movers l'a noté, on est intrigué de remarquer que ces trois mots ont huit consonnes qui y figurent dans le même ordre qu'elles occupent dans les quatre premiers mots du vs suivant. Il est possible que l'on ait affaire ici à une variante de ces

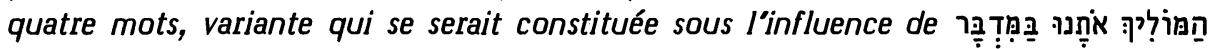
(au vs 6), puis qui aurait été juxtaposée à la leçon originale de la rédaction I par le rédacteur II qui l'aurait traitée comme un complément temporel achevant le vs 17 .

Wichelhaus (112) a cependant fait remarquer que le vs 18 postule ces trois mots. רת se situe en effet par rapport à ce complément temporel. De même que, "lorsque le Seigneur guidait Israël sur la route" du désert (cf. Dt 8,2), celui-ci voulait "l'abandonner" pour retourner en Egypte, "maintenant", il veut reprendre "la route de l'Egypte".

On a objecté à la leçon du *M qu'un participe y paraît dans une situation où on attendrait un infinitif. Mais Gesenius (Lehrgebäude 793) a fait remarquer que ce même phénomène se reproduit deux autres fois en Jérémie : הרֵ en 10,23 et le ketib שומע en 17,23.

Le comité considère donc comme vraisemblable (quoique incertain) que ces trois mots soient une ajoute due à la rédaction II. Etant donné que nous visons justement ici à reconstituer cet état littéraire dont le *M est le meilleur témoin, la leçon de celuici a reçu la note " $A$ ".

Interprétation proposée :

RL, reprenant Luther (qui s'inspirait de Rashi et de Radaq), a interprété ces mots au sens de "alors qu'il te guidait sur le droit chemin". Mais Keil a fait remarquer 
que תỵ̣g se réfère à une situation historique précise (celle qui a déjà été évoquée au vs 6). Ón traduira donc: "à l'époque où il était ton guide sur la route", en notant qu'il s'agit de la conduite d'Israël par Dieu à travers le désert après l'Exode.

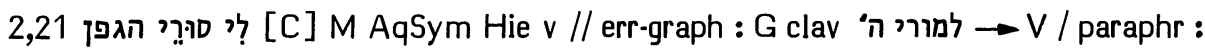
$S T$

17,13 יסוּרוּר [B] MQ 4Q-a Aq Sym S // err-graph : MK G? V? יסורי / facil-synt : v T clav סוריך(?/)

Options de nos traductions :

2,21 : Après avoir dit : “Mais moi, je t'avais plantée en Sôréq, tout entière en

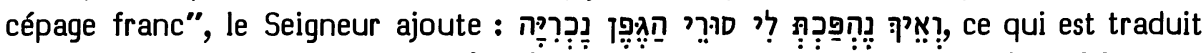
par TOB : "Comment as-tu dégénéré en vigne inconnue aux fruits infects ?" et par 33 : “Comment t'es-tu changée pour moi en sauvageons d’une vigne étrangère ?" J12 lisaient au lieu des 3e et $4 \mathrm{e}$ mots et de l'article qui suit : : “Comment t’es-tu transformée en plante infecte (J2 : changée en plant dégénéré), Vigne bâtarde!" Sans note, RSV donne: "How then have you turned degenerate and become a wild wine ?", NEB : "yet now you are turned into a wine debased and worthless!" et RL : "Wie bist du mir denn geworden zu einem schlechten, wilden Weinstock ?"

17,13 : 13a s'est achevé par: "tous ceux qui t'abandonnent seront honteux".

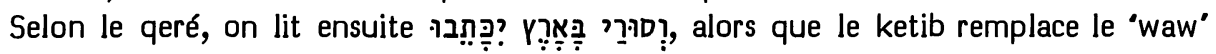
initial par un 'yod'. Le qeré de ce mot est traduit par TOB : "ceux qui s"écartent de moi sont condamnés".

A la suite de Luther, $R L$ rend la syntaxe plus aisée en ne traduisant pas le suffixe de la 1e pers. : "und die Abtrünnigen".

RSV et $\mathrm{J}$ disent avoir conjecturé un suffixe de la $2 \mathrm{e}$ pers. pour traduire "those who turn away from thee" et "et tes dissidents (J3 : ceux qui se détournent de toi)". Sans note, NEB traduit : "(all...) who forsake thee".

\section{Origines des corrections :}

2,21 : La conjecture de 312 a été proposée par Duhm (à travers les apparats de HSAT34 et Cent). Celui-ci dérivait cette forme de la racine araméenne (= sentir mauvais), soulignant l'analogie avec la dérivation de (= verjus). Notons que Michaelis (OEB) avait conjecturé ici סָּר au sens de coloquinte, à partir de l'arabe

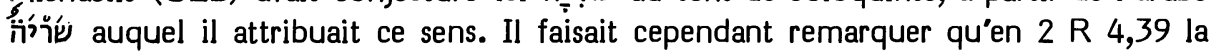
coloquinte est appelée "vigne champêtre". Aurivillius (583) formula des doutes à l'égard du sens de ce mot arabe en citant deux autres désignations de la coloquinte en cette langue, puis Rosenmüller ajouta qu'il est encore plus incertain que les hébreux aient jamais nommé ainsi la coloquinte.

17,13 : Clericus, considérant qu'ici c'est sûrement Jérémie qui parle, conclut qu'il faut suivre la $* V$ en interprétant comme si on lisait ici le suffixe 2e pers. m. sg. Cette 
suggestion a été adoptée par Dathe (critiqué par Schnurrer), Ewald, Giesebrecht, Rudolph. Elle est requise par les apparats de SBOT, HSAT34, BH2 et Cent.

Brockington prétend, à tort, que NEB a lu ici 'רֶּ ?ִ avec le *G. Il s'agit là d'une proposition de Duhm adoptée par Cornill et $\mathrm{BH} 3$.

\section{Les témoins anciens :}

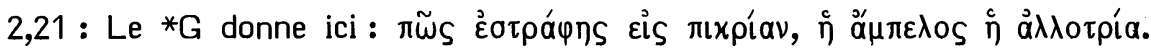
Spohn a suggéré une Vorlage מורי Mais il est vraisemblable qu'en cette confusion du 'samek' avec le 'mem', le ${ }^{*} G$ s'est laissé influencer par la Septante de Dt 32,32:

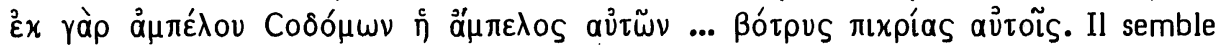
aussi que le ${ }^{*} G$, au lieu de $ל$, a lu la préposition 'lamed' directement liée au mot suivant. AqSym corrigent cela en insérant $\mu$ ol que les recensions origénienne et antiochienne adoptent.

La leçon originelle de la *V semble être celle que donne l'édition Weber : “quomodo ergo conversa es in pravum vinea aliena", le mot "mihi" n'ayant été inséré que dans les mss du XIIle siècle de l'université de Paris à partir de Hie. Celui-ci manifeste sa connaissance de la leçon du *M par l'emploi du verbe "recedat" dans la paraphrase qu'il fait de ce passage (où "per amaritudinem" correspond à la leçon du *G) : "ut per amaritudinem recedat a Domino, et fiat vitis aliena".

La *S ("et comment t'es-tu tournée contre moi et t'es-tu révoltée comme une vigne étrangère ?") et le *T ("et comment vous êtes-vous transformés devant moi par vos oeuvres corrompues, avez-vous dévié de derrière ma crainte, êtes-vous devenus comme une vigne qui ne sert à rien ?") ont paraphrasé le *M.

17,13 : Selon Janzen (178), 4Q-a atteste le ketib. Pourtant la première lettre est un peu voûtée comme un 'waw' et non anguleuse comme un 'yod'.

Aucune version n'atteste ici le suffixe de la 1e pers. sg. du *M. A part cela, toutes attestent sa leçon; Aq et Sym insérant un xaı qui montre qu'ils ont lu le qeré (comme aussi la *S : ומודודא ( Ne témoignant pas de la connaissance du 'waw', il se peut que le

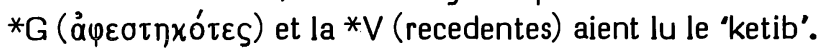

Toutes les éditions de la $* V$ antérieures à l'édition Weber portaient (contre les mss les plus anciens): "recedentes a te", leçon qui a inspiré Clericus et ses successeurs. La même facilitation syntactique apparaît dans la paraphrase du *T.

\section{Choix textuels :}

La construction סורי הגפן נכריה est apparue à Michaelis (OEB) comme "grammaticalement vicieuse", les deux derniers mots devant avoir tous deux l'article ou être tous deux sans article. On trouve cependant des constructions identiques en (Ez 42,12) que König en rapproche (Synt $\S 334 \mathrm{~m})$. Le mot סריר transformation, comme on en retrouve avec le même verbe en Lv 13,20 ou Ps 114,8. Enfin יל? est ici un dativus incommodi.

Cornill a prétendu que le mot סור au sens de "sauvageon" n'est pas attesté ailleurs. Il faut cependant, avec David ben Abraham (II 350,30s), rapprocher cet état construit pluriel de ce mot (suivi du génitif הגפן) de l'état suffixal pluriel de ce même mot, dans le qeré de Jr 17,13 où il est suivi du suffixe 1e pers. sg. Ces 
deux mots sont rapprochés aussi par Hayyuj (Kitâb 74,6) qui y voit des adjectifs (opinion adoptée ensuite par Ibn Ezra en Sapha Berura 26b et par Isaïe de Trani).

La racine סור signifiant "quitter la route", il s'agit ici de sarments qui ont dégénéré en revenant à l'état sauvage. En 17,13, le Seigneur désigne par ce mot ceux qui l'ont quitté, qui ont apostasié en abandonnant son alliance.

Reste une difficulté en 17,13: le passage soudain d'un suffixe de la $2 e$ pers. désignant le Seigneur en 13a à un suffixe de la 1e pers. le désignant en 13b. Il est évident que l'assimilation du second suffixe au premier est ici une facilitation syntactique qui est 'dans l'air' et dont Schnurrer avait raison de se défier. Reventlow (229234) estime d'ailleurs que 13a et 13b ne doivent pas s'articuler comme deux membres parallèles, mais comme une plainte et la réponse du juge à qui elle est adressée.

En 2,21 , le comité a attribué la note " $C$ " au $* M$ dont la construction est difficile. En 17,13, le comité a choisi, avec 4 " $\mathrm{B}$ " et 2 " $\mathrm{C}$ ", le qeré qui permet d'avoir une forme parallèle à celle qui apparaît en 2,21; alors que le ketib s'explique comme une simple erreur graphique.

Interprétations proposées :

En 2,21: "Comment t'es-tu changée pour moi en sauvageons d'une vigne inconnue."

En 17,13 : "Espoir d'Israël, Seigneur, tous ceux qui t'abandonnent seront saisis de honte ! - Et ceux qui se détournent de moi seront inscrits dans la terre, parce qu'ils ont abandonné la fontaine d'eaux vives, le Seigneur."

פ' למי מי [C] M Sym V // facil-synt : S T / err-graph : G clav

Options de nos traductions :

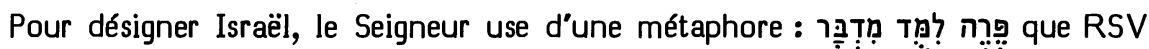
traduit : "a wild ass used to the wilderness", RL : "wie eine Wildeselin in der Wüste", TOB : "Une ânesse sauvage habituée à la steppe !", J3 : "ânesse sauvage, habituée au désert".

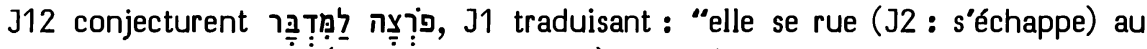

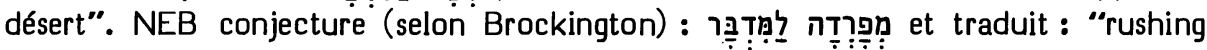
alone into the wilderness".

Origines des corrections :

$\mathrm{J1}$ attribue sa conjecture à Köhler. Celui-ci (Beobachtungen 35) a en effet proposé

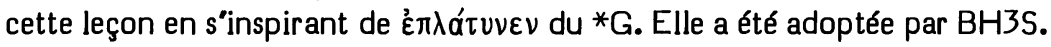

Quant à NEB, elle a suivi ici Driver (98).

Les témoins anciens :

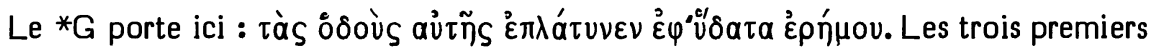
mots traduisent le dernier mot du *M du vs 23 : Clericus, Trommius et Schleusner estiment qu'il suppose פְִָ̣ dans la Vorlage du *G, 
alors que Cappel (Notae 520) et Spohn optent pour פִ̣ qui a ce sens en araméen; tandis que Wichelhaus (150) hésite entre ces deux possibilités. Le mot suivant a été lu למי

Dans le *M, la graphie הרֶ est protégée par la massore (Weil §3560) spécifiant que ce mot est écrit 5 fois avec "alef' (Gn 16,12; Os 8,9; Jb 6,5; 11,12; 39,5) et une fois (ici) avec 'hé'. D'ailleurs les mss du Caire et d'Alep précisent en mp que l'on a ici le seul cas où ce mot s'écrit avec 'hé'.

Le *M est appuyé directement par Sym (ערדא דיליף מדברא selon Syh) et la *V (onager adsuetus in solitudine).

Une préposition comparative a été explicitée avant le premier mot par la *S (איך ערדא דמתילף במדברא) et le *T (כערדא דמדורה במדברא).

Il n'y a pas à tenir compte de la leçon attribuée à "l'hébreu" par les fragments chrysostomiens de la chaîne de Ghisleri. Ici, comme dans tout le contexte où ils sont fort abondants, ils ne correspondent ni à Th, ni à Aq, ni à Sym et leur sont généralement inférieurs (vocalisations fantaisistes de la Vorlage, confusions de racines, traductions très larges).

\section{Choix textuel :}

Ainsi que nous l'avons noté, Köhler et Driver, gênés par cette seconde comparaison avec l'onagre qui semble se développer à partir de la comparaison avec la chamelle, ont voulu, à la suite du ${ }^{*} G$, y voir un simple développement de la comparaison avec la chamelle. En cette option, ils avaient été précédés par Grätz et ont été suivis par Rudolph, Steinmann, Weiser. Plus radicalement, Cornill et Volz ont voulu éliminer les sept premiers mots du vs 24 qui seraient une ajoute provenant de 14,6. Ils ont été suivis en cela par Schmidt, Nötscher et Bright. Quant à Duhm (suivi par Con-

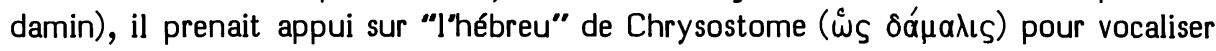

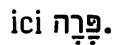

Le *M est cependant suffisamment appuyé par Sym, la *V, la *S et le ${ }^{*} \mathrm{~T}$ pour que le comité lui ait attribué 4 "C $C$ " et 2 "B".

\section{Interprétation proposée :}

Bailey et Holladay ont montré que la comparaison avec l'onagre est bien en place ici où on décrit sa femelle en chaleur humant le vent. Cela exprime bien l'attrait qu'Israël ressent pour les Baals.

La comparaison avec la jeune chamelle (au vs 23) porte sur le fait que le jeune animal de cette espèce est folâtre et difficile à capturer, courant tantôt en un sens, tantôt en l'autre. Cependant aucune réaction particulière ne caractérise la chamelle lorsqu'elle est en chaleur. L ânesse, par contre, en ce cas, a les réactions qui sont ici décrites.

Ajoutons que le prophète s'est adressé à Israël au féminin depuis 2,16 jusquà 2,23a. Puis viennent, disposées en chiasme, deux comparaisons. D'abord "une chamelle légère entrecroisant ses traces" illustre ce qui précède: "vois ton parcours dans le vallon, prends conscience de ce que tu as fait". Puis "onagre habitué à la steppe" (accordé au masculin en tant qu'épicène) illustre ce qui suit (où les féminins se réfèrent directement à Israël) : "dans l'ardeur de son (= qeré) désir, elle aspire 
le vent; son rut, qui le refrénera ? Quiconque la recherche n'a pas à s'épuiser; en son mois on la trouve".

\section{2,31 הדור אתם ראר [B] M // err-divis et usu : G / err-divis : V / usu : S T}

Options de nos traductions :

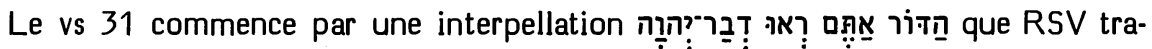
duit : "And you, O generation, heed the word of the LORD", J12 : "Engeance que vous êtes ! (J3 : Et vous, de cette génération) voyez la parole de Yahvé", RL : "Du böses Geschlecht, merke auf des HERRN Wort !", TOB : "Vous, hommes de ce temps, comprenez la parole du SEIGNEUR !

NEB conjecture l'omission de cette phrase.

Origine de la correction :

C'est Duhm qui a proposé d'omettre ces cinq mots en y voyant l'annotation marginale d'un lecteur, omission requise ensuite par les apparats de BH3S.

Les témoins anciens :

La présence de cette phrase est attestée par tous les témoins.

Le ${ }^{*} G$ et la $* V$ ont lié les deux premiers mots au vs précédent, le ${ }^{*} G$ traduisant

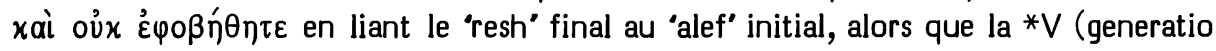
vestra) a vu dans le second mot un possessif lié au premier.

Pour ces deux mots, le *M a l'appui de la *S (אנתון דרא) et du *T (qui glose : את דרא אתון

Seule la $* V$ a traduit littéralement les trois mots suivants (videte verbum Domini). Le rapprochement surprenant de "voyez" avec "parole" a amené le *G (áxoúoate), la *S (קמעו) et le *T (קבילו) à choisir un verbe mieux adapté.

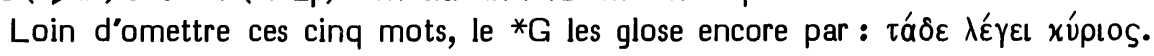

\section{Choix textuel :}

Il est fort probable que cette apostrophe d'un prédicateur à ses contemporains vise à actualiser le message du prophète. Elle contient d'ailleurs un certain nombre de particularités qui la rendraient surprenante de la part de Jérémie : הָ au sens de “contemporains!", puis la reprise immédiate du vocatif par le pronom ot enfin l'expression "voyez la parole de YHWH". D'ailleurs cette apostrophe apparaît excédentaire par rapport à la structure très régulière du vs 30 et à celle de la suite du vs 31.

La traduction des deux premiers mots par le $* G$ a pu être influencée par les expressions analogues que l'on rencontre en 3,8 et 5,22. Ici, elle a dû être appelée par $\pi \alpha\left\llcorner\delta \varepsilon\left\{\alpha\right.\right.$ oủx $\varepsilon^{3} \delta \varepsilon^{\prime} \xi \alpha \sigma \theta \varepsilon$ qui achève $30 a$ et où le traducteur optait déjà pour une $2 \mathrm{e}$ pers. pl. à la place de la 3e pers. pl. du *M. Quant au remplacement du verbe "voir" par "entendre" ou "accueillir", il est évidemment facilitant.

Il est intéressant de noter que cette apostrophe constitue un développement rédactionnel antérieur à la clôture de la rédaction I (représentée par le ${ }^{*} \mathrm{G}$ ) et qu'ici 
c'est le *M (témoin caractéristique de la rédaction II) qui l'a conservée sous la forme la plus originale alors que le ${ }^{*} G$ y a ajouté une glose complémentaire. Aussi le comité a-t-il attribué à la leçon du *M 2 " $A$ " et 4 "B".

Interprétation proposée :

"Vous, contemporains, voyez la parole du Seigneur !"

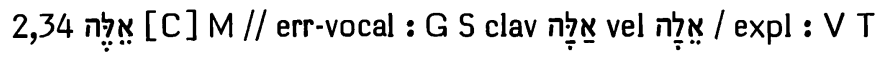

Options de nos traductions :

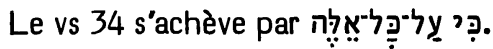

Ces mots sont rattachés à ce qui précède par RL : "sondern die alledem widerstanden" et par TOB : "C'est bien sur tout cela que..."

Ils sont rattachés au vs suivant par RSV : "Yet in spite of all these things..." et par $\mathrm{J3}$ : "Et malgré tout cela..."

$\mathrm{J12}$ ont seulement explicité un verbe : $\mathrm{J1}$ : “Oui, pour eux tous tu es responsable (J2 : répondras)".

NEB traduit, sans note : "but by your sacrifices under every oak", ce qui, selon Brockington, suppose une vocalisation $\underline{\underline{n}}$ du dernier mot avec le *G.

Origine de la correction :

La correction mentionnée par Brockington remonte à Châteillon (notes sur sa traduction latine) qui hésitait entre une vocalisation 'elah' (la plus fréquente) ou 'allah' (= Jos 24,26$)$ que Hie attribue ici au ${ }^{*}$ G. Soggin (Bemerkungen), après Condamin, l'a remise en vedette.

Les témoins anciens :

Le *G (סpú) et la *S (אילן) ont lu ce que Châteillon suggère. Mais le *G maintient auparavant la préposition hy du ${ }^{*} M$ (qu'il traduit par é $\left.\pi^{\prime}\right)$, dont Houbigant a remarqué qu'elle rend cette leçon fort improbable; alors que la *S a facilité en traduisant par תกת.

La *V et le *T ont (comme le feront J12) explicité des verbes: "memoravi" et עבדת.

\section{Choix textuel :}

Deux membres du comité ont attribué la note " $C$ " à la leçon du ${ }^{*} G$, comprenant "auprès de tout térébinthe" au sens de : partout.

Les quatre autres membres ont attribué au * $M$ la note " $C$ ", estimant qu'il ne s'agit là que d'une difficulté d'exégèse pour laquelle il existe des solutions acceptables.

Interprétations proposées :

On peut choisir entre trois exégèses :

1/ Celle que propose Yéfet ben Ely : "Mais c'est en plus de toutes ces choses"; c'està-dire que la mise à mort de ces innocents n'est pas l'une de celles que la Torah permet 
(comme celle du voleur pris en effraction), mais elle s'ajoute à tous ces crimes (que je vient d'énumérer).

2/ Celle que propose Rashi : "Mais c'est à cause de toutes ces choses", c'est-à-dire parce qu'ils te réprimandaient sur tous ces points, que tu les as mis à mort.

3/ Celle que propose Radaq : il fait passer ces mots au début du verset suivant, ce qui suggère de comprendre : "Mais, en plus de toutes ces choses, tu as été jusqu’à dire..."

Notons cependant que la place actuelle du sof-pasuq était déjà admise lorsque le ${ }^{*} G$ a traduit. On préférera donc les deux premières exégèses.

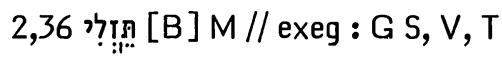

\section{Options de nos traductions :}

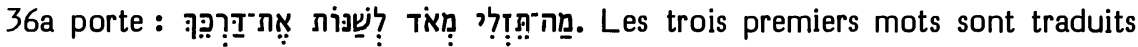
par RSV : "How lightly you gad about", J12: "Que tu mets de frivolité", RL : "Was läufst du denn so leichtfertig", NEB : "Why do you so lightly" et TOB : "comme tu t'avilis".

Estimant que le *M signifie : "comme tu vas beaucoup", $J 3$ dit changer légèrement la vocalisation pour traduire : "Que tu mets de légèreté".

Origine de la correction :

$S^{\prime}$ inspirant de la $* V$ et de la ${ }^{*} S$ pour traduire : "Warum erniedrigst du dich doch

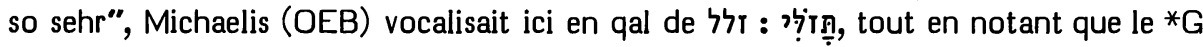
avait vocalisé en hifil du même verbe : par Giesebrecht (au sens de "wie höchst geringfügig achtest du es"), Oort, Duhm, puis adoptée par les apparats de HSAT34, BH23S et Cent (qui donne, par erreur : têzallî).

\section{Les témoins anciens :}

Les analyses de Michaelis semblent bien correspondre aux vocalisations présupposées par la traduction du ${ }^{*} G$ ( $\left.\chi \alpha \tau \varepsilon \varphi p o ́ v \eta o \alpha \varsigma\right)$ et par celles de la *V (vilis es facta) et de la *S (מזדללתי).

Le *T (את מסתכלא לחדא) ne doit pas être traduit, avec les polyglottes d'Anvers et de Londres : "(quare) tu contemplaris admodum". Ce verbe a ici le sens de "agir sottement" comme c'est le cas, en ce même targum de Jonathan, pour ... אסתכלית אסתכלית לחדא 2 S 24,10). Il semble que le *T s'inspire ici du contexte.

\section{Choix textuel :}

Il n'est pas nécessaire d'admettre que les versions anciennes aient vocalisé autrement que le *M. En effet, Rashi (qui lisait évidemment le $* M$ ) dérive cette forme de זל au sens de "compter pour peu de chose". Les glossaires BDE donnent ici à ce verbe (comme l'ont fait la $* V$ et la ${ }^{*}$ ) un sens passif : "seras avilée"; alors que les glossaires ACF lui donnent (comme l'a fait le ${ }^{*} G$ ) un sens actif : "avileras". Joseph Qara opte pour un sens réflexif : "Comme tu fais peu de cas de toi et te méprises toimême". 
Le comité a donc attribué à la leçon du *M la note " $\mathrm{B}$ ", en estimant que la difficulté se situe au plan de l'exégèse.

\section{Interprétation proposée :}

Judah ben Qoreish (Bargès $105=$ Katz 198) donnait à cette forme le sens de "tu cours", en notant qu'en berbère, on dit de celui qui court : תאזי.

David ben Abraham (I 488,27ss) voit ici un sens dérivé de l'araméen, le targum traduisant וייל par ואזל

Hayyuj (Kitâb 26,13ss) rattache cette forme à la racine faisant remarquer qu'entre le 'taw' et le 'zaïn', il y a une lettre quiescente défective qui serait la première radicale. C'est pour attester la présence de cette lettre que le șéré est suivi d'un meteg dont Menahem de Posquières confirme la présence ici.

Radaq pousse plus loin l'analyse (Mikhlol 84a). Selon les données regroupées par Chomsky (127), il rapproche cette forme de тחฺ̣ (Gn 49,6), (Dt 33,21) qui sont toutes des inaccomplis qal de racine 'péalef', selon lui (opinion que, selon Chomsky, note 202, il partage avec Hayyuj). Il en va de même du hifil מִ $(\operatorname{Pr} 17,4)$.

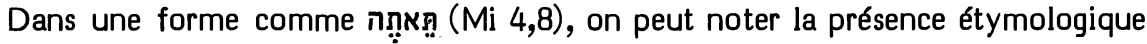
du 'alef' quiescent.

Dans la forme qui nous occupe, le meteg attesté par Hayyuj et par Menahem de Posquières n'est attesté ni par le ms d'Alep, ni par celui de Leningrad, ni par l'édition Ben Hayim, ni par la Minhat Shay. Mais il est présent dans le ms du Caire, dans le ms Paris BN hébr 2 et dans plusieurs autres, ainsi que dans l'édition Baer.

S'accordent pour dériver cette forme de אזל : Judah ibn Balaam, Joseph Qimhi (Galuy 91), Moshe ben Sheshet, Tanḥum Yerushalmi, Joseph ibn Nạ̣mias.

Michaelis, Giesebrecht et Rudolph ont objecté à ce sens que l'adverbe ממאi ne lui convient pas. Rappelons que, en CT1, 198s, nous avions déjà trouvé cet adverbe déterminant le verbe dras vite". Ici, on peut traduire : "Comme tu te hâtes de partir pour changer de chemin". Il s'agit des démarches vers l'Egypte "pour boire l'eau du Nil" $(2,18)$ qui succèdent aux démarches vers Assur "pour boire l'eau du Fleuve" (ibid.).

\section{3,1A לאמר [B] M Aq T // paraphr : V / abr-elus : G S om}

Options de nos traductions :

Ce vs commence par לִ que RL traduit : "Und er sprach".

Ce mot est omis par NEB (se fondant sur le ${ }^{*} G$ ), RSV et J3 (se fondant sur le *G et la $*$ S), ainsi que TOB. termes".

J12 complètent par conjecture : “La parole de Yahvé me fut adressée en ces

Origines des corrections :

Clericus a complété par conjecture וידבר יהוה אלי avant ce mot. Michaelis (OEB) fait de même, usant du verbe ויאמר. 
L'omission de ce mot (comme encore absent de la Vorlage du $* G$ ) a été proposée par Oort et Duhm, puis requise par l'apparat de BH3. Cornill (SBOT) propose l'omission tout en admettant qu'il peut s'agir du reste mutilé d'un texte originel.

Un complément conjectural est proposé par les apparats de HSAT34, BHS. Cent hésite entre les deux solutions.

Les témoins anciens :

A l'appui de sa consigne d'omission, $\mathrm{BH} 3$ cite l'absence de ce mot en un $\mathrm{ms}$ du *M. Il s'agit du ms Kenn 491 du XIVe siècle, témoin sans importance. La massore (Weil §3072) précise que nous avons ici un des neuf cas où un verset commence par ce mot. Cette massore figure trois fois dans le ms de Leningrad (sur Am 8,5; Za 7,3 et Ps 105,11). Selon Ginsburg (Massorah IV 101), cette liste est l'une des plus anciennes de la massore. Elle suffit à assurer fermement la leçon du *M qui est appuyée formellement par $\mathrm{Aq}$ (à qui la recension origénienne a emprunté $\lambda^{\prime} \varepsilon \gamma_{\nu}$ qu'elle insère ici sous astérisque) et le *T (למימר).

$\mathrm{La} * \mathrm{~V}$ paraphrase cela par "vulgo dicitur".

Le ${ }^{*} G$ ancien et la ${ }^{*} S$ omettent ce mot dont ils n'ont su que faire.

\section{Choix textuel :}

La présence de ce mot étant bien attestée, alors que son omission s'explique aisément, le comité lui a attribué la note "B", sans se prononcer sur son origine, ni son interprétation.

Interprétations proposées :

L'interprétation la plus ancienne est celle de Jérôme et de Yéfet ben Ely reprise par Zwingli et Olivetan : "on a coutume de dire". Rashi et Rosenmüller comprennent : "je pourrais dire". On peut objecter à cette interprétation qu'elle manque de parallèles dans l'hébreu biblique.

Keil a fait remarquer que l'expression לאמר n'est pas réservée à l'introduction de discours après les verbes signifiant 'dire'. Cette expression fait suite, en Jos 22,11, à "les fils d'Israël entendirent"; en 2 S 3,12, à "Abner envoya des messagers"; en

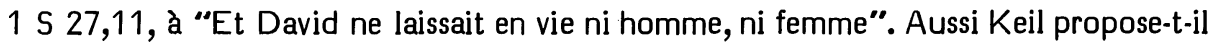
ici de voir en cette expression une explicitation du contenu de מִ (en 2,37b). Cette interprétation a déjà été proposée avant lui par Radaq, Luther, Münster, Vatable, Tremellius, Masius. Rappelons que nous avons déjà rencontré cette expression sans verbe introductif (mais précédée d'un datif) en Jg 16,2 (cf. CT1, 111).

Si l'on remarque que 2,36-37, reprochant au peuple son alliance avec l'Egypte, peut ne pas être un élément primitif de ce contexte, on obtiendrait une liaison beaucoup plus naturelle de ce לאמר avec 2,35b dont il pouvait être originellement la suite directe.

Si l'on traduit 35b par : “Or moi, voici que je te poursuis en justice, parce que tu dis : "je n'ai pas péché" "', on peut ne pas traduire לאמר au début de 3,1, mais noter en ce lieu, qu'une formule introductive présente 3,1-5 comme le contenu de l'accusation annoncée en $35 \mathrm{~b}$. 


\section{Options de nos traductions :}

Dans un contexte parlant de l'inconduite d'une femme, 1a s'achève par : nִ que RSV traduit : "Would not that land be greatly polluted ?", J : “N'est-elle pas totalement profanée, cette terre-là ?", TOB ne s'en distingue que pour l'adverbe : "irrémédiablement", RL : "Ist's nicht so, dass das Land unrein würde ?"

Selon Brockington, NEB se fonde sur le ${ }^{*} G$ pour corriger le quatrième mot en

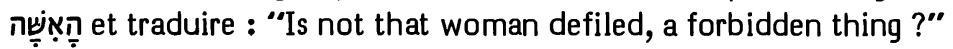

Origine de la correction :

Cette correction a été proposée par Houbigant et adoptée par Giesebrecht, Oort, Duhm, Cornill, puis par les apparats de HSAT34, $\mathrm{BH} 23$.

\section{Les témoins anciens :}

La leçon du *M est appuyée ici par la *S et le *T (ארא nienne du $* G(\tilde{\eta} \gamma \tilde{\eta})$.

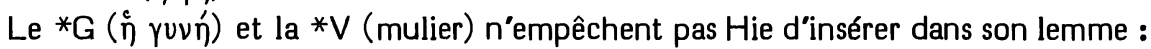
"sive : terra illa".

\section{Choix textuel :}

La leçon de la *V a été utilisée à tort par HSAT34 et BH23 comme un témoin pour une leçon הִִ̣, alors que, dans son commentaire, Hie dit très clairement : "'mulier illa', pro quo in Hebraico 'terram' legimus".

Rudolph suggère que la leçon $\gamma u v \eta n$ du ${ }^{*} G$ ancien peut être une déformation d'une leçon originelle $\gamma \eta$. Wichelhaus (134) a estimé que le traducteur grec a été gêné par le passage soudain de l'image à la chose représentée. Spohn hésitait entre ces deux explications de la leçon du *G. Ziegler (Beiträge 38) estime que la leçon $\gamma \tilde{\eta}$, dans la recension origénienne, provient d'une correction de la leçon yuví à partir du *M. Il est fort possible que $\Gamma \mathrm{H}$ ait été d'abord corrompu en $\Gamma \mathrm{YNH}$, puis restauré par recension. Il est également possible que la leçon үuví provienne dans le ${ }^{*} G$ d'une correction erronée de $\gamma \tilde{n}$ faussement considéré comme issu d'une corruption de ce mot.

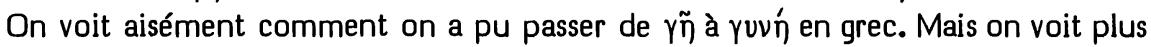
difficilement comment on serait passé en hébreu de la leçon facile האשה à la leçon difficile הארץ. Aussi le comité a-t-il attribué ici au *M la note "B".

\section{Interprétation proposée :}

Dt 24,4 explique le passage entre l'interdiction de reprendre la femme répudiée et la souillure du pays : lorsqu'une femme répudiée est devenue la femme d'un autre homme et que celui-ci l'a répudiée lui aussi ou est mort, le premier mari ne peut reprendre cette femme qui est devenue impure pour lui, car ce serait une abomination devant le Seigneur et "tu ne jetteras pas dans le péché le pays que le Seigneur ton Dieu te donne en héritage". En Jr 3,1, la femme profanée symbolise le pays qui s'est donné aux Baals. Si le Seigneur le reprenait pour sien, ne serait-ce pas une abomina- 
tion ? Jr 3,2b ("tu as profané le pays par ton inconduite, ton immoralité") montre que le thème de la souillure du pays est bien présent à l'esprit du prophète lorsqu'il fait le procès de l'inconduite des habitants de celui-ci. Nous verrons d'ailleurs que 3,9 semble bien présupposer ici cette leçon.

On pourra donc traduire : "N’est-il pas totalement profané, ce pays-là ?"

\section{3,5 חִ [A] $[A]$ \\ 4,16A חִּנִ [A]}

\section{Options de nos traductions :}

3,5: Après 5a ("Gardera-t-il rancune pour toujours, aura-t-il de la rancoeur à

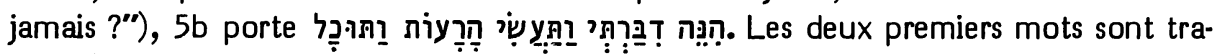
duits par RSV : "Behold, you have spoken", RL : "Siehe, so redest du" et TOB : "Mais, tout en parlant".

J12 conjecturaient donne : "This is how you spoke" et 33 : "Tu parles ainsi".

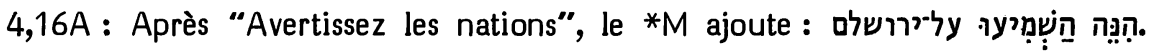
Influencée par la mise en page de $\mathrm{BH} 23 \mathrm{~S}$, RSV relie le premier mot à ce qui précède ("Warn the nations") et l'explicite en "that he is coming".

Selon Brockington, NEB corrige ce mot en eṇ qu'elle traduit (en construisant comme RSV): "Tell all this to the nations". Sans note, J3 fait de même : "Faites savoir ceci aux nations". RL et TOB ne traduisent pas ce mot.

\section{Origines des corrections :}

3,5: C'est Volz (Studien) qui a proposé la vocalisation adoptée par J12. Il traduit : "So war dein Reden und Handeln". Mais, dans l'esprit de Volz, ce "so" devait reprendre le contenu d'une forme originelle de 5a qui décrivait la perversion du peuple; cette forme originelle ayant été ensuite remplacée par celle que nous trouvons dans le *M actuel. Rudolph est donc inconséquent lorsqu'il adopte la correction vocalique de Volz, sans tenir compte de sa critique de 5a. Notons qu'en traduisant : "Siehe, so...", RL intègre la leçon de Luther $(=* M)$ et celle de Volz-Rudolph.

4,16: Ici, c'est Ehrlich qui a proposé cette correction vocalique, voyant en ce mot un adverbe de lieu: "hierher". NEB dépend plus directement de Driver (100) qui traduit ce mot par "these things", reconnaissant pourtant que cette forme du pronom n'apparaît nulle part ailleurs comme l'objet direct d'un verbe.

Les témoins anciens et choix textuels :

En 3,5 comme en 4,16A l'ensemble de la tradition textuelle appuie le $* M$.

Interprétations proposées :

3,5: La réserve formulée par Driver en 4,16 vaut ici aussi contre la suggestion de Volz. Si on conjecture ici ị̣? au sens de "ces choses", le prophète insiste plus sur le 
contenu des paroles prononcées. Si on lit הִֵּ̣, le prophète insiste plus sur le fait que ces paroles aient été prononcées: "Voilà, tu as parlé, puis tu..." Dans un cas comme dans l'autre, il s'agit de montrer l'inconséquence de la conduite de la femme-peuple : après avoir prétendu attendrir par ses paroles le Dieu fidèle (vss 4-5a), le peuple a commis des crimes et il s'en tirerait?

4,16: Ehrlich renvoie à son commentaire sur Ps 134,1 pour prétendre ici que חִ suivi de l'impératif est "unhebräisch". En effet, avant d'affirmer cela en ses Randglossen, il avait fait remarquer, dans son commentaire sur הְִּּה (Ps 134,1) qu'on ne retrouvait nulle part ailleurs dans la Bible ṇa suivi d'un impératif. Il y a donc un cercle vicieux lorsqu'Ehrlich s'appuie ici sur cette remarque dont notre cas (de $\mathrm{Jr}$ $4,16)$ prouve la fausseté. Au contraire ces deux cas où cette particule est suivie d'un impératif s'appuient l'un l'autre. Pour traduire ici iṇ̣, on peut s'inspirer de Graf ("wohlan !") et insérer "allons !" avant l'impératif (ainsi que Pléiade, TOB et J3 l'ont fait en Ps 134,1).

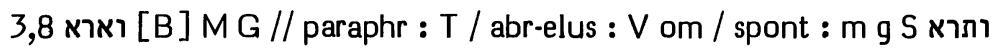

Options de nos traductions :

Le *M commence ce vs par וְִ̣ que TOB traduit : "Et moi j’ai vu."

Brockington dit que NEB s'appuie sur un ms pour lire en trag? the "she saw too"; alors que J appuie en outre cette correction sur des mss grecs et sur la ${ }^{*} \mathrm{~S}$, en traduisant : "Elle a vu aussi". Sans rien noter, RSV traduit : "She saw".

Quant à RL, elle ne traduit pas ce mot.

Origines des corrections :

Pour son omission de ce mot, RL dépend de la $* V$ par l'intermédiaire de Luther.

La traduction adoptée par (RSV), J et NEB a été suggérée par Châteillon qui, dans une note sur sa traduction latine, se fonde sur le "vetus interpres". Il s'agit là de la $* V$ qui, du fait de sa non-traduction de ce mot, aboutit à ce sens. La correction en jusqu'aux apparats de HSAT2, BH23S et Cent.

Les témoins anciens :

Le ms du *M invoqué ici par Brockington est le ms Kenn 187 de la fin du XIIIe siècle dont l'autorité est négligeable.

Le ${ }^{*} G$ ancien lit ici (comme le $* M$ ) la 1e pers. ( $x a i$ cĩóov).

La recension antiochienne lit $(\varepsilon)\llcorner\delta \varepsilon(\nu)$. En cela, Ziegler (éd. Göttingen) suggère un contact avec la ${ }^{*}$ S. Celle-ci traduit en effet, en remaniant les mots qui suivent : . וחזת כלהין צבותה.

$L a * V$, nous l'avons dit, omet ce verbe dans sa traduction.

La périphrase du*T (וגלי קדמי) se fonde sur le *M. 
Choix textuel :

Déjà, Abulwalid (Luma 311,5ss) écrivait : "iil se peut que וארא soit à la place de ותרא, car cette proposition fait suite à ותרא בגודה אחותה יהודה". Et Moshé ben Sheshet, rapportant cette opinion, comparait ce cas à celui de יגאל בגאל qui est pour en Rt 4,4 (cf. CT1, 134). En effet cette leçon à la 3e pers. f. sg. est 'dans l'air' comme le montrent ses attestations dispersées dans la tradition textuelle.

La lectio difficilior à la le pers. sg. étant attestée à la fois par le ${ }^{*} G$ ancien et par le * $M$, le comité lui a attribué la note " $\mathrm{B}$ ".

Interprétation proposée :

Avec Venema, Rosenmüller et Keil, il faut mettre ce "et j'ai vu" qui commence ce vs en parallèle avec le "et j'ai dit" qui commençait le vs précédent. Quant à ce que le Seigneur a vu, ce n'est pas ce qui suit immédiatement ("en raison de tous ses adultères, j'avais répudié Israël l'apostate et lui avais donné son acte de divorce"), mais c’est $8 \mathrm{~b}:$ : "que... sa soeur, la traîtresse Juda n’a pas éprouvé de crainte, elle est allée se prostituer, elle aussi". On pourra donc traduire : "Et j'ai vu que - alors que, en raison de ... divorce - sa soeur, la traîtresse Juda n'en a pas éprouvé de crainte..."

C'est à cause de la longue suite de trois propositions qui sépare לא de que cette négation a été introduite par un 'waw' de reprise auquel König (Synt $\$ 360 \mathrm{~b}$ ) reconnaît une valeur adversative.

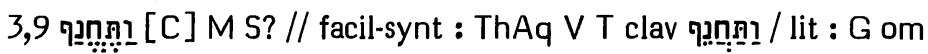

\section{Options de nos traductions :}

Les mots sont traduits par RSV : "she polluted the land", par J : "elle a profané le pays", par RL : "hat das Land unrein gemacht" et par NEB : "She defiled the land", Brockington précisant que cette traduction suppose que l'on vocalise

TOB traduit : "la terre elle-même est profanée", en notant que la *S, le *T et la *V, vocalisant autrement, ont compris : "elle a profané la terre".

\section{Origine de la correction :}

La majorité des traducteurs du XVIe siècle (Pagnini, Prédicants, Zwingli, Brucioli, Olivetan, Vatable, Calvin, Estienne, Pellican, Châteillon, Ge, Tremellius, Pasteurs, $\mathrm{KJ}$ ) a compris ce qal comme transitif et la particule qui le suit comme le signe d'accusatif. Cependant, Luther ("ist das land verunreiniget"), Münster (pollueretur terra) et Jud (terra pollueretur) ont compris ce qal comme intransitif et n'ont pas tenu compte de la particule qui suit.

C'est Ewald qui semble avoir été le premier à justifier sa traduction par une correction vocalique du verbe en hifil, vocalisation adoptée ensuite par von Orelli, Grätz, Duhm et requise par les apparats de HSAT234, BH23S et Cent.

\section{Les témoins anciens :}

Le ${ }^{*} G$ ancien omet ces trois mots. L'ajoute origénienne (et antiochienne) attri- 


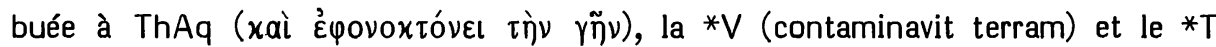
(וחייבת ית ארעא) ont donné au verbe valeur transitive.

Il est moins sûr que la *S (à laquelle Brockington faisait appel) ait lu de même. Certes, la *S (טנפת ארעא) a bien été vocalisée en paél dans les polyglottes par Gabriel Sionita. Mais la traduction arabe (תס) que Pethion ibn Ayyub en donne correspond à une vocalisation en peal. On peut donc craindre que Sionita se soit laissé influencer ici par les autres versions dans le choix du paél.

Radaq (Mikhlol 17a) signale comme exceptionnel que le "nun' porte ici un qameș, bien qu'il ne porte pas d'accent pausal. Cependant c'est un patah qu'on lit dans les mss du Caire, d'Alep et de Leningrad, ainsi que dans les éditions Ben Hayim et Minḥat Shay. Ni l'apparat de Norzi, ni celui de Ginsburg ne mentionnent de variante sur ce point. L'édition de Baer semble donc avoir eu tort de se fier à ce dire de Radaq. D'ailleurs la mp du ms d'Alep dit que cette forme apparaît 2 fois dans la Bible (ici et en Ps 106,38 où le patạ̣ ne fait aucun doute) sans signaler qu'elles se distingueraient par la vocalisation.

\section{Choix textuel :}

En ses Shorashim, Radaq hésite entre une interprétation de ce qal comme transitif, ou une interprétation de comme "avec". Menahem de Posquières opte pour ce sens de la particule, avec interprétation du verbe en intransitif. Joseph ibn Nahmias donne au verbe qal le sens transitif qu'aurait un hifil; mais il ajoute que d'autres l'interprètent comme intransitif, ce qui suppose que la particule את y jouerait le même rôle qu'elle joue à côté du sujet en 2 R 6,5 (ce qui correspond, ici, à l'exégèse de Luther, Münster et Jud).

Le fait que le verbe porte un tifha engage à interpréter la particule qui suit au

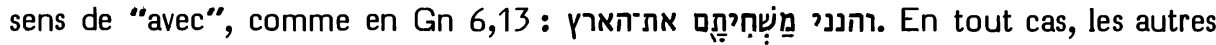
emplois du même verbe dans le proche contexte, en qal $(3,1)$ et en hifil $(3,2)$ nous encouragent à réserver au qal, ici aussi, le sens intransitif.

Etant donné que nous ne pouvons dire avec certitude si cette vocalisation en qal est ici primitive, le comité ne lui a attribué que la note "C". Mais il semble bien que l'interprétation de ce verbe en transitif constitue ici une facilitation syntaxique.

Interprétations proposées :

Le fait que ces trois mots sont absents de la rédaction I (représentée par le ${ }^{*} G$ ) nous encourage à y voir une glose visant à expliquer pourquoi 3, 1 conclut de l'inconduite du peuple que le pays est profané. En parallèle avec la phrase qui suit, un glossateur a ajouté : "et elle s'est profanée avec le pays", c'est-à-dire : en contaminant le pays par sa propre profanation.

Cependant, Blau (Gebrauch 14, note 2) voit ici en "le pays" un sujet senti comme accusatif, ce qui lui semble justifier suffisamment la particule. Il opte donc pour "et le pays a été profané". 


\section{Options de nos traductions :}

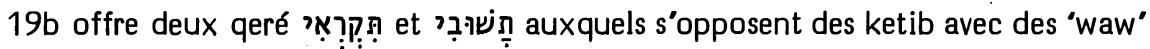
finaux.

Ont traduit selon le qeré : J12: “J'avais pensé : tu m'appelleras 'Mon père' et tu ne te sépareras pas de moi" et RL : "Und ich dachte, du würdest mich dann 'Lieber Vater' nennen und nicht von mir weichen".

TOB note qu'elle traduit avec le ketib : “Et je disais : 'Vous m'appellerez : Mon Père !, vous ne vous détournerez plus de moi'", ce que $J 3$ fait aussi sans rien noter : "Je me disais : Vous m'appellerez 'Mon Père' et vous ne vous séparerez pas de moi".

Le "you" de l'anglais actuel permet à RSV et à NEB de rester dans l'ambiguité : "And I thought you would call me, My Father, and would not turn from following me" et : "I said, You shall call me Father and never cease to follow me". Faisant usage du pronom "thou", Ge et KJ optaient clairement pour le qeré.

Origine de la correction :

Tous les traducteurs du XVIe siècle semblent avoir traduit le qeré, à la suite de $l a * V$. Grotius et C.B. Michaelis expliquaient le qeré sans même mentionner l'existence de la variante. C'est Houbigant qui a fait remarquer que le qeré assimilait aux suffixes de 19a et que les formes plurielles sont tout aussi acceptables du fait que la permutation entre les nombres est chose coutumière.

Venema traduit par des pluriels: "at dixi; Pater mi ! inclamabitis mihi, neque a post me recedetis". Son commentaire ne traite pas de cette initiative. Rosenmüller, lui, considère que le ketib est ici, "comme dans la plupart des autres lieux", primitif. Hitzig estime que le qeré est facilitant. Optent aussi pour le ketib : Keil, von Orelli, Giesebrecht, Cornill, Rudolph et l'apparat de BHS.

\section{Les témoins anciens :}

Le $* G$ ancien et antiochien lit ici le ketib avec la $* 5$, alors que la recension origénienne lit le qeré avec la $* V$ et le $* T$.

Choix textuel et interprétation proposée :

Ce cas n'a pas été soumis au comité.

Il est difficile de choisir entre le qeré (qui peut être une assimilation à 19a) et le ketib (qui peut assimiler à 20).

On peut relever cependant deux arguments qui semblent faire pencher la balance en faveur du qeré :

$1 /$ Il y a un contraste explicite entre le comportement espéré en 19b et celui qui est déploré en 20. Etant donné que le sujet de ces deux comportements est le même, il est vraisemblable que l'on a assimilé $19 \mathrm{~b}$ à 20 pour rendre cette identité plus explicite. $2 /$ Cependant, c'est le singulier qui est le mieux en place en 19b, et cela pour deux motifs : d'abord, c'est lui qui correspond le mieux au suffixe singulier de אבי; et, d'autre part, c'est lui que le parallèle structurel avec 3,4 fait attendre ici.

On pourra donc traduire comme $\mathrm{J12}$. 


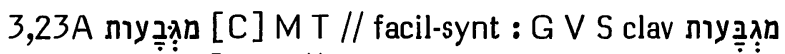

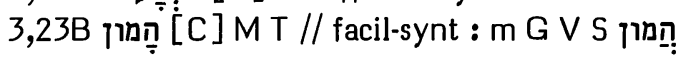

\section{Options de nos traductions :}

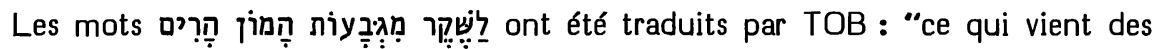
collines est faux, on ne fait que du bruit sur les montagnes", par RSV : "the hills are a delusion, the orgies on the mountains" et par RL : "es ist ja nichts als Betrug mit den Hügeln und mit dem Lärm auf den Bergen".

$\mathrm{J}$ dit suivre le ${ }^{*} G$, la ${ }^{*} S$ et la $* V$ pour traduire : "les hauteurs ( $J 3$ : collines) ne sont que duperie, ainsi que le brouhaha (J3 : tumulte) des montagnes".

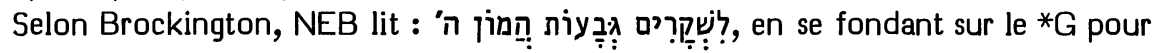
vocaliser le 3e mot.

\section{Origines des corrections :}

Après que Michaelis (Observationes) les ait suggérées, les deux corrections principales ont été explicitées par Graf comme constituant la Vorlage du $* G$ et de la $* V$ : d'abord vocaliser le 3e mot en état construit (en insérant éventuellement un 'waw' auparavant), puis éliminer le 'mem' prépositionnel avant le 2e mot (éventuellement en se contentant d'omettre le dagesh du 'gimel' et en considérant ce mot comme le

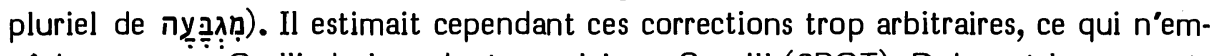
pêcha pas von Orelli de les adopter, suivi par Cornill (SBOT), Duhm et les apparats de HSAT34, BH23S et Cent.

\section{Les témoins anciens :}

De Rossi (Scholia) a trouvé la vocalisation ñ en 36 de ses manuscrits, dans l'édition princeps (1488) de la Bible hébraïque et en marge de celle de Félix de Prato. Cependant Radaq, en son commentaire, précise que le 'hé' de ce mot porte ici un qames, ce qui empêche d'y voir un état construit qui requerrait un ḥatef patah. Norzi confirme que, quoique beaucoup de mss portent ici un hatef patạ, il est écrit, dans la marge d'un ms de Tolède, que la vocalisation correcte en un ms soigné est avec qameṣ. Cette note figure en effet dans le ms de Rossi 782 que Norzi a possédé et qui a été copié à Tolède en 1277. D'ailleurs la vocalisation avec qameș se trouve dans les mss du Caire, d’Alep et de Leningrad, ainsi que dans les éditions Brescia 1494, Félix de Prato (texte) et Ben Hayim.

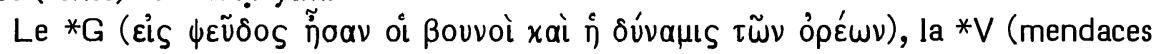

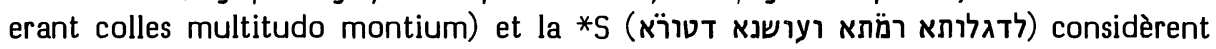
toutes trois המון comme un état construit et n'ont pas lu de 'mem' prépositionnel avant גבות. Il en va de même de AqSym pour $\pi \lambda \tilde{\eta} \theta$ os ỏpéwv.

Le *T offre ici une paraphrase ("C'est en vain que nous avons célébré un culte sur les collines et sans profit que nous nous sommes agités sur les montagnes") qui atteste une préposition avant le mot המון גבות et qui laisse caractère d'état absolu.

\section{Choix textuel :}

Sur ces deux points, le comité a attribué la note " $C$ " à la lectio difficilior du $* M$. En effet les facilitations syntaxiques des versions sont 'dans l'air'. Elles ont été adop- 
tées spontanément par la traduction des Prédicants de Zurich: "Es fallend die bühel und aller hoch pracht der bergen" et Zwingli : "Mendaces sunt colles et pompa montium"; alors que la traduction très littérale d'Arias Montano aboutit à l'inintelligible : "in vanum a collibus, turba, montibus".

Interprétations proposées :

De Dieu a proposé de prendre ici רִִ̣ comme un infinitif hifil de Nous verrons en Ps 75,7 un cas où cette interprétation est tentante. Mais ici le parallèle avec תư suffisamment caractéristique pour que nous options pour le sens "montagnes".

Ce parallélisme a poussé Nägelsbach à comprendre מגבעות (lu sans dagesh dans le 'gimel") comme signifiant ici "collines". Mais mieux vaut garder au 'mem' initial sa valeur de préposition et lui reconnaître éventuellement une certaine double fonction à l'égard du parallèle "montagne".

Nägelsbach a, par contre, peut-être raison de considérer

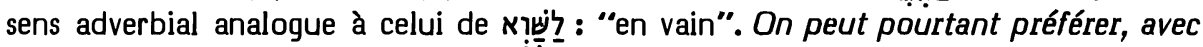
Venema, reconnaître une valeur emphatique au "lamed" : “ce n'est que pur mensonge, ce qui vient des collines".

Montagnes et collines évoquent ici les hauts-lieux (cf, Ez 20,28) et les célébrations cultuelles qui s'y déroulent (cf. l'expression "manger sur les montagnes" en Ez 18,6 etc.). D’ailleurs le mot Il semble être employé ici à la fois comme une évocation de l'enthousiasme cultuel et comme ayant une nuance péjorative qu'il tient de sa mise en parallèle avec "pur mensonge". Le fait qu'il soit à l'état absolu engage en effet à en faire le prédicat d'une seconde phrase nominale très brève : "c'est du brouhaha, les montagnes (c'est-à-dire : le culte qui se déroule sur les montagnes)."

\section{4,2 בו ... ובו $[A]$}

\section{Options de nos traductions :}

En 2b, ובו sont traduits par RSV, RL, TOB et J3 en respectant les pronoms suffixes de la 3 e pers. m. sg. du *M.

J12 et NEB (selon Brockington) conjecturent בובך et traduisent : "en toi ... en toi" et "like you and in you".

\section{Origine de la correction :}

Estimant, avec le *T et Rashi, que l'antécédent du pronom suffixe 3e pers. m. sg. n'est pas le Seigneur, mais Israël, Leiste en a conclu que le prophète aurait dû écrire

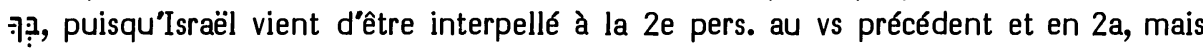
que le prophète s'est permis, comme souvent, un changement soudain de personne. Cependant, cette correction a été proposée par Grätz (Studien 60) et adoptée par Volz (Studien) et par Rudolph ainsi que par les apparats de HSAT4, BH3S et Cent. 
Les témoins anciens :

Tous les témoins attestent les suffixes $3 e$ pers. m. sg.

\section{Choix textuel :}

Il s'agit donc là d'une conjecture facilitante, motivée par une exégèse qui veut assimiler à Gn 22, 18; 26,4.

Le comité a attribué la note " $A$ " à la leçon du *M.

\section{Interprétation proposée :}

Il serait peu naturel que ces suffixes se réfèrent à Israël. Il est plus vraisemblable qu'ils portent sur le tétragramme qui vient d'être mentionné en 2a. D’ailleurs, le verbe

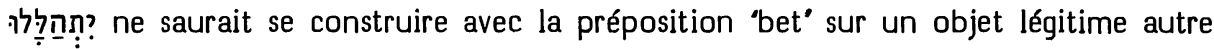
que le Seigneur.

Si les serments qu'Israël prononce au nom de YHWH sont marqués du signe de la vérité et de la justice, alors les nations acquerront de l'estime pour le Seigneur et seront saisies d'enthousiasme pour lui. On peut donc traduire : "alors les nations feront appel à lui pour se bénir, c'est de lui qu'elles se loueront".

4,16A cf. p. 479.

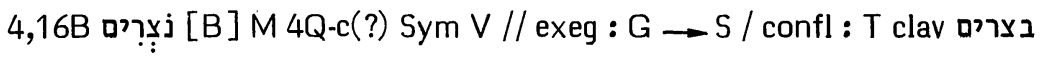

Options de nos traductions :

Selon le *M, le vs 16 porte: "Avertissez les nations, allons! proclamez contre Jérusalem que des ذَבְרִ viennent d'un pays lointain, et ils ont poussé leur cri contre les villes de Juda". mis".

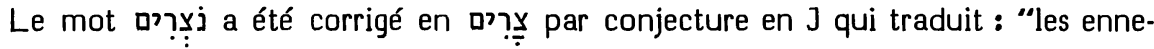

Selon Brockington, NEB lit, avec le *G : נִצִרִים quand elle traduit : "hordes of invaders".

Sans rien noter, RSV traduisait : “Besiegers", RL : "Belagerer" et TOB : “Des assiégeants".

Origines des corrections :

Après que Schleusner (sur Michaelis, Observationes) ait mis en lumière le lien étroit que les versions anciennes établissent entre צור et וצר e le conjecture a été adoptée par Oort, Condamin, Volz, Nötscher, Rudolph, Weiser, Bright et les apparats de HSAT4 et BH3S.

Quant à la correction vocalique de NEB, elle repose sur une proposition de Driver (100).

Les témoins anciens :

4Q-c semble lire ici la leçon du *M. 
En traduisant par ovotpoyá, le ${ }^{*} G$ a rattaché ce mot à la racine צר à laquelle ce mot correspond en 0 s 4,19; 13, 12, alors que les verbes se correspondent en $\operatorname{Pr} 30,4$.

La leçon du *M a été lue ici par Sym (נטורה) et par la *V (custodes).

En traduisant: "des rassemblements de peuples" (כנכא דעמ̈מ), la *S semble

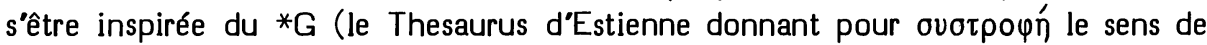
"rassemblement d'une foule séditieuse"). Selon Grotius, Théodotion aurait lu ici בצרים (vindemiatores). Là-dessus, Vogel note que cette leçon de Th est de beaucoup préférable à celle du *M. Mais Clericus a eu raison de mettre en doute l'attribution à Théodotion de cette leçon qu'aucune édition des Hexaples ne mentionne.

C'est du *T que Grotius doit vouloir parler. Celui-ci porte en effet ici משרית בוצרים avec abet'

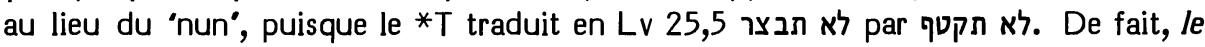
*T semble donner ici une conflation de cette leçon avec celle de la *S.

\section{Choix textuel :}

Il est intéressant de noter que Rashi expliquait ce mot comme "ceux qui mettent le siège (מצור) contre eux". Tous les glossaires donnent en premier le sens de "assié-

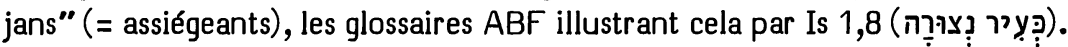

Il faut pourtant mentionner à titre de curiosité une exégèse qui a eu un certain succès au moyen âge. Abulwalid (Luma 273,7s) rapporte : "on dit que cela signifie 'des gens de Nebucadneșar" ". Radaq raconte en ses Shorashim que son père a accepté cette exégèse et lui-même semble faire de même en son commentaire, alors que Moshé ben Sheshet, Judah ibn Balaam et Tanḥum Yerushalmi se contentent de la mentionner. Menahem de Posquières l'a réfutée en disant: “Cela me semble étrange de désigner des gens à partir d'un nom propre. Je ne trouve cela dans l'Ecriture que lorsque ce nom est déjà un nom de groupe, comme זבולוני ,זולון."

Cependant, le plus ancien exégète dont un commentaire sur ce livre nous ait été conservé, Yéfet ben Ely, traduit ici "des gardes" et explique qu'ils cernent les villes et se déploient dans la campagne pour éviter qu'un homme d'entre les assiégés s'en échappe.

Is $1,7 \mathrm{~s}$ montre que l'on dévaste en même temps tout l'arrière-pays pour isoler la ville ainsi cernée. Ce guet de l'ennemi cernant une ville $(\mathrm{Jr} 1,15)$ et mettant à mort ceux qui tentent d'en sortir $(5,6 ; 6,25)$ est une réalité d'expérience pour les contemporains de Jérémie; le נִּרוּ (Ez 6,12) devant s'attendre à mourir de faim.

Si Is 1,8 nous montre que le verbe נצר est devenu en ce sens un verbe technique, il n'y a pas besoin de faire appel à un autre sens de base que celui de "garder", puisque son synonyme שמר est employé en 2 S 11,16 au sens de "assiéger", justifiant ainsi l'exégèse de Rashi et des glossaires.

La mention des "gardiens des champs" en 4,17 nous engage ici à ne pas quitter la leçon du *M à laquelle le comité a attribué la note " $\mathrm{B}$ ".

Interprétation proposée :

On peut donc traduire par "assiégeants" en expliquant éventuellement en note qu'il s'agit de troupes qui ne viennent pas précisément pour donner l'assaut à la ville, mais pour la cerner et l'isoler. 


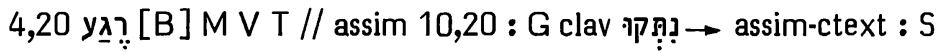

Options de nos traductions :

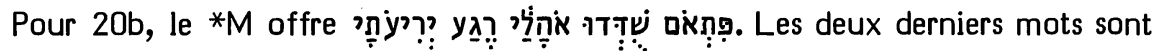
traduits par RSV : “my curtains in a moment", par $j$ : "mes abris, en un clin d'oeil", par TOB : "en un instant, mes tentes".

A la suite de Luther, RL ne traduit pas l'avant-dernier mot, se contentant d'avoir rendu le premier par "plötzlich".

Selon Brockington qui se réfère à la $* S$, NEB vocalise y.]̣ quand elle traduit : "their covering torn to shreds".

Origine de la correction :

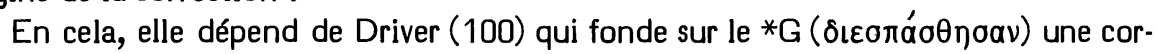
rection en traduisant elle aussi par un verbe, le laisse au singulier en cette situation où il précède un sujet pluriel; ce que la syntaxe permet en effet.

Driver se doute-t-il que Spohn avait déjà suggéré pour le ${ }^{*} G$ la Vorlage qu'il propose?

Les témoins anciens :

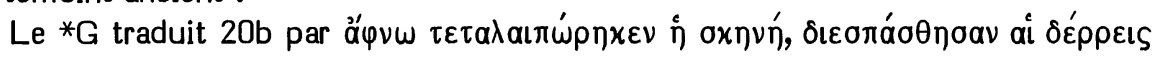
Hov.

Il est frappant de noter qu'en 10,20 le * ${ }^{*}$ donne une traduction très semblable :

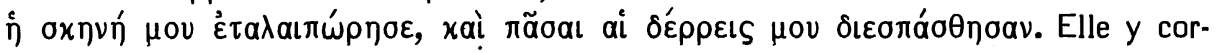

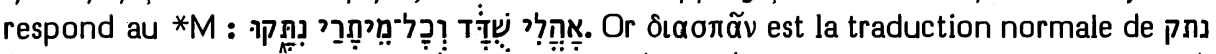

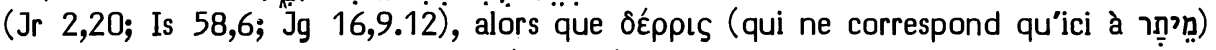

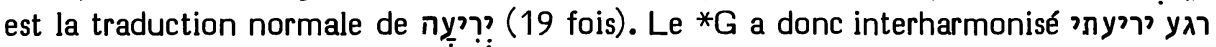
et מיתרי נתקו, si bien qu'en 4,20 ce n'est pas (ou quelque leçon analogue) qu'il traduit, mais c'est la traduction de נתקר de 10,20 qu'il introduit.

La ${ }^{*} S$ a pu emprunter au ${ }^{*} G$ l'idée de traduire par un verbe. Elle a choisi ce verbe en fonction du contexte.

La*V (subito) et le *T (זמן ח (זא ) traduisent le *M.

Choix textuel :

Le ${ }^{*} \mathrm{G}$ ne pouvant attester ici une Vorlage autonome, nous n'avons pas de variante qui puisse entrer en concurrence avec le ${ }^{*} M$ que le comité a d'ailleurs jugé satisfaisant en lui attribuant 1 " $A$ ", 4 "B" et 1 "C $\mathrm{C}$ ".

Interprétation proposée :

On peut traduire: “Soudain mes tentes sont dévastées, mes abris en un clin d'oeil." 
Options de nos traductions :

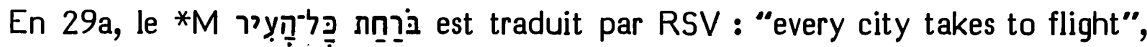
par RL : “Aus allen Städten werden sie ... fliehen", par TOB : "toute ville prend la fuite" et par J3: "toute la ville est en fuite".

A la place du 3e mot, J12 lisaient avec le *G : "le pays". Selon Brockington,

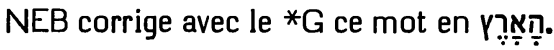

Origine de la correction :

Michaelis a traduit ici "fliehet das ganze Land". En OEB, il explique que l'accord du ${ }^{*} G$ et du ${ }^{*} T$ sur cette leçon lui donne un poids au moins équivalent à celui de la leçon du *M.

L'option de Michaelis a été suivie par Ewald, Hitzig, Graf, Grätz, Giesebrecht, Cornill, Oort, Duhm et requise par les apparats de SBOT, HSAT34, BH23S et Cent.

Les témoins anciens :

Le *M a ici l'appui de la *V (civitas) et de la*S (קריתא).

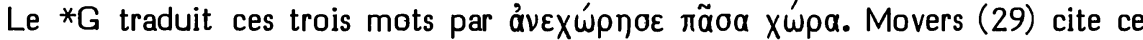
cas avec 5 autres où il soupçonne le $* M$ d'avoir assimilé un mot à un autre que lui offrait le contexte proche, alors que le ${ }^{*} G$ nous aurait conservé ici la dissymétrie originelle du texte.

Le *T porte ici יתבי ארעא selon Ben Hayim et selon la polyglotte de Londres. Mais tous les mss cités en l'édition Sperber (auxquels s'ajoute l'Urbinates 1) s'accordent avec l'édition princeps de Félix de Prato et la polyglotte d'Anvers pour lire ici יתבי קרתא qui a les plus grandes chances d'être la leçon originale du *T.

\section{Choix textuel :}

Notons que, dans la tradition textuelle du ${ }^{*} \mathrm{~T}$, il est possible que la variante interne ארy soit issue d'une assimilation aux deux occurrences de ce mot dans les deux vss précédents.

Quant au *G de Jérémie, notons qu'on n'y rencontre jamais le mot "ville" correspondant à une leçon "terre" du *M. Mais on y retrouve plusieurs autres fois le mot

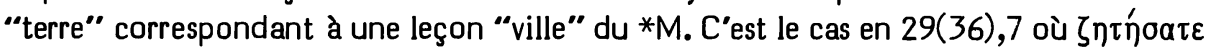

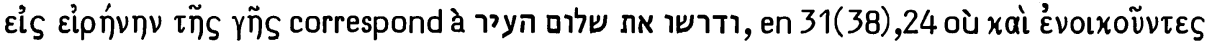

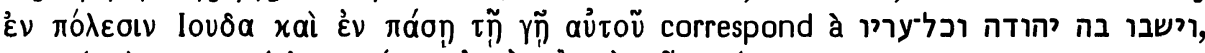

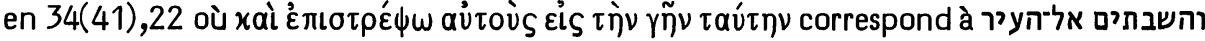

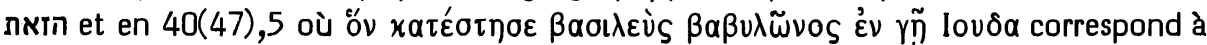
אשר הפקיד מלך־בבל בערי יהודה (4)

Assez souvent, $c^{\prime}$ est seulement une partie de la tradition textuelle du *G (incluant le ms Alexandrinus) qui a "terre" là où le *M a "ville". C'est le cas en 32(39),29; 37(44),8; 39(46),16 par exemple.

Si le traducteur grec de Jérémie n'éprouve pas de difficulté à faire correspondre $\gamma \tilde{\eta}$ à

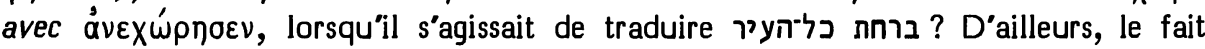


qu'il ait choisi ici le mot $\chi w ́ p a$, alors qu'en 4,20.23.27.28 il traduisait par $\gamma \tilde{\text { ñ }}$ peut nous servir d'indice qu'il n'a probablement pas lu ici en sa Vorlage.

A propos de la leçon du ${ }^{*} M$, il faut reconnaître que la répétition de כל־העיר dans le même vs (au lieu de la complémentarité habituelle entre "pays" et "ville") est, à première vue, surprenante. Mais, si l'on réfléchit qu'il sera dit en $29 \mathrm{~b}$ que chaque ville est abandonnée et que personne ne les habite plus, on comprend qu'il faut qu'il ait été dit auparavant que l'on a fui les villes, et non le pays, d'autant plus qu'en 29a, il a été encore précisé où l'on s'est enfui : vers les abris naturels des grottes, des taillis et des rochers, et non pas à l'étranger. Jérémie appelle ici "villes" des petites agglomérations démunies de remparts qui puissent leur permettre de soutenir un siège. Nombreuses ont été les invasions qui ont amené les gens de Juda à déserter leurs "villes" et à leur préférer l'abri des rocs et des grottes.

Le comité a considéré ici la leçon "ville" comme très probablement primitive et lui a attribué la note " $B$ ".

Interprétation proposée :

Dans 29b le suffixe כל־העיר et ąֶe reprend donc à comprendre cette expression, malgré l'article, au sens de "toute ville"; à moins qu'on ne comprenne ici ce singulier en collectif : "tout ce qui existe en fait de ville". On peut donc traduire : "toute la population des villages est en fuite".

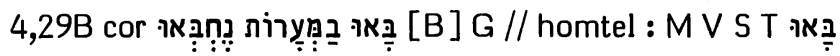

Options de nos traductions :

Après avoir dit que toute la population des villages est en fuite, le *M nous dit

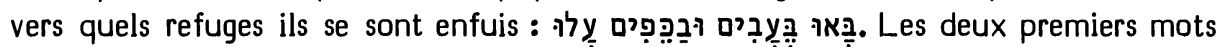
sont traduits par RSV : "they enter thickets", par J: "on s'enfonce dans les taillis", par RL : "(werden sie....) und in die dichten Wälder laufen" et par TOB : "on pénètre dans les taillis".

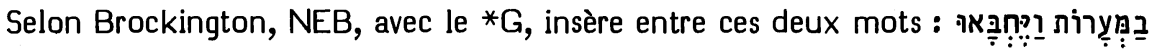
pour traduire : "they creep into caves, they hide in thickets".

Origine de la correction :

Workman (cité par Köhler, Beobachtungen 19) semble avoir été le premier à suggérer que le ${ }^{*} \mathrm{M}$ a été ici victime d'un homéotéleuton. C'est Volz (Studien) qui a proposé pour les mots omis la leçon בette leçon a été adoptée ensuite par Rudolph, Steinmann, Weiser, Bright et par les apparats de BH3S et Cent, en mettant le verbe à l'inaccompli inverti.

Les témoins anciens :

Le *M a été lu ici par la *V (ingressi sunt ardua), la *S (עלו בלובא) et le *T (לוע) (למערק בחרשיא

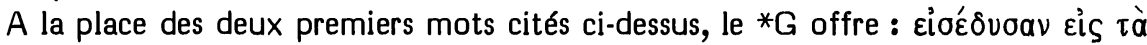

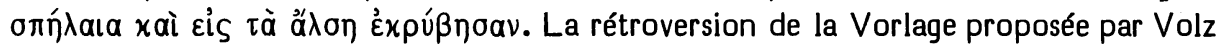


semble exacte. En effet, le verbe חבא ne réapparaît qu'une fois en Jérémie : en 49,10 sous la forme נִח que la mm (Weil $\$ 2035$ ) interprète comme se rattachant à cette racine. Or, le *G $(29,11)$ l'y traduit par $x \rho \nu \beta \tilde{\eta} \nu$ al. Quant au substantif ne réapparaît qu'une fois en Jérémie : en 7,11 où Concluons de cela que si nous nous fondons sur des parallèles pris dans le ${ }^{*} G$ de Jérémie, la rétroversion de Volz est fort vraisemblable et que son verbe à l'accompli est mieux en place entre deux accomplis que ne le serait l'inaccompli inverti de Rudolph.

\section{Choix textuel :}

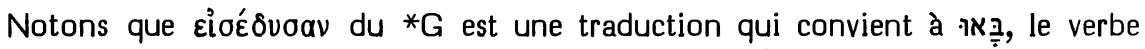

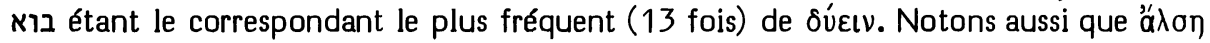

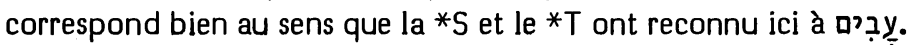

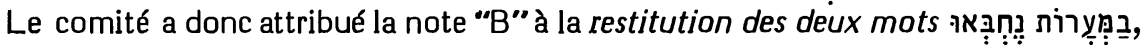

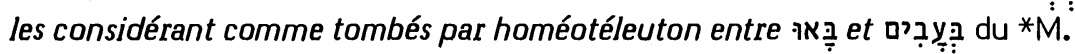

Interprétation proposée :

Il aurait été étonnant que les grottes n'aient pas été mentionnées ici comme les lieux de refuge les plus traditionnels (cf. en Is 2,19 l'expression ובאו במערות צרים). On pourra donc traduire : "On a pénétré dans les cavernes, on s'est caché dans les fourrés et on est monté sur les rochers."

\section{4,30 שדוד / שדודה /B] M T // transl : Th Aq(?) V S clav-elus : G om}

\section{Options de nos traductions :}

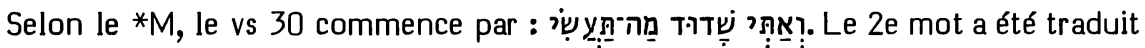
par RSV : "O desolate one", par RL : "du Ueberwältigte", par J3 : "la dévastée". Ce mot est omis par J12, NEB et TOB qui se fondent sur son absence dans le ${ }^{*}$ G.

Origine de la correction :

Cappel (Notae 521) a fait remarquer cette omission du ${ }^{*} \mathrm{G}$.

Cornill, tout en notant la difficulté syntaxique posée par ce participe de forme masculine, jugeait en SBOT qu'il faut le conserver. Dans son commentaire, il l'omet comme métriquement inacceptable, omission dans laquelle il est suivi par Schmidt, Nötscher, Rudolph, Penna, Weiser, Bright et par les apparats de HSAT34, BH23S et Cent.

Les témoins anciens :

Le ${ }^{*} G$ ancien est seul à omettre ce mot.

La leçon du *M est traduite littéralement par le *T (מתבזוא).

Les autres versions l'ont traduite par un féminin : Th (d'où provient l'ajoute des

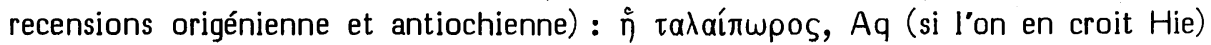
et la *V : "vastata", la*s : בזיזתא. 


\section{Choix textuel :}

Cette mise au féminin est une facilitation translationnelle.

La difficulté syntaxique causée par la présence de ce mot masculin en ce contexte peut suffire à expliquer son omission par le *G. Mais, même si l'on devait conclure qu'il était absent de la recension I, cela ne nous autoriserait pas à l'omettre dans la recension II dont tous les témoins l'attestent. Aussi le comité a-t-il attribué la note "B" à la leçon du *M.

\section{Interprétation proposée :}

Pour expliquer la forme masculine du participe, Ewald (Lehrbuch 457s) a fait remarquer qu'en arabe, certains adjectifs de la forme qatôl demeurent aussi au masculin avec des substantifs féminins. Se doutait-il que Tanhum Yerushalmi avait déjà apporté la même explication dans son commentaire?

Hitzig, Keil et Graf préfèrent considérer ce participe comme affectant le verbe qui le suit et prenant donc valeur d'adverbe, ce qui expliquerait qu'il demeure invariable.

Luzzatto, subtilement, note que אתי doit être ici féminin parce que ce pronom fait entrer en scène la femme parée dont le comportement est décrit dans la suite du vs, alors que שדוד doit être masculin, parce que ce participe passif résume l'état du peuple tel qu'il a été évoqué au vs 29 . Or la femme de la parabole symbolise, au vs 30 , l'état du peuple au moment où le prophète lui parle, c'est-à-dire au moment où il met encore toute sa coquetterie à s'attacher des amants, alors que ce n'est qu'au vs 31 que cette femme sera présentée dans l'état où l'oracle du vs 29 voyait déjà le peuple : dévasté et sur le point de succomber. Il faudrait donc sous-entendre en ce début du vs 30 : “Et toi (femme adultère vouée à devenir ainsi peuple) dévasté, que vas-tu faire..."

On pourrait traduire : "Et toi, vouée à cette dévastation"; (alors que, si le participe était au féminin, on devrait comprendre : "et toi, une fois dévastée", ce qui serait, ici où il est masculin, un contre-sens).

\section{נאם יהוה 5,2 ואם}

\section{Options de nos traductions :}

RSV, RL, NEB et TOB achèvent 5,1 et commencent 5,2 comme le fait le *M.

$\mathrm{J}$ ajoute : "déclare (J3 : dit) Yahvé" à la fin de 5,1, disant que ces mots, présents dans le *G, ont été omis par le *M.

\section{Origine de la correction :}

Cette ajoute, fondée sur le ${ }^{*} \mathrm{G}$, a été demandée par Cornill, disant que le rythme l'exige. Il a été suivi par Rudolph, Bright et les apparats de Cent et BHS.

Volz (Studien), suivi par Schmidt, adopte cette leçon à la place de ואם par quoi commence 5,2. 
Les témoins anciens :

Le passage du vs 1 au vs $2 s^{\prime}$ opère dans la $* V$, la $* S$ et le $* T$ comme dans le $* M$.

C'est à la place de ואם du *M que le *G donne $\lambda \varepsilon ́ \gamma \varepsilon l$ xúplos.

\section{Choix textuel :}

Cappel (Notae 521) et Schleusner (Opuscula) avaient estimé que le *G a lu אמר au lieu de ואם, puis a rattaché ce mot au vs précédent en le glosant.

Rudolph, lui, a pensé que נאם יהוה avait été omis, par étourderie, avant ואם Mais cette explication ne peut tenir, à moins d'admettre que le ${ }^{*} G$, de son côté, a omis ואם pour des motifs non précisés.

Si l'on considère les cinq premiers chapitres de Jérémie, on y note un cas $(3,10)$ où le *M a נאם יהוה sans que rien n'y corresponde dans le *G, mais (en plus de ce cas-ci) quatre cas $(1,17 ; 2,2.17 .19)$ où c'est le ${ }^{*} G$ qui atteste $\lambda \varepsilon ́ \gamma \varepsilon l$ xúplos sans que le *M ne porte נאם יהוה (expression à laquelle ces mots correspondent en cette partie du livre).

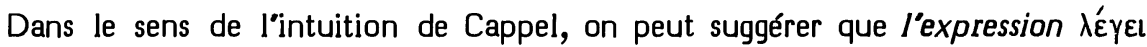
xúplos a été suggérée ici au *G par le mot נאם lu. En effet, beaucoup d'exégètes ont senti l'utilité d'exprimer par une glose que c'est une déclaration du Seigneur que 5,1 contient. Ainsi Grätz propose de restituer au début de ce chapitre : “Et une parole du Seigneur me fut adressée en ces termes". C'est une restitution analogue que le *G a tentée en fin de 5,1.

Le comité a attribué au *M la note " $\mathrm{B}$ ".

Interprétation proposée :

Pour mettre en valeur l'oracle qui commence en 5,1, la tradition représentée par les mss du Caire, d’Alep et de Leningrad place ici le début d'un seder.

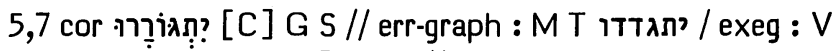

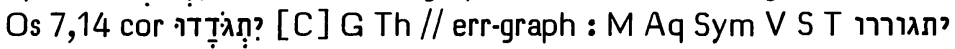

\section{Options de nos traductions :}

$1 /$ En Jr 5,7b, après : "et je les ai rassasiés et ils ont commis l'adultère", le *M

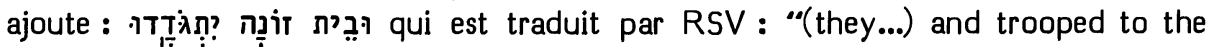
houses of harlots", par RL: "(sie...) und liefen ins Hurenhaus", par TOB : "ils se bousculent chez la prostituée" et par J3 : "ils se précipitaient à la maison de la prostituée".

Disant s'appuyer sur 2 mss hébreux et le ${ }^{*} G, J 12$ traduisaient : "ils hantaient la maison de la prostituée". NEB traduit : "(they...) and haunted the brothels", Brockington disant qu'elle lit avec 2 mss deux 'resh' à la place des deux 'dalet' du verbe. $\mathrm{J12}$ estiment que le verbe du *M signifie "se faisaient des incisions". NEB le traduit par "and gashed themselves in".

2/ En Os 7,14, après avoir dit : "quand ils se lamentent sur leurs couches", le *M ajoute : עִלִ 
Selon Brockington, NEB corrige le verbe en qu'elle traduit : "(for all their ... and ) gashing of themselves". J dit corriger de même quand elle traduit : "ils se lacèrent". Sans mentionner de correction, RSV traduit : "they gash themselves", RL : "Sie ritzen sich wund" et TOB : "ils se font des incisions". J attribue au *M le sens de : "ils habitent (J3 : résident) en hôtes", et NEB celui de : "rolling about".

Origines des corrections :

$1 /$ En Os 7,14 où toutes nos traductions corrigent, Pasteurs avait traduit : "ils se deschiquetent" en se référant à $1 \mathrm{R} 18,28$ où on a deux 'dalet'. Aussi Rivet (cité par Pole) avait-il diagnostiqué que le *G a lu deux 'dalet' au lieu des deux 'resh'. Puis Doederlein (sur Grotius) a opté pour cette leçon, suivi par Michaelis (OEB XVIII 78), ajoutant à cela le témoignage de mss de Kennicott. La plupart des exégètes ont fait de même, ainsi que les apparats de HSAT234, BH23S et Cent.

2/ En Jr 5,7, c'est Michaelis (Supplementa 265 et Observationes) qui, d'abord en hésitant, puis plus fermement (après que de Rossi ait publié ses Variae Lectiones) a proposé la correction des 'dalet' en 'resh'. Il a été suivi en cela par Grätz (Studien 98), Giesebrecht, Oort, Duhm, Cornill, Volz, Nötscher, Rudolph, Steinmann, Bright. La correction est requise par les apparats de HSAT34, BH23S.

Les témoins anciens :

$1 /$ en Os 7,14, de Rossi signale 5 mss et la première main de 7 autres, ainsi que l'édition princeps des Prophètes (Soncino 1486) qui lisent la leçon avec deux 'dalet'. Comme Michaelis (OEB XVIII 78, note) le fait remarquer, il faut ajouter à cela le 2e ms de Königsberg, selon Lilienthal (350).

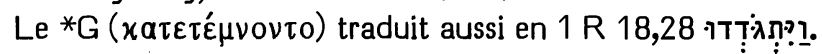

Th a suivi le ${ }^{*}$ G. Aq (מתנתפין) et Sym (מתגוררין) ont tous deux vu ici la racine גרר (= tirer), Sym lui donnant ici le même sens spécifique que la *V (ruminabant) lui reconnaîtra.

La *S (מתכתשין) a cru reconnaître ici la racine araméenne גרין (= irriter, provoquer).

Le *T (דהוו כנשין) a lu le *M.

2/ en Jr 5,7, de Rossi a attaché une grande importance au fait que deux mss espagnols très soigneux appuient la leçon avec deux 'resh'.

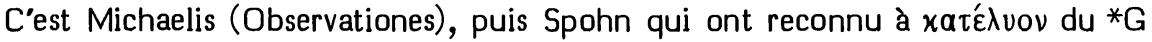
une Vorlage identique à cette variante.

La *S (אתכתשו), lisant de même, a pris la même option qu'en Os 7,14.

La traduction de la *V (luxuriabantur) semble motivée par le contexte.

Le *T (מסתיעין) a dérivé la leçon du *M de

Choix textuel :

La seule signification bien attestée pour le hitpoél de גד est "se faire des incisions rituelles" en signe de deuil (Dt 14,1; Jr 16,6; 47,5) ou pour attendrir Dieu (1 R 18,28; Jr 41,5; Mi 4,14). Quant au hitpolél de גר, 1 R 17,20 lui donne clairement le sens de 
"être reçu habituellement chez quelqu'un à titre d"hôte". Or les contextes rendent assez clair que c'est cette seconde expression que l'on attend en Jr 5,7, alors que c'est la première que la phrase précédente appelle en Os 7, 14.

Une liste de mots figurant une fois dans la Bible avec 'dalet' et une fois avec 'resh' est considérée par Ginsburg (Massorah IV 254s) comme l'une des plus anciennes parties de la massore. Elle figure dans la Okhla de Paris et dans celle de Halle ( $\$ 7)$, dans le ms des Prophètes de Petrograd (sur Is 4,4 et sur Jr 5,7). Elle a été éditée dans la massore finale de la Bible rabbinique de Félix de Prato et dans celle de Ben Hayim (au début de la lettre 'dalet'). Or, en tous ces états, elle contient, en les opposant, nos deux cas de Jr 5,7 et Os 7,14.

Il est frappant de noter que la cohérence des deux contextes et le témoignage du ${ }^{*} G$ nous engageraient à inverser l'opposition de ces deux cas, plaçant en Jr 5,7 la forme caractérisée par 'resh' et en Os 7,14 la forme caractérisée par 'dalet'. On peut donc se demander si la liste massorétique en question, dans un de ses états anciens du type de ceux en lesquels elle s'offre dans le ms de Petrograd (où les mots en question ne sont accompagnés d'aucun contexte), n'a pas eu pour effet (comme nous l'avions noté pour une autre liste en CT1, 332) de stabiliser une double déformation textuelle. Une confusion de 'dalet' avec 'resh' ayant eu lieu dans la tradition textuelle prémassorétique en l'un des deux cas, la massore en question, employée à contre-sens aurait amené à inverser la dissymétrie qu'elle entendait maintenir, c'est-àdire à déformer en sens inverse l'autre cas.

Aussi est-il apparu au comité que la massore susdite nous engage à corriger ces deux cas à la fois, rendant ainsi sa portée véritable à l'opposition qu'elle mentionne. C'est pourquoi le comité a opté, dans les deux cas, pour la leçon du *G, lui attribuant, en Jr 5,7, 4 " $C$ " (contre 2 " $C$ " à la leçon du *M) et, en Os 7,14, 4 "C" (contre 1 " $C$ " au *M).

En chacun de ces deux cas, les quelques mss aberrants du *M semblent témoigner de déformations secondaires, plutôt que préserver des vestiges de la leçon originale.

Interprétations proposées :

En Jr 5,7 : "ils sont les hôtes habituels de la prostituée".

En Os 7,14 : "pour du blé et du vin nouveau ils se lacèrent".

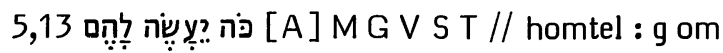

Options de nos traductions :

Ces trois mots sont traduits normalement par RSV, RL, TOB et J3.

$J 12$ transposaient ces mots après les six premiers mots du vs 14 .

NEB les omet en disant se fonder sur le ${ }^{*} G$.

Origines des corrections :

La transposition effectuée par $\mathrm{J12}$ a été proposée par Duhm et adoptée par Volz (Studien), Nötscher, Rudolph, Penna, Steinmann, Weiser et Bright ainsi que par les apparats de $\mathrm{BH} 3 \mathrm{~S}$ et Cent.

L'omission a été proposée par Cornill (SBOT) et adoptée par Condamin et Schmidt, ainsi que par les apparats de HSAT34 et BH2. 
Les témoins anciens :

Se fondant sur l'édition Sixtine du ${ }^{*} G$ (reprise par la polyglotte de Londres qui y ajoute en apparat les variantes de l'Alexandrinus), Clericus notait que ces trois mots sont absents dans le *G "à moins que ses manuscrits ne soient mutilés". Il notait toutefois leur présence dans l'édition d'Alcala (et dans la polyglotte d'Anvers qui en dérive), mais il estimait que, “comme bien d’autres choses, ils sont nés de la cervelle des gens d'Alcala".

Spohn retenait ces mots en notant leur présence en Syh sans astérisque (c'est-à-dire comme faisant partie du ${ }^{*} G$ ancien). Movers (22), lui, y voyait l'une de ces nombreuses phrases dont l'absence dans le *G montre qu'il s'agit d'ajoutes rédactionnelles du *M.

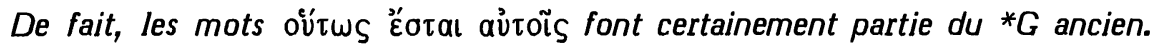
En effet, quoique le ms Alexandrinus et quelques autres témoins les aient omis par homéotéleuton, ils sont présents dans le Vaticanus, le Sinaiticuś et le papyrus Chester Beatty 966 (fin du IIe ou début du IIIe siècle) ainsi que le précise Kenyon dans son édition (p. 28, note), c'est-à-dire dans les trois plus anciens témoins du *G.

Tous les autres témoins (la ${ }^{*} V$, la ${ }^{*} S$ et le ${ }^{*} T$ ) attestent d’ailleurs leur présence.

\section{Choix textuel :}

Cet homéotéleuton étant seulement un accident intérieur à la tradition textuelle $d u{ }^{*} G$, le comité a attribué la note "A" à la leçon du *M.

\section{Interprétation proposée :}

Il est possible que nous ayons affaire à une glose : "qu"il leur soit fait ainsi" exprimant l'accord d'un lecteur : que le glaive et la famine frappent ceux qui ne croient pas à la parole du Seigneur ou bien qu'ils frappent les faux prophètes ! (selon l'interprétation que l'on adopte pour le lien du vs 13 avec le vs 12), ou encore : que ces faux prophètes deviennent semblables au vent (vs 13a)!

En tout cas, cette glose serait antérieure à l'achèvement de la rédaction $I$ et Schuttermayr (Beobachtungen 228ss) estime qu'il peut s'agir d'une digression due à Jérémie lui-même.

\section{5,16 אשפתו [B] M ThAq V T // abr-elus : G om 16a / assim Ps 5,10 : S}

\section{Options de nos traductions :}

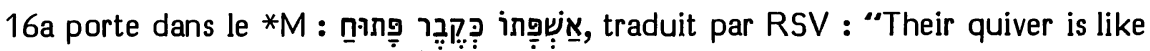
an open tomb", par J : "Son carquois est un sépulcre béant", par RL : "Seine Köcher sind wie offene Gräber" et par TOB : "Leur carquois est un sépulcre béant".

Selon Brockington, NEB corrige avec la *S le premier mot en שְׁפְּ pour traduire : "their jaws are a grave, wide open".

\section{Origine de la correction :}

Michaelis (Observationes) a conjecturé cette correction qui a été adoptée par Ehrlich et mentionnée dans les apparats de BH3S. Driver (Abbreviations 123) entendait décrypter ici le *M en 
Notons qu'ici une conjecture de Volz (אַׁשֶׁר פִיהו) a eu un plus large succès, ayant été adoptée par Schmidt, Nötscher, Rudolph, Penna, Steinmann et Weiser.

Les témoins anciens :

Le ${ }^{*} G$ ancien omet $16 a$. Dans les recensions origénienne et antiochienne, í

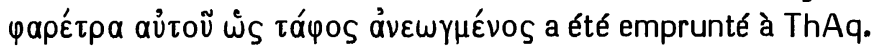

Pour le premier mot, le *M a été lu par la *V (faretra eius) et le *T (בית אזיניה).

קרונם Pour traduire ici par par

\section{Choix textuel :}

Tov (Critique 195) considère 16a comme un élément provenant probablement du prophète Jérémie lui-même, mais que le rédacteur I n'avait pas incorporé, alors que le rédacteur II l'a incorporé.

Il faut cependant noter que $l e{ }^{*} G$ commence à condenser et à simplifier déjà

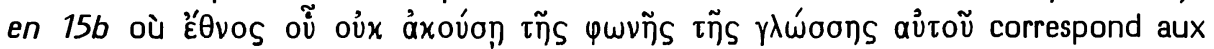
quatorze mots du $* M$. Il semble donc que ce soit la difficulté du $* M$ (représentant en ce cas la rédaction I) qui a amené le ${ }^{*} \mathrm{G}$ à omettre $16 \mathrm{a}$ et qui a amené la $* S$ à faire appel au parallèle de $P s 5,10$ pour le traduire.

Le comité a attribué à la leçon du *M 3 "B" et 3 "A".

\section{Interprétation proposée :}

Michaelis reprochait à la leçon du ${ }^{*} M$ une certaine incohérence : il est difficile de comparer le carquois d'où l'on tire les flèches au sépulcre où tombent ceux qu'elles tuent.

Radaq explique que le prophète compare le carquois à un sépulcre ouvert parce que les flèches qu'il contient mettront à mort tous ceux qu'elles rencontreront et c'est comme s'ils étaient déjà tous ensevelis dans le carquois.

Il est amusant de noter en IntB le contraste entre Hyatt qui considère la conjecture de Volz "more appropriate to the figure involved here" et Hopper estimant que "Their quiver is like an open tomb" is one of the finest of Jeremiah's figures... Nothing could set forth more vividly than this metaphor the sense of the deadliness of the enemies' arrows".

On pourra donc traduire : "Son carquois est comme un sépulcre béant."

\section{5,22 ויתגעשו ולא יוכלו MV T // facil-synt : G S sg}

Options de nos traductions :

Après : “moi qui ai mis le sable comme limite à la mer, frontière définitive qu'elle

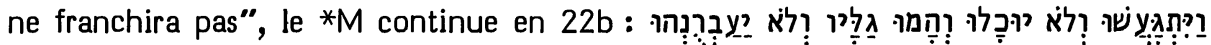
qui est traduit par RSV : "Though the waves toss, they cannot prevail, though they roar, they cannot pass over it", par NEB : "Its waves heave and toss but they are powerless; roar as they may, they cannot pass" et par 33 : "ses flots s'agitent, mais sont impuissants, ils mugissent, mais ne la franchissent pas". 
J12 traduisent: "elle s'agite, impuissante, ses vagues mugissent, mais ne la franchissent pas". TOB traduit: "Elle bouillonne mais reste impuissante, ses vagues peuvent mugir, elles ne la passeront pas". Elles expliquent qu'elles se fondent sur le *G et la *S (à quoi $J 2$ ajoute par erreur la $* V$ ) pour mettre les deux premiers verbes au singulier. RL traduit de même : "Und wenn es auch aufwallt, so vermag es doch nichts; und wenn seine Wellen auch toben, so dürfen sie doch nicht darüber gehen."

\section{Origine de la correction :}

C'est Houbigant qui a conjecturé de mettre au singulier le premier verbe, voyant dans son 'waw' final une dittographie de celui qui précède la négation suivante. La mise au singulier des deux verbes a été requise par les apparats de BH23S, de HSAT34 et de Cent, selon le ${ }^{*} G$ et la $* S$. Cette correction a été adoptée par Schmidt, Nötscher, Rudolph, Penna, Steinmann, Weiser et Bright, la plupart d'entre eux voyant également dans le 'waw' final du second verbe une dittographie de celui qui commence le mot suivant.

Les témoins anciens :

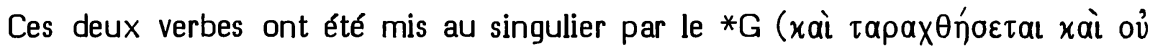

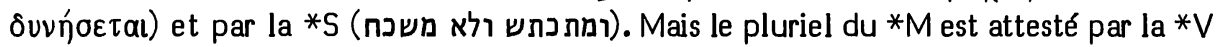
(et commovebuntur et non poterunt) et par le *T (ומטרפין ולא יכלין).

\section{Choix textuel :}

Ce cas n'a pas été soumis au comité.

Il est frappant de noter qu'au XVIe siècle, alors que Pagnini, Brucioli, Münster, Olivetan, Jud, Calvin, Châteillon, Ge, Tremellius, Pasteurs, $\mathrm{KJ}$ respectent la forme plurielle de ces deux verbes, Luther s'accorde avec Prédicants et Zwingli pour les traduire par des singuliers. Il semble donc que le succès de la correction d'Houbigant dans les apparats des Bibles allemandes (HSAT et BH) depuis un siècle tient en partie à la possibilité qu'elle offre de fonder la traduction traditionnelle de Luther.

Ehrlich a fait remarquer que, même en prose, il arrive que l'on doive attendre la phrase suivante pour connaître le sujet de la phrase que l'on vient d'entendre et il cite à ce propos le début du Lévitique : ריקרא אל־משה וידבר יהוה אליו.

On peut constater de la part du ${ }^{*} G$ et de la ${ }^{*} S$ (ainsi que des traductions du $X V I e$ siècle qui ont fait de même) un souci de facilitation syntaxique dans l'assimilation de ces verbes à la forme singulière de celui qui les précède.

\section{Interprétation proposée :}

"Ils ont eu beau s'agiter : ils n'y peuvent rien; ils auront beau mugir, ses flots : ils ne le franchissent pas." 


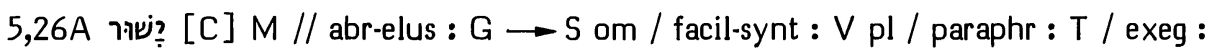
AqSym(?)

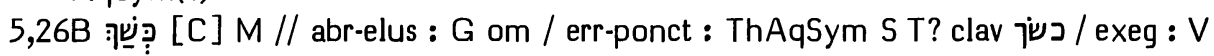

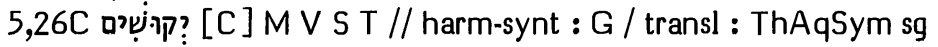

Options de nos traductions :

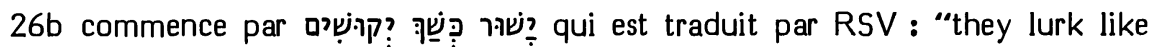
fowlers lying in wait", par RL : "um sie zu fangen, wie"s die Vogelfänger tun", par TOB : "aux aguets comme l'oiseleur accroupi" et par J3 : "ils guettent comme des oiseleurs à l'affût". Seule $\mathrm{J} 3$ précise qu'elle a mis le verbe au pluriel d'après le contexte.

J12 suivent une conjecture qu'elles disent appuyée en partie par Aq et Sym :

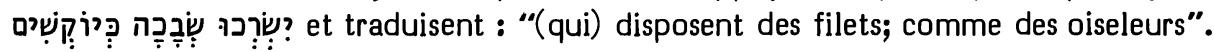

Disant l'hébreu inintelligible, NEB traduit : "who lay snares like a fowler's net",

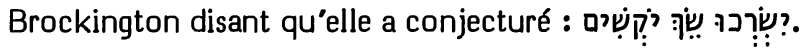

\section{Origines des corrections :}

On pourrait d'abord se demander si RL n'a pas corrigé le *M. C'est improbable, car elle a à peine retouché Luther qui traduisait très librement : "sie zu fahen, wie die vogeler thun mit kloben".

Quant aux éléments qui sont communs à 312 et à NEB, la vocalisation de $26 \mathrm{C}$ a été requise par Volz (Studien) et la correction de $26 \mathrm{~A}$ et de la première lettre de 26B en ?ִuְ:? a été proposée par Rudolph (Text 282). J12 ont adopté l'ensemble de la conjecture de Rudolph telle que l'avaient proposée les apparats de BH3S. La traduction de NEB en est, elle aussi, fort proche. On peut se demander si le témoignage de Brockington sur sa base hébraïque est exact.

Les témoins anciens :

De nos trois mots, le ${ }^{*} G$ n'a retenu que $26 C$ (le plus facile à interpréter) et en a fait le complément d'objet du verbe qui le suit (dont le *M le sépare par un zaqef

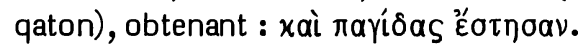

La recension origénienne insère sous astérisque, entre le substantif et le verbe :

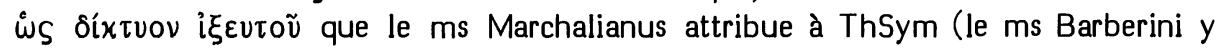
ajoutant $\mathrm{Aq}$, alors que Hie attribue cela à AqSym). Hie paraît indiquer que AqSym ont interprété 26A comme un adjectif dérivé de la racine 2 = être droit. Schleusner

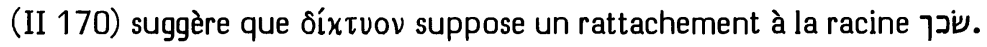

$L a * V$ donne, pour ces trois mots : "insidiantes quasi aucupes / laqueos (ponentes)". Le participe initial y traduit 26A, alors que "quasi aucupes" veut traduire

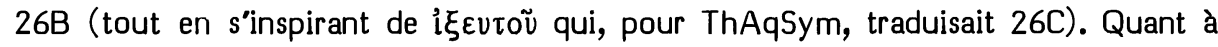
"laqueos", le fait que ce mot soit à l'accusatif, comme complément d'objet de "ponentes" qui le suit, et le fait qu'il commence ici un nouveau colon nous indiquent

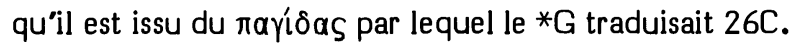

La *S donne pour ces mots : פירא (ואקימו). Ici les deux derniers mots (qu'Ephrem a raison de lire au singulier) traduisent 26B que le traducteur a dérivé de שن . Auparavant, il a suivi les traces du ${ }^{*} G$ en ne traduisant pas $26 A$ et en faisant de $26 \mathrm{C}$ le complément du verbe qui le suit. 
Le *T donne ici : "avec ruse ils répandent le sang innocent, comme le vêtement des chasseurs". Komlosh (Targum 40) a raison de dire que les étymologies auxquelles le targumiste fait appel en cette phrase ne sont pas toujours claires et semblent se fonder sur de simples assonances.

\section{Choix textuels :}

Le comité a estimé que la tradition textuelle n’apporte rien qui soit préférable au ${ }^{*} M$ qu'elle essaie d'interpréter avec plus ou moins de succès. Aussi a-t-il attribué au *M, pour cette phrase, la note "C".

\section{Interprétations proposées :}

26A : Parmi les versions anciennes, la $* V$ est la seule à avoir traduit clairement ce mot (en le mettant au pluriel pour faciliter son articulation syntaxique avec ce qui כנמר על־דרך אַשׁוּר en embuscade, guetter" se retrouve en (Os 13,7) que Roediger (1383a) en a rapproché. Il a été reconnu ici à ce verbe par Yéfet ben Ely, Rashi, les glossaires ADF ("aguettera") BCE ("égardera"), Joseph Qimḥi (Galuy 155, I.1), Radaq (commentaire et Shorashim), Isaïe de Trani, Joseph ibn Nahmias, Abravanel, etc.

Radaq a donné au singulier de ce verbe une valeur particularisante. Keil a précisé que le choix du singulier a été motivé par le fait que la conduite décrite ne s'exerce pas en société mais est l'oeuvre d'individus isolés.

26C : ?קיריש: signifie-t-il "pièges" ou "oiseleurs"? Ont opté pour la première éventualité : le *G (suivi par la*V et la *S), Yéfet ben Ely, Rashi, les glossaires ADEF ("pièges"), BC ("açopements"), Joseph Qimhi (Galuy 64,23), Radaq (commentaire), Isaïe de Trani, Joseph ibn Naḥmias, Abravanel.

Le sens de "oiseleurs" semble bien avoir été reconnu à ce mot par ThAqSym

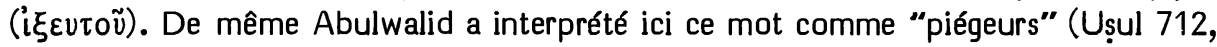
8) ou "chasseurs" (Ușul 712,9 et 748,14). Menaḥem de Posquières et Tanḥum Yerushalmi comprennent de même. Dans ses Shorashim (sur שיק) Radaq a donné comme paradigme à ce mot aִy qu'il a classé (Mikhlol 20a,14) parmi les adjectifs de type qâtûl qui sont équivalents à des participes de type qôțél. Remarquant cette modification dans l'exégèse de Radaq, Pagnini (Thesaurus 918), qui avait d'abord traduit "laqueos", estime donc possible de traduire "aucupes", traduction dans laquelle il sera suivi par Tremellius, puis par Buxtorf (Lexicon), de Dieu, Cocceius, Gesenius (Thesaurus 621b). König (Lehrgebäude II 124s) reconnaît ici à ce mot le sens de "oiseleurs", mais il estime que le shureq est issu du holem de ש̇ịฺ, du fait que la $2 e$ syllabe radicale a été libérée de l'accent par l'ajoute de la désinence du pluriel.

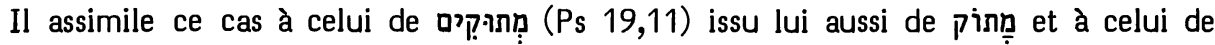
(Is 23,13Q) issu de

26B : L'exégèse de ce mot étant la plus incertaine, nous avons préféré traiter auparavant des deux mots qui l'entourent. Notons d'abord que Menahem ben Saruq classe ce cas dans le 2e sens du bilittère (pour des serpents) ou "prêter avec usure". De même Rashi (qui interprète 26C au 
sens de "pièges") comprend "quand mord le piège que l'on fait pour prendre les chevreuils dans la forêt" et il explique : "quand son pied entre au milieu, il lui mord le pied et le saisit". Les glossaires ACDEF donnent ici : "comme mordement".

Le premier sens que Menahem reconnaissait à ce bilittère était celui de "repos". C'est à celui-ci que David ben Abraham et Yéfet ben Ely rattachent notre cas. Mais David estime que "reposant" est un nom que l'on donne au filet à oiseaux parce qu'il repose à terre jusqu'à ce que l'oiseau tombe sur lui, alors que Yéfet y voit une désignation du guetteur qui est assis à distance, paisible, en silence pour que le gibier ne le détecte pas. Cette interprétation de Yéfet sera reprise par Menahem de Posquières et Isaïe de Trani, le premier précisant qu'il s'agit d'un adjectif substantivé, comme ריבֵา (Jb 11,4), ou bien que ce peut être un infinitif comme לִ (Is 45,1).

Joseph Qimhi (Galuy 64,23) donne à ce mot un sens transitif : “celui qui fait reposer des pièges", c'est-à-dire qui les pose. Radaq (commentaire et Shorashim sur שור et sur (שכך) hésite entre les analyses en adjectif et en infinitif. En Mikhlol 128a, il opte pour l'infinitif. Il adopte l'interprétation transitive de son père, interprétation qui, sur son autorité, sera adoptée par tous les traducteurs du XVIe siècle et reprise par Buxtorf en son Lexicon.

De Dieu a réagi contre cette interprétation, observant qu'en aucun endroit de la Bible שכך n'a le sens de "tendre ou poser des pièges". Mais partout son qal est employé au sens intransitif de "se reposer, cesser" (et son hifil au sens de "faire reposer"). Il en conclut qu'il faut lui donner ici aussi ce sens intransitif, sans se douter qu'il retrouve ainsi l'exégèse proposée par Yéfet ben Ely. Sur ce point, de Dieu a été précédé par Cocceius et suivi par Gousset, C.B. Michaelis, Roediger, Hitzig, Ewald, Keil, Graf.

La traduction la mieux fondée serait donc: "Chacun épie comme un oiseleur blotti (littéralement : comme le blottissement des oiseleurs)."

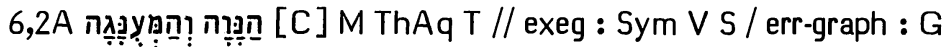

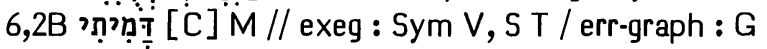

Options de nos traductions :

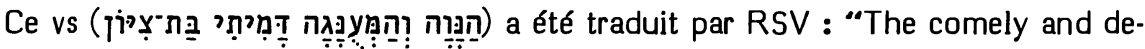
licately bred I will destroy, the daughter of Zion" et par J3: "La belle, la délicate, je la détruis, la fille de Sion !"

Sans note, TOB traduit : "Toi, la belle Sion, la charmante, la coquette, tu es réduite au silence".

Selon Brockington, NEB corrige le 3e mot en (ה) delightful and lovely : her end is near".

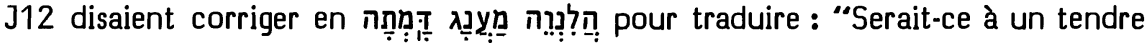
pâturage qu'est comparable la fille de Sion ?" RL traduit de même: "Die Tochter Zion ist wie eine liebliche Aue." 
Origines des corrections :

Houbigant a suggéré de corriger le premier mot en לְְִִ et d'omettre la conjonction qui précède le deuxième.

C'est Michaelis (Observationes) qui a suggéré d'interpréter le "hé' initial comme interrogatif.

Graf a uni ces deux suggestions en offrant pour le premier mot la correction que J12 ont adoptée et en traduisant : "Gleicht denn die Tochter Zion's einer Trift...?"

La correction du 3e mot en (ה) du *T. Dans son commentaire, il traduit : "Ist einer lieben Trift gleich geworden die Jungfrau Zion ?"”

La forme de la conjecture adoptée par $\mathrm{J12}$ a été proposée par Rudolph, précisant que le 2e mot est "non attesté mais inattaquable". Elle a été requise par les apparats de $\mathrm{BH} 3 \mathrm{~S}$ et, sous une forme très proche, par Cent. L'ont adoptée : Penna, Steinmann et Hyatt.

TOB repose vraisemblablement sur une exégèse du *M.

Les témoins anciens :

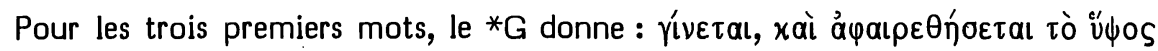
oov. Cappel (Notae 521b) a suggéré que le traducteur a rattaché le premier mot au vs précédent en le dérivant du verbe מנח En effet, ces deux verbes se correspondent en Jb 38,15 et $\operatorname{Pr} 30,7$. Enfin un 'resh' semble avoir été lu au lieu du 'dalet' du 3e mot.

On peut se demander pourtant si nous n'avons pas affaire ici, comme en d'autres cas relevés par Tov (Pseudo-Variants 173), à une volonté du traducteur grec d'éviter de traduire les racines דמם et.

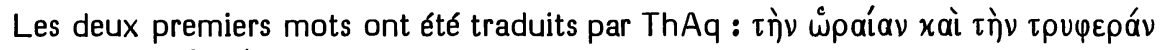

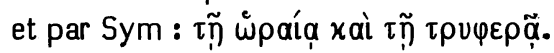

Sym a rendu le troisième par דמיתה.

$\mathrm{La} * \mathrm{~V}$ (speciosae et delicatae adsimilavi) est conforme à Sym.

La*S (למעדנתא ולמפנקתא דמיתי) a interprété le verbe en 2e pers. f. sg.

Le *T ("belle et délicate, comment as-tu corrompu tes voies") a fait de même en paraphrasant ce verbe.

\section{Choix textuel :}

Le ${ }^{*} G$ semble avoir utilisé ici sa Vorlage comme un prétexte pour construire librement.

Pour les deux premiers mots, le $* M$ est attesté directement par ThAq et par le *T. Nous verrons que leur interprétation en datif par $S y m$, la $* V$ et la $* S$ a été répétée ensuite par de nombreux exégètes qui lisaient le *M.

Il en va de même de l'interprétation du verbe au sens transitif de "j'ai comparé" par Sym et la $* V$ ou de l'interprétation de sa désinence en 2e pers. f. sg. par la *S et le *T.

L'éventuelle Vorlage du *G n’étant pas préférable au *M, le comité a attribué à celui-ci 3 "C" et 3 "B", estimant que la difficulté est surtout d'ordre exégétique. 


\section{Interprétation proposée :}

1/ Le verbe דִִ̣ pose deux questions aux exégètes :

- Sa désinence a été interprétée comme une 2 e pers. f. sg. par la *S, le *T, Jacob ben Reuben, Abulwalid (Luma 369,1ss) et Nägelsbach, ce dernier reconnaissant cependant que les massorètes l'ont interprétée en 1e pers. sg. En effet, on rencontre, spécialement dans les liures de Jérémie et d’Ezéchiel, de nombreux cas où des désinences de ce type caractérisent la $2 \mathrm{e}$ pers. f. sg. de l'accompli et ont été ensuite normalisées par les vocalisateurs en shewa (cf. Jr 2,33; 3,4.5; 31,21; 46,11; Ez 16,13. 18.22.31.43.47.51). Mais il y a d'autres cas de désinences non normalisées (par ex.

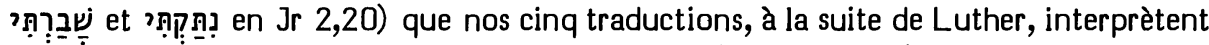
comme $2 e$ pers. f. sg., alors que les vocalisateurs (suivis par $\mathrm{KJ}$ ) avaient voulu y voir des premières personnes du singulier ayant Dieu pour sujet. On peut donc se demander avec Bright s'il n'en irait pas de même ici. Comme nous le verrons plus loin, il semble bien qu'ici il faille donner raison à la grande majorité des exégètes qui ont lu, avec les vocalisateurs, une 1e pers. sg.

- Ce verbe a été interprété par Sym, la*V, Radaq, Parhon, Isaïe de Trani, Abravanel, Pagnini, Prédicants, Zwingli, Münster, Olivetan, Jud, Châteillon, Ge, Tremellius, Pasteurs, KJ etc. au sens de : "J'ai comparé la fille de Sion à une נוענגה et à une". Mais Mercerus (sur Thesaurus3 de Pagnini, col 477) a fait remarquer que ce serait le seul cas où le qal de ce verbe aurait ce sens qui est ailleurs réservé au piél. A quoi Houbigant a ajouté que ce sens de "comparer" suppose que la réalité à laquelle on compare soit introduite par 'lamed'. Enfin Michaelis (Observationes) a fait remarquer que les articles des deux premiers mots n'auraient, dans cette exégèse, aucune raison d'être, puisque l'on peut comparer Sion à 'une' femme délicate et non à 'la' femme délicate.

Ces diverses objections expliquent pourquoi Rashi, Menahem de Posquières, Tanḥum Yerushalmi, Joseph Qimḥi (cité par Radaq en son commentaire), Brucioli, Michaelis (OEB), Gesenius (Thesaurus 343a), Rosenmüller, Hitzig, Keil, etc. ont compris : "La מענגה et la je l'ai détruite, la fille de Sion". Le parallèle le plus précis

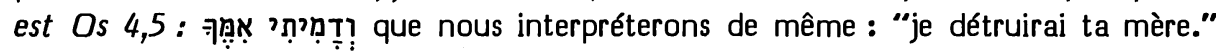

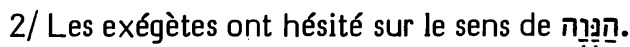

- Luther semble avoir été le premier à l'interpréter au sens de (= pâturage). Houbigant (qui ne tient pas compte des voyelles) accepte cette interprétation. Cornill, admirant en Luther un "instinct génial" corrige la vocalisation, suivi en cela par de nombreux exégètes dont Rudolph, BH3S, Cent, $\mathrm{J12}$ et, naturellement, RL. On a fait valoir en faveur de cela que cette image prépare bien les bergers et leurs troupeaux qui interviendront au vs suivant. Volz a d'ailleurs suggéré que la forme נְִ̣ du *M pouvait être un féminin de ce mot et Bright a été jusqu'à dire que cette forme signifie normalement un pâturage, quoique HALAT (641) précise que le singulier absolu de cette forme n'est pas employé en ce sens. Mais en So 2,6 nous lirons le pluriel absolu en ce sens.

- Estimant qu'il fallait avoir ici un synonyme du mot qui suit, la plupart des exégètes se sont divisés entre deux interprétations :

a/ ThAq, Sym, la *V, le *T, Yéfet ben Ely, le glossaire C, Reuchlin, Luther (en leçon gonflée), Prédicants, Zwingli, Brucioli, Münster, Olivetan, Jud, Châteillon, Tremellius, 
$\mathrm{KJ}$ ont vu ici une forme défective de נִָָ (mot dont l'alef est d'ailleurs normalement quiescent) et ont donc traduit "la belle".

b/ David ben Abraham (II 259,7 à 260,10), Abulwalid (Usul 415,18ss), Radaq, Pagnini, Vatable, Pasteurs et la marge de $\mathrm{KJ}$ ont compris ce mot au sens de "celle qui réside

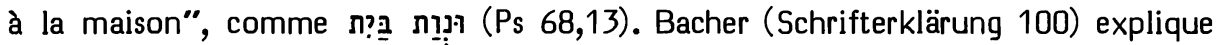
que cette désignation exprime une dure critique $:$ il s'agit de celle qui, par goût pour le confort et la jouissance, demeure chez elle; de même, ils se laissent enfermer chez eux par les ennemis parce qu'ils ont cru pouvoir s'épargner les combats défensifs.

On pourra donc choisir, pour ce mot, entre "la jolie" et "la casanière" (pour ne pas dire : la pantouflarde).

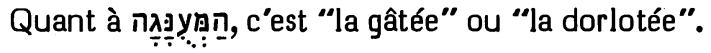

6,6 השקר [C] M S / censtr : G clav : Sym V / paraphr : T

Options de nos traductions :

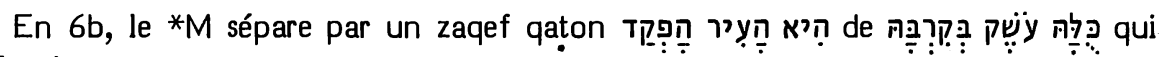
achève le vs.

Les trois premiers mots sont traduits par RSV : “This is the city which must be punished", par RL: "denn es ist eine Stadt, die heimgesucht werden soll" et par J3: "c"est la ville qui va recevoir ma visite".

J12, traduisant : "c'est la ville du mensonge", disaient suivre le *G.

TOB dit lire le verbe au féminin : “c'est la ville qui est livrée".

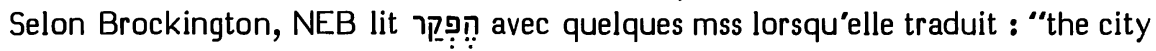
whose name is Licence".

Origines des corrections :

Cappel (Notae 522) a fait remarquer que le ${ }^{*} G$ semble avoir lu ici qui a paru préférable à Michaelis (Observationes) et a été adoptée par Grätz (Psalmen 135,5), Oort, Cornill, Volz (Studien), Schmidt, Nötscher, Penna, Steinmann, Bright et requise par les apparats de HSAT34, $\mathrm{BH} 3$ et Cent.

La mise du verbe au féminin a été proposée par Clericus.

La correction adoptée par NEB a été proposée par Volz (commentaire), vocalisant du *M, de Rossi (Scholia) notait qu'en hébreu ce verbe signifie "errer". Il en concluait que le ${ }^{*} G$ avait lu cela. C'est chez Driver que NEB a trouvé cette leçon, avec la traduction qu'elle en donne.

\section{Les témoins anciens :}

De Rossi cite en faveur de la graphie avec 'resh' final son ms 596 et peut-être son ms 196. Elle est attestée aussi par l'édition princeps de la Bible (Soncino 1488). Mais il faut noter que l'édition princeps des Prophètes (Soncino 1486), ainsi que les éditions suivantes de la Bible (Brescia 1494, Félix de Prato 1517, Ben Hayim etc.) portent la graphie avec 'dalet' final. Cette graphie est confirmée par une mp donnée ici par l'édition Ben Hayim ainsi que par les mss du Caire, d’Alep et de Leningrad. 
Cette $\mathrm{mp}$ précise que cette forme est présente deux fois dans la Bible, le ms du Caire attestant que la seconde occurrence est en Lv 5,23.

Le ${ }^{*} G$ traduit ce mot par $\psi \varepsilon v \delta \delta$ ́́s dont il fait normalement usage en ce livre pour traduire שֶׁק. Mais rien ne prouve qu'il avait ce mot en sa Vorlage. Schleusner (V 558) estime en effet qu'il a seulement traduit librement le *M.

Le ms Barberini attribue à $A q \dot{\eta}$ áóxxos. Ziegler (éd. Göttingen) a raison de refuser cette attribution. Cette traduction très libre et de paternité inconnue est textuel-

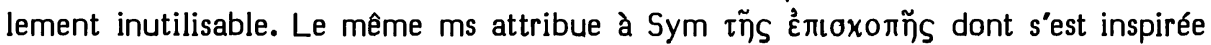
la *V (visitationis). Ici, le "hé" semble avoir été lu en article.

Le *M a été lu par la *S (דאתפקדת) et a servi de base à la paraphrase du *T (דאתפקידו לה חובהא).

\section{Choix textuel :}

La leçon difficile du ${ }^{*} M$ semble être à la base de toute la tradition textuelle. Le comité lui a attribué la note " $\mathrm{C}$ ".

Interprétations proposées :

Luther (die heimgesucht werden sol) et $\mathrm{KJ}$ (to be visited) donnent à ce verbe une valeur future. En cela, ils dépendent de la traduction des Prédicants de Zurich (die man straaffen sol) et seront suivis fidèlement par RSV, RL et J3.

La plupart des exégètes ont compris ce verbe comme signifiant "subir une visite", c'est-à-dire une enquête visant à constater (comme dans le cas de Sodome) ses crimes et à déterminer la punition qu'ils méritent.

Ce verbe étant au masculin, il ne faut pas lui donner comme sujet le mot "ville". Aussi Venema, sans tenir compte du zaqef, a-t-il eu l'idée de lui donner pour sujet le mot Rudolph ont préféré donner à ce verbe valeur impersonnelle. Cela engagerait à traduire, en respectant les teamîm: "Voici la ville dont il a été contrôlé que tout est oppression en son sein."

Cependant, Luzzatto s'est opposé à cette exégèse en faisant remarquer que le hofal est le passif du hifil et qu'à aucun de ces deux modes ce verbe n'a le sens d'enquêter et, par extension, de châtier, mais bien de "mettre en dépôt" ou de "établir comme commissaire, comme fondé de pouvoir". Il estime que cela veut dire ici : "c'est la ville à propos de laquelle il y a eu livraison au pouvoir de l'ennemi". Cela signifierait à la fois que le Seigneur s'interdit d'intervenir actuellement et qu'il se réserve de reprendre un jour son dépôt. Luzzatto ne savait pas que Yéfet ben Ely interprétait déjà ceci au sens de אלתי ובכבל עליהא אלעדו : "sur qui l'ennemi a reçu plein pouvoir". Peut-être jugera-t-on l'expression de ce sens par ce verbe trop elliptique pour être vraisemblable. Il est pourtant frappant de noter que la TOB a retrouvé ce sens. 
Options de nos traductions :

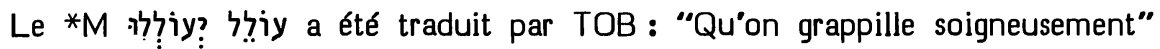
et par $\mathrm{J3}$ : "On va grappiller, grappiller".

Sur la base d'une conjecture, RSV donne: "Glean thoroughly". NEB, selon Brockington, corrige avec le *G le 2e mot en ל̧̣ị pour traduire : "Glean" et $\mathrm{J12}$ faisaient de même pour traduire : "Grappille, grappille".

\section{Origine de la correction :}

Giesebrecht, suivi par Condamin et Penna, changeant en 'waw' le 'yod' initial du second mot et le transférant à la fin du premier, proposait de lire ici deux impératifs pluriels. Cornill voit en cela la Vorlage du ${ }^{*} G$, mais propose de mettre ces deux impératifs au singulier, suivi par Volz, Schmidt, Steinmann et Cent. Rudolph, proposant la même leçon, interprète la première forme en infinitif absolu, ce en quoi il est suivi par Weiser, Hyatt et Bright. Il propose la même leçon dans les apparats de BH3S.

\section{Les témoins anciens :}

Le $* G$ a traduit en effet deux impératifs pluriels $x \alpha \lambda \alpha \mu \alpha \tilde{\alpha} \sigma \theta \varepsilon x \alpha \lambda \alpha \mu \tilde{\alpha} \sigma \theta \varepsilon$.

Tous les autres témoins ont traduit plus ou moins littéralement le *M. La*S :

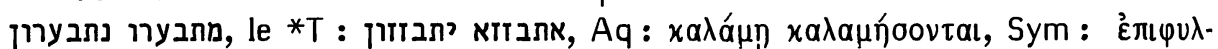

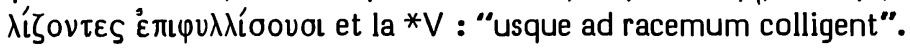

\section{Choix textuel :}

Le ${ }^{*} G$ a assimilé ces verbes à l'impératif qui commence 9b. Il a d'ailleurs mis cet impératif au pluriel, réalisant ainsi une harmonisation complète.

Notons qu'aucun témoin n'appuie la mise au singulier des verbes de 9a que presque tous les critiques demandent à partir de Duhm en estimant que le Seigneur s'adresse ici au prophète.

Le comité a attribué au *M la note " $\mathrm{B}$ " en estimant que nous avons ici un cas classique d'infinitif absolu renforçant un verbe de même conjugaison (poél).

\section{Interprétation proposée :}

Luzzatto estime que l'on a ici un commentaire de la menace (formulée en $8 b$ ) : פן־אשימך שממה Si tu ne te laisses pas corriger, alors, après le premier désastre dont le Seigneur t'a frappé, les ennemis reviendront grappiller le reste qui t’aura été laissé, de même que l'on revient cueillir après la vendange les grappes qui avaient été oubliées.

On pourra donc traduire en un sens volontatif : “que l’on grappille soigneusement", le Seigneur s'adressant aux ennemis. Au début de 9b le mot הִ̣ a été interprété par Radaq comme un impératif adressé par chaque ennemi à son compagnon, alors que le *T y voit un appel adressé par le prophète au Seigneur. Luzzatto y voit un infinitif ayant, avec son complément et le suffixe $2 \mathrm{e}$ pers. $\mathrm{m}$. sg. qui affecte celui-

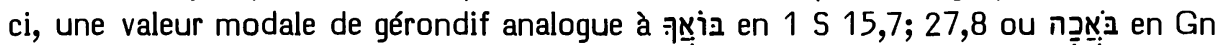
10,19.30; 13,10; 25,18. La 2e personne du suffixe y a la signifiaction d'un appel à 
l'expérience de l'interlocuteur. On pourrait traduire : "en repassant la main, comme le vendangeur sur les pampres".

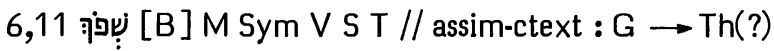

\section{Options de nos traductions :}

Après que le prophète ait dit : "Je suis rempli de la fureur du Seigneur", il con-

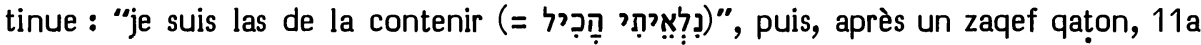

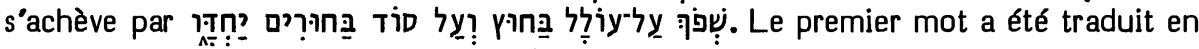
impératif par la plupart de nos traductions : RSV : "Pour it out", J : "Déverse-la donc", RL : "So schütte ihn aus", TOB : "Répands-la".

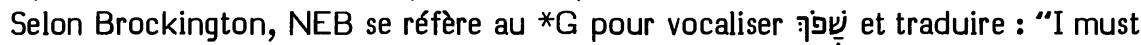
pour it out".

Origine de la correction :

Cette correction en infinitif absolu a été proposée par Ewald1 (mais Ewald2 est revenu au *M, interprété en impératif). Elle a été adoptée par Grätz, Ehrlich (Miqra, mais il y a renoncé en Randglossen), Duhm, Cornill, Condamin, Volz et par les apparats de $\mathrm{BH} 2$ (selon Addenda), HSAT4, $\mathrm{BH} 3$.

Pour obtenir le même sens, אִ: a a été proposé par les apparats de HSAT3 et Cent.

Les témoins anciens :

Ont interprété le *M en impératif : la *V (effunde) et la *S (ואשודי).

L'ont interprété en infinitif : Sym ('ُxxćaı) et le *T (למשפך).

Offrent une 1e pers. sg. : le ${ }^{*} G\left({ }^{\prime} \times X \times \tilde{\omega}\right)$ et Th $\left({ }^{\prime} \xi \xi^{\prime} \times \varepsilon \alpha\right)$. Cette dernière leçon est attribuée à Aq par le ms Barberini, mais Ziegler (éd. Göttingen) propose de l'attribuer plutôt à Th.

\section{Choix textuel :}

Le ${ }^{*} G$, en traduisant, a assimilé ce verbe à la 1e pers. sg. des deux précédents et Th a poussé plus loin cette assimilation en le mettant à l'aoriste. "B".

Cela ne saurait nous engager à quitter le *M auquel le comité a attribué la note

Interprétation proposée :

Selon le Talmud Babli (Shabbat 119b), Rab Hamnuna (vers 300, à Sura en Babylonie) lisait ce mot en impératif : “Rab Hamnuna disait : Jérusalem n’a été détruite que parce qu'on y a privé d'enseignement les enfants d’âge scolaire, ainsi qu'il est dit : 'répands sur l'enfant dans la rue'. Pourquoi 'répands'? parce que l'enfant est dans la rue".

Cependant, la quasi-totalité des exégètes juifs médiévaux comprennent ce mot comme un infinitif, Rashi et Radaq disant qu'il a la valeur de לשפך.

La majorité des traducteurs de la première moitié du XVIe siècle lisent ici un infinitif (Pagnini, Brucioli, Münster, Olivetan, Rollet, Châteillon), la plupart com- 
prenant : "je suis lassé de me retenir de la répandre..." Cependant, sous l'influence de la vieille traduction allemande faite sur la *V ("Geúss auss" en Kurrelmeyer IX 25,37), les Prédicants de Zurich traduisent ici : "geüss auss", suivis par Zwingli (effunde) et Luther (schütte aus) que RL a conservé.

Münster traduisait librement l'infinitif par une première personne : "ut me continere non valeam quin illam effundam". En 1545, Robert Estienne édite la traduction de Jud qui donne ici "effundam", séparé par une virgule de "fatigor continendo" qui précède. Vatable glose cela en "debilior sum quam ut diutius illam indignationem Domini possim continere : effundam ergo illam". Dans sa réédition d'Olivetan à Genève en 1553, Estienne introduira cette interprétation: "ie la répandray". La Geneva Bible en 1560 la lui empruntera : "I wil powre it out" et celle-ci sera suivie par KJ (de même qu'Estienne sera suivi par la révision des Pasteurs de Genève en 1588). Sur ce point, NEB s'est montrée plus fidèle que RSV à la tradition biblique anglaise issue de Genève et, plus précisément, d’Estienne.

L'interprétation du *M en infinitif assimile au mot qui précède et évite que l'ordre cruel soit donné de déverser la fureur de Dieu sur les petits enfants. L'accentuation massorétique (qui n'établit qu'une disjonction mineure entre ce mot et ce qui précède) favorise cette interprétation.

Il est cependant fort probable que Rab Hamnuna, la *V, la *S, les Prédicants de Zurich, Zwingli et Luther ont eu raison de préférer l'impératif. Dans ce cas, nous avons une réponse de Dieu à la plainte du prophète qui s'est dit rempli de la fureur du Seigneur et s"épuisant à la contenir: "Déverse-la sur l'enfant dans la rue et aussi sur la bande des jeunes !"

\section{6,15 הבדביש: [A ] M G V S // paraphr : T}

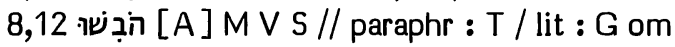

Options de nos traductions :

Pour ce mot, nos traductions offrent la même option dans les deux lieux parallèles. J1 traduit : "Ils seront honteux", J2 : "Ils auront honte", RL : "Sie werden mit Schande dastehen", TOB : "Ils sont confondus" et J3 : "Les voilà dans la honte".

Selon Brockington, NEB vocalise, en ces deux cas : הִ pour traduire : "Are they ashamed... ?" RSV traduisait de même : "Were they ashamed... ?"

Origine de la correction :

C'est Driver qui a emprunté à Grätz et à Ehrlich cette correction en estimant que le sens requiert clairement une question. Il a été suivi en cela par Bright.

Les témoins anciens :

Le ${ }^{*} G$ ancien ne possède que le premier des deux passages. Il y appuie le $* M$

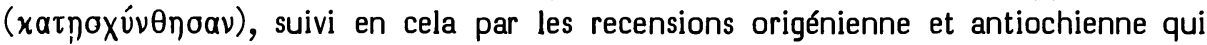
étendent cette traduction à l'autre passage.

Dans les deux passages la $* V$ (confusi sunt) et la *S (בהתו) traduisent le *M que le *T paraphrase (עליהון למבהת). 


\section{Choix textuel :}

La tradition textuelle étant entièrement cohérente, le *M a reçu la note " $A$ " sur ce point, dans les deux passages parallèles. En effet, l'absence du second passage dans le ${ }^{*} G$ pose un problème littéraire et non textuel.

Interprétations proposées :

L'exégèse juive médiévale attribue souvent à ce verbe le sens d'une interrogation dont la particule serait sous-entendue. C'est le cas d'Abulwalid (Luma 356,3), de Menahem de Posquières, Radaq, Tanḥum Yerushalmi, Judah ibn Balaam et c'est la seconde exégèse proposée par Joseph ibn Nạ̣mias.

Déjà Hie précisait à propos de ce verbe, en 6,15 et en 8,12, qu'il faut lui donner ce sens interrogatif. La plupart des éditions anciennes de la *V (par ex. l'édition Froben 1495 ou les éditions Estienne 1532, 1540, 1545) n'ont rien qui laisse deviner ce sens. Mais l'édition Gadolo 1495 qui est accompagnée de la glose (où a été inséré le commentaire de Hie sur 6,15) place des points d'interrogation à la fin du premier colon en 6,15 et en 8,12 .

Les lecteurs de la glose, comme d’ailleurs ceux de la Bible Rabbinique (où Félix de Prato et Ben Hayim avaient placé le commentaire de Radaq) étaient donc habitués à cette interprétation. Cela explique que Pagnini et Brucioli (qui en dépend) aient traduit en interrogation ces deux passages. Il est curieux que Münster a traduit 6,15 en interrogation et 8,12 en affirmation. Rollet prouve sa dépendance en faisant de même. Estienne, Tremellius, Pasteurs, Ge et $\mathrm{KJ}$ étendent aussi le sens interrogatif à 8,12. On peut donc constater que l'intérêt que Driver, Bright et NEB ont porté à la correction de Grätz et d'Ehrlich est motivé ici encore par la tradition biblique anglaise.

Une autre exégèse du $* M$ qui a eu un certain succès est celle du $* T$ qui paraphrase : "ils auraient dû en avoir honte". Cette exégèse est adoptée ensuite par Rashi. Elle est donnée en premier lieu par Joseph ibn Nahmias. Elle a été adoptée par la traduction des Prédicants de Zurich. Zwingli l'expose en son commentaire. Finalement, c'est elle que Rudolph a choisie.

Ces deux exégèses peu naturelles visent à concilier l'affirmation הבִ̣ avec la né-

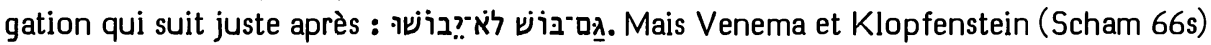
s'orientent dans une voie plus prometteuse en distinguant le sens du hifil intransitif de celui du qal. L'affirmation signifie : "leur confusion est manifeste" (parce que leurs faux espoirs sont anéantis); alors que la négation signifie : "ils n'éprouvaient absolument aucun sentiment de honte" (c'est-à-dire aucun remord de conscience les incitant à faire pénitence).

בעמי 6,27A בעמי [C] M Aq2 Sym V S T // err-vocal : G ThAq1 clav

6,27B מבצר [C] M Aq2 T // lic : ThAq1 V S / assim-ctext : G / err-graph : Sym12 מצר מצור מבר

Options de nos traductions :

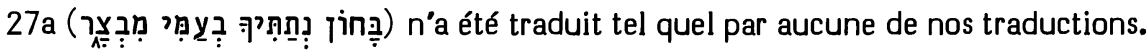

Sans note, RSV donne: "I have made you an assayer and tester among my people". 
Selon Brockington, NEB transfère à la fin du dernier mot la conjonction qui précède le suivant, obtenant מִבְבר et traduisant : "I have appointed you an assayer of my people; (you will know) how to test them".

J traduit : "Je t'ai établi comme celui qui éprouve (J1 : éprouveur de) mon peuple", RL : "Ich habe dich zum Prüfer gesetzt für mein Volk" et TOB : "Chez mon peuple, je te nomme essayeur de métaux". J et TOB indiquent qu'elles ont omis le dernier mot.

\section{Origines des corrections :}

RSV reprend une suggestion d"Houbigant : donner à מבצר le sens de "explorator" à partir du sens du verbe arabe qui est "voir". Michaelis (OEB) a adopté cette proposi-

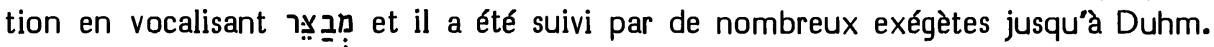

NEB suit ici une proposition de Driver.

C'est Giesebrecht qui a proposé d'omettre ce mot, à titre de glose, omission requise par les apparats de HSAT34, BH3S et Cent.

\section{Les témoins anciens :}

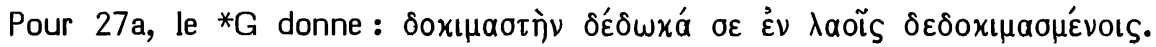

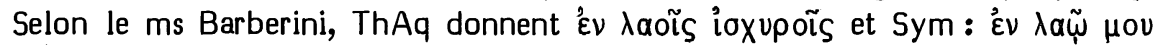

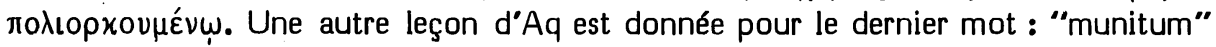

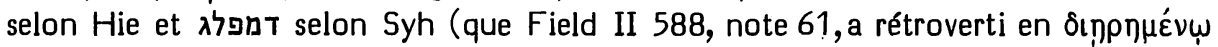
où il voit une forme corrompue de $\left.\delta ı \eta \mu \varepsilon^{\prime} \nu \omega\right)$. Il s'agit probablement de la 2 e traduction d'Aquila dont l'existence est bien attestée pour Jérémie et Ezéchiel (cf. Field I p. XXVs).

Il est difficile de dire à quel traducteur les recensions origénienne ( $\lambda \alpha$ ỗ

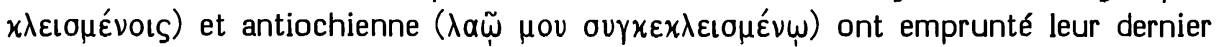
mot. Hie attribue à Sym : "clausum" et "circumdatum". Cela nous engagerait à y voir un autre état de la traduction de Sym.

La *V traduit: "probatorem dedi te in populo meo robustum", la *S : בחורא יהבתך בעמי עשינא et le *T : בחיר יהבתך בעמי ככרך תקיף.

\section{Choix textuel :}

Une vocalisation בעמי est postulée par le *G (suivi par ThAq1). Les autres témoins (Aq2, Sym, la *V, la *S et le*T) vocalisent comme le *M.

Le ${ }^{*} G$ s'est inspiré du premier mot pour traduire le dernier, sans que l'on puisse en tirer des conclusions sur sa Vorlage.

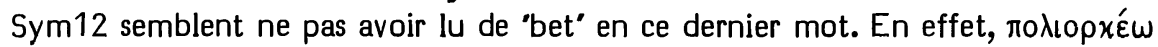

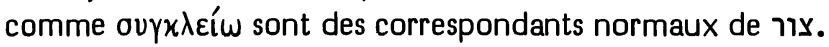

La $* V$ et la ${ }^{*} S$ se sont inspirées de ThAq1 qui est une traduction large du *M que $A q 2$ et le $* T$ veulent traduire avec plus d'exactitude.

Le comité a estimé que toutes ces variantes dérivaient vraisemblablement du * $M$ auquel il a attribué, pour ces deux mots, la note " $C$ ". 
Interprétation proposée :

Le mot מבצר pose en ce vs deux problèmes distincts.

1/ Le premier concerne son interprétation en ce contexte. Il faut d'abord noter que nos cinq traductions admettent comme allant de soi le sens de "essayeur" ou "éprouveur" (de métaux) pour jịne. C'est en effet le sens que lui ont reconnu le *G, la $* V$, la traduction des Prédicants de Zurich et celles de Zwingli, Luther et Jud. Notons cependant qu'Abulwalid (Ușul 88,17-20) lui donne ici le sens de "château, tour, bâtiment élevé". Cette exégèse est aussi celle de Rashi et la première qu'offrent les glossaires (AF : "brétoche", BCDE : "fort"). Elle a été adoptée par Judah ibn Balaam, Tanḥum Yerushalmi, Radaq, Moshé ben Sheshet, Isaïe de Trani, Abravanel, Pagnini, Brucioli, Münster, Vatable, Estienne, Châteillon, Ge, Pasteurs, KJ. En effet, (Is 23, 13Q) est, selon Radaq et König (cf. ci-dessus, p. 500), le pluriel de ce mot. Or on s'accorde à reconnaître à cette forme plurielle, comme à ${ }^{\prime} \underline{\text { Inב }}$ (Is 32,14), le sens de "tour de guet". Or ici (Jr 6,27), les exégètes partisans de cette interprétation estiment qu'il y a un jeu de mots, la comparaison avec la tour de guet (מָּר évoquant à la fois la forteresse (מִבְבְר) et l'observation, l'exploration qui est exprimée en 27b par ובחנת את דרכם. Il est évident que, si l'on attribue ici (avec toutes nos traductions) à בִ le sens de "essayeur" ou "éprouveur" de métaux, le mot מבצר paraît tout à fait déplacé dans son contexte, et on est tenté, ou bien de lui trouver à partir de l'arabe un sens improbable, ou bien de l'omettre. Mais, si nous reconnaissons que מבצר ne peut pas être une glose tardive, la présence de ce mot nous engagera (ainsi que Calvin l'a finement noté) à préférer pour jiṇ̣ un sens de "tour de guet" que suggèrent les parallèles de Is 23,13; 32,14.

2/ Le deuxième problème relève en effet de la critique littéraire : c'est celui que pose la présence en 6,27 du mot מִבְב et celle, dans le vs suivant, de Les trois mots se retrouvent en effet (très bien en place, cette fois) en 1,18

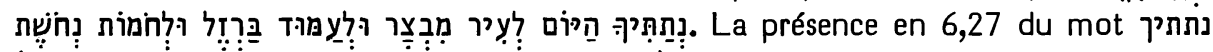
(qui, lui, y est aussi bien en place qu'en 1,18 ) n'aurait-elle pas offert à un glossateur l'occasion d'insérer en 6,27s trois mots provenant de 1,18 ? C'est une hypothèse qui se présente spontanément à l'esprit.

Mais il faut noter que le ${ }^{*} G$ atteste déjà formellement "bronze et fer" dans le vs 28 et a lu מבצר (ou un autre mot à sa place) dans le vs 27 . Si ce sont des gloses, elles font donc partie de la rédaction I. Il est d'ailleurs improbable que "bronze et fer" qui qualifient négativement le peuple en 6,28 y soient une reprise voulue de 1,18 où ces mots sont en ordre inverse, séparés l'un de l'autre, et expriment l'endurance du prophète, objet de l'hostilité de son peuple.

'D'autre part, si nous adoptons pour en 27a une reprise voulue de 1,18a, ayant pour but de spécifier la tâche de cette forteresse à laquelle le prophète a été comparé : “C'est en tant que tour de guet que je t'ai établi sur mon peuple comme forteresse : tu connaîtras et tu guetteras leur

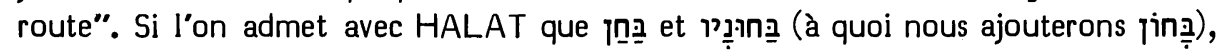
au sens de "donjon, tour", sont diverses vocalisations d'un terme technique emprunté à l'égyptien (cf. Erman/Grapow I 471), alors que le verbe בחן est un terme 
d'usage courant en hébreu pour désigner l'action de tester les métaux précieux en les fondant, on comprend qu'une interprétation pseudo-étymologique spontanée ait permis au prophète de passer du substantif au verbe et d'introduire ainsi l'image qui sera développée dans les vss 28-30.

\section{מאשתם מאש תם 6,29 [B ] MQ G V // paraphr : T / err-divis : MK}

\section{Options de nos traductions :}

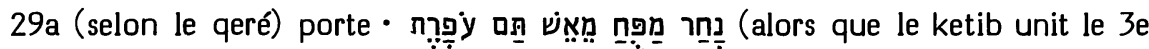
et le $4 \mathrm{e}$ mots). Il est traduit par RSV : "The bellows blow fiercely, the lead is consumed by the fire", par RL : "Der Blasebalg schnaubte, das Blei wurde flüssig vom Feuer", par TOB : "Le soufflet ronfle, le feu fait disparaître le plomb" et par J3 : "Le soufflet est haletant, pour que le plomb soit dévoré par le feu".

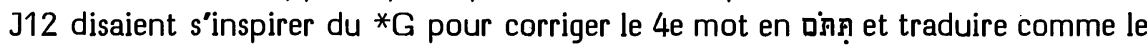
fera J3.

Selon Brockington, NEB corrige les 2e et 3e mots en "The bellows puff and blow, the furnace glows ... lead".

\section{Origines des corrections :}

Clericus a proposé de corriger le $4 \mathrm{e}$ mot en תמה pour mieux accorder ce verbe au substantif à désinence féminine qui le suit. Cette correction a été adoptée par Houbigant. C'est Graf qui a préféré un inaccompli (que $\mathrm{J} 12$ retiendront) estimant que cette correction aboutissait au sens de : "le plomb aurait dô disparaître sous l'effet du feu" (qui lui paraît requis par le contexte) et qu'il suffit d'une haplographie du 'taw' pour expliquer la leçon du *M. Graf a été suivi par Oort, Duhm et les apparats de HSAT234 et Cent.

La conjecture de NEB est empruntée à Driver (Passages 85).

Les témoins anciens :

מאשתם est catalogué dans une liste massorétique de "15 mots qui sont écrits comme un, mais lus comme deux" (Okhla Diaz Esteban $\S 82=$ Frensdorff $§ 99$ ).

Parmi les versions anciennes, seule la $* S$ a lu ici le ketib (מן נורהון).

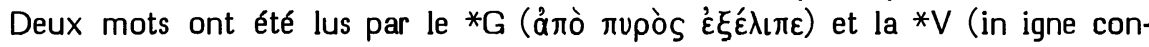
sumptum est).

Dans une très ample paraphrase, le *T use du premier mot ("au milieu du feu") et deux fois du deuxième ("a fait silence" et "ont cessé").

Choix textuel et interprétation proposée :

Cappel (Critica 189) a considéré qu'ici le qeré a seulement pour but de corriger une erreur commise par le ketib dans la division des mots. Cependant la ${ }^{*} S$ nous atteste l'existence de deux traditions d'interprétation distinctes.

Ewald1 semble avoir traduit le ketib par simple étourderie, car il ne dit pas un mot de cette option dans son commentaire. Ewald2 a justifié cette option qui a été suivie par Nägelsbach et von Orelli. Keil a objecté qu'elle supposerait une forme du mot "feu" avec désinence féminine qui n'est attestée nulle part. 
La plupart des difficultés concernant ce mot et son contexte immédiat tiennent au fait quâ la suite de Michaelis (Observationes), la plupart des exégètes (Ewald, Graf, Nägelsbach, von Orelli, Giesebrecht, Duhm, Volz, Schmidt, Nötscher, Driver, Rudolph) ont imaginé que "plomb" incluait ici tous les métaux moins nobles desquels il s'agit de séparer l'argent par fusion. Selon cette interprétation on est surpris de voir que Jérémie dise ici que "le plomb a disparu", alors qu'il va affirmer juste après que "c"est en vain que l'on épure". D'autres exégètes (Hitzig, Henderson, Keil, Luzzatto, Knabenbauer, Condamin, Hyatt, Bright) se sont pourtant souvenus de l'interprétation qui a été courante depuis Rashi jusqu'à Houbigant inclus (et que Schleusner rappelle, en éditant les Observationes de Michaelis) : dans l'antiquité, on fondait le minerai d'argent avec du plomb pour assurer l'extraction de tout l'argent contenu (cf. Forbes VIII 240). Pour séparer l'argent des métaux moins nobles auxquels il était mélangé, on faisait fondre du plomb dans un creuset et, quand il était fondu, on ajoutait le minerai d'argent. Sous l'influence de la chaleur, au contact de l'air, le plomb se transforme en litharge qui s'absorbe peu à peu, tandis que l'argent, se séparant de toute autre substance, se rassemble au fond du creuset. Jérémie suppose ici que, contrairement à l'ordinaire, le plomb dont on disposait a été complètement transformé et absorbé, sans que l'argent soit sorti de sa gangue. Selon cette interprétation, le *M est entièrement satisfaisant : “Le soufflet ahane; sous l'action du feu, le plomb est épuisé : c'est en vain que l’on épure, épure; les mauvais ne se détachent pas. Argent de rebut, voilà comment on les nomme."

Le comité a attribué au qeré du *M la note " $B$ ".

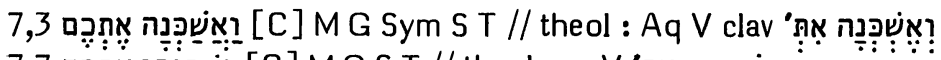

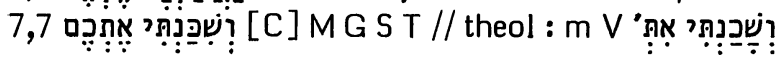

\section{Options de nos traductions :}

$1 /$ Au vs 3, cette expression du *M est traduite par RSV : "and I will let you dwell", par NEB : "that I may let you live" et par J3: "et je vous ferai demeurer".

$J 12$ disaient se fonder sur $A q$ et sur la $* V$ pour traduire : "et je resterai avec vous". Sur les mêmes fondements, TOB donne : "pour que je puisse habiter avec vous". De même, RL traduit : "so will ich bei euch wohnen".

2/ Au vs 7, l'expression du *M est traduite par RSV : "then I will let you dwell", par NEB : "Then will I let you live" et par J3 : "Alors je vous ferai demeurer".

$\mathrm{J12}$ disaient conjecturer : "alors je resterai avec vous". TOB, se référant au vs 3, traduit : "je pourrai alors habiter avec vous" et RL, de même : "so will ich... bei euch wohnen".

\section{Origines des corrections :}

Depuis Zainer, la vieille traduction allemande fondée sur la *V (Kurrelmeyer IX 28 , apparat) donnait au vs $3:$ "und ich wird wonen bei euch" et au vs $7:$ "ich wil bey euch wonen". Fidèle au * $M$, la traduction des Prédicants de Zurich donnait au vs 3 : "so wil ich euch lassen ... wonen" et au vs 7 : "so wil ich euch ... wonen lassen". 
Luther est demeuré sous l'influence de Zainer, lorsqu'il a traduit au vs 3 et au vs 7 :

"So wil ich bey euch wonen".

Parmi les exégètes plus récents, la forme intransitive ("j'habiterai avec vous") a été choisie par Knabenbauer, Ehrlich, Volz, Rudolph, Bright et par les apparats de $\mathrm{BH} 3 \mathrm{~S}$ qui demandent de corriger les deux formes piél du *M en qal.

Il est curieux de noter qu'Olivetan donnait au vs 3 une traduction intransitive ("ie demoureray avec vous") et au vs 7 une traduction transitive ("ie vous feray habiter"). Rollet, Estienne et Calvin l'ont suivi fidèlement en cette dissymétrie, alors que lés autres traducteurs du XVIe siècle (Pagnini, Zwingli, Brucioli, Münster, Jud, ChâteilIon, Ge, Tremellius, Pasteurs, $\mathrm{KJ}$ ) s'accordent avec la traduction des Prédicants sur deux formes transitives.

\section{Les témoins anciens :}

Lilienthal (174) a relevé, dans le premier ms de Königsberg, une vocalisation qal du verbe וֹשָׁِכַנתי au vs 7 . Cela a engagé de Rossi (Scholia) à étudier ses mss sur ce point. Il a trouvé la vocalisation qal en 5 d'entre eux et dans la 1e main de 3 autres.

Au vs 3 la forme piél sation qal qui se retrouverait en Ps 55,7 (où la mp la caractérise aussi comme "hapax"). De même, au vs 7, la forme piél 'ִ̣ est protégée par une mp "hapax' contre une vocalisation qal (qui se trouve en 6 autres endroits de la Bible). Ces $3 \mathrm{mp}$ sont données par les mss d'Alep et de Leningrad. Elles nous assurent qu'au vs 3 et au vs 7, c'est la forme piél (à valeur transitive) qui est la leçon authentique $d u{ }^{*} M$.

En ces deux endroits, une traduction transitive est donnée par le ${ }^{*} G$ ( $x$ à $x \alpha \tau o เ x i \tilde{\omega}$

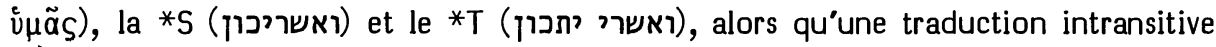
est donnée par la $* V$ (habitabo vobiscum).

Au vs 3, on connaît en outre Aq (ואשרא עמכון) dont la traduction est intransititive et Sym (et confirmabo vos) dont la traduction est transitive.

\section{Choix textuel :}

Dans le glossaire de Bâle $(=\mathrm{C})$, le cahier contenant les folios 41 à 48 a disparu entre 1920 et 1940. Darmesteter en ayant fait une copie auparavant, Banitt a pu faire usage de cette copie (déposée actuellement à la bibliothèque du Jewish Theological Seminary de New York) dans son édition de ce glossaire. L'exactitude de cette copie nous est d'ailleurs confirmée par une ajoute de seconde main faite au plus ancien glossaire de Parme (=D) qui offre exactement les mêmes données : le verbe ואשכנה (vs 3) est traduit : "é pozeré" que Banitt rend par "et je ferai demeurer", et le glossateur ajoute que אתכם est "comme עמכם "De fait, le verbe "poser" en ancien français peut avoir un sens intransitif ou un sens transitif. Mais il faut noter que le lexique de Banitt (Introduction 157) offre 32 cas d'emploi intransitif du verbe "pozer", alors qu'il n'y aurait qu'un seul autre emploi transitif (en Jr 22,7). Il est donc bien plus vraisemblable que le sens soit ici intransitif et cela nous est confirmé par la note exégétique portant sur le mot suivant.

Nous avons là la seule donnée fournie sur nos cas par les glossaires. Elle est d'autant plus précieuse qu'il semble que la littérature rabbinique ancienne et Rashi ne nous fournissent ici aucune donnée. Par contre, les commentateurs judéoarabes (à partir 
de Yéfet ben Ely) et occidentaux (à partir de Radaq) semblent unanimes à donner ici des interprétations transitives.

Il est possible d'établir que l'expression : "j"habiterai avec vous en ce lieu" pour dire l'habitation du Seigneur dans le temple ne serait pas à sa place en cet oracle de Jérémie, alors que l'expression : "je vous ferai habiter en ce lieu" pour dire la promesse faite à Israël de demeurer de façon stable en son pays y est bien en place.

En effet, en cet oracle Dieu parle de son habitation dans le sanctuaire en disant, non pas qu'il y habite, mais qu'il "y fait habiter son nom" (vs 12 à propos de Silo), selon la formule deutéronomique classique (Dt 12,11; 16,2.6.11; 26,2). Il arrive certes souvent que Dieu soit dit habiter "au milieu" de son peuple (Ex 25,8; 29,45. 46; Nb 5,3; 35,34), mais jamais "avec"lui.

Certains exégètes (Volz, Studien) ont prétendu que l'expression "ce lieu" devait désigner ici le temple et (Ehrlich) qu'elle ne pouvait pas, en tout cas, désigner la Terre sainte. Il importe cependant de distinguer "mon lieu" (qui désigne évidemment au vs 12 le sanctuaire) de "ce lieu" qui est explicité au vs 7 par "la terre que j’ai donnée à vos pères". D'ailleurs, au vs 14 , "la maison sur laquelle mon nom est invoqué et en laquelle vous placez votre confiance" est distinguée de "le lieu que j'ai donné à vous et à vos pères", quoiqu'elle lui soit coordonnée, les deux étant menacés de la même destruction. D”ailleurs "ce lieu" est une expression très fréquente en Jérémie et, sur 30 emplois, seuls 4 pourraient désigner le temple $(27,22 ; 28,3$ bis.6), les autres désignant ou bien Jérusalem (par ex. 19,12) ou bien l'ensemble de la Terre sainte (par ex. 28,$4 ; 32,37)$.

Le comité, au vs 3, a attribué 5 " $C$ " à la leçon du * $\mathrm{M}$ et 1 " $\mathrm{C}$ " à la vocalisation en qal; alors qu'au vs 7 il a attribué 6 " $C$ " à la leçon du *M.

Il est probable que la tradition de lecture représentée par $A q$, la *V, le glossaire $C$ et quelques mss du *M a été influencée par une théologie de la Shekhinah.

\section{Interprétation proposée :}

Ces piél ont la même portée que le piél de חיה en Ex 1,17.18.22 etc. où il signifie: "laisser en vie", c"est-à-dire : ne pas tuer. Ici, ce sera donc "laisser résider en ce lieu", c'est-à-dire : ne pas déporter.

\section{7,4 ה?חִ}

Options de nos traductions :

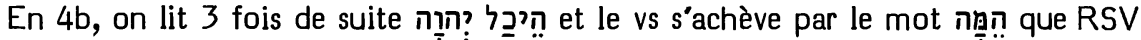
traduit par "This is", J12 par "C'est là", RL par "hier ist" (trois fois) et J3 par "C'est".

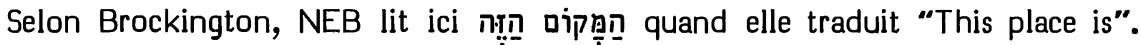
TOB dit lire de même pour traduire : "II est ici”".

Origine de la correction :

Il semble que ce soit Torczyner (Bibelstellen 276) qui a proposé le premier de voir

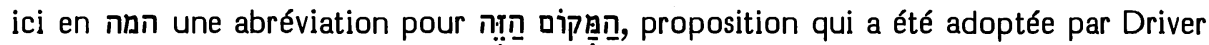
(Abbreviations 122). 


\section{Les témoins anciens :}

C'est vraisemblablement la leçon du $* M$ que le $* G$ traduit par '́otív, suivi par la * $V$ (est) et recensé par AqSym en cioúv.

Le *T paraphrase 4b en: “Devant le temple du Seigneur, vous célébrez le culte; devant le temple du Seigneur, vous sacrifiez; devant le temple du Seigneur, vous vous prosternez; trois fois par an vous vous présentez devant lui." Lorsque la *S offre ici : "le temple du Seigneur, c'est vous", nous donne-t-elle un condensé de cette paraphrase, ou subit-elle l'influence de 1 Co 3,16?

\section{Choix textuel :}

Ce pluriel masculin a surpris un certain nombre d'exégètes. Cependant on retrouve en $2 \mathrm{Ch} 8,11$ le même pronom nạn désignant la résidence de l'arche et se trouvant là aussi sujet d'une phrase nominale dont le prédicat est singulier. Dans un cas comme dans l'autre, ce pronom semble signifier "ces bâtiments". Houbigant évoque à ce pro-

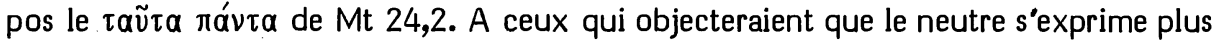
naturellement en hébreu par le féminin, Luzzatto rappelle que le féminin réservé en hébreu biblique à exprimer un déplacement d'un lieu vers un autre et ne serait donc pas à sa place en cette phrase.

Le comité a attribué à la leçon du *M la note "B".

Interprétation proposée :

On pourra traduire : "C'est le temple du Seigneur", ou de façon un peu plus appuyée : "C'est bien le...".

7,7 cf. p. 513.

\section{7,24 במעצות בשררות [B] M V S T // abr-transl : G}

\section{Options de nos traductions :}

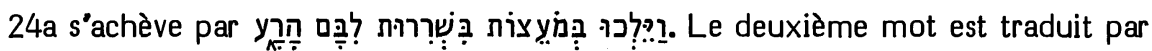
RSV : "in their own counsels", par RL : "nach ihrem eignen Rat", par TOB : "à leur guise" et par 33 : "selon leurs desseins".

312 omettaient ce mot avec le *G.

Selon Brockington, NEB vocalise תִִּ pour traduire : "in disobedience".

Origine des corrections :

Constatant que ce mot ne revient pas ailleurs en Jérémie, que son insertion syntaxique est difficile, et estimant qu'il manque dans le ${ }^{*} G$, Giesebrecht a proposé de l'omettre, suivi en cela par Duhm, Cornill, Ehrlich, Nötscher, Rudolph, Penna, Steinmann, Bright, ainsi que par les apparats de HSAT34, BH23S et Cent.

La vocalisation adoptée par NEB a été proposée par Driver (Roots 410s). 
Les témoins anciens :

Le *M a été lu par la *V (in voluntatibus), la *S (בתר תרעיתהון) et le *T (בעיצתהון).

Pour ce mot et le suivant, le ${ }^{*} G$ n'offre que toĩs $\varepsilon^{\prime} \nu \theta v \mu \eta ́ n \alpha a \sigma$ qui correspond à שרות en 3,17. Les recensions du ${ }^{*} G$ n'ont rien ajouté car elles ont vu vraisemblablement là une traduction allégée visant à exprimer les deux mots de la Vorlage par un seul mot grec.

Choix textuel :

Il est fort possible que le ${ }^{*} G$, considérant ce texte comme surchargé, a estimé suffisant de traduire seulement שרות (qu'il avait déjà rencontré une fois et traduit ainsi).

S'il y a vraisemblablement surcharge du texte hébreu, il est probable que c'est בשררות (qui apparaît 7 autres fois en Jérémie) qui a été ajouté pour gloser le mot précédent par un glossateur deutéronomiste antérieur à la rédaction I. Ce glossateur a pu s'inspirer de Ps 81,13.

Cette surcharge du texte pose, en tout cas, un problème de critique littéraire plutôt que de critique textuelle. C'est ce que le comité a voulu exprimer en attribuant à la leçon du *M la note " $B$ ".

Interprétation proposée :

On pourra traduire : "ils ont marché suivant les desseins, l'obstination de leur coeur mauvais" en signalant en note que "l'obstination" est vraisemblablement une glose du mot précédent.

Nous trouverons un problème de critique littéraire lié au même mot en 13,10.

7,25 אליכם

Options de nos traductions :

Dans le *M, 25a dit : “Depuis le jour où vos pères sont sortis du pays d’Egypte jusqu'en ce jour-ci" et $25 \mathrm{~b}$ continue : "j"ai envoyé vers vous tous mes serviteurs, les prophètes; chaque jour, de grand matin, j'envoyais".

Le "vers vous" du début de 25b a été respecté par J et RL. Mais RSV, NEB et TOB ont traduit "vers eux", NEB (selon Brockington) s'appuyant sur un ms pour corriger en

Origine de la correction :

C'est Houbigant qui, se fondant sur la ${ }^{*} \mathrm{~S}$, a proposé cette correction du pronom suffixe, proposition qui a été adoptée par Oort, Bright et l'apparat de BH3.

Les témoins anciens :

Dans la tradition textuelle du $* M$ la variante n'est attestée que par la première main du ms 93 de Kennicott. Or une bévue de copiste corrigée ensuite ne constitue pas un témoignage textuel. 
Le *G ancien porte le pronom de la 2e pers. pl. (seule la tradition textuelle des catenae ayant la 3 e pers. pl.), ce qui est d'autant plus frappant que le ${ }^{*} G$ (comme la *V et la *S) a lu en 25a "leurs pères" (au lieu de "vos pères" du *M).

La tradition textuelle de la $* V$ offre un visage analogue : Malgré "leurs pères" en 25a, ses témoins les plus anciens portent ici "vers vous". Mais "vers eux" est attesté par la recension théodulfienne et par l'édition princeps (bien que Nicolas de Lyre précise que l'hébreu a ici la 2e personne).

Seule la *S semble attester ici le suffixe de la 3e pers. pl. (לותהון) en ses témoins les plus anciens (par ex. le ms Ambrosianus), en harmonie avec "leurs pères" qui précède.

Le *T appuie le *M.

\section{Choix textuel :}

Le *M unit donc en un même vs : “Depuis le jour où vos pères sont sortis du pays d'Egypte jusqu'en ce jour-ci, j'ai envoyé vers vous tous mes serviteurs, les prophètes..." Comment le Seigneur a-t-il pu envoyer "vers nous" les prophètes à une époque (celle où nos pères sont sortis d'Egypte) où nous n'existions pas encore?

Le ${ }^{*} G$, la ${ }^{*} V$ et la ${ }^{*} S$ ont essayé de résoudre cette difficulté en corrigeant "vos pères" en "leurs pères" et en unissant 25a au vs précédent: "Ils se sont tournés en arrière et non en avant, depuis le jour où leurs pères..." La seconde partie du vs constitue alors une nouvelle phrase. Notons à ce propos que l'édition de Göttingen du *G a eu tort de modeler sa ponctuation sur celle du $* M$ (en suivant Rahlfs en cela), alors que Swete (suivant en cela l'édition Sixtine) plaçait une virgule avant 25a qu'il séparait de 25b par un point. Quant à la *V, sa ponctuation nous est indiquée par Hie qui commente à part 24-25a, puis 25b-26. Pour la *5, le ms Ambrosianus place un signe diviseur important entre $25 \mathrm{a}$ et $25 \mathrm{~b}$.

La $* S$ et des éléments minoritaires des traditions textuelles du ${ }^{*} G$ et de la $* V$ ont ajouté à cela, en cette nouvelle phrase, une assimilation du pronom de la $2 \mathrm{e}$ pers. pl. ("vers vous") au possessif de la 3e pers. pl. qu'elles lisaient en "leurs pères" de la phrase précédente.

Cette leçon "vers vous" constitue donc, chez les témoins qui l'attestent, une déformation secondaire faisant suite à une première correction (celle de "vos pères" en "leurs pères"). Or on ne saurait adopter la modification secondaire sans tenir compte de la correction initiale.

Ici, le comité a attribué au *M, bien appuyé, la note "B".

Interprétation proposée :

Il faut concevoir le pronom de "vers vous" comme intégrant à la fois toutes les générations d'Israël, de même qu'au vs 26 les pronoms de la 3e pers. pl. intégreront toutes ces générations dans le bilan que le Seigneur ( ${ }^{\prime}$ 'adressant là à Jérémie) tirera de leur comportement. 


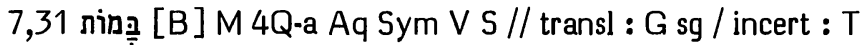

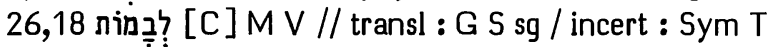

Mi 3,12 לִבְבמוֹת [C] M V // transl : G S sg / incert : Sym T

Options de nos traductions :

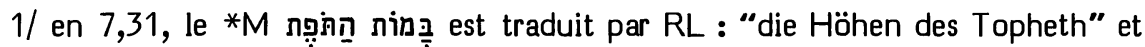
par J3 : "les hauts lieux de Tophèt".

RSV dit qu'elle s'appuie sur le ${ }^{*} G$ et le ${ }^{*} T$ pour lire ici un singulier: "the high place of Topheth". En notant le même appui, J12 traduisaient : "le haut lieu de Tophèt". Selon Brockington, NEB se fonde sur le *G pour vocaliser תֵַּ̣ et traduire : "a shrine of Topheth". Sans note textuelle, TOB traduit : "le tumulus du Tafeth".

2/ en Mi 3,12 et en Jr 26,18 qui le cite, le *M לִ est traduit de façon équivoque par NEB : "rough heath".

J1, en Mi, se fondant sur le *G, la *S et le *T, traduisait : "un haut lieu en forêt", alors qu'en $\mathrm{Jr}$, se fondant sur le ${ }^{*}$, elle traduisait "une hauteur boisée", traduction que $\mathrm{J} 2$ étendait aux deux endroits en se fondant, en Mi, sur les versions et, en Jr, sur le *G. TOB dit, en Mi, qu'elle suit le *G pour traduire "une hauteur broussailleuse", traduction qu'elle étend à Jr où elle renvoie à sa note de Mi. Dans les deux endroits, sans note textuelle, RSV traduit : "a wooded height", RL : "zu einer Höhe wilden Gestrüpps", alors que $\mathrm{J3}$ reprend la traduction de $\mathrm{J} 2$.

Origines des corrections :

1/ 7,31 : Considérant le pluriel de ce mot comme surprenant, Giesebrecht estimait qu'il faut peut-être rétablir le singulier. C'est ce qu'ont fait Oort, Duhm (se fondant sur le *G et estimant qu'il n'y a eu probablement qu'une seule bâmâ de Tophet dans la vallée de Ben-Hinnom), Cornill, Nötscher, Rudolph, Penna, Weiser, Bright, ainsi que les apparats de HSAT34, BH3 et Cent.

2/ En Mi 3,12, c'est Wellhausen (Kleinen Propheten) qui a proposé de mettre ce mot au singulier, voyant ici une annonce que le temple de Jérusalem deviendrait comme l'une des bâmôt dévastées, dans un site revenu à l'état sauvage, qui ne manquaient pas alors en Palestine, après la destruction du royaume du Nord. Duhm (sur Jr 26,18) a estimé que la mise au pluriel, dans le $* M$, pouvait viser à éviter que le temple soit comparé à une bâmâ, en introduisant une comparaison plus neutre avec des "hauteurs boisées". Bon nombre d'exégètes ont suivi la proposition de Wellhausen en Mi 3,12 et Jr 26,18. Elle a été adoptée par les apparats de HSAT34, BH23 en Mi, et par celui de Cent dans les deux endroits.

Les témoins anciens :

4Q-a, conservé en 7,31 (Janzen 174), y appuie le pluriel du *M.

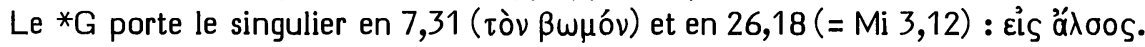

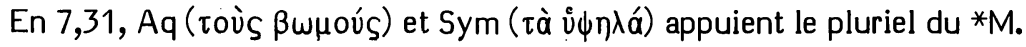

Seule la Syh nous atteste Sym (לתללא) en 26,18 et en Mi 3,12. Le ms Ambrosianus place des seyamé sur ce mot en Jr, mais pas en Mi (où il donne, pour Th : לרומא). Il 
semble peu prudent de tirer des conclusions de l'absence ou de la présence de seyamé en un unique ms pour déterminer si Sym et Th ont opté pour le pluriel ou le singulier.

$\mathrm{La} * \mathrm{~V}$ atteste clairement le pluriel (excelsa) dans les trois endroits.

La *S donne en 7,31 לבול dont la valeur plurielle est sûre. En Mi 3,12 et Jr 26,18, elle traduit ce mot par לבית dont la valeur de singulier est sûre.

Le *T donne en 7,31 במת, en Mi 3,12 et Jr 26,18 לחישת. La vocalisation de ses témoins est trop incertaine pour que l'on puisse déterminer si la syllabe finale porte en ces endroits un patah ou un qames qui distingueraient le singulier du pluriel.

\section{Choix textuel :}

1/ Il est dit en 7,31 : “Et ils ont construit les bâmôt du Tophét qui sont dans la vallée de Ben-Hinnom pour brûler leurs fils et leurs filles par le feu, ce que je n'avais pas commandé et qui n'était pas monté à mon coeur". Deux passages analogues s'offrent en Jérémie. En 19,5: "Et ils ont construit les bâmôt du Baal pour brûler leurs fils au feu en holocauste au Baal, ce que je n'avais pas commandé et que je n'avais pas dit et qui n'était pas monté à mon coeur". En 32,35 : "Et ils construisirent les bâmôt du Baal qui sont dans la vallée de Ben-Hinnom pour faire passer leurs fils et leurs filles à Molèk, ce que je ne leur avais pas commandé et ce qui n'était pas monté à

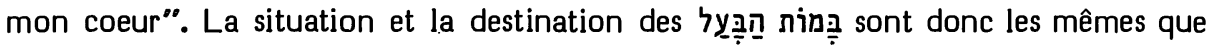

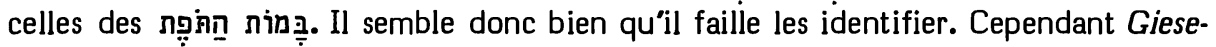
brecht n'a pas manifesté de surprise à l'égard du pluriel de ce mot lorsque ces bâmôt sont attribuées au Baal. Cela suffit à expliquer que ni Oort, ni Duhm, ni Cornill, ni Nötscher, ni Penna, ni Bright, ni les apparats de HSAT34 ne corrigent en singulier. D'ailleurs le ${ }^{*} G$ a traduit ici par des pluriels : í $\psi \eta \lambda \alpha ́$ en 19,5 et $\beta \omega \mu$ oús en 32,35 . Par souci de cohérence, Rudolph corrige 19,5 et 32,35 en singulier; alors que $\mathrm{BH} 3$ et Cent corrigent 19,5, mais non 32,35 et que Weiser fait l'inverse.

En 19,13 il est dit que les maisons de Jérusalem et les maisons des rois de Juda seront dit Tophét. Rappelons qu'en 2 R 23,8 (CT1,419) nous avons déjà vu le *G traduire le pluriel par un singulier.

De ces divers parallèles, ainsi que des témoignages textuels qui appuient le pluriel du *M en 7,31, le comité a conclu que sa leçon plurielle y méritait la note " $B$ ".

2/ Etant donné que Jr 26,18 cite formellement Mi 3,12 et que les attestations textuelles y sont analogues (le pluriel du *M y étant appuyé par la $* V$, alors que le singulier du ${ }^{*} G$ l'est par la ${ }^{*} S$ ), on peut formuler une conclusion identique pour ces deux problèmes. $L$ 'appui textuel du *M y étant moindre que celui dont il jouit en $\mathrm{Jr}$ 7,31 , le comité lui a attribué la note "C".

Rappelons ici ce que nous avons dit en Is 53,9 (ci-dessus, p. 400) sur les problèmes lexicographiques complexes liés aux mots tradition massorétique. Notons cependant que nous avons en parallèle un pluriel :

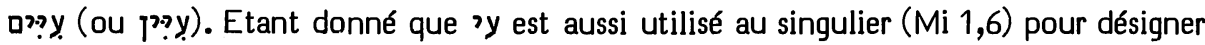
un édifice ruiné, nous pouvons considérer ces deux pluriels comme intentionnels et s'appuyant l'un l'autre. 
Interprétation proposée :

1/ En 7,31, ces bâmôt signifient les sanctuaires ou les autels dont il était fait usage pour ces sacrifices d'enfants. Rien n'empêche qu'il y en ait eu plusieurs dans la vallée de Ben-Hinnom. On pourra donc traduire "les hauts lieux du Tophét".

2/ En Mi 3,12 et Jr 26,18, dans le sens évoqué par Wellhausen, on peut comprendre le pluriel comme désignant ces nombreuses ruines et hauts lieux dévastés que I'on rencontrait dans la campagne et dans la forêt après la destruction du royaume du Nord. On pourra donc traduire : "la montagne du temple deviendra l'un de ces hauts lieux que l'on rencontre en forêt."

\section{8,3 gV T // abr-elus : 4Q-c* m G S om}

Options de nos traductions :

Après avoir dit que la mort serait préférable à la vie

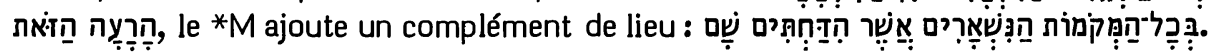

Ce complément est traduit par TOB : "ceux qui survivront dans tous les lieux où je les aurai dispersés".

RSV donne seulement : "in all the places where I have driven them", J : "en tous lieux où je les aurai chassés", RL : "an allen Orten, wohin ich sie verstosse" et NEB : "wherever I have banished them". Brockington dit qu'elle omet הנשארים (2) avec un $\mathrm{ms}$; J ajoutant, pour cette omission, le témoignage du ${ }^{*} \mathrm{G}$ et de la ${ }^{*} \mathrm{~S}$.

Origine de la correction :

L'omission de ce mot a été proposée par Hitzig et adoptée par Ewald2, Graf, Luzzatto, Knabenbauer, von Orelli, Giesebrecht, Oort, Duhm, Cornill, Condamin, Volz, Nötscher, Rudolph, Penna, Steinmann, Weiser, Bright et par les apparats de SBOT, HSAT234, BH23S et Cent.

Les témoins anciens :

Il semble bien qu'en 4Q-c un correcteur ait inséré ce mot au-dessus de la ligne où il manquait.

Le *G ancien ne traduit pas ce mot, mais il allège tout le contexte, omettant aussi הרעה en 3a et ne donnant que ò la fin pour de 3

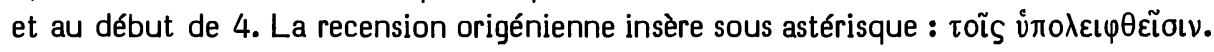

$\mathrm{La} * \mathrm{~S}$ omet ce mot.

Un ms de Kennicott omet ce mot et un autre l'efface.

La *V (quae derelicta sunt) et le *T (דישתארון) le traduisent.

\section{Choix textuel :}

On sent que l'omission de ce mot est 'dans l'air'. Mais on ne saurait conclure à partir des allègements $d u{ }^{*} G$ que ce mot ne figurait pas dans la rédaction I et que sa présence dans le *M est due à une simple répétition accidentelle à partir de $3 a$.

Deux membres du comité ont attribué pourtant la note " $C$ " à l'omission de ce 
mot, considérant qu'il ne s'agissait que d'une répétition accidentelle caractérisant la forme textuelle protomassorétique.

Un autre membre a attribué au *M la note " $A$ " considérant que, même si la présence de ce mot $n$ 'est pas originelle en $3 b$, elle constitue une initiative littéraire et non un accident textuel. Les trois autres membres ont attribué au *M la note " $C$ ", considérant la deuxième position comme plus probable que la première, du fait de ce que nous avons pu constater jusqu 'ici sur la fidélité $d u * M$ à son patrimoine textuel et sur la facilité avec laquelle le ${ }^{*} G$ allège ce qui lui fait difficulté.

Interprétations proposées :

Selon la $* V$ et la recension origénienne du ${ }^{*} G$, ce mot qualifie celui qui le précède : "en tous les lieux qui subsisteront et où je les aurai dispersés", c'est-à-dire les lieux qui n'ont pas été détruits par l'ennemi, mais où ils seront menacés par de nouveaux dangers (comme les compagnons de Jérémie qui devront fuir en Egypte après s'être d'abord réfugiés auprès de Godolias à Miçpa).

Selon le ${ }^{*} T$, ce mot a le même antécédent qu'il avait en $3 a:$ "en tous les lieux où ils subsisteront, eux que j'y aurai dispersés". La raison d'être de ce mot serait alors d'expliciter le pronom suffixe de suivi Radaq qui suggère de l'interpréter comme s'il précédait בכל־המקמות.

\section{8,5 ירושלם [B] M 4Q-a ThAq V S // paraphr : T / abr-elus : m om / lit : G om}

Options de nos traductions :

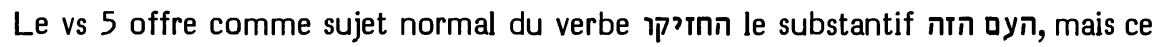

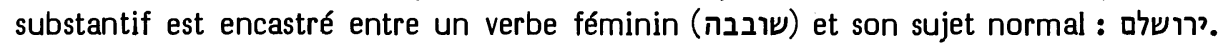

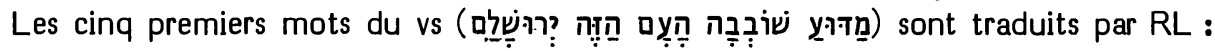
"Warum will denn dies Volk zu Jerusalem irregehen", par TOB : "Pourquoi alors ce peuple, Jérusalem, se détourne-t-il" et par 33 : "Pourquoi ce peuple-là est-il rebelle, pourquoi Jérusalem (est-elle...)".

J12 traduisaient: "Pourquoi ce peuple-là reste-t-il rebelle (J1 : égaré)" disant omettre "Jérusalem" avec le ${ }^{*} G$ et un ms hébreu. Avec le premier de ces deux appuis, NEB traduit : "Then why are this people so wayward" omettant aussi ce mot. C'est ce que fait aussi, sans note, RSV : "Why then has this people turned away."

Origine de la correction :

Cette omission a été proposée par Hitzig, suivi par Giesebrecht, Oort, Duhm etc. et par les apparats de SBOT, HSAT234, BH3S et Cent.

Les témoins anciens :

4Q-a atteste בה העם הזה à la fin d'une ligne (cf. Janzen 174). L'importance de la lacune qui suit suggère que le mot "Jérusalem" y était présent puisque, avec ce mot, on obtient 40 lettres ou espaces, alors que, pour les deux lacunes d'importance semblable qui suivent, on en obtient 53 et 47.

Le ms 126 de Kennicott (XVe siècle) omet ce mot. 


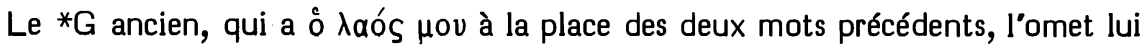
aussi. Une ajoute astérisée de la recension origénienne l'insère en l'empruntant à ThAq.

La $* V$ et la $* S$ attestent ce mot, alors que le *T le paraphrase en "habitants de Jérusalem".

\section{Choix textuel :}

Le mot ay est, en Ex 5,16, sujet d'un verbe au f. sg.: : stantif est suivi d'un participe f. sg. dont il est le sujet en J 18,7: Lorsque le mot "peuple" est seulement une foule d'individus, il s'accorde normalement au m. pl. Mais en $\mathrm{Jg} 18,7$ et $\mathrm{Jr}$ 8,5a il s'agit de la population d'une ville et cette dernière prête à des personnifications féminines. L'accord $\mathrm{m}$. pl. interviendra d'ailleurs en $5 b$.

Il est fort possible que le mot "Jérusalem" ait été ajouté, dans la tradition prémassorétique, pour expliciter ce sens et justifier ainsi la désinence féminine du verbe. En tout cas, cette initiative constituerait alors un événement littéraire et non un accident textuel.

D’ailleurs le ${ }^{*} G$ ancien semble avoir, de son côté, assimilé ici l’expression “ce peuple" à "mon peuple" de $7 b$.

Le comité a attribué à ce mot du *M 3 "B" et 1 "A". Cependant un membre a voté " $C$ " pour la leçon du ${ }^{*} G$ et un autre " $C$ " pour l'omission de "ce peuple" (estimant que le *M présente ici une leçon gonflée).

Interprétations proposées :

En traduisant : "Pourquoi ce peuple-là est-il rebelle, pourquoi Jérusalem est-elle continuellement rebelle", $\mathrm{J} 3$ a poussé le parallélisme.

Si l’on estime que "Jérusalem" constitue ici une glose, on pourra préférer : “Pourquoi est-il rebelle, ce peuple - Jérusalem - d'une rébellion continuelle" qui respecte mieux le caractère de substantif abstrait du mot

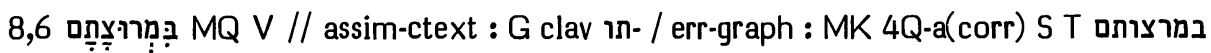
/abr-graph : 4Q-a* במרצתם

Options de nos traductions : 'șadé'.

Dans le *M un qeré

Interprétant le ketib au sens de "leurs courses", J1 suit le qeré qu'elle traduit : "leur course" (= J23). Attestent la même option sans note: RSV ("to his own course"), RL ("ihren Lauf") et NEB ("in headlong career").

TOB opte pour le ketib qu'elle traduit : “à sa guise".

Origine de la correction :

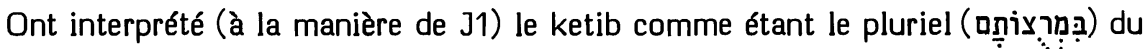
qeré : Hitzig, Henderson, Graf, Nägelsbach, von Orelli, Giesebrecht, Rudolph, BH3S et Gordis ( $\$ 61)$. 
Se fondant sur la *S et le $* T$, Michaelis a vu dans le ketib un substantif abstrait dérivé de la racine רצה, ce qu'il estimait ne pas correspondre à la fin du vs.

C'est Ewald qui (sans même évoquer l'existence d’un ketib !) a dérivé מְּרִ de רצה (Lehrbuch 418s) en traduisant : "(ein jeder...) in seine Begierden".

Keil estimait que le ketib était seulement une faute de scribe; ce que Cornill a admis, tout en précisant que la ${ }^{*} S$ et le ${ }^{*} T$ l'ont vocalisé "nach ihrem eigenen Gutdünken".

Les témoins anciens :

4Q-a portait une graphie défective. Un 'waw' a été ajouté au-dessus de l'intervalle séparant le "șadé" du 'taw'.

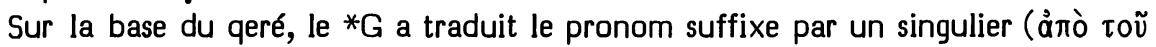

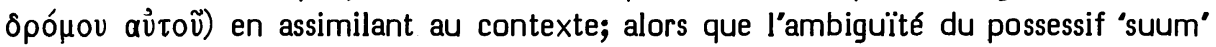
permet à la *V (ad cursum suum) plus de souplesse.

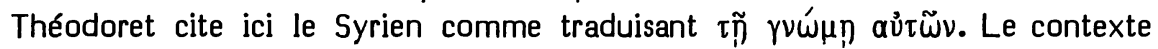
montre qu'il s'agit bien là d’une traduction exacte de la *S (בצבינהון) en grec.

Le *T traduit ברעות נפשהון.

\section{Choix textuel :}

Ce cas n'a pas été soumis au comité.

Il faut noter que מִרְּ se retrouve en 23,10 où le *G, la *V et la *S s'accordent à reconnaître au substantif le sens de "course", alors que le *T le traduit comme en 8,6 .

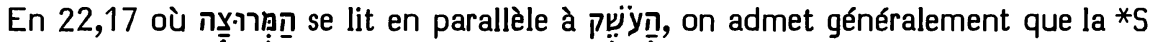

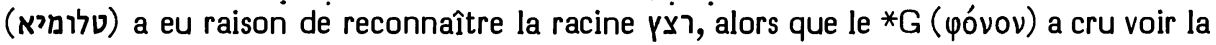
racine רצו, tandis que la *V (cursum) a vu la racine רוץ. Ici aussi, le *T traduit par l'expression רעות נפש

Pour en revenir à 8,6, il est fort probable que les traductions de la *S et du *T ont eu pour Vorlage le ketib interprété à partir de la racine רצה, ainsi que Clericus l'a diagnostiqué. Mais celui-ci et Michaelis ont eu raison de préférer le sens de "course" (= qeré) à cause de "comme un cheval qui se précipite dans le combat" qui suit immédiatement.

Interprétation proposée :

"Tous retournent à leur course, comme un cheval qui fonce au combat".

"Course" au sens de "manière de courir" a deux très bons parallèles pour ce mot en $2 \mathrm{~S} 18,27$.

\section{8,8}

Options de nos traductions :

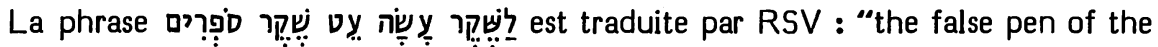
scribes has made it into a lie". j1 dit se fonder sur une conjecture de Duhm (I"hébreu signifiant : "a transformé") quand elle traduit : "c'est en mensonge que l’a transformée 
le calame frauduleux des scribes". J23 traduisent : “c'est en mensonge que l'a changée le calame mensonger des scribes", J2 seule mentionnant qu'il y a eu correction. RL traduit : "Ist's ... lauter Lüge, was die Schreiber daraus machen". Pour traduire : "scribes with their lying pens have falsified it", Brockington nous dit que NEB ponctue :

Sans note textuelle, TOB traduit : "elle est devenue une loi fausse sous le burin menteur des scribes".

\section{Origines des corrections :}

$\mathrm{Ge}$ (reprise littéralement par $\mathrm{KJ}$ ) semble avoir été la première traduction occidentale qui a explicité un pronom comme complément de ce verbe : "certeinly in vaine made he it..." Ce ne sera que dans les éditions postérieures de KJ que ce "it" sera imprimé en cursive (pour souligner qu'il n'est pas dans l'hébreu).

Michaelis traduit : "Die lügenhafte Feder der Gelehrten verwandelt es in Lügen". En Observationes, il précise que, lorsque ce verbe est construit avec la préposition "lamed", il a le sens de "transformer quelque chose en autre chose".

Ewald traduit de même: "zur Lüge hat es gemacht..." Graf estime qu'il faut sous-entendre un suffixe complétant ce verbe par une référence à la Torah. Duhm précise qu'il faut comprendre ce verbe au sens de qu'ici le suffixe 3e pers. f. sg. a, comme souvent, été écrit sans mappiq et corriger en écrivant ce mappiq. Cette correction a été adoptée par Rudolph, Steinmann, Weiser, Hyatt et elle a été requise par les apparats de $\mathrm{BH} 3 \mathrm{~S}$ et Cent.

\section{Les témoins anciens :}

Le ${ }^{*} G$ ancien porte ici $\dot{\varepsilon} \gamma \varepsilon \nu \eta ́ \theta \eta$. Cette traduction correspond-elle à une vocalisation pual, comme Cornill le suggère, ou bien à un qal (à sujet impersonnel) traduit par un passif dont vy, complément d'objet de ce qal, devient le sujet ? Cette deuxième interprétation peut être appuyée par le fait que "l"hébreu" de Chrysostome dit lire

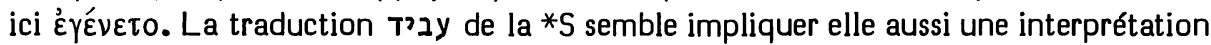
en passif du qal impersonnel. La TOB n'a-t-elle pas fait de même?

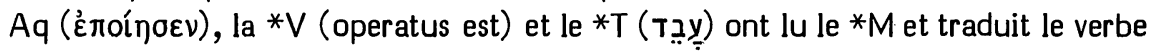
sans lui supposer un pronom suffixe comme complément.

\section{Choix textuel :}

Tous les témoins semblent donc avoir lu ici le ${ }^{*} M$. C'est ce que quatre membres du comité ont estimé en donnant à celui-ci la note " $A$ ". Deux autres membres lui ont attribué la note " $\mathrm{B}$ ", admettant comme vraisemblable que le *G vocalisait autrement ce verbe.

Interprétations proposées :

Aquila comprenait: “C'est pour l'iniquité que l'iniquité des scribes a fabriqué le calame".

La $* \mathrm{~V}$ a compris: “C'est un mensonge que le calame mensonger des scribes a fabriqué".

Le *T a compris : "C'est en vain que le scribe a fabriqué le calame mensonger". 
L'interprétation d'Aquila supposerait que le zaqef soit placé sur le mot qui suit le verbe; alors que celle du ${ }^{*} T$ supposerait qu'on l'anticipe d'un mot et s'accorde mal avec le pluriel de "scribes".

Mieux vaut donc suivre la $* V$ en faisant de "le calame de mensonge des scribes" le sujet de עשה.

Radaq a rapproché les mots à comprendre ici : "a oeuvré en vain", "a travaillé pour rien" en donnant au verbe la valeur intransitive qu'il a par exemple en $1 R$ 20,40 ou en Rt 2,19.

A la suite de Michaelis, la quasi-totalité des exégètes actuels ont donné au verbe suivi du "lamed" le sens de "transformer en", ce qui les a obligés à trouver au verbe un complément d'objet (un suffixe référant à la Torah) exprimant la chose qui a été transformée. Radaq fait preuve d'un sens plus fin de la syntaxe en reconnaissant à l'expression לַ une valeur adverbiale de "en vain", "pour rien".

On pourra donc reconnaître un jeu de mots dans la reprise de en deux sens distincts. Le sens de la phrase semble être : “C'est en vain qu’a travaillé le calame mensonger des scribes".

8,12 cf. p. 508.

8,13A אִ אִ [C] MV // assim-ctext : Aq S T / assim $10: G$

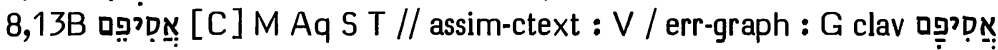

Options de nos traductions :

Sans note textuelle, les deux premiers mots du vs 13 sont traduits par RSV : "when I would gather them", par RL : “Ich will unter ihnen Lese halten", par TOB : “Je suis décidé à en finir avec eux" et par $\mathrm{J3}$ : "Je vais les supprimer".

J2 se référait au *G pour traduire : "Je voudrais récolter chez eux" (traduction large qui sera retenue par $\mathrm{RL}$ et que $\mathrm{J1}$ fondait sur "je voudrais récolter leur récolte",

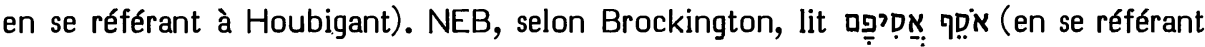
au *G pour le second mot) qu"elle traduit : "I would gather their harvest".

Origine de la correction :

Dans une partie de ses Notes omise par la réédition de Francfort, Houbigant proposait en effet de comprendre l'infinitif absolu au sens d'un inaccompli 1e pers. sg. : "je compte récolter" et de lire ensuite le substantif (= récolte) : "leur récolte". Puis le Seigneur se plaint de ne trouver ni raisins ni figues à récolter.

C'est Movers (14) qui a proposé la vocalisation que NEB retiendra, en lui attribuant le sens qu'elle exprimera. Cette vocalisation a été adoptée par Giesebrecht, Duhm, Cornill, Volz, Nötscher, Rudolph, Penna, Weiser et par les apparats de BH3S et Cent.

Les témoins anciens :

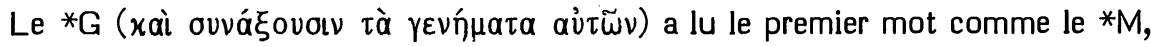
mais a interprété cet infinitif absolu en 3e pers. pl. parce qu'il lit ce vs juste après du vs 10. Il semble avoir vocalisé איורשים le second mot. 
Aq (בגמוריא אגמור אנון), la *S (מספו אסיף אנון) et le *T (שיצאה אשיצינון) semblent avoir lu le second mot comme le *M et interprété l'infinitif absolu comme un simple renforcement de l'action exprimée par la forme personnelle.

La *V (congregans congregabo eos) a respecté le sens de l'infinitif absolu et lui a assimilé la forme personnelle qu'elle a traduite comme si elle lisait אְִ̣̣.

\section{Choix textuel :}

Parmi les exégètes judéoarabes antérieurs a Hayyuj, David ben Abraham (I 127, 60s) suivait exactement l'option d'Aq, de la ${ }^{*} S$ et du ${ }^{*} T$ en traduisant : קטע אקטעה (I) alors que Yéfet ben Ely suivait l'option de la *V en traduisant : אחשרהם חשרא.

Hayyuj (Kitâb 108,1-8) explique l'option de David ben Abraham et de ses prédécesseurs en disant que quelqu'un a prétendu que cet infinitif סוף (et qu'il a donc, comme la forme personnelle qui le suit, le sens de : destruction et extirpation), car l'ajoute de la lettre 'alef' y est semblable à l'ajoute de cette lettre

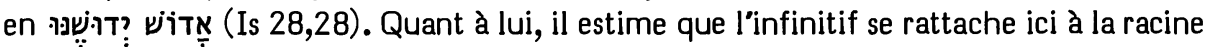
סאס, alors que la racine qui le suit est de la racine devant donc être : "en les rassemblant, je les ferai cesser".

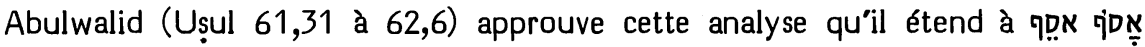
(So 1,2). Il ajoute que cette association de deux racines distinctes est une finesse stylistique, car elle permet une assonance qu'une seule racine n'offrirait pas, et cela sans troubler le sens, parce que le qal de אסף et le hifil de peuvent tous deux avoir le sens de "supprimer" ou "exterminer". Il cite, en Jérémie, un autre cas

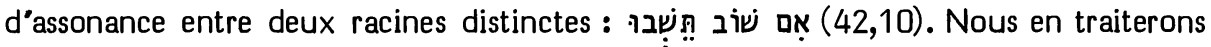
un autre en 10,25.

Les options simplifiantes $d^{*} A q$, de la ${ }^{*} S$, du $* T$ et de la $* V$ apportent donc un témoignage indirect à la leçon complexe du $* M$ qui trouve un excellent appui dans le parallèle de So 1,2.

Pour ces deux verbes, le comité a donc attribué au *M 3 " $B$ " et 3 " $C$ ".

Interprétation proposée :

La fin du vs 12 était une annonce d'extermination, alors que la suite du vs 13 dira la déception de celui qui récolte les fruits. Il semble donc qu'il faille préserver les deux images dans la traduction tout en indiquant en note l'existence d'une assonance.

On pourra donc traduire :

"En (les) récoltant, je les exterminerai", ou “en (les) cueillant, je les supprimerai".

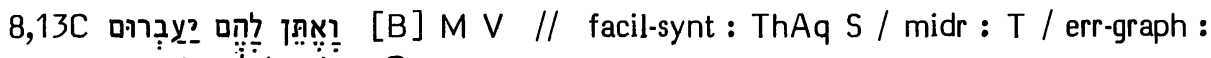

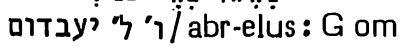

Options de nos traductions :

Les trois derniers mots du vs 13 ont été traduits par RSV: "and what I gave them has passed away from them", par RL : "und was ich innen gegeben habe, das soll ihnen genommen werden", par TOB : "je les donne à ceux qui leur passeront dessus" et par 33 : "je leur ai fourni des gens qui les piétinent". 
J12 traduisaient: “C'est que je leur ai procuré des ravageurs qui les ravagent", $\mathrm{J1}$ prétendant adopter la conjecture de Rothstein/Rudolph : מִבְצְרְרים du dernier mot.

Selon Brockington, NEB se fonde sur le ${ }^{*} G$ pour omettre ces trois mots.

\section{Origines des corrections :}

En 1930, Rudolph (Text 282) disait qu'il renonçait à une conjecture présentée d'abord par lui en 1927 et que le fait que ces trois mots manquent dans le *G l'entraînait maintenant à y voir une déformation de ואין להם ענבים qui serait une répétition erronée du début de 13b. Mais en 1947, dans son commentaire, notant que

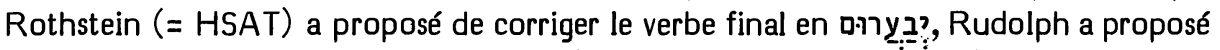
la conjecture retenue par J12, ajoutant (pour des motifs rythmiques) un mot de plus qui aurait été omis ensuite par haplographie. Cette dernière option de Rudolph a été adoptée par Steinmann et signalée par BHS.

L'omission de ces trois mots a été proposée par Cornill (SBOT). Le fait qu'ils manquent dans le *G lui semble indiquer qu'il s'agit d'une glose visant à assurer une transition avec le vs 14 . Cette proposition a été adoptée par Oort, Duhm, Penna et Bright.

\section{Les témoins anciens :}

Wichelhaus (108) estime (à la suite de Michaelis, Observationes) que le *G a omis ces mots parce qu'il ne les comprenait pas.

Les recensions origénienne et antiochienne ont réparé cette omission par un em-

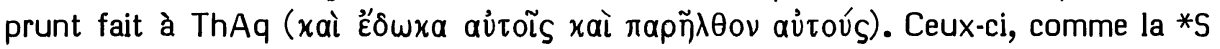
ont inséré une conjonction avant le dernier verbe pour rendre la syntaxe plus aisée. Notons que la forme $\pi \alpha \rho \tilde{\eta} \lambda \theta \varepsilon v$, retenue par Field et Ziegler, constitue une déformation secondaire.

$L a * V$ (et dedi eis quae praetergressa sunt) traduit le *M sur lequel le *T midrashise : "du fait que je leur ai donné ma Torah à partir du Sinaï et qu'ils l'ont transgressée".

Tous ces témoins ont lu dans le dernier verbe un 'resh'. Cependant, de Rossi mentionne 4 mss et la première main de 4 autres qui ont lu ici un 'dalet'. Il semble que ce soit une erreur de scribe contre laquelle la $\mathrm{mp}$ des mss d'Alep et du Caire ainsi que de l'édition Ben Hayim a essayé de protéger cette forme en la signalant comme hapax (mais la forme concurrente serait, elle aussi, hapax !). L'absence de raphé sur cette lettre dans les mss du Caire, d'Alep et de Leningrad est la meilleure garantie que la tradition tibérienne la lit comme un 'resh'.

\section{Choix textuel :}

La leçon du ${ }^{*} M$ est suffisamment difficile pour que l'on ne soit pas tenté d'y voir une glose tardive. Elle semble être à l'origine de toutes les autres. C'est pourquoi le comité lui a attribué la note " $\mathrm{B}$ ", estimant que les difficultés qu'elle présente sont du domaine de l'exégèse. 
Interprétations proposées :

En interprétant le verbe final comme : "ils les transgresseront", David ben Abraham (II 363,76ss) explicite "mes préceptes que" avant ce verbe. Abulwalid (Luma $253,27)$ explicite en même position "des décrets" ou "des préceptes". Ces exégèses qui se situent dans la ligne du *T ont été adoptées par Menahem de Posquières, Judah ibn Balaam, Tanḩum Yerushalmi, Rashi et Isaïe de Trani.

Yéfet ben Ely hésitait entre trois interprétations :

$1 /$ "et ceux à qui je les ai donnés, les déporteront",

2/ "et ceux que je leur ai donnés (= les préceptes), ils les transgresseront",

3/ "et ceux que je leur ai donnés (= les produits de la terre) leur échapperont".

Notons ici que cette forme complète du commentaire de Yéfet est donnée par le ms Hebr I 570 de la Bibliothèque Saltykov-Shchedrin (dans une partie copiée par Daniel Firuz à la fin du XVIIe siècle), alors que le ms Or 2549 de la British Library (qui est du $X I e$ siècle) ne donne que les deux dernières interprétations.

Jacob ben Reuben reprend les interprétations 1 et 3 de Yéfet. Selon Menahem de Posquières, Moïse Qimhi opte pour l'interprétation 3. Son frère, Radaq, fait de

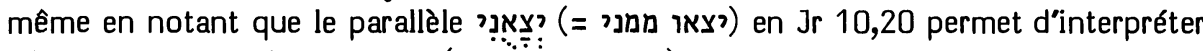
ici יעברו מהם יעם au sens des quitteront).

Selon que l'on sous-entend une particule relative avant le premier verbe ou avant le second, on obtient ou bien : "et les produits que je leur ai donnés leur échapperont", ou bien : "et je leur ai donné des produits qui leur échapperont". Etant donné qu'on rencontre plus souvent des relatives à particule sous-entendue en fonction de sujet (cf. Jg 5,14 en CT1, 84-86 et Is 41,24; 48,14 ci-dessus p. 357) qu'en fonction de complément d'objet (Is 41,2 cf. ibid.), la première construction semble préférable. C'est celle que de Dieu a retenue.

On pourra donc traduire : "Les biens que je leur ai donnés leur échappent". C'est - ainsi que Hie l'a compris - un bilan de la récolte décevante qui vient d'être évoquée. Cela semble mieux en place dans le contexte immédiat.

Il faut cependant mentionner la $2 \mathrm{e}$ interprétation de Yéfet dont nous avons vu qu'elle est la plus traditionnelle dans le judaïsme et qui correspond très bien aux deux premiers mots du verset (en même temps qu'elle suppose un sens global analogue à celui de Is 5,2): "Les dons que je leur ai faits, ils les délaissent" (c'est-à-dire : les préceptes que je leur ai donnés, ils les transgressent, si bien qu'ils ne portent en eux aucun fruit).

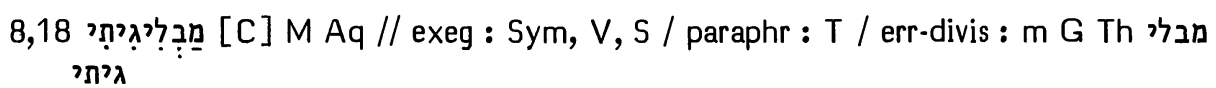

Options de nos traductions :

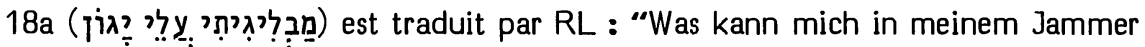
erquicken ?"

NEB conjecture : "How can I bear my sorrow ?" que Brockington prétend rat-

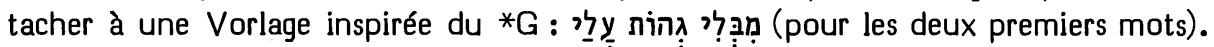
Se rattachent plus naturellement à cette Vorlage : RSV ("My grief is beyond healing") 
et TOB ("Mon affliction est sans remède") qui disent toutes deux s"inspirer du *G.

Les deux premiers mots de cette leçon sont attribués par 31 à "grec, Duhm, Condamin, Nötscher, Rudolph". Elle les transfère à la fin du vs précédent (après avoir omis "oracle de Yahvé") en traduisant: "sans remède possible". Pour le mot suivant, elle conjecture J2 fait de même (en omettant le mot "possible"). Quant à J3, maintenant "oracle de Yahvé" au vs 17, elle place toute la leçon susdite dans le vs 18 , sous la forme: “Sans remède, la peine m'envahit".

\section{Origines des corrections :}

L'interrogatif initial de RL et de NEB engagerait (contre le témoignage de

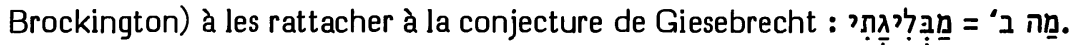

RSV et TOB suivent Duhm (et BH2, Condamin, Cent) qui lit en début du vs 18 :

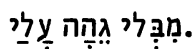

L'ensemble complexe de corrections de $\mathrm{J1}$ provient en réalité de Volz à travers Rudolph (et BH3S).

Les témoins anciens :

Le premier mot du vs 18 est traduit par le *G ảvíata. Spohn a suggéré que le traducteur lisait en deux mots מבלי גיתי, en dérivant le second de la racine guérir). Il faisait remarquer en même temps que Kennicott et de Rossi ont trouvé plusieurs mss divisant eux aussi cela en deux mots.

De fait, Th (si on lui attribue, avec Ziegler, la leçon que le ms Barberini attribue à $\mathrm{Aq}$ ) a lu de même (en dérivant le second mot de la racine גאה) lorsqu'il a traduit :

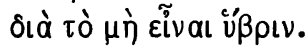

Le plus ancien des mss cités par de Rossi comme divisant ce mot semble bien être le ms Londres, British Library Add 21,161 (ancien Ebner 2 de Nürnberg) du XIIe siècle. Il a exactement la même vocalisation que le $* M$ (et non pas qụ que le ${ }^{*} G$ et Th suggéreraient). Notons d'ailleurs que ce mot ne figure pas dans la liste massorétique des "15 mots qui sont écrits comme un, mais lus comme deux" dont nous avons traité ci-dessus (p. 512), ni dans la liste complémentaire de David ben Abraham (II $4,1 s s$ ). Mais il figure dans une liste que Ginsburg (Massorah $v$ \$182) présente comme "l'une des parties les plus anciennes et populaires de la massore" : celle des 8 mots qui portent à la fois un merka et un tifḩa. Or il est intéressant de noter qu'un autre de ces 8 mots ( iñ oixías oov). Les manuscrits massorétiques médiévaux semblent donc nous avoir conservé les traces d'une ancienne lecture de מבליגיתי en deux mots; lecture qui nous est formellement attestée par le ${ }^{*} G$ et Th, mais qui a été supplantée ensuite par une lecture en un mot dont Aq semble bien être pour nous le plus ancien et le meilleur témoin. Mais l'établissement du texte authentique de la leçon d'Aq pose des problèmes délicats qu'il nous faut aborder maintenant.

Montfaucon ne connaissait aucun fragment hexaplaire sur ce verset. Field est le premier éditeur de fragments des Hexaples qui en ait édité trois, sous forme de rétroversion grecque à partir du ms Ambrosianus de la Syh. Les leçons que la Syh attribuait 
à Th et à Sym ont été ensuite insérées par Field en son Auctarium, sous leur forme grecque authentique que le ms Barberini lui avait livrée entre temps. Ce ms les attribuait à Aq et à Sym, mais Ziegler a eu raison de préférer les attributions offertes par la Syh. La découverte de l'original grec a amené Field à corriger, pour ce mot, sa rétro-

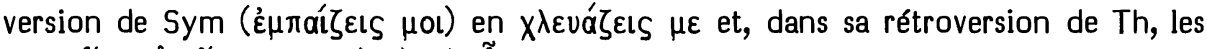

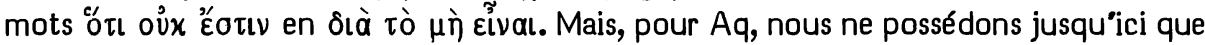
la leçon de la Syh : פציחותא דילי et sa rétroversion proposée par Field (et reproduite

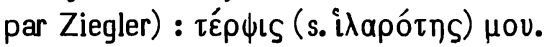

$\mathrm{La} * \mathrm{~V}$ traduit ce mot par "dolor meus", mais Hie précise : "In hebraico autem, non tam 'dolor' est, qui Graece dicitur ỏovvin, quam $\mu \varepsilon\llcorner\delta$ ía $\mu \alpha$, quod nos interpretari possumus 'rictum' oris dolore contracti et habentem risus similitudinem". Jérôme, reconnaissant que, dans 'I'hébreu', il y a plutôt $\mu \varepsilon ı \delta$ ́́a $\mu \alpha$ que le "dolor meus" par lequel il a traduit מבליגיתי, nous offre une suggestion précieuse pour améliorer la rétroversion de Aq. En effet, en Am 5,9, pour le *M "qui subridet', Aquila interpretatus est $\delta \mu \varepsilon เ \delta$ เ

Il est donc vraisemblable qu'en $\mathrm{Jr} 8,18$, lorsque Jérôme exprime ce qui est 'in Hebraico' par le mot grec $\mu \varepsilon ı \delta$ ía $\mu \alpha$, il emprunte ce mot à la traduction de Aq, comme il le fait souvent en des cas semblables. D'ailleurs, alors que le substantif $\mu \varepsilon ı$ ó́a $\mu \alpha$ n'apparaît pas dans le ${ }^{*} G$, le verbe $\mu \varepsilon ı \delta$ เã $n^{\prime} y$ apparaît qu'une seule fois. C'est en Si 21,20 où $\mu \varepsilon เ \delta$ เáocl se trouve justement traduit par מתפצח dans ce même ms Ambrosianus de la Syh qui nous a livré la leçon de Aq. Cela nous offre une confirmation très suffisante pour attribuer à $A q$, en $\mathrm{Jr} 8,18$ : $\mu \varepsilon 1 \delta$ ía $\mu \alpha$ á $\mu$ ov.

On peut donc considérer que la *V (dolor meus) s'en inspire librement, alors que Sym ( $\chi \lambda \varepsilon \nu a ́ \zeta \xi ı \varsigma \mu \varepsilon)$ interprète ce mot comme une forme verbale.

Le *T paraphrase : “du fait qu'ils ont tourné en dérision les prophètes qui s'adressaient à eux". Il semble avoir vu dans le 'mem' initial la préposition p̣ en lui attribuant une valeur motivante et $s^{\prime} \hat{e} t r e$ inspiré de la racine ay (dont il fait usage dans sa traduction) pour décrypter la suite du mot. Sym avait fait de même.

La *S בלית ב (= je me suis usé), ce qui est une autre interprétation partielle de notre mot.

\section{Choix textuel et interprétation proposée :}

Après avoir cité une opinion (d'Abulwalid en Ușul 94,20 à 95,25) selon laquelle ce mot serait combiné d'un participe masculin et d'un participe féminin et suivi d'un suffixe 1e pers., Radaq (Mikhlol 64b) ajoute : "Mais, ce qui est plus exact, c'est que

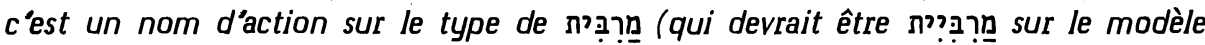

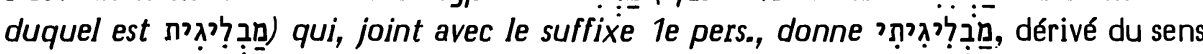
de ואבליגה מעט (Jb 10,20). C'est ainsi que mon frère R. Moshé a écrit à juste titre dans son livre Tahboshèt." Il répète la même opinion en son commentaire où il ajoute qu'ici et en Jb 10,20 le sens est "prendre sur soi, se maîtriser". Dans les Shorashim, il ne donne plus que l'exégèse de son frère, sans le nommer.

Notons que cette exégèse en substantif, au sens de "ma maîtrise de moi", était déjà celle que Yéfet ben Ely donnait en son commentaire. Ce sera aussi celle de Rashi qui comprend ici "mon hablâgâh", ce que les glossaires CDE (avec référence à Menahem ben Saruq) et AF traduisent par "mon détènement". 
Depuis David ben Abraham (I 231,96-101), une autre exégèse rivalise avec celle-ci. Il attribue en effet à cette racine, en Jb 10,20; Ps 39,14 et Jr 8,18, le sens de "vivre à l'aise" qui sera retenu plus tard par le Lexicon de Buxtorf ("se récréer") et par Grotius comprenant ici "en ma consolation".

Il semble que ce soit Schultens (en sa dissertation "de verbis et sententiis ambigua et duplici significatione valentibus", Opera minora 383) qui, sans connaître ici la leçon d'Aq, a donné la meilleure explication de cette double tradition exégétique : “Comme il ressort d'une comparaison avec l'arabe, בלג pour les anciens. hébreux signifiait proprement 'sourire', $\mu \varepsilon \imath \delta \hat{\imath} \tilde{\alpha} \nu$, sens qui n'était pas encore tombé dans l'oubli à l'époque de Jérôme. D'ailleurs, les arabes appellent בליג la bouche qui sourit avec les dents séparées et découvertes et אבלרג celui qui a coutume de sourire avec les dents découvertes, qu'il s'agisse là d'un vrai sourire ou d'une douleur qui se déguise en sourire".

L'ambiguïté du sourire exprimé par le verbe grec ressort clairement de certains de ses emplois rapportés ici par Estienne (Thesaurus VI 685) qui lui donne le sens de "rire du bout des dents", ce qui correspond exactement au sens que Schultens attribuait à l'analogué arabe de notre racine hébraïque. La définition que Jérôme donnait du 'rictus' correspond, elle aussi, à cela.

On pourra donc traduire : "mon rictus voile (litt.: est sur) le chagrin; à mon propos, mon coeur est malade."

Gesenius (Thesaurus 207b), Ewald (Lehrbuch 429), Olshausen (Lehrbuch 412) ont accepté l'analyse en substantif féminin que les deux frères Qimhi ont donnée de ce mot.

Le comité a attribué la note " $C$ " à la leçon du *M.

Notons, à titre de curiosité, que la conjecture de Giesebrecht a eu un lointain précurseur. Judah ibn Balaam dit en effet : "Ce qui est plaisant, et dont il vaut mieux rire que pleurer, c'est l'opinion d'Ibn Giqatilla qui a estimé que c'est un nom et que le 'mem' y a la valeur de maîtrise de soi !'... Mais, à notre avis, cette construction ne se rencontre jamais avec les noms. L'assimilation du

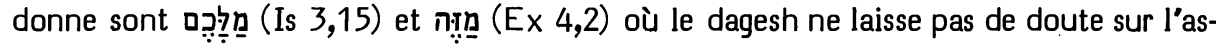
similation qui, des deux mots, en fait un seul."

Dernière remarque : Ziegler a le tort de suivre Rahlfs en plaçant un point avant le début du vs 18 dans son édition du *G. Swete avait raison de suivre la Sixtine en omettant toute ponctuation au début de ce vs. Cela correspond exactement aux dires de Hie spécifiant que les Septante ont lié ceci à ce qui précède. La mise en page du ms Sinaiticus met d'ailleurs en valeur une coupure à la fin du vs 18 qui y apparaît clairement comme complétant celui qui le précède. Il faut donc comprendre le ${ }^{*} G$ : “Car voici que j'enverrai vers vous des serpents mortels qui ne se laissent pas charmer, et ils vous mordront de morsures inguérissables qu'aggravera (litt. : avec) la douleur de votre coeur désespéré." 


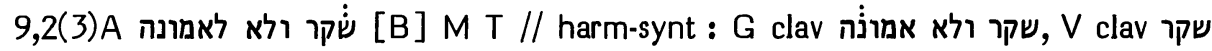
לשקר ולא לאמונה Sym? S clav ולא אמונה

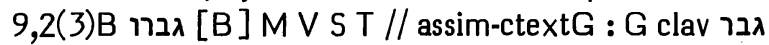

\section{Options de nos traductions :}

Par un zaqef qaton, le *M divise clairement 2a en deux membres dont le premier

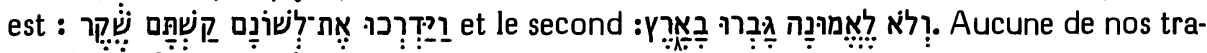
ductions n’a respecté cette syntaxe.

RL traduit : "Sie schiessen mit ihren Zungen lauter Lüge und keine Wahrheit und treiben's mit Gewald im Lande."

Disant suivre le *G, RSV traduit : "They bend their tongue like a bow; falsehood and not truth has grown strong in the land", J : "Ils bandent leur langue comme un arc; c'est le mensonge et non la vérité qui prévaut en ce pays", NEB : "The tongue is their weapon, a bow ready bent. Lying, not truth, is master in the land", Brockington précisant que cela suppose une omission du 'lamed' avant le deuxième mot du second membre et une mise au singulier de son troisième mot.

Sans mentionner de correction, TOB traduit: "Leur langue est comme un arc tendu. Leur essor dans le pays sert le mensonge, non la vérité."

\section{Origines des corrections :}

RL s'est contenté de reprendre la syntaxe de Luther qui se singularise parmi les traducteurs du XVIe siècle en joignant les mots "mensonge" et "vérité" et en les rattachant au premier membre, ce qui est caractéristique de la syntaxe de la *V.

RSV, J et NEB suivent le ${ }^{*}$ G. Cette option a été proposée par Duhm et adoptée par Cornill, Volz, Nötscher, Rudolph, Penna, Steinmann, Weiser, Bright ainsi que par les apparats de HSAT4, BH3S et Cent.

La traduction de TOB suppose qu'un 'lamed' a été inséré avant le dernier mot du premier membre. Cette proposition a été formulée par Clericus, Houbigant, Oort et Ehrlich. Clericus rattachait ce mot et les deux suivants au premier membre, alors que Houbigant et Ehrlich (comme TOB) les rattachent au second membre.

\section{Les témoins anciens :}

Seul le *T suit la syntaxe du *M.

Les autres versions joignent toutes "mensonge" et "vérité". Mais le *G fait de "mensonge" le sujet du verbe du second membre (qu'il traduit par un singulier): "Le mensonge et non la vérité a dominé sur la terre". La *V et la *S (comme le *M) donnent les mêmes sujets aux verbes des deux membres, la *V faisant de "mensonge" et "vérité" des caractéristiques de l'arc: "comme un arc de mensonge et non de vérité", alors que la *S en fait des caractéristiques de la domination sur la terre : "par le mensonge et non par la vérité ils ont dominé sur la terre". Sym (ודגלותא semble se rattacher à cette dernière exégèse.

\section{Choix textuel :}

Le comité a estimé que toutes les variantes constituent ici des harmonisations syntaxiques qui veulent établir un lien étroit joignant "le mensonge et non la vérité". Contre ces facilitations, il a attribué la note d'ensemble " $B$ " à la syntaxe du *M. 
Interprétations proposées :

Le verbe דר au qal, avec l'arc pour complément, signifie "tendre l'arc". Ce même verbe à la même forme, avec la flèche pour complément (Ps 58,8; 64,4), signifie "ajuster la flèche". Ici il faut lier l'usage du hifil (dont la forme est identique à celle de double accusatif, pour exprimer l'acte complexe qui consiste à "armer" l'arc en le tendant et en y ajustant la flèche. La langue est comparée à l'arc et le mensonge à la flèche. Le sens est donc: "Ils ont armé leur langue - leur arc - avec le mensonge". C'est l'interprétation qu'avait donnée à cette phrase la traduction des Prédicants de Zurich : "Jre zungen habend sy gespannen wie ein bogen, lugenen auszeschiessen", Ge : "And they bend their tongues like their bowes for lies", Pasteurs : "Ils ont fait tirer mensonge à leur langue comme à leur arc".

Comme Luzzatto l'a noté, l'expression לא לאמונה signifie quelque chose de contraire à la אמונה et d'incompatible avec elle. On pourra donc traduire par "déloyauté". Selon le sens que l'on accordera à la préposition 'lamed', on peut donc traduire : "Leur pouvoir promeut la déloyauté dans le pays", ou bien “C'est grâce à la déloyauté qu'ils ont pris le pouvoir dans le pays."

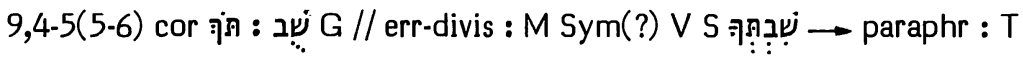

Options de nos traductions :

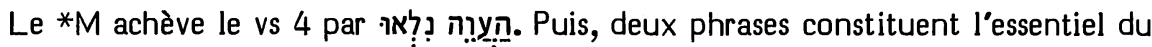
vs 5 (avant de le conclure par "oracle du Seigneur"), d'abord:

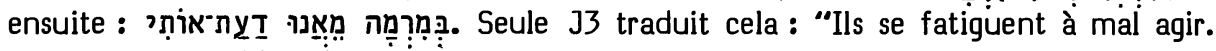
Tu habites au milieu de la mauvaise foi ! C'est par mauvaise foi qu'ils refusent de me connaître."

En disant suivre le ${ }^{*} \mathrm{G}, \mathrm{J} 12$ corrigeaient les deux derniers mots du vs 4 et les deux

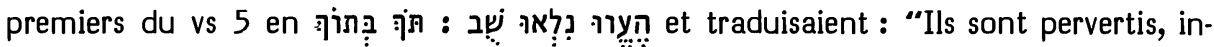
capables de revenir ( $\mathrm{J} 1$ : inaptes à se convertir). Fraude sur fraude! Tromperie sur tromperie ! Ils se refusent à connaître Yahvé !"' Corrigeant de la même manière (selon Brockington) le premier mot du vs 5, NEB traduit : "deep in their sin, they cannot retrace their steps. Wrong follows wrong, deceit follows deceit; they refuse to acknowledge me". Se référant au *G, RSV traduit : "they commit iniquity and are too weary to repent. Heaping oppression upon oppression, and deceit upon deceit, they refuse to know me." Avec le même appui, TOB traduit : “Dans leur perversion, ils ne peuvent plus revenir. Brutalité sur brutalité, tromperie sur tromperie! Ils refusent de me connaître." RL traduit de même : "Sie freveln, und es ist ihnen leid umzukehren. Es ist allenthalben nichts als Trug unter ihnen, und vor lauter Trug wollen sie mich nicht kennen."

\section{Origine de la correction :}

C'est Cappel (Critica 689) qui a reconnu que le ${ }^{*} G$ offre pour le premier mot du * $M$ au vs 5 les deux mots indiqués par J12. Cette leçon a été adoptée partiellement par Houbigant et Michaelis (OEB et Observationes), intégralement par Ewald, Giese- 
brecht, Oort, Duhm, Volz (KAT), Schmidt, Nötscher, Rudolph, Penna, Steinmann, Weiser, Hyatt, Bright ainsi que les apparats de SBOT, HSAT3, BH3S et Cent.

Les témoins anciens :

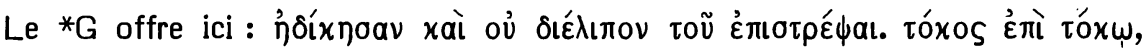

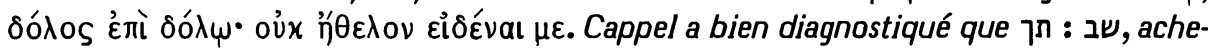
vant un vs et commençant l'autre, correspondait dans la Vorlage du ${ }^{*} G$ au mot par lequel le ${ }^{*} M$ commence le vs 5 . Schleusner (II 99s) a eu raison de conclure que oú

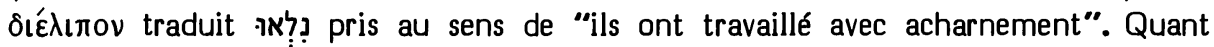
à n’óíxnoav, il est fort possible qu'il ne s'agit là que d'une interprétation de l'infinitif qui lui correspond dans le *M.

Toutes les autres versions ont lu le premier mot du vs 5 selon le *M: Sym (מותבא דילך) selon une leçon marginale anonyme de la Syh que Spohn, Field et Ziegler lui attribuent de façon vraisemblable), la *V (habitatio tua), la *S (מותבך) et le *T qui paraphrase : "ils sont assis dans leur synagogue" (ce que BHS a tort de joindre à la leçon du ${ }^{*} G$ ).

\section{Choix textuel :}

On ne saurait nier que le $* M$ est grammaticalement satisfaisant. La seule difficulté qu'il présente est le surgissement soudain d'un pronom suffixe de la $2 e$ pers. $s$. isolé dans le contexte. Mais nous avons vu d'autres occurrences de ce phénomène.

Pourtant la Vorlage du ${ }^{*} G$ frappe l'attention du critique par la qualité stylistique de la double répétition quis qui, d'autre part, valorise au mieux les 2e, 3e et $4 \mathrm{e}$ mots du vs 5 . A A

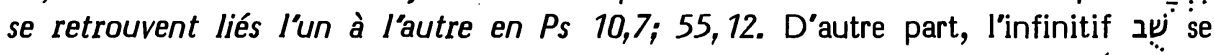
construira aisément avec le verbe qui le précède, si l'on comprend ce verbe (comme en 6,$11 ; 20,9)$ au sens de "ne plus être capable", "n'avoir plus la force de", ce qui est un diagnostic encore plus sombre sur l'impossibilité de la conversion que ne l'était en 5ourra alors être considéré comme une apposition à à

Le comité a attribué à cette leçon 3 "B" et 2 "C $\mathrm{C}$ ", alors que la leçon du * $\mathrm{M}$ a reçu 1 "C".

\section{Interprétation proposée :}

"Ils ont entraîné leur langue aux paroles menteuses, aux actes pervers. Ils n'ont plus la force de revenir. (5) Coup de force sur coup de force, tromperie sur tromperie, ils refusent de me connaître - oracle du Seigneur."

\section{9,6)7 בת־עי MV S // glos : G T}

Options de nos traductions :

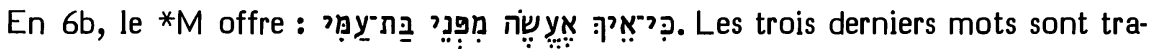
duits par RSV : "because of my people", par RL : "wenn ich ansehe die Tochter meines Volks", par NEB : “my people" et par J3 : "pour la fille de mon peuple". 
Disant suppléer "la méchanceté" avant "mon peuple" (par quoi elle traduit l'expression בת־עמי, ainsi qu'elle le précise sur 4,11), TOB traduit "face à la méchanceté de mon peuple" en se fondant sur le *G et le *T.

C'est à la place de cette expression que $\mathrm{J12}$ lisent "leur méchanceté".

\section{Origines des corrections :}

C'est en s'inspirant du mot "nequitiâ" que Sionita avait suppléé dans sa traduction de la *S pour la rendre plus claire, que Houbigant a inféré derrière le mot rovnpías (que le ${ }^{*} G$ offre en position analogue) une Vorlage תyר qui serait tombée dans le *M parce qu'elle y précédait בת qui s'achevait par la même lettre. La construc-

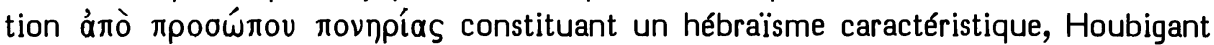
estimait que ce mot ne pouvait être issu d'une initiative du traducteur.

Notant que le *T avait inséré dans la même situation müller) s'est fondé sur lui et sur le ${ }^{*} G$ pour insérer dans le $* M$ le mot yูi.

La correction d'Houbigant a été adoptée par Ewald, Hitzig, Graf, Giesebrecht, Oort, Condamin, Schmidt et les apparats de SBOT et HSAT2; alors que Nötscher et l'apparat de Cent préfèrent substituer בת רע רע

La correction adoptée par. $\mathrm{J12}$ provient de Volz, Rudolph, Steinmann, Bright et a été suggérée par les apparats de BH3S.

Les témoins anciens :

Il faut noter que, dans le ${ }^{*} G$, le mot novnpías a été obélisé par la recension origénienne consciente de son absence dans l'hébreu protomassorétique. Quand le ms Sinaiticus l'omet, s'agit-il d'une recension sur l'hébreu ou d'un indice du caractère secondaire de ce mot dans le ${ }^{*} G$ ? On ne peut en tout cas tirer de la traduction hébraïsante de מפני par le *G les conclusions qu'Houbigant prétend en tirer à propos du mot suivant. Sollamo signale en effet (93s) que le ${ }^{*} G$ de $\mathrm{Jr}$ a tendance à stéréotyper cette traduction hébraïsante dont la fréquence (30 fois) le caractérise. Mais, du fait de cette tendance, cette traduction ne nous dit rien sur la présence dans sa Vorlage d'un équivalent pour le mot qui suit, mot qui a pu être appelé par des parallèles intérieurs au grec (cf. le *G de Jr 4,4; 44(51),3.22).

A part le ${ }^{*} T$ dont nous avons mentionné l'ajoute, les autres versions (*V et ${ }^{*} S$ ) $n$ 'insèrent rien ici.

\section{Choix textuel :}

Ce cas n'a pas été soumis au comité.

Houbigant aurait dû tirer de l'initiative de Sionita une conclusion inverse : $s^{\prime}$ ajoutant aux deux insertions offertes par le ${ }^{*} G$ et le ${ }^{*} T$, elle prouve qu'une glose de ce type est ici 'dans l'air' et qu'il faut donc s'en défier, car elle risque d'être liée à une méconnaissance du sens réel du *M.

Interprétation proposée :

Ici, en effet, il s'agit d'expliquer pourquoi "je vais les épurer et les éprouver" : "car comment agirai-je lorsqu'il s'agit de la fille de mon peuple ?" Le Seigneur ne peut 
se permettre de laisser, sans intervenir, la corruption contaminer son peuple. Cette exégèse a été proposée par Radaq et par Luzzatto.

\section{בפיהם M 4Q-a V S // assim-ctext : G T clav בפיו (8,7}

\section{Options de nos traductions :}

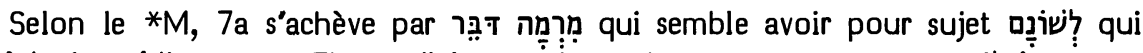
précède immédiatement. 7b se divise en deux phrases :

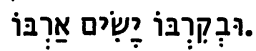

RSV traduit assez littéralement : "Their tongue is a deadly arrow; it speaks deceitfully; with his mouth each speaks etc." Plus largement, 33 traduit : "Leur langue est une flèche meurtrière, leurs paroles sont de mauvaise foi; de bouche, on souhaite etc." Encore plus librement et en mettant au pluriel tous les verbes et suffixes, RL traduit (en suivant Luther): "Ihre falschen Zungen sind tödliche Pfeile; mit dem Munde reden sie etc."

En disant suivre le ${ }^{*} \mathrm{G}, \mathrm{J12}$ traduisaient : "Leur langue est une flèche meurtrière, les paroles de leur bouche des tromperies; on souhaite etc." Sans éclaircissement de Brockington ni note, NEB traduit de même : "Their tongue is a cruel arrow, their mouths speak lies. One speak etc."

Quant à TOB, notant qu'elle corrige le premier possessif en singulier, elle donne : "Flèche meurtrière que sa langue ! Il profère la tromperie. Des lèvres, on offre etc."

Origines des corrections :

C'est Ewald2 qui a suggéré de lire Tִִִּ ạ à la place du dernier mot de 7a; alors que Cornill, se fondant sur le *G, omet en outre le premier mot de $7 \mathrm{~b}$, suivi en cela par Rothstein en $\mathrm{BH} 2$ et en HSAT34. C'est cette option que J12 a adoptée.

Adoptent aussi cette leçon, mais en mettant au singulier les pronoms suffixes de "langue" et de "bouche" : Volz, Rudolph et les apparats de BH3S.

L'apparat de Cent (suivi par TOB) se contente de corriger le *M sur un point : "sa langue". Pour la transition de 7a à 7b, il garde la syntaxe du *M.

Les témoins anciens :

Depuis "leur langue" jusqu’à "en sa bouche" $4 Q-a$ (Janzen 175) nous est conservé et appuie le *M. La *V (lingua eorum dolum locuta est / in ore suo) et la*S (לשנהלון appuient le *M dans la distinction des deux suffixes et dans la place de l'atnah.

Le *G a assimilé le second suffixe au premier et a reculé d'un mot la place. de

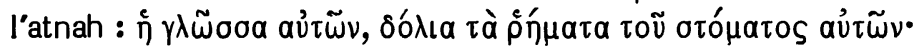

Sans modifier la syntaxe du *M, le *T assimile le second suffixe (בפומהון) au premier.

\section{Choix textuel :}

Ce cas n’a pas été soumis au comité.

Ehrlich a fait remarquer que "en sa bouche", du fait qu'il sert de contraire à "en son for intérieur"(בקרבו), est intouchable. On retrouve en effet ce contraste entre 
le for intérieur et la bouche ( $\operatorname{Ps} 62,5)$ ou les lèvres ( $\operatorname{Pr} 26,24)$ comme une opposition classique.

Le substantif Pr 26,28; Lm 4,4). On en fera donc le sujet du verbe qui le suit.

Ayant méconnu le contraste entre la bouche et le for intérieur, le ${ }^{*} G$ a assimilé le deuxième suffixe au premier. Il n'y a aucun motif pour l'imiter en cela.

Interprétation proposée :

En 7b, il faut sous-entendre אִ (= chacun) comme antécédent des deux pronoms suffixes et sujet des deux verbes au singulier. On pourra donc traduire: "Flèche meurtrière que leur langue! Elle profère la tromperie. De sa bouche, chacun etc."

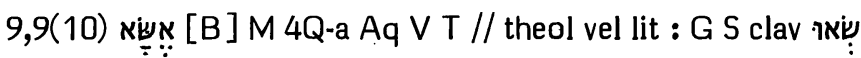

\section{Options de nos traductions :}

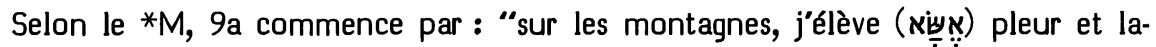
mentation". La forme de ce verbe (1e pers. sg.) a été respectée par RL : "ich muss... (weinen)", NEB : "will I raise", TOB : "s"élève ma (plainte)" et 33 : "j"élève".

RSV, se fondant sur le *G et la *S, corrige en impératif : "Take up". J12 faisaient de même en se référant au *G : "élevez".

\section{Origine de la correction :}

C'est Houbigant qui, trouvant au vs suivant une 1e pers. sg. qui doit avoir Dieu pour sujet, a estimé impossible d'avoir ici aussi une 1e pers. sg. qui, sans que cela soit mentionné, doit avoir un sujet différent (le prophète ou la fille de Sion). Aussi préfère-t-il, en corrigeant avec le ${ }^{*} G$ et la ${ }^{*} S$ en faire parler Dieu (comme c'est le cas dans le vs qui précède et en celui qui suit). Cette correction a été adoptée par Oort, Cornill, Condamin, Volz, Nötscher, Rudolph, Penna, Steinmann, Weiser, ainsi que par les apparats de HSAT34, BH235 et Cent.

\section{Les témoins anciens :}

Ici 4Q-a (Janzen 175), la *V (adsumam) et le *T (אנא מרים) appuient la 1e pers. sg. du *M.

L'impératif pluriel est attesté par le ${ }^{*} G(\lambda a ́ \beta \varepsilon \tau \varepsilon)$ et la $* S$ (שקולו), alors que Aq

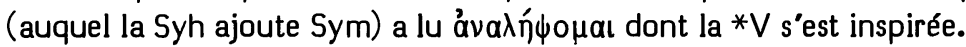

\section{Choix textuel :}

On retrouve ailleurs en Jérémie un "je" de lamentation faisant immédiatement suite (sans mention d'un changement de sujet) à un "je" divin d'annonce du châtiment. C'est le cas en 8,18; 10,19. Ailleurs, c'est un passage non signalé du "je" de la plainte au "je" du jugement : 10,19-22. Parfois, d'ailleurs, le "je" de la lamentation est introduit comme une parole venant du Seigneur $(14,17)$. Il est donc permis de se demander si ce n'est pas faire preuve d'un esprit trop cartésien que de vouloir distinguer toujours avec précision entre la compassion éprouvée par le prophète et celle qu'éprouve le Seigneur lorsqu'il lui faut châtier son peuple. 
Il n'est cependant pas impossible que la 1e personne dont le $* M$ fait usage ici soit issue d'une retouche rédactionnelle visant à assimiler la forme de ce verbe à celles des verbes initiaux des versets qui l'encadrent.

Le comité a estimé cependant plus probable que le ${ }^{*} G$ a réagi comme Houbigant, ou bien qu'il a voulu éviter que l'on risque d'attribuer à Dieu le "je" non introduit de

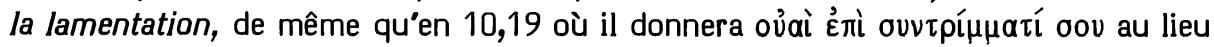

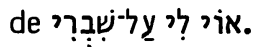

Considérant donc la leçon du *M comme ou bien originale, ou bien issue d'une initiative littéraire, le comité lui a attribué 4 " $B$ " et 2 " $A$ ".

Interprétation proposée :

"Sur les montagnes, j’élève pleur et lamentation."

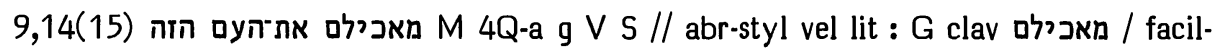

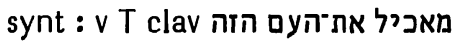

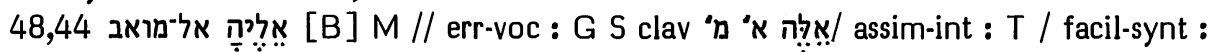

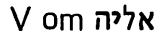

Options de nos traductions :

1/ 9,14 : Ici, le *M explicite le pronom suffixe de מאכילְ. par Jתיהעם הזה J traduit : "(Je) vais leur ( 33 : lui) donner, à ce peuple, ... à manger".

La plupart des autres traductions omettent le suffixe sans le noter. RL traduit : “ich will dies Volk ... speisen", RSV et NEB : "I will feed this people".

TOB se fonde sur le *G pour omettre "ce peuple" et traduire : "Je vais leur faire avaler".

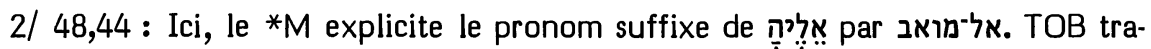
duit : "(Je vais faire venir) sur elle, sur Moab".

RL ne tient pas compte du premier de ces trois mots: “(ich will) über Moab (kommen lassen)".

RSV corrige ce premier mot selon le *G et la *S lorsqu'elle traduit: "(I will bring), these things upon Moab". Avec les mêmes appuis, J traduit : "(je vais amener) ces fléaux (J3 : tout cela) sur Moab". Sans note, NEB traduit de même : "All this (will I bring) on Moab".

\section{Origines des corrections :}

1/ 9,14: Au XVIe siècle, seule une minorité de traducteurs (Münster, Arias Montano, Châteillon, Tremellius, Pasteurs, KJ) traduisent à la fois le suffixe "eux" et "ce peuple".

Les autres (Pagnini, Prédicants, Luther, Zwingli, Brucioli, Olivetan, Jud, Calvin, $\mathrm{Ge}$ ) ne traduisent pas le pronom suffixe frayant ainsi la voie à Houbigant qui propose de l'omettre, suivi en cela par Oort et Volz.

L'omission de "ce peuple" a été proposée par Giesebrecht, se fondant sur le *G. Il a été suivi par Duhm, Cornill, Condamin, Nötscher, Rudolph, Penna, Steinmann, ainsi que par les apparats de SBOT, HSAT4, BH23S et Cent. 
2/ 48,44 : Au XVIe siècle, ceux qui traduisent à la fois "vers elle" et "vers Moab" ou ceux qui ne traduisent que "vers Moab" sont à peu près les mêmes qui explicitaient ou n'explicitaient pas le pronom suffixe en 9,14. La seule différence est que Olivetan, Jud, Calvin et Ge passent ici dans la première catégorie.

En chacun de ces deux cas, RL s'est donc contentée de reprendre la traduction allégée de Luther.

Ici, c'est encore Houbigant qui, le premier, a proposé de lire à la place du premier mot le démonstratif pluriel qu'il attribue à la Vorlage du *G et de la *S. Cette proposition a été adoptée par Movers (16), Grätz, Oort, Cornill, Condamin, Volz, Nötscher, Rudolph, Penna, Weiser, Bright et par les apparats de SBOT, HSAT234, BH23S.

L'omission de ce mot a été proposée par Giesebrecht sans succès.

Les témoins anciens :

1/ 9,14: 4Q-a (Janzen 175) atteste à la fois le suffixe "eux" et le début (avant lacune) de "ce peuple".

Le *G n’atteste que le suffixe (aủioús) auquel la recension origénienne ajoute

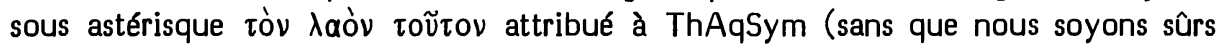
que ces trois traducteurs traduisaient aussi le suffixe).

Le suffixe et "ce peuple" sont tous deux traduits par la *S (להון לעמא הנא) et la *V (eos populum istum). Mais le suffixe est omis par la tradition textuelle récente de la *V et n'est pas exprimé par le *T (על עמא הדין).

2/ 48,44 : En traduisant le premier mot par $\tau \alpha \tilde{v} \tau \alpha$, le $* G(31,44)$ prouve qu'il a lu 'alef', 'lamed' et 'hé' en ce lieu, précédant les $2 e$ et $3 e$ mots qu'il traduit ensuite. La ${ }^{*} \mathrm{~S}$ (הלין) dépend du*G.

La *V n'a pas traduit le premier mot.

Le *T a traduit le suffixe f. sg. de ce mot par un suffixe m. pl. (עליהון). En effet, il traduit ici, comme plusieurs fois dans le proche contexte, "Moab" par "Moabites".

\section{Choix textuel :}

On peut considérer que l'explicitation d'un pronom suffixe par un substantif en apposition est une caractéristique du ${ }^{*} M$ de Jérémie, puisque cette particularité syntaxique s'y retrouve en 11,$15 ; 27,8 ; 31,2 ; 41,2.3 ; 48,44 ; 51,56$ et dans le ketib de 43,11 . Le plus souvent, le ${ }^{*} G$ n'exprime pas ce suffixe, mais cela ne signifie pas nécessairement qu'il ne le lisait pas dans sa Vorlage. En effet, en 9,14; 27,8; 41,2.3 le ${ }^{*} G$ offre, dans le contexte proche, des 'moins' par rapport au *M, 'moins' qu'il faut vraisemblablement interpréter comme des allègements stylistiques. Mais ce qui est beaucoup plus intéressant à noter, c'est qu'en deux cas le ${ }^{*} G$ nous montre qu'il a lu le suffixe dans sa Vorlage sans l'interpréter comme tel:

1/ en 31,2 le 'waw' suffixal de להרגיעi ישראל a été interprété par le *G $(38,2: \mu \grave{j}$

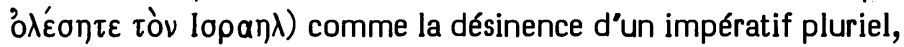

2/ en 48,44, ainsi que nous l'avons vu, le "hé' suffixal de אליקה אל־מואב a été interprété par le *G comme la finale du démonstratif אִ.

$\mathrm{Si}$, en ces deux cas, le ${ }^{*} \mathrm{G}$ nous montre avoir lu ces suffixes pléonastiques qui constituent un trait caractéristique de la syntaxe du ${ }^{*} \mathrm{M}$ de Jérémie, on a tout motif de 
penser que l'absence dans le ${ }^{*} G$ des autres tournures pléonastiques de même type est à interpréter comme des omissions visant à alléger le style. En effet, dans le seul cas où un ms de Qumrân peut témoigner (4Q-a en 9,14), il appuie le *M, nous confirmant qu'il ne s'agit pas, en ces pléonasmes, d'initiatives rédactionnelles tardives qui seraient propres à la tradition littéraire du*M.

Alors que 9,14 n'a pas été soumis au comité, celui-ci, en 48,44, a attribué 5 “ $\mathrm{B}$ ” et 1 " $C$ " à la leçon du $* M$.

Interprétations proposées :

$1 / 9,14$ : "je vais leur faire manger, à ce peuple, ..."

2/ 48,44: "je vais faire venir vers elle, vers Moab, ..."

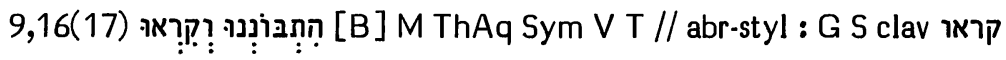

Options de nos traductions :

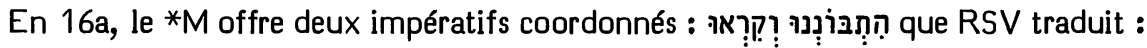
"Consider, and call", J1 : "Attention! faites appel", J2 : "Holà! appelez", RL : "Gebt acht und bestellt", TOB : "Informez-vous! Faites venir" et J3: "Pensez à appeler".

NEB se fonde sur le ${ }^{*} G$ pour ne garder que le second de ces impératifs qu'elle traduit : "Summon".

Origine de la correction :

C'est pour des motifs de métrique que Cornill a proposé d'omettre (avec le ${ }^{*} G$ ) le premier impératif, suivi en cela par Ehrlich, Volz, Schmidt, Steinmann, Bright et par les apparats de HSAT34, BH23 et Cent.

Les témoins anciens :

Ici où deux impératifs se suivent, le ${ }^{*} G$ ne traduit pas le premier. A la fin du vs où un inaccompli $3 e$ pers. f. pl. en précède deux autres, le ${ }^{*} G$ ne traduit que l'un des trois. Il semble bien que l'on ait affaire à deux allègements stylistiques.

La *S suit ici le *G en son omission.

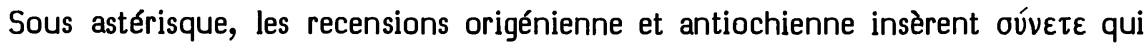

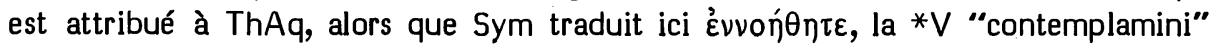
et le *T אסתכלו.

Choix textuel :

Le comité a estimé ici très probable que le ${ }^{*} G$ a omis ce mot. Aussi a-t-il attribué à la leçon du *M la note " $B$ ".

Interprétation proposée :

Cet impératif enjoint au peuple de prendre conscience de la situation paradoxale : avant que personne ne soit mort, il faut déjà s'occuper de réserver des pleureuses, car il y aura tant de morts qu'aucune ne sera plus disponible. On peut donc traduire : "Préoccupez-vous de faire appel..." 
Options de nos traductions :

Le Seigneur a dit au vs 24 qu'il allait visiter quiconque est מוּל 25a, En il cite, pour expliciter cela, un certain nombre de peuples qui pratiquaient la circonci-

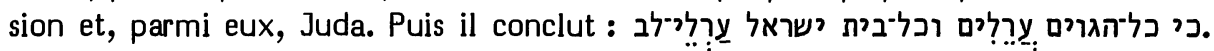
La première de ces deux affirmations est traduite par RSV : "for all the nations are uncircumcised" et par TOB : "Car toutes les nations sont incirconcises", alors que RL ajoute une nuance : "Denn alle Heiden sind nur unbeschnitten".

J dit conjecturer avec Rudolph הִִ̣ à la place du quatrième mot et traduit : “Car tous ces peuples-là". NEB, sans rien noter, fait de même : "for all alike, the nations etc."

\section{Origine de la correction :}

C'est Rudolph (Text 282) qui a proposé cette audacieuse conjecture en laquelle il a été suivi par Penna, Steinmann et par les apparats de BH3S et Cent.

On semble avoir oublié que Châteillon fut le premier à trouver cette échappatoire puisqu'il traduisait ainsi 25b en latin : "Sunt enim \& hae gentes omnes, \& omnis Israel praeputiato corde" et en français: "Car toutes ces nacions, e tous ceux de la maison d'Israel, ont le coeur empellé".

Les témoins anciens :

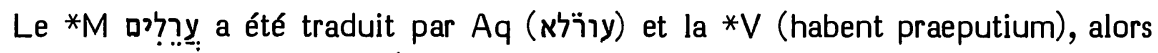
que ce mot est glosé par oapxí dans le ${ }^{*} G$, et par בבסרהון dans la *S et dans le *T.

\section{Choix textuel :}

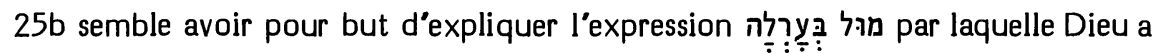
désigné en $24 \mathrm{~b}$ ceux contre qui il voulait sévir. L'auteur de $25 \mathrm{~b}$ dit que, parmi les nations énumérées en 25a, toutes les nations (païennes) sont incirconcises (et sont donc entièrement "en prépuce"), alors que toute la maison d’Israël (désignée en 25a par "Juda") est incirconcise de coeur (et donc "circoncise (de chair) en prépuce (de coeur)". Alors que 25a intégrait Juda parmi un certain nombre de nations pratiquant la circoncision, l'auteur de $25 \mathrm{~b}$ considère comme un fait indubitable que "toutes les nations sont incirconcises." Ou bien il s'agit là d'un anachronisme ethnologique, ou bien - et c'est plus probable - il veut dire que l'intervention chirurgicale que l'on pratique traditionnellement en certaines nations ne suffit pas à en faire des "circoncis" au sens abrahamique du mot.

Toute correction serait ici arbitraire et facilitante, alors que la glose du*G, de la *S et du *T essaie d'établir, en s'inspirant d'Ez 44,7, une symétrie qui ne semble pas correspondre aux intentions de l'auteur.

Le comité a attribué au *M la note " $B$ ".

Interprétation proposée :

Avec RSV et TOB, on traduira littéralement : “car toutes les nations sont incirconcises". Une note expliquera la contradiction apparente existant entre cette affirmation et le passage qui précède. 
Options de nos traductions :

En chacun de ces vss se lit thee", par J12 : "nul ne t'est comparable", par RL : "dir ... ist niemand gleich", par TOB : "il n'y a personne comme toi" et par J3 : "nul n'est comme toi".

Selon Brockington, NEB corrige, avec Th, le premier mot en מִֵאַ quand elle traduit : "where can one be found like thee ?"

Origine de la correction :

C'est Michaelis (Observationes) qui a préféré la leçon de Th avec, pour Vorlage, un ${ }^{2} \underline{\text { N }}$ interrogatif, comme en araméen, et un 'mem' prépositionnel d'origine. Cette proposition a été adoptée par Hitzig et par S.R. Driver (cité par Condamin).

Les témoins anciens :

4Q-b (Janzen 181s) et le ${ }^{*} G$ ancien omettent les vss 6-8 et 10. Les recensions origénienne et antiochienne empruntent à Th une ajoute astérisée où ce mot est traduit par $\pi 0 ́ \theta \varepsilon v$.

Les autres versions reconnaissent ici une négation et ne valorisent pas spécialement le 'mem' : la *V (non est ... nullus est), la *S et le *T (לית).

Choix textuel :

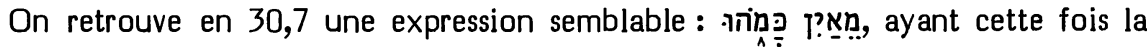
vocalisation que Brockington requiert ici. NEB la traduit aussi là en interrogatif, alors que le ${ }^{*} G$ (qui y est conservé : 37,7 ) l'interprète en négation d'existence : xaì oủx Ẻơt

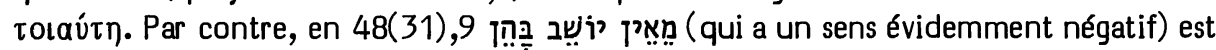
traduit en interrogatif par le ${ }^{*} G$ : тó $\theta \varepsilon v$ Évolxos aủrñ̃; Les diverses couches $d u{ }^{*} G$ sont donc assez instables dans leur traduction de ce mot, qu'il soit vocalisé d'une manière ou de l'autre.

D’ailleurs Joüon ( $\$ 154 \mathrm{~K}$ ) explique que "אִ (originairement 'où ?') exprime d'abord la non-existence dans le lieu, à savoir l'absence, puis, par extension, la nonexistence tout court". Selon Bauer/Leander (633t), il s'agit d'une question rhétorique qui s'est transformée en assertion.

Estimant qu'il s'agit surtout ici d'une question d'exégèse, le comité a attribué à la leçon du *M 4 "B" et 2 "A".

Interprétation proposée :

Nous avons déjà rencontré en Is 40,17 (ci-dessus, p. 285) et 41,24 (ci-dessus, p. 295) la préposition p̣ au sens de "moins que (rien)." Dans un sens analogue de "Steigerung der Nichtexistenz" (König, Syntax $\S 352 x$ ), nous pouvons traduire : "Il n'y a absolument personne comme toi."

Cependant, Bogaert (Mécanismes 233) estime que l'interrogation rhétorique a été un procédé cher à la rédaction II. On pourra donc préférer l'interprétation: "Oì y en a-t-il un comme toi ?" 
Options de nos traductions :

Après avoir dit de l'argent laminé qu'il est apporté de Tarshish, le * $M$ ajoute : qui quiָ Uphas" et par TOB : "or d"Oufaz".

Se fondant sur la *S et le *T, J donne : "et de l'or d’Ophir". Selon Brockington, NEB lit avec la *S מִ̣iוֹ quand elle traduit : "and the gold from Ophir".

Origine de la correction :

Gesenius (Thesaurus 137a) a estimé plus probable que nous ayons ici une corruption de "Ophir". Ont conclu comme lui : Ewald, Henderson, Graf, Giesebrecht, Oort, Duhm, Cornill, Ehrlich, Condamin, Nötscher, Penna, Steinmann, ainsi que les apparats de HSAT34, BH23 et Cent.

Les témoins anciens :

Le *G a transcrit la leçon du *M en Mwyas, les témoins hésitant entre 'sigma'

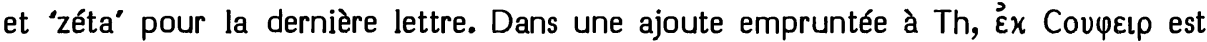
repérable comme le point de départ de nombreuses corruptions textuelles. Cette forme, elle-même corrompue, a été restaurée en מן אופיר par une scolie marginale de la Syh.

Cette scolie est identique à la leçon que la ${ }^{*} S$ donne ici. Le $* T$, lui aussi, a interprété en מאופיר.

La leçon de la *V "de Ofaz" a été corrompue en "de Ophyr" en une partie de la tradition textuelle (le ms de la Sorbonne et les éditions les plus anciennes).

Choix textuel :

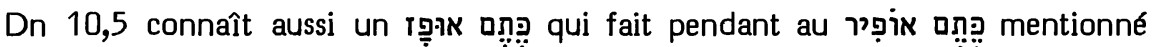

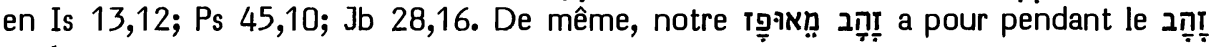
en 1 R 10,11; 2 Ch 9,10.

Comme le toponyme "Ouphaz" n'apparaît que deux fois dans la Bible et que les géographes ne sont pas parvenus à l'identifier, il est tentant de le corriger en "Ophir" qui (quoique tout aussi mal identifié) est mentionné 12 fois dans la Bible. Simons ( $\$ 185)$ a eu le tort de céder ici à cette tentation.

Notons encore en $1 \mathrm{R}$ 10,18 l'expression qui nous confirme dans la décision de résister à une assimilation facilitante à "Ophir". C'est pourquoi le comité a attribué ici la note " $C$ " à la leçon du * $M$, en déconseillant aux géographes d'interrompre leurs recherches.

Interprétation proposée :

Le parallèle avec מִּ? (qui est dit ici de l'argent) a engagé certains (sous l'influence de $1 \mathrm{R} 10,18$ et de la transcription du ${ }^{*} G$ ) à interpréter ce mot en participe. Cependant, le parallèle encore plus caractéristique avec מ̣ת engage plutôt à reconnaître ici et en Dn 10,5 un toponyme. 
10,13 לקול תתו הַמוֹ [A ] M ThAq T // lic : Sym V S / abr-elus : G

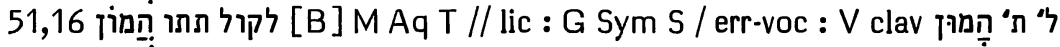

\section{Options de nos traductions :}

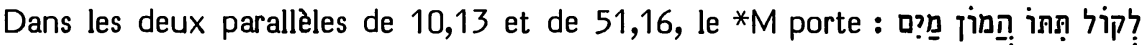
政 qui est traduit par RSV : "When he utters his voice there is a tumult of waters in the heavens", par J: “Quand il donne de la voix, c'est un mugissement d'eaux dans le ciel", par RL : "Wenn er donnert, so ist Wasser der Menge am Himmel" et par TOB : "du fait qu'il accumule des eaux torrentielles dans les cieux".

Brockington dit que, dans les deux endroits, NEB conjecture pour les trois pre-

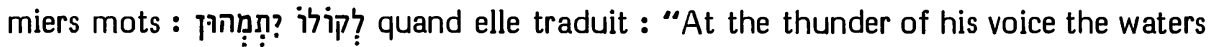
in heaven are amazed".

\section{Origine de la correction :}

C'est Volz qui a proposé la conjecture que NEB a retenue. Cette conjecture avait été signalée par $\mathrm{BH}$.

\section{Les témoins anciens :}

1/ 10,13 : Aux trois premiers mots, le *G ne fait correspondre que xai $\pi \lambda \tilde{\eta} \theta 0 \varsigma$. A la place de la conjonction, les recensions origénienne et antiochienne donnent sous

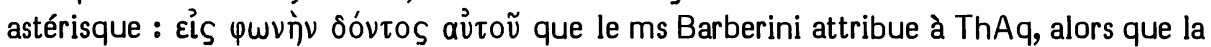

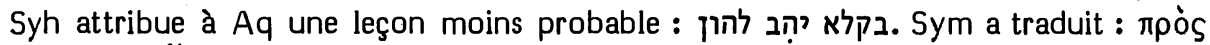

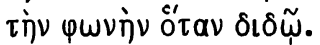

Pour les trois premiers mots, la *V donne : "ad vocem suam dat multitudinem", la *S : יהב קלא דרגושיא.

Le *T est très littéral : לקל מתניה רכפת : לחר מת

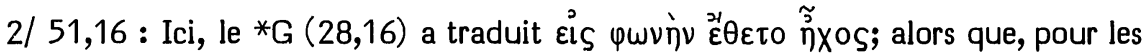
deux premiers mots du $* M$, le ms Barberini attribue à $A q$ une leçon identique à celle qu'il attribue à ThAq en 10,13, et il attribue à Sym une leçon qui ne se distingue de celle de 10,13 que par l'insertion de aũroũ après le substantif.

Pour les trois premiers mots, la *V donne: "dante eo vocem multiplicantur".

Les leçons de la*S et du *T sont les mêmes qu'en 10,13.

Choix textuels :

La syntaxe difficile du ${ }^{*} M$ est confirmée par l'identité des deux passages. Il est probable que c'est sa difficulté qui a découragé le ${ }^{*} G$ en 10,13 , alors que ThAq et le *T ont opté pour une traduction-décalque (comme ils le feront aussi en 51,16).

Sym, la $* V$ et la $* S$ ont pris la liberté de faire entrer une forme personnelle du verbe "donner" dans leur traduction de 10,13; alors qu'en 51,16 la *V a cru voir en המון un verbe à la $3 e$ pers. pl., tandis que Sym et la *S (auxquels s'ajoute ici le ${ }^{*} G$ ) ont repris leur option de 10,13.

Etant donné cette possibilité d'une variante dans la Vorlage de la $* V$ en 51,16 , le comité y a attribué la note " $B$ " à la leçon du *M; alors qu'en 10,13 il lui a donné un “ $A$ ", puisqu'aucun témoin n'y suggère une variante. 
Interprétations proposées :

Pour 10,13a (= 51,16a), l'exégèse qui semble, à première vue, la plus littérale est celle de JPS : "At the sound of His giving a multitude of waters in the heavens, He causeth the vapours to ascend from the ends of the earth." C'est l'exégèse proposée par de Dieu. Plus librement, on pourra traduire : "Au bruit (qu'il fait) en chargeant d'eau les cieux, il fait monter les nuées des extrémités de la terre".

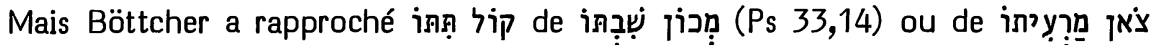
(Ps 100,3), étant donné que l'expression נתן קול est très naturelle. On obtient alors les traductions de RSV, J ou RL qui sont donc également possibles et peut-être même plus probables que celle de JPS.

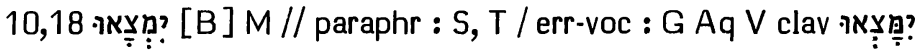

Options de nos traductions :

Pour ce vs, le *M donne : "Car ainsi parle le Seigneur : 'Me voici frondant les

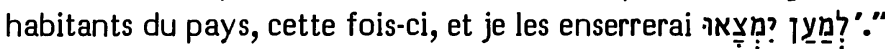

Les deux derniers mots ont causé des difficultés aux traducteurs. RSV les traduit : "that they may feel it".

J dit suivre une conjecture d'Houbigant en traduisant : "pour qu'ils me trouvent".

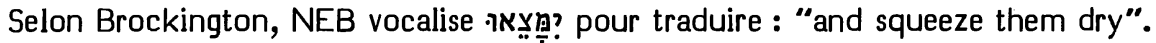
Vocalisant de même, TOB traduit : "pour qu'ils n"échappent pas" en précisant : “lit : pour qu'ils soient trouvés". De même, RL traduit : “damit sie sich finden lassen”.

Origines des corrections :

C'est en s'inspirant de la *S qu'Houbigant a ajouté le suffixe de la 1e pers. sg. à ce verbe. Il a été suivi par Condamin, Nötscher, Penna, Steinmann et l'apparat de Cent.

La vocalisation en nifal a été proposée par von Orelli et adoptée par Ehrlich et Weiser. C'est Driver (suivi par Bright) qui, acceptant cette correction, interprète la forme ainsi obtenue comme "standing for ?ִ. so that the clause may be translated 'and I will squeeze them tight that they may be drained dry'," traduction que NEB a schématisée en la déformant.

Les témoins anciens :

A l'occasion de $9,9(10)$, nous avons signalé que le *G fait disparaître les suffixes de la 1e pers. en 10,19a en les remplaçant par la 2e pers. C'est ainsi que, pour מַפִַ il donne : $\tilde{\eta} \pi \lambda \eta \gamma \eta \dot{~ o o v . ~ C ' e s t ~ d e ~ c e l a ~ q u ' i l ~ s ' i n s p i r e ~ p o u r ~ g l o s e r ~ l e ~ v e r b e ~ f i n a l ~ d e ~ 10,18 ~}$ en : "̊́ origénienne et antiochienne. Aq (selon la Syh) traduit le verbe par דנתכססון que Field, s'inspirant d'une leçon gonflée de la recension antiochienne, a rétroverti en $\bar{\varepsilon} \lambda \varepsilon \gamma \times \theta \tilde{\omega}$ oıv. Etant donné que, dans les autres livres, Aq use de ce verbe pour traduire יכח, il semble s'agir ici de la première version d'Aq.

Dans son commentaire, Hie garde, pour traduire l'hébreu, "ut inveniantur" par quoi il traduit également le ${ }^{*} \mathrm{G}$. Dans toute la tradition textuelle de la ${ }^{*} \mathrm{~V}$ (sauf les mss 
de l'Université de Paris), cela sera déformé en "ut non inveniantur". La leçon authentique sans négation sera rétablie par Estienne dans son édition de 1532. La censure l'amène à préciser (dans l'apparat de son édition de 1540) qu'il l'a tirée de la polyglotte d'Aicala.

La *S ("pour qu'ils me cherchent et me trouvent") et le *T ("pour qu'ils reçoivent la rétribution de leurs fautes") ont paraphrasé à partir du *M.

Choix textuel :

La leçon du *M a servi de point de départ d'un côté aux paraphrases de la *S et $d u{ }^{*} T$, et de l'autre à la vocalisation facilitante en nifal du ${ }^{*} G$, de Aq et de la ${ }^{*} V$.

Etant donné qu'elle offre un sens excellent, le comité a attribué la note " $B$ " à cette leçon qui a été sentie comme difficile par les traducteurs.

Interprétations proposées :

La meilleure interprétation semble bien être celle qui a été trouvée par Michaelis (Observationes), puis adoptée avec enthousiasme par Leiste, avant d'être redécouverte par Böttcher (Proben 130, note d; Aehrenlese et Neue Aehrenlese), puis oubliée à nouveau. Elle consiste à voir dans les trois verbes de ce bref oracle des termes techniques de l'art du frondeur. En 1 S 31,3 il est en effet dit de Saül :

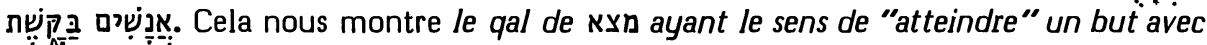
un projectile dans un contexte de tir. De même le verbe מטה qui lui correspond en

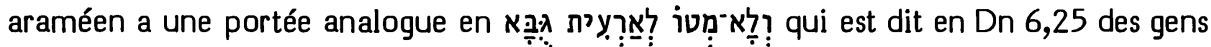
que l'on a jetés dans la fosse aux lions. Quant au hifil de il semble signifier ici "enserrer" un projectile dans la fronde. Böttcher (Proben 130, note d) estime à ce propos que le substantif de même racine en $\operatorname{Pr} 26,8$ signifie une collection de pierres

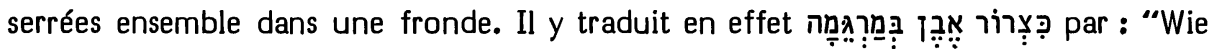
Stein-Eingebind in eine Streuschleuder". Il s'agirait là du tî à mitraille où l'on rassemble des projectiles que l'on tire ensemble. Rappelons que nous avons suggéré (CT1, 383s) à propos de 2 R 3,25B que le verbe peut désigner parfois l'action de machines de jet plus puissantes que des frondes manuelles. En ce sens מצא aurait ici le sens de "atteindre son but". On pourrait donc traduire : "Me voici frondant les habitants du pays... et je les enserrerai pour qu'ils atteignent le but".

Il peut être bon de mentionner aussi l'exégèse que Yéfet ben Ely attribue ici au "Fayyumite", c'est-à-dire à Saadya Gaon. Celui-ci faisait de ce verbe final l'introduction du vs suivant : “... pour qu'ils découvrent : 'malheur à moi à cause de mon désastre...'". Cette attestation formelle par Yéfet confirme l'attribution à Saadya par Bacher (Grammatiker 39, n.14) de cette opinion que Ibn Ezra (Șahot 483) réfère à "un individu". Notons d'ailleurs que Joseph Bonfils (I 114) précisera que c'est en son commentaire du Deutéronome que "le Gaon" a présenté cette exégèse dans une liste de dix cas où l'exégèse requiert que l'on enjambe d'un verset sur le suivant. On peut retenir de cela que le "but" visé par le frondeur divin est cette constatation faite par Israël, aux vss 19s, de l'étendue de son désastre. 


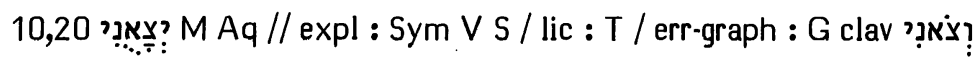

Options de nos traductions :

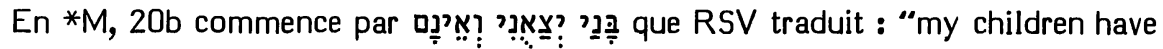
gone from me, and they are not"," J : "Mes fils m"ont quitté : ils ne sont plus", RL : "Meine Kinder sind von mir gegangen und nicht mehr da", NEB : "my sons have left me and are gone".

TOB traduit avec le *G : "Mes enfants et mon cheptel, ils ne sont plus".

Origine de la correction :

Cappel (Notae 523b) a fait remarquer que le ${ }^{*} G$ a lu Houbigant a adopté cette leçon, suivi par Duhm, Cornill, Ehrlich, Nötscher et par les apparats de HSAT34, BH3 (une partie d'entre eux omettant "mes fils").

\section{Les témoins anciens :}

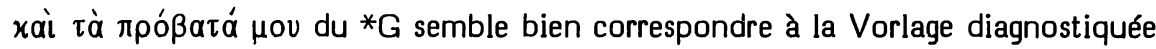
par Cappel (à condition de corriger en ḥireq le pataḥ de la dernière syllabe).

A la place de cela, Aq traduit littéralement ${ }^{2} \dot{\xi} \tilde{\eta} \lambda \theta o^{\prime} \nu \mu \varepsilon$, alors qu'une préposition

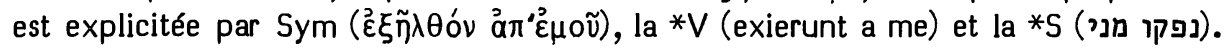

Le *T traduit librement le *M par

\section{Choix textuel :}

Ce cas n'a pas été soumis au comité.

La traduction du ${ }^{*} G$ provient vraisemblablement d'une confusion entre 'yod" et 'waw' au début de ce mot, ainsi que d'une difficulté à interpréter la relation existant entre le verbe יצא et son suffixe. Cette traduction anticipe le thème des bergers et du troupeau qui caractérisera le vs 21 .

Nous avons déjà discuté (ci-dessus, p. 387) le cas d’un suffixe verbal sous-entendant une préposition. Pour le verbe יצא (au qal), on rencontre le lieu d'origine exprimé par un accusatif en $\mathrm{Gn} 44,4$, Ex 9,29 et $\mathrm{Nb}$ 35,26. Rien n'empêche donc que le suffixe ait ici cette valeur.

Une fois résolue cette difficulté grammaticale, notons que le thème des "fils qui ne sont plus" sera repris en 31,15 dans les mêmes termes. Ici une ajoute du "petit bétail" serait une platitude. Si les "fils" sont évoqués, c'est qu'en leur absence, il n'y a plus personne pour redresser la tente abattue.

Interprétation proposée :

Le vs 17 et le thème classique de la femme privée de ses fils (cf. 31,15) suggèrent d'interpréter la 1e pers. sg. en féminin : "Mes fils m'ont quittée : ils ne sont plus." 
10,24 יסרני ... תמעטני [B] M V S // facil-synt : G, T

Options de nos traductions :

Aux deux verbes de ce vs, le $* M$ donne des suffixes 1e pers. sg.: :

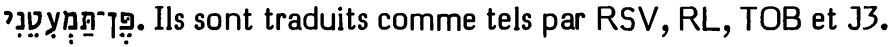

Mais $\mathrm{J} 12$ disaient se fonder sur le ${ }^{*} \mathrm{G}$ pour traduire : “Corrige-nous... pour ne pas

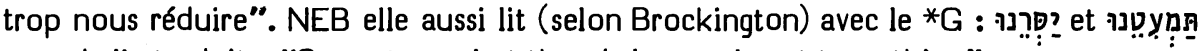
quand elle traduit : "Correct us... lest thou bring us almost to nothing".

Origine de la correction :

Cette mise des suffixes au pluriel, en se fondant sur le ${ }^{*} G$, a été proposée par Grätz et adoptée par Duhm (estimant qu'un individu ne peut pas être réduit à un petit nombre), Cornill, Rudolph, Bright, ainsi que par les apparats de HSAT34, BH3S et Cent.

Les témoins anciens :

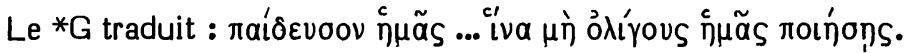

Le *T opte pour la 3e pers. pl. : איתא עליהון יסורין ... יזערון

$\mathrm{La} * \mathrm{~V}$ et la $* S$ ont la 1 e pers. sg. comme le $* \mathrm{M}$.

Choix textuel :

Si l'on admet, avec Hitzig, qu'il est clair que c'est le peuple qui parle ici, on devra conclure, avec von Orelli, que la "réduction à un petit nombre" serait l'anéantissement du peuple.

Le comité a attribué la note " $B$ " à la lectio difficilior du *M.

Interprétation proposée :

Keil a eu raison de faire remarquer que le hifil de vyn ne signifie pas "diminuer" (ce qui pourrait être la conséquence d'une correction mesurée), mais "réduire à un petit nombre". On traduira donc: "Corrige-moi, Seigneur, mais suivant la justice, non selon ta colère : tu me réduirais à quelques-uns".

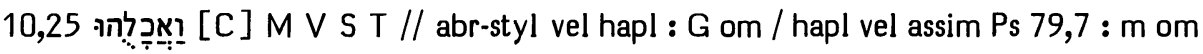

Options de nos traductions :

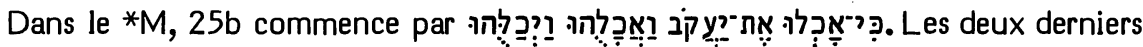
mots sont traduits par RSV : "they have devoured him and consumed him", par RL : "(sie haben...) und verschlungen, sie haben ihn vernichtet", par TOB : "on le dévore, on l'achève" et par $\mathrm{J3}$ : "elles l'ont dévoré et achevé".

Suivant le *G, J12 traduisaient cela seulement par : "(elles ont...) et achevé".

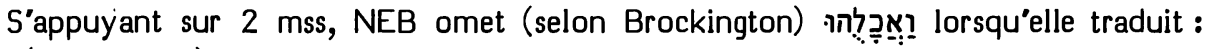
"(they have...) and made an end of him". 
Origine de la correction :

C'est Kennicott (Dissertatio super ratione 495) qui a proposé d'omettre ce mot où il voit une variante du suivant. L'ont suivi dans cette omission: Movers (cité par Wichelhaus, 97), Grätz, Giesebrecht, Duhm, Cornill, Ehrlich, Condamin, Nötscher, Rudolph, Penna, Steinmann, Weiser, ainsi que les apparats de HSAT34, BH23S et Cent.

Notons que Hitzig et Oort préfèrent omettre le dernier mot et que Volz hésite entre les deux.

\section{Les témoins anciens :}

Selon de Rossi, un ms du * $M$ omet les deux derniers mots, un autre omet le premier d'entre eux, et la 1e main de deux autres omet le second d'entre eux. Ce sont là des haplographies ou une assimilation au parallèle de Ps 79,7 qui n'a pas ces mots. Une massore (Ginsburg, Massorah $\kappa \S 462$ ), précisant que l'avant-dernier se trouve 3 fois dans la Bible, garantit sa présence ici; alors que, dans la massore éditée, dans le $\mathrm{ms}$ du Caire et dans celui d'Alep, une mp précise que le dernier est hapax.

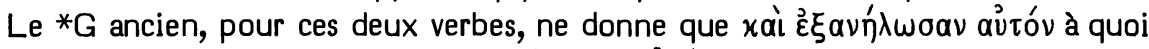

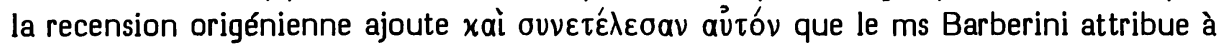
ThAqSym. Cette dernière leçon supplante la première dans la recension antiochienne. Comme Doederlein (Hexaplen 238) l'a bien vu, ces deux verbes grecs traduisent le dernier verbe de l'hébreu. Cela signifie qu'Origène, en intercalant son ajoute astérisée, a établi un faux diagnostic sur la déficience du *G. En effet, on ne rencontre qu’en

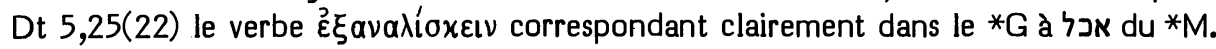
Par contre, ce verbe grec correspond ailleurs 13 fois à כלה du *M (dont Jr 9,15; 49,37). Il serait d'ailleurs étrange que le ${ }^{*} G$ qui vient de faire usage de $x a \tau \varepsilon \sigma \theta^{\prime} \varepsilon ı$ pour traאכל אכל (comme 16 autres fois en Jérémie) ait échangé soudain ce correspondant contre un verbe qu'il n'utilise ailleurs en ce livre que pour traduire כלה.

Nous ne savons pas comment ThAqSym traduisaient l'avant-dernier verbe.

$L a * V$, la $* S$ et le ${ }^{*} T$ ont traduit clairement les deux derniers verbes du $* M$.

\section{Choix textuel :}

Nous avons relevé assez d'allègements stylistiques de la part du *G de Jérémie pour que l'on puisse sans imprudence en diagnostiquer un autre ici, à moins qu'il ne s'agisse d'une haplographie.

D'ailleurs, $c$ 'est la présence de ces deux verbes juxtaposés qu'il faut considérer comme une spécificité littéraire de Jr 10,25 par rapport à son parallèle caractéristique de Ps 79,6-7. Le 'waw' qui précède l'avant-dernier verbe lui donne valeur de reprise emphatique de la forme identique (3e pers. pl. de l'accompli de אכל) qui le précède de trois mots. Le dernier verbe appuie cette emphase par une paronomase. Ces verbes répétés évoquent des bêtes fauves qui s'acharnent à dépecer leur proie jusqu'à l'avoir dévorée entièrement.

Rappelons que nous avons déjà traité en 8,13 d'une assonance créée par la juxtaposition de deux verbes de racines distinctes, mais de sens analogue.

Le comité a attribué ici au * $M$ la note " $C$ ". 
Interprétation proposée :

"Car on a dévoré Jacob, on l’a dévoré, on l'a exterminé." On pourra indiquer en note l'effet d'assonance.

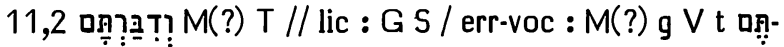

Options de nos traductions :

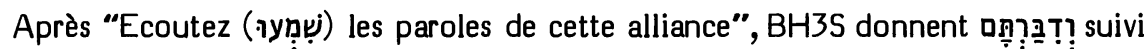
d'un complément de destinataires : "aux gens de Juda et aux habitants de Jérusalem".

Ce texte est donc caractérisé par le fait qu'un accompli inverti à la 2e pers. m. sg. fait suite à un impératif m. pl.

Quatre de nos traductions n'offrent pas de notes- textuelles. Cependant deux d'entre elles harmonisent sur le singulier : RSV ("Hear ... and speak") et NEB ("Listen ... and repeat them"), alors que les deux autres harmonisent sur le pluriel : RL ("Höret ... dass ihr sie sagt") et J3 ("Ecoutez ... vous les direz").

Par contre J12 ("Ecoutez ... et parle") et TOB ("Ecoutez ... tu parleras") prétendent avoir corrigé en singulier avec le ${ }^{*} \mathrm{G}$ (selon $\mathrm{J12}$, alors que TOB y ajoute la ${ }^{* S}$ et le *T) le pluriel "parlez" (selon J12) ou "vous parlerez" (selon TOB) de "l'hébreu'.

\section{Origine de la correction :}

Commençons par préciser qu'avant la publication (en 1931) du fascicule de Jérémie de $\mathrm{BH} 3$, toutes les éditions dont les critiques faisaient usage portaient ici la vocalisation exemple dans l'édition de Varsovie 1860-1866) pouvaient y lire dans le commentaire de Radaq une remarque énigmatique: "Jonathan (le targumiste) a traduit ודברתם par ותמללון. Il semble qu'il lisait ודברתם avec un qameș sous le 'taw', alors que nous le trouvons, dans tous les manuscrits soignés, avec un segol sous le 'taw'." Cette conjecture de Radaq pouvait paraître surprenante, étant donné que la leçon du *T ici mentionnée correspondait littéralement à une vocalisation segol (et non qameș) du 'taw': Il n'y avait d'ailleurs, semblait-il, pas à douter sur ce point, puisque cette leçon se retrouvait, à côté du texte du *M, dans la colonne 'Targum' de ces mêmes Miqraot Gedolot et qu'on la retrouvait dans les éditions antérieures du *T : celle de Félix de Prato, celle de Ben Hayim et celles des polyglottes d'Anvers et de Londres. On la retrouve d'ailleurs encore dans le texte de l'édition que Sperber a donné du *T en 1962. Celui, cependant, qui aurait contrôlé les éditions anciennes du commentaire de Radaq (par ex. Soncino 1486, Lisbonne 1492 ou les Bibles Rabbiniques de Félix de Prato et de Ben Hayim) y aurait remarqué que Radaq y donnait comme leçon du *T ותמללינון (= et tu les diras), ce qui fondait bien sa conjecture. Citant son témoignage sous cette forme authentique, Norzi (dans une ajoute qu'il a faite à son commentaire, selon le ms autographe Londres BL Add 27,198) concluait en disant : "cependant, dans les livres dont nous disposons, le *T porte ותמללון". Aussi la Bible Minḥat Shay (qui donne en bas de pages la première édition du commentaire de Norzi) ne tient-elle pas compte dans son texte de la conjecture de Radaq. 
Cependant, Houbigant, notant que le verbe qui nous occupe est repris au début

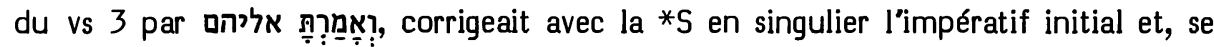
fondant sur le ${ }^{*} G$, demandait d'interpréter notre verbe, non pas comme 'loquemini', mais comme "haec loqueris'. Cette interprétation suppose une correction vocalique qu'Houbigant, qui ne tient pas compte des voyelles, ne mentionne pas.

Michaelis (Observationes), ajoutant à la mention du vs 3 celle de la fin du vs 5

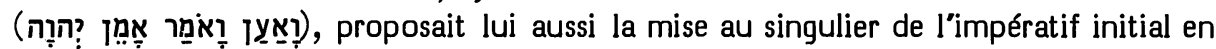
se fondant sur la *S, alors qu'il corrigeait notre verbe en ici l'appui du *G. En réparant cet oubli, Schleusner (éditeur de Michaelis) proposait formellement de vocaliser les consonnes $d u * M$ en rence de l’édition Sixtine, l'édition Aldine du ${ }^{*} G$ traduisait l'impératif initial par un singulier : ${ }^{\prime \prime}$ xovoov.

Hitzig suivait Schleusner dans la correction vocalique que celui-ci avait proposée pour notre verbe. Il estimait par contre devoir préserver la forme plurielle de l'impératif initial qui était nécessaire pour expliquer la corruption vocalique du verbe suivant. Cet impératif pluriel visait, selon lui, à inviter les auditeurs à l'attention, avant que ne soit indiqué au prophète ce qu'il aurait à leur dire. Les propositions textuelles de Hitzig ont été adoptées par Graf (ajoutant que la corruption vocalique a pu être facilitée par les deux 108 , où il estime que $2 a$ anticipe ce que Jérémie dira en $6 \mathrm{~b}$ aux destinataires dont l'énumération en 6a reprend celle qui a été donnée en 2b), Duhm (estimant que 2a est un avertissement initial adressé aux auditeurs de Jérémie : 'prenez au sérieux votre Torah !', l'anachronisme ayant échappé au rédacteur qui se représente ici Jérémie comme recevant du Seigneur sa mission de prédicateur du Deutéronome), Cornill, Condamin, Weiser ainsi que par les apparats de SBOT et HSAT3.

La double proposition de Houbigant, Michaelis et Schleusner a été reprise par l'apparat de BH2, alors que Ehrlich l'a modifiée en remplaçant l'impératif initial par un infinitif absolu.

Oort a proposé de remplaçer les six premiers mots du vs 2 par רבָּ̃ Volz a refusé l'option de l'apparat de $\mathrm{BH} 2$ (et de Ehrlich), estimant que l'on se représente mal le Seigneur disant à son prophète: "écoute les paroles de cette alliance !" Aussi adopte-t-il la correction de Oort en considérant que 2a a été faussement importé à partir de 6b. Il est suivi en cela par Nötscher, Steinmann et Bright ainsi que par les apparats de HSAT4 et de BH3.

Rudolph laisse intacts le vs 2 et les deux premiers mots du vs 3 (sous la forme où il les lisait dans le texte traditionnel du $* M$, c'est-à-dire avec notre verbe au pluriel), mais il voit en tout ce passage une fausse anticipation du contenu du vs 6 et l'omet donc à ce titre. Dans les deux premières éditions de son commentaire (1947 et 1958),

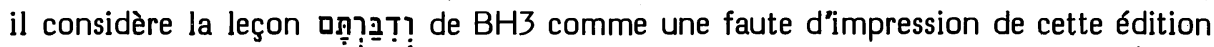
(opinion que Bright lui emprunte), alors que, dans la 3e édition (1968) il reconnaît qu'il s'agit bien de la leçon du ms de Leningrad.

Les apparats de la Biblia Hebraica offrent donc un spectacle curieux. En BH2,

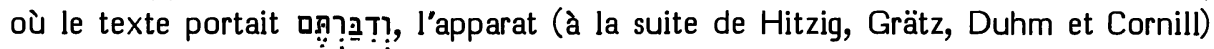
proposait de lire l'apparat (à la suite de Oort et Volz) proposait de lire רậ et qu'en BHS (où le texte 
lit encore la leçon que proposait l'apparat de BH2) l'apparat (où Rudolph a fait passer l'option de son commentaire) propose de lire texte portait trouve être devenue celle du texte, on finit par noús proposer d'en revenir à la leçon que l'on demandait autrefois de quitter.

\section{Les témoins anciens :}

Le seul témoin dont le texte ne pose aucun problème est la *V. Elle porte deux pluriels : "audite ... et loquimini".

En ses éditions (depuis la polyglotte de Paris), la *S porte deux singuliers (שמע ... Nous avons vu qu"Houbigant et Michaelis se sont fondés sur ce singulier de l'impératif initial pour corriger le pluriel de l'hébreu. D'ailleurs HSAT3 et Volz (Studien) continuent à attribuer à la ${ }^{*} S$ cette particularité. Cependant le ms Ambrosianus offre שמער ... ואמר, leçon qui est attribuée aussi par Herbert Thorndike (dans l'apparat à la *S qui constitue le ch. III de l'Appendice de la polyglotte de Londres) à un ms de J. Usher et à un autre ms passé de la possession de Th. Erpenius en celle de l'université de Cambridge.

Schleusner, nous l'avons dit, signalait que l'édition Aldine du ${ }^{*} G$ portait deux singuliers. D'autres témoins de cette version appuient cette édition, alors que d'autres portent deux pluriels. Il est cependant certain que l'édition Sixtine avait raison de

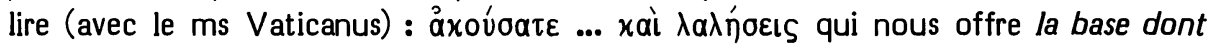
sont parties ces deux harmonisations divergentes.

Comme nous l'avons signalé, toutes les éditions du *T, de l'édition princeps à celle de Sperber incluse, portent (à côté de קבילו qui traduit l'impératif initial du*M) la leçon ותמללו? qu qui traduit littéralement la leçon classique Nous avons pourtant signalé que Radaq, dans les éditions anciennes de son commentaire, attribuait au *T une leçon ותמללינון. Or cette leçon est celle du ms Reuchlin des Prophètes qui est notre plus ancien témoin du ${ }^{*} \mathrm{~T}$, et elle est attribuée par Sperber (sous une forme très proche : ותמלילנון) au ms Londres BL Or 1474 auquel il faut ajouter (sous cette dernière forme) le ms Urbinates 1 dont Sperber n'a pas fait usage.

On peut donc constater que, dans leur forme authentique, le ${ }^{*} G$, la ${ }^{*} S$ et le ${ }^{*} T$ sont issus d'un texte où un verbe à la $2 e$ pers. sg. faisait suite à un impératif pluriel. Plus précisément encore, la forme authentique du ${ }^{*} T$ semble bien se référer, ainsi

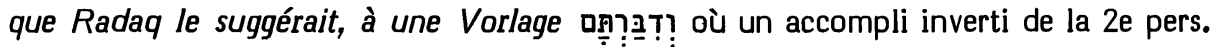
m. sg. était complété par un pronom suffixe de la 3e pers. m. pl., c'est-à-dire la forme exacte que Rudolph a fini par reconnaître présente dans le ms hebr B 19A de la Bibliothèque Saltykov Shchedrin de Leningrad. On pourrait être tenté de conclure de cela que ce ms nous a enfin livré le texte authentique du *M. Mais la situation n'est pas aussi claire que cela.

Il faut noter en effet que toutes les éditions anciennes que nous avons pu contrôler (Soncino 1488, Lisbonne 1492, Brescia 1494, Félix de Prato et Ben Hayim) et tous les autres mss anciens auxquels nous avons eu accès ( $m s$ du Caire; ms d’Alep; ms des Prophètes de Berne; mss Erfurt 3; Madrid univ 1; de Rossi 782; Hamburg 6, 27; Copenhague 1, 2, 4, 5, 8; New York JThS 232; Londres BL Add 15.451, 21.161; Vat ebr 3, 468, 482, Urbinates 1; Paris BN hébr 2, 6, 26, 82) portent dans leur texte la finale 
avec segol, les mss Reuchlin des Prophètes et de Rossi 2 se distinguant (comme c'est normal pour la catégorie pseudo-Ben Naphtali à laquelle ils appartiennent) par une finale avec séré. Quant au ms de Petrograd des Prophètes, il porte ici un patah, correspondant normal du segol dans l'écriture babylonienne.

Le ms de Leningrad semble donc entièrement isolé dans son témoignage pour la leçon avec qameș. A cela s'ajoute un fait inquiétant que révèle l'étude du facsimilé du ms de Leningrad. Ce mot y achève la dernière ligne de la colonne centrale d'une page écrite sur le côté chair du parchemin. Or l'écriture ayant pâli, il est clair que bon nombre des voyelles des deux dernières colonnes de cette page ont été réécrites d'un trait beaucoup plus épais que ceux qui viennent du vocalisateur originel. Et ledit qameș, parfaitement lisible, fait évidemment partie de ces voyelles réécrites. La question qui se pose à nous est de savoir si celui qui a réécrit a été fidèle à la vocalisation originale ou si, connaissant la conjecture de Radaq, il ne s'y serait pas conformé dans cette réécriture. Pour nous orienter dans la solution de cet inquiétant dilemme, il nous faudrait trouver un témoignage sur cette vocalisation avec qames qui soit certainement indépendant de Radaq. Or il semble bien qu'il en existe un auquel personne n'a encore fait appel.

Le ms New York JThS 232 que Goshen-Gottstein (HUB Sample Edition [45]) date du Xe siècle, en accord avec Yeivin (Codex 374), alors que son possesseur précédent, E.N. Adler (Catalogue 5), le datait du IXe siècle, provient de Yezd en Iran et est l'un des seuls mss qui contienne un texte à leçons principalement "orientales". Comme nous l'avons indiqué ci-dessus il porte dans son texte la leçon courante avec

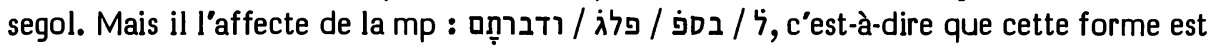
hapax dans le livre de Jérémie et qu'elle fait l'objet d'une controverse, certains vocalisant qameș sa dernière syllabe. Voilà donc l'existence de cette vocalisation attestée à une époque et dans un milieu où l'influence de Radaq n'est pas à craindre. Cela donne donc une certaine probabilité à l'hypothèse que celui qui a réécrit le qames dans le ms de Leningrad a été fidèle à la vocalisation originale, la massore du ms de New York étant vraisemblablement antérieure (ou contemporaine) à la première vocalisation du ms de Leningrad.

Etant donné que le *T (en sa forme authentique) nous apporte lui aussi un témoignage formel sur l'existence d'une lecture de ce mot avec qames et qu'un glissement de la vocalisation qames vers la vocalisation segol s'explique beaucoup plus aisément (par une harmonisation avec l'impératif pluriel qui précède) qu'un glissement en sens inverse, il ne semble pas déraisonnable de suggérer que le ms de Leningrad constitue ici le seul témoin survivant de la vocalisation originelle du $* M$.

On pourrait élever contre une telle conclusion l'objection suivante. Il existe une massore très ancienne attestée par le ms Londres BL Or 4445 (sur Gn 44,4), par le ms de Petrograd des Prophètes (sur Is 48,7 et Jr 12,2) et dans le ms Paris BN hébr 1 (sur Gn 44,4). Dans son état le plus ancien, elle énumère 11 cas (Gn 44,4; Ex 19,10; 29, 8; Dt 4,9; 6,7; 6,8; Is 48,7; Jr 12,2; 27,3; Ez 43,24; Dn 9,7) où un accompli s'achève en 咛- et qui constituent des hapax bibliques. Or la leçon grad offre ici ne figure pas dans cette liste. On serait donc tenté de conclure que cette leçon ne fait pas partie intégrante du "texte massorétique". Mais il importe de noter que cette liste qui, dans les quatre exemplaires que nous venons d'en mentionner, 
présente le même ensemble de cas, n'est ni exacte, ni complète. En effet, un cas ne devrait pas y figurer. C'est oִ (Ex 29,8) qui n'est pas hapax, cette forme se retrouvant en $\mathrm{Nb} 20,26$. Et certains autres cas y manquent : ainsi ?ִ $(\mathrm{Nb}$ 17,19)

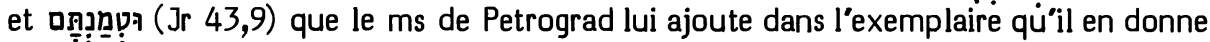

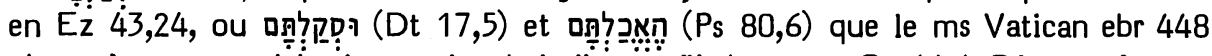
ajoute à un exemplaire incomplet de la liste qu'il donne en Gn 44,4. D'autres formes manquent en tous ces exemplaires : ainsi זٓ (Ps 90,5) qui ne figure que dans la grande liste de 40 cas où la massore finale éditée ( 1 \$22) mélange ces cas à d’autres appartenant à d’autres catégories de finales en oṇ- (entre autres 6 cas d'accomplis "lamed-hé" finissant en

De l'étude de cette liste, on peut seulement conclure que les massorètes étaient conscients de la fragilité de ces finales vocalisées qameș et qu'ils étaient soucieux de les protéger contre une vocalisation facilitante en segol. Mais ils n'ont jamais réalisé un dénombrement complet de ces formes rares. Et il est possible que celle que le ms de Leningrad nous offre en $\mathrm{Jr} 11,2$ avait déjà disparu de presque tous les témoins massorétiques avant que les massorètes ne tentent cette entreprise de sauvetage.

\section{Choix textuel :}

Ce cas n'a pas été soumis au comité.

Pour les motifs mis en avant, à partir d'Houbigant, par les partisans de cette leçon et à cause du bon appui qu'elle reçoit de la plupart des témoins textuels, la leçon du ms de Leningrad a bien des chances de représenter la forme originale de ce texte; une forte pression s'étant ensuite exercée dans tous les secteurs de la tradition textuelle pour harmoniser cette forme avec celle de l'impératif qui la précède.

Interprétation proposée :

“(1) La parole qui vint à Jérémie de la part du Seigneur : (2) - Ecoutez les termes de cette alliance! - Tu les exposeras aux gens de Juda et aux habitants de Jérusalem (3) et tu leur diras : "Ainsi parle le Seigneur..."

11,13 מזבחות לבשת M V S T // abr-styl vel hom vel lit: G om / hom : m om

Options de nos traductions :

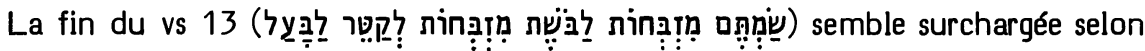
le $* M$ que RSV, TOB et J3 respectent pourtant. Il semble que ce soit aussi le cas de RL lorsqu'elle traduit (en suivant Luther de près) : “... Schandaltäre habt ihr aufgerichtet, um dem Baal zu opfern".

Mais $\mathrm{J} 12$ et NEB disent suivre le ${ }^{*} \mathrm{G}$ en omettant le $2 \mathrm{e}$ et le $3 e$ mots.

Origine de la correction :

C'est Movers (33) qui a formulé l'hypothèse que ces deux mots sont une variante des suivants. Giesebrecht a proposé de les omettre à titre de glose, suivi en cela par Condamin, Volz, Nötscher, Rudolph (qui reprend l'hypothèse de la variante marginale), Weiser et Bright (qui hésite entre les deux hypothèses), ainsi que les apparats 
de SBOT, HSAT2, BH3S et Cent. Driver (Glosses 152) les stigmatise, lui aussi, comme une glose.

Les témoins anciens :

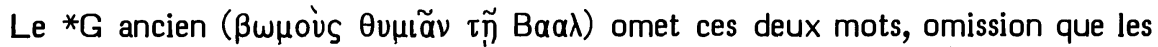
recensions origénienne et antiochienne réparent en insérant après $\beta \omega \mu$ oús : $\tau \tilde{n}$ aioxúvṇ

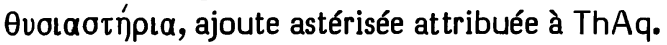

Ces deux mots sont attestés aussi par la *V (aras confusionis), la *S (לחבח (לבהתתא) et le *T (איגורין לבהתא).

Volz (Studien) les signale comme absents dans les mss Kenn 30 et 180. Dans le second (Hamburg 27 que nous avons pu contrôler), ils ont été ajoutés en marge par le vocalisateur. Il s'agissait d'un saut du premier מזבחות au second.

\section{Choix textuel :}

Autant l'absence de ces mots peut être accidentelle, autant leur présence ne saurait l'être, car elle est le résultat d’une initiative littéraire. Cette initiative est-elle à mettre au compte de l'auteur lui-même ? Cela n'a rien d'impossible puisque 3,24 nous est un indice que הַּ peut désigner Baal dans l'original de ce livre.

Un membre du comité a voté "C" pour omettre les trois derniers mots qu"il considérait comme une glose des deux qui les précèdent. Les cinq autres membres ont attribué au *M la note "C", considérant cette finale chargée comme un élément constitutif de la rédaction II et estimant probable que c'est le *G qui a allégé volontairement ou a été mutilé par accident. En tout cas, le fait qu'aucun témoin n'omette le nom de Baal dans la fin du verset nous montre que la présence ici du nom "Boshèt" n'est pas liée à une opération de débaalisation semblable à celle que nous avons analysée pour certains noms propres à propos de 2 S 2,8 (cf. CT1, 228ss).

Interprétation proposée :

“Car aussi nombreux que tes villes sont tes dieux, ô Juda! Et autant Jérusalem a de rues, autant vous avez érigé d'autels pour la Honte, d'autels qui fument pour Baal."

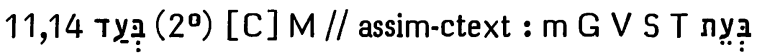

Options de nos traductions :

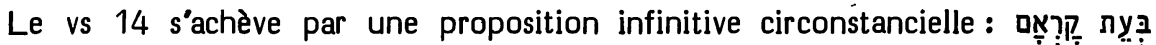

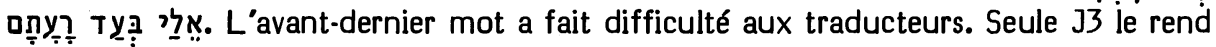
littéralement : "quand ils crieront vers moi à cause de leur malheur". RL suit la traduction large de Luther : "wenn sie zu mir schreien in ihrer Not."

Se fondant sur de nombreux mss et les versions, TOB corrige "à cause de" du *M en "au temps de (leur malheur)". J12 faisaient de même avec l'appui de 34 mss hébreux. Sans note, RSV traduit : "in the time of their trouble" et NEB : "in the hour of disaster". 
Origine de la correction :

Cappel (Notae 523b) a fait remarquer que le *G et la *V ont lu ici בְ̣ comme avant-dernier mot. L'édition de Halle du *M a noté cette leçon en quelques mss d'Erfurt. Puis Lilienthal l'a notée dans le 2e ms de Königsberg. Cela a amené Michaelis (OEB), notant qu'elle a été lue par le *G, la *V, la *S et le *T, à l'adopter, en ajoutant : "Je ne dois cependant pas taire le doute qui s'éveille en moi à l'égard de la leçon que j'ai choisie. בעת רעתם est une leçon si facile et coulante qu'il est vraiment incompréhensible que, si Jérémie avait réellement écrit cela, des copistes en aient tiré le difficile בעד qui s'est révélé obscur pour tant d'exégètes cultivés. Une lectio difficilior qui, en fin de compte, prête à une exégèse satisfaisante jouira toujours d'une préférence marquée, en comparaison avec la leçon facile, devant le tribunal de la critique".

De Rossi, ayant mentionné 23 mss, la première main de 9 autres et la Bible d'Alcala en faveur de cette leçon תבִ̣ ajoute qu'elle est attestée comme ayant figuré dans le fameux 'sépher Hilleli' et qu'elle se trouve en certains mss espagnols dont l'un qui est ancien et très soigneux. De cela, il conclut que Michaelis a eu raison de la choisir.

L'ont choisie aussi : Graf, Giesebrecht, Oort, Duhm, Cornill, Condamin, Volz, Nötscher, Penna, Steinmann, Bright, ainsi que les apparats de SBOT, HSAT234, BH23 et Cent.

\section{Les témoins anciens :}

Parmi les mss du *M auxquels nous avons accès, la leçon Tyַąe est attestée ici (pour la 2e fois en ce vs) par les mss de Leningrad, du Caire, d'Alep, de Petrograd, de Berne, Reuchlin des Prophètes; Madrid univ 1; New York JThS 232; Londres BL Add 15.451; de Rossi 2, 782; Copenhague 1, 2, 8; Vat ebr 468, 482; Paris BN hébr 2, 6, 26, 82. La leçon תỵ̣ est attestée ici (elle aussi pour la 2e fois en ce vs) par les mss Erfurt 3; Londres BL Add 21.161; Vat ebr 3, Urbinates 1; Copenhague 4, 5; Hamburg 6, 27.

Dans les mss du Caire, de Petrograd, Vat ebr 468 et New York JThS 232, une mp signale la séquence qui achève le vs 12).

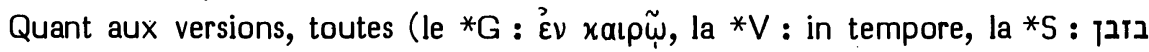
et le *T : בעידן) attestent clairement comme leur Vorlage la leçon בִִּ :

\section{Choix textuel :}

On a prétendu que, après des verbes signifiant la prière ou l'intercession, la préposition בעד est normale pour introduire en complément la personne en faveur de laquelle on intercède (comme c'est le cas deux fois ici en 14a), mais qu'elle ne serait pas à sa place pour introduire la mention de la situation malheureuse à laquelle on demande qu'elle soit arrachée. Il est vrai que notre cas est le seul où cette préposition apparaît en ce sens. Mais il faut noter que nous avons un problème comparable pour les usages faits de cette même préposition après le piél de כפר employé au sens de "expier". Cette préposition introduit d'ordinaire en complément la personne en faveur de laquelle a lieu l'expiation. Mais, ici aussi, il y a une exception : c'est Ex 32,30

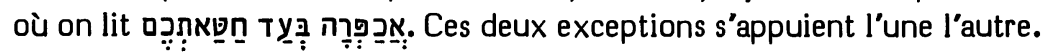


La leçon תỵạ reprendrait matériellement la fin du vs 12 et créerait une répétition lourde et dénuée de sens de cette même semi-préposition qui introduit l'infinitif dont dépend ce complément.

Le fait que Tỵ sạ soit attesté par presque toutes les éditions et par l'ensemble des mss du texte tibérien classique, ainsi que l'appui que la massore apporte à cette leçon suffisent pour établir qu'elle est ici la leçon la plus autorisée pour représenter le texte massorétique. Etant donné qu'elle est syntaxiquement justifiable, quatre membres du comité ont estimé devoir protéger cette lectio difficilior pour les motifs mis en avant par Michaelis... qui l'a abandonnée.

Deux autres membres ont attribué à la leçon תỵְ̣ la note " $C$ " en notant que l'on rencontre à partir du vs 11 de nombreuses répétitions en un parallélisme très matériel (de

\section{Interprétation proposée :}

Nous avons cité en commençant la bonne traduction de $\mathrm{J} 3$ qui est conforme à l'interprétation donnée par Venema.

\section{1,15A לידידי M AqSym V // exeg : G S / paraphr : T}

11,15B הרבים [B] M // facil-synt : Aq V S / err-graph : G clav הרנים / paraphr : T

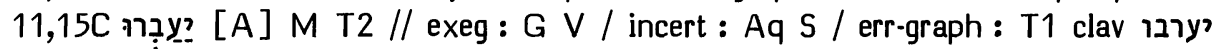

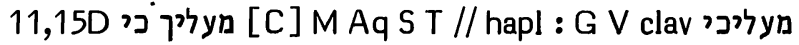

11,15E תעלזי M Aq // lic : V / exeg-ctext : G / err-graph : S T clav מעליכי מיזי

Options de nos traductions :

15a est composé, selon le $* M$, de trois phrases et $15 \mathrm{~b}$ de deux autres. La 1e

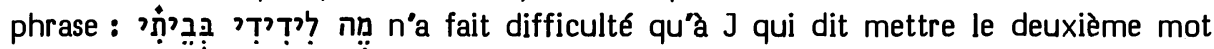
au féminin avec le *G. Cette phrase est traduite par RSV et NEB : "What right has my beloved in my house", par RL : "Was macht mein geliebtes Volk in meinem Hause ?", par J et TOB : “Que vient faire en ma Maison ma bien-aimée ?"

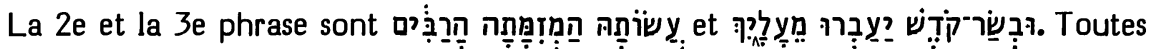
nos traductions isolent les deux premiers mots de la 2e phrase. Ils sont traduits par RSV : "when she has done vile deeds" et par NEB : "with her shameless ways". Ce n'est qu'ici que ces deux traductions placent le point d'interrogation de leur première phrase. RL traduit : "Sie treiben lauter Bosheit.", J1 : "Sa façon d'agir est finasserie !", J2 : "Sa façon d'agir est fourberie !", TOB : "Sa manière d'agir est pleine de finesse.", J3 : "Elle a accompli ses mauvais desseins."

Toutes corrigent le troisième mot de la $2 \mathrm{e}$ phrase pour en faire le sujet de la troisième que RL est seule à finir à l'atnah : "und meinen, Gelübde und heiliges Opferfleisch könnten die Schuld von ihnen nehmen;".

La 4e et la 5e phrase du vs sont אִ Rַ RL traduit ces deux phrases par : "und wenn sie übel tun, sind sie guter Dinge darüber". Les autres traductions omettent le premier mot de la $4 \mathrm{e}$ phrase et font du deuxième le complément d'objet du verbe de la 3e phrase, ce qui donne pour RSV : "Can vows and sacrificial flesh avert your doom ?", pour J : "Est-ce que les voeux et la viande sacrée te débarras- 
seront de ton mal ?", pour TOB : "Est-ce que les voeux et la viande sacrée peuvent éloigner de toi ton malheur ?", pour NEB : "Can the flesh of fat offerings on the altar ward off the disaster that threatens you ?" RSV, J et TOB disent avoir corrigé le 3e mot de la 2e phrase en "vows" ou "voeux" avec le *G pour en faire le sujet de la phrase suivante (RL ayant fait de même avec "Gelübde"), alors que Brockington dit

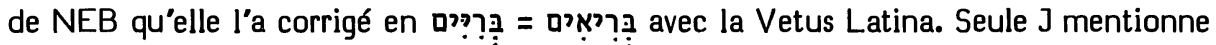

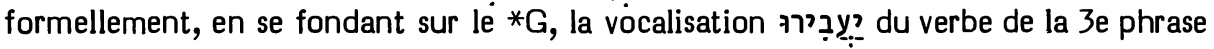
et l'omission du premier mot de la $4 \mathrm{e}$ phrase.

NEB estime vraisemblablement avoir suffisamment traduit la $5 e$ phrase avec "... that threatens you"; alors que RSV la traduit par "Can you then exult ?", J3 par : "pour que tu puisses exulter ?" et TOB par "Serait-ce ainsi que tu pourrais lui échapper ?" Quant à J12, elles donnent : "Pourrais-je te rendre pure à cause de cela ?" et “Pourrais-je pour cela te rendre pure ?" en conjecturant

\section{Origines des corrections :}

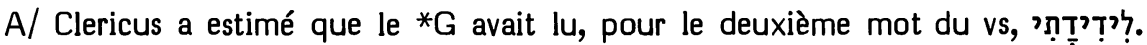
La mise au féminin de ce mot a été adoptée ensuite par Houbigant et Michaelis (ÓEB), puis par de nombreux exégètes, jusqu'aux apparats de HSAT34, BH23 et Cent.

B/ Cappel (Critica 678) a estimé que, à la place du 3e mot de la 2e phrase, le *G avait lu Jִִ̣ précédé du "hé' interrogatif. Michaelis (OEB et Observationes) et Spohn l'ont suivi én ce diagnostic. Michaelis a adopté cette correction, suivi par Ewald, Hitzig, Keil (citant aussi Dathe et Dahler), Grätz, Oort, Cornill, Condamin (citant S.R. Driver), Volz, Rudolph (Text 282), Nötscher, Penna, Steinmann, Weiser, Bright, ainsi que les apparats de HSAT34 et BH3S.

Répliquant à Cappel, Buxtorf jr (Anticritica 661) a estimé que le *G, ayant sous

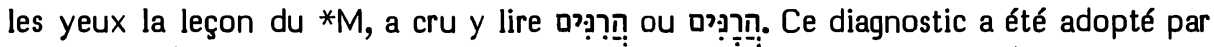
Schleusner (II 581) et le *M a été corrigé ainsi par Graf (citant Maurer), Nägelsbach, Knabenbauer, von Orelli, ainsi que les apparats de SBOT et HSAT2.

Giesebrecht a relevé, en Irénée IV, 17 : "Non enim adipes et carnes pingues auferent a te iniustitias tuas" et il en a conclu qu'un témoin semblait se manifester là pour la leçon הַח quilil avait conjecturée à la place du $3 e$ mot de la 2e phrase et du "hé" final qui le précédait. Cette leçon a été adoptée ensuite par Duhm, Ehrlich et l'apparat de Cent, alors que l'apparat de BH2 hésitait entre elle et la Vorlage du *G telle que Cappel l'avait restituée.

Driver (109) a restitué, pour le "adipes" d'Irénée, la Vorlage que retiendra NEB et qui a été adoptée aussi par Hyatt (Original 58).

C/ Le verbe de la 3e phrase a été lu comme transitif par Prédicants, Zwingli, Luther, Houbigant. Il a été vocalisé po- par Michaelis (Observationes), ainsi que par les apparats de SBOT, HSAT234, BH23S et Cent.

D/ Houbigant a proposé d'inverser les deux mots de la 4e phrase. Il a été suivi en cette proposition par Rothstein (= HSAT234); alors que Michaelis a proposé de voir dans le premier mot de cette phrase une dittographie du pronom suffixe du mot pré- 
cédent (à orthographier מעליכי). L'élimination de ce mot à titre de dittographie a été requise ensuite par les apparats de SBOT, $\mathrm{BH} 235$ et Cent.

E/ Ni Houbigant, ni Michaelis n'avaient proposé de corriger le verbe de la $5 e$ phrase. Cornill, en SBOT, a proposé de le corriger en en quִ en quoi il reconnaissait la Vorlage du ${ }^{*} G$. Mais, en son commentaire, il a vu ensuite en cette Vorlage une déformation de la leçon du *M (à travers une graphie תלצי), ce qui n'a pas empêché S.R. Driver (et Condamin qui le cite) d'adopter la proposition de SBOT. C'est ce que TOB a fait aussi sans le préciser.

D’autres Vorlagen ont été proposées pour le ${ }^{*} G$ : et Schleusner (II 140), par Grätz (Studien 108).

C'est Rudolph (Text 282) qui a proposé la conjecture que 312 ont adoptée, car elle avait été requise par Rudolph dans l'apparat de BH3.

Les témoins anciens :

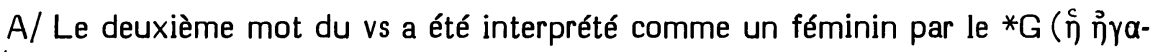
$\pi \eta \mu \varepsilon ́ v \eta)$ et la *S (חביבתי); alors que le ms Barberini attribue à AqSym une traduction

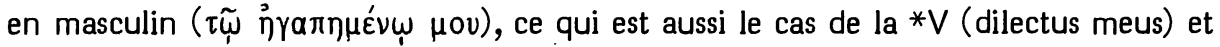
du *T qui paraphrase לעמא דהוה חביב קדמי

B/ Le 3e mot de la 2e phrase a été traduit comme s'il qualifiait le mot qui le pré-

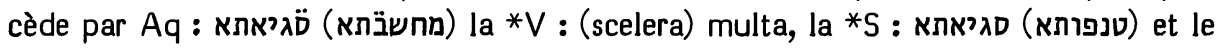

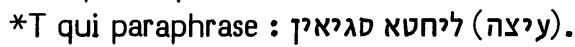

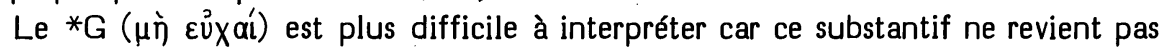
ailleurs dans le ${ }^{*} G$ de Jérémie. Il est cependant frappant de noter que le verbe $\varepsilon \mathfrak{c} v$ $X \varepsilon \sigma \theta a \mathrm{al}$, dans les autres livres prophétiques, c'est-à-dire en Jonas $(1,16 ; 2,10)$ et en Isä̈e $(19,21)$, correspond toujours à l'hébreu נדר (que le *G a cru aussi lire en המנדים Am 6,3); alors qu'en ses deux emplois du livre de Jérémie (7,16 où il correspond à

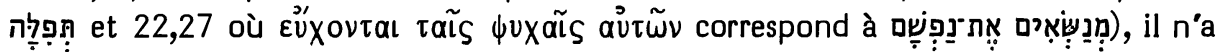
pas le sens de "faire un voeu", mais celui de "prier". Or le substantif ?ִִ̣ apparaît trois fois en ce livre $(7,16 ; 14,12$ et au vs qui précède : 11,14) et toujours en un contexte de prière, le *G l'ayant traduit par le substantif $\delta$ Énols $(J r 11,14 ; 14,12)$ ou par le verbe $\delta \varepsilon \tilde{i} 0$ al $(7,16$ corrigé ainsi par Ziegler, Beiträge 20). On sait qu'une forme à

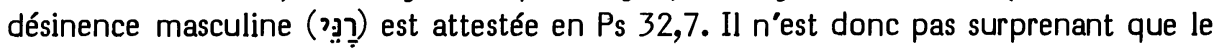
*G qui, en Jr 7,16 et 1 ।,14, a toujours fait précéder ou suivre sa traduction de

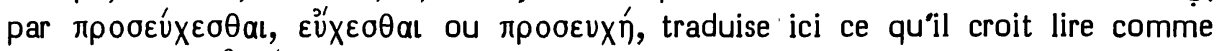

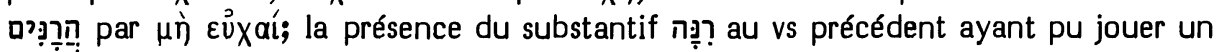
rôle déterminant dans sa fausse lecture de sa Vorlage.

Ceux qui veulent voir en ce mot des "viandes grasses" à la suite de Giesebrecht ou des "animaux gras" à la suite de Driver construisent sur le sable. En effet, Irénée (IV 17, lignes 59-87) a attribué à Jérémie une suite de textes (Jr 6,20; 7,2-4.21-25; $9,24)$ établissant que Dieu requiert de son peuple la conversion et non le sacrifice. Ensuite (ibid., lignes 90-110) il attribue à Isaïe une autre suite de textes pour montrer que le peuple n'a pas reçu les "sacrifices, holocaustes et oblations" comme une exi- 
gence primordiale de Dieu, mais comme une initiation au véritable culte qu'il désire. Irénée cite ici tour à tour : Is 43,23-24; 66,2 et 58,6-9. Et c'est entre ces deux derniers textes qu'on lit la phrase suivante : "Non enim adipes et carnes pingues auferent a te injustitias tuas", selon la vieille traduction latine de l'Adversus Haereses. Dom Sabatier a été imprudent d'éditer cela comme une version latine ancienne de Jr 11,15, alors qu'Irénée qui, en tout ce chapitre, cite ses sources avec précision ne mentionne pas ici le livre de Jérémie. Comme on le sait, le grec original d'Irénée est ici perdu. Cependant, Dom Rousseau, dans la reconstitution qu'il en a donnée dans son édition, a restitué ici : oủ yà que la vieille latine d'Irénée. En effet, le traducteur arménien d'Irénée, reconnaissant lui aussi en cette phrase un emprunt à Jérémie, a donné un texte identique au *G de Jérémie. Lisait-il cela dans le grec d'Irénée qu'il traduisait ? Ou bien est-ce le traducteur latin qui a traduit fidèlement une phrase inspirée à Irénée par Jr 11,15, mais composée librement par lui en y mentionnant les "graisses" (mot qui vient de figurer dans la citation d'Is 43,24) à la place des eủxaí, et les "injustices" (mot qui apparaîtra juste après dans la citation d'Is 58,6 ) à la place des "méchancetés" ? Concluons donc que cette leçon "adipes" représente un témoin secondaire (latin) d'une allusion possible (Jérémie n'étant pas mentionné) à une traduction (grecque) du texte biblique. En faire usage pour la critique du texte hébreu supposerait d'abord qu'elle permette d'accéder à un état plus primitif du ${ }^{*} G$ que celui qu'offre sa tradition directe, ce que personne n'osera prétendre.

C/ Le verbe de la 3e phrase a été lu comme transitif par le *G (ả la $\lambda$ oṽouv) et la

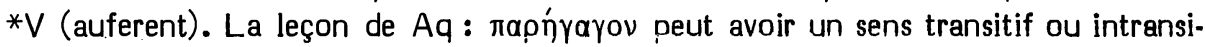
tif. Il en va de même de celle de la*S (נעברון) dont la vocalisation est trop peu sûre pour qu'on puisse trancher avec certitude. Cependant Sionita s'accorde avec Ishodad pour la lire comme transitive.

Le *T offre ici une leçon gonflée à la base d'une paraphrase où מערבין suppose une Vorlage יערבו, alors que la leçon du*M y est traduite par יגלון que les mss Reuchlin et Urbinates 1, ainsi que les éditions de Félix de Prato, de Ben Hayim, des polyglottes d'Anvers et de Londres vocalisaient en peal (intransitif), alors que Sperber le vocalise en afal (transitif) sur la base de deux mss tardifs.

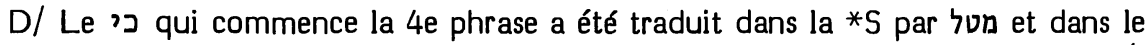

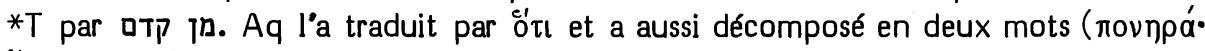
č $\tau ו=~ כ ת$ ) le second mot de cette phrase.

Le *G (ảmò oõ̃ tàs xaxías oov) et la *V (a te malitias tuas) ne l'ont pas traduit. Il semble que, pour le dernier mot de la phrase précédente et pour le premier mot de celle-ci, la Vorlage du *G ne portait que מעליכי. Pour ce passage difficile, la*V semble s'être laissé guider par le *G.

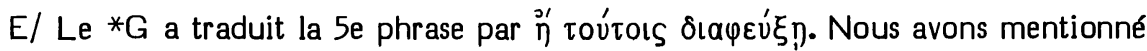
plus haut les tâtonnements de ceux qui ont essayé de reconstituer sa Vorlage. Mieux vaut y renoncer, d'autant plus que c'est la seule occurrence de ce verbe dans le $* G$ de Jérémie. 


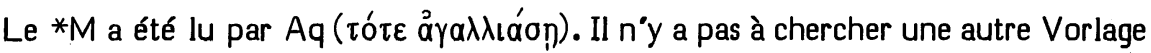
derrière la traduction plus libre (in quibus gloriata es) de la *V dont le début $s^{\prime}$ inspire encore $d u * G$.

La *S (בען) et le *T (בען הויתא תקיפא), ainsi que Frankl (551) l'a remarqué, ont lu la même Vorlage (תע) ou bien l'une de ces versions dépend de l'autre.

\section{Choix textuel :}

A/ Ce cas n’a pas été soumis au comité. Quoi qu'en aient pensé les apparats critiques sous l'influence de Clericus, Houbigant et Michaelis, le substantif qu'il est utilisé, comme ici, avec une valeur de collectif, peut avoir la portée d'un féminin. C'est ce que Hitzig a fait remarquer, suivi en ce jugement par von Orelli et König (Syntax §247f) qui voit en ce substantif, à l’époque biblique, un "nomen

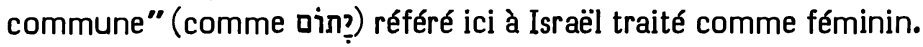

Ce mot ne pose donc pas de problème textuel mais seulement exégétique. Son interprétation en masculin par AqSym, la $* V$ et le $* T$ repose vraisemblablement sur une tradition midrashique que nous rapporte $R$. Isaac (vers 250) dans le Talmud Babli (Menahot 53b) : “A l'heure où le Temple allait être détruit, le Saint béni soit-il rencontra Abraham qui se tenait dans le temple et il lui dit : 'Qu'est-ce que mon bienaimé a à faire en ma maison ?' Il lui dit : 'Je suis venu pour les affaires de mes fils'. Il lui dit : 'Tes fils ont péché et ont été déportés'. Il lui dit : ' $N$ 'auraient-ils pas péché par inattention?' Il lui dit : עשותה המזמתה. Il lui dit : 'Ne serait-ce pas une minorité d’entre eux qui a péché ?' Il lui dit : הרבים"... et le midrash continue jusqu’à la fin du vs 16.

L'interprétation féminine $d u{ }^{*} G$ et de la ${ }^{*} S$ s'accorde mieux avec les suffixes $2 e$ pers. f. sg. des derniers mots de la $3 e$ et de la $4 e$ phrases, ainsi qu'avec le verbe $2 e$ pers.f. sg. de la $5 e$ phrase.

$B /$ Ni la confusion du 'bet' avec 'nun' commise par le *G, ni la facilitation syntaxique $d^{*} \mathrm{Aq}$, de la $* \mathrm{~V}$, de la ${ }^{*} \mathrm{~S}$ et du $* T$ ne rendent compte du 3 e mot de la $2 \mathrm{e}$ phrase. Radaq n'aboutit pas à un meilleur résultat en comprenant ce mot au sens de : "elle a commis l'abomination (avec) les (dieux) nombreux".

Au XVIe siècle, la facilitation syntaxique des versions ( $=$ a commis des abominations nombreuses) a été adoptée par Pagnini, Prédicants, Zwingli, Luther, Brucioli, Olivetan, Arias Montano, Châteillon, Tremellius; alors que l'interprétation de Radaq a été adoptée par Münster, Rollet, Calvin, Estienne, Ge et KJ.

Mieux vaut pourtant, avec le Talmud, Rashi, Menahem de Posquières, Pasteurs,

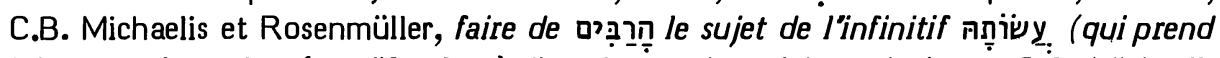
ici une valeur de gérondif, c'est-à-dire de quasi-participe, ainsi que C.B. Michaelis l'a noté) en considérant le pronom suffixe 3e pers. f. sg. qui affecte cet infinitif comme pléonastique, c'est-à-dire anticipant le substantif qui le suit. A propos de 9,14 (ci-dessus, p. 540),nous avons traité de cette particularité syntaxique du livre de Jérémie, particularité qui a été relevée ici par Menahem de Posquières et C.B. Michaelis. Quant à la double finale féminine de הַ (qui fait assonance avec la finale du mot précédent), elle a d'assez nombreux parallèles qui ont été évoqués ici par Menahem de Posquières, Radaq et plusieurs autres. 
Une certaine incertitude demeure parmi les exégètes sur le sens ici de הרבים: "les grands" ou "la plupart" ? Le Talmud optait pour le 2e sens et le contexte ("ce peuple" en 14 et "la maison d'Israël et la maison de Juda" en 10.17, ainsi que "les gens de Juda et les habitants de Jérusalem" en 2.9.12) favorise ce sens.

Pour ce mot, le comité a attribué au *M la note "B".

C/ La plupart des versions ont interprété comme transitif le verbe de la 3e phrase. Au XVIe siècle, Prédicants, Zwingli et Luther ont fait de même, alors que Pagnini, Brucioli, Münster, Olivetan, Calvin, Arias Montano, Châteillon, Ge, Tremellius, Pasteurs, $\mathrm{KJ}$ estiment probablement être plus fidèles au *M en le lisant comme intransitif, c'est-à-dire en qal (ainsi que le *T semble bien l'avoir fait).

Mais Rosenmüller voit en יעברו un inaccompli hifil contracté, du type de celui que nous avons rencontré ci-dessus (p. 534) en וידרכו (9,2). Comme exemple de forme contractée non invertie, il cite ajoute à cela contractées de I'inaccompli hifil soient particulièrement fréquentes dans les verbes dont la première radicale est une gutturale et qui incluent un 'resh' ou un 'lamed'.

Le parallèle d'Ag 2,12 engage à interpréter la "chair de sainteté" comme désignant les sacrifices. Il semble exister un parallèle contrasté entre la première phrase : ובשר־קדש יעברו מעליך : Cel la troisième nous amène à donner au verbe de la 3e phrase un sens transitif (en l'interprétant en hifil, sans avoir à le corriger pour cela) et à lui donner pour sujet ou bien הְִ̣̣ (qui a déjà joué ce rôle à l'égard de l'infinitif de la 2e phrase), ou bien un sujet impersonnel. Notons que, suivi de le hifil de ce verbe a le sens de "retirer, enlever".

Estimant qu'il ne s'agit ici que d'une question d'interprétation, le comité a attribué au *M, pour ce verbe, 4 "A" et 2 "B".

$D /$ Le *G (suivi ici par la*V) a omis כ כ parce que, ayant fait de "prières et viandes saintes" le sujet du verbe יעברו (transitif), il veut faire de "tes méchancetés" son complément d'objet. Il n'est pas impossible qu'une haplographie du 'kaf' ait motivé aussi cette omission dont la cause la plus obvie semble être le caractère très condensé

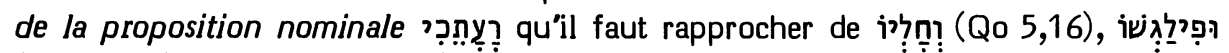

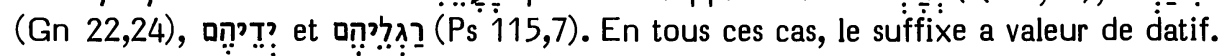

Il existe entre כי (introduisant la $4 \mathrm{e}$ phrase) et אז (introduisant la 5e) un balancement : "lorsque ... alors" qui se retrouve en Gn 49,4; 1S 6,3; Jb 3, 13.

Le mot הy semble signifier ici plutôt "malheur" que "méchanceté", ainsi que le suggèrent ses emplois les plus proches (en 12.14 et 17a).

Etant donné la possibilité ici d'une dittographie dans le $* M$, le comité ne lui a attribué que la note " $\mathrm{C}$ ".

E/ Ce cas n'a pas été soumis au comité.

Il semble bien que le ${ }^{*} G$ a traduit en fonction de son propre contexte. Quant au *T (dont la *S semble dépendre), sa Vorlage semble ne pas avoir porté le 'lamed'. Cependant le contraste entre "malheur" et "exulter" semble bien intentionnel. 
Depuis Abulwalid (Ușul 528,21-23) qui proposait de voir ici (comme en 51,39 dont nous traiterons plus loin) des spasmes d'agonie, certains exégètes comme Tanhum Yerushalmi ont donné à thy le sens de "être bouleversé". Mais le sens habituel de ce verbe confère à cette finale une ironie amère.

\section{Interprétation proposée :}

“Qu’est-ce que ma bien-aimée a à faire dans ma maison; alors qu'ils sont nombreux, ceux qui la commettent, l'abomination? Qu'ils fassent passer loin de toi, même la viande sacrée! Lorsque le malheur t’atteindra, alors tu pourras jubiler !"

Il semble que "la bien-aimée" soit le peuple des fidèles du temple, alors que ceux qui "commettent l'abomination" sont des responsables religieux qui s'adonnent à l'idolâtrie en privant le peuple de la connaissance de la Torah. Eh bien ! qu'ils privent aussi le peuple des sacrifices. Alors, le malheur viendra et on verra bien si on a encore le coeur de s'adonner aux réjouissances cultuelles!

11,16A פרי [B] M Aq V // expl : S / assim Ez 31,3-9 : G T

Options de nos traductions :

En 16a il est dit que "le Seigneur te donnera pour nom : qui est traduit par RSV : "A green olive tree, fair with goodly fruit", par RL : "einen grünen, schönen, fruchtbaren Oelbaum", par TOB : "Olivier toujours vert, beau par ses fruits magnifiques", par $\mathrm{J3}$ : "Olivier verdoyant orné de fruits superbes".

$J 12$ disaient suivre le ${ }^{*} \mathrm{G}$ en traduisant: "Olivier verdoyant à la belle stature". NEB a fait de même en traduisant: "an olive tree, leafy and fair", ce qui, selon Brockington, suppose l’omission de פְִִ

Origine de la correction :

Houbigant, estimant inacceptable la juxtaposition des 4 e et $5 e$ mots, proposait, en se fondant sur la *S, d'insérer entre eux ויפה.

Michaelis, en OEB, remarquait que le *G n'atteste pas פרת. En Observationes, il proposait de le suivre, suivi en cela par Oort, Ehrlich, Volz, Nötscher, Rudolph, Penna, Steinmann, Weiser et Bright, ainsi que par les apparats de HSAT34, BH23S et Cent.

Les témoins anciens :

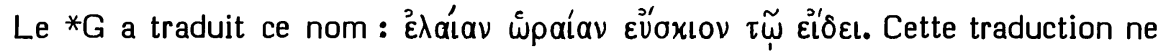
laisse pas apparaître qu'elle ait lu le $4 \mathrm{e}$ mot du *M. Les correspondances claires sont celle qui existe entre son $2 e$ mot et le $3 e$ du $* M$ et celle qui existe entre le $5 e$ mot du ${ }^{*} G$ et celui du ${ }^{*} M$. Reste le $3 e$ mot du ${ }^{*} G$ qui ne correspond bien ni au $2 e$ ni au $4 \mathrm{e}$ $\mathrm{du}{ }^{*} \mathrm{M}$. Il est fort possible que le ${ }^{*} G$ ait voulu alléger une Vorlage identique au ${ }^{*} M$ que le traducteur estimait lui aussi surchargée et difficile à articuler syntaxiquement.

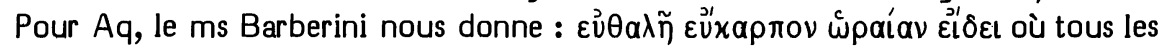
mots du *M sont traduits. On peut hésiter sur le bien-fondé de l'omission du 3e mot par Ziegler. 
La * $\vee$ (olivam uberem pulchram fructiferam speciosam) traduit, elle aussi, tous les mots du *M.

La *S (זיתא עביטא שפיר פארא ושפיר חזוא) les atteste tous et répète même le 3e entre le $4 \mathrm{e}$ et le $5 \mathrm{e}$.

Le *T (דשפיר בריויה ויאי בחזויה וסוכיה מטלן באילניא) qualifie l'olivier par une paraphrase où se retrouvent les deux options caractéristiques du *G : pas de mention des fruits, mais du fait que l'arbre offre de l'ombre.

Choix textuel :

Il semble bien que le ${ }^{*} G$ et le ${ }^{*} T$, dans leur omission des fruits et leur mention de l'ombre offerte par l'arbre, ont été influencés par la description du grand cèdre (Ez 31,3-9) auquel est comparé Pharaon.

Estimant le *M bien appuyé par $A q$, la $* V$ et la $* S$, le comité lui a attribué la note "B". Il est normal, en effet, que, dans ce nom donné par le Seigneur, il y ait redondance et emphase.

Interprétations proposées :

Yéfet ben Ely traduit : "beau de fruits et de figure". Cela implique une ellipse de "et beau de" avant le dernier mot. Cette ellipse qui a été explicitée par la *S l'a été aussi par Abulwalid (Luma 259,12s), Radaq et Joseph ibn Nạ̣mias.

En Luma 344,16, Abulwalid propose une autre interprétation : considérer le 3e et le $4 \mathrm{e}$ mots de l'hébreu comme permutés, le sens devant être : "aux fruits de belle figure". C'est également l'exégèse de Judah Hadassi $(67 \mathrm{~b}, 10)$.

Clericus, C.B. Michaelis et Venema s'accordent pour interpréter : "Un olivier verdoyant, beau par ses fruits magnifiques", interprétation satisfaisante qui a été retenue par TOB.

\section{1,16B וְרִעו [B] M // exeg : G AqSym S, T / exeg-ctext : V}

Options de nos traductions :

En 16b, il est dit que le feu est mis à l'olivier et le vs s'achève par Ces deux mots sont traduits par RSV : "and its branches will be consumed", par RL : "so dass seine Aeste verderben müssen", par TOB : "et on casse ses branches", par J3 : "ses rameaux sont atteints".

J12 traduisaient: "ses rameaux brûlent", disant corriger le premier mot en

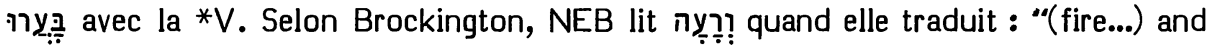
consumes its branches".

\section{Origines des corrections :}

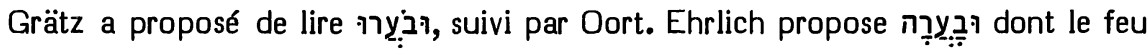
serait le sujet. La vocalisation retenue par J12 a été proposée par Volz et adoptée par Nötscher, Rudolph, Penna, Steinmann, Weiser ainsi que par les apparats de HSAT4, $\mathrm{BH} 3 \mathrm{~S}$ et Cent. 
NEB dépend de Driver qui se contentait d'interpréter la forme du $* M$ comme un 'lamed-hé' retenant sa finale archaïque en 'waw'; le sujet en étant le feu qui broute ou consume les rameaux de l'olivier.

Les témoins anciens :

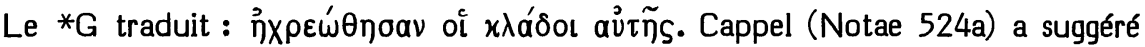
que ce sens dérive du sens de base "être mauvais". C"est aussi la première opinion de Schleusner (en Observationes de Michaelis). En son Thesaurus, Schleusner y a vu une traduction large, au sens de "briser", les rameaux brisés devenant inutiles.

La Syh attribue à AqSym אתמהלין (= ont été affaiblis).

La *V traduit "et combusta sunt frutecta eius" que Hie glose : "ita ut comburerentur et redigerentur ad nihilum rami, sive frutecta eius". Sa traduction semble donc s'inspirer librement de celles $d u{ }^{*} G$ et de AqSym, mais surtout du contexte.

La *S en dépend aussi lorsqu'elle traduit (selon l'Ambrosianus et l'édition de Mossul) ותתחבלו ות ou (selon les polyglottes de Paris et de Londres).

Le *T a vu là une autre réalisation du bilittère רע lorsqu'il a traduit : ויתחברון.

Choix textuel :

Estimant que toutes les versions ne représentent probablement que des exégèses, le comité a attribué au *M la note " $B$ ".

Interprétation proposée :

Le sens à donner à ce verbe ici dépendra en partie de celui que l'on aura donné,

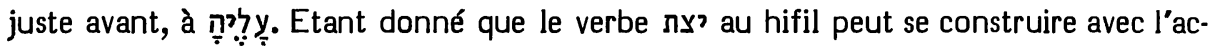
cusatif de l'objet incendié ou avec l'accusatif du feu que l'on allume, mais que ce verbe ne se construit pas avec une autre préposition que 'bet', il vaut mieux ne pas suivre la plupart des exégètes qui voient ici la préposition by, mais plutôt Joseph Qimhị qui, selon le commentaire de son fils David, comprend "son feuillage". Notons à ce propos que la forme plurielle de ce substantif est attestée, à propos de l'olivier, en

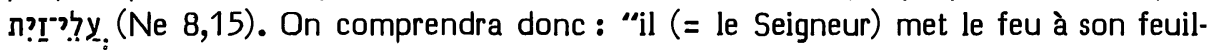
lage".

En ce cas, on pourra, avec Hitzig, Giesebrecht, Duhm et Cornill, donner à notre verbe le sens de "être mauvais", c'est-à-dire qu'après l'incendie, les rameaux de l'olivier, noircis et privés de leurs feuilles, ont piètre allure (comme les figues de Jr 24,2

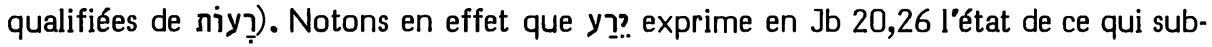
siste après un incendie. Ce sens paraît préférable à celui de "et on brise ses branches" qui introduirait, inutilement, une autre image. On traduira donc: "et ses branches ont une triste allure". 


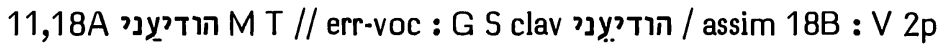

11,18B הראיתני M Aq Sym V S T // assim-ctext : G 1p

Options de nos traductions :

Le *M porte ici : "Or le Seigneur m'a fait connaître ... alors, tu m'as fait voir..." Ce passage de la 3e à la 2e personne a été traduit littéralement par RSV et J3.

J12, pour faciliter la transition, ont ajouté "Yahvé" en vocatif, avant le verbe du 2e membre, conjecturant que ce mot, écrit en abrégé, est tombé par haplographie.

TOB traduit : “Quand le SEIGNEUR m’a mis au courant ... alors j’ai découvert", en disant qu'elle traduit le $2 \mathrm{e}$ verbe avec le ${ }^{*} \mathrm{G}$.

RL ("Der HERR tat mir kund ... und er zeigte es mir") et NEB ("It was the LORD who showed me ... he opened my eyes") ont, sans note, traduit le verbe du $2 \mathrm{e}$ membre par une 3e personne.

Origines des corrections :

Au XVIe siècle, le passage de la $3 e$ à la 2e personne a été respecté par Pagnini, Brucioli, Münster, Jud, Calvin, Ge, Tremellius, Pasteurs, KJ.

Ont harmonisé sur la 3e personne : Luther ("Der HERR hat mirs offenbart ... und zeigt mir") et Châteillon ("E le Seigneur m'a si bien donné a connoitre e montré").

Ont harmonisé sur la 2e personne : Prédicants ("Dises hab ich HERR von dir erlernet ... so du mir ... gezeiget hast"), Zwingli ("Haec, o Domine, te doctore ... cum tu mihi ... ostenderes"), Olivetan ("Et toy Seigneur me las donne a cognoistre ... Lors tu mas manifeste") non retouché par Rollet ni Estienne.

Grätz (Studien 109) a d'abord mis le premier verbe à la 2e personne pour l'assimiler au second. Puis (Emendationes), il a préféré mettre le 2e verbe à la 3e personne pour l'assimiler au premier. En cette dernière option (reprenant celle de Luther), il a été suivi par Steinmann et l'apparat de Cent.

La correction adoptée par TOB avait été proposée par Erbt, Cornill (qui le cite), Volz, Schmidt, Penna, Bright, ainsi que par les apparats de HSAT34.

La conjecture adoptée par J12 avait été proposée par Duhm, Nötscher, Rudolph, ainsi que par les apparats de $\mathrm{BH} 3 \mathrm{~S}$.

Les témoins anciens :

1/ En 18A, l’accompli 3e pers. m. sg. du *M a été vocalisé en impératif m. sg. par le *G ( $\gamma v \omega$ ẃpıoóv $\mu 0 \iota)$ et par la *S (חוני).

$\mathrm{La} * \mathrm{~V}$ l’a assimilé (demonstrasti mihi) à 18B.

Le *T (אלפני) traduit le *M.

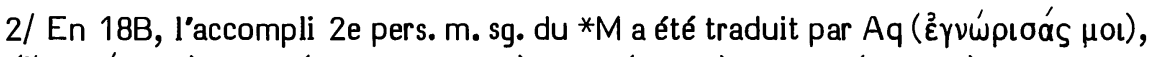
Sym ( $\left.\varepsilon^{\prime 2} \delta \varepsilon \xi \alpha_{S}^{\prime} \mu o l\right)$, la *V (ostendisti mihi), la *S (חויתני) et le *T (אחזיתני).

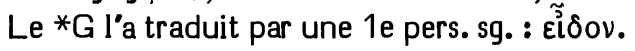

Choix textuel :

Ces deux cas n'ont pas été soumis au comité. 
Le *M offre ici tour à tour un accompli de la 3e pers. m. sg. ayant pour sujet le Seigneur, et un accompli de la 2e pers. m. sg. ayant probablement le même sujet, quoiqu'il ne soit pas explicité.

Pour pouvoir vocaliser le premier en impératif, le ${ }^{*} G$ et la ${ }^{*} S$ ont omis la conjonction qui précède le tétragramme, conjonction qui est attestée par $A q$, la ${ }^{*} \mathrm{~V}$ et le ${ }^{*} \mathrm{~T}$. Quant à la 1e pers. du ${ }^{*} \mathrm{G}$ en $18 \mathrm{~B}$, c'est une assimilation au verbe qui précède immédiatement.

La rudesse de la syntaxe du ${ }^{*} M$ est sûrement primitive par rapport aux assouplissements divers des versions anciennes et des traductions du XVIe siècle ou d'aujourd'hui.

D’ailleurs, cette rudesse convient bien au début de cette "confession" (cf. Hubmann 51).

Interprétation proposée :

“Or le Seigneur m’a fait connaître et j’ai connu; c'est alors que tu m'as fait voir leurs agissements."

11,19 עי [A [A] M G Aq V S // lic : Sym / paraphr : T

\section{Options de nos traductions :}

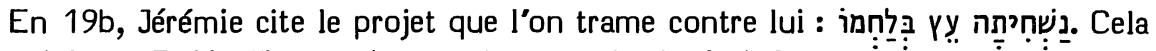
est traduit par RSV : "Let us destroy the tree with its fruit".

Sans note, TOB traduit : “Détruisons l'arbre en pleine sève" et RL : “Lasst uns den Baum in seinem Saft verderben". Pour le 3e mot, J dit conjecturer in ạ quand elle traduit : "Détruisons l'arbre dans sa vigueur"; alors que Brockington prête la

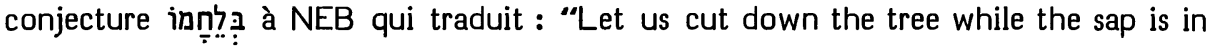
it".

Origines des corrections :

Moshe ben Sheshet rapporte que certains estiment que le 'mem' du 3e mot appartient au suffixe.

Sans connaître ce prédécesseur, Clericus a proposé de traduire le *M : "in virore ejus", reconnaissant ici le mot nֵ et le suffixe in- dont il estime bien établi qu'il peut valoir pour la 3e pers. m. sg.

Dahood (Lexicography IV 409) obtient la même analyse en postulant ici un 'mem' enclitique.

Hitzig a proposé la conjecture que J retiendra à la suite de Graf, Grätz (Studien 109), Giesebrecht, Oort, Duhm, Cornill, Condamin, Schmidt, Nötscher, Rudolph, Penna, Steinmann, Weiser et des apparats de SBOT, HSAT234, BH23S et Cent.

Les témoins anciens :

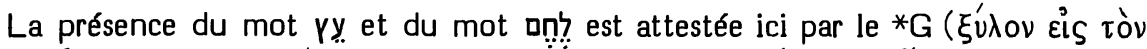

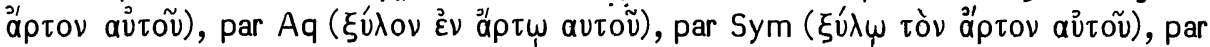
la *V (lignum in panem eius), par la *S (קיסא בלחמה). 
La paraphrase du *T ("un poison mortel dans sa nourriture") repose aussi sur les mêmes mots.

\section{Choix textuel :}

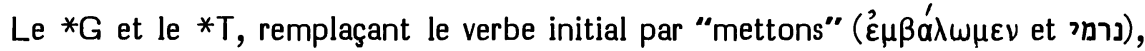
voient en ce "bois" un poison (de même que le "bois" de Ex 15,25 est un contrepoison). Cette exégèse est celle que préfère Yéfet ben Ely et qu'adopteront (à la suite de Rashi, Radaq et Nicolas de Lyre) Pagnini, Prédicants, Zwingli, Brucioli, Münster, Olivetan, Rollet, Estienne et Calvin.

Cependant Yéfet ben Ely dit que d'autres comprennent le premier mot au sens de "arbre" et le second au sens de "son fruit". Cette exégèse sera proposée par Abulwalid (Ușul 351,22) : “On a appelé l’ensemble des fruits on en Jr 11,19 dont le sens, selon moi, est 'détruisons l'arbre en son fruit', c'est-à-dire détruisons-le et détruisons sa parole à notre propos." Cette exégèse est aussi celle que donnent Ibn Ezra (en son commentaire sur Ex 16,4), Judah ibn Balaam et Tanhum Yerushalmi. C'est cette exégèse qu’adopteront Luther, Châteillon, Geneva Bible, Pasteurs et King James.

On a objecté à cette seconde exégèse que oṇ ne se retrouve pas ailleurs comme désignant le fruit d'un arbre. Cependant Rosenmüller et Gesenius (Thesaurus 753a) ont relevé que le mot (= nourriture) se dit en arabe du fruit de l'arbre. D'ailleurs, au niveau de la métaphore, la parole de Dieu que porte le prophète Jérémie est présentée comme une nourriture en 15,16. Cette motivation du sens qu'a ici l'hébreu semble préférable à celle de Schultens (Opera minora 297), expliquant qu'en arabe an se dit du coeur ou de la moelle des arbres et de la pulpe des fruits. En effet, il ne s'agit ici ni de la moelle de l'arbre, ni de la pulpe du fruit, mais bien du fruit lui-même, en tant qu'il est une nourriture pour les hommes.

En faveur de cette exégèse, il faut rappeler qu'en Dt 20,19-20 (où il est parlé de l'interdiction d'abattre des arbres fruitiers à des fins militaires) on retrouve exactement les deux formes verbales (hifil de immédiat. Or, le terme employé en Dt 20,20 pour caractériser cet arbre est “arbre

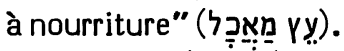

Ehrlich (Miqra) a suggéré que le 'bet' motive ici l'abattage (comme en Ez 3,20 : בחטאתו ימות). Il s'agirait d'abattre l'arbre à cause de la nourriture vénéneuse (les prophéties inacceptables : 11,21; 26,11; 36,23) qu'il porte. König (Wörterbuch 198b) préfère voir dans ce 'bet' une sorte de "bet" de concomitance, au sens de "en même temps que".

Tous les témoins textuels appuyant le ${ }^{*} M$, le comité a attribué à celui-ci la note "A".

Interprétation proposée :

"Détruisons l'arbre en même temps que la nourriture qu'il produit" semble préférable à "à cause de la nourriture..." 


\section{Options de nos traductions :}

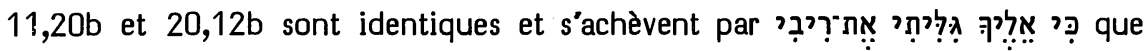
$\mathrm{J} 3$ traduit : "car c'est à toi que j'ai exposé ma cause".

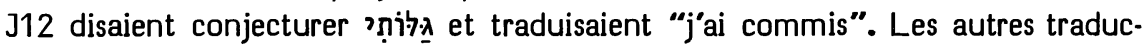
tions ont fait de même, sans le dire, RSV traduisant : "have I committed", RL : "ich habe ... befohlen", NEB : "I have committed" et TOB : "je remets".

Origine de la correction :

La plupart des traducteurs du XVIe siècle (Pagnini, Brucioli, Münster, Olivetan, Jud, Estienne, Calvin, Châteillon, Geneva Bible, Tremellius, Pasteurs, King James) traduisent ici ce verbe selon le sens normal du piél de la réalisation 'lamed-hé' du bilittère : “j”ai révélé, exposé, manifesté".

Luther ("ich hab ... befolhen") suit ici une option du groupe zurichois responsable de la traduction des Prédicants ("hab ich empfolhen" en 11,20 et "empfilh ich" en 20,12). En effet, Zwingli traduit : "commendo" et Pellican glose (sur 11,20) : "Tibi ergo resigno causam istam meam". Houbigant traduira aussi "detuli".

Habitués à la traduction de Luther, Hitzig a estimé que nous avions ici une forme 'lamed-hé' ayant le sens de la forme géminée et Ewald2 s'est demandé s'il ne fallait pas lire, à la place de la vocalisation du *M, celle que $\mathrm{J12}$ ont conjecturée plus tard. Cette correction vocalique a été requise ensuite par Grätz, Oort, Duhm, Cornill, Condamin, Nötscher, Rudolph, Steinmann, Weiser, et les apparats de HSAT34, BH3S et Cent.

\section{Les témoins anciens :}

Tous (*G : å ${ }^{*} \varepsilon x a ́ d \lambda v \psi \alpha, * V$ : revelavi, *S : גלית et *T : אמרית) appuient la vocalisation du *M.

\section{Choix textuel :}

Hitzig a fait remarquer que le piél du 'lamed-hé', qui, en Jr 33,6, sera construit avec la préposition 'lamed', est construit en 11,20 et 20,12 avec la préposition qui est justement la préposition avec laquelle le qal du géminé est construit en $\operatorname{Pr} 16,3$ et Ps 22,9. Mais Grotius, Rosenmüller et Keil ont fait remarquer qu'on glisse tout naturellement de "faire confidence" à "confier". On a objecté à cela que Jérémie ne peut pas "révéler" au Seigneur ce que lui a fait connaître $(11,18)$ celui qui sonde les reins et le coeur (vs 20a). Mais Jérémie veut dire par là que, conscient de la clairvoyance du Seigneur, il n'entend rien dissimuler de ce qui constitue le dossier de sa cause; le Seigneur lui ayant révélé les intentions de ses ennemis et lui, Jérémie, exposant en toute spontanéité en ses "confessions" son désarroi et ses requêtes. La volonté d'ouverture totale de Jérémie sous le regard du Seigneur s'exprimera encore en 12,3; 17,16b.

Etant donné l'unanimité des témoins, le comité a attribué au *M la note "A". 
Interprétation proposée :

La traduction de $\mathrm{J} 3$ a été donnée ci-dessus.

12,4A לא יראה M V S // expl : 4Q-a, G / paraphr : T

ארחתנו 12,4B אחריתנו M Aq Sym V S T // permut : G clav

Options de nos traductions :

Le *M achève le vs 4 par un rappel que les ennemis de Jérémie disaient : לא ?ִ?ְׁ

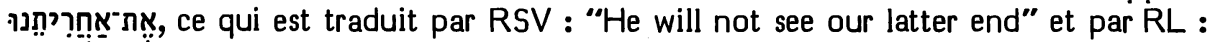
"Er weiss nicht wie es uns gehen wird."

$J 3$ traduit : "Dieu ne voit pas notre destinée" en disant expliciter le sujet avec le *G.

TOB traduit: "Il ne voit pas nos chemins", disant se fonder sur le *G pour la traduction du dernier mot.

J12 cumulaient ces deux corrections en : "Dieu ne voit pas nos chemins". NEB fait de même : "God will not see what we are doing", Brockington précisant qu'elle

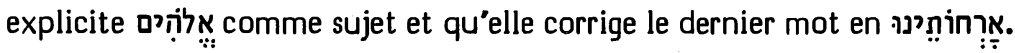

Origines des corrections :

La leçon mentionnée par Brockington pour le dernier mot est la Vorlage que Cappel (Notae 524b) a suggérée pour le ${ }^{*} G$ et que Houbigant a préférée au *M, suivi en cela par Michaelis (Observationes), Ewald2, Grätz (Studien 110), Oort, Duhm, Cornill, Ehrlich, Volz, Schmidt, Nötscher, Rudolph, Penna, Weiser, Bright et par les apparats de BH3S et Cent.

Ont proposé d'expliciter le sujet "Dieu" avec le ${ }^{*} G$ : Oort, Cornill, Volz (Studien), Rudolph, Penna, Steinmann et les apparats de Cent et de BHS.

Les témoins anciens :

Avant la dernière lettre du 2e mot, 4Q-a semble insérer un 'kaf' (qui a peut-être été gratté ensuite, selon Janzen 176). Puis il place le tétragramme (qu'une lacune interrompt après la 2e lettre). La 1e main semble donc avoir lu ici : "le Seigneur ne te fera pas voir..." et la seconde main : "le Seigneur ne voit pas...".

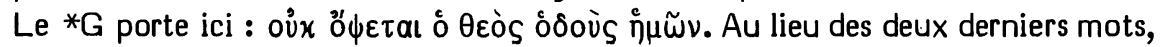

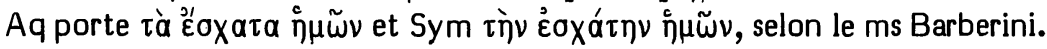

Le *M est appuyé par la *V (non videbit novissima nostra), la *S (לא נחזא חרתן) et le *T (לא גלי קדמוהי סופנא).

Choix textuel :

Le fait que $4 Q-a$ et le ${ }^{*} G$ explicitent le sujet du verbe par deux noms divins différents montre clairement que la non-explicitation du sujet dans le ${ }^{*} M$ et les autres témoins est primitive.

Il est difficile de dire si la métathèse du 'het' et du 'resh' que présuppose la traduction du $* G$ repose sur une erreur de lecture (inverse de celle qu'il a commise en 9,1 où ארח est traduit par Ěoxatov) ou sur une variante en sa Vorlage. Elle semble 
liée en tout cas au fait que le traducteur identifie Dieu comme étant le sujet du verbe. De ce fait, il a attribué aux ennemis de Jérémie le blasphème classique de Ps 73,11; 94,7; Jb 22,13-14; Is 29, 15 : Dieu ignore la conduite des hommes, il n'y fait pas attention.

Cependant, mieux vaut admettre avec Joseph Qara, Menahem de Posquières, Venema, Nägelsbach, Keil, von Orelli et Rothstein (HSAT) que c'est Jérémie qui est le sujet de ce verbe. En effet, en 11,20 $(=20,12)$, celui-ci vient de dire à propos de ses ennemis : "je verrai la vengeance que tu tireras d'eux", c'est-à-dire qu'il a confiance que cette vengeance aura lieu de son vivant. Cela parce que ses ennemis préparent sa mort, tandis qu'ils se moquent de ses oracles en disant $(17,15)$ : “Où est la parole du Seigneur? Qu'elle se réalise donc !" Ici, le prophète se plaint de ce que ses ennemis estiment certain que, grâce à leurs complots contre lui, Jérémie ne leur survivra pas : il ne sera plus là pour voir se réaliser la fin qu'il prophétise pour eux.

Estimant que le ${ }^{*} M$ est bien appuyé contre la leçon du ${ }^{*} G$ et offre un sens satisfaisant, le comité lui a attribué la note " $\mathrm{C}$ " en $4 \mathrm{~B}$ (alors que $4 \mathrm{~A}$ ne lui a pas été soumis).

Interprétation proposée :

"Il ne verra pas notre fin."

12,9A צִבְּר: $[A]$

Options de nos traductions :

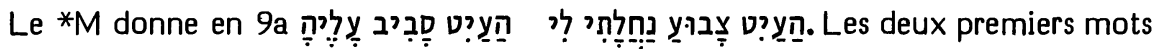
sont traduits par RSV : "Is ... like a speckled bird of prey ?", par J12: "serait-il un oiseau au plumage diapré", par RL : "wie der bunte Vogel", par TOB : "est-il ... un oiseau bigarré" et par J3: "serait-il un rapace bigarré".

Selon Brockington, NEB vocalise la 2e syllabe du $2 \mathrm{e}$ mot avec ḥolem quand elle traduit : "Is ... a hyena's lair".

Origine de la correction :

Cette correction vocalique a été requise par Ehrlich pour justifier l'exégèse "hyène". Elle a été adoptée dans le même but par Driver (Birds 139s).

Les témoins anciens :

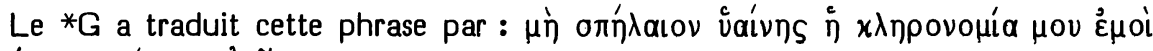

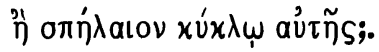

Les autres témoins s'accordent plus ou moins dans l'interprétation des deux premiers mots avec la plupart des traductions récentes; la $* \mathrm{~V}$ traduisant par "avis disco-

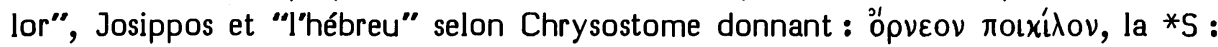
טירא מצירתא et le *T : עופא דמתבדר.

Choix textuel :

Le deuxième mot n'a pas besoin de correction vocalique pour signifier "hyène". 
C'est ce que le comité a estimé avec KBL (791b), Barr (235) et HALAT (936a). Aussi a-t-il attribué au * $M$ la note " $A$ " en considérant le problème comme purement exégétique.

\section{Interprétation proposée :}

Il semble que ce soit Bochart (Hierozoicon I 830,72 ss et 838,35 à 840,6 ) qui a proposé, le premier, de comprendre ici le $2 e$ mot du $* M$ comme 'hyène', en conformité avec la traduction du *G. Cette interprétation a été adoptée par Schultens ( $\mathrm{Ha}$ masa 442ss), Venema, Michaelis (Supplementa 2064), Gesenius (Thesaurus 1149a), et elle est tombée ensuite en défaveur, lorsque Hitzig (suivi par Graf et Keil) a fait remarquer la situation asyndétique qu'aurait ce mot 'hyène', si on garde pour le mot qui le précède le sens d'oiseau de proie. Keil estimait même que le sens de "hyène', en lequel les juifs du moyen âge ont fait usage de ce mot, dérive d'une fausse exégèse de Jr 12,9. Il ne connaissait pas encore le texte hébreu de Si 13,18 où ce mot apparaît en ce sens dans un passage qui n'a aucun rapport avec notre passage de Jérémie.

Hitzig a bien vu que c'est le sens du mot précédent qui déterminera le choix entre

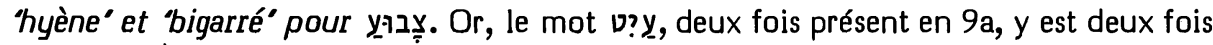
traduit orńर aıov par le ${ }^{*}$ G. Cappel (Notae 524b) s'est contenté de qualifier cette traduction de distante par rapport à l'hébreu. C'est encore Bochart qui a été le premier à suggérer que le ${ }^{*} G$ a compris ce mot au sens de la racine arabe viy dont un dérivé à désinence féminine signifie, dit-il (I 839,21ss), un lieu où le sol est bas et excavé, comme dans les vallées ou les grottes souterraines. Ignorant (?) ce prédécesseur, Driver (Birds 139) rapproche le mot hébreu du substantif arabe gâyitu(n) qu'il trouve défini en Freytag comme "un lieu bas où quelqu'un peut se cacher". Notons que Michaelis (OEB et Observationes), faisant appel à la même racine arabe, vocalisait ce mot הִ et le traduisait (en lui donnant le suivant pour sujet) : "effodit hyaena".

Alors que l'exégèse classique du *M entend les deux vיy de ce vs au sens de "oiseau de proie", le *G les a compris tous deux au sens de "caverne"; tandis que Driver suggère qu"il y a ici un jeu de mots, le premier étant pris au sens de "tanière" (d'une hyène) et le second au sens collectif de "oiseaux de proie". Barr (129) a fait remarquer que la possibilité d'un jeu de mots présuppose que la fusion du 'ghaïn' et du 'caïn' ait déjà eu lieu en hébreu biblique avant l'époque de Jérémie. Il ajoute que cela lui paraît d'ailleurs probable.

Barr (235) se demande pourtant comment le sens de 'hyène' a pu être oublié par les exégètes postérieurs au ${ }^{*} G$ en ce passage de Jérémie. Il semble qu'il faille déplacer la question. C'est parce que le sens de 'tanière' a été oublié pour la première occurrence de ce mot ici, que le sens de hyène' est apparu inadéquat pour le mot suivant. Il a fallu en effet attendre HALAT pour que le sens de "dépression, enfoncement de terrain' soit attribué à la première occurrence de yיט en ce verset. Emerton (Jeremiah 12,9, p. 187s) adopte également cette interprétation.

On pourra donc traduire 12,9a: "Est-ce que mon héritage est pour moi une tanière de hyène avec des rapaces tout autour au-dessus d'elle ?" Cet "héritage' du Seigneur est en ce vs la Terre Sainte devenue 'tanière de hyène', c'est-à-dire lieu où le fort déchire le faible en se repaissant de sa chair (Ez 22,25.27). Aussi les 'rapaces', c'est-à-dire les peuples voisins, font-ils cercle autour, pour avoir part à la curée en dévorant ce qui reste des charognes. 


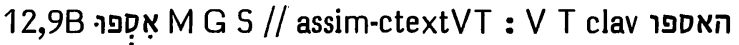

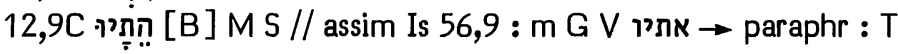

Options de nos traductions :

En 9b, le *M porte : “allez, rassemblez (אִסְפו) toutes les bêtes sauvages, faites venir (הִִֶּ) pour dévorer".

La valeur transitive du deuxième impératif et la valeur causative du troisième ont été respectées (en explicitant un complément pour ce dernier) par RSV : “assemble... bring them...", TOB : "(Allez) rassembler... Amenez-les..." et J3 : "Rassemblez... faites-les venir..."

Disant suivre la $* V, J 12$ traduisent par des formes réflexives et intransitives : "rassemblez-vous... venez (J1 : arrivez)..." RL fait de même : "sammelt euch... kommt..." Quant à NEB, elle se contente de traduire le premier et le troisième impératifs par "come" (corrigeant ce dernier en אֵָת avec 3 mss, selon Brockington), en omettant de traduire le deuxième.

\section{Origines des corrections :}

A la suite de la ${ }^{*} V$, la plupart des traducteurs du XVIe siècle (Pagnini, Luther, Brucioli, Münster, Olivetan, Rollet, Estienne, Calvin, Pasteurs) ont compris ici : "rassemblez-vous... venez..." Seuls Jud et Tremellius ont traduit selon le *M: "congregate omnes bestias (Jud : feras)... facite (Jud : efficite) ut veniant..." Une position intermédiaire est tenue par Prédicants, Zwingli, la réédition (1557) de Pagnini par Estienne, Calvin (en variante à son lemme), Châteillon, Ge et $\mathrm{KJ}$. Elle traduit $9 \mathrm{~B}$ selon le $* M$ et $9 \mathrm{C}$ selon la $* \mathrm{~V}$.

Traduisant ces deux impératifs selon Luther et la $* V$, Houbigant ne commente que $9 \mathrm{C}$ où il propose la correction que reprendra Brockington, en disant se fonder sur le *G contre la *S qui appuie le *M. Michaelis répète (en se trompant de correspondants) ces informations, à titre informatif, dans ses Observationes. Ces données erronées sont copiées par Rosenmüller.

Cornill ouvre la voie que NEB suivra, omettant 9B et corrigeant 9C comme Houbigant l'avait fait.

Condamin reprend cette correction de $9 \mathrm{C}$ et il corrige 9B en impératif nifal. Font de même : Nötscher, Rudolph, Penna, Steinmann, Weiser et les apparats de HSAT34, Cent et BHS.

A la manière de $\mathrm{KJ}$, Volz garde le *M en 9B et corrige 9C. Les apparats de $\mathrm{BH} 23$ ont fait de même.

\section{Les témoins anciens :}

Les "trois mss" du *M qui lisent ici la forme mentionnée par Brockington sont le ms Reuchlin des Prophètes, le ms des jésuites de Cologne (dont la 2e main corrige) et le ms Urbinates 2 (collationnés par Kennicott) auxquels Ginsburg ajoute le ms Londres BL Add 14760.

Parmi les versions, seule la *S appuie le *M pour 9B et 9C (כנשו ... איתו).

$\mathrm{La} * \mathrm{~V}$, nous l'avons dit, offre l'option qui sera retenue par Pagnini et Luther : "congregamini... properate". 
Le *G tient la position intermédiaire qui sera celle de $\mathrm{KJ}$ et de Volz: ovvará-

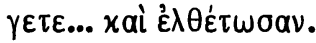

La paraphrase du *T ("ceux qui tuent avec le glaive se rassembleront (contre elle), les rois des peuples et leurs armées viendront contre elle pour la dévaster") suppose la même option que celle de la *V.

Choix textuel et interprétation proposée :

En 9B, qui n’a pas été soumis au comité, la leçon du *M est protégée, dans le ms de Leningrad, par une $\mathrm{mp}$ " 6 ".

En 9C, la leçon du *M est protégée par une massore (Ginsburg Massorah $\kappa$ §1457) précisant que cette forme apparaît 3 fois dans la Bible. Comme le montre une massore couplée éditée dans la massore finale (sous אתיו), c'est pour éviter la contamination mutuelle des deux leçons qui rivalisent ici que cette massore les protège toutes deux.

Hayyuj (Kitâb 152,5s) estime qu'ici le 'hé' tient la place d'un 'alef'. Abulwalid (Luma 90,9s) et Radaq (étendant cela à Is 21,14 en Mikhlol 119b) optent pour cette analyse, attribuant donc à cette forme ici le sens d'un qal. Nous avons noté une tradition de substitution analogue en 2 S 3,18 (CT1 234s).

Cette tradition exégétique, comme les variantes de 4 mss et les options du ${ }^{*} G$, de la *V et du *T montrent qu'une interprétation de cet impératif en "venez" est 'dans l'air'. Il faut voir là une influence exercée par le parallèle de Is 56,9: "vous

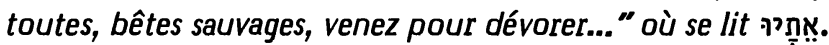

Aucune de nos traductions ne suit l'option exégétique de Radaq en Is 21,14 où la valeur causative de l'impératif est celle qui convient le mieux au contexte et où la tradition textuelle est cohérente. C'est donc faire inutilement violence au *M que de lui supposer ici un autre sens. D'ailleurs la valeur transitive de l'impératif précédent appuie ce sens.

Contre l'assimilation à Is 56,9 , le comité a attribué ici au *M la note " $\mathrm{B}$ ".

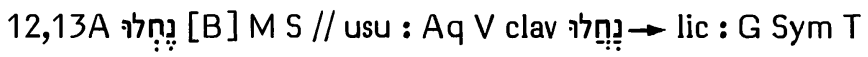

Options de nos traductions :

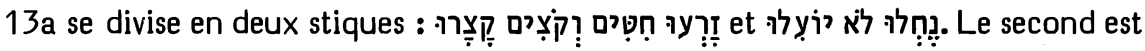
traduit par RSV : "they have tired themselves out but profit nothing", par J : "ils se sont épuisés sans profit", par RL : "sie liessen's sich sauer werden, aber sie konnten's nicht geniessen", par TOB : “on s"épuise et on n'aboutit à rien".

NEB a traduit : "they sift but get no grain", Brockington précisant qu’elle vocalise

Origine de la correction :

Cette correction vocalique a été requise par Michaelis (OEB). Mais il traduisait : "(man...) erbet Grundstücke, und hat keinen Vortheil davon".

C'est Driver qui a proposé de reconnaître ici et en Ps 82,8 la racine 'nhll' au sens de "cribler", la dérivation à partir d'un 'pé-nun" (et non plus d'un 'lamed-hé') postulant cette correction vocalique. 
Les témoins anciens :

Une dérivation à partir de la racine (= hériter) sous-tend les traductions littérales d’Aq ( $\varepsilon^{\prime} x \lambda \eta \rho o v o ́ \mu \eta \sigma a \nu$ selon le ms Barberini) et de la *V (hereditatem ac-

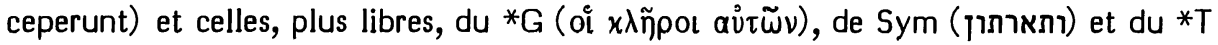
(ומעללתהון).

Seule la *S (ולאו) traduit clairement le *M.

\section{Choix textuel :}

Au XVIe siècle, les traducteurs ont beaucoup hésité entre l'interprétation en 'lamed-hé' (qui correspond à la vocalisation du *M) et celle en 'pé-nun' (que leur suggérait la $* V$ ). Jusqu'à la révision de 1540, Luther optait pour la première (Sie lassens jr sauer werden) à la suite de Pagnini (aegrotaverunt). Mais Prédicants, Zwingli, Brucioli, Olivetan et Münster ayant opté pour "ils ont reçu en héritage", Luther, en 1540, corrige en "und was sie gewinnen" (WA.DB IV 97). Jud, Estienne, Châteillon et Calvin (en son lemme: "hereditatem adepti sunt") restent dans cette tradition. Mais Calvin donne en variante : "vel, fatigati sunt" et expose à la fois les deux leçons en son commentaire. C'est que Vatable (dans les notes de la Bible de 1545) avait clairement opté contre le texte de la *V et de Jud en glosant : “aegrotaverunt, [quia] non profecerunt. Vel, dolore quodam animi affecti sunt [prophetae] quod non profuerint [verba eorum ]". C'est sous son influence que Ge, Tremellius, Pasteurs et KJ ont pris définitivement parti pour l'interprétation en 'lamed-hé".

La vocalisation qui la requiert est protégée ici par une mp qui unit cette forme à Am 6,6.

Contre l'interprétation de la *V, Hitzig a fait remarquer que le verbe נחל ne s'applique pas au fait de faire une récolte.

Contre l'interprétation de Driver, on peut dire d'abord que le fait qu'ait existé en hébreu biblique un verbe נחל au sens de "tamiser, cribler" se heurte à la double difficulté que ce sens aurait été totalement oublié par la tradition postérieure et que "tamiser" se dit $(A m 9,9)$ : 1 : On peut dire ensuite que, du fait du parallélisme poétique entre les deux premiers stiques du vs 13 , il ne faut pas voir en ce verbe l'expression d'une action faisant chronologiquement suite à "semer" et "moissonner", mais une action résumant tout le cycle des travaux des champs, ce qu'évoque bien: "ils se sont épuisés de fatigue".

Aussi le comité, estimant le $* M$ satisfaisant (bien que presque toutes les versions l'aient assimilé au verbe très usuel נחל), lui a attribué la note " $B$ ".

Interprétation proposée :

“Ils ont semé du blé et ce sont des épines qu'ils ont moissonnées. Ils se sont épuisés de fatigue sans en tirer nul profit." 
Options de nos traductions :

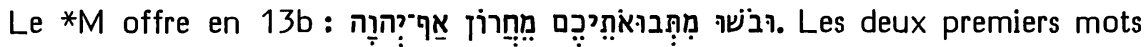
sont traduits par TOB : "Rougissez donc de ce qui vous en revient."

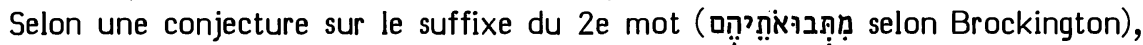
NEB donne : "They are disappointed of their harvest", RSV: "They shall be ashamed of their harvest", RL : "Sie konnten ihres Ertrages nicht froh werden", J : "ils ont honte de leurs récoltes" (J12 disant suivre le *G pour ce dernier mot).

Origine de la correction :

Au XVIe siècle, on rencontre trois types de traductions :

$1 /$ respectent le suffixe $2 e$ pers. pl. du $2 e$ mot et comprennent le premier mot en impératif (même s'ils le traduisent largement par un futur) : Pagnini, Prédicants, Brucioli, Zwingli, Olivetan, Rollet, Jud, Estienne, Tremellius, Pasteurs.

$2 /$ respectent le suffixe 2e pers. pl. du 2e mot, mais comprennent le premier mot comme un accompli : Münster, Vatable, édition de Pagnini par Estienne (1557), Calvin, Ge, KJ.

$3 /$ traduisent un suffixe $3 e$ pers. pl. pour le 2 e mot, en comprenant le premier mot comme un accompli : Luther et Châteillon (latin et français). C'est cette troisième option que presque toutes nos traductions actuelles ont adoptée.

Sans mentionner de correction, Houbigant traduisait : "erubescunt de proventibus suis". Hitzig traduit de même en corrigeant le suffixe, suivi en cela par Luzzatto (hésitant), Grätz (Studien 115), Graf, Giesebrecht, Oort, Duhm, Cornill, Ehrlich, Condamin, Volz, Schmidt, Nötscher, Rudolph, Penna, Steinmann, Weiser, Bright et les apparats de HSAT34, BH23S et Cent.

Les témoins anciens :

Tous ont respecté le suffixe de la 2e pers. pl. du 2e mot, ayant compris le premier mot comme un impératif.

Choix textuel et interprétation proposée :

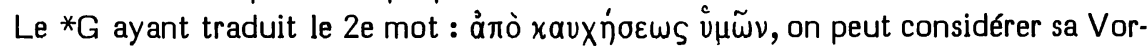
lage comme douteuse bien que Schleusner (III 298) y voit une traduction large, envisageant la récolte comme l'objet dont on se vante. C'est pourquoi le comité n'a attribué qu'un " $B$ " à la leçon du * $M$.

Il est cependant clair que la correction conjecturale du suffixe de ce mot en $3 e$ pers. pl. est ici une assimilation à 13a; alors que l'achèvement de cet oracle par un impératif (apostrophant ceux dont il était parlé à la 3e pers.) a seulement pour effet de donner plus d'intensité à l'avenir menaçant qui y est annoncé.

Il semble que le complément qui suit a pour but d'expliciter (par la reprise de la même préposition) le contenu du $2 \mathrm{e}$ mot :

“Rougissez de ce qui vous en revient, c'est-à-dire de l'ardente colère du Seigneur." 
Options de nos traductions :

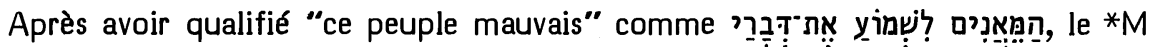

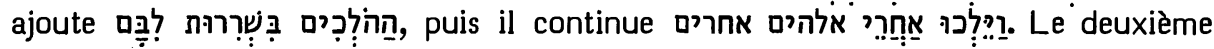
de ces membres de phrase est normalement traduit par RSV, J, RL et TOB.

NEB donne seulement pour cela: "(This wicked nation) has refused to listen to my words; they have followed other gods", Bruckington précisant qu'elle a omis, avec le *G, le deuxième membre de phrase.

Origine de la correction :

Schmidt (227) a omis "die gehen in der Halsstarrigkeit ihres Herzens", le considérant comme une ajoute probable, du fait que ce membre de phrase manque dans le *G (ce qu'il a pu voir affirmé par l'apparat critique de $\mathrm{BH} 2$ ).

A la suite de Movers (12), Tov (Aspects 164) voit en ce membre de phrase une formule de style deutéronomistique ajoutée dans l'édition II de Jérémie.

Les témoins anciens :

Pour les trois membres de phrase que nous avons cités ci-dessus, le ${ }^{*} G$ donne :

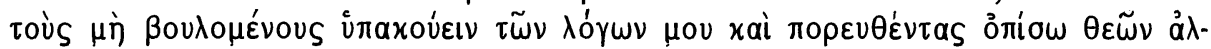
$\lambda o \tau p i \omega v$. Pour le deuxième participe, on peut se demander s'il ne faudrait pas préférer à cette leçon de Ziegler et Rahlfs (conforme à la 1e main du Vaticanus et à une correction du Sinaiticus) la leçon nopevopévous (de la 1e main du Sinaiticus et d'une correction du Vaticanus).

Le point d'insertion de l'ajoute astérisée attribuée à ThAq montre qu'Origène estimait, comme ses successeurs du XXe siècle, que le 2e membre de phrase est absent du $* G$ ancien.

Tous les autres témoins ( $T h, A q, S y m$, la $* V$, la $* S$ et le $* T$ ) attestent la présence de ce membre de phrase.

\section{Choix textuel :}

Si l'on devait voir en ce membre de phrase du *M une ajoute caractéristique de la rédaction II, nous devrions attribuer au *M, sur ce point, la note " $A$ ", en considérant cette innovation littéraire comme une partie intégrante de la forme canonique protomassorétique. En ce cas, le ${ }^{*} G$ s'en distinguerait seulement comme le représentant d'un état littéraire plus ancien et moins développé. Rappelons d'ailleurs qu'en 7,24 (ci-dessus, p. 517) nous avons soupçonné le mot בשררות d'avoir été ajouté par un glossateur. Mais nous avons dû considérer le ${ }^{*} G$ comme attestant un allègement stylistique postérieur à l'insertion de ce mot.

Ici non plus, on ne peut pas considérer le ${ }^{*} G$ comme un clair témoin de l'absence de ce membre de phrase. En effet, il commence sa traduction du 3e membre par un participe. Il est donc vraisemblable qu'il a traduit le premier mot du $2 e$ membre, puis qu'il a sauté de là au deuxième mot du 3 e membre... à moins que ce ne soit le glossateur qui ait inséré, après le participe ההלכים, les mots בשררות לבם וילכו.

Trois membres du comité ont estimé que l'on a là une ajoute caractéristique de 
la rédaction II et ont donc attribué au *M la note " $A$ ". On retrouve en effet cette expression typique en Jr 11,8, à l'intérieur d'un 'plus' du *M qui semble bien constituer une ajoute deutéronomistique portant sur deux versets presque entiers. D'autre

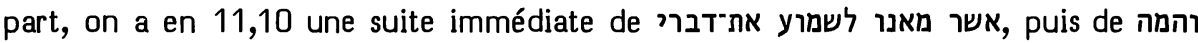
ל non séparés par le membre de phrase en question.

אחרי שררות לבם Notons cependant qu'en 9,13, on rencontre l'un après l'autre et ואחרי הבעלים (aussi bien dans le *G que dans le *M) qui sont les équivalents du $2 e$ et du 3e membres de phrase en 13,10. D'autre part, Thiel (148-150), après une analyse détaillée, conclut que le 'moins' du ${ }^{*} G$ en $11,7-8$ ne doit pas s'interpréter comme un état rédactionnel plus ancien, mais comme une omission accidentelle ou intentionnelle.

Il est possible qu'ici aussi on ait dans le ${ }^{*} G$ (ou déjà dans sa Vorlage) le résultat d'une omission accidentelle ou intentionnelle. Il peut s'agir en effet d'un saut de l'une des occurrences du verbe "aller" à l'occurrence suivante. Giesebrecht a estimé ici que le ${ }^{*} G$ a effectué intentionnellement cet abrègement, de même qu'il a omis intentionnellement de traduire הרע au début de ce vs. Tenant compte de ces éventualités, les trois autres membres du comité ont estimé que le ${ }^{*} G$ pouvait dépendre, par voie $d$ 'omission, d'une Vorlage identique au *M. Aussi ont-ils attribué au *M la note " $B$ ", du fait de cette situation textuelle plus complexe.

Interprétation proposée :

Cette phrase ne pose aucune difficulté particulière.

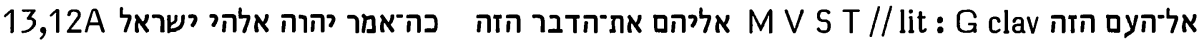

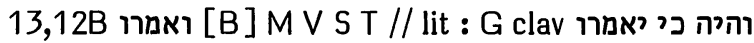

Options de nos traductions :

Le *M donne en 12a: "Et tu leur diras (ואמרת אליהם) cette parole : 'Ainsi parle le Seigneur le Dieu d'Israël : Toute cruche, on la remplit de vin" ". Puis il continue en 12b par : "Et ils te diront (ואמרו אליך) : 'Ne savons-nous pas fort bien que toute cruche, on la remplit de vin ?" "Enfin, il commence le vs 13 par : "Et tu leur diras (ואמרת אליהם): :Ainsi parle le Seigneur...'”.

La succession linéaire des trois introductions est assez fidèlement rendue par RSV : "You shall speak to them... And they will say to you... Then you shall say to them..." Le mouvement s'anime un peu plus en NEB : "You shall say this to them... They will answer... Then you shall say to them...", puis en RL : "Sage innen... Und wenn sie zu dir sagen... so antworte innen..." et en TOB : "Tu leur diras... Et si l'on te rétorque... alors tu leur diras..."

J3, traduisant : "Tu leur diras... Et s'ils te répondent... Tu leur diras...", dit que, pour $12 \mathrm{~B}$, elle suit le ${ }^{*} \mathrm{G}$; alors que $\mathrm{J12}$ ajoutaient à cela une correction selon le ${ }^{*} G$ de $12 \mathrm{~A}$ en : "Tu diras à ce peuple : 'Toute cruche etc."'. 
Origines des corrections :

Giesebrecht a suivi le *G seulement dans sa correction de 12B, imité en cela par HSAT3 et Weiser.

Cornill, Volz, Nötscher, Rudolph, Penna, Steinmann ont ajouté à cela une adoption plus ou moins complète du texte du *G pour $12 \mathrm{~A}$.

J12 disent dépendre de Rudolph qui, pour 12B, décèle (après Volz) dans le *M une haplographie de ואם אמרו.

Les témoins anciens :

En $12 \mathrm{~A}$ et en $12 \mathrm{~B}$ la $* \mathrm{~V}$, la ${ }^{*} \mathrm{~S}$ et le ${ }^{*} \mathrm{~T}$ suivent le $* \mathrm{M}$; alors que le ${ }^{*} \mathrm{G}$, à la place

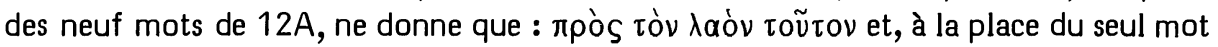

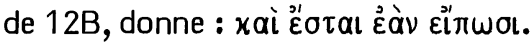

\section{Choix textuel :}

$12 \mathrm{~A}$ n’a pas été soumis au comité. Ici, la Vorlage du ${ }^{*} G$ jouit clairement d’une autonomie littéraire à l’égard du *M.

En 12B, on peut d'ailleurs mettre en question le diagnostic d'haplographie que Volz et Rudolph ont porté sur le *M. En effet, la Vorlage qu'ils ont suggérée pour le ${ }^{*} G$ (et qui leur a permis de formuler ce diagnostic) ne rend pas compte de l'hébraïsme והיה כי qui transparaît assez nettement derrière le xai हैotal عُáv du *G, qu'il sous-tend d'ailleurs en 3,16 et 15,2.

Le comité considère comme plus probable qu'en 12B (comme c'est le cas en 12A) la Vorlage du ${ }^{*} G$ et le ${ }^{*} M$ sont littérairement autonomes. Ne voulant pourtant pas nier absolument la possibilité $d^{\prime} u n$ accident textuel subi par le ${ }^{*} M$, il lui a attribué la note "B".

Bien que cela déborde le cadre de cette analyse textuelle, notons que la succession linéaire des trois introductions dans le $* M$ semble plus originelle que le mouvement qui les anime dans la Vorlage du *G. $D$ 'autre part, la présence dans le *M de $12 A$ de l'introduction oraculaire solennelle: "Ainsi parle le Seigneur, le Dieu d'Israël" semble primitive. Elle a pour but de transformer un dicton quotidien en oracle et de frapper ainsi la curiosité du public auquel s'adresse Jérémie.

Interprétation proposée :

Voir le début du traitement de ces cas.

\section{3,18 מִרי 1C] M T // usu et assim-ctext : G V S clav}

\section{Options de nos traductions :}

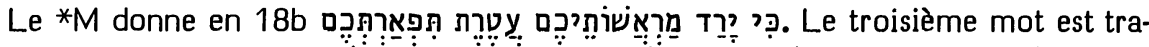
duit : "de votre tête" par J (se fondant sur le ${ }^{*} G$ ) et TOB (selon les versions), "from your head" par RSV (se fondant sur le *G, la *V et la *S), "(ist) euch vom Haupt (gefallen)" par RL.

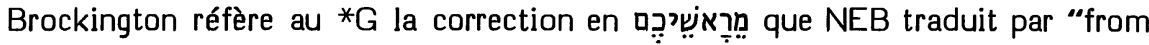
your heads". 
Origines des corrections :

Dans l'édition princeps (1527) de sa traduction, Pagnini avait traduit "de capitibus vestris". Deux ans plus tard, dans son Thesaurus (2259), il traduisait ce mot par "magnitudines vestrae". Servet, rééditant Pagnini en 1542, sur la base d'exemplaires retouchés par lui, donnera ici "principatus vester" (que Vatable reprendra). Estienne, rééditant Pagnini en 1557, notera que le sens littéral est "principalitates vestrae" (que $\mathrm{KJ}$ reprendra en "your principalities").

L'erreur commise par Pagnini en sa première édition aura des effets durables, puisque "de votre tête" (ou "de vos têtes") seront les traductions de : Prédicants, Zwingli, Luther, Brucioli, Olivetan, Rollet, Estienne, Calvin et Geneva Bible.

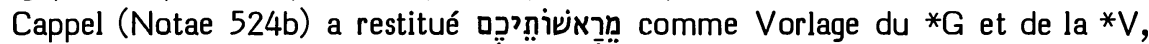
leçon que Clericus a adoptée, suivi en cela par Henderson, Grätz (Studien 146), von Orelli et finalement Dahood (Notes 462). Rosenmüller fait remarquer que la seule

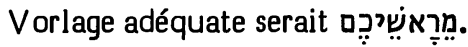

Sans mentionner de correction, Ewald et Hitzig (sous l'influence de la traduction de Luther) traduisent "de vos têtes". Giesebrecht corrige selon la Vorlage diagnostiquée par Rosenmüller, suivi en cela par Oort, Duhm, Cornill, Ehrlich, Condamin, Nötscher, Rudolph, Penna, Steinmann, Weiser, Hyatt et les apparats de SBOT, BH3S

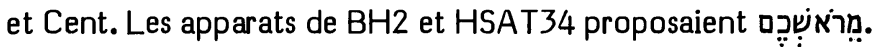

Les témoins anciens :

Le *G a traduit : åmò $\chi \varepsilon \varphi \alpha \lambda \tilde{\eta} \varsigma$ $\tilde{\nu} \mu \tilde{\omega} \nu$, suivi par la *V : "de capite vestro" et la *S : מן רישכון.

Avec יקרכון, le *T a suivi la vocalisation du *M.

Choix textuel :

En ugaritique 'rish' (= tête) forme tantôt des pluriels à désinence féminine, tantôt des pluriels à désinence masculine. C'est ce qui amenait Dahood à penser qu'il pourrait se contenter (comme Clericus) d'une simple correction vocalique du *M pour y lire "de vos têtes". Mais, en hébreu biblique, les 150 emplois du pluriel de שx sont tous à désinence masculine. Mieux vaut donc renoncer à l'espoir de justifier l'erreur de traduction de Pagnini et de Luther à si bon marché.

Considérant la variante comme facilitante, le comité a attribué ici à la leçon du *M la note "C".

Interprétation proposée :

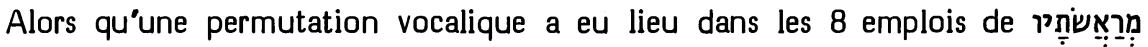
au sens de "à son chevet", cette permutation n'a pas eu lieu ici. La meilleure interpré-

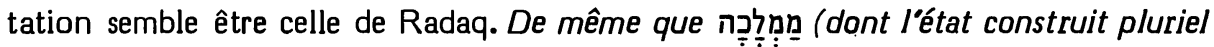

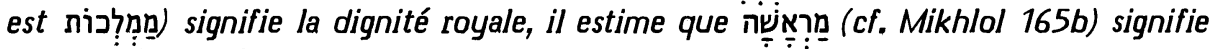
la dignité princière. Le pluriel signifiant l'ensemble des insignes du principat ou de l'autorité. Puisque le verbe précède ce sujet, le fait qu'il ne s'accorde pas avec lui ne fait pas difficulté.

On pourra donc traduire : "Car ils sont déchus les signes de votre autorité", ou, plus simplement : "car elle est déchue, votre majesté". 
Options de nos traductions :

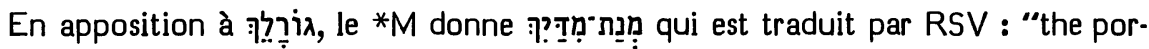
tion (I) have measured out to you", par RL : "und dein Teil, den (ich) dir zugemessen habe", par TOB : "la part que (je) te mesure" et par J3 : "la part qui t'est allouée".

$J 12$ traduisaient : "le salaire de ta rébellion", corrigeant le second mot en מִ. Selon Brockington, NEB vocalise מִ? מִ? pour traduire : "the portion of the rebel". On se réfère au ${ }^{*} G$ pour ces corrections.

\section{Origines des corrections :}

Cappel (Notae 524b) a remarqué que le ${ }^{*} G$ a cru reconnaître ici le substantif מִרִ. Schleusner (en annotant les Observationes de Michaelis) adopte la leçon du *G, suivi par Volz, Schmidt, Nötscher, Rudolph, Steinmann et les apparats de BH23S ( $\mathrm{BH} 2 \mathrm{~S}$ vocalisant comme Brockington, alors que $\mathrm{BH} 3$ vocalise comme $\mathrm{J12}$ ).

Les témoins anciens :

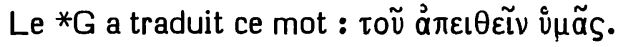

Selon Syh, Aq porte ici מתכלינותא דילכי qui défie les rétroversions.

$\mathrm{La} * \mathrm{~V}$ rend le *M par "mensurae tuae".

Frankl a noté l'étroite proximité existant entre la*S (דירתותכי) et le *T (אחסנתיך).

Choix textuel et interprétation proposée :

C'est la présence, juste après, de מאחר (interprété en un sens d'apostasie) qui semble avoir orienté le *G vers une lecture 'resh' de la lettre que le *M lit en 'dalet'. Cependant מרו se construit avec l'accusatif, avec la préposition 'bet', et trois fois avec घy, mais jamais avec מ̣.

מִ est l’état suffixal d'un pluriel à désinence masculine formé à partir de Tַ qui, dérivant de מדT, signifie à la fois "mesure" et "vêtement" (car on mesurait dans le vêtement déployé : cf. Rt 3,15 où ce verbe est employé). Le ${ }^{*} G$ est un témoin indirect de la désinence masculine.

L'expression: "la part de tes mesures" est à rapprocher de מנת־חלקי en Ps 16,5. Le mot "mesure" est au pluriel, car il faut plusieurs remplissages de la mesure pour obtenir la pleine part.

Le sens est donc bien "la part qu"on te mesure", en parallèle avec "ton lot" qui précède.

Le fait que ce mot porte un tebîr engage à construire : “Cela qui constitue ton lot, la part qui t'est allouée, cela provient de moi, oracle du Seigneur !"

Le glissement entre le 'resh' et le 'dalet' étant facile, le comité a attribué au *M la note "C". 


\section{3,27 אחר? [C] M Sym // err-voc : G Aq V / ign-synt : S T om}

\section{Options de nos traductions :}

Après : "Malheur à toi Jérusalem! tu ne te purifies pas", la péricope s'achève dans le *M par : made clean) ?", 33 : "Combien de temps encore ?", RL : “Wann (wirst du) doch endlich (rein werden) ?"

Sans note, J12 traduisaient: "Combien de temps tarderas-tu encore ?...".

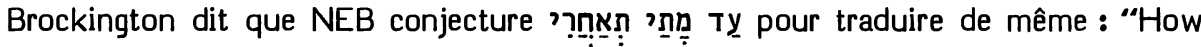
long, how long will you delay ?"

TOB dit suivre le ${ }^{*} G$ et la $* V$ en traduisant : "(Tu ne veux pas te purifier) en me suivant ... combien de temps encore ?"

\section{Origines des corrections :}

Cappel (Notae 524b) a fait remarquer que le *G et la*V ont vocalisé אַ (ce que Calvin avait déjà suggéré pour la *V). Schleusner (éditant les Observationes de Michaelis) adopte cette leçon, suivi en cela par TOB (qui a dû s'inspirer des apparats informatifs de $\mathrm{BH} 23 \mathrm{~S}$ ).

La conjecture de NEB a été proposée par Volz, adoptée par Nötscher, puis retouchée par Rudolph.

Les témoins anciens :

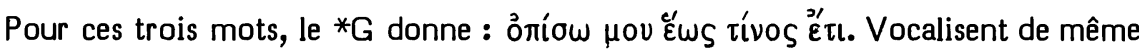
le premier mot : Aq (selon Syh) : בתרי מתום תוב et la *V : “post me usquequo adhuc".

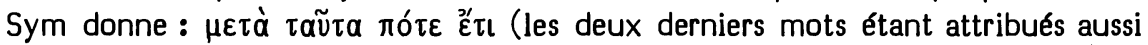
à Aq selon le ms Barberini).

La *S donne : עמא לאמתי תובי. Le dernier mot, que Sionita a interprété en impératif féminin : "convertere", peut bien être une corruption interne de תוב qui achève le vs dans la Syh et dans Aq.

Le *T paraphrase : “(Tu ne te convertiras pas) jusqu'à maintenant il y a pour toi prolongation durant beaucoup de jours".

\section{Choix textuel :}

La seule variante clairement repérable porte sur la vocalisation de la finale du premier mot. Elle n'est pas préférable au *M. Ce mot n’a pas été exprimé par la*S et le *T qui n'ont pas su qu'en faire dans cette syntaxe peu claire.

Pour les deux derniers mots, tous les témoins tâtonnent.

Le comité a attribué au *M la note " $C$ ".

Interprétations proposées :

Ces trois derniers mots semblent avoir pour raison d'être de laisser entrouverte une espérance après le "Malheur à toi Jérusalem ! tu ne te purifies pas" qui précède. L'adverbe final a probablement le sens de "à nouveau" plutôt que celui de "encore". On pourrait comprendre : "Après combien de temps (seras-tu pure) à nouveau ?" Au sens de "encore" on aurait : "Après (que) combien de temps (se soit) encore (écoulé) ?" en sous-entendant à la fin : "te décideras-tu à te purifier ?" 
Options de nos traductions :

Ces quatre derniers mots du $* M$ en ce vs sont traduits par RSV, RL, TOB et J3. $\mathrm{J} 12$ et NEB les omettent comme manquant dans le ${ }^{*} \mathrm{G}$.

Origine de la correction :

Duhm considère ces mots comme une variante à $4 \mathrm{~b}$.

A ce titre, ces mots sont omis ici par Volz, Schmidt, Rudolph, Steinmann, Weiser et leur omission est requise par les apparats de $\mathrm{BH} 3 \mathrm{~S}$.

Les témoins anciens :

Th, Sym, la *V, la *S et le *T attestent ces mots que le ${ }^{*} G$ omet.

Choix textuel :

Movers (11) estimait que ces mots sont dans le $* M$ une répétition issue de 4b.

Selon Janzen (12), והכלמו (de 3) et (de 4) sont des variantes qui proviennent d'une confusion entre les deux liquides 'lamed' et 'resh'. S'il en est ainsi, on ne saurait insérer le premier de ces mots avant le second (en 4), ainsi que Duhm, Cornill et Rudolph le proposent.

Tov (Critique 195) voit en ces quatre mots de 3b un élément provenant probablement du prophète Jérémie lui-même, inséré par le rédacteur II en cet endroit.

Faut-il considérer ces mots comme originaux, ou comme une ajoute rédactionnelle voulue, ou encore comme l'insertion accidentelle d'une variante destinée à $4 b$ ?

Le comité, penchant plutôt pour la deuxième solution, a attribué la note " $\mathrm{B}$ " au *M dont l'interprétation, ici, ne fait pas difficulté.

14,4A בעבור [B] M Sym V S1 T // exeg : G $\rightarrow$ S2

14,4B חתה M G // lic : Sym T, V / abr-elus : S om

Options de nos traductions :

Le *M de ce vs commence par cause of the ground which is dismayed", par RL : "die Erde lechzt", par TOB : "A cause du sol craquelé" et par $\mathrm{J3}$ : "Parce que le sol est tout crevassé".

$J 1$ ("Dans ses productions le sol s'arrête") et J2 ("Le sol cesse de produire") disent traduire le verbe selon le ${ }^{*} G$.

NEB ("the produce of the land has failed"), selon Brockington, se réfère au *G pour lire le premier mot : עברֶ, sans préposition.

Origines des corrections :

C'est Houbigant qui a proposé d'omettre la préposition du premier mot et de le lire au sens de "proventus".

Oort a conjecturé, pour le verbe, חדלה. 
Condamin, à partir de ces deux suggestions, a proposé de lire : עבור האדמה חדל (se référant au *G pour le verbe) qu'il traduit : "les produits du sol ont cessé". 112 semblent se fonder sur son option.

\section{Les témoins anciens :}

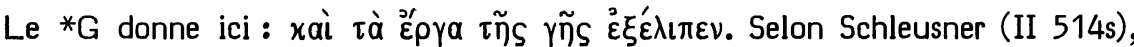
ici comme en Gn 3,17, le ${ }^{*} G$ a lu le ${ }^{*} M$ en donnant au premier mot le sens de "produit" de la terre. Frankel (Einfluss 10) ajoute à cela Gn 8,21 et Frankl (547) est d'accord avec Schleusner, ajoutant que la *S (qui traduit ces trois mots du *M par : a omis le verbe, tandis qu'elle a traduit deux fois le premier mot : d'abord en son sens obvie, puis dans celui que le *G lui a reconnu.

Sym traduit : מטל ארעא אזדכיו, la *V : "propter terrae vastitatem" et le *T : בדיל חובי יתבי ארעא אתברו chose que le *M.

\section{Choix textuel :}

4B n'a pas été soumis au comité. Notons qu'on retrouve en Is 7,8 et $51,6 l e{ }^{*} G$

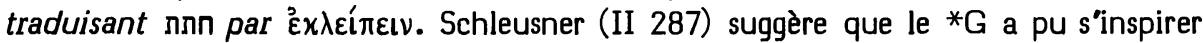
de l'arabe où la 4e forme de $ّ$ ذँ signifie "diminuer".

$4 \mathrm{~A}$ est principalement une question d'exégèse. Ici le comité a attribué la note " $B$ " au * $M$ pour laisser ouverte la possibilité (assez faible) qu'une corruption ancienne le distingue de la Vorlage du ${ }^{*} G$.

Interprétation proposée :

Cette phrase est à rapprocher de 2 S 12,21: : : “ 21 cause de l'enfant qui était (encore) vivant, tu as jeoné et tu pleuras"' (le 3 e mot y étant probablement un accompli en fonction de relative). Ici, on pourra traduire de façon analogue : "A cause du sol qui était crevassé - car il n'y avait pas eu de pluie dans le pays -, les laboureurs ont été consternés et se sont voilé la tête."

\section{4,4C בארץ [A] M 4Q-a Th V T // lit : G S om}

Options de nos traductions :

La proposition explicative כי לאזהיה גשם בארץ est traduite normalement par RSV, J, RL.

TOB et NEB omettent le dernier mot, NEB se fondant sur le *G.

Origine de la correction :

Cette omission a été requise par Giesebrecht, Duhm, Cornill et les apparats de $\mathrm{BH} 23$ et Cent.

Les témoins anciens :

Ici 4Q-a (Janzen 178) atteste la présence de ce mot que le ${ }^{*} G$ et la $* S$ sont seuls à omettre, une ajoute hexaplaire sous astérisque l'ayant emprunté à Th. 
Choix textuel :

La phrase du *M est identique à $1 \mathrm{R} 17,7 \mathrm{~b}$. Le *M aurait-il subi une assimilation à ce parallèle, assimilation à laquelle la Vorlage du * $\mathrm{G}$ aurait échappé ?

Même si la présence de ce mot ici n'est pas originelle, il s'agit d'un développement littéraire qui caractérise le type textuel protomassorétique dans son ensemble.

Aussi le comité a-t-il attribué au *M la note " $A$ ".

יהוה 14] M V S T // assim 17,13 : m G add מקוה ישראל

\section{Options de nos traductions :}

J est la seule de nos traductions qui, après avoir traduit "Yahvé" avec 13 mss et le *G.

Origine de la correction :

L'ajoute de ce mot a été requise ici par Cornill, Condamin, Steinmann, Bright, ainsi que par les apparats de HSAT34, BH2 et Cent.

\section{Les témoins anciens :}

Sur les 9 mss du *M que Kennicott cite comme insérant ici ce mot, nous avons pu en contrôler quatre. Alors que le ms des Prophètes de Berne le vocalise et le munit d'un zaqef gadol, le vocalisateur du ms des Jésuites de Cologne l'a rayé et ceux des mss Hamburg 27 et Berlin Or fol 2 l'ont laissé sans voyelles ni accents. Il faut donc se défier de la portée des listes de sigles de Kennicott.

Le *G insère ici xúpı́; alors qu’aucun témoin de la ${ }^{*} \mathrm{~V}$, de la ${ }^{*} S$, ni du ${ }^{*} \mathrm{~T}$ ne semble attester la présence de ce mot.

Choix textuel :

L'émergence ici de ce mot à la fois dans le *G et dans la tradition textuelle du *M s'explique par le fait qu'il figure en cette position dans le parallèle de 17,13 auquel chacune de ces deux traditions textuelles a emprunté l'identification de ce מקוה ישראל.

Estimant cette assimilation presque certainement secondaire, le comité a attribué au *M la note "B".

\section{לא (B] M S T(?) // usu : m G V T(? ולא 14,18}

Options de nos traductions :

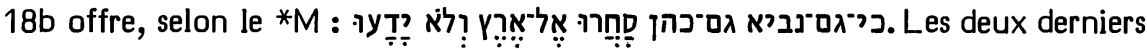
mots sont bien traduits comme une proposition coordonnée à la précédente par RSV, J, NEB et TOB.

Cependant RL les traduit en relative déterminant le substantif qui précède : "Sogar Propheten und Priester müssen in ein Land ziehen, das sie nicht kennen." 
Origine de la correction :

De fait, les apparats de SBOT, HSAT234 et BH23 demandent d'omettre la conjonction qui précède la négation.

Pourtant RL n’a pris ici aucune initiative textuelle sur ce point où elle se contente de reproduire la traduction de Luther. En effet, au XVIe siècle, (sous l'influence de la *V) la proposition sur laquelle s'achève le vs 18 a été traduite comme une relative par Pagnini (en 1527), Prédicants, Zwingli, Luther, Brucioli, Münster, Olivetan, Rollet, Estienne, Jud, Châteillon, Ge et KJ.

Comme nous l'avions noté à propos de 13,18, ici aussi c'est la réédition par Servet de la traduction de Pagnini qui inaugure la traduction exacte de cette phrase comme coordonnée à la précédente. $A$ travers les notes de Vatable, cette traduction sera adoptée par Calvin, Tremellius, Pasteurs et elle figure en marge de KJ.

Ont traduit en relative, sans note textuelle (sous l'influence de Luther): Vogel (annotant Grotius) et Michaelis. Ont voulu justifier cette interprétation traditionnelle en omettant la copule : Graf, von Orelli, Grätz, Condamin, Bright et les apparats que nous avons signalés.

Keil et Knabenbauer veulent tirer du *M l'interprétation de la ${ }^{*} V$ et de Luther.

Les témoins anciens :

Seule la ${ }^{*} S$ et une partie de la tradition textuelle du ${ }^{*} T$ appuient ici la conjonction du *M.

Quoiqu'une massore (Weil §2539) protège ici la présence de cette conjonction (en indiquant que la séquence constituée par ce mot et le suivant ne se retrouve qu'en Jb 9,5), 13 mss de Kennicott et d'autres de de Rossi l'omettent (avec l'édition Soncino 1488 de la Bible).

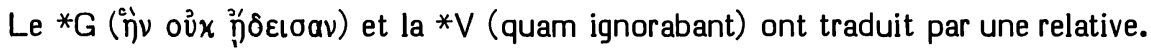

Dans le *T, la leçon ולא בקרו (= * M) est donnée par toutes les éditions et par les mss yéménites cités par Sperber. Mais la conjonction est omise par les témoins tibériens (le ms du Jew's College de Londres cité par Sperber, le ms Reuchlin et le ms Urbinates 1). Il est donc difficile de dire quelle est la leçon authentique.

\section{Choix textuel :}

En Jérémie, le mot אר est déterminé par une relative, ayant pour verbe l'accompli de ידע 'י en quatre endroits : en 16,13; 17,4; 22,28 avec la particule et 15,14 sans cette particule. On comprend que l'on soit tenté d'assimiler à cette construction qui est ici 'dans l'air'.

Contre cette leçon évidemment facilitante, le comité a attribué au *M la note " $B$ ".

Interprétation proposée :

Déjà Yéfet ben Ely (comme beaucoup d'autres après lui) donnait au *M le sens de la variante.

Mieux vaut donner à cette proposition finale le sens de "sans rien comprendre". Les prophètes qui donnaient au peuple de vaines assurances (vss 13-15) et les prêtres qui étaient associés à eux (26,7.8.11) parcourent le pays meurtri et ravagé sans pouvoir interpréter le sens de la catastrophe ni savoir comment réagir. On peut donc traduire 
avec 33 : "tant le prophète que le prêtre sillonnent le pays : ils ne comprennent plus !" Les parallèles de 3,2; 9,18; 46,8 montrent que l'absence d'article avant ארץ ne doit pas empêcher de traduire : "le pays".

15,8A להם [B] M AqSym V S T // abr-styl : G om 15,8B אם בחור להם [B] M G V // facil-synt : S ins

\section{Options de nos traductions :}

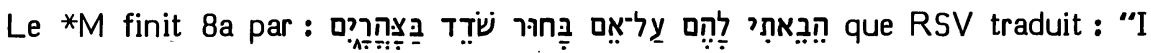
have brought against the mothers of young men a destroyer at noonday", RL : "Ich liess kommen über die Mütter der jungen Mannschaft den Verderber am hellen Mittag", TOB : “En plein midi, j’ai fait venir le dévastateur sur la mère du jeune guerrier", J3 : "Sur la mère du jeune guerrier, j'amène le dévastateur en plein midi". En traduisant "Sur les mères des jeunes guerriers j'ai amené un bandit qui opère en plein midi" et "Sur les mères des jeunes guerriers j'amène le dévastateur en plein midi", J12 disaient omettre avec le *G "sur eux" après le verbe "j"amène" (ou "j'ai amené").

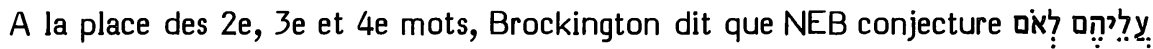
quand elle traduit : "I brought upon them a horde of raiders to plunder at high noon".

\section{Origines des corrections :}

Déjà au XVIe siècle, le deuxième mot n’a pas été traduit par Luther, ni par Olivetan (qui se réfère au ${ }^{*} G$ ), suivi en cela par Rollet et par Estienne.

A la place des $2 \mathrm{e}$, $3 e$ et $4 \mathrm{e}$ mots, Houbigant a conjecturé (en s'inspirant de la ${ }^{*} \mathrm{~S}$ ) : עy. Penna le suivra. Sans corriger le *M, C.B. Michaelis s'était déjà inspiré de la *S pour traduire: "sur la mère et le jeune homme", estimant qu'on a ici une asyndèse. Grätz a suivi Houbigant, mais en gardant le 2e mot qu'il corrige en yליהם

L'omission du 2e mot a été requise par Oort, Duhm, Cornill, Condamin, Nötscher, Weiser, Bright, ainsi que par les apparats de HSAT34, BH2.

La conjecture

Les témoins anciens :

Le ${ }^{*} G$ ne traduit pas לה qui semble à première vue en effet inutile dans le contexte. Cependant, la recension origénienne répare cette omission par une ajoute astérisée (aủtoĩs) empruntée à AqSym.

Ce mot a été traduit par la*V (eis), la*S et le *T (yלהון).

La *S explicite ועל entre le $4 \mathrm{e}$ et le 5e mot qu’aucun autre témoin ne sépare.

Choix textuel et interprétations proposées :

Au vs 7 le Seigneur a privé son peuple de ses enfants, mais on ne s'est pas converti. Aussi (vs 8) les veuves y abondent. Vers cette foule de femmes seules (לִ dont le suffixe masculin ne fait pas de difficulté), il amène, contre celle qui était mère d'un jeune homme (et aurait donc da être défendue par lui s'il était encore en vie), un dévastateur-en-plein-midi (c'est-à-dire qui n'a pas à dissimuler ses approches, tant il est sûr de sa supériorité). 
Comme on le voit, להם a pour but de référer le verbe aux nombreuses veuves qui viennent d'être mentionnées, les trois mots suivants dépeignant un "cas" particulièrement tragique pour illustrer le drame.

Estimant l'omission du $2 e$ mot nettement facilitante et considérant l'ajoute de וע par la *S comme purement translationnelle, le comité a attribué au *M la note "B".

Si l'on veut tenir compte du fait que les mots "mère" et "jeune homme" sont séparés par un tebir, on peut traduire "... contre celle qui était mère, un jeune homme qui dévaste en plein midi". Ces mots sont à considérer comme des collectifs : "... contre celles qui étaient mères (mais n'ont plus de fils pour les défendre), j'enverrai des jeunes gens (qui ont l'âge de leurs fils tués) qui dévastent..."

Selon que l'on y lit veavíoxov (avec le Sinaïticus) ou veavíoxous (avec le Vaticanus), le ${ }^{*} G$ appuie la première ou la deuxième exégèse.

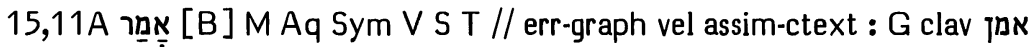

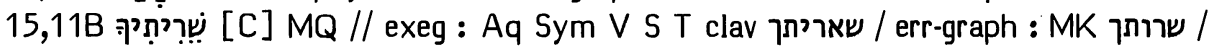
constr : $\mathrm{G}$

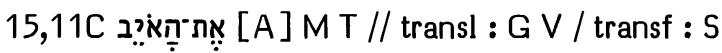

Options de nos traductions :

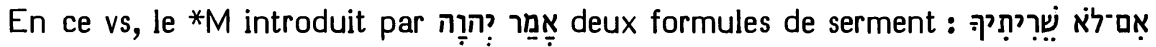

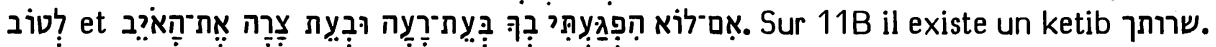

Ce vs est traduit par RL : "Der HERR sprach : Wohlan, ich will etliche von euch übrig lassen, denen es wieder wohlgehen soll, und will euch zu Hilfe kommen in der Not und Angst unter der Feinden".

Brockington précisant qu'elle lit le ketib, NEB traduit : "The LORD answered, But I will greatly strengthen you; in time of distress and in time of disaster I will bring the enemy to your feet."

TOB traduit: "Le SEIGNEUR dit : Je le jure, ce qui reste de toi est pour le bonheur; je le jure, je ferai que l'ennemi te sollicite au moment du malheur et de l'angoisse."

Disant lire $11 \mathrm{~A}$ selon le ${ }^{*} \mathrm{G}$ et corriger 11B par conjecture, RSV traduit: "So let it be, O LORD, if I have not entreated thee for their good, if I have not pleaded with thee on behalf of the enemy in the time of trouble and in the time of distress !"

J12 traduisaient: “En vérité, Yahvé, je t'ai servi de mon mieux. J'ai intercédé auprès de toi pour mon ennemi, au temps de son malheur et de sa détresse." Elles disaient lire en 11A אָ אָמִ avec le *G, avoir conjecturé 11B et s'être inspirées du *G pour traduire les six derniers mots du vs.

J3 traduit : “En vérité, Yahvé, ne t'ai-je pas servi de mon mieux ? Ne t’ai-je pas supplié au temps du malheur et de la détresse ?"' Elle reprend les deux premières corrections de $\mathrm{J} 12$ et y ajoute une omission conjecturale de 11C. 
Origines des corrections :

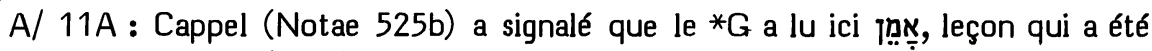
adoptée par Michaelis (OEB), Duhm et Cornill, puis liée par les critiques plus récents à la correction qu'ils proposeront en 11B.

B/ 11B : Au XVIe siècle, Pagnini, Luther, Brucioli, Münster, Olivetan, Rollet, Estienne, Jud, Geneva, Tremellius, Pasteurs et $\mathrm{KJ}$ ont traduit ici comme s'ils lisaient

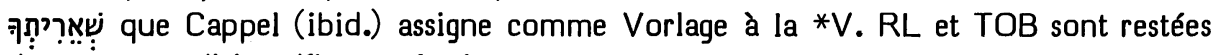
dans cette tradition d'interprétation.

Prédicants (leyt ich dich) et Zwingli (dirigo te) semblent s'être inspirés du *G, comme le fera Houbigant en proposant de corriger en אשרתיך et de traduire "ego te ducam".

Cappel (ibid.), puis de Dieu et Schnurrer adoptent le qeré qu'ils dérivent de au sens syriaque, araméen et éthiopien de "délier, habiter".

Michaelis (Observationes) choisit le ketib, suivi en cela par la plupart des auteurs jusqu'en 1914, attribuant d'ailleurs à cette leçon des sens variés (le plus souvent "conforter", dérivé de שר au sens qu'il a en araméen).

En adoptant la leçon du ${ }^{*} G$ en $11 \mathrm{~A}$, Condamin et Volz (Studien) proposent

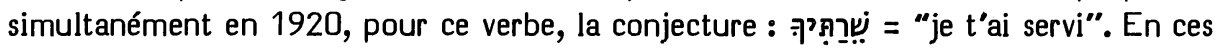
deux corrections, ils ont été suivis par Nötscher, Rudolph, Penna, Steinmann, Weiser, Bright et les apparats de $\mathrm{BH} 3 \mathrm{~S}$.

C/ 11C : Michaelis (OEB) avait corrigé 11C par conjecture et l'avait fait passer au début du vs 12 .

Cent a jugé que 11C est une glose explicative en excès dans le vers.

Les témoins anciens :

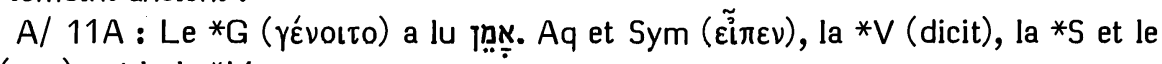
*T (אמר) ont lu le *M.

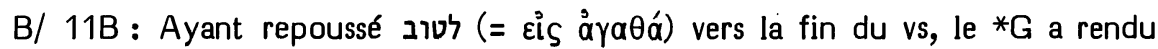
לאשר (suivi d’une terminaison) interprété en gérondif.

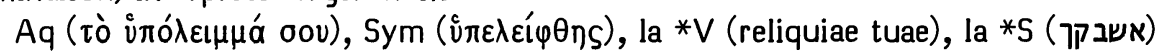
et le *T (סופך) ont vraisemblablement interprété le *M comme une graphie défective pour שאריתך où certains ont vu un substantif et d'autres un verbe.

C/ 11C : Ici, le *M a été clairement lu par le *T (בעיל דבבא). Le *G (תpòs tòv ĖX $\chi \rho o ́ v)$ et la *V (adversus inimicum) ont explicité une préposition qui ne correspond pas à la particule d'accusatif du *M. La *S a fait passer ce mot (בעלדבבא) avant les quatre qui le précèdent dans le *M. De plus, elle lui a adjoint מצפון =) מן גרביא provenant du vs 12 .

\section{Choix textuels :}

A/ 11A : Il se peut qu'ici le 'resh' et le 'nun' aient été confondus accidentellement, comme cela a eu lieu en d'autres endroits énumérés par Talmon (Amen 126, 
note 11). Cependant, le ${ }^{*} G$, comme la plupart de ses partisans plus récents, a été vraisemblablement guidé par le souci de placer le vs 11 dans la bouche de Jérémie, en continuité directe avec la plainte du vs 10 . En effet les parallèles de 17,16 ou 18,20 engagent à chercher ici une protestation d'innocence du prophète et l'on sait qu'en $P s 7,4 s$ et en Jb 31,5-39, on a des protestations d'innocence introduites par les formules de serment אִ ou ou

Pourtant Cornill, qui choisit ici la leçon du ${ }^{*} G$, confesse ne pas pouvoir citer de parallèle biblique pour "Amen" introduisant une formule de serment. Gerstenberger (Complaints 402, note 36) qualifie même de "artificielle" la fonction que la Vorlage du *G attribue ici à cet "Amen". Ces objections ont amené Talmon (Amen) à essayer de démontrer que "Amen" peut servir d'introduction à une formule de serment. De fait, en corrigeant par conjecture Is 25,2 et $\mathrm{Jr} 3,19$, il parvient à y lire ce mot comme introduisant une affirmation commençant par כי. Mais il existe encore un fossé entre une telle affirmation et une formule de serment commençant par ou par אם ליל לי ליל Une telle formule sous-entend en effet une introduction du type de חלילה לי חני חי יהוה si elle est placée dans la bouche d'un homme, ou du type de חי־אני (cf. Ez 5,11; 14,16.20; 16,48 etc.) si c'est le Seigneur qui s'engage lui-même. Concluons donc que Talmon a donné quelque vraisemblance au fait que "Amen" puisse, en hébreu biblique, introduire une affirmation; mais que ce mot n'appartient pas aux formules introductoires de serments en אם ou en אם

Ces serments peuvent fort bien ne pas exprimer la proposition principale dont אם-לא אם אם par lequel ils commencent (cf. 50,45 pour un autre serment en où c'est encore le Seigneur qui s'engage).

Talmon dit ne connaître qu'un seul autre cas où une déclaration divine commence par אמר יהוה (mais où le tétragramme est suivi par d'autres noms divins). C'est Jr 46, 25. La massore (Weil \$2541) connaît, elle, encore un autre cas où cette expression commence un verset (en introduisant une déclaration divine) : c'est $P s \quad 68,23$ où le tétragramme n'est suivi d'aucun autre nom divin.

Non seulement le "Amen" du ${ }^{*} G$ semble donc mal en place ici, mais, ainsi que nous le verrons à propos de $11 \mathrm{~B}$ et de $11 \mathrm{C}$, une interprétation de ce vs comme une promesse faite par le Seigneur à Jérémie s'accorde bien avec le contenu du * $M$, alors que son interprétation comme une protestation d'innocence faite par Jérémie forcerait à d'autres retouches. Aussi le comité a-t-il attribué ici au *M la note "B".

$B / 11 B$ : Ici encore, on ne saurait faire confiance au ${ }^{*} G$ que ne suivent aucun de ceux qui le suivaient en $11 \mathrm{~A}$. Quant à la conjecture de Condamin et Volz, elle a été adoptée avec enthousiasme par les exégètes postérieurs à 1920, quoiqu'elle n’ait aucun fondement ni dans le texte, ni dans la tradition d'interprétation qu'il nous faut maintenant brièvement retracer.

Nous avons vu que toutes les versions ont cru lire ici (avec presque tous les exégètes du XVIe siècle) une graphie défective verbale ou nominale de la racine שאר, au sens de "rester". Cette interprétation est aussi celle de Menahem ben Saruq (שר §12), Abraham ha-Babli (207,6), David ben Abraham (II 274,18), Rashi, les glossaires ABCDEF, Joseph Qara, Jacob Tam (36), Ibn Ezra (sur Gn 25,24), Joseph ibn Nahmias et Radaq (Shorashim, sous שאר) qui voit ici un substantif (car son père, Joseph 
Qimḥi, a montré que, le verbe de cette racine n’étant usité ni au qal ni au piél, on devrait avoir השארת s'il s'agissait d'un verbe). Il estime que le hireq du 'taw' tient

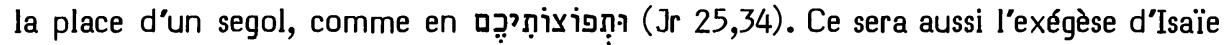
de Trani et d'Abravanel. Pagnini (Thesaurus 2455) se fonde sur l'analyse de Radaq, mais il explique que "Rab. Dones, Rab. Iehudah, \& Rab. Ionah" déduisent cette forme de la racine שרוה.

En effet, Dunash ben Labrat (59*, 4), contre Menahem ben Saruq, rapporte que "il est dit que l'interprétation de ce mot est "je t'ai délivré des entraves"". Et, comme Pagnini l'atteste, cette interprétation a été adoptée par Judah Hayyuj (Kitâb 217,5s) et par Rabbi Jonah, c'est-à-dire Abulwalid (Uṣul 749,23s).

La tradition d'interprétation à laquelle Dunash fait allusion remonte à Yéfet ben Ely qui interprète : "je te délivrerai de leurs entraves" et qui explique : "J'ai tra-

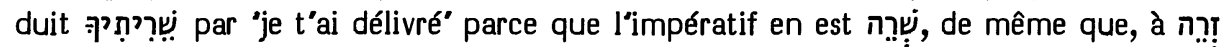

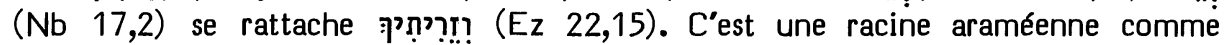

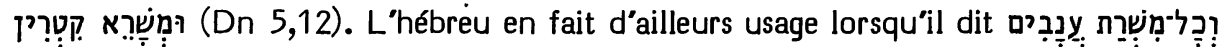
$(\mathrm{Nb} 6,3)$ :

Comme nous l'avons déjà signalé, Joseph Qimhi (Galuy 26) a suivi Dunash en cette exégèse. Il a précisé qu'il s'agit d'une forme piél. Cette analyse a été adoptée par Menahem de Posquières (se référant à Judah Hayyuj et signalant le désaccord d'Ibn Ezra), Moshé ben Sheshet, Judah ibn Balaam et Tanhum Yerushalmi.

Il semble bien que l'exégèse de Yéfet et de Dunash correspond à l'intention qu'ont eue les massorètes en n'intégrant pas ce mot dans la liste des mots ayant une seule fois un 'alef' qu'on ne fait pas ressortir (לא מפקין). Cette liste de 17 (ou 16) mots se trouve dans la massore éditée (sur 2 R 16,7), dans la Okhla (Frensdorff \$199), dans la seconde partie de la Okhla du ms de Halle ( $\$ 153)$ et en Ginsburg (Massorah $\aleph \$ 15)$. En tous ces états, elle inclut שְִִׁרית de 1 Ch 12,39, mais elle n'inclut pas notre mot. Dunash (59*, 1) a d'ailleurs fait appel à cette massore pour réfuter Menahem ben Saruq.

Le comité a attribué au qeré du *M 3 "B" et 3 "C".

C/ 11C : Contre les aménagements translationnels du ${ }^{*} G$ et de la ${ }^{*} V$ et contre la transposition de la ${ }^{*}$, le comité a attribué au *M la note " $A$ ", estimant que, de ces trois difficultés, c'est celle qui a le moins de poids.

\section{Interprétation proposée :}

Si on lisait en dehors de tout contexte les vss 11-12 et les vss 13-14, on interpréterait spontanément 11-12 comme une promesse de protection faite par le Seigneur à Jérémie et 13-14 comme un oracle de condamnation contre Israël. Mais qu'est-ce que cela vient faire en ce contexte, juste après que le prophète se soit plaint (au vs 10) d'être dans tout le pays un homme contesté et contredit, et d'être maudit par tous ? Et qu'est-ce que cela vient faire juste avant le vs 15 où il dira : “Toi, tu le sais, Seigneur. Souviens-toi de moi, et prends soin de moi, et en ma faveur tire vengeance de ceux qui me persécutent. Ne m’enlève pas à cause de ta patience. Sache que je supporte l'insulte à cause de toi." ?

L'interprétation de Smith (Use) est celle qui rend le mieux compte de cette situation : introduits par "le Seigneur a dit" (vs 11), Jérémie cite tour à tour, en un con- 
traste voulu, une promesse de protection que le Seigneur lui a faite et un oracle de destruction qu'il a pour mission de proférer contre le peuple. Cela a pour but de montrer d'abord que le porteur de tels oracles ne peut être qu'un signe de contradiction que tous maudissent et que les autorités persécutent, et de montrer ensuite que si le Seigneur patiente trop longtemps avant de réaliser son oracle (cf. 17,15), la promesse de protection que le Seigneur lui a faite risque de n'être qu'un mirage illusoire $(15,18)$, car la mort l'aura enlevé avant que cette promesse n'ait eu l'occasion de se réaliser.

Dans cette perspective, la promesse du Seigneur que Jérémie rappelle au vs 11 comporte deux assurances :

- d'abord : "j'ai ouvert tes entraves pour le bonheur" qui fait allusion à des événements comme 40,4 (ou déjà 38,10-13),

- ensuite la phrase qui constitue $11 \mathrm{~b}$ et dont l'exégèse requiert quelques précisions syntaxiques.

Le qal de $y$ פ, ainsi que nous l'avons noté ci-dessus p. 348, signifie le plus souvent "se trouver sur la route de quelqu'un" ou bien en lui faisant obstacle, ou bien en le sollicitant. Dans ce dernier sens, le complément indiquant celui que l'on sollicite est introduit par la préposition 'bet' (cf. Jr 7,16; 27,18). Cela a pour conséquence que, lorsque le hifil est employé au sens de causatif du qal, on trouvera à l'accusatif ce ou celui qui serait le sujet du qal, alors que le complément introduit par 'bet' garde la même valeur. La traduction la plus naturelle sera alors ici: "j'ai fait que l'ennemi te sollicite au temps du malheur et au temps de la détresse", ce qui peut s'appliquer aux événements qui seront racontés en 37,3; 38,14-16; 40,4s; 42,1-3. C'est d'ailleurs l'interprétation proposée par de Dieu, interprétation que NEB et TOB ont retenue.

\section{5,12 ונחשת [B] M Aq Sym V // transl : G Th, S T}

Options de nos traductions :

Le dernier mot du vs 12 a été traduit par RSV : "and bronze", par J et TOB : "et le bronze", alors que RL traduit en permutant les deux derniers mots : "und Kupfer (aus dem Norden)".

NEB omet ce mot par conjecture.

Origine de la correction :

La King James traduisait ce dernier mot par "and the steele". Comme la Bible des Pasteurs de Genève (traduisant : "et l'acier"), elle dépendait en cela, à travers le Thesaurus (1392) de Pagnini, du dictionnaire de Radaq où celui-ci nous apprend que son père (= Joseph Qimḥi) donnait toujours à תֶֶׁn le sens de "acier". La Bible des Pasteurs glosait ainsi ce vs: "comme s'il disoit, tout ainsi que l'acier surmonte la dureté du fer, ainsi aussi le Seigneur surmontera par sa force toutes les machinations $\&$ tous les efforts des Iuifs à l'encontre de toi".

On comprend que des exégètes anglais aient préféré omettre ce mot qui, au sens de "bronze", ne pouvait plus permettre cette exégèse à laquelle $\mathrm{KJ}$ les avait accoutumés, mais qui surprenait déjà Henderson, se demandant : "How our translators came to render נִִ̣ by 'steel', is unaccountable." 
Les témoins anciens :

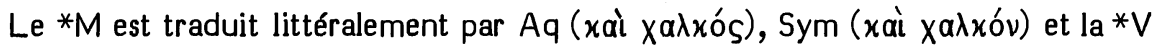
(et aes).

Le mot a été traduit par les autres versions en des syntaxes modifiées pour l'adapter à leur contexte : le ${ }^{*} G$ (auquel Hie associe Th) : xa $\alpha$ xo ṽv, la *S (qui a trans-

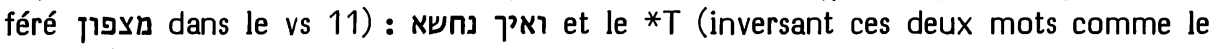
fera RL) : וכנחשא יתיתי מציפונא.

\section{Choix textuel :}

En face de ces adaptations translationnelles s'orientant en des sens divers, le comité a attribué au *M la note " $B$ ".

\section{Interprétation proposée :}

Nous avons interprété le vs 11 comme citant deux assurances données par Dieu à Jérémie. Dans le même sens, ce vs semble faire allusion à l'assurance sur laquelle s'achevait le récit de sa vocation $(1,18 \mathrm{~s})$ : "Quant à moi, voici qu'aujourd"hui je t'établis comme une place forte, et comme un pilier de fer et comme un rempart de bronze... ils te combattront, mais ils ne pourront rien contre toi, car moi je suis avec toi - oracle du Seigneur - pour te délivrer."

On comprendra donc : "le fer peut-il briser le fer du nord et le bronze". C'est le sens que propose Grotius, estimant que le "fer du nord" est celui que fabriquaient les Chalybes, peuplade du sud du Pont-Euxin (sur lesquels cf. Bochart, Phaleg 182, 60 à 184,10) qui a donné son nom (chalybs) en latin au fer trempé, c'est-à-dire à l'acier. Selon Forbes (IX 284s) la technique de carburation du fer remonte vers 1200 av. J.-C., alors que la trempe de l'acier semble remonter au $8 \mathrm{e}$ siècle av. J.-C. La Bible anglaise pourrait donc retrouver l'acier qui lui était familier, mais sous la forme de "l'acier et le bronze" plutôt que sous celle de "le fer du nord et l'acier".

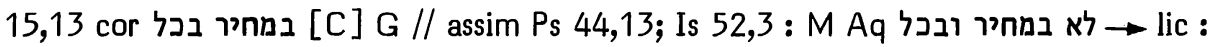
Sym V / paraphr : T / harm 17,3:S

17,3B במתיך [B] M Th V crrp // constr : S, T / lacun : G

17,3C בחטאת [B] M Th // lic : V, Sym / paraphr: T / harm 17,3: S / lacun: G

Options de nos traductions :

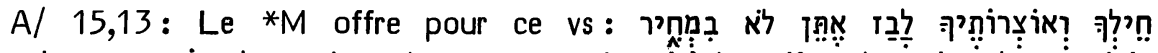

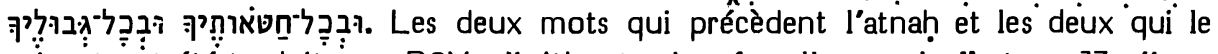
suivent ont été traduits par RSV : "without price, for all your sins" et par J3 : "sans contrepartie, à cause de tous tes péchés".

312 traduisaient : "cela paiera pour tous tes péchés", disant suivre le *G, alors que le *M offre: "sans paiement et pour tous tes péchés". De même, RL traduit : "als Lohn für alle deine Sünden".

NEB omet les vss 13 et 14 en se contentant de noter : “cp. 17,3.4". 
B/ 17,3BC : En effet, le *M offre en 17,3, en parallèle à 15,13:

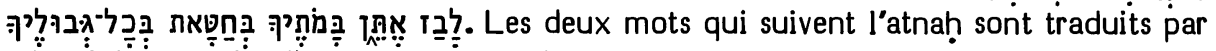
RL : "deine Opferhöhen ... um der Sünde willen". A propos de 17,3A nous traiterons du transfert du premier mot de $3 b$ au début de 3a que Luther (suivi par RL) a effectué.

$D$ 'après le $* T$ et une partie de la tradition juive, TOB intervertit ces deux mots et traduit : "à cause de la faute des hauts lieux". 33 avait fait de même : "à cause du péché de tes hauts lieux".

Assimilant explicitement ces deux mots à leurs correspondants de 15,13 (qu'elle a omis), NEB traduit : "for no payment, because of your sin".

RSV conjecture: "as the price of your sin", alors que le *M offre : "your high places for $\sin ^{\prime \prime}$.

J12 reproduisaient explicitement ici la traduction qu'elles avaient donnée des correspondants de ces deux mots en 15,13: "cela paiera pour tous tes péchés".

\section{Origines des corrections :}

A/ 15,13 : Hitzig estime qu'ici la forme primitive est celle que le $* M$ donne dans le parallèle de 17,3 : במתיך et qu'on est passé de là à la leçon du ${ }^{*} G$ (en 15,13) : במחיר, et enfin à la leçon du *M en 15,13 : לא במחיר. Il a été suivi en cela par Graf, Nägelsbach, Giesebrecht et Ehrlich (Miqra).

Duhm estime que la forme primitive est במחיר et que les deux autres en découlent. Il est suivi en cela par Cornill. Rudolph, en accord avec Grätz (Studien 154) et les apparats de $\mathrm{BH} 23 \mathrm{~S}$ et de Cent, propose les deux corrections qui ont été retenues par J12: omettre la négation qui précède במחיר, et omettre le 'waw' qui précède le mot suivant.

La plupart des exégètes estiment que les vss $15,13-14$ sont des intrus dont la place authentique est en 17,3-4. A ce titre, ils sont omis par SBOT, Volz, Schmidt, Steinmann, Weiser et Bright.

B/ 17,3B et 17,3C : L'interversion de ces deux mots (qui sera retenue par TOB et J3) a été proposée d'abord par Menahem de Posquières et par Moshé ben Sheshet, puis par leur jeune contemporain Radaq. Parmi les traducteurs du XVIe siècle, elle a été adoptée par les usagers de la Bible rabbinique de Félix de Prato: Prédicants, Zwingli, Münster, Olivetan, Rollet, Estienne, Servet puis Estienne rééditant Pagnini, Jud et la Geneva Bible. Il semble que ce soit une information fournie par le commentaire de Cornill qui a donné à TOB (après J3) l'idée de procéder à cette interversion (que Clericus avait également adoptée entre-temps).

C/ 17,3B : La leçon du *M en 15,13 (לא במחיר) a été adoptée ici par Ewald, Oort, Volz et Nötscher, puis par NEB.

La leçon du ${ }^{*} G$ en 15,13 (במחיר) a été adoptée ici par Grätz (Studien 154), Duhm, Cornill, Schmidt, Rudolph, Penna, Steinmann, Weiser, Bright et par les apparats de HSAT34, BH3S et Cent. 
D/ 17,3C : Pour ce mot, le *M a été respecté par Hitzig, Graf, Nägelsbach, Giesebrecht, Condamin et l'apparat de $\mathrm{BH} 2$.

Une correction en בחטאתיך a été adoptée par Ewald, Oort, Duhm, Cornill, Schmidt, les apparats de HSAT34 et de Cent, puis RSV et NEB.

Enfin la leçon du $* M$ (et du ${ }^{*} G$ ) en 15,13 (בכל־חטארתיך) a été adoptée ici par Grätz (Studien 154), Nötscher, Rudolph, Penna, Steinmann, Weiser, Bright et les apparats de $\mathrm{BH} 3 \mathrm{~S}$, puis $\mathrm{J12}$.

\section{Les témoins anciens :}

A/ 15,13: La leçon du *M בִמְִ est protégée ici par une massore (Weil §1862) intégrant ce cas parmi les 8 occurrences de cette forme dans la Bible. Une autre massore (Weil §2543) protège la conjonction (qui introduit le mot suivant) en précisant que nous avons ici l'un des 5 versets où l'on trouve deux fois massore nous fournit une donnée précieuse, car aucun autre témoin textuel n'atteste ici cette conjonction.

Le *G donne en effet, à la place des deux mots du *M précédant l'atnah et des

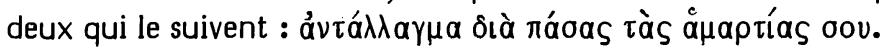

Aq et Sym ne nous sont connus que pour les deux mots précédant l'atnah. Aq les

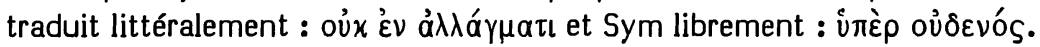

La *V traduit : "gratis in omnibus peccatis tuis".

La *S omet les deux premiers mots en restructurant tout le vs qui devient : "tes possessions et tes richesses et toutes tes frontières, je les livre au pillage à cause de tes péchés".

Le *T traduit littéralement les deux premiers mots (לא בדמין) et paraphrase les deux suivants : "pour les péchés du culte que vous avez rendu aux idoles".

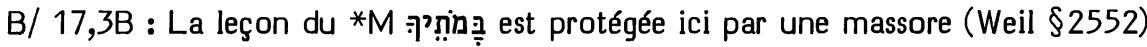
attestant que cette forme se rencontre trois fois dans la Bible (en 2 S 1,19.25 et ici) et qu'elle est une fois écrite défective (ici). Notons que le ms d'Alep nous livre (ici) la $\mathrm{mm}$ dans un meilleur état que le ms de Leningrad.

Les vss 17,1-4 étant absents dans le ${ }^{*} G$, une ajoute astérisée empruntée à Th donne pour ce mot : xaì tà í $\psi \eta \lambda a ́$ oov et la *V traduit "excelsa tua".

La *S a été ici presque parfaitement harmonisée avec sa leçon de 15,13, la seule différence étant dans la place du mot "toutes" placé ici avant le deuxième substantif (et non avant le troisième).

TOB a tort d'invoquer, à la suite de Radaq, le *T à l'appui d'une interversion de 3B et de 3C. En effet, ici, il ne traduit pas formellement ce mot, mais il paraphrase le suivant exactement comme il avait paraphrasé son correspondant en 15,13: "pour les péchés du culte que vous avez rendu aux idoles". Il est d'ailleurs intéressant de noter que ni Menahem de Posquières, ni Moshé ben Sheshet ne prétendaient retrouver dans le *T l'inversion qu'ils proposaient.

C/ 17,3C : Dans le ms du Caire, une mp protège cette forme comme unique en spécifiant que le 'tèt' doit y être vocalisé qameș. Th traduit littéralement ce mot par $\varepsilon \nu$ a $a$ aptıa dans l'ajoute astérisée qui lui est attribuée, alors que Sym traduit plus

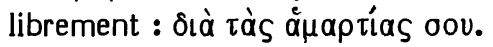


La plupart des mss de la *V (appuyés par Hie) donnent ici : "propter peccata". Cette leçon est protégée par le correctoire d'Hugues de St Cher contre l'ajoute du possessif "tua" que l"on rencontre, entre autres, dans le ms de Cava et dans ceux de l'université de Paris.

La *S et le *T ont été, pour ce mot, parfaitement harmonisés aux leçons que nous en avons données en 15,13.

\section{Choix textuel :}

A propos de l'interprétation de 15,11, nous avons proposé, avec Smith (Use), de voir en 15,13-14 une citation d'un oracle de condamnation que Jérémie avait reçu mission de proférer contre le peuple. Ainsi que la plupart des exégètes le reconnaissent, cet oracle nous est livré en 17,3-4 en son contexte originel.

Il est normal que la forme citée ne soit pas identique à la forme originelle. Aussi devons-nous affirmer d'emblée le principe qu'il faut respecter l'autonomie des deux parallèles sans les contaminer l'un par l'autre.

Constatons d'abord un fait paradoxal : alors que 17,3-4 est le lieu originel de cet oracle, le ${ }^{*} G$ ne nous le livre qu'en 15,13-14. On peut se demander si le traducteur n'aurait pas enrichi sa traduction de ces versets par des données puisées en 17,3-4. Il ne semble pas en être ainsi. C'est bien, en effet, 15,13-14, avec ses particularités caractéristiques, qu'il traduit : "tous" précédant "péchés" et ne précédant pas "tré-

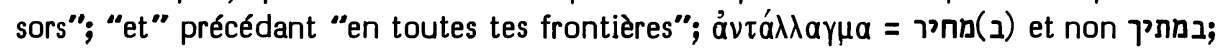
absence des 6 premiers mots de 17,4; puis, au vs 14 : "est allumé" et non "vous avez allumé"; "sur vous" et non "à jamais". Ce constat nous permettra de faire usage du *G comme d'un témoin textuel portant formellement sur 15, 13-14.

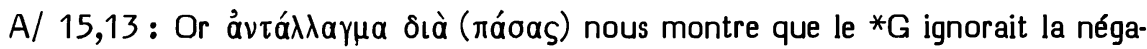
tion initiale et la conjonction intermédiaire que le $* M$ offre en sa leçon de 15,13: לא במחיר וב(כל) et qu'il ignore en 17,3 : במתיך ב(חטאת). On peut donc en conclure que ces deux éléments sont des apports tardifs dans le *M de 15,13. Il semble bien que l'insertion de la négation ait été motivée par une assimilation à $P s \quad 44,13$ où à Is 52,3 , cette assimilation ayant été suggérée par un faux rattachement syntaxique de במחיר à ce qui le précède ("je livrerai au pillage") et non à ce qui suit ("pour tous tes péchés"). L'ajoute de la conjonction avant le mot suivant est liée à cette fausse syntaxe.

Le comité s'est divisé sur la qualification de l'événement qui est survenu au ${ }^{*} M$. Deux membres, considérant cette ajoute d'une négation comme un événement littéraire, ont considéré le *M comme littérairement autonome et lui ont attribué la note "C". Les quatre autres membres ont vu en cette assimilation à des parallèles connus un accident textuel et ont estimé pouvoir opter ici pour la leçon du ${ }^{*} G$, avec la note " $\mathrm{C}$ ". L'ensemble du comité est d'accord pour estimer que le témoignage secondaire du ${ }^{*} M$ de 17,3 suffit à prouver que le ${ }^{*} M$ de 15,13 est, pour ces mots, issu de la Vorlage $d u * G$.

B/ 17,3B : Contre Hitzig, Graf, Nägelsbach, Giesebrecht et Ehrlich (Miqra), il semble bien qu'il faille considérer, avec la grande majorité des critiques, la leçon 
במחיר comme une corruption dl s'agit là essentiellement d'une erreur graphique. La fausse lecture a pu être motivée par le fait que les vss 1-2 évoquaient les cultes idolâtres. Les "bâmôt" sont donc 'dans l'air'.

Cependant, nous ne possédons plus de témoignage textuel attestant l'existence de la forme originelle במחיר en ce vs qui en est pourtant le lieu d'origine. Il nous faut donc nous résigner à en rester ici à une phase secondaire de l'histoire textuelle, cette phase étant caractéristique du type textuel protomassorétique (qui, seul, nous a préservé ce passage en son lieu d'origine).

Aussi, le comité a-t-il décidé par 4 "B" et 2 " $A$ " de garder ici la leçon du *M.

C/ 17,3C : Du fait que Th appuie formellement ici le *M, le comité a considéré que le pluriel de la *V, l'ajoute d'un possessif par Sym et les harmonisations de la *S et du *T sont des événements secondaires. Il a donc attribué au *M 4 " $B$ " et 2 " $A$ ".

Il semble bien que, dans la forme originelle, le "bet' ait été ici porteur d'un article faisant de ce mot une reprise du mot par lequel commence la péricope (au début de 17,1). Cependant cet état originel, lui aussi, nous échappe.

Interprétations proposées :

En 15,13 on pourra traduire: “Tes biens et tes trésors, je les livre au pillage, en paiement pour tous tes péchés, et cela sur tout ton territoire."

En 17,3 on traduira: "Tes biens, tous tes trésors, je les livre au pillage, tes hauts lieux, à cause du péché qui a lieu sur tout ton territoire." On pourrait indiquer en note que le texte primitif, qui n'est plus attesté aujourd'hui de façon directe, portait vraisemblablement ici : “... pillage en paiement de ce péché, sur tout..."

15,14A cor והעבדתיך [C] G // euphem et err-graph : M Aq Sym V והעברתי / harm $17,4: \mathrm{S}, \mathrm{T}$

Options de nos traductions :

Aucune de nos traductions ne donne le contenu du $* M$ en son texte. En effet, nous avons vu que NEB omet les vss 13-14.

Avec plusieurs mss hébreux, le *G et la *S, J traduit : "je te rendrai esclave". Sans note, RSV donne : "I will make you serve", RL : "und will dich zum Knecht ... machen", TOB : “je t'asservis".

Origine de la correction :

Châteillon semble être le premier de la longue suite d'exégètes qui dit avoir collationné le contenu des deux textes hébreux parallèles de 15,13-14 et 17,3-4 et avoir choisi de corriger והעברתיך que le * ${ }^{*} M$ porte ici en ${ }^{*} M$ porte en 17,4 , en motivant ce choix par le diagnostic d'une corruption de 'dalet' en 'resh' dont le *M de 15,14 aurait été victime.

Cappel (Critica 589), notant qu'ici $(15,14)$ le *G a lu un 'dalet' alors que le *M lisait un 'resh', signale que la même opposition entre les deux mêmes racines se retrouve en 7,29. 
Schnurrer hésite ici entre les leçons והעבדתי et, mais il refuse d'introduire ici la leçon והעבדתיך, estimant que les témoins qui l'attestent l'ont empruntée au parallèle de 17,4.

Cependant, cette dernière leçon est adoptée ici par Hitzig, Graf, Henderson, Grätz (Studien 154), Knabenbauer, von Orelli, Giesebrecht, puis par les apparats de HSAT34, BH23S et Cent, ainsi que par tous ceux des exégètes récents qui n'omettent pas purement et simplement 15,13-14.

\section{Les témoins anciens :}

Comme cela fut le cas en 11,2, Radaq tire ici de son étude du *T une conjecture sur la Vorlage de celui-ci qu'il estime avoir été והעבדתי avec 'dalet'. Il ajoute : “Nous lisons pourtant ce mot avec 'resh', ce qui est la leçon des mss soignés et dignes de confiance".

La massore 'hapax' que l'on rencontre sur ce mot dans le ms d'Alep ne suffit pas à le protéger, car la leçon conjecturée par Radaq serait, elle aussi, un hapax biblique. C'est pourtant bien cette leçon avec 'dalet' que Joseph Qara lit et commente ici en semblant ne pas en connaître d'autre. Norzi, selon ses autographes de Londres et de Budapest (car l'édition Minhat Shay a été victime d'un homéotéleuton), disait connaître un ms portant ici un 'dalet' et un autre ajoutant à cela qu'il faut lire ici un 'resh'.

De Rossi, en ses Variae lectiones et en ses Scholia, mentionne $13 \mathrm{mss}$ et la première main de 13 autres qui lisent ici la leçon avec 'dalet', alors qu'il n'y en a que deux et la première main de 4 autres pour ajouter ici à cette leçon le suffixe de la $2 e$ pers. m. sg. (= 17,4). Il faut ajouter à cela que la leçon avec 'dalet' est attestée aussi par le ms de Petrograd des Prophètes. Mais les témoins principaux du texte tibérien classique ( $m s d^{\prime} A l e p, m s$ du Caire, $m s$ de Leningrad et édition Ben Hayim) attestent clairement la leçon avec 'resh' corroborée en outre par les témoignages susmentionnés de Radaq et de Norzi.

Nous avons dit, à propos des cas précédents, que le ${ }^{*} G$ semble bien avoir traduit en 15,13-14 ce qu'il y lisait et non un texte collationné sur les deux parallèles à la manière de Châteillon et de ses successeurs. Cela nous permet donc de prendre au

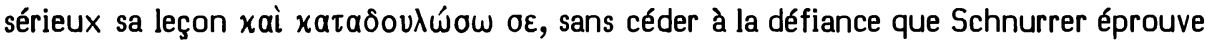
envers elle. Il semble bien que le ${ }^{*} G$ lisait ici dans sa Vorlage la leçon que le $* M$ offre en 17,4 .

La *V traduit ici: "et adducam (inimicos tuos)". Mais Hie ajoute par deux fois (en son lemme et en son commentaire): "sive "servire te faciam inimicis tuis" ". Faut-il voir en cette variante (qui est la seule qu'il donne en ce verset) une allusion au ${ }^{*} G$ ou à $17,4 \ldots$ ou bien la conscience d'une hésitation dans la tradition textuelle de l'hébreu?

Le ms Barberini donne ici pour Aq ( $x a \grave{i}) \pi \alpha \rho a \beta ı \beta a ́ o w ~ o \varepsilon$ et pour Sym (xai)

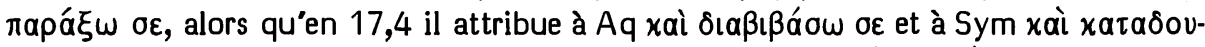

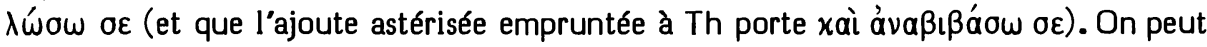
donc considérer les leçons d'Aq et de Sym en 15,14 comme traduisant ce qu'ils y lisent. En lisant l'apparat de Kennicott, on espère trouver en son ms 180 ( $=$ Hamburg 27-28) la Vorlage exacte de ces deux versions : והעברתיך. Mais on y lit clairement un 
'dalet' et ce ms doit donc s'ajouter à ceux qui assimilent au parallèle de 17,4. Il est plus probable que $A q$ et $5 y m$ ont déjà lu ici la leçon du ${ }^{*} M$ et ont tiré du ${ }^{*} G$ le complément $o \varepsilon$.

La *S (ואשעבדך) et le *T (ותשתעבדון) ont été (comme en 15,13) harmonisés avec le parallèle de 17,4.

Choix textuel :

Il est faux de dire que le *M est inintelligible. Son exégèse la plus probable serait : "et je [les] ferai passer avec tes ennemis dans un pays que tu ne connais pas", le verbe initial ayant comme complément d"objet les "biens" et les "trésors" dont il a été question au début du vs 13.

Cependant l'expression "un pays que vous ne connaissez pas" (en 16,13 qui s'adresse au peuple) ou "un pays qu'ils ne connaissent pas" (en 22,28 où il s'agit de Konyahu et de sa descendance) désigne clairement ailleurs le pays où l'on va être déporté. Il faut donc considérer que la leçon primitive, en cet oracle, a bien des chances d'être qui ont été exposés en 15,13, deux membres du comité ont attribué ici la note "C" au $* M$ qu'ils estiment littérairement autonome, alors que les quatre autres, considérant que le *M a subi un accident textuel, attribuent la note " $C$ " à la leçon du *G. Il y a en effet quelque chose d'accidentel dans la confusion du 'resh' et du 'dalet'. Mais il se peut que l'omission du pronom suffixe de la 2e pers. m. sg. soit intentionnelle.

Notons en effet que, si l'on garde ce suffixe, on lit : "et je t'asservirai à tes ennemis" et, si on l'omet, on obtient : "et j'asservirai tes ennemis". Il se peut donc que l'on soit passé de והעבדתי והעבדתיך par une correction euphémique et que l'on soit passé ensuite de là à la leçon du *M par une erreur graphique. Ces deux événements avaient cependant déjà eu lieu, semble-t-il, avant le $2 \mathrm{e}$ siècle de notre ère. Le vote de la majorité du comité correspond donc assez bien à la visée initiale du comité (CT1, p. *68s), alors que le vote de la minorité correspond à ses conclusions (ibid., p. *114).

Interprétation proposée :

L'option de la majorité du comité est donc: "Et je t'asservirai à tes ennemis dans un pays que tu ne connais pas"; alors que l'option de la minorité serait: "Et je les ferai passer avec tes ennemis dans un pays que tu ne connais pas."

15,14B cf. p. 611.

15,16A נמצאר [B] M V Jsp // lic : S T / perm : G clav מנאצי 15,16B ואכלם [B] MV // lic : Jsp S T / err-voc : G

Options de nos traductions :

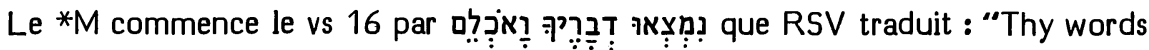
were found, and I ate them", J : “Quand tes paroles se présentaient, je les dévorais", 
RL : "Dein Wort ward meine Speise, sooft ich's empfing" et TOB : “Dès que je trouvais tes paroles, je les dévorais" (en précisant que l"hébreu porte : "tes paroles se trouvaient").

Selon Brockington, NEB se réfère au *G pour corriger $16 \mathrm{~A}$ en بִ pe $16 \mathrm{~B}$ en

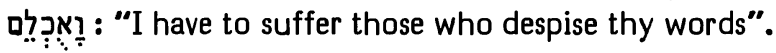

\section{Origines des corrections :}

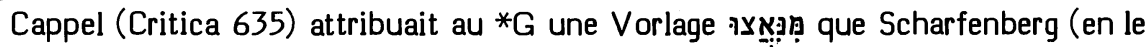
rééditant), propose de vocaliser plutôt comme Brockington le fera. Michaelis estime

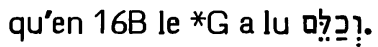

En omettant la conjonction avant ce dernier mot, Duhm corrige ces deux mots selon cette Vorlage du ${ }^{*} G$, suivi en cela par Cornill et Hyatt. Cette correction a été adoptée, en considérant le dernier mot comme une glose, par HSAT34, BH2 et Condamin.

Cependant le *M a été considéré comme satisfaisant par Giesebrecht, Volz, Rudolph et toute leur suite.

L'option de NEB correspond à la proposition de Driver, avec la seule différence que, pour tirer des consonnes du *M le sens de "je les ai supportés" (qu"il n'entend pas attribuer au ${ }^{*} G$ ), il vocalise sissant un qal de יכל, NEB a probablement voulu éviter d'ajouter un 'yod'.

Les témoins anciens :

A/ 16A : L'ensemble des critiques, depuis Scharfenberg, s'est accordé pour attri-

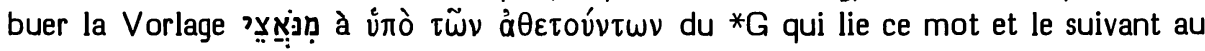
vs 15.

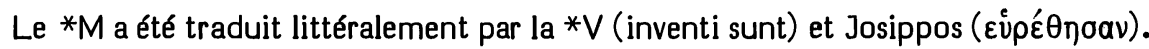

La *S (ונטרת) et le *T (קבילית) - comme TOB le fera - ont pris la liberté de rendre le nifal par un verbe actif à la 1e pers. sg.

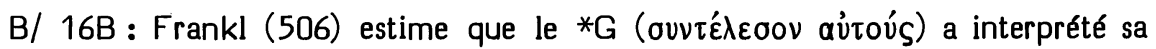
Vorlage comme un impératif afel de כלה.

Ici encore, le *M a été traduit littéralement par la *V (et comedi eos); alors que

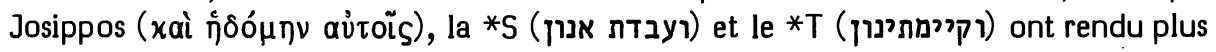
librement la métaphore.

\section{Choix textuel et interprétation proposée :}

En 23,17 nous verrons aussi le ${ }^{*} G$ trouver "ceux qui refusent la parole du Seigneur" en un participe piél de נאץ où le *M voit ceux qui refusent Jérémie. Ici, le *G a cru lire quelque chose de semblable qu'il rattache, en complément, au vs précédent.

Cependant, le *M du vs 16 offre une excellente expression de la passion avec laquelle Jérémie s'assimile les paroles de Dieu. Zimmerli (78) estime très probable qu'Ezéchiel 3,1-3 est sous l'influence de Jr 15,16. Cette image est d'ailleurs dans la ligne des expressions de Ps 19,11; 119,103 qui vantent la parole de Dieu comme plus douce que le miel. 
Quant au nifal initial de ce vs, Holladay (Further 23) a repris et développé une suggestion de Knox qui y voyait une allusion à la découverte du livre de la Torah sous le roi Josias. En effet, en $2 R$ 22,13; 23,2, il est parlé des "paroles du livre (ou : du livre de l'alliance) qui a été trouvé" (הנמצא = הussi pourrait-on traduire ici : "Lorsque tes paroles furent trouvées, je les mangeai". Il ne s'agit vraisemblablement pas là d'une référence du prophète à sa vocation initiale, mais à un moment important de sa destinée de porteur de la parole de Dieu.

Le ${ }^{*} M$ a de sérieuses chances de représenter en ces deux cas le texte original. C'est pourquoi le comité lui a attribué la note "B".

16,7A cor לחם לחם [C] G V (vel confl) // cor (vel hapl) / hapl vel err-

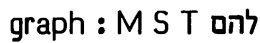

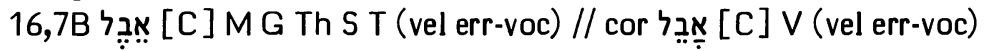

Options de nos traductions :

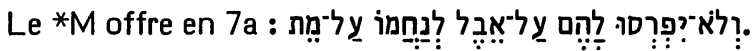

Aucune de nos traductions ne laisse intact le troisième mot du *M.

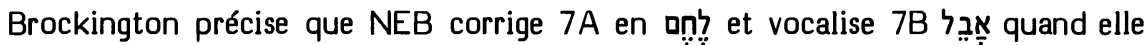
traduit : "No one shall give the mourner a portion of bread". J et TOB corrigent de même pour traduire : "On ne rompra pas le pain à (J3 : pour) qui est dans le deuil." Sans note, RSV traduit de même : "No one shall break bread for the mourner."

RL suppose au moins la première correction quand elle traduit : "Auch wird man keinem das Trauerbrot brechen."

\section{Origine des corrections :}

Comme la $* V$, la vieille traduction allemande (Kurrelmeyer IX 60,1s) a donné une double traduction de 7A : "unter in das brot" dont la première seule correspond à la leçon du *M. Par étourderie, Luther n'a retenu que la seconde ("brod"). Il corrige son étourderie en "unter sie" dans la révision de 1540. Alerté par cette erreur de Luther (?), Münster, tout en traduisant par "inter eos", fait remarquer que la *V a lu ici להם En disant s'inspirer du *G, Olivetan supplée "le pain" avant de traduire "pour iceulx", estimant que le ${ }^{*} G$ a fait de même. Se fondant sur la $* V$ et le ${ }^{*}$, Châteillon corrige en $\mathrm{a}$, traduisant : "e ne departira-on point de pain au dueil". Calvin refuse formellement cette correction. Tremellius supplée "cibum" à côté de "illis" en se référant au rituel de consolation de l'endeuillé auquel il est fait allusion en Ez 24,17. En se référant à ce même texte, Pasteurs et $\mathrm{KJ}$ insèrent la mention du pain dans une leçon marginale.

Grotius corrige en se fondant sur le *G et la *V. Cappel (Critica 596), estimant que le ${ }^{*} G$ a bien lu an au lieu de la leçon du $* M$, conserve cependant (Notae 525b) cette dernière. Houbigant corrige avec le ${ }^{*} G$ en reconnaissant que la $* V$ atteste ici une leçon gonflée (ainsi que Clericus l'avait déjà fait remarquer). Kennicott (Dissertatio Generalis §177) choisit aussi la variante, en invoquant le parallèle de Is 58,7 (dont C.B. Michaelis estimait qu'il s'accordait bien avec la leçon du *M). J.D. Michaelis et Rosenmüller corrigent cependant. Ewald considère אותם et comme nécessaires 
pour évoquer les participants à la cérémonie mortuaire. Il estime que, dans ce contexte, le "pain" peut être sous-entendu. Hitzig corrige en לֶֶֶ, et vocalise 7B : ainsi que Houbigant le supposait dans sa traduction. Böttcher (Aehrenlese) opte pour une ajoute de לִ ạ après

La double correction de Hitzig a été adoptée par Luzzatto, Giesebrecht, Oort, Duhm, Cornill, Condamin, Ehrlich, Schmidt, Rudolph, Penna, Hyatt, Bright et les apparats de HSAT34, BH23S et Cent. La correction de Böttcher a été préférée par Graf et par l'apparat de SBOT. Le mot לִ et les $4 \mathrm{e}$ et $5 \mathrm{e}$ mots du *M ont été compris par von Orelli, Volz, Nötscher, Steinmann et Weiser au sens de 'pain-de-deuil'.

Les témoins anciens :

A/ 7A : Kennicott, dans son apparat, disait lire la leçon לח peut-être dans son ms 237. Dans sa Dissertatio Generalis ( $\$ 177)$, il y ajoute qu'il l'a notée aussi dans le ms 301 (tous deux allemands du XIIIe siècle) et dans son "codex" 651 qui est une édition (laquelle?) du Midrash Rabba. Cette seconde attestation paraît impossible à repérer. En effet ce vs semble n'être cité qu'en Ekha Rabbati IV 4 (p. 145 de l'éd. Buber). Or ni là (dans le texte et en sa longue note), ni dans l'édition du Midrash Rabba de Wilna (p. 56a, 4) on ne trouve mentionnée une leçon לח. Tout le contexte de la citation confirme d'ailleurs la leçon להם du * Si la leçon avec 'ḥet' a pénétré dans la tradition massorétique, ce doit donc être de façon très passagère et par erreur. En effet, de Rossi n'a trouvé cette leçon en aucun de ses mss et elle est inconnue de Radaq, Norzi, J.H. Michaelis et Ginsburg.

Comme Hitzig l'a fait remarquer pour le ${ }^{*} G$ et comme Clericus l'a fait pour la * $V$, ces deux versions semblent avoir lu להם לח qui transparaît en ápros ... aủंw̃uv et en "inter eos ... panem".

La *S (ליהון) et le *T (להון) ont traduit le *M.

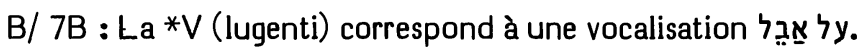

La vocalisation du $* M$ a été lue par le ${ }^{*} G\left(\varepsilon^{\prime} \nu \pi \varepsilon ́ v \theta \varepsilon i\right)$, Th ( (באבלא) et le *T (על אבלא).

Choix textuel :

A/ 7A : Graf a bien montré la complexité du problème textuel qui se pose ici : “Que פר doive s'entendre ici de la fraction et distribution du pain ne fait aucun doute. Mais ce qui est douteux, c'est :

- si l'on doit se contenter de suppléer anֶ, de sorte que le verbe seul assume ici la fonction de פרס לחם en Is 58,7 (cf. פרש לחם Lm 4,4),

- ou bien si לח est tombé à côté de להח,

- ou finalement si de

Comme Graf le fait remarquer, si on lit ici

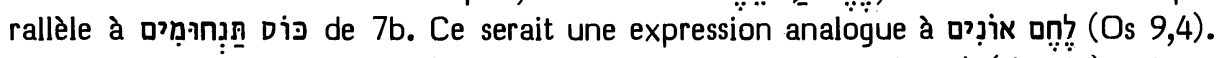

Il faut cependant, avec Ewald, souligner la raison d’être de לִ (du *M) qui, en

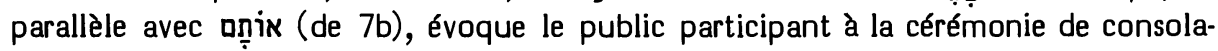
tion de l'endeuillé (celui-ci étant évoqué par les pronoms suffixes $3 e$ pers. m. sg. en $7 \mathrm{a}$ et en $7 b)$. 
Les seules leçons qui sont directement attestées sont להם לחם לה nost quâ titre de base vraisemblable de cette leçon (si on la considère comme une leçon gonflée) que l'on peut atteindre la leçon ạ̣ (car les 'codices' de Kennicott sont trop incertains pour apporter un témoignage direct).

Un membre du comité a opté ici pour le *M לִִ̣. Deux autres membres ont opté

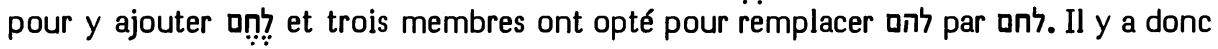
une nette majorité pour la présence de לחici, alors que les voix s'équilibrent pour la présence ou l'omission de להם, tous ces votes ayant été faits avec la note " $C$ ".

7B : Les trois membres du comité qui omettent להם en 7A votent ici "C" pour

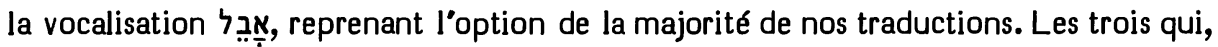
en $7 A$, juxtaposent les deux leçons, votent ici “ $C$ ” pour la vocalisation qu’appuient le $* M$ et le ${ }^{*} G$.

Interprétations proposées :

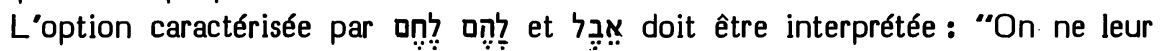
rompra pas le pain de deuil pour consoler quelqu'un au sujet d'un mort. On ne leur fera pas boire la coupe des consolations au sujet du père de quelqu'un ou au sujet de la mère de quelqu'un."

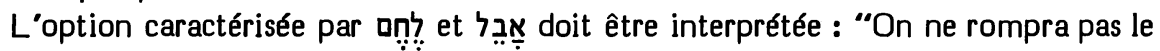
pain pour un endeuillé afin de le consoler au sujet d'un mort. Au sujet du père de l'un et de la mère d'un autre, on ne leur fera pas boire la coupe des consolations."

\section{6,7C אותם [B] MV S T // abr-styl : G om}

Options de nos traductions :

Aucune de nos traductions ne respecte le suffixe pluriel du $* M$.

J, NEB et TOB disent se fonder sur le *G pour traduire "lui" et "him". RSV et $\mathrm{RL}$ traduisent par un singulier sans rien noter.

\section{Origine de la correction :}

Parmi les partisans de la double correction de Hitzig en 7AB, c'est Giesebrecht qui a, le premier, souligné l'intérêt de la variante du ${ }^{*} G$ et l'a adoptée, suivi en cela par Oort qui demande de corriger en אותו, correction qu'adopteront Cornill, Ehrlich, Volz, Schmidt, Nötscher, Rudolph, Weiser, Bright ainsi que les apparats de HSAT34, $\mathrm{BH} 3 \mathrm{~S}$ et Cent.

\section{Les témoins anciens :}

Le suffixe pluriel du *M a été lu ici par la *V (eis), la *S (אנון) et le *T (כתהן).

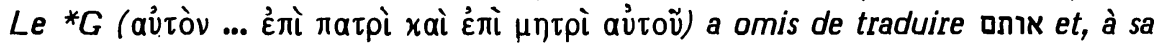
place, exprimé le suffixe possessif de אביו, en respectant la syntaxe de l'hébreu dans la traduction des deux derniers mots du vs. 
Choix textuel et interprétations proposées :

Le comité a refusé l'allègement stylistique du ${ }^{*} G$ et conservé le ${ }^{*} M$ qui, d'ailleurs, ne fait pas difficulté, en lui attribuant la note " $B$ ".

A la fin du cas précédent, des interprétations de ce mot ont été données en fonction des deux options entre lesquelles le comité s'était divisé.

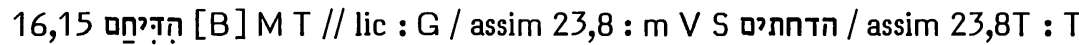

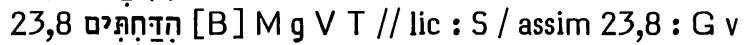

Options de nos traductions :

Dans le $* M, 16,14-15$ et 23,7-8 constituent deux passages parallèles. En chacun, on commence par parler du Seigneur à la 3e pers., puis, sans introduction, il prend la parole à la 1e pers. Mais ce passage n'a pas lieu au même endroit en ces deux parallèles: En 16,15 il a lieu après le dernier verbe de la relative : הִ̣ alors qu'en 23,8 il a lieu

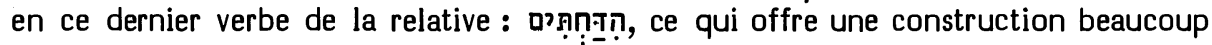
plus dure.

Toutes nos traductions respectent le *M en 16,15; alors que seule TOB le respecte en 23,8 en traduisant: "(Vivant est le SEIGNEUR qui a fait monter, qui a amené la descendance des gens d'Israël du pays du nord et de tous les pays où) je l'ai dispersée".

Selon Brockington, NEB se fonde sur le ${ }^{*} G$ pour lire ici la leçon que le $* M$ offrait dans le parallèle de 16,15 et traduire : "he had dispersed them". Se fondant aussi sur le *G, RSV traduit "he had driven them" et J : "il les avait dispersés". RL traduit de même : "(wohin) er sie verstossen hatte".

Origine de la correction :

Sur ce point, Hitzig (en 23,8) a mis en garde contre une assimilation à 16,15 qu'il estimait facilitante et qu'Houbigant avait effectuée sans même la mentionner. Cette assimilation a cependant été proposée ici par Giesebrecht, Oort, Duhm, Condamin, Penna, Steinmann, Bright et les apparats de SBOT, HSAT34, BH2 et Cent.

\section{Les témoins anciens :}

Kennicott et de Rossi ne signalent pas de variante en 23,8, mais seulement en 16,15 où un ms, la 1e main de deux autres et peut-être deux autres encore ont assimilé à la leçon du parallèle de 23,8.

En 16,15 , le $* G$ a traduit librement par un passif : '́ $\xi \hat{\omega}$ ônoav; alors qu'en 23 ,

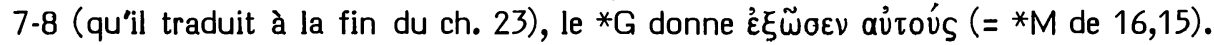
Notons cependant que l'antiochienne, dans l'ajoute qu'elle insère entre les vss 6 et

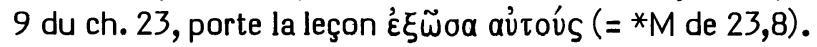

En 16,15 , la $* V$ a lu la leçon que le $* M$ offre en 23,8 , car elle traduit: "eieci eos" (que Hie confirme sans mentionner de variante). Ce n'est pas un événement intérieur au latin, puisqu'en 23,8 la $* V$ traduit non plus par un parfait, mais par un plus-que-parfait : "eieceram eos" (quelques mss déformant ici en "eiecerat") avec l'accord, ici encore, de Hie, sans mention par lui de variante. 
Comme la $* V$, la $* S$ a lu en 16,15 la leçon que le $* M$ offre en 23,8 ; puisqu'elle traduit littéralement : דדחקת אנון en 16,15, alors qu'elle traduit librement par un passif דאתבדרו en 23,8.

Quant au *T, aucun de ses témoins ne porte en 23,8 la leçon du *M de 16,15. Mais, en 16,15, la polyglotte d'Anvers porte la leçon à la 1e pers. par laquelle le ${ }^{*} T$ traduit le *M en 23,8.

\section{Choix textuel :}

A l'inverse de la tendance des exégètes récents, il y a donc plus de versions (la *V et la ${ }^{*}$ ) qui ont lu dans leur Vorlage en 16,15 la leçon du ${ }^{*} M$ de 23,8; alors qu'une seule (le ${ }^{*}$ ) a lu dans sa Vorlage de 23,8 la leçon du *M de 16,15.

Contre ces assimilations, le comité a attribué la note " $\mathrm{B}$ " à chacune des deux leçons du *M.

Une assimilation de la leçon de 23,8 à celle de 16,15 serait en tout cas facilitante, car elle ferait disparaître en $23,7-8$ ce passage de la 3 e à la 1e personne qui se retrouve, légèrement déplacé, en 16,14-15 et que l'on doit donc considérer comme caractéristique de cette petite péricope.

Notons que nous retrouvons ici une particularité qui nous avait frappés lorsque nous comparions (ci-dessus, p. 597) 15,13-14 à 17,3-4. C'est la deuxième occurrence de cette péricope qui paraît à la plupart des critiques comme l'insertion littérairement primitive de cette péricope, alors que le ${ }^{*} G$ l'a traduite normalement en sa première occurrence, mais l'a déplacée (après l'avoir peut-être omise) en sa seconde occurrence, de même qu'il traduisait normalement 15,13-14, mais omettait 17,3-4. Il se peut qu'en ces deux cas ce soit la Vorlage du ${ }^{*} G$ qui ait omis, lors de leur seconde occurrence, des textes qu'elle estimait superflus car répétitifs.

\section{Interprétations proposées :}

En 16,15 le texte ne fait aucune difficulté.

En 23,8, la formule de serment sera: "Vivant est le Seigneur qui a fait monter et qui a amené la descendance de la maison d'Israël du pays du nord et de tous les pays où je les ai dispersés, pour qu'ils s'établissent sur leur sol."

\section{6,18 ראשרנה [B] M גoiл V S T // abr-elus : G om}

\section{Options de nos traductions :}

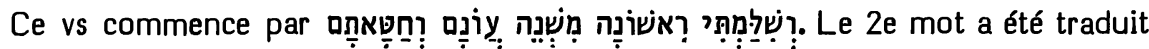
par RL : "zuvor", par NEB : "first" et par TOB : "je commence par".

RSV et $J$, se fondant sur le ${ }^{*} G$, omettent ce mot.

Origine de la correction :

L'omission de ce mot a été proposée par Grätz, Duhm, Condamin, Ehrlich, Nötscher, Steinmann, Bright et par les apparats de SBOT et BH23. 
Les témoins anciens :

Ce mot ne figure pas dans le *G. Mais Origène (III, 231B) dit l'avoir trouvé

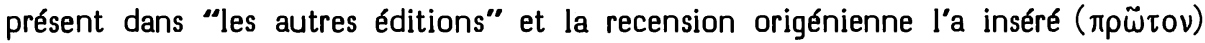
à partir de ThAq.

Il a été lu ici par la *V (primum), la *S (קדמית) et le *T (כקדמאין).

Choix textuel :

Comme Hitzig l'a fait remarquer, l'auteur de Is 65,7 lisait déjà ici ce mot. Il semble bien, en tout cas, que le ${ }^{*} G$ ou sa Vorlage l'a omis comme difficile à interpréter en ce contexte qu'il semble surcharger. Le ${ }^{*} G$ a été allégé aussi en $13 \mathrm{~b}$ et en $17 \mathrm{a}$.

Même s'il s'agit d'une ajoute rédactionnelle, il fait partie du type textuel protomassorétique. Aussi le comité lui a-t-il attribué la note " $\mathrm{B}$ ".

Interprétation proposée :

Cet adverbe semble avoir servi au rédacteur pour situer cet oracle de châtiment par rapport à l'oracle de restauration contenu dans les vss 14-15. On peut donc traduire : "Et d'abord je vais les payer etc."

\section{7,2 כזכר בניהם מזבחותם [A ] M g T // lic : S / homtel : s om / lacun : G}

\section{Options de nos traductions :}

Le *M du vs 2 commence par par RSV : "while their children remember their altars", RL : "denn ihre Söhne denken an ihre Altäre" et J3 : "car leurs fils se souviennent de leurs autels". TOB traduit : "Comme ils parlent de leurs enfants, ainsi parlent-ils de leurs autels."

312 conjecturaient avec Volz pour les deux premiers mots : duisaient : "comme un mémorial contre eux, (leurs autels...)" en disant que ces mots sont omis par la *S. NEB adopte la même conjecture et traduit: "to bear witness against them. (Their altars...)".

Origine de la correction :

Houbigant a pris argument d'une omission des 4 premiers mots de ce vs par la *S pour en proposer le transfert à la fin du vs. Selon Duhm, ces quatre mots constituent une glose qui trouble la suite du texte. Aussi les omet-il, suivi par Cornill et Nötscher. Condamin omet les deux premiers mots en notant l'absence de ces mots dans la *S. Volz propose à leur place la conjecture forme où $\mathrm{J12}$ la citent) par Rudolph et Steinmann.

\section{Les témoins anciens :}

Il est faux de dire avec $\mathrm{BH} 23$, à la suite d'Houbigant et de Volz, que ces premiers mots du vs 2 manquent dans la *S. Cela n'est vrai que des éditions dérivées de la polyglotte de Paris. Mais l'édition de Mossul, ainsi que le ms Ambrosianus et les mss consultés par Thorndike dans l'apparat de la polyglotte de Londres lisent ici מא דמתדכריק בלבהון , מדבחיהון (ד), ces mots étant précédés et suivis par explique qu'ils soient tombés par homéotéleuton dans la source de Sionita ou en son édition. 
Les vss 1 à 4 manquent dans le *G, mais l'ajoute astérisée qui les supplée dans la recension origénienne porte les premiers mots du vs 2 qui figurent aussi dans la *V et dans le *T.

Notons en passant que la ${ }^{*} S s^{\prime} e s t$ inspirée du vs 1 dans la traduction très libre que nous venons de citer.

\section{Choix textuel :}

Le comité a attribué la note " $A$ " à la leçon du *M.

Interprétations proposées :

Il vient d'être dit que la faute de Juda, c'est-à-dire l'idolâtrie, est gravée sur leur coeur. Dans ce contexte, la traduction la plus naturelle sera ici celle qui a été choisie par Yéfet ben Ely, Rashi et Radaq : “Comme ils se souviennent de leurs enfants, (ainsi ils se souviennent de) leurs autels." C'est celle que TOB a choisie ici.

Il est également possible de traduire avec RSV, à la suite du vs précédent : "tandis que leurs fils se souviennent de leurs autels".

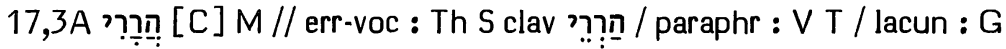

Options de nos traductions :

Avant la suite du vs que nous avons citée ci-dessus ( p. 594) en traitant de 17,3BC, le *M porte הִרִרִ que que TOB traduit: "Toi, le dévot des cultes sur la montagne, dans la nature" en disant que le sens littéral est : "le montagnard dans la campagne". $\mathrm{J3}$ traduit : "O ma montagne dans la plaine".

$J 12$ voyaient là le sens du ${ }^{*} M$, mais conjecturaient : "les montagnes en pleine campagne". Sans note textuelle, un pluriel est donné aussi par RSV : "on the mountains in the open country" et RL : "auf Bergen und Feldern"; alors que NEB, selon Brockington, lit avec Th הִ qu quand elle traduit : "in the mountain country".

Origine de la correction :

Houbigant, ne tenant pas compte des voyelles, avait traduit : "in montibus et in agris". Schleusner (en annotant les Observationes de Michaelis), sous cette influence et celle de Luther ("auff bergen und feldern"), vocalise ici הַ en s'inspirant de l'ajoute astérisée de la recension origénienne. Ajoutons que Luther dépendait lui-même de la traduction des Prédicants de Zurich (der bergen und der välden) et de Zwingli (montium et agrorum). Cette vocalisation a été adoptée par Ewald, Duhm, Cornill, Condamin, Volz, Schmidt, Nötscher, Rudolph, Weiser, Bright et par les apparats de $\mathrm{BH} 23 \mathrm{~S}$.

Notons ici que Luther a transféré audacieusement במתיך (qui commence 3b) au début de 3a pour traduire: "Aber ich wil deine Höhen, beide auf bergen und feldern, sampt deiner habe und alle deinen schetzen, jnn die rappuse geben." 
Les témoins anciens :

Le ${ }^{*} G$ omet les vss $1-4$, mais l'ajoute astérisée qui les supplée offre ici xaì ỏpéwv, le mot ópéwv sans xaí étant attribué à Th. La *S éditée et le ms Ambrosianus s'accordent aussi pour placer les seyamé sur ובטורו. Th et la *S rattachent ce mot et le suivant à la fin du vs 2 .

Le *T paraphrase: "Du fait que vous rendez un culte sur les montagnes" et motive par là l'oracle de destruction qui suit.

$\mathrm{La} * \mathrm{~V}$ estime avoir suffisamment traduit ce mot lorsqu'elle a rendu l'avant-dernier mot du vs 2 (גבות) par "montibus". Aussi unit-elle l'option syntaxique de Thet de la *S à la paraphrase du *T en traduisant les deux derniers mots du vs 2 et les deux premiers du vs 3 par : "in montibus excelsis sacrificantes in agro".

\section{Choix textuel et interprétation proposée :}

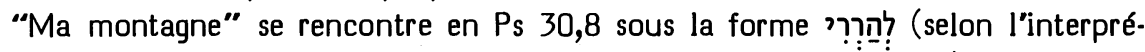
tation de Quin, Aq, Yéfet ben Ely, Rosenmüller, Ewald, Delitzsch etc.). Cette interprétation est d'ailleurs confirmée par la vocalisation de Gn 14,6: :

Ici aussi, Menahem ben Saruq (premier sens de הר) interprète ce mot ainsi. Mais Nägelsbach a tort de classer Rashi et Radaq parmi les partisans de cette exégèse.

Yéfet ben Ely a expliqué en effet que ce mot est un adjectif d'origine comme la forme nisbé de l'arabe. De même, Rashi rapproche ce mot de (Is 13,20) qu'il interprète comme "ceux qui habitent dans la Araba". De même ici, il s'agit des "montaniers', c'est-à-dire de ceux qui habitent dans la montagne. Menahem de Posquières voit dans le 'yod' final un 'yod' généalogique (analogue au sens de l'adjectif הַ הַחִ̣ en 2 S 23,33; 1 Ch 11,34.35). Cet homme est rattaché généalogiquement à la montagne parce qu'il y rend un culte aux idoles comme l'Ecriture vient de le relater ("sur les collines élevées"). Comme le fera encore plus explicitement son jeune contemporain Radaq, Menaḥem lie בשדה à la suite, contre l'accentuation massorétique. Il interprète ainsi 3a: "Toi, montagnard, qui es toujours dans les montagnes à sacrifier aux idoles, à cause de ce que tu fais en haut dans les montagnes, en bas dans la campagne je livrerai au pillage tes biens et tous tes trésors. Cela veut dire : toi tu me fais des malheurs en haut dans la montagne, et moi je te fais un malheur et une vengeance en bas en ce que les ennemis se partagent ton butin."

Fidèle aux teamîm, Yéfet fait de בשדה une spécification du mot qui précède.

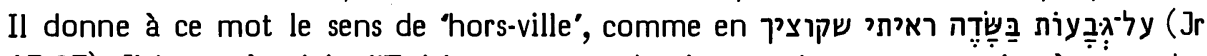
13,27). Il interprète ici : “Toi le montagnard qui est toujours en excursion à cause des hauts-lieux et des autels". En ce sens, on pourrait donc traduire : "Montagnard d'excursion", c'est-à-dire toi qui te rattaches à la montagne non par ton origine ni par ton habitat, mais par tes sorties hors-ville.

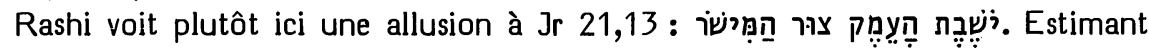
que מישר et sont équivalents, il voit ici un vocatif : "ô habitant de la montagne campagnarde !" Il s'agirait là d'une désignation de Jérusalem chère à Jérémie.

En préférant l'interprétation de Yéfet, le comité a attribué 5 " $\mathrm{C}$ " à la leçon du *M.

Un membre du comité a cependant attribué la note " $C$ " à la vocalisation nַ? postulée par Th. En effet, Joseph Qara rapporte que Menahem ben Helbo interprétait 
ces deux mots au sens de "les montagnes (où l'on rendait culte aux idoles) seront abaissées comme un champ cultivable".

Notons pour finir qu'au XVIe siècle, le sens de "montagnard" a été adopté ici par Pagnini, Vatable, Calvin et la Bible des Pasteurs de Genève.

17,3B cf. p. 594.

17,3 C cf. p. 594.

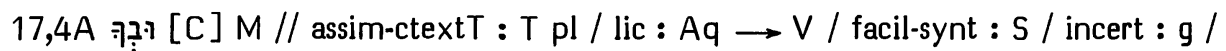
lacun : $\mathrm{G}$

Options de nos traductions :

Le vs 4 commence par : n'est traduit tel qu'il est par aucune de nos versions.

Disant s'inspirer des commentateurs juifs ainsi que de Aq et de la *V, TOB traduit ainsi les trois premiers mots : “Tu feras la grande 'remise', seul, éloigné de l’héritage".

Brockington dit que NEB corrige ce mot en 7 Tִ $^{\prime}$ lorsqu'elle traduit ces trois mots : "You will lose possession of the patrimony". RSV conjecture de même en traduisant : "You shall loosen your hand from your heritage", et J en traduisant : "Tu devras te dessaisir de (J1 : lâcher) ton héritage".

RL ne traduit pas ce mot : "Und du sollst aus deinem Erbe verstossen werden."

Origines des corrections :

RL copie Luther. Celui-ci dépend ici de la traduction des Prédicants de Zurich : "Jr werdend auch von dem erblande ... gestossen", Zwingli expliquant que "et in te" a en ce contexte la valeur de "et ipsa". La non-traduction de ce mot se retrouve chez Olivetan, Rollet, Estienne, Jud et Châteillon. Aucune interprétation de ce mot ne le satisfaisant, Michaelis (OEB) décide de l'omettre. Ensuite (Observationes), il se demande s'il ne faudrait pas lire ici $\underset{7 T ?}{7}$ ?. La première suggestion de Michaelis n'a pas eu de succès, mais la seconde a été adoptée par Graf, Nägelsbach, Knabenbauer, von Orelli, Giesebrecht, Ehrlich (Miqra), Cornill, Condamin, Volz, Schmidt, Nötscher, Rudolph, Penna, Steinmann, Weiser, Bright et les apparats de SBOT, HSAT234, $\mathrm{BH} 23 \mathrm{~S}$ et Cent.

Houbigant et Ewald ont proposé de lire ici (דבד au sens de 'seul'.

Les témoins anciens :

La forme originelle de l'ajoute astérisée pour ces trois premiers mots du $* M$ en

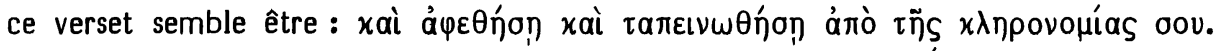
Cependant, presque tous les témoins de cette ajoute insèrent $\mu$ óv verbe (ce mot étant omis par le texte de la Syh, par Eusèbe et par l'Arménienne, c'est-à-dire par les meilleurs témoins de la recension origénienne). Et le ms Barberini dit que Aq lit ici uóvn oú. Doederlein (Hexapla 239) a suggéré que le 2e verbe peut 
correspondre aux racines מך ou cette suggestion a été reprise par Schleusner ( $V$ 262). La leçon $d^{\prime} A q(1 e$ édition ?) est une traduction large de la leçon du *M. Ceux qui en ont inséré le premier mot dans l'ajoute astérisée (dont la *V "sola" s'est inspirée) n'avaient probablement pas compris que le $2 e$ verbe visait à traduire le $2 e$ mot du ${ }^{*} M$.

La*S a traduit librement les deux premiers mots par ואעברך.

Pour le *T, Sperber, en accord avec le ms Urbinates 1, les éditions de Félix de

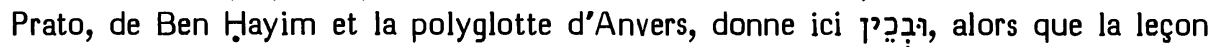
authentique est וּבְכוֹ ( lin, la polyglotte de Londres et les Miqraot Gedolot.

\section{Choix textuel :}

Aucune variante ne mérite d’être prise plus au sérieux que la leçon difficile du * $\mathrm{M}$ que le comité a choisie avec la note " $\mathrm{C}$ ".

Il est étonnant que la conjecture-refuge de Michaelis ait eu un tel succès, alors que ses insuffisances ont été dénoncées clairement au cours des deux derniers siècles. Ehrlich (Randglossen) a fait remarquer que le parallèle de Dt 15,3 qui a inspiré cette conjecture demanderait que l'on insère, dans l'accompli qui précède, la préformante du hifil; ce que Volz a fait, alors que Rudolph et ses suiveurs ont cru pouvoir s'en dispenser.

D'autre part, Keil a fait observer qu'en Dt 15,3, le mot Tִ ְִ est le sujet du verbe ถู (qu'il faut donc comprendre comme une 3 e pers. f.) et non le complément d'objet de ce verbe (compris comme une $2 e$ pers. $m$.). Il a fait remarquer aussi

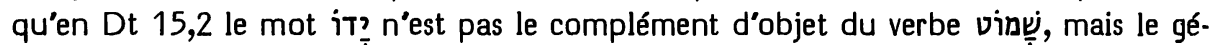
nitif de d'une fausse construction syntaxique que cette conjecture à succès s'est inspirée.

Interprétation proposée :

On peut comprendre, avec Keil : “Et tu laisseras en jachère, et cela par ta faute, ton patrimoine...".

Mais, si l'on veut mieux rendre compte de la préposition qui précède le $3 \mathrm{e} \mathrm{mot,} \mathrm{on}$ préférera: "Et tu pratiqueras la jachère, et cela par ta faute, en quittant ton patrimoine..." Pour n'avoir pas pratiqué la jachère de la $7 e$ année en observance de la Torah, ils seront exilés, ce qui les obligera à laisser le pays en jachère (cf. Lv 26,3435.43). C'est l'interprétation de Yéfet ben Ely.

17,4B קדחתם [B] M V S // assim 15,14: $m$ Th v T / lacun : G 15,14B עד־עולם M G V S T // assim 17,4 : m :

Options de nos traductions :

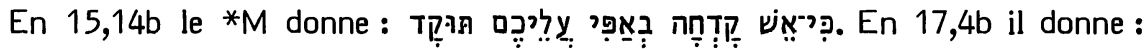

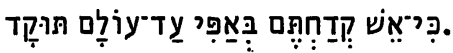


A/ Pour le premier verbe, toutes nos traductions respectent la spécificité de 15,14. Celle de 17,4 est respectée par RL ("ihr habt ... angezündet"), TOB ("vous avez fait jaillir") et $\mathrm{J3}$ ("que vous avez allumé").

Mais Brockington dit que NEB y lit la leçon de 15,14 (qu'elle a omis) quand elle traduit en 17,4 : "is a blazing (fire)". RSV traduit de même : "is kindled".

B/ Pour les $5 \mathrm{e}$ et $6 \mathrm{e}$ mots de $17,4 \mathrm{~b}$, toutes nos traductions respectent la spécificité de 17,4. Mais, pour le 5e mot de 15,14b, l'une d'entre elles: RSV, sans note textuelle, assimile à 17,4 en traduisant : "for ever".

\section{Origines des corrections :}

En 15,14, Ewald optait pour une leçon gonflée : עליכם עד־עולם, alors que Graf a préféré assimiler sur ce point 15,14 à 17,4, suivi en cela par l'apparat de $\mathrm{BH} 2$.

Grätz (Studien 154), reconstituant "un bon texte" à partir d'une collation des

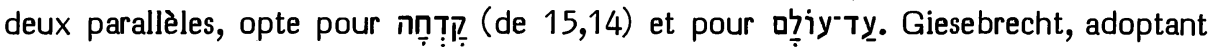
ce texte, estime qu'il est celui qui dérive le plus naturellement de

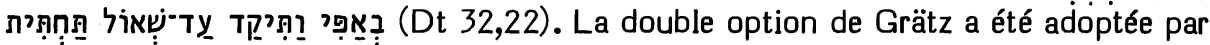
Duhm, Cornill, Schmidt, Nötscher, Rudolph, Penna, Weiser, Bright, ainsi que par les apparats de $\mathrm{BH} 35$ et Cent.

Les apparats de HSAT34 se contentent d'assimiler en 17,4 le premier verbe à la leçon de 15,14.

Les témoins anciens :

Pour le premier verbe, de Rossi cite $3 \mathrm{mss}$, la 1e main d'un quatrième et la $2 \mathrm{e}$ main d'un cinquième qui ont assimilé la leçon de 15,14 à celle de 17,4; alors que Kennicott en cite deux qui ont fait l'assimilation inverse.

Pour le 5e mot de 15,14b, de Rossi cite 6 mss qui l'assimilent à la leçon de 17,4; alors que l'assimilation inverse n'est mentionnée ni par Kennicott, ni par de Rossi. Notons qu'ici toutes les versions respectent les leçons spécifiques du $* M$ en chacun des deux lieux parallèles.

Pour le premier verbe, la leçon du *M est attestée par toutes les versions en 15,14, mais il n'en va pas de même en 17,4 où l'ajoute astérisée attribuée à Th porte $\dot{\varepsilon} x x \varepsilon ́$ xavtal qui est la leçon par laquelle le ${ }^{*} G$ de 15,14 traduisait קדחה. De même, le *T porte ici אפק מן קדמי, comme en 15,14. Par contre, אקדחתון de la *5 traduit clairement

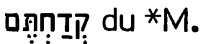

En 17,4, l’édition de la *V de San Girolamo se présente comme si elle était la première à choisir ici la leçon "succendistis" qui a l'appui de quelques mss anciens et de Hie et qui correspond exactement au $* M$, alors que la leçon concurrente "succendisti" (que portait encore l'édition Weber) est issue d'une assimilation au contexte. De fait, Robert Estienne l'avait déjà placée dans le texte de son édition de 1557, après l'avoir fait figurer dans l'apparat de son édition de 1540, l'ayant extraite d'un ms de Saint-Germain et d'un autre de Saint-Denis. Le premier de ces mss est le ms Paris BN lat 11553 et le second, le ms Paris BN lat 93. 
Choix textuel :

Le cas 15,14B n'a pas été soumis au comité.

Celui-ci, en 17,4B, a attribué au *M la note " $\mathrm{B}$ " pour le protéger contre une assimilation au parallèle de 15,14.

Il est fort possible que Dt 32,22a soit la source de Jr 17,4b et de Jr 15,14b.

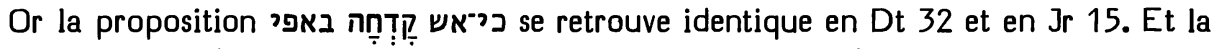

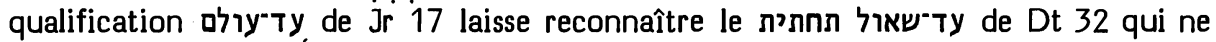
transparaît nullement dans le yלכיכם Jr 15. Mais il serait faux de conclure de cela que cette dernière leçon et la leçon קדחת de 17 sont moins authentiquement “jérémiennes" que leurs concurrentes où Dt 32 se reconnaît plus clairement. En effet, le prophète réutilise cette phrase de Dt 32 en l'actualisant et cette actualisation se traduit par une entrée en scène de la 2e pers. pl. Cette entrée en scène s'effectue en un point qui diffère pour chacun des deux réemplois jérémiens de Dt 32. En 15,14b, la $2 \mathrm{e}$ pers. pl. n'intervient que dans le dernier membre de phrase, alors qu'en 17,4b, elle a lieu dès le premier verbe. Nous avions rencontré quelque chose de semblable dans notre étude de deux autres textes parallèles de Jérémie (16,15 et 23,8 traités ci-dessus, pp. 605-606) où la 1e pers. sg. intervenait en un point qui différait pour chacun des deux textes parallèles. Cependant cette intervention du Seigneur à la 1e pers. était une caractéristique authentiquement jérémienne de ces deux textes parallèles. Il en va de même de l'entrée en scène de la 2e pers. pl. en Jr 15,14b et en Jr 17,4b. C'est elle qui donne à ces deux réemplois de Dt 32 leur caractère d'oracle prophétique.

Pourquoi, en chacun de ces deux endroits, le prophète passe-t-il de la 2e pers. sg. à la 2e pers. pl. ? On pourrait suggérer que c'est parce que le contexte de Dt 32,22 est à la 3e pers. pl. Il est donc normal que des actualisations de ce texte gardent le pluriel qui évoque le Cantique de Moïse comme étant leur source, alors que cette actualisation transforme en une apostrophe adressée aux contemporains du prophète ce qui, dans le Cantique, était une méditation du Seigneur sur le sort de ses fils et de ses filles (Dt 32,19).

Interprétations proposées :

Si l'on veut garder l'image de l'hébreu on traduira en 15,14: “car le feu a pris à mes narines et il brôle contre vous" et en 17,4: "car le feu de mes narines que vous avez allumé brûlera pour toujours."

17,13 cf. p. 469.

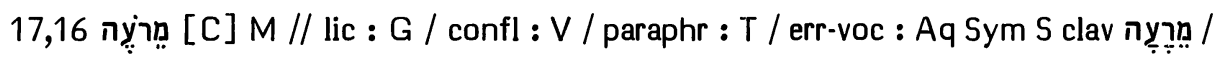
incert : 4Q-a

46,16 הרבה כושל [B] [B] // exeg: Aq V T / lic : G S

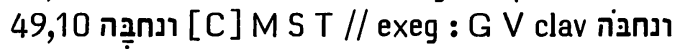

Options de nos traductions :

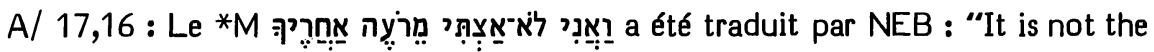
thought of disaster that makes me press after thee", Brockington disant qu'elle lit

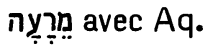


J conjecture לִ לִרִ pour traduire: "Pourtant je ne t’ai pas poussé au pire". De même, RSV : "I have not pressed thee to send evil", TOB : "Moi, je n'ai pas abondé dans ton sens en hâtant le malheur" et RL : "Aber ich habe dich nie gedrängt, Unheil kommen zu lassen".

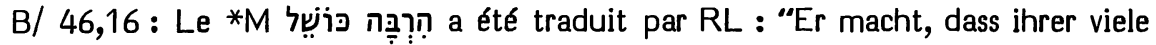
fallen", par TOB : “Il chancelle terriblement" et par J3 : “Il en fait trébucher beaucoup".

RSV se réfère au *G pour traduire: "Your multitude stumbled". Sur le même appui NEB fonde (selon Brockington) une correction en הִ pour traduire : “The rabble of Egypt stumbles". J12 conjecturent הִ pour le premier mot qu'elles rattachent au vs 15, puis elles traduisent le second selon le *G, ce qui donne: "(Oui, Yahvé l'a culbuté) de belle façon : il a chancelé".

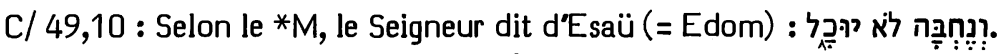

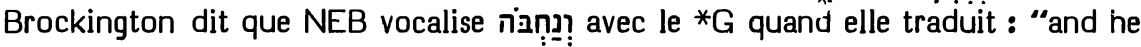
has nowhere to conceal himself":.

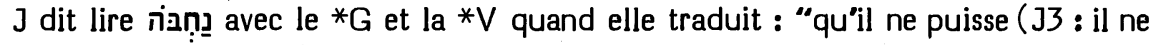
peut) plus se dissimuler ( $\mathrm{J1}$ : masquer)". Sans note, RSV traduit : "and he is not able to conceal himself", RL : "dass er sich nicht verbergen kann" et TOB : "Il ne peut se camoufler."

\section{Origines des corrections :}

A/ 17,16: Châteillon a suggéré de comprendre מרעה au sens de "nuire" et a traduit ainsi les deux premières phrases du vs, en notant leur parallélisme : "Si êt-ce que ie ne tâche pas a nuire, en te suivant, e ne desire pas la piteuse iournée". Michaelis (Observationes) a vocalisé avec la *S : מִ. Giesebrecht a fait de même, en se fondant sur Aq et Sym, suivi en cela par Oort, Dúhm, Cornill, Condamin, Steinmann, Hyatt et les apparats de HSAT34. Une correction en לִ לִ a été suggérée par Volz2 et adoptée par Nötscher, Rudolph, Penna, Bright et les apparats de BH3S et Cent.

Notons que Grätz (Studien 155) avait suggéré de vocaliser en infinitif ị̣ ou תִִּ

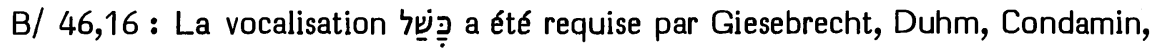
Ehrlich, Rudolph et les apparats de HSAT34, BH2S et Cent. Cornill y a ajouté une vocalisation en infinitif adverbial (nַ) du mot précédent. Puis Volz (Studien 297) a proposé la syntaxe que $J 12$ retiendront après qu'elle ait été adoptée par Nötscher et l'apparat de $\mathrm{BH} 3$.

Notons que NEB a essayé d'accommoder avec les consonnes du *M une conjecture (= ton ramassis) que RSV avait adoptée clandestinement à la suite de Giesebrecht, Duhm, Condamin, Penna et des apparats de $\mathrm{BH} 2$ et Cent.

C/ 49,10 : Ici, une vocalisation en infinitif a été adoptée par Michaelis (Observationes), Ewald, Graf, Böttcher, Nägelsbach, Grätz, von Orelli, Giesebrecht, Duhm, 
Ehrlich, Cornill, Volz, Nötscher, Rudolph, Penna, Weiser et par les apparats de HSAT34, BH23S et Cent.

\section{Les témoins anciens :}

A/ 17,16: 4Q-a est consonnantiquement identique au *M, la négation ayant été

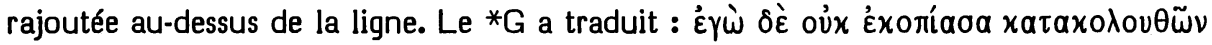
óríow oov.

Cette traduction large du $4 \mathrm{e}$ mot du $* \mathrm{M}$ a été unie à une traduction plus littérale en une leçon gonflée par la *V : "et ego non sum turbatus te pastorem sequens".

Le *T offre une paraphrase très libre du *M : "Quant à moi, à propos de ta parole, je n'ai pas négligé de prophétiser sur eux pour qu'ils se convertissent à ta crainte."

$\mathrm{Aq}$ (1e édition?) donne au lieu des $4 \mathrm{e}$ et $5 \mathrm{e}$ mots du ${ }^{*} \mathrm{G}:$ Éxparaíwoa árò

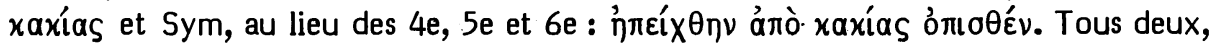

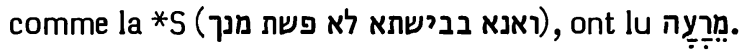

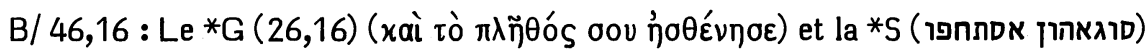
ont traité le second mot comme une forme verbale personnelle dont le premier serait le sujet.

Aq (אסגי מתכשלנא), la *V (multiplicavit ruentes) et le *T (אסגיאר מתקליהון) ont gardé la construction du $* M$.

C/ 49,10 : C'est une lecture du premier mot en accompli 3e pers. m. sg. qui fonde la traduction de la *S (ואתטשי) et la paraphrase du *T : "s'il cherche à se cacher".

Le *G $(29,11)(\chi \rho \cup \beta \tilde{\nu} \nu a l)$ et la $* V$ (et celari) semblent avoir lu ici un infinitif.

\section{Choix textuels :}

A/ 17,16 : La plupart des exégètes ont compris ici, avec Abulwalid, Vatable, Calvin et la Bible de Genève : "Je ne me suis pas hâté d"être pasteur à ta suite", estimant que cela fait allusion aux tentatives de Jérémie $(1,6)$ pour échapper à la vocation prophétique. Le parallélisme existant ici entre אתאויתי ot oriente naturellement vers cette exégèse. D'ailleurs, Berridge (140) a montré qu'une analyse correcte des parallélismes en Jr 2,8 illustre cette désignation des prophètes comme "pasteurs". Mais la construction normale du verbe ארץ devait être avec 'lamed' et l'infinitif (cf. Ex 5, 13; Jos 10,13; $\operatorname{Pr} 28,20)$. Or ici ce verbe est construit avec la préposition ph et un participe. Il ne suffit pas, pour rendre compte de cette construction, de prétendre, avec Abulwalid (Luma 58,7-9) que cette préposition est ici excédentaire.

Cette préposition semblant avoir une valeur privative, Yéfet ben Ely a compris: "Je ne me suis pas entêté dans mon refus d"être pasteur à ta suite"; mais, dès que tu m'as donné des assurances (1,7-10), je n'ai plus résisté. Joseph ibn Nahmias donne, lui aussi, en premier, cette exégèse. On peut objecter à cette interprétation qu'elle détruit le parallélisme avec le membre de phrase suivant. Cependant, les 4 membres du comité qui ont adopté cette exégèse comme justifiant bien le $* \mathrm{M}$ ont estimé que "être berger derrière" implique une tâche d'intercession qui, dans le cas de Jérémie, est clairement exprimée en 18,20; 14,11 et se prolongera en 2 M 15,14. 
On obtient ainsi un bon parallélisme : 'je ne me suis pas dérobé à la tâche d'intercesseur' correspond bien à 'le jour fatal, je ne l'ai pas souhaité'.

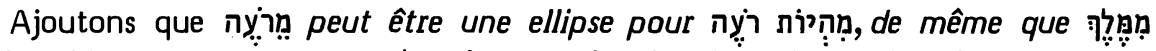

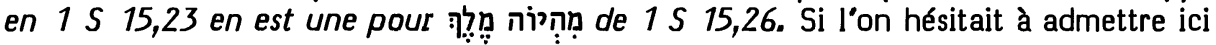
cette ellipse et si l'on était tenté de corriger avec Grätz (Studien 155) ce participe en

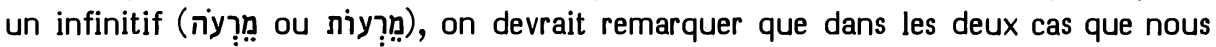
rapprochons de celui-ci $(46,16$ et 49,10$)$ le livre de Jérémie semble se servir de participes là où l'on attendrait des infinitifs, ainsi que Wernberg-Mpller (Observations 64s) l'a noté.

Le comité a donc attribué ici au *M 2 "B" et 2 "C". Deux autres membres ont cependant préféré suivre $\mathrm{Aq}$ et Sym en adoptant la vocalisation

$B / 46,16$ : L'exégèse la plus classique (représentée par $R L$ et J3) donne le Seigneur

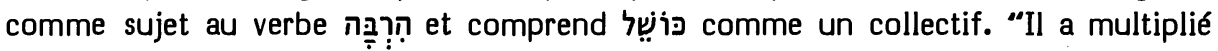
les trébuchants", c'est-à-dire : "il en a fait trébucher beaucoup".

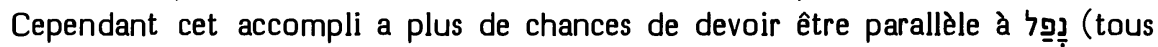
deux ayant pour sujet le mot איש qui suit ce verbe), ou bien d'avoir pour sujet "Apis" que le Seigneur vient de bousculer au vs précédent. En ce cas, il faut donner au hifil de רבה le sens de "faire souvent" (ou de "faire beaucoup") une action exprimée par le verbe qui le suit. Mais, dans ces constructions, le verbe suivant est normalement à l'infinitif, cet infinitif étant le plus souvent précédé d'un 'lamed', mais pouvant également ne pas l'être (cf. Is 23,16 ).

Le comité a estimé qu'ici Wernberg-Mpller avait raison d'attribuer à ce participe la valeur de l'infinitif que l'on attendrait normalement, le sens le plus vraisemblable étant celui que TOB a donné : “il chancelle terriblement". Cela prépare fort bien le 口ํㅡ qui suit et qui vient amplifier ce qui précède : "il chancelle ... et même il tombe"

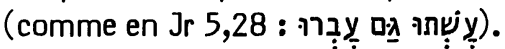

Estimant que la leçon du $* M$ n'a pas de concurrente sérieuse parmi des témoins textuels qui s"évertuent à l'interpréter, le comité lui a attribué la note " $B$ ".

C/ 49,10 : Abulwalid (Luma 165,1-4), Moshe ibn Giqatilla (en Hayyuj, Treatises, texte p. 76 et traduction p. 88), Menahem de Posquières, Judah ibn Balaam, Radaq et Tanḥum Yerushalmi voient en cette forme

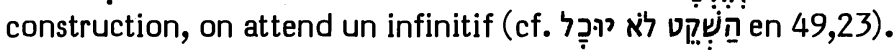

Cependant Keil et König (Lehrgebäude I 624) ont raison d'affirmer que cette forme peut être un accompli ou un participe, mais non un infinitif.

Ce cas est apparu au comité comme appuyant la thèse présentée à propos des deux précédents par Wernberg-Mpller. Aussi a-t-il attribué au *M 3 " $\mathrm{B}$ " et 3 "C".

Ajoutons que cet usage fait par le livre de Jérémie de participes au sens d'infinitifs a aussi été signalé par Wernberg-Mpller (Observations 65) en Jr 22,30.

Interprétations proposées :

A/ 17,16 : "Je ne me suis pas dérobé à être berger à ta suite."

Mais citons, au moins à titre de curiosité, l'interprétation proposée par Nägelsbach: "je ne me suis pas hâté de quitter la profession de berger pour te suivre". 
Etant donné que les membres de la tribu de Lévi ne participaient aux fonctions cultuelles qu'à partir de 30 ans ( $\mathrm{Nb} 4,3$ ) ou de 25 ans ( $\mathrm{Nb}$ 8,24), Jérémie qui appartenait à une famille sacerdotale $(1,1)$, mais qui se situe encore comme un tion $(1,6)$ n'était vraisemblablement pas encore au service du sanctuaire. Or, les familles sacerdotales n'exerçaient pas l'agriculture, mais elles élevaient des troupeaux (Nb 35,2-3) et disposaient pour cela de terres de pâture autour de leurs villes. A ce titre, une terre de pâture dépendait d’Anatot (Jos 21,18) dont Jérémie $(1,1)$ était originaire.

B/ 46,16: En fonction de l'option que nous prendrons en 46,15, on peut traduire ainsi ces deux vss : "(15) Pourquoi Apis a-t-il fui ? Pourquoi ton Taureau n'a-t-il pas tenu ? Oui, le Seigneur l'a bousculé. (16) Il est tout chancelant. Chacun tombe même sur son compagnon et ils disent etc."

C/ 49,10 : “Car c'est moi qui dénude Esaü, je mets à découvert ses cachettes : il ne peut plus se dissimuler."

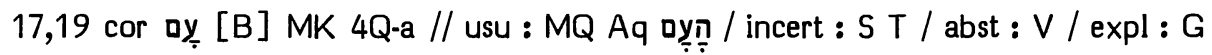

Options de nos traductions :

Le Seigneur ordonne à Jérémie d'aller se tenir à la porte l'article. Ce toponyme est traduit par J : "la porte des Enfants du peuple", par RL : "das Tor des Volks" (= Luther) et par TOB : "la grande porte (en notant : Litt. la porte des fils du peuple).

RSV et NEB traduisent : "the Benjamin Gate" en conjecturant, selon Brockington,

Origine de la correction :

Cette conjecture a été suggérée par Ewald, puis adoptée par Grätz (Studien 156), Ehrlich, Volz et Steinmann.

Von Orelli, tout en identifiant cette porte à celle de Benjamin, proposait de corri-

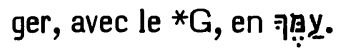

Les témoins anciens :

4Q-a porte ici une graphie identique au ketib du *M.

Le ${ }^{*} G$ donne ici $v i \tilde{\omega} \nu \lambda a o \tilde{v}$ oov. Aq fait précéder le deuxième substantif par l'article toũ.

La *V (filiorum populi) ne saurait départager ketib et qeré.

L'état emphatique araméen de la *S et du *T (בני עמא) ne garantit pas la présence d'un article dans leur Vorlage.

Choix textuel :

La correction de RSV et de NEB est donc une conjecture. Elle est d'ailleurs peu probable, car on ne voit guère comment ce nom de porte bien connu du livre de 
Jérémie (20,2; 37,13; 38,7) aurait été ici déformé en un toponyme intelligible, mais non connu par ailleurs.

Le ketib reçoit ici l'appui précieux de 4Q-a. C'est à partir de ce oy indéterminé que le ${ }^{*} G$ et le qeré $d u{ }^{*} M$ semblent avoir divergé, le ${ }^{*} G$ le déterminant par un possessif et le qeré par un article (sous l'influence de parallèles comme Jr 26,23; 2 R 23,6 et 2 Ch 35,5.7).

L'absence d'article du ketib correspond à une particularité que nous avons déjà signalée en ce livre (en 14,18, ci-dessus p. 588) à propos du mot ארץ On peut y ajouter encore דרכים 3,2 et 6,16.

Le comité a donc attribué la note "B" à la lectio difficilior du ketib.

Interprétation proposée :

Etant donné notre grande incertitude sur le sens que revêt cette expression ici (laïcs, foule, gens du vulgaire, israélites opposés à des étrangers) et sur la situation de cette porte (porte du Temple ou porte de la ville), mieux vaut traduire littéralement, à la manière de $\mathrm{J}$ : "la porte des Enfants du peuple".

\section{7,25 ושרים [A]}

Options de nos traductions :

Ce mot est traduit normalement par J3 ("et des princes"), alors que TOB le traite en incise : " - avec leurs ministres -".

RL, J12, RSV et NEB l'omettent.

Origine de la correction :

Michaelis (Observationes) avait vu en ce mot une épexégèse de מלכים qui le précède.

Graf l'a omis, suivi par Nägelsbach, Grätz, Giesebrecht, Duhm, Cornill, Nötscher, Rudolph, Penna, Steinmann, Weiser, Bright, ainsi que les apparats de $\mathrm{BH} 3 \mathrm{~S}$.

Les témoins anciens :

Tous traduisent normalement ce mot du $* M$.

\section{Choix textuel :}

Graf a motivé l'omission de ce mot d'abord par le fait que les שרים ne siègent pas sur le trône de David, puis par le fait qu'ils n'ont pas d'autres sous leurs ordres (comme le laisserait croire המה ושריהם, 8 mots plus loin). Il estime que l'omission de ce mot rend à ce passage une allure normale, analogue à celle de ses parallèles de 22,4 et de 13,13. L'insertion ici de ce mot s'expliquerait aisément par le fréquent rapprochement en ce livre des מלכים (1,18; 2,26; 25,18; 32,32; 44,17.21).

Giesebrecht a fait remarquer que la pénétration de cette ajoute est fort ancienne, puisque tous les témoins textuels l'attestent.

Une autre thèse sur l'origine de ce texte surchargé est présentée par les apparats de $\mathrm{BH} 2, \mathrm{HSAT} 34$. Volz (Studien 153), en accord avec eux, estime que ce mot est 
primitif ici. Mais ce seraient les 9 mots suivants (de ושריהם à qui auraient été ajoutés à partir de 22,4. Une ajoute analogue aurait pénétré en 13,13 à partir de la même source.

Ne vaut-il pas mieux admettre que l'on a ici une maladresse remontant à l'auteur lui-même? Après avoir joint spontanément מלכים ושרים, il qualifie le premier de ces deux termes par "siégeant sur le trône de David, montés sur des chars et sur des chevaux", puis il renoue la liste des sujets du verbe initial "et entreront" en reprenant les deux termes déjà énoncés au moyen de l'expression : "eux et leurs princes".

Interprétation proposée :

Cette maladresse de la construction devra être mise en lumière par une ponctuation adéquate ou par une note.

כחמר

Options de nos traductions :

Ce mot est traduit par RSV : "of clay", par RL : "aus dem Ton", par NEB : "out of the clay" et par TOB : "avec de l'argile".

J traduit : "comme cela arrive à l'argile" et dit suivre plusieurs mss en lisant “comme l'argile".

Origine de la correction :

Le sens donné ici à ce mot par $\mathrm{J}$ correspond à une leçon marginale de la King James Bible. Depuis ce temps-là, c'est l'interprétation la plus courante chez ceux qui adoptent la leçon avec 'kaf' qui, nous allons le voir, ne saurait être envisagée comme une correction critique.

Les hésitations entre 'bet' et 'kaf' :

L'édition princeps des Prophètes (Soncino 1486), l'édition princeps de la Bible (Soncino 1488) et (selon Ginsburg) l'édition Naples 1491-1493 lisent ce mot avec la préposition 'kaf'.

L'édition de Isaïe et Jérémie publiée à Lisbonne en 1492 est la première à donner ici la préposition 'bet'. En cela, elle a été suivie par l'édition Brescia 1494.

L'édition des Prophètes de Pesaro 1515 porte (selon Ginsburg) la leçon avec 'kaf'.

La leçon avec 'bet' est donnée par la polyglotte d'Alcala de 1514-1517 (selon Ginsburg) et par les trois premières éditions que Bomberg a publiées à Venise : la Bible rabbinique de Félix de Prato (1516-1517), l’édition in-quarto de 1517 et l’édition in-quarto des frères Adelkind en 1521.

On aurait pu croire la leçon avec 'bet' déjà victorieuse, mais le choix de la leçon avec 'kaf' par Jacob ben Hayim, dans sa Bible massorétique de 1524-1525, inversa la situation. Cette leçon était pourtant en contradiction avec le lemme de Rashi que cette édition donnait en marge et avec la mm qu'elle donnait sur Jb 10,9. La grande influence de cette édition s'est fait sentir dans le fait que, alors que la polyglotte d'Alcala 
portait la leçon avec 'bet', la polyglotte d'Anvers, aussi bien en son texte hébreu que dans le volume où figure la traduction interlinéaire de Pagnini retouchée par Arias Montano, porte la leçon avec 'kaf' (qui passera de là dans la polyglotte de Walton). Cela a entraîné d’ailleurs une retouche de la traduction "ex luto" de Pagnini (préservée par Servet et Estienne) en "velut lutum" par Arias Montano qui se veut plus près de ce qu'il croit être le *M. Ensuite, la leçon avec 'kaf' a été celle des éditions classiques d'Athias et de Van der Hooght, cette dernière ayant servi de base de collation à Kennicott et à de Rossi. C'est également elle que l'on retrouve dans les deux premières éditions de la Biblia Hebraica de Kittel (qui se fondait sur Ben Hayim). A ce titre, elle est adoptée tout naturellement par bon nombre d'exégètes antérieurs à la parution de BH3. C'est le cas de Venema, Graf, Nägelsbach, von Orelli, Ehrlich (Miqra), Volz. Puis elle est conservée, à titre de correction, par Nötscher, Rudolph, Penna, Steinmann, Weiser, Bright et Thiel $(214, n .13)$.

La leçon avec 'bet' a cependant été choisie par Münster dans sa Bible de 1534 et a régné dans les traductions du XVIe siècle (sous l'influence de Pagnini qui se fonde sur l'édition de Félix de Prato et sous celle de Luther qui se fonde sur l'édition Brescia 1494). D'ailleurs Elias Levita, dans les mss de Munich et de Paris de son Sepher Zikronot, opte pour elle. Les premières éditions critiques de la Bible hébraïque opteront aussi pour elle. C'est le cas de l'édition de Halle (faisant appel à la massore), de la Bible Minhat Shay (en conformité avec le jugement de Norzi), de l'édition d'Houbigant (disant se fonder sur les meilleurs mss) et de l'édition Baer (faisant appel à la massore).

Les vingt-huit mss du $* M$ que nous avons pu contrôler portent tous la leçon avec 'bet'. La massore lui apporte un double appui qui est sans équivoque. Nous avons en effet mentionné que Ben Hayim donne sur Jb 10,9 une mm attestant que rencontre que là et en Jr 18,6 (où une mp " 2 " correspondant à cette massore est donnée par le ms de Berne des Prophètes, le ms Vatican ebr 482 et les mss 2 et 7 de Copenhague). Dans le ms d'Alep et dans celui du Caire, une mp précise en Jr 18,4 que במֵn ne se rencontre que là et en $\mathrm{Na} 3,14$. Une mp "2", en accord avec cela, est donnée sur Jr 18,4 par le ms de Leningrad, le ms Urbinates 1, le ms Paris BN hébr 6 et le ms 6 de Hamburg. Nous n'avons rencontré aucune massore discordante.

La situation est si limpide du côté des massores et des manuscrits qu'il est surprenant qu'une faute typographique commise en 1486 ait pu, grâce au prestige de Ben Hayim, dominer les Bibles hébraïques jusqu'au jour où la Biblia Hebraica a décidé de reproduire le ms de Leningrad.

\section{Les versions anciennes :}

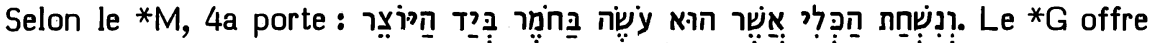

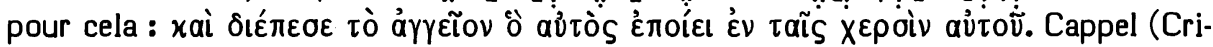
tica 670 et 745s), qui lisait dans la polyglotte d’Anvers la leçon כמחמ, a estimé que le * $G$ a omis ce mot et les deux suivants et a estimé que ces trois mots ont été insérés ici à tort par le *M à partir de 18,6 (opinion qui sera reprise par Hitzig, Grätz, Condamin et Schmidt). Buxtorf Jr (Anticritica 609), qui lisait lui aussi la leçon avec 'kaf', a estimé que le ${ }^{*} G$ n'avait omis que ce seul mot (qu'Ewald omettra ensuite). Scharfenberg (en ses notes sur Cappel), qui lisait la leçon avec 'bet', a estimé que le ${ }^{*} G$ a assez bien traduit le *M. Cependant Giesebrecht estime que le *G a lu בידיו au lieu de 
ces trois mots et il opte pour cette leçon, suivi par Oort, Duhm, Cornill et les apparats de HSAT234, $\mathrm{BH} 2$ et Cent.

Dans la recension origénienne, une ajoute astérisée attribuée à ThAq rend ce mot

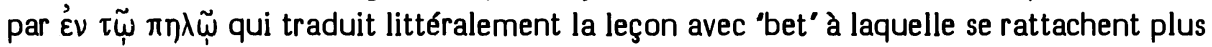
librement les traductions de la *V (e luto), de la *S et du*T (דטינא).

\section{Choix textuel :}

Notons que la *S a réuni en sa traduction le mot "vase" ( $=2 \mathrm{e}$ mot du $* M)$ et le mot "d'argile" (= 6e mot du *M) en מאנא דטינא. Scharfenberg a eu raison de supposer

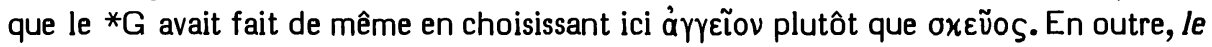
${ }^{*} G$ a opéré un allègement stylistique en évitant de répéter encore deux fois en ce vs le mot "potier" qui a figuré déjà deux fois dans les deux vss qui précèdent. On comprend, par contre, que Cappel et Buxtorf, qui lisaient dans le *M la leçon avec 'kaf', y voyaient un sens que rien n'évoquait dans le *M.

Le comité a attribué la note "B" à la leçon avec "bet".

Interprétations proposées :

Certains exégètes ont mis en doute que la préposition 'bet' puisse servir à introduire le matériau avec lequel on fabrique quelque chose. Noldius (146a) donne des exemples qui suffisent largement à établir ce sens pour cette préposition. On pourra donc traduire: “Lorsque l'objet qu'il était en train de façonner avec l'argile ratait sous la main du potier..."

On pourrait aussi proposer : “Lorsque l'objet qu'il était en train de faire ratait, l'argile étant sous la main du potier, ..."

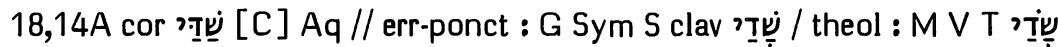

\section{Options de nos traductions :}

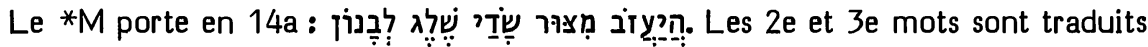
par TOB : "ce qui ... jaillit des rochers dans la campagne"; par J3: "le rocher de la campagne" et par RL : "auf den Steinen im Felde". J12 traduisait librement : "du roc altier", comprenant le * $M$ au sens de "roc (qui domine) la campagne".

RSV conjecture : "the crags of Sirion".

Selon Brockington, NEB lit שִִׁ ou ou quạ quand elle traduit : "on the rocky slopes".

Origines des corrections :

La conjecture de RSV a été proposée par Grätz (Studien 157) et adoptée par Duhm, Cornill, Rudolph et Hyatt, ainsi que par les apparats de SBOT et de Cent.

La première des corrections que mentionne Brockington a été proposée par Gordis (Root 37) au sens de "écoulement, torrent" et adoptée par Driver (Hebrew 168). Ils semblent ignorer que Michaelis (Observationes) avait déjà estimé que le *M peut signifier "irrigation" selon l'arabe 
Les témoins anciens :

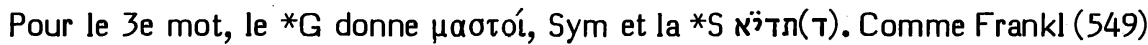

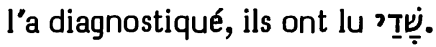

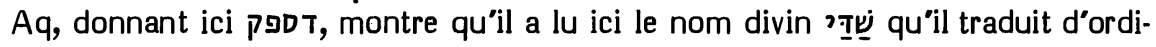
naire ainsi.

La leçon du *M est attestée ici par la*V (agri) et le *T (חקלי).

\section{Choix textuel :}

Il est difficile en ce contexte de faire une place à ce mot au sens de 'champ'.

Notons que la plupart des témoins (le *G, Aq, Sym et la ${ }^{*} S$ ) lisent la première consonne comme un 'shin' et que l'interprétation 'le roc de Shaddaï', qui était celle d'Aq, a été reprise par Abravanel. Il s'agirait selon lui du nom d'un pic de la chaîne du Liban toujours enneigé et remarquable pour son altitude. Cette exégèse a été reprise par Luzzatto et par Weiser. Alors qu'un membre du comité gardait la leçon du *M avec la note "D", les cinq autres adoptaient cette correction avec la note " $\mathrm{C}$ ".

Il est probable que la vocalisation du ${ }^{*} M$ est issue d'un tiqqun, ce nom évoquant peut-être le souvenir de cultes païens.

Interprétation proposée :

"Est-ce que la neige du Liban abandonne le Roc de Shaddaï ?"

Notons le nom propre Șurishaddaï qui apparaît cinq fois dans le livre des Nombres.

\section{8,14B ?ִ ? [A] [A ] M V // exeg : G Aq Sym S T}

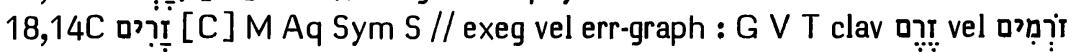

Options de nos traductions :

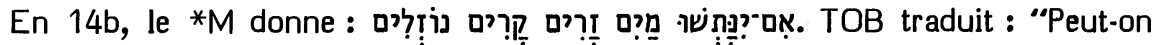
rejeter les eaux qui viennent de loin et s'écoulent toutes fraîches."

Disant faire deux conjectures en 14B et en 14C, RSV traduit : “Do the mountains waters run dry, the cold flowing streams." RL se contente de : "und das Regenwasser verläuft sich nicht so schnell". Selon Brockington, NEB se réfère au *G pour lire "Wẹ:? en 14B, et elle conjecture ț en 14C quand elle traduit : "Will the cool rain streaming in torrents ever fail ?"

Corrigeant de même en 14B et lisant ou tarir les eaux orgueilleuses, fraîches et courantes ?"' J3, ne gardant que la 1e correction, traduit : "Tarissent-elles, les eaux des pays étrangers, les eaux fraîches et courantes ?"

Origines des corrections :

A/ 14B : La permutation de consonnes adoptée par NEB a été proposée par Grätz (Studien 157), suivi par Giesebrecht, Condamin, Ehrlich et les apparats de HSAT34, $\mathrm{BH} 23 \mathrm{~S}$ et Cent. 


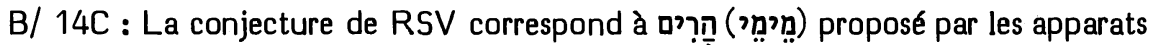
de $\mathrm{BH} 2$ et Cent, ou à הִ מִ (מירים (u par Penna et Hyatt. Notons que HSAT34 et Con-

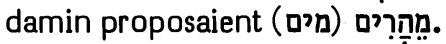

La correction de 312 a été proposée par Cappel (Notae 526b) diagnostiquant en cette leçon la Vorlage du *G, puis adoptée par Nägelsbach (comparant avec Ps 124,5).

C'est Luther qui a traduit Iִ מַ par "das Regenwasser". Clericus, se fondant sur la $* V$ et le ${ }^{*} T$, lit ici la leçon que NEB retiendra après que Gordis (Root 39) l'ait adoptée.

Les témoins anciens :

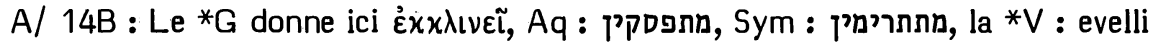
possunt, la *S : מתכלין et le *T : Toutes les versions semblent avoir lu le *M en s'aidant du contexte. En tout cas, aucun de ces correspondants ne se retrouve dans les traductions qu'elles donnent de נשנ Jr Jr 51,30; Is 19,5; 41,17.

B/ 14C : Le *M a été lu ici par Aq, Sym et la *S (נוכר̈).

Volz (Studien 158) et Rudolph estiment que ßıаıws du *G correspond ici à une

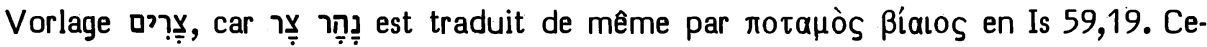
pendant, Schleusner (I 563) estime plus probable que le ${ }^{*} G$ a dérivé la leçon du ${ }^{*} M$ de d'une expression où figure

Selon Perles (I 29), le *T (מי מטר נחתין) a cru lire ici la même racine, car, en Ps 77,

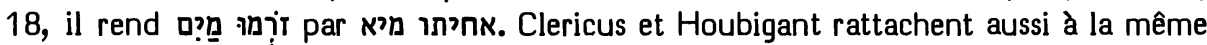
racine la traduction de la *V: "erumpentes".

\section{Choix textuel :}

A/ 14B : Alors que Rashi et Menahem de Posquières se contentent de considérer ce verbe comme synonyme de celui du membre de phrase précédent, David ben Abraham (II 294,43ss) estime que ce verbe a le sens ici de ינשתו, c'est-à-dire "est absorbée par la terre", ce qu'il illustre par Is 19,5. Abraham ha-Babli $(200,13)$ juge de même, suivi en cette exégèse par C.B. Michaelis, Gesenius (Thesaurus 931b) et Keil.

Radaq estime que le 'taw' a été écrit ici à la place du 'țeț', le verbe שvن étant souvent employé en parallèle avec zry. En cette suggestion, il a été suivi par Pagnini (Thesaurus 1530), Buxtorf (Lexicon 498) et Venema.

Le sens normal du verbe du *M est respecté ici par Yéfet ben Ely, Menahem ben Saruq, Abulwalid (Ușul 470,9), Ewald et Hitzig, ce dernier estimant très parlante cette image dans le cas des eaux de sources qui peuvent tarir, mais ne sont jamais déracinées, c'est-à-dire qu'elles se remettent à sourdre à partir de la même origine, comme la souche qui émet à nouveau des surgeons.

Estimant que toutes les versions ont eu le ${ }^{*} \mathrm{M}$ pour Vorlage, le comité lui a attribué la note "A".

B/ 14C : Le parallèle avec $\operatorname{Pr} 25,25$ engage à donner ici à pרים le sens de 'froides'. Il semble que plusieurs témoins anciens ont cru lire en $14 \mathrm{C}$ la racine זרם $\mathrm{Si}$ on 
lui donne, avec le *T et NEB, le sens d'eaux de pluie, cela ne s'accorde pas très bien avec le qualificatif de 'froides'.

Mieux vaut donc, avec $\mathrm{Aq}$, Sym et la *S, comprendre $14 \mathrm{C}$ au sens de 'étrangères'. L'expression מים זרים a en effet été comprise en ce sens par toutes les versions en $2 R$ 19,24. Si l'on interprète le "roc de Shaddai" comme l'un des sommets neigeux du nord (Hermon ?), il n'y a pas de difficulté à comprendre par les "eaux étrangères qui coulent froides" les sources initiales du Jourdain.

Le comité a attribué à cette leçon du *M la note "C".

Interprétation proposée :

“Est-ce que changent de source (litt. : se déracinent) les eaux venant de loin qui sourdent froides ?"”

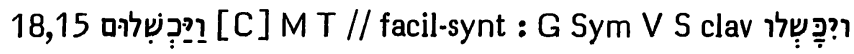

Options de nos traductions :

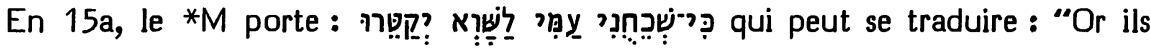
m'avaient oublié, eux les membres de mon peuple; ils encensaient la vanité", ce dernier mot étant un collectif signifiant les faux dieux. Ensuite, 15b commence par ("et ils les firent trébucher en leurs routes, les voies d'antan")

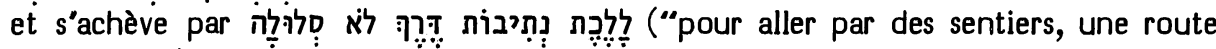
non frayée").

Le verbe initial de 15b a été interprété par TOB comme ayant pour sujet "les faux dieux" : "(... à ceux qui ne sont rien,) qui le font trébucher". Même construction en RL : "(... den nichtigen Göttern.) Die haben sie zu Fall gebracht". Quant à J3, elle donne à ce verbe pour sujet les chefs du peuple, en traduisant par un impersonnel : "on les fait trébucher".

RSV et $J 12$ disent suivre le ${ }^{*} G$, la $* V$ et la ${ }^{*} S$ en traduisant : "they have stumbled" et : "ils ont bronché". Sans note, NEB traduit de même : "so they stumble".

Origine de la correction :

Houbigant (qui ne s'intéresse pas aux voyelles) a proposé de lire ici ויכשלו en notant que seul le *T lit ici le suffixe 'mem' du *M. Michaelis (Observationes) a souligné à son tour ce relatif isolement du $* \mathrm{M}$, estimant que les autres versions ont lu

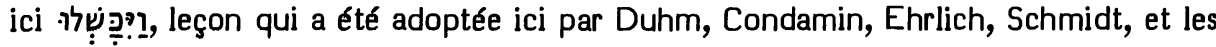
apparats de HSAT34, BH2 et Cent; alors que Giesebrecht et Bright lisent un inaccompli inverti qal et $\mathrm{BHS}$ un inaccompli coordonné nifal.

Les témoins anciens :

Le *T (ואטעיאונון) appuie le *M.

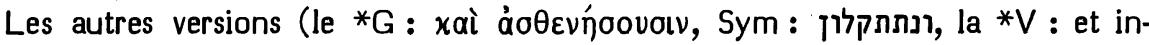
pingentes et la *S : ואתתקלו ( n'ont pas lu de pronom suffixe et ont vocalisé ce qu'elles lisaient ou bien en nifal, ou bien en qal. 
Choix textuel :

Il est difficile de déterminer le sujet du hifil qu'offre le *M.

Il semble donc que l'option prise par la plupart des versions (à la suite du ${ }^{*} G$ ) est facilitante.

Notons d'ailleurs une facilitation analogue en 2 Ch 28,23 où le *M dit des dieux

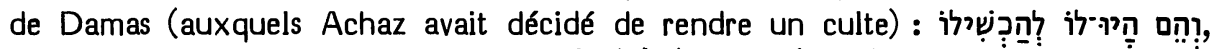

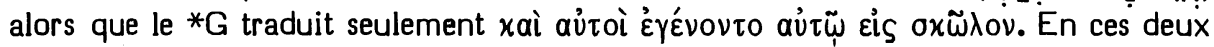
cas, il semble que le ${ }^{*} G$ veuille éviter de faire des faux dieux le sujet d'une action ayant Israël pour complément d'objet.

Le comité a attribué ici au *M la note "C".

Interprétation proposée :

“... ils encensaient les dieux de néant. Et ceux-ci les firent trébucher en leurs routes, les voies d'antan, de sorte qu'ils marchent par des sentiers, une route non frayée."

Les "voies d'antan" sur lesquelles ils ne sont plus capables d'avancer d'un pas assuré sont identiques aux "sentiers d'antan" (même génitif : achìy en Jr 6,16). Il s'agit de la conduite traditionnelle des générations passées fidèles à la parole de Dieu. En Jr 6,16, cette expression a pour parallèle le דֶּרֶר הַט (= la route du bonheur), alors qu'ici elle a pour contraire la "route non frayée".

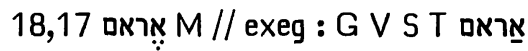

Options de nos traductions :

Après avoir dit: "je les disperserai devant leurs ennemis", le Seigneur ajoute :

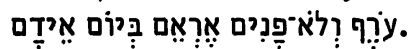

TOB dit lire le verbe "voir' à la forme causative avec le *G, la*V, la *S, le *T et des commentateurs juifs lorsqu'elle traduit "je leur montre ma nuque et non ma face". J se fonde sur le ${ }^{*} G$, la $* V$ et la ${ }^{*} S$ pour traduire: “C $C$ 'est mon dos et non ma face que je leur montrerai". Traduisent de même, sans note, RL ("Ich will ihnen den Rücken und nicht das Antlitz zeigen"), RSV ("I will show them my back, not my face") et NEB ("I will turn my back toward them and not my face").

Origines de la correction :

RL a seulement copié ici Luther qui, à travers la vieille traduction allemande (Kurrelmeyer IX 68,55) : "ich zaig in", dépendait de la *V (ostendam eis). De même, RSV reprend seulement la traduction de Ge et de KJ : "I wil shew them".

Au XVIe siècle, la tradition biblique italienne respectait cette forme qal du *M (Brucioli traduisant : "Il collo \& non la faccia vedro à loro"), et de même la tradition biblique française (Olivetan, Rollet et Estienne traduisant: "ie leur verray le dos \& non pas la face", alors que Pasteurs remplace le 'dos' par le 'cheignon du col').

La grande influence conjointe de la ${ }^{*} V$ et de Luther explique que Rothstein (= HSAT 234) ait proposé de corriger le verbe en hifil (אַ), suivi en cela par Condamin, Ehrlich, Volz, Schmidt, Nötscher, Rudolph, Penna, Steinmann, Weiser, Bright et les apparats de SBOT, $\mathrm{BH} 23 \mathrm{~S}$ et Cent. 
Les témoins anciens :

En faveur de la vocalisation patah du 'alef', de Rossi ne cite aucun témoin. Ni la Bible de Halle, ni la Minhat Shay, ni Baer n'ont de note sur ce mot. Cependant $\mathrm{BH} 235$ l'attribuent aux "orientaux" et HSAT3 à une "tradition babylonienne", sans qu'il soit possible de savoir sur quoi se fonde cette information (à laquelle HSAT4 a d'ailleurs renoncé). Ginsburg dit avoir trouvé cette vocalisation dans le ms Londres BL Or 1474. Ce témoin isolé copié à la fin du XVIe siècle n'a aucune autorité.

Il est donc impossible d'ébranler le monolithisme de la tradition textuelle du *M. Cela rend d'autant plus surprenant le fait que toutes les versions ont traduit comme

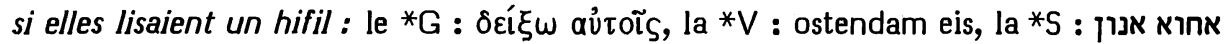
et le *T : אחזינון.

Choix textuel et interprétation proposée :

Ce cas n'a pas été soumis au comité.

Un motif pour lequel Luther a conservé ici l'interprétation de la vieille traduction allemande par le verbe 'zeigen' est certainement que Pagnini (ostendam eis $=* \mathrm{~V}$ ), Prédicants ("wil ich ... bieten") et Zwingli ("ipsis advertam") avaient pris la même option. Pagnini était même allé jusquầ classer (en 1529, dans la première édition de son Thesaurus, col. 2247) cette forme ארִֵ de Jr 18,17 dans le hifil de ראה (Dans la 3e édition de son Thesaurus (coll. 2576 et 2582), Cevallerius et Mercerus déplaceront cette forme dans le qal en traduisant par "videbo" au lieu de "ostendam" que donnait Pagnini.

C'est Radaq qui avait amené Pagnini à ce classement surprenant en commentant ainsi : "Mesure contre mesure. De même qu'ils ont tourné vers moi la nuque et non la face, de même je tournerai vers eux la nuque et non la face. אראם veut dire je me tournerai vers eux. C'est-à-dire que lorsque viendra le jour de leur ruine, je leur cacherai ma face et je ne les verrai pas avec la face pour les sauver. Il n'y aura de vision que de la nuque, ce qui signifie dissimulation de la face et rejet derrière le dos".

La quasi-totalité des exégètes est demeurée sous l'influence de Radaq, de Luther ou de $\mathrm{KJ}$. Pourtant l'exégèse la plus naturelle est celle des traductions de Brucioli et d'Olivetan. Elle a été adoptée par Venema, Ehrlich (Miqra) et Joüon (126g). Radaq a eu raison de voir ici une sorte de talion par rapport à Jr 2,27; 32,33 ("ils ont tourné vers moi la nuque et non la face"). Mais ce talion ne consiste pas, comme Radaq et la quasi-totalité des exégètes l'ont pensé, en ce que le Seigneur, au jour de leur ruine, tournera à son tour vers eux sa nuque et non sa face. Il consistera en ce que, ce jour-là, le Seigneur les dispersant, comme par un sirocco, devant leur ennemi, les contemplera de nuque et non de face, au jour de leur ruine, c'est-à-dire qu'en les dispersant il assistera à leur fuite. En effet, mettre en fuite l'ennemi de quelqu'un se dit en hébreu biblique (Ex 23,27; Ps 18,41) : donner à quelqu'un son ennemi 'de nuque' (१ָ̣ y avec valeur adverbiale). Donc, voir de nuque et non de face, c'est voir fuir.

On pourra donc traduire : "C'est de nuque et non de face que je les verrai". 


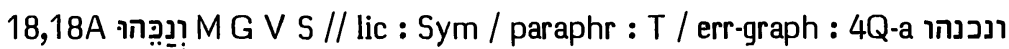
18,18B בלשרן [B] M 4Q-a G V // paraphr : T / expl : S

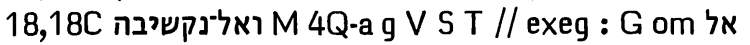

\section{Options de nos traductions :}

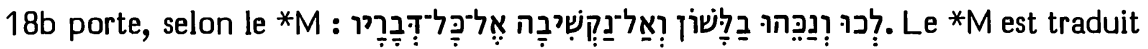
par RSV : "Come, let us smite him with the tongue, and let us not heed any of his words", par NEB : "Come, let us invent some charges against him; let us pay no attention to his message", par TOB : “Allons donc le démolir en le diffamant, ne prêtons aucune attention à ses paroles" et par J3: "Venez! Dénigrons-le et ne prêtons attention à aucune de ses paroles."

$\mathrm{J12}$ ont corrigé $18 \mathrm{~B}$ selon la ${ }^{*} \mathrm{~S}$ et omis la négation de $18 \mathrm{C}$ avec le ${ }^{*} \mathrm{G}$ pour traduire : "Venez! frappons-le par sa propre langue : soyons attentifs à chacune de ses paroles". RL n'a retenu que la 1e de ces corrections en traduisant : "Kommt, lasst uns inn mit seinen eigenen Worten schlagen und nichts geben auf alle seine Reden".

\section{Origines des corrections :}

Houbigant a noté que la *S semble avoir lu ici בלשרנו. Grätz (Studien 158s) a proposé d'omettre la négation en $18 \mathrm{C}$ avec le ${ }^{*} \mathrm{G}$. Giesebrecht a fait remarquer que cette omission suppose que le mot suivant soit compris au sens de "prenons-le à ses propres mots".

L'ajoute du pronom suffixe en 18B a été jointe à l'omission de la négation en $18 \mathrm{C}$ par Volz, Schmidt, Rudolph, Steinmann, Weiser et les apparats de HSAT4 et de BH3S.

Ehrlich (Miqra) s'est contenté de la 1e correction; alors que la $2 \mathrm{e}$ seule a été adoptée par Cornill, Nötscher, Penna, Hyatt et l'apparat de HSAT 3.

\section{Les témoins anciens :}

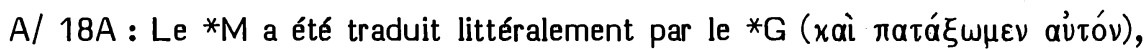
la *V (et percutiamus eum) et la *S (נמחיוהי).

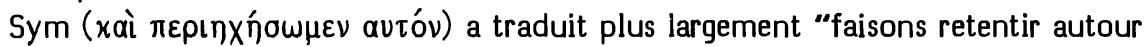
de lui" (des propos menaçants). Le *T a fait de même en traduisant ce mot et le suivant par : "apportons contre lui des témoignages mensongers".

4Q-a écrit ici ונכנהו. Janzen (180) considère cette insertion d'un 'nun' comme

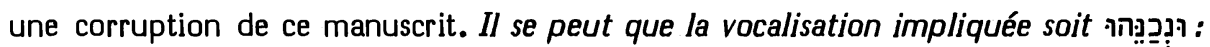
"et donnons-lui des titres flatteurs". Jb 32,21-22 considère en effet l'acte qu'exprime le piél de ce verbe comme un péché grave. Evoquons à ce propos Jr 12,6: “Ne te fie pas à eux quand ils te disent de bonnes choses."

$B / 18 B$ : Le *M (auquel 4Q-a est identique) est traduit littéralement par le ${ }^{*} G$ et la *V. Il est paraphrasé comme nous l'avons dit par le*T.

La *S est seule à expliciter un pronom suffixe : בלשנה.

C/ 18C : 4Q-a atteste, avec une ajoute astérisée, la *V, la *S et le *T, la négation du $* M$ que le ${ }^{*} G$ omet. 


\section{Choix textuel :}

Seul 18B a été soumis au comité. Etant donné qu'ici le $* G$ appuie le $* M$ pour l'absence du pronom suffixe, il serait bien surprenant que la *S seule témoigne d'un état original de la tradition protomassorétique qui, dans tous les autres témoins, aurait été assimilé à la tradition du ${ }^{*}$ G. Plutôt que de supposer avec Rudolph que le * $M$ a subi une haplographie du 'waw' final, le comité a admis avec Houbigant que le pronom suffixe est une explicitation interprétative du traducteur syriaque. Aussi a-t-il attribué à la leçon du * $M$ la note " $B$ ".

En 18A, la leçon intéressante de 4Q-a est trop isolée pour qu'on puisse lui attribuer un grand poids. Avec elle, 18B fait d'ailleurs pléonasme et la phrase finale du vs s'articule mal.

En $18 C$, c'est le ${ }^{*} G$ qui est isolé, alors que $4 Q$-a apporte son appui au *M flanqué des autres versions. D’ailleurs, Cornill, quoique partisan de la leçon du ${ }^{*} G$, a fait remarquer que ce verbe ne signifie jamais 'épier' avec une mauvaise intention, mais 'prêter l'oreille' avec une attention accueillante à ce que quelqu'un veut dire. C'est ce qui a amené Volz à corriger ce verbe par conjecture, en complément de l’omission de la négation. Si on garde ici la leçon du *M : "et ne faisons attention à aucune de ses paroles", on obtient un excellent contraste avec la supplique qui est ainsi introduite : "Fais attention à moi, Seigneur !" L'omission de la négation par le * ${ }^{*}$ est associée par Wichelhaus $(133)$ à trois cas $(5,2 ; 7,10 ; 9,4)$ où le $* G$ prend la liberté d'ajouter une négation.

Interprétation proposée :

En Jb 5,21 la calomnie dénonciatrice est appelée 'le fouet de la langue'. Il n'est donc pas étonnant que les ennemis de Jérémie complotent de le 'frapper (à mort) par la langue', ce qui présuppose qu'ils se refusent à se laisser toucher par ses oracles. En effet, ceux qui seraient tentés d'admettre que c'est au nom du Seigneur qu'il parle n'oseraient pas condamner Jérémie (26,16-19).

On pourra done traduire littéralement: "Venez! Frappons-le avec la langue" ou, plus librement: "dénigrons-le" avec 33 ou "Allons donc le démolir en le diffamant" avec TOB.

\section{ריבי ?י?ריבְי [B,19] M Aq Sym V // exeg : G S T clav}

Options de nos traductions :

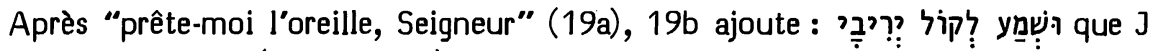
traduit : "et entends ( $\mathrm{J1}$ : perçois) ce que disent mes adversaires", NEB : "and hear what my opponents are saying against me", TOB : "écoute ce que disent mes accusateurs" et RL : "und höre die Stimme meiner Widersacher".

En traduisant: "and hearken to my plea", RSV dit suivre le ${ }^{*} G$ et se réfère à la $*$ S et au $* T$.

Origine de la correction :

C'est Giesebrecht qui a proposé de corriger ici en ירִ? suivi en cela par Ehrlich, Volz (hésitant), Steinmann, Weiser, Bright et l'apparat de BH2. 
Les témoins anciens :

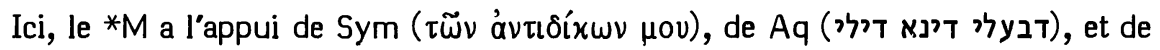
la *V (adversariorum meorum).

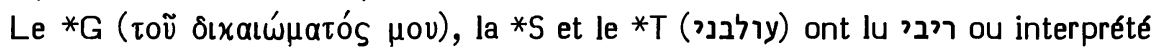
ainsi le *M.

Choix textuel :

L'adjectif ?ִ (= adversaire) ne réapparaît dans le *M qu'en Is 49,25 et Ps 35,1.

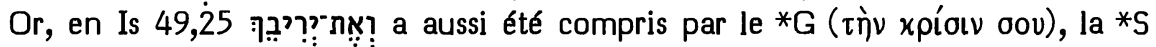
(ודיניכי) et le *T (ורית פורענותיך) au sens de ריב (= procès); alors qu'en Ps 35,1, seule la *S (דיני) lui donne ce sens.

Il semble donc qu'en Jérémie comme en Isaïe les trois mêmes versions ont confondu ce mot avec le substantif abstrait d'usage plus fréquent

Aussi le comité a-t-il attribué ici au *M 5 "B" et 1 " $A$ ".

Interprétation proposée :

La variante aboutit à un parallélisme plat, alors que le ${ }^{*} M$ fait du Seigneur l'arbitre entre Jérémie et ses adversaires, écoutant les déclarations de chacune des parties opposées. La traduction ne fait pas difficulté.

18,20 כי־כרו שוחה לנפשי כB] M 4Q-a Aq Sym V S T // assim vs 22 (ketib) : G clav כ' כ' - שיחה ל לנפשי

Options de nos traductions :

Après avoir dit: "entends ce que disent mes adversaires!", le prophète fait du Seigneur l'arbitre de son procès : ils complotent contre lui alors qu'il intercédait pour eux. C'est ce qu'exprime le vs 20 du *M: “Est-ce que l'on rend le mal pour le bien ? Or ils creusaient une fosse pour mon âme! Rappelle-toi comme je me tenais devant toi pour parler d'eux en bonne part, pour détourner d'eux ta fureur".

La deuxième phrase de ce vs est traduite normalement par RSV, J, RL et TOB. Mais NEB l'omet par conjecture en notant sa similitude avec le vs 22 .

Origine de la correction :

Giesebrecht ayant estimé que cette phrase est une glose issue du vs 22, elle a été omise ici par Duhm, Volz, Schmidt, Rudolph, Steinmann et par l'apparat de BH3.

Les témoins anciens :

Selon Janzen (180) une lacune de 4Q-a fait exactement place à cette phrase, mais ne pourrait inclure le 'plus' du *G.

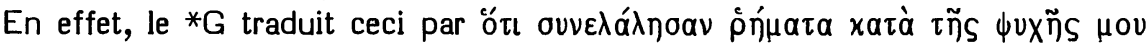

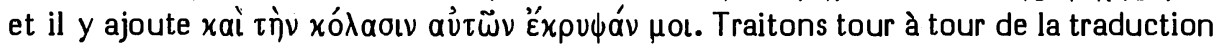
qu'il offre de la phrase du *M et du 'plus' qu'il y ajoute.

1/ Le complément d'objet du verbe ำ est écrit avec 'yod' en Ps 57,7; 119,85 (pluriel); Jr 18,22 (ketib). Il est écrit שוּח avec 'waw' en Jr 18,20.22 (qeré). $L$ 'existence d'une graphie avec 'yod' explique que le ${ }^{*} G$ ait confondu ce mot signi- 


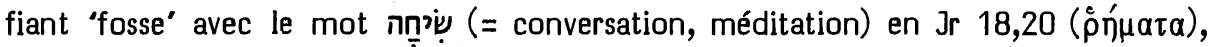

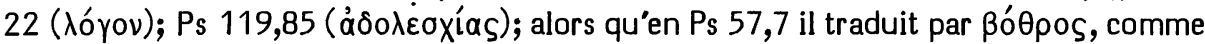
en $\operatorname{Pr} 22,14$ où il apparaît en un autre contexte. Lorsque le ${ }^{*} G$ a compris ce mot

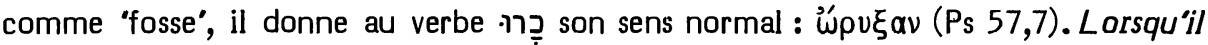
l'a compris comme 'conversation', il s'inspire de cette option pour traduire le verbe :

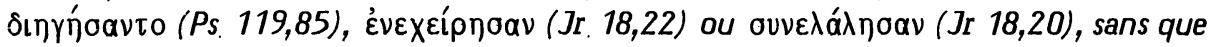
nous ayons a supposer qu'il ait lu autre chose.

2/ Dans le parallèle tout proche de Jr 18,22 où le *M offre

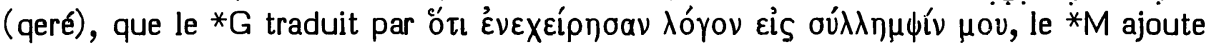

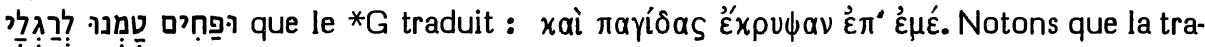
duction du dernier mot par le $*$ G suppose une assimilation aux deux autres cas où le même verbe a le même substantif pour objet direct (Ps 140,6; 142,4) et où il a en effet pour objet indirect יל. En Jr 18,20, le 'plus' du *G présuppose une Vorlage

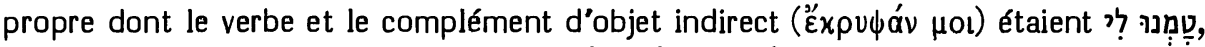

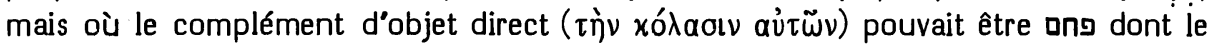
'mem' final aurait été compris comme un suffixe 3 e pers. m. pl. et non comme la désinence du pluriel (que le ${ }^{*} M$ et le ${ }^{*} G$ attestent en 18,22 ).

En Jr 18,20 un obèle de la recension d'Origène montre que celui-ci lisait dans l'hébreu (et dans les autres colonnes de ses hexaples) un texte ayant la même ampleur que notre *M. Il en va de même pour la*V, la *S et le *T.

Choix textuel :

Il est normal qu'au vs 20 Jérémie se contente d'ébaucher, sous forme d'incise, la description du complot ourdi contre lui par ses adversaires, alors qu'en $22 b$ il reprendra cette description sur un mode plus ample.

En tout cas, en 18,20, la phrase que NEB voudrait omettre fait partie de toute la tradition textuelle. Aussi le comité a-t-il résolu de la maintenir. Il n'a cependant attribué au *M que la note " $B$ " à cause d'une incertitude sur la vocalisation "yod" ou 'waw' du 3e mot dans la Vorlage du *G.

Interprétation proposée :

Nous avons traduit l'ensemble de ce vs au début de l'étude de ce cas.

19,1A ĩ [B] MV S T // facil-synt : $G$

אלי 19,1B יהוה [B] M V T // expl : m G S t add

Options de nos traductions :

En début de cette péricope, le *M introduit l'ordre divin donné à Jérémie par

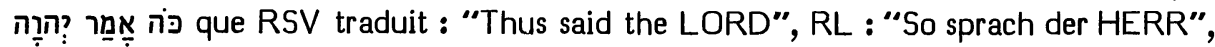
NEB : "These are the words of the LORD" et TOB : "Ainsi parle le SEIGNEUR."

$\mathrm{J}$ traduit : "Alors Yahvé dit à Jérémie", se fondant sur le *G pour lire "alors" en $1 A$ et s"inspirant du complément "à moi" du *G pour conjecturer "à Jérémie". 
Origines des corrections :

Duhm estime que le *G a luici אַָ א' ר"אַל et que cette leçon est peut-être originale. Volz s'inspire du 'plus' final du *G pour ajouter "à Jérémie", parce que cette péricope $(19,14 ; 20,1-3)$ parle de Jérémie à la 3e personne. Il est suivi en cela par Penna, Steinmann, Weiser; alors que HSAT4, Cent et Bright y ajoutent la leçon ֵㅡ de la Vorlage du *G. Schmidt lit "à Jérémie" après $1 B$ et adopte la leçon du * ${ }^{*}$ en $1 A$. En cette double correction, il est suivi par Rudolph et les apparats de BH3S.

\section{Les témoins anciens :}

לֵֵ est ajouté après 1B par 6 mss du *M, la 1e main de 4 autres et la 2 e main de 2; ainsi que par les éditions princeps de Soncino des Prophètes (1486) et de la Bible (1488). Cependant, la massore précise que 13,1;17,19 et 27,2 sont les trois seuls endroits où se rencontre la formule כה אמר יהוה אלי

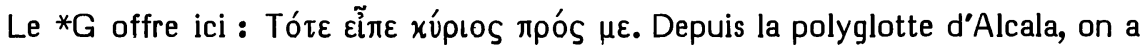
conjecturé $\tau a \delta \delta \varepsilon$ à la place du premier mot. Mais Ziegler (Beiträge 22) a eu raison de résister à cette conjecture.

La *S (הכנא אמר לי מריא (ה) suit le *M en 1A et le *G en 1B.

$L a * V$ (haec dicit Dominus) appuie exactement le *M.

Selon tous les mss ( $y$ compris Urbinates 1 ) et les éditions de Félix de Prato et de la polyglotte d'Anvers, le *T (כדנן אמר (כ) appuie entièrement le *M. Seules l'édition de Ben Hayim et des éditions plus récentes (polyglotte de Londres, Miqraot Gedolot) ajoutent à cela יל .

\section{Choix textuel :}

A/ 1A : La nouvelle source du livre de Jérémie qui commence ici ne comporte aucune référence temporelle à la péricope précédente. C'est le fait qu'il s'agisse dans le ch. 18 et en cette péricope-ci d'un vase d'argile qui a amené le rédacteur à lier ces deux récits. Le ${ }^{*} G$ a voulu établir par son $\tau o ́ \tau \varepsilon$ une succession immédiate pour séparer plus clairement les deux événements tout en les mettant en relation. Il est peu probable

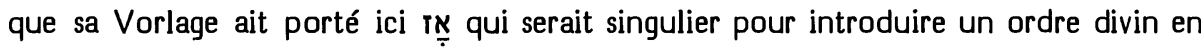
début de péricope.

Le caractère primitif du ${ }^{*} M$ apparaît en ce qu'il n'établit aucune soudure facilitante avec la péricope précédente. Nous avons déjà signalé cette particularité en CT1, $172 \S 5$ où nous avons noté la tendance du ${ }^{*} G$ à estomper les hétérogénéités littéraires.

Ici, le comité a attribué au *M la note " $B$ ".

$B / 1 B$ : Les traducteurs sentent le besoin d'expliciter ici la mention du destinataire de l'ordre divin. Le contexte montre clairement qu'il s'agit de Jérémie. Le *G et la *S (ou leur Vorlage) ont ajouté : "à moi". Des témoins récents du *T ont fait de même. Si ce complément avait existé dans le texte prémassorétique, on ne comprend pas pourquoi il aurait été supprimé plus tard. Le comité, par 4 "B" et 2 "A", a donc décidé de ne pas l'insérer.

Interprétation proposée :

On se contentera de traduire "Ainsi a dit le Seigneur", en réservant pour une note la mise en situation de cette péricope. 
Options de nos traductions :

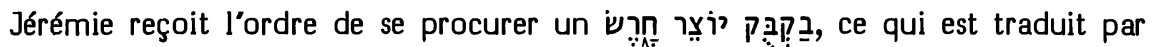
RSV : "a potter's earthen flask", par RL : "einen irdinen Krug vom Töpfer".

TOB traduit "une gargoulette" et omet "de celui qui façonne l'argile" qu'elle considère comme une glose de l'hébreu.

Sans rien noter, $\mathrm{J3}$ ne traduit que la première détermination: "une cruche de potier", alors que $\mathrm{J12}$ ("une cruche en argile") et NEB ("an earthenware jar") ne traduisent que la seconde.

Origines des corrections :

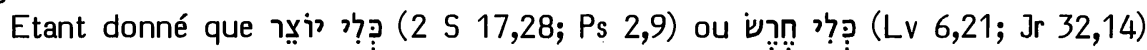
pourraient suffire, Ehrlich, Volz et l'apparat de HSAT4 ont proposé d'omettre ici la seconde détermination, alors que Rudolph, Penna et les apparats de $\mathrm{BH} 3 \mathrm{~S}$ et de Cent proposaient d'omettre la première.

\section{Les témoins anciens :}

Le $* G$, voulant mettre sur le même plan les deux déterminations, traduit large-

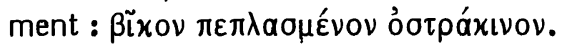

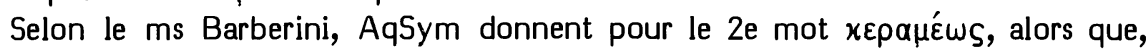
selon la Syh, Aq donne pour ce mot : דגדולא que Bernstein (406s), croyant à une faute de copie de Norberg, a voulu corriger en דגבולא. Mais le facsimilé de Ceriani confirme pleinement la lecture de Norberg, et Payne Smith (655) a estimé non-fondée la correction conjecturale de Bernstein que Field (dont dépend Ziegler) a pourtant suivie. Mieux vaut donc, pour Aq (1e version ?) en rester à la leçon syriaque du ms Ambrosianus de la Syh qui pourrait équivaloir à $\pi \lambda \alpha$ á $\mu \alpha \tau$ so selon Spohn.

$\mathrm{La} * \mathrm{~V}$ a traduit "lagunculam figuli testeam".

Le *T donne זלוע דחסף פחר et la *S simplifie en בגבוגא דפחרא.

Choix textuel et interprétation proposée :

Ce cas n'a pas été soumis au comité.

A part la *S qui n'a traduit que la première détermination, les autres témoins attestent les deux, en tendant à rattacher directement la deuxième au substantif בְּ?

Ceux qui estiment que l'on a ici une leçon gonflée hésitent sur celle des deux déterminations qui serait adventice. On pourrait en effet penser que יiְ a été inséré après coup pour relier cette péricope à la précédente où il s'agit du "potier". Mais le fait que cette cruche soit désignée en 19,11 comme אֶֶת engage à ne pas l'omettre ici. Quant à (cf. Is 30,14) qu'il ne s'agit pas ici d'une cruche en un matériau que l'on pourrait aisément réparer, mais d'une cruche qui, une fois fracassée, est bonne à être jetée aux ordures. D’ailleurs, Nägelsbach estime que רִ̣i’, étant un terme générique, a besoin d'être déterminé ici comme un 'fabricant de poteries', de même que Is 44,9 parlera

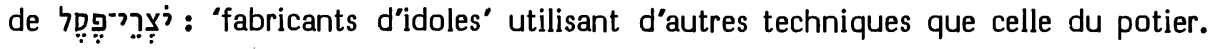


La traduction littérale serait donc: "une gargoulette de celui qui façonne l'argile". Si l'on veut à tout prix alléger la traduction, on pourra se contenter de "une gargoulette de céramique".

19,1D מומקני העם / glos : G S T 19,1E ומזקני הכהנים MV S T // homarc-int : G

Options de nos traductions :

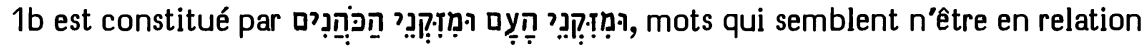
avec aucun verbe.

A/ 1D : Toutes nos traductions suppléent ici un verbe. J se fonde sur la *S et le *T pour traduire : "prends avec toi quelques (J3 : des) anciens du peuple." Selon

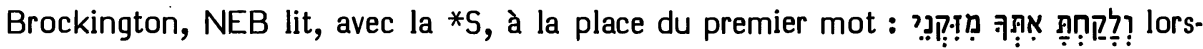
qu'elle traduit: "Then take with you some of the elders of the people". Sans note, RSV traduit : "and take some of the elders of the people", RL : "und nimm mit etliche von den Aeltesten des Volks" et TOB : "et fais choix de quelques anciens parmi le peuple."

B/ 1E : Faisant suite aux traductions que nous venons de citer, ces mots sont rendus en J3 par : "et des anciens des prêtres", en NEB par "and of the priests", en RSV par "and some of the senior priests", en RL par "und von den Aeltesten der Priester" et en TOB par : "et parmi les prêtres".

$J 12$ disaient suivre le ${ }^{*} \mathrm{G}$ en traduisant "et quelques prêtres" au lieu de "et quelques anciens des prêtres".

Origines des corrections :

A/ 1D : C'est Vogel (en ses notes sur Grotius) qui a estimé nécessaire ou bien de suppléer ולקח ou bien de référer à ces compléments le verbe précédent en en assouplissant le sens. Michaelis (Observationes) opte pour la 1e solution en insérant ce verbe juste après le premier complément. Schnurrer estime que les versions anciennes se sont contentées d'expliciter ce verbe entre la conjonction et la préposition du premier mot de 1D. Hitzig propose d'insérer là le verbe suggéré par Vogel, suivi en cela par Duhm, Cornill, Penna et l'apparat de SBOT. Grätz a proposé d'insérer avant 1D les mots ולקחת עמך, suivi en cela par Ehrlich, Rudolph, Weiser, Bright et les apparats de HSAT34 et de BH3S. Oort et Volz ont préféré user de l'impératif de ce verbe.

B/ 1E : Nägelsbach a fait remarquer que les "anciens des prêtres" ne se retrouvent qu'en Is 37,2 ( = 2 R 19,2). BH2 ayant noté l'absence de cette qualification de "anciens" dans les mss Vaticanus et Sinaiticus du ${ }^{*} G$, son omission a été proposée par Rothstein (HSAT34) suivi par Schmidt, Nötscher, Rudolph, Penna, Steinmann, Weiser, et les apparats de BH3S et de Cent. 
Les témoins anciens :

A/ 1D : Alors que Hie atteste clairement le *M en son lemme (et de senioribus populi), la $* V$ omet la conjonction initiale (a senioribus populi), faisant ainsi de $1 \mathrm{~b}$ deux compléments du verbe "accipe". Cette conjonction est aussi absente de 2 mss de Kennicott, d'un de de Rossi et de la première main de deux autres, ainsi que des éditions princeps de Soncino des Prophètes (1486) et de la Bible (1488). Cependant,

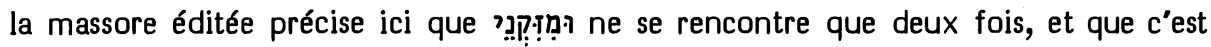
en ce même vs.

Les autres versions suppléent, entre la conjonction et le premier mot, "conduis"

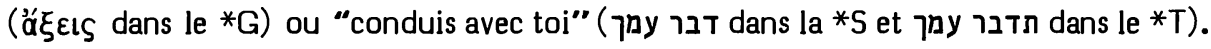

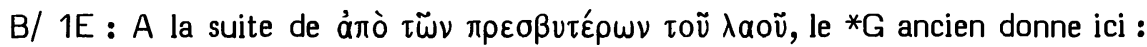

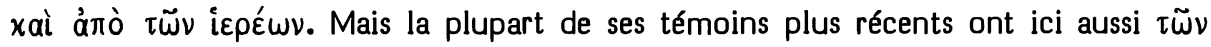
$\pi \rho \varepsilon \sigma \beta v \tau \varepsilon ́ \rho \omega \nu$ avant les deux derniers mots et il est fort vraisemblable que l'absence de ces mots dans la tradition textuelle ancienne $d u{ }^{*} G$ est due à un homéoarcton interne au grec.

Tous les autres témoins appuient ici le *M.

\section{Choix textuel :}

A/ 1D : Comme Keil l'a noté, la présence du 'waw' initial rend peu probable qu'un verbe ait disparu ici du texte, car on comprend mal pourquoi on aurait ensuite ajouté ce 'waw' qui fait difficulté et a été omis à ce titre par la *V et par quelques témoins du *M.

Suivi par Judah ibn Balaam, Abulwalid (Luma 253,13s) proposait déjà de suppléer ici ולקחת עמך מזקני. C'est la même intuition qui a amené la plupart des versions à expliciter ce qui leur a semblé utile pour le sens.

Pour tenir compte du fait que le 'waw' initial manque en certains témoins, le comité n'a attribué au *M que la note "B".

\section{$\mathrm{B} / 1 \mathrm{E}$ : Ce cas n’a pas été soumis au comité.}

Rudolph estime peu vraisemblable que Jérémie ait pu avoir accès aux “anciens des prêtres". Notons qu'il est seulement demandé à Jérémie de prendre avec lui quelquesuns de ces "anciens". Il peut s'agir là de la même catégorie que celle qui sera qualifiée en $\mathrm{Ne} \mathrm{12,7} \mathrm{de} \mathrm{רִאִשִי} \mathrm{הכהנים} \mathrm{et} \mathrm{qui} \mathrm{étaient} \mathrm{vingt-trois} \mathrm{au} \mathrm{retour} \mathrm{de} \mathrm{l’Exil.} \mathrm{Il} \mathrm{n'est} \mathrm{nulle-}$ ment invraisemblable que le prêtre Jérémie ait eu alors un accès aisé à certains de ces notables, car ce seront justement les événements narrés en Jr 19-20 qui le feront entrer en conflit avec eux.

Interprétations proposées :

On peut associer ces deux catégories de personnes à la gargoulette, en donnant au verbe qui précède le sens de "se procurer" : "et procure-toi une gargoulette ... et certains des anciens du peuple et certains des anciens des prêtres". C'est la 2e solution de Vogel.

On peut aussi associer ces deux catégories de personnes à Jérémie comme sujets de l'infinitif absolu initial : "Avec quelques-uns des anciens du peuple et quelques-uns 
des anciens des prêtres, va te procurer une gargoulette". C'est l'option de Rashi. Elle peut se fonder sur la mention en 19,10 de "les hommes qui sont allés avec toi".

20,12 cf. p. 570.

21,7 וְְּ (30) [B] M Aq V T // facil-synt : m G S t om

Options de nos traductions :

Après avoir mentionné à l'accusatif Sédécias roi de Juda et ses serviteurs, cet

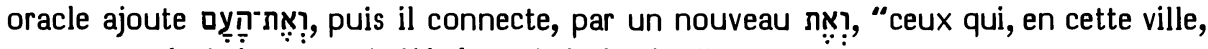
sont rescapés de la peste, de l'épée et de la famine".

$\mathrm{J3}$ a vu là une nouvelle catégorie : "le peuple et ceux qui, de cette ville, seront rescapés".

NEB a donné à cette dernière conjonction une valeur épexégétique: "and the people, all in this city who survive".

$J 12$ disaient suivre le ${ }^{*} \mathrm{G}$ en traduisant : "et la population de cette ville qui aura échappé". Sans note, RSV a traduit de même : "and the people in this city who survive", ainsi que TOB : "et les gens qui, dans cette ville, auront survécu" et RL : "und dem Volk, das in dieser Stadt ... übriggelassen wird."

Origine de la correction :

Ici RL a copié Luther qui semble être le seul, parmi les traducteurs du XVIe siècle, à ne tenir aucun compte de ce dernier ואת et à traiter הנשארים comme une simple épithète de "le peuple" qui précède. Une valeur épexégétique est reconnue à cette conjonction par une note d'Estienne en sa rédition de Pagnini, puis par Calvin et par Tremellius, tous les autres y voyant l'ajoute d'une nouvelle catégorie.

Sous l'influence de la traduction de Luther, c'est Hitzig qui a proposé d'omettre ce dernier ואת, suivi en cela par Ewald2, Graf, Nägelsbach, von Orelli, Giesebrecht, Oort, Duhm, Cornill, Condamin, Volz, Nötscher, Rudolph, Penna, Steinmann, Weiser, Bright et par les apparats de SBOT, HSAT234, BH23S et Cent.

\section{Les témoins anciens :}

BH3 dit que ce dernier ואת est omis par 9 mss. Deux de ceux-ci appartiennent à la collection de Rossi et celui-ci signale que cette omission a été corrigée ensuite. Il en va de même du seul des 7 mss que signale Kennicott que nous avons pu contrôler : le Paris BN hébr 2.

Le *G et la *S n'ont pas tenu compte de ce mot. Cependant Aq (ולהנון ד) et la *V (et qui) l'ont traduit en y voyant l'ajoute d'une catégorie.

Dans la tradition textuelle du *T, l'édition princeps de Félix de Prato et deux mss yéménites omettent ce mot. Mais tous les autres témoins (entre autres le ms Reuchlin et le ms Urbinates 1) l'attestent. 


\section{Choix textuel :}

Le fait que des témoins minoritaires du ${ }^{*} M$ et du ${ }^{*} T$ s'unissent ici au ${ }^{*} G$ et à la *S pour omettre ce mot montre que cette facilitation syntaxique est 'dans l'air'. Pour protéger le *M contre elle, le comité a attribué à celui-ci la note "B".

\section{Interprétations proposées :}

Noldius (293) classe ce vs en tête de 9 autres vss en ce livre $(22,25 ; 23,33 ; 25,20$; $32,29 ; 40,8 ; 42,1 ; 46,26 ; 49,14 ; 52,15)$ où il reconnaît à la conjonction 'waw' le sens explicatif de 'nempe, nimirum' (= à savoir). König (Synt §375c) a fait remarquer que l'usage épexégétique du 'waw' dénote un certain manque de rigueur dans la construction littéraire puisque l'on coordonne une donnée qui mériterait d’être articulée de façon plus précise avec ce qui précède. Précisons avec Keil qu'ici une absence de ce ואת amènerait à comprendre ce qui suit comme qualifiant seulement "le peuple" et non toutes les personnes mentionnées auparavant. On pourra donc traduire ici : "à savoir ceux qui, en cette ville, sont rescapés etc."

Notons pourtant que ạ̦ qui précède ce mot peut avoir ici le sens restreint des "hommes de guerre" qu'il a souvent dans la Bible. On aurait, en ce cas, une énumération à 4 termes : le roi, ses ministres, la troupe "et ceux qui, en cette ville, sont rescapés etc."

\section{2,6 נושבְה [A] ] MK ] MQ // incert : G V S T}

\section{Options de nos traductions :}

Un oracle sur la maison du roi de Juda commence ainsi : "Tu es pour moi Ga-

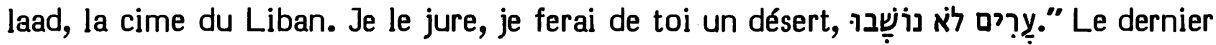
mot de ce vs offre un ketib avec un "hé' final au lieu du 'waw'. Ces trois derniers mots sont traduits par NEB : "a land of unpeopled cities" et par J3 : "en villes inhabitées."

RSV et $\mathrm{J12}$ disent conjecturer une mise au singulier du substantif quand elles traduisent : "an uninhabited city" et "en ville inhabitée". Sans note, RL traduit : "zur Stadt ohne Einwohner" et TOB reprend J12.

\section{Origine de la correction :}

C'est Rothstein, en $\mathrm{BH} 2$, qui, se fondant sur le ketib du 3e mot, a conjecturé de mettre le premier au singulier, suivi en cela par Condamin, Schmidt, Penna, Hyatt, Bright et les apparats de $\mathrm{BH} 3$ et de Cent.

\section{Les témoins anciens :}

Tous ont gardé ici le mot "villes" au pluriel.

\section{Choix textuel :}

C'est une fausse interprétation du ketib de ce verbe qui a amené certains exégètes à conjecturer une correction de son sujet en singulier.

En effet, Bauer/Leander ( $384 c^{\circ}$ et $3150^{\circ}$ ) et Gordis ( $\$ 18$ ) interprètent ce ketib comme étant une survivance de l'ancienne 3 e pers. pl. f. de l'accompli, forme qui est 
tombée en désuétude en hébreu à partir du moment où s'est constituée la forme plus jeune de la 3e pers. f. sg. (à partir de l'ancienne forme en -at) qui se confondait avec elle.

Le comité a donc attribué la note " $A$ " aussi bien au ketib qu'au qeré qui ne se distinguent que parce que le premier représente un état plus ancien de la langue.

Interprétation proposée :

"(comme) des villes inhabitées".

22,14 14 [C] [C] M // exeg : G Aq V S T

Options de nos traductions :

Jérémie décrit Joiaqim en 14a comme "celui qui dit : 'je vais me bâtir un palais

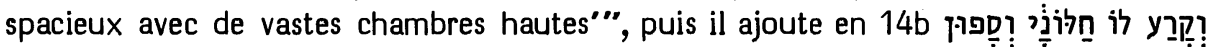

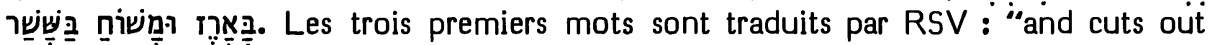
windows for it", par TOB : "qui y perce des fenêtres" et par RL : "und lässt sich Fenster ausbrechen".

J traduit : "qui y perce des ouvertures", J12 disant corriger le *M qui offre : "mes ouvertures".

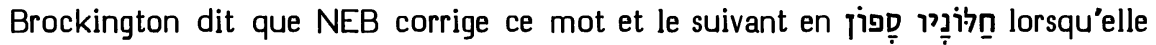
traduit 14b: "(I will..) set windows in it, panel it with cedar and paint it with vermilion !"

\section{Origines des corrections :}

A part Tremellius (et des leçons marginales en Pasteurs et en $\mathrm{KJ}$ ) qui comprend ici "mes fenêtres" (leçon qui sera reprise par Boysen, cité par Schleusner annotant les Observationes de Michaelis), les traducteurs du XVIe siècle interprètent cette forme comme un pluriel au sens de 'fenêtres'. Buxtorf (Lexicon 231 et Thesaurus 79) voit ici un pluriel irrégulier. C.B. Michaelis ajoute qu'il est de type syriaque. Son fils Johann David objecte à cela que c'est seulement à l'état construit que les syriens donnent cette terminaison à leur pluriel. En OEB IV 244 il attache un grand prix à une variante ?ִ חַ qu'il a trouvée dans les fragments de Gotha. Bien qu'un correcteur l'ait rayée ensuite, il estime important que le ponctuateur ait montré qu'il l'adoptait en vocalisant le 'waw' final avec un shewa. Ni Kennicott, ni de Rossi n'ont retrouvé cette variante dans les autres mss qu'ils ont collationnés. Ce dernier a seulement trouvé attestée par la 1e main de son ms 380 (allemand copié en 1296) la leçon a ח qui lui semble être une graphie défective pour le pluriel en ם- que Starck (qu'il cite) proposait ici. Malgré ce silence des autres mss, Michaelis (Observationes) conjecture de faire passer le 'waw' du début du mot suivant à la fin de celui-ci et de lire qui a été adoptée par Hitzig qui y ajoute une vocalisation en 'ḥolem' de la syllabe finale de ספון. En cet état, la conjecture est adoptée par Graf, Nägelsbach, von Orelli, Giesebrecht, Oort, Nötscher, Penna et les apparats de SBOT, HSAT23 et BH3.

L'option de Starck a été reprise par Olshausen (Lehrbuch \$111c), Knabenbauer, Cornill, Volz, Schmidt et les apparats de $\mathrm{BH} 2$ et de Cent. 
Les témoins anciens :

Le *G, Aq, la *V, la *S et le *T ont compris ici "fenêtres" au pluriel.

Choix textuel :

Il est probable que les versions anciennes représentent déjà la tradition d'interprétation en pluriels de ces finales en '-aï', tradition que nous avons exposée selon Radaq en CT1, 86 à propos de $\mathrm{Jg} 5,15 \mathrm{~A}$ et qui, ici, est attestée aussi par Hayyuj (Kokovzov 51) sur Ez 13,18, ainsi que par Menahem de Posquières et Judah ibn Balaam. Cependant, nous avons eu déjà l'occasion (loc. cit.) de traiter de Jg 5,15; en CT1, 513 de 2 Ch 33,19; ci-dessus p. 138s de Is 19,9 et ci-dessus p. 469ss de Jr 17,13. Et en aucun de ces cas nous n'avons pu retenir l'interprétation en pluriel.

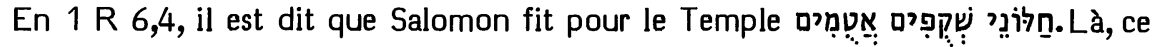
mot a été vocalisé en état construit pluriel, quoiqu'une telle forme soit mal en place avant deux participes passifs et que les versions l'aient traduite comme s'il s'agissait d'un pluriel à l'état absolu. Cependant ces deux formes consonnantiques finissant en 'yod' s'appuient l'une l'autre et le comité a donc estimé ne pas devoir corriger en Jr 22,14 une forme difficile que les témoins les plus anciens semblent avoir déjà eue sous les yeux. Aussi lui a-t-il attribué 4 " $C$ " et 2 " $B$ ".

Interprétation proposée :

Nous ne pouvons espérer rendre compte de façon satisfaisante de ces finales en 'yod' que les versions anciennes ont considérées comme des pluriels absolus.

Le sens qui conviendrait le mieux à la fois à $1 \mathrm{R}$ 6,4 et à Jr 22,14 serait "un fenêtrage", c'est-à-dire un ensemble de fenêtres.

Cela donnerait en $1 \mathrm{R}$ 6,4: "Et il fit à la maison un fenêtrage : des encadrées grillagées", et en Jr 22,14: "Toi qui dis : "je vais me bâtir un palais spacieux avec de vastes chambres hautes - qu'on l'ajoure d'un fenêtrage - et une couverture de cèdre et un enduit de vermillon".. Les trois premiers mots de 14b feraient figure d'incise dans les projets que rêve le bâtisseur.

22,16 אז טוב / לו lit : G

Options de nos traductions :

En un rappel du règne du père de Joiaqim, il est dit : "Ton père n'a-t-il pas mangé et bu ? Et il a accompli le droit et la justice", puis le vs 15 s'achève par le constat :

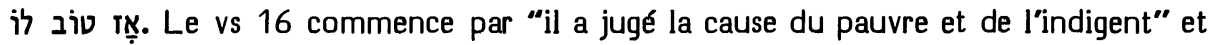
ce bilan s'achève par : אִ טוֹ

Ces deux derniers mots sont traduits par RSV : "then it was well", par J23: "Alors tout allait bien" et par TOB : "et c"était le bonheur".

RL reprend ici la formule qu'elle a employée à la fin du vs 15 : "und es ging inm gut".

J1 et NEB omettent ces deux mots, Brockington fondant cette omission sur le *G. 
Origines des corrections :

Pagnini se trouvait avoir explicité ici dans sa traduction le même complément (ei). quầ la fin du vs 15. Cela explique que Luther fasse de même, en traduisant en 16 comme en 15 : "und ging jm wol".

Grätz (Studien 199) a estimé qu'il fallait omettre le constat qui achève le vs 15 et compléter par celui du vs 16. Il est suivi en cela par Condamin.

Oort omet le constat du vs 16, suivi en cela par Duhm, Cornill, Schmidt, Nötscher, Rudolph, Penna, Steinmann, Bright et par les apparats de BH3S et de Cent, beaucoup de ces critiques omettant ou modifiant le constat du vs 15 .

\section{Les témoins anciens :}

4Q-a porte ces deux mots à la place et sous la forme où le *M les présente.

Kennicott cite 5 mss comme ajoutant לו au constat du vs 16 .

Voici comment le ${ }^{*} G$ traite $15 b$ et 16 a que nous avons traduits selon le $* M$ au début de cette étude. Ayant rattaché "ton père" à 15a, il donne ensuite: "Ils ne mangent pas et ne boivent pas. Il aurait été meilleur que tu accomplisses le droit et la justice. Ils n'ont pas connu, ils n'ont pas jugé le jugement pour l'humble ni le jugement de l'indigent." Le ${ }^{*} G$ construit donc ces phrases très différemment et il amplifie

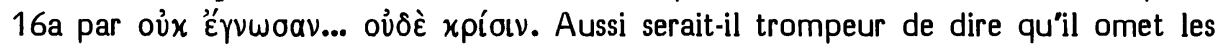
deux mots que nous étudions. Il nous offre plutôt une autre rédaction de 15b et de 16a.

Les deux mots du *M sont attestés par la *S (ועבד Tשפיר) et par le *T (בכין הוה טב).

ThAq et Sym, en explicitant aủiū, ont assimilé la traduction de ce constat à celui du vs 15.

$\mathrm{La} * \mathrm{~V}$, elle aussi, a explicité un possessif : “in bonum suum".

\section{Choix textuel :}

Il est normal que l'on ait tenté de compléter ces deux mots du vs 16 par celui qui les suit au vs 15; puis que certains critiques aient voulu les omettre comme une reprise fautive du constat concluant le vs 15 , alors que d'autres omettaient le premier constat comme une anticipation indue du second.

Le comité a estimé devoir protéger ces deux mots contre une assimilation à leur parallèle du vs 16 . Il a reconnu également au ${ }^{*} G$ et au ${ }^{*} M$ une spécificité d'ordre littéraire. Il faut donc éviter qu'ils se contaminent l'un l'autre.

La note "B" a été attribuée ici au *M.

Interprétation proposée :

Ce constat n'est pas une simple reprise de celui qui concluait le vs 15 . Il est dit en effet au vs 15 que la pratique du droit et de la justice était profitable au père de Joiaqim, alors qu'il est dit ici que, du fait que le père de Joiaqim jugeait la cause du pauvre et de l'indigent, "alors cela allait bien", c'est-à-dire qu'une justice bien rendue assurait la paix sociale et la prospérité dans le pays. 
Options de nos traductions :

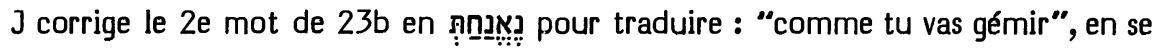
fondant sur le $* G$, la $* V$ et la $* \mathrm{~S}$. Avec les mêmes appuis, RSV traduit : "how you will groan". Sans note, TOB traduit : "comme tu gémis" et RL : "wie wirst du stöh. nen".

NEB traduit comme l'a fait RSV, Brockington disant qu'elle a vocalisé נְּ avec le $*$ G.

\section{Origines des corrections :}

Cappel (Notae 527b), pour lire avec Arias Montano "quam gratiosa eris", estimait qu'il fallait ponctuer comme Brockington le proposera. Mais il notait que le ${ }^{*} G$ et la *V semblent avoir lu une forme de אנח.

Houbigant estime l'interprétation d'Arias Montano inacceptable en ce contexte immédiat et s'inspire du *G pour comprendre "comme tu gémiras", ce qui était l'interprétation des Prédicants de Zurich et de Zwingli.

Ewald estime que cette forme verbale tient ici la place de

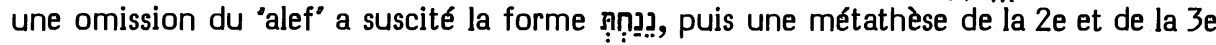
consonnes a évité la répétition de la consonne 'nun' en début de mot. Il suggère que le ponctuateur interprétait peut-être déjà ainsi cette forme. L'interprétation de Hitzig a été adoptée par Graf, von Orelli, König (Lehrgebäude I 368s), Steinmann, Hyatt et Bright.

Attribuent cette métathèse à une erreur de copie et demandent donc de la corriger : Böttcher (Lehrbuch II 490, n.1), Giesebrecht, Cornill, Gesenius/Kautzsch (84, n.1), Volz, Nötscher, Rudolph, Penna et Weiser, ainsi que les apparats de SBOT, $\mathrm{BH} 3 \mathrm{~S}$ et Cent.

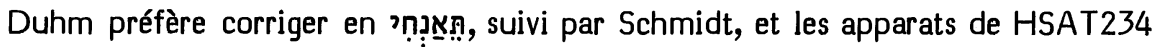
et $\mathrm{BH} 2$.

Les témoins anciens :

Le ${ }^{*} \mathrm{G}$ traduit ce verbe par $\chi \alpha \tau \alpha \sigma \tau \varepsilon \nu a ́ \xi \varepsilon ı$. Ce verbe grec correspond en ses quatre autres emplois au nifal de אנח.

Dans le même sens, la *V traduit par "congemuisti" et la *S par מתנחא אנתי selon les éditions ou par מתתנחת selon le ms Ambrosianus.

Le *T מא־תעבדין a improvisé en fonction du contexte.

Choix textuel et interprétation proposée :

Seul Abraham ha-Babli $(211,15)$ attribue ici au *T une leçon discordante : מה נהנת (= à quoi serviras-tu ?). Menahem ben Saruq (13) attribue cette exégèse (qu'il considère comme classique et que Brucioli reprendra en 1532) aux 'anshé pitrôn', c'est-àdire aux dépositaires de la tradition interprétative. Quant à lui, il dérive cette forme du

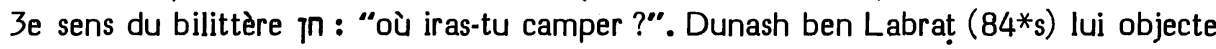
que מה ne signifie pas "où ?" et il propose de dériver cette forme verbale de nח au sens 
de "comment trouveras-tu grâce ?". Cette dérivation est d'ailleurs celle que proposait Yéfet ben Ely. Quant à Hayyuj (Kitâb 171,17) il considérait comme improbable que cette forme dérive de חנח.

Abulwalid (Opuscules 143) estime pourtant que cette dernière dérivation n'est pas impossible : puisqu'au début de ce vs לקשֶֶֶׁ, nous pouvons avoir ici une forme allégée pour

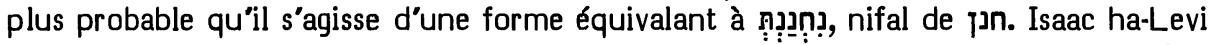
ben Eleazar (Sephat Yeter, fol. 162), analysant de même, cite en parallèle ?ְ:? (Ez 22,16), en faisant remarquer la vocalisation différente du 'nun' initial.

Radaq (Mikhlol 129b), lui aussi, donne comme forme de base נְְִִּ estimant qu'ici le șéré du 'nun' compense l'absence d'un dagesh.

En face de ces tâtonnements des exégètes médiévaux, il est frappant que le * $G$, la * $V$ et la *S aient dérivé cette forme de et que Hitzig ait suggéré que les ponctuateurs du*M interprétaient ainsi cette forme.

En effet, le séré initial se laisse mal expliquer dans l'hypothèse d'une dérivation à partir de חנ, dérivation rendue elle-même peu probable par le fait qu'aucun autre emploi du nifal de ce verbe n'est attesté.

Kuriakos $(37, \mathrm{n} .7)$ explique le séré comme un allongement vocalique qui compense l'élision du 'alef' de אנח qui s'emploie normalement au nifal. Quant à la métathèse de la deuxième et de la troisième radicales, König (Lehrgebäude I 367) estime

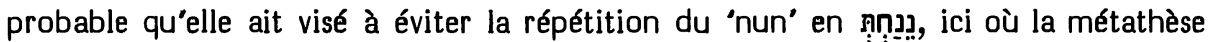
est possible (alors qu'en נִ elle n'est pas possible). Concluons de cela que le *M était probablement interprété par celui qui l'a vocalisé comme "tu gémis", en accord avec les versions anciennes.

Notons cependant que Ben Yehuda $(3610, n .3)$ a proposé de reconnaître ici un verbe נחנך au sens de "être la l. 12 de l'inscription d'Eshmunazar. Etant donné que ces deux mots y introduisent une plainte, on pourrait tout aussi bien les traduire : "je me plains :" . Le rapprochement de ces deux formes dont l'analyse est difficile est suggestif.

Le comité a estimé qu'il faut interpréter ce mot au sens de "comme tu vas gémir". Mais 3 membres du comité ont estimé que la métathèse du 'nun' et du 'ḥet' se justifiait phonétiquement, alors que les 3 autres y ont vu une faute scribale. La note " $C$ " a été attribuée à chacune de ces deux propositions.

23,8 cf. p. 605.

23,10 אְַָָ [B] M Aq V // err-vocal : G S / paraphr : T

Options de nos traductions :

La phrase est traduite par RSV : "because of the curse the land mourns", par RL : "und wegen des Fluches vertrocknet das Land", par TOB : "le pays est en deuil, plein d'imprécations" et par $\mathrm{J3}$ : “oui, à cause d'une malédiction, le pays est en deuil". 
312 vocalisait le 3 e mot de ces gens, le pays est en deuil". Selon Brockington, NEB fait de même pour traduire : "and because of them the earth lies parched".

Origine de la correction :

Cappel (Notae 527b) assignait cette Vorlage אֵל au ${ }^{*} G$ en estimant que le sens n'en était "pas moins commode". Cette variante a été adoptée par Houbigant, Hitzig, Grätz, Ehrlich, Volz (Studien 193) et Nötscher. Elle est mentionnée à titre informatif par $\mathrm{BH} 235$ et par Cent.

\section{Les témoins anciens :}

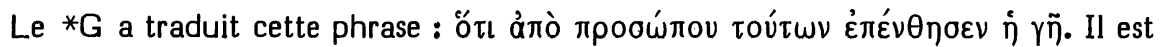
évident qu'il a vocalisé notre mot אي.̧. I. Meyer (117s, n.1) estime que cette interprétation tient au fait que les 4 premiers mots du vs 10 manquaient, par homéoarcton, dans la Vorlage du ${ }^{*} G$ et que le traducteur a donc interprété ce mot comme reprenant le contenu des deux compléments de $9 \mathrm{~b}$ qui avaient été déjà introduits par

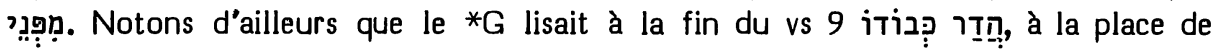

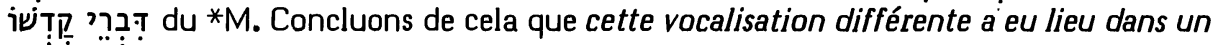
contexte littérairement distinct de celui qu'offre le *M.

$\mathrm{Aq}$ (דלוט), la recension origénienne (ópxov) et la *V (maledictionis) montrent que la vocalisation du ${ }^{*} M$ est solidement enracinée dans la tradition protomassorétique.

La *S (הלין) a suivi ici le *G, alors que le *T (מומי דשקר) a paraphrasé le *M.

\section{Choix textuel :}

Le comité a attribué ici au *M 4 "B" et 2 "C $\mathrm{C}$ ".

Interprétation proposée :

Juste après la mention des adultères, il semble bien que cette 'malédiction' soit celle par laquelle le Seigneur châtie les désobéissances à son alliance (Jr 11,3.8; Ez 16, $59 ; 17,16-18)$. On retrouve le même motif pour expliquer que "la malédiction a dévoré le pays" en Is 24,5-6.

On pourra donc traduire : “oui, à cause de la malédiction, le pays est dans le deuil"; le mot 'malédiction' étant aussi sans article en Is 24,6 et en Ez 16,59; 17,18.

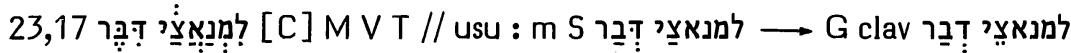

Options de nos traductions :

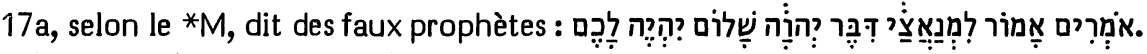
Seule de nos traductions, $\mathrm{J} 3$ traduit ici le *M: “Ils osent dire à ceux qui me méprisent : 'Yahvé a parlé : vous aurez la paix !'”

Disant suivre le ${ }^{*} G, J 12$ traduisaient : "Ils disent à ceux qui méprisent la parole de Yahvé : 'Vous aurez la paix !"' Avec le même appui, TOB traduit : "Ils osent dire à ceux qui méprisent la parole du SEIGNEUR : 'Pour vous, tout ira bien!'” Selon 
Brockington, NEB a vocalisé, avec le ${ }^{*} G$ : למנאצֵי דִבַר pour traduire : "They say to those who spurn the word of the LORD, "Prosperity shall be yours"'. Sans note, RSV ("They say continually to those who despise the word of the LORD, 'It shall be well with you" ") et RL ("Sie sagen denen, die des HERRN Wort verachten : Es wird euch wohlgehen") traduisent de même.

\section{Origine de la correction :}

Cappel (Notae 528a) a suggéré comme Vorlage du *G la leçon qu’adoptera NEB. Houbigant a adopté clandestinement cette leçon dans sa traduction. La correction explicite a été effectuée par Michaelis (OEB), suivi par Hitzig, Grätz, Giesebrecht, Oort, Duhm, Ehrlich, Rudolph, Bright, ainsi que par les apparats de SBOT, HSAT34, $\mathrm{BH} 23 \mathrm{~S}$ et Cent.

\section{Les témoins anciens :}

Le ms babylonien Eb 22 respecte la vocalisation du *M tibérien pour le participe constituant le $3 \mathrm{e}$ mot de cette phrase. Mais il vocalise le mot suivant $7{ }^{\prime} \bar{\tau}$, à cause de la grande fréquence de l'expression ידוּר ידוּר

C'est probablement pour le même motif que le ${ }^{*} G$ a traduit ici : $\lambda \varepsilon ́$ rovar toĩs

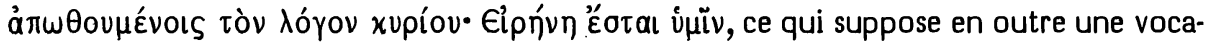
lisation de ce participe en état construit pluriel avec un sẹeré final.

La *S semble avoir vocalisé comme le ms Eb 22 quand elle traduit : ואמרין לאילין דמרגזין • בפתגמה דמריא שלמא נהוא לכון

Le *M a été lu par la *V: "Dicunt his qui blasphemant me locutus est Dominus pax erit vobis" et par le *T : אמרין ... לדמרגזין קדמי מליל י" שלמא יהי לכון :.

\section{Choix textuel :}

La vocalisation du ms Eb 22 et de la *S est évidemment facilitante et constitue une première étape vers celle qui sous-tend la traduction du ${ }^{*} G$.

L'expression יהות n'est pas normale pour introduire un oracle prophétique. Mais on peut comprendre que Jérémie n'ait pas voulu placer dans la bouche des faux-prophètes (dont il s'agit ici) l'expression כה־אמר יהוה qui introduit normalement les oracles. Notons que l'expression יהוה se retrouvera en 23,35.37 où Jérémie dit au peuple comment interroger des prophètes dont l'authenticité est incertaine.

Keil a fait remarquer, d'autre part, que l'expression דִַּבר יהוה désigne un oracle prophétique plutôt que les préceptes de la Torah. Or on verrait mal de prétendus prophètes donner un oracle à des gens qui nous sont justement caractérisés comme méprisant les oracles.

Par 3 "B" et 3 "C" le comité a choisi la leçon du *M.

Interprétation proposée :

Celle de $\mathrm{J} 3$ que nous avons citée en commençant est satisfaisante. 


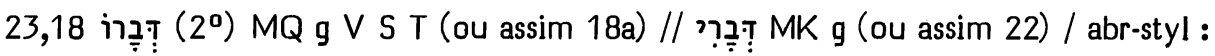
$\mathrm{G}$ om

Options de nos traductions :

En 18a, le *M offre: "Mais qui donc s'est tenu au conseil du Seigneur pour voir

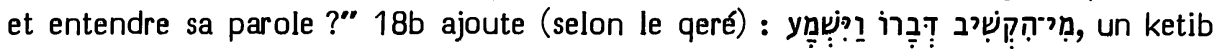
lisant :

Le qeré a été lu ici par RSV, J, RL et NEB; alors que TOB a lu le ketib : “Qui est attentif à ma parole ? Qui entend ?"”

Origine de la correction :

Le ketib a été préféré par Ewald, Hitzig, Graf, Keil, Nägelsbach, Weiser et par l'apparat de SBOT.

Les témoins anciens :

Alors que le ${ }^{*} G$ ancien ne traduisait pas ce mot, la recension origénienne lit ici le ketib ( $\mu \circ v)$, tandis que la recension antiochienne lit le qeré ( aủtoṽ).

La *V (verbum illius), la *S (פתגמה) et le *T (למימריה) ont lu le qeré.

Choix textuel :

Ce cas n’a pas été soumis au comité. Il peut prêter à deux jugements en sens opposés : ou bien le qeré assimile au stique précédent, ou bien le ketib assimile au vs 22 où la 1e pers. est utilisée.

Un passage brusque de la 3e à la 1e pers. constitue une lectio difficilior que nous avons déjà adoptée en 23,8 (ci-dessus, p. 606). La recension origénienne nous montre en tout cas que ce ketib est anciennement attesté dans la tradition protomassorétique.

Interprétations proposées :

Pour le ketib : "Qui a écouté ma (qeré : sa) parole et l’a entendue ?"”

23,23 נאם-2] M ] M G Th V S T // abr-styl : g om

23,24 נאם [A] M ThAqSym g V S T // lit : G om

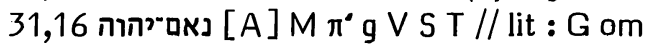

31,17 נאם־יהוה

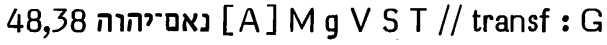

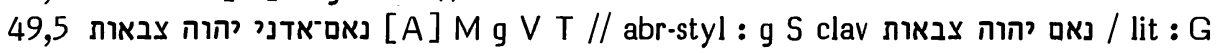

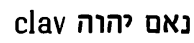

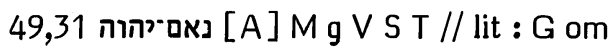

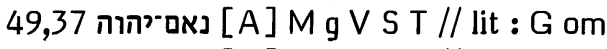

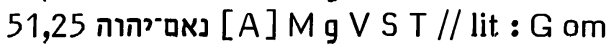

Options de nos traductions :

En tous ces cas, RSV, TOB, RL et $\mathrm{J} 3$ traduisent exactement le *M.

En 31,16.17; 49,31.37, J12 omettaient ces mots avec le ${ }^{*}$ G. En 49,5, elles les omettaient par conjecture. 
En $23,23.24 ; 31,16.17 ; 49,31.37$ et 51,25 , Brockington fonde sur le ${ }^{*} G$ l'omission de ces mots par NEB. En 48,38 et 49,5, il présente cette omission comme conjecturale.

En d'autres endroits où le *M offre l'expression "oracle du Seigneur" (9,2.5.21; 30,11; 48,25; 50,20.35), J12 l'omettaient. Elles se fondaient sur le *G (sauf en 30,11 et 50,20$)$. 31 était seule à l'omettre en 8,17.

Origines des corrections :

Les apparats critiques varient dans les omissions qu'ils requièrent. SBOT demande d'omettre cette formule en 9,21; 49,31. HSAT2 demande de l'omettre en 9,21. BH2 en 48,25 . $\mathrm{BH} 35$ en 8,$17 ; 9,2.5 .21 ; 30,11 ; 31,16.17 ; 48,25 ; 50,35$ (BH3 ajoutant 51,25 et BHS : 49,31 et 50,20). Cent en 9,21; 23,23.24; 31,16.17; 48,25; 49,37; 51,25.

Les témoins anciens :

En $23,23.24 ; 31,16.17 ; 48,38 ; 49,31.37$ et 51,25 , le *M a l'appui complet de la *V, de la *S et du *T pour l'expression נאם-יהוה.

En 23,$24 ; 31,16.17 ; 49,31.37$ et 51,25 , le ${ }^{*} G$ ancien ne traduit pas cette expression qui y est insérée cependant par les recensions origénienne et antiochienne appuyées, en 23,24 par ThAqSym et en 31,16.17 par toutes les colonnes des hexaples autres que celle du *G.

En 23,23, il semble bien que l'omission de cette expression soit un allègement stylistique secondaire dans la tradition textuelle du ${ }^{*} G$. En effet, les témoins de la recension origénienne ne la font pas précéder d'un astérisque. Et d'ailleurs, lorsqu'en ce contexte cette expression est réinsérée en des ajoutes astérisées, elle l'est sous la

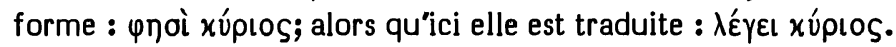

En 48,38 , le ${ }^{*} G$ a traduit cette expression en l'anticipant de quatre mots par rapport au $* M$.

En 49,5, où le *M porte lאם־אדני יהוה צבאות, le *G n’a que عĩin xúplos que la recension antiochienne a complété par $\tau \tilde{\omega} \nu \delta v v a ́ \mu \varepsilon \omega \nu$ avant quoi la recension origénienne répète xúplos. Ici la *S s'accorde avec l'antiochienne pour offrir deux noms divins; alors que la $* V$ et le ${ }^{*} \mathrm{~T}$, comme l'origénienne, en offrent trois.

\section{Choix textuels :}

En 5,2 (cf. ci-dessus, p. 493), nous avions noté que, pour les cinq premiers chapitres de ce livre, cette expression figurait cinq fois dans le ${ }^{*} G(1,17$; 2,2.17.19; $5,1)$ et non dans le ${ }^{*} M$, alors qu'elle figurait une fois $(3,10)$ dans le $* M$ et non dans le *G.

Dans le reste du livre, comme ici, le *M atteste cette expression plus souvent que ne le fait le ${ }^{*}$. Il est fort possible qu'il s'agisse souvent de gloses rédactionnelles caractéristiques de la recension II. En certains cas, l'absence de cette expression dans le ${ }^{*} G$ doit provenir d'allègements stylistiques dont cette traduction est coutumière.

Considérant qu'en ces cas l'ajoute ou l'omission de cette expression constitue une initiative d'ordre littéraire, le comité y a attribué au *M la note " $A$ ". 


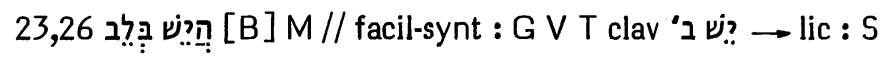

\section{Options de nos traductions :}

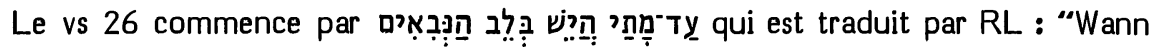
wollen doch die Propheten aufhören" (= Luther), par 11 : "Combien de temps encore sera présente cette pensée au coeur des prophètes", par J2: "Combien de temps auront-ils cette pensée au coeur, les prophètes", par $\mathrm{J3}$ : "Jusqu"à quand y aura-t-il au sein des prophètes" et par TOB : "Jusques à quand! Y a-t-il quelque chose dans la tête de ces prophètes".

RSV se réfère à la *S pour conjecturer le complément "lies" lorsqu’elle traduit : "How long shall there be lies in the heart of the prophets".

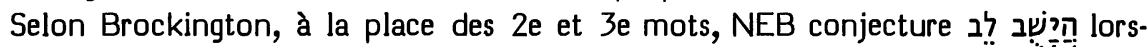
qu'elle traduit: "How long will it be till they change their tune, these prophets".

\section{Origines des corrections :}

C'est Duhm qui a proposé la conjecture qu'adoptera NEB. Il s'inspirait en cela de Giesebrecht qui, dans sa $2 \mathrm{e}$ édition, renonça à sa suggestion, ainsi que le signale Condamin. La conjecture de Duhm a été adoptée par Cornill, Schmidt et l'apparat de BH2, puis reprise récemment par Holladay (Recovery 426).

\section{Les témoins anciens :}

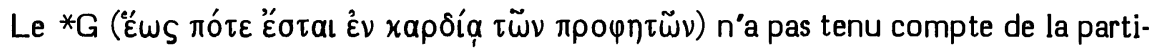
cule interrogative qui précède le $3 \mathrm{e}$ mot. Il en va de même des autres versions qui ont traduit ce mot par "istud" (*V) ou אית (*S et *T).

$\mathrm{La} * \mathrm{~S}$ a remplacé le 'coeur' par la 'bouche'. En outre, elle a traduit les mots qui suivent par "des prophéties fausses, des prophéties de la ruse de leur coeur". C'est de cette paraphrase que RSV a cru pouvoir s'inspirer pour donner un sujet ("lies") au verbe "be".

\section{Choix textuel et interprétations proposées :}

Ces variantes sont des facilitations qui sont 'dans l'air'.

Déjà Yéfet ben Ely disait que certains considèrent comme superflue la particule interrogative qui précède le $3 \mathrm{e}$ mot. Mais il ajoutait que d'autres exégètes de son époque (notant qu'en 23,30 le Seigneur condamnera les prophètes qui se volent l'un à l'autre ses paroles) s'inspiraient pour interpréter ce nִּ du dialogue entre Sédécias et Jérémie en 37,17 où le roi demande au prophète en secret : où Jérémie lui répond vie., puis lui communique l'oracle du Seigneur. On pourrait donc traduire : "jusqu'à quand ( $y$ aura-t-il) dans le coeur des prophètes (la question) : 'est-ce qu'il y a (une parole du Seigneur) ?'; eux qui prophétisent le mensonge et sont les prophètes de la fraude de leur coeur, (27) eux qui ont pour dessein de..."

Cependant, la meilleure exégèse semble bien être celle qui a été proposée par de Dieu, puis reprise par Graf, Keil et Rothstein. Elle suppose d'abord qu'on laisse en suspens les 2 premiers mots du vs : "Jusques à quand ?", ainsi que Menahem de Posquières l'avait déjà proposé. Nous avons déjà signalé une aposiopèse analogue à la fin de 13,27 (ci-dessus, p. 583). On rencontre aussi עד־מת en aposiopèse en Ps 6,4; 
90,13; Is 6,11. Cette exégèse suppose aussi que l'on interprète le "hé' initial du vs 27 comme une particule interrogative. En effet, l'interrogation ouverte par alourdie de déterminations portant sur הַet reste en suspens, en anacoluthe, à la fin du vs 26 . Aussi est-elle reprise au début du vs 27 qui continue la phrase. On obtient ainsi : "Jusques à quand (cela va-t-il durer) ? Y a-t-il dans le coeur [= est-ce l'intention] des prophètes qui prophétisent le mensonge et sont les prophètes de la fraude de leur coeur [ = de la fraude qu'ils inventent ]... (27) est-ce qu'ils ont pour dessein de faire oublier mon nom à mon peuple par leurs songes qu'ils se racontent l'un à l'autre..."

Estimant que les versions ne se distinguent du ${ }^{*} M$ que par des facilitations évidentes, le comité a attribué à celui-ci la note "B".

23,29 כB] M G T // abr-styl : V S om

Options de nos traductions :

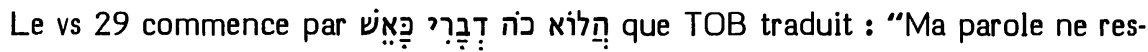
semble-t-elle pas à ceci : à un feu".

Sans note, RSV, RL et $\mathrm{J3}$ ne traduisent pas le 2e mot. A la place de ce mot, $\mathrm{J12}$ ("Ma parole ne brûle-t-elle pas comme feu ?") et NEB ("Do not my words scorch like fire ?") conjecturent כịj.

Origines des corrections :

Au XVIe siècle déjà, la quasi-totalité des traductions ne tenaient pas compte du 2e mot de ce vs. C'est Cornill qui a proposé formellement de l'omettre, suivi en cela par Schmidt, Bright ainsi que les apparats de HSAT34, BH2 et Cent.

C'est Venema qui a eu l'idée de chercher en כה un substantif dérivé du verbe כוה (= brûler). Hensler (cité par Rosenmüller) a préféré y voir un infinitif de ce verbe, alors que Perles (II 24) préfère lire un accompli et Volz un participe (comme $J 12$ et NEB), suivi en cela par Nötscher, Rudolph, Steinmann, Weiser ainsi que les apparats de $\mathrm{BH} 3 \mathrm{~S}$.

\section{Les témoins anciens :}

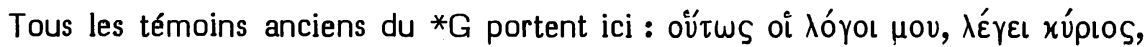

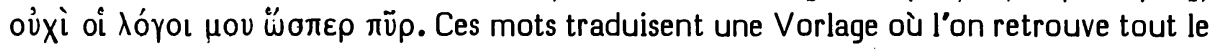

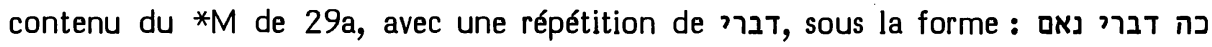
יהוה הלוא דברי כאש. Les recensions origénienne et antiochienne omettent les 6 premiers mots et continuent par oủxì oútws oi etc., se trouvant avoir abandonné $\lambda \varepsilon ́ \gamma \varepsilon l$ xúplos qui correspondait, dans le *G ancien, à נאם יהוה. Ziegler (Beiträge 100) a eu tort d'omettre, avec les recensions, les six premiers mots $d u{ }^{*} G$ ancien, à titre de doublet.

Le mot כה noa été traduit ni par la *V, ni par la *S.

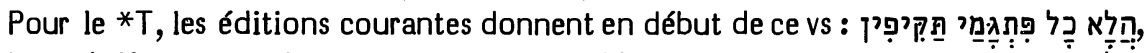
Sperber n'offrant pas de variante. Or le ms Urbinates 1 porte 


\section{Choix textuel :}

Il semble que la leçon courante du *T (qui correspond à un sebir babylonien signalé en ms T.-S. D 1,4 recto) soit issue d'une corruption interne et que le ms Urbinates 1 nous offre la leçon originale identique au $* M$.

Le ${ }^{*} G$ ancien nous témoigne qu'en une étape antérieure à la bifurcation de la Vorlage $d u{ }^{*} G$ et du texte prémassorétique, הלוא et étaient déjà présents. On ne saurait donc, à l'intérieur de la tradition protomassorétique, considérer la non-traduction de כar certains témoins comme une attestation d'une forme textuelle antérieure à celle dont témoigne le *M.

Le comité a attribué ici au *M la note " $B$ ".

\section{Interprétation proposée :}

“Ma parole n'est-elle pas comme ceci : comme un feu - oracle du Seigneur et comme un marteau qui fracasse le roc !" L'expression "comme ceci" vise à introduire les deux comparaisons à la fois.

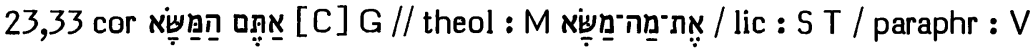

\section{Options de nos traductions :}

Aucune ne traduit ici le *M אֶת Celles qui ont des notes disent se fonder sur le *G et la *V pour lire "C'est vous le fardeau", NEB : "You are his burden", RL : "Ihr seid die Last" et TOB : "C'est vous la charge".

Origine de la correction :

C'est Cappel (Notae 528a) qui a suggéré cette Vorlage pour le *G. Puis cette leçon a été adoptée par Houbigant, Venema, Doederlein, Michaelis (Observationes, avec l'accord de Schleusner), Hitzig, Graf, Grätz (Studien 204), Knabenbauer, von Orelli, Giesebrecht, Perles (I 40), Oort, Duhm, Ehrlich, Cornill, Condamin, Volz, Schmidt, Nötscher, Rudolph, Penna, Steinmann, Weiser, Bright et les apparats de SBOT, HSAT234, BH23S et Cent.

\section{Les témoins anciens :}

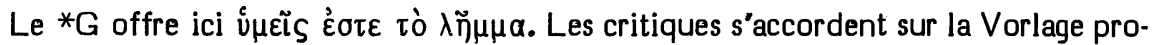
posée par Cappel, sauf Michaelis (Observationes) et Wernberg-Moller (Pronoun) qui suggèrent

La * $V$ "ut quid vobis onus" paraphrase le * $M$, sans se séparer entièrement de la Vieille Latine dont Hie avait conservé la leçon : "vos estis onus", leçon qui a d'ailleurs pénétré à nouveau dans l'édition Clémentine de la *V, par l'intermédiaire des mss de l'université de Paris.

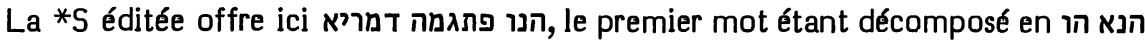
par le ms Ambrosianus. Cette traduction, comme celle du *T (כדין נבואתא), rend librement le *M. 
Choix textuel :

Il est frappant que Rashi, dans son commentaire, éprouve le besoin de gloser le *M par אתם למשא. להק qui lui semble un maillon nécessaire entre ces trois mots et ceux qui les suivent.

Un certain nombre d'exégètes de valeur : Schnurrer, Rosenmüller, Ewald, Nägelsbach, Keil et Luzzatto ont refusé de quitter ici la leçon du *M. Schnurrer, Ewald et Keil proposent de comprendre את au sens de "quant à", "pour ce qui est de", la conjonction qui suit ces trois mots introduisant l'apodose, avec la valeur de "eh bien !" : "Pour ce qui est de 'quel est le fardeau', eh bien! je me délesterai de vous - oracle du Seigneur." On a une construction semblable en Is 57,12: ואת־מעשיך ולא־יועילוך : "pour ce qui est de tes oeuvres, eh bien ! elles ne te seront d'aucun profit." Ce serait une réponse irritée à la question ironique qui vient d'être posée au prophète en jouant sur le double sens de "oracle" et "fardeau" du mot משא :quel est le fardeau/oracle du Seigneur". La réponse reprendrait littéralement le improbable que cette signification très fine ait été insérée après coup dans le texte si

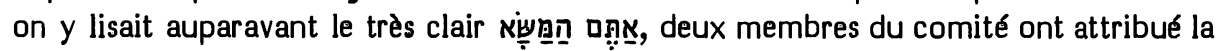
note " $C$ " à la leçon du * $M$ en la considérant comme originale.

Cependant, en $\mathrm{Jb} 7,20$ nous reconnaîtrons dans le *M une correction théologique ayant pour but d'éviter l'affirmation que Job est un fardeau (même terme מִֵِ pour le Seigneur. Là encore, le *G sera indemne de cette correction. Déjà Volz avait estimé qu'ici. la leçon du ${ }^{*} M$ est le produit d'une correction visant à sauver l'honneur d'Israël. Mieux vaut admettre qu'ici et en $\mathrm{Jb} 7,20$ il s'agit de corrections théologiques visant à sauver l'impassibilité transcendante du Seigneur à qui rien ne peut peser. C'est pourquoi trois des membres du comité ont attribué ici à la leçon du * $G$ la note " $C$ ", alors qu'un autre lui attribuait un "B".

Interprétation proposée :

La leçon choisie par la majorité du comité a été bien traduite par RSV, J3 et TOB.

Nous avons traduit ci-dessus la leçon du *M retenue par la minorité.

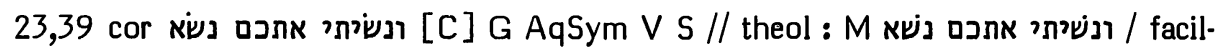

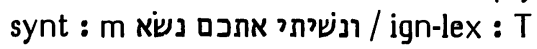

Options de nos traductions :

Aucune de nos versions ne respecte les points diacritiques à droite de

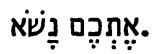

Avec 5 mss, NEB, selon Brockington, place à gauche le point diacritique du premier verbe quand elle traduit : "I ... will carry you like a burden". J23 ajoute à cela les versions pour traduire : "je vous soulèverai" que J1 faisait suivre de : "à fond". TOB se fonde sur d'autres mss hébreux pour traduire : "je vais bel et bien me charger de vous". RL traduit : "will ich euch aufheben wie eine Last". 


\section{Origine de la correction :}

Au XVIe siècle, les traducteurs ont été très hésitants. Lisaient deux fois le point diacritique à droite (avec les éditions de Brescia 1494, Félix de Prato et Ben Hayim) en interprétant les verbes au sens de "oublier": Pagnini, Brucioli, Vatable, Arias Montano, Tremellius, Geneva, Pasteurs, KJ. Lisaient la première fois le point diacritique à droite et la seconde fois à gauche (avec les éditions de Soncino 1488, Bomberg 1521, Münster 1534) en interprétant le premier verbe au sens de "oublier" et le second au sens de "emporter" : Münster, Olivetan et Rollet. Traduisaient seulement par "emporter" (quoiqu'aucune édition hébraïque ne porte les deux points diacritiques à gauche) : Prédicants, Zwingli, Luther, Jud, Calvin, Estienne, Châteillon, ainsi que des leçons marginales en Servet et Geneva.

Le premier à proposer formellement de corriger la ponctuation du *M semble avoir été Calmet. Mais notons que Grotius et Venema croyaient lire ici dans le *M le verbe "porter".

Michaelis (OEB) choisit la leçon mixte de Münster qu'il dit lire en l'édition infolio d'Estienne (= 1557). En Observationes, il précise que c'est la ponctuation qui s'accorde le mieux avec la graphie du premier verbe avec 'yod' et du second avec 'alef'.

Corrigent en plaçant à gauche les deux points diacritiques : Ewald, Henderson, Graf, Nägelsbach, Knabenbauer, von Orelli, Giesebrecht, Oort, Duhm, Ehrlich, Cornill, Condamin, Volz, Nötscher, Rudolph, Penna, Steinmann, Weiser, Bright et les apparats de SBOT, HSAT234, BH23S et Cent.

\section{Les témoins anciens :}

De Rossi signale pour le premier verbe le point diacritique à gauche en un ms et la première main de quatre autres. Pour le second verbe, il le signale en six mss et la première main de huit autres.

Dans les mss d’Alep et de Leningrad, ainsi qu'en Ben Ḥayim, une mp protège chacune de ces deux formes verbales comme hapax.

Le * ${ }^{*}(\lambda \alpha \mu \beta a ́ v \omega)$ a lu un 'śin' dans le premier verbe et n'a pas tenu compte de

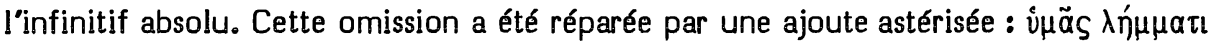
dans les recensions origénienne et antiochienne, cette ajoute étant attribuée à AqSym par le ms Marchalianus.

Ont lu aussi deux “śin”: la *V (tollam vos portans) et la *S (אשקולכון משקל).

Le *T (שלח רוגזי ואירטוֹש יתכון מירטש: a tâtonné en réutilisant ici le verbe qui lui avait servi pour traduire au vs 33 le verbe נטש qui revient ici juste après dans le *M.

\section{Choix textuel :}

Notons d'abord que les attestations de la variante massorétique avec les deux points diacritiques à gauche sont négligeables. Quant à la leçon mixte attestée par certaines éditions anciennes, quelques mss de Rossi et les traductions de Münster, d'Olivetan et de Michaelis, elle est une facilitation causée par la graphie avec 'alef' de l'infinitif absolu. La leçon authentique $d u{ }^{*} M$ est sûrement celle qui porte les deux points diacritiques à droite.

Cependant, les exégètes juifs du moyen âge ont hésité sur le sens de ce verbe. Rashi et les glossaires, se référant à Gn 32,33 et Jr 51,30, ont compris "tressaillir", 
c'est-à-dire : sautant et se déplaçant d'un lieu à l'autre. En s'inspirant du *T, David ben Abraham (II 635,23 confirmé par I 9,178s) a compris "je vous délaisserai de délaissement". Abulwalid (selon le ms de Londres du Kitâb al-Ușul et selon le ms de l'Escorial de la traduction d'Ibn Tibbon, sur נשה fait précéder ce sens par celui de "faire réclamation", comme on réclame une créance. Radaq, Joseph ibn Nahmias et Isaïe de Trani reprendront le sens: "je vous oublierai d'oubli" que Yéfet ben Ely avait donné ici en son commentaire.

Nous avons détecté en 23,33 une correction théologique probable visant à éviter que le Seigneur ne porte un fardeau. Si l'on remarque qu'au vs 33 le mot מַwe pré-

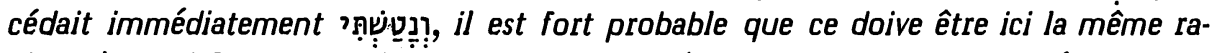
cine נשن qui figurait originellement dans la même situation et que son élimination (par placement à droite des deux points diacritiques) soit une correction théologique analogue à celle que nous avons décelée au vs 33. Il n'y a en effet aucune difficulté à ce qu'une graphie avec 'yod' soit issue d'une forme 'lamed-alef' dont le 'alef' normal apparaît d'ailleurs clairement dans l'infinitif absolu qui suit. Aussi la note " $C$ " a-t-elle été attribuée à la leçon du ${ }^{*} G$, de AqSym, de la $* V$ et de la*S par trois membres du comité, alors qu'un autre lui at tribuait la note " $\mathrm{B}$ ".

Pourtant, deux membres du comité ont attribué la note " $B$ " à la leçon du * $M$ en estimant que la présence ici d'un verbe phonétiquement proche de celui que l'on attendrait, mais distinct de lui, est une finesse de l'auteur. Notons cependant que le sens probable de "oublier" serait mieux suivi par "délaisser" que par "jeter à terre" que signifie $ש$ שט, juste après.

Interprétation proposée :

Comme au vs 33, il y a ici une réponse au jeu de mot ironique sur "oracle" et "fardeau". On pourra donc traduire : "à cause de cela, me voici qui vais vous soulever comme un fardeau et vous jeter loin de ma face, vous et la ville que j'avais donnée à vous-mêmes et à vos pères".

\section{4,9 לרעה [B] M AqSym g V S T // lit : G om}

Options de nos traductions :

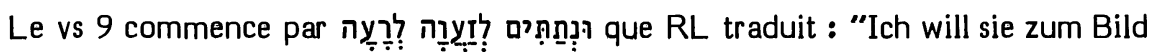
des Entsetzens, ja des Unglücks, machen", TOB : "avec horreur, je fais d'eux un exemple terrifiant" et J3: "J'en ferai un objet d"horreur, une calamite"."

Disant omettre le 3e mot avec le *G, RSV traduit : "I will make them a horror", $J 12$ : "J'en ferai un objet d"horreur" et NEB : "I will make them repugnant".

\section{Origine de la correction :}

C'est Cappel (Notae 528a) qui a fait remarquer que le $* G$ a omis ce mot. Movers (32) a noté que ce mot manque dans les parallèles de 15,4; 29,18 et 34,17. Il y voit donc ici une interpolation. L'ont éliminé à ce titre : Ewald ( $y$ voyant une dittographie erronée du mot précédent), Hitzig, Graf, Grätz, Giesebrecht, Oort, Duhm, Cornill, Condamin, Ehrlich, Schmidt, Nötscher, Rudolph, Penna, Steinmann, Bright ainsi que les apparats de SBOT, HSAT234, BH23S et Cent. 
Les témoins anciens :

Le ${ }^{*} G$ ancien omet ce mot. AqSym le traduisent : zis $x \alpha x \alpha ́$. La recension antiochienne insère cette traduction à la fin de $9 a$.

Le *M a été lu ici par la *V (adflictionemque), la *S (ללבישתא) et le *T (לבישא). La*S a même ajouté auparavant : ולנידא.

Choix textuel :

Keil a fait remarquer que לְְרִ peut avoir ici pour rôle de faire pendant à vs 5 et du vs 6. Von Orelli estime que ce mot correspond à הרות du à va 8 . Il n'est cependant pas impossible que ce soit une glose. En ce cas, on la considérera comme constitutive du texte protomassorétique puisque tous les témoins de ce texte l'attestent.

Au cas où ce serait un doublet du mot qui précède, étant donné que celui-ci figure seul dans le *G, il faudrait considérer לרעה comme la forme du doublet qui caractérise le texte protomassorétique, et on devrait alors considérer לזעוה comme la forme du doublet qui y a pénétré après coup ou bien à partir de la Vorlage du ${ }^{*} G$, ou bien à partir des parallèles de 15,$4 ; 29,18 ; 34,17$. Mais cela n'est qu'hypothèse et nous $n$ 'avons aucun indice que ce type textuel ait existé sans ce mot.

Le comité a attribué au *M la note "B".

Interprétation proposée :

Si l'on a traduit aux vss 5 et 6 לִ לִּוֹבְ par "pour le bonheur", on pourra traduire ici לִ ְִ par "pour le malheur".

\section{ולחרפת 25,9 ולחרבות}

Options de nos traductions :

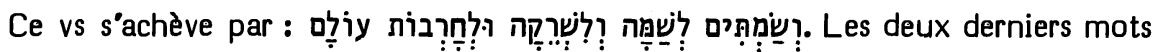
sont traduits par RL : "und zur ewigen Wüste", par TÖB : "en champs de ruines", par 33 : "des ruines pour toujours" et par NEB : "a scandal for ever".

Disant suivre le ${ }^{*}$ G, RSV traduit : "and an everlasting reproach" et J12: "pour toujours... et un opprobre".

Origine de la correction :

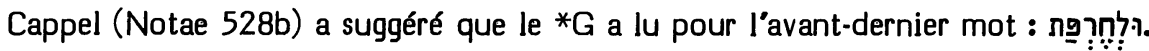
Cette leçon est adoptée par Hitzig, Oort, Duhm, Cornill, Condamin, Volz, Nötscher, Rudolph, Penna, Steinmann, Weiser, Bright et les apparats de HSAT234, BH23S et Cent.

Les témoins anciens :

Pour ce mot, le *G porte xaì عis ỏveıótopóv qui correspond normalement à la Vorlage suggérée par Cappel.

A la place de cela, AqSym ont ולחורבא qui est la traduction de la *S.

La*V offre "et in solitudines" et le *T ולחורבת (selon le ms Urbinates 1). 
Choix textuel :

Ceux qui préfèrent ici la leçon du ${ }^{*} G$ le font parce qu'ils considèrent que des habitants ne peuvent être transformés en ruines. Mais il faut remarquer que le châtiment porte sur le pays et ses habitants, c'est-à-dire sur les villes autant que sur leurs habitants.

Notons d'ailleurs qu'au vs 11 où, à propos du pays, on retrouve les compléments

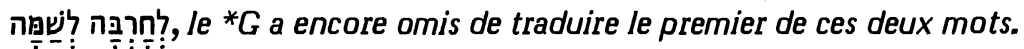

Cependant Dn 9,2 parle des 70 années dont le Seigneur avait parlé à Jérémie

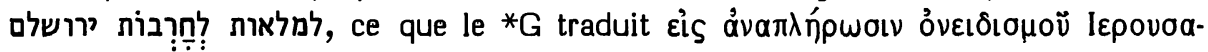
$\lambda \eta \mu$. Il y a évidemment référence formelle à Jr 25,9-11 où le mot pluriel תị n’⿳亠丷厂 n’apparaît qu'en 25,9 . Il semble que le ${ }^{*} \mathrm{G}$ de Daniel cite le ${ }^{*} \mathrm{G}$ de Jérémie, avec son équi-

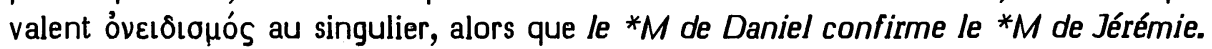

En 25,18 on retrouvera dans un ordre différent les mêmes trois compléments

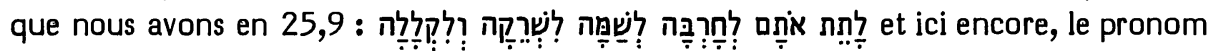
suffixe 3 e pers. m. pl. a pour antécédents à la fois des villes et leurs habitants. Le *G

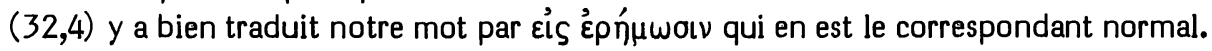
Mais pour éviter de faire porter ce complément sur les habitants, il a traduit le pronom suffixe par un féminin (aưás), ce qui le fait porter seulement sur "Jérusalem et les villes de Juda" et non sur "son roi et ses princes". En 25,9 et en 25,18 le traducteur grec n’a pas compris que la syntaxe hébraïque admet de coordonner des compléments dont certains ne portent que sur une partie des antécédents qui viennent d'être regroupés sous un même pronom suffixe.

La majorité du comité a estimé qu'il fallait respecter ici la tradition textuelle du *M qu'elle considère comme plus probablement originale que celle du *G. Le *M a donc reçu 3 " $\mathrm{B}$ " et 2 " $\mathrm{C}$ ", alors que le *G recevait 1 "C".

Interprétation proposée :

“(Je les vouerai à l'anathème), à la désolation et au persiflage, j’en ferai des ruines à jamais."

\section{5,14 עבד [B] M ThAq V S T // substit-synt : Sym fut / lacun : G om}

Options de nos traductions :

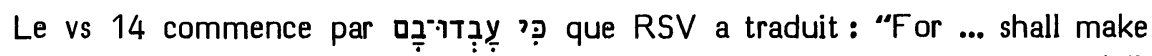
slaves ... of them", RL : "Und ... sie sollen ... dienen" et TOB : “Ils seront asservis".

Disant conjecturer un futur, J traduit : "Car elles ... seront asservies" et NEB : "They will be the victims", Brockington précisant qu'elle corrige le verbe en

Origine de la correction :

Michaelis (Observationes) a estimé que l'accompli admettait mal une traduction en futur.

Luzzatto a cru voir ici un cas de la coutume scribale de non-répétition d'une lettre lorsqu'elle apparaît à la fois comme dernière lettre d'un mot et comme première lettre du mot suivant (cf. CT1, 401). 
Ont préféré voir ici une haplographie d'un 'yod' : Ehrlich (Miqra), Cornill, Nötscher, Rudolph, Weiser et les apparats de HSAT34, BH23S.

Les témoins anciens :

Le ${ }^{*} G$ ancien n'a pas ce vs. Cependant les recensions origénienne et antiochienne l'insèrent après 25,13 en traduisant ce verbe par éóoúlevoav que les mss Barberini et

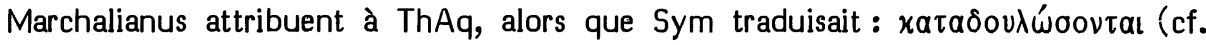
Field).

La *V (servierunt), la *S (שעבדו) et le *T (אפלחו) ont traduit par des passés.

\section{Choix textuel :}

Rashi dit qu'il faut comprendre cet accompli comme si c'était un inaccompli. Radaq dit que c'est un passé au sens de présent. Cependant, ici où il s'agit d'une action humaine, Cornill a raison de dire, contre Hitzig et Keil, qu'un accompli à valeur prophétique ne serait pas en place.

Il est d'ailleurs frappant de voir que ThAq, la *V, la *S et le ${ }^{* T}$ ont compris cet accompli comme un passé.

Du fait que le $* G$ ancien ne possède pas ce verset, il est permis de se demander s'il ne constitue pas une addition faite ex eventu. Cela expliquerait que le glossateur ait placé en 14a un accompli à sens de passé avant de se réorienter vers l'avenir en 14b avec un accompli inverti.

Considérant que seul Sym pourrait avoir lu ici un inaccompli, le comité a attribué à la leçon du *M la note " $B$ ".

Interprétations proposées :

Les parallèles de 22,13; 27,7; 30,8; 34,9.10 montrent que l'expression -עבר signifie : "accomplir un ouvrage en utilisant les services d"un autre", et, en conséquence : "réduire quelqu'un en esclavage".

Les vss 13 et 14 du *M peuvent se traduire ainsi : “(13) Je ferai venir contre ce pays toutes mes paroles que j’ai prononcées contre lui, tout ce qui est écrit dans ce livre, ce que Jérémie a prophétisé contre toutes les nations. (14) Car aussi ce sont elles, des nations nombreuses et de grands rois, qui les ont réduits en esclavage, et je les rétribuerai selon leurs actes et selon l'oeuvre de leurs mains." Dans le vs 14, le premier "les" désigne les membres du peuple de Dieu, et le deuxième "les" désigne les nations et les rois. C'est ce que Michaelis (Observationes) a établi de façon convaincante.

Il est vraisemblable que le texte prémassorétique a interprété à tort "ce que Jérémie a prophétisé contre toutes les nations" comme une explicitation de "tout ce qui est écrit dans ce livre", alors qu'il s'agissait du titre des oracles contre les nations. C'est cette fausse interprétation qui aurait obligé un glossateur à introduire l'explication embarrassée que constitue le vs 14.

Il ne faut pas oublier que Rashi, Radaq et Luzzatto n'ont vu aucune difficulté à interpréter en futur le verbe qui nous occupe. 
Options de nos traductions :

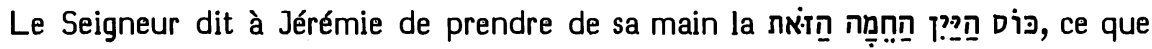
RSV traduit : "this cup of the wine of wrath", RL : "diesen Becher mit dem Wein meines Zorns", NEB : "this cup of fiery wine" et J3 : "cette coupe de vin de colère".

$\mathrm{J12}$ omettaient par conjecture le $3 \mathrm{e}$ mot et traduisaient : "cette coupe de vin".

TOB, avec le *G, traduisait : "cette coupe de vin, de vin capiteux".

\section{Origines des corrections :}

Cappel (Notae 528b) considère que le ${ }^{*} G$ a lu ner, annotant les Observationes de Michaelis, se demande s'il ne faudrait pas adopter

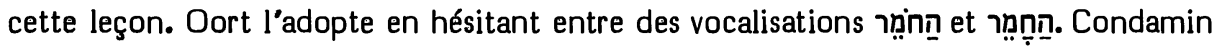
l'adopte en vocalisant המְֶ.

Gênés par le fait que le 2e et le 3e mots ont tous deux des articles, Bright corrige le $2 \mathrm{e}$ mot en état construit sans article, alors que Ehrlich et les apparats de $\mathrm{BH} 2$ et de HSAT4 voient en ce mot une glose, tandis que Cornill, Nötscher, Rudolph, Penna, Steinmann et les apparats de HSAT3, BH3S et Cent considèrent le 3e mot comme une glose. Quant à Volz, il estime que ces deux mots sont une glose explicative signifiant : "le vin, c'est la colère".

Les témoins anciens :

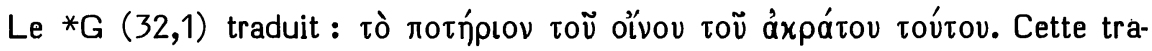
duction doit être rapprochée de celle de $P s$ 75,9 où il est dit qu'il y a une Dij dans la

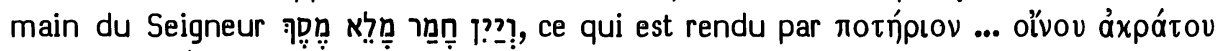

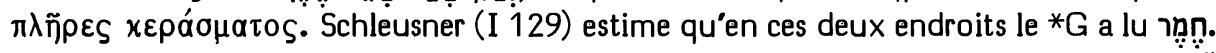

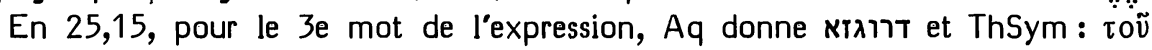
$\theta v \mu o u ̈$ (cf. Field).

La *V traduit : "calicem vini furoris huius", la *S : כסא דחמרא דחמתא הדא et le *T : כסא דחמר לוטא הדין.

\section{Choix textuel :}

Ce cas n'a pas été soumis au comité.

Les quatre mots en question ont été lus par tous les témoins. Seul $l e{ }^{*} G$ semble s'être inspiré du Ps 75,9 pour traduire les $2 e$ et 3 e mots.

A la différence de $\mathrm{Jg}$ 16,14 et de Jr 25,26 (dont nous traiterons ci-après), הביב, qui est le premier des deux mots précédés de l'article, n'est pas vocalisé en état construit. Cela veut dire que les vocalisateurs ont considéré le mot suivant comme une apposition de celui-ci : le vin signifie la colère.

Interprétation proposée :

Comme Hitzig l'a finement noté, le démonstratif הזאת porte sur le mot כוס, tandis que (en 15b) le pronom accusatif isic porte sur היין. On traduira donc :

"Prends de ma main cette coupe du vin qui est la colère et tu le feras boire à toutes les nations." 
Options de nos traductions :

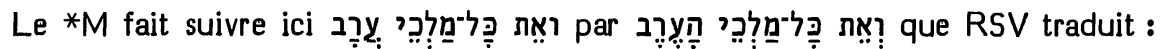
"and all the kings of the mixed tribes", RL : "(alle Könige...) und die der Mischvölker", TOB : "tous les rois des métis" et J3 : "et tous les rois du ramassis des étrangers".

$\mathrm{J} 12$ omettait par conjecture ces quatre mots.

NEB, traduisant "all the kings of Arabia", disait suivre le *G et prétendait que le *M ajoute : "and all the kings of the Arabs".

Origine de la correction :

Henderson a suggéré que les $5 \mathrm{e}$ à $8 \mathrm{e}$ mots peuvent être une dittographie des 4 premiers. C'est l'avis de Grätz, Giesebrecht, Oort, Duhm, Condamin, Ehrlich, Nötscher, Rudolph, Penna, ainsi que des apparats de BH3S.

\section{Les témoins anciens :}

Par haplographie, les 4 premiers mots ont été omis dans le ms Kenn 145, et les 4 suivants dans le ms Kenn 101.

Pour l'ensemble des 8 premiers mots, le *G $(32,10)$ donne seulement : xà̀ rávias

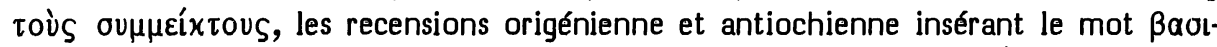

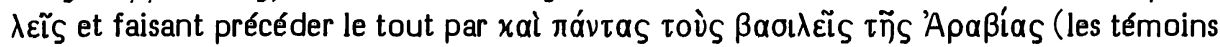
de l'origénienne insérant oúv après la conjonction initiale, omettant l'article toús et attribuant cette ajoute à ThAq).

Les huit premiers mots du vs sont traduits par la *V : "et cunctis regibus Arabiae

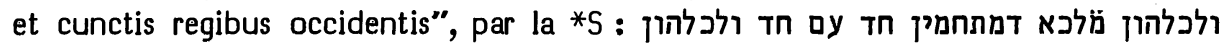

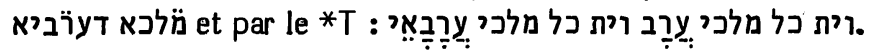

\section{Choix textuel :}

La traduction donnée ici par le ${ }^{*} G$ ancien est celle par laquelle il a rendu بִ̣?

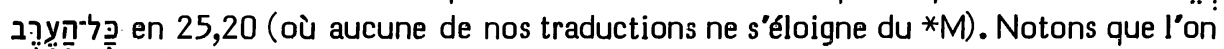

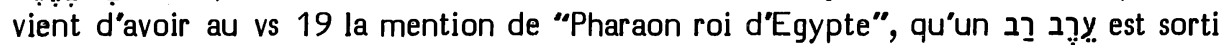

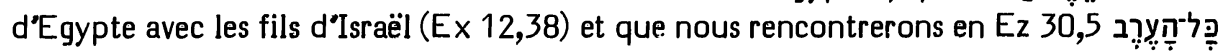
semblant désigner une catégorie d'étrangers qui mettent leurs armes au service de l'E. gypte. On peut donc conclure qu'en 25,20 les trois mots cités sont bien en place.

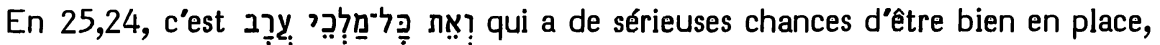
comme l'indique le qualificatif "qui habitent dans le désert" (cf. 3,2: "comme un arabe dans le désert").

Il semble donc bien que le ${ }^{*} G$ a modelé le début du vs 24 sur celui du vs 20, alors que le ${ }^{*} \mathrm{M}$ a ajouté en doublet à la leçon originelle du vs 24 une variante où עִ̣ est remplacé par

Aucun témoin textuel ne nous permet cependant de restaurer la leçon qui a le plus de chances d'être originelle. Il faut donc accepter la conflation du *M comme caractérisant le texte protomassorétique. C'est ce que le comité a fait en lui attribuant 4 "C" et 2 "B". 
Interprétation proposée :

Le mot "métis" utilisé par TOB prête à confusion. Mieux vaut utiliser le terme dont on se sera servi dans l'Exode. Donc: "Tous les rois d'Arabie et tous les rois du ramassis des étrangers." Une note pourra indiquer que seule la 1e catégorie de rois semble en place en ce contexte.

\section{5,26 הארץ [B] M g V // paraphr : T / lit : G S om}

\section{Options de nos traductions :}

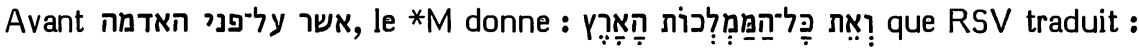
"and all the kingdoms of the world", RL: "alle Königreiche der Welt" et TOB : "et tous les royaumes de la terre".

Disant omettre le dernier mot avec le ${ }^{*} \mathrm{G}, \mathrm{J}$ traduit : "et tous les royaumes" et NEB : "and all the kingdoms".

Origine de la correction :

L'omission de ce mot a été proposée par Graf, Nägelsbach, Luzzatto, von Orelli, Giesebrecht, Oort, Duhm, Cornill, Condamin, Nötscher, Rudolph, Penna, Bright et les apparats de SBOT, HSAT 234, BH23S et Cent.

Les témoins anciens :

Dans les mss d'Alep et de Leningrad, une mp signale comme hapax l'état construit précédé d'un article :

Après ce mot, le ${ }^{*} G$ n'a pas traduit le mot suivant, omission que les recensions

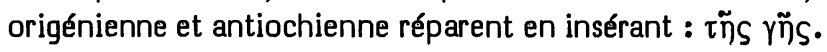

Cette omission se retrouve dans la $*$ S.

La *V (et omnibus regnis terrae) et le *T (וית כל מלכות עממיא) ont lu ce mot que le *T a paraphrasé pour éviter un double emploi avec ce qui suit.

Choix textuel :

Alors qu'en 25,15 les vocalisateurs avaient considéré le second mot muni de l'article comme une apposition du premier (cf. ci-dessus, p. 655), nous retrouvons ici la même situation qu'en $\mathrm{Jg} 16,14$ (dont nous avons traité en CT1, 112). Nous pourrons aussi y voir un indice que le mot הארץ a des chances de ne pas être primitif en ce contexte.

Notons cependant que Is 23, 17 (où la mention des 70 ans indique une dépendance à l'égard du livre de Jérémie) lisait déjà ici ce mot (le *G y ayant simplifié

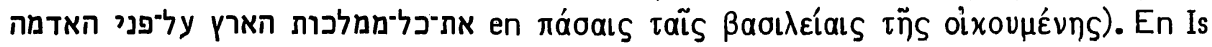
23,17 l'absence d'article avant le premier mot indique un effort pour normaliser l'expression.

Il est difficile de dire si, ici, le ${ }^{*} G$ ne lisait pas encore ce mot ou si il a allégé sa traduction (comme l'a fait le ${ }^{*} G$ de Is 23,17 ).

Qu'il s'agisse ou non d'une glose, le mot הארץ fait partie du texte protomassorétique, comme l'indique son attestation par les recensions du ${ }^{*} G$, par la $* V$ et (indirectement) par le *T. Aussi le comité lui a-t-il attribué 4 " $\mathrm{B}$ " et 2 " $\mathrm{A}$ ". 
Interprétation proposée :

"et tous les royaumes de la terre qui sont sur la surface du sol."

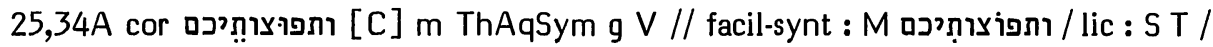
abr-elus : $\mathrm{G}$ om

Options de nos traductions :

Le mot "(dass ihr...) und zerstreut werdet", par TOB : "Vous serez dispersés" et par J3 : "et pour votre dispersion".

En se fondant sur le ${ }^{*} \mathrm{G}, \mathrm{J} 12$ et NEB ont omis ce mot.

Origine de la correction :

Voyant en ce mot un hapax dépourvu de sens, Houbigant a conjecturé : והתפצרתם (= vous serez brisés). Quant à Stade (Deuterozacharja 68, n.2), il a proposé d'omettre ce mot, suivi en cela par Duhm, Cornill, Condamin, Nötscher, Rudolph, Penna, Steinmann, Bright et les apparats de SBOT, HSAT34, BH23.

\section{Les témoins anciens :}

Les éditions Halle et Ginsburg du $* M$, ainsi que de Rossi (Scholia) mentionnent ici dans les mss et les éditions des variantes portant sur la vocalisation. Voici le résultat des contrôles que nous avons pu faire :

-1) vocalisent le 'pé' avec ḥolem et le 'taw' avec hireq : les mss du Caire, d'Alep, de Leningrad, New York JThS 332, Reuchlin des Prophètes, Vatican ebr 482, Madrid Univ 1, Paris BN 82, de Rossi 2, Copenhague 2 et 8, les éditions Lisbonne 1492, Félix de Prato 1517 (Biblia rabbinica et éd. in- $4^{\circ}$ ), Ben Hayim. En faveur de cette leçon, il faut ajouter le témoignage du ms Cambridge A 43,1 (serugin en ponctuation palestinienne publié par Kahle en Masoreten des Westens II 94).

-2) vocalisent le 'pé' avec shureq et le 'taw' avec șéré : les mss Petrograd des Prophètes, Erfurt 3, Vatican ebr 468, Urbinates 1, Londres BL Add 15451 et 21161, Hamburg 6 et 27, Copenhague 3 et 5, les éditions Soncino 1488 et Brescia 1494. -3) des formes mixtes proposent ḥolem et șéré (ms Berne des Prophètes, Vatican ebr 3, Copenhague 1 et éd. Bomberg 1521).

-4) portaient sous le 'taw' un șéré qui a été corrigé en ḥireq : Paris BN 2 et 26, de Rossi 782.

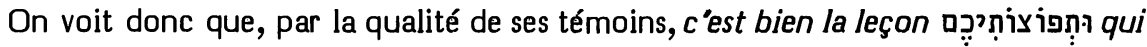
peut prétendre à être la leçon du *M de tradition tibérienne classique.

Le ${ }^{*} G$ ancien $(32,20)$ ne traduit pas ce mot. Cette omission est réparée par une

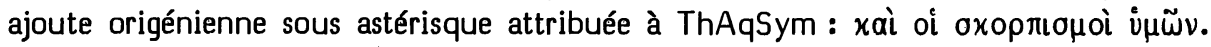
Cette leçon, comme "et dissipationes vestrae" de la *V, suppose la variante vocalique

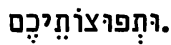

Ont lu ici une forme verbale : la *S (ותתברון) et le *T (ותתבדרון). 
Choix textuel :

Saadya (Kutub al-Lughah 209) analyse ce mot (qu'il vocalise avec holem et hireq) comme un accompli 1e pers. sg. affecté d'un suffixe 2e pers. m. pl.

Dans son commentaire édité par Kokovzov (28), Hayyuj s’exprime ainsi : “Ce mot est exceptionnel. C'est un combiné de nom et de verbe, c'est-à-dire de תפוצות qui est le pluriel de תפוצה et de והפיצותי".

Abulwalid (Luma 326,26ss) dit de ce mot : “On devrait avoir והפיצותיכם, mais on a changé le 'yod' en 'waw' et le 'hé' en 'taw', cette seconde mutation ayant aussi eu lieu en תרגלתי (Os 11,3)." Judah ibn Balaam analyse de même.

Menahem de Posquières voit à ce mot un sens principalement nominal : "et les jours de vos dispersions s'accompliront". Rashi interprétait de façon analogue. Les glossaires aussi donnent des interprétations nominales : "et vos épandus" en BCF (ce participe étant mis au féminin par A plus littéral) et "et vos épandements" en DE. Joseph Qara comprend : “les têtes de petit bétail que vous gardiez lorsque vous étiez en fonction seront dispersées". Moshé ben Sheshet voit ici un combiné d'un nom et d'un accompli hifil. Mais il ajoute qu'il se peut que ce soit seulement un nom avec hireq à la place de șéré.

Radaq commente ainsi : “Ce mot se présente sous une forme anormale car le "pé" est avec ḥolem et le 'taw' avec ḥireq, alors qu'il eât été exact que le 'pé' ait un shureq et le 'taw' un séré, puisqu'il est une forme de תפוצה sur le modèle de

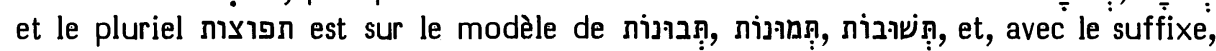

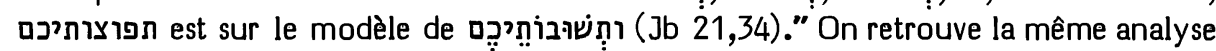
dans les Shorashot Keseph d'Ibn Kaspi et dans le Maase Efod de Duran. Isaïe de Trani, analysant de même, estime qu'il faut sous-entendre comme verbe מלאו du stique précédent dont ce substantif est le 2e sujet en parallèle avec מִיְֶ? qui quécède.

On peut se demander si les mss qui portent ici un shureq et un séré ont été influencés par le commentaire de Radaq. Mais la vocalisation babylonienne du ms de Petrograd des Prophètes est certainement antérieure à Radaq et issue d'un tout autre milieu. Mieux vaut donc admettre que cette vocalisation en shureq et șéré est une survivance d'une vieille exégèse traditionnelle attestée par ThAqSym et par la *V, cette vocalisation ayant été ensuite inférée par Radaq, par voie de conjecture.

$C^{\prime}$ est vraisemblablement parce qu'il le jugeait inintelligible que le ${ }^{*} G$ a passé ce mot sous silence.

La vocalisation en ḥolem et ḥireq du texte tibérien classique vise à obtenir ici un verbe au sens de "et je vais vous mettre en pièces", ce qui constitue une facilitation syntactique.

Le comité a estimé préférable de choisir la vocalisation en shureq et séré à laquelle il a attribué la note "C".

\section{Interprétation proposée :}

Dans la ligne d'Isaïe de Trani et de Venema, on peut traduire littéralement : “car s'accomplissent vos jours pour le massacre et vos dispersions, quand vous tomberez comme un vase précieux. En tenant compte des glissements de sens entre les réalisations 'aiïn-waw' et 'pé-nun' du bilittère $ү$ g, on pourra traduire en un français plus coulant : "car il est venu le temps où vous serez massacrés et pulvérisés, quand vous tomberez comme un vase précieux". 
Options de nos traductions :

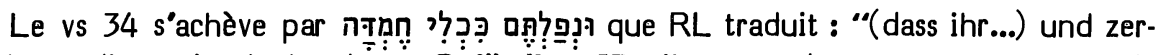
brechen müsst wie ein kostbares Gefäss" et $\mathrm{J3}$ : “vous tomberez comme un vase de choix". TOB donne : "et vous tombérez comme des récipients précieux".

Suivant le *G, RSV donnait : "and you shall fall like choice rams", 312 : "vous tomberez comme des béliers de choix" et NEB : "and you shall fall like fine rams", Brockington précisant que cela suppose une correction du 2e mot en en •

\section{Origines des corrections :}

Estimant que le ${ }^{*} G$ a lu ככרי, Doederlein préférait cette leçon, suivi par Schleusner (sur les Observationes de Michaelis), Ewald, Oort, Duhm, Cornill et l'apparat de SBOT. Michaelis (OEB) a préféré restituer comme Vorlage et adopter כאילי, suivi en cela par Condamin, Nötscher, Rudolph, Penna, Steinmann, Bright et les apparats de $\mathrm{BH} 3 \mathrm{~S}$.

Les témoins anciens :

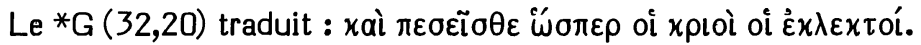

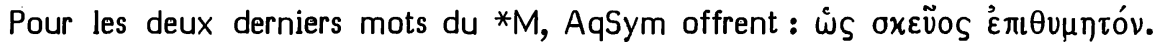

Traduisent le substantif par un pluriel : la *V (et cadetis quasi vasa praetiosa), la *S (ותפלון איך מאני רגתא) et le *T qui paraphrase : "et vous tomberez, vous qui étiez précieux comme des vases désirés".

\section{Choix textuel :}

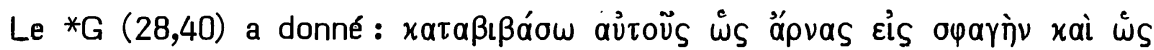

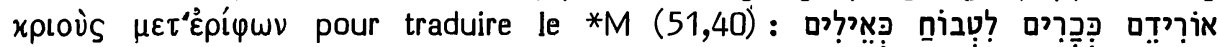

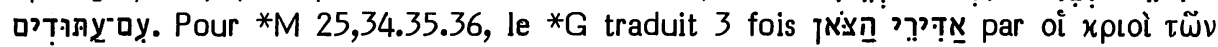

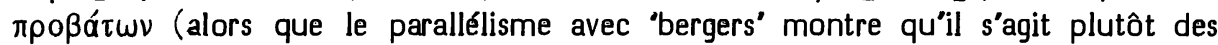
maîtres du troupeau). On comprend que ce contexte de xpló, $s^{\prime}$ ajoutant à la présence

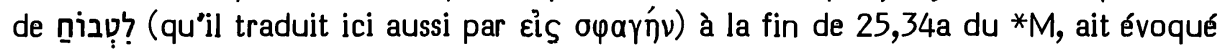
à la mémoire du ${ }^{*} G$ la traduction qu'il a donnée (en 28,40 ) pour $51,40($ du $* M$ ) et qu'il ait donc traduit ככלי comme s'il lisait כאילי... ce qui ne veut pas dire qu'il a lu en sa Vorlage ce mot qui s'accorderait mal avec le génitif מלי כמל כמדי

Au contraire, l'expression כלי חמדה est classique (Os 13,15; Na 2,10; Dn 11,8; 2 Ch 32,27; 36,10).

Le caractère tendancieux de la traduction du ${ }^{*} G$ se manifeste dans le fait qu'il n’a pas tenu compte du premier mot de cette $2 e$ partie du verset (cf. ci-dessus le cas 34A).

Quant à la mise au pluriel du mot "vase" par la *V, la *S et le *T, c'est une assimilation translationnelle à la désinence du verbe précédent.

Le comité a attribué au *M la note " $B$ ".

Interprétation proposée :

La comparaison avec le "vase précieux" ne veut pas dire que les chefs des nations 
sont particulièrement précieux pour le Seigneur. La comparaison porte plutôt sur la perte irréparable que cause la chute du vase précieux (c'est-à-dire de verre ou de cristal). La chute le pulvérise. Nous avons proposé une traduction à propos du cas précédent.

\section{חרב 25,38 חר (10) [C] M ThAqSym V S // assim 46,16; 50,16 : m G T}

Options de nos traductions :

L'expression

Pour le premier mot, NEB (selon Brockington) lit רֶ? avec 20 mss quand elle traduit : "the cruel sword". Sans rien noter, RSV ("the sword of the oppressor") et TOB ("l'épée impitoyable") lisent de même. Quant à J12, c'était sur le *G qu’elles entendaient fonder la traduction : "l"épée dévastatrice".

RL traduit : "von seinem gewaltigen Schwert".

Origines des corrections :

Michaelis (OEB) a proposé la correction du premier mot en בִִ̣, correction adoptée par Ewald, Hitzig, Graf, Nägelsbach, Keil, Knabenbauer, von Orelli, Grätz, Giesebrecht, Oort, Condamin, Volz, Nötscher, Penna, Steinmann, Weiser, Bright et les apparats de HSAT234, BH23 et Cent.

Rudolph (commentaire et BHS) préfère lire ịฺฺ̣n.

Les témoins anciens :

Le ms de Leningrad indique en mp que cette expression est hapax. Cela pour la protéger contre une assimilation à l'expression חרב היונה qui se trouve en Jr 46,16 et 50,16. Cette assimilation a d'ailleurs eu lieu de la part de la première ou de la seconde main dans une vingtaine de mss cités par de Rossi, ainsi que dans l'édition princeps de la Bible hébraïque (Soncino 1488).

Pour les 6 derniers mots que le ${ }^{*} M$ offre en ce vs, le ${ }^{*} G(32,24) n$ 'offre que :

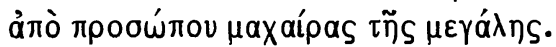

Au lieu de $\mu a x a i p a s$, ThAqSym offrent ỏprñs.

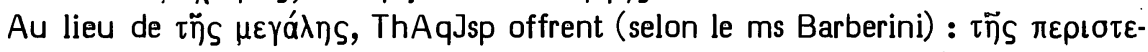

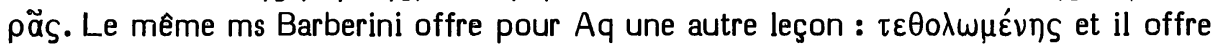

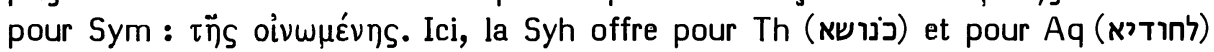
des leçons difficiles à interpréter.

$L a * V$ traduit ces deux mots par "irae columbae".

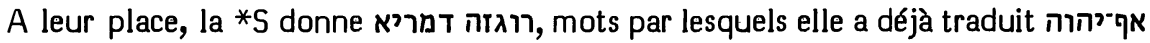
à la fin du vs précédent. Notons que la recension antiochienne du ${ }^{*} G$, offrant ici :

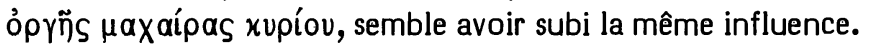

Dans la même ligne que Sym, le *T paraphrase : "l'épée de l'ennemi qui enivre comme le vin".

Choix textuel :

Un des membres du comité a estimé que חרון du *M est une leçon qui assimile au proche contexte. Aussi a-t-il attribué un " $\mathrm{C}$ " à la variante חִֶ?. 
Les cinq autres membres ont vu en cette variante une assimilation aux parallèles de 46,16 et de 50,16. Aussi ont-ils attribué à la leçon du *M la note "C".

Interprétation proposée :

Avec certaines des traductions hexaplaires et la $* V$, Yéfet ben Ely et David ben Abraham (II 46,55ss) comprenaient ici היונה au sens de "la colombe". De cela, Tanhum Yerushalmi dérivait le sens de "la naïve, celle qui se laisse tromper'.

Rashi hésite entre deux sens : ou bien "celle qui est enivrée de vin" (selon le *T) dérivé de p", ou bien le sens de "oppression" auquel Menahem ben Saruq dit (en traitant du monolittère 'nun') que certains potérim rattachent העיר היונה de So 3,1.

De fait, les glossaires hésitent entre ces deux sens, ABF proposant "la vineuse" alors que CDE proposent "l'engigneuse" (= la perfide).

Radaq voit en ce mot un participe qal de ינה au sens de "priver quelqu'un injustement de son patrimoine". Isaïe de Trani, acceptant cette interprétation, voit en nos deux mots une formule abrégée pour חרון חרב היונה. Schnurrer cite comme abréviation analogue כעדר הקצובות en Ct 4,2 où le mot "brebis" est sous-entendu. Il estime que I'expression חרב היונה devait être assez familière aux auditeurs du prophète pour que "épée" se présente spontanément à leur esprit comme le mot sous-entendu.

On pourra donc traduire ici : "la fureur de la dévastatrice" en indiquant en note qu'il s'agit de l'épée et en renvoyant à 46,16 et à 50,16 où l'on veillera à traduire : “l’épée dévastatrice".

\section{על ארמיא 26,1 הדבר הזה 27,1 : S add M G T // assim 27}

\section{Options de nos traductions :}

1a est constitué par un complément de temps : "Au début du règne de Joiaqim, היה : הils de Josias, roi de Juda", puis 1b donne, en introduction de l'oracle suivant RSV, RL et TOB se contentent de traduire cela.

Au verbe initial, J donne pour complément : “à Jérémie" et NEB : "to Jeremiah". Elles appuient cette ajoute sur la ${ }^{*} S$ à laquelle $\mathrm{J}$ associe la Vieille Latine.

\section{Origine de la correction :}

Keil a estimé que بִ ế était tombé après les trois premiers mots. Notant que la *S a lu ces mots, Giesebrecht les adopte, suivi en cela par Oort, Ehrlich (Miqra), Volz, Nötscher, Rudolph, Penna, Weiser, Bright, Wanke et les apparats de SBOT, HSAT34, BHS et Cent.

\section{Les témoins anciens :}

Ne mentionnent pas le destinataire de cette parole venant du Seigneur : le $* M$, le ${ }^{*} \mathrm{G}$, la $* \mathrm{~V}$ et le ${ }^{*} \mathrm{~T}$.

Après "advint cette parole", la *S insère "à Jérémie" (ער ארמיא).

Volz (Studien 208) a prétendu que la Vet Lat, elle aussi, atteste la mention de ce destinataire au même endroit. Cette donnée lui a été empruntée par Nötscher, Rudolph, Penna, Bright, Wanke et les apparats de BH3S et Cent. Il est vrai que Saba- 
tier donne ici : "factum est verbum istud ad Jeremiam a Domino, dicens" qu'il réfère à une citation de ce vs faite par Jérôme dans son commentaire du début du chapitre 27. En effet, dans le lemme du commentaire de Jérôme sur 26,1, les mots "ad Jeremiam" ne figurent pas. Mais, si l'on se réfère à la remarquable édition critique que Reiter a donnée de Hie (CSEL 59, reprise par le CC), on remarque qu'à l'endroit indiqué par Sabatier ( = p. 332, l. 8 du CSEL) aucun ms de Hie n'atteste ce "ad Jeremiam" que seules les éditions antérieures portaient et que Reiter a omis à juste titre.

\section{Choix textuel :}

Cornill, en SBOT (69), estimait difficile de se passer ici de la mention du destinataire qu'il insérait donc dans son texte (p. 28). Ehrlich (Miqra) jugeait de même en faisant remarquer qu'on ne trouve jamais en ce livre une prophétie où soit mentionnée l'année où elle a été prononcée et où ne soit pas mentionné le nom de celui qui l'a prononcée.

Plus tard, tous deux ont changé d'avis. Cornill, en son commentaire, estime que le fait que l'on attende ici le complément "à Jérémie" et que la *S l'atteste en effet ne peut prévaloir contre le fait que le ${ }^{*} M$ et le ${ }^{*} G$ s'accordent pour l'omettre. Ehrlich, en ses Randglossen, estime que la mention de ce complément par le traducteur syriaque ne suffit pas à prouver qu'il le lisait dans sa Vorlage. Il estime d'ailleurs que, dans un livre dont le vs 1,1 affirme clairement que l'auteur est Jérémie, on peut se dispenser, une fois en passant, de mentionner que c'est à lui que tel oracle s'adressait.

Nous avons déjà refusé en 19,1B (ci-dessus, p. 631) d’ajouter la mention de Jérémie comme destinataire dans un cas où le ${ }^{*} G$, la $* S$ et plusieurs mss du *M et du *T l'attestaient. Ici, le fait que cette ajoute ait pénétré dans la *S et dans une partie très secondaire de la tradition latine tardive, sans qu'il ait pu y avoir la moindre relation entre ces témoins, montre qu'elle était 'dans l'air' et qu'il s'agit d'une assimilation à 27,1 .

Considérant la lectio difficilior du ${ }^{*} M$ et du ${ }^{*} G$ comme solidement attestée, le comité lui a attribué la note "B".

\section{בית 26,10 שער־יהוה [B] M G V // expl : m g v S T ins}

\section{Options de nos traductions :}

Il est dit ici que les princes de Juda siégèrent

J traduit : "à l'entrée de la Porte Neuve du Temple de Yahve" en disant se fonder sur des mss hébreux, la ${ }^{*} V$, la ${ }^{*} S$ et le $* T$ (à quoi $J 2$ ajoute le ${ }^{*} G$ ) pour insérer : “du Temple". Sans note, RSV traduit de même : "in the entry of the New Gate of the house of the LORD". Le Temple est également mentionné par RL : "vor das neue Tor am Hause des HERRN" et par TOB : "à l'entrée de la porte Neuve du Temple".

NEB se contente de : "at the entrance of the new gate".

Origine de la correction :

Au XVIe siècle, la plupart des traducteurs (Pagnini et ses rééditions, Prédicants, Zwingli, Luther, Brucioli, Münster, Jud, Châteillon, Tremellius) traduisent le *M sans le gloser. 
C'est Olivetan qui recopie sans la corriger la traduction que Le Fèvre d'Etaples avait donnée de la *V : "en l'entrée de la neufve porte de la maison du Seigneur", ce que ne retoucheront ni Rollet ni Estienne. Calvin (“in foribus portae templi Iehovae novae") et les Pasteurs de Genève ("a l'entree de la porte neuve de la maison de l'Eternel") ne manifesteront aucune conscience du caractère superflu du mot "maison" ou "temple".

Seule, parmi les productions genevoises, la Geneva Bible (et la King James qui la recopiera en cela) met en italique le mot "House" quand elle traduit : "in the entrie of the newe gate of the Lords House".

Habitué à la présence de ce mot dans la Bible anglaise, Henderson estime qu'il a été omis dans le texte courant du *M. Son insertion est requise par Giesebrecht, Oort, Condamin, Volz, Nötscher, Rudolph, Penna, Steinmann, Weiser, Bright et les apparats de HSAT4, BH23S et Cent.

\section{Les témoins anciens :}

Pour protéger le *M contre cette ajoute, une mp (dans la massore éditée) précise que la séquence בפתח שער יהוה est hapax. A cela, le ms du Caire ajoute que c'est la séquence פתח שער בית־יהוה que l'on rencontre ailleurs. Ce qui est en effet le cas en Jr 36,10; Ez 8,14 et 10,19.

Ces précautions des massorètes n'ont pas empêché le mot בית de pénétrer ici dans les première ou deuxième mains de 35 mss énumérés par de Rossi.

Ziegler a eu tort d'intégrer dans son édition du *G $(33,10)$ le mot oíxou qui n'est attesté que par le ms Marchalianus et deux minuscules alors que les témoins anciens (entre autres le Vaticanus et le Sinaiticus) l'ignorent.

Les apparats critiques, jusqu’a BHS incluse, mentionnent la *V comme témoin pour l'ajoute de ce mot. De fait les éditions Weber et San Girolamo l'omettent avec les témoins les plus anciens. Hie confirme deux fois cette omission : dans son lemme et en son commentaire.

La *S a inséré דביתה et le *T בית מקדשא.

\section{Choix textuel :}

Une ajoute si naturelle a pénétré en des témoins secondaires très variés de la tradition textuelle, alors que les témoins anciens du ${ }^{*} G$ comme de la tradition protomassorétique (le ${ }^{*} M$ et la ${ }^{*} V$ ) ne l'ont pas. Cela suffit à démontrer que l'absence de בית est ici primitive. Aussi le comité a-t-il attribué au *M la note "B".

Interprétation proposée :

“à l'entrée de la Porte Neuve du Seigneur".

26,18 cf. p. 519. 
27,1 יהויקם / צדקיהו L / lit : G om v 1

Options de nos traductions :

Selon le ${ }^{*} M$, ce vs commence par : “Au début du règne de Joiaqim, fils de Josias, roi de Juda".

Toutes nos traductions donnent le nom de "Sédécias" au lieu de celui de "Joiaqim". Celles qui portent des notes disent avoir corrigé, J voyant en cette correction une conjecture, alors que Brockington la fonde sur 3 mss et TOB sur quelques mss hébreux, la *S et la version arabe.

Origine de la correction :

Clericus conjecturait que "Sédécias frère de" était tombé avant "Joiaqim". Avant lui, Calmet, se fondant sur la *S et l'Arabe, avait proposé de remplacer "Joiaqim" par "Sédécias". Cette proposition avait déjà été faite, à titre de conjecture, par Pellican et Münster (en Critici Sacri). Elle a été adoptée par Houbigant, Doederlein, Michaelis (OEB), Kennicott (Dissertatio super ratione 503s et Dissertatio secunda 346), Schleusner (éditant les Observationes de Michaelis), Ewald, Henderson, Nägelsbach, Keil, Luzzatto, Grätz (Studien 289), Knabenbauer, von Orelli, Giesebrecht, Oort, Condamin, Ehrlich, Penna, Weiser et les apparats de HSAT34, BH23S et Cent.

\section{Les témoins anciens :}

Le nom צדקיהו remplace celui de Joiaqim dans le 2e ms de Königsberg (Lilienthal 277ss), dans la 1e main du ms Reuchlin des Prophètes (selon Rosenmüller) et dans la marge d'un ms de Vienne (Kenn 590). La massore éditée (ainsi que celles des mss d'Alep et de Leningrad) confirme cependant ici la leçon יהויקם en spécifiant que c'est, avec Jr 52,2, l'un des deux cas où ce nom a un 'yod' défectif en sa dernière syllabe.

Le ${ }^{*} G(34,1)$ omet ce vs. Lilienthal (278), du fait qu'une version arabe manuscrite conservée à Oxford porte ici le nom de Sédécias, a cru pouvoir conclure qu’à une époque plus ancienne le ${ }^{*} G$ contenait ce vs avec cette variante. Mais Walton (Polyglotte, prolegomena 97a) dit seulement de ce ms du fonds Selden qu'il concorde parfois avec le ${ }^{*} G$. De fait, il s'agit de la traduction de Pethion Ibn Ayyub, faite à partir de la *S (cf. Frank 138s).

La *S porte en effet ici (selon les éditions et selon l’Ambrosianus) le nom de Sédécias.

Cependant une ajoute astérisée de la recension origénienne (attribuée à Aq), adoptée aussi par l'antiochienne, porte ici le nom Iwaxelu. De même la *V (Ioachim) et le *T (יהויקים).

\section{Choix textuel :}

Rosenmüller a fait remarquer qu'une simple substitution du nom de Sédécias à celui de Joiaqim ne suffit pas à faire de ce vs une introduction convenable de ce qui suit. En effet 51,59 engage à placer les événements racontés au ch. 27 après la 4e année de Sédécias et non au début de son règne. Duhm a donc conclu que le ${ }^{*} G$, en omettant ce vs, offre un état littéraire plus primitif. Un copiste, voyant que les événements qui suivent manquaient d'une référence chronologique, a cru pouvoir 
appliquer le principe d'herméneutique juive traditionnelle selon lequel les péricopes qui n'ont pas de date propre se réfèrent à la date de la péricope qui précède. Aussi a-t-il répété ici 26,1 qui introduisait la péricope précédente, en se bornant à y ajouter le complément facilitant "à Jérémie". D’ailleurs, nous verrons en 28,1 que ce glossateur y est encore intervenu avec une maladresse évidente.

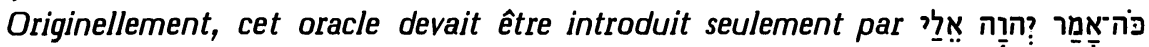
qui, dans le ${ }^{*} M$, commence 27,2 et qui s'y articule aujourd'hui très mal àvec $\overline{2} \overline{7}, 1 b$ ("il y eut cette parole à Jérémie de la part du Seigneur disant :")

Le vs 1 , dans la forme qu'il a dans le $* M$, fait partie intégrante de la rédaction II, comme l'indique son attestation par Aq et la $* V$, témoins du texte protomassorétique.

Le remplacement du nom de Joiaqim par celui de Sédécias, qui a eu lieu en quelques témoins, est une correction secondaire influencée par les vss 3 et 12.

Le comité a attribué au * $\mathrm{M}$ la note " $\mathrm{B}$ " en estimant que le jugement que ce verset est une ajoute secondaire relève de la critique littéraire plutôt que de la critique textuelle.

Interprétation proposée :

“Au début du règne de Joiaqim, fils de Josias, roi de Juda, il y eut cette parole à Jérémie de la part du Seigneur disant :"

On indiquera en note que ce vs qui fait partie de la rédaction II (qu'atteste le texte protomassorétique) est probablement une reprise malheureuse de l'introduction $(26,1)$ de la péricope précédente, alors que les vss 3 et 12 montrent clairement que les événements rapportés en ce chapitre ont lieu sous Sédécias.

\section{7,3A ושלחמִּם [A] M 4Q-c G V S T // abr-styl-int : g Hie}

Options de nos traductions :

Au vs 2, le Seigneur a ordonné à Jérémie : "Fabrique-toi des liens et des barres de joug et tu les mettras sur ton cou". Puis le vs 3 commence par רְְ (cet envoi étant destiné "au roi de Moab, au roi des fils d’Ammon, au roi de Tyr et au roi de Sidon, par l'entremise des ambassadeurs qui sont venus à Jérusalem vers Sédécias, roi de Juda"). Ce verbe est traduit par TOB : "tu en enverras" et par J3 : "Puis envoieles".

En disant suivre le ${ }^{*} G$ lucianique et (selon Brockington) lire "Then send" et $\mathrm{J12}$ : "Puis envoie (J1 : expédie) un message". En disant conjecturer, RSV traduit : "Send word". RL traduit de même : "und schicke Botschaft".

\section{Origine de la correction :}

Estimant peu vraisemblable que les ambassadeurs aient accepté de transmettre un tel envoi à leurs maîtres, Hitzig propose d'omettre le pronom suffixe du verbe et de suppléer רָּ̣ comme objet de cet envoi. Le suivent en l'omission de ce suffixe pluriel : Grätz (Studien 290), Giesebrecht, Duhm, Cornill, Condamin, Schmidt, Nötscher, Rudolph, Penna, Steinmann, Weiser, Bright et les apparats de HSAT34, BH23S et Cent. 
Les témoins anciens :

Le pronom suffixe de la 3e pers. pl. est attesté par 4Q-c, le ${ }^{*} G(34,2$ : aủroús), la *V (eas), la *S (אנרן) et le *T (ותשלחינון).

Certes, l'antiochienne omet aủroús, mais il s'agit là d'un simple allègement stylistique semblable à celui que le ${ }^{*} G$ a déjà effectué en ne traduisant pas le pronom

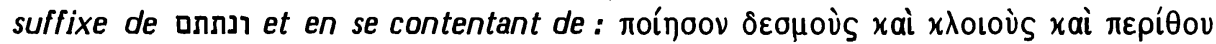

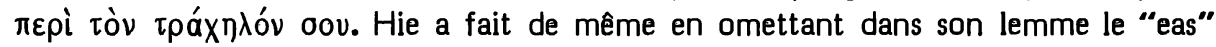
de la *V : "ponesque eas in collo tuo et mittes ad regem etc."

\section{Choix textuel :}

Ces allègements stylistiques intérieurs au grec et au latin ne sauraient avoir valeur d'indice sur la Vorlage hébraïque. C'est pourquoi le comité a attribué ici au *M la note " $A$ ".

\section{Interprétation proposée :}

On peut être tenté de traduire avec Ehrlich (Miqra) et avec TOB : "tu en mettras sur ton cou et tu en enverras etc." En effet, si le suffixe pluriel n'implique pas une valeur partitive, il n'implique pas non plus que Jérémie ait d'abord mis sur son cou tous les jougs qu'il allait envoyer aux rois.

Quant à l'invraisemblance décelée par Hitzig, Volz y oppose que "il est parfaitement possible que Jérémie ait envoyé aux princes orientaux des barres de joug et des liens."

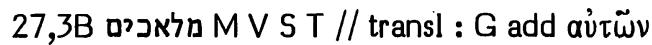

Options de nos traductions :

Selon le *M, le Seigneur commande à Jérémie de faire ses envois "par l'entremise

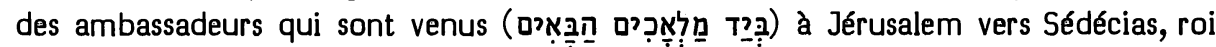
de Juda". Le 2e mot cité est traduit selon le *M par RSV, RL et NEB.

En se fondant sur le *G, J traduit : "par l'entremise de leurs envoyés" et TOB : "par leurs ambassadeurs". Elles explicitent un possessif.

Origine de la correction :

L'ajoute de ce possessif a été requise par Giesebrecht, Oort, Duhm, Cornill, Rudolph, Penna, Steinmann, Weiser, Bright et les apparats de HSAT34, BH23S et Cent.

\section{Les témoins anciens :}

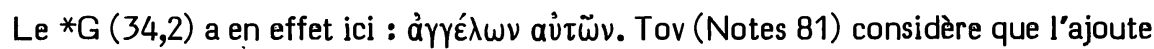
de ce possessif ne repose probablement pas sur une variante de la Vorlage.

Ni la $* V$, ni la $* S$, ni le $* T$ n'offrent ici de possessif.

\section{Choix textuel :}

Ce cas n'a pas été soumis au comité.

Ceux qui corrigent ont estimé "surprenant" (Giesebrecht, Rudolph) que ce substantif soit dépourvu d'article, alors que le participe qui le suit est précédé d'un article. 
Cependant Gesenius/Kautzsch (\$126w) et König (Syntax \$411d) groupent de nombreux exemples de cette construction.

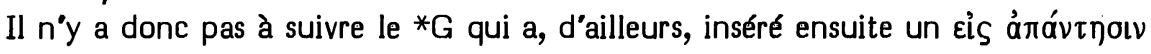
aủนw̃v auquel Tov ne reconnaît pas plus de chances d’être primitif.

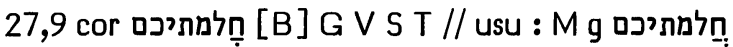

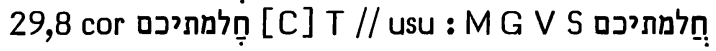

\section{Options de nos traductions :}

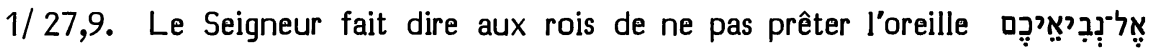

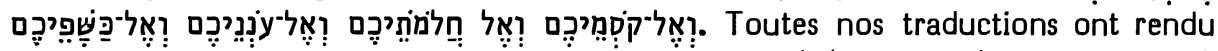
le troisième substantif comme un nom d'agent. RL ("(auf ihre...) Traumdeuter") suit Luther ("(ewern...) Treumdeutern").

Estimant que le mot du *M signifie "songes", RSV dit se fonder sur le *G, la*V et la *S pour traduire : "your dreamers", J pour traduire: "(vos...) songe-creux" et TOB : "vos oniromanciens".

Selon Brockington, NEB lit avec le *G women" en notant : "lit. women who have dreams".

2/ 29,8. Le Seigneur fait dire aux déportés de ne pas prêter l'oreille

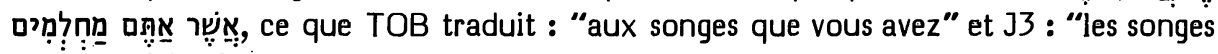
que vous faites".

Par conjecture, RSV traduit : "to the dreams which they dream", J12: "leurs songes, fruits de leur rêves" et RL : "auf die Träume, die sie träumen".

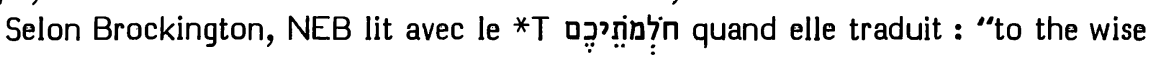
women whom you set to dream dreams".

\section{Origines des corrections :}

1/ 27,9. Selon Houbigant, le *M signifie "vos songes", mais le contexte réclame "vos songeurs"; aussi corrige-t-il en חלְnמִ estimant que le *G, la *V et la*S ont lu cette Vorlage. Il est suivi en cela par Henderson (qui justifie ainsi "your dreamers" de KJ), Duhm (qui justifie ainsi l'interprétation de Luther), Cornill, Condamin, Nötscher, Rudolph, Penna, Weiser ainsi que par les apparats de SBOT, HSAT34, BH23S et Cent.

2/ 29,8. Croyant déceler dans le 'mem' initial du dernier mot une dittographie de celui qui achève le mot précédent, Hitzig propose de le corriger en חịn. Il est suivi en cela par Olshausen (Lehrbuch 580), Graf, Grätz, Penna et les apparats de HSAT2 et BH2.

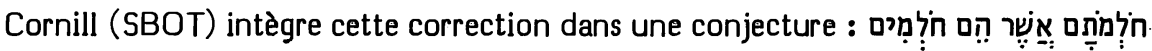
qui est adoptée par Duhm, Condamin, Rudolph, Steinmann, Weiser, Bright et par les apparats de HSAT34 et BH3S.

Pour traduire : "vos conteurs de songes dont vous provoquez vous-mêmes les

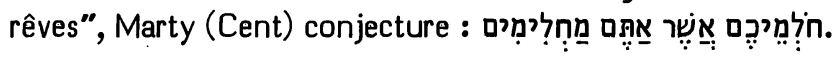


Les témoins anciens :

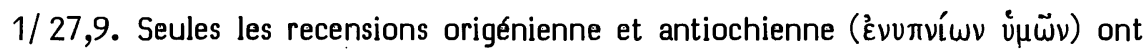
compris ce mot au sens de "songes".

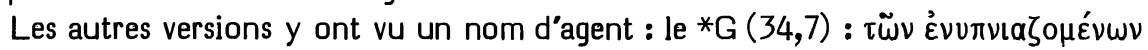
iniiv, la *V (et somniatores), la *S (ולחלמן חלמי : et le *T qui paraphrase . חלמיכון

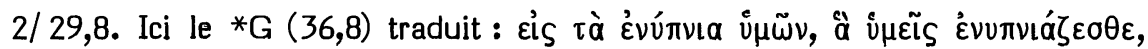

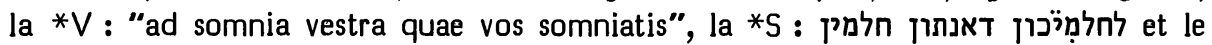
*T : מן חלמי חלמיכון דאתון מחלמין.

Choix textuel et interprétation proposée :

En 27,9, le fait que ce mot soit entouré par quatre noms d'agents rend extrêmement probable qu'il s'agisse d'un mot appartenant à la même catégorie. C'est d'ailleurs l'interprétation de la quasi-totalité des versions anciennes.

De même, au XVIe siècle, le sens de "songeurs" ou de "interprètes des songes" est donné à ce mot par Prédicants, Zwingli, Luther, Münster, Olivetan, Calvin, Jud, Vatable, Châteillon, Geneva. Seuls Pagnini, Brucioli et Tremellius tiennent au sens de "songes". Quant à Pasteurs et à KJ, ils donnent "songeurs" en ayant conscience de quitter l'hébreu dont ils précisent en marge qu'il signifie "songes".

Ehrlich (suivi par Volz) a vu ici l'adjectif verbal aịn. Cette forme donne en hébreu des noms de professions. On ne leur connaît pas de pluriels dans la Bible. Mais, dans la langue de la Mishna, ils forment leurs pluriels en "-ôt". Ainsi תiֹ

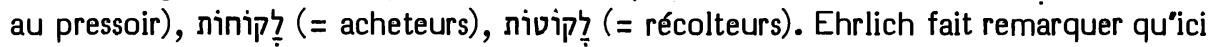
חלִ (correction proposée par la plupart des critiques) signifierait un individu à qui il arrive d'avoir des rêves, alors que tendent avoir des songes prophétiques. Ehrlich propose donc de corriger en qames la vocalisation hatef-patah que le * $\mathrm{M}$ a attribuée au 'ḥet' en ayant assimilé cette forme au

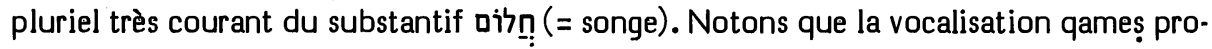
posée par Ehrlich pour la première syllabe de ces pluriels dans la Mishna reçoit l'appui de Segal (Beayot 154ss) qui, citant plusieurs autres exemples, propose lui aussi ici cette correction en semblant ignorer Ehrlich. Le comité a donc accepté en 27,9 cette correction vocalique avec la note "B" et au sens de "vos songeurs".

En 29,8, la plupart des traducteurs interprètent le participe final comme s'il avait valeur de qal, au sens de "songeant". Cependant, il s'agit bien d'un hifil analogue à celui dont nous avons traité en 11,15 (ci-dessus p. 563) en y faisant remarquer que ces formes contractées du hifil sont particulièrement fréquentes dans les verbes dont la première radicale est une gutturale et qui incluent dans leur radical un 'lamed' ou un 'resh': Si l'on donne à ce hifil son sens normal de causatif et si on lit le substantif avec la vocalisation que nous lui avons attribuée en 27,9 , nous pouvons traduire : "et ne prêtez pas l'oreille à vos songeurs dont vous provoquez les songes".

Le comité a donc attribué ici la note "C" à la correction du hatefef-patạ du "ḥet" en qameș. En effet, cette correction a des appuis textuels plus faibles ici que dans le cas précédent. 
28,1 בשנה ההיא בראשית ממלכת צדקיה מלך־יהודה בשנה הרבעית M V S T // lit :

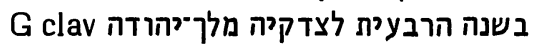

Options de nos traductions :

Selon le *M, le ch. 28 commence par : “En cette année, au début du règne de Sédécias, roi de Juda, dans la quatrième année, au cinquième mois". Cette datation surchargée est respectée par RSV, J, RL et TOB. Cependant TOB considère (en note) comme peut-être préférable la leçon du ${ }^{*} G$ qui, omettant la mention du 'début du règne', se contente de la 'quatrième année'.

Selon Brockington, NEB omet la mention de la 'quatrième année' et, au lieu

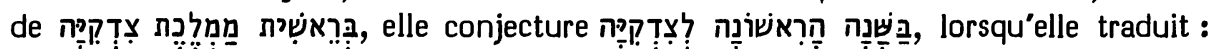
“That same year, in the fifth month of the first year of the reign of Zedekiah king of Judah."

Origine de la correction :

C'est Driver (Once 86) qui a proposé la correction retenue par NEB.

Les témoins anciens :

La datation du $* \mathrm{M}$ a l'appui des recensions origénienne et antiochienne, de la*V, de la $* S$ et du $* T$.

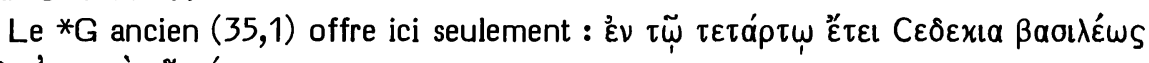

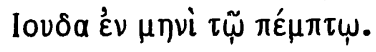

Choix textuel :

Driver estimait que "en la première année" avait été abrégé en "bet-shin' et "héresh' et que cette abréviation avait été mal décryptée par le * $M$ en "en la quatrième année". Janzen (195, n.24) a eu raison d'objecter que l'on n'a aucun indice que les noms de nombres aient été abrégés par leurs initiales en des textes bibliques anciens. Il est en effet invraisemblable de supposer qu'un 'shin' ait pu représenter à la fois le mot 'année(s)' et les chiffres 3, 6, 7, 8, 30, 60, 70, 80 etc.

Le *M combine les données du *G (la 4e année de Sédécias) avec d’autres données (en cette année, au début du règne) qui lui sont propres. Schenker (Metamorphose 512) a montré que ces deux données propres au $* M$ se rattachent à un système de datation qui caractérise la rédaction II. Il est à peu près certain que la datation du *G est plus primitive ici. Mais tous les témoins du texte protomassorétique appuient les ajoutes caractéristiques du système du *M. Estimant que les variantes qui le distinguent de la datation du ${ }^{*} G$ se situent au niveau littéraire et non textuel, le comité a attribué ici au système de datation du *M la note " $A$ ".

\section{Interprétation proposée :}

En donnant la traduction que nous avons proposée au début de ce cas, les traducteurs pourront noter que la date du *G "en la quatrième année de Sédécias, roi de Juda, au cinquième mois" est probablement plus primitive que la datation surchargée que le *M offre ici. 


\section{Options de nos traductions :}

Selon le * $M$, Jérémie dit des prophètes antérieurs à lui qu'ils ont prophétisé sur de nombreux pays et sur de grands royaumes Les Les deux derniers mots sont traduits par RL : "von Unheil und Pest", par TOB : "le malheur, la peste" et par 33 : "le malheur et la peste".

Sans note, RSV traduit : "famine, and pestilence". Notant qu'elles suivent plusieurs mss hébreux, 312 traduisaient : "la famine et la peste" et NEB traduit comme RSV, Brockington précisant que, pour 8A, elle lit 23 mss.

\section{Origine de la correction :}

C'est Châteillon qui, dans les notes de la traduction latine qu'il publia en 1551, semble avoir été le premier à suggérer : "Considère si, pour הyר, il ne faudrait pas lire בyר, c'est-à-dire : famine". Calvin, dans son commentaire, a fait remarquer que $8 \mathrm{~A}$ a un sens générique et se trouve inséré entre deux espèces de maux. Aussi conclut-il que ce mot doit être pris ici au sens de famine.

Ont adopté la correction suggérée par Châteillon : Houbigant, Kennicott (Dissertatio generalis §54), Ewald, Grätz, Oort, Condamin, Ehrlich, Volz, Nötscher, Penna ainsi que les apparats de HSAT34 et BH2.

Les témoins anciens :

Le ms d'Alep et la massore éditée précisent en mp que la leçon que le *M tibérien classique offre pour $8 \mathrm{~A}$ constitue un hapax. Cependant, de Rossi signale une trentaine de mss dont la première ou la seconde main lisent ici לרעב précédé ou non d'une conjonction.

Pour ces deux mots, le *M a l'appui d'une ajoute astérisée des recensions origénienne et antiochienne qui est attribuée à ThAq par le ms Marchalianus : xaì cỉ xaxà xaì eis Өávarov, de la *S (ולבישתא ולמותנא) et du *T (ולבישא ולמותא).

$L a * V$ offre "et de adflictione et de fame", leçon qui est appuyée par la paraphrase qu'en donne Hie : "et adversa et rerum omnium penuriam". Au lieu de 8AB, elle offre donc une leçon gonflée de $8 \mathrm{~A}$ et elle omet $8 \mathrm{~B}$.

Le ${ }^{*} \mathrm{G}$ omet $8 \mathrm{~A}$ et $8 \mathrm{~B}$.

\section{Choix textuel :}

L'omission de ces deux mots par le ${ }^{*} G$ est très vraisemblablement primitive, למלחמה qui les précède offrant un contraste exact et suffisant avec לשלום du vs 9.

Les ajoutes qui caractérisent les formes textuelles se rattachant plus ou moins au *M se présentent sous trois formes distinctes:

-1) la *V offrant un état où ולרעה a déjà reçu pour variante ולרעב, mais où 8B ne s'est pas encore introduit,

-2) le *M tibérien classique où ולרעה est suivi par 8B, forme attestée aussi par ThAq, par la *S et par le ${ }^{*}$,

-3) une déformation facilitante du *M où $8 A$ a été déformé en ולרעב, sous l'effet de $8 \mathrm{~B}$ qui le suit. 
L'élément le plus stable dans les couches anciennes de ces formes textuelles est bien ולרעה. Cela nous interdit de considérer cette leçon comme une déformation secondaire de ולרעב. En effet, si le mot précédent était לחרול ולחמה (et non quar-

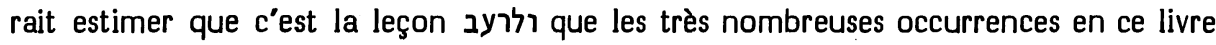
du trio למלחמה exigeraient ici. Mais le mot (ayant pour signification ici de faire contraste avec לשרבר du vs 9) s'accorde au moins aussi bien avec une glose rédactionnelle ולרעה qui vise à en élargir la portée.

Considérant que l'état le plus ancien du texte protomassorétique ne devait probablement ajouter ici que $8 \mathrm{~A}$ (mais que cet état $n$ 'est plus attesté directement, puisque la *V n'en offre qu'une forme gonflée), le comité a attribué la note " $B$ " à la leçon du *M tibérien pour $8 \mathrm{~A}$ (dont la leçon ולרעב est une déformation) et la note "C" au $* M$ pour $8 B$ (où la $* V$ atteste indirectement l'absence de ce mot). $L$ 'appui que le ${ }^{*} M$ reçoit de ThAq, de la ${ }^{*} S$ et du ${ }^{*} T$ pour une leçon qui n'est pas primitive engage à ne pas le corriger.

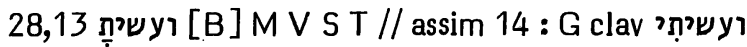

Options de nos traductions :

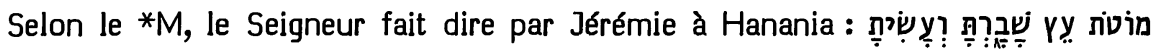

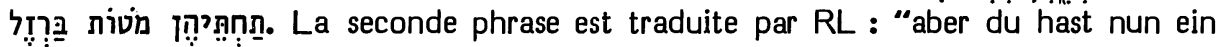
eisernes Joch an seine Stelle gesetzt", par NEB : "in their place you shall get bars of iron", par TOB : "à leur place tu feras des barres de fer" et par J3 : "Eh bien! Tu vas les remplacer par des jougs de fer".

Disant suivre le *G, RSV traduisait : "but I will make in their place bars of iron" et J12: "Eh bien! je vais les remplacer par des jougs de fer !"

Origine de la correction :

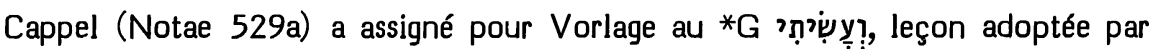
Grätz, Giesebrecht, Oort, Duhm, Cornill, Condamin, Schmidt, Penna, Steinmann et par les apparats de SBOT, HSAT234, BH3 et Cent.

Les témoins anciens :

Le *G $(35,13)$ offre ici xaì nolńow.

La *V (et facies), la *S (עבד) et le *T (ותעביד) ont lu la 2e pers. du*M.

Choix textuel :

Estimant que la leçon $d u{ }^{*} G$ anticipe à tort le contenu du vs 14 , le comité a attribué ici au *M la note "B".

Interprétations proposées :

On préférera la 2e interprétation proposée par Yéfet ben Ely : "en brisant des barres de bois, tu as fait à leur place des barres de fer". La révolte contre le joug du roi de Babylone alourdira et durcira ce joug. Cette exégèse a été reprise (sans qu'ils 
aient eu conscience de son ancienneté) par Venema, Michaelis, Hitzig, Keil, Ehrlich, Weiser et RL.

On peut aussi comprendre que le Seigneur demande à Hanania d'accomplir un geste prophétique : "tu as brisé des barres de bois, aussi feras-tu à leur place des barres de fer".

Il est par contre peu conforme au contexte d'interpréter cela comme un ordre de Dieu à Jérémie (ce qui priverait de contenu la parole de Dieu à Hanania, ou bien la couperait en deux).

\section{9,1 יתר [B] M V S T // abr-elus : G om}

Options de nos traductions :

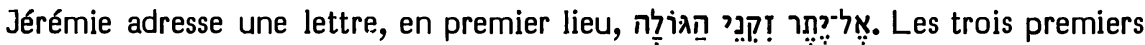
mots sont traduits par RL : "an den Rest der Aeltesten", par NEB : "to the remaining elders" et par 33 : "à ceux qui restaient des anciens".

RSV dit suivre le *G pour omettre le 2e mot et traduire : "to the elders".

TOB, sans note, traduit : "à tous les anciens".

Quant à J12, par conjecture, elles transféraient le mot ר? plus loin dans le vs, avant "tout le peuple".

Origines des corrections :

L'omission de ce mot est requise par Giesebrecht, Oort, Penna, ainsi que par les apparats de SBOT, HSAT2 et BH2.

Le transfert réalisé par $\mathrm{J12}$ avait été proposé par Volz, Nötscher et les apparats de HSAT4, BH3 et Cent.

Les témoins anciens :

La leçon du *M est attestée par la *V (reliquias), la *S (שרכא) et le *T (שאר). Le ${ }^{*} G(36,1)$ ne traduit pas ce mot.

\section{Choix textuel :}

L'interprétation de ce mot a causé assez de difficultés aux exégètes pour que l'on doive juger facilitante son omission par le ${ }^{*} G$. Aussi le comité a-t-il attribué au *M la note "B".

Interprétations proposées :

Il est à craindre que les fatigues du voyage et de l'adaptation aux conditions de vie de l'exil aient causé de nombreux décès parmi les plus âgés des déportés. Le sens le plus naturel est donc "ceux qui survivaient". Sur ce sens de cette racine, cf. ciaprès Jr 34,7.

Houbigant a suggéré que ce mot signifie ici "l'élite de" et BHS cite, pour appuyer ce sens, Gn 49,3. 


\section{9,12 והלכתם [B] M ThAq V // lit : G / abr-elus : S / assim-ctext : T}

Options de nos traductions :

Le *M offre en 12a : וקראתם אתי והלכתם והתפללתם אלי que RSV traduit : “Then you will call upon me and come and pray to me". 32 traduisait : "Alors, quand vous m'invoquerez et que vous viendrez m'adresser vos prières", RL : "Und ihr werdet mich anrufen und hingehen und mich bitten", TOB: "Vous m'invoquerez, vous ferez des pèlerinages, vous m'adresserez vos prières", J3 : “Vous m'invoquerez et vous viendrez, vous me prierez".

NEB se fondait sur la *S pour omettre le 3e mot et traduire : "If you invoke me and pray to me". Sans note, J1 traduisait de même: "Alors quand vous m'invoquerez et m'adresserez vos prières".

Origine de la correction :

Giesebrecht omet ce 3e mot en l'estimant corrompu. Duhm et Cornill ainsi que les apparats de $\mathrm{BH} 2$ et de Cent le corrigent par conjecture. Il est omis par Volz, Nötscher, Rudolph, Penna, Steinmann, Weiser et par les apparats de BH3S.

Les témoins anciens :

Movers (13) estimait que le ${ }^{*} G(36,12)$ omet ici les $3 e, 4$ et $5 e$ mots. De fait, ce sont les deux derniers mots du vs précédent et les 3 premiers mots de celui-ci

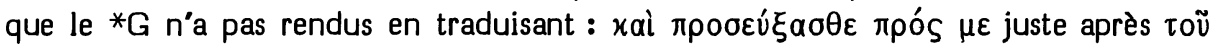
$\delta \circ v ̃ v a l$ íĩ $\tau \alpha \tilde{\tau} \tau \alpha$. En suppléant à ce manque, une ajoute astérisée empruntée à ThAq

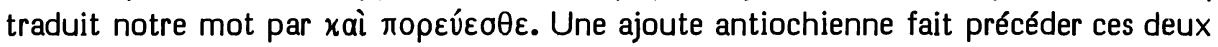

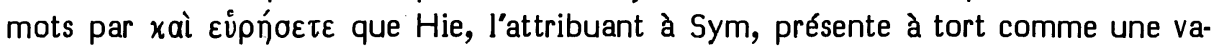
riante portant sur notre mot, alors qu'il s'agit d'une retouche anticipée de רוּמְצִ du du

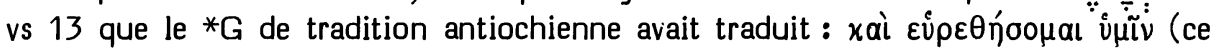
qui correspondrait mieux aux 2 premiers mots du vs 14).

La*V (et ibitis) traduit le *M.

Le *T donne ici ואקבל צלותכון que Volz (Studien) a considéré à juste titre comme une improvisation du traducteur.

La *S n’a pas traduit ce verbe, mais elle a omis aussi les deux derniers mots de ce vs et trois mots du vs suivant.

Choix textuel :

Il est difficile de savoir quelle Vorlage le ${ }^{*} G$ avait sous les yeux. En tout cas, c'est au niveau littéraire que le *M s'en distingue par un 'plus' de cinq mots.

$L a * S$ qui abrège beaucoup le contexte s'est trouvée en difficulté devant ce mot et l'a omis, alors que le *T l'a remplacé par ce qui semblerait requis ici par un parallélisme plat avec ce qui suit.

Les témoignages de ThAq et de la *V suffisent à montrer que cette leçon difficile est une partie intégrante du texte protomassorétique. Aussi le comité lui a-t-il attribué 4 "B" et 2 "C". 
Interprétations proposées :

Yéfet ben Ely attribuait à ce verbe le sens de "vous marcherez selon ma Torah", Rashi et Radaq celui de "vous marcherez sur ma route". C'est probablement pour faciliter une exégèse de ce type que les teamîm séparent ce verbe de ce qui le suit.

Le plus probable est que ce verbe et le suivant (= "vous irez m'adresser vos prières") explicitent le contenu de "vous m'invoquerez" qui les précède immédiatement.

Il est cependant possible que ce verbe, au sens quasi-adverbial de "avec persévérance", complète "vous m'invoquerez".

\section{9,19A אליהם M Th g V S T // facil-synt : m שליכם / lacun : G

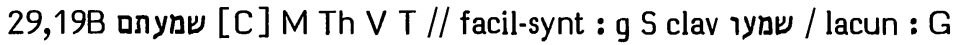

\section{Options de nos traductions :}

Après avoir achevé le vs 18 en annonçant aux exilés qu'il dispersera parmi les nations ceux de leurs frères qui ne sont pas partis en exil avec eux, le Seigneur motive ainsi cette décision au vs 19 : "parce qu'ils n'ont pas écouté mes paroles - oracle du Seigneur - alors que j'ai envoyé vers eux mes serviteurs les prophètes, les envoyant de grand matin... mais vous n'avez pas écouté - oracle du Seigneur !" Et le vs 20 commencera par: "Quant à vous, écoutez la parole du Seigneur, tous les déportés que j’ai envoyés de Jérusalem à Babylone". Le *M effectue donc un soudain passage à

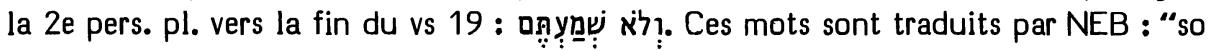
you did not listen".

Disant se fonder sur la *S et des mss grecs, TOB traduit: "Mais ils n'écoutent pas", alors que $\mathrm{J12}$ présentaient comme une conjecture : "sans qu'ils les écoutent" et $\mathrm{J3}:$ "mais ils ne les ont pas écoutés".

Suivant Luther, RL traduit : "der ich meine Knechte, die Propheten zu euch gesandt habe; aber ihr wolltet nicht hören". De même, RSV traduit : "which I persistently sent to you by my servants the prophets, but you would not listen", sans note.

\section{Origine de la correction :}

La Bible des Prédicants de Zurich a traduit ici 19B par une 3e pers.: "aber sy habend nit gefolget", Zwingli expliquant : "nous avons supprimé la rudesse du changement de personne". Clericus estimera lui aussi que la $* V$, en suivant ici le $* M$, s'est permis un barbarisme qui est intolérable en latin. Corrigeront en 3e pers. : Ewald, Giesebrecht, Duhm, Condamin, Penna et les apparats de HSAT34, BH2 et Cent.

Les témoins anciens :

Les vss 16 à 20 manquent dans le ${ }^{*} G$ ancien.

1/19A : Le *M tibérien classique a ici l'appui de l'ajoute origénienne et antiochienne empruntée à Th, ainsi que de la*V, de la ${ }^{*} S$ et du ${ }^{*} T$.

Une variante אליכם est attestée par les 1e ou 2e mains de 22 mss cités par de 
Rossi, ainsi que par les éditions princeps des Prophètes (Soncino 1486) et de la Bible (Soncino 1488) et par l'édition de Brescia 1494.

2/ 19B : Th appuie le *M en traduisant : xà oủx ỉxoúoate. La plupart des témoins de l'ajoute origénienne et antiochienne basée sur Th donnent ici cependant $x \alpha \grave{i}$

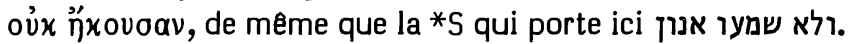

La*V (et non audistis) et le *T (ולא קבילתון) appuient ici le *M.

\section{Choix textuel :}

Cette apostrophe soudaine en fin de verset constitue une lectio difficilior.

Le cas 19A n’a pas été soumis au comité. Ici Luther dépend de l'édition Brescia 1494 à partir de laquelle il traduit. Cette variante du $* \mathrm{M}$ constitue une facilitation syntactique : "j"ai envoyé vers vous mes serviteurs" préparant: "vous n’avez pas écouté".

Dans le cas 19B, la facilitation syntactique qu'offre la variante s'est effectuée en sens inverse : "ils n'ont pas écouté" constitue une suite plus naturelle pour " $\mathrm{j}$ 'ai envoyé vers eux mes serviteurs".

Ici, le comité a attribué la note " $C$ " à la leçon difficile du * $M$ qui est bien appuyée par Th et par la *V.

Interprétation proposée :

La conclusion : "mais vous n'avez pas écouté" est si fréquente en Jérémie (7,13; 25,3.4 etc.) qu'elle vient tout naturellement sous le calame de celui qui écrit la lettre. Ainsi, il associe à l'endurcissement de ceux dont il parle, l'endurcissement passé de ceux auxquels il écrit; ce qui lui offre une occasion de les exhorter à entendre, maintenant.

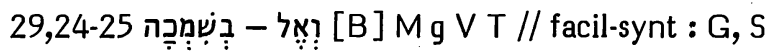

Options de nos traductions :

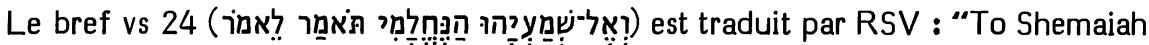
of Nehelam you shall say", par RL: "Und wider Schemaja von Nehelam sollst du sagen", par TOB : "A Shemayahou, le Néhlamite, tu diras ceci" et par J3 : "Et à Shemayahu de Nahlam, tu parleras ainsi".

Selon Brockington, NEB omet les deux derniers mots lorsqu'elle traduit seulement : "To Shemaiah the Nehlamite".

Le début du vs 25 porte, selon le *M: "Ainsi a parlé le Seigneur Sabaot, le Dieu d'Israël en ces termes : puisque tu as envoyé en ton nom etc." A la place du vs 24 et de cela, $\mathrm{J} 12$ s'estimaient réduites à conjecturer et à abréger de façon un peu drastique : "Or Shemayahu, de Nahlam, envoya de son propre chef etc."

Origines des corrections :

C'est Duhm qui, décelant en ces deux vss du *M une grande confusion, conjec-

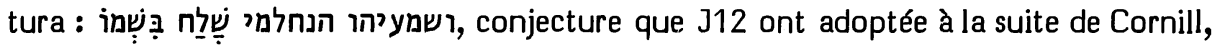
Schmidt et des apparats de $\mathrm{BH} 3$ et Cent. 
NEB dépend d'une conjecture de Rudolph reprise par Steinmann et par l'apparat de BHS.

\section{Les témoins anciens :}

Le ${ }^{*} G$ ancien (36) se contente de ع̇pعĩ pour traduire les deux derniers mots du

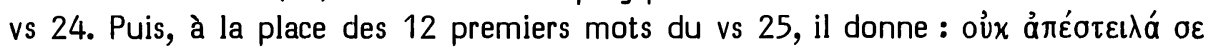

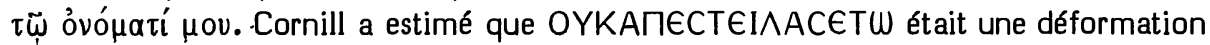
intérieure au ${ }^{*} G$ de $C Y A \Pi \in C T \in I \wedge A C \in N T W$. Mais Ziegler (Beiträge 50s) estime plus probable que la traduction du ${ }^{*} G$ repose sur une option exégétique qui lui est propre.

Au lieu des deux derniers mots du vs 24 , une Vorlage אֵַ est attribuée à la *S par les apparats de BH23S et par Volz (Studien). C'est une erreur. En effet, la 2e pers.

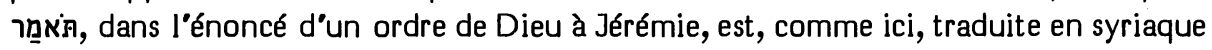
par l'impératif אמ̣ en 21,8 et 45,4 (alors que l'accompli est : cf. deux mots plus loin et 29,16.31). Ces données sont empruntées au ms Ambrosianus. Les apparats susdits se sont laissés égarer par la traduction "respondit" que les polyglottes de Paris

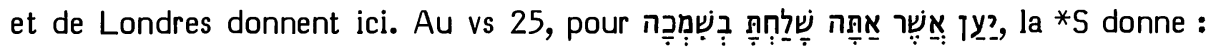
ושדר בשמה

Pour la fin du vs 24 et le début du vs 25 , le *M est attesté par l'ajoute qui figure dans les recensions origénienne et antiochienne du $* G$. Il l'est aussi par la $* V$ (quoique celle-ci, comme le ${ }^{*} G$ ancien, se contente de "dices" pour traduire les deux derniers mots du vs 24 ).

Le *T traduit littéralement le *M pour l’ensemble de ce passage.

\section{Choix textuel :}

Pour comprendre le $* M$, il faut admettre qu'après que les exilés aient reçu la lettre 29,4-23, Shemayahu envoya au prêtre Sephanya une lettre qui est reproduite en 29, 26-28 et que Șephanya lut à Jérémie $(29,29)$. Jérémie reçut alors du Seigneur un oracle destiné à Shemayahu. La citation de cet oracle commence au vs 25 et s'interrompt au vs 28 , après la reproduction de la lettre de Shemayahu. Le motif de cette inter-

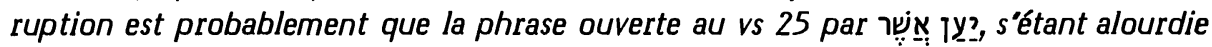
de cette reproduction de la lettre, semble impossible à continuer, au jugement du narrateur. Aussi la continuation de cet oracle est-elle remplacée, à partir du vs 30 , par l'introduction et la citation d'un nouvel oracle adressé, lui, aux exilés et parlant de Shemayahu à la 3e personne.

Duhm a donc eu raison de déceler dans cette fin du ch. 29 une grande confusion. Mais le responsable de cette confusion est le narrateur lui-même. Il ne s'agit pas d'un accident textuel dont le $* M$ aurait été ensuite victime.

Loin de nous livrer accès à un état textuel plus primitif, le ${ }^{*} G$ et la ${ }^{*} S$ ont, chacun à sa manière, essayé de rendre le développement plus logique, en faisant disparaître le יען אשר du vs 25 , pour lui éviter de rester en suspens. Cette phrase, le *G la remplace par un oracle et la *S par un récit.

Le comité a attribué au *M la note "B".

\section{Interprétation proposée :}

"Et à Shemayahu de Nehelam, tu parleras en ces termes : (25) Ainsi a parlé le Seigneur Sabaot, le Dieu d'Israël, en ces termes : puisque tu as envoyé en ton nom etc." 
Options de nos traductions :

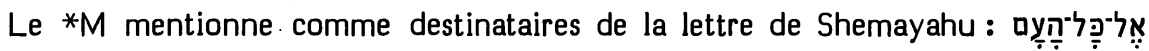

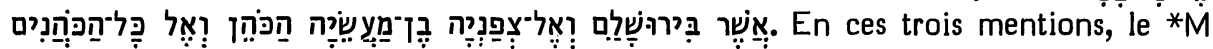
est suivi par RSV et RL.

Signalant l'absence dans le ${ }^{*} G$ de la 1 e et de la 3e mention, 312 les place entre parenthèses, TOB les place entre tirets et NEB les omet. $J 3$ ne place que la $3 e$ entre parenthèses.

Origine de la correction :

Duhm a estimé que seule la $2 \mathrm{e}$ mention est primitive. En cela, il a été suivi par Cornill, Condamin, Ehrlich, Rudolph, Weiser et par les apparats de HSAT234, BH23S. La 1e et la 3e mention ont été omises par Volz, Schmidt, Nötscher, Steinmann, Bright et Cent.

\section{Les témoins anciens :}

Le *G (36) ne porte ici que la 2e mention : xaì mpòs Copovíav víòv Maaoaíov

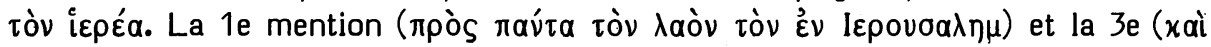

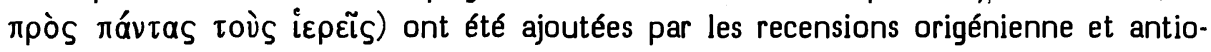
chienne.

Les trois mentions sont attestées par la $* \mathrm{~V}$, la $* S$ et le $* T$.

Choix textuel :

Il est vraisemblable que le ${ }^{*} \mathrm{G}$, constatant que la lettre qui suit ne concerne que Sephanya (vss 26s), a omis la 1e et la 3e mention comme hors de place ici.

Même si c'était le ${ }^{*} M$ qui avait glosé ici, il s'agirait d'une initiative littéraire. C'est pourquoi le comité lui a attribué la note " $\mathrm{A}$ ".

Interprétation proposée :

Il est fort possible que dans son zèle inquisitorial, Shemayahu ait envoyé plusieurs lettres à plusieurs destinataires et que seule est citée ici celle qui était destinée à Șephanya, parce que celui-ci en donne connaissance à Jérémie. On traduira donc : "puisque tu as envoyé en ton nom des lettres à tout le peuple qui est à Jérusalem, et au prêtre Ṣephanya fils de Maaséya et à tous les prêtres, en ces termes :"

\section{9,26 [C] בְּדִדים [C M // assim-ctext : G V S T sing}

Options de nos traductions :

Shemayahu dit à Șephanya : “le Seigneur t’a institué prêtre à la place du prêtre

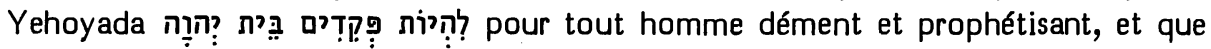
tu le mettes aux ceps et au carcan". Les 4 mots cités sont traduits par RSV : "to have charge in the house of the LORD" et par J : "pour exercer la surveillance dans le Temple de Yahvé". 
Selon Brockington, NEB lit, avec le *G, פִ à à la place du 2e mot quand elle traduit : "as officer in charge of the LORD's house". De même, TOB : "comme prêtre responsable, dans le Temple" et RL : "dass du Aufseher sein sollst im Hause des HERRN".

Origine de la correction :

C'est Luzzatto qui a fait remarquer que Shemayahu aurait dô mettre le $2 \mathrm{e}$ mot au singulier. Corrigent ainsi : Giesebrecht, Oort, Duhm, Cornill, Condamin, Ehrlich, Volz, Rudolph, Penna, Weiser, Bright et les apparats de SBOT, HSAT234, BH23S et Cent.

Les témoins anciens :

Le *M est seul à offrir ici (sans variante) le pluriel.

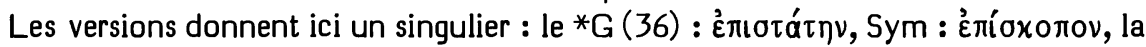
*V : “dux", la *S : פקודא et le *T : סגן כהניא.

Choix textuel :

L'isolement absolu du ${ }^{*} \mathrm{M}$ est impressionnant. Il est cependant très probable que les versions ont facilité en fonction du contexte.

Le comité a attribué à la lectio difficilior du *M 5 " $\mathrm{C}$ " et 1 “ $\mathrm{B}$ ".

Interprétations proposées :

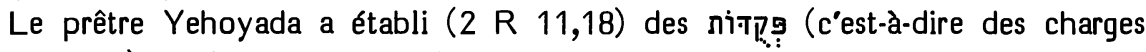
d'inspecteurs) sur la maison du Seigneur. Șephanya dont la fonction sera précisée en Jr 52,24 comme celle de "prêtre en second" (cf. CT1, 418s) n'a pas succédé à Yehoyada dans sa charge de grand prêtre. Mais Dieu a confié à Șephanya cette responsabilité d'établir des inspecteurs dans laquelle Yehoyada s'était illustré jadis.

On peut donc traduire: "Le Seigneur t’a institué prêtre, à la place du prêtre Yehoyada, pour qu'il y ait des inspecteurs dans le Temple du Seigneur sur tout homme dément et prophétisant, et que tu mettes celui-ci aux ceps et au carcan".

Shemayahu suggère à Sephanya de se souvenir que Yehoyada a expulsé Athalie du Temple (2 R 11,15).

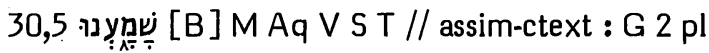

Options de nos traductions :

Le vs 5 commence ainsi, selon le * $M$ : "Car ainsi a dit le Seigneur : Nous avons

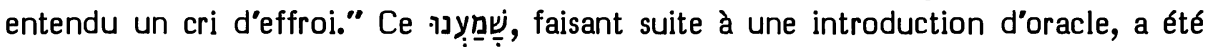
respecté par RSV, RL, TOB et J3.

En s'inspirant du vs 6, J12 conjecturaient : "j’ai perçu”.

Selon Brockington, NEB lit avec le *G hear". 
Origines des corrections :

Une correction en שמעy a été requise par Volz, Rudolph, Steinmann, Weiser, et par les apparats de $\mathrm{BH} 35$.

Movers (38) estimait que c'est plutôt l'introduction "car ainsi a dit le Seigneur" qui est ici hors de place. Cette opinion est aussi celle de Duhm, Rudolph, Bright et des apparats de HSAT4 et de BH3. Ont omis cette introduction : Schmidt, Nötscher, Steinmann et Weiser.

L'adoption de la leçon du *G a été suggérée comme alternative par Bright.

\section{Les témoins anciens :}

Tous les témoins attestent l'introduction : “ainsi a dit le Seigneur".

Le ${ }^{*} G(37,5)$ traduit le verbe par ảxov́oco $\theta \varepsilon$.

Les autres versions ont respecté la 1e pers. pl. du *M: Aq : ク̉xov́oa $\mu \varepsilon v$, la *V : “audivimus", la *S : שמען et le *T : שמענא

\section{Choix textuel :}

Le ${ }^{*} G$ a assimilé aux deux impératifs pluriels qui commencent le vs 6. Cela lui permet d'harmoniser avec l'introduction.

Le comité a attribué à la lectio difficilior du *M 5 " $B$ " et 1 "C $C$ ".

Interprétation proposée :

Un "nous avons entendu" introduit par "ainsi a dit le Seigneur Dieu" se retrouve au début d'Abdias (ce "nous avons entendu" et ce qui le suit en Abd 1.3 semble avoir inspiré Jr 49,14-16 où figure "j'ai entendu" sans cette introduction).

Il faut considérer en ces deux cas "ainsi a dit le Seigneur" comme une large introduction valant pour l'ensemble de l'oracle, sans que cela implique que le Seigneur prenne la parole immédiatement après cette formule qui vise essentiellement à diviser le texte biblique en péricopes distinctes.

La meilleure interprétation de "nous avons entendu" en Jr 30,5 est celle qui a été proposée par Schnurrer (et reprise par Rosenmüller). Ce seraient les déportés qui parleraient ainsi de la terreur causée parmi les païens qui les entourent par l'approche du Jour du Seigneur.

\section{היו ב g V S T // err-graph : G clav [ורי 30,7}

\section{Options de nos traductions :}

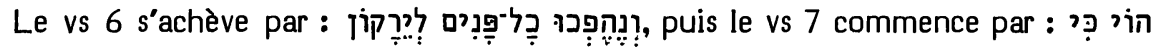

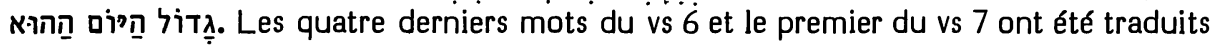
par RSV : "Why has every face turned pale ? Alas !", par RL : "wie ... alle Angesichter so bleich sind ? Wehe !", par TOB : "Tous les visages se décomposent, blêmissent. Malheur !" et par J3 : "Pourquoi tous les visages sont-ils devenus livides ? Malheur !"

Corrigeaient avec le ${ }^{*} \mathrm{G}(37,6)$ le premier mot du vs 7 en (en le liant au vs 6) : J12: "Pourquoi tout visage s'est-il altéré, est-il devenu livide ?" et NEB : "(Why then do I see...) every face changed, all turned pale ?" 
Origine de la correction :

C'est Rothstein (BH2) qui a proposé cette correction, suivi en cela par Volz, Schmidt, Nötscher, Rudolph, Steinmann, Weiser et les apparats de HSAT34, BH23S et Cent.

Les témoins anciens :

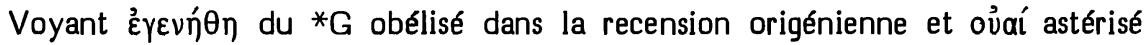
juste après, Spohn y a reconnu deux traductions du mot par lequel commence le vs 7

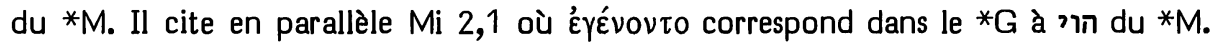

Si l'on en croyait l'édition Sperber, on pourrait penser que le *T a lu la même Vorlage que le ${ }^{*} G$. Il fonde en effet sur deux mss yéménites de la British Library et sur le ms Reuchlin des Prophètes l'omission de ו au début du vs 7. Cependant cette particule exclamative est attestée par le ms Reuchlin, de même qu'elle l'est par le ms Urbinates 1 dont Sperber n'a pas fait usage. Nous n'avons pu contrôler les deux mss yéménites qui n'ont guère de poids en face de la convergence de tous les autres témoins du *T.

La *V (vae) et la*S ( フ) lisent la particule exclamative.

Choix textuel :

Le nifal de הפך lié par la préposition "lamed" à un nom de couleur indique normalement le changement de couleur d'un sujet (cf. Lv 13,16.17). Par contre, on ne "devient" pas "verdeur" ainsi que le propose la variante. Le *G semble donc reposer sur une erreur de lecture.

Dans le *M, la plainte mortuaire "hôy' est ici isolée, sans mention immédiate de son destinataire, comme en Is 1,24. Elle est suivie de sa motivation introduite par comme en Jr 48,1; 50,27.

Le comité a attribué 4 "C" à la leçon du *M et 2 "C" à celle du *G.

Interprétation proposée :

On pourra traduire avec Dhorme : "(Pourquoi...) et tous les visages ont-ils tourné au vert ? (7) Malheur ! Car etc."

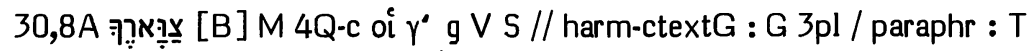

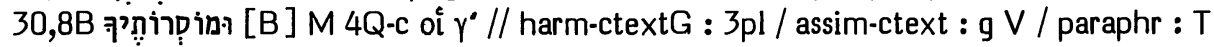

Options de nos traductions :

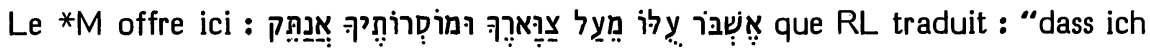
das Joch auf deinem Nacken zerbrechen will und deine Bande zerreissen." et J3 : "je briserai le joug qui pèse sur ta nuque et je romprai tes chaînes".

Disant suivre le ${ }^{*} \mathrm{G}$, RSV donne : "that I will break the yoke from off their neck, and I will burst their bonds", J12 : "je briserai le joug pesant (J2 : qui pèse) sur leur nuque et (J2 et je) romprai leurs chaînes", NEB : "I will break their yoke off their necks and snap their cords", Brockington précisant que cela suppose une leçon •

Disant aussi suivre le *G, TOB donne : “je briserai son joug, je l'enlèverai de son cou, je romprai ses liens." 


\section{Origines des corrections :}

Estimant que "son joug" signifie le joug qui est imposé à Jacob, Houbigant, $s^{\prime \prime i n s p i r a n t ~ d u ~ * G, ~ p r o p o s e ~ d e ~ l i r e ~ e n s u i t e ~ " s o n ~ c o u " ~ e t ~ " s e s ~ l i e n s " . ~ C e t t e ~ c o r r e c t i o n ~}$ est adoptée par Schleusner (annotant les Observationes de Michaelis), Grätz (Studien 295), Duhm, Cornill, Nötscher, Rudolph, Penna, Weiser et les apparats de SBOT, BH3S et Cent.

Proposent de lire avec le *G "leur cou" et "leurs liens" : Condamin, Volz et Bright.

Les témoins anciens :

Les suffixes de la $2 \mathrm{e}$ pers. sg. que le ${ }^{*} \mathrm{M}$ offre en $8 \mathrm{~A}$ et en $8 \mathrm{~B}$ sont attestés par 4Q-c.

En évitant d'attribuer un possessif au joug, le ${ }^{*} G(37,8)$ offre deux possessifs de la 3e pers. pl. (aủiũv) pour le cou et les liens.

Selon le ms Barberini, les "trois" (= ThAqSym) corrigent ces deux possessifs en oov.

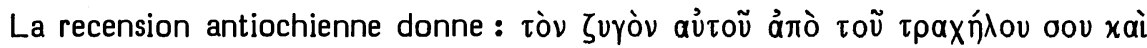

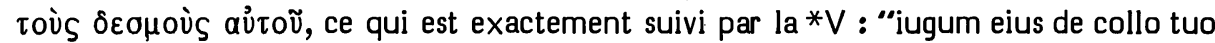
et vincula illius" appuyée par Hie.

Pour ces trois possessifs, la *S est conforme au *M.

Quant au *T, il paraphrase : “je briserai le joug des peuples de vos nuques et je romprai vos liens."

\section{Choix textuel :}

Remarquons d'abord que le ${ }^{*} M$ et le ${ }^{*} G$ s'accordent pour donner comme possessif aux "liens" ceux qui sont liés, alors que l"antiochienne et la $* V$, assimilant au cas du "joug", leur donnent comme possessif celui qui lie.

D'autre part, le point de départ d'Houbigant est inexact. Comme Giesebrecht l'a noté, en effet, les $2 \mathrm{e}$, 3e et $4 \mathrm{e}$ mots sont ici une citation d'Is 10,27 où il était dit :

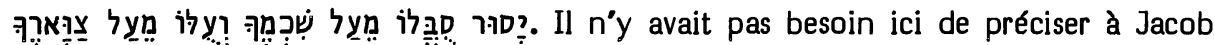

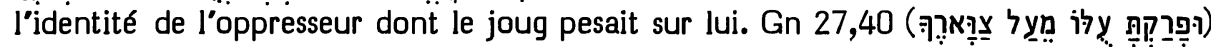
confirme que le suffixe 3e pers. m. sg. du "joug" désigne bien celui qui l'impose et non celui sur lequel il porte.

Que, par contre, dans le contexte immédiat, le suffixe des "liens" puisse désigner

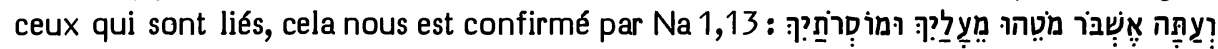

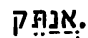

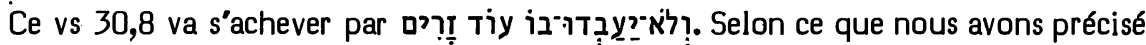
à propos de 25,14 (ci-dessus, p. 654), l'expression ouvrage en utilisant les services d'un autre", et, en conséquence : "réduire quelqu'un en esclavage". Cette phrase se traduira donc : "Et des étrangers ne le réduiront plus en esclavage."

En 8b, comme en 7, il est donc parlé de Jacob à la 3e personne. Le bref passage à la $2 e$ pers. en $8 a$ donne une résonance affective à l'annonce que l'oracle d'Is 10,27 va se réaliser "en ce jour". Ce changement soudain constitue une lectio difficilior en

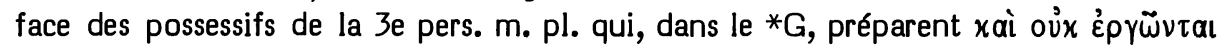

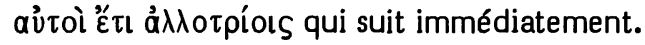


Interprétation proposée :

“Et il arrivera en ce jour - oracle du Seigneur Sabaot - que je briserai 'son joug de dessus ton cou' et que je romprai tes liens. Et des étrangers ne le réduiront plus en esclavage."

31,3 לי [B] M Sym V // glos : S / assim 2 : G clav לו / paraphr : T

Options de nos traductions :

Après une introduction: "ainsi a dit le Seigneur", le vs 2 a rappelé : "Il a trouvé grâce dans le désert, le peuple des réchappés du glaive. Allons lui donner le repos, à Israël." Puis 3a offre, sans introduction: "De loin, le Seigneur m'est apparu

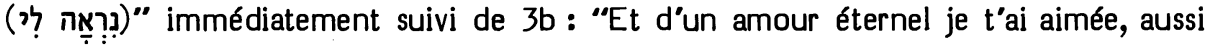
t'ai-je maintenu ma faveur", les pronoms de la $2 \mathrm{e}$ pers. f. sg. étant explicités au vs 4 par le vocatif : "vierge Israël".

Les deux derniers mots de 3a sont traduits par RL : "ist mir erschienen", par TOB et J3: "m'est apparu".

J12 se fondaient sur le *G pour traduire : "lui est apparu". RSV, de même : "appeared to him" et NEB : "appeared to them", ce qui, selon Brockington, traduit iל, avec le ${ }^{*}$ G.

Origine de la correction :

Se fondant sur le ${ }^{*} G$ et le contexte, Châteillon, dans les notes à sa traduction latine, a proposé cette correction qui a été adoptée par Houbigant, Ewald, Grätz (Studien 340), Oort, Duhm, Cornill, Condamin, Ehrlich, Nötscher, Rudolph, Penna, Weiser, Bright et par les apparats de SBOT, HSAT34, BH3S et Cent.

Les témoins anciens :

La massore précise que la séquence de ces deux mots ne se retrouve qu'en Lv

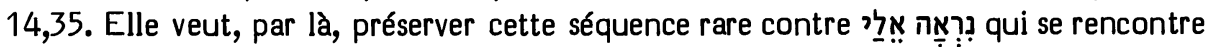
4 fois (Gn 48,3; Ex 3,16; Jg 13,10; Dn 8,1).

Le *G $(38,3)$ donne ici aư $\tau \tilde{\omega}$, alors que Sym donne $\mu$ ol, suivi par la *V (mihi).

La *S traduit le *M et le glose par une formule de transition : לי ואמר לי

Le *T paraphrase 3a: “Jérusalem a dit : dès autrefois, le Seigneur s'est révélé à nos pères. Prophète, dis-leur :"

\section{Choix textuel :}

Le * $\mathrm{M}$ a ici une lectio difficilior. Celle-ci rend le texte beaucoup plus vivant en faisant intervenir, pour un bref monologue, Israël qui vient d’être nommé et à qui le Seigneur va s'adresser aux vss 4 et 5.

Estimant ici la leçon $d u{ }^{*} M$ bien ancrée dans la tradition textuelle protomassorétique par les témoignages convergents de Sym, de la ${ }^{*} V$ et de la ${ }^{*} S$, le comité lui a attribué la note "B". 
Interprétation proposée :

En 2b, la plupart des traductions récentes interprètent l'infinitif absolu הִ comme équivalant à un accompli 3 e pers. $\mathrm{m}$. sg. qui aurait pour sujet Israël : "Israël $s^{\prime}$ est mis en route vers son repos". Cependant, se référant à Is 42,16 et 52,12 (à quoi l'on peut ajouter Ex 33,14), Yéfet ben Ely faisait du Seigneur le sujet de cet infinitif absolu. En ce sens, Schnurrer voit en cet infinitif absolu l'équivalent d'un inaccompli 1e pers. sg. Rosenmüller adopte cette exégèse en notant qu'elle s'accorde bien avec l'introduction: "ainsi a dit le Seigneur" par laquelle ce vs 2 a commencé. Cette exégèse a été adoptée ensuite par Hitzig, Henderson, Nägelsbach, Keil et Luzzatto. On peut comprendre l'infinitif absolu comme un impératif de la 1e pers.: "allons!" ou un présent d'intention : "je m'en vais..." En fin de vs, le nom "Israël" explicite quel est le "peuple" dont il est ici question.

Cette expression du dessein divin ("je m'en vais lui donner le repos, à Israël") prépare bien la constatation par Israël de l'entrée en scène de son sauveur : "De loin, le Seigneur m’est apparu", puis l'intervention du Seigneur qui enchaîne : “- Et d'un amour éternel je t'ai aimée, aussi t'ai-je maintenu ma faveur". La conjonction qui relie $3 \mathrm{~b}$ à $3 a$ n'est pas plus surprenante que celle qui liait $30,8 \mathrm{~b}$ à $8 \mathrm{a}$.

\section{עמו 31,7 [מך [C] M 4Q-c V S // exeg : G T clav}

\section{Options de nos traductions :}

“Car ainsi a dit le Seigneur : Acclamez Jacob dans la joie. Réservez un accueil

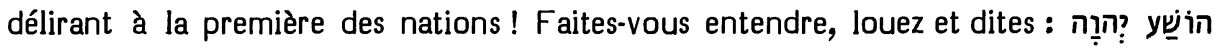

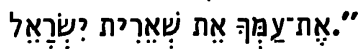

Aucune de nos traductions $n^{\prime}$ a traduit le ${ }^{*} M$ pour les quatre premiers mots de cette acclamation. Mais, en disant suivre le ${ }^{*} \mathrm{G}, \mathrm{J}$ a traduit : “Yahvé a sauvé son peuple", TOB : "le SEIGNEUR délivre son peuple" et NEB : "The LORD has saved his

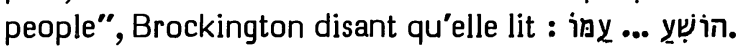

Sans note, RSV traduisait de même et RL traduisait: "Der HERR hat seinem Volk geholfen".

\section{Origine de la correction :}

Cette correction a été proposée par Houbigant, suivi par Venema, Schleusner (annotant les Observationes de Michaelis), Giesebrecht, Oort, Duhm, Cornill, Condamin, Ehrlich, Volz, Nötscher, Rudolph, Penna, Steinmann, Weiser, Hyatt, Bright et les apparats de SBOT, HSAT34, BH235 et Cent.

Les témoins anciens :

La vocalisation du premier mot est protégée par une massore (Weil §2630) précisant qu'elle ne se retrouve qu'en Ps 86,2.

4Q-c vocalise הושיע, mais confirme ממך du *M.

Le ms babylonien Eb 10, lui aussi, vocalise הiֹש עמך (cf. , Yeivin III 110).

La *V (salva Domine populum tuum) et la *S (פרוק מריא לעמך) appuient le *M. 


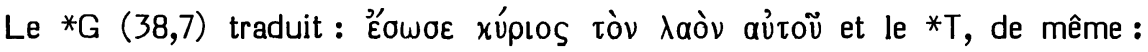
פרק "י ית עמיה.

Choix textuel :

Il est peu probable que le ${ }^{*} G$ et le ${ }^{*} T$ s'accordent pour lire une Vorlage distincte du *M. Leur traduction indique plutôt qu'ils ont bien compris que cet impératif a plus valeur d'acclamation que de supplication. Comme en Ps 118,25 et dans les acclamations du jour des Rameaux, il ne faut pourtant pas éliminer l'aspect de supplication. Mais c'est la certitude que la supplication sera exaucée qui lui donne une tonalité d'acclamation triomphale.

Le comité a attribué ici au *M 3 "B" et 2 " $C$ " et au *G 1 "C $C$ ".

Cornill, en SBOT, a suggéré que la leçon du *M pouvait être une correction théologique tenant au fait que le salut d'Israël acclamé ici n'est pas encore pleinement réalisé et, à ce titre, doit demeurer objet de supplication. On comprendrait mal, en ce cas, qu'une retouche théologique qui aurait eu lieu dans la tradition textuelle prémassorétique (car déjà attestée par 4Q-c) n’ait pas touché le *T.

Interprétation proposée :

“Sauve, Seigneur, ton peuple, le reste d'Israël !"

31,9 ובתחנונים [B] M V S // exeg : Aq Sym Hie T / lic : G

Options de nos traductions :

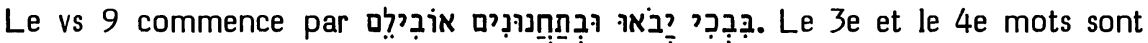
traduits par TOB : “ils crient : 'Grâce !' et je les pousse' et par J3 : “dans les supplications je les ramène".

Se référant à la ${ }^{*} V$ et au ${ }^{*} T$, RSV disait suivre le ${ }^{*} G$ quand elle traduisait : "and with consolations I will lead them back". Avec le ${ }^{*} \mathrm{G}, \mathrm{J} 12$ traduisaient : "dans les consolations je les ramène" et NEB : "but I will comfort them and be their escort", Brockington disant qu'elle lit וּבְתָנַחוּמוּים RL traduit : "aber ich will sie trösten und leiten".

Origine de la correction :

Houbigant a assigné pour Vorlage au *G la leçon que cite Brockington et a corrigé ainsi le *M, suivi en cela par Duhm, Cornill, Volz, Nötscher, Rudolph, Weiser, Bright et par les apparats de HSAT34, BH3S et Cent.

Les témoins anciens :

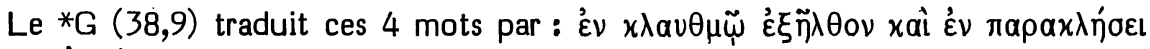

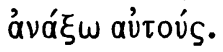
$\mu \tilde{\omega} \nu$.

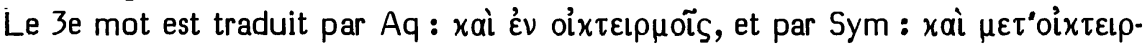

La *V traduit: "et in precibus". Cependant Hie traduisait "et in misericordia" qui a pénétré dans le texte ${ }^{*} V$ de l'université de Paris et dans certaines éditions. 
La*S traduit ובתחננתא.

Le *T paraphrase ces 4 mots en: “Lors de leur déportation, ils s'exilaient en pleurant. Quand ils reviendront de leurs lieux d'exil, je les ferai approcher avec d'abondantes compassions."

\section{Choix textuel :}

A propos d'Is 57,18 (ci-dessus, p. 416) nous avons noté que le verbe $\pi \alpha \rho a x \alpha-$ $\lambda \varepsilon \nu_{\nu}$ ne signifie pas toujours "consoler" dans le ${ }^{*} G$, mais qu"il peut y signifier : "appeler pour faire venir vers soi". Cela explique que, à la différence d'Houbigant, Schleusner (IV 201) ne voit pas de difficulté à ce que le ${ }^{*} G$ ait traduit ici largement la leçon du *M. Ajoutons que la traduction du verbe "venir" par "sortir" montre que le * G dépend ici de la même tradition exégétique que le *T. Pour eux, les deux premiers mots décrivent l'atmosphère du départ en exil et les deux suivants celle du retour.

Radaq, s'appuyant sur le sens de en Jos 11,20 et Esd 9,8, donne à è le sens de "miséricorde et clémence". UUne exégèse de même tradition est sûrement à l'origine des traductions de Aq, de Sym, de Hie et du *T.

Notons que l'on a déjà en Jr 3,21 l'association montre que le glossaire $C$ ("et en prières"), la *V et la *S ont vraisemblablement raison de donner à ce mot ici (en un contexte analogue) son sens ordinaire de "supplications".

Voyant ici un problème d'exégèse plutôt que de critique textuelle, le comité a attribué au *M 3 "A" et 3 "B".

Interprétation proposée :

En Jr 3,21s pleurs et supplications marquent la conversion. En Za 12,10, les תחנונים sont un don divin qui est à l'origine de la conversion. 33 semble donc avoir raison de traduire : "En larmes ils reviennent, dans les supplications je les ramène."

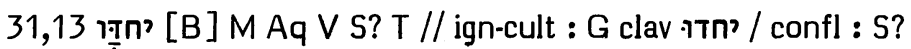

\section{Options de nos traductions :}

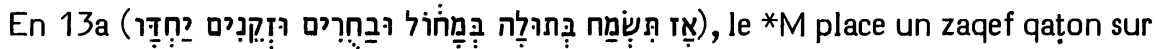
le $4 \mathrm{e}$ mot. RL traduit: "Alsdann werden die Jungfrauen fröhlich beim Reigen sein, die junge Mannschaft und die Alten miteinander", TOB : "Alors les jeunes filles dansent et elles s'épanouissent, ainsi que les jeunes gens et les vieillards" et $\mathrm{J3}$ : "Alors la vierge prendra joie à la danse, et, ensemble, les jeunes et les vieux".

$\mathrm{J12}$ et NEB (selon Brockington) disent vocaliser le dernier mot quand elles traduisent : "jeunes et vieux seront contents (J2 : heureux)" et "young men and old shall rejoice". Sans note, RSV traduisait de même : "and the young men and the old shall be merry".

\section{Origine de la correction :}

Cappel (Notae 530a) avait remarqué que le ${ }^{*} G$ a cru lire ici le verbe $n$ TTn (= se réjouir) et Venema avait été tenté par cette leçon. Notant que 17 mss Kennicott s'ac- 
cordent avec le ${ }^{*} G$ pour ne pas lire de conjonction avant le 5 e mot, Michaelis (OEB) envisageait de traduire, en s'inspirant du ${ }^{*} G$ : “alors la jeune fille se réjouira dans la ronde des jeunes gens, et les vieillards se réjouiront". En gardant, pour le reste, la structure du $* M$, Duhm suit le $* G$ dans son interprétation du dernier mot comme un inaccompli 3e pers. m. pl. au sens de "se réjouissent". Font de même : Cornill, Rudolph, Penna, Steinmann, Weiser, ainsi que les apparats de BH3S et de Cent.

\section{Les témoins anciens :}

Pour le dernier mot, la vocalisation du *M a été lue par $A q$ (אכחז), la *S (même traduction), la *V (simul) et le *T (כחה). Notons que la *S semble ajouter en une leçon gonflée : נחדון (à moins que cela ne soit qu'une explicitation de la reprise du verbe initial).

Comme Michaelis (Observationes) l'a remarqué plus tard, le ${ }^{*} G(38,19)$, habitué à une civilisation où jeunes filles et jeunes hommes se distraient ensemble et ayant une Vorlage où le 5 e mot n'est pas précédé d'un waw, voit ici les jeunes filles s'amuser en compagnie des jeunes gens. Au contraire, selon le ${ }^{*} M$, les jeunes filles manifestent leur joie par leurs danses, tandis que jeunes hommes et vieillards mènent ensemble leurs propres réjouissances, comme c'est demeuré la coutume pour les hommes jeunes et âgés à Simḥat Torah.

La syntaxe du ${ }^{*} M$ a de bons parallèles en 6,$12 ; 13,14 ; 31,8 ; 48,7 ; 49,3$.

Jugeant cette syntaxe excellente et estimant que le ${ }^{*} G$ a méconnu ici une donnée culturelle, le comité a attribué au *M la note " $B$ ".

Interprétation proposée :

Il est normal d'expliciter le verbe "se réjouir" dans le 2e membre de phrase : “Alors la jeune fille prendra joie à la danse, alors que jeunes gens et vieillards se réjouiront ensemble".

31,16.17 cf. p. 644.

\section{1,24 וְנָסְער [B] M G // exeg : Aq Sym V S T}

Options de nos traductions :

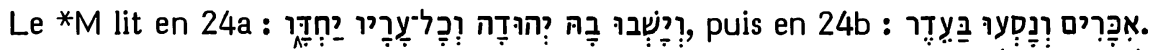
Les deux derniers mots sont traduits par Ji2 : "et ceux qui marchent ( $\mathrm{j} 2$ : vont) avec un troupeau", J3: "et ceux qui conduisent le troupeau", RL : "und die mit Herden umherziehen".

RSV conjecture, en se référant à la *V, à la *S et au *T : "and those who wander

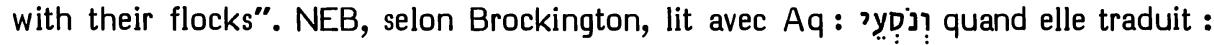
"and shepherds who wander with their flocks". Sans note textuelle, TOB se contente de traduire : "et nomades" pour ces deux mots. 
Origine de la correction :

C'est Michaelis (Observationes) qui a proposé de lire ici la leçon que reprendra Brockington, en reconnaissant un syriacisme dans cet usage de l'état construit. Cette leçon a été adoptée ensuite par Grätz (Studien 342), Giesebrecht, Cornill, Volz, Schmidt, Penna, Bright et par les apparats de HSAT34, BH23S et Cent.

Les témoins anciens :

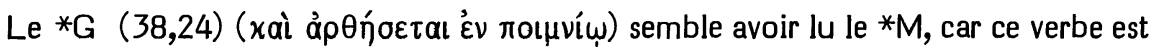
le correspondant du qal de $y$ נס en Nb 2,17 et de son hifil en 1 R 5,31 et en 2 R 4,4.

Le *T a interprété ce verbe comme une relative implicite et l'a traduit par דנטלין. C'est vraisemblablement la même interprétation qui motive les traductions en parti-

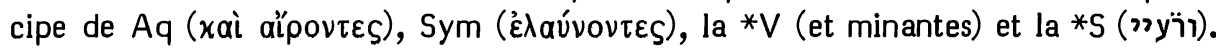

\section{Choix textuel :}

Un participe à l'état construit précédant une préposition ferait une difficulté syntactique équivalant à celle que constituerait une interprétation de ce verbe en relative implicite.

Estimant ici aussi qu'il s'agit d'un problème plus exégétique que textuel, le comité a attribué au *M 4 "B" et 2 "A".

Interprétations proposées :

Is 7,24 et 5,5 montrent que les cultures dévastées deviennent des terres de pâturage. A l'inverse, la remise en valeur par les laboureurs des champs qui entourent les villes oblige les bergers à s'en éloigner avec leurs troupeaux pour faire paître ceuxci. On devra donc reculer d'un mot l'atnah pour comprendre : "Juda et toutes ses villes ensemble y habiteront en laboureurs. Et on décampera avec le troupeau". C'est l'exégèse de Luzzatto.

Les teamîm semblent postuler l'exégèse de la plupart des versions: "Juda et toutes ses villes ensemble y habiteront, les laboureurs et ceux qui nomadisent avec le troupeau."

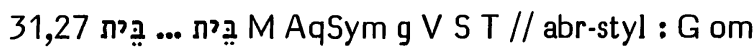

Options de nos traductions :

Le *M donne en ce vs: "Voici que des jours viennent - oracle du Seigneur où j'ensemencerai la maison d'Israël et la maison de Juda de semences d'hommes et de semences de bêtes". La mention de la "maison" d'Israël et de la "maison" de Juda est respectée par RSV, J et RL.

TOB dit suivre le ${ }^{*} G$ en mentionnant seulement ici "Israël et Juda". Sans note, NEB fait de même.

Origine de la correction :

L'omission des deux בִּ a été requise par Cornill pour des motifs de métrique. Il a été suivi en cela par les apparats de HSAT34 et de Cent. 
Les témoins anciens :

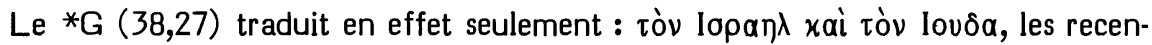
sions origénienne et antiochienne insérant sous astérisque, avant chacun des noms de peuple : oĩxov qui est attribué par le ms Marchalianus à AqSym.

Les autres témoins (la *V, la *S et le *T) traduisent les deux בְּית du *M.

\section{Choix textuel :}

Ce cas n’a pas été soumis au comité.

Egalement pour des motifs de métrique, Cornill proposait de suivre aussi le *G en ne conservant au vs 28 a que le premier et le dernier des cinq infinitifs construits qui s'y succèdent. Ni Cent, ni TOB, ni NEB ne l'ont suivi en cette seconde proposition qui montre que le ${ }^{*} G$ semble alléger systématiquement en ce contexte.

\section{1,35 sipn [B] M S // transl : Aq V T sg / assim-ctext : G om}

\section{Options de nos traductions :}

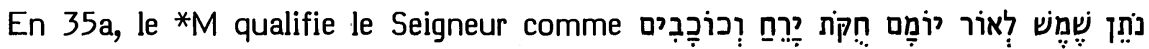
לְאוֹר לָירליה RSV traduit cela : "who gives the sun for light by day and the fixed order of the moon and the stars for light by night" et TOB : "qui établit le soleil comme lumière du jour, la lune et les étoiles dans leur ordre, comme lumière de la nuit".

J12 et NEB omettent avec le *G le mot sipn..

33 corrige ce mot en nị quand elle traduit : “lui qui établit le soleil pour éclairer le jour, commande à la lune et aux étoiles pour éclairer la nuit". RL traduit de même : “der die Sonne dem Tage zum Licht gibt und den Mond und die Sterne der Nacht zum Licht bestellt".

Origines des corrections :

Se fondant sur l'absence de ce mot dans le *G, Knabenbauer suggère qu'il est ici, dans le *M, une glose empruntée au vs 36. Aussi est-il omis par Giesebrecht, Oort, Duhm, Condamin, Penna, Bright et les apparats de HSAT34.

Pour l'assimiler aux participes qui l'entourent, Volz (Studien) conjecture une correction en קin, suivi en cela par Nötscher, Rudolph, Steinmann et Weiser.

Les témoins anciens:

La massore (Weil \$2640) précise que nous avons affaire ici à un pluriel en graphie défective.

En effet certaines versions rendent ce mot par un singulier : Aq : áxpí $\beta \varepsilon ı \alpha \nu$, la *V : “ordinem", le *T : :

Si l'on en croit les éditions, la *S donnerait ici ודוברא au singulier. Cependant le ms Ambrosianus place sur ce mot les seyamé.

Le ${ }^{*} G(38,36)$ ne traduit pas ce mot, assimilant ainsi le cas de la lune et des étoiles à celui du soleil. 


\section{Choix textuel :}

BHS mentionne un ms du $* M$ comme omettant ce mot (en accord avec le ${ }^{*} G$ ). Il s'agit du ms 681 de Kennicott, c'est-à-dire du Mahzor in-8 $8^{\circ}$ WC 1,10 de Corpus Christi dont la valeur de témoin du *M est nulle.

En Jr 33,25 nous retrouverons mentionnée, en parallèle avec "mon alliance avec

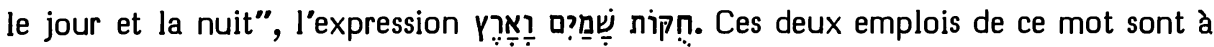

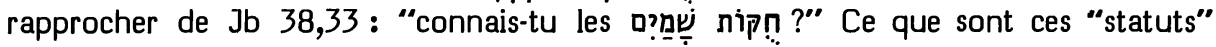
des cieux nous est expliqué par les deux vss précédents : "Peux-tu nouer les liens des Pléiades ou desserrer les cordes d'Orion, faire apparaître les signes du zodiaque en leur saison, conduire l'Ourse avec ses petits ?" (Jb 38,31s).

Le mot רiא est en Jr 31,35 un infinitif construit que Rashi traduit : "pour éclaircir", c'est-à-dire : "pour qu'il y ait de la lumière". Or le soleil assure directement par sa présence qu'il y ait de la lumière durant le jour. Mais la modulation nuancée de ténèbres et de lumière qui se déroule durant les nuits est assurée par les mécanismes subtils et délicats des phases de la lune, ainsi que par la connexion des étoiles en constellations et les mouvements complexes des astres. C'est cet ensemble complexe de normes qui constitue "les statuts de la lune et des étoiles".

Estimant que la mise au singulier de ce mot par certaines versions est une initiative translationnelle, le comité a attribué ici au *M la note " $B$ ".

Interprétation proposée :

"lui qui établit le soleil pour qu'il y ait de la lumière durant le jour, les statuts de la lune et des étoiles pour qu'il y ait de la lumière durant la nuit".

\section{בזרע M Aq V S T // theol : G clav בכל-זרע 31,37}

Options de nos traductions :

Au vs 37 , le ${ }^{*} M$ introduit par "Ainsi a dit le Seigneur" une condition sentie comme irréalisable : "Si l'on mesurait les cieux d'en haut et si l'on sondait les fondements de la terre en bas." Cette condition sert de protase à une apodose montrant qu'un abandon d'Israël par le Seigneur ne peut avoir lieu. Le *M la formule ainsi :

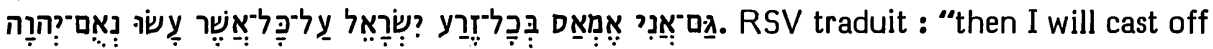
all the descendants of Israel for all that they have done, says the LORD", RL : "dann würde ich auch verwerfen das ganze Geschlecht Israels für all das, was sie getan haben, spricht der HERR", NEB : "then I could spurn the whole race of Israel because of all they have done. This is the very word of the LORD" et 33 : "alors moi aussi je rejetterai toute la race d'Israël pour tout ce qu'ils ont fait, oracle de Yahvé".

$\mathrm{J} 12$ et TOB se fondent sur le ${ }^{*} G$ pour omettre le premier 3 , J12 traduisant : "je rejetterai la race d'Israël" et TOB : "je pourrais rejeter la descendance d'Israël".

Origine de la correction :

Cette omission a été proposée par Duhm et adoptée par Volz, Schmidt, Steinmann, Bright et les apparats de HSAT34, BH23S et Cent. 
Les témoins anciens :

Le *G $(38,35)$ traduit seulement tò үévos lopan $\lambda$; alors que le "tout" du *M est inséré par la recension origénienne, ayant été traduit par $A q$, la*V, la *S et le ${ }^{*} \mathrm{~T}$.

\section{Choix textuel :}

Ce cas n’a pas été soumis au comité.

Le ${ }^{*} G$, comme les traducteurs et exégètes récents, s'est placé dans une perspective de destinée individuelle. Dans cette perspective, c'est une piètre consolation d'obtenir la garantie que le Seigneur ne rejettera pas tous les descendants d'Israël, car cela risque de signifier qu'il rejettera néanmoins la plupart d'entre eux. Mieux vaut obtenir la garantie qu'Israël ne sera pas rejeté c'est-à-dire que le Seigneur gardera sa faveur à quiconque est fils d'Israël. D'ailleurs le *G ne s'est pas contenté d'omettre ce "tout". Il a inséré, pour plus de sûreté une négation avant le verbe qui précède, obtenant le raisonnement suivant : "Si l'on mesurait ... et si l'on sondait ... alors même je ne rejetterais pas la race d'Israël ..." Le * $G$ de Jérémie ne craint pas d'ajouter ou d'omettre des négations dans sa traduction, ce qui a été noté par Wichelhaus (133) et par nous (ci-dessus, p. 628).

De fait, la perspective dans laquelle se place ce texte est différente. Le risque envisagé est que les fautes accumulées par les générations d'Israël aient pour effet un rejet global de la descendance de Jacob-Israël. Or cet oracle assure que le Seigneur en restera à des châtiments limités, mais n'ira jamais jusqu'au rejet global.

En cette perspective, le *M est satisfaisant.

Interprétation proposée :

"alors moi aussi je rejetterais en bloc la race d'Israël à cause de tout ce qu'ils ont commis - oracle du Seigneur."

31,40A הפגרים והדשן [A] M Th Aq Jsp g V // lacun : G / paraphr : S / midr : T

\section{Options de nos traductions :}

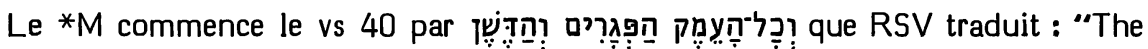
whole valley of the dead bodies and the ashes", J : "Et toute la vallée (J1 : dépression), avec ses cadavres et sa cendre", RL : "Und das ganze Tal der Leichen und der Asche" et TOB : "Toute la vallée des cadavres et des cendres".

NEB dit omettre avec le ${ }^{*} G$ le $3 e$ et le $4 \mathrm{e}$ mot, lorsqu'elle se contente de traduire : “All the valley".

\section{Origine de la correction :}

C'est Duhm qui a suggéré que ces deux mots, que le ${ }^{*} G$ ne lisait pas encore, sont une glose marginale d'un lecteur curieux ou scandalisé, se demandant ce qu'il adviendra des cadavres et des cendres si cette vallée au sud-est du temple devient sainte dans l'avenir. Volz le suit en ce jugement et ces deux mots sont omis par Schmidt. 
Les témoins anciens :

Ces deux mots sont traduits par Th, Aq, Josippos, une ajoute des recensions origénienne et antiochienne, ainsi que la $* V$.

Ils ont été paraphrasés par la *S en : "où l'on jette le fumier et la cendre" et midrashisés par le *T en: "où sont tombés les cadavres de l'armée des Assyriens".

Quant au ${ }^{*} G(38,40)$, ce sont les quatre premiers mots du vs qu'il omet, cette omission s'expliquant probablement par un homéoarcton sur וכל

\section{Choix textuel :}

On ne peut donc fonder sur le ${ }^{*} G$ une omission de ces deux mots qui demeurera conjecturale.

Aussi le comité a-t-il attribué en cela au *M 4 "A" et 2 "B".

Interprétation proposée :

Le mot דשן דésigne les cendres grasses des cadavres. Il s'agit ici vraisemblablement des monceaux d'ordures et des cadavres de bêtes impures ou trouvées impropres au sacrifice que l'on brûlait hors de la porte de la ville donnant sur la vallée de Hinnom (la "porte des tessons" de 19,2).

König (Syntax §3330) interprète ces deux mots comme une apposition de celui qui précède. L'auteur veut dire : “Et toute la vallée - (y compris la partie où il y a actuellement) les cadavres et les cendres -".

Nous retrouverons en 32,11 deux mots faisant figure d'apposition, dans une situation analogue.

\section{1,40B Ty $\left(1^{\circ}\right)[A] M G \vee S T$}

\section{Options de nos traductions :}

Les espaces mentionnés auparavant sont limités par deux termes, d'abord

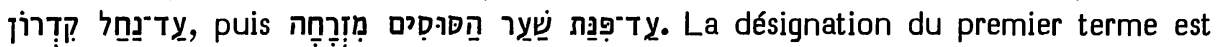
traduite par RSV : "as far as the brook Kidron", par RL : "bis zum Bach Kidron", par NEB : "as far as the gorge of the Kidron" et par TOB : "le long de la vallée du Cédron".

J traduit : "attenant au ravin (J1 : à la vallée) du Cédron" en lisant לy au lieu du premier mot, correction que $\mathrm{J} 12$ fondaient sur un ms hébreu, alors que J3 la présente comme une conjecture.

Origine de la correction :

C'est Volz qui a proposé cette correction, suivi par Rudolph, Steinmann, Bright et les apparats de $\mathrm{BH} 3 \mathrm{~S}$.

Les témoins anciens :

לy est lu ici par le ms 150 de Kennicott dont celui-ci (Dissertatio Generalis 83, n.b) montre les nombreuses variantes. Notons qu'un autre ms de Kennicott a la même variante pour le ty suivant et qu'une douzaine de mss lisent $7 y$ à la place du by du vs précédent. 
La leçon du *M est attestée ici par le *G $(38,40)$ : "̌́ws, la *V : "usque ad", la *S : ע ע et le *T : דע.

Choix textuel :

Ce ms isolé du *M n'a aucun poids en face de l'appui que tous les témoins apportent ici à la forme classique $d u{ }^{*} M$. Aussi le comité a-t-il at tribué à celle-ci la note "A".

Interprétation proposée :

“jusqu'au ravin du Cédron".

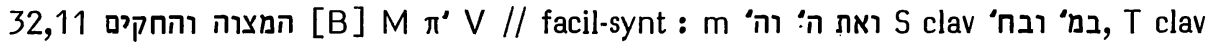
/ כמ׳ וכח׳ ign-real : G om

Options de nos traductions :

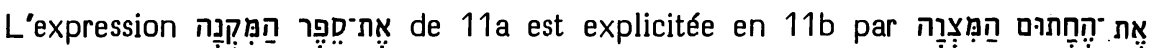

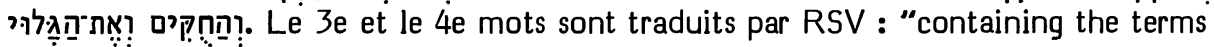
and conditions", par TOB : " - les prescriptions et les règlements! -" et par J3 : "(avec les stipulations et les clauses)".

$\mathrm{J12}$ transféraient ces mots en fin du vs et traduisaient, selon la ${ }^{*} S$ et le *T : "selon les prescriptions légales".

RL et NEB omettent ces deux mots, NEB précisant qu’elle suit en cela le *G.

Origines des corrections :

Constatant que le ${ }^{*} \mathrm{G}$ les omet, Venema s'est demandé si ces deux mots étaient authentiques. Hitzig2 en doute. Stade (Miscellen 8, 176) les omet, suivi en cela par Ehrlich, Schmidt et les apparats de SBOT et de BH2.

Ce sont les 4 derniers mots qui sont omis par Oort, Duhm et les apparats de HSAT34.

Transfèrent le 3e et le $4 \mathrm{e}$ mot de 11b à la fin du vs 10 : Volz, Nötscher, Rudolph, Steinmann, Weiser et l'apparat de BHS.

$\mathrm{BH} 3$ proposait plusieurs options, dont celle qui a été retenue par $\mathrm{J12}$.

Les témoins anciens :

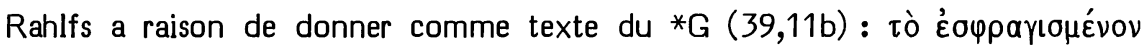
xà tò åveץ mots. En tout cas, le ${ }^{*} G$ ancien n'a pas traduit les $3 e$ et 4 e mots de $11 \mathrm{~b}$.

Pour ces deux mots, les recensions origénienne et antiochienne insèrent : $\tau \grave{\nu}$

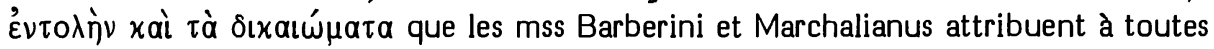
les colonnes hexaplaires autres que le ${ }^{*} \mathrm{G}$.

$\mathrm{La} * \mathrm{~V}$ les traduit : "stipulationes et rata".

La *S (בפוקדנא ובנמוסא) et le *T (כהלכתא וכדחזי) ont facilité par des prépositions l'insertion syntaxique de ces mots. 
Notons ici une variante intérieure au *M.

Selon le ms de Leningrad (III 280 du facsimilé), et selon l'édition Ben Hayim, les 'orientaux' lisent ici ואת המצוה והחקים. Or c'est la leçon qu'attestent le ms de Petrograd des Prophètes et le ms New York JThS 232 datant tous deux du Xe siècle (la marge de ce dernier précisant que ce mot est un ketib welô qeré).

Norzi a estimé que c'est ce ואת que le Talmud Babli (Nedarim 38a, ligne 1) désigne comme un ketib welô qeré, quoique toutes les éditions du Talmud portent ici זאת. De fait, le ms Vatican ebr 110 du Talmud porte bien ici ואת, ce qui confirme le jugement de Norzi.

Cette variante orientale semble être une retouche visant à mieux insérer dans le contexte ces deux mots.

Choix textuel :

Estimant que ces deux mots appartiennent en tout cas à la forme protomassorétique du texte, le comité leur a attribué la note "B", sans ajouter ואת.

Nous avons déjà rencontré en 31,40A (ci-dessus, p. 692) une apposition analogue constituée par deux mots.

$L e{ }^{*} G$ semble ne pas avoir su interpréter ces mots.

Interprétation proposée :

Parmi les documents doubles retrouvés dans les grottes de Murabbaat, les documents 21,23 et 28 (DJD II) se caractérisent par le fait que la partie scellée du document ne comporte que les données essentielles de l'acte, alors que la partie ouverte contient l'acte en son état complet.

Il n'est pas impossible que l'apposition constituée par ces deux mots veuille spécifier quelles sont les parties de l'acte ("les stipulations et les clauses" selon $\mathrm{J} 3$ ou "the terms and conditions" selon RSV) qui figuraient dans la partie scellée. C'est vraisemblablement ainsi que la $* V$ a compris la chose.

On pourra donc traduire : “Et je pris le document d'achat, la partie scellée, (contenant) le stipulé et les clauses, et la partie ouverte". On ne précise pas le contenu de la partie ouverte, car elle contenait l'acte en sa totalité.

בן דדי

Options de nos traductions :

Le mot 'Ṭד est traduit par RSV : "my cousin", par RL : "meines Vetters", par TOB : "fils de mon oncle".

Estimant que le *M signifie "mon oncle", NEB, selon Brockington, se fonde sur 11 mss pour introduire "ִָּ avant ce mot et traduire : "my cousin". Se fondant sur plusieurs mss hébreux, le *G et la *S, J fait de même et traduit : "mon cousin".

Origine de la correction :

Dans son commentaire sur Gn 9,26, Iba Ezra rapporte que Saadya estimait qu'il manquait ici le mot "fils de" avant "mon oncle". 
Dans l'édition princeps de sa traduction, en 1527, Pagnini avait traduit ici : "patruelis mei" ( $=$ mon cousin). Mais, dans les errata, il demande de corriger cela en "patrui mei" (= mon oncle). Dans la réédition de cette traduction par Estienne ce mot n’a pas été corrigé, mais il l'a été dans celles qui ont été faites par Servet et par Arias Montano. Au XVIe siècle, ce mot a été interprété comme "mon oncle" par Brucioli, Olivetan, Rollet et Châteillon. Il l'a été comme "mon cousin" par Prédicants, Zwingli, Luther, Münster, Jud, Estienne et Pasteurs. Tremellius traduit : "patruelis mei", tout en notant que l'hébreu porte : "patrui". Quant à Ge et à KJ, toutes deux portent "mine uncles sonne", l'usage de la cursive leur ayant permis de sortir de cette difficulté.

Houbigant a proposé d'insérer ici בן, suivi en cela par Giesebrecht, Oort, Duhm, Cornill, Condamin, Volz, Nötscher, Rudolph, Penna, Steinmann, Weiser, Bright et les apparats de HSAT34, BH23S et Cent.

Les témoins anciens :

La recension origénienne fait savoir par un obèle que le mot víoũ $d u{ }^{*} G(39,12)$ n'est pas attesté dans l'hébreu que lit Origène.

Cependant de Rossi atteste ici la présence de dans la 1e ou la 2e main de 11 mss. Mais le témoignage des témoins du texte tibérien classique est ferme sur l'omission de ce mot.

La *V traduit ici "patruelis mei" et la *S : בר דדי

Le *T, selon le ms 116 de la collection Montefiore, porte ici בר דודי, à ce que dit l'édition Sperber. Luzzatto (commentaire) dit avoir trouvé cette leçon en deux mss du *T. L'un de ces mss était le ms Montefiore dont Hirschfeld (Catalogue $§ 7$ ) nous dit que Luzzatto (Miscellen 132ss) l’a étudié. Celui-ci précise qu'il a été écrit en 1487. On a deux motifs d'admettre que cette leçon de ce ms tardif n'est pas primitive dans le *T.

1/Un témoin manuscrit plus ancien (ms Urbinates 1) a ici אח אבי, en accord avec la polyglotte d'Anvers, alors que les éditions Félix de Prato et Ben Hayim écrivent אחבי Une variante ancienne est apportée par le ms Reuchlin qui offre ici la leçon בר־אחבי (non attestée par l'édition Sperber).

2/ Selon les données fournies par Sperber, le ms Montefiore écrivait au vs בר אחבי 9 , ce qui donne, au vs 12, à sa leçon בר דודי, l'allure d'une retouche postérieure.

\section{Choix textuel :}

Au vs 7, Hanaméel avait été qualifié de ces 3 mots en les séparant de "Hanaméel" qui précède.

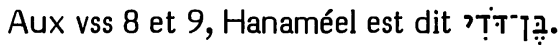

En fonction de ces données, Hanaméel est évidemment le fils de Shallum, celuici étant l'oncle de Jérémie.

Selon le *M, le mot Tं, aux vss 7, 8 et 9, signifie donc clairement "oncle".

$\mathrm{La} * \mathrm{~V}$ interprète bien ainsi ce mot aux vss 8 (filius patrui mei) et 9 (filio patrui mei). Mais, au vs 7, elle fait de ךדт une épithète de "Hanaméel fils de Shallum", en traduisant cette épithète par "patruelis tuus", ce qui explique qu'au vs 12 elle n'éprouve aucune difficulté à traduire יד̣ंT par "patruelis mei" (= mon cousin). 


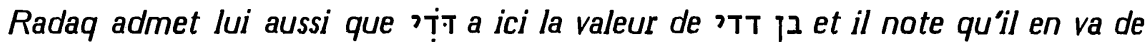
même pour la situation de Loth par rapport à Abraham, Gn 12,5 le disant alors que Gn 14, 16 le dit אַיִ.

Par 4 "C" et 2 "B", le comité a estimé probable que le *M est ici le témoin du texte primitif, quoique les possibilités d'une mutilation du texte existent.

\section{Interprétation proposée :}

En 7, on traduira : "Hanaméel, fils de ton oncle Shallum".

En 8 et 9 : "Hanaméel, le fils de mon oncle".

En 12 : “mon cousin Hanaméel".

\section{2,26 אל־ירמיהו [B] M AqSym g V S T // assim-ctext : G תpós $\mu \varepsilon$}

\section{Options de nos traductions :}

Le *M porte en ce vs : "Et il y eut une parole du Seigneur à Jérémie, disant :" Le complément "à Jérémie" est traduit par RSV, RL, NEB et TOB; alors que J le remplace par un pronom de la 1e pers. sg. : “me fut adressée (J1 : m'arriva)" en se fondant sur le ${ }^{*}$ G.

Origine de la correction :

Ont opté pour lire sִ avec le *G : Giesebrecht, Duhm, Cornill, Condamin, Volz, Nötscher, Rudolph, Penna, Steinmann, Weiser, Bright et les apparats de SBOT, HSAT34 et BH3S.

Les témoins anciens :

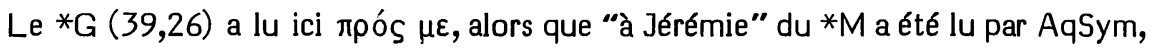
la recension origénienne, la $* \mathrm{~V}$, la $* \mathrm{~S}$ et le $* \mathrm{~T}$.

Choix textuel :

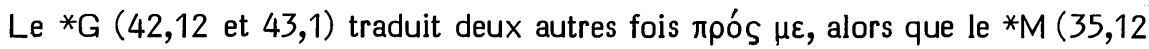

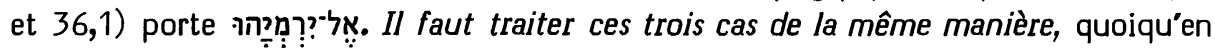
ces deux autres cas les critiques n'aient pas été tentés de suivre le ${ }^{*} \mathrm{G}$.

Ici, le ${ }^{*} M$ offre une lectio difficilior. En effet, en 32,16, Jérémie donnait une introduction à la 1e pers. pour la supplique qu'il cite aux vss 17 à 25 . Mais, puisqu'au vs 25 il s'adresse encore au Seigneur à la 2 e pers. et que le vs 26 parlera du Seigneur à la $3 e$ pers., il n'est pas surprenant que cela soit lié à un passage de la 1e à la $3 e$ pers. à propos de Jérémie.

Ici, la leçon du ${ }^{*} M$ est attestée par tous les témoins du texte protomassorétique. Aussi le comité lui a-t-il attribué la note "B". 
Options de nos traductions :

Selon le *M, il est dit en 29a: “Alors entreront les Chaldéens qui combattent

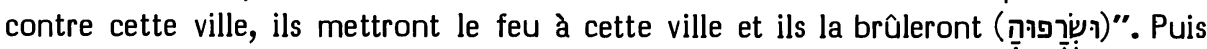

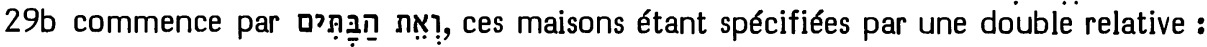
"sur les toits desquelles on encensait au Baal et l'on répandait des libations aux dieux étrangers afin de m'irriter".

Voici comment nos traductions ont rendu le *M pour le dernier mot de 29a et les deux premiers de 29b : RSV : “(The Chaldeans ... will ...) and burn it, with the houses", RL : "(die Chaldäer ... werden ...) sie ... und verbrennen samt den Häusern", NEB : "(The Chaldeans ... will ...) and burn it down, with the houses", TOB : "(les Chaldéens...) et ils l'incendieront avec les maisons".

Disant suivre le *G, J12 traduisaient: "ils brûleront les maisons". J3 traduit de même, sans note.

Origine de la correction :

Cette correction a été proposée par Cornill (SBOT) qui, se référant au ${ }^{*} G$, édite ושרפו את הבתים, correction adoptée par HSAT34, BH2 et Cent.

Les témoins anciens :

Le ${ }^{*} G(39,29)$ offre ici : xaì xataxav́oovouv tàs oixías.

Les autres témoins attestent le $* M: l a * V$ (et comburent eam et domos), la *S et le*T (ונוקדונה בנורא ובتא) (ויוקדונה וית בתיא).

Choix textuel :

Il faut rapprocher ce cas de 19,13 où il est dit en 13a : "Et les maisons de Jérusalem et les maisons des rois de Juda deviendront, comme le lieu de Tophet, impures".

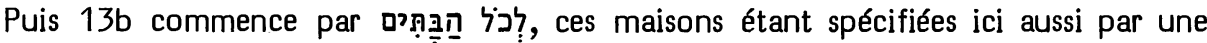
double relative : “sur les toits desquelles on encensait à toute l'armée des cieux et l'on répandait des libations aux dieux étrangers". Cela a pour but de spécifier pourquoi ces maisons sont vouées à être rendues impures (par les cadavres qu'elles contiendront selon 33,5). C'est à cause des cultes idolâtres qui se sont déroulés sur leurs toits à elles toutes.

En 32,29, il s'agit de spécifier que l'incendie de la ville sera motivé par les cultes idolâtres qui se sont déroulés sur certaines de ses maisons. Ehrlich (sur Gn 6,18) a bien montré que lorsque l'on veut coordonner un second complément d'objet à un premier qui est constitué par un pronom suffixe, il est nécessaire de le caractériser

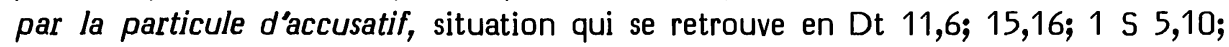
Is 38,6; Za 5,4; Ne 9,24. D'autre part, Giesebrecht a fait remarquer que le suffixe de

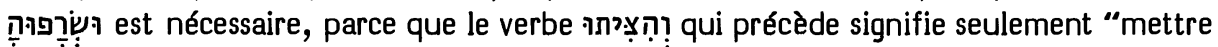
le feu", mais non détruire par le feu.

Le comité a estimé probable que le ${ }^{*} G$ s'est contenté ici de traduire de façon libre et facilitante. Aussi a-t-il attribué au *M 3 " $A$ " et 3 " $B$ ". 
Interprétation proposée :

"... et ils la brûleront, avec toutes les maisons sur les toits desquelles..."

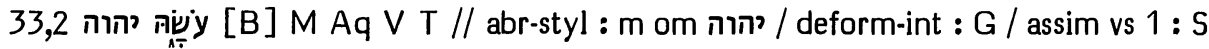

Options de nos traductions :

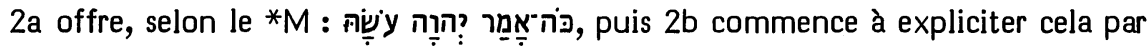

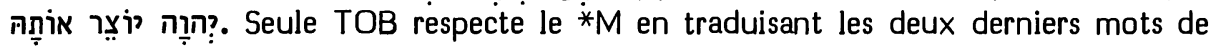
$2 a$ et les trois premiers de $2 b$ par : "le SEIGNEUR qui fait la chose, le SEIGNEUR qui la façonne".

RL traduit : "der HERR, der alles macht, schafft."

Disant suivre le ${ }^{*}$ G, RSV donne : "the LORD who made the earth, the LORD who formed it", J : "Yahvé qui a fait la terre, lui donnant forme" et NEB : "the LORD who made the earth, who formed it". Brockington précise que, pour le dernier

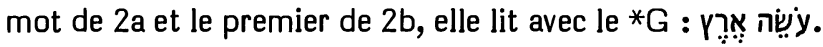

Origines des corrections :

Pour ces deux mots, Houbigant avait proposé de lire, avec le ${ }^{*} G$ : עשה האדמה: “qui fecit terram". Cornill (SBOT) corrige en עאר עy suivi par Oort, Duhm (omettant l'article), Condamin, Nötscher, Penna, Steinmann, Bright et les apparats de HSAT234, BH23 et Cent.

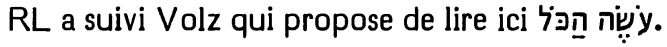

Les témoins anciens :

Les $1 \mathrm{e}$ ou $2 \mathrm{e}$ mains de $11 \mathrm{mss}$ omettent la $2 \mathrm{e}$ occurrence du tétragramme en ce vs.

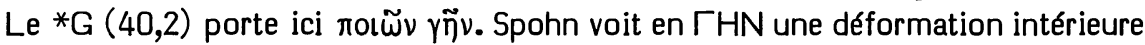
au grec de $A Y T H N(=* M)$. La recension origénienne insère xúplos que le ${ }^{*} G$ avait omis ensuite.

Aq, au lieu de $\gamma \tilde{n} v$, lit

Pour le dernier mot de $2 a$ et les trois premiers de $2 b$, la leçon originelle de la *V semble être: "quae facturus est, Dominus formaturus illud". L'édition Clémentine offrait ici : "qui facturus est et formaturus illud", ce qui était d'ailleurs la leçon de l'édition princeps et des mss de l'Université de Paris. Parmi les éditeurs antérieurs au XXe siècle, seul Robert Estienne, selon le texte de ses éditions de 1532 et de 1557 et selon les apparats de celles de 1540 et de 1545, éditait la variante : "qui facturus est : dominus formaturus illud". L'insertion de ce $2 \mathrm{e}$ "dominus" a pour témoins l'ensemble des mss anciens. Quant à l'omission de "et" entre ce mot et le suivant, l'apparat de l'édition de San Girolamo estime qu'elle a des chances de nous restituer le texte originel, bien qu'il soit incapable de citer sur ce point d'autre témoin qu'Estienne. Tous les éditeurs citent le relatif initial sous la forme "qui". Cependant le ms de Cava, celui de Tolède et la $2 \mathrm{e}$ main de celui de Ratisbonne offrent ici la lectio difficilior "quae" qui correspondrait assez exactement au * $M$. Il semble que c'est une corruption de "quae" en "qui" qui a entraîné ensuite une omission du $2 \mathrm{e}$ "dominus" qui, du fait de cette corruption, avait perdu sa raison d'être. 
La *S a remplacé les trois suffixes de la 3e pers. f. sg. par des suffixes de la 2e pers. se référant à Jérémie.

Le *T (דעבדה יוי ברא יתה) traduit le *M.

\section{Choix textuel :}

En Is 46,11 on trouve aussi des suffixes 3e pers. f. sg. à valeur neutre reprenant le complément implicite de verbes qui les précèdent. On y retrouve aussi יצר au sens de : former un dessein.

Le comité a attribué ici la note " $B$ " à la leçon du *M à laquelle ne s'opposent que des facilitations.

Interprétation proposée :

“Ainsi parle le Seigneur qui réalise cela. Celui qui projette cela pour le mettre en place, son nom est le Seigneur."

33,4 הִחרֶרֶ M oi $\gamma^{\prime} \vee \mathrm{S} / /$ paraph : T / assim-ctext : G 33,5A אֶּ

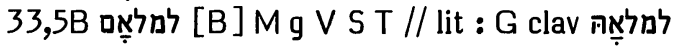

\section{Options de nos traductions :}

Le vs 4a ("Car ainsi a dit le Seigneur Dieu d’Israël à propos des maisons de cette

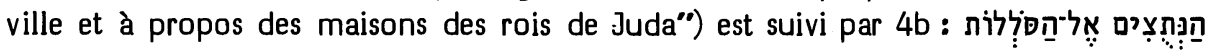

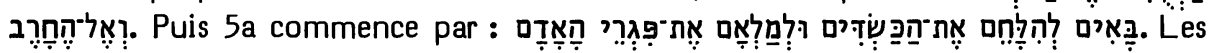
mots : "les cadavres des gens" sont ensuite spécifiés par deux relatives : "que j'ai abattus dans ma colère et dans ma fureur, et à cause de la méchanceté desquels j’ai caché à cette ville ma face".

Toutes nos traductions font de הנתצים une épithète des “maisons" mentionnées auparavant.

RSV supprime הכשדים avant tet traduit ainsi la fin du vs 4 et le début du vs 5 : "which were torn down to make a defense against the siege mounds and before the sword: The Chaldeans are coming in to fight and to fill them with the dead bodies of men".

J12 disaient corriger avec le ${ }^{*} \mathrm{G}$ le dernier mot du vs 4 et le $5 e$ mot du vs 5 . Elles traduisaient: "qui vont être détruites. Contre les travaux d'approche et les palissades on va engager le combat ( $\mathrm{J1}$ : la lutte) avec les Chaldéens, mais cela n'aboutira qu’à remplir la ville de cadavres, ceux ( 11 : avec les cadavres) des gens".

RL traduit : “die abgebrochen wurden, um Bollwerke zu machen zur Abwehr im Kampf gegen die Chaldäer und um sie zu füllen mit den Leichnamen der Menschen".

NEB omet les $3 e$ et $4 \mathrm{e}$ mots du vs 5 et traduit : "which are to be razed to the ground, concerning siege-ramp and sword, and attackers who fill the houses with the corpses ot those".

TOB traduit "qui toutes sont renversées, au sujet des chaussées d'investissement, au sujet de l'épée : On s'est mis à résister aux Chaldéens seulement pour remplir ces maisons des cadavres des hommes". 
$J 3$ corrige avec le ${ }^{*} G$ le 5 e mot du vs 5 et traduit : "qui vont être détruites grâce aux terrassements et à l'épée; au sujet de ceux qui combattent contre les Chaldéens pour remplir la ville de cadavres, eux".

\section{Origines des corrections :}

Se fondant sur le ${ }^{*} \mathrm{G}$, Rothstein $(\mathrm{BH} 2)$ a proposé de corriger le dernier mot du vs 4 en הn (en quoi il a été suivi par Duhm et Cent) et de corriger le suffixe du 5e mot du vs 5 en למלאיאו. J12 ont adopté ces deux corrections, alors que J3 a adopté la seconde.

De Dieu et Schnurrer avaient proposé d'interpréter le premier את du vs 5 comme introduisant un nominatif. Cornill (SBOT) a préféré l'omettre, suivi en cela par Giesebrecht et Oort, puis par RSV; NEB étendant l'omission au mot suivant.

\section{Les témoins anciens :}

L'édition princeps des Prophètes (Soncino 1486) et celle de la Bible (Soncino 1488) s'accordent avec la 1e ou 2e main de 14 mss énumérés par de Rossi pour lire אל à la place du premier את vo 5 .

Pour les 5 derniers mots du vs 4 et les 5 premiers du vs 5 , le $* G(40,4 s)$ donne :

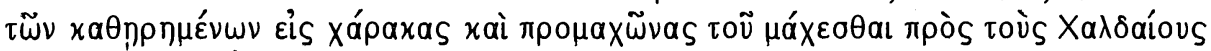

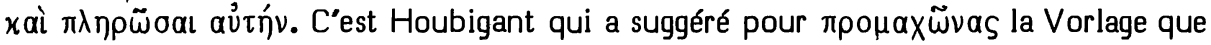
Rothstein retiendra.

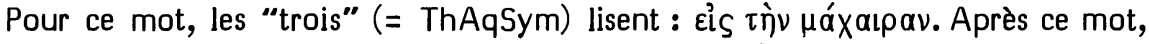

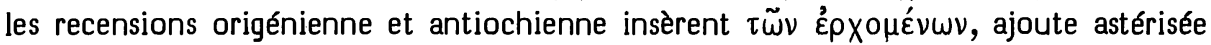
attribuée à ThSym par le ms Barberini.

Pour traduire les $2 \mathrm{e}$, 3e et $4 \mathrm{e}$ mots du vs 5 , la recension antiochienne offre :

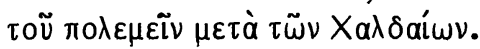

La traduction du suffixe du 5 e mot du vs 5 a été corrigée selon le *M par la recension origénienne en aủroús.

La *V traduit: "quae destructae sunt et ad munitiones et gladium venientium ut dimicent cum Chaldaeis et impleant eas".

La *S traduit : דעקרו אנון גיסא בחרבא . דאתו למתכתשו עם כלדיא . ולממלא אנון :

Le *T paraphrase: “qu'ils ont détruites. Et ils accumulent des levées de terre pour fortifier le rempart à l'approche de ceux qui tuent avec l'épée. Ils venaient pour combattre avec les Chaldéens, et pour les remplir".

\section{Choix textuel :}

Le cas du dernier mot du vs 4 n'a pas été soumis au comité. Le *M y a l'appui de ThAqSym, de la *V et de la*S. C'est également lui qui sert de base à la paraphrase du *T. Quant à la traduction très libre du *G, Spohn a eu raison d’y voir une adaptation au contexte et Schleusner (IV 462) ne suggère pas pour elle une Vorlage distincte du *M.

En 33,5A, il se peut que le $\pi \rho o ́ s ~ d u{ }^{*} G$ corresponde à la variante par plusieurs mss du *M, variante qui assimile aux deux אֶ de $4 \mathrm{~b}$. Cependant, tous les autres témoins appuient la leçon אֶ du *M tibérien classique à laquelle le comité a attribué la note "B". 
En 33,5B, la tradition textuelle du ${ }^{*} \mathrm{G}$ se distingue de la tradition protomassorétique à propos du pronom suffixe. La première, par une 3e pers. f. sg., se réfère à la ville, alors que la seconde, par une $3 e$ pers. $\mathrm{m}$. pl., se réfère aux maisons. Estimant qu'il fallait respecter cette divergence littéraire, le comité a attribué au *M la note "B".

Interprétation proposée :

Selon 4a, la parole du Seigneur porte sur (לy ) "les maisons de cette ville" et "les maisons des rois de Juda". La *V, NEB et TOB ont considéré les deux אֶ: de $4 \mathrm{~b}$ comme parallèles aux deux לy de $4 \mathrm{a}$. C'est une facilitation syntaxique.

On lit en Is 22,10, à propos des habitants de Jérusalem assiégée par les Assyriens sous Ezéchias : "vous avez démoli les maisons pour fortifier les murailles". En s'inspirant de ce passage, le ${ }^{*} G$ et le ${ }^{*} T$ de Jr 33,4 ont compris ici que l'on a démoli les maisons pour faire avec leurs matériaux des remblais défensifs. Il est vraisemblable que la division des vss dans le *M suppose cette exégèse qui est celle de RSV et de RL.

Mais le mot סְִִֹל qui réapparaît 10 autres fois dans la Bible y signifie toujours une chaussée ou un remblais de siège. Il en va d'ailleurs de même en Jr 32,24 où ce mot précédait comme ici le mot רִ̣. Il semble donc préférable de ne pas tenir compte de la division en versets $d u{ }^{*} M$ et de comprendre : "on vient s'exposer aux remblais de siège et à l'épée pour combattre contre les Chaldéens et pour les remplir (= ces maisons) des cadavres des gens..."

Durant le siège, on ne pouvait enterrer les morts hors de la ville. On devait donc empiler les morts dans celles des maisons qui avaient été rendues inhabitables parce que l'on en avait retiré les pierres de bel appareil pour fortifier le rempart. Cela rendra ces maisons impures (cf. 19,13).

On pourrait donc traduire les vss 4 et 5 : “Car ainsi a dit le Seigneur Dieu d'Israël à propos des maisons de cette ville et à propos des maisons des rois de Juda qui ont été démolies : On vient (s'exposer) aux remblais (de siège) et à l'épée pour combattre contre les Chaldéens et pour remplir ces (maisons) des cadavres des gens que j'ai abattus dans ma colère et dans ma fureur, et à cause de la méchanceté desquels j'ai caché à cette ville ma face."

\section{להם לה 33,6 לה M G S // assim-ctext : g v T clav}

Options de nos traductions :

Dans le $* M$, le premier pronom suffixe de ce vs est de la $3 e$ pers. f. sg., alors que le vs 5 s'est achevé par un suffixe 3 e pers. m. pl. et que deux suffixes $3 e$ pers. m. pl. suivront dans le vs 6 .

Cette particularité du *M a été respectée par RSV : "Behold, I will bring to it health", NEB : "but now I will bring her healing", TOB : "Mais je ferai poindre sa convalescence."

Se fondant sur le ms Alexandrinus du *G, la *V et le *T, J1 traduisait : “Voici : je presse leur rénovation" et $\mathrm{J2}:$ "Voici : je hâte leur rétablissement". J3 se fonde sur les versions pour traduire : "Voici que moi, je leur porte remède". Du fait du pronom 
"ihnen" qui suit, la traduction ambigüe de RL (“Siehe, ich will sie heilen") semble recouvrir la même option.

Origine de la correction :

C'est Grätz (Studien 345) qui a proposé cette correction en להם, suivi en cela par Condamin, Volz, Nötscher, Rudolph, Penna, Steinmann, Weiser, Bright et les apparats de $\mathrm{BH} 3 \mathrm{~S}$.

Pour éviter la dissonance de ce suffixe f. sg. du *M avec celui de רפאתים, Duhm omet ce dernier mot, alors que Giesebrecht et $\mathrm{BH} 2$ en corrigent le suffixe en 3e pers. f. sg., correction à laquelle Oort, HSAT3 et Cent ajoutent une correction semblable du suffixe de להם.

\section{Les témoins anciens :}

De Rossi précise qu'aucun ms connu de lui ne lit להם à la place du 3e mot de ce vs.

Le ${ }^{*} G$ ancien $(40,6)$ porte ici aủṇ̃. La leçon aủoús du ms Alexandrinus assimile à ce qui entoure.

A lire l'apparat de l'édition San Girolamo de la *V, on croirait que l'édition Weber a été la première à choisir ici la leçon "ei". De fait, cette leçon apparaît déjà dans les apparats des éditions Estienne de 1540 et 1545, puis est adoptée dans le texte de celle de 1557. Toutes les éditions antérieures portaient la leçon "eis" qui a été reprise ensuite par la Sixtine et la Clémentine. Il est pourtant évident que celle-ci est une assimilation à "eorum, eos, illis" qui l'entourent.

La *S appuie le *M avec לה.

Le *T, avec להון, assimile au contexte.

\section{Choix textuel :}

La lectio difficilior du ${ }^{*} M$ étant bien appuyée par le ${ }^{*} G$, la ${ }^{*} V$ et la ${ }^{*} S$ contre une assimilation qui est "dans l'air', le comité lui a attribué la note " $\mathrm{B}$ ".

Interprétation proposée :

Il a été parlé au vs 5 des "maisons" qui, après avoir été démolies, sont pleines de cadavres et de "cette ville" à laquelle le Seigneur a caché sa face. Au vs 6, le premier suffixe porte sur la ville et le deuxième sur les maisons : "Voici que je vais pousser sa cicatrisation et (sa) guérison, et je vais les guérir". Cela constitue l'élément central de l'oracle qui avait été introduit au début du vs 4.

L'image de la cicatrisation réapparaît pour la réparation des brèches d'une ville en $\mathrm{Ne} 4,1 ; 2$ Ch 24,13.

33,9 לי לשם ששון [B] M Aq g T // facil-synt : m V S לי לי לששון / abr-styl et facil-synt : לששון G clav

Options de nos traductions :

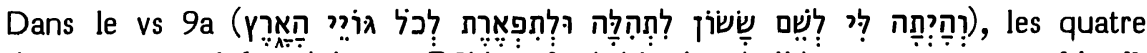
premiers mots ont été traduits par RSV : "And this city shall be to me a name of joy", 
par TOB : "Ce sera pour moi un joyeux renom" et par J3 : "Jérusalem deviendra pour moi un nom plein d'allégresse".

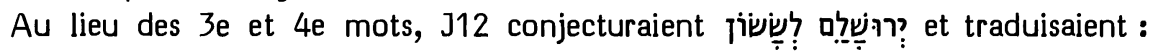
"Et Jérusalem me deviendra un sujet de joie".

Omettant par conjecture le $4 \mathrm{e}$ mot, NEB traduit : "This city will win me a name". RL traduit : "Und das soll mein Ruhm und meine Wonne ... sein".

Origines des corrections :

Houbigant a proposé d'insérer un 'lamed' au début du $4 \mathrm{e}$ mot, suggestion qui a été retenue par Michaelis (Observationes) puis par Oort.

Giesebrecht voit en לי ליושלם les restes de.

Ont uni ces deux corrections : Volz, Nötscher, Rudolph, Steinmann, Weiser, Bright et les apparats de $\mathrm{BH} 35$ et Cent.

Duhm a adopté la correction d'Houbigant en omettant les $2 \mathrm{e}$ et $3 \mathrm{e}$ mots. Ont fait de même en omettant seulement le $3 e$ mot : Cornill (SBOT), Condamin et les apparats de HSAT23 et de $\mathrm{BH} 2$.

Se sont contentés d'omettre le $4 \mathrm{e}$ mot : Ehrlich et l'apparat de HSAT4.

Les témoins anciens :

Deux mss et la première main de deux autres ont ici la leçon conjecturée par Houbigant. Cependant la leçon du $* M$ tibérien classique est appuyée dans le ms du Caire par une $\mathrm{mp}$ caractérisant comme hapax la séquence du $3 \mathrm{e}$ et du $4 \mathrm{e}$ mot de ce vs.

Le *G $(40,9)$ donne, pour les quatre premiers mots du *M: xaì Ěotal Ės

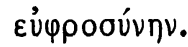

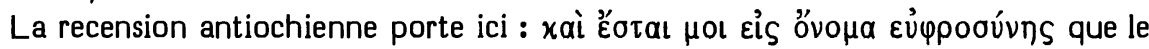
ms Barberini attribue à Aq. De même, le *T : ויהון קדמי לשום דחדוא.

$\mathrm{La} * \mathrm{~V}$ traduit : "et erit mihi in nomen et in gaudium".

La*S porte aussi : ותהוא לי לשמא ולבוסמא.

Choix textuel :

Il se peut que le *M ait ajouté ici לִ que les parallèles de Dt 26,19; Jr 13,11; So 3,19.20 appellent en ce contexte.

Cependant, si, avec le ${ }^{*}$ G, on omet ’?, on doit comprendre que ce sont "toutes les nations de la terre" qui éprouvent de la joie à la nouvelle des événements évoqués aux vss 6-8. Mais comment l'attitude de ces mêmes nations en face de ces mêmes événements est-elle dépeinte par le verbe $ז \lambda$, de tonalité contraire, dans la fin de ce même vs?

Il semble donc plus vraisemblable que $c$ 'est le ${ }^{*} G$ qui a allégé ce passage, en en normalisant la syntaxe. $L a * V$ et la $* S$ se sont contentées de cette normalisation, sans allègement du contenu.

En tout cas, le ${ }^{*} M$ ne peut être le résultat d'un accident textuel. S'il n'est pas primitif, il s'agit d'un développement littéraire. C'est pourquoi le comité lui a attribué la note "B". 
Interprétation proposée :

Le sujet du verbe initial peut être Jérusalem. Mais ce peut être aussi un féminin à valeur neutre résumant les interventions divines annoncées aux vss 6-8.

On traduira alors : "Et cela sera pour moi un joyeux renom, un titre de gloire et une parure auprès de toutes les nations de la terre".

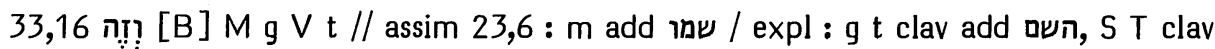
add שמ̣ח / lacun : G

Options de nos traductions :

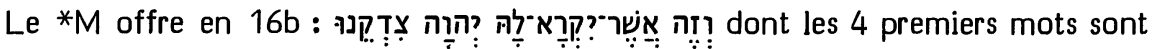
traduits par RL : "und man wird es nennen".

J dit ajouter "le nom" avec Th et la *V quand elle traduit : "Voici le nom dont on appellera la Ville". Sans prétendre s'éloigner du *M, RSV donne: "And this is the name by which it will be called", NEB : "and this shall be her name" et TOB : "Voici le nom dont on la nommera".

Origine de la correction :

Ce qui pourrait faire croire à tort que RSV a corrigé le ${ }^{*} M$, c'est qu'elle écrit en caractère romain les mots "is the name" que $K J$ écrivait en italique. Déjà, Olivetan, traduisant : "Et cestuy est le nom duquel...", avait copié la traduction que Le Fèvre $d^{\prime} E$ taples donnait de la *V, en se bornant à faire usage de petits caractères pour "le nom", afin de montrer que ces mots ne sont pas dans l'hébreu.

Hitzig a estimé que שמו n’était pas ici nécessaire pour le sens, mais rhétoriquement souhaitable. Giesebrecht a proposé d'insérer ou bien ou bien on pụ̣, proposition reprise par Giesebrecht, Rudolph et les apparats de HSAT3 et BH3S. La première de ces corrections a été retenue par Penna, Bright et la seconde par Nötscher, Weiser et l'apparat de HSAT4.

\section{Les témoins anciens :}

En assimilant au parallèle de 23,6, cinq mss ont inséré ici שמו, selon de Rossi.

Le ${ }^{*} \mathrm{G}$ omet cette péricope. Cependant, la recension origénienne traduit ceci par

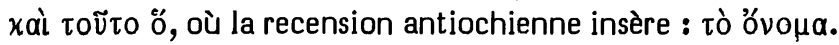

Malgré les protestations des correctoires d'Hugues de Saint Cher, de Guillaume de Mara et de Saint Jacques, le ms de la Sorbonne insérait "nomen". L'apparat de San Girolamo laisserait croire que toutes les éditions de la *V antérieures à celle de Weber portaient ce mot (de même que le pluriel "vocabunt", deux mots plus loin). C'est inexact, car la leçon originelle : "et hoc est quod vocabit eam" figurait déjà dans les apparats des éditions Estienne de 1540 et 1545, puis dans le texte de celle de 1557.

La *S insère ici שמה, comme la plupart des témoins du *T (quoique le ms Urbinates 1 et le ms Montefiore insèrent שמא, et que l'un des mss yéménites de Sperber n'insère rien). 
Choix textuel :

Ces insertions sont ou bien des explicitations, ou bien une assimilation au parallèle de 23,6. La lectio difficilior du $* M$ ayant l'appui de la recension origénienne et de la *V, le comité lui a attribué la note " $B$ ".

Interprétation proposée :

"Et voici comment on la nommera".

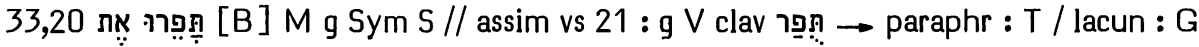

Options de nos traductions :

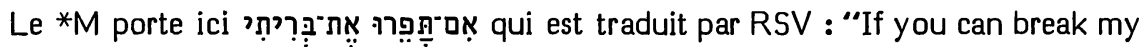
covenant", par J : “Si vous pouvez briser (J3 : rompre) mon alliance" et par TOB : "si vous réussissez à rompre mon alliance".

Brockington disant qu'elle lit תוּפר avec la *V, NEB traduit: "If the law that I made ... could be annulled". RL traduit de même : "Wenn mein Bund ... aufhörte".

Origine de la correction :

Zwingli a repris ici la traduction de la *V : "si irritum fieri potest", ce qui donne, dans la traduction des Prédicants : "Mag mein pund ... krafftloss werden". C"est de cela que Luther s'est inspiré pour traduire: "Wenn mein bund auffhören wird". Habitué à cette traduction, Michaelis (OEB) trouve que le *M sonne ici un peu bizarrement. En Observationes, il dit préférer רִִ̣. Cette correction est adoptée par Grätz (Studien 345), Giesebrecht, Oort, Duhm, Volz, Nötscher, Penna, Steinmann et les apparats de HSAT34, BH23 et Cent.

Les témoins anciens :

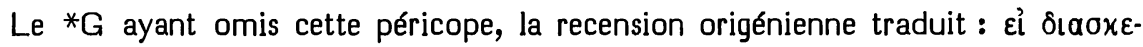

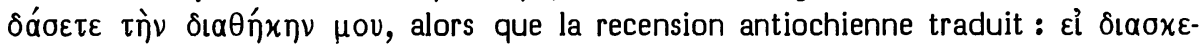

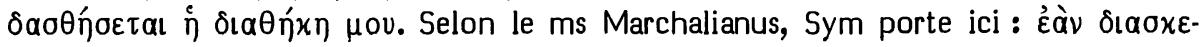

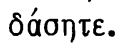

אן משכחין אנתון : En accord avec le *M, l'origénienne et Sym, la *S donne למבטלו דוברי

En accord avec l'antiochienne, la *V donne: "si irritum fieri potest pactum meum".

Le *T paraphrase : “De même qu'il est impossible que soit abolie mon alliance que j'ai conclue". Notons qu'en 31,37 le *T a paraphrasé de même, en une négation, une hypothèse irréalisable.

\section{Choix textuel :}

$L$ 'antiochienne, la $* V$ et le ${ }^{*} T$ ont assimilé à la forme passive de ce verbe qui se lit au vs suivant.

En face de cette leçon facilitante, la leçon du ${ }^{*} M$ exprime une ironie mordante. Le comité l'a retenue avec la note " $\mathrm{B}$ ". 
Interprétation proposée :

Celle de TOB est excellente.

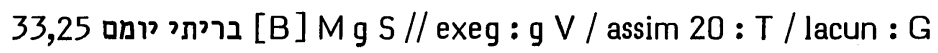

Options de nos traductions :

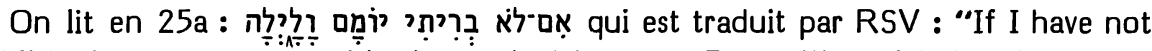
established my covenant with day and night", par RL : "Wenn ich jemals meinen Bund nicht hielte mit Tag und Nacht" et par TOB : "Moi qui ai fait alliance avec le jour et la nuit".

J12 s'appuient sur Duhm pour conjecturer : “S'il n'est pas vrai que j'ai créé le jour et la nuit". J3 donne : "Si je n"ai pas créé le jour et la nuit".

Selon Brockington, NEB se réfère au *T pour insérer בִרְְ après les deux premiers mots, en traduisant : "If I have not made my law for day and night".

Origines des corrections :

C'est Houbigant qui, en parallèle avec le dernier mot de ce vs, a conjecturé בִרְִ qui aurait été assimilé par le $* M$ aux trois בריתי qui précèdent (aux vss 20 et 21). Cette conjecture a été reprise par Duhm, Cornill, Rudolph, Steinmann et par les apparats de HSAT34 et de Cent.

Les témoins anciens :

Le ${ }^{*} G$ omettant cette péricope, la recension origénienne donne ici : $\varepsilon \grave{l} \mu \grave{j} \delta$ เ $\alpha$ -

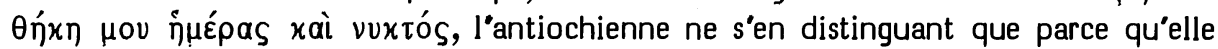

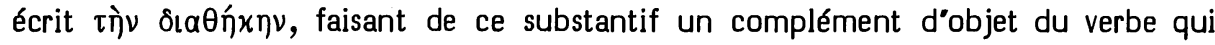
achève le vs.

Réservant à la fin du vs la traduction de la négation, la *V donne ici : "si pactum meum inter diem et noctem ... (non posui)".

La*S traduit : אלא הוא קימי דאיממא ודלליא.

Le *T paraphrase dans les mêmes termes qu'au vs 20 : "De même qu'il est impossible que soit abolie mon alliance que j'ai conclue avec le jour et avec la nuit."

\section{Choix textuel :}

Les particularités les plus typiques de 25 a peuvent s'appuyer sur des parallèles caractéristiques.

1/ Le fait que בריתי soit construit sans une préposition "avec", pour lier ce mot à son complément "jour et nuit", se retrouve en 20 a et trois fois en Lv $26,42$.

2/ Le fait que יị ait ici valeur de substantif, et non d'adverbe, se retrouve en $20 \mathrm{~b}$ et en $\mathrm{Ez} 30,16$ où ce mot sert de génitif à un état construit qui le précède. König (Wörterbuch 145b et Syntax §318c) donne à cette forme une valeur collective : le domaine diurne.

Considérant que cette leçon difficile mais justifiable est bien appuyée par les recensions grecques et par la *S, le comité lui a attribué la note " $\mathrm{B}$ ". 
Interprétations proposées :

La présence de la négation engage à faire de 25a une phrase autonome : “Si je n'ai pas fait alliance avec le jour et la nuit."

On peut cependant considérer les $3 \mathrm{e}, 4 \mathrm{e}$ et $5 \mathrm{e}$ mots comme une expression servant de complément au verbe final et qui exercerait à son égard une double fonction anticipée (2 S 23,5 montrant que la construction de ce substantif avec ce verbe est possible). On traduira alors : “Si je n’ai pas établi mon alliance avec le jour et la nuit ainsi que les statuts du ciel et de la terre."

\section{4,7 [B] M g V S T // lit : G om}

Options de nos traductions :

En 7a, le *M dit que l'armée du roi de Babylone combattait

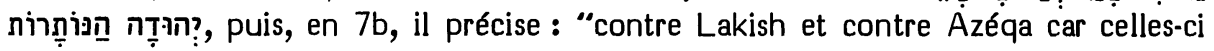
étaient restées parmi les villes de Juda, villes fortes".

Ont respecté en 7a l'expression "toutes les villes de Juda" : RSV, RL et J3.

Ont omis כל sans note : J12. L'ont omis en se fondant sur le *G : NEB et TOB.

Origine de la correction :

Après que Giesebrecht ait signalé que le ${ }^{*} G$ omet ce mot et le dernier mot de $7 \mathrm{a}$, Duhm et Cornill ont proposé d'omettre les 5 derniers mots de 7 a, suivis en cela par Schmidt.

Condamin se contente d'omettre les deux mots qui sont absents du *G. L'apparat de HSAT34 fait de même.

Cent n'omet que כל.

Les témoins anciens :

Pour les mots que nous avons cités, le ${ }^{*} G(41,7)$ se contente de traduire : $\varepsilon$ đ̇̀

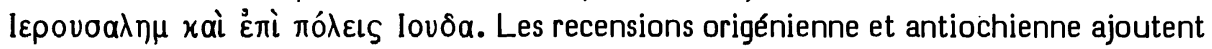

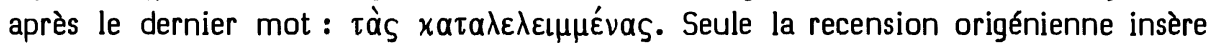

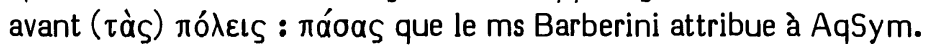

Le mot כ est traduit par la*V, la*S et le*T.

Choix textuel :

Il semble que le traducteur grec ait allégé ce texte de deux mots qui lui semblaient inutiles dans la construction embarrassée du *M. En tout cas, même si le *M a glosé, il s'agirait d'une initiative littéraire et non d'un accident textuel. Aussi le comité lui a-t-il attribué la note "B".

Interprétation proposée :

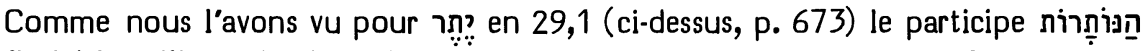
signifie ici les villes qui subsistaient, c'est-à-dire qui n'avaient pas encore été prises par les Babyloniens. Or 7b nous précise qu'il n'y en avait plus alors que deux : Lakish et Azéqa qui, en tant que villes spécialement bien fortifiées, avaient pu résister jus- 
qu'alors. Nous avons vu en 4,29 (ci-dessus, p. 490) que certaines des "villes de Juda" étaient des villages non fortifiés que l'on désertait à l'approche de l'ennemi. $2 \mathrm{Ch}$ 11,9 cite Lakish et Azéqa parmi 15 villes de Juda (et de Benjamin) que Roboam avait fortifiées.

Il semble que ce soit l'emploi peu motivé du mot "tout" qui a obligé le narrateur à nuancer cela par les précisions qu'il apporte en $7 b$.

On pourra donc traduire : "Et l'armée du roi de Babylone combattait contre Jérusalem et contre toutes les villes de Judá qui subsistaient, (c'est-à-dire) contre Lakish et contre Azéqa, car c’étaient elles qui restaient parmi les villes de Juda, (étant) des villes fortes."

34,12A מהוה (10) M G V S T // abr-styl : v t om

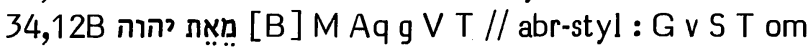

\section{Options de nos traductions :}

Le *M s"exprime ici de façon redondante: "Et il y eut une parole du Seigneur

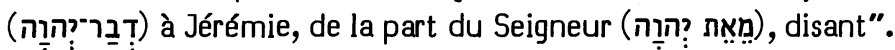

Cette redondance est respectée par RSV " "The word of the LORD came to Jeremiah from the LORD") et par TOB ("La parole du SEIGNEUR s'adressa donc à Jérémie - de la part du SEIGNEUR").

Sans note, NEB allège en : "Then this word came from the LORD to Jeremiah".

J dit se fonder sur le *G et la *S pour omettre "de la part de Yahvé" et traduire : “Mais (J3 : Alors) la parole de Yahvé fut adressée (J1: arriva) à Jérémie en ces termes". RL traduit : "Da geschah des HERRN Wort zu Jeremia".

\section{Origines des corrections :}

Les grandes traductions classiques du XVIe siècle et du début du XVIIe (Luther, Pasteurs, $\mathrm{KJ}$ ) respectent la redondance. Vers la fin du XVIIIe siècle (Houbigant, Michaelis, Rosenmüller), on a pris l'habitude d'alléger en "une parole du Seigneur" ou "une parole de la part du Seigneur", sans rien noter.

Voyant en ce vs une reprise de 8 a, Giesebrecht estime que c'est par assimilation à ce lieu qu'un glossateur postérieur au traducteur grec a emprunté le complément

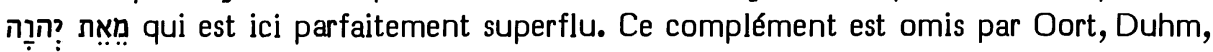
Condamin, Volz2, Nötscher, Penna, Weiser, ainsi que par les apparats de SBOT, HSAT24, BH23 et Cent.

\section{Les témoins anciens :}

La tradition textuelle du *M semble être ici entièrement cohérente.

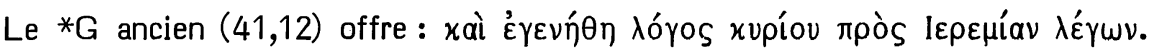

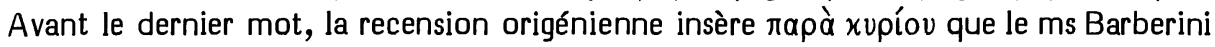
attribue à Aq.

L'apparat de San Girolamo laisserait croire que c'est l'édition de Gobelinus Laridius (Cologne 1530) qui a donné pour la première fois la $* V$ sous sa forme complète ("et factum est verbum Domini ad Hieremiam a Domino dicens"). De fait, la poly- 
glotte d'Alcala offrait déjà cette leçon, alors que les éditions plus anciennes omettaient "Domini" et que certains mss (dont le palimpseste de Léon et l'Amiatinus) omettaient "a Domino".

\section{La *S omet "de la part du Seigneur".}

Le *T traduit ici: "Et il y eut une parole de prophétie de devant le Seigneur, avec Jérémie, de devant le Seigneur, disant". Cette leçon est offerte par le ms Urbinates 1 et par les éditions de Félix de Prato et de Ben Hayim, ainsi que par les mss yéménites utilisés par Sperber et les éditions récentes. Le premier “de devant le Seigneur" a été omis par les mss Reuchlin et Montefiore, alors que le second l'est par la polyglotte d'Anvers.

\section{Choix textuel :}

Le cas 12a n'a pas été soumis au comité.

Dans sa leçon redondante, le * $M$ a donc l'appui $d^{\prime} A q$, de la recension origénienne, de la $* V$ et du $* T$. On peut donc la considérer comme caractéristique du texte protomassorétique. A ce titre, le comité lui a attribué la note " $B$ ".

Les traditions textuelles de la ${ }^{*} V$ et du ${ }^{*} T$ nous montrent qu'un allègement est 'dans l'air'.

Rudolph a estimé imprudent d'omettre des mots en ce passage qui appartient à la source $C$ de Mowinckel (discours en prose de Jérémie qui nous ont été conservés avec des retouches deutéronomistes). Bright les a omis parce qu'il les estime rudes pour nos oreilles. Mais il estime qu'ils peuvent être originaux, les redondances étant une caractéristique des discours en prose de Jérémie. Rudolph3 (222s) estime que ces redondances ont amené le ${ }^{*} G$ et les exégètes plus récents à toutes sortes d’abrègements parce qu’ils ont méconnu cette caractéristique.

\section{4,14 שב [B] M Aq Sym V S T // transl : G}

Options de nos traductions :

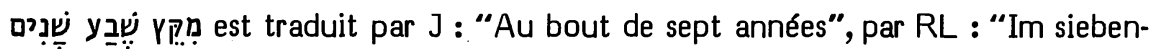
ten Jahre", par NEB : "Within seven years" et par TOB : "Au bout d’une période de sept ans".

En disant suivre le *G, RSV traduit : "At the end of six years".

Origine de la correction :

Une correction du 2e mot en بִ̣ a été adoptée par Ehrlich et par l'apparat de $\mathrm{BH} 2$.

Les témoins anciens :

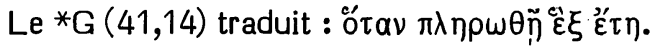

Le chiffre 7 est donné ici par Aq, Sym, la*V, la*S et le *T.

Choix textuel :

Spohn estime que le ${ }^{*} G$ n'a rien lu d'autre que le ${ }^{*} M$, mais qu'il s'est exprimé autrement. 
La massore (Weil §2661) rapproche cela de Dt 15,1 où se présente la même difficulté : en ces deux contextes, cette expression ne peut pas signifier: "après 7 ans". En effet, ici, il est dit clairement dans la suite du vs 14 que c'est après que l'esclave ait servi durant 6 ans qu'on doit le libérer. De même, en Dt 31,10, c'est la 7e année qui est l'année de la Shemittâh. On rencontre d'autres exemples de cette expres-

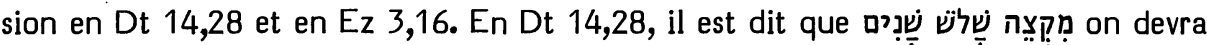
sortir la dîme et la mettre à la disposition du lévite, de l'étranger résident, de l'orphelin et de la veuve. Or Dt 26,12 précise que cette "année de la dîme" est la 3e et non la 4e. Enfin, en Ez 3,16, une révélation est faite à Ezéchiel מִקְצֵ très probable que celui qui introduit ainsi cette révélation veut dire qu'elle s'est produite le 7 e jour (et non le 8e).

Il faut donc voir là un chiffre arrondi du genre de ceux que nous employons en disant : "15 jours" ou "dans 8 jours". Cf. "après 8 jours" en Jn 20,26.

Le comité a attribué au *M la note "B".

Interprétations proposées :

Ou bien : "en la septième année" ou bien : "sur la fin d"une période de sept ans".

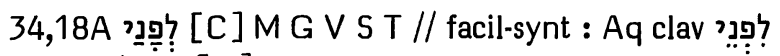

34,18B [A [A $[\mathrm{A}]$

Options de nos traductions :

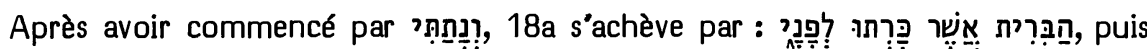

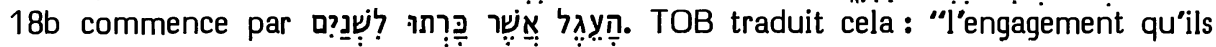
avaient décidé d'accepter devant moi, en coupant en deux un taurillon".

Selon Brockington, NEB vocalise לִפְּנִ quand elle traduit : "to which you yourselves had agreed; (so I will make you) like the calf of the covenant when they cut it into two".

Disant ajouter par conjecture le mot "like", RSV traduit : "the covenant which they made before me, (I will make) like the calf which they cut in two". J12 disant ajouter par conjecture le mot "comme", J traduit : "l'accord (J3 : l'alliance) conclu(e) par eux en ma présence, (je vais les rendre) comme le ( $\mathrm{J} 3$ : pareils au) veau qu'ils ont coupé en deux". RL traduit : "des Bundes ... den sie vor mir geschlossen haben, (so zurichten) wie das Kalb, das sie in zwei Stücke geteilt haben".

\section{Origines des corrections :}

Pagnini, dans sa première édition (1527) traduisait ici : "Et dabo viros qui transgressi sunt pactum meum, qui non statuerunt verba foederis, quod percusserunt in conspectu meo ut vitulum quem conciderunt in duas partes". Luther s'en est inspiré pour traduire en 1532 : "Und wil die leute, so meinen bund ubertretten, und die wort des bundes, den sie fur mir gemacht haben, nicht halten, so machen, wie das kalb, das sie jnn zwey stück geteilet haben". Durant sa vie, Luther n’a jamais retouché cette traduction qui s'est transmise jusqu'au XXe siècle dans les éditions de sa Bible. En 1532 aussi, Brucioli s'est inspiré de Pagnini en traduisant ici : "come il vitello". 
Michaelis (Observationes) a fait remarquer que la plupart des exégètes se sont inspirés ensuite de Luther pour interpréter l"hébreu en "comme le veau". Il semble que Ehrlich (Miqra) ait été le premier à corriger en hạỵg, ce en quoi il a été suivi par Volz, Nötscher, Rudolph, Steinmann, Hyatt et les apparats de BH3S et Cent.

Giesebrecht, lui, a proposé la correction vocalique que Driver, puis NEB reprendront.

Les témoins anciens :

La séquence

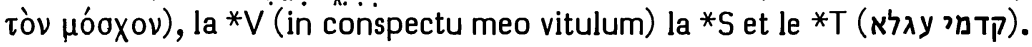

Seul Aq offre une variante en vocalisant comme Giesebrecht, Driver et NEB le conjectureront : '́v

\section{Choix textuel et interprétation proposée :}

Un certain nombre d'exégètes ont compris le mot "le taurillon" comme un deuxième accusatif du verbe initial : "je ferai les hommes qui ont transgressé ... le veau qu'ils ont coupé...", c'est-à-dire : "je rendrai ces hommes comme le veau qu'ils ont coupé".

Il faut cependant noter que le verbe initial du vs 18 sera repris (avec tous les déterminants qui l'ont suivi et ont abouti à laisser la construction en suspens) par 萑 au début du vs 20 où le complément de destinataire de "je les livrerai" apparaîtra enfin en "aux mains de leurs ennemis et aux mains de ceux qui en veulent à leur vie". Cela nous engage à comprendre les vss 18 et 19 comme une longue phrase qui se perd dans les sables. Tout cela commence par "je livrerai les hommes qui ont transgressé mon alliance". Puis la suite du vs $18 \mathrm{com}$ mente : "ont transgressé mon alliance" et le vs 19 commente : "les hommes". Dans ces perspectives, la similitude de structure entre les 4 derniers mots de 18a et les 4 premiers mots de $18 \mathrm{~b}$ nous engage à comprendre ceux-ci comme une apposition à ceux-là, interprétation qui est d'ailleurs celle de Yéfet ben Ely.

On pourra donc traduire ainsi les vss 18-20a : "(18) Je livre les hommes qui ont transgressé mon alliance, qui n’ont pas honoré les termes de l'alliance qu'ils avaient coupée ( $=$ conclue) devant moi - le taurillon qu'ils avaient coupé en deux et ils étaient passés entre ses morceaux - (19) les princes de Juda et les princes de Jérusalem, les eunuques et les prêtres et tout le peuple du pays, ceux qui sont passés entre les morceaux du taurillon, (20) je les livre au pouvoir de leurs ennemis, au pouvoir de ceux qui en veulent à leur vie".

En 18A, le comité a attribué 3 " $B$ " et 3 " $C$ " à la lectio difficilior du $* M$ (contre la vocalisation de $\mathrm{Aq}$ ).

En 18B où la tradition textuelle est entièrement cohérente, le ${ }^{*} M$ a reçu la note “A". 
Options de nos traductions :

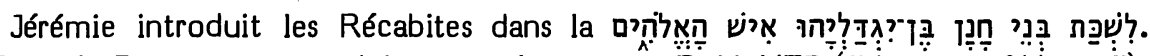
Le $2 \mathrm{e}$ et le $3 \mathrm{e}$ mots sont traduits normalement par RSV, NEB ("the sons of Hanan"), RL ("der Söhne Hanans") et TOB ("des fils de Hanân").

En se fondant sur $1 \mathrm{~ms}$ hébreu, $1 \mathrm{~ms}$ grec, l'Arabe et le *T, J traduit ici : “de Ben-Yohanân".

\section{Origine de la correction :}

Se référant à 1 Ch 4,20 où paraît le nom : "Ben-Hanan", Volz propose ici cette correction, ou bien "Ben-Yoḥanan". La première leçon est adoptée par Nötscher, Steinmann et l'apparat de BH3 (alors que celui de HSAT4 hésite entre les deux corrections).

\section{Les témoins anciens :}

De Rossi signale la leçon בן dans la 1e main de son ms 211 (Prophètes, allemand du XIIIe s.). Le ms Urbinates 2 offre ici בִִּ

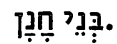

Les éditions du *G $(42,5)$ ont beaucoup varié pour ces deux mots. La polyglotte

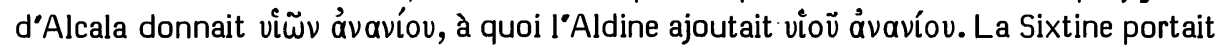

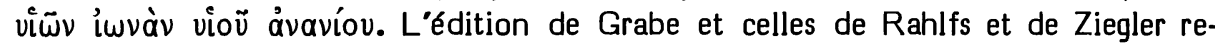
prennent la leçon de la polyglotte d'Alcala, alors que celle de Swete reprend la Sixtine. Le ms Vaticanus porte ici : YIUNIUNANYIOYANANIOY et le ms Sinaiticus : YIUNANNANYIOYANANIOY. Les versions coptes sont proches du Vaticanus, mais elles omettent le viwv initial et, pour les cinq lettres suivantes, la Sahidique lit ıwavav, alors que la Bohaïrique lit ıwavvav. Il semble que ces leçons anciennes sont issues d’un doublet dont le Sinaïticus nous apporterait l'état le plus ancien. La leçon $v i \omega \nu$ avvav y serait issue d'une recension sur le texte protomassorétique, alors que la leçon viov avaviou y constituerait la leçon originelle du ${ }^{*} G$, issue d'une Vorlage בן חנניה ou.

Avec le *M, la *V offre ici "filiorum Anan" et la*S דבני חנן.

Le *T se divise entre plusieurs leçons. Le ms Reuchlin, ainsi que les éditions de Félix de Prato et de Ben Hayim offrent ici בר חנן. Le ms Urbinates 1, la polyglotte d’Anvers et les mss yéménites utilisés par Sperber offrent בני חנן. Le ms Montefiore omet le premier mot.

La version arabe éditée dans les polyglottes de Paris et de Londres porte ici בן יונדב.

\section{Choix textuel :}

Remarquons d'abord qu'une mise au singulier du mot "fils" est ici "dans l'air". On la trouve attestée en effet chez des témoins divers : le ${ }^{*} G$ ancien, la moitié de la tradition textuelle du $* T$ et la première main d'un ms du *M.

Cependant le pluriel de ce mot, qui constitue ici une lectio difficilior, est fermement attesté par le $* \mathrm{M}$, le doublet du ${ }^{*} \mathrm{G}$ ancien, la $* \mathrm{~V}$, la $* S$ et la moitié de la tradition textuelle du $* T$. 
Enfin, une leçon Yoḥanan pour le 2e mot aurait une base très fragile : seul un ms $d u{ }^{*} M$ l'atteste formellement (mais faisant suite au pluriel du mot "fils"). Dans le ms Vaticanus, YIUNIUNAN semble issu de YIUNANNAN (du Sinaiticus) par une dittographie de IUN suivie d'une haplographie de NAN. Enfin l'Arabe des polyglottes a probablement pour base une leçon dérivée de celle du Vaticanus (à travers les versions coptes ?) et elle l'a assimilée au nom de "Yonadab" qui apparaît au vs 6 .

Le comité a attribué au *M la note " $B$ ".

Interprétation proposée :

Il est difficile de dire si "les fils de Hanân, fils de Yigdalyahu, l'homme de Dieu" sont les membres d'une famille ou les disciples d'une école prophétique.

\section{6,16 אל־ברוך [B] M g V S T // abr-elus : G om}

Options de nos traductions :

Après que Baruch eût lu aux princes le rouleau des oracles de Jérémie, ceux-ci se tournèrent effrayés l'un vers l'autre, puis - selon le *M - "ils dirent à Baruch : 'Il nous faut absolument rapporter au roi toutes ces paroles'."

Le complément "à Baruch" est traduit ici par RSV, RL, TOB et J3.

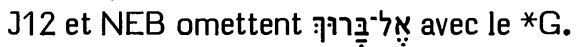

Origine de la correction :

Notant l'absence de ce complément dans le *G, Hitzig et Giesebrecht le considèrent comme une ajoute postérieure et il est omis par Oort, Duhm, Cornill, Condamin, Volz, Nötscher, Rudolph, Penna, Steinmann, Weiser, Bright et les apparats de HSAT4, BH23S et Cent.

Les témoins anciens :

Ce complément est omis ici par le ${ }^{*} G$ ancien $(43,16)$, mais inséré par les recensions origénienne et antiochienne.

Il est attesté par la $* \mathrm{~V}, \mathrm{la} * \mathrm{~S}$ et le $* \mathrm{~T}$.

Choix textuel :

La présence de ce complément dans le $* M$ ne vient pas d'un accident textuel. Il s'agit ou bien d'une glose rédactionnelle, ou bien d'un élément du texte original omis par le *G. Aussi le comité a-t-il attribué au *M la note " $B$ ".

Il faut noter que $l e{ }^{*} G$ a allégé le contexte en traduisant. Il n'a rien qui corresponde au dernier mot de 15b (qui lui semblait inutile après qu'il ait traduit le dernier mot de 15a). En 17b, il a omis les trois premiers mots comme inutiles.

Il semble bien qu'ici le traducteur a été gêné par l'expression dont il a traduit le verbe par ouveßouגeúoavto. Cela l'a amené à considérer les paroles qui suivent comme le contenu de cet entretien et non comme une information adressée à Baruch. Selon le $* M$, cette information amorce la mise en garde explicite du vs 19. 
Options de nos traductions :

Les princes demandent à Baruch : "informe-nous donc de la manière dont tu as écrit toutes ces paroles מִִ̣". Ce dernier mot du vs 17 est traduit par TOB : “sous sa dictée", alors que RSV en fait une phrase : "Was it at his dictation ?"

$J$ et NEB l'ont omis avec le *G. RL l'a omis aussi.

Origine de la correction :

Venema a traité ce mot comme une phrase.

Schleusner (annotant les Observationes de Michaelis) l'a considéré comme interpolé. Il a été omis par Ewald, Knabenbauer, Giesebrecht, Oort, Duhm, Cornill, Condamin, Volz, Schmidt, Nötscher, Rudolph, Penna, Steinmann, Weiser, Bright et par les apparats de SBOT, HSAT24, BH23S et Cent.

Les témoins anciens :

Le *G $(43,17)$ n’a pas traduit ce mot. La recension origénienne, sous astérisque, a ajouté : '̇x ơó́ Hexaples (autres que celle des $L X X$ ), avec un repère de leçon qu'il a - comme le suivant - mal placé.

$\mathrm{La} * \mathrm{~V}, \mathrm{la} * \mathrm{~S}$ et le $* T$ traduisent littéralement ce mot du*M.

Choix textuel :

On a souvent objecté au *M que ce mot anticipe la réponse que Baruch va donner au vs 18. C'est inexact. Etant admis que les princes savent que ces oracles ont été écrits par Baruch après avoir été prononcés par Jérémie, ils interrogent maintenant Baruch sur le "comment" (מיֵ) de la rédaction, sur la relation existant entre la pronon-

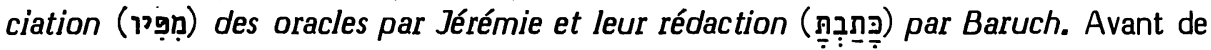
lire les oracles au roi, ils veulent en effet éclaircir la répartition des responsabilités entre Jérémie et Baruch. Baruch a-t-il agi de sa propre initiative, et éventuellement à l'insu de Jérémie, ou bien celui-ci a-t-il pris l'initiative de faire rédiger ses oracles par Baruch? Au vs 18, le scribe Baruch va leur préciser que toutes les paroles contenues dans le rouleau ont bien été dites par Jérémie à son scribe pendant que celui-ci les écrivait. Que la rédaction ait eu lieu sur l'initiative de Jérémie ne fait donc aucun doute. C'est pourquoi les princes, au vs 19, demanderont à Baruch de disparaître avec Jérémie pour échapper aux poursuites que le roi allait certainement lancer contre eux deux (vs 26).

A propos de 36,16 , nous avons noté la tendance du $* G$ à alléger, en ce contexte, sa traduction. Ici, l'omission de ce mot par le ${ }^{*} G$ aboutit à assimiler la fin du vs 17 à la fin du vs 16. Notons encore l'omission par le ${ }^{*} G$ de "avec de l'encre", à la fin du vs 18. La présence ici de מִִ̣ dans le texte massorétique est, en tout cas, solidement attestée et le comité lui a attribué 4 "B" et 2 " $C$ ". 
Interprétation proposée :

“Informe-nous donc sur la manière dont tu as mis par écrit toutes ces paroles sorties de sa bouche."

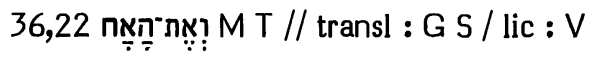

Options de nos traductions :

Après avoir dit que le roi trônait dans le palais d'hiver, au neuvième mois, le *M

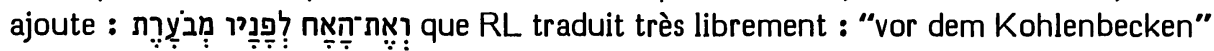
qui essaie seulement de corriger l'anachronisme du "fur dem Camin" de Luther.

Se fondant sur le ${ }^{*} G$, la ${ }^{*} S$ et le ${ }^{*} T, \mathrm{~J}$ traduit : "et le feu d'un brasero brûlait devant lui". TOB fait de même, en disant qu’en hébreu une consonne semble mal transmise.

Sans note, RSV traduit : "and there was a fire burning in the brazier before him", et NEB : "with a fire burning in a brazier in front of him".

Origine de la correction :

NEB a suivi ici RSV qui s'est contentée d'écrire en caractères romains le mot "fire" que KJ écrivait en italiques afin de montrer qu'elle l'avait ajouté pour les besoins de sa traduction.

C'est Schleusner qui (en annotant les Observationes de Michaelis) propose de corriger le premier mot en וִִ̣, estimant que le ${ }^{*} G$ avait lu cela. Cette suggestion a été adoptée par Duhm, Cornill, Condamin, Ehrlich, Schmidt, Volz, Nötscher, Rudolph, Penna, Steinmann, Weiser, Bright et les apparats de HSAT4, BH3S et Cent.

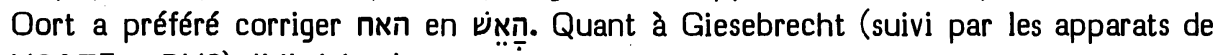

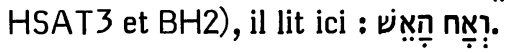

Les témoins anciens :

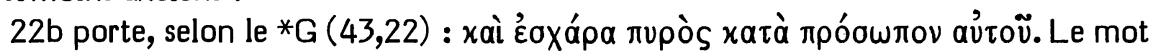

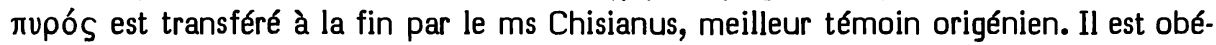

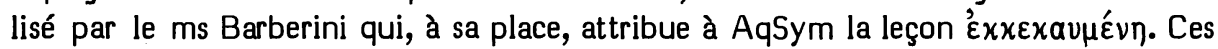
deux indices montrent que la tradition origénienne voyait en nupós $d u{ }^{*} G$ un (mauvais) correspondant du participe final, ce qui sera d'ailleurs (contre Schleusner) l'opinion de Spohn.

La *V traduit librement : "et posita erat arula coram eo plena prunis". La *S

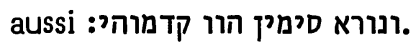

Le *T traduit : וית נורא קדמוהי מדלקין. Münster a noté que le targumiste a compris מדלקא qui correspond mieux au singulier du *M. La leçon majoritaire y a été ajoutée en marge.

\section{Choix textuel :}

Ici, le problème est double. D'un côté, la particule ְְ affectant le nominatif חֵ̣ surprend. D'un autre côté, on estime que ce substantif convient mal comme sujet pour le participe final. 
1/On sait que, avec des verbes passifs, la particule את peut précéder le sujet, parce que celui-ci serait le complément d'objet du verbe actif correspondant. König (Syntax §108-110) donne des exemples caractéristiques de cette construction où la particule d'accusatif nous indique que ce que nous prenons pour un sujet est, en réalité, le complément d'objet de la forme active qui a été conservé, malgré la mise au passif du verbe en question. Il estime que, du fait du mode pual du participe final de Jr 36,22, on possède là les meilleures analogies pour expliquer le ?ְ initial de notre phrase. Blau (Gebrauch \$6) adopte cette explication dont nous ferons, d’ailleurs, encore usage en 38,23.

2/ Volz (Studien), puis Rudolph, ont estimé que le féminin du participe final s'accordait mal avec הָָ. De fait, Albrecht (Geschlecht 88), constatant qu’en hébreu les réceptacles sont plús souvent masculins, a vu dans le fait que ce participe soit au féminin un argument pour corriger ici le texte. Cependant (p. 89) il admet qu'un tiers de ces substantifs sont féminins, ce qui ôte toute valeur contraignante à son argument. D'ailleurs BDB et HALAT caractérisent ce substantif אַ (= brasero) comme féminin.

Le comité, estimant qu'on ne peut opposer au ${ }^{*} M$ aucune Vorlage distincte et que les versions offrent seulement des traductions plus ou moins libres, a attribué à sa leçon ici 4 "C $\mathrm{C}$ " et 2 "B".

Interprétation proposée :

"Et le brasero qui est devant lui était allumé". Le narrateur écrit pour des lecteurs qui connaissent la disposition intérieure du palais d'hiver des rois de Juda. $L a * S$ et la $* V$ se sont représenté le brasero comme un radiateur mobile. $D$ 'autre part, la *S et le *T traduisent largement par "le feu".

שלשה 38,10 שלשים

Options de nos traductions :

Le roi Sédécias ordonne au Kushite Ebed-Mélek de prendre avec lui trente

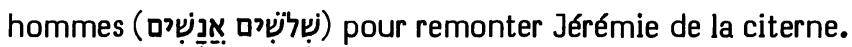

Le nombre "trente" a été respecté par $\mathrm{J3}$.

Se fondant sur un ms hébreu, J12 et NEB ont traduit "trois". Sans note, RSV, $R L$ et $T O B$ ont fait de même.

Origine de la correction :

Ewald1 a corrigé en "trois" le "trente" du * $M$ en lequel Ewald2 dit déceler une erreur graphique évidente. Cette correction a été adoptée par Hitzig, Graf, von Orelli, Giesebrecht, Oort, Duhm, Cornill, Condamin, Ehrlich, Volz, Schmidt, Nötscher, Rudolph, Penna, Steinmann, Weiser, Hyatt, Bright, ainsi que par les apparats de SBOT, HSAT234, BH23S et Cent.

Les témoins anciens :

Avant Volz et $\mathrm{BH} 3$ cette correction n'était présentée que comme conjecturale. De fait, le seul appui qu'on lui connaisse est le ms 96 de Kennicott que celui-ci pré- 
sente comme un ms allemand de la fin du XIVe siècle conservé à St John de Cambridge et portant ici שלשה. C'est dire que son autorité est pratiquement nulle.

Le nombre "trente" est lu ici par tous les autres témoins du *M, et par le *G $(45,10)$, la $* V$, la $*$ S et le *T.

\section{Choix textuel :}

En CT1, 312.321, nous avons trouvé, à propos des compagnons de David, des confusions entre "trois" et "trente". Or il faut reconnaître que, pour remonter un homme d'une citerne, un plus trois, c'est-à-dire quatre, est un nombre plus convenable que un plus trente.

Certains ont vu, d'autre part, dans la forme plurielle אנשים une objection contre le nombre "trente" du *M. Cependant Nägelsbach et Keil ont mentionné des parallèles qui, ainsi que Rudolph l'a reconnu, réfutent cette objection tirée de la syntaxe.

Le nombre "trente" se justifie si l'on rapproche, avec Yéfet ben Ely, cette mesure prise par le roi de la déclaration faite aux princes par le roi, lorsqu'il avait livré Jérémie en leur pouvoir (vs 5) : "car le roi ne peut rien contre vous". Etant donné que ce sont ces mêmes princes qui ont descendu Jérémie dans la citerne (vs 6), après avoir réclamé sa mise à mort (vs 4), trente hommes ne sont pas de trop pour éviter qu'ils mettent quelque entrave à l'accomplissement de la mission d'Ebed-Mélek et pour qu'ils comprennent que le roi met son autorité en jeu en prenant cette décision de faire remonter le prophète de la citerne.

L'état de la tradition textuelle impose, en tout cas, que l'on attribue à la leçon "trente" la note "A".

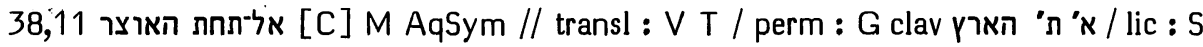

\section{Options de nos traductions :}

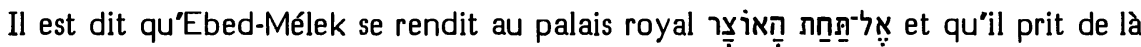
de vieilles loques et de vieilles hardes. Les trois mots cités sont traduits par TOB : "sous le trésor".

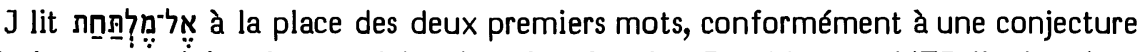
de Perles, et traduit : "au vestiaire du trésor". Selon Brockington, NEB lit de même quand elle traduit : "the wardrobe" où le troisième mot semble avoir été omis. En effet, disant qu'elle conjecturait, RSV traduisait : "to a wardrobe of the storehouse". RL traduit : "in die Kleiderkammer".

\section{Origine de la correction :}

C'est Ehrlich (Miqra) qui, en 1901, fut le premier à conjecturer nמ̣ à la place des deux premiers mots, en s'inspirant de 2 R 10,22. En 1906, Perles (Dictionary 389) a repris cette proposition sans mentionner ce prédécesseur. Puis elle a été adoptée par Condamin, Volz, Nötscher, Rudolph, Penna, Steinmann, Weiser, Hyatt, Bright et par les apparats de HSAT4, BH3S et Cent.

Perles (II 17s), notant qu'en éthiopien le mot 'eltâh' désigne un vêtement, a proposé ensuite de corriger seulement en 
feldt (Cuneiform 46) a proposé de dériver ce substantif de la racine ugaritique "Ih". Cependant, UT (Glossary \$179) interprète 'milh' (1109:1) comme un toponyme et Aistleitner ( $\$ 1503)$ ne se prononce pas sur le sens de ce mot qui serait le seul dérivé de la racine postulée par Eissfeldt.

\section{Les témoins anciens :}

Le mot תחת a été lu et interprété comme la préposition “sous" par le *G $(45,11)$

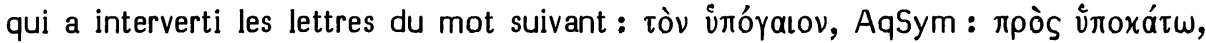
la *V : "sub", la *S : דלתחת et le *T : אוצר a e été lu ici par AqSym, la $* V$, la *S et le *T.

"L'hébreu" que Ziegler présente comme cité par Chrysostome selon la catena

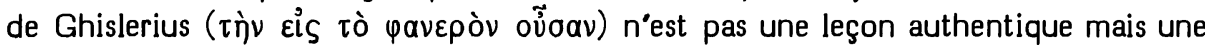
vague glose, ainsi que le montre le contexte de la citation.

\section{Choix textuel :}

Le seul point où le texte prête à hésitation est le troisième mot : faut-il le lire הארץ avec le *G ou האוצר avec les autres témoins?

Le comité a attribué la note " $C$ " à la leçon du * $M$, estimant que le sens trouvé ici par le *G postulerait plutôt תחת האדמה תחתיות הארץ ours que le *M a un excellent appui en AqSym.

Ehrlich (Randglossen) a prétendu à tort que, si אל־תחת était originel ici, cette préposition complexe devrait être rattachée par 'lamed' au substantif qu'elle introduit. C'est inexact, comme le prouvent Lv 14,42; Jg 6,19; 1 S 21,5; Jr 3,6; Za 3,10bis; alors que la construction postulée par Ehrlich ne se rencontre qu'en Ez 10,2.

\section{Interprétation proposée :}

Le substantif conjecturé ici par Ehrlich et Perles ferait double emploi avec le mot qui suit et que plusieurs critiques omettent d'ailleurs ici par conjecture. Ce mot peut fort bien désigner une pièce où l'on tenait en réserve les vêtements et les couvertures. Il est fort possible que des étoffes usées aient été jetées dans un sous-sol où l'on venait chercher les guenilles dont on avait besoin.

On pourrait traduire : "Et il se rendit au palais royal, au sous-sol de la réserve, et il y prit..."

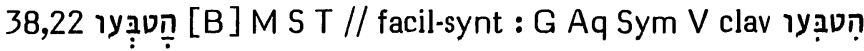

Options de nos traductions :

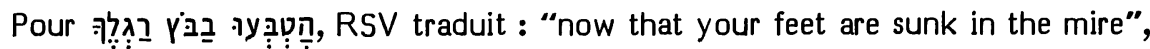
J : "tes pieds pataugent dans le bourbier" et TOB : "tes pieds s'enfoncent dans la boue".

Selon Brockington, NEB lit הִ הִuִa avec Aq, lorsqu"elle traduit : "they have let your feet sink in the mud". De même, RL traduit : "(haben dich...) und in den Sumpf geführt". 
Origine de la correction :

$L a * V$ ayant ici traduit le verbe comme un hifil dont "tes pieds" serait le complément d'objet (demerserunt ... pedes tuos), Zwingli s'est laissé influencer par elle en traduisant : "et in lutum demerserint pedes tuos". La traduction des Prédicants de Zurich fait de même: "(die menner...) und deine füss ins kaat gestossen habind". Préoccupé par l'allègement du style, Luther suit tout spontanément cette option : "deine Tröster haben dich uberredt und verfürt, und in schlam gefürt". Cependant, la forme passive du verbe avait été respectée par Pagnini, Brucioli et elle le sera par Münster, Olivetan, Jud, Estienne, Châteillon, Calvin, Ge, Tremellius, Pasteurs et KJ.

Sous l'influence de la traduction de Luther, Graf a proposé de vocaliser le verbe en hifil, estimant que cela convient mieux à la graphie en singulier (sans 'yod') du substantif final. Cette correction vocalique a été adoptée par Ewald2, Giesebrecht, Duhm, Cornill, Ehrlich, Volz et les apparats de HSAT34 et BH23.

\section{Les témoins anciens :}

Les témoins anciens du $* G(45,22)$ donnent pour ce verbe : KATA^YCOYCIN que Bos (cité par Spohn qui le suit) corrige en KATA $\triangle Y C O Y C I N$, correction qui a été adoptée par Ziegler. Le texte vulgaire du ${ }^{*} G$ (selon la plupart des mss, et l'édition

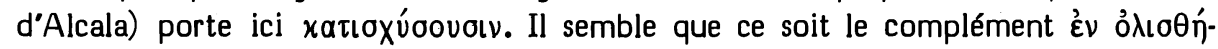

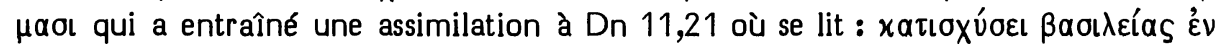
ỏıı

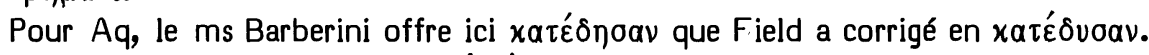
Sym traduit, selon le même témoin : '̇ßártıoav.

$\mathrm{La} * \mathrm{~V}$ offre ici "demerserunt".

$\mathrm{La} * \mathrm{~S}$ traduit ורנו en Ex 15,4 où le sens est évidemment intransitif.

Le *T aussi a lu ici un hofal : אשתקעא.

\section{Choix textuel :}

Le mot "tes pieds" étant à l'accusatif, il est sâr que le *G, Aq, Sym et la *V ont lu ici un hifil; alors que la ${ }^{*} S$ et le *T s'accordent avec le *M pour lire un hofal.

Quant au mot רֵּרֶ, Radaq précise que l'on a ici la graphie défective d'une forme plurielle. Or c'est bien par un pluriel que le ${ }^{*} G, A q$, Sym, la $* V$ et la ${ }^{*} S$ ont traduit ce mot, le seul témoin clair pour un singulier étant noóós oov que les recensions origénienne et antiochienne donnent ici. Le *T a traduit par mais le fait que le verbe soit au féminin pluriel lève l'équivoque en faveur du pluriel.

Une vocalisation du verbe en hifil est ici facilitante, car elle permet de maintenir pour ce verbe le même sujet que pour les deux verbes précédents et pour le verbe suivant. De fait, "tes amis intimes" n'ont pas eu besoin de "faire enfoncer tes pieds dans la boue". Ils se sont contentés de "te séduire" pour "l'emporter sur toi": "tes pieds s'enfoncent dans la boue, tandis qu'eux s'éclipsent". Les amis ont seulement attiré le roi de Juda dans un bourbier. L'envasement ne nécessite plus d'intervention de tiers. Ce sont les tentatives de l'embourbé pour se tirer de là qui le font enfoncer.

La situation historique s'accorde bien avec le hofal du *M: les alliés égyptiens de Sédécias ont séduit le roi en lui laissant espérer qu'ils l'aideraient s'il se trouvait 
en difficulté. Or ces alliés ont fait demi-tour $(37,7)$ et ont abandonné Sédécias dans le bourbier où il s'est mis du fait de sa révolte contre Nabuchodonosor ( $E z$ 17,13-16).

Cinq membres du comité ont attribué au hofal du *M la note " $B$ ", alors qu'un membre attribuait au hifil la note " $C$ ".

Interprétation proposée :

"tes pieds s'enfoncent dans le bourbier".

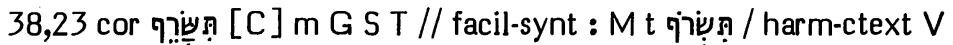

Options de nos traductions :

Après qu'il ait été dit à Sédécias qu'il n'échapperait pas aux mains des Chaldéens, 23b ajoute: "car tu seras saisi par la main du roi de Babylone

Le qal du verbe n"est retenu par aucune de nos traductions.

Disant suivre des mss hébreux, ainsi que le ${ }^{*} G$ et le ${ }^{*} T, \mathrm{~J}$ donne : "elle sera incendiée". Selon Brockington, NEB lit avec le *G will be burnt down". Sans note, RSV traduit : "(this city) shall be burned", RL : "(diese Stadt) wird ... verbrannt werden" et TOB : "(la ville) est incendiée".

Origine de la correction :

$1 /$ Les traducteurs du XVIe siècle.

RL dépend ici de Luther ("und diese Stad wird mit Fewr verbrennet werden"). Ici encore, Luther ne se rend pas compte qu'il n'est pas fidèle au *M quant à la forme du verbe. C'est qu'en copiant la traduction des Prédicants de Zurich ("und dise statt wird verbrennt werden") il a seulement fait attention à expliciter le complément que ceux-ci avaient omis. Ici encore, la traduction des Prédicants est fidèle à celle de Zwingli : "et urbs ista igni comburetur".

N’ont pas craint de traduire littéralement le *M: Münster ("combures", adopté par Estienne dans sa réédition de Pagnini, ainsi que par Calvin), Jud ("incendes") et Arias Montano ("cremabis"), ainsi que la marge de KJ précisant que l"hébreu porte ici : "thou shalt burne".

Ont utilisé une glose discrète : Pagnini ("comburere facies" maintenu par la réédition de Servet), Brucioli ("farai ardere") et Olivetan ("feras brusler" maintenu par Rollet et Estienne).

La leçon de la *V harmonisait avec ce qui précède. Elle a été adoptée ici par Tremellius ("comburet") reprenant une option de Châteillon ("cremabit" et "mettra a feu").

Olivetan a senti la nécessité d'expliquer sa traduction par une note marginale inspirée du commentaire de Radaq : "c'est : tu seras cause de faire brusler". Reprise en marge par Estienne, cette paraphrase servira de traduction à la Geneva Bible ("shalt thou cause to be burnt"), à la bible des Pasteurs de Genève ("et seras cause que cette ville-ci sera bruslee") et à KJ ("thou shalt cause this citie to be burnt").

Nous voyons donc qu'ici, comme dans le cas précédent - et dans plusieurs autres cas que nous avons signalés auparavant en Jérémie -, Luther (publiant sa traduction 
des prophètes en 1532) dépend étroitement de la traduction des Prédicants de Zurich (publiée en 1529), traduction qui exprime des options de Zwingli, comme cela apparaîtra clairement lorsque celui-ci publiera en 1531 sa traduction latine de Jérémie, en introduction à sa "complanatio Jeremiae Prophetae". Or Kessler (Sabbata 203s) nous a laissé une description de la manière dont les Prédicants de Zurich travaillaient à leur traduction (pour celle de Jérémie, cela eut lieu de mars à juin 1528) : Tous les matins à huit heures, après une prière, Caspar Megander lisait un chapitre ou un demi-chapitre en latin selon la Vulgate. Puis Pellican lisait cela à partir de l'hébreu en le traduisant en latin et en signalant les différences par rapport à la Vulgate. Ensuite, Huldrich Zwingli traduisait le même texte en latin à partir de la Septante, en mettant en valeur les éclaircissements qu'elle apportait dans les passages difficiles. Enfin, Leo Jud mettait en bon allemand ce que les autres avaient traduit en latin, en tenant compte des éclaircissements que $Z$ wingli avait donnés en latin.

En résumé, l'apport de Zwingli consistait surtout en des éclaircissements à partir de la Septante. Or, ici, en face de la traduction inexacte de la*V ("conburet") et de l'hébreu peu intelligible en ce contexte ("tu brûleras") l'édition Aldine (dont Zwingli

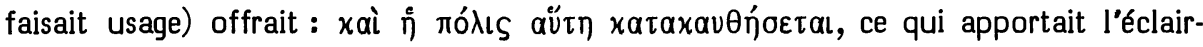
cissement requis et ce qui sera donc retenu par la traduction latine de Zwingli et la forme allemande que Jud lui a donnée en conclusion du travail des Prédicants. On comprend donc que Zwingli, dans sa préface à la Complanatio Isaiae (98,3-7) ait conclu que "il y a une infinité de lieux où il apparaît clairement que les Septante ont lu ou divisé autrement et mieux que les rabbins ne l'ont fait ensuite. Ceux qui comparent, avec un jugement non prévenu, leur traduction avec le texte des hébreux savent bien cela".

\section{2/ La critique postérieure.}

Estimant que les ponctuateurs se sont laissés égarer par la présence de la particule กְּ, Venema propose de vocaliser le verbe en nifal avec le *G, la *S et le *T. Le suivent en cela : Lilienthal (285), Ewald, Hitzig, Graf, Nägelsbach, Giesebrecht, Oort, Duhm, Ehrlich, Cornill, Condamin, Volz, Schmidt, Nötscher, Rudolph, Penna, Steinmann, Weiser, Bright et les apparats de SBOT, HSAT234, BH23S et Cent.

\section{Les témoins anciens :}

Au ms Kenn 224 (= Königsberg 2) signalé par Lilienthal comme portant la vocalisation nifal cinq autres dont la première ou la seconde main portent cette vocalisation que Ginsburg a rencontrée en trois mss de la British Library de Londres. La leçon ๆ่าׁุุ est attestée ici par les témoins du texte tibérien classique. La massore éditée (sur Ex 29, 14 et sur Jos 11,6) précise que nous avons ici l'une des trois occurrences de la séquence

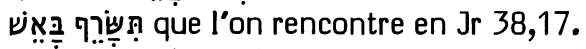

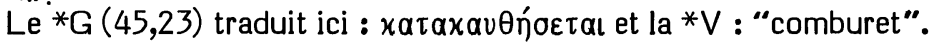

La leçon תאקד de la *S traduit ici un nifal, comme le montre une comparaison avec Lv 21,9. La leçon du *M serait traduite par תוקד, comme le montre Ex 29,14.

Le *T (תתוקד) appuie ici la vocalisation nifal. Seul l'un des mss yéménites utilisés par Sperber lit ici תוקיד (= * M). 
Choix textuel :

Déjà Judah ben Qoreish (selon Ibn Ezra, Sephat Jether §104) estimait qu'ici, il faut interpréter la préformante comme n’étant pas celle de la 2e pers. Il jugeait que l'on devrait avoir ici la même forme qu'au vs 17 (dont le simân est déformé dans les éditions du Sephat Jether, mais exact dans le ms de Rossi 314), c'est-à-dire ףำ

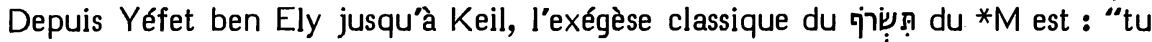
auras été, par tes agissements, la cause que cette ville sera brûlée". Cette exégèse semble pourtant un peu trop subtile. Mieux vaut admettre avec Venema que la vocalisation massorétique a méconnu ici un cas de passif ayant maintenu le complément d'objet (du verbe actif) introduit par la particule אֵ. En 36,22 (ci-dessus p. 716), nous avons déjà présenté cette particularité qui a d'ailleurs été reconnue par la vocalisation massorétique en Jr 35,14a; $38,4 a$ et 50,20a.

Le comité a attribué 4 "C" à cette correction vocalique et 2 "C $C$ " à la leçon du *M.

Interprétation proposée :

"Et cette ville sera incendiée."

38,28 והיה כאשר נלכדה ירושלם והיה, Vet Lat om

Options de nos traductions :

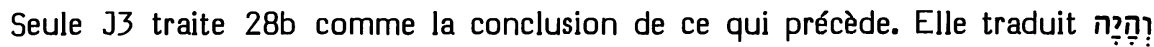
范 par : "Et il y était quand Jérusalem fut prise".

Considèrent $28 \mathrm{~b}$ comme l'introduction de la péricope qui suit : $\mathrm{J12}$ traduisant : “Or, quand Jérusalem fut prise...", TOB : "Et quand Jérusalem fut prise..." et RL : "Und es geschah, dass Jerusalem erobert wurde".

RSV transfère 28b au début de 39,3 où il le traduit: "When Jerusalem was taken".

NEB dit suivre le ${ }^{*} G$ en omettant $28 b$.

Origines des corrections :

Michaelis (OEB) a transféré 38,28b au début de 39,3, suivi en cela par Duhm, Volz, Schmidt, Steinmann, Hyatt, Bright et l'apparat de SBOT.

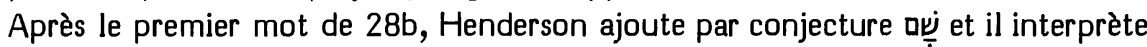
cette phrase comme $\mathrm{J} 3$ le fera et comme $\mathrm{KJ}$ le faisait.

Se fondant sur le ${ }^{*}$ G, Ehrlich (Miqra) a proposé d'omettre 38,28b, puis, en Randglossen, il le conserve comme authentique.

Les témoins anciens :

Selon Kennicott (et de Rossi qui copie ses données), 28b manque en ses mss 93, 112 et 180 (ainsi que dans les premières mains d'un ms Kenn et d'un ms de Rossi auquel celui-ci en ajoute un second en ses scholia). Nous n'avons pu contrôler que le ms 180 de Kennicott. Il est faux qu'il omette 28b. L'erreur de collation tient à ce que Kennicott avait assigné comme base de référence pour les collations l'édition de Van 
der Hooght. Or, celle-ci place 28b au début de 39,1; alors que le ms 180 de Kennicott (= Hamburg 27) le place en fin de 38,28 . Il se peut que la même erreur de repérage se soit reproduite en d'autres collations.

Trois mss de Kennicott, ainsi que les premières mains d'un autre et de deux mss de Rossi lisent ויה à la place du premier mot.

Selon les témoins grecs anciens (les mss Vaticanus et Sinaiticus), le ${ }^{*} G(46,1)$

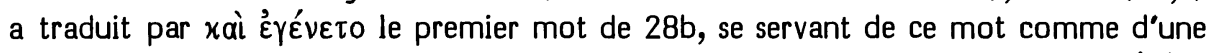
introduction pour 39,1. Les recensions origénienne et antiochienne ajoutent jंvíx $\alpha$

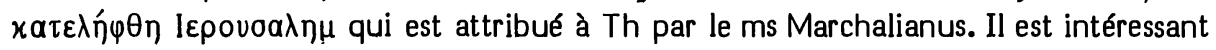
de noter que Syh place sous astérisques la totalité des vss 1 et 2 du ch. 39 et que 38,28b - 39,2 est justement absent du palimpseste de Würzburg (Ranke, Par 312) qui est ici le seul témoin de la Vetus Latina.

La *V ("et factum est ut caperetur Hierusalem") et le *T (והוה כד אתכבישת ירושלם) attestent ici le *M.

$\mathrm{La} *$ S omet $28 \mathrm{~b}$.

\section{Choix textuel :}

L'omission de $28 \mathrm{~b}$ par la $* S$ et par quelques mss du $* M$ peut $s$ 'expliquer par un homéotéleuton, les deux derniers mots de $28 b$ étant identiques à ceux de $28 \mathrm{a}$

Quant au remplacement de ויהי en quelques mss du ${ }^{*} M$, c'est une assimilation à une tournure plus usuelle. Notons cependant que l'on retrouve en Jérémie deux autres cas $(3,9 ; 37,11)$ où est suivi par un inaccompli inverti. Là comme

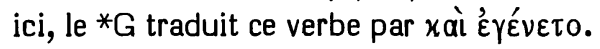

Les deux types d'abréviations qu'offrent le ${ }^{*} G$ ancien et la Vieille Latine permettent d'éviter la difficulté que présente le $* M$ : difficulté qui consiste à laisser croire que 39,1 fournit la date de l'événement mentionné en 38,28b.

Le comité a attribué ici au *M la note "C", en estimant que la difficulté offerte par le ${ }^{*} M$ se situe au niveau de la critique littéraire et de l'exégèse.

\section{Interprétations proposées :}

\section{$1 /$ Les divisions traditionnelles.}

Comme on le sait, la division en chapitres $n$ 'est pas traditionnelle dans le *M. Elle a été instaurée au moyen âge dans la *V. Notons tout de suite que, selon la plupart des témoins de la $* V$, ainsi que selon ses éditions anciennes, le ch. 39 commence par "Anno nono Sedeciae", c'est-à-dire qu'il coïncide avec la division en chapitres de BHS.

Voici les témoignages les plus sûrs sur les divisions du texte tibérien classique. Une setuma commence au milieu du vs 28 et s'achève à la fin de 39,14 selon le ms d’Alep et celui du Caire. Cela est appuyé et commenté par Yéfet ben Ely (selon le ms London BL or 2504 , les autres étant plus ou moins mutilés) : "Ce qu'il dit : fait allusion à ce qu'il dira à la fin de la péricope $(39,14)$ :

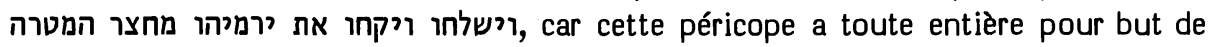
faire connaître ce qui arriva au moment où Jérusalem fut prise. Et il a dit au début de la péricope : והיה כאשר נלכדה. Il veut dire : il advint, lorsque Jérusalem fut prise, que les princes du roi de Babylone envoyèrent prendre Jérémie de la cour de garde et le 
livrèrent à Gedalayahu". Ce commentaire repose sur un découpage en péricopes identique à celui des mss d'Alep et du Caire. Ce découpage se retrouve dans le ms Reuchlin des Prophètes, le ms Erfurt 3, le ms Madrid Univ 1 et le ms Paris BN 82. Parmi les éditions anciennes, celle de Lisbonne 1492 semble être la seule à l'attester. Une variante de ce découpage est celle qu'offrent l'édition Soncino 1488 et l'édition Brescia 1494. Elles délimitent la péricope de la même manière, mais considèrent 38,28a et $38,28 \mathrm{~b}$ comme deux versets indépendants. Ajoutons qu'Abravanel (question 3 sur la 14e prophétie de Jérémie) commence lui aussi une péricope par 38,28b. Parmi les traducteurs du XVIe siècle, ont placé 28b en début du ch. 39 : Pagnini (en son édition de 1527), Prédicants, Zwingli, Luther, Jud, Rollet et Châteillon. Notons en passant que Luther, en traduisant : "Und es geschah, das Jerusalem gewonnen ward", a recopié l'édition GKW 4299 de la vieille traduction allemande (qui était seule à traduire ainsi le premier verbe) : "und es geschah dass iherusalem ward gewunnen". L'originalité principale de Luther est d'avoir fait passer cette phrase de la fin du ch. 38 au début du ch. 39. Toutes les autres éditions de la vieille allemande (selon Kurrelmeyer IX $146,61 \mathrm{~s}$ ) traduisaient le premier verbe par : "und es wart gethan".

Un autre découpage traite comme une seule péricope 38,27 à 39,14. C'est le cas du ms modèle de Norzi (de Rossi 782), du ms Urbinates 2 et du ms des Jésuites de Cologne. Aucune édition ancienne ne représente directement ce découpage.

Le ms des Prophètes de Petrograd offre le découpage suivant : 38,27-28b constitue une péricope, 39,1 en constitue une autre, puis 39,2-14 en constitue encore une autre. Ce passage à une nouvelle péricope à la fin du vs 28 (mais ni au début, ni au milieu de ce vs) se retrouve dans les éditions imprimées par Bomberg: la bible rabbinique de Félix de Prato, la bible in $4^{\circ}$ du même, la bible in $4^{\circ}$ de 1521 et la bible massorétique de Jacob ben Hayim. On retrouve encore cette particularité dans la bible Minhat Shay. A la différence des éditions antérieures, les éditions Bomberg (et celles qui les suivront) portent en marge la division en chapitres. Il se peut que cela ait joué un rôle dans le fait qu'elles ont transféré au début de 39,1 le début de péricope que les éditions de Soncino, de Lisbonne et de Brescia plaçaient au milieu de 38,28 .

Pour conclure, notons que le ms de Leningrad combine les divisions offertes par le ms de Petrograd et celles qu'offre la tradition classique des mss d'Alep et du Caire en y ajoutant encore une division au début du vs 28.

\section{2/ Les interprétations impliquées.}

La division en versets unit donc $38,28 \mathrm{~b}$ à ce qui le précède, alors que la division en péricopes du texte tibérien classique unit $38,28 \mathrm{~b}$ à ce qui le suit. Deux exégèses traditionnelles sont impliquées par ces deux découpages :

a) Dans le sens de la division en versets, Menahem de Posquières glose 28b en insérant והיה Vatable (en ses notes sur la bible Estienne de 1545) fera allusion à cette exégèse en disant que "d'autres" comprennent $28 \mathrm{~b}$ de Jérémie : "erat [ibi] quando fuit capta Ierusalem". Estienne a fait passer cela dans le texte de sa réédition de la traduction de Pagnini (1557), puis cette interprétation a passé (avec cette glose) à la King James à travers la Geneva Bible, Tremellius et la bible des Pasteurs de Genève. 
b) Selon l'explication donnée par Yéfet ben Ely, la division en péricopes, qui fait de 38,28b l'introduction d'une péricope s'achevant par 39,14, entend articuler les inaccomplis invertis de 39,14 sur le והיה initial de 38,28b, en considérant 39,1-13 comme un ensemble de données commentant les mots : "lorsque Jérusalem eut été prise". C'est avec l'inaccompli inverti du début de 39,3 que Grotius articule 38,28b, considérant 39,1-2 comme une parenthèse. Schnurrer formule l'hypothèse que ces deux versets sont la glose d'un rédacteur soucieux d'ajouter des précisions chronologiques. Cela est possible, mais il ne faudrait pas croire que la Vieille Latine nous ait conservé le témoignage d'un état où ces deux versets ne figuraient pas encore. En effet, elle omet aussi 28b qui, en cette hypothèse, était primitivement connecté à 39,3.

\section{3/ Conclusion.}

Le comité propose en premier lieu l'interprétation de Grotius : “(38,28b) Et il arriva, lorsque Jérusalem eut été prise - (39,1-2) (c'était) en l'année... - (39,3), que tous les princes du roi de Babylone vinrent..."

En second lieu, il propose l'interprétation de Menahem de Posquières, de KJ et de $\mathrm{J3}$ qui correspond à la division en versets : “( $38,28 \mathrm{~b})$ et il (y) était lorsque Jérusalem fut prise. $(39,1-3)$ En l'année... tous les princes du roi de Babyone vinrent..."

Plusieurs motifs rendent cette seconde interprétation moins probable. D'abord, elle ne tient pas compte d'une particularité syntactique qui réapparaît dans le livre de Jérémie : l'articulation de והיה avec des inaccomplis invertis. Puis, elle oblige à

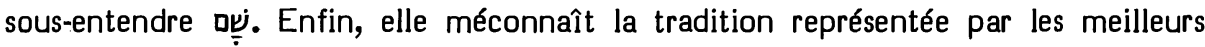
témoins tibériens classiques, tradition portant sur le découpage d'une péricope commençant au milieu du vs 38,28 et s'achevant par le vs 39,14.

\section{9,3 סממגרגר [B] M g V T // err-graph : G S clav סמגד}

\section{Options de nos traductions :}

3b rapporte les noms de certains des "princes du roi de Babylone" : . Ces noms sont transcrits par RSV: "Nergal-sharezer, Samgar-nebo, Sarsechim the Rabsaris, Nergal-sharezer the Rabmag" et par J3: "Nergalsaréser, Samgar-Nebo, Sar-Sekim, haut dignitaire, Nergalsaréser, grand mage".

Se fondant sur 39,13 et sur la liste babylonienne des officiers de Nabuchodonosor, J12 avaient conjecturé : “Nergalsaréser, prince de Sîn-Magir, le grand officier, Nebushazbân, le haut dignitaire". De même, RL offre : "Nergal-Sarezer, der Fürst von Sin-Magir, der Oberhofmeister, und Nebuschasban, der Oberkämmerer".

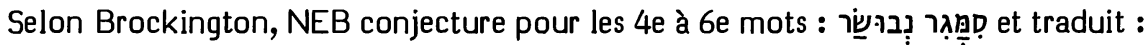
“Nergalsarezer of Simmagir, Nebusarsekim the chief eunuch, Nergalsarezer the commander of the frontier troops". De même, TOB lit : "Nergal-Sarèçèr, de Sîn-Maguir, Nebou-Sarsekim, chef du personnel de la cour, Nergal-Sarèçèr, le généralissime". 


\section{Origines des corrections :}

Grätz (Geschichte II/A 400, note) a proposé d'abord d'éliminer l'une des mentions de Nergal-Scharezer comme dittographie, puis de séparer le $5 e$ mot de celui qui le précède et de l'unir à celui qui le suit, et enfin de considérer Nebushazban $(39,13)$ et Nebusarsekim $(39,3)$ comme deux formes du même nom dont l'une doit être corrompue.

Un événement essentiel pour la critique textuelle de ce vs a été la publication, en 1925, de la liste à laquelle J12 font allusion. Cette liste a été exploitée par Rudolph (Text 283s). Celui-ci a conjecturé (en tenant compte aussi des suggestions de Grätz) de

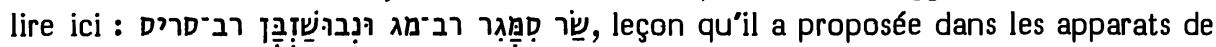
$\mathrm{BH} 3 \mathrm{~S}$ ainsi que dans son commentaire. C'est dans cet état qu'elle a été adoptée par J12 et par RL.

NEB et TOB se sont contentées des corrections directement impliquées par les données que fournit la liste susdite.

Les témoins anciens :

Ziegler (Beiträge 80s) a corrigé par conjecture les formes onomastiques fournies

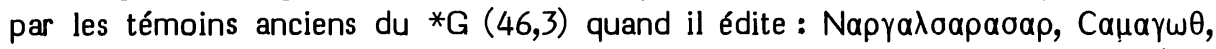

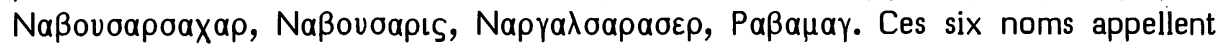
les remarques suivantes :

a) Dans le premier comme dans le troisième, la syllabe centrale oap n'est pas attestée par les témoins anciens.

b) Pour le premier, la forme attestée la plus ancienne est Mapyavaoap. Il est aisé de conjecturer que cette forme (que l'édition Sixtine avait retenue) dérive de Napra入aoap (que Rahlfs avait conjecturée). Notons que, par rapport à l'hébreu (et au baby-

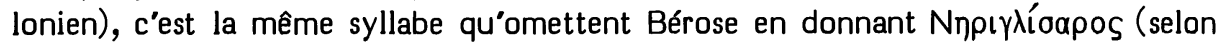
Eusèbe, citant le Contre Apion de Josèphe en Praeparatio IX 40,4-5) et Abydénos

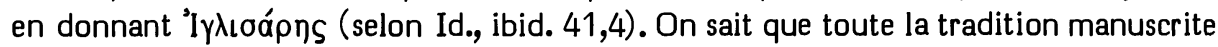
directe du Contre Apion (I \$147) dérive du ms Laurentianus LXIX 22 qui porte

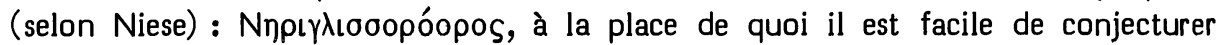

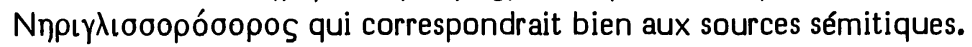

c) Pour le deuxième, la forme ancienne C $\alpha \mu \alpha \gamma \omega \theta$ (déjà retenue par les éditions Aldine, Sixtine et Rahlfs) suppose, pour la lettre finale, une lecture 'dalet' qui est aussi attestée par la *S. Il faut relever aussi ici la leçon du ms Alexandrinus : Eloo $\mu \mu \alpha \gamma \alpha \theta$.

d) Après ce deuxième nom, tous les témoins anciens, ainsi que les éditions d'Alcala, Aldine, Sixtine et Rahlfs ajoutent un xaí dont l'obèle de la recension origénienne montre l'appartenance à la couche ancienne du ${ }^{*} G$. Ainsi se trouve attestée, en contraste avec le ${ }^{*} M$ et la ${ }^{*}$, la liaison de נבו au mot qui suit (et non à celui qui précède).

e) Pour le troisième nom, la forme attestée par les témoins anciens (et retenue par les éditions Aldine, Sixtine et Rahlfs) est Naßovoaxap.

f) Pour le quatrième, la seule variante notable est Naßwoapıs chez Josèphe (Ant $X$ $\S$ 135). Notons qu'une vocalisation ḥolem de la 2e syllabe est attestée aussi par certains témoins du *M (cf. éditions Minhat Shay et Baer), alors que les témoins du texte tibérien classique (mss du Caire, d’Alep et de Leningrad et édition Ben Hayim) s'accordent sur le shureq. 
g) Ziegler ne distingue le cinquième nom du premier que sur un point très secondaire ('epsilon' au lieu de 'alpha' dans la dernière syllabe).

h) Pour les deux derniers noms, il faut noter d'abord que, chez tous les témoins anciens (ainsi que dans les éditions Aldine, Sixtine et Rahlfs), les trois premières syllabes sont Narapras. Ensuite viennent les deux syllabes vaoep (selon la plupart des témoins, dont le ms Vaticanus, et les éditions Sixtine et Rahlfs) ou vaoap (selon le ms Sinaiticus et l'édition Aldine). Ces deux syllabes sont liées aux trois qui précèdent par la tradition textuelle des catenae, l'édition Aldine et celle de Rahlfs (les deux premiers témoins les faisant suivre par $\left.x \alpha^{\prime}\right)$. Mais la plupart des autres mss placent le $x a i ́$ (que la recension origénienne obélise) avant ces deux syllabes que l'édition Sixtine unit à ce qui suit. Notons enfin que la lettre finale du dernier nom ('gamma' selon un correcteur du ms Sinaiticus et de nombreux mss) a subie une déformation (intérieure au grec) en 'thêta' dans le ms Vaticanus (forme retenue par les éditions Aldine et Sixtine), à travers 'tau' (attesté par la première main du ms Sinaiticus).

$\mathrm{La} * \mathrm{~V}$ (Neregel Sereser Semegar Nabu Sarsachim Rabsares Neregel Sereser Rebmag) montre la ferme cohérence de la tradition textuelle protomassorétique. Cette cohé-

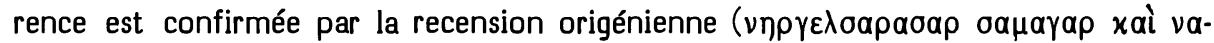

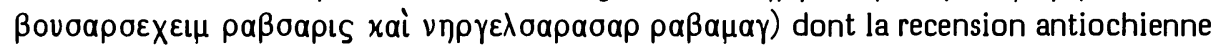
se distingue sur quatre points : d'abord elle porte un 'delta' (cf. *S) à la fin du $2 \mathrm{e}$ nom, puis elle insère un $2 \mathrm{e}$ xaí après le $3 e$ nom, ensuite elle déforme le $5 \mathrm{e}$ nom en

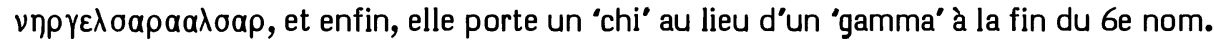
On notera aussi l'identité qui existe entre le ${ }^{*} T$ et le ${ }^{*} M$, ainsi que l'absence de variantes notables dans la tradition textuelle du *M.

$\mathrm{La} * S$ tient (comme souvent) une place intermédiaire entre la forme textuelle protomassorétique et celle du ${ }^{*}$ G. Elle présente l'intérêt de séparer clairement les

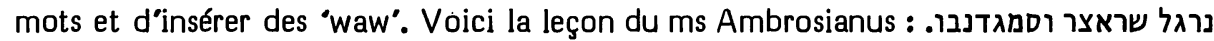
. On notera le blocage entre le 4e et le 5e mot du * $M$ (que celui-ci unit par un maqqef).

Choix textuel :

1/ Histoire de la critique du mot Dֵַ

C'est en 1925 que Unger (Namen) a publié une liste d'officiers de la cour de Nabuchodonosor II où figurait, au 2e rang, parmi "les grands du pays d"Akkad" : "Nergal-sharri-ușur amêlu Sin-magir" où l'éditeur comprenait Sin-magir comme une région sur laquelle ce prince exercerait son autorité. Il a été communément admis parmi les exégètes que ce "grand" est identique au premier des "princes du roi de Babylone" qui sont mentionnés en Jr 39,3.

En 1972, von Soden (Funktionär 86-90) a montré de façon convaincante que, dans cette liste, il faut comprendre "simmagir" comme un titre de haut fonctionnaire utilisé entre 660 et 410, c'est-à-dire depuis Shamash-shum-ukin jusqu’à Darius II.

Il est intéressant de retracer l'histoire des traitements que la critique avait fait subir au mot d'en retrouver l'origine.

Grotius interprétait ce mot au sens de "gardien" (du temple de Nabo) en donnant au 'mem' une valeur épenthétique. Hitzig, à partir du persan, donnait à ce mot le sens 
de "échanson" (littéralement : celui qui tient la coupe). Cette interprétation a été adoptée par Graf, alors que Nägelsbach formulait des réserves et que Keil estimait méthodologiquement inacceptable de faire appel au néopersan pour expliquer des titres de fonctions babyloniens. Il estimait prudemment que "nous ne disposons pas encore des instruments requis pour déterminer si les leçons Samgar-Nebu et Sarsekim sont fautives ou non et, si oui, pour pouvoir les corriger". Schrader (cité par von Orelli) comprenait ce mot et celui qui le suit comme : "sois favorable, Nebo".

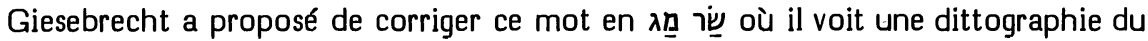
titre de רַ qui est attribué plus loin au même Nergalschareser. Il conclut de là qu'il faut omettre les mots "Nergalschareser Samgar". Le suivent dans cette omission : Oort, Duhm, Ehrlich (Miqra), Cornill, Condamin, Volz (Studien) et les apparats de HSAT34, BH2 et Cent. Il est donc frappant que la liste néobabylonienne a authentifié justement ces mots dont les critiques postérieurs à Giesebrecht avaient admis l'inauthenticité.

Sur la base des données fournies par Unger, qui voyait en Sin-magir une région, Rudolph - nous l'avons dit - a conjecturé ֵㅡ avant ce mot et a été suivi en cette conjecture (diffusée en BH3S) par J12 et RL. Comme Von Soden (Funktionär 86) l'a fait remarquer, cette ajoute conjecturale est inutile si l'on voit en 'simmagir' un titre de fonction.

\section{2/ Décision du comité :}

Il est très probable qu”une équivalence doit être établie entre "Nergal-shari-ușur amêlu Sin-magir" et le premier des princes du roi de Babylone mentionné en 39,3. On pourrait même aller jusqu’à envisager que la leçon qu'offre ici le ms Alexandrinus : NHPГЄАCACACAPЄICCAMAГA סמגר qui serait rigoureusement identique à la titulature néobabylonienne. Mais, si l'on traduisait ici : "Nergalsaréser le simmagir", avec une note expliquant que l'on ne sait guère en quoi consistait la fonction désignée par ce titre, on remonterait jusque dans la préhistoire du texte biblique, alors que l'on serait forcé de conserver à côté un "Nebusarsekim" dont rien ne nous permet de corriger le nom, vraisemblablement corrompu.

Estimant que, parmi les formes textuelles existantes, c'est le *M qui nous offre l'état le moins corrompu de ces noms, le comité lui a attribué la note "B".

Interprétation proposée :

On se bornera à transcrire le $* M$, ainsi que l'ont fait RSV et J3. Il serait bon d'indiquer en note qu'il s'agit là très probablement de "Nergal-shari-uṣur le simmagir" dont une inscription néobabylonienne atteste le nom et le titre, sans que l'on puisse préciser en quoi consistait cette fonction. On pourra ajouter que ce prince devint ensuite roi de Babylone, en succédant à son beau-frère Evilmarduk. 
Options de nos traductions :

Après deux inaccomplis invertis à la $3 e$ pers. pl., le $* M$ achève le vs 4 par un

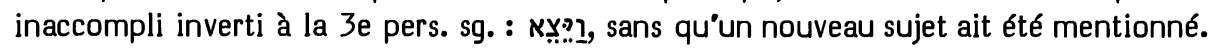

Aucune de nos traductions ne respecte ce singulier. En s"inspirant de 52,7, J traduit : "ils prirent (le chemin)", $\mathrm{J3}$ disant suivre la $* V$ et la $* \mathrm{~S}$, alors que $\mathrm{J12}$ disaient conjecturer. Sans note, RSV traduit : "and they went", RL : "und entwichen", NEB : “They escaped” et TOB : “et ils s”éloignèrent”.

Origine de la correction :

La mise de ce verbe au pluriel ne constitue pas une initiative de la part de RL, car Luther offrait ici : "und zogen" qu'il avait copié dans la traduction des Prédicants de Zurich: "unnd zugend". Zwingli (perrexeruntque), dont le commentaire nous montre qu'il était surtout préoccupé par la traduction des deux mots suivants, avait adopté spontanément ici la forme plurielle que la $* \mathrm{~V}$ donne à ce verbe. Olivetan a fait de même : en traduisant "et sont yssus", il recopie la traduction que Le Fèvre d'Etaples avait donnée de la ${ }^{*} V$. La traduction de Zwingli a été conservée par Jud, de même que la forme plurielle d’Olivetan a été conservée par Rollet, Estienne, Châteillon et les Pasteurs de Genève. Ont respecté le singulier du ${ }^{*} M$ au XVIe siècle : Pagnini et ses rééditions, Brucioli, Münster, Vatable, Ge, Tremellius et $\mathrm{KJ}$.

Giesebrecht a proposé de lire ici, selon 52,7, ובירֶ, suivi en cela par Duhm, Ehrlich, Nötscher, Rudolph, Steinmann, Weiser et les apparats de HSAT2, BH3S et Cent; alors que Penna et les apparats de HSAT34 et de BH2 lisent

Les témoins anciens :

De Rossi a lu cette dernière leçon en 10 mss auxquels, en ses Scholia, il en ajoute deux autres. Cependant les témoins du texte tibérien classique appuient unanimement la lectio difficilior constituée par le singulier.

Le ${ }^{*} G$ ancien omet les vss 4-13 que les recensions origénienne et antiochienne

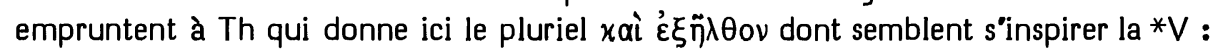
"et egressi sunt" et la *S : ונפקו. Constatant que l'Arabe de la polyglotte de Londres porte ici le pluriel "et ils sortirent", de Rossi en conclut qu’à une époque plus ancienne, le ${ }^{*} G$ contenait ces versets avec cette variante. Nous avons montré ci-dessus (p. 665) que ces ajoutes arabes tirées du ms Selden proviennent en réalité d'une version faite sur la*S.

Le *T ונפק appuie le *M.

\section{Choix textuel :}

Les deux verbes précédents sont au pluriel, ayant pour sujets "Sédécias roi de Juda et tous les hommes de guerre" et ces sujets sont repris au début du vs 5 comme antécédents du complément "derrière eux". Ce contexte suggère ici une mise de ce verbe au pluriel. C'est ce qu'ont fait la leçon minoritaire du $* M, T h$, la $* V$ et la*S, tous ces témoins se contentant de reprendre ici le verbe précédent ductions qu'ils en avaient données. Le verbe singulier du *M (appuyé seulement par le *T) mérite donc d’être respecté à titre de lectio difficilior. 
Ce passage a deux parallèles, l'un en $2 \mathrm{R} 25,4$ et l'autre en Jr 52,7. En CT1, $423 \mathrm{~s}$, nous avons traité des relations entre les divers correspondants de ce mot. Nous y avons montré que Jr 39,4 est un essai de clarification de 2 R 25,4 dont le singulier

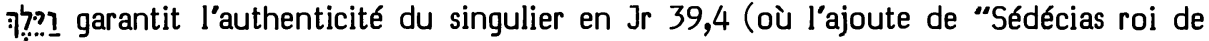
Juda" a eu justement pour but de fournir un sujet à ce singulier). Ces parallèles nous offrent donc la possibilité de retracer la genèse littéraire de notre texte en apportant une confirmation à la conclusion atteinte par la critique textuelle.

Pour ces divers motifs, le comité a attribué à la leçon du *M 5 "B" et 1 " $C$ ".

Interprétation proposée :

On peut, avec Vatable, expliciter "le roi" comme sujet de ce verbe : "et (le roi) sortit en direction de la Araba".

39,8 $\left.22^{\circ}\right)[B]$ M Th g T / exeg : g S pl / lacun : G

Options de nos traductions :

Lorsque Jr 39,8 énumère les bâtiments brûlés par les Chaldéens lors de la prise de Jérusalem, il mentionne "la maison du roi a été traduite par RSV : "and the house of the people".

Se fondant sur la *S pour mettre le premier substantif au pluriel, J traduit : "et les maisons des particuliers". De même, RL traduit : "und die Häuser der Bürger" et TOB : "(Quant...) et aux maisons bourgeoises".

Entre le premier et le deuxième substantifs, NEB (selon Brockington) insère par conjecture : יהוה וְאֶת et traduit : "and the house of the LORD and the houses of the people".

Origines des corrections :

Lisant dans le commentaire de Radaq que le mot maison a ici valeur de pluriel, car il est à prendre en un sens collectif, Pagnini traduisait : "\& domos populi". Ont adopté cette traduction par un pluriel : Prédicants, Zwingli, Luther (“und der Bürger heuser"), Brucioli, Münster, Olivetan, Rollet, Estienne, Jud, Châteillon, Ge, Pasteurs, $\mathrm{KJ}$. Ont traduit par un singulier : Calvin (en notant que le sens est pluriel) et Arias Montano. Tremellius traduit par un pluriel en notant que l'hébreu a le singulier.

Une correction du premier substantif en fondant sur la $* S$ ) et adoptée par Venema, Michaelis (Observationes), Oort, Duhm, Volz, Nötscher, Penna, Weiser et les apparats de SBOT, HSAT34, BH2 et Cent.

L'insertion retenue par NEB avait été proposée par Ewald, Cornill, Rudolph et Bright. Les apparats de BH3S hésitent entre ces deux corrections.

Les témoins anciens :

Le *M n'a pas de variante sur ce point.

Le *G omettant les vss 4-13, la recension origénienne porte ici tòv ö́xov toṽ $\lambda \alpha \circ$ ṽ (attribué à $T h$ ) à quoi correspond la $* \mathrm{~V}$ (domum vulgi), alors que la recension

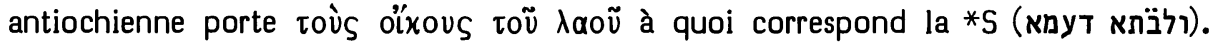

Le *T (וית בית עמא) traduit littéralement le *M. 
Choix textuel :

Le singulier du $* M$ constitue une lectio difficilior bien appuyée par Th, la *V et le *T. Le comité lui a attribué la note "B".

\section{Interprétation proposée :}

Du fait que le temple est mentionné dans les parallèles de $2 \mathrm{R} 25,9$ et de Jr 52,13, les exégètes suggèrent périodiquement d'interpréter ici "la maison du peuple" comme une désignation du temple. Cela a été proposé par Abravanel, Ehrlich (Miqra, puis abandonné en Randglossen) et Landsberger (House 152).

Mieux vaut commencer par noter que dans les parallèles en question le temple précède "la maison du roi"; alors que le fait que "la maison du peuple" suive cette expression amène à penser que cela tient la place de ce qui suit cette expression en ces parallèles, c'est-à-dire de "et toutes les maisons de Jérusalem et toute maison de grand" (cf. CT1, 424s). Par rapport à cette dernière formule, la formule "et la maison du peuple" usitée par Jr 39,8 est littérairement secondaire. De cela nous avons un indice dans une tendance que manifeste le contexte immédiat de Jr 39,8-10, celle d'introduire le mot ay en des lieux où les deux parallèles l'ignorent : ainsi à la fin de 39,9a où העם הנשארים (emprunté au début de 9a) fait contraste avec ההמון 2 R 25, 11 et iמדלת tient la place de 52,15, ou encore en 39,10 où ומן־העם האדלים de 2 R 25,12 et de ומדלות Je 52,16. Il y a donc bien des chances que l'expression soit ici aussi littérairement secondaire. Mais cela nous indique en même temps qu'elle a toutes les chances de constituer la forme originelle de ce texte de 39,8.

Du fait que, pour ces versets, le rédacteur du ch. 39 abrège beaucoup sa source, il est vraisemblable qu'il s'agit pour lui d'opposer l'ensemble des demeures du peuple à la demeure du roi et qu'il faut donc donner à ce singulier valeur de collectif ainsi que l'ont proposé Radaq et Joseph ibn Nahmias.

On traduira donc, comme l'avait fait Pagnini, "et les demeures du peuple"; en indiquant en note, comme l'a fait Tremellius, que l'hébreu a ici un singulier ayant probablement valeur de collectif.

39,9 39 (2) [A] M Th g S T // lacun : G

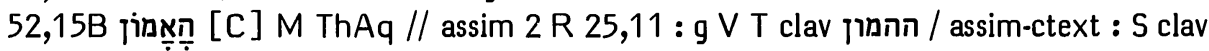
aע / homarc : G om

Options de nos traductions :

Dans les trois parallèles ( 2 R 25,11; Jr 52,15 et Jr 39,9) on a d'abord en ce vs : ואת יתר הֶהִמוֹן : Plus loin dans le même verset, 2 R 25,11 offre

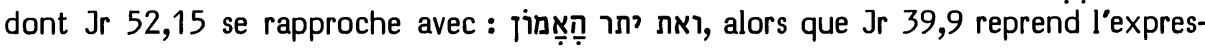
sion pạ laquelle ce vs avait commencé.

1/ 39,9 : En sa reprise, cette expression a été traduite par RSV : “and the people who remained", par TOB : "bref, ce qui restait de la bourgeoisie"; alors que RL a gardé la traduction large de Luther : "alle miteinander".

J a assimilé à 52,15: "et ce qui restait des artisans". NEB a fait de même : "and any remaining artisans". 


\section{2/52,15:}

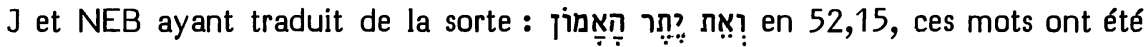
traduits par RSV : "together with the rest of the artisans", par RL : "und was übriggeblieben war von den Werkleuten" et par TOB : "et le reste des artisans".

Origine de la correction en 39,9:

Ewald a assimilé ce texte à son parallèle de $2 \mathrm{R} 25,11$. Mais une assimilation au parallèle de Jr 52,15 a été requise par Hitzig, Giesebrecht, Duhm, Rudolph, Penna (?), Weiser, Bright et par les apparats de $\mathrm{BH} 235$ et Cent.

Les témoins anciens :

1/ 39,9 : Le ${ }^{*} G$ ancien omet les vss 4 à 13. La leçon du *M est attestée par tous les autres témoins, c'est-à-dire : les recensions origénienne et antiochienne en une ajoute attribuée à $T h$, la $* V$, la ${ }^{*} S$ et le ${ }^{*} T$.

2/ 52,15: Peut-être par homéoarcton, le *G ancien a omis presque tout ce vs et, entre autres, ces mots; alors que la recension antiochienne a assimilé au parallèle de

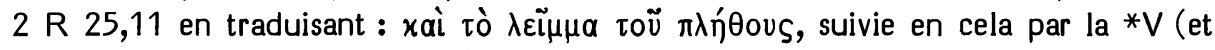
ceteros de multitudine) et le *T (וית שאר המונא).

La *S (ושרכא דעמא) a assimilé au début du vs (ainsi que le *M avait fait en 39,9).

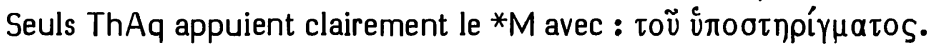

\section{Choix textuels :}

En 39,9 où tous les témoins sont unanimes (à part le ${ }^{*} G$ qui omet le passage), il nous faut attribuer au *M la note " $A$ " (quoique $J$ et NEB s"en éloignent).

Par contre, en 52,15 toutes nos traductions sont fidèles au $* M$, alors que les témoins anciens sont très dispersés, la leçon ההמון étant bien attestée par la recension antiochienne et la $* V$ (qui dépendent probablement de Sym) ainsi que par le *T. Cependant la leçon האמון du *M est suffisamment attestée par ThAq pour que l'on résiste à la tentation d'assimiler au parallèle de $2 R 25,11$. C'est pourquoi le comité a conservé ici la leçon du * $\mathrm{M}$ en lui attribuant 4 "C $\mathrm{C}$ " et 2 " $\mathrm{B}$ ". Nous avons cependant expliqué en $\mathrm{CT} 1,425$ pourquoi elle a peu de chances de représenter l'état littéraire primitif de ce passage.

Interprétation proposée :

En 39,9 : "et le reste de la population qui avait été laissée".

En 52,15: "et le reste des artisans". 


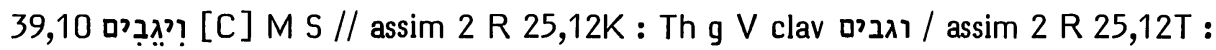
$T$ / lacun : $G$

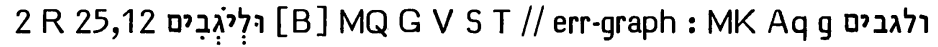

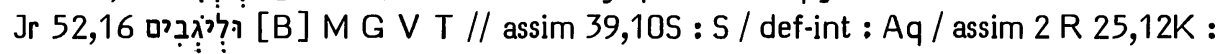
Th

\section{Options de nos traductions :}

$1 / 2$ R 25,12 et Jr 52,16: Il est dit que le chef des gardes (Nebuzaradân) laissa une partie des petites gens du pays (2 R 25,12 offrant pour le dernier mot un ketib ולגבים). RSV traduit en ces deux endroits: "to be vinedressers and plowmen", J : "comme vignerons et (comme) laboureurs", RL : "Weingärtner und Ackerleute", NEB : "to be vine-dressers and labourers", TOB : "pour cultiver les vergers et les champs".

2/ Jr 39,10 : Après avoir dit que Nebuzaradân laissa au pays de Juda une partie

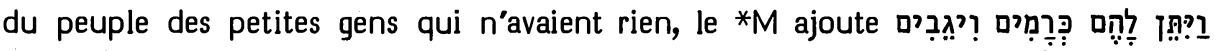

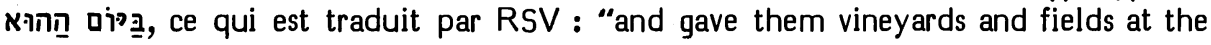
same time", par J : "en même temps ... il leur distribua des vignes et des champs", par RL : "zur selben Zeit ... und gab ihnen Weinberge und Felder" et par TOB : "et c'est alors qu'il leur donna des vergers et des champs".

Selon Brockington, NEB vocalise les 3e et $4 \mathrm{e}$ mots duit : "At the same time ... and made them vine-dressers and labourers."

Origine de la correction :

Cornill assimile les 6 mots que nous avons cités de Jr 39,10 aux deux des parallèles que nous avons cités.

Ehrlich (Randglossen) propose la correction que NEB retiendra en y ajoutant celle de לה en en

Les témoins anciens :

1/ 2 R 25,12 : Le qeré du *M est appuyé ici par le *G antiochien (عiৎ̧ ả $\mu \pi \varepsilon$ -

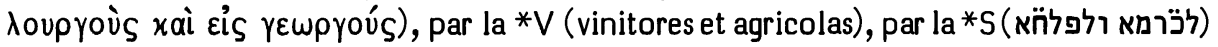
et par le *T (למהוי מפלחין בחקלין ובכרמין).

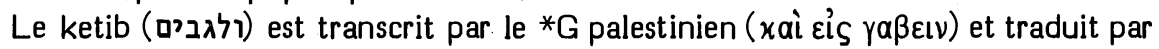

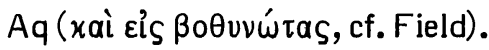

2/ Jr 52,16: La traduction du *G est identique à celle que le ${ }^{*} G$ antiochien donne en $2 \mathrm{R} 25,12$.

Le ketib de 2 R 25,12 transparaît ici dans la leçon גאבים que Syh attribue à Th

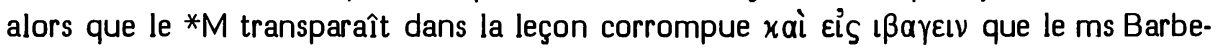
rini attribue à Aq.

Le * $M$ est traduit par la *V (in vinitores et in agricolas) et par le *T (identique à $2 \mathrm{R} 25,12)$.

La *S (לכולמא ולפולחנא) offre une contamination des traductions qu'elle a données aux deux parallèles. 
3/ Jr 39,10: Le *G omet les vss 4 à 13. Les recensions origénienne et antio-

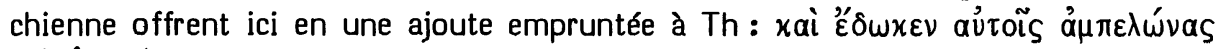

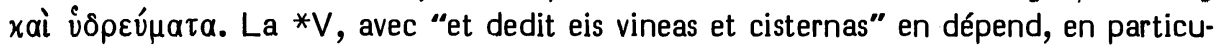

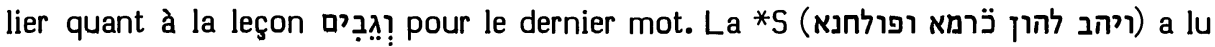
le *M. Le *T assimile sa traduction à celle qu'il a donnée dans les deux parallèles.

\section{Choix textuel :}

La forme littérairement originelle de ce passage est vraisemblablement celle que le *M donne en $\mathrm{Jr} 52,16$ et que le qeré du *M donne en $2 \mathrm{R} 25,12$, forme qui est appuyée par le ${ }^{*} G$ de Jr 52,16, le ${ }^{*} G$ antiochien et la $* S$ de $2 R$ 25,12, ainsi que la $* V$ et le *T en ces deux endroits.

Le ketib du ${ }^{*} M$ en $2 R$ 25, 12 semble être une corruption aboutissant à remplacer cette racine, difficile à situer, par un mot plus courant.

Le comité a attribué la note "B" à la leçon du *M en 2 R 25,12 et en Jr 52,16.

En Jr 39,10 la forme littéraire originelle qu'offraient les deux parallèles a subi des surcharges rédactionnelles qu'il faut respecter. La seule question qui se pose au niveau textuel est de savoir si וְִ̣ qui a été lu ici par Th (dont les recensions origénienne et antiochienne ainsi que la *V dépendent) doit être préféré à a le ${ }^{*} M$. Etant donné le jugement que nous avons porté sur le qeré et le ketib du ${ }^{*} M$ en 2 R 25,12 , le comité a préféré la leçon du *M à laquelle il a attribué 3 " $B$ ", 2 "C $C$ " et 1 " $D$ ".

Interprétation proposée :

吼 ę et le participe qui en dérive désignent une plantation d'arbres fruitiers ( $y$ compris la vigne) et ceux qui la cultivent. Quant à ạ?, Schwarzenbach (Terminologie 90s) a bien montré que c'est le sens de "champ" (le participe correspondant signifiant ceux qui le cultivent) qui lui convient le mieux.

39,11 בB [ ] M Th g T // facil-synt : Sym g V S / lacun : G

\section{Options de nos traductions :}

Selon le *M, le verbe ments : le premier (Jérémie) étant introduit par -לy et le second (Nebuzaradân) étant introduit par Tב. Cette semi-préposition est traduite par RSV : “through (Nebuzaradan)" et par TÓB : “(prit des dispositions) dont il confia l'exécution à (Nebouzaradân)".

Selon Brockington, NEB omet la semi-préposition, avec la $* V$, quand elle traduit : "to (Nebuzaradan)". J dit conjecturer en traduisant de même : "à (Nebuzaradân)". RL traduit de même au datif (comme le montre l'apposition qui le suit) le complément "Nebusaradan".

Origine de la correction :

Dans la ligne de la *V, “Nebuzaradân” a été simplement traité comme un complément au datif par Prédicants, Zwingli, Luther, Jud, Châteillon, Tremellius. La 
traduction française de Châteillon use de la préposition "au (senêchal N.)", alors que Ge use de "unto (N.)" et KJ de "to (N.)".

La semi-préposition a été traduite "per manum" par Pagnini, Münster et Calvin, "per la mano" par Brucioli. Les seules traductions un peu élaborées qui ont été données au XVIe siècle sont celles de Olivetan (suivi par Rollet et Estienne) : "(avait fait commandement), par la commission donnée à (N.)" et des Pasteurs de Genève : "(avait fait un mandement) avec commission donnée à (N.)".

Sans s'exprimer sur ce point, bon nombre d'exégètes ont négligé la semi-préposition. Son omission a été formellement requise par les apparats de HSAT34, BH3 et Cent.

\section{Les témoins anciens :}

Les vss 4 à 13 sont absents du *G ancien.

La leçon T2ב̣ du *M a été retenue par le *T et traduite littéralement par Th ( $\left.X \varepsilon \iota^{\prime}\right)$, traduction adoptée par l'ajoute de la recension origénienne.

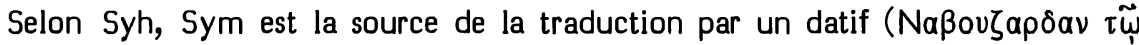
á $\rho\lfloor\mu \alpha \gamma \varepsilon i \rho \omega)$ que comporte l'ajoute de la recension antiochienne. La *V (Nabuzaradan magistro) et la *S (לנבוזרדן) ont traduit de même.

Choix textuel :

Considérant la traduction par un datif comme une facilitation syntaxique, le comité a attribué ici au *M la note "B".

Interprétation proposée :

Comme Hitzig l'a bien vu, Nebuzaradân reçoit l'ordre et est responsable de son exécution à laquelle il va veiller avec la collaboration des autres "grands du roi de Babylone" (vss 13s).

On peut traduire comme TOB : “Au sujet de Jérémie, Nabuchodonosor ... prit des dispositions dont il confia l'exécution à Nebuzaradân..., lui enjoignant :"

\section{ויקחהו 40] M S T // transl : AqSym V / abr-styl : G clav}

\section{Options de nos traductions :}

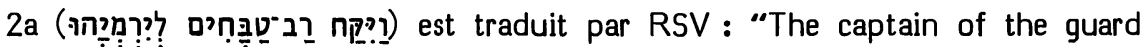
took Jeremiah", par J12: "Le commandant de la garde, ayant (donc) pris à part Jérémie", par RL : "Als nun der Oberste der Leibwache Jeremia hatte zu sich holen lassen" et par $\mathrm{J3}$ : "Le commandant de la garde prit donc Jérémie".

Sans note, TOB allège en : "Le chef de la garde personnelle l'avait donc pris en charge".

Selon Brockington, NEB vocalise nקי? q quand elle traduit : “... and took it upon himself to say to Jeremiah".

\section{Origines des corrections :}

L'allègement réalisé par TOB avait été proposé par Cornill qui, estimant inadmissible la construction au datif du complément et se fondant sur le ${ }^{*} G$, lisait à la place 


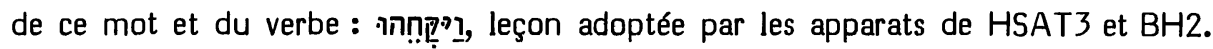

La conjecture vocalique de NEB se situe dans la ligne de certaines corrections de יקח en proposées par Driver (Misreadings 235s, Roots 415).

Les témoins anciens :

Ont reproduit dans leur traduction le 'lamed' de l'hébreu : la *S et le *T. Ont traduit ce complément par un accusatif : AqSym et la*V.

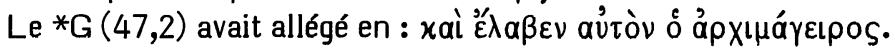

Choix textuel :

Déjà en 37(44),21; 38(45),6.13 le *G avait remplacé le nom de Jérémie par un pronom. En ce début du ch. 40(47), le ${ }^{*} G$ abrège beaucoup : au vs 1 , il n'a rien qui

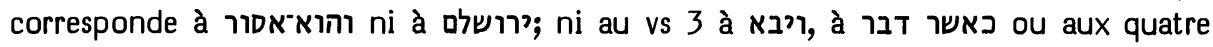
derniers mots du vs. Ici, il est possible que l'allègement ait été motivé par une gêne à l'égard de cet emploi du datif.

Le comité a attribué à la lectio difficilior du *M la note " $B$ ".

Interprétation proposée :

Le narrateur avait situé au vs précédent la parole dite par le Seigneur à Jérémie comme une parole lui ayant été adressée après que Nebuzaradân l'eût renvoyé de Rama, l'ayant pris alors qu'il se trouvait enchaîné parmi ceux qui étaient en route vers la déportation. Puis, en 2a, le narrateur traite ce dernier événement comme le point de départ d'un bref récit (vss 2-6) racontant les propositions faites alors par Nebuzaradân à Jérémie et comment Jérémie choisit d’aller demeurer à Miṣpa auprès de Godolias.

Dans ce contexte, le "lamed" introduisant le complément "Jérémie" a été interprété par H.ayyuj (Kokovzov 33) comme l'équivalent d'une particule d'accusatif. Abulwalid (Luma 38,14) fait de même en citant de nombreux cas semblables. Gesenius/ Kautzsch cite encore plus de cas de ce rattachement lâche du complément d'objet au verbe. Giesebrecht a suggéré que nous avons ici une construction prégnante avec le verbe קרא sous-entendu. On aurait alors : "( $\mathrm{L}^{\prime}$ )ayant donc pris, le commandant de la garde (fit appeler) Jérémie et lui dit :"

40,5A [C] [C] M // lic : Th, Sym, V, S, T / abr-elus : G om

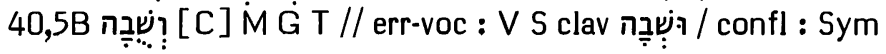

Options de nos traductions :

Au vs 4, le commandant de la garde a proposé à Jérémie de l'accompagner à Babylone ou de se rendre là où il le voudrait dans le pays. Le vs 5 commence par :

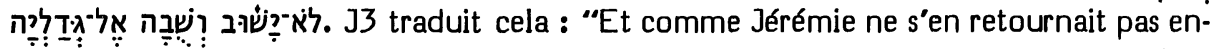
core, il ajouta: 'Tu peux te tourner vers Godolias'." Ne retouchant que très légèrement Luther, RL donne : "Denn weiter hinaus wird kein Wiederkehren möglich sein. Darum magst du umkehren zu Gedalja".

Disant omettre "et il ne retournait pas encore", $\mathrm{J12}$ traduisaient : "Donc tu peux te tourner vers Godolias". 


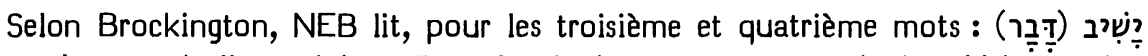

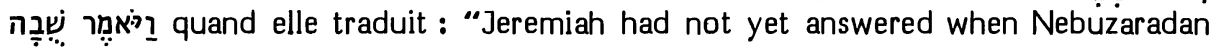
went on, "Go back to Gedaliah'."

TOB dit suivre le ${ }^{*} G$, la ${ }^{*} S$ et le $* T$ et supposer un déplacement de deux mots quand elle traduit : "Si tu ne veux pas rester avec moi, retourne donc auprès de Guedalias".

\section{Origines des corrections :}

Disant que les 3 premiers mots sont absents du ${ }^{*} G$, Cappel (Notae 532) les estime superflus, suivi en cela par Movers (20, note 1 ). Ils sont omis comme glose corrompue par Giesebrecht, Oort, Duhm, Cornill, Condamin, Bright, ainsi que par SBOT, HSAT234 et Cent de qui 312 dépendent.

La correction de NEB vient de Ewald, Nägelsbach et Knabenbauer. Sa source lointaine semble être une glose d’Estienne sur sa Bible de 1557: "Adhuc enim ille non responderat se velle reverti". Cela a suggéré une interprétation de $5 \mathrm{~A}$ en "Et il ne répondait pas encore" à Vogel (cité par Doederlein sur Grotius), Dathe (cité par Schnurrer), Michaelis (Observationes), Henderson. Schleusner (éditant les Observationes de Michaelis) a objecté qu'il faudrait alors un hifil suivi du complément Mais König (Syntax §383b) estime que le contexte permet d'user du qal dans le sens du hifil. Ajoutons que le verbe (au hifil) est usité sans le complément דבר au sens de "répondre" en Est 4,13.15. Notons que Menahem de Posquières cite déjà cette interprétation.

La traduction de TOB avait déjà été proposée par Grotius, se fondant sur le *T.

Les témoins anciens :

1/ $5 \mathrm{~A}$ : Pour les 22 mots qui commencent par וٕ̣ du vs 4 et s'achèvent par $5 \mathrm{~A}$,

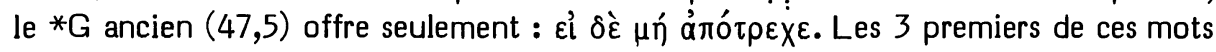
résument les 6 premiers des 22 mots susdits, alors que le $4 \mathrm{e}$ mot du ${ }^{*} G$ traduit le dernier mot du vs 4 selon le $* M$. Le ${ }^{*} G$ a donc omis $5 A$, tandis qu'il abrégeait tout ce qui précède.

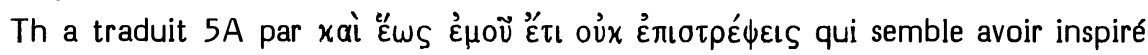
la *V traduisant : "et mecum noli venire".

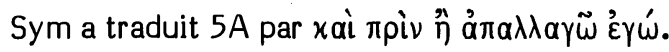

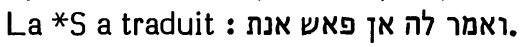

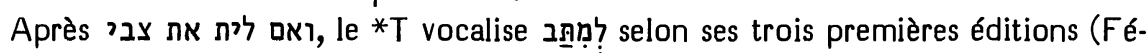
lix de Prato, Ben Hayim, polyglotte d’Anvers), un ms yéménite et le ms Montefiore. Avec לִ לִמִ̣, le ms Urbinates 1 se rattache à cette leçon "habiter" qui semble ici la leçon primitive du *T et qui parâit appuyée par une graphie pleine en une citation faite par Radaq. Cependant une vocalisation לִמְּ (= revenir) est donnée par le ms Reuchlin et deux mss yéménites. La polyglotte de Londres édite ici לִ לִ לִ avec le même sens.

2/ 5B : Le *M est appuyé ici par xà ảváotpeфov du *G et par ותוב du *T.

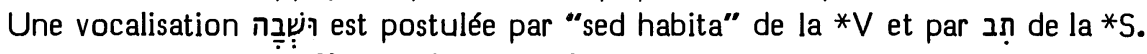
Avec הפוך עמרו, Sym offre une leçon gonflée, si l'on en croit Syh. 


\section{Choix textuel :}

1/5A: Toutes les versions ont essayé d'intégrer cette phrase dans le discours de Nebuzaradân en tâtonnant et en prenant de grandes libertés.

A cause de leur éparpillement, aucune ne permet d'accéder à une Vorlage qui pourrait rivaliser avec le $* M$ auquel le comité a attribué la note " $C$ " du fait de son isolement.

2/ 5B : La vocalisation de la *V et de la *S anticipe inutilement l'impératif qui va suivre (et que la ${ }^{*} S$ omet). D’ailleurs les prépositions distinctes qui, dans le ${ }^{*} M$, suivent ces deux impératifs confirment les vocalisations du ${ }^{*} M$. Aussi le comité a-t-il attribué ici au *M la note "C".

\section{Interprétation proposée :}

Alors que toutes les versions anciennes essayaient d'intégrer cette phrase dans le discours de Nebuzaradân, Yéfet ben Ely est le premier à attester une interprétation nouvelle. Citons-le selon le ms Hebr I 570 de la Bibl Saltykov-Shchedrin et selon le ms Orient 2503 de la British Library (le ms Orient 2504, quoique le plus ancien, étant ici mutilé) : “Il a été dit que ועודנו לא ישוב porte sur l'ennemi et que le commandant de la garde tranquillise Jérémie sur la perspective du retour de l'ennemi dans le pays. Et il a été dit que cela porte sur Dieu, c'est-à-dire que Dieu demeure encore irrité et que, pour le moment il n'est pas disposé à ce qu'ils soient libérés. Et il a été dit que cela porte sur Israël et que le commandant de la garde avait dit : tous ces fléaux sont venus sur ce peuple à cause de leurs fautes et, après cela, ils ne sont pas revenus vers Dieu et être avec eux n'est pas un sort désirable. Et il a été dit enfin que cela n'est pas une parole du commandant de la garde, mais que c'est seulement une parole du rédacteur qui fait savoir que Jérémie n’était pas retourné selon l'avis du commandant des gardes qui lui avait proposé de se rendre à Babylone, ni non plus vers un autre lieu. Et lorsque celui-ci constata qu'il n'était pas disposé à sortir du pays d'Israël, il reprit la parole pour lui dire : Mais, si tu le veux, rends-toi auprès de Gedalyahu et sois dans son groupe".

Cette dernière interprétation a été reprise par Radaq et par Menahem de Posquières, puis par Schnurrer, Luzzatto et Keil. Il faut préciser que le verbe שרוב signifie vraisemblablement ici "se retirer". Quant à l'expression לאוֹ לא, BDB (728b) la considère comme l'équivalent de . ou : "et avant qu'il se fût retiré, il ajouta : 'retire-toi auprès de Godolias". Pour Jérémie, "se retirer" signifierait refuser d'accompagner Nebuzaradân à Babylone. Jérémie hésite à exprimer ainsi son refus de l'offre généreuse qui lui a été faite. Mais Nebuzaradân, constatant son manque d'enthousiasme, veut le mettre à l'aise en lui intimant comme un ordre ce qu'il pressent être l'objet de son désir. 


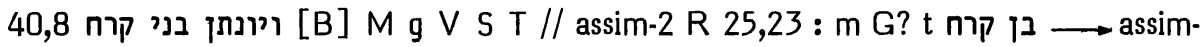
40,8M : g v clav בן קרח ויונתן

Options de nos traductions :

Parmi ceux qui vinrent trouver Godolias à Mișpa, 8b mentionne : . Ces noms sont transcrits normalement par RL, NEB, TOB et J3.

A leur place, J12 donnent seulement : "Johanan, fils de Qaréah", disant se fonder sur 6 mss hébreux, le *G et les passages parallèles pour omettre: "et Jonathan". RSV traduit de même : "Johanan the son of Kareah".

Origine de la correction :

Considérant "Jonathan" comme une fausse leçon issue de "Johanan" et constatant que le ${ }^{*} G$ et le parallèle de 2 R 25,23 ont ici seulement : "Johanan fils de Qaréah", Ewald adopte cette leçon, suivi en cela par Giesebrecht, Ehrlich (Miqra), Cornill, Condamin, Volz, Schmidt, Nötscher, Penna, Bright et les apparats de SBOT, HSAT234, BH23 et Cent.

\section{Les témoins anciens :}

De Rossi mentionne deux mss de Kennicott et la première main de trois des siens (auxquels il en ajoute un autre en ses Scholia) comme omettant יונתן et lisant ensuite ב; cette dernière variante se trouvant aussi attestée par la première ou la seconde main de 26 autres mss et, dit-il, par l'édition princeps des Prophètes (Soncino 1486). Notons pourtant qu'elle ne figure pas dans l'exemplaire de cette édition que possède le Jewish Theological Seminary de New York.

La séquence "et Johanan et Jonathan" est attestée ici par la mp du ms du Caire comme unique. Par contre la mp "7" que BHS donne sur "et Jonathan" ne figure pas dans le ms de Leningrad. Il s'agit d'une donnée extrapolée par Weil à partir d'une mm se référant à $1 \mathrm{Ch} 2,32$. Weil s'est inspiré de la mp “7" donnée ici par l'édition Ben Hayim.

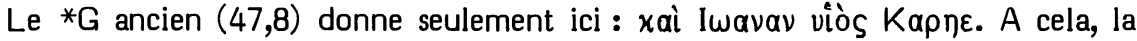
recension antiochienne ajoute : $x a \grave{~ I ~} \omega \nu \alpha \theta \alpha v$, alors que la recension origénienne

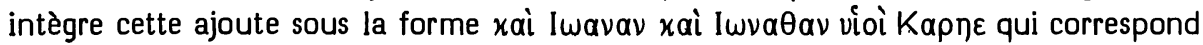
exactement au $* M$.

Il est intéressant de noter que les premières éditions de la *V, en accord avec des mss de l'université de Paris, portaient ici : "\& Iohanan filius Caree \& Ionathan", qui correspond à la recension antiochienne du ${ }^{*} G$, alors que les mss anciens et les éditions suivantes portent : "et Iohanan et Ionathan filii Caree", identique à la recension origénienne et au *M.

La ${ }^{*}$, elle aussi, y est identique, alors que la tradition textuelle du $* T$ se divise entre les trois leçons qu'atteste la tradition textuelle du $* M$, le ms Urbinates 1 apportant son appui à celle du *M tibérien classique.

Choix textuel :

La leçon authentique du *M étant appuyée par la recension origénienne et par la * $V$, on peut la considérer comme caractéristique du texte protomassorétique. 
Il se peut qu'il y ait à l'origine de cette leçon une conflation de deux formes du nom du "fils de Qaréah". La tradition textuelle du *G de 2 R 25,23, divisée entre l $\omega \nu \alpha \nu$ et I $\omega \alpha \theta \alpha \nu$, semble d'ailleurs hésiter entre elles.

Il est possible que le ${ }^{*} G$ de $\mathrm{Jr} 40,8$ ait conservé ici l'état littérairement originel, mais il est tout aussi possible que les variantes textuelles de Jr 40,8 aient toutes plus ou moins assimilé à la forme "Johanan fils de Qaréah" qui se trouve dans le parallèle de 2 R 25,23 et dans la suite de l'histoire (Jr 40,13-16; 41,11-16; 42,1.8; 43,2.4.5). Notons, d'autre part, que ce parallèle de 2 R 25,23 semble éliminer d'autres données onomastiques fournies par Jr 40,8 lorsqu'il mentionne, juste après: "et Seraya fils de Tanhumèt, le Netophatite" au lieu de "et Seraya fils de Tanhumèt, et les fils de Ephaï le Netophatite".

En attribuant au *M la note " $\mathrm{B}$ ", le comité a voulu éviter que l'on assimile cette leçon rare à ses parallèles.

Interprétation proposée :

"Et Yohanân et Yonatân, les fils de Qaréah."

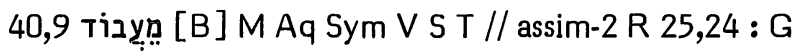

Options de nos traductions :

est traduit par RSV : “Do not be afraid to serve the Chaldeans", par J12: "Ne redoutez pas d'être soumis aux Chaldéens", par RL: "Fürchtet euch nicht, den Chaldäern untertan zu sein", par TOB : "Acceptez sans crainte le régime des Chaldéens" et par 33 : "Ne craignez pas de servir les Chaldéens".

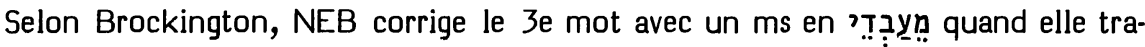
duit : "Have no fear of the Chaldaean officers".

\section{Origine de la correction :}

Thenius a estimé que la leçon 'ي du 3e mot est littérairement plus originel. Parmi les commentateurs de Jérémie, cette leçon a été choisie ici par Duhm, Cornill, Condamin, Volz, Schmidt, Nötscher, Penna et les apparats de HSAT34 et BH23.

Les témoins anciens :

L'apparat de Kennicott attribue la variante susdite à son ms 224 qui est le 2e ms de Königsberg. Pourtant, Lilienthal (286), dans le commentaire détaillé qu'il donne des variantes de ce ms, ne mentionne pas celle-ci.

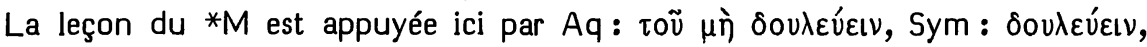
la *V : "servire", la *S : למלמפלח : et le *T.

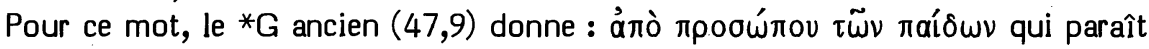
s'inspirer du parallèle de 2 R 25,24. 
Choix textuel :

En ce parallèle, il est frappant de noter que le ${ }^{*} G$ palestinien offre rápoóov qui semble traduire מעבר (sans 'yod' final), alors que le *G antiochien se contente de ámó pour traduire tout ce mot.

Etant donné que le jugement sur la priorité littéraire des formes offertes par les deux parallèles est très incertain, nous avons là un motif de plus pour ne pas les assimiler. C'est pourquoi le comité a attribué au *M la note " $\mathrm{B}$ ".

Notons d'ailleurs qu'en 41,18, il sera dit que les réfugiés judéens fuient en Egypte parce qu'ils craignent "les Chaldéens", et non "les serviteurs des Chaldéens".

Interprétation proposée :

A ces résistants de la veille qui craignent les représailles du vainqueur, Godolias, voulant les encourager à déposer les armes, déclare: "Ne craignez pas de vous soumettre aux Chaldéens." Il n'y a pas là de double emploi avec ce qui suit et qui insiste de façon précise sur les initiatives qu'ils doivent prendre: "Demeurez dans le pays, soyez soumis au roi de Babylone et vous vous en trouverez bien". Il ajoute ensuite (vs 10) que lui, Godolias, responsable "devant les Chaldéens qui vont venir chez nous", leur ordonne de faire les récoltes et de retourner s'établir dans leurs villages.

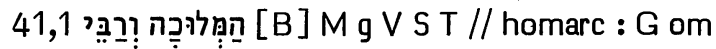

Options de nos traductions :

Il est raconté que vint vers Godolias quelqu'un qui nous est présenté comme :

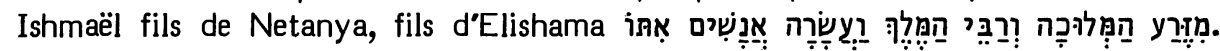

RSV, RL et TOB ont compris les $3 e$ et $4 \mathrm{e}$ mots comme qualifiant Ishmaël : "I'un des grands du roi", alors que J3 a traduit : "avec des grands du roi".

Selon Brockington, NEB s'est fondée sur le ${ }^{*} G$ pour omettre ces deux mots.

Origine de la correction :

Movers (5) a vu en ce $3 e$ et ce $4 \mathrm{e}$ mots une leçon marginale tentant d'expliquer ceux qui les précèdent. $A$ titre de glose absente du ${ }^{*} G$, ils ont été omis par Ewald1 (alors que Ewald2 les rétablit), Hitzig, Graf, Nägelsbach (hésitant), Giesebrecht, Oort, Duhm, Cornill, Ehrlich (Randglossen), Volz, Schmidt, Nötscher, Rudolph, Penna, Steinmann, Bright, ainsi que par les apparats de SBOT, HSAT2, BH3S et Cent.

\section{Les témoins anciens :}

Le *M a été traduit littéralement par la *S : ורורבני מלכא : le *T : ורבי מלכא et la *V : "et optimates regis". Notons ici que l'édition princeps et celles qui l'ont suivie (par exemple, les éditions Froben 1495 et Gadolo 1495) donnaient pour le premier substantif "optimas", la leçon authentique ayant été rétablie par la polyglotte d'Alcala.

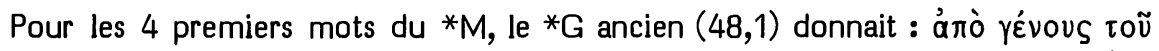

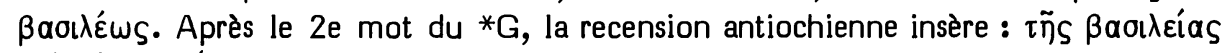

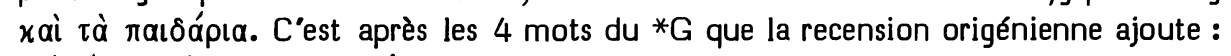

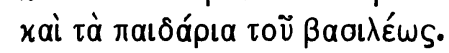




\section{Choix textuel :}

Comme le recenseur antiochien l'a bien compris, il semble que le ${ }^{*} G$ a omis le $2 e$ et le $3 e$ mots de l'hébreu par un homéoarcton. Il se peut cependant qu'une difficulté à interpréter l'articulation syntaxique des $3 \mathrm{e}$ et $4 \mathrm{e}$ mots ait joué aussi un rôle dans cet allègement translationnel. Notons qu'en ce contexte le ${ }^{*} G$ omet un grand nombre de données dont la répétition ou même la mention lui semble inutile, alors que ces répétitions constituent une caractéristique de ce récit. Par exemple, le *G se contente en ce récit de la première mention du père de Godolias (en 40,5 du *M), puis il omet la plupart des autres (en 40,6.7.9.14.16; 41,1.2.6.18). De même, le nom du père d'Ishmaël est mentionné dans la présentation la plus ample de son identité (en 41,1 du *M), mais il est omis dans la plupart des autres occurrences (en 40,14.15; 41,2.6.9.10.11.16.18). Il en va de même du nom du père de Yohanân (en 40,15.16; 41,13.16; 42,1.8; 43,4.5). Dans 41,1 qui nous occupe actuellement, le *G n'a tenu compte du toponyme "Mișpa" que dans la première de ses deux mentions. Pour ce qui est de l'allègement du contenu de la narration, notons qu'en 41,6, le *G ne traduit que 9 mots de l'hébreu sur 20; en 41,7, il en traduit 8 sur 16.

Si la non-traduction du $3 e$ et du 4 e mots de l'hébreu par le *G peut avoir un motif accidentel, leur présence dans le $* \mathrm{M}$ ne tient pas à un accident. C'est pourquoi le comité leur a attribué la note "B".

Notons en passant que 2 R 25,23-26 ne nous offre qu'un 'digest' très allégé de Jr 40,7 - 41,18. Il est normal que les deux mots qui nous intéressent y aient été omis.

\section{Interprétation proposée :}

Quatre interprétations sont possibles:

$1 /$ Ishmaël-fils-de-Netanya-fils-d'Elishama, de souche royale, ainsi que des grands du roi et dix hommes,

2/ Ishmaël ... ainsi que des grands du roi au nombre de dix hommes,

3/ Ishmaël ... qui appartenait à la souche royale et aux grands du roi, ainsi que dix hommes,

4/ Ishmaël fils de Netanya qui était fils de cet Elishama qui appartenait à la souche royale et aux grands du roi, ainsi que dix hommes.

Tout homme de souche royale n'est pas nécessairement l'un des "grands du roi", c'est-à-dire un haut fonctionnaire. Or on connaît un Elishama qui exerçait l'office de "Sopher" et est mentionné à ce titre comme le premier de "tous les princes" ( $\mathrm{Jr} 36$, 12) en la $5 e$ année de Yehoyaqim, c'est-à-dire en 604. Il n'est pas impossible que son petit-fils soit chef d'une bande de résistants insoumis dix-huit ans plus tard.

Yéfet ben Ely estime probable que cet "Elishama de souche royale" est celui qui constitue le point d'arrivée de l'étrange généalogie de 1 Ch 2,34-41. On sait en effet que, selon $1 \mathrm{Ch} 2,4 \mathrm{~s}$, l'aîné des fils survivants de Juda était Pereṣ dont l'aîné était Heșrôn. Or David descendait (1 Ch 2,9-15) de Ram, fils cadet de Heșrôn, alors que l'aîné de Heșrôn était Yerahméel dont la descendance est donnée en 1 Ch 2,25-33 avec une conclusion : "tels furent les fils de Yerahméel". Un maillon de cette descendance est constitué $(2,31)$ par un certain Sheshan dont il nous est dit qu'il eut pour fils Ahlaï. Mais une autre tradition, en 2,34, affirme qu'il n'eut pas de fils et qu'il donna sa fille en mariage à son serviteur égyptien et que c'est de cette lignée que, à la 13e 
génération, naquit un certain Elishama dont cette liste annexe a pour but d'authentifier la généalogie.

Richter (Untersuchungen 123s), sans connaître les commentaires de Yéfet sur Jérémie et sur les Chroniques, a identifié lui aussi l'Elishama de 1 Ch 2,41 avec celui de $\mathrm{Jr}$ 36,12. Rudolph, dans son commentaire des Chroniques, s'est opposé à cette identification (sans en proposer d'autre) en disant que le Chroniste n'aurait pas rapporté cette liste annexe si cet Elishama n'était pas un homme vivant à son époque, c'est-à-dire après 400 av. J.-C. Mais il faut peut-être mettre en question ce principe et admettre que le Chroniste a enregistré des matériaux chronologiques discordants dont certains avaient perdu leur actualité à son époque. Et il est fort possible que c'est la prétention de notre Ishmaël à se rattacher à cet Elishama de souche royale qui a valu à cette petite liste d'être conservée.

Si l'on reconnaît quelque vraisemblance à ces rapprochements, on s'accordera avec Ehrlich (Miqra) pour préférer la 4 e interprétation.

Précisons pour finir que le livre de Jérémie offre aussi en 39,13 le mot רַ comme équivalent de שִִ̣ (désignant les mêmes personnes en 39,3).

41,3b [B] M g T // praem-'waw' : m g V S t / abr-styl : G om

Options de nos traductions :

Après avoir dit au vs 2 qu'Ishmaël et ses hommes "frappèrent Godolias fils d'Ahiqam fils de Shaphan avec l'épée et il le mit à mort, lui que le roi de Babylone avait établi comme préfet dans le pays", le narrateur poursuit sa phrase au vs 3 en ajoutant d’autres catégories de personnes qu'ils mirent à mort en même temps : "et tous les juifs qui étaient avec lui, avec Godolias à Miṣpa, et les Chaldéens qui se trouvaient là; les hommes de guerre, Ishmaël (les) frappa". RSV, J, RL et TOB traduisent cela en allégeant plus ou moins cette phrase mal construite.

Selon Brockington, NEB se fonde sur le ${ }^{*} G$ pour omettre $3 b$, c'est-à-dire : אִ

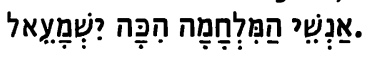

Origine de la correction :

La suppression de ces mots a été réalisée par Schmidt.

Les témoins anciens :

A l'occasion du cas précédent, nous avons montré que le ${ }^{*} \mathrm{G}$ (48) abrège ce qui lui semble inutile. On comprend donc que, dans le vs 2 , il omet : "fils d"Ahiqam fils de Shaphan avec l'épée et il le mit à mort" (évitant ainsi le passage du verbe pluriel au verbe singulier) et, dans le vs $3:$ "avec Godolias", et : "les hommes de guerre, Ishmaël les frappa".

Une conjonction a été ajoutée au début de $3 b$ par la recension antiochienne, $\mathrm{la} * V$ et la ${ }^{*}$ S. Cette conjonction est attestée aussi par une vingtaine de mss du $* M$ et par un certain nombre de témoins du *T(l'absence de conjonction y étant pourtant attestée par les premières éditions de Félix de Prato et de Ben Ḥayim, ainsi que par le ms Urbinates 1). 
La recension origénienne n'a pas cette conjonction. D'ailleurs, les mss d'Alep et de Leningrad garantissent son absence par une massore (Weil §2692) attestant que ce vs est (avec Ex 40,29 et Lv 7,3) l’un des trois où se succèdent ואת את ואת את

\section{Choix textuel :}

Même si 3b est une glose, il s'agirait d'une initiative littéraire et cela suffit pour que le comité attribue la note " $B$ " à la leçon du *M.

Il est cependant plus vraisemblable que c’est le *G qui a allégé après coup une rédaction redondante motivée par une incohérence du récit primitif. En effet, alors que 3a disait qu'Ishmaël et ses hommes massacrèrent tous les Judéens qui se trouvaient avec Godolias à Miṣpa, les vss 10-14 nous parleront du sort des réchappés de ce massacre. On comprend donc que le rédacteur ou un glossateur ancien ait senti le besoin de retoucher le récit en précisant (en 3b) que seuls les hommes de guerre avaient été victimes du massacre.

\section{Interprétation proposée :}

“Ce sont les hommes de guerre qu'Ishmaël a frappés", à insérer entre tirets, comme une précision ajoutée après coup.

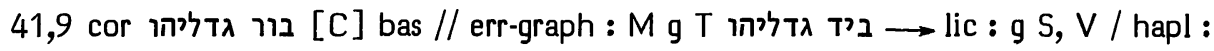
בור גדל בריחור

\section{Options de nos traductions :}

Le vs 9 commence par : "et la citerne où Ishmaël jeta les cadavres des hommes" et s'achève par : “c'est celle qu'avait faite le roi Asa contre Basha roi d'Israël. C'est elle que Ishmaël fils de Netanyahu remplit de massacrés". Entre ces deux passages, le

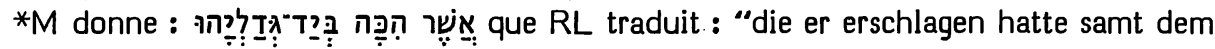
Gedalja" et NEB : "whose death he had caused by using Gedaliah's name".

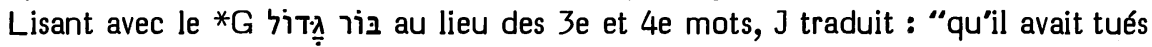
était une grande citerne". S"appuyant aussi sur le *G, RSV traduit: "whom he had slain was the large cistern" et TOB : "qu'il avait massacrés était la grande citerne".

\section{Origine de la correction :}

C'est Movers (32) qui, se fondant sur le *G, a proposé cette correction, suivi en cela par Hitzig, Graf, von Orelli, Giesebrecht, Oort, Duhm, Cornill, Condamin, Volz, Schmidt, Driver, Nötscher, Rudolph, Penna, Steinmann, Weiser, Bright et les apparats de SBOT, HSAT234, BH235 et Cent (plusieurs d'entre eux ajoutant des articles à ces mots).

\section{Les témoins anciens :}

Le ${ }^{*} G(48,9)$ donne $\varphi \rho \varepsilon ́ \alpha \rho ~ \mu \varepsilon ́ \gamma \alpha$ à la place du 3e et du 4 e mots. Ayant cru que ces deux mots n'avaient pas été traduits, le recension origénienne insère, avant les deux

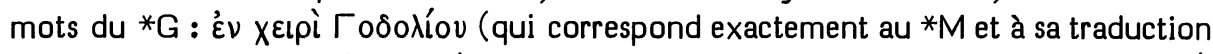
littérale par le *T : ביד גדליה), alors que la recension antiochienne insère : $\mu \varepsilon \tau \grave{\alpha}$ Гoס́oגíov (que la *S suivra avec עם גדליא) pour faciliter l'interprétation. 
$L a * V$ facilite elle aussi avec "propter Godoliam".

Choix textuel :

Avant que Hitzig n'ait déclenché parmi les critiques un enthousiasme pour la leçon du ${ }^{*} G$, Michaelis (OEB) avait été tenté de lire un 'resh' à la place du 'dalet' final du $3 e$ mot et se demandait s'il n'existerait pas un ms qui attestât cette leçon. Or de Rossi l'a trouvée attestée en son ms 226 dont il dit (Codices I 145) que ce ms allemand du XIIe ou XIIIe siècle a été écrit avec un soin insuffisant. Sans avoir relevé ce fait, Michaelis continuait à hésiter en ses Observationes.

Ehrlich (Miqra et Randglossen) a critiqué la leçon du *G en disant qu'il n'y a pas besoin de préciser qu'une citerne où l'on peut jeter une centaine de cadavres est une grande citerne. Aussi a-t-il proposé de respecter le $4 \mathrm{e}$ mot du $* \mathrm{M}$ et de se contenter de lire רị à la place du 3e mot avec le *G.

Ehrlich a eu raison de relever le caractère peu satisfaisant de la leçon indéterminée sans article, alors que la présence d'articles ne pourrait être justifiée ni par la leçon du *M, ni par celle du *G. Si, par contre, on lit בור גדליהו, on obtient une leçon déterminée : "La citerne de Godolias", c'est-à-dire la citerne où a été jeté le cadavre de Godolias; cet événement dramatique ayant valu ce nom à une citerne dont on nous explique ensuite que c'était celle que le roi Asa etc.

Avec la leçon proposée par Ehrlich, on obtient la base d'où ont divergé la leçon $d u{ }^{*} M$ et celle $d u{ }^{*} G$. On comprend parfaitement que la présence du verbe avant a appelé une lecture Tִִּ de la part d'un copiste du texte prémassorétique, alors que la séquence הו הוא a prêté à haplographie dans la Vorlage du *G.

Etant donné que le traducteur du *G a sûrement lu בור en sa Vorlage et qu'il est impossible de donner un sens vraiment satisfaisant au mot בי בי du $* M$ en ce contexte, le comité a adopté cette correction, quatre de ses membres attribuant la note " $\mathrm{C}$ " à la leçon proposée par Ehrlich, alors que deux autres attribuaient cette note à בור גדול que le *G a lu ici.

On ne saurait tirer un argument textuel de la leçon trouvée par de Rossi. On sait en effet qu'en de nombreux mss le 'resh' ne se distingue du 'dalet' que par l'absence de rafé. Il se peut que cela ait été le cas dans le ms que ce copiste peu soigneux a recopié.

Interprétation proposée :

“Et la citerne où Ishmaël jeta les cadavres des hommes qu'il avait abattus, c'est la citerne de Godolias. C'est celle etc..."

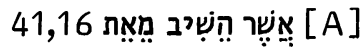

Options de nos traductions :

16a dit que Yohanân fils de Qaréah et tous les chefs de troupes qui étaient avec

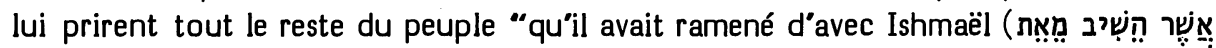

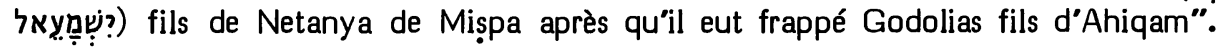
Puis, après avoir énuméré ce dont se composait ce "reste du peuple", le vs s'achève par : "qu"il avait ramené de Gabaon". 
NEB se contente de transférer le complément “de Miṣpa" juste après le verbe "prirent".

Les autres traductions corrigent par conjecture les mots "qu'il avait ramené d'avec Ishmaël" : RSV donnant : "whom Ishmael ... had carried away captive", J : "que Yishmaël ... avait emmené... (J3 ajoute : comme prisonniers)", RL : "das Ismael ... weggeführt hatte" et TOB : "ceux que Yishmaël ... avait emmenés captifs."

Origine de la correction :

A la place des trois premiers mots de la relative, Houbigant a conjecturé

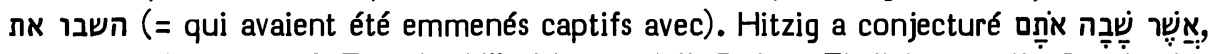
suivi en cela par Graf, Ewald2, Nägelsbach, Keil, Duhm, Ehrlich, Cornill, Coñ்amin, Volz, Nötscher, Rudolph, Penna, Steinmann, Weiser et par les apparats de SBOT, HSAT234, BH3S et Cent.

\section{Les témoins anciens :}

Ces trois mots ont été lus par tous les témoins. Le *G $(48,16)$ porte: ờs

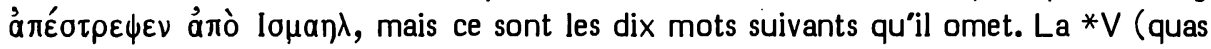
reduxerat ab Ismahel), la *S (דאהפך מן לות אשמעיל) et le *T (דאתיב מלות ישמעאל) nomettent rien en ce verset.

Choix textuel :

La leçon du *M a reçu la note " $A$ " puisqu"elle est attestée par tous les témoins.

Interprétation proposée :

La rédaction de ce verset est très confuse et surchargée. Mais nous avons déjà rencontré de nombreux exemples d'une telle confusion dans les récits de ce livre. Il est donc très vraisemblable que, comme souvent déjà, le ${ }^{*} G$ (ou sa Vorlage) a omis les éléments qui troublent le sens, en prolongeant de 8 mots son omission habituelle du patronyme d'Ishmaël.

On peut traduire le *M : "qu'il avait ramené d’avec Ishmaël fils de Netanya (celuici les ayant emmenés) de Miṣpa etc."

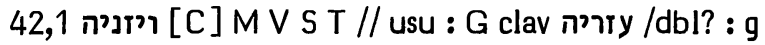

Options de nos traductions :

A "tous les chefs de troupes et Yohanân fils de Qaréah", ce vs ajoute . Seule RL transcrit ici : "Jesanja, der Sohn Hoschajas".

Se fondant sur le *G, RSV donne: "and Azariah the son of Hoshaiah", J et TOB : "et Azarya, fils de Hoshaya", NEB : "and Azariah son of Hoshaiah".

Origine de la correction :

Cette correction a été proposée par Ewald, Hitzig, Graf, Nägelsbach, von Orelli, Giesebrecht, Oort, Duhm, Ehrlich, Cornill, Condamin, Volz, Schmidt, Nötscher, Rudolph, Penna, Steinmann, Weiser, Bright et les apparats de SBOT, HSAT234, BH23S et Cent. 
Les témoins anciens :

Le *G porte ici $(49,1)$ : xaì AJapías viòs Maaoaíov. Les recensions origénienne

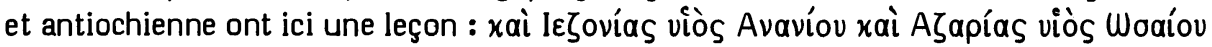
(ant. : Iwoaíov).

La leçon du *M est attestée par la*V, la *S et le *T.

Choix textuel :

En 40,8 la finale "eux et leurs hommes" qualifie comme des chefs de troupes qui vinrent vers Godolias à Miṣpa : Ishmaël fils de Netanyahu, Yohanân et Yonathân

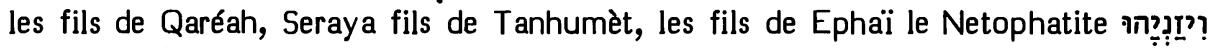

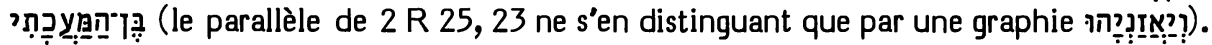

Ici $(42,1)$ le chef de troupe qui nous intéresse est mentionné après Yohanân fils de Qaréah.

En 43,2 sera mentionné avant ce dernier un certain par pour lequel

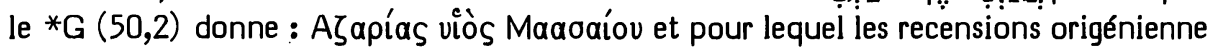

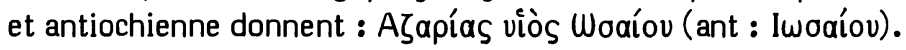

Il est surprenant que la critique textuelle ait emboîté le pas à Ewald, faisant confiance au ${ }^{*} G$ lorsqu'il assimile notre Yezanya au Azarya de 43,2; alors que la plupart des critiques refusent de suivre le ${ }^{*} G$ lorsque, en 42,1 et en 43,2 , il assimile le nom rare Hoshaya (qui, en dehors de ces deux cas, ne réapparaît qu'en Ne 12,32) au nom fréquent Maaséya ( 23 fois dans la Bible). Notons d'ailleurs que Azarya, lui aussi, est un nom fréquent (47. fois), alors que Yaazanya ou Yezanya est un nom relativement rare (6 fois).

Il est frappant d'ailleurs que l'on n'ait pas attaché plus d'intérêt à la leçon des recensions origénienne et antiochienne qui semblent dériver d'une Vorlage : ריזניה qui permettrait d'expliquer le *M comme le résultat d'un homéoarcton (sur בן בן at nous restituerait une liste à trois noms où se trouveraient les deux noms qui réapparaîtront en 43,2, sans que l'on ait besoin d'imaginer que le nom rare Yezanya soit venu remplacer le nom fréquent Azarya dans le texte protomassorétique.

Notons pourtant que la leçon originale du ms Sinaiticus était en 42,1 : KAIAZAPIAC/YIOCANNANIOY, avant que le patronyme ait subi d'abord l'omission d'un 'nu', puis, tardivement, une correction en woalov. Cela nous montre que "fils de Hananya" peut avoir figuré dans le *G en une autre position que celle où le connaissent les deux recensions susdites.

Il est donc apparu au comité très imprudent de se fonder ici sur le ${ }^{*} G$ pour assimiler ce nom à celui qui est offert en 43,2, mais encore trop peu prudent de se fonder sur les deux recensions pour reconstituer une base de laquelle le * $M$ serait accidentellement issu.

Etant donné que le ${ }^{*} \mathrm{M}$ est bien appuyé par la ${ }^{*} \mathrm{~V}$, la ${ }^{*} \mathrm{~S}$ et le ${ }^{*} \mathrm{~T}$, le comité lui a attribué la note " $C$ ".

Interprétation proposée :

"et Yezanya fils de Hoshaya". On pourra indiquer en note qu'il n'est pas impossible que le texte portait autrefois "et Yezanya fils de Hananya et Azarya fils de Hoshaya". 
Options de nos traductions :

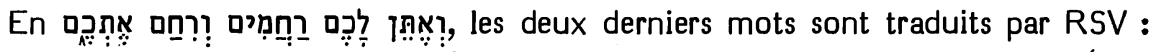
"that he may have mercy on you", par J : "pour qu'il vous prenne en pitié (J1 : ait en compassion)", par NEB : "and he too will have compassion on you" et par TOB : "vous prenant en pitié, il".

RS traduit cela : "(ich will...) und mich über euch erbarmen".

Origine de la correction :

$\mathrm{RL}$ a conservé ici la traduction de Luther. Celui-ci a suivi la traduction des Prédicants de Zurich : "unnd wil mich euwer erbarmen". Zwingli avait en effet gardé ici la *V (et miserebor vestri) sans noter que l'hébreu s'en distinguait par l'usage de la 3e personne (qui a été respectée par les autres traducteurs du XVIe siècle : Pagnini, Brucioli, Münster, Olivetan, Jud, Rollet, Châteillon, Calvin, Estienne, Ge, Tremellius, Pasteurs, KJ).

Constatant que le *M n'a que le *T pour appui, Houbigant l'a corrigé en première personne, en accord avec les autres versions. Il a été suivi par Knabenbauer et Delitzsch (Fehler §58b), ainsi que par l'apparat de $\mathrm{BH} 2$.

Les témoins anciens :

Le *T (רירחים עליכון) est seul à appuyer le *M.

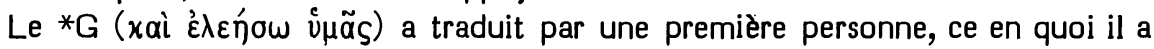
été suivi par la *V et la *S (וארחמכון).

\section{Choix textuel :}

Certains exégètes (dont RSV, J1, RL et NEB) ont interprété l'expression ואתן רל לכם רחמים au sens de "je vous témoignerai de la compassion" ou "j"aurai compassion

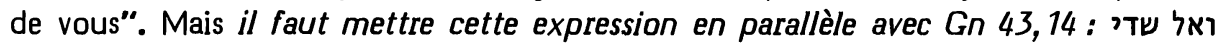
יתן לכם רחמים לפני האיש qui signifie : "et que El Shaddaï vous donne des compassions devant cet homme (c'est-à-dire : lui fasse éprouver de la compassion à votre égard)", l'effet de la compassion suscitée étant exprimé juste après par un accompli inverti en

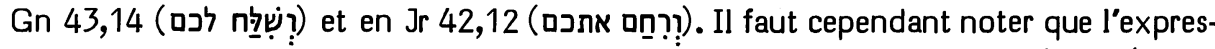

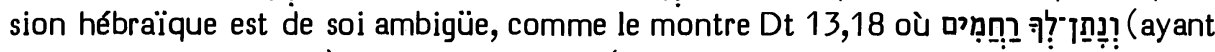
le Seigneur pour sujet) est suivi de (ayant aussi le Seigneur pour sujet, comme le montre le contexte). C'est pour éviter cette ambiguité que l'expression a été un peu modifiée en $1 \mathrm{R} 8,50$ (en un contexte très semblable à celui de $\mathrm{Jr}$ 42,12) : רִּנ:

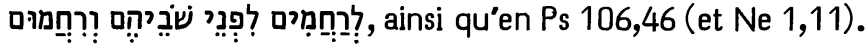

Etant donnée cette interprétation des trois premiers mots de 12a, la leçon du *M est bien en place pour les deux derniers (alors que le ${ }^{*} G$ a assimilé à la 1e pers. du verbe précédent en se laissant égarer par l'ambiguité susdite). Aussi le comité a-t-il attribué au *M la note " $B$ ".

Interprétation proposée :

"Et je vous donnerai (d’éveiller) la pitié, et il vous prendra en pitié". 


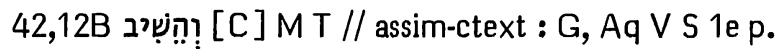

Options de nos traductions :

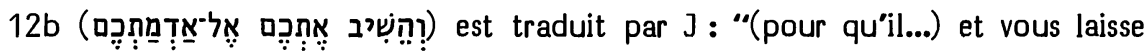
revenir sur votre sol".

RL donne : "(ich will...) und euch wieder auf eure Aecker bringen".

Brockington dit que NEB vocalise וְ quand elle traduit : "he will let you stay on your own soil". De même, RSV traduit (sans note) : "(that he may...) and let you remain in your own land" et TOB, en s'inspirant de Aq, la *V et la *S : "il vous laissera sur votre terre".

Origines des corrections :

Comme pour le cas précédent, RL a conservé la traduction de Luther. Celui-ci a suivi la traduction des Prédicants de Zurich : "(Ich...) wil euch widerfüren" et de

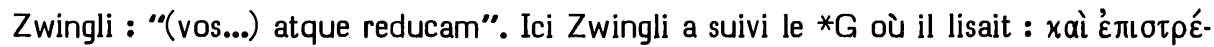
$\psi \omega$ ij $\mu \tilde{a} s$.

Pagnini a fait les deux options contraires (3e pers. avec le *M, mais dérivation à partir de רשב avec la *V) quand il traduit : "\& habitare faciet vos", recopié par Calvin et suivi en ces deux options par Jud : "\& permittet vobis habitare" et par la Geneva Bible : "and he shal cause you to dwell".

Il semble que le premier traducteur du XVIe siècle qui ait suivi exactement le *M soit Brucioli qui, en 1532, donnait : “\& faravvi ritornare" (alors qu”en 1540 il corrigera en "\& faravvi habitare", sous l'influence probable de Pagnini). Ont été aussi fidèles au *M : Münster, Olivetan, Rollet, Vatable, Arias Montano, Châteillon, Estienne, Tremellius, Pasteurs, $\mathrm{KJ}$.

On voit donc que les trois options entre lesquelles nos traductions se divisent étaient déjà celles qui se partageaient les suffrages des traducteurs du XVIe siècle.

Michaelis avait traduit ici : "und er wird euch in eurem Lande ferner zu wohnen verstatten". En OEB, il précise qu'il a vocalisé tôt à la place du 'hé' un 'alef' et à le vocaliser qameș avec le *G (plutôt que 'holem', avec la $* V$ et la*S). Il développe cela en ses Observationes.

La première option de Michaelis (qui correspondait à la traduction de Pagnini) a été reprise par Ewald, Hitzig, Graf, Giesebrecht, Oort, Duhm, Cornill, Condamin, Volz, Nötscher, Penna, Steinmann et par les apparats de SBOT, HSAT34, BH3 et Cent.

Les témoins anciens :

Seul le *T (ויתיב יתכון) appuie ici le *M.

Le *G $(49,12)$ donne : $x \alpha \grave{~} \varepsilon$ mı

Aq. corrige cela (selon Syh) en ואותבכון (qui est identique à la leçon de la *S), suivi par la *V : "et habitare vos faciam".

\section{Choix textuel :}

II se peut que les versions aient lu les mêmes consonnes qu'elles ont interprétées en infinitifs absolus se rattachant aux racines כשב ou שוב pers. est sûrement liée à leur option en $12 \mathrm{~A}$. 
Contre un rattachement à la première de ces racines, on a objecté que, les fugitifs se trouvant auprès de Bethléem, il ne saurait s'agir pour eux de "revenir vers leur sol". Mais ces gens, il y a peu de temps, étaient dispersés dans les pays voisins $(40,11)$ et Godolias avait engagé chacun à habiter à nouveau sa ville $(40,10)$. Or ils sont en train de fuir vers l'Egypte. Et Jérémie leur apporte ici l'assurance que cette fuite est inutile, car le roi de Babylone autorisera et favorisera leur retour "vers leur sol", $c$ 'est-à-dire vers leurs patrimoines familiaux.

אל־הארץ אשר־תתי Ajoutons que l'on retrouve en 30,3 un hifil de שוב (suivi de לאבר ?

Comme en d'autres cas, le hifil a ici le sens de "laisser faire", "autoriser à faire", plutôt que de "faire faire".

La leçon du *M est satisfaisante en ce sens et le comité lui a attribué la note "C".

Interprétation proposée :

"et il vous laissera revenir vers votre sol".

43,10 ושמתי [B] M Aq V T // lit : G v S 3e p.

Options de nos traductions :

Le Seigneur déclare, selon le *M: “Me voici qui envoie, et je prendrai Nabucho-

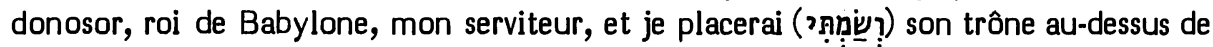
ces pierres que j'ai cachées et il étendra son baldaquin sur elles". La 1e pers. du *M est respectée pour ce verbe en RL : "(ich....) und will ... setzen" et en TOB : "je placerai".

Disant suivre le *G, RSV donne : "my servant, and he will set", J : "mon serviteur; il installera" et NEB : "my servant ... and he will place", Brockington précisant qu'elle corrige en "רֶׁ:

Origine de la correction :

Cette correction a été proposée par Giesebrecht, Oort, Duhm, Cornill, Volz, Schmidt, Nötscher, Rudolph, Penna, Steinmann, Weiser, Bright et les apparats de HSAT34, BH23S et Cent.

Les témoins anciens :

Le *G $(50,10)$ porte ici une 3e pers. : xaì Өńocl, suivi en cela par la *S (ונרמא).

Aq (אסים selon Syh) et le *T (ואשרי) attestent la 1e pers. du *M.

Seuls deux mss de la $* V$ attestent "et ponet", sa leçon authentique étant : "et ponam".

Choix textuel :

Ici comme en 25,9 et 27,6 le Seigneur, selon le *M, désigne Nabuchodonosor comme "mon serviteur", titre que le *G ne lui donne en aucun de ces trois endroits. Ici la variante sur la personne du verbe est vraisemblablement liée à la présence ou à l'absence de ce titre et à une autre variante sur la personne du verbe suivant: "que j'ai cachées" selon le *M, mais "que tu as cachées" selon le *G. Il ne s'agit pas là de 
simples accidents, mais d'un remaniement littéraire dont le ${ }^{*} M$ ou le ${ }^{*} G$ a pris l'initiative.

En attribuant au *M la note " $B$ " le comité a refusé de contaminer l'un par l'autre ces deux états littéraires.

\section{3,12 וְחִ [B] M AqSym T // assim-ctext : G V S 3e p.}

Options de nos traductions :

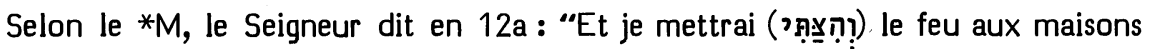
des dieux de l'Egypte et il les brûlera et il les fera captifs" (ces "il" désignant, selon le contexte, Nabuchodonosor). Pour le premier verbe, la 1e pers. du *M est respectée par RL : "Und ich will ... (in Brand) stecken" et par TOB : "Je mettrai (le feu)".

Disant suivre le ${ }^{*} G$, la $* V$ et la ${ }^{*} S$, RSV traduit : "He shall kindle (a fire)", J : "il mettra (le feu)" et NEB : "He will set (fire)", Brockington précisant qu'elle corrige en

\section{Origine de la correction :}

Cette correction a été proposée par Houbigant et Schleusner (éditant les Observationes de Michaelis), puis reprise par Giesebrecht, Oort, Duhm, Cornill, Condamin, Ehrlich, Volz, Schmidt, Nötscher, Rudolph, Penna, Steinmann, Weiser, Bright et les apparats de SBOT, HSAT34, BH23S et Cent.

Les témoins anciens :

La séquence de ce mot et du suivant est protégée par une massore "6" que Ginsburg (Massorah IV 518, §543) considère comme l'une des listes les plus anciennes de la massore.

La 1e pers. du *M est attestée ici par AqSym (אגוזל selon Syh), et par le *T (ואדליק).

Le ${ }^{*} G(50,12)$ traduit : xaì xav́ocl, suivi par la *V (et succendet) et par la *S (ונשבוק).

\section{Choix textuel :}

Il est évident que la 3e pers. assimile aux deux verbes qui précèdent et aux deux qui suivent, alors que la le pers. $d u{ }^{*} M$ doit se comprendre comme celle dont nous avons traité au vs 10 : c'est le Seigneur qui agit par son serviteur. C'est pourquoi on attribue au Seigneur l'action en un premier verbe. Ensuite d'autres verbes, ayant pour sujet Nabuchodonosor, explicitent le déroulement de l'action.

Ici le comité a attribué au *M 5 " $\mathrm{B}$ " et 1 " $C$ ". 
Options de nos traductions :

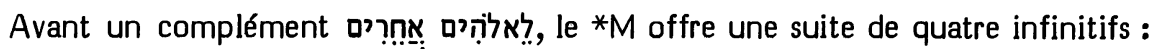

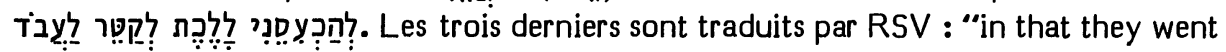
to burn incense and serve", par J : "en allant encenser et servir", par RL : "und hingingen und opferten und dienten" et par TOB : "en allant brûler des offrandes et rendre un culte".

Selon Brockington, NEB omet avec le ${ }^{*} G$ le dernier de ces infinitifs quand elle traduit : "by going ... by burning sacrifices".

Origine de la correction :

Cet infinitif a été considéré par Movers (33) comme une glose explicitant celui qui précède. A ce titre, il est omis par Giesebrecht, Oort, Duhm, Ehrlich, Nötscher, Penna, Bright et les apparats de HSAT4, BH2 et Cent.

\section{Les témoins anciens :}

Dans le ${ }^{*} G(51,3), \theta v \mu$ iãv exprime à la fois le $3 e$ et le $4 \mathrm{e}$ infinitif. $A q$ insère en-

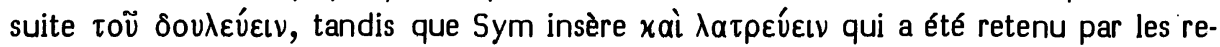
censions origénienne et antiochienne ainsi que par la $* V$ (et colerent); alors que la *S suit le ${ }^{*} G$ en ne traduisant pas de manière spécifique le $4 \mathrm{e}$ infinitif.

Le *T (למפלח) traduit le *M.

\section{Choix textuel :}

Au vs 8 , le premier et le 3 e infinitif se retrouvent sans le 2e ni le 4e; le 3e se trouvant là et au vs 5 directement lié au complément commun qu'ils ont au vs 3 . En comparaison avec cela, le vs 3 paraît surchargé. Mais cela ne veut pas dire que la forme plus légère du *G ne provienne pas d'un allègement translationnel. C'est bien un tel allègement qui semble en effet avoir eu lieu en $3 b$ où les "autres dieux" sont caractérisés dans le *M par la relative : "qu'ils n"ont pas connus, eux, vous et vos pères", alors que le *G semble avoir simplifié cela en "que vous n'avez pas connus".

Ajoutons que la liaison du verbe עבד par un 'lamed' à la divinité que l'on sert ne se retrouve qu'en Jg 2,13.

Talmon (Double 163s) a vu ici dans le 3e et le 4 e infinitifs deux leçons au choix. Cependant, la rareté de la construction du 4 e avec "lamed" laisse plutôt croire qu'il a été ajouté comme une touche complémentaire dans une phrase où le $3 \mathrm{e}$ infinitif $s^{\prime}$ articulait formellement avec le complément (comme c'est le cas dans les vss 5 et 8 ).

Originelle ou non, la leçon du ${ }^{*} M n^{\prime} e s t$ pas issue d'un accident textuel et elle est bien appuyée textuellement. Aussi le comité lui a-t-il attribué la note " $\mathrm{B}$ ".

\section{Interprétation proposée :}

Comme en 41,17 où l'on trouve לרלְֶֶ, le 2e infinitif souligne qu'il s'agit d'une initiative prise. Quant au $4 \mathrm{e}$ infinitif, il souligne la gravité de l'action exprimée par le 3e : brûler des offrandes constitue la "aboda zara".

On traduira donc: "afin de m'indigner en prenant l'initiative de brôler des offrandes, se mettant ainsi au service d'autres dieux". 
Options de nos traductions :

Ici le *M rappelle "les méfaits de vos pères et les méfaits des rois de Juda et les

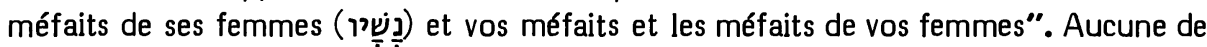
nos traductions ne traduit : "de ses femmes".

RSV corrige en "of their wives". NEB fait de même sans note. J12 conjecturent : "de leurs femmes" que TOB donne sans note. RL donne : "ihrer Frauen".

$J 3$ corrige d'après le *G en "de vos princes".

Origines des corrections :

Quoique l'édition de San Girolamo ne le signale pas, les éditions courantes de la *V, au début du XVIe siècle, portaient ici "uxorum eorum". C'est le cas de l'édition Froben 1495, de l'édition Gadolo 1495 et de la polyglotte d'Alcala. Cela explique que la vieille traduction allemande (Kurrelmeyer IX 162,42) porte ici "ire weyb" (suivie par les Prédicants de Zurich: "jrer weyberen", Zwingli : "uxorum eorumdem" et Luther : "jrer Weiber") et que Le Fèvre d'Etaples traduise : "de leurs femmes" (repris par Rollet, Châteillon et Estienne, ainsi que Ge et KJ : "their wives"). Il semble qu'il ait fallu attendre Rudolph (suivi par Steinmann, Bright et BHS) pour que cette inter-

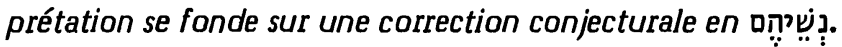

Houbigant voyait dans le *G ("vos princes") la traduction large d'une leçon qui a été adoptée par Ewald, Graf, Giesebrecht, Cornill, Condamin, Ehrlich et SBOT.

Michaelis (Observationes) tirait plutôt du ${ }^{*} G$ une leçon שריכם qui a été préférée par Volz, Nötscher, Penna et les apparats de HSAT234, BH23 et Cent.

Les témoins anciens :

La leçon authentique de la *V (uxorum eius) et le *T (נשוהי) appuient le *M.

C'est à la place de "et les méfaits de ses femmes et vos méfaits" que le *G $(51,9)$

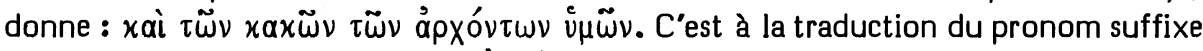
de נשיו que se rattache la leçon aưroũ de Aq (ainsi que Ziegler l'a bien vu). C'est aussi à la traduction du même suffixe qu'il faut (contre Ziegler, mais avec l'Auctarium de Field) rattacher la leçon Éxáotov aviũv de Sym (première apparition d'une interprétation que Radaq rendra classique).

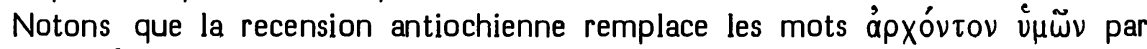

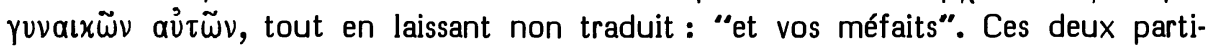
cularités se retrouvent dans la *S (דנשיהון) qui, en outre, laisse non traduit : "et les méfaits de vos femmes".

Choix textuel et interprétation proposée :

Les leçons "vos princes" (ou "ses princes") assimilent à des parallèles comme 8,1 ou 44,17.21. Cela constitue de la part du ${ }^{*} G$ une option littérairement distincte.

La leçon "leurs femmes" (de la recension antiochienne, de la *S et de certaines éditions de $\mathrm{la} * \mathrm{~V}$ ) est une facilitation translationnelle qui s'est imposée à Luther et à $\mathrm{KJ}$ (à travers les traductions de Zurich et les traductions françaises dont dépend la Geneva Bible), avant d’être transformée en conjecture textuelle par Rudolph. 
Notons qu'on peut fonder formellement cette traduction sur le $* M$ en donnant au suffixe singulier un sens distributif à la suite de Sym, Radaq, Isaïe de Trani, Zwingli (en son commentaire), Münster, Servet (rééditant Pagnini), Tremellius, Pasteurs, C.B. Michaelis, Hitzig, Nägelsbach et Weiser.

Cependant, Calvin référait ce suffixe singulier à Juda, ce qui lui permettait également de lui reconnaître un sens de pluriel. Il a été suivi en cela par C.B. Michaelis (en des notes manuscrites citées par son fils Johannes David en ses Observationes), et par Keil.

Yéfet ben Ely trouvait plus naturel de référer ce suffixe à l'un des rois de Juda, sans préciser lequel. Lightfoot (cité par C.B. Michaelis) a suggéré qu'il pouvait s'agir de Salomon. König (Syntax §348v) s'est demandé si le mot ự (dont c'est le seul emploi en Jérémie) ne serait pas ici une allusion au triple emploi de ce mot en $1 \mathrm{R}$ 11,3.4.8 à propos de Salomon (seuls emplois, également, dans les livres des Rois). L'auteur de $\mathrm{Jr} 44,9$ se refuserait, par pudeur, à mentionner nommément Salomon, mais se contenterait de cette allusion assez transparente.

Estimant cette exégèse plus probable que les deux précédentes, le comité a attribué au *M 4 "B" et 2 "C".

\section{ובפתרוס 44,15 ב [A ] M G V T // facil-synt : v S clav}

\section{Options de nos traductions :}

Parmi ceux qui contestent l'oracle de Jérémie, le vs 15 mentionne: "tous les hommes qui savaient que leurs femmes brûlaient des offrandes à d'autres dieux et toutes les femmes présentes - une grande assemblée - et tout le peuple qui habitait au pays d'Egypte, à Patros". La dernière catégorie est traduite fidèlement au *M par RSV et TOB en respectant l'asyndèse.

$\mathrm{J}$ et RL coordonnent "à Patros" avec ce qui précède ( $\mathrm{J12}$ disant suivre en cela la *S).

NEB omet par conjecture la dernière catégorie (de "et tout le peuple" à "Patros").

\section{Origines des corrections :}

En donnant: "und in Pathros", RL garde la traduction de Luther. Il s'agit là d'une facilitation translationnelle propre à celui-ci. Habitué à cette traduction, Ewald reproduit la conjonction sans rien noter. C'est Graf qui a demandé d'insérer dans l'hébreu cette conjonction, suivi en cela par von Orelli (hésitant), Nötscher, Penna et par les apparats de HSAT4, BH23S et Cent.

C'est Stade (Aequivalent 296) qui a requis l'omission que NEB réalisera après Giesebrecht, Cornill, Volz, Rudolph, Steinmann et Bright.

Les témoins anciens :

Le membre de phrase omis par Stade et ceux qui l'ont suivi est attesté par tous les témoins textuels.

Seuls la *S et deux mss de la *V ont fait précéder "à Patros" d’une conjonction. 
Choix textuel et interprétation proposée :

Graf a fait remarquer qu'en Is 11,11 "Patros" (comme désignant la Haute-Egypte) est coordonné à "Miṣraïm" (désignant donc seulement la Basse-Egypte). Il semble ignorer que Bochart (Phaleg 276,22) avait déjà proposé d'ajouter en Jr 44,15 une conjonction et notait (ibid 30-34) que Cassien et Pline l'Ancien coordonnent eux aussi l'Egypte et la Thébaïde comme deux régions distinctes.

Mais, en Ez 29,14, il est dit que les Egyptiens déportés seront ramenés dans le pays de Patros où est leur domicile, ce qui laisse entendre que les habitants de Patros sont désignés comme Egyptiens. Ammien Marcellin (XXII 16) apporte ici des précisions intéressantes: "On nous rapporte que l'Egypte avait autrefois trois provinces : l'Egypte elle-même, la Thébaïde et la Lybie". Ainsi l'on pouvait désigner comme Mișraïm ou bien la Haute et la Basse Egypte, ou bien la Basse Egypte, par opposition à la Haute Egypte que désigne le toponyme Patros.

Cela explique qu'en Jr 44,1 l'absence de conjonction après l'atnah présente Migdol, Tahpanhés, Nof et le pays de Patros comme diverses régions du pays d’Egypte. Estimant très probable que nous nous trouvons ici dans la même situation, le comité a considéré comme facilitante l'ajoute de la conjonction et attribué la note " $\mathrm{A}$ " à l'asyndèse du ${ }^{*} M$ que le ${ }^{*} G$ et la $* V$ appuient.

\section{4,19 וכי [B] M G Th Sym V T // glos : و S}

Options de nos traductions :

Dans le $* M$, le vs 19 semble continuer et achever le discours à la 1e pers. pl. commencé au vs 16 . Il est simplement introduit par lִ que $\mathrm{J} 3$ traduit par "D'ailleurs" en se contentant d'indiquer en note : "Les femmes prennent ici la parole".

RSV traduisait: "And the women said, "When" ", en se référant à la *5. $J 12$ disaient suivre le Grec lucianique et la marge de Syh en traduisant: "Et les femmes

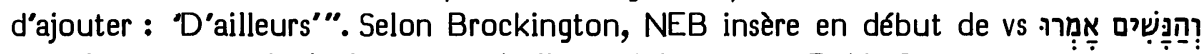
avec la Septante lucianique quand elle traduit comme RSV. Ce sont quelques mss grecs et la *S que suit TOB quand elle traduit : "Les femmes ajoutèrent : "Et quand" ".

RL se contente de traduire: "Und wenn (wir) Frauen". Les Prédicants de Zurich traduisaient de même : "Zuletst als wir weyber".

Origine de la correction :

C'est Stade (Aequivalent 297) qui, à partir de la *S des polyglottes, de la marge de Syh et de la recension de Lucien, a suggéré que le texte ancien commençait le vs 19 par les mots : ותענינה כל הנשים ותאמרנה et que ces mots auraient été omis ici après que les $2 e$ et $3 e$ d'entre eux aient été insérés dans le vs 15 . Sous cette forme ou sous une forme plus brève, une ajoute précisant que ce sont les femmes qui parlent a été adoptée au début de ce vs par Giesebrecht, Volz, Nötscher, Rudolph, Penna, Steinmann, Bright et les apparats de BH2S. 
Les témoins anciens :

Le simple

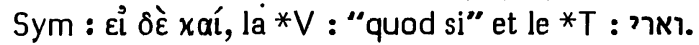

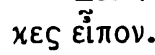

Les recensions origénienne et antiochienne insèrent auparavant : xaì aî ruvaĩ-

La *S donne, à la place de ce premier mot du*M: וענכי כלהין נשא ואמו̈ כד.

Choix textuel :

C'est la mention de "nos maris" en 19b qui a amené certains à insérer cette glose au début du vs. En effet, le contenu des vss 16 à 18 avait été naturellement mis dans la bouche des hommes qui ont été mentionnés en premier au vs 15 .

Du point de vue de la critique du texte, il faut cependant considérer comme un facteur décisif l'accord du ${ }^{*} M, d u{ }^{*} G$ et de la ${ }^{*} V$ sur la leçon brève, d’autant plus que les deux témoins de la glose varient sur l'extension de celle-ci. Aussi le comité a-t-il attribué ici au *M 5 " $B$ " et 1 " $A$ ".

Interprétation proposée :

Il faut comprendre les vss 16 à 19 comme une synthèse des arguments formulés en cette assemblée par toutes les catégories énumérées au vs 15 . Aussi ne faut-il pas s'étonner si le "nous" des contestataires exprime tour à tour des positions communes aux représentants des deux sexes et un argument typiquement féminin (en 19b). Van Selms (107s) a orienté son exégèse en ce sens.

On pourra donc traduire comme $\mathrm{J} 3$ en notant, au début du vs 16 , le contenu synthétique de l'argumentation qui commence là.

\section{4,21 אִ אִ [B] M Sym g V T // facil-synt : G om, S sg}

Options de nos traductions :

21b commence par un suffixe 3e pers. m. pl. lié à une particule d'accusatif : 茓 servant de complément d'objet à : "le Seigneur s'est rappelé".

NEB donne pour antécédent à ce suffixe le mot אֶּ (au début du vs), compris comme un collectif, et elle traduit l'ensemble: "(The LORD did not forget) those (sacrifices which....)."

RSV dit suivre la *S en remplaçant le pluriel du suffixe par un singulier et en traduisant: "(did not the LORD remember) it". Sans note, J traduit : "(n'est-ce pas) cela (dont Yahvé s'est souvenu)", RL : "(der HERR hat gedacht) an das (Opfern, das...)" et TOB : “(n'est-ce pas) ce que (le SEIGNEUR rappelle)".

\section{Origine de la correction :}

La traduction des Prédicants de Zurich avait évité la reprise de רִֵֶ (m.sg.)

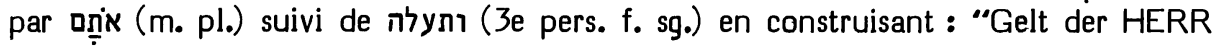
habe an das röuchwerck das jr ... geröucht habend gedacht und habe es ... gfasst". Luther s'est inspiré de cette simplification en construisant: "Ja, ich meine auch, der HERR hab gedacht an das reuchern, so jr ... getrieben habt ... und hats ... genomen". 
Pour réaliser une simplification semblable dans le texte, Giesebrecht a proposé d'unifier tout cela sur le f. sg. en corrigeant en תiֶׁקִ et et corrections (et souvent pour la première aussi) il a été suivi par Oort, Duhm, Ehrlich, Volz, Nötscher, Rudolph, Weiser, Bright et par les apparats de HSAT234 et de BH23S.

Les témoins anciens :

Les Prédicants de Zurich s’étaient inspirés du*G qui construisait : oúxì $\tau$ oũ

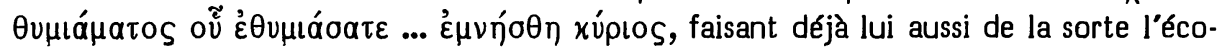
nomie de cette reprise difficultueuse par le pluriel א̦̣ik.

Pour exprimer cette reprise, Sym (suivi par la recension origénienne) insère

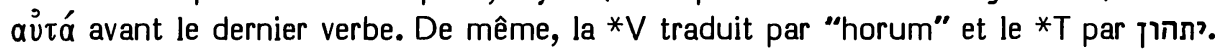

La *S met le suffixe au singulier : לה.

Choix textuel :

L'appui que lui apportent Sym et la ${ }^{*} V$ permet de considérer le suffixe pluriel de la particule d'accusatif comme leçon authentique du texte protomassorétique. A ce titre, le comité lui a attribué la note "B".

Notons d’ailleurs que la leçon ași avec sa graphie défective est garantie ici dans le *M par une massore que Ginsburg (Massorah IV 164s, §1444) considère comme l'une des plus anciennes listes massorétiques.

Remarquons aussi que le substantif הַ reprend les multiples activités cultuelles énumérées au vs 19 et que sa forme intensive a, en ce même livre $(5,13)$, un parallèle

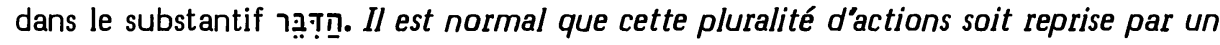

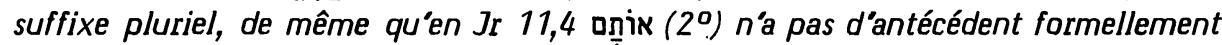
pluriel, mais seulement : "ce que j"ai commandé à vos pères", ce qui implique une pluralité de préceptes.

Interprétation proposée :

On peut faire valoir cette pluralité en traduisant : “n”est-ce pas tout cela dont le Seigneur s'est souvenu", puis on exprimera le sujet féminin (à valeur neutre) du verbe suivant en continuant : "et cela qui etc."

44,23 gV T // lic: : / abr-styl : G om

Options de nos traductions:

Après "c'est pourquoi ce malheur vous est arrivé", 23b s'achève par: que RSV traduit: "as at this day", J : "comme c'est le cas aujourd"hui", RL : "so wie es heute ist" et TOB : "c'est bien la situation actuelle".

Selon Brockington, NEB se fonde sur le ${ }^{*} G$ pour omettre ces deux mots.

Origine de la correction :

Ces deux mots ont été omis par Hitzig (comme provenant de la fin du vs précédent), ainsi que par Bright (sans note) et par l'apparat de SBOT. 
Les témoins anciens :

Ces mots n'ont pas été traduits par le ${ }^{*} G(51,23)$. Mais une ajoute astérisée, signalée comme présente en toutes les autres colonnes des hexaples, les a insérés dans les

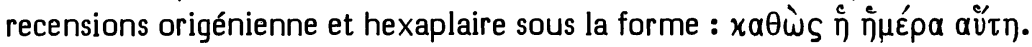

La *V les traduit : "sicut et die hac" (la plupart des témoins récents ayant assimilé en "sicut est dies haec" à la fin du vs 22) et le *T : כיומא הדין, alors que la *S traduit plus largement : איך יומנא.

\section{Choix textuel :}

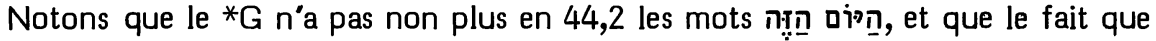

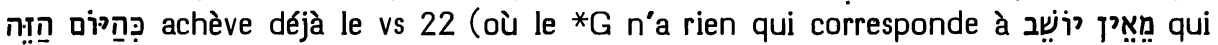
précède) explique que, dans sa tendance à alléger le texte, le ${ }^{*} G$ ait pu les omettre ici.

Le comité a montré par 4 "A" et 2 " $B$ " que l'absence de ces deux mots dans le ${ }^{*} G$ n'était pas un argument suffisant pour conclure que leur présence dans le ${ }^{*} M$ soit accidentelle.

Interprétation proposée :

“comme c'est le cas aujourd"hui". La répétition de cette constatation à la fin de deux vss successifs vise à créer un effet de martèlement à la fin de ce réquisitoire du prophète.

\section{4,25A אתם ונשיכם [B] Mg V S T // assim-ctext : G}

\section{Options de nos traductions :}

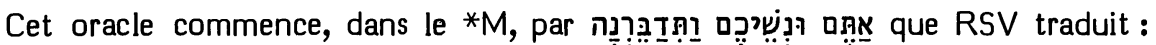
"You and your wives have declared", RL : "Ihr und eure Frauen habt ... geredet" et $\mathrm{J3}$ : "Vous et vos femmes, ... vous avez promis".

J12 suivaient le *G avec: "Vous, les femmes, ce que (votre bouche) promet", TOB aussi avec: "Avec vous, les femmes, aussitôt dit". Selon Brockington, NEB lit pour les deux premiers mots : made your actions match) your words".

Origine de la correction :

Cette correction a été adoptée par Giesebrecht, Oort, Duhm, Cornill, Volz, Schmidt, Nötscher, Rudolph, Penna, Steinmann, Weiser, Bright et par les apparats de HSAT234, BH23S et Cent.

\section{Les témoins anciens :}

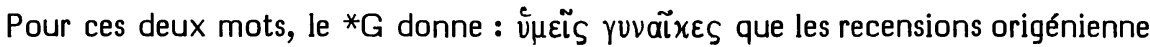

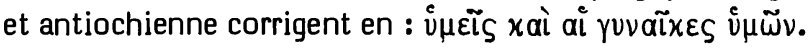

Le *M est appuyé par la *V : "vos et uxores vestrae", la *S : אנתון ונשיכון et le *T : אתון ונשיכון. 
Choix textuel :

Le texte protomassorétique est ici cohérent. A ce titre, le comité lui a attribué 5 "B" et 1 "C".

Il faut noter que le ${ }^{*} G$ n'a rien qui corresponde aux cinq derniers mots du vs 24 .

Etant donné que le verbe qui suit ici les mots qui nous concernent est au féminin pluriel, la leçon du ${ }^{*} M$ est ici une lectio difficilior, puisqu'elle met au premier plan un vocatif masculin pluriel.

Interprétation proposée :

Ces deux mots indiquent seulement à qui s'adresse l'oracle qui suit. Ils demeurent en suspens comme c'était déjà le cas pour 16a ou pour 21 .

De même que nous avons (ci-dessus, p. 756) interprété les vss 16 à 19 comme une synthèse des arguments formulés par toutes les catégories énumérées au vs 15 , de même ici sont mentionnées deux catégories (les hommes et leurs femmes) qui se répartissent les actions rappelées dans la suite du vs.

On traduira donc: "Vous et vos femmes!" Rashi comprend ainsi ce qui suit : "Elles ont en effet parlé avec vos bouches" et il commente : "Il veut dire que ce que les femmes disaient, cela était dans vos bouches, car c'est ainsi que vous leur aviez ordonné de le dire". Abravanel adopte cette interprétation. Déjà, Yéfet glosait ainsi ce passage : "il leur dit : 'vous et vos femmes'. Vous avez imposé à vos femmes, lorsque vous êtes arrivés en Egypte, d'encenser la Melèkèt ha-Shamayim, comme vous avez dit (18s) : 'Et depuis que nous avons cessé d'encenser la Melèkèt ha-Shamayim et de lui verser des libations, nous avons manqué de tout et nous avons péri par l'épée et par la famine. C'est pourquoi nous encensons la Melèkèt ha-Shamayim et il faut lui verser des libations.' Et, lorsque vous avez parlé ainsi, elles ont fait cela, et elles l'ont établi fermement, c'est-à-dire que vous n'annulez pas les voeux de vos femmes et que vous ne déclarez pas: 'ceci est un voeu nul, puisque vous faites voeu de ce qui répugne à la raison et à la tradition indiscutée'. Et elles sont allées et elles ont fait ce que vous voyez."

44,25B

Options de nos traductions :

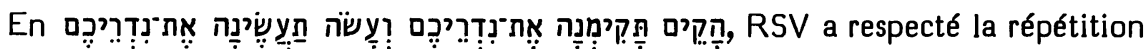
du même complément d'objet : "your vows ... your vows". RL a fait de même : "eure Gelübde ... eure Gelübde".

J2 et TOB disent suivre plusieurs mss lorsque J et TOB donnent "vos libations" à la place de la reprise de ce complément.

Sans note, NEB donne ici : "your words".

Origines des corrections :

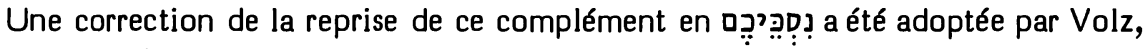
Nötscher, Rudolph, Penna, Steinmann, Weiser, et par les apparats de BH3S et Cent. 
Une correction de la première occurrence de ce complément en proposée par Schmidt et l'apparat de $\mathrm{BH} 2$; alors que cette correction pour la reprise a été proposée par l'apparat de HSAT34.

Les témoins anciens :

La répétition du complément est évitée par le ${ }^{*} G$ (alors que les recensions origé-

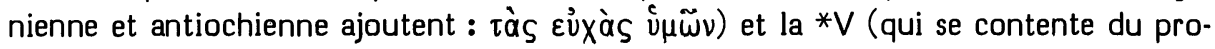
nom "ea").

La *S (נדר̈) est ici fidèle au *M, mais c'était pour la première occurrence qu'elle dissimilait sa traduction avec מומרכון

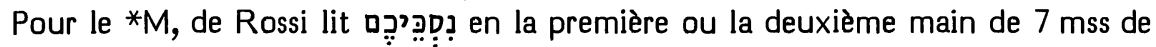
Kennicott ou de lui. Cependant le ms d'Alep et la massore éditée protègent ici la

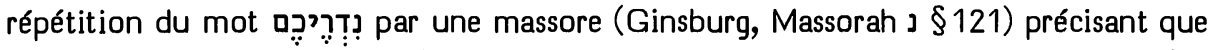
ce mot figure 4 fois dans la Bible, dont 2 fois en ce vs.

Le seul des mss ayant la variante que nous avons pu contrôler est le ms Urbinates

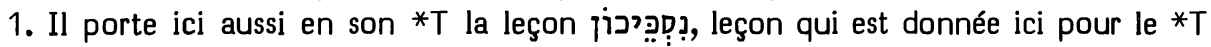
par les éditions de Félix de Prato, de Ben Hayim et de la polyglotte de Londres. Les autres témoins du *T ont ici נְְִִר?יכוֹ, mais il faut noter que c'est pour la première occurrence que le ms Reuchlin dissimile en

\section{Choix textuel :}

Ce cas n'a pas été soumis au comité.

La répétition du complément attestée dans le *M est formellement appuyée par la massore et l'est indirectement par le pronom de la ${ }^{*} V$ et par l'omission de la reprise, pour alléger le style, dans le ${ }^{*} G$.

La variante du $* M$ semble avoir son origine dans la leçon de certains des meilleurs témoins du *T où une dissimilation a eu lieu pour éviter la reprise du complément, alors que d'autres types de dissimilations ont eu lieu sur la première occurrence dans la *S et dans le ms Reuchlin du *T.

Interprétations proposées :

Schnurrer, suivi par Ehrlich (Miqra), a suggéré que 25b est dit par les hommes à leurs femmes timides: "Validez donc vos voeux et accomplissez donc vos voeux". En répétant le mot "voeux", l'oracle souligne la responsabilité des maris, puisque, pour les voeux des épouses ( $\mathrm{Nb}$ 30,14), l'autorisation de valider ou l'annulation était du ressort de ceux-ci.

On peut aussi, avec Abravanel, estimer que l'oracle s'adresse aux maris et parle de leurs femmes: "Elles valident entièrement vos voeux". Mais la première interprétation donne à $25 \mathrm{~b}$ un relief plus marqué et permet de ne pas changer de locuteur.

On pourra donc traduire ainsi l'ensemble du vs: "Ainsi a dit le Seigneur Sabaot, Dieu d'Israël : 'Vous et vos femmes'. Elles ont en effet parlé avec vos bouches et vous avez complété par votre intervention en disant : 'Il faut que nous accomplissions les voeux que nous avons faits de brûler des offrandes à la reine des cieux et de lui faire des libations. Validez donc vos voeux et accomplissez donc vos voeux !'” 
Options de nos traductions :

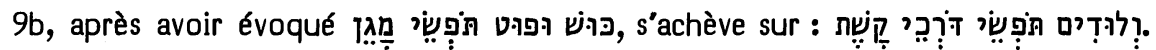
RSV traduit cela: "men of Lud, skilled in handling the bow", NEB: "Lydians grasping their bent bows!", TOB : "gens de Loud qui manient et qui bandent l'arc".

Disant omettre un mot, J traduit : "Ludiens, qui bandez l'arc !"

RL traduit seulement : “und die Schützen aus Lud!"

Origines des corrections :

Alors que Pagnini (et Ludim appraehendentes, tendentes arcum) avait traduit fidèlement le *M, Zwingli (Lydi quoque arcum tendentes) et surtout les Prédicants (jr Lydier mit den bogen) l'ont beaucoup allégé. C'est d'eux que s'est inspiré Luther que RL a conservé ici.

C'est Houbigant qui, frappé par l'absence de conjonction avant le second participe, a décidé d'omettre le premier, estimant qu'il avait été répété par erreur à partir de sa première occurrence, trois mots avant. L'ont suivi en cette omission : Giesebrecht, Oort, Duhm, Cornill, Condamin, Nötscher, Rudolph, Penna, Weiser, Bright et les apparats de SBOT, HSAT234, BH23S et Cent.

Les témoins anciens :

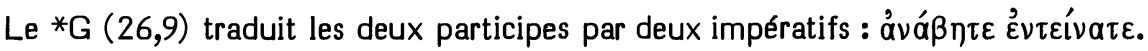
Pour le premier (attesté par tous les témoins du ${ }^{*} G$ ), Ziegler a adopté la conjecture

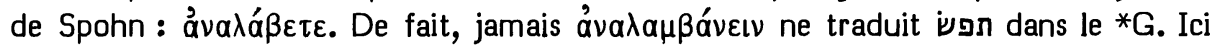
Spohn a eu tort d'attribuer au ${ }^{*} G$ la prétention de traduire littéralement le ${ }^{*} M$. AqSym (בד שקלין אנתון מתחין אנתון) et la *V (arripientes et iacientes) ont traduit par deux participes et interprété le premier conformément au *M.

La *S a usé d'une paraphrase : "qui savent tirer (avec l'arc)".

Le *T a ici la même traduction paraphrasée : דנגדין ומחן (בקשתא) que la plu-

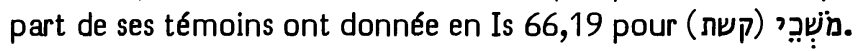

Choix textuel :

La tradition textuelle est unanime ici à donner deux verbes. L'omission du premier participe du *M serait donc conjecturale.

Il arrive ailleurs au ${ }^{*} M$ de Jérémie de répéter un même verbe à quelques mots de

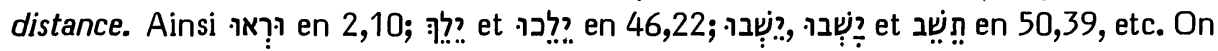
comprend que le *G ait profité de certaines de ces répétitions pour prendre des libertés, ainsi que nous le constaterons encore en 46,22 . Ici, le ${ }^{*} G$ a choisi d'abord de traduire nos deux participes par des impératifs pluriels, en parallèle avec les trois im-

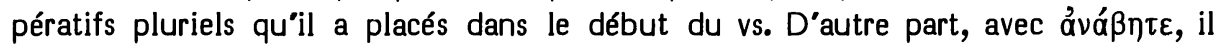
reprend le verbe qu'il a (en conformité avec le $* M$ ) utilisé une fois dans la question du vs 7 et deux fois dans la réponse du vs 8 . En effet, il n'a pas pu suivre l'hébreu qui reprend ce verbe au début du vs 9 , car, lorsqu'il s'agit de monter à cheval, le *G préfère (comme au vs 4) faire usage de émıaíveıl pour traduire לע. 
A propos de 2 S 20,19, nous avons déjà montré (CT1 298) que l'on a d'excellents parallèles en hébreu biblique pour la juxtaposition de deux participes pluriels à l'état construit, en dépendance d'un même génitif.

Le comité a attribué ici au *M la note " $B$ ".

Interprétation proposée :

“que sortent les guerriers, Kush et Put qui empoignent le bouclier, et les Ludiens qui empoignent et tendent l'arc".

\section{6,12 קלונך [B] M AqSym V S T // assim-ctext : G Th(?)}

Options de nos traductions :

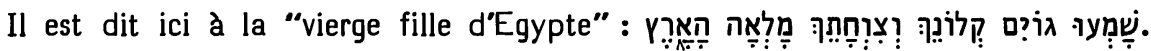
Le 3e mot est traduit par RSV : "your shame", par RL: "deine Schande", par j12 et TOB : "ta honte" et par J3: "ton déshonneur".

Selon Brockington, NEB corrige avec le ${ }^{*} G$ en קị quand elle traduit : “your cry".

Origine de la correction :

Cappel (Notae 533a) a assigné au ${ }^{*} G$ la Vorlage que NEB préférera au *M. Il l'estimait déjà préférable comme constituant un meilleur parallèle pour le substantif qui suit. Il a été suivi en ce choix par Michaelis (Observationes), Giesebrecht, Oort, Duhm, Cornill, Ehrlich, Bright et les apparats de SBOT, HSAT34 et BH2.

Les témoins anciens :

Le *G $(26,12)$ a traduit $\varphi \omega v \eta ́ v$ oov.

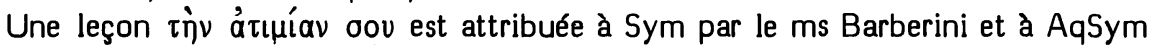

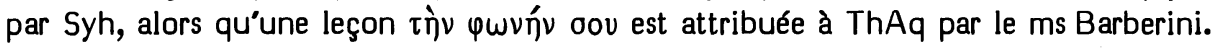
Pour $\mathrm{Aq}$, la première leçon est plus vraisemblable que la seconde. Faut-il retenir de la 2e leçon du ms Barberini que Th faisait précéder la leçon du ${ }^{*} G$ par un article? La*V (ignominiam tuam), la *S (צערכי) et le*T (קלניך) appuient le *M.

\section{Choix textuel :}

L'image qui est impliquée par le *M en $12 a$ est celle qui nous est présentée en 2 S 13,19 où une vierge qui vient d'être violée quitte, en mettant ses mains sur sa tête et en poussant des cris, la maison où elle a été déshonorée. Jr 2,37 a déjà fait allusion à cette image à propos de la vierge Israël $(2,32)$. Ici, c'est la vierge Egypte, déshonorée parce que ses armées ont été vaincues sur l'Euphrate, qui crie son déshonneur parmi les nations. "Déshonneur" et "cris" sont donc d'excellents parallèles, moins plats que ceux que le ${ }^{*} G$ leur substitue; xpauyń appelant tout naturellement $\varphi \omega \nu \eta ́$ à cause de

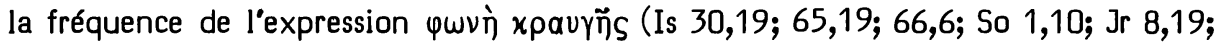
25(32), 36; 51(28),54).

Le comité a attribué à la leçon du *M la note " $\mathrm{B}$ ". 
Interprétation proposée :

"Les nations ont entendu ton déshonneur, la terre est pleine de ta clameur".

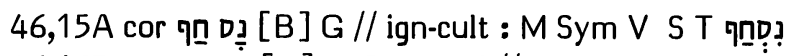

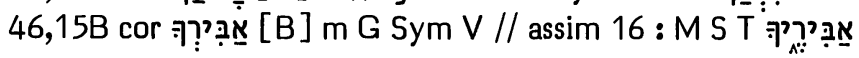

\section{Options de nos traductions :}

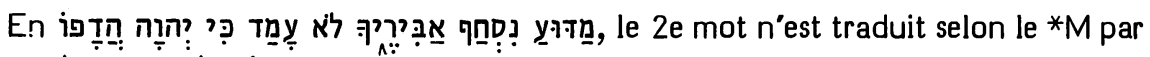
aucune de nos traductions.

RL traduit ce mot et le suivant : “deine Gewaltigen zu Boden fallen".

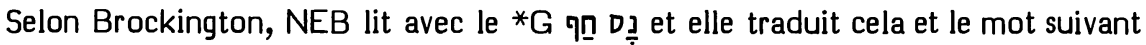
par "does Apis flee... your bull-god". De même, J traduit : "Apis s'est enfui (J3: a-t-il fui), ton Puissant" ( $\mathrm{J1}$ signalant qu'elle met cet autre mot au singulier), RSV : "has Apis fled... your bull" et TOB : "Apis s'enfuit! Ton Taureau".

\section{Origines des corrections :}

Le 2e mot étant au singulier et le 3e semblant être au pluriel, les traducteurs du XVIe siècle ont pris des options diverses. Les ont mis tous deux au singulier : Pagnini, Brucioli, Münster, Olivetan, Calvin. Les ont mis tous deux au pluriel : Prédicants, Zwingli, Luther, Jud, Châteillon, Ge, $K J$. Vatable a respecté le $* M$ en traduisant, selon Radaq : "repulsus est unusquisque fortium tuorum", suivi en cela par Tremellius et Pasteurs.

RL, qui garde ici la traduction de Luther, manifeste une dépendance caractéristique à l'égard de Prédicants (sind ... gefallen) et de Zwingli (ceciderunt) dans la traduction du premier verbe par "fallen". Au XVIe siècle, ils semblent en effet avoir été les seuls à faire ainsi.

Cappel (Notae 533a) est le premier à avoir suggéré que le ${ }^{*} G$ a divisé le $2 e$ mot en deux, en lisant: "Apis a fui." Doederlein a estimé que cette leçon du ${ }^{*} G$, méritait d'être remarquée. Dans les notes à sa traduction allemande de Jérémie (1778), Michaelis se demandait si ce n'était pas la vraie leçon. En 1780, Kennicott (Dissertatio Generalis \$45) plaidait résolument en faveur de cette leçon. Michaelis, impressionné par la connaissance que le ${ }^{*} G$ doit avoir des choses d'Egypte répète son intérêt pour cette leçon en OEB (1781), Supplementa $\$ 803$ (1792) et Observationes (1793).

Une division en deux du 2e mot est requise ensuite par Giesebrecht, Duhm, Cornill, Condamin, Penna, Steinmann, Bright, ainsi que par les apparats de SBOT, HSAT3 et Cent.

Les témoins anciens :

De Rossi attribue une graphie אבירך à une soixantaine de mss, à quoi il faut ajouter l'édition princeps de la Bible (Soncino 1488) et celle de Brescia 1494. Cependant la graphie avec un 2e 'yod' est attestée par l'édition princeps des Prophètes (Soncino 1486), par celles de Félix de Prato et de Ben Hayim, ainsi que par les mss du Caire, d'Alep et de Leningrad. On doit donc la considérer comme la leçon du texte tibérien classique. 
Les trois premiers mots du $* M$ ont pour correspondants dans le ${ }^{*} G(26,15)$ :

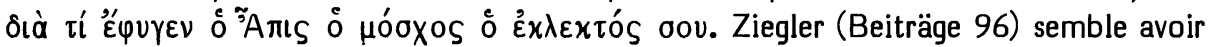
raison de ne pas interpréter "veau" et "choisi" comme un doublet pour le 3e mot de l'hébreu, mais plutôt comme constituant une paraphrase ("ton veau de choix")

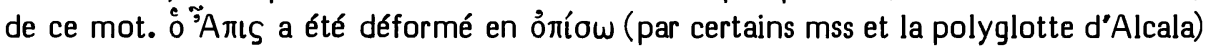
ou omis (par les recensions origénienne et antiochienne); alors que le ms Vaticanus fait précéder cette leçon originale par un doublet : AПOCOY.

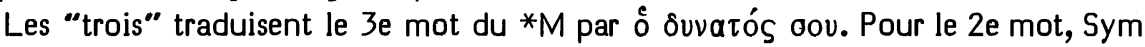

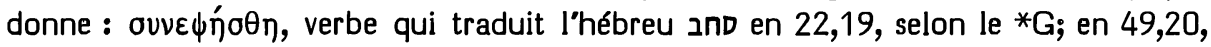
selon le ${ }^{*} G(29,21)$ et selon Sym; ainsi qu'en 50,45, selon Aq. Notons aussi qu'en

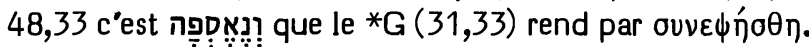

La *V traduit "conputruit fortis tuus". Comme Sym, elle a interprété le verbe à partir de 2 D, ainsi que le montre la traduction qu'elle a donnée de cette racine en 38,11 .

La *S a conservé la racine verbale du *M: אסתחפו עשקיכי Comme le *T (אתברו גברך), elle opte pour le double pluriel.

\section{Choix textuel :}

König (Syntax 211, note) avait objecté à cette correction en "Apis a fui" que l'on ne connaît pas de cas où un esprit doux correspond à la gutturale "ḥet'. Cependant il a été clairement établi depuis (Donner/Röllig II 318 et HALAT 325b) que H. (nom égyptien de Apis) se transcrit en araméen et en phénicien avec un "het'.

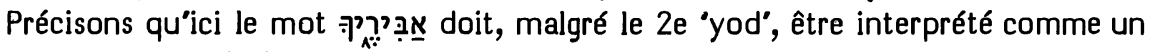
singulier, ainsi que l'indique le verbe qui suit et le pronom suffixe final du vs.

En faveur de la correction, il faut mentionner que :

1/ אִֵַ désigne le taureau en Ps 22,13; 50,13; 68,31; Is 10,13K; 34,7, ce mot constituant donc un bon parallèle pour Apis;

2 / aux vss 14 et 19, il est question de Memphis (Noph) où le culte d'Apis a revêtu une pompe particulière vers cette époque;

$3 /$ les vss $20-24$ constituant une antistrophe par rapport aux vss $14-19$, l'Egypte y est comparée à une génisse (vs 20) et ses soldats à des veaux gras (vs 21); or, il est dit

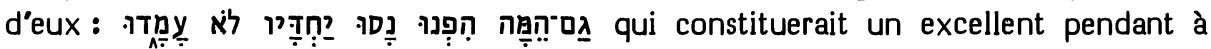
约 la présence au vs 15 (auquel le vs 21 correspond);

4/ le fait que les divinités étrangères perdent pied devant le Seigneur d'Israël a de bons parallèles en Is 19,$1 ; 21,9 ; 46,1 ; \mathrm{Jr} 50,2$.

Le comité a donc attribué à la Vorlage du *G la note "B", estimant que, par rapport à cette leçon, le ${ }^{*} M n^{\prime}$ a pas fait preuve d'une initiative littéraire notable. Le nom divin ๆn, étant hapax dans la Bible, y a seulement été méconnu, puis la vocalisation pausale du mot suivant a été interprétée en pluriel (par une graphie avec 'yod") en assimilant à 46,16: “ils tombent aussi l'un sur l'autre et disent : 'Debout ! retournons vers notre peuple et vers notre pays natal".

Interprétation proposée :

"Pourquoi Apis a-t-il fui, ton taureau n'a-t-il pas tenu debout". Ici, le taureau Apis est mentionné comme symbolisant la puissance de l’Egypte. 
46,16 cf. p. 613.

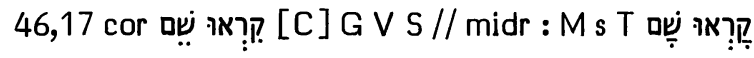

Options de nos traductions :

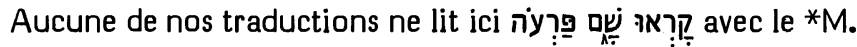

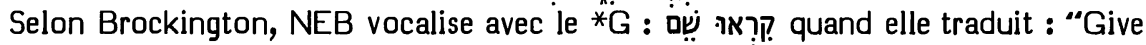
Pharaoh ... the title". TOB dit faire de même avec le ${ }^{*} G$ et la ${ }^{*} V$ en traduisant : "Surnommez le pharaon". Avec les mêmes appuis, J12 traduisent : “Donnez ce nom au (J2 : à) Pharaon". Sans note, RSV traduit : "Call the name of Pharaoh" et RL : "Nennet den Namen des Pharao".

'J3 ne corrige que le 2e mot : “On a donné ce nom à Pharaon”.

Origine de la correction :

C'est Cappel (Notae 533a) qui a assigné comme Vorlage au *G la leçon que NEB adoptera et qui a été adoptée auparavant par Houbigant, Michaelis (OEB), Ewald, Hitzig, Graf, Grätz (Studien 390), Knabenbauer, von Orelli, Giesebrecht, Oort, Duhm, Cornill, Condamin, Volz, Nötscher, Rudolph, Penna, Steinmann, Weiser, Bright et par les apparats de SBOT, HSAT34, BH23S et Cent.

La demi-correction de 33 a été requise par HSAT2.

Les témoins anciens :

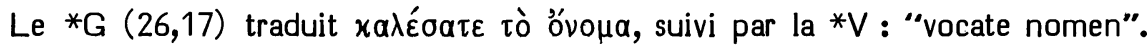

Le *M est appuyé par le *T : זמינו לתמן.

La *S offre pour le 2e mot un doublet: תמן שמה. Cependant Ephrem, en son commentaire, ne cite que la $2 \mathrm{e}$ partie du doublet et semble interpréter en impératif le verbe קר, ce qui correspond mieux à sa graphie sans "aleph" que l'interprétation en parfait que Sionita en a donnée.

Choix textuel :

Le fait que la $* V$ et la $* S d^{\prime} E$ phrem concordent avec le ${ }^{*} G$ (qu'aucune recension grecque ne semble avoir retouché) indique que la tradition de vocalisation $d u{ }^{*} M$ n'était pas encore fermement établie à l'époque protomassorétique. La vocalisation du *M a été comprise par Raba (vers 325), selon le Talmud Babli (Moed Qatan 16a) au sens de "on a convoqué (littéralement : appelé là) le Pharaon", pour montrer que l'on doit assigner une seconde fois en justice celui qui, comme Pharaon, a "laissé passer le rendez-vous". Mais קרא, en ce sens, se construit normalement avec la préposition 'lamed' ou avec אִ.

Le texte consonnantique $d u{ }^{*} M$ convient mieux à la vocalisation de la variante.

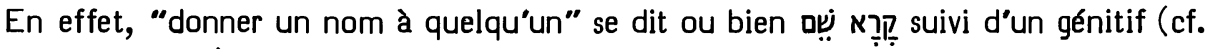
Is 8,3; Jr 20,3), ou bien קִ ş suivi de 'lamed' introduisant la personne qui reçoit le nom (cf. Is 30,7). D'autre part, la vocalisation de la variante forme un meilleur con-

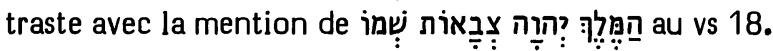


Alors que deux membres du comité attribuaient au $* M$ la note " $C$ ", quatre attribuaient cette note à la Vorlage du ${ }^{*} G$ et de la ${ }^{*} V$, préférant ne pas mélanger les deux leçons comme J3 l'a fait.

Il se peut que l'interprétation donnée aux consonnes par le Talmud ait constitué une sorte de 'al-tiqré" qui a éliminé dans la tradition de lecture du *M la vocalisation plus ancienne que le ${ }^{*} \mathrm{G}$, la $* \mathrm{~V}$ (et la ${ }^{*} \mathrm{~S}$ ) nous ont conservée.

Interprétation proposée :

“Donnez ce nom à Pharaon, roi d’Egypte : ‘Vacarme ... qui laisse passer l’heure!’”

בא בה 46,20 [C] M // facil-synt : m G V S בא בא

Options de nos traductions :

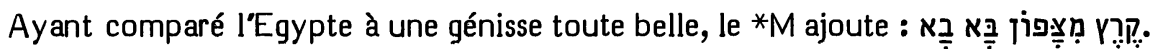

$\mathrm{J}$ traduit : "un taon venu du Nord s'est posé sur elle", J2 précisant que le dernier mot est lu בְּ avec des mss hébreux, le * $G$, la *V, la *S et le *T. De même, RSV traduit (sans note) : "but a gadfly from the north has come upon her", TOB (sans note) : "mais, du nord, des taons viennent sur elle". NEB (corrigeant comme J2) traduit : "but a gadfly from the north descended on her".

Pour ces quatre mots, RL se contente de : "aber es kommt von Norden der Schlächter".

\section{Origines des corrections :}

Sous l'influence de la $* V$, les Prédicants de Zurich avaient traduit: "sein treyber wirt jm von Mitnacht herkummen", en accord avec Zwingli : "stimulator veniet ei ab Aquilone". Luther, pour se rapprocher du *M, a omis le complément au datif, mais il n'a pas traduit la répétition du verbe, options que $R L$ a conservées.

C'est Châteillon qui a noté que le ${ }^{*} \mathrm{G}$ et la $* V$ semblent avoir lu ב̇a à la place du dernier mot, leçon qui lui semble plus authentique. Cappel (Notae 533ä) admet cette Vorlage pour le ${ }^{*} G$. Ayant trouvé cette leçon dans un ms du $* M$, Houbigant la préfère, suivi en cela par Venema, Michaelis (Observationes), Rosenmüller, Ewald1, Henderson, Grätz (Studien 391), Giesebrecht, Oort, Duhm, Volz, Nötscher, Rudolph, Penna, Steinmann, Weiser, Bright et par les apparats de SBOT, HSAT2, BHS et Cent.

Les témoins anciens :

Houbigant a relevé le dernier mot écrit avec un 'hé' dans un ms de l'Oratoire, puis Kennicott dans la 1e ou la 2e main de 84 codices à quoi de Rossi en a ajouté 23 de sa collection.

Nous avons pu contrôler 28 mss et 3 éditions anciennes. Pour le 2e mot, nous avons trouvé la leçon avec 'hé' attestée par 3 d'entre eux : le ms Paris BN héb 6, le $\mathrm{ms}$ de Berne des Prophètes et le ms de Rossi 2, ainsi que par les premières mains de 4 autres : le ms Vatic ebr 3, les mss Londres BL Add 15451 et 21161 et le ms Paris BN héb 2. Elle figure également dans l'édition princeps des Prophètes (Soncino 1486) et dans l'édition princeps de la Bible (Soncino 1488). 
La leçon avec 'aleph' est donnée par les autres mss : ceux d'Alep, du Caire et de Leningrad, les mss New York JThS 232, Petrograd et Reuchlin des Prophètes, Urbinates 1 et 2, Vatic ebr 468 et 482, de Rossi 782, Madrid univ 1, Paris BN héb 26 et 82, Hamburg hebr 6 et 27, Copenhague 1,2, 4, 5 et 8. C'est elle qu'atteste le ms Heb $4^{\circ} 1399$ de Jérusalem qui est le seul ms babylonien cité ici par Yeivin. Elle figure aussi dans les éditions Lisbonne 1492, Brescia 1494, Félix de Prato 1517 (folio et quarto), Polyglotte d’Alcala 1517, Bomberg 1521 et Ben Hayim 1525.

Ajoutons que l'on trouve une massora parva "hapax' sur la séquence des deux derniers mots dans la Bible de. Ben Hayim ainsi que dans les mss New York JThS 232, Vatic ebr 468, Madrid univ 1, Paris BN héb 6 et Hamburg hebr 6.

Dans la Bible de Ben Hayim, cette massore en contredit une autre qui est donnée sur Ez 7,6 et qui précise que la séquence בָא בָּ se rencontre deux fois : là et en Jr 46, 20. C'est cette massore que donnent ici le ms d'Alep, le ms Petrograd des Prophètes, les mss Paris BN héb 2, Urbinates 1, Londres BL Add 15451, Berne des Prophètes et $V$ atic ebr 482. Comme Ginsburg (Massorah IV 179, $\S 70$ ) l'a noté, le but de cette massore est d'éviter la leçon avec 'hé' en Jr 46,20. Mais faudrait-il alors penser que la massore 'hapax' en Jr 46,20 avait au contraire pour but d'appuyer cette leçon (qu'elle accompagne dans le ms Paris BN héb 6) ?

Ce passage est cité dans le Talmud Yerushalmi (Yoma III 4). L'édition princeps (Venise 1523) et le ms Scaliger y attestent la leçon avec 'hé', alors que les éditions postérieures (qui ne disposaient pourtant pas d'autres mss) ont assimilé au texte reçu (avec 'aleph'). Il est cité aussi dans le Talmud Babli (Yoma 32b). Le plus ancien ms conservé est ici celui de Munich (hebr 95) qui porte la leçon avec 'hé', alors que toutes les éditions (à commencer par celle de Venise 1520-1523) donnent la leçon avec 'aleph'; quoique 'le targum de Rab Joseph' soit cité juste après qui explique : יתון עלה (dont la Vorlage est évidemment la leçon avec "hé").

Notons que la Bible Soncino 1488 place un mappiq dans le 'hé' final, alors qu'aucun des mss où nous avons trouvé la leçon avec "hé' ne porte de mappiq. C'est ce qui fait dire à Hayyuj en son commentaire (Kokovzov 35) qui lit ici la leçon avec "hé" (quoique le lemme du ms fragmentaire édité par Kokovzov ait été assimilé au texte reçu) : “Ou bien בבה avec "hé" est comme בא avec 'aleph', comme tu sais que souvent ils ont écrit un 'hé' à la place d'un 'aleph', ou bien ị̣̄ avec "hé' raphé est comme กฺ̣ avec 'hé' mappiq, comme c'est le cas pour

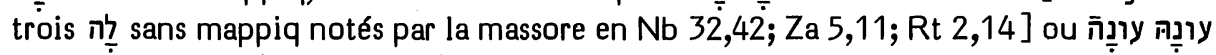
en un même sens (en Nb 15,31)."

Parmi les glossaires hébreu-français, seuls le glossaire $C$ et la $2 \mathrm{e}$ main du glossaire $D$ traitent de ces mots. Tous deux portent la leçon avec 'he' et traduisent "vint (ou : venant) en li', 'en li' signifiant 'en elle'.

La leçon avec 'aleph' est formellement attestée par Yéfet ben Ely, Menahem de Posquières, Tanhum Yerushalmi, Moshé ben Sheshet, Radaq et Abravanel.

A la place des deux derniers mots du $* M$, le ${ }^{*} G(26,20)$ donne $\tilde{\eta} \lambda \theta \varepsilon v \varepsilon^{3} \pi^{\prime} \alpha u ̉ \tau \eta ́ v$.

Il n'y a pas à tenir compte de ce que les fragments de Chrysostome publiés dans la

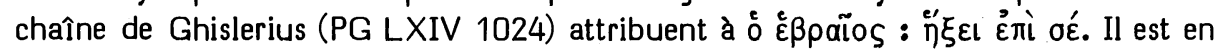
effet difficile de préciser l'origine et l'intention de ces leçons.

La*V donne ici : "veniet ei", la *S : אתא עליה et le *T : כלתון עלה. 
Choix textuel et interprétation proposée :

Le fait que la leçon avec "hé" ne porte pas de mappiq peut indiquer que, conformément à la première suggestion de Hayyuj, elle a été interprétée par les scribes qui l'ont transmise comme une graphie anormale pour בְָ (comme en Ez 14,4 où un בְ̣ écrit sans mappiq a pour qeré בְֵ

Il se peut cependant que les versions aient lu cette leçon avec 'hé' et que ce soit ce fait qui les aient orientées vers l'explicitation d'un complément qui est ici 'dans l'air'.

Il est pourtant intéressant de noter que les bons hébraïsants sentent autrement la forme du complément qu'ils estiment nécessaire ici.

Menahem de Posquières (lisant la leçon avec 'aleph') estime qu'il y a ellipse du mot la même suggestion dans les apparats de HSAT34 et de BH2.

Luzzatto estime que בה ne peut être authentique ici, mais que l'on devrait avoir הִ. C'est d'ailleurs ainsi que Schwally (Reden 193, n.3) propose de corriger, suivi en cela par Ehrlich.

On trouve en effet au vs בא עליהם באו לה 22 et au vs בקו 22.

Alors que la séquence בִּ בְּ serait une maladresse sylistique, la leçon avec 'aleph' veut, par la répétition du verbe, produire un effet d'insistance en évoquant les retours incessants du taon que la génisse essaie en vain de chasser.

Mais la prononciation "bâ bâ" est équivoque. Parmi ceux qui étaient habitués à entendre ces mots, certains, ne saisissant pas cet effet d'insistance, mais sentant plutôt le besoin d'un complément, comprenaient "vient sur elle" au lieu de "vient, vient". Ainsi s'expliquerait que la leçon avec "hé" (au sens de בְּ ) soit issue d'une fausse interprétation de cette prononciation, puis que les scribes qui se transmettaient cette leçon aient voulu, en lui refusant le mappiq, la critiquer implicitement et suggérer une interprétation en בְ:.

Le comité a attribué à la leçon avec "aleph" la note "C".

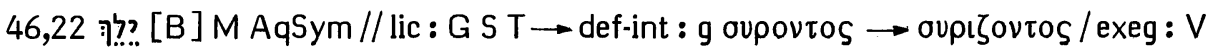

Options de nos traductions :

Lorsque les ennemis viendront en grand nombre, avec leurs cognées, comme des bûcherons pour abattre sa forêt, 22a dit de l'Egypte : par RSV : "She makes a sound like a serpent gliding away" et par TOB : "Elle file en douce comme un serpent".

Selon Brockington, NEB corrige le verbe en pị avec le ${ }^{*} G$ quand elle traduit : "Hark, she is hissing like a snake". Avec le même appui, J12 traduisaient : "Ecoutez! on dirait un serpent qui siffle" et $\mathrm{J3}$ : "Sa voix est comme le bruit du serpent qui siffle". RL traduit de même : "Man hört sie heranziehen wie eine zischende Schlange".

Origine de la correction :

En se fondant sur le ${ }^{*} G$, Houbigant corrige le verbe final en 2 . Ewald, avec le même appui, lit pị̂, suivi en cela par Condamin, Volz, Nötscher, Penna, Steinmann, Weiser, Bright et les apparats de HSAT34, BH3 et Cent. 
Les témoins anciens :

Tous les témoins du *G $(26,22)$ portent ici oupí̧ovtos. A sa place, Spohn a conjecturé oúpovtos, en notant que le ${ }^{*} G$ emploie ce verbe à propos des serpents en Dt 32,24 et Mi 7,17. Avant la publication posthume (1824) du commentaire de Spohn, Schleusner (V 228) avait (en 1821) formulé la même conjecture. Celle-ci a été adoptée par Köhler (Emendationen 179). Cependant Ziegler (Beiträge 24) refuse cette conjecture pour deux motifs. Il se demande d'abord : “qui aurait l'idée de transformer oúpovtos (qui convient bien au contexte) en oupí̧ovtos ?" A cela on peut

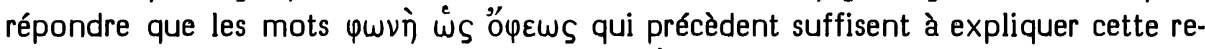

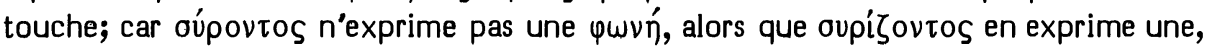

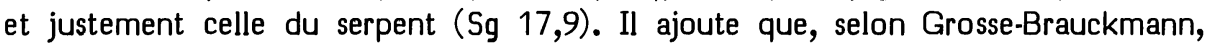
"le verbe oúpeıv est employé toujours comme transitif". Mais il suffit de contrôler Dt 32,24 ou Is 30,28 pour constater que ce verbe a dans la Bible des emplois intransitifs. Notons d'ailleurs qu'en Dn 11,26, Ziegler suit Schleusner (III 266) et Field lorsque

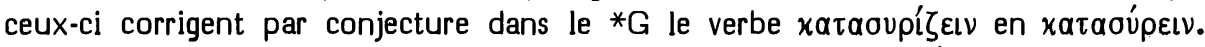
Si l'on admet donc ici aussi la correction conjecturale du ${ }^{*} G$ en oúpovtos, il n'est pas nécessaire de lui attribuer une Vorlage distincte du ${ }^{*} M$.

Lorsque la *V traduit ici "vox eius quasi aeris sonabit", elle semble interpréter le verbe selon la leçon de tous les témoins du *G et le substantif selon le sens "bronze" de cette racine. Il se peut que Jérôme ait été influencé en outre par le "velut aes sonans" de 1 Co $13,1$.

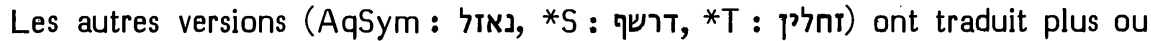
moins librement le *M.

\section{Choix textuel :}

Le verbe הלך peut convenir au serpent (cf. Gn 3,14). Dans son commentaire sur Gn 3,8, Ibn Ezra cite l'usage que Jr 46,22 fait du mot hip pour montrer que ce mot peut signifier le bruit de la démarche.

Tremellius a glosé ici : “Il ne s'agit plus de mugir et de faire un terrible vacarme (cf. 46,17$)$ comme l'Egypte faisait auparavant. Mais elle rampera à terre et ne se fera pas plus entendre que le glissement d'un serpent". Comme "Apis a fui" $(46,15)$ l'a annoncé et comme "ils font demi-tour, ils s'enfuient" $(46,21)$ nous y a préparé, il s'agit de l'Egypte qui fuit devant l'envahisseur. Sa fuite est comparée à la fuite silencieuse des serpents qui déguerpissent d'un bois où les bûcherons pénètrent en force pour abattre les arbres. Il y a vraisemblablement là une allusion au symbole royal égyptien de l'uraeus dressé dardant sa langue. Mais c'est une allusion ironique et dérisoire : le serpent file en douce, délogé par les bûcherons.

Le comité a attribué au *M la note " $B$ ".

Interprétation proposée :

“Son bruit est semblable à celui d'un serpent qui s'en va". 
46,23A מקר? [B] M G Aq V // assim-ctext : S T pl 46,23B רַבְּ [B] MV S T // assim-ctext : G sg

\section{Options de nos traductions :}

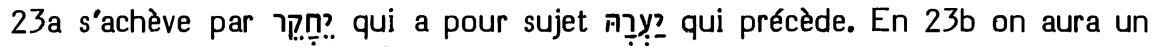

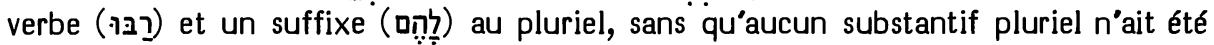

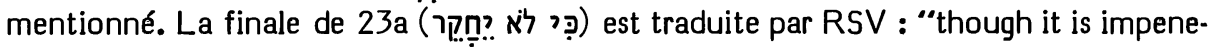
trable", par NEB : "and it flaunts itself no more", TOB : "même si elle est impénétrable" et 33 : "alors qu”elle était impénétrable".

Disant suivre plusieurs mss hébreux, 312 traduisaient : "Oui, on ne peut les compter". De même, RL traduit : "denn sie sind nicht zu zählen".

\section{Origine de la correction :}

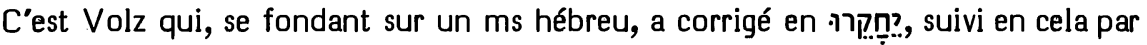
Rudolph (qui se réfère à plusieurs mss), Steinmann, Weiser et les apparats de BH3S.

Les témoins anciens :

Dans la tradition textuelle du *M, seule la première main du ms de Rossi 345 a la désinence plurielle יחקרו. Il s'agit d'Haphtarot écrites en marge d'un ms allemand du Targum d’Onqelos datant du XIVe siècle ou du début du XVe siècle (de Rossi, Codices I 192). Cette erreur de son scribe ne mérite aucune autorité textuelle.

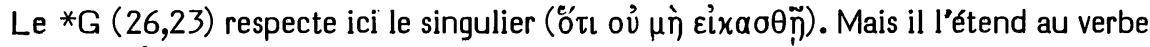
suivant ( $\pi \lambda \eta \theta \dot{v} v \varepsilon \mathrm{l})$.

Le singulier est attesté aussi par Aq (דלא תתעקב) et par la *V (qui supputari non potest).

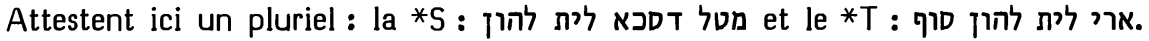

Le pluriel du deuxième verbe est respecté par la $* V$, la *S et le *T (Aq n’y étant pas connu).

\section{Choix textuel}

Alors que le ${ }^{*} G$ a assimilé le verbe suivant à celui-ci (en le mettant au singulier), la $*$ S et le $* T$ ont réalisé l'assimilation inverse (en traduisant ce verbe-ci par un pluriel).

La lectio difficilior du ${ }^{*} M$ se présente comme le point de départ de ces deux assimilations en sens opposés. Le comité lui a attribué la note " $\mathrm{B}$ ".

Interprétation proposée :

A la fin du vs 22, il a été parlé des "arbres" et au début du vs 23 de la "forêt". L'interprétation la plus naturelle consiste à voir ici une construction en chiasme, notre verbe se référant à la forêt et le suivant aux arbres.

On traduira donc :

"Abattez sa forêt, oracle du Seigneur, car elle est impénétrable; car ils sont plus nombreux que les sauterelles, ils sont innombrables."

On pourra indiquer en note que les deux pluriels de 23b peuvent se référer aux arbres (mentionnés à la fin du vs 22) ou aux habitants de l’Egypte (que ces arbres représentent). 
Ajoutons une dernière précision sur le verbe initial de ce vs : des exégètes le comprennent comme un accompli et, de fait, il semble que presque toutes celles des éditions qui font usage du meteg (la première étant celle de Lisbonne 1492) ont, jusqu'à $\mathrm{BH} 3$ inclus, placé un meteg à côté du qameṣ. Cela tient probablement au fait que les principales de ces éditions (Lisbonne 1492, Félix de Prato 1517, et Ben Hayim 1525) impriment en marge le commentaire de Radaq. Or celui-ci y dit que les mss soignés portent ici un meteg. Cependant, le ms d’Alep, le ms du Caire (selon un film plus clair que le facsimilé édité) et le ms de Leningrad n'ont pas de meteg. C'est pourquoi BHS n'en a pas. Il est donc parfaitement possible de lire ici un impératif avec qameș hatutuf dans la 1e syllabe, comme c'est le cas pour חַר en Jr 2,12 (selon l'exégèse de Radaq). D'ailleurs, Yéfet ben Ely traduit ici par ư impératif.

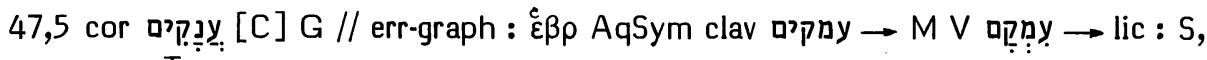
exeg : $\mathrm{T}$

Options de nos traductions :

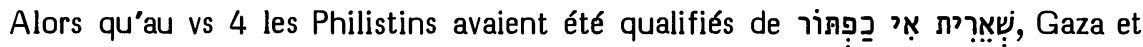

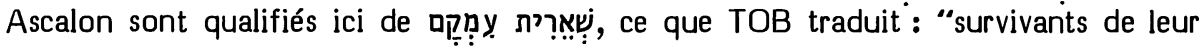
plaine" et 33 : "toi qui restes de leur vallée".

Sans note, NEB traduit : "Poor remnant of their strength".

Se fondant sur le *G, RSV donne : "O remnant of the Anakim" et J12 : "reste des Anaqim". RL donne : “der Rest der Enakiter".

Origine de la correction :

Grotius a noté que le ${ }^{*} G$ a lu ici ענקים et il préfère cette leçon, suivi en cela par Houbigant, Gesenius (Thesaurus 1045b), Graf, Grätz (Geschichte I 193, note), Schwally (Reden 196, n.1), Giesebrecht, Oort, Duhm, Ehrlich, Condamin, Volz, Rudolph, Nötscher, Penna, Steinmann, Weiser et par les apparats de SBOT, HSAT234, BH23S et Cent.

Les témoins anciens :

Le ${ }^{*} G(29,5)$ porte ici $\varepsilon v a x ı \mu$ (la polyglotte d'Alcala étant seule à donner un 'mu' à la place du 'nu').

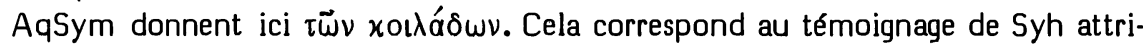
buant à l'hébreu

La *V traduit le *M : "vallis earum”.

La * ${ }^{*}$ ב a essayé de traduire en s'inspirant du contexte.

Le *T תוקפון s'est, selon Michaelis (Observationes), laissé influencer par le samaritain où py est usité (selon Castle 2800) au sens de "force et fermeté". Sur ce sens de cette racine (remis en vogue à partir de l'ugaritique), cf. HALAT 803a.

Choix textuel et interprétation proposée :

$1 /$ Un certain nombre d'arguments peuvent être apportés en faveur du *M: 
- a) En Jr 49,4, nous verrons certains témoins du ${ }^{*} G$ introduire des Anaqim là où il faut lire avec le *M le pluriel de pמo.

- b) Après que Juda ait pris Gaza, Ascalon, Eqron et leurs territoires, il est dit ( $\mathrm{Jg}$

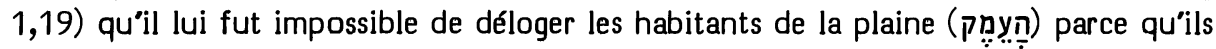
avaient des chars de fer. En Jg 1,34, il est dit que les Amorites refoulèrent dans la montagne les fils de Dan et qu'ils ne les laissèrent pas descendre dans la plaine (לֵֵֵֵֵ) On peut donc estimer que, pour les villes philistines, "leur plaine" peut avoir un sens topographique satisfaisant : la plaine côtière qui les jouxte.

2/ On pourrait estimer que la leçon de la polyglotte d'Alcala se fonde sur une Vorlage la plaine-vallée du Jourdain. La leçon de AqSym et "l"hébreu" de Syh s"accorderaient bien avec une telle Vorlage dont pourraient diverger à la fois la leçon des autres témoins du $* G$ et celle du $* M$.

3/ Cependant, en faveur de la leçon: "les survivants des Anaqim", il faut noter

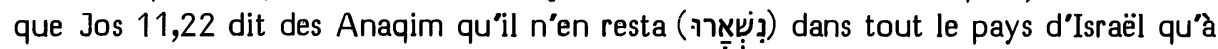
Gaza, à Gat et à Ashdod. Encore à l'époque de David, Gat est le domicile de géants (1 S 17,4; 2 S 21,16-22). Une désignation des habitants de ces villes comme 军 serait donc une périphrase littéraire parallèle à l'autre périphrase littéraire: dont le vs 4 faisait usage pour désigner les Philistins.

Il n’y a pas à craindre que le *G ait créé ici cette allusion littéraire, car il a mé-

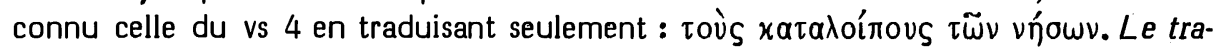
ducteur a donc plutôt tendance à gommer qu'à amplifier ces allusions.

On ne peut prendre appui sur le seul témoignage de la Polyglotte d'Alcala (qui a tendance à modeler son ${ }^{*} G$ sur son ${ }^{*} M$ ) pour attribuer au ${ }^{*} G$ une Vorlage עמקים Le témoignage combiné de AqSym et de "l"hébreu" de Syh nous montre cependant que l'on a probablement en cette leçon une forme de transition (caractérisant le texte protomassorétique) entre la leçon y y et la leçon D'ailleurs, il y a peu de chances qu'une expression ne désignant les habitants de la vallée du Jourdain qu'en 1 Ch 12,16 soit ici à sa place.

Ajoutons encore qu'en Jr 49,4 Evaxı est en ${ }^{*} G(30,4)$ un doublet qui n'est attesté que par une partie secondaire de la tradition textuelle. On ne peut s'appuyer dessus pour déceler chez le traducteur grec de Jérémie une tendance à voir des Anaqim là où il s'agit de vallées. En effet, il prouve par ailleurs $(21,13 ; 49(30), 4 ; 48(31), 8)$ qu'il connaît bien le sens du mot 쓰.

Le comité a attribué ici à la leçon עִ עִ la note " $\mathrm{C}$ " en considérant la variante du *M comme issue d'une confusion du 'nun' avec le 'mem', très aisée dans l'écriture ancienne.

\section{7,7 תשקטי [C] M T // facil-synt : G V S 3e p. $\rightarrow$ assim $6:$ g 2e p.}

Options de nos traductions :

Le vs 6 a contenu une apostrophe à l'épée : "Hélas, épée du Seigneur, jusques à

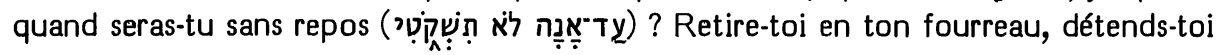


et calme-toi !" Selon le *M, le vs 7 porte un verbe où le Seigneur s'adresse encore à l'épée à la 2 e pers., puis celle-ci sert d'antécédent à deux suffixes de la $3 e$ pers.:

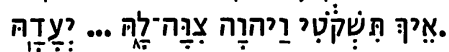

Selon Brockington, NEB corrige ce verbe en vị pạ avec le ${ }^{*} G$ quand elle traduit : "How can it rest". RSV s'appuie en outre sur la *V pour traduire: "How can it be quiet", à quoi $\mathrm{J12}$ ajoute la ${ }^{*} \mathrm{~S}$, alors que $\mathrm{J3}$ invoque l'ensemble des versions pour traduire "Comment se reposerait-elle". De même, TOB donne : "Comment peut-elle se reposer" et RL : "Aber wie kann es aufhören".

Origine de la correction :

Au XVIe siècle les successions de la $2 e$ et de la 3e pers. ont été respectées au vs 7 par Pagnini, Brucioli, Münster, Olivetan, Vatable, Estienne, Calvin, Tremellius et Pasteurs.

Ont suivi la *V en généralisant la 3e pers. : Prédicants, Zwingli, Jud, Rollet, Ge et $\mathrm{KJ}$.

Ont généralisé la 2e pers. : Luther et Châteillon.

C'est Houbigant qui a proposé la correction que Brockington reprendra. Il a été suivi en cela par Graf, Hitzig2, Ewald2, Keil, Grätz (Studien 392), Schwally (Reden 196, n.2), Giesebrecht, Oort, Duhm, Cornill, Condamin, Ehrlich, Volz, Nötscher, Rudolph, Penna, Steinmann, Weiser, Bright et les apparats de SBOT, HSAT234, BH3S et Cent.

Les témoins anciens :

Dans la tradition textuelle du $* G$, seuls le ms Alexandrinus et le minuscule 410

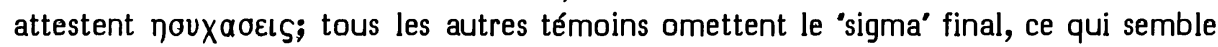
être la leçon authentique $d u{ }^{*} G$ (la variante interne provenant d'une assimilation secondaire à ce même mot déjà présent au vs précédent).

La*V (quiescet) et la *S (תשלא) suivent le*G.

Le *T (תנוחין) respecte l'alternance des personnes du *M.

Choix textuel :

L'assimilation secondaire que nous avons décelée dans la tradition textuelle du * G inviterait à considérer que le *M a fait de même, assimilant la forme de ce verbe à celle qui se trouve au vs précédent. C'est pourquoi la leçon du ${ }^{*} G$ a reçu de deux membres du comité la note " $C$ " et d'un autre la note " $D$ ".

Cependant une interprétation en 3e pers. est ici tellement 'dans l'air' qu'Abulwalid (Luma 363,23 à 364,1), suivi par Judah ibn Balaam et Tanḥum Yerushalmi (puis par Ewald1 qui les ignore), a voulu donner un sens de 3e pers. à cette désinence en 'yod'. La lectio difficilior du ${ }^{*} M$ est donc sérieusement menacée d'être assimilée à la $3 e$ pers. des suffixes qui suivent (à moins que l'assimilation inverse n'ait lieu, comme chez Luther). Mieux vaut donc, avec Böttcher, estimer que le prophète, en débutant ce vs, continue d'abord de s'adresser à l'épée et que c'est au moment où il prononce le nom du Seigneur qu'il se tourne vers ses auditeurs pour achever son oracle en rappelant le verdict prononcé par celui-ci contre Ascalon et la bande côtière. Ces changements de personnes sont assez classiques et celui-ci accentue le relief 
de cette fin d'oracle. C'est pourquoi trois membres du comité, faisant confiance à la fidélité des copistes du *M, ont attribué à sa leçon la note " $C$ ".

Interprétation proposée :

Il faut traduire la fin de l'oracle comme un aparté : "Mais comment te reposeraistu... - Le Seigneur lui a donné des ordres : il lui a assigné pour objectif Ascalon et le rivage de la mer".

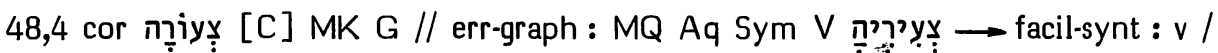
lic : $\mathrm{S}, \mathrm{T}$

Options de nos traductions :

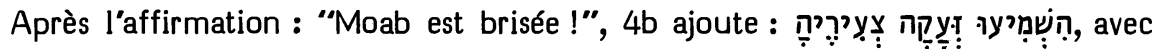
un ketib צyוריה pour le dernier mot. TOB traduit : "ses petits font entendre de grands cris", J3 : "ses petits font entendre un cri" et RL : "Man hört ihre Kleinen schreien".

RSV se fonde sur le *G : "a cry is heard as far as Zoar". Selon Brockington, NEB corrige, avec le ${ }^{*} G$, le dernier mot en as far as Zoar". S'inspirant du ${ }^{*} G$ et du $* M, J 12$ traduisaient : "annonce-t-on à grands cris (J1 : à plein gosier) jusqu’à Coar".

Origine de la correction :

Cappel (Notae 534a) a fait remarquer qu’à la place du dernier mot, le *G, à partir du ketib, a lu "vers Șoar". Se fondant sur le parallèle d'Is 15,5, Calmet opte pour cette leçon, suivi en cela par Venema, Doederlein, Michaelis (OEB), Ewald, Graf, Grätz (Studien 392), Schwally (Reden 197, n. 1), Knabenbauer, Giesebrecht, Oort, Duhm, Cornill, Condamin, Ehrlich, Volz, Nötscher, Rudolph, Penna, Steinmann, Weiser, Bright et les apparats de SBOT, HSAT234, BH23S et Cent.

\section{Les témoins anciens :}

Le ${ }^{*} G(31,4)$ a lu pour le 3e mot : عis Zoropa. Pour cela, Aq donne : oi $\mu$ txpoì

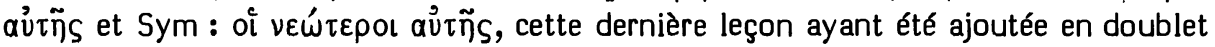
par la recension antiochienne.

Selon toutes les éditions, la *V porte: "adnuntiate clamorem parvulis eius". Cependant, il semble que sa leçon originale soit celle du ms de Cava qui porte "parvuli" ( = Aq, Sym et l'antiochienne), l'impératif précédent a entraîné une mise de ce mot au datif (alors que l'article oi protégeait les leçons grecques contre cette déformation).

\section{La*S (מסכניה) a traduit librement le *M.}

Pour le *T, Sperber donne שלטוניהון et n"indique comme attestant la variante que le ms Montefiore. De fait, cette leçon est aussi celle du ms Urbinates

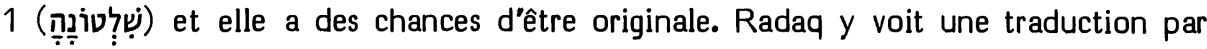
antiphrase.

Michaelis (OEB), faisait remarquer que le codex 154 de Kennicott porte צעורה, mais que ce mot y correspond à ì et non à notre mot. Il estimait cependant qu'il 
devait s'agir là d'une survivance de la leçon que le *G lisait en sa Vorlage. Schleusner, éditant en 1793 les Observationes de Michaelis, rappelait le placement surprenant de cette leçon dans le ms 154 et les conclusions que Michaelis tirait d'elle, conclusions qu'il approuvait. Il aurait pu lire pourtant, dans le vol. III des Variae Lectiones que de Rossi publia en 1786, que celui-ci lisait, à la place de notre mot, la leçon צyורה en ses deux mss espagnols 26 et 187. D’ailleurs, Kennicott (ou son collationneur) s'est trompé. C'est à notre mot que cette leçon correspond aussi dans le ms Reuchlin des Prophètes ( $=$ Kennicott 154) où on lit dans le texte : רִ̣̣̂ et en marge : ק : •. • ignoré des critiques du XVIIIe siècle, donne lui aussi comme ketib צyורה. Rappelons encore que le ms Copenhague 2 (= Kenn 178) écrit צyירה.

Choix textuel et interprétation proposée :

Aq et Sym nous témoignent que le qeré du $* M$ repose sur une tradition très ancienne.

Cependant, la leçon "vers Șoar" que le *G a lue ici a de fortes chances de représenter le texte original de cet oracle. En effet Jr 48,5 (où sont mentionnées Luhit et Horonaïm) reprend Is $15,5 \mathrm{~b}$ (ou sa source). Or, en Is 15,5 a sont mentionnées Șoar et Eglat Shelishiya. D'autre part, en Jr 48,34 on retrouve unies S.oar, Horonaïm et Eglat Shelishiya. Il y a donc de grandes chances pour qu'en 48,4 (alors que Horonaïm figurait déjà au vs 3), Șoar soit à sa place, sous la forme : "faites entendre une clameur vers Șoar" que le *G y a lue.

D'autre part, il y a de grandes chances pour qu'ici le ketib courant צyוריה ait été contaminé par le qeré et que la forme la plus ancienne du ketib soit celle qui a survécu dans le ms New York JThS 232 du Xe siècle, dans le ms Reuchlin des Prophètes et dans les deux mss espagnols de de Rossi : צyורה.

Il est frappant de noter qu'en Is 15,5, 1Q-a écrit le nom de Șoar y en permutant la $2 \mathrm{e}$ et la $3 \mathrm{e}$ lettre, par rapport à la leçon du *M. Or le *G transcrit ce toponyme Cnywp en Gn 14,2.8; 19,22.23.30; Dt 34,3 et Is 15,5, ce qui suppose la graphie de 1QIs-a.

On peut donc en conclure que la Vorlage $d u{ }^{*} G$ a survécue dans le vieux ketib $d u * M$. C'est la leçon que le comité propose ici avec la note " $C$ ". Pour ne pas mélanger deux leçons, on vocalisera le verbe en impératif, avec le *G.

Le qeré paraît être issu d'une confusion entre 'yod' et 'waw'.

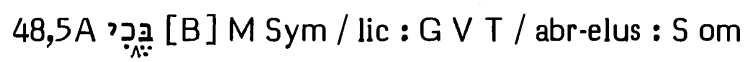

Options de nos traductions :

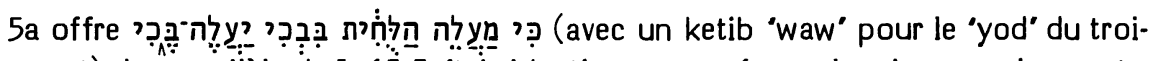
sième mot). Le parallèle de Is 15,5 était identique au qeré pour les cinq premiers mots, mais offrait ỉ à la place du sixième qui, ici, a fait difficulté à beaucoup d'exégètes.

Ici, les trois derniers mots ont été traduits librement par NEB : "men go up weeping bitterly". 
J traduit : “on la monte en pleurant", conjecturant ị en se référant au parallèle d'Isaïe. TOB fait de même : "on la gravit tout en pleurs".

Disant conjecturer, RSV ne traduit pas le sixième mot : "they go up weeping". RL traduit 5a : “denn sie gehen mit Weinen die Steige von Luhith hinauf".

Origine de la correction :

Houbigant a estimé que le sixième mot est issu de בי בו d'une dittographie du qui commence 5b. Il propose donc ici d'assimiler au parallèle de Is 15,5, suivi en cela par Lowth (sur Isaïe), Movers (32), Delitzsch (sur Isaïe), Grätz (Studien 392), Schwally (Reden 197, n.1), Giesebrecht, Oort, Duhm, Cornill, Condamin, Volz, Nötscher, Rudolph, Penna, Weiser, Bright et par les apparats de SBOT, HSAT234, BH23S et Cent.

A l'inverse, Venema a estimé que la leçon de Jérémie est primitive par rapport à celle d'Isaïe, suivi en ce jugement par Michaelis (Observationes) et Graf.

Quant à Ehrlich, il omet le sixième mot, à titre de dittographie du suivant.

Les témoins anciens :

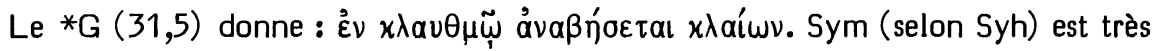
littéral : בבכיא תסק בכתא.

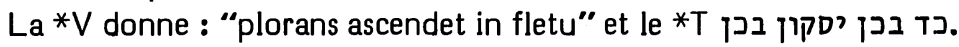

La *S n'a pas traduit le sixième mot : כד בכין נסקון

Calvin a noté que certains traduisent ce dernier mot comme si c'était un participe בכה. Cette remarque vaut pour le *G, la*V et le *T.

\section{Choix textuel :}

Au XVIe siècle, les traducteurs ont hésité. Le sixième mot a été omis par Luther, Brucioli, Olivetan et Estienne. D'autres ont exprimé la répétition par deux mots de racines distinctes. Ainsi Münster : "cum fletu \& lamento", Jud : "in fletu et ploratu" ou Ge : "the mourner ... with weping", ou encore Châteillon : "en pleurant piteusement". D'autres n'ont pas craint de répéter la même racine. Ainsi Pagnini : "in fletu ... cum fletu" ou Pasteurs : "pleur avec pleur". D'autres enfin, à la suite de Zwingli ("pervadet fletus"), ont voulu exprimer l'intensité d'une inondation ou encore la continuité des pleurs avec Tremellius ("continuus ascendet fletus") et KJ ("continuall weeping shall go up").

Notons ici que, pour le troisième mot, le ketib avec 'waw' donne תin qui a

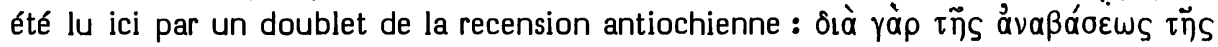
$\pi \lambda \alpha x \omega ́ \delta$ ovs. Ce ketib suppose une interprétation: “Car, en montée faite de strates, un pleur monte sur un pleur".

Les versions qui ont fait usage d'un participe se sont probablement contentées $d$ 'interpréter une Vorlage semblable au $* M$. Voulant éviter une assimilation au parallèle d'Isaïe (que, d'ailleurs, aucun témoin n'atteste ici), le comité a attribué au *M la note “B".

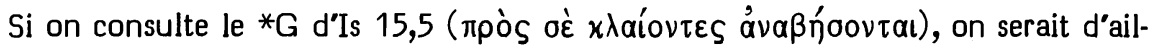
leurs plutôt tenté d'assimiler en sens inverse. 
Interprétation proposée :

Keil, à la suite de Radaq, estime que la reprise en $6 e$ mot du $4 \mathrm{e}$ vise une insistance (sous forme d'accusatif adverbial) : "avec pleur on monte, avec pleur".

Mais un maqqef lie les deux derniers mots. Mieux vaut donc, avec C.B. Michaelis, interpréter le verbe comme un hifil au sens de 14,2 (où s'élève). On pourra donc traduire : "Car la montée de Luhit, sur un pleur fait monter un pleur", ou, plus librement : "Car monter à Luhit fait monter pleur sur pleur".

\section{8,5B צִ [ִ] [B] M Sym V t // exeg : Th g S / abr-elus : G T om}

\section{Options de nos traductions :}

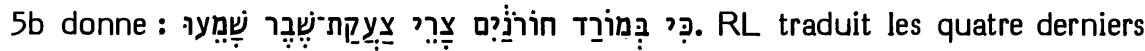
mots : "die Feinde hören ein Jammergeschrei".

Disant omettre צרי avec le *G, RSV traduit : "they have heard the cry of destruction", J : "on entend des cris ( 33 : une clameur) de détresse (J1 : sur le désastre, J3 : de désastre)", NEB : "cries of 'Disaster !' are heard" et TOB : "on entend des appels venant du désastre".

\section{Origine de la correction :}

Cappel (Notae 534a) a fait remarquer que le ${ }^{*} G$ a omis ce mot. Il est omis aussi par Ewald, Hitzig, Schwally (Reden 197, n.1), Giesebrecht, Oort, Duhm, Cornill, Ehrlich, Volz, Nötscher, Rudolph, Penna, Weiser, Bright et par les apparats de SBOT, HSAT234, BH23S et Cent.

Les témoins anciens :

Après le toponyme 'Horonaïm', le parallèle de Is 15,5 donne tant ce mot.

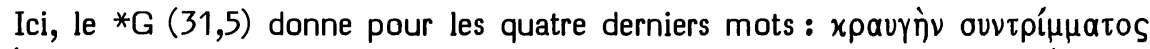

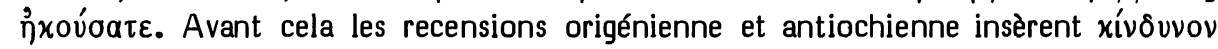
qu'elles empruntent à Th. Ce même mot est donné par Aq (selon Syh) pour צִִ רִָ en Jr 4,31 (Ziegler y transférant l'attribution à Th).

Selon Syh, Sym traduit ce mot בבלדבבא, en en faisant le sujet du verbe final. La *V traduit de même : "hostes ululatum contritionis audierunt".

La *S traduit : אולצנא וגעתא דתברא נעבדון, le premier mot correspondant normalement à (cf. Jr 14,8; 15,11; 16,19 etc.).

Sperber donne ici pour le *T : מעיקי Mais ce mot n'est attesté que par le ms Londres BL Or 2211 (dont il reproduit le texte). Il est omis par tous les autres témoins qu'il cite (plus le ms Urbinates 1).

\section{Choix textuel :}

Graf a fait remarquer qu'il ne suffit pas de prétendre avec Ewald que צר est ici inauthentique. Il faut aussi y expliquer sa présence. Hitzig a suggéré que ce pouvait

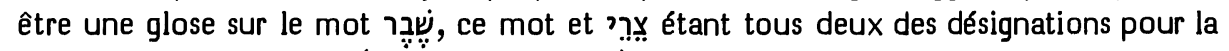
voyelle 'é" fermé. Grätz (Stưdien 393, note) a réfuté cela, précisant que, chez les gram- 


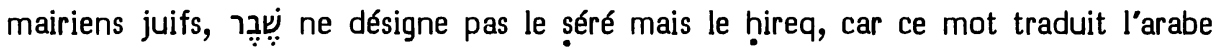
kesrâ.

Ehrlich (suivi par Volz et par Rudolph) a vu en ce mot une forme corrompue de י.. Ce serait une note marginale notant une particularité du mot suivant qui est écrit ici avec un 'șadé' (alors que, dans le parallèle d'Isaïe, il l'est avec un 'zaïn').

Depuis Sym jusqu’à Luther, en passant par la *V et Radaq, des exégètes ont reconnu en ce mot un cas d'emploi du pluriel construit de צִ (= adversaire), avec la valeur d'un état absolu.

Yéfet ben Ely traduit ici ce mot par (= désastres) et précise qu'on le re-

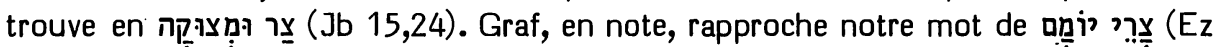
$30,16)$ où Yéfet lui donne d'ailleurs encore la même traduction. $L$ 'interpretation que Th et la *S ont donnée ici de ce mot n'est pas très éloignée de cela.

Comme Driver l'a noté, si l'on devait omettre un mot ici, ce serait plutôt au suivant qu'il faudrait penser, en le considérant comme un emprunt fait au parallèle rajeuni de Is 15,5 .

Le comité a attribué la note "B" à cette lectio difficilior du *M en l'estimant suffisamment appuyée par les autres emplois de ce mot que nous venons de citer.

Interprétation proposée :

“Car, dans la descente de Horonaïm, on a entendu les désastres de la clameur de catastrophe" (c'est-à-dire : les désastres qu'annonce la clameur de catastrophe).

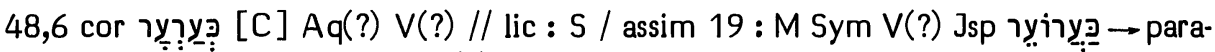
phr : $\mathrm{T} /$ harm-ctext : $\mathrm{G} A \mathrm{q}(?)$

Options de nos traductions :

Après avoir dit: "fuyez, sauvez (impératifs m.pl.) votre vie", le *M ajoute :

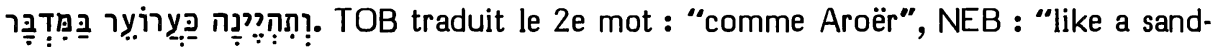
grouse" et RL : "wie ein Strauch".

Disant suivre le *G et Aq, RSV donne : "like a wild ass" et J1: "(devenez) semblable à l'onagre", J23 : "(imitez) l'onagre".

Origine de la correction :

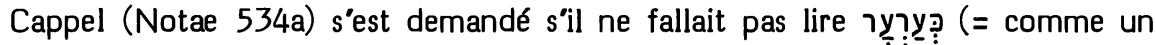
arbre isolé). Il a noté que le ${ }^{*} G$ avait lu Tin (= comme un onagre). Graf a estimé que la vocalisation du ${ }^{*} M$ venait d'une assimilation au vs 19 . Aussi, la proposition de Cappel a-t-elle été retenue par Nägelsbach, Knabenbauer, Oort, Duhm, Ehrlich, Kuschke (186) et par l'apparat de $\mathrm{BH} 2$.

La leçon du ${ }^{*} G$ a été préférée par Rosenmüller, Grätz (Studien 393) et Cornill, ainsi que par les apparats de SBOT et Cent.

Les témoins anciens :

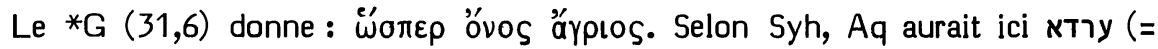

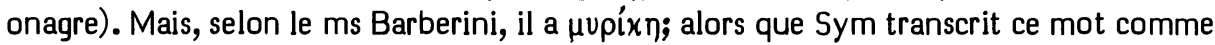
un toponyme : Apońp et que Josippos a ai $\mu v \tilde{i} x a l$. 
Pour la *V, l'édition de San Girolamo hésite entre "myrice" (de la plupart des témoins) et "myricae" (de l'Amiatinus et de nombreuses éditions), le pluriel étant appuyé par Josippos.

La*S traduit איך עקרא (= comme une souche).

Le *T paraphrase : "comme la tour d'Aroër, ceux qui campent sous des tentes dans le désert".

\section{Choix textuel :}

La leçon "onagre" est une harmonisation avec le mot qui suit.

Yéfet ben Ely s'accorde avec Sym et le *T pour reconnaître ici le toponyme que cette graphie désigne partout ailleurs où elle apparaît. Il glose : "que vos villes ne deviennent ruinées comme la ville d'Aroër qui est ruinée dans le désert". Et il ajoute : "Il se peut que cette Aroër soit 'Aroër qui est devant Rabbah' (Jos 13,25)".

David ben Abraham (II 429,41s) rapproche ce mot de רִy (Ps 102,18; Jr 17,6) disant que certains voient en ces trois endroits la mention d'un oiseau que l'on nomme (en arabe) le לולו.

Menahem ben Saruq (137b) classe sous le 8 e sens de 7 yr 17,6 et 48,6, estimant que le contexte, et plus spécialement Jr 17,8, montre qu'il s'agit d'un arbre.

Dunash ben Labrat (105*) reproche à Menạem d'avoir uni ces deux passages.

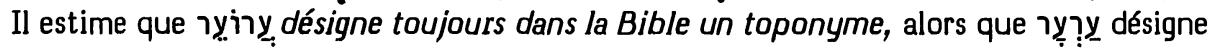
un arbre. Il propose donc pour 48,6 la même exégèse que Yéfet.

Jacob Tam (85) estime que, si Dunash avait raison, le désert ne devrait pas être mentionné et il faudrait comprendre "comme les villes d"Aroër" (cf. Is 17,2). Il estime que Jr 50,12 montre que les localisations de Jr 48,6 (dans le désert) et de Jr 17,6 (dans la steppe) sont équivalentes. C'est donc. Menahem, estime-t-il, qui a raison.

Radaq partage le point de vue de Menahem et de Jacob Tam. Il paraphrase : "après que vous serez sortis de vos villes et que vous vous serez enfuis, vos villes seront comme le lans dan le désert, et c'est un grand arbre dans la plaine désertique". Dans ses Shorashim, il donne des traductions du nom de cet arbre, traductions dont on ne retrouve les formes authentiques que dans les éditions anciennes de cet ouvrage ou dans ses manuscrits. Ainsi, il dit que certains identifient cet arbre à celui que l'on appelle en arabe אל אבהל (selon l'édition de Naples, 18 août - 15 septembre 1490, attribuée à Joseph ben Jacob ou à Azriel ben Joseph Ashkenazi, édition appuyée en cela par les mss New York JThS 2978 et 2979), alors que les éditions plus récentes offrent אל בהל . Il ajoute que cet arbre est celui que l'on appelle en langue vulgaire מרכי (selon l'édition de Naples, 10 février 1491 par Isaac ben Judah ben David Cattorzi, leçon retenue par Pagnini : 'myrice', Thesaurus1, col. 1859), alors que les éditions plus récentes donnent un 'bet' au lieu du 'kaf'. Il dit enfin que certains sont d'avis que cet arbre est celui qui est appelé en langue vulgaire יונברי (selon les deux éditions cidessus et Pagnini, ibid., 'iuniperus"), alors que l'édition Venise 1546 donne un 'kaf' à la place du 'bet', ce qui, dans la 3e édition du Thesaurus de Pagnini, a amené Mercerus et Cevallerius (col. 2124) à transcrire 'ioncheri' et à voir là une espèce de jonc.

Gesenius (Thesaurus 1074a) considère La phrase והיה כערער בערבה en Jr 17,6 est très semblable à celle qui nous occupe et, dans les deux contextes, apparaît le verbe בטר בטר II est donc très probable que Menahem, 
Jacob Tam et Radaq ont raison d'y voir deux mentions du même arbre. Dunash, cependant, a raison de souligner qu'en ses autres emplois (il y en a 17) la vocalisation "ô-é" désigne un toponyme. Aussi 4 membres du comité ont-ils estimé devoir corriger

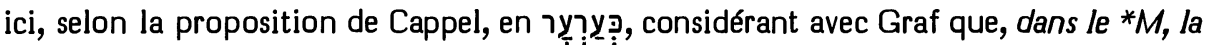
vocalisation a été assimilée à celle de la ville mentionnée en 48,19 . Ils ont attribué la note " $C$ " à cette correction, alors que les 2 autres ont attribué " $C$ " au ${ }^{*} M$, pensant avec Gesenius qu'il n'est pas nécessaire de le corriger pour obtenir un sens pluriel vers lequel Josippos et la $* V$ semblent nous orienter. En effet, Calvin, Keil et Condamin ont vu ici dans la leçon du $* M$ un équivalent du nom d'arbre, avec une intention allusive.

Notons qu'au niveau de la préhistoire littéraire de ce texte, il est vraisemblable que l'usage fait de ce mot en Jr 48,6 est à expliquer en fonction de

Interprétation proposée :

Abulwalid (Ușul 557,6s) considère qu'il n'est pas improbable que l'arbre mentionné en Jr 17,6 soit le ערע des arabes qui est un arbre des montagnes. Celsius (II 195ss) est de cet avis et précise que, par ce nom, les arabes désignent le genièvre (ce qui coïncide avec la dernière opinion rapportée par Radaq) et non le tamaris (= la 'myrica' qu'une leçon d'Aq, la *V et Josippos ont cru identifier ici). Löw (III 37) précise qu'il $s^{\prime}$ agit très probablement du Juniperus oxycedrus et il estime que le toponyme s'y réfère aussi.

On pourra donc traduire : "comme un genièvre dans le désert".

48,7A במעשיך [C] M AqSym // abr-elus : G T om / abst : g V S

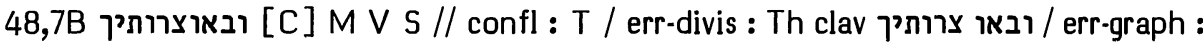

בצורותיך ובאוצרות

Options de nos traductions :

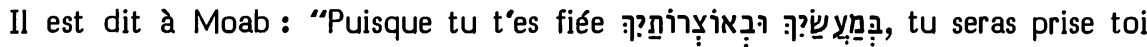
aussi". Ces deux mots sont traduits par RL : "auf deine Bauwerke... und auf deine Schätze", par NEB : "in your defences and your arsenals", par TOB : "en tes efforts et tes trésors" et par J3 : "à tes oeuvres et à tes trésors."

Disant suivre le *T pour le premier mot, RSV traduit : "in your strongholds and your treasures".

$J 12$ disaient suivre le ${ }^{*} G$ en se contentant, pour ces deux mots, de "à tes forteresses".

Origines des corrections :

Michaelis (Observationes), Rosenmüller, Spohn et Movers (13) ont estimé que le *G a traduit le premier mot par év óxupúnaoó oov et qu'il n'attestait pas le second. A partir de là, Ewald op.te pour corriger le premier mot en מִ à quoi Giesebrecht

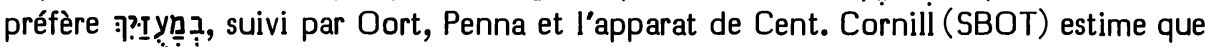
c'est le second mot que le ${ }^{*} G$ a lu ובמצדותיך. Il est suivi en cela par Volz et l'apparat 
de $\mathrm{BH} 2$. Duhm hésite entre ces deux corrections, suivi en cela par Rudolph, Steinmann, Weiser, Bright et les apparats de $\mathrm{BH} 33$.

Les témoins anciens :

Pour ces deux mots, le *G $(31,7)$ offre seulement $\varepsilon$ 'v óxupúua oí oov. Les hexaples

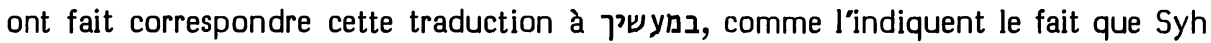
attribue, à la place de ce mot, על עבדא דילכי à AqSym et le fait que c'est après ce

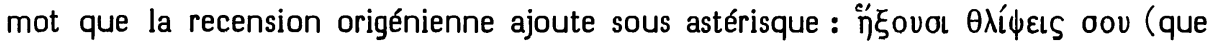

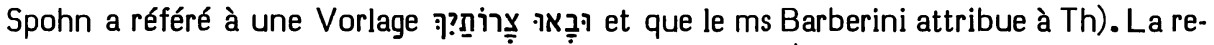

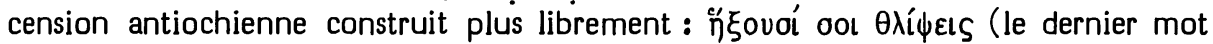
étant transformé par Josippos en $\theta \lambda i ́ \beta 0 \nu \tau \varepsilon \varsigma)$.

La même identification a été faite par la *V (in munitionibus tuis et in thesauris tuis) et par la*S (על חסביכי ועל גז̈יכי).

Le *T semble ne pas avoir traduit le premier mot mais avoir traduit deux fois le second : באוצרך ובבית גנזך.

\section{Choix textuel :}

Cappel (Notae 534a) a estimé que c'est le premier mot que le ${ }^{*} G$ a omis et qu'il

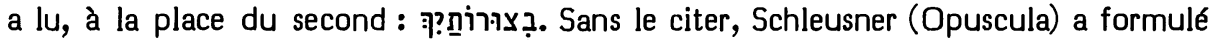
le même diagnostic qui est confirmé par le fait que, dans le ${ }^{*} G$ de Jérémie, la racine oxup* correspond 9 fois à la racine בצר et jamais à un dérivé de iy ou de עון

La fausse identification faite par les hexaples a influencé les recensions origénienne et antiochienne, ainsi que la $* V$ et la $* S$ qui, toutes, juxtaposent inconsciemment deux traductions du second mot. Il est étonnant que le $* T$ ait fait de même.

Déjà Th avait probablement fait cette fausse identification, puisque c'est après la leçon du *G, qu’il insérait une traduction écartelée du 2e mot du*M (où il confirme la présence de la $3 e$ et de la 4 e consonne que le ${ }^{*} G$ semblait ne pas avoir lues).

Du point de vưe de la préhistoire littéraire de ce texte, pourtant, c'est plutôt ce second mot que l'on pourrait considérer ici comme une glose empruntée au parallèle

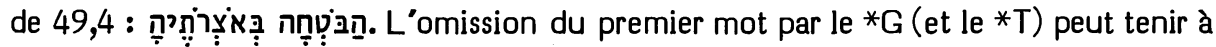
la difficulté d'en préciser le sens.

Du fait qu'elles dépendent d'une fausse identification du 'moins' offert par le ${ }^{*} G$, les recensions grecques, la $* V$ et la $* S$ ne peuvent apporter ici un témoignage sur le texte protomassorétique. Cependant, la présence du premier mot y est attesté directement par la leçon de AqSym et indirectement par le fait que Th donne du second mot une traduction qui présuppose clairement que le premier a été traduit déjà auparavant.

Le second mot étant donc attesté à partir de Th avec toutes ses consonnes et aucune variante n'étant attestée pour le premier, le comité 'a attribué la note "C" à la leçon du *M pour ces deux mots.

Interprétation proposée :

Il semble qu'il faille donner ici à "oeuvres", avec Keil, le sens général de "entreprises", en y incluant à la fois les initiatives diplomatiques et les préparatifs de défense, les "trésors" servant à financer ces initiatives.

Donc : "Puisque tu t'es fiée à tes entreprises et à tes trésors". 
48,9A צִ M Aq V S T // exeg : G / lic : Sym

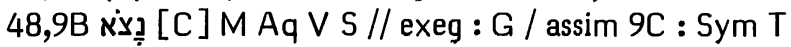

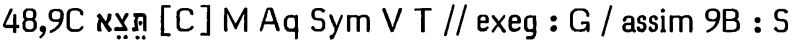

\section{Options de nos traductions :}

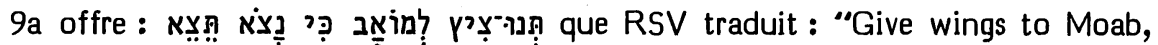
for she would fly away", RL : "Gebt Moab Flügel, denn es wird davon müssen, als flöge es" et J3 : “Donnez des ailes à Moab, pour qu'elle puisse s'envoler".

Disant suivre le ${ }^{*} \mathrm{G}, \mathrm{J} 12$ traduisaient : “donnez un tombeau à Moab, puisqu'elle est à fond dévastée" et TOB : "Erigez un monument funéraire à Moab, elle n'est plus que ruines".

Selon Brockington, NEB conjecture, au lieu des deux derniers mots : נִצִּה תִצֶה quand elle traduit : "Let a warning flash to Moab, for she shall be laid in ruins".

Origines des corrections :

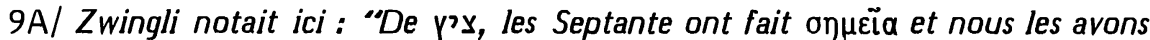
imités". Il traduit en effet : "Date signum Moab", suivi par la Bible des Prédicants de Zurich : "Gebend dem Moab eyn zeychen" et Olivetan (précisant qu'il suit le *G) : "Donnez le signe à Moab". Cette proposition sera reprise par Grätz (Studien 394) lisant צִ avec le *G, puis Giesebrecht et Ehrlich. Volz corrige de même en donnant à ce mot le sens de 'tombeau', suivi en cela par Nötscher, Rudolph, Steinmann, Weiser et les apparats de $\mathrm{BH} 35$.

9B/ Refusant qu'un 'aleph' puisse tenir la place d'un 'hé', Houbigant corrige ici en נצה au sens de 'voler'. Il sera suivi en cela par Duhm et Cent. Se référant à Jr 4,7, Schwally (Reden 197, n.3) donne à ce verbe le sens de 'être détruit', suivi en cela par Volz, Nötscher, Rudolph, Steinmann, Weiser et les apparats de BH3S.

9C/ Houbigant corrige en תצ au sens de "tu t'envoleras". Michaelis (Observationes) se contente de vocaliser sens, Schwally (ibid.) corrige en הצ̧ת, suivi par les mêmes qu’en 9B; alors que Duhm et Cent donnent à cette correction le sens de "elle s'envolera".

Les témoins anciens :

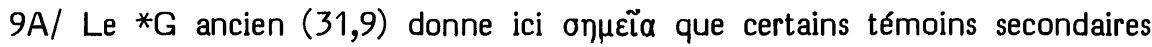
mettent au singulier.

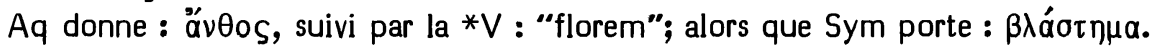
La *S (כלילא) et le *T (כתרא) s'accordent sur le sens de 'couronne'.

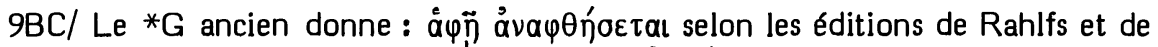

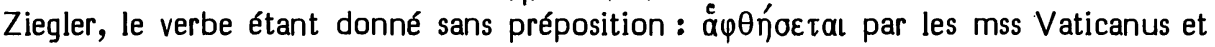
Sinaiticus.

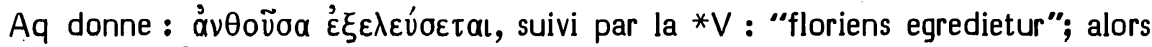

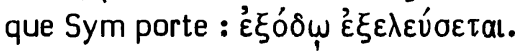

La *S donne : דמחרב חרבא et le *T : מגלא תגלי 
Choix textuels et interprétation proposée :

$9 \mathrm{~A} /$ Ce cas n’a pas été soumis au comité. La traduction d’Aq et de la *V : “donnez une fleur à Moab" semble mal convenir au contexte. On comprend donc que Zwingli et Olivetan se soient tournés vers le ${ }^{*} G$ et que l'idée de Volz de donner ici à la Vorlage צִ (conjecturée pour le *G) le sens de "tombeau" ait assuré à cette correction un grand succès, car elle paraît bien convenir à la suite (si on l'interprète au sens de : "elle sera entièrement détruite"). Mais le mot צִ̣ qui apparaît en Jr 31,21 semble y signifier des jalons balisant un parcours et il n'a pas été compris par le ${ }^{*} G$

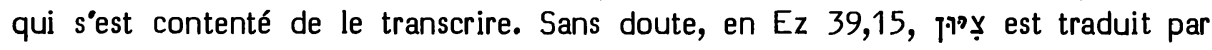

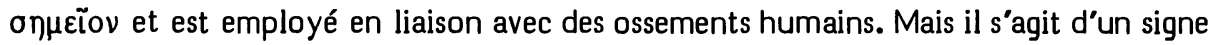
de repère notifiant aux croque-morts qu'ils doivent les emporter. Quant à 2 R 23,17

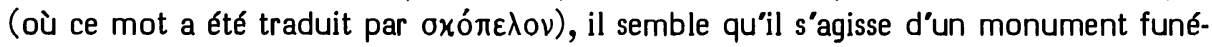
raire, une stèle signalant un tombeau. On peut donc conclure d'abord qu'il est peu

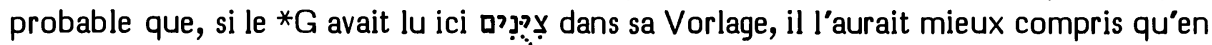
Jr 31,21 où il n'a pas su interpréter ce mot. Ensuite, si Moab est menacé d'une totale destruction, on pourrait comprendre à la rigueur : "donnez-lui des tombeaux", mais “donnez-lui des stèles funéraires" n'est pas très adapté à ce contexte.

Mieux vaut admettre, avec Duhm, que le $* G$ a tenté une exégèse du mot צ'. Michaelis (Supplementa §2130) a estimé que le *G a pensé aux צִ qui (en Nb 15, 38.39) servent de signe rappelant l'obligation d'observer les commandements.

Moran (Ugaritic 70) a suggéré que le mot 'ṣ̂ṣ̣̂̂ma' ou 'ṣieṣima', glose ugaritique interprétée au sens de "salines", peut avoir aussi le sens de "sel(s)". Cela permettrait de comprendre, en Jr 48,9 : "donnez du sel à Moab, car elle va être complètement dévastée", cela évoquant l'action d’Abimélek $(\mathrm{Jg} 9,45)$ semant du sel sur Sichem après l'avoir détruite. Mais le singulier 'sss' est apparu, après la publication de l'article de Moran, en d'autres textes ugaritiques (PRU $5 \$ \S 96$ et 97) où il ressort clairement $(\S 97,21)$ que 'șs. est ce dont on tire 'mlht'. Cela impose donc le sens de "saline" en le distinguant clairement de celui de "sel". Après la publication de ces derniers textes, Dahood (Libri 550) a voulu conserver la proposition de Moran, estimant que "mettez une saline sur Moab" peut signifier "répandez une grande quantité de sel". Une telle métaphore ne serait pas très bien adaptée à ce contexte. Rappelons-nous d'ailleurs que le seul autre cas où Moran (ibid.) a proposé de reconnaître à ce mot hébreu le sens de "sel" est Si 43,19. Mais ce n'est pas le mot ציצים qui y est parallèle à כמלח. C'est le mot כסנה (selon le ms de Masada) ou כספיר (selon le ms B). Tout engage donc à y garder à ציצים le sens de "fleurs" en y voyant les cristaux efflorescents du givre (כפור) qui sont comparés à des ramifications épineuses (ou à des saphirs) et à des concrétions salines (stique précédent). Donc rien ne prouve qu'il soit légitime de transférer dans la lexicographie de l'hébreu biblique le sens de "saline" que 'șs" possède en ugaritique.

Le sens de "aile" a été donné ici à צ צar David ben Abraham (II 527,29s), Abulwalid (Ușul 608,8s), Rashi, Radaq, Pagnini, etc. Ce sens a été attribué ici à ce mot par les dictionnaires de Pagnini (Thesaurus 2040), Buxtorf (Lexicon 647), Gesenius (Thesaurus 1158b), Gesenius/Buhl (682b), König (Wörterbuch 387a), BDB (851b). Mais $\mathrm{KBL}$ et HALAT ont omis ce sens, considérant comme acquise une correction selon le *G. Rappelons pourtant que Graf, Duhm et Cornill estimaient ce sens bien fondé 
et le plus apte à expliquer cet emploi du mot. En effet le mot ציצין traduit le mot סנפיר (= nageoire) dans tous ses emplois (Lv 11,9.10.12; Dt 14,9.10) aussi bien dans le targum du Pseudo-Jonathan que dans celui d'Onqelos. Le Neofiti se contente de transcrire צנפירין en marge de Dt 14,9-10. Ce même mot désigne aussi les 'ailes' d'une armée (cf. Levy, Chald. Wörterb.II 322b) dans le

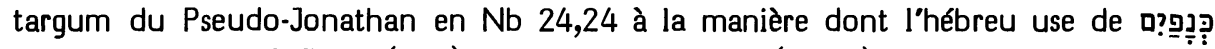

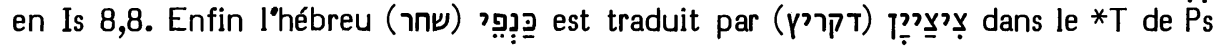
139,9. Notons enfin qu'Is 25,11 nous présente une image étrange : Moab qui va être foulé sur place, comme la paille et qui étend les mains, au milieu de la montagne "comme le nageur les étend pour nager". Il n'est donc pas étonnant que l'on trouve ici un mot signifiant certainement en araméen "nageoire", mais pouvant être étendu au sens de "aile" en araméen palestinien (le mot pour désigner l'aurore étant typiquement palestinien).

9BC/ La traduction du *G est analogue à celle de אي̣ pạ å áva $\varphi \theta \underline{n}$ en Jr 21,12

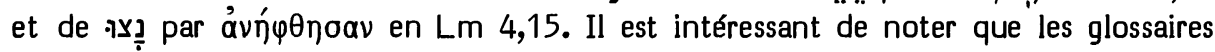
$A$ et $F$ donnent ici comme deuxième sens : "anprenant anpranra" (= enflammant enflammera).

Notons que Sym et le $* T$ ont assimilé 9B à 9C, alors que la $* S$ a assimilé en sens inverse.

Le sens de "voler" a été reconnu à l'infinitif נִָ par penahem ben Saruq (qui en fait le premier sens du monolittère 'șadé"), H.ayyuj (qui, comme Menahem, l'associe à Lm 4,15 et à Lv 1,16 en Kitâb 190,17s), Abulwalid (Ușul 447,25-32), Rashi, les glossaires ABCDEF (qui le mentionnent tous comme premier sens), Joseph Qimhi (Zikkarôn 56,3s et Galuy 88 en bas), Judah ibn Balaam, Menahem de Posquières, Judah ibn Balaam, Joseph Qara, Joseph ibn Naḥmias, Ibn Ezra (sur Lm 4,15), Radaq, Tanḥum Yerushalmi, Isaïe de Trani, Pagnini, Buxtorf (Lexicon 481), C.B. Michaelis.

J.D. Michaelis (Observationes) a préféré donner à cet infinitif le sens de "être dévasté". En effet, en 4,7, , tation de l'infinitif en 48,9 ne peut pas s'accorder avec la vocalisation que le *M donne au mot suivant. Par contre, pour quelqu'un qui se trouve en butte à de grands périls, le souhait que des ailes lui soient données pour qu'il puisse s'envoler constitue une métaphore classique : "Qui me donnera des ailes (אִ צִ au au singulier, comme ici) comme celles de la colombe, que je m'envole et trouve un gîte. Voici que je m'éloignerais en fuyant" (Ps 55,7s). Moab est d'ailleurs comparé, en Is 16,2, “à l'oiseau en fuite, à la nichée expulsée". Il suffit d'admettre que la finale de ce mot en "aleph' veut faciliter son association au verbe qui suit et souligner la paronomase qui relie les trois mots de ce vs que nous étudions.

Quant à אي̣n, il n'est nullement nécessaire ni même souhaitable d’en corriger la vocalisation pour le rattacher à une racine identique à celle de l'infinitif qui précède. Il faut lui maintenir sa racine יצא qui justifie le 'aleph' final (qui est passé de lui au

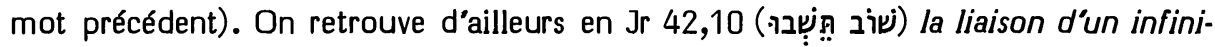
tif absolu à un verbe de racine différente par assonance, finesse stylistique dont nous avons déjà traité (ci-dessus, p. 527) à propos de Jr 8,13:

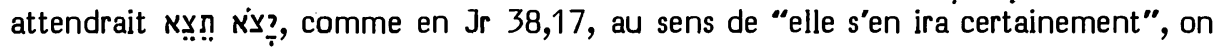




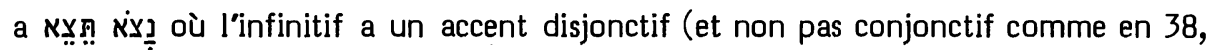
17), et cela pour faire sentir l'inattendu de la juxtaposition de ces deux verbes: “à tire-d'aile, elle s'en ira", le verbe יצא ayant ici, comme en 48,7 le sens de "partir pour l'exil". Il y a donc une ironie sarcastique en 9a: "Donnez des ailes à Moab, car à tire-d'aile elle s'en ira".

Pour ces deux mots, le comité a attribué au *M la note " $\mathrm{C}$ ".

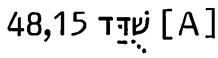

Options de nos traductions :

Pour le *M Städte werden erstiegen" et Jj : "Moab est ravagé; on a escaladé ses villes".

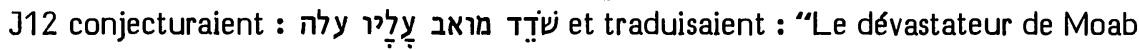
est monté contre lui".

Disant changer une consonne, TOB donne: "Le dévastateur de Moab monte à l'attaque de ses villes". Sans note, RSV donne : "The destroyer of Moab and his cities come up" et NEB : “The spoiler of Moab and her cities has come up".

\section{Origines des corrections :}

Michaelis a traduit : "Der Verwüster ersteigt Moab und dessen Städte" en précisant qu'il a retouché la vocalisation. En OEB, il explique qu'en s'inspirant du vs 18, il a vocalisé Tịu. En cela, il sera suivi par Ewald, Graf, Grätz (Studien 394), Oort, Ehrlich, et les apparats de SBOT et HSAT2.

Ewald avait traduit, après cette correction : “der Zerstörer Moabs und seiner Städte steigt auf". Cornill, après avoir accepté cette correction en SBOT, a fait remarquer en son commentaire que cette construction est allemande, mais non hébraïque. Pour remédier à cette objection, on a complété la revocalisation du premier mot par une correction conjecturale du troisième (cf. J12). Cette deuxième conjecture a été ajoutée par Peake, Condamin (qui le cite), Volz, Nötscher, Rudolph, Penna, Steinmann, Weiser et les apparats de BH3S.

\section{Les témoins anciens :}

Volz (commentaire) demande de lire, avec des mss du *M, Țֵ(i) i et, à propos de cela, il se réfère à Sym. En ses Studien (309), il est plus explicite : “Divers mss du *M ont שותו דמשלח : שוד : et il est rapporté, de la part de Sym, dans le contexte de ces mots. Aussi, je tiens le participe Ț̣(i)é pour la meilleure leçon". Si Volz avait consulté l'Auctarium de Field, il y aurait constaté que la leçon grecque de Sym (rapportée par le ms Barberini) est : xaì ó $\gamma u \mu \nu \tilde{\omega} \nu$ aủij̀ ávé $\beta \eta$ où il est évident que les quatre premiers mots entendent traduire littéralement le troisième mot du ${ }^{*} M$, sans qu'on puisse en conclure que Sym lisait le premier mot du vs autrement que l'avait fait le ${ }^{*} G$.

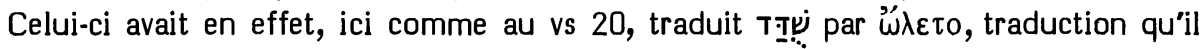
avait, de plus, étendue au vs 18 (où le *M vocalise Rossi dit seulement que certains d'entre eux ont ici une graphie pleine. Kennicott en mentionne six. Nous avons eu accès à deux d'entre eux : le ms Reuchlin des Pro- 
phètes et le ms des Jésuites de Cologne. Tous deux vocalisent en pual comme le *M. La conjecture de Michaelis demeure donc, malgré Volz, tout aussi conjecturale qu'auparavant. En effet le $* M$ est, en plus du ${ }^{*} G$, attesté par tous les autres témoins connus: la *V (vastata est), la *S (אתבזו) et le *T (אתביזו). Ce dernier a le pluriel, car il traduit "Moab" par "les Moabites".

\section{Choix textuel :}

En face de cette conjecture, le comité a attribué au *M la note " $A$ ".

En plus de l'objection de Cornill, il faut noter, avec Giesebrecht, qu'une syntaxe plaçant le sujet en premier et le verbe en quatrième place, après les compléments, serait languissante.

Interprétation proposée :

Les deux premiers mots de ce vs seront repris en conclusion de l'oracle (en fin du

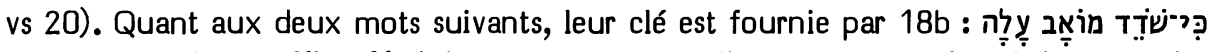
רִ. L'usage d'un suffixe féminin pour le premier mot de $9 \mathrm{~b}$. D'ailleurs, en ce chapitre, féminin et masculin alternent pour Moab. Les deux événements mentionnés par les deux verbes ne sont pas successifs mais simultanés : "Moab est dévasté; il a escaladé ses villes". On peut, ou bien expliciter "le dévastateur" au lieu de "il", ou bien indiquer en note que le sujet de "a escaladé" sera explicité au vs 18 où il sera dit à la "fille qui habite Dibon": "car le dévastateur de Moab a escaladé contre toi (c'est-à-dire : pour t'attaquer)".

48,31 יהגה [B] M 2Q Th AqSym g // paraphr : V S T / incert : G / assim-ctext : m אהגה

Options de nos traductions :

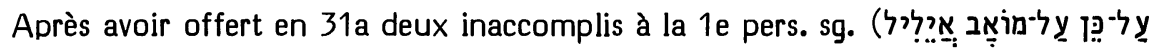

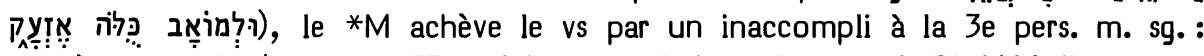

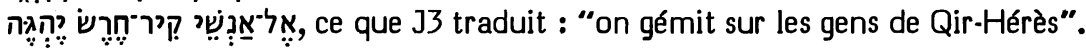

A la place du dernier verbe, J12, disant suivre le qeré et un ms hébreu, traduisaient : "je veux ... gémir". Brockington disant qu’elle lit אִ avec un ms, la NEB traduit: "I will moan" et TOB traduit: "je gémis". Sans note, RSV donne: "I mourn" et RL : "(Darum) muss ich ... klagen".

Origine de la correction :

La traduction des Prédicants de Zurich avait traduit ces trois inaccomplis par des pluriels impersonnels: "Und darumb wirt man ... heulen/und ... wirt yederman schreien ... wirt man eyn klag füren".

Luther préfère les mettre tous à la 1e pers. sg. : "Darumb mus ich ... heulen, und ... schreien, und ... klagen". Calvin fera de même : "meditabor, inquit, ad viros Kircheres".

La Geneva Bible et $\mathrm{KJ}$ se contentent d'expliciter, comme sujet du troisième inaccompli : "mine heart shall mourne". 
C'est Houbigant qui, disant se fonder sur le "clamabo" de la *V, a proposé de corriger en אהגה. Ewald lit de même, estimant que la 1e pers. du *M tient à une influence de Is 16,11 et Jr 48,36 où (les gens de) Qir-Hérès sont l'objet d'émotions énoncées à la 1e pers. Corrigent de même Henderson, Grätz (Studien 395), Schwally (Reden 199, n.2), Giesebrecht, Oort, Condamin, Volz, Nötscher, Rudolph, Penna, Weiser, Bright ainsi que les apparats de $\mathrm{BH} 23 \mathrm{~S}$ et de Cent.

Les témoins anciens :

La leçon Scholia de celui-ci).

Depuis l'édition du *M par Baer (122), on attribue aux Orientaux cette leçon en qeré pour ce mot. De fait, ce mot ne figure pas dans la liste de ces variantes du ms de Leningrad ni dans celle de l'édition Ben Hayim. Mais le ms New York JThS 232 (qui porte la leçon classique), attribue aux Babyloniens un ketib והגה. C'est justement la leçon qui est dans le texte du ms de Petrograd qui attribue aux Babyloniens un qeré אה et aux Occidentaux un qeré " Cependant le seul fragment babylonien que Yeivin (IV 246) ait publié ici porte la leçon classique avec 'yod'.

$2 Q$ appuie le $* M$ pour les trois verbes de ce vs.

Le *G $(31,31)$ lie 31b au verbe qui précède (et qu’il traduit comme le précédent

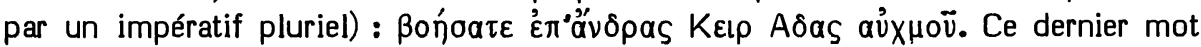
désespère les exégèses. Estimant que notre verbe n'avait pas été traduit par ce mot "sécheresse" au génitif, la recension origénienne a ajouté : xai $\mu \varepsilon \lambda \varepsilon \tau$ ́ńoc que le ms

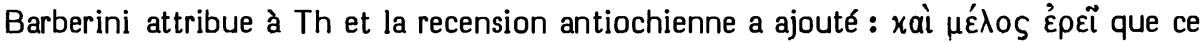
ms attribue à AqSym. La conjonction tient probablement à la nécessité d'insérer cette ajoute dans la traduction qui ne s'y prête pas.

La *V (lamentantes), la *S (נהוון רנין) et le *T (דוון) ont tenté de ce mot des paraphrases où la 1e pers. n'apparaît pas. En effet, le "clamabo" relevé par Houbigant traduit, en réalité, le verbe précédent.

Choix textuel :

La tradition textuelle du ${ }^{*} M$ est suffisamment cohérente et appuyée par $2 Q$, Th et AqSym pour que le comité ait attribué la note "B" à sa lectio difficilior.

Déjà Tanhum Yerushalmi estimait qu'il serait normal d’avoir ici la 1e pers. comme pour les deux verbes précédents.

L'origine littéraire de ce vs est en Is 16,7 où les deux premiers verbes sont à la

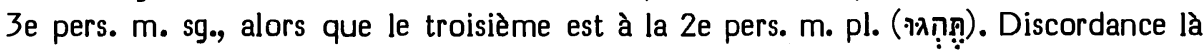
aussi, mais d'un autre type.

\section{Interprétations proposées :}

Un sujet "mon coeur" a été sous-entendu ici par Yéfet ben Ely, Menaḥem de Posquières, Moshé ben Sheshet et Vatable. Radaq et C.B.Michaelis sous-entendent "Moab". D'autres donnent à ce verbe un sujet impersonnel: "on médite" ou "on gémit". 
Options de nos traductions :

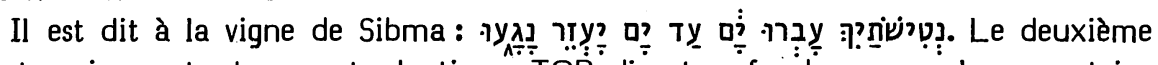
?ִ est omis par toutes nos traductions, TOB disant se fonder pour cela sur certains mss hébreux, le ${ }^{*} G$ et le parallèle d'Isaïe.

\section{Origine de la correction :}

Voyant dans le second ọ une répétition erronée du premier, Hitzig a omis ce mot, suivi en cela par Graf, Schwally (Reden 199, n.2), von Orelli, Giesebrecht, Oort, Duhm, Ehrlich (Miqra), Cornill, Condamin, Volz, Nötscher, Rudolph, Penna, Weiser, Bright ainsi que les apparats de HSAT234, BH23S et Cent.

\section{Les témoins anciens :}

Deux mss de Kennicott omettent ce mot : le premier est le ms Corpus Christi WB4,8 de la fin du XIVe s. avec une version latine; le second appartient à la Bibliothèque du Collège Gonville et Caïus, ses livres sont dans l'ordre de la Bible anglicane et il n'a pas de massore. Ces témoins n'ont donc aucune autorité particulière.

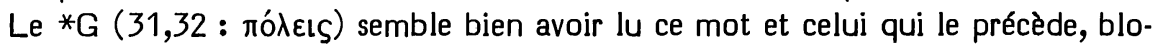
qués, sous la forme corrompue ערים Il atteste donc indirectement sa présence (contre ce que TOB prétend à la suite de HSAT4 et de Cent).

Selon Syh, AqSym donnent ici עדמא לימא דיעזיר, ce qui est la leçon de la*S. Du quatrième au sixième mot, le *T n'a eu qu’à copier le *M.

La *V porte : "usque ad mare Iazer".

\section{Choix textuel :}

C'est à partir du début du XIXe s. que les exégètes ont acquis la conviction qu'aucun lac important ne pouvait être lié au site éventuel de Yazèr. Cependant, Delitzsch a fait remarquer que le bassin artificiel du Temple était nommé "mer" et qu’à Damas des bassins de marbre sont appelés 'baharât'. Il estime donc qu'un étang-réservoir peut suffire pour justifier l'appellation de "mer de Yazèr" (= Keil et Nägelsbach).

Notons d'ailleurs que bon nombre d'exégètes ont construit ici la phrase de deux manières qui évitent cette expression. D'abord Zwingli, Vatable, Calvin et Grotius ont vu ici en "Yazèr" une ellipse pour "les rameaux ou les hommes de Yazèr". Dans ce cas, il est dit à la vigne de Sibma : "Tes sarments dépassaient la mer; jusqu’à la mer, ceux de Yazèr atteignaient". Ensuite, Reland (825) et Michaelis (Observationes) ont envisagé de construire : “Tes sarments dépassaient la mer jusqu’à la mer; ils atteignaient Yazèr".

Mieux vaut admettre que Jr 48,32a émane de Is $16,8-9$ où on en retrouve presque tous les éléments. Il est donc très probable que dans la forme originelle de cet oracle, on ne lisait (comme c'est le cas en Is 16,8) que עד־יעזר נגעו. Mais l'attestation presque universelle du mot (entre les deux premiers de ces mots) dans la tradition textuelle de Jr 48,32 nous indique que ce mot a pénétré là lors du remaniement littéraire qui a abouti à la forme de cet oracle qui caractérise le livre de Jérémie. Il ne faut donc pas voir là un accident textuel postérieur. 
C'est pourquoi le comité a attribué ici au *M la note "B".

Interprétation proposée :

Celui qui a fait subir à cet oracle son dernier remaniement littéraire ne semble pas avoir été soucieux de se conformer à la topographie. Il est donc inutile de vouloir sauver les données géographiques. Mieux vaut traduire, avec l'ensemble des exégètes juifs médiévaux (et comme les teamîm le suggèrent) : “Tes sarments passaient la mer, ils atteignaient jusqu’à la mer de Yazèr". On pourra noter que le rédacteur veut exprimer de façon hyperbolique la large diffusion et l'estime dont jouissaient les vins ou les plants de vignes issus des vignobles de Sibma. On ajoutera que le parallèle d'Isaïe offre un état de ce poème qui a probablement servi de source au rédacteur.

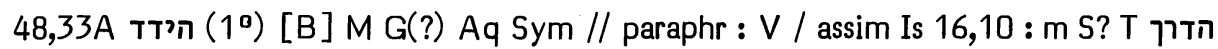
48,33B הידד לא הידד [B] M G(?) Aq Sym // paraphr : V, S, T

Options de nos traductions :

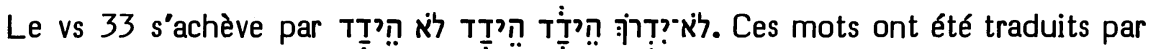
RSV : "no one treads them with shouts of joy; the shouting is not the shout of joy" et par NEB : "nor shall shout follow shout from the harvesters - not one shout".

Lisant הִ à la place du 3e mot et à la place du 6e, J traduit : "le fouleur ne foule plus, le cri de joie ne résonne plus" "la première correction s'appuyant sur la $* V$, la $* S$, le $* T$ et le parallèle de Is 16,10 , alors que la seconde est conjecturale. RL traduit: “der Kelterer wird nicht mehr keltern, der Winzer wird nicht mehr sein Lied singen".

Omettant les trois derniers mots, TOB traduit : "finis, les cris qui accompagnaient le foulage".

Origines des corrections :

En comparant les trois premiers mots à leurs parallèles en Is 16,10 , Hitzig a estimé que le rédacteur de la forme qu’a cet oracle dans le livre de Jérémie a cru lire הידד dans הדרן. Graf, lui, attribue cette erreur à un copiste. Le participe d'Is 16,10 a été introduit ici à la place du 3e mot (ou du 3e et du 4e) par Grätz (Studien 396), Schwally (Reden 199, n.2), Giesebrecht, Oort, Duhm, Cornill, Condamin, Ehrlich, Volz, Nötscher, Rudolph, Penna, Weiser, Bright et par les apparats de HSAT234, BH23S et Cent.

Pour le 6e mot, la conjecture retenue par J a été proposée par Rudolph.

C'est Ehrlich (Randglossen) qui a proposé d'omettre les trois derniers mots à titre de glose signifiant : “le mot הידד (qui précède) n"est pas הידד".

Les témoins anciens :

Le seul témoin babylonien cité ici par $\mathrm{BH} 3$ est le ms Oxford Bibl. Bodl Heb d 26 (édité par Yeivin IV 246). Il porte en 33A la leçon pï qui assimile à Is 16,10. Il faut noter que ce ms ajoute à l'hébreu le *T verset par verset. Notons en outre que le scribe du ms de Petrograd, lui aussi, a écrit ici ces quatre consonnes. Puis le vocalisa- 
teur a transformé le 'resh' en 'dalet' et inséré un 'yod' entre les deux premières lettres en vocalisant cette forme avec șéré et qameṣ. Il a laissé le 'kaf' final sans raphé et la massore a spécifié que le mot Ṭִִ figure 3 fois en ce vs.

De 2Q, on ne connaît, pour ces 6 mots, que le 'dalet' qui achève le dernier.

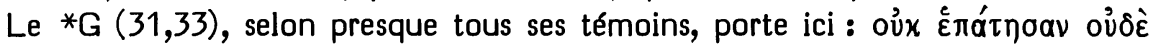

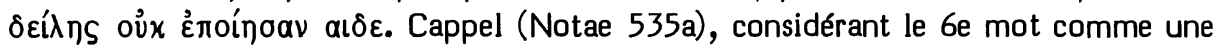
ajoute postérieure, lit à la place des $3 \mathrm{e}, 4 \mathrm{e}, 5 \mathrm{e}$ et $7 \mathrm{e}$ : $a\llcorner\delta \varepsilon \delta, \alpha\llcorner\delta \varepsilon \delta$ oủx $a\llcorner\delta \varepsilon \delta$. Il estime

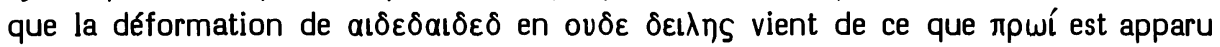
juste avant. Ziegler conjecture de même, en semblant ne pas connaître Cappel. S'il en est ainsi, le ${ }^{*} G$ atteste très exactement le ${ }^{*} M$. Mais un copiste ancien, l'estimant inintelligible, l'aurait corrigé très librement.

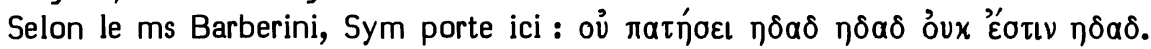
Aq y serait identique, quoique le copiste de ce ms (mais non celui de Syh) y ait omis par haplographie l'un des deux premiers $\eta \delta \propto \delta \delta$.

$\mathrm{La} * \mathrm{~V}$ a traduit largement : "nequaquam calcator uvae solitum celeuma cantabit".

Selon le ms Ambrosianus, la*S donne: לא נעצרון עצוֹרא ולא נענון ולא נאמרון יהי יהי. Cette traduction est paraphrasée. Il est difficile de dire si sa Vorlage différait du *M et assimilait à Is 16,10.

Le *T donne : לא יעצרון עיצורין ולא ירימון בקלהון. Les trois premiers mots sont identiques au parallèle de Is 16,10 et les trois suivants traduisent largement à la manière de la $* V$.

\section{Choix textuel :}

En 33A quelques témoins semblent avoir assimilé au parallèle d'Is 16,10. Cependant, pour ces six mots, le $* M$ est fermement appuyé par Aq et Sym. Il l'est aussi probablement par le ${ }^{*} G$. Les autres traductions ont plus ou moins paraphrasé ce texte qui leur semblait difficile à interpréter. Soucieux de sauver la forme jérémienne de cet oracle d'une assimilation à sa forme isaïenne, le comité a attribué ici au *M 5 " $\mathrm{B}$ " et 1 " $C$ ".

\section{Interprétation proposée :}

Hayyuj (Kokovzov 37) a rapproché les trois derniers mots de זنאת לאיזאת (Ez $21,31)$ qu'il comprend comme : cela ne sera pas comme ce que l'on en connaît bien. On peut comprendre ici : “On ne foulera plus avec hédad ! Hédad ne sera plus hédad”. Le mot 'hédad' est une onomatopée exprimant le cri par lequel s'encouragent ceux qui foulent la vendange. Mais ce mot a été employé métaphoriquement en Is 16,9 et le sera en Jr 51,14 pour désigner la clameur guerrière de l'envahisseur. C'est cela ce 'hédad' qui ne sera plus le "hédad' joyeux de ceux qui foulent au pressoir. 


\section{Options de nos traductions :}

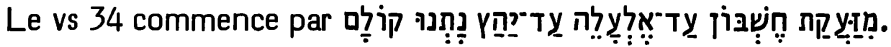

TOB omet le 'mem" de 34A et traduit les quatre premiers mots: "Les appels au secours de Heshbôn, on les entend jusqu”a Eléalé". RL traduit de même : "Das Geschrei von Hesbon wird gehört bis Eleale".

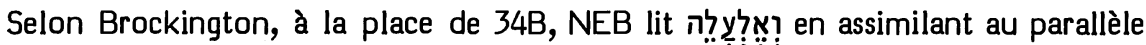
de Is 15,4 quand elle traduit : "Heshbon and Elealeh utter cries of anguish". RSV corrige de même : "Heshbon and Ele-aleh cry out".

J unit ces deux corrections quand elle traduit : "Les hurlements (J3 : cris) de Heshbôn et (J3 et "de") Eléalé".

Origines des corrections :

Michaelis (OEB) a vocalisé 34A : mission du 'mem' a été proposée par Oort, Volz, Nötscher et les apparats de HSAT4 et de Cent.

A cette omission, une correction de 34B en וְאלְלְy (qui avait été proposée par Duhm) a été ajoutée par Rudolph, Weiser et les apparats de BH3S.

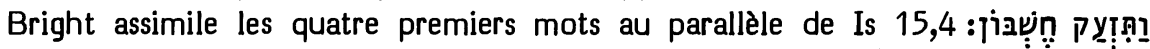

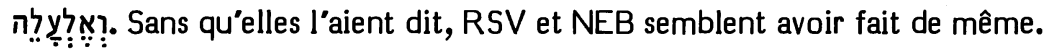

Les témoins anciens :

$2 \mathrm{Q}$, lacuneux pour 34B, appuie le *M en 34A.

Pour les quatre premiers mots, le ${ }^{*} M$ est traduit littéralement par le ${ }^{*} G(31,34)$ :

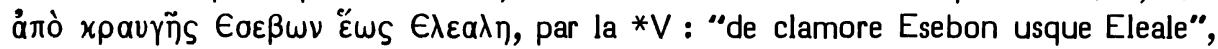
par la*S : מן יללתא דחשבון ועדמא לאלעלא et par le *T : מצוחת חשבון עד אלעלה.

Choix textuel :

Le comité a donc attribué au $* M$ la note " $A$ ", estimant qu'il est littérairement dépendant d'Is 15,4 et que les difficultés qu'il présente sont d'ordre exégétique.

Interprétation proposée :

Yéfet ben Ely (selon le ms London BL Or 2504) a compris : "A cause de la (puissance de la) clameur de Heshbôn (qui s'est fait entendre) jusqu'à Eléalé, leurs voix se sont élevées jusqu”à Yahaș". En Is 15,4 on avait : "Heshbôn et Eléalé clamèrent; leur voix s'est fait entendre jusqu'à Yahaș". La construction d'Isaïe est plus simple, "leur" ayant pour antécédents les deux villes qu'on vient de nommer. En Jérémie, la construction plus subtile suppose que "leurs" a pour antécédent ou bien les voisins qui s'associent à la lamentation de deuil, ou bien les réfugiés de Heshbôn qui, dans leurs lieux de refuge, se lamentent. 
48,38 cf. p. 644.

4יליל 48,39 הילילו

\section{Options de nos traductions :}

Avant : "comme Moab a honteusement tourné le dos!", le *M donne . חירלילוּ. Ces trois mots sont traduits par RSV : "How it is broken! How they wail !", par RL : "O wie ist es zerschlagen, wie heulen sie !", par TOB : “Comment! Il s'est effondré ! hurlez !" et par J3 : “Comme il a été détruit ! Gémissez !".

J12 omettaient avec le *G le 3e mot et traduisaient : “Ah! (J2 : Quoi !) il a été brisé !" NEB fait de même et traduit : "in her dismay".

Origine de la correction :

Schleusner (sur les Observationes de Michaelis) a estimé que le $* G$ avait omis le 3e mot. Ont fait de même : Schwally (Reden 199, n.4), Duhm, Volz, Nötscher, Rudolph, Weiser, Bright et les apparats de SBOT et $\mathrm{BH} 35$.

Les témoins anciens :

Pour le 2 e et le $3 e$ mot, le ${ }^{*} G$ ancien $(31,39)$ donne : $x \alpha \tau \eta ́ \eta \lambda \alpha \xi \varepsilon$ et la recension

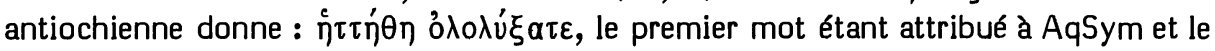
second à ThSym.

La *V traduit ces trois mots: "quomodo victa est et ululaverunt", la *S: איכנא אתתברו ואיללו. et le *T : איכדין אתברו אילילו.

\section{Choix textuel :}

L'ajoute par la $* V$ et la $* S$ d'une conjonction avant le $3 e$ mot est translationnelle.

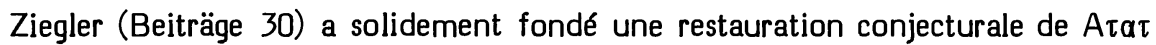

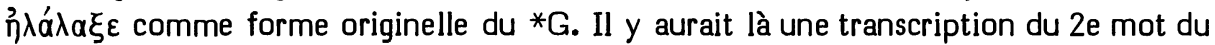
*M (analogue à celle qui a été donnée au vs 1 ), puis une traduction du 3 e ( $n^{\prime}$ en exprimant pas la désinence du pluriel). $S^{\prime}$ il en est ainsi, $l e{ }^{*} G$ ne saurait attester une absence de ce 3e mot (ainsi que le prétendent les apparats de HSAT4 et de BH23).

Il est encore moins exact de prétendre, avec l'apparat de BHS, que AqSym omettent ce mot. En effet, nous avons cité la leçon de Sym (selon le ms Barberini). Pour la leçon de Aq, il faut se référer aux données fournies par le ms Ambrosianus de Syh. Celui-ci donne comme texte du ${ }^{*} G$ :

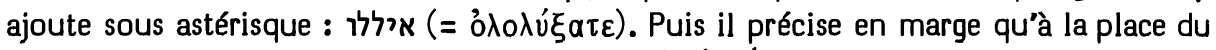
premier de ces deux mots, AqSym ont אזדכי (= = bue). La conclusion de cela est que nous connaissons la leçon de Aq pour le premier verbe, alors que, pour le second, nous ne sommes pas en mesure de préciser comment il l'a traduit.

Retenons donc que l'on ignore si la Vorlage du ${ }^{*} G$ portait le 'waw' final du second verbe. C'est pourquoi le comité a attribué au *M ici la note " $B$ ". 
Interprétation proposée :

Etant donné le parallélisme existant entre ce vs et 48,20 , mieux vaut lire le second verbe comme un impératif (plutôt que comme un accompli). On pourra donc traduire : "Comme il est brisé ! hurlez !"

48,44 cf. p. 539.

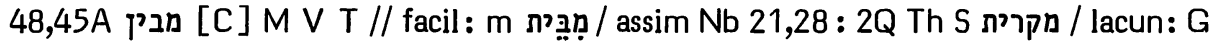

Options de nos traductions :

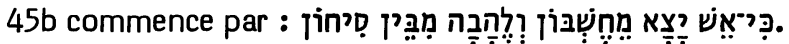

Pour l'avant-dernier mot, aucune de nos traductions ne se fonde sur le* $M$.

Lisant מִגבית avec 3 mss, J et TOB traduisent : "du palais de" et NEB "from the palace of". De même, RSV donne : "from the house of" et RL : "aus dem Hause".

Origine de la correction :

Cette leçon a été conjecturée par Venema. Ne la rencontrant que dans le ms 2 de Kennicott, Michaelis (Observationes) hésitait à l'adopter. C'est pourtant ce qu'ont fait Ewald2, von Orelli, Giesebrecht, Oort, Duhm, Ehrlich (Miqra), Cornill, Condamin, Volz, Nötscher, Rudolph, Penna, Weiser, Bright et les apparats de SBOT, HSAT23 et BHS.

Ont préféré lire מקרית avec le parallèle de Nb 21,28 : Grätz (Studien 397), Knabenbauer et l'apparat de $\mathrm{BH} 2$.

Ont hésité entre ces deux corrections : Ewald1 et les apparats de HSAT4 et BH3.

Les témoins anciens :

La leçon מִבְב a pour appuis trois mss sans autorité particulière : le ms Kenn 2 (de 1304), le ms de Rossi 26 (sans massore) et la première main du ms de Rossi 1252 (XIVe s.). Le massorète du ms New York JThS 232 a noté comme unique la séquence des deux derniers mots pour protéger cette lectio difficilior contre des facilitations du type de celles qui ont attiré les critiques.

Le *G ancien omet les vss 45 à 47.

$2 \mathrm{Q}$, selon l'interprétation très probable de Baillet (DJD III 68s), lit pour ce mot מקרית. C'est également la leçon qu'ont lue ici Th (à qui les recensions origénienne et

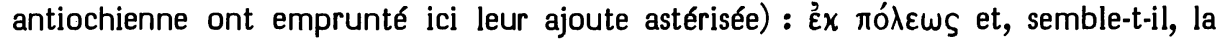
*S : מקרית en Nb 21,28).

La leçon du *M a été lue ici par la *V : "de medio" et par le *T : מבין.

Choix textuel :

La leçon qu'ont lue ici $2 \mathrm{Q}$, Th et la *S est une assimilation à la source de $\mathrm{Nb}$ 21,28. Quant à מבית, elle apparaît clairement comme une facilitation issue de מִִֵיך Face aux deux autres, cette dernière leçon se présente comme spécifique de l'état littéraire jérémien de cet oracle. Sa difficulté explique qu'on lui ait cherché ces deux échappatoires. 
Le comité a attribué à la leçon du *M 4 "C" et 2 "B".

Interprétation proposée :

Refusant d'admettre, avec Movers (15) et Hitzig, que le rédacteur a pris ici Sihon pour une ville, Keil a estimé que ce nom n'intervient pas ici comme personne isolée, mais comme chef d'armée. On peut donc traduire les deux derniers mots : “des rangs de Sihon" en notant : "littéralement : 'd'entre' ou 'du milieu de'." Sur le sens de P’्̣, cf. ci-dessus, p. 324, à propos d’Is 44,4.

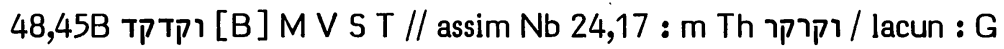

Options de nos traductions :

De la flamme qui a été mentionnée juste avant, il est dit ici :

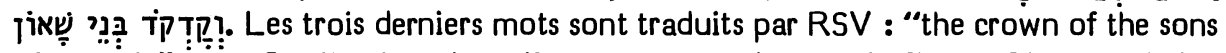
of tumult", par J: "et le crâne d'une engeance de tumulte", par RL: "und den Scheitel der kriegerischen Leute" et par TOB : "le crâne des tapageurs".

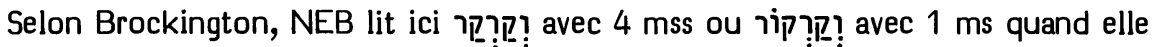
traduit: "(they devour the homeland of Moab) and the country of the sons of tumult".

Origine de la correction :

NEB semble dépendre ici de Driver (Myths 45) qui, presque seul parmi les critiques, considère en ce contexte la leçon avec deux 'resh' comme plus primitive que la leçon avec deux 'dalet'.

\section{Les témoins anciens :}

Aucun des cinq mss que de Rossi mentionne ici comme témoins de la leçon avec 'resh' n'a une autorité particulière. Soulignons plutôt que les mss du Caire, d'Alep et de Leningrad attestent en $\mathrm{mp}$ le caractère unique de la graphie de ce mot (pour

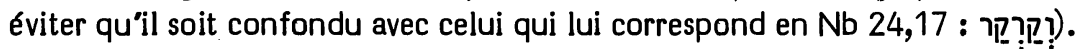

La leçon avec deux 'dalet' a été lue ici par la *V (et verticem), la*S (ורשנא) et le *T (ויקירי).

Le *G ancien omettant les vss 45 à 47 , Th (à qui les recensions origénienne et

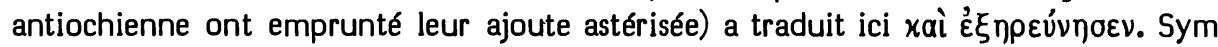
faisait usage du même verbe (au futur) pour traduire le parallèle de Nb 24,17. Il est très probable que la Vorlage dont Th disposait ici avait été assimilée à la leçon avec deux 'resh' que la tradition massorétique offre en $\mathrm{Nb} 24,17$. Th et Sym ont interprété ce verbe en prenant pour clé la racine חק.

Choix textuel :

Nous aborderons cette question plus à fond à propos du parallèle des Nombres où le comité propose de corriger en adoptant la leçon du Samaritain (et du parallèle de Jérémie). 
Considérant ici la leçon avec deux 'resh' comme une assimilation à la forme *M du parallèle des Nombres, le comité a attribué à la leçon avec deux "dalet" 5 "B" et 1 "C".

Interprétation proposée :

Jr 48,45 reprend $\mathrm{Nb} 24,17$ dans un contexte transformé. Cela oblige à donner ici au "crâne" le sens métaphorique que nous lui avons déjà reconnu (ci-dessus, p. 467) en Jr 2,16.

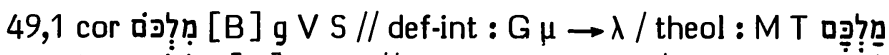

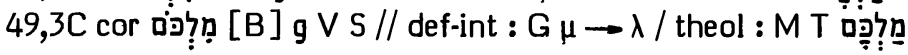

Options de nos traductions :

En ces deux endroits où le *M porte מִִ̣̣, nos traductions portent "Milcom" (RSV, NEB) ou "Milkom" (RL, J, TOB).

Origine de la correction :

Alors que Pagnini traduisait "rex eorum" (suivi en cela par Prédicants, Münster, Olivetan, Calvin, Estienne, Ge, Tremellius, $\mathrm{KJ}$ ), Zwingli transcrivait "Malcham" en

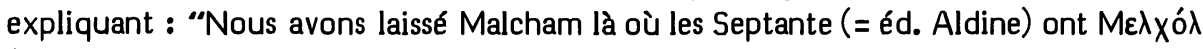
(qu'ailleurs nous voyons rendu par Moloch) qui est le dieu des Ammonites que Jérôme aussi rend par Melchom. Il est cependant incertain s'il s'agit ici du dieu Moloch, de leur roi ou de Melchom, nom propre du roi. Quant à moi, il me semble qu'il faut traduire 'pourquoi leur Moloch occupe-t-il Gad ?'". De fait ce mot a été transcrit par Luther (Malchom), Brucioli (en 1532: Malcham et Melchom, avant d'adopter en 1540 : il Re loro), Jud (Malcham), Châteillon (Melcom repris par la marge de KJ) et Pasteurs (Malcam).

Notons que la leçon du *M sera interprétée en nom propre par Nägelsbach et von Orelli.

Cappel (Notae 535) a fait remarquer que le $* G$ a achevé sa transcription par un 'lambda', une mutation de liquide ayant eu lieu parce qu'aucun mot grec ne s'achève par 'mu'. Aussi la transcription 'Melchom' ou 'Milkom' a-t-elle été adoptée ici par Rosenmüller, Ewald, Hitzig, Graf, Schwally (Reden 200, n.2), Knabenbauer, Giesebrecht, Oort, Duhm, Cornill, Condamin, Ehrlich, Volz, Nötscher, Rudolph, Penna, Steinmann, Weiser, Hyatt, Bright et par les apparats de SBOT, HSAT234, BH23S et Cent.

Les témoins anciens :

Seul le *T (מלכהון) a interprété ici le 'mem' final en pronom suffixe.

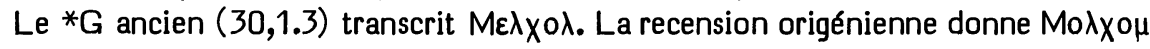

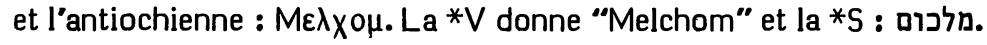




\section{Choix textuel :}

Ici, comme en 48,1; 49,7.23, il faut considérer le nom de peuple introduit par 'lamed' (לבני עמון) comme un titre extérieur au contenu de l'oracle. En ce cas, le suf-

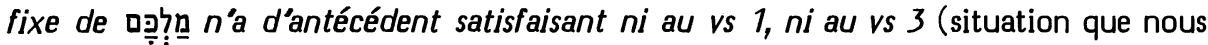
avions déjà rencontrée en $\mathrm{CT} 1,263$ sà propos de $2 \mathrm{~S} 12,30$ et $1 \mathrm{Ch} 20,2)$.

Une leçon מִ̣ a ici le témoignage indirect du ${ }^{*} G$ et direct des recensions origénienne et antiochienne, de la *V et de la*S.

Ajoutons que le contexte de 49,3 favorise la présence d'un nom divin : il part en déportation (comme Camosh en 48,7) suivi de "ses prêtres". En 49,1, Calvin estimait que "son peuple" imposait que l'on comprenne ici notre mot comme désignant le roi.

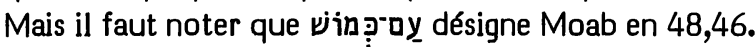

Le sens de מִל comme nom du dieu des Ammonites étant clairement attesté par le contexte en 1 R 11,5.33; 2 R 23,13, le comité a choisi ici cette leçon en lui attribuant la note "B".

La correction vocalique du ${ }^{*} M$ a probablement visé à faire disparaître le nom d'une idole.

\section{9,3A गу [B] M G V S T // assim Nb 21,24 : m Sym тy}

Options de nos traductions :

Le vs 3 commence par un impératif : "Hurle, Heshbôn", et cet ordre est motivé : '. Ce toponyme est transcrit "Ai" par RSV, RL et NEB ou "Aï" par TOB.

$\mathrm{j} 3$ conjecture "Ar" en se référant à $\mathrm{Nb} 21,28$, alors que $\mathrm{J12}$ remplaçaient le 2e et le 3e mot par "le dévastateur est monté", disant adopter une conjecture de Volz.

\section{Origines des corrections :}

Une correction en רע a été proposée ici par Graf, Grätz (Studien 397s) et par les apparats de SBOT et HSAT2.

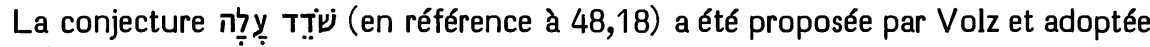
par Nötscher, Rudolph, Penna, Weiser et les apparats de BH3S.

\section{Les témoins anciens :}

L'édition princeps de la Bible (Soncino 1488) porte ici tỵ. Cette leçon se retrouve dans le ms Kennicott 253 qui, copié en 1495, dépend de cette édition. Notons que l'édition princeps des Prophètes (Soncino 1486) et l'édition Lisbonne 1492, comme toutes les autres éditions et mss connus du ${ }^{*} \mathrm{M}$, s'accordent sur le toponyme la mp signale ici que la forme est hapax, la ville de Cisjordanie étant toujours appelée

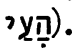

Cet isolement de l’édition Soncino 1488 en cette leçon rend plus frappante la

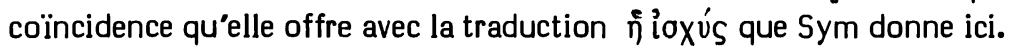

Selon la polyglotte d'Alcala, les éditions Aldine, Sixtine, Rahlfs et Göttingen, le * $G(30,3)$ transcrit ici $\Gamma$ al, ce qui apporte un appui précieux à la leçon du *M. Parmi les onciaux, seul le ms Marchalianus appuie cette leçon, ce mot ayant été omis dans le 
ms Vaticanus et transformé en xaı (avant $x \varepsilon x \rho a \xi \alpha \tau \varepsilon$ ) dans l'Alexandrinus et une

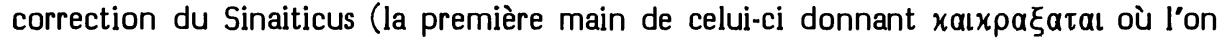
peut reconnaître peut être un reste de ce mot). Notons en tout cas que la transcription du "aïn' par 'gamma' est un signe d'ancienneté.

La ${ }^{*} S$ et le ${ }^{*} T$ reproduisent la forme du ${ }^{*} M$, alors que la ${ }^{*} V$ la transcrit par “Ahi".

Choix textuel :

La leçon de l'édition Soncino 1488 et de la Vorlage de Sym constitue probablement une assimilation à $\mathrm{Nb} 21,24$. "B".

La leçon $d u{ }^{*} M$ jouissant $d$ 'un large appui textuel, le comité lui a attribué la note

Interprétation proposée :

Depuis Venema, quelques exégètes ont voulu considérer ce mot comme un appellatif : "elle a été dévastée en ruine". Cependant, c'est un toponyme que l'on attend après cet accompli pual, comme en 48,15.20.

Notons en passant que l'expression Jos 8,28 à propos de rỵ.

Ce toponyme de Jr 49,3 semble ne pas avoir retenu sérieusement l'attention des géographes. Il n'est cependant nullement impossible que notre connaissance de la topographie ancienne de la Transjordanie offre encore des lacunes.

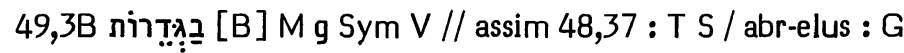

Options de nos traductions :

Après Ces deux derniers mots sont traduits par RSV : "and run to and fro among the hedges", par TOB : "errez dans les murailles !" et par J3 : "errez dans les enclos!"

Pour le dernier mot, $\mathrm{J12}$ conjecturaient תבְּר avec votre peau tailladée !" (J1) et "allez couverts d'incisions !" (J2). NEB conjecture de même en se référant au *T et donne : "and score your bodies with gashes". RL donne : "und lauft hin und her mit Ritzwunden !".

Origine de la correction :

Giesebrecht a proposé de lire ici proposée par Duhm, Volz, Nötscher, Driver, Rudolph, Penna, Weiser et les apparats de $\mathrm{BH} 3 \mathrm{~S}$ et Cent.

Les témoins anciens :

Ces deux mots n'ont pas été traduits par le *G ancien $(30,3)$. Sym a traduit xaì

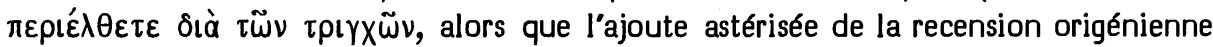

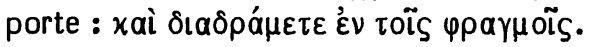

La *V offre : "circuite per sepes", la *S : ואתכִתשו בחהדאמו : et le *T ביעיען. 


\section{Choix textuel :}

Joseph ibn Nahmias a estimé que le *T a lu בגדדות avec deux 'dalet'. Il note en effet que le *T traduit normalement la racine המם במד (ce qu'on peut contrôler en Jr 16,6; 41,5; 47,5 et 48,37). Il se pourrait que le *T ait assimilé ici à 48,37 où

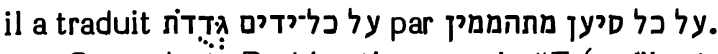

Cependant, Rashi estime que le *T (qu'il retraduit en hébreu : התגודדו בחיילות) a seulement voulu traduire le verbe והתשוטטנה, alors que le mot suivant est compris au sens des enclos pour le petit bétail.

Menahem de Posquières dit que le sens de בגדרות est ici celui que lui donne le *T de Jonathan : בכותליא. De fait, le *T traduit bien ainsi ce mot en Na 3,17. Faudrait-il admettre que le ${ }^{*} T$ dont faisait usage Menahem de Posquières attestait cette traduction ici aussi?

Il se peut que le ${ }^{*} G$ n'ait pas su comment interpréter ces mots.

Sym et la recension origénienne ont lu ici le $* M$, comme le montre Ps 89(88),

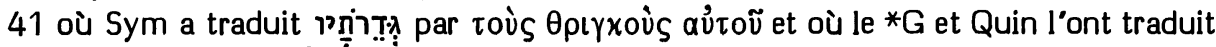

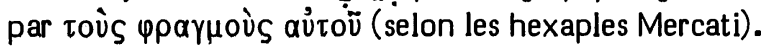

La *S semble représenter la même option que le*T. En effet, en 41,5 ומתכתשין de la *S correspond à ומתהממין du *T. Quant au 2e mot, "l'un l'autre" de la*S correspond à "en bande" du *T.

Considérant que la leçon du *M est bien attestée par Sym, par la recension origénienne et par la *V, le comité lui a attribué 4 " $\mathrm{B}$ " et 2 "C".

Interprétation proposée :

Selon Yéfet ben Ely, "entre les haies" exprime une situation où il n'y a plus d'agglomérations civilisées où l'on puisse habiter. On peut rapprocher cela de eís

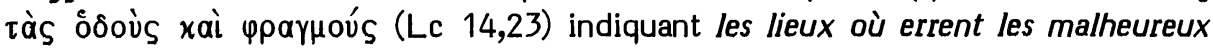
au voisinage des villes.

On pourra donc traduire : "errez le long des haies".

49,3C cf. p. 795.

49,4A בעמקים [B] MG Sym V // facil-synt : S T suff 2s / dbl : g clav בעמקים 49,4B זב עמקך [B] M Sym? V // lit : G om / assim 4A : g S pl / transl : T

Options de nos traductions :

4a porte : מַה Les cinq premiers mots sont traduits par RL: "Was rühmst du dich deines Tales, deines wasserreichen Tales", par TOB : "Pourquoi te vantes-tu de ta vallée ? Ruisselante est ta vallée", et par NEB : "Why do you boast of your resources, you whose resources are melting away".

RSV omet les $4 \mathrm{e}$ et $5 \mathrm{e}$ mots en traduisant : "Why do you boast of your valleys".

J traduit : “Quoi (J3 : Comme) tu te glorifies (J3 : glorifiais) de ta Vallée", disant conjecturer l'omission de ces mots et une correction du troisième en singulier affecté d'un possessif. 
Origines des corrections :

Le possessif que toutes nos traductions insèrent l'avait déjà été par Luther (qui mettait aussi le 5e au pluriel) : "Was trotzestu auff deine Awen? Deine awen sind verseufft."

L'omission des 4e et 5e mots a été requise par Schwally (Reden 200, n.2), Cornill, Condamin, Ehrlich, Volz2, Driver, Rudolph, Penna, Steinmann, Weiser et par les apparats de $\mathrm{BH} 23 \mathrm{~S}$ et Cent. La plupart d'entre eux ajoutent un possessif au 3e mot que certains mettent au singulier.

Les témoins anciens :

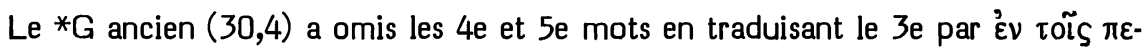

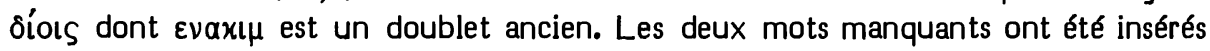

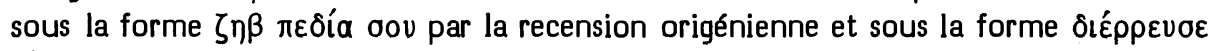
בעוֹמקא : . דבְ. עומקא דילכי

La*V donne: "in vallibus/defluxit vallis tua",la*S: בעוֹמקיכי . et le *T : במישרך חרובו תוקפך.

\section{Choix textuel :}

Comme nous l'avons déjà noté ci-dessus (p. 772) à propos de 47,5, la mention des Anaqim est ici secondaire (n’ayant pénétré qu'en seconde place et demeurant absente de certains témoins, dont la première main du ms Sinaiticus). Autant ils sont à leur place dans la plaine côtière de la Méditerranée, autant ils seraient déplacés en Transjordanie. Ils sont donc issus d'une mauvaise lecture du $3 e$ mot (pour lequel le ${ }^{*} G$ ancien appuie le $* M$ ).

A ce 3 e mot, la ${ }^{*} S$ et le ${ }^{*} T$ ont ajouté un possessif dont l'absence est confirmée par Sym et la *V.

La présence des $4 \mathrm{e}$ et $5 \mathrm{e}$ mots est assurée par tous les témoins du texte protomassorétique.

$\mathrm{La} * \mathrm{~V}$ et le ${ }^{* T}$ lisent le 5 e mot au singulier, alors qu'il est lu au pluriel par les recensions grecques et la $*$ S. On peut hésiter pour Sym où Ceriani discerne au-dessus du 'mîm' un point pâle.

La mise au pluriel du 4e mot par le *T n'est que translationnelle.

Le comité a estimé que la mise au pluriel du $5 e$ mot est une assimilation au $3 e$ (où l'ajoute d'un possessif est une facilitation). Aussi a-t-il retenu la forme textuelle du * $M$ avec la note "B".

Interprétation proposée :

Ici comme en 47,5 , le $* T$ a interprété le $* M$ comme offrant un jeu de mots entre les sens de "vallée" et de "force". Cependant le verbe İ (à interpréter ici comme un participe prédicat d'une phrase nominale) convient bien à une "vallée" dont il exprime la fertilité (cf. ארבת חלב ודבש), 20 fois dans la Bible). L'exégèse : "suintante (du sang des massacrés)" supposerait une ellipse dure et ne serait pas en place. En effet le vs 4 exprime la sotte confiance de Rabbah avec laquelle l'oracle d'effroi du vs 5 fera contraste. 
On peut traduire : "Pourquoi te vantes-tu des vallées ? fertile est ta vallée, fille insoumise", en notant sur "fertile" : littéralement "ruisselante", au sens de "ruisselante de lait et de miel'.

\section{9,4C מB [ M g / glos : G V S T}

\section{Options de nos traductions :}

Les mots מי יבוא אלי expriment, au style direct, la fausse confiance de Rabbah (comme 4B l'avait fait au style indirect). Toutes nos traductions insèrent auparavant un mot d'introduction.

$\mathrm{J12}$ dit se fonder sur quelques mss et les versions pour insérer "tu dis" (que $\mathrm{J3}$ omet). Sans note, RSV insère : "saying", RL : "und sprichst", NEB : "and say" et TOB : “disant".

Origine de la correction :

Kennicott (Dissertatio generalis 105, sur cod. 570) estimait nécessaire d'insérer אמרה בלבבה avec son ms 570 qu'il datait du XIIIe siècle (dans son apparat, il faisait précéder le premier mot par un "hé"). Ont inséré : Giesebrecht, Oort, Cornill, Condamin, Rudolph, Penna, Steinmann, Weiser, Bright et les apparats de SBOT, HSAT34, BH3S et Cent.

Les témoins anciens :

Parmi les versions, seul le ms 710 du ${ }^{*} G(30,4)$ n'insère rien. L'insertion du *G

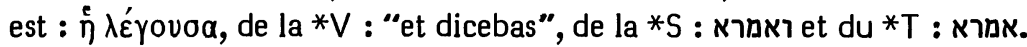

\section{Choix textuel :}

Parmi les témoins de l'insertion qu'ils proposent, les apparats de HSAT et de $\mathrm{BH}$ citent, avant les versions, des mss hébreux. De fait, l'apparat de Kennicott attribue une insertion האמרה בלבבה à ses 'codices' 258, 260, 264, 396 et 570, le codex 253 ayant la même leçon avec une graphie pleine du ḥolem. A cela, de Rossi ajoute la 1 e main de son codex 579 et la 2 e main de ses codices 463 et 554 , ainsi que les Prophètes de Soncino 1486 et les Bibles de Soncino et de Brescia. On pourrait donc, à première vue, croire que cette insertion est attestée par 12 témoins hébreux.

En réalité, ces 12 sigles se ramènent à un seul témoin : le ms 570 de Kennicott, passé dans la collection de Rossi sous le $n^{\circ}$ 579. Lorsque Bruns avait collationné ce petit ms (in $12^{\circ}$ ) pour Kennicott, il appartenait à Isaac Treves de Venise. Bruns l'avait daté du XIIe siècle alors que de Rossi (Codices II 93) le date de la fin du XIVe ou du début du XVe s. De Rossi estime que ce ms a servi de base à l'édition Soncino des Prophètes de 1485-6 (qui n'apporte donc pas ici un témoignage distinct du sien. Le codex 258 de Kennicott est d'ailleurs cette édition de laquelle dépend le codex 260 ( $=$ Bible Soncino de 1488) et les codices 264 et 396 ( $=$ deux exemplaires de la Bible de Brescia 1494). Quant au ms 253 de Kennicott, nous venons de dire (ci-dessus, p. 796) qu'il a reproduit l'édition Soncino 1488. Enfin les deuxièmes mains des mss 463 et 554 de de Rossi dépendent elles aussi de l'une ou l'autre de ces trois éditions 
anciennes, comme en dépendent sûrement la traduction "quae dicit in corde sue" donnée ici par Pagnini et la traduction "und sprichst in deinem hertzen" donnée par Luther. Zwingli, dans son commentaire en 1531, a été le premier a préciser que : "Hebraica sic habent ad verbum : Quae fidit thesauris suis, quis veniet ad me ?". Il avait en effet pu constater l'absence de toute formule d'introduction dans l'édition de Lisbonne 1492 ou dans la polyglotte d’Alcala ou encore dans la Bible de Félix de Prato et dans les éditions Bomberg qui la suivirent.

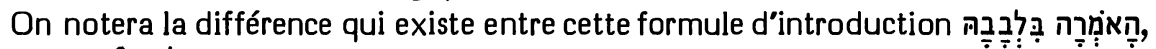

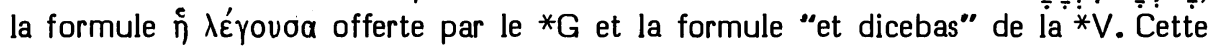
diversité montre que l'on a là les émergences variées d'une glose qui est 'dans l'air'.

Le comité a attribué la note " $B$ " à la forme sobre du *M.

Interprétation proposée :

Selon le niveau de traduction auquel on se situe, on pourra ou non éviter cette glose.

49,5 cf. p. 644.

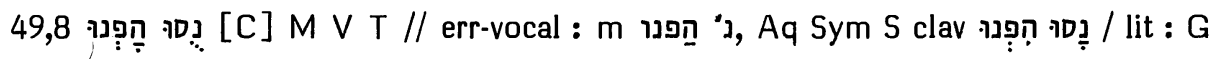

Options de nos traductions :

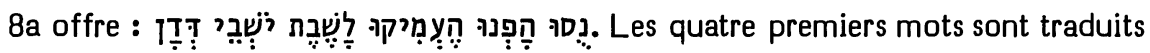
par RSV : "Flee, turn back, dwell in the depths", par RL : "Flieht, wendet euch und verkriecht euch tief", par TOB : "Fuyez! Tournez le dos! Réfugiez-vous dans des trous" et par 33 : "Fuyez! Détournez-vous! Cachez-vous bien".

J12 traduisaient: "Fuyez! Faites demi-tour (J2 : tournez le dos) ! abritez (J2 : cachez)-vous bien", disant conjecturer pour le 2e mot, alors que l'hébreu devrait être traduit par un passé composé : "ils ont fait demi-tour" ou "ils ont tourné le dos".

En sens inverse, lorsque NEB traduit : “(The people of Dedan) have turned and fled and taken refuge in remote places", Brockington précise que, avec Aq, elle voca-

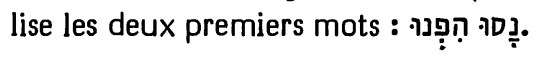

\section{Origines des corrections :}

Suggèrent de lire ici un impératif hifil הַפְּ : Ewald, Graf, Grätz (Studien 481), Cornill, Rudolph et les apparats de HSAT34, $\mathrm{BH} 23$ et Cent.

La correction retenue par NEB avait été suggérée en hésitant par Giesebrecht, puis plus fermement par Duhm.

Les témoins anciens :

Deux témoins du *M vocalisent en impératif hifil, le "hé" portant un patah : l'édition princeps de la Bible (Soncino 1488) et le ms babylonien New York JThS 504,2 (= Yeivin III 118). Les autres témoins s'accordent sur une vocalisation en hofal avec qameș hatufuf (y compris le ms babylonien Oxford, Bibl Bodl, heb d 26, fol. 11r (= Yeivin IV 248) qui écrit la préformante du hofal avec un shureq, selon l'habitude 


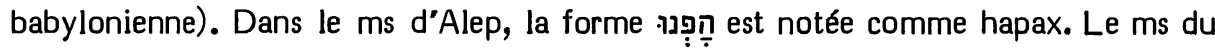
Caire note son qameș comme hapax.

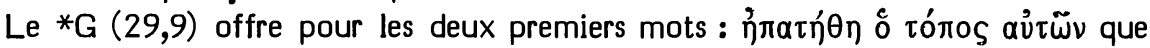
l'on doit considérer comme littérairement distinct du $* M$. Aq et Sym traduisent :

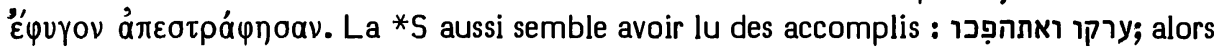
que la *V (fugite terga vertite) et le *T (ערוקו גלו) ont lu des impératifs.

Choix textuel et interprétation proposée :

Yéfet ben Ely commentait : "Il ordonne au peuple de Dedan de fuir de Dedan. Et le sens de הפנו, c'est 'tournez le dos en déroute'. Quant à ce qu'il dit une expression du passé, c'est-à-dire : 'ô vous qui habitiez profond', comme s'il leur disait : 'ô vous qui vous étiez aménagé des retraites si profondes afin que nul ne puisse accéder jusqu’a vous, maintenant fuyez et partez dans la direction où vos visages sont tournés, car il n'y a plus de possibilité de tenir devant l'ennemi'."

Hayyuj (Kokovzov 37) dit de הפנו : "C'est une forme rare et curieuse se rattachant au passif. Il s’agit d'un impératif, car la conjugaison est ה̣ etc. et le passif

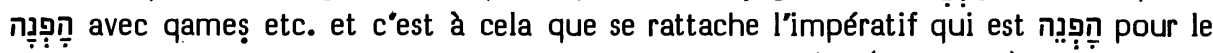

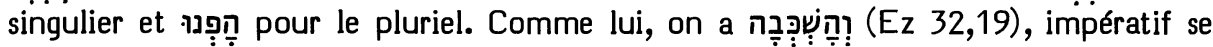

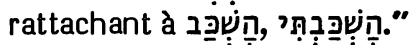

Abulwalid (Luma 96,5 et $336,12-14$ ) estime que le qameṣ est ici à la place d'un patah, car il s'agit d'un impératif hifil.

Radaq, dans son commentaire, affirme que les passifs n'ont pas d'impératifs et qu'il faut donc comprendre cette forme comme un accompli du hofal.

Nous avons dit qu'en 1488, l'édition princeps de la Bible vocalisait le 'hé' avec patah, alors que les éditions postérieures le vocalisaient avec qameṣ. Pagnini, en 1526, dans ses Institutiones (333b et 379b), atteste tour à tour ces deux vocalisations, utilisant pour la seconde le qameș accompagné d'un shewa, ce qui est la manière dont le qameș haţuf est écrit ici par les premières éditions imprimées chez Bomberg (les deux éditions de 1517 et celle de 1521). Dans l'édition princeps (1527) de sa traduction, Pagnini traduit ici : "vertite vos". Mais dans son Thesaurus, en 1529 (col. 1917), il précise que, dans son manuscrit, il avait écrit au-dessus "versi sunt", mais que l'imprimeur a gardé sa traduction initiale, parce qu'il avait omis de la barrer. En rééditant Pagnini, Servet (1542) rectifiera cette faute qui aura pour effet que les traducteurs du XVIe siècle oscilleront entre les deux options, l'impératif étant choisi par Prédicants, Zwingli, Luther, Brucioli, Olivetan, Rollet, Châteillon, Jud, Pasteurs, KJ; alors que l'accompli du passif l'est par Münster, Calvin, Estienne, Arias Montano, Geneva, Tremellius et la marge de $\mathrm{KJ}$.

La possibilité d'un impératif du hofal a cependant été admise par Gesenius (Lehrgebäude 271, Anm.2), Olshausen (Lehrbuch §260), Böttcher (Lehrbuch §916), König (Lehrgebäude I 534), Gesenius/Kautzsch (131, n.2) BDB (815b), Bauer/Lean$\operatorname{der}\left(333 k^{\prime}\right)$, au moins à titre d'exception.

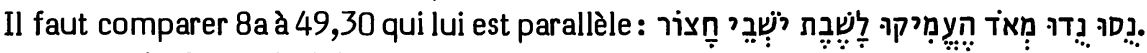
On y trouve de façon indubitable deux impératifs juxtaposés en début du vs et cela peut servir de clé pour interpréter le début de 8a. Cela confirme l'analyse de Hayyuj. Contre le dogmatisme de Radaq, il semble que l'on doive admettre que l'on a ici un impératif hofal au sens de "soyez mis en déroute" que Yéfet lui reconnaissait ici. 
On pourra donc traduire : "Fuyez, soyez mis en déroute, vous qui vous êtes fait des demeures profondes, habitants de Dedan". Le 2e impératif vise une intervention de l'ennemi contre les fuyards. Il s'agit donc bien d'un passif.

Le comité a attribué au *M la note " $\mathrm{C}$ ".

49,10 cf. p. 613

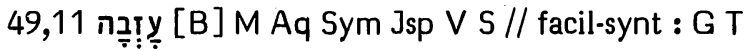

Options de nos traductions :

11a porte I will keep them alive", ] : "laisse tes orphelins, je les ferai vivre", RL : "Verlass nur deine Waisen, ich will sie am Leben erhalten" et TOB : "Ne te fais pas de souci pour tes orphelins, c'est moi qui les élèverai".

Selon Brockington, NEB corrige le premier mot en pịy et le rattache au vs précédent en traduisant : "(there is no one) to help him. What! am I to save alive your fatherless children ?"

Origine de la correction :

La proposition de corriger ce mot en participe et de le faire passer à la fin du vs 10 vient de Driver.

Les témoins anciens :

Le *M est ici garanti par une massore (Weil §2084).

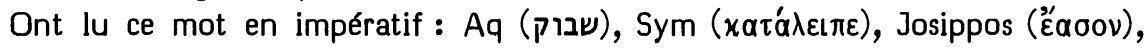
la *V (relinque) et la *S (שבוק).

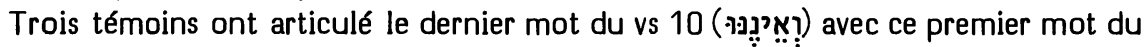
vs 11 :

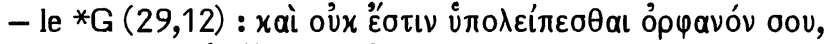

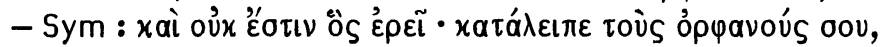

- le *T qui, après avoir traduit ce mot en fin du vs 10 , le reprend sous forme d'une négation au début du vs 11 : וליתנון : אתון בית ישראל לא תשתבקון יתמיכון.

Choix textuel :

C'est la difficulté d'admettre cet ordre: "abandonne tes orphelins" et d'en comprendre ici le sens qui a amené à faire appel au dernier mot du vs précédent (en le déformant) pour y trouver une négation qui permette d'inverser la portée de cet impératif.

Driver, par conjecture, a déformé le premier mot du vs 11 et l'a fait passer à la fin du vs 10 en attribuant ici au verbe zry le sens de "aider" à partir de l'éthiopien. Cependant Barr (141) a fait remarquer que quelque incertitude existe sur l'usage éthiopien de ce verbe auquel Driver se réfère. Barr hésite d'ailleurs à admettre pour ce verbe hébreu un homonyme qui contredise exactement un autre homonyme à l'intérieur du 
même champ sémantique. Pourtant Driver (Problems 76, n.3) estimait, 18 ans plus tard, avoir découvert 5 homonymes pour ce verbe. Mais HALAT, qui se contente de mentionner un deuxième sens (= plâtrer, réparer, arranger), montre que même ce deuxième sens n'est pas universellement admis.

Le comité a conservé ici la leçon du *M en lui attribuant 4 " $B$ " et 2 " $A$ ".

Interprétation proposée :

“Laisse tes orphelins, c'est moi qui les ferai vivre. Et tes veuves pourront compter sur moi." Dieu vient de dire au vs 10 que c'est lui qui va dépouiller Esaü et ravager sa race, ses frères et ses voisins. Il encourage ici les hommes de ce peuple qu'il condamne à lui confier ceux qu'ils vont laisser orphelins, comme on les confie à un proche. Puis, au vs 12 : “Car ainsi a parlé le Seigneur : Voici que ceux dont ce n’était pas le jugement de boire la coupe la boiront sûrement !" Calvin estime que l'ironie amère de ce passage consiste en ce que l'on s'attendrait à ce que Dieu dise à Edom (après le vs 10) : T'imagines-tu que je prendrai soin de tes enfants et que j'aiderai tes veuves ? Tu as tort d'attendre cela de moi. Mais le prophète démoralise beaucoup plus les Edomites en présentant Dieu qui s'offre ironiquement à être le tuteur futur de leurs orphelins et de leurs veuves, alors qu'il affirme ensuite solennellement (vs 12) que ceux-ci aussi, quoique non responsables, devront boire la coupe du châtiment. La dureté du vs 13 rend cette interprétation assez vraisemblable et les autres exégèses apparaissent comme des tentatives d'atténuation.

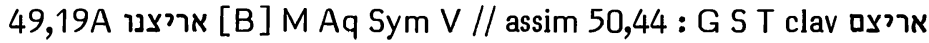 אריצנו MG S T // assim 49,19 : V clav אריצם 40,44A}

\section{Options de nos traductions :}

Notons d'abord l'étroit parallélisme qui existe entre 49,19-21 et 50,44-46. Une

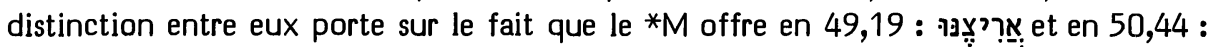
אַרִ (avec un ketib 'waw' au lieu du 'yod'). Cette différence dans les pronoms suffixes n'a été respectée par aucune de nos traductions. NEB, traduisant dans les deux cas "I will chase every one away", semble avoir harmonisé sur la base du singulier.

Disent corriger en 49,19 sur la base du *G, de la *S (et du *T) : RSV : "I will make them run away", J : "les ferai-je (J3 : je les ferai) déguerpir" et TOB : "je les fais déguerpir".

Origine de la correction :

La distinction entre le suffixe singulier de 49,19 et le suffixe pluriel de 50,44 est exprimée par presque tous les traducteurs du XVIe siècle. Font exception Luther et Tremellius qui unifient sur le singulier. De même, Grätz (Studien 482) estime que le suffixe singulier est mieux en place que le suffixe pluriel.

Généralisent le suffixe pluriel : Giesebrecht, Oort, Duhm, Cornill, Nötscher, Penna, Bright et les apparats de HSAT34, BH23 et Cent. 
Les témoins anciens :

Le ${ }^{*} G$ traduit aux deux endroits $(29,20$ et 27,44$)$ par un pronom pluriel : aúroús. En 49,19, nous connaissons Aq et Sym qui ont un pronom singulier.

Ont aussi généralisé le pluriel : la ${ }^{*} S$ et le $* T$, alors que la $* V$ a généralisé le singulier (ce qui a pu influencer le choix de Luther).

Choix textuel :

Giesebrecht a raison d'estimer qu'en ce contexte ce suffixe désigne les Edomites. C'est pourquoi le suffixe singulier constitue une lectio difficilior qui n'est pourtant nullement improbable.

En 49,19, le *M est bien appuyé par Aq, Sym et la *V; aussi le comité lui a-t-il attribué la note "B", contre une assimilation facilitante au parallèle de 50,44.

Aucune de nos versions n'avouant qu'elle y quitte le $* M$, le cas du suffixe de 50,44 n'a pas été soumis au comité. Il semble cependant qu'il faille y sauvegarder le pluriel du suffixe qui peut fort bien être textuellement original en ce lieu où le *M et le ${ }^{*} G$ s'accordent (même si ce pluriel est littérairement secondaire).

Interprétation proposée :

"Aussi, en un clin d'oeil, je le fais déguerpir loin d'elle". Une note devrait indiquer que "le" désigne le peuple d'Edom considéré comme un troupeau dont le Seigneur, à la fin du verset, va défier le berger. Ce troupeau qui paissait sur la prairie se débande à l'approche du lion qui montait de la jungle du Jourdain.

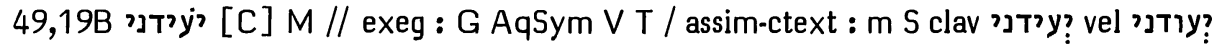
50,44B יוֹעדני [B] M // exeg : G V S T

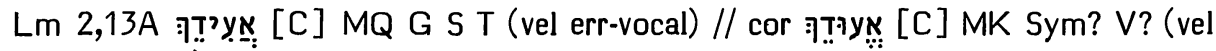
err-vocal)

Options de nos traductions :

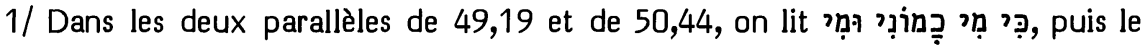
verbe qui suit est

Traduisent ces cinq mots de la même façon en ces deux endroits : RSV : "For who is like me ? Who will summon me ?", J : “Qui en effet est mon égal ? Qui pourrait m'assigner en justice ?", RL : "Denn wer ist mir gleich, wer will mich meistern...?" et TOB : "Car qui est comme moi ? Qui pourrait m'assigner en justice ?"

Selon Brockington, NEB, aux deux endroits, conjecture pour le dernier verbe : ?ִּרִ lorsqu'elle traduit : "For who is like me ? Who is my equal ?"

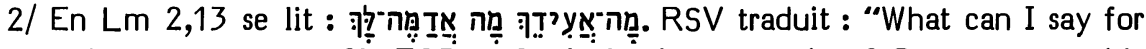
you, to what compare you ?", TOB : "Quel témoignage te citer ? Que comparerai-je à toi ?" et RL : "wem soll ich dich vergleichen, und wie soll ich dir zureden ?"

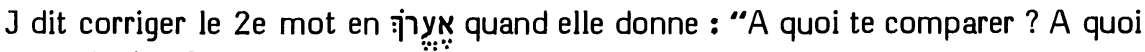
te dire semblable ?" 
Selon Brockington, NEB le vocalise you ? Whose plight is like yours ?"

Origines des corrections :

1/ NEB a reconnu en 49,19 et 50,44 le verbe Ty au sens de "être semblable". Cela avait été proposé par Ehrlich (Randglossen) et Seidel (10s).

2/ Pour Lm 2,13 Meinhold a proposé la conjecture que $J$ a retenue après qu'elle ait été diffusée par les apparats de HSAT34, BH3S et Cent.

Les témoins anciens :

Dans sa liste des variantes entre les orientaux et les occidentaux, la Bible de Ben Hayim attribue aux orientaux un ketib יעודני en Jr 49,19. Selon Strack, c'est ce que la première main du ms de Petrograd avait écrit ici. La liste de ces variantes selon le ms de Leningrad mentionne comme ketib oriental יועדני. On serait tenté de voir là une erreur provenant d'une assimilation à 50,44. Cependant le ms babylonien New York JThS 504,2 (= Yeivin III 118) offre ici cette leçon. Il est cependant encore plus intéressant de noter que le ms babylonien Oxford Bibl Bodl Heb d 26, foll. 11v et $14 \mathrm{r}$ (= Yeivin IV 249 et 254) distingue la vocalisation des deux parallèles de Jérémie,

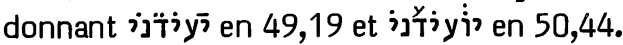

En Lm 2,13, le ms babylonien Berlin Or qu 680 porte nal T.-S. A 39,18 (= Yeivin V 288). Il porte 'waw' est attesté aussi par le ms Erfurt 3, le ms de Rossi 782, les mss Paris BN hébr 26 et 105, ainsi que les éditions Ben Ḥayim et Minḥat Shay.

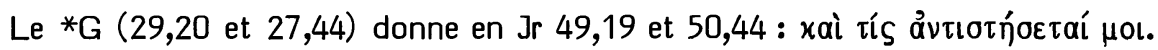

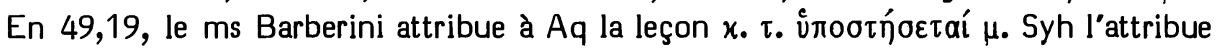
aussi à Sym. S'en inspirant, la *V donne en 49,19 et 50,44: "et quis sustinebit me". Dans les deux endroits, le *T donne : ומן דיערעינני. La*S donne en 49,19: או מנו שיאי

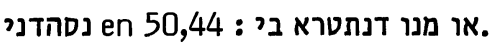

En Lm 2,13, le *G porte $\mu \alpha \rho \tau$ אסהדכי : et le *T : אסהד בך. Syh attribue à Sym une leçon dont elle semble bien apporter en

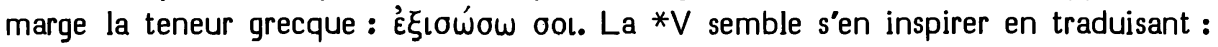
"comparabo te".

\section{Choix textuel :}

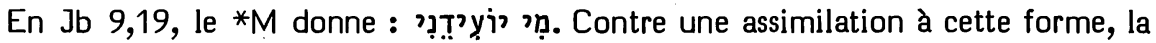
massore éditée protège les deux cas de Jérémie en précisant que ce sont les deux

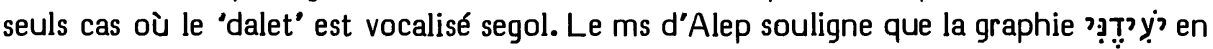
Jr 49,19 est hapax. Les vocalisateurs ont considéré ces trois formes comme des hifil de 7 y. Cependant la graphie exceptionnelle de Jr 49,19 (appuyée par la vocalisation

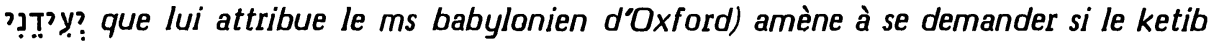
ne correspond pas à un hifil de Ty qui aurait subi une assimilation vocalique au parallèle de Jr 50,44. Le ketib oriental יעודני en Jr 49,19 reposerait sur ce même rattachement à yוy (à titre de qal). 
C'est pourquoi le comité a attribué en 49,19 au * $M$ la note " $C$ " et en 50,44 (où la vocalisation correspond parfaitement au ketib) la note " $B$ ".

En Lm 2,13, la plupart des critiques, à partir de Kelso, ont invoqué la *V à l'appui de la conjecture de Meinhold. Ehrlich a pourtant montré que lorsque le verbe ערן exprime une comparaison, c'est la chose à comparer qui est son sujet et non la personne qui compare. Comme il le précise, en Is 40,18 ce verbe signifie "établir, instituer", son complément étant (= דִ une comparaison). Dans les autres cas où ce verbe exprime une comparaison, il s'agit de "se mettre sur les rangs pour concourir avec quelqu'un" et non de "comparer quelqu'un (ou quelque chose) avec un autre". On pourrait invoquer comme analogue Ps 89,7. Mais là, c'est au qal de דמה que est parallèle, alors qu'ici il s'agirait du piél.

Ici, les membres du comité se sont divisés à égalité entre le ketib avec "waw' ( 3 " $\mathrm{C} "$ ") et le qeré avec "yod" (3."C").

Interprétations proposées :

En Jérémie, le sens original de l'expression semble être analogue à celui de Jb 9,19: “qui me fera comparaître", c'est-à-dire qui aura l'autorité de me forcer à comparaître devant un tribunal pour y rendre compte de ma conduite. Ce sens correspond exactement à la graphie de 50,44.

En Lm 2,13, la dérivation à partir de yוy est certaine. Or il est frappant de noter que Menahem ben Saruq unit Lm 2,13; Jr 49,19; 50,44 comme constituant un sens particulier (son 10e sens) distinct du sens "témoin" (son 6e sens). Hayyuj, en analysant les verbes faibles, ne peut évidemment maintenir sous une même racine Jr et Lm. Mais, sous עוד (Kitâb 110,3s), il maintient Lm 2,13 comme appartenant à un sens distinct de celui de "témoigner". Tanḥum Yerushalmi, en son commentaire des Lamentations, traite de nos trois cas de manière très nuancée : "Le sens de אעידך ici est la comparaison, à cause du voisinage de מה אדמה לך. Et il a été dit qu'il relève du sens de "témoignage" et qu'il a la même valeur que מה אעיד בך... Et il a été interprété aussi : "par quoi donc te concurrencerai-je", par dérivation à partir de ונועדתי לך (Ex 25,22), mais cela n'est pas de sa racine et son sens ne s'y rattache pas non plus.

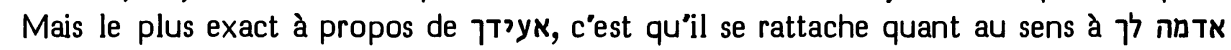
et אשוה לך en considération du contexte. On rencontre aussi, semblable à lui quant au sens, quoique appartenant à la racine de ונועדתי à première radicale faible : Jr 49, 19; 50,44 : "qui serait comme moi et qui me ressemblerait". Et cela tient au fait qu'un sens particulier se retrouve identique en deux racines distinctes : l'une à première radicale faible et l'autre à deuxième radicale faible". Ainsi Tanḩum adapte l'intuition de Menahem aux catégories grammaticales instaurées par Hayyuj. Ehrlich et Albrektson ont eux aussi proposé de comprendre ce verbe comme un synonyme des deux qui le suivent et qui sont, comme lui, introduits par מה. Lisant donc ici selon le ketib un qal ou selon le qeré un hifil de Tוy, on pourrait comprendre : "à quoi puis-je te comparer". Il n'est cependant pas impossible que le hifil, comme en $1 \mathrm{R} 21,10.13$, puisse signifier ici : "quel témoignage pourrais-je produire à propos de ton cas", c'est-à-dire : quel autre cas de malheur semblable pourrais-je te citer pour te consoler? 
La graphie de Jr 49,19 selon la première main du ms de Petrograd et selon le ketib oriental de la Bible Ben Hayim semble correspondre à un qal de עוד, alors que cette graphie, selon le ketib occidental (et la vocalisation du ms babylonien d'Oxford) correspond bien à un hifil de la même racine. Il se peut qu'il y ait eu là une assimilation à ce qui précède. En effet, Tanhum Yerushalmi a bien noté que le fait que "qui est comme moi" précède notre verbe suggère pour lui un sens: "qui est semblable à moi" vers lequel la classification de Menahem ben Saruq nous orienterait. Il est donc permis d'hésiter ici entre ce sens et un sens identique à celui de $\mathrm{Jr} 50,44$ vers lequel nous oriente la vocalisation du *M occidental.

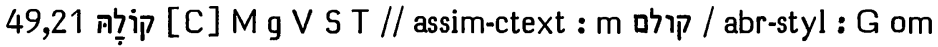

\section{Options de nos traductions :}

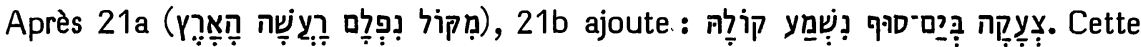
dernière phrase est traduite par RSV : "the sound of their cry shall be heard at the Red Sea", par NEB : "it cries out, and the cry is heard at the Red Sea" et par TOB : litt. : "Un cri! son bruit est entendu à la mer des Joncs".

Omettant le dernier mot avec le ${ }^{*} G$, J traduit : "l'écho en retentit jusqu’a la mer des Roseaux !" et RL: "und ihr Geschrei wird man am Schilfmeer hören".

\section{Origine de la correction :}

Déjà Luther $(=R L)$ ne gardait du dernier mot que le possessif. Ont omis ce dernier mot : Duhm, Cornill, Volz, Nötscher, Rudolph, Weiser, Bright et les apparats de $\mathrm{BH} 3 \mathrm{~S}$.

\section{Les témoins anciens :}

Les éditions antérieures à celle de Ben Hayim portaient קị avec d'assez nom-

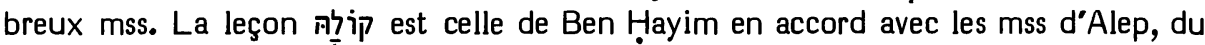
Caire et de Leningrad. On peut donc la considérer comme caractéristique du texte tibérien classique. Elle a en outre l'appui de la recension origénienne, de la $* \mathrm{~V}$, de la *S et du*T.

Selon la conjecture de Schleusner (annotant les Observationes de Michaelis), le

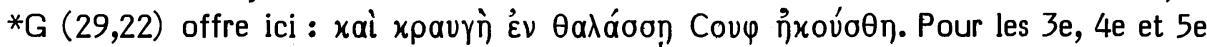

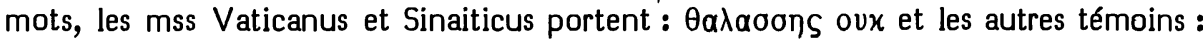
oov $\varepsilon \nu \theta \alpha \lambda \alpha \sigma o$ ) (à quoi les recensions origénienne et antiochienne ont ajouté $\varepsilon \rho v \theta \rho \alpha$, parce que סוף leur semblait ne pas avoir été traduit). Le *G a voulu alléger le style en ne traduisant pas le dernier mot qui lui semblait superflu. Lorsqu'elle a comblé cette omission par ì $\varphi \omega \nu n ́$ oov, la recension antiochienne a assimilé le possessif à celui qu'elle lisait auparavant dans le ${ }^{*} \mathrm{G}$.

\section{Choix textuel :}

Le parallèle de 50,46 se contente pour ce stique de : déjà pour le stique précédent, les deux parallèles diffèrent notablement. 
Une vingtaine de mss ont lu ou lisent 23B avec la préposition 'kaf'. Le *M est pourtant protégé contre cette variante facilitante par une massore (Weil §2420) qui précise que cette leçon avec 'kaf' ne se rencontre qu'en Is 57,20; Jr 6,23; 50,42; Lm 2,13.

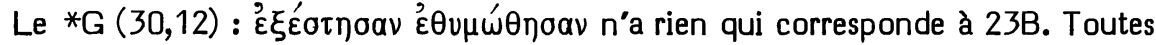
les autres colonnes des hexaples attestent ' $\varepsilon v$ $\theta a \lambda a ́$ oon, la leçon avec "bet' pour ce mot étant appuyée aussi par la *V (in mari) et la *S (בימא); alors que le *T semble n'attester que dans les éditions de Félix de Prato, Ben Hayim, polyglotte de Londres et Miqraot Gedolot, ce mot manquant dans la polyglotte d'Anvers et dans les mss cités par Sperber et consultés par nous (quoiqu'il transparaisse dans la suite de la paraphrase).

Pour $23 \mathrm{C}$, le ${ }^{*} G$ nous l'avons vu, a traduit par un verbe pluriel. Le substantif du *M est attesté par la *V (sollicitudine) et par Sym : מן מרניתא. La *S a interprété le "hé" final en suffixe f. sg. : דחלתה.

Le *T paraphrase largement : "ils ont été brisés : une crainte (dans la mer) et une préoccupation les ont saisis comme ceux qui naviguent calmement en mer et ne peuvent se reposer". Cependant le ms Urbinates 1 lit au lieu de cela: "... les ont saisis et ils voudraient se reposer, mais ils ne le peuvent pas."

\section{Choix textuel :}

En 23A, la seule question qui puisse se poser est celle du rattachement de ce mot à ce qui précède ou à ce qui suit. La division en cola et commata des mss anciens de la *V le rattache à ce qui suit (en accord avec Sym); alors que la *S (comme le *M) le rattache à ce qui précède, ainsi que le montre la ponctuation du ms Ambrosianus et le commentaire d'Ephrem.

En 23B, la présence de ce mot est certaine dans la tradition textuelle protomassorétique. Le comité a attribué la note " $B$ " à la leçon avec "bet', considérant la leçon avec 'kaf' comme une facilitation syntactique influencée par Is 57,20.

En $23 \mathrm{C}$, le texte protomassorétique s'accorde sur une lecture en substantif. Le comité a attribué la note " $\mathrm{B}$ " à la leçon du * $\mathrm{M}$, contre une interprétation du hé" final en suffixe.

Interprétation proposée :

Le parallèle de Is 57,20 invite à faire de la mer le sujet du verbe final. Les teamîm demandent ici de lier le verbe נמגר à ce qui précède et suggèrent de considérer les deux mots suivants comme une brève phrase nominale. Le nifal de évoque une agitation houleuse : "Parce qu'elles ont entendu une mauvaise nouvelle, elles (= Hamath et Arpad) sont agitées". C'est la mention de cette agitation qui évoque l'image de la mer en une brève parabole : "Dans la mer il y a du trouble, elle ne peut se calmer". Notons

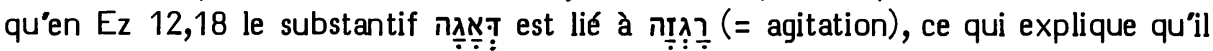
fasse contraste ici avec le calme de la mer apaisée. Cependant le mot avoir plutôt en hébreu biblique le sens psychologique de 'préoccupation'. La subtilité littéraire de ce passage consiste justement à évoquer le trouble psychologique de la population des deux villes par un verbe qui évoque la houle marine, puis dans cette 
brève parabole, à dépeindre l'agitation de la mer par un substantif abstrait évoquant la préoccupation et les soucis.

49,25A לא [B] M G S T // abr-elus : V om

49,25B משושי [B] M G // deform-int : g/ exeg : ThAqSym V S T

\section{Options de nos traductions :}

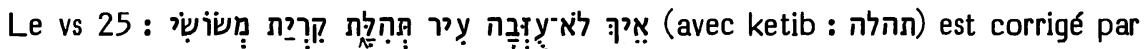
toutes nos traductions : seules NEB et $j 3$ gardent la négation. Celle-ci est omise (selon la *V) par RSV, J12, RL et TOB. Le suffixe 1e pers. sg. du dernier mot n'est exprimé que par TOB. Il est omis (selon AqSym, la*V, la *S et le*T) par RSV, $\mathrm{J}, \mathrm{RL}$ et NEB.

\section{Origines des corrections :}

Sous l'influence de la $* \mathrm{~V}$, la traduction des Prédicants de Zurich présente déjà ces deux options: "Solt aber ein söliche lobliche und herzliche stat verlassen werden ?", en accord avec Zwingli : "Sed num desertur urbs celeberrima, civitas gratissima ?"

La négation a été formellement omise par Houbigant et Weiser.

Le 'yod' final du dernier mot a été omis par Grätz (Studien 484), Duhm, Condamin, Volz, Nötscher et les apparats de BH2 et Cent.

Ces deux corrections ont été jointes par Giesebrecht, Rudolph, Penna, Steinmann, Bright et les apparats de $\mathrm{BH} 3 \mathrm{~S}$.

Les témoins anciens :

La négation est attestée par le ${ }^{*} G(30,14)$, la $* S$ et le $* T$, seule la $* V$ l'ayant omise.

La plupart des témoins du *G donnent ici n̉yámioav pour traduire le dernier mot. Ziegler a cependant eu raison de lire ici î̀v ỉrámnoa avec le ms 534, leçon qui traduit le *M. Cela suppose que le relatif initial est tombé par haplographie après $x \omega ́ \mu \eta \nu$ dans la 'plupart des témoins et que le 'nu' final a été ajouté par dittographie au sein

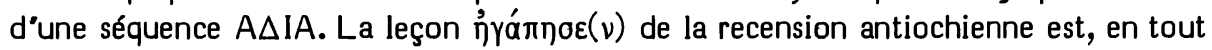
cas, secondaire.

Ont traduit ce mot par un substantif, sans exprimer le 'yod' final : AqSym : Eụpooúvns (Syh attribuant cela aussi à Th), la *V : "laetitiae", la*S (דחדותא). Pour les quatre derniers mots du vs, le $* T$ reprend exactement la traduction dont il a fait usage pour les $3 \mathrm{e}$ à $6 \mathrm{e}$ mots de Is 22,2 .

\section{Choix textuel :}

1/ 25A : La difficulté offerte ici par cette négation a été sentie par les exégètes juifs. Abulwalid (Luma 284,23s) estimait, comme Jérôme, qu'en cette phrase la négation est redondante. Judah ibn Balaam estime que ce n'est ici qu'une ajoute stylistique liée au genre littéraire de la qinâh. Il cite en illustration deux passages du Coran où une négation a une valeur purement explétive, ce qui suggère pour ce texte : "Pourquoi n'en aurait-il pas été ainsi ? Elle a été désertée..." 
Cette difficulté est liée au sens que l'on reconnaît au pual de riy que cette négation introduit. Nous avons vu, ci-dessus (p. 803) à propos de 49,11, Driver donner à ce verbe le sens de "aider"; ce qui explique ici la traduction de NEB. Notons qu'ici Rashi donne d'abord à ce verbe le sens de "accumuler de la terre autour du rempart de la ville pour l'épauler", sens qu'il retrouve en Ne 3,8. Ce sens "fut enforcée" est donné ici (souvent en concurrence avec le sens "fut laissée") par les glossaires ABCDEF. Menahem de Posquières lui aussi donne ce sens en premier. Mais il ajoute : “Certains disent que l'on a ici la signification habituelle : comment les gens ne l'ontils pas quittée avant que ne vienne sur elle ce malheur ?" De même Grotius glose : "Pourquoi ont-ils voulu la défendre ? C'est à cause de cela qu'ils ont été exterminés, comme la suite le montre". En effet, si l'on traduit "pourquoi n'a-t-elle pas été évacuée", on obtient un lien excellent avec le vs 26 : “C'est pourquoi ses jeunes gens tomberont sur ses places et tous les hommes de guerre périront en ce jour-là - oracle du Seigneur !" C'est parce que l'on a commis l'imprudence de se laisser enfermer dans la ville pour la défendre que toute l'armée y sera exterminée et que la ville sera détruite. Keil et Nägelsbach s'accordent sur cette exégèse qui valorise pleinement la négation sans avoir besoin d'inverser le sens habituel du verbe.

Le comité a attribué ici au *M 5 "B" et 1 " $A$ ", car il a le clair appui du *G.

2/ 25B : Le 'yod' final du dernier mot a été jugé excédentaire par Yéfet ben Ely (comme il l'avait été par ThAqSym, par la *V, la *S et le *T). De même, Grotius a vu ici un 'yod' paragogique qu'il estime emprunté au dialecte des Syriens dont il s'agit ici. Tanḥum Yerushalmi a eu raison de lier ce problème à celui de l'interprétation du qeré le deuxième mot a évidemment la valeur de rallèle exact de משiׁi. Cornill a proposé la même exégèse. L'omission de ce 'yod" final est en tout cas facilitante.

Considérant que cette omission est due, dans les versions, à des motifs exégétiques, le comité a attribué ici au *M la note "B".

\section{Interprétation proposée :}

Pour le sens du dernier mot, le qeré susdit suggère donc de garder au 'yod' final son sens habituel de suffixe de la 1e pers. sg. Il est cependant difficile de préciser si le prophète parle ici au nom du roi (ou de la population) de Damas ou s'il parle au nom du Seigneur compatissant (ou sarcastique). Nous avons déjà rencontré plusieurs fois (cf, ci-dessus, p. 113 en Is 15,5 et p. 804 en Jr 49,11) des emplois de la 1e pers. sg. qui posaient des problèmes analogues.

Quant à la valeur de la négation en ce contexte, elle est semblable à celle qu'elle a en 2 S 1,14.

On traduira donc :

“Comment n’a-t-elle pas été évacuée, la ville dont j’étais fier, la cité de ma joie ?” 


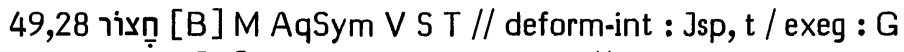

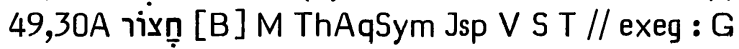
49,33 חִ̣ [ִ [B] M AqSym V S T // exeg : G

Options de nos traductions :

En ces trois endroits de l'oracle contre Qédar, le *M offre la graphie רִֹ semble bien être celle d'un toponyme que RSV, J, RL et TOB transcrivent sans le retoucher.

En se référant au *G, NEB, selon Brockington, vocalise

Origine de la correction :

Knabenbauer a fait remarquer que le ${ }^{*} G$ a lu ici cette vocalisation avec séré qui correspond bien aux données d'Is 42,11.

Les témoins anciens :

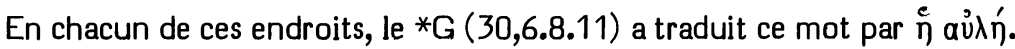

Sur le vs 33, le ms Barberini atteste que AqSym transcrivent $\alpha$ owp et, sur le vs 30, il attribue cette transcription à Josippos en disant que ThAqSym transcrivent de même. Sur le vs 28 , c'est la transcription aoap qu'il attribue à Josippos, alors que Syh attribue à AqSym une transcription identique à la leçon du $* M$.

$\mathrm{La}^{*} \mathrm{~V}$, aux trois endroits, transcrit "Asor".

La *S et le *T copient la graphie du *M. Cependant, sur le vs 28 , Sperber, disant copier le ms Or 2211 de la British Library, écrit חצר avec deux points horizontaux (= șéré) sur le "șadé". N'a-t-il pas confondu avec les deux points verticaux du ḥolem ? En tout cas, le ms Urbinates 1 confirme la leçon identique au ${ }^{*} M$ de tous les autres témoins du *T.

Choix textuel :

Dans l'apparat de BH3, Rudolph attribuait au *G une Vorlage de $B H S$, il se contente de citer en grec la leçon du ${ }^{*} G$. C'est en effet Cappel (Notae 536b) qui avait fait remarquer que cette leçon avec 'ṣéré correspond parfois dans le

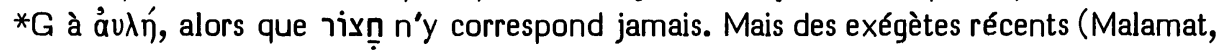
Mari 147, n. 20 et Dumbrell 107) ont suggéré que ce dernier mot peut, en Jr 49, avoir valeur de collectif au sens de "villages de tentes". Il est fort possible que le *G l'ait déjà interprété ainsi. Théodoret interprète en effet ici aủdń comme désignant "l'ensemble de l'établissement des Sarrasins qui sont des bergers habitant sous la tente".

Quant à l'exégèse du * $M$, Yéfet ben Ely (qui habitait la Palestine) nous la fournit en ces termes : "Ces ממלכות חצור, ce sont les bédouins qui habitent dans les steppes... Il s'agit de royaumes, comme il est dit (Jr 25,24): 'tous les rois d'Arabie"' (cf. cidessus, p. 656s.). En Gn 25,16 les fils d'Ismaël (dont Qédar est le deuxième) sont dits

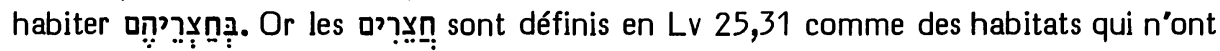
pas de rempart. Selon Is 42,11, c'est en ce type d'habitat que réside Qédar. Cela correspond bien aux caractéristiques données en Jr 49,31 : "une nation ... qui n’a ni porte ni verrou". Le butin mentionné en 49,29 semble bien indiquer qu'il s'agit ici de tentes. 
Il n'est cependant pas impossible que le dernier rédacteur de Jr 49,33 ait compris "Hașôr' comme un nom de ville (comme le montre un parallèle avec 51,37 où Babylone apparaît dans un contexte semblable).

Pour ces trois cas, le comité a attribué à la leçon du * $M$ la note "B".

\section{Interprétation proposée :}

Mieux vaut se contenter de transcrire "Haçor' comme un toponyme, tout en notant que ce mot en cet oracle désigne initialement par un terme collectif les villages de tentes des bédouins semi-sédentaires.

49,30B נבוכדראצר [A] M g V S T // lit : G om

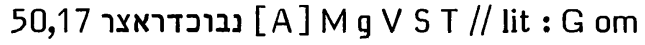

Options de nos traductions :

En ces deux endroits où le *M mentionne : נבוכדראצר מלך בבל, le nom et le titre sont exprimés par RSV, RL, TOB et 33.

NEB, disant suivre le ${ }^{*} G$, ne retient que le titre et omet le nom. $J 12$ agissaient ainsi dans le premier cas et non dans le second.

Origines des corrections :

Schwally (Reden 203) a estimé qu'en 49,30 le nom et le titre royal sont une glose venue du titre de l'oracle $(49,28)$. Bright estime que cette glose a servi à adapter un poème plus ancien à une campagne de Nabuchodonosor.

En 50,17, Duhm omet le nom, suivi en cela par Cornill et Penna.

En 49,30, c'est le titre royal qui est omis par Rudolph et Steinmann.

L'omission du nom en 49,30 et en 50,17 a été requise par l'apparat de SBOT.

Les témoins anciens :

Le ${ }^{*} G(30,8$ et 27,17$)$ omet le nom dans les deux endroits. Cette omission y est réparée par les recensions origénienne et antiochienne.

En ces deux cas, le ${ }^{*} M$ est appuyé par la ${ }^{*} V$, la ${ }^{*} S$ et le ${ }^{*} T$.

Choix textuel :

Tous les témoins protomassorétiques $s$ accordant sur la leçon du $* M$ en ces deux endroits, le comité a attribué à celle-ci la note " $\mathrm{A}$ ", estimant que $c$ 'est au niveau littéraire qu'il diffère du ${ }^{*} G$. 
49,30C עליכם / (20) MK S (ou assim 29) / עליהם V T (ou assim-ctext) / abrstyl : g om

Options de nos traductions :

Après "car Nabuchodonosor roi de Babylone a conçu contre vous un dessein",

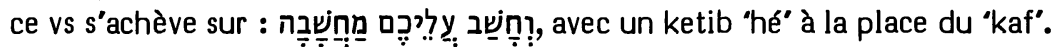

Le pronom suffixe $2 \mathrm{e}$ pers. m. pl. du deuxième mot est exprimé par RSV, J et RL. Ce mot. est omis par allègement translationnel en NEB.

TOB prétend que "quelques mss ajoutent "contre eux"' qu'elle omet.

Origine de la correction :

Voyant dans la 3e pers. pl. du ketib du suffixe l'indice d'une ajoute (car elle s'accorde mal au contexte), Duhm omet ce mot avec le *G. Il est suivi en cela par Volz, Rudolph, Steinmann et les apparats de $\mathrm{BH} 235$.

Les témoins anciens :

Tous les témoins tibériens classiques offrent ici ce qeré-ketib. Les éditions anciennes du *M (Soncino 1486 et 1488, Lisbonne 1492, Brescia 1494 et polyglotte d'Alcala) offraient le qeré dans le texte. Ont placé dans leur texte la leçon avec 'hé' : l'édition de Félix de Prato, les éditions Bomberg $4^{\circ}$ de 1517 et de 1521, l'édition Ben Hayim, etc. La plupart des mss portent ou bien le qeré-ketib, ou bien le qeré dans le texte. Quelques rares mss (par exemple le ms Urbinates 2) ne donnent que la leçon avec "hé".

La $* V$ et le *T traduisent ici le suffixe 2 e pers. m. pl.

$\mathrm{La} * \mathrm{~S}$ traduit le suffixe de la $3 e$ pers. m. pl., mais elle a déjà traduit la première occurence de עליכם.

Selon l'Aldine et la Sixtine, le $* G(30,8)$ ne traduit pas cet avant-dernier mot du

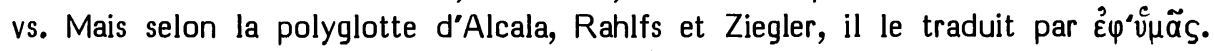
Ces mots sont en effet absents dans les mss Vaticanus et Sinaiticus, mais les témoins origéniens ne les marquent pas par un astérisque, montrant qu'ils ne les considèrent pas comme une ajoute faite au ${ }^{*} \mathrm{G}$ ancien.

\section{Choix textuel :}

Ce cas n'a pas été soumis au comité.

L'omission de ce mot par une partie de la tradition textuelle du ${ }^{*} G$ constitue presque sûrement un allègement stylistique (à partir du qeré qui répète "contre vous" d'une manière qui peut paraître inutile).

Mais ce qeré lui-même semble bien être une facilitation (transformant le 'contre eux' du ketib, pour l'assimiler au 'contre vous' qui précède). Le ketib constitue ici la lectio difficilior que Keil a estimée préférable.

Interprétation proposée :

Etant donné que le vs 29 a parlé à la 3e pers. pl. des "fils de l'Orient" et que 30a s'est adressé à la 2e pers. pl. aux "habitants de Haçor", il semble que nous ayons ici en $30 \mathrm{~b}$ une conclusion chiastique dont le premier élément s'adresse à la $2 \mathrm{e}$ pers. pl. 
aux "habitants de Haçor", alors que le deuxième élément conclut à la 3e pers. pl. sur le sort des "fils de l'Orient".

49,31 cf. p. 644.

49,33 cf. p. 813.

49,37 cf. p. 644.

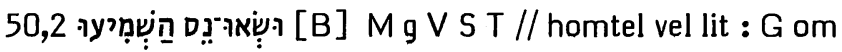

Options de nos traductions :

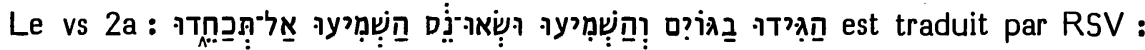
"Declare among the nations and proclaim, set up a banner and proclaim, conceal it not", par RL : "Verkündet's unter den Völkern und lasst's erschallen, richtet das Banner auf! Lasst's erschallen und verbergt es nicht", par TOB : "F aites-le savoir parmi les nations, faites-le entendre et signalez-le, faites-le entendre, ne le cachez pas" et par J3: "Annoncez-le parmi les nations, publiez-le, hissez un signal et publiezle, ne cachez rien".

J12 et NEB se fondent sur le ${ }^{*} G$ pour omettre les $4 \mathrm{e}, 5 \mathrm{e}$ et $6 \mathrm{e}$ mots.

Origine de la correction :

Movers (13) a classé ces trois mots dans la catégorie des ajoutes que le $* \mathrm{M}$ a empruntées à des passages parallèles. Les ont donc omis : Duhm, Cornill, Condamin, Volz, Nötscher, Rudolph, Weiser, Bright et les apparats de BH3S et Cent.

Les témoins anciens :

Le ${ }^{*} G(27,2)$ omettait ces trois mots. Les recensions origénienne et antiochienne

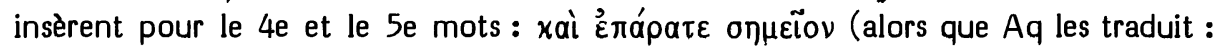
ארימו אתא , selon Syh). Pour le 6e, l'antiochienne donne : ảxovtíoa tع et l'origénienne : åxovotòv roińoate.

Ces trois mots sont normalement traduits par la $* \mathrm{~V}$, la $* S$ et le $* T$.

Choix textuel :

Il se peut que la Vorlage du ${ }^{*} G$ ait été victime ici d'un homéotéleuton.

A supposer que le *M ait amplifié ici une forme plus brève attestée par la Vorlage du ${ }^{*} G$, il s'agirait d'une initiative littéraire se situant au niveau du texte protomassorétique.

Le comité a attribué au *M 3 "A" et 3 "B".

Interprétation proposée :

Cette ample introduction veut annoncer l'ampleur de l'oracle qui suit. Il ne faut donc pas craindre de la traduire avec ampleur, comme l'ont fait RSV, RL ou J3. 
Options de nos traductions :

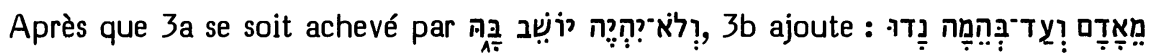
הִל Ces cinq derniers mots sont traduits par RSV : "both man and beast shall flee away", par J : "hommes et bêtes ont fui, ont disparu", par RL : "sondern Menschen und Vieh daraus fliehen werden" et par TOB : "hommes et bêtes, tout a fui ... plus rien !"

Avec le ${ }^{*} G$, NEB omet les deux derniers mots et traduit la fin de $3 a$ et les trois premiers mots de 3b par : "where neither man nor beast shall live".

Origine de la correction :

Ici encore, Movers (14) estime que ces deux mots absents du ${ }^{*} G$ ont été empruntés par le $* M$ au lieu parallèle $(9,9)$. Cette opinion est présentée comme probable par les apparats de $\mathrm{BH} 23$ et avec hésitation par celui de $\mathrm{BHS}$.

Les témoins anciens :

Le ${ }^{*} G(27,3)$ omet ces deux derniers mots en liant le début de $3 b$ à la fin de $3 a$ :

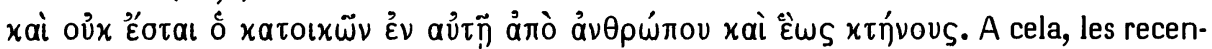

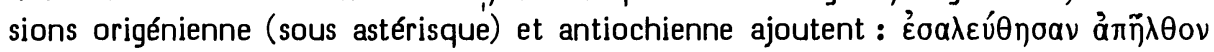
que Ziegler, avec le ms Barberini, attribue à Th, alors que le ms Marchalianus l'attribue à Aq.

Ces deux derniers mots sont traduits normalement par la*V, la *S et le *T.

\section{Choix textuel :}

Le *M a-t-il glosé en se conformant à 9,9, comme le suggère Movers ? Hitzig objecte à cela que la variante dans la forme du premier verbe נדו au lieu de montre qu'il n'y a pas eu emprunt pur et simple. En tout cas l'ajoute ou l'omission de ces mots constitue une initiative littéraire et non un accident textuel. C'est pourquoi le comité a attribué ici au *M la note " $A$ ".

Interprétation proposée :

Celle de $J$ est exacte et suffisamment littérale.

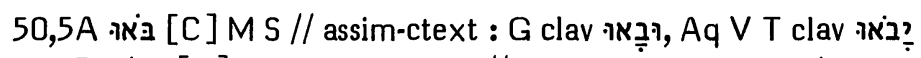

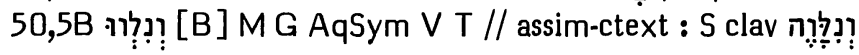

Options de nos traductions :

5a a dit à la 3e pers. pl. : “Ils réclameront Sion et c'est dans cette direction que

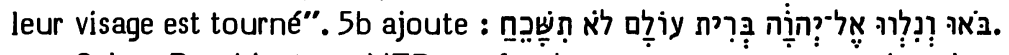

Selon Brockington, NEB se fonde sur un ms pour corriger le premier mot en

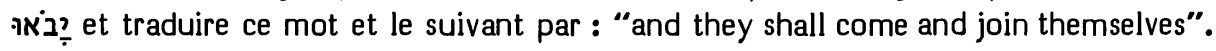
TOB corrige avec Aq la vocalisation du premier mot pour traduire de même : "ils viennent et se joignent". 
$\mathrm{J}$ corrige le deuxième mot selon la *S quand elle traduit: "Venez! Attachonsnous." Sans note, RSV traduit de même : "Come, let us join ourselves" et RL : "Kommt, wir wollen uns ... zuwenden".

Origines des corrections :

Déjà les traducteurs du XVIe siècle se partagent, pour la plupart, entre ces deux options.

Le sens "venez et unissez-vous" est retenu par Pagnini (et Arias Montano), Brucioli, Vatable, Estienne, Calvin (en lemme) et Pasteurs.

Le sens "ils viendront et se joindront" (que retiendront NEB et TOB) a été adopté (sous l'influence de la*V) par Prédicants, Zwingli, Tremellius et il est présenté comme le sens littéral par Münster et Calvin.

Le sens "venez et joignons-nous" (que retiendront J, RSV et RL) a pour initiateur Luther et a été adopté par Münster, Olivetan, Rollet, Jud, Châteillon, Ge, KJ.

Pour justifier cette dernière exégèse, Graf a proposé de corriger 5B en רְְְ? correction qui a été adoptée par Volz, sans tenir compte du fait que Keil y avait objecté qu'en ce sens, le nifal seul est usité. Pour répondre à cette objection, Grätz

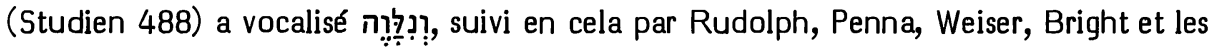
apparats de SBOT, BH3S et Cent.

Pour justifier l'exégèse de la *V et de Zwingli, une correction de $5 \mathrm{~A}$ en ריבְאי a été proposée par Giesebrecht, Ehrlich et l'apparat de HSAT2; alors que corrigeaient en יִּבְאר: Duhm, Nötscher et les apparats de HSAT34 (Oort et Cornill hésitant entre ces deux corrections).

Les témoins anciens :

Les versions anciennes se répartissent entre deux options qui correspondent aux deux exégèses que nous venons de distinguer.

L'exégèse "ils viendront et se joindront" peut invoquer l'appui du ${ }^{*} G(27,5)$ :

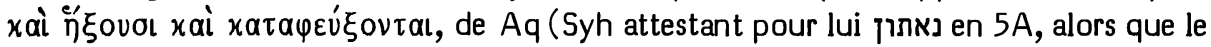

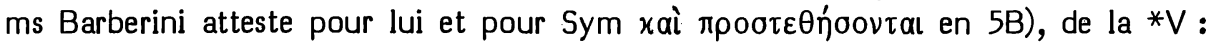
"venient et adponentur" et du *T : יתון ויתוספון.

Quant à l'exégèse "venez, joignons-nous", elle peut invoquer l'appui de la *S : תו נתלוא.

Un ms du *M semble apporter son appui à la première exégèse : le Kenn 182 du milieu du XIVe siècle. Mais il porte aussi le *T et Kennicott (Dissertatio generalis 86 et $n . b$ ) a noté que ses variantes hébraïques coïncident souvent avec la leçon du *T, ce qui est le cas pour יבאו en $5 A$.

Un autre $\mathrm{ms}$ du *M semble appuyer la seconde exégèse : le Kenn 253 qui écrit en 5B : ונלוה. Mais ce ms, écrit en 1495, n'a aucune autorité. Notons à ce propos qu'une massore (Weil §3146) garantit ici la leçon courante du $* M$.

Choix textuel :

Pour ces deux mots, le *M offre une lectio difficilior ("venez et ils se joindront") à partir de laquelle les différentes traductions anciennes et modernes divergent en sens opposés. 
Il importe de noter que, tout au long de l'histoire de l'exégèse, on a essayé de tirer du *M l'une ou l'autre des deux exégèses facilitantes que nous avons mentionnées.

1/ Pour pouvoir lire "venez et joignez-vous", 5B a été interprété comme une forme rare d'impératif nifal par Radaq (Mikhlol 54a), Ewald (Lehrbuch §226c), Hitzig, Olshausen ( \$264), Nägelsbach, Keil. Bauer/Leander (322v, cf. 3210) admet aussi la survivance en hébreu biblique d'une vieille forme d'impératif nifal de ce type.

2/ D'autres ont estimé que 5A offre une forme rare d'accompli. Cela a été suggéré par Tanḥum Yerushalmi, puis admis par de Dieu et Schleusner (en ses notes sur les Observationes de Michaelis).

Mais on ne peut traiter de cette leçon difficile du *M sans mentionner $\mathrm{Jl} 4,11$ où

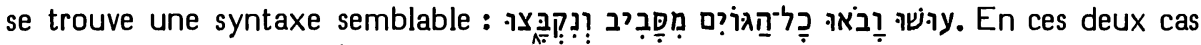
qu'il rapproche, König (Syntax \$172) attribue à l'accompli inverti le sens de "et que l'on se joigne" ou "et que l'on se rassemble". Cette exégèse très normale semble bien répondre aux conditions textuelles du $* M$.

Le comité a attribué à celui-ci en $5 \mathrm{~A}$ la note " $\mathrm{C}$ ", car il y est moins appuyé par les versions; alors qu'en 5B, il lui a attribué la note " $\mathrm{B}$ ", car il y est mieux appuyé. Cependant, le parallèle syntaxique de $\mathrm{Jl}$ 4,11 lui apporte un appui complémentaire.

Interprétation proposée :

Celle qui respecte le mieux la grammaire courante est: "Venez! et que l’on se joigne au Seigneur par une alliance perpétuelle qui ne s'oublie pas."

Les partisans de la forme ancienne de l'impératif nifal ont été assez persévérants, de Radaq à Bauer/Leander, pour que l'on puisse proposer aussi : "Venez et joignezvous au Seigneur... !"

משכיל 50,9 משככיל

Options de nos traductions :

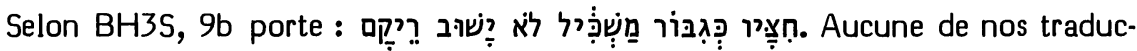
tions ne traduit sous cette forme le troisième mot. J12 disaient y corriger le 'shin' en "śin" pour traduire "victorieux" (que TOB offre aussi). Sans note, les autres lisent de même : RSV : "skilled", RL : "(eines) guten (Kriegers)", NEB : "practised" et J3 : "habile".

Histoire du *M:

Alors que l'édition de Brescia 1494 (selon l'exemplaire de New York JThS) et la polyglotte d'Anvers (dans le texte hébreu et dans l'interlinéaire) omettent le point diacritique de cette lettre, la plupart des éditions le placent à gauche. C'est le cas de Soncino 1488, Lisbonne 1492, Bomberg in $8^{\circ} 1521$, Ben Hayim (contre sa massore), Münster 1534, Minhat Shay, Letteris, Miqraot Gedolot, BH2.

Placent le point à droite : polyglotte $d^{\prime}$ Alcala, Félix de Prato, Bomberg in $8^{\circ}$ 1517, polyglotte de Londres, Halle, Baer et BH3S.

Nous avons trouvé trois mss qui placent le point à gauche : le ms Paris BN hébr 2 (contre sa massore), le ms Urbinates 1 et le ms Vatican ebr 3. 
Nous en avons trouvé vingt-cinq qui le placent à droite : Alep, Caire, Leningrad, Prophètes de Reuchlin, de Petrograd, de Berne, mss New York JThS 232, Urbinates 2, de Rossi 2 et 782, Vatican ebr 468 et 482, Londres BL Add 15451 et 21161, Madrid univers 1, Hamburg 6 et 27, Paris BN hébr 6, 26 et 82, Copenhague 1, 2, 4, 5 et 8. Onze d'entre eux ont une massore qui garantit ce placement du point en attestant que cette forme ne se retrouve qu'en Os 9,14.

Notons que Ginsburg est arrivé à des résultats semblables dans l'apparat de son édition : il mentionne le point à droite dans $27 \mathrm{mss}$ et 3 éditions, et le point à gauche en 3 mss et 6 éditions.

On peut conclure de cela que la forme donnée par BH3S représente bien la forme du texte tibérien classique dont Ben Hayim s’était éloigné.

Histoire de la critique du texte :

Sous l'influence de Félix de Prato, Pagnini (suivi par Vatable) a traduit: "orbantis". Lisent de même Brucioli (1532) : "che priva", Tremellius : "interficientis", Pasteurs : "ne faisant que destruire", la marge de KJ : "Or, destroyer".

Mais l'influence de Ben Hayim s'est imposée à la majorité des traducteurs : Prédicants : "der ... bericht ist", Zwingli, Jud et Châteillon latin : "periti", Luther : "guten", Münster et Calvin : "prudenter agentis", Olivetan et Rollet : "qui en besogne prudemment", Arias Montano : "prosperantis", Estienne : "qui s'en aide habilement", Brucioli (1540) : "prudente", Châteillon : "un bien apprins", Geneva : "which is expert" et KJ : "expert man".

Si l'on remonte aux débuts de l'exégèse littérale juive, le sens de "privant d'enfants" (supposant qu'on lise ici le point à droite) est celui qui a été retenu par Yéfet ben Ely, Abulwalid (Ușul 720,29), Parḥon, Radaq, Menahem de Posquières, Isaïe de Trani et Altschüler.

Seuls deux glossaires se prononcent sur ce mot : la seconde main de $E$ donne "ésilant", c'est-à-dire : privant d'enfants. Le glossaire C donne "antillant", c'està-dire : procédant intelligemment. Elias Levita (Zikronot) classe ce mot sous selon les mss de Munich et de Paris. Font de même : Pagnini (Thesaurus1 2575), Mercerus (sur Thesaurus3 de Pagnini 2961), Buxtorf (Lexicon), Cocceius, Gousset, Roediger. Ce mot est classé sous par Gesenius/Buhl, BDB, König (Wörterbuch) et $\mathrm{KBL}$.

Ont interprété ce mot en lisant le point à gauche : de Dieu, Clericus, Houbigant, Venema, Doederlein, Schleusner (annotant les Observationes de Michaelis), Rosenmüller (incertain), Ewald, Hitzig, Graf, Henderson, Nägelsbach, Keil, Knabenbauer, von Orelli, Giesebrecht, Oort, Cornill, Condamin, Ehrlich, Volz, Nötscher, Rudolph, Penna, Weiser, Bright. C'est pour cette leçon qu'optent les apparats de HSAT2, BH3S et Cent. Etant donné que cette leçon figure dans le texte de $\mathrm{BH} 2$, celle-ci (ainsi que HSAT34 qui se fondent sur elle) n'a pas à prendre d'initiative pour opter en sa faveur.

Michaelis a opté pour la leçon avec le point à droite. Ont fait de même : Gesenius (selon Roediger), Maurer et Umbreit (selon Keil).

Les versions anciennes :

Ont lu ici un 'sin" : le *G $(27,9)$ : ouvetoũ (recopié par Sym) et la *S : דמצלח. 


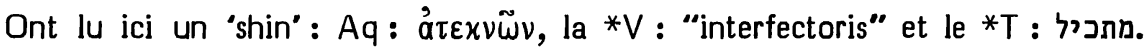

\section{Choix textuel :}

Cette dernière leçon peut être considérée comme caractéristique du texte protomassorétique.

On lui a objecté que le sens "orbare" (= priver d'enfants) n'apparâ̂t qu'au piél de ce verbe, alors que c'est "abortare" (= avorter) qui est le sens du hifil. De fait, il est vrai que le seul autre emploi du hifil $(0$ s 9,14) signifie "faire une fausse couche, ne pas porter à terme". Mais ce sens se retrouve pour le piél en Ex 23,26; Jb 21,10; Gn 31,38; Ml 3,11; 2 R 2,19. Puisque le piél a les deux sens, on ne voit pas ce qui conduirait à préférer l'un de ces deux sens pour le hifil. Et s'il devait en être ainsi, il serait normal d'attribuer plutôt au hifil le sens de : rendre une autre personne 倠 (= orbatus).

Certes un "guerrier réussissant" convient bien à ce qui suit immédiatement. Mais l'image d'un guerrier privant les mères de leurs enfants trouverait de bonnes analogies en $1 \mathrm{~S} 15,33$ et en Jr 15,7-9. Notons que le placement du point à gauche assimile à une forme plus usuelle.

Le comité a attribué 3 " $\mathrm{B}$ " et 1 "C" à la leçon qui place le point à droite, alors que celle qui place le point à gauche a reçu 2 " $\mathrm{B}$ ".

Interprétation proposée :

"Leurs flèches sont comme un guerrier qui prive (les mères) de (leurs) enfants et qui ne revient pas sans avoir accompli son oeuvre."

50,11 דששא [C] ] M T // err-graph : m G Aq V

Options de nos traductions :

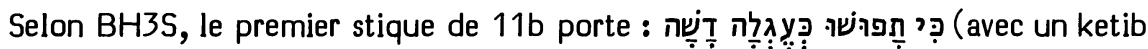
'yod" au lieu du 'waw' final du deuxième mot). NEB traduit cela: "though you run free like a heifer after threshing".

A la place du dernier mot, 33 lit comme une génisse dans l'herbe". Disant suivre le *G et la ${ }^{*} V, J 12$ traduisaient : "Bondissez tels des veaux mis au pré". Sans note, RSV traduit : "though you are wanton as a heifer at grass", RL : "(Wenn ihr) ... und hüpft wie die Kälber im Grase" et TOB : “Oui, gambadez comme génisses dans les prés".

Histoire du *M et de son exégèse ancienne :

Le dernier mot était écrit avec un 'alef' final (Tְְִׁ) par les éditions Soncino 1486 et 1488, Lisbonne 1492, Brescia 1494, polyglotte d’Alcala, Félix de Prato, Bomberg in $8^{\circ} 1517$ et 1521, Münster 1534, Halle, texte de base de Kennicott, Baer et $\mathrm{BH} 2$.

La leçon avec 'hé' final est celle que portent ici les éditions Ben Hayim, polyglotte d'Anvers (texte et interlinéaire), polyglotte de Londres, Minḥat Shay, Letteris et $\mathrm{BH} 3 \mathrm{~S}$. 
Le seul ms babylonien qui nous soit connu est ici le ms Oxford Bibl Bodl Heb d 26, $13 r$ ( = Yeivin IV 252). Il porte la leçon avec "hé'. Les mss d'Alep et du Caire la donnent avec une mp soulignant que cette forme est hapax. Donnent aussi cette leçon : les Prophètes Reuchlin, Petrograd et New York JThS 232, les mss Leningrad, Vatican ebr 3, 468, 482, Madrid univ 1, de Rossi 2 et 782, Paris BN hébr 2 (2e main), 26 et 82, Copenhague 2, 4 et 5.

La leçon avec 'alef' final est celle qu'offrent les Prophètes de Berne, les mss Paris BN hébr 2 (1e main) et 6, Urbinates 1 et 2, Hamburg 6 et 27, Londres BL Add 15451 et 21161, Copenhague 1 et 8.

Yéfet ben Ely lisait la leçon avec 'hé' et traduisait (= foulant ou dépiquant les céréales sur l’aire).

David ben Abraham (I 408 6), selon les deux seuls mss que nous en avons, lit aussi la leçon avec "hé'. Il classe ce mot sous le bilittère דש (et non sous (שא ) et en donne la même traduction que Yéfet.

Menahem ben Saruq écrit ce mot avec 'alef', mais le classe exactement de même en précisant que ce bilittère a le sens de כתישה (= piler ou battre les céréales).

Dunash ben Labrat. $\left(78^{*}\right)$, reprochant à Menạem ce classement, affirme explicitement que ce mot est écrit avec 'alef' et qu'il faut donc le rattacher au verbe דשא La vache qui se nourrit de nourri au אִ אִ אִ ( travaille à dépiquer sur l'aire serait maigre et étique, et il insinue à l'adresse de Menaḥem : “Chercherais-tu à semer le trouble dans le coeur des simples qui n'ont pas accès aux codices soignés en prétendant que ce mot s'écrit avec 'hé' ? Mais même s'il s'écrivait avec "hé', cela ne l'empêcherait pas de se rattacher à la racine דשא, puisque "alef' et "hé" s'échangent dans toute l'Ecriture".

Ḥayyuj (Kitâb 16,12) a pris l'option inverse de celle que vient de proposer Dunash. Il compte en effet notre mot parmi ceux où un 'alef' tient la place d'un 'hé',

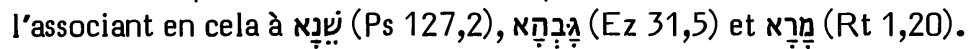

Abulwalid (Luma 88,25 à 89,14) entre à son tour dans le débat : "Il arrive que 'alef' remplace 'hé' dans l'Ecriture, bien que la prononciation demeure la même. C'est le cas en ושנא (2 R 25,29) ou en 1,20). Abu Zakarya (= Hayyuj) en a déjà fait la remarque dans le premier chapitre de son traité sur les verbes à lettres faibles où il cite encore דשא (Jr 50,11) parmi les cas où un 'alef' est écrit à la place d'un 'hé'. Cependant ce mot s'écrit avec un 'hé' et il porte la massore : hapax et écrit avec "hé. Je traite de ce cas parce qu'un célèbre grammairien a critiqué l'opinion d’Abu Zakarya que דשא (Jr 50,11) se rattache à שָּ̣ (1 Ch 21,20). Lui-même le rat-

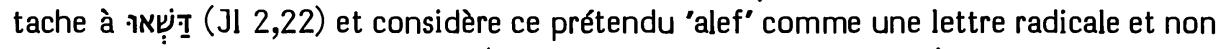
comme tenant la place d'un 'hé' (ainsi que le disait Abu Zakarya). Aussi dit-il que ce mot signifie 'herbeuse' au sens de 'broutant de l'herbe'. C'est là une erreur, car l'adjectif verbal masculin des verbes terminés par 'alef' a la forme לִִ̣ comme

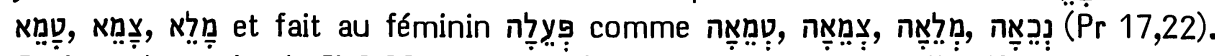
Or le verbe devrait donc être 范 vient de le pense Abu Zakarya". 
Histoire de la critique textuelle :

Bochart (Hierozoicon I 301s) écrit: "Les bovidés, chez les Juifs, engraissaient surtout à l'époque du dépiquage; car la Loi interdisait de museler le boeuf qui dépique. Ces bêtes pouvaient donc, durant le dépiquage, manger à satiété. C'est pourquoi Osée compare les Israélites à une génisse “qui est habituée à dépiquer et qui aime cela" (10,11). C'est dans le même sens que Jr 50,11 dit que "vous serez gras comme une génisse qui dépique". En effet, je ne lis pas דשא avec "alef", mais דשה avec "hé" que je rencontre en de nombreuses éditions de Venise, Bâle, Anvers et Leyde. D'ailleurs $R$. Jonah et Qimhi nous apprennent que c'est cette leçon que portent les plus anciens manuscrits... Mais mon principal motif pour choisir cette leçon, c'est que l'autre ne saurait tenir, quoique ce soit elle que choisissent les exégètes les plus récents. En effet, que serait une génisse דשא avec 'alef'. On dit que דשאה et que l'on désigne ainsi une génisse qui se nourrit d'herbe et que cette pâture engraisse. Mais même ce mot דשאה n'est pas ce que l'on prétend. En effet, le verbe דש דש signifie pas 'se nourrir d'herbe', mais 'se couvrir d'herbe'. Ainsi en Gn 1,11 : 'que la terre se couvre d'herbe', ou en Jl 2,22 : 'les pâturages du désert se sont couverts d'herbe' ... Donc דשאה serait 'se couvrant d'herbe', ce qui pourrait se dire de la terre ou d'un champ, mais non d'un animal".

Pour répondre à cette objection, Michaelis (Observationes) corrige en mant que c'est ce que le ${ }^{*} G$ et la $* V$ ont lu ici. La vocalisation du *M lui semble correspondre à la leçon avec 'hé'. Ewald adopte cette vocalisation comme étant celle qui correspond le mieux au texte consonnantique. Cette correction vocalique a été adoptée par Knabenbauer, Cornill et l'apparat de SBOT. Hitzig estime que cette vocalisation est en effet celle qu'avait en tête le scribe qui a instauré la leçon avec 'alef', alors que la vocalisation avec deux qameș et la leçon avec "hé' correspondent à l'exégèse authentique de ce texte. Selon Grätz (Studien 488) il attribue le sens de "nourrie d"herbe". Corrigent ici en Rudolph, Penna, Weiser, Bright et les apparats de HSAT34 et BH23S.

Ajoutons que Luther, qui lisait dans les éditions anciennes de la *V "vituli", avait traduit le mot précédent par "Kelber". Cela explique pourquoi la plupart des critiques, habitués à cette leçon, corrigent le féminin singulier en un masculin pluriel. Cornill (qui n'a sans doute jamais fréquenté les rues de Pampelune le jour de la Saint Firmin) estime que des veaux sont plus typiques qu'une vachette comme exemple de pétulance.

\section{Les témoins anciens :}

Les témoins que nous avons mentionnés plus haut suffisent à montrer que la leçon avec "hé' final est celle du texte tibérien classique. La mp des mss d'Alep et du Caire concorde avec le fait que ce mot ne figure pas dans la liste offerte par la Okhla de Halle (46b, marge supérieure) des 13 mots qui s'achèvent par un 'alef' tenant la place d'un "he' (liste où figurent Ps 127,2; Ez 31,5 et Rt 1,20 que Hayyuj lui a associés), ni dans aucune des listes relevées par Ginsburg (Massorah IV 11 \$21) des mots hapax s'achevant par 'alef'.

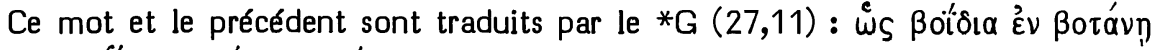

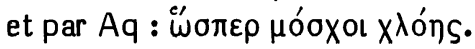


La *S porte : איך ע dont le dernier mot (= à l'engrais) est trop large pour qu'on puisse préciser celle des deux leçons sur laquelle il se base.

Le *T : כעגלי רבקא peut sembler avoir le même sens que la *S si on se fonde sur Levy (Chald. Wört. II 403a). Mais les données fournies par Gesenius (Thesaurus 1260a) montrent qu'il traduit la leçon avec "hé". Notons en outre que, pour le premier mot, la polyglotte d'Anvers et les éditions anciennes de Radaq lisent qui est probablement la leçon originale.

La *V, selon l'édition Clémentine, portait ici : “ut vituli super herbam". Cependant, le plus ancien apparat critique, celui de Robert Estienne en 1540, attestait que "vitulus" est ici la leçon sur laquelle s'accordaient les deux mss de St Denis et les trois mss de St Germain des Prés qu'il avait collationnés. Cette leçon a été adoptée par les éditions Weber et San Girolamo, après qu'Estienne l'ait eu fait passer dans le texte de son édition de 1557. Notons que la traduction du féminin y yar le masculin "vitulus" se retrouve en $1 \mathrm{~S} 16,2$.

Choix textuel :

Du fait du parallèle qu'offre Os 10,11, la leçon avec "hé" se trouve ici bien en place. Anderlind (44) estime qu'un boeuf qui dépique absorbe en moyenne 30 litres de blé par jour. Cette leçon est d'ailleurs attestée par le *M tibérien classique et la vocalisation lui correspond bien.

L'objection de Bochart sur le sens de la leçon avec 'alef' s'ajoute à celle d'Abulwalid sur sa justification grammaticale. Cependant toutes les versions, sauf le *T, semblent l'avoir lue.

Le comité a attribué à la leçon avec "hé" 3 "B" et 3 "C".

Interprétation proposée :

"... comme une génisse qui foule l'aire".

50,14 כי ליהוה חטאה

Options de nos traductions :

14b est traduit normalement par RSV, RL, TOB et J3.

$\mathrm{J} 12$ et NEB fondent leur omission de ces trois mots sur le fait qu'ils manquent dans le ${ }^{*} \mathrm{G}$.

Origine de la correction :

Movers (12) estime que le *M a glosé en s'inspirant de תחת אשר חטאו ליהוה du vs 7. 14b est omis par Cornill, Volz, Nötscher, Rudolph, Weiser, Bright et les apparats de $\mathrm{BH} 3 \mathrm{~S}$.

Les témoins anciens :

Le ${ }^{*} G(27,14)$ omet ces mots qui sont insérés sous astérisque sous la forme

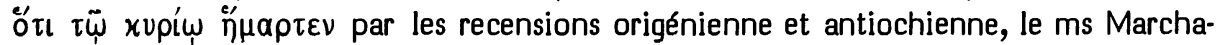
lianus attribuant cette insertion à toutes les colonnes hexaplaires autres que celle de la Septante. 
Ces mots sont absents de la *S éditée des polyglottes de Paris et de Londres. Ils sont traduits מטל דלמריא חטת dans le ms Ambrosianus et l'édition de Mossul.

Ils sont traduits normalement par la *V et le *T.

Choix textuel :

Hitzig a objecté à Movers que ces mots sont nécessaires à l'équilibre du vs et que la "vengeance du Seigneur" mentionnée en 15b semble bien les présupposer. En tout cas, l'ajoute ou l'omission de ces mots constitue une initiative littéraire et non un accident textuel. C'est pourquoi le comité a attribué ici au *M la note " $A$ ".

50,15 סביב [A] M S T // lit : G om

Options de nos traductions :

Ce vs commence par הָרִ que RSV traduit : "Raise a shout against her round about", J : "Poussez contre elle le cri de guerre, de tous côtés!", RL : "Erhebet das Kriegsgeschrei ringsum" et TOB : "Poussez un hourra tout autour d'elle."

NEB se fonde sur le ${ }^{*} G$ pour omettre le troisième mot et traduire : "Shout in triumph over her".

Origine de la correction :

NEB semble assez isolée en cette omission.

Les témoins anciens :

Ce mot du $* M$ est traduit normalement par la $* V$, la ${ }^{*} S$ et le $* T$. Les recensions origénienne et antiochienne l'insèrent sous la forme : xúx $\lambda \omega$, le ms Barberini astérisant cela.

Le *G $(27,15)$ ne traduit pas ce mot.

Choix textuel :

L'omission du *G peut tenir au fait que tous ses témoins donnent pour le mot

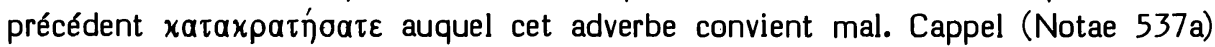

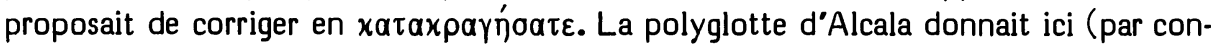

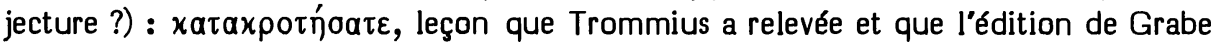
a adoptée, suivie en cela par Schleusner (sur les Observationes de Michaelis), Rahlfs

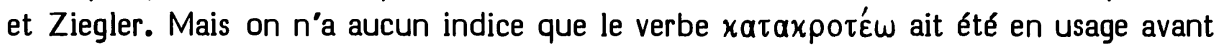
l'époque byzantine. Voyant là une conjecture ingénieuse, Spohn préfère ne pas corriger le *G.

Quoiqu'il en soit de la leçon authentique du *G, la présence du mot סביב dans le ${ }^{*} M$ ne peut provenir d'un accident textuel. C'est pourquoi le comité a attribué à ce mot la note "A".

Interprétation proposée :

NEB et TOB ont tort d'interpréter le verbe précédent comme exprimant la clameur d'enthousiasme qui salue la reddition de Babylone. Il s'agit plutôt du cri de guerre que poussent contre elle les assaillants qui l'entourent de toutes parts. 
50,17 cf. p. 814.

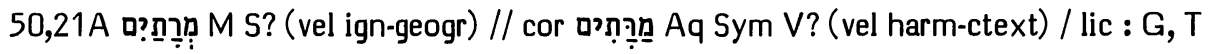

Options de nos traductions :

RSV, J, RL et NEB respectent la vocalisation de ce mot en le transcrivant comme un nom de pays.

TOB écrit "Marratim" en notant : "Ce mot signifie en akkadien 'lagune' et désigne la région à l'embouchure du Tigre et de l'Euphrate. La lecture juive traditionnelle a perdu le sens géographique de 'Marratim' et a interprété le mot comme 'merataïm', c.-à-d. 'double apostasie' ou 'double amertume' ".

Origine de la correction :

C'est Duhm qui a adopté ici la vocalisation "Marrâtim", y voyant la désignation d'une région du sud de la Babylonie. Il semble cependant que la quasi-totalité des exégètes et des apparats ont préféré conserver la transcription du *M.

Les témoins anciens :

Toutes les versions ont essayé de traduire ce mot: le *G $(27,21)$ par $\pi\llcorner x \rho \tilde{s}$,

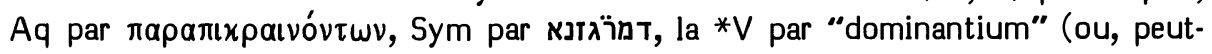

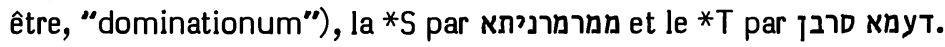

Histoire de l'exégèse :

Peu après, le mot Tị a été compris par le *T comme étant un toponyme, et cela du fait que ce toponyme revient en Ez 23,23 (ce qui n'est pas le cas pour le mot qui nous occupe).

Cependant, il ne faudrait pas croire que l'on ait attendu la découverte du toponyme 'Marratu' dans les inscriptions cunéiformes pour interpréter notre mot, lui aussi, comme un toponyme. La première exégèse donnée par Yéfet ben Ely est : "Il se peut que ce soit le nom d'un lieu dans le pays des Chaldéens." Menaḥem de Posquières dit : "c'est un nom de lieu du pays de Babylone". Le glossaire C, lui aussi, interprète ce mot comme un toponyme. Cependant les commentateurs médiévaux les plus connus ont dérivé ce mot de מר (Rashi et les autres glossaires) au sens de "contrariété" ou de (Radaq) au sens de "rébellion". Presque tous les traducteurs du XVIe siècle ont fait de même (à la suite de Nicolas de Lyre qui traduisait l'hébreu par "rebellantium" que reprendront Pagnini et Arias Montano). C'est Tremellius (suivi par Grotius) qui reprendra l'exégèse en toponyme, y voyant le pays des Mardes en Arménie, dans la haute vallée du Tigre. KJ dépend de lui lorsqu'elle transcrit : Merathaim (que RSV et NEB ont conservé).

Selon Andreas (815s), les documents cunéiformes ont attesté l'existence d'un toponyme 'Marratu' avec le déterminatif 'nâru' indiquant qu'il ne s'agit pas d'un pays, ni d'une mer, mais d'eaux qui sont distinctes de celle-ci. Ce toponyme signifiant probablement 'eau amère', il est fort possible qu'il s'agisse de lagunes qui se situaient à l'embouchure du Tigre et de l'Euphrate. 
Choix textuel et interprétation proposée :

Ce cas n'a pas été soumis au comité.

Les documents cunéiformes ne permettent pas de conclure que "Marratim" ait été le nom d'une région de Chaldée, ainsi que l'ont prétendu Duhm, BDB et la note de TOB. Il est fort possible que, dans la forme originelle de cet oracle, "le pays des Marrâtim "voulait désigner la Babylonie, à la fois comme le pays de ceux qui habitent dans la région de la lagune de Marratu (= de l'eau amère) et comme le pays de ceux qui sont cause d'amertume.

La vocalisation en duel qu'offre le *M opte clairement pour un sens: "la double amertume" avec la même valeur superlative que prend la vocalisation double méchanceté) dans le nom de Kûshân Rishâtaïm (Jg. 3,8.10). Le sens visé est donc: "le pays de la double amertume".

Le *T avait dérivé ce mot de la racine se rebeller), dérivation qui avait été retenue par Radaq, Nicolas de Lyre et Pagnini. Une dérivation à partir de (= être amer) a été retenue par le ${ }^{*} \mathrm{G}, \mathrm{Aq}$, Rashi et les glossaires. Elle offre l'avantage de laisser transparaître l'étymologie du toponyme babylonien.

On peut hésiter entre deux options :

$1 /$ En se fondant sur Aq, Sym et (indirectement) la*V, corriger la vocalisation en 吅 et traduire : "le pays des Marrâtim", en indiquant en note le double sens que nous avons proposé ci-dessus.

2/ Garder la vocalisation du *M et traduire "le pays de Merataïm" en indiquant en note que cela signifie, en un sens superlatif : "de la double amertume", ce mot évoquant un toponyme du sud de la Babylonie.

50,21B אחריהם [B] M // lic : V, S, T / glos : g Th / abr-elus : G om

Options de nos traductions :

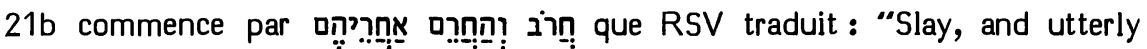
destroy after them."

Selon Brockington, NEB se réfère à la ${ }^{*} S$ pour corriger les deux derniers mots en

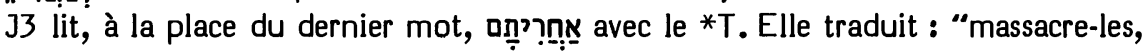
extermine-les jusqu'au dernier". De même, RL traduit : "vertilge sie und vollziehe den Bann an ihren Nachkommen". TOB traduit: "Massacre et offre-moi ceux qui y restent".

Plaçant le troisième mot en premier et conjecturant un verbe auparavant, J12 traduisaient : "mets-toi à leur poursuite; manie l’épée, extermine-les".

Origines des corrections :

La correction du troisième mot en

Le remplacement des deux derniers mots par Nötscher, Penna et les apparats de HSAT4 et BH3.

L'option de $\mathrm{J12}$ est celle de Rudolph qui conjecture et en $\mathrm{BHS})$. 
Les témoins anciens :

Le *G $(27,21)$, traduisant assez littéralement les deux premiers mots, n'a rien qui corresponde au troisième. Ziegler (Beiträge 87 ) voit en ce dernier mot un doublet de la part du *M. Janzen (25) hésite sur cette interprétation et serait plutôt tenté (118) de voir ici une haplographie de la part du *G.

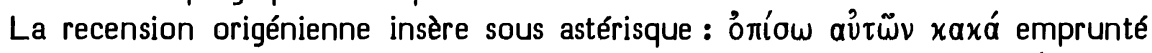
à Th. La recension antiochienne fait de même en usant de la préposition : $x a \tau o ́ \pi ı \sigma \theta \varepsilon v$. Il est difficile d'expliquer ici l'ajoute de xaxá (qui manque d'ailleurs dans l'Arménienne).

Pour traduire les deux derniers mots, la *S se contente de וחרובי אנון (le "yud" étant omis par le ms Ambrosianus). La *V les traduit par : "et interfice quae post eos sunt".

Le *T les traduit : ייתון לגמרא שארהון selon tous les témoins cités par Sperber (auxquels s'ajoute le ms Urbinates 1). Lorsque Giesebrecht disait que le *T a traduit le dernier mot par שאריתהון, il leçon de la polyglotte de Londres et des Miqraot Gedolot. Cette leçon n’a aucune chance de représenter ici le texte original du*T.

\section{Choix textuel :}

La leçon difficile du $* M$ est à la base des traductions larges de la $* V$, de la $* S$ et du *T. L'ajoute de $x a x a ́$ par les recensions du ${ }^{*} G$ vise probablement à en expliciter le sens en fournissant un complément d'objet direct au verbe והחרם

Il se peut que l'omission du dernier mot par le ${ }^{*} G$ soit un moyen d'échapper à la difficulté syntactique.

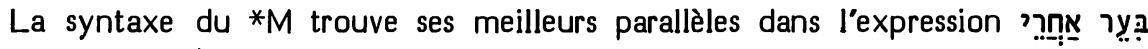
(1R 14,10; 21,21).

Estimant que la triple occurrence de la séquence "het-resh" constitue ici une assonance voulue par l'auteur, le comité a attribué au *M la note " $\mathrm{B}$ ".

Interprétation proposée :

"Anathématise derrière eux" signifie : détruis tous les êtres vivants que les guerriers, massacrés ou enfuis, ont laissés derrière eux sans défense.

On traduira donc : "et voue à l'anathème ce qu'ils laissent".

50,26A בַּאו [B] M Aq(?) Sym V S T // transl : G Aq(?) clav : 50,26B מ. [C] M V t // expl : Aq(?) S T / incert : Aq(?) Sym / lic : G

Options de nos traductions :

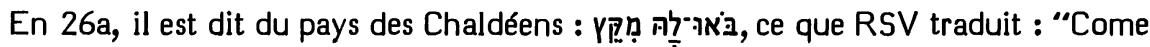
against her from every quarter", RL : "Kommt her gegen dies Land von allen Enden", TOB : "Venez vers elle du bout du monde" et J3 : "Venez-y de partout".

J12 corrigeaient le dernier mot en et traduisaient: "Venez-y tous sans exception".

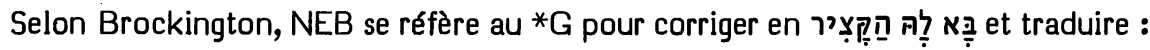
"Her harvest-time has come". 


\section{Origines des corrections :}

La suggestion de corriger le dernier mot en מקצה (en se référant à 51,31) a été formulée par Houbigant et adoptée par Giesebrecht, Cornill, Ehrlich, Rudolph et les apparats de $\mathrm{BH} 23 \mathrm{~S}$.

La correction de NEB repose sur une conjecture de Coste (cité par Cornill), conjecture proposée en alternative par l'apparat de $\mathrm{BH} 3$.

\section{Les témoins anciens :}

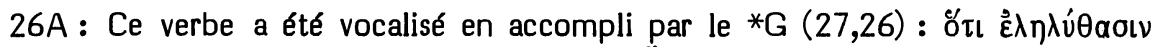
et par la leçon que le ms Barberini attribue à $A q$ : $\hat{\eta ்}^{\wedge} \theta$ ov .

Les autres témoins (Aq selon Syh qui lui attribue la leçon de la *S : תו, Sym selon Syh : עולו ly, la *V : "venite" et le *T : עולו ont lu un impératif selon la vocalisation du *M.

26B : $L a * V$ a respecté l'absence de suffixe après ce mot : "ab extremis finibus". Notons cependant que l'édition princeps de la $* V$ insérait "terrae" avant le dernier mot, cette insertion n'étant appuyée par aucun des mss cités par l'édition de San Girolamo. Cette absence de suffixe se retrouve attestée par une partie de la tradition textuelle du *T, une leçon marginale du ms Reuchlin s'accordant avec l'édition Ben Hayim et les polyglottes d'Anvers et de Londres pour lire מסטרא, alors que les autres témoins lisent un 'hé' à la place du 'alef' final.

La *S a explicité un pronom suffixe : מן חדריה, alors que le ms Barberini attri-

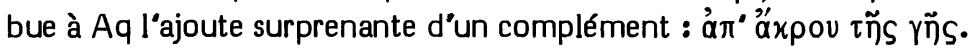

On ne peut se prononcer sur les leçons que Syh attribue à Aq (מן שולמא) et à Sym (כלהון), car la première peut être incomplète et le suffixe de la seconde a bien des chances de ne pas avoir de correspondant formel dans le texte grec.

Enfin le ${ }^{*} G$ traduit ce mot et le précédant par oi xaıpoì aủiñs. Il semble que le traducteur ait opéré très librement en donnant au substantif le sens qu'il a en hébreu tardif et déjà en Lm 4,18.

\section{Choix textuel :}

En 26A, le *M étant fermement appuyé par la plupart des témoins reçoit la note "B". La vocalisation $d u{ }^{*} G$ dépend de son interprétation des deux mots suivants.

En 26B, la situation est beaucoup plus confuse. Aussi le *M reçoit-il la note "C", bien que l'on ne puisse pas prouver qu'aucun témoin ait lu une Vorlage différente.

\section{Interprétation proposée :}

De Dieu (sur Ez 33,1) et Schultens (en Opera minora 121 sur Gn 19,4) ont

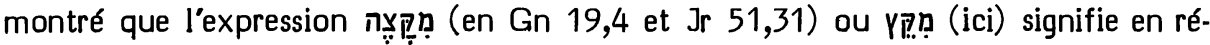
alité "en totalité, tous ensemble". Schultens a donné des parallèles convaincants tirés de l'arabe. Ce sens était déjà connu du *G de Gn 19,4 qui traduisait ă $\mu \alpha$ (alors que dans les deux passages de Jérémie, il a eu des difficultés avec cette expression) et de Sym ici (où Field restitue $\pi a ́ v \tau \varepsilon S$ comme Vorlage de la leçon que Syh lui attribue). Le lexicographe judéoarabe David ben Abraham (II 565,19-21) disait déjà clairement qu'en Nb 22,41 l'expression קצה העם signifie en réalité : 'l'armée toute entière d'une 
extrémité à l'autre', alors que l'on serait tenté de croire qu'il s'agit seulement d'une partie de l'armée.

Cette interprétation a été reprise ici par Venema, C.B. Michaelis, Gesenius (Thesaurus 1227b et 1229b) et par Rudolph (traduisant : "ohne Ausnahme"). Il n'est pas nécessaire de corriger en pִpִ pour interpréter ainsi ce texte.

On pourra donc traduire : "Venez vers elle de partout."

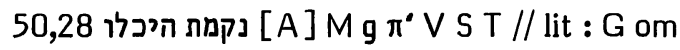

Options de nos traductions :

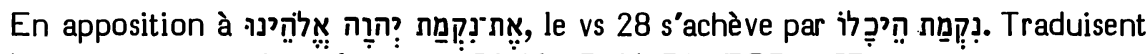
ces deux mots comme ils le feront en 51,11 : RSV, RL, TOB et 33 .

Les omettent avec le ${ }^{*} G: J 12$ et NEB.

Origine de la correction :

Movers (48) voit en ces mots une glose qui a dû être apportée au *M peu de temps après la destruction du temple. Les omettent : Cornill, Nötscher, Rudolph et l'apparat de $\mathrm{BHS}$ (qui les dit empruntés à 51,11).

\section{Les témoins anciens :}

Seul le ${ }^{*} G$ ancien $(27,28)$ omet ces mots dont la présence est attestée par les recensions origénienne et antiochienne, toutes les colonnes des hexaples (selon le ms Marchalianus), la *V, la *S et le *T qui, tous, les traduisent littéralement.

\section{Choix textuel :}

La présence ou l'absence de ces mots ne relève pas d'un accident textuel, mais d'une initiative littéraire. Aussi le comité a-t-il attribué la note " $A$ " à leur présence dans le $* M$, présence attestée d'ailleurs par l'ensemble des témoins du texte protomassorétique.

Giesebrecht a fait remarquer que cette apposition en fin de verset est bien en place ici, car le vs suivant (29) s'achèvera par une apposition semblable.

Interprétation proposée :

"La vengeance de son temple" signifie ici la vengeance pour la profanation subie par son temple.

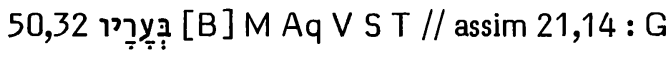

Options de nos traductions :

Les vss 31.32 constituent un petit oracle où Babylone est désignée par le surnom masculin : Le troisième mot est traduit normalement par "dans ses villes" ou "à ses villes" en RSV, J, RL et TOB. 
Selon Brockington, NEB se fonde sur le *G pour le corriger en in "in the heath around her".

Origine de la correction :

Cette Vorlage a été attribuée au *G par Cappel (Notae 537). Ont proposé de corriger ainsi : Giesebrecht, Oort, Duhm, Cornill et l'apparat de SBOT.

Les témoins anciens :

Le *G $(27,32)$ traduit ici les trois premiers mots par : xaì åvá $\psi \omega$ $\delta \rho v \mu \tilde{\omega}$ aủtñs, ce qui est exactement la traduction qu'il a donnée en 21,14 pour :

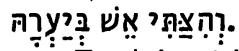

Traduisent littéralement ici "en ses villes": Aq, la *V, la *S et le *T.

Choix textuel :

Le genre masculin ou féminin des possessifs dépendant ici du genre du substantif "arrogance", les deux variantes ne se distinguent que par une permutation de trois lettres dans l'hébreu.

Les "villes de Babylone" (c'est-à-dire les agglomérations dont elle est la métropole) sont mentionnées aussi en 51,43. Les "villes" d'une "ville" sont une expression un peu surprenante mais usuelle dans le livre de Jérémie, expression qui semble avoir

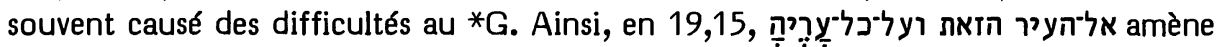

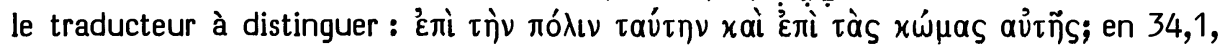

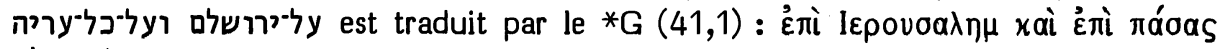

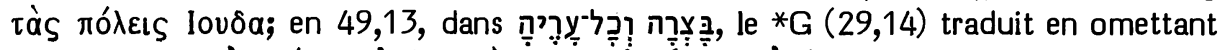

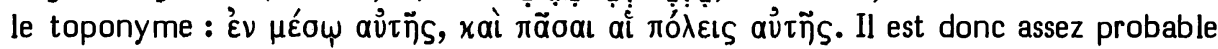
que c'est pour échapper à une difficulté semblable que, profitant de la similitude du contexte, le ${ }^{*} G$ a interprété en fonction de ce qui se lisait en 21,14.

Notons cependant que les mots אִ̣ గִ réapparaissent encore trois fois en

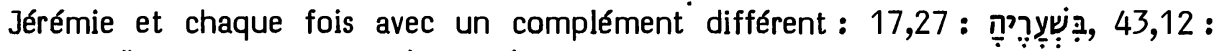

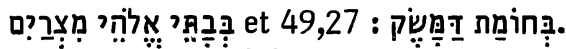

Alors que Jérémie offre une expression qui y est parfaitement en place et que le ${ }^{*} G$ semble avoir eu parfois de la peine à traduire, il n'y a donc aucun motif de suivre ce traducteur dans une assimilation au parallèle de 21,14.

Aussi le comité a-t-il attribué au *M la note "B".

\section{0,36 Th M M Aq // assim-ctext : Th Sym V S T / ign-lex : G}

Options de nos traductions :

Sans note textuelle, ce mot est traduit par RSV : "the diviners" et par NEB : "the false prophets".

TOB dit changer une consonne pour lire "les devins", alors que le *M signifierait littéralement : "ceux qui bavardent".

$\mathrm{J}$ traduit : "ses devins", J2 précisant qu’elle suit en cela la $* \mathrm{~V}$, la ${ }^{*} \mathrm{~S}$ et le ${ }^{*} \mathrm{~T}$. RL traduit de même : "ihre Wahrsager". 


\section{Origines des corrections :}

La *V (divinos eius) explicitait un possessif. Luther a copié ici la traduction des Prédicants de Zurich qui faisait de même : "jre weissager". Ici RL a conservé Luther.

Il en va de même pour J dont la traduction ("ses devins") copie Olivetan qui copiait Le Fèvre d'Etaples qui traduisait la *V.

Quant à TOB, elle fait allusion à une correction du 'dalet' en 'resh', correction qui a été proposée ici par Haupt et dont nous avons traité ci-dessus, p. 333 s, à propos d'Is 44,25.

\section{Les témoins anciens :}

Faute de savoir traduire ce substantif, le ${ }^{*} G(27)$ a répété la traduction du substantif suivant en l'insérant, la 2e fois, dans le vs 37.

Sym traduit : toùs ßpaxíovas aủiñs.

Malgré des attestations hésitantes (Aq selon le ms Marchalianus et AqTh selon le ms Barberini), Field et Ziegler s'accordent pour attribuer à Th seul la leçon : $\tau \grave{\alpha}$

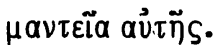

Syh attribue à $\mathrm{Aq}$ : גב̈. Comme Ziegler le propose, cela doit traduire : tov̀s '̇́aı par le *M.

Une même exégèse est offerte ici par la *V : “divinos eius", la *S : et le *T : קסמהא (seul le mauvais ms Londres BL Or 2211 sur lequel Sperber fonde son édition ayant omis ici le pronom suffixe).

Choix textuel :

Ce cas n'a pas été soumis au comité.

L'ajoute d'un pronom suffixe par la plupart des versions est une assimilation facilitante aux deux substantifs pluriels qui précèdent et à celui qui suit.

Interprétation proposée :

"les devins".

50,38A Aרֶ? [C] M V T // assim-ctext : و S / abr-elus : G om

Options de nos traductions :

Le mot ברֶn est traduit par RSV : "A drought", par RL : "Dürre" et par J3 : "Sécheresse".

Selon Brockington, NEB se fonde sur la *S pour vocaliser sword". J12 faisaient de même en traduisant : "Epée" que TOB conserve sans rien noter.

Origine de la correction :

N'attachant aucune autorité à la vocalisation, Houbigant a traduit ici "Gladius". Corrigent en ce sens la vocalisation : Ewald, Graf, Henderson, Nägelsbach, Knabenbauer, Giesebrecht, Oort, Duhm, Cornill, Condamin, Ehrlich, Volz, Nötscher, Rudolph, Penna, Weiser, Bright et les apparats de SBOT, HSAT234, BH23S et Cent. 
Les témoins anciens :

La forme du *M est protégée par deux massores: l'une donnée par le ms du Caire précise qu'elle est unique en ce contexte (de 35-38), l'autre donnée par le ms de Leningrad précise que רịn se rencontre 16 fois dans la Bible précédé ou non de prépositions. Ben Hayim édite ici ces deux massores.

Ce mot n'est pas traduit dans le *G. Cependant une ajoute des recensions origénienne et antiochienne le traduit par $\mu a ́ x a \iota p a \nu$.

La *S traduit de même par חרבץ.

La vocalisation du *M est appuyée par la *V : “siccitas” et le *T : שרבא.

Choix textuel :

La division en versets dans le ${ }^{*} M$ fait, elle aussi, difficulté.

Les six חרב (tous suivis de ou ou constituent l'articulation essentielle de l'ensemble qui comprend les vss 35, 36, 37 et 38a. Cet ensemble se divise en deux strophes semblables dont chacune est constituée par un élément long à plusieurs compléments (35 et 37a) suivi de deux éléments brefs à un seul complément suivi d'un accompli inverti (36a-b et 37b-38a). Cette structure suggérerait donc de lier 38a à ce qui le précède plutôt qu'à ce qui le suit.

Il semble que tous les témoins se sont heurtés à la même anomalie à laquelle ils ont apporté des solutions différentes; cette anomalie consistant en ce que, au sein de cette structure rigoureusement construite, les cinq premiers éléments commençant par חִִ̣ recevaient comme conclusion un élément commençant par ברֶ̆ Trois solutions ont été apportées à cette anomalie.

$1 /$ Le *G a omis le mot qui faisait difficulté, rattachant son complément au verbe par lequel s'achevait l'élément précédent.

2/ L'ajoute des recensions grecques et la *S ont assimilé la vocalisation de ce mot à celle des cinq חִ חư qui jouaient la même fonction que lui à l'égard des éléments précédents.

3/ Le *M (et le *T qui dépend de lui) a démantelé l'ensemble constitué par ces deux strophes en en séparant le dernier élément auquel sa vocalisation rendait difficile de jouer la fonction que l'on en aurait attendu.

La division en cola et commata de la *V ignore l'unité ample du verset hébreu. Elle traite comme une unité chacun des éléments brefs et divise en deux unités chacun des éléments longs.

En face de ces divers tâtonnements, il faut se demander si l'anomalie que ces divers témoins ont cru constater est inacceptable en cette structure poétique ou si elle n'en constitue pas, au contraire, une finesse. Structurer un rythme rigoureux qui prend pour appui la reprise en martèlement d'un même mot, puis faire varier le coloris vocalique du dernier appui de ce rythme, est-ce commettre une faute contre la poésie ? Ou est-ce qu'un tel reproche ne méconnaît pas le fait que la création d'un rythme rigoureux permet justement de mettre en relief une subtile rupture de rythme, rupture qui apporte à l'oeuvre son achèvement?

Le comité a attribué ici à la vocalisation du *M 3 "B" et 3 " $\mathrm{C}$ ". 
Interprétation proposée :

"Sécheresse contre ses eaux : qu'elles tarissent!" Il serait utile d'indiquer en note l'identité consonantique existant entre "épée" et "sécheresse".

50,38B יתהַהללו [C] M // harm-ctext : G? Aq Sym V S T clav

Options de nos traductions :

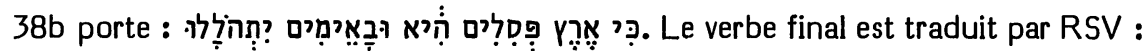
"they are mad", par J12: "ils sont fous" et J3: "ils se passionnent", par RL : "sind sie toll geworden" et par TOB : "les font délirer".

Selon Brockington, NEB se fonde sur le *G pour vocaliser "for it is a land of idols that glories in its dreaded gods".

Origine de la correction :

Ne tenant pas plus compte de la vocalisation que dans le cas précédent, Houbigant traduisait ici "gloriantur" en reprenant la *V (alors que Pagnini avait traduit exactement le *M par "insanient"). La vocalisation que retiendra NEB a été proposée ici par Michaelis (OEB), Hitzig, von Orelli, Giesebrecht, Oort, Condamin, Ehrlich et Penna.

Les témoins anciens :

De Rossi a observé la vocalisation du 'hé' en patạ en deux de ses mss. Cependant, la vocalisation en ḥolem a le ferme appui des autres témoins du *M. Les deux mss susdits représentent donc plutôt des erreurs occasionnelles qu'une autre tradition textuelle.

On peut hésiter sur la vocalisation que le ${ }^{*} G$ a donnée à sa Vorlage. En effet, le

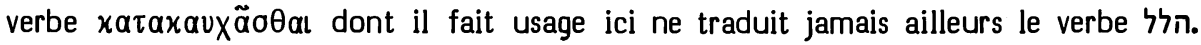

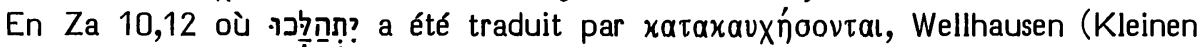
Propheten) suggère que le ${ }^{*} G$ a lu יתהוללו. Le fait que le $* G(9,23 s)$ traduise cinq fois par $x a u x \tilde{a} 0 \theta$ a le hitpael de הלל rend cependant plus vraisemblable qu'il vocalisait ici aussi avec patah.

Il semble bien d’ailleurs que ce soit cette leçon qu'ont lue ici Aq ( $\varepsilon \gamma x \alpha u x \tilde{\omega} v \tau a l)$,

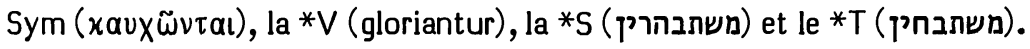

Choix textuel :

Ici encore, le ${ }^{*} M$ ne nous offre pas la vocalisation que sa syntaxe laisserait attendre. Le complément de ce verbe est introduit, en effet, par la préposition 'bet', ce qui laisserait attendre que le "hé" soit vocalisé patạ (au sens de "se vanter de"). C'est ce que les versions ont fait en harmonisant à ce contexte et peut-être en s'inspirant de Ps 97,7 : המתהַללים באלילים. Mais nous avons justement ici, comme complément dans le $* M$, un mot qui ne signifie pas purement et simplement "idoles" (que Aq, la $* S$ et le $* T$ ont pourtant cru y lire).

C'est pourquoi le comité a attribué 5 " $C$ " à la vocalisation du $* M$ et 1 " $C$ " à la variante. 
Interprétation proposée :

"Et par les Terribles ils deviendront fous", ou, plus librement : "et les Terreurs les feront délirer". Cette désignation péjorative donnée aux idoles prépare la modification vocalique du verbe final.

50,44A-B cf. pp. 804-805.

\section{1,1 לב קמי [B] M Sym // transl : Aq g S / exeg vel lit : G / confl : g T}

Options de nos traductions :

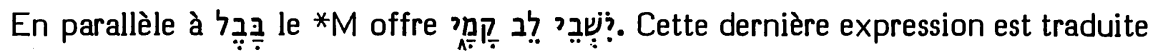
par J: "les habitants de Leb Qamaï", par TOB : "les habitants du "coeur de mes adversaires"” et par RL: "seine Bewohner, die sich gegen mich erhoben haben".

Disant que Leb Qamai est un correspondant chiffré pour la Chaldée, RSV traduit : "the inhabitants of Chaldea".

Selon Brockington, NEB conjecture à la place des deux derniers mots : קִמְבּוּל "those who live in Kambul".

Origines des corrections :

Cette dernière conjecture a été formulée par Sarsowsky (150s) et Rudolph l'a jugée aussi arbitraire que stérile. Elle n'a pas eu de succès avant d'être adoptée par NEB.

A partir de Michaelis, les options des traductions ont été fort variées. On peut les classer en trois groupes :

$1 /$ celles qui, comme $\mathrm{J}$, se contentent de transcrire ces deux mots : Rosenmüller, ASV, Condamin, Volz, Cent, Bright, JPS12, Bright et Osty;

2/ celles qui, comme TOB et RL, traduisent ces deux mots hébreux : Michaelis, Cahen, Nägelsbach, Keil, von Orelli, HSAT34, Rudolph, Buber et BHD;

3/ celles qui, comme RSV, décryptent l'expression : Hitzig, Henderson, Giesebrecht, Segond, Crampon, HSAT2, Cornill, Nötscher, BRF, ZB, Dhorme, Penna, Weiser, NAB, Eü et $\mathrm{DHH}$.

Il faut mettre hors concours Ewald qui, dans sa traduction, transcrypte ces mots en : "Aädlach" (= inversion de "Chaldäa").

Notons qu'au XVIe siècle presque tous les traducteurs traduisaient cette expression. Cependant Pagnini juxtaposait traduction et décryptage, alors que Châteillon se bornait à transcrire.

Notons encore que le possessif de RL ("seine") vient de la *V à travers Luther et la traduction des Prédicants de Zurich. Ce possessif a d'ailleurs eu du succès aussi dans la tradition française où "ses habitans qui ont esleve leur coeur contre moy", par quoi Le Fèvre d’Etaples traduisait la*V, a été simplement recopié par Olivetan, Rollet et Estienne. 
Les témoins anciens :

Les mêmes options se retrouvent chez les versions anciennes :

1 / Sym transcrit en $\lambda \varepsilon \beta$ $\alpha \mu \eta \eta$ (le 'mu' ayant été déformé en 'bêta' dans les témoins de sa leçon).

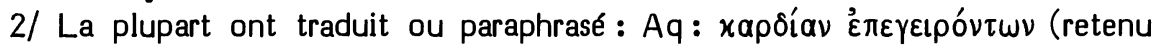
ici par la recension origénienne), la *V : "qui cor suum levaverunt contra me", la *S :

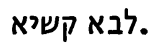

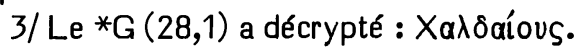

4/ Juxtaposent traduction (ou paraphrase) et décryptage (comme le fera Pagnini) :

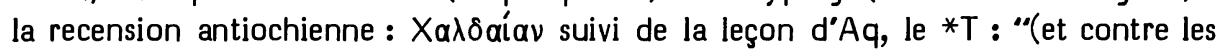
habitants) du pays des Chaldéens, des peuples meurtriers et qui sont beaux de stature".

\section{Choix textuel :}

Sarsowsky motive sa conjecture par le diagnostic qu'ici la tradition de l'atbash date de l'époque talmudique.

De fait, ce langage chiffré (échangeant 'taw' et 'alef', 'bet' et 'shin', etc.) se re-

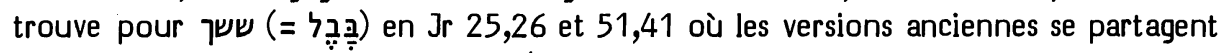
entre les mêmes options, la plupart (les recensions origénienne et antiochienne, ThAq, Sym et la $* V$ ) s'accordant pour transcrire, alors que la $* S$ traduit, que le $* T$ décrypte et que le ${ }^{*} \mathrm{G}$ omet le mot (en 28,41 ) ou la phrase (en 32,12).

Faut-il dire qu'en 51(28),1 le *G ne connaissait pas encore l'atbash mais lisait en clair dans sa Vorlage (à la place de לב קמי du texte protomassorétique) la leçon כשים? Ou faut-il dire que, ayant décrypté cet atbash, il l'a traduit de la même manière que dans les deux endroits (vss 24 et 35 de ce chapitre) où il lisait en clair l'expression ?שבי כשוֹים ?

Comme Rudolph l'a fait remarquer, les usages allusifs faits en 50,21 de מרתים et de פקוד (cf. ci-dessus, p. 828) nous encourageraient à admettre que c'est l'auteur des chapitres 50-51 qui a lui-même trouvé pour la Chaldée cette désignation cryptique: "le coeur de mes adversaires". D'ailleurs, Bright a estimé tout à fait possible que ces désignations chiffrées de Babylone ou de la Chaldée aient commencé à entrer en usage durant l'exil babylonien, comme un moyen de protéger les écrivains. En tout cas, de tels subterfuges trouvent leur sens plein dans ce Sitz im Leben, mais perdent leur motivation essentielle après l'écroulement de l'empire babylonien. Dans ces perspectives, on comprend parfaitement que le traducteur du ${ }^{*} G$ et celui du ${ }^{*} T$, n'ayant plus rien à redouter, aient décrypté ceux de ces 'atbash' dont la clé leur avait été transmise et omis ceux dont la clé leur échappait (Shéshak, dans le cas du *G).

Considérant donc l'atbash de 51,1 comme au moins constitutif de la forme textuelle protomassorétique, le comité lui a attribué la note " $\mathrm{B}$ ".

\section{Interprétation proposée :}

On pourra traduire : "le coeur de mes adversaires" en indiquant en note qu'il s'agit d'une expression chiffrée désignant les Chaldéens. Une traduction d'ensemble suit le prochain cas. 


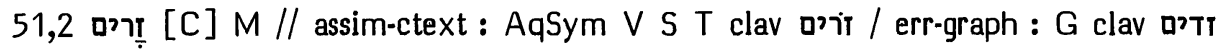

Options de nos traductions :

Ici, est traduit par TOB : “J’envoie contre elle des étrangers qui la vannent".

Le troisième mot est vocalisé aירị par J qui traduit "des vanneurs" et, selon Brockington, par NEB qui traduit : "winnowers". Elles disent se fonder sur Aq, J ajoutant Sym et la *V. Sans note, traduisent de même : RSV : "winnowers" et RL : "Worfler".

Origine de la correction :

A la suite de la *V, le sens de "vanneurs" a été attribué ici à ce mot par Pagnini, Prédicants, Zwingli, Luther, Brucioli, Münster, Olivetan, Jud, Vatable, Rollet, Arias Montano, Estienne, Châteillon, Calvin, Ge, Tremellius, Pasteurs et KJ. Cependant, Münster note que l'on devrait lire זורים ici pour fonder ce sens, aussi certains comprennent-ils ce mot du * $M$ au sens de "étrangers".

Une correction vocalique en זִ̣ a été proposée ici par Michaelis (OEB), Ewald, Nägelsbach, Knabenbauer, Giesebrecht, Oort, Duhm, Cornill, Condamin, Ehrlich, Volz, Nötscher, Rudolph, Penna, Weiser, Bright et par les apparats de SBOT, HSAT234, BH3S et Cent.

Les témoins anciens :

Comme Cappel (Notae 537b), Michaelis (Observationes) et Schleusner (ibid.) l'ont relevé, le *G $(28,2)$ a lu ici deux 'dalet' à la place des 'resh' des deux derniers

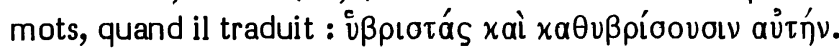

Lisant ici des 'resh', les autres versions ont traduit "vanneurs": AqSym : $\lambda \iota x$ -

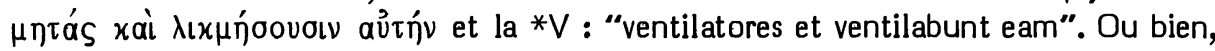
elles ont paraphrasé à partir de ce sens : la *S : בזוזא ונבזונה et le *T : בזוזין ויבזונה.

\section{Choix textuel :}

Comme nous l'avons déjà dit à propos d'Is 29,5 (ci-dessus, p. 204), Yéfet ben Ely lui aussi comprend ici "des vanneurs", sens qui est retenu aussi par le glossaire C ("espandeurs et espandront li") et qui est accepté (en second lieu) par Radaq pour qui ce mot viendrait alors de זרְָ, adjectif verbal du type

Le mot proposé par Radaq n'étant pas attesté ailleurs (alors que Iִ est très fréquent comme pluriel de étrangers" avec Radaq (en premier lieu), Tanḥum Yerushalmi, Joseph ibn Nạ̣mias et Abravanel. Dans une note sur la 3e édition du Thesaurus de Pagnini, Mercerus a estimé que l'on a ici une paronomase, opinion qui est aussi celle de C.B. Michaelis et de Rosenmüller. Nous avons déjà noté à propos de 8,13 (ci-dessus, p. 527), de 42,10 et de 48,9 (ci-dessus, p. 784s) d'autres cas où une apparence de figure étymologique recouvre, en fait, une paronomase.

Le mot "étrangers" ici prépare la mention des "rois des Mèdes" (au vs 11). Cette paronomase est préparée par l'usage métaphorique de ṇִ à la fin du vs précédent (où il prépare également le vs 11). Notons à titre de parallèle qu'en Za 2,4 des empires étrangers sont venus pour vanner Juda. 
Les verbes ont subi aussi des corrections conjecturales variées.

Les témoins anciens :

$3 A$ et $3 C$ : En chacun de ces endroits, de Rossi et Ginsburg mentionnent la vocalisation patah en un certain nombre de témoins du *M. L'édition Soncino 1488 semble seule à donner cette vocalisation en ces deux endroits. L'édition Brescia 1494 (selon l'exemplaire du JThS de New York) la donne en 3A seulement. Selon Strack (annotant $\mathrm{Jr}$ 51,3 du ms de Petrograd) le ms 7 de Tschufutkalé atteste que les occi-

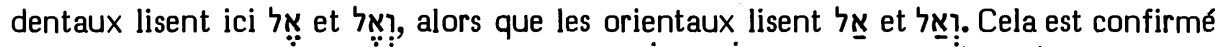
par le fait que ledit ms de Petrograd porte cela correspond à la vocalisation tibérienne patah. De même, le seul ms babylonien que Yeivin (IV 255) donne ici (le ms Oxford Bibl Bodl Heb d 26, fol 14v) porte א̌ et

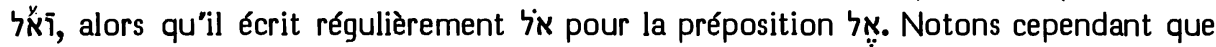
l'on trouve la leçon avec segol attestée pour $3 \mathrm{~A}$ et $3 \mathrm{C}$ par les mss habituels du texte tibérien classique, par l'édition Lisbonne 1492, la polyglotte d'Alcala, Félix de Prato, les éditions Bomberg in $8^{\circ}$ de 1517 et 1521, Ben Hayim etc. Notons enfin que deux témoins très anciens, le ms Londres BL Add 21161 (ancien Ebner 2 de Nürnberg) et le ms Urbinates 2 du Vatican, donnent la leçon avec segol en $3 A$ et la leçon avec patah en $3 \mathrm{C}$.

Le *G $(28,3)$ ne traduit aucun de ces deux mots. Ne les lisait-il pas dans sa Vorlage ? Il est plus probable qu'il les lisait comme prépositions et qu'il les a omis, parce qu'il ne savait comment les traduire en ce contexte exceptionnel. La recension origénienne insère $\mu$ ń aux deux endroits. La recension antiochienne et de nombreux autres

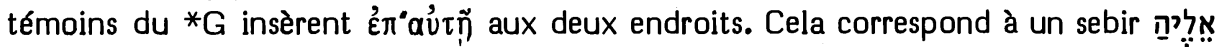
que Ginsburg cite selon son ms 3 et Baer selon le ms Oxford 69. C'est d'ailleurs ici l'exégèse de Yéfet ben Ely et de Judah ibn Balaam.

La *V donne ici : "non (tendat) ... et non (ascendat)". Comme ולא et de la *S, cela correspond clairement à la vocalisation patah.

Si l'on en croit Sperber, le *T porte לא en 3A en en en la leçon de Ben Hayim et de la polyglotte d'Anvers (alors que Félix de Prato lisait לא לא לא לח $3 A$ et en 3C). Cependant la leçon originale du *T semble être la leçon inverse (לה en 3A et ולא en 3C). Elle est en effet attestée par le ms babylonien Oxford Bibl Bodl Heb d 26, fol. 14v (Yeivin IV 255), par le ms Urbinates 1 et par la citation que Radaq fait du *T en son commentaire (selon l'édition Soncino 1486).

3B : Ce ketib qui répète ce mot n’a été traduit par aucune des versions anciennes.

3D : On reconnaît dans les traductions de la *V (ascendat) et du *T (יסק) la

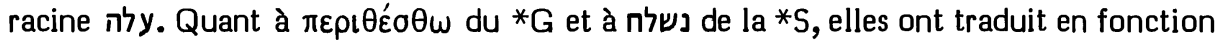
du contexte : il s'agit pour elles de revêtir ou de ne pas dévêtir la cuirasse.

\section{Choix textuel :}

La lectio difficilior du *M tibérien classique a découragé bien des exégètes. Il semble cependant que l'on se soit surtout demandé s'il fallait lire deux fois segol (en $3 A$ et $3 C$ ) ou s'il fallait y lire deux fois patah. Il est pourtant possible que l'on 
ait là deux assimilations en sens inverses issues d'une leçon originelle qui portait אִ

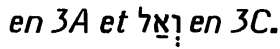

Nous venons d'indiquer que cette leçon mixte a bien des chances d'être la Vorlage de la leçon authentique du *T et que pour le *M elle est attestée par le ms Ebner 2 de Nürnberg et par le ms Urbinates 2. A cela s'ajoutent les mss 3, 305 et 826 de de Rossi (auxquels il ajoute en ses Scholia son ms 993) et le ms Londres BL Add 15250 (cité par Ginsburg). Mais c'est aussi la leçon que lisaient ici Rashi, Joseph Qara et Nicolas de Lyre.

La répétition de ידרך par le ketib n’a pas d'appui en dehors du *M. Moshe ben Sheshet estime pourtant qu'il faut répéter ce mot et comprendre : "Vers celui qui était en train de tendre (son arc) que maintenant d'autres tendent vers lui leur arc." L'ellipse du relatif après la préposition initiale trouve un parallèle en 1 Ch 15,12:

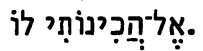

En 3D," on ne peut être sûr que les versions ont lu la forme rare du *M. Mais on ne saurait non plus prouver le contraire.

En 3A et 3D, le comité a donné au *M la note "B". En 3B, le comité a choisi le ketib avec la note "C". Sur $3 C$, le comité s'est divisé, trois membres attribuant à la leçon avec patah la note " $D$ " (car elle convient mieux au jussif qui suit) et les trois autres attribuant la même note à la leçon avec segol (car c'est celle du *M tibérien classique).

Interprétations proposées :

Si l'on opte pour la leçon avec patah en 3C, on pourra traduire : "Vers celui qui est en train de tirer, que tire le tireur d'arc. Et que celui-là ne se rengorge pas dans sa cuirasse. Et n'épargnez pas ses jeunes guerriers."

Si l'on opte pour la leçon avec segol en 3C, on pourra traduire : "Vers celui qui est en train de tirer, que tire le tireur d'arc, et vers celui qui se rengorge dans sa cuirasse. Et n'épargnez pas ses jeunes guerriers."

51,7 גוים

Options de nos traductions :

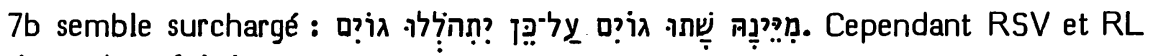
traduisent deux fois le mot גורים

Mais J dit suivre le ${ }^{*} G$, la $* V$ et la $* S$ pour en omettre la seconde occurrence. NEB et TOB font de même, sans note.

Origine de la correction :

L'omission de ce mot est requise par Giesebrecht, Oort, Duhm, Cornill, Condamin, Volz, Nötscher, Rudolph, Penna, Bright et par les apparats de SBOT, HSAT24 et $\mathrm{BH} 23 \mathrm{~S}$. 


\section{Les témoins anciens :}

Absent du ${ }^{*} G(28,7)$, ce mot est ajouté ( $\left.{ }^{3 \prime} \theta \vee \eta\right)$ par les recensions origénienne et antiochienne.

Il est absent de la ${ }^{*} \mathrm{~V}$ et de la ${ }^{*} \mathrm{~S}$, mais le ${ }^{*} \mathrm{~T}$ l'atteste.

\section{Choix textuel :}

Le comité a estimé que l'absence de ce mot dans le * $G$ ancien, dans la *V et dans la *S a bien des chances de n'être qu'un allègement translationnel. Aussi a-t-il attribué la note "B" au *M où l'insistance sur le mot גורם est voulue et non accidentelle.

Interprétation proposée :

"Les nations ont bu de son vin, c'est pourquoi les nations deviennent folles (ou : sont en délire)."

51,11 מַלְכי [B] M G(?) V Jsp T // assim-28 : g S sg

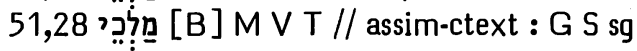

Options de nos traductions :

Aux vss 11 et 28, le *M parle des "rois des Mèdes" au pluriel. Ce pluriel est respecté par RSV, RL, TOB et 33 .

J12 et NEB se fondent sur le *G pour traduire par un singulier : "le roi des

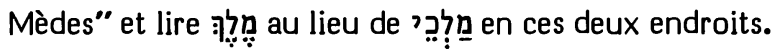

Origine de la correction :

Ont proposé de mettre "roi" au singulier au vs 28 : Giesebrecht, Ehrlich, Bright. Ont fait cette proposition aux vss 11 et 28 : Duhm, Cornill, Condamin, Nötscher, Penna et les apparats de HSAT34, BH2 et Cent.

\section{Les témoins anciens :}

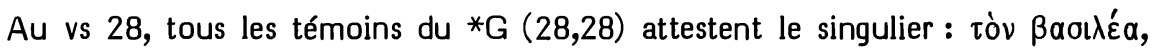
aisément motivé par le suffixe m. sg. du dernier mot du *M. Au vs 11, la première main du ms Sinaiticus porte le pluriel $\beta \alpha \sigma \iota \lambda \varepsilon \omega \nu$. Il est improbable que cette leçon provienne d'une recension sur le *M. Mieux vaut donc admettre qu'elle représente ici le ${ }^{*} G$ ancien et que le singulier $\beta a \sigma \imath \lambda \varepsilon \omega \varsigma$ (attesté par les autres témoins du ${ }^{*} G$ ) provient d'une assimilation au ${ }^{*} G$ du vs 28 . En ces deux endroits, la ${ }^{*} S$ porte le singulier (qui ne se distingue du pluriel que par l'absence des seyamé).

Le pluriel est attesté aux vss 11 et 28 par la ${ }^{*} \mathrm{~V}$ et le ${ }^{*} \mathrm{~T}$. Josippos fait de même pour le vs 11 , le seul de ces vss où sa leçon nous est connue.

Choix textuel et interprétation proposée :

Il est caractéristique que la Bible ne parle jamais du roi des Mèdes au singulier, mais toujours au pluriel : "les rois des Mèdes" (Jr 25,25; 51,11.28; Est 10,2; Dn 8,20). Nous avons rencontré aussi en 25,24 (cf. ci-dessus, p. 656s) et en 49,28 (cf. ci-dessus, p. 813) la mention de "tous les rois des Arabes" et des "royaumes de Haçor" que nous avons interprétés comme des royaumes de bédouins semi-sédentaires. Pour ce qui est 
de cet oracle contre Babylone, rappelons qu’en 50,41 il a été annoncé : “Voici qu’un peuple arrive du nord et une grande nation et des rois nombreux sont suscités à partir des confins de la terre." Cela préparait bien la formule de 51,11: "Le Seigneur a suscité l'esprit des rois des Mèdes". En tous ces cas où l'on est surpris par le pluriel de ce mot, on peut admettre que "roi" désigne un chef d'armée (cf. en ce sens Jb 29,25). 1 R 11,24 montre de façon suggestive qu'il suffit qu'un chef de bande se fixe en un lieu habité pour qu'il puisse y être proclamé roi. Il s'agit donc ici d'une coalition des chefs d’armées de la Médie. Qu'ils fussent alors sous l'autorité de quelque suzerain, cela n'est pas mentionné. On sait d'ailleurs que la Perse n'est nommée qu'en Ezéchiel, Esdras-Néhémie, 2 Ch 36, Esther et Daniel.

Dans le cas de Jr 25,22 (“tous les rois de Tyr et tous les rois de Sidon"), il s'agit probablement de tous les chefs vassaux de Tyr et de Sidon.

Le comité a estimé que, dans ces deux cas de 51,11 et 51,28, une mise au singulier est une facilitation attirante, alors que la déformation d'un singulier en pluriel a moins de chances d'avoir eu lieu. Aussi a-t-il attribué au *M la note "B".

Notons qu'au vs 28 , le *M a seul respecté une situation extrêmement complexe (ce pluriel servant d'antécédent apparent à deux suffixes f. sg. et à un suffixe m. sg.).

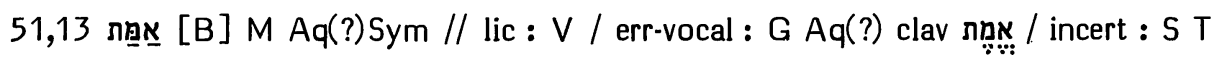

Options de nos traductions :

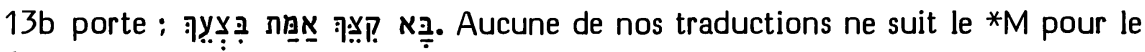
troisième mot.

Selon Brockington, NEB lit אמֶ: avec le *G quand elle traduit les deux derniers mots : "your destiny is certain".

$\mathrm{J}$ conjecture pour ce mot duisent de même, sans note: RSV : "the thread of your life is cut", RL : "Dein Lebensfaden wird abgeschnitten" et TOB : "tu as touché tous tes gains".

Origine de la correction :

Houbigant, ne tenant pas compte de la vocalisation, traduit : “certa est ruina tua". Cela suppose une vocalisation que Venema a explicitée (en lui attribuant d'ail-

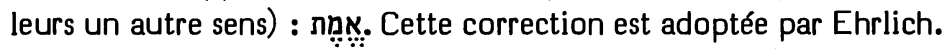

La conjecture retenue par $\mathrm{J}$ a pour auteur Volz. Elle est adoptée par les apparats de HSAT4 et de Cent.

Les témoins anciens :

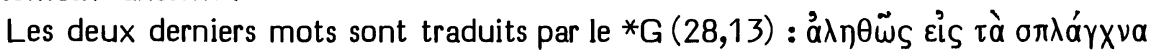
oov. Cela suppose une Vorlage אמִּ: où la vocalisation du premier dépend de la variante consonnantique portant sur le second.

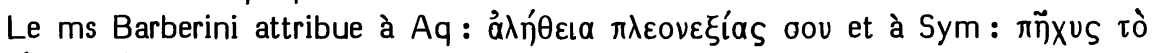
$\chi \tau \eta ๊ \mu \alpha ́$ oov (Field et Ziegler corrigeant en $\tau \mu \tilde{\eta} \mu \alpha$ ). Pour le premier mot, Syh attribue à Aq et à Sym la leçon אמתא et pour le second, elle attribue à Sym : דפסא דילכי qui appuie la correction proposée en restaurant, de plus, un génitif. 
Au lieu de "coudée", la *V a traduit "pedalis (praecisionis tuae)", c'est-à-dire : la mesure d'un pied à laquelle tu es coupée.

La *S traduit : עשנת מחותכי (selon le ms Ambrosianus) et le *T : סעורן בישתיך. Il est difficile de préciser quelle vocalisation du premier mot ces traductions présupposent.

\section{Choix textuel :}

On ne saurait - ainsi que l'a fait NEB - emprunter au ${ }^{*} G$ une retouche secondaire sans la variante principale dont elle dépend.

Estimant le sens du *M satisfaisant, le comité lui a attribué la note " $B$ ", car aucune des variantes éventuelles ne lui est préférable.

Interprétation proposée :

Le sens : "la coudée de ta coupure" évoque l'image que nous avons déjà rencontrée en Is 38,12 (ci-dessus, p. 266). Achevant la dernière coudée de son tissage, le tisserand, après avoir enroulé sa toile, va couper les fils de chaîne, pour la séparer du métier à tisser. Cette exégèse remonte vraisemblablement à Sym et, en tout cas, à Judah ben Qoreish (Bargès $11=$ Katz 22), David ben Abraham (I 113,133-135 et 258,66-68), Tanhum Yerushalmi, Schleusner (sur les Observationes de Michaelis), Böttcher (Proben 289,m), Graf, Nägelsbach, Duhm, von Orelli et Rudolph. Comme Böttcher (Lehrbuch II 396,12) l'a noté, le second mot est un infinitif de forme sem-

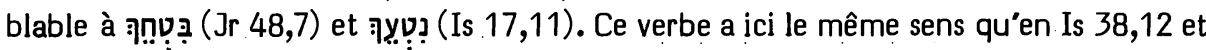
Jb 6,9.

On traduira donc: "Ta fin est arrivée, la coudée où tu vas être coupée", avec une note sur la métaphore du tissage qui s'achève.

51,16 cf. p. 545.

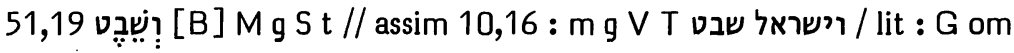

Options de nos traductions :

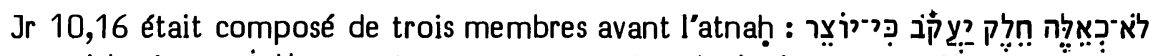

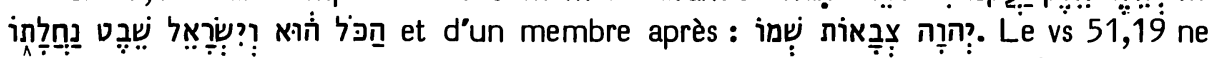

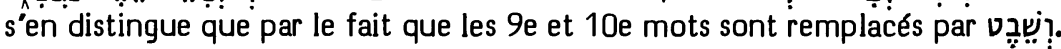

J, NEB et TOB s'appuyant sur 27 mss hébreux, sur la $* V$ et le *T, ont assimilé Jr 51,19 au parallèle de 10,16. Ont fait de même sans note : RSV et RL.

Origine de la correction :

RL et RSV se sont contentées ici de suivre Luther qui (sous l'influence de la * $V$ ?) avait inséré ici le nom d’Israël et $\mathrm{KJ}$ qui (à la suite de $\mathrm{Ge}$ ) l'avait inséré en italique en se référant au parallèle de 10,16.

C'est Kennicott (Dissertatio secunda 422 s et Dissertatio generalis \$47) qui a considéré ici la leçon la plus explicite comme la "vraie leçon". Ont opté de même : 
Michaelis (OEB), Rosenmüller, Henderson, Ehrlich (Miqra), Condamin, Volz (Studien 87), Nötscher, Rudolph (sur 10,16), Penna, Weiser, Bright et les apparats de HSAT34 et $\mathrm{BH} 35$.

Les témoins anciens :

La leçon du *M est assimilée à celle du parallèle de 10,16 par une trentaine de mss. Cependant la leçon

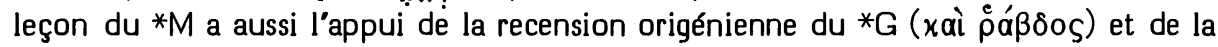
*S (ושבטא).

L'ont assimilée au parallèle de 10,16: la *V (et Israhel sceptrum), la recension

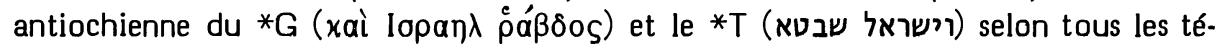
moins cités par Sperber. Notons pourtant que, selon le ms Urbinates 1, le *T appuie le *M.

Le *G $(10,16$ et 28,19$)$ a, aux deux endroits, essentiellement la même traduction :

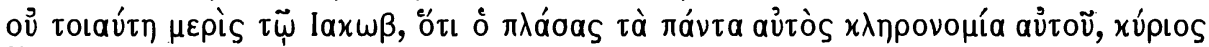

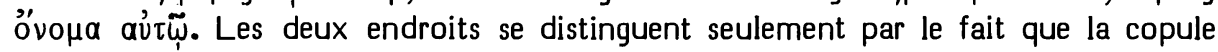
'̌otı est explicitée en 10,16 dans la première phrase nominale et en 28,19 dans la deuxième. Le ${ }^{*} G$ ne semble donc avoir lu dans sa Vorlage ni ושבט 51,19 ni en 10,16.

Choix textuel :

Pour le ${ }^{*} \mathrm{G}$, aux deux endroits, un seul membre de phrase intègre ce qui, dans le ${ }^{*} M$, en constitue deux. La Vorlage du ${ }^{*} G$ semble, en effet, avoir lié étroitement : . Cet état textuel se rattache à la spiritualité lévitique (cf. Dt 18,2; Jos 13,33) : c'est celui qui a tout formé qui constitue l'héritage de Jacob.

Movers (19) a bien vu que le texte offert par le *M en Jr 10,16 a un sens analogue à celui de Dt 32,9 : c'est Israël qui est la tribu d’héritage de celui dont le nom est le Seigneur Sabaôt.

Il n'est pas impossible que la formule ambigüie que le *M offre en 51,19 soit à I'origine d'une abréviation dans le ${ }^{*} G$ (des deux endroits) et d'une explicitation dans le *M de 10,16.

Sans se prononcer sur cette reconstitution du développement littéraire, le comité a estimé qu'il ne fallait pas assimiler ce passage à son parallèle, ni à l'état littéraire différent qu'offre le ${ }^{*} G$. Contre ces assimilations, il a attribué au ${ }^{*} \mathrm{M}$ la note "B".

Interprétation proposée :

En 51,19 , on peut traduire : “Celui qui est la part de Jacob n'est pas comme elles ( $=$ les idoles), car c'est lui le formateur de tout et le bâton (c'est-à-dire : le lot) de son héritage. Il a pour nom le Seigneur Sabaôt."

En 10,16, on traduira: “Celui qui est la part de Jacob n'est pas comme elles, car c'est lui qui a tout formé et c'est Israël qui est la tribu de son héritage. Il a pour nom le Seigneur Sabaôt." 
Options de nos traductions :

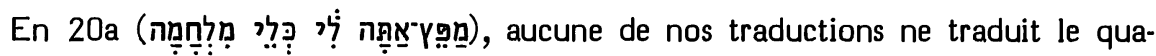
trième mot par un pluriel.

Selon Brockington, NEB conjecture une vocalisation mot et le suivant : "my weapon of war". J fait de même en traduisant : "une arme de guerre". Sans note, RSV traduit comme NEB et TOB traduit comme J. RL traduit : "meine Kriegswaffe".

Origine de la correction :

La $* V$ traduisait 20a: "conlidis tu mihi vasa belli" en considérant le premier mot comme un participe. Pagnini, y voyant un substantif, a traduit: "Malleus es mihi, instrumenta bellica". Sous l'influence de la *V, Luther a d'abord traduit : "Du zerschmeissest meine kriegs woffen". Lors de la révision de janvier 1541, conformément à l’option de Pagnini, il corrige en : “Du bist mein Hamer, mein Kriegswoffen". Dans le second possessif, la disparition du " $e$ " final indique probablement que le substantif qui suit est senti comme un singulier.

Pour fonder cette traduction, Hitzig prétend qu'ici la vocalisation séré de la finale de ce mot a valeur de singulier, prétention que Graf recopie, mais qui n'a pas convaincu leurs successeurs. Giesebrecht estime que la forme plurielle que les versions et le * $M$ ont donnée à ce mot tient à ce qu'on l'interprétait faussement comme un accusatif dépendant du premier mot (considéré comme participe). Aussi corrige-t-il le séré en hịreq, suivi en cela par Oort, Duhm, Cornill, Condamin, Rudolph, Weiser et les apparats de HSAT34, BH23S et Cent.

Les témoins anciens :

Le pluriel est attesté par toutes les versions: le ${ }^{*} G(28,20)$ : oxeún, la ${ }^{*} V$ : “vasa", la *S : מואני et le *T : מני.

Choix textuel :

Le comité a attribué au *M la note " $A$ ", la variante n’étant que conjecturale.

Interprétation proposée :

L'expression sִą s'emploie toujours au pluriel même dans des cas où la syntaxe (Dt 1,41) laisserait attendre un singulier. Ce pluriel semble inclure toutes les pièces d'un équipement de combat. C'est vraisemblablement cette valeur de "panoplie" qu'avait l'expression choisie par Luther en 1541 : "mein Kriegswoffen" (de même, en Jg 9,54; 1 S 17,54; 20,40, Luther traduit le pluriel כליו par "seyn waffen"). 
Giesebrecht semble avoir fait erreur en pensant que la vocalisation massorétique

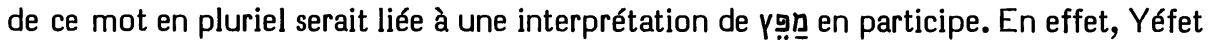
ben Ely est le commentateur judéoarabe le plus proche des massorètes dont l'oeuvre nous ait été conservée. Or, il traduit ici ce premier mot du vs par טברזין que Dozy (II 21a) définit comme une "hache à deux tranchants que l'on pendait souvent à l'arçon de la selle".

On pourra donc traduire les deux derniers mots de 20a: "un équipement de combat" ou "un armement".

51,25 cf. p. 644.

51,28 cf. p. 842.

51,29 $[A]$ M t // ign-gram : G V S T sg

Options de nos traductions :

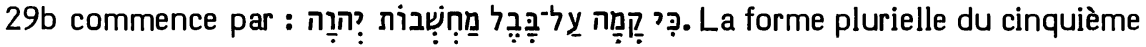
mot a été respectée par RŚV qui traduit les deux derniers mots : “the LORD's purposes", NEB : "the LORD's designs", RL : “die Gedanken des HERRN" et TOB : "les projets du SEIGNEUR".

J traduit : "le plan de Yahvé", 31 disant suivre en cela 15 mss hébreux, le *G et la*s.

Origine de la correction :

Ayant interprété

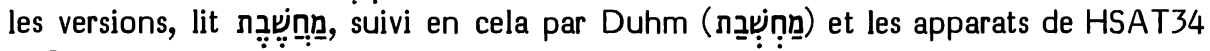
et Cent.

Les témoins anciens :

Les apparats de $\mathrm{BH} 23$ disent que 15 mss hébreux lisent ici tion repose sur les données fournies par de Rossi qui dit avoir rencontré la graphie défective en $8 \mathrm{mss}$ de la collation de Kennicott et 7 autres de sa collection. Mais ni Kennicott, ni lui, ne précisent la vocalisation de ces mss. Cependant, l'un de ceuxci (le Kenn 116) est le ms Londres BL Harley 5509 dont Ginsburg cite la vocalisation comme étant identique à celle du *M. Il en va de même du seul autre que nous avons eu l'occasion de contrôler : le Kenn 154 (= Reuchlin des Prophètes). Il est très probable qu'il en va de même pour les autres et que de Rossi a engagé les apparats critiques sur une fausse piste en invoquant ces graphies défectives à l'appui du singulier "cogitatio".

Ce singulier a, par contre, l'appui de la plupart des versions : le ${ }^{*} G(28,29)$ : $\lambda o \gamma ı$ ós, la *V : “cogitatio" et la *S : מחשבתה.

Pour le *T, Sperber donne : מחשבתא qu'il vocalise en pluriel sans indiquer de variante. Cependant, ce mot est vocalisé en singulier par les mss Reuchlin et Urbi- 
nates 1, ainsi que par les éditions de Félix de Prato et Ben Hayim, c'est-à-dire par tous les témoins les plus anciens.

\section{Choix textuel :}

Il est fort probable que nous ayons en respondre un qeré קמוּ) un cas analogue à celui que nous avons rencontré en 22,6 (cidessus, p. 636s) d'une 3e pers. f. pl. archaïque en "-âh" que les versions et la plupart des exégètes ont méconnue en la prenant pour un singulier. C'est cette confusion qui a entraîné chez les traducteurs une mise au singulier du substantif qui en est le sujet.

Le comité a donc attribué au *M la note "A".

Interprétation proposée :

"quand les projets du Seigneur contre Babylone se réalisent".

51,33 ny (20 $\left(^{\circ}\right)$ Aq V // abr-styl : G S T om

Options de nos traductions :

Il est dit de Babylone qu'elle est comme une aire au moment où on la foule.

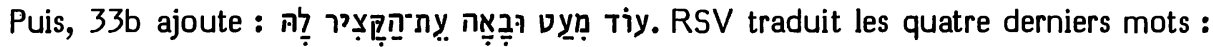
"and the time of her harvest will come", NEB : "harvest-time will come" et J3: "et ce sera pour elle le temps de la moisson".

$\mathrm{J12}$ se fondait sur le *G, la *S et le *T pour traduire : "et ce sera l'arrivage des épis moissonnés". Avec les mêmes appuis, TOB traduit : "et la moisson viendra sur elle". RL traduit de même : "es wird ihre Ernte gar bald kommen".

Origine de la correction :

La traduction des Prédicants de Zurich n’avait pas explicité le mot ny : "aber bald wirt jr ärnd kommen". Luther prend la même liberté : "Es wird jre erndte gar schier komen".

L'omission de ce mot a été formellement proposée, en se fondant sur le ${ }^{*} \mathrm{G}$, par Cornill, Volz, Rudolph, Bright et les apparats de BH23S.

Les témoins anciens :

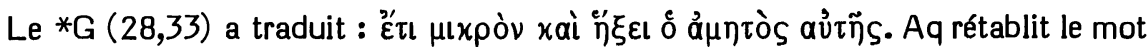

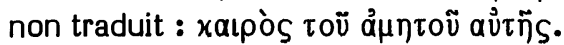

Allègent leur traduction à la manière du *G : la *S (ומטא קטפה) et le *T (qui paraphrase : וייתון בזוזין עלה (1).

La *V traduit littéralement : "et veniet tempus messionis eius".

Choix textuel :

Ce cas n'a pas été soumis au comité.

C'est le fait que le mot תy figure déjà en 33a qui a amené certains traducteurs à l'omettre en 33b. A cela s'est ajouté une fausse interprétation de ment où on la foule"). La plupart des exégètes y ont vu le moment où les bêtes foulent 
l'aire pour dépiquer les céréales. Aussi a-t-on fait remarquer qu'il est impossible que le moment du dépiquage précède celuui de la moisson. Mais c'est le verbe שוֹ que l'on emploie d'ordinaire en ce sens de "fouler pour dépiquer". Et Dalman (III 72), faisant écho à une suggestion de Hitzig (qu'il ne mentionne pas), voit en ce "foulage" celui par lequel on aplanit et durcit le sol de l'aire afin de la préparer à son office. Il est alors tout à fait normal que le moment de cette préparation précède celui de la moisson.

Interprétation proposée :

"La fille Babylone est pareille à une aire au moment où on l'aplanit. Encore un peu et viendra pour elle le temps de la moisson."

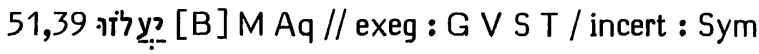

Options de nos traductions :

Après : "Tandis qu'ils s'échauffent, je leur prépare un festin", le *M continue : , puis il achève ce vs par: "et qu'ils s'endorment d'un sommeil éternel dont ils ne s"éveilleront pas - oracle du Seigneur".

Les trois mots hébreux cités ont été traduits par $\mathrm{J3}$ : "je les ferai boire afin qu'ils soient en joie". Sans note, NEB traduit : "and make them so drunk that they will writhe and toss". Disant interpréter avec le *G, la $* V$ et la ${ }^{*} S$, TOB traduit : “je vais les rendre ivres morts".

Corrigeant selon le $* G$ et la $* V$, RSV donne : "and make them drunk, till they swoon away". Ajoutant à ces témoins la *S et le *T, J12 donnent : "je les ferai boire, qu'ils en soient hébétés". RL traduit de même : "und will sie trunken machen, dass sie matt werden".

Origine de la correction :

C'est Grotius qui a estimé qu'à la place du $3 e$ mot le ${ }^{*} G$ avait lu ị a été adoptée par Giesebrecht, Oort, Duhm, Cornill, Ehrlich, Volz, Rudolph, Penna, Weiser et par les apparats de HSAT34, BH23S et Cent.

La traduction de NEB se fonde sur Driver.

Les témoins anciens :

Le *G traduit: "ö $\pi \omega \varsigma$ $x \alpha \rho \omega \theta \tilde{\omega} \sigma$. Or la racine $x \alpha \rho 0^{*}$ ne correspond jamais à ףלy. Mieux vaut donc admettre avec Spohn que le ${ }^{*} G$ a traduit ici en fonction du contexte. La *V (ut sopiantur) et la *S (ונתתברון) ont traduit de même et le *T (נדאי) יהון תקיפין a paraphrasé dans le même sens.

Aq (å $\gamma \alpha \lambda \lambda \iota a ́$ oovial) traduit le *M.

Syh attribue à Sym נذון dont l'interprétation est très incertaine (cf. Field).

Choix textuel et interprétation proposée :

L'interprétation proposée par NEB remonte à Abulwalid (Ușul 528, 9-28) qui la tire du fait que l'homonyme arabe peut signifier "le tremblement qui prend le 
moribond ou le malade du fait de sa faiblesse, ou encore l'ivrogne du fait du relâchement de ses tendons". Il étend cette interprétation à Is 22,2 et à Jr 11,15 (cf. ci-dessus, p. 564). Ont adopté cette suggestion ici : Judah ibn Balaam, Tanhum Yerushalmi (sur Jr 11,15), Schultens (Origines II 105-109), Schleusner (annotant les Observationes de Michaelis).

Ce sens n'est pas impossible ici et l'on pourrait considérer Dn 5,6 comme un midrash qui s'en inspire. Cependant, on peut avec Radaq (Shorashim) préférer le sens normal "car l'ivresse apporte beaucoup de joie, de rires et de bouffonnerie" auxquels fait suite l'accablement d'un profond sommeil. Il y a une ironie amère dans : “je les enivrerai pour qu'ils s'ébaudissent et s'endorment d'un sommeil éternel dont ils ne s'éveilleront pas."

Le comité a attribué à la leçon du *M la note "B".

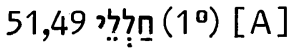

\section{Options de nos traductions :}

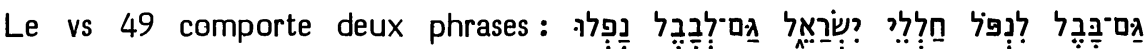

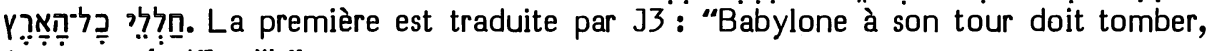
ô vous, tués d'Israël."

Selon Brockington, NEB corrige le quatrième mot en לִ quand elle traduit : "Babylon must fall for the sake of Israel's slain." Conjecturant de même, 312 traduisent : "Babylone, à son tour, doit tomber pour les tués d"Israël", TOB : "à son tour Babylone doit tomber pour les victimes d'Israël". Sans note, RSV traduit : "Babylon must fall for the slain of Israel" et RL : "Und Babel muss fallen für die Erschlagenen Israels".

Origine de la correction :

La correction retenue par NEB a été proposée par Oort, Cornill, Condamin, Volz, Nötscher, Rudolph, Penna, Weiser, Bright et par les apparats de SBOT, HSAT34, $\mathrm{BH} 3 \mathrm{~S}$ et Cent.

\section{Les témoins anciens :}

Les vss 44b-49a manquent dans le ${ }^{*} G(28)$. Dans une ajoute que les recensions origénienne et antiochienne ont empruntée à Th, les $2 \mathrm{e}, 3 \mathrm{e}, 4 \mathrm{e}$ et $5 \mathrm{e}$ mots de $49 \mathrm{a}$

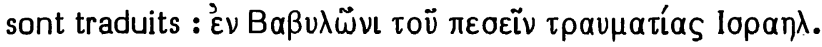

La *V traduit 49a : "et quomodo fecit Babylon ut caderent occisi in Israhel".

Le *T traduit cela : אף בבבל אתרמיאו קטילי ישראל, le ms Urbinates 1 omettant le premier 'bet' du $2 \mathrm{e}$ mot.

La *S des polyglottes de Paris et de Londres donne pour ce vs : ואף בבביל נפלון קטنילא בכלה ארעא. Cependant, dans l'apparat du vol. VI de la polyglotte de Londres, Thorndike a décelé, à partir des mss dont il disposait qu'un homéoarcton a omis après le 3e mot de cette leçon : קטنילא דאיסראיל ואף מן בביל נפלון. De fait, cet homéoarcton n'a eu lieu ni dans le ms Ambrosianus, ni dans l'édition de Mossul. 
Choix textuel :

La variante de la plupart de nos traductions est donc purement conjecturale.

Les versions anciennes ont essayé d'interpréter un texte identique au *M. En effet, Th, la *S et le *T ont explicité une préposition avant le 2e mot, mais la *V nous atteste qu'elle ne lisait pas cette préposition dans sa Vorlage. D’autre part, la *V, la ${ }^{*} S$ et le ${ }^{*} T$ ont traduit le $3 e$ mot comme si leurs traducteurs lisaient la $3 e$ pers. pl. d'un accompli, mais Th nous montre qu'il a bien lu un infinitif précédé de 'lamed'.

Le comité a donc attribué au *M la note "A".

Interprétation proposée :

Tremellius, Michaelis (Observationes), Ewald, Hitzig, Graf, Henderson, von Orelli, Giesebrecht, Duhm et Ehrlich ont interprété le $4 \mathrm{e}$ et le $5 \mathrm{e}$ mots comme un vocatif, ainsi que nous l'avons vu faire à J3. Ce n'est pas impossible.

La traduction la plus naturelle serait pourtant : "A Babylone tomberont aussi des tués d'Israël, de même que pour Babylone sont tombés des tués de toute la terre." Ce vs complète 47b qui avait dit de Babylone : “et tous ses tués tomberont au milieu d'elle". Les "tués d'Israël" mentionnés en 49a sont ceux qui n’auront pas obéi aux ordres donnés en 51,6.45. Cette interprétation de 49a est celle de Yéfet ben Ely.

בראש 51,58A ב בדי אש

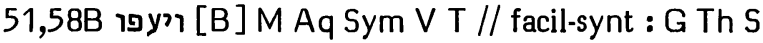

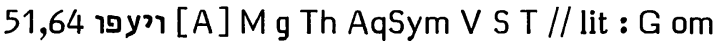

Options de nos traductions :

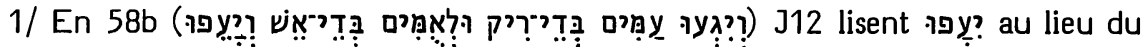
dernier mot et traduisent : “Ainsi les peuples travaillent pour le néant et les nations peinent pour le feu". RSV traduit de même, sans note textuelle : "The peoples labor for nought, and the nations weary themselves only for fire", RL : "dass die Arbeit der Heiden umsonst sei und dem Feuer verfalle, was die Völker mit Mühe erbaut haben", TOB : “Les peuples peinent en vain, les nations s'éreintent pour du feu !" et J3: “Ainsi les peuples ont-ils peiné pour le néant, les nations se sont épuisées pour du feu".

Selon Brockington, NEB conjecture un holem au lieu du séré de l'avant-dernier mot quand elle traduit : "Worthless now is the thing for which the nations toiled; the peoples wore themselves out for a mere nothing".

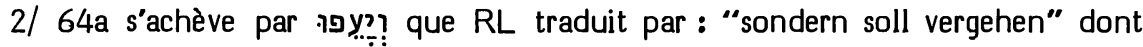
"Babel" est le sujet. TOB traduit ce verbe par "Elles s'éreintent", en précisant que ce mot ne semble pas en rapport avec ce qui précède et qu'il reprend la finale du vs 58.

RSV et $\mathrm{J}$ se fondent sur le ${ }^{*} \mathrm{G}$ pour omettre ce mot. NEB l'omet sans rien noter. 
Les sources des options de Luther conservées par RL :

Luther unit syntaxiquement 58b à 58a comme une consécutive : “Die Mauren der grossen Babel, sollen untergraben, und jre hohe Thor, mit Fewr angesteckt werden, Das der Heiden erbeit verlorn sey, und verbrant werde, was die Völcker mit mühe erbawet haben". Cette traduction rend très librement l'hébreu. Les deux compléments "seulement pour rien" et "seulement pour du feu" sont rendus par deux verbes ("verlorn sey und verbrant werde"), alors que le verbe initial de $58 \mathrm{~b}$ et son verbe final sont rendus par deux substantifs ("erbeit" et "mit mühe") et un verbe ("erbawet haben"). En tout cela, Luther suit des options de Zwingli ("Et quod gentes ac populi labore et fatigatione operati sunt, in vanum et in ignem abibit") et des Prédicants de Zurich ("Und das die Heyden und völcker mit grosser müg und arbeyt gearbeyt habend / wirt zu nüt / und im fheür verzert"). La coordination étroite des "Heyden" et des 'Völcker' a été dissociée par Luther, car elle n'a de fondement ni dans le *M, ni dans la *V. Les Zurichois ont emprunté cette coordination à la Vieille Allemande (Kurrelmeyer IX 198,22ss) : “und die arbeite der volck und der leut die werdent zenichten in dem fewer und verderbent". Notons que cette vieille traduction, faite sur la $* \mathrm{~V}$, maintenait cependant la traduction du verbe final de $58 \mathrm{~b}$ par un verbe précédé d'une conjonction, littéralité à laquelle les Prédicants et Luther ont renoncé, alors qu’elle a été conservée au XVIe s. par Pagnini, Münster, Tremellius, Pasteurs, puis KJ.

En 64, Luther traduit ויעפו par un verbe au singulier auquel il attribue pour sujet Babylone, mentionnée dans le début du vs : “Also sol Babel versenckt werden, und nicht auffkomen von dem Unglück, das ich uber sie bringen wil, sondern vergehen". Cette option vient de Zwingli ("Sic ... Babylon et fatigabitur") et des Prédicants ("Also wirt Babylon ... unnd ... undergetruckt werden"). Elle se fonde sur la *V dont les éditions antérieures à l’édition Weber offraient ici : “sic submergetur Babylon ... et dissolvetur".

\section{Origines des corrections :}

La correction de NEB en 58A semble dépendre d'une conjecture de Perles (I 50).

La conjonction qui précède 58B a été omise ou remplacée par un 'yod' par Graf, Nägelsbach, Grätz (Studien 493), Giesebrecht, Oort, Duhm, Cornill, Condamin, Ehrlich, Volz, Nötscher, Rudolph, Penna, Weiser, Bright et les apparats de SBOT, HSAT234, BH23S et Cent.

Notant que le ${ }^{*} G$ omet ו ו verbe qui est omis par Oort, Condamin et les apparats de HSAT34.

Les témoins anciens :

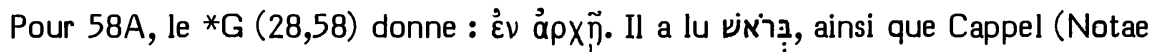
539a) l'a diagnostiqué.

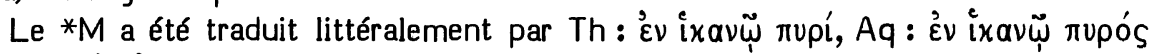

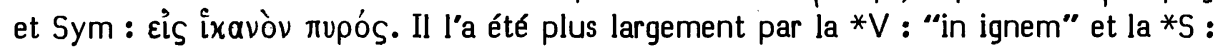
בנורא, alors que le *T a paraphrasé : תסיף אישתא.

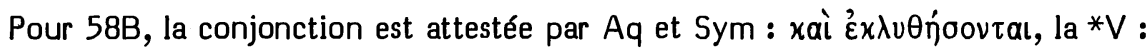
“et disperibunt” et le *T : רישתלהון.

Elle n'a été traduite ni par le *G, ni par Th, ni par la *S. 
En 64, le *G omet ce verbe et עִ עִ qui achève le vs. En effet, le fait que la recension dont dépend le $* \dot{G} \dot{G}$ a placé les oracles contre les nations avant 25,15 (du *M) lui interdit de faire figurer ces paroles en ce lieu qui, pour cette recension, est le milieu du livre.

Ce verbe est attesté ici par tous les autres témoins. Il a été traduit littéralement par AqSym : ונשתח et plus ou moins largement par la recension origénienne : xà દootá-

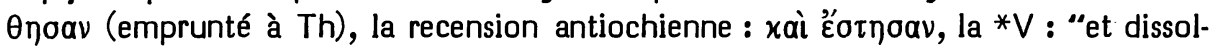
ventur", la *5 : ונתטרפון et le *T : וישתלהון.

\section{Choix textuels :}

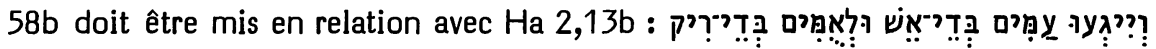

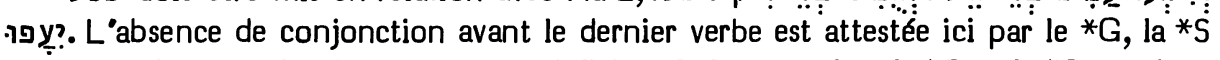
et lie $* T$, alors que la *V donne : "et deficient". Sur ce point, le ${ }^{*} G$ et la ${ }^{*} S$ ont donc harmonisé les deux textes sur la base de $\mathrm{Ha} 2,13$, alors que la *V les a harmonisés sur la base de Jr 51,58. Soucieuse de conserver à chacun des textes sa spécificité,

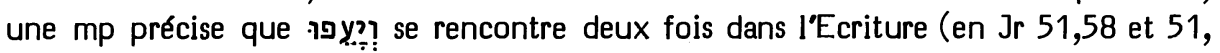
64). Le comité a attribué au * $M$ la note " $B$ " en 58B.

En 58A, l'erreur graphique commise par le ${ }^{*} G$ n’a pas contaminé la tradition textuelle protomassorétique où $\mathrm{Th}, \mathrm{Aq}$ et Sym appuient formellement le *M auquel le comité a attribué la note "B".

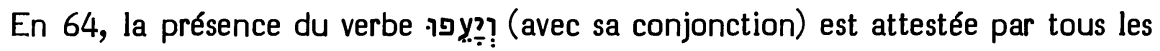
témoins de la rédaction représentée par le texte protomassorétique. C'est pourquoi le comité a, sur ce point, attribué la note " $A$ " à la leçon du * $M$.

La reprise de ויעפו avant la notice conclusive de $64 \mathrm{~b}$ semble vouloir conserver le souvenir d'un état textuel où cette notice suivait immédiatement 58 dont elle aurait été séparée ensuite par l'insertion des vss 59-64a. S'il en est ainsi, le *M a donc gardé là le souvenir d'un état textuel antérieur à l'état rédactionnel offert par le *G (où les vss $59-64$ font déjà suite au vs 58 ).

Il est intéressant de noter que, dans cet état ancien, le verbe final de 58b était déjà précédé de sa conjonction, puisque c'est ainsi que ce 'siman' est utilisé au vs 64 .

Interprétations proposées :

Dans l'état de cette phrase offert par Jr 51,58b, il faut comprendre la situation

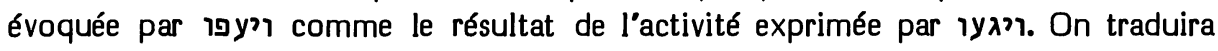
donc: "Ainsi les peuples se donnent de la peine pour rien et les nations pour le feu, et ils s'épuisent."

Quant à la fin du vs 64, on la traduira : “C'est jusqu’à 'et ils s'épuisent' que vont les paroles de Jérémie". On peut indiquer en note que cette notice conclusive fait pendant au titre "Paroles de Jérémie" que le *M a placé au début de 1,1 (alors que le *G omet la notice conclusive et glose 1,1 en : “La parole de Dieu qui survint sur Jérémie", sous l'influence de $\mathrm{Jr} 1,2$ et de 0 s 1,1). 
Options de nos traductions :

Si on compare ce vs à ses deux parallèles 2 R 25,4 (cf. CT1 423s) et Jr 39,4 (cidessus, p. 729s), on note que le roi Sédécias est explicitement mentionné en Jr 39,4 et qu'il l'est par une simple 3e pers. m. sg. en 2 R 25,4, alors qu'en Jr 52,7 il est absent.

Cette absence du roi a été respectée ici par RSV, RL et TOB.

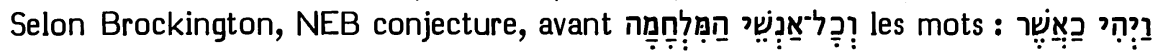

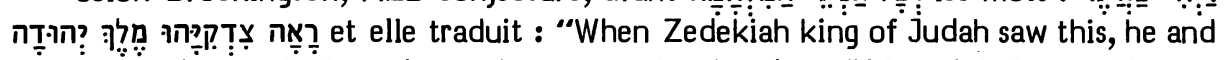
ali his armed escort". Avec des conjectures moins étendues, J12 traduisaient : “Voyant cela, le roi et tous les guerriers (J2: hommes de guerre)", et $\mathrm{J3}$ se contente de : "Alors le roi et tous les hommes de guerre".

Origines des corrections :

Des ajoutes conjecturales de l'un ou l'autre de ces types ont été proposées ici par Thenius (cité par Hitzig2 qui le suit), Nägelsbach, Giesebrecht, Condamin, Ehrlich, Volz, Nötscher, Rudolph, Weiser, Bright et les apparats de HSAT34, BH23S et Cent.

Les témoins anciens :

Aucun ne mentionne le roi en ce vs.

Choix textuel :

Sur ce point, le comité a voulu protéger le " $M$ " contre une assimilation aux parallèles. Celle-ci serait purement conjecturale. C'est pourquoi le *M a reçu la note " $A$ ".

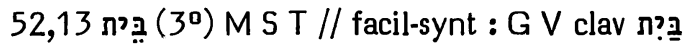

Options de nos traductions :

Après avoir dit que Nebuzaradân brûla la maison du Seigneur et la maison du roi

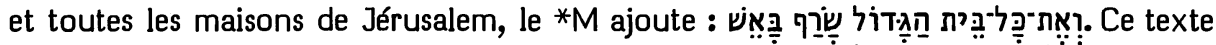
a deux parallèles dont nous avons déjà traité : 2 R 25,9 (en CT1 424s) et Jr 39,8 (ci-dessus, p. 730s).

Seule TOB traduit ici clairement le *M: “(il mit le feu ... à toutes les maisons de Jérusalem), du moins à celles des personnes haut placées".

RSV ("every great house he burned down") et RL ("alle grossen Häuser verbrannte er mit Feuer") traduisent sans note textuelle comme si elles lisaient le 3e mot à l'état absolu.

$J$ omet par conjecture cette dernière phrase du vs 13 .

NEB omet (sans le dire) le $2 \mathrm{e}$ mot et corrige (selon Brockington) le $4 \mathrm{e}$ mot en

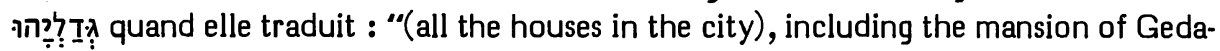
liah, were burnt down". 
Origines des corrections :

Vocalisent le 3e mot à l'état absolu : Hitzig, Nägelsbach et Duhm.

Omettent la mention de cette dernière catégorie de maisons : Giesebrecht, Cornill, Ehrlich, Volz, Nötscher, Rudolph, Weiser et les apparats de HSAT34 et BH23S.

Quant à la conjecture de NEB, celle-ci l'a aussi adoptée en 2 R 25,9.

Les témoins anciens :

En $2 \mathrm{R} 25,9$, alors que le ${ }^{*} \mathrm{G}$ palestinien et la $* V$ s'abstenaient de traduire le mot גדול, le ${ }^{*} G$ ancien le rendait par un adjectif ("toute grande maison"), comme s'il lisait le substantif précédent à l'état absolu.

Ici, le ${ }^{*} G(\pi \tilde{a} \sigma \alpha \nu$ oixía $\mu \varepsilon \gamma a ́ \lambda \eta \nu)$ et la *V (omnem domum magnam) font de même.

Ici (comme en 2R 25,9), la*S (ולכלהון בתא דרורבנא) et le *T (וית כל בתי דרברביא) ont lu, avec le *M, le 3e mot à l’état construit (et le suivant comme substantif).

Choix textuel et interprétation proposée :

Au $X V$ Ie siècle, sous l'influence de la $* V$, la plupart des traducteurs ont compris ici : "toute grande maison". C'est le cas de Pagnini, Prédicants, Zwingli, Luther, Brucioli, Münster, Olivetan, Rollet, Jud, Châteillon, Arias Montano, Geneva Bible.

C'est Estienne, annotant sa Bible de 1557, qui a proposé d'interpréter : “omnes domos magnatum", traduction que Tremellius a adoptée, suivi par la Bible des Pasteurs : "toutes les maisons des grands" et la King James Bible: "all the houses of the great men".

C'est le sens que retient König (Syntax \$337p), traduisant: “jedes Haus der Vornehmen". Le mot "grand" y est pris au sens qu'il a en 2 R 4,8; 5,1.

Ayant voté " $C$ " en 2 R 25,9 en faveur de la vocalisation de "maison" en état construit, le comité a attribué ici la note " $\mathrm{B}$ " à cette leçon en estimant que la présence de l'article ensuite accroît sa probabilité.

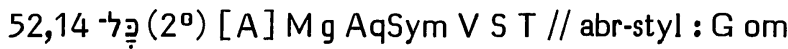

Options de nos traductions :

Le complément d'objet du verbe "abattirent" ("tous les remparts qui entouraient Jérusalem") et son sujet ("toute la troupe des Chaldéens qui étaient avec le commandant des gardes") sont l'un et l'autre précédés ici par ־’

Traduisent deux fois ce mot : RSV et RL.

Se fondent sur le ${ }^{*} G$ pour l'omettre avant le sujet: J12. Font de même sans note : NEB, TOB et $\mathrm{J3}$.

Origine de la correction :

Cette omission a été proposée par Cornill (en SBOT), puis adoptée par Rudolph, Weiser et les apparats de Cent et de BHS. 
Les témoins anciens :

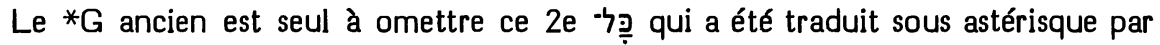
$\pi \tilde{a} \sigma a$ (leçon attribuée à AqSym) dans la recension origénienne.

Ce mot a été normalement traduit par la ${ }^{*} \mathrm{~V}, \mathrm{la} * \mathrm{~S}$ et le ${ }^{*} \mathrm{~T}$.

\section{Choix textuel :}

$\mathrm{J} 2$ a tort de prétendre que ce 25 ,10. En effet, ce mot figure en 2 R 25,10; alors qu'en Jr 39,8 manquent les sept mots qui constituent en 52,14 le sujet du verbe.

Rudolph estime que ce $2 \mathrm{e}$ - $ל$ כִ a été répété à tort à partir du premier. Cette hypo-

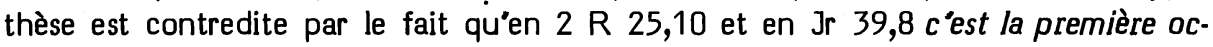
currence de ce mot qui est absente (et dont la présence semble donc plus discutable).

Considérant que le ${ }^{*} G$ a procédé ici à un allègement stylistique, le comité a attribué au *M la note " $A$ ".

\section{2,15A ומדלות העם [B M Aq V S T // lit : G om}

\section{Options de nos traductions :}

Les catégories de gens que Nebuzaradân a déportées ne se distinguent en Jr 52,15a de celles qui sont énumérées en $2 R$ 25,11 que parce que le *M insère au début :

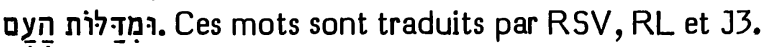

Ils sont omis par J12, NEB et TOB.

Origine de la correction :

L'omission de ces deux mots a été proposée par Châteillon (latin) se fondant sur le parallèle des Rois. Il a été suivi en cela par Michaelis (Observationes), Hitzig, Graf, Keil, Knabenbauer, von Orelli, Giesebrecht, Oort, Duhm, Condamin, Ehrlich, Volz, Nötscher, Rudolph, Weiser, Bright et les apparats de SBOT, HSAT234 et BH3S.

\section{Les témoins anciens :}

Ces deux mots manquent dans le ms 84 de Kennicott que celui-ci (Dissertatio generalis 78) date de 1136, date que de Rossi (I p. LXIII) met en doute à la suite de

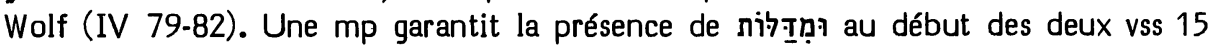
et 16 en graphie pleine.

De ce vs, le ${ }^{*} G$ n'atteste que les $3 e, 4 e$ et $5 e$ mots. Il $n$ 'atteste pas non plus les deux premiers mots du vs 16 .

Dans une ajoute astérisée attribuée à Aq, ces mots figurent sous la forme : åjò

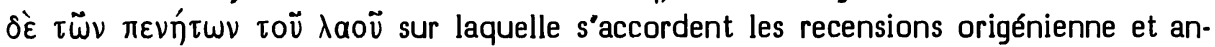
tiochienne.

Ils sont attestés par la *V: “de pauperibus autem populi", la *S : ומן מסכנא דעמא et le *T : ומחשיכי עמא.

\section{Choix textuel :}

La présence de ces deux mots est donc fermement attestée dans le texte protomassorétique de ce passage. Cependant les deux parallèles de 2 R 25,11 et de Jr 39,9 
s'accordent pour nous montrer qu'ils constituent une glose. De plus, la mention des "plus pauvres du peuple" semble déplacée parmi les catégories des gens déportés par Nebuzaradân. Il s'agit probablement de la mauvaise insertion dans le texte d'une variante marginale destinée à rivaliser avec les deux premiers mots du vs 16 . Ce mauvais placement de la variante tient probablement à ce que l'on a cru à tort que l'élément variant était ומדלות (par rapport à ואת יתר alors que c'était הער a (qui tient en effet la place de הארץ de 2 R 25,12 et de Jr 52,16 dans l'expression ומן העם הדלים qu'offre le parallèle de $\mathrm{Jr} 39,10$ ).

Quoi qu'il en soit du caractère littérairement secondaire de ces deux mots, le comité leur a attribué 5 " $\mathrm{B}$ " et 1 " $\mathrm{A}$ " parce que le ${ }^{*} T$ ne permet pas d'améliorer sur ce point la tradition textuelle sans faille qu'offrent les témoins protomassorétiques.

Interprétation proposée :

“Nebuzaradân, commandant des gardes, déporta une partie des pauvres du peuple et le reste de la population laissée dans la ville..."

52,15B cf. p. 731.

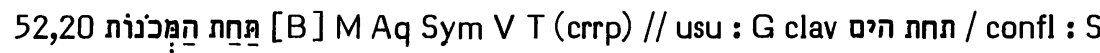

Options de nos traductions :

Parmi les objets de bronze pris par le chef des gardes, le $* M$ mentionne ici :

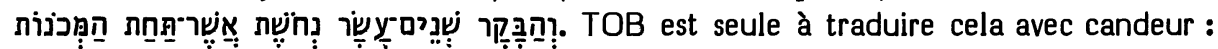
"les douze boeufs de bronze qui supportaient les bases roulantes".

En notant que les deux derniers mots manquent dans l'hébreu, RSV traduit : "the twelve bronze bulls which were under the sea, and the stands". Sans note textuelle, J traduit de même : "aux ( 1 : les) douze boeufs de bronze qui étaient sous la Mer et aux (J1 : les) bases roulantes".

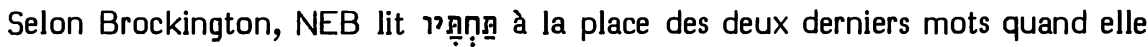
traduit : "and of the twelve oxen supporting it".

RL traduit : "die zwölf kupfernen Rinder darunter und die Gestelle".

Origines des corrections :

Au XVIe siècle, la plupart des traducteurs ont suivi la $* V$ et le sens obvie du $* M$ en plaçant les boeufs sous les bases : Pagnini, Prédicants, Zwingli, Brucioli, Münster, Olivetan, Rollet, Jud, Châteillon, Arias Montano, Estienne, Ge, Tremellius, KJ.

Luther a attribué un autre sens à กחฺ en traduisant : “die zwelff eherne Rinder, die an stat des gestüls stunden". Pasteurs interprète de même : "qui servaient de soubassemens". Cette exégèse sera adoptée par Buxtorf jr (Anticritica 936), Doederlein, Scharfenberg (note 800 sur Cappel, Critica 987), C.B. Michaelis et Rosenmüller. Elle sera réfutée par Graf.

Radaq estimait devoir (contre les teamîm) séparer תחת du mot suivant et admettre entre eux une ellipse de ㅁ̣ (qui vient d’être mentionnée auparavant). Cette exégèse 
en fonction d'une ellipse a été adoptée par Vatable et Grotius. Se sont fondés sur le *G pour insérer ce mot dans le texte : Cappel (Notae 539b), Houbigant, Venema, Michaelis (OEB), Oort, Volz, Nötscher, Bright et l'apparat de Cent.

D'autres ont estimé que la mention des 12 boeufs et de leur placement sous les bases venait d'un rédacteur inconscient de la situation réelle et ont proposé de l'omettre : Nägelsbach, von Orelli, Giesebrecht, Duhm, Cornill, Condamin, Ehrlich, Rudolph, Penna, Weiser et les apparats de HSAT234 et BH3S.

D'autres enfin corrigent l'avant-dernier mot en תחתיו et le font suivre d'une conjonction : Hitzig, Graf, Keil et Knabenbauer.

Les témoins anciens :

Le *G offre iñs $\theta a \lambda a ́$ oons à la place de המכנות.

La *S essaie de combiner ces deux leçons : דתחית גסוהי דימא

Les autres témoins traduisent le *M selon son sens obvie: Aq ưò tàs $x \varepsilon \lambda \omega ́$ vas

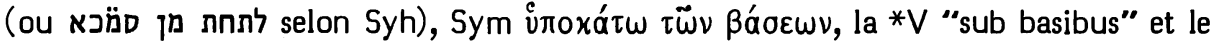

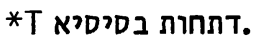

\section{Choix textuel :}

La leçon du ${ }^{*}$ G semble être une correction facilitante.

En effet, le *M semble placer les boeufs sous les bases. Or on sait bien par $1 \mathrm{R}$ 7,25 que les douze boeufs étaient sous la mer, alors que $1 \mathrm{R} 7,38$ nous apprend qu'une cuve était sur chacune des dix bases. Il est vrai cependant que $2 R 16,17$ nous a appris que le roi Achaz avait fait modifier les bases et en avait retiré le (ou les) cuve(s) et qu'il avait remplacé les boeufs comme support de la mer par un support de pierre. Il est donc assez normal que $2 R$ 25,16 (selon le $* M$ et le ${ }^{*} G$ ) mentionne tour à tour les deux colonnes $(=1 R 7,15-22)$, la mer $(=1 R 7,23-26)$ et les bases $(=1 R 7,27-34)$, mais que ce verset ne mentionne ni les douze boeufs ni la (ou les) cuve(s).

Il est évident que le parallèle de Jr 52 a le souci d’être aussi complet que possible. On s'en rend compte en notant que 12 sortes de vases sont énumérées en Jr 52,18s et que seules 6 d'entre elles figuraient dans le parallèle de 2 R 25,14-15. Il n'est donc pas étonnant que le rédacteur de Jr 52,20 (sans remarquer le motif qui avait amené $2 \mathrm{R} \mathrm{25,16}$ à ne pas mentionner les boeufs) ait senti le besoin, juste après la mention de והבקר שנים עשר נחשת אשר תחת Dans cette ajoute (que suivait והמכנות, comme en 2 R 25,16), le mot devait avoir valeur adverbiale. C'est par une corruption secondaire que le 'waw' de והמכנות fut omis et que ce mot fut lié à תחת interprété en préposition.

On pourrait formuler une autre hypothèse : Après avoir été retirés de sous la mer par Achaz, les 12 boeufs auraient été placés sous les 10 'bases' qui avaient été débarrassées par lui de leurs cuves. Mais, étant donné que ces bases avaient chacune quatre roues ( $1 \mathrm{R} 7,30.33)$ et que la modification opérée par Achaz avait consisté à détacher les תוֹ et non les roues, une telle disposition est assez difficile à imaginer.

La critique textuelle ne nous permet plus de remonter à la forme primitive de l'ajoute du rédacteur de Jr 52,20. Etant donnée la cohérence de la tradition textuelle protomassorétique, le comité a attribué à la leçon du *M la note " $B$ ". 


\section{Interprétation proposée :}

Avec Menahem de Posquières et Radaq, il faut considérer que (malgré les teamîm) תחת doit être interprété en adverbe et séparé du mot qui le suit. Donc: "les deux colonnes, la mer unique et les douze boeufs qui étaient dessous, les bases, ce qu’avait fait le roi Salomon pour la maison du Seigneur".

\section{2,22 ורמונים}

Options de nos traductions :

22a a décrit le chapiteau de la première colonne: "Et il y avait sur elle un chapiteau de bronze. Et la hauteur d'un chapiteau était de cinq coudées. Et un entrelac et des grenades entouraient le chapiteau, le tout en bronze". 22b ajoute : . Ces mots sont traduits par RSV : "And the second pillar had the like, with pomegranates", par RL: "und eine Säule war wie die andere, die Granatäpfel auch", par NEB : "The other pillar, with its pomegranates, was exactly like it" et par TOB : "la deuxième avait mêmes dimensions et mêmes grenades".

$J$ omet par conjecture le dernier mot.

Origine de la correction :

Se fondant sur le parallèle de 2 R 25,17, Giesebrecht omet ce dernier mot, suivi en cela par Duhm, Volz, Nötscher et les apparats de HSAT234 et de Cent.

Depuis Cappel (Notae 539b), la plupart des critiques estiment que ce dernier mot est le début d'une phrase mutilée et ils essaient d'en reconstituer le contenu en s'inspirant $d u * G$.

Les témoins anciens :

Au lieu de ce dernier mot du ${ }^{*} M$, le ${ }^{*} G$ donne en effet : o̊x

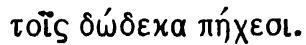

Pour AqSym, le ms Barberini atteste : xai ́óal, puis $\tau \tilde{\omega} \pi \eta \times v$ (sic!) et enfin (attribué aux 'trois") toĩs $\delta \varepsilon ́ x \alpha$ (à la place des mots suivants du *G).

$\mathrm{La} * \mathrm{~V}$ a sauté par homéotéleuton depuis le premier ורמונים du vs 22 jusqu'après le 2 e mot (הרמנים) du vs 23.

La*S et le *T traduisent littéralement le *M.

Choix textuel :

Le ${ }^{*} G$ traduit-il une Vorlage dont le $* M$ nous livrerait le début mutilé ? Il faut

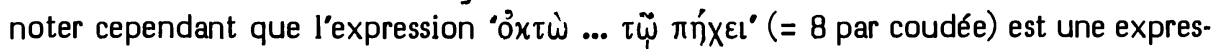
sion typiquement grecque qui n'aurait pas de correspondant exact dans l'hébreu biblique où vraisemblablement dans le ${ }^{*} G$ d'une glose visant à combler une lacune présumée, glose s'inspirant du nombre de 96 fourni par la phrase suivante de l'hébreu.

Il est permis de douter de l'authenticité de la partie des leçons que le ms Barberini attribue à AqSym et aux "trois" en excédent de la leçon du *M.

$L$ 'ampleur de l’homéotéleuton de la *V interdit de faire appel à son témoignage. 
Ne décelant aucune Vorlage hébraïque qui puisse être opposée au ${ }^{*} M$, le comité $a$ attribué à sa leçon la note " $\mathrm{C}$ ". On peut se demander en effet si la seconde occurrence de ce mot en ce vs ne serait pas une répétition erronée de la première. Il est cependant fort possible qu'après la mention globale de similitude exprimée par teur ait voulu mettre en valeur, comme donnée sur laquelle porte cette similitude, les "grenades" sur lesquelles venait de s'achever la description du premier chapiteau.

Notons en passant qu'il est inexact de dire que le parallèle de 2 R 25,17 offre 列 ont été tirés par le rédacteur du livre des Rois de la matière offerte par le vs 23 de Jérémie, après qu'il ait omis les 9 mots qui les précèdent et celui qui les suit.

Interprétation proposée :

"Et la seconde colonne en avait un semblable, avec des grenades."

\section{2,25 שֵ [B] M g Aq Sym V T // facil-synt : S / abr-styl : G om}

Options de nos traductions :

Parmi les notables judéens que le roi de Babylone mit à mort à Ribla, le *M mentionne : ְְְִ RSV traduit les quatre premiers mots : "and the secretary of the commander of the army", J : "le secrétaire du chef de l'armée", RL : "dazu den Schreiber des Feldhauptmanns" et TOB : "ainsi que le secrétaire du chef de l'armée".

Selon Brockington, NEB réduit ces quatre mots à à ?ִִ̣ quand elle traduit : "the adjutant-general".

Origine de la correction :

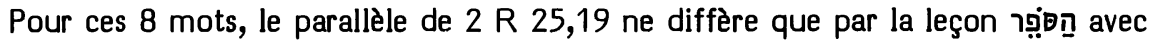
article. En ce lieu, Stade/Schwally (en SBOT) a omis les mots שר הצבא qu'il considère comme une glose grammaticalement impossible. NEB a adopté cette correction en $2 \mathrm{R}$ 25,19 , puis y a assimilé le parallèle de $\mathrm{Jr} 52,25$.

Les témoins anciens :

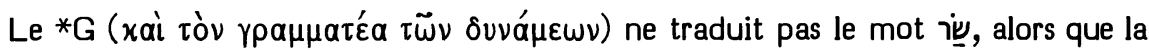

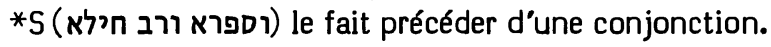

La leçon du $* M$ est attestée par les recensions origénienne et antiochienne qui

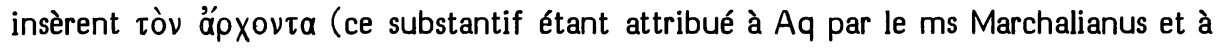
וית : Sym par le ms Barberini), la *V: "et scribam principem militum" et le *T ספרא רב חילא

Choix textuel et interprétation proposée :

$L$ 'ajoute recensionnelle du ${ }^{*} G$, la $* V$ et le $* T$ ont compris : "et le secrétaire, commandant de la milice", sens qui - du fait de l'article - s'impose en 2 R 25,19. Cependant, ici où il n'y a pas d'article, on pourrait aussi comprendre : "et le secrétaire du commandant de la milice" (avec nos traductions). 
Sans vouloir trancher ce point d'exégèse, le comité a attribué ici au *M la note "B".

Notons que la seconde interprétation s'accorde mieux avec ce qui suit : "celui qui enrôlait les gens du pays".

La non-traduction de 2 e par le $* G$ doit-elle être interprétée comme un indice que le ${ }^{*} G$ disposait d'une Vorlage plus primitive et plus sobre (alors que le $* M$ aurait inséré ce mot par assimilation au parallèle des Rois) ? Il semble plutôt que le ${ }^{*} G$ (ou sa Vorlage) a omis ce mot par allègement stylistique (de même qu'il n'a pas traduit les deux noms propres du vs 24 , ni les deux premiers mots du vs 25 , ni le 2 e verbe du vs 27, ni l'ensemble de 27b).

52,28 שבע [B] M g V T // glos : S / lacun : G

Options de nos traductions :

Les vss 28 à 30 donnent les nombres de déportés des trois déportations dont la première est datée de "l'an sept", la deuxième de "l'an dix-huit de Nabuchodonosor" et la troisième de "l'an vingt-trois de Nabuchodonosor".

S'accordent avec le *M pour la date de la première déportation : RSV, J, RL et TOB. du *M.

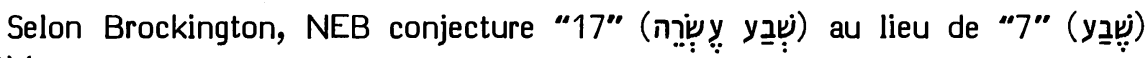

Origine de la correction :

C'est Ewald (Geschichte III 1, 435, n.1) qui a jugé que ער était tombé après שבע dans le *M. Il estime en effet que le nombre des déportés est trop faible pour qu'il puisse s'agir de la première déportation qui eut lieu sous Yoyakîn et qu'une mention de celle-ci serait d'ailleurs déplacée en ce contexte. Cette correction a été adoptée par Graf, Keil, von Orelli, Giesebrecht, Duhm, Cornill, Rudolph, Weiser et par les apparats de $\mathrm{BH} 3 \mathrm{~S}$.

Les témoins anciens :

Le $* G$ ancien omet les vss $28-30$.

L'ajoute des recensions origénienne et antiochienne s'accorde avec la $* V$, la $* S$ et le *T pour attester le chiffre "7" du *M.

La *S ajoute, après ce chiffre, דמלכותה qui le glose de façon exacte.

Choix textuel :

La précision et le caractère restreint des nombres donnés par ces trois versets amènent à penser qu'ils émanent d'une source de bonne qualité distincte du livre des Rois. Faisant remarquer que la mention de la "septième" année au vs 28 et celle de la "dix-huitième" année au vs 29 correspondent au comput babylonien (omettant l'année dans laquelle l'avènement a eu lieu), Condamin a estimé qu'il fallait maintenir ici le chiffre "7". 
En 1956, Wiseman (66-74) a publié la tablette 21946 du British Museum où est formellement mentionnée la prise de Jérusalem et la déportation de son roi en la $7 e$ année de Nabukudurriușur.

Cazelles (Vie 22, n.8) attache une grande importance à l'équivalence existant entre ces données et celles que fournit Jr 52,28.

Le comité a, sur ce point, attribué au *M la note " $\mathrm{B}$ ". 


\section{LAMENTATIONS}

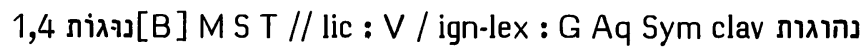

Options de nos traductions :

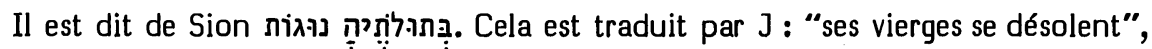
par RL : "ihre Jungfrauen sehen jammervoll drein", par NEB : "her virgins are cruelly treated" et par TOB : "ses jeunes filles sont affligées".

RSV dit suivre le ${ }^{*} G$ en traduisant: "her maidens have been dragged away".

Origine de la correction :

Après avoir envisagé comme possible (Critica 647) que le *G ait lu ici Cappel (Notae 539a) a estimé cela certain. Cette leçon est adoptée par Ewald et Schneedorfer, puis par Th. H. Robinson dans les apparats de BH3S.

Les témoins anciens :

Dans le *M une mp attire l'attention sur l'unicité de la forme נוּר ת et sur sa graphie pleine.

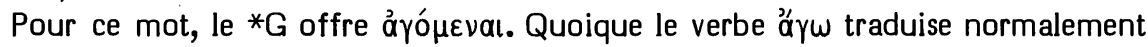
$\lambda$ נה, on peut se demander, avec Albrektson, si le ${ }^{*} G$ a réellement lu ici la Vorlage suggérée par Cappel. Il se peut que le traducteur, ne sachant comment interpréter la forme hébraïque unique qu'il avait sous les yeux, a traduit la forme la plus proche qui lui venait à l'esprit.

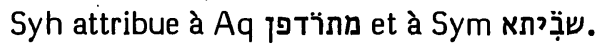

La*V traduit "squalidae" et la *S ממכן.

Selon v. d. Heide, le *T de tradition yéménite traduit ce mot par מתאבלן, alors que les témoins occidentaux paraphrasent : "sont en deuil (ספדן) car elles ont cessé de sortir au 15 de Ab et au jour des Expiations, qui se célébrait au 10 de Tishri, pour dansèr en rondes".

Choix textuel :

Si la correction proposée par Ewald a eu peu de succès, c'est parce qu'elle n'est pas conforme au parallélisme, alors qu'un dérivé de יגה le respecte au contraire fort bien.

Aucune des versions ne témoignant pour une Vorlage préférable au ${ }^{*} M$, le comité a attribué à celui-ci la note " $\mathrm{B}$ ". 
Interprétation proposée :

La paraphrase du *T doit se comprendre dans la perspective d'une tradition rapportée en Mishna Taanit IV 8 : "Rabban Shiméon ben Gamaliel a déclaré : 'Il n'y avait pas pour Israël de jours de fêtes comparables au 15 de Ab et au jour des Expiations. En ces jours-là, les garçons de Jérusalem sortaient avec des vêtements blancs qu'ils avaient empruntés afin de ne pas faire honte à ceux qui n'en avaient pas, et il fallait les purifier. Quant aux filles de Jérusalem, elles sortaient et dansaient dans les vignes. Elles disaient ceci : 'Lève donc les yeux, jeune homme, et vois qui tu veux choisir pour toi'."

Salmon ben Yeruḥam traduit ici עואתקה מתחסראת par. Ce substantif pluriel désigne les jeunes filles nubiles tenues à la maison. Quant à la $5 e$ forme de חסר elle désigne particulièrement les soupirs causés par le regret de ne pas pouvoir obtenir ou faire quelque chose. Salmon en explicite ici le sens en disant que c'étaient ces jeunes filles qui, aux jours de fêtes, accueillaient les pèlerins avec des instruments de musique et des louanges, comme le montre $\mathrm{Jg} 21,19.21$, et de même elles sortaient au devant des. soldats quand ils revenaient d'expédition. C'étaient elles qui, avec des tambourins, proclamaient les prouesses comme le montre $1 \mathrm{~S} 18,6 \mathrm{~s}$.

Saadya traduisait de même le mot נוגות, sans le commenter spécialement.

Les grammairiens, d'Ibn Ezra à Chomsky (170 et n.329), voient ici un participe nifal de יגה. Celui-ci précise que le ḥolem issu de 'â' se transforme normalement en shureq lorsque l'accent tonique glisse à la syllabe suivante.

Notons que le verbe יגה (que nous avons déjà rencontré ci-dessus p. 377 en Is 51,23) se retrouve en $\operatorname{Lm} 1,5.12 ; 3,32$ s.

Presque tous les exégètes anciens et récents ont rapproché ce mot de דִ̣̂n (So 3,18). Déjà Daniel al Qumisi, au IXe siècle, y traduisait le premier mot par ,מתחסריך, traduction adoptée aussi par Yéfet ben Ely. Ils y voient ceux qui soupirent de regret à cause des rassemblements festifs qui ne peuvent plus avoir lieu ou auxquels ils ne peuvent plus se rendre.

Ces deux cas se fournissant un appui mutuel, on pourra traduire ici : "ses jeunes filles sont affligées" en notant qu'elles soupirent de regret parce que l'interruption des solennités cultuelles (du fait de la destruction du temple) ne leur donne plus l'occasion de participer aux danses festives qui leur permettaient de trouver des prétendants (cf. Jg 21,19-21 et Mishna Taanit IV 8).

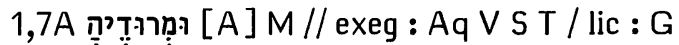 ומרורי [B] M // exeg : G Aq V S T / harm-ctext : t clav}

\section{Options de nos traductions :}

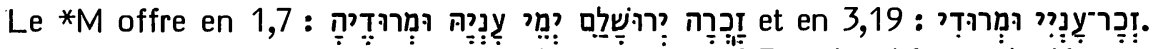
Les deux substantifs coordonnés sont traduits par J en 1,7 : “de misère et de détresse (J1 : marasme)" et en 3,19 : "ma misère et mon angoisse"; par RL en 1,7 : "da sie elend und verlassen ist" et en 3,19 : "wie ich so elend und verlassen ... bin"; par NEB en 1,7 : "of misery and wandering" et en 3,19: "my distress and my wanderings"; par TOB en 1,7 : “d'errance et d'humiliation" et en 3,19: “de mon humiliation et de mon errance". 
Disant corriger par conjecture le second substantif en chacun des deux endroits, RSV donne en 1,7 : "of her affliction and bitterness" et en 3,19: "my affliction and my bitterness".

Origine de la correction :

C'est Châteillon qui (en annotant sa traduction latine) semble avoir été le premier à suggérer que le 'dalet' de ce substantif pouvait être fautif en 3,19. Aussi traduit-il : "\& acerbitatis" et non: "\& rebellionis". Calmet a proposé de corriger en מִּרוּ qu'il traduit : “de mon amertume". Houbigant a conjecturé ומריר : "\& amaritudinis meae

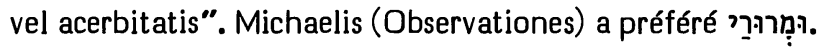

C'est en 1,7 que Löhr (en HSAT4) a proposé la correction הַּרְּ quị que BHS mentionne à titre informatif.

\section{Les témoins anciens :}

En 1,7, le *G traduit $x a i$ å̉

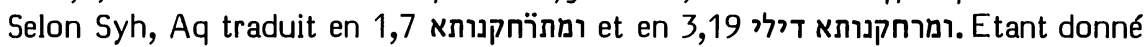

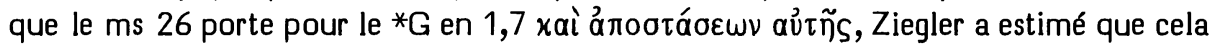
correspondait à la leçon que Syh offre pour Aq.

En 1,7, la *V traduit "et praevaricationis" et en 3,19 "et transgressionis meae".

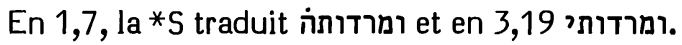

En 1,7, le *T paraphrase ומרדא ושליטא בכל עלמא. Comme le note Cahen, il semble avoir interprété ce mot à partir de רדת (= dominer), de même qu'il a interprété le mot précédent à partir de (= demeure) en paraphrasant : "quand elle demeurait dans les châteaux et les villes fortes".

En 3,19, le *T yéménite, selon v. d. Heide, donne ומא דמרידו בי סנאי, alors que le *T de tradition occidentale donne, pour le 2e mot דאמרירו.

\section{Choix textuel :}

En 1,7, la leçon du $* G$ (que la recension antiochienne met au singulier) signifie "et de ses expulsions". Il s'agit d'une traduction large de l'hébreu, ainsi que Schleusner (I 423) l'a suggéré. En 3,19, la traduction du *G doit être rapprochée de celle de רדה

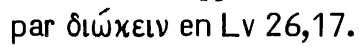

L'usage probable que Aq a fait du substantif åmóotaoıs pour traduire notre substantif en 1,7 (et peut-être en 3,19) indique qu'il y a reconnu la racine à laquelle

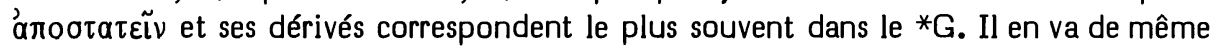
pour la*V.

La *S a choisi un substantif offrant les mêmes consonnes que celui de l'hébreu. Selon la tradition yéménite, le ${ }^{*} T$ a fait de même en 1,7 et en 3,19. Selon la tradition occidentale, par contre, il semble avoir lu un 'resh' au lieu du 'dalet' en 3,19.

Cette dernière leçon serait donc la seule variante qu'offrirait la tradition textuelle. Mais le fait que מרוד se retrouve lié à יע en Lm 1,7 et en Is 58,7 montre que cette variante $n$ 'a que fort peu de chances d'être originale ici. C'est pourquoi le comité a attribué au *M la note " $A$ " en 1,7 et la note " $B$ " en 3,19 où la leçon du *T de tradition occidentale a été motivée probablement par le voisinage de לִ qu qui était en parallèle avec 
Interprétation proposée :

En Is 58,7, il est mentionné, parmi les oeuvres de miséricorde :

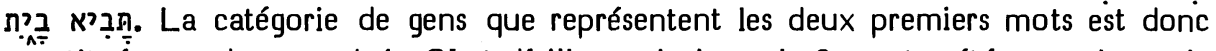
constituée par des sans-abris. C'est d'ailleurs ainsi que le $2 \mathrm{e}$ mot a été compris par le

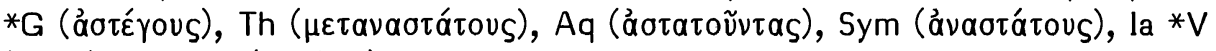
(vagos) et le *T (מטלטלין). La *S s'est inspirée du contexte pour traduire les deux premiers mots par ולאכסליקיא.

Dans son commentaire, Parḥon (sur Lm 1,7) donne d'abord à ומרודיה un sens de "misère et abaissement" qu'il dit valable aussi pour 3,19 et pour Is 58,7. Puis il ajoute que certains donnent à ce mot le sens de טלטול (= vagabondage, errance) en fonction de la traduction que le $* T$ offre pour Is 58,7. En son commentaire sur Lm 3,19, Parhon adopte ce dernier point de vue en donnant à ומרודי l'équivalent טלטולי

Radaq n'a pas commenté les Lamentations. Cependant il traite deux fois de ce mot en ses Shorashim. Une première fois sous מרù il donne le sens de "misère et abaissement" et une deuxième fois sous רוu il dit que ce mot peut avoir en Lm 1,7 et 3,19 le sens de טלטול qu'il a en Is 58,7, selon le *T. Il ajoute d'ailleurs que le *T, en Jr 2,31, traduit aussi אטלטלנא plopar.

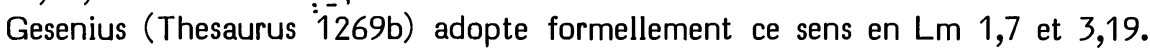
HALAT (598b) fait de même, à la suite de Rudolph (Text 101) et de Nöldeke (Untersuchungen 539s). Ce dernier (539, n.4) proposait en 1,7 de corriger en singulier :

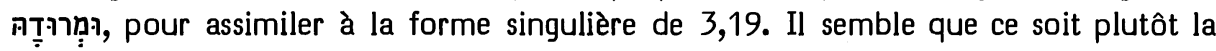
forme singulière de 3,19 qui, dans le *M, est facilitante. Cependant, Tanḥum Ye-

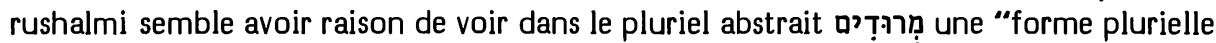
sans pluralité réelle, comme נעורים , et leurs semblables". Une correction en בִ en 3,19 n'aurait donc aucune influence sur le sens. C'est pourquoi le comité a estimé inutile de prendre position sur ce point.

On traduira donc en 1,7: "en ses jours de misère et d'errance" et en 3,19: “de ma misère et de mon errance".

Ajoutons que Nyberg (Studien 92) a bien montré que le verbe רוּ est un verbe typiquement bédouin signifiant "changer de pâturage, chercher pour soi et son peuple

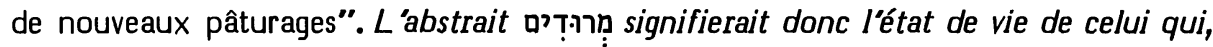
n'ayant pas de domicile fixe, est à la merci de l'accueil qui lui sera fait.

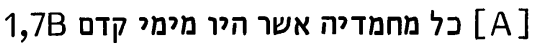

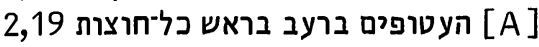

Options de nos traductions :

Les vss 1,7 et 2,19 sont, dans les trois premières lamentations, les deux seuls qui semblent constitués par 4 lignes (et non 3 ).

Ces 4 lignes ont été traduites en 1,7 et en 2,19 par RSV, RL et TOB.

$\mathrm{J12}$ et NEB omettent par conjecture la $2 \mathrm{e}$ ligne de 1,7 et la dernière de 2,19. $\mathrm{J3}$ omet la $2 \mathrm{e}$ ligne de 1,7 et traduit entre parenthèses la dernière de 2,19. 
Origines des corrections :

Cette dernière présentation vient de Ewald qui estimait invraisemblable que le poète ait, en ces deux seuls cas, dérogé à la loi qui gouverne la structure de ces trois poèmes. Böttcher (Aehrenlese) avait déjà considéré la dernière ligne de 2,19 comme excédentaire.

Les deux lignes mentionnées ont été omises ou, du moins, considérées comme des gloses, par Budde (Klagelied 9, 10, 265s et 270), Dyserinck, Löhr, Oort, Paffrath, Dennefeld, Wiesmann, Kraus, Plöger, Kaiser et par les apparats de HSAT234, BH23S et Cent.

Les témoins anciens :

Tous attestent la présence des quatre lignes en chacun de ces deux vss.

Choix textuel :

Voyant ici un cas de critique littéraire, le comité a attribué au *M la note " $A$ ", quant à la présence de ces deux lignes.

Le problème littéraire :

Contre l'omission de la 2e ligne de 1,7, Ehrlich a objecté que cette ligne est nécessaire pour fournir un complément d'objet au verbe initial de ce vs. En effet, les "jours de sa misère et de son errance" ne peuvent constituer l'objet de ce souvenir qui doit consister en une situation ancienne. Ces mots, décrivant la situation de Jérusalem au moment où celle-ci se lamente, constituent plutôt un complément circonstan- ciel, ainsi que nous les avons traduits en conclusion du cas précédent.

Cela a amené Rudolph (cité par Haller qui le suit) à omettre plutôt la 3e ligne de 1,7. Cette proposition a été acceptée par Nötscher, Weiser, Albrektson et Gottlieb.

Meek (suivi par Hillers) a estimé que la $2 e$ et la $3 e$ lignes sont deux variantes caractérisant deux éditions anciennes des Lamentations, variantes qui figureraient maintenant côte à côte, sous forme de leçon gonflée, dans toute la tradition textuelle.

Nägelsbach et Gordis ont estimé que ce que l'on considère d'ordinaire comme la 1e et la 2e lignes de 1,7 ne constitue en réalité qu'un seul membre de cette strophe : un distique nettement plus ample que les deux suivants. En 2,19, par contre, Gordis serait disposé à admettre que la dernière ligne est adventice. On suggère d'ordinaire que son contenu a pu être emprunté à 2,11 et à 4,1.

En tout cas, ces considérations portent sur des développements antérieurs à l'état que la critique textuelle permet d'atteindre.

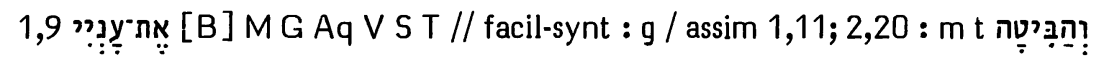

Options de nos traductions :

Dans les deux premières lignes de cette strophe, les verbes et les pronoms suffixes ont évoqué 6 fois, par la 3e pers. f. sg., Jérusalem. La troisième ligne commence par

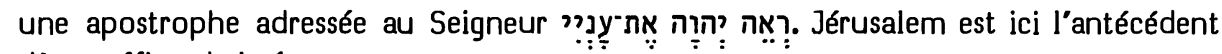
d'un suffixe de la 1e pers. sg. 
Ce changement de personne a été respecté par RSV, J, RL et TOB.

Selon Brockington, NEB se fonde sur la Vieille Latine pour corriger en en et traduire : "Look, LORD, upon her misery".

Origine de la correction :

C'est Robinson qui semble avoir pris l'initiative de cette correction. Dans l'apparat de $\mathrm{BH} 3$, il la fonde sur la Vieille Latine; dans l'apparat de BHS, sur Ambroise et la Bohaïrique.

\section{Les témoins anciens :}

La 1e pers. ( et par la Sahidique. Ambroise est le seul témoin de la Vieille Latine que Sabatier cite ici. Il lit "humilitatem eius". Sa leçon et celle de la Bohaïrique représentent deux émergences périphériques d'une facilitation qui est évidemment 'dans l'air'.

La 1e pers. est attestée par $\mathrm{Aq}$, la*V, la *S et le *T yéménite.

A la place de ce mot, le *T occidental donne ותהי מסתכל. Ces mots traduisent pro-

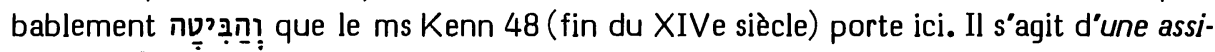
milation à $1, \overline{1} 1$ et à 2,20 où se lit, en effet

Choix textuel :

Comme Budde l'a fait remarquer, en cette lamentation, tous les passages au discours direct sont non introduits (cf. 11b, 12a et 18a).

Contre facilitations et assimilations, le comité a attribué au *M la note " $B$ ".

Interprétation proposée :

"Vois, Seigneur, ma misère".

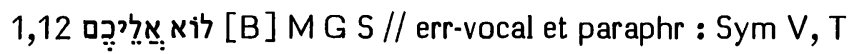

Options de nos traductions :

Avant les impératifs: "regardez et voyez s'il est une douleur semblable à ma

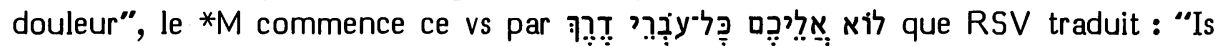
it nothing to you, all you who pass by ?", NEB : "Is it of no concern to you who pass by ?" et TOB : "Rien de tel pour vous tous qui passez sur le chemin".

J corrige les deux premiers mots en לוּא אַ et traduit : "Vous tous qui passez par le chemin".

RL traduit : "Euch allen, die ihr vorübergeht, sage ich".

Origines des corrections :

Cappel (Notae 540a) a suggéré de vocaliser le premier mot avec shureq, suivi en cela par Clericus, Pareau et plusieurs autres. La conjecture retenue par $\mathrm{J}$ a été proposée par Haller et Penna.

RL dépend ici de Luther qui traduisait : "Euch sage ich, allen, die jr fur uber gehet." A part l'insertion de "sage ich", il suit ici les Prédicants de Zurich. Ceux-ci, 
traduisant : "O jr alle die hie fürgond", démarquaient la vieille traduction allemande faite sur la *V (Kurrelmeyer IX 207,21s) qui, depuis l'édition Zainer, donne ici : "O ir all die do gend". On reconnaît donc, jusquầ $R L$, le "o vos omnes qui transitis" de la $* V$.

Les témoins anciens :

La *V dépend ici de Sym telle que l'atteste Syh אוֹ אנתון כלכון. Field estime cette

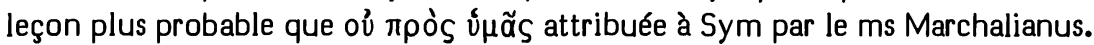

Cette dernière glose marginale a plutôt pour but de rectifier la leçon ol $\pi \rho \circ$ u a $_{S}$ que ce $\mathrm{ms}$ (en accord avec presque tous les témoins) donne pour le ${ }^{*} \mathrm{G}$. La leçon oi avait été donnée pour le ${ }^{*} G$ par les éditions de la polyglotte d'Alcala, l'Aldine, la Sixtine, Grabe et Swete. La leçon oủ avait été conjecturée par Cappel (Critica 609). Elle a été adoptée par Rahlfs et Ziegler sur la foi des mss 62 et 407.

La*S לא לכון atteste ici le *M.

Le *T de tradition occidentale glose אשבעית לכון. Selon v. d. Heide, les plus anciens témoins de la tradition yéménite portent אשלחית pour le premier verbe; la leçon occidentale l'a supplantée dans les témoins plus récents.

\section{Choix textuel :}

La lectio difficilior du $* M$ est bien attestée par le ${ }^{*} G$ et la $* S$. Il est probable que Sym et la *V d'une part, le *T d'autre part paraphrasent une Vorlage dont ils vocalisaient le premier mot avec shureq. Le lamed initial est en tout cas certain, à cause de l'ordre alphabétique.

Considérant que la difficulté est ici d'ordre exégétique, le comité a attribué au *M la note "B".

Interprétation proposée :

Vers le milieu du IIIe siècle, R. Joḥanan (selon le Talmud Babli Sanhedrin 104b) interprétait les deux premiers mots dans un sens apotropaïque : "Que cela ne vous atteigne pas !" Cette exégèse est celle de Saadya, Rashi, Ibn Ezra, Pagnini, Brucioli, Olivetan, Vatable, Estienne. Leur donnant ce sens, Rudolph (Text 102s) considère ces mots comme une glose (du fait de leur mauvaise insertion dans le contexte) qui aurait remplacé le début originel du vs.

Salmon ben Yeruham attribue une valeur interrogative à la négation initiale et explicite un verbe : "N"est-ce pas vers vous que je crie ?" Il est frappant de noter que, sans connaître Salmon, Ewald interprète de même en explicitant le même verbe.

Mieux vaut cependant garder à cette négation sa pleine valeur : “Cela ne vous concerne pas, vous tous qui passez sur la route !" Cette valeur négative a pour but de heurter le public des passants. Elle implique, grâce à la contradiction qu'elle entend susciter, une valeur d'affirmation intense. Par là, elle prépare les deux impératifs avec lesquels elle forme contraste : "Regardez et voyez s'il est une douleur semblable à ma douleur !" Cette exégèse a l'avantage de respecter pleinement le *M et d'être la plus discrète dans les sous-entendus qu'elle postule. Calvin l'a proposée en second et elle a été adoptée par Tremellius. 


\section{Options de nos traductions :}

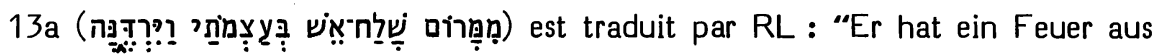
der Höhe in meine Gebeine gesandt und lässt es wüten” et par TOB : “De là-haut, il a envoyé du feu dans mes os; il en est le maître".

Disant omettre la conjonction qui précède le dernier mot, RSV traduit : “From on high he sent fire; into my bones he made it descend". Sans note, NEB donne : "He sent down fire from heaven, it ran through my bones". J traduit : “D”en (J1 : De là) haut il a envoyé un feu qu'il a fait descendre dans mes os ( $\mathrm{J1}$ : qu'en mes os il a précipité)."

\section{Origines des corrections :}

La correction retenue par RSV a été proposée par Dyserinck ( (1ieu du dernier mot), Budde (Klagelied 266), Löhr, Kelso, Schneedorfer, Rudö̈ph (Text 103), Nötscher, Weiser, Hillers et par les apparats de HSAT1 et Cent.

Ont préféré lire ici un accompli (הṬṬin) : Penna, Plöger et les apparats de BH3S.

Les témoins anciens :

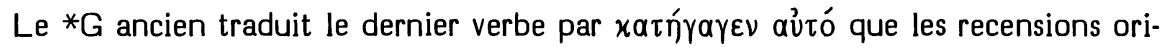
génienne et antiochienne font précéder d'une conjonction.

Le ms Ambrosianus de Syh attribue à Aq pour ce verbe דרא (= il les a vannés). Rudolph (Text 103) se demande cependant s'il ne faut pas lire pour le premier mot רדא (ce qui traduirait alors le*M). De fait, Ceriani (p. 93 de ses notes sur son édition de Syh) précise que la 1e main a placé un point inférieur sur un grattage, en dessous de la 2 e lettre.

Si on corrige ainsi la leçon de Aq, Ziegler fait remarquer qu'elle devient identique

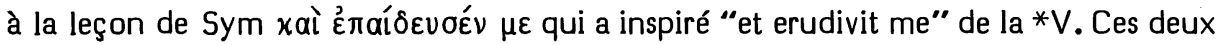
dernières leçons ne se distingueraient de Aq que par la traduction du suffixe en $1 e$ pers.

La*S ו ${ }^{*}$ a fait de même, en interprétant le verbe à la manière du *G.

Après avoir paraphrasé le début du vs par : "des cieux il a envoyé le feu dans mes châteaux forts", le *T traduit ce verbe par וכבש יתהון. Comme Aq, il interprète donc en pluriel le pronom suffixe (alors que le ${ }^{*} G$ attribuait à celui-ci le "feu" comme antécédent).

Choix textuel :

Après "d'en-haut il envoie", la vocalisation de ce verbe en référence à ירד (= descendre) semble une facilitation contre laquelle le comité a voulu protéger la leçon du *M en lui attribuant la note " $B$ ".

Interprétation proposée :

Le sens de "éduquer", retenu par Sym et par la *V, se réfère à l'araméen רדא.

Salmon ben Yeruhamam a interprété ce verbe dans le sens du *T : "J'ai interprété

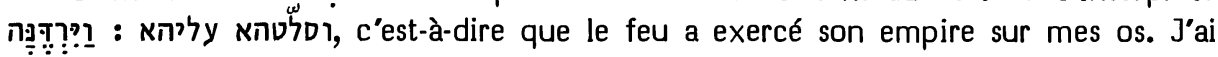




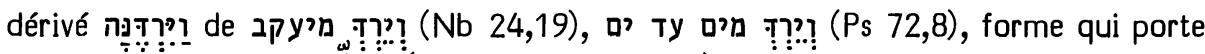
un dagesh. Et le sens (= exercer un empire) s'accorde avec le dagesh et avec le

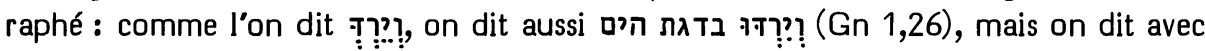

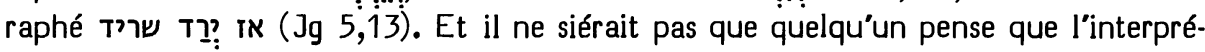

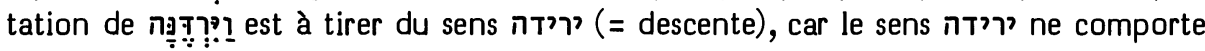
pas le dagesh lene." Par cette dernière remarque, il veut dire que jamais dans la Bible le 'dalet' du verbe ירד ne porte de dagesh.

Menahem ben Saruq classe lui aussi $\operatorname{Lm} 1$,13 avec Ps 72,8; Gn 1,26 et Jg 5,13 dans le même sens (le 2e) du bilittère Tר. Hayyuj (Kitâb 208,11) classe sous רדה, sans les distinguer par le sens, Lm 1,13; Ps 72,8; Nb 24,19; Is 41,2 et Jg 5,13.

Mais David ben Abraham (II 595,20-23) distingue un sens de 'domination' qu'il reconnaît en Gn 1,28 et Ps 72,8 d'un sens de 'colère' qu'il reconnaît en Lm 1,13. De même, Abulwalid (Ușul 666,31 à 667,3) déclare : “Il (= Hayyuj) a mentionné

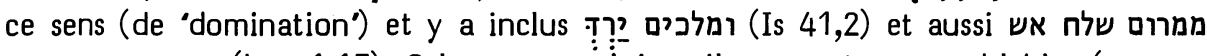

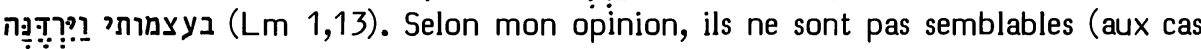
relevant du sens 'domination'), mais il aurait dâ en faire un autre sens. A mon avis, en effet, le targum a raison de dire en Is 41,2 : ומלכין יתבר. Et, de même, je dirai que le sens de וירדנה est 'et il les a brisés', à savoir : les os". Ibn Barûn (89) unit lui aussi Is 41,2 et Lm 1,13 où il voit le sens de 'détruire et consumer' en se fondant sur l'arabe 'ר́. Judah ibn Balaam, sur Is 41,2, dit qu’en Lm 1,13 ce verbe a le sens de "briser et détruire'. En son commentaire ici, Tanḥum Yerushalmi formule la même opinion. Kopf (203), sans mentionner ses prédécesseurs, se fonde sur le même verbe arabe. Il voit ici un des rares cas d'inaccomplis 3e pers. f. pl. avec préformante 'yod' et il traduit : "et ils dépérissent", à savoir : mes os.

Ibn Ezra estime que le sujet de ce verbe est le feu, car w a des accords masculins (par ex. Jb 20,26) et que le sens est semblable à celui de ㅋำ? ?? ( Lv 25,53), c'est-àdire 'dominer sur'. Gerlach qui a adopté cette interprétation (sans savoir qu'elle remonte à Salmon) a très bien répondu aux objections que l'on peut élever contre elle en notant que :

- שீִ a aussi un accord masculin en Jr 48,45;

- le suffixe $3 e$ pers. f. sg. peut porter sur les os compris comme un collectif (cf. Ewald, Lehrbuch §317a);

- רדו au sens de 'dominer sur' se construit avec l'accusatif en Lv 25,53 et Ps 68,28. Ce dernier sens a été adopté ici par Keil, Driver (Lamentations 137) et Albrektson. Ce feu envoyé dans les os et qui prend possession de ceux-ci exprime bien les terribles douleurs dont il s'agit.

On traduira donc : "De là-haut il a envoyé en mes os un feu qui les a subjugués." 


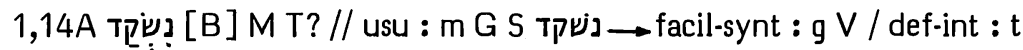

1,14B לy

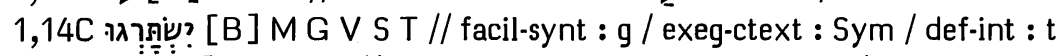

1,14D

\section{Options de nos traductions :}

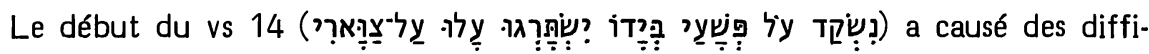
cultés aux traducteurs.

Disant corriger 14A par conjecture, RSV traduit : "My transgressions were bound into a yoke; by his hand they were fastened together; they were set upon my neck". Sans note, TOB traduit : "Le voilà lié, le joug formé de mes révoltes; dans sa main elles se sont nouées; elles sont hissées sur mon cou".

Interprétant autrement $14 \mathrm{~A}, \mathrm{RL}$ traduit : "Schwer ist das Joch meiner Sünden; durch seine Hand sind sie zusammengeknüpft. Sie sind mir auf den Hals gekommen".

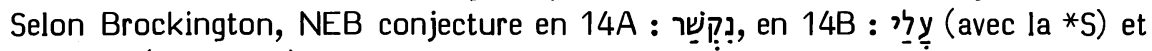
en 14D : iy (avec Sym). Elle traduit: "My transgressions were bound upon me, his own hand knotted them round me; his yoke was lifted on to my neck".

Faisant appel à $27 \mathrm{mss}$ hébreux, à des témoins du ${ }^{*} \mathrm{G}$ et à la $* \mathrm{~V}, \mathrm{~J} 23$ lisent לy en $14 \dot{C}$ et elles corrigent $14 \mathrm{D}$ comme NEB l'a fait. Elles traduisent : "Il a surveillé mes péchés ( $\mathrm{J} 3$ : guetté mes crimes) : de sa main il m'enlace, son joug est sur mon cou". $\mathrm{J1}$ multipliait les conjectures.

\section{Origines des corrections :}

Zwingli et Luther (sous l'influence de la $* V$ ) avaient traduit le premier verbe comme si le point diacritique était à droite: "vigilatum est" et "sind erwachet".

Les corrections que $\mathrm{J} 23$ retiendront en $14 \mathrm{AB}$ ont déjà été mentionnées par Mercerus (annotant Pagnini, Thesaurus3 3100) disant que certains conjecturent qu'il faut lire ici hy by (= joug). A qui Mercerus se réfère-t-il ? Il se peut qu'il déduise cette Vorlage de la paraphrase que Joseph Qara donne en son commentaire (qu'il pouvait lire en l'édition

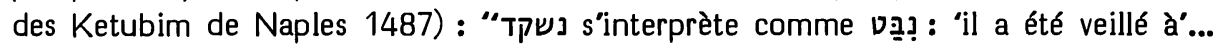
Le Saint béni-soit-il a veillé à faire venir sur moi le malheur". Joseph Qara dépend peut-être ici de Tobia ben Eliezer qui (selon le ms de Rossi 206) donne en second lieu la paraphrase שהיה הק'ב'ה' שוקד על פשy. Tobia ben Eliezer se place ici dans la perspective ouverte par les trois premières exégèses du midrash Ekha Rabbati (p. 77). Plaçant le point diacritique à droite (en jouant sur le fait que ce mot n'est pas écrit avec 'samek' mais avec 'śin'), elles paraphrasent les trois premiers mots שקד איך להביא עלי הרעה 'stong.

Cappel (Critica 517, 544 et 729) fonde sur le ${ }^{*} G$ la correction de ces deux mots que Mercerus estimait conjecturale. Le même Cappel, en sa Critica, la jugeait préférable au $* M$, suivi en cela par Doederlein, Michaelis (OEB), Pareau, Perles (Miscellany 127), Penna, Wiesmann, Meek, Hillers, Gordis, Gottlieb et par les apparats de HSAT3, BH3 et Cent.

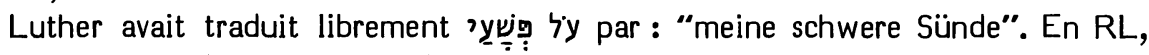
l'adjectif "schwer" a une autre origine : Praetorius a conjecturé, pour le verbe initial, 


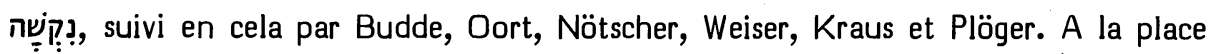
des deux premiers mots, Rudolph (Text 103) et Haller suggèrent •

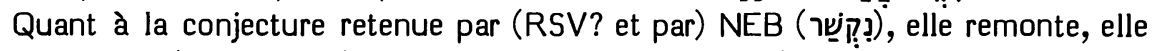
aussi, à Cappel (Notae 540a) suivi par Houbigant. Celui-ci (s'inspirant d'une interprétation de Radaq) offre en alternative נצקד qui a été préféré par Böttcher (Aehrenlese) et Thenius.

Après avoir omis le "joug" en 14B, 323 et NEB le réintroduisent en 14D. Faisaient déjà de même : Budde, Rudolph, Haller, Wiesmann, Meek, Hillers et l'apparat de Cent.

Les témoins anciens :

1/ 14A : Sur la deuxième lettre de ce mot, l'édition princeps des Ketubim (Naples 1487) ne place pas de point diacritique. Les éditions suivantes (Soncino 1488, Brescia 1494, Félix de Prato et Bomberg in $4^{\circ}$ 1517) placent ce point à droite. La polyglotte $d^{\prime}$ Alcala, Bomberg in $4^{\circ} 1521$ et Ben Hayim placent ce point à gauche. A partir de là, la plupart des éditions font de même. Cependant on retrouvera le point à droite jusque dans l'édition Minḥat Shay et en $\mathrm{BH} 2$.

De Rossi (Scholia) a trouvé le point placé à droite en 25 de ses mss (à quoi s'ajoute la 1e main de deux autres). Sur 27 mss que nous avons contrôlés, le point à droite n'apparaît que dans 3 d'entre eux : ms des Jésuites de Cologne, Erfurt 3 et Hamburg 4. Les 24 autres portent le point à gauche : le ms de Leningrad, Urbinates 1 et 2, de Rossi 2, 7, 782, Vatican ebr 3, 7, 468, 482, Paris BN hebr 5 et 26, Copenhague 1, 2, 4, 5, 9, 11, Londres BL Add 19776 et 21161, Madrid Univ 1, Milan 5, Kassel, Hamburg 28.

On peut ajouter que certains mss (tel le ms Urbinates 1) précisent en mp que cette forme est unique, son $\boldsymbol{E}$ ayant le point à gauche. Ces données montrent que le point à gauche caractérise le texte tibérien classique.

2/ 14AB : La plupart des versions ont lu en 14A le point à droite.

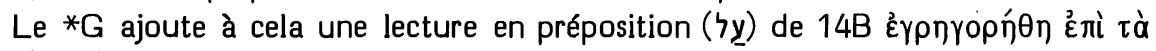

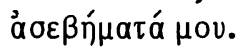

Faisant du 3e mot le sujet de 14A, la *S traduit librement, en lisant 14AB, comme l'avait fait le *G, אתתעירו עלי החהית.

La recension antiochienne se distingue $d u{ }^{*} G$ en traduisant $14 \mathrm{~A}$ par un actif

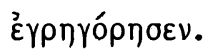

$L a * V$ "vigilavit iugum iniquitatum mearum" fait de même et vocalise 14B comme le *M.

Le *T tâtonne pour trouver un sens à 14A (qu'il lit probablement avec le point à gauche) : אתיקר ניר מרודי. A la suite d'une déformation de 'yod' en 'waw' en 14B, la tradition yéménite a défiguré cette leçon en איתקיד נור מרודי.

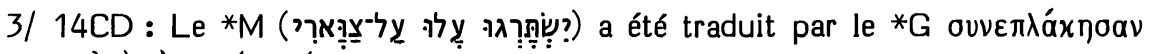

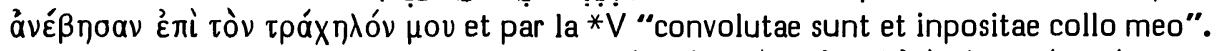

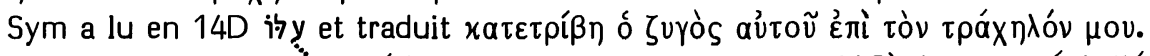

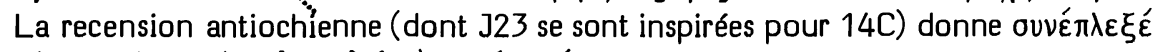

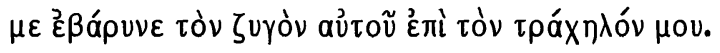


Lisant 14D comme Sym, la ${ }^{*} \mathrm{~S}$ traduit par un pluriel pour harmoniser avec 14C : אסתרגו נירוהי על צורי

Le *T paraphrase le *M en 14C אשתבשו כשבשין דגופנא. Pour 14C, Lagarde a אתבשו אתיבשו donné fausse restauration des Miqraot Gedolot pour la leçon fautive que donnaient l'édition princeps de Félix de Prato et celle de Ben Hayim. Cette leçon fautive avait été mal corrigée en אשבשו par la polyglotte d'Anvers. Celle de Londres offre ici la leçon authentique אשתבשו qu'attestent tous les mss utilisés par van der Heide et ceux que nous avons contrôlés (Urbinates 1, Milan 5, de Rossi 7, Hamburg 4 et Copenhague 11).

En 14D, le *T traduit littéralement le *M.

\section{Choix textuels :}

En 14D, l'expression yִ est garantie par plusieurs parallèles. En effet, le joug "monte sur" un animal selon $\mathrm{Nb}$ 19,2 et $1 \mathrm{~S} 6,7$. Il est placé "sur le cou" selon Dt 28,48; Jr 28,14 et 30,8.

Cela étant acquis, 14B appelle naturellement la vocalisation ty.

En 14A, un certain nombre d'arguments s'opposent à ce que l'on place le point diacritique à droite :

- La racine שקד figurant 18 fois dans la Bible, cette leçon est ici facilitante.

- Le verbe שקד est usité 12 fois au qal et deux au pual. Un nifal ici constituerait un hapax.

- Ce nifal de שקד s'accorderait mal avec 14B vocalisé selon le *M et il requerrait une vocalisation en préposition, ce que nous venons de refuser.

- A supposer que la leçon originelle soit yַ processus on est passé de là à la lectio difficilior du *M.

En 14C, il n'y a aucun motif pour adopter la leçon évidemment facilitante de l'antiochienne.

Le comité a attribué au *M 5 " $\mathrm{B}$ " et 1 "C" en 14A. Il lui a attribué la note "B" en 14BCD.

\section{Interprétation proposée :}

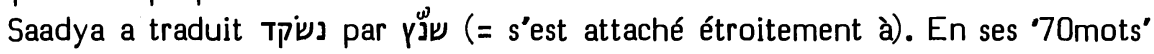

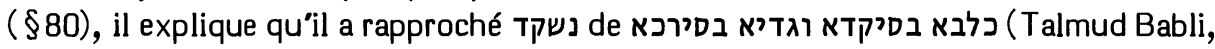
Baba Qamma 22a). Selon Radaq (Shorashim, sur שקד), Hay Gaon se réfère au même passage lu de même pour fonder le même sens. Selon une glose du ms de Rouen, Abulwalid (Ușul 743,13) adopte pour ce mot la traduction de Saadya. C'est en se fondant sur le contexte que Menaḥem ben Saruq lui reconnaît le sens de "est lié, est attaché".

Ignorant le sens de ce mot, Salmon ben Yeruham s'inspire du sens de "vigilance" en estimant que le 'śn' a peut-être ici la même valeur que le 'shin', puisque סריון et שריון s'emploient dans le même sens. David ben Abraham (II 347,16-22) s'oriente

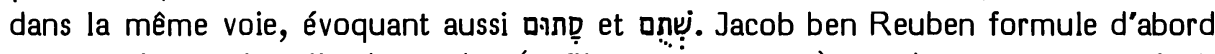
cette option, puis celle de Saadya (qu'il ne nomme pas), en donnant comme équi-

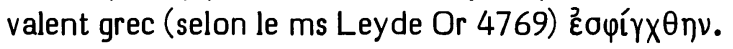


Tobia ben Eliézer mentionne les deux mêmes options et en ajoute une troisième : le 'dalet' tiendrait la place d'un 'resh'. Le sens serait : "marqué en rouge", comme en סקרו בסיקרא (Mishna Bekorot IX 7).

Rashi fait appel à l'araméen où l'on appelle l'aiguillon מסקדא (cf. Midrash Wayyiqra Rabba 675,7 et note de Margulies in loco; cf. note de Löw sur Krauss, Lehnwörter II 347b). Il en conclut que ce mot signifie que les péchés ont été marqués par Dieu avec un poinçon ("pointurés", dit-il en français), comme un mémorial, pour ne pas oublier leur nombre et leur rétribution. Les glossaires (ABDEF) suivent cette exégèse.

Dans le sens proposé par Saadya et retenu par Radaq, Ewald estime que le verbe ש doit être une expression technique pour "attacher" un joug au cou d'un animal. Cette interprétation a été adoptée aussi par Keil et Albrektson. Il n'y a rien de surprenant à ce que le sens de certains termes techniques de l'agriculture n'ait pas été préservé par une tradition ferme.

Comme Gerlach l'a fait remarquer, il ne faut pas considérer "le joug de mes révoltes" comme "le joug qui m'a été imposé à cause de mes révoltes', mais comme 'le joug formé de mes révoltes'. C'est-à-dire que ses révoltes sont les liens du joug. Les

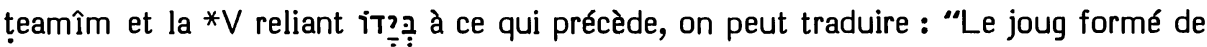
mes révoltes a été attaché par sa main".

14C évoque les Dalman (II 101) commente ce passage en disant que lorsque les liens du joug ne sont pas seulement liés mais entrelacés, ils résistent particulièrement bien aux efforts que la bête tentera pour secouer le joug. Il faut reconnaître ici à la forme hitpaèl une valeur réflexive : "elles (= mes révoltes) se sont entrelacées".

L'expression "yִ yִ étant une expression technique peut être traduit librement : "elles mont saisi le cou", avec une note : "littéralement : "elles sont montées sur mon cou', expression technique employée pour la fixation du joug".

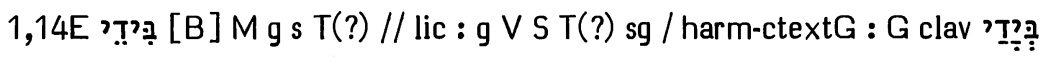

Options de nos traductions :

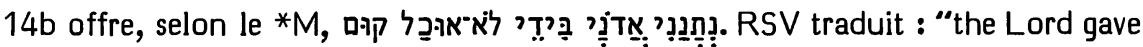
me into the hands of those whom I cannot withstand", RL : "Der Herr hat mich in die Gewalt derer gegeben, gegen die ich nicht aufkommen kann" et TOB : "Le Seigneur m'a livrée en de telles mains que je ne peux pas tenir debout".

A la place du 3e mot, J conjecture et traduit : "Le Seigneur m'a mise à leur merci, je ne puis plus tenir !"

Selon Brockington, NEB conjecture doned me to its hold, and I could not stand".

Origines des corrections :

La conjecture retenue par $\mathrm{J}$ a été proposée par Budde, Haller et les apparats de $\mathrm{BH} 3$ et de Cent. Celle de NEB s'en inspire probablement. 
Les témoins anciens :

L'ensemble des témoins anciens du *G, en accord avec la polyglotte d'Alcala et les éditions Aldine, Sixtine, Grabe, Swete et Rahlfs, offrent ici ótı ع̋ow

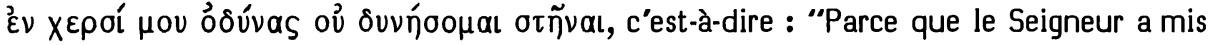
à ma disposition des douleurs, je ne puis résister". Pour rendre cela plus conforme au

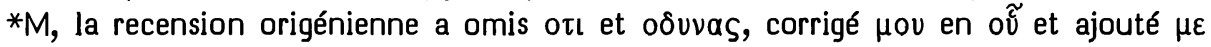
après le verbe initial. De ces différentes corrections (qui sont toutes connexes), Ziegler ne retient que l'omission de oovvas qu'il considère comme un doublet déformé des syllabes qui suivent. Il aboutit ainsi à un texte inintelligible qui a fort peu de chances d'être original. Mieux vaut admettre avec Scharfenberg (note 24 sur Cappel, Critica 518), Schleusner (IV 49), Rosenmüller et Gerlach que le traducteur a entendu, au lieu

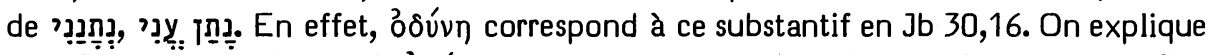
ainsi à la fois la présence de óóvias dans le *G et la non traduction du pronom suffixe du premier verbe. Cette erreur initiale du traducteur explique pourquoi il a vocalisé ensuite en pronom suffixe de la 1e pers. sg. la finale de $14 \mathrm{E}$.

La *V a traduit librement le *M par un singulier "in manu de qua". Quelques minuscules du *G ont aussi le singulier êv XEıpí.

La leçon originelle de la *S porte le singulier באידא, des témoins minoritaires et plus tardifs offrant le pluriel באידיד.

La tradition textuelle du *T est assez divisée. Le singulier est attesté par la tradition yéménite (ביד) et par les mss Urbinates 1, Milan ebr 5 et de Rossi 7 qui ont בידא Le pluriel est offert sous la forme בידי par le ms Copenhague hebr 11 et par la polyglotte de Londres, alors qu'il est offert sous la forme בידוי par le ms Hamburg hebr 4 et les éditions Félix de Prato, Ben Hayim, polyglotte d’Anvers et Miqraot Gedolot.

Choix textuel et interprétation proposée :

Le verbe קום construit avec l'accusatif signifie "faire face à quelqu'un" (Ex 15,

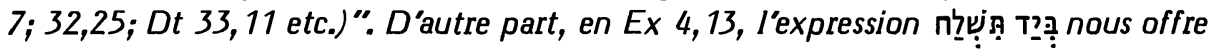
le singulier de l'état construit que le ${ }^{*} M$ porte en $14 E$ dans une construction identique : le complément d'objet direct sous-entendu du verbe qui suit l'état construit remplit la fonction de génitif à l'égard de cet état construit. Cela donne en Ex 4,13: "par l'intermédiaire (de celui que) tu enverras" et ici : "au pouvoir (de quelqu'un à qui) je ne puis faire face". Cette syntaxe elliptique est tout à fait classique (cf. Ewald, Lehrbuch 820; König, Syntax $\$ 337 v$; Gesenius/Kautzsch $\S 130 d$ ).

L'ajoute d'un pronom suffixe pluriel est ici une facilitation qui est 'dans l'air', comme le montre la traduction de la Geneva Bible : "the Lord hathe delivered me into their hands, nether am I able to rise up".

Voulant protéger contre cette facilitation l'excellente syntaxe du *M, le comité lui a attribué la note “B". 


\section{1,16 و g Sym S T / hapl : m G V}

Options de nos traductions :

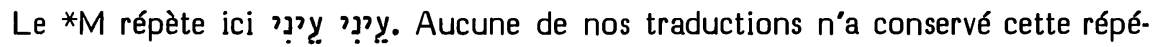
tition.

En la mentionnant en note, 33 traduit librement: "mes yeux". Traduisent de même sans note : RSV "my eyes" et TOB "mes deux yeux".

J1 disait omettre la répétition en traduisant : "mon oeil". RL traduit de même : "und mein Auge".

Selon Brockington, NEB corrige la première occurrence en بִִِ̣ qu'elle relie à ce qui précède en traduisant : "I weep over my plight".

\section{Origines des corrections :}

Houbigant diagnostique ici une dittographie accidentelle, suivi en cela par Pareau, Thenius, Budde (Klagelied 10, 267), Dyserinck, Löhr, Bickell, Oort, Kelso, Paffrath, Rudolph (Text 104), Haller, Nötscher, Dennefeld, Penna, Wiesmann, Weiser, Kraus, Albrektson, Plöger, Hillers, Kaiser et par les apparats de HSAT234, BH23S et Cent.

\section{Les témoins anciens :}

De Rossi signale la non répétition de ce mot en 4 mss collationnés pour Kennicott, en la 1e main d'un ms de sa propre collection et dans toutes les versions anciennes.

Une $\mathrm{mp}$ du $\mathrm{ms}$ de Leningrad atteste que la répétition de ce mot est unique dans l’Ecriture. Une mm (Weil $\$ 2501$ et Ginsburg, Massorah y§284) mentionne les 29 emplois de cette forme dans la Bible en spécifiant qu'elle figure deux fois en ce verset.

De Rossi a tort de dire que toutes les versions anciennes omettent cette répétition.

Lorsque le *T donne: "et mes deux yeux", il entend exprimer cette répétition comme, plus tard, Luther le fera: "und meine beide Augen".

Si les témoins du ${ }^{*} G$ ancien et de la $* V$ s'accordent pour ne pas répéter "mon oeil", la recension origénienne répète cette expression.

Sym, en ajoutant à la traduction du *G דלא שלִיא (= sans cesse), entend aussi rendre cette répétition, ainsi que Ceriani (Prolegomena 22s) l'a noté. Geiger (Sym-

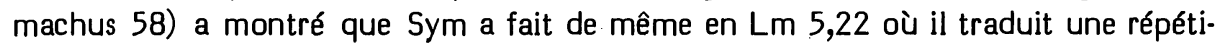
tion du verbe מאס par: "si tu continues à nous mépriser". Ajoutons que la tradition exégétique représentée par Sym sera attestée plus tard par Salmon ben Yeruḥam et par Rashi qui attribuent à la répétition de "mon oeil" la valeur de : "sans cesse" (alors que Saadya lui reconnaît le sens de "fréquemment").

Albrektson dit que la *S semble n'avoir lu qu'une fois "mon oeil". En effet, la présence des seyamé sur ijì peut constituer une donnée textuelle fragile. Mais le fait que le participe qui suit (מרדין) est clairement au pluriel indique que le traducteur syriaque a voulu exprimer par ce pluriel la répétition du substantif. En cela il s'accorde, comme souvent, avec la recension antiochienne, telle que Théodoret et quelques

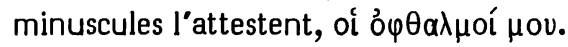


Choix textuel :

Le comité a attribué au *M la note " $\mathrm{B}$ ". Il a estimé en effet plus probable que la répétition est ici primitive. Les témoins qui ne l'attestent pas ou bien ont été victimes d'une haplographie ou bien ont voulu simplifier en traduisant.

L'auteur des Lamentations nous présentera en 3,51 son oeil comme lui faisant mal, à force de pleurer. En 2,11, il dira que ses yeux s'épuisent dans les larmes. D'autre part, on retrouve en 3,48 "mon oeil" comme sujet du qal de ירד ayt pour complément d'objet "des ruisseaux d'eau". Enfin, on rencontre en Jr 4,19 "mes entrailles, mes entrailles" (qui servent de parallèle à "mes yeux" en Lm 2,11), la répétition évoquant la douleur causée.

Ici, nous n'avons pas une véritable répétition, puisque seule la première occurrence est à l'état absolu (évoquant la douleur), alors que la seconde a fonction de sujet dans une phrase explicitant le motif de la douleur. König (Stilistik 301s) a relevé de nombreux cas de répétitions inauthentiques (où les deux mots identiques juxtaposés ont des fonctions différentes).

Interprétation proposée :

On pourra donc traduire : "Mon oeil ! mon oeil répand des eaux".

Il est intéressant de noter que Budde (Klagelied 10), Dyserinck et Löhr estiment améliorer la métrique en ne répétant pas ce mot. Cependant, Budde (KHC) estime que ce raccourcissement ne suffit pas pour rétablir le rythme de la qinah. En effet, Meek précise que cette omission aboutit à une structure " 3 et 3" qui n'est pas une variante du mètre de la qinah. Aussi conclut-il que le maintien de la répétition est favorisé par le fait qu'elle permet d'obtenir le rythme " 3 et 2 et 2 " qui est une variante de ce mètre.

1,19b [B] M g V T // glos : G S clav add ולא מצאו

Options de nos traductions :

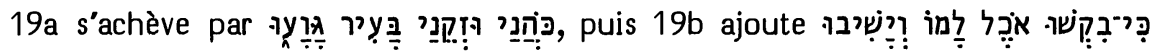

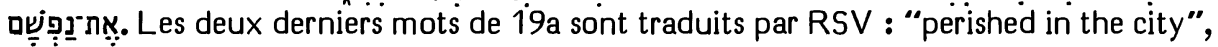
par J : "expiraient dans la ville", par RL : "sind in der Stadt verschmachtet" et par TOB : “ont expiré dans la Ville".

Selon Brockington, NEB se réfère au *G pour ajouter, à la fin de 19a, quand elle traduit: "my priests and my elders in the city went hungry and could find nothing, although they sought etc."

Origine de la correction :

Thenius se demande si ce 'plus' du *G n'appartient pas au texte original. Il est adopté comme tel par Dyserinck, Budde (Klagelied 267), Löhr, Bickell, Haller, Kraus et par les apparats de $\mathrm{BH} 23$ et Cent. Tous ces critiques ont adopté ce 'plus' à la place des trois derniers mots de $19 \mathrm{~b}$. 
Les témoins anciens :

L'obèle de la recension origénienne montre que xaì oủx eũ̃pov n'avait pas de Vorlage dans l'hébreu auquel Origène avait accès. Ce 'plus' se trouve aussi dans la *S . - (לא אשכחו

Il n’est attesté ni dans la *V, ni dans la paraphrase du *T.

\section{Choix textuel :}

On ne voit pas par quel processus les mots ולא מצאו auraient disparu du texte prémassorétique et y auraient été remplacés par les trois derniers mots du $* M$, alors que ces trois mots sont attestés par la tradition textuelle unanime.

C'est par pure conjecture que NEB transfère le 'plus' du *G à la fin de 19a en traduisant inexactement

Il est frappant que, dans le lemme de son commentaire, Saadya (selon le ms Cambridge, T.S. Ar 28.41) introduit פלם ביגדו à l'endroit où NEB le conjecture; alors que Salmon ben Yeruḥam introduit la même glose là où le *G et la *S la placent. Cela montre que cette glose est 'dans l'air'.

Le comité a attribué ici au *M 4 "B" et 2 "A".

Interprétation proposée :

“Je fais appel à mes amants :

ce sont eux qui m'ont trompée!

mes prêtres et mes anciens :

en pleine ville ils se meurent,

car ils se cherchaient de la nourriture

pour ranimer leur vie."

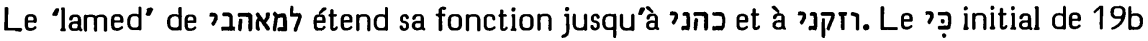
ne vise pas à expliquer pourquoi ils se meurent (ce qui requerrait la mention de l'échec de la tentative), mais à expliquer pourquoi c'est en pleine ville qu'ils se meurent : ils ont dû sortir de chez eux pour essayer de trouver de la nourriture.

\section{1,21A שִׁמעו [C]}

Options de nos traductions :

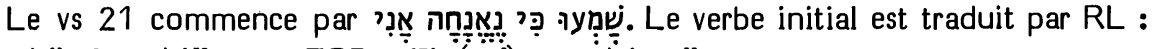
"Man hört's wohl" et par TOB : “Ils ( $\left.\mathrm{m}^{\prime}\right)$ entendaient".

RSV, disant suivre le ${ }^{*} G$ et la ${ }^{*} S$, traduit : "Hear" dans un contexte qui suggère une valeur plurielle pour cet impératif.

Selon Brockington, NEB lit yֵַ avec la *S quand elle traduit : "Hear (me)". J fait de même en traduisant : "entends(-moi)".

\section{Origines des corrections :}

Une correction en impératif pluriel a été proposée par Dyserinck, Budde (Klagelied 267), Oort. 
L'impératif singulier a été préféré par Löhr, Abelesz (34), Budde (KHC), Rudolph (Text 105), Haller, Nötscher, Wiesmann, Weiser, Kraus, Plöger, Hillers, Gordis et les apparats de HSAT34, BH3S et Cent.

Les témoins anciens :

Le *G traduit par ảxoúỡ ${ }^{*}$ ón.

La *S donne שמע. Gottlieb (21, n.88) relève plusieurs exemples d'usages indifférents des formes קטלו par la *S (selon le ms Ambrosianus) pour le sg. ou le pl. et il en conclut que la $* S$ offre une base trop fragile pour une correction en singulier ici. Nöldeke' (Grammatik §50) signale, même dans des mss très anciens, l'omission du 'wau' final du pluriel dans le parfait et l'impératif après une consonne (position où il n'était plus prononcé).

Pour Aq, Syh donne שמ̣̂ en marge. Cette leçon est rigoureusement identique à celle qu'elle donne dans son texte pour le ${ }^{*} G$. Field semble pourtant avoir raison d'adopter la suggestion de Ceriani (Prolegomena 24): cette scholie veut suggérer qu'une leçon $\eta^{\prime} x o v o a v$ correspond en $A q$ à celle du *G.

La *V, avec "audierunt", vocalise comme le *M. Le *T vocalise de même avec שמעו אומיא ménite.

Choix textuel :

Il se peut que la vocalisation en accompli assimile à la ligne suivante. Il se peut aussi que la vocalisation en impératif (avant ’כ̣) assimile au vs précédent qui commence par un impératif avant cette même conjonction.

Pareau, favorable à la leçon du *M, signale des reprises emphatiques de la même forme verbale à la ligne suivante, en 3,43s.59s, où il s'agit aussi d'accomplis.

En ce domaine où la certitude est faible, le comité a attribué à la leçon du *M la note "C".

Interprétation proposée :

Le premier accompli a pour sujet les passants. Celui de la ligne suivante a pour sujet ses ennemis :

“On m'entendait gémir...

pas un ne me consolait.

Tous mes ennemis ont entendu parler de mon malheur...

ils se sont réjouis de ce que tu as fait."

\section{1,21B הַבְבָאת [B] M G V T // facil-styl : S imper}

Options de nos traductions :

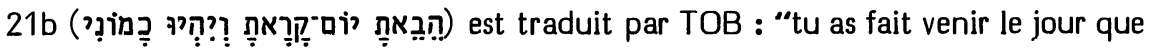
tu avais fixé. Qu'eux aussi soient comme moi !"

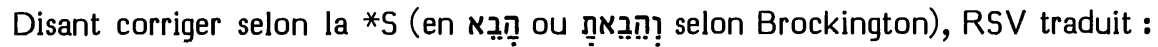
"Bring thou the day thou hast announced, and let them be as I am", J : "Fais venir 
(J1 : Amène) le jour que tu avais proclamé, pour qu'ils soient comme moi !", NEB : "but hasten the day thou hast promised when they shall become like me". RL traduit de même : "So lass doch den Tag kommen, den du verkündet hast, dass es innen gehen soll wie mir."

Origine de la correction :

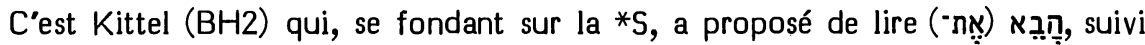
en cela par Perles (II 26), Rudolph (Text 105), Haller, Nötscher, Penna, Weiser, Kraus, Plöger et par les apparats de BH3S.

Les témoins anciens :

Ont traduit ce verbe par un passé : le *G ė̃ńrayes, la *V “adduxisti” et le *T איתיתא. -

La *S l’a traduit par l'impératif איתא.

\section{Choix textuel :}

RL n'a fait ici que copier Luther : "So las doch ... komen". Vatable estimera possible cette traduction du *M. Zwingli (adduces) et les Prédicants de Zurich (du wirst ... bringen) ont traduit par un futur, ainsi que le feront $\mathrm{Ge}$ et $\mathrm{KJ}$ (thou wilt bring), Tremellius (adduces) et les Pasteurs de Genève (tu ameneras).

Les exégètes juifs médiévaux se divisaient déjà entre trois exégèses :

- une exégèse en optatif-déprécatif : Saadya, Rashi, Ibn Ezra et Tanḥum Yerushalmi, - une exégèse en accompli prophétique : Tobia ben Eliézer,

- une exégèse en passé : Joseph Qara.

Ces trois exégèses étaient, dès le début du Xe siècle, considérées par Salmon ben Yeruḥam comme traditionnelles : "Et pour ce qu'il dit : הבאת יום קראת ויהיו כמוני, il y a trois interprétations.

Le premier sens, c'est qu'ils ont dit : “O Seigneur, tu as déjà fait venir sur Israël le jour que tu avais annoncé, c'est-à-dire le jour de la Galut, comme dit l'Ecriture : 'Ma colère s'enflammera contre lui, ce jour-là' (Dt 31,17). Et maintenant, qu'ils deviennent comme moi, que vienne sur eux tout ce dont tu les as menacés, comme il est dit : 'Ceux qui n'avaient pas été condamnés à boire la coupe l'ont bien bue. Et toi, serais-tu donc quitte ? Tu ne seras pas quitte : tu la boiras certainement' (Jr 49,12)."

Le deuxième sens, c'est : "Il est venu sur eux le jour que tu avais annoncé et ils deviendront comme moi, ainsi que tu l'avais promis en disant : 'Car un jour de vengeance est dans mon coeur' (Is 63,4). Et tu as dit : 'Au jour où je me lèverai enfin, car j'ai décidé de rassembler les nations' (So 3,8)."

Et le troisième sens, c'est qu'ils ont dit : "Puisses-tu faire venir sur ces ennemis tous les fléaux dont tu les as menacés et les réduire à l'impuissance comme je le suis, alors qu'eux sont en train de se réjouir tandis que les Israélites qui sont avec eux sont malheureux. Et comme le disait la femme cruelle : 'Qu'il ne soit ni à moi ni à toi ! Tranchez!'(1 R 3,26)."

Considérant comme possible que la $* S$ représente ici non une variante mais cette dernière exégèse, le comité a attribué au *M4 " $B$ " et 2 " $A$ ". 
Interprétation proposée :

Les $2 e$ et $3 e$ sens de Salmon sont 'dans l'air' comme des facilitations évidentes. Mais en cette lamentation $(1,12)$, "le jour" est celui de la colère de Dieu contre son peuple et le "moment fixé" (1,15), celui de son écrasement (cf. 2,22). C'est le jour dont les ennemis espéraient la venue $(2,16)$. Ce contexte favorise le premier sens proposé par Salmon (et adopté par Gerlach, Albrektson et Meek). Il permet de conserver à cet accompli la valeur de celui qui le précède immédiatement. Cela implique que les deux derniers mots, formant contraste, introduisent le développement du vs 22a :

“Tu as fait venir le jour que tu avais proclamé, mais ils deviendront comme moi.

(22) Toute leur méchanceté viendra devant toi et traite-les

comme tu m'as traitée à cause de toutes mes révoltes."

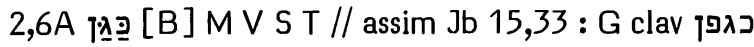
2,6B מד: מA $[$ i ] M G V S // paraphr : T

Options de nos traductions :

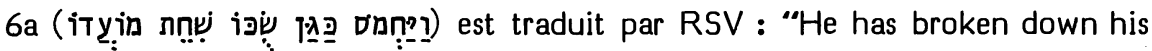
booth like that of a garden, laid in ruins the place of his appointed feasts", par J : "Il a forcé comme un jardin son enclos, démoli (J3 : abattu) son lieu de réunion (J1 : rencontre)", par TOB : "Il dévaste et le Jardin, et sa Cabane; il ravage son lieu de Rendez-vous".

Selon Brockington, NEB corrige avec le ${ }^{*} \mathrm{G}$ 的 stripped his tabernacle as a vine is stripped, and made the place of assembly a ruin".

RL traduit: "Er hat sein eigenes Zelt zerwühlt wie einen Garten und seine Wohnung vernichtet."

Origines des corrections :

Cappel (Critica 648) a fait remarquer que le ${ }^{*} G$ a lu dans sa Vorlage la leçon que NEB retiendra pour $6 \mathrm{~A}$. Celle-ci a été adoptée par Schleusner (Curae), Ewald, Löhr, Praetorius (144s), Budde (KHC), Driver (Once 80) et par l'apparat de BHS.

On pourrait penser qu'en 6B, RL a lu ụִ comme l'apparat de BH3, se fondant sur la $* V$, le propose. Mais RL a conservé ici la traduction de Luther: "seine Wonunge". C'est probablement lui qui s'est inspiré de la $* V$ pour traduire ainsi.

Les témoins anciens :

Le *G traduit 6 A par $\stackrel{\omega}{*}$ ă $\mu \pi \varepsilon \lambda o v$.

Le *M a été traduit par la *V (quasi hortum), la *S (איך גנתא) et le *T (כגינתא).

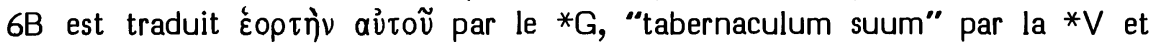

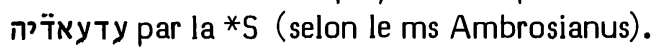

Le *T paraphrase : "le lieu destiné à faire l'expiation pour son peuple". 
Choix textuels et interprétation proposée :

Le ${ }^{*} G$ et la $* S$ ont interprété $6 B$ en un sens temporel de 'fête(s)', alors que la $* V$, le *T (et Luther) l'ont compris en un sens local (en s'inspirant de Tỵin מִ̣ik) comme : 'le lieu où il rencontre (son peuple)'. Il ne s'agit là que d'une question d'exégèse. Aussi le comité a-t-il attribué au *M la note " $A$ ".

Etant donné la similitude entre ${ }^{\lambda}$ et $\lambda$, il est probable que le ${ }^{*} G$ a lu dans sa Vorlage (peut-être sous l'influence de Jb 15,33) la leçon כגפן. Notons d'abord que ce

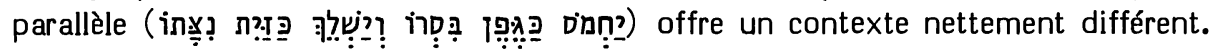
Ensuite, si l'on admet qu'en Lm 2,6 le sens du verbe initial doit être : "abattre brutalement", Robinson a objecté à cette correction que l'on ne voit pas en quoi une vigne (ou un vignoble) pourrait constituer un exemple typique de quelque chose que l'on abat ainsi.

Le plus ancien exégète littéral juif dont l'interprétation nous ait été conservée est Judah ben Qoreish (Bargès 108s = Katz 202). Il comprend : "il l'a dégarni de sa haie comme on enlève la haie d'un jardin". David ben Abraham (I. 560,60s) interprète lui aussi : "il ôte la haie et rend accessible le verger".

Le sens de "haie" a été donné aussi à đִ̣ par C.B. Michaelis, rapprochant ce mot de ingẹ: (Is 5,5), interprétation adoptée par Pareau et Rosenmüller.

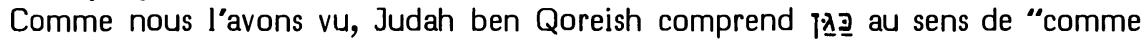
d'un jardin" (et non de "comme un jardin"). A cette interprétation, Thenius objecte que, dans les exemples que l'on peut donner pour l'ellipse d'un état construit entre la préposition 'kaf' et un substantif, le mot servant de terme de comparaison (dont la reprise fait l'objet de cette ellipse) précède la comparaison où a lieu cette ellipse, ce qui lui permet de servir de clé pour la résoudre. Cette affirmation est inexacte. En effet, König (Stilistik 206, 14-36) fait alterner les cas où l'ellipse suit l'expression du mot et ceux où elle la précède. Parmi ces derniers, on peut noter comme parallèle caractéristique de notre cas (cf. König ibid. 204,1) : :

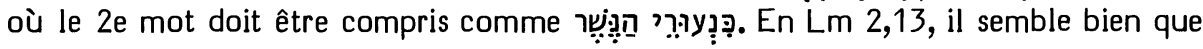

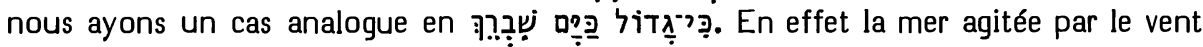
est cause du "brisement" des vaisseaux de Tarsis (Ps 48,8) ou du "brisement" de Tyr

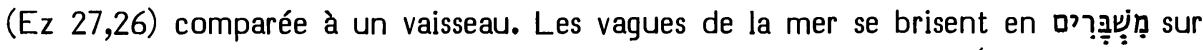
le rivage. On peut donc comprendre note) avait déjà relevé ce genre d'ellipse comme typique de la poésie hébraïque.

On peut donc considérer comme syntaxiquement satisfaisante une traduction: "Il a démantelé sa haie comme on démantèle celle d'un jardin". A la différence d'un vignoble qui demande plusieurs années pour porter son fruit, un jardin ne constitue pas une plantation durable. On peut planter en jardin une pièce de terre pour un temps limité. Durant ce temps, on l'entoure d'une haie protectrice. Si l'on décide ensuite de mettre en culture une autre pièce de terre et de laisser reposer la première, on enlève la haie. Il s'agit ici probablement d'une haie d'épines entrelacées du type décrit par Sonnen (84).

L'auteur veut donc dire ici que le Seigneur démantèle les enclos des parvis sacrés à la manière d'un paysan qui démantèle la haie d'épines sèches d'une terre dont il interrompt la culture.

En 6A, le comité a attribué au *M 4 " $B$ " et 2 " $C$ ". 


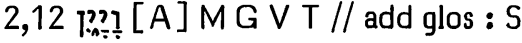

Options de nos traductions :

Dans ce vs, les enfants et les nourrissons demandent à leurs mères Ces mots sont traduits normalement par RSV, RL, NEB et TOB.

Le dernier mot est omis par J.

Origine de la correction :

Ont proposé d'omettre ce mot (comme déplacé dans la bouche de petits enfants) : Budde (Klagelied 9 et 269), Löhr, Haller, Kraus et les apparats de HSAT34, BH23 et Cent.

\section{Les témoins anciens :}

Ce mot est attesté par le ${ }^{*} G$, la $* V$ et le $* T$.

La *S y ajoute même ומשחא qui est le correspondant normal de

Choix textuel :

Rudolph (Text 107) a fait remarquer qu'à l'époque biblique on n'avait pas idée de la nocivité de l'alcool pour les enfants. Wiesmann ajoute qu'en certains pays de vignobles on sert du vin aux petits enfants. Il n'y a donc aucune invraisemblance à ce que le vin soit mentionné ici.

La séquence été choisie à cause de la séquence de quatre "â" qu'elle offre.

Aucun témoin ne s'opposant au *M, le comité lui a attribué la note " $A$ ".

2,13A cf. p. 805.

2,13B מה אשוה־לך ואנחמך [A ] MV S T // lic : G

Options de nos traductions :

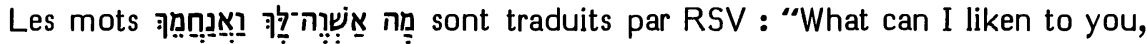
that I may comfort you", par RL : "wem soll ich dich vergleichen, damit ich dich tröste", par NEB : "To what can I compare you for your comfort" et par TOB : "Qu'égalerai-je à toi afin de te consoler".

J se fonde sur le ${ }^{*} G$ pour traduire : "qui pourra te sauver et (J3 : et te) consoler".

Origine de la correction :

Cappel (Notae 540b) avait estimé que le ${ }^{*} G$ (qu'il lisait tiৎ oẃoદl) semblait avoir lu en sa Vorlage. Schleusner (Curae) était d'accord avec ce diagnostic.

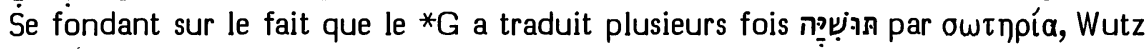
(240 et 317) suggère que cette version a lu en sa Vorlage une permutation du 'waw' et du 'shin', אִ leçon qui a été adoptée ici par Paffrath. Haller préfère corriger en

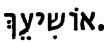




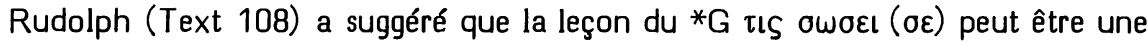

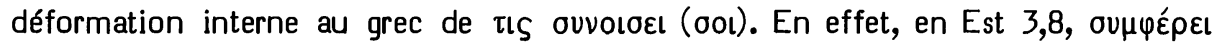
correspond à nịֶ.

Les témoins anciens :

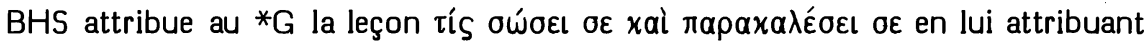

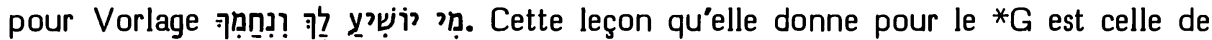
Rahlfs basée sur tous les mss (certains omettant le premier o $\sigma$ et d'autres insérant un

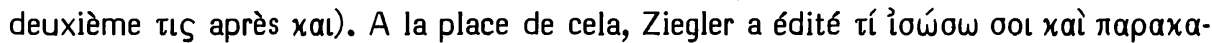

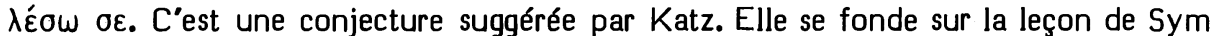

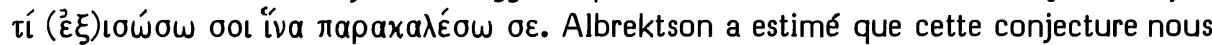
offre certainement la leçon originale du ${ }^{*} \mathrm{G}$.

La leçon de Sym ne nous est connue que par Syh où elle est référée par erreur à la première ligne du vs. Cependant, la rétroversion de Field est fort probable. Par contre, la conjecture de Katz supposerait que la leçon originelle du ${ }^{*} G$ ait subi ensuite

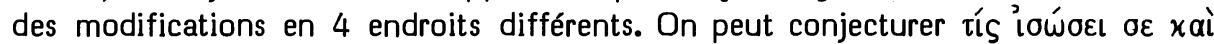

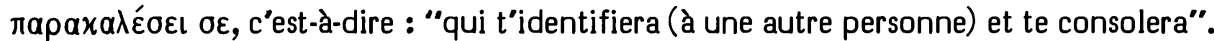
Il suffirait alors de l'omission d'un 'iota' pour expliquer l'état actuel des témoins du *G. Cela supposerait en outre que le traducteur grec ait pris la liberté de traduire deux premières personnes par des troisièmes personnes, ce qui n'excède pas les initiatives que l'on peut imputer à ce traducteur, pourtant assez littéral.

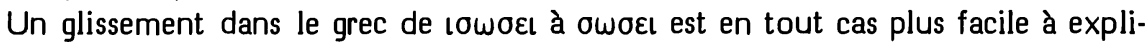
quer qu'un glissement en hébreu de la leçon proposée par Haller à celle que porte le *M.

Considérant que $l e{ }^{*} G$ originel n'est rien d'autre qu'une traduction libre du ${ }^{*} M$, le comité a attribué à celui-ci la note " $A$ ". En effet, les autres témoins le traduisent fidèlement.

Interprétation proposée :

Comme nous l'avons indiqué ci-dessus, p. 376 : “Qu’égalerai-je à toi pour que je te console?"

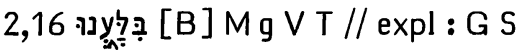

Options de nos traductions :

Les ennemis menaçants ont dit ב. Ce mot est traduit par TOB : "Nous engloutissons".

Sans note, RSV traduit : "We have destroyed her", J : "Nous l'avons engloutie" et $\mathrm{RL}:$ " $\mathrm{Ha}$ ! wir haben sie vertilgt".

Selon Brockington, NEB vocalise

Origines des corrections :

Une correction en Kelso, Haller, Penna, Wiesmann et par les apparats de $\mathrm{BH} 23$.

La vocalisation de ce verbe en qal a été proposée par Albrektson. 
Les témoins anciens :

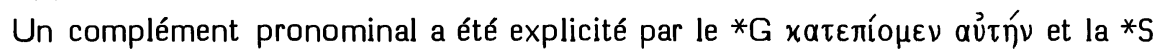
בלענה.

L'absence de complément a été respectée par l'obèle de la recension origénienne, par la *V "devoravimus" et par le *T (selon la tradition occidentale שיצינא et selon la tradition yéménite חבלנא "חסלנא).

\section{Choix textuel :}

Déjà au XVIe siècle, on voit se distinguer les traducteurs qui n'explicitent aucun complément (Pagnini, Prédicants, Zwingli, Brucioli, Münster, Olivetan, Estienne, Calvin, Jud, Arias Montano, Tremellius) de ceux qui en explicitent un : Luther (Heh, wir haben sie vertilget), Châteillon (Nous l'avons engloutie), Geneva (Let us devoure it), Pasteurs (Nous les avons abismés) et $\mathrm{KJ}$ (We have swallowed her). D'ailleurs quelques témoins de la $* \mathrm{~V}$ avaient, eux aussi, ajouté un complément "eam". Une telle explicitation constitue une facilitation qui est 'dans l'air'. Contre cette facilitation, notons que le piél de ce même verbe est déjà apparu en 2,2 et en 2,8 sans complément.

Quant à la vocalisation de ce verbe en qal, elle a son origine dans la suggestion faite par Jacob (Erklärung, 287) de rattacher certains emplois de ce verbe hébreu à la racine arabe בלג = "atteindre". Cette suggestion a été adoptée par Driver (Studies IV 40s; Hebrew Notes I 52s) et Guillaume (Note). Albrektson semble avoir été le premier à y rattacher Lm 2,16, alors que KBL et HALAT (qui ont intégré la suggestion de Jacob) le rattachent au sens le plus courant de "engloutir".

Aucun des lexicographes judéoarabes ne semble avoir eu l'idée suggérée par Jacob (alors que tous, depuis Judah ben Qoreish, Bargès $65=$ Katz 108, rattachent ce verbe à la racine arabe בלע (בל ). Cependant la plupart d'entre eux distinguent de "engloutir" un autre sens: "détruire". C'est le cas de David ben Abraham (I 233,155), d'Abulfaradj Harûn (fol 24a) et d'Abulwalid (Ușul 96,28). Ici Saadya et Salmon ben Yeruham reconnaissent ce deuxième sens, le premier explicitant un pronom suffixe (אהלכנאהם selon le lemme du commentaire et l'édition Ratzaby de la traduction, selon l'édition Kafạ de la traduction), le second respectant l'absence de complément.

Schüpphaus (ThWAT I 659) est d'ailleurs sceptique sur le rattachement à l'arabe בלג de certains emplois de l'hébreu בל est partagé par Gottlieb.

Pour ce qui est de l'emploi du piél de ce verbe au vs 16, il est évident qu'ici où il a pour sujets les ennemis de Jérusalem, il fait écho au vs 5 où il a pour sujet "le Seigneur comme un ennemi" et au vs 2 où il a pour sujet "le Seigneur". Au vs 2, il a pour parallèle הִ הִ ex et au va vadya et Salmon ont donc raison de lui donner en ces trois endroits le sens de "détruire".

Il semble d'ailleurs que ce sens soit dérivé du sens de "engloutir" en passant par les images de l'engloutissement par la terre ( $\mathrm{Nb}$ 16,30.32.34) ou par le shéol ( $\mathrm{Pr}$ 1,12) ou par l'abîme (Ps 69,16) ou par le monstre (Jr 51,34). En ce vs 16 qui a com-

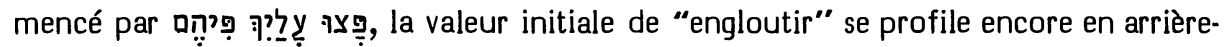
fond. Par contre, en 2,8, la mention de la "main" montre que le sens de "détruire" a acquis son autonomie. Il y a donc glissement d'un sens vers l'autre. 
Le comité a attribué ici au *M la note "B".

Interprétation proposée :

"Nous avons détruit". Cet accompli envisage comme déjà accomplie l'action dont la réussite est certaine.

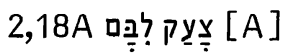

Options de nos traductions :

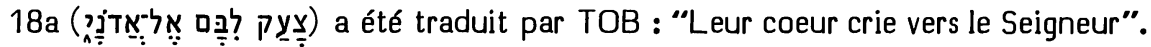

Disant conjecturer, RSV traduit: "Cry aloud to the Lord!" RL traduit de même : "Schreie laut zum Herrn".

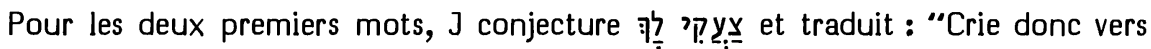
le Seigneur".

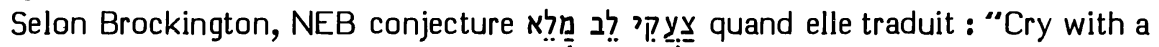
full heart to the Lord".

Origines des corrections :

Schleusner (Curae) a proposé de lire le premier verbe en impératif adressé à la "fille Sion" (sans tenir compte du 2e mot). Kaiser.

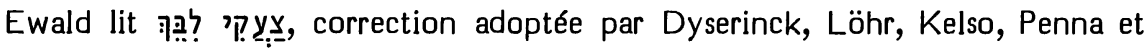

Bickell a proposé Dennefeld, Weiser, Plöger, et par les apparats de $\mathrm{BH} 23$ et de Cent.

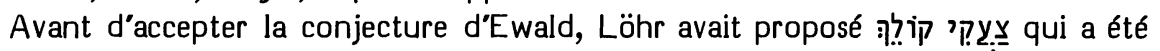
adopté par Oort et par les apparats de HSAT234.

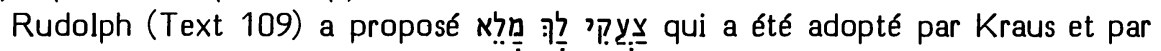
l'apparat de BHS.

La conjecture retenue par NEB vient de Driver (Once 92).

Les témoins anciens :

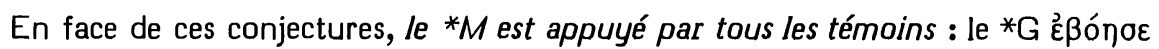

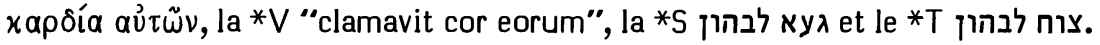

Choix textuel :

Le comité a attribué au *M la note " $A$ ".

Interprétation proposée :

Voir le cas suivant. 
Options de nos traductions :

Avant deux impératifs f. sg. (אַ), 18b commence par un vocatif 政 par TOB : "Rempart de la Belle Sion" et par J3 : "rempart de la fille de Sion".

Omettant par conjecture le premier mot, RSV traduit : "O daughter of Zion". RL traduit de même : “du Tochter Zion".

A la place de ce mot, $\mathrm{J12}$ conjecturaient הֶֶֶ.

Origines des corrections :

Houbigant avait conjecturé בתולת à la place de ce mot. Schleusner (Curae) avait estimé que presque personne n'approuverait cette conjecture. De fait, elle a été adoptée par Dyserinck, Bickell, Löhr, Oort, Dennefeld, Penna et par les apparats de HSAT234, BH2 et Cent.

La conjecture retenue par $\mathrm{J12}$ a été proposée par Budde (Klagelied 270), Rudolph (Text 109), Haller, Nötscher, Weiser, Kraus, Plöger et Kaiser.

L'omission de ce premier mot a été proposée par Börmel (cité par Pareau).

Les témoins anciens :

Au singulier ou au pluriel, le mot "rempart" est attesté par tous les témoins.

Omettant le mot suivant, le ${ }^{*} G$ traduit $\tau \varepsilon i ́ x \eta C l \omega \nu$. La recension origénienne met ce mot au singulier $\tau \varepsilon i ̃ x o \zeta$ et elle s'accorde avec la recension antiochienne pour

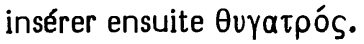

Si le *G s'accorde avec le *M pour demander au rempart de laisser couler un torrent de larmes, cette audacieuse prosopopée a paru inacceptable à la $* \mathrm{~V}$ et à la ${ }^{*} \mathrm{~S}$. C'est pourquoi la $* V$ a explicité une préposition avant ce mot: "clamavit cor eorum ad Dominum super muros filiae Sion", tandis que la *S fait de ce mot le génitif de celui qui le précède מריא דשורא דברת צהיון.

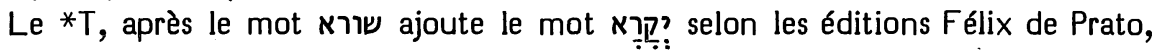
Ben Hayim, polyglotte d’Anvers et Miqraot Gedolot ou le mot Telon la polyglotte de Londres. Ce sont des corruptions de la leçon mss Urbinates 1, Milan 5, de Rossi 7 et Copenhague 11, ainsi que la tradition yéménite; alors que le ms Hamburg 4 donne le mot

\section{Choix textuel :}

Alors que deux membres du comité donnaient au ${ }^{*} M$ la note " $C$ ", les quatre autres, avec la même note, se fondaient sur le ${ }^{*} \mathrm{G}$ pour omettre le mot $ת$, estimant que le ${ }^{*} \mathrm{M}$ a assimilé ici à 2,8 où il offre aussi, comme le ${ }^{*} G$, à la fin de la première ligne, les trois mêmes mots חומת בת־ציון.

Il a été dit en 1,4 et 2,8 que les routes de Sion, son glacis et son rempart sont en deuil. Is 14,31 dit : "Lamente-toi, porte ! clame, ville !" En Ha 2,11, "la pierre crie du mur et, de la charpente, la poutre lui répond". Une invitation à répandre des larmes adressée au rempart de Sion n'a donc rien d'invraisemblable. Dans la suite, c'est Sion elle-même qui se dessine derrière ce vocatif : "rempart de Sion !", ce que facilite le fait que המ̣in est féminin. 
Interprétation proposée :

Le vs 18 est en ce livre le seul cas où l'atnah figure au milieu de la première ligne d'une strophe de trois lignes. Comme Nägelsbach l'a suggéré, c'est parce que 18a a, en cette deuxième lamentation, le rôle d'un élément de transition. On peut, en effet, diviser ce poème en quatre parties :

- du vs 1 au vs 12, l'auteur parle de Sion à la 3e personne;

- du vs 13 au vs 17, il s'adresse à elle pour tenter de la consoler en l'éclairant sur les motifs des malheurs qui la frappent;

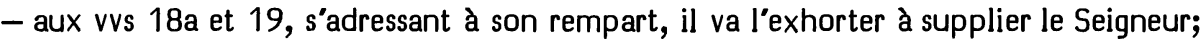
- les vss 20 à 22 expriment cette supplication.

On peut donc considérer 18a comme une introduction à ce qui suit. Ce "Leur coeur a crié vers le Seigneur" constitue un sommaire anticipé des 3e et 4e parties de cette lamentation. Ensuite commence la prosopopée audacieuse et grandiose. On pourra donc traduire :

"Leur coeur a crié vers le Seigneur -

Rempart de Sion,

laisse couler tes larmes comme un torrent,

jour et nuit.

Ne t'accorde pas de relâche,

que ta prunelle soit sans repos."

2,19 cf. p. 866.

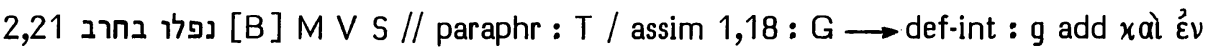
$\lambda \iota \mu \tilde{\omega}$

Options de nos traductions :

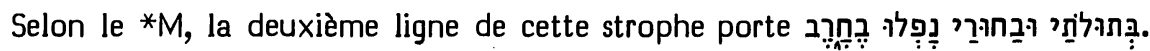
Cette phrase, qui ne fait pas difficulté, est traduite normalement par RSV, J, RL et TOB.

Selon Brockington, NEB, en se référant au ${ }^{*} G$, ajoute à la fin de cette ligne

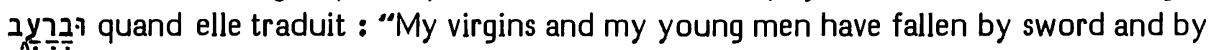
famine".

Origine de la correction :

C'est Wiesmann qui a estimé, en se référant à 4,9, que ce mot peut fort bien être originel et qu'il offrirait un complément bienvenu à cette ligne un peu courte.

Les témoins anciens :

Jusquà Rahlfs inclus, les éditions du *G donnaient, pour cette ligne de l'hébreu et pour le verbe initial de la ligne suivante, $\pi \alpha \rho \theta \varepsilon ́ v 0 \iota$

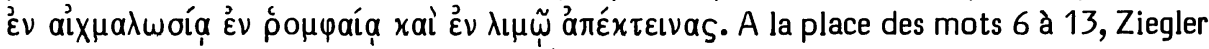

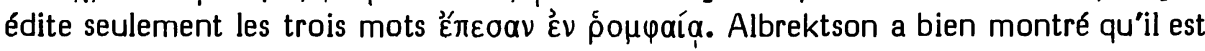


imprudent de corriger ainsi le texte offert par tous les témoins du ${ }^{*} G$, et cela sur la seule base d'une leçon marginale anonyme de Syh.

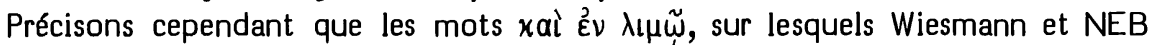
fondent leur ajoute, sont absents du papyrus de Würzburg (Ranke, Par 98), seul témoin ici de la Vieille Latine, ainsi que des deux seuls témoins que nous possédons de la Sahidique : un fragment publié par Deiber (562) et le papyrus Bodmer XXII/Mississipi II (204). Ces deux témoins, issus d'états anciens du *G, s'accordent sur cette omission. Cela permet de suggérer que ces mots constituent dans la tradition grecque une ajoute secondaire qui a eu lieu sous l'influence des très nombreux parallèles de Jérémie où "par la famine" s'ajoute à "par l'épée". Quant aux recensions origénienne et antiochienne, elles omettent à la fois la mention de l'épée et celle de la famine.

La leçon marginale anonyme de Syh provient probablement de l'une des colonnes hexaplaires.

Le * $M$ est traduit littéralement par la *V "ceciderunt in gladio" et par la *S נפלו בחרבא. Il est paraphrasé par le *T : “sont tombés tués par l'épée".

\section{Choix textuel :}

Le fait que les deux premiers mots de cette $2 e$ ligne de 2,21 sont exactement identiques à ceux de la 3e ligne de 1,18 a amené le ${ }^{*} G$ a assimiler la fin de cette ligne-ci à la fin de celle-là. Par contre, la fin donnée par le *M à la 2e ligne de 2,21 n’a aucun parallèle dans les Lamentations.

Le comité a donc attribué au *M la note “ $B$ ".

\section{3,5A יל ע [A] MG S // lic: V / paraphr : T}

3,5B ראש ותלא $[B]$ M Sym V // lic : S / exeg et lic : G T

\section{Options de nos traductions :}

Le vs 5 est traduit par RSV : "he has besieged and envelopped me with bitterness and tribulation", par RL : "Er hat mich ringsum eingeschlossen und mich mit Bitternis und Mühsal umgeben", par NEB : "He has built up walls around me, behind and before" et par TOB : "Il amoncelle contre moi et il met tout autour poison et difficulté".

$\mathrm{J12}$, après avoir conjecturé 'ִִ̣ pour le $2 \mathrm{e}$ mot, ont lu, en s'inspirant du *G,

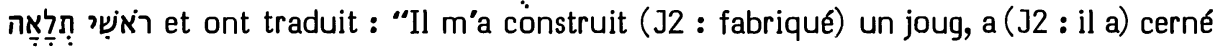
ma tête de fatigue". Ne gardant que la 2e correction, J3 traduit : "Il a élevé contre moi des constructions, cerné ma tête de tourment."

\section{Origines des corrections :}

Châteillon a suggéré ולענ à la place du dernier mot, suivi en cela par Calmet, Börmel (cité par Schleusner, Curae, qui le suit), Löhr, Ehrlich, et par l'apparat de $\mathrm{BH} 3$.

Cappel (Critica 547), faisant remarquer que le *G a lu le 4 e mot au sens de "tête",

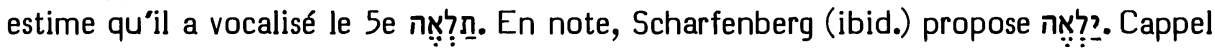
(Notae 540b) juge cependant que le "fiel" s'accorde mieux que la "tête" avec la "las- 
situde". Ont proposé cependant de lire ici "tête" en conjecturant auparavant un "joug" (= J12) : de Hoop Scheffer (cité par Dyserinck) et Haller.

La correction des deux derniers mots adoptée par J a été proposée par Praetorius (326), Rudolph (Text 110) et Gottlieb.

NEB, quand elle traduit le dernier mot par "behind", dépend d'une suggestion de Guillaume (cité par Gottlieb).

Les témoins anciens :

Il n'y a pas trace de "joug" dans ce vs.

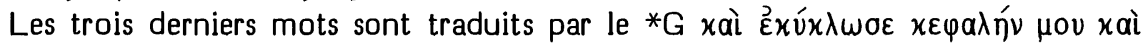

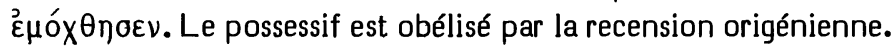

Sym (במרתא ובלאותא) appuie le *M.

$\mathrm{La} * \mathrm{~V}$ traduit "aedificavit in gyro meo et circumdedit me felle et labore".

Les témoins les plus anciens de la *S offrent ici מרדא וחורבא. Avant l'édition d'Albrektson, celle de Mossul était seule à offrir cette leçon, les autres éditions donnant toutes מררא ועמלא à la suite de la polyglotte de Paris. Comme Albrektson l'a fait remarquer, le 'dalat' du premier mot provient de la mauvaise ponctuation d'un 'resh'. Quant au 2e mot, il suggère que, selon les témoins anciens, c'est une traduction large du *M, alors que les éditions (à la suite du ms Pariṣ syr 8) semblent avoir un texte recensé sur le $* M$.

Le *T paraphrase ainsi les quatre premiers mots: "Il a édifié contre moi des retranchements et il a encerclé la ville et il a arraché les chefs des (ou : du) peuple(s)". Le dernier mot est traduit ושלהי אינון = et il les a fatigués), la leçon ושלחו אצון de la plupart des témoins yéménites étant, selon v. d. Heide (87), une corruption dont le sens n'est pas clair.

\section{Choix textuel :}

Comme Albrektson l'a bien vu, les particularités de la traduction grecque dérivent toutes d'une interprétation de ראש comme signifiant "tête". Puis, le fait que l'équivalent grec de ce mot $(\chi \varepsilon \varphi a \lambda \eta ́)$ soit féminin a facilité l'interprétation du mot suivant comme un verbe à la $3 e$ pers. f. sg. de l'inaccompli.

Quant à la paraphrase du *T, elle se rencontre avec celle $d u * G$ pour le sens donné à l'avant-dernier mot et pour l'interprétation du dernier en verbe.

Le comité a considéré le ${ }^{*} \mathrm{M}$ comme suffisamment bien appuyé par Sym et par la $* V$, ainsi que par la traduction plus libre de la ${ }^{*} S$, pour lui attribuer la note "B".

\section{Interprétation proposée :}

Les trois premiers mots appartiennent au vocabulaire décrivant le siège d'une ville. Entre les deux premiers, il faut sous-entendre רמצִ (comme en Dt 20,20) ou P.? (comme en 2 R 25,1 et Ez 4,2) ou encore מִצִ (comme en Qo 9,14). Quant au hifil de נקף, il signifie "cerner" et se rattache par hy à celui que l'on cerne ( 2 R 6, 14; Ps 17,9; 88,18; Jb 19,6). Le complément qui sépare les deux verbes vaut donc pour eux deux.

Le mot ראن désigne une herbe amère d'où on extrait un poison. On emploie aussi ce mot pour désigner le venin de serpent. Il faut noter que les 12 occurences de ce mot 
dans la Bible ont toutes une signification métaphorique. Il n'y a donc aucune difficulté à ce que l'effet produit par le poison apparaisse ici en parallèle avec "harassement, dépression", ces deux substantifs abstraits ayant valeur d'appositions par rapport aux deux verbes d'action qui les précèdent.

On pourra donc traduire :

“Il m'assiège et me cerne, empoisonnement et épuisement.

Il me fait croupir dans les ténèbres

comme les morts de jadis."

\section{3,11 ויפסחני 3 [ ] M S T // exeg : G / usu : Aq clav}

\section{Options de nos traductions :}

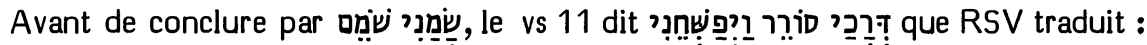
"He led me off my way and tore me to pieces", J12: "Rendant épineux mes sentiers, il m'a déchiré", RL : "Er lässt mich den Weg verfehlen, er hat mich zerfleischt", TOB : "il détourne mes chemins; il me laisse en friche" et J3 : "Faisant dévier mes chemins, il mª déchiré."

Selon Brockington, NEB se fonde sur Aq pour ponctuer "He has made my way refractory and lamed me."

\section{Origine de la correction :}

Jacob ben Reuben a déjà suggéré, en $2 e$ lieu, d'interpréter ce verbe comme si l'on avait un 'samek' à la place du 'shin'. Une correction en ce sens a été proposée par Wiesmann, Kraus et Plöger.

\section{Les témoins anciens :}

Comme traduction du ${ }^{*} G$ pour ce mot, la polyglotte d'Alcala, l'Aldine, la Six-

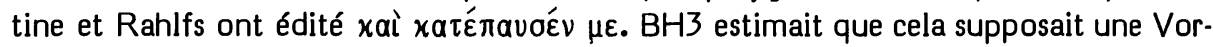

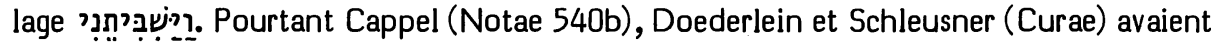

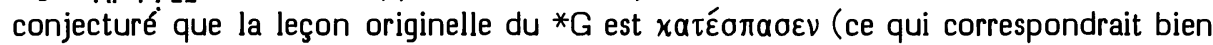
au sens que l'on reconnaît d'ordinaire au ${ }^{*} M$ ). Ziegler (Beiträge 55) a donc adopté cette leçon après l'avoir rencontrée sous forme de correction dans le ms Paris BN Coislin 4, minuscule du XIIIe ou XIVe siècle. Presque tous les témoins grecs ont la

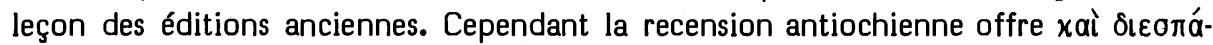

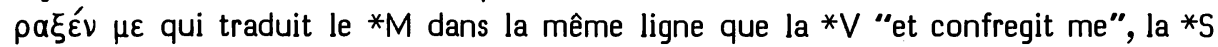
פשחני et le *T ושסעני.

Aq, selon Syh, traduit ואחגרני (= et m'a rendu boîteux).

\section{Choix textuel :}

Il n'est pas certain que les critiques aient eu raison de vouloir corriger la leçon du *G juste au moment où les lexicographes reconnaissent ce sens de "mettre au repos" à la leçon du *M. En effet, KBL et Jenni (233) s'accordent sur une dérivation à partir de l'akkadien 'pašahu' (= être en repos). Il est donc fort possible que le ${ }^{*} G$ ait

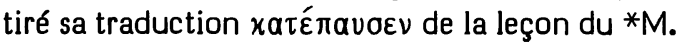


Considérant la lecture $d^{\prime} \mathrm{Aq}$ comme une assimilation à une racine plus connue, le comité a attribué à la lectio difficilior du *M la note " $C$ ".

Interprétation proposée :

Salmon ben Yeruham a traduit ce verbe par l'arabe ופסכני, disant qu'il s'est

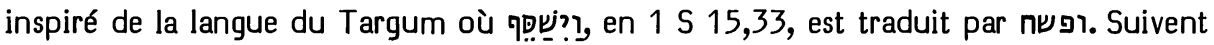
son option : Menahem ben Saruq, David ben Abraham (II 487,14s), Abulfaraj Harûn (fol. 77a) et Abulwalid (Ușul 590,23-28). Ce dernier explique que, dans la langue arabe, le verbe פ se dit pour séparer une articulation de son lieu. Cela est formellement confirmé par une citation du Kitâb al 'Ayn faite par El-Azharî en son Tahdhîb (VII 186).

Il est cependant assez difficile d'insérer dans le contexte cette "mise en pièces" ou cette "dislocation". Au cas où il s'agirait de la poursuite de la métaphore du vs 10 où "il" ( = le Seigneur non nommé) était représenté comme une bête fauve aux aguets

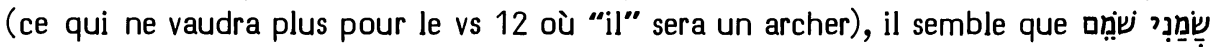
(= vs 11b) soit un résultat trop modeste pour décrire l'état dans lequel une bête fauve laisse celui qu'elle vient de mettre en pièces.

Notons d'ailleurs que Saadya traduisait ce verbe par ופצכני (selon Kafah, alors que Ratzaby a eu tort d'assimiler cette traduction à celle de Salmon et d'Abulwalid), c'est-à-dire "et il m'a déchiré". Ce verbe arabe est utilisé pour des choses ayant une enveloppe dont la déchirure laisse s'écouler le liquide qu'elle contient.

Comme Löhr l'a noté, la difficulté de ce vs se trouve dans le mot סר̣iס. En HK, il traduisait les deux premiers mots du vs (avec presque tous ses prédécesseurs depuis Radaq) par : "Er trieb mich abseits" et en HSAT3, il conservait la traduction de son prédécesseur Baethgen (HSAT2) : "Er hat meine Wege in die Irre geführt". Mais en HSAT4, il a préféré : “Er hat meine Wege mit Dornen umstellt", leçon qui a été adoptée par Rudolph (Text 110s) et qui retient l'intérêt de HALAT. Driver (Lamentations $140, n .1$ ) objecte cependant à Rudolph que cette interprétation n'a l'appui d'aucune version ancienne. Il peut donc être utile de rappeler les lettres de noblesse de cette exégèse que Rudolph rattachait à Rashi.

De fait, 50 ans avant Rashi, l'espagnol Ibn Ghayyath, dans son commentaire sur Qo 7,6 (que Kafah attribue faussement à Saadya quand il l'édite en Megillot 239), citait déjà "certains" qui, en Lm 3,11, dérivent סירים (= épines). Peut-être fait-il allusion à Menahem ben Saruq qui, après avoir cité ce verbe sous le $3 \mathrm{e}$ sens (= diverger) du bilittère 7 , ajoute qu'il est aussi possible de le rattacher au premier sens (= épines). Abulwalid (Opuscules 94) opte pour cette dernière dérivation en laquelle il sera suivi par Judah ibn Balaam (Kokovzov 145) voyant en cette forme un polel accompli dénominatif de סירים. Parḥon (Aruk 44d) et Tanhum Yerushalmi suivent cette option. Lorsque Rashi fait de même, il se rattache donc à une tradition plus ancienne. C'était, en effet, l'option de tous les poterim dont les glossaires nous ont été conservés (ABDEF) et qui traduisaient : "épinat" : D, "espinét" : F, "épinoys" : $B$, "épinozes" : $E$ et "espines" : A. Cette exégèse a été encore adoptée par Joseph Qara et par Joseph Qimḥi (Galuy 127,3). Les glossaires DEF citent, pour éclairer le

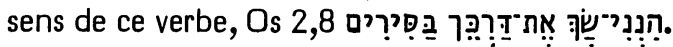


On peut donc considérer cette exégèse comme la mieux attestée dans la tradition d'exégèse littérale juive du moyen âge. Elle permet de donner au verbe suivant, avec Saadya, le sens de "déchirer" (cf. Gerlach) et de traduire, avec J12: "Rendant épineux mes sentiers, il m'a déchiré". On peut traduire les deux derniers mots : “il m’a frappé de stupeur", ce qui prépare l'image de la cible pour l'archer (vs 12).

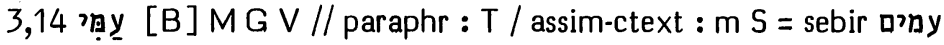

\section{Options de nos traductions :}

J et TOB ont traduit 14a: "Je suis devenu (TOB : Me voilà) la risée de tout mon peuple", RL : "Ich bin ein Hohn für mein ganzes Volk".

Selon Brockington, NEB se fonde sur de nombreux mss pour corriger yַg en 口יפ et traduire: "I have become a laughing-stock to all nations". Sans note, RSV traduisait de même : "I have become the laughingstock of all peoples".

\section{Origine de la correction :}

Cappel (Critica 1006) interprète le sebir affectant le mot rạg (selon la scholie marginale de Ben Hayim) comme une attestation que cela est écrit pour dère, à ce propos, les sebirin comme des équivalents des qerés. A ce titre, ce mot est interprété en pluriel par Lowth (Poesis 451, note), Rosenmüller, Ewald (Lehrbuch 464), Thenius et Bickell. Il est corrigé en pluriel par Olshausen (Lehrbuch 208), Knabenbauer, Löhr, Budde, Oort, Ehrlich, Penna, Albrektson, Kaiser et les apparats de HSAT2, BH23S et Cent.

\section{Les témoins anciens :}

De Rossi (Variae Lectiones et vol. IV, Appendix 237a) mentionne 42 mss collationnés pour Kennicott et 18 collationnés par lui-même comme portant le pluriel a y comme leçon de la 1e ou de la 2e main. Nous avons contrôlé 28 mss. Seul le ms

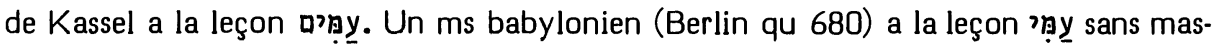
sore, ainsi que 12 mss à vocalisation tibérienne (Urbinates 2, de Rossi 2 et 782, Vatican ebr 7, 468 et 482, Copenhague 1, 4 et 9, Erfurt 3, Londres BL Add 21161, Hamburg 28). 12 autres mss à vocalisation tibérienne ont une $\mathrm{mp}$ précisant que l'on a ici l'un des trois cas (2 S 22,44; Ps 144,2 et Lm 3,14) où l'on conjecture עמים, tout en lisant עמי (Leningrad, Urbinates 1, Paris BN hébr 3, 5 et 26, Vatican ebr 3, Milan ebr 5, Madrid univ 1, de Rossi 7, Hamburg 4, Copenhague 5 et 11). Enfin deux autres ont une mp incomplète: "3" (Copenhague 2) ou fausse: "qeré ayי" (Londres BL Add 19776).

La leçon ' par la recension antiochienne et plusieurs autres mss) et de la $* V$ (populo meo). C'est elle que le *T paraphrase en פמריצי עמי

Seule la *S (עממ̄) appuie la leçon

Choix textuel :

L'attestation externe de cette dernière leçon est donc très faible si on la compare à celle de sa rivale. 
Ajoutons quelques précisions sur la tradition de ce sebir. David ben Abraham (I 184,126-129) le considère comme l'exemple classique d'une orientation exégétique donnée par la massore. C'est en ce sens aussi que l'interprètent Abulwalid (Luma 266,1-4) et Radaq (Mikhlol 10b). Notons cependant que Salmon ben Yeruham, tout en connaissant ici l'interprétation en pluriel, la considère comme moins probable que l'interprétation en singulier. Sur Ps 144,2, il ne mentionne pas la tradition du sebir. Sur Samuel, nous n'avons pas de commentaire de lui. Quant à Yéfet ben Ely, il interprète Ps 144,2 et 2 S 22,44 sans tenir compte de l'existence d'un sebir; alors que nous n'avons pas de commentaire de lui sur les Lamentations. Saadya, lui, traduit ce mot par un pluriel en Ps 144,2 sans mentionner le sebir en son commentaire. En Lm 3,14 il le traduit par un singulier et cette partie de son commentaire ne nous a pas été conservée. Pour Samuel, nous n'avons de lui ni traduction, ni commentaire.

Cappel, nous l'avons dit, considère ces sebirin comme des indications par lesquelles la massore nous informe que יạֵ est écrit pour opposé à cette interprétation. Il considère en effet ces trois sebirin comme des mises en garde, de la part des massorètes, de peur que quelqu'un n'écrive ou ne lise le pluriel, ainsi que le contexte le suggérerait.

En ses témoins les plus anciens qui semblent être le ms du Caire sur $2 \mathrm{~S} 22,44$ et le ms de Leningrad sur Ps 144,2 et Lm 3,14, cette massore dit en effet clairement סברi עמים וקר עמי tion de lecture) soit influencé par le sebir. Notons que le ms d’Alep (qui n'existe plus pour Lm 3,14) n'a pas de mention du sebir en $2 \mathrm{~S} 22,44$ ni en Ps 144,2.

En Lm 3,14, le double fait que עמי soit précédé par et qu'il soit l'antécédent du suffixe pluriel de נגינת suggère une interprétation en pluriel עמים (a) Cependant, la lectio difficilior du singulier est parfaitement justifiée, car le suffixe pluriel constitue une reprise normale pour le collectif ay, alors que et en $\mathrm{Jg} 14,3$.

Il est probable qu'en Lm 3,14 l'interprétation de ce mot en pluriel tient à une relecture interprétant collectivement ce poème.

Le comité a attribué au singulier ' en CT1, p. 308s.

Interprétation proposée :

"Je suis devenu la risée de tout mon peuple."

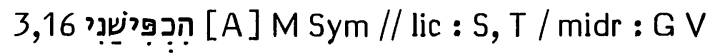

Options de nos traductions :

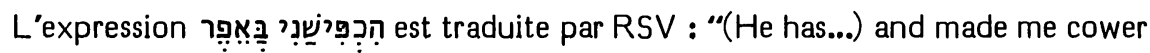
in ashes", par RL : "er drückte mich nieder in die Asche" et par TOB : "il m'enfouit dans la cendre".

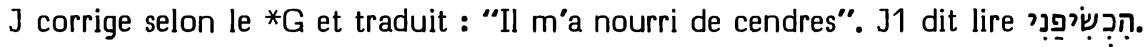
Sans note, NEB donne : "fed on ashes, I am racked with pain". 
Origine de la correction :

Wutz (500), se fondant sur l'assyrien, conjecture, à partir du *G et de la *V,

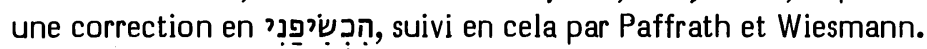

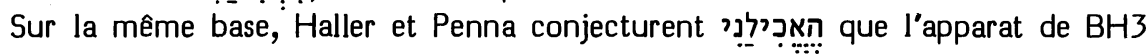
avait suggéré comme Vorlage pour le *G.

Les témoins anciens :

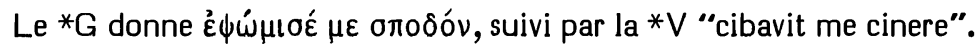

Sym traduit טמרני בקטמא (= il m'a enfoui).

La *S traduit ופלני בקטמא בקמא (= il m’a aspergé).

La leçon qu'offre ici le *T est caractéristique de la transmission du texte de ce témoin dans le livre des Lamentations. Les éditions de Félix de Prato, Ben Hayim, polyglottes d'Anvers et de Londres et Miqraot Gedolot s'accordent sur la leçon כנע יתי בקיטמא. Les mss de tradition yéménite s'accordent à peu près sur כנעינני באפרא. Mais les leçons des mss occidentaux ont, pour le verbe, subi les déformations les plus variées, le copiste du ms Copenhague 11 ayant même désespéré de copier ce mot à la place duquel il a laissé un blanc.

Choix textuel et interprétation proposée :

L'akkadien 'kušapu' est inapte à fonder la Vorlage conjecturée par Wutz pour le *G. Quant à la suggestion faite par Haller, elle s’éloigne trop du *M pour être probable.

Mieux vaut rapprocher la traduction du ${ }^{*} G$ (et de la ${ }^{*} V$ ) d'un passage du midrash Ekha Rabbati (128s) : "הכפישני באפר. C'est ce que nous avons reçu de la tradition : le soir du $9 d^{\prime} A b$, qu'on ne mange pas de viande ni ne boive de vin ni ne prenne deux plats cuits. Rab, lorsqu'il mangeait le repas du 9 d'Ab, prenait sa bouchée et la plongeait dans la cendre pour accomplir ce qui est dit הכפישני באפר." Or le *G signifie littéralement : il m’a donné une bouchée $(\psi \omega \mu$ úov) de cendre.

Levy (Talm. Wörterb. II 390) rapproche notre verbe du Midrash Bereshit Rabba (début de la par. 75) où R. Siméon ben Yannaï (cf. Bacher, Amoräer III 623) cite : "Maintenant je me lève !" (Ps 12,6) en commentant : "Aussi longtemps que Jérusa-

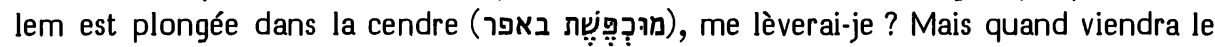
jour dont il est dit : "Hors de la poussière ébroue-toi, (התנyרי? ברת dresse-toi, trône, Jérusalem !' (Is 52,2), à ce moment-là, 'que toute chair fasse silence devant le Seigneur !' (Za 2,17). Pourquoi ? 'Parce qu'il s'ébroue (נער) hors de sa sainte demeure"."

L'exégèse de Rab et du traducteur grec semble bien s'inspirer de Ps 102, 10 ("J'ai mangé de la poussière comme nourriture"). Mais elle suppose que Lm 3,16 est compris au sens que R. Siméon ben Yannaï (après Sym) lui reconnaîtra : "Il m’a plongé dans la cendre".

Dans le même sens, Saadya traduit ici וטמّרני באלרמאד. La signification de cette

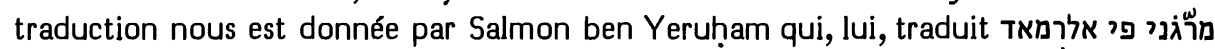

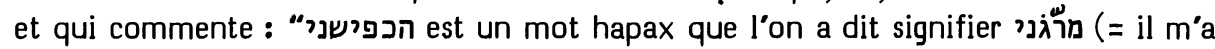
laissé me vautrer). Il ( = Saadya) a dit que le 'bet' et le 'phé' sont la même chose, le sens de ce mot étant donc הכבישני, c'est-à-dire טמריני (= il m'a enfoui). C'est ainsi

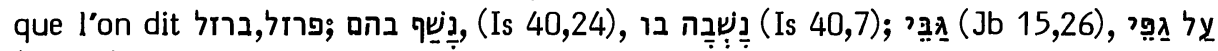
(Pr 9,3) et bien des cas semblables à cela, car on les appelle des lettres permutables... Et la signification du fait que je me suis enseveli dans la cendre, c'est une allusion à 
בבית לעפרה (Jr 6,26) et comme והתפלשי באפר sespressions semblables telles que עפר התפלשי (Mi 1,10). Que l'anonyme cité par Salmon soit bien Saadya, cela ressort d'abord du fait qu'il lui attribue la traduction que celui-ci donne de ce verbe et ensuite du fait que, dans un bref exposé sur la permutabilité du 'bet' et du 'phé' (én son commentaire sur Ps 112,9), Saadya fait le même rapprochement entre Is 40,24 et 40,7. Notons cependant que, dans son Agron (248), celui-ci donne pour traduction à notre

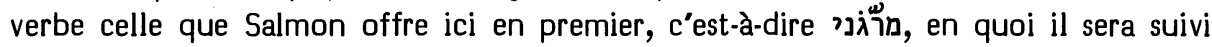
par David ben Abraham (II 126,81) et par Tanḥum Yerushalmi; alors que Abulfaraj Harûn (fol. 21b) traduit en faisant usage de la 5 e forme de ce verbe (= se rouler par terre).

Dans la ligne des derniers rapprochements établis par Salmon, Menahem ben Saruq dit que, en fonction du contexte, ce mot a le sens de פלישה. Joseph Qimhi (Galuy 111) estime difficile de comprendre le sens de cette explication et préfère se fonder sur une expression du Talmud Babli (Yebamot 107b) במדה כפושה, participe passif qu'il interprète comme "retournée, renversée". Cette dernière exégèse était déjà celle de Rashi et des glossaires (ABDEF) qui traduisaient ce mot par "adenta moi" (= me renversa). C'est à cette tradition que Reuchlin (253) fait allusion en attribuant aux Juifs la traduction "versavit me in cinere". S'inspireront de ces données : les Prédicants de Zürich "und ... umbzogen", Zwingli "provolvit me", Luther "Er weltzet mich" et Münster "versavitque me".

Une autre ligne d'exégèse se rattache à Ibn Ezra: "il m'a souillé" (גאלני). Le même sens réapparaît dans une partie inédite du Aruk de Parhọon (selon le ms Oxford, Bibl Bodl, 135, car le ms Stern a une lacune en cet endroit) לִ. Radaq cite ce sens de "souiller", mais lui préfère "envelopper, recouvrir". Sous son influence, ce sens sera le plus répandu au XVIe siècle : Pagnini "operire fecit me"; Brucioli "fecemi coprire"; Olivetan, Estienne, Châteillon et Pasteurs de Genève "m"a couvert"; Geneva Bible et King James "hath covered me".

Le sens de "enfouir, plonger", que Saadya (à la suite de Sym et de R. Siméon ben Yannaï) avait d'abord adopté, réapparaît chez Tobia ben Eliezer qui paraphrase הטביעני בתוך האפר, Jud "praecipitavit me", Arias Montano "immersit me", Tremellius "deprimit me", Buxtorf (Lexicon) “depressit, subegit". Sans connaître l'hypothèse formulée par Salmon ben Yeruham (et par Saadya?) d'une permutation du 'bet' et du 'phé', Peiser (Miscellen 350s) a proposé de motiver ce sens par cette permutation, en se fondant sur la langue des lettres d'El-Amarna. En effet, comme Böhl ( $\$ 9 c$ ) l'a relevé, en des contextes où le sens de "fouler" est indubitable, le cananéen de ces lettres orthographie ce verbe 7 fois 'kapâshu', une fois 'kapâzu', une fois 'qapâsu' et seulement 3 fois 'kabâshu'. L'hypothèse des linguistes judéoarabes du Xe siècle se trouve ainsi confirmée.

Concluons donc que le sens le plus probable est : “il m'a enfoncé (littéralement : foulé) dans la cendre" et que l'interprétation du ${ }^{*} G$ et de la $* V$ se rattache, en réalité, à ce sens.

Etant donné que tous les témoins semblent donc bien avoir lu le *M, le comité lui a attribué la note " $A$ ". 
Options de nos traductions :

est traduit par TOB : "tu me rejettes loin de la paix".

Selon Brockington, NEB se fonde sur la *S pour vocaliser le verbe nus quand elle traduit : "peace has gone out of my life". J aussi dit suivre la $* S$ et la $\bar{*} \overline{\mathrm{V}}$ quand elle traduit : "Mon âme est exclue de la paix". Traduisent de même, sans note, RSV : "my soul is bereft of peace" et RL: "Meine Seele ist aus dem Frieden vertrieben."

Origine de la correction :

Cette retouche vocalique a été proposée par Schleusner (Curae), Michaelis (Observationes), Oort, Haller, Penna et Wiesmann.

Les témoins anciens :

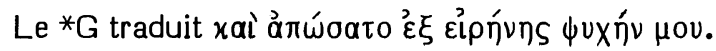

La $* V$ donne "et repulsa est a pace anima mea". L'édition d'Estienne 1532 a été la première à insérer les mots "a pace" qui manquaient dans les précédentes comme dans les mss les plus anciens dont nous disposons actuellement. Dans son apparat de 1540, l'éditeur fondait cette insertion sur les mss Sangermanenses oblongus et latus, le premier étant l'actuel ms Paris, BN, lat 11504 et le second (disparu depuis) constituait le premier volume d'une Bible dont le second est le ms Paris, BN, lat 11553 que Quentin (116) considère comme “un des plus importants exemplaires de la Vulgate".

La*S traduit ואתטעית מן שלמא נפשי

Les éditions du *T mentionnées en 3,16 ont toutes וקצת מלמשאל שלם נפשי. Les 5 mss occidentaux que nous avons contrôlés (Urbinates 1, Milan ebr 5, de Rossi 7,

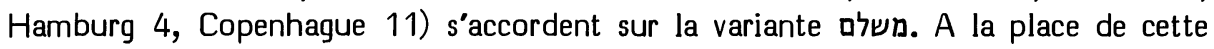
leçon, la tradition yéménite donne ושבקת משלמא נפשי.

\section{Choix textuel :}

Rosenmüller a attribué au ${ }^{*} G$ une Vorlage nנִ̣?? qui a été adoptée par Knabenbauer, Budde (KHC) et Kaiser, ainsi que par les apparats de $\mathrm{BH} 23$ et Cent. De fait, le ${ }^{*} G$ a assimilé ce verbe aux quatre qui précèdent (dans les vss 15 et 16 ) dont le sujet est le "il" anonyme du vs 10 (= le Seigneur). Zwingli s'est inspiré du *G pour traduire "depulit a tranquillitate animam meam" que la traduction des Prédicants de Zurich rend par "Er hat mein seel von der ruw verstossen".

Luther (Meine Seele ist aus dem Friede vertrieben) a préféré s'inspirer de la vieille traduction allemande faite sur la *V (Kurrelmeyer IX 214,59): "und mein sele die ist aufgetriben". De même, Le Fèvre d'Etaples avait traduit la *V par "Mon ame a este deboutee", traduction au passif qu'Olivetan, Rollet et Estienne conservent : "Mon ame est deboutee arriere de paix" suivis par Châteillon ("Je suis dessaisi de paix") et Calvin (Et remota fuit a pace anima mea). Ces traductions par un passif se rattachent donc à la ${ }^{*} V$ et c'est dans le but de les justifier qu’à partir de Schleusner un certain nombre de critiques ont proposé de vocaliser ce verbe en nifal, quoique ce verbe ne soit usité dans la Bible qu'au qal et au hifil.

Refusant ces deux options, le comité a attribué au *M la note " $B$ ". 
Interprétation proposée :

Les exégètes littéraux du *M hésitent depuis longtemps entre deux exégèses de cette forme verbale :

1/ Depuis Saadya jusqu’à GNB en passant par Radaq (Shorashim), Pagnini, Brucioli, Münster, la Geneva Bible et les Pasteurs de Genève, certains ont vu ici une 3e pers. f. sg. à valeur intransitive dont le sujet est "mon âme". Cela s'harmonise bien avec les 3 verbes à la 1e pers. sg. qui suivent.

2/ Depuis Salmon ben Yeruham jusqu'à TOB en passant par Tremellius et la King James, d'autres ont vu ici une 2e pers. m. sg. constituant une apostrophe adressée au Seigneur qui sera aussi désigné à la fin du vs 23 par un pronom suffixe 2e pers.

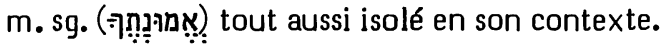

Ici, cette seconde interprétation semble préférable. Cette interpellation prépare en effet la première mention du tétragramme qui aura lieu au vs suivant. Notons d'ailleurs que ce même verbe est employé au sens transitif de "repousser avec dégoût" et avec le Seigneur pour sujet en ses deux autres emplois en ce livre $(2,7 ; 3,31)$.

On pourra donc traduire avec TOB : "Tu me rejettes loin de la paix."

3,19 cf. p. 864.

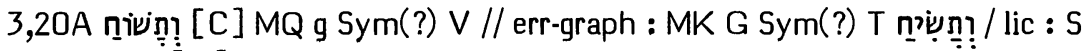

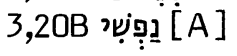

Options de nos traductions :

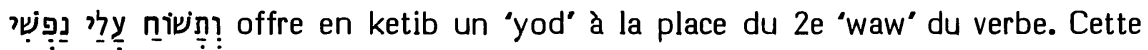
phrase est traduite par RSV : "My soul ... and is bowed down within me", par J : "mon âme, et elle s'effondre (J1 : défaut) en moi" et par TOB : "(Je...) et je suis miné par mon propre cas".

RL traduit : "denn meine Seele sagt mir's".

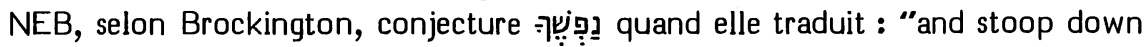
to me".

\section{Origines des corrections :}

Selon les éditions de Constantinople et de Mantoue (mais non selon l'édition Buber), le Midrash Tanhuma donne sur Ex 15,7 une liste de Tiqquné Sopherim mentionnant Lm 3,20. Seul le ms Oxford, Bibl Bodl, Opp Add fol 66 offre la leçon prétendue originale : על ע. Cette même leçon est donnée comme "originale" par l'appendice ( §57) à l'édition Baer/Strack des Diqduqé ha-Teamîm d'Aaron ben Asher (liste basée sur un ms de Hermann Lotze hérité par Baer), par la liste no 158 du ms Paris, BN, hébr 148 de la Okhla, par la liste $\S \S 206$ de la Massorah de Ginsburg et par quelques autres massores manuscrites.

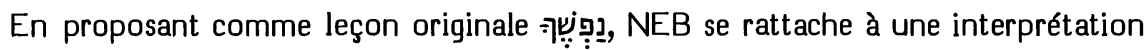
plus récente de ce tiqqun proposée par Geiger (315), Ginsburg (Introduction 361), Kahle en Bauer/Leander (77), les apparats de BH3S et Albrektson. 


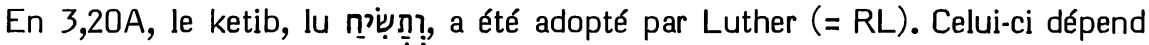
probablement ici de la Bible de Brescia 1494 qui, comme l'édition princeps de la Bible de Soncino 1488, offre ici en son texte la leçon avec 'yod' sans variante marginale. Le ketib en ce sens a été adopté ensuite par Châteillon (latin "\& animo mecum meditor", français "e considere en mon esperit"), Tremellius "meditatur apud me anima mea", C.B. Michaelis "idque meditatur anima mea". De même, Calmet donne comme premier sens de l'hébreu : "(Mon âme...) \& pensera à elle-même" et Houbigant traduit "\& secum ipsa meditatur anima mea". Dathe s'est fondé sur le *G et Sym pour choisir ce ketib. Schleusner (Curae) qui le cite fait de même et interprète "meque consolaberis". Pareau les suit en comprenant "\& (hoc) cogitat in me animus meus". Parmi les critiques plus récents, ce ketib est adopté en un sens analogue par Thenius, Bickell, Wiesmann, Albrektson et Gottlieb.

\section{Les témoins anciens :}

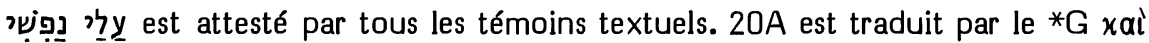

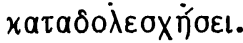

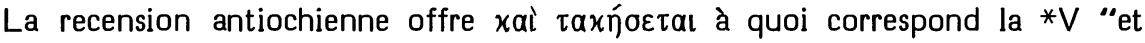
tabescet".

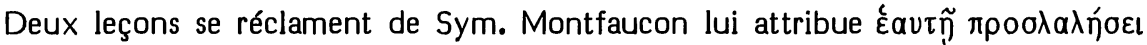
disant retrouver cette leçon sur une fiche dont il ne sait plus l'origine. Field consi-

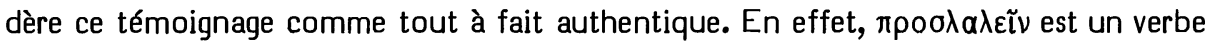
qui n'apparaît que deux fois dans le ${ }^{*} G$, alors qu'il figure quatre fois en des leçons attribuées à Sym (dont trois fois pour traduire le verbe שיח). Cependant la Syh attribue à Sym ici la leçon מתכפפא qui correspond évidemment au qeré.

La *S porte ici ותפנא et le *T ותצי

\section{Choix textuel :}

L'expression השיב נפש a traduit l'expression en Lm 1,11.16.19. Il est possible que le traducteur syriaque, ne sachant comment interpréter ici sa Vorlage, $s^{\prime}$ est rappelé cette tournure familière.

Pour la leçon "originale" du tiqqun, la tradition la plus ancienne est celle qui est rapportée par Qirqisani (Anwar 153,6 et 160,18s). L'original serait עליך נפשך. Martin (Pugio 278, 305 et 695s) rapporte le même témoignage à partir de sources juives qui ont disparu depuis. Cette tradition suppose une interprétation de 20a selon le qeré : "ton âme s'effondrera en toi".

Selon McCarthy (120-123), ce tiqqun de tradition relativement tardive n'est pas authentique. Comme bon nombre des tiqqunim traditionnels, son origine est plutôt homilétique que critique. Lisant au début du vs 20 "tu te souviendras sûrement", quelqu'un a imaginé qu'originellement la suite devait être : "et ton âme s'effondrera en toi", mais que cette expression scandaleuse avait été corrigée ensuite par les scribes.

Si l'authenticité de ce tiqqun s'effondre, la tradition textuelle unanime assure au *M en $20 B$ la note " $A$ ".

En $20 \mathrm{~A}$, le qeré a été lu par la recension antiochienne, la $* V$ et Sym tel que la Syh l'atteste. Vocalisé ḥolem, il se rattache à ${ }^{2}$ (= se tapir). Ou bien, il s'agit d'une 
vocalisation anormale de la racine שיח (= se dissoudre) selon KBL et Bauer/Leander (399). Le ketib doit être rattaché à nie, comme le *G, Sym (selon Montfaucon) et le *T l'attestent.

En faveur du ketib, on peut établir un parallèle avec Ps 77,7 où ce verbe suit, comme ici, le verbe זכר.

Cependant, la présence du complément יל̌y rapproche notre vs de façon caracté-

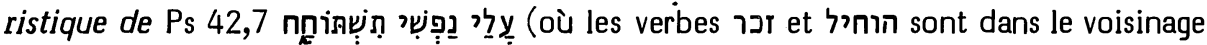
immédiat, comme c'est le cas ici aussi).

Interprétant ici ce verbe par la 7e forme du verbe (= se tapir, se recroqueviller), Salmon ben Yeruham mentionne deux parallèles qui nous orienteraient bien,

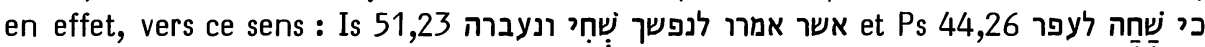
אלה אזכרה ואשפכה עלי נפשי qui nous orienterait plutôt vers le sens de "se dissoudre".

Deux membres du comité ont opté ici pour le ketib, au sens de "méditer", avec la note "C".

Avec la même note, les quatre autres membres ont préféré le qeré.

Interprétation proposée :

"Et mon âme se replie sur moi."

3,22 g Aq Sym V 1pl, S T 3pl / def-int : g / lacun : G

Options de nos traductions :

Le vs 22 est composé de deux membres qui semblent parallèles

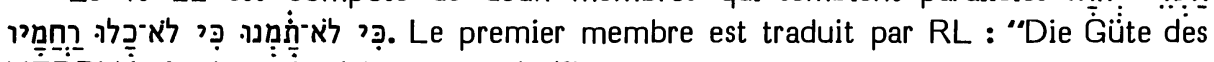
HÉRRN ist's, dass wir nicht gar aus sind".

Selon Brockington, NEB lit "the LORD's true love is surely not spent". RSV dit suivre la *S et le *T en traduisant: "The steadfast love of the LORD never ceases". Se fondant sur les mêmes témoins, TOB traduit : "Les bontés du SEIGNEUR ! C'est qu'elles ne sont pas finies!" Sans note, J traduit de même : "Les faveurs de Yahvé ne sont pas finies (J1 : à bout)."

Origine de la correction :

Les $4 \mathrm{e}$ et $5 \mathrm{e}$ mots ont été traduits par la *V "non sumus consumpti". En 1526, dans ses Institutiones (47ab), Pagnini les traduisait : "non consumptae sunt", disant

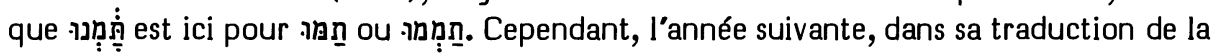
Bible, il reproduisait l'option de la *V. Enfin, en 1529, dans son Thesaurus (2731), il donnait les deux traductions au choix, disant que Rashi et Ibn Ezra les admettent toutes deux comme possibles.

De fait, les traducteurs du XVIe siècle se sont divisés entre elles. Ont interprété ce verbe en 1e p. pl. : Brucioli, Münster, Olivetan, Luther (après la révision de janvier 1541), Estienne, Ge, Tremellius, Pasteurs et KJ. L'ont interprété en 3e pers. pl. (dont le premier mot est le sujet) : Zwingli, Prédicants, Luther (jusqu’à la révision de 1541), Châteillon. C'est également cette exégèse que Calvin préfère comme convenant mieux au contexte. 
Scharfenberg (sur Cappel, Critica 599, n.151) a suggéré que, selon l'édition de la polyglotte d'Alcala, le *G semble avoir lu in. Schleusner (Curae) reprend cette suggestion. De Rossi, relevant cette leçon dans le ms Kenn 109, estime qu'elle a servi aussi de Vorlage à la *S et au *T. Cette leçon a été adoptée par Pareau, Loewe/Wolfssohn (cité par Rosenmüller), Bickell, Budde (KHC), Oort, Gesenius/Kautzsch ( $\$ 200$ ), Ehrlich, Rudolph (Text 112), Haller, Nötscher, Penna, Wiesmann, Meek, Weiser, Kraus, Plöger, Hillers, Gottlieb, Kaiser et par les apparats de HSAT234, BH235 et Cent.

\section{Les témoins anciens :}

Le ms 109 de Kennicott est le ms Londres, BL, Harley 5709. Ce ms que Margoliouth (I 130) date du XIIIe ou XIVe s。 n'a aucune autorité particulière.

Probablement à cause d'un homéotéleuton, les plus anciens témoins grecs du *G n'ont rien qui corresponde aux vss 22 à 24 . La plupart des autres témoins offrent une double traduction du vs 22 et des deux premiers mots du vs 23 . Dans la $2 e$ de ces tra-

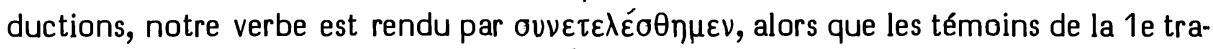

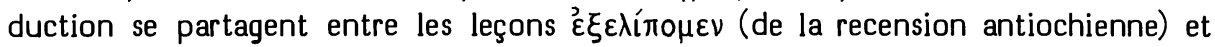

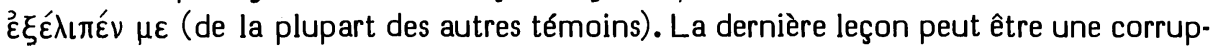
tion de l'avant-dernière. S'il en est ainsi, les deux traductions ont interprété l'hébreu en 1e pers. pl.

Aq (גמרנן), Sym (אתטלקנן) et la *V (sumus consumpti) ont fait de même.

Le *T (פסקו) l'a interprété en 3e pers. pl. et la *S (גמרין) semble avoir fait de même.

\section{Choix textuel :}

Hayyuj (Kitâb 270,3-5) a fait remarquer que la vocalisation de cette forme est anormale, car on devrait avoir ou ou

Du fait que, dans le membre parallèle, le verbe est à la 3e pers. pl., Abulwalid (Luma 76,19-24; 93,20-22; 287,21-23) estime que le 'nun' tient ici la place du redoublement du 'mem', la forme normale étant ing. Il retrouve cette particularité en Ps 64,7 où le verbe a un sens transitif, alors qu'ici il est intransitif. Cette opinion a été adoptée par Radaq (Mikhol 127a et 128a).

Celui-ci indique que son père Joseph voyait en cette forme la 1e pers. pl. d'une réalisation exceptionnelle "aïn-waw' de ce bilittère. En ses Shorashim, Radaq hésite entre l'opinion d'Abulwalid et celle de son père. Rashi, Ibn Ezra et les glossaires AF ont hésité de même, alors que le glossaire $D$ opte pour la 3e pers. pl. et les glossaires BE pour la 1e pers. pl. Abulwalid est suivi aussi par Parhon (Aruk 74a) et Duran (101), ses fidèles admirateurs.

Nous avons noté ci-dessus (p. 171) que les grammairiens récents ne reconnaissent d’ordinaire pas comme authentiques les cas où leurs prédécesseurs croyaient déceler en hébreu biblique une dissimilation progressive des géminées.

Il est surprenant que la Bible n'offre jamais les formes que Hayyuj juge normales, mais que l'on y rencontre 4 fois ( $N b$ 17,28; Jr 44,18; Ps 64,7; Lm 3,22) la vocalisa-

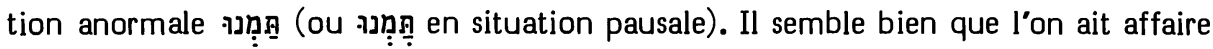
là à une vocalisation tendancieuse. Il s'agit en réalité de formes de la 1e pers. pl., mais 
les vocalisateurs ont voulu, par cette vocalisation anormale, suggérer la possibilité d'une interprétation en $3 e$ pers. pl. qui se présente spontanément à l'esprit dans les deux derniers cas et éventuellement dans le premier.

Le comité a voulu respecter cette particularité du $* M$ qui pose un problème plutôt exégétique que textuel. Aussi lui a-t-il attribué la note " $\mathrm{B}$ ".

\section{Interprétation proposée :}

Une exégèse en 3e pers. pl. constituerait ici un glissement facilitant (pour le motif qui l'a fait choisir par Abulwalid). On préfèrera donc, avec Albrektson (et la révision de Luther) : “C'est aux faveurs du Seigneur que nous devons de ne pas avoir disparu; ses compassions ne sont pas épuisées." Cependant, Gottlieb a raison de faire remarquer que l'apparition de ce "nous" (qui resurgira aux vss 40 à 47) ne saurait suffire à prouver que l'ensemble de ce poème ait un sens originel collectif.

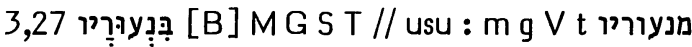

\section{Options de nos traductions :}

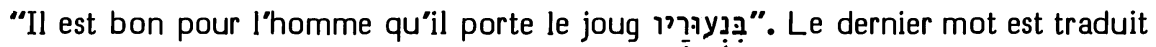
par RSV et NEB : "in his youth", par RL : "in seiner Jugend" et par TOB : "dans sa jeunesse".

$\mathrm{J}$ traduit : "dès sa jeunesse", J1 précisant qu'elle suit plusieurs mss hébreux et grecs ainsi que la*V.

Origine de la correction :

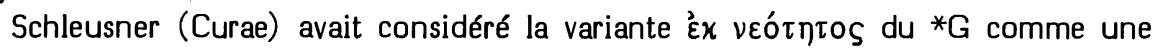
simple liberté translationnelle. De Rossi, relevant une variante avec la préposition 'mem' en de nombreux mss, s'est opposé à ce jugement. La leçon מִ̣ạ a été adoptée ici par Pareau, Dennefeld et Wiesmann.

\section{Les témoins anciens :}

Cette variante est attestée par la première ou la seconde main de 5 mss de Kennicott et de $16 \mathrm{mss}$ de de Rossi. Cependant le ms de Leningrad et la massore éditée précisent par une mp que cette leçon avec 'bet' est hapax, pour éviter qu'on l'assimile à la leçon avec 'mem' qui se rencontre trois fois dans la Bible.

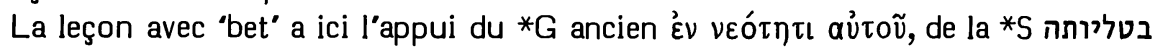
et de la tradition occidentale du *T בטליותיה.

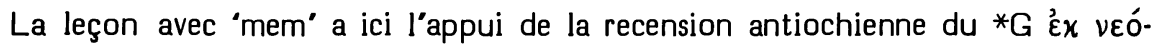

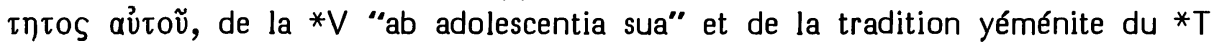
- Tמן עולמוי

Une leçon de "Théodotion" a été citée ici par de Rossi, Rosenmüller, Henderson et Thenius. Il s'agit seulement d'un faux décryptage de l'abréviation "Theod." qui, chez Schleusner (Curae), signifie ici "Théodoret". 
Choix textuel :

La variante assimile à une forme plus usuelle. Elle suppose une conception de la Torah comme joug du Seigneur que l'homme doit porter dès sa jeunesse; alors qu'il s'agit plutôt ici d'un principe de pédagogie, ce que signifie 'porter le joug' étant décrit dans les trois versets suivants.

Le comité a attribué à la leçon avec "bet' la note "B".

Interprétation proposée :

"Il est bon pour l'homme qu'il porte le joug dans sa jeunesse."

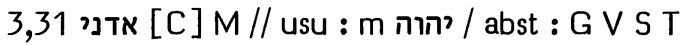

Options de nos traductions :

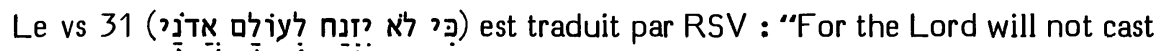
off for ever", par RL : "Denn der Herr verstösst nicht ewig" et par TOB : “Car le Seigneur ne rejettera pas pour toujours."

Diagnostiquant une haplographie de אדם avec le dernier mot, 31 donne : "Car Il ne rejette pas à perpétuité les humains, le Seigneur" et J23: "Car le Seigneur ne rejette pas les humains pour toujours."

Selon Brockington, NEB conjecture l'ajoute de duit : "for the Lord will not cast off his servants for ever".

Origines des corrections :

C'est Lowth (Isaiah, Preliminary XXXII, note) qui, pour améliorer le mètre, a proposé d'insérer עבדיו avant le dernier mot. Budde (KHC) a conjecturé une haplographie de אדם suivi par Wutz, Paffrath (qui le cite), Rudolph (Text 112), Haller, Nötscher, Wiesmann et Meek.

Les témoins anciens :

Lowth a prétendu fonder son ajoute sur le *T. En effet, celui-ci est le seul témoin qui ajoute quelque chose en ce vs qu'il paraphrase diversement selon la tradition occidentale : “Car le Seigneur ne repousse pas pour toujours ses serviteurs en les livrant aux mains de leurs ennemis" et selon la tradition yéménite : “Car leur maître, le Seigneur, $n$ 'abandonne pas son peuple dans la détresse."

En BH3S, Robinson propose de corriger en tétragrammes les emplois du nom divin אדני qui figurent en ce livre. Ici, la leçon du *M est cependant protégée par une massore (Ginsburg, Massorah $\kappa \$ 114$ ) attestant que c'est un des 14 endroits où le nom divin s'écrit ainsi en ce livre. Le ms de Leningrad place ici la mp correspondante. La Okhla de Halle (Diaz Esteban §151) offre une liste des 134 lieux où, dans toute la Bible, le nom divin est écrit אדני. Elle intègre les 14 cas des Lamentations qui figuraient dans la liste précédente, c'est-à-dire que celui qui nous concerne y figure explicitement. Cependant des mss et des éditions anciennes portent ici le tétragramme. 
Choix textuel :

Schleusner (Curae) et Pareau (57) ont objecté à Lowth que le *T de ce livre est trop paraphrastique pour qu'on puisse en tirer une ajoute textuelle. Le fait que les traditions occidentale et yéménite divergent sur ce point appuie encore leur objection.

Quant à la graphie du nom divin, il est fort possible que la tradition massorétique ne nous permette pas de remonter plus haut que le début de notre ère. Dès que le qeré perpétuel "Adonaï" s'est imposé pour le tétragramme, le risque d'une confusion des graphies s'est, en effet, accru. C'est pourquoi le comité s'est contenté de donner au *M, sur ce point, la note " $C$ ", car le témoignage des versions ne permet pas de trancher entre les deux graphies.

Interprétation proposée :

"Car le Seigneur ne rejettera pas pour toujours."

3,51A עיני [A] M G V S // facil-styl : g pl / abst : T

3,51B עוללה [B] M G V S T // incert : Sym

Options de nos traductions :

L'expression est est traduite par RL : "Mein Auge macht mir Schmerz" et $\mathrm{J1}$ : "Mon oeil me fait souffrir".

Sans note, le premier mot est mis au pluriel par RSV : "my eyes cause me grief", J et TOB : "Mes yeux me font mal".

Selon Brockington, NEB corrige le premier mot en et le le fait passer à la fin du vs 50, puis elle corrige le 2e mot en

Origine des corrections :

Les deux conjectures de NEB ont été proposées par Perles (I 18) et adoptées par Driver (Abbreviations 119s) après qu'elles aient été diffusées par les apparats de HSAT4 et de Cent.

Les témoins anciens :

En $51 \mathrm{~A}$, le singulier du $* M$ est attesté par le $* G$, la $* V$ et la $* S$.

La recension antiochienne prend la liberté de traduire ces deux mots par des

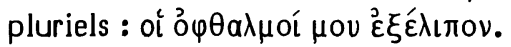

La vocalisation du *T est trop incertaine pour qu'il puisse témoigner sur ce point où ses témoins divergent.

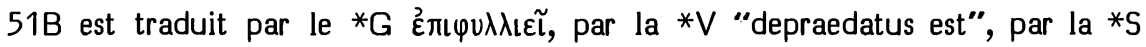
אתטרפת et par le *T אסתקפת.

Selon Syh, Sym traduit ce verbe par עברת. Origène, selon l'apparat de la Sixtine

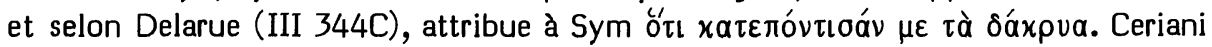
(Prolegomena 47), Field et Ziegler ont raison de demeurer sceptiques sur le libellé exact de la leçon de Sym. Cette incertitude porte a fortiori sur sa Vorlage. 
Choix textuel :

En 51A, le fait que le verbe suivant est au singulier confirme la vocalisation de ce substantif en singulier. Les traductions par des pluriels (ici comme en 48 et 49) sont évidemment facilitantes. Le comité a donc attribué au * $M$ la note " $A$ ".

En 51B, rien ne suggère une autre Vorlage que le ${ }^{*} M$. Le témoignage de Sym demeurant douteux, le comité a attribué au *M la note " $B$ ".

Interprétation proposée :

Le poél ou le poal de ללy construit avec la préposition "lamed" apparaît 5 fois en ce livre (1,12.22bis; 2,20; 3,51). Le sens est d'ordinaire "agir avec dureté". Ici "mon oeil" peut signifier "ce que je vois". On pourrait alors traduire : "Ce que je vois m'afflige, à cause de toutes les filles de ma ville." Mais "mon oeil" peut aussi signifier, comme aux vss 48 et 49 , la source des larmes. Or, nous avons déjà, en 1,16, vu le pleureur se plaindre de la douleur que lui cause son oeil. On pourra donc traduire : "Mon oeil me fait mal, à cause..."

\section{3,56 לרוחתי לשועתי [A ] M // exeg : g, Sym S / paraphr : T / perm : G}

Options de nos traductions :

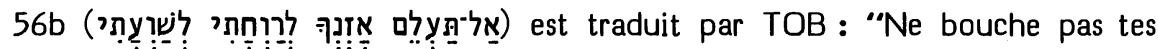
oreilles à mon halètement et à mon appel au secours !", par RL : "Verbirg deine Ohren nicht vor meinem Seufzen und Schreien!" et par RSV (disant que l"hébreu est "uncertain") : "Do not close thine ear to my cry for help !"

$\mathrm{J}$ dit lire avec le ${ }^{*} \mathrm{G}$, pour le $4 \mathrm{e} \mathrm{mot,} \mathrm{"à} \mathrm{ma} \mathrm{prière"} \mathrm{et} \mathrm{J12}$ omettent le mot suivant. $\mathrm{J1}$ traduit : "Ne ferme pas ton oreille à ma prière" et $\mathrm{J2}$ : "A ma prière ne ferme pas ton oreille". Sans omettre le dernier mot, J3 traduit : "ne sois pas sourd à ma prière, à mon appel".

Disant qu'elle inverse les deux derniers mots, NEB traduit : “do not turn a deaf ear when I cry, 'Come to my relief'."

Origines des corrections :

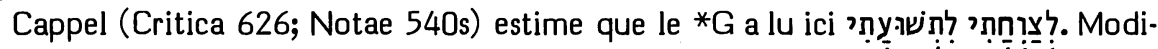
fiant seulement en 'yod' le premier 'taw' du dernier mot, Houbigant adopie ces deux leçons. Ewald était tenté d'adopter la première leçon et de considérer le dernier mot comme une glose. Il est suivi en ces propositions par Löhr, Budde (KHC), Rudolph (Text 115), Meek et les apparats de $\mathrm{BH} 2$ et de Cent.

Dyserinck adopte la suggestion de Houbigant pour le dernier mot seulement, suivi en cela par Budde (Klagelied 272), Hillers et l'apparat de HSAT2.

L'avant-dernier mot a été omis par Bickell, Ehrlich, Paffrath et Wiesmann.

C'est le dernier mot qu'omettent Haller, Nötscher, Dennefeld, Penna, Weiser, Kraus, Rudolph (KAT), Albrektson, Plöger, Gottlieb, Kaiser et les apparats de HSAT34 et de BH3. Quant à BHS, elle hésite entre les deux derniers mots. 140).

L'inversion des deux derniers mots a été proposée par Driver (Lamentations 
Les témoins anciens :

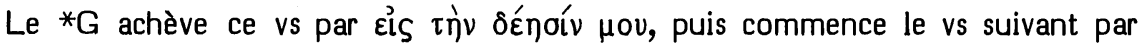

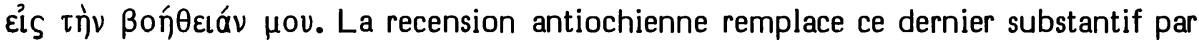
xpaujñv.

Syh donne pour Sym : למנפשו לי ולמשרזבו.

La *V traduit: "a singultu meo et clamoribus" et la * אלא ארוח לי ופרוקיני.

Le *T paraphrase : "d'accueillir ma prière pour que tu me donnes de l'espace à cause de ma supplication".

\section{Choix textuels :}

Buxtorf jr (575s) a objecté à Cappel que צִ̣ ne s'utilise jamais dans un sens de 'prière' dans la Bible. Ce mot ne correspond d'ailleurs jamais à ó́noıs qui, par contre,

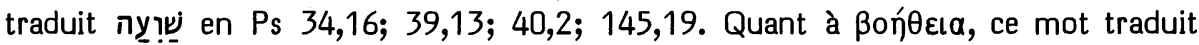
חִרִ en Est 4,14. Le traducteur grec a donc précédé Driver dans son inversion des deux mots.

La recension antiochienne et la $* V$ ont donné au premier mot le sens du second, alors que Sym et la *S ont donné au second le sens du premier.

Quant au *T, sa paraphrase, qui lui permet de respecter le sens le plus naturel des deux mots, l'oblige à donner des significations différentes aux deux prépositions 'lamed'.

Les difficultés offertes par la leçon du *M sont à l'origine de ces diverses options.

Considérant que les versions ont seulement essayé de tirer parti de la lectio difficilior du *M, le comité a attribué à celle-ci 4 "A" et 2 "B".

Interprétation proposée :

"Ne cache pas ton oreille à ma délivrance, à ma supplication."

Cahen a fait remarquer que cela signifie : lorsque je te supplie de me délivrer. Mais c'est l'idée de la délivrance qui domine dans l'esprit du poète, ce qui explique la transposition des mots.

\section{3,59 שָשפטָט [B] M Aq V T // assim-ctext : G S}

Options de nos traductions :

Précédé par trois accomplis et suivi par deux autres, le ${ }^{*} \mathrm{M}$ offre un impératif :

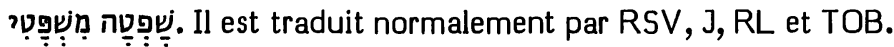

Selon Brockington, NEB se fonde sur le *G pour vocaliser ${ }^{*}$ et traduire : "thou... and gavest judgement in my favour".

Origine de la correction :

Cappel (Critica 596) a estimé que le *G a lu ici que la *S a fait de même. Cette leçon a été adoptée par Oort, Haller, Weiser et Kraus, alors que Rudolph (Text 115) s'est contenté de proposer la modification vocalique que NEB a adoptée. 
Les témoins anciens :

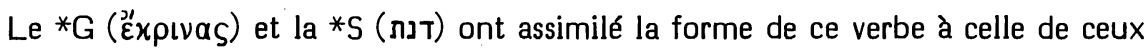
qui l'entourent.

L'impératif du *M est attesté par Aq (דון), la *V (judica) et le *T (דון).

Choix textuel et interprétation proposée :

Cet impératif est en parallèle avec le prohibitif de $56 \mathrm{~b}$ et l'impératif de 63 . Ce sont des appels qui percent à travers une narration des débuts de l'intervention salvatrice du Seigneur. Ils préparent déjà le passage aux inaccomplis qui aura lieu en 64-66.

Considérant ici la variante comme assimilante, le comité a attribué au *M la note "B". On peut traduire : "Rends-moi justice !"

\section{3,66 שמי יהוה [B] M T // facil-synt : G V, g S}

Options de nos traductions :

Les inaccomplis 2e pers. m. sg. des vss 64-66 s'adressent au Seigneur. Les traduc-

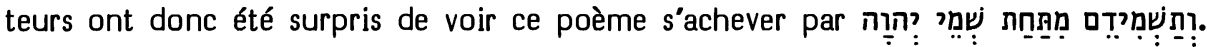
Cette discordance a cependant été respectée par RL : "und vertilge sie unter dem Himmel des HERRN" et par TOB : "tu ... et les extirperas de dessous les cieux du SEIGNEUR".

Disant suivre la *S, RSV traduit : "Thou wilt ... and destroy them from under thy heavens, O LORD." Sans note, NEB fait de même : "and exterminate them from beneath thy heavens, O LORD."

J dit suivre des mss grecs et la *S quand elle traduit : "extirpe-les de dessous (J1 : d'au-dessous de) tes cieux !"

\section{Origines des corrections :}

Lowth (Poesis 260, note) a estimé qu'ici l'état construit tenait la place d'un état absolu. Kennicott (Dissertatio generalis §26) a jugé que le 'mem' final de celui-ci avait dû être omis par un scribe en fin de ligne. Un état absolu a été instauré ici par Dyserinck, Oort, Paffrath, Dennefeld et Penna.

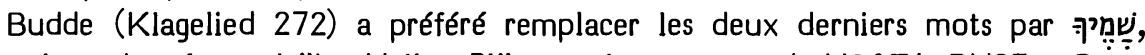
correction adoptée par Löhr, Haller, Plöger et les apparats de HSAT4, BH23 et Cent.

Rudolph adopte cette leçon en conservant ensuite le tétragramme. Il a été suivi par Nötscher, Wiesmann, Meek, Weiser et Kraus.

Les témoins anciens :

L'état construit est attesté par le *T שמי מרומא דיי (ou שמיה דיי, selon la tradition yéménite).

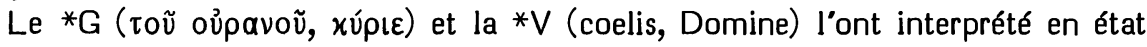
absolu, faisant du tétragramme un vocatif. Ce vocatif a été transféré dans le premier membre de ce vs par la recension antiochienne.

La recension origénienne a fait précéder ce vocatif par un possessif 2e pers. sg. (oov). La*S a fait de même שמיך מריא. 


\section{Choix textuel :}

Toutes ces variantes sont des échappatoires causées par la difficulté syntaxique $d u{ }^{*} M$. Le comité a attribué à celui-ci la note "B".

La syntaxe du *M se caractérise ici par le fait que le nom de celui à qui le poète s'adresse apparaît en génitif à la fin de la phrase qui lui est adressée. Ce procédé stylistique se retrouve en $1 \mathrm{R}$ 22,15 où Michée fils de Yimlâ répond au roi : "Monte et réussis ! et le Seigneur livrera aux mains du roi !" Même en des cas où la syntaxe nous surprend, le nom de Dieu est préféré à un pronom suffixe, lorsqu'il s'agit d'élargir la finale d'un poème. Ainsi, la finale du Ps 50 où Dieu conclut: "Je lui ferai voir le salut de Dieu."

\section{Interprétation proposée:}

Déjà en 2,22, dans un vs qui est, lui aussi, le dernier d'une lamentation et qui commence de même par une 2e pers. adressée au Seigneur, on rencontre l'expression אַף־־יהוח (= la colère du Seigneur). Cet usage du tétragramme en génitif, pour conclure dés passages où le pleureur s'adresse au Seigneur, a un caractère d'ampleur et de solennité. Il s'agit en 3,66 de souligner que les cieux sont la résidence du Seigneur. On trouve une expression d'une solennité semblable en Gn 19,24: “Et le Seigneur fit pleuvoir sur Sodome et sur Gomorrhe du soufre et du feu provenant du Seigneur à partir des cieux." Ici, la nuance est d'universalité : sous tous les cieux que le Seigneur domine et non seulement sous nos cieux, c'est-à-dire ceux de notre pays.

\section{4,3 תנין [A ] MQ M G V S T // subst-graph : MK}

\section{Options de nos traductions :}

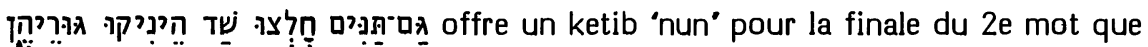
RSV traduit : "the jackals", J et TOB : "les chacals" et RL : "Schakale".

Selon Brockington, NEB corrige en "

Origine de la correction :

Cette correction a été suggérée par Houbigant et adoptée par Löhr, Kelso et Driver (Monsters 246, n.6).

\section{Les témoins textuels :}

La graphie (Frensdorff §206). Ce mot a été cependant transcrit selon le ketib citant "l"hébreu".

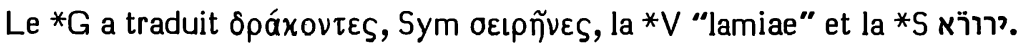

\section{Choix textuel :}

En CT1, 549, nous avons déjà noté, à propos de Ne 2,13, que l'on rencontre dans la Bible des confusions entre תנים, forme plurielle signifiant "chacals", et תנין singulier signifiant "dragon". Ce qeré-ketib représente un tel glissement d'une forme à l'autre.

Il semble bien que ce soit Bochart (Hierozoicon I 46,33-54) qui a proposé de voir ici des cétacés, l'expression "découvrent leur mamelle" lui semblant bien s'accorder 
avec le fait que les mamelles des cétacés sont, d'ordinaire, dissimulées en des poches cutanées d'où elles sortent lorsqu'elles sont gonflées par le lait. Cette exégèse a été adoptée par Pareau et Michaelis (Supplementa §2603).

Il est cependant peu probable que l'auteur des Lamentations veuille faire allusion ici aux particularités des mamelles des cétacés. Les chacals, par contre, offrent une bonne comparaison avec les autruches qui seront mentionnées en 3b. Ces deux animaux sont mentionnés souvent ensemble dans la Bible: Is 13,2 1s; 34, 13; 43,20; Mi 1,$8 ;$ Jb 30,29.

Estimant qu'il n'y a aucun motif pour lire ici un pluriel du mot תנין, le comité a attribué au qeré du * $M$ la note " $A$ ". Le ketib avec 'nun' en constitue une simple variante graphique du type de celle que nous avons rencontrée en Ne 2,13.

Interprétation proposée :

"Même les chacals tendent la mamelle, allaitent leurs petits."

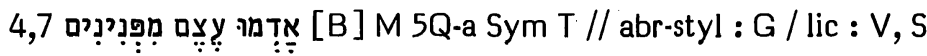

Options de nos traductions :

אדמו עצם מפנינים est traduit par RSV: "their bodies were more ruddy than coral", par J : "plus vermeil que le corail était leur corps", par RL : "ihr Leib war rötlicher als Korallen" et par TOB : "plus roses de corps que le corail".

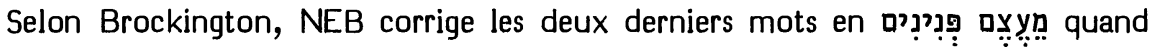
elle traduit : "they were ruddier than branching coral".

Origine de la correction :

La conjecture de NEB a été proposée par Budde (KHC) citant Bickell. Elle a été adoptée par Driver (Lamentations 140s) et Gottlieb.

\section{Les témoins anciens :}

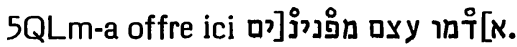

Selon la plupart des mss, la polyglotte d'Alcala et l'édition Aldine, le ${ }^{*} G$ traduit

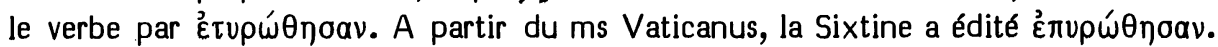

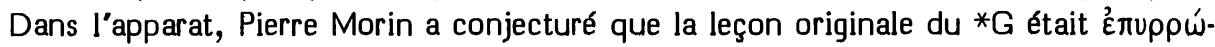
$\theta$ noav, leçon admise très largement par la suite. Le ${ }^{*} G$ n'a pas traduit le $2 e$ mot et a donné pour le 3e úrè $\lambda i ́$ íous.

Origène, selon l'apparat de la Sixtine et selon Delarue (III 346F), attribue à Sym

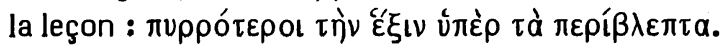

La *V traduit: "rubicundiores ebore antiquo" et la *S סמקו גרמיהון מן סרדון.

Quant au *T, Lagarde lui attribue סמיקו חיזו יתיר מן גוהרין. A la place du dernier mot qu'il a conjecturé, on lit יוהרין dans les éditions de Félix de Prato, Ben Hayim, polyglottes d'Anvers et de Londres, Miqraot Gedolot. Au lieu des deux derniers

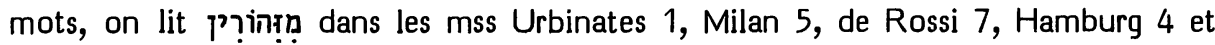
Copenhague 11. La tradition yéménite offre la même leçon consonnantique en omettant la mater lectionis 'waw'. 
Choix textuel :

Le fragment de $5 Q$ appuie le $* M$ sur le point précis où la conjecture voulait le modifier.

La difficulté syntaxique du *M tient à l'interprétation de la fonction du $2 \mathrm{e}$ mot.

Le ${ }^{*} \mathrm{G}$ a omis ce mot. En effet, il l'omet ailleurs aussi (Ez 24,2bis; 40,1; Gn 7,13; Ex 12,17.51; Lv 23,21; Dt 32,48; Jos 5,11 etc.) lorsqu'il a la valeur de "même" dans l'expression : "en ce jour-même". Il l'a donc compris ici comme jouant le même rôle à l'égard du sujet du verbe initial : "eux-mêmes".

Sym et le *T ont vu en ce mot une apposition au sujet sous-entendu de ce verbe et lui ont donné le sens de "apparence".

La *S l'a mis au pluriel et l'a affecté d'un suffixe pour pouvoir en faire le sujet du verbe.

Lui donnant le sens de "os", la *V l'a traduit par "ivoire" et a fait déjà porter sur lui la préposition comparative qui le suit.

Reconnaissant la leçon du ${ }^{*} M$ à l'origine de ces diverses options, le comité lui a attribué la note " $\mathrm{B}$ ".

Interprétation proposée :

Le $2 \mathrm{e}$ mot est ici un accusatif modal exprimant le point de vue sous lequel s'effectue la comparaison. Ce mot semble avoir ici le sens de "corps".

On pourra donc traduire : "De corps, ils étaient plus vermeils que les coraux."

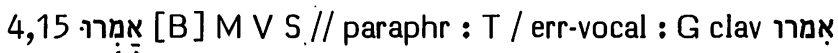

\section{Options de nos traductions :}

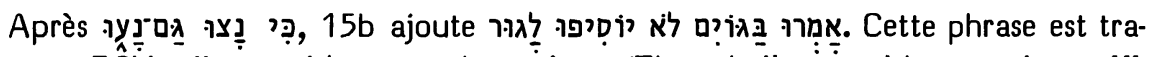
duite par RŜं : "men said among the nations, "They shall stay with us no longer" ", par RL : "so sagte man auch unter den Heiden: 'Sie sollen nicht länger bei uns bleiben" '" et par TOB : "mais on dit chez les nations : 'Ils ne peuvent plus être nos hôtes'."

Selon Brockington, NEB omet אִַ et unit le complément suivant aux deux verbes précédents: “They hastened away, they wandered among the nations, unable to find any resting-place". J fait de même : "S'ils partaient et fuyaient chez les nations, ils ne pouvaient $s^{\prime} y$ fixer ( $\mathrm{J} 3$ : y séjourner)."

Origine de la correction :

Lowth (Isaiah, Preliminary XLIV, n.2) a vu dans les deux premiers mots de 15b une interprétation marginale qui, par erreur, a abouti dans le texte. Budde (Klagelied 8, 275) les omet, suivi par Dyserinck, Löhr, Kraus, Albrektson, Gottlieb, Kaiser et par les apparats de HSAT234 et BH23.

Budde (KHC) suggère de n'omettre que le premier mot, suivi par Rudolph (Text 119), Haller, Nötscher, Penna, Weiser, Plöger et par l'apparat de Cent.

Les témoins anciens :

Ces deux mots sont traduits par le ${ }^{*} G$, la $* V$ et la $* S$. Ils sont paraphrasés par le *T. 
Le *G traduit ce verbe (comme קראו auparavant) par un impératif.

\section{Choix textuel :}

Gottlieb, à propos de קראו למו, a suggéré une distinction entre une glose au sens que la critique littéraire donne d'ordinaire à ce mot (pour désigner des mots insérés après coup dans le texte) et une glose au sens d'une parenthèse qui est extérieure au mètre d'une poésie. Azarya de Rossi (Meor 182a) avait déjà fait remarquer que, dans la poésie biblique, il existe certains mots qui n'entrent pas dans la mesure du vers. Il cite comme exemple ויאמר en Dt 32,20.

Il ne faudrait donc pas confondre ici ces deux types de gloses et méconnaître la signification de ces parenthèses.

Le comité a attribué au *M la note " $B$ " qui porte sur sa vocalisation en accompli (et non en impératif).

Interprétation proposée :

La fin de 15a était : "ils fuient et ils errent". 15b ajoute "on dit parmi les nations : "ils ne recommenceront plus à se fixer"." Le verbe גור est employé pour toute résidence autre que le patrimoine familial, que cette résidence soit en Terre Sainte ou en dehors. Voyant les Israélites fugitifs et errant, les peuples païens concluent donc que : "ils ne se fixeront plus jamais nulle part". C'est la naissance du thème populaire du 'Juif errant'.

4,18 צִ צִד [B] M g Aq Sym S T // exeg-ctext : V / assim Jb 18,7; Pr 4,12 :5Q-b(?) צרו / assim-ctext : G

Options de nos traductions :

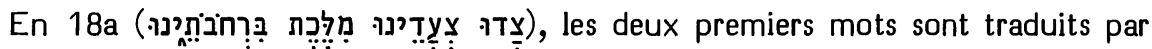
RSV : "Men dogged our steps", par RL: "Man jagte uns", par TOB : "On nous fait la chasse à la trace" et par J3 : "On observait nos pas".

312 inséraient בִִִִינוּ après le premier mot et traduisaient : “Nos ennemis observaient nos pas."

Selon Brockington, NEB vocalise le premier mot we go out, we take to by-ways".

Origines des corrections :

L'insertion réalisée par $\mathrm{J12}$ avait été proposée par Dyserinck, Budde (Klagelied 275), Löhr et par les apparats de BHS et Cent.

Les témoins anciens :

5QLm-b offre ici un fragment que Milik transcrit דינוצ' la 2e lettre paraît plutôt être un 'resh' qu'un 'dalet'. De Rossi a relevé cette leçon en son ms 507, la lecture n'étant pourtant pas certaine.

Judah Halévi (Kuzari 115) donne comme exemple d'un mot écrit d'une manière qui ne correspond pas à l'analogie צד, c'est-à-dire le verbe qui nous occupe. Il estime 
que l'on attendrait צר et que c'est un cas typique où la tradition de transmission du texte doit primer sur l'analogie. Précisons tout de suite que ce passage du Kuzari nous a été conservé intact par la traduction hébraïque d'Ibn Tibbon selon ses éditions et selon les mss de Rossi 625 et 676 (cf. de Rossi IV 237) mais non par la tradition textuelle arabe de ce livre. Celle-ci n'est constituée que par deux témoins. Or, selon Baneth, l'un d'eux inverse les deux leçons צרו צ' צ' alors que l'autre omet le passage où l'auteur suggérait de lire cette dernière forme. Ces scribes n'ont pas voulu admettre que le 'compagnon' suggère, comme plus conforme à l'analogie, une leçon autre que celle du *M. Un contemporain de Judah Halévi, Ibn Ezra (Șahot 249,15 à 251,4), a été, lui aussi, scandalisé par cette suggestion hâtive, ainsi que nous le verrons.

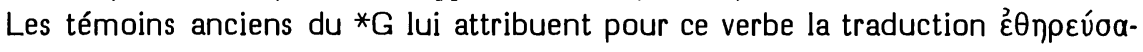
$\mu \varepsilon v$. Il est difficile de dire si c'est dans la Vorlage du ${ }^{*} G$ ou dans la transmission de son texte qu'a eu lieu une assimilation aux possessifs qui précèdent et qui suivent, ainsi qu'au verbe צפינו du vs 17. La recension antiochienne rectifie cela en lisant

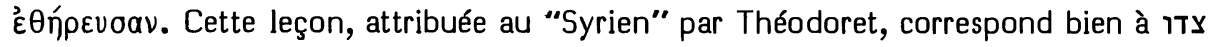
que la *S donne ici et que Syh attribue à Sym (alors qu'elle attribue

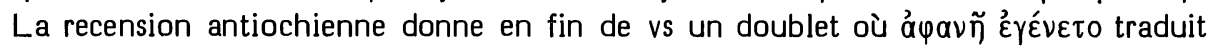
notre verbe.

\section{$L a * V$ traduit à partir du contexte "lubricaverunt".}

Le *T porte צִ sִ sִ selon les éditions, la tradition yéménite et le ms

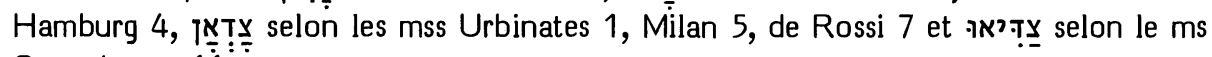
Copenhague $1 \overline{1}$ :

\section{Choix textuel :}

Toutes les versions appuient la leçon avec 'dalet'.

Yequtiel ben Judah atteste que ce verbe est milra . Cela correspond à une interprétation en 'lamed-hé' qui est celle d'Aq, du doublet de l'antiochienne et du *T, ainsi que de Saadya.

Le *G, Sym et la *S ont interprété ce verbe comme un “ä̈n-yod'. C'est l'exégèse de Salmon ben Yeruham, de David ben Abraham (II 500,14s), de Hayyuj (Kitâb 66,16; alors que 201,12s est inauthentique, selon l'apparat de la p. $L X X)$ et de Radaq (Shorashim), ainsi que de Rashi.

Dans le Kuzari, la suggestion du 'compagnon' se fonde sur des parallèles comme Jb 18,7 ou $\operatorname{Pr} 4,12$, ainsi que sur le contraste avec ạn Ibn Ezra objecte à cela que la rapidité des poursuivants est mentionnée au vs 19 et qu'au vs 20 il est parlé de la capture du roi dans leurs fosses. Il estime donc qu'il faut lire la leçon avec 'dalet' en l'interprétant au sens de : se lancer sur les traces de quelqu'un pour lui donner la chasse.

NEB vocalise ce verbe en 'aïn- 'aïn' en considérant le mot suivant comme son sujet. Il faut objecter à cela, avec Gottlieb, que ce mot n'est jamais, dans la Bible, sujet d'un verbe exprimant le mouvement.

A propos de l'insertion conjecturée par Dyserinck, notons que Budde, peu après l'avoir adoptée, y a renoncé (en $\mathrm{KHC}$ ) lorsque Bickell l'a convaincu que la métrique ne requérait pas cette correction.

Le comité a attribué au *M la note " $\mathrm{B}$ ", estimant que le problème se situe ici dans le domaine de l'exégèse. 


\section{$\operatorname{Lm} 4,18$}

Interprétation proposée :

Aux arguments d'Tbn Ezra, on peut ajouter que ce verbe est déjà apparu en 3,52 : "mes ennemis m'ont pris en chasse comme un oiseau".

On pourra traduire : "Sur nos traces, on nous prend en chasse, nous empêchant de nous en aller par nos routes." Les תiֹin sont en effet les points de départ des routes, aux portes des villes (cf. Na 2,5). 


\title{
INDICES
}

\author{
Index des textes bibliques \\ Index des principaux auteurs cités \\ Index des facteurs usités dans les apparats critiques \\ Bibliographie
}





\section{INDEX DES TEXTES BIBLIQUES}

Genèse

$1,1 \mathrm{~s} \quad 282$

$1,2 \quad * 23$

$1,3 \quad 458$

$1,4 \quad 22$

$1,11 \quad 823 \mathrm{~s}$

$1,26 \quad 871$

$1,27 \quad 93$

$1,28 \quad 871$

$3,2 \quad 312$

$3,4 \quad * 63$

$3,8.14 \quad 769$

$3,15 \quad 467$

$3,17 \quad 585$

$3,22 \quad 393$

$4,2 \quad 440$

$4,13 \quad * 49$

$4,22 \quad * 63$

$4,25 \quad * 62$

$6,13 \quad 482$

$6,18 \quad 697$

$7,13 \quad 911$

$8,21 \quad 222,585$

$8,22 \quad 135$

$9,26 \quad 694$

$10,17 \quad 361$

$10,19.30 \quad 506$

$11,1.9 \quad 81$

$12,5 \quad 696$

$13,10 \quad 506$

$14,2 \quad 212,775$

$14,3 \quad 212$

$14,6 \quad 609$

$14,8 \quad 775$

$14,9 \quad 252$

$14,16 \quad 696$

$16,12 \quad 472$

18,6

367

\begin{tabular}{|c|c|}
\hline $18,24.26$ & 15 \\
\hline 19,4 & 830 \\
\hline 19,21 & 3 \\
\hline $\begin{array}{l}19,22 \mathrm{~s} \\
19,24\end{array}$ & $\begin{array}{l}775 \\
93,909\end{array}$ \\
\hline $19,25.29$ & 3 \\
\hline 19,30 & 775 \\
\hline 22,9 & 409 \\
\hline 22,14 & $* 64$ \\
\hline 22,18 & 486 \\
\hline 22,24 & 563 \\
\hline 23,8 & 404 \\
\hline 24,21 & 292 \\
\hline 25,16 & 813 \\
\hline 25,18 & 503 \\
\hline 25,24 & 591 \\
\hline 26,4 & 486 \\
\hline 27,40 & 275 \\
\hline 31,38 & 821 \\
\hline 31,40 & 273 \\
\hline $31,44 \mathrm{~s}$ & 234 \\
\hline 32,33 & 650 \\
\hline 33,10 & 5 \\
\hline 34,30 & 290 \\
\hline $36,31 \cdot 39$ & 241 \\
\hline 37,4 & 402 \\
\hline 37,35 & 415 \\
\hline 40,7 & 317,400 \\
\hline 40,16 & 139 \\
\hline 41,2 & 138 \\
\hline 41,6 & 258 \\
\hline 41,18 & 138 \\
\hline $41,23.27$ & 258 \\
\hline 41,40 & 272,895 \\
\hline 41,45 & 148,150 \\
\hline 41,50 & 150 \\
\hline 41,57 & 337 \\
\hline 43,3 & 73 \\
\hline 43,14 & 748 \\
\hline
\end{tabular}

\begin{tabular}{|c|c|}
\hline 43,33 & 70s \\
\hline 44,4 & 548,554 \\
\hline 46,20 & 150 \\
\hline 46,31 & 278 \\
\hline 46,34 & 440 \\
\hline 47,3 & 440 \\
\hline 47,19 & 476 \\
\hline 48,3 & 683 \\
\hline 49,3 & $* 59,673$ \\
\hline 49,4 & $\begin{array}{l}* 59, * 64, \\
563\end{array}$ \\
\hline 49,6 & 476 \\
\hline 49,11 & *59 \\
\hline 49,12 & $* 60$ \\
\hline 49,15 & 22 \\
\hline 49,21 s.24 & $* 60$ \\
\hline 49,27 & 236 \\
\hline \multicolumn{2}{|l|}{ Exode } \\
\hline 1,12 & $386,388 \mathrm{~s}$ \\
\hline $1,17 \mathrm{~s}$ & 515 \\
\hline 1,19 & *62 \\
\hline 1,22 & 515 \\
\hline 2,2 & 22 \\
\hline 2,3 & 220 \\
\hline 2,10 & 438 \\
\hline 2,18 & 367 \\
\hline 3,16 & 683 \\
\hline 3,17 & 278 \\
\hline 4,2 & 532 \\
\hline 4,9 & 43 \\
\hline 4,13 & 876 \\
\hline 5,13 & 615 \\
\hline 5,16 & 523 \\
\hline 6,3 & 280 \\
\hline 7,24 & 138 \\
\hline 8,4 & 432 \\
\hline
\end{tabular}




\begin{tabular}{|c|c|c|c|c|c|}
\hline $8,13 \mathrm{~s}$ & 233 & 32,30 & 557 & \multicolumn{2}{|l|}{ Nombres } \\
\hline 9,29 & 548 & 32,34 & 74 & & \\
\hline 10,3 & 4 & 33,14 & 684 & & \\
\hline 12,3 & 315 & 34,7 & 74 & & \\
\hline 12,12 & 436 & 34,24 & 4 & 2,17 & 688 \\
\hline 12,13 & 65 & 40,15 & 393 & 4,3 & 617 \\
\hline 12,17 & 911 & 40,29 & 744 & 5,3 & 515 \\
\hline $12,23.27$ & 65 & & & 6,3 & 592 \\
\hline 12,29 & 436 & & & 6,4 & 192 \\
\hline 12,38 & 656 & & & 8,24 & 617 \\
\hline 12,51 & 911 & & & $9,20.23$ & 441 \\
\hline 14,21 & 85 & Lévitique & & 13,22 & 347 \\
\hline 14,31 & 438 & & & 14,19 & 15 \\
\hline 15,1 & 238 & & & 15,31 & 767 \\
\hline 15,2 & $87 s, 812$ & & & $15,38 \mathrm{~s}$ & 783 \\
\hline 15,7 & 876,899 & 1,15 & 220 & 16,22 & 449 \\
\hline 15,13 & 416 & 1,16 & 784 & $16,30.32$ & 886 \\
\hline 15,15 & 451 & 5,21 & 430 & 16,34 & 886 \\
\hline 15,19 & 281 & 5,23 & 430,505 & 17,2 & 216,592 \\
\hline 15,25 & 569 & 6,21 & 632 & 17,19 & 555 \\
\hline 16,4 & 569 & 7,3 & 744 & 17,28 & 902 \\
\hline 16,7 & 93 & 7,35 & $388 s$ & 18,29 & 402 \\
\hline 17,13 & $102 s$ & $11,9 \mathrm{~s} .12$ & 784 & 19,2 & 874 \\
\hline 18,13 & 25,88 & 12,4 & 312 & 19,11 & 330 \\
\hline 19,10 & 554 & 13,7 & 4 & 20,16 & 437 \\
\hline 19,16 & 219 & $13,16 \mathrm{~s}$ & 681 & 20,19 & 225 \\
\hline $20,4-6.12$ & *32 & 13,20 & 470 & 20,26 & 555 \\
\hline 22,19 & 73 & 14,35 & 683 & 21,17 & 192 \\
\hline 23,23 & 437 & 14,42 & 718 & 21,24 & $796 s$ \\
\hline 23,24 & 367 & $16,15 \mathrm{~s} .32$ & 393 & 21,28 & 793,796 \\
\hline 23,26 & 821 & 20,12 & 76 & 23,19 & 272 \\
\hline 23,27 & 626 & 21,6 & 129 & 24,7 & 352 \\
\hline 25,6 & 389 & 21,9 & 721 & 24,13 & 222 \\
\hline 25,8 & 515 & 21,10 & 393 & 24,17 & 413,795 \\
\hline 25,22 & 807 & 21,12 & 389 & 24,19 & 871 \\
\hline 29,8 & $554 \mathrm{~s}$ & 21,18 & 86 & 24,24 & 784 \\
\hline 29,14 & 721 & 22,25 & $388,392 \mathrm{~s}$ & 30,14 & 760 \\
\hline 29,29 & 388 & 23,21 & 911 & 31,12 & 236 \\
\hline 29,45 & 515 & 25,5 & 487 & 32,34 & 128 \\
\hline 30,25 & 389 & 25,31 & 813 & 32,42 & 767 \\
\hline $30,31 \mathrm{~s}$ & 393 & 25,53 & 871 & $35,2 \mathrm{~s}$ & 617 \\
\hline 31,11 & 390 & 26,17 & 865 & 35,26 & 548 \\
\hline 32,20 & 216 & $26,34 s$ & 611 & 35,34 & 515 \\
\hline 32,22 & 22 & 26,42 & 706 & & \\
\hline 32,25 & 876 & 26,43 & 611 & & \\
\hline
\end{tabular}


Dt

Deutéronome

$1,28 \quad 451$

$1,41 \quad 846$

$2,36 \quad 128$

$3,24 \quad 443$

$4,9 \quad 554$

$4,27 \quad 290$

$5,25 \quad 550$

$6,7 \mathrm{~s} \quad 554$

$6,24 \quad 93$

$7,8 \quad 93$

$7,26 \quad 149$

$8,2 \quad 468$

$8,3 \quad 275$

$8,9 \quad 408$

$8,15 \quad 210$

$8,16 \quad 185$

$9,26 \quad 278$

$11,4 \quad 281$

$11,6 \quad 697$

$12,1 \quad 515$

$13,18 \quad 748$

$14,1 \quad 365,494$

$14,9 \mathrm{~s} \quad 784$

$14,28 \quad 710$

$15,1 \quad 710$

$15,2 \mathrm{~s} \quad 611$

$15,16 \quad 697$

$16,2.6 .11 \quad 515$

$17,5 \quad 555$

$17,13 \quad 178$

$18,2 \quad 845$

$18,14 \quad 13$

$18,20.22 \quad 178$

$20,8 \quad 451$

$20,19 \quad 569$

$20,20 \quad 891$

$24,4 \quad 478$

$25,4 \quad 823$

$26,2 \quad 515$

$26,8 \quad 436$

$26,19 \quad 703$

$28,22 \quad 43$

$28,32 \quad 204$

\begin{tabular}{|ll|ll}
28,48 & 874 & 11,15 & 386,438 \\
29,22 & $1-3,118$ & 11,16 & 28 \\
31,10 & 710 & 11,20 & 333,686 \\
31,11 & 4 & 11,22 & 772 \\
31,17 & 881 & 13,25 & 779 \\
$31,19.21$ & 213 & 13,33 & 845 \\
31,26 & 213 & 15,22 & 115 \\
31,28 & 48 & 21,18 & 617 \\
32,6 & 365 & 22,11 & 477 \\
$32,8 s$ & 436 & 24,11 & 429 \\
32,9 & 845 & 24,26 & 474 \\
32,14 & 192 & 24,27 & 213
\end{tabular}

Juges

$1,19.34 \quad 772$

$2,13 \quad 752$

$2,22 \quad 42$

$3,8.10 \quad 828$

$5,13 \quad 871$

$5,14 \quad 529$

$5,16 \quad 638$

$6,10 \quad 278$

$6,19 \quad 718$

$7,7 \quad 451$

$9,45 \quad 783$

$9,46 \quad 429$

$9,54 \quad 846$

$10,8 \quad 52$

$10,16 \quad 437$

$11,26.33 \quad 128$

$13,10 \quad 683$

$13,14 \quad 192$

$13,21 \quad 4$

$14,3 \quad 895$

$15,5 \quad 192$

$16,2 \quad 477$

$16,9 \quad 488$

$16,12 \quad 488$

$16,14 \quad 655,657$

$16,21.25 \quad 72$

$18,7 \quad 523$

$20,38.40 \quad 219$

21,19-21 864 
Rt

Ruth

\begin{tabular}{|ll|ll}
28,14 & 12 & 3,26 & 881 \\
28,16 & 107 & 5,17 & 22 \\
31,2 & 534 & 5,31 & 638 \\
31,3 & 547 & 6,4 & 638 \\
& & 7,15 & 250 \\
& & $7,15-34$ & 858 \\
II Samuel & & 7,37 & 102 \\
& & 7,38 & 858 \\
1,9 & 275 & 8,13 & 365 \\
1,14 & 812 & 8,50 & 748 \\
2,8 & 556 & 8,56 & 438 \\
3,12 & 477 & 10,11 & 544 \\
3,18 & 575 & 10,15 & 249 \\
3,25 & 22 & 10,18 & 544 \\
3,31 & 112 & $11,3 s$ & 754 \\
6,21 & 342 & 11,5 & 796 \\
7,11 & 342 & 11,8 & 754 \\
11,16 & 487 & 11,24 & 843 \\
11,24 & 387 & 11,33 & 796 \\
$12,1-7$ & 31 & 13,7 & 46 \\
12,21 & 585 & 13,9 & 93 \\
12,24 & 357 & 13,24 & 117 \\
12,30 & 796 & 16,12 & 151 \\
13,19 & 762 & 17,7 & 586 \\
13,20 & 426 & 17,20 & 494 \\
14,7 & 327 & 18,2 & 4 \\
14,13 & 402 & 18,28 & 494 \\
17,11 & 437 & 18,32 & 195 \\
17,28 & 632 & 18,44 & 225 \\
18,27 & 524 & 19,12 & 228 \\
$19,40 s$ & 169 & 20,24 & 249 \\
20,19 & 762 & $21,10.13$ & 807 \\
$21,16-22$ & 772 & 22,15 & 909 \\
22,8 & 69 & $22,19.23$ & 279 \\
22,44 & $374,894 s$ & & \\
22,48 & 287 & & \\
23,5 & 707 & II Rois & \\
23,30 & 116,233 & & \\
23,33 & 609 & 2,19 & 821 \\
24,10 & 475 & 3,4 & 122 \\
& & 3,25 & 547 \\
I Rois & & 4,4 & 688 \\
& & 4,8 & 855 \\
2,8 & 56 & 4,39 & 469 \\
& & 5,1 & 855
\end{tabular}

I Samuel

$1,1 \quad 214$

$4,4 \quad 367$

$5,10 \quad 697$

$6,3 \quad 563$

$6,7 \quad 874$

$9,7 \quad 413$

$11,9 \quad 135$

$14,11 \quad 309 \mathrm{~s}$

$14,15 \quad 69$

$14,22 \quad 534$

$14,50 \quad 233$

$15,7 \quad 506$

15,23.26 315, 616

$15,33.821,893$

$16,2 \quad 825$

$16,11 \quad 126$

$17,4 \quad 772$

$17,20 \quad 330$

$17,25 \quad 563$

$17,54 \quad 846$

$18,6 \mathrm{~s} \quad 864$

$19,1 \quad 276$

$19,23 \quad 395$

$20,19 \quad 476$

$20,20.36 \quad 387$

$20,40 \quad 846$

$21,5 \quad 718$

$25,21 \quad 526$

$25,27 \quad 360$

$25,34 \quad 367$

$26,21 \quad 475$

$27,8 \quad 506$

$27,11 \quad 327,477$

28,3

334 


\begin{tabular}{ll|ll|ll}
6,5 & 482 & 25,10 & $856 \mathrm{~s}$ & 32,12 & 399 \\
6,14 & 891 & 25,11 & $731 \mathrm{~s}$ & 32,27 & 660 \\
$7,1.16$ & 195 & 25,12 & 731,857 & 33,19 & 638 \\
7,18 & 195 & $25,14-16$ & 858 & $35,5.7$ & 618 \\
11,7 & 330 & 25,17 & $859 \mathrm{~s}$ & 35,23 & 387 \\
11,14 & 58 & 25,19 & 860 & 36,10 & 660 \\
$11,15.18$ & 679 & 25,23 & $739 s, 747$ & & \\
12,10 & 310 & $25,23-26$ & 742 & & \\
13,6 & 401 & 25,24 & 740 & Esdras & \\
$16,5 \mathrm{~s}$ & 45 & 25,29 & 822 & & \\
16,7 & 592 & & & 1,2 & 296 \\
16,9 & 64 & & & 3,6 & 336 \\
16,17 & 858 & IChroniques & 5,11 & 360 \\
17,25 & 117 & & & 9,8 & 686 \\
18,22 & 399 & $2,4 s .9-15$ & 742 & & \\
18,24 & 249 & 2,18 & 408 & & \\
18,34 & $249 \mathrm{~s}$ & $2,25-41$ & 742 & Néhémie & \\
19,2 & 633 & 2,32 & 739 & & \\
19,9 & 251 & 2,41 & 743 & 1,11 & 748 \\
19,11 & 86 & 4,20 & 712 & 2,13 & $909 \mathrm{~s}$ \\
19,15 & 253 & 10,2 & 534 & 3,8 & 812 \\
19,17 & $86,252 \mathrm{~s}$ & $11,34 \mathrm{~s}$ & 609 & 4,1 & 702 \\
19,19 & $253 \mathrm{~s}$ & 12,16 & 772 & 8,15 & 566 \\
19,20 & $254 \mathrm{~s}$ & 12,39 & 592 & 9,6 & 254 \\
19,21 & 249 & 15,12 & 841 & 9,24 & 697 \\
19,23 & $(255 \mathrm{~s})$ & 16,19 & 290 & 11,32 & 79 \\
19,24 & 256,624 & 20,2 & 796 & 12,7 & 634 \\
19,26 & $257 \mathrm{~s}$ & 20,8 & 277 & 12,32 & 747 \\
$19,27 \mathrm{~s}$ & 257,259 & 21,20 & 822 & 13,21 & 48 \\
19,32 & 387 & 22,12 & 342 & & \\
19,35 & 260 & 26,16 & 44 & & \\
$20,4-6$ & 260 & 29,11 & 223 & Esther & \\
$20,7-9$ & 261 & & & & \\
$20,9 \mathrm{~s}$ & 263 & & & 1,6 & 139 \\
22,13 & 602 & II Chroniques & 1,9 & 23 \\
23,2 & 602 & & & 2,21 & 317 \\
23,6 & 618 & 8,11 & 516 & 3,8 & 885 \\
23,8 & 520 & 9,10 & 544 & 4,13 & 737 \\
23,12 & 262 & 11,9 & 708 & 4,14 & 907 \\
23,13 & 796 & 14,10 & 431 & 4,15 & 737 \\
23,17 & 783 & 15,16 & $* 62$ & 6,1 & $272 \mathrm{~s}$ \\
25,1 & 891 & 16,10 & 154 & 6,2 & 317 \\
25,4 & 730,854 & 16,12 & 401 & 6,14 & 400 \\
25,5 & 156 & 24,13 & 702 & 8,15 & 139 \\
25,9 & $731,854 \mathrm{~s}$ & 28,23 & 625 & 10,2 & 842
\end{tabular}


II Maccabées

$15,14 \quad 615$

Job

1,6-12 279

2,1-6 279

$3,13 \quad 563$

$3,15 \quad 106$

$3,16 \quad 406$

$4,16 \quad 228$

$5,21 \quad 628$

$6,5 \quad 472$

$6,9 \quad 844$

$7,20 \quad 649$

$8,12 \quad 258$

$9,5 \quad 3,587$

$9,6 \quad 69$

$9,7 \quad 146 \mathrm{~s}$

$9,13 \quad 211,418$

$9,19 \quad 806 \mathrm{~s}$

$10,9 \quad 619 \mathrm{~s}$

$10,15 \quad 237$

$10,20 \quad 531 \mathrm{~s}$

$11,4 \quad 501$

$11,12 \quad 472$

$11,17 \quad 264 \mathrm{~s}$

$12,21 \quad 170$

$12,24 \quad 173$

$13,1 \quad 447$

$14,21 \quad 459$

$15,2 \quad 14$

$15,24 \quad 203,778$

$15,26 \quad 896$

$15,29 \quad 225 \mathrm{~s}$

$15,33 \quad 882 \mathrm{~s}$

$17,2 \quad 225$

$18,7 \quad 912 \mathrm{~s}$

$18,13 \quad 108$

$19,3 \quad 563$

$19,6 \quad 891$

$19,17 \quad 216$

$19,24 \quad 214$

\begin{tabular}{|ll|ll}
20,4 & 327 & 9,7 & 107 \\
20,16 & 295 & 10,1 & 414 \\
20,26 & 566,871 & 10,7 & 535 \\
21,10 & 821 & 11,3 & $139 s$ \\
21,12 & 305 & 12,6 & 896 \\
21,13 & 76 & 16,1 & $* 26$ \\
21,34 & 659 & 16,2 & 263 \\
$22,13 s$ & 572 & 16,6 & 88 \\
22,24 & 14 & 16,8 & 267 \\
24,19 & 135 & 17,9 & 891 \\
26,13 & 317 & 17,10 & 243 \\
27,3 & 275 & 17,11 & $* 26$ \\
27,4 & 538 & 17,14 & $264 s$ \\
28,8 & 185 & 18,8 & 69 \\
28,16 & 544 & 18,41 & 626 \\
28,25 & 282 & 19,5 & $* 26$ \\
29,6 & 185 & 19,9 & 167 \\
29,11 & 447 & 19,11 & 500 \\
29,25 & 843 & 19,14 & 355 \\
30,4 & 351 & 19,24 & $* 26$ \\
30,16 & 876 & 22,9 & 570 \\
30,29 & 910 & 22,13 & 764 \\
$31,5-39$ & 591 & 22,16 & 538 \\
31,15 & 451 & 22,17 & $* 26$ \\
31,32 & 288 & 25,3 & 175 \\
$32,21 s$ & 325,627 & 29,1 & $* 26$ \\
33,18 & 276 & 30,8 & 609 \\
34,26 & 73 & 32,7 & 509 \\
36,11 & 76 & 33,6 & 243 \\
36,24 & 12 & 33,7 & 281 \\
38,15 & 502 & 33,14 & 546 \\
$38,31-33$ & 690 & 33,19 & 458 \\
39,5 & 472 & 34,16 & 907 \\
41,18 & 102 & 35,1 & 629 \\
& & 36,10 & 4 \\
Psaumes & & 36,12 & 298 \\
& & 38,5 & 169 \\
2,9 & $* 26,632$ & 39,13 & 907 \\
4,3 & $* 26$ & 39,14 & 532 \\
5,6 & 380 & 40,2 & 907 \\
5,10 & $496 s$ & 40,7 & 402 \\
6,4 & 646 & 42,5 & $* 26,273$, \\
$7,4 s$ & 591 & & 485,901 \\
8,6 & $* 42$ & 42,7 & 901 \\
& & &
\end{tabular}


Ps

\begin{tabular}{|c|c|c|c|c|c|}
\hline 42,10 & 278 & 68,13 & 504 & 92,12 & 447 \\
\hline 43,4 & 61 & 68,15 & 60 & 94,4 & 422 \\
\hline 44,13 & 597 & 68,28 & 287,871 & 94,7 & 572 \\
\hline 44,26 & 901 & 68,31 & 764 & 94,9 & 375 \\
\hline 45,3 & 389 & 69,16 & 886 & 95,5 & 48 \\
\hline 45,8 & 389s, 393 & 69,21 & 416 & 97,7 & 835 \\
\hline 45,10 & 544 & 69,27 & 402 & 99,8 & 15 \\
\hline 45,16 & 61 & 71,4 & 6 & 100,3 & 546 \\
\hline 46,5 & 809 & 72,8 & 871 & 102,10 & 896 \\
\hline 46,7 & 451 & 73,2 & 464 & 102,18 & 779 \\
\hline 48,8 & 883 & 73,9 & 140 & 103,5 & 883 \\
\hline 49,2 & $264 s$ & 73,11 & 572 & 104,17 & 809 \\
\hline 49,15 & 140 & 73,28 & 464 & 105,11 & 477 \\
\hline 50,7 & 48 & 75,5 & 380 & 105,12 & 290 \\
\hline 50,10 & 458 & 75,7 & 485 & 105,26 & 438 \\
\hline 50,13 & 764 & 75,9 & 655 & 105,28 & *62 \\
\hline 50,23 & 93,909 & 77,7 & 901 & 106,24 & 192 \\
\hline $51,18.21$ & 402 & 77,18 & 623 & 106,30 & *62 \\
\hline 53,6 & 203,206 & 77,19 & 69 & 106,38 & 482 \\
\hline 54,5 & 178 & 77,21 & 441 & 106,46 & 748 \\
\hline $55,7 \mathrm{~s}$ & 514,784 & 78,50 & 276 & 107,23 & 162,168 \\
\hline 55,12 & 535 & 79,2 & 187 & 107,30 & 168 \\
\hline $56,5.11 \mathrm{~s}$ & 263 & $79,6 \mathrm{~s}$ & $549 s$ & 109,4 & 130 \\
\hline 57,6 & 263 & 80,2 & 440 & 109,19 & 168 \\
\hline 57,7 & $629 s$ & 80,6 & 555 & 111,8 & 214 \\
\hline 57,12 & 263 & 80,11 & 8 & 112,9 & 897 \\
\hline 58,3 & 221,425 & 81,9 & 48 & 114,8 & 470 \\
\hline 58,8 & 534 & 81,13 & 517 & 115,7 & 563 \\
\hline 58,12 & 263 & 82,8 & 575 & 118,14 & 87,812 \\
\hline 59,10 s & 263 & 85,5 & 451 & 118,24 & 88 \\
\hline 59,18 & 90,263 & 86,2 & 270,684 & 119,32 & 419 \\
\hline 60,4 & 69 & 86,14 & $177 \mathrm{~s}$ & 119,85 & $629 s$ \\
\hline 60,8 & 263 & 87,4 & 211 & 119,103 & 601 \\
\hline 60,13 & 88 & 88,18 & 891 & 119,105 & 167 \\
\hline 62,5 & 538 & 89,7 & 807 & 119,122 & 271 \\
\hline 62,10 & 284 & 89,11 & 418 & 121,6 & 420 \\
\hline 63,2 & 210 & 89,28 & 108 & 124,5 & 623 \\
\hline 64,4 & 534 & 89,36 & 404 & 126,6 & 62 \\
\hline 64,5 & 387 & 89,41 & 798 & 127,2 & 822,824 \\
\hline 64,7 & 425,902 & 89,48 & $264 s$ & 134,1 & 480 \\
\hline 64,8 & 387 & 90,2 & 414 & 136,13 & 86 \\
\hline 65,10 & 563 & 90,5 & 555 & 139,9 & 784 \\
\hline 66,15 & $35 s$ & 90,6 & 258 & 139,20 & 107 \\
\hline 66,17 & 243 & 90,13 & 647 & 140,6 & 630 \\
\hline 68,11 & 60 & 91,15 & $436 s$ & 142,4 & 630 \\
\hline
\end{tabular}


Ps

\begin{tabular}{|c|c|c|c|c|c|}
\hline 143,4 & 40 & 30,25 & 351 & 1,8 & 487 \\
\hline 144,2 & 374,894 & & & 1,9 & $1 \mathrm{~s}, 117,128$ \\
\hline 144,12 & 217,413 & & & 1,10 & $1 \mathrm{~s}$ \\
\hline 145,4 & $442 s$ & Qohélet & & 1,11 & 402 \\
\hline 145,19 & 907 & & & 1,12 & $(3-5), 232$ \\
\hline 147,2 & 122 & 5,16 & 563 & 1,13 & 425 \\
\hline 148,6 & 214 & 9,14 & 891 & 1,17 & $(6 s), 28,166$ \\
\hline \multirow[t]{3}{*}{149,2} & 428 & 10,5 & 823 & 1,20 & $(7-9), 335$ \\
\hline & & & & 1,21 & (9s) \\
\hline & & & & $1,21-31$ & 9 \\
\hline \multirow[t]{2}{*}{ Proverbes } & & Cantique & & 1,22 & 335 \\
\hline & & & & $1,22-26$ & 10 \\
\hline 1,8 & 333 & 4,2 & 662 & 1,24 & 681 \\
\hline 1,12 & 886 & 7,6 & *27 & 1,26 & 13,149 \\
\hline 2,22 & 175 & 8,6 & 89 & 1,27 & 9s \\
\hline 4,12 & $912 s$ & & & $1,29 \mathrm{~s}$ & (10s) \\
\hline 6,23 & 167 & & & 1,31 & $(11-13), 235$ \\
\hline 7,23 & 367 & Sagesse & & 2,3 & 96,209 \\
\hline 8,29 & 328 & & & & 302 \\
\hline 9,3 & 896 & 2,12 & 21 & 2,4 & 96 \\
\hline 10,17 & 288 & 17,9 & 769 & 2,6 & (13s), 15, 24 \\
\hline 11,25 & 237 & & & $2,7 \mathrm{~s}$ & 13 \\
\hline 15,17 & 822 & & & 2,9 & $(14 s), 16$ \\
\hline 15,31 & 447 & Siracide & & 2,10 & 14s, (16), 19 \\
\hline 16,3 & 570 & & & 2,11 & 18 \\
\hline 16,15 & 275 & 6,2 & 35 & 2,12 & (16-18), 24 \\
\hline 17,4 & 476 & 13,18 & 573 & $2,13-17$ & 18 \\
\hline 17,22 & 822 & 17,17 & 436 & 2,14 & 217 \\
\hline 18,24 & 54 & 21,20 & 531 & 2,15 & 193,217 \\
\hline 20,12 & 447 & 36,17 & $65 s$ & 2,17 & 18 \\
\hline 22,14 & 630 & 40,27 & 30 & 2,19 & 15s, 18, \\
\hline 22,15 & 220 & 43,13 & 373 & & (19s), 491 \\
\hline $23,13 s$ & 82 & 43,19 & 783 & 2,21 & $15 \mathrm{~s}$ \\
\hline 23,28 & 175 & & & 3,1 & (20s), 275 \\
\hline 25,12 & 447 & & & $3,2 \mathrm{~s}$ & $20 \mathrm{~s}$ \\
\hline 25,13 & 135 & & & 3,4 & 21,24 \\
\hline 25,25 & 623 & Isaïe & & 3,5 & $21,71,99 s$ \\
\hline 26,8 & 547 & & & 3,6 & 97 \\
\hline 26,18 & 373 & 1,2 & 3,27 & 3,7 & 21,305 \\
\hline $26,24.28$ & 538 & $1,3 \mathrm{~s}$ & 239 & 3,8 & 225 \\
\hline 27,17 & 329 & 1,4 & 3 & 3,10 & $(21 s)$ \\
\hline 28,4 & 42 & 1,5 & 125,229 & 3,11 & 22,61 \\
\hline 28,20 & 615 & 1,6 & 60 & 3,12 & $22,(23-25)$ \\
\hline 30,4 & 487 & 1,7 & $(1.3), 178$ & & 25,125 \\
\hline 30,7 & 502 & & 426,487 & 3,13 & $(25 s)$ \\
\hline
\end{tabular}




\begin{tabular}{|c|c|c|c|c|c|}
\hline \multirow{3}{*}{$\begin{array}{l}3,14 \mathrm{~s} \\
3,15\end{array}$} & 25 & 8,1 & 48 & 10,30 & (78s) \\
\hline & 195,232 , & 8,2 & $(47-49), 155$ & 10,33 & 80,369 \\
\hline & 532 & 8,3 & 48,765 & 10,34 & $(79-81), 280$ \\
\hline 3,17 & 467 & 8,6 & (49s) & 11,1 & $104 \mathrm{~s}$ \\
\hline 3,24 & $(26-29), 223$ & 8,7 & $50 \mathrm{~s}$ & 11,4 & $44,(81 s)$ \\
\hline 3,25 & $26 s$ & 8,8 & (50s), 169, & 11,6 & $36,(82 s)$ \\
\hline 4,3 & 150 & & 784 & 11,7 & 116 \\
\hline 4,5 & (29s) & 8,9 & $(52-54)$ & 11,8 & 310 \\
\hline 4,6 & 30 & 8,10 & 51,54 & 11,11 & $(83 s), 755$ \\
\hline 5,1 & (30s) & 8,11 & $(54-56), 60$ & 11,12 & 122 \\
\hline $5,1-7$ & 192 & 8,12 & $57 s, 60$ & 11,14 & 14 \\
\hline 5,2 & 529 & $8,13 \mathrm{~s}$ & $(56-59)$ & 11,15 & $(85 s), 91 s$ \\
\hline 5,3 & 31 & 8,19 & 33,59 & 12,2 & $(87-90), 812$ \\
\hline 5,5 & 194, 688, & 8,20 & 60,407 & 13,2 & $86,(90-92)$ \\
\hline & 883 & 8,21 & (59s) & 13,3 & 92 \\
\hline 5,6 & 194 & 8,23 & 102,213 & 13,4 & 228 \\
\hline 5,7 & 31 & 9,1 & 407 & 13,7 & 451 \\
\hline 5,9 & (31s) & 9,2 & $50,(60.63)$ & 13,8 & 71 \\
\hline 5,13 & (33s), 289s & 9,3 & 97,179 & 13,11 & 92,106, \\
\hline 5,14 & 60 & 9,4 & 330 & & 125,177 \\
\hline 5,17 & $(34-36)$ & 9,8 & 198 & 13,12 & $92-94,544$ \\
\hline 5,18 & $(36-38)$ & 9,10 & $(63 s)$ & 13,13 & $(92 s), 94$ \\
\hline 5,20 & 22 & 9,11 & 14 & 13,14 & 92 \\
\hline 5,24 & 382 & 9,13 & 229 & 13,15 & 156 \\
\hline 5,25 & 187,303 & 9,15 & 50 & 13,17 & $92 s$ \\
\hline 5,26 & $(38 s), 61$ & 9,16 & $(65 s)$ & 13,19 & 1s, 67, \\
\hline $5,27.30$ & 39 & 9,17 & 69 & & 117,128 \\
\hline 6,5 & $278 s$ & 9,18 & $66,(66-69)$ & 13,20 & 94,609 \\
\hline 6,8 & $55,278 s$ & 9,19 & $(69-71)$ & 13,21 & 94,910 \\
\hline 6,9 & 40 & 10,3 & 72 & 13,22 & $(93-95), 241$, \\
\hline 6,10 & $(39-41)$ & 10,4 & $(71-74)$ & & 265,910 \\
\hline 6,11 & 278s, 426, & 10,5 & 77 & 14,1 & 209 \\
\hline & 647 & 10,6 & 327 & 14,2 & $(96), 103$ \\
\hline 6,12 & 44 & 10,12 & $(74 s), 126$, & & 120 \\
\hline 6,13 & $(41-44)$ & & 160,239 & 14,4 & $(96-100)$ \\
\hline 7,1 & $(44-46)$ & 10,13 & 764 & 14,6 & (101s) \\
\hline 7,2 & 45,50 & 10,16 & 176 & 14,11 & 290 \\
\hline 7,8 & 161,585 & 10,18 & 256 & 14,12 & $(102-104)$ \\
\hline 7,9 & 198 & 10,19 & 127 & 14,14 & $273,399 s$ \\
\hline 7,11 & (46s) & 10,24 & 77,382 & 14,16 & 69,380 \\
\hline 7,17 & 209 & 10,25 & $(75-77), 78$, & 14,17 & $72,106 \mathrm{~s}$ \\
\hline 7,18 & 39 & & 127,382 & & 159 \\
\hline $7,18-20$ & 59 & 10,26 & 78 & 14,19 & $73,(104 s)$ \\
\hline 7,20 & 467 & 10,27 & $(77 s), 682$ & 14,21 & $86,(105-$ \\
\hline 7,24 & 688 & 10,28 & 77 & & 107) \\
\hline
\end{tabular}




\begin{tabular}{ll|ll|ll}
14,23 & 206 & $17,12 \mathrm{~s}$ & $96,(133 \mathrm{~s})$ & 22,17 & $(157 \mathrm{~s}), 160$ \\
14,29 & 110 & 18,1 & 153 & 22,18 & $160,202 \mathrm{~s}$ \\
14,30 & $(107-110)$ & 18,2 & $135-137$ & 22,19 & $(158-160)$, \\
14,31 & 60,67, & 18,4 & $(134 \mathrm{~s})$ & & 239 \\
& 110,888 & 18,7 & $(135-137)$ & 22,24 & 229 \\
14,32 & 108 & 19,1 & 138,207, & 23,1 & $(160 \mathrm{~s}), 162$, \\
15,1 & 120,154 & & 764 & & 164 \\
15,2 & $(110 \mathrm{~s}), 115$ & 19,2 & 71 & 23,2 & 164,169 \\
15,3 & $(111 \mathrm{~s})$ & 19,5 & 623 & $23,2 \mathrm{~s}$ & $(161-164)$, \\
15,4 & 111,791 & 19,7 & $(137 \mathrm{~s}), 166$ & & 168 \\
15,5 & $(113 \mathrm{~s}), 317$, & 19,8 & 138 & 23,4 & $(164-166)$ \\
& $774-778$, & 19,9 & $(138 \mathrm{~s}), 140 \mathrm{~s}$, & 23,5 & $(166 \mathrm{~s})$ \\
& 780,812 & & 240,638 & 23,10 & $(167-170)$ \\
15,6 & 115,258 & 19,10 & $(139-141)$ & 23,11 & $(170 \mathrm{~s})$ \\
15,9 & $(114-118)$, & 19,12 & $(141 \mathrm{~s})$ & 23,12 & 168 \\
& $120 \mathrm{~s}, 125$, & 19,14 & $(142 \mathrm{~s})$ & 23,13 & 500,511 \\
& 155,357 & 19,16 & $91 \mathrm{~s}$ & 23,14 & $160 \mathrm{~s},(171 \mathrm{~s})$ \\
16,1 & $(118-122)$ & 19,18 & $(143-150)$, & 23,16 & 616 \\
$16,1-5$ & 119 & & 362 & 23,17 & 657 \\
16,2 & 784 & 19,19 & 150 & 24,4 & $(172-174)$ \\
16,4 & $121,(122 \mathrm{~s})$, & 19,20 & 431 & $24,5 \mathrm{~s}$ & 642 \\
& 147,226 & 19,21 & 560 & 24,6 & 127 \\
16,5 & 120 & $19,23-25$ & 312 & 24,10 & 161 \\
16,7 & $120,(123-$ & 20,1 & 312 & 24,16 & $(174-177)$, \\
& $125), 382$, & 20,2 & $(151)$ & & 271,278 \\
& 787 & $20,3-5$ & 151 & 24,17 & 176 \\
16,8 & 382,788 & 21,1 & $(152 \mathrm{~s})$ & 24,21 & 238 \\
16,9 & $113,125 \mathrm{~s}$, & 21,2 & $125,(153 \mathrm{~s})$ & 24,22 & 72 \\
& 788,790 & $21,4 \mathrm{~s}$ & 154 & 24,23 & 193 \\
16,10 & $61,(125 \mathrm{~s})$, & 21,8 & $117,(154 \mathrm{~s})$ & 25,2 & $(177 \mathrm{~s}), 204$, \\
& $789 \mathrm{~s}$ & 21,9 & 157,764 & & 591 \\
16,11 & 113,126, & 21,13 & 153 & $25,3 \mathrm{~s}$ & 369 \\
& 787. & 21,14 & 90,575 & $25,3-5$ & 178 \\
16,12 & 400 & 21,17 & 127 & 25,4 & $(178 \mathrm{~s})$ \\
16,14 & $(126 \mathrm{~s})$ & 22,1 & 153,197 & 25,5 & $(179 \mathrm{~s}), 203$ \\
17,1 & 128,161 & 22,2 & 811,850 & 25,6 & 20 \\
17,2 & $(127-129)$, & 22,3 & $(155 \mathrm{~s})$ & 25,9 & 346 \\
& 799 & 22,5 & 197,229, & 25,10 & 97 \\
17,4 & 176 & & 448 & 25,11 & 784 \\
17,5 & $(129 \mathrm{~s})$ & 22,6 & $(156)$ & $26,3 \mathrm{~s}$ & 180 \\
17,6 & 123,132 & 22,7 & 157,458 & 26,4 & $87 \mathrm{~s}, 90$ \\
17,9 & $(130-133)$, & 22,10 & 701 & $26,5.7$ & $(180-182)$ \\
& 426 & 22,11 & 193 & 26,6 & 180 \\
17,10 & 125,178 & 22,13 & 308,310 & 26,8 & $180,(182 \mathrm{~s})$ \\
17,11 & 844 & 22,14 & 32 & 26,9 & 180 \\
& & & & &
\end{tabular}




\begin{tabular}{|c|c|c|c|c|c|}
\hline 26,12 & 186 & 30,6 & 153, (209. & 33,19 & 229 \\
\hline $26,12 s$ & $183 s$ & & 211), 295 & 33,21 & 169 \\
\hline 26,14 & 33,184 & 30,7 & $(211 s), 418$ & 33,23 & (235s) \\
\hline 26,15 & $60 \mathrm{~s}$ & & 765 & 34,1 & 302 \\
\hline \multirow[t]{2}{*}{26,16} & (183-186), & 30,8 & 212, (212- & 34,4 & 238 \\
\hline & 207 & & 214) & 34,5 & 197, (236- \\
\hline $26,17 \mathrm{~s}$ & 183s, 186 & 30,13 & 244 & & 239), 240 \\
\hline \multirow[t]{2}{*}{26,19} & 33, (186- & 30,14 & 632 & 34,6 & 238,240 \\
\hline & 188) & 30,17 & $214 s$ & 34,7 & 237s, (239s), \\
\hline 26,20 & 188 & 30,18 & 216,351 & & 764 \\
\hline 27,1 & 317 & 30,19 & (215s), 762 & 34,11 & $240 s$ \\
\hline \multirow[t]{2}{*}{27,2} & (188-192), & 30,20 & 216 & 34,12 & 139,(240s), \\
\hline & 193 & 30,21 & 447 & & 284 \\
\hline 27,3 & 193s, 196 & 30,22 & (216s) & 34,13 & 910 \\
\hline 27,4 & $(193 s)$ & 30,27 & (218s) & 34,14 & 71,241 \\
\hline 27,6 & 107 & 30,28 & 769 & 34,15 & 71, 94, 206, \\
\hline \multirow[t]{2}{*}{27,8} & (194-196), & 30,30 & 623 & & 241 \\
\hline & 232 & 30,32 & 42, (219s) & 34,16 & 71, (241- \\
\hline $27,9 s$ & 382 & 30,33 & (221) & & 243) \\
\hline 27,13 & 335 & 31,2 & 209 & 34,30 & 34 \\
\hline $28,1-4$ & (196-198) & 31,9 & 373 & $35,5 \mathrm{~s}$ & 247 \\
\hline 28,9 & 393 & 32,1 & 275 & 35,6 & (243s) \\
\hline 28,12 & 97 & 32,5 & 150 & 35,7 & (244s) \\
\hline 28,14 & 382 & 32,6 & $(221 \mathrm{~s})$ & 35,8 & $(245-247)$ \\
\hline 28,15 & 298,382 & 32,10 & 102 & 35,9 & 116 \\
\hline 28,18 & 298 & 32,12 & 189, 192 & 36,4 & 248 \\
\hline 28,19 & 371 & 32,13 & $(222 s)$ & 36,5 & (248), 257 \\
\hline 28,25 & (198-200) & 32,14 & 511 & 36,6 & 152 \\
\hline 28,27 & 201 & 32,15 & 224 & 36,7 & $149,399 s$ \\
\hline 28,28 & (200s), 527 & 32,19 & $(223 s)$ & 36,9 & (248s) \\
\hline 28,29 & 212 & 32,20 & 22 & 36,19 & (249s) \\
\hline 29,1 & $116,202 s$ & 33,1 & $22,153 \mathrm{~s}$ & $36,20-23$ & 380 \\
\hline \multirow[t]{2}{*}{29,3} & 102, (202s), & & $(224-226)$ & 36,22 & 61 \\
\hline & $205 s$ & 33,2 & (226s) & 37,2 & 633 \\
\hline \multirow[t]{2}{*}{29,5} & 178, 202, & 33,3 & $227,(227 s)$ & 37,9 & $(251), 257$ \\
\hline & $(203 s), 838$ & 33,4 & $(228 s)$ & 37,10 & 331 \\
\hline 29,7 & $204,(205 s)$ & 33,5 & $9,(229 \mathrm{~s})$ & 37,11 & 86 \\
\hline 29,8 & 206,303 & 33,6 & (230s) & 37,12 & (251s) \\
\hline 29,9 & 206, (207s) & 33,7 & $5,195,(231$. & 37,16 & 253 \\
\hline 29,10 & 207 & & 233) & 37,18 & $86,(252 s)$ \\
\hline 29,15 & 572 & 33,8 & (233s) & 37,20 & (253s), 257 \\
\hline 29,17 & 127 & 33,11 & $229,(234 s)$ & 37,21 & 209, (254s), \\
\hline \multirow[t]{2}{*}{29,22} & 138, (208s), & 33,13 & 239 & & 277 \\
\hline & 255,277 & 33,15 & 40 & 37,22 & $249,254 \mathrm{~s}$ \\
\hline 29,23 & 58 & 33,18 & 217 & 37,24 & (255s) \\
\hline
\end{tabular}




\begin{tabular}{|c|c|c|c|c|c|}
\hline 37,25 & (256s) & $40,6-8$ & 258 & 41,25 & 288, (295. \\
\hline $37,27 \mathrm{~s}$ & $(257-259)$ & 40,7 & $173,896 s$ & & 298), 342 \\
\hline 37,28 & $259 s$ & 40,9 & 91,279 & 41,26 & 299 \\
\hline 37,29 & $\begin{array}{l}32,246, \\
(259 s)\end{array}$ & 40,10 & $\begin{array}{l}61,80 \\
(280 s)\end{array}$ & $\begin{array}{l}41,27 \\
41,28 s\end{array}$ & $\begin{array}{l}(298-300) \\
299\end{array}$ \\
\hline 37,33 & 209 & 40,11 & 283,300 & 41,29 & $265,(300 s)$ \\
\hline 37,34 & 246 & & 416 & 42,1 & 302,314 \\
\hline 37,36 & $33,(260)$ & 40,12 & $(281 s), 283$ & 42,2 & 305 \\
\hline 37,38 & 303 & 40,13 & 282 & 42,3 & (301s) \\
\hline 38,1 & 33 & 40,14 & $(282 s)$ & 42,4 & $302,(302 s)$ \\
\hline 38,5 & $(260), 272$ & $40,14-16$ & 283 & 42,5 & 279,282 \\
\hline 38,6 & 261,697 & 40,16 & 425 & & 328,375 \\
\hline 38,7 & (261) & 40,17 & 283, (283- & 42,6 & (303-306), \\
\hline 38,8 & $(261-263)$ & & 285), 294s, & & 307,321 \\
\hline 38,9 & (263s) & & 543 & 42,7 & 72,307 \\
\hline 38,10 s & 263,266 & 40,18 & 807 & 42,11 & 337,813 \\
\hline \multirow[t]{4}{*}{38,11} & $90,(264 \mathrm{~s})$ & 40,21 & (285s) & 42,14 & 294,414 \\
\hline & 276,290 & 40,22 & 286 & 42,16 & 319,684 \\
\hline & 295,301 , & 40,24 & $896 s$ & 42,17 & 344 \\
\hline & 354,375 & 40,27 & 246 & $42,18 s$ & 308 \\
\hline \multirow[t]{2}{*}{38,12} & 263,265 & 41,1 & 302 & $42,18-22$ & 307 \\
\hline & $\begin{array}{l}(266), 277 \\
415,844\end{array}$ & 41,2 & $\begin{array}{l}(286 s), 357 \\
529,871\end{array}$ & $\begin{array}{l}42,19 \\
42,20\end{array}$ & $\begin{array}{l}(306 s), 335 \\
(307-309)\end{array}$ \\
\hline \multirow[t]{2}{*}{38,13} & $263,(267)$ & 41,3 & $(287 s), 298$ & $42,21 \mathrm{~s}$ & 308 \\
\hline & 277 & 41,4 & 299, 316, & 42,22 & (309s) \\
\hline \multirow[t]{2}{*}{38,14} & $(268-270)$ & & 328 & 42,24 & $302 s,(310 s)$ \\
\hline & 337 & 41,6 & 71 & 43,1 & 342 \\
\hline \multirow[t]{2}{*}{38,15} & (271-273), & 41,7 & 346 & 43,3 & 312,343 \\
\hline & 275 & 41,8 & 314,354 & 43,4 & $(311-313)$ \\
\hline 38,16 & $(273-275)$ & 41,9 & 278,354 & 43,7 & 452 \\
\hline $38,16-20$ & 272 & 41,10 & $292 s, 448$ & 43,8 & 306,314 \\
\hline \multirow[t]{3}{*}{38,17} & 265,269 & 41,11 & 103, (289), & 43,9 & 302 \\
\hline & $(275 s), 290$ & & 345 & 43,10 & 287s, (313s), \\
\hline & 293 & 41,12 & 284 & & 354 \\
\hline 38,18 & 277 & 41,14 & 34,265 & 43,13 & $(314-316)$ \\
\hline 38,19 & (276s) & & (289s) & 43,14 & $(316-318)$ \\
\hline $38,19 s$ & $209 s$ & 41,17 & 300,623 & $43,16-21$ & 319 \\
\hline 38,21 & 261 & 41,18 & 319 & 43,18 & 71 \\
\hline 39,6 & 61 & 41,21 & $208,290 s$ & 43,19 & (318s) \\
\hline 40,1 & $278 s$ & 41,22 & (290s) & 43,20 & 319,910 \\
\hline 40,2 & 279 & 41,23 & $(292 s), 342$ & 43,21 & 342 \\
\hline 40,3 & 278s, 319 & 41,24 & 265,285 & 43,23 & 8,561 \\
\hline $40,4 \mathrm{~s}$ & 197 & & (293-295), & 43,24 & 342,561 \\
\hline \multirow[t]{2}{*}{40,6} & (278s), 304, & & 357, 529, & 43,25 & (319s) \\
\hline & 321 & & 543 & 43,27 & 322 \\
\hline
\end{tabular}




\begin{tabular}{|c|c|c|c|c|c|}
\hline 43,28 & $\begin{array}{l}(320-322), \\
355,396\end{array}$ & 45,24 & $\begin{array}{l}345,(345- \\
347)\end{array}$ & $\begin{array}{l}49,20 \\
49,21\end{array}$ & $\begin{array}{l}300,437 \\
300,(368 s)\end{array}$ \\
\hline $44,1 \mathrm{~s}$ & 354 & 46,1 & 764 & 49,22 & 83,367 \\
\hline 44,2 & 342 & $46,4.7$ & 331 & & 460s \\
\hline 44,3 & $323,427 \mathrm{~s}$ & 46,11 & 288 & 49,23 & 370 \\
\hline 44,4 & $(322.324)$ & 47,1 & 379 & 49,24 & $(369 s)$ \\
\hline 44,5 & $\begin{array}{l}794 \\
(324 s)\end{array}$ & 47,3 & $\begin{array}{l}(348 s), 349 s, \\
449\end{array}$ & 49,25 & $\begin{array}{l}367,369 s, \\
431,629\end{array}$ \\
\hline 44,6 & $\begin{array}{l}213,299 \\
303\end{array}$ & $\begin{array}{l}47,4 \\
47,5-15\end{array}$ & $\begin{array}{l}(349 s) \\
380\end{array}$ & $\begin{array}{l}49,26 \\
50,1\end{array}$ & $\begin{array}{l}434 \\
23,353\end{array}$ \\
\hline 44,7 & $\begin{array}{l}279,(325- \\
329), 342\end{array}$ & 47,6 & $\begin{array}{l}320,358, \\
396\end{array}$ & $\begin{array}{l}50,4 \\
50,9\end{array}$ & $\begin{array}{l}\text { (370s) } \\
225\end{array}$ \\
\hline 44,8 & 277 & 47,9 & 346 & 50,11 & $(371-373)$ \\
\hline 44,9 & 344,632 & 47,14 & (350s) & 51,4 & $167,(374)$ \\
\hline $44,11 \mathrm{~s}$ & $(329-331)$ & 48,1 & 325, (351s), & 51,6 & 585 \\
\hline 44,12 & $55 s$ & & 452 & $51,7 \mathrm{~s}$ & 225 \\
\hline 44,13 & $329 s$ & 48,4 & 312 & 51,9 & 396 \\
\hline 44,14 & 61 & 48,6 & 141 & 51,11 & 346 \\
\hline 44,18 & $287 s$ & 48,7 & 554 & 51,13 & 375 \\
\hline 44,19 & 351 & 48,8 & 452 & 51,14 & $429 s$ \\
\hline 44,21 & $\begin{array}{l}(331 s), 342, \\
454\end{array}$ & 48,9 & $\begin{array}{l}(352 s), 354, \\
459\end{array}$ & $\begin{array}{l}51,16 \\
51,18\end{array}$ & $\begin{array}{l}265,(375) \\
416\end{array}$ \\
\hline 44,22 & 332 & 48,10 & $265,(353 s)$ & 51,19 & (376) \\
\hline 44,24 & $\begin{array}{l}282,(332 s), \\
375\end{array}$ & 48,11 & $\begin{array}{l}352,(354 s), \\
356\end{array}$ & $\begin{array}{l}51,20 \\
51,23\end{array}$ & $\begin{array}{l}300 \\
(377), 864\end{array}$ \\
\hline 44,25 & $(333 s), 380$ & 48,12 & $299,356 s$ & & 901 \\
\hline 44,26 & $314,(334 s)$ & 48,13 & 282 & 51,29 & 377 \\
\hline 44,28 & $(335 s), 335$ & 48,14 & 227 , (355- & 52,1 & 378 \\
\hline 45,1 & $\begin{array}{l}286,357, \\
501\end{array}$ & 48,15 & $\begin{array}{l}358), 529 \\
357\end{array}$ & 52,2 & $\begin{array}{l}(378-380) \\
896\end{array}$ \\
\hline $45,3 \mathrm{~s}$ & 296 & 48,18 & 458 & 52,3 & 353,597 \\
\hline 45,4 & 325 & 48,36 & 787 & 52,5 & (380s), 385 \\
\hline 45,8 & $(336 s), 341$ & 49,1 & 302 & 52,6 & (381s), 398 \\
\hline 45,9 & $\begin{array}{l}12,(338- \\
340), 341\end{array}$ & $\begin{array}{l}49,4 \\
49,6\end{array}$ & $\begin{array}{l}279 \\
105\end{array}$ & $\begin{array}{l}52,8 \\
52,11\end{array}$ & $\begin{array}{l}(382 s), 451 \\
147\end{array}$ \\
\hline 45,10 & $(341)$ & 49,7 & (358-361), & 52,12 & 684 \\
\hline 45,11 & (341s) & & 406 & 52,13 & 384 \\
\hline 45,12 & $\begin{array}{l}282,312 \\
375\end{array}$ & $\begin{array}{l}49,8 \\
49,10\end{array}$ & $\begin{array}{l}(303-306) \\
416\end{array}$ & $52,13-15$ & $\begin{array}{l}(385-395) \\
399\end{array}$ \\
\hline 45,13 & 342 & 49,12 & $149,(361 \mathrm{~s})$ & 52,14 & 12, (383s), \\
\hline 45,14 & $137,(343)$ & 49,14 & (363) & & 385 \\
\hline 45,15 & 279 & 49,17 & 159, (364- & 52,15 & $380,(384 s)$ \\
\hline 45,16 & (344s) & & 367), 394, & $53,1-10$ & 391,399 \\
\hline 45,21 & $290 s$ & 49,19 & $\begin{array}{l}409 \\
(367 s)\end{array}$ & 53,2 & $\begin{array}{l}383,388 s, \\
391,460\end{array}$ \\
\hline
\end{tabular}




\begin{tabular}{|c|c|c|c|c|c|}
\hline 53,3 & $\begin{array}{l}388,391 \mathrm{~s} \\
\text { (395s) }\end{array}$ & $\begin{array}{l}58,12 \\
58,14\end{array}$ & $\begin{array}{l}452 \\
399 s\end{array}$ & $\begin{array}{l}64,2 \\
64,3\end{array}$ & $\begin{array}{l}(445 s) \\
414,(446 s)\end{array}$ \\
\hline 53,4 & $279,391 \mathrm{~s}$ & 59,5 & $294 s$ & & 454 \\
\hline 53,5 & $392,(396 s)$ & 59,10 & 33 & 64,4 & 349, (447- \\
\hline 53,6 & 406 & 59,16 & 61,431 & & 450) \\
\hline 53,7 & 398 & 59,17 & 303,417 & 64,6 & 265,449 , \\
\hline 53,8 & *41s, (397. & 59,18 & (416s) & & (450s) \\
\hline & 399), 406 & 59,19 & 417 & 64,8 & 213 \\
\hline 53,9 & (399s), 520 & 59,21 & 464 & 64,9 & 426 \\
\hline 53,10 & 392, (400- & 60,1 & (417s) & 65,1 & (451s) \\
\hline & 403) & 60,4 & 344,364 , & $65,2 \mathrm{~s}$ & $455 s$ \\
\hline $53,11 \mathrm{~s}$ & $392,(403$ & & $367,460 \mathrm{~s}$ & 65,4 & (452s) \\
\hline & 407) & 60,5 & (418s) & 65,5 & $332,(453 s)$ \\
\hline 53,12 & 398 & 60,7 & (419s) & 65,6 & $(454), 455$ \\
\hline 54,1 & 398, 404s, & 60,10 & 193 & 65,7 & $(455 s), 607$ \\
\hline & 426 & 60,13 & 420 & 65,9 & 445 \\
\hline $54,1-3$ & 300 & 60,17 & *19, 24 & $65,13-15$ & $(456), 456 s$ \\
\hline 54,2 & (407s) & 60,19 & $(420 s), 421$ & 65,16 & 456 \\
\hline 54,5 & 428 & 61,3 & 452 & 65,17 & 375 \\
\hline 54,7 & $415 s$ & 61,4 & (421) & 65,18 & (457) \\
\hline 54,8 & 416 & 61,6 & $380,(422 s)$ & 65,19 & 762 \\
\hline 54,11 & 79 & 61,7 & $382,(423 s)$ & 65,20 & 437 \\
\hline 54,13 & $367,(408 s)$ & 61,8 & $382,(425 s)$ & 66,2 & 197, (458), \\
\hline 55,1 & $341,(409 s)$ & 61,10 & 413 & & 561 \\
\hline 55,9 & 427 & 62,2 & 452 & $66,2-4$ & 90 \\
\hline 56,5 & (410s), 412 & 62,4 & $150,(426)$ & 66,5 & (459s) \\
\hline 56,8 & 122 & & 437 & 66,6 & 336,762 \\
\hline 56,9 & 575 & 62,5 & 367,409 & 66,10 & 50 \\
\hline 56,10 & 147 & & $(427-429)$ & 66,12 & (460s) \\
\hline 56,12 & (411s) & 62,9 & 147 & 66,17 & (461s) \\
\hline 57,8 & (412) & 63,1 & 386, (429. & 66,18 & $(462-464)$ \\
\hline 57,9 & (413) & & 431) & 66,19 & $(464 s), 761$ \\
\hline 57,11 & (414) & 63,3 & $386,(431 s)$ & 66,20 & 137 \\
\hline 57,12 & 649 & 63,4 & 881 & 66,22 & 375,427 \\
\hline 57,13 & 445 & 63,6 & $(432-434)$ & 66,24 & 290 \\
\hline 57,14 & 245 & 63,9 & $(434-437)$ & & \\
\hline 57,16 & 415 & 63,11 & $(438-441)$ & & \\
\hline 57,17 & (414s) & $63,11-14$ & 439 & Jérémie & \\
\hline 57,18 & 61, (415s), & 63,14 & $265,(441 s)$ & & \\
\hline & 686 & 63,15 & $439,(442-$ & $1,1 \mathrm{~s}$ & 617, 663, \\
\hline 57,20 & 810 & & 444) & & 853 \\
\hline 58,6 & 488 & 63,17 & $448 s$ & 1,6 & 279,617 \\
\hline $58,6-9$ & 561 & 63,18 & (444s) & $1,7-10$ & 615 \\
\hline 58,7 & 602s, 864, & 63,19 & $13,42,444-$ & 1,14 & 174 \\
\hline & 866 & & 446 & 1,15 & 487 \\
\hline
\end{tabular}




\begin{tabular}{|c|c|c|c|c|c|}
\hline 1,17 & 493,645 & 3,17 & 517 & 6,16 & 618,625 \\
\hline $1,18 \mathrm{~s}$ & $\begin{array}{l}\text { 511, 594, } \\
618\end{array}$ & 3,19 & $\begin{array}{l}\text { 192, (483), } \\
591 .\end{array}$ & $\begin{array}{l}6,20 \\
6,21\end{array}$ & $\begin{array}{l}560 \\
70 s\end{array}$ \\
\hline 2,2 & 493,645 & 3,20 & 483 & 6,23 & 810 \\
\hline 2,6 & 469 & 3,21 & 686 & 6,25 & 487 \\
\hline 2,8 & 615 & 3,23 & (484s) & 6,26 & 897 \\
\hline 2,10 & 761 & 4,2 & (485s) & 6,27 & 500, (509. \\
\hline 2,12 & 771 & 4,4 & 536 & & 512) \\
\hline 2,13 & 119 & 4,8 & 112 & 6,28 & $511 \mathrm{~s}$ \\
\hline \multirow[t]{2}{*}{2,16} & $(466 s), 468$ & 4,11 & 536 & 6,29 & $512,(512 s)$ \\
\hline & 795 & 4,16 & (479s), & 6,30 & 512 \\
\hline $2,16-23$ & 472 & & (486s) & $7,2-4$ & 560 \\
\hline \multirow[t]{2}{*}{2,17} & $(468 s), 493$ & 4,17 & 487 & 7,3 & (513-515) \\
\hline & 645 & 4,19 & 878 & 7,4 & (515s) \\
\hline 2,18 & 468,476 & 4,20 & (488), 490 & 7,7 & $(513-515)$ \\
\hline 2,19 & 493,645 & 4,23 & *23, 490 & 7,11 & 491 \\
\hline 2,20 & 488,503 & $4,27 \mathrm{~s}$ & 490 & 7,12 & 515 \\
\hline 2,21 & $(469-471)$ & 4,29 & (489-491), & 7,13 & 676 \\
\hline 2,23 & 471 & & 492,708 & 7,14 & 515 \\
\hline 2,24 & $(471-473)$ & 4,30 & (491s) & 7,16 & 560,593 \\
\hline 2,26 & 618 & 4,31 & 777 & 7,19 & 628 \\
\hline 2,27 & 626 & 5,1 & $142,492 s$ & $7,21-25$ & 560 \\
\hline 2,30 & 473 & & 645 & 7,24 & (516s) \\
\hline \multirow[t]{2}{*}{2,31} & 89, (473s), & 5,2 & $(492 s), 628$, & $7,24-26$ & 518 \\
\hline & 866 & & 645 & 7,25 & $(517 s)$ \\
\hline 2,32 & 762 & 5,3 & 535 & 7,29 & 598 \\
\hline 2,33 & 503 & 5,6 & 487 & 7,31 & (519-521) \\
\hline 2,34 & (474s) & 5,7 & (493-495) & 7,33 & 187 \\
\hline $2,35-37$ & 477 & 5,12 & 496 & 8,1 & 753 \\
\hline 2,36 & (475s) & 5,13 & (495s), 757 & 8,3 & (521s) \\
\hline 2,37 & 762 & 5,15 & 38, 497 & 8,4 & 521 \\
\hline \multirow[t]{2}{*}{3,1} & (476-479), & 5,16 & (496s) & 8,5 & $(522 s), 535$ \\
\hline & 482 & 5,22 & $473,(497 s)$ & 8,6 & (523s) \\
\hline $3,1-5$ & 477 & 5,26 & $(499-501)$ & 8,7 & 268 \\
\hline \multirow[t]{2}{*}{3,2} & 479, 482, & 5,28 & 616 & 8,8 & (524-526) \\
\hline & 588,618 & 6,1 & 219 & 8,10 & 526 \\
\hline 3,4 & 483 & 6,2 & $(501-504)$ & 8,12 & (508s), 527 \\
\hline $3,4 \mathrm{~s}$ & 480,503 & 6,3 & 467 & 8,13 & (526-529), \\
\hline 3,5 & (479s) & 6,4 & $*^{*} 22$ & & 550,784 \\
\hline 3,6 & 718 & 6,6 & (504s) & & 838 \\
\hline 3,7 & 7 & 6,8 & 506 & 8,14 & 528 \\
\hline 3,8 & 473, (480s) & 6,9 & (506s) & 8,17 & 530 \\
\hline 3,9 & $(481 s), 723$ & 6,11 & $(507 s), 535$ & 8,18 & (529-532), \\
\hline 3,10 & $7,493,645$ & 6,12 & 174,687 & & 538 \\
\hline 3,16 & 580 & 6,15 & 508 & 8,19 & 762 \\
\hline
\end{tabular}




\begin{tabular}{ll|ll|ll}
9,1 & 571 & 11,14 & $(556-558)$, & 15,11 & $(589-593)$, \\
9,2 & $(533 \mathrm{~s}), 645$ & & 560,563 & & 594,597, \\
$9,4 \mathrm{~s}$ & $628,(534 \mathrm{~s})$ & 11,15 & $540,(558-$ & & 777 \\
9,5 & 645 & & $564), 850$ & 15,12 & $590,(593 \mathrm{~s})$ \\
9,6 & $(535-537)$ & 11,16 & $* 22,(564-$ & $15,12-14$ & 592 \\
9,7 & $(537 \mathrm{~s})$ & & $566)$ & 15,13 & $(594-598)$, \\
9,9 & $(538 \mathrm{~s}), 546$, & 11,17 & 563 & & $598-600$, \\
& 817 & 11,18 & $(567 \mathrm{~s}), 570$ & & 606 \\
9,13 & 579 & 11,19 & $(568 \mathrm{~s})$ & 15,14 & $587,594 \mathrm{~s}$, \\
9,14 & $(539-541)$, & 11,20 & $(570 \mathrm{~s}), 572$ & & $597,(598-$ \\
& 562 & 11,21 & 569 & & $600), 606$ \\
9,15 & 550 & 12,2 & 554 & & $(611-613)$ \\
9,16 & $(541)$ & 12,3 & 570 & 15,15 & 601 \\
9,18 & $* 23,588$ & 12,4 & $(571 \mathrm{~s})$ & 15,16 & $569,(600-$ \\
9,21 & 187,645 & 12,6 & 627 & & $602)$ \\
9,24 & 542 & 12,9 & $(572-575)$ & 15,18 & 593 \\
9,25 & $(542)$ & 12,10 & 467 & 16,4 & 187 \\
$10,6 \mathrm{~s}$ & $(543)$ & 12,13 & $(575-577)$ & 16,6 & 494,798 \\
$10,6-8$ & 543 & 13,1 & 631 & 16,7 & $(602-605)$ \\
10,9 & $(544)$ & 13,10 & $(578 \mathrm{~s})$ & 16,13 & 387,600, \\
10,10 & 543 & 13,11 & 427,703 & & 607 \\
10,13 & $(545 \mathrm{~s})$ & 13,13 & $579,618 \mathrm{~s}$ & 16,14 & $605 \mathrm{~s}$ \\
10,16 & 845 & 13,14 & 687 & 16,15 & $(605 \mathrm{~s}), 613$ \\
10,17 & 548 & 13,18 & $(580 \mathrm{~s})$ & 16,17 & 607 \\
10,18 & $174,(546 \mathrm{~s})$ & 13,25 & $(582)$ & 16,18 & $(606 \mathrm{~s})$ \\
10,19 & 539,546 & 13,27 & $(583), 609$, & 16,19 & 777 \\
$10,19-22$ & 538 & & 646 & $17,1-4$ & $596,608 \mathrm{~s}$ \\
10,20 & $488,(548)$ & 14,2 & 777 & 17,2 & $(607 \mathrm{~s})$ \\
10,21 & 548 & 14,3 & $(584)$ & 17,3 & $(594-598)$, \\
10,23 & 568 & 14,4 & $584,(584-$ & & $(608-610)$ \\
10,24 & $(549)$ & & $586)$ & $17,3 \mathrm{~s}$ & 598,606 \\
10,25 & $527,(549-$ & 14,6 & 472 & 17,4 & $587,594 \mathrm{~s}$, \\
& $551)$ & 14,8 & $(586)$ & & $597-600$ \\
11,2 & $(551-555)$, & 14,11 & 615 & & $(611-613)$ \\
& 563,599 & 14,12 & 560 & 17,6 & 240,779 \\
11,3 & 552,642 & $14,13-15$ & 587 & 17,13 & $(469-471)$, \\
11,4 & 552,757 & 14,17 & 538 & & 586,638 \\
11,6 & 552 & 14,18 & $(586-588)$, & 17,15 & 572,593 \\
$11,7 \mathrm{~s}$ & 579 & & 618 & 17,16 & 570,591, \\
11,8 & 642 & 15,2 & 580, & & $(613-617)$ \\
11,9 & 57,563 & 15,4 & $651 \mathrm{~s}$ & 17,19 & $(617 \mathrm{~s}), 631$ \\
11,10 & 563,579 & 15,7 & 588 & 17,23 & 468 \\
11,12 & 557,563 & $15,7-9$ & 821 & 17,25 & $(618 \mathrm{~s})$ \\
11,13 & $(555 \mathrm{~s})$ & 15,8 & $107,(588 \mathrm{~s})$ & 17,27 & 832 \\
& & & & &
\end{tabular}




\begin{tabular}{|c|c|c|c|c|c|}
\hline 18,4 & $(619-621)$ & 22,23 & (640s) & 25,36 & 762,809 \\
\hline 18,6 & 620 & 22,25 & 636 & 25,38 & (661s) \\
\hline 18,14 & $(621-624)$ & 22,27 & 560 & 26,1 & $(662 s), 666$ \\
\hline 18,15 & $(624 s)$ & 22,28 & 587,600 & 26,7 & 587 \\
\hline 18,17 & (625s) & 22,30 & 616 & 26,10 & $(663 s)$ \\
\hline 18,18 & $(627 s)$ & 23,6 & 704 & 26,11 & 559,587 \\
\hline 18,19 & $(628 s)$ & 23,7 & $605 s$ & $26,16-19$ & 628 \\
\hline \multirow[t]{2}{*}{18,20} & 591, 615, & 23,8 & $(605 s), 613$ & 26,18 & (519-521) \\
\hline & $(629 s)$ & & 644 & 26,23 & 618 \\
\hline 18,22 & $629 \mathrm{~s}$ & 23,9 & 642 & 27,1 & $662 s,(665 s)$ \\
\hline \multirow[t]{2}{*}{19,1} & $(630-635)$ & 23,10 & $524,(641 s)$ & 27,2 & 631,666 \\
\hline & 663 & 23,17 & $601,(642 s)$ & 27,3 & 554,666 , \\
\hline 19,2 & 692 & 23,18 & (644) & $\cdot$ & $(666-668)$ \\
\hline 19,5 & 520 & 23,22 & 644 & 27,6 & 750 \\
\hline 19,7 & 187 & 23,23 & 393 & 27,7 & 654 \\
\hline 19,9 & $69-71$ & $23,23 s$ & (644s) & 27,8 & 540 \\
\hline 19,10 & 635 & 23,26 & (646s) & 27,9 & (668s) \\
\hline 19,11 & 632 & 23,27 & 646 & 27,12 & 666 \\
\hline 19,12 & 515 & 23,29 & $(647 s)$ & 27,14 & 165 \\
\hline \multirow[t]{2}{*}{19,13} & 520, 697, & 23,30 & 646 & 27,18 & 593 \\
\hline & 701 & 23,33 & $636,(648 \mathrm{~s})$ & 27,20 & 225 \\
\hline 19,14 & 631 & & 651 & 27,22 & 515 \\
\hline 19,15 & 832 & $23,35.37$ & 643 & 28,1 & (670) \\
\hline $20,1-3$ & 631 & 23,39 & $(649-651)$ & 28,2 & 165 \\
\hline 20,2 & 618 & 24,2 & 566 & 28,3 s. 6 & 515 \\
\hline 20,3 & 765 & $24,5 \mathrm{~s}$ & 652 & 28,8 & (671s) \\
\hline 20,9 & 535 & 24,9 & $(651 \mathrm{~s})$ & 28,9 & 672 \\
\hline 20,12 & (570s), 572 & $25,3 \mathrm{~s}$ & 676 & 28,13 & $(672 s)$ \\
\hline 20,16 & 3 & 25,9 & $85,(652 s)$ & 28,14 & 874 \\
\hline 21,7 & (635s) & & 750 & 28,19 & 845 \\
\hline 21,8 & 677 & 25,11 & 653 & 28,41 & 837 \\
\hline 21,12 & 784 & 25,13 & 654 & 29,1 & $(673), 707$ \\
\hline 21,13 & 609,772 & 25,14 & (653s) & $29,4-23$ & 677 \\
\hline 21,14 & $831 \mathrm{~s}$ & 25,15 & $(655), 657$ & 29,7 & 489 \\
\hline 22,3 & 7 & 25,18 & 618,653 & 29,8 & (668s) \\
\hline 22,4 & $618 s$ & $25,19 \mathrm{~s}$ & 656 & 29,12 & (674s) \\
\hline 22,6 & $(636 s), 648$ & 25,20 & 636 & $29,13 s$ & 674 \\
\hline 22,7 & 514 & 25,22 & 843 & 29,16 & 677 \\
\hline 22,13 & 12,654 & 25,24 & $(656 s), 813$ & $29,16-20$ & 675 \\
\hline 22,14 & $(637 \mathrm{~s})$ & & 842 & 29,18 & $651 \mathrm{~s}$ \\
\hline 22,15 & $638 s$ & 25,25 & 842 & 29,19 & (675s) \\
\hline 22,16 & (638s) & 25,26 & $655,(657 s)$ & $29,24 s$ & (676s) \\
\hline 22,17 & 524 & 25,34 & $592,(658$ & 29,25 & $165,(678)$ \\
\hline 22,19 & 764 & & 661) & 29,26 & (678s) \\
\hline
\end{tabular}




\begin{tabular}{|c|c|c|c|c|c|}
\hline $29,26-28$ & $677 \mathrm{~s}$ & 32,35 & 520 & 38,7 & 618 \\
\hline $29,29.31$ & 677 & 32,37 & 515 & 38,10 & (716s) \\
\hline 30,2 & 165 & 33,2 & (698s) & $38,10-13$ & 593 \\
\hline 30,5 & (679s) & $33,4 \mathrm{~s}$ & (699-701) & 38,11 & $(717 s), 764$ \\
\hline 30,6 & 680 & 33,5 & $697,701 \mathrm{~s}$ & 38,13 & 736 \\
\hline \multirow[t]{2}{*}{30,7} & 543, (680s), & 33,6 & (701s) & $38,14-16$ & 593 \\
\hline & 682 & $33,6-8$ & 503 & 38,17 & 721,784 \\
\hline \multirow[t]{3}{*}{30,8} & 654, (681- & 33,9 & (702-704) & 38,22 & (718-720) \\
\hline & 683), 684, & 33,16 & (704s) & 38,23 & *21, 716, \\
\hline & 874 & 33,20 & (705s), 706 & & $(720-722)$ \\
\hline 30,11 & 645 & 33,25 & $690,(706 s)$ & 38,27 & 724 \\
\hline 31,2 & 540,684 & 34,7 & $673,(707 s)$ & 38,28 & $(722-725)$ \\
\hline 31,3 & (683s) & 34,9 & 654 & $39,1 \mathrm{~s}$ & $723 s$ \\
\hline $31,4 s$ & 683 & 34,12 & (708s) & $39,1-14$ & 725 \\
\hline $31,5 \mathrm{~s}$ & 198 & 34,14 & (709s) & $39,2-14$ & 724 \\
\hline 31,7 & (684s) & 34,17 & $651 \mathrm{~s}$ & 39,3 & $722,(725-$ \\
\hline 31,8 & 687 & 34,18 & (710s) & & $728)$ \\
\hline 31,9 & (685s) & $34,19 \mathrm{~s}$ & 711 & 39,4 & $(729 s), 854$ \\
\hline 31,13 & (686s) & 34,20 & 187 & $39,4-13$ & $729 s, 734 s$ \\
\hline 31,15 & 548 & 34,22 & 489 & 39,8 & (730s), 854 \\
\hline $31,16 \mathrm{~s}$ & (644s) & 35,4 & (712s) & $39,8-10$ & 731 \\
\hline 31,21 & 503,783 & 35,12 & 696 & 39,9 & $(731 s), 856$ \\
\hline 31,24 & (687s) & 35,14 & 722 & 39,10 & $(733 s), 857$ \\
\hline 31,27 & (688s) & 36,1 & 696 & 39,11 & (734s) \\
\hline 31,28 & 489,689 & 36,10 & 664 & 39,13 & 726,735 \\
\hline 31,34 & 70,320 & 36,12 & $742 s$ & & 743 \\
\hline 31,35 & 420, (689s) & $36,15 s$ & $713 s$ & 39,14 & $723 s, 735$ \\
\hline 31,36 & 689 & 36,16 & (713) & 39,16 & 489 \\
\hline 31,37 & (690s), 705 & 36,17 & $713,(714 s)$ & $40,1-6$ & 736 \\
\hline \multirow[t]{2}{*}{31,40} & (691-693), & $36,18 \mathrm{~s}$ & $713 \mathrm{~s}$ & 40,2 & (735s) \\
\hline & 694 & 36,22 & (715s), 722 & $40,4 \mathrm{~s}$ & 593 \\
\hline $32,7-9$ & $695 s$ & 36,23 & 569 & 40,5 & 489, (736- \\
\hline 32,10 & 48,693 & 36,24 & 419 & & 738) \\
\hline 32,11 & $692,(693 s)$ & 36,26 & 714 & $40,5-7$ & 742 \\
\hline 32,12 & (694-696) & 37,3 & 593 & 40,8 & 636, (739s), \\
\hline 32,14 & 632 & 37,7 & 720 & & 747 \\
\hline $32,16-25$ & 696 & 37,8 & 489 & 40,9 & (740s), 742 \\
\hline 32,24 & 701 & 37,11 & 723 & 40,10 & 741,750 \\
\hline 32,25 & 48 & 37,13 & 618 & 40,11 & 750 \\
\hline 32,26 & (696) & 37,17 & 646 & $40,13-16$ & 740,742 \\
\hline \multirow[t]{2}{*}{32,29} & 489,636 & 37,21 & 736 & 41,1 & (741-743) \\
\hline & $(697 s)$ & 38,4 & 722 & 41,2 & $742 s, 540$ \\
\hline 32,32 & 618 & $38,4-6$ & 717 & 41,3 & $540,(743 s)$ \\
\hline 32,33 & 626 & 38,6 & 736 & 41,5 & 494,798 \\
\hline
\end{tabular}




\begin{tabular}{|c|c|c|c|c|c|}
\hline $41,6 s$ & 742 & 46,9 & $464 s,(761 s)$ & 48,25 & 645 \\
\hline 41,9 & (744s) & 46,10 & 237 & 48,26 & 433 \\
\hline $41,9-11$ & 742 & 46,11 & 503 & 48,30 & 125 \\
\hline $41,10-14$ & 744 & 46,12 & (762s) & $48,30-36$ & 126 \\
\hline $41,11-16$ & 740 & $46,14-19$ & 764 & 48,31 & $124,(786 s)$ \\
\hline 41,13 & 742 & 46,15 & 614,617 & 48,32 & (788s) \\
\hline 41,16 & $742,(745 s)$ & & $(763 s), 769$ & 48,33 & 61,125 \\
\hline 41,17 & 752 & 46,16 & (613-617), & & $764,(789 s)$ \\
\hline 41,18 & 742 & & 661s, 764 & 48,34 & 775, (791) \\
\hline \multirow[t]{2}{*}{42,1} & 636,740 & 46,17 & $(765 s), 769$ & 48,36 & 88,113 \\
\hline & $742,(746 s)$ & 46,18 & 765 & 48,37 & 112,467 \\
\hline $42,1-3$ & 593 & 46,20 & $(766-768)$ & & $797 s$ \\
\hline 42,8 & 740,742 & $46,20-24$ & 764 & 48,38 & $111 \mathrm{~s},(644 \mathrm{~s})$ \\
\hline \multirow[t]{2}{*}{42,10} & 527, 784, & 46,21 & $768 s$ & 48,39 & (792s) \\
\hline & 838 & 46,22 & 761, 768, & 48,40 & 51 \\
\hline 42,12 & $(748-750)$ & & (768s), 770 & 48,44 & (539-541) \\
\hline 43,2 & 740,747 & 46,23 & (770s) & 48,45 & 467, (793- \\
\hline $43,4 s$ & 740,742 & 46,25 & 591 & & 795), 871 \\
\hline 43,9 & 555 & 46,26 & 636 & $48,45-47$ & $793 s$ \\
\hline 43,10 & (750s) & 47,2 & 174 & 48,46 & 796 \\
\hline 43,11 & 540 & 47,5 & 467, 494, & 49,1 & $795 s$ \\
\hline \multirow[t]{2}{*}{43,12} & 158, (751), & & $(771 s), 798 s$ & 49,2 & 797 \\
\hline & 832 & 47,6 & 772 & 49,3 & 112,687 , \\
\hline 44,1 & 755 & 47,7 & $(772-774)$ & & $(795-798)$ \\
\hline 44,2 & 758 & 48,1 & 681, 792, & 49,4 & 772, 781, \\
\hline 44,3 & 536, (752) & & 796 & & (798-801) \\
\hline $44,5.8$ & 752 & 48,2 & 115 & 49,5 & $(644 s), 799$ \\
\hline 44,9 & (753s) & 48,3 & 809 & 49,7 & 796 \\
\hline 44,15 & (754s) & 48,4 & (774s) & 49,8 & $(801-803)$ \\
\hline $44,15-18$ & 756 & 48,5 & 775, (775 & 49,10 & 491, (613- \\
\hline $44,16-19$ & 759 & & 778) & & $617), 803 s$ \\
\hline 44,17 & 618,753 & 48,6 & (778-780) & 49,11 & $(803 s), 812$ \\
\hline 44,18 & 902 & 48,7 & 687, (780s), & 49,12 & 804,881 \\
\hline 44,19 & (755s), 757 & & 785,796 & 49,13 & 804,832 \\
\hline \multirow[t]{2}{*}{44,21} & 618, 753, & 48,8 & 772 & 49,14 & 636 \\
\hline & (756s), 759 & 48,9 & (782-785), & $49,14-16$ & 680 \\
\hline 44,22 & 536,758 & & 786,838 & 49,18 & $1 \mathrm{~s}$ \\
\hline 44,23 & (757s) & 48,15 & (785s), 797 & 49,19 & (804-808) \\
\hline \multirow[t]{2}{*}{44,25} & 165, (758- & 48,18 & 110s, 115, & $49,19-21$ & 804 \\
\hline & 760) & & $785 s, 796$ & 49,20 & 764 \\
\hline 44,28 & 290 & 48,19 & 778,780 & 49,21 & (808s) \\
\hline 45,4 & 677 & 48,20 & 785s, 793, & 49,22 & 51 \\
\hline $46,4.7 s$ & 761 & & 797 & 49,23 & 616, 796, \\
\hline 46,8 & 588 & 48,22 & 115 & & (809-811) \\
\hline
\end{tabular}




\begin{tabular}{|c|c|c|c|c|c|}
\hline 49,25 & 88, (811s) & 51,7 & (841s) & \multicolumn{2}{|c|}{ Lamentations } \\
\hline 49,26 & 812 & 51,11 & 831, 839, & & \\
\hline 49,27 & 832 & & (842s) & 1,4 & $(863 s), 888$ \\
\hline 49,28 & (813s), 842 & 51,13 & (843s) & 1,5 & 864 \\
\hline 49,29 & $813-815$ & 51,14 & 790 & 1,7 & 211, (864- \\
\hline 49,30 & 802, (813- & 51,16 & $545 s$ & & 867) \\
\hline & 816) & 51,19 & (844s) & 1,9 & (867s) \\
\hline 49,31 & $(644 s), 813$ & 51,20 & (846s) & 1,11 & $867 s, 900$ \\
\hline 49,33 & $(813 s)$ & 51,24 & 837 & 1,12 & 864,868 , \\
\hline 49,36 & 122 & 51,25 & (644s) & & (868s), 906 \\
\hline 49,37 & $550,(644 s)$ & 51,28 & (842s) & 1,13 & 426, (870s) \\
\hline 50,2 & $764,(816)$ & 51,29 & (847s) & 1,14 & (872-876) \\
\hline 50,3 & $(817)$ & 51,30 & 623,650 & 1,15 & 882 \\
\hline 50,5 & (817-819) & 51,31 & 830 & 1,16 & (877s), 900 \\
\hline 50,9 & (819-821) & 51,33 & (848s) & 1,18 & $868,889 s$ \\
\hline 50,11 & $(821-825)$ & 51,34 & 886 & 1,19 & (878s), 900 \\
\hline 50,12 & 779 & 51,35 & 837 & 1,20 & 879 \\
\hline 50,14 & (825s) & 51,37 & 814 & 1,21 & (879-882) \\
\hline 50,15 & (826) & 51,39 & (849s) & 1,22 & 882,906 \\
\hline 50,16 & $661 \mathrm{~s}$ & 51,40 & 660 & $2,1-12$ & 889 \\
\hline 50,20 & 645,722 & 51,41 & 837 & $2,2.5$ & 886 \\
\hline 50,21 & (827-829), & 51,43 & 832 & 2,6 & (882s) \\
\hline & 837 & 51,45 & 851 & 2,7 & 899 \\
\hline 50,26 & $(829-831)$ & 51,49 & (850s) & 2,8 & 886,888 \\
\hline 50,27 & 681 & 51,54 & 762 & 2,11 & 878 \\
\hline $50,28.31$ & 831 & 51,58 & 128, (851. & 2,12 & (884) \\
\hline 50,32 & (831) & & 853) & 2,13 & 376,805 \\
\hline 50,35 & 645 & 51,59 & 665 & & 807, 810, \\
\hline $50,35-38$ & 834 & $51,59-64$ & 853 & & $883,(884 s)$ \\
\hline 50,36 & $333,(832 s)$ & 51,64 & (851-853) & $2,13-17$ & 889 \\
\hline 50,37 & 833 & 52,7 & $729 s,(854)$ & 2,16 & 882, (885- \\
\hline 50,38 & (833-836) & 52,13 & $731,(854 \mathrm{~s})$ & & 887) \\
\hline 50,39 & 761 & 52,14 & (855s) & 2,18 & (887-889) \\
\hline 50,40 & $1 \mathrm{~s}$ & 52,15 & 636,731 , & 2,19 & $(866 s), 889$ \\
\hline 50,41 & 843 & & $(731 \mathrm{~s}),(856 \mathrm{~s})$ & 2,20 & $867 \mathrm{~s}, 906$ \\
\hline 50,42 & 810 & 52,16 & 731,857 & $2,20-22$ & 889 \\
\hline 50,44 & (804-808) & $52,18 \mathrm{~s}$ & 858 & 2,21 & (889s) \\
\hline 50,45 & 591, 764, & 52,20 & (857-859) & 2,22 & 882,909 \\
\hline & 804 & 52,22 & (859s) & 3,5 & (890-892) \\
\hline 50,46 & 804,808 & 52,23 & 860 & 3,11 & (892-894) \\
\hline 51,1 & $(836 s), 839$ & 52,24 & 679,861 & 3,12 & 893 \\
\hline 51,2 & 204, (838s) & 52,25 & (860s) & 3,14 & 130, 374, \\
\hline 51,3 & (839-841) & $52,27-30$ & 861 & & (894s) \\
\hline 51,6 & 851 & 52,28 & (861s) & 3,15 & 865 \\
\hline
\end{tabular}


Lm

\begin{tabular}{ll|ll|ll}
3,16 & $(895-897)$, & 5,11 & 591 & 23,15 & 6 \\
& 898 & 7,6 & 767 & 23,19 & $412 \mathrm{~s}$ \\
3,17 & $(898 \mathrm{~s})$ & 7,7 & 174 & 23,23 & 189,827 \\
3,19 & $(864-866)$ & 7,16 & 147 & 23,24 & 147 \\
3,20 & $(899-901)$ & $8,7 \mathrm{~s}$ & $310,461 \mathrm{~s}$ & 23,49 & 415 \\
3,22 & $(901-903)$ & 8,11 & 462 & 24,2 & 911 \\
3,23 & 899 & 8,14 & 664 & 24,17 & 602 \\
3,27 & $(903 \mathrm{~s})$ & 10,2 & 718 & 25,14 & 431 \\
3,31 & $899,(904 \mathrm{~s})$ & 10,13 & 452 & 26,20 & 328 \\
$3,32 \mathrm{~s}$ & 864 & 10,19 & 664 & 27,4 & 365 \\
$3,40-47$ & 903 & 12,18 & 810 & 27,10 & 464 \\
$3,43 \mathrm{~s}$ & 880 & 12,19 & 351 & 27,26 & 883 \\
3,48 & 878 & 13,2 & 393 & 28,7 & 204 \\
3,51 & $878,(905 \mathrm{~s})$ & 13,18 & 638 & 28,10 & 400 \\
3,52 & 914 & 14,1 & 347 & 28,18 & 415 \\
3,56 & $(906 \mathrm{~s}), 908$ & 14,4 & 760 & 29,10 & 362 \\
3,59 & $880,(907 \mathrm{~s})$ & $14,16.20$ & 591 & 29,14 & 755 \\
3,60 & 880 & $16,13.18$ & 503 & 30,5 & 464,656 \\
$3,63-66$ & 908 & 16,22 & 503 & $30,6.15 \mathrm{~s}$ & 362 \\
3,66 & $(908 \mathrm{~s})$ & 16,25 & $412 \mathrm{~s}$ & 30,16 & 706,778 \\
4,1 & 67,867 & $16,31.43$ & 503 & 30,17 & 150 \\
4,3 & $(909 \mathrm{~s})$ & 16,47 & 503 & 31,3 & 132 \\
4,4 & 538,603 & 16,48 & 591 & $31,3-9$ & 565 \\
4,7 & $(910 \mathrm{~s})$ & 16,51 & 503 & 31,5 & $822-824$ \\
4,9 & 889 & 16,59 & 642 & 31,12 & 204 \\
4,15 & $784,(911 \mathrm{~s})$ & 17,10 & 258 & 32,19 & 802 \\
4,17 & 913 & $17,13-16$ & 720 & 33,1 & 830 \\
4,18 & $830,(912)$ & $17,16-18$ & 642 & 33,10 & 165 \\
$4,19 \mathrm{~s}$ & 913 & 17,23 & 80 & $33,14 \mathrm{~s}$ & 437 \\
4,21 & 433 & 17,24 & 18 & $33,18 \mathrm{~s}$ & 275 \\
5,17 & 204 & 18,6 & 485 & 34,8 & 464 \\
5,22 & 872 & 19,7 & 95,476 & 37,1 & 93 \\
& & 19,12 & 258 & $38,2 \mathrm{~s}$ & $464 \mathrm{~s}$ \\
& & 20,28 & 485 & 39,1 & $464 \mathrm{~s}$ \\
& & 20,38 & 347 & 39,8 & 463 \\
Ezéchiel & & 21,12 & 451,463 & 39,15 & 783 \\
& & $21,14 \mathrm{~s}$ & 329 & 39,27 & 470 \\
$2,7 \mathrm{~s}$ & 129 & 21,20 & 451 & 40,1 & 911 \\
$3,1-3$ & 601 & 21,31 & 790 & 42,12 & 470 \\
3,16 & 710 & 22,6 & 71 & 43,7 & 400 \\
3,20 & 569 & 22,15 & 592 & 43,24 & $554 \mathrm{~s}$ \\
4,2 & 891 & 22,16 & 57 & 44,6 & 129 \\
4,13 & 351 & $22,25.27$ & 573 & 44,7 & 542 \\
& & $23,6.12$ & 189 & 48,35 & 315 \\
& & & & &
\end{tabular}


Dn

$\begin{array}{ll}\text { Daniel } & \\ & \\ 2,22 & 360 \\ 2,34 & 216 \\ 2,38 & 98 \\ 3,19 & 360 \\ 4,16 & 107 \\ 5,6 & 850 \\ 5,12 & 592 \\ 5,17 & 530 \\ 5,25-28 & 176 \\ 6,25 & 547 \\ 8,1 & 683 \\ 8,5 & 288 \\ 8,20 & 842 \\ 9,2 & 653 \\ 9,7 & 554 \\ 9,19 & 46 \\ 9,24 & 226 \\ 10,5 & 544 \\ 11,7 & 105 \\ 11,8 & 660 \\ 11,21 & 719 \\ 11,26 & 769 \\ 14,2 s & 212\end{array}$

\begin{tabular}{|c|c|c|c|}
\hline 8,9 & 472 & Jonas & \\
\hline 9,4 & 351,603 & & \\
\hline $9,8.11$ & 809 & 1,3 & 170 \\
\hline 9,14 & 820s & 1,7 & 44 \\
\hline 10,10 & 56 & 1,16 & 560 \\
\hline 10,11 & $37,824 s$ & 2,10 & 560 \\
\hline 11,3 & 659 & 3,4 & 3 \\
\hline 12,8 & 809 & & \\
\hline 13,7 & 500 & & \\
\hline 13,12 & 487 & & \\
\hline 13,15 & 660 & Michée & \\
\hline \multirow[t]{4}{*}{14,3} & 275 & & \\
\hline & & 1,2 & 308 \\
\hline & & 1,6 & 620 \\
\hline & & 1,8 & 910 \\
\hline \multirow[t]{2}{*}{ Joël } & & 1,10 & 897 \\
\hline & & 2,1 & 221,681 \\
\hline 1,16 & 61 & 3,8 & 14 \\
\hline 2,10 & 69 & 3,12 & $(519-521)$ \\
\hline 2,22 & 822,824 & 4,8 & 476 \\
\hline \multirow[t]{3}{*}{4,11} & 819 & 4,14 & 494 \\
\hline & & 5,5 & 92,467 \\
\hline & & $5,10.13$ & 107 \\
\hline \multirow[t]{2}{*}{ Amos } & & 6,16 & 30 \\
\hline & & 7,17 & 419,769 \\
\hline $1,3-2,5$ & 26 & & \\
\hline 4,3 & 147 & & , \\
\hline 4,11 & 1.3 & & \\
\hline 5,8 & 281 & Nahum & \\
\hline 5,9 & 531 & & \\
\hline 5,11 & 189, 192 & 1,5 & 69,305 \\
\hline 6,3 & 560 & 1,13 & 682 \\
\hline 6,6 & 576 & 2,5 & 914 \\
\hline 8,5 & 477 & 2,6 & 367 \\
\hline 8,9 & 69 & 2,7 & 336 \\
\hline 9,5 & 451 & 2,9 & 164 \\
\hline 9,6 & 281 & 2,10 & 660 \\
\hline 9,7 & 156 & 2,11 & 451 \\
\hline \multirow[t]{3}{*}{9,9} & 576 & 3,7 & 336 \\
\hline & & 3,11 & 433 \\
\hline & & 3,14 & 298,620 \\
\hline Abdias & & 3,17 & 798 \\
\hline $1-3$ & 680 & & \\
\hline
\end{tabular}


$\mathrm{Ha}$

Habaquq

$1,10 \quad 234$

$4,13 \quad 165$

5,4

697

$1,12 \quad 220$

$5,11 \quad 767$

$6,12 \quad 165$

$1,13 \quad 175$

477

$2,11 \quad 888$

7,3

192

2,13

853

3,13

308

Sophonie

1,2

527

1,8

93

7,14

153

9,1

9,8

206

$10,8 \quad 39$

$10,12 \quad 835$

$11,2 \quad 80,223 \mathrm{~s}$

$12,1 \quad 153$

$12,10 \quad 686$

$13,9 \quad 354$

$1,10 \quad 762$

$1,17 \quad 350$

2,6 503

$2,9 \quad 127$

$3,1 \quad 662$

$3,4 \quad 320$

$3,8 \quad 881$

$3,13 \quad 538$

$3,19 \mathrm{~s} \quad 703$

Aggée

$1,6 \quad 351$

$2,12 \quad 563$

$2,18 \quad 336$

Zacharie

2,4

838

2,8

279

2,15

96

2,17

896

3,9

451

3,10

718

4,6

165

4,10

445

$\begin{array}{ll}\text { Malachie } & \\ & \\ 1,1 & 153 \\ 1,8 & 236 \\ 1,13 & 236,425 \\ 1,14 & 388 \\ 3,11 & 821 . \\ 3,15.19 & 177 \\ 3,20 & 823\end{array}$

Luc

$14,23 \quad 798$

$19,43 \quad 203$

Jean

2,28s $\quad 187$

$16,20 \quad 62$

$19,27 \quad 429$

Actes des Apôtres

8,23

*41

I Corinthiens

$2,9 \quad 446$

$3,16 \quad 516$

$13,1 \quad 769$

\begin{tabular}{l|l} 
Matthieu & II Corinthiens
\end{tabular}

$5,5 \quad 62$

$5,27 \quad 179$

$5,28 \quad 222$

$7,25 \quad 179$

$24,2 \quad 516$

$24,9 \quad 459$

27,52s $\quad 187$

$6,4 \mathrm{~s} \quad * 51$

Apocalypse

5,12

121

Marc

$7,21 \mathrm{~s} \quad 222$ 



\section{INDEX DES PRINCIPAUX AUTEURS}

AARON BEN ASHER 899

AARON BEN JOSEPH 6s, 23, 44, 107, 111, 132, 191, 204, 233, 265, 294, 315-317, 348, 351, 386-388, 401

ABRAHAM BEN YEHUDA 191

ABRAHAM BEN YEHUDA HQAZAN 386

ABRAHAM FARISSOL 386s

ABRAHAM HA-BABLI 95, 98, 264, 591, 623, 640

ABRAVANEL 1, 12, 17, 19, 23s, 27, 33, 43s, 53, 61, 85, 95, 107, 130, 191, 220, $290,294 \mathrm{~s}, 317,384,431,440,500,503,511,592,724,731,759 \mathrm{~s}, 767,838$ ABU ISHAQ AZ-ZAJJAJ 68

ABULFARAJ HARÛN 86, 270, 276, 886, 893, 897

ABULWALID MERWAN IBN ĞANAH 6, 24, 48, 53, 55s, 68, 76, 86, 92, 95, 98, 103, $105,132,140,171,176,185,191,195,225 s, 233,237,264,270,273,294$, $307,310,315,317,321,323,332,348,351,360,372-374,388,392,394$, $396,402,437,441,449,451,453,462,481,487,503$ s, 509, 511, 527, 529, $531,564 \mathrm{~s}, 569,575,592,615 \mathrm{~s}, 623,634,641,651,659,736,773,780,783 \mathrm{~s}$, $802,811,820,822-825,849,871,874,886,893,893,895,902 \mathrm{~s}$

ABYDENOS 726

ADELKIND B. ${ }^{*} 24,619$

ADLER E.N. 554

AISTLEITNER J. 83, 292, 718

ALBA CECILIA A. 120, 293, 359

ALBRECHT K. 716

ALBREKTSON B. 433, 807, 863, 877, 884-886, 889, 891, 903

ALBRIGHT W.F. 43, 399

ALCALA *30, *36, *38, *40, *68s

ALI BEN ISRAEL 67

ALLEGRO J.M. 281, 322s

ALLEMANDE, vieille traduction $46,98,124,159,207,354,466,508,513,602$, $625,724,753,852,869,898$

ALT A. 292

ALTSCHUELER D. 386s

ALTSCHUELER N. 386

ALTSCHUELER Y. 301, 820

AMBROISE 868

ANDERLIND L. 825

ANDREAS F.C. 827

AP-THOMAS D.R. 288 
ARIAS MONTANO B. ${ }^{*} 66 \mathrm{~s},{ }^{*} 69,12,43,76,95,291,323 \mathrm{~s}, 366,368,416,435$, $442,467,485,539,562 \mathrm{~s}, 620,640,650,695,720,730,749,802,818,820$, $827,838,855,857,886,897$

ARISTOTE * 41

ARTAPAN 148

ATHIAS J. 189, 620

AURIVILLIUS C. 102s, 110, 113, 117, 136, 469

AUROGALLUS M. * 23

AZRIEL BEN JOSEPH ASHKENAZI 779

BACH R. 91

BACHER W. 8, 312, 504, 547, 896

BADUEL C. ${ }^{*} 58$

BAER S. 28, 322, 476, 482, 620, 726, 787, 840, 899

BAETHGEN F. 893

BAHBOUT S. 22

BAILEY K.E. 472

BAILLET M. 284, 793

BANCROFT R. ${ }^{*} 62$

BANETH D.H. 913

BANITT M. 514

BAR BAHLUL H. 146

BARLOW W. ${ }^{*} 61$

BARNABÉ , épître de 119

BARR J. 90, 299, 573, 803

BARRIOS-AUSCHER D. *7

BARTH H. 106, 202, 218

BARTH J. 7, 176, 299

BARTHÉLEMY D. 380

BASILE DE CÉSARÉE 114, 119

BAUDRIER H. ${ }^{*} 38 \mathrm{~s}$

BAUER H. 185, 400, 543, 636, 819, 901

BAUMGARTNER W. 114

BAY M. de *46

BEGRICH J. 401

BELTRAN DE HEREDIA $V .{ }^{*} 36$

BEN HAYIM JACOB *24, 42, 62, 107, 189, 350, 364s, 399, 418, 439s, 476, 489, $495,504,528,619$ s, 631, 650, 694, 739, 767, 787, 806, 808, 819-821, 830, $834,840,894$

BEN-HAYIM Z. 303

BENOIT J. * $45,{ }^{*} 49$

BENOIST R. * $44-{ }^{*} 49,{ }^{*} 68-{ }^{*} 70$

BERGMEIER R. 415

BERNARD J. *28 


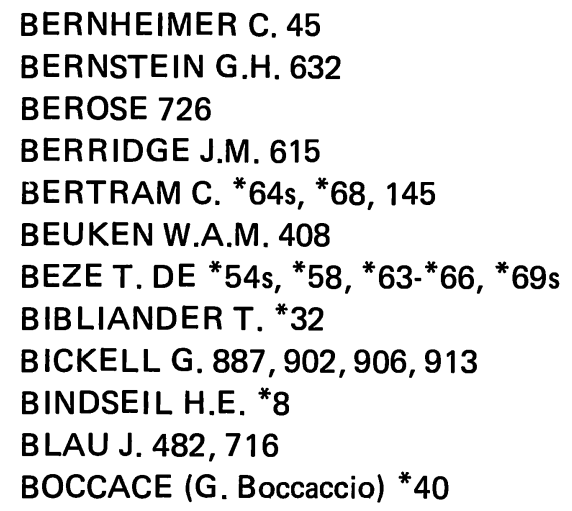
126s, 134, 137s, 141-143, 151-153, 157, 159-163, 165s, 170, 172, 174s, 177, 183, 186, 188, 194, 196, 198, 200, 205, 207s, 211, 216-219, 221, 226-231, $234,236,238,243 s, 246,255-257,259,264,266 s, 269,271 s, 274,276,278$, 285s, 288, 291s, 296, 298, 301, 303, 305-307, 309-311, 318s, 322, 324-327, $329-331,334 s, 338 s, 341$, 343s, 350, 355-357, 359, 363s, 370s, 376s, 380, 382, 395 , 397, 399, 401, 404, 407s, 410, 412-415, 417-423, 425s, 441, 443-446, 448, 450s, 454, 458s, 461, 463s, 470s, 474, 478-482, 484-486, 488-490, 493s, 496 , 499, 501, 504, 506-508, 510, 512, 515-517, 519, 521, 525s, 528-530, 533s, 537, 543, 545s, 549, 559, 564s, 571s, 574s, 580, 582s, 588s, 601, 605, 608, $610,612-614,617,621 \mathrm{~s}, 637 \mathrm{~s}, 640,642 \mathrm{~s}, 645 \mathrm{~s}, 649,653,660,665 \mathrm{~s}, 668,670 \mathrm{~s}$, 676, 679, 681, 683-688, 694, 698, 705s, 710, 711s, 720, 725, 730, 733-735, 737, 740, 743, 749s, 752, 755, 757s, 762s, 765, 768, 773s, 783s, 782, 786, 791, $794,801,803,805 s, 813,817,828 s, 832 s, 835 s, 838 s, 843,846,850 s, 854,857$, 860s, 868, 872, 875, 877-880, 882, 885, 887, 889, 892, 894, 898s, 901, 904s, 907, 909-912 
BRØNNO E. 143

BRONZNICK N.M. 103

BROWNLEE W.H. 40, 43, 390, 392

BRUCE F.F. 390

BRUCIOLI A. ${ }^{*} 18,{ }^{*} 24-{ }^{*} 26,{ }^{*} 40,3,7,12,14,17,24,27,32$ s, 37, 44s, 48, 53, 61, $76,95,98,101,107,122,124,129,141,144,159,176,207,224,242,252$, 284s, 291, 301, 317, 323, 334, 338, 346, 366, 368, 373, 379, 400, 411, 416, 435, 438s, 442, 452-454, 463, 467, 481, 498, 503, 507, 509, 511, 514, 539, 562s, $567,569 \mathrm{~s}, 574,576 \mathrm{~s}, 581,587,590,625 \mathrm{~s}, 640,650,663,669,695,710,719 \mathrm{~s}$, 729s, 735, 748, 763, 773, 776, 795, 802, 818, 820, 838, 855, 857, 869, 886, 897, 899,901

BRUGES L. de *48

BRUGMANN K. 200

BRUNS P.I. 190, 800

BUBER M. 78, 147, 267

BUBER S. 86, 184

BUCER M. * 49

BUDDE K. 9, 73, 333, 346s, 363s, 367, 381, 395, 867s, 873, 875, 878, 884, 888, $904,908,910$ s, 913

BUDE L. * $40,{ }^{*} 44$

BUGENHAGEN J. * 23

BUHL F. 140, 176, 236, 444, 783, 820

BUISSON F. ${ }^{*} 49-{ }^{*} 51,{ }^{*} 54 \mathrm{~s},{ }^{*} 67$

BUJANDA J.M. de ${ }^{*} 36$

BURKITT F.C. 49

BURROWS N. 66, 221, 271

BUXTORF J., jr. 85, 202, 418s, 434, 559, 620, 857, 895, 907

BUXTORF J., sr. 18, 86, 207, 419, 467, 500s, 532, 621, 623, 783s, 820, 897

BUYSSON J.-B. ${ }^{*} 39$

CAHEN S. 836, 865

CALMET A. 650, 665, 774, 864, 890, 900

CALVIN J. ${ }^{*} 5,{ }^{*} 25,{ }^{*} 28 s,{ }^{*} 33,{ }^{*} 39 s,{ }^{*} 44,{ }^{*} 49-{ }^{*} 51,{ }^{*} 54 s,{ }^{*} 64 s,{ }^{*} 68 s \quad 12,47,59$, 62 , 76, 98s, 102, 111, 144, 176, 207, 218, 247, 284, 286, 289, 366, 368, 376, 435, 439, 449, 455, 481, 498, 511, 514, 539s, 562s, 567, 569s, 574, 576s, 581, $583,587,602,610,615,635,650,664,669,671,719 s, 730,735,748 s, 754$, 763, 773, 776, 780, 786, 788, 795s, 802, 818, 820, 838, 869, 886, 898, 901

CAPPEL L. ${ }^{*} 5,21-23,25,35,39,61,64,85 s, 97,101,122,127,178 \mathrm{~s}, 202,217$, $224,268,271,338,366,390,397,405,419,432-434,450,463,466,472,491$, 493, 502, 504, 512, 534s, 548, 557, 559s, 566, 571, 573, 581-583, 590, 598, $601 s, 620 s, 623,640,642 s, 648,651 s, 655,672,686,737,762,765 s, 774,777 s$, $780 s, 790,795,813,826,832,838 s, 852,858 s, 863,868 s, 872$ s, $882,884,892$, 894s, 906s

CARMIGNAC J. 179, 294 
CASSIEN J. 755

CASTLE E. 146, 195s, 771

CASTRO L. de *37, *41s

CAVALLETTI S. 238

CAZELLES H. 862

CELSIUS 0. 780

CERIANI A.M. 632, 799, 870, 877, 880, 905

CERSOY M. 31

CEVALLERIUS cf. CHEVALIER A.

CHAMBERLAIN J.V. 390

CHAMBERS B.T. * $46,{ }^{*} 48 \mathrm{~s}$

CHANTRAINE P. 200

CHARLES QUINT ${ }^{*} 47 s,{ }^{*} 56,{ }^{*} 68$

CHASTEL P. du * 33

CHÂTEILLON S. ${ }^{*} 40,{ }^{*} 49-{ }^{*} 55,{ }^{*} 66 s,{ }^{*} 69,12,14,17,24,27,33,37 s, 44 s, 47$, $53,59,62,76,95,98,101,107,109,124,126,129,136,144,170,176,203$, $207,214,242,248,253,291,301,317,321,323,334,338,346,366,368-370$, $373,376,384,386,401 \mathrm{~s}, 411,429,439,442,447,452-455,461-463,474,480 \mathrm{~s}$, $498,503,507,511,514,539,542,562 s, 567,569 s, 574,576 s, 587,598 s, 602$, $610,614,650,663,669,671,683,695,719 s, 724,729 s, 734 s, 748 s, 753,763$, $766,773,776,795,802,818,820,836,838,855-857,865,886,890,897$ s, 900 s CHAUCER G. 58

CHEVALIER A. ${ }^{*} 65,626,779$

CHEYNE T.K. 8, 53, 77, 80, 108, 113, 140, 142, 160, 238, 245, 269, 282, 291, $304,315,336,361,413,422$ s

CHIFFLOT T.G. ${ }^{*} 6 \mathrm{~s}$

CHOMSKY W. 476, 864

CHRYSOSTOME J. 325, 359, 364, 405, 466, 472, 525, 572, 718, 767

CLERICUS J. 23, 29, 46, 87, 109, 136, 145, 155, 213, 219, 226, 266, 294, 297, $359,385,401,470$ s, 476, 495, 504, 524, 533, 559, 562, 565, 568, 581, 595, 602 s, 623, 665, 675, 820, 868

COCCEIUS J. 18, 117, 129, 223, 351, 467, 500s, 820

COLUMELLE 201

CONDAMIN A. $165,240,296,385,546,574,585,590 s, 655,660,682,707,836$, 861

CORAN 286, 811

CORDOBA F.F. de ${ }^{*} 38$

CORNILL C.H. 468, 472, 477, 491s, 495, 503, 506, 524s, 528, 537, 541, 560, 580, $586,591,595,647,654,655,663,668,677,688 s, 697 s, 700,703,733,780$, 785s, 812, 824s, 831, 848, 855

CORRECTOIRE DE GUILLAUME DE MARA 88, 227, 405, 704

CORRECTOIRE D'HUGUES DE ST CHER 597, 704

CORRECTOIRE DE ST-JACQUES 88, 704

CORTE P. de * 48 
COSTE E. 830

COSTE J. 179s

COSTER A. ${ }^{*} 37,{ }^{*} 42 \mathrm{~s}$

COTTON P. * 66

COVERDALE M. * $55-{ }^{*} 57,{ }^{*} 59-{ }^{*} 61,{ }^{*} 63 \mathrm{~s}, 25$

COWLEY A. 362

CRAMPON A. ${ }^{*} 6$

CRANMER T. * $56 \mathrm{~s},{ }^{*} 61$

CRESPIN J. * 40

CROATTO J.S. 258

CROMWELL T. *56s

CRUCIGER C. * 23

CYRILLE D'ALEXANDRIE 119

DAHOOD M. 431, 568, 581, 783

DALMAN G. 199s, 351, 849, 875

DANIEL AL QUMISI 864

DARLOW T.H. * 48

DARMESTETER A. 514

DATHE J.A. 101, 131, 154, 294, 470, 737, 900

DAVID BEN ABRAHAM 7, 17, 24, 44, 67s, 86, 95, 98, 107, 132, 140, 176, 191, 225, 232, 265s, 270, 276, 294s, 310, 316s, 329, 351, 423, 430, 449, 463, 470, 476, $501,504,527,529 \mathrm{~s}, 532,591,623,651,662,779,783,822,830,844,871,874$, $883,886,895,897,913$

DAVIDSON I. 97, 295

DAVIES N. de G. 281

DEIBER A. 890

DELITZSCH FRANZ 2, 6s, 20, 47-49, 53, 68, 102s, 110, 114, 123, 128-132, 136, $138,167,173,179,200,212 \mathrm{~s}, 241,263 \mathrm{~s}, 271,286 \mathrm{~s}, 293,304,314,318,321$, $328,332,357,360,378,387,423,430,439,451,454,462,776,788$

DELITZSCH FRIEDRICH 284

DENCK H. ${ }^{*} 20$ s, ${ }^{*} 56,{ }^{*} 69$

DENNEFELD L. 903

DERENBOURG J. 361,365

DHORME E. * 6,681

DIETTRICH G. 4, 59, 78, 128, 139, 164, 232, 358, 440

DIEU L. de 73, 280, 425, 449, 454, 485, 500s, 590, 646, 700, 819s, 830

DIEZ MACHO A. 394

DILLMANN A. 335

DIODATI J. *54

DODD C.H. ${ }^{*} 10$

DOEDERLEIN J.C. $39,64,85,92,99,101,116 s, 122,131,134,136,142,145,211$, $217,223,225,235,242,278,285,294,320,350,362,408,494,550,610,648$, $660,665,737,763,774,820,857,872,892$ 
DONNER H. 66, 128, 199, 212, 292, 764

DOUEN O. ${ }^{*} 55,{ }^{*} 67$

DOZY R. 847

DRIVER G.R. * $10 s, 13 s, 26,35,57,75,84-86,112,153,156-158,166,170 s, 177$, $183,193 s, 196 s, 203,216,224,227,236 s, 240,244,247,266 s, 276,288,290$, $294,317,334,342,344,350,358 s, 374,378,380,383$, 390, 401, 413, 418, $423,432,444,472,479,486,488,496,504,508-510,512,515$ s, 546, 556, 559s, 566, 572s, 576, 601, 670, 736, 778, 794, 803s, 849, 886s, 893, 905-907 DRIVER S.R. 287, 304, 321, 560

DRUSIUS J. 39

DUHM B. 9, 14, 17, 19s, 38, 49, 51, 57s, 63s, 66, 74, 77s, 92-94, 102, 105, 108, 110-113, 117s, 120, 124s, 127, 131, 134, 136, 139-141, 145, 155s, 162-166, $168,179,188,201,203,214,219,221,228 s, 234,239-241,247,258 s, 271$, 274, 279-282, 285s, 289, 293, 304, 309, 311, 322, 324, 327, 330s, 340, 349, 352 , 356, 358, 368, 371, 378, 385s, 399, 407, 412, 419, 421, 428, 435, 445-447, $454 \mathrm{~s}, 460$, 463, 465s, 469s, 472s, 495, 506, 519, 524s, 530, 533, 548, 552, $567,584,590,595,601,607,624,631,640,646,658,665,674,676-678$, $680,685,687,690 s, 702 s, 706 s, 722,740,781-783,791,797,801,808,814-$ $816,818,827 \mathrm{~s}, 842$

DUMBRELL W.J. 813

DUNASH BEN LABRAT 68, 232, 270, 365, 437, 592, 640, 779s, 822s

DUPONT-SOMMER A. 294

DURAN cf. ISAAC D.

DURELL D. 35, 385

DYSERINCK J. 870, 878s, 885, 888, 906, 908, 912 s.

ECKER R. 276

EHRENTREU H. 12, 389

EHRLICH A.B. 23, 34, 61, 75, 105, 113, 126, 137, 160, 165, 181, 196s, 203, 214, $220,235 \mathrm{~s}, 239,245,253,287,300,311 \mathrm{~s}, 317,323,325,328,340-342,360$, $381,385,395,406,427,449,479 s, 496,498,515,533,537,552,569,572$, $611,626 \mathrm{~s}, 632,654 \mathrm{~s}, 663,667,669,697,703,709,711,717 \mathrm{~s}, 722,731,733$, $743,745,760,776,778,789,806 s, 843,867$

EISSFELDT $0.408,717 \mathrm{~s}$

EITAN I. 140, 160, 171s

EL-ABÂS 171

EL-AZHARî 171, 195s, 893

ELIAS LEVITA *25, 56, 67, 95, 145, 189, 377, 440, 620, 820

ELIEZER BEN YEHUDA 160, 185, 233, 641

ELIEZER DE BEAUGENCY 12, 17, 19, 24, 43, 53, 107, 129, 191, 220, 273, 295,

$317,322,332,348,351,360,376,384,388 s, 410,437,440,447,454$

ELLIGER K. 283, 287, 312, 314, 316s, 397

EMERTON J.A. 177, 184, 573

EPHRAIM BEN R. ISAAC DE REGENSBURG 97 
EPHREM LE SYRIEN 4, 37, 40, 59, 114, 119, 128, 131, 308, 325, 499, 765, 810 ERASME D. ${ }^{*} 40,{ }^{*} 56$

ERBT W. 567

ERMAN A. 511

ERPENIUS T. 553

ESTIENNE H. 276, 487, 532

ESTIENNE R. ${ }^{*} 29-{ }^{*} 36,{ }^{*} 40 s,{ }^{*} 43 s,{ }^{*} 47,{ }^{*} 58 s,{ }^{*} 61,{ }^{*} 63,{ }^{*} 67-{ }^{*} 69,{ }^{*} 712,12,14,17$, $24,27,32,44 \mathrm{~s}, 47,61,76,88,95,98 \mathrm{~s}, 101,107,124,136,144,159,176$, $207,213,218,242,247,252,280,284,286,317,321,323 s, 346,355,366$, $368,381,384,400,416,418,438,449,453,455,461 \mathrm{~s}, 467,481,508 \mathrm{~s}, 511$, $514,562,567,569 \mathrm{~s}, 574,576 \mathrm{~s}, 581,587 \mathrm{~s}, 590,595,610,612,620,625,635$, $650,664,695,698,702,704,719 s, 724,729 s, 735,737,748 s, 753,773,776$, $795,802,818,820,825,836,838,855,857,869,886,897 \mathrm{~s}, 901$

EUSEBE DE CESAREE 55, 104, 114, 116, 143, 148, 175, 188, 217, 232, 306, 323, $356,371,380,610,726$

EWALD H. 1, 22, 47, 106, 131, 242, 271, 286, 289, 293, 304s, 315, 318, 321s, 332, 402 , 451, 467, 470, 481, 489, 492, 507, 512s, 521, 524s, 532, 534, 536s, 544, 559,570 s, 581, 595s, 602s, 608-610, 612, 614, 617, 620, 623, 640, 644, 649651,660 s, 665, 671, 675, 683, 714, 716, 721, 730, 732, 737, 739, 746s, 749, 753s, 765s, 768, 773, 777, 780, 785, 787, 793, 795, 801, 819s, 833, 836, 838, $851,861,863,867,869,875 s, 882,887,894,906$

EZRA BEN EZEKIEL HA-BABLI 160

FELDMANN F. 160

FIELD F. 52, 104, 140, 307, 405, 466, 510, 528, 530s, 535, 632, 654, 753, 769, $785,830,833,843,869,880,885,900,905$

FIRUZ DANIEL 529

FISCHER J. 184, 294, 302, 415, 429s

FITZMYER J.A. 234

FOHRER G. 284

FORBES R.J. 353, 513, 594

FOREIRO F. 4, 33, 46s, 53, 55, 111, 124, 129, 136, 145, 159, 170, 178s, 193, 207, $213,252 \mathrm{~s}, 317,338-340,366,376,386,389,399 \mathrm{~s}, 439$

FORSTER J. ${ }^{*} 23,400$

FRANK R.M. 665

FRANKEL Z. 585

FRANKL P.F. 562, 582, 585, 601, 622

FREEDMAN D.B. 28

FRENSDORFF S. 42, 291

FREYTAG G.W. 573

FROSCHAUER C. ${ }^{*} 21$ 
GADOLO B. *29s, 461, 509, 741, 753

GALLO J. * 37

GEIGER A. $89,123,146,435,453,877,899$

GERLACH E. 871, 875s, 882, 894

GERSHOM MEOR HA-GOLA 97

GERSHON BEN NATHAN 386

GERSTENBERGER E. 591

GESENIUS W. 7s, 12, 18, 20, 26, 28, 32, 39, 50, 53, 68, 71, 73, 79, 81, 85, 99, $101,103 \mathrm{~s}, 106,118,123,129,131,134,136,139,142,146,151,155,170$, $185,187,195,200,203,206,213,215,217,220,225 s, 231,241 s, 263,266 s$, $270,277,279,284 s, 292,315,318,329,332$ s, 342, 359s, 379, 395, 400, 423, $430,450,452,462,467 \mathrm{~s}, 500,503,532,544,569,573,623,771,779 \mathrm{~s}, 783$, $802,820,825,831,866$

GHISLERIUS M. 472, 718, 767

GIESEBRECHT F. 49, 470, 475s, 478, 506, 510, 516, 519s, 522, 526, 530, 532, 539s, 555, 559s, 579s, 585, 601, 604, 612, 614, 618, 620, 624, 627-629, 646, $662,667,673 \mathrm{~s}, 682,684,689,695 \mathrm{~s}, 702-704,707 \mathrm{~s}, 711,715,728 \mathrm{~s}, 736 \mathrm{~s}$, $750-752,755,757 \mathrm{~s}, 761-763,780,786,797,800 \mathrm{~s}, 804 \mathrm{~s}, 811,818,828-832$, $841 s, 846 s, 849,855,859$

GINSBERG H.L. 34, 59, 158

GINSBURG C.D. 4, 28, 32, 42, 123, 147, 190, 220, 225, 291s, 365, 371, 442, 477, $482,495,530,550,574 \mathrm{~s}, 592,603,619,626,658,721,751,757,760,767,820$, $824,840,847,877,899,904$

GLASSIUS S. 48

GOBELINUS LARIDIUS 708

GORDIS R. 292, 410, 621, 623, 867

GOTTLIEB H. 880, 886, 903, 912s

GOTTSTEIN M.GOSHEN 184, 272, 554

GOUSSET J. 337, 402s, 501, 820

GRABE J.E. 70, 712, 826, 869, 876

GRAF K.H. 467, 480, 484, 502, 512, 525, 552, 557, 559, 587, 603, 610, 612, 618, $620,646,657,719,728,754 s, 771,773,776-778,780,783,789,796,809,818$, $852,857,861$

GRAFTON W. *57

GRAJAL G. de * 37

GRAETZ H. 21, 23, 39, 52, 65, 75, 80, 82, 109, 118, 124, 131s, 134, 139, 173s, $183,203,210,221,231,272,276,283,285,288,291,298,305,310$ s, 320, 322 , 324, 336, 348, 362, 395, 407, 415s, 444, 457, 459, 472, 485, 493s, 504, $508 \mathrm{~s}, 540,549 \mathrm{~s}, 552,560,565,567,588,595 \mathrm{~s}, 606,612,614,616,621 \mathrm{~s}, 627$, $633,639,672,682,688,702,705,726,777 \mathrm{~s}, 782,789,793,804,811,818,824$ GRAVE B. de * $47 \mathrm{~s}$

GRAY G.B. 80, 137, 151, 158, 196

GREENBERG M. 82 
GREENSLADE S.L. ${ }^{*} 55-{ }^{*} 57$

GREGOIRE XIII * 39 , * $47 \mathrm{~s}$

GROISBEECK G. de * 45

GROSSE-BRAUCKMANN E. 769

GROTIUS H. 145, 213, 425, 449, 483, 487, 532, 570, 602, 650, 725, 727, 737, 771, $788,812,827,849,858$

GRUENBERG S. 210s

GUEVARA J. de * 37

GUILLAUME A. 299, 305, 387s, 390, 886, 890

GUNDERT W. * 16

GUNKEL H. 103, 211

GUTHE H. 9,82

HAETZER L. ${ }^{*} 20-{ }^{*} 23,{ }^{*} 56,{ }^{*} 69$

HAGGADA PASCALE 436

HAGHEN J. VAN DER *48

HAHN A. 459

HALEVY J. 116s, 179, 211, 222, 234, 912s

HALLER M. 153, 281, 385, 868, 884s, 896, 906

HARLEMIUS J. * 40

HAUPT P. * $15,333,833$

HAY GAON 874

HAYYUJ cf. JUDAH H.

HEIDE A. VAN DER $865,869,874,891$

HENDERSON E. 467, 581, 593, 656, 664, 668, 722, 737, 787, 845, 903

HENDRY G.S. * $9 \mathrm{~s}$

HENRY VIII *57, *70

HENSLER C.G. 211,647

HENTEN J. * $46-{ }^{*} 48$

HÉRODOTE 362

HERZ HOMBERG 386, 388

HIE (JÉRÔME) *31, *64, 42, 50, 52, 67, 69, 97, 104, 106s, 110, 115s, 119-121, $131,134,138,143-147,149 \mathrm{~s}, 158,162,169,175 \mathrm{~s}, 181,232,262,265,267 \mathrm{~s}$, $273,288,317,359,369,377,380,383,386,398,407,418,422,429,436,444$, $449,462,465,470,474,477$ s, 509s, 518, 531s, 566, 597, 599, 605, 612, 634, $648,663 \mathrm{~s}, 671,674,685 \mathrm{~s}, 769,811$

HIPPOLYTE DE ROME 349

HIRSCHFELD H. 695

HITZIG F. 3, 8, 19s, 48s, 85, 105s, 108, 128, 131s, 134, 136, 155, 173, 176, 182,

$194,206,213,215,220,263,285-287,292,307,310,314 s, 325,335,423$, $437,452,483,492,503,513,523,543,549 s, 552,562,566,568,570,573$, 576s, 595-597, 599, 603, 605, 607, 620, 632s, 635, 637, 640-643, 648, 652, 654s, 666-668, 673, 684, 693, 704, 713, 727, 732, 735, 744-746, 754, 757, 777, 788s, 794, 824, 826, 835s, 839, 846, 849, 855s, 858 
HOFFMANN G. 116

HOLLADAY W.L. 22, 472, 602

HOOGHT E. VAN DER 189-191, 620, 722

HOOP SCHEFFER J.G. de 891

HOPPER S.R. 497

HOUBIGANT C.F. ${ }^{*} 5,{ }^{*} 16,1 \mathrm{~s}, 8,13,23,29 \mathrm{~s}, 36,39,45,64,72,74,82,85,87,93$, $106,108,110,116 \mathrm{~s}, 122,127,131,136,145,156 \mathrm{~s}, 159,162 \mathrm{~s}, 177,186,189$, $193,202,213-215,226,234,242,248,253,257,267,269,271,275$ s, 278, 285s, 305, 310, 313, 320, 322-324, 334, 336, 339s, 343, 346, 348, 355, 357, $367,375,380,383,397,401,403-405,408,415,427,432,438,450,455,457 \mathrm{~s}$, 466s, 478, 483, 498, 502s, 510, 512s, 516s, 526, 533s, 536, 538-540, 546, 548, 552s, 555, 559s, 562, 564, 570s, 574, 577, 584, 588, 590, 602s, 605, 607s, 610, 620,623 s, 627, 640, 642s, 648, 658, 665, 668, 671, 673, 682-685, 695, 698, $700,703,706,708,730,746,751,753,761,765 s, 768,771,773,776,782,787$, $809,811,820,830,833,835,839,843,858,865,873,877,888,900,906$ HUBMANN F.D. 568

HUMBERT P. 302, 333, 343

HUNAEUS A. * 46

HUNKIN J.W. * 10

HYATT J.P. 497, 559

IBN ANBÂRî 68

IBN BARÛN 68, 86, 196, 871

IBN EL-A' RÂBî 171, 195s

IBN EZRA (ABRAHAM) ${ }^{*} 14,{ }^{*} 26,6,12,17,19,24,27,32,44,53,61 \mathrm{~s}, 67 \mathrm{~s}, 75 \mathrm{~s}$, $85,92,95,107,111,129,132,155,158,176,185,191,219 s, 241,243,264 s$, $270,285,295,301,310,317,323,332,340,348,351,360,376,381,386-388$, 400s, 422, 427, 437s, 440s, 449, 451-453, 462, 471, 547, 569, 591s, 694, 722, $769,784,823,864,869,871,881,897,901 \mathrm{~s}, 913 \mathrm{~s}$

IBN GHAYYATH 893

IBN-MANẒUR 196, 199

IKEN C. 145,148

INQUISITION ESPAGNOLE * $34,{ }^{*} 36-{ }^{*} 38,{ }^{*} 40,{ }^{*} 43,{ }^{*} 69 \mathrm{~s}$

IRÉNÉE DE LYON 560s

IRWIN W.H. 181

ISAAC DURAN 56, 659, 902

ISAAC ELYAH KOHEN 386s

ISAAC HA-LEVI BEN ELEAZAR 641

ISAAC IBN GIQATILLA 185

ISAAC LOPEZ 384

ISAAC NATHAN cf. NATHAN

ISAAC NATHAN BEN KALONYMOS *24

ISAAC OROBIO DE CASTRO 387 
ISAAC TREVES 800

ISAAC TROKI 386s

ISAIE BEN MALI 386, 388

ISAIE DE TRANI 1, 6, 12s, 17, 23, 27, 33, 44, 56, 73, 76, 95, 107, 191, 220, 233, $264,348,351,358,360,440,449,466,471,500$ s, 503, 511, 529, 592, 651, $659,662,754,784,820$

ISHODAD DE MERV 78, 121, 289, 561

IWRY S. 41, 43, 258

JACKSON J.J. 197

JACOB B. 886

JACOB BEN REUBEN 107, 233, 351, 386-389, 449, 466, 503, 529, 874, 892

JACOB IBN AMRAM 387

JACOB TAM 270, 591, 779s

JACQUEMOT J. * 65

JACQUES ler ${ }^{*} 61 \mathrm{~s},{ }^{*} 69 \mathrm{~s}$

JAHNOW H. 9

JAMES F. 243, 253, 420

JANZEN J.G. 470, 537s, 540, 543, 584s, 627, 670, 829

JASTROW M. 104

JELLINEK A. 410

JENNI E. 892

JÉRÔME (cf. HIE)

JONAS J. *23

JOSEPH BEN JACOB 779

JOSEPH BEN NATHAN 384

JOSEPH BONFILS 547

JOSEPH IBN KASPI 191, 467, 659

JOSEPH IBN NAHMIAS 466, 476, 482, 500, 509, 565, 591, 615, 651, 731, 784, 798,838

JOSEPH QARA 191, 233, 264, 270, 273, 294, 317, 386, 449, 462s, 466, 475, 572, $591,599,609,659,823,841,872,881,893$

JOSĖPHE, FLAVIUS *52, 143, 147s, 150, 170, 237, 309, 726

JOSIPPOS 572, 601, 692, 779-781, 813

JOSHUA SEGRE 386, 388

JOÜON P. 543

JUBB G. 385, 400

JUBILES, livre des 436

JUD L. * 21 , " 32 , * $58,{ }^{*} 67,14,17,24,27,32 \mathrm{~s}, 37 \mathrm{~s}, 45,47,53,61,76,95,98,124$, $159,176,207,253,317,323,366,384,402,442,449,454,456 \mathrm{~s}, 481 \mathrm{~s}, 498$, $503,508,511,514,539 s, 567,570,574,576 s, 587,590,595,610,650,663$, $669,695,719-721,724,729$ s, 734, 748, 763, 773, 776, 795, 802, 818, 820, $823,838,855,857,886,897$

JUDAH BEN DAVID CATTORZI 779 
JUDAH BEN QOREISH 6, 68, 86, 98, 103, 132, 191, 225, 264s, 334, 476, 722, 844, 883, 886

JUDAH HADASSI 565

JUDAH H.AYYUJ 24, 27s, 31, 53, 75s, 107, 165, 182, 206, 225, 273, 351, 419, $471,476,527,575,592,616,638,641,659,736,767,784,790,802,807$, 822s, 871, 902, 913

JUDAH IBN BALAAM 7, 12, 24, 27, 51, 53, 55s, 75s, 92, 107, 140, 171, 176, 185, $191,214,225,273,276,294,307,310,315,348,351,355,365,372$ s, 388, $401,419,422,437 \mathrm{~s}, 449,452 \mathrm{~s}, 476,487,509,511,529,532,569,592,616$, $634,638,659,773,811,840,850,871,893$

JUDAH IBN TIBBON 6, 651, 913

JUNIUS (= Jon, F. du) ${ }^{*} 63,{ }^{*} 67$

JUSTIN MARTYR 119

KAFAḤ J.D. 886, 893

KAHLE P. $394,658,899$

KAISER $0.48,68 s, 75,78,227,243$

KATZ cf. WALTERS P.

KAUTZSCH E. ${ }^{*} 15,19,48,171,237,304,308,353,668,736$

KEIL C.F. 468, 477, 481, 483, 512, 524, 549, 570, 573, 587, 611, 616, 623, 634, $636,643,649,652,662,722,728,777,780$ s, 788, 794, 812, 815, 818, 871, 875 KELSO J.A. 807

KENNICOTT B. ${ }^{*} 5,4,10,16,45,87,108,133,157,177,190$ s, 202, 222, 226, 279, $377,550,586,602-604,612,620,635,665,671,692,722,763,766,775,785$, $800,818,844,847,856,908$

KENYON F.G. 496

KESSLER J. 721

KITÂB AL- ${ }^{\circ} A Y N$ 68, 195, 893

KITTEL R. ${ }^{*} 2,{ }^{*} 7,{ }^{*} 11,{ }^{*} 15 \mathrm{~s}, 43,45,65,82,120,123,125 \mathrm{~s}, 138 \mathrm{~s}, 154,168,173$, $224,238,296,304,316,345,365,386,401,431,620,881$

KLOPFENSTEIN M.A. 509

KLOSTERMANN A. 139, 210, 268, 287, 423, 423, 456, 458

KLOSTERMANN E. 116

KNABENBAUER J. 242, 514, 689, 748, 813, 824, 898

KNOBEL A. 37, 60, 86, 95, 125, 131, 134, 136, 146, 179, 213, 225, 279, 315, 332s, 372,464

KNOX R. 602

KOCHER D. 8

KOEHLER L. 281, 285, 316, 344, 385, 471s, 769

KOENIG E. 8, 11, 18s, 32, 47, 51, 56, 74, 81, 95, 108, 123, 125, 130, 134, 138, 154, $160,171,196,200,210$ s, 229, 235, 239, 245, 263, 266, 278-280, 285s, 302, $324,340,360,386,393,411,447,452,470,481,500,511,543,569,636$, $641,692,703,716,737,754,764,783,819,855,878$

KOENIG J. 55, 172, 210, 280s, 302, 317s, 333, 392, 405 
KOLB F. *21

KOMLOSH Y. 389, 500

KOPF L. 871

KOPPE J.B. 6, 21s, 38, 91, 101, 138-140, 155, 170, 183, 193, 198-200, 217, 223, 269s, 279, 336, 340, 345, 350, 353, 372, 379, 397, 420, 428, 433

KRAUS H.-J. * 17

KROCHMAL A. 66, 68

KURIAKOS L.M. 641

KUTSCHER E.Y. 8, 40, 67, 72, 82, 96, 128, 152s, 159, 171s, 184, 192, 197, 206, $208,221,228,262,267 s, 272,280,287,294,306,320,324,331,335,339,342$, $352,356,363,365,383,390,404,421,458$

LAGARDE P. DE $17,57,65,73,81,127,130,132$

LANDESBERG D.I. 435

LANDSBERGER B. 290

LANDSBERGER F. 731

LANE E.W. 83

LARBEN F. DE * 48

LARCHER C. 22

LAUTERBACH A. * 18s, 24, 53, 64, 123, 204

LEENE H. 340

LEEUWEN C. VAN 103

LE FE'VRE J. * 45

LE FÈVRE D’ÉTAPLES J. *27, * 48, *54, *57, 136, 664, 704, 729, 753, 833, 836, 898

LEHMANN M.R. 258

LEISTE A.F.G. 467, 485, 547

LEMAIRE P. 115

LEON L. DE *37s, *41-*43

LETTERIS M. 189

LEUSDEN J. 189

LEUZE N. DE * 48

LEVI BEN YEFET 67, 107, 372

LEVY J. 37, 140, 258, 273, 784, 825, 895

LIEBERMAN S. 299

LIEBMANN E. 175, 179, 187

LIGHTFOOT J. 754

LILIENTHAL T.C. 28, 87, 190, 279, 322, 350, 383, 494, 514, 557, 665, 721, 740 LOEFGREN 0. 271

LOEHR M. 865, 880, 887, 890, 893, 906, 909

LOEW I. 875

LOEWE J. 902

LOEWENSTAMM S.E. 89s

LOEWINGER S. 272

LOHFINK N. 58, 86

LOHMANN P. 91 
LOHSE E. 294

LOTZE H. 899

LOUVAIN (Théologiens de) ${ }^{*} 46-{ }^{*} 48,{ }^{*} 68 \mathrm{~s}$

LOWTH R. ${ }^{*} 16,8,13,15 s, 21 s, 25 s, 29 s, 32,35 s, 46,52 s, 57 s, 64,70 s, 73,79$, $85,93,99,108,110,113,122,125,127 \mathrm{~s}, 131,133,136,141 \mathrm{~s}, 154,157,177$. $179,182 s, 189 s, 198,202,205,208 s, 211,213-215,217,219 s, 223,226,235$, 237, 240, 242, 245, 247, 253-255, 275, 280, 284s, 292s, 295, 297, 306, 310s, $320,322,324,329,336,339$ s, 342, 345, 348, 351, 353-355, 357, 367, 369, 372, $374 s, 381,383,385,397,400 s, 403$, 410s, 414s, 420, 428, 433s, 435, 438, 441, $448,455,458,463,465,776,883,894,904,908,911$

LUCKENBILL D.D. 250

LUETKEMANN L. 37, 42, 52, 80, 104, 121, 123

LUST J. 228

LUTHER M. *5, *16- $27,{ }^{*} 30,{ }^{*} 56,{ }^{*} 59-{ }^{*} 61,{ }^{*} 64,{ }^{*} 66,{ }^{*} 68,{ }^{*} 71,3,7,12,14,17$, $24,27,32-34,37 s, 41,44-47,53,61-64,76,90,95,98,101,107,109,118 s$, 122-124, 126, 130, 136s, 141-145, 157-159, 176, 180, 190, 198, 204-207, 209, 212s, 224, 243, 252, 284s, 291, 301, 304, 308s, 317, 321, 323s, 332, 334, 336, $338,340,345 \mathrm{~s}, 348,354,357,366,368,373,376,378 \mathrm{~s}, 381,386 \mathrm{~s}, 401 \mathrm{~s}, 407$, $411,422,426,429,435,439,441 \mathrm{~s}, 446,449,452-455,457 \mathrm{~s}, 463,467 \mathrm{~s}, 477$, 479-482, 498s, 503, 505, 511, 514, 533, 537, 539s, 555s, 559, 562s, 567, 569s, $574,576 \mathrm{~s}, 581,587 \mathrm{~s}, 590,595,602,608,610,620,623,625 \mathrm{~s}, 635,639,650$, $663,668 s, 675 s, 695,705,708,710,715,719 s, 724,729-731,734,748 s, 753 s$, $756,761,763,766,773,776,778,786,795,799,801 s, 804,808,818,820,824$, $833,836,838 s, 844,846,848,852,855,857,868,872,877,881-883,886$, 897s, 900 s, 903

LUZZATTO S.D. 5, 7, 28, 32, 34, 75s, 81, 85, 89, 126, 129s, 138s, 142, 151, 155 , $160,170,203,206,213,215,219$ s, 225, 233, 250, 267, 271, 286, 298, 315, 332 , 337, 340, 345, 348, 359s, 379, 389, 396, 400, 402s, 425, 429, 438, 452, $492,505 s, 516,534,537,603,622,653 s, 679,688,695,738,768$

LYRE N. DE cf. NICOLAS D.L.

MAALSTAD K. $311 \mathrm{~s}$

McCARTHY C. 5, 355, 408, 900

MAIMONIDE (Moshe ben Maïmon) *24

MAISTRET J. *48s

MALAMAT A. 813

MANASSEH BEN ISRAEL 386s

MANÉTHON 148

MARCELLIN A. 755

MARCOURT A. ${ }^{*} 28$

MARE H. DE *28

MARGOLIOUTH G. 902

MARGULIES M. 875

MARGUERITE DE NAVARRE * 40

MAROT C. * 40 
MARTI K. 29, 31, 80, 83s, 113, 152, 155, 219, 229, 238, 255, 298

MARTIN R. 900

MARTINEZ DE CANTALAPIEDRA M. * $37 \mathrm{~s}$

MARTINI C.D.A. 395, 400

MARTY J. 430, 668

MASCLEF F. ${ }^{*} 5$

MASIUS A. 477

MAURER F.J. 559, 820

MEEK T.J. 867

MEGANDER C. 721

MEIER E. 106

MEINHOLD J. 806s

MELANCHTON P. ${ }^{*} 23$

MENAHEEM BEN HִELBO 609

MENAHEM BEN SARUQ 53, 92, 98, 107, 191, 226, 233, 270, 294s, 305, 334, $451,500,531,591 \mathrm{~s}, 609,623,640,662,779,784,807 \mathrm{~s}, 822 \mathrm{~s}, 871,874,893$, 897

MENAHEM, disciples de 270

MENAḦEM BEN SHELOMO 233

MENAHEM DE LONZANO 270

MENAḤEM DE POSOUIĖRES 466, 476, 482, 487, 500s, 503, 509, 529, 562, 572, $592,595 \mathrm{~s}, 609,616,623,638,646,659,724 \mathrm{~s}, 737 \mathrm{~s}, 767 \mathrm{~s}, 787,798,812,820$, $823,827,859$

MÉNANDRE D'ÉPHÈSE 170

MERCATI G. 798

MERCERUS J. ${ }^{*} 64 \mathrm{~s}, 24,46,53,86,98,284,400,419,503,626,779,820,838,872$ MEYER I. 642

MEYER R. 65, 292

MICHAELIS C.B. 467, 483, 501, 562, 565, 588, 602, 623, 637, 754, 777, 784, 787, $831,838,857,883,900$

MICHAELIS J.D. ${ }^{*} 3,{ }^{*} 17,3,11 \mathrm{~s}, 17,21,23,46,48,55,64,68,85,95 \mathrm{~s}, 99 \mathrm{~s}, 104 \mathrm{~s}$, $108,113,122,128,131,136,139,141 \mathrm{~s}, 145,154,158,166,168 \mathrm{~s}, 173 \mathrm{~s}, 178$, $189,207,211,213,217,219,223,225 s, 264,280,284,286 s, 293,295,297 s$, $311,313,336,350,357,361 \mathrm{~s}, 367,386,397,402$, 408, 417, 429s, 433s, 441, 448, 467, 469s, 475s, 484, 489, 496s, 502-504, 510, 513, 524-526, 528, 534, 543 , 552s, 557-560, 562, 564, 571, 573-575, 583, 587, 590, 602, 610s, 614, 618, $621,624,633,643,648,650,653 s, 660 \mathrm{~s}, 665,673,687 \mathrm{~s}, 703,705,708,711$, $715,722,730,737,745,749,753 s, 762 s, 765 s, 771,774-776,780,782-786$, $788,791,820,824,835 s, 838 s, 845,851,856,858,865,872,898,910$

MICHAELIS J.H. 28, 68, 459, 603

MIDRASH

Bamidbar Rabba 191

Bereshit Rabba 263, 337, 896

Ekha-Rabbati 317, 603, 872, 895 
Mekhilta de R. Ishmaël 238, 436

Mekhilta de R. Simon ben Yoḥaï 436

Pesiqta 149

Pesiqta de Rab Kahana 147

Pesiqta Hedhatta 410

Pesiqta Rabbati 147

Qohelet 215

Rabba (Est) 23

Shemot Rabba 191

Shir ha-Shirim Rabba 185

Tanhuuma 51, 191, 193, 315, 899

Tanḥuma Buber 46, 193, 438

Tehillim 184, 191

Wayyiqra Rabba 98, 220, 294, 875

Yalquț ha-Makhiri 146, 315

Yalquț Shimeoni 146s, 438 MILIK J.T. 26, 912

MISHNA

Aboda Zara 195

Bekorot 875

Erubin 195

Gițtin 299

Hagiga 5

Shabbat 82, 273

Taanit 864

Zabim 5

MOEHLE A. 307

MOSHE DE COUCY ${ }^{*} 24$

MOÏSE cf. MOSHE

MONTFAUCON B. DE 106, 217, 306, 530, 900s

MORAN W.L. 68,783

MORANO J. *28

MORE T. 58

MORIN P. 910

MORROW F.J. 52, 84, 159, 164, 168, 281, 452

MOSHE BEN NAHMAN 386s

MOSHE BEN SHESHET 466, 476, 481, 487, 511, 568, 592, 595s, 659, 767, 787, 823,841

MOSHE DE SALERNE 387

MOSHE EL SHEIK 387

MOSHE HA-KOHEN DE TORRESILLAS 386

MOSHE IBN GIQATILLA 67, 225, 616

MOSHE KOHEN IBN CRISPIN 384, 386

MOUCHY A. DE * 45 
MOVERS F.C. $468,489,496,526,540,550,555,578,584,674,680,737,741,744$, $752,776,780,794,816 s, 825 s, 831,845$

MOWINCKEL S. 38, 709

MUENSTER S. ${ }^{*} 19,{ }^{*} 23 \mathrm{~s},{ }^{*} 28,{ }^{*} 57,{ }^{*} 59-{ }^{*} 61,{ }^{*} 66 \mathrm{~s}, 7,10,12,14,17,24,27,32 \mathrm{~s}$, $37,44 \mathrm{~s}, 47,53,59,61,76,95,98,101 \mathrm{~s}, 107,124,129,137,142,144 \mathrm{~s}, 159$, $170,176,204,207,242,252,284,286,301,317,323,334,338,355,366$, 368 , 373, 376, 387, 402, 429, 435, 438s, 442, 449, 452s, 455, 463, 477, 481, 498, 503, 507-509, 511, 514, 539, 562s, 567, 569s, 574, 576s, 587, 590, 595, $602,620,650,663,665,669,695,719 s, 729 s, 735,748 s, 754,763,773,776$, $795,802,820,838,852,855,857,886,897,899,901$

MUILENBURG J. 319

MUSCULUS W. 301, 317, 366, 386

MUSIL A. 115

MUTIUS H.G. VON 68

NAEGELSBACH C.W.E. 109, 146, 233, 329, 485, 503, 505, 572, 609, 616, 623, 632 s, 717, 728, 778, 795, 858, 867, 889

NATHAN I. 419

NATHAN BEN YEHIEL 147, 195s, 299

NESTLE E. 104

NEUBAUER A. 384s

NICOLAS DE LYRE ${ }^{*} 29,{ }^{*} 64,378,462,466 s, 518,569,827 s, 840$

NIEHAUS J. 176

NIESE B. 726

NISSEL J.G. 207

NOELDEKE T. 866,880

NOETSCHER F. 26, 390, 536, 620, 662, 704, 712

NOLDIUS C. $73,280,324,621,636$

NORBERG M. 632

NORTH C.R. 286, 292, 307, 317-319, 322, 336, 344, 363, 380, 401, 408

NORZI Y.S. 18, 42, 194, 244, 270, 377, 418, 482, 551, 599, 603, 620, 694, 724 NOTH M. 334

NYBERG H.S. 271s, 866

OECOLAMPADE J. ${ }^{*} 18 \mathrm{~s},{ }^{*} 24,2-5,7,12,14,17,24,27,32 \mathrm{~s}, 37,44 \mathrm{~s}, 47,53,61-63$, $76,95,98,101,107,124,129,137,144,159,176,182,204,207,212,242$, $252,285,291,317,321,323,338,346,366,368,373,378 s, 400 s, 416,435$, $439,442,452-454,457$

OESCH J.M. 22, 51, 119s, 188

OKHLA we-OKHLA 100, 134s, 147, 177, 185, 220, 347, 393, 418, 431, 512, 592, $824,899,904,909$

OLIVETAN P.R. ${ }^{*} 25-{ }^{*} 29,{ }^{*} 44,{ }^{*} 57,7,12,14,17,19,24,27,32 \mathrm{~s}, 37,44 \mathrm{~s}, 47$, $53,61,76,98,101,107,124,129,136,141,144,159,170,176,207,213$, $242,252,284,291,301,317,321,323,334,338,346,348,354,366,368$, 
$373,381,384 \mathrm{~s}, 387,400-402,407,411,416,429,435,438 \mathrm{~s}, 442,449,452-454$, 456s, 461, 463, 467, 477, 481, 498, 503, 507s, 514, 539s, 562s, 567, 569s, 574, 576s, 581, 587s, 590, 595, 602, 610, 625s, 650, 664, 669, 695, 704, 719s, 729s, 735 , 748s, 763, 773, 776, 782s, 795, 802, 818, 820, 833, 836, 838, 855, 857, $869,886,897 \mathrm{~s}, 901$

OLSHAUSEN J. 637, 802, 894

OORT H. 83, 286, 292, 311, 315, 324, 326-328, 331, 341, 345, 353, 360, 368, 415, $417,426,435,443,448,455,458,477,486,519,533,538 \mathrm{~s}, 552,564,571$, $584,588,604,633,639,655,693,702,708,715,730,818,824,850,852$, $858,898,907$

ORELLI C. VON 351, 381, 484, 546, 549, 603, 617, 652

ORIGÈNE 550, 578, 607, 630, 695, 879, 905, 910

ORLINSKY H.M. 45, 100, 221, 365

OSIANDER A. * $21,{ }^{*} 30$

OSTY E. ${ }^{*} 6,302,317 \mathrm{~s}$

OTTLEY R.R. 187

PAGNINI S. * $18 \mathrm{~s},{ }^{*} 23-{ }^{*} 27,{ }^{*} 32,{ }^{*} 37,{ }^{*} 44,{ }^{*} 52,{ }^{*} 56,{ }^{*} 58-{ }^{*} 61,{ }^{*} 64-{ }^{*} 67,7,12,14$, 17 s, 23s, 27, 32s, 37, 44-46, 48, 53, 59, 61, 68, 76, 86, 95, 98s, 102, 107, 111, 124, 129s, 136, 141, 144s, 158s, 170, 176, 182, 204, 212s, 218s, 224, 226, $233,243,252,284,291,301,304,317 \mathrm{~s}, 321,323,334,346,355,366,368$, $373,379,384,386,400,411,416,422,435,438 s, 441 s, 449$, 452s, 462s, 467, $481,498,500,503 s, 507,509,511,514,539,562 s, 567,569 s, 574,576 s, 581$, 587, 590, 592s, 595, 610, 620, 626, 639, 650, 663, 669, 695, 710, 719s, 724, 729-731, 735, 748s, 754, 761, 763, 773, 776, 779, 783s, 795, 801s, 818, 820, $823,827 \mathrm{~s}, 835-838,846,852,855,857,869,886,897,899,901$

PAREAU J.H. 868, 872, 877, 880, 882, 902s, 905, 910

PARHON S. 7, 23, 44, 53, 107, 191, 265, 295, 466, 503, 820, 866, 893, 897, 902 PASTEURS DE GENEVE ${ }^{*} 55,{ }^{*} 64{ }^{*} 67,7,11 \mathrm{~s}, 14,17,24,27,32 \mathrm{~s}, 37,44 \mathrm{~s}, 47,53$, $59,62,76,95,99,107,110,122,124,129,136,145,160,176,207,243,252$, $280,284,286,301,304,317,321,323,334,337,346,355,366,368,373$, $384,387,416,422,426,435,438-440,442,449,453,456,461-463,467,481$, 498, 503s, 508s, 511, 514, 534, 539, 562s, 567, 569s, 574, 576s, 587, 590, $593,602,610,615,637,650,664,669,695,708,719 s, 724,729 s, 735,748 s$, $754,763,773,776,795,802,820,838,852,855,857,881,886,897,899,901$ PAYNE SMITH R. 632

PEAKE A.S. 785

PEISER F.E. 897

PELLICAN C. 176, 203, 207, 317, 366, 481, 570, 665, 721

PENNA A. 623, 704, 729, 870

PERLES F. 65, 66, 80, 82, 216, 301s, 623, 647, 717, 852, 872, 905

PERROT C. ${ }^{*} 65$

PETHION IBN AYYUB AL-SAHHÂR 467, 482, 665, 729

PETUCHOWSKI M. 299 
PIERRE LE MANGEUR * 52

PINSKER S 67, 139, 394, 840

PLESSIS D'ARGENTRÉ C. DU * $35,{ }^{*} 44,{ }^{*} 48 \mathrm{~s}$

PLINE L'ANCIEN 201, 755

POLE M. 494

POLLARD A.W. ${ }^{*} 56,{ }^{*} 61$

PORTONARIIS A. DE * $36-{ }^{*} 38$

PORTONARIIS D. DE * $37-{ }^{*} 39$

PORTONARIIS G. DE * 34 - $^{*} 39$

PORTONARIIS P. DE * 38

PORTONARIIS V. DE (I'ancien) * 38

PORTONARIIS V. DE (le jeune) * 37 s

PRAETORIUS F. 385, 872, 891

PRATO F. DE * $18,{ }^{*} 24,{ }^{*} 26,18,61,122,128,144 \mathrm{~s}, 155,158 \mathrm{~s}, 226,323,419$, $439,484,489,495,509,551,561,595,631,635,650,695,709,712,724,737$, $743,760,763,810,815,819 \mathrm{~s}, 840,848,874,876,888,896,910$

PRÉDICANTS DE ZURICH ${ }^{*} 9,{ }^{*} 21-{ }^{*} 23,{ }^{*} 25,{ }^{*} 59-{ }^{*} 61,{ }^{*} 69,61,76,95,107,144$, $159,176,203,207,248,252,317,323,366,368,373,384,435,439,442$, $467,481,485,498,503,505,508 s, 511,513 s, 534,539,559,562 s, 567,569 s$, $574,576 s, 581,587,590,595,608,610,626,640,650,663,669,675,695$, 705, 719-721, 724, 729s, 734, 748s, 753, 755-757, 761, 763, 766, 773, 782, $786,795,802,811,820,833,836,838,848,852,855,857,868,881,886,897 s$, 901

PROCKSCH O. 2, 78, 82, 91, 118, 126, 152, 186, 235, 239, 261, 272

PROCOPE 59, 131, 462

PROCOPE DE GAZA 306, 338, 356

OIMḤI DAVID (RADAQ) * 14, *18s, *26, 1, 6, 12, 17-19, 23s, 27s, 32s, 44, 46, 51, $53,56,59,61,68,73,76,78,86-88,92,95,98,102,106 \mathrm{~s}, 111,129,145,155$, $176,185,191,201,204,206,213 s, 220,224,226,232 s, 243,264,270,284 s$, 292 , 294s, 308, 315, 317, 321, 323s, 328, 332, 334, 336, 351, 354s, 360s, 372, $376,378,387 \mathrm{~s}, 401,419,422$, 425, 427, 431, 436, 438, 440s, 449, 451-453, 455 , 462s, 466, 468, 475-477, 482, 484, 487, 497, 500s, 503s, 506s, 509, 511, $515,522,526,529,531,537,551,553 \mathrm{~s}, 562,565 \mathrm{~s}, 569,575,581,591 \mathrm{~s}, 595 \mathrm{~s}$, $599,603,608$ s, 616, 623, 626, 638, 641, 651, 654, 659, 662, 675, 686, 696, 719s, 730s, 737s, 753s, 763, 767, 771, 774, 777-780, 783s, 787, 802, 819s, 823$825,827 \mathrm{~s}, 838-840,850,857,859,866,873-875,893,895,897,899,902,913$ QIMḤI JOSEPH 27s, 122, 176, 191, 232, 270, 317, 334, 351, 387, 476, 500s, 503, $566,591 \mathrm{~s}, 784,823,893,897,902$

OIMḤI MOSHE 295, 529, 531

QIRQISANI Y. 900

QUENTIN H. 898

QUIROGA G. DE * $35,{ }^{*} 43$ 
RABIN C. 174

RADAQ (cf. QIMHI)

RAHLFS A. 72, 379, 456, 518, 532, 578, 693, 712, 726s, 782, 796, 815, 826, 869, $876,885,889,892$

RANKE E. 723, 890

RASHI (SALOMON ISḤAQI) * 14, * 18, *26, 6, 19, 23s, 27, 31, 33, 44, 51, 53, 61s, $67,76,85,92,95,107,111,130,132,158,176,185,191,195,221,224,226$, $243 s, 247,265,270,273,286,294,315 s, 323 s, 351 s, 355,360,373,376,381$, $385,413,427,431,436,439 s, 447,449,452 s, 456,462 s, 466,468,475,477$, $485,487,500,503,507,509,511,513 s, 529,531,562,569,591,608 s, 619$, $623,635,649 s, 654,659,662,675,690,783 s, 798,812,823,827 s, 841,869$, $875,877,881,893,897,901 \mathrm{~s}, 913$

RATZABY J. 185, 886, 893

REGEL J. *21

REICHERT O. *23

REIDER J. 224, 390

REITER S. 663

RELAND A. 788

REUCHLIN J. * 19, 68, 98, 226, 466, 503, 897

REUSCH F.H. * $43,{ }^{*} 68$

REVENTLOW H. Graf 471

REYNOLDS J. *61, *63

RICHTER G. 743

RIGNELL L.G. 7, 49, 337, 380

RIVET A. 494

ROBERTS B.J. 405

ROBINSON T.H. 868, 883, 904

ROEDIGER A. 500s, 820

ROERER G. * 23,62

ROGERS J. *56s

ROLLET P. * $27 \mathrm{~s}, 17,24,32,45,47,61,76,95,98,101,124,144,159,170,176$, $204,207,213,242,280,301,346,366,381,402,435,453,462,507,509$, $514,562,567,569,574,577,581,587 s, 590,595,610,625,650,664,695,720$, $724,729 s, 735,748 s, 753,773,802,818,820,836,838,855,857,898$

ROORDA T. 38

ROSENMUELLER E.F.C. 8, 29s, 32, 39, 54, 68, 73, 85, 102, 116s, 128, 136, 139, 142 , 145s, 155, 179, 187, 189, 200, 203, 208, 213, 217, 220, 235, 241, 271, $285,318,332,342,348,351,411,439,449,452,454,459,464,467,469,477$, $481,483,503,505,562 s, 569 s, 574,581,602,609,647,649,665,680,684$, $708,766,778,780,795,820,836,838,845,857,876,883,894,898,902 s$ ROSSI A. DE 912

ROSSI G. DE 4, 32s, 87, 99, 120, 122, 124, 190-192, 194, 207, 213, 219s, 226, $231,279,289,313,350,357,359 s, 399,425,433,442,466,484,494,504$, $514,528,530,550,557,599,603,612,620,635,637,650,658,661,664$, $671,676,695,702,712,721 \mathrm{~s}, 729,739,745,760,763,766,770,775,785$, $794,800,835,840$ s, 847, 856, 873, 877, 894, 902s 
ROST L. 198

ROTAN J.-B. * 65

ROTHSTEIN D. 528, 559, 625, 633, 636, 681, 700, 768

ROUILLÉ G. * $35,{ }^{*} 38-{ }^{*} 40$

ROUSSEAU A. 561

RUBEN P. 244, 368

RUBINSTEIN A. 390, 394, 421

RUDELIUS J. * 30

RUDOLPH W. 112, 118, 127, 478s, 493, 499, 502s, 506, 509, 520, 528, 542, 552s, $560,580,588,611,632,634,677,709,726,728,743,753,789,791,813$ s, $828,831,836 s, 856,866 s, 869 s, 873,883,885,887,893,907$ s

RUNNING L.G. 232

RYSSEL V. 335, 340, 453

SAADYA GAON 7, 10, 12, 17, 19, 23-25, 27, 33, 44, 48, 53, 55, 68, 73, 76, 92, 95, $103,105,107,129,142,146,176,182,185,191,197,218,220,224 s, 241-243$, $264,266,270,273,276,288,294,301,307,315,317,321,323,332,345,348$, 351,360 s, 365, 373, 376, 381, 384, 386, 388, 410, 423, 425, 427, 436, 439s, 442, 449s, 452s, 455, 462s, 547, 659, 694, 864, 869, 874s, 877, 879, 881, 886, 893-897, 899

SAADYA IBN DANAN 387,400

SABATIER P. 561, 662, 868

SAEB $\emptyset$ M. 53

SAHL 316

SALAMANQUE, Théologiens de * $36 \mathrm{~s},{ }^{*} 40-{ }^{*} 42,{ }^{*} 71$

SALMON BEN YERUHAAM 387s, 864, 869s, 874, 877, 879, 881s, 886, 893, 895$897,899,901,913$

SANCHO F. ${ }^{*} 34,{ }^{*} 36 \mathrm{~s},{ }^{*} 41 \mathrm{~s}$

SARSOWSKY A. 836s

SASSON V. 219

SAWYER J. 43

SCHARFENBERG J.G. 217, 268, 601, 620s, 857, 876, 890, 902

SCHELLING J.F. 319

SCHENKER A. 670

SCHERSCHEWKY Ts. 301

SCHINDLER V. 294

SCHLEUSNER J.-F. 35, 84, 104, 106, 156, 245, 268, 307, 372, 416, 464, 471, 486, $493,499,505,513,535,552 \mathrm{~s}, 559 \mathrm{~s}, 566,577,582,585,608,611,623,637$, $655,660,665,682,684,700,714 \mathrm{~s}, 737,751,769,775,781,792,808,819 \mathrm{~s}$, $826,838,844,850,865,876,882,884,887$ s, 892, 898, 900, 902s, 905, 907 SCHMIDT H. 498, 578, 631, 743, 760

SCHNURRER C.F. 470s, 590, 599, 649, 662, 680, 684, 700, 725, 737s, 760

SCHOORS A. 292

SCHORR Y.H. 435

SCHRADER E. 728 
SCHROEDER N.G. 430

SCHUEPPHAUS J. 886

SCHULTENS A. 14, 24, 151, 156, 295, 372, 532, 569, 573, 830, 850

SCHUNCK K.D. 211

SCHUTTERMAYR G. 495

SCHWALLY F. 104, 768, 782, 792, 799, 814

SCHWARZENBACH A.W. 734

SCIO DE SAN MIGUEL P. * 69

SCOTT R.B.Y. 153

SCULLION J.J. 411

SECKER T. 30, 35, 52, 57, 70s, 141s, 145, 223s, 235, 237, 297, 342, 351, 372, 385

SEELIGMANN I.L. 35, 104, 127, 150, 176, 187, 193, 227, 374, 405s, 412

SEGAL M.Z. 669

SEGOND L. ${ }^{*} 6,{ }^{*} 12$

SELWYN W. 60-62

SERVET M. ${ }^{*} 19,{ }^{*} 67,95,98,102,111,203,318,323,366,368,416,439,442$, $462,581,595,620,650,695,720,754,802$

SHAKESPEARE W. ${ }^{*} 61$

SHALOM MODENA 345

SHELOMO ASTRUC 387, 389

SHELOMO BEN MELEK 387s

SHELOMO LEVI 387

SHEMUEL HACCOHEN GAON 365

SHEMUEL LANYADO 386

SIMON R. * $12,{ }^{*} 55,{ }^{*} 67,323$

SIMONIS J. 190

SIMONS J. 252, 544

SIONITA GABRIEL 37, 59, 65, 77, 128, 232, 289, 308, 433, 467, 482, 536, 561, $583,607,765$

SKEHAN P.W. 43, 52

SMITH G.V. 592, 597

SMITH M. *62

SMITH W.R. 77s

SODEN W. VON 727s

SOGGIN J.A. 474

SOLLAMO R. 151, 536

SONNEN J. 883

SOPHERIM cf. TRAITE S.

SORBONNE, Théologiens de * $30-{ }^{*} 33,{ }^{*} 35,{ }^{*} 41,{ }^{*} 44-{ }^{*} 49,{ }^{*} 69 \mathrm{~s}$

SOTO D. DE *36s

SPERBER A. $65,365,551,553,561,587,611,647,681,695,704,709,774,777$, $810,813,829,833,840,845,847$

SPOHN G.L. 470, 472, 478, 488, 494, 496, 530, 535, 559, 632, 681, 698, 700, 709,

$715,719,761,769,780$ s, 826

STADE B. 9, 28, 249, 658, 693, 754s, 860 
STARCK J.F. 637

STENNING J.F. 128

STIER R. 459

STRACK H. 120, 365, 394, 806, 840

STRUENSEE C.G. 113, 131, 434

STRUGNELL J. 84, 377

STRYRODE G. * 48

SUKENIK E.L 251, 272, 397

SWETE H.B. 518, 532, 712, 869, 876

TALMON S. 70, 171, 181, 184, 210, 253, 422, 590s

TALMUD BABLI 147

Aboda Zara 149

Baba Bathra 273

Baba Mesia 273

Baba Qamma 874

Berakot 312, 408

Ketubot 233

Menahot 146, 562

Moed Qațan 765

Nazir 409

Nedarim 694

Sanhedrin 158, 176, 869

Shabbat 12, 27, 103, 507

Sota 33,408

Taanit 70, 408, 436, 449

Yebamot 409, 897

Yoma 767

TALMUD YERUSHALMI

Halla 199

Shebiit 105

Soța 440

Yebamot 299

Yoma 767

TANHUM YERUSHALMI 68, 76, 86, 107, 232, 294, 310, 373, 384, 387s, 401, $476,487,492,500,503,509,511,529,564,569,592,616,662,767,773$, $784,787,807 \mathrm{~s}, 812,819,838,844,850,866,871,881,893,897$

THENIUS 0. $257,740,854,877 \mathrm{~s}, 883,900$

THEODOR J. 312

THÉODORET DE CYR 119, 306s, 359, 524, 877, 903, 913

THIEL W. 579

THOMAS W. 83, 108, 394 
THOMPSON J.A. * 7

THORNDIKE H. 553, 607, 850

TILETANUS J. * 46

TOBIA BEN ELIEZER 872, 875, 881, 897

TOBIA LE TRADUCTEUR 295

TORCZYNER H. 89, 219, 515

TOSEFTA

Ohalot 299

Sabbat 132

Yebamot 299

TOV E. 497, 502, 578, 584, 667

TRAITÉ SOPHERIM 61

TREMELLIUS I. " $61,{ }^{*} 63-{ }^{*} 68,7,12,14,17,24,27,31-33,37,39,44 \mathrm{~s}, 47,53,59$, $61,76,95,99,102,107,119,124,129,136,145,176,223,243,247,253,280$, $286,301,317,323,334,337,346,368,373,386,407,424,435,439,442,449$, 452s, 456, 459, 462, 467, 477, 481, 498, 500, 503, 509, 514, 539, 562s, 567, $570,574,576 s, 587,590,602,637,650,663,669,695,719 s, 724,729-731$, $734,748 s, 754,763,769,773,776,795,802,804,820,827,838,851$ s, 855, $857,869,881,886,897,899-901$

TROMMIUS A. $156,471,826$

TUR-SINAI N.H. 72s

TURRETIN B. ${ }^{*} 66$

TYNDALE W. ${ }^{*} 56,{ }^{*} 59-{ }^{*} 61,{ }^{*} 63 \mathrm{~s}, 25$

ULBRICH H. ${ }^{*} 18$

UMBREIT F.W.C. 820

UNGER E.727s

USHER J. 553

VALLEZILLO R. DE ${ }^{*} 35,{ }^{*} 41 \mathrm{~s}$

VAN DER KOOIJ A. 149,169

VAN SELMS A. 756

VAN WINGHE C. ${ }^{*} 48$

VATABLE F. ${ }^{*} 32,{ }^{*} 34,{ }^{*} 36-{ }^{*} 44,{ }^{*} 58 s,{ }^{*} 69,{ }^{*} 71,17,19,32 \mathrm{~s}, 53,59,76,98,102$, $107,110,144,170,176,203,218,317,366,368,387,477,481,504,508$, $511,576 \mathrm{~s}, 581,587,610,615,650,669,724,729 \mathrm{~s}, 749,763,773,787 \mathrm{~s}, 818$, $820,823,838,858,869,881$

VAUX R. DE ${ }^{*} 6$

VELTHUSEN J.C. 267

VENEMA H. 467, 481, 483, 485, 505, 509, 565, 572s, 620, 623, 626, 647s, 650, $659,673,684,686,693,714,721 \mathrm{~s}, 730,766,774,776,793,797,820,831$, 843,858 
VERCELLONE C. 250

VERMIGLI P.M. ${ }^{*} 63,{ }^{*} 68$

VITRINGA C. 14, 47, 67, 73, 102, 106, 117, 145, 213, 220, 241, 280, 286, 315, $318,325,365,372,411,423 \mathrm{~s}, 429,437,452,459,464$

VOGEL G.J.L. 93, 101, 186, 211, 223s, 255, 280, 285, 322, 334, 385, 397, 467, $480,487,587,633 s, 737$

VOLZ H. ${ }^{*} 18,{ }^{*} 20,{ }^{*} 22 \mathrm{~s}$

VOLZ P. 283, 316, 348, 352, 386, 479, 490-492, 497, 499, 502-504, 515, 530, 536s, $545,552 \mathrm{~s}, 556,574,580,582-584,590 \mathrm{~s}, 607,611,614,618,623,627 \mathrm{~s}, 631$, $647,655,662,667,673 s, 677,680,689,691-693,698,703,716,753,759$, $770,782 \mathrm{~s}, 785 \mathrm{~s}, 796,809,818,828,843$

WALLENSTEIN M. 40

WALTERS P. (= KATZ) 72, 885

WALTON B. 324, 665

WARSZAWSKI L. 27, 32, 40, 66, 116, 139, 169, 220, 273

WATSON W.G.E. 313

WEBER R. 459, 470, 612, 664, 702, 825, 852

WEIL G.E. 4, 48, 118, 236, 248, 291, 308, 327, 363, 371, 374, 414, 472, 477, 587, $591,596,684,689,710,739,744,803,818,845,877$

WEISER A. 520, 811

WEISZ H. 290, 372, 429, 454

WELLHAUSEN J. 132, 257s, 286, 519, 521, 835

WERNBERG-M $\emptyset$ LLER P. 294, 404, 616, 648

WESTERMANN K. 318, 385

WHITCHURCH E. * 57

WICHELHAUS J. 468, 472, 478, 528, 550, 628, 691

WICKES W. 347

WIESMANN H. 884, 889s, 892

WILDBERGER H. 9, 38, 43, 55, 57, 60, 66, 68, 73, 82s, 94s, 101, 113, 120, 124, $152,178,198,202,228,245,255,258,277$

WHITTINGHAM W. ${ }^{*} 57$

WINCKLER H. 252

WISEMAN D.J. 862

WITZEL G. ${ }^{*} 20$

WOLF J.C. 856

WORDSWORTH W.A. 392

WORKMAN G.C. 490

WUTZ F. 106, 884, 896 
XÉNOPHON 201

XIMENES Cardinal ${ }^{*} 69$

YALON H. 207, 390

YEFET BEN ELY 1, 7, 10, 12, 17, 19, 23s, 27, 32s, 43s, 50s, 53, 55, 59, 68, 76, $92,95,105,107,110 \mathrm{~s}, 123,129,138,140,158,170$ s, 176, 182, 187, 191s, $197,204,215,220,224 s, 233,241-245,263 s, 266,270,273,276,279,286$, $294,314-317,321,323,332,336,340,348,351,360,372,376,382,384,387 \mathrm{~s}$, $401,411,423,427,431,437 \mathrm{~s}, 440 \mathrm{~s}, 449 \mathrm{~s}, 452 \mathrm{~s}, 462,467,474,477,487,500 \mathrm{~s}$, $503,505,515,527,529,531,547,565,569,587,592,608 s, 611,615,623$, $641,646,651,662,672,675,684,711,717,722 \mathrm{~s}, 725,738,742 \mathrm{~s}, 754,759$, $767,778 s, 787,791,798,802,812$ s, 820, 822, 827, 838, 840, 847, 851, 864, 895

YEIVIN I. 120, 293, 359, 554, 684, 789, 801, 806, 840

YEQUTIEL BEN JUDAH 913

YOUNG E.J. 300

YUSUF AL-BAṢIR 295

ZAINER G. 124, 334, 513s, 869

ZAMORA A. DE * 19

ZIEGLER B. ${ }^{*} 23,13,40,42,71,83,116,140,143,169,179,184,187,199,205$, $239,262,266,287,294,300,307,325,338,343,356,377,379 s, 404,412$, 422 , 456, 466, 478, 480, 505, 507, 528, 530-532, 535, 560, 564, 578, 631s, $647,664,677,712,718 s, 726 s, 753,761,764,769,777,782,790,792,815$, $817,826,829,833,843,865,869$ s, 876, 885, 889, 892, 905

ZIMMERLI W. 601

ZIMMERN H. 333

ZUCKERMANDEL M.S. 299

ZWINGLI H. *21s, *32, " $69,144,176,203,207,248,252,317,321,323,366,368$, $384 \mathrm{~s}, 435,439$, 442, 452-455, 467, 477, 481, 485, 498, 503, 508s, 511, 514, $539,559,562 s, 567,569 s, 574,576 s, 581,587,590,595,608,610,626,640$, $650,663,669,675,695,705,719,721,724,729 s, 734,748 s, 753 s, 761,763$, $766,773,776,782 \mathrm{~s}, 788,795,801 \mathrm{~s}, 811,820,838,852,855,857,872,881$, $886,897 \mathrm{~s}, 901$ 
(Les autres abréviations sont obvies. On trouvera leur clé en BH3 ou en BHS)

abr (abréviation) cf. p. XV : 87

abr-elus (abréviation élusive) cf. p. XV : 26, 101, 152, 158, 160, 161, 167, 172, 174, $198(2), 224,239,244,257(3), 268,287,293,297,298,300,306,324,326$, $350,432,438,447,453,457,476,480,491,496,499(2), 521,522,527,545$, $584,606,658,673,674,678,713,722,736,775,777,780,797,811,828,833$

abr-graph (abréviation graphique) cf. p. XV : 523

abr-styl (abréviation stylistique) cf. p. XV : 29, 163, 164, 180(2), 183, 207, 222, 248(2), 282, 283, 326, 409(2), 416, 446, 539, 541, 549, 555, 588, 604, 619, $632,644(3), 647,688,698,702,708(2), 714,735,743,752,757,759,808,815$, $841,848,855,860,910$

abr-styl-int (abréviation stylistique interne) cf. p. XV : 666

abr-transl (abréviation translationnelle) cf. p. XIV : 214, 516

abst (abstention) cf. p. XII : 3, 6, 19, 23, 31, 33, 36, 81, 101, 117, 122, 126, 170, $194,200,207(2), 212,216,217,218,223,229,235,271,289,292,321,324$, $373,396,400,425,430,459,543,617,780,904,905$

ampl (amplification) cf. p. XV : 96, 102

ampl-styl (amplification stylistique) cf. p. XV : 326

assim (assimilation) cf. p. XIV : 15, 25, 44, 47(2), 59, 69, 85, 92, 93, 110, 116, 118, $123(2), 139,152,153,154,160,183,188,202,205,236,248,252(2), 253$, $254,256,264,269,272,287,300,306,307(5), 318(2), 321,326,329,330$, $338,344,353,364,400,403,412,413,415,443,448,458,460,461,464$, $483,488,489,496,517,526,544,549,564,567,574,586,594,605(3), 611(2)$, $629,638,644(2), 655,656,660,661,662,672,683,698,699,704,705,706$, $731,733(4), 739(2), 740,753,761,763,772,778,782,788,789,793,794,796$, $797,798,804(2), 815,831,839(2), 842,844,867,879,882,888,889,912$

assim-ctext (assimilation au contexte) cf. p. XIV : 11, 16(2), 34, 41, 77, 78, 101, $113,114,127,130(2), 142,158,161,183(2), 193,196(4), 226,231,257,261$, $267,283,289,292,293,303(2), 313,334,343,344,364,371,374(2), 376$, $378,383,384,395,400,403,407,410,411,414,415,419,421,450,445$, $455,456,457,458,462,488,507,509,523,526(2), 533,537,556,567,574$, $580,589,610,660,674,678,679,681,689,694,696,699,701,729,731$, $748,749,751,758,762,770(2), 786,792,805,808,815,817(2), 832,833$, $838,839,842,872,894,898,907,912$ 
assim-int (assimilation interne) cf. p. XIV : 109, 341, 539

assim-usu (assimilation à une forme plus usuelle) cf. p. XIV : 111, 268

attenu (atténuation) cf. p. XV : 14

bas (base) cf. p. XII : 65, 82, 257, 602, 744

clav (clavis) cf. p. XII : 829

confl(at) (conflatio) cf. p. XVI : 26, 82, 143, 212, 250, 251, 268, 276, 341, 486, $602,613,671,686,736,780,836,857$

constr (construction) cf. p. XVI : 34, 71, 90, 107, 113, 137, 139, 161, 166, 167(2), $179,200,246,266,273,322,457,492,504,589,594$

cor (correction) cf. p. XII : 3, 16, 23, 54, 65, 82, 96, 114, 116, 138, 139, 143, 161, $188,224,227,231,233,236,252,257(3), 261(2), 307,318,329,332,336$, $354,358,360,361,364(2), 369,377,379,397,399,403(3), 451,461,464$, $490,493(2), 534,594,598,602(3), 617,621,640,648,649,658,668(2), 720$, $744,763(2), 765,771,774,778,795(2), 805,827,839(2), 888$

crrp (corrompu) cf. p. XII : 257, 263, 326(2), 594, 857

dbl (doublet) cf. p. XVI : 21, 746, 798, 872

def(orm)-int (déformation interne) cf. p. XV : 105, 114(2), 116, 139, 183, 186, $251,302,370,432,464,478,698,733,768,795(2), 811,813,872(3), 889,901$

dissim (dissimilation) cf. p. XVI : 363, 424, 759, 761

dittogr (dittographie) cf. p. XV : 81

emph (emphase) cf. p. XV : 452

err (erreur) cf. p. XV : 34, 60, 63(2), 222, 251(2), 326, 403

err-divis (erreur de division) cf. p. XV : 118, 329, 346, 473(2), 512, 529, 534, 780

err-graph (erreur graphique) cf. p. XV : 21, 34, 52, 54, 75, 96, 104, 116(2), 134, $135,138,158,167,171,177,188,202,203,205,219,224,227(2), 233,251$, $257,273,281,286,307,336,351,352,356,361,377,380,397,418,432$, $461(2), 466,469(2), 471,493(2), 501(2), 509,523,526,527,548,558(3)$, $582,589(2), 598,602,619,622,627,680,716,725,733,744,771,774,780$, $788,821,838,851,899$ 
err-ponct (erreur de ponctuation) cf. p. XVI : 127, 130, 194, 200, 224, 244, 499, 621,809

err-synt (erreur syntaxique) cf. p. XV : 297, 420

err-voc(al) (erreur de vocalisation) cf. p. XVI : 23, 36, 54, 78, 117, 118, 154, 198, $211,217,218,226(2), 235,264,276,278,286,289,297,343,348,357,399$, $425,430,474,509,539,545,546,551,567,583,600,602(2), 608,613,641$, $736,801,805(2), 843,868,870,872,911$

euphem (euphémisme) cf. p. XV : 598

exeg (exégèse) cf. p. XV : 6, 13, 34, 66, 71(2), 104, 137, 139, 155, 167, 177, 198, $217,218,221,224,231,264,266,267,269,272,275,293,314,316,324$, $341(2), 351,407,414,422,425,427,429,453,457,464,475,486,493,499(2)$, $501(2), 504,524,529,543,558(2), 565,582,584,589,613(2), 622(2), 625$, $627,628,637,640,656,684,685,687,694,706,730,768,771,777,782(3)$, $805(2), 811,813(3), 836,839,849,864(2), 870,877,890,892,898,901,906$

exeg-ctext (exégèse en fonction du contexte) cf. p. XV : 558, 565, 872, 912

expl (explicitation) cf. p. XV : 9, 31(2), 59, 81, 82, 83, 87, 130, 166, 215, 226, $228,230,234,243,257,281,305,354,360,361,417,462,474,478,548$, $564,571,617,627,630,663,704,829,885$

expl-graph (explicitation d'une graphie) cf. p. XV : 422

facil (facilitation) cf. p. XIV : 69, 83, 793

facil-styl (facilitation stylistique) cf. p. XIV : 332, 880, 888, 905

facil-synt (facilitation syntaxique) cf. p. XIV : 7, 90, 101, 110, 118, 122, 135, 161, $179,268,273,280,290,322,330,339,356,357(2), 367,368,371,378,381$, $395,400,423,438,444,446,448,452,469,471,481,484(2), 497,499,527$, $539(2), 549,558,588,610,624,630,633,635,646,649,658,675(2), 676$, $693,697,702(2), 710,718,720,734,754,756,766,772,774,798,803,809$, $851,854,860,867,872(2), 908$

facil-voc(al) (facilitation vocalique) cf. p. XIV : 31(2), 49, 71, 109, 298

glos (glose) cf. p. XVI : 29, 63, 69, 228, 297, 298, 314, 349, 382, 420, 535, 542, $633,683,755,800,828,861,878,884$

hapl (haplographie) cf. p. XV : 161, 245, 261, 329, 549(2), 558, 602, 744, 839, 877 
harm (harmonisation) cf. p. XIV : 38, 127, 172, 338, 346, 355(2), 464, 506, 594(2), 598,665

harm-ctext (harmonisation au contexte) cf. p. XIV : 74, 79, 96, 141, 152, 154, 174, $186,207,219,224,227,241,271,289(2), 310,324,379,397,409,426,439$, $441,445,681(2), 720,778,827,835,864,875$

harm-int (harmonisation interne) cf. p. XIV : 397

harm-synt (harmonisation syntaxique) cf. p. XIV : 10, 36, 207(2), 345, 499, 533

hom (homéoarcton ou homéotéleuton) cf. p. XV : 133(2), 267, 279, 415, 555(2), 578

homarc (homéoarcton) cf. p. XV : 41, 257, 306, 731, 741

homarc-int (homéoarcton interne) cf. p. XV : 633

homtel (homéotéleuton) cf. p. XV : 259, 377, 409, 454, 490, 495, 607, 722, 816

ign-cult (ignorance culturelle) cf. p. XV : 236, 686, 763

ign-geogr (ignorance géographique) cf. p. XV : 827

ign-gram (ignorance grammaticale) cf. p. XV : 847

ign-hist (ignorance historique) cf. p. XV : 295

ign-lex(ic) (ignorance lexicographique) cf. p. XV: 33, 65, 255(2), 429, 640, 649, 832,863

ign-ling (ignorance linguistique) cf. p. XV : 396

ign-real (ignorance des realia) cf. p. XV : 350, 693

ign-styl (ignorance stylistique) cf. p. XV : 151

ign-synt (ignorance syntaxique) cf. p. XV : 182, 205, 254(2), 272, 427, 583, 652

incert (incertain) cf. p. XIII : 46, 47, 49, 52, 59, 60, 75, 96, 118, 143, 153, 180, $188,257,263,303,330,336,341,348,350,370,397,418,426,434,451$, $453,461,519(3), 558,582,610,613,617,632,636,786,829,843,849,905$

lacun (lacune) cf. p. XII : 15, 29, 41, 71, 271, 272, 282, 397(2), 411, 423, 456, $594(2), 607,608,610,611,653,675(2), 691,704,705,706,729,730,731$, $733,734,793,794,859,861,901$ 
lic (licence) cf. p. XIV : 7, 19, 41, 54, 79, 107, 118, 160(2), 174, 178, 194, 205(2), $210,216,218,219,223,224,233,244,246,248,267,272,283,287,298,338$, $345,356,358,371,380,402,445,447,453,454,506,509,545(2), 548,551$, $558,568,575,577,584,594(2), 600(2), 605(2), 607,610,613(2), 627,632$, $646,648,658,685,715,717,736,744,757,768,771,774,775,778,782$, $827,828,829,843,851,863,864,872,875,884,890(3), 895,899,910$

lic-elus (licence élusive) cf. p. XVI : 248

lic-synt (licence syntaxique) cf. p. XIV : 348

lit (littéraire) cf. p. XIII : 161, 210, 224, 244, 256, 368, 444, 468, 481, 508, 522, $538,539,555,578,579(2), 584,585,638,644(7), 651,657,665,670,671(2)$, $674,699,707,750,798,801,809(2), 814(2), 816,817,825,826,831,836$, $844,851,856,859$

midr (midrash) cf. p. XV : 26, 77, 116, 118, 130(2), 174, 193, 211, 230, 255(2), $273,286,289,306,336,350,371,375,399,400,402,413,429,454,527$, $691,765,895$

modern (modernisation) cf. p. XV : 266, 267

modern-graph (modernisation graphique) cf. p. XV: 82, 127, 196(2), 302, 306 modern-lex (modernisation lexicale) cf. p. XV : 65

paraphr (paraphrase) cf. p. XIV : 26, 29, 56, 78, 79, 152, 167, 177, 179, 200, 211, $228,230,231,234,235,240,263,358,446,448,466,469,476,480,499$, $504,508(2), 512,522,529,534,546,558(2), 568,571,574,594(2), 608,613$, $627(2), 641,648,657,681(2), 683,691,699,705,761,778,786,789(2), 809$, $851,868,879,882,889,890,894,906,911$

perm(ut) (permutation) cf. p. XV : 66, 571, 600, 640, 717, 906

rest (restauration) cf. p. XVI : 41, 429

schem (schème) cf. p. XIV : 16, 409

spont (spontané) cf. p. XIII : 319, 480, 712

subst-graph (substitution graphique) cf. p. XVI : 909

substit-lexic (substitution lexicale) cf. p. XVI : 325

subst(it)-synt (substitution syntaxique) cf. p. XVI : 240, 246, 305, 313, 320, 325, 341,653 
theol (théologique) cf. p. XV: 3, 39, 65, 113, 125, 143, 145, 229, 231, 320, 354, $358,360,369,403(2), 431,434(2), 451,513,538,621,648,649,690,795(2)$

transcr-harm (transcription harmonisante) cf. p. XIV : 104

transf (transféré) cf. p. XIII : 202, 589, 644

transI (translationnel) cf. p. XIV : 7, 87, 102, 126, 245, 305, 322, 399, 443, 489, $491,499,519(3), 589,593,619,667,689,709,715,717,735,753,792,798$, 829,836

usu (usuel) cf. p. XIV : 41, 82, 114(2), 157, 170, 212, 223, 253, 263, 326, 331, 335, $345,358,373,375,438,442,459,473(2), 544,575,580,586,617,642$, 668(2), $671,746,819,857,872,892,903,904$ 
Ne sont pas expliqués dans cette bibliographie les sigles qui le sont en: Theologische Realenzyklopädie, Abkürzungsverzeichnis zusammengestellt von Siegfried Schwertner, Berlin \& New York 1976.

Les sigles des livres bibliques sont ceux de la Bible de Jérusalem, c'est-à-dire, dans l'ordre où ces livres y figurent : Gn, Ex, Lv, Nb, Dt, Jos, Jg, Rt, 1-2 S, 1-2 R, 1-2 Ch, Esd, Ne, Tb, Jdt, Est, 1-2 M, Jb, Ps, Pr, Qo, Ct, Sg, Si, Is, Jr, Lm, Ba, Ez, Dn, Os, Jl, Am, Ab, Jon, Mi, Na, Ha, So, Ag, Za, Ml, Mt, Mc, Lc, Jn, Ac, Rm, 1-2 Co, Ga, Ep, Ph, Col, 1-2 Th, 1-2 Tm, Tt, Phm, He, Jc, 1-2 P, 1-2.3 Jn, Ap.

Aaron ben Asher Aaron ben Joseph

Abel

Abelesz

Abraham ben Yehuda Abraham ha-Babli

\section{Abraham ibn Ezra Abravanel}

Abulfaraj Harûn Abulwalid, Luma

-- Opuscules Riqmah

-- Ușul

Adler, Catalogue

Aistleitner

Alba Cecilia

Albrecht, Geschlecht

Albrektson
Diqduqé ha-Ṭeamîm, éd. S.Baer/H.L.Strack, Leipzig 1879. Aaron ben Joseph (Commentaire d'Is 1-60) lu en: Mss Leiden, Bibl Acad, Or 4742; Or 4787.

Abel F.M., Géographie de la Palestine, 2 vol.(EtB) Paris 1933-1938.

Abelesz A., Die syrische Uebersetzung der Klagelieder..., Privigye 1895.

Yesod Miqra, lu en : Ms Leiden, Bibl Acad, Or 4739. Abraham ha-Babli (traité grammatical) édité en: Appendice à la notice sur la lexicographie hébraïque, par A. Neubauer: JA 42 (1863) 195-216; lu en: ms Oxford, Bibl Bodl, Bodl. 135.

cf. Ibn Ezra.

Isaac ben Judah Abravanel (Commentaires sur la Bible) 6 vol., Jerusalem 1955-1963.

Kitâb al-Mushtamil, lu ven : Ms London, BL, Or 2592. Abulwalid Merwan ibn Ganah, Kitâb al-Lumae, éd. J.Derenbourg (BEHE.H 66), Paris 1886.

Opuscules et traités, éd. J. et H.Derenbourg, Paris 1880. Sepher ha-Riqmah ... betargumo ha- ${ }^{c}$ ibri shel R.Yehudah ibn Tibbon, ed. M.Wilensky, 2 vol., Berlin 1909 (Repr. Jerusalem 1964).

Kitâb al-Ușul, édité en: The Book of Hebrew Roots, ed. by A. Neubauer ... Oxford 1875; traduit en : Sepher Haschoraschim ... in's Hebräische übersetzt von Jehuda ibn Tibbon, ed. W.Bacher, Berlin 1896, lu en : Ms London, BL, Or 4837.

Catalogue of Hebrew Manuscripts in the Collection of Elkan Nathan Adler, Cambridge 1921.

Aistleitner J., Wörterbuch der Ugaritischen Sprache (BVSAW.PH 106/3) Berlin 4/1974.

Alba Cecilia A., Biblia Babilonica. Isaias, Madrid 1980. Albrecht K., Das Geschlecht der hebräischen Hauptwörter : ZAW 15 (1895) 313-325, 16 (1896) 41-121.

Albrektson B., Studies in the Text and Theology of the Book of Lamentations (STL 21) Lund 1963. 
Albright

Allegro, Meaning

Altschüler

Anderlind

Andreas

Ap-Thomas

Aq

Arias Montano

ASV

Aurivillius

bab

Bach

Bacher, Amoräer

-- Grammatiker

-- Schrifterklärung

Baer

Bahbout, Interpretazione

Bailey/Holladay

Baillet, Recueil

Banitt

Bar Bahlul

Barnabé, épître de

Barr

Barth $\mathrm{H}$.

--Worte

Barth J.

Barthélemy, Etudes

Basile
Albright W.F., The High Place in Ancient Palestine: Volume du congrès de Strasbourg 1956 (SVT 4) Leiden 1957, 242-258.

Allegro J.M., The Meaning of בין in Isaiah XLIV,4: ZAW 63 (1951) 154-156.

Altschüler Y., Meșudat Șiyon et Meșudat David, éditées en : Migraot Gedolot.

Anderlind L., Ackerbau und Thierzucht in Syrien, insbesondere in Palästina : ZDPV 9 (1886) 1-73.

Andreas F.C., Aginis : PRE I 810-816.

Ap-Thomas D.R., Two Notes on Isaiah : FS Thatcher, Sydney 1967, 45-61.

Aquila, cité selon *G (éd. Göttingen).

Hebraicorum Bibliorum V.T. latina interpretatio, opera olim X. Pagnini, nunc vero B. Arias Montani, Polyglotte d'Anvers VII.

(American Standard Version). The Holy Bible ... Newly Edited by the American Revision Committee, Standard Edition, New York 1901.

Aurivillius C., Dissertationes ad sacras literas et philologiam orientalem pertinentes, Göttingen 1790.

= babylonien.

Bach R., Die Aufforderungen zur Flucht und zum Kampf im atl. Prophetenspruch: WMANT 9, Neukirchen 1962.

Bacher W., Die Agada der palästinensischen Amoräer, 3 Bde., Strassburg 1892-1899.

Abraham Ibn Esra als Grammatiker, Strassburg 1882. Aus der Schrifterklärung des Abulwalîd Merwân ibn Ganâh, Leipzig 1889.

Cf. *M (éd. Baer); Aaron ben Asher.

Bahbout S., Sull'interpretazione dei vv. 10-11 del cap.3 di Isaia : AStE 1 (1963-64) 23-26.

Bailey K.E./Holladay W.L., The "Young Camel" and "Wild Ass" in Jr 2,23-25 : VT 18 (1968) 256-260.

Baillet M., Un recueil liturgique de Qumrân, grotte 4 : "les paroles des luminaires": RB 68 (1961). 196-250. cf. Glossaire C.

Duval R., Lexicon Syriacum auctore Hassano Bar-Bahlule, 3 vol., Paris 1888-1901.

Ed. G.Oger/A.Laurent (TDEHC) Paris 1907.

Barr J., Comparative Philology and the Text of the Old Testament, Oxford 1968.

Israel und das Assyrerreich..., Hamburg 1974.

Die Jesaja-Worte in der Josiazeit (WMANT 48) Neukirchen 1977.

Die Nominalbildung in den semitischen Sprachen, Leipzig 2/1894.

Barthélemy D., Etudes d'histoire du texte de l'A.T. (OBO 21) Fribourg 1978.

Basile de Césarée, Commentaire d'Isaïe, PG 30 117-668. 
Bauer/Leander

Baumgartner, Zweiter Bericht

BDB

Begrich

- Studien

Ben Hayim

Ben-Ḧayim, Șurat

\section{Ben Yehuda}

Bereshit Rabba

Bergmeier, Streben

Bergsträsser

Bernheimer

Bernstein

Berridge

Beuken, Identity

BFC

$\mathrm{BH} 2, \mathrm{BH} 3, \mathrm{BH} 7, \mathrm{BHS}$

$\mathrm{BH} 23 \mathrm{~S}$

$\mathrm{BHD}$

Bickell

BIOSCS

$\mathrm{BL}$

Blau, Gebrauch

Bleek4

$\mathrm{BN}$

Bochart, Hierozoicon

- Phaleg

Böhl
Bauer H./Leander P., Historische Grammatik der hebräischen Sprache des A.T. Mit einem Beitrag von P. Kahle, Halle 1922.

Baumgartner W., Der Palästinische Handschriftenfund, Zweiter Bericht : ThR 19 (1951) 97-154.

Brown F., Driver S.R., Briggs C.A., A Hebrew and English Lexicon of the Old Testament, Oxford 1907.

Begrich J., Der Psalm des Hiskia (FRLANT, NF 25) Göttingen 1926.

Studien zu Deuterojesaja, München 1963.

cf. *M (éd. Ben Hayim).

Ben-Hayim Z., Șurat ha-kinnuyim ha-ḥavurim ... bimsorotéhâ shel ha-lashôn ha-'ivrit : Sefer Assaf, Jérusalem 1953, 66-99.

Ben Yehuda E., Thesaurus totius hebraitatis et veteris et recentioris, 16 vol., Berlin (1908)-1959.

cf. Midrash Bereshit Rabba.

Bergmeier R., Das Streben nach Gewinn - des Volkes ịy: ZAW 81 (1969) 93-97.

Bérgsträsser G., Hebräische Grammatik, 2 Bde, Leipzig 1918-1929.

Bernheimer C., Codices hebraici Bybliothecae Ambrosianae (FontAmb 5) Florence 1933.

Bernstein G.H., Syrische Studien: ZDMG 3 (1849) $385-$ 428.

Berridge J.M., Prophet, People and the Word of Yahweh, Zürich 1970.

Beuken W.A.M., Isaiah 54 : The Multiple Identity of the Person Addressed : OTS 19 (1974) 29-70.

La Bible ... en français courant, Alliance Biblique Universelle 1982.

cf. *M (éd. $B H 2$ ), *M (éd. $B H 3), * M(e ́ d . ~ B H 7), * M$ (éd. $\mathrm{BHS})$.

$=\mathrm{BH} 2 \& \mathrm{BH} 3 \& \mathrm{BH}$.

Die Bibel in heutigem Deutsch. Die Gute Nachricht des A. und N.T..., Stuttgart 2/1982.

Bickell G., Kritische Bearbeitung der Klagelieder : WZKM 8 (1894) 101-121.

Bulletin of the International Organization for Septuagint and Cognate Studies, 1968 -

British Library.

Blau J., Zum angeblichen Gebrauch von את vor dem Nominativ : VT 4 (1954) 7-19.

Bleek F., Einleitung in das Alte Testament... Vierte Auflage ... bearbeitet von J.Wellhausen, Berlin 1878.

Bibliothèque Nationale.

Bochart S., Hierozoicon, ed. J. Leusden, 2 vol., Leiden 3/1692.

Bochart S., Opera omnia I 1-318, ed. J. Leusden, Leiden 3/1692.

Böhl Fr.M.Th., Die Sprache der Amarnabriefe (LSSt V/2) Leipzig 1909. 
Böttcher

-- Aehrenlese

-_ Lehrbuch

-- Proben

Bogaert, Mécanismes

Bonnard

Bredenkamp

Brenz

BRF

Bright J.

Brockelmann, Syntax

Brockington

Brdnno, Aussprache

Bronznick

Brownlee, Meaning

-- Mšnty

-- Servant

- Text

Bruce, Exegesis

Brucioli

-_(éd. 1540)

Bruns, Mendis

Buber

--Bemerkungen

Budde
Böttcher F., Neue exegetisch-kritische Aehrenlese, ... hrsg. von F.Mühlau, 3 Bde, Leipzig 1863-1865.

Exegetisch-kritische Aehrenlese zum A.T., Leipzig 1849. Ausführliches Lehrbuch der hebräischen Sprache..., hrsg. von F.Mühlau, 2 Bde, Leipzig 1866-1868.

Proben alttestamentlicher Schrifterklärung..., Leipzig 1833. Bogaert P.M., Les mécanismes rédactionnels en Jr 10,1-16 ( $L X X$ et TM) et la signification des suppléments : BEThL 54 (1981) 222-238.

Bonnard P.E., Le Second Isaïe, son disciple et leurs éditeurs (EtB) Paris 1972.

Bredenkamp C.J., Der Prophet Jesaia erläutert, Erlangen 1887.

Brentius J., Esaias Propheta, commentariis explicatus, Francoforti 1555.

La Bible traduite ... par les membres du Rabbinat français, 2 vol., Paris 1899-1906.

Jeremiah, Garden City 1965.

Brockelmann C., Hebräische Syntax, Neukirchen-Vluyn 1956.

Brockington L.H., The Hebrew Text of the Old Testament. The Readings Adopted by the Translators of the New English Bible, Oxford 1973.

Bronno E., Die Aussprache der hebräischen Laryngale nach Zeugnissen des Hieronymus, Aarhus 1970.

Bronznick N.M., The Semantics of Root hls in its Branches (hebr) : Leshonenu 41 (1976-7) 161-175.

Brownlee W.H., The Meaning of the Qumran Scrolls for the Bible, New York 1964.

On Mšhty in the Qumran Scrolls : BASOR 134 (1954) 27s. The Servant of the Lord in the Qumran Scrolls : BASOR 132 (1953) 8-15.

The Text of Isaiah 6,13 in the Light of DSIa : VT 1 (1951) 296-298.

Bruce F.F., Biblical Exegesis in the Qumran Texts, London 1960.

Brucioli A., La Biblia quale contiene i sacri libri... Tradotti nuovamente de la hebraica verita in lingua toscana per Antonio Brucioli, Venezia 1532.

I sacrosanti libri del Vecchio Testamento, Tradotti dalla Ebraica verita in Lingua Italiana, \& con breve \& catholico commento dichiarati per Antonio Brucioli, 3 vol., Venezia 1540.

Bruns P.I., De mendis typographicis editionis $V$ an der Hooghtianae a Kennicotto non sublatis : RBML 12 (1783) 225-235.

Buber M./Rosenzweig F., Die Schrift. Verdeutscht, 4 Bde, Köln 1956-1968.

Bemerkungen zu Jesaja: MGWJ 74 (1930) 191-194, 340-344.

pour $\mathrm{Lm}$ : Budde K./Bertholet A./Wildeboer G., Die fünf Megillot (KHC 17) Freiburg 1898. 
-- Jesaja

-- Klagelied

Burkitt, Waters

Burrows

-- Readings

Buxtorf, Lexicon

-- Thesaurus

Buxtorf jr

Cahen

Calmet

Calvin

Cappel, Critica

- Notae

Carmignac, Passages

- - Textes

Castle

Cavalletti

Cazelles, Vie

CD

Celsius

Cent

Ceriani, Prolegomena

Cersoy

Chamberlain, Functions

Chantraine
Zu Jesaja 1 - 5 : ZAW 50 (1932) 38-72.

Das hebräische Klagelied : ZAW2 (1882) 1-52; Zum hebräischen Klagelied : ZAW 11 (1891) 234-247.

Burkitt F.C., The Waters of Shiloah that go softly: JTS 12 (1911) $294 \mathrm{~s}$.

The Dead Sea Scrolls of St. Mark's Monastery, vol.I. ... ed. M.Burrows, New Haven 1950.

Variant Readings in the Isaiah Manuscript : BASOR 111 (1948) $16-23$ et 113 (1949) 24-32.

Buxtorf J., sr., Lexicon hebraicum et chaldaicum..., Bâle 9/1689.

Thesaurus grammaticus linguae sanctae hebraeae, Basel 4/1629.

Buxtorf J., jr., Anticritica seu vindiciae veritatis hebraicae, adversus L. Cappelli Criticam..., Basel 1653.

Cahen S., La Bible, traduction nouvelle, 18 vol., Paris 1831-1851.

Calmet A., Commentaire littéral sur tous les livres de l'A. et du N.T., t. VI, Paris 1726.

Calvin J., Commentarii in Isaiam prophetam \& Praelectiones in Jeremiam prophetam et Lamentationes : Corpus Reformatorum LXIV-LXVI, Brunswick 1887-1889.

Cappellus L., Critica sacra, auxit G.J.L.Vogel (vol.1) / J.G.Scharfenberg (vol. 2-3), 3 vol., Halle 2/1775-1786. Commentarii et notae criticae in V.T., Amsterdam 1684. Carmignac J., Six passages d'Isaïe éclairés par Qumran : FS Bardtke, Berlin 1968, 37-46.

Carmignac J./Guilbert P., Les textes de Qumran traduits et annotés, vol. 1, Paris 1961.

Castellus (Castel) E., Lexicon heptaglotton, 2 vol., London 1686.

Cavalletti S., La spada sul Cielo: Anton 30 (1955) 185-187. Cazelles $H$., $L a$ vie de Jérémie dans son contexte national et international : BEThL 54 (1981) 21-39.

Cairo Document (ou : Document de Damas).

Celsius O., Hierobotanicon sive de plantis Sacrae Scripturae dissertationes breves, 2 vol., Amsterdam 1748.

("La Bible du Centenaire") La Sainte Bible. Traduction nouvelle d'après les meilleurs textes avec introductions et notes, 4 vol., Paris 1928-1947; pour Is 1-19: CausseA./ Jaeger C., pour Is 20-39 : Lods A., pour Is 40-55: Humbert P., pour Is 56-66: Marty J., pour Jr : Bruston E., pour Lm : Aubert L.

Ceriani A.M., Prolegomena in editionem versionis syriacae ex textu LXX (MSP I.1) Milano 1861.

cf. Ms Ambrosianus.

Cersoy M., L'apologue de la vigne au chapitre 5 e d'Isaïe : RB 8 (1899) 40-49.

Chamberlain J.V., The Functions of God as Messianic Titles in the Complete Isaiah Scroll : VT 5 (1955) 366-72.

Chantraine P., Dictionnaire étymologique de la langue grecque, Paris 1980. 
Châteillon

Chaucer

Cheyne

Chomsky

Chrysostome

cité par

cité selon

Clericus

Cocceius

Condamin

-- Composition

corr(ect)

Correctoire de

Guillaume de Mara

Correctoire d'Hugues

de St Cher

Correctoire de

Coste

St Jacques

Cowley

Crampon

Critici Sacri

Croatto/Soggin

Cross, Qumran

CT1

Cyrille
Cornill

Biblia Sacra ex Sebastiani Castellionis interpretatione, Francfort 1697; La Bible nouvellement translatée... par Sebastian Chateillon, Bâle 1555.

The Complete Works of Geoffrey Chaucer, ed. F.N.Robinson, London s.d.

Cheyne T.K., The Book of the Prophet Isaiah, Critical Edition of the Hebrew Text (SBOT 10) Leipzig 1899. Chomsky W., David Kimhi's Hebrew Grammar Systematically Presented and Critically Annotated, New York 1952.

pour Is : cf. Pseudo-Chrysostome; pour Jr : Fragmenta in Jeremiam, PG LXIV 739-1038.

renvoi à un auteur qui prend appui sur une source sans en rapporter explicitement le contenu.

citation de seconde main puisée chez un intermédiaire.

Clericus (Le Clerc) J., V.T. Prophetae ab Esaia ad Malachiam usque..., Amsterdam 1731.

Cocceius J., Lexicon et commentarius sermonis hebraici et chaldaici V.T., Amsterdam 1669.

Condamin A., pour Is : Le livre d'Isaïe (EtB) Paris 1905; pour Jr : Le livre de Jérémie (EtB) Paris 1920.

Cornill C.H., Das Buch Jeremia, Leipzig 1905.

Die Composition des Buches Jesaja : ZAW 4 (1884) 83-105. = correctum.

cité par : *V (éd. San Girolamo).

cité par : *V (éd. San Girolamo).

cité par : *V (éd. San Girolamo).

Coste J., Le texte grec d'Isaïe 25,1-5 : RB 61 (1954) 36-66.

Cowley A., Aramaic Papyri of the Fifth Century B.C., Oxford 1923.

Crampon A., La Sainte Bible, Tournai 1939.

Critici Sacri. Editio nova in novem tomos distributa, Amsterdam 1698.

Croatto J.S./Soggin J.A., Die Bedeutung von שדמות im Alten Testament : ZAW 74 (1962) 44-50.

Cross F.M./Talmon S., Qumran and the History of the Biblical Text, Cambridge, Mass. 1975.

D.Barthélemy, Critique textuelle de l'A.T. 1. Josué, Juges etc. (OBO 50/1) Fribourg 1982.

Cyrille d'Alexandrie, Commentaire d'Isaïe, PG LXX 9. 1450.

Dahood, Lexicography IV Dahood M., Hebrew-Ugaritic Lexicography IV : Bib 47 (1966) 403-419.

-- Libri

I libri profetici e sapienziali dell' A.T. alla luce delle scoperte di Ebla e di Ugarit : CivCatt 129 (1978) II 547-556. Two Textual Notes on Jeremia : CBQ 23 (1961) 462-464. Dalman G., Arbeit und Sitte in Palästina, 7 Bde (SDPI 3/BFChTh.M 14.17.27.29.33.36.41) Gütersloh 1928-1942. 
-- Pflügelänge

Darlow/Moule

Daniel al Qumisi

David ben Abraham

Davidson

Davies

Deiber

Delitzsch

$--1$

-- Psalter

Delitzsch, Fehler

Dennefeld

$\mathrm{DHH}$

Dhorme

Diettrich

Dieu de

Diez Macho, Manuscritos

Dillmann/Kittel

Disciples de Menahem DISO

Document de Damas Doederlein

-- Hexaplen

Donner

Donner/Röllig

Dozy

Driver

-- Abbreviations
Pflügelänge, Saatstreifen und Erntestreifen in Bibel und Mischna : ZDPV 28 (1905) 27-35.

Darlow T.H./Moule H.F., Historical Catalogue of the Printed Editions of Holy Scripture in the Library of the British and Foreign Bible Society, 4 vol., London 1903-1911. Pitrôn Sheném 'Aśar ed. I.D.Markon, Jérusalem 1957. David ben Abraham al Fasi, Hebrew-Arabic Dictionary of the Bible, ed. S.L.Skoss, 2 vol. (YOS.R 20-21) New Haven 1936-1945.

Davidson I., Thesaurus of Mediaeval Hebrew Poetry, 4 vol., New York 1924-1933.

Davies N.de G., The Rock Tombs of El Amarna VI, London 1908.

cf. Sahidique.

Delitzsch Franz, en Is : Commentar über das Buch Jesaia (BC 3/1) Leipzig 4/1889.

en Is : Biblischer Commentar über den Prophet Jesaia (BC 3/1) Leipzig 1866.

Commentar über den Psalter, 2 Bde, Leipzig 1859-1860.

Delitzsch Friedrich, Die Lese- und Schreibfehler im Alten Testament..., Berlin 1920.

Dennefeld L., Les grands prophètes (SB(PC) VII), Paris 1946.

Dios habla hoy. La Biblia con Deuterocanónicos. Versión Popular. Sociedades Biblicas Unidas 1979.

Dhorme E., traduction de Jérémie et des Lamentations en : La Bible. L'A.T., vol.2 (Bibliothèque de la Pléiade 139) Paris 1959.

Diettrich G., Ein Apparatus criticus zur Pešitto zum Propheten Jesaia (BZAW 8) Giessen 1905.

Dieu L. de, Critica Sacra sive animadversiones..., editio nova, Amsterdam 1693.

Diez Macho A., Manuscritos hebreos y arameos de la Biblia, Roma 1971.

Dillmann A., Der Prophet Jesaja erklärt, für die 6e Auflage umgearbeitet von R.Kittel (KeH 5) Leipzig 1898.

Liber Responsionum, ed. S.G.Stern, Wien 1870.

Jean Ch.-F./Hoftijzer J., Dictionnaire des inscriptions sémitiques de l'ouest, Leiden 1965.

édité en Lohse 63-107.

Doederlein J.C., en Is : Esaias, Altorf 2/1780; en Jr : cf. Grotius; en Lm : Zu den Hexaplen des Origenes : RBML 6 (1780) 195-207.

Zu den Hexaplen des Origenes : RBML 1 (1777) 217-256. Donner H., Israel unter den Völkern : SVT 11, Leyde 1964.

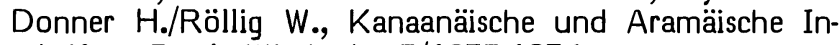
schriften, 3 vol., Wiesbaden 3/1973-1976.

Dozy R., Supplément aux dictionnaires arabes, 2 vol., Leiden 3/1967.

Driver G.R., pour Jr: Linguistic and Textual Problems : Jeremiah : JQR 28 (1937-1938) 97-129.

Abbreviations in the Massoretic Text: Textus 1 (1960) 112-131. 
-- Birds

--Drink

-- Ezekiel

-_ Glosses

-- Hebrew

- Hebrew Notes

-- Hebrew Notes I

-- hêmâh

-- Homonyms

-- Isaianic

-- Lamentations

- LTP

-- Misreadings

- Mistranslations

-- Monsters

-- Myths

-- Notes

-- Once

-- Passages

-- Problems

-- Roots

- Scrolls

-- Servant

-- Studies IV

-- Studies V

-- Studies VII

--TLP

-- Verbs

-- Words

Driver/Miles

Driver, Tenses
Birds in the Old Testament : PEQ 87 (1955) 5-20, 129-140. 'Another little Drink' - Isaiah 28 : 1-22 : FS D.W.Thomas, Cambridge 1968, 47-67.

Ezekiel : Linguistic and Textual Problems : Bib 35 (1954) 145-159, 299-312.

Glosses in the Hebrew Text of the O.T. : L'A.T. et l'Orient, Louvain 1957, 123-161.

Hebrew Notes on Prophets and Proverbs : JTS 41 (1940) 162-175.

Hebrew Notes : VT 1 (1951) 241-250.

Hebrew Notes : ZAW 52 (1934) 51-56.

On hêmâh 'hot anger, fury' and also 'fiery wine' : ThZ 14 (1958) 133-135.

Hebrew Homonyms : FS W.Baumgartner (SVT 16) Leiden 1967, 50-64.

Isaianic Problems : FS Eilers, Wiesbaden 1967, 43-57. Hebrew Notes on 'Song of Songs' and 'Lamentations', FS Bertholet, Tübingen 1950, 134-146.

Linguistic and Textual Problems : Isaiah I-XXXIX : JTS 38 (1937) 36-50; Linguistic and Textual Problems : Isaiah XL-LXVI : JTS 36 (1935) 396-406.

Misreadings in the O.T.: WO 1 (1947-1952) 234-238. Mistranslations : PEQ 79 (1947) 123-126.

Mythical Monsters in the O.T. : FS Levi della Vida, 2 vol., Roma 1956, I 234-249.

Myths of Qumran : ALUOS 6 (1966-8) 23-48.

Notes on Isaiah : BZAW 77 (1958) 42-48.

Once again Abbreviations : Textus 4 (1964) 76-94.

Two Misunderstood Passages of the O.T.: JTS 6 (1955) 82-87.

Problems in the Hebrew Text of Job : FS Rowley (VTS 3) Leiden 1955, 72-93.

Hebrew Roots and Words : WO 1 (1947-1952) 406-415. Hebrew Scrolls : JTS NS2 (1951) 17-30.

Isaiah 52,13 - 53,12 : the Servant of the Lord (BZAW 103) Berlin 1968, 90-105.

Studies in the Vocabulary of the O.T. IV : JTS 33 (1932) 38-47.

Studies in the Vocabulary of the O.T. V : JTS 34 (1933) 33-44.

Studies in the Vocabulary of the O.T. VII : JTS 35 (1934) 380-393.

Isaiah I-XXXIX : Textual and Linguistic Problems : JSS 13 (1968) 36-57.

Some Hebrew Verbs, Nouns, and Pronouns : JTS 30 (1929) 371-378.

Difficult Words in the Hebrew Prophets : Studies in Old Testament Prophecy, H.H.Rowley ed., Edinburgh 1950, 52-72.

Driver G.R. and Miles J.C., The Babylonian Laws, 2 vol., Oxford 1952-1955.

Driver S.R., A Treatise on the Use of the Tenses in Hebrew ... Oxford 1892. 
Duhm (1), 2, 5

Dumbrell

Dunash

-- Contre Saadya

Dupont-Sommer, Ecrits

Duran

Dyserinck

Ecker

Ehrentreu,

Sprachliches XXX

Ehrlich

-- Miqra

Eissfeldt, Cuneiform

Eitan, Contribution

-- Loan Word

El-Azharî

Elias Levita

-- Zikronot

Eliézer de Beaugency

Elliger

-- Nochmals

-- Verhältnis

Emerton, Jeremiah 12,9

-- Notes

-- Problem
Duhm B., pour Is : Das Buch Jesaia (HK III/1) Göttingen 1892, 2/1902, 5/1968; pour Jr : Das Buch Jeremia (KHC 11) Tübingen 1901.

Dumbrell W.J., Jeremiah 49,28-33: An Oracle against a Proud Desert Power : Australian Journal of Biblical Archaeology 2,1 (1972) 99-109.

Teshubot de Dunash ben Labrat [contre Menahem], ed. A.Sáenz-Badillos, Granada 1980.

Teshubot Dunash ha-Levi ben Labrat cal Rabbi Saadya Gaon..., hrsg. ... von R. Schroeter, Breslau 1866.

Dupont-Sommer $A$., Les écrits esséniens découverts près de la Mer Morte, Paris 1959.

Duran Profiat, Maase Efod... hrsg. von J.Friedländer und J.Kohn, Wien 1865.

Dyserinck J., De Klaagliederen uit het hebreeuwsch opnieuw vertaald : ThT 26 (1892) 359-380.

Ecker R., Die arabische Job-Uebersetzung des Gaon Saadja, München 1962.

Ehrentreu H., Sprachliches und Sachliches aus dem Talmud XXX : JJLG 8 (1910) 4-8.

Ehrlich A.B., pour la Bible, sauf les Psaumes : Randglossen zur hebräischen Bibel, 7 Bde, Leipzig 1908-1914; pour les Psaumes : Die Psalmen, Berlin 1905.

Miqra ki-Pheshuto, 3 Bde, Berlin 1899-1901.

Eissfeldt O., The Alphabetical Cuneiform Texts from Ras Shamra Published in "Le Palais royal d'Ugarit" vol.II, 1957 : JSSt 5 (1960) $1-49$.

Eitan I., A Contribution to Isaiah Exegesis : HUCA 12-13 (1937-38) 55-88.

An Egyptian Loan Word in Is 19 : JQR NS 15 (1924/25) 419s.

El-Azharî Muhammad ibn Ahmad, Tahdhîb al-lugha, ed. by 'Abd al-Salem Muhammad Harun, 15 vol., Le Caire 1964-1967.

Cf. Radaq, Shorashim.

lu en: Ms Paris BN hebr 134 \& 135 et en Ms München, Staatsbibl, hebr 74.

Eliézer de Beaugency (Commentaire sur Isaïe) lu en : Ms Oxford, Bibl Bodl, Opp 625; ed. J.W.Nutt, London 1879. Elliger K., Deuterojesaja, 1. Teilband 40,1 - 45,7 (BK 11) Neukirchen-Vluyn 1978.

Nochmals textkritisches zu Jes 53: FS Ziegler, Würzburg 1972, II 137-144.

Deuterojesaja in seinem Verhältnis zu Tritojesaja (BWANT 63) Stuttgart 1933.

Emerton J.A., Notes on Jeremiah 12,9 and on some suggestions of J.D. Michaelis... ZAW 81 (1969) 182-191. Notes on two verses in Isaiah; FS Fohrer (BZAW 150) Berlin 1980, 12-25.

A Textual Problem in Isaiah 25,2 : ZAW 89 (1977) 64-73. 
Ephrem

\section{Erman/Grapow}

Estienne, Thesaurus

Estienne

- (Bibles de 1532 et de 1540)

-_ (Bible de 1545)

-_ (Bible de 1557)

\section{Eü}

\section{Eusèbe}

-_ Onomasticon

- Praeparatio

Ewald

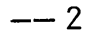

- Geschichte

- Lehrbuch

Feldmann

Félix de Prato

Field

Fischer

- Schrift

Fitzmyer, Sefîre

Fohrer

Forbes

Foreiro
Ephrem Syrus. Commentaria; pour Is 1,1 - 43,8 et Jr: Opera omnia II, Roma 1740; pour Is 43,9 - 66,24 et Lm : Hymni et sermones, ed. J. Lamy, Malines 1886.

Erman A. und Grapow H., Wörterbuch der Aegyptischen Sprache, 6 vol., Leipzig 1925-1950.

Henricus Stephanus, Thesaurus graecae linguae, ed. A.F. Didot, 9 vol., Paris 1831-1865.

La Bible, qui est toute la Sainte Escripture contenant le Vieil et le Nouveau Testament ou Alliance, ed. Robert Estienne, [Genève] 1553.

cf. *V (éd. Estienne).

Biblia (avec *V, traduction de L. Jud et notes de Vatable), ed. Robertus Stephanus, Paris 1545.

Biblia Utriusque Testamenti de quorum nova interpretatione (=S.Pagnini) et copiosissimis annotationibus... ed. Robertus Stephanus, [Genève].1557.

(Einheitsübersetzung) Die Bibel. Altes und Neues Testament, Stuttgart 1980.

Eusebius Werke IX. Der Jesajakommentar, éd. J.Ziegler (GCS) Berlin 1975; lu aussi en : ms Florence, Laur., XI 4. Das Onomasticon der biblischen Ortsnamen, ed. E. Klostermann, Leipzig 1904.

Werke VIII : Die Praeparatio Evangelica, hrsg. von $\mathrm{K}$. Mras, 2 Bde (GCS) Berlin 1954-1956.

Ewald $H_{\text {., }}$ pour Is et Jr : Die Propheten des Alten Bundes erklärt, 2 Bde, Stuttgart 1840-1841; pour Lm : Die Psalmen und die Klagelieder erklärt 3, Göttingen 1866, 321-348. Die Propheten des Alten Bundes erklärt, 2e Ausgabe, 3 Bde, Göttingen 1867-1868.

Geschichte des Volkes Israel bis Christus, 3 Bde, Göttingen 1843-1852.

Ausführliches Lehrbuch der hebräischen Sprache des Alten Bundes, Göttingen 7/1863.

Feldmann F., Das Buch Isaias (EHAT 14) 2 vol., Münster $1925-1926$. cf. *M (éd. F élix de Prato).

Field F., Hexaplorum quae supersunt ... fragmenta, 2 vol., Oxford 1875.

Fischer J., Das Buch Isaias, 2 vol. (HS VII/1) Bonn $1937-$ 1939.

In welcher Schrift lag das Buch Isaias den LXX vor? (BZAW 56) Giessen 1930.

Fitzmyer J.A., The Aramaic Inscriptions of Sefîre, Roma 1967.

Fohrer G., Das Buch Jesaja (ZBK) Zürich, vol. 1-2 : 2/1966-1967, vol. 3 : 1964.

Forbes R.J., Studies in Ancient Technology, 9 vol., Leiden 2/1964-1972.

Foreiro F., Iesaiae prophetae vetus et nova ex Hebraico versio, cum commentario, Anvers 2/1566; éd. Venise 1/1565 reproduite en Critici Sacri. 
Frank R.M.

Frankel, Einfluss

Frankl

Freedman/Cohen

Frensdorff, Massora

*G, $g$

*G (éd Aldine)

*G (éd. Brooke/McLean

*G (éd. Göttingen)

*G (éd. Rahlfs)

*G (éd. Sixtine)

*G (éd. Swete)

*G

Gadolo

$\mathrm{Ge}$

Gehman, Errors

Geiger

- Symmachus

-- Zeitschriften

Gerlach

Gerstenberger, Complaints

Gesenius

-_ Lehrgebäude

- - Thesaurus

Gesenius/Buhl cf. Pethion Ibn Ayyub.

Frankel Z., Ueber den Einfluss der palästinischen Exegese auf die alexandrinische Hermeneutik, Leipzig 1851.

Frankl P.F., Studien über die Septuaginta und Peschito zu Jeremia : MGWJ 21 (1872) 444-456, $497-509$ et 545557.

Freedman D.B./Cohen M.B., The Masoretes as Exegetes : Selected Examples : Masoretic Studies 1 (1974) 35-53. Frensdorff S., Die Massora Magna, Hannover 1876.

Grec ancien ( $G=$ leçon principale, $g=$ leçons secondaires), édité en :

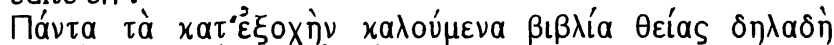

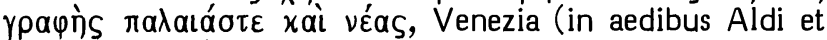
Andreae soceri) 1518.

Brooke A.E./McLean N., The Old Testament in Greek, According to the Text of Codex Vaticanus... with a Critical Apparatus, Cambridge 1906ss.

Septuaginta. Vetus Testamentum Graecum, auctoritate Academiae Scientiarum Gottingensis editum, Göttingen 1926ss.

Rahlfs A., Septuaginta, id est Vetus Testamentum graece iuxta LXX interpretes, 2 vol., Stuttgart 1935.

Vetus Testamentum iuxta Septuaginta, ex auctoritate Sixti V. editum, Roma 1587.

Swete H.B., The Old Testament in Greek According to the Septuagint, 3 vol., Cambridge 1907-1912.

lu en: Papyrus 965; Ms Alexandrinus; Ms Sinaiticus; Ms Vaticanus.

Gadolo Bernardin, cf. *V (éd. Gadolo).

("Geneva Bible") The Bible and Holy Scriptures Conteyned in the Olde and Newe Testament. Translated According to the Ebrue and Greke, Genève 1560.

Gehman H.S., Some Types of Errors of Transmission in the LXX : VT 3 (1953) 396-400.

Geiger A., Urschrift und Uebersetzungen der Bibel... Frankfurt 2/1928.

Symmachus, der Uebersetzer der Bibel : JZWL 1 (1862) 39-64.

Hebräische Zeitschriften : ZDMG 15 (1861) 416-419. Gerlach E., Die Klagelieder Jeremiä, Berlin 1868.

Gerstenberger E., Jeremiah's Complaints. Observations on Jer 15,10-21 : JBL 82 (1963) 393-408.

Gesenius W., Der Prophet Jesaia neu übersetzt, Leipzig 2/1829; Commentar über den Jesaia, 2 vol., Leipzig 1821. Ausführliches grammatisch-kritisches Lehrgebäude der hebräischen Sprache..., Leipzig 1817.

Thesaurus philologicus criticus linguae hebraicae et chaldaicae V.T., 3 vol. (vol. III ed. A. Roediger) Leipzig 2/1829-1858.

Gesenius W., Hebräisches und aramäisches Handwörterbuch über das A.T., bearbeitet von F. Buhl u.a., Leipzig 17/1915. 
Gesenius/Kautzsch

Giesebrecht

-- Immanuelweissagung Ginsberg, Allusion

-- Emendations

Ginsburg, Introduction

-_ Massorah

Ginzé Schechter

Glassius

Glossaire A

Glossaire B

Glossaire C

Glossaire D

Glossaire E

Glossaire $F$

GNB

Gordis

-- Root

Gordon C.H.

Gottlieb

[Goshen-]Gottstein, Bemerkungen

-- Jesaia-Rolle

\section{Gottstein}

Gousset

Grabe

Grätz

-- Geschichte

-- Psalmen

-- Studien

Graf
Gesenius W./Kautzsch E., Hebräische Grammatik, Leipzig 26/1896.

Giesebrecht F., Das Buch Jeremia (HK II/1) Göttingen 1894.

Die Immanuelweissagung: ThStKr 61 (1888) 217-264. Ginsberg H.L., An Unrecognized Allusion to Kings Pekah and Hoshea of Israel : ErIs 5 (1958) 62s.

Some Emendations in Isaiah: JBL 69 (1950) 51-60. Ginsburg C.D., Introduction to the Massoretico-Critical Edition of the Hebrew Bible, London 1897.

Ginsburg C.D., The Massorah..., 4 vol., London 18801905.

cf. *M (éd. Ginsburg)

Genizah Studies in Memory of Doctor Solomon Schechter, 3 vol. (TSJTSA 7-9) New York 1928-1929.

Glassius S., Philologiae sacrae... libri quinque, Amsterdam 4/1711.

lu en: Ms Paris, BN, hébr 302; édité en : Lambert M./ Brandin L., Glossaire hébreu-français du XIIIe siècle. Paris 1905.

lu en : Ms Paris, BN, hébr 301.

lu en: Ms Basel, Universitätsbibliothek, A III 39; édité en : Banitt M., Le Glossaire de Bâle édité et annoté, 2 vol., Jerusalem 1972.

lu en : Ms Parma, Bibl Palatina, 2924.

lu en : Ms Parma, Bibl Palatina, 2780.

lu en : Ms Leipzig, Universitätsbibl, hebr 102.

Good News Bible. Today's English Version, New-York 1976.

Gordis R., en Is et $\mathrm{Jr}$ : The Biblical Text in the Making, New-York 2/1971; en Lm: The Song of Songs and Lamentations, New-Y York 1974.

The Biblical Root SDY-SD : JTS 41 (1940) 34-43. cf. UT.

Gottlieb $\mathrm{H}_{\mathrm{O}}$., A Study on the Text of Lamentations (AJut 48.T 12) Arrhus 1978.

[Goshen-]Gottstein M.H., Bemerkungen zu Eissfeldt's variae lectiones der Jesaiah-Rolle : Bib 34 (1953) 212-221. Die Jesaia-Rolle im Lichte von Peschitta und Targum: Bib 35 (1954) 51-71.

cf. Goshen-Gottstein.

Gousset J., Commentarii linguae ebraicae, Amsterdam 1702.

cf. Ms Alexandrinus.

Graetz $\mathrm{H}$., Emendationes in plerosque sacrae scripturae V.T. libros..., ed. W. Bacher, 3 vol., Breslau 1892-1894. Geschichte der Juden von den ältesten Zeiten bis auf die Gegenwart, vol. I, Leipzig 1873; vol. II/A, Leipzig 1875. Kritischer Commentar zu den Psalmen, 2 vol., Breslau 1882-1883.

Exegetische Studien zum Propheten Jeremia : MGWJ 32 (1883) 49-63, 97-116, 146-160, 193-208, 289-296, $337-$ 346, 385-398, 481-496.

Graf K.H., Der Prophet Jeremia erklärt, Leipzig 1862. 
Gray

Greenberg, Stabilization

Grotius

Güting

Guillaume, Note

- Readings

- Root

Gunkel

- Jesaia 33

Haggada pascale

Haggadot ha-Talmud

HALAT

Halévy

Haller

Hatch/Redpath

Haupt

Hayyuj

-- Kitâb

-- Treatises

Heide van der

Henderson

Hérodote

Hie

Hillers

Hirschfeld, Catalogue

Hitzig

-_ Psalmen
Gray G.B., The Book of Isaiah 1-27 (ICC) Edinburgh 1912. Greenberg M., The Stabilization of the Text of the Hebrew Bible : JAOS 76 (1956) 157-167.

Grotius H., Annotationes in Vetus Testamentum, auxerunt G.J.L. Vogel et J.C. Doederlein, 3 vol., Halle 1775-1776. Güting E., Die Mischna, Terumot bearbeitet von..., Berlin 1969.

Guillaume A, A Note on בלע: JTS NS 13 (1962) 320322.

Some Readings in the Dead Sea Scroll of Isaiah : JBL 76 (1957)40-43.

A Root שואה in Hebrew : JTS NS17 (1966) 53s.

Gunkel H., Schöpfung und Chaos, Göttingen 1895.

Jesaia 33, eine prophetische Liturgie : ZAW 42 (1924) 177-208.

Die Pessach-Haggada, ed. E.D. Goldschmidt, Berlin 1936. Haggadoth ha-Talmud, Constantinople 1511.

Koehler L./Baumgartner W., Hebräisches und Aramäisches Lexikon zum Alten Testament, dritte Auflage neu bearbeitet von W. Baumgartner u.a., Leiden 1967ss.

Halévy J., Le livre d'Isaïe 1-39: Recherches bibliques V, Paris 1914, 234-851.

en Is, Jr : Haller M., Das Judentum (SAT II/3) Göttingen 2/1925; en Lm : Haller M./Galling K., Die fünf Megilloth ... (HAT18) Tübingen 1940, 91-113.

Hatch E./Redpath H.A., A Concordance to the Septuagint... 2 vol., Oxford 1897-1906.

Haupt P. (Notes sur SBOT) cf. SBOT ad locum.

Hayyuj Judah ben David (Commentaire sur les Prophètes) fragm. éd. en Kokovzov.

Kitâb al-Af âl. The Weak and Geminative Verbs in Hebrew, ed. M. Jastrow, Leiden 1897.

Two Treatises on Verbs Containing Feeble and Double Letters... Transl. into Hebrew by R. Moses Giqatilla ... The Treatise on Punctuation ... Transl. by Ibn Ezra, ed. J.W. Nutt, London 1870.

van der Heide $A$., The Yemenite Tradition of the Targum of Lamentations, Leiden 1981.

Henderson E., The Book of the Prophet Jeremiah and that of the Lamentations, London 1851.

Herodotus, Historiae, ed. C.Hude, 2 vol., Oxford 3/1927. (Commentaires de Jérôme sur Is et sur Jr 1-6) édité en : Opera, ed. D.Vallarsi IV 2/1767; et pour Is : CChr.SL 73, 2 vol., ed. M.Adriaen, Turnhout 1963; pour Jr : CSEL 59, ed. S.Reiter, Wien 1913; pour Is, lu en : Ms Roma, Bibl Vat, Palat lat 172; Vat lat 321.

Hillers D.R., Lamentations (AncB) Garden City 1972. Hirschfeld H., Descriptive Catalogue of the Hebrew Mss. of the Montefiore Library, London 1904.

Hitzig F., en Is : Der Prophet Jesaja, Heidelberg 1833; en Jr : Der Prophet Jeremia (KeH 3) Leipzig 1841, 2/1866. Die Psalmen, 2 vol., Leipzig 1863-1865. 
Hoffmann, Versuche Holladay, Further

-- Passage

-- Recovery

Hopper

Houbigant

-- (éd. Francfort)

HS

HSAT2

HSAT3

HSAT4

HSAT234

HUB

-- Sample Edition

Hubmann

Hummel, Mem

Hyatt

-- Original

Ibn Barûn

Ibn Ezra

-_ Moznaïm
Hoffmann G., Versuche zu Amos: ZAW 3 (1883) 87-126. Holladay W.L., Jeremiah and Moses : Further Observations: JBL 85 (1966) 17-27.

Isa. 3,10-11 : An Archaic Wisdom Passage : VT 18 (1968) 481-487.

The Recovery of Poetic Passages of Jeremiah : JBL 85 (1966) 401-435.

cf. Hyatt.

Houbigant C.F., Biblia Hebraica cum notis criticis et versione latina ad notas criticas facta..., 4 vol., Paris 1753. Notae Criticae ... ad exemplar Parisiense denuo recusae, 2 vol., Frankfurt 1777.

Die Heilige Schrift des Alten Testaments, Bonn 1929ss. Kautzsch E., u.a. (Hrsg.) Die Heilige Schrift des Alten Testaments..., zweite, mehrfach berichtigte Ausgabe, 2 Bde, Freiburg 1896; pour Is 1-35: Guthe $H$., pour Is 36-39: Kautzsch E., pour Is 40-66 : Ryssel V., pour Jr : Rothstein J.W., pour Lm : Baethgen F.,(HSAT2 = simple correction de HSAT1).

Kautzsch E., u.a. (Hrsg.) Die Heilige Schrift des Alten Testaments..., dritte, völlig neu gearbeitete, mit Einleitungen und Erklärungen zu den einzelnen Büchern versehene Auflage, 2 Bde, Tübingen 1909-1910; pour Is 1-35: Guthe

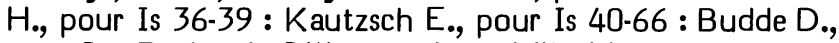
pour Jr : Rothstein J.W., pour Lm : Löhr M.

Kautzsch E., u.a. (Hrsg.) Die Heilige Schrift des Alten Testaments..., vierte, umgearbeitete Auflage..., hrsg. von A.Bertholet, 2 Bde, Tübingen 1922-1923; pour Is 1-35: Guthe $H_{\text {., }}$ pour Is $36-39$ : Eissfeldt O., pour Is 40-66: Budde D., pour Jr : Rothstein J.W., pour Lm : Löhr M. $=$ HSAT2 \& HSAT3 \& HSAT4.

The Hebrew University Bible. The Book of Isaiah ed. by M.H.Goshen-Gottstein. 1,1-22,10, Jérusalem 1975; 22,1044,28, Jerusalem 1981.

The Book of Isaiah. Sample Edition with Introduction by M.H.Goshen-Gottstein, Jerusalem 1965.

Hubmann F.D., Untersuchungen zu den Konfessionen Jer 11,18-12,6 und Jer 15,10-21 (Forschung zur Bibel 30) Würzburg 1978.

Hummel H.D., Enclitic Mem in Early Northwest Semitic, Especially Hebrew : JBL 76 (1957) 85-107.

The Book of Jeremiah, Introduction and Exegesis by J.P.Hyatt... (IntB V 775-1142) Nashville 1956.

The Original Text of Jeremiah 11,15-16: JBL 60 (1941) 57.60.

Abû Ibrâhîm Ișhâq ibn Barûn, Kitâb al-Muwâzana bîn al-Lugha al- ${ }^{c}$ Ibrâniya wal-'Arabiya, éd. P.Kokovzov, St. Petersbourg 1890.

Ibn Ezra Abraham ben Meir, pour Is : The Commentary of Ibn Ezra on Isaiah ed... M.Friedlaender, 3 vol., London 1873-1877; pour Lm : Miqraot Gedolot.

Mozné Leshon ha-Qodesh, Offenbach 1791. 
-- Șạ̣ot

-_ Sapha Berura

-- Sephat Jether

Ibn Kaspi

Ibn Manzûr

Imbonati

Irénée

Irwin

-- Syntax

Isaac ha-Levi ben Eleazar Isaïe de Trani

Ishodad de Merv

Iwry

--Qumrân

J

$\mathrm{J1}$

J2

J3

$J 123$

Jackson

Jacob, Erklärung

Jacob ben Reuben

Jacob Tam

Jahnow

James

Janzen
Sepher Șahot, ed. C.del Valle Rodriguez, Salamanca 1977. Sapha Berüra, ed. G. Lippmann, Fürth 1839.

Sephat Jether... zur Verteidigung R. Saadia's gegen... Dunasch ben Librat, ed. G.Uppmann, Frankfurt 1843; lu en : Ms Parma, Bibl. Palatina 2217.

cf. Joseph ibn Kaspi.

Lisân el-'Arab, 15 vol., Beyrouth 1968.

Imbonati C., Bibliotheca latino-hebraica, Roma 1694. Irénée de Lyon, Contre les hérésies, livre IV éd. A. Rousseau et al. (SC 100) Paris 1965.

Irwin W.H., Isaiah 28-33 Translation with Philological Notes (BibOr 30) Roma 1977.

Syntax and Style in Isaiah 26 : CBQ 41 (1979) 240-261. Sephat Yeter, lu en : Ms Oxford, Bibl Bodl, Hunt 477. Commentary ... on Prophets and Hagiographa, ed. J. Wertheimer, 3 vol., Jerusalem 1959.

Eynde C. van den, Commentaire d'Išo 'dad de Merv sur l'A.T., vol. IV : Isaïe et les Douze (CSCO.S 128-129) Louvain 1969; vol. V : Jérémie, Ezéchiel, Daniel (CSCO.S 146-147) Louvain 1972.

Iwry S., Mașsēeāh and Bāmāh in 1QIs-a 6,13: JBL 76 (1957) $225-232$.

The Qumrân Isaiah and the End of the Dial of Ahaz : BASOR 147 (1957) 27-33.

$=\mathrm{J3}$.

La Sainte Bible. Traduite en français sous la direction de l'Ecole Biblique de Jérusalem..., Paris 1948ss; pour Is : Auvray P. et Steinmann J. 1951, pour Jr : Gelin A. 1951.

La Sainte Bible. Traduite en français sous la direction de l’Ecole Biblique de Jérusalem...., 2ème édition revue, Paris 1957ss; pour Is : Auvray P. et Steinmann J. 1957, pour Jr : Gelin A. 1959.

La Sainte Bible de Jérusalem. La Sainte Bible traduite en français sous la direction de l'École Biblique de Jérusalem, nouvelle édition entièrement revue et augmentée, Paris 1973.

$=\mathrm{J} 1 \& \mathrm{~J} 2 \& \mathrm{J3}$.

Jackson J.J., Style in Isaiah 28 and a Drinking Bout of the Gods : FS J. Muilenburg, Pittsburg 1974, 85-98.

Jacob B., Erklärung einiger Hiob-Stellen : ZAW 32 (1912) 278-287.

Sepher ha- ${ }^{\mathrm{C}}$ Osher, lu en : Ms Leiden, Bibl Acad, Or 4746 et 4769.

Hakra'ot Rabbénu Jacob Tam, édité en : Sepher Teshubot Dunash... ed. H. Filippowski, London 1855.

Jahnow $H_{\text {., }}$ Das Hebräische Leichenlied : BZAW 36, Giessen 1923.

James F., A Critical Examination of the Text of Isaiah, Ann Arbor 1959.

Janzen J.G., Studies in the Text of Jeremiah, Cambridge Mass. 1973. 
Jastrow

Jellinek

Jenni

Jérôme

Joseph Bonfils

Joseph ibn Kaspi

Joseph ibn Nahmias

Joseph Qara

Joseph Qimḥi

Josèphe

Josippos

Joüon

JPS1

JPS2

Jsp

JThS

JTS

Jubilés

Jud

Judah ben Qoreish

-- (éd. Barges)

- (éd. Katz)

Judah Hadassi

Judah Halévi, Kuzari

Judah Hayyuj

Judah ibn Balaam
Jastrow M., A Dictionary of the Targumim, the Talmud... and the Midrashic Literature, 2 vol., New York 1950. Jellinek A., Bet ha-Midrasch, 6 vol., Jerusalem 2/1938. Jenni E., Das hebräische Pi`el, Zürich 1968.

cf. Hie.

Șophnat Paneah,, ed. D.Herzog, 2 vol., Heidelberg, 1911. 1930.

Shorashot Keseph, lu en : Ms Paris, BN, hébr 1244.

Commentar zu dem Buche Jeremias von Rabbi Josef ibn Nachmias ... hgg. von M.L.Bamberger, Frankfurt a.M. 1913. Commentaires sur les Prophètes postérieurs et sur les Lamentations, lus en : ms de Rossi 255; ms Paris, BN, hébr 162 et 163; ms München, Staatsbibl, hebr 52.

pour Jr: éd. L.Schlosberg, Paris 1881; pour Lm: éd. princeps des Ketubim, Naples 1487; éd. Buber, Breslau 1900.

cf. Qimhi.

Josephus Flavius, Opera, ed. B.Niese, 7 vol., Berlin 18851895; Oeuvres complètes de Flavius Josèphe traduites en français sous la direction de T.Reinach, Paris 1900ss. cité selon Ziegler (éd. Göttingen du *G).

Joüon P., Grammaire de l'hébreu biblique, Rome 1923. The Holy Scriptures According to the Masoretic Text... The Jewish Publication Society of America, Philadelphia 1917.

A new translation of The Holy Scriptures according to the Masoretic text... The Jewish Publication Society of America, 3 vol., Philadlephia 1967-1982.

= Josippos.

Jewish Theological Seminary of America (New York). Journal of Theological Studies, Oxford 1899-1949, NS 1950 ss.

Livre des Jubilés, traduit en : Charles R.H., The Apocrypha and Pseudepigrapha of the O.T. in English..., vol. II, Oxford 1913, 1-82.

Jud L., (traduction latine de la Bible) édité en Estienne (Bible de 1545).

Risâlah, lu en Ms Oxford, Bibl Bodl, Hunt 573.

Risâlah. Epistola de studii targum utilitate..., ed. J.J.L. Barges et D.B.Goldberg, Paris 1857.

Sepher Igeret Rabbi Yehudah... trad. par M.Katz, TelAviv 1950.

Jehuda Hadassi, Sepher Eshkol ha-Kopher, Gozlow 1836. Kitâb al-Radd wal-Dalîl fîl-Dîn al-Dhalîl, ed. D.H.Baneth, Jerusalem 1977.

cf. Hayyuj.

Judah ibn Balaam (Commentaire sur Is et Jr), lu en : Ms Leningrad, Bibl Saltykow-Shchedrin, Hebr Ar I 1377. Sur Is édité par J.Derenbourg en REJ 17 (1888) 172-201, 18 (1889) 71-82, 19 (1889) 84-99, 20 (1890) 225-236, 22 (1891) $47-61$ et 190-207, 23 (1891) 43-62 et 206-229. Sur Jr édité par J. Israelson en F S Harkavy, hebr. Abteil., 273-308, St. Petersburg 1908. 
Kafah, Megillot

Kahle, Geniza

-- Masoreten des Westens Masoreten des Westens, 2 vol., Stuttgart 1927-1930.

Kaiser

$--2$

Kasovsky, Thesaurus Mishnae

Keil

Kelso

Kennicott, Dissertatio generalis

-_ Dissertatio secunda

-- Dissertatio super ratione

Kessler, Sabbata

Kittel

$\mathrm{KJ}$

Klopfenstein, Scham

Knabenbauer

Knobel

Köhler

-- Beobachtungen

-- Emendationen

König

-- Hermeneutik

-- Lehrgebäude

-- Stilistik

-- Synt

-- Wörterbuch

Koenig
Kafah J.D., Hamesh Megillot, Jerusalem 1962.

Kahle P., The Cairo Geniza, Oxford 2/1959.

Kaiser O., en Is : Das Buch des Propheten Jesaja. Kap.

1-12 (ATD 17) Göttingen 5/1981; Der Prophet Jesaja.

Kap. 13-39 (ATD 18) Göttingen 1973; en Lm : Ringgren

H./Kaiser O., Das Hohelied. Klagelieder, Das Buch Esther

(ATD XVI/2) Göttingen 3/1981, 291-386.

Der Prophet Jesaja. Kap 1-12 (ATD 17) Göttingen 2/ 1963.

Kasovsky C.Y., Thesaurus Mishnae, 4 vol., Jerusalem 1960.

Keil C.F., Biblischer Commentar über den Propheten Jeremia und die Klagelieder (BC 3/2) Leipzig 1872.

Kelso J.A., Die Klagelieder, Leipzig 1901.

Kennicott B., Dissertatio generalis in V.T. hebraicum, Oxford 1780.

Dissertatio secunda super ratione textus hebraici... vertit G.A.Teller, Leipzig 1765.

Dissertatio super ratione textus hebraici... vertit G.A. Teller, Leipzig 1756.

cf. *M (éd. Kennicott)

Johannes Kesslers Sabbata, St. Gallen 1902.

Kittel R., en Is : cf. *M (éd. BH23S).

("King James Bible") The Holy Bible, Containing the Old and New Testament, London 1611.

Klopfenstein M.A., Scham und Schande nach dem Alten Testament (AThANT 62) Zürich 1972.

Knabenbauer J., en Is 1.37: Commentarius in Isaiam prophetam (CSS III/1.1) Paris 1887. En Jr: Commentarius in Ieremiam prophetam (CSS III/2) Paris 1889.

Knobel A., Der Prophet Jesaia (KeH 5) Leipzig 2/1854. Köhler L., Deuterojesaja stilkritisch untersucht (BZAW 37) Giessen 1923.

Beobachtungen am hebräischen und griechischen Text von Jeremia Kap. 1-9 : ZAW 29 (1909) 1-39.

Emendationen, FS Marti (BZAW 41), Giessen 1925, $173-$ 180.

König E., Das Buch Jesaja, Gütersloh 1926.

Hermeneutik des Alten Testaments, Bonn 1916.

Historisch-kritisches Lehrgebäude der hebräischen Sprache, 2 Bde, Leipzig 1881-1895.

Stilistik, Rhetorik, Poetik, Leipzig 1900.

Historisch-Komparative Syntax der hebräischen Sprache, Leipzig 1897.

Hebräisches und aramäisches Wörterbuch zum A.T., Leipzig $2 \& 3 / 1922$.

Koenig J., traduction d'Isaïe en : la Bible. L'A.T., vol.2 (Bibliothèque de la Pléiade 139) Paris 1959. 
-- Herméneutique

-- Réouverture

\section{Kokovzov}

Komlosh, Countenance

- Targum

Kopf

Koppe

Kraus

Krauss, Lehnwörter

Kuriakos

Kurrelmeyer

Kuschke

Kutscher

Lagarde

Lambert

Landsberger, House

Larcher

Leene

Leeuwen van

Le Fèvre d'Etaples

Lehmann

Leiste

Lemaire/Baldi

Levy, Chald. Wörterb.
L'herméneutique analogique du Judaïsme antique d'après les témoins textuels d'Isaïe : SVT 33, Leyde 1982.

Réouverture du débat sur la première main rédactionnelle du rouleau ancien d'Isaïe de Qumrân (1QIs-a) en 40,7-8 : Revue de Qumran, 11 (1983) 219-37.

Kokovzov P., Mi-Sifré ha-Balshanut ha-'Ivrit bimé habénayim, St. Petersbourg 1916. (Repr. Jerusalem 1970). Komlosh Y., The Countenance of the Servant of the Lord, was it Marred ? : JQR 65 (1974-5) 217-220.

The Targum Yirmiyahu : Bar-Ilan 7-8 (1969) 38-48.

Kopf L., Arabische Etymologien und Parallelen zum Bibelwörterbuch : VT 8 (1958) 161-215; 9 (1959) 247-287. Koppe J.B., R. Lowth's ... Jesaias ... mit Zusätzen und Anmerkungen, 4 vol., Leipzig 1779-1781.

Kraus H.-J., Klagelieder (BK 20) Neukirchen-Vluyn 2/1960. Krauss S., Griechische und lateinische Lehnwörter im Talmud, Midrasch und Targum mit Bemerkungen von Immanuel Löw, 2 vol., Berlin 1898-1899.

Kuriakos L.M., Non-paradigmatic Forms of Weak Verbs in Masoretic Hebrew, Quilon 1973.

Kurrelmeyer W., Die erste deutsche Bibel, 10 Bde (BLVS 234. 238. 243. 246. 249. 251. 254. 258. 259. 266) Stuttgart 1904-1915.

Kuschke A., Jeremia 48,1-8 zugleich ein Beitrag zur historischen Topographie Moabs., FS Rudolph, Verbannung und Heimkehr, Tübingen 1961, 181-196.

Kutscher E.Y., The Language and Linguistic Background of the Isaiah Scroll (STDJ 6) Leiden 1974.

Lagarde P. de, Kritische anmerkungen zum buche Isaias 1-17,10 : Semitica I, Göttingen 1878, 1-32.

cf. *T (éd. Lagarde).

Lambert M., Traité de grammaire hébraïque, Hildesheim 2/1972.

Landsberger F., The House of the People : HUCA 22 (1949) 149-155.

Larcher C., Le livre de la Sagesse ou la Sagesse de Salomon I (EtB) Paris 1983.

Leene $H_{\text {., }}$ Universalism or Nationalism ? : Bijdragen 35 (1974) 309-334.

C. van Leeuwen, Isa 14,12 hôlêš cal gwym and Gilgamesh XI,6 : JBL 99 (1980) 173-184.

La Saincte Bible en Françoys (trad. par J. Le Fèvre d'Etaples) Anvers 1530.

Lehmann M.R., A New Interpretation of the Term שדמות : VT 3 (1953) 361-371.

Leiste A.F.G., Observationes in vaticiniorum Ieremiae aliquot locos: Sylloge commentationum theologicarum, II, Helmstadt 1801, 203-246.

Lemaire P./Baldi D., Atlas Biblique, Louvain 1960.

Levy J., Chaldäisches Wörterbuch über die Targumim und einen grossen Teil des rabbinischen Schrifttums, 2 Bde, Leipzig 3/1881. 
- - Talm. Wörterb.

Liebmann E.

Lilienthal

Lisân el- ${ }^{c} A r a b$

Löfgren

Löhr

Löw

Loewenstamm, Strength

Loewinger, Variants

Lohfink, Isaias

Lohmann

Lohse

Loisy

Lonzano

Lowth

- Poesis

Luckenbill D.D.

Lütkemann

Lust

Luther

Luzzatto

_- Miscellen

-_Propheten

*M, m

*M (éd. Baer)

*M (éd. Ben Hayim)

*M (éd. BH2)
Wörterbuch über die Talmudim und Midrashim, 4 Bde, Berlin 2/1924.

Der Text zu Jesaja 24-27 : ZAW 22 (1902) 1-56.285-304, 23 (1903) 209-286, 24 (1904) 51-104, 25 (1905) 145171.

Lilienthal T.C., Commentatio critica sistens duorum codicum manuscriptorum ... notitiam, Königsberg 1770.

cf. Ibn Manzûr.

Löfgren O., Zur Charakteristik des 'vormasoretischen' Jesajatextes : Orientalia Suecana 4 (1955) 53-66.

Löhr M., Die Klagelieder des Jeremia (HK III/2.2) Göttingen 1893.

Löw I., Die Flora der Juden, 4 vol., Wien-Leipzig, 19281934.

Loewenstamm S.E., "The Lord is my Strength and my Glory" : VT 19(1969) 464-470.

Loewinger S., The Variants of DSI II : VT 4 (1954) 157. Lohfink N., Isaias 8,12-14: BZ NF 7 (1963) 98-104. Lohmann P., Die anonymen Prophetien gegen Babel aus der Zeit des Exils, Rostock 1910.

Lohse E., Die Texte aus Qumran, Darmstadt 1971.

Loisy A., Histoire critique du texte et des versions de la Bible, I Histoire du texte hébreu de l'A.T., Amiens 1892. Lonzano Menahem de, Sheté Yadôt, Venise 1618.

Lowth R., Isaiah. A New Translation with ... Notes, London 1778.

De sacra poesi hebraeorum, adnot. J.D.Michaelis, ed. secunda, Göttingen 1770.

Ancient Records of Assyria and Babylonia, 2 vol., Chicago 1926-1927.

Lütkemann L./Rahlfs A., Hexaplarische Randnoten zu Is 1-16 (MSU 6) Berlin 1915.

Lust J., Elijah and the Theophany on Mount Horeb : BEThL 41 (1976) 91-99.

Luther M., édité en WA.

pour Is : Luzzatto S.D., Il Profeta Isaia volgarizzato e commentato..., Padova 1855.

Miscellen: Wissenschaftliche Zeitschrift für jüdische Theologie 5 (1844) 124-137.

pour $\mathrm{Jr}$ : Erläuterungen über einen Teil der Propheten und Hagiographen, Lemberg 1876.

Texte massorétique $(M=$ leçon principale, $m=$ leçon( $(s)$ secondaire(s)), édité en:

pour Is : Baer S., Liber Jesaiae, Leipzig 1872; pour Jr : Liber Jeremiae, Leipzig 1890; pour Lm : Quinque Volumina, Leipzig 1886.

Biblia Rabbinica. A Reprint of the 1525 Venice Edition edited by Jacob ben Hayim ibn Adoniya, Jerusalem 1972. Torah Nebiim u-Ketubim. Biblia Hebraica, ... edidit R. Kittel, editio altera emendatior stereotypica iterum recognita, 2 vol., Leipzig 1913; pour Is : Kittel R., pour Jr : Rothstein J.W., pour Lm : Kittel R., (BH2 = simple correction de $\mathrm{BH} 1$ ). 
*M (éd. BH3)

*M (éd. BH7)

*M (éd. BHS)

*M (éd. Bomberg inquarto 1517)

*M (éd. Bomberg inquarto 1521)

*M (éd. Brescia 1494)

*M (éd. Félix de Prato)

*M (éd. Ginsburg)

*M (éd. Halle)

*M (éd. Kennicott)

*M (éd. Letteris)

*M (éd. Lisbonne 1492)

*M (éd. Minḥat Shay)

*M (éd. Münster)

*M (éd. Naples 1487)

*M (éd. Soncino 1486)

*M (éd. Soncino 1488)

Maalstad

McCarthy

Malamat, Mari

Manuel du Lecteur

Margoliouth

Marti

Martin, Pugio
Torah Nebiim u-Ketubim. Biblia Hebraica, ... edidit R. Kittel. Textum masoreticum curavit $P$. Kahle, editionem tertiam denuo elaboratam ad finem perduxerunt, Stuttgart (1929-)1937; pour Is : Kittel R., pour Jr : Rudolph W., pour Lm : Robinson Th.H.

= (réimpression de $\mathrm{BH} 3$ avec un choix de leçons de 1Q-a) editionem septimam auxerunt et emendaverunt A.Alt et O.Eissfeldt, Stuttgart 1951.

Torah Nebiim u-Ketubim. Biblia Hebraica Stuttgartiensia... Editio funditus renovata, ... ediderunt K.Elliger et W.Rudolph. Textum masoreticum curavit H.P.Rüger, masoram elaboravit G.E.Weil, Stuttgart (1967-)1977; pour Is : Thomas D.W., pour Jr : Rudolph W., pour Lm : Robinson Th.H.

(Bible hébraïque) 1 vol. in-4º Venise (Bomberg) 15161517.

(Bible hébraïque) 1 vol. in-4º, Venise (Bomberg) 1521.

(Bible) Brescia (Gershom Soncino) 1494.

(Bible rabbinique, editio princeps), 4 vol., Venise (Bomberg) 1516-1517.

Ginsburg C.D., The Later Prophets, London 1926; The Writings, London 1926.

Michaelis J.H., Biblia Hebraica, Halle 1720.

Kennicott B., Vetus Testamentum Hebraicum cum variis lectionibus, 2 vol., Oxford 1776-1780.

Sepher Torah Nebiim u-Ketubim..., éd. par M.L.Letteris, Berlin 1866.

(Isaïe et Jérémie avec Radaq), Eliezer Toledano, Lisbonne 1492.

(Bible avec commentaire textuel de Y.S.Norzi), 4 vol., Mantova 1742-1744.

cf. Münster.

(Ketubim avec des commentaires variés) Naples (Joseph ben Jacob Ashkenazi) 26 septembre 1487.

(Prophètes postérieurs avec Radaq) Soncino (Joshua Shelomo Soncino) 1486.

(Bible hébraïque, editio princeps) Soncino 1488.

Maalstad K., Einige Erwägungen zu Jes. XLIII 4 : VT 16 (1966) 512-514.

McCarty C., The Tiqqune Sopherim and Other Theological Corrections of the O.T. (OBO 36) Fribourg 1981. Malamat A., Mari and the Bible : Some Patterns of Tribal Organization and Institutions : JAOS 82 (1962) 143-150. Manuel du Lecteur d'un auteur inconnu, éd. J.Derenbourg : JA XVI, VIe série (1870) pp. 309-550.

Margoliouth G., Catalogue of the Hebrew and Samaritan Manuscripts in the British Museum, 3 vols., London, 1899. 1915.

Marti K., Das Buch Jesaja (KHC 10) Tübingen 1900. Martin R., Pugio fidei adversus Mauros et Judaeos, Leipzig 1687. 
Masius

Massore éditée

Meek

Meinhold

Mekhilta

Mekhilta de-Rabbi Shimeon ben Yohaii

Menahem ben Saruq Menahem, Disciples de...

Menahem de Lonzano

Menahem de Posquières

Meyer I.

Meyer

-- Probleme

Michaelis C.B.

Michaelis

-- Observationes

-- OEB

- Spicilegium

-- Supplementa

Michaelis J.H.

Michel

Midrash Bereshit Rabba

Midrash Ekha Rabbati Midrash Rabba

Midrash Tanḩuma 20; ms Oxford, Bibl Bodl, Opp. Add. fol. 66.

Midrash Tanḥuma (1520) Midrash Tanḥuma, édition Constantinople 1520-1522.

Masius A., In quaedam Loca cap. 2, 3 \& 4 Jeremiae, en Critici Sacri.

cf. *M (éd. Ben Hayim).

The Book of Lamentations, Introduction and Exegesis by Th.J.Meek... (IntB VI 1-38) Nashville 1956.

Meinhold J., Threni 2,13 : ZAW 15 (1895) 286.

Mekhilta de-Rabbi Ishmael, ed. J.Z.Lauterbach, 3 vol., Philadelphia 1949.

ed. J.N.Epstein et E.Z.Melamed, Jerusalem 1955.

Sefer Mahbberet, ed. H.F ilipowski..., London 1854.

cf. Disciples.

cf. Lonzano.

commentaires sur Jérémie et Ezéchiel lus en : ms Paris BN hébr 192.

Jeremia und die falschen Propheten (OBO 13) Fribourg 1977.

Meyer R., Hebräische Grammatik, 4 Bde, Berlin 19661972.

Probleme der hebräischen Grammatik: ZAW 63 (1951) 221-235.

sur Jr : Commentaire sur Jérémie, en *M ed. Halle; sur Lm : Notae uberiores in Threnos Jeremiae : Uberiorum adnotationum ... in Hagiographos ... volumen secundum, Halle 1720, 781-826.

Michaelis J.D., Deutsche Uebersetzung des Alten Testaments mit Anmerkungen..., 13 Bde, Göttingen 2/17731785.

Obervationes philologicae et criticae in Jeremiae vaticinia et Threnos, ed. J.F.Schleusner, Göttingen 1793.

Orientalische und exegetische Bibliothek; pour Is : 14 (1779) $99-155$ et $14 \mathrm{a}$ (1779) 3-223; pour Jr : 15 (1780) 154-187, 17 (1781) 160-187 et 18 (1782) 183-195; pour Lm : 19(1782) 132-138.

Spicilegium geographiae hebraeorum exterae post Bochartum, 2 vol., Göttingen 1769 et 1780.

Supplementa ad lexica hebraica, 6 vol., Göttingen 1792. (Bible de Halle) cf. *M (éd. Halle).

Michel D., Grundlegung einer hebräischen Syntax I, Neukirchen 1977.

édité en : Bereshit Rabba, mit kritischem Apparat und Kommentar von J.Theodor und C.Albeck, 3 Bde (VAWJ) Berlin 1931-1936; lu en : Mss London, BL, Add 16,406 et 27,169; Ms Paris, BN, hébr 149.

Midrasch Echa Rabbati, ed. S.Buber, Wilna 1899.

édité en: Sepher Midrash Rabba, 2 vol., Wilna 1851. Pour Megillot : lu en Ms Oxford, Bibl Bodl, Seld A sup 102. Pour Qo-Est : lu en Ms Roma, Bibl Vat, ebr 291. Pour la Torah : lu en Ms Oxford, Bibl Bodl, Opp Add fol 3.

lu en : ms de Rossi 261; ms Oxford, Bibl Bodl, Hunt. Don. 
Midrash Tanḩuma (1563) Midrash Tanhuma, édition Mantoue 1563.

Midrash Tanḥuma (Buber) Midrasch Tanchuma, ed. S.Buber, Wilna 1885.

Midrash Tehillim

Midrash Tehillim, ed. S.Buber, Wilna 1885.

Midrash Wayyiqra Rabba

Milik, Note

Minḥat Shay

Miqraot Gedolot

édité par M.Margulies, 5 vol., Jerusalem 1953-1960.

Milik J.T., Note sui manoscritti di 'Ain Fešna : Bib 31 (1950) 204-225.

cf. *M (éd. Minhat Shay).

pour Is et Jr : Miqraot Gedolot Nebiim u-Ketubim..., éd. par J.Levensohn et J.M.Mendelsohn, 12 vol., Varsovie 1860-1866; pour Lm : Miqraot Gedolot Hamisha Humshé Torah..., éd. Schulzinger, 6 vol., New York 1950.

Mishna

Montfaucon

Mischnajot, 8 Bde, Basel 3/1968.

Moran, Root

- Ugaritic

More Thomas

Montfaucon B. de, Hexaplorum Origenis quae supersunt, 2 vol., Paris 1713.

Moran W.L., The Putative Root ${ }^{\mathrm{c}} \mathrm{tm}$ in Is 9,18: CBQ 12 (1950) 153s.

Ugaritic șiṣûma and Hebrew șîs: Bib 39 (1958) 69-71. The Apologye of Syr Thomas More, Knyght; ed. A.I.Taft, London 1930.

Morrow

Moshé ben Sheshet

Movers

Mowinckel,

Psalmenstudien

Ms

$-710$

- A

- Alep

-- Alexandrinus

- Ambrosianus

- Barberini

-- Basel, Univ Bibl, A III 39

- Berlin, Staatsbibl, Or fol 1213

- ... Or qu 680

--Bern, Burger-Bibl, 92

-- Budapest, Bibl Acad Scient Hungaricae, coll Kaufmann 44

Morrow F.J., The Text of Isaiah at Qumran, Ann Arbor 1973.

A Commentary upon the Books of Jeremiah and Ezeqiel by Mosheh ben Shesheth ed. ... S.R.Driver, London 1871. Movers F.C., De utriusque recensione vaticiniorum Ieremiae graecae alexandrinae et hebraicae masorethicae indole et origine..., Hamburg 1837.

Mowinckel S., Psalmenstudien, 6 vol., Oslo 1921-1924. Manuscrit. Les manuscrits sont cités d’après microfilms sauf indication contraire.

de *G, cf. Lütkemann.

de *G, cf. Ms Alexandrinus.

de *M, édité en : Goshen-Gottstein M.H., The Aleppo Codex, vol.I : Plates, Jerusalem 1976.

de ${ }^{*} G$, édité en : J.E.Grabe, Septuaginta interpretum..., 4 vol., Oxford 1707-1720.

de ${ }^{*} S$, édité en : Ceriani A.M., Translatio syra Pescitto V.T. ex codice Ambrosiano, 2 vol., Milano 1876; de Syh, édité en: Ceriani A.M., Codex syro-hexaplaris Ambrosianus photolithographice editus, Milano 1874.

$=86$ en *G (éd. Göttingen).

Glossaire (C) hébreu-français : 1S-Am, 183 fol., XIII. de *M, Bible complète (sauf 2 S 12,20-24,15; Jr 44,26Ez 8,3; Is 7,24-31,1) 461 fol., avant 1100 (= Erfurt $3=$ Kenn 602).

de *M, Ketubim avec vocalisation babylonienne.

de *M, Prophètes avec massores, 634 p., XIII (= Kenn 149).

Norzi Y.S., Goder Peres sur le Pentateuque et les Megillot ( $=3 \mathrm{e}$ autographe) et sur le reste de la Bible $(=2 \mathrm{e}$ autographe), 4 vol. 
-- Caire, Synagogue karaïte

-- Cambridge, University Library, T.-S.

-- Chisianus

-- Cologne, Jésuites

-- Copenhague, Kong Bibl, hebr 1

-- ... hebr 2

- -... hebr 4

- -...hebr 5

-- ... hebr 8

-- ... hebr 9

- ... hebr 11

-- Erfurt 3

-- Florence, Laur., XI 4

-- Halle, Univ Bibl, Y b $10 \mathrm{Q}$

-- Hamburg, Staatsbibl, hebr 4

- - ... hebr 6

-- ... hebr 27

-- Kassel, Murhardsche Bibl., $2^{\circ} \mathrm{Ms}$ theol 3

-- Leiden, Bibl Acad, Or 4739

-_ ... Or 4742

- ... Or 4746

- ... Or 4769

- ... Or 4787

- -... Scaliger 3

-- Leipzig, Univ Bibl, hebr 102

-- Leningrad

-- Bibl Saltykov Shchedrin, Hebr I 568-569 de *M, Prophètes avec Massore (Moshe ben Asher), 599 fol, 895. Aussi édité en : Codex Cairo of the Bible from the Karaite Synagoge at Abbasiya, 2 vol., Jerusalem 1971; El Codice de Profetas de El Cairo, Madrid 1979ss.

Collection Taylor-Schechter de fragments provenant de la Geniza du Caire.

$=88$ en ${ }^{*} G$ (éd. Göttingen).

$=$ Paris, BN, hébr 1-3.

de *M, Bible avec massores, 761 p., 1251 (= Kenn 173). de *M, Bible avec massores, 521 fol., 1301 (= Kenn 178). de *M, Prophètes postérieurs et Ketubim avec massores, 232 fol., 1462 (= Kenn 175).

de *M, Bible avec massore, 363 fol. (=Kenn 172).

de *M, Prophètes antérieurs. et postérieurs, 191 fol. (= Kenn 171).

de *M, Ketubim, 66 fol. (= Kenn 171).

de *M, Pentateuque et Megillot avec Targum, Haftarot, 290 fol. (= Kenn 177).

= Berlin, Staatsbibl, Or fol 1213.

Catena in 16 prophet. contenant le commentaire d'Eusèbe sur Isaïe, 440 fol., XI.

Okhla we-Okhla, 134 fol. (première partie éditée en Okhla, éd. Diaz Esteban).

de *M, Pentateuque et Megillot avec Targum, 519 p. (= Kenn 612).

de *M, Prophètes postérieurs avec massores, 201 p. ( $=$ Kenn 612).

de *M, Prophètes avec massores, 169 fol. (= Kenn 180). de *M, Pentateuque et Hagiographes avec massores, 280 fol., vers 1300 (=Kenn 157).

Abraham ben Yehuda, Yesod Miqra, 248 fol. (= Warner 1).

Aaron ben Joseph, Commentaire sur Is 1-60, fol. 34-72 (= Warner 4).

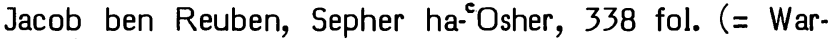
ner 8).

Jacob ben Reuben, Sepher ha- ${ }^{\circ}$ Osher, 330 fol. (= Warner 31).

Aaron ben Joseph, Commentaire sur Is 1.60 , fol. $37-113$ (= Warner 49).

édité en: Talmud Yerushalmi. Codex Leiden, Scal3, 4 vol., Jerusalem s.a.

Glossaire (F) hébreu-français : Gn - 2 Ch, 233 fol.

Ms Leningrad, Bibl. Saltykov Shchedrin, hebr B 19A de * $M$, édité en: Pentateuch, Prophets and Hagiographa. Codex Leningrad B 19A, 3 vol., Jérusalem 1970.

Yéfet ben Ely, Commentaire sur Is, 332 et 362 fol., 1503. 
-- ... Hebr I 570

- ... Hebr Ar I 1377

-- London, BL, Add 15,451

- - ... Add 16,406

- - ... Add 19,776

- -... Add 21,161

Add 27,169

Add 27,198

-_... Or 2501-2502

- ... Or 2503

- - ... Or 2504

- - ... Or 2548

-_... Or 2549

-- ... Or 2592

- -... Or 4837

-- Madrid, Bibl Univ, hebr 1

-- Marchalianus

- Milano, Ambrosiana ebr 5, (B35 inf)

-- München, Staatsbibl. hebr 52

-_... hebr 74

- -... hebr 77

- - ... hebr 95

-- New York, JThS, 232

--... 2918-2919

- - ... 2978

- ... 2979

-- Nürnberg, Ebner 2

-- Oxford, Bibl Bodl, 135

-- ... Hunt 477
Yéfet ben Ely, Commentaire sur Jr, 375 fol.

Judah ibn Balaam, Commentaires sur les Prophètes antérieurs et postérieurs, 144 fol.

de *M, Bible avec massore, 508 fol., XIII.

Midrashim Bereshit Rabba, Sifra, Sifré, 386 fol., XII. de *M, Pentateuque, Megillot et Haftarot; Jekutiel ben Jehuda Kohen : En ha-Qoré sur Pentateuque, Esther, Lamentations, 252f, 1395.

de *M, Prophètes et Hagiographes avec massores, 258 fol., XII (= Nürnberg, Ebner 2; = Kenn 201).

Midrashim Bereshit Rabba et Wayyiqra Rabba, 409 fol., XII.

Norzi Y.S., Goder Peres sur toute la Bible $(=1 \mathrm{er}$ autographe), premier et second autographes de la préface, 642 fol.

Yéfet ben Ely, Commentaire sur Is 27,13-66,24; 251 et 274 fol., XVI.

Yéfet ben Ely, Commentaire sur Jr 14,19-22; 15,9-10; 26-52,16, 252 fol.

Yéfet ben Ely, Commentaire sur Jr 26,20-27,5; 33,1752,31, 142 fol.

Yéfet ben Ely, Commentaire sur Is (fragm.), 187 fol, fin $X$.

Yéfet ben Ely, Commentaires sur Jr et Ez (fragm.), 308 fol., XI.

Abulfaraj Harûn, Kitâb al-Mushtamil, 86 fol.

Abulwalid Merwan ibn Ganah, Kitâb al-Usul, 214 fol., XIV.

de *M, Bible avec massore, 340 fol., Toledo 1280.

$=Q$ en ${ }^{*} G$ (éd. Göttingen).

Pentateuque, Megillot, Job avec Targum et Rashi, 304 fol., (= Kenn 185).

Joseph Bekhor Shor sur le Pentateuque, Ralbag sur les Megillot et Joseph Qara sur les Lamentations, 297 fol. Elias Levita, Sefer Zikronot, 2 vol., 578 \& 596 fol.

Tobia ben Eliezer, Commentaire sur les Megillot, 58 fol. Talmud, édité en: Der Babylonische Talmud, nach der einzigen vollständigen Handschrift ... vervielfältigt ... von H.L.Strack, 2 Bde, Leiden 1912.

de *M, Prophètes postérieurs avec massore, 112 fol., X-XI (= ENA 346).

A.Schultens, Dictionnaire hébreu inédit: lettres 'alef' (578p.) et 'dalet'-'zaïn' (non paginé).

Radaq, Shorashim, Espagne XIVe-XVe s.

Radaq, Shorashim, Italie XVe s.

$=$ London, BL, Add 21,161.

Abraham ha-Babli, Traité grammatical; Parḥon, Maḥberet ha- ${ }^{\circ}$ Aruk, 231 fol. ( = Neubauer 1466).

Isaac ha-Levi ben Eleazar, Sephat Yeter, 184 fol. ( $=$ Neubauer 1458). 
-_... Hunt 573

- ... Hunt Don 20

- ... Mich 562

- ... Opp 34

- ... Opp 187

- ... Opp 625

- ... Opp 629

-- ... Opp Add fol 3

- ... Opp Add fol 66

- ... Opp Add 4to 170

-_ ... Poc 320

- ... Poc 344

-- ... Seld. A sup 102

-- Paris, BN, hébr 1.3

-- ... hébr 5

-- ... hébr 6

-- ... hébr 26

- ... hébr 82

-- ... hébr 105

-_... hébr 134 \& 135

- ... hébr 148

-- ... hébr 149

-—... hébr 162

-- ... hébr 163

hébr 192

hébr 301

-- ... hébr 302

-- ... hébr 1325

- Parma, Bibl Palatina, 2217

- ... 2401

- ... 2668
Judah ben Qoreish, Risâlah etc., 85 fol. (= Neubauer 1448).

Midrash Tanhuma, 196 fol. (= Neubauer 153).

Norzi Y.S., Goder Peres sur le Pentateuque et les Megillot $(=2 \mathrm{e}$ autographe) 279 fol. ( $=$ Neubauer 1444).

Rashi, Commentaire sur la Bible, 329 fol., (= Neubauer 186).

Midrash Tanhuma, 116 fol. (= Neubauer 156).

Eliézer de Beaugency, Commentaire sur Isaïe, fol. 175220 ( $=$ Neubauer 1465 ).

Jekutiel ben Judah Kohen, ${ }^{\mathrm{C}}$ En ha-Qoré, 95 fol. (= Neubauer 1442).

Midrash Rabba sur la Torah, 460 fol. (= Neubauer 147). Midrash Tanhuma, 109 fol. (= Neubauer 2491).

Tanhum Yerushalmi, Epitome des commentaires sur Jos, $\mathrm{Jg}, \dot{\mathrm{S}}, \mathrm{R}$ et Is, 118 fol. (= Neubauer 2489).

Tanhum Yerushalmi, Commentaires sur Megillot et Daniel (= Neubauer 363).

Tanhum Yerushalmi, Commentaires sur Jérémie etc. (= Neubauer 319).

Midrash Rabba sur Megillot, fol. 118-362 (= Neubauer 164).

de *M, Bible avec massore, 3 vol., $144 \& 232 \& 192$ fol., 1286 ( $=$ Kenn 158; = Ms des Jésuites de Cologne).

de *M, Pentateuque, Megillot et Haftarot avec massores, 307 fol. 1298 (= Kenn 206).

de *M, Prophètes et Ketubim avec massores, 361 fol., 1298 (= Kenn 206).

de *M, Bible avec massore, 460 fol., Toledo $1272(=$ Kenn 209).

de *M, Prophètes antérieurs et postérieurs avec massore, 389 fol., Burgos 1207.

de *M, Ketubim, Jos, Jg et $\mathrm{S}$ avec massore, 212 fol., Toledo 1198 (= Kenn 326).

Elias Levita, Sefer Zikronot, 2 vol. 514 \& 606 fol.

Okhla we-Okhla, 112 fol.

Midrashim Bereshit Rabba, Wayyiqra Rabba et début de Bamidbar Rabba, 144 fol.

Joseph Qara, commentaires bibliques; Pseudo-Saadya sur Dn, 228 fol., XIII.

Joseph Qara sur Sam, Is, Jr, 146 fol., XIV.

Menahem de Posquières sur Jérémie et Ezéchiel.

Glossaire (B) hébreu-français : Jos-Esd, 128 fol., XIII.

Glossaire (A) hébreu-français : Gn - 2 Ch, 177 fol., 1241. Joseph ibn Kaspi, Shorashot Keseph, 416 fol., XV. Isaïe triglotte $\left({ }^{*} \mathrm{M},{ }^{*} \mathrm{~T}\right.$, arabe de Saadya) $128 \mathrm{fol}$.

Oeuvres diverses, dont Sephat Jether d'Abraham ibn Ezra, fol. 99-104 (= de Rossi 314).

Yalqut Shiméoni sur les Prophètes, 444 fol., XV (= de Rossi 1172).

de *M, Bible avec massore utilisée par Norzi, 371 fol., Toledo 1277 (= de Rossi 782). 
- ... 2808

- ... 2879

- ... 2924

- ... 2994

- ... 3218

- ... 3254

-- Petrograd

-- Reuchlin des Prophètes

-- Roma, Bibl Vat, ebr 3

- -... ebr 7

- ... ebr 72

-- ... ebr 110

- ... ebr 120

- ... ebr 291

- ... ebr 402

-_ ... ebr 468

- - ... ebr 482

- -... lat 321

- ... Neofiti 1

- ... Palat lat 172

- ... Urbin ebr 1

-_... Urbin ebr 2

-- Rossi de

-- Sinaiticus

-- Urbinates 1,2

- - Vatican

-- Vaticanus
Glossaire (E) hébreu-français : Gn - Jl, 178 fol., XIV (= de Rossi 637).

de *M, Bible avec massore, 318 fol., XIII (= de Rossi 2); édité en : Sperber A., The Parma Bible (CCHMA II/2.3) Copenhague 1959.

Tobia ben Eliezer, Commentaire sur les Megillot, 64 fol. (= de Rossi 206).

Glossaire (D) hébreu-français : Gn - Ne, 217 fol., 1279 (= de Rossi 60).

Joseph Qara sur les Prophètes, 173 fol., XIV-XV (= de Rossi 255).

Pentateuque avec massore, *T d'Onqelos et sa massore, Rashi et Ramban; Megillot et Haphtarot avec massore, *T et Rashi, 1064 p., 1475 (= de Rossi 7).

Midrashim (Tanhuma, Pesiqta, Ekha Rabbati), 202 fol. ( = de Rossi 261).

de $* M$, édité en : Strack H.L., Prophetarum posteriorum codex babylonicus Petropolitanus, St Pétersbourg 1876. de ${ }^{*} \mathrm{M}$ et ${ }^{*} \mathrm{~T}(=$ Kenn 154) édité en : Sperber A., Codex Reuchlinianus No 3 of the Badische Landesbibliothek in Karlsruhe (CCHMA II/1) Copenhague 1956.

de $* M$, Bible avec massore, 575 fol., avant 1309 (= Kenn 476).

de *M, Pentateuque et Ketubim avec massore, 464 fol., XIV ( $=$ Kenn 484).

Shelomo Parhon, Commentaire sur les Nebiim et les Ketubim, 127 fol.

Talmud Babli, Soțah, Nedarim, Nazir, 100 fol.

Talmud Babli, Menahot, Bekorot, Keritot, Meîlâ, Tamid, Qinnim, Arakin, Temura, Middot, 242 fol.

Midrash Rabba sur Qo-Est, fol. 217-304.

Joseph Qimhi, Sepher ha-Galuy; Jacob Tam, Hakraot; traités grammaticaux, 121 fol.

de $* M$, Bible avec massore, 481 fol., 1215 (= Kenn 506). de $* M$, Bible avec massores, 558 fol., $1216(=$ Kenn 242). Commentaire de Jérôme sur Isaïe (cap. 1-40), 189 fol., X. Targum palestinien sur le Pentateuque, 449 fol., 1504. Commentaire de Jérôme sur Isaïe (cap. 1-35), 187 fol., IX. de ${ }^{*} M$ et ${ }^{* T}$, Bible avec targum et massores, 979 fol., 1294 (= Kenn 228).

de *M, Bible avec massores, XII ( $=$ Kenn 225).

cf. Ms Parma.

Codex Sinaiticus de ${ }^{*} G$, édité en : Tischendorf C., Bibliorum codex Sinaiticus Petropolitanus..., 4 vol., St Pétersbourg 1862; Lake H./K., Codex Sinaiticus Petropolitanus et Friderico-Augustanus Lipsiensis, Oxford 1922.

cf. Roma, Bibl Vat, Urbin ebr 1,2.

cf. Roma, Bibl Vat.

Codex Vaticanus de ${ }^{*} \mathrm{G}$, cité par : *G (éd. Brooke/McLean ou éd. Göttingen) et édité en : Vercellone C./Cozza I., Bibliorum Sacrorum graecus codex Vaticanus... editus, 6 vol., Roma 1869-1881. 
Müller H.-P.

Münster

Muilenburg

Musculus

Musil, Arabia

Mutius von, Sprachvergleichung

NAB

Nägelsbach C.W.E.

Nathan ben Yehiel

NEB

Nestle, Miscellen

Neubauer/Driver

Nicolas de Lyre

Niehaus, Raz

Nöldeke, Grammatik

-- Untersuchungen

Nötscher $F$.

-- Hapaxlegomena

Noldius

North

Norzi

Noth, Aufsätze

Nyberg

-- Studien

Oecolampade
Glauben und Bleiben : Studies on Prophecy (SVT 26)

Leiden 1974, 25-54.

Münster S., Veteris Instrumenti tomus secundus, Prophetarum oracula atque Hagiographa continens..., Bâle 1535. The Book of Isaiah, Chapters 40-66, Introduction and Exegesis by J.Muilenburg (IntB V 381-773) Nashville 1956. Musculus W., In Esaiam prophetam commentarii, Bâle 1557.

Musil A., Arabia Petraea, 2 vol., Wien 1907. von Mutius H.G., Hebräisch-arabische Sprachvergleichung im Jesajakommentar Abraham ibn Esras : Biblische Notizen 6 (1978) 15-18.

The New American Bible, Catholic Biblical Association of America, Washington 1970.

pour Is : Der Prophet Jesaja (THBW 14) Bielefeld 1877; pour Jr: Der Prophet Jeremia (THBW 15/1) Bielefeld 1868; pour Lm : Die Klagelieder (THBW 15/2) Bielefeld 1868.

Sepher ha- ${ }^{c}$ Aruk ... éd. par S.Schlesinger, Tel-Aviv 1968. The New English Bible. The Old Testament. Oxford/Cambridge 1970.

Nestle E., Miscellen : ZAW 24 (1904) 122-138.

The Fifty-third Chapter of Isaiah According to the Jewish Interpreters, I. Texts edited ... by A. Neubauer, II Translations by S.R.Driver and A.Neubauer, Oxford 1876-1877. cf. *V (éd. Gadolo).

Niehaus J., Raz-Peshar in Isaiah 24 : VT 31 (1981) 376-378. Nöldeke Th., Kurzgefasste syrische Grammatik, Leipzig 2/1898.

Untersuchungen zur semitischen Grammatik : ZDMW 37 (1883) 525-540.

en Jr: Das Buch Jeremias (HS VII/2) Bonn 1934; en Lm : Echter-Bibel, Die Klagelieder, Wür zburg 1947.

Entbehrliche Hapaxlegomena in Jesaia: VT 1 (1951) 299-302.

Noldius C., Concordantiae particularum ebraeo-chaldaicarum..., ed. I.G.Tympius, Jena 1734.

North C.R., The Second Isaiah, Oxford 1964.

Norzi Y.S.' (commentaire textuel sur le *M) édité en: *M (éd. Minhat Shay) et en Miqraot Gedolot; lu en : Ms Budapest, Bibl Acad Scientiarum Hungaricae, Kaufmann 44; Ms Oxford, Bibl Bodl, Mich 562; Ms London, BL, Add 27,198.

Noth M., Aufsätze zur biblischen Landes- und Altertumskunde, 2 vol., Neukirchen-Vluyn, 1971.

Nyberg H.S., Hiskias Danklied Jes. 38,9-20 : ASTI 9 (1973) 85-97.

Studien zum Hoseabuche, Uppsala 1935.

Oecolampadius J., In Iesaiam prophetam hypomnematôn, Bâle 1525. 
Oesch

Okhla

-- (Diaz Esteban)

-- (Frensdorff)

Olivetan

Olshausen, Lehrbuch

Oort, Emendations -- Jez

Orelli von

Origène

Orlinsky, Madhebah

-- Mèḥâ̂rîm

-- State

-- Studies I

-- Studies IV

Osty

Oxford Dictionary

Paffrath

Pagnini

-- (1542)

$--(1557)$

-- Institutiones

-- Thesaurus

Papyrus 965, 966

Pareau

Parḥon

-- ${ }^{c}$ Aruk
Oesch J.M., Petucha und Setuma (OBO 27) Fribourg 1979. lue en : Ms Paris, BN, hébr 148; Ms Halle, Univ Bibl, Y b $10 \mathrm{Q}$.

Diaz Esteban F., Sefer Oklah we-Oklah, Madrid 1975. Frensdorff S., Das Buch Ochlah W'ochlah (Massora), Hannover 1864.

Olivetan P.R., La Bible... en laquelle sont contenus le Vieil Testament et le Nouveau, translatez en Françoys, Neuchâtel 1535.

Olshausen J., Lehrbuch der hebräischen Sprache, Braunschweig 1861.

Textus hebraici emendationes..., ed. H.Oort, Leiden 1900. Kritische Aanteekeningen op Jez. 40-66: ThT 25 (1891) 461-477.

von Orelli C., Die Propheten Jesaja und Jeremia (KK A/4) München 2/1891.

Origenes, Opera omnia, ed. C.Delarue, 4 vol., Paris 1733. 1759.

Orlinsky H.M., Madhebah in Isaiah 14,4 : VT 7(1957) $202 \mathrm{~s}$.

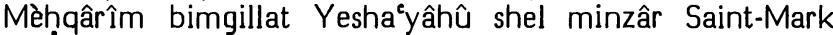
(7): Tarbiz 24 (1954) 4-8.

Qumrân and the Present State of Old Testament Text Studies: The Septuagint Text : JBL 78 (1959) 26-33. Studies in the St. Mark's Isaiah Scroll : JBL 69 (1950) 146-166.

Studies in the St. Mark's Isaiah Scroll, IV : JQR 43 (1952/53) 329-340.

La Bible. Traduction française sur les textes originaux par E.Osty, Paris 1973.

The Compact Edition of the Oxford English Dictionary, 2 vol., Oxford 1980.

Paffrath Th., Die Klagelieder (HS VII/3) Bonn 1932. Pagnini S., Biblia ... nova translatio ... Lyon 1527.

Biblia Sacra ex Santis Pagnini tralatione ... recognita ... Lyon 1542 (éditée par Michaël Villanovanus = Michel Servet).

cf. Estienne (Bible de 1557).

Habes hoc in libro ... Hebraicas Institutiones, Lyon 1526. Osar Leshon ha-Qodesh, hoc est Thesaurus linguae sanctae ..., Lyon 1529; ... auctum et recognitum ... opera J.Merceri ... et al., ed. B.C.Bertram, Lyon 3/1577.

de ${ }^{*} G$, édités en: The Chester Beatty Biblical Papyri VI, by F.G.Kenyon, Text, London 1937, 1-28 et Plates, Dublin 1958, 75-103.

Pareau J.H., Threni Jeremiae philologice et critice illustrati, Leiden 1790.

Parhon Shelomo ibn, (Commentaire sur les Prophètes et les Ketubim) lu en : Ms Roma, Bibl Vat, ebr 72.

Mahberet ha. ${ }^{c} A r u k$, ed. S.G.Stern, Poznan 1844; lu en : Ms Oxford, Bibl Bodl 135. 
Pasteurs

Payne Smith

Peiser, Miscellen

Pellican

Penna A.

Perles

- Dictionary

-- Miscellany

- Notes

Pesiqta Rabbati

Pesiqta de-Rab Kahana

Pethion Ibn Ayyub

Pieper

Pinsker

- - Liqquté qadmoniot

Pléiade

Plöger

Pole M.

Polyglotte d'Alcala

-- d'Anvers

- - de Londres

- - de Paris

Praetorius F.

-- Nachträge

Prédicants

Procope

Procksch
La Bible ... Le tout reveu et conferé sur les textes Hebrieux et Grecs par les Pasteurs et Professeurs de l’Eglise de Geneve, Genève 1588.

Payne Smith R., Thesaurus Syriacus, 2 vol., Oxford 18791901.

Peiser F.E., Miscellen : ZAW 17 (1897) 347-351.

Pellicanus C., Prophetae posteriores omnes ... commentariis C.P. ... enarrati, Zürich 1534.

Geremia, Torino 1952.

Perles F., Analekten zur Textkritik des Alten Testaments, 2 Bde, München 1895 \& Leipzig 1922.

The Fourteenth Edition of Gesenius-Buhl's Dictionary : JQR 18 (1906) 383-390.

A Miscellany of Lexical and Textual Notes on the Bible : JQR NS2 (1911) 97-132.

Notes critiques sur le texte de l’Ecclésiastique : REJ 35 (1897) 48-64.

ed. M.Friedmann, Wien 1880.

ed. S.Buber, Lyck 1868; ed. B.Mandelbaum, 2 vol., New York 1962.

Frank R.M., The Jeremias of Pethion Ibn Ayyub al-Sahhâr : CBQ 21 (1959) 136-170.

Pieper A., Jesaias II, Milwaukee 1919.

Pinsker S., Einleitung in das Babylonisch-Hebräische Punktationssystem..., nebst einer Grammatik der hebräischen Zahlwörter (Jesod Mispar) von Abraham ben Esra, Wien 1863.

Liqquté qadmoniot, 234 p. \& suppléments, 228 p. Wien 1860.

La Bible. Ancien Testament. 2. vol. (Bibliothèque de la Pléiade 120. 139) Paris 1956-1959.

Würthwein E./Galling K./Plöger O., Die fünf Megilloth... (HAT 18) Tübingen 2/1969, 127-164.

Synopsis criticorum ... III, Frankfurt 1712.

Biblia Complutensis (1515-1517), reprint Roma 1983 s. Biblia Sacra hebraice, chaldaice, graece et latine, 8 vol., Anvers 1569-1572.

Biblia Sacra polyglotta, ed. B.Walton, 6 vol., London 1657. Biblia 1. hebraica, 2. samaritana, 3. chaldaica, 4. graeca, 5. syriaca, 6. latina, 7. arabica, 10 vol., Paris 1629-1645. pour Is: Die Gedichte des Deuterojesaias, Berlin 1922; pour Lm : Threni I, 12.14. II, 6.13 : ZAW 15 (1895) 143146; Threni III, 5.16 : ibid. 326.

Nachträge und Verbesserungen zu Deutero-Jesaias, Halle 1927.

Das Vierde teyl des alten Testaments. Alle Propheten... durch die Predicanten zu Zürich inn Teutsch vertolmätschet, Zürich 1529.

Procopus Gazaeus, Commentarius in Isaiam prophetam : PG 87, 1801-2717.

Procksch O., Jesaia I (KAT 9/1) Leipzig 1930. 
In Isaiam prophetam interpretatio Sancti Joannis Chrysostomi... ex armenio in latinum sermonem a Patribus Mekitharistis, Venise 1887.

Q

1Q-a

1Q-b

1Q Hodayot

1QSa

$2 \mathrm{Q}$

4Q161

4Q163

4Q165

4Q174

$4 \mathrm{Q} 176$

4Q504

4Q-a, 4Q-b etc.

5QLm

11QMelchisédec

Qimhi David

Qimhi. Joseph, Galuy

-- Zikkarôn

Qirqisani, Anwar

Qobes

Quentin

Quin

Rabin, Miscellanea

Radaq

- Mikhlol

- Shorashim

Ranke, Par
= Qumrân.

1QIs-a, édité en : Scrolls from Qumrân Cave I ... from photographs by John C.Trever, Jerusalem 1972.

1QIs-b, édité en Sukenik et en DJD I 66-68.

édité en : Sukenik, pl. 35-58.

$=$ Règle de la Congrégation : DJD I 108-118.

2QJr édité en DJD III 62-69 et pl. XIII.

= 4QpIs-a : DJD V 11-15.

=4QpIs-c : DJD V 17-27.

= 4QpIs-e : DJD V 28-30.

Florilège : DJD V 53-57.

Tanhumim : DJD V 60-67.

Paroles des luminaires (1er exemplaire) : DJD VII 137-168. lus en: photographies ( $\mathrm{Jr}$ 4Q-a et 4Q-b ayant été édités partiellement en Janzen).

édité en DJD III 174-178 et pl. XXXVIIs.

Midrash eschatologique sur Melchisédec, éd. A.S. Van der Woude (OTS 14) Leiden 1965, 358-366.

cf. Radaq.

Sepher ha-Galuj, ed. H.J.Mathews, Berlin 1887; lu en ms Vatican ebr 402.

Sefer Zikkarôn, éd. W.Bacher, Berlin 1888.

Yusuf Abu Yackub al-Kirkisani, Kitab al-Anwar wal-Maraqib, ed. L.Nemoy, 4 vol., New York 1939-1943.

Qobes perushim lesefer Yeshayahu, éd. I. Bar Rav, 2 vol., Jérusalem 1971.

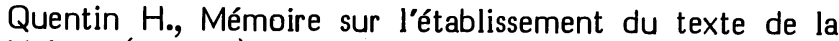
Vulgate (CBLa 6) Roma 1922.

Quinta.

Rabin Ch., Etymological Miscellanea (ScrHie 8) Jerusalem 1961, 384-400.

Radaq (R. David Qimḥi) (Commentaire sur la Bible), édité en : Miqraot Gedolot; pour Is 1-20,18 en: Finkelstein L. The Commentary of David Kimhi on Isaiah, New York 1926.

Sepher Mikhlol..., ed. Isaac ben Aaron Rittenberg, Lyck 1862.

Sepher ha-Shorashim... 'im qeșat nimmuqim she-hosiph... Elias Levita, Venezia 1546; lu en : éd. attribuée à Joseph ben Jacob ou Azriel ben Joseph Ashkenazi, Naples 18 août - 15 septembre 1490; éd. Isaac ben Judah ben David Cattorzi, Naples 10 février 1491; mss New York JThS 2978 et 2979.

Ranke E., Par palimpsestorum Wirceburgensium, Wien 1871. 
Rashi

Ratzaby

Reider, Contributions

-- Mšnty

Reland

Reuchlin

Reventlow

Richter, Untersuchungen

Rignell

-- Chapter 1
RL Orakel
RL

Roberts, Text

Robinson

Roediger

Rollet

Rosenmüller

de Rossi, Meor de Rossi

-- Codices

-- Scholia

Rost, Zu Jesaja

Rothstein

Rowlands, Targum

RSV
Rashi (R.Shelomo ben Isaac) (Commentaire sur la Bible); édité en : Miqraot Gedolot; pour Is en Maarsen I., Parshandatha II Isaiah, Jerusalem 1933; et lu en : Ms Oxford, Bibl Bodl. Opp. 34.

Ratzaby J., Remains of Saadyah's Commentary on Isaiah : Tarbiz 18 (1946-1947) 46-56.

Reider J., Contributions to the Scriptural Text : HUCA 24 (1952-1953) 85-106.

On Mšhty in the Qumran Scrolls : BASOR 134 (1954) $27 \mathrm{~s}$.

Reland A., Palaestina ex monumentis veteribus illustrata, 2 vol., Utrecht 1714.

Reuchlin J., De rudimentis hebraicis libri III, Pforzheim 1506.

Reventlow H. Graf, Liturgie und prophetisches Ich bei Jeremia, Gütersloh 1963.

Richter G., Untersuchungen zu den Geschlechtsregistern der Chronik : ZAW 34 (1914) 107-141.

Rignell L.G., A Study of Isaiah Ch. 40-55, Lunds Universitets Årsskrift. N.F. 1/52/5, Lund 1956.

Isaiah Chapter 1 : StTh 11 (1957) 140-158.

Das Orakel "Maher-salal Has-bas" : StTh 10 (1956) 40-52. (Revidierte Lutherbibel) Die Bibel oder Die ganze Heilige Schrift des Alten und Neuen Testaments nach der Uebersetzung M.Luthers, Stuttgart 1967.

Roberts, B.J., Text, OT : IDB IV, Nashville 1962, 580a594b.

cf. *M (éd. BH3S); en Lm : Robinson Th.H., Notes on the Text of Lamentations : ZAW 51 (1933) 255-259.

cf. Gesenius, Thesaurus.

La Bible en françoys, ed. Ph.Rollet, Lyon 1551.

Rosenmüller E.F.C., pour Is : Jesajae Vaticinia (Scholia in V.T. III/1-3) Leipzig 3/1829-1834; pour Jr et Lm : Ieremiae Vaticinia et Threni (VIII/1-2) Leipzig 18261827.

Rossi Azarya de, Sepher Meor ${ }^{c}$ Einayim..., Mantova 1574. Rossi J.B. de, Variae lectiones Veteris Testamenti, 4 vol., Parma 1784-1788.

Manuscripti codices hebraici Bibliothecae J.B. de R..., 3 vol., Parma 1803.

Scholia critica in V.T. libros, Parma 1798.

Rost L., Zu Jesaja 28,1ff : ZAW 53 (1935) 292.

cf. HSAT et $\mathrm{BH} 2$.

Rowlands E.R., The Targum and the Peshitta Version of the Book of Isaiah : VT 9(1969) 178-191.

(Revised Standard Version) The Bible Containing the Old and New Testaments... Translated from the Original Languages, Being the Version Set forth A.D. 1611, Revised A D. 1881-1885 and A.D. 1901, Compared with the Most Ancient Authorities and Revised A.D. 1952, New York 1952. 
Rubinstein, Agreement

- - Variant

Rudolph

- Jesaja

- Text

Running, Investigation

*S, s

Saadya

- Agron

-- Kitâb al-Amânât

--Kutub al-Lughah

--70 mots

-- Siddur

Sabatier

Saeb $b$

Sahidique

Salmon ben Yeruham
Rubinstein A., Formal Agreement of Parallel Clauses in the Isaiah Scroll : VT 4 (1954) 316-21.

Isaiah 52,14 - מ̣: - and the DSIa Variant : Bib 35 (1954) 475-479.

Rudolph W., pour Jr: Jeremia (HAT 1/12) Tübingen 1/1947, 2/1968; pour Lm : Das Buch Ruth. Das Hohe Lied. Die Klagelieder (KAT XVII/1-3) Gütersloh 1962, 187-269.

Jesaja XV-XVI, FS Driver, Oxford 1963, 130-143.

Zum Text des Jeremia: ZAW NF 7 (1930) 272-286;

Der Text der Klagelieder: ZAW 56 (1938) 101-122.

Running L.G., An Investigation of the Syriac Version of Isaiah : I = AUSS 3 (1965) 138-157, II = AUSS 4 (1966) 37-64, III = AUSS 4 (1966) 135-148.

Syriaque ( $\mathrm{s}=$ leçon principale, $\mathrm{s}=$ leçons secondaires), éditée en Polyglottes de Paris et de Londres et en édition de Mossul, 1886-1891; lue en: Ms Ambrosianus; pour Is, témoins cités selon Diettrich; pour $\mathrm{Lm}$ : éditée en $\mathrm{Al}$ brektson, 41-54.

Saadya Gaon, Oeuvres complètes III Version arabe d'Isaïe, éd. J.Derenbourg, Paris 1896. Pour Lm : Traduction éditée par J.D.Kafah en Hamesh Megillot, 331-353, Jérusalem 1962 et par Y.Ratzaby: Tarbiz 13 (1942) 92-106. Commentaire édité partiellement par Y.Ratzaby en Bar-Ilan 20-21 (1983) 349-381 et en Sinaï 95 (1984) 97-119, et lu en Ms Cambridge T.-S. Ar 1b.41 et 97, Ar 23.97, Ar 26. 20, Ar 27.106 et Ar 28.41 et 109.

Ha-Agron, ed. N.Allony, Jerusalem 1969.

Kitâb al-Amânât wa $a^{\mathrm{l} l}-\mathrm{I}^{\mathrm{c}}$ tiqâdât von Sacadja b. Jûsuf alFajjûmî ed. S.Landauer, Leiden 1880.

Fragments de ses Kutub al-Lughah édités par Skoss en : A Study of Inflection in Hebrew from Saadia Gaon's Grammatical Work 'Kutub al-Lughah': JQR 33 (1942-3) 171212.

Les soixante-dix mots hapax ed. N.Allony : FS Ignace Goldziher II Hebr. Section, Jérusalem 1958, 1-48.

Siddur R.Saadja Gaon, ed. I. Davidson, S.Assaf, B.I.Joel, Jerusalem 1970.

cf. Vet. Lat. (éd. Sabatier).

Saebp M., Zur Traditionsgeschichte von Jesaia 8,9-10: ZAW 76 (1964) 132-143.

pour Lm : Papyrus Bodmer XXII et Mississipi Coptic Codex II, publié par R.Kasser, Cologny 1964; Deiber A., Fragments coptes inédits de Jérémie : RB 5 (1908) 554566.

Salmon ben Yeruham (Commentaire des Lamentations), lu en : Ms Leningrad, Bibl Saltykov Shchedrin, Hebr I 560; Mss London, BL, Or. 2515 et 2516; Paris, BN, hébr 295. 
Sarsowsky

Sasson, Unrecognized

Sawyer, Reading

SBOT

Scharfenberg

Schelling

Schenker, Metamorphose

Scherschewski

Schleusner

-- Curae

- Opuscula

Schmidt

Schneedorfer

Schnurrer

Schoors

Schorr, Tiqqune Schultens, Dictionnaire

- - Hamasa

\section{- Job \\ - Opera minora \\ -- Origines II \\ Schunck}

Schuttermayr, Beobachtungen

Schwally, Miscellen

-- Reden
Sarsowsky A., Notizen zu einigen biblischen, geographischen und ethnographischen Namen : ZAW 32 (1912) 146-151.

Sasson V., An Unrecognized "Smoke-Signal" in Isaiah 30,27 : VT 33 (1983), 90-95.

Sawyer J., The Qumran Reading of Isaiah 6,13: ASTI 3 (1964) 111-113.

The Sacred Books of the Old Testament. A Critical Edition of the Hebrew Text ... with Notes ... under the Editorial Direction of P.Haupt, 16 vol., Leipzig 1894-1904; pour Is : Cheyne T.K., pour Jr : Cornill C.H.

Scharfenberg J.G., notes sur : Cappel, Critica.

Schelling J.F., Descriptio codicis manuscripti hebraeo biblici qui Stuttgardiae ... asservatur, Stuttgart 1775.

Schenker A., Nebukadnezzars Metamorphose vom Unterjocher zum Gottesknecht : RB 89 (1982) 498-527.

Scherschewski Ts., Biûrîm ba-Miqrâ : ha-Shahar 2 (1871) 24.

Schleusner J.-F., Novus Thesaurus philologico-criticus sive lexicon in $L X X$ et reliquos interpretes graecos... V.T., 5 vol., Leipzig 1820-1821.

Curae exegeticae et criticae in Threnos Jeremiae : RBML 12 (1783) 1-57.

Opuscula Critica ad Versiones Graecas V.T. pertinentia, Leipzig 1812.

Schmidt H., Die grossen Propheten (SAT II/2) Göttingen 1923.

Schneedorfer L.A., Das Buch Jeremias, des Propheten Klagelieder und das Buch Baruch, Wien 1903.

Schnurrer C.F., Observationes ad Jeremiae vaticinia: Commentationes theologicae editae a J.G.Velthusen... 3-5, Leipzig 1795-1798.

Schoors A., I Am God Your Saviour. A Form-Critical Study of the Main Genres in Is 45-55, (VT.S, 24) Leiden 1973.

Schorr Y.H., Tiqqune Sopherim : He-Halûs 5 (1860) 91s. Schultens A., Dictionnaire hébreu inédit, lu en ms New York, JThS, 2918.

Thomae Erpenii grammatica arabica ... accedunt excerpta anthologiae ... quae inscribitur Hamasa Abi Temmam ... notis illustrata, Leyde 2/1767.

Liber Jobi ... cum commentario, 2 vol., Leiden 1737. Opera minora, Leiden 1769.

Originum hebraearum t.II cum vindiciis t.I, Leiden 1738. Schunck K.-D., Jes 30,6-8 und die Deutung der Rahab im AT : ZAW 76 (1966) 48-56.

Schuttermayr G., Beobachtungen zu Jes 5,13: BZ NF 9 (1965) 215-232.

Schwally F., Miscellen : ZAW 11 (1891) 169-183, $253-$ 260.

Die Reden des Buches Jeremia gegen die Heiden : ZAW 8 (1888) 177-217. 
Schwarzenbach, Terminologie

Scott, Inside

Scullion, Texts

Secker

Seeligmann

-- Phôs

Segal, Beayot

Segond

Seidel

Servet M.,

Simon

Simons

Sionita

Skehan, State

Smith, Use

Soden von, Funktionär

Soggin, Bemerkungen

Sollamo

Sonnen

Speculum

Sperber

Spohn

Stade, Aequivalent

-- Deuterozacharja

-- Geschichte

- Miscellen 8

- Zu Jes

Steinmann

Stenning

Strugnell

Sukenik
Schwarzenbach A.W., Die geographische Terminologie im Hebräischen des Alten Testamentes, Leiden 1954.

Scott R.B.Y., Isaiah XXI 1-10; The Inside of a Prophet's Mind : VT 2 (1952) 278-282.

Scullion J.J., Some Difficult Texts in Is cc. 56-66 in the Light of Modern Scholarship : UF 4 (1972) 105-128. Secker Th., cité par Lowth.

Seeligmann I.L., The Septuagint Version of Isaiah, Leiden 1948.

$\Delta \varepsilon \tilde{\xi} \xi a l$ aũน $\varphi \tilde{\omega} \varsigma$ : Tarbiz 27 (1957) 127-141.

Segal M.Z., Beayot millim : Leshonénu 10 (1939) 150156.

La Sainte Bible, traduite ... par L.Segond, édition revue avec références, London 1910 (Repr. 1979).

Seidel M., Héqer Millîm : Leshonénu 3 (1930-1) 5-14. cf. Pagnini (1542).

Simon R., Histoire Critique du Vieux Testament, nouvelle edition \& qui est la premiere imprimée sur la copie de Paris, Rotterdam 1685.

Simons J., The Geographical and Topographical Texts of the Old Testament (SF SMD 2), Leiden 1959.

Gabriel Sionita, éditeur de la *S dans la polyglotte de Paris. Skehan P.W., Qumran and the Present State of O.T. Text Studies : The MT : JBL 78 (1959) 21-23.

Smith G.V., The Use of Quotations in Jeremiah 15,11-14 : VT 29 (1979) 229-231.

von Soden W., Der neubabylonische Funktionär 'simmagir' und der Feuertod des Shamash-shum-ukin : ZA 62 (1972) 84-90.

Soggin J.A., Einige Bemerkungen über Jeremias 2,34: VT 8 (1958) 433-435.

Sollamo R., Renderings of Hebrew Semiprepositions in the Septuagint (AASF.DHL 19) Helsinki 1979.

Sonnen J., Landwirtschaftliches vom See Genesareth : Bib 8 (1927) 65-87, 188-208, 320-337.

Liber qui appellatur speculum ... ed. F.Weihrich (CSEL 12) Wien 1887.

cf. *T (éd. Sperber).

Spohn G.L., Jeremias vates e versione judaeorum alexandrinorum, 2 vol., Leipzig 1824.

Stade B., Das vermeintliche aramäisch-assyrische Aequivalent der מלכת השמים Jr 7; 44 : ZAW 6 (1886) 289-339. Deuterozacharja : ZAW 1 (1881) 1-96.

Geschichte des Volkes Israel I, Berlin 1887.

Miscellen 8 : ZAW 5 (1885) 175-178.

Zu Jes. 3,1.17.24 etc. : ZAW 26 (1906) 129-141.

Steinmann J., Le prophète Jérémie, Paris 1952.

cf. *T (éd. Stenning).

Strugnell J., Notes en marge du volume $V$ des “Discoveries in the Judaean Desert of Jordan": RdQ 7 (1970) 163-276.

Sukenik E.L., The Dead Sea Scrolls of the Hebrew University, Jerusalem 1955. 
Syh

Sym

Syropalestinienne

*T, t

*T (éd. Lagarde)

*T (éd. Sperber)

*T (éd. Stenning)

*T fragmentaire

*T Neofiti

*T yéménite des

Lamentations

Talmon, Amen

-- Aspects

- Case

-- Double

-- DSIa

Talmud Babli

-- (éd. Bomberg)

Talmud Yerushalmi -- (ed. 1523)

Tanḥum Yerushalmi

Tanḥuma

Th

Thenius

Théodoret

Thiel

Thomas More
Syrohexaplaire, cf. ms Ambrosianus.

Symmaque, cité selon *G (éd. Göttingen).

The Bible in the Syropalestinian Version, ed. M.H.GoshenGottstein. I Pentateuch and Prophets, Jerusalem 1973.

Targum ( $T=$ leçon principale, $t=$ leçons secondaires), édité en : Félix de Prato, Ben Hayim, Polyglottes d’Anvers et de Londres; lu en : Ms Reuchlin; Ms Roma, Bibl Vat, Urbin ebr 1; Ms Paris, BN, hébr 1325; Ms Parme, de Rossi 7; Ms Milano, Ambrosiana, ebr 5; Ms Hamburg, Staatsbibl, hebr 4; Ms Copenhague, Kong Bible, hebr 11.

Hagiographa chaldaice, P. de Lagarde edidit, Leipzig 1873. Sperber A., The Bible in Aramaic, 5 vol., Leiden 1959-1973. Stenning J.F., The Targum of Isaiah, Oxford 1949.

éd. M.L.Klein, The Fragment-Targums of the Pentateuch, 2 vol. (AnBib 76) Rome 1980.

lu en : Ms Roma, Bibl Vat, Neofiti 1.

cf. Heide van der.

Talmon S., Amen as an Introductory Oath Formula: Textus 7 (1969) 124-129.

Aspects of the Textual Transmission of the Bible in the Light of Qumran Manuscripts : Textus 4 (1964) 95-132. A Case of Faulty Harmonization : VT 5 (1955) 206-208. Double Readings in the Massoretic Text : Textus 1 (1960) 144-184.

DSIa as a Witness to Ancient Exegesis of the Book of Isaiah : Cross, Qumran 116-126.

Der Babylonische Talmud, ed. L.Goldschmidt, 9 Bde, Den Haag 1933-1935; lu en : Ms München, Staatsbibl, hebr 95; ms Roma, Bibl Vat, ebr 110 et 120.

The Babylonian Talmud. First Edition Venice 1520-1523 (Bombergi) 22 vol., reprint Jerusalem 1968-1970.

lu en : Ms Leiden, Bibl Acad, Scaliger 3.

édité en : Talmud Yerushalmi nidfas bebeit D. Bombergi..., Venezia 1523.

Tanhum Yerushalmi, lu en : Ms Oxford, Bibl Bodl, Opp Add 4to 170 (Epitome des commentaires sur Jos, Jg, S, $R$ et Is), Ms Oxford, Bibl Bodl, Poc 344 (Commentaire sur Jérémie, etc.) et Ms Oxford, Bibl Bodl, Poc 320 (Commentaire sur Megillot et Daniel); pour Lm : édité par G.Cureton, Londres 1843.

cf. Midrash Tanhuma.

Théodotion, cité selon *G (éd. Göttingen).

Thenius O., Die Bücher der Könige (KeH 9) Leipzig 1849; pour Lm: Hitzig F./Thenius O., Das Hohe Lied. Die Klagelieder ( $\mathrm{KeH} 16)$ Leipzig 1855.

Theodoretus Cyrensis. Opera Omnia, I.L.Schulze edidit, 5 vol. Halle 1769-1774; en Is : Theodoret von Kyros. Kommentar zu Jesaia (MSU 5) Berlin 1932.

Thiel W., Die deuteronomistische Redaktion von Jeremia 1-25, WMANT 41, Neukirchen-Vluyn 1973.

cf. More Thomas. 
Thomas, Root

tib

TOB

Tobia ben Eliezer

Torczyner

-- Bibelstellen

Tosefta

Tov

- Aspects

-- Critique

- Notes

- Pseudo-Variants

Traité Sopherim

Tremellius

Trommius

Tur-Sinai, Contribution

Ug

Unger, Namen

UT

*V, $v$

*V (éd. Estienne 1532)

*V (éd. Estienne 1540)

*V (éd. Estienne 1545)

*V (éd. Froben 1495)

*V (éd. Gadolo 1495)

*V (éd. San Girolamo)
Thomas W., The Root סני = (1934) 236-238, 55 (1937) 174-176.

= tibérien.

Traduction Oecuménique de la Bible. Edition intégrale. Ancien Testament, Paris 1975.

Commentaire sur les Lamentations : lu en Ms München, Staatsbibl, hebr 77; ms Parma, Bibl Palat, 2879. Edité par Greenup A.W., London 2/1908.

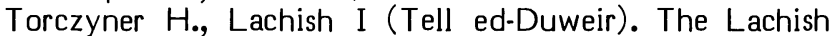
Letters, London 1938.

Dunkle Bibelstellen: Festschrift Karl Marti (BZAW 41) Giessen 1925, 274-280.

éditée en : Tosephta based on the Erfurt and Vienna codices, ed. by M.S.Zuckermandel, Jerusalem 2/1937; pour Zeraïm, Moëd, Nashim : ed. par Saul Lieberman, New York 1955ss.

Tov E., The Septuagint Translation of Jeremiah and Baruch, Missoula 1976.

Some Aspects of the Textual and Literary History of the Book of Jeremiah : BEThL 54 (1981) 145-167.

$L$ 'incidence de la critique textuelle sur la critique littéraire dans le livre de Jérémie : RB 79 (1972) 189-199.

Exegetical Notes on the Hebrew Vorlage of the LXX of Jeremiah 27 (34) : ZAW 91 (1979) 73-93.

On "Pseudo-Variants" Reflected in the Septuagint : JSS 20 (1975) 165-177.

Masseket Sopherim..., éd. H.Higger, New York 1937. Bibliorum pars quarta, id est, Prophetici libri omnes ... latini recens ex Hebraeo facti ... ab Immanuele Tremellio \& Francisco Junio, Londres 1585.

Trommius A., Concordantiae graecae versionis vulgo dictae LXX interpretum..., 2 vol., Amsterdam 1718. Tur-Sinai N.H., A Contribution to the Understanding of Isaiah I-XII (ScrHie 8) Jerusalem 1961, 154-188.

Ugaritica I à VI, éd. Cl. F.A.Schaeffer, Paris 1939-1969. Unger E., Namen im Hofstaate Nebukadnezars II : ThLZ 50 (1925) 481-486.

Gordon C.H., Ugaritic Textbook. Grammar - Texts in Transliteration - Glossary (AnOr 38), Roma 1965.

Vulgate $(V=$ leçon principale, $v=$ leçons secondaires $)$, éditée en :

Biblia ... Parisiis, ex officina Roberti Stephani, 1532. Biblia ... Parisiis, ex officina Roberti Stephani, 1540. cf. Estienne, Bible de 1545.

Biblia integra : summata : distincta..., Bâle 1495.

Liber vite. Biblia cum glosis ordinariis et interlinearibus... simulque cum expositione Nicolai de Lyra, Venise 1495. Biblia Sacra iuxta latinam vulgatam versionem, ... studio monachorum abbatiae pontificiae Sancti Hieronymi in urbe ordinis Sancti Benedicti edita, Roma 1926ss. 
*V (éd. Weber)

Van der Kooij

-- Commentary

Van Selms

Vatable

Venema

Vercellone

Vermeylen

Vet lat (éd. Sabatier)

Vitringa

Vogel

Volz

-- Studien

Wallenstein

Walters, Text

Walton

Wanke

Warzsawski

Watson, Pairs

Wayyiqra Rabba

Weil

Weippert

Weiser A.

Weisz

Wellhausen, Kleinen Propheten

-- Rec. Dillmann

Wernberg-Móller, Note
Weber R., e.a., Biblia Sacra iuxta vulgatam versionem, 2 vol., Stuttgart 1969.

Van der Kooij A., Die alten Textzeugen des Jesajabuches (OBO 35) Fribourg 1981.

A Short Commentary on Some Verses of the Old Greek of Isaiah 23 : BIOSCS 15 (1982) 36-50.

Van Selms A., Telescoped Discussion as a Literary Device in Jeremiah : VT 26 (1976) 99-112.

Vatablus F. (annotations sur l'A.T.) cf. Estienne (Bible de 1545).

Venema $\mathrm{H}$., Commentarius ad librum prophetiarum Jeremiae, 2 vol., Leeuwarden 1765.

Vercellone C., Variae lectiones Vulgatae latinae Bibliorum editionis, 2 vol., Roma 1860-1864.

Vermeylen J., Du prophète Isaïe à l'apocalyptique, Is 1.35 (EtB) Paris 1977.

Sabatier P., Bibliorum sacrorum latinae versiones antiquae seu Vetus Italica, 2 vol., Reims 1743.

Vitringa C., Commentarius in librum prophetiarum Jesaie, 2 vol., Bâle 1732.

Vogel G.J.L., cf. Grotius et Cappel, Critica.

Volz P., pour Is : Jesaia II (KAT 9/2) Leipzig 1932; pour Jr : Der Prophet Jeremia (KAT 10) Leipzig 1/1922, 2/1928. Studien zum Text des Jeremia (BWAT 25) Leipzig 1920.

Wallenstein M., Some Aspects of the Vocabulary and Morphology of the Hymns of the Judaean Scrolls : VT 7 (1957) 209-213.

Walters P./Gooding D.W., The Text of the Septuagint, Cambridge 1973.

cf. Polyglotte de Londres.

Wanke G., Untersuchungen zur sogenannten Baruchschrift (BZAW 122) Berlin 1971.

Warzsawski L., Die Peschitta zu Jesaja (Kap. 1-39), Berlin 1897.

Watson W.G.E., Fixed Pairs in Ugaritic and Isaiah : VT 22 (1972) 460-468.

cf. Midrash Wayyiqra Rabba.

Weil G.E., Massorah gedolah iuxta codicem Leningradensem B 19A, vol.I : Catalogi, Roma 1971.

Weippert H., Die Prosareden des Jeremiabuches (BZAW 132) Berlin 1973.

En Jr: Der Prophet Jeremia Kap. 1-25,13 (ATD 20) Göttingen 1952; en Lm : Ringgren H./Weiser A., Das Hohe Lied. Klagelieder. Das Buch Esther (ATD 16/2) Göttingen 1958.

Weisz H., Die Peschitta zu Deuterojesaia, Halle 1893. Wellhausen J., Die Kleinen Propheten übersetzt, mit Noten (Skizzen und Vorarbeiten V) Berlin 1892.

Rec. A.Dillmann, Der Prophet Jesaja : DLZ 11 (1890) $1121-1123$.

Wernberg-Mbller P., A Note on "to stink" : VT 4 (1954) 322-325. 
- - Observations

-- Pronoun

Westermann

Wichelhaus

Wickes

Wiesmann

Wildberger

Wiseman

Wolf J.C.

Wutz

Yalon, Rec. Burrows

Yalqut ha-Makhiri

Yalqut Shiméoni

Yéfet ben Ely

Yeivin

- Codex

Yequtiel ben Judah

yer

Young
Observations on the Hebrew Participle : ZAW 71 (1959) 54-67.

The Pronoun אתמה and Jeremiah's Pun : VT 6 (1956) $315 s$.

Westermann K., Das Buch Jesaja. Kap. 40-66 (ATD 19) Göttingen 1966.

Wichelhaus J., De Ieremiae versione alexandrina, Halle 1847.

Wickes W., Two Treatises on the Accentuation of the O.T. On Psalms, Proverbs and Job (1881). On the Twenty-One Books (1887) (LBS) New York 1970.

Wiesmann H., Die Klagelieder übersetzt und erklärt, Frankfurt/Main 1954.

Wildberger H., Jesaja (BK 10) Neukirchen-Vluyn 1972ss. Wiseman D.J., Chronicles of Chaldaean Kings, London 1956.

Bibliotheca hebraea, 4 vol., Hamburg 1715-1733.

Wutz F., Die Transkriptionen von der Septuaginta bis zu Hieronymus, 2 vol. (BWAT) Stuttgart 1925-1933.

Yalon H., Rec. M.Burrows, The Dead Sea Scrolls : QS 27 (1950-51) 163-175.

sur Is : édité par Y.Z.K.Spira, Berlin 1894.

édité en : Yalqut Shiméoni, 7 vol., Salonique 1521-1527; lu en : Ms Parma, Bibl Palatina, 2401.

Yéfet ben Ely (Commentaires sur la Bible), lu en : Ms Leningrad, Bibl. Saltykov-Shchedrin, Hebr I 568-569

(pour Is); 570 (pour Jr); Mss London, BL, Or 2501-2502 (pour Is); Or 2503-2504 (pour Jr); Or 2548 (pour Is); Or 2549 (pour Jr); Or 2550 (pour les Petits Prophètes).

Yeivin I., Geniza Bible Fragments with Babylonian Massorah and Vocalization, 5 vol., Jerusalem 1973.

The Aleppo Codex of the Bible. A Study of its Vocalization and Accentuation, Jerusalem 1968.

Yequtiel ben Judah ha-Kohen, 'Aïn ha-Qoré, lu en : Ms Oxford, Bibl Bodl, Opp 629. yerushalmi

Young E.J., The Book of Isaiah, 3 vol., Grand Rapids 1976-1977.

("Zürcher Bibel") Die Heilige Schrift des Alten und des Neuen Testaments, Zürich 1955.

Ziegler J., éditeur du *G (éd. Göttingen).

en Is : Untersuchungen zur Septuaginta des Buches Isaias : (ATA XII/3) Münster 1934.

- Beiträge
Beiträge zur Ieremias-Septuaginta (NAWG.PH) Göttingen 1958. 
$--E B$

-- Notizen

-- Sylloge

-- Vorlage

Zimmerli

Zwingli
Echter-Bibel, Das Buch Isaias, Würzburg 1948.

Textkritische Notizen zu den jüngeren griechischen Uebersetzungen des Buches Isaias (NAWG.NF I 4, 75-102) Göttingen 1939.

Sylloge, Göttingen 1971.

Die Vorlage der Isaias-Septuaginta (LXX) und die erste Isaias-Rolle von Qumrân (1QIs-a) : JBL 78 (1959) 34-59. Zimmerli W., Ezechiel (BK 13) Neukirchen-Vluyn 1969. Zwingli $H_{\text {., }}$ pour Is : Complanationis Isaiae prophetae, foetura prima ... Zürich 1529; rééd. en CR CI, 1-412, Zürich 1959; pour Jr : Complanationis Ieremiae prophetae, foetura prima ... Zürich 1531; rééd. en CR CI, 413 681, Zürich 1959. 